Universidade de SÃo PAUlo

Instituto DE QuímicA

Programa de Pós-Graduação em Química

Luiz Felipe Guain Teixeira

Calibração de Funcionais de Densidade

para Cálculos de Constante de

Acoplamento Indireto Spin-Spin

Versão corrigida da Dissertação conforme Resolução CoPGr 5890

O original se encontra disponível na Secretaria de Pós-Graduação do IQ-USP

São Paulo

Data do Depósito na SPG:

$30 / 11 / 2018$ 

Luiz Felipe Guain Teixeira

\section{Calibração de Funcionais de Densidade \\ para Cálculos de Constante de \\ Acoplamento Indireto Spin-Spin}

Dissertação apresentada ao Instituto de Química da Universidade de São Paulo para obtenção do Título de Mestre em Ciências (Química)

Orientador: Lucas Colucci Ducati

São Paulo 
Autorizo a reprodução e divulgação total ou parcial deste trabalho, por qualquer meio convencional ou eletronico, para fins de estudo e pesquisa, desde que citada a fonte.

Ficha Catalográfica elaborada eletronicamente pelo autor, utilizando o programa desenvolvido pela Seção Técnica de Informática do ICMC/USP e adaptado para a Divisão de Biblioteca e Documentação do Conjunto das Químicas da USP

Bibliotecária responsável pela orientação de catalogação da publicação: Marlene Aparecida Vieira - CRB - 8/5562

G898c

Guain Teixeira, Luiz Felipe

Calibração de Funcionais de Densidade para Cálculos de Constante de Acoplamento Indireto SpinSpin / Luiz Felipe Guain Teixeira. - São Paulo, 2019 .

$641 \mathrm{p}$.

Dissertação (mestrado) - Instituto de Química da

Universidade de São Paulo. Departamento de Química Fundamental.

Orientador: Ducati, Lucas Colucci

1. Teoria do Funcional da Densidade. 2. DFT. 3. Ressonância Magnética Nuclear. 4. RMN. 5. Constantes de Acoplamento Indireto Spin-Spin. I. T. II.

Ducati, Lucas Colucci, orientador. 


"If you don't know where you are going, any road will get you there." Lewis Carroll

"In the universe the difficult things are done as if they were easy."

Lao-Tsu

"It is a capital mistake to theorize before one has data. Insensibly one begins to twist facts to suit theories rather than theories to suit facts." Sherlock Holmes

"Research is what I am doing when I don't know what I am doing." Werner von Braun

"The numbers are meaningless, but the trends are important." Larry Burggraf 



\section{Agradecimentos}

À FAPESP, pelo apoio financeiro de minha bolsa de mestrado (\#2016/19365-7), participação em congresssos e ajuda financeira da infra-estrutura do laboratório; ao CNPq pela bolsa inicialmente concedida e ajuda financeira da infra-estrutura do programa; à CAPES pela ajuda financeira da infra-estrutura do programa; e ao LNCC pelo acesso ao supercomputador Santos Dumont.

Aos meus pais Denise e Wilson, e meu irmão Thiago, pelo imenso apoio e suporte recebido durante o mestrado, a graduação e toda a minha formação.

Ao professor e orientador Lucas Colucci Ducati, o qual eu sou imensamente grato pela orientação de meu mestrado, pela amizade e pela minha formação como pesquisador.

Ao Bruno, pelo carinho, pelo apoio e pelas várias horas que me ouviu falando sobre o desenvolvimento de todo o projeto até a dissertação.

Aos colegas de laboratório Marcelo e Patrick, pelas discussões científicas, pelas ótimas contribuições no projeto e na minha formação como pesquisador.

Aos meus colegas da Turma 22 do curso de Ciências Moleculares Artur, Estêvão, Felipe, Gabriel, Lucas, Paulo, Renzo, Rodolfo, Rodrigo e Thiago, pelos anos de graduação, pelas discussões científicas, pela amizade e pela troca de conhecimento.

Aos demais colegas do curso de Ciências Moleculares, pela troca de conhecimento, pelas conversas, pelas discussões científicas, e momentos juntos.

Aos colegas de pós-graduação Veronica, Antonio Ricardo e outros, pelas disciplinas juntos, pelas discussões científicas, pela amizade e pela troca de conhecimento.

Aos professores Kaline Coutinho, Sylvio Canuto, Fernando Ornellas, Ataualpa Braga, Antonio Carlos Borin, Fabio Rodrigues, Vitor Zamarion, Thiago Correra, Lucas Rodrigues e outros, pelas discussões científicas e pelo apoio na formação como mestre.

Aos demais professores que tive contato na graduação, no ensino médio e fundamental, e um abraço especial ao Maurício Rodrigues, pela inspiração, pelos ensinamentos, pelas 
conversas e pela amizade.

Àqueles que indiretamente estiveram envolvidos, seja pela prestação de serviços que mantêm o instituto, a universidade e a cidade funcionando, pela contribuição indireta através da parcela dos impostos destinada à universidade e às agências de fomento à pesquisa, ou pela luta por um acesso gratuito aos conhecimentos, pela valorização da ciência brasileira, por uma educação mais justa, inclusiva e igualitária.

A todos um grande e sincero "muito obrigado"! 


\section{Resumo}

Guain Teixeira, L. F. Calibração de Funcionais de Densidade para Cálculos de Constante de Acoplamento Indireto Spin-Spin. Dissertação - Programa de PósGraduação em Química. Instituto de Química, Universidade de São Paulo, São Paulo.

O presente trabalho descreve a investigação de funcionais de densidade para os cálculos das constantes escalares de acoplamento indireto spin-spin para diferentes tipos de átomos. 26 DFTs são inicialmente avaliados para um conjunto de calibração contendo constantes de acoplamento indireto spin-spin das moléculas $\mathrm{HF}, \mathrm{CO}, \mathrm{H}_{2} \mathrm{O}, \mathrm{NH}_{3}, \mathrm{PH}_{3}$, $\mathrm{PF}_{3}, \mathrm{BHF}_{2}, \mathrm{BF}_{3}, \mathrm{~F}_{2} \mathrm{O}, \mathrm{CH}_{4}, \mathrm{C}_{2} \mathrm{H}_{2}, \mathrm{C}_{2} \mathrm{H}_{4}$ e $\mathrm{C}_{2} \mathrm{H}_{6}$. As estratégias utilizadas envolvem principalmente o ajuste da porcentagem de troca orbital Hartree-Fock $\left(E_{X}^{\mathrm{HF}}\right)$, a fim de melhorar a precisão. Estudos anteriores sugeriram que a utilização de uma certa porcentagem de troca exata contribui para obter resultados mais precisos para as constantes de acoplamento. Do total, BHandH, B1B95, a família B97 e a família $\omega$ B97 forneceram bons resultados para o conjunto de calibração. Em geral, DFTs híbridos contendo entre 30\% e $50 \%$ de $E_{X}^{\mathrm{HF}}$ em sua composição apresentam valores mais precisos para as constantes de acoplamento. Os funcionais modificados B1B95 40\% $E_{X}^{\mathrm{HF}}, \mathrm{BHandH} 40 \% E_{X}^{\mathrm{HF}}$ e B972B95 $60 \% E_{X}^{\mathrm{HF}}$ apresentam ótima precisão para rotinas de otimização de geometria e cálculo da constante de acoplamento. Para funcionais corrigidos no longo alcance, a porcentagem $E_{X}^{\mathrm{HF}}$ não é bem definida, mas pode ser ajustada em termos de três parâmetros. Uma versão de $\omega$ B97XD com $\gamma$ incrementado para 0,35 tem ótima precisão, assim como uma 
versão de $\omega$ B97X com $\alpha$ incrementado para 0,2. Versões corrigidas no longo alcance de B1B95 e BHandH fornecem excelentes precisões com $\alpha=0,4, \alpha+\beta=1,0$ e $\gamma$ ajustado ao funcional. Os funcionais de longo alcance e o B972B95 60\% $E_{X}^{\mathrm{HF}}$ desafiam os níveis de teoria SOPPA(CCSD) e SOPPA(CC2), que apresentam boa precisão independente do tipo de núcleo envolvido no acoplamento. O termo do contato de Fermi está principalmente associado às diferenças nos resultados para as constantes de acoplamento calculadas entre os métodos. Segundo o teorema de Janak, os funcionais de longo alcance estão mais próximos do comportamento exato de um funcional; o aumento da troca exata em DFTs híbridos leva a um aumento da localização eletrônica, levando a concavidades menores. A utilização de um conjunto teste com mais tipos de acoplamento reforça a ótima precisão obtida com B1B95 40\% $E_{X}^{\mathrm{HF}}$, BHandH $40 \% E_{X}^{\mathrm{HF}}$ e suas versões de longo alcance.

Palavras-chave: Teoria do Funcional da Densidade, DFT, Ressonância Magnética Nuclear, RMN, Constantes de Acoplamento Indireto Spin-Spin, Calibração. 


\section{Abstract}

Guain Teixeira, L. F. Density Functional Calibration for Indirect Spin-Spin

Coupling Constant Calculations. Masters Thesis - Graduate Program in Chemistry. Instituto de Química, Universidade de São Paulo, São Paulo.

This work seeks to describe the investigation of density functionals for calculating indirect spin-spin scalar coupling constants for different types of atoms. 26 DFTs are initially evaluated for a calibration set containing $\mathrm{HF}, \mathrm{CO}, \mathrm{H}_{2} \mathrm{O}, \mathrm{NH}_{3}, \mathrm{PH}_{3}, \mathrm{PF}_{3}, \mathrm{BHF}_{2}$, $\mathrm{BF}_{3}, \mathrm{~F}_{2} \mathrm{O}, \mathrm{CH}_{4}, \mathrm{C}_{2} \mathrm{H}_{2}, \mathrm{C}_{2} \mathrm{H}_{4}$ and $\mathrm{C}_{2} \mathrm{H}_{6}$ indirect spin-spin coupling constants. The strategies used mainly involve adjusting the percentage of Hartree-Fock orbital exchange $\left(E_{X}^{\mathrm{HF}}\right)$ in order to increase accuracy. Previous studies have suggested that the use of a certain percentage of exact exchange contributes to obtain more accurate results for coupling constants. Overall, BHandH, B1B95, B97 family and $\omega$ B97 family have provided good results for the calibration set. In general, hybrid DFTs containing between $30 \%$ and $50 \%$ $E_{X}^{\mathrm{HF}}$ in their composition show more accurate values for the coupling constants. The modified functionals B1B95 40\% $E_{X}^{\mathrm{HF}}$, BHandH $40 \% E_{X}^{\mathrm{HF}}$ and B972B95 $60 \% E_{X}^{\mathrm{HF}}$ have optimal accuracy for geometry optimization and coupling constant calculation routines. For long-range corrected functionals, $E_{X}^{\mathrm{HF}}$ percentage is not well defined but can be adjusted in terms of three parameters. A version of $\omega$ B97XD with $\gamma$ increased to 0.35 has great accuracy, as well as a version of $\omega \mathrm{B} 97 \mathrm{X}$ with $\alpha$ increased to 0.2 . Long-range corrected versions of B1B95 and BHandH provided excellent accuracies with $\alpha=0.4, \alpha+\beta=1.0$ and 
$\gamma$ adjusted to the functional. Long-range functionals and B972B95 $60 \% E_{X}^{\mathrm{HF}}$ challenge SOPPA(CCSD) and SOPPA(CC2) levels of theory, which have good accuracy regardless of the core type involved in the coupling. Fermi-contact term is mainly associated with the differences from results of calculated coupling constants between methods. According to Janak's theorem, long-range functionals are closest to the exact behavior of a functional; increasing exact exchange in hybrid DFTs leads to an increased electronic localization, leading to lower concavities. Using a test set with more coupling types reinforces the optimum accuracy obtained with B1B95 $40 \% E_{X}^{\mathrm{HF}}$, BHandH $40 \% E_{X}^{\mathrm{HF}}$ and their long-range versions.

Keywords: Density Functional Theory, DFT, Nuclear Magnetic Resonance, NMR, Indirect Spin-Spin Coupling Constant, Benchmark. 


\section{Sumário}

\begin{tabular}{lll}
\hline 1 & Introdução & 15
\end{tabular}

1.1 Ressonância Magnética Nuclear . . . . . . . . . . . . . . . . . . . . . . . . 15

1.2 Teoria do Funcional da Densidade . . . . . . . . . . . . . . . . . . . . . 22

$1.3 \quad$ Funcionais e o cálculo de propriedades magnéticas . . . . . . . . . . . . . . 27

1.4 Exatidão e comportamento dos funcionais $\ldots \ldots \ldots$. . . . . . . . 30

\begin{tabular}{lll}
\hline 2 & Objetivos & 35
\end{tabular}

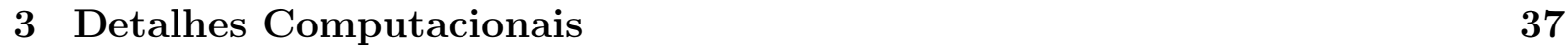

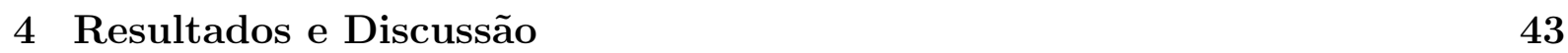

4.1 Precisão dos funcionais da literatura . . . . . . . . . . . . . . . . . . 43

4.2 Variação da porcentagem de $E_{X}^{\mathrm{HF}}$ para os funcionais híbridos . . . . . . . . 48

$4.2 .1 \quad$ Geometrias experimentais . . . . . . . . . . . . . . . . . . 48

4.2 .2 Geometrias otimizadas . . . . . . . . . . . . . . . . . . 51

4.3 Correções vibracionais para os funcionais testados . . . . . . . . . . . . . 56

4.4 Geração de novos funcionais combinando $E_{X}^{\mathrm{HF}}, E_{X}^{\mathrm{DFT}}$ e $E_{C}^{\mathrm{DFT}} \ldots \ldots$. . . . 73

4.4 .1 Geometrias experimentais . . . . . . . . . . . . . . 73

4.4 .2 Geometrias otimizadas . . . . . . . . . . . . . . . . . . . . 81

4.5 Variação da porcentagem de $E_{X}^{\mathrm{HF}}$ para os funcionais de longo alcance . . . 87

4.5.1 Geometrias experimentais . . . . . . . . . . . . . . . 87

4.5 .2 Geometrias otimizadas . . . . . . . . . . . . . . . . . . . . . 91

4.6 Geração de novos funcionais de longo alcance. . . . . . . . . . . . . . . . . 96

$4.6 .1 \quad$ Geometrias experimentais . . . . . . . . . . . . . 96

4.6 .2 Geometrias otimizadas . . . . . . . . . . . . . . . . . 105

4.7 Comparação com SOPPA(CC2) e SOPPA(CCSD) $\ldots$. . . . . . . . . . . . . 109 
4.8 Análise dos termos FC, SD, PSO e DSO $\ldots \ldots \ldots \ldots$

4.9 Teste de precisão e Teorema de Janak . . . . . . . . . . . . . . . . . . . . 130

4.10 Teste com diferentes tipos de acoplamento . . . . . . . . . . . . . . . . . 174

$\begin{array}{lll}5 & \text { Recomendações para uso dos funcionais } & 179\end{array}$

\begin{tabular}{lll}
\hline & Conclusões & 183
\end{tabular}

\begin{tabular}{lll}
\hline 7 & Referências Bibliográficas & 185
\end{tabular}

$\begin{array}{lll}8 & \text { Anexos } & 193\end{array}$

8.1 Precisão dos funcionais da literatura . . . . . . . . . . . . . . . . . . . . . 194

8.2 Variação da porcentagem de $E_{X}^{\mathrm{HF}}$ para os funcionais híbridos . . . . . . . 198

$8.2 .1 \quad$ Geometrias Experimentais . . . . . . . . . . . . . . . 198

8.2 .2 Geometrias Otimizadas . . . . . . . . . . . . . . . . 216

8.3 Correções vibracionais para os funcionais testados . . . . . . . . . . . . . . 222

8.3 .1 Correções vibracionais das CAISS calculadas . . . . . . . . . . . . . 224

8.3.1.1 Precisão dos funcionais da literatura . . . . . . . . . . . . . 224

8.3.1.2 Variação da porcentagem de $E_{X}^{\mathrm{HF}}$ para os funcionais híbridos - Geometrias Experimentais . . . . . . . . . . 230

8.3.1.3 Variação da porcentagem de $E_{X}^{\mathrm{HF}}$ para os funcionais híbridos - Geometrias Otimizadas . . . . . . . . . . . . . 284

8.3 .2 Utilização de CAISS empíricas . . . . . . . . . . . . . . . . . 302

8.3.2.1 Precisão dos funcionais da literatura . . . . . . . . . . . . . 302

8.3.2.2 Variação da porcentagem de $E_{X}^{\mathrm{HF}}$ para os funcionais híbridos - Geometrias Experimentais . . . . . . . . . . . . 308

8.3.2.3 Variação da porcentagem de $E_{X}^{\mathrm{HF}}$ para os funcionais híbridos-Geometrias Otimizadas . . . . . . . . . . . . 362

8.4 Geração de novos funcionais combinando $E_{X}^{\mathrm{HF}}, E_{X}^{\mathrm{DFT}}$ e $E_{C}^{\mathrm{DFT}} \ldots . . .380$

8.4 .1 Geometrias Experimentais . . . . . . . . . . . . . . 380

$8.4 .1 .1 \quad$ Troca B . . . . . . . . . . . . . . . . . . . 380 
$8.4 .1 .2 \quad$ Troca B971 . . . . . . . . . . . . . . . . . . . . . 389

$8.4 .1 .3 \quad$ Troca B972 . . . . . . . . . . . . . . . . . . . 398

$8.4 .1 .4 \quad$ Troca B98 . . . . . . . . . . . . . . . . . . . . . . . 407

$8.4 .1 .5 \quad$ Troca $\mathrm{O} \ldots \ldots \ldots \ldots \ldots \ldots$

8.4 .1 .6 Troca PBE . . . . . . . . . . . . . . . . . 425

8.4 .1 .7 Troca PW91 . . . . . . . . . . . . . . . . . . . . . . 434

8.4 .1 .8 Troca S . . . . . . . . . . . . . . . . . 443

8.4 .1 .9 Troca TPSS . . . . . . . . . . . . . . . . . . . 452

8.4 .2 Geometrias Otimizadas . . . . . . . . . . . . . . . . . . . . . . 461

8.5 Variação da porcentagem de $E_{X}^{\mathrm{HF}}$ para os funcionais de longo alcance $\ldots 487$

$8.5 .1 \quad$ Geometrias Experimentais $\ldots \ldots \ldots$. . . . . . . . . . . 487

8.5 .2 Geometrias Otimizadas . . . . . . . . . . . . . . . . . . 511

8.6 Geração de novos funcionais de longo alcance. . . . . . . . . . . . . . . . 520

$8.6 .1 \quad$ Geometrias Experimentais $\ldots \ldots \ldots \ldots 20$

$8.6 .1 .1 \quad$ B1B95 (LC-BB95) . . . . . . . . . . . . . 540

$8.6 .1 .2 \quad$ BHandH (LC-SLYP) . . . . . . . . . . . . . 564

8.6 .2 Geometrias Otimizadas . . . . . . . . . . . . . . . . 588

8.7 Comparação com SOPPA(CC2) e SOPPA(CCSD . . . . . . . . . . . 609

8.8 Análise dos termos FC, SD, PSO e DSO . . . . . . . . . . . . . . 610

8.9 Teste de precisão e Teorema de Janak $\ldots \ldots \ldots$. . . . . . . . . . . . 620

8.10 Teste com diferentes tipos de acoplamento . . . . . . . . . . . . . 633

$\begin{array}{llr}9 & \text { Súmula Curricular } & 641\end{array}$ 



\section{Introdução}

\subsection{Ressonância Magnética Nuclear}

A espectroscopia de Ressonância Magnética Nuclear (RMN) é uma indispensável ferramenta em química e bioquímica, sendo uma das técnicas mais utilizadas nos últimos anos na elucidação estrutural de moléculas orgânicas e inorgânicas em solução. Com o desenvolvimento de campos mais altos, sondas mais sensíveis e novas sequências de pulsos, hoje é possível obter espectros de RMN 1D, 2D e 3D com quantidades menores de amostra e maior rapidez.1

Os níveis de energia estudados na espectroscopia RMN são os autoestados resultantes do hamiltoniano de spin efetivo da molécula, de acordo com a Equação 1.1, em que $\boldsymbol{B}$ é o campo magnético externo, $\boldsymbol{I}_{K}$ é o operador de spin nuclear, $\gamma_{K}$ é a razão magnetogírica nuclear, $\boldsymbol{\sigma}_{K}$ é o tensor blindagem, $\boldsymbol{D}_{K L}$ é o acomplamento direto e $\boldsymbol{K}_{K L}$ é o acomplamento indireto.

$$
H=-\sum_{K} \gamma_{K} \hbar \boldsymbol{B}^{T}\left(1-\boldsymbol{\sigma}_{K}\right) \boldsymbol{I}_{K}+\frac{1}{2} \sum_{K \neq L} \gamma_{K} \gamma_{L} \hbar^{2} \boldsymbol{I}_{K}^{T}\left(\boldsymbol{D}_{K L}+\boldsymbol{K}_{K L}\right) \boldsymbol{I}_{L}
$$

O momento de dipolo magnético nuclear, $\boldsymbol{M}_{K}$, está relacionado com o operador de spin nuclear através da razão magnetogírica nuclear, $\boldsymbol{M}_{K}=\gamma_{K} \hbar \boldsymbol{I}_{K}$. O acoplamento indireto também pode ser expresso em termos de $\gamma_{K}$, conforme a Equação $1.2, \boldsymbol{K}_{K L}$ reflete mais diretamente o papel dos elétrons no acoplamento dos núcleos, enquanto $\boldsymbol{J}_{K L}$ considera a natureza dos núcleos e é mais utilizado para expressar o acoplamento indireto.

$$
\boldsymbol{J}_{K L}=h \frac{\gamma_{K}}{2 \pi} \frac{\gamma_{L}}{2 \pi} \boldsymbol{K}_{K L}
$$

Para sistemas isotrópicos, por exemplo moléculas com rápida reorientação, o acoplamento direto desaparece, e o tensor blindagem e o acoplamento indireto podem ser 
tratados como grandezas escalares.

O tensor blindagem e o acoplamento indireto podem ser obtidos das derivadas de segunda ordem da energia $E=E\left(\boldsymbol{B},\left\{\boldsymbol{M}_{K}\right\}\right)$, obtidas em torno de $\boldsymbol{B}=0$ e $\boldsymbol{M}_{K}=0$, através do tratamento pertubativo, conforme a Equação 1.3 . Os termos de primeira ordem são nulos para sistemas de camada fechada; termos de ordem superior são desprezados devido às diminutas pertubações.

$$
E=E_{0}+\frac{1}{2} \boldsymbol{B}^{T}\left(\frac{\mathrm{d}^{2} E}{\mathrm{~d} \boldsymbol{B}^{2}}\right) \boldsymbol{B}+\sum_{K} \boldsymbol{B}^{T}\left(\frac{\mathrm{d}^{2} E}{\mathrm{~d} \boldsymbol{B} \mathrm{d} \boldsymbol{M}_{K}}\right) \boldsymbol{M}_{K}+\frac{1}{2} \sum_{K \neq L} \boldsymbol{M}_{K}^{T}\left(\frac{\mathrm{d}^{2} E}{\mathrm{~d} \boldsymbol{M}_{K} \mathrm{~d} \boldsymbol{M}_{L}}\right) \boldsymbol{M}_{L}
$$

O tensor blindagem e o acoplamento indireto, pela comparação entre as Equações 1.1 e 1.3. são obtidos por $\boldsymbol{\sigma}_{K}=\frac{\mathrm{d}^{2} E}{\mathrm{~d} \boldsymbol{B} \mathrm{d} \boldsymbol{M}_{K}}+\mathbf{1}$ e $\boldsymbol{K}_{K L}=\frac{\mathrm{d}^{2} E}{\mathrm{~d} \boldsymbol{M}_{K} \mathrm{~d} \boldsymbol{M}_{L}}-\boldsymbol{D}_{K L}$. Desta forma, as propriedades de RMN podem ser obtidas a partir do hamiltoniano molecular, apresentado na Equação 1.4, em que $\boldsymbol{m}_{i}=g \mu_{B} \boldsymbol{s}_{i}$ é o dipolo magnético eletrônico, $\boldsymbol{\pi}_{i}=-i \boldsymbol{\nabla}_{i}+\boldsymbol{A}^{\text {tot }}\left(\boldsymbol{r}_{i}\right)$ é o momento linear canônico eletrônico e $\boldsymbol{B}^{\text {tot }}=\boldsymbol{\nabla}_{i} \times \boldsymbol{A}^{\text {tot }}$ é o campo magnético total.

$$
\begin{array}{r}
H\left(\boldsymbol{B},\left\{\boldsymbol{M}_{K}\right\}\right)=\frac{1}{2} \sum_{i} \pi_{i}^{2}-\sum_{i} \boldsymbol{m}_{i} \cdot \boldsymbol{B}^{\mathrm{tot}}\left(\boldsymbol{r}_{i}\right)-\sum_{K} \frac{Z_{K}}{r_{i K}}+\frac{1}{2} \sum_{i \neq j} \frac{1}{r_{i j}} \\
+\frac{1}{2} \sum_{K \neq L} \frac{Z_{K} Z_{L}}{R_{K L}}-\sum_{K} \boldsymbol{M}_{K} \cdot \boldsymbol{B}^{\mathrm{tot}}\left(\boldsymbol{R}_{K}\right)+\sum_{K>L} \boldsymbol{M}_{K}^{T} \boldsymbol{D}_{K L} \boldsymbol{M}_{L}
\end{array}
$$

Utilizando o potencial vetor $\boldsymbol{A}^{\text {tot }}\left(\boldsymbol{r}_{i}\right)=\boldsymbol{A}_{O}\left(\boldsymbol{r}_{i}\right)+\sum_{K} \boldsymbol{A}_{K}\left(\boldsymbol{r}_{i}\right)$ no calibre (gauge) de Coulomb $(\nabla \cdot \boldsymbol{A}=0)$, com $\boldsymbol{A}_{O}\left(\boldsymbol{r}_{i}\right)=\frac{1}{2} \boldsymbol{B} \times \boldsymbol{r}_{i O}$ e $\boldsymbol{A}_{K}\left(\boldsymbol{r}_{i}\right)=\alpha^{2} \frac{\boldsymbol{M}_{K} \times \boldsymbol{r}_{i K}}{r_{i K}^{3}}$ na Equação 1.4. são obtidas as Equações 1.5, 1.6, 1.7 e 1.8 para as derivadas de $H\left(\boldsymbol{B},\left\{\boldsymbol{M}_{K}\right\}\right)$.

$$
\begin{aligned}
& \frac{\mathrm{d} H}{\mathrm{~d} \boldsymbol{B}}=\boldsymbol{h}_{B}^{O R B}+\boldsymbol{h}_{B}^{S P N} \\
& \frac{\mathrm{d} H}{\mathrm{~d} \boldsymbol{M}_{K}}=\boldsymbol{h}_{K}^{P S O}+\boldsymbol{h}_{K}^{S D}+\boldsymbol{h}_{K}^{F C} \\
& \frac{\mathrm{d}^{2} H}{\mathrm{~d} \boldsymbol{B} \mathrm{d} \boldsymbol{M}_{K}}=-\mathbf{1}+\boldsymbol{h}_{B K}^{D I A} \\
& \frac{\mathrm{d}^{2} H}{\mathrm{~d} \boldsymbol{M}_{K} \mathrm{~d} \boldsymbol{M}_{L}}=\boldsymbol{D}_{K L}+\boldsymbol{h}_{K L}^{D S O}
\end{aligned}
$$

O operador orbital (ORB) corresponde à soma dos momentos angulares eletrônicos 
$\left(\boldsymbol{l}_{i O}\right)$, e o operador de spin $(\mathrm{SPN})$ corresponde à soma dos spins eletrônicos.

$$
\begin{gathered}
\boldsymbol{h}_{B}^{O R B}=\frac{1}{2} \sum_{i} \boldsymbol{l}_{i O}=-\frac{i}{2} \sum_{i} \boldsymbol{r}_{i O} \times \boldsymbol{\nabla}_{i} \\
\boldsymbol{h}_{B}^{S P N}=-\sum_{i} \boldsymbol{m}_{i}=\sum_{i} g \mu_{B} \boldsymbol{s}_{i}
\end{gathered}
$$

O operador Paramagnético Spin-Órbita (PSO), ou operador Orbital Hiperfino (OH), acopla os momentos nucleares magnéticos com o movimento orbital eletrônico $\left(\boldsymbol{l}_{i K}\right)$.

$$
\boldsymbol{h}_{K}^{P S O}=\alpha^{2} \sum_{i} \frac{\boldsymbol{l}_{i K}}{r_{i K}^{3}} .
$$

Já os operadores Spin-Dipolar (SD) e Contato de Fermi (FC) acoplam os momentos magnéticos nucleares com o spin eletrônico, representados nas Equações 1.12 e 1.13 . respectivamente:

$$
\begin{gathered}
\boldsymbol{h}_{K}^{S D}=\alpha^{2} \sum_{i} \frac{r_{i K}^{2} \boldsymbol{m}_{i}-3\left(\boldsymbol{m}_{i} \cdot \boldsymbol{r}_{i K}\right) \boldsymbol{r}_{i K}}{r_{i K}^{5}} \\
\boldsymbol{h}_{K}^{F C}=-\frac{8 \pi \alpha^{2}}{3} \sum_{i} \delta\left(\boldsymbol{r}_{i K}\right) \boldsymbol{m}_{i} .
\end{gathered}
$$

O operador FC representa a interação direta entre o momento dipolar eletrônico e a fonte de campo magnético (momento magnético nuclear) e tem contribuição significativa para o Hamiltoniano molecular eletrônico quando o elétron se encontra próximo ao núcleo.

O operador diamagnético (DIA) é expresso pela Equação 1.14 .

$$
\boldsymbol{h}_{B K}^{D I A}=\frac{\alpha^{2}}{2} \sum_{i} \frac{\left(\boldsymbol{r}_{i O} \cdot \boldsymbol{r}_{i K}\right) \mathbf{1}-\boldsymbol{r}_{i K} \boldsymbol{r}_{i O}^{T}}{\boldsymbol{r}_{i K}^{3}}
$$

O operador diamagnético spin-orbita (DSO) é expresso pela Equação 1.15, e é a resposta da função de onda não perturbada imersa no campo magnético.

$$
\boldsymbol{h}_{K L}^{D S O}=\frac{\alpha^{4}}{2} \sum_{i} \frac{\left(\boldsymbol{r}_{i K} \cdot \boldsymbol{r}_{i L}\right) \mathbf{1}-\boldsymbol{r}_{i K} \boldsymbol{r}_{i L}^{T}}{\boldsymbol{r}_{i K}^{3} \boldsymbol{r}_{i L}^{3}}
$$


Dentro da aproximação não-relativística descrita por Ramsey, $\sqrt[2] 3]{3}$ o tensor blindagem e tensor da constante de acoplamento nuclear indireta spin-spin $(\boldsymbol{J})$, pela teoria de perturbação independente do tempo não-degenerada, são dados pelas Equações 1.16 e 1.17 respectivamente, sendo $\left|n_{S}\right\rangle$ estado singleto, $\left|n_{T}\right\rangle$ estado tripleto.

$$
\begin{gathered}
\boldsymbol{\sigma}_{K}=\left\langle 0\left|\boldsymbol{h}_{B K}^{D I A}\right| 0\right\rangle-2 \sum_{n_{S} \neq 0} \frac{\left\langle 0\left|\boldsymbol{h}_{B}^{o r b}\right| n_{S}\right\rangle\left\langle n_{S}\left|\left(\boldsymbol{h}_{K}^{P S O}\right)^{T}\right| 0\right\rangle}{E_{n_{S}}-E_{0}} \\
\boldsymbol{J}_{K L}=h \frac{\gamma_{K}}{2 \pi} \frac{\gamma_{L}}{2 \pi}\left[\left\langle 0\left|\boldsymbol{h}_{K L}^{D S O}\right| 0\right\rangle-2 \sum_{n_{S} \neq 0} \frac{\left\langle 0\left|\boldsymbol{h}_{K}^{P S O}\right| n_{S}\right\rangle\left\langle n_{S}\left|\left(\boldsymbol{h}_{L}^{P S O}\right)^{T}\right| 0\right\rangle}{E_{n_{S}}-E_{0}}\right. \\
\left.-2 \sum_{n_{T} \neq 0} \frac{\left\langle 0\left|\boldsymbol{h}_{K}^{S D}+\boldsymbol{h}_{K}^{F C}\right| n_{T}\right\rangle\left\langle n_{T}\left|\left(\boldsymbol{h}_{L}^{S D}\right)^{T}+\left(\boldsymbol{h}_{L}^{F C}\right)^{T}\right| 0\right\rangle}{E_{n_{T}}-E_{0}}\right]
\end{gathered}
$$

Assim a descrição da constante de acoplamento indireta spin-spin não relativística (Equação 1.17) é composta por quatro mecanismos distintos: FC (Contato de Fermi), SD (Spin Dipolar), PSO (Paramagnético Spin Órbita) e DSO (Diamagnético Spin Órbita) onde a priori todos os termos são importantes e nenhum deles pode ser ignorado.

Teoricamente, a estimativa dos parâmetros da RMN através de teoria da mecânica quântica, como o tensor de blindagem nuclear $(\boldsymbol{\sigma})$ e a constante de acoplamento nuclear indireta $(\boldsymbol{J})$, tem se tornado rotina por proporcionar resultados detalhados da estrutura eletrônica e geometria de moléculas, sendo frequentemente usada como ferramenta complementar em interpretação e atribuição de espectros de RMN ${ }^{4}[7$

Ambas as equações de Ramsey, $\sqrt[2] 3]{3}$ apresentam uma parte diamagnética que corresponde ao valor obtido para a função de onda eletrônica no estado não perturbado; e uma parte paramagnética que representa a relaxação da função de onda em resposta a uma perturbação externa, nesse caso o campo magnético homogêneo $\boldsymbol{B}$.

No tensor blindagem nuclear (Equação 1.16) não há contribuição da parte de spin, diferentemente do tensor de constante de acoplamento spin-spin (Equação 1.17) em que o compontente paramagnético geralmente é mais importante que o orbital. Entretanto, há casos em que a componente orbital pode ser significativa e dominante, apesar de raros. .89 
Os primeiros dois termos da Equação 1.17 representam a contribuição orbital para o tensor de acoplamento, com a soma de todos os estados singletos excitados $\left(n_{S}\right)$; o terceiro termo respresenta a contribuição de spin, com a soma sobre todos os estados tripletos $\left(n_{T}\right)$.

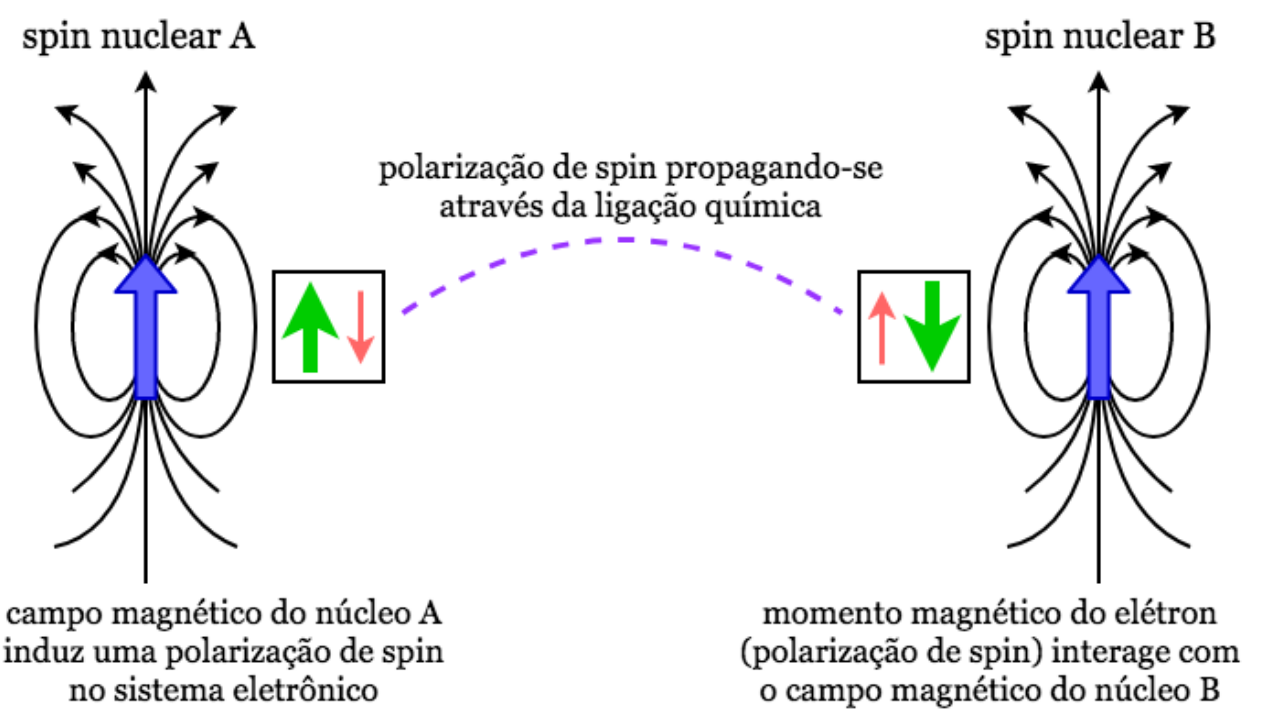

Figura 1.1: Mecanismo de transmissão dos termos FC e SD

spin do núcleo $\mathrm{A}$

spin do núcleo $\mathrm{B}$

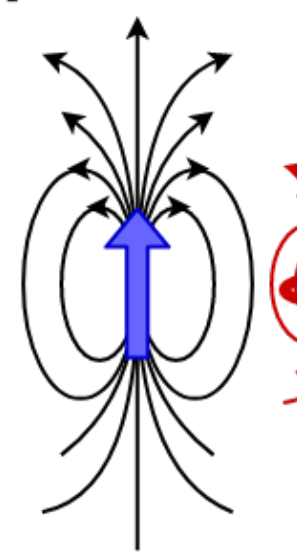

campo magnético do núcleo $\mathrm{A}$ induz uma corrente de densidade eletrônica com um momento magnético associado propagação da densidade de corrente através da ligação química
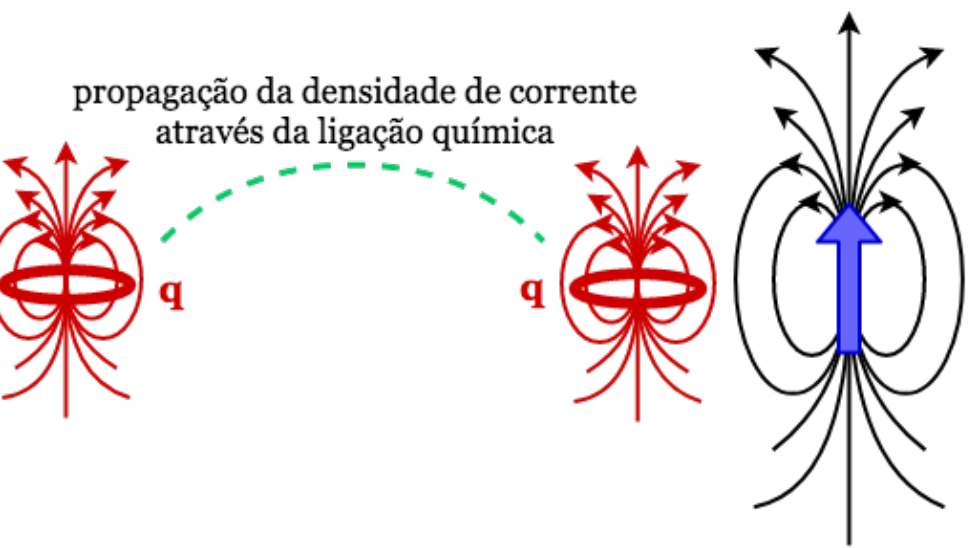

momento magnético da corrente de densidade eletrônica interage com o campo magnético do núcleo $\mathrm{B}$

Figura 1.2: Mecanismo de transmissão dos termos PSO e DSO

A Figura 1.1 mostra o mecanismo de transmissão dos termos FC e SD e a Figura 1.2 ilustra o mecanismo de transmissão dos termos PSO e DSO ${ }^{10}$ Nota-se que as contribuições DSO e PSO são originadas do movimento orbital eletrônico e as contribuições FC e SD e 
SD-FC são originadas do spin eletrônico, ou seja, do momento magnético eletrônico.

Na maioria dos casos, o operador FC é o termo dominante na contribuição do valor da constante de acoplamento indireto spin-spin e desacopla spins eletrônicos emparelhados em um núcleo permitindo a interação com o momento magnético dipolar do núcleo vizinho. O termo SD-FC não contribui para a constante de acoplamento isotrópica, porém é importante para os acoplamentos anisotrópicos. O termo PSO se dá pela interação do momento magnético nuclear com o momento orbital eletrônico. Já a contribuição do termo DSO geralmente é a menor das quatro existentes.

Pela forma dos operadores que descrevem os mecanismos de acoplamento propostos por Ramsey, nota-se que DSO, PSO e SD tratam da parte externa ou de valência da função de onda eletrônica, enquanto que FC estima a qualidade da mesma na região próxima aos núcleos ou no caroço.

A estimativa das três contribuições PSO, FC e SD são muito custosas computacionalmente. O uso direto das expressões das somas sobre todos os estados (Sum Over States) requer conhecimento de todos os estados singletos e tripletos excitados, portanto não pode ser calculado na prática. . $^{-}$

Ao invés disso, as três contribuições para o acoplamento spin-spin são obtidas através da teoria da resposta linear, onde três equações de resposta singleto e sete equações de resposta tripleto para cada núcleo são resolvidas:11,12

Mesmo com essas simplificações na estimativa dos estados singletos e tripletos, o cálculo das constantes de acoplamento tem alto custo computacional, pois além de envolver a perturbação de estados de campos magnéticos gerados pelo núcleo estacionário, necessita da perturbação de estados tripletos. ${ }^{13}$ Estes estados tripletos por sua vez dependem fortemente da qualidade da função de onda e conseqüentemente do conjunto de funções de base empregado e a precisão dos resultados requer uma alta flexibilidade na descrição dos estados eletrônicos. 14

Para a descrição dos estados tripletos tem-se empregado vários funcionais de densidade e métodos ab initio correlacionados eletronicamente, por não apresentarem problemas de instabilidade tripleto como é característico no Hartree-Fock. ${ }^{22}$ 
A Figura 1.3 ilustra os níveis de teoria disponíveis na literatura para estimar os parâmetros de $J$ e $\sigma \stackrel{23}{23}$ Cada nível de teoria usa diferentes aproximações para estimar os operadores da energia de perturbação de segunda ordem (FC, SD e PSO). Em nível Hartree-Fock, por exemplo, apesar de não aconselhada, é utilizada a perturbação finita FP-HF, mais conhecida pelos físicos como RPA (Random Phase Approximation). Já em nível DFT usa-se a perturbação acoplada, CP-DFT, e em nível Coupled Cluster há disponível duas aproximações equivalentes: a Resposta Linear LR-CCSD ou a Equação de movimento (EOM - Equation-of-Motion) EOM-CCSD.

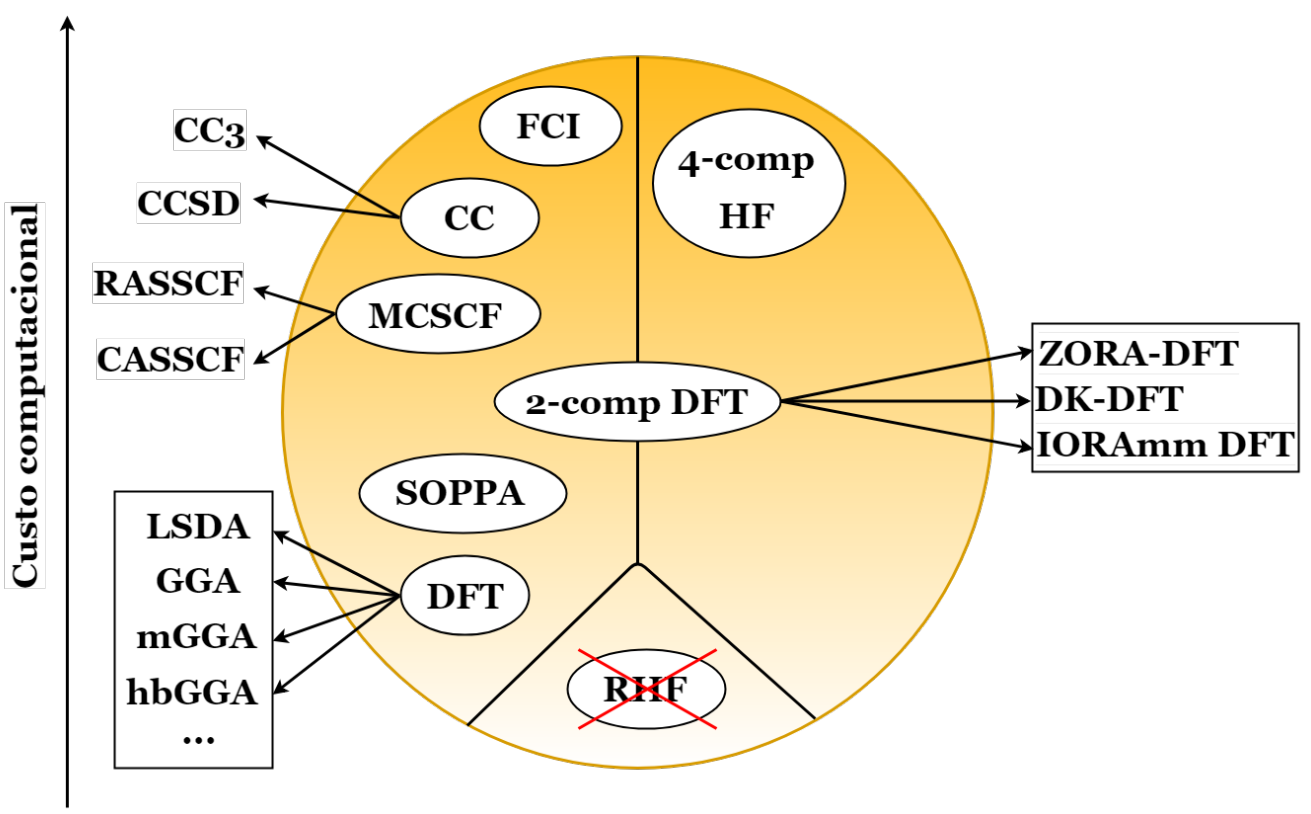

Figura 1.3: Níveis de teoria disponíveis para estimar constantes de acoplamento spin spin $(J)$ e tensor blindagem $(\sigma)$.

Embora os parâmetros de RMN para pequenas moléculas possam ser calculados por um grande número de métodos incluindo Coupled Cluster e CAS (Complete Active Space), funções de base grandes e flexíveis são necessárias para obtenção de valores precisos de tensor blindagem e acoplamento spin-spin para núcleos como ${ }^{13} \mathrm{C},{ }^{19} \mathrm{~F}$ e $\left.{ }^{17} \mathrm{O} \cdot[4] 23\right]$ O método do funcional de densidade (DFT) é o único método capaz de tratar rotineiramente sistemas com mais de 20 átomos com razoável precisã ${ }^{23}$ pois, as aproximações para os cálculos das constantes de acoplamento neste nível tem sido aprimoradas exaustivamente $\frac{22|25| 228}{2[28}$ 


\subsection{Teoria do Funcional da Densidade}

O tempo gasto em função do custo computacional se comporta em uma escala linear em relação ao tamanho do sistema molecular, possibilitando o estudo dos acoplamento de estruturas biopoliméricas como a valinomicina, que contém 168 átomos e 7587 acoplamentos únicos com carbono. $\stackrel{29}{ }$ Nestes sistemas as constantes de acoplamento têm um papel importante, como o caso dos acoplamentos vicinais (três ligações) na determinação de ângulos diedros desde os trabalhos clássicos de Karplus, 30 do geminal (duas ligações), dos acoplamentos a uma ligação (especialmente envolvendo ${ }^{13} \mathrm{C}$ e ${ }^{15} \mathrm{~N}$ ) e ao longo alcance envolvendo núcleos de ${ }^{1} \mathrm{H}$ usados para determinação e elucidação de estruturas moleculares. $24[32[33$

Isso faz do DFT um poderoso método em química quântica para cálculos de propriedade de estado fundamental e excitado em grandes sistemas moleculares. A descrição de correlação eletrônica dentro da teoria da mecânica quântica é imprescindível para predição de propriedades moleculares com boa precisão.

Em sua forma original, o método DFT associa a energia molecular como um funcional universal da densidade eletrônica $\rho(\mathbf{r})$, com os orbitais moleculares calculados a partir de um potencial (semi)local. ${ }^{34}$ De modo mais geral, esse potencial também pode ser não-local e depender explicitamente dos orbitais, fazendo com que as aproximações sejam desenvolvidas dentro desses critérios.

$$
\rho(\mathbf{r})=\left\langle\Psi\left|\sum_{i=1}^{N} \delta\left(\mathbf{r}-\mathbf{r}_{i}\right)\right| \Psi\right\rangle
$$

A teoria do funcional de densidade utiliza a densidade eletrônica $\rho(\mathbf{r})$, obtida a partir da função de onda de várias partículas $\Psi\left(\mathbf{r}_{1}, \ldots, \mathbf{r}_{N}\right)$ através da Equação 1.18. Desta maneira, em vez de resolver a equação de Schrödinger para obter a função de onda de muitas partículas, a resolução é feita para a densidade eletrônica, e é conhecida como equações de Kohn-Sham. ${ }^{35}$ 


$$
\begin{gathered}
\left(-\frac{\hbar^{2}}{2 m} \nabla^{2}+V_{e f f}(\mathbf{r})\right) \phi_{i}(\mathbf{r})=\varepsilon_{i} \phi_{i}(\mathbf{r}) \\
\rho(\mathbf{r})=\sum_{i=1}^{N}\left|\phi_{i}(\mathbf{r})\right|^{2} \\
E[\rho]=T_{s}[\rho]+\int \mathrm{d}^{3} r V_{e x t}(\mathbf{r}) \rho(\mathbf{r})+E_{H}[\rho]+E_{X C}[\rho]
\end{gathered}
$$

A Equação 1.19 envolve a solução dos orbitais $\phi_{i}$ para obtenção da densidade $\rho$ através da Equação 1.20. Para a Equação 1.21, $T_{s}[\rho]=\sum_{i=1}^{N} \int \mathrm{d}^{3} r \phi_{i}^{\star}(\mathbf{r})\left(-\frac{\hbar^{2}}{2 m} \nabla^{2}\right) \phi_{i}(\mathbf{r})$ é a energia cinética, $E_{H}[\rho]=\frac{e^{2}}{2} \int \mathrm{d}^{3} r \int \mathrm{d}^{3} r^{\prime} \frac{\rho(\mathbf{r}) \rho\left(\mathbf{r}^{\prime}\right)}{\left|\mathbf{r}-\mathbf{r}^{\prime}\right|}$ é a energia coulômbica, $E_{X C}[\rho]$ é a energia de troca-correlação e $V_{\text {ext }}(\mathbf{r})$ é o potencial externo, que são as interações elétron-núcleo para sistemas moleculares. Desta forma, o potencial efetivo na Equação 1.19 é dado pela forma descrita na Equação 1.22 .

$$
V_{e f f}(\mathbf{r})=V_{e x t}(\mathbf{r})+e^{2} \int \mathrm{d}^{3} r^{\prime} \frac{\rho\left(\mathbf{r}^{\prime}\right)}{\left|\mathbf{r}-\mathbf{r}^{\prime}\right|}+\frac{\delta E_{X C}[\rho]}{\delta \rho(\mathbf{r})}
$$

A determinação da energia de troca-correlação é um grande desafio na teoria do funcional densidade. A energia pode ser separada em um termo de troca e outro de correlação, conforme a Equação 1.23. Diversos funcionais de troca e correlação foram desenvolvidos para obter uma expressão da energia de troca-correlação.

$$
E_{X C}[\rho]=E_{X}[\rho]+E_{C}[\rho]=\int \mathrm{d}^{3} r \varepsilon_{X}[\rho] \rho(\mathbf{r})+\int \mathrm{d}^{3} r \varepsilon_{C}[\rho] \rho(\mathbf{r})
$$

Perdew sugeriu uma escada de funcionais atingindo o "paraíso da mecânica quântica", em que cada degrau era representado por uma classe de funcionais: local density approximation LDA(degrau 1), generalized gradient approximations GGA(degrau 2), GGA híbrido(degrau 3), e assim por diante. ${ }^{\sqrt[36]{6}}$ Dentro dessa hierarquia, propriedades moleculares estáticas podem ser calculadas por derivadas da energia. A classe de funcionais LDA (LSDA no caso geral) assume o tratamento local da densidade como um gás uniforme de elétrons, representada na Equação 1.24. O funcional energia de troca-correlação $\left(E_{X C}\right)$ 
depende somente do valor da densidade em cada ponto do espaço. $\underline{37}$

$$
E_{X}^{L S D A}\left[\rho_{\alpha}, \rho_{\beta}\right]=-2^{1 / 3} C_{X} \int\left(\rho_{\alpha}^{4 / 3}+\rho_{\beta}^{4 / 3}\right) d \vec{r}
$$

Em que a energia de troca é dada por $E_{X}[\rho]=\int \rho(\vec{r}) \varepsilon_{X}[\rho(\vec{r})] d \vec{r}$. A aproximação por um gás uniforme de elétrons geralmente é válida para o tratamento da densidade eletrônica de metais simples, sendo o único caso em que é possível definir a energia de troca-correlação com grande precisão. ${ }^{38}$ A energia de troca $\varepsilon_{X}$ foi aproximada por Slater como $\varepsilon_{X}^{L D A}=-C_{X} \rho^{1 / 3}$, e diversas proposições, como Perdew-Wang (PW) e Vosko-WilkNusair (VWN), foram feitas para a energia de correlação $\varepsilon_{C} \cdot \frac{37}{37}$

Os funcionais GGA consideram a não-uniformidade do gás de elétrons, e o tratamento dado leva em conta não apenas uma densidade $\rho$ localmente constante, mas também seu

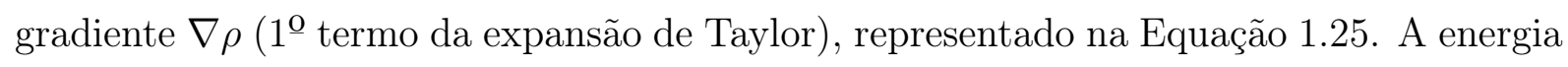
de troca-correlação é obtida através de um funcional $F$ que depende de $\rho$ e $\nabla \rho . \sqrt[38]{3}$

$$
E_{X C}^{G G A}\left[\rho_{\alpha}, \rho_{\beta}\right]=\int F\left(\rho_{\alpha}(r), \rho_{\beta}(r), \nabla \rho_{\alpha}(r), \nabla \rho_{\beta}(r)\right) d r
$$

Uma das primeiras propostas para o funcional $F$ foi feita por Becke (apresentado na Equação 1.26), conhecida como B (ou B88), que apresenta um funcional de troca com comportamento assintótico correto para a densidade de energia, porém incorreto para o potencial de troca. .37

$$
\varepsilon_{X}^{B 88}=\varepsilon_{X}^{L D A}+\Delta \varepsilon_{X}^{B 88} \quad, \quad \Delta \varepsilon_{X}^{B 88}=-\beta \rho^{1 / 3} \frac{x^{2}}{1+6 \beta x \sinh ^{-1} x} \quad, \quad x=\frac{|\nabla \rho|}{\rho^{4 / 3}}
$$

Um dos funcionais de correlação propostos mais popular foi desenvolvido por Lee-YangParr (apresentado na Equação 1.27), conhecido como LYP, que não inclui correlação de spin paralelos pra situações com todos os spins alinhados. 


$$
\begin{gathered}
\varepsilon_{C}^{L Y P}=-4 a \frac{\rho_{\alpha} \rho_{\beta}}{\rho^{2}\left(1+d \rho^{-1 / 3}\right)}-a b \omega\left\{\frac { \rho _ { \alpha } \rho _ { \beta } } { 1 8 } \left[144\left(2^{2 / 3}\right) C_{F}\left(\rho_{\alpha}^{8 / 3}+\rho_{\beta}^{8 / 3}\right)+(47-7 \delta)|\nabla \rho|^{2}\right.\right. \\
\left.-(45-\delta)\left(\left|\nabla \rho_{\alpha}\right|^{2}+\left|\nabla \rho_{\beta}\right|^{2}\right)+2 \rho^{-1}(11-\delta)\left(\rho_{\alpha}\left|\nabla \rho_{\alpha}\right|^{2}+\rho_{\beta}\left|\nabla \rho_{\beta}\right|^{2}\right)\right] \\
\left.+\frac{2}{3} \rho^{2}\left(\left|\nabla \rho_{\alpha}\right|^{2}+\left|\nabla \rho_{\beta}\right|^{2}-|\nabla \rho|^{2}\right)-\left(\rho_{\alpha}^{2}\left|\nabla \rho_{\alpha}\right|^{2}+\rho_{\beta}^{2}\left|\nabla \rho_{\beta}\right|^{2}\right)\right\}, \\
\omega=\frac{e^{-c \rho^{-1 / 3}}}{\rho^{14 / 3}\left(1+d \rho^{-1 / 3}\right)} \quad, \quad \delta=c \rho^{-1 / 3}+\frac{d \rho^{-1 / 3}}{\left(1+d \rho^{-1 / 3}\right)}
\end{gathered}
$$

Das diversas outras propostas feitas para o funcional, encontram-se algumas populares como OPTimized eXchange (OPTX), Perdew-Wang 1986 (PW86), Perdew-Wang 1991 (PW91) e Perdew-Burke-Ernzerhof (PBE), bem como combinações delas (BLYP e OLYP, por exemplo).

Para ordens superiores do gradiente, também conhecido como meta-GGA, termos como o laplaciano $\left(\nabla^{2} \rho\right)$ também aparecem nos funcionais. Becke propôs um funcional de correlação (B95) que não apresenta problema de auto interação. Também são metaGGA funcionais como Tao-Perdew-Staroverov-Scuseria (TPSS), que pode ser considerado um aprimoramento do PBE. $\underline{37}$

Os funcionais GGA híbridos (também conhecidos como hiper-GGA) - como ACM, B3, B97 e PBE0 - apresentam a energia de troca-correlação como uma combinação linear de termos de troca-correlação obtidos por funcionais GGA, LSDA e termo de troca exata obtido por métodos HF. As contribuições de cada termo da combinação são determinadas para aproximar dos dados experimentais. Para o funcional GGA híbrido B3LYP, a energia de troca-correlação é dada pela Equação 1.28, com valores típicos de $a \sim 0,2, b \sim 0,7$ e $c \sim 0,8$. Já o funcional BHandH apresenta metade da energia de troca proveniente da troca exata, e a outra metade proveniente do modelo LSDA de Slater, conforme a Equação 1.29

$$
E_{X C}^{B 3 L Y P}=(1-a) E_{X}^{L S D A}+a E_{X}^{e x a t o}+b \Delta E_{X}^{B 88}+(1-c) E_{C}^{L S D A}+c E_{C}^{L Y P}
$$




$$
E_{X C}^{B H a n d H}=\frac{1}{2} E_{X}^{e x a t a}+\frac{1}{2}\left(E_{X}^{L S D A}+E_{C}^{L Y P}\right)
$$

O funcional BHandH inicialmente proposto por Becke foi implementado em programas como o Gaussian 09 de acordo com a Equação $1.30{ }^{39}$ A energia de correlação é incluída com fator de 1 ao invés de $1 / 2$.

$$
E_{X C}^{B H a n d H}=\frac{1}{2} E_{X}^{e x a t a}+\frac{1}{2} E_{X}^{L S D A}+E_{C}^{L Y P}
$$

A teoria DFT dependente do tempo (TD-DFT), por sua vez, permite o cálculo de propriedades dinâmicas (dependente da frequência). ${ }^{40}$ Contudo, ainda há vários casos em que o desempenho da teoria DFT é pouco satisfatório.41 


\subsection{Funcionais e o cálculo de propriedades magnéticas}

Mesmo com auxílio de métodos teóricos, muitos dos comportamentos observados experimentalmente envolvendo tanto deslocamento químico, quanto constantes de acoplamento, não são claramente explicados, mas apenas observados e relatados sem maiores detalhes sobre sua origem e sobre os efeitos envolvidos no sistema molecular em questão. Por exemplo, somente em 2009 um efeito observado em vários compostos contendo átomos pesados, em especial iodo, foi explicado e teve sua origem elucidada; $\stackrel{42}{\mathrm{42}} \mathrm{em} 2012$ foi verificada uma inesperada dependência geométrica dos tensores de segunda ordem nas constantes de acoplamento nunca antes observados, sugerindo afetar também as contribuições dos tensores de segunda ordem do tensor blindagem.

Os esforços computacionais para melhorar a precisão ainda são altos, podendo se tornar impraticável o uso do método DFT em sistemas de interesse na química, bioquímica e ciência de materiais, dependendo do tamanho do sistema molecular. Para propriedades moleculares de resposta, os problemas são severos, como por exemplo, o fato da resposta linear da teoria DFT dependente do tempo subestimar a transferência de carga das energias de excitação.44 A ruim performance na predição do espectro eletrônico e de outras propriedades de resposta estão relacionadas, pois a primeira pode ser escrita na forma dependente da "soma sobre todos os estados" (SOS) das energias de excitação e momentos de transição. Isso leva a uma exaustiva procura por um funcional de densidade adequado para cada tipo de propriedade.

Embora possa ser insatisfatório o uso de diferentes funcionais de troca-correlação para os diferentes sistemas e propósitos, esta abordagem parece ser a solução mais prática para o momento. Deste modo, uma escolha pertinente sobre os funcionais de troca $\left(E_{X}\right)$ e correlação $\left(E_{C}\right)$ deve ser feita quando se utiliza o método do funcional de densidade. Nesse sentido, dentro dos cálculos de parâmetros da RMN, alguns estudos têm sido reportados com a finalidade de se encontrar o melhor funcional de densidade para a predição de valores precisos das constantes de acoplamento spin-spin e deslocamento químico.

Maximoff avaliou 96 acoplamentos ${ }^{1} J_{\mathrm{CH}}$ usando diferentes níveis de sofisticação com o 
DFT (LDA, GGAs, hybrid GGAs e meta-GGAs), obtendo o menor erro absoluto para o não-empírico GGA PBE. Este funcional se mostrou ser mais eficiente que o popular funcional de densidade B3LYP, que é conhecido pela boa precisão em estimar acoplamentos do tipo $J_{\mathrm{CH}}$ e $J_{\mathrm{HH}} \cdot{ }^{45}$ Contudo, Melo e Malkin apresentaram uma pobre performance do PBE e PW86 para o cálculo de acoplamentos spin-spin envolvendo tetraidretos de átomos pesados e átomos eletronegativos do primeiro período.25, 46

Tozer e colaboradores demonstraram que o PBE apresenta uma boa precisão na obtenção dos valores de acoplamentos ${ }^{1} J_{\mathrm{CH}}$ em comparação com o popular B3LYP, confirmando o que foi observado por Maximoff. Contudo, a mesma performance não é mantida quando átomos de ${ }^{15} \mathrm{~N},{ }^{17} \mathrm{O}$ e ${ }^{19} \mathrm{~F}$ estão envolvidos nos acoplamentos, tornando o PBE menos preciso que o funcional B3LYP. Além disso, os autores reportaram que os funcionais B972 e B973 demonstram ter uma boa qualidade para todos os tipos de acoplamentos estuda$\operatorname{dos} . \underline{47}$

Os autores também apontaram a melhora na precisão dos valores obtidos principalmente para o acoplamento ${ }^{1} J_{\mathrm{HF}}$ da molécula de $\mathrm{HF}$, com o aumento da porcentagem de troca orbital Hartree-Fock $\left(E_{X}^{\mathrm{HF}}\right)$, ao longo dos funcionais utilizados: $\operatorname{PBE}(0 \%)$, B3LYP(20\%), B972(21\%) e B973(27\%) 뇨 Entretanto, não exploraram a idéia sobre a influência do termo $E_{X}^{\mathrm{HF}}$ na precisão dos acoplamentos calculados.

Kupka reportou uma série de trabalhos avaliando teoricamente os acoplamentos spinspin existentes para moléculas simples como $\mathrm{H}_{2} \mathrm{O}, \mathrm{HF}, \mathrm{F}_{2}, \mathrm{~F}_{2} \mathrm{O}$, que apresentam valores com baixa precisão quando calculados em nível DFT [8] [9, [4] O autor obteve resultados precisos utilizando uma família de funcionais, BHandH e BHandHLYP, também chamada de "meio a meio" e que apresentam $50 \%$ de troca orbital Hartree-Fock $\left(E_{X}^{\mathrm{HF}}\right)$.

O mesmo autor estudou a precisão de 39 DFTs, juntamente com métodos ab initio SOPPA(CCSD) e SOPPA(CC2) para as mesmas moléculas previamente estudadas pelo autor. ${ }^{50}$ Os acoplamentos mostraram uma boa precisão para a família de funcionais B97, além de suas versões com correção de longa escala (long-range-corrected). Acoplamentos ${ }^{1} J_{\mathrm{XH}}$ apresentam uma precisão em torno de $5 \%$ para $\omega$ B97XD. Para ${ }^{1} J_{\mathrm{NN}}$ o uso do mesmo funcional mostra resultados satisfatórios, mas não tão ruins como o caso do acoplamento 
${ }^{1} J_{\mathrm{CO}}$. O que mostra que nenhum único funcional pode ser recomendado como único para predição dos acoplamentos.

Esta maneira exaustiva de procurar um funcional adequado para a propriedade de interesse pode ser "perigoso", pois é necessário evitar cancelamento de erros, no sentido de se evitar obter a "resposta correta pelo motivo errado".

Falhas em propriedades de resposta e espectrais vão ao encontro com o errôneo comportamento assimptótico e a falta de descontinuidade dos potenciais de troca e correlação aproximados para moléculas isoladas. Há uma relação entre a falha da teoria DFT dependente do tempo TD-DFT e a aproximação adiabática usada em praticamente todos os cálculos de propriedades dinâmicas e espectrais.

O comportamento assimptótico de um potencial (não-local) sentido por um elétron é correto na teoria Hartree-Fock, por não haver problemas com erros de auto-interação. Essas características da teoria Hartree-Fock são originadas do exato cancelamento da repulsão Coulômbica pelo termo de troca na energia e no potencial, desejável em um funcional aproximado, pois é comportamento correto de um funcional exato. Isso é uma explicação plausível para o que Tozer e colaboradores observaram a respeito do aumento da troca $E_{X}^{\mathrm{HF}}$ na melhoria dos valores das propriedades de RMN. De alguma forma, o aumento da inclusão de $E_{X}^{\mathrm{HF}}$ pode anular/diminuir o problema de auto-interação. Deste modo é conveniente gerar funcionais objetivamente que comportem-se similarmente ao funcional de densidade exato.

Pesquisadores tem determinado importantes atributos para o funcional exato, sem conhecer sua real forma. Duas características são exploradas no nível DFT: o teorema equivalente ao "teorema de Koopman" e o "teorema da linha reta" de Janak. 51 


\subsection{Exatidão e comportamento dos funcionais}

O teorema de Koopman define que a energia do HOMO (orbital molecular ocupado de maior energia) é $\varepsilon^{\mathrm{HOMO}}=-\mathrm{IP}(N)$, para o qual IP é o potencial de ionização. Assumindo uma adição adiabática de elétrons, este teorema pode ser extendido como $\varepsilon^{\text {HOMO* }}=$ $\mathrm{IP}(N+1)$, em que o HOMO* seria o LUMO (orbital molecular desocupado de menor energia) do sistema de $N$ elétrons, ou seja, $\operatorname{IP}(N+1)=\mathrm{EA}(N)$, em que EA é a afinidade eletrônica. O teorema pode ser aplicado a um sistema de $N$ elétrons usando os seguintes critérios dados pelas equações 1.31 e 1.32 , de modo que os HOMOs da espécie neutra e da espécie aniônica sejam ajustados para o melhor grau possível.

$$
\begin{gathered}
j^{2}=\sum_{i=0}^{1}\left[\varepsilon^{\text {HOMO }}(N+i)+\operatorname{IP}(N+i)\right]^{2}, \\
I P(N)=E(N-1)-E(N),
\end{gathered}
$$

O funcional exato deve ter $j^{2}=0$ e um funcional aproximado $j^{2} \simeq 0$. O teorema de Janak diz que para uma adição fracionada de elétrons em um sistema, a energia total deve variar linearmente entre os números inteiros e ser descontínua nos números inteiros de elétrons.

Para quantificar a linha reta ou a linearidade, um gráfico de $\Delta N$ versus energia relativa é gerado juntamente com um ajuste quadrático da função $f(x)=a x^{2}+b x+c$. O termo $a$ no intervalo $N \pm 1$ nos dá a curvatura, que será nulo para o funcional exato ou próximo de zero para o funcional aproximado. Adicionalmente, o termo $b$ no intervalo $-1<\Delta N<0$ é o valor exato de $-I P$ e no intervalo $0<\Delta N<1$ é o valor de $-E A$. Usando a escala relativa de energia $(c=0$ ou $c=E(N)$ ), é importante dizer que o ajuste do DFT é feito somente por primeiros princípios.

Esse critério para gerar um funcional aproximado pode ser utilizado para os funcionais de correção de longo alcance (LC) em que a repulsão eletrônica $r_{12}^{-1}$ é um termo de troca separado por um intervalo de escala, 521 que se torna a troca "exata" ( $\left.E_{X}^{\mathrm{HF}}\right)$ para grandes 
valores de $r_{12}$, levando a um potencial com um perfil assimptótico correto.

Uma maneira flexível para a descrição da repulsão eletrônica é dada pela expressão de três parâmetros da Equação 1.33, sendo $\gamma$ o parâmetro de separação de intervalo de escala com valores típicos de 0,3 até 0,5 u.a. dentro de um funcional de troca com escala de separação (RSE), que por sua vez é parametrizado com uma separação função de erro erf. O termo de separação de longo alcance é o segundo termo do lado direito da Equação 1.33. em que $\alpha$ quantifica a fração do $E_{\mathrm{X}}$ no limite de curto alcance, enquanto $\alpha+\beta$ fornece a fração $E_{\mathrm{X}}$ no limite do longo alcance, com a correção de longo alcance (LC) respeitando a expressão $\alpha+\beta=1$.

$$
\frac{1}{r_{12}}=\frac{1-\left[\alpha+\beta \operatorname{erf}\left(\gamma r_{12}\right)\right]}{r_{12}}+\frac{\alpha+\beta \operatorname{erf}\left(\gamma r_{12}\right)}{r_{12}}
$$

Funcionais LC híbridos podem melhorar significativamente as excitações de transferência de carga (CT). Contudo, nem toda excitação de transferência de carga leva a uma grande separação espacial dos orbitais. Nos métodos Coulomb-atenuados (CAM), a correção LC é incompleta. O funcional CAM-B3LYP leva a $\alpha+\beta=0,65$. A parametrização global dos funcionais RSE desenvolvidos para excitações CT não são necessariamente precisas para outras propriedades e a sua performance é sensível aos valores de $\alpha, \beta$ e $\gamma \cdot \underline{53}$

Os funcionais $\omega$ B97 e $\omega$ B97X apresentam 100\% de troca exata para longo alcance, com troca B97 para curto alcance e correlação B97. O $\omega$ B97X difere do $\omega$ B97 basicamente pela adição de cerca de $16 \%$ de troca exata no curto alcance do primeiro, enquanto o

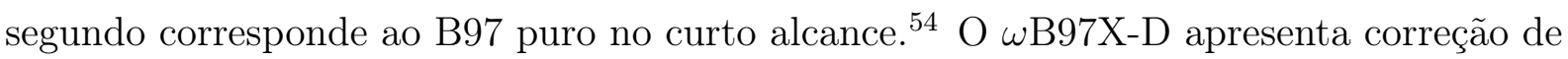
dispersão empírica para a energia, além de utilizar cerca de $22 \%$ de troca exata no curto alcance. $\underline{55}$

O parâmetro $\gamma$ é um funcional da densidade e também dependente do sistema $\stackrel{56}{\text { Um }}$ ajuste não empírico foi proposto de modo que $\gamma$ leve a um funcional ajustado que apresente uma energia HOMO $\left(\varepsilon^{\mathrm{HOMO}}\right)$ que descreva a energia do potencial de ionização -IP.

A melhora na descrição de energias de transferência de carga e outros gaps de energia por funcionais LC ajustados e funcionais RSE com parametrização global fixa tem sido reportada na literatura. $[66$ 
A energia $\operatorname{DFT} E(N)$ varia linearmente com o número inteiro de elétrons $N_{i}$. $\mathrm{Na}$ falta de um tratamento explícito, funcionais aproximados geralmente não produzem um comportamento linear para $E(N)$ em moléculas, mesmo com valores de $E(N)$ sendo bem precisos. Ao invés disso, pode haver uma pronunciada curvatura em $E(N)$. Essa curvatura indica erro de deslocalização (DE), que está relacionada com a imprecisão das propriedades magnéticas por DFT [1] 61, 62 Há uma estreita relação entre o DE e o erro de auto-interação eletrônica. Curva positiva (perfil convexo) indica uma alta deslocalização eletrônica, que é obtida tipicamente com funcionais puros. Curva negativa (perfil côncavo) indica uma alta localização, que é tipicamente obtido para funcionais híbridos com altas frações de $E_{\mathrm{X}}$ e $E_{X}^{\mathrm{HF}}$.

O erro DE afeta diretamente propriedades físicas e químicas moleculares, uma vez que covalência pode ser considerada como uma forma de deslocalização. Funcionais de longo alcance tendem a produzir comparativamente pequenas curvaturas de $E(N)$ e consequentemente, presumidamente pequenos valores de DE.

Autschbach e colaboradores utilizaram a idéia da descrição da repulsão eletrônica da expressão de três parâmetros para ajustar alguns funcionais já existentes com relação à $\gamma$ e testar a acurácia dos mesmos para diversas propriedades moleculares como: dicroísmo circular, rotação óptica, hiperpolarizabilidade e acoplamento hiperfino da Ressonância Paramagnética Eletrônica (RPE), mas não foi testada para acoplamentos spin-spin em RMN 61

O ajuste foi baseado na predição correta do potencial de ionização, basendo-se na condição abaixo:

$$
\varepsilon^{H O M O}(N)+\operatorname{IP}(N)=0
$$

sendo $N$ o número do elétron referência do sistema molecular estudado.36 $40,41,44$

Em um funcional RSE aproximado, $\varepsilon^{H O M O}$ e IP dependem fortemente de $\gamma$ da Equação 1.33. Deste modo, pode-se achar um valor de $\gamma$ que satisfaça a Equação 1.34 com um $\varepsilon^{\text {HOMO }}$ e IP $=E(N-1)-E(N)$, calculado com o mesmo funcional. 56 O correspondente valor de $\gamma^{*}$ determina o funcional ajustado. Vale salientar que o mesmo valor de $\gamma^{*}$ não 
deve satisfazer a Equação 1.34 para diferentes valores de $N$, logo deve-se minimizá-la utilizando a sua forma representada pela Equação 1.31 . 57

Assim o ajuste gerará um funcional híbrido com intervalo de troca com escala de separação que balanceie a troca HF e DFT, a fim de minimizar o erro de delocalização em um funcional com gap ótimo $\Delta E_{K S}$, que está relacionado com o gap fundamental da derivada descontínua de $\Delta_{\mathrm{XC}}$.

$$
\Delta \varepsilon_{\mathrm{F}}=E A-I P=\varepsilon_{\mathrm{LUMO}}-\varepsilon_{\mathrm{HOMO}}+\Delta_{\mathrm{XC}}
$$

Pelo Teorema de Janak, temos que $\frac{\partial E}{\partial n_{i}}=\varepsilon_{i}$, em que $0 \leqslant n_{i} \leqslant 1$ é a ocupação eletrônica do orbital $i$ e $\varepsilon_{i}$ é a energia orbital correspondente. Para funcionais exatos, $\varepsilon_{i}$ é constante, e portanto $\frac{\partial^{2} E}{\partial n_{i}^{2}}=0$. Assim, a energia total varia linearmente com a adição fracionada de um elétron no orbital $i$. Entretanto, muitos dos funcionais utilizados na literatura não possuem tal comportamento, sendo esperado que valores de $\frac{\partial^{2} E}{\partial n_{i}^{2}}$ mais próximos a 0 correspondam a funcionais quase exatos e valores distantes de 0 a funcionais bastante inexatos.

A Equação 1.36 ajusta a energia total $\mathrm{E}_{+}(n), \operatorname{com} 0 \leqslant n \leqslant 1$, entre a forma neutra e o cátion a partir das energias moleculares $\mathrm{E}_{\text {neutra }}$ e $\mathrm{E}_{\text {cátion }}$, e das energias orbitalares $\varepsilon_{\text {neutra }}^{\mathrm{HOMO}}$ do orbital ocupado de maior energia $(\mathrm{HOMO})$ e $\epsilon_{\text {cátion }}^{\mathrm{LUMO}}$ do orbital desocupado de menor energia (LUMO) $\underline{\underline{62}}$

$$
\mathrm{E}_{+}=\left\{\left(E_{0}-E_{\oplus}\right) n+\left[\left(\epsilon_{\oplus}^{L U M O}-E_{0}+E_{\oplus}\right)(1-n)+\left(E_{0}-E_{\oplus}-\epsilon_{0}^{H O M O}\right) n\right] n(1-n)\right\}
$$

Da mesma maneira, a Equação 1.37 ajusta a energia total $\mathrm{E}_{-}(n)$, com $0 \leqslant n \leqslant 1$, entre o ânion e a forma neutra a partir das energias moleculares $E_{\text {neutra }}$ e $E_{\hat{a ̂ n i o n}}$, e das energias orbitalares $\epsilon_{\text {neutra }}^{\mathrm{LUMO}}$ e $\varepsilon_{\text {ânion }}^{\mathrm{HOMO}} \underline{62}$

$$
\mathrm{E}_{-}=\left\{\left(E_{\ominus}-E_{0}\right) n+\left[\left(\epsilon_{0}^{L U M O}-E_{\ominus}+E_{0}\right)(1-n)+\left(E_{\ominus}-E_{0}-\epsilon_{\ominus}^{H O M O}\right) n\right] n(1-n)\right\}
$$


Como apresentado anteriormente, não há um consenso sobre a característica que o funcional deve conter para predizer as constantes de acoplamento indireto spin-spin com razoável precisão. Além disso, nenhum trabalho sistemático modificando as porcentagens de troca orbital Hartree-Fock $\left(E_{X}^{\mathrm{HF}}\right)$, comumente chamada de troca exata, foi reportado até agora. Somente alguns testes isolados foram feitos a fim de melhorar a precisão de algumas moléculas orgânicas e inorgânicas. 


\section{Objetivos}

O objetivo deste trabalho é avaliar a precisão dos funcionais de densidade previamente utilizados ou não na literatura para estimar propriedades magnéticas, verificando a precisão nos valores das constantes de acoplamento indireto spin-spin obtidas pela comparação dos valores teóricos com os experimentais. Propor novos funcionais gerados a partir de funcionais existentes como tentativa de encontrar funcionais ainda mais precisos, mas que ainda possuam sentido físico. Os melhores funcionais serão comparados com métodos altamente correlacionados SOPPA(CCSD) e SOPPA(CC2), que apresentam bons resultados nos valores dos acoplamentos para todos os tipos de núcleos. Assim, será proposto um funcional que consiga descrever de forma satisfatória todos os tipos de constantes de acoplamento. 


\section{Detalhes Computacionais}

A determinação de um conjunto de moléculas para calibração considerou o tratamento de diversos tipos de acoplamentos, envolvendo $J_{\mathrm{HH}}$ em diversos ambientes, $J_{\mathrm{CH}}, J_{\mathrm{NH}}$, $J_{\mathrm{OH}}, J_{\mathrm{FH}}, J_{\mathrm{PH}}, J_{\mathrm{BF}}, J_{\mathrm{OF}}, J_{\mathrm{PF}}, J_{\mathrm{CC}}$ e $J_{\mathrm{CO}}$. Para tanto foram utilizadas para calibração 26 constantes de acoplamento indireto spin-spin (CAISS) encontradas dentre 13 moléculas:

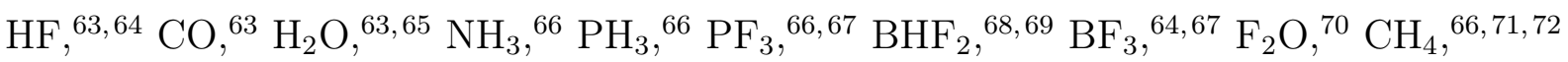
$\mathrm{C}_{2} \mathrm{H}_{2},{ }^{66 \mid 67} \mathrm{C}_{2} \mathrm{H}_{4}{ }^{66} \mathrm{e} \mathrm{C}_{2} \mathrm{H}_{6}, \frac{66][67}{6}$ todas com geometrias obtidas experimentalmente. As moléculas elencadas são usualmente presentes em diversos estudos na literatura para predição de diversas propriedades, inclusive constantes de acoplamento. $45,47 \sqrt[50]{50}$

Os funcionais que apresentaram os melhores resultados após o conjunto de análises foram submetidos para teste com um conjunto maior de moléculas, envolvendo mais tipos de acoplamento. O conjunto-teste utilizado será detalhado abaixo.

Para analisar a precisão dos resultados teóricos das CAISS, foram utilizados critérios como o desvio médio (DM), o desvio médio absoluto (DMA) e a porcentagem de desvio médio absoluto (PDMA) (de acordo com as equações 3.1, 3.2 e 3.3, respectivamente) com o intuito de obter quais resultados com melhor precisão para o conjunto.

$$
\begin{gathered}
\mathrm{DM}=\frac{1}{N} \sum_{i}^{N} J_{\text {calc }_{i}}-J_{\exp _{i}} \\
\mathrm{DMA}=\frac{1}{N} \sum_{i}^{N}\left|J_{\text {calc }_{i}}-J_{\text {exp }}\right| \\
\mathrm{PDMA}=100 \% \times \frac{1}{N} \sum_{i}^{N}\left|\frac{J_{\text {calc }_{i}}-J_{\text {exp }}}{J_{\text {exp }}}\right|
\end{gathered}
$$

Os critérios estatísticos foram obtidos considerando todas as 26 CAISS avaliadas. Também foram calculados apenas para as moléculas sem pares de elétrons isolados (SPI) - $\mathrm{CH}_{4}, \mathrm{C}_{2} \mathrm{H}_{2}, \mathrm{C}_{2} \mathrm{H}_{4}$ e $\mathrm{C}_{2} \mathrm{H}_{6}$, totalizando 15 CAISS - e para as moléculas com pares de 
elétrons isolados (CPI) - HF, CO, $\mathrm{H}_{2} \mathrm{O}, \mathrm{NH}_{3}, \mathrm{PH}_{3}, \mathrm{PF}_{3}, \mathrm{BHF}_{2}, \mathrm{BF}_{3}$ e $\mathrm{F}_{2} \mathrm{O}$, totalizando 11 CAISS. Tal distinção foi feita na tentativa de associar a precisão da CAISS com a presença/ausência de par(es) de elétrons isolados, conforme já descrito por Seminario para a série $\mathrm{H}, \mathrm{C}, \mathrm{N}, \mathrm{O}$ e $\mathrm{F}{ }^{73} \mathrm{~A}$ diferença $\Delta(\mathrm{CPI}-\mathrm{SPI})$ entre os parâmetros estatísticos desses conjuntos também é exibida, de modo que valores próximos a zero indicam precisões similares para os conjuntos CPI e SPI.

Em uma primeira análise, foram selecionados os seguintes 26 DFTs disponíveis na lite-

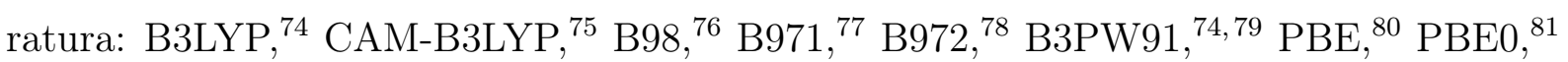

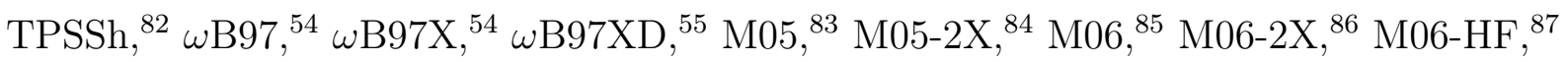

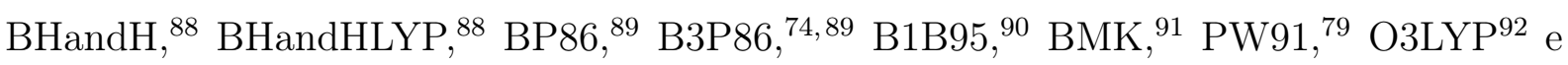
$\mathrm{X} 3 \mathrm{LYP},{ }^{93}$ todos previamente utilizados com sucesso na obtenção de valores precisos para vários tipos de acoplamentos.

Os cálculos foram feitos com conjuntos de base aug-pcJ-2 ${ }^{\frac{18}{18}}$ e HuzIII-su3 $3^{94}$ utilizando o Gaussian 09 ${ }^{39}$ A base aug-pcJ-2 possui qualidade quádruplo- $\zeta$ e é contraída, enquanto a HuzIII-su3 possui triplo- $\zeta$ e é descontraída nas funções gaussianas do tipo "s", ou seja, mais flexível, o que pode melhorar a descrição dos termos FC e SD dos acoplamentos em alguns casos. Ambas as bases apresentam qualidade mínima triplo- $\zeta$ e incluem expoentes orbitais extremamente grandes, que são necessários para uma descrição adequada de constantes de acoplamento. $\stackrel{4}{ }$

Os DFTs foram submetidos à variação da porcentagem de energia de troca HartreeFock $\left(E_{X}^{\mathrm{HF}}\right)$ de 0 a $100 \%$ em incrementos de $10 \%$ (do coeficiente $\alpha_{\mathrm{HF}}$ ) de acordo com a Equação 3.4 - que corresponde ao quanto de troca exata, obtida do método HartreeFock, é utilizada para computar a energia de troca. A modificação foi feita através dos $\operatorname{IOp}(3 / 76), \operatorname{IOp}(3 / 77)$ e $\operatorname{IOp}(3 / 78)$ do pacote Gaussian 09! $\underline{.9}$

$$
E_{X}=\alpha_{\mathrm{HF}} E_{X}^{\mathrm{HF}}+\alpha_{\mathrm{DFT}} E_{X}^{\mathrm{DFT}}, \text { em que } \alpha_{\mathrm{HF}}+\alpha_{\mathrm{DFT}}=1
$$

Para os DFTs que possuem correção de longo alcance (CLA), a porcentagem de $E_{X}^{\mathrm{HF}}$ depende da distância radial, e portanto utiliza-se os parâmetros $\alpha, \beta$ e $\gamma$ da Equação 1.33 para ajustar as correções. O parâmetro $\alpha$ determina a porcentagem de $E_{X}^{\mathrm{HF}}$ no 
limite de curto alcance, e $\alpha+\beta$ no limite de longo alcance. As variações foram feitas considerando as restrições $0 \leq \alpha \leq 1,0 \leq \beta \leq 1$ e $\alpha+\beta \leq 1$. Separadamente foram feitas variações do parâmetro $\gamma$ para ajustar a taxa de variação da função erf na Equação 1.33 . As modificações foram feitas com os $\operatorname{IOp}(3 / 107), \operatorname{IOp}(3 / 108), \operatorname{IOp}(3 / 119), \operatorname{IOp}(3 / 120)$, $\operatorname{IOp}(3 / 130)$ e $\operatorname{IOp}(3 / 131)$ do pacote Gaussian $09 \stackrel{39}{.}$

A Figura 3.1, adaptada do trabalho de Yanai et al sobre o método atenuado por Coulomb (CAM-B3LYP), apresenta 3 comportamentos distintos para porcentagem de troca exata nos DFTs. A maioria dos funcionais da literatura estudados, como o B3LYP, apresentam o comportamento da Figura 3.1a. Os funcional $\omega$ B97 tem comportamento similar à Figura 3.1b e o CAM-B3LYP à Figura 3.1c, O $\omega$ B97X e $\omega$ B97XD apresentam um comportamento que remetem à combinação das Figuras $3.1 \mathrm{~b}$ e $3.1 \mathrm{c}$.

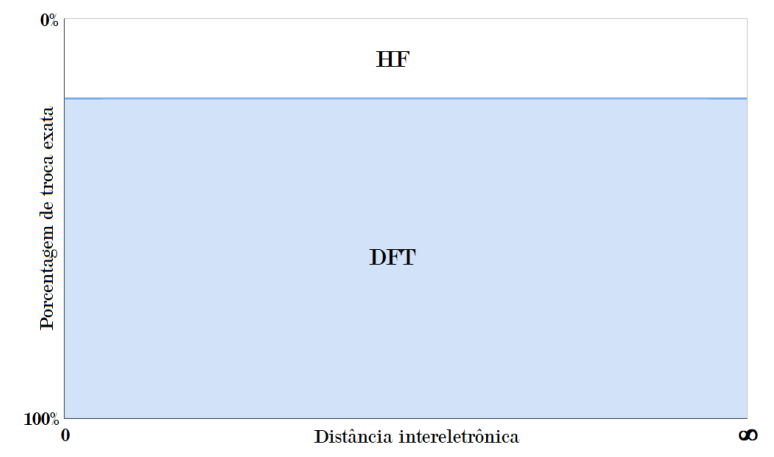

(a) Sem correção de longo alcance

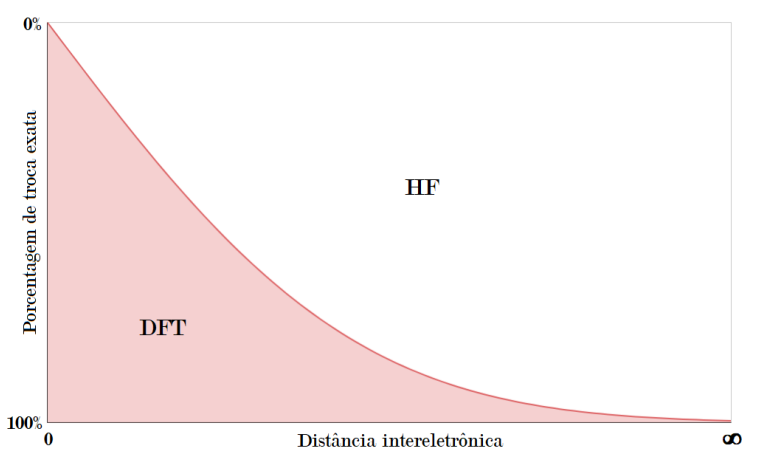

(b) Correção de longo alcance

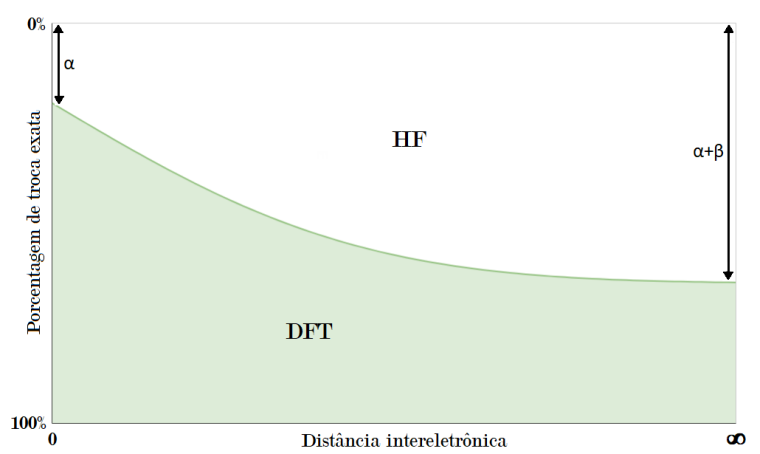

(c) Método atenuado por Coulomb

Figura 3.1: Contribuições de $E_{X}^{\mathrm{HF}}$ e $E_{X}^{\mathrm{DFT}}$ em função da distância entre dois elétrons. O caso constante corresponde ao caso $\alpha E_{X}^{\mathrm{HF}}+(1-\alpha) E_{X}^{\mathrm{DFT}}$, com $\alpha$ constante.

Utilizando a PDMA como critério, foram determinados os funcionais mais precisos para o conjunto de calibração com geometrias experimentais. A otimização das geome- 
trias moleculares foi realizada para obter geometrias de equilíbrio, buscando diminuir a instabilidade tripleto. ${ }^{95}$ As CAISS foram obtidas utilizando as geometrias otimizadas com os DFTs mais precisos. O cálculo de otimização foi feito com as versões original e modificadas dos DFTs, e a propriedade obtida com a versão modicada foi avaliada em ambos casos de geometria otimizada.

Os resultados obtidos para CAISS através do cálculos teóricos correspondem a valores na geometria de equilíbrio (estável), e portanto devem ser feitas correções para tratar adequadamente sistemas reais. Para tanto as correções consideram o efeito das vibrações (valor de ponto zero) e o efeito da temperatura. As correções de temperatura de 0 a 300 K são menores em magnitude do que as correções do valor de ponto zero. ${ }^{7}$ Levando isso em conta, apenas correções vibracionais foram calculadas.

A correção vibracional das CAISS foi feita utilizando a keyword .VIBANA do programa Dalton2016. ${ }^{96}$ Apenas os funcionais BHandH e PBE0 foram avaliados, pois são os funcionais disponíveis, dentre os melhores obtidos sem CLA, no Dalton2016 para esta propriedade. Devido ao alto custo computacional do cálculo de correções vibracionais, operações de simetria foram utilizadas sempre que possível para simplificar o tratamento das estruturas moleculares.

Os resultados das correções vibracionais foram utilizados como tentativa de correção dos resultados previamente obtidos. Duas estratégias foram utilizadas para avaliar a influência das correções vibracionais nos resultados obtidos até este momento. A primeira adiciona as correções vibracionais às CAISS obtidas teoricamente, de acordo com a Equação 3.5. Já a segunda considera as CAISS empíricas como referência, subtraindo as correções vibracionais das CAISS experimentais, de acordo com a Equação 3.6. Em ambas, novos valores de DM, DMA e PDMA foram calculados considerando a substituição indicada pelas Equações 3.5 e 3.6 nas Equações 3.1 , 3.2 e 3.3 .

$$
\begin{aligned}
& J_{\text {corr }_{i}}=J_{\text {calc }_{i}}+J_{\text {vibcor }_{i}} \Longrightarrow \text { DM, DMA, PDMA: } J_{\text {calc }_{i}} \rightarrow J_{\text {corr }_{i}} \\
& J_{\text {emp }_{i}}=J_{\text {exp }}-J_{\text {vibcor }_{i}} \Longrightarrow \text { DM, DMA, PDMA: } J_{\text {exp }_{i}} \rightarrow J_{\text {emp }}
\end{aligned}
$$


A combinação de diferentes funcionais de troca e correlação, juntamente à variação da $E_{X}^{\mathrm{HF}}$ através dos $\operatorname{IOp}(3 / 76), \operatorname{IOp}(3 / 77)$ e $\operatorname{IOp}(3 / 78)$, permite obter diferentes funcionais. Desta forma, foram escolhidos 9 funcionais de troca - B, ${ }^{97}$ B971, ${ }^{77}$ B972, ${ }^{78}$ B98, ${ }^{76} \mathrm{O}, \underline{98}$

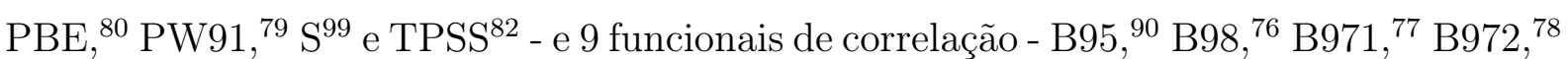

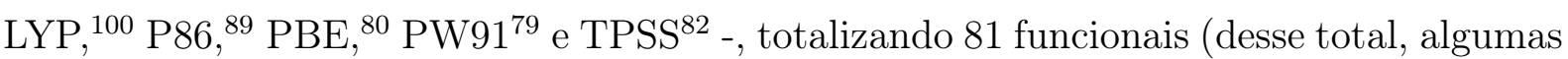
combinações reproduziram resultados já obtidos com os funcionais da literatura, como o BHandH e o B1B95).

Os 2 melhores resultados para cada troca e cada correlação com os funcionais gerados foram utilizados para cálculo de otimização e da propriedade. A porcentagem de desvio absoluto (PDA) indica a contribuição de cada componente para cálculo da média (PDMA). Algumas das CAISS apresentam maior imprecisão do que outras para os diferentes DFTs. Os valores do DM, do DMA e da PDMA também foram recalculados, excluindo algumas das CAISS menos precisas, para os resultados dos funcionais de troca e correlação com geometrias otimizadas e com geometrias experimentais.

A estratégia de longo alcance pode ser aplicada a funcionais puros para obter DFTs com CLA ${ }^{101}$ Desta forma, os funcionais LC-BLYP e LC-B98 foram utilizados como tentativa de reproduzir os resultados já obtidos para as variações de parâmetros dos funcionais CAM-B3LYP, $\omega$ B97, $\omega$ B97X e $\omega$ B97XD (os parâmetros fixos foram ajustados aos dos funcionais da literatura).

Os funcionais LC-B1B95 e LC-BHandH também foram construídos variando $\alpha$ de $0 \%$ a $50 \%$ (com incremento de 10\%), $\alpha+\beta$ de $70 \%$ a $100 \%$ (também incrementado em $10 \%$ ) e $\gamma$ de 0,05 a 0,75 (com incremento de 0,05), de modo a obter cálculos precisos das CAISS com geometrias experimentais. A otimização de geometrias e cálculo das CAISS foi realizada para os melhores funcionais obtidos anteriormente.

Os métodos ab initio SOPPA(CC2) e SOPPA(CCSD), 102 com base aug-cc-pVTZ$\mathrm{J}, 21$ foram utilizados para obter as CAISS nas geometrias experimentais com o pacote Dalton2016. ${ }^{96}$ Tais resultados foram comparados com os melhores resultados até então obtidos para os DFTs, de modo a avaliar se a teoria DFT, menos custosa computacionalmente, é vantajosa para calcular CAISS frente a métodos altamente correlacionados. O 
valor total das CAISS foi comparado tanto com os métodos SOPPA quanto com os valores experimentais; por sua vez os componentes FC, SD, PSO e DSO não podem ser medidos experimentalmente. Desta forma os termos FC, SD, PSO e DSO dos melhores funcionais foram comparados com os termos FC, SD, PSO e DSO dos métodos SOPPA(CC2) e SOPPA(CCSD).

Testes de precisão foram realizados a partir do Teorema de Janak para as concavidades da energia. Os cálculos da energia (cálculo de um único ponto) do cátion e do ânion moleculares de cada uma das 13 moléculas do conjunto de calibração foram feitos para os melhores funcionais. A curvatura média das curvas determinadas pelas Equações $1.36 \mathrm{e}$ 1.37 foram obtidas para a determinação da exatidão dos funcionais avaliados.

O conjunto-teste utilizado envolve 33 moléculas: $\mathrm{CH}_{3} \mathrm{NH}_{2}, \frac{103}{2}$ etanamida,,$\frac{103}{10}$ ureia,,$\frac{103}{2}$ $\mathrm{CH}_{3} \mathrm{~F},{ }^{104} \mathrm{CH}_{2} \mathrm{~F}_{2},{ }^{104} \mathrm{CHF}_{3},{ }^{104} \mathrm{CF}_{4},{ }^{104} \mathrm{HCCF},{ }^{105} \mathrm{C}_{2} \mathrm{H}_{3} \mathrm{~F},{ }^{103}$ gem $-\mathrm{C}_{2} \mathrm{H}_{2} \mathrm{~F}_{2},{ }^{103}$ cis $-\mathrm{C}_{2} \mathrm{H}_{2} \mathrm{~F}_{2},{ }^{103}$

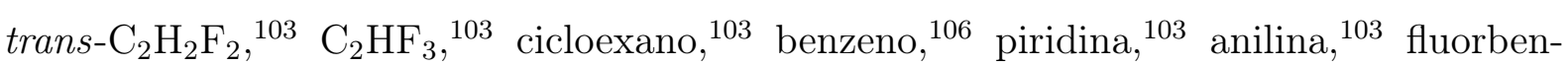

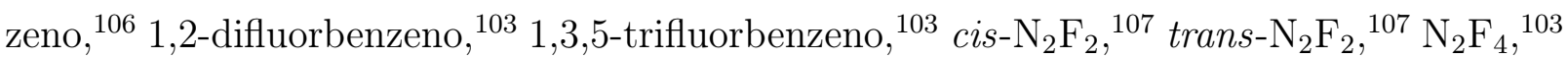

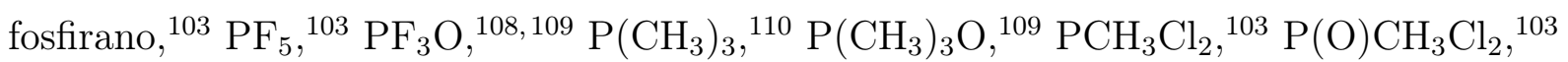
$\mathrm{P}\left(\mathrm{N}\left(\mathrm{CH}_{3}\right)_{2}\right)_{3},{ }^{1111} \mathrm{SiH}_{4}{ }^{112} \mathrm{e} \mathrm{SiF}_{4},{ }^{112}$ e totaliza 84 CAISS. Os valores foram obtidos com os conjuntos de base aug-pcJ-2 e HuzIII-su3. Alguns DFTs originais também foram submetidos ao conjunto teste para comparação.

Algumas das constantes experimentais tiveram seu sinal ajustado de acordo com o sinal obtido em todos os cálculos - são elas: ${ }^{3} J_{\mathrm{FF}}$ da molécula de $c i s-\mathrm{N}_{2} \mathrm{~F}_{2},{ }^{3} J_{\mathrm{FF}}$ da molécula de trans $-\mathrm{N}_{2} \mathrm{~F}_{2},{ }^{1} J_{\mathrm{NF}}$ da molécula de $\mathrm{N}_{2} \mathrm{~F}_{4},{ }^{1} J_{\mathrm{PC}}$ da molécula de $\mathrm{PCH}_{3} \mathrm{Cl}_{2},{ }^{2} J_{\mathrm{PH}}$ da molécula de $\mathrm{P}(\mathrm{O}) \mathrm{CH}_{3} \mathrm{Cl}_{2},{ }^{1} J_{\mathrm{PN}}$ da molécula de $\mathrm{P}\left(\mathrm{N}\left(\mathrm{CH}_{3}\right)_{2}\right)_{3},{ }^{1} J_{\mathrm{NC}}$ da molécula de $\mathrm{CH}_{3} \mathrm{NH}_{2},{ }^{1} J_{\mathrm{NC}}$ e ${ }^{2} J_{\mathrm{NC}}$ da molécula de etanamida, ${ }^{1} J_{\mathrm{CF}}$ da molécula de $\mathrm{CH}_{3} \mathrm{~F},{ }^{1} J_{\mathrm{CF}}$ da molécula de $\mathrm{CH}_{2} \mathrm{~F}_{2}$, ${ }^{1} J_{\mathrm{CF}}$ da molécula de $\mathrm{CHF}_{3},{ }^{1} J_{\mathrm{CF}}$ da molécula de $\mathrm{CF}_{4},{ }^{2} J_{\mathrm{FF}}$ da molécula de gem- $\mathrm{C}_{2} \mathrm{H}_{2} \mathrm{~F}_{2}$ e ${ }^{1} J_{\mathrm{NC}},{ }^{2} J_{\mathrm{NC}}$ e ${ }^{3} J_{\mathrm{NH}}$ da molécula de anilina. 


\section{Resultados e Discussão}

\subsection{Precisão dos funcionais da literatura}

Os valores das CAISS obtidos com os 26 DFTs encontrados na literatura, utilizando função de base aug-pcJ-2, estão apresentados nas Tabelas 8.1 e 8.2, assim como os valores de DM, DMA e PDMA. Os valores das CAISS também foram obtidos com função de base HuzIII-su3 para os 26 DFTs, e estão apresentados nas Tabelas 8.3 e 8.4 .

Utiliza-se a PDMA total como principal critério para avaliar a diferença entre os valores calculados e os experimentais das CAISS. A Figura 4.1 apresenta os valores da PDMA para os DFTs da literatura testados utilizando as bases aug-pcJ-2 e HuzIII-su3.

Considerando a base aug-pcJ-2 (Figura 4.1a) dentre os DFTs da literatura, o BHandH apresentou o melhor resultado, seguido de $\omega$ B97X, $\omega$ B97XD, $\omega$ B97, B971, B98, PBE0, B972, CAM-B3LYP e B1B95. Os demais DFTs apresentam PDMA superior a 25\%.

Para a base HuzIII-su3 (Figura 4.1b), os melhores resultados são obtidos com wB97X, $\omega \mathrm{B} 97 \mathrm{XD}, \mathrm{BHandH}, \omega \mathrm{B} 97, \mathrm{~B} 971, \mathrm{~B} 972, \mathrm{~B} 98$ e B1B95. Os demais funcionais apresentam PDMA superior a 25\%, incluindo o CAM-B3LYP e o PBE0.

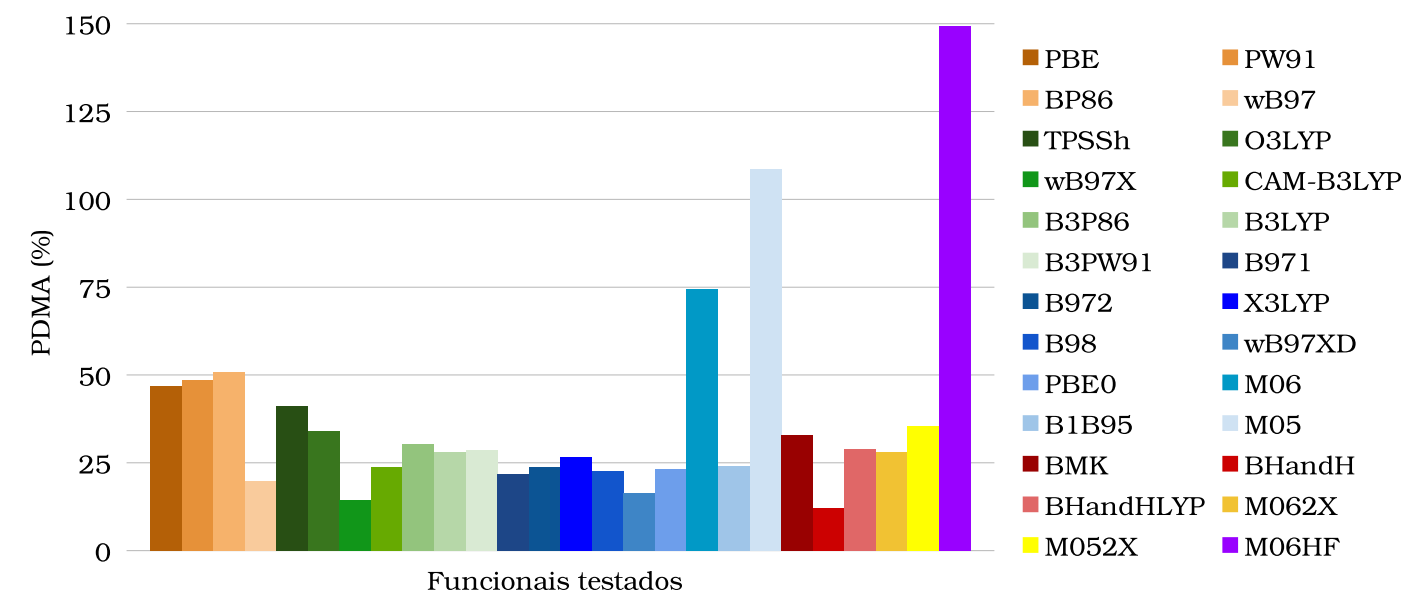

(a) aug-pcJ-2 


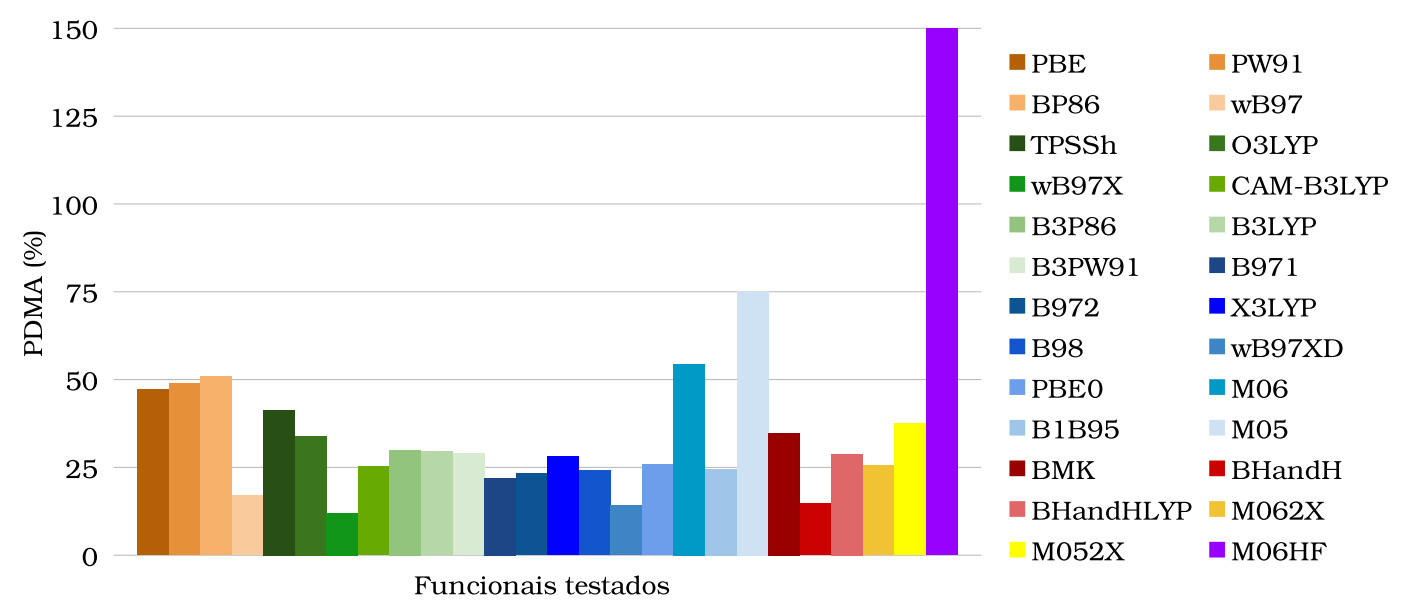

(b) HuzIII-su3

Figura 4.1: PDMA das CAISS utilizando funcionais da literatura. Os funcionais estão ordenados em ordem crescente de porcentagem de $E_{X}^{\mathrm{HF}}$. O maior valor de PDMA é obtido com o funcional M06HF (149,27\% para aug-pcJ-2 e 290,31\% para HuzIII-su3).

Os valores de PDMA dos funcionais obtidos com cada uma das bases estão apresentados na Tabela 4.1. De maneira geral, os melhores DFTs contemplam os funcionais da família B97 (B971, B972 e B98), incluindo as versões de longo-alcance ( $\omega$ B97, $\omega$ B97X e $\omega$ B97XD), o BHandH e o B1B95. De fato, a escolha adequada de base não altera significativamente os resultados (menos de $3 \%$ para os 10 melhores), e ao comparar as Figuras $4.1 \mathrm{a}$ e $4.1 \mathrm{~b}$ é notável que o comportamento de cada funcional é similar.

Tabela 4.1: Valores de PDMA total para os melhores funcionais da literatura.

\begin{tabular}{lcc}
\hline Funcional & aug-pcJ-2 & HUzIII-su3 \\
\hline BHandH & $12,21 \%$ & $14,69 \%$ \\
$\omega$ B97X & $14,49 \%$ & $12,08 \%$ \\
$\omega$ B97XD & $16,48 \%$ & $14,22 \%$ \\
$\omega$ B97 & $19,64 \%$ & $17,04 \%$ \\
B971 & $21,89 \%$ & $21,98 \%$ \\
B98 & $22,55 \%$ & $24,09 \%$ \\
PBE0 & $23,18 \%$ & $25,82 \%$ \\
B972 & $23,84 \%$ & $23,26 \%$ \\
CAM-B3LYP & $23,87 \%$ & $25,19 \%$ \\
B1B95 & $24,17 \%$ & $24,59 \%$ \\
\hline
\end{tabular}

A Figura 4.2 apresenta os valores do DM para os DFTs da literatura testados utilizando 
os conjuntos de base aug-pcJ-2 e HuzIII-su3, e a Figura 4.3 apresenta os valores do DMA. Nota-se que o DM apresenta valores próximos a zero que surgem, em geral, do cancelamento entre constantes superestimadas e constantes subestimadas. Além disso, as bases utilizadas resultam em valores de DM muito distintos, e portanto o DM não é bom para comparação.

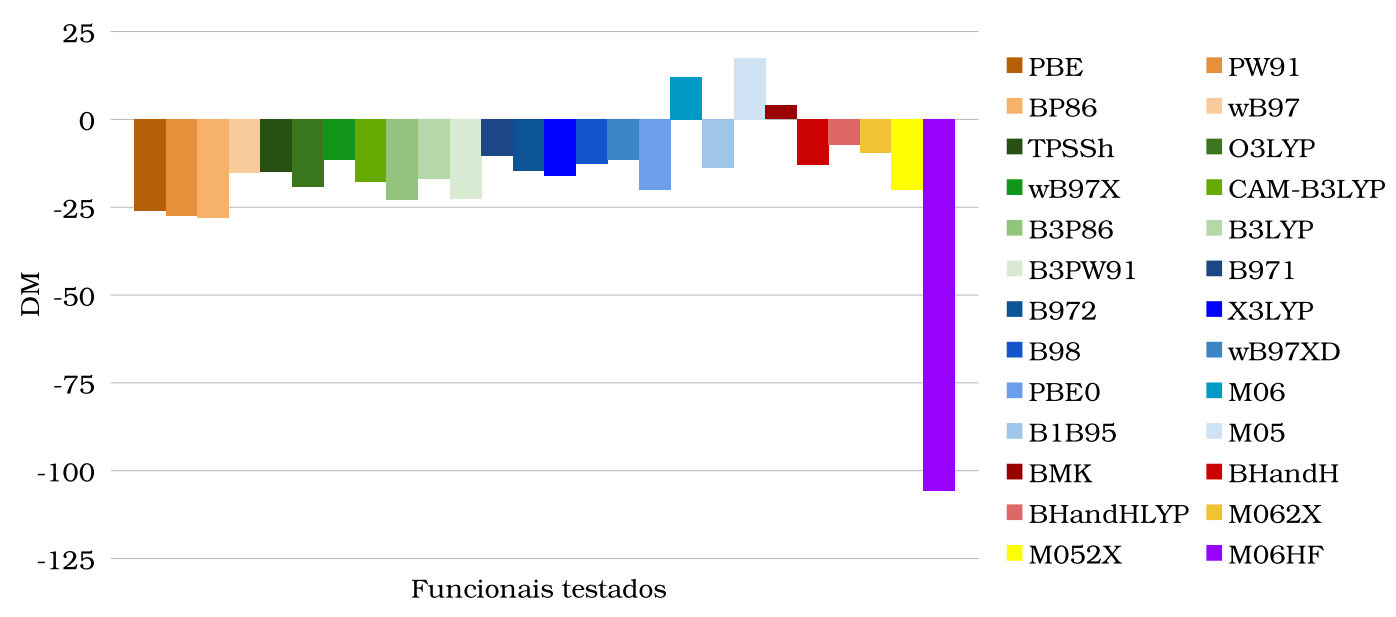

(a) aug-pcJ-2

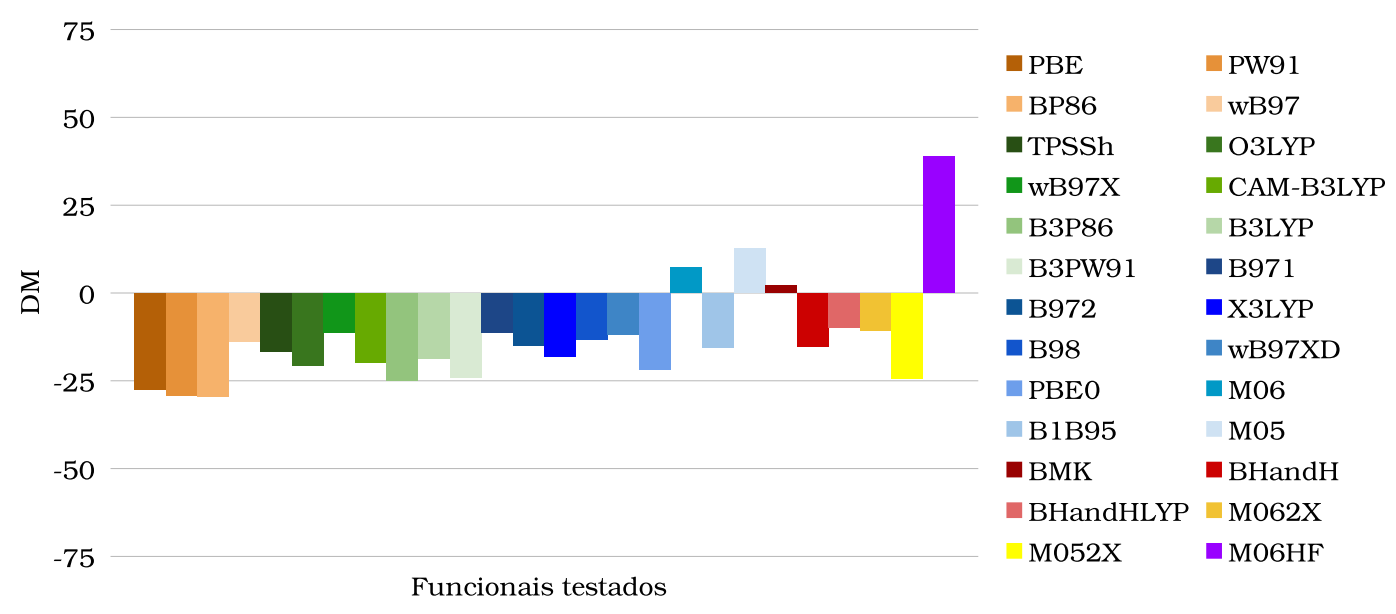

(b) HuzIII-su3

Figura 4.2: DM (em Hz) das CAISS utilizando funcionais da literatura. Os funcionais estão ordenados em ordem crescente de porcentagem de $E_{X}^{\mathrm{HF}}$.

Os valores de DMA (Figura 4.3) são mais adequados que o DM pois a média não possibilita cancelamentos. Nota-se que os funcionais $\omega$ B97, $\omega$ B97X, $\omega$ B97XD, B971, B972 e B1B95 apresentam valores de DMA menores que $20 \mathrm{~Hz}$ para ambos conjuntos de base, e os DMAs do B98 e do BHandH estão próximos de 20 Hz. Assim o DMA permite comparar a precisão do conjunto. Entretanto, o DMA não considera a magnitude da constante, e 
portanto o desvio de, por exemplo, $1 \mathrm{~Hz}$ pode ser grande ou pequeno a depender da CAISS; por isso a PDMA é preferida.

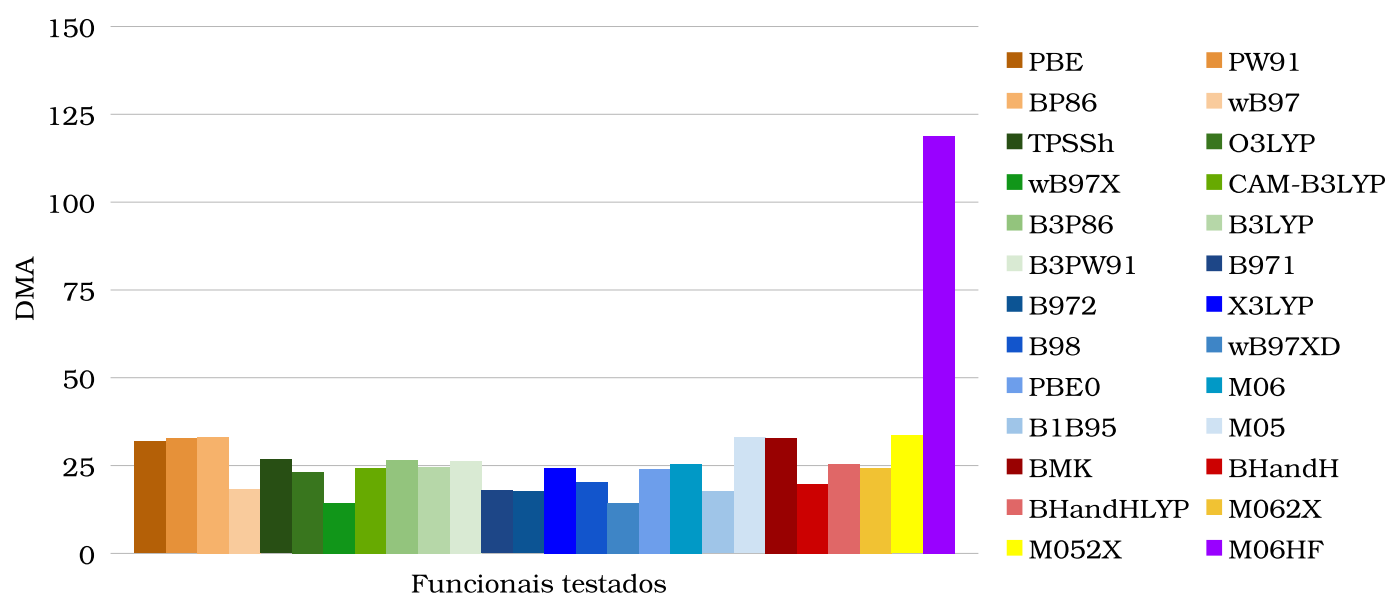

(a) aug-pcJ-2

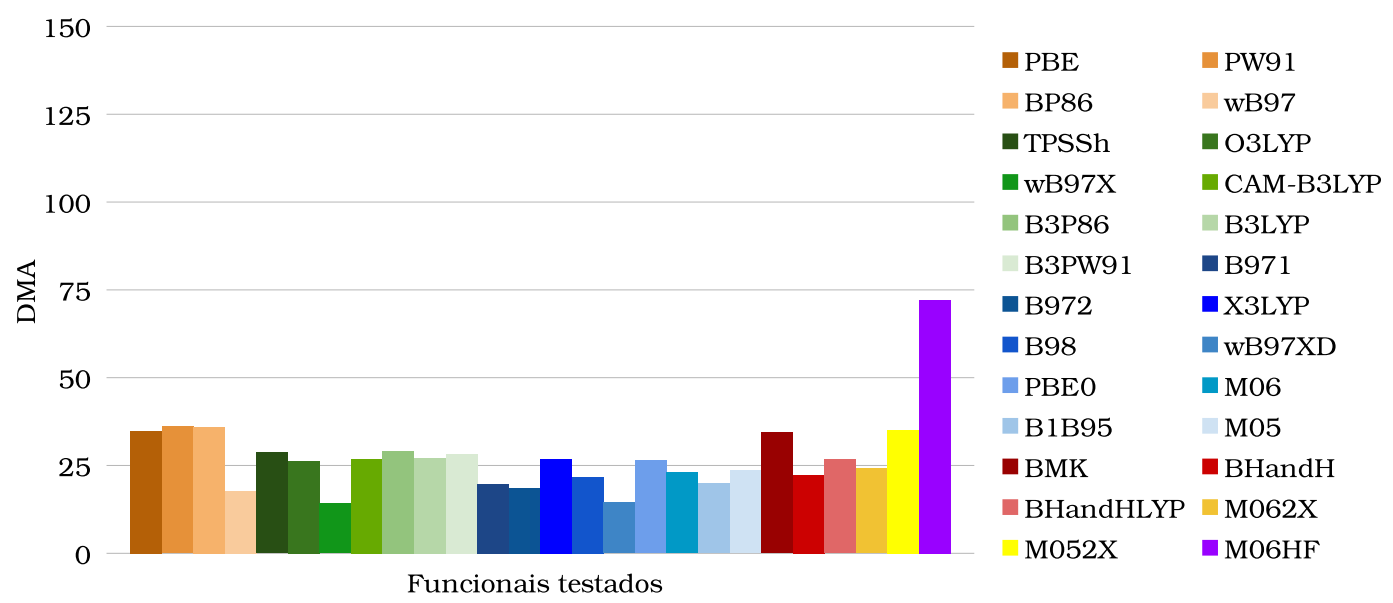

(b) HuzIII-su3

Figura 4.3: DMA (em Hz) das CAISS utilizando funcionais da literatura. Os funcionais estão ordenados em ordem crescente de porcentagem de $E_{X}^{\mathrm{HF}}$.

Os funcionais da literatura são, de modo geral, mais precisos para as CAISS de moléculas SPI do que para as CAISS de moléculas CPI. Tal comportamento se deve à presença dos pares de elétrons isolados. ${ }^{73}$ Os funcionais M06 e BMK, entretanto, apresentam melhor precisão para o conjunto SPI para ambos conjuntos de base. O funcional M05 apresenta precisões similares para os conjuntos SPI e CPI com HuzIII-su3, sendo ligeiramente melhor para o SPI. E o funcional M06HF é mais impreciso para CPI do que SPI com HuzIII-su3, mas com aug-pcJ-2 ocorre o oposto; apesar disso o M06HF, dentre os funcionais da literatura, apresenta o resultado mais impreciso, sendo portanto não 
recomendado para cálculo de CAISS. Os funcionais M05 e M06 também não são muito precisos, e portanto devem ser evitados, assim como os funcionais puros PBE, PW91 e BP86.

Funcionais puros ou com uma pequena porcentagem de troca exata não apresentam resultados muito precisos, assim como funcionais com uma elevada porcentagem de troca exata. A utilização de DFTs da literatura com um pouco de troca exata é bom para o

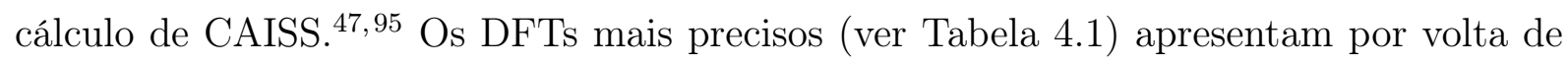
$20 \%$ a $50 \%$ de troca exata em sua composição. É importante destacar que os funcionais CAM-B3LYP, $\omega$ B97, $\omega$ B97X e $\omega$ B97XD apresentam uma porcentagem de troca exata para curto alcance representada pelo $\alpha$ (apresentada nas Tabelas 8.1 a 8.4), incrementanda continuamente até $\alpha+\beta$ no longo alcance.

Com base nas melhores precisões entre $20 \%$ e $50 \% E_{X}^{\mathrm{HF}}$ com os DFTs mencionados na Tabela 4.1, novos testes podem ser feitos variando a porcentagem de $E_{X}^{\mathrm{HF}}$ presente nos funcionais. Para tanto é necessário trabalhar CAM-B3LYP, $\omega$ B97, $\omega$ B97X e $\omega$ B97XD separadamente dos demais DFTs. Na próxima seção será discutida a variação da porcentagem de troca exata para os funcionais sem correção de longo alcance (CLA); e na Seção 4.5 será discutido para os funcionais de longo alcance. 


\subsection{Variação da porcentagem de $E_{X}^{\mathrm{HF}}$ para os funcionais híbridos}

\subsubsection{Geometrias experimentais}

Os resultados da variação da porcentagem de $E_{X}^{\mathrm{HF}}$ para os DFTs da literatura testados com base aug-pcJ-2 estão apresentados nas Tabelas 8.5 a 8.22, e a PDMA total dos resultados com base HuzIII-su3 na Tabela 8.23 A Figura 4.4 apresenta os valores da PDMA dos funcionais da literatura variando a porcentagem de $E_{X}^{\mathrm{HF}}$ usando os conjuntos de base aug-pcJ-2 e HuzIII-su3.

Os funcionais PBE e PBE0, B3LYP e BHandHLYP, M05 e M05-2X, e M06 e M06-HF estão associados a uma mesma variação de porcentagem de $E_{X}^{\mathrm{HF}}$ pois possuem o mesmo funcional puro como origem, diferindo portanto apenas na composição de troca exata.

De maneira geral, os valores de PDMA são menores para funcionais com valores de $E_{X}^{\mathrm{HF}}$ entre $30 \%$ e $50 \%$. De fato, certa porcentagem da energia de troca exata contribui para a obtenção de resultados mais precisos comparados com o uso apenas da $E_{X}^{\mathrm{DFT}}$,

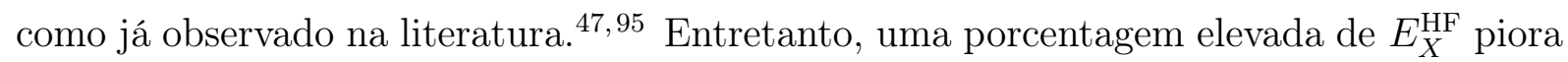
consideravelmente a precisão dos resultados, conforme observado na Figura 4.4 .

Ao comparar as Figuras 4.4a e 4.4b, de modo geral o comportamento de cada DFT é bastante similar entre as bases. A maior discrepância obtida refere-se aos funcionais da família M06 (M06, M06-2X e M06-HF). É possível que a utilização uma base contraída (aug-pcJ-2) e outra parcialmente descontraída e mais flexível (HuzIII-su3) acarretem as diferenças geradas. Apesar disso, essa família de funcionais não apresentou os resultados mais precisos dentre os DFTs estudados, e portanto essa diferença significativa de comportamento não foi investigada.

Os resultados mais precisos para a variação da porcentagem de $E_{X}^{\mathrm{HF}}$ com aug-pcJ-2 são obtidos com B1B95 50\% $E_{X}^{\mathrm{HF}}$, BHandH 50\% $E_{X}^{\mathrm{HF}}$ (original), B98 $50 \% E_{X}^{\mathrm{HF}}, \mathrm{BHandH}$ $40 \% E_{X}^{\mathrm{HF}}, \mathrm{B} 1 \mathrm{~B} 9540 \% E_{X}^{\mathrm{HF}}, \mathrm{B} 97150 \% E_{X}^{\mathrm{HF}}, \mathrm{B} 97140 \% E_{X}^{\mathrm{HF}}, \mathrm{B} 9840 \% E_{X}^{\mathrm{HF}}, \mathrm{B} 97240 \%$ $E_{X}^{\mathrm{HF}}$ e B972 50\% $E_{X}^{\mathrm{HF}}$ - todos com PDMA inferior a $20 \%$. 


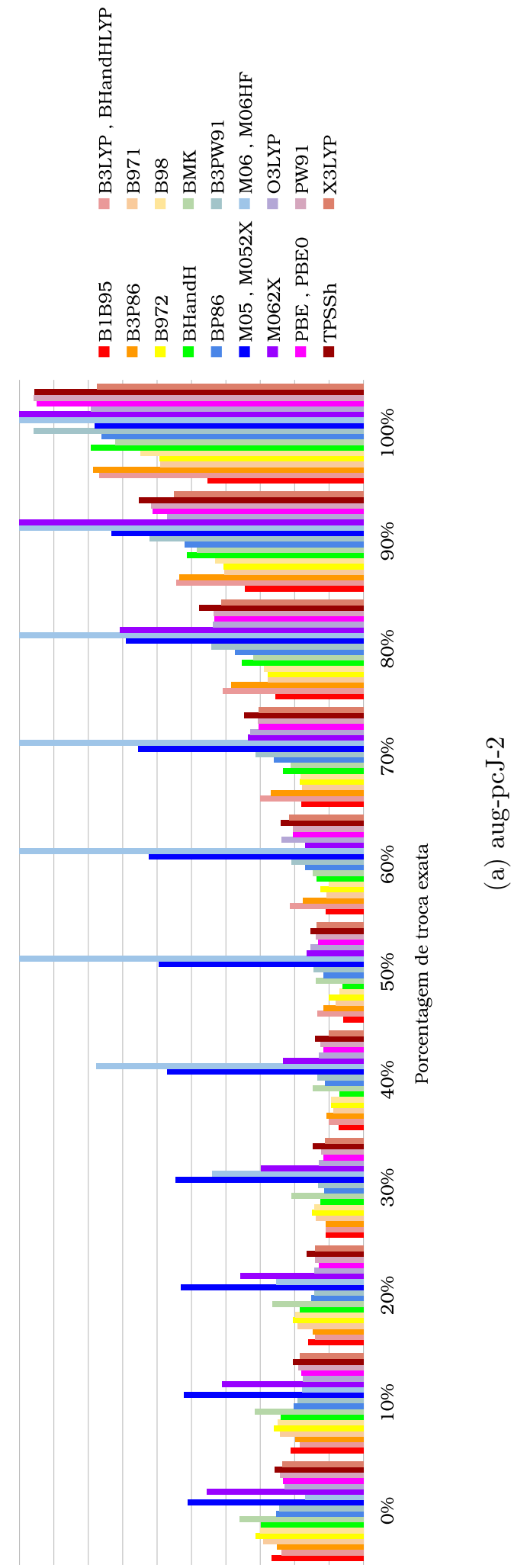

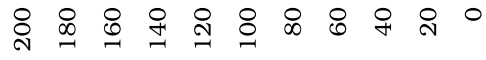
(\%) VWAd

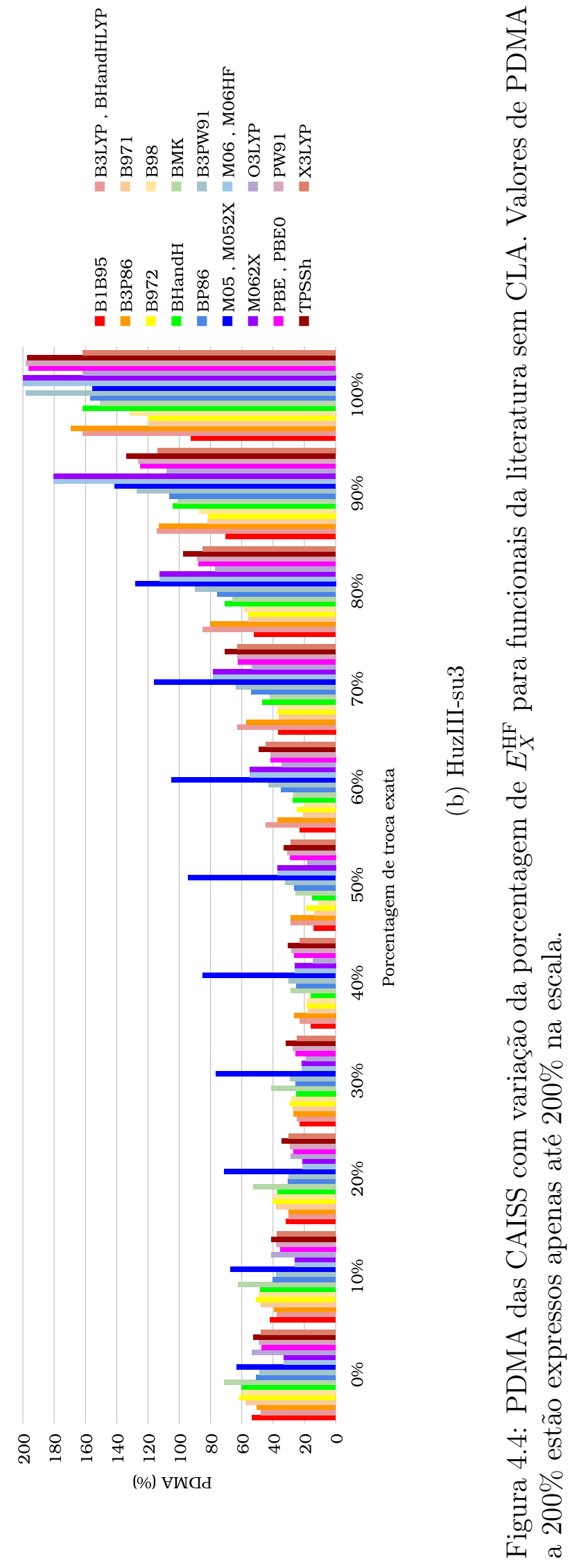


Os resultados mais precisos com a base HuzIII-su3 também são obtidos com os funcionais B1B95, B971, B972, B98 e BHandH com $40 \% E_{X}^{\mathrm{HF}}$ e $50 \% E_{X}^{\mathrm{HF}}$; além disso os funcionais O3LYP $30 \% E_{X}^{\mathrm{HF}}$, O3LYP $40 \% E_{X}^{\mathrm{HF}}$ e O3LYP $50 \% E_{X}^{\mathrm{HF}}$ também apresentam resultados com boa precisão.

A Tabela 4.2 apresenta os valores de PDMA para cada um desses funcionais. Os funcionais derivados de B1B95, B971, B972, B98 e BHandH têm PDMAs próximos entre as bases utilizadas. Por outro lado os funcionais derivados de O3LYP apresentam PDMAs menores que 20\% para HuzIII-su3, enquanto que para aug-pcJ-2 são acima de 25\%. Além disso, o O3LYP original não apresentou PDMA inferior a 25\% para nenhuma das bases.

Tabela 4.2: Valores de PDMA total para os melhores funcionais variando a porcentagem de troca exata.

\begin{tabular}{lcc}
\hline Funcional & aug-pcJ-2 & HuzIII-su3 \\
\hline B1B95 50\% $E_{X}^{\mathrm{HF}}$ & $11,69 \%$ & $13,9 \%$ \\
BHandH 50\% $E_{X}^{\mathrm{HF}}$ & $12,21 \%$ & $14,7 \%$ \\
B98 50\% $E_{X}^{\mathrm{HF}}$ & $14,08 \%$ & $11,1 \%$ \\
BHandH 40\% $E_{X}^{\mathrm{HF}}$ & $14,17 \%$ & $15,8 \%$ \\
B1B95 40\% $E_{X}^{\mathrm{HF}}$ & $14,31 \%$ & $15,8 \%$ \\
B971 50\% $E_{X}^{\mathrm{HF}}$ & $16,15 \%$ & $13,6 \%$ \\
B971 40\% $E_{X}^{\mathrm{HF}}$ & $17,34 \%$ & $17,4 \%$ \\
B98 40\% $E_{X}^{\mathrm{HF}}$ & $18,65 \%$ & $18,4 \%$ \\
B972 40\% $E_{X}^{\mathrm{HF}}$ & $18,93 \%$ & $18,4 \%$ \\
B972 50\% $E_{X}^{\mathrm{HF}}$ & $19,95 \%$ & $18,7 \%$ \\
O3LYP 40\% $E_{X}^{\mathrm{HF}}$ & $26,01 \%$ & $14,5 \%$ \\
O3LYP 30\% $E_{X}^{\mathrm{HF}}$ & $26,03 \%$ & $18,7 \%$ \\
O3LYP 50\% $E_{X}^{\mathrm{HF}}$ & $30,63 \%$ & $18,0 \%$ \\
\hline
\end{tabular}

A base aug-pcJ-2 possui qualidade quádruplo- $\zeta$, enquanto a HuzIII-su3 possui triplo$\zeta$; desta forma é assumido que a qualidade quádruplo- $\zeta$ torna a aug-pcJ-2 uma base de qualidade superior à HuzIII-su3, e portanto não houve continuidade no estudo com o funcional O3LYP. É importante destacar que a base aug-pcJ-2 é contraída, enquanto a HuzIII-su3 é descontraída nas funções gaussianas do tipo "s", ou seja, mais flexível, o que pode melhorar a descrição dos termos FC e SD dos acoplamentos em alguns casos.

Desta forma, os estudos seguintes com os funcionais sem CLA consideram os fun- 
cionais BHandH, B1B95, B971, B972 e B98 e suas versões modificadas. Isso se deve ao fato de apresentarem resultados mais precisos no conjunto de calibração, e portanto são bons candidatos para estimar diferentes tipos de acoplamento. O funcional PBE0 também foi incluído (apesar de ter PDMA superior a 20\% até nas versões modificadas) para comparação, e sua escolha se deve à sua boa precisão para sistemas com metais de transição. $\underline{113}$

\subsubsection{Geometrias otimizadas}

Os valores obtidos para as CAISS, com base aug-pcJ-2, utilizando geometrias experimentais e otimizadas são apresentados nas Tabelas 8.24 a 8.29 para B1B95, B971, B972, B98, BHandH e PBE0. Para cada DFT foi considerado, a princípio, apenas seu ajuste com a porcentagem de $E_{X}^{\mathrm{HF}}$ de menor PDMA com geometrias experimentais e as porcentagens adjacentes $( \pm 10 \%)$, de modo a verificar o valor mínimo de PDMA.

A Figura 4.5apresenta a PDMA total, assim como a PDMA dos conjuntos CPI e SPI, para os funcionais B1B95, B971, B972, B98, BHandH e PBE0 originais e modificados. A notação $\mathrm{DFT}_{1} / / \mathrm{DFT}_{2}$ é adotada, indicando que a otimização de geometrias é feita com o $\mathrm{DFT}_{1}$, e o cálculo da propriedade com o $\mathrm{DFT}_{2}$; a ausência da notação indica que não há otimização das geometrias, logo trata-se das geometrias experimentais.

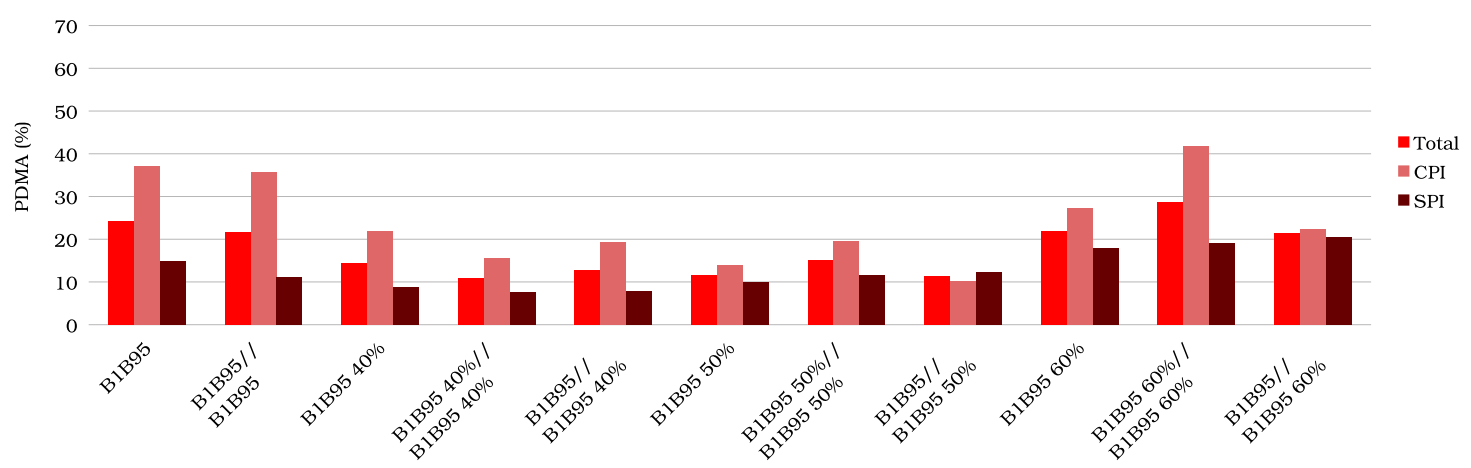

(a) B1B95 


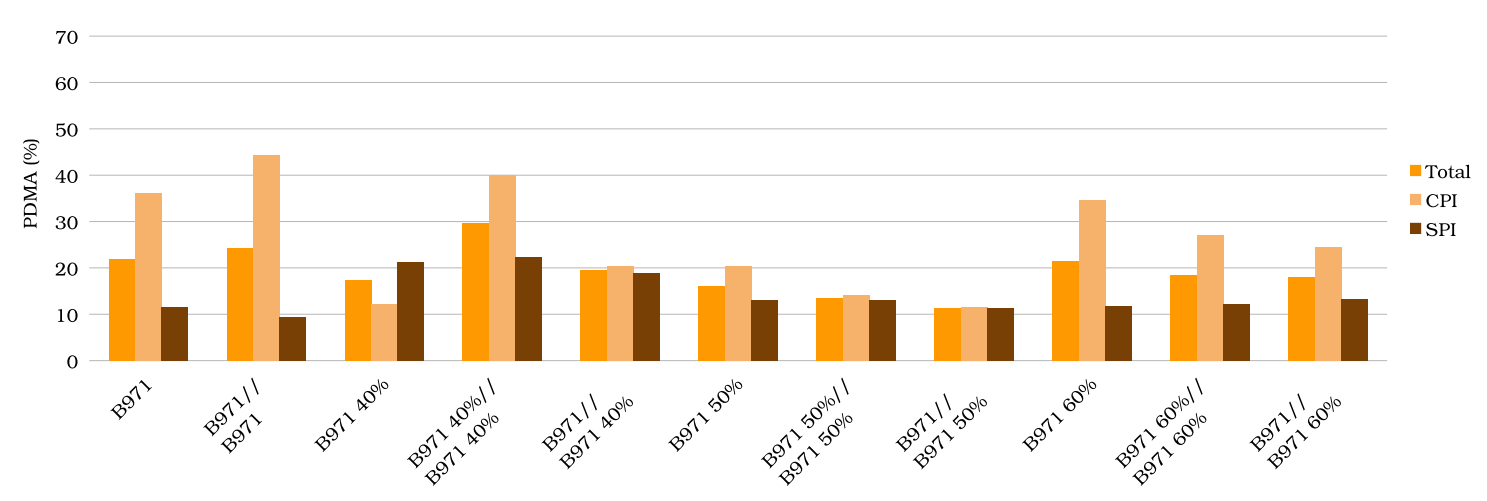

(b) B971

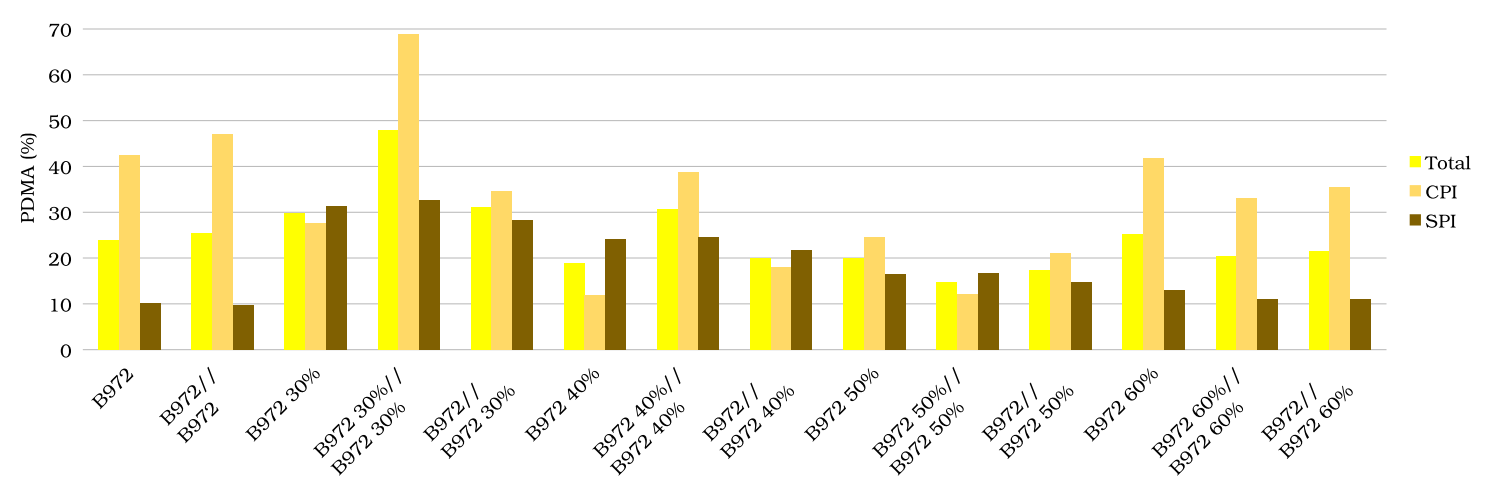

(c) B972

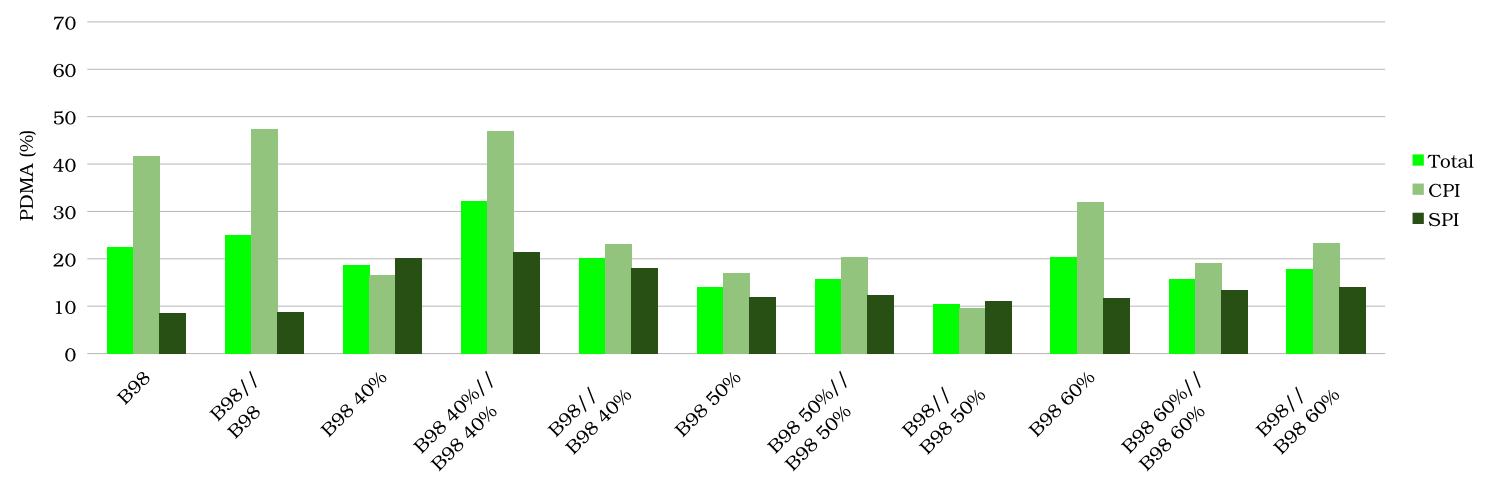

(d) B98

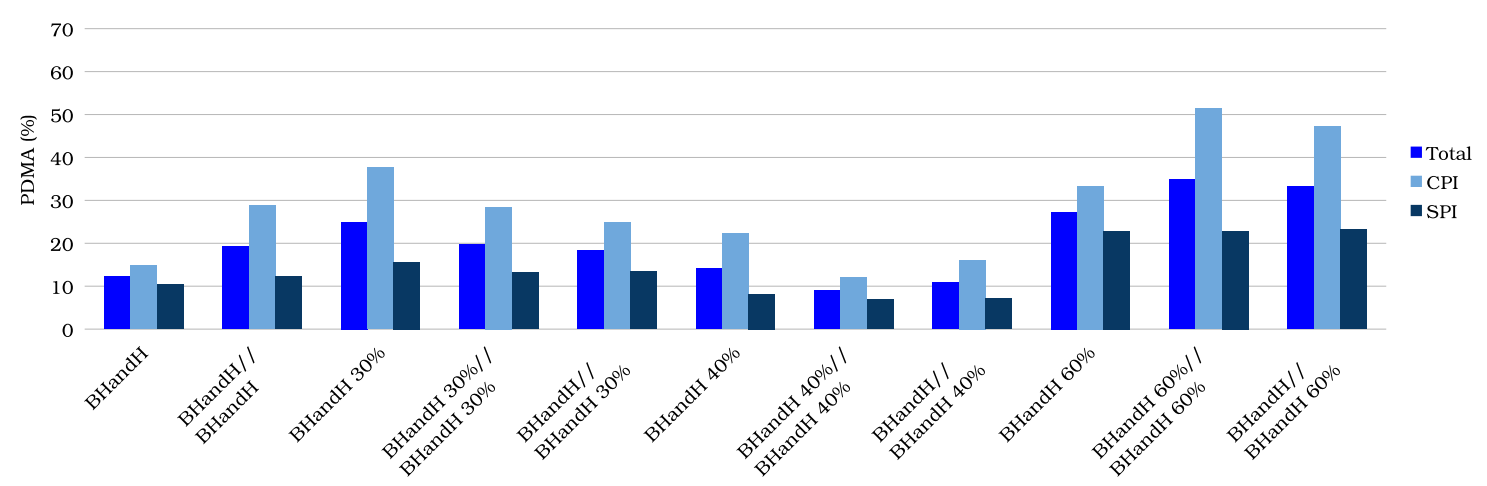

(e) BHandH 


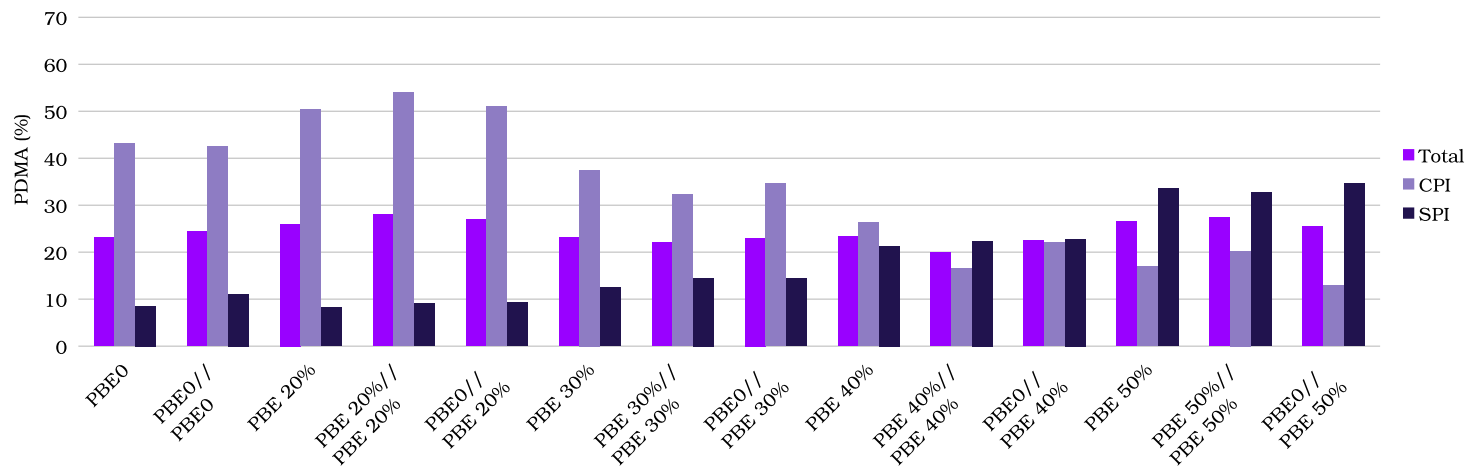

(f) PBE0

Figura 4.5: Comparação entre as PDMAs obtidas com geometrias teóricas e experimentais para os funcionais selecionados com base aug-pcJ-2. As médias são calculadas para as 26 CAISS, para as 11 CAISS das moléculas CPI e para as 15 CAISS das moléculas SPI.

O funcional B1B95 (que originalmente possui $28 \%$ de $E_{X}^{\mathrm{HF}}$ e PDMA $=24,17 \%$ ), mostrado na Figura 4.5a, tem seu melhor resultado com B1B95 40\%//B1B95 40\% (PDMA $=10,96 \%)$. Comparando com B1B95 40\% (14,31\%) e B1B95//B1B95 40\% (12,72\%), os valores da PDMA SPI são próximos, logo a melhor precisão para o cálculo B1B95 40\%//B1B95 40\% é devida aos valores mais precisos obtidos para o conjunto de moléculas CPI. Já o resultado B1B95//B1B95 40\% (11,38\%) é mais balanceado para moléculas CPI e SPI. O melhor resultado com geometria experimental é obtido com B1B95 50\% $(11,69 \%)$.

O funcional B971 (que originalmente possui $21 \%$ de $E_{X}^{\mathrm{HF}}$ e PDMA $=21,89 \%$ ), mostrado na Figura 4.5b, tem seu melhor resultado com B971//B971 50\% (11,38\%). Comparando com B971 50\% (16,15\%) e B971 50\%//B971 50\% (13,54\%), a melhora da precisão se deve principalmente a melhora da CAISS das moléculas CPI, mas também há melhora para as moléculas SPI. Os resultados obtidos para B971//B971 50\% indicam uma boa precisão tanto para moléculas CPI quanto SPI. O melhor resultado com geometria experimental é obtido com B971 50\% (16,15\%).

O funcional B972 (que originalmente possui $21 \%$ de $E_{X}^{\mathrm{HF}}$ e PDMA $=23,84 \%$ ), mostrado na Figura 4.5c tem seu melhor resultado com com B972 50\%//B972 50\% (14,83\%). Comparando com B972 50\% (19,95\%) e B972//B972 50\% (17,38\%), a melhora da precisão se deve principalmente a melhora da PDMA CPI, que varia muito mais entre os ajustes do 
que a PDMA SPI. Os resultados obtidos para B972 50\%//B972 50\% tem melhor precisão para moléculas CPI do que SPI (na maioria dos casos foi o contrário). O melhor resultado com geometria experimental é obtido com B972 40\% (18,93\%).

O funcional B98 (que originalmente possui 21,98\% de $E_{X}^{\mathrm{HF}}$ e PDMA $=22,55 \%$ ), mostrado na Figura 4.5d, tem seu melhor resultado com com B98//B98 50\% (10,44\%). Comparando com B98 50\% (14,08\%) e B98 50\%//B98 50\% (15,68\%), a melhora da precisão se deve principalmente a melhora da CAISS das moléculas CPI, mas também há melhora para as moléculas SPI. Os resultados obtidos para B98//B98 50\% indicam uma boa precisão tanto para moléculas CPI quanto SPI (sendo um pouco mais preciso para CPI do que SPI). O melhor resultado com geometria experimental é obtido com B98 50\% (14,08\%).

O funcional BHandH (que originalmente possui $50 \%$ de $E_{X}^{\mathrm{HF}}$ e PDMA $=12,21 \%$ ), mostrado na Figura 4.5e, tem seu melhor resultado com com BHandH 40\%//BHandH 40\% (9,04\%). Comparando com BHandH 40\% (14,17\%) e BHandH//BHandH 40\% (10,94\%), os valores da PDMA SPI são próximos, logo a melhor precisão para o cálculo BHandH 40\%//BHandH 40\% é devida aos valores mais precisos obtidos para o conjunto de moléculas CPI. A PDMA CPI, além de ter maiores variações, é sempre maior que a PDMA SPI para todos ajustes. O melhor resultado com geometria experimental é obtido com BHandH $(12,21 \%)$.

O funcional PBE0 (que originalmente possui $25 \%$ de $E_{X}^{\mathrm{HF}}$ e PDMA $=23,18 \%$ ), mostrado na Figura 4.5f, tem seu melhor resultado com com PBE 40\%//PBE 40\% (19,92\%). Comparando com PBE 40\% (23,41\%) e PBE0//PBE 40\% (22,50\%), os valores da PDMA SPI são próximos, logo a melhor precisão para o cálculo PBE 40\%//PBE $40 \%$ é devida aos valores mais precisos obtidos para o conjunto de moléculas CPI. Apesar disso, a melhora da precisão CPI conforme o aumento da porcentagem de $E_{X}^{\mathrm{HF}}$ também acarreta na piora da precisão SPI. O melhor resultado com geometria experimental é obtido com PBE $30 \%$ $(23,07 \%)$.

De maneira geral, o ajuste da porcentagem de troca exata melhora a precisão (com exceção do BHandH) relativa ao DFT original para geometrias experimentais, conforme já observado. Já a otimização das geometrias, tanto com o DFT original quanto com 
o modificado, melhora a precisão no cálculo das CAISS comparado com a geometria experimental (apenas o B98//B98 50\% teve uma ligeira piora).

O resultado mais preciso é obtido com BHandH 40\%//BHandH 40\%, seguido de B1B95 40\%//B1B95 40\%. Apesar disso, os resultados para o conjunto de moléculas SPI são mais precisos do que os resultados para o conjunto de moléculas CPI. Já os resultados com B971//B971 50\% e B98//B98 50\% também apresentaram uma ótima precisão, e as precisões para os conjuntos CPI e SPI estão muito mais próximas, indicando um bom ajuste independente da presença ou não de pares isolados. Essas 4 metodologias, portanto, são recomendadas para otimização seguida do cálculo de CAISS que envolvam acoplamentos similares aos do conjunto de calibração - as 2 primeiras pela excelente precisão geral, e as 2 últimas pela independência da precisão decorrente da presença de pares isolados nas moléculas. 


\subsection{Correções vibracionais para os funcionais testados}

A correção vibracional das CAISS foi calculada no pacote Dalton2016 $6^{\sqrt{96}}$ com BHandH, BHandH 40\% e PBE0 40\%, utilizando geometrias otimizadas obtidas com o Gaussian 09 ${ }^{39}$ As coordenadas atômicas de algumas moléculas foram reorientadas para permitir a utilização de elementos de simetria molecular. A comparação com os resultados anteriores está apresentada nas Tabelas 8.30 e 8.31 .

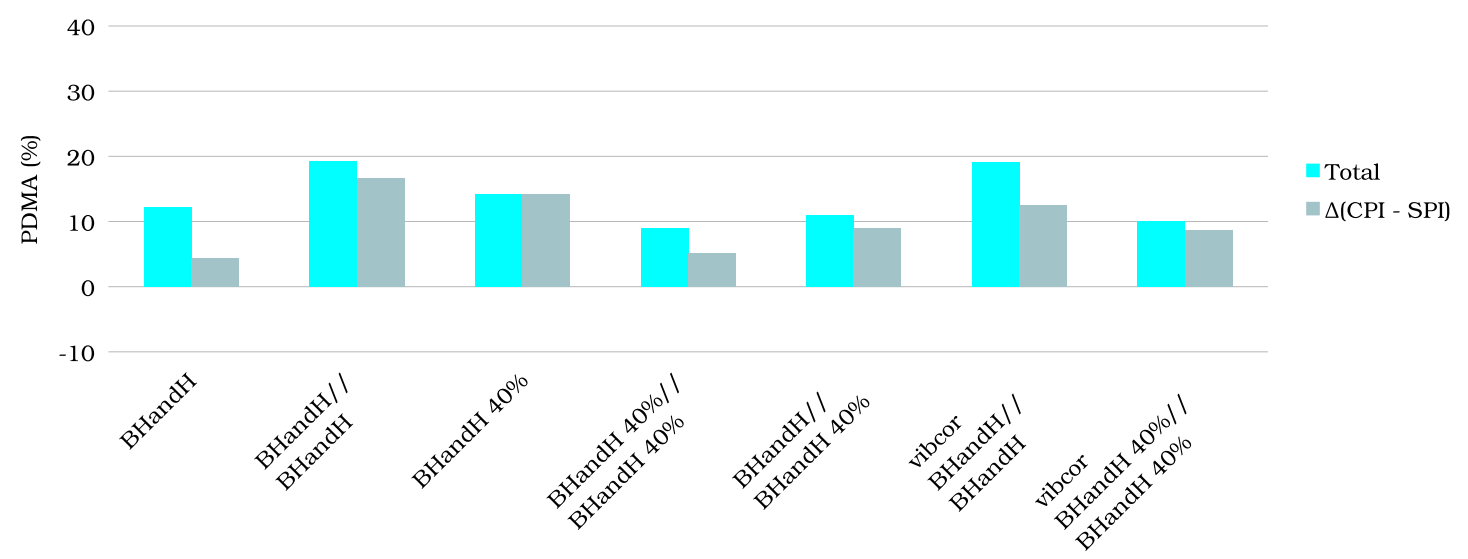

(g) BHandH

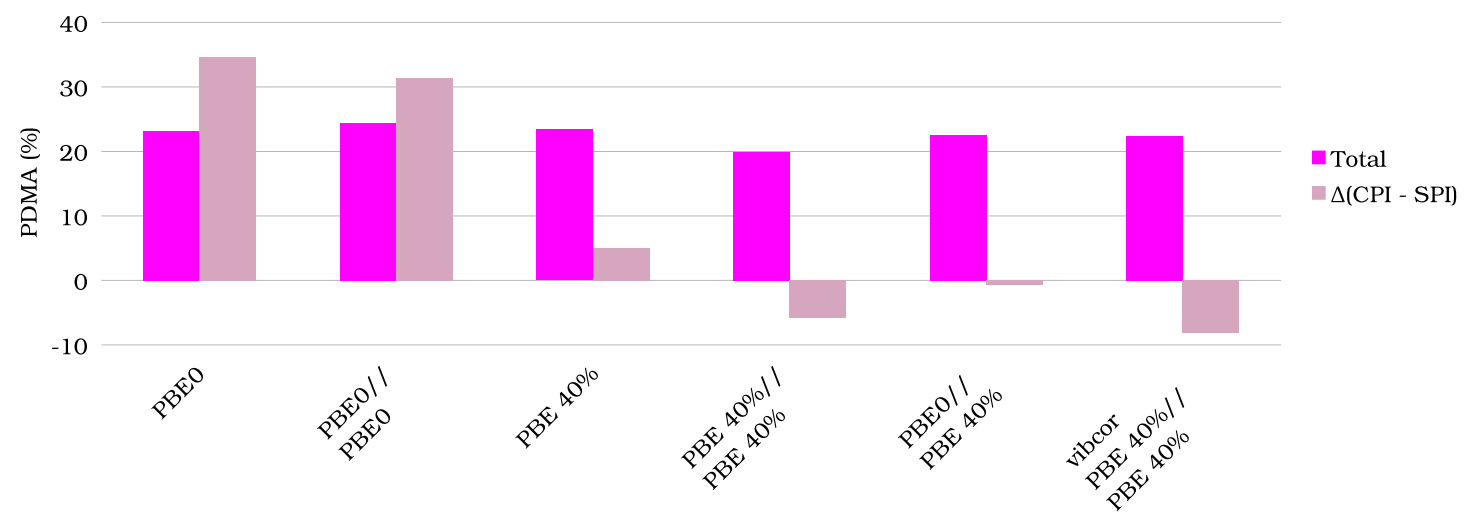

(h) PBE0

Figura 4.6: Comparação entre as PDMAs obtidas pelas correções vibracionais das CAISS e os resultados sem correção, com base aug-pcJ-2, para os funcionais implementados no Dalton. As médias são calculadas para todas as 26 CAISS, assim como a diferença das médias dos conjuntos CPI e SPI.

A Figura 4.6 apresenta os valores de PDMA total e $\Delta(\mathrm{CPI}-\mathrm{SPI})$, comparando com os resultados sem correção vibracional. O termo vibcor foi adicionado para indicar os resultados das correções vibracionais. 
O resultado para vibcor $\mathrm{BHandH} / / \mathrm{BHandH}(\mathrm{PDMA}=19,07 \%)$ tem precisão próxima ao resultado sem correção BHandH//BHandH (19,31\%), e o tratamento para moléculas CPI e SPI tem PDMA mais próximas para a correção vibracional $(\Delta(\mathrm{CPI}-\mathrm{SPI})=12,45 \%$ $\times 16,59 \%)$. O resultado para vibcor $\mathrm{BHandH}$ 40\%//BHandH 40\% (10,04\%) também tem precisão próxima ao resultado sem correção BHandH 40\%//BHandH 40\% (9,04\%), e os conjuntos para moléculas CPI e SPI têm precisões um pouco mais distantes para a correção vibracional $(8,62 \% \times 5,16 \%$, respectivamente). Por sua vez o resultado para vibcor PBE 40\%//PBE 40\% (22,34\%) tem precisão razoavelmente próxima ao resultado sem correção PBE 40\%//PBE 40\% (19,92\%), e os conjuntos para moléculas CPI e SPI têm precisões um pouco mais distantes para a correção vibracional $(-8,11 \% \times-5,85 \%$, respectivamente), desta vez com uma pior precisão para sistemas SPI do que CPI.

A adição de correções vibracionais no cálculo das CAISS não altera significativamente a precisão do conjunto de calibração. A Tabela 4.3 contém as correções vibracionais para cada constante de acoplamento obtidas com BHandH, BHandH 40\% e PBE0 40\%. As correções obtidas com BHandH, BHandH 40\% e PBE0 $40 \%$ para cada uma das CAISS possuem valores próximos e com magnitudes, em geral, muito menor que a magnitude das CAISS experimentais. Desta forma é assumido que o cálculo das correções vibracionais com outros DFTs deve resultar em valores próximos aos da Tabela 4.3 .

Para verificar as diferenças entre os conjuntos de correções vibracionais obtidos e a validade de assumir que as correções independem do funcional, são apresentados CAISS empíricos (subtraindo as correções vibracionais dos valores experimentais) com BHandH, BHandH 40\% e PBE0 $40 \%$ na Tabela 8.32, que também têm valores próximos.

As duas estratégias utilizadas para avaliar se a adição das correções vibracionais influencia significativamente os resultados obtidos é utilizada para corrigir os dados das Tabelas 8.1 a 8.2, 8.5 a 8.22, e 8.24 a 8.29. A adição das correções vibracionais às CAISS obtidas teoricamente $\left(J_{\text {corr }_{\mathrm{i}}}\right)$ estão apresentadas nas Tabelas 8.33 a 8.110, Já a utilização das CAISS empíricas $\left(J_{\mathrm{emp}_{\mathrm{i}}}\right)$ como referência estão apresentadas nas Tabelas 8.111 a 8.188

As correções para as PDMAs dos funcionais da literatura estão apresentadas na Figura 
4.7 (Tabelas 8.33 a 8.38; e 8.111 a 8.116). De fato, os resultados para $J_{\text {corr }_{\mathrm{i}}}$ apresentam resultados similares para os três funcionais (Figuras $4.7 \mathrm{a}, 4.7 \mathrm{c}$ e $4.7 \mathrm{e}$ ). Da mesma forma, os resultados para $J_{\mathrm{emp}_{\mathrm{i}}}$ são também similares (Figuras 4.7b, 4.7d e 4.7f).

Tabela 4.3: Correções vibracionais (em Hz) das CAISS obtidas com BHandH e PBE0.

\begin{tabular}{ccccc}
\hline & Funcional & BHandH & BHandH & PBE0 \\
& $E_{X}^{\mathrm{HF}}(\%)$ & 50,00 & 40,00 & 40,00 \\
\hline $\mathrm{HF}$ & ${ }^{1} J_{\mathrm{HF}}$ & $-32,8$ & $-33,2$ & $-34,8$ \\
$\mathrm{CO}$ & ${ }^{1} J_{\mathrm{CO}}$ & 0,7 & 0,8 & 0,7 \\
$\mathrm{H}_{2} \mathrm{O}$ & ${ }^{1} J_{\mathrm{JOH}}$ & 1,1 & 1,2 & 1,4 \\
$\mathrm{H}_{2} \mathrm{O}$ & ${ }^{2} J_{\mathrm{HH}}$ & 1,5 & 1,4 & 1,5 \\
$\mathrm{NH}_{3}$ & ${ }^{1} J_{\mathrm{NH}}$ & 0,8 & 0,7 & 0,5 \\
$\mathrm{NH}_{3}$ & ${ }^{2} J_{\mathrm{HH}}$ & 0,9 & 0,9 & 0,8 \\
$\mathrm{PH}_{3}$ & ${ }^{1} J_{\mathrm{PH}}$ & $-6,8$ & $-7,3$ & $-7,5$ \\
$\mathrm{PF}_{3}$ & ${ }^{1} J_{\mathrm{PF}}$ & 0,7 & 1,8 & 2,2 \\
$\mathrm{BHF}_{2}$ & ${ }^{1} J_{\mathrm{BF}}$ & $-4,3$ & $-4,5$ & $-4,4$ \\
$\mathrm{BF}_{3}$ & ${ }^{1} J_{\mathrm{BF}}$ & $-2,1$ & $-2,2$ & $-2,2$ \\
$\mathrm{~F}_{2} \mathrm{O}$ & ${ }^{1} J_{\mathrm{OF}}$ & $-14,3$ & $-13,1$ & $-15,3$ \\
$\mathrm{CH}_{4}$ & ${ }^{1} J_{\mathrm{CH}}$ & 2,5 & 2,3 & 2,4 \\
$\mathrm{CH}_{4}$ & ${ }^{2} J_{\mathrm{HH}}$ & $-0,3$ & $-0,3$ & $-0,3$ \\
$\mathrm{C}_{2} \mathrm{H}_{2}$ & ${ }^{1} J_{\mathrm{CC}}$ & 0,7 & 0,4 & 0,9 \\
$\mathrm{C}_{2} \mathrm{H}_{2}$ & ${ }^{1} J_{\mathrm{CH}}$ & 3,3 & 3,1 & 3,2 \\
$\mathrm{C}_{2} \mathrm{H}_{2}$ & ${ }^{2} J_{\mathrm{CH}}$ & 0,3 & 0,4 & 0,2 \\
$\mathrm{C}_{2} \mathrm{H}_{2}$ & ${ }^{3} J_{\mathrm{HH}}$ & 0,6 & 0,5 & 0,7 \\
$\mathrm{C}_{2} \mathrm{H}_{4}$ & ${ }^{1} J_{\mathrm{CC}}$ & 0,7 & 0,4 & 1,0 \\
$\mathrm{C}_{2} \mathrm{H}_{4}$ & ${ }^{1} J_{\mathrm{CH}}$ & 1,9 & 1,8 & 2,0 \\
$\mathrm{C}_{2} \mathrm{H}_{4}$ & ${ }^{2} J_{\mathrm{CH}}$ & $-0,4$ & $-0,3$ & $-0,5$ \\
$\mathrm{C}_{2} \mathrm{H}_{4}$ & ${ }^{2} J_{\mathrm{HH}}$ & 0,2 & 0,3 & 0,2 \\
$\mathrm{C}_{2} \mathrm{H}_{4}$ & ${ }^{3} J_{\mathrm{HH}}$ & 0,3 & 0,3 & 0,4 \\
$\mathrm{C}_{2} \mathrm{H}_{4}$ & ${ }^{3} J_{\mathrm{HH}}$ & 0,6 & 0,5 & 0,7 \\
$\mathrm{C}_{2} \mathrm{H}_{6}$ & ${ }^{1} J_{\mathrm{CC}}$ & 0,9 & 0,8 & 0,9 \\
$\mathrm{C}_{2} \mathrm{H}_{6}$ & ${ }^{1} J_{\mathrm{CH}}$ & 1,9 & 1,8 & 1,8 \\
$\mathrm{C}_{2} \mathrm{H}_{6}$ & ${ }^{2} J_{\mathrm{CH}}$ & $-0,2$ & $-0,2$ & $-0,2$ \\
\hline & & & & \\
\hline
\end{tabular}

A PDMA, portanto, independe do funcional utilizado para obter as correções vibracionais. Além disso, as duas estratégias para corrigir as CAISS tem resultados próximos (como nas Figuras 4.7a e 4.7b, por exemplo), que apresentam comportamento parecido 
ao obtido inicialmente para os DFTs da literatura (Figura 4.1).

Para melhor verificar as diferenças existentes entre os resultados iniciais para os DFTs da literatura e suas correções, os DFTs com PDMA inferior a 25\% (sem correções) são comparados aos valores de PDMA obtidos para cada uma das correções realizadas.

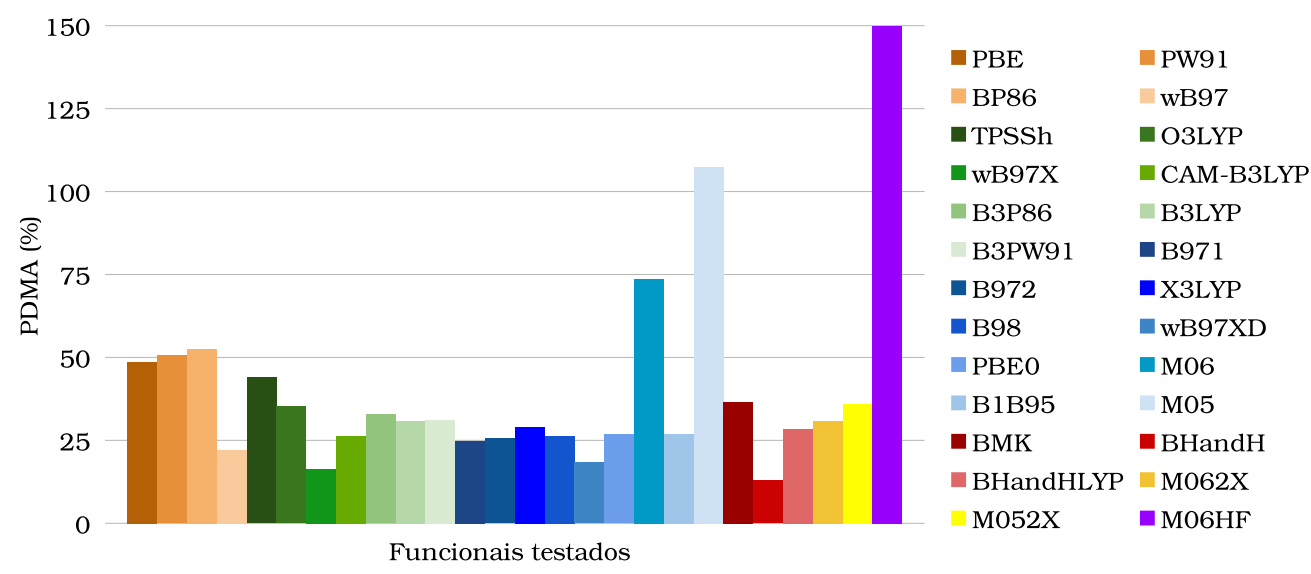

(a) $J_{\text {corri }}$ BHandH

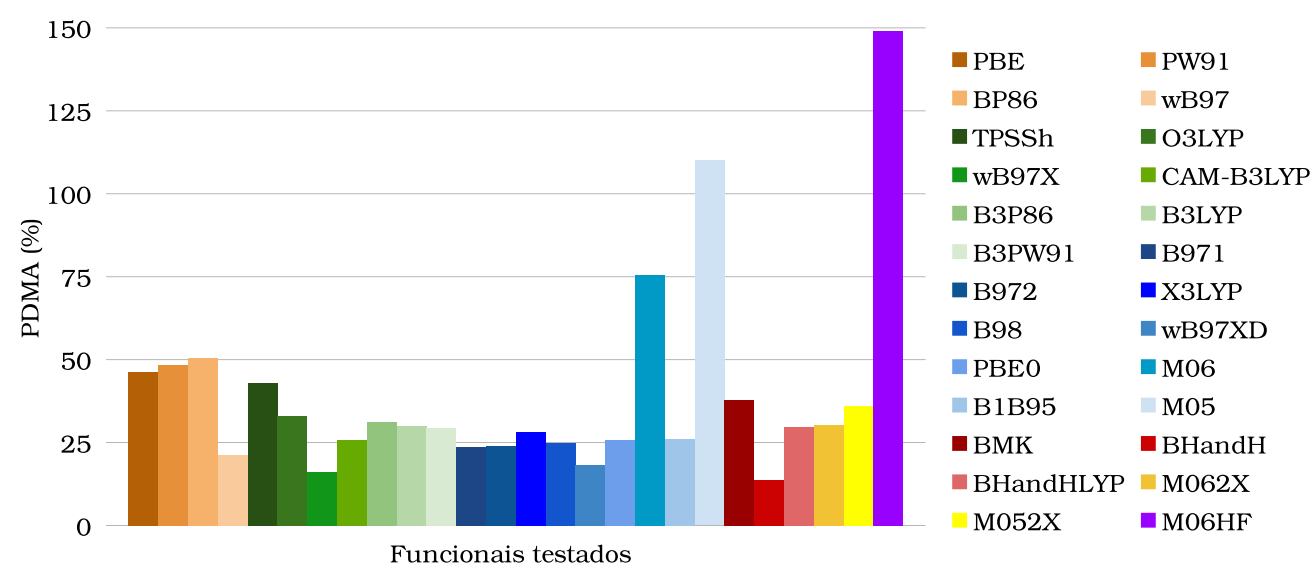

(b) $J_{\mathrm{emp}_{\mathrm{i}}} \mathrm{BHandH}$

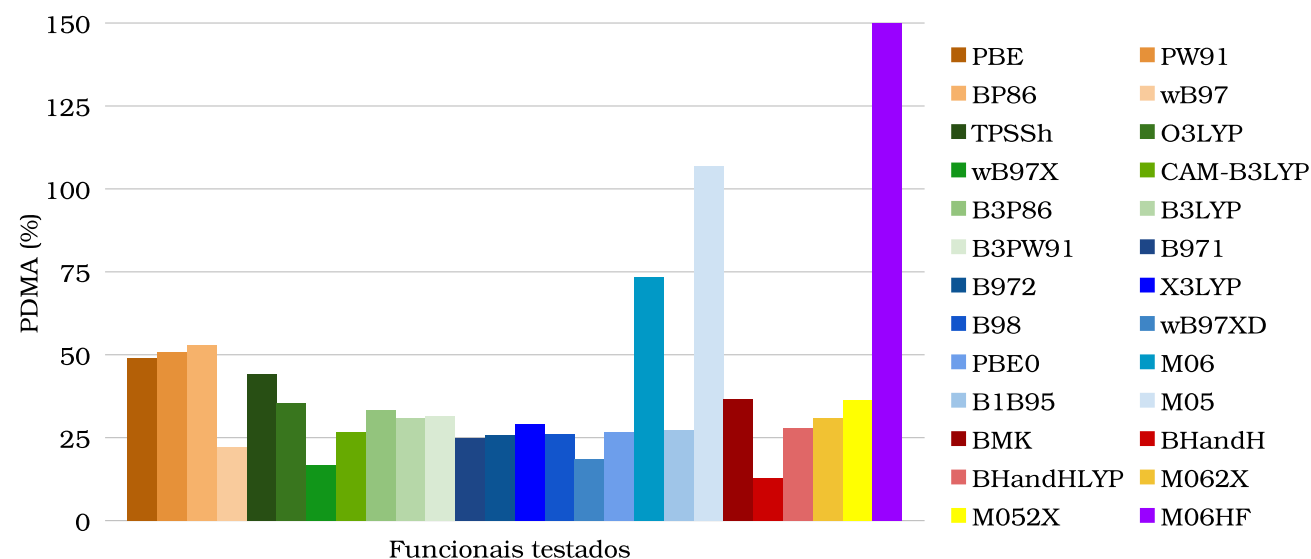

(c) $J_{\text {corr }_{i}}$ BHandH $40 \%$ 


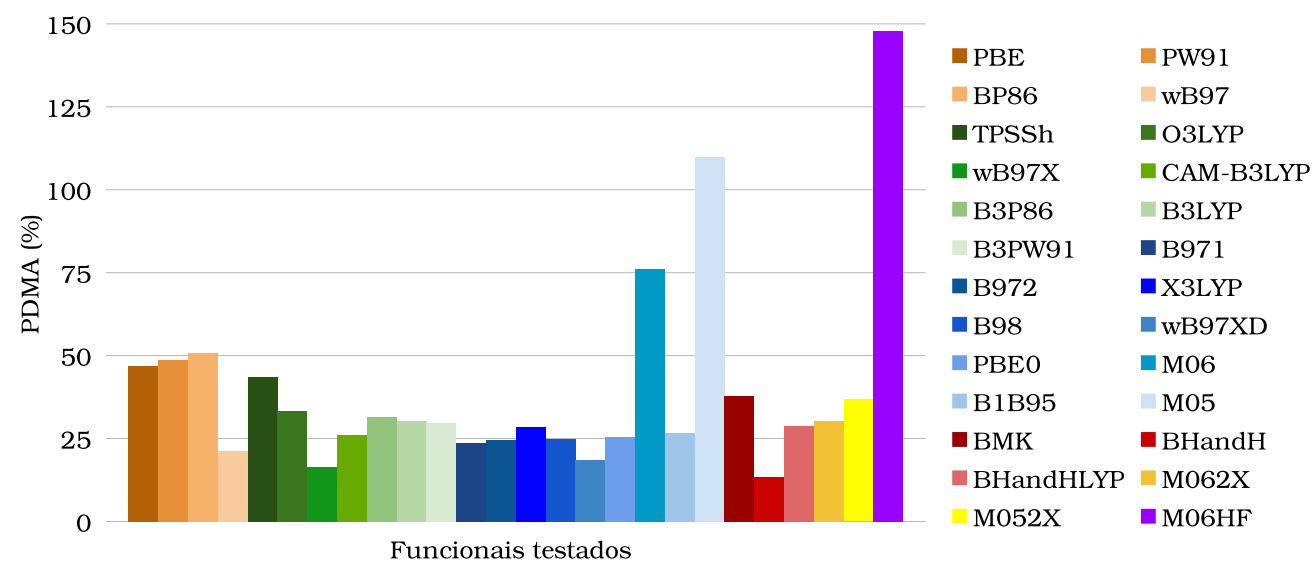

(d) $J_{\mathrm{emp}_{\mathrm{i}}}$ BHandH $40 \%$

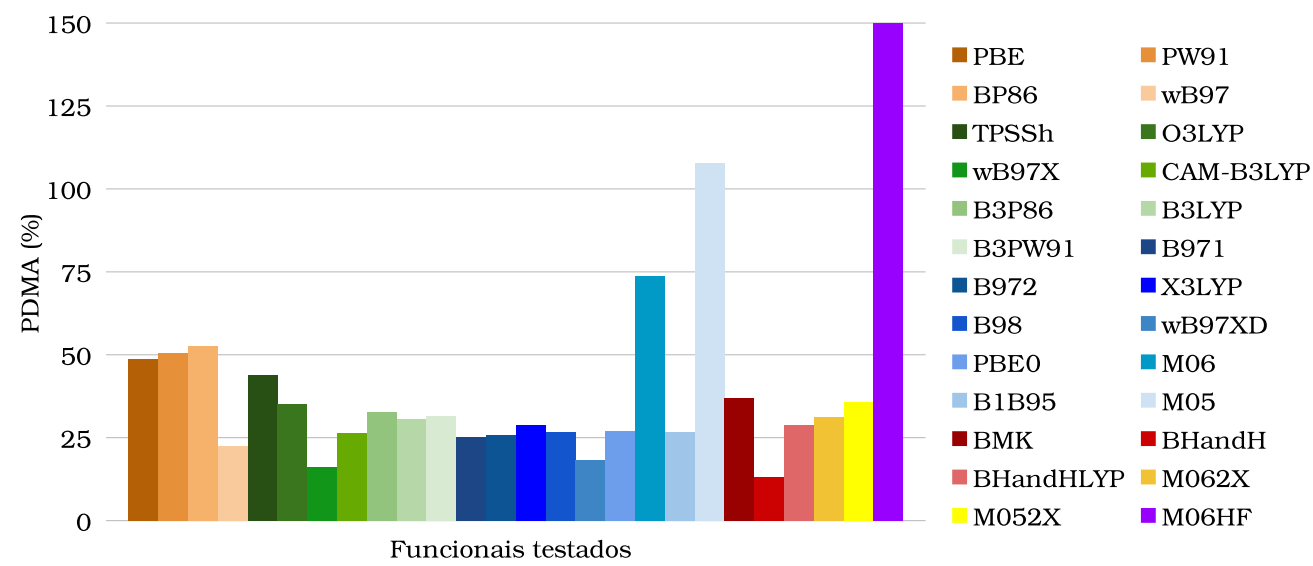

(e) $J_{\text {corr }_{i}}$ PBE $40 \%$

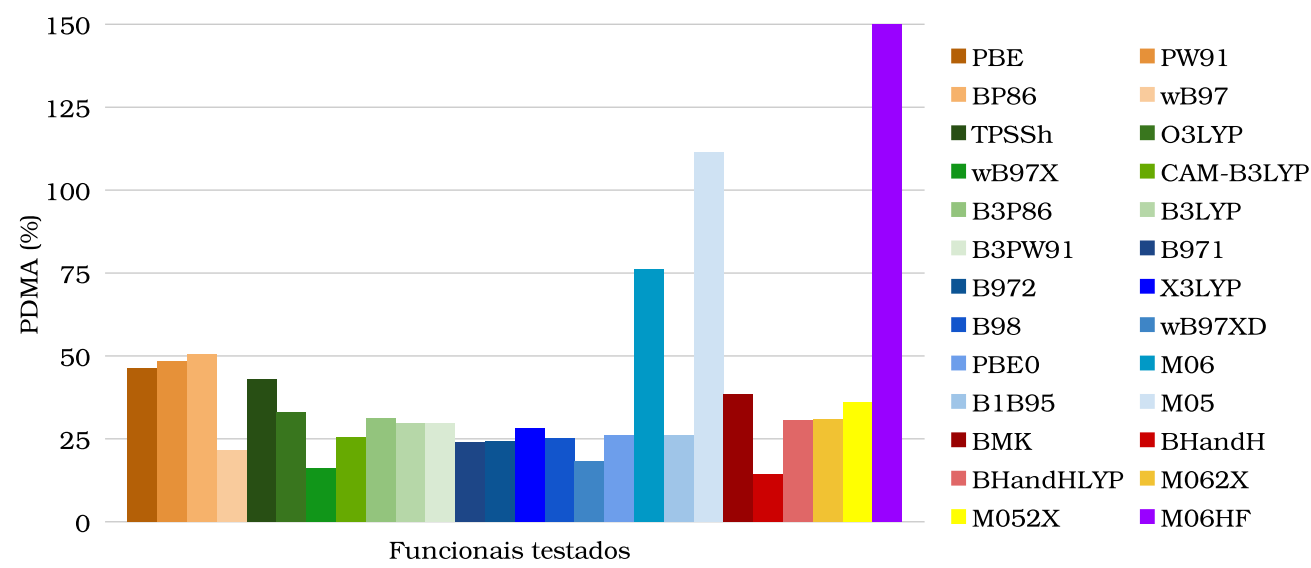

(f) $J_{\mathrm{emp}_{\mathrm{i}}} \mathrm{PBE} 40 \%$

Figura 4.7: PDMA para funcionais da literatura, com base aug-pcJ-2, utilizando as correções vibracionais para correção das CAISS teóricas $\left(J_{\text {corr }_{\mathrm{i}}}\right)$ ou experimentais $\left(J_{\mathrm{emp}_{\mathrm{i}}}\right)$.

A Tabela 4.4 apresenta os 10 DFTs mais precisos da literatura e seus valores de PDMA. Primeiramente, os valores de PDMA para cada DFT estão próximos (a maior diferença é 
de 4\% para o B98). Os 5 DFTs com melhor precisão (BHandH, $\omega$ B97X, $\omega$ B97XD, $\omega$ B97 e B971) continuam tendo as melhores precisões, na mesma ordem. Estes são os resultados com melhor precisão em todas correções feitas, ou seja, os demais funcionais da literatura não são mais precisos do que esses 10 DFTs.

Tabela 4.4: Comparação entre as PDMAs dos funcionais da literatura obtidas considerando as correções vibracionais. Estão indicados os funcionais utilizados para obter as correções vibracionais, assim como qual estratégia de correção dos dados foi utilizada.

\begin{tabular}{|c|c|c|c|c|c|c|c|}
\hline \multirow{2}{*}{$\begin{array}{l}\text { Correção } \\
\text { Funcional }\end{array}$} & \multirow{2}{*}{-} & $J_{\text {corr }}$ & $J_{e m p_{i}}$ & $J_{c o r r_{i}}$ & $J_{e m p_{i}}$ & $J_{\text {corr }_{i}}$ & $J_{e m p_{i}}$ \\
\hline & & \multicolumn{2}{|c|}{ BHandH } & \multicolumn{2}{|c|}{ BHandH $40 \%$} & \multicolumn{2}{|c|}{ PBE $40 \%$} \\
\hline BHandH & $12,21 \%$ & $12,91 \%$ & $13,67 \%$ & $12,89 \%$ & $13,44 \%$ & $13,25 \%$ & $14,25 \%$ \\
\hline$\omega \mathrm{B} 97 \mathrm{X}$ & $14,49 \%$ & $16,29 \%$ & $16,12 \%$ & $16,65 \%$ & $16,53 \%$ & $16,23 \%$ & $16,09 \%$ \\
\hline$\omega B 97 X D$ & $16,48 \%$ & $18,32 \%$ & $18,09 \%$ & $18,68 \%$ & $18,47 \%$ & $18,26 \%$ & $18,08 \%$ \\
\hline$\omega \mathrm{B} 97$ & $19,64 \%$ & $22,08 \%$ & $21,17 \%$ & $22,52 \%$ & $21,19 \%$ & $22,35 \%$ & $21,47 \%$ \\
\hline B971 & $21,89 \%$ & $24,84 \%$ & $23,65 \%$ & $24,78 \%$ & $23,67 \%$ & $25,12 \%$ & $23,94 \%$ \\
\hline B98 & $22,55 \%$ & $26,24 \%$ & $24,94 \%$ & $26,14 \%$ & $24,84 \%$ & $26,55 \%$ & $25,28 \%$ \\
\hline PBE0 & $23,18 \%$ & $26,70 \%$ & $25,71 \%$ & $26,66 \%$ & $25,52 \%$ & $27,04 \%$ & $26,15 \%$ \\
\hline B972 & $23,84 \%$ & $25,53 \%$ & $24,07 \%$ & $25,85 \%$ & $24,47 \%$ & $25,76 \%$ & $24,28 \%$ \\
\hline $\begin{array}{l}\text { CAM- } \\
\text { B3LYP }\end{array}$ & $23,87 \%$ & $26,32 \%$ & $25,63 \%$ & $26,56 \%$ & $26,01 \%$ & $26,28 \%$ & $25,55 \%$ \\
\hline B1B95 & $24,17 \%$ & $26,88 \%$ & $26,16 \%$ & $27,16 \%$ & $26,55 \%$ & $26,81 \%$ & $26,10 \%$ \\
\hline
\end{tabular}

Os resultados da variação da porcentagem de $E_{X}^{\mathrm{HF}}$ também foram corrigidos (Tabelas 8.39 a 8.92 ; e 8.117 a 8.170, e os valores de PDMA total estão apresentados na Figura 4.8. Apenas variações dos funcionais BHandH, B1B95, B971, B972 e B98 apresentam resultados com PDMA inferior a 20\%, com valor mínimo utilizando por volta de $40 \%$ a $50 \% E_{X}^{\mathrm{HF}}$ (de acordo com a Figura 4.4a).

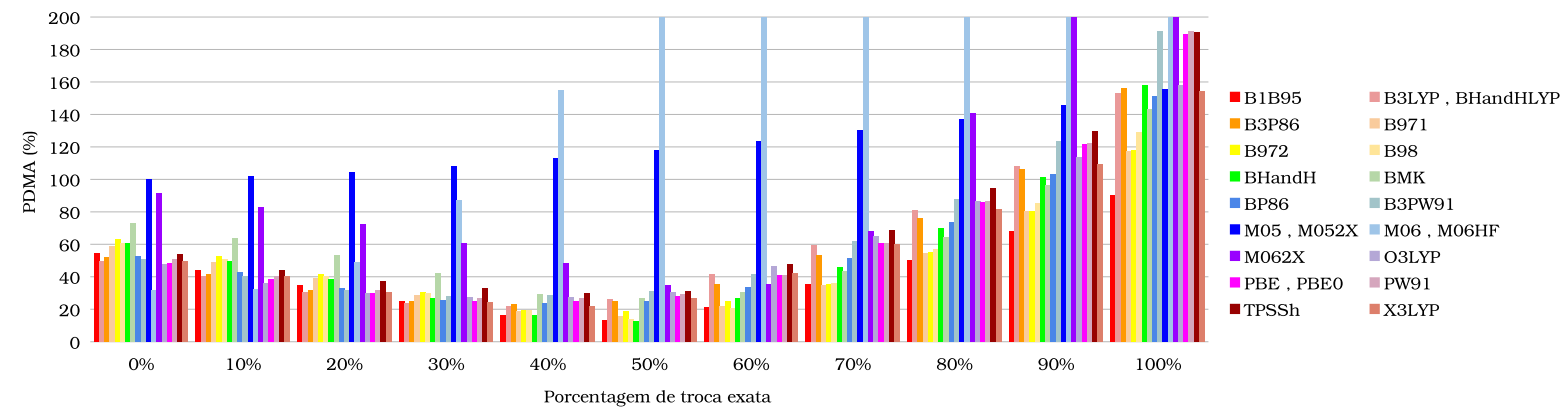

(a) $J_{\text {corri }}$ BHandH 


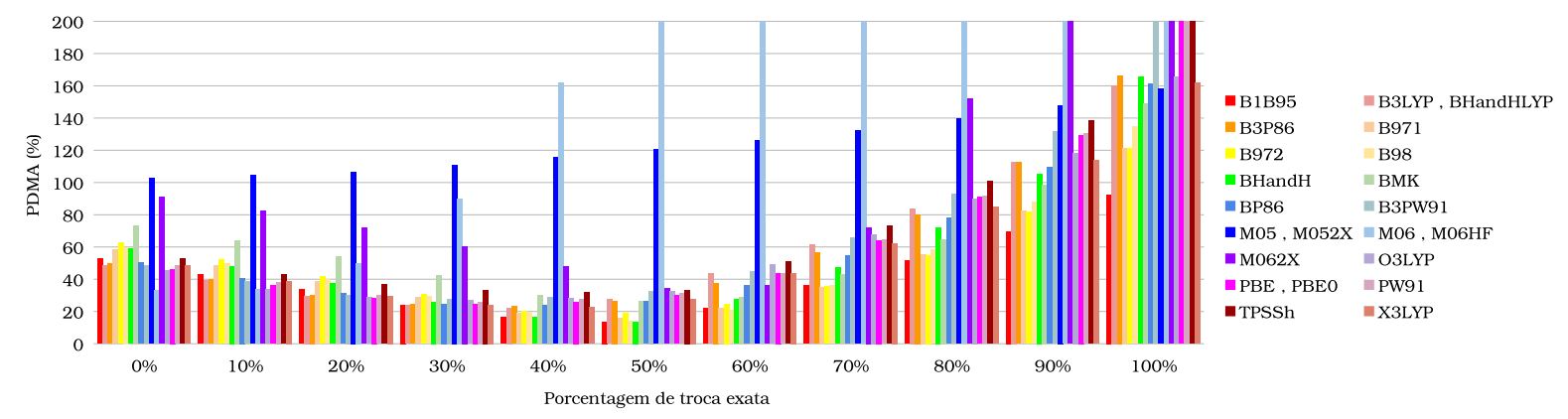

(b) $J_{\text {empi }}$ BHandH

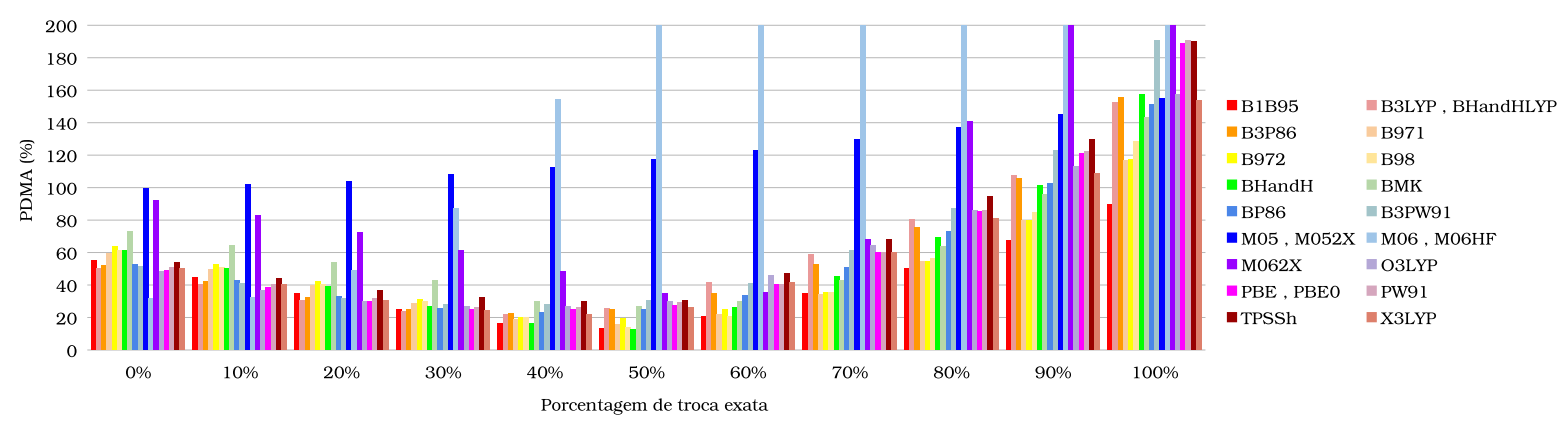

(c) $J_{\text {corr }}$ BHandH $40 \%$

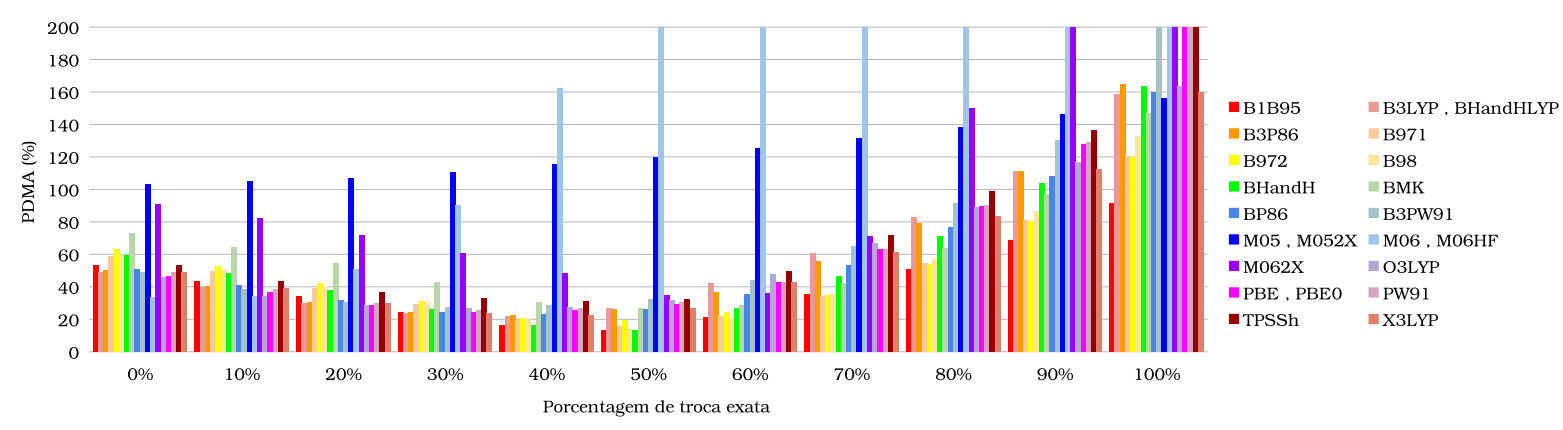

(d) $J_{\text {empi }}$ BHandH $40 \%$

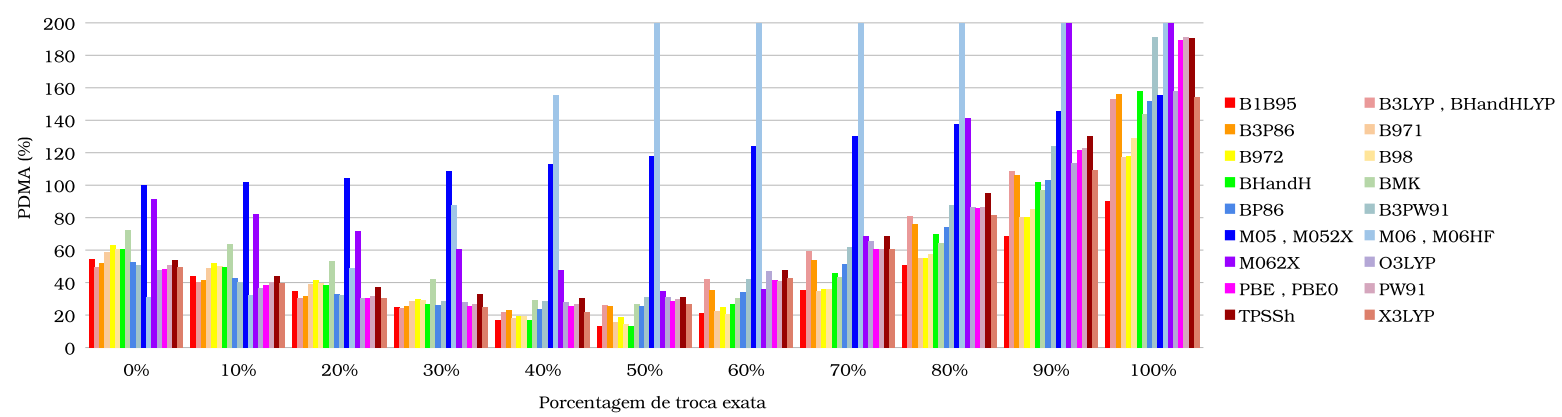

(e) $J_{\text {corri }}$ PBE $40 \%$ 


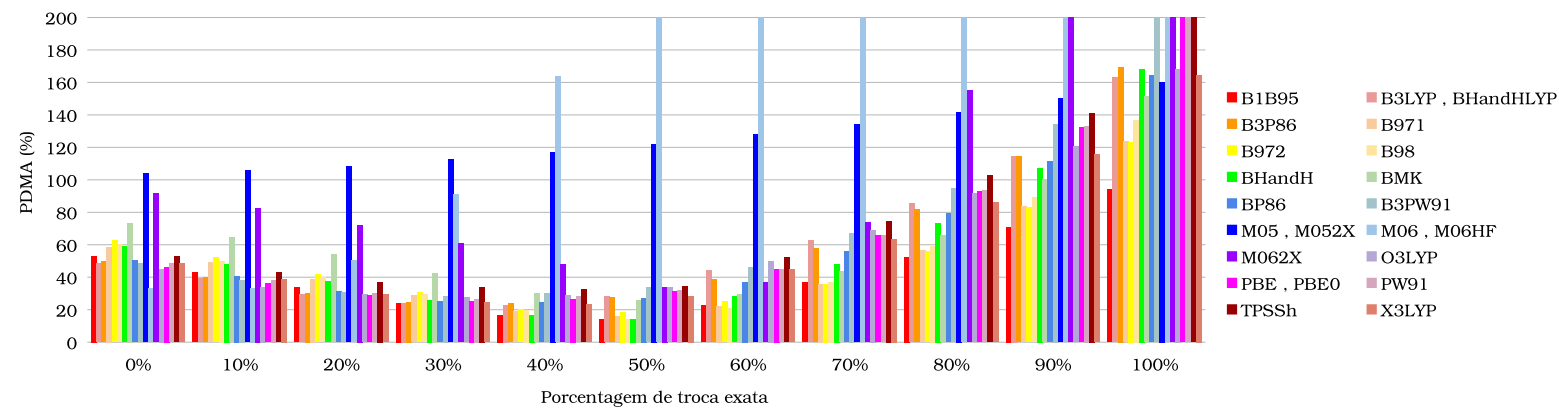

(f) $J_{\mathrm{emp}_{\mathrm{i}}}$ PBE $40 \%$

Figura 4.8: PDMA das CAISS com variação da porcentagem de $E_{X}^{\mathrm{HF}}$ para funcionais da literatura sem CLA, utilizando as correções vibracionais para correção das CAISS teóricas $\left(J_{\text {corr }_{\mathrm{i}}}\right)$ ou experimentais $\left(J_{\mathrm{emp}_{\mathrm{i}}}\right)$. Valores de PDMA superiores a $200 \%$ estão expressos apenas até $200 \%$ na escala.

Os resultados para B1B95, B971, B972, B98, BHandH e PBE0 envolvendo a otimização de geometrias foram corrigidos da mesma maneira (Tabelas 8.93 a 8.110, e 8.171 a 8.188), e os valores de PDMA total estão apresentados na Figuras 4.9, 4.10, 4.11, 4.12, 4.13 e 4.14, respectivamente. Novamente, os resultados com melhores precisões são reproduzidos.

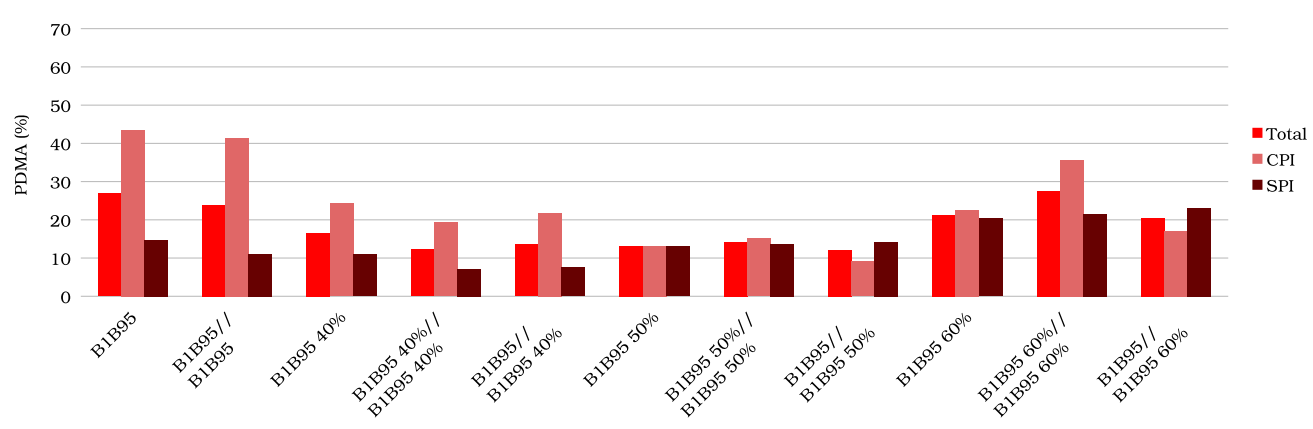

(a) $J_{\text {corr }}$ BHandH

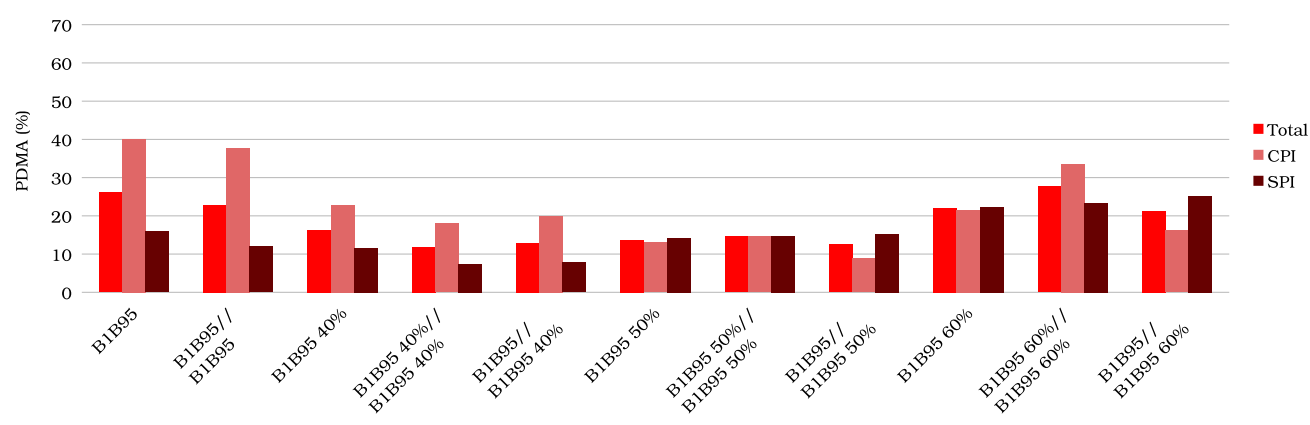

(b) $J_{\text {empi }}$ BHandH 


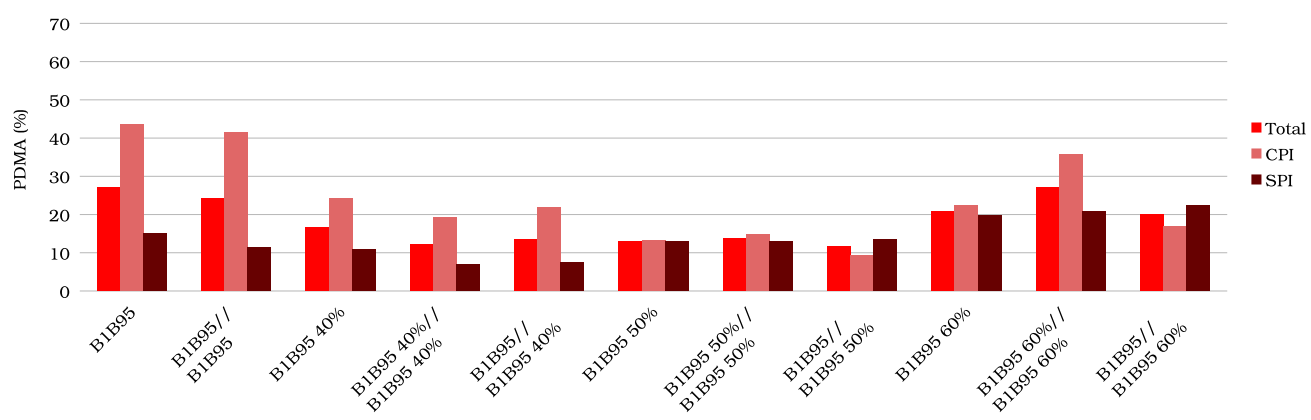

(c) $J_{\text {corr }}$ BHandH $40 \%$

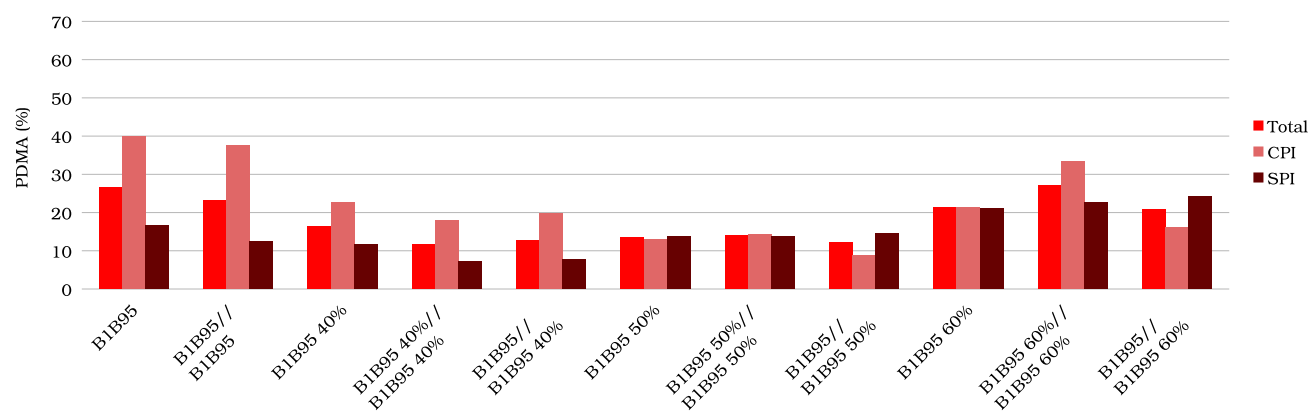

(d) $J_{\mathrm{emp}_{\mathrm{i}}}$ BHandH $40 \%$

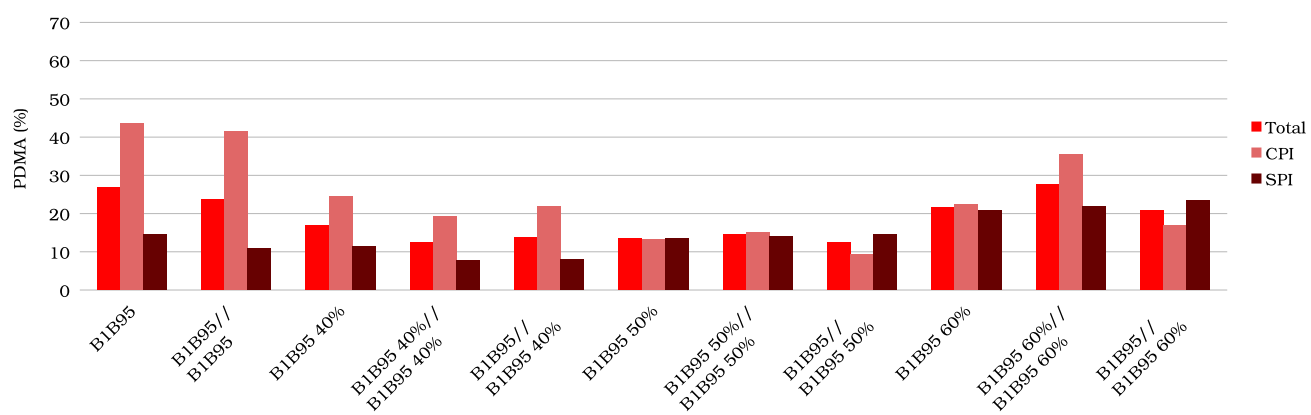

(e) $J_{\text {corri }}$ PBE $40 \%$

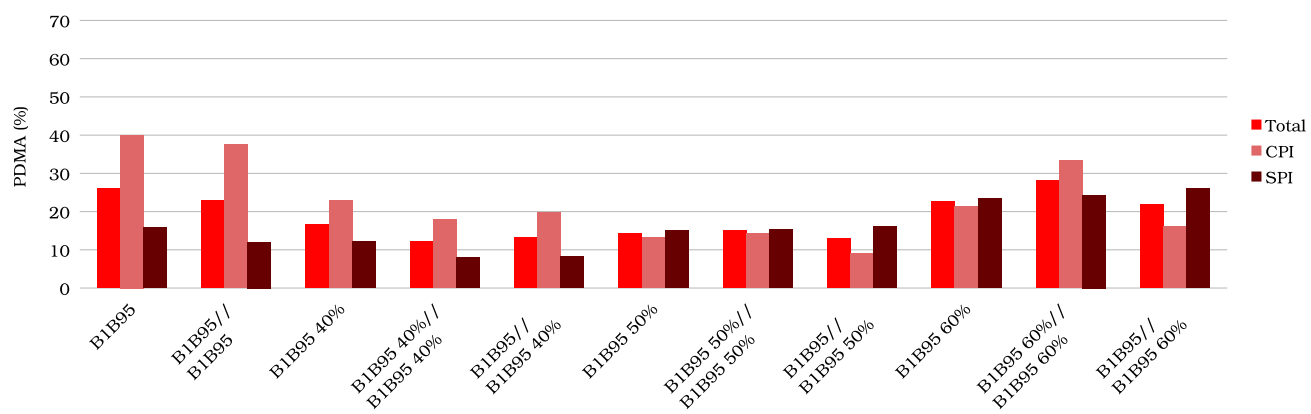

(f) $J_{\mathrm{emp}_{\mathrm{i}}} \mathrm{PBE} 40 \%$

Figura 4.9: Comparação entre as PDMAs obtidas com geometrias teóricas e experimentais para B1B95 com base aug-pcJ-2, utilizando as correções vibracionais para correção das CAISS teóricas $\left(J_{\text {corr }_{\mathrm{i}}}\right)$ ou experimentais $\left(J_{\mathrm{emp}_{\mathrm{i}}}\right)$. As médias são calculadas para as 26 CAISS, para as 11 CAISS das moléculas CPI e para as 15 CAISS das moléculas SPI. 


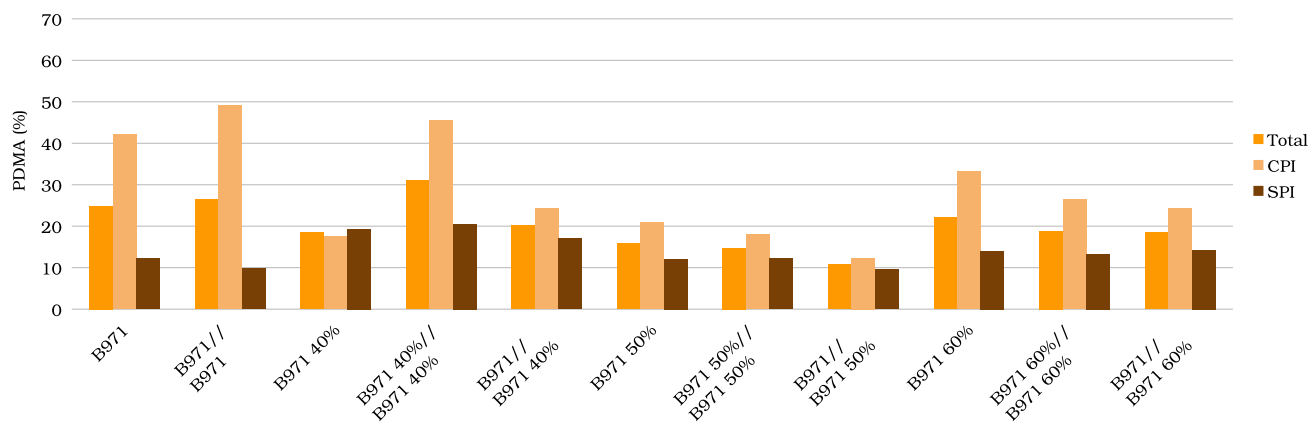

(a) $J_{\text {corri }}$ BHandH

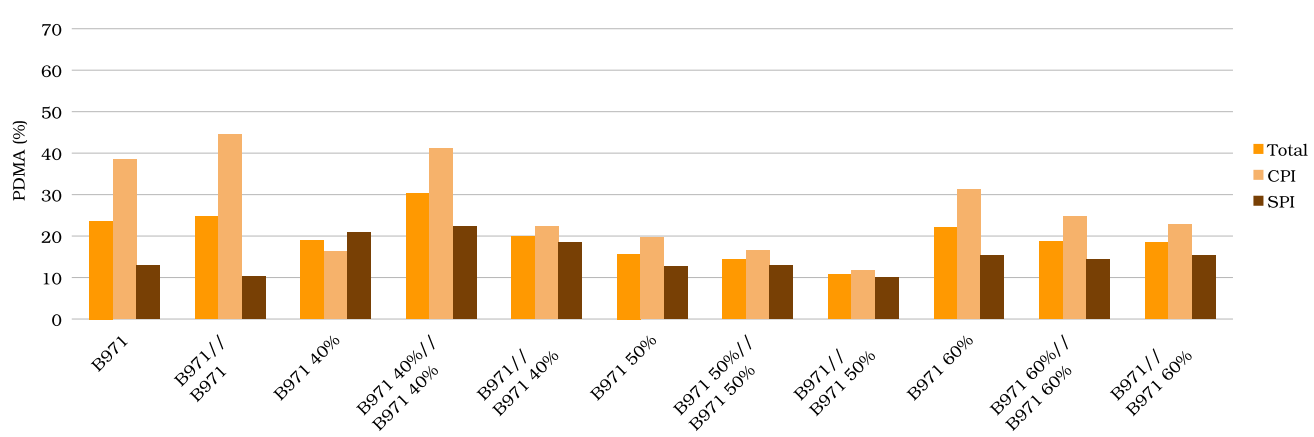

(b) $J_{\mathrm{emp}_{\mathrm{i}}} \mathrm{BHandH}$

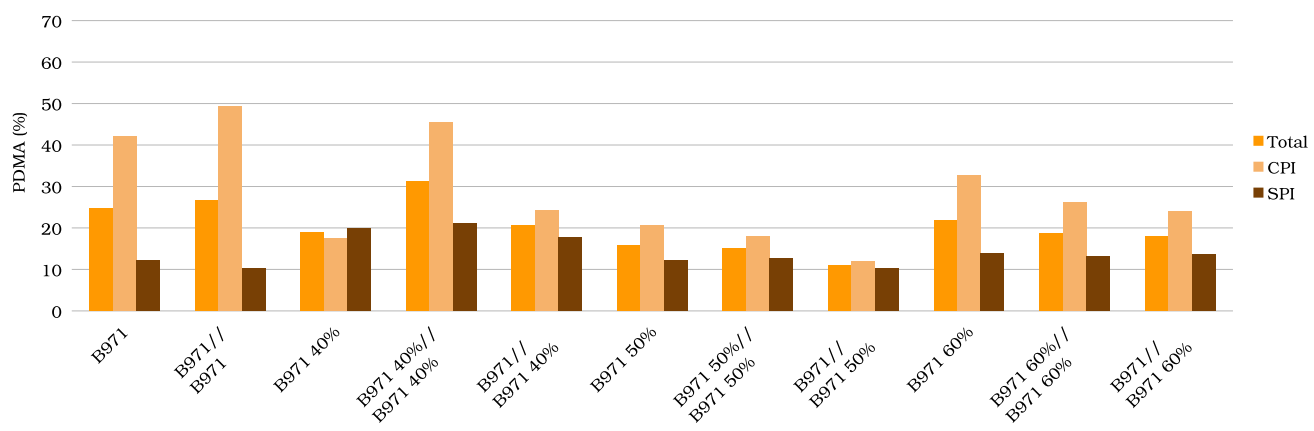

(c) $J_{\text {corr }_{\mathrm{i}}}$ BHandH $40 \%$

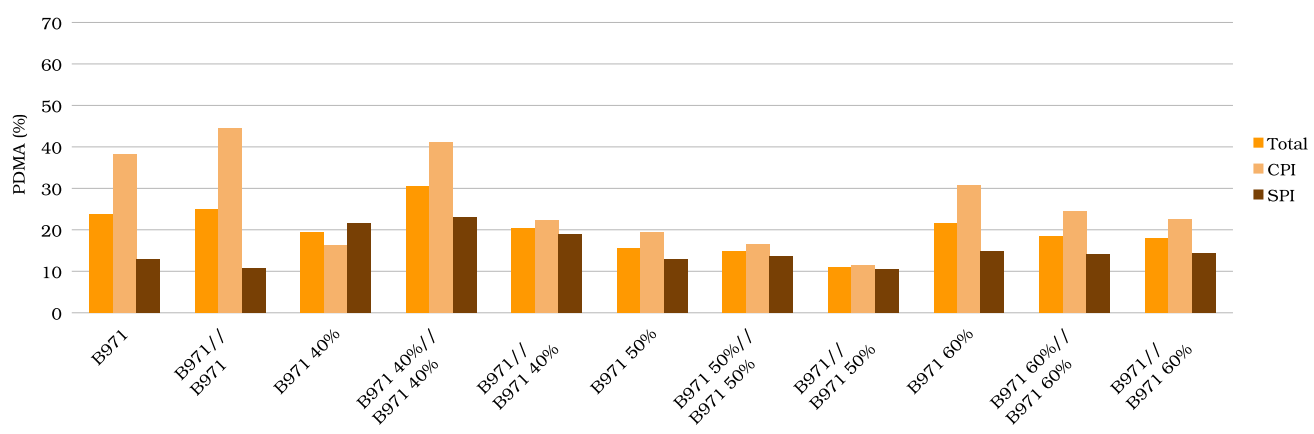

(d) $J_{\mathrm{emp}_{\mathrm{i}}}$ BHandH $40 \%$ 


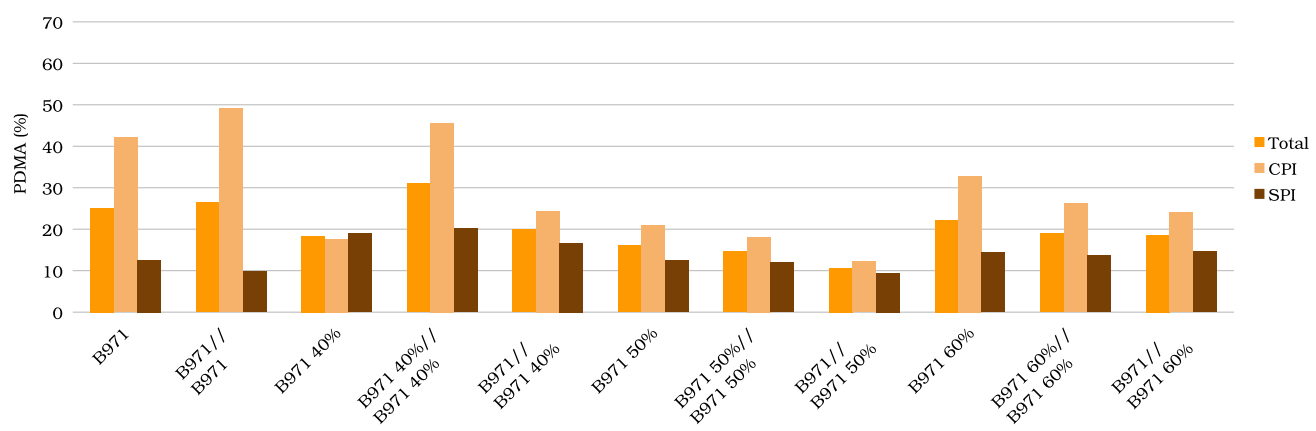

(e) $J_{\text {corr }}$ PBE $40 \%$

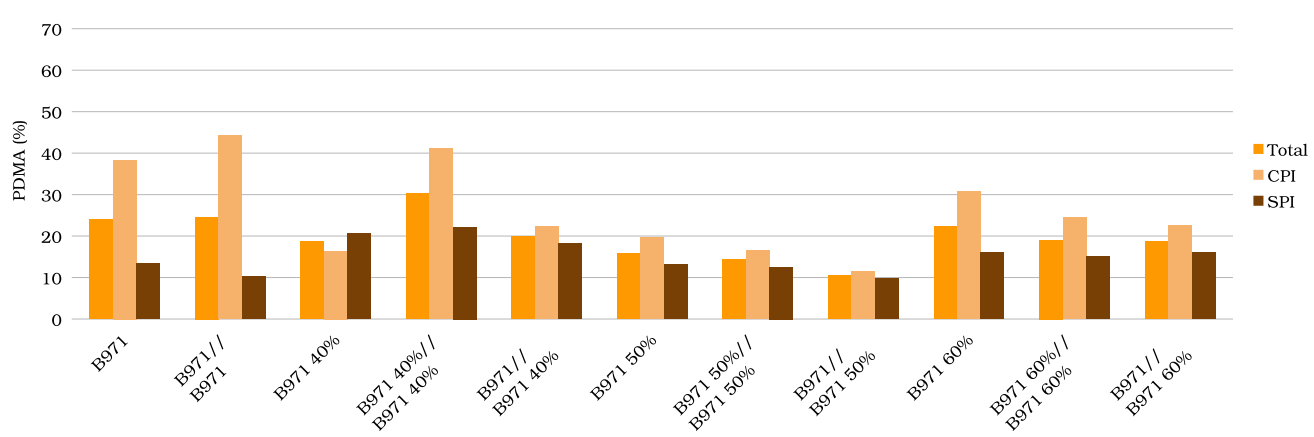

(f) $J_{\mathrm{emp}_{\mathrm{i}}} \mathrm{PBE} 40 \%$

Figura 4.10: Comparação entre as PDMAs obtidas com geometrias teóricas e experimentais para B971 com base aug-pcJ-2, utilizando as correções vibracionais para correção das CAISS teóricas $\left(J_{\text {corr }_{\mathrm{i}}}\right)$ ou experimentais $\left(J_{\mathrm{emp}_{\mathrm{i}}}\right)$. As médias são calculadas para as 26 CAISS, para as 11 CAISS das moléculas CPI e para as 15 CAISS das moléculas SPI.

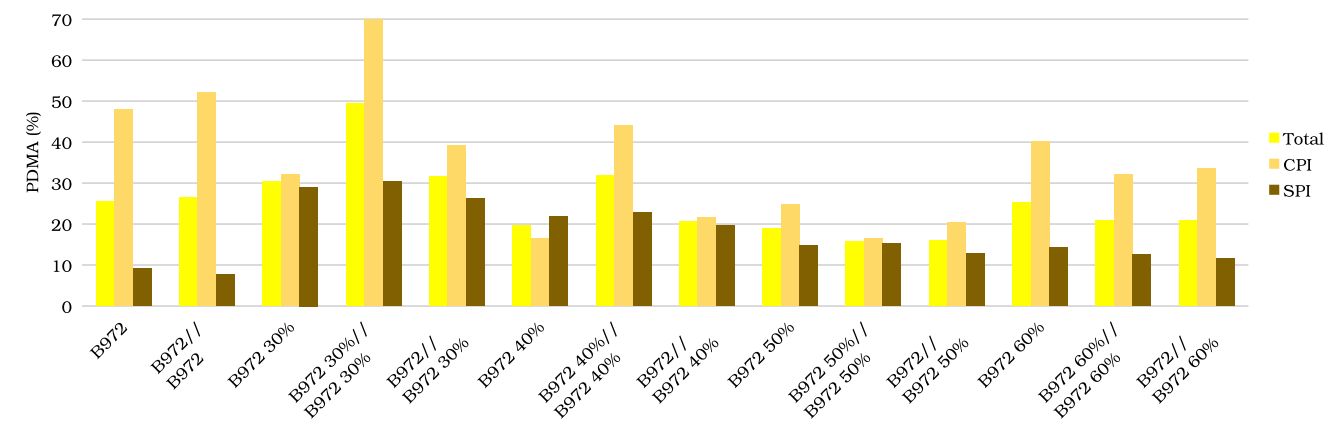

(a) $J_{\text {corr }}$ BHandH

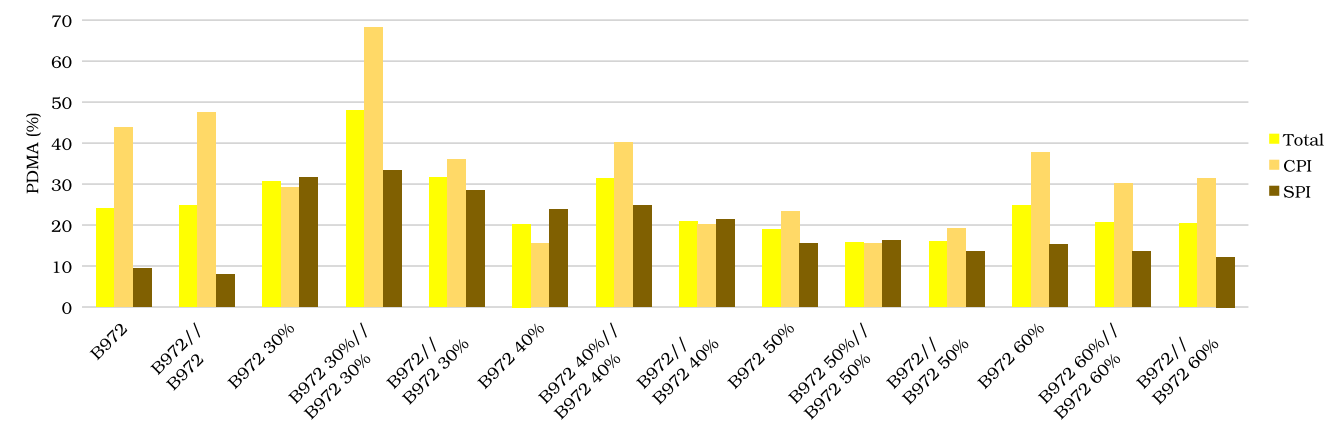

(b) $J_{\text {empi }}$ BHandH 


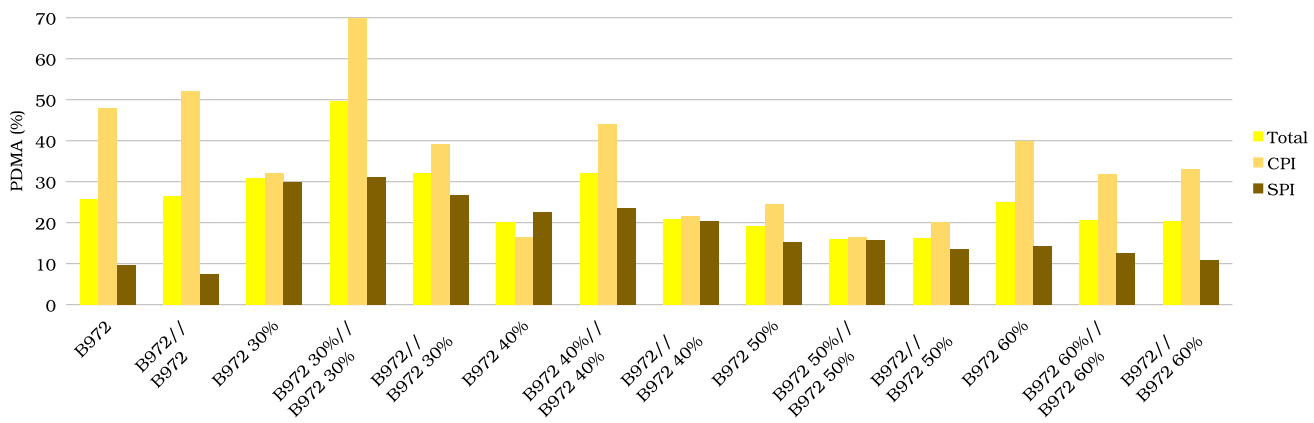

(c) $J_{\text {corr }}$ BHandH $40 \%$

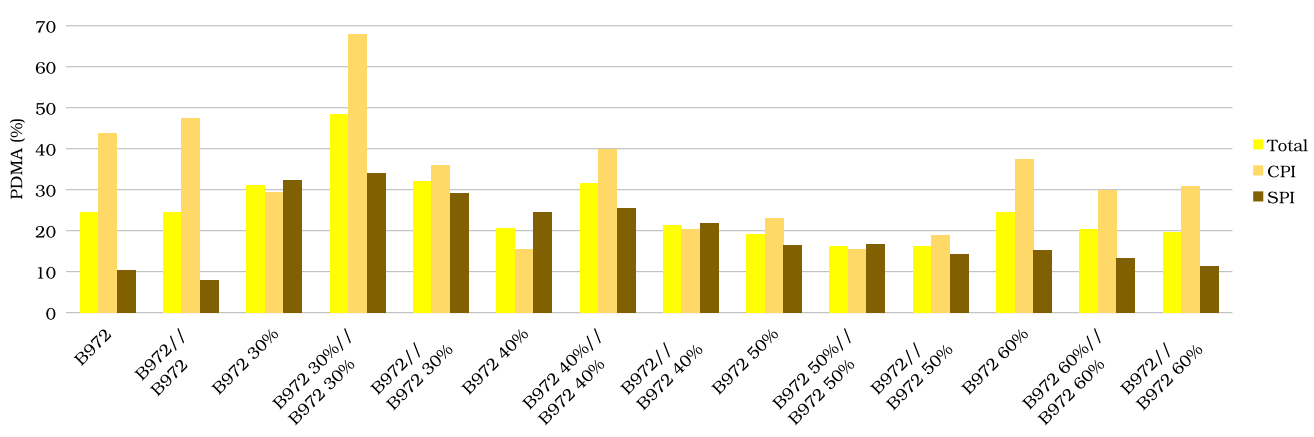

(d) $J_{\mathrm{emp}_{\mathrm{i}}}$ BHandH $40 \%$

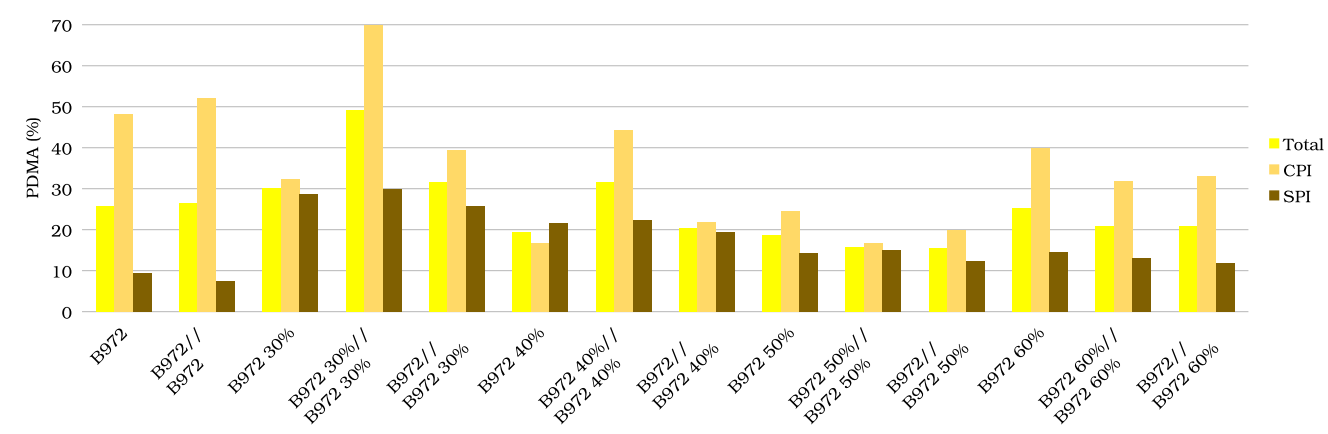

(e) $J_{\text {corri }}$ PBE $40 \%$

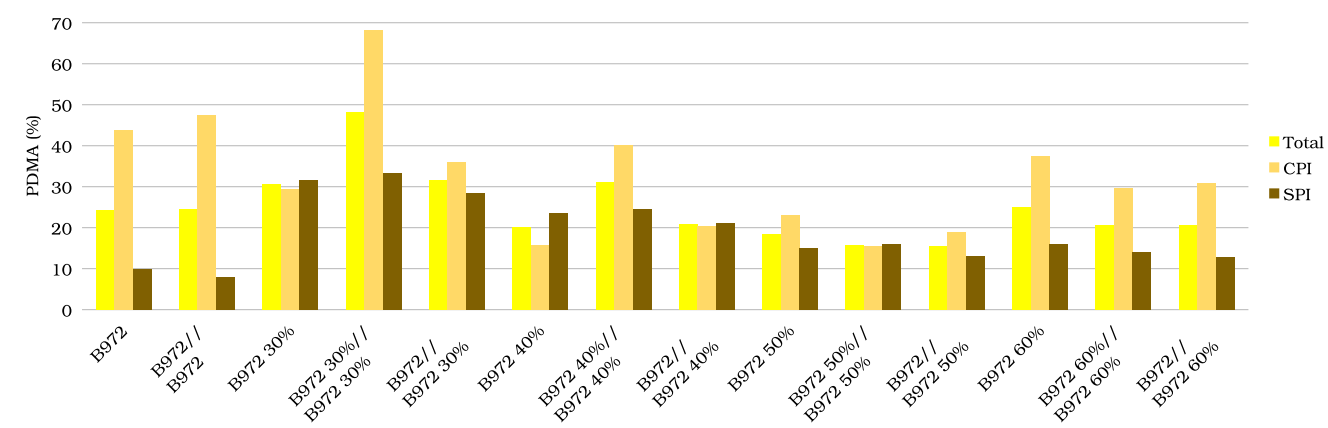

(f) $J_{\mathrm{emp}_{\mathrm{i}}} \mathrm{PBE} 40 \%$

Figura 4.11: Comparação entre as PDMAs obtidas com geometrias teóricas e experimentais para B972 com base aug-pcJ-2, utilizando as correções vibracionais para correção das CAISS teóricas $\left(J_{\text {corr }_{\mathrm{i}}}\right)$ ou experimentais $\left(J_{\mathrm{emp}_{\mathrm{i}}}\right)$. As médias são calculadas para as 26 CAISS, para as 11 CAISS das moléculas CPI e para as 15 CAISS das moléculas SPI. 


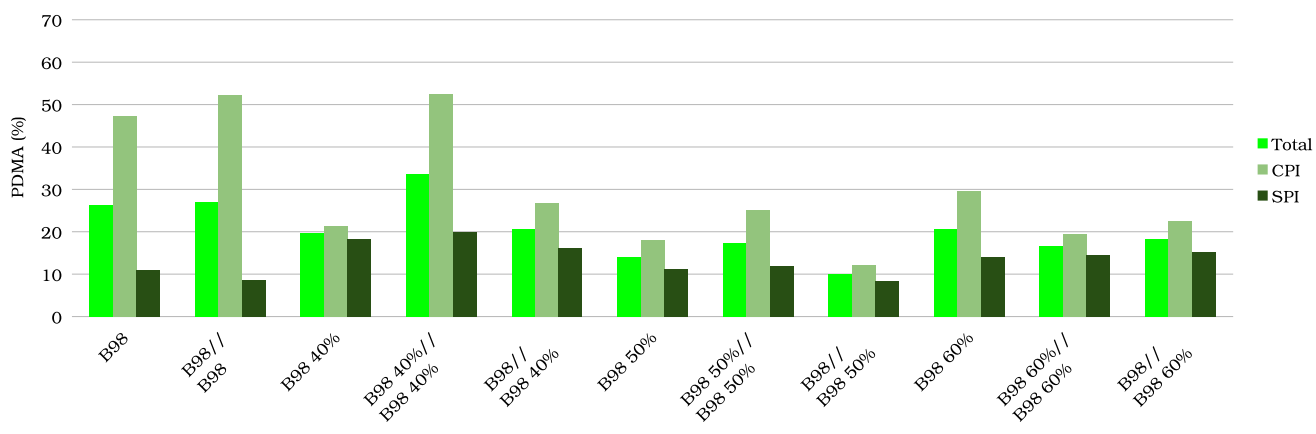

(a) $J_{\text {corr }_{i}}$ BHandH

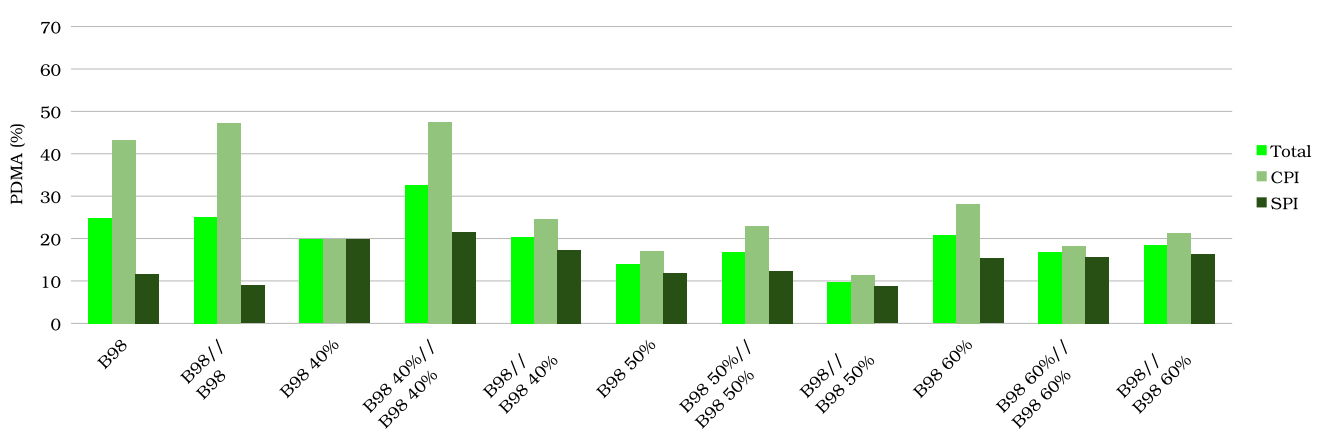

(b) $J_{\mathrm{emp}_{\mathrm{i}}} \mathrm{BHandH}$

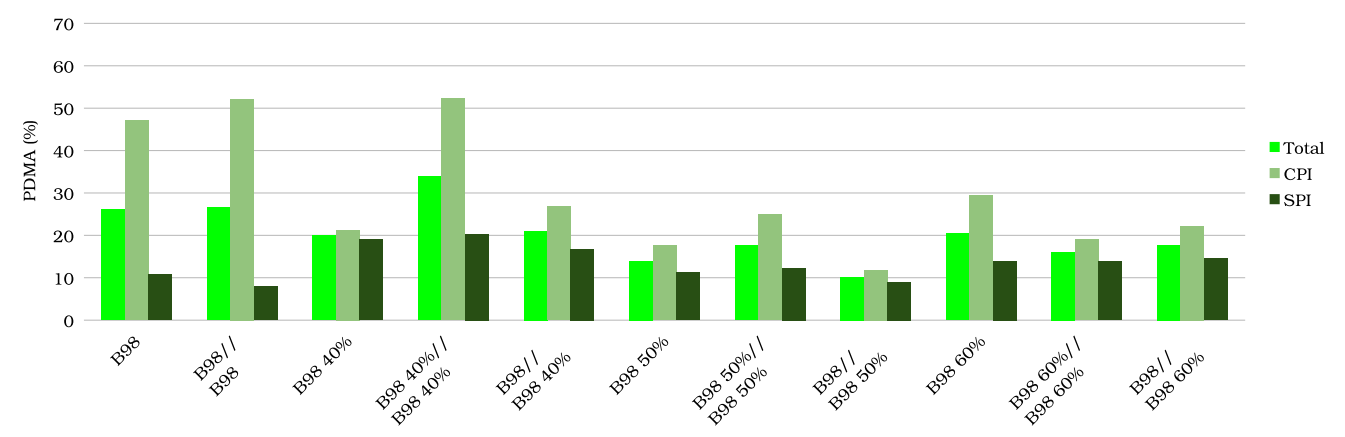

(c) $J_{\text {corr }_{\mathrm{i}}}$ BHandH $40 \%$

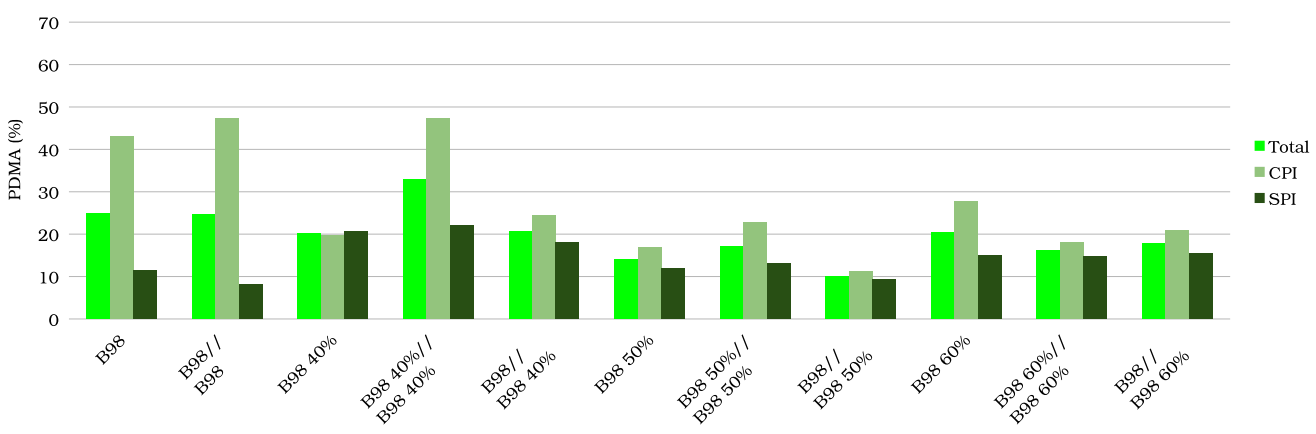

(d) $J_{\mathrm{emp}_{\mathrm{i}}}$ BHandH $40 \%$ 


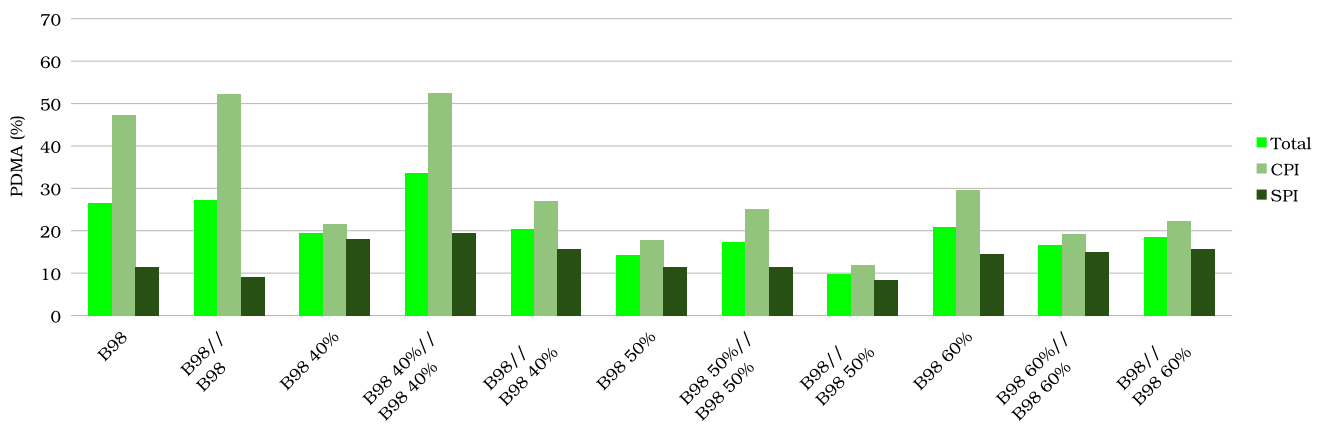

(e) $J_{\text {corr }}$ PBE $40 \%$

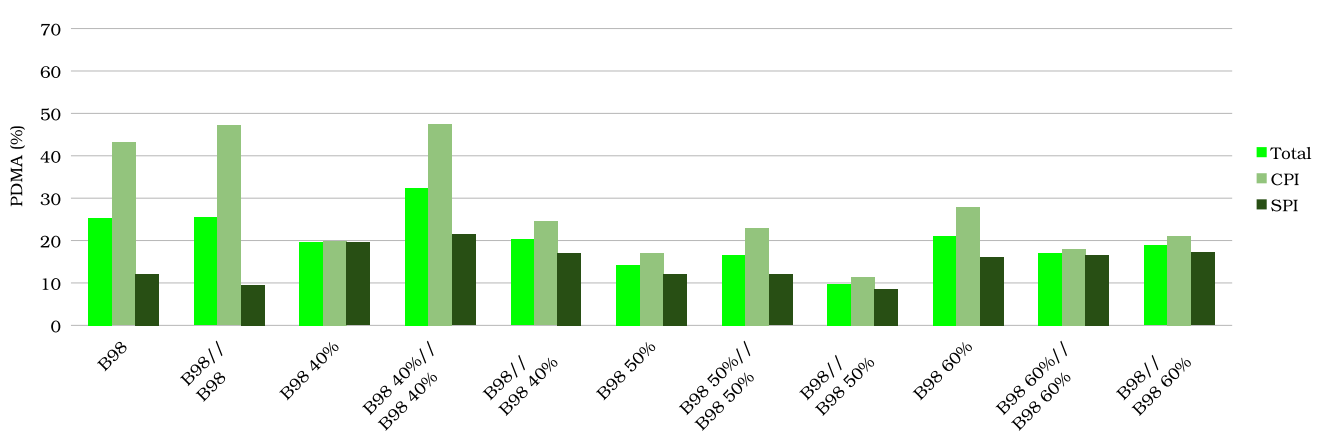

(f) $J_{\mathrm{emp}_{\mathrm{i}}} \mathrm{PBE} 40 \%$

Figura 4.12: Comparação entre as PDMAs obtidas com geometrias teóricas e experimentais para B98 com base aug-pcJ-2, utilizando as correções vibracionais para correção das CAISS teóricas $\left(J_{\text {corr }_{i}}\right)$ ou experimentais $\left(J_{\mathrm{emp}_{\mathrm{i}}}\right)$. As médias são calculadas para as 26 CAISS, para as 11 CAISS das moléculas CPI e para as 15 CAISS das moléculas SPI.

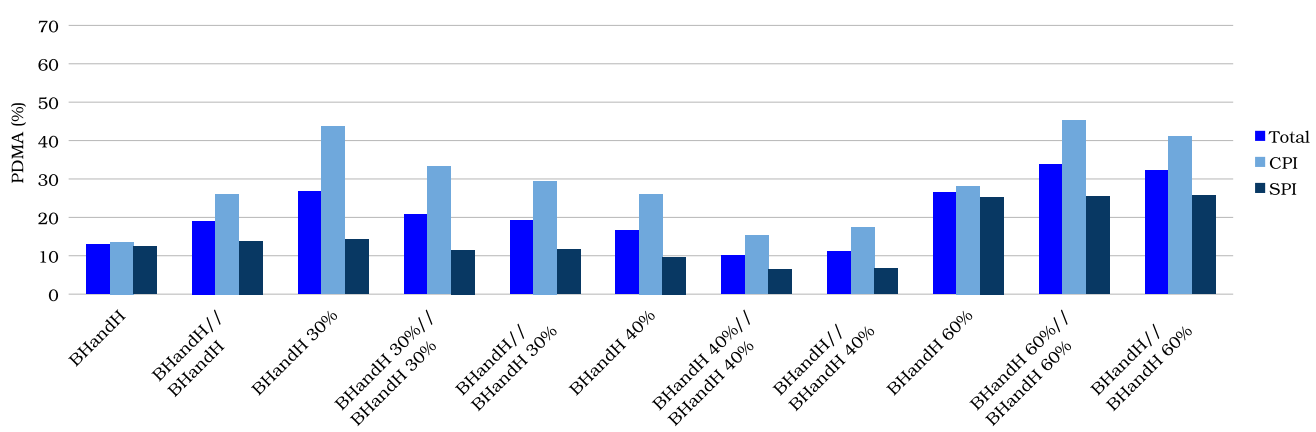

(a) $J_{\text {corr }}$ BHandH

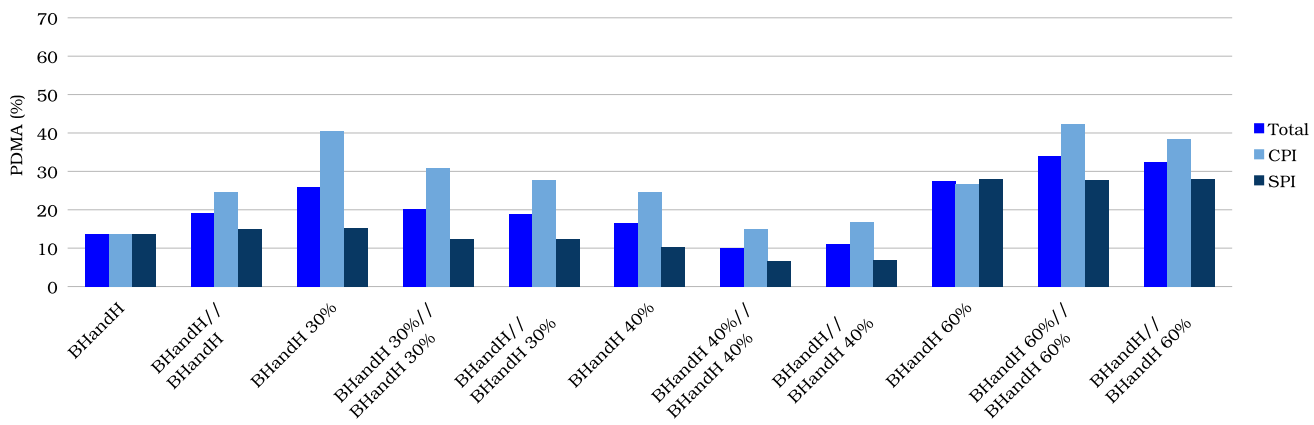

(b) $J_{\text {empi }}$ BHandH 


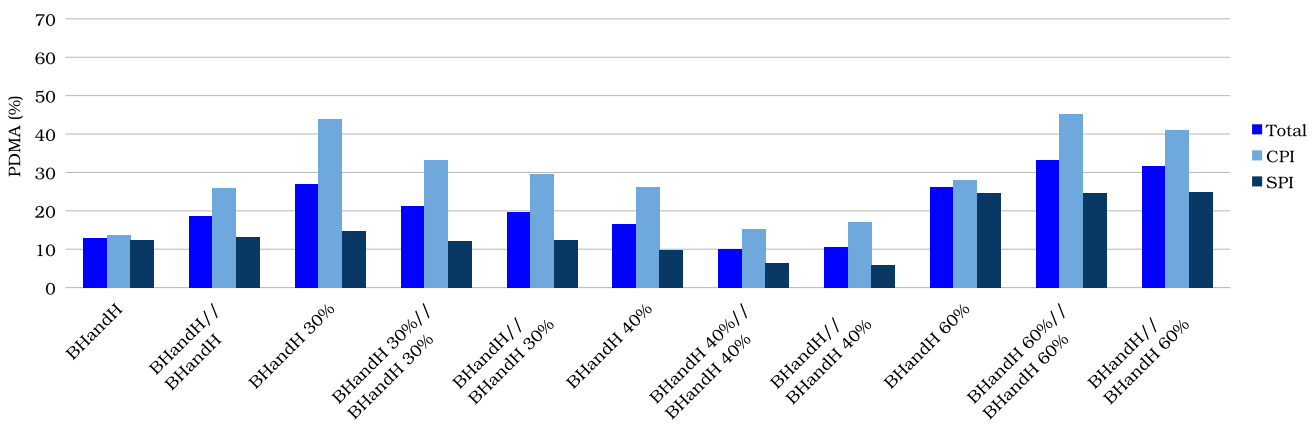

(c) $J_{\text {corr }_{i}}$ BHandH $40 \%$

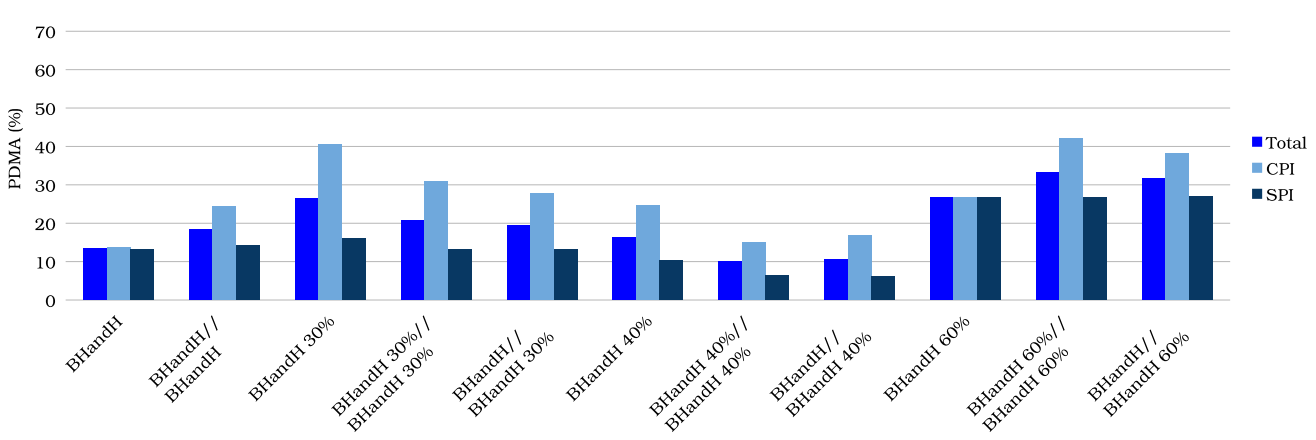

(d) $J_{\mathrm{emp}_{\mathrm{i}}}$ BHandH $40 \%$

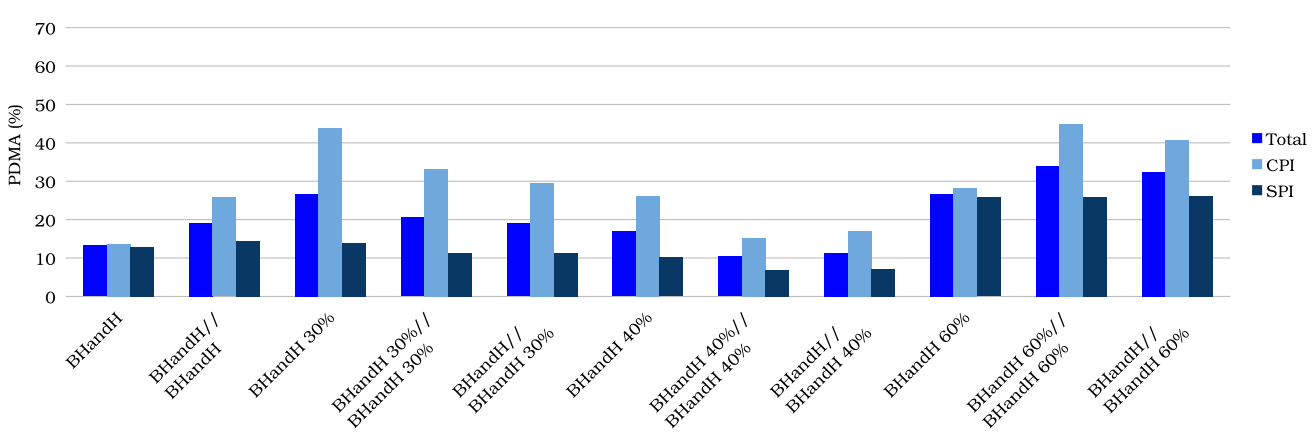

(e) $J_{\text {corr }_{i}}$ PBE $40 \%$

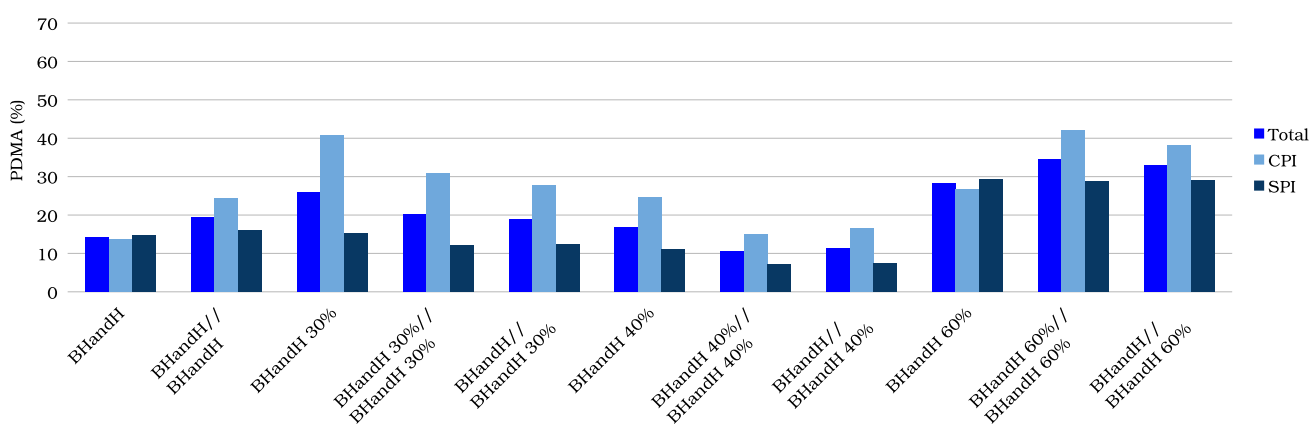

(f) $J_{\mathrm{emp}_{\mathrm{i}}} \mathrm{PBE} 40 \%$

Figura 4.13: Comparação entre as PDMAs obtidas com geometrias teóricas e experimentais para BHandH com base aug-pcJ-2, utilizando as correções vibracionais para correção das CAISS teóricas $\left(J_{\text {corr }_{\mathrm{i}}}\right)$ ou experimentais $\left(J_{\mathrm{emp}_{\mathrm{i}}}\right)$. As médias são calculadas para as 26 CAISS, para as 11 CAISS das moléculas CPI e para as 15 CAISS das moléculas SPI. 


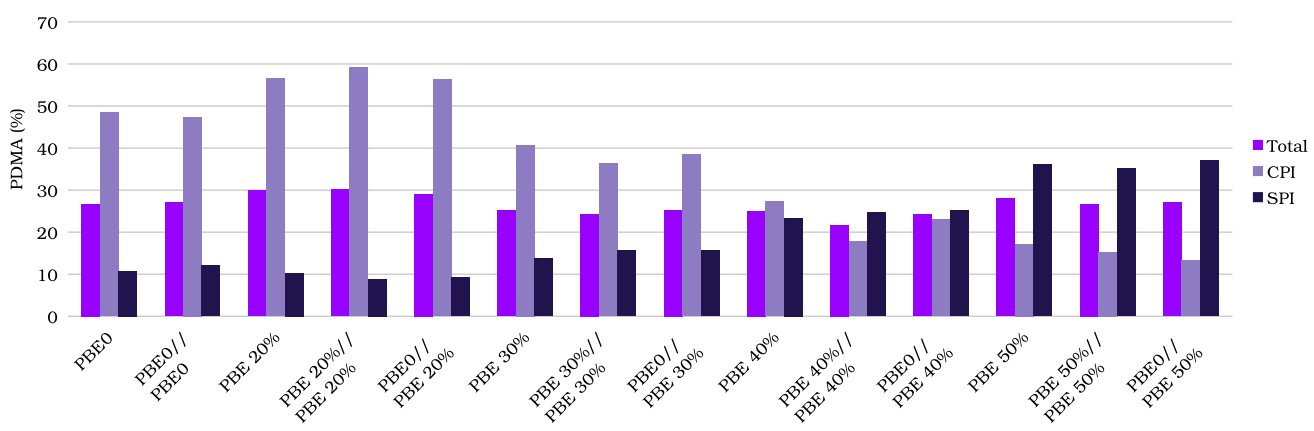

(a) $J_{\text {corr }_{i}}$ BHandH

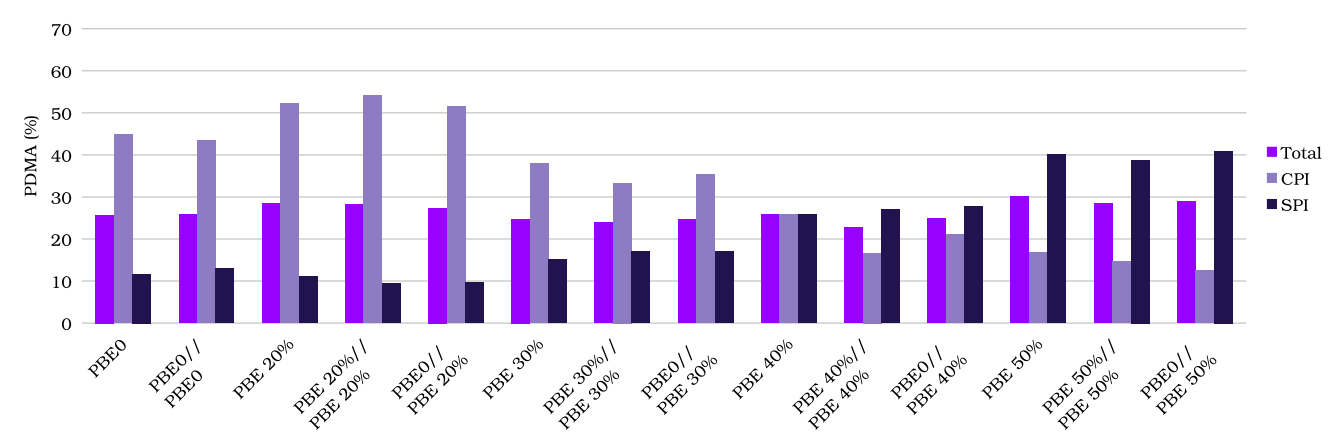

(b) $J_{\mathrm{emp}_{\mathrm{i}}} \mathrm{BHand \textrm {H }}$

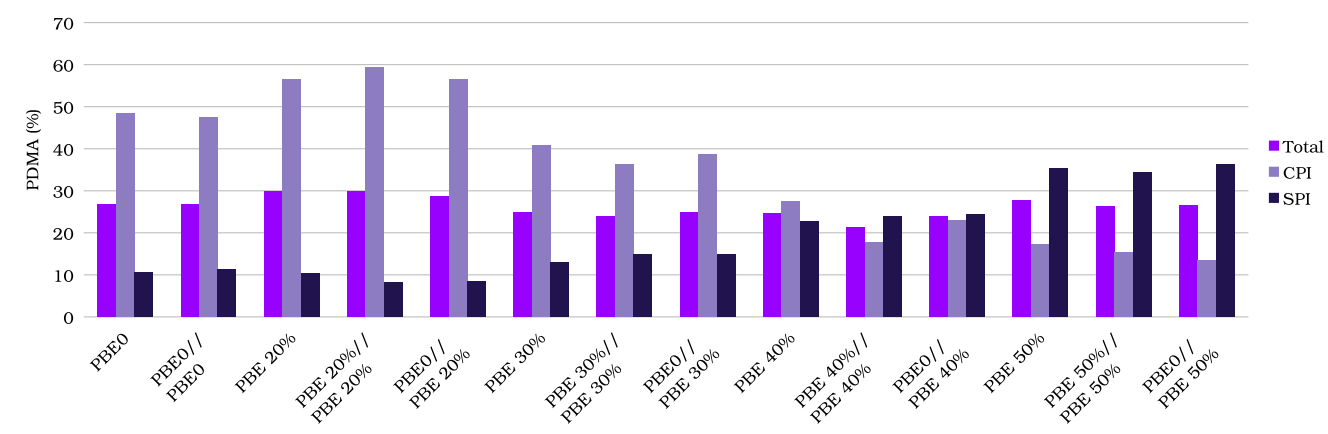

(c) $J_{\text {corr }_{\mathrm{i}}}$ BHandH $40 \%$

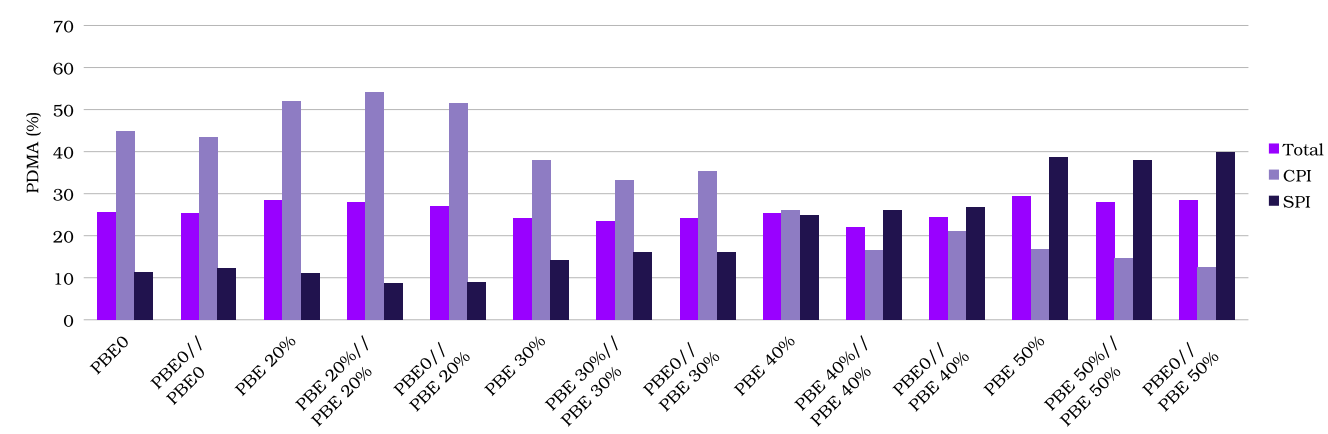

(d) $J_{e^{2} p_{i}}$ BHandH $40 \%$ 


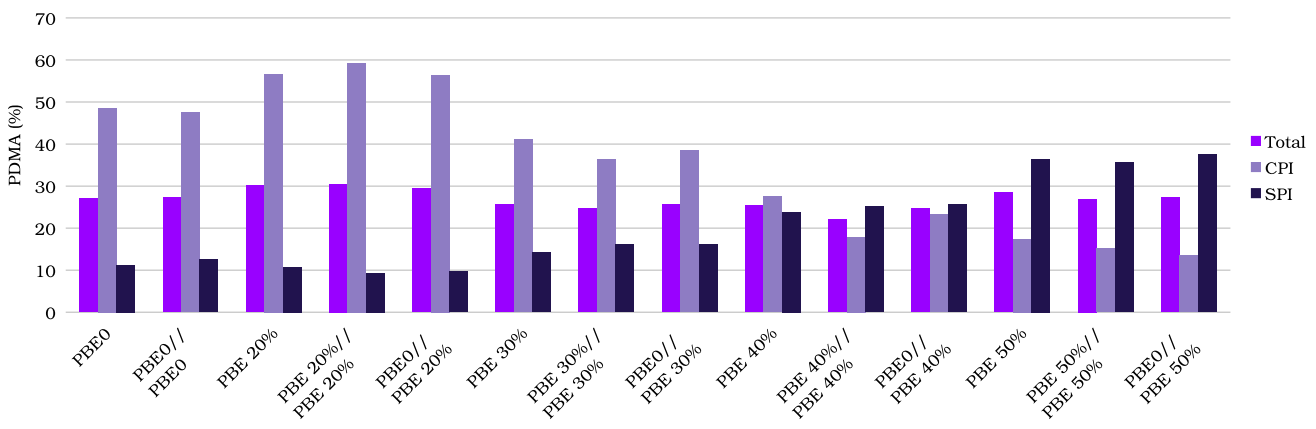

(e) $J_{\text {corr }}$ PBE $40 \%$

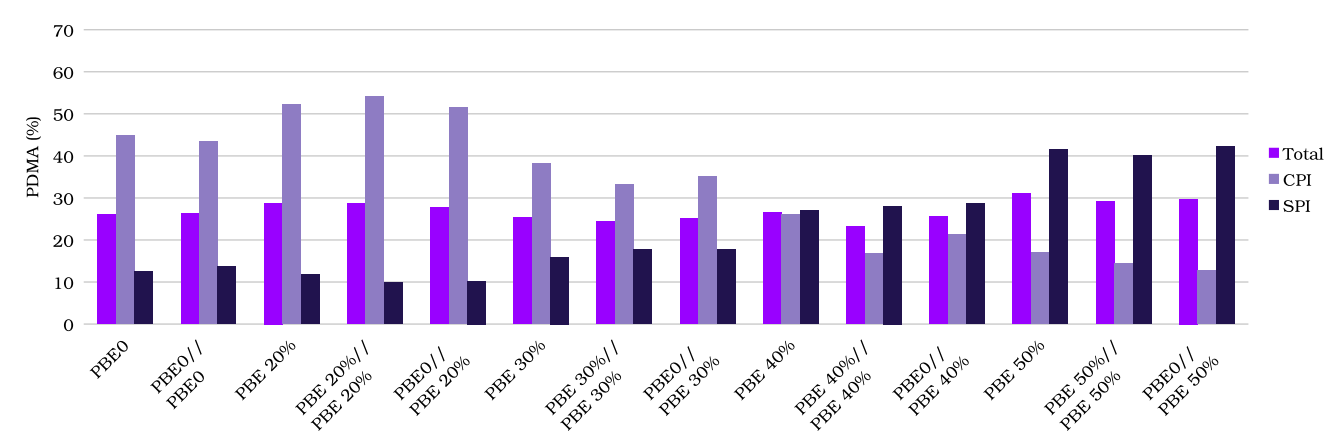

(f) $J_{\mathrm{emp}_{\mathrm{i}}} \mathrm{PBE} 40 \%$

Figura 4.14: Comparação entre as PDMAs obtidas com geometrias teóricas e experimentais para PBE0 com base aug-pcJ-2, utilizando as correções vibracionais para correção das CAISS teóricas $\left(J_{\text {corr }_{\mathrm{i}}}\right)$ ou experimentais $\left(J_{\mathrm{emp}_{\mathrm{i}}}\right)$. As médias são calculadas para as 26 CAISS, para as 11 CAISS das moléculas CPI e para as 15 CAISS das moléculas SPI.

Retomando, o cálculo das correções vibracionais é importante para descrever os sistemas com maior exatidão. Entretanto, a utilização das correções vibracionais não providenciou PDMAs menores, e a ordem de precisão dos funcionais não foi, de maneira geral, alterada. Portanto é considerado que o tratamento das correções vibracionais não melhora a precisão do conjunto das CAISS obtidos. Devido ao grande custo computacional empregado para se calcular as correções vibracionais das CAISS frente aos resultados praticamente inalterados, é decidido utilizar apenas as constantes obtidas sem correções vibracionais. 


\subsection{Geração de novos funcionais combinando $E_{X}^{\mathrm{HF}}, E_{X}^{\mathrm{DFT}}$ e $E_{C}^{\mathrm{DFT}}$}

\subsubsection{Geometrias experimentais}

Vários funcionais são gerados através da combinação de diferentes funcionais de troca $E_{X}^{\mathrm{DFT}}\left(\mathrm{B}, \mathrm{B} 971, \mathrm{~B} 972, \mathrm{~B} 98, \mathrm{O}, \mathrm{PBE}, \mathrm{PW} 91, \mathrm{~S}\right.$ e TPSS) e de correlação $E_{C}^{\mathrm{DFT}}(\mathrm{B} 95, \mathrm{~B} 98$, B971, B972, LYP, P86, PBE, PW91 e TPSS), além da variação da porcentagem de $E_{X}^{\mathrm{HF}}$, possibilitando obter CAISS mais precisas.

Os resultados estão apresentados nas Tabelas 8.189 a 8.197, 8.199 a 8.207, 8.209 a 8.217, 8.219 a 8.227, 8.229 a 8.237, 8.239 a 8.247, 8.249 a 8.257, 8.259 a 8.267 e 8.269 a 8.277, para geometrias experimentais com base aug-pcJ-2.

A Figura 4.15 apresenta os resultados de PDMA total com base aug-pcJ-2. Para melhor visualização, os resultados estão organizados por funcional de troca.

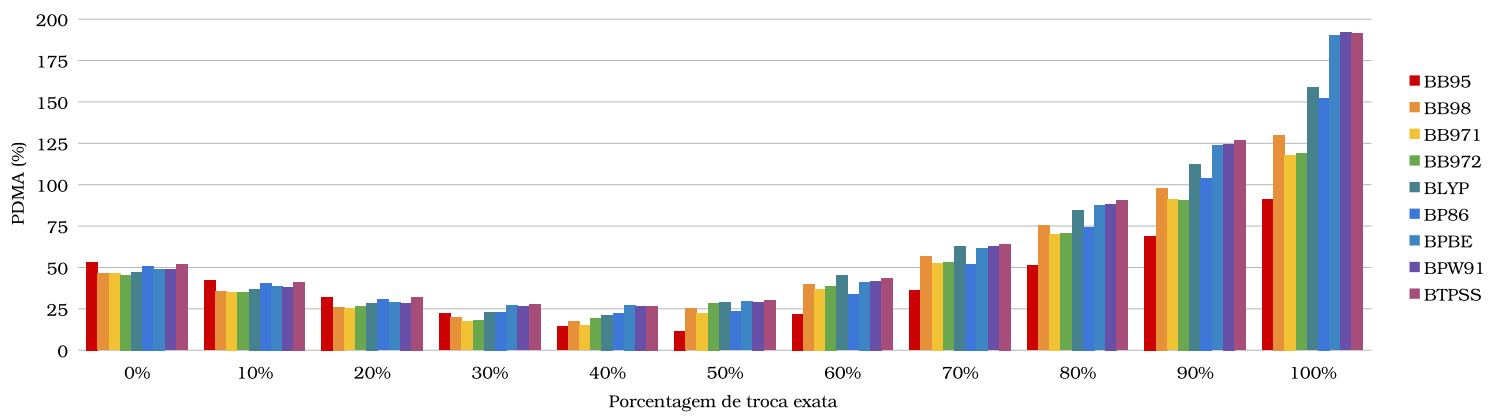

(a) Troca B

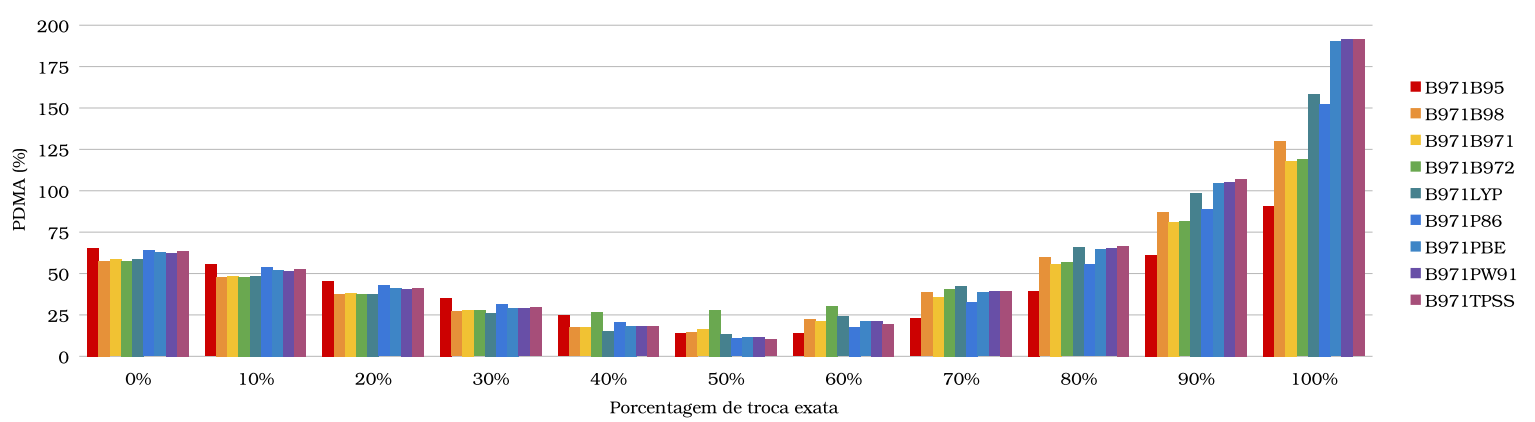

(b) Troca B971 


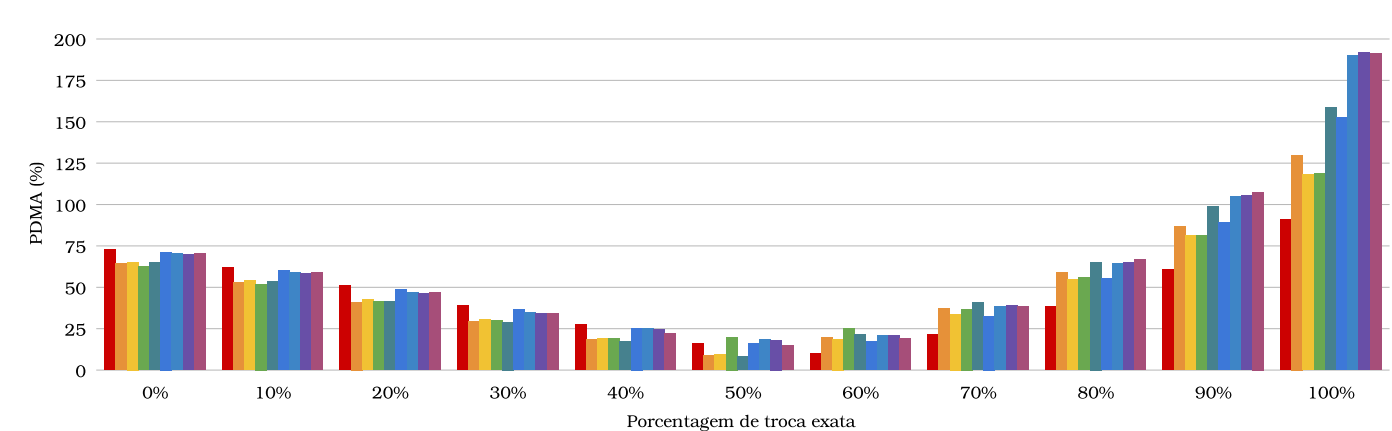

(c) Troca B972

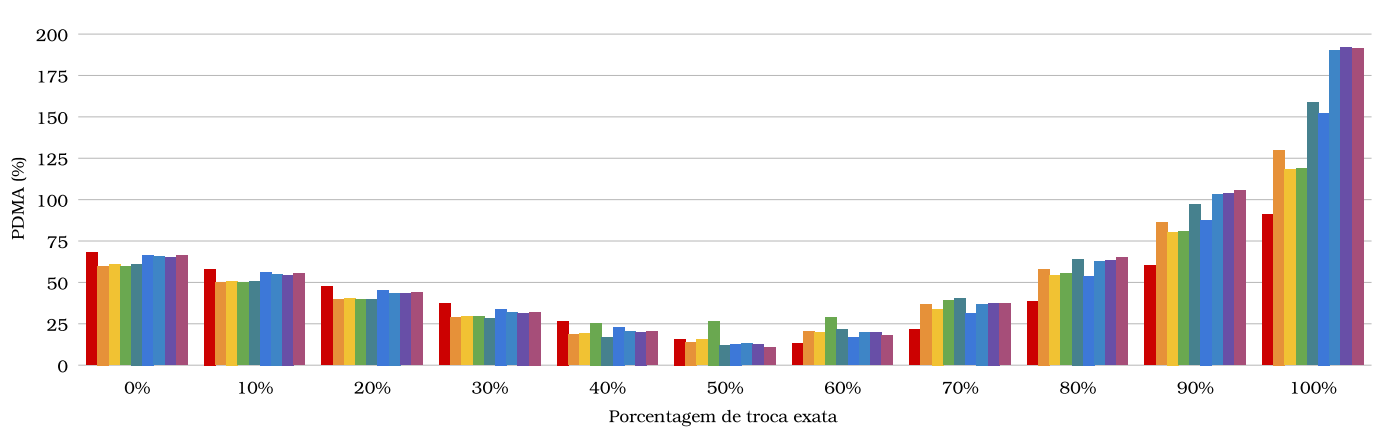

- B972B95

B972B971

$\square$ B972B972
- B972LYP

- $\mathrm{B} 972 \mathrm{P} 86$

B972PBE

B972PW91

B972TPSS

(d) Troca B98

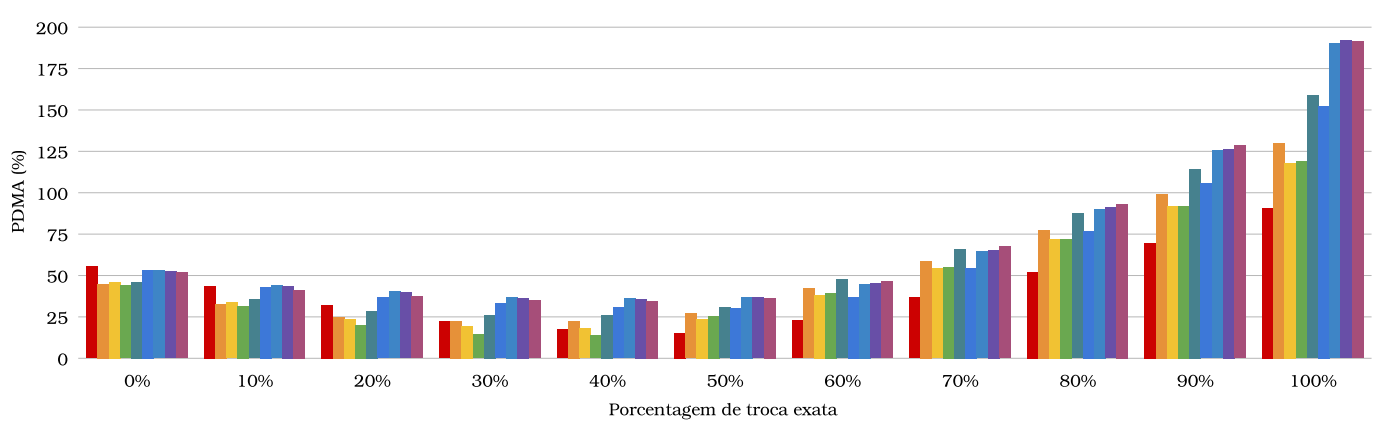

- B98B95

В98B98

- B98B971

- B98B972

-B98LYP

B98P86

- $\mathrm{B} 98 \mathrm{PBE}$

- B98PW91

- B98TPSS

(e) Troca O

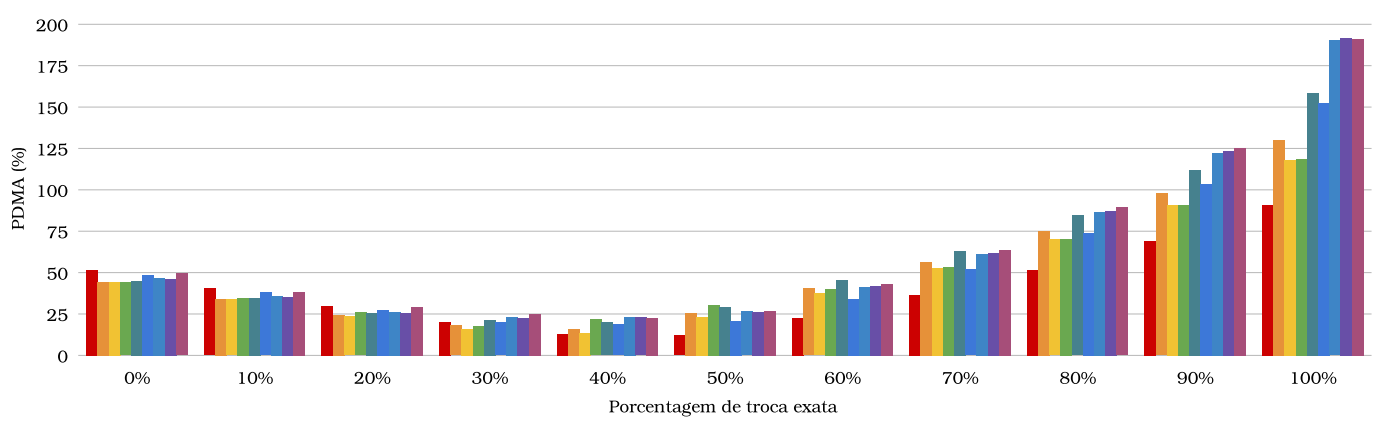

- PBEB95

PBEB98

$\triangle$ PBEB971

- PBEB972

- PBELYP

- PBEP86

- PBEPBE

- PBEPW91
PBETPSS

(f) Troca PBE 

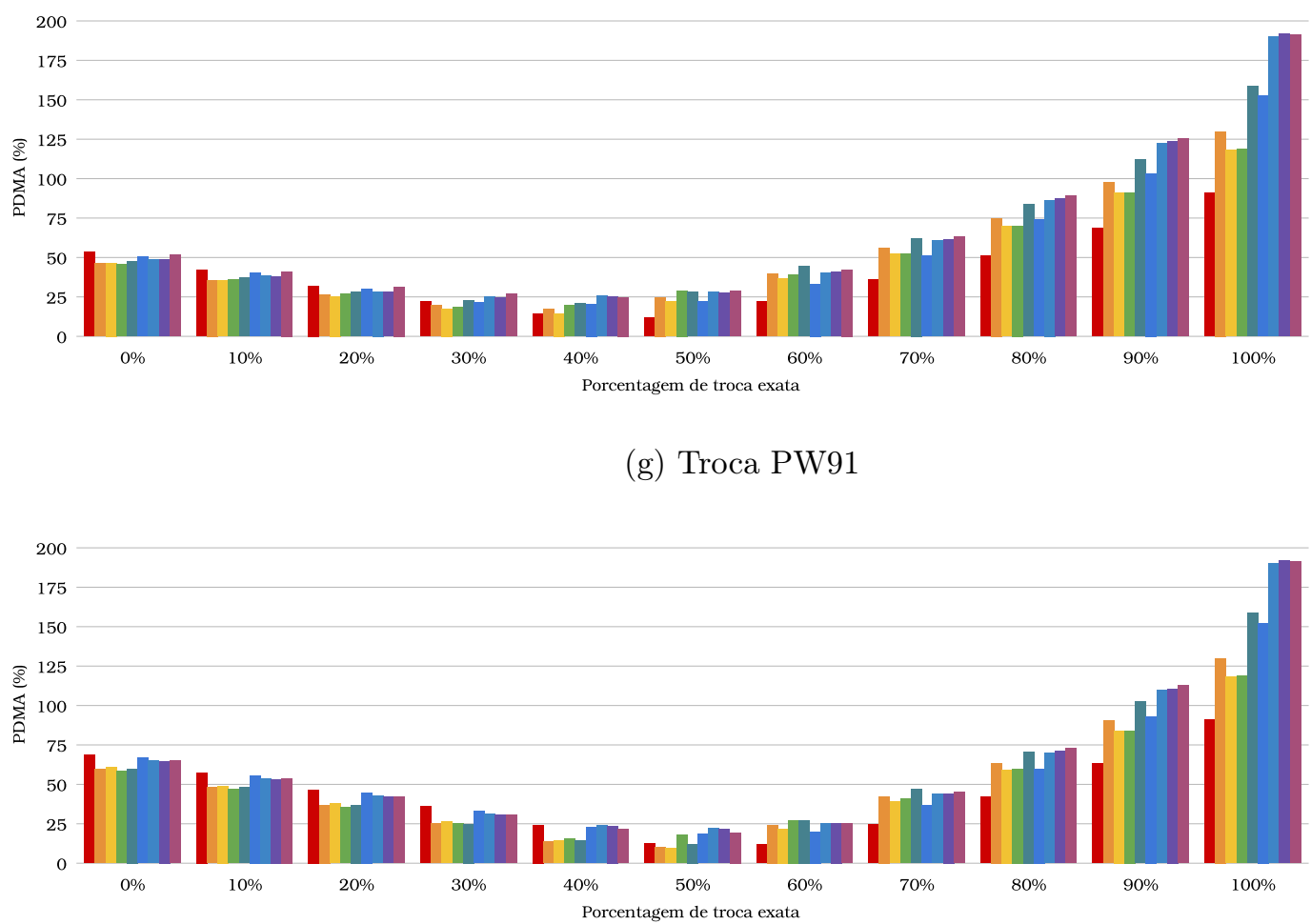

$\because \mathrm{SPBE}$

-SPW91

$\because$ STPSS

(h) Troca S

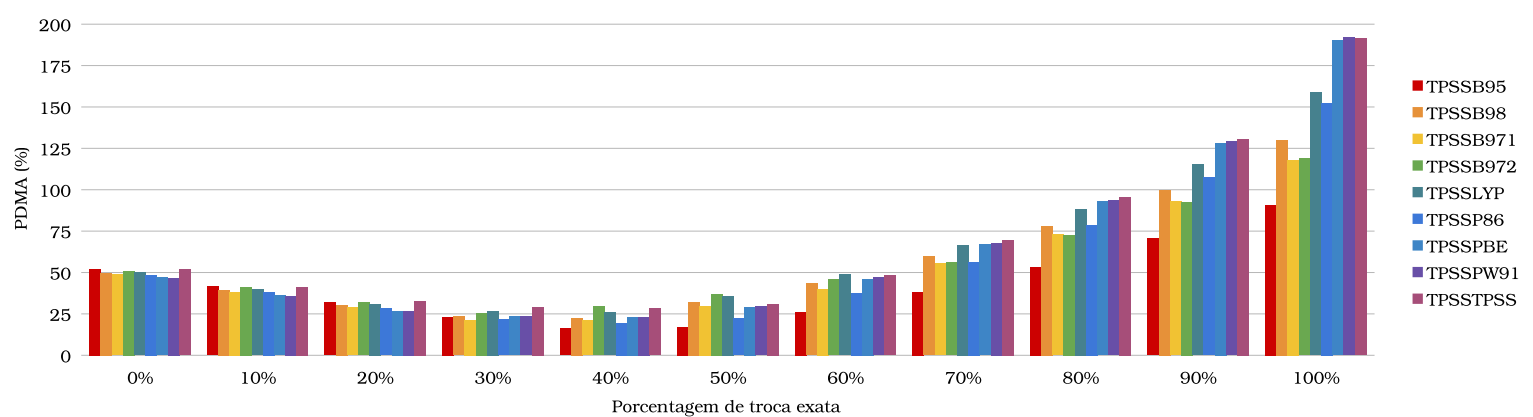

(i) Troca TPSS

Figura 4.15: PDMA para CAISS com diferentes funcionais de troca e correlação e variando a porcentagem de $E_{X}^{\mathrm{HF}}$ com a base aug-pcJ-2. Cada um dos gráficos (a) a (i) corresponde a uma das trocas avaliadas, e cada cor de coluna corresponde a uma das correlações.

As precisões já obtidas com B1B95, B971, B972, B98, BHandH (SLYP 50\% $E_{X}^{\mathrm{HF}}$ ) e PBE0 (ver Figura 4.4a) são reproduzidas. Ótimas precisões também são obtidas com B972LYP 50\% $E_{X}^{\mathrm{HF}}, \mathrm{SB} 97150 \% E_{X}^{\mathrm{HF}}$, B972B95 60\% $E_{X}^{\mathrm{HF}}$, B971TPSS 50\% $E_{X}^{\mathrm{HF}}$ e B98TPSS $50 \% E_{X}^{\mathrm{HF}}$, entre vários outros.

Considerando todos os funcionais com troca B (Figura 4.15a), a melhor precisão é obtida com o funcional BB95 50\%. Considerando todos os funcionais com troca B971 (Figura 4.15b), a melhor precisão é obtida com o funcional B971TPSS 50\%. Para cada 
uma das trocas estudadas é possível determinar os resultados com melhores precisões, e tais dados estão resumidos na Tabela 4.5 .

Da mesma forma, considerando todos os funcionais com correlação B95 (colunas vermelhas das Figuras 4.15a a 4.15i), a melhor precisão é obtida com o funcional B972B95 60\%. Considerando todos os funcionais com correlação B98 (colunas laranjas das Figuras $4.15 \mathrm{a}$ a 4.15i), a melhor precisão é obtida com o funcional B972B98 50\%. Para cada uma das correlações estudadas também é possível determinar os resultados com melhores precisões, e tais dados estão resumidos na Tabela 4.6 .

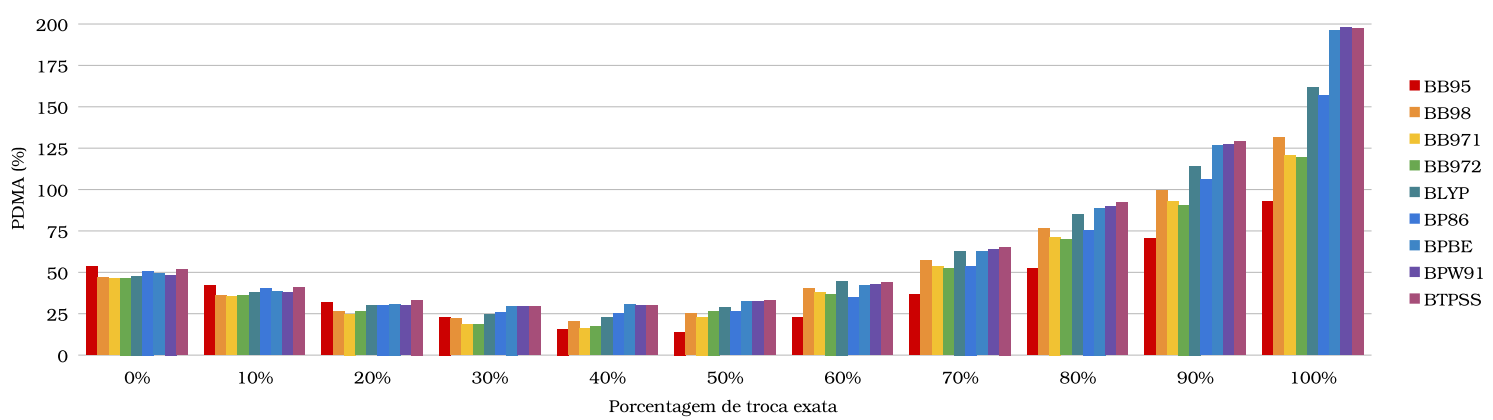

(a) Troca B

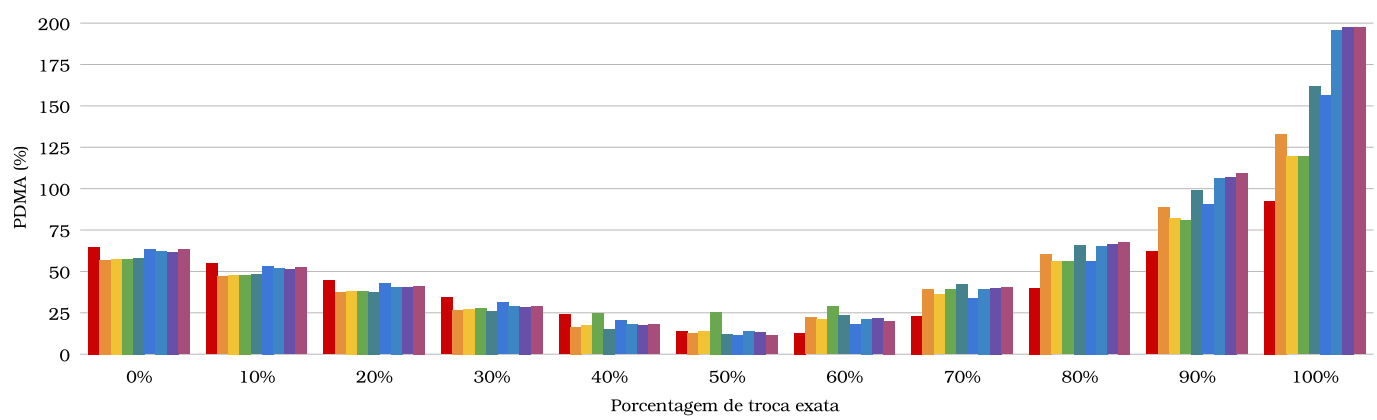

-B971B95 B971B98 - B971B971 B971B972 -B971LYP -B971P86 - $\mathrm{B} 971 \mathrm{PBE}$ - B971PW91

(b) Troca B971

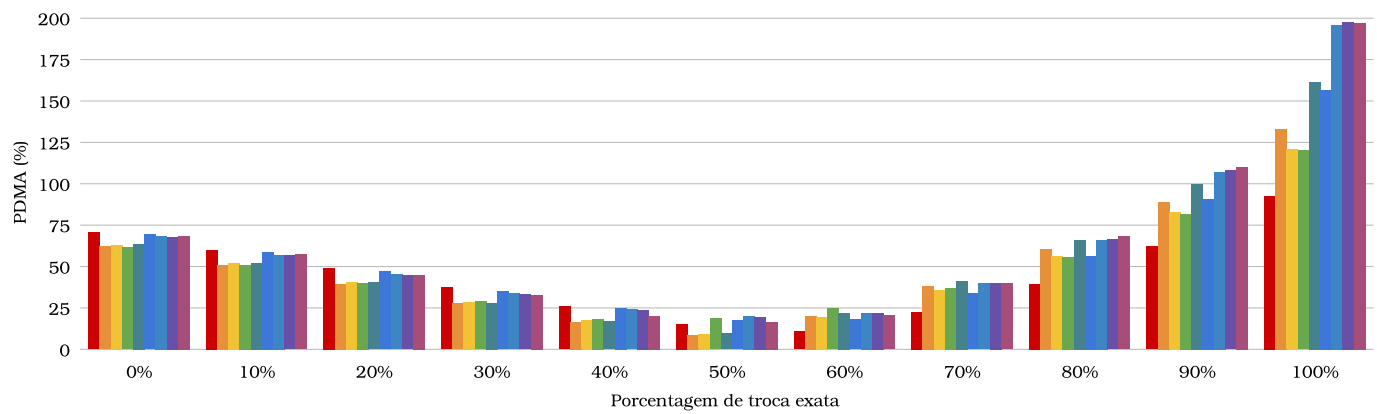




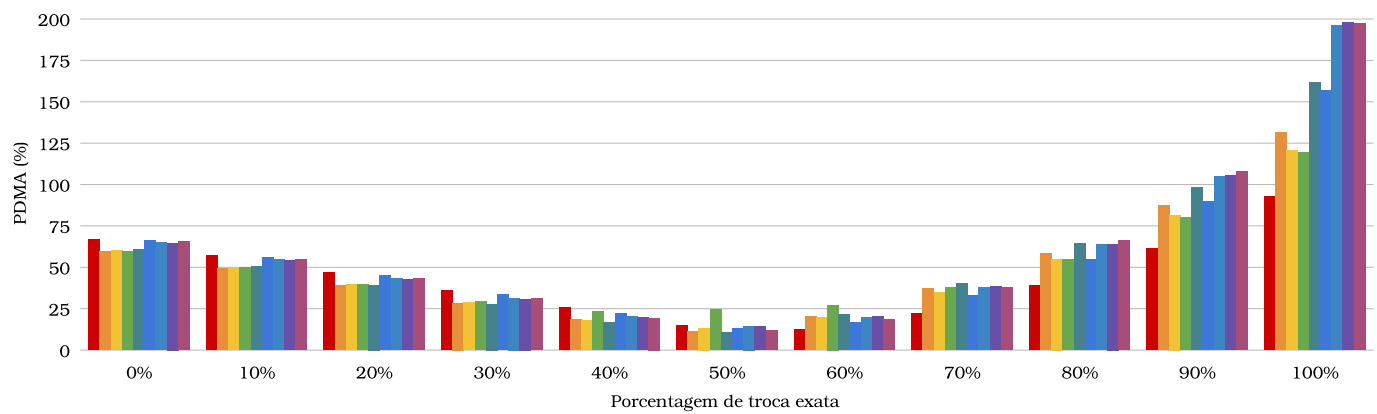

(d) Troca B98

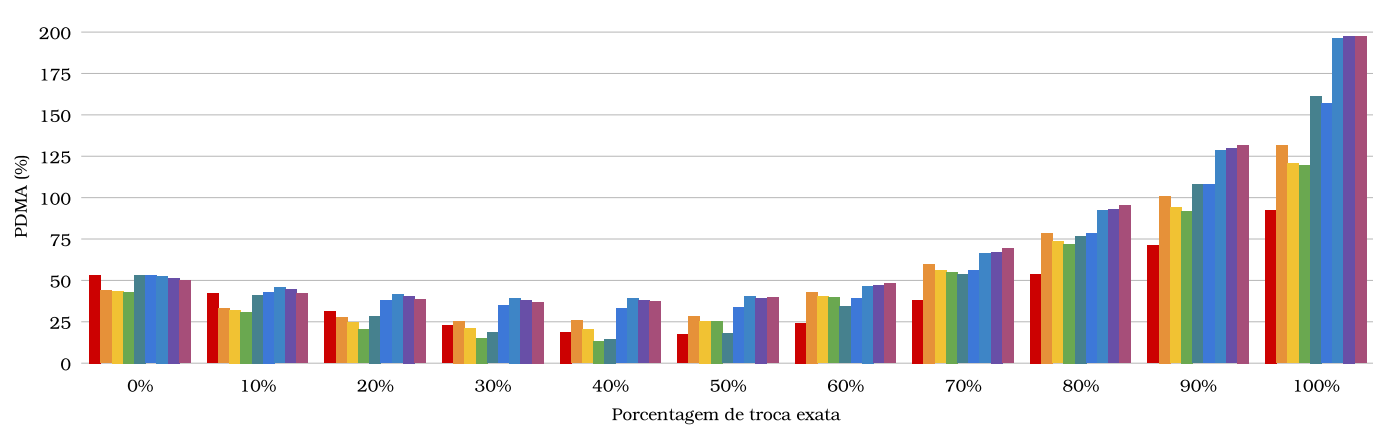

$\triangle \mathrm{OPBE}$

- OPW91

- OTPSS

(e) Troca $\mathrm{O}$

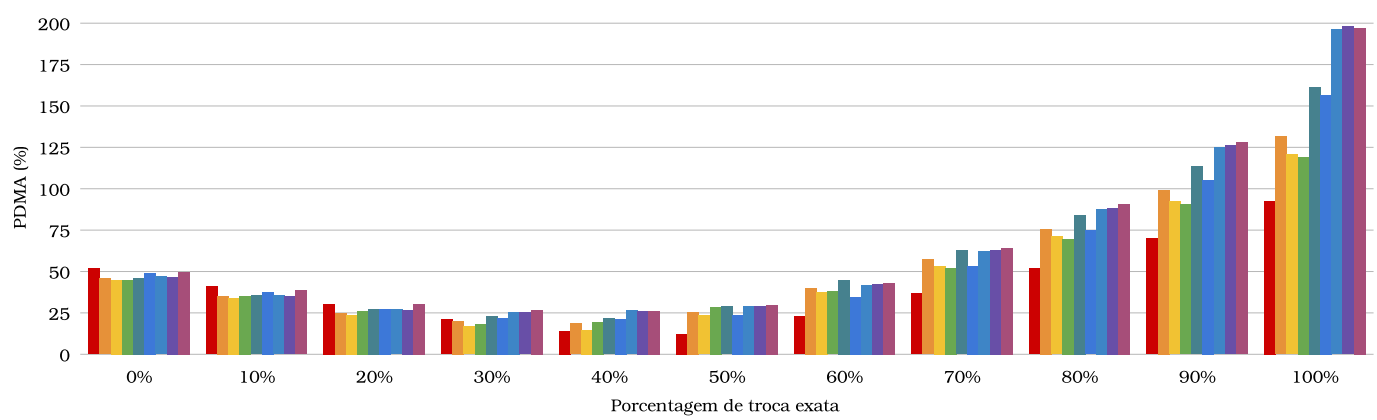

(f) Troca PBE

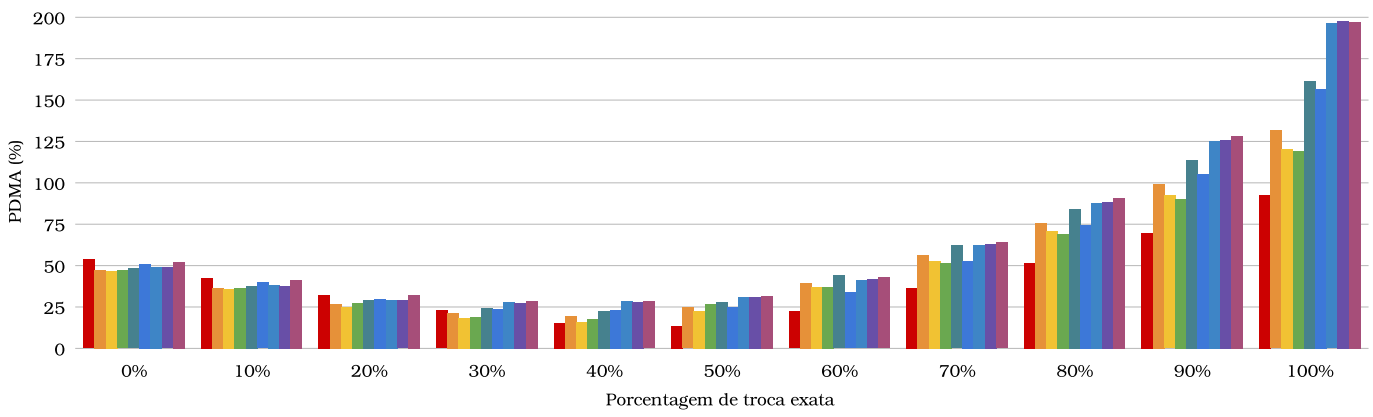

- PW91B95

- PW91B98 - PW91B971

- PW91B972

- PW91LYP

- PW91P86

- PW91PBE

PW91PW91
PW91TPSS

(g) Troca PW91 


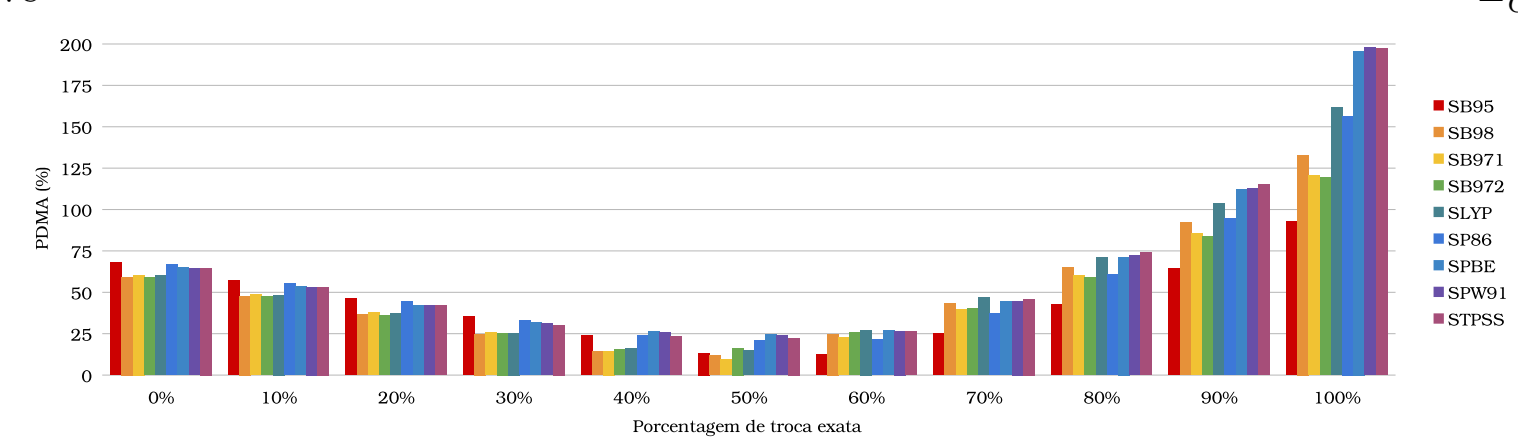

(h) Troca S

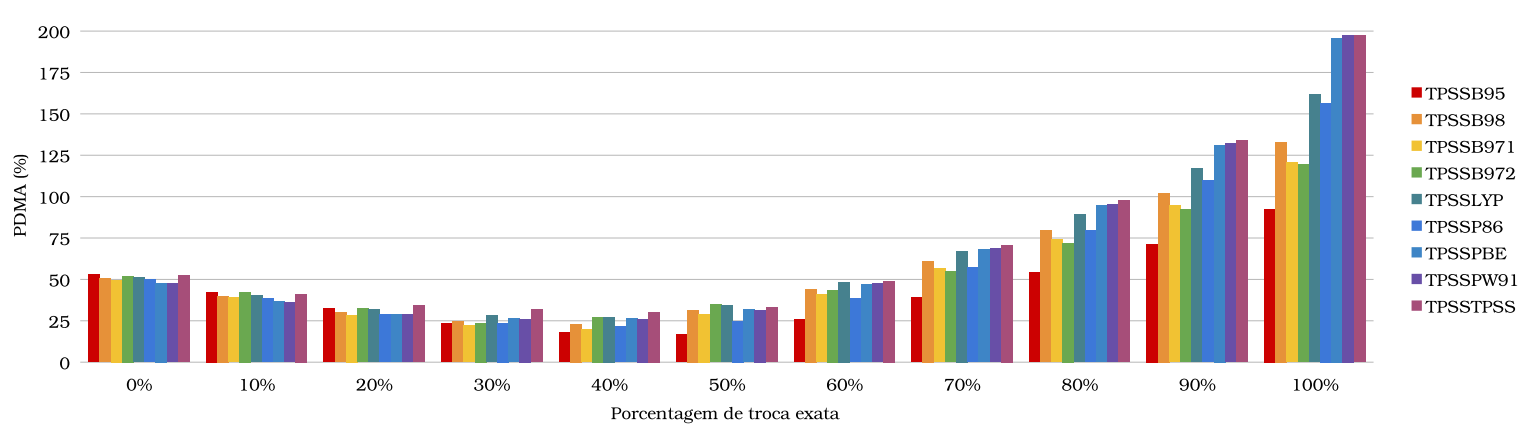

(i) Troca TPSS

Figura 4.16: PDMA para CAISS com diferentes funcionais de troca e correlação e variando a a porcentagem de $E_{X}^{\mathrm{HF}}$ com a base HuzIII-su3. Cada um dos gráficos (a) a (i) corresponde a uma das trocas avaliadas, e cada cor de coluna corresponde a uma das correlações.

A combinação de funcionais de troca e correlação também é calculada para geometrias experimentais com a base HuzIII-su3, e a Figura 4.16 apresenta os resultados para as PDMAs. Os valores das PDMAs obtidas estão apresentados nas Tabelas 8.198, 8.208, $8.218,8.228,8.238,8.248,8.258,8.268$ e 8.278 .

Em uma análise geral, os valores obtidos com base HuzIII-su3 (Figura 4.16) são bastante similares aos obtidos com a base aug-pcJ-2 (Figura 4.15). Para melhor comparar os funcionais obtidos com cada base, a Tabela 4.5 apresenta os dois melhores funcionais para cada funcional de troca, e a Tabela 4.6 apresenta os dois melhores funcionais para cada funcional de correlação. 


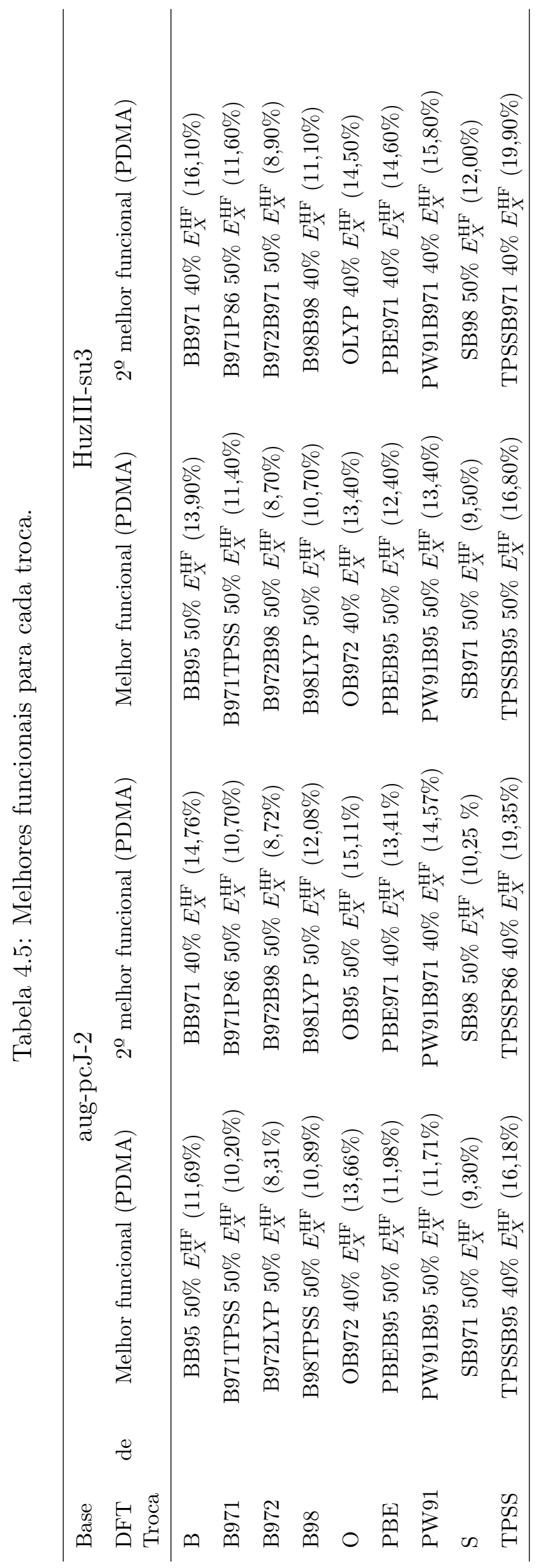


Os resultados entre aug-pcJ-2 e HuzIII-su3 são, em geral, similares. Os funcionais de troca B, B971, PBE, PW91, S e TPSS apresentam os mesmos dois melhores funcionais (apenas o funcional TPSSB95 teve melhor precisão com $40 \% E_{X}^{\mathrm{HF}}$ para aug-pcJ-2 e 50\% $E_{X}^{\mathrm{HF}}$ para HuzIII-su3, e como o intervalo mínimo entre os diferentes funcionais testados é de $10 \% E_{X}^{\mathrm{HF}}$, é possível supor que o mínimo da PDMA está entre 40 e $\left.50 \% E_{X}^{\mathrm{HF}}\right)$. A troca O apresenta o mesmo funcional com melhor resultado, e o $2^{\underline{O}}$ melhor funcional aparece como $3^{\mathrm{O}}$ ou $4^{\underline{\mathrm{O}}}$ melhor utilizando a outra base. As trocas B972 e B98 apresentam o mesmo funcional como melhor para HuzIII-su3 e $2^{\mathrm{O}}$ melhor para aug-pcJ-2, e outro funcional também aparece como $3^{\mathrm{O}}$ ou $4^{\mathrm{O}}$ melhor utilizando a outra base. Como os valores de PDMA são bastante próximos, os resultados são consistentes.

Os funcionais de correlação B972, LYP, P86, PBE, PW91 e TPSS apresentam os mesmos dois melhores funcionais (para a correlação B971, os dois funcionais apresentados na Tabela 4.6 foram considerados o melhor funcional com aug-pcJ-2, pois as PDMAs eram iguais). A correlação B971 apresenta, para os dois melhores resultados para HuzIII-su3, os resultados que são considerados o melhor resultado para aug-pcJ-2. As correlações B95 e B98 apresentam o mesmo melhor funcional, e o $2^{\mathrm{O}}$ melhor aparece como $3^{\mathrm{O}}$ ou $4^{\mathrm{O}}$ melhor utilizando a outra base. Como os valores de PDMA são bastante próximos, os resultados também são consistentes.

As precisões dos funcionais para as bases aug-pcJ-2 e HuzIII-su3, dadas as pequenas mudanças nos valores das PDMAs, são praticamente as mesmas. Em especial, as ordens observadas para os melhores funcionais são muito parecidas. A opção pela utilização da base aug-pcJ-2 se deve, além de seu desenvolvimento para o estudo de propriedades magnéticas, ao fato de ser quádruplo- $\zeta$ (frente à HuzIII-su3, que é triplo- $\zeta$ ).

\subsubsection{Geometrias otimizadas}

No total, 26 dos funcionais gerados estão elencados nas Tabelas 4.5 e $4.6 \mathrm{com}$ base augpcJ-2. Cada um desses funcionais destacados foi utilizado para otimização de geometrias e cálculo das CAISS, e os dados estão apresentados nas Tabelas 8.279 a 8.304. 
Tabela 4.7: Comparação da precisão dos melhores funcionais obtida com geometrias teóricas e experimentais combinando troca e correlação. As médias foram calculadas para todas as 26 CAISS e para somente 23 CAISS (excluindo ${ }^{1} J_{\mathrm{BF}}$ da molécula de $\mathrm{BF}_{3}$ e ${ }^{2} J_{\mathrm{CH}} \mathrm{e}^{2} J_{\mathrm{HH}}$ da molécula de $\mathrm{C}_{2} \mathrm{H}_{4}$ ).

\begin{tabular}{lcccc}
\hline Geometrias & Experimentais & Otimizadas & Experimentais & Otimizadas \\
CAISS & Total & Total & Sem 3 piores & Sem 3 piores \\
Funcionais & $E_{X}^{\mathrm{HF}}(\mathrm{PDMA})$ & $E_{X}^{\mathrm{HF}}(\mathrm{PDMA})$ & $E_{X}^{\mathrm{HF}}(\mathrm{PDMA})$ & $E_{X}^{\mathrm{HF}}(\mathrm{PDMA})$ \\
\hline BB95 & $50 \%(11,69 \%)$ & $40 \%(10,96 \%)$ & $40 \%(8,22 \%)$ & $40 \%(7,17 \%)$ \\
BB971 & $40 \%(14,76 \%)$ & $30 \%(14,46 \%)$ & $30 \%(9,55 \%)$ & $30 \%(10,50 \%)$ \\
B971P86 & $50 \%(10,70 \%)$ & $60 \%(12,63 \%)$ & $50 \%(10,15 \%)$ & $60 \%(8,10 \%)$ \\
B971PBE & $50 \%(11,84 \%)$ & $60 \%(16,21 \%)$ & $50 \%(9,25 \%)$ & $50 \%(8,65 \%)$ \\
B971PW91 & $50 \%(11,48 \%)$ & $60 \%(15,76 \%)$ & $50 \%(9,16 \%)$ & $50 \%(8,55 \%)$ \\
B971TPSS & $50 \%(10,20 \%)$ & $60 \%(14,96 \%)$ & $50 \%(8,05 \%)$ & $50 \%(8,23 \%)$ \\
B972B95 & $60 \%(10,03 \%)$ & $60 \%(8,58 \%)$ & $60 \%(9,18 \%)$ & $60 \%(7,80 \%)$ \\
B972B971 & $50 \%(9,34 \%)$ & $50 \%(12,95 \%)$ & $50 \%(9,26 \%)$ & $50 \%(9,51 \%)$ \\
B972B98 & $50 \%(8,72 \%)$ & $50 \%(13,81 \%)$ & $50 \%(9,13 \%)$ & $50 \%(8,90 \%)$ \\
B972LYP & $50 \%(8,31 \%)$ & $50 \%(14,60 \%)$ & $50 \%(8,63 \%)$ & $50 \%(8,25 \%)$ \\
B98LYP & $50 \%(12,08 \%)$ & $60 \%(15,82 \%)$ & $50 \%(8,82 \%)$ & $50 \%(8,50 \%)$ \\
B98P86 & $50 \%(12,80 \%)$ & $60 \%(12,63 \%)$ & $60 \%(10,68 \%)$ & $60 \%(8,00 \%)$ \\
B98PBE & $50 \%(13,01 \%)$ & $60 \%(15,99 \%)$ & $50 \%(9,81 \%)$ & $60 \%(9,06 \%)$ \\
B98PW91 & $50 \%(12,50 \%)$ & $60 \%(15,61 \%)$ & $50 \%(9,59 \%)$ & $60 \%(8,85 \%)$ \\
B98TPSS & $50 \%(10,89 \%)$ & $60 \%(14,29 \%)$ & $50 \%(8,39 \%)$ & $50 \%(8,65 \%)$ \\
OB95 & $50 \%(15,11 \%)$ & $40 \%(15,84 \%)$ & $40 \%(9,03 \%)$ & $40 \%(8,64 \%)$ \\
OB972 & $40 \%(13,66 \%)$ & $30 \%(14,01 \%)$ & $30 \%(8,02 \%)$ & $30 \%(9,27 \%)$ \\
PBEB95 & $50 \%(11,98 \%)$ & $40 \%(9,28 \%)$ & $40 \%(7,88 \%)$ & $40 \%(7,78 \%)$ \\
PBEB971 & $40 \%(13,41 \%)$ & $30 \%(13,19 \%)$ & $30 \%(9,83 \%)$ & $30 \%(11,27 \%)$ \\
PW91B95 & $50 \%(11,71 \%)$ & $40 \%(10,24 \%)$ & $40 \%(8,09 \%)$ & $40 \%(7,48 \%)$ \\
PW91B971 & $40 \%(14,57 \%)$ & $30 \%(13,77 \%)$ & $30 \%(9,95 \%)$ & $30 \%(11,18 \%)$ \\
SB971 & $50 \%(9,30 \%)$ & $40 \%(14,89 \%)$ & $50 \%(7,41 \%)$ & $40 \%(12,47 \%)$ \\
SB972 & $40 \%(15,36 \%)$ & $30 \%(20,84 \%)$ & $50 \%(11,48 \%)$ & $40 \%(16,29 \%)$ \\
TP988 & $50 \%(10,25 \%)$ & $40 \%(12,14 \%)$ & $50 \%(8,33 \%)$ & $40 \%(11,20 \%)$ \\
\hline TPSSP86 & $40 \%(19,18 \%)$ & $40 \%(11,44 \%)$ & $30 \%(8,85 \%)$ & $40 \%(9,64 \%)$ \\
& $40 \%(14,30 \%)$ & $30 \%(9,86 \%)$ & $30 \%(9,46 \%)$ \\
\hline
\end{tabular}

Para cada funcional, é avaliada a princípio a porcentagem de $E_{X}^{\mathrm{HF}}$ de menor PDMA total para geometrias experimentais e as porcentagens adjacentes $( \pm 10 \%)$, e a otimização é feita apenas com o funcional construído (visto que majoritariamente não há um funcional original como referência). Os resultados da PDMA considerando a otimização 
de geometrias estão apresentados na terceira coluna da Tabela 4.7. A segunda coluna da Tabela 4.7 contém os melhores resultados com geometrias experimentais (Figura 4.15).

Apenas os resultados com troca B972 e TPSS têm mesma porcentagem de $E_{X}^{\mathrm{HF}}$ resultando no menor valor de PDMA tanto para geometrias otimizadas quanto experimentais. Os resultados com troca B971 e B98 têm um aumento de $10 \%$ da $E_{X}^{\mathrm{HF}}$ para a otimização de geometrias, e os resultados com troca B, O, PBE, PW91 e S têm diminuição de 10\%.

De maneira geral, a precisão melhora para os resultados com troca B, PBE, PW91 e TPSS, e piora para troca B971, B98 e S. De todos, o funcional B972B95 $60 \% E_{X}^{\mathrm{HF}}$ apresenta a melhor precisão $(\mathrm{PDMA}=8,58 \%)$ para a otimização e cálculo das CAISS, seguido de PBEB95 40\% $E_{X}^{\mathrm{HF}}(9,28 \%)$, PW91B95 40\% $E_{X}^{\mathrm{HF}}(10,24 \%)$, BB95 $40 \% E_{X}^{\mathrm{HF}}$ $(10,96 \%)$ e TPSSB95 40\% $E_{X}^{\mathrm{HF}}(11,44 \%)$, ou seja, os resultados com correlação B95 são os mais precisos com geometrias otimizadas.

Entretanto, a mudança da porcentagem de $E_{X}^{\mathrm{HF}}$ necessária para obter PDMA mínimo encontrada na maioria dos DFTs pode ser um indicativo de que a precisão é dependente das CAISS consideradas. Assim, para melhor investigar a dependência da precisão em relação aos tipos de acoplamento, é observada a porcentagem de desvio absoluto (PDA) de cada uma das CAISS, conforme apresentado na Figura 4.17. Cabe ressaltar que o comportamento da Figura 4.17 não é observado apenas para BB95, B972B95, B98LYP, OB972 e SB971, mas para todos os funcionais construídos avaliados na otimização de geometrias (ver funcionais na Tabela 4.7).

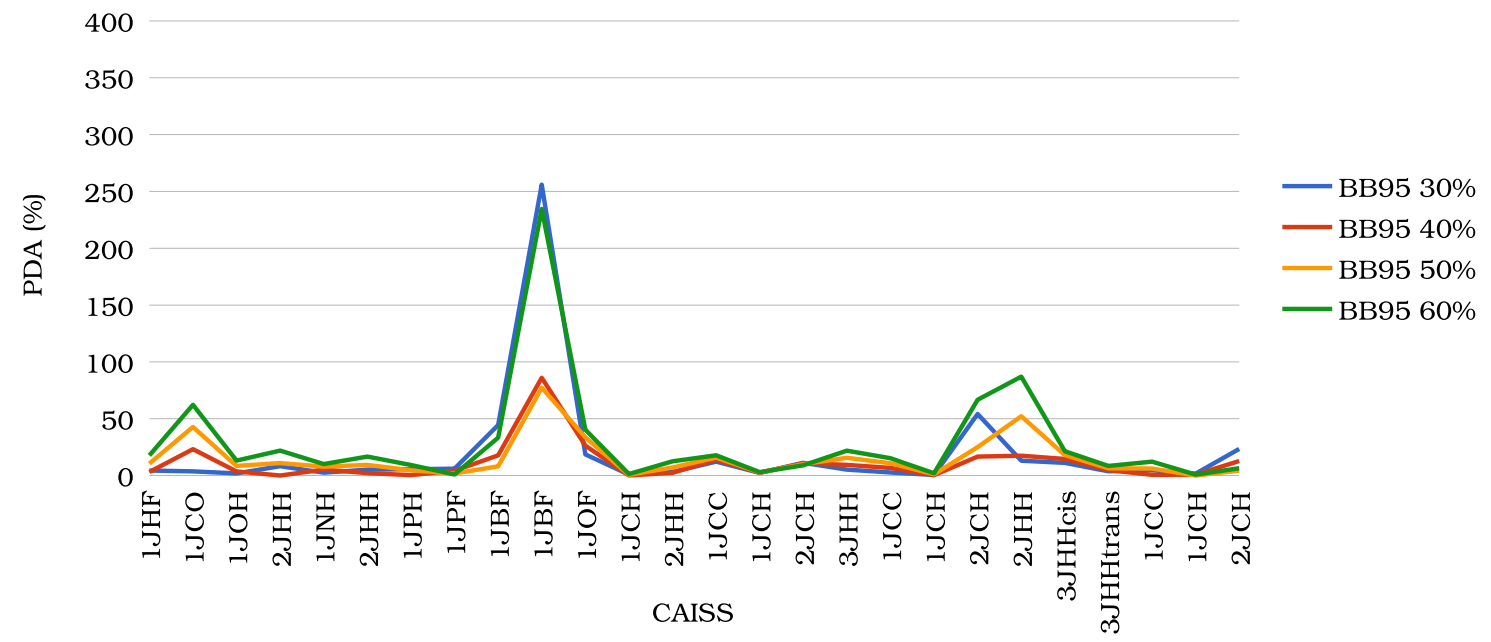

(a) BB95 


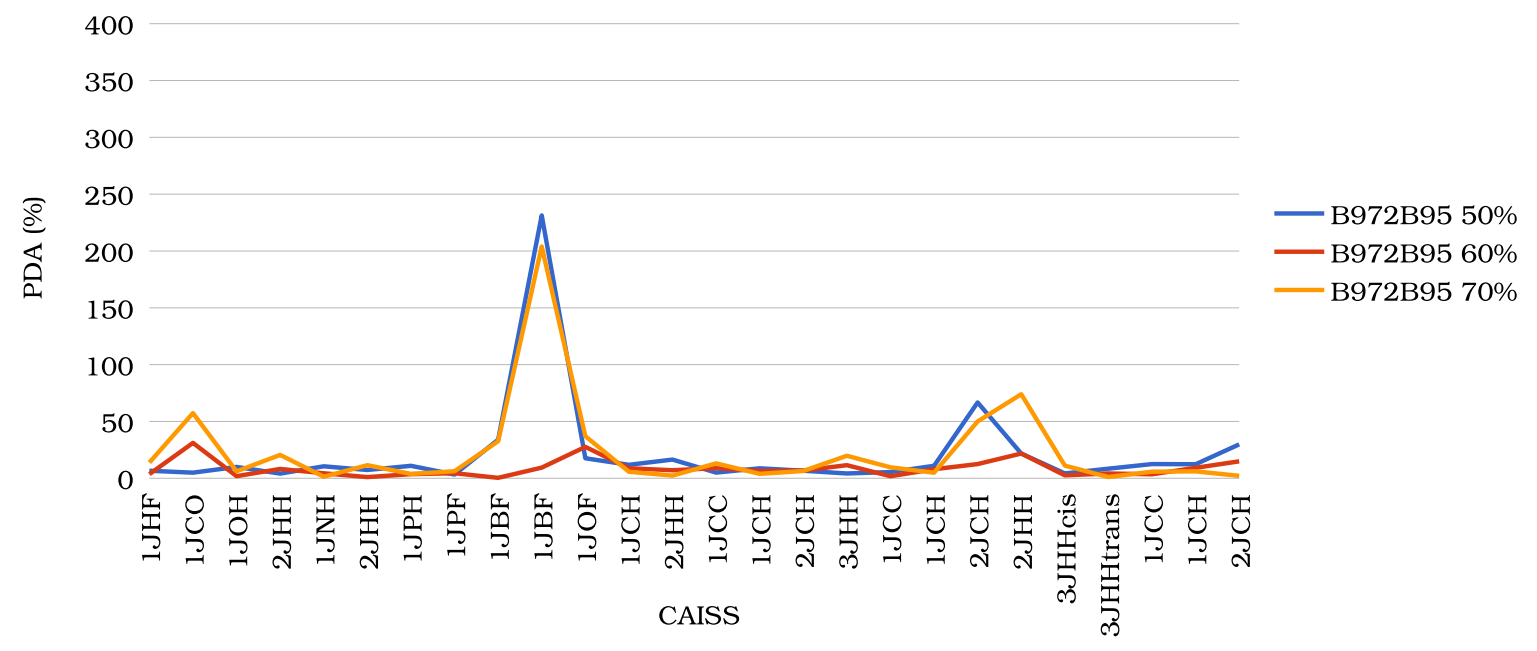

(b) B972B95

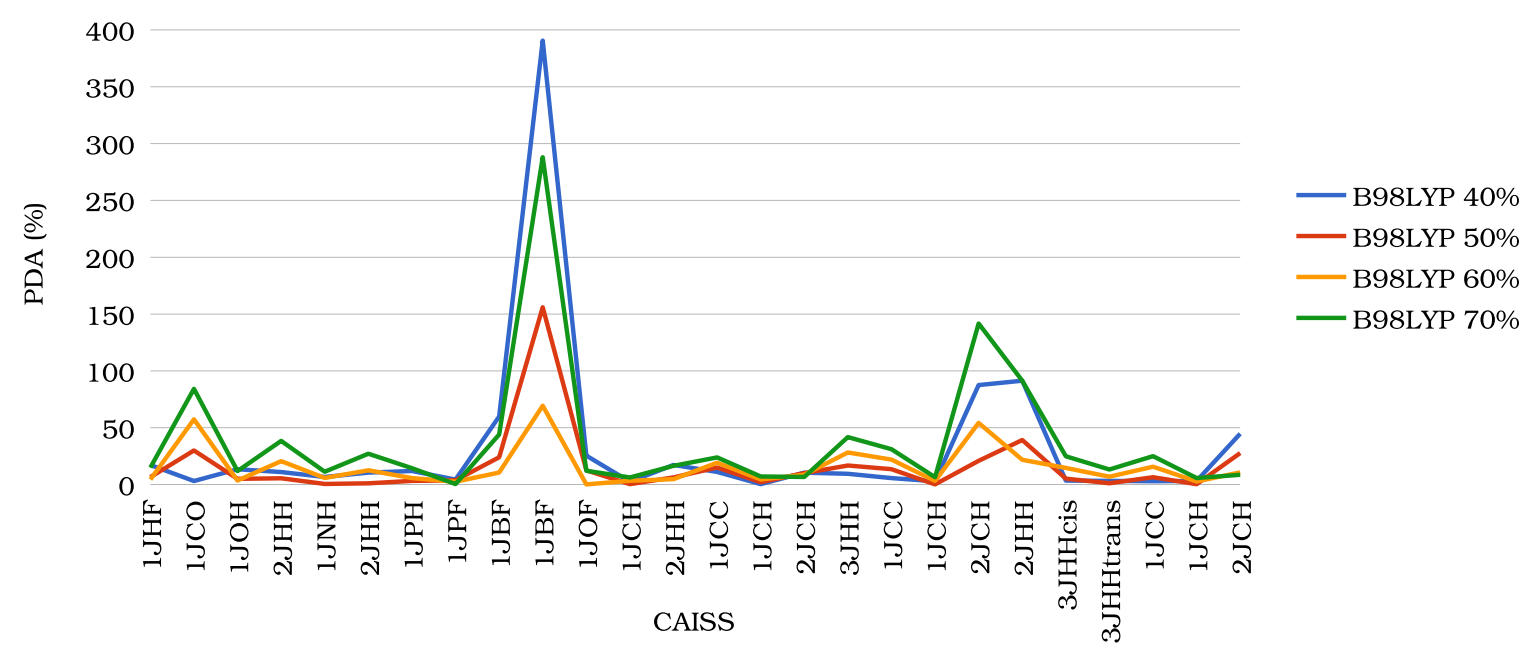

(c) B98LYP

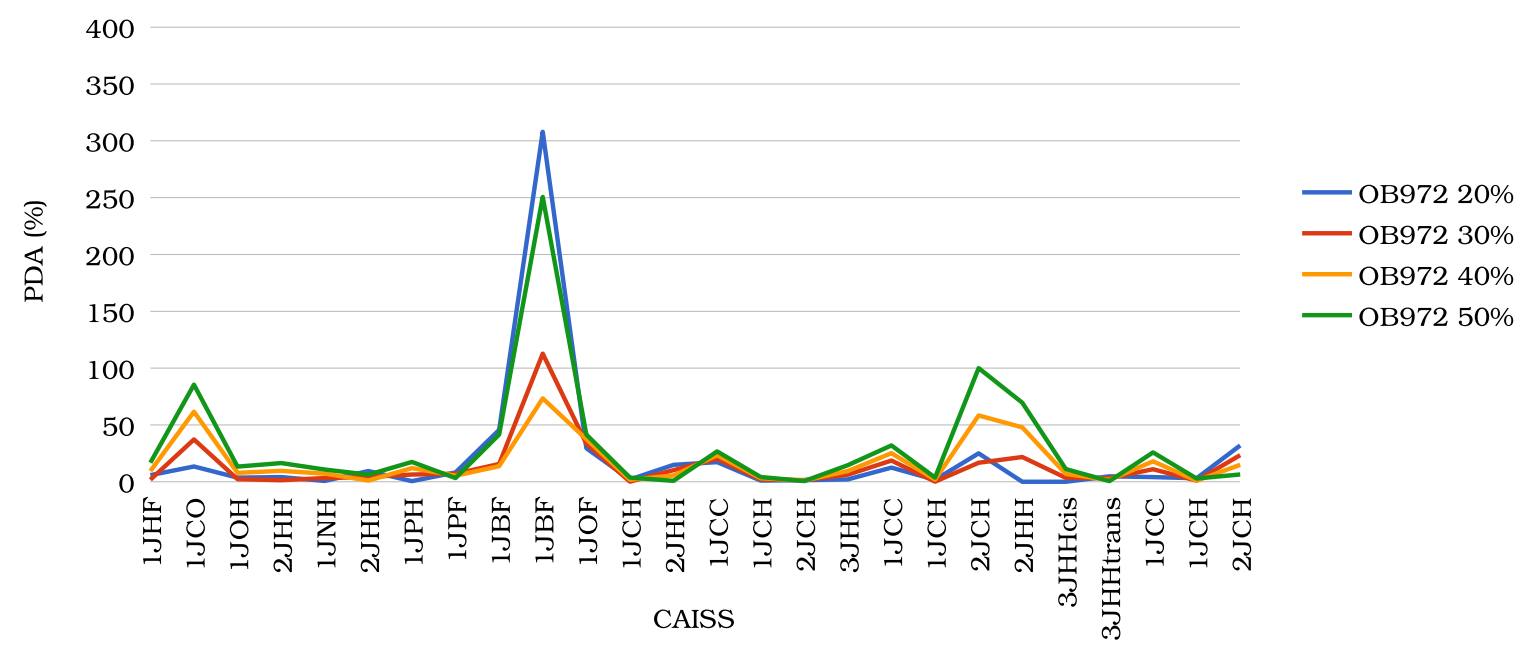

(d) OB972 


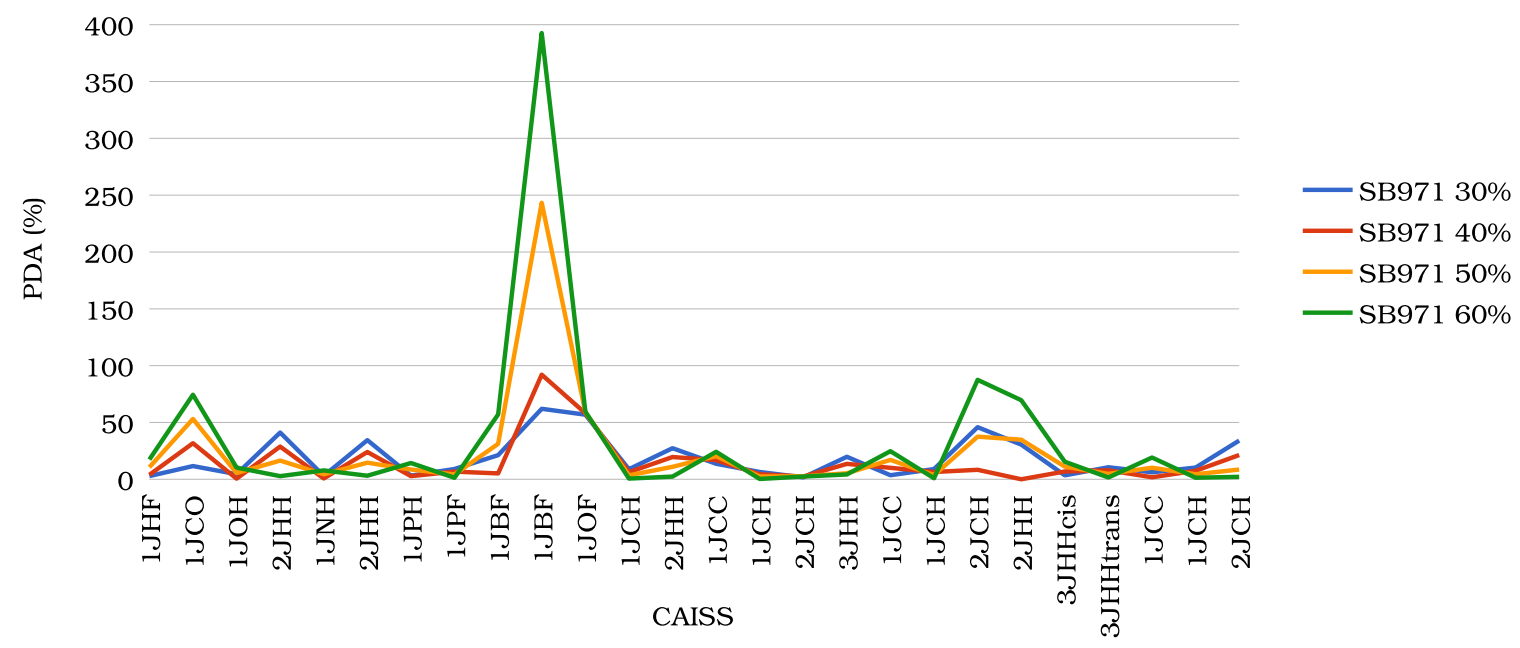

(e) SB971

Figura 4.17: PDA das CAISS com otimização de geometrias para algumas combinações de troca e correlação entre 20 e $70 \%$ de $E_{X}^{\mathrm{HF}}$. As geometrias teóricas são obtidas no mesmo nível teórico. Os demais resultados apresentam comportamento similar.

As constantes ${ }^{1} J_{\mathrm{BF}}$ da molécula de $\mathrm{BF}_{3},{ }^{2} J_{\mathrm{CH}}$ e ${ }^{2} J_{\mathrm{HH}}$ da molécula de $\mathrm{C}_{2} \mathrm{H}_{4}$ são as principais contribuições para que a PDMA seja maior, e portanto são feitos todos cálculos de DM, DMA e PDMA com a exclusão dessas 3 constantes (apresentados nas Tabelas 8.189 a 8.304). Os valores das PDMAs excluindo essas 3 CAISS estão apresentados nas quarta e quinta colunas da Tabela 4.7 para os melhores funcionais com geometrias experimentais e otimizadas, respectivamente.

Para boa parte dos DFTs houve mudanças significativas nos valores de DM, DMA e PDMA (ver Tabelas 8.189 a 8.304, indicando que a precisão não é independente do tipo de acoplamento. Para o funcional B972B95 60\% $E_{X}^{\mathrm{HF}}$, a exclusão das 3 constantes não altera a porcentagem de $E_{X}^{\mathrm{HF}}(60 \%)$, e a PDMA total varia de 10,03\% para 9,18\% considerando as geometrias experimentais, e de 8,58\% para 7,80\% para as geometrias teóricas. A pequena variação da PDMA (inferior a $1 \%$ ) para a remoção de ${ }^{1} J_{\mathrm{BF}}$ da molécula de $\mathrm{BF}_{3}$ e de ${ }^{2} J_{\mathrm{CH}} \mathrm{e}^{2} J_{\mathrm{HH}}$ da molécula de $\mathrm{C}_{2} \mathrm{H}_{4}$ é um indicativo de que a precisão do funcional é independente dos tipos de acoplamento considerados.

Pequenas variações de PDMA também são observadas para os funcionais B972B971 $50 \% E_{X}^{\mathrm{HF}}$ (de $9,34 \%$ para $9,26 \%$ para geometrias experimentais, e de $12,95 \%$ para $9,51 \%$ para geometrias teóricas), B972B98 $50 \% E_{X}^{\mathrm{HF}}$ (de 8,72\% para 9,13\% para geometrias 
experimentais, e de 13,81\% para 8,90\% para geometrias teóricas) e B972LYP $50 \% E_{X}^{\mathrm{HF}}$ (de $8,31 \%$ para $8,63 \%$ para geometrias experimentais, e de $14,60 \%$ para $8,25 \%$ para geometrias teóricas), e todos têm $50 \% E_{X}^{\mathrm{HF}}$ como melhor precisão. Para o funcional B971P86 a PDMA varia de $10,70 \%$ para $10,15 \%$ para geometrias experimentais (com $50 \% E_{X}^{\mathrm{HF}}$ ), e de 12,69\% para 8,10\% para geometrias teóricas (com $\left.60 \% E_{X}^{\mathrm{HF}}\right)$. A maior variação da PDMA para os demais funcionais indica que a precisão é dependente dos tipos de acoplamento considerados.

Assim dos funcionais construídos a partir da troca, correlação e porcentagem de $E_{X}^{\mathrm{HF}}$, o B972B95 60\% $E_{X}^{\mathrm{HF}}$ apresenta ótimos resultados para o cálculo de CAISS, inclusive após a otimização de geometrias. Em geral, utilizar o funcional de correlação B95 é uma boa estratégia para obter CAISS precisas, e está contido em alguns dos DFTs que produzem bons resultados. A utilização do funcional de troca B972 também é uma estratégia razoável para obter CAISS precisas, e também está contido em alguns dos DFTs que produzem bons resultados. O ajuste por volta de $40 \%$ a $50 \% E_{X}^{\mathrm{HF}}$ resulta nas melhores precisões; desta forma o B972B95 60\% $E_{X}^{\mathrm{HF}}$ é destacado pela alta porcentagem de $E_{X}^{\mathrm{HF}}$ presente. 


\subsection{Variação da porcentagem de $E_{X}^{\mathrm{HF}}$ para os funcionais de longo alcance}

\subsubsection{Geometrias experimentais}

A variação da porcentagem de $E_{X}^{\mathrm{HF}}$ para CAM-B3LYP, $\omega$ B97, $\omega$ B97X e $\omega$ B97XD foram feitas através dos $\operatorname{IOp}(3 / 107), \operatorname{IOp}(3 / 108), \operatorname{IOp}(3 / 119), \operatorname{IOp}(3 / 120), \operatorname{IOp}(3 / 130)$ e IOp(3/131). Para tanto, é preciso considerar que $\alpha$ representa a porcentagem de $E_{X}^{\mathrm{HF}}$ a distâncias próximas de zero, e $\alpha+\beta$ representa a porcentagem de $E_{X}^{\mathrm{HF}}$ a distâncias tendendo ao infinito, de acordo com a Figura 3.1. A Tabela 4.8 apresenta os valores originais dos parâmetros $\alpha, \alpha+\beta$ e $\gamma$ para os DFTs estudados.

Tabela 4.8: Parâmetros originais dos funcionais de longo alcance.

\begin{tabular}{lccc}
\hline Funcionais & $\alpha$ & $\alpha+\beta$ & $\gamma$ \\
\hline CAM-B3LYP & $19,00 \%$ & $65,00 \%$ & 0,33 \\
$\omega$ B97 & $0,00 \%$ & $100,00 \%$ & 0,40 \\
$\omega$ B97X & $15,77 \%$ & $100,00 \%$ & 0,30 \\
$\omega$ B97XD & $22,20 \%$ & $100,00 \%$ & 0,20 \\
\hline
\end{tabular}

Para que a variação da porcentagem de $E_{X}^{\mathrm{HF}}$ seja feita de 0 a $100 \%$, O parâmetro $\alpha+\beta$ foi fixado igual a 100\%. Desta forma, $\alpha$ foi variado de 0 a $100 \%$ em intervalos de 10\%, e $\beta=100 \%-\alpha$. Apesar disso, é visto que a correção de longo alcance não implica que $\alpha$ deva ser zero e $\alpha+\beta=1$, e portanto é possível utilizar valores diferentes, de acordo com a Figura 3.1 (baseada no trabalho de Yanai et al sobre o método atenuado por Coulomb - CAM-B3LYP) ${ }^{[75}$ Por esse motivo também são adotados valores de $\alpha+\beta$ iguais a $80 \%$, $60 \%, 40 \%$ e 20\%. A variação de $\alpha$, entretanto não pode ser feita até $100 \%$, mas até o valor de $\alpha+\beta$ (pois $\beta$ deve ser não negativo). O valor de $\gamma$ não foi alterado.

Os resultados obtidos com base aug-pcJ-2 para as variações desses 4 funcionais estão apresentados nas Tabelas 8.305 a 8.324. Não foi possível obter os resultados desejados nos casos em que $\alpha$ ou $\beta$ são iguais a zero, visto que quando ajustados para zero, o programa Gaussian 09 retorna o valor original do funcional para tal parâmetro. 

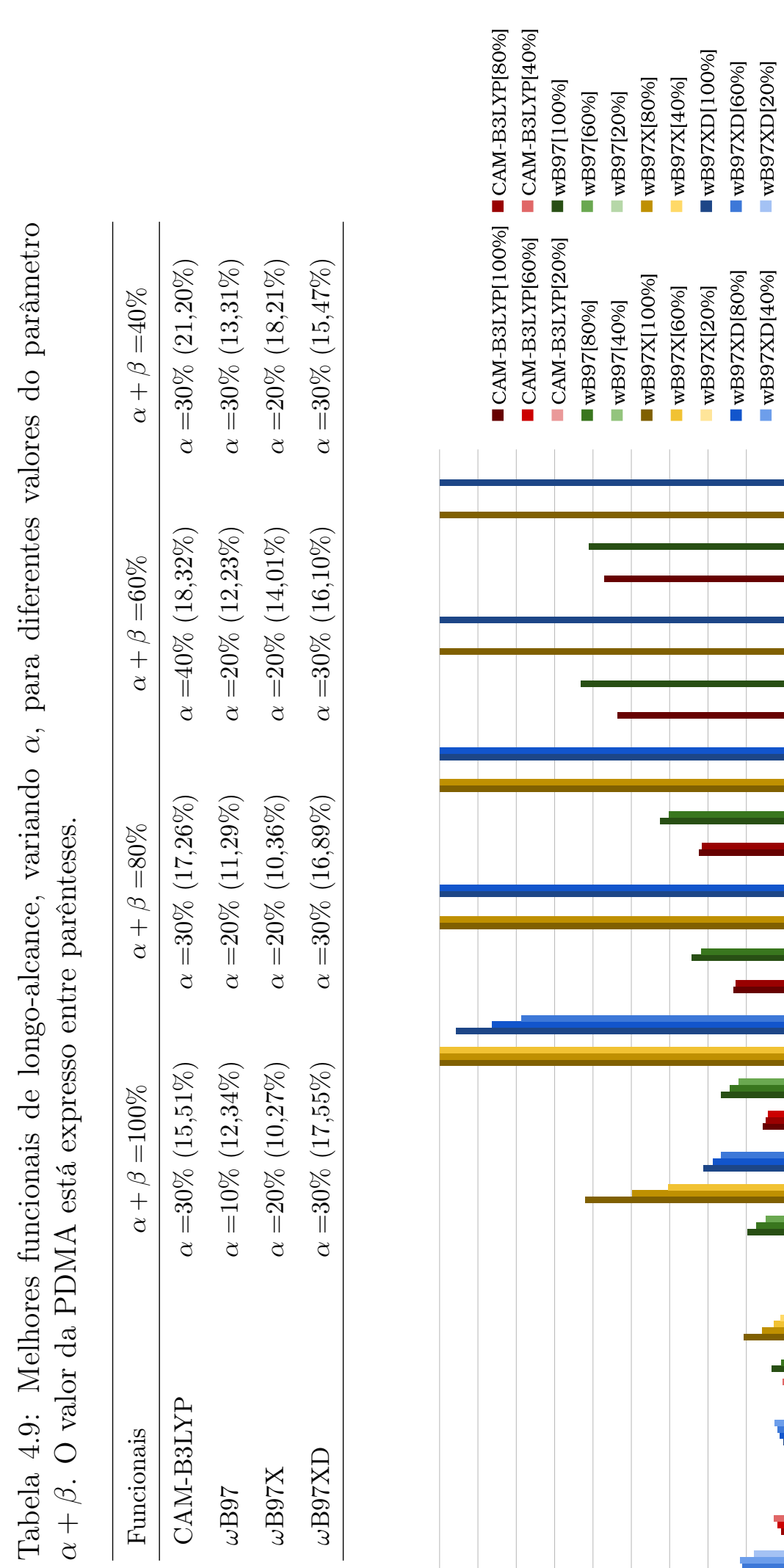

$\mathbb{1}$
$\hat{0}$
0
0
0
0
$\frac{0}{\pi}$
$\frac{\pi}{\pi}$

চें ळ

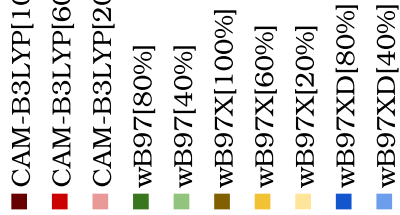

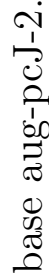
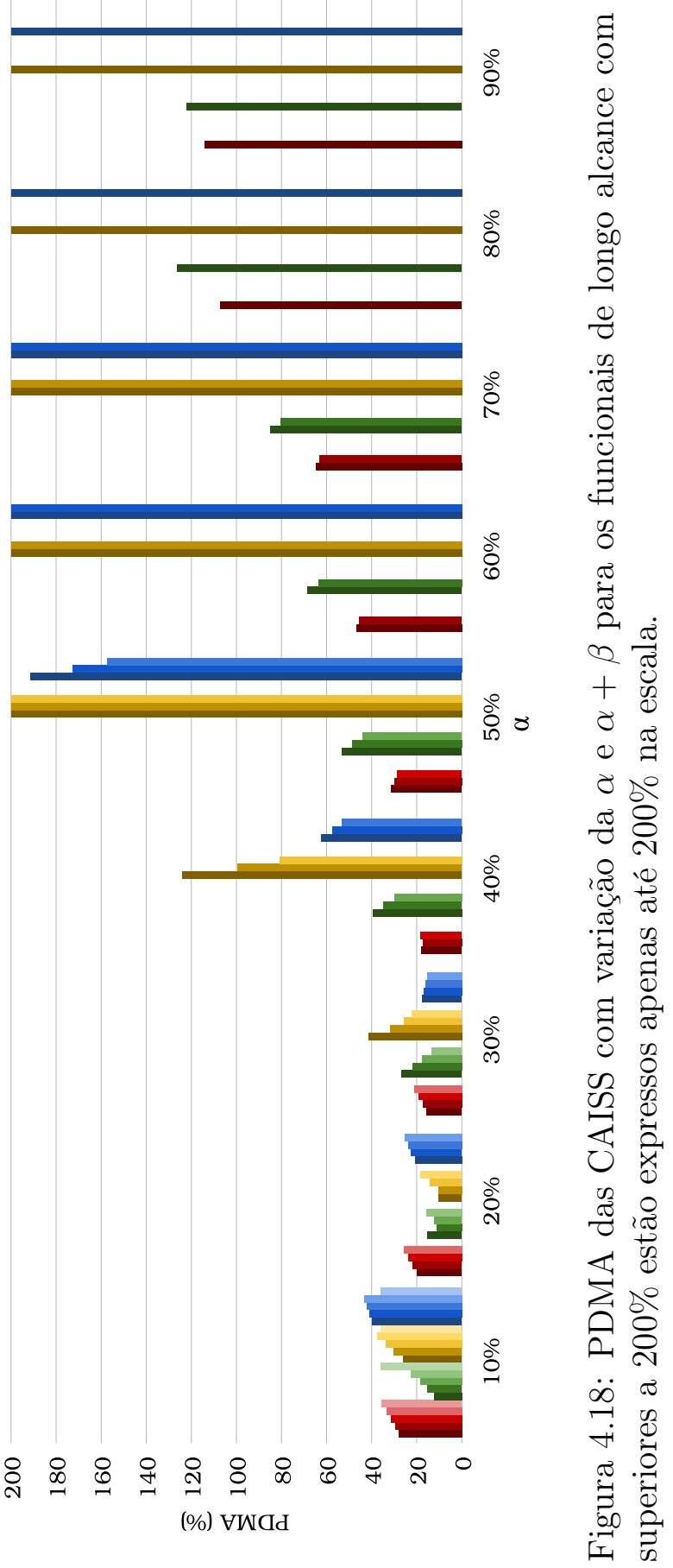
Com base nos resultados para os DFTs sem correção de longo alcance, é esperado que o mínimo do PDMA não seja obtido nos valores extremos. Entretanto, especialmente para as variações de 0 a $40 \%$ (em que $\alpha+\beta=40 \%$ ) e de 0 a $20 \%$ (em que $\alpha+\beta=20 \%$ ), essa consideração pode ser problemática pois há poucos valores investigados na variação. Para a variação de 0 a 20\%, temos somente as CAISS para o caso em que $\alpha=10 \%$ e $\beta=10 \%$ (neste caso, as PDMAs para os 4 funcionais são superiores a $30 \%$, e portanto não devemos encontrar boas precisões nessa variação).

A Figura 4.18 apresenta os valores de PDMA total para as variações de $\alpha$ e $\alpha+\beta$. O valor de $\alpha+\beta$ está expresso entre colchetes na legenda da Figura 4.18 ao lado do nome do funcional. Para avaliar mais adequadamente os melhores resultados, cada uma das variações (com $\alpha+\beta$ fixado) foi avaliada separadamente, e a porcentagem $\alpha$ de $E_{X}^{\mathrm{HF}}$ que gerou a menor PDMA está destacada na Tabela 4.9 (a variação com $\alpha+\beta=20 \%$ não é incluída pois as PDMAs excedem 30\%).

A notação "DFT $(\alpha|\alpha+\beta| \gamma)$ " é adotada para tornar mais breve a descrição dos parâmetros, e "\#" indica que o parâmetro não é alterado; assim "DFT(\#|\#|\#)" corresponde ao próprio DFT original. Desta forma, o melhor resultado foi obtido com $\omega \mathrm{B} 97 \mathrm{X}(0,2|1,0| \#)$, seguido de $\omega \operatorname{B} 97 \mathrm{X}(0,2|0,8| \#)$ e $\omega \mathrm{B} 97(0,2|0,8| \#)$. Os funcionais $\omega$ B97XD e CAM-B3LYP também deram bons resultados, porém não tão precisos pois as PDMAs não são inferiores a 15\%. O melhor resultado para $\omega$ B97XD ainda pode ser superado para casos com $\alpha \geqslant 40 \%$, que não puderam ser investigados. O resultado com $\operatorname{CAM-B3LYP}(0,3|1,0| \#)$, ainda assim, é muito melhor que o CAM-B3LYP original, e isso está principalmente relacionado com o aumento de $\alpha+\beta$.

Para CAM-B3LYP e $\omega$ B97X, os melhores resultados assemelham-se à idealização da correção de longo alcance (Figura 3.1b), enquanto que para $\omega$ B97XD o método atenuado por Coulomb (Figura 3.1c) é mais similar; $\omega$ B97 apresenta características mistas.

Uma outra maneira de ajustar a porcentagem de $E_{X}^{\mathrm{HF}}$ dos funcionais de longo alcance envolve a variação do parâmetro $\gamma$. Como não existem grandes restrições como no caso de $\alpha$ e $\beta$, foi escolhido variar o $\gamma$ de 0,25 a 0,65 em intervalos de 0,05 mais o valor de 0,75 (o último intervalo é de 0,10 pois o valor de $\gamma$ é grande comparativamente aos DFTs da 
literatura. Os valores de $\alpha$ e $\alpha+\beta$ não foram variados. Os resultados estão apresentados nas Tabelas 8.325 a 8.328 .

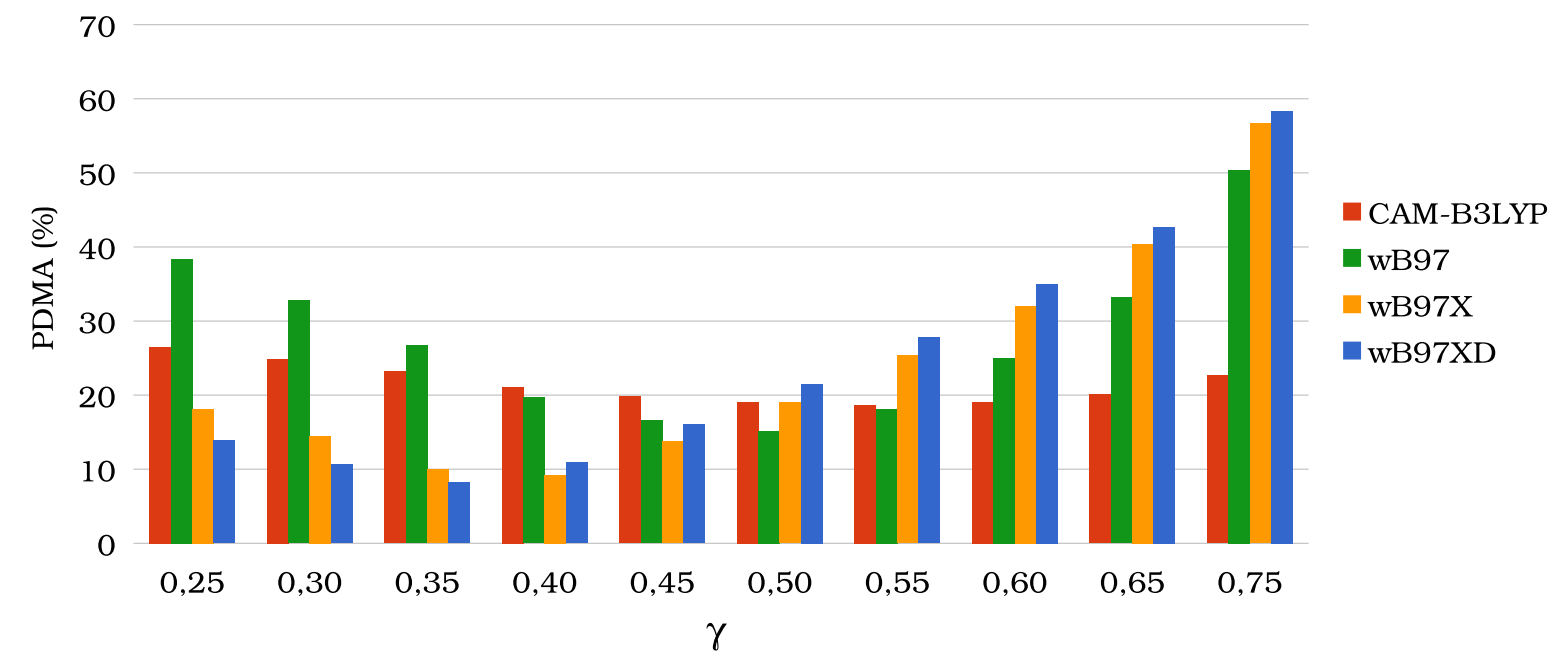

Figura 4.19: PDMA das CAISS com variação do parâmetro $\gamma$ entre 0,25 e 0,75 com base aug-pcJ-2.

A Figura 4.19 apresenta as PDMAs totais obtidas para as modificações dos DFTs de longo alcance. O melhor resultado é do funcional $\omega \mathrm{B} 97 \mathrm{XD}(\#|\#| 0,35)$ (PDMA = 8,17\%), seguido de $\omega \operatorname{Bg7X}(\#|\#| 0,40)(9,18 \%)$, ambos com ótima precisão. Os funcionais $\omega \mathrm{B} 97(\#|\#| 0,50)(15,13 \%)$ e CAM-B3LYP $(\#|\#| 0,55)(18,66 \%)$ também são bastante precisos, porém as PDMAs são superiores a 15\%. Todos apresentam um incremento do parâmetro $\gamma$ em relação ao funcional original, cujos parâmetros estão apresentados na Tabela 4.8. O incremento de $\gamma$ está associado ao incremento da porcentagem $E_{X}^{\mathrm{HF}}$ nos DFTs.

Tabela 4.10: Melhores modificações dos funcionais de longo alcance usando geometrias experimentais.

\begin{tabular}{lcc}
\hline Funcionais & Original & Modificados \\
\hline CAM-B3LYP & $(0,19|0,65| 0,33)$ & $(0,3|1,0| \#)$ \\
$\omega$ B97 & $(0,0|1,0| 0,40)$ & $(0,2|0,8| \#)$ \\
$\omega$ B97X & $(0,1577|1,0| 0,30)$ & $(0,2|1,0| \#)$ e $(\#|\#| 0,40)$ \\
$\omega$ B97XD & $(0,2220|1,0| 0,20)$ & $(\#|\#| 0,35)$ \\
\hline
\end{tabular}

Desta maneira, a utilização dos parâmetros modificados apresentados na Tabela 4.10 para os DFTs de longo alcance permite obter resultados com ótima precisão para geo- 
metrias experimentais. É interessante notar que, para CAM-B3LYP, o aumento de $\alpha$ e $\alpha+\beta$ em relação ao original corresponde a um incremento na porcentagem de $E_{X}^{\mathrm{HF}}$. Para $\omega \mathrm{B} 97 \mathrm{X}$ e $\omega \mathrm{B} 97 \mathrm{XD}$, o aumento de $\alpha$ em relação ao original também corresponde a um incremento na porcentagem de $E_{X}^{\mathrm{HF}}$, assim como o aumento de $\gamma$ em relação ao original também corresponde a esse incremento. Já para $\omega$ B97 existe um balanço entre a diminuição de $\alpha+\beta$, que corresponde ao decremento da porcentagem de $E_{X}^{\mathrm{HF}}$, e o aumento de $\alpha$ (e portanto não há uma simples comparação com a porcentagem de $E_{X}^{\mathrm{HF}}$ do funcional original).

\subsubsection{Geometrias otimizadas}

Os melhores funcionais foram avaliados considerando a otimização das geometrias moleculares. A otimização foi feita tanto com o funcional modificado quanto com o original - para tanto foi utilizada a notação "DFT $1 / / \mathrm{DFT}_{2}$ ", indicando que a otimização de geometrias foi feita com o "DFT,", e o cálculo da propriedade com o "DFT 2 " (a ausência da notação indica que não houve otimização, e portanto as geometrias experimentais foram consideradas no cálculo da propriedade).

Os resultados com otimização de geometrias para os DFTs de longo alcance estão apresentados nas Tabelas 8.329 a 8.337. O CAM-B3LYP apresentou PDMA total de $21,73 \%$, sendo ligeiramente melhor que as geometrias experimentais (23,18\%). Nenhuma das modificações a partir do CAM-B3LYP foi investigada para geometrias otimizadas, visto que a família $\omega$ B97 apresentou resultados mais precisos.

A Figura 4.20 apresenta os resultados para a variação de $\alpha$ e $\alpha+\beta$ do $\omega$ B97X. Em primeiro lugar, a utilização de $\alpha=20 \%$ resulta nas melhores precisões obtidas, sendo ligeiramente mais preciso que o funcional original. O melhor resultado foi obtido com $\omega \operatorname{B} 97 \mathrm{X}(0,2|1,0| \#) / / \omega \operatorname{B} 97 \mathrm{X}(0,2|1,0| \#)(\mathrm{PDMA}=10,55 \%)$; a diferença para o resultado envolvendo as geometrias experimentais consiste na ligeira inversão da precisão dos conjuntos CPI e SPI, que são bastante próximos. O resultado obtido com $\omega \operatorname{B} 97 \mathrm{X}(0,2|0,8| \#) / / \omega \operatorname{B} 97 \mathrm{X}(0,2|0,8| \#)(12,06 \%)$ tem aumento de PDMA inferior a $2 \%$ em relação ao com geometrias experimentais, mas seus resultados para CPI e SPI são 
muito mais balanceados em relação ao obtido para geometrias experimentais. Os valores de PDMA são menores para $\alpha+\beta=100 \%$, e aumentam conforme $\alpha+\beta$ diminui.

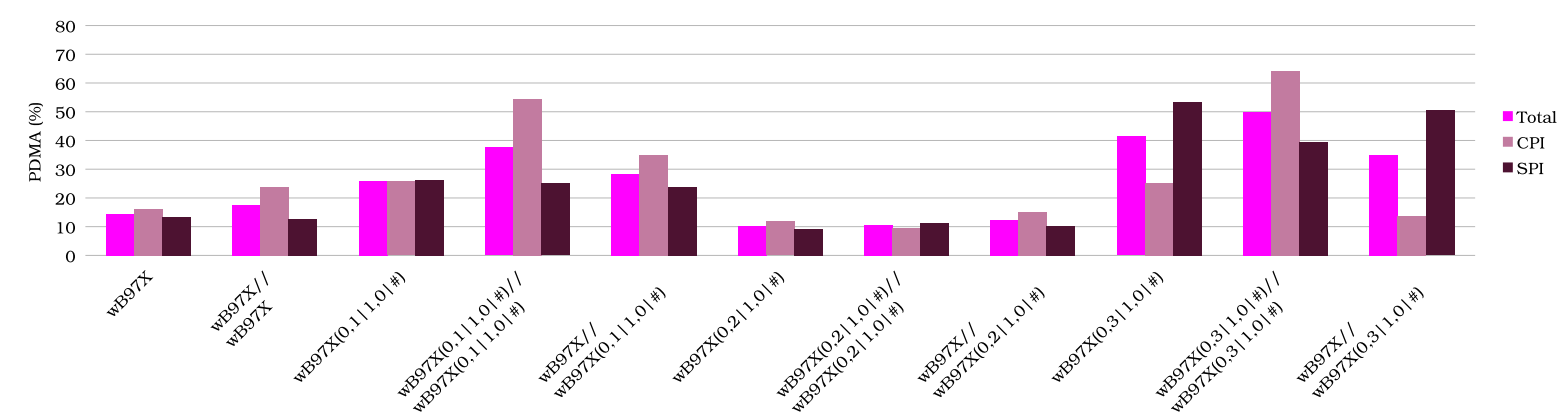

(a) $\alpha+\beta=100 \%$

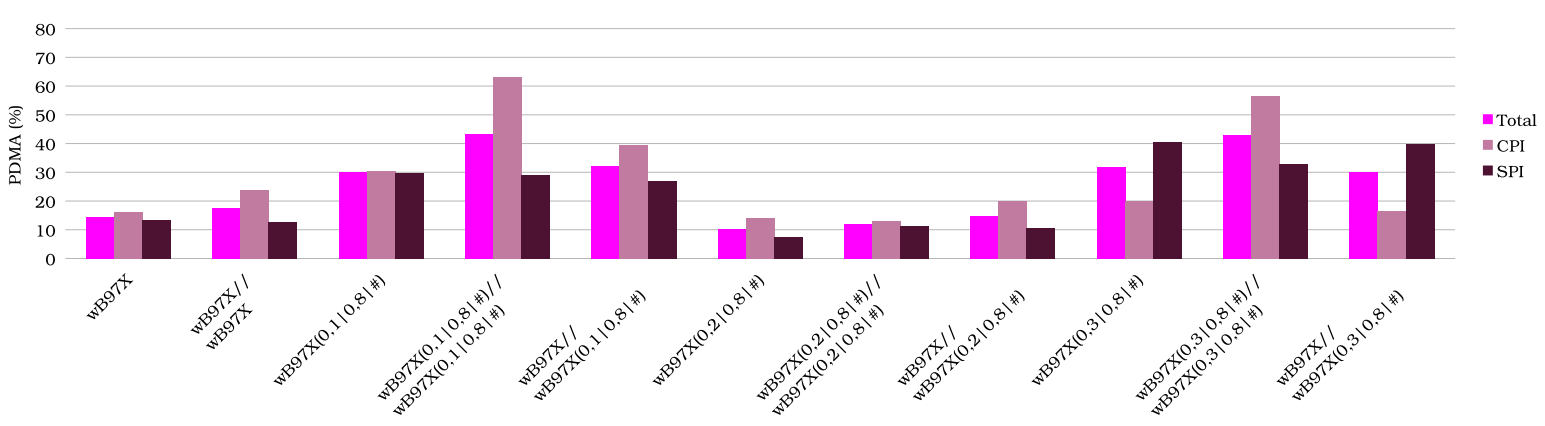

(b) $\alpha+\beta=80 \%$

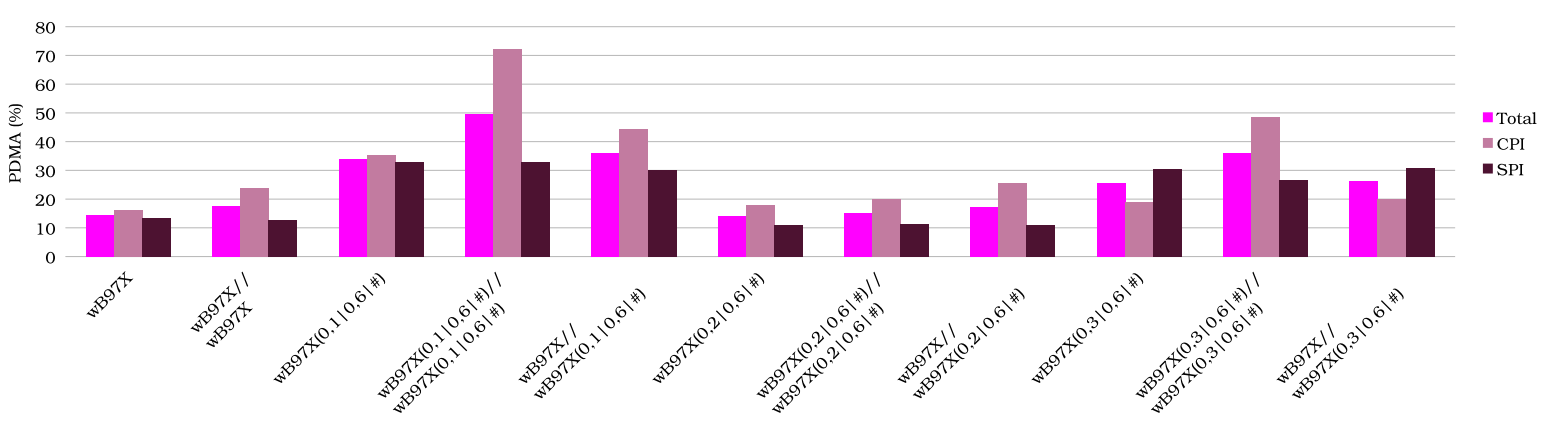

(c) $\alpha+\beta=60 \%$

Figura 4.20: Comparação entre as PDMAs obtidas com base aug-pcJ-2 para geometrias teóricas e experimentais para o $\omega$ B97X com $\alpha=10 \%, 20 \%$ ou 30\%. As médias são calculadas para todas as 26 CAISS, para as 11 CAISS das moléculas CPI e para as 15 CAISS das moléculas SPI.

A Figura 4.21 apresenta os resultados para a variação de $\alpha$ e $\alpha+\beta$ do $\omega$ B97. Os resultados envolvendo cálculo de otimização não superam os melhores resultados com geometrias experimentais. O melhor resultado foi obtido com $\omega \mathrm{B} 97 / / \omega \mathrm{B} 97(0,2|1,0| \#)$ $(\mathrm{PDMA}=12,81 \%)$, porém esse resultado é muito mais preciso para as moléculas CPI 
do que as SPI, enquanto os resultados com geometrias experimentais e com otimizadas usando o funcional modificado são ambos muito balanceados. O resultado obtido com $\omega \mathrm{B} 97(0,2|0,8| \#) / / \omega \mathrm{B} 97(0,2|0,8| \#)(13,82 \%)$ tem um maior aumento de PDMA, comparado às geometrias experimentais, no conjunto CPI. Para $\alpha=10 \%$, os valores de PDMA são menores para $\alpha+\beta=100 \%$, e aumentam conforme $\alpha+\beta$ diminui; para $\alpha=30 \%$, os valores de PDMA são menores para $\alpha+\beta=60 \%$, e aumentam conforme $\alpha+\beta$ aumenta.

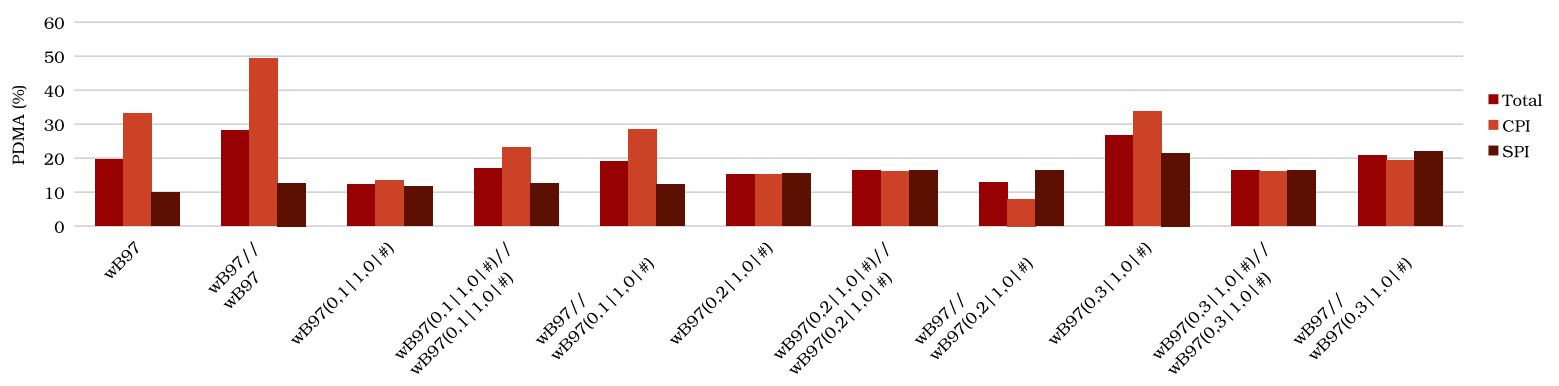

(a) $\alpha+\beta=100 \%$

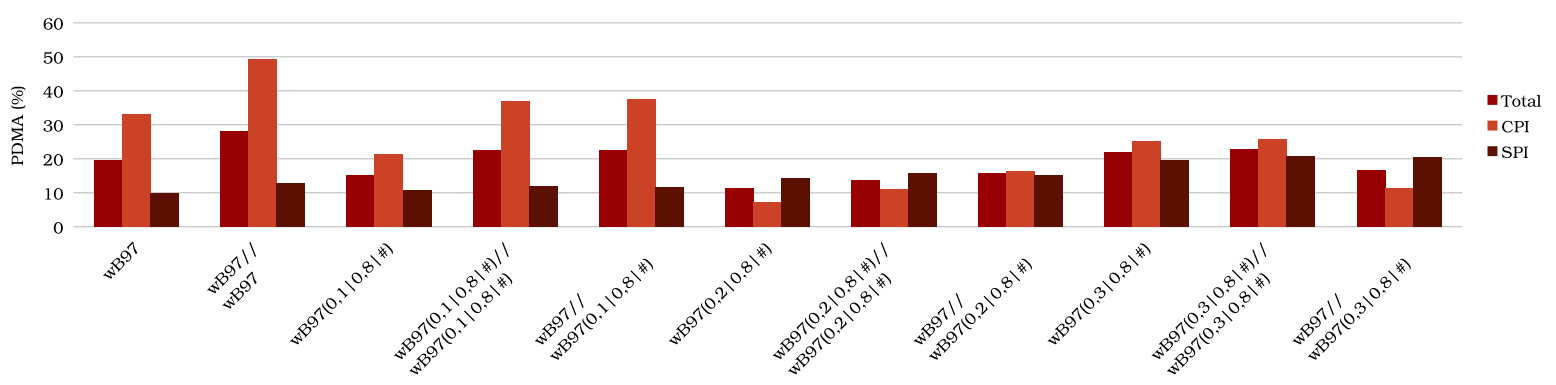

(b) $\alpha+\beta=80 \%$

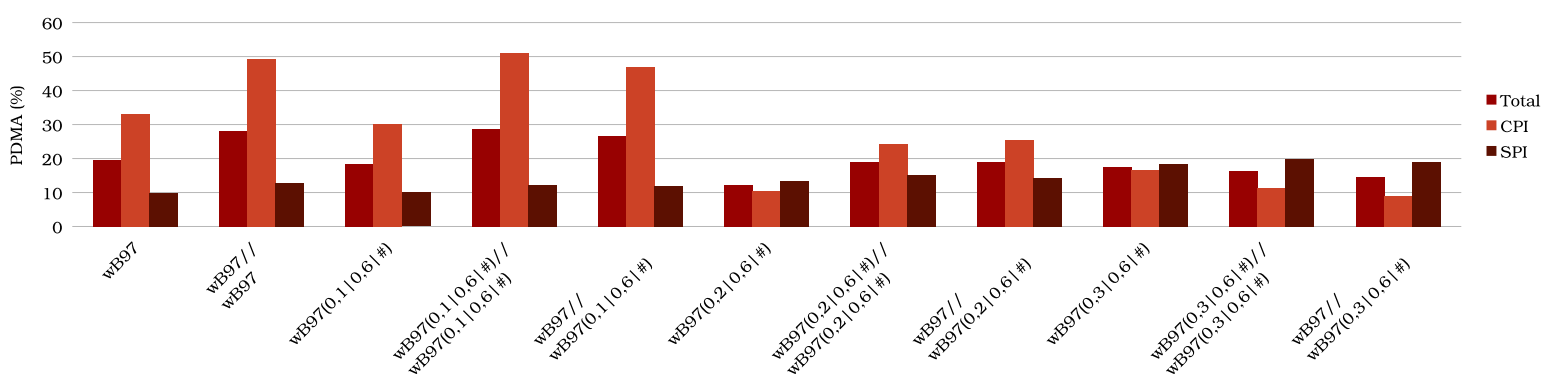

(c) $\alpha+\beta=60 \%$

Figura 4.21: Comparação entre as PDMAs obtidas com base aug-pcJ-2 para geometrias teóricas e experimentais para o $\omega$ B97 com $\alpha=10 \%, 20 \%$ ou 30\%. As médias são calculadas para todas as 26 CAISS, para as 11 CAISS das moléculas CPI e para as 15 CAISS das moléculas SPI.

O $\omega$ B97XD, apesar de não ter apresentado funcionais modificados com precisões tão boas quanto as modificações do $\omega$ B97X e $\omega$ B97, apresenta uma ótima precisão (ver Figura 
4.19 para a variação do parâmetro $\gamma$. Desta forma, a Figura 4.22 apresenta os resultados envolvendo otimização de geometrias para a variação de $\gamma$ do $\omega$ B97XD. De modo geral, todos esse resultados apresentam boas precisões (PDMAs totais abaixo de 20\%). Os resultados para $\omega \mathrm{B} 97 \mathrm{XD} / / \omega \mathrm{B} 97 \mathrm{XD}(\#|\#| 0,35)(\mathrm{PDMA}=9,42 \%)$ e $\omega \operatorname{B} 97 \mathrm{XD}(\#|\#| 0,35) / /$ $\omega \mathrm{B} 97 \mathrm{XD}(\#|\#| 0,35)(10,98 \%)$ são bastante precisos, com o segundo mais balanceado (entre CPI e SPI) do que o primeiro. O resultado para $\omega \mathrm{B} 97 \mathrm{XD} / / \omega \mathrm{B} 97 \mathrm{XD}(\#|\#| 0,40)$ $(9,37 \%)$ empata com o $\omega \mathrm{B} 97 \mathrm{XD} / / \omega \mathrm{B} 97 \mathrm{XD}(\#|\#| 0,35)$ como os melhores dentre os resultados para as geometrias otimizadas, sendo o primeiro ligeiramente mais balanceado.

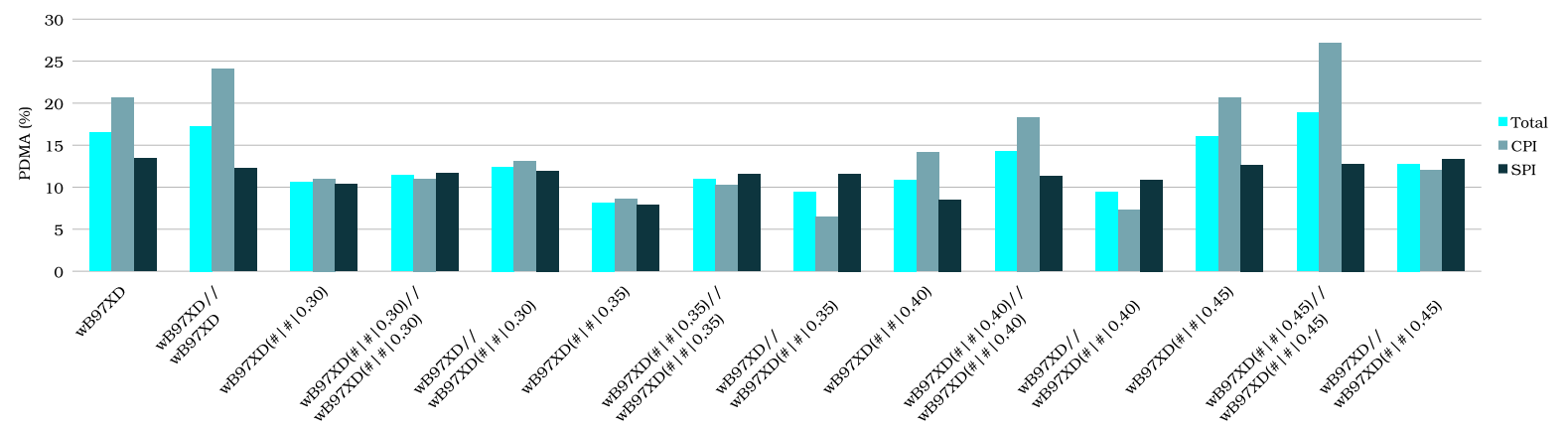

Figura 4.22: Comparação entre as PDMAs obtidas com geometrias teóricas e experimentais para o $\omega$ B97XD variando $\gamma$. As médias são calculadas para todas as 26 CAISS, para as 11 CAISS das moléculas CPI e para as 15 CAISS das moléculas SPI.

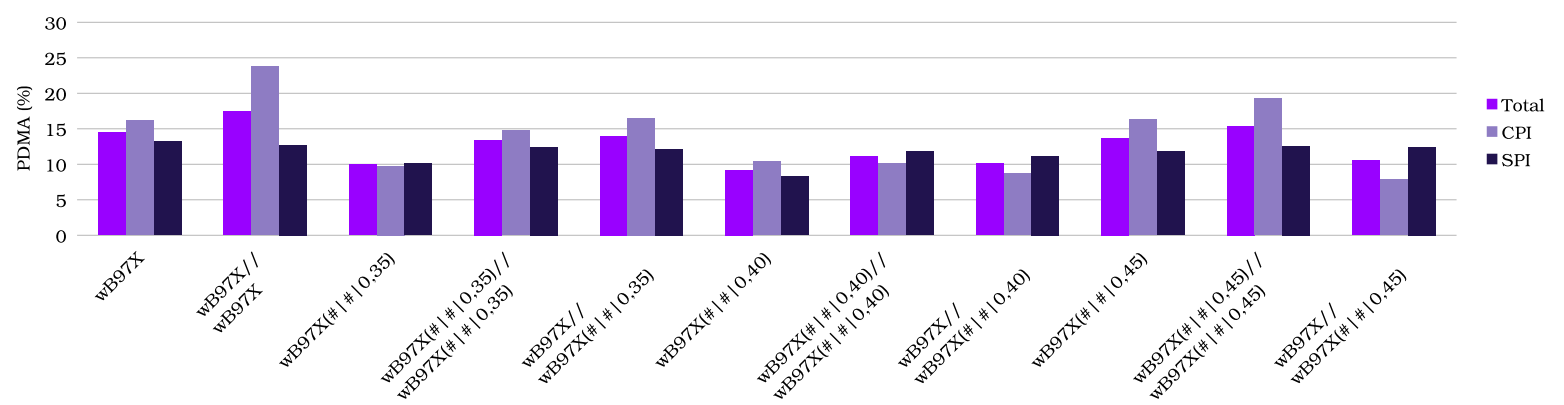

Figura 4.23: Comparação entre as PDMAs obtidas com geometrias teóricas e experimentais para o $\omega \mathrm{B} 97 \mathrm{X}$ variando $\gamma$. As médias são calculadas para todas as 26 CAISS, para as 11 CAISS das moléculas CPI e para as 15 CAISS das moléculas SPI.

A Figura 4.23 apresenta os resultados envolvendo otimização de geometrias para a variação de $\gamma$ do $\omega$ B97X. Esses resultados também apresentam, em geral, boas precisões (PDMAs totais abaixo de 20\%). Os resultados para $\omega$ B97X// $\omega$ B97X(\#|\#|0,40) (PDMA $=10,13 \%)$ e $\omega \operatorname{B9} 9 \mathrm{X}(\#|\#| 0,40) / / \omega \mathrm{B} 97 \mathrm{X}(\#|\#| 0,40)(11,09 \%)$ são bastante precisos, sendo 
ambos um pouco mais precisos para o conjunto CPI do que o SPI (o resultado para geometrias experimentais é um pouco mais preciso para o conjunto SPI). O resultado para $\omega \mathrm{B} 97 \mathrm{XD} / / \omega \mathrm{B} 97 \mathrm{XD}(\#|\#| 0,45)(10,53 \%)$ também é bem preciso, porém menos balanceado que o $\omega \mathrm{B} 97 \mathrm{X} / / \omega \mathrm{B} 97 \mathrm{X}(\#|\#| 0,40)$ e o $\omega \mathrm{B} 97 \mathrm{X}(\#|\#| 0,40) / / \omega \mathrm{B} 97 \mathrm{X}(\#|\#| 0,40)$.

Desta forma, os funcionais de longo alcance da família do $\omega$ B97 são ótimos para cálculo das CAISS. A ligeira mudança de parâmetros é capaz de melhorar a precisão geral das CAISS. De modo geral, o aumento de $\alpha, \alpha+\beta$ ou $\gamma$, que correspondem ao aumento da porcentagem de $E_{X}^{\mathrm{HF}}$, melhoram a precisão dos funcionais de longo alcance. Destacam-se os funcionais modificados $\omega \operatorname{B97X}(20 \%|100 \%| \#)$ e $\omega \operatorname{B97XD}(\#|\#| 0,35)$, que apresentam ótimos resultados para geometrias experimentais e após otimização das geometrias (tanto para o conjunto CPI quanto SPI). 


\subsection{Geração de novos funcionais de longo alcance}

\subsubsection{Geometrias experimentais}

A estratégia de correção de longo alcance é tão interessante quanto a utilização de funcionais híbridos, em especial pois melhora a descrição de fenômenos como excitações envolvendo transferência de carga ${ }^{\frac{75}{75}}$ Dessa forma, é interessante tentar construir funcionais de longo alcance a partir dos DFTs já testados. Para tanto, é necessário utilizar o DFT puro para a construção do funcional de longo alcance, nos moldes da Figura 3.1b. Com os $\operatorname{IOp}(3 / 107), \operatorname{IOp}(3 / 108), \operatorname{IOp}(3 / 119), \operatorname{IOp}(3 / 120), \operatorname{IOp}(3 / 130)$ e $\operatorname{IOp}(3 / 131)$, é possível construir variedade de combinações de $\alpha, \alpha+\beta$ e $\gamma$ para obter novos funcionais.

Os funcionais de longo-alcance, em geral, surgiram de DFTs já conhecidos. É o caso do CAM-B3LYP e da família $\omega$ B97 (baseados no B3LYP e B97, respectivamente). Para tentar reproduzir CAM-B3LYP, $\omega$ B97, $\omega$ B97X e $\omega$ B97XD, os funcionais BLYP e B98B98 são utilizados com os valores de $\gamma$ ajustados aos dos funcionais (no caso do B98B98, três parametrizações distintas são feitas para tentar reproduzir $\omega$ B97, $\omega$ B97X e $\omega$ B97XD).

Os resultados para a variação de $\alpha$ e $\alpha+\beta$ estão apresentados nas Tabelas 8.338 a 8.357. A Figura 4.24 apresenta os valores de PDMA total obtidos com esses funcionais construídos. É notável que, especialmente para a família LC-B98, os resultados não reproduzem o comportamento da Figura 4.18, e portanto não foram reproduzidos exatamente os funcionais de longo alcance. A Tabela 4.11 evidencia que os resultados são bastante diferentes, principalmente para as tentativas de reproduzir o $\omega$ B97X e o $\omega$ B97XD. Desta forma, contornar esse problema requer um aprofundamento no funcionamento do código do software e nas opções de IOp disponíveis, de modo que se consiga construir um funcional a partir dos funcionais puros. No caso dos funcionais híbridos, a construção pôde ser feita mais facilmente (como o SLYP $50 \% E_{X}^{\mathrm{HF}}$, que é o próprio BHandH).

Os funcionais construídos LC-BLYP e LC-B98, apesar de não remeterem ao CAMB3LYP e à família $\omega$ B97, apresentam alguns bons resultados. O LC-BLYP $(30 \%|100 \%| 0,33)$ e o LC-B98(50\%|60\%|0,40) apresentam valores de PDMA inferior a 20\%, conforme a Tabela 4.11. As versões LC-B98(X) e LC-B98(XD) tem PDMAs superiores a $20 \%$. 

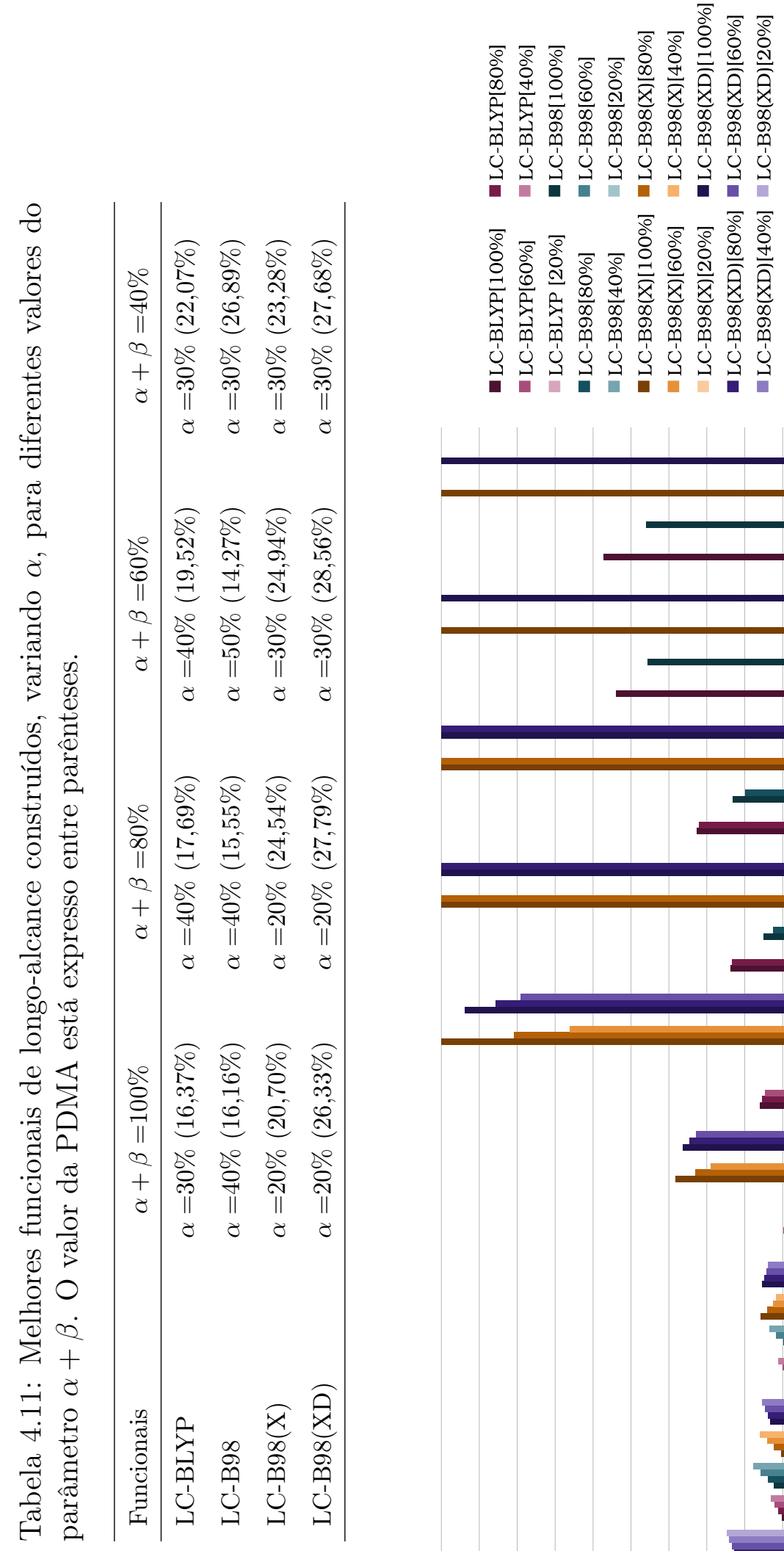

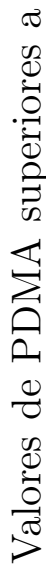

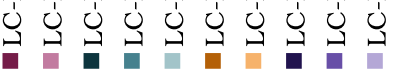
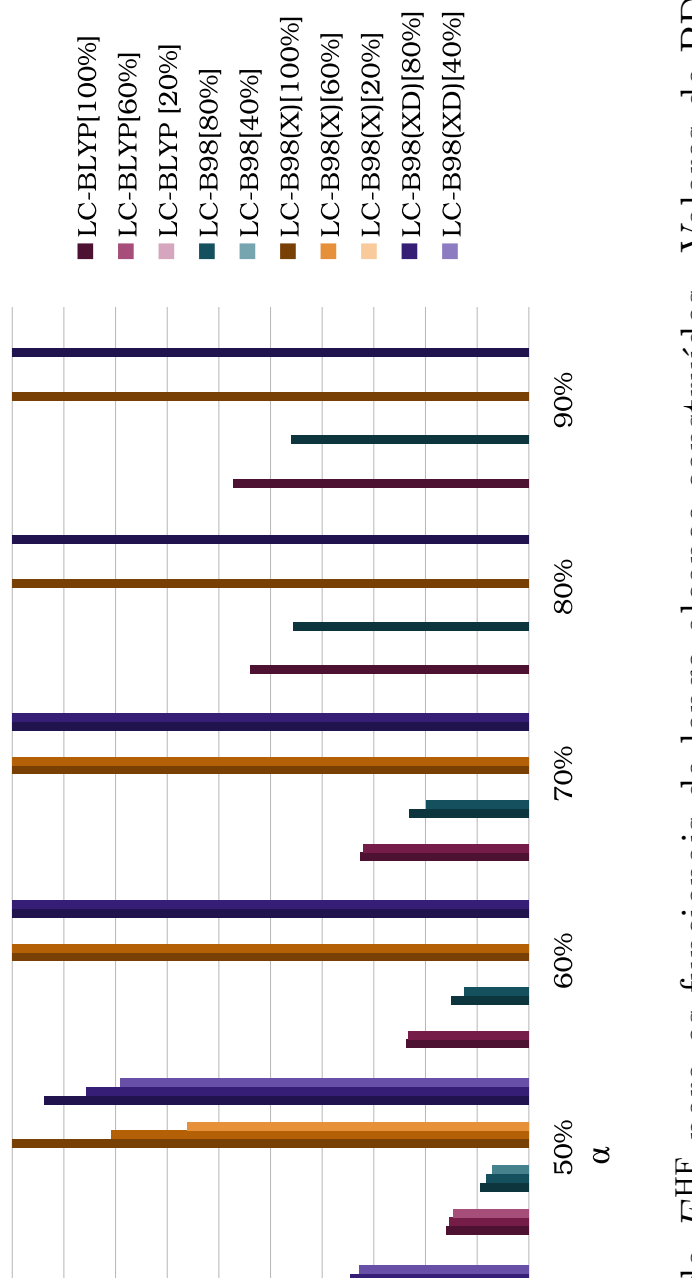

ซี

\%

.

명

吕

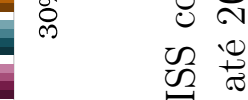

$\ll$

वें उू तै

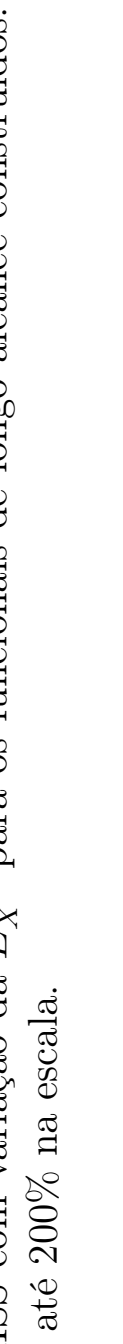


Mesmo sendo complexa a reprodução dos funcionais já disponíveis, é possível estudar o comportamento de funcionais puros com CLA, conforme visto para o BLYP e o B98. Desta forma, são escolhidos os funcionais puros BB95 e SLYP para obter versões de longo alcance do B1B95 e do BHandH, respectivamente. Os resultados das variações de $\alpha$, $\alpha+\beta$ e $\gamma$ para LC-B1B95 (LC-BB95) estão apresentados nas Tabelas 8.358 a 8.381 , e para LC-BHandH (LC-SLYP) nas Tabelas 8.382 a 8.405.

Os valores de PDMA total para LC-B1B95 estão apresentados na Figura 4.25. Algumas relações devem ser destacadas: 1) para $\alpha$ pequeno, a PDMA decresce com o aumento de $\gamma ; 2$ ) para $\alpha$ moderado (próximo a 50\%), a PDMA cresce com o aumento de $\gamma ; 3$ ) para $\gamma$ próximo de zero, a diminuição de $\alpha+\beta$ não têm grande impacto na PDMA; 4) para $\gamma$ muito grandes (0,75 ou maior), a PDMA decresce com a diminuição de $\alpha+\beta$. Assim, para duas variáveis fixas, é possível dizer qual o valor necessário da terceira variável para se obter os resultados mais precisos.

A partir da Figura 4.25 (e das Tabelas 8.358 a 8.381), o mínimo global da PDMA $(8,78 \%)$ é obtido com LC-B1B95(40\%|100\%|0,40). Os DFTs LC-B1B95(40\%|100\%|0,35), LC-B1B95(50\%|100\%|0,25), LC-B1B95(40\%|90\%|0,40), LC-B1B95(40\%|90\%|0,45), LCB1B95(50\%|90\%|0,25), LC-B1B95(40\%|80\%|0,45) e LC-B1B95(50\%|80\%|0,25) também apresentam resultados bastante precisos (PDMA inferior a 10\%).

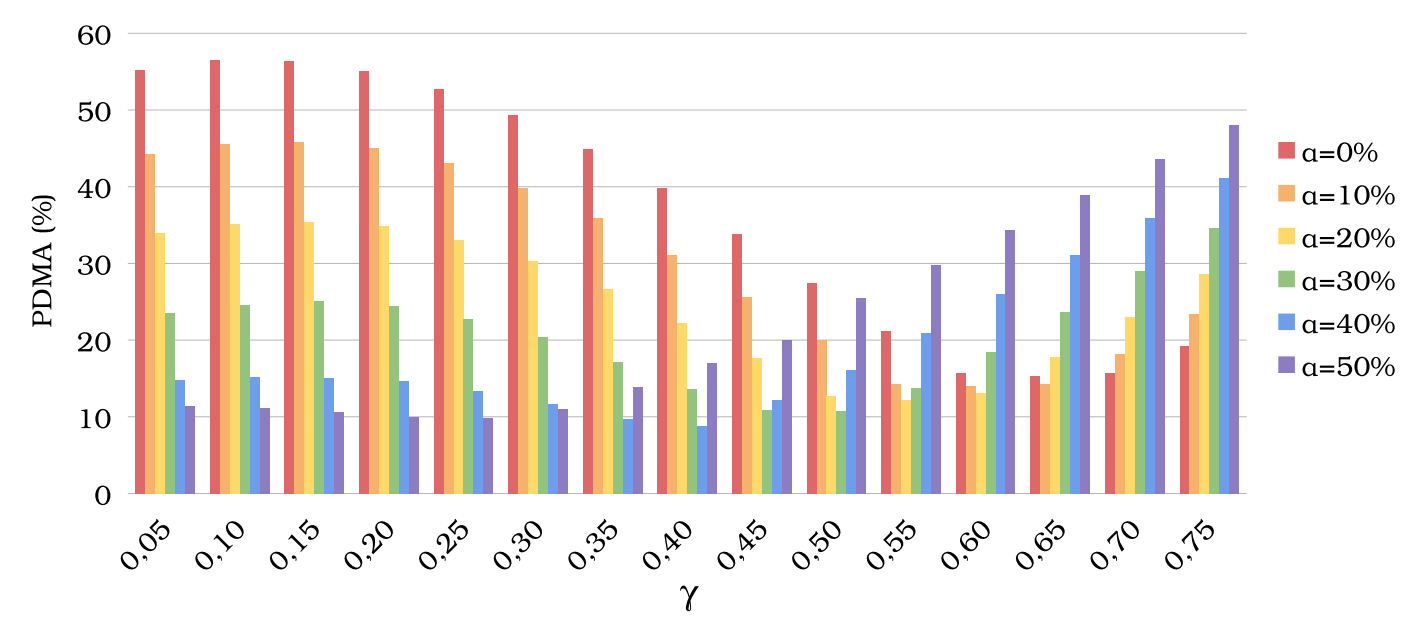

(a) $\alpha+\beta=100 \%$ 


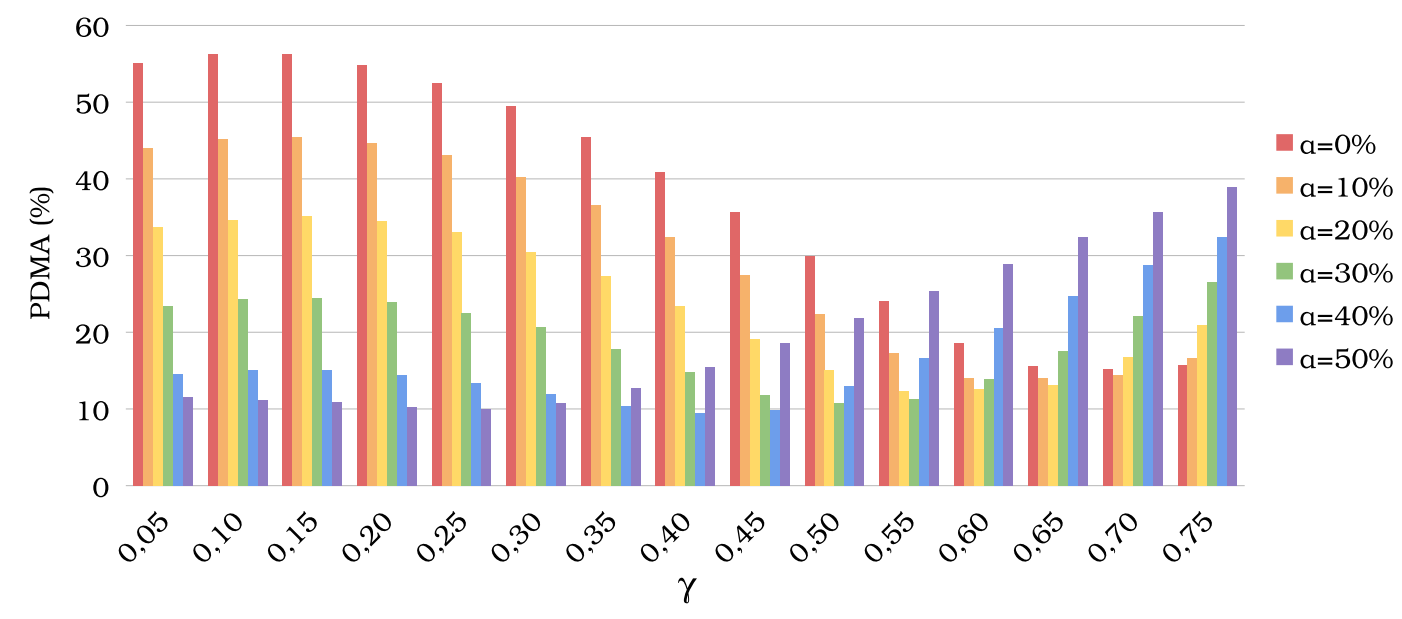

(b) $\alpha+\beta=90 \%$

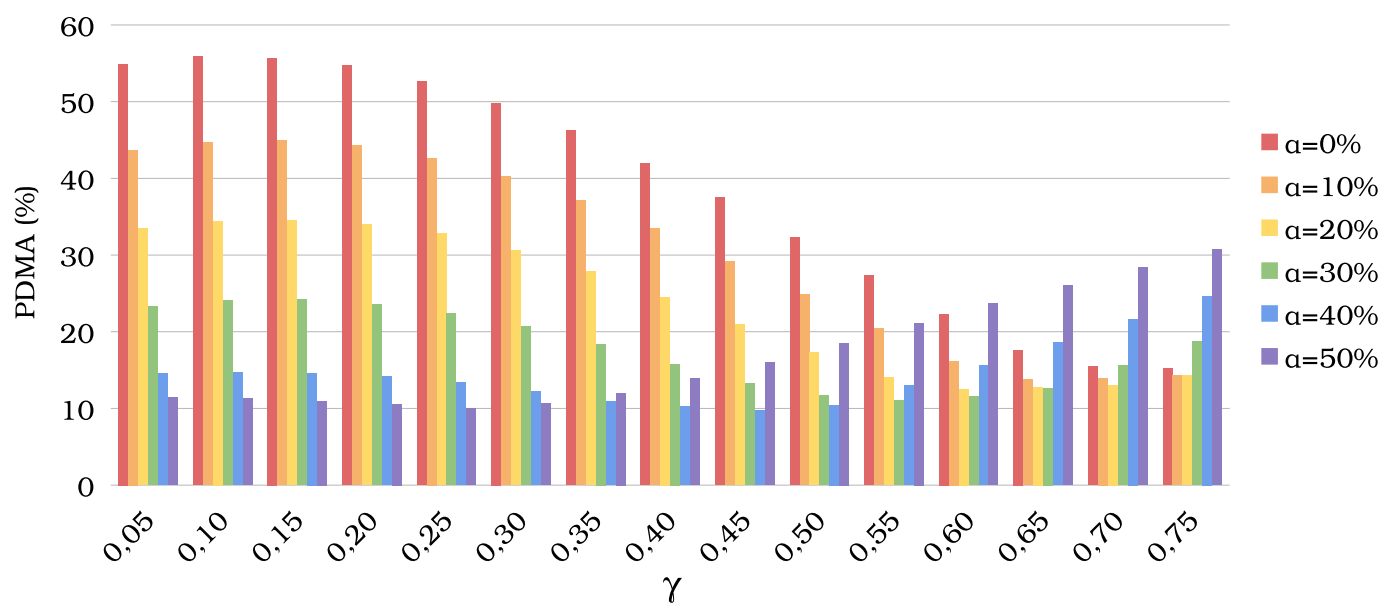

(c) $\alpha+\beta=80 \%$

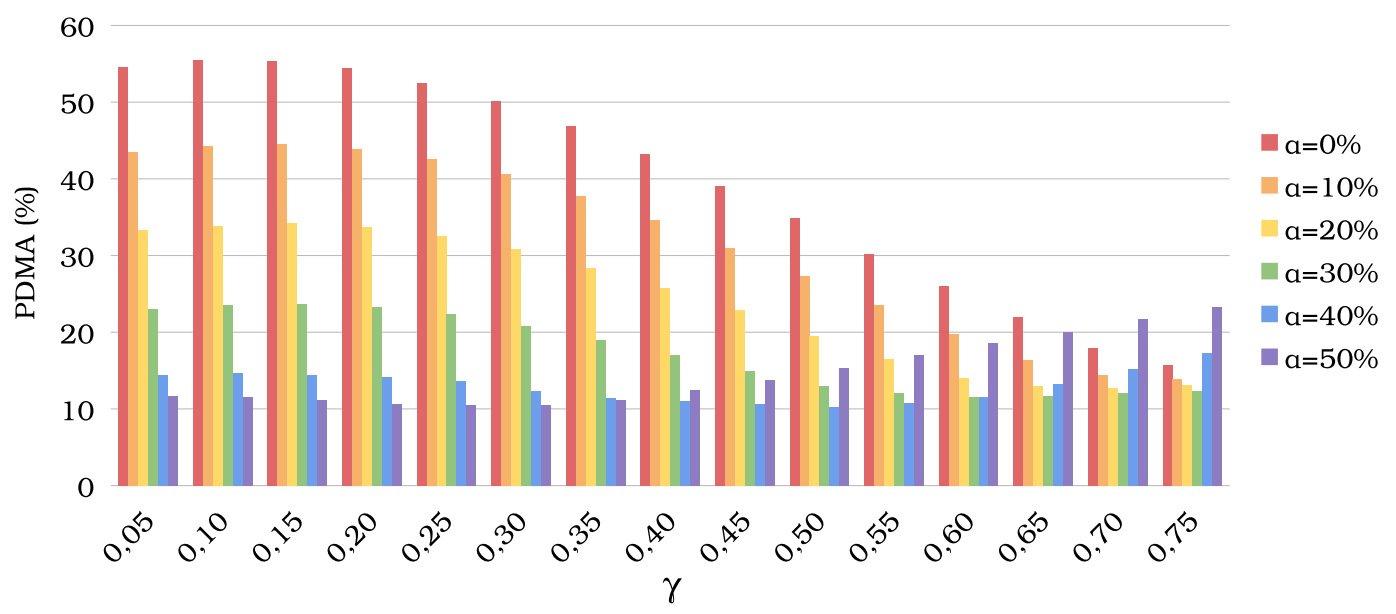

(d) $\alpha+\beta=70 \%$

Figura 4.25: PDMAs obtidas com LC-B1B95 na base aug-pcJ-2 para geometrias experimentais, variando $\alpha, \alpha+\beta$ e $\gamma$. 
Destaca-se o fato de que, para um dado $\alpha+\beta$, há uma relação entre o aumento de $\alpha$ e a diminuição de $\gamma$. A racionalização dessa relação envolve a porcentagem de $E_{X}^{\mathrm{HF}}:$ o aumento de $\alpha$ incrementa a porcentagem de $E_{X}^{\mathrm{HF}}$ do DFT; já a diminuição de $\gamma$ decrementa a porcentagem de $E_{X}^{\mathrm{HF}}$ do DFT, de modo a balancear o incremento provocado pelo aumento de $\alpha$.

A Figuras 4.25a a 4.25d podem ser interpretadas como superfícies 3D, nas quais se nota um vale dos valores mínimos. A visualização, entretanto, não é trivial, e assim é mais adequado apresentar os dados de outra maneira. A Figura 4.26 apresenta as curvas de níveis obtidas para tais superfícies, permitindo melhor visualização da região dos mínimos e da relação entre $\alpha$ e $\gamma$ (como uma curva parametrizada nessa superfície).

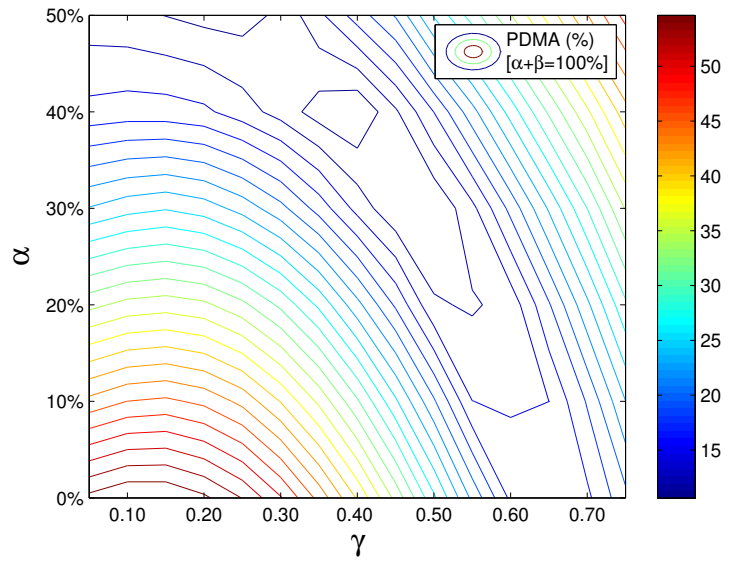

(a) $\alpha+\beta=100 \%$

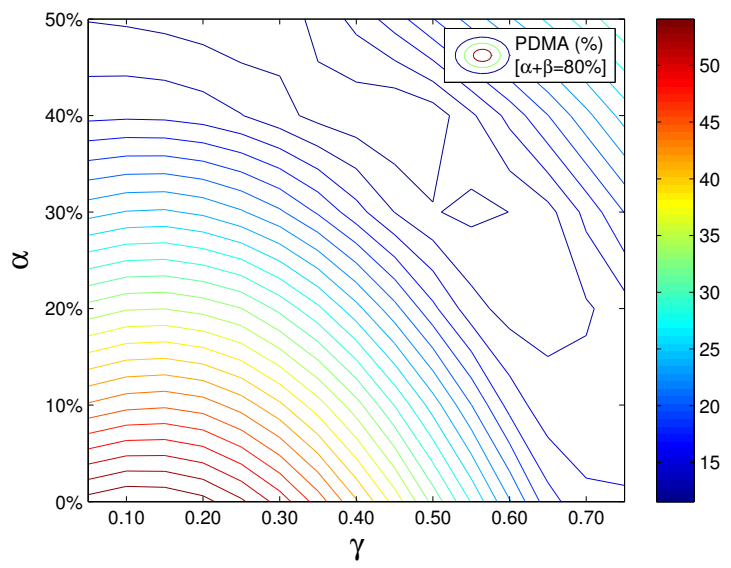

(c) $\alpha+\beta=80 \%$

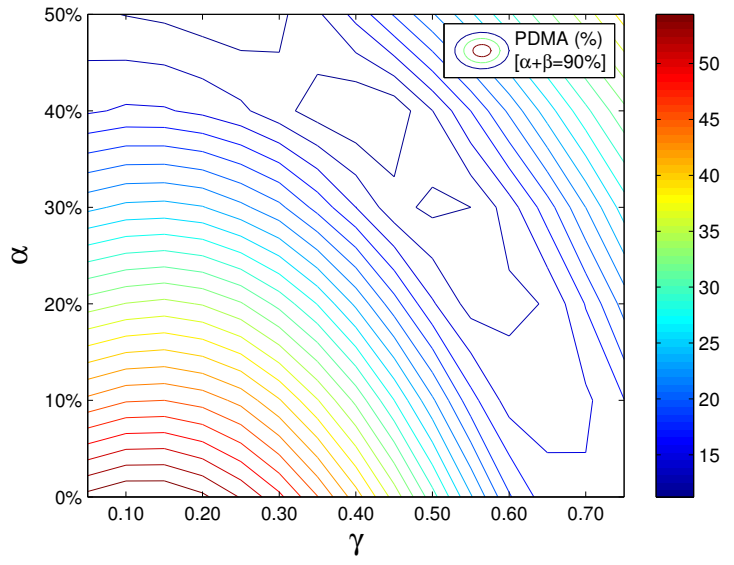

(b) $\alpha+\beta=90 \%$

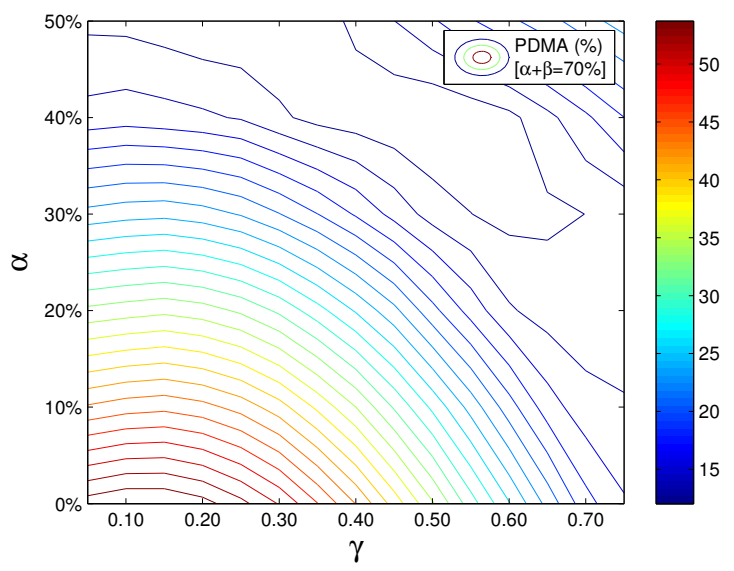

(d) $\alpha+\beta=70 \%$

Figura 4.26: Superfícies geradas a partir das PDMAs obtidas com LC-B1B95 na base aug-pcJ-2 para geometrias experimentais, variando $\alpha$ e $\gamma$ ( $\alpha+\beta$ fixos). 
Comparando as Figuras 4.26a a 4.26d, também nota-se que a curva que relaciona $\alpha$ e $\gamma$ desloca-se com a diminuição de $\alpha+\beta$, que também pode ser racionalizado em termos da porcentagem de $E_{X}^{\mathrm{HF}}$. A diminuição de $\alpha+\beta$ decrementa a porcentagem de $E_{X}^{\mathrm{HF}}$, logo um aumento de $\alpha$ ou $\gamma$ é necessário para balancear.

A Figura 4.27 representa uma projeção da superfície 4D gerada pelos valores de $\gamma, \alpha$, $\alpha+\beta$ e PDMA. É possível associar um corte nessa superfície com a região dos mínimos de PDMA, parametrizando $\alpha, \alpha+\beta$ e $\gamma$.

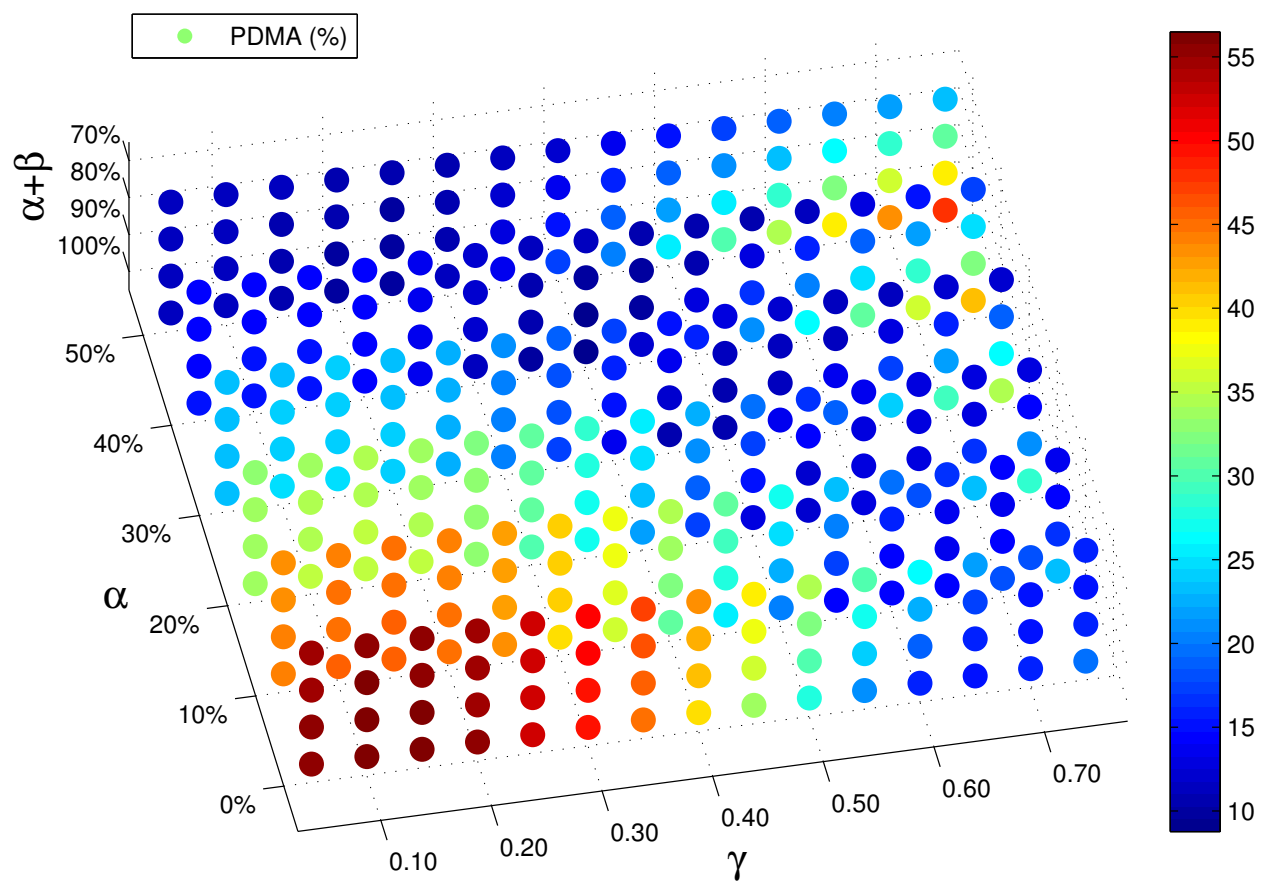

Figura 4.27: Distribuição das PDMAs obtidas com LC-B1B95 na base aug-pcJ-2 para geometrias experimentais, variando $\alpha, \alpha+\beta$ e $\gamma$.

Na Figura 4.27 é possível encontrar a região dos mínimos de PDMA (em azul escuro), assim como os maiores PDMAs obtidos (em vermelho escuro); além disso, as tendências apontadas entre $\alpha, \alpha+\beta$ e $\gamma$ também podem ser verificadas.

Os valores de PDMA total para LC-BHandH estão apresentados na Figura 4.28. Comparando com a Figura 4.25, percebe-se que o comportamento é similar, e portanto valem todas as considerações feitas acerca das tendências de $\alpha, \alpha+\beta$ e $\gamma$. A diferença se deve às precisões obtidas, que estão relacionadas ao funcional puro utilizado.

A partir da Figura 4.28 (e das Tabelas 8.382 a 8.405), o mínimo global da PDMA 
$(10,49 \%)$ é obtido com LC-BHandH $(40 \%|100 \%| 0,30)$ (parâmetros próximos ao do LCB1B95). Os funcionais LC-BHandH(40\%|100\%|0,25), LC-BHandH(40\%|90\%|0,35), LCBHandH(40\%|90\%|0,30), LC-BHandH(40\%|80\%|0,35), LC-BHandH(40\%|80\%|0,30) e LCBHandH(40\%|70\%|0,40) também são bastante precisos (PDMA inferior a 11,5\%).

A Figura 4.29 apresenta as curvas de níveis obtidas para as superfícies 3D das Figuras $4.28 \mathrm{a}$ a $4.28 \mathrm{~d}$, em que também há uma região de mínimos e uma relação entre $\alpha$ e $\gamma$. A comparação com a Figura 4.26 mostra que essa relação entre $\alpha$ e $\gamma$, entretanto, acontece com valores menores (por exemplo, o $\gamma$ do PDMA mínimo (para $\alpha=0 \%$ e $\alpha+\beta=100 \%$ ) é menor para LC-BHandH), e portanto a porcentagem de $E_{X}^{\mathrm{HF}}$ que gera melhor precisão difere para LC-BHandH e LC-B1B95.

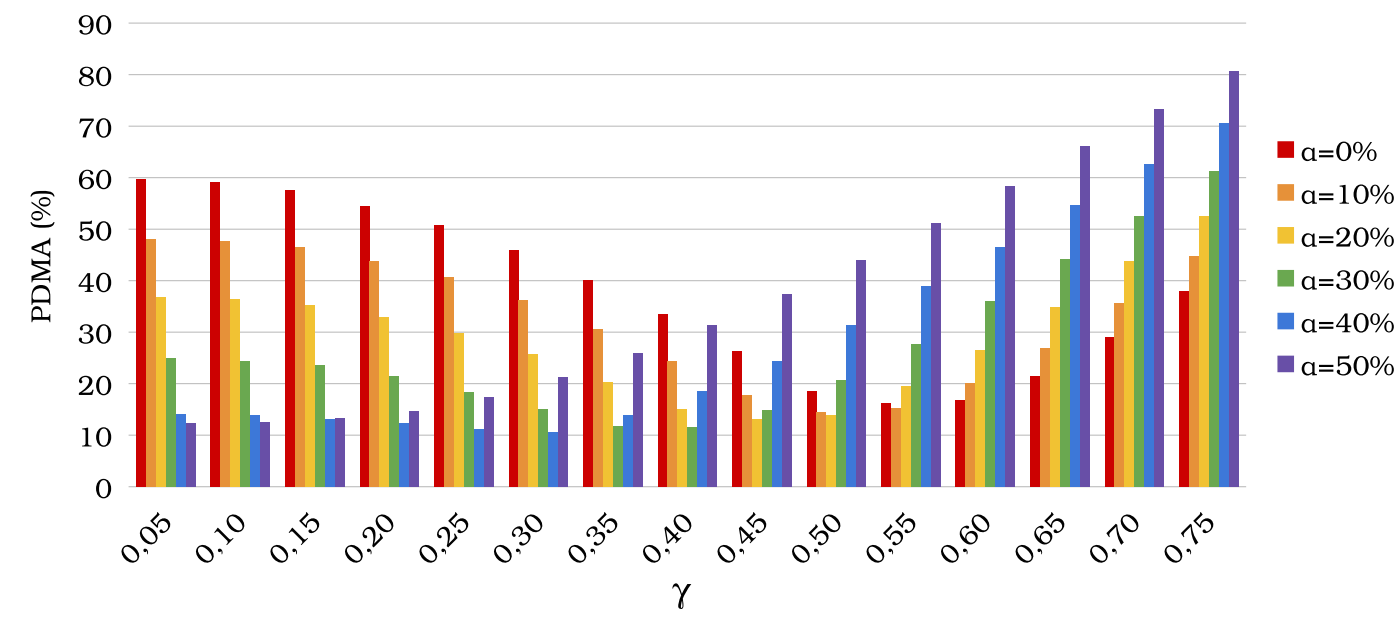

(a) $\alpha+\beta=100 \%$

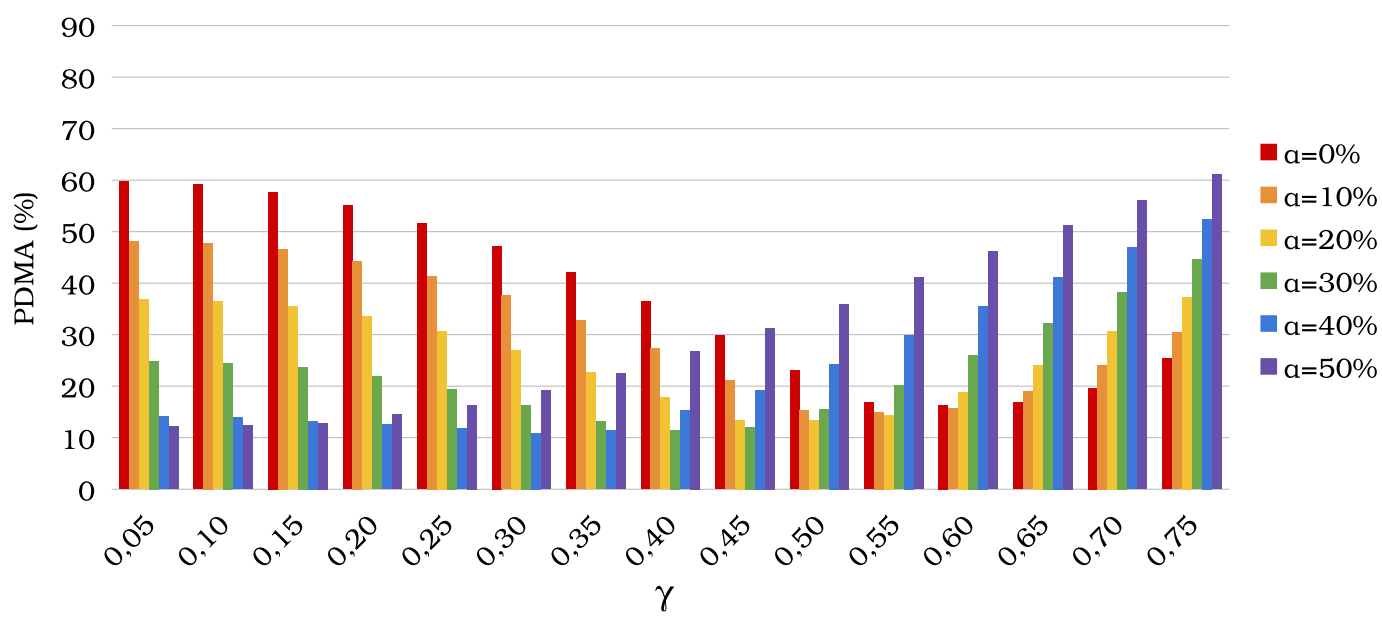

(b) $\alpha+\beta=90 \%$ 


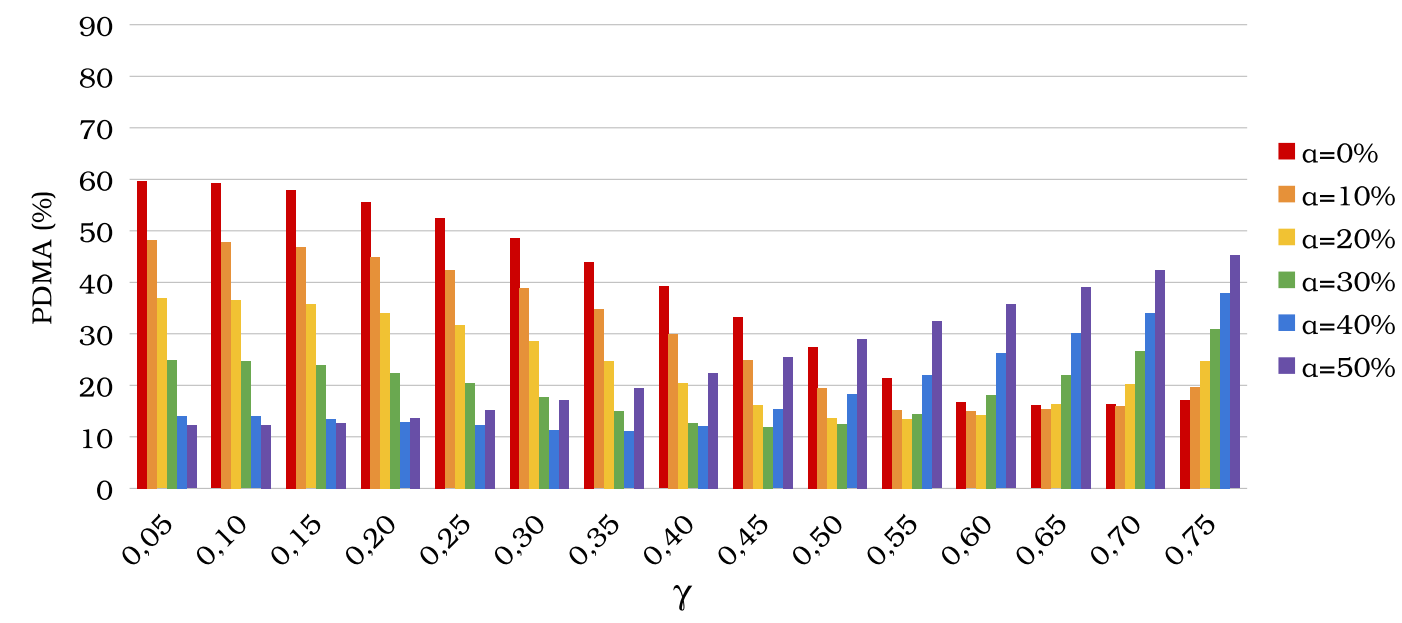

(c) $\alpha+\beta=80 \%$

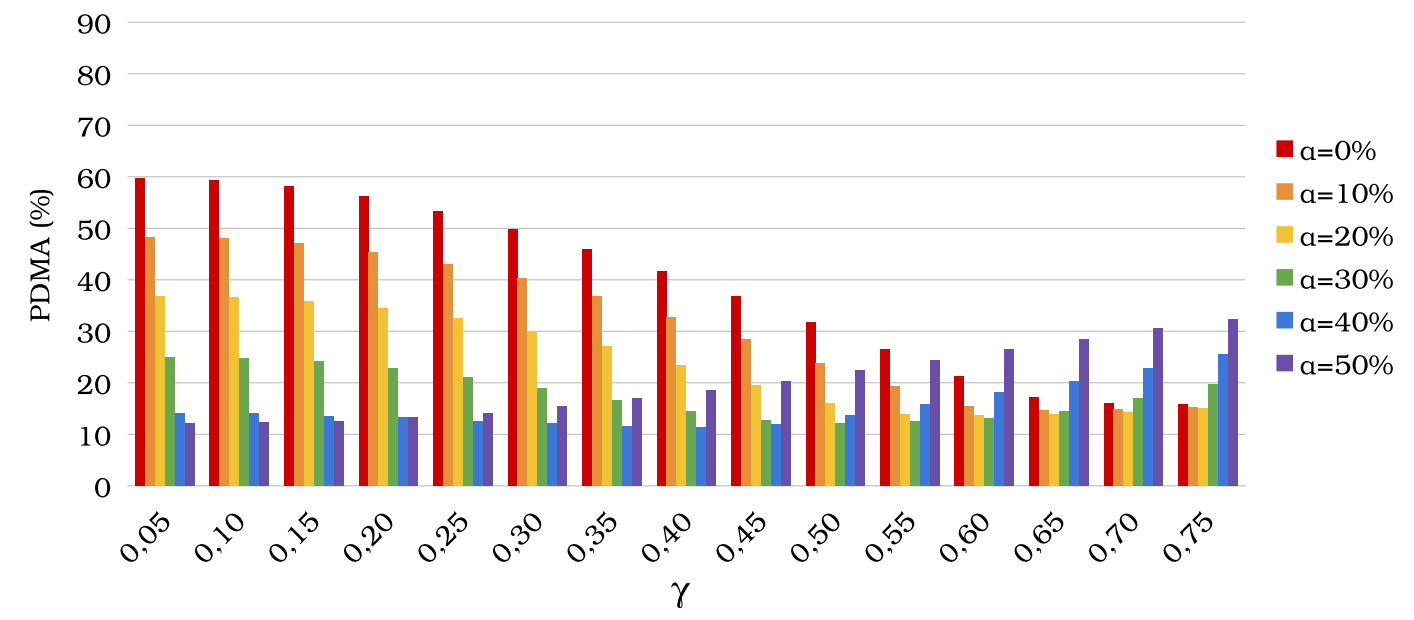

(d) $\alpha+\beta=70 \%$

Figura 4.28: PDMAs obtidas com LC-BHandH na base aug-pcJ-2 para geometrias experimentais, variando $\alpha, \alpha+\beta$ e $\gamma$.

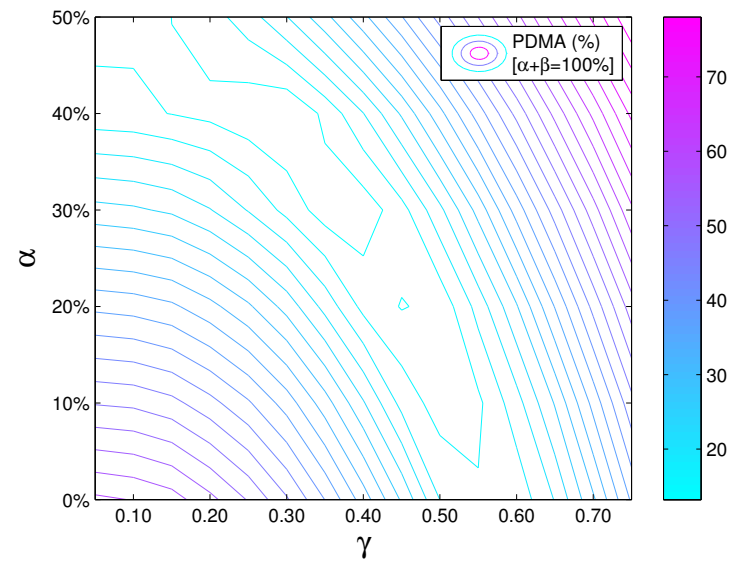

(a) $\alpha+\beta=100 \%$

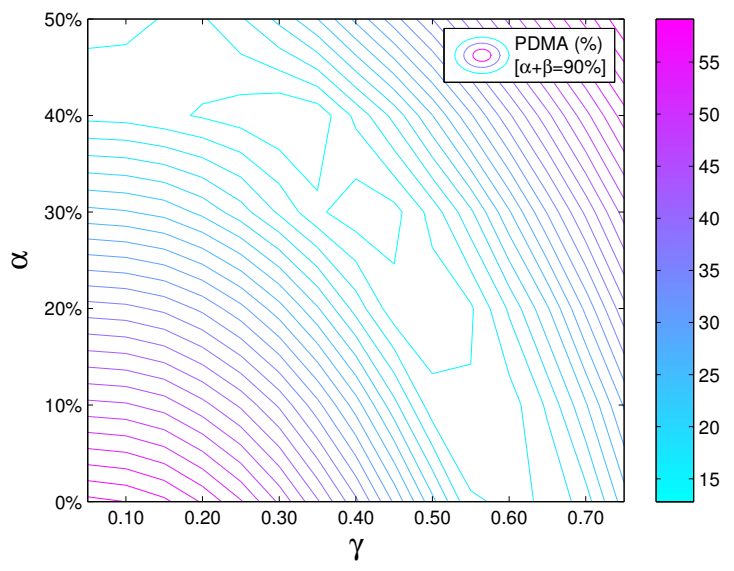

(b) $\alpha+\beta=90 \%$ 


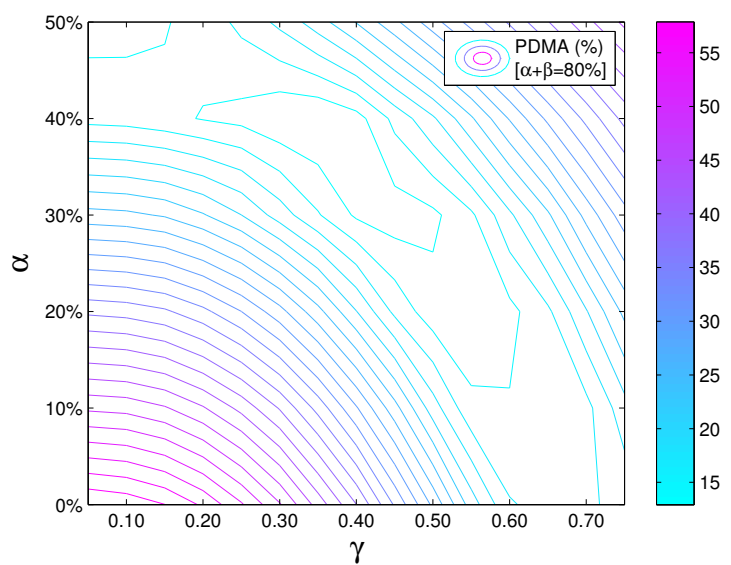

(c) $\alpha+\beta=80 \%$

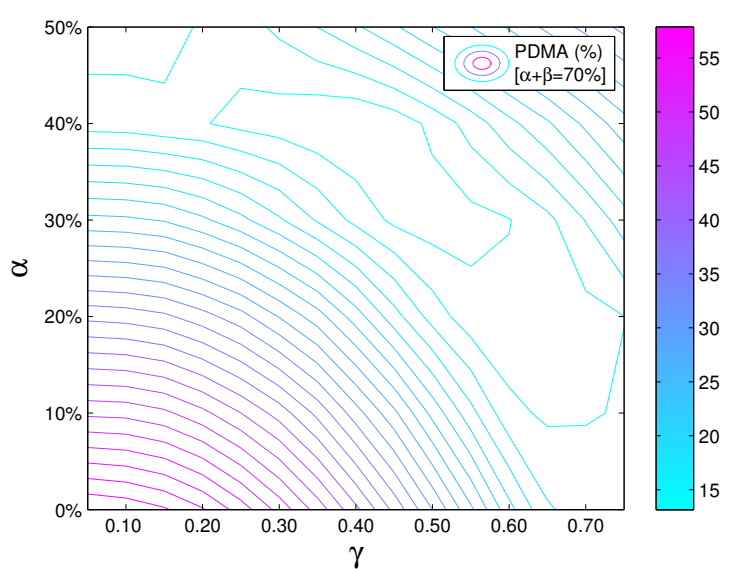

(d) $\alpha+\beta=70 \%$

Figura 4.29: Superfícies geradas a partir das PDMAs obtidas com LC-BHandH na base aug-pcJ-2 para geometrias experimentais, variando $\alpha$ e $\gamma(\alpha+\beta$ fixos).

A Figura 4.30 apresenta a projeção da superfície 4D a partir de $\gamma, \alpha, \alpha+\beta$ e PDMA.

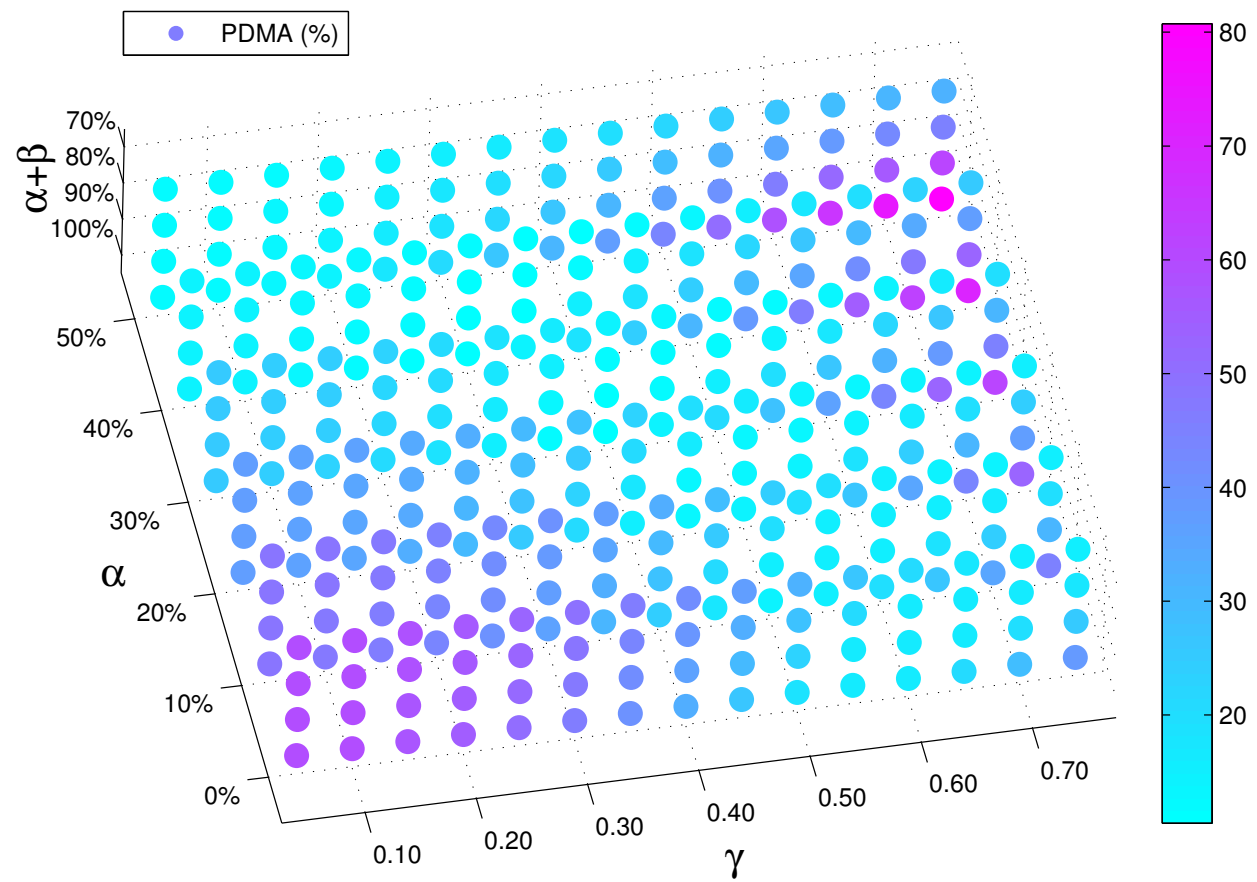

Figura 4.30: Distribuição das PDMAs obtidas com LC-BHandH na base aug-pcJ-2 para geometrias experimentais, variando $\alpha, \alpha+\beta$ e $\gamma$.

Desta forma, LC-B1B95(40\%|100\%|0,40) e LC-BHandH(40\%|100\%|0,30) são ótimos para cálculo de CAISS com geometrias experimentais, sendo um pouco mais precisos para o conjunto SPI do que o conjunto CPI. Com isso, a estratégia de CLA pode ser 
aplicada a outros funcionais puros. A combinação de $\alpha=40 \%$ e $\alpha+\beta=100 \%$ é sugerida para o cálculo de CAISS para os funcionais construídos; o valor de $\gamma$ precisa ser avaliado para cada funcional e corresponde a um ajuste fino da porcentagem de $E_{X}^{\mathrm{HF}}$.

\subsubsection{Geometrias otimizadas}

A otimização de geometrias é investigada considerando LC-B1B95(40\%|100\%|0,40) e LC-BHandH $(40 \%|100 \%| 0,30)$ como pontos de referência. O ajuste considerou $\alpha \pm 10 \%$, $\alpha+\beta \pm 10 \%$ e $\gamma \pm 0,05$ a princípio, de modo a verificar o mínimo da PDMA. Os resultados estão apresentados para LC-B1B95 nas Tabelas 8.406 a 8.417, e para LC-BHandH nas Tabelas 8.418 a 8.426 .

A Figura 4.31 apresenta os valores de PDMA para a otimização com LC-B1B95. O funcional LC-B1B95(40\%|70\%|0,35) apresenta a melhor precisão (PDMA = 8,20\%). Para $\alpha=40 \%$ e $\alpha+\beta=100 \%$, o menor valor é obtido com $\gamma=0,25$ (9,10\%). PDMAs inferiores a $10 \%$ são obtidas com $\alpha=40 \%$, envolvendo $\gamma$ entre 0,20 e 0,25 para $\alpha+\beta=100 \%$, e migrando para $\gamma$ entre 0,25 e 0,40 para $\alpha+\beta=70 \%$, evidenciando um balanço entre o aumento de $\gamma$ e a diminuição de $\beta$.

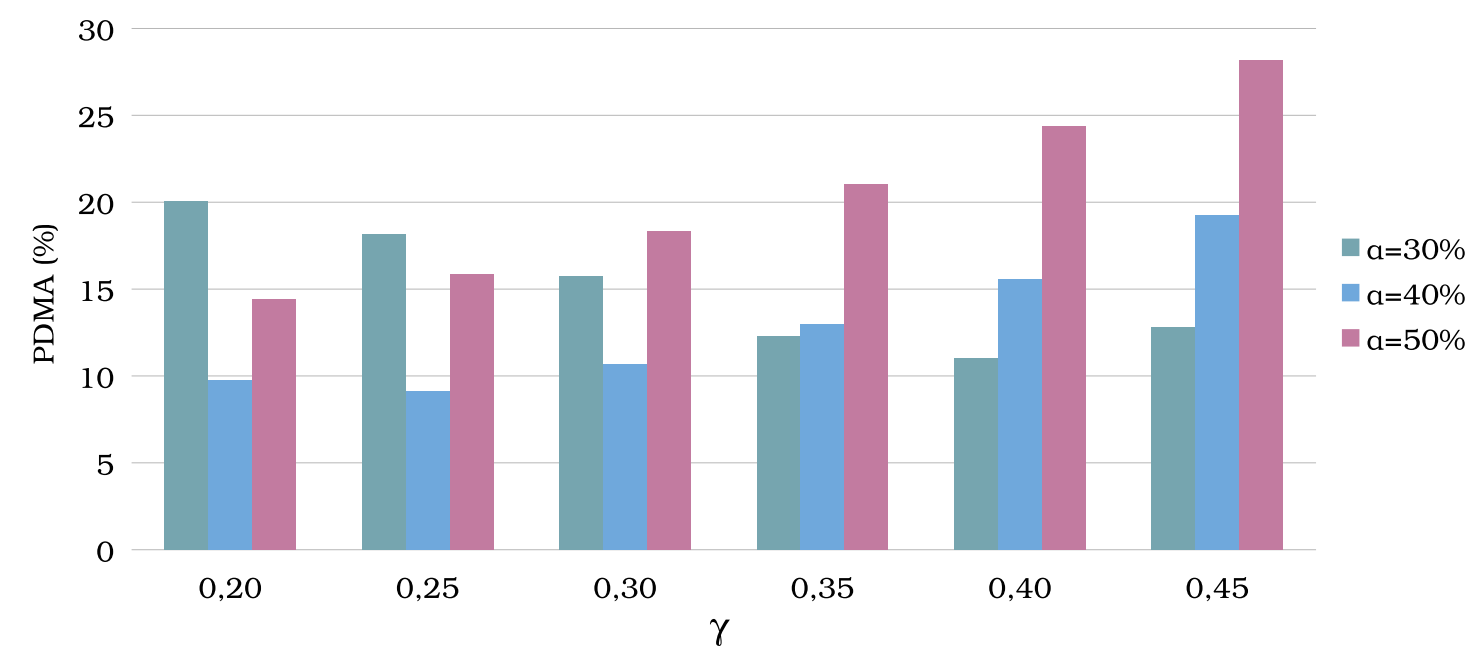

(a) $\alpha+\beta=100 \%$ 


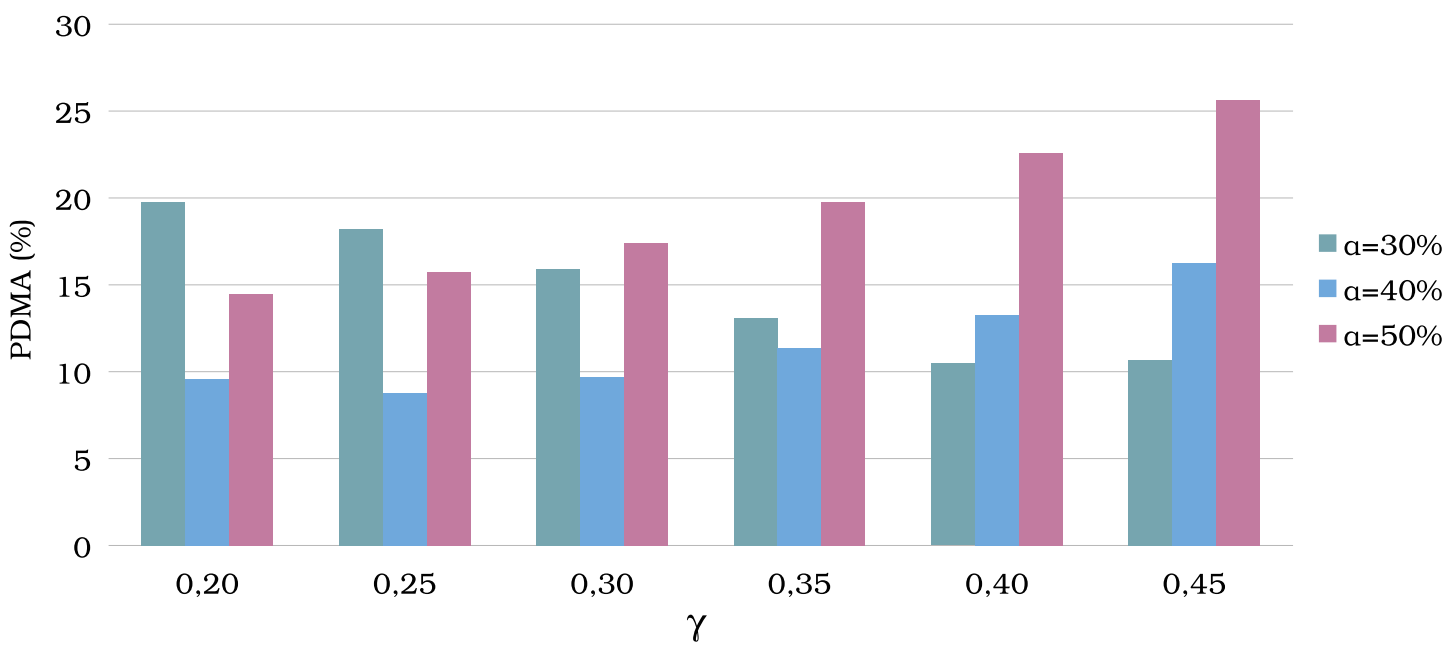

(b) $\alpha+\beta=90 \%$

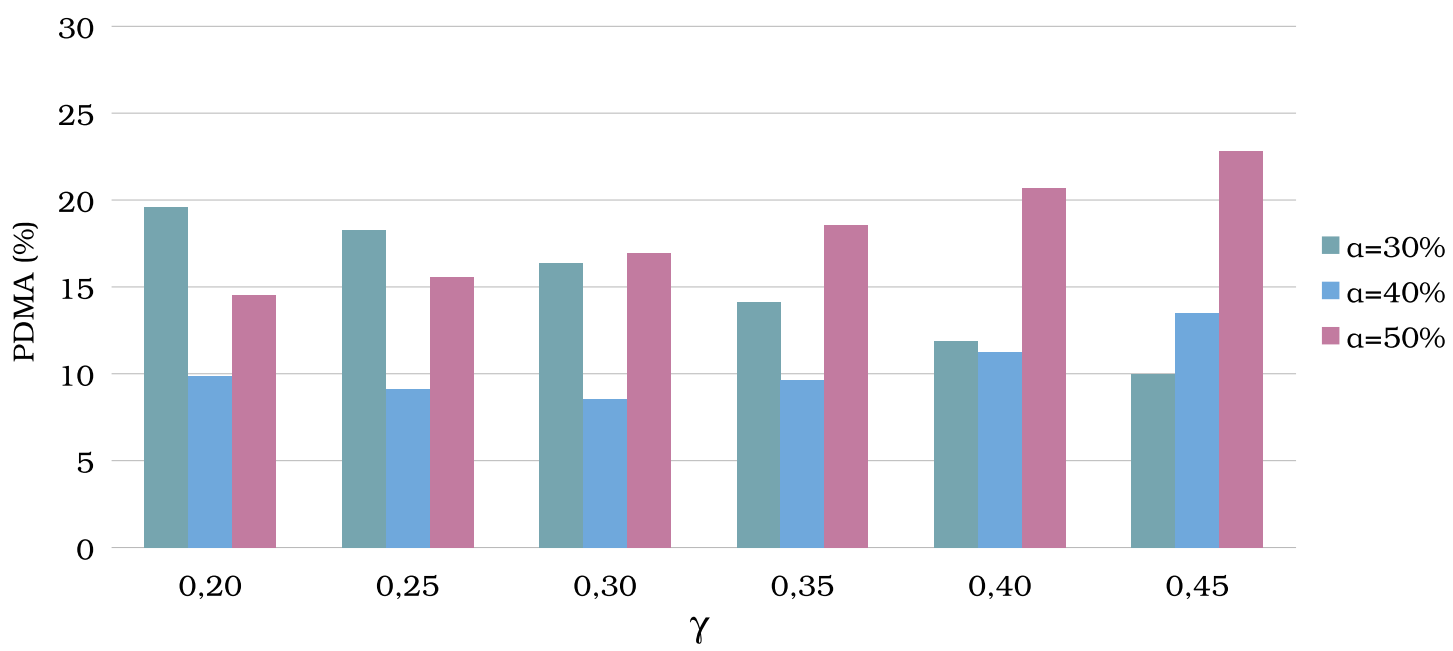

(c) $\alpha+\beta=80 \%$

$$
30
$$

$$
25
$$

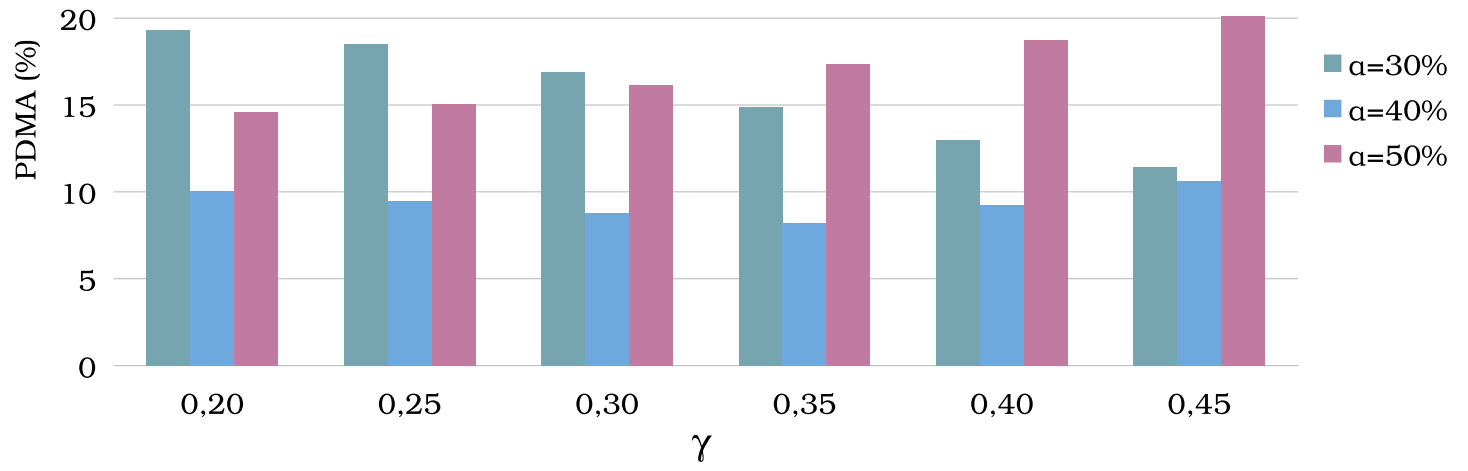

(d) $\alpha+\beta=70 \%$

Figura 4.31: PDMAs obtidas com LC-B1B95 na base aug-pcJ-2 para geometrias otimizadas, variando $\alpha, \alpha+\beta$ e $\gamma$. 
A Figura 4.32 apresenta os valores de PDMA para a otimização com LC-BHandH. Os funcionais LC-BHandH(40\%|90\%|0,05) e LC-BHandH(40\%|80\%|0,05) apresentam a melhor precisão (PDMA $=8,98 \%)$. Para $\alpha=40 \%$ e $\alpha+\beta=100 \%$, o menor valor é obtido com $\gamma=0,10(9,08 \%)$. A utilização de $\gamma$ próximo a zero torna os funcionais similares, e portanto para $\alpha=40 \%$, valores $\gamma$ entre 0,05 e 0,10 e $\alpha+\beta$ entre $80 \%$ e $100 \%$, as PDMAs beiram $9 \%$, formando um patamar na superfície.

O valor mínimo da PDMA com geometrias otimizadas é obtido, para $\alpha$ e $\alpha+\beta$ fixos, com um valor de $\gamma$ menor do que o necessário para obter o valor mínimo da PDMA com geometrias experimentais. Isso indica que, para a otimização de geometrias e cálculo da CAISS com um dado DFT, a porcentagem de $E_{X}^{\mathrm{HF}}$ que gera resultados mais precisos é ligeiramente menor do que a necessária para cálculo das CAISS na geometria experimental.

Deste modo, a utilização de $\alpha=40 \%$, associada a valores de $\alpha+\beta$ próximos a 1 e valores pequenos de $\gamma$, permite obter ótimos resultados para realizar cálculo de otimização seguido do cálculo das CAISS. Os funcionais LC-B1B95(40\%|100\%|0,25), LCB1B95(40\%|70\%|0,35), LC-BHandH(40\%|100\%|0,10) e LC-BHandH(40\%|80\%|0,15) são escolhidos dentre os ótimos resultados para cálculo de CAISS com geometrias otimizadas para comparação com os melhores funcionais obtidos nas seções anteriores.

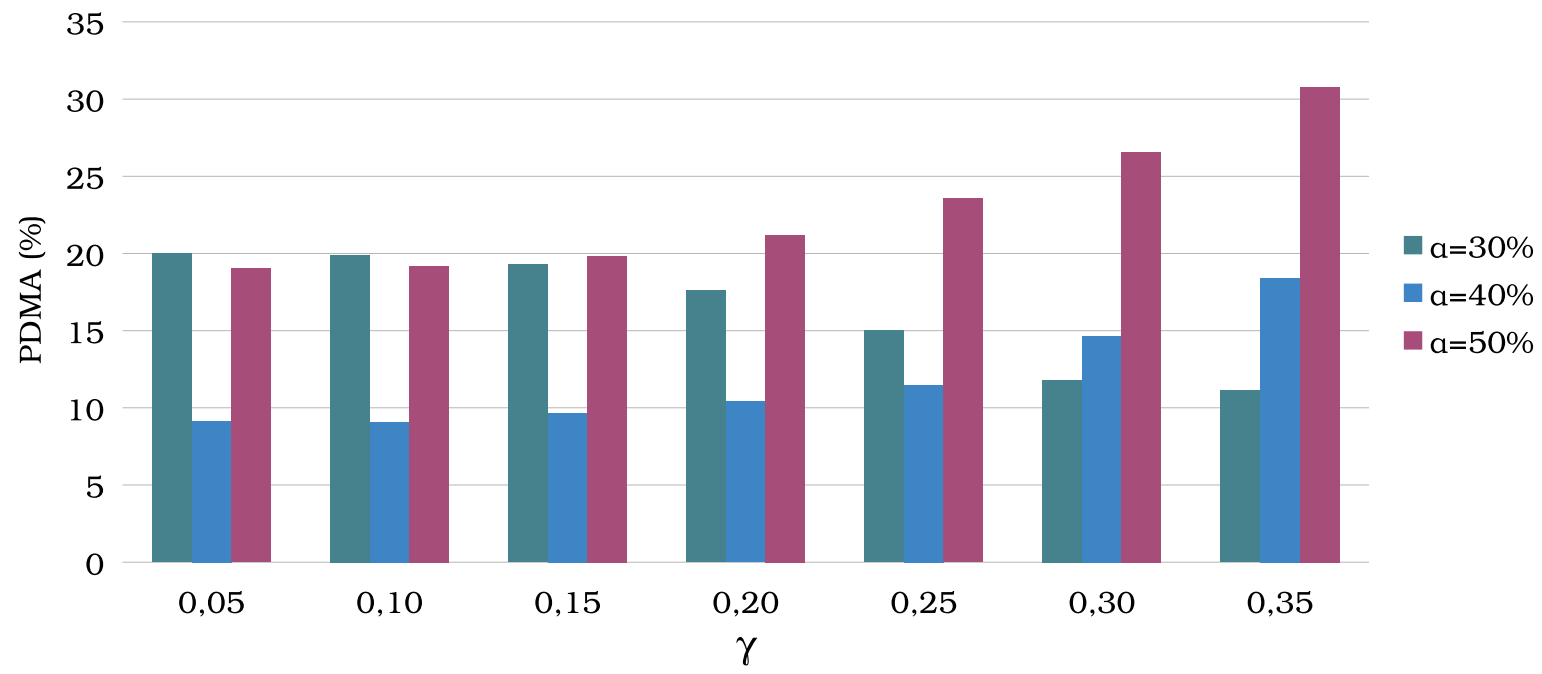

(a) $\alpha+\beta=100 \%$ 


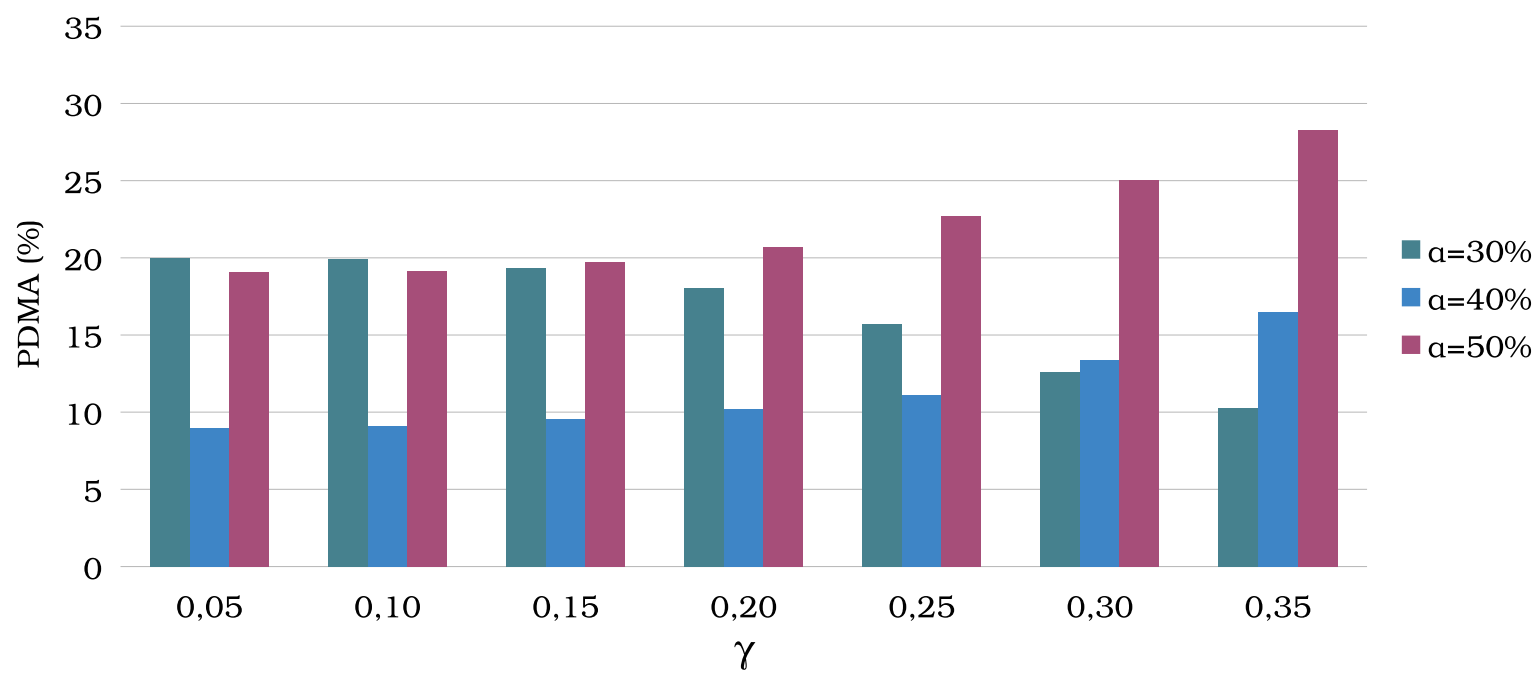

(b) $\alpha+\beta=90 \%$

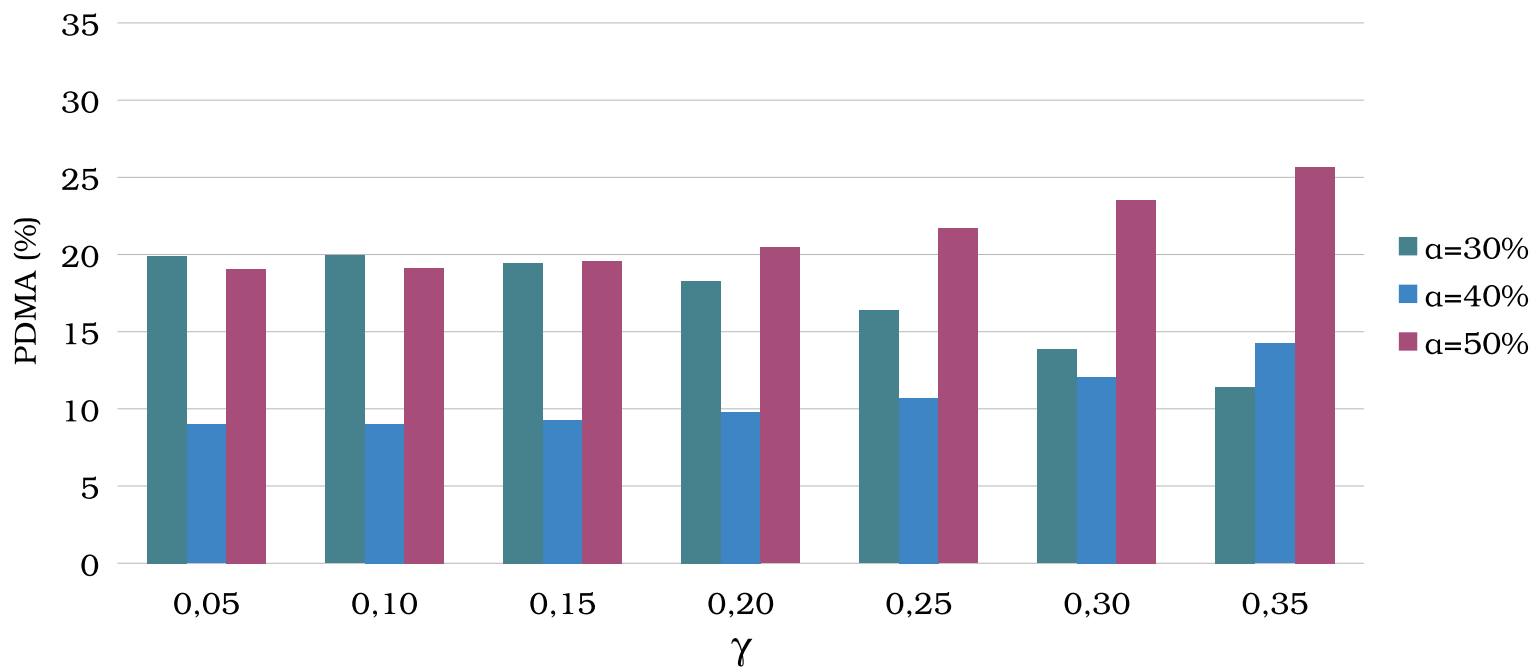

(c) $\alpha+\beta=80 \%$

Figura 4.32: PDMAs obtidas com LC-BHandH na base aug-pcJ-2 para geometrias otimizadas, variando $\alpha, \alpha+\beta$ e $\gamma$.

O LC-B1B95 $(40 \%|100 \%| 0,25)$ e o LC-BHandH(40\%|100\%|0,10) associam-se aos resultados mais precisos com geometria experimental por uma diminuição de $\gamma$, sendo o último localizado num patamar de 9\% de PDMA. O LC-B1B95(40\%|70\%|0,35) associa-se ao LCB1B95(40\%|100\%|0,25) por uma compensação entre a diminuição de $\alpha+\beta$ e o aumento de $\gamma$. E o LC-BHandH $(40 \%|80 \%| 0,15)$ corresponde à uma situação próxima do patamar de $9 \%$. 


\subsection{Comparação com SOPPA(CC2) e SOPPA(CCSD)}

As precisões dos cálculos com SOPPA(CCSD) e SOPPA(CC2) na base aug-cc-pVTZ-J para geometrias experimentais estão apresentadas na Tabela 8.427. Os métodos ab initio SOPPA(CCSD) e SOPPA(CC2) devem apresentar saturação de base para o cálculo das CAISS, visto que ambos apresentam o mesmo conjunto de resultados para as geometrias experimentais, e portanto a mesma precisão $(\mathrm{PDMA}=12,42 \%)$. Além disso, a precisão para as moléculas SPI (9,60\%) é melhor que a precisão para as moléculas CPI (16,25\%), indicando que os métodos ab initio SOPPA(CCSD) e SOPPA(CC2) também apresentam imprecisões para tipos diferentes de acoplamento.

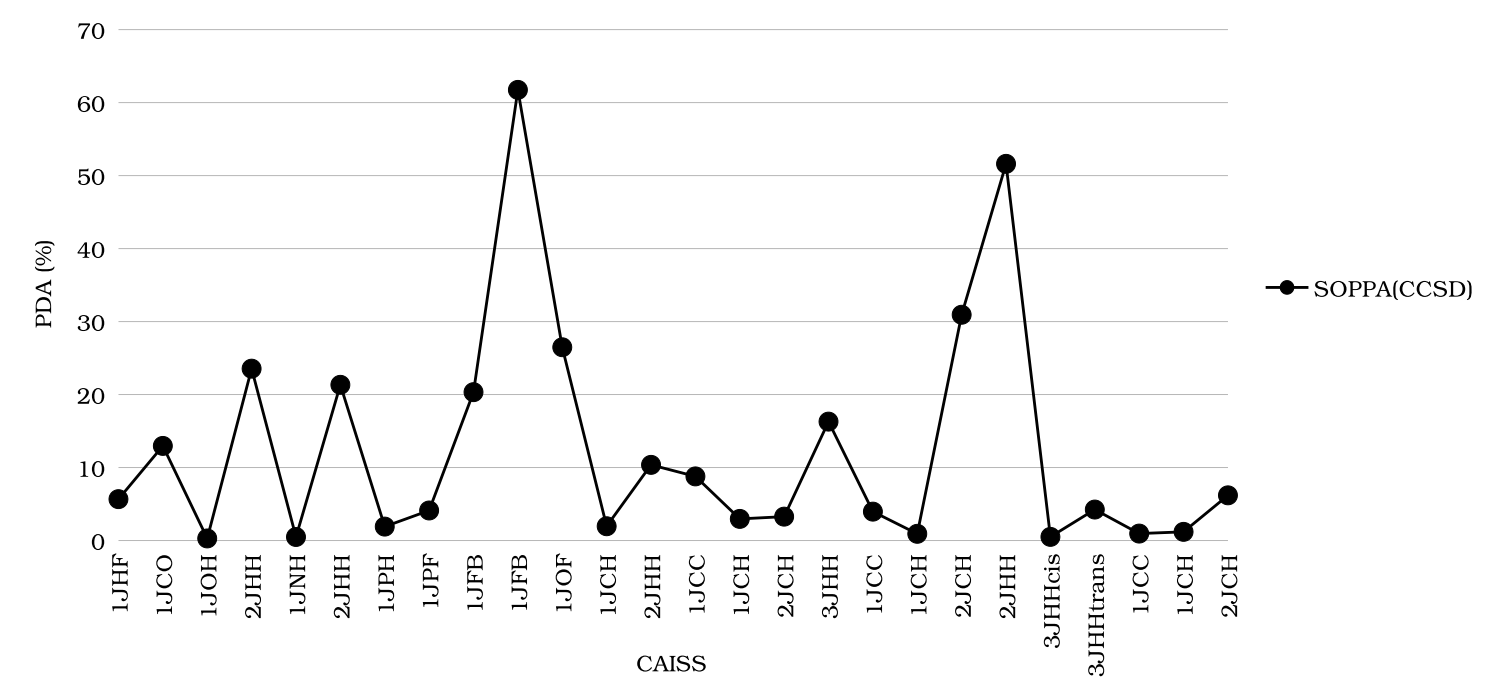

Figura 4.33: PDA das CAISS com SOPPA(CCSD) e SOPPA(CC2). As geometrias são experimentais.

A Figura 4.33 apresenta as PDAs para os métodos SOPPA(CCSD) e SOPPA(CC2). Apenas os valores da PDA para a constante ${ }^{1} J_{\mathrm{BF}}$ da molécula de $\mathrm{BF}_{3}$ e as constantes ${ }^{2} J_{\mathrm{CH}}$ $\mathrm{e}^{2} J_{\mathrm{HH}}$ da molécula de $\mathrm{C}_{2} \mathrm{H}_{4}$ são superiores a $30 \%$, indicando a inexatidão no cálculo dessas 3 constantes. De fato, a precisão do conjunto melhora desconsiderando essas constantes (de $12,42 \%$ para $7,76 \%$ ), tanto para o conjunto CPI (de 16,25\% para $11,71 \%$ ) quanto para SPI (de $9,60 \%$ para $4,73 \%$ ).

A Figura 4.34 apresenta a comparação do valores de PDA de SOPPA(CCSD) e dos melhores resultados DFT (e suas versões originais). 


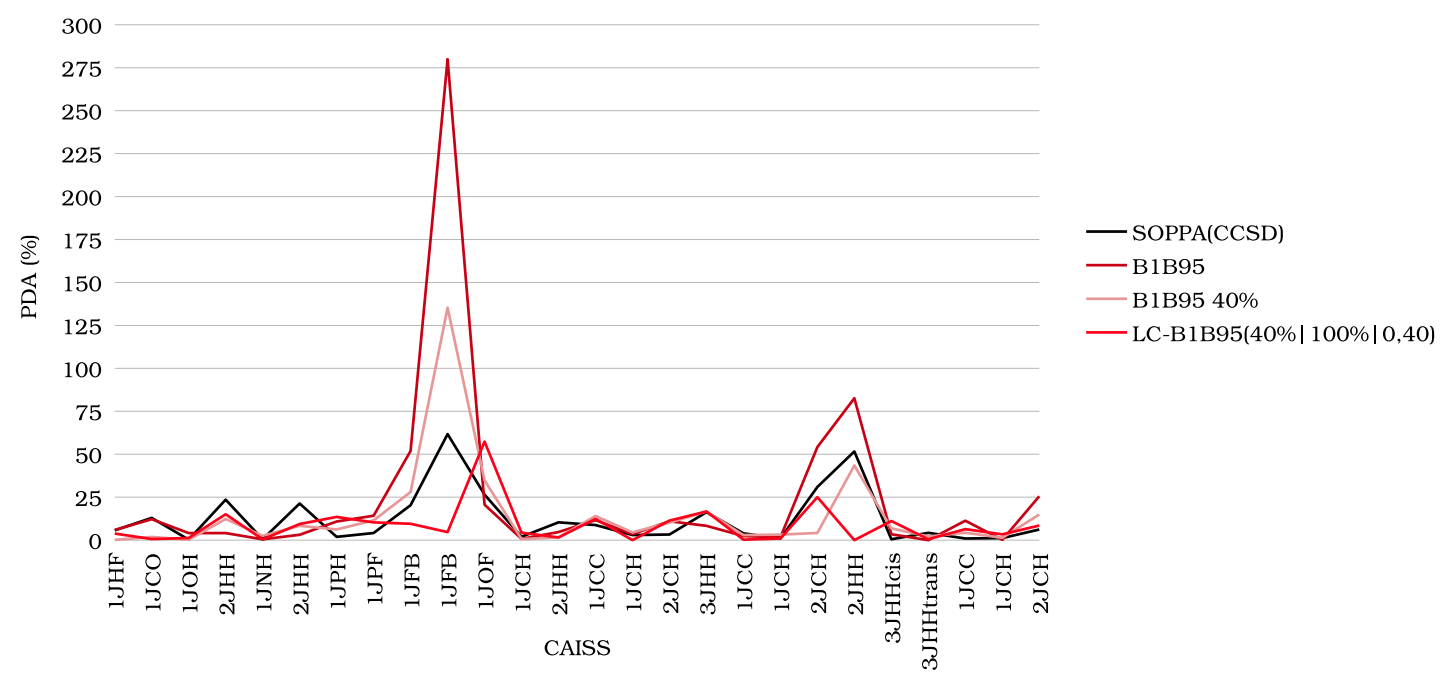

(a) Comparação com B1B95
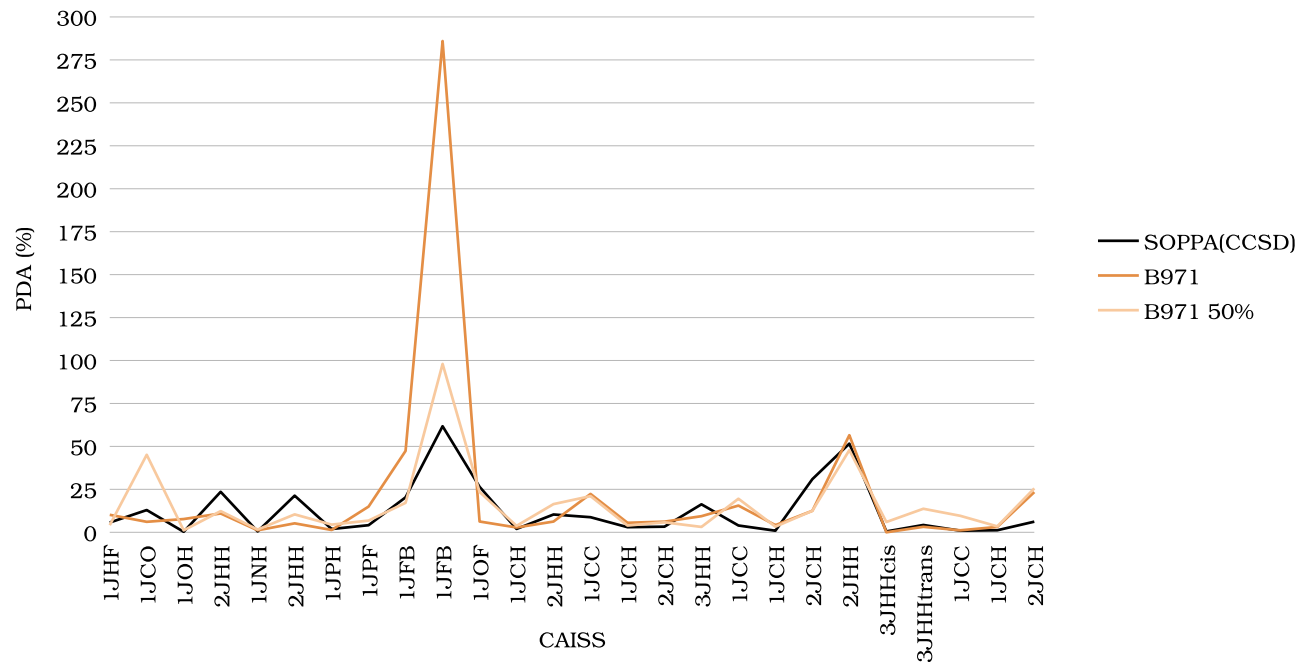

(b) Comparação com B971

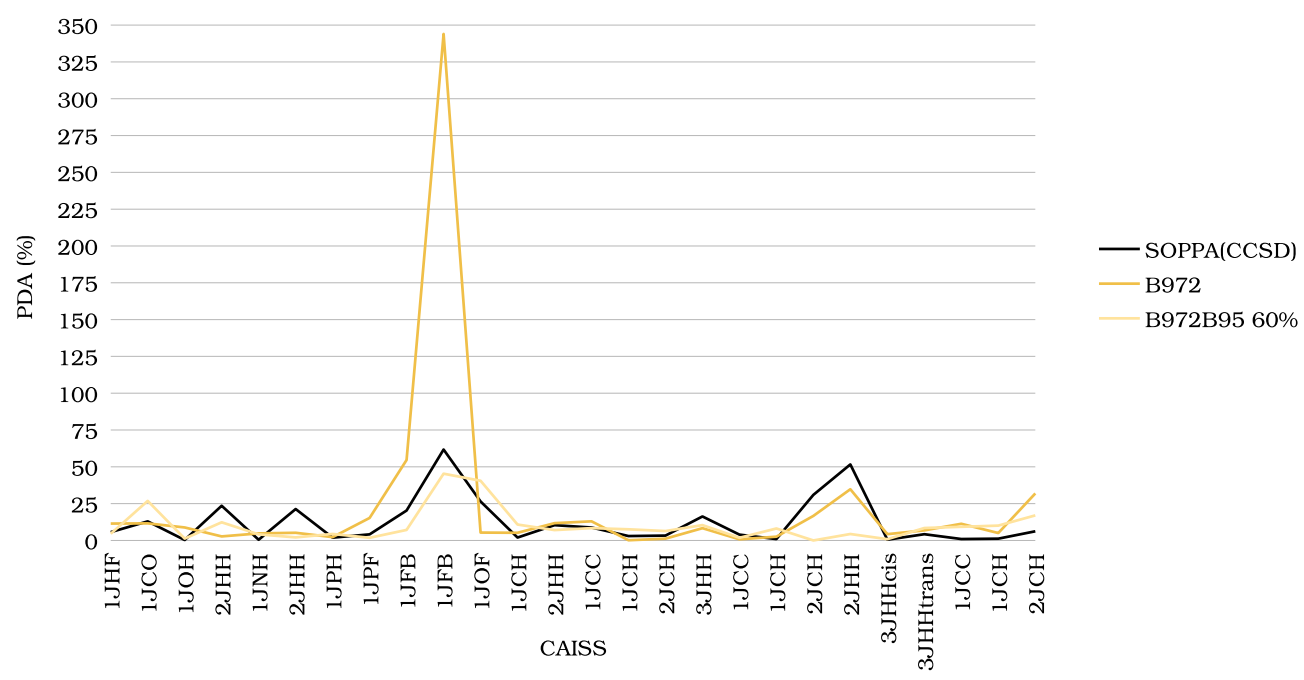

(c) Comparação com B972 


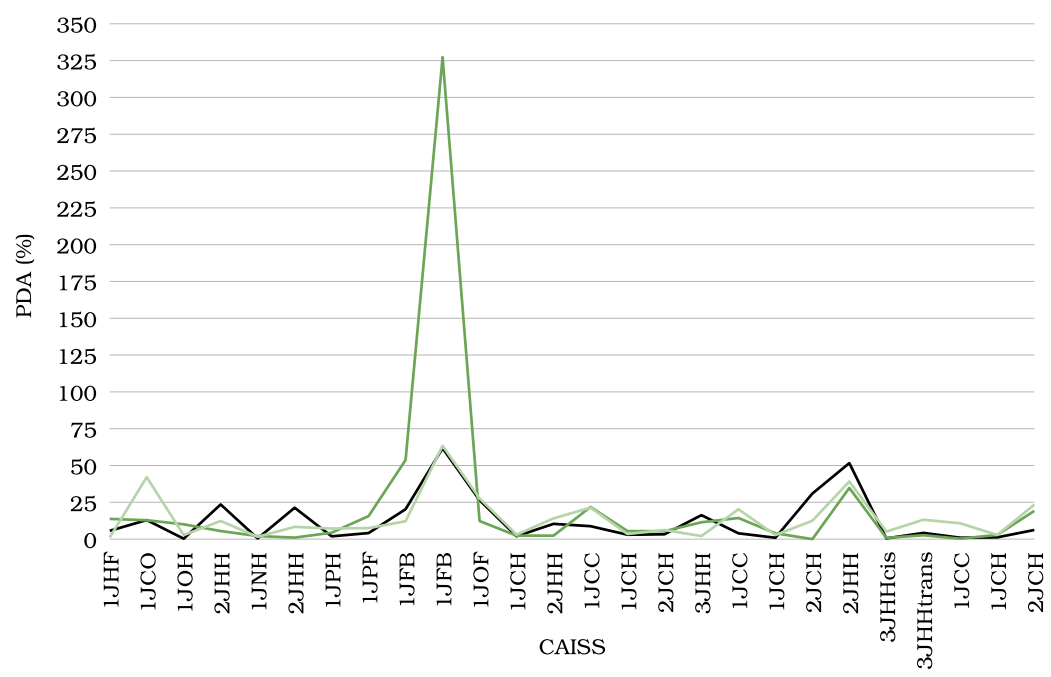

(d) Comparação com B98

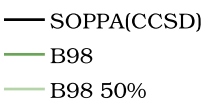

- SOPPA(CCSD)

- BHandH

BHandH $40 \%$

— LC-BHandH $(40 \%|100 \%| 0,30)$

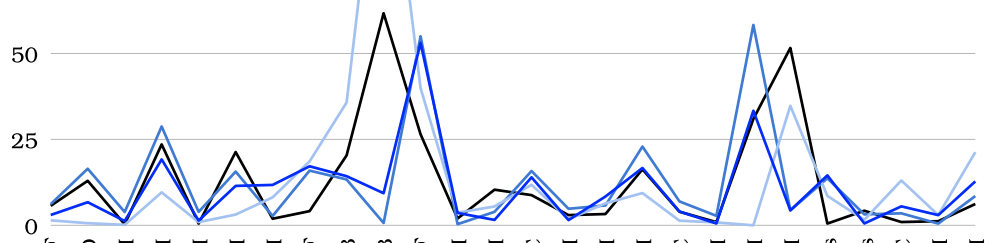

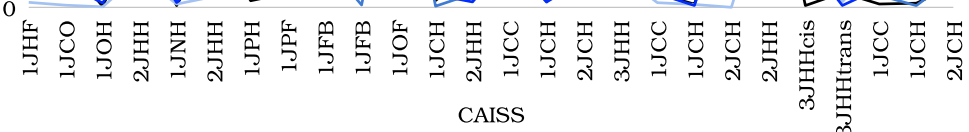

(e) Comparação com BHandH

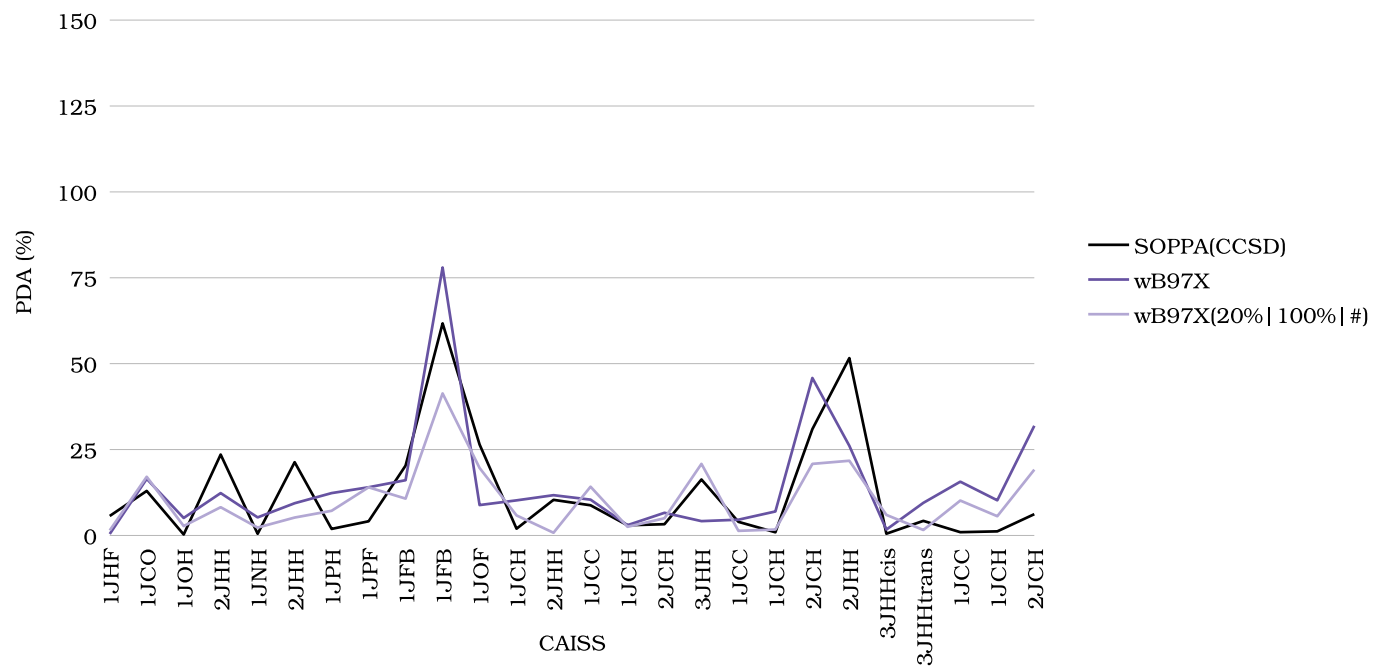

(f) Comparação com $\omega$ B97X 


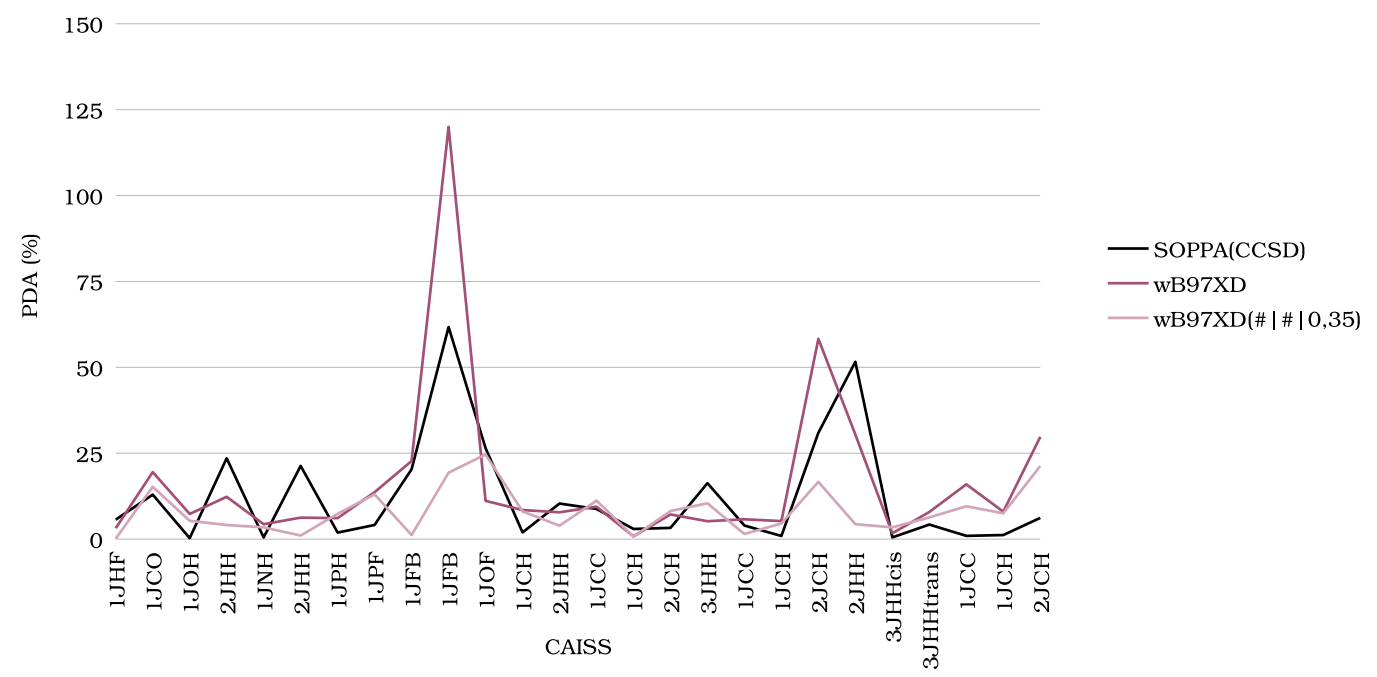

(g) Comparação com $\omega$ B97XD

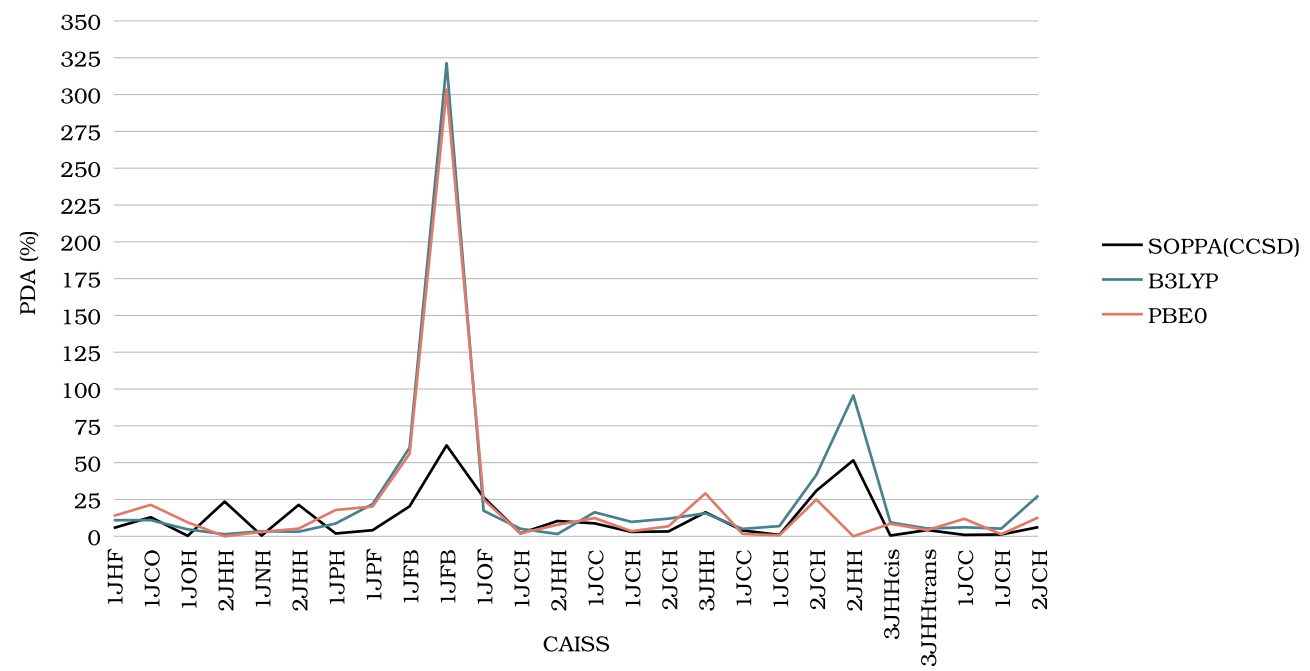

(h) Comparação com B3LYP e PBE0

Figura 4.34: PDA das CAISS com SOPPA(CC2), BHandH 40\%, B1B95 40\% e B972B95 60\%. As geometrias para BHandH 40\%, B1B95 40\% e B972B95 60\% são otimizadas, e para SOPPA $(\mathrm{CC} 2)$ as geometrias são experimentais.

No geral, as principais diferenças entre SOPPA(CCSD) e os DFTs estão associadas à ${ }^{1} J_{\mathrm{BF}}$ da molécula de $\mathrm{BF}_{3}$ e às ${ }^{2} J_{\mathrm{CH}}$ e ${ }^{2} J_{\mathrm{HH}}$ da molécula de $\mathrm{C}_{2} \mathrm{H}_{4}$ (vamos nos referir ao conjunto destas 3 constantes daqui para a frente como " $3 \mathbf{P}$ ").

O B1B95 (Figura 4.34a) apresenta inexatidões próximas ao SOPPA(CCSD) para as CAISS no geral, entretanto é muito mais inexato para 3P. O B1B95 40\% $E_{X}^{\mathrm{HF}}$ aumenta a exatidão das $3 \mathrm{P}$ e da ${ }^{2} J_{\mathrm{CH}}$ da molécula de $\mathrm{C}_{2} \mathrm{H}_{6}$, superando o $\mathrm{SOPPA}(\mathrm{CCSD})$ nas ${ }^{2} J_{\mathrm{CH}} \mathrm{e}$ ${ }^{2} J_{\mathrm{HH}}$ da molécula de $\mathrm{C}_{2} \mathrm{H}_{4}$. E o LC-B1B95 $(40 \%|100 \%| 0,40)$ melhora bastante a exatidão, 
sendo o mais exato para a ${ }^{1} J_{\mathrm{BF}}$ da molécula de $\mathrm{BF}_{3}$; entretanto a ${ }^{1} J_{\mathrm{OF}}$ da molécula de $\mathrm{F}_{2} \mathrm{O}$ é mais inexata que o SOPPA(CCSD).

O B971 (Figura 4.34b) apresenta inexatidões próximas ao SOPPA(CCSD) para as CAISS no geral, entretanto é muito mais inexato para ${ }^{1} J_{\mathrm{BF}}$ da molécula de $\mathrm{BF}_{3}$. Já o B971 $50 \% E_{X}^{\mathrm{HF}}$ aumenta a exatidão da ${ }^{1} J_{\mathrm{BF}}$ da molécula de $\mathrm{BF}_{3}$ aproximando-se do SOPPA(CCSD), mas piora significativamente na ${ }^{1} J_{\mathrm{CO}}$ da molécula de CO.

O B972 (Figura 4.34c) apresenta inexatidões próximas ao SOPPA(CCSD) para as CAISS no geral, entretanto é muito mais inexato para ${ }^{1} J_{\mathrm{BF}}$ da molécula de $\mathrm{BF}_{3}$. Já o B972B95 60\% $E_{X}^{\mathrm{HF}}$ aumenta a exatidão das $\mathbf{3 P}$ e piora da ${ }^{1} J_{\mathrm{CO}}$ da molécula de $\mathrm{CO}$, sendo um resultado com exatidão próxima para todas CAISS.

O B98 (Figura 4.34d) apresenta inexatidões próximas ao SOPPA(CCSD) para as CAISS no geral, entretanto é muito mais inexato para ${ }^{1} J_{\mathrm{BF}}$ da molécula de $\mathrm{BF}_{3}$. Já o $\mathrm{B} 9850 \% E_{X}^{\mathrm{HF}}$ aumenta a exatidão da ${ }^{1} J_{\mathrm{BF}}$ da molécula de $\mathrm{BF}_{3}$ e piora da ${ }^{1} J_{\mathrm{CO}}$ da molécula de CO.

O BHandH (Figura 4.34e) apresenta inexatidões próximas ao SOPPA(CCSD) para as CAISS no geral, entretanto é mais exato para ${ }^{1} J_{\mathrm{BF}}$ da molécula de $\mathrm{BF}_{3}$ e ${ }^{2} J_{\mathrm{HH}}$ da molécula de $\mathrm{C}_{2} \mathrm{H}_{4}$ e mais inexato para ${ }^{1} J_{\mathrm{OF}}$ da molécula de $\mathrm{F}_{2} \mathrm{O}$ e ${ }^{2} J_{\mathrm{CH}}$ da molécula de $\mathrm{C}_{2} \mathrm{H}_{4}$. O BHandH $40 \% E_{X}^{\mathrm{HF}}$ piora a exatidão das ${ }^{1} J_{\mathrm{BF}}$ das moléculas de $\mathrm{BHF}_{2}$ e $\mathrm{BF}_{3}$. E o LC-BHandH(40\%|100\%|0,30) repete a tendência do BHandH; entretanto é mais exato que o BHandH em várias CAISS.

O $\omega$ B97X (Figura 4.34f) apresenta inexatidões próximas ao SOPPA(CCSD) para as CAISS no geral, entretanto é mais inexato para ${ }^{1} J_{\mathrm{CC}},{ }^{1} J_{\mathrm{CH}} \mathrm{e}{ }^{2} J_{\mathrm{CH}}$ da molécula de $\mathrm{C}_{2} \mathrm{H}_{6}$. E o $\omega \operatorname{B} 97 \mathrm{X}(20 \%|100 \%| \#)$ melhora bastante a exatidão da e das ${ }^{1} J_{\mathrm{CC}},{ }^{1} J_{\mathrm{CH}}$ e ${ }^{2} J_{\mathrm{CH}}$ da molécula de $\mathrm{C}_{2} \mathrm{H}_{6}$, sendo mais balancedo que o $\mathrm{SOPPA}(\mathrm{CCSD})$.

O $\omega$ B97XD (Figura 4.34g) apresenta inexatidões próximas ao SOPPA(CCSD) para as CAISS no geral, entretanto é mais inexato para ${ }^{1} J_{\mathrm{BF}}$ da molécula de $\mathrm{BF}_{3},{ }^{2} J_{\mathrm{CH}}$ da molécula de $\mathrm{C}_{2} \mathrm{H}_{4}$ e ${ }^{1} J_{\mathrm{CC}},{ }^{1} J_{\mathrm{CH}}$ e ${ }^{2} J_{\mathrm{CH}}$ da molécula de $\mathrm{C}_{2} \mathrm{H}_{6}$. E o $\omega \operatorname{Bg} 97 \mathrm{XD}(\#|\#| 0,35)$ melhora bastante a exatidão das $\mathbf{3 P}$, sendo mais balanceado que o SOPPA(CCSD).

O B3LYP e o PBE0 (Figura 4.34h) apresentam inexatidões próximas ao SOPPA(CCSD) 
para as CAISS no geral. Ambos são muito mais inexatos para ${ }^{1} J_{\mathrm{BF}}$ da molécula de $\mathrm{BF}_{3}$. O B3LYP também é mais inexato para ${ }^{2} J_{\mathrm{CH}}$ e ${ }^{2} J_{\mathrm{HH}}$ da molécula de $\mathrm{C}_{2} \mathrm{H}_{4}$ que o SOPPA(CCSD), mas o PBE0 é mais exato nessas CAISS.

Assim, funcionais como B972B95 60\% $E_{X}^{\mathrm{HF}}, \omega \mathrm{B} 97 \mathrm{X}(20 \%|100 \%| \#), \omega \mathrm{B} 97 \mathrm{XD}(\#|\#| 0,35)$, LC-B1B95(40\%|100\%|0,40) e LC-BHandH(40\%|100\%|0,30) se mostram tão bons quanto os métodos ab initio SOPPA(CC2) e SOPPA(CCSD) no cálculo de CAISS com geometrias experimentais, indicando que esses métodos DFT permitem obter valores tão precisos quanto os métodos SOPPA por um custo computacional consideravelmente menor. 


\subsection{Análise dos termos FC, SD, PSO e DSO}

O valor total calculado para as constantes spin-spin resulta da soma de 4 componentes: FC, SD, PSO e DSO (ver Equações 1.11 a 1.15). A comparação de cada um desses componentes foi feita em relação SOPPA(CC2) e SOPPA(CCSD) (pois não podem ser medidos experimentalmente); o valor total, entretanto, pode ser comparado com os métodos SOPPA e os valores experimentais. A comparação é feita em termos dos valores dos componentes em hertz, pois não é possível obter uma medida como a PDMA considerando que alguns termos são próximos a zero, gerando imprecisão numérica. Os valores de cada termo para as 26 CAISS do conjunto de calibração estão apresentados nas Tabelas 8.428 a 8.453 ,

A Figura 4.35 apresenta os componentes da cada uma 26 CAISS obtidas com as geometrias experimentais, comparando os melhores funcionais (e suas versões originais) e o $\operatorname{SOPPA}(\mathrm{CCSD})$.

A contribuição FC é a principal componente das CAISS, e o termo PSO pode também ser importante para o valor total. Os termos SD e DSO são muito menores, no geral, quando comparados com FC e PSO. Em alguns poucos casos, entretanto, a contribuição diamagnética não é negligenciável (por exemplo, na ${ }^{2} J_{\mathrm{HH}}$ da molécula de $\mathrm{C}_{2} \mathrm{H}_{4}$ ).

Os termos FC e SD são mais sensíveis do que as contribuições PSO e DSO à variações na porcentagem de $E_{X}^{\mathrm{HF}}$ e à escolha do método teórico. Isso está associado à descrição dos estados tripletos necessários para calcular esses valores. O aumento da troca exata ajuda (para a maioria dos funcionais originais) a diminuir o erro de auto-interação presente nos DFTs e que afeta principalmente os termos FC, SD e PSO $114[115$ A magnitude do termo FC em geral é muito maior que a do termo SD, e portanto o último é negligenciável. 

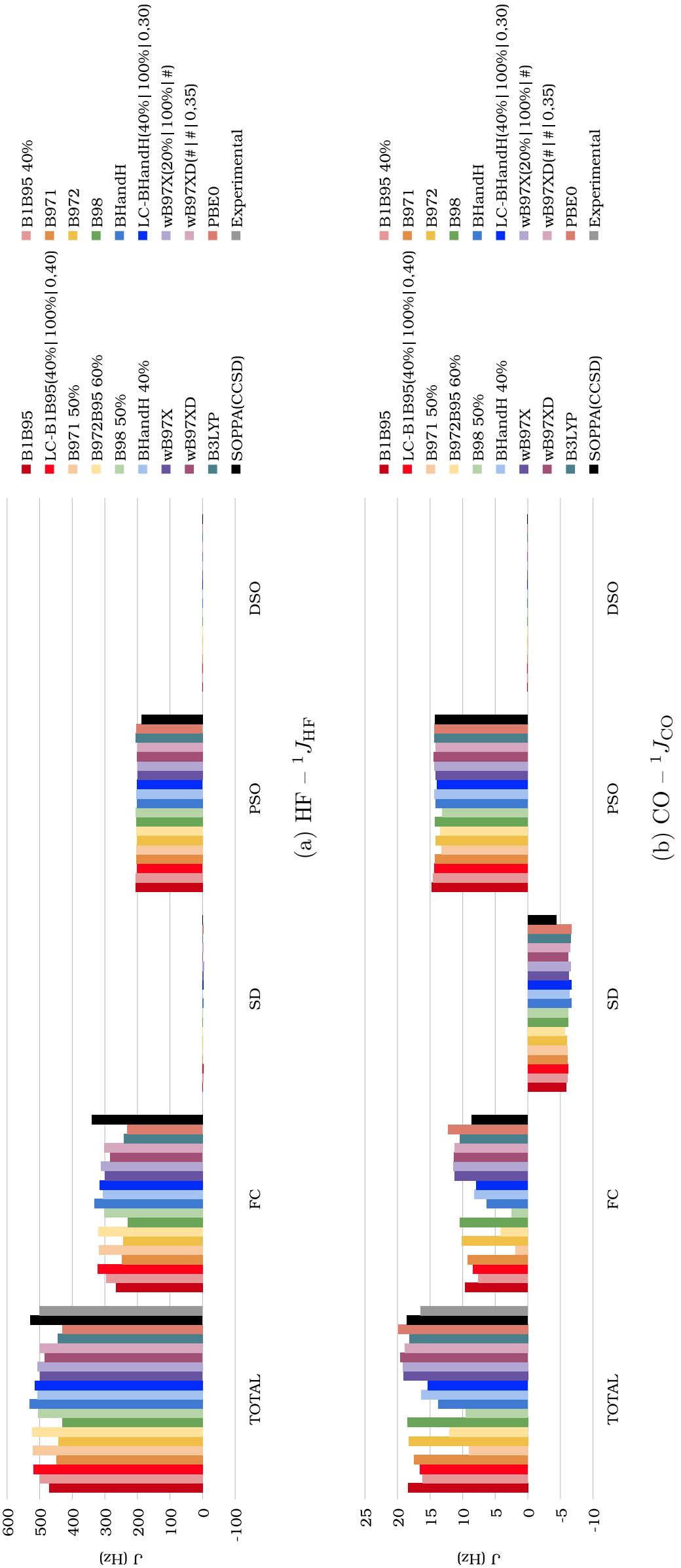

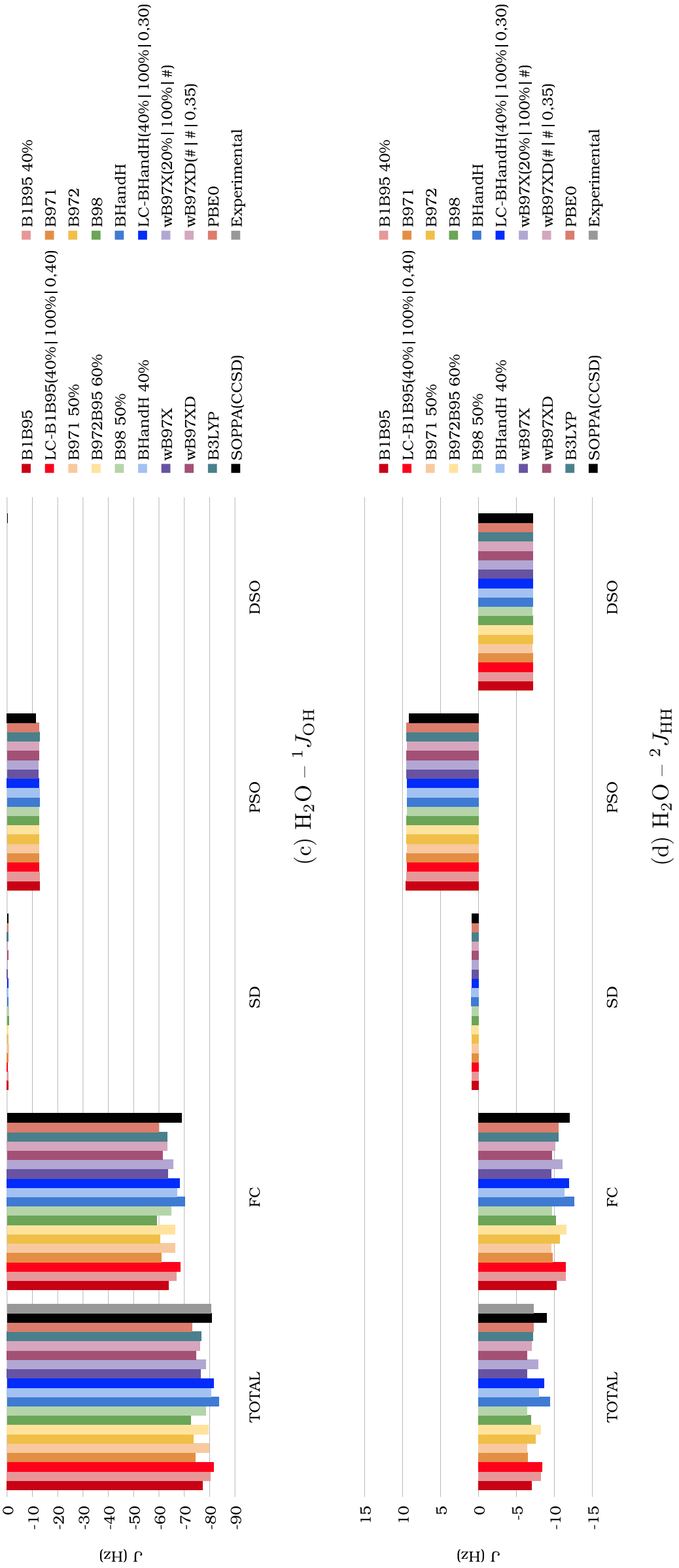

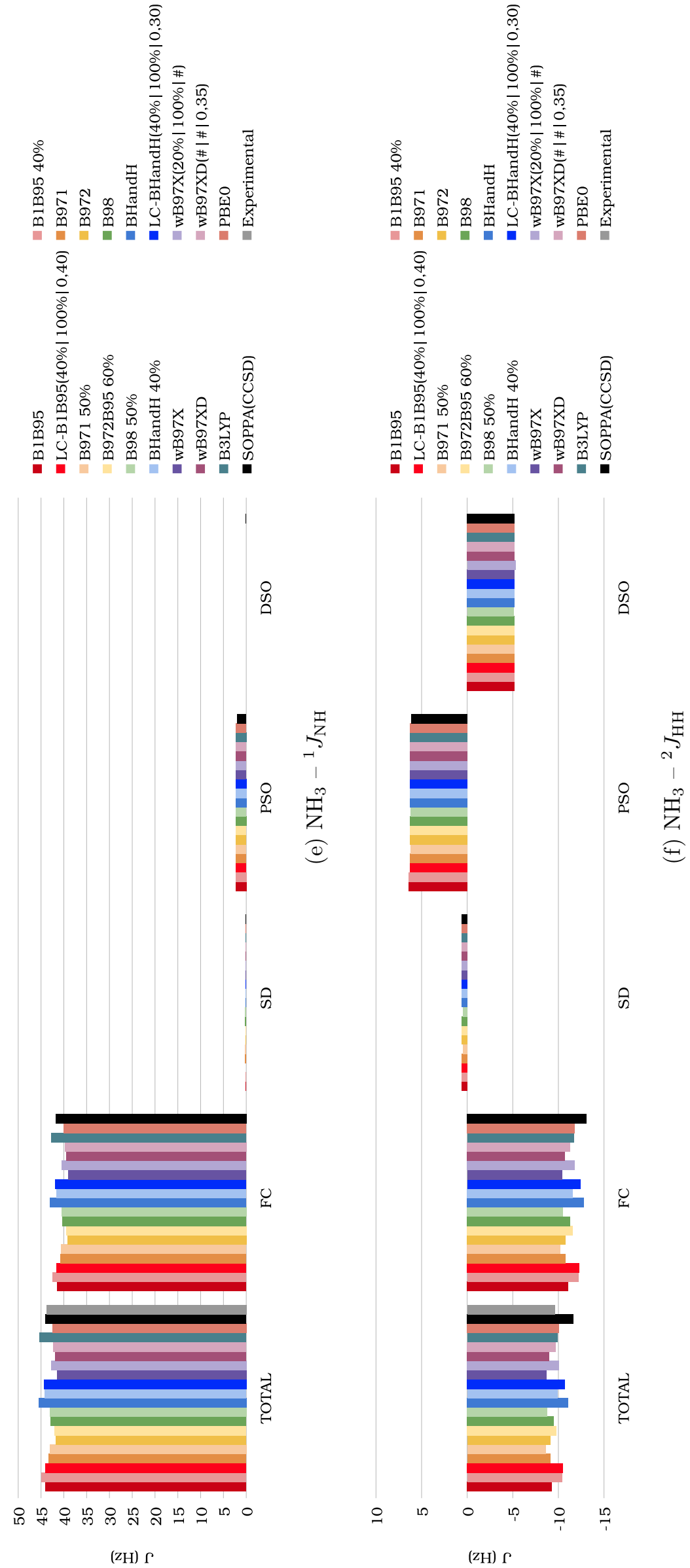

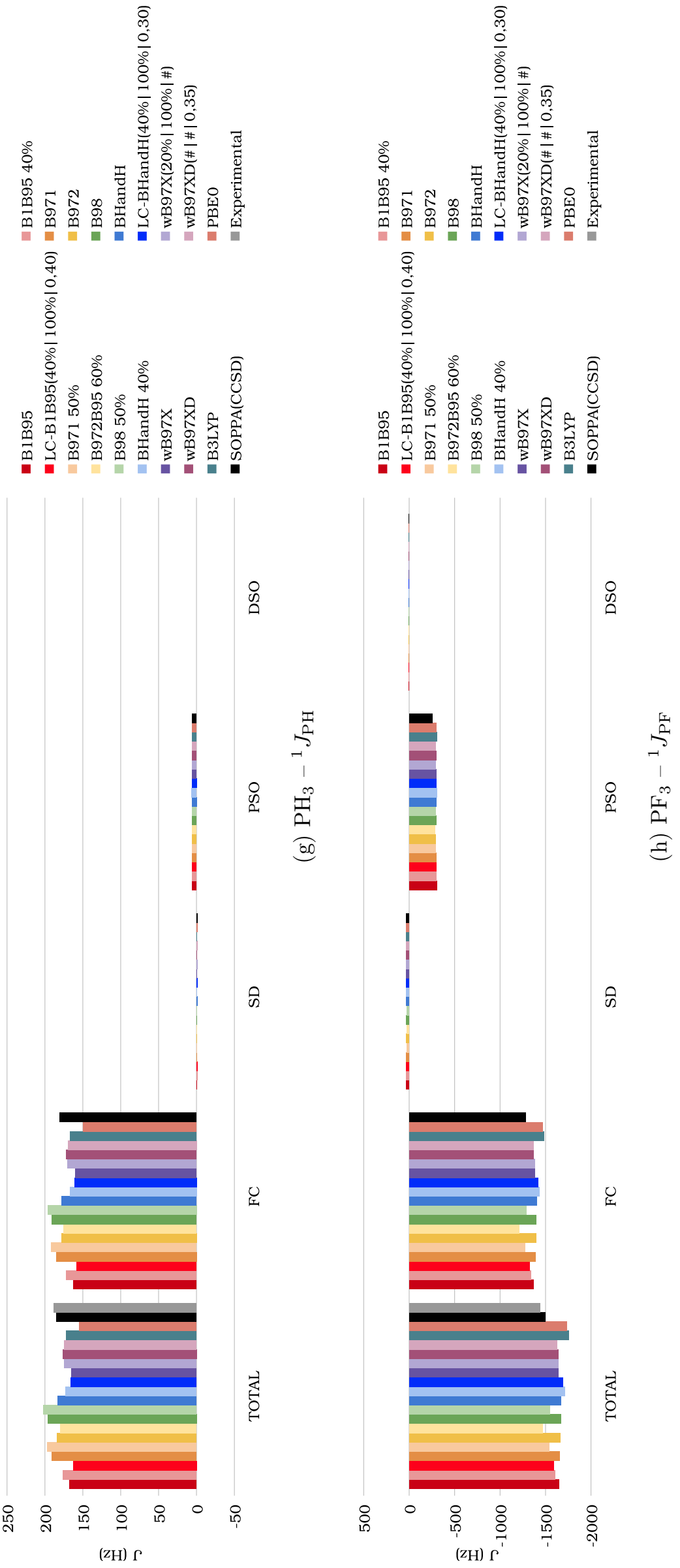

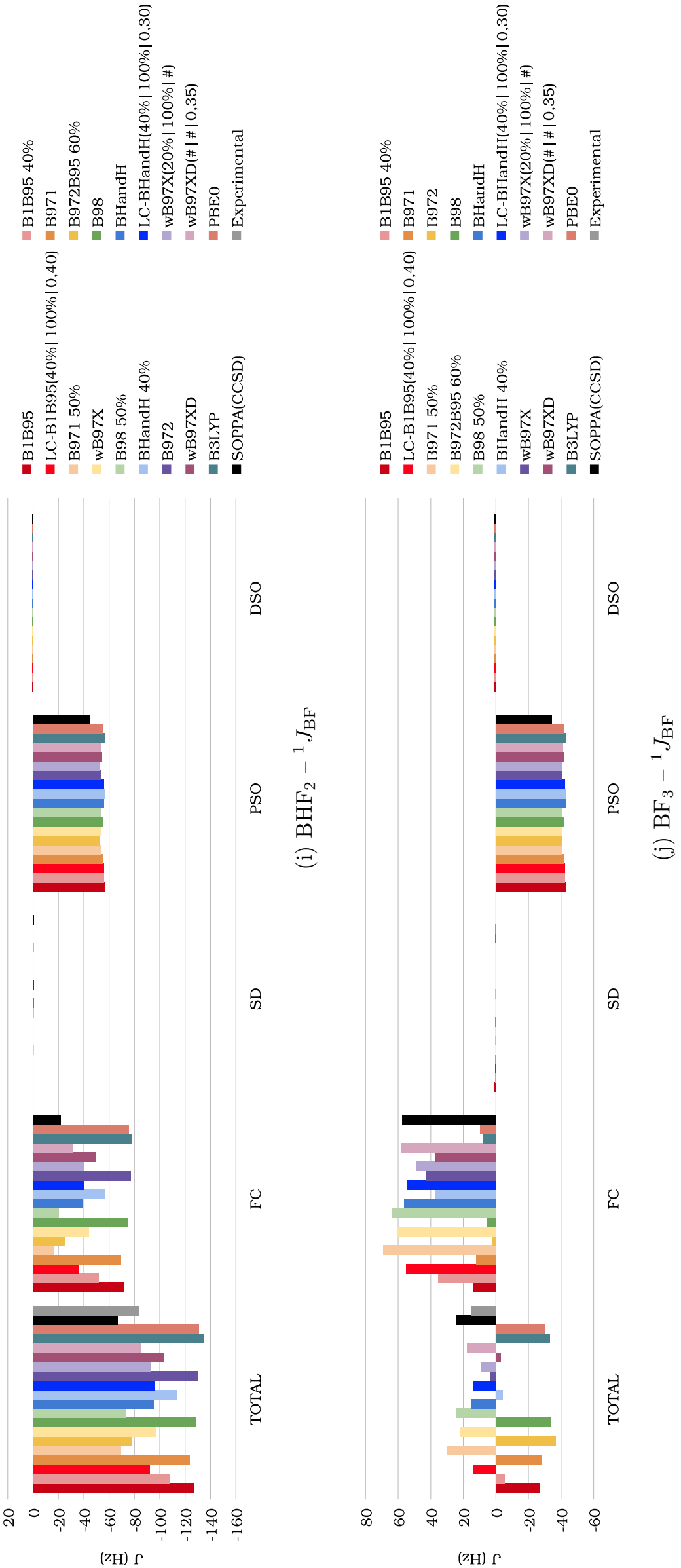

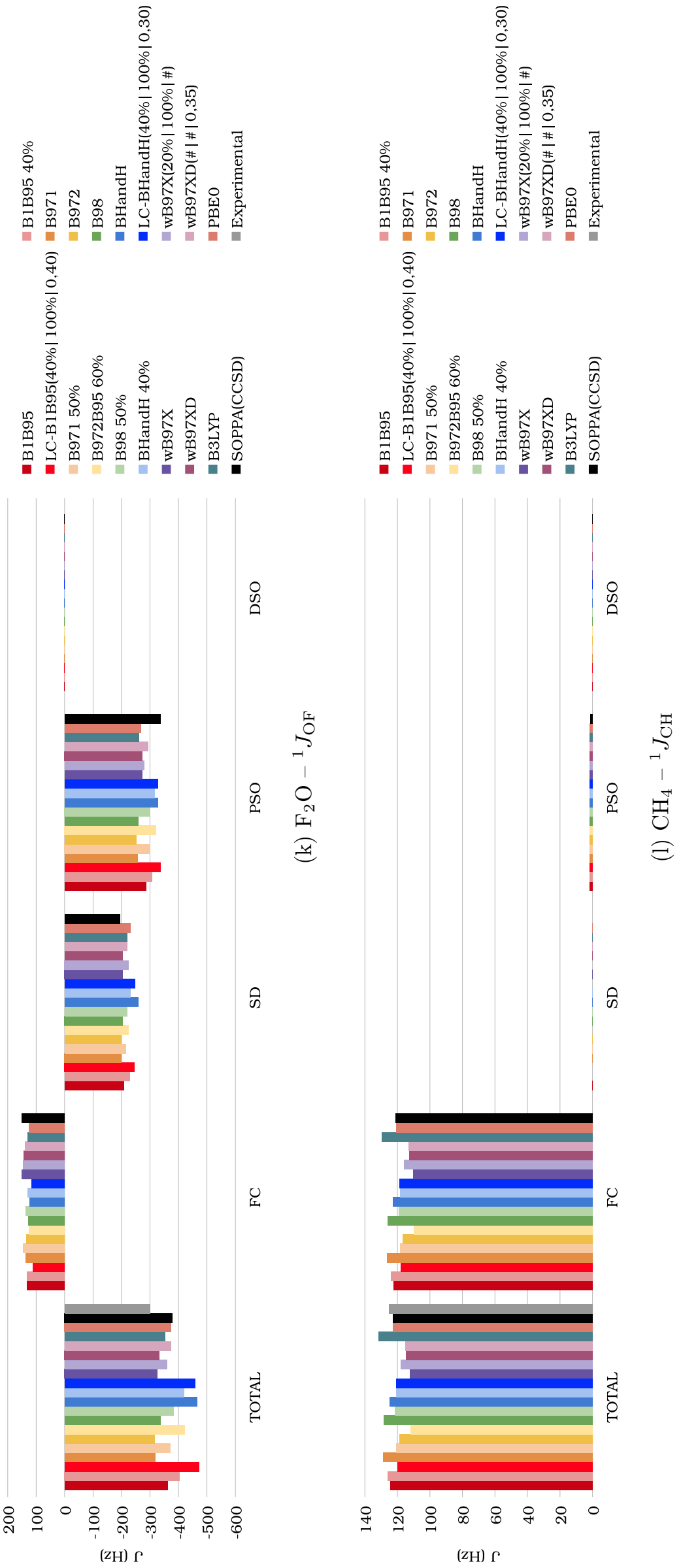

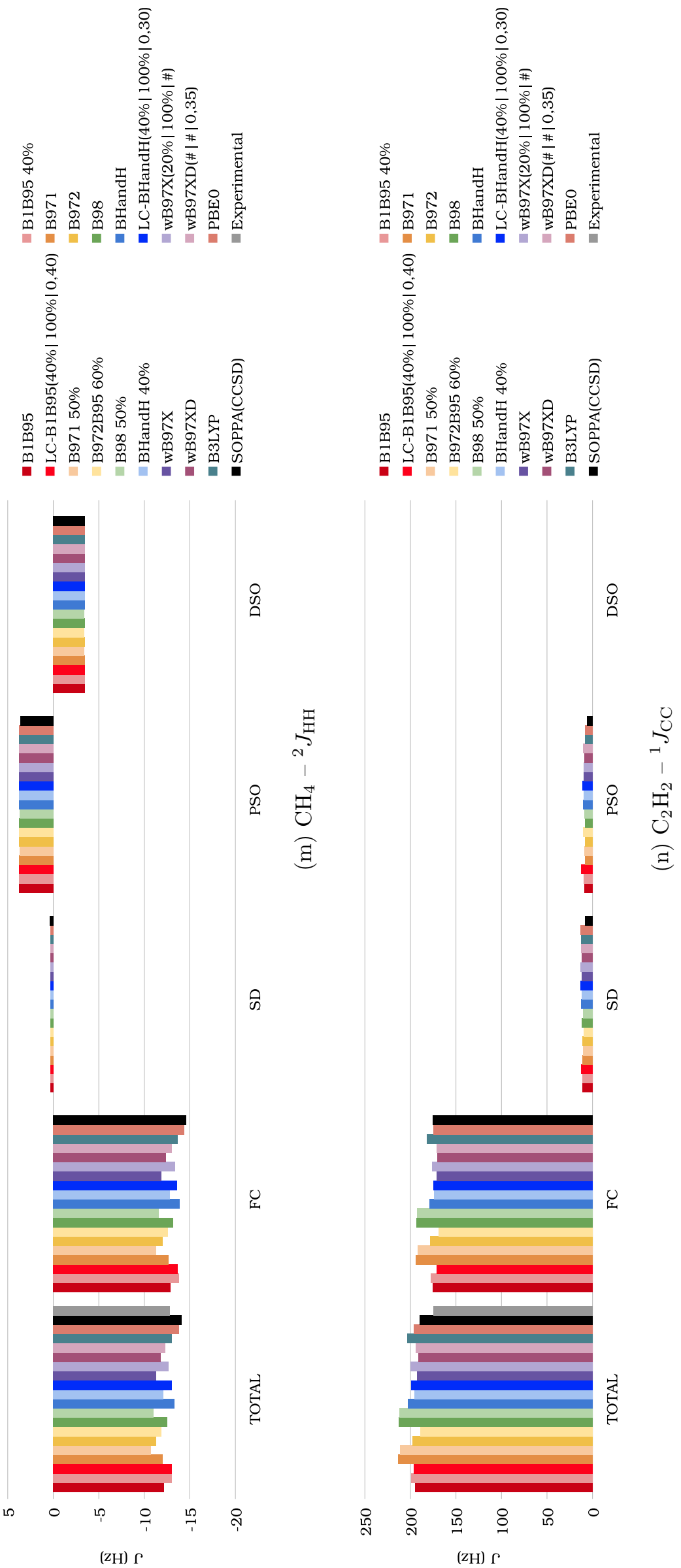

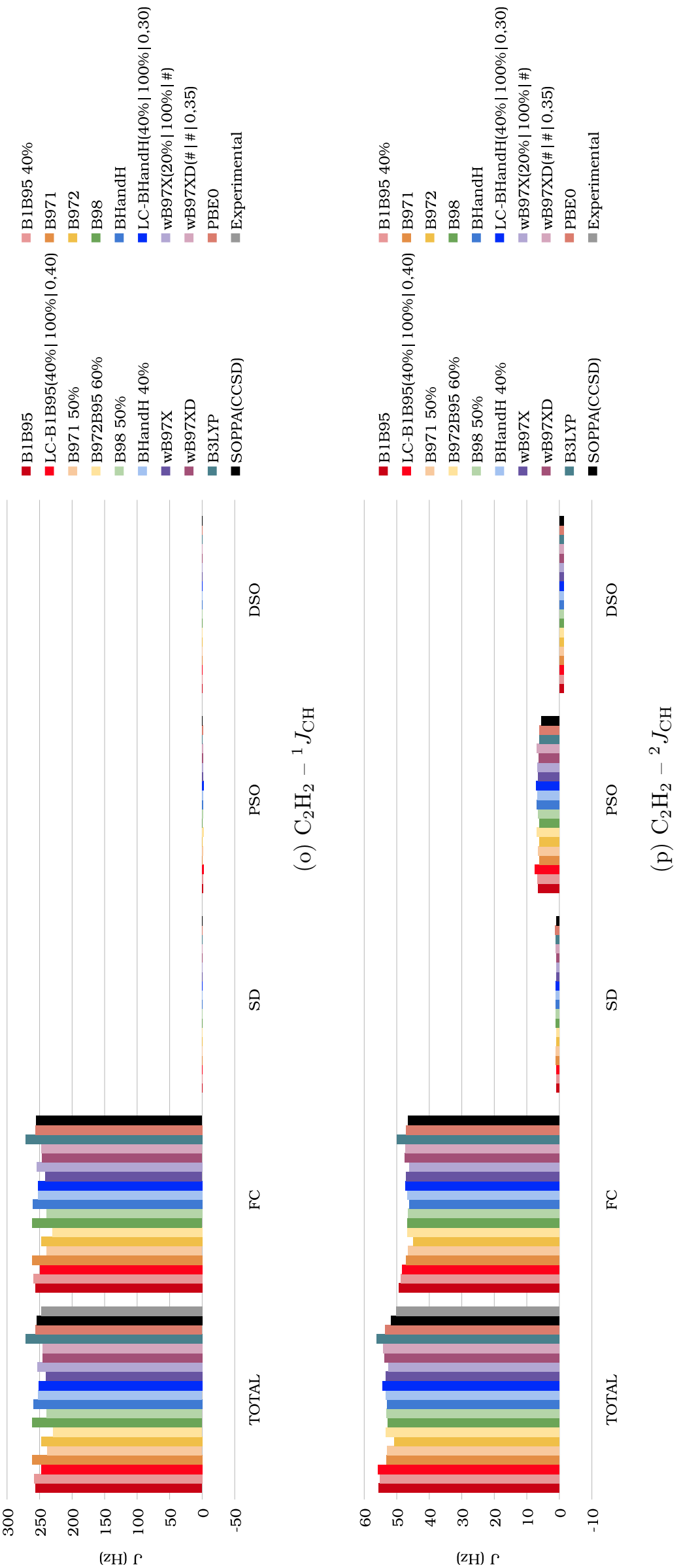

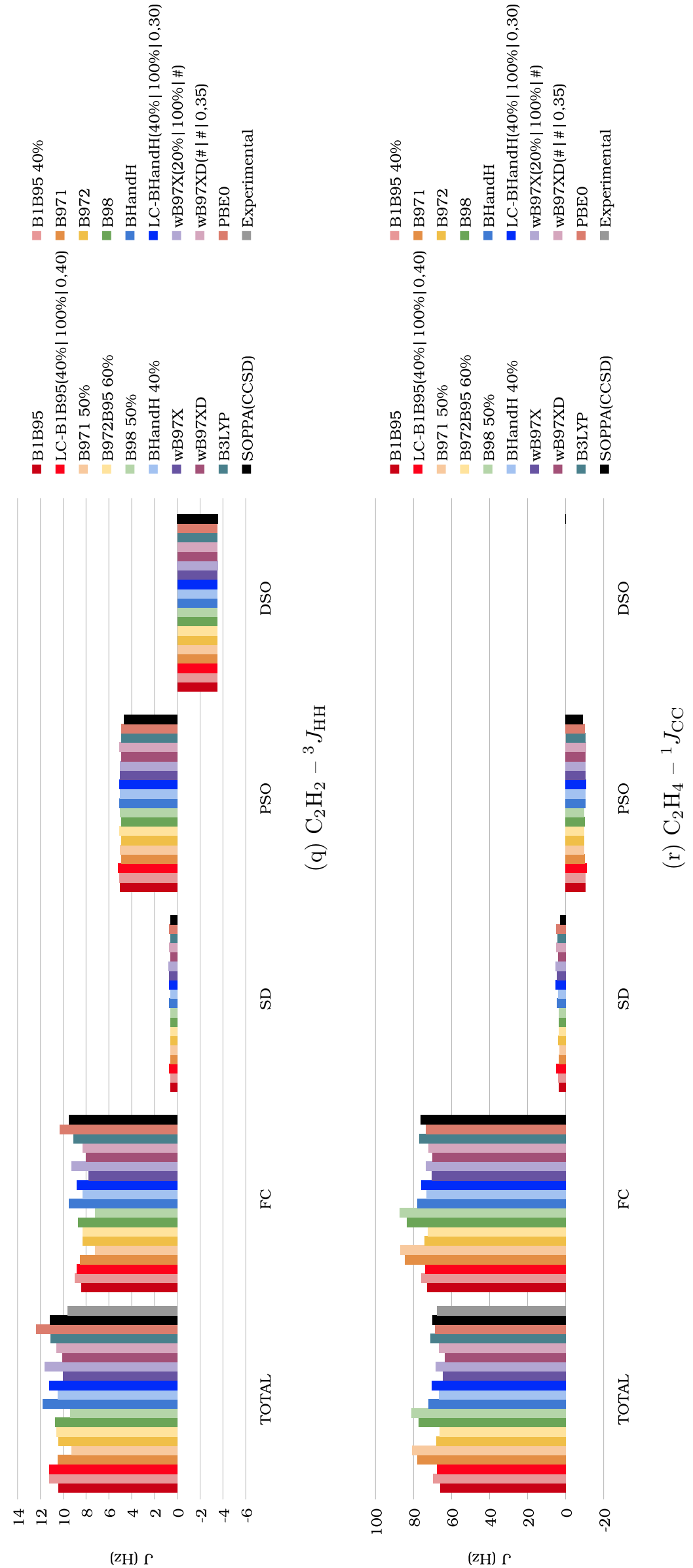

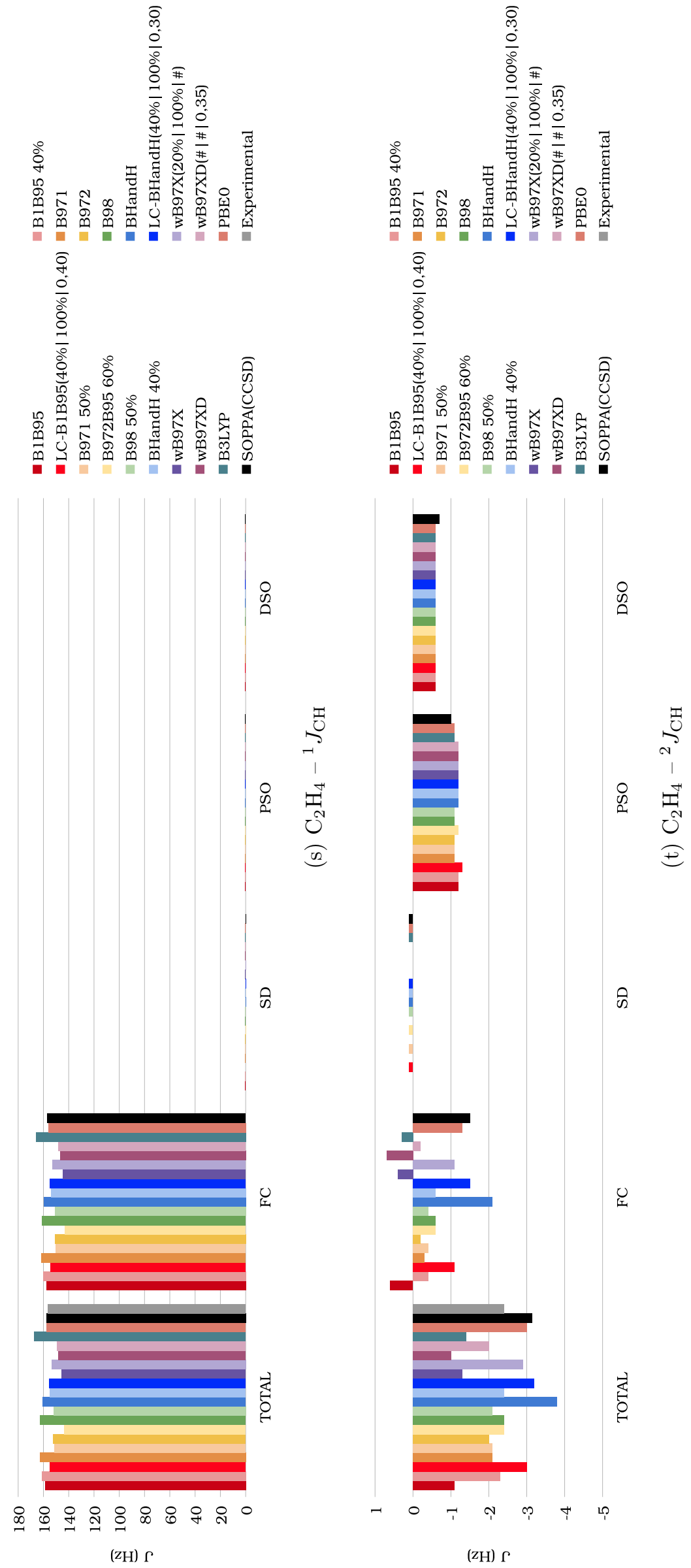

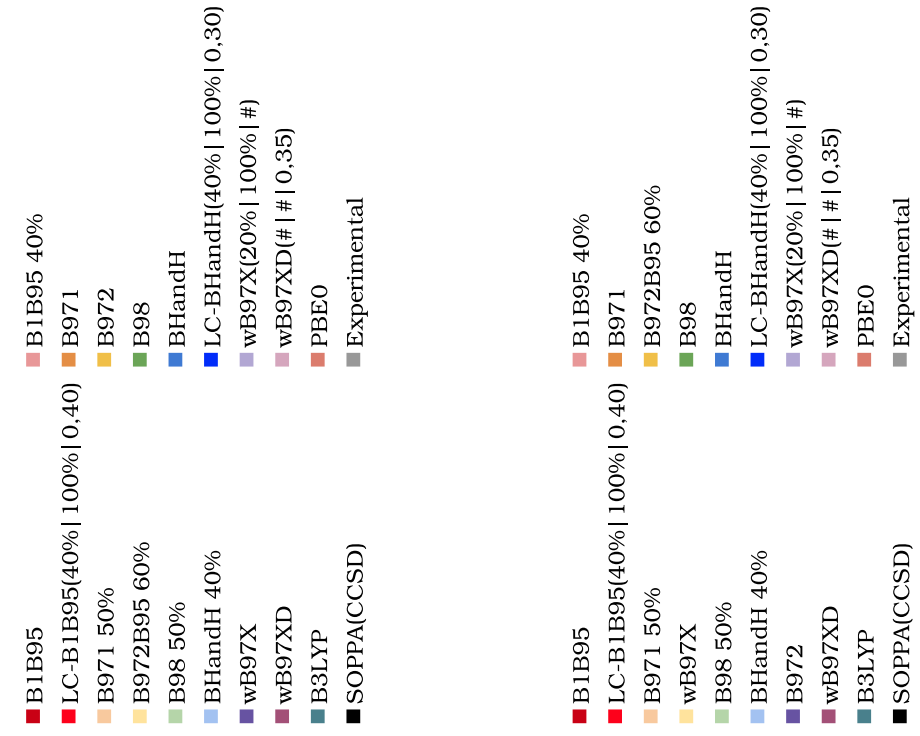

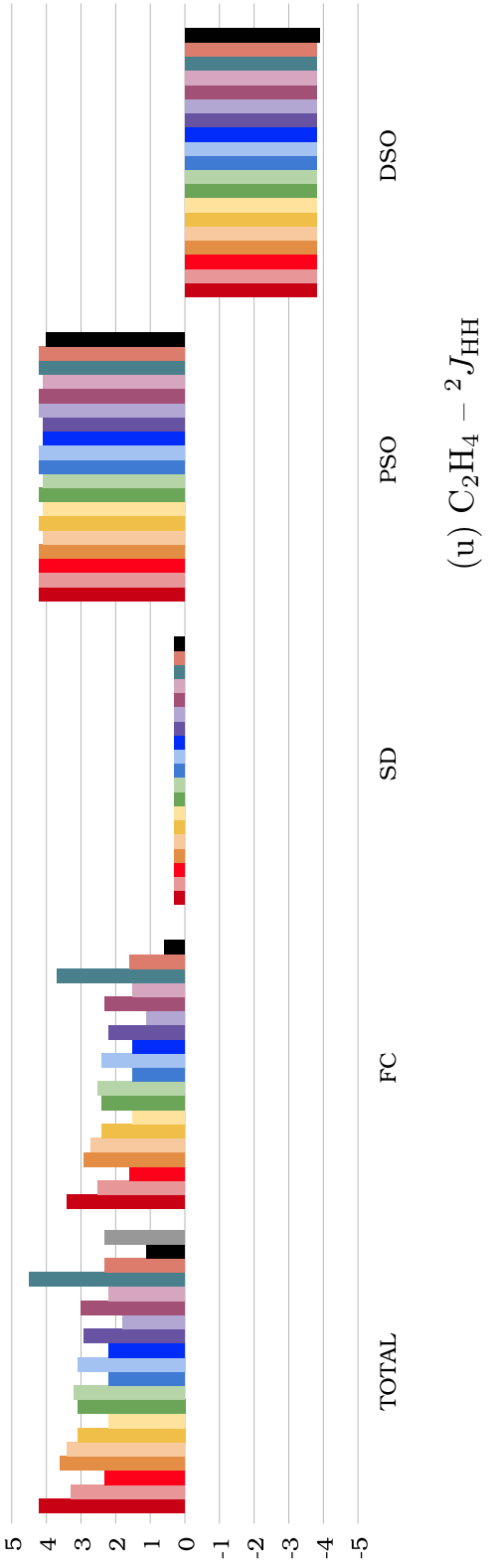

(zH) $\Gamma$
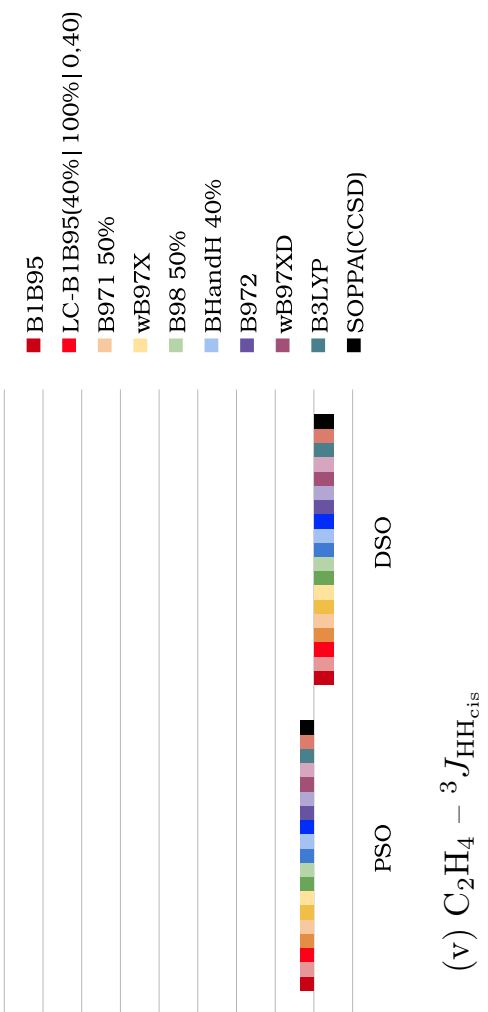

के

谣

농

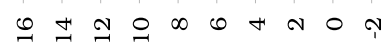

(zH) $\Gamma$ 

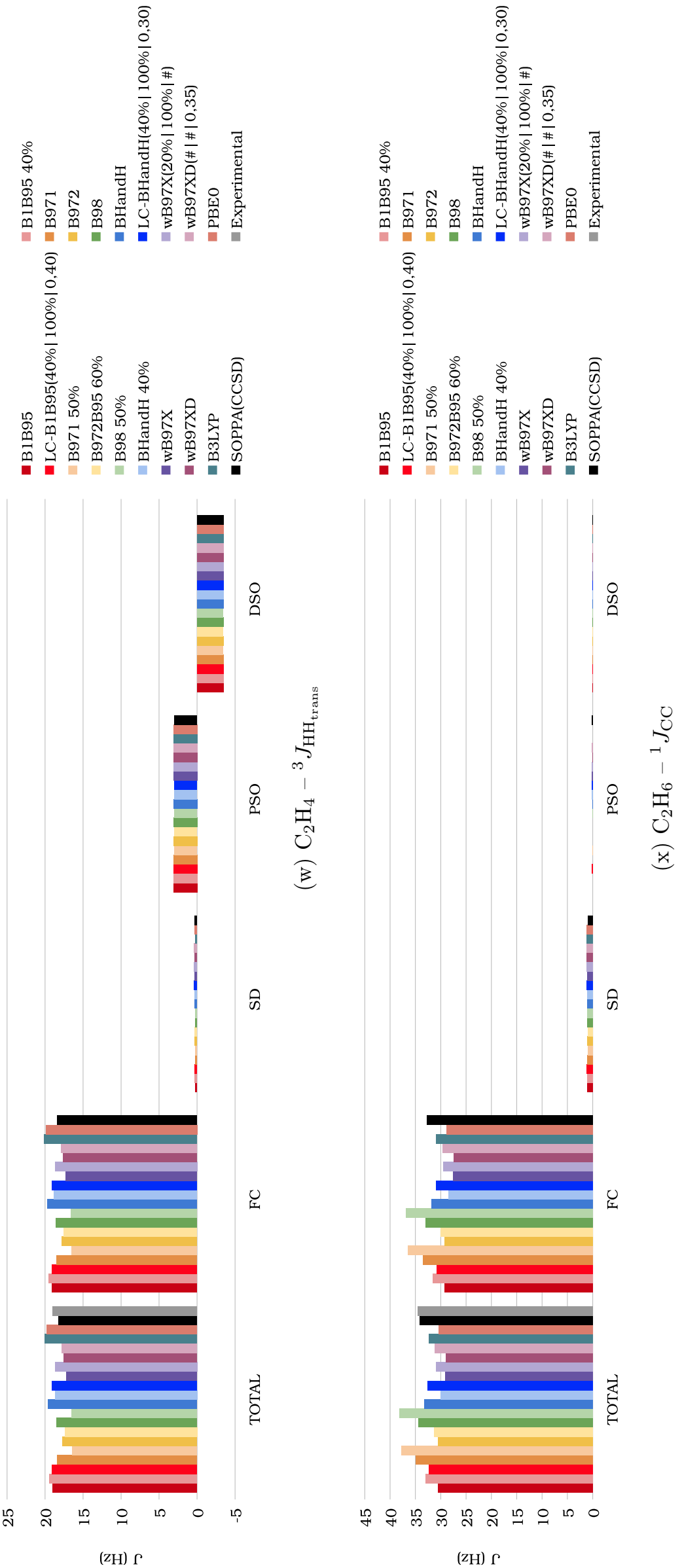

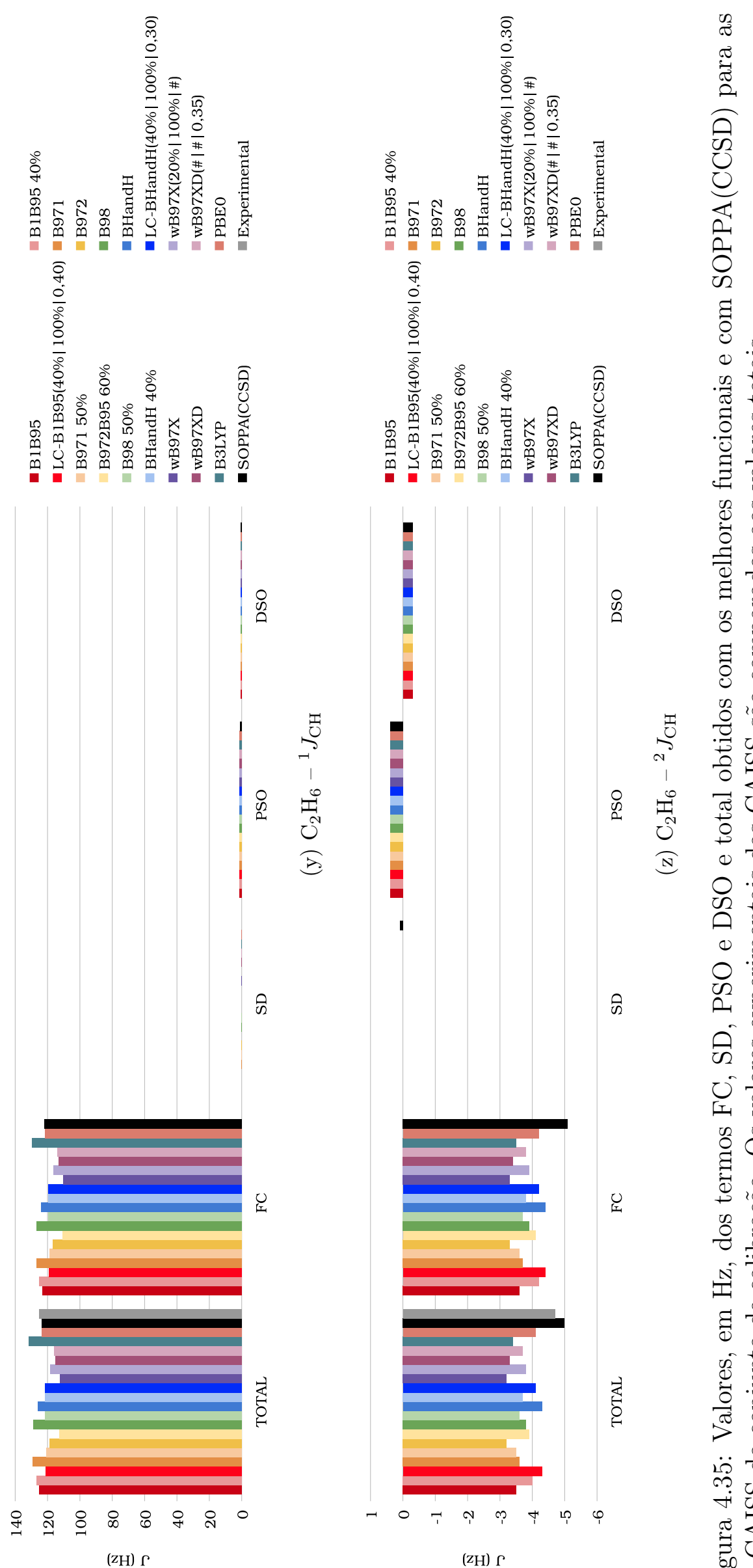

ฮ̊
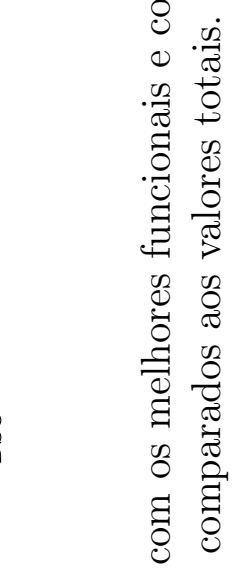
As diferenças observadas entre os resultados obtidos com os DFTs e o SOPPA(CCSD) decorrem dos valores do termo FC predominarem largamente nas diferenças dos valores das CAISS calculadas. Usando como exemplo as constantes ${ }^{1} J_{\mathrm{BF}}$ da molécula de $\mathrm{BF}_{3}$ (Figura 4.35j) e ${ }^{2} J_{\mathrm{CH}} \mathrm{e}^{2} J_{\mathrm{HH}}$ da molécula de $\mathrm{C}_{2} \mathrm{H}_{4}$ (Figuras $4.35 \mathrm{t}$ e $4.35 \mathrm{u}$, respectivamente), é notável que a tendência observada entre os valores totais das constantes é praticamente reproduzida pela tendência observada entre os valores de FC, e os termos SD, PSO e DSO possuem quase o mesmo valor para os diferentes métodos.

No caso da constante ${ }^{1} J_{\mathrm{BF}}$ da molécula de $\mathrm{BF}_{3}$ (Figura 4.35j), deve-se notar que os funcionais B1B95, B1B95 40\% $E_{X}^{\mathrm{HF}}, \mathrm{B} 971, \mathrm{~B} 98, \mathrm{BHandH} 40 \% E_{X}^{\mathrm{HF}}, \mathrm{B} 972, \omega \mathrm{B} 97 \mathrm{XD}$, B3LYP e PBE0 resultam em um valor total negativo, e a CAISS experimental é positiva. Isso se deve ao balanço entre os termos FC e PSO, e os termos FC, embora todos positivos, apresentam diferentes magnitudes para os métodos avaliados.

No caso da constante ${ }^{2} J_{\mathrm{CH}}$ da molécula de $\mathrm{C}_{2} \mathrm{H}_{4}$ (Figura 4.35t), deve-se notar que os funcionais B1B95, $\omega$ B97X, $\omega$ B97XD e B3LYP apresentam termo FC positivo. Apesar do valor total ser negativo para todos os métodos, eles apresentam diferentes magnitudes. Já a constante ${ }^{2} J_{\mathrm{HH}}$ da molécula de $\mathrm{C}_{2} \mathrm{H}_{4}$ (Figura 4.35u) apresenta diferentes magnitudes para o valor total devido às diferentes magnitudes do termo FC.

O termo SD da constante ${ }^{1} J_{\mathrm{CO}}$ da molécula de CO (Figura 4.35b) apresenta diferentes valores para os DFTs comparados, além de magnitudes comparáveis ao termo FC, eventualmente anulando o valor do FC, e portanto o termo PSO contribui majoritariamente para o valor total. Kupka descreve a dificuldade de obter a constante ${ }^{1} J_{\mathrm{CO}}$ com desvio

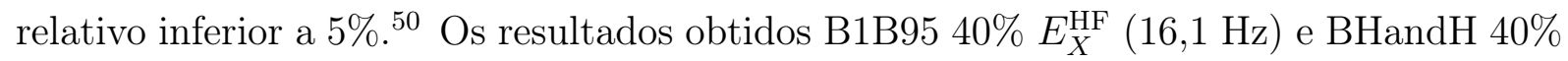
$E_{X}^{\mathrm{HF}}(16,3 \mathrm{~Hz})$ são bem próximos do valor experimental $(16,4 \mathrm{~Hz})$, superando resultados no limite de base completa para os funcionais B1B95 e BHandH obtidos por Kupka.

Vale ressaltar que o SOPPA(CCSD) e o SOPPA(CC2), apesar de serem reconhecidos pela boa predição de constantes de acoplamento spin-spin, não apresentam o valor mais próximo do valor experimental em todos os casos, sendo muitas vezes superado pelos DFTs estudados, conforme apontado na seção anterior. 


\subsection{Teste de precisão e Teorema de Janak}

A precisão dos funcionais para cálculo das CAISS através da PDMA define os melhores resultados, mas é preciso verificar se os funcionais são exatos. Os valores de energia utilizados para obter os perfis de energia e as concavidades resultantes dos melhores funcionais estão apresentados nas Tabelas 8.454 a 8.485 para geometrias experimentais, nas Tabelas 8.486 a 8.504 para geometrias otimizadas.

A Figura 4.36 apresenta a variação de energia relativa à espécie neutra de cada uma das 13 moléculas do conjunto de calibração para B1B95, B971, B972, B98, BHandH, wB97X e $\omega$ B97XD. Primeiramente, nenhum desses DFTs, encontrados na literatura, apresentam comportamento linear, e portanto não são funcionais exatos. De fato, muitos funcionais da literatura não satisfazem essa propriedade, assim como diversas outras propriedades de um funcional exato. Apesar disso, $\omega$ B97X e $\omega$ B97XD apresentam concavidades muito próximas a zero, especialmente para a parte aniônica.
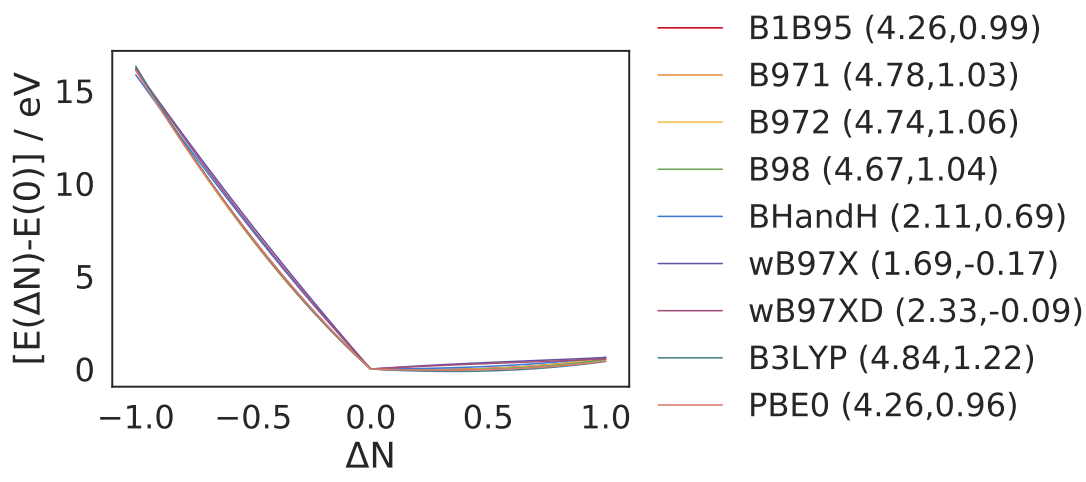

(a) $\mathrm{HF}$

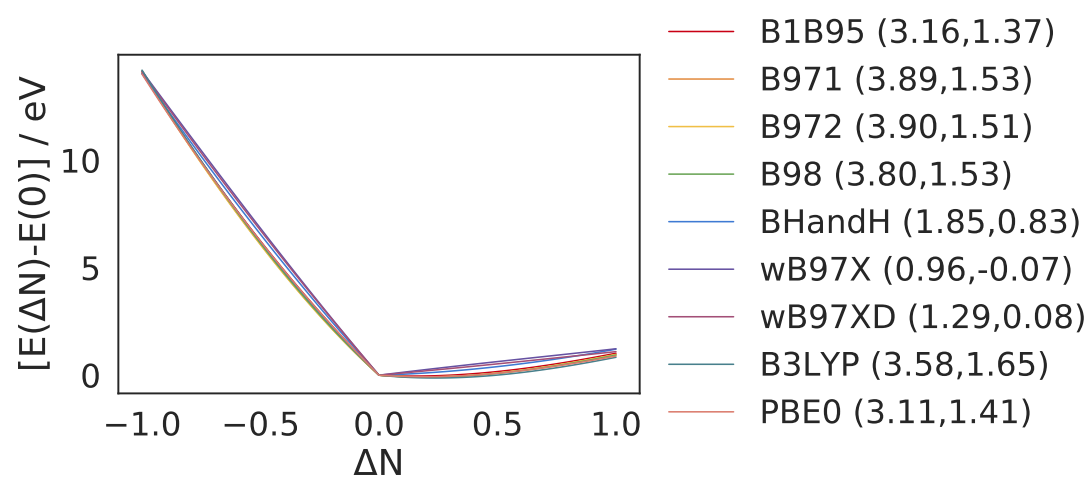

(b) $\mathrm{CO}$ 


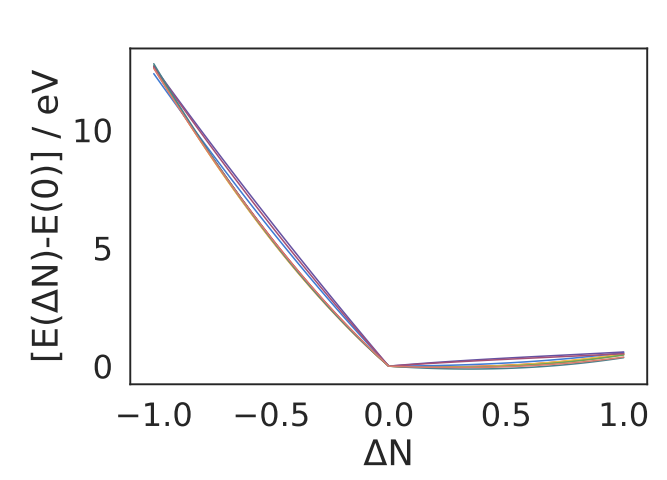

B1B95 (3.55,0.88)

B971 (3.99,0.93)

B972 $(3.96,0.94)$

B98 $(3.89,0.94)$

BHandH $(1.76,0.63)$

wB97X $(0.97,-0.16)$

WB97XD $(1.59,-0.10)$

B3LYP $(4.02,1.10)$

PBEO $(3.52,0.87)$

(c) $\mathrm{H}_{2} \mathrm{O}$

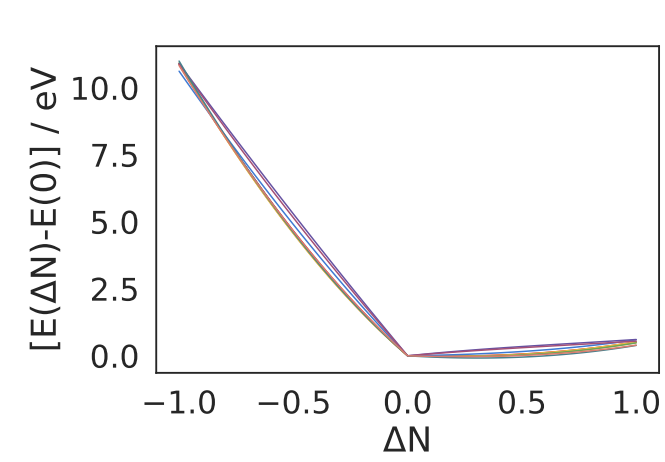

B1B95 $(3.11,0.78)$

B971 (3.55,0.82)

B972 (3.53,0.82)

B98 (3.45,0.83)

BHandH $(1.65,0.55)$

wB97X $(0.64,-0.16)$

WB97XD $(1.19,-0.11)$

B3LYP $(3.50,0.97)$

PBEO $(3.04,0.75)$

(d) $\mathrm{NH}_{3}$

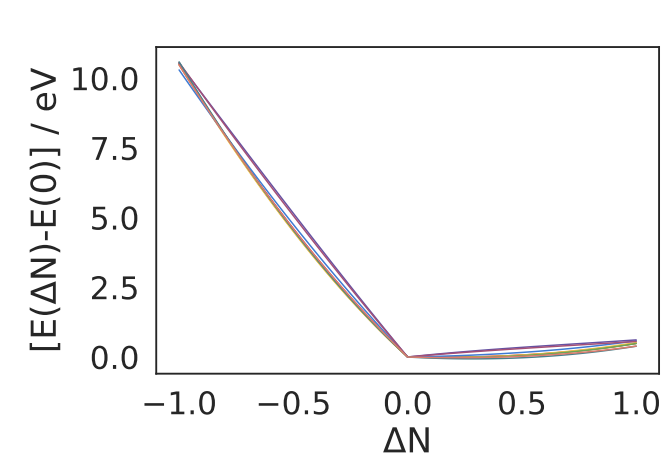

$\begin{array}{ll}- & \text { B1B95 }(2.60,0.70) \\ - & B 971(2.99,0.75) \\ - & B 972(2.98,0.75) \\ - & B 98(2.92,0.77) \\ & B H a n d H(1.59,0.51) \\ & \text { wB97X }(0.45,-0.16) \\ & \text { wB97XD }(0.87,-0.11) \\ - & B 3 L Y P(2.91,0.88) \\ & \text { PBE0 }(2.56,0.69)\end{array}$

(e) $\mathrm{PH}_{3}$

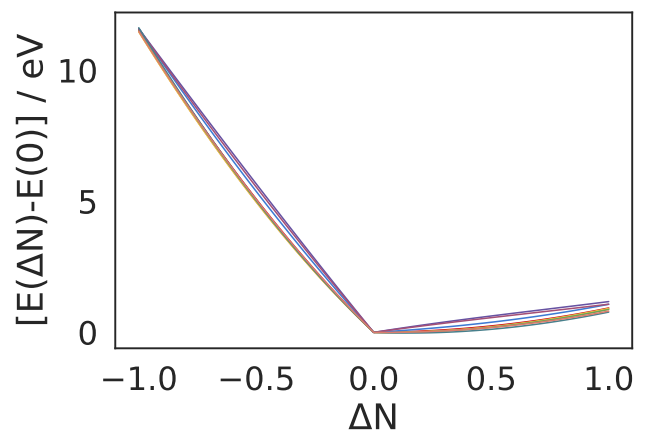

B1B95 $(2.73,0.88)$

B971 (3.04,0.97)

B972 (3.04,0.96)

B98 $(2.99,0.97)$

BHandH $(1.69,0.60)$

wB97X (0.52,-0.15)

WB97XD $(0.97,-0.10)$

B3LYP $(3.04,1.08)$

PBEO $(2.70,0.90)$

(f) $\mathrm{PF}_{3}$ 


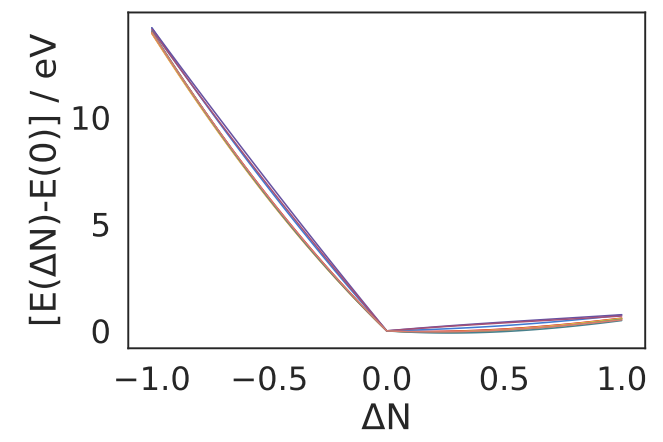

B1B95 (3.04,0.85)

B971 (3.35,0.97)

B972 (3.36,0.90)

B98 $(3.30,0.97)$

BHandH (1.84,0.49)

wB97X $(0.76,-0.14)$

WB97XD $(1.26,-0.11)$

B3LYP $(3.37,1.10)$

PBEO $(3.09,0.85)$

(g) $\mathrm{BHF}_{2}$

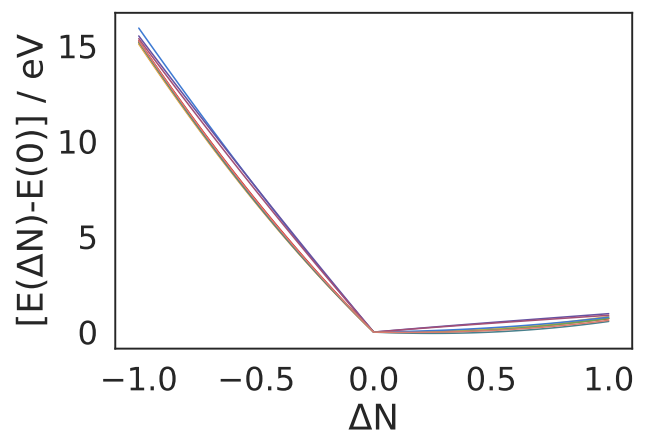

B1B95 (2.92,0.75)

B971 (3.27,0.98)

B972 (3.27,0.99)

B98 $(3.21,0.98)$

$\mathrm{BHandH}(1.61,0.66)$

wB97X (0.77,-0.08)

wB97XD $(1.21,-0.09)$

B3LYP $(3.31,1.12)$

PBEO $(3.03,0.90)$

(h) $\mathrm{BF}_{3}$

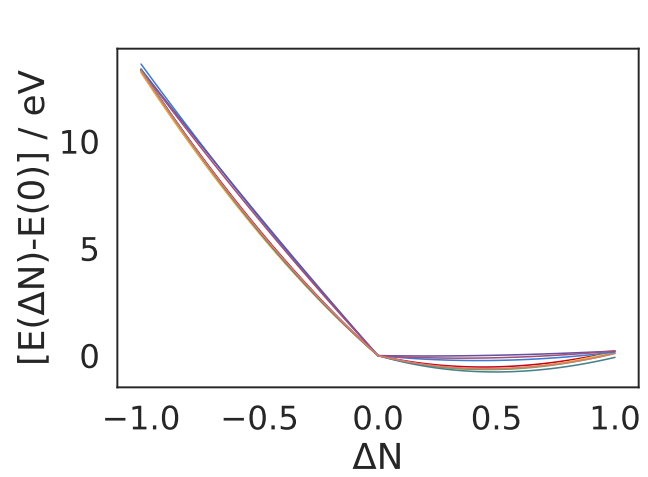

B1B95 (3.23,2.51)

B971 (3.65,2.86)

B972 (3.64,2.90)

B98 $(3.57,2.83)$

$\mathrm{BHandH}(1.52,1.24)$

wB97X $(0.83,0.36)$

WB97XD $(1.43,0.83)$

B3LYP $(3.69,2.89)$

PBEO $(3.34,2.62)$

(i) $\mathrm{F}_{2} \mathrm{O}$

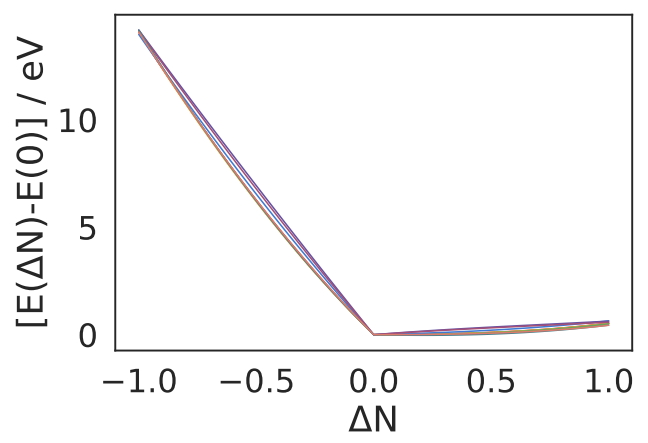

B1B95 (3.12,0.64)

B971 (3.42,0.63)

B972 (3.41,0.65)

B98 $(3.35,0.64)$

$\mathrm{BHandH}(1.77,0.45)$

wB97X (0.60,-0.15)

WB97XD $(1.18,-0.11)$

B3LYP $(3.43,0.78)$

PBEO $(3.10,0.59)$

(j) $\mathrm{CH}_{4}$ 


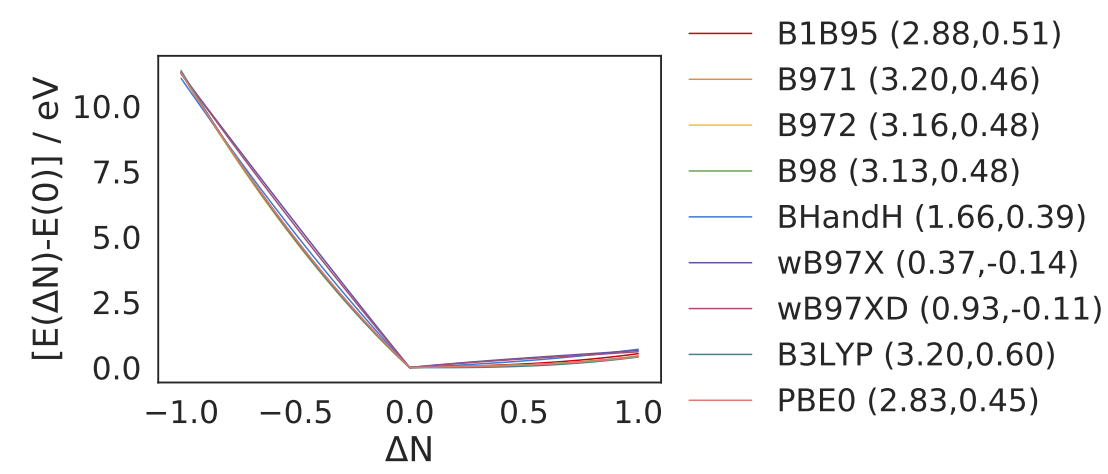

(k) $\mathrm{C}_{2} \mathrm{H}_{2}$

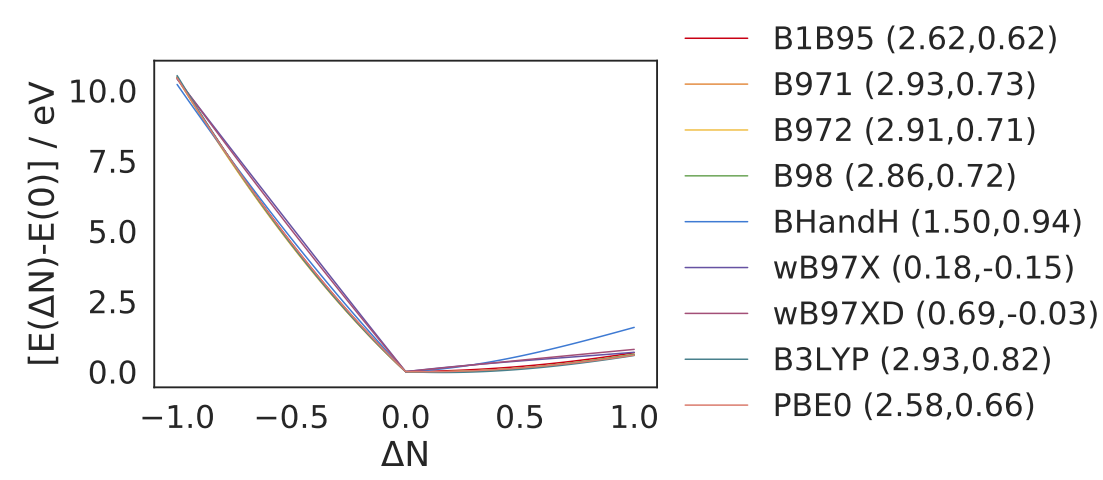

(l) $\mathrm{C}_{2} \mathrm{H}_{4}$

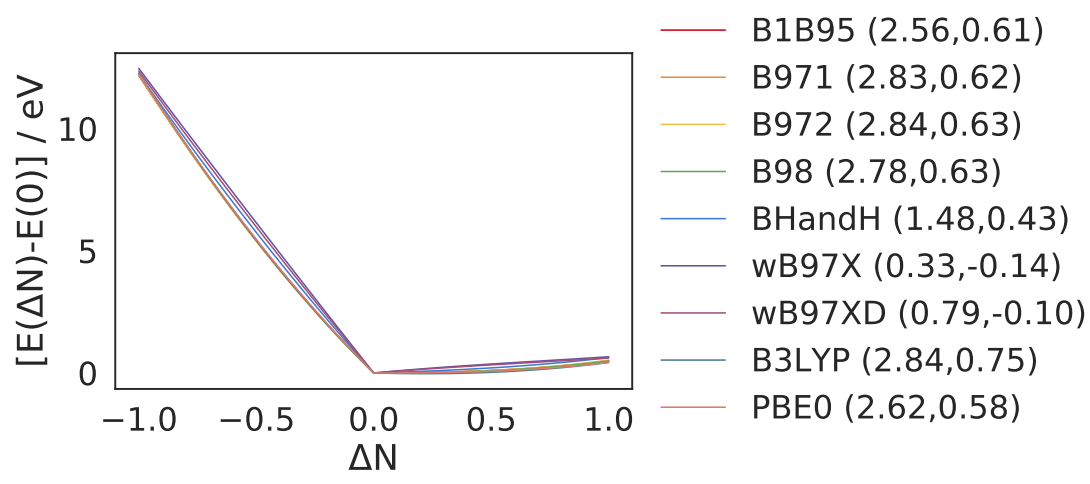

(m) $\mathrm{C}_{2} \mathrm{H}_{6}$

Figura 4.36: Avaliação do Teorema de Janak para funcionais da literatura com geometrias experimentais na base aug-pcJ-2. $\Delta N=-1$ corresponde ao cátion e $\Delta N=1$ ao ânion. A curvatura das curvas catiônica e aniônica estão indicadas, respectivamente, ao lado DFT.

De maneira geral, os valores de concavidade são positivos (exceto a parte aniônica do $\omega$ B97X e do $\omega$ B97XD), indicando a delocalização eletrônica - característico de um DFT. (Se fosse realizado um cálculo Hartree-Fock, a curvatura seria negativa, indicando a localização eletrônica. ${ }^{61}$ A parte aniônica do $\omega$ B97X e do $\omega$ B97XD (exceto para a molécula de $\mathrm{F}_{2} \mathrm{O}$ ) apresenta um comportamento ideal de funcional, em que não há muita 
delocalização nem muita localização eletrônica; desta forma a parte catiônica governa a delocalização eletrônica presente nesses funcionais.

A concavidade é maior para a parte catiônica do que para a parte aniônica (ver descrição da Figura 4.36). A concavidade para os hidrocarbonetos é ligeiramente menor que para as demais moléculas. Os valores de concavidade aproximam-se de zero na seguinte ordem de funcionais sem correção de longo alcance: B3LYP, B971, B972, B98, PBE0, B1B95 e BHandH, que corresponde com a ordem crescente de porcentagem de $E_{X}^{\mathrm{HF}}$ presente nesses DFTs. Dessa forma, o aumento da porcentagem de $E_{X}^{\mathrm{HF}}$ está associado com a diminuição da concavidade, indo ao encontro do comportamento exato.

De fato, o comportamento das contribuições $E_{X}^{\mathrm{HF}}$ e $E_{X}^{\mathrm{DFT}}$ em função da distância intereletrônica torna inviável atribuir uma percentagem independente de geometria ou do campo médio dos elétrons, e portanto não são comparados aos demais. Entretanto, pode-se notar que $\omega \mathrm{B} 97 \mathrm{X}$ apresenta concavidades menores que o $\omega \mathrm{B} 97 \mathrm{XD}$, sendo dentre os DFTs avaliados o mais próximo de um funcional exato.

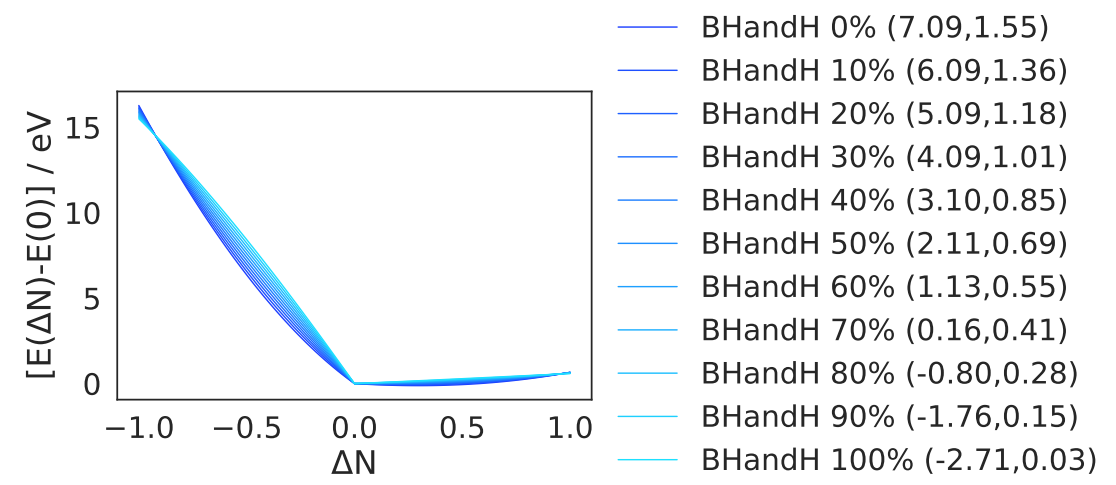

(a) $\mathrm{HF}$

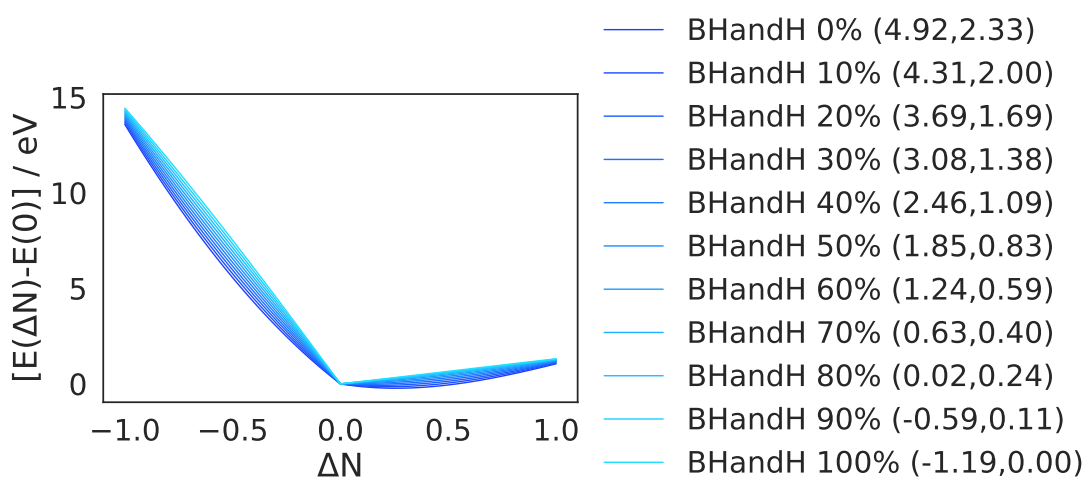

(b) $\mathrm{CO}$ 


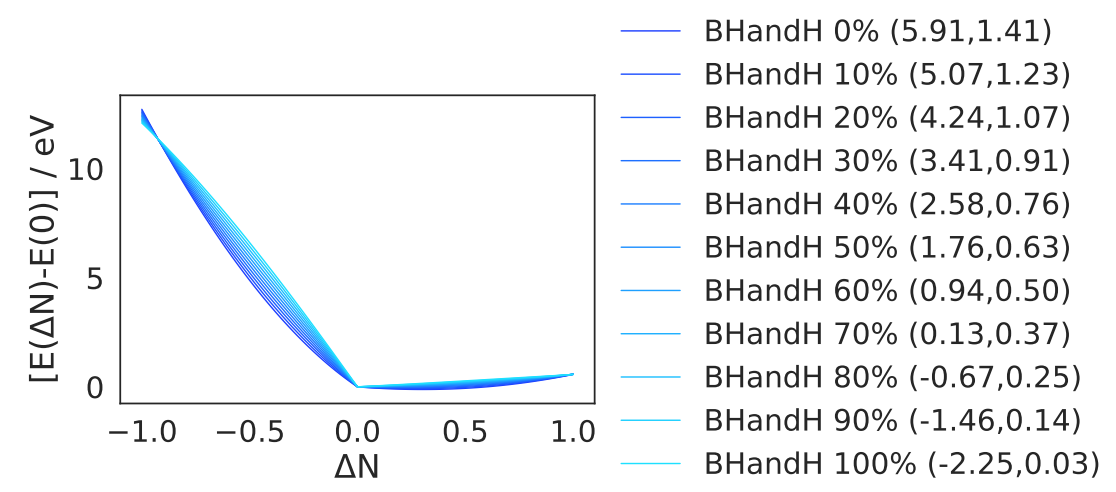

(c) $\mathrm{H}_{2} \mathrm{O}$

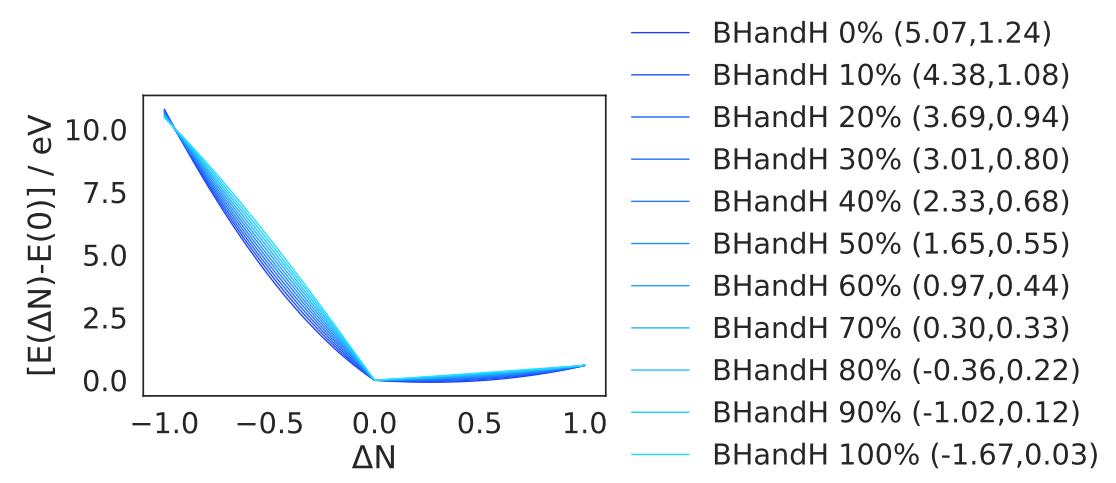

(d) $\mathrm{NH}_{3}$

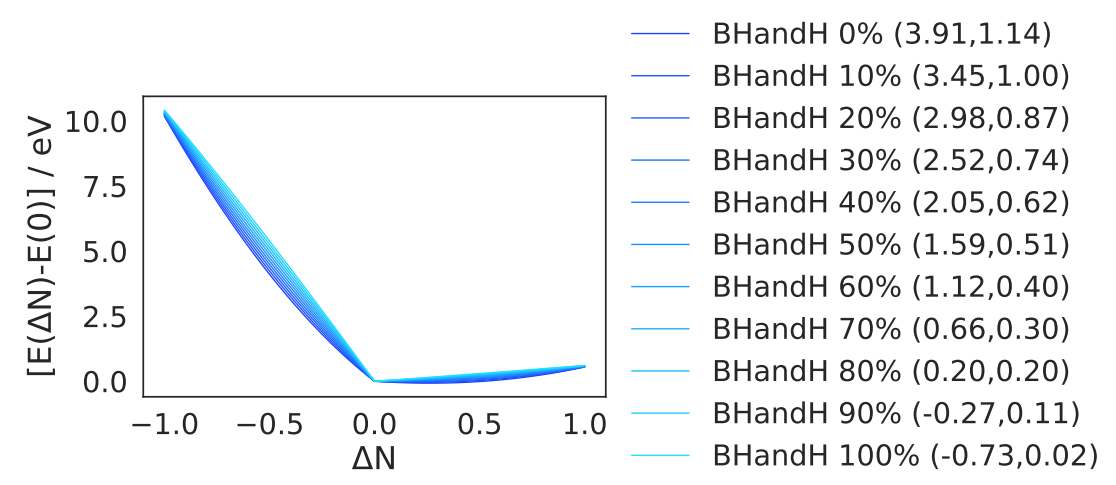

(e) $\mathrm{PH}_{3}$

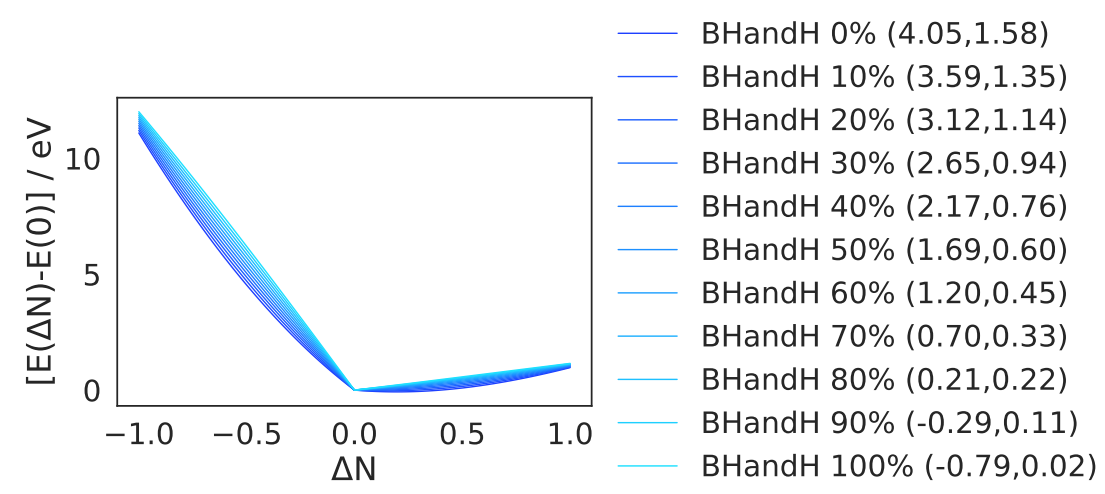

(f) $\mathrm{PF}_{3}$ 


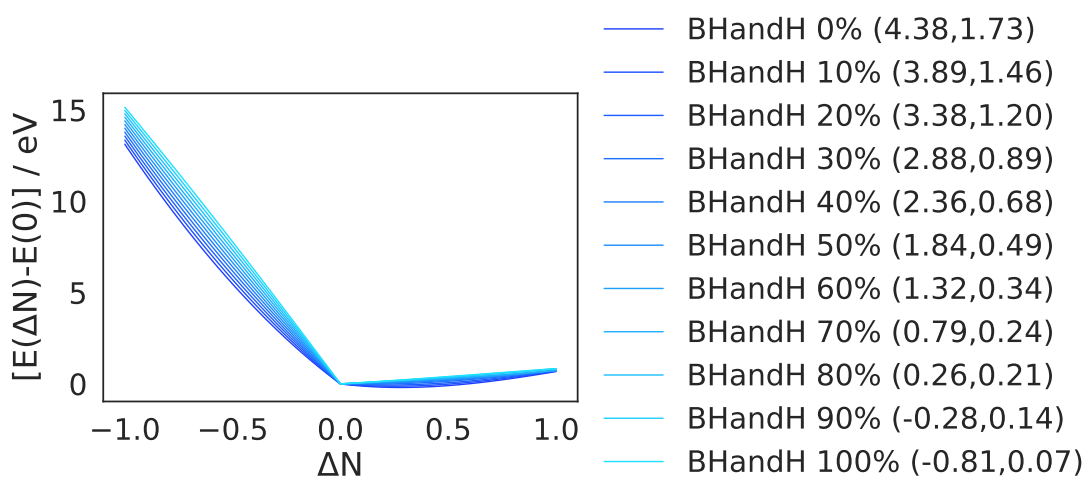

(g) $\mathrm{BHF}_{2}$

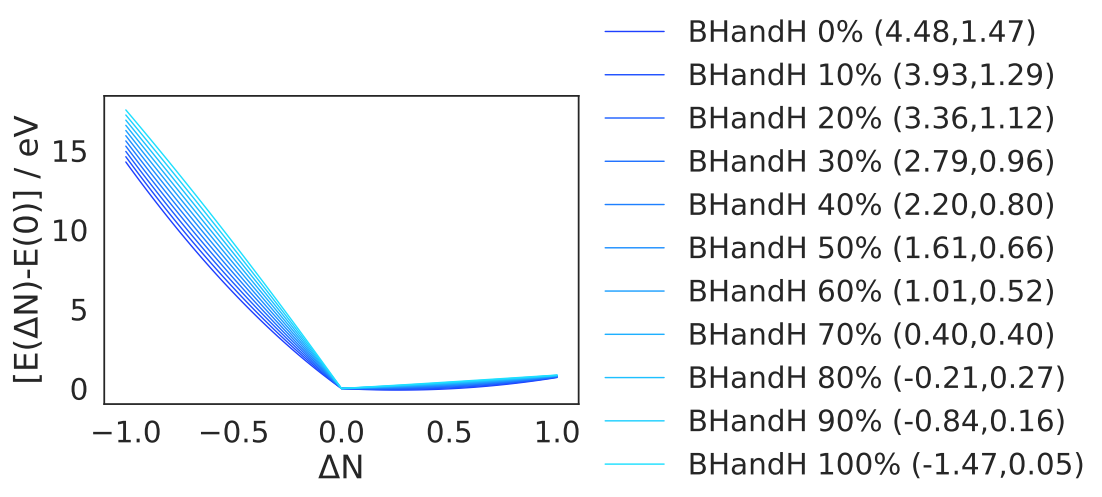

(h) $\mathrm{BF}_{3}$

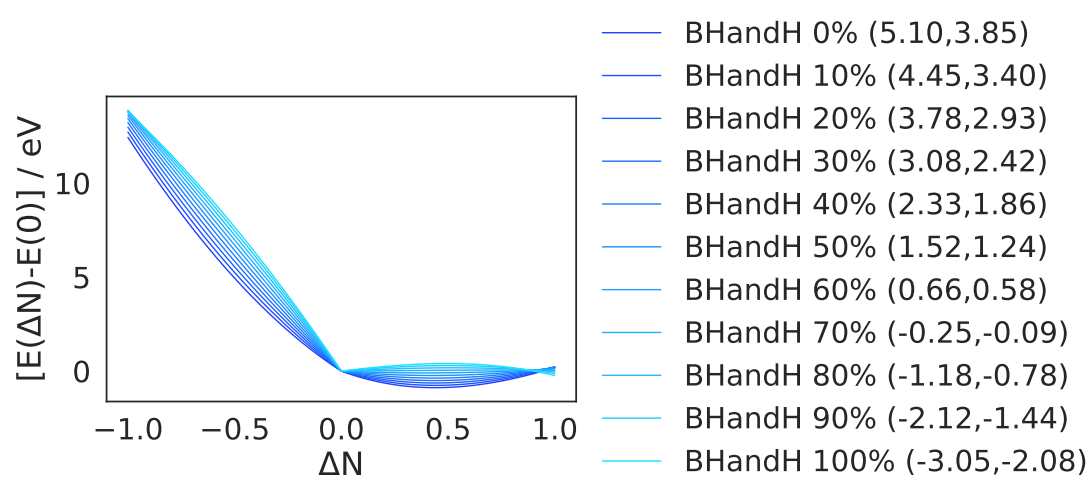

(i) $\mathrm{F}_{2} \mathrm{O}$

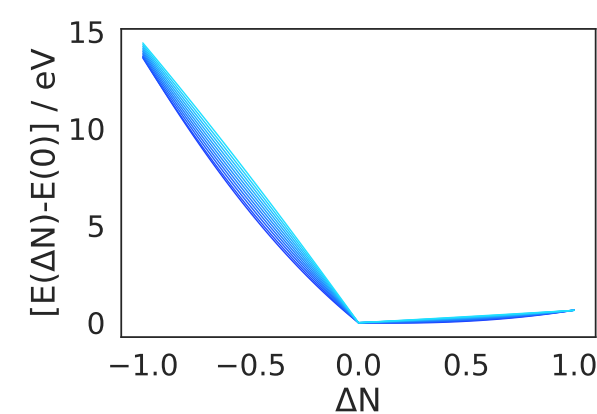

BHandH 0\% $(4.75,0.99)$

BHandH 10\% $(4.07,0.87)$

BHandH 20\% (3.50,0.76)

BHandH 30\% $(2.92,0.65)$

BHandH 40\% $(2.35,0.55)$

BHandH 50\% $(1.77,0.45)$

BHandH $60 \%(1.19,0.36)$

BHandH $70 \%(0.62,0.27)$

BHandH $80 \%(0.04,0.18)$

BHandH 90\% $(-0.54,0.10)$

BHandH 100\% (-1.11,0.02)

(j) $\mathrm{CH}_{4}$ 


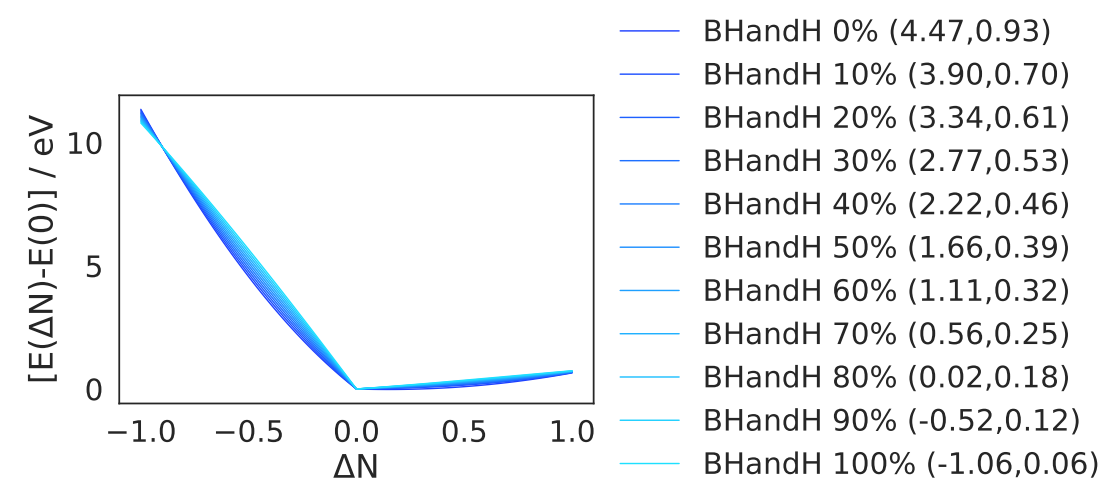

(k) $\mathrm{C}_{2} \mathrm{H}_{2}$

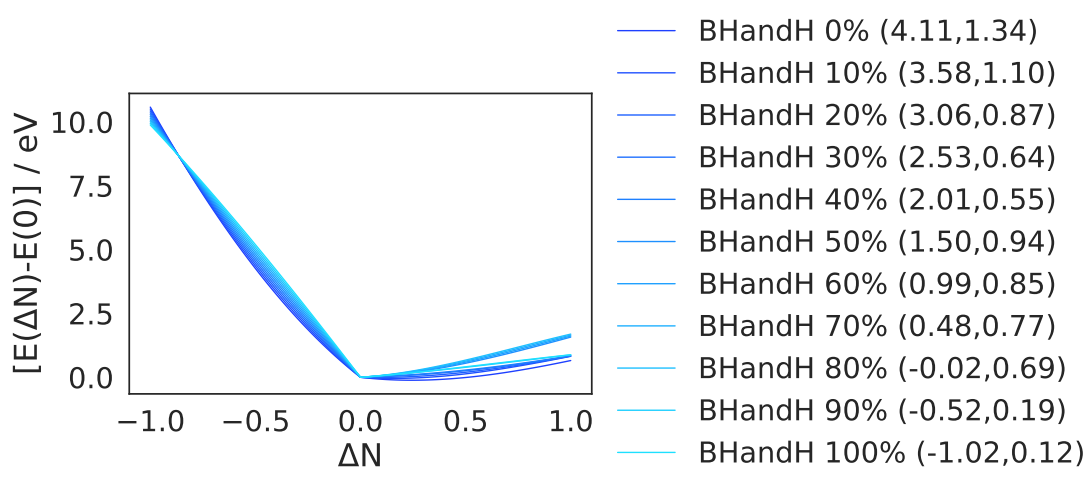

(l) $\mathrm{C}_{2} \mathrm{H}_{4}$

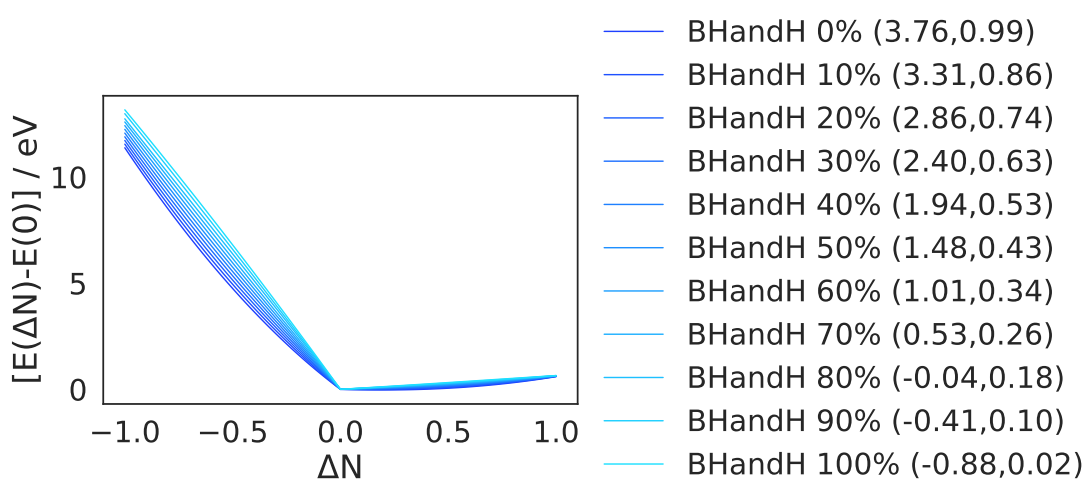

(m) $\mathrm{C}_{2} \mathrm{H}_{6}$

Figura 4.37: Avaliação do Teorema de Janak para BHandH variando a porcentagem de $E_{X}^{\mathrm{HF}}$ com geometrias experimentais na base aug-pcJ-2. $\Delta N=-1$ corresponde ao cátion e $\Delta N=1$ ao ânion. A curvatura das curvas catiônica e aniônica estão indicadas, respectivamente, ao lado DFT.

A influência da porcentagem de $E_{X}^{\mathrm{HF}}$ do DFT nas curvas de energia está apresentada na Figura 4.37 para o BHandH. É notável que o incremento da $E_{X}^{\mathrm{HF}}$ diminui a concavidade, que passa a ter valores negativos por volta de $80 \% E_{X}^{\mathrm{HF}}$. De fato, a utilização de $80 \%$ $E_{X}^{\mathrm{HF}}$ no BHandH apresenta concavidades consideravelmente próximas de 0 , e portanto, 
segundo o Teorema de Janak, devem corresponder aproximadamente a funcionais exatos. Entretanto, as melhores precisôes foram obtidas utilizando $50 \% E_{X}^{\mathrm{HF}}$ para o $\mathrm{BHandH}$, que apresentam concavidades um pouco mais distantes de 0. Além disso, o resultado com $80 \% E_{X}^{\mathrm{HF}}$ ainda não é tão preciso para o cálculo das CAISS.

A Figura 4.38 apresenta os resultados de concavidade obtidos com B1B95 30\%, 40\% e $50 \% E_{X}^{\mathrm{HF}}$, e a Figura 4.39 para B972B95 50\%, 60\% e $70 \% E_{X}^{\mathrm{HF}}$. Ambos apresentam a mesma tendência observada na Figura 4.37; o incremento da $E_{X}^{\mathrm{HF}}$ diminui a concavidade, a parte catiônica apresenta maiores concavidades e portanto determina a delocalização eletrônica nos funcionais.

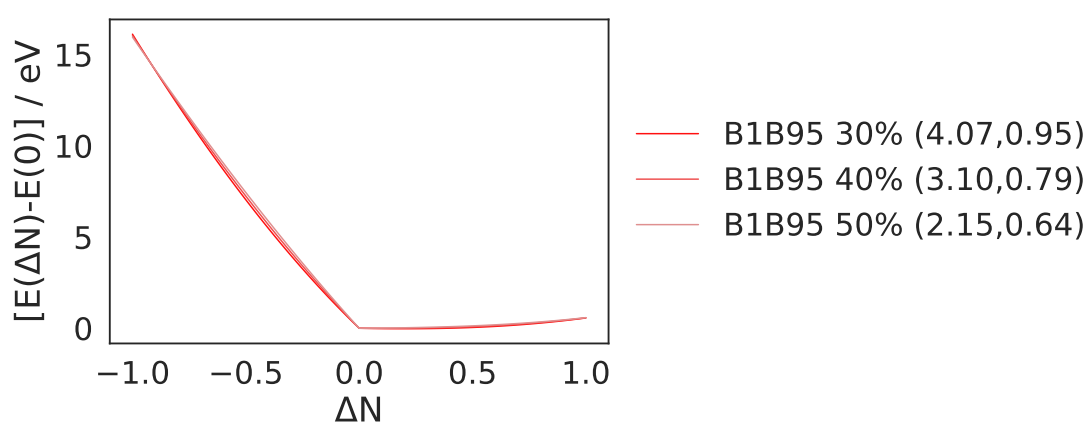

(a) $\mathrm{HF}$

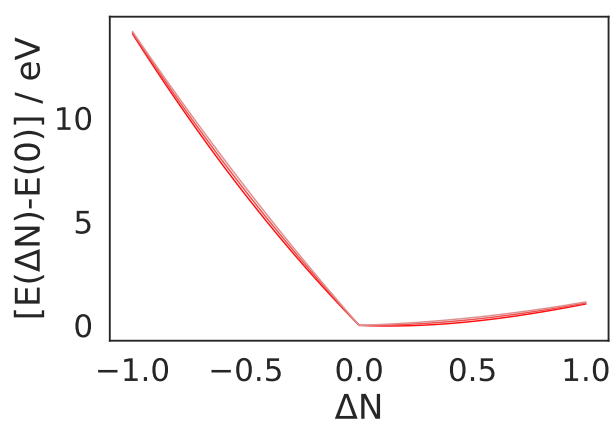

B1B95 30\% $(3.04,1.31)$

B1B95 40\% $(2.42,1.03)$

B1B95 50\% $(1.81,0.77)$

(b) $\mathrm{CO}$

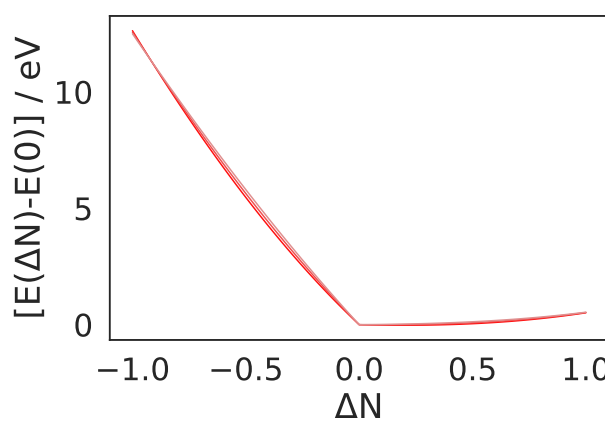

B1B95 30\% $(3.39,0.86)$

B1B95 40\% $(2.59,0.71)$

B1B95 50\% $(1.79,0.57)$

(c) $\mathrm{H}_{2} \mathrm{O}$ 


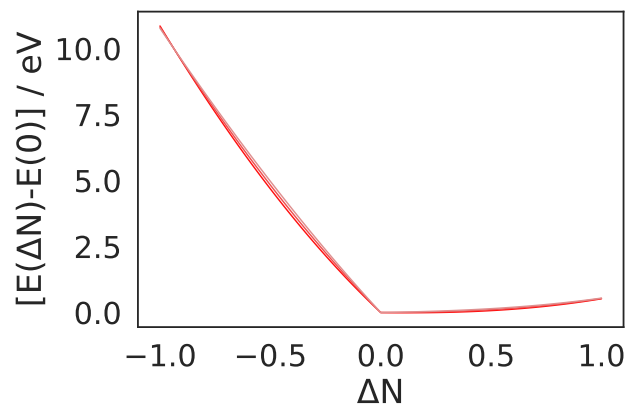

B1B95 30\% $(2.98,0.75)$

B1B95 40\% $(2.31,0.63)$

B1B95 50\% $(1.65,0.51)$

(d) $\mathrm{NH}_{3}$

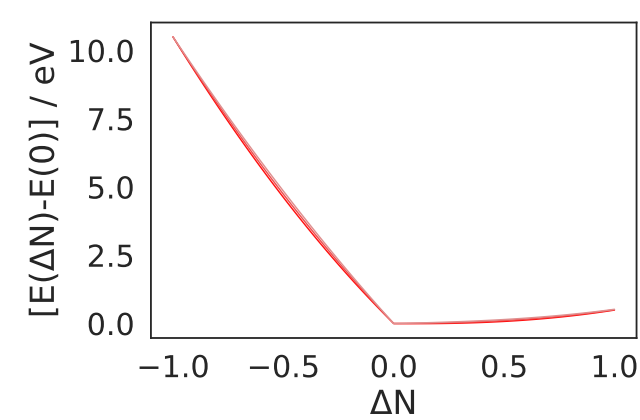

B1B95 30\% $(2.51,0.68)$

B1B95 40\% $(2.05,0.56)$

B1B95 50\% $(1.59,0.46)$

(e) $\mathrm{PH}_{3}$

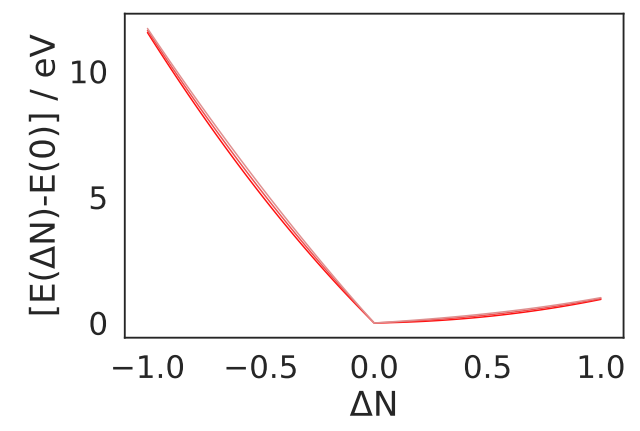

B1B95 30\% $(2.98,0.75)$

B1B95 40\% $(2.31,0.63)$

B1B95 50\% $(1.65,0.51)$

(f) $\mathrm{PF}_{3}$

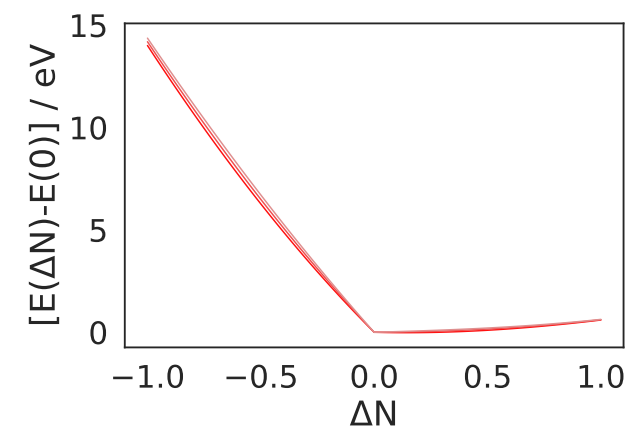

B1B95 30\% $(2.93,0.80)$ B1B95 40\% $(2.42,0.60)$ B1B95 50\% $(1.90,0.43)$

(g) $\mathrm{BHF}_{2}$ 


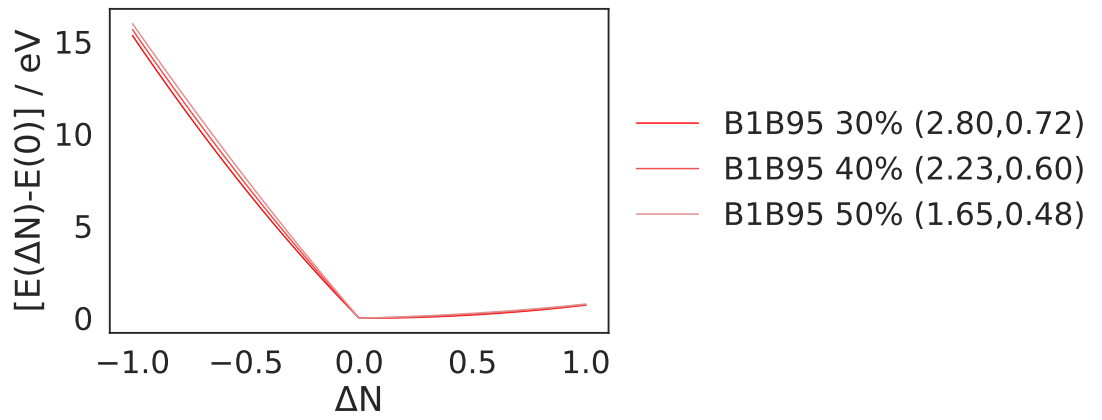

(h) $\mathrm{BF}_{3}$

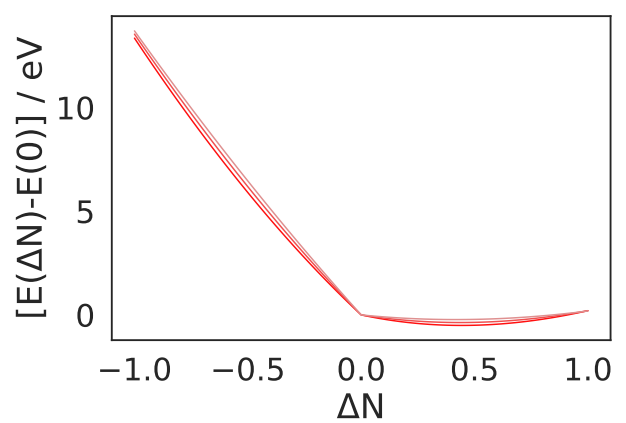

B1B95 30\% $(3.09,2.40)$

B1B95 40\% $(2.35,1.85)$

B1B95 50\% $(1.56,1.24)$

(i) $\mathrm{F}_{2} \mathrm{O}$

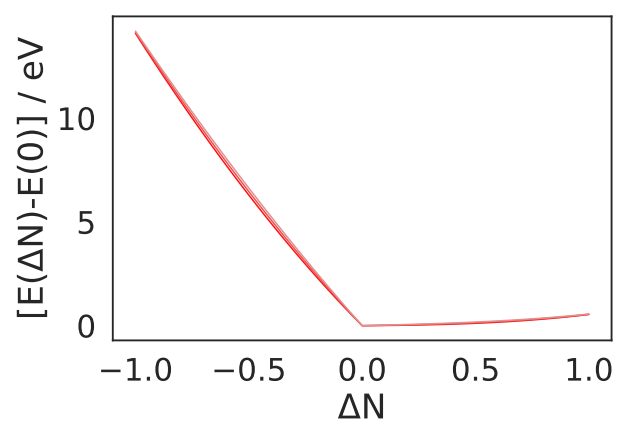

B1B95 30\% $(3.00,0.62)$

B1B95 40\% $(2.43,0.52)$

B1B95 50\% $(1.87,0.42)$

(j) $\mathrm{CH}_{4}$

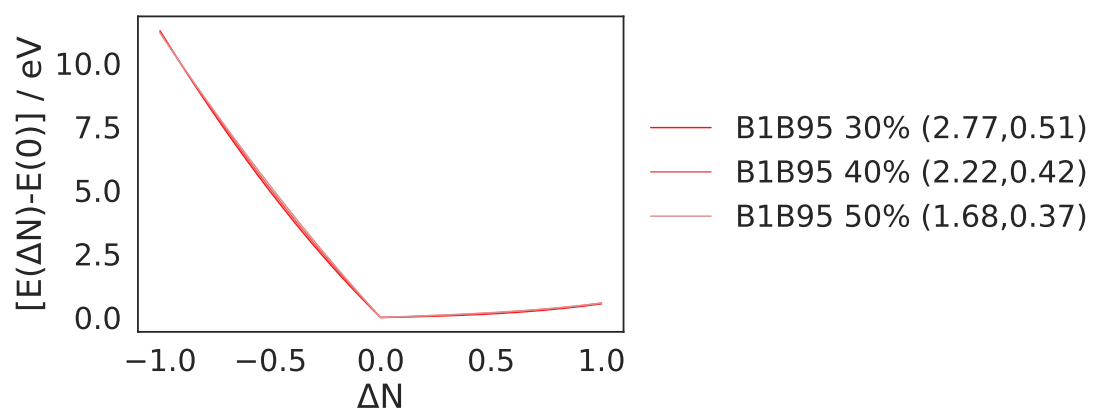

(k) $\mathrm{C}_{2} \mathrm{H}_{2}$ 


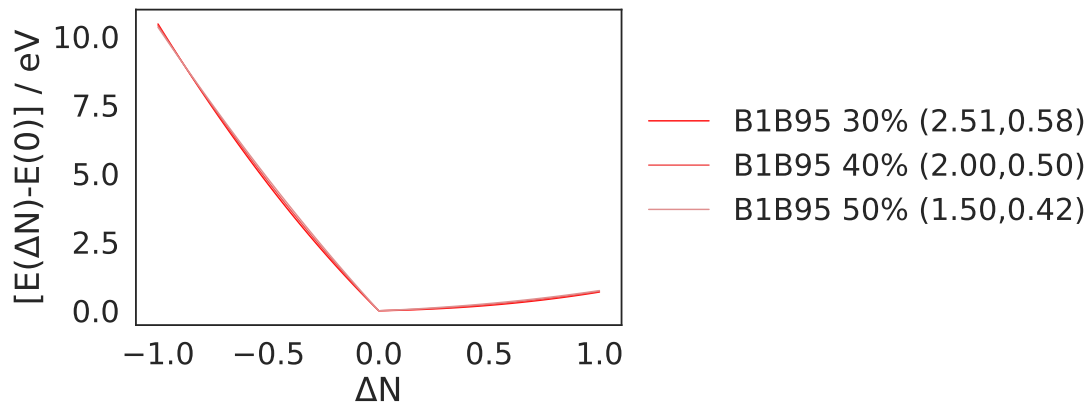

(l) $\mathrm{C}_{2} \mathrm{H}_{4}$

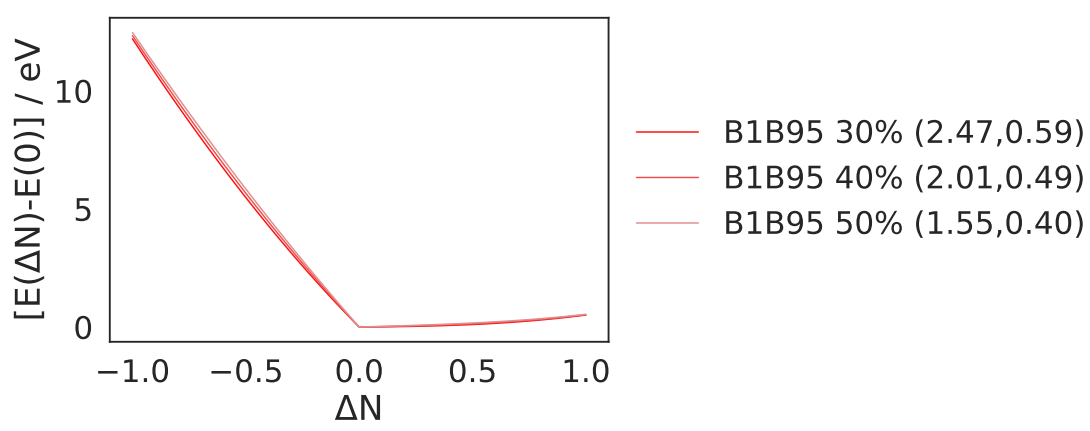

(m) $\mathrm{C}_{2} \mathrm{H}_{6}$

Figura 4.38: Avaliação do Teorema de Janak para B1B95 variando a porcentagem de $E_{X}^{\mathrm{HF}}$ com geometrias experimentais na base aug-pcJ-2. $\Delta N=-1$ corresponde ao cátion e $\Delta N=1$ ao ânion. A curvatura das curvas catiônica e aniônica estão indicadas, respectivamente, ao lado DFT.

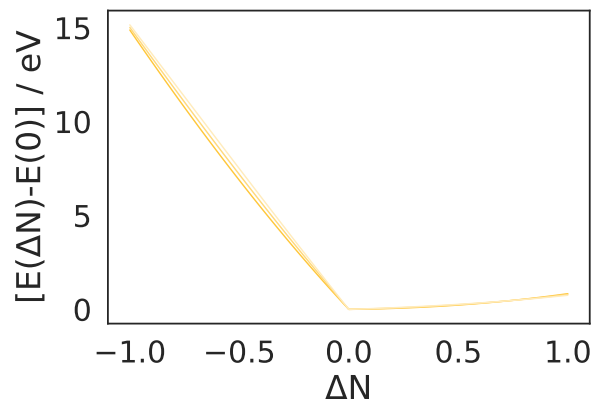

B972B95 50\% $(2.25,0.75)$

B972B95 60\% $(1.29,0.59)$

B972B95 70\% $(0.33,0.43)$

(a) $\mathrm{HF}$

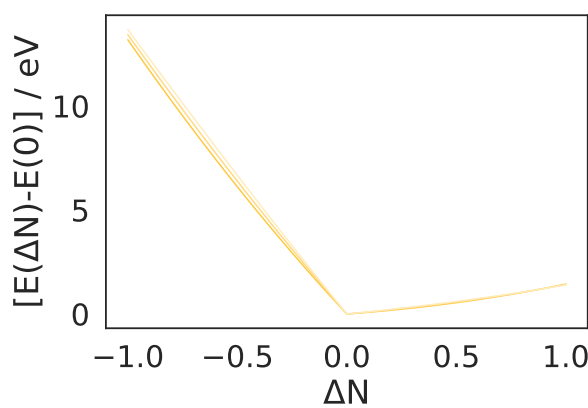

B972B95 50\% $(1.90,0.70)$

B972B95 60\% $(1.29,0.54)$

B972B95 70\% $(0.68,0.39)$

(b) $\mathrm{CO}$ 


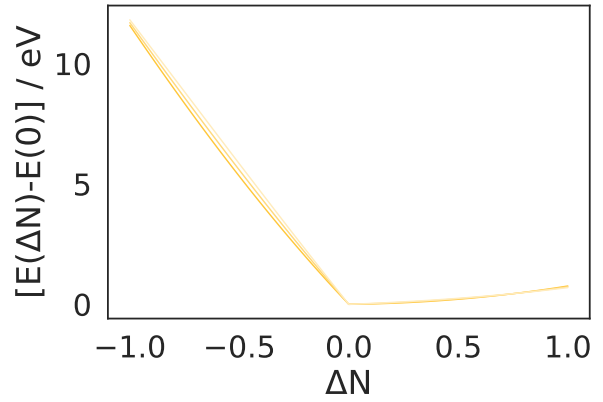

B972B95 50\% $(1.89,0.68)$

B972B95 60\% $(1.09,0.53)$

B972B95 70\% $(0.29,0.39)$

(c) $\mathrm{H}_{2} \mathrm{O}$

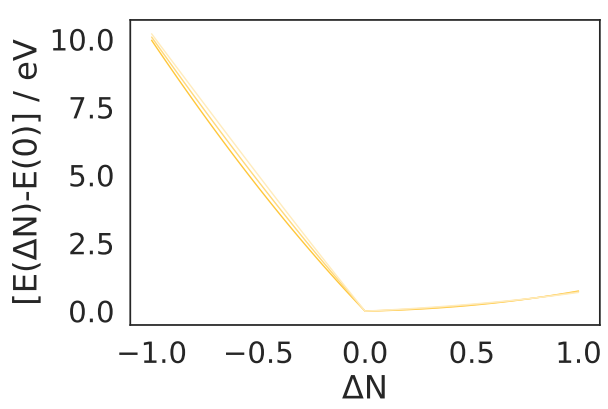

B972B95 50\% $(1.72,0.61)$

B972B95 60\% $(1.06,0.48)$

B972B95 70\% $(0.40,0.35)$

(d) $\mathrm{NH}_{3}$

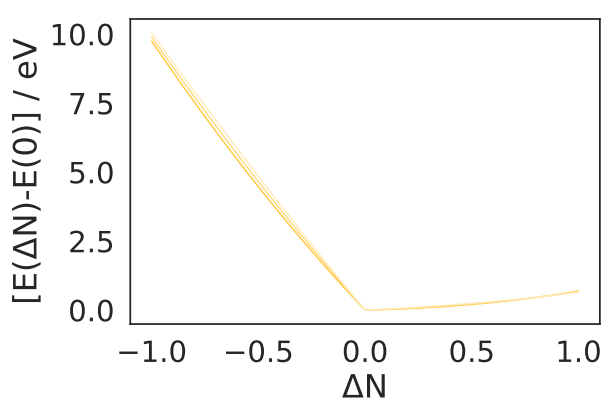

B972B95 50\% $(1.60,0.56)$

B972B95 60\% $(1.15,0.44)$

B972B95 70\% $(0.69,0.32)$

(e) $\mathrm{PH}_{3}$

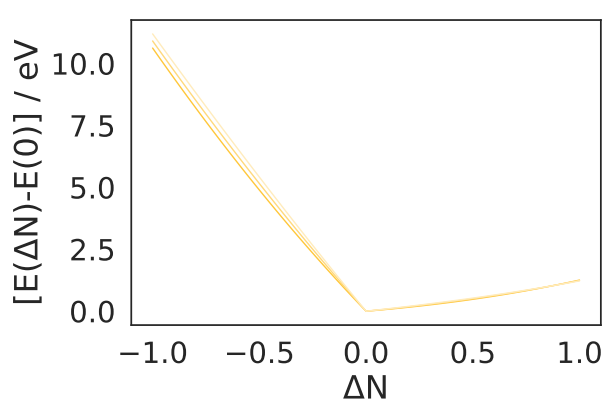

B972B95 50\% $(1.67,0.59)$

B972B95 60\% $(1.20,0.46)$

B972B95 70\% $(0.72,0.33)$

(f) $\mathrm{PF}_{3}$ 


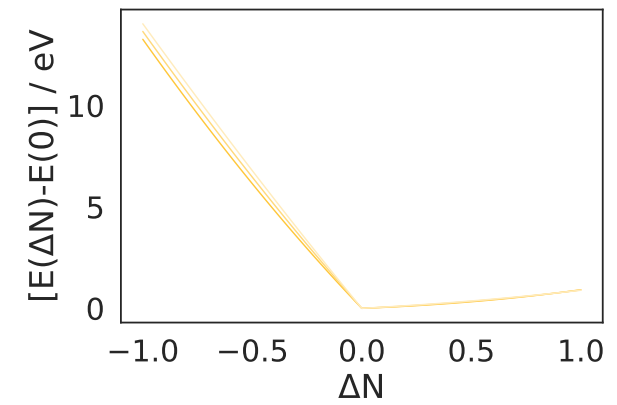

B972B95 50\% $(1.95,0.53)$

B972B95 60\% $(1.43,0.43)$

B972B95 70\% $(0.91,0.32)$

(g) $\mathrm{BHF}_{2}$

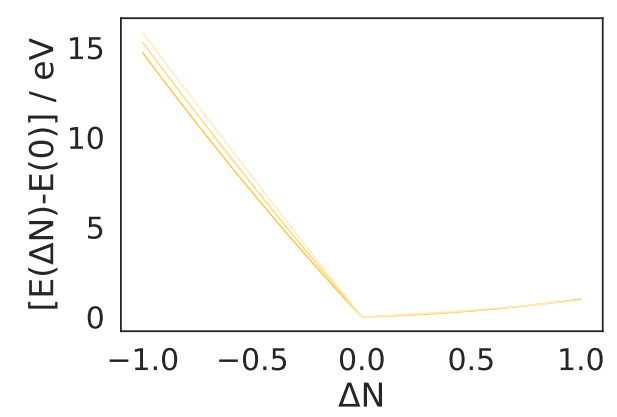

B972B95 50\% $(1.68,0.67)$

B972B95 60\% $(1.09,0.53)$

B972B95 70\% $(0.49,0.38)$

(h) $\mathrm{BF}_{3}$

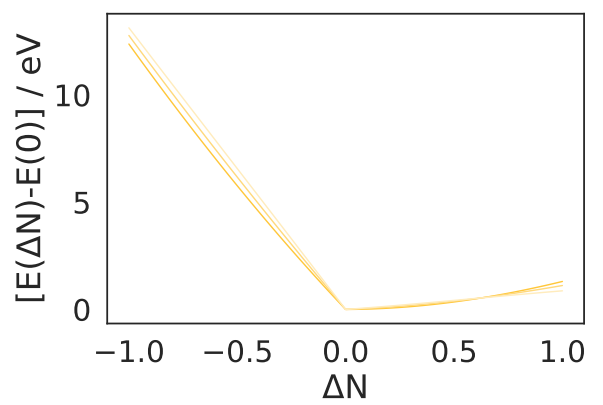

B972B95 50\% $(1.69,1.21)$

B972B95 60\% $(0.87,0.69)$

B972B95 70\% $(-0.01,0.05)$

(i) $\mathrm{F}_{2} \mathrm{O}$

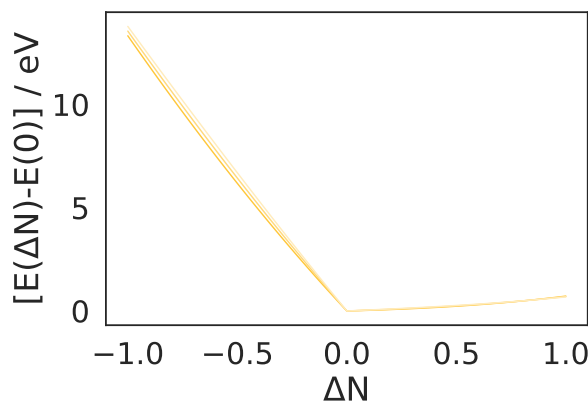

B972B95 50\% $(1.93,0.52)$

B972B95 60\% $(1.36,0.41)$

B972B95 70\% $(0.78,0.30)$

(j) $\mathrm{CH}_{4}$ 


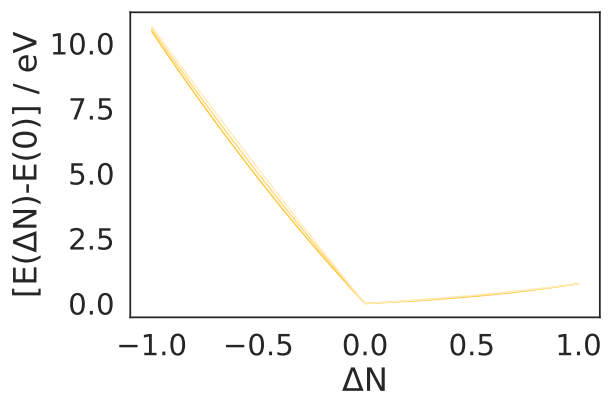

B972B95 50\% $(1.71,0.46)$

B972B95 60\% $(1.17,0.36)$

B972B95 70\% $(0.63,0.27)$

(k) $\mathrm{C}_{2} \mathrm{H}_{2}$

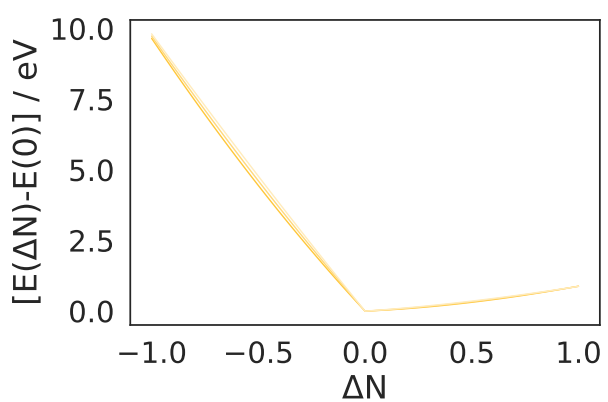

B972B95 50\% $(1.53,0.51)$

B972B95 60\% $(1.02,0.42)$

B972B95 70\% $(0.52,0.33)$

(l) $\mathrm{C}_{2} \mathrm{H}_{4}$

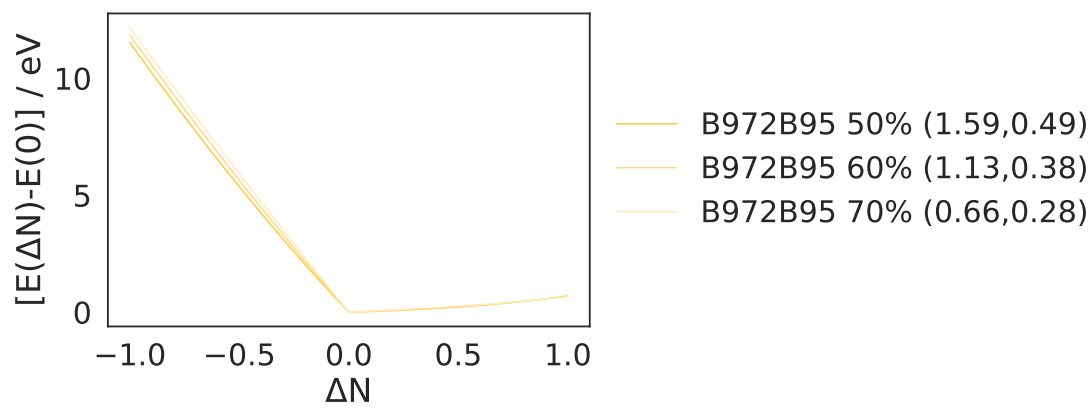

(m) $\mathrm{C}_{2} \mathrm{H}_{6}$

Figura 4.39: Avaliação do Teorema de Janak para B972B95 variando a porcentagem de $E_{X}^{\mathrm{HF}}$ com geometrias experimentais na base aug-pcJ-2. $\Delta N=-1$ corresponde ao cátion e $\Delta N=1$ ao ânion. A curvatura das curvas catiônica e aniônica estão indicadas, respectivamente, ao lado DFT.

As geometrias otimizadas também foram consideradas para avaliar o efeito da otimização na concavidade. A Figura 4.40 apresenta as curvas de energia nos níveis BHandH $30 \%, 40 \%, 50 \%$ (original) e $60 \% E_{X}^{\mathrm{HF}}$. Novamente, o aumento da porcentagem de $E_{X}^{\mathrm{HF}}$ no funcional gera a diminuição da concavidade, tornando-a menos positiva (nos valores avaliados não chega a ser negativa). 


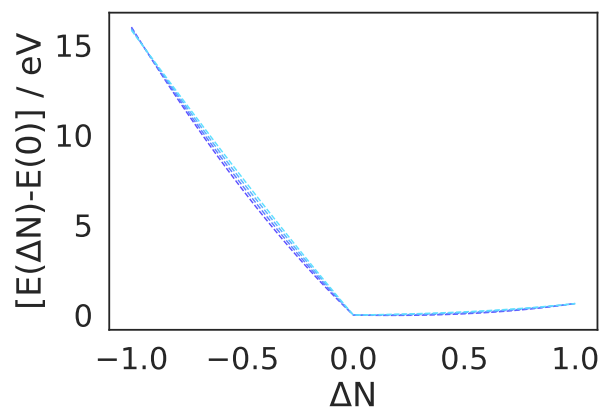

BHandH 30\% $(4.09,1.01)$

BHandH 40\% (3.10,0.85)

BHandH 50\% $(2.12,0.70)$

BHandH 60\% $(1.15,0.55)$

(a) $\mathrm{HF}$

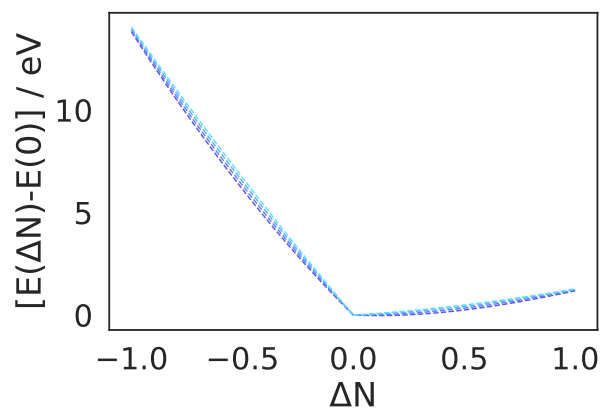

BHandH 30\% $(3.08,1.38)$

BHandH $40 \%(2.47,1.09)$

BHandH $50 \%(1.86,0.83)$

BHandH $60 \%(1.25,0.60)$

(b) $\mathrm{CO}$

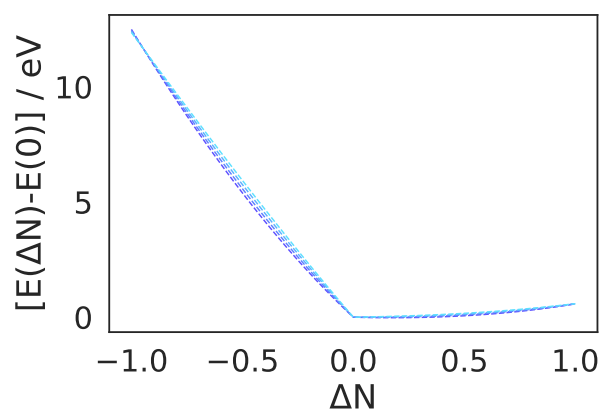

BHandH 30\% $(3.40,0.91)$

BHandH 40\% $(2.58,0.77)$

BHandH 50\% $(1.77,0.63)$

BHandH 60\% $(0.96,0.50)$

(c) $\mathrm{H}_{2} \mathrm{O}$

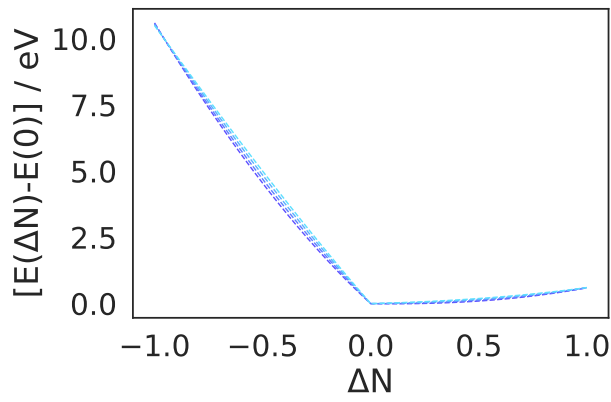

BHandH 30\% $(3.00,0.80)$

BHandH 40\% $(2.33,0.68)$

BHandH 50\% $(1.65,0.56)$

BHandH $60 \%(0.99,0.44)$

(d) $\mathrm{NH}_{3}$ 


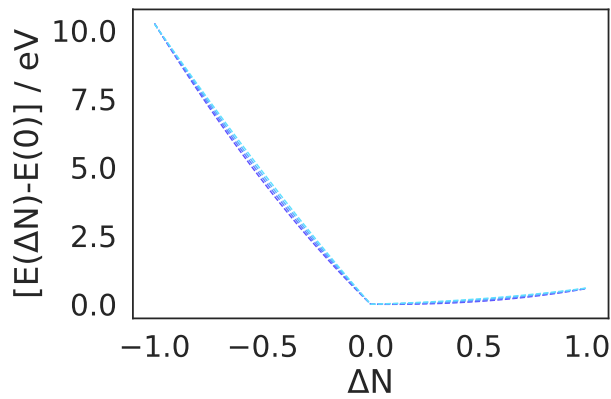

BHandH 30\% $(2.52,0.74)$

BHandH 40\% $(2.06,0.62)$

BHandH 50\% $(1.60,0.51)$

BHandH $60 \%(1.14,0.40)$

(e) $\mathrm{PH}_{3}$

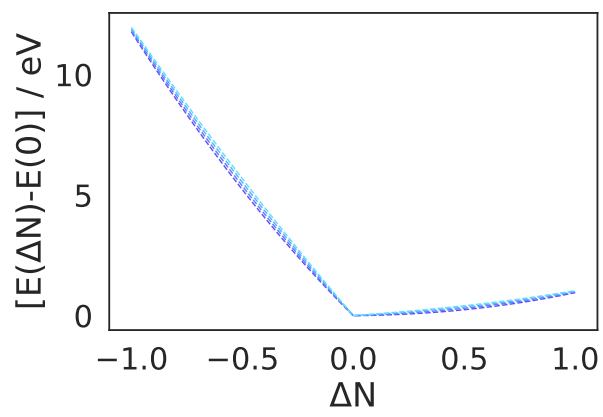

BHandH 30\% $(2.64,0.93)$

BHandH 40\% $(2.16,0.74)$

BHandH 50\% $(1.68,0.58)$

BHandH $60 \%(1.20,0.44)$

(f) $\mathrm{PF}_{3}$

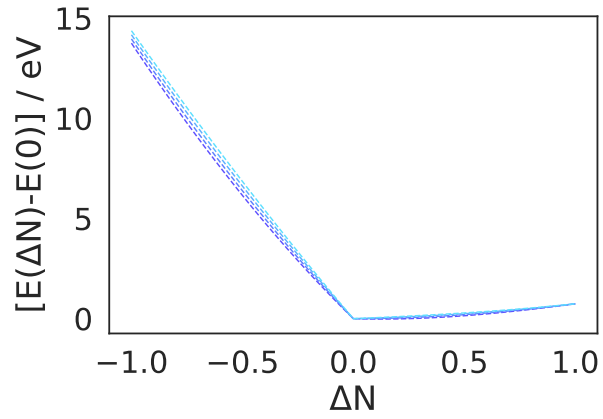

BHandH $30 \%(2.89,0.89)$

BHandH $40 \%(2.38,0.68)$

BHandH 50\% $(1.86,0.49)$

BHandH 60\% $(1.33,0.34)$

(g) $\mathrm{BHF}_{2}$

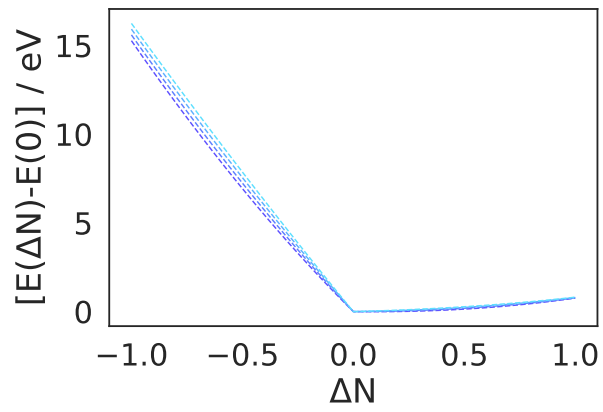

BHandH 30\% $(2.80,0.96)$

BHandH 40\% $(2.22,0.81)$

BHandH 50\% $(1.62,0.66)$

BHandH 60\% $(1.02,0.53)$

(h) $\mathrm{BF}_{3}$ 


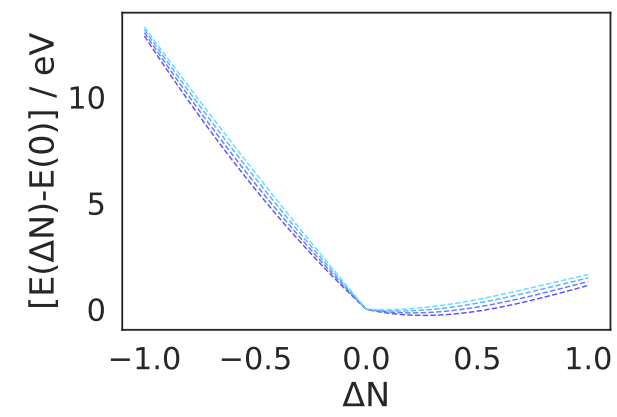

BHandH 30\% $(3.15,2.61)$

BHandH $40 \%(2.43,2.20)$

BHandH $50 \%(1.68,1.80)$

BHandH $60 \%(0.89,1.43)$

(i) $\mathrm{F}_{2} \mathrm{O}$

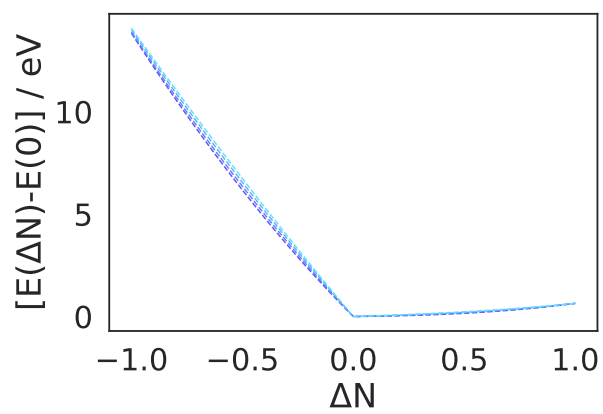

BHandH $30 \%(2.96,0.65)$

BHandH 40\% $(2.35,0.55)$

BHandH 50\% $(1.78,0.45)$

BHandH 60\% $(1.18,0.36)$

(j) $\mathrm{CH}_{4}$

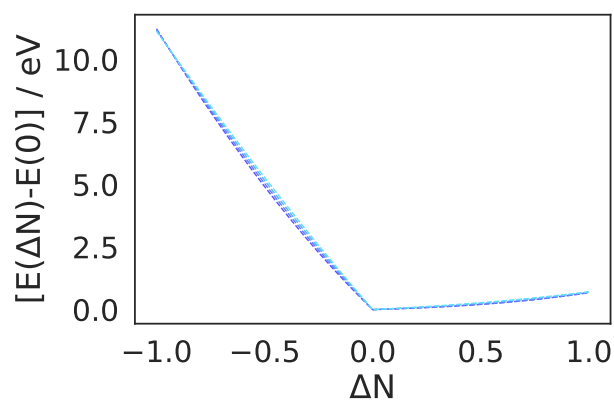

BHandH 30\% $(2.78,0.54)$

BHandH 40\% $(2.22,0.47)$

BHandH 50\% $(1.67,0.39)$

BHandH 60\% $(1.11,0.32)$

(k) $\mathrm{C}_{2} \mathrm{H}_{2}$

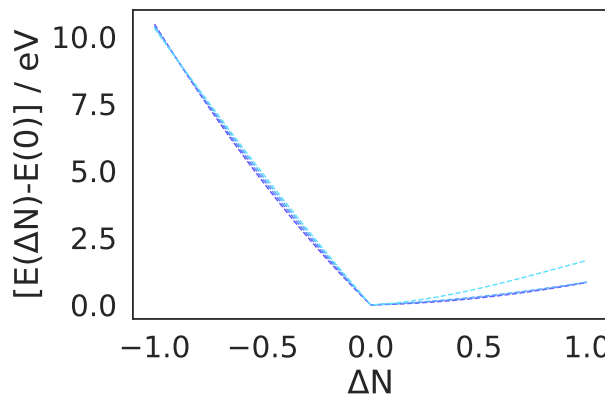

BHandH 30\% $(2.54,0.64)$

BHandH 40\% $(2.02,0.55)$

BHandH 50\% $(1.51,0.47)$

BHandH 60\% $(0.99,0.86)$

(1) $\mathrm{C}_{2} \mathrm{H}_{4}$ 


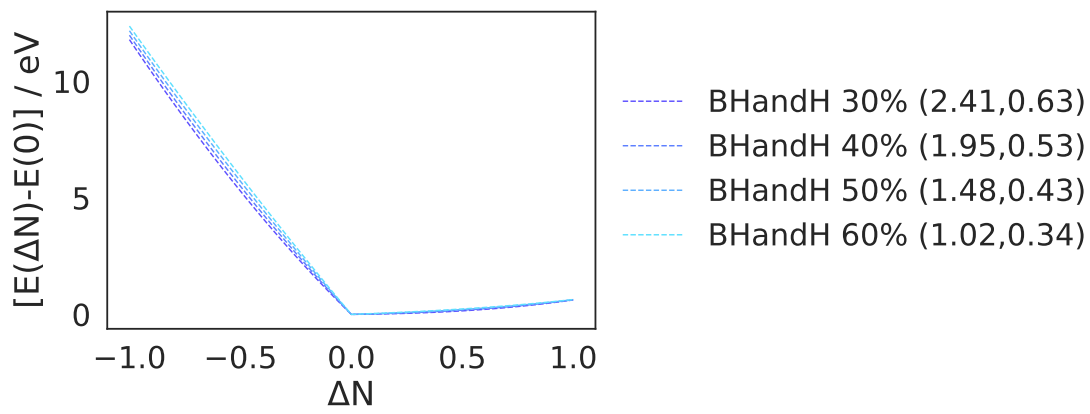

(m) $\mathrm{C}_{2} \mathrm{H}_{6}$

Figura 4.40: Avaliação do Teorema de Janak para BHandH variando a porcentagem de $E_{X}^{\mathrm{HF}}$ com geometrias otimizadas na base aug-pcJ-2. $\Delta N=-1$ corresponde ao cátion e $\Delta N=1$ ao ânion. A curvatura das curvas catiônica e aniônica estão indicadas, respectivamente, ao lado DFT.

Contrastando a Figura 4.40 com a Figura 4.37, os valores de concavidade obtidos não são alterados, e portanto a otimização de geometrias não influencia consideravelmente na exatidão dos funcionais. Isso evidencia que as geometrias otimizadas não apresentam grandes mudanças em relação às geometrias experimentais, pois grandes mudanças na geometria (por exemplo, mudanças conformacionais) devem influenciar no perfil observado, uma vez que as energias relativas são dependentes da geometria. .61

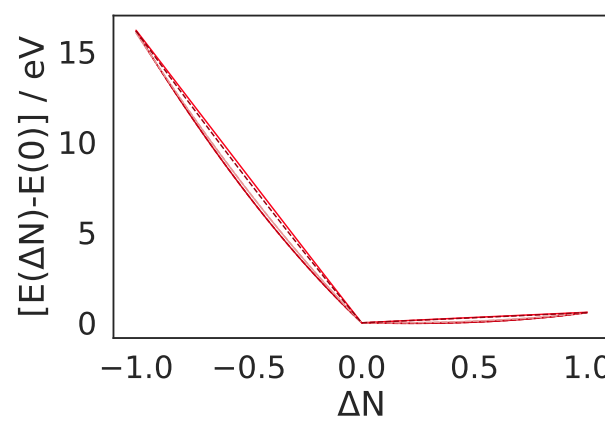

Exp B1B95 $(4.26,0.99)$

Exp B1B95 40\% (3.10,0.79)

Exp LC-B1B95 $(40 \%|100 \%| 0,40)(0.11,-0.02)$

Otm B1B95 otm $(4.26,0.99)$

Otm B1B95 40\% (3.11,0.79)

Otm LC-B1B95(40\%|100\%|0,25) $(1.05,0.00)$

(a) $\mathrm{HF}$

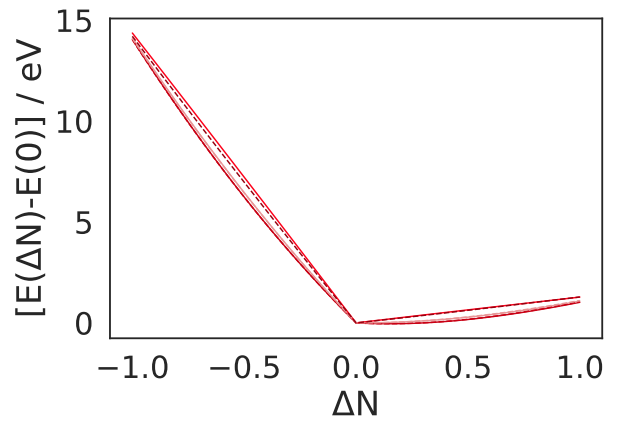

Exp B1B95 $(3.16,1.37)$

Exp B1B95 40\% $(2.42,1.03)$

Exp LC-B1B95 $(40 \%|100 \%| 0,40)(-0.15,-0.02)$

Otm B1B95 otm $(3.16,1.37)$

Otm B1B95 40\% $(2.42,1.03)$

Otm LC-B1B95(40\%|100\%|0,25) $(0.53,0.07)$

(b) $\mathrm{CO}$ 


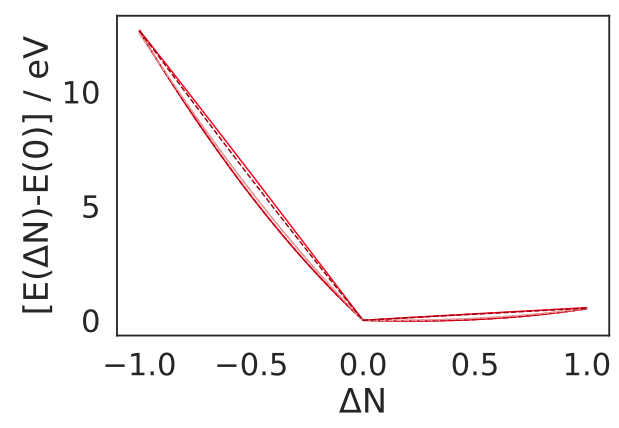

Exp B1B95 $(3.55,0.88)$

Exp B1B95 40\% $(2.59,0.71)$

- Exp LC-B1B95 $(40 \%|100 \%| 0,40)(-0.23,-0.03)$ Otm B1B95 otm $(3.56,0.89)$ Otm B1B95 40\% $(2.60,0.71)$ Otm LC-B1B95 $(40 \%|100 \%| 0,25)(0.60,-0.01)$

(c) $\mathrm{H}_{2} \mathrm{O}$

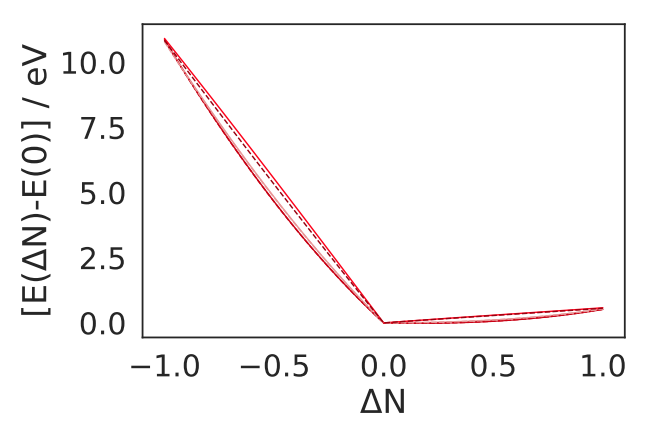

Exp B1B95 $(3.11,0.78)$

Exp B1B95 40\% $(2.31,0.63)$

Exp LC-B1B95 $(40 \%|100 \%| 0,40)(-0.31,-0.02)$

Otm B1B95 otm $(3.11,0.78)$

Otm B1B95 40\% $(2.32,0.63)$

Otm LC-B1B95 $(40 \%|100 \%| 0,25)(0.41,-0.01)$

(d) $\mathrm{NH}_{3}$

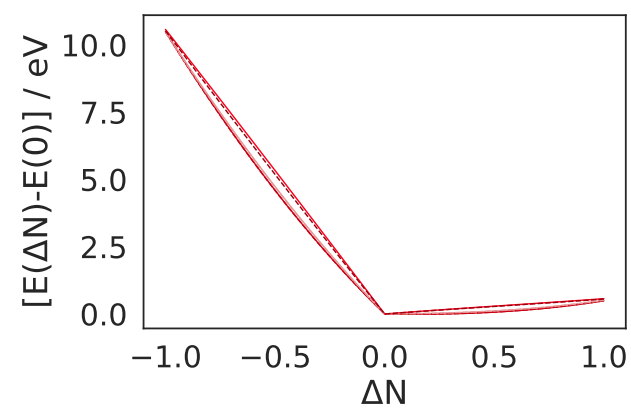

Exp B1B95 $(2.60,0.70)$

Exp B1B95 40\% $(2.05,0.56)$

Exp LC-B1B95 $(40 \%|100 \%| 0,40)(-0.18,-0.03)$

Otm B1B95 otm $(2.61,0.70)$

Otm B1B95 40\% $(2.06,0.57)$

Otm LC-B1B95 $(40 \%|100 \%| 0,25)(0.31,-0.02)$

(e) $\mathrm{PH}_{3}$

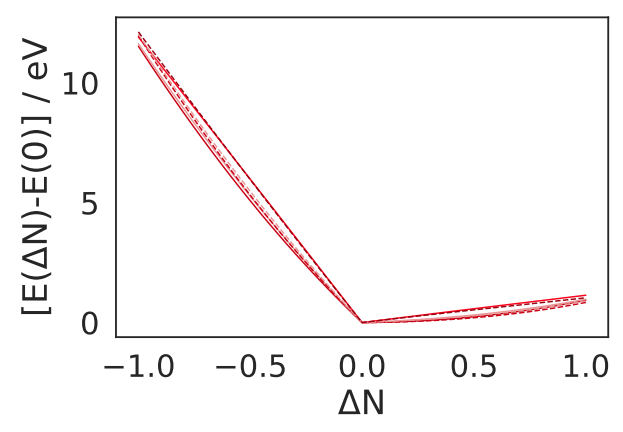

$\operatorname{Exp}$ B1B95 $(2.73,0.88)$

Exp B1B95 40\% $(2.16,0.67)$

Exp LC-B1B95 $(40 \%|100 \%| 0,40)(-0.10,-0.03)$

Otm B1B95 otm $(2.71,0.87)$

Otm B1B95 40\% $(2.15,0.66)$

Otm LC-B1B95 $(40 \%|100 \%| 0,25)(0.39,-0.05)$

(f) $\mathrm{PF}_{3}$ 


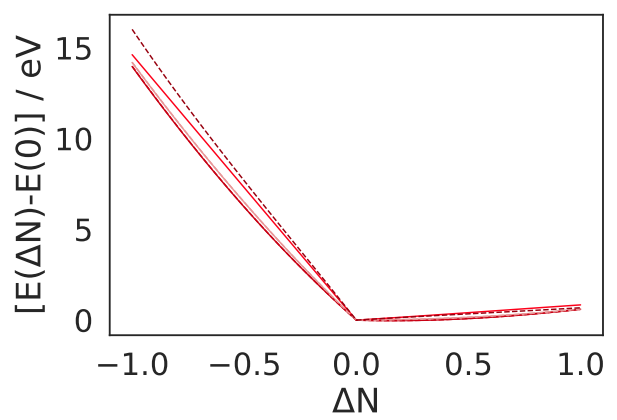

Exp B1B95 (3.04,0.85)

Exp B1B95 40\% $(2.42,0.60)$

Exp LC-B1B95 $(40 \%|100 \%| 0,40)(0.05,0.03)$

Otm B1B95 otm $(3.04,0.85)$

Otm B1B95 40\% $(2.43,0.60)$

Otm LC-B1B95(40\%|100\%|0,25) (1.33,-0.03)

(g) $\mathrm{BHF}_{2}$

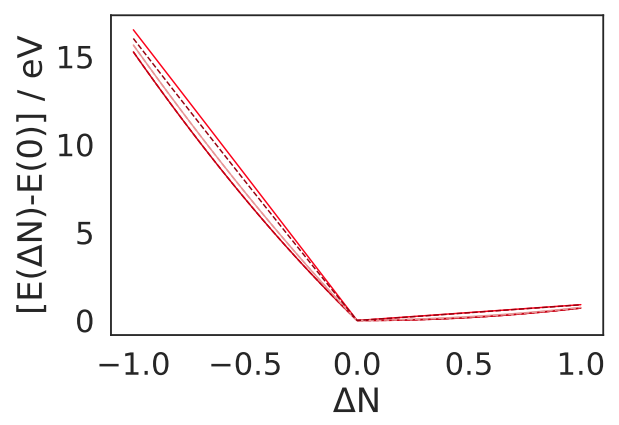

Exp B1B95 (2.92,0.75)

Exp B1B95 40\% $(2.23,0.60)$

Exp LC-B1B95(40\%|100\%|0,40) $(-0.07,-0.00)$

Otm B1B95 otm $(2.92,0.75)$

Otm B1B95 40\% $(2.23,0.69)$

Otm LC-B1B95 $(40 \%|100 \%| 0,25)(0.44,0.02)$

(h) $\mathrm{BF}_{3}$

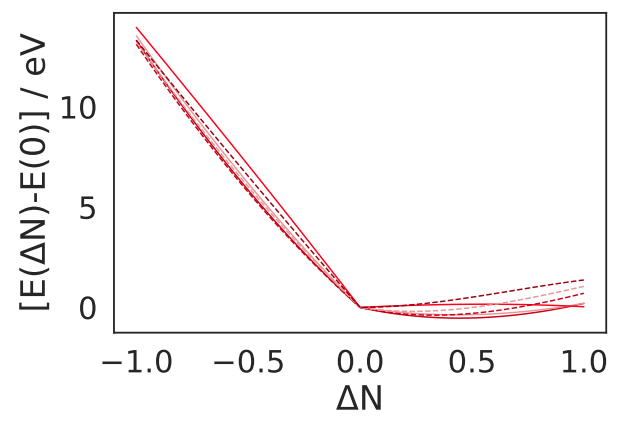

Exp B1B95 $(3.23,2.51)$

Exp B1B95 40\% $(2.35,1.85)$

Exp LC-B1B95 $(40 \%|100 \%| 0,40)(-0.45,-0.57)$

Otm B1B95 otm $(3.27,2.60)$

Otm B1B95 40\% $(2.43,2.12)$

Otm LC-B1B95(40\%|100\%|0,25) $(0.47,0.70)$

(i) $\mathrm{F}_{2} \mathrm{O}$

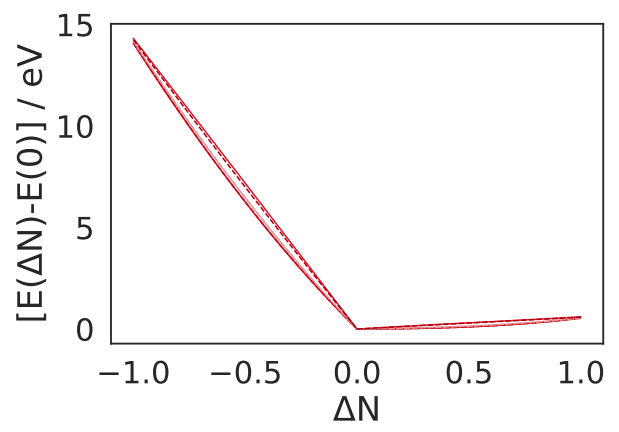

Exp B1B95 (3.12,0.64)

Exp B1B95 40\% $(2.43,0.52)$

Exp LC-B1B95 $(40 \%|100 \%| 0,40)(-0.11,-0.02)$

Otm B1B95 otm $(3.12,0.64)$

Otm B1B95 40\% (2.44,0.52)

Otm LC-B1B95 $(40 \%|100 \%| 0,25)(0.53,-0.02)$

(j) $\mathrm{CH}_{4}$ 


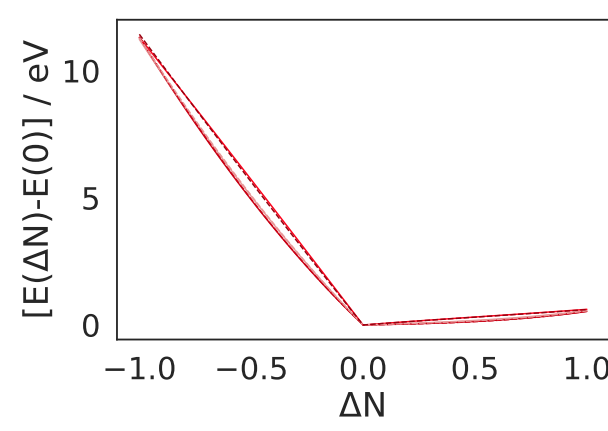

- Exp B1B95 $(2.88,0.51)$

- Exp B1B95 40\% $(2.22,0.42)$

- Exp LC-B1B95 $(40 \%|100 \%| 0,40)(-0.23,-0.02)$

- Otm B1B95 otm $(2.89,0.55)$

Otm B1B95 40\% $(2.23,0.45)$

Otm LC-B1B95 $(40 \%|100 \%| 0,25)(0.38,-0.02)$

(k) $\mathrm{C}_{2} \mathrm{H}_{2}$

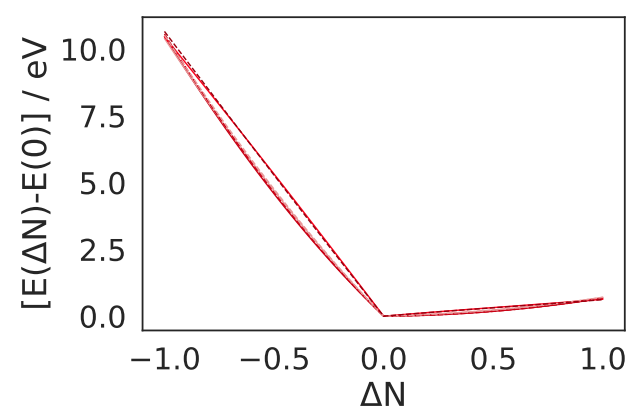

Exp B1B95 $(2.62,0.62)$

Exp B1B95 40\% $(2.00,0.50)$

Exp LC-B1B95 $(40 \%|100 \%| 0,40)(-0.36,-0.02)$

Otm B1B95 otm $(2.63,0.62)$

Otm B1B95 40\% $(2.02,0.49)$

Otm LC-B1B95 $(40 \%|100 \%| 0,25)(0.20,-0.02)$

(l) $\mathrm{C}_{2} \mathrm{H}_{4}$

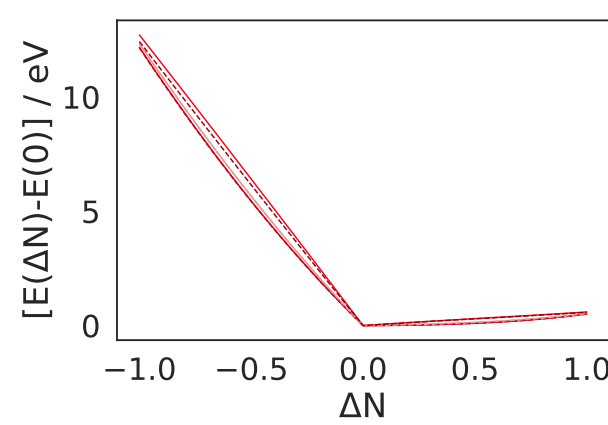

- Exp B1B95 $(2.56,0.61)$

Exp B1B95 40\% $(2.01,0.49)$

- Exp LC-B1B95 $(40 \%|100 \%| 0,40)(-0.21,-0.03)$

--.-- Otm B1B95 otm $(2.58,0.61)$

Otm B1B95 40\% $(2.03,0.49)$

----- Otm LC-B1B95 $(40 \%|100 \%| 0,25)(0.25,-0.02)$

(m) $\mathrm{C}_{2} \mathrm{H}_{6}$

Figura 4.41: Avaliação do Teorema de Janak para melhores funcionais baseados no B1B95 na base aug-pcJ-2. $\Delta N=-1$ corresponde ao cátion e $\Delta N=1$ ao ânion. A curvatura das curvas catiônica e aniônica estão indicadas, respectivamente, ao lado DFT.

A Figura 4.41 apresenta os resultados de concavidade obtidos com os melhores funcionais baseados no B1B95. O B1B95 (PDMA = 24,17\% exp. $21,61 \%_{\text {otm. }}^{\text {geom. }}$. $)$ é o menos exato, e o B1B95 40\% $E_{X}^{\mathrm{HF}}(14,31 \%$ exp. geom. $10,96 \%$ otm. $)$ tem diminuição das concavidades. O LCB1B95(40\%|100\%|0,40) (8,78\% exp. $)$ apresenta o comportamento mais próximo do exato. As concavidades não são alteradas para a otimização das geometrias (o funcional de longo alcance tem $\gamma$ diferente $(9,10 \%$ otm. $)$ para geometrias experimentais e otimizadas $)$. 


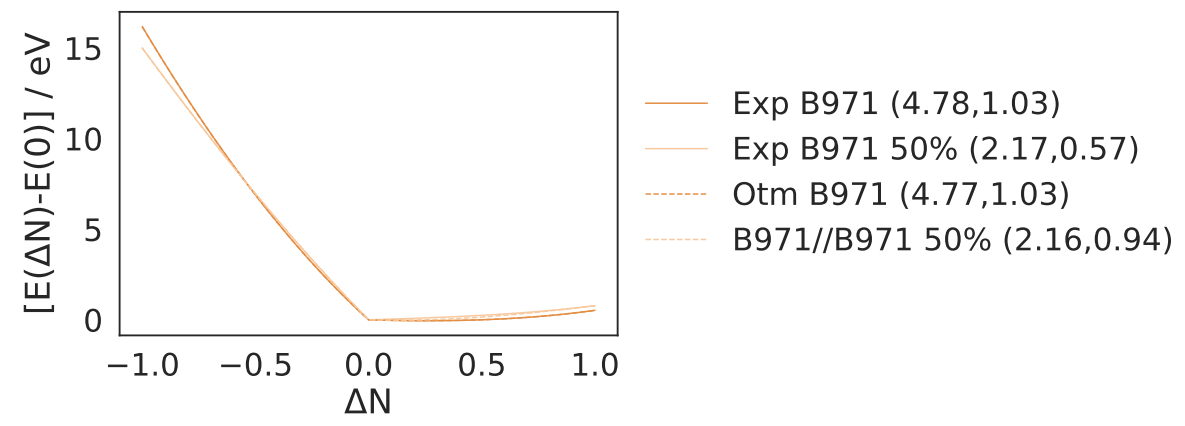

(a) $\mathrm{HF}$

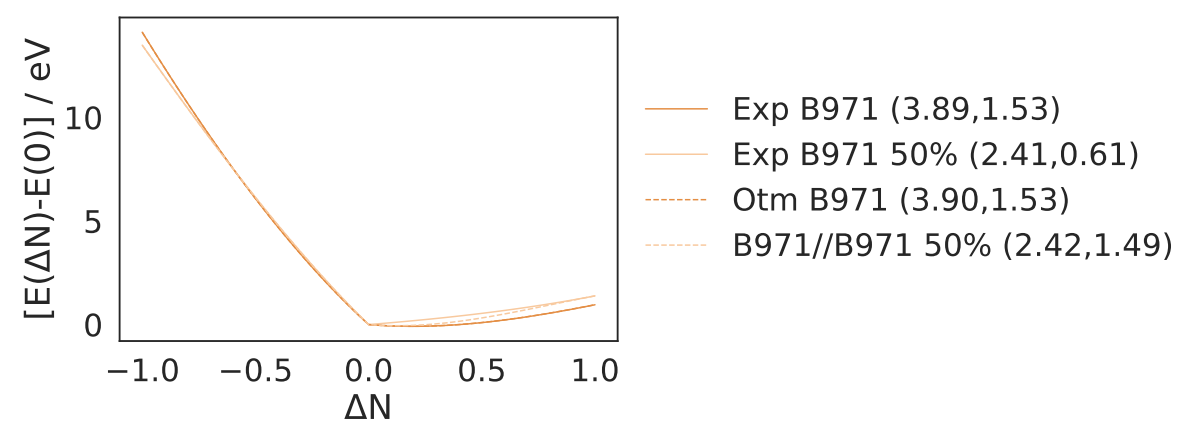

(b) $\mathrm{CO}$

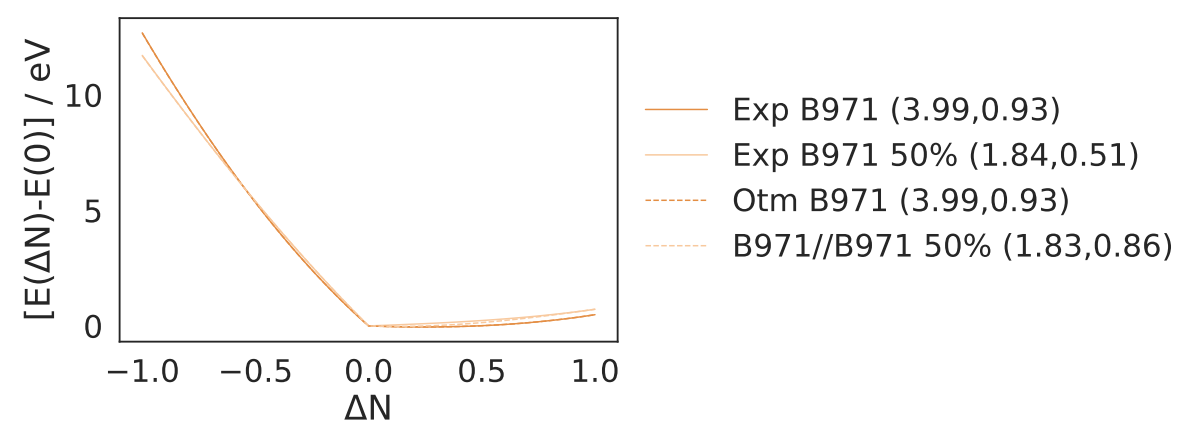

(c) $\mathrm{H}_{2} \mathrm{O}$

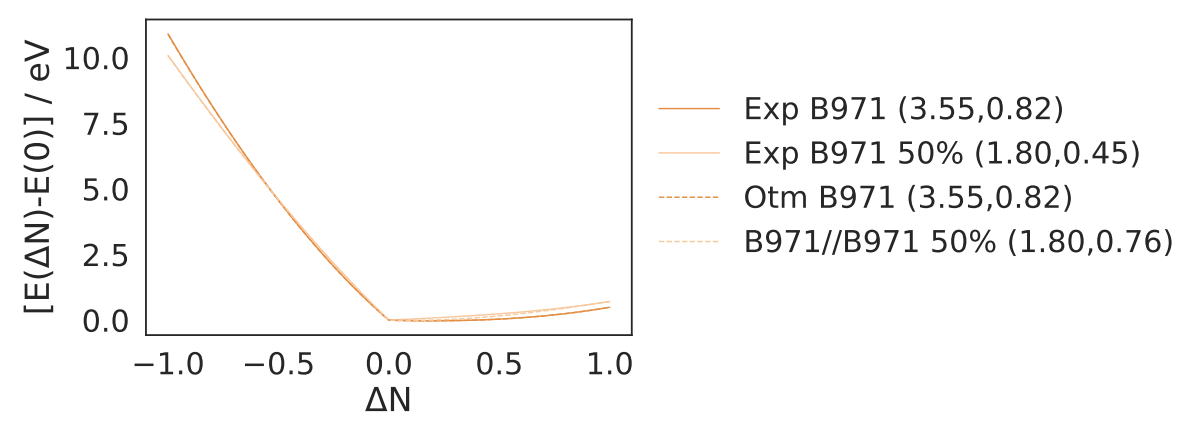

(d) $\mathrm{NH}_{3}$ 


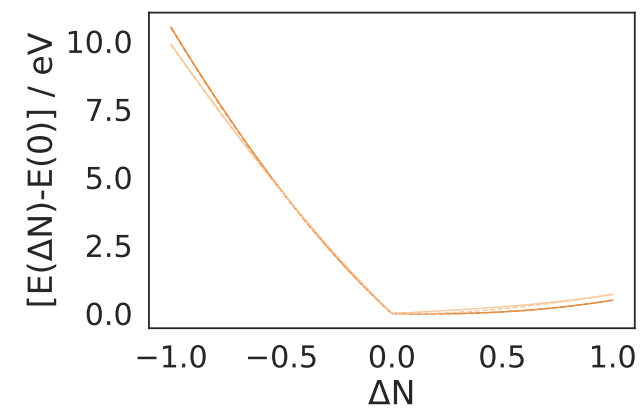

Exp B971 $(2.99,0.75)$

Exp B971 50\% $(1.79,0.41)$

Otm B971 $(3.00,0.75)$

B971//B971 50\% $(1.80,0.71)$

(e) $\mathrm{PH}_{3}$

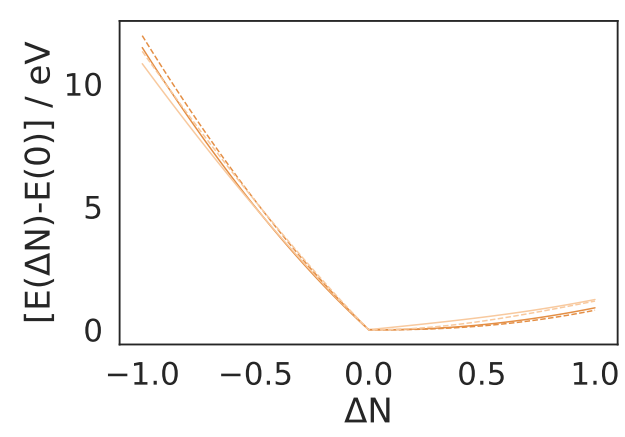

Exp B971 $(3.04,0.97)$

Exp B971 50\% $(1.81,0.45)$

Otm B971 $(3.00,0.97)$

B971//B971 50\% $(1.76,0.95)$

(f) $\mathrm{PF}_{3}$

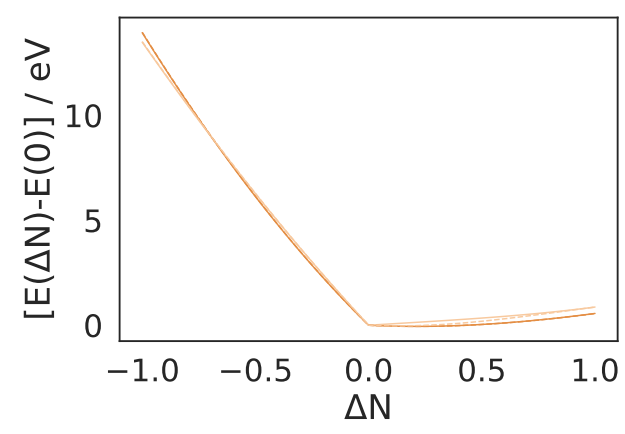

Exp B971 $(3.35,0.97)$

Exp B971 50\% $(1.90,0.36)$

Otm B971 $(3.34,0.97)$

B971//B971 50\% $(1.89,0.97)$

(g) $\mathrm{BHF}_{2}$

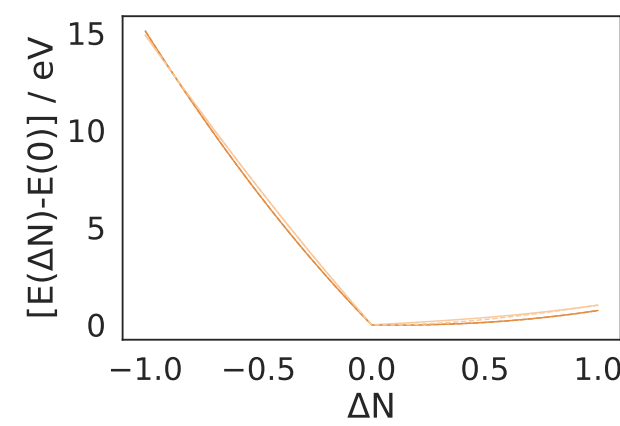

Exp B971 $(3.27,0.98)$

Exp B971 50\% $(1.63,0.53)$

Otm B971 $(3.26,0.98)$

B971//B971 50\% $(1.62,0.93)$

(h) $\mathrm{BF}_{3}$ 


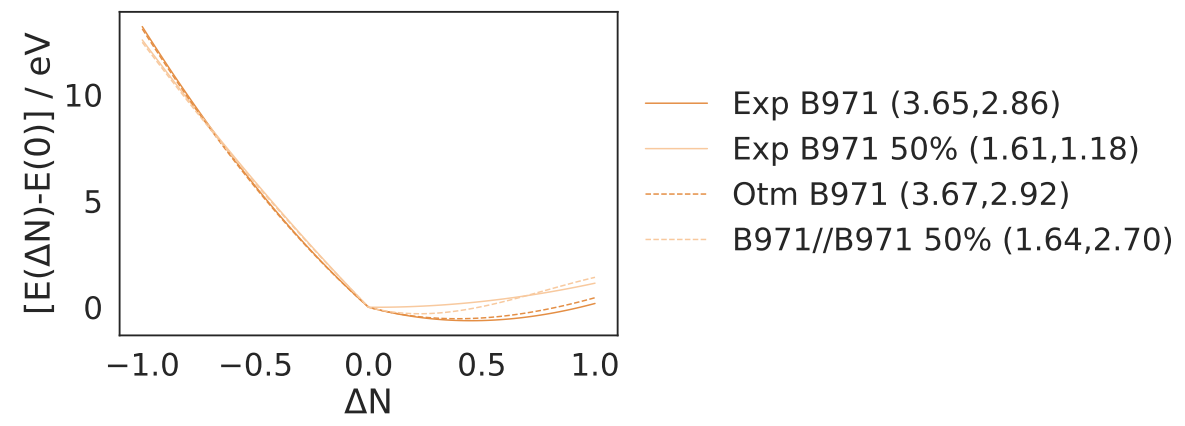

(i) $\mathrm{F}_{2} \mathrm{O}$

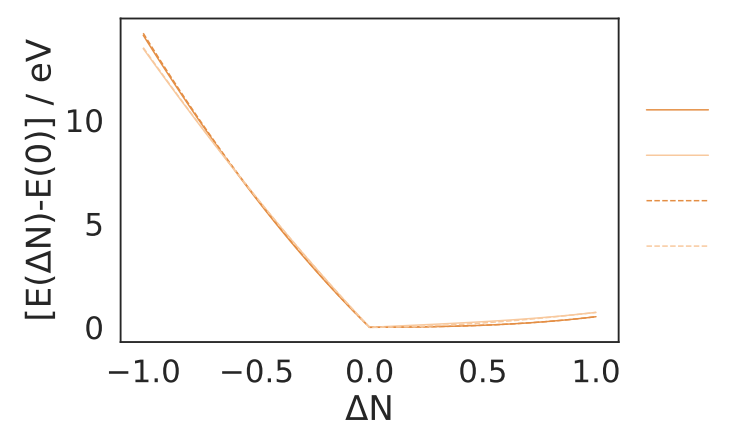

Exp B971 $(3.42,0.63)$

Exp B971 50\% $(1.85,0.36)$

Otm B971 $(3.48,0.63)$

B971//B971 50\% $(1.91,0.60)$

(j) $\mathrm{CH}_{4}$

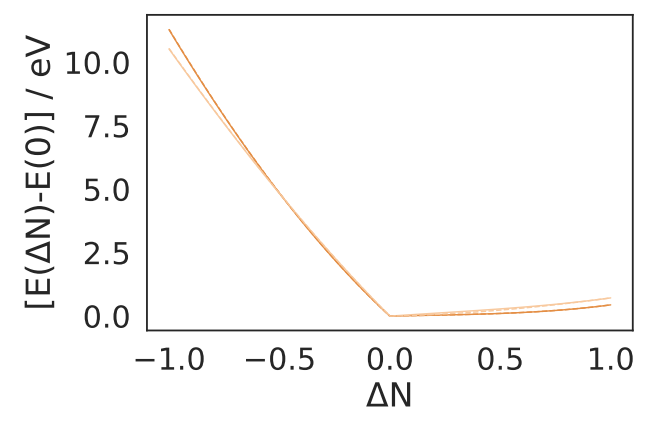

Exp B971 $(3.20,0.46)$

Exp B971 50\% $(1.73,0.29)$

Otm B971 $(3.20,0.46)$

B971//B971 50\% $(1.73,0.48)$

(k) $\mathrm{C}_{2} \mathrm{H}_{2}$

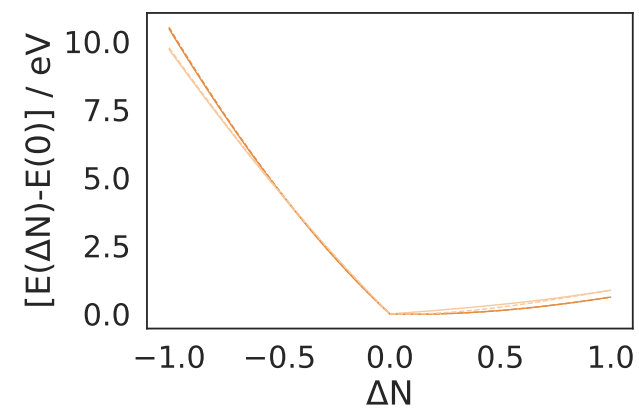

Exp B971 $(2.93,0.73)$

Exp B971 50\% $(1.57,0.36)$

Otm B971 (2.94,0.73)

B971//B971 50\% $(1.57,0.75)$

(l) $\mathrm{C}_{2} \mathrm{H}_{4}$ 


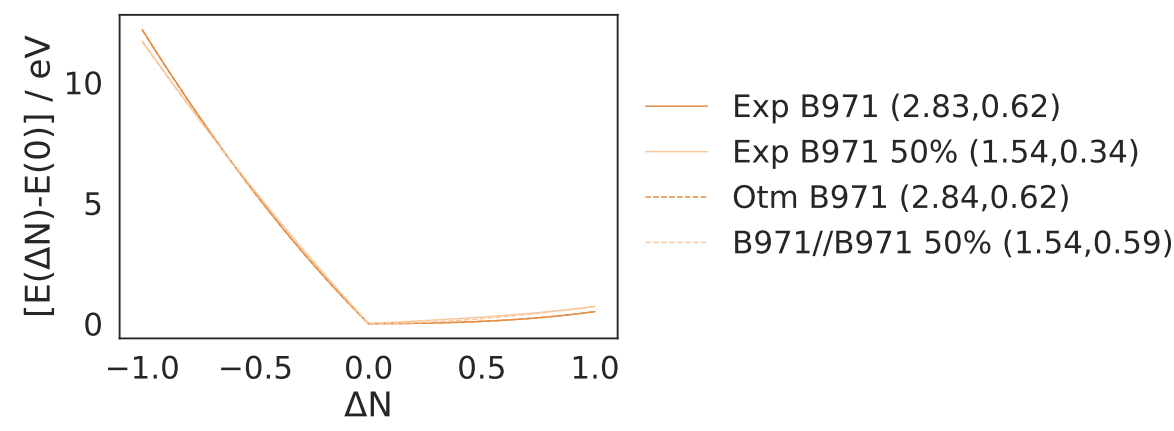

(m) $\mathrm{C}_{2} \mathrm{H}_{6}$

Figura 4.42: Avaliação do Teorema de Janak para melhores funcionais baseados no B971 na base aug-pcJ-2. $\Delta N=-1$ corresponde ao cátion e $\Delta N=1$ ao ânion. A curvatura das curvas catiônica e aniônica estão indicadas, respectivamente, ao lado DFT.

A Figura 4.42 apresenta os resultados de concavidade obtidos com os melhores funcionais baseados no B971. O B971 (21,89\% exp. $_{\text {geom. }}^{\text {ex }} 24,16 \%$ otm. $)$ é o menos exato, e o B971 $50 \% E_{X}^{\mathrm{HF}}(16,15 \%$ exp. $)$ tem diminuição das concavidades. A otimização das geometrias com B971 e cálculo de propriedade com B971 50\% $E_{X}^{\mathrm{HF}}(11,38 \%$ otm. $)$ altera a concavidade aniônica das moléculas, e portanto não é uma estratégia consistente para cálculo das CAISS.

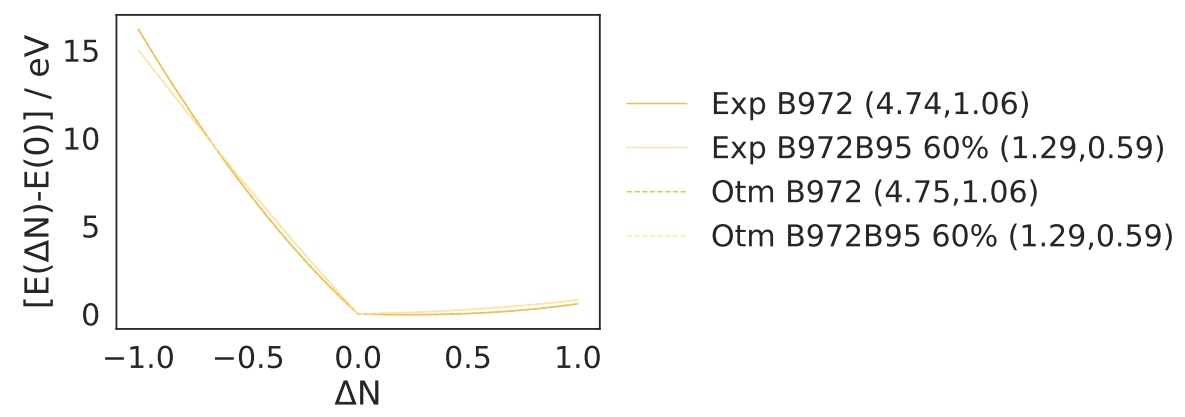

(a) $\mathrm{HF}$

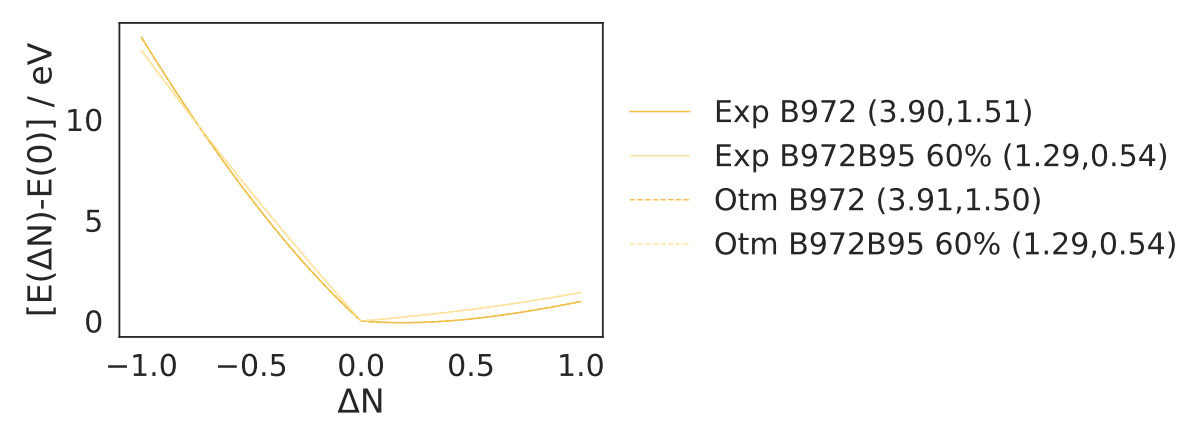

(b) $\mathrm{CO}$ 


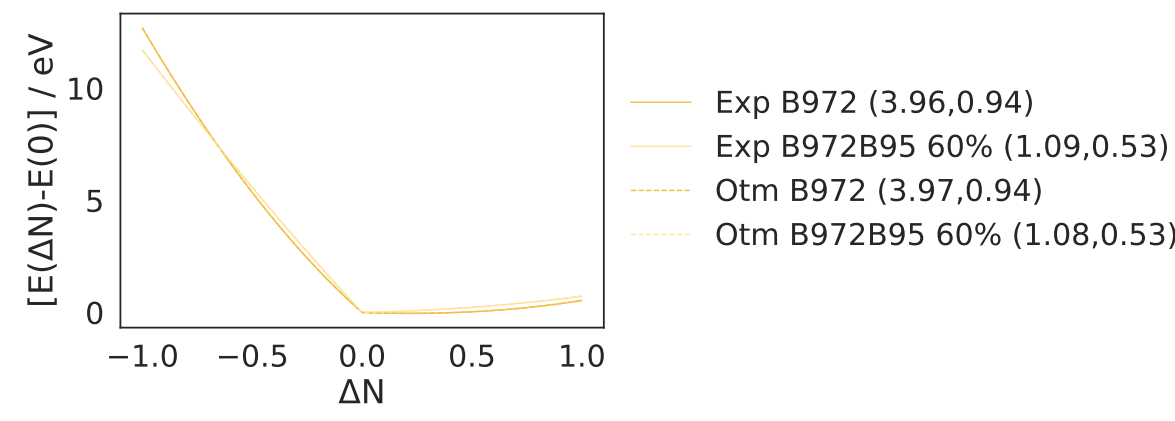

(c) $\mathrm{H}_{2} \mathrm{O}$

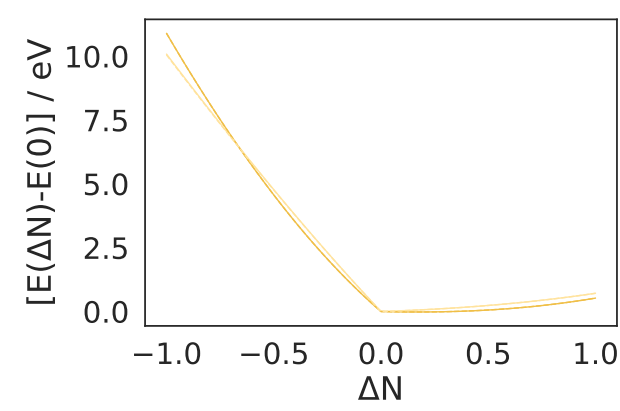

Exp B972 (3.53,0.82)

Exp B972B95 60\% $(1.06,0.48)$

Otm B972 (3.53,0.82)

Otm B972B95 60\% $(1.05,0.48)$

(d) $\mathrm{NH}_{3}$

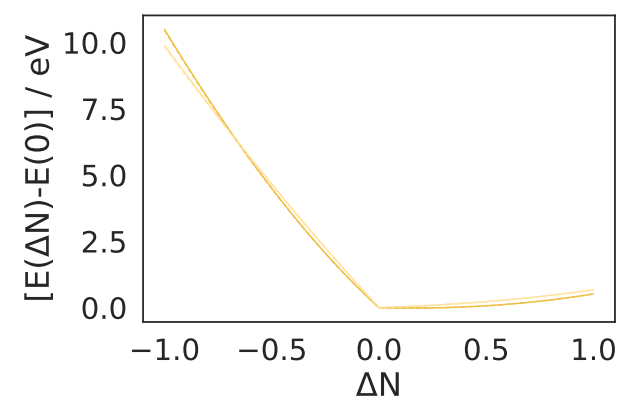

Exp B972 (2.98,0.75)

Exp B972B95 60\% $(1.15,0.44)$

Otm B972 $(2.99,0.76)$

Otm B972B95 60\% $(1.14,0.44)$

(e) $\mathrm{PH}_{3}$

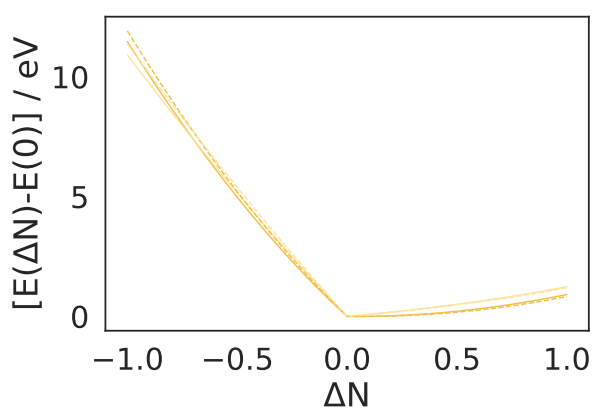

Exp B972 (3.04,0.96)

Exp B972B95 60\% $(1.20,0.46)$

Otm B972 (2.99,0.96)

Otm B972B95 60\% $(1.19,0.44)$

(f) $\mathrm{PF}_{3}$ 


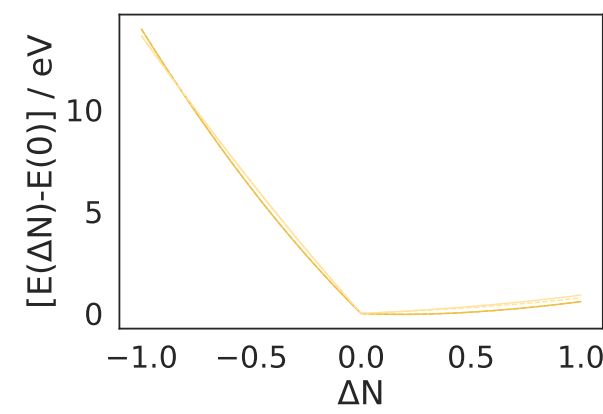

Exp B972 $(3.36,0.90)$

Exp B972B95 60\% $(1.43,0.43)$

Otm B972 $(3.36,0.90)$

Otm B972B95 60\% $(1.44,0.37)$

(g) $\mathrm{BHF}_{2}$

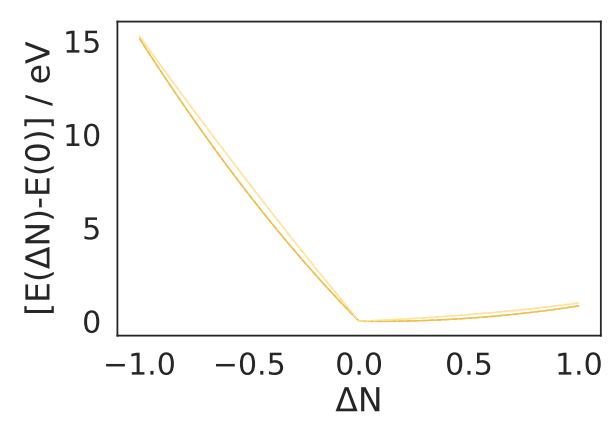

Exp B972 $(3.27,0.99)$

Exp B972B95 60\% $(1.09,0.53)$

Otm B972 $(3.26,0.99)$

Otm B972B95 60\% $(1.08,0.53)$

(h) $\mathrm{BF}_{3}$

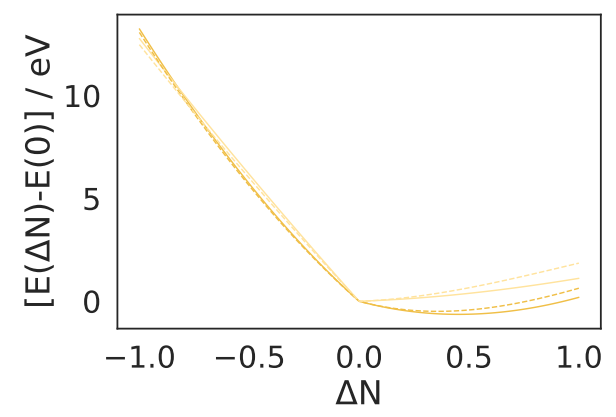

Exp B972 $(3.64,2.90)$

Exp B972B95 60\% $(0.87,0.69)$

Otm B972 $(3.67,2.96)$

Otm B972B95 60\% $(1.00,1.08)$

(i) $\mathrm{F}_{2} \mathrm{O}$

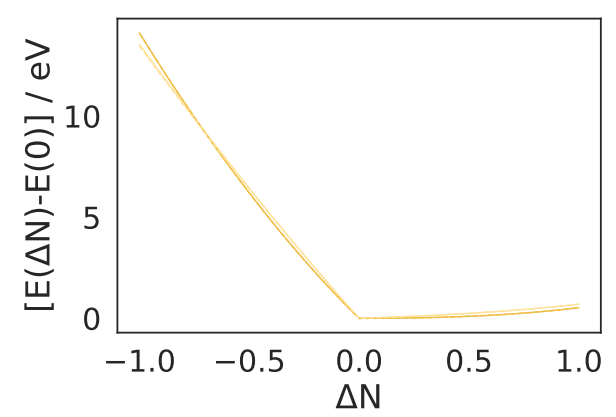

Exp B972 (3.41,0.65)

Exp B972B95 60\% $(1.36,0.41)$

Otm B972 $(3.41,0.65)$

Otm B972B95 60\% $(1.34,0.41)$

(j) $\mathrm{CH}_{4}$ 


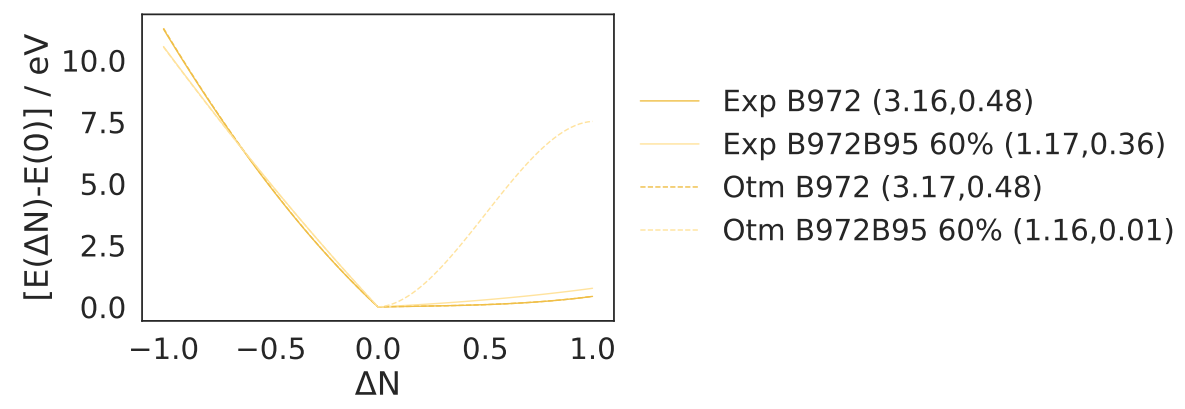

(k) $\mathrm{C}_{2} \mathrm{H}_{2}$

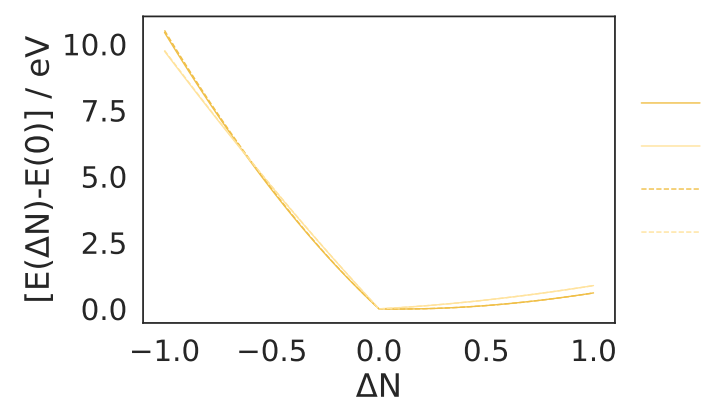

$\operatorname{Exp} B 972(2.91,0.71)$

Exp B972B95 60\% $(1.02,0.42)$

Otm B972 $(2.92,0.70)$

Otm B972B95 60\% $(1.01,0.42)$

(l) $\mathrm{C}_{2} \mathrm{H}_{4}$

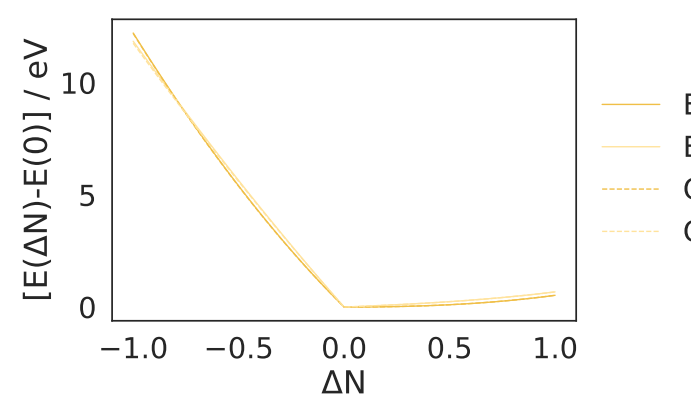

Exp B972 $(2.84,0.63)$

Exp B972B95 60\% $(1.13,0.38)$

Otm B972 $(2.86,0.63)$

Otm B972B95 60\% $(1.12,0.38)$

(m) $\mathrm{C}_{2} \mathrm{H}_{6}$

Figura 4.43: Avaliação do Teorema de Janak para melhores funcionais baseados no B972 na base aug-pcJ-2. $\Delta N=-1$ corresponde ao cátion e $\Delta N=1$ ao ânion. A curvatura das curvas catiônica e aniônica estão indicadas, respectivamente, ao lado DFT.

A Figura 4.43 apresenta os resultados de concavidade obtidos com os melhores funcionais baseados no B972. O B972 (23,84\% $\left.\%_{\text {exp. }}^{\text {geom. }}, 25,54 \%_{\text {otm. }}^{\text {geom. }}\right)$ é o menos exato, e o B972B95 $60 \% E_{X}^{\mathrm{HF}}(10,03 \%$ exp. geom. $, 8,58 \%$ otm. $)$ tem diminuição das concavidades. As concavidades não são alteradas para a otimização das geometrias. O B972B95 $60 \% E_{X}^{\mathrm{HF}}$ é o funcional híbrido mais próximo do comportamento exato.

A Figura 4.44 apresenta os resultados de concavidade obtidos com os melhores funcionais baseados no B98. O B98 (22,55\% $\underset{\text { exp. }}{\text { geom. }}$, 25,09\% otm. $\left._{\text {otm }}^{\text {geom }}\right)$ é o menos exato, e o B98 $50 \% E_{X}^{\mathrm{HF}}(14,08 \%$ exp. $)$ tem diminuição das concavidades. A otimização das geometrias 
com B98 e cálculo de propriedade com B98 $50 \% E_{X}^{\mathrm{HF}}(10,44 \%$ otm. $)$ altera a concavidade aniônica das moléculas.

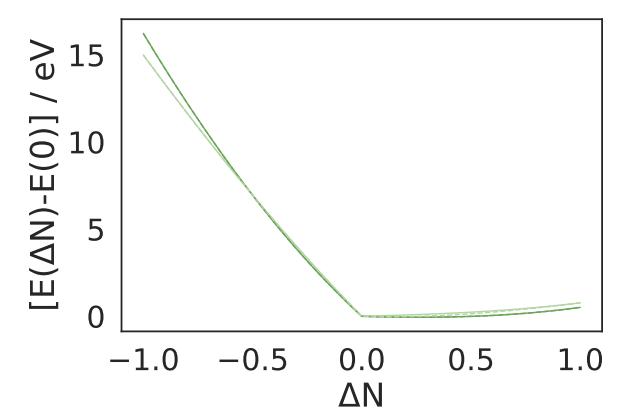

$\operatorname{Exp} B 98(4.67,1.04)$

Exp B98 50\% $(2.15,0.60)$

Otm B98 $(4.67,1.04)$

B98//B98 50\% $(2.15,0.96)$

(a) $\mathrm{HF}$

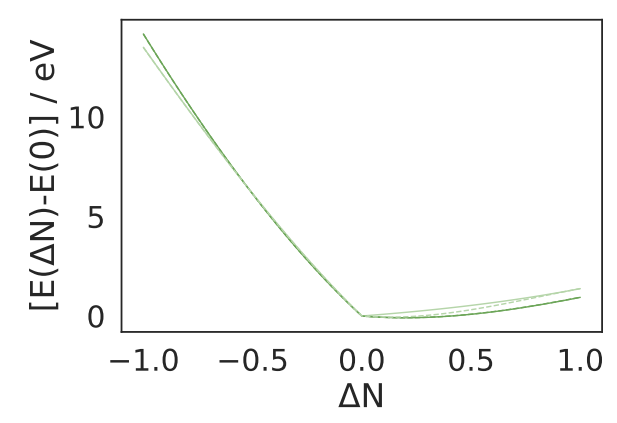

Exp B98 $(3.80,1.53)$

Exp B98 50\% $(2.39,0.62)$

Otm B98 $(3.81,1.52)$

B98//B98 50\% $(2.40,1.50)$

(b) $\mathrm{CO}$

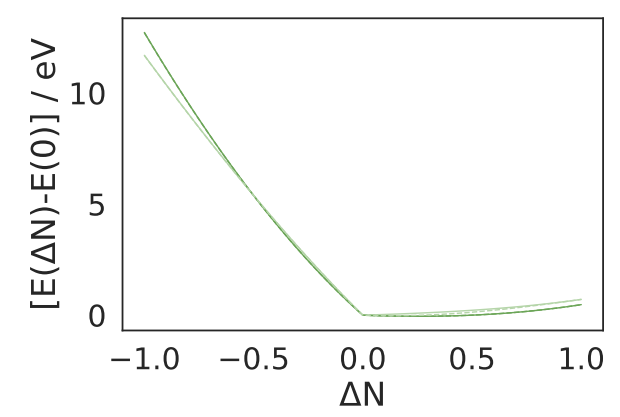

Exp B98 $(3.89,0.94)$

Exp B98 50\% $(1.81,0.54)$

Otm B98 $(3.89,0.94)$

B98//B98 50\% $(1.81,0.88)$

(c) $\mathrm{H}_{2} \mathrm{O}$

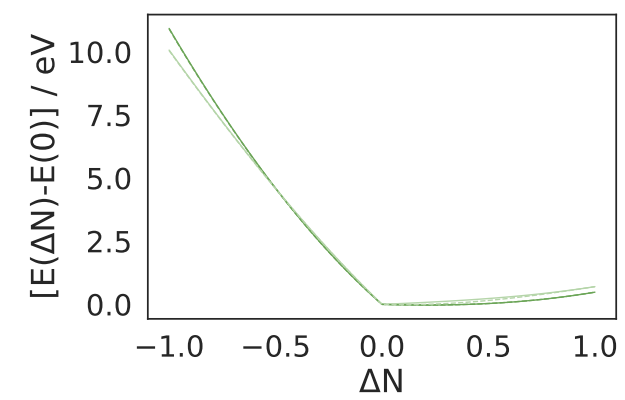

Exp B98 $(3.45,0.83)$

Exp B98 50\% $(1.78,0.48)$

Otm B98 $(3.45,0.83)$

B98//B98 50\% $(1.77,0.78)$

(d) $\mathrm{NH}_{3}$ 


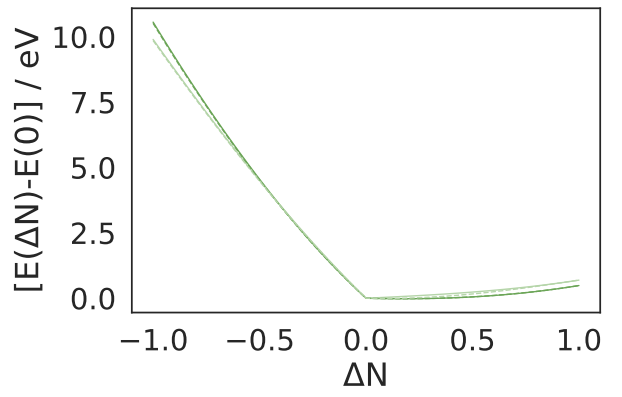

Exp B98 $(2.92,0.77)$

Exp B98 50\% $(1.78,0.44)$

Otm B98 $(2.93,0.76)$

B98//B98 50\% $(1.79,0.73)$

(e) $\mathrm{PH}_{3}$

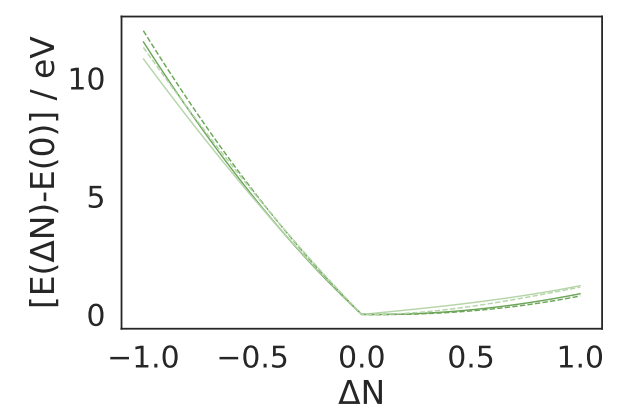

Exp B98 $(2.99,0.97)$

Exp B98 $50 \%(1.80,0.47)$

Otm B98 $(2.94,0.97)$

B98//B98 50\% $(1.75,0.96)$

(f) $\mathrm{PF}_{3}$

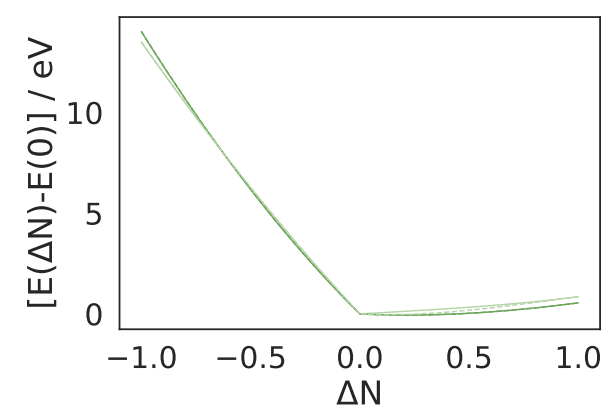

Exp B98 $(3.30,0.97)$

Exp B98 50\% $(1.90,0.38)$

Otm B98 $(3.30,0.97)$

B98//B98 50\% $(1.90,0.97)$

(g) $\mathrm{BHF}_{2}$

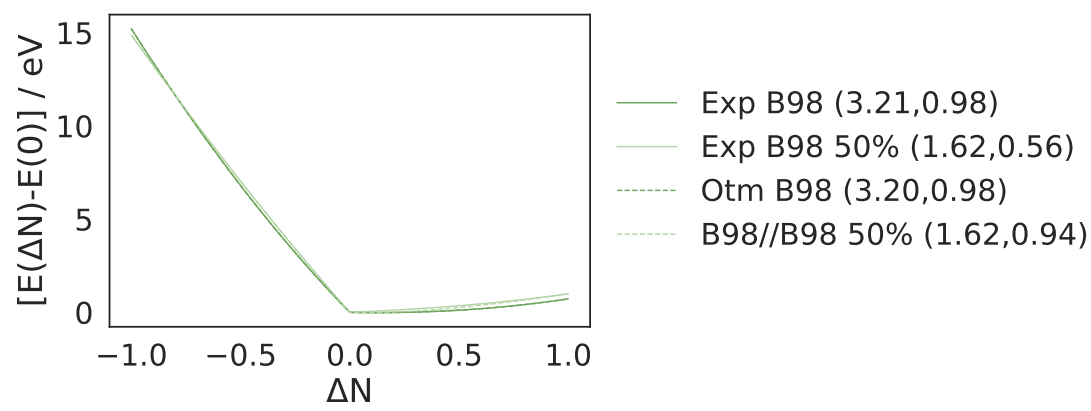

(h) $\mathrm{BF}_{3}$ 


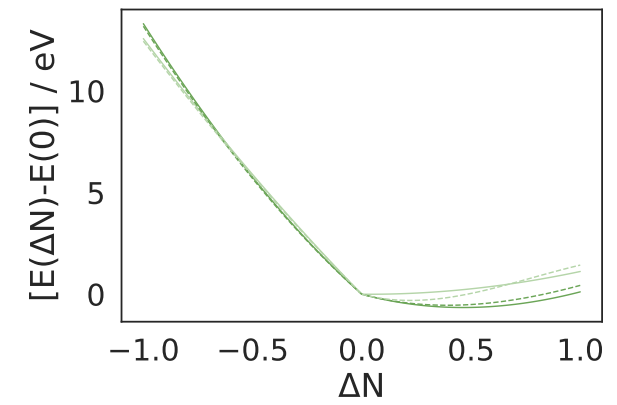

Exp B98 $(3.57,2.83)$

Exp B98 50\% $(1.59,1.18)$

Otm B98 $(3.60,2.90)$

B98//B98 50\% $(1.63,2.71)$

(i) $\mathrm{F}_{2} \mathrm{O}$

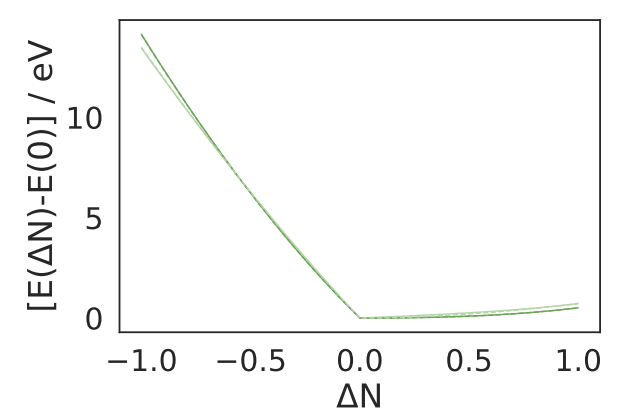

\section{Exp B98 $(3.35,0.64)$}

Exp B98 50\% $(1.84,0.39)$

Otm B98 $(3.34,0.64)$

B98//B98 50\% $(1.89,0.62)$

(j) $\mathrm{CH}_{4}$

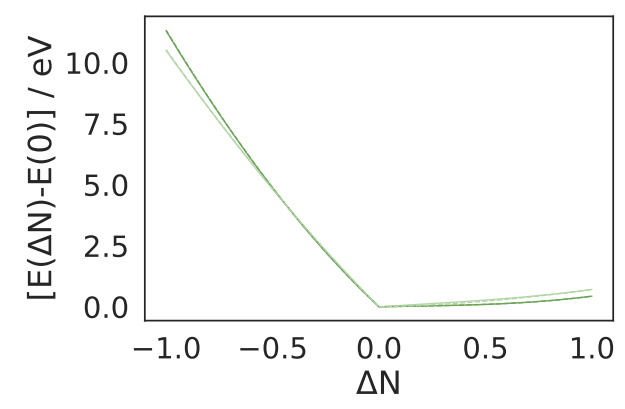

Exp B98 $(3.13,0.48)$

Exp B98 50\% $(1.71,0.31)$

Otm B98 $(3.13,0.48)$

B98//B98 50\% (1.72,0.50)

(k) $\mathrm{C}_{2} \mathrm{H}_{2}$

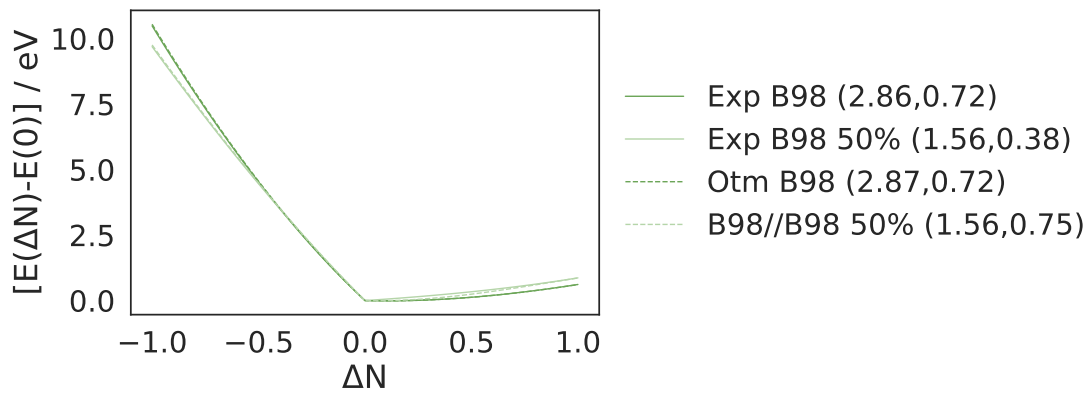

(l) $\mathrm{C}_{2} \mathrm{H}_{4}$ 


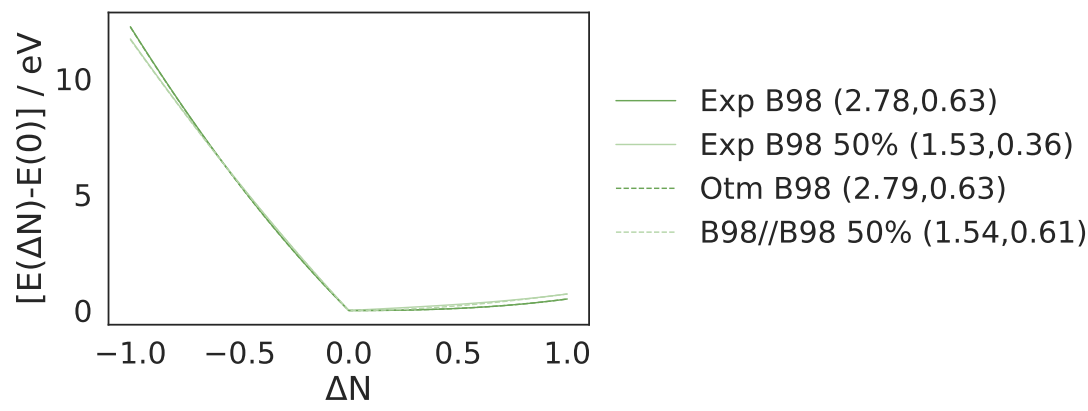

(m) $\mathrm{C}_{2} \mathrm{H}_{6}$

Figura 4.44: Avaliação do Teorema de Janak para melhores funcionais baseados no B98 na base aug-pcJ-2. $\Delta N=-1$ corresponde ao cátion e $\Delta N=1$ ao ânion. A curvatura das curvas catiônica e aniônica estão indicadas, respectivamente, ao lado DFT.

A Figura 4.45 apresenta os resultados de concavidade obtidos com os melhores funcionais baseados no BHandH. O BHandH $40 \% E_{X}^{\mathrm{HF}}\left(14,17 \%_{\text {exp. }}^{\text {geom. }}, 9,04 \%_{\text {otm. }}^{\text {geom. }}\right)$ é o menos exato, e o BHandH (12,21\% exp. geom. 19,31\% otm. $\left._{\text {oem. }}^{\text {gem }}\right)$ tem diminuição das concavidades. O LC-BHandH(40\%|100\%|0,30) (10,49\% exp. $\left._{\text {geom. }}\right)$ apresenta o comportamento mais próximo do exato. As concavidades não são alteradas para a otimização das geometrias (o funcional LC tem $\gamma$ diferente $\left(9,08 \%_{\text {otm. }}^{\text {geom. }}\right)$ para geometrias experimentais e otimizadas $)$.

Os funcionais LC-BHandH(40\%|100\%|0,30) e LC-B1B95(40\%|100\%|0,40) (Figuras 4.45 e 4.41, respectivamente) são bastante próximos do comportamento exato. Entretanto, enquanto o LC-BHandH(40\%|100\%|0,30) apresenta concavidades ligeiramente mais próximas de zero, o LC-B1B95(40\%|100\%|0,40) apresentou PDMA ligeiramente mais preciso para o conjunto de calibração.

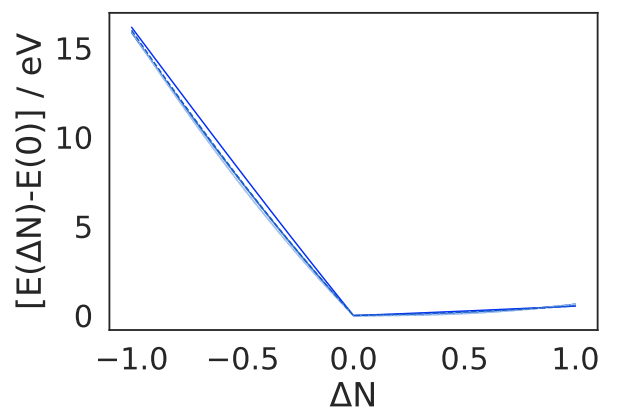

Exp BHandH $(2.11,0.69)$

Exp BHandH 40\% (3.10,0.85)

Exp LC-BHandH $(40 \%|100 \%| 0,30)(0.63,0.05)$

Otm BHandH otm $(2.12,0.70)$

Otm BHandH 40\% $(3.10,0.85)$

Otm LC-BHandH $(40 \%|100 \%| 0,10)(2.19,0.28)$

(a) $\mathrm{HF}$ 


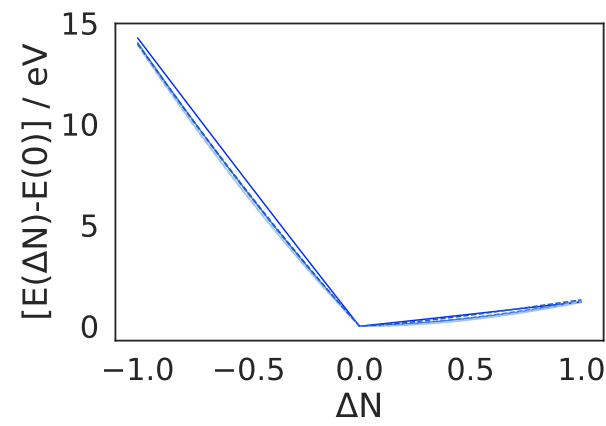

Exp BHandH $(1.85,0.83)$

Exp BHandH 40\% $(2.46,1.09)$

Exp LC-BHandH $(40 \%|100 \%| 0,30)(0.27,0.03)$

Otm BHandH otm $(1.86,0.83)$

Otm BHandH 40\% $(2.47,1.09)$

- Otm LC-BHandH $(40 \%|100 \%| 0,10)(1.59,0.42)$

(b) $\mathrm{CO}$

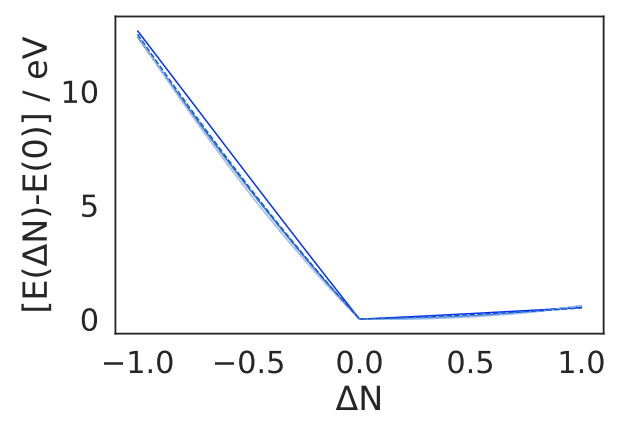

Exp BHandH $(1.76,0.63)$

Exp BHandH 40\% $(2.58,0.76)$

Exp LC-BHandH $(40 \%|100 \%| 0,30)(0.21,0.05)$

Otm BHandH otm $(1.77,0.63)$

Otm BHandH $40 \%(2.58,0.77)$

Otm LC-BHandH $(40 \%|100 \%| 0,10)(1.68,0.21)$

(c) $\mathrm{H}_{2} \mathrm{O}$

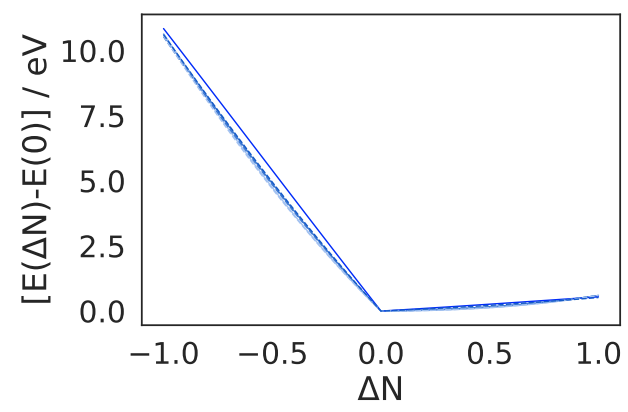

Exp BHandH $(1.65,0.55)$

Exp BHandH $40 \%(2.33,0.68)$

Exp LC-BHandH $(40 \%|100 \%| 0,30)(0.07,0.04)$

Otm BHandH otm $(1.65,0.56)$

Otm BHandH 40\% $(2.33,0.68)$

Otm LC-BHandH $(40 \%|100 \%| 0,10)(1.43,0.16)$

(d) $\mathrm{NH}_{3}$

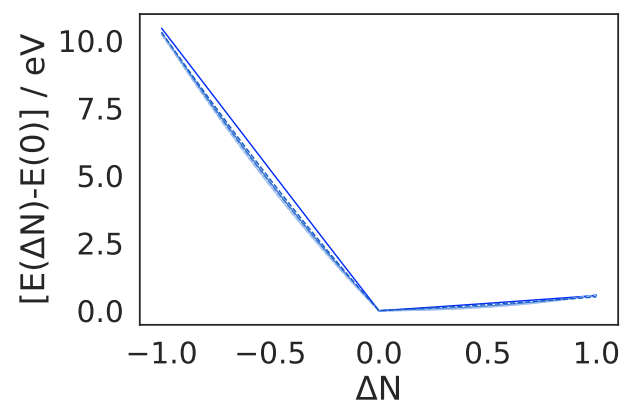

Exp BHandH $(1.59,0.51)$

Exp BHandH $40 \%(2.05,0.62)$

Exp LC-BHandH $(40 \%|100 \%| 0,30)(0.06,0.03)$

Otm BHandH otm $(1.60,0.51)$

Otm BHandH 40\% $(2.06,0.62)$

Otm LC-BHandH $(40 \%|100 \%| 0,10)(1.19,0.12)$

(e) $\mathrm{PH}_{3}$ 


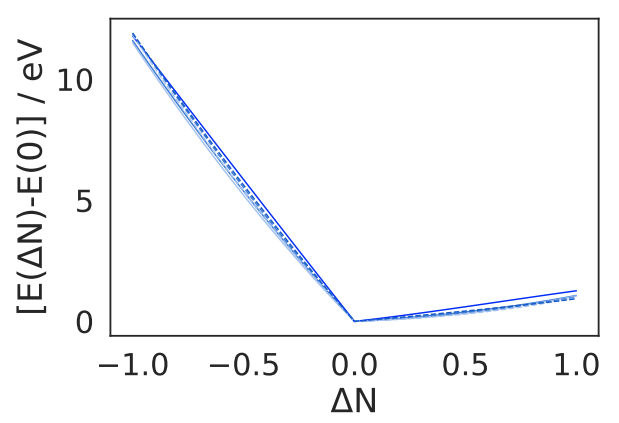

Exp BHandH $(1.69,0.60)$

Exp BHandH 40\% $(2.17,0.76)$

Exp LC-BHandH $(40 \%|100 \%| 0,30)(0.16,0.11)$

Otm BHandH otm $(1.68,0.58)$

Otm BHandH 40\% $(2.16,0.74)$

Otm LC-BHandH(40\%|100\%|0,10) $(1.29,0.16)$

(f) $\mathrm{PF}_{3}$

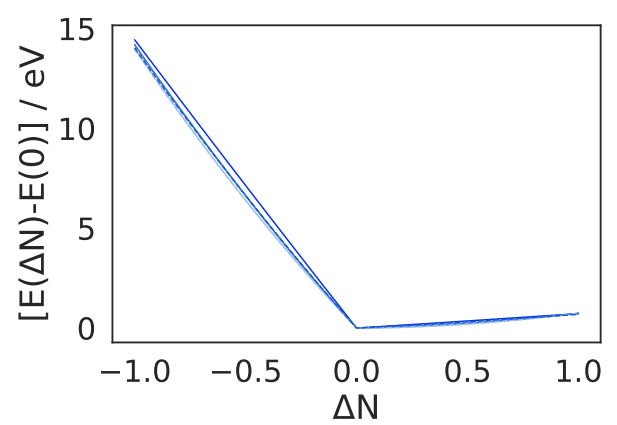

Exp BHandH $(1.84,0.49)$

Exp BHandH 40\% $(2.36,0.68)$

Exp LC-BHandH $(40 \%|100 \%| 0,30)(0.31,0.02)$

Otm BHandH otm $(1.86,0.49)$

Otm BHandH 40\% $(2.38,0.68)$

Otm LC-BHandH $(40 \%|100 \%| 0,10)(1.49,0.11)$

(g) $\mathrm{BHF}_{2}$

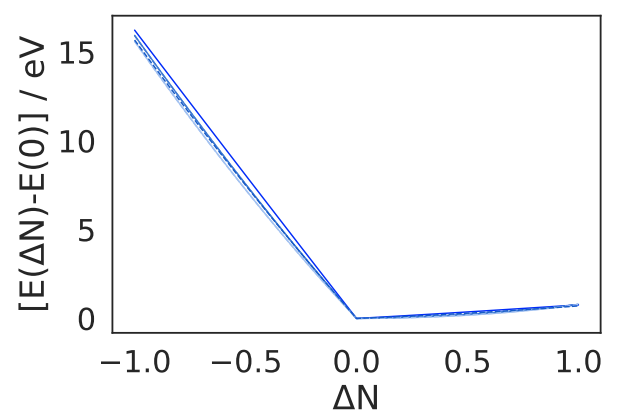

Exp BHandH $(1.61,0.66)$

Exp BHandH 40\% (2.20,0.80)

Exp LC-BHandH $(40 \%|100 \%| 0,30)(0.19,0.06)$

Otm BHandH otm $(1.62,0.66)$

Otm BHandH 40\% $(2.22,0.81)$

Otm LC-BHandH $(40 \%|100 \%| 0,10)(1.33,0.23)$

(h) $\mathrm{BF}_{3}$

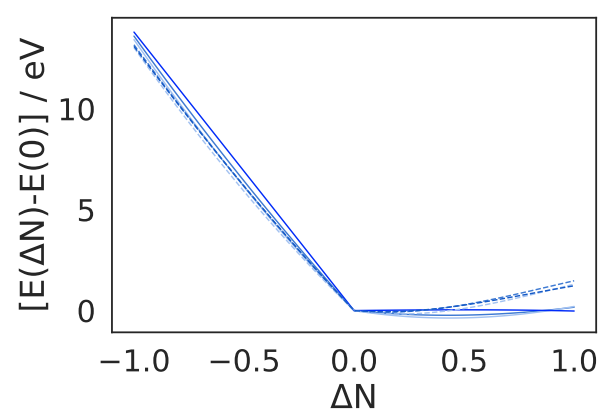

Exp BHandH $(1.52,1.24)$

Exp BHandH 40\% $(2.33,1.86)$

Exp LC-BHandH $(40 \%|100 \%| 0,30)(-0.01,-0.19)$

Otm BHandH otm $(1.68,1.80)$

Otm BHandH 40\% $(2.43,2.20)$

Otm LC-BHandH $(40 \%|100 \%| 0,10)(1.53,1.37)$

(i) $\mathrm{F}_{2} \mathrm{O}$ 


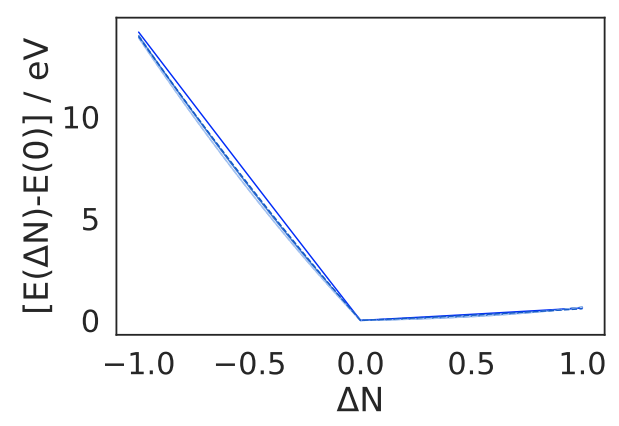

Exp BHandH $(1.77,0.45)$

Exp BHandH $40 \%(2.35,0.55)$

- Exp LC-BHandH $(40 \%|100 \%| 0,30)(0.15,0.03)$

Otm BHandH otm $(1.78,0.45)$

Otm BHandH $40 \%(2.35,0.55)$

Otm LC-BHandH $(40 \%|100 \%| 0,10)(1.45,0.10)$

(j) $\mathrm{CH}_{4}$

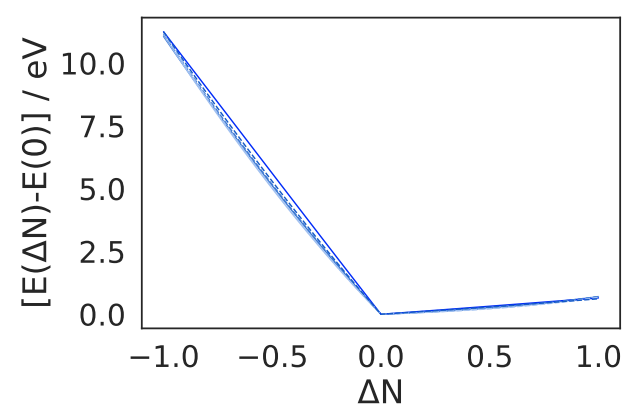

Exp BHandH $(1.66,0.39)$

Exp BHandH 40\% $(2.22,0.46)$

Exp LC-BHandH $(40 \%|100 \%| 0,30)(0.07,0.02)$

Otm BHandH otm $(1.67,0.39)$

Otm BHandH $40 \%(2.22,0.47)$

Otm LC-BHandH $(40 \%|100 \%| 0,10)(1.33,0.07)$

(k) $\mathrm{C}_{2} \mathrm{H}_{2}$

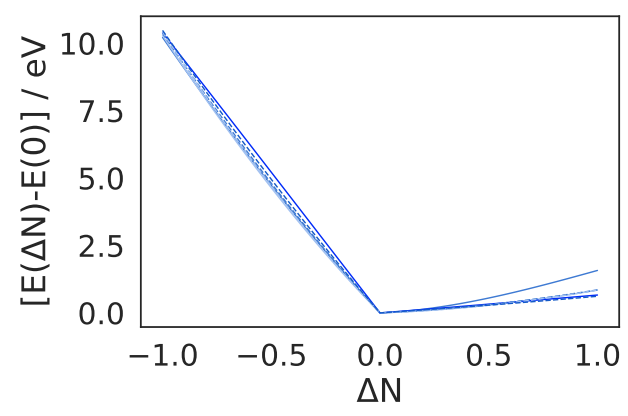

Exp BHandH $(1.50,0.94)$

Exp BHandH 40\% $(2.01,0.55)$

- Exp LC-BHandH $(40 \%|100 \%| 0,30)(-0.08,0.03)$

Otm BHandH otm $(1.51,0.47)$

Otm BHandH 40\% $(2.02,0.55)$

Otm LC-BHandH $(40 \%|100 \%| 0,10)(1.14,0.08)$

(l) $\mathrm{C}_{2} \mathrm{H}_{4}$

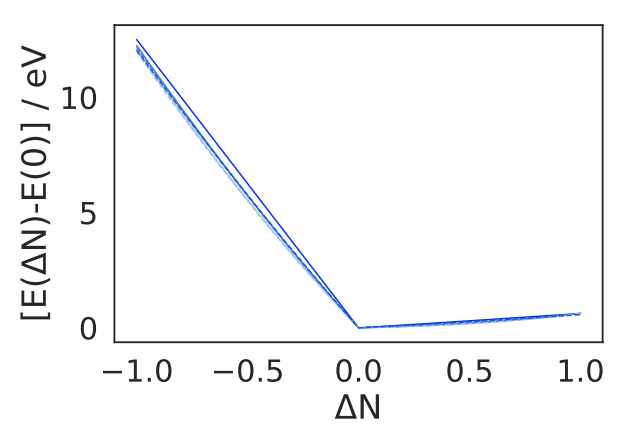

Exp BHandH $(1.48,0.43)$

Exp BHandH $40 \%(1.94,0.53)$

Exp LC-BHandH $(40 \%|100 \%| 0,30)(-0.01,0.03)$

Otm BHandH otm $(1.48,0.43)$

Otm BHandH 40\% $(1.95,0.53)$

Otm LC-BHandH $(40 \%|100 \%| 0,10)(1.07,0.09)$

(m) $\mathrm{C}_{2} \mathrm{H}_{6}$

Figura 4.45: Avaliação do Teorema de Janak para melhores funcionais baseados no BHandH na base aug-pcJ-2. $\Delta N=-1$ corresponde ao cátion e $\Delta N=1$ ao ânion. A curvatura das curvas catiônica e aniônica estão indicadas, respectivamente, ao lado DFT. 
A Figura 4.46 apresenta os resultados de concavidade obtidos com os melhores funcionais baseados no $\omega$ B97X. O $\omega$ B97X (14,49\% exp. $\left., 17,41 \%_{\text {otm. }}^{\text {geom. }}\right)$ é o mais exato para geometrias experimentais, sendo as concavidades razoavelmente próximas de zero. O $\omega \mathrm{B} 97 \mathrm{X}(20 \%|100 \%| \#)\left(10,27 \%_{\text {exp. }}^{\text {geom. }}, 10,55 \%\right.$ otm. . $)$ diminui a concavidade catiônica para a otimização, sendo similar ao $\omega$ B97X (a concavidade catiônica é um pouco mais próxima de zero).

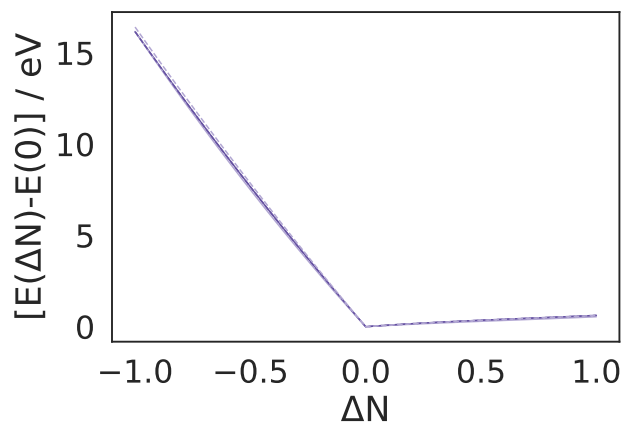

Exp wB97X $(1.69,-0.17)$

Exp wB97X(20\%|100\%|\#) $(2.33,-0.09)$

Otm wB97X $(1.69,-0.17)$

Otm wB97X(20\%|100\%|\#) $(1.42,-0.17)$

(a) $\mathrm{HF}$

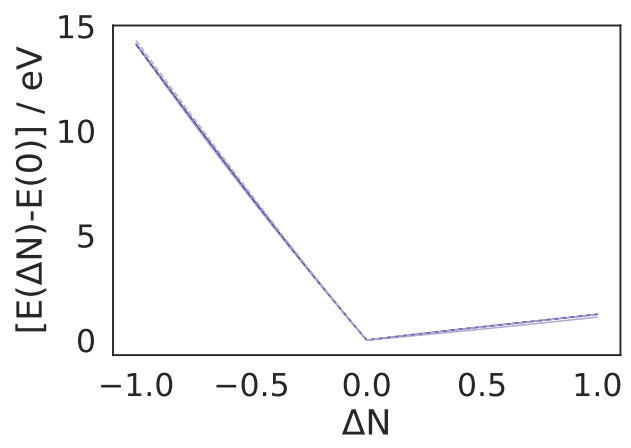

Exp wB97X $(0.96,-0.07)$

Exp wB97X(20\%|100\%|\#) $(1.29,0.08)$

Otm wB97X $(0.97,-0.07)$

Otm wB97X(20\%|100\%|\#) $(0.86,-0.06)$

(b) $\mathrm{CO}$

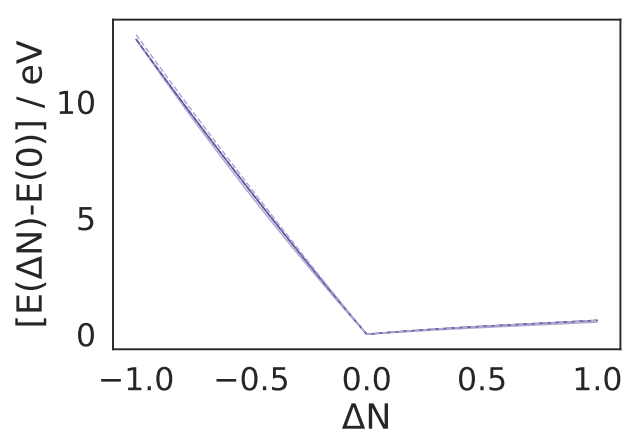

Exp $w B 97 X(0.97,-0.16)$

$\operatorname{Exp} w B 97 \times(20 \%|100 \%| \#)(1.59,-0.10)$

Otm wB97X $(0.97,-0.16)$

Otm wB97X(20\%|100\%|\#) $(0.77,-0.16)$

(c) $\mathrm{H}_{2} \mathrm{O}$ 


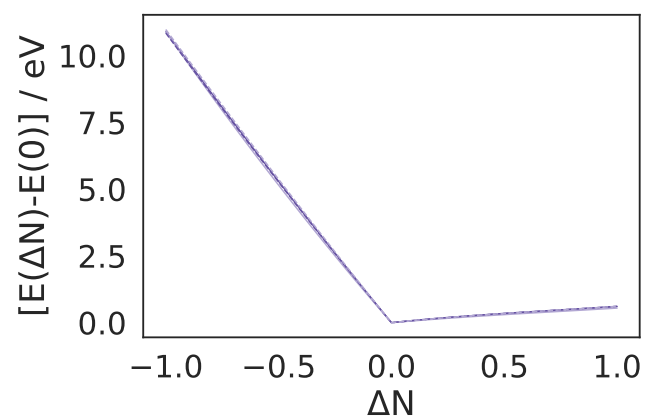

Exp wB97X $(0.64,-0.16)$

Exp wB97X(20\%|100\%|\#) $(1.19,-0.11)$

Otm wB97X $(0.64,-0.16)$

Otm wB97X(20\%|100\%|\#) $(0.49,-0.16)$

(d) $\mathrm{NH}_{3}$

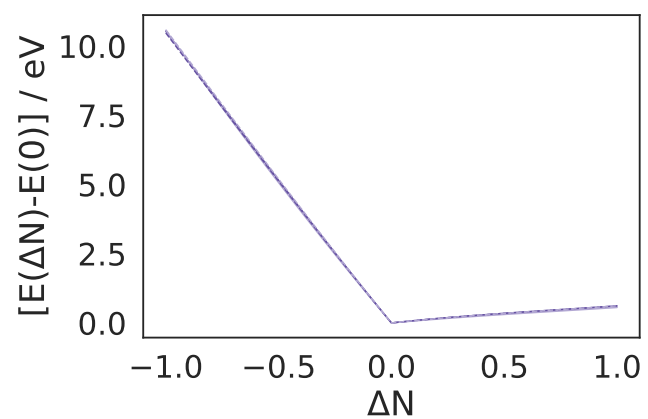

Exp wB97X $(0.45,-0.16)$

Exp wB97X(20\%|100\%|\#) $(0.87,-0.11)$

Otm wB97X $(0.47,-0.16)$

Otm wB97X(20\%|100\%|\#) $(0.40,-0.16)$

(e) $\mathrm{PH}_{3}$

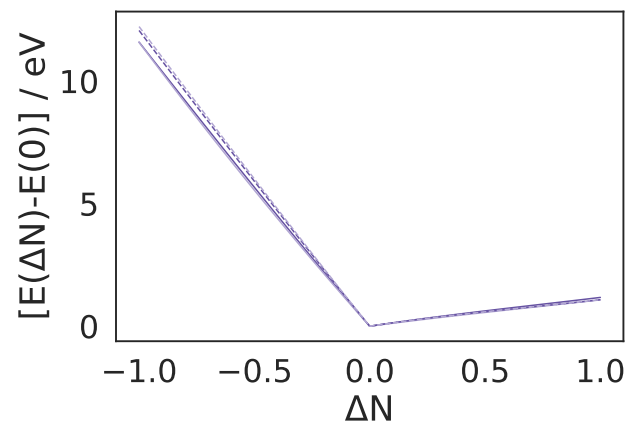

Exp wB97X $(0.52,-0.15)$

Exp wB97X(20\%|100\%|\#) $(0.97,-0.10)$

Otm wB97X $(0.48,-0.20)$

Otm wB97X(20\%|100\%|\#) $(0.42,-0.19)$

(f) $\mathrm{PF}_{3}$

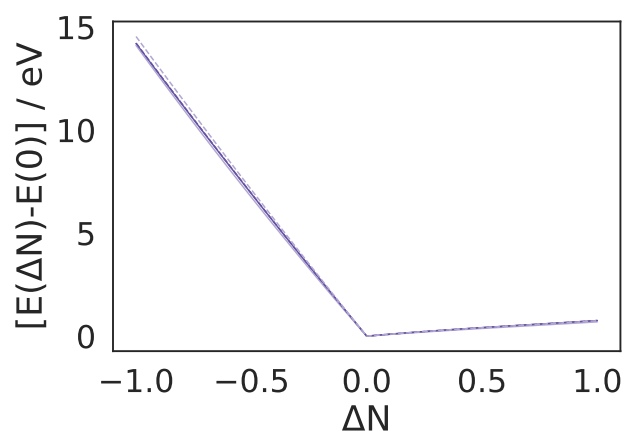

Exp wB97X $(0.76,-0.14)$

$\operatorname{Exp} w B 97 X(20 \%|100 \%| \#)(1.26,-0.11)$

Otm wB97X $(0.75,-0.13)$

Otm wB97X(20\%|100\%|\#) $(0.67,-0.14)$

(g) $\mathrm{BHF}_{2}$ 


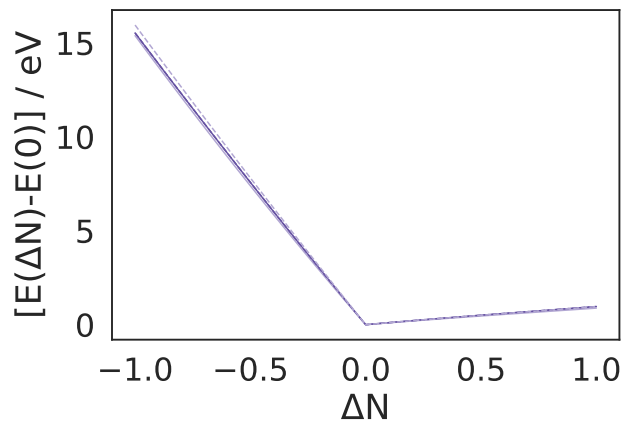

Exp wB97X $(0.77,-0.08)$

Exp wB97X(20\%|100\%|\#) $(1.21,-0.09)$

Otm wB97X $(0.76,-0.08)$

Otm wB97X(20\%|100\%|\#) $(0.66,-0.08)$

(h) $\mathrm{BF}_{3}$

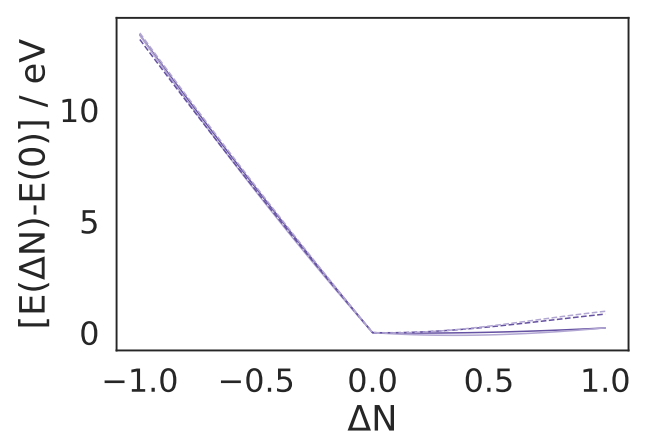

Exp wB97X $(0.83,0.36)$

Exp wB97X(20\%|100\%|\#) $(1.43,0.83)$

Otm wB97X $(0.88,0.64)$

Otm wB97X(20\%|100\%|\#) $(0.73,0.75)$

(i) $\mathrm{F}_{2} \mathrm{O}$

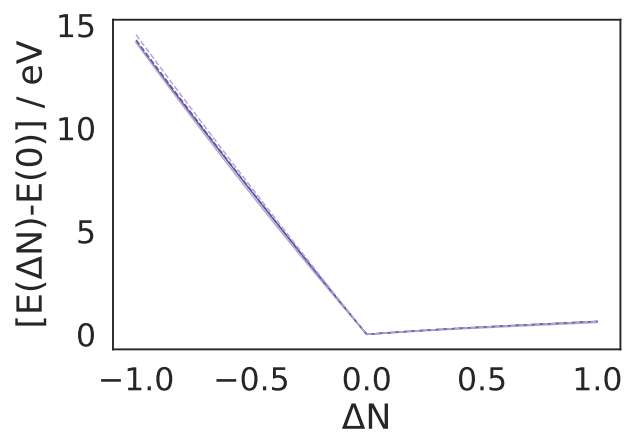

Exp $w B 97 X(0.60,-0.15)$

$\operatorname{Exp} w B 97 X(20 \%|100 \%| \#)(1.18,-0.11)$

Otm wB97X $(0.69,-0.15)$

Otm wB97X(20\%|100\%|\#) $(0.57,-0.15)$

(j) $\mathrm{CH}_{4}$

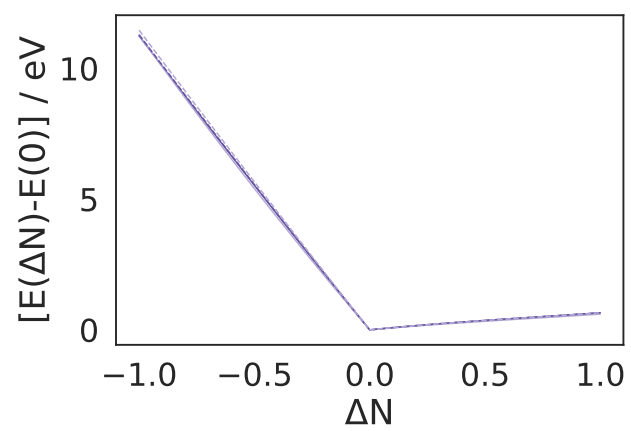

Exp wB97X $(0.37,-0.14)$

Exp wB97X(20\%|100\%|\#) $(0.93,-0.11)$

Otm wB97X $(0.37,-0.13)$

Otm wB97X(20\%|100\%|\#) $(0.28,-0.14)$

(k) $\mathrm{C}_{2} \mathrm{H}_{2}$ 


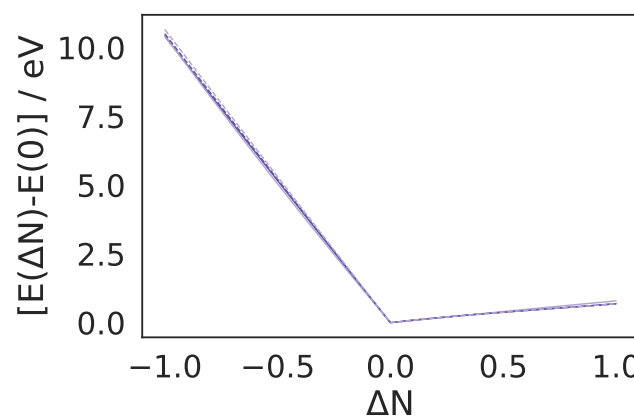

Exp wB97X $(0.18,-0.15)$

Exp wB97X(20\%|100\%|\#) $(0.69,-0.03)$

Otm wB97X $(0.18,-0.14)$

Otm wB97X(20\%|100\%|\#) $(0.10,-0.15)$

(l) $\mathrm{C}_{2} \mathrm{H}_{4}$

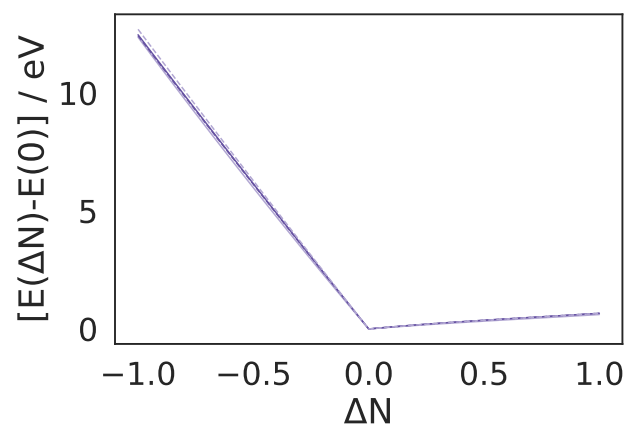

Exp wB97X $(0.33,-0.14)$

Exp wB97X(20\%|100\%|\#) $(0.79,-0.10)$

Otm wB97X $(0.34,-0.14)$

Otm wB97X(20\%|100\%|\#) $(0.28,-0.14)$

(m) $\mathrm{C}_{2} \mathrm{H}_{6}$

Figura 4.46: Avaliação do Teorema de Janak para melhores funcionais baseados no $\omega$ B97X na base aug-pcJ-2. $\Delta N=-1$ corresponde ao cátion e $\Delta N=1$ ao ânion. A curvatura das curvas catiônica e aniônica estão indicadas, respectivamente, ao lado DFT.

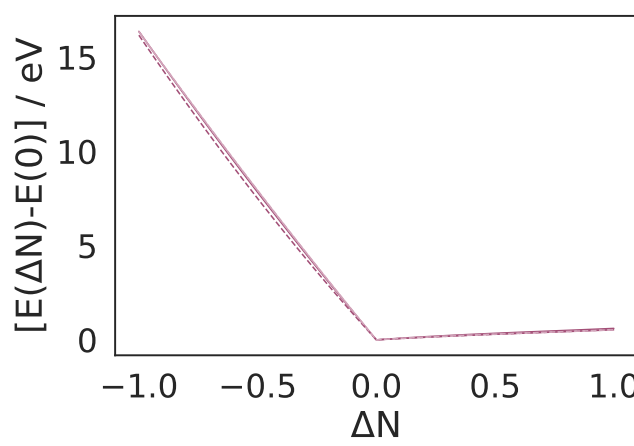

Exp wB97XD (1.41,-0.18)

Exp wB97XD(\#|\#|0,35) $(1.01,-0.14)$

Otm wB97XD $(2.33,-0.09)$

Otm wB97XD(\#|\#|0,35) $(1.02,-0.14)$

(a) $\mathrm{HF}$

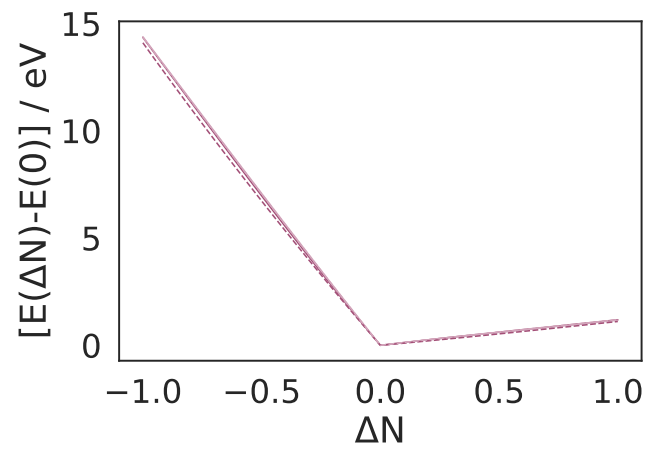

Exp wB97XD $(0.83,-0.07)$

$\operatorname{Exp} w B 97 X D(\#|\#| 0,35)(0.45,-0.09)$

Otm wB97XD $(1.29,0.09)$

Otm wB97XD $(\#|\#| 0,35)(0.46,-0.08)$

(b) $\mathrm{CO}$ 


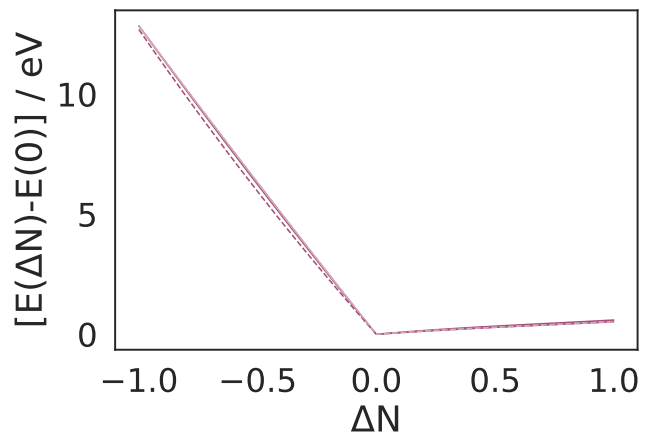

Exp wB97XD $(0.75,-0.17)$

Exp wB97XD(\#|\#|0,35) $(0.41,-0.13)$

Otm wB97XD $(1.60,-0.10)$

Otm wB97XD(\#|\#|0,35) $(0.42,-0.12)$

(c) $\mathrm{H}_{2} \mathrm{O}$

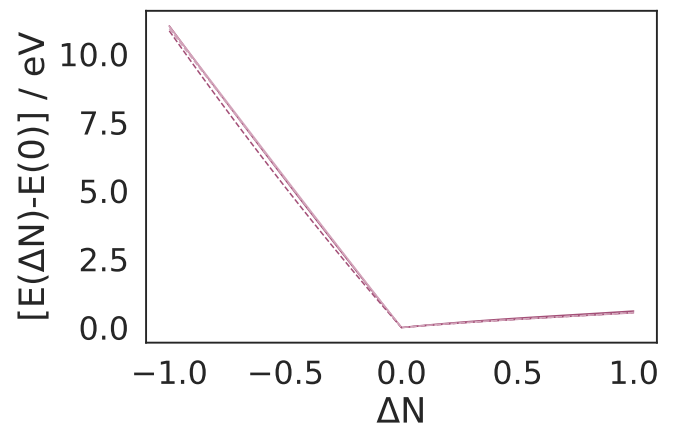

$\operatorname{Exp} w B 97 X D(0.47,-0.17)$

Exp wB97XD(\#|\#|0,35) $(0.17,-0.13)$

Otm wB97XD $(1.19,-0.11)$

Otm wB97XD(\#|\#|0,35) $(0.18,-0.12)$

(d) $\mathrm{NH}_{3}$

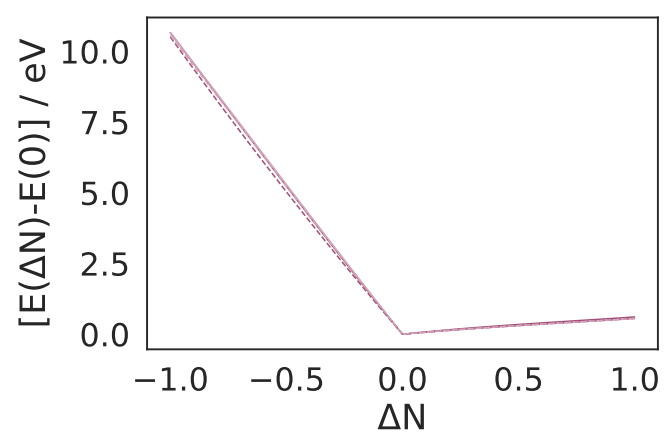

$\operatorname{Exp} w B 97 X D(0.37,-0.16)$

$\operatorname{Exp} w B 97 X D(\#|\#| 0,35)(0.15,-0.12)$

Otm wB97XD $(0.88,-0.11)$

Otm wB97XD(\#|\#|0,35) $(0.16,-0.11)$

(e) $\mathrm{PH}_{3}$

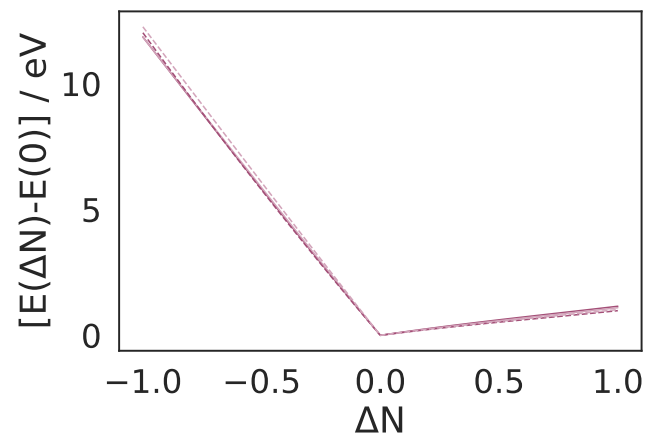

Exp wB97XD $(0.44,-0.16)$

$\operatorname{Exp} w B 97 X D(\#|\#| 0,35)(0.23,-0.13)$

Otm wB97XD $(0.94,-0.13)$

Otm wB97XD(\#|\#|0,35) $(0.21,-0.16)$

(f) $\mathrm{PF}_{3}$ 


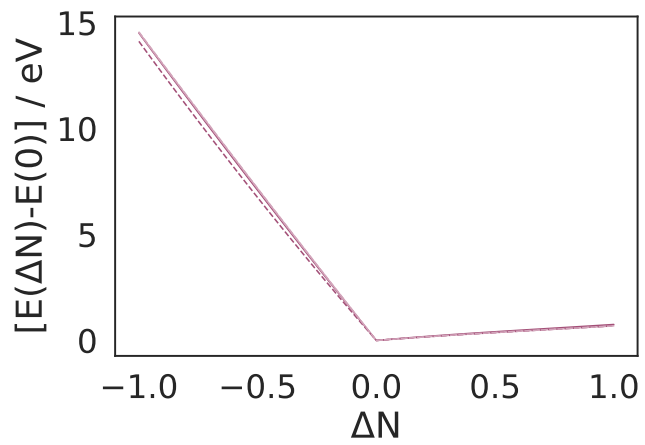

Exp wB97XD $(0.67,-0.14)$

$\operatorname{Exp} w B 97 X D(\#|\#| 0,35)(0.43,-0.11)$

Otm wB97XD $(1.26,-0.11)$

Otm wB97XD $(\#|\#| 0,35)(0.43,-0.12)$

(g) $\mathrm{BHF}_{2}$

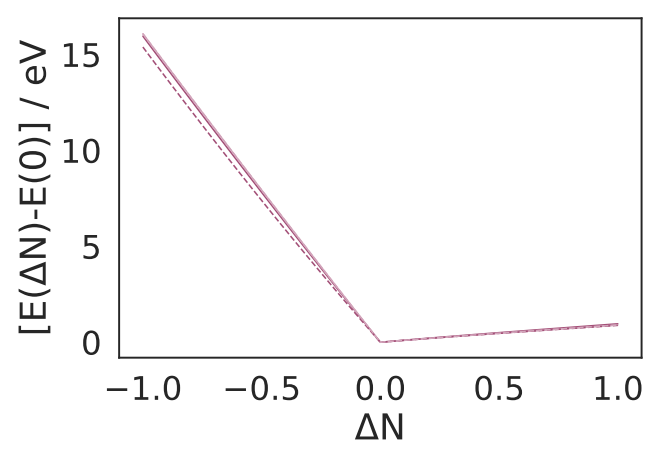

Exp wB97XD $(0.66,-0.08)$

$\operatorname{Exp} w B 97 X D(\#|\#| 0,35)(0.42,-0.07)$

Otm wB97XD (1.21,-0.09)

Otm wB97XD(\#|\#|0,35) $(0.42,-0.07)$

(h) $\mathrm{BF}_{3}$

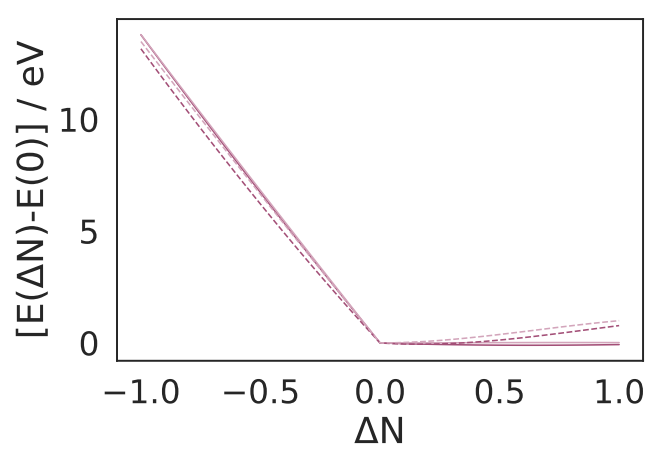

Exp wB97XD $(0.65,0.25)$

$\operatorname{Exp} w B 97 X D(\#|\#| 0,35)(0.31,-0.02)$

Otm wB97XD $(1.47,1.04)$

Otm wB97XD $(\#|\#| 0,35)(0.38,0.48)$

(i) $\mathrm{F}_{2} \mathrm{O}$

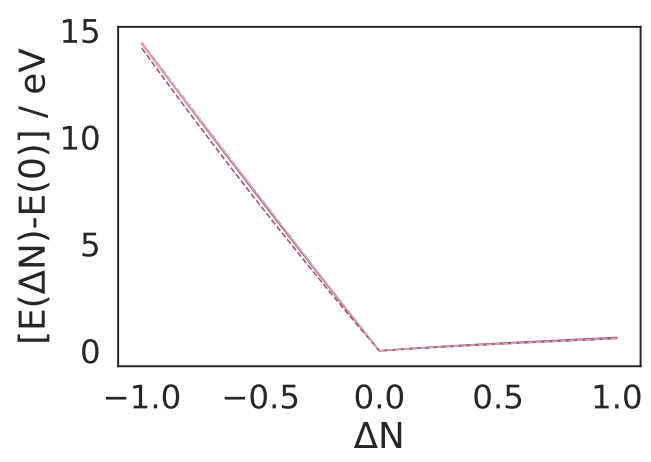

Exp wB97XD $(0.49,-0.15)$

$\operatorname{Exp} w B 97 X D(\#|\#| 0,35)(0.22,-0.11)$

Otm wB97XD $(1.18,-0.11)$

Otm wB97XD (\#|\#|0,35) $(0.28,-0.11)$

(j) $\mathrm{CH}_{4}$ 


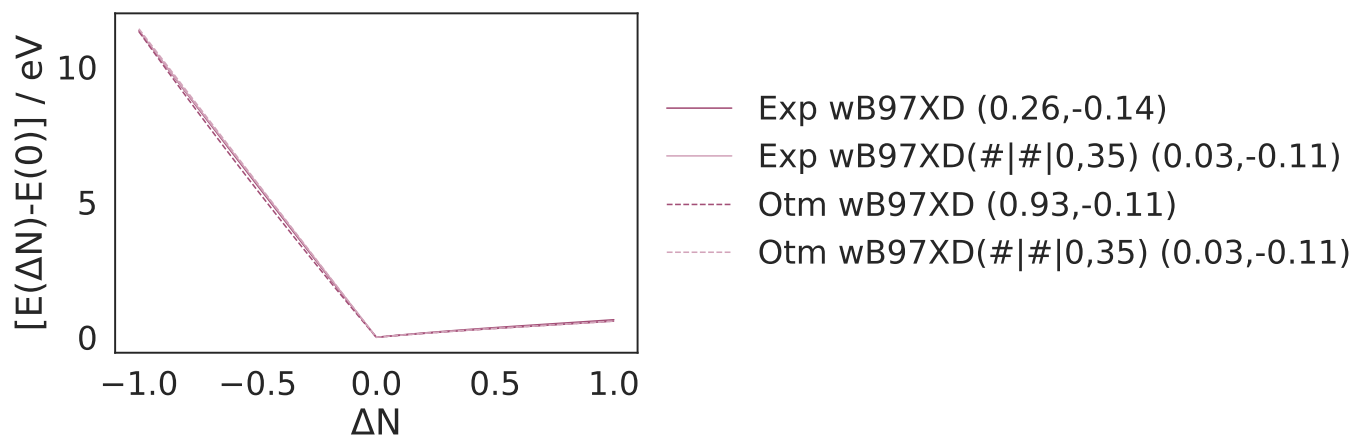

(k) $\mathrm{C}_{2} \mathrm{H}_{2}$

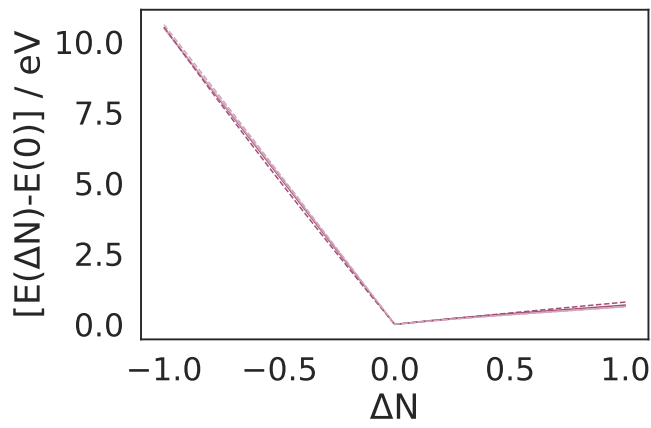

Exp wB97XD $(0.08,-0.15)$

Exp wB97XD(\#|\#|0,35) $(-0.14,-0.11)$

Otm wB97XD $(0.70,-0.03)$

Otm wB97XD(\#|\#|0,35) $(-0.13,-0.11)$

(l) $\mathrm{C}_{2} \mathrm{H}_{4}$

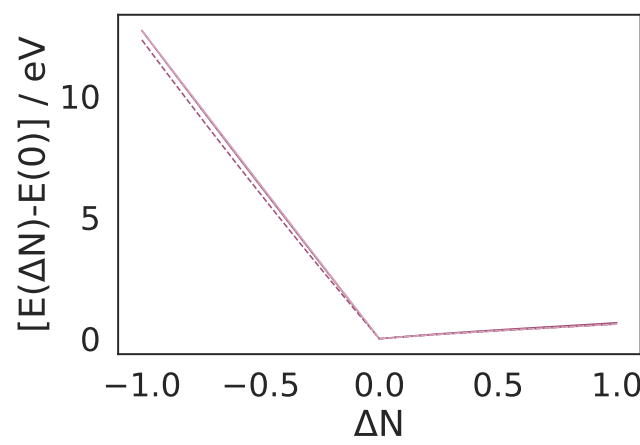

$\operatorname{Exp} w B 97 X D(0.26,-0.14)$

$\operatorname{Exp} w B 97 X D(\#|\#| 0,35)(0.05,-0.11)$

Otm wB97XD $(0.80,-0.10)$

Otm wB97XD $(\#|\#| 0,35)(0.06,-0.11)$

(m) $\mathrm{C}_{2} \mathrm{H}_{6}$

Figura 4.47: Avaliação do Teorema de Janak para melhores funcionais baseados no $\omega$ B97XD na base aug-pcJ-2. $\Delta N=-1$ corresponde ao cátion e $\Delta N=1$ ao ânion. A curvatura das curvas catiônica e aniônica estão indicadas, respectivamente, ao lado DFT.

A Figura 4.47 apresenta os resultados de concavidade obtidos com os melhores funcionais baseados no $\omega \mathrm{B} 97 \mathrm{XD}$. O $\omega \mathrm{B} 97 \mathrm{XD}(\#|\#| 0,35)\left(8,17 \%_{\text {exp. }}^{\text {geom. }}, 10,98 \%_{\text {otm. }}^{\text {geom. }}\right)$ é o mais exato, e não varia com a otimização. O $\omega$ B97XD (16,48\% exp. geom. 17,27\% otm. $\left._{\text {oeom. }}^{\text {gem }}\right)$ aumenta a concavidade catiônica para a otimização.

De modo geral, os DFTs híbridos originais melhoram as concavidades ao serem ajus- 
tados (com exceção do BHandH), devido ao aumento da porcentagem de $E_{X}^{\mathrm{HF}}$. Para os DFTs com CLA, há uma ligeira melhora nas concavidades pois os originais já têm um comportamento muito próximo a um DFT exato (concavidades próximas de 0).

Assim, os funcionais de longo alcance apresentam um comportamento, de acordo com o Teorema de Janak, mais próximo do funcional ideal. Os funcionais construídos LCBHandH(40\%|100\%|0,30) e LC-B1B95(40\%|100\%|0,40) são os menos inexatos dentre os investigados. O $\omega \mathrm{B} 97 \mathrm{XD}(\#|\#| 0,35)$ também destaca-se pela melhora da precisão do funcional original envolvendo apenas o incremento de $\gamma$. Já o $\omega$ B97X é o funcional original com as concavidades mais próximas a zero. Para os funcionais sem CLA, o B972B95 60\% $E_{X}^{\mathrm{HF}}$ destaca-se como o menos inexato. O BHandH, dentre os funcionais sem CLA não modificados, é o menos inexato e com resultado mais preciso para as CAISS.

Com base nos funcionais avaliados, o BHandH e o $\omega$ B97X são os mais recomendados para cálculo de CAISS sem realizar quaisquer modificações. Os funcionais LCBHandH(40\%|100\%|0,30), LC-B1B95(40\%|100\%|0,40) e $\omega \operatorname{B97XD(\# |\# |0,35)~são~ótimos~}$ para obter CAISS precisas, superando o desempenho dos métodos SOPPA. 


\subsection{Teste com diferentes tipos de acoplamento}

Os métodos mais precisos para o cálculo das CAISS no conjunto de calibração são submetidos ao conjunto teste, com mais tipos de acoplamento. As geometrias moleculares são otimizadas para que não seja necessário determinar as geometrias experimentais.

Os DFTs B1B95 40\% $E_{X}^{\mathrm{HF}}$, LC-B1B95(40\%|100\%|0,25), LC-B1B95(40\%|70\%|0,35), BHandH $40 \% E_{X}^{\mathrm{HF}}, \mathrm{LC}-\mathrm{BHandH}(40 \%|100 \%| 0,10)$, LC-BHandH(40\%|80\%|0,15), B972B95 $60 \% E_{X}^{\mathrm{HF}}, \omega \mathrm{B} 97 \mathrm{X}(20 \%|100 \%| \#)$ e $\omega \mathrm{B} 97 \mathrm{XD}(\#|\#| 0,35)$ são utilizados. Também são incluídos os métodos B971//B971 50\% $E_{X}^{\mathrm{HF}}$ e B98//B98 50\% $E_{X}^{\mathrm{HF}}$. A comparação é feita com os funcionais da literatura PBE0, B1B95, B3LYP, B971, B972, B98, BHandH, wB97X e $\omega$ B97XD. Os resultados com conjunto de base aug-pcJ-2 obtidos estão apresentados nas Tabelas 8.505 e 8.506. Os cálculos também são realizados na base HuzIII-su3, e os resultados estão apresentados nas Tabelas 8.507 a 8.508 .

A Figura 4.48 apresenta os valores da PDMA obtidas no conjunto de calibração. A comparação das Figuras 4.48a e 4.48b demonstra que a escolha entre as bases aug-pcJ-2 e HuzIII-su3 não influencia os resultados, pois as PDMAs entre as bases diferem menos de 3,5\% e, principalmente, a ordem de precisão dos funcionais é mantida. Também destacase que todos os valores de PDMA estão entre 30\% e 50\%, indicando a dificuldade de predição de alguns tipos de acoplamento.

As versões modificadas dos funcionais da literatura B1B95, B971 e B98 não apresentam melhoria de precisão; as versões modificadas do BHandH apresentam uma melhora da precisão relativa ao original; e as versões modificadas dos funcionais da literatura B972, $\omega B 97 X$ e $\omega$ B97XD apresentam uma piora da precisão relativa aos originais.

Para facilitar a indicação dos valores da PDMA, a base aug-pcJ-2 é abreviada como "agJ2" e a base HuzIII-su3 como "huz3".

O BHandH $40 \% E_{X}^{\mathrm{HF}}\left(\mathrm{PDMA}=33,12 \%_{\mathrm{agJ} 2}, 35,10 \%\right.$ huz 3$)$ apresenta a melhor precisão entre todos os funcionais avaliados, seguido do LC-BHandH(40\%|100\%|0,10) $(33,54 \%$ agJ2, 35,80\% huz3 $)$ e do LC-BHandH(40\%|80\%|0,15) (34,20\% agJ2, 36,69\% huz3) - este último está de acordo com a situação próxima do patamar de LC-BHandH(40\%|100\%|0,10). Estas 
versões modificadas superam o funcional original BHandH $\left(43,60 \%_{\text {agJ2 }}, 44,62 \%\right.$ huz 3$)$.

O funcional original B1B95 (34,47\% agJ2, 37,31\% huz3) e suas versões B1B95 40\% $E_{X}^{\mathrm{HF}}$ $\left(33,87 \%_{\text {ag.J2 }}, \quad 36,00 \%_{\text {huz3 }}\right), \quad$ LC-B1B95 $(40 \%|100 \%| 0,25) \quad\left(33,89 \%_{\text {agJ2 }}, \quad 35,91 \%_{\text {huz } 3}\right) \quad$ e LC-B1B95(40\%|70\%|0,35) (36,11\% agJ2, 38,41\% huz3) também apresentam boas precisões, seguido de $\omega$ B97X $\left(37,41 \%_{\text {agJ2 }}, 38,75 \%_{\text {huz } 3}\right)$ e $\omega$ B97XD $\left(37,64 \%_{\text {agJ2 }}, 38,71 \%_{\text {huz } 3}\right)$. Entretanto o LC-B1B95(40\%|70\%|0,35) é ligeiramente menos preciso que o B1B95, e é superado pelo LC-B1B95(40\%|100\%|0,25).

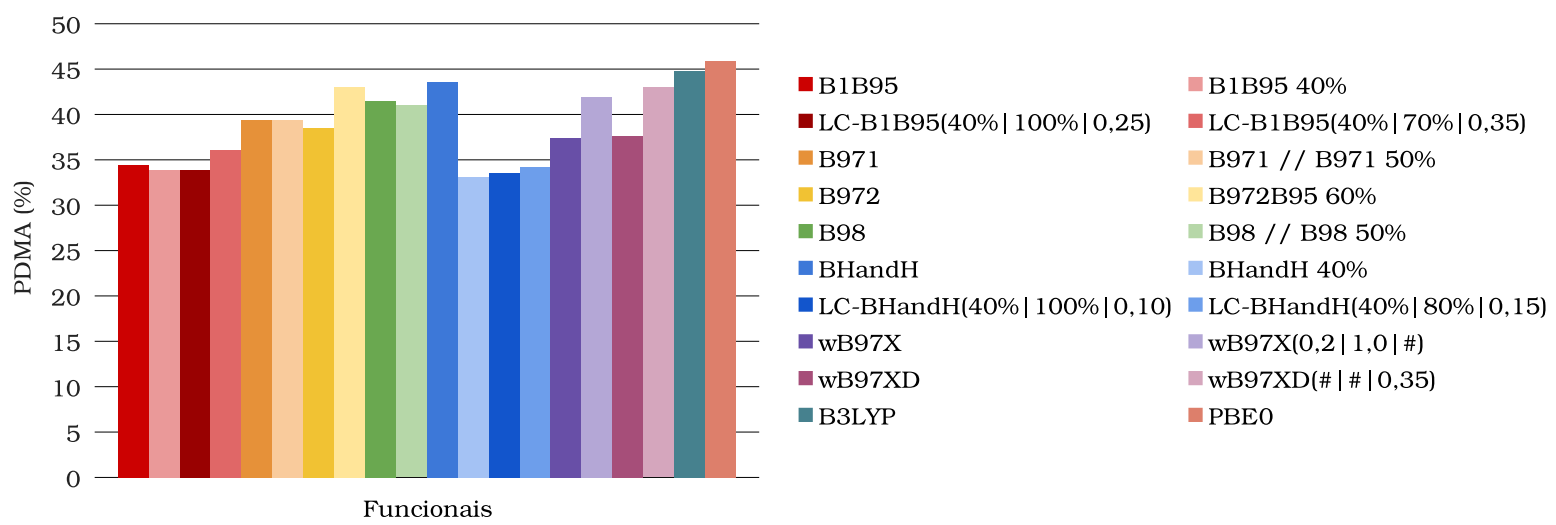

(a) aug-pcJ-2

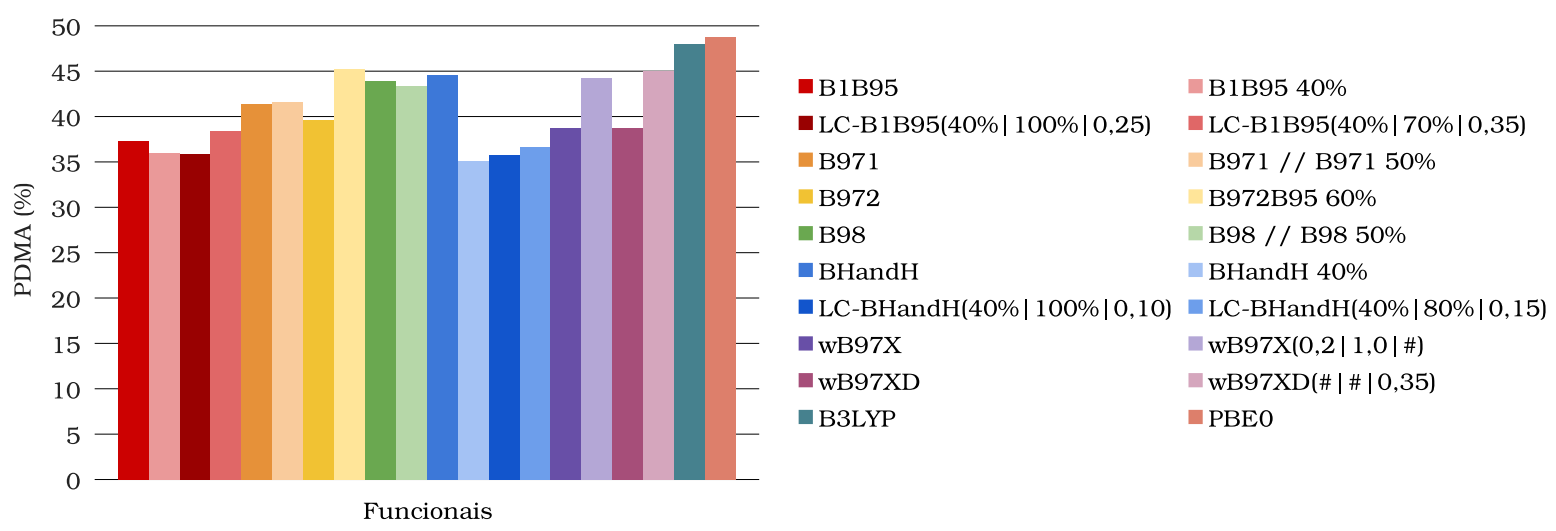

(b) HuzIII-su3

Figura 4.48: PDMA das CAISS do conjunto teste com as bases aug-pcJ-2 e HuzIII-su3 para funcionais selecionados. As geometrias são otimizadas no mesmo nível teórico (exceto para B971//B971 50\% e B98//B98 50\%).

Os métodos B971//B971 50\% $E_{X}^{\mathrm{HF}}\left(39,35 \%\right.$ agJ2, 41,56\% $\left.\%_{\mathrm{huz} 3}\right)$ e B98//B98 $50 \% E_{X}^{\mathrm{HF}}$ $\left(40,99 \%_{\text {agJ2 }}, 43,31 \%_{\text {huz3 }}\right)$ apresentam precisões próximas aos funcionais B971 (39,42\% agJ2, $41,43 \%$ huz 3$)$ e B98 $\left(41,47 \%_{\text {agJ }}, 43,89 \%\right.$ huz 3$)$, respectivamente. 

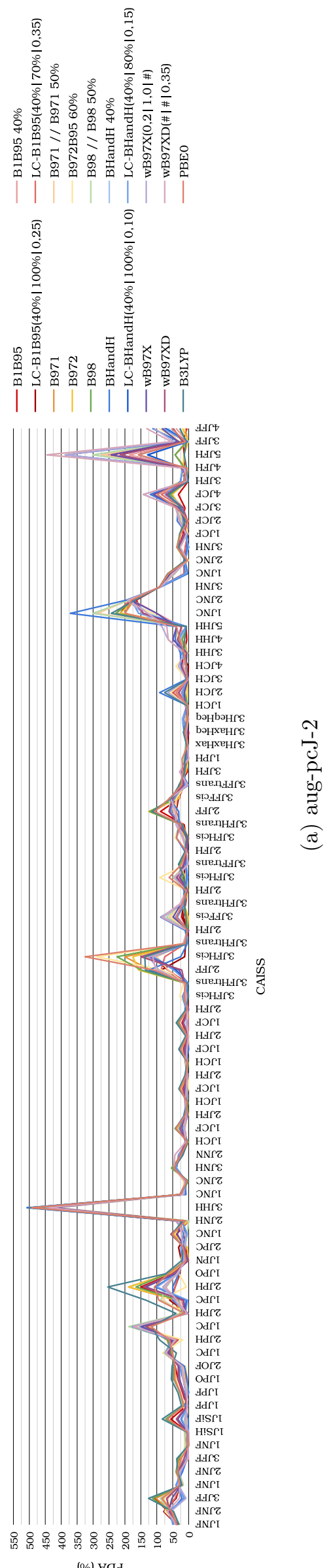

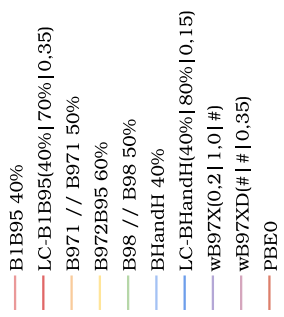

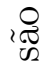
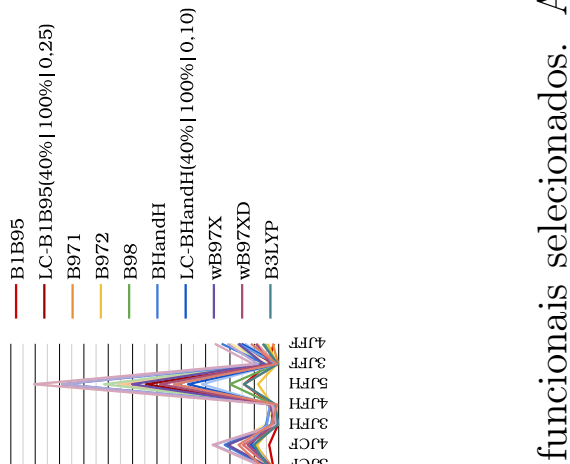

ลี่

$\dddot{2}$

声

昰

อ

i

ن

do 0

ส

of 10

పิ స్

In

듀요

㻤

율율욜

要这

ㅇ. 을

थ

$\circlearrowright$

is

它

$\varangle$ है

ค

के

म

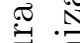

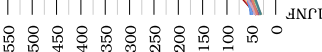

(\%) VGd 
O funcional B972B95 $60 \% E_{X}^{\mathrm{HF}}\left(43,07 \%_{\mathrm{ag} J 2}, 45,26 \%\right.$ huz3 $)$ é superado por funcionais da literatura como o B972 (38,53\% agJ2, 39,65\% huz $)$. Da mesma maneira, os funcionais de longo alcance $\omega \operatorname{B} 97 \mathrm{X}(20 \%|100 \%| \#)\left(41,91 \%_{\text {agJ } 2}, 44,23 \%\right.$ huz3 $)$ e $\omega \operatorname{Bg} 9 \mathrm{XD}(\#|\#| 0,35)$ $\left(42,97 \%_{\text {agJ2 }}, 45,02 \%_{\text {huz } 3}\right)$ são superados por suas versões originais. O B3LYP $(44,77 \%$ agJ2, $\left.47,95 \%_{\text {huz } 3}\right)$ e o PBE0 $\left(45,91 \%_{\text {agJ2 }}, 48,73 \%\right.$ huz 3$)$ apresentam maior imprecisão dentre os DFTs avaliados no conjunto teste, e portanto são menos indicados para o cálculo de CAISS.

A Figura 4.49 apresenta as PDAs para as CAISS do conjunto teste. A escolha da base também não altera as precisão das constantes individualmente.

No geral, as constantes ${ }^{1} J_{\mathrm{PC}}$ da molécula de $\mathrm{P}(\mathrm{O}) \mathrm{CH}_{3} \mathrm{Cl}_{2},{ }^{2} J_{\mathrm{PH}}$ da molécula de $\mathrm{P}\left(\mathrm{CH}_{3}\right)_{3},{ }^{3} J_{\mathrm{HH}}$ da molécula de $\mathrm{CH}_{3} \mathrm{NH}_{2},{ }^{3} J_{\mathrm{FH}_{\text {cis }}}$ da molécula de gem- $\mathrm{C}_{2} \mathrm{H}_{2} \mathrm{~F}_{2},{ }^{1} J_{\mathrm{NC}}$ e ${ }^{2} J_{\mathrm{NC}}$ da molécula de piridina e ${ }^{5} J_{\mathrm{FH}}$ da molécula de fluorbenzeno têm resultados muito pouco precisos. Os resultados para algumas outras constantes também são pouco precisos.

Os funcionais híbridos BHandH $40 \% E_{X}^{\mathrm{HF}}$, B1B95 $40 \% E_{X}^{\mathrm{HF}}$ e B1B95 são sugeridos para investigar CAISS de sistemas similares aos estudados no conjunto teste. Os funcionais de longo-alcance LC-BHandH(40\%|100\%|0,10), LC-B1B95(40\%|100\%|0,25), $\omega$ B97X e $\omega$ B97XD também são sugeridos. 


\section{Recomendações para uso dos funcionais}

A utilização de conjuntos de base como aug-pcJ-2, HuzIII-su3 e aug-cc-pVTZ-J é recomendada para descrever mais adequadamente as propriedades magnéticas. Conjuntos de base que não possuam qualidade mínima triplo- $\zeta$ não são adequados, e devem incluir expoentes orbitais extremamente grandes para melhor descrever as regiões próximas aos núcleos atômicos.

Dentre todos os funcionais avaliados, são recomendados os funcionais BHandH, BHandH $40 \% E_{X}^{\mathrm{HF}}, \mathrm{B} 1 \mathrm{~B} 95, \mathrm{~B} 1 \mathrm{~B} 9540 \% E_{X}^{\mathrm{HF}}, \omega \mathrm{B} 97 \mathrm{X}, \omega \mathrm{B} 97 \mathrm{XD}, \mathrm{LC}-\mathrm{BHandH}(40 \%|100 \%| 0,10)$ e LC-B1B95(40\%|100\%|0,25). Estes funcionais apresentam ótimas precisões para cálculo das CAISS tanto no conjunto de calibração quanto no conjunto teste, além de apresentarem comportamentos razoavelmente exatos, e seus resultados são tão bons quanto os métodos SOPPA.

Tabela 5.1: Porcentagem de troca exata recomendada nos DFTs híbridos da literatura ajustados para o cálculo de CAISS em geometrias experimentais.

\begin{tabular}{lllll}
\hline Funcional & $E_{X}^{\mathrm{HF}}$ & & Funcional & $E_{X}^{\mathrm{HF}}$ \\
\cline { 1 - 2 } B1B95 & $50 \%$ & & M05 & $0 \%$ \\
B3LYP & $40 \%$ & & M05-2X & $0 \%$ \\
BHandHLYP & $40 \%$ & & M06 & $0 \%$ \\
B3P86 & $40 \%$ & & M06-HF & $0 \%$ \\
B971 & $50 \%$ & & M06-2X & $50 \%$ \\
B972 & $40 \%$ & & O3LYP & $40 \%$ \\
B98 & $50 \%$ & & PBE & $30 \%$ \\
BHandH & $50 \%$ & & PBE0 & $30 \%$ \\
BMK & $50 \%$ & & PW91 & $30 \%$ \\
BP86 & $40 \%$ & & TPSSh & $40 \%$ \\
B3PW91 & $30 \%$ & & X3LYP & $40 \%$ \\
\hline
\end{tabular}

Dentre os funcionais da literatura, recomenda-se utilizar BHandH, $\omega$ B97X, $\omega$ B97XD, $\omega B 97$, B971, B98, PBE0, B972, CAM-B3LYP e B1B95 para cálculo de CAISS. Funcionais M06HF, M05, M06, BP86, PW91 e PBE não são adequados para esse tipo de cálculo. 
É recomendado utilizar entre 30\% e 50\% de troca exata nos funcionais híbridos para obter CAISS mais precisas. A Tabela 5.1 apresenta a porcentagem de $E_{X}^{\mathrm{HF}}$ recomendada para cada um dos DFTs híbridos da literatura utilizados. O ajuste dos funcionais das famílias M05 e M06 não é aconselhado, sendo preferível utilizar as versões originais (evitando M06HF).

É recomendado utilizar 40\% de troca exata nos funcionais B1B95, BHandH e PBE0 (PBE) para rotinas de otimização de geometrias e cálculo das CAISS; para o B972 utilizar 50\% de troca exata. Para B971 e B98, é recomendado utilizar 50\% de troca exata e realizar a otimização com as versões originais destes DFTs.

Para os funcionais híbridos construídos a partir de funcionais de troca e de correlação, é recomendado utilizar entre $30 \%$ e $50 \%$ de troca exata nos funcionais híbridos para obter CAISS mais precisas. A Tabela 5.2 apresenta a porcentagem de $E_{X}^{\mathrm{HF}}$ recomendada para cada um dos DFTs híbridos construídos. Recomenda-se utilizar troca B971 ou B98 com correlação LYP, P86, PBE, PW91 ou TPSS, ou então utilizar troca B, B972, O, PBE, PW91 ou S com correlação B95, B971, B972 ou B98.

Tabela 5.2: Porcentagem de troca exata recomendada nos DFTs híbridos construídos para o cálculo de CAISS em geometrias experimentais.

\begin{tabular}{llllllllll}
\hline $\begin{array}{l}E_{X}^{\text {DFT }} \\
E_{C}^{\mathrm{DFT}}\end{array}$ & B95 & B971 & B972 & B98 & LYP & P86 & PBE & PW91 & TPSS \\
\hline B & $50 \%$ & $40 \%$ & $30 \%$ & $40 \%$ & $40 \%$ & $40 \%$ & $30 \%$ & $30 \%$ & $40 \%$ \\
B971 & $60 \%$ & $50 \%$ & $40 \%$ & $50 \%$ & $50 \%$ & $50 \%$ & $50 \%$ & $50 \%$ & $50 \%$ \\
B972 & $60 \%$ & $50 \%$ & $40 \%$ & $50 \%$ & $50 \%$ & $50 \%$ & $50 \%$ & $50 \%$ & $50 \%$ \\
B98 & $60 \%$ & $50 \%$ & $40 \%$ & $50 \%$ & $50 \%$ & $50 \%$ & $50 \%$ & $50 \%$ & $50 \%$ \\
O & $50 \%$ & $40 \%$ & $40 \%$ & $40 \%$ & $40 \%$ & $50 \%$ & $40 \%$ & $40 \%$ & $40 \%$ \\
PBE & $50 \%$ & $40 \%$ & $30 \%$ & $40 \%$ & $40 \%$ & $40 \%$ & $30 \%$ & $30 \%$ & $40 \%$ \\
PW91 & $50 \%$ & $40 \%$ & $30 \%$ & $40 \%$ & $40 \%$ & $40 \%$ & $30 \%$ & $30 \%$ & $40 \%$ \\
S & $60 \%$ & $50 \%$ & $40 \%$ & $50 \%$ & $50 \%$ & $50 \%$ & $50 \%$ & $50 \%$ & $50 \%$ \\
TPSS & $40 \%$ & $40 \%$ & $30 \%$ & $40 \%$ & $40 \%$ & $40 \%$ & $40 \%$ & $40 \%$ & $40 \%$ \\
\hline
\end{tabular}

Para a otimização de geometria e cálculo das CAISS, recomenda-se troca B972 com correlação B95 e 60\% de troca exata. Apesar disso, usar troca B972 ou correlação B95 também pode gerar bons resultados.

Dos funcionais com CLA, é recomendado realizar o ajuste dos parâmetros $\alpha, \alpha+\beta$ 
e $\gamma$ de acordo com a Tabela 5.3. Para a otimização de geometrias e cálculo das CAISS, também são sugeridos os ajustes da Tabela 5.3 para a família $\omega$ B97.

Tabela 5.3: Melhores modificações dos funcionais de longo alcance usando geometrias experimentais.

\begin{tabular}{lccc}
\hline Funcionais & $\alpha$ & $\alpha+\beta$ & $\gamma$ \\
\hline CAM-B3LYP & $30 \%$ & $100 \%$ & 0,33 \\
$\omega$ B97 & $20 \%$ & $80 \%$ & 0,40 \\
$\omega$ B97X & $20 \%$ & $100 \%$ & 0,30 \\
& $15,77 \%$ & $100 \%$ & 0,40 \\
$\omega$ B97XD & $22,20 \%$ & $100 \%$ & 0,35 \\
\hline
\end{tabular}

É recomendado utilizar os funcionais construídos LC-B1B95 e LC-BHandH, construídos a partir dos funcionais BB95 e SLYP, respectivamente, com os parâmetros $\alpha, \alpha+\beta$ e $\gamma$ de acordo com a Tabela 5.4. Para a otimização de geometrias e cálculo das CAISS, é sugerido utilizar o parâmetro $\gamma$ de 0,25 para o LC-B1B95 e 0,10 para o LC-BHandH; os parâmetros $\alpha$ e $\alpha+\beta$ são mantidos de acordo com a Tabela 5.4 .

Tabela 5.4: Melhores modificações dos funcionais de longo alcance usando geometrias experimentais.

\begin{tabular}{llccc}
\hline Funcionais & Corresponde & $\alpha$ & $\alpha+\beta$ & $\gamma$ \\
\hline LC-B1B95 & LC-BB95 & $40 \%$ & $100 \%$ & 0,40 \\
LC-BHandH & LC-SLYP & $40 \%$ & $100 \%$ & 0,30 \\
\hline
\end{tabular}




\section{Conclusões}

A utilização dos conjuntos de base aug-pcJ-2 e HuzIII-su3 produz resultados semelhantes, e portanto é mais garantido que os resultados obtidos independem da base utilizada. Entretanto, é importante ressaltar que essas bases foram construídas para cálculo de propriedades magnéticas, e assim é recomendado o uso de um conjunto de base adequado para cálculo de propriedades magnéticas (qualidade mínima triplo- $\zeta$ com função de polarização)!

Os funcionais BHandH, B1B95, B971, B972, B98, $\omega$ B97X e $\omega$ B97XD apresentam, portanto resultados bastantes promissores. É interessante notar que todos esses funcionais são funcionais de Becke (ou desenvolvidos a partir dos funcionais de Becke), e são

superiores aos demais DFTs. A variação da porcentagem de $E_{X}^{\mathrm{HF}}$ contribui para uma considerável melhora na precisão dos funcionais. A adição de correções vibracionais ou a otimização de geometrias não apresentam melhoras significativas na precisão dos DFTs para as condições estudadas.

Por outro lado, a variação da porcentagem de $E_{X}^{\mathrm{HF}}$ em função da distância intereletrônica permite obter resultados ainda mais precisos, sendo promissor investir em funcionais que apresentem correção de longo alcance. Além disso, também apresentam, pelo Teorema de Janak, um comportamento mais próximo do desejado para um funcional exato. Os funcionais $\omega \operatorname{B} 97 \mathrm{XD}(\#|\#| 0,35)$ e $\omega \operatorname{B97X}(0,2|1,0| \#)$ são ótimos para o conjunto de calibração, porém não são tão precisos para o conjunto teste quanto suas versões originais. Já os funcionais LC-BHandH(40\%|100\%|0,10) e LC-B1B95(40\%|100\%|0,25) são precisos para os dois conjuntos, sendo portanto dois DFTs que precisam ser melhor estudados em outros aspectos para avaliar a viabilidade em outros usos.

Os diversos funcionais diferem principalmente no contato de Fermi, indicando a necessidade de melhorar a descrição dos estados tripletos incluídos na expressão de Ramsey para obter as constantes indiretas de acoplamento spin-spin. Os DFTs obtidos também 
não são funcionais exatos, assim como os encontrados na literatura, porém estão mais próximos do comportamento ideal (com exceção do BHandH, devido a diminuição da porcentagem de $E_{X}^{\mathrm{HF}}$ ); os funcionais que obedecem o Teorema de Janak não apresentam resultados muito precisos para as CAISS. Entretanto os funcionais de longo alcance, além de apresentarem ótimas precisões, tem comportamento mais próximo do desejado para um funcional exato, o que os torna atrativo.

Novamente, foram encontrados resultados muito satisfatórios, mas que necessitam ser submetidos a uma quantidade e variedade muito maior de testes para atestar a eficácia desse funcionais. De qualquer maneira, é possível encontrar DFTs que sejam precisos para diferentes tipos de acoplamento, permitindo avaliar um maior número de sistemas adequadamente.

Dentre os funcionais da literatura, o BHandH, o B1B95, o $\omega$ B97X e o $\omega$ B97XD são os mais recomendados para cálculo de CAISS envolvendo átomos de H, B, C, N, O, F e P. Os híbridos BHandH 40\% $E_{X}^{\mathrm{HF}}$ e B1B95 40\% $E_{X}^{\mathrm{HF}}$ são recomendados, bem como o ajuste da porcentagem de $E_{X}^{\mathrm{HF}}$ de um DFT a valores próximos de 40\%. Os funcionais com CLA $\omega \operatorname{B97XD}(\#|\#| 0,35)$ e $\omega \operatorname{B97X}(0,2|1,0| \#)$ são bons, mas no conjunto teste é preferível utilizar as versões originais; já os LC-BHandH(40\%|100\%|0,10) e LC-B1B95(40\%|100\%|0,25), apesar de pouco avaliados, são bastante promissores para esse tipo de cálculo. 


\section{Referências Bibliográficas}

[1] Keeler, J. Understanding NMR Spectroscopy; Wiley: Chiester, 2010.

[2] Ramsey, N. F. Phys. Rev. 1950, 78, 699.

[3] Ramsey, N. F. Phys. Rev. 1953, 91, 303.

[4] Helgaker, T.; Jaszuński, M.; Ruud, K. Chem. Rev. 1999, 99, 293.

[5] Autschbach, J.; Ziegler, T. Coordin. Chem. Rev. 2003, 238, 83-126.

[6] Autschbach, J. Principles and Applications of DFT in Inorg. Chem.. In , Vol. 112 of Structure and Bonding; Kaltsoyannis, N.; MacGrady, J. E., Eds.; Springer: Heidelberg, 2004; Chapter The calculations of nmr parameters in transition metal complexes, pages 1-48.

[7] Kaupp, M.; Buhl, M.; Malkin, V. G. Calculation of NMR and EPR Parameters, Theory and Applications; Wiley-VCH: Darmstadt, 2004.

[8] Kupka, T. Magn. Reson. Chem. 2009, 47, 959.

[9] Kupka, T. Magn. Reson. Chem. 2009, 47, 674.

[10] Autschbach, J.; Guennic, B. L. J. Chem. Educ. 2007, 84, 156.

[11] Olsen, J.; Jorgensen, P. J. Chem. Phys. 1985, 82, 3235.

[12] Vahtras, O.; Agren, H.; Jorgensen, P.; Jensen, H. J. A.; Padkjaer, S. B.; Helgaker, T. J. Chem. Phys. 1992, 96, 6120.

[13] Helgaker, T.; Lutnaes, O. B.; Jaszunski, M. J. Chem. Theory Comput. 2007, 3, 86.

[14] Barone, V. in Recent Advances in Density Functional Methods, Part I 1996, Ed. D. P. Chong, (World Scientific Publ. Co., Singapore). 
[15] Sauer, S. P. A.; Provasi, P. F.; Aucar, G. A. J. Chem. Phys. 2001, 115, 1324.

[16] Helgaker, T.; Jaszunski, M.; Ruud, K.; Gorska, A. Theor. Chem. Acc. 1998, 99, 175.

[17] Benedikt, U.; Auer, A. A.; Jensen, F. J. Chem. Phys. 2008, 129, 064111.

[18] Jensen, F. J. Chem. Theory Comput. 2006, 2, 1360.

[19] Jensen, F. J. Chem. Theory Comput. 2008, 4, 719.

[20] Manninen, P.; Vaara, J. J. Comput. Chem. 2006, 27, 434.

[21] Provasi, P. F.; Sauer, S. P. A. J. Chem. Phys. 2010, 133, 054308.

[22] Helgaker, T.; Watson, M.; Handy, N. C. J. Chem. Phys. 2000, 113, 9402.

[23] Helgaker, T.; Jaszunski, M.; Pecul, M. Prog. Nucl. Magn. Reson. Spectrosc. 2008, $53,249$.

[24] Krivdin, L. B.; Contreras, R. H. Ann. Report. NMR Spectrosc. 2007, 61, 133.

[25] Malkin, V. G.; Malkina, O. L.; Salahub, D. R. Chem. Phys. Lett. 1994, 221, 91.

[26] Dickson, R. M.; Ziegler, T. J. Phys. Chem. 1996, 100, 5286-5290.

[27] Sychrovsky, V.; Grafenstein, J.; Cremer, D. J. Chem. Phys. 2000, 113, 3530-3547.

[28] Autschbach, J.; Ziegler, T. J. Chem. Phys. 2000, 113, 936-947.

[29] Watson, M.; Salek, P.; Macak, P.; Jaszunski, M.; Helgaker, T. Chem. Eur. J. 2004, 10, 4627 .

[30] Karplus, M. J. Chem. Phys. 1958, 30, 11.

[31] Karplus, M. J. Am. Chem. Soc. 1963, 85, 2870.

[32] Peralta, J. E.; Barone, V.; Contreras, R. H. J. Am. Chem. Soc. 2001, 123, 9162.

[33] Breitmaier, E.; Voelter, W. Carbon-13NMR Spectroscopy: High-resolution Methods and Applications in Organic Chemistry and Biochemistry.; VCH: New York, 1987. 
[34] Kohn, W.; Sham, L. Phys. Rev. A 1965, 140, 1133.

[35] Kohn, W.; Sham, L. J. Phys. Rev. 1965, 140, A1133-A1138.

[36] Perdew, J. P.; Ruzsinszky, A.; Constantin, L. A.; Sun, J.; Csonka, G. I. J. Chem. Theory Comput. 2009, 5, 902.

[37] Jensen, F. Introduction to Computational Chemistry; Wiley: Chichester, 2nd ed.; 2007.

[38] Rode, B. M.; Hofer, T. S.; Kugler, M. D. The Basics of Theoretical and Computational Chemistry; Wiley-VCH: Weinheim, 2007.

[39] Frisch, M. J. et al. "Gaussian 09, Revision D.", Gaussian, Inc., Wallingford, CT, 2009 .

[40] Marques, M. A. L.; Ullrich, C. A.; Nogueira, F.; Rubio, A.; Burke, K.; Gross, E. K. U. Time-Dependent Density Functional Theory; Vol. 706 of Lecture Notes in Physics; Springer: Berlin, 2006.

[41] Cohen, A. J.; Mori-Sańchez, P.; Yang, W. Chem. Rev. 2 2012, 112, 289.

[42] Neto, A. C.; Ducati, L. C.; Rittner, R.; Tormena, C. F.; Contreras, R. H.; Frenking, G. J Chem Theory Comput 2009, 5, 2222.

[43] Ducati, L. C.; Contreras, R. H.; Tormena, C. F. J. Phys. Chem. A 2012, 116, 4930.

[44] Dreuw, A.; Weisman, J. L.; Head-Gordon, M. J. Chem. Phys. 2003, 119, 2943.

[45] Maximoff, S. N.; Peralta, J. E.; Barone, V.; Scuseria, G. J. Chem. Theory Comput. 2005, 1, 541 .

[46] Melo, J. I.; de Azua, M. C. R.; Peralta, J. E.; Scuseria, G. E. J. Chem. Phys. 2005, 123, 204112.

[47] Keal, T. W.; Helgaker, T.; Sałek, P.; Tozer, D. J. Chemical Physics Letters 2006, $425,163-166$. 
[48] Keal, T.; Helgaker, T.; Salek, P.; Tozer, D. Chem. Phys. Lett. Phys Lett 2006, $425,163$.

[49] Kupka, T. Magn. Reson. Chem. 2009, 47, 210.

[50] Kupka, T.; Nieradka, M.; Stachów, M.; Pluta, T.; Nowak, P.; Kjaer, H.; Kongsted, J.; Kaminsky, J. J. Phys. Chem. A 2012, 116, 3728.

[51] Cohen, A. J.; Mori-Sánchez, P.; Yang, W. Chemical Reviews 2012, 112, 289-320 PMID: 22191548.

[52] Iikura, H.; Tsuneda, T.; Yanai, T.; Hirao, K. A. J. Chem. Phys. 2001, 115, 3540.

[53] Rohrdanz, M. A.; Herbert, J. M. J. Chem. Phys. 2008, 129, 034107.

[54] Chai, J.-D.; Head-Gordon, M. The Journal of Chemical Physics 2008, 128, 084106.

[55] Chai, J.-D.; Head-Gordon, M. Phys. Chem. Chem. Phys. 2008, 10, 6615-6620.

[56] Baer, R.; Livshits, E.; Salzner, U. Annu. Rev. Phys. Chem. 2010, 61, 85.

[57] Kuritz, N.; Stein, T.; Baer, R.; Kronik, L. J. Chem. Theory Comput. 2011, 7, 2408 .

[58] Körzdörfer, T.; Sears, J. S.; Sutton, C.; Brédas, J. L. J. Chem. Phys. 2011, 135, 204107.

[59] Kronik, L.; Stein, T.; Refaely-Abramson, S.; Baer, R. J. Chem. Theory Comput. $2012,8,1515$.

[60] Foster, M. E.; Wong, B. M. J. Chem. Theory Comput. 2012, 8, 2682.

[61] Autschbach, J.; Srebro, M. Accounts of Chemical Research 2014, 47, 2592-2602.

[62] Duignan, T. J.; Autschbach, J.; Batista, E.; Yang, P. Journal of Chemical Theory and Computation 2017, 13, 3614-3625.

[63] Huber, K.; Herzberg, G. Molecular Spectra and Molecular Structure. IV. Constants of Diatomic Molecules; Van Nostrand Reinhold Co.: New York, 1979. 
[64] Roy, R. J. L. J. Mol. Spect. 1999, 194, 189.

[65] Hoy, A. R.; Bunker, P. R. J. Mol. Struct. 1979, 74, 1.

[66] Herzberg, G. Electronic Spectra and Electronic Structure of Polyatomic Molecules; Van Nostrand: New York, 1966.

[67] Kuchitsu, K. Structure of Free Polyatomic Molecules - Basic Data; Springer: New York, 1998.

[68] Hellwege, K. H.; Hellwege, A. Group II: Atomic and Molecular Physics Volume 7: Structure Data of Free Polyatomic Molecules; Springer-Verlag: Berlin, 1976.

[69] Westwood, N. P. C.; Lewis-Bevan, W.; Gerry., M. C. L. J. Mol. Spect. 1984, 106, 227.

[70] Kirchhoff, W. J. Mol. Struct. 1972, 41, 333.

[71] Hirota, E. J Mol Spect. 1979, 77, 213.

[72] Sverdlov, L.; Kovner, M. A.; Krainov, E. P. Vibrational Spectra of Polyatomic Molecules; Wiley: New York, 1974.

[73] Seminario, J. M.; Politzer, P. Modern Density Functional Theory: A Tool For Chemistry; Elsevier: Amsterdam, 1995.

[74] Becke, A. D. The Journal of Chemical Physics 1993, 98, 5648-5652.

[75] Yanai, T.; Tew, D. P.; Handy, N. C. Chemical Physics Letters 393, 51 - 57.

[76] Schmider, H. L.; Becke, A. D. The Journal of Chemical Physics 1998, 108, 96249631.

[77] Hamprecht, F. A.; Cohen, A. J.; Tozer, D. J.; Handy, N. C. The Journal of Chemical Physics 1998, 109, 6264-6271.

[78] Wilson, P. J.; Bradley, T. J.; Tozer, D. J. The Journal of Chemical Physics 2001, 115, 9233-9242. 
[79] Perdew, J. P.; Burke, K.; Wang, Y. Phys. Rev. B 1996, 54, 16533-16539.

[80] Perdew, J. P.; Burke, K.; Ernzerhof, M. Phys. Rev. Lett. 1996, 77, 3865-3868.

[81] Adamo, C.; Barone, V. The Journal of Chemical Physics 1999, 110, 6158-6170.

[82] Tao, J.; Perdew, J. P.; Staroverov, V. N.; Scuseria, G. E. Phys. Rev. Lett. 2003, 91, 146401.

[83] Zhao, Y.; Schultz, N. E.; Truhlar, D. G. The Journal of Chemical Physics 2005, $123,161103$.

[84] Zhao, Y.; Schultz, N. E.; Truhlar, D. G. Journal of Chemical Theory and Computation 2006, 2, 364-382.

[85] Zhao, Y.; Truhlar, D. G. Theoretical Chemistry Accounts 2008, 120, 215-241.

[86] Zhao, Y.; Truhlar, D. G. Theoretical Chemistry Accounts 2008, 120, 215-241.

[87] Zhao, Y.; Truhlar, D. G. The Journal of Physical Chemistry A 2006, 110, 1312613130.

[88] Becke, A. D. The Journal of Chemical Physics 1993, 98, 1372-1377.

[89] Perdew, J. P. Phys. Rev. B 1986, 33, 8822-8824.

[90] Becke, A. D. The Journal of Chemical Physics 1996, 104, 1040-1046.

[91] Boese, A. D.; Martin, J. M. L. The Journal of Chemical Physics 2004, 121, 34053416.

[92] COHEN, A. J.; HANDY, N. C. Molecular Physics 2001, 99, 607-615.

[93] Xu, X.; Goddard, W. A. Proceedings of the National Academy of Sciences 2004, 101, 2673-2677.

[94] Huzinaga, S. The Journal of Chemical Physics 1965, 42, 1293-1302. 
[95] Lutnæs, O. B.; Helgaker, T.; Jaszuński, M. Molecular Physics 2010, 108, 25792590 .

[96] Aidasand, K. et al. "Dalton, a molecular electronic structure program, Release Dalton2016.", 2015 "The Dalton quantum chemistry program system", WIREs Comput. Mol. Sci. 2014, 4:269-284 (doi: 10.1002/wcms.1172).

[97] Becke, A. D. Phys. Rev. A 1988, 38, 3098-3100.

[98] Hoe, W.-M.; Cohen, A. J.; Handy, N. C. Chemical Physics Letters 2001, 341, 319 - 328.

[99] Hohenberg, P.; Kohn, W. Phys. Rev. 1964, 136, B864-B871.

[100] Lee, C.; Yang, W.; Parr, R. G. Phys. Rev. B 1988, 37, 785-789.

[101] Iikura, H.; Tsuneda, T.; Yanai, T.; Hirao, K. The Journal of Chemical Physics 2001, 115, 3540-3544.

[102] Kjaer, H.; Sauer, S. P. A.; Kongsted, J. J. Chem. Phys. 2010, 133, 144106.

[103] Berger, S.; Braun, S.; Kalinowski, H. O. NMR Spectroscopy Of The Non-Metallic Elements; John Wiley \& Sons: Bonn, 1997.

[104] Frankiss, S. G. The Journal of Physical Chemistry 1963, 67, 752-755.

[105] Middleton, W. J.; Sharkey, W. H. Journal of the American Chemical Society 1959, 81, 803-804.

[106] Wray, V.; Ernst, L.; Lustig, E. Journal of Magnetic Resonance (1969) 1977, 27, $1-21$.

[107] Noggle, J. H.; Baldeschwieler, J. D.; Colburn, C. B. The Journal of Chemical Physics 1962, 37, 182-189.

[108] Maier, L.; Schmutzler, R. J. Chem. Soc. D 1969, 961-962. 
[109] Gray, G. A.; Albright, T. A. Journal of the American Chemical Society 1977, 99, 3243-3250.

[110] Ducati, L. C. Adaptação de métodos de estrutura eletrônica em cálculos de propriedades de ressonância magnética nuclear e barreiras de rotação interna, Thesis, Universidade Estadual de Campinas, 2010.

[111] Gray, G. A.; Albright, T. A. Journal of the American Chemical Society 1976, 98, $3857-3861$.

[112] Cowley, A. H.; White, W. D. Journal of the American Chemical Society 1969, 91, 1917-1921.

[113] Moncho, S.; Autschbach, J. Journal of Chemical Theory and Computation 2010, 6, 223-234 PMID: 26614333.

[114] Patchkovskii, S.; Ziegler, T. The Journal of Physical Chemistry A 2002, 106, 10881099.

[115] Gudmundsdóttir, H.; Zhang, Y.; Weber, P. M.; Jónsson, H. The Journal of Chemical Physics 2013, 139, 194102. 


\section{Anexos}

As seguintes abreviações são utilizadas nas tabelas a seguir:

$\begin{array}{lll}\text { Funcionais } & \longrightarrow & \text { Func. } \\ \text { Experimental } & \longrightarrow & \text { Exp. } \\ \text { Empírico } & \longrightarrow & \text { Emp. } \\ \Delta \text { (CPI-SPI }) & \longrightarrow & \Delta \text { CS } \\ \text { CAM-B3LYP } & \longrightarrow & \text { CAMB3 } \\ \text { B3PW91 } & \longrightarrow & \text { B3W91 } \\ \omega \text { B97XD } & \longrightarrow & \text { w97XD } \\ \text { BHandH } & \longrightarrow & \text { BHH } \\ \text { BHandHLYP } & \longrightarrow & \text { BHLYP } \\ \text { LC-BB95 } & \longrightarrow & \text { LCB95 } \\ \text { LC-SLYP } & \longrightarrow & \text { LCSLP }\end{array}$




\subsection{Precisão dos funcionais da literatura}

Tabela 8.1: Constantes de acoplamento utilizando funcionais da literatura (0 a $\left.21 \% E_{X}^{\mathrm{HF}}\right)$ com base aug-pcJ-2.

\begin{tabular}{|c|c|c|c|c|c|c|c|c|c|c|c|c|c|c|c|}
\hline & Func. & $\mathrm{PBE}$ & PW91 & BP86 & $\omega \mathrm{B} 97$ & TPSSh & O3LYP & $\omega \mathrm{B} 97 \mathrm{X}$ & CAMB3 & B3P86 & B3LYP & B3W91 & B971 & B972 & Exp. \\
\hline & $\% E_{X}^{\mathrm{HF}}$ & 0,00 & 0,00 & 0,00 & 0,00 & 10,00 & 11,61 & 15,77 & 19,00 & 20,00 & 20,00 & 20,00 & 21,00 & 21,00 & - \\
\hline $\mathrm{HF}$ & ${ }^{1} J_{\mathrm{HF}}$ & 376,0 & 364,2 & 355,3 & 455,6 & 390,6 & 396,4 & 497,9 & 455,6 & 407,3 & 445,4 & 408,9 & 449,1 & 442,8 & 500,0 \\
\hline $\mathrm{CO}$ & ${ }^{1} J_{\mathrm{CO}}$ & 24,1 & 24,9 & 24,9 & 23,9 & 20,3 & 21,9 & 19,1 & 18,3 & 21,6 & 18,2 & 21,6 & 17,4 & 18,3 & 16,4 \\
\hline $\mathrm{H}_{2} \mathrm{O}$ & ${ }^{1} J_{\mathrm{OH}}$ & $-67,2$ & $-66,3$ & $-64,8$ & $-71,8$ & $-72,5$ & $-69,4$ & $-76,5$ & $-77,7$ & $-70,1$ & $-76,8$ & $-70,6$ & $-74,4$ & $-73,5$ & $-80,6$ \\
\hline $\mathrm{H}_{2} \mathrm{O}$ & ${ }^{2} J_{\mathrm{HH}}$ & $-4,7$ & $-4,8$ & $-4,6$ & $-6,6$ & $-5,3$ & $-8,0$ & $-6,4$ & $-7,4$ & $-6,3$ & $-7,2$ & $-6,8$ & $-6,5$ & $-7,5$ & $-7,3$ \\
\hline $\mathrm{NH}_{3}$ & ${ }^{1} J_{\mathrm{NH}}$ & 40,8 & 40,8 & 40,0 & 39,0 & 45,8 & 41,1 & 41,5 & 45,2 & 41,4 & 45,3 & 41,7 & 43,3 & 41,7 & 43,8 \\
\hline $\mathrm{NH}_{3}$ & ${ }^{2} J_{\mathrm{HH}}$ & $-7,8$ & $-8,0$ & $-7,8$ & $-8,5$ & $-8,1$ & $-10,1$ & $-8,7$ & $-10,2$ & $-9,3$ & $-9,9$ & $-9,8$ & $-9,1$ & $-9,1$ & $-9,6$ \\
\hline $\mathrm{PH}_{3}$ & ${ }^{1} J_{\mathrm{PH}}$ & 133,7 & 137,6 & 136,9 & 159,3 & 200,5 & 165,5 & 165,0 & 162,3 & 152,3 & 171,9 & 154,6 & 190,7 & 184,0 & 188,2 \\
\hline $\mathrm{PF}_{3}$ & ${ }^{1} J_{\mathrm{PF}}$ & $-1801,0$ & $-1815,2$ & $-1802,5$ & $-1663,0$ & $-1731,7$ & $-1687,8$ & $-1643,0$ & $-1749,1$ & $-1749,4$ & $-1755,9$ & $-1751,4$ & $-1656,7$ & $-1661,2$ & $-1441,0$ \\
\hline $\mathrm{BHF}_{2}$ & ${ }^{1} J_{\mathrm{BF}}$ & $-172,8$ & $-177,6$ & $-177,9$ & $-111,8$ & $-142,5$ & $-157,4$ & $-97,5$ & $-125,7$ & $-143,2$ & $-134,5$ & $-142,6$ & $-123,8$ & $-129,9$ & $-84,0$ \\
\hline $\mathrm{BF}_{3}$ & ${ }^{1} J_{\mathrm{BF}}$ & $-75,8$ & $-80,9$ & $-83,3$ & $-14,8$ & $-47,2$ & $-63,7$ & 3,3 & $-22,4$ & $-45,2$ & $-33,2$ & $-44,5$ & $-27,9$ & $-36,6$ & 15,0 \\
\hline $\mathrm{F}_{2} \mathrm{O}$ & ${ }^{1} J_{\mathrm{OF}}$ & $-278,0$ & $-290,5$ & $-290,1$ & $-310,7$ & $-320,1$ & $-297,3$ & $-326,5$ & $-386,6$ & $-360,6$ & $-352,0$ & $-362,9$ & $-318,8$ & $-316,0$ & $-300,0$ \\
\hline $\mathrm{CH}_{4}$ & ${ }^{1} J_{\mathrm{CH}}$ & 119,3 & 120,1 & 117,5 & 109,4 & 138,8 & 119,5 & 112,5 & 128,9 & 120,0 & 131,7 & 121,0 & 128,8 & 118,8 & 125,3 \\
\hline $\mathrm{CH}_{4}$ & ${ }^{2} J_{\mathrm{HH}}$ & $-11,8$ & $-12,0$ & $-11,8$ & $-11,2$ & $-11,3$ & $-13,2$ & $-11,3$ & $-13,2$ & $-12,9$ & $-13,0$ & $-13,4$ & $-12,0$ & $-11,3$ & $-12,8$ \\
\hline $\mathrm{C}_{2} \mathrm{H}_{2}$ & ${ }^{1} J_{\mathrm{CC}}$ & 188,7 & 188,8 & 187,3 & 194,2 & 190,8 & 191,5 & 193,0 & 202,0 & 193,4 & 203,3 & 193,8 & 213,8 & 197,5 & 174,8 \\
\hline $\mathrm{C}_{2} \mathrm{H}_{2}$ & ${ }^{1} J_{\mathrm{CH}}$ & 249,8 & 252,5 & 247,4 & 236,3 & 282,3 & 254,5 & 240,2 & 266,9 & 251,9 & 271,8 & 254,0 & 261,3 & 247,3 & 247,6 \\
\hline $\mathrm{C}_{2} \mathrm{H}_{2}$ & ${ }^{2} J_{\mathrm{CH}}$ & 54,1 & 54,6 & 54,6 & 51,8 & 57,7 & 52,6 & 53,4 & 57,0 & 54,0 & 56,1 & 54,0 & 53,2 & 50,7 & 50,1 \\
\hline $\mathrm{C}_{2} \mathrm{H}_{2}$ & ${ }^{3} J_{\mathrm{HH}}$ & 10,4 & 10,5 & 10,2 & 10,4 & 12,6 & 11,8 & 10,0 & 11,1 & 11,2 & 11,1 & 11,7 & 10,5 & 10,4 & 9,6 \\
\hline $\mathrm{C}_{2} \mathrm{H}_{4}$ & ${ }^{1} J_{\mathrm{CC}}$ & 61,3 & 60,6 & 59,5 & 65,6 & 71,5 & 63,9 & 64,5 & 70,6 & 64,7 & 71,0 & 65,3 & 78,1 & 68,1 & 67,6 \\
\hline $\mathrm{C}_{2} \mathrm{H}_{4}$ & ${ }^{1} J_{\mathrm{CH}}$ & 151,8 & 153,0 & 149,7 & 142,7 & 174,3 & 154,4 & 145,4 & 164,4 & 153,7 & 167,1 & 155,1 & 162,8 & 152,3 & 156,3 \\
\hline $\mathrm{C}_{2} \mathrm{H}_{4}$ & ${ }^{2} J_{\mathrm{CH}}$ & $-0,5$ & $-0,4$ & 0,0 & $-2,2$ & $-1,7$ & $-1,9$ & $-1,3$ & $-1,7$ & $-1,6$ & $-1,4$ & $-2,0$ & $-2,1$ & $-2,0$ & $-2,4$ \\
\hline $\mathrm{C}_{2} \mathrm{H}_{4}$ & ${ }^{2} J_{\mathrm{HH}}$ & 4,5 & 4,5 & 4,6 & 2,3 & 8,2 & 2,8 & 2,9 & 4,0 & 3,2 & 4,5 & 2,8 & 3,6 & 3,1 & 2,3 \\
\hline $\mathrm{C}_{2} \mathrm{H}_{4}$ & ${ }^{3} J_{\mathrm{HH}_{\mathrm{c}}}$ & 11,7 & 11,9 & 11,6 & 11,5 & 12,5 & 12,3 & 11,5 & 13,3 & 12,1 & 12,8 & 12,4 & 11,7 & 11,2 & 11,7 \\
\hline $\mathrm{C}_{2} \mathrm{H}_{4}$ & ${ }^{3} J_{\mathrm{HH}_{\mathrm{t}}}$ & 18,7 & 19,0 & 18,5 & 17,0 & 22,5 & 19,3 & 17,2 & 20,0 & 19,0 & 20,0 & 19,4 & 18,4 & 17,7 & 19,0 \\
\hline $\mathrm{C}_{2} \mathrm{H}_{6}$ & ${ }^{1} J_{\mathrm{CC}}$ & 25,7 & 25,1 & 24,2 & 28,5 & 34,4 & 27,5 & 29,1 & 32,5 & 28,0 & 32,4 & 28,3 & 34,9 & 30,6 & 34,5 \\
\hline $\mathrm{C}_{2} \mathrm{H}_{6}$ & ${ }^{1} J_{\mathrm{CH}}$ & 119,5 & 120,3 & 117,6 & 109,0 & 138,9 & 119,9 & 112,4 & 129,1 & 120,6 & 131,7 & 121,6 & 129,1 & 118,9 & 125,2 \\
\hline $\mathrm{C}_{2} \mathrm{H}_{6}$ & ${ }^{2} J_{\mathrm{CH}}$ & $-2,9$ & $-2,9$ & $-2,7$ & $-3,2$ & $-3,8$ & $-3,6$ & $-3,2$ & $-3,6$ & $-3,5$ & $-3,4$ & $-3,7$ & $-3,6$ & $-3,2$ & $-4,7$ \\
\hline \multirow[t]{3}{*}{ Total } & $\mathrm{DM}$ & $-26,05$ & $-27,51$ & $-28,10$ & $-15,09$ & $-14,90$ & $-19,33$ & $-11,56$ & $-17,75$ & $-22,80$ & $-16,85$ & $-22,56$ & $-10,51$ & $-14,69$ & - \\
\hline & DMA & 31,85 & 32,72 & 33,03 & 18,42 & 26,71 & 23,2 & & 24,35 & 26, & 24,62 & 26,41 & & & - \\
\hline & PDMA & 46,79 & 48,56 & 50,85 & 19,64 & 41,22 & 33,97 & 14,49 & 23,87 & 30,38 & 27,96 & 28,73 & 21,89 & 23,84 & - \\
\hline \multirow[t]{3}{*}{ CPI } & DM & $-61,24$ & $-65,15$ & $-64,98$ & $-31,85$ & $-46,46$ & $-46,34$ & $-24,79$ & $-48,96$ & $-54,76$ & $-48,15$ & $-54,79$ & & $-35,26$ & - \\
\hline & DMA & 69,87 & 71,77 & 72,02 & 35,14 & 51,88 & 49,86 & 26,35 & 50,09 & 57, & 49,45 & 57,6 & 34 , & 36,99 & - \\
\hline & PDMA & 83,81 & 87,39 & 89,78 & 33,06 & 56,46 & 66,48 & 16,20 & 36,17 & 56,19 & 42,17 & 54,80 & 36,11 & 42,37 & - \\
\hline \multirow[t]{3}{*}{ SPI } & DM & $-0,25$ & 0,10 & $-1,06$ & $-2,80$ & 8,24 & 0,48 & $-1,85$ & 5,1 & 0,6 & 6,1 & $1, \mathrm{C}$ & 5,6 & 0, & - \\
\hline & DMA & 3,96 & 4,07 & 4,43 & 6,16 & 8,25 & 3,69 & 5,40 & 5,47 & 3,58 & 6,41 & 3,51 & 5,71 & 3,44 & - \\
\hline & PDMA & 19,65 & 20,09 & 22,31 & 9,80 & 30,05 & 10,13 & 13,24 & 14,85 & 11,45 & 17,55 & 9,60 & 11,47 & 10,24 & - \\
\hline \multirow[t]{3}{*}{$\Delta \mathrm{CS}$} & DM & $-60,98$ & $-65,25$ & $-63,92$ & $-29,05$ & $-54,70$ & $-46,82$ & $-22,94$ & $-54,11$ & $-55,41$ & $-54,25$ & $-55,87$ & $-38,14$ & $-35,66$ & - \\
\hline & DMA & 5,91 & 67,70 & 67,58 & & 43,63 & 46,17 & 20,95 & 44,62 & 54,27 & 43,04 & 54,14 & 28,80 & 33,55 & - \\
\hline & PDMA & 64,16 & 67,30 & 67,47 & 23,25 & 26,41 & 56,35 & 2,96 & 21,32 & 44,74 & 24,62 & 45,20 & 24,64 & 32,13 & - \\
\hline
\end{tabular}


Tabela 8.2: Constantes de acoplamento utilizando funcionais da literatura (21 a $100 \%$ $\left.E_{X}^{\mathrm{HF}}\right)$ com base aug-pcJ-2.

\begin{tabular}{|c|c|c|c|c|c|c|c|c|c|c|c|c|c|c|c|}
\hline & $\begin{array}{l}\text { Func. } \\
\% E_{X}^{\mathrm{HF}}\end{array}$ & $\begin{array}{l}\text { X3LYP } \\
21,80\end{array}$ & $\begin{array}{c}\text { B98 } \\
21,98\end{array}$ & $\begin{array}{l}\omega 97 \mathrm{XD} \\
22,20\end{array}$ & $\begin{array}{l}\text { PBE0 } \\
25,00\end{array}$ & $\begin{array}{c}\text { M06 } \\
27,00\end{array}$ & $\begin{array}{l}\text { B1B95 } \\
28,00\end{array}$ & $\begin{array}{c}\text { M05 } \\
28,00\end{array}$ & $\begin{array}{l}\text { BMK } \\
42,00\end{array}$ & $\begin{array}{l}\mathrm{BHH} \\
50,00\end{array}$ & $\begin{array}{l}\text { BHLYP } \\
50,00\end{array}$ & $\begin{array}{l}\text { M062X } \\
54,00\end{array}$ & $\begin{array}{l}\text { M052X } \\
56,00\end{array}$ & $\begin{array}{l}\text { M06HF } \\
100,00\end{array}$ & $\begin{array}{c}\text { Exp. } \\
-\end{array}$ \\
\hline $\mathrm{HF}$ & ${ }^{1} J_{\mathrm{HF}}$ & 453,2 & 431,2 & 484,2 & 430,8 & 678,3 & 470,4 & 828,5 & 550,8 & 530,8 & 526,8 & 485,6 & 583,3 & 177,7 & 500,0 \\
\hline $\mathrm{CO}$ & ${ }^{1} J_{\mathrm{CO}}$ & 17,7 & 18,5 & 19,6 & 19,9 & 17,9 & 18,4 & 9,1 & 18,7 & 13,7 & 10,9 & 7,4 & 3,9 & 4,4 & 16,4 \\
\hline $\mathrm{H}_{2} \mathrm{O}$ & ${ }^{1} J_{\mathrm{OH}}$ & $-77,8$ & $-72,5$ & $-74,7$ & $-73,0$ & $-100,6$ & $-77,3$ & $-108,3$ & $-86,9$ & $-83,7$ & $-86,5$ & $-91,6$ & $-89,3$ & $-54,8$ & $-80,6$ \\
\hline $\mathrm{H}_{2} \mathrm{O}$ & ${ }^{2} J_{\mathrm{HH}}$ & $-7,5$ & $-6,9$ & $-6,4$ & $-7,3$ & $-16,8$ & $-7,0$ & $-18,6$ & $-6,7$ & $-9,4$ & $-11,2$ & $-7,1$ & $-4,6$ & 8,8 & $-7,3$ \\
\hline $\mathrm{NH}_{3}$ & ${ }^{1} J_{\mathrm{NH}}$ & 45,8 & 42,9 & 41,9 & 42,5 & 52,4 & 44,0 & 44,3 & 47,8 & 45,5 & 49,0 & 53,2 & 43,8 & 37,7 & 43,8 \\
\hline $\mathrm{NH}_{3}$ & ${ }^{2} J_{\mathrm{HH}}$ & $-10,2$ & $-9,5$ & $-9,0$ & $-10,1$ & $-18,0$ & $-9,3$ & $-15,8$ & $-10,2$ & $-11,1$ & $-13,5$ & $-11,0$ & $-6,3$ & $-5,4$ & $-9,6$ \\
\hline $\mathrm{PH}_{3}$ & ${ }^{1} J_{\mathrm{PH}}$ & 174,3 & 196,4 & 176,7 & 154,6 & 247,5 & 167,8 & 171,8 & 137,9 & 183,1 & 201,3 & 166,9 & 118,3 & 159,3 & 188,2 \\
\hline $\mathrm{PF}_{3}$ & ${ }^{1} J_{\mathrm{PF}}$ & $-1753,0$ & $-1666,4$ & $-1637,8$ & $-1732,1$ & $-1526,9$ & $-1645,5$ & $-1389,0$ & $-1646,1$ & $-1670,4$ & $-1651,5$ & $-1625,7$ & $-1705,4$ & $-1876,6$ & $-1441,0$ \\
\hline $\mathrm{BHF}_{2}$ & ${ }^{1} J_{\mathrm{BF}}$ & $-131,5$ & $-129,1$ & $-103,1$ & $-131,0$ & $-36,1$ & $-127,6$ & 20,8 & $-104,0$ & $-95,2$ & $-81,9$ & $-116,5$ & $-105,2$ & $-275,0$ & $-84,0$ \\
\hline $\mathrm{BF}_{3}$ & ${ }^{1} J_{\mathrm{BF}}$ & $-29,1$ & $-34,1$ & $-3,0$ & $-30,5$ & 64,9 & $-27,0$ & 127,1 & 5,1 & 15,1 & 24,3 & $-20,0$ & $-3,5$ & $-196,7$ & 15,0 \\
\hline $\mathrm{F}_{2} \mathrm{O}$ & ${ }^{1} J_{\mathrm{OF}}$ & $-359,4$ & $-336,9$ & $-333,4$ & $-374,9$ & $-308,4$ & $-361,9$ & $-302,9$ & $-377,3$ & $-465,0$ & $-488,0$ & $-429,2$ & $-520,8$ & $-1503,5$ & $-300,0$ \\
\hline $\mathrm{CH}_{4}$ & ${ }^{1} J_{\mathrm{CH}}$ & 132,9 & 128,3 & 114,7 & 122,8 & 139,6 & 124,4 & 98,5 & 159,2 & 124,9 & 140,7 & 143,7 & 115,3 & 67,5 & 125,3 \\
\hline $\mathrm{CH}_{4}$ & ${ }^{2} J_{\mathrm{HH}}$ & $-13,2$ & $-12,5$ & $-11,8$ & $-13,8$ & $-25,9$ & $-12,2$ & $-21,2$ & $-14,3$ & $-13,3$ & $-16,0$ & $-12,1$ & $-6,6$ & $-15,5$ & $-12,8$ \\
\hline $\mathrm{C}_{2} \mathrm{H}_{2}$ & ${ }^{1} J_{\mathrm{CC}}$ & 204,4 & 212,9 & 191,3 & 196,4 & 193,6 & 195,2 & 209,7 & 342,7 & 202,4 & 220,1 & 227,8 & 224,7 & 251,3 & 174,8 \\
\hline $\mathrm{C}_{2} \mathrm{H}_{2}$ & ${ }^{1} J_{\mathrm{CH}}$ & 273,8 & 261,1 & 245,6 & 256,2 & 299,5 & 256,2 & 247,8 & 296,0 & 259,5 & 288,5 & 270,2 & 208,7 & 90,6 & 247,6 \\
\hline $\mathrm{C}_{2} \mathrm{H}_{2}$ & ${ }^{2} J_{\mathrm{CH}}$ & 56,2 & 52,8 & 53,7 & 53,5 & 50,3 & 55,6 & 36,5 & 62,0 & 53,0 & 54,1 & 56,9 & 49,6 & 45,3 & 50,1 \\
\hline $\mathrm{C}_{2} \mathrm{H}_{2}$ & ${ }^{3} J_{\mathrm{HH}}$ & 11,2 & 10,7 & 10,1 & 12,4 & 17,1 & 10,4 & 20,6 & 12,0 & 11,8 & 14,8 & 9,3 & 7,4 & 5,2 & 9,6 \\
\hline $\mathrm{C}_{2} \mathrm{H}_{4}$ & ${ }^{1} J_{\mathrm{CC}}$ & 72,0 & 77,3 & 63,7 & 68,7 & 64,8 & 66,0 & 76,4 & 127,3 & 72,3 & 86,0 & 91,2 & 85,1 & 85,9 & 67,6 \\
\hline $\mathrm{C}_{2} \mathrm{H}_{4}$ & ${ }^{1} J_{\mathrm{CH}}$ & 168,6 & 162,5 & 148,1 & 157,3 & 183,7 & 158,8 & 141,6 & 195,6 & 160,6 & 180,1 & 177,6 & 141,8 & $-61,3$ & 156,3 \\
\hline $\mathrm{C}_{2} \mathrm{H}_{4}$ & ${ }^{2} J_{\mathrm{CH}}$ & $-1,6$ & $-2,4$ & $-1,0$ & $-3,0$ & $-6,4$ & $-1,1$ & $-13,9$ & $-4,7$ & $-3,8$ & $-6,0$ & $-2,5$ & $-1,6$ & 13,0 & $-2,4$ \\
\hline $\mathrm{C}_{2} \mathrm{H}_{4}$ & ${ }^{2} J_{\mathrm{HH}}$ & 4,4 & 3,1 & 3,0 & 2,3 & $-13,4$ & 4,2 & $-14,6$ & 5,2 & 2,2 & 1,6 & 3,7 & 6,1 & 4,1 & 2,3 \\
\hline $\mathrm{C}_{2} \mathrm{H}_{4}$ & ${ }^{3} J_{\mathrm{HH}_{\mathrm{c}}}$ & 13,0 & 11,8 & 11,5 & 12,7 & 17,1 & 12,1 & 16,2 & 13,5 & 13,3 & 14,9 & 12,9 & 9,5 & 4,5 & 11,7 \\
\hline $\mathrm{C}_{2} \mathrm{H}_{4}$ & ${ }^{3} J_{\mathrm{HH}_{\mathrm{t}}}$ & 20,2 & 18,5 & 17,5 & 19,8 & 21,6 & 19,0 & 19,2 & 21,1 & 19,6 & 22,7 & 18,8 & 14,9 & 5,8 & 19,0 \\
\hline $\mathrm{C}_{2} \mathrm{H}_{6}$ & ${ }^{1} J_{\mathrm{CC}}$ & 33,1 & 34,4 & 29,0 & 30,4 & 29,4 & 30,6 & 24,8 & 48,7 & 33,3 & 40,6 & 48,9 & 40,9 & 46,8 & 34,5 \\
\hline $\mathrm{C}_{2} \mathrm{H}_{6}$ & ${ }^{1} J_{\mathrm{CH}}$ & 132,9 & 128,8 & 115,2 & 123,5 & 139,1 & 125,0 & 98,2 & 160,2 & 125,8 & 141,3 & 145,0 & 117,4 & 81,1 & 125,2 \\
\hline $\mathrm{C}_{2} \mathrm{H}_{6}$ & ${ }^{2} J_{\mathrm{CH}}$ & $-3,5$ & $-3,8$ & $-3,3$ & $-4,1$ & $-5,5$ & $-3,5$ & $-4,6$ & $-5,1$ & $-4,3$ & $-5,1$ & $-3,7$ & $-2,7$ & $-3,3$ & $-4,7$ \\
\hline \multirow[t]{3}{*}{ Total } & $\mathrm{DM}$ & $-16,08$ & $-12,61$ & $-11,64$ & $-20,04$ & 12,07 & $-13,82$ & 17,58 & 3,98 & $-12,86$ & $-7,19$ & $-9,43$ & $-20,01$ & $-105,70$ & - \\
\hline & DMA & 24,40 & 20,22 & 14,39 & 24,04 & 25,43 & 17,61 & 33,00 & 32,73 & 19,73 & 25,55 & 24,34 & 33,54 & 118,91 & - \\
\hline & PDMA & 26,59 & 22,55 & 16,48 & 23,18 & 74,41 & 24,17 & 108,73 & 32,87 & 12,21 & 28,90 & 28,05 & 35,34 & 149,27 & - \\
\hline \multirow[t]{3}{*}{ CPI } & $\mathrm{DM}$ & $-47,13$ & $-37,03$ & $-25,99$ & $-50,18$ & 19,39 & $-35,99$ & 47,83 & $-28,35$ & $-35,23$ & $-32,84$ & $-38,99$ & $-47,88$ & $-215,00$ & - \\
\hline & DMA & 48,24 & 40,46 & 27,92 & 52,20 & 43,43 & 37,10 & 60,88 & 38,84 & 41,15 & 43,11 & 40,74 & 64,12 & 223,38 & - \\
\hline & PDMA & 39,43 & 41,68 & 20,60 & 43,19 & 66,99 & 37,04 & 113,68 & 19,29 & 14,76 & 27,35 & 40,86 & 41,15 & 230,30 & - \\
\hline \multirow[t]{3}{*}{ SPI } & DM & 6,69 & 5,29 & $-1,12$ & 2,07 & 6,70 & 2,44 & $-4,59$ & 27,69 & 3,55 & 11,61 & 12,24 & 0,43 & $-25,54$ & - \\
\hline & DMA & 6,93 & 5,37 & 4,47 & 3,39 & 12,23 & 3,32 & 12,55 & 28,25 & 4,03 & 12,67 & 12,32 & 11,12 & 42,30 & - \\
\hline & PDMA & 17,18 & 8,52 & 13,47 & 8,51 & 79,85 & 14,73 & 105,10 & 42,84 & 10,35 & 30,04 & 18,67 & 31,07 & 89,85 & - \\
\hline \multirow[t]{3}{*}{$\Delta \mathrm{CS}$} & DM & $-53,81$ & $-42,32$ & $-24,87$ & $-52,25$ & 12,69 & $-38,43$ & 52,42 & $-56,03$ & $-38,77$ & $-44,45$ & $-51,23$ & $-48,31$ & $-189,46$ & - \\
\hline & DMA & 41,31 & 35,09 & 23,45 & 48,81 & 31,19 & 33,78 & 48,33 & 10,59 & 37,13 & 30,44 & 28,42 & 53,00 & 181,08 & - \\
\hline & PDMA & 22,25 & 33,17 & 7,13 & 34,68 & $-12,86$ & 22,31 & 8,58 & $-23,55$ & 4,41 & $-2,69$ & 22,19 & 10,09 & 140,46 & - \\
\hline
\end{tabular}


Tabela 8.3: Constantes de acoplamento utilizando funcionais da literatura (0 a $\left.21 \% E_{X}^{\mathrm{HF}}\right)$ com base HuzIII-su3.

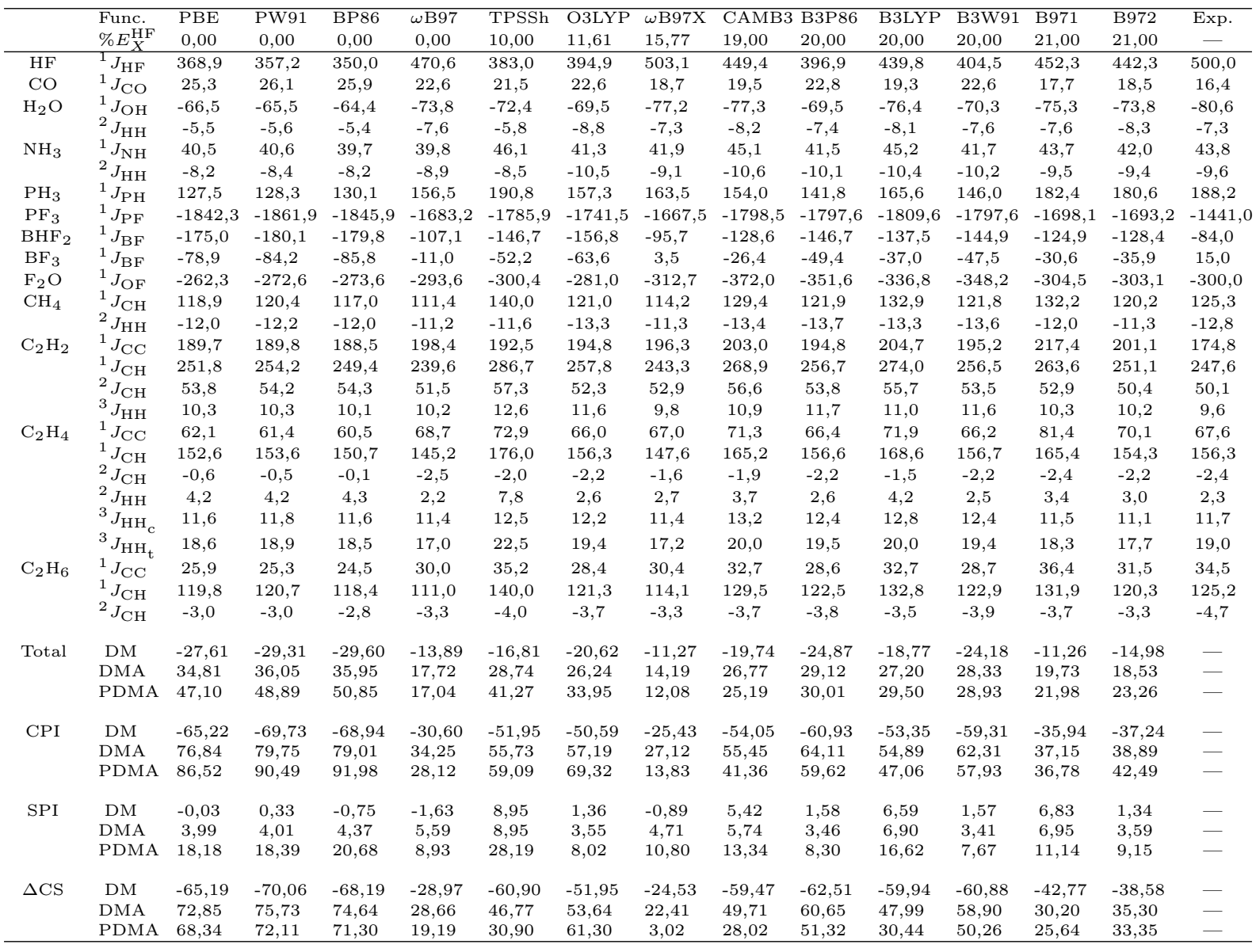


Tabela 8.4: Constantes de acoplamento utilizando funcionais da literatura (21 a 100\% $\left.E_{X}^{\mathrm{HF}}\right)$ com base HuzIII-su3.

\begin{tabular}{|c|c|c|c|c|c|c|c|c|c|c|c|c|c|c|c|}
\hline & Func. & X3LYP & B98 & $\omega 97 X D$ & PBE0 & M06 & B1B95 & M05 & BMK & $\mathrm{BHH}$ & BHLYP & M062X & M052X & M06HF & Exp. \\
\hline & $\% E_{X}^{\mathrm{HF}}$ & 21,80 & 21,98 & 22,20 & 25,00 & 27,00 & 28,00 & 28,00 & 42,00 & 50,00 & 50,00 & 54,00 & 56,00 & 100,00 & - \\
\hline $\mathrm{HF}$ & ${ }^{1} J_{\mathrm{HF}}$ & 446,6 & 434,2 & 487,9 & 426,5 & 623,4 & 465,7 & 769,8 & 553,8 & 525,4 & 522,7 & 510,4 & 559,9 & 607,5 & 500,0 \\
\hline $\mathrm{CO}$ & ${ }^{1} J_{\mathrm{CO}}$ & 18,9 & 19,0 & 19,6 & 21,1 & 22,9 & 19,5 & 16,6 & 21,4 & 15,0 & 12,3 & 6,9 & 5,2 & $-6,1$ & 16,4 \\
\hline \multirow[t]{2}{*}{$\mathrm{H}_{2} \mathrm{O}$} & ${ }^{1} J_{\mathrm{OH}}$ & $-77,4$ & $-73,4$ & $-75,2$ & $-72,7$ & $-96,1$ & $-77,2$ & $-102,4$ & $-86,2$ & $-83,4$ & $-86,0$ & $-92,4$ & $-86,0$ & $-97,5$ & $-80,6$ \\
\hline & ${ }^{2} J_{\mathrm{HH}}$ & $-8,3$ & $-7,9$ & $-7,3$ & $-8,1$ & $-16,8$ & $-7,9$ & $-17,7$ & $-7,6$ & $-10,2$ & $-12,0$ & $-8,3$ & $-5,4$ & $-22,6$ & $-7,3$ \\
\hline \multirow{2}{*}{$\mathrm{NH}_{3}$} & ${ }^{1} J_{\mathrm{NH}}$ & 45,7 & 43,3 & 42,3 & 42,4 & 52,7 & 44,0 & 45,2 & 46,7 & 45,5 & 48,9 & 52,5 & 43,0 & 54,0 & 43,8 \\
\hline & ${ }^{2} J_{\mathrm{HH}}$ & $-10,6$ & $-9,9$ & $-9,5$ & $-10,5$ & $-19,5$ & $-9,8$ & $-18,6$ & $-10,5$ & $-11,5$ & $-13,9$ & $-11,4$ & $-5,9$ & $-22,1$ & $-9,6$ \\
\hline $\mathrm{PH}_{3}$ & ${ }^{1} J_{\mathrm{PH}}$ & 166,2 & 188,9 & 173,4 & 143,1 & 248,3 & 160,2 & 199,4 & 135,8 & 179,0 & 184,8 & 145,3 & 86,4 & 293,2 & 188,2 \\
\hline $\mathrm{PF}_{3}$ & ${ }^{1} J_{\mathrm{PF}}$ & $-1804,3$ & $-1707,8$ & $-1665,6$ & $-1779,6$ & $-1580,6$ & $-1691,9$ & $-1433,9$ & $-1679,5$ & $-1730,4$ & $-1713,3$ & $-1645,0$ & $-1733,1$ & $-1267,3$ & $-1441,0$ \\
\hline $\mathrm{BHF}_{2}$ & ${ }^{1} J_{\mathrm{BF}}$ & $-134,7$ & $-130,9$ & $-102,3$ & $-134,0$ & $-66,1$ & $-129,6$ & $-23,2$ & $-109,0$ & $-98,7$ & $-86,1$ & $-104,2$ & $-102,6$ & 30,7 & $-84,0$ \\
\hline $\mathrm{BF}_{3}$ & ${ }^{1} J_{\mathrm{BF}}$ & $-33,4$ & $-37,1$ & $-3,6$ & $-34,1$ & 31,8 & $-30,2$ & 78,8 & $-1,2$ & 10,5 & 19,2 & $-10,3$ & $-2,5$ & 127,6 & 15,0 \\
\hline $\mathrm{F}_{2} \mathrm{O}$ & ${ }^{1} J_{\mathrm{OF}}$ & $-343,8$ & $-321,3$ & $-319,7$ & $-360,4$ & $-304,7$ & $-353,1$ & $-301,6$ & $-374,0$ & $-458,1$ & $-470,2$ & $-437,8$ & $-533,1$ & $-479,3$ & $-300,0$ \\
\hline \multirow[t]{2}{*}{$\mathrm{CH}_{4}$} & ${ }^{1} J_{\mathrm{CH}}$ & 133,4 & 132,4 & 116,5 & 124,3 & 141,4 & 125,3 & 104,5 & 159,4 & 125,2 & 141,6 & 138,2 & 110,4 & 154,5 & 125,3 \\
\hline & ${ }^{2} J_{\mathrm{HH}}$ & $-13,4$ & $-12,5$ & $-11,9$ & $-13,9$ & $-21,7$ & $-12,3$ & $-18,4$ & $-14,7$ & $-13,4$ & $-16,2$ & $-12,0$ & $-5,2$ & $-20,1$ & $-12,8$ \\
\hline \multirow[t]{4}{*}{$\mathrm{C}_{2} \mathrm{H}_{2}$} & ${ }^{1} J_{\mathrm{CC}}$ & 205,5 & 216,5 & 194,2 & 197,4 & 201,6 & 197,2 & 211,4 & 335,2 & 203,6 & 221,5 & 223,5 & 219,9 & 388,7 & 174,8 \\
\hline & ${ }^{1} J_{\mathrm{CH}}$ & 275,9 & 263,8 & 248,3 & 258,6 & 306,7 & 258,9 & 247,3 & 298,2 & 262,3 & 291,9 & 267,8 & 212,2 & 374,4 & 247,6 \\
\hline & ${ }^{2} J_{\mathrm{CH}}$ & 55,8 & 52,4 & 53,2 & 53,0 & 50,4 & 55,0 & 40,5 & 61,2 & 52,5 & 53,5 & 56,5 & 50,7 & $-21,5$ & 50,1 \\
\hline & ${ }^{3} J_{\mathrm{HH}}$ & 11,1 & 10,6 & 9,9 & 12,2 & 14,5 & 10,3 & 16,3 & 11,9 & 11,7 & 14,7 & 9,1 & 7,7 & 45,7 & 9,6 \\
\hline \multirow[t]{6}{*}{$\mathrm{C}_{2} \mathrm{H}_{4}$} & ${ }^{1} J_{\mathrm{CC}}$ & 72,8 & 80,7 & 66,0 & 69,5 & 70,4 & 67,2 & 76,8 & 128,6 & 72,9 & 86,9 & 87,0 & 78,5 & 264,5 & 67,6 \\
\hline & ${ }^{1} J_{\mathrm{CH}}$ & 169,4 & 165,4 & 150,1 & 158,4 & 185,2 & 160,1 & 144,6 & 195,2 & 161,6 & 180,2 & 172,5 & 137,3 & 257,7 & 156,3 \\
\hline & ${ }^{2} J_{\mathrm{CH}}$ & $-1,8$ & $-2,7$ & $-1,3$ & $-3,2$ & $-6,5$ & $-1,3$ & $-10,9$ & $-4,8$ & $-4,0$ & $-6,2$ & $-2,2$ & $-0,7$ & $-72,6$ & $-2,4$ \\
\hline & ${ }^{2} J_{\mathrm{HH}}$ & 4,1 & 2,9 & 2,7 & 2,1 & $-8,6$ & 3,9 & $-9,3$ & 4,8 & 1,9 & 1,2 & 3,8 & 6,5 & $-28,2$ & 2,3 \\
\hline & ${ }^{3} J_{\mathrm{HH}_{\mathrm{c}}}$ & 12,9 & 11,7 & 11,4 & 12,6 & 14,9 & 12,0 & 13,8 & 13,4 & 13,3 & 14,9 & 12,7 & 9,4 & 38,5 & 11,7 \\
\hline & ${ }^{3} J_{\mathrm{HH}_{\mathrm{t}}}$ & 20,2 & 18,5 & 17,6 & 19,8 & 19,3 & 19,0 & 17,6 & 21,1 & 19,7 & 22,7 & 18,6 & 14,7 & 50,4 & 19,0 \\
\hline \multirow[t]{3}{*}{$\mathrm{C}_{2} \mathrm{H}_{6}$} & ${ }^{1} J_{\mathrm{CC}}$ & 33,3 & 36,1 & 30,3 & 30,7 & 31,8 & 31,2 & 24,8 & 48,2 & 33,5 & 40,9 & 46,6 & 37,0 & 60,6 & 34,5 \\
\hline & ${ }^{1} J_{\mathrm{CH}}$ & 133,4 & 131,9 & 116,9 & 124,2 & 141,3 & 125,9 & 104,9 & 160,0 & 125,8 & 140,7 & 139,4 & 111,6 & 157,3 & 125,2 \\
\hline & ${ }^{2} J_{\mathrm{CH}}$ & $-3,6$ & $-3,9$ & $-3,4$ & $-4,2$ & $-5,2$ & $-3,6$ & $-4,2$ & $-5,3$ & $-4,4$ & $-5,2$ & $-3,8$ & $-2,1$ & $-10,1$ & $-4,7$ \\
\hline \multirow[t]{3}{*}{ Total } & $\mathrm{DM}$ & $-18,12$ & $-13,23$ & $-11,71$ & $-21,92$ & 7,15 & $-15,63$ & 12,58 & 2,20 & $-15,37$ & $-9,83$ & $-10,83$ & $-24,28$ & 38,96 & - \\
\hline & DMA & 26,91 & 21,77 & 14,47 & 26,37 & 23,02 & 19,87 & 23,53 & 34,33 & 22,21 & 26,73 & 24,18 & 35,10 & 72,15 & - \\
\hline & PDMA & 28,05 & 24,09 & 14,22 & 25,82 & 54,40 & 24,59 & 75,25 & 34,81 & 14,69 & 28,75 & 25,46 & 37,46 & 290,31 & - \\
\hline \multirow[t]{3}{*}{ CPI } & DM & $-52,36$ & $-40,35$ & $-27,35$ & $-55,20$ & 4,95 & $-41,02$ & 33,77 & $-31,93$ & $-41,62$ & $-39,50$ & $-39,56$ & $-55,91$ & 34,29 & - \\
\hline & DMA & 53,75 & 42,25 & 28,94 & 57,49 & 37,53 & 42,24 & 41,55 & 43,15 & 46,55 & 45,32 & 43,04 & 67,82 & 79,11 & - \\
\hline & PDMA & 44,81 & 43,60 & 18,99 & 48,29 & 46,69 & 40,58 & 75,12 & 25,01 & 18,70 & 24,09 & 36,60 & 40,39 & 141,60 & - \\
\hline \multirow[t]{3}{*}{ SPI } & DM & 6,99 & 6,65 & $-0,24$ & 2,49 & 8,76 & 2,98 & $-2,96$ & 27,22 & 3,87 & 11,93 & 10,24 & $-1,08$ & 42,38 & - \\
\hline & DMA & 7,23 & 6,75 & 3,87 & 3,55 & 12,37 & 3,47 & 10,31 & 27,87 & 4,37 & 13,11 & 10,36 & 11,11 & 67,05 & - \\
\hline & PDMA & 15,77 & 9,79 & 10,71 & 9,34 & 60,06 & 12,86 & 75,35 & 42,00 & 11,75 & 32,17 & 17,29 & 35,32 & 399,37 & - \\
\hline \multirow[t]{3}{*}{$\Delta \mathrm{CS}$} & DM & $-59,36$ & $-46,99$ & $-27,11$ & $-57,69$ & $-3,81$ & $-44,00$ & 36,73 & $-59,15$ & $-45,49$ & $-51,43$ & $-49,80$ & $-54,83$ & $-8,09$ & - \\
\hline & DMA & 46,51 & 35,50 & 25,07 & 53,94 & 25,15 & 38,76 & 31,25 & 15,27 & 42,18 & 32,21 & 32,68 & 56,71 & 12,06 & - \\
\hline & PDMA & 29,04 & 33,81 & 8,28 & 38,94 & $-13,36$ & 27,72 & $-0,23$ & $-16,99$ & 6,95 & $-8,08$ & 19,30 & 5,07 & $-257,78$ & - \\
\hline
\end{tabular}




\subsection{Variação da porcentagem de $E_{X}^{\mathrm{HF}}$ para os funcionais híbridos}

\subsubsection{Geometrias Experimentais}

Tabela 8.5: Constantes de acoplamento B1B95 com base aug-pcJ-2.

\begin{tabular}{|c|c|c|c|c|c|c|c|c|c|c|c|c|c|}
\hline & $\% E_{X}^{\mathrm{HF}}$ & $0 \%$ & $10 \%$ & $20 \%$ & $30 \%$ & $40 \%$ & $50 \%$ & $60 \%$ & $70 \%$ & $80 \%$ & $90 \%$ & $100 \%$ & Exp. \\
\hline $\mathrm{HF}$ & ${ }^{1} J_{\mathrm{HF}}$ & 403,9 & 427,5 & 451,2 & 475,2 & 499,3 & 523,6 & 548,0 & 572,6 & 597,4 & 622,3 & 647,4 & 500 \\
\hline $\mathrm{CO}$ & ${ }^{1} J_{\mathrm{CO}}$ & 23,4 & 21,7 & 19,9 & 18,1 & 16,1 & 14,0 & 11,8 & 9,6 & 7,3 & 4,9 & 2,4 & 16,4 \\
\hline $\mathrm{H}_{2} \mathrm{O}$ & ${ }^{1} J_{\mathrm{OH}}$ & $-70,3$ & $-72,8$ & $-75,3$ & $-77,9$ & $-80,4$ & $-83,0$ & $-85,6$ & $-88,2$ & $-90,8$ & $-93,5$ & $-96,2$ & $-80,6$ \\
\hline $\mathrm{H}_{2} \mathrm{O}$ & ${ }^{2} J_{\mathrm{HH}}$ & $-4,2$ & $-5,2$ & $-6,2$ & $-7,2$ & $-8,2$ & $-9,2$ & $-10,3$ & $-11,3$ & $-12,4$ & $-13,5$ & $-14,7$ & $-7,3$ \\
\hline $\mathrm{NH}_{3}$ & ${ }^{1} J_{\mathrm{NH}}$ & 41,9 & 42,7 & 43,4 & 44,1 & 44,9 & 45,6 & 46,4 & 47,2 & 47,9 & 48,7 & 49,5 & 43,8 \\
\hline $\mathrm{NH}_{3}$ & ${ }^{2} J_{\mathrm{HH}}$ & $-7,0$ & $-7,8$ & $-8,7$ & $-9,5$ & $-10,4$ & $-11,3$ & $-12,1$ & $-13,0$ & $-13,9$ & $-14,8$ & $-15,8$ & $-9,6$ \\
\hline $\mathrm{PH}_{3}$ & ${ }^{1} J_{\mathrm{PH}}$ & 146,7 & 154,4 & 161,8 & 169,2 & 176,5 & 183,6 & 190,6 & 197,4 & 204,1 & 210,7 & 217,0 & 188,2 \\
\hline $\mathrm{PF}_{3}$ & ${ }^{1} J_{\mathrm{PF}}$ & $-1716,6$ & $-1695,0$ & $-1669,0$ & $-1639,2$ & $-1606,4$ & $-1571,1$ & $-1533,7$ & $-1494,9$ & $-1454,9$ & $-1414,1$ & $-1372,8$ & -1441 \\
\hline $\mathrm{BHF}_{2}$ & ${ }^{1} J_{\mathrm{BF}}$ & $-174,7$ & $-157,8$ & $-141,0$ & $-124,2$ & $-107,5$ & $-91,0$ & $-74,6$ & $-58,3$ & $-42,2$ & $-26,3$ & $-10,5$ & -84 \\
\hline $\mathrm{BF}_{3}$ & ${ }^{1} J_{\mathrm{BF}}$ & $-78,7$ & $-60,1$ & $-41,7$ & $-23,4$ & $-5,3$ & 12,6 & 30,3 & 47,9 & 65,3 & 82,6 & 99,7 & 15 \\
\hline $\mathrm{F}_{2} \mathrm{O}$ & ${ }^{1} J_{\mathrm{OF}}$ & $-266,9$ & $-301,3$ & $-334,9$ & $-368,7$ & $-404,3$ & $-443,7$ & $-490,0$ & $-548,8$ & $-631,2$ & $-765,1$ & $-1048,5$ & -300 \\
\hline $\mathrm{CH}_{4}$ & ${ }^{1} J_{\mathrm{CH}}$ & 120,7 & 122,0 & 123,3 & 124,7 & 126,1 & 127,5 & 129,0 & 130,4 & 131,9 & 133,4 & 134,9 & 125,3 \\
\hline $\mathrm{CH}_{4}$ & ${ }^{2} J_{\mathrm{HH}}$ & $-10,3$ & $-11,0$ & $-11,7$ & $-12,4$ & $-13,0$ & $-13,7$ & $-14,4$ & $-15,0$ & $-15,7$ & $-16,4$ & $-17,0$ & $-12,8$ \\
\hline $\mathrm{C}_{2} \mathrm{H}_{2}$ & ${ }^{1} J_{\mathrm{CC}}$ & 187,9 & 190,2 & 192,9 & 195,8 & 199,3 & 203,2 & 207,7 & 213,0 & 219,2 & 226,6 & 235,5 & 174,8 \\
\hline $\mathrm{C}_{2} \mathrm{H}_{2}$ & ${ }^{1} J_{\mathrm{CH}}$ & 250,6 & 252,5 & 254,5 & 256,6 & 258,8 & 261,2 & 263,7 & 266,5 & 269,6 & 273,2 & 277,3 & 247,6 \\
\hline $\mathrm{C}_{2} \mathrm{H}_{2}$ & ${ }^{2} J_{\mathrm{CH}}$ & 55,5 & 55,7 & 55,7 & 55,5 & 55,2 & 54,6 & 53,8 & 52,6 & 51,1 & 49,1 & 46,4 & 50,1 \\
\hline $\mathrm{C}_{2} \mathrm{H}_{2}$ & ${ }^{3} J_{\mathrm{HH}}$ & 9,1 & 9,5 & 10,0 & 10,6 & 11,2 & 12,0 & 13,0 & 14,1 & 15,4 & 17,0 & 18,9 & 9,6 \\
\hline $\mathrm{C}_{2} \mathrm{H}_{4}$ & ${ }^{1} J_{\mathrm{CC}}$ & 58,9 & 61,2 & 63,8 & 66,5 & 69,6 & 73,0 & 76,8 & 81,2 & 86,5 & 92,8 & 100,8 & 67,6 \\
\hline $\mathrm{C}_{2} \mathrm{H}_{4}$ & ${ }^{1} J_{\mathrm{CH}}$ & 153,4 & 155,3 & 157,2 & 159,2 & 161,3 & 163,5 & 165,9 & 168,5 & 171,4 & 174,7 & 178,7 & 156,3 \\
\hline $\mathrm{C}_{2} \mathrm{H}_{4}$ & ${ }^{2} J_{\mathrm{CH}}$ & 1,0 & 0,3 & $-0,4$ & $-1,3$ & $-2,3$ & $-3,4$ & $-4,7$ & $-6,3$ & $-8,1$ & $-10,4$ & $-13,4$ & $-2,4$ \\
\hline $\mathrm{C}_{2} \mathrm{H}_{4}$ & ${ }^{2} J_{\mathrm{HH}}$ & 6,0 & 5,4 & 4,7 & 4,0 & 3,3 & 2,5 & 1,6 & 0,6 & $-0,5$ & $-1,9$ & $-3,5$ & 2,3 \\
\hline $\mathrm{C}_{2} \mathrm{H}_{4}$ & ${ }^{3} J_{\mathrm{HH}_{\mathrm{C}}}$ & 11,5 & 11,7 & 11,9 & 12,2 & 12,5 & 12,8 & 13,3 & 13,9 & 14,7 & 15,6 & 16,9 & 11,7 \\
\hline $\mathrm{C}_{2} \mathrm{H}_{4}$ & ${ }^{3} J_{\mathrm{HH}_{\mathrm{t}}}$ & 18,3 & 18,5 & 18,8 & 19,0 & 19,4 & 19,9 & 20,4 & 21,1 & 22,0 & 23,2 & 24,7 & 19 \\
\hline $\mathrm{C}_{2} \mathrm{H}_{6}$ & ${ }^{1} J_{\mathrm{CC}}$ & 25,1 & 27,1 & 29,0 & 31,0 & 33,0 & 35,0 & 37,1 & 39,2 & 41,3 & 43,5 & 45,7 & 34,5 \\
\hline $\mathrm{C}_{2} \mathrm{H}_{6}$ & ${ }^{1} J_{\mathrm{CH}}$ & 120,6 & 122,2 & 123,7 & 125,3 & 126,9 & 128,5 & 130,1 & 131,8 & 133,4 & 135,0 & 136,7 & 125,2 \\
\hline $\mathrm{C}_{2} \mathrm{H}_{6}$ & ${ }^{2} J_{\mathrm{CH}}$ & $-2,2$ & $-2,7$ & $-3,1$ & $-3,6$ & $-4,0$ & $-4,5$ & $-5,0$ & $-5,4$ & $-5,9$ & $-6,4$ & $-6,9$ & $-4,7$ \\
\hline \multirow[t]{3}{*}{ Total } & DM & $-20,82$ & $-18,49$ & $-15,97$ & $-13,28$ & $-10,52$ & $-7,80$ & $-5,23$ & $-3,02$ & $-1,62$ & $-2,08$ & $-8,15$ & - \\
\hline & DMA & 27,72 & 22,53 & 19,82 & 17,06 & 14,84 & 15,13 & 18,06 & 22,59 & 28,10 & 37,87 & 54,82 & - \\
\hline & PDMA & 53,39 & 42,20 & 32,19 & 22,08 & 14,31 & 11,69 & 21,91 & 35,98 & 51,20 & 68,97 & 90,89 & - \\
\hline \multirow[t]{3}{*}{ CPI } & DM & $-49,40$ & $-44,96$ & $-40,13$ & $-34,95$ & $-29,69$ & $-24,62$ & $-20,01$ & $-16,43$ & $-14,94$ & $-18,09$ & $-34,85$ & - \\
\hline & DMA & 59,60 & 48,05 & 42,09 & 35,84 & 29,93 & 29,24 & 34,14 & 42,57 & 53,03 & 72,98 & 109,09 & - \\
\hline & PDMA & 84,86 & 66,46 & 50,03 & 33,85 & 21,92 & 13,99 & 27,38 & 45,90 & 65,14 & 86,28 & 112,26 & - \\
\hline \multirow[t]{3}{*}{ SPI } & DM & 0,13 & 0,92 & 1,75 & 2,60 & 3,55 & 4,53 & 5,61 & 6,81 & 8,15 & 9,66 & 11,44 & - \\
\hline & DMA & 4,35 & 3,81 & 3,48 & 3,29 & 3,77 & 4,79 & 6,27 & 7,94 & 9,83 & 12,13 & 15,03 & - \\
\hline & PDMA & 30,31 & 24,41 & 19,10 & 13,44 & 8,73 & 10,00 & 17,90 & 28,71 & 40,98 & 56,28 & 75,22 & - \\
\hline \multirow[t]{3}{*}{$\Delta \mathrm{CS}$} & $\mathrm{DM}$ & $-49,53$ & $-45,88$ & $-41,87$ & $-37,55$ & $-33,24$ & $-29,15$ & $-25,62$ & $-23,23$ & $-23,08$ & $-27,75$ & $-46,29$ & - \\
\hline & DMA & 55,25 & 44,24 & 38,61 & 32,54 & 26,15 & 24,45 & 27,87 & 34,63 & 43,20 & 60,86 & 94,06 & - \\
\hline & PDMA & 54,55 & 42,05 & 30,93 & 20,41 & 13,20 & 3,99 & 9,48 & 17,19 & 24,16 & 30,00 & 37,04 & - \\
\hline
\end{tabular}


Tabela 8.6: Constantes de acoplamento B3LYP com base aug-pcJ-2.

\begin{tabular}{|c|c|c|c|c|c|c|c|c|c|c|c|c|c|}
\hline & $\% E_{X}^{\mathrm{HF}}$ & $0 \%$ & $10 \%$ & $20 \%$ & $30 \%$ & $40 \%$ & $50 \%$ & $60 \%$ & $70 \%$ & $80 \%$ & $90 \%$ & $100 \%$ & Exp. \\
\hline $\mathrm{HF}$ & ${ }^{1} J_{\mathrm{HF}}$ & 393,4 & 418,4 & 443,6 & 469,1 & 494,8 & 520,8 & 547,0 & 573,4 & 600,0 & 626,9 & 654,0 & 500 \\
\hline $\mathrm{CO}$ & ${ }^{1} J_{\mathrm{CO}}$ & 21,7 & 19,9 & 17,9 & 15,8 & 13,6 & 11,4 & 9,0 & 6,5 & 4,0 & 1,4 & $-1,2$ & 16,4 \\
\hline $\mathrm{H}_{2} \mathrm{O}$ & ${ }^{1} J_{\mathrm{OH}}$ & $-71,7$ & $-74,4$ & $-77,1$ & $-79,8$ & $-82,5$ & $-85,3$ & $-88,1$ & $-91,0$ & $-93,8$ & $-96,7$ & $-99,6$ & $-80,6$ \\
\hline $\mathrm{H}_{2} \mathrm{O}$ & ${ }^{2} J_{\mathrm{HH}}$ & $-5,3$ & $-6,4$ & $-7,5$ & $-8,6$ & $-9,7$ & $-10,8$ & $-12,0$ & $-13,2$ & $-14,4$ & $-15,6$ & $-16,8$ & $-7,3$ \\
\hline $\mathrm{NH}_{3}$ & ${ }^{1} J_{\mathrm{NH}}$ & 44,2 & 45,0 & 45,8 & 46,6 & 47,5 & 48,3 & 49,2 & 50,0 & 50,9 & 51,8 & 52,7 & 43,8 \\
\hline $\mathrm{NH}_{3}$ & ${ }^{2} J_{\mathrm{HH}}$ & $-8,4$ & $-9,3$ & $-10,3$ & $-11,2$ & $-12,2$ & $-13,2$ & $-14,2$ & $-15,2$ & $-16,2$ & $-17,2$ & $-18,2$ & $-9,6$ \\
\hline $\mathrm{PH}_{3}$ & ${ }^{1} J_{\mathrm{PH}}$ & 157,6 & 166,1 & 174,5 & 182,7 & 190,9 & 198,8 & 206,7 & 214,3 & 221,8 & 229,2 & 236,3 & 188,2 \\
\hline $\mathrm{PF}_{3}$ & ${ }^{1} J_{\mathrm{PF}}$ & $-1810,3$ & $-1784,6$ & $-1754,5$ & $-1720,8$ & $-1684,0$ & $-1644,8$ & $-1603,8$ & $-1561,4$ & $-1518,1$ & $-1474,0$ & $-1429,6$ & -1441 \\
\hline $\mathrm{BHF}_{2}$ & ${ }^{1} J_{\mathrm{BF}}$ & $-167,7$ & $-150,2$ & $-132,7$ & $-115,4$ & $-98,2$ & $-81,2$ & $-64,4$ & $-47,8$ & $-31,4$ & $-15,2$ & 0,7 & -84 \\
\hline $\mathrm{BF}_{3}$ & ${ }^{1} J_{\mathrm{BF}}$ & $-70,2$ & $-51,0$ & $-32,1$ & $-13,3$ & 5,1 & 23,4 & 41,5 & 59,5 & 77,2 & 94,8 & 112,2 & 15 \\
\hline $\mathrm{F}_{2} \mathrm{O}$ & ${ }^{1} J_{\mathrm{OF}}$ & $-280,0$ & $-316,8$ & $-353,7$ & $-392,3$ & $-434,8$ & $-484,4$ & $-547,0$ & $-634,0$ & $-773,3$ & $-1056,7$ & $-2138,3$ & -300 \\
\hline $\mathrm{CH}_{4}$ & ${ }^{1} J_{\mathrm{CH}}$ & 131,0 & 132,6 & 134,1 & 135,7 & 137,4 & 139,0 & 140,7 & 142,4 & 144,1 & 145,9 & 147,6 & 125,3 \\
\hline $\mathrm{CH}_{4}$ & ${ }^{2} J_{\mathrm{HH}}$ & $-11,9$ & $-12,7$ & $-13,4$ & $-14,2$ & $-14,9$ & $-15,7$ & $-16,4$ & $-17,2$ & $-17,9$ & $-18,6$ & $-19,4$ & $-12,8$ \\
\hline $\mathrm{C}_{2} \mathrm{H}_{2}$ & ${ }^{1} J_{\mathrm{CC}}$ & 199,3 & 202,3 & 205,8 & 209,7 & 214,3 & 219,6 & 225,8 & 233,3 & 242,3 & 253,2 & 266,8 & 174,8 \\
\hline $\mathrm{C}_{2} \mathrm{H}_{2}$ & $J_{\mathrm{CH}}$ & 271,1 & 273,5 & 276,1 & 278,9 & 281,8 & 285,0 & 288,6 & 292,6 & 297,3 & 302,7 & 309,4 & 247,6 \\
\hline $\mathrm{C}_{2} \mathrm{H}_{2}$ & ${ }^{2} J_{\mathrm{CH}}$ & 56,9 & 56,8 & 56,5 & 56,0 & 55,1 & 53,9 & 52,3 & 50,1 & 47,2 & 43,5 & 38,5 & 50,1 \\
\hline $\mathrm{C}_{2} \mathrm{H}_{2}$ & ${ }^{3} J_{\mathrm{HH}}$ & 10,2 & 10,7 & 11,4 & 12,3 & 13,3 & 14,5 & 15,9 & 17,6 & 19,7 & 22,2 & 25,4 & 9,6 \\
\hline $\mathrm{C}_{2} \mathrm{H}_{4}$ & ${ }^{1} J_{\mathrm{CC}}$ & 66,6 & 69,5 & 72,8 & 76,4 & 80,5 & 85,3 & 91,1 & 98,1 & 107,2 & 119,6 & 137,7 & 67,6 \\
\hline $\mathrm{C}_{2} \mathrm{H}_{4}$ & ${ }^{1} J_{\mathrm{CH}}$ & 165,4 & 167,7 & 170,0 & 172,5 & 175,1 & 178,0 & 181,2 & 185,0 & 189,5 & 195,2 & 203,3 & 156,3 \\
\hline $\mathrm{C}_{2} \mathrm{H}_{4}$ & ${ }^{2} J_{\mathrm{CH}}$ & 0,3 & $-0,5$ & $-1,6$ & $-2,7$ & $-4,1$ & $-5,7$ & $-7,7$ & $-10,1$ & $-13,4$ & $-18,0$ & $-24,8$ & $-2,4$ \\
\hline $\mathrm{C}_{2} \mathrm{H}_{4}$ & ${ }^{2} J_{\mathrm{HH}}$ & 6,0 & 5,3 & 4,5 & 3,6 & 2,7 & 1,6 & 0,4 & $-1,0$ & $-2,9$ & $-5,5$ & $-9,2$ & 2,3 \\
\hline $\mathrm{C}_{2} \mathrm{H}_{4}$ & ${ }^{3} J_{\mathrm{HH}_{\mathrm{C}}}$ & 12,4 & 12,7 & 13,0 & 13,4 & 13,8 & 14,5 & 15,3 & 16,3 & 17,8 & 19,9 & 23,2 & 11,7 \\
\hline $\mathrm{C}_{2} \mathrm{H}_{4}$ & ${ }^{3} J_{\mathrm{HH}_{\mathrm{t}}}$ & 19,8 & 20,0 & 20,4 & 20,8 & 21,4 & 22,2 & 23,1 & 24,4 & 26,1 & 28,5 & 32,3 & 19 \\
\hline $\mathrm{C}_{2} \mathrm{H}_{6}$ & ${ }^{1} J_{\mathrm{CC}}$ & 29,2 & 31,3 & 33,5 & 35,7 & 37,9 & 40,2 & 42,6 & 44,9 & 47,3 & 49,8 & 52,2 & 34,5 \\
\hline $\mathrm{C}_{2} \mathrm{H}_{6}$ & ${ }^{1} J_{\mathrm{CH}}$ & 130,5 & 132,3 & 134,1 & 135,9 & 137,7 & 139,6 & 141,5 & 143,3 & 145,2 & 147,2 & 149,1 & 125,2 \\
\hline $\mathrm{C}_{2} \mathrm{H}_{6}$ & ${ }^{2} J_{\mathrm{CH}}$ & $-2,5$ & $-3,0$ & $-3,4$ & $-3,9$ & $-4,5$ & $-5,0$ & $-5,5$ & $-6,0$ & $-6,6$ & $-7,1$ & $-7,7$ & $-4,7$ \\
\hline \multirow[t]{3}{*}{ Total } & DM & $-21,44$ & $-18,84$ & $-16,05$ & $-13,16$ & $-10,27$ & $-7,50$ & $-5,08$ & $-3,47$ & $-3,67$ & $-9,15$ & $-44,94$ & - \\
\hline & DMA & 31,00 & 27,28 & 25,15 & 23,26 & 22,08 & 24,21 & 29,19 & 35,22 & 43,70 & 58,15 & 104,92 & - \\
\hline & PDMA & 47,46 & 37,15 & 28,17 & 21,85 & 20,00 & 26,65 & 42,62 & 60,21 & 81,70 & 109,06 & 153,61 & - \\
\hline \multirow[t]{3}{*}{ CPI } & DM & $-57,96$ & $-53,11$ & $-47,91$ & $-42,55$ & $-37,31$ & $-32,54$ & $-28,82$ & $-27,25$ & $-30,38$ & $-46,56$ & $-135,34$ & - \\
\hline & DMA & 64,84 & 55,31 & 49,18 & 43,21 & 38,47 & 41,10 & 50,09 & 61,15 & 76,84 & 105,56 & 208,85 & - \\
\hline & PDMA & 74,70 & 56,69 & 41,66 & 30,08 & 21,36 & 25,16 & 44,72 & 64,96 & 86,59 & 112,56 & 162,70 & - \\
\hline \multirow[t]{3}{*}{ SPI } & DM & 5,35 & 6,29 & 7,31 & 8,40 & 9,56 & 10,86 & 12,32 & 13,97 & 15,92 & 18,29 & 21,35 & - \\
\hline & DMA & 6,19 & 6,72 & 7,53 & 8,63 & 10,07 & 11,82 & 13,87 & 16,20 & 19,40 & 23,39 & 28,70 & - \\
\hline & PDMA & 27,48 & 22,82 & 18,27 & 15,81 & 19,00 & 27,74 & 41,08 & 56,72 & 78,12 & 106,49 & 146,95 & - \\
\hline \multirow[t]{3}{*}{$\Delta \mathrm{CS}$} & $\mathrm{DM}$ & $-63,31$ & $-59,40$ & $-55,22$ & $-50,95$ & $-46,87$ & $-43,40$ & $-41,14$ & $-41,23$ & $-46,30$ & $-64,86$ & $-156,69$ & - \\
\hline & DMA & 58,65 & 48,59 & 41,66 & 34,58 & 28,41 & 29,28 & 36,22 & 44,95 & 57,44 & 82,18 & 180,15 & - \\
\hline & PDMA & 47,22 & 33,87 & 23,39 & 14,26 & 2,36 & $-2,58$ & 3,64 & 8,24 & 8,47 & 6,07 & 15,74 & - \\
\hline
\end{tabular}


Tabela 8.7: Constantes de acoplamento B3P86 com base aug-pcJ-2.

\begin{tabular}{|c|c|c|c|c|c|c|c|c|c|c|c|c|c|}
\hline & $\% E_{X}^{\mathrm{HF}}$ & $0 \%$ & $10 \%$ & $20 \%$ & $30 \%$ & $40 \%$ & $50 \%$ & $60 \%$ & $70 \%$ & $80 \%$ & $90 \%$ & $100 \%$ & Exp. \\
\hline $\mathrm{HF}$ & ${ }^{1} J_{\mathrm{HF}}$ & 357,7 & 381,4 & 405,4 & 429,5 & 454,0 & 478,6 & 503,5 & 528,5 & 553,8 & 579,3 & 605,0 & 500 \\
\hline $\mathrm{CO}$ & ${ }^{1} J_{\mathrm{CO}}$ & 24,7 & 23,1 & 21,3 & 19,5 & 17,5 & 15,5 & 13,4 & 11,3 & 9,1 & 6,8 & 4,4 & 16,4 \\
\hline $\mathrm{H}_{2} \mathrm{O}$ & ${ }^{1} J_{\mathrm{OH}}$ & $-65,2$ & $-67,8$ & $-70,3$ & $-72,9$ & $-75,5$ & $-78,1$ & $-80,8$ & $-83,4$ & $-86,1$ & $-88,9$ & $-91,6$ & $-80,6$ \\
\hline $\mathrm{H}_{2} \mathrm{O}$ & ${ }^{2} J_{\mathrm{HH}}$ & $-4,6$ & $-5,6$ & $-6,5$ & $-7,6$ & $-8,6$ & $-9,6$ & $-10,7$ & $-11,8$ & $-12,9$ & $-14,0$ & $-15,2$ & $-7,3$ \\
\hline $\mathrm{NH}_{3}$ & ${ }^{1} J_{\mathrm{NH}}$ & 40,3 & 41,1 & 41,8 & 42,6 & 43,4 & 44,2 & 45,0 & 45,8 & 46,6 & 47,5 & 48,3 & 43,8 \\
\hline $\mathrm{NH}_{3}$ & ${ }^{2} J_{\mathrm{HH}}$ & $-7,8$ & $-8,7$ & $-9,5$ & $-10,4$ & $-11,3$ & $-12,2$ & $-13,1$ & $-14,1$ & $-15,0$ & $-15,9$ & $-16,9$ & $-9,6$ \\
\hline $\mathrm{PH}_{3}$ & ${ }^{1} J_{\mathrm{PH}}$ & 138,4 & 146,6 & 154,6 & 162,6 & 170,5 & 178,2 & 185,8 & 193,3 & 200,6 & 207,8 & 214,8 & 188,2 \\
\hline $\mathrm{PF}_{3}$ & ${ }^{1} J_{\mathrm{PF}}$ & $-1804,0$ & $-1778,3$ & $-1748,1$ & $-1714,4$ & $-1677,8$ & $-1638,8$ & $-1598,0$ & $-1555,9$ & $-1512,8$ & $-1469,1$ & $-1425,0$ & -1441 \\
\hline $\mathrm{BHF}_{2}$ & ${ }^{1} J_{\mathrm{BF}}$ & $-175,5$ & $-158,4$ & $-141,4$ & $-124,6$ & $-107,9$ & $-91,3$ & $-74,9$ & $-58,7$ & $-42,7$ & $-26,9$ & $-11,3$ & -84 \\
\hline $\mathrm{BF}_{3}$ & ${ }^{1} J_{\mathrm{BF}}$ & $-81,4$ & $-62,6$ & $-44,1$ & $-25,8$ & $-7,7$ & 10,1 & 27,8 & 45,3 & 62,7 & 79,9 & 96,9 & 15 \\
\hline $\mathrm{F}_{2} \mathrm{O}$ & ${ }^{1} J_{\mathrm{OF}}$ & $-287,8$ & $-324,9$ & $-362,3$ & $-401,4$ & $-444,6$ & $-495,1$ & $-558,7$ & $-646,9$ & $-786,4$ & $-1061,9$ & $-1993,1$ & -300 \\
\hline $\mathrm{CH}_{4}$ & ${ }^{1} J_{\mathrm{CH}}$ & 119,3 & 120,8 & 122,3 & 123,8 & 125,4 & 127,0 & 128,6 & 130,2 & 131,8 & 133,5 & 135,2 & 125,3 \\
\hline $\mathrm{CH}_{4}$ & ${ }^{2} J_{\mathrm{HH}}$ & $-11,8$ & $-12,5$ & $-13,3$ & $-14,0$ & $-14,7$ & $-15,4$ & $-16,1$ & $-16,8$ & $-17,5$ & $-18,2$ & $-18,9$ & $-12,8$ \\
\hline $\mathrm{C}_{2} \mathrm{H}_{2}$ & ${ }^{1} J_{\mathrm{CC}}$ & 189,8 & 192,5 & 195,7 & 199,3 & 203,5 & 208,5 & 214,4 & 221,5 & 230,2 & 241,0 & 254,8 & 174,8 \\
\hline $\mathrm{C}_{2} \mathrm{H}_{2}$ & ${ }^{1} J_{\mathrm{CH}}$ & 251,0 & 253,4 & 255,8 & 258,5 & 261,4 & 264,5 & 268,1 & 272,2 & 276,9 & 282,7 & 289,8 & 247,6 \\
\hline $\mathrm{C}_{2} \mathrm{H}_{2}$ & ${ }^{2} J_{\mathrm{CH}}$ & 54,7 & 54,6 & 54,4 & 53,9 & 53,0 & 51,8 & 50,2 & 47,9 & 44,9 & 40,9 & 35,4 & 50,1 \\
\hline $\mathrm{C}_{2} \mathrm{H}_{2}$ & ${ }^{3} J_{\mathrm{HH}}$ & 10,2 & 10,9 & 11,6 & 12,5 & 13,6 & 14,9 & 16,4 & 18,3 & 20,6 & 23,5 & 27,1 & 9,6 \\
\hline $\mathrm{C}_{2} \mathrm{H}_{4}$ & ${ }^{1} J_{\mathrm{CC}}$ & 60,6 & 63,4 & 66,4 & 69,9 & 73,8 & 78,5 & 84,2 & 91,5 & 101,2 & 115,3 & 138,2 & 67,6 \\
\hline $\mathrm{C}_{2} \mathrm{H}_{4}$ & ${ }^{1} J_{\mathrm{CH}}$ & 152,0 & 154,1 & 156,4 & 158,8 & 161,3 & 164,2 & 167,5 & 171,3 & 176,2 & 182,8 & 193,0 & 156,3 \\
\hline $\mathrm{C}_{2} \mathrm{H}_{4}$ & ${ }^{2} J_{\mathrm{CH}}$ & 0,0 & $-0,8$ & $-1,8$ & $-2,9$ & $-4,2$ & $-5,9$ & $-7,9$ & $-10,6$ & $-14,3$ & $-19,7$ & $-28,7$ & $-2,4$ \\
\hline $\mathrm{C}_{2} \mathrm{H}_{4}$ & ${ }^{2} J_{\mathrm{HH}}$ & 4,7 & 4,0 & 3,2 & 2,3 & 1,3 & 0,1 & $-1,2$ & $-2,9$ & $-5,2$ & $-8,5$ & $-13,8$ & 2,3 \\
\hline $\mathrm{C}_{2} \mathrm{H}_{4}$ & ${ }^{3} J_{\mathrm{HH}_{\mathrm{c}}}$ & 11,6 & 11,9 & 12,3 & 12,7 & 13,3 & 14,0 & 15,0 & 16,3 & 18,2 & 21,1 & 26,1 & 11,7 \\
\hline $\mathrm{C}_{2} \mathrm{H}_{4}$ & ${ }^{3} J_{\mathrm{HH}_{\mathrm{t}}}$ & 18,6 & 18,9 & 19,3 & 19,9 & 20,5 & 21,4 & 22,5 & 24,1 & 26,3 & 29,6 & 35,2 & 19 \\
\hline $\mathrm{C}_{2} \mathrm{H}_{6}$ & ${ }^{1} J_{\mathrm{CC}}$ & 25,0 & 27,0 & 29,0 & 31,1 & 33,2 & 35,3 & 37,5 & 39,7 & 41,9 & 44,2 & 46,5 & 34,5 \\
\hline $\mathrm{C}_{2} \mathrm{H}_{6}$ & ${ }^{1} J_{\mathrm{CH}}$ & 119,4 & 121,1 & 122,8 & 124,5 & 126,2 & 128,0 & 129,8 & 131,6 & 133,4 & 135,3 & 137,1 & 125,2 \\
\hline $\mathrm{C}_{2} \mathrm{H}_{6}$ & ${ }^{2} J_{\mathrm{CH}}$ & $-2,7$ & $-3,1$ & $-3,6$ & $-4,1$ & $-4,5$ & $-5,0$ & $-5,5$ & $-6,0$ & $-6,6$ & $-7,1$ & $-7,6$ & $-4,7$ \\
\hline \multirow[t]{3}{*}{ Total } & DM & $-27,22$ & $-24,73$ & $-22,06$ & $-19,30$ & $-16,53$ & $-13,91$ & $-11,62$ & $-10,13$ & $-10,39$ & $-15,54$ & $-45,36$ & - \\
\hline & DMA & 32,75 & 29,10 & 26,30 & 23,93 & 22,01 & 20,78 & 22,32 & 28,30 & 36,78 & 51,08 & 92,90 & - \\
\hline & PDMA & 50,09 & 39,59 & 29,44 & 22,06 & 21,47 & 23,46 & 35,35 & 54,05 & 76,90 & 107,03 & 157,02 & - \\
\hline \multirow[t]{3}{*}{ CPI } & DM & $-64,19$ & $-59,55$ & $-54,55$ & $-49,44$ & $-44,45$ & $-39,95$ & $-36,51$ & $-35,23$ & $-38,55$ & $-54,21$ & $-129,51$ & - \\
\hline & DMA & 71,54 & 63,56 & 57,47 & 51,40 & 45,57 & 40,47 & 41,35 & 51,81 & 67,27 & 95,05 & 185,27 & - \\
\hline & PDMA & 88,11 & 70,82 & 54,58 & 40,40 & 28,41 & 17,98 & 27,23 & 46,53 & 67,48 & 92,50 & 137,68 & - \\
\hline \multirow[t]{3}{*}{ SPI } & $\mathrm{DM}$ & $-0,11$ & 0,81 & 1,76 & 2,81 & 3,93 & 5,19 & 6,63 & 8,28 & 10,26 & 12,82 & 16,35 & - \\
\hline & DMA & 4,30 & 3,82 & 3,44 & 3,78 & 4,73 & 6,33 & 8,37 & 11,07 & 14,42 & 18,83 & 25,17 & - \\
\hline & PDMA & 22,21 & 16,69 & 10,99 & 8,61 & 16,37 & 27,48 & 41,30 & 59,57 & 83,81 & 117,68 & 171,21 & - \\
\hline \multirow[t]{3}{*}{$\Delta \mathrm{CS}$} & $\mathrm{DM}$ & $-64,08$ & $-60,35$ & $-56,31$ & $-52,24$ & $-48,38$ & $-45,13$ & $-43,14$ & $-43,51$ & $-48,81$ & $-67,03$ & $-145,86$ & - \\
\hline & DMA & 67,24 & 59,74 & 54,03 & 47,62 & 40,84 & 34,14 & 32,97 & 40,74 & 52,85 & 76,21 & 160,11 & - \\
\hline & PDMA & 65,90 & 54,12 & 43,59 & 31,80 & 12,03 & $-9,50$ & $-14,06$ & $-13,04$ & $-16,33$ & $-25,18$ & $-33,52$ & - \\
\hline
\end{tabular}


Tabela 8.8: Constantes de acoplamento B971 com base aug-pcJ-2.

\begin{tabular}{|c|c|c|c|c|c|c|c|c|c|c|c|c|c|}
\hline & $\% E_{X}^{\mathrm{HF}}$ & $0 \%$ & $10 \%$ & $20 \%$ & $30 \%$ & $40 \%$ & $50 \%$ & $60 \%$ & $70 \%$ & $80 \%$ & $90 \%$ & $100 \%$ & Exp. \\
\hline $\mathrm{HF}$ & ${ }^{1} J_{\mathrm{HF}}$ & 427,3 & 443,9 & 461,4 & 480,0 & 499,7 & 520,6 & 542,8 & 566,1 & 590,8 & 616,7 & 643,9 & 500 \\
\hline $\mathrm{CO}$ & ${ }^{1} J_{\mathrm{CO}}$ & 15,8 & 14,7 & 13,5 & 12,2 & 10,7 & 9,0 & 7,3 & 5,3 & 3,2 & 1,0 & $-1,3$ & 16,4 \\
\hline $\mathrm{H}_{2} \mathrm{O}$ & ${ }^{1} J_{\mathrm{OH}}$ & $-67,7$ & $-69,8$ & $-72,1$ & $-74,5$ & $-77,0$ & $-79,7$ & $-82,5$ & $-85,5$ & $-88,8$ & $-92,2$ & $-95,7$ & $-80,6$ \\
\hline $\mathrm{H}_{2} \mathrm{O}$ & ${ }^{2} J_{\mathrm{HH}}$ & $-0,6$ & $-1,6$ & $-2,7$ & $-3,8$ & $-5,1$ & $-6,4$ & $-7,7$ & $-9,2$ & $-10,8$ & $-12,5$ & $-14,3$ & $-7,3$ \\
\hline $\mathrm{NH}_{3}$ & ${ }^{1} J_{\mathrm{NH}}$ & 37,6 & 38,6 & 39,6 & 40,7 & 41,9 & 43,1 & 44,4 & 45,9 & 47,3 & 48,9 & 50,6 & 43,8 \\
\hline $\mathrm{NH}_{3}$ & ${ }^{2} J_{\mathrm{HH}}$ & $-3,4$ & $-4,3$ & $-5,2$ & $-6,3$ & $-7,4$ & $-8,6$ & $-9,9$ & $-11,2$ & $-12,7$ & $-14,3$ & $-16,1$ & $-9,6$ \\
\hline $\mathrm{PH}_{3}$ & ${ }^{1} J_{\mathrm{PH}}$ & 161,9 & 168,1 & 174,7 & 181,6 & 188,9 & 196,6 & 204,6 & 213,1 & 221,9 & 231,1 & 240,7 & 188,2 \\
\hline $\mathrm{PF}_{3}$ & ${ }^{1} J_{\mathrm{PF}}$ & $-1613,6$ & $-1608,3$ & $-1597,4$ & $-1581,8$ & $-1562,1$ & $-1539,1$ & $-1513,4$ & $-1485,6$ & $-1456,2$ & $-1425,8$ & $-1394,8$ & -1441 \\
\hline $\mathrm{BHF}_{2}$ & ${ }^{1} J_{\mathrm{BF}}$ & $-145,0$ & $-130,5$ & $-115,6$ & $-100,5$ & $-85,1$ & $-69,6$ & $-54,0$ & $-38,4$ & $-22,8$ & $-7,2$ & 8,1 & -84 \\
\hline $\mathrm{BF}_{3}$ & ${ }^{1} J_{\mathrm{BF}}$ & $-55,7$ & $-38,9$ & $-21,9$ & $-4,7$ & 12,4 & 29,7 & 47,1 & 64,5 & 81,9 & 99,3 & 116,8 & 15 \\
\hline $\mathrm{F}_{2} \mathrm{O}$ & ${ }^{1} J_{\mathrm{OF}}$ & $-189,8$ & $-221,6$ & $-254,8$ & $-289,8$ & $-327,7$ & $-370,4$ & $-421,2$ & $-486,9$ & $-582,5$ & $-752,8$ & $-1221,3$ & -300 \\
\hline $\mathrm{CH}_{4}$ & ${ }^{1} J_{\mathrm{CH}}$ & 102,5 & 105,7 & 109,1 & 112,7 & 116,5 & 120,6 & 125,0 & 129,6 & 134,4 & 139,6 & 145,1 & 125,3 \\
\hline $\mathrm{CH}_{4}$ & ${ }^{2} J_{\mathrm{HH}}$ & $-5,8$ & $-6,7$ & $-7,6$ & $-8,5$ & $-9,6$ & $-10,7$ & $-11,8$ & $-13,1$ & $-14,4$ & $-15,8$ & $-17,3$ & $-12,8$ \\
\hline $\mathrm{C}_{2} \mathrm{H}_{2}$ & ${ }^{1} J_{\mathrm{CC}}$ & 186,1 & 190,1 & 194,4 & 199,4 & 205,0 & 211,6 & 219,4 & 228,8 & 240,5 & 255,4 & 275,1 & 174,8 \\
\hline $\mathrm{C}_{2} \mathrm{H}_{2}$ & ${ }^{1} J_{\mathrm{CH}}$ & 200,6 & 207,3 & 214,3 & 221,7 & 229,5 & 237,9 & 247,0 & 256,9 & 268,0 & 280,6 & 295,5 & 247,6 \\
\hline $\mathrm{C}_{2} \mathrm{H}_{2}$ & ${ }^{2} J_{\mathrm{CH}}$ & 51,0 & 51,9 & 52,5 & 53,0 & 53,2 & 53,0 & 52,5 & 51,2 & 49,1 & 45,6 & 40,1 & 50,1 \\
\hline $\mathrm{C}_{2} \mathrm{H}_{2}$ & ${ }^{3} J_{\mathrm{HH}}$ & 6,2 & 6,6 & 7,1 & 7,6 & 8,4 & 9,3 & 10,5 & 12,0 & 14,0 & 16,7 & 20,5 & 9,6 \\
\hline $\mathrm{C}_{2} \mathrm{H}_{4}$ & ${ }^{1} J_{\mathrm{CC}}$ & 63,4 & 66,1 & 69,1 & 72,5 & 76,4 & 80,8 & 86,2 & 92,8 & 101,2 & 112,9 & 130,5 & 67,6 \\
\hline $\mathrm{C}_{2} \mathrm{H}_{4}$ & ${ }^{1} J_{\mathrm{CH}}$ & 126,1 & 130,5 & 135,2 & 140,1 & 145,4 & 151,2 & 157,4 & 164,3 & 172,1 & 181,3 & 193,0 & 156,3 \\
\hline $\mathrm{C}_{2} \mathrm{H}_{4}$ & ${ }^{2} J_{\mathrm{CH}}$ & 2,5 & 1,9 & 1,1 & 0,2 & $-0,8$ & $-2,1$ & $-3,7$ & $-5,8$ & $-8,5$ & $-12,5$ & $-18,8$ & $-2,4$ \\
\hline $\mathrm{C}_{2} \mathrm{H}_{4}$ & ${ }^{2} J_{\mathrm{HH}}$ & 6,0 & 5,6 & 5,2 & 4,7 & 4,1 & 3,4 & 2,5 & 1,4 & 0,0 & $-2,0$ & $-5,1$ & 2,3 \\
\hline $\mathrm{C}_{2} \mathrm{H}_{4}$ & ${ }^{3} J_{\mathrm{HH}_{\mathrm{c}}}$ & 9,3 & 9,6 & 9,8 & 10,2 & 10,5 & 11,0 & 11,6 & 12,4 & 13,6 & 15,3 & 18,0 & 11,7 \\
\hline $\mathrm{C}_{2} \mathrm{H}_{4}$ & ${ }^{3} J_{\mathrm{HH}_{\mathrm{t}}}$ & 13,3 & 13,8 & 14,3 & 14,9 & 15,6 & 16,4 & 17,4 & 18,6 & 20,2 & 22,5 & 25,9 & 19 \\
\hline $\mathrm{C}_{2} \mathrm{H}_{6}$ & ${ }^{1} J_{\mathrm{CC}}$ & 25,4 & 27,6 & 30,0 & 32,4 & 35,1 & 37,8 & 40,8 & 43,9 & 47,2 & 50,7 & 54,4 & 34,5 \\
\hline $\mathrm{C}_{2} \mathrm{H}_{6}$ & ${ }^{1} J_{\mathrm{CH}}$ & 101,2 & 104,7 & 108,4 & 112,3 & 116,5 & 120,9 & 125,5 & 130,4 & 135,6 & 141,2 & 147,0 & 125,2 \\
\hline $\mathrm{C}_{2} \mathrm{H}_{6}$ & ${ }^{2} J_{\mathrm{CH}}$ & $-0,6$ & $-1,1$ & $-1,7$ & $-2,2$ & $-2,8$ & $-3,5$ & $-4,2$ & $-4,9$ & $-5,7$ & $-6,6$ & $-7,5$ & $-4,7$ \\
\hline \multirow[t]{3}{*}{ Total } & $\mathrm{DM}$ & $-15,04$ & $-13,12$ & $-10,93$ & $-8,50$ & $-5,88$ & $-3,16$ & $-0,44$ & 1,98 & 3,60 & 2,77 & $-8,92$ & - \\
\hline & DMA & 27,95 & 23,47 & 18,69 & 13,67 & 10,48 & 12,53 & 15,65 & 21,69 & 29,58 & 42,27 & 68,67 & - \\
\hline & PDMA & 58,49 & 48,70 & 38,43 & 27,82 & 17,34 & 16,15 & 21,45 & 35,84 & 55,59 & 81,12 & 118,03 & - \\
\hline \multirow[t]{3}{*}{ CPI } & DM & $-24,92$ & $-22,78$ & $-20,13$ & $-17,07$ & $-13,79$ & $-10,52$ & $-7,58$ & $-5,71$ & $-6,33$ & $-13,52$ & $-47,66$ & - \\
\hline & DMA & 49,65 & 41,00 & 31,53 & 21,27 & 15,37 & 21,59 & 29,75 & 39,93 & 52,89 & 75,52 & 128,26 & - \\
\hline & PDMA & 73,76 & 58,48 & 42,83 & 26,75 & 12,12 & 20,42 & 34,57 & 54,31 & 75,37 & 99,24 & 132,83 & - \\
\hline \multirow[t]{3}{*}{ SPI } & DM & $-7,79$ & $-6,03$ & $-4,19$ & $-2,21$ & $-0,07$ & 2,23 & 4,80 & 7,63 & 10,88 & 14,72 & 19,49 & - \\
\hline & DMA & 12,05 & 10,62 & 9,27 & 8,10 & 6,90 & 5,89 & 5,32 & 8,32 & 12,48 & 17,89 & 24,97 & - \\
\hline & PDMA & 47,29 & 41,52 & 35,20 & 28,61 & 21,17 & 13,02 & 11,83 & 22,30 & 41,09 & 67,83 & 107,17 & - \\
\hline \multirow[t]{3}{*}{$\Delta \mathrm{CS}$} & $\mathrm{DM}$ & $-17,12$ & $-16,75$ & $-15,93$ & $-14,87$ & $-13,72$ & $-12,75$ & $-12,38$ & $-13,34$ & $-17,21$ & $-28,24$ & $-67,15$ & - \\
\hline & DMA & 37,60 & 30,38 & 22,25 & 13,17 & 8,47 & 15,70 & 24,43 & 31,61 & 40,41 & 57,62 & 103,30 & - \\
\hline & PDMA & 26,47 & 16,96 & 7,63 & $-1,86$ & $-9,04$ & 7,39 & 22,74 & 32,00 & 34,28 & 31,42 & 25,65 & - \\
\hline
\end{tabular}


Tabela 8.9: Constantes de acoplamento B972 com base aug-pcJ-2.

\begin{tabular}{|c|c|c|c|c|c|c|c|c|c|c|c|c|c|}
\hline & $\% E_{X}^{\mathrm{HF}}$ & $0 \%$ & $10 \%$ & $20 \%$ & $30 \%$ & $40 \%$ & $50 \%$ & $60 \%$ & $70 \%$ & $80 \%$ & $90 \%$ & $100 \%$ & Exp. \\
\hline $\mathrm{HF}$ & ${ }^{1} J_{\mathrm{HF}}$ & 420,6 & 441,5 & 463,7 & 487,2 & 512,0 & 538,2 & 565,8 & 595,0 & 625,6 & 657,8 & 691,6 & 500 \\
\hline $\mathrm{CO}$ & ${ }^{1} J_{\mathrm{CO}}$ & 16,9 & 15,3 & 13,5 & 11,5 & 9,2 & 6,8 & 4,2 & 1,4 & $-1,6$ & $-4,8$ & $-8,3$ & 16,4 \\
\hline $\mathrm{H}_{2} \mathrm{O}$ & ${ }^{1} J_{\mathrm{OH}}$ & $-66,8$ & $-69,6$ & $-72,5$ & $-75,6$ & $-78,9$ & $-82,3$ & $-86,0$ & $-90,0$ & $-94,1$ & $-98,5$ & $-103,1$ & $-80,6$ \\
\hline $\mathrm{H}_{2} \mathrm{O}$ & ${ }^{2} J_{\mathrm{HH}}$ & $-1,2$ & $-2,2$ & $-3,2$ & $-4,3$ & $-5,5$ & $-6,7$ & $-8,0$ & $-9,5$ & $-11,0$ & $-12,6$ & $-14,3$ & $-7,3$ \\
\hline $\mathrm{NH}_{3}$ & ${ }^{1} J_{\mathrm{NH}}$ & 36,3 & 37,5 & 38,9 & 40,3 & 41,8 & 43,4 & 45,1 & 47,0 & 48,9 & 50,9 & 53,1 & 43,8 \\
\hline $\mathrm{NH}_{3}$ & ${ }^{2} J_{\mathrm{HH}}$ & $-3,3$ & $-4,2$ & $-5,1$ & $-6,0$ & $-7,1$ & $-8,2$ & $-9,4$ & $-10,7$ & $-12,1$ & $-13,6$ & $-15,2$ & $-9,6$ \\
\hline $\mathrm{PH}_{3}$ & ${ }^{1} J_{\mathrm{PH}}$ & 152,4 & 159,5 & 167,0 & 175,0 & 183,4 & 192,2 & 201,4 & 211,1 & 221,2 & 231,6 & 242,5 & 188,2 \\
\hline $\mathrm{PF}_{3}$ & ${ }^{1} J_{\mathrm{PF}}$ & $-1626,4$ & $-1621,0$ & $-1610,4$ & $-1595,3$ & $-1576,6$ & $-1555,0$ & $-1531,2$ & $-1505,7$ & $-1479,1$ & $-1452,1$ & $-1424,9$ & -1441 \\
\hline $\mathrm{BHF}_{2}$ & ${ }^{1} J_{\mathrm{BF}}$ & $-151,4$ & $-134,7$ & $-117,6$ & $-100,3$ & $-82,9$ & $-65,4$ & $-48,0$ & $-30,7$ & $-13,4$ & 3,5 & 20,3 & -84 \\
\hline $\mathrm{BF}_{3}$ & ${ }^{1} J_{\mathrm{BF}}$ & $-64,0$ & $-44,6$ & $-25,1$ & $-5,4$ & 14,1 & 33,8 & 53,5 & 73,1 & 92,7 & 112,2 & 131,6 & 15 \\
\hline $\mathrm{F}_{2} \mathrm{O}$ & ${ }^{1} J_{\mathrm{OF}}$ & $-187,3$ & $-217,9$ & $-249,8$ & $-283,7$ & $-320,6$ & $-362,5$ & $-412,9$ & $-478,9$ & $-577,4$ & $-761,7$ & $-1349,0$ & -300 \\
\hline $\mathrm{CH}_{4}$ & ${ }^{1} J_{\mathrm{CH}}$ & 94,6 & 98,6 & 102,8 & 107,2 & 111,9 & 116,9 & 122,2 & 127,8 & 133,7 & 139,9 & 146,5 & 125,3 \\
\hline $\mathrm{CH}_{4}$ & ${ }^{2} J_{\mathrm{HH}}$ & $-5,4$ & $-6,1$ & $-6,9$ & $-7,8$ & $-8,7$ & $-9,7$ & $-10,7$ & $-11,9$ & $-13,0$ & $-14,3$ & $-15,6$ & $-12,8$ \\
\hline $\mathrm{C}_{2} \mathrm{H}_{2}$ & ${ }^{1} J_{\mathrm{CC}}$ & 172,7 & 177,5 & 182,8 & 188,8 & 195,6 & 203,4 & 212,5 & 223,4 & 236,6 & 253,1 & 274,3 & 174,8 \\
\hline $\mathrm{C}_{2} \mathrm{H}_{2}$ & ${ }^{1} J_{\mathrm{CH}}$ & 189,9 & 197,4 & 205,4 & 213,7 & 222,6 & 232,0 & 242,2 & 253,1 & 265,2 & 278,6 & 294,1 & 247,6 \\
\hline $\mathrm{C}_{2} \mathrm{H}_{2}$ & ${ }^{2} J_{\mathrm{CH}}$ & 49,1 & 50,0 & 50,8 & 51,4 & 51,8 & 51,9 & 51,5 & 50,6 & 48,9 & 46,1 & 41,6 & 50,1 \\
\hline $\mathrm{C}_{2} \mathrm{H}_{2}$ & ${ }^{3} J_{\mathrm{HH}}$ & 6,1 & 6,5 & 6,9 & 7,4 & 8,1 & 8,9 & 9,9 & 11,2 & 12,9 & 15,1 & 18,0 & 9,6 \\
\hline $\mathrm{C}_{2} \mathrm{H}_{4}$ & ${ }^{1} J_{\mathrm{CC}}$ & 54,6 & 58,0 & 61,7 & 66,0 & 70,8 & 76,3 & 82,9 & 91,0 & 101,4 & 115,7 & 137,0 & 67,6 \\
\hline $\mathrm{C}_{2} \mathrm{H}_{4}$ & ${ }^{1} J_{\mathrm{CH}}$ & 117,8 & 122,9 & 128,4 & 134,1 & 140,3 & 146,9 & 154,1 & 161,9 & 170,8 & 181,1 & 194,0 & 156,3 \\
\hline $\mathrm{C}_{2} \mathrm{H}_{4}$ & ${ }^{2} J_{\mathrm{CH}}$ & 2,6 & 2,0 & 1,3 & 0,5 & $-0,4$ & $-1,7$ & $-3,2$ & $-5,2$ & $-8,0$ & $-11,9$ & $-18,1$ & $-2,4$ \\
\hline $\mathrm{C}_{2} \mathrm{H}_{4}$ & ${ }^{2} J_{\mathrm{HH}}$ & 5,6 & 5,4 & 5,1 & 4,7 & 4,2 & 3,7 & 3,0 & 2,2 & 1,1 & $-0,5$ & $-2,9$ & 2,3 \\
\hline $\mathrm{C}_{2} \mathrm{H}_{4}$ & ${ }^{3} J_{\mathrm{HH}_{\mathrm{C}}}$ & 8,9 & 9,1 & 9,4 & 9,7 & 10,1 & 10,6 & 11,1 & 11,8 & 12,8 & 14,3 & 16,6 & 11,7 \\
\hline $\mathrm{C}_{2} \mathrm{H}_{4}$ & ${ }^{3} J_{\mathrm{HH}_{\mathrm{t}}}$ & 12,8 & 13,3 & 13,8 & 14,4 & 15,1 & 15,9 & 16,8 & 17,9 & 19,4 & 21,4 & 24,4 & 19 \\
\hline $\mathrm{C}_{2} \mathrm{H}_{6}$ & ${ }^{1} J_{\mathrm{CC}}$ & 21,9 & 24,5 & 27,3 & 30,2 & 33,3 & 36,6 & 40,1 & 43,8 & 47,8 & 52,0 & 56,4 & 34,5 \\
\hline $\mathrm{C}_{2} \mathrm{H}_{6}$ & ${ }^{1} J_{\mathrm{CH}}$ & 93,2 & 97,4 & 101,8 & 106,4 & 111,4 & 116,6 & 122,1 & 127,9 & 134,1 & 140,6 & 147,5 & 125,2 \\
\hline $\mathrm{C}_{2} \mathrm{H}_{6}$ & ${ }^{2} J_{\mathrm{CH}}$ & $-0,5$ & $-0,9$ & $-1,4$ & $-1,9$ & $-2,4$ & $-3,0$ & $-3,6$ & $-4,2$ & $-4,9$ & $-5,7$ & $-6,5$ & $-4,7$ \\
\hline \multirow[t]{3}{*}{ Total } & DM & $-19,05$ & $-16,53$ & $-13,71$ & $-10,65$ & $-7,40$ & $-4,05$ & $-0,75$ & 2,25 & 4,37 & 3,58 & $-12,05$ & - \\
\hline & DMA & 31,30 & 26,09 & 20,73 & 14,98 & 11,64 & 14,03 & 17,62 & 23,42 & 32,18 & 45,12 & 75,85 & - \\
\hline & PDMA & 62,60 & 51,97 & 41,18 & 29,79 & 18,93 & 19,95 & 25,17 & 36,94 & 55,71 & 81,27 & 118,82 & - \\
\hline \multirow[t]{3}{*}{ CPI } & DM & $-28,65$ & $-25,57$ & $-21,95$ & $-17,95$ & $-13,82$ & $-9,69$ & $-6,04$ & $-3,53$ & $-3,75$ & $-11,65$ & $-56,05$ & - \\
\hline & DMA & 53,99 & 44,41 & 34,12 & 23,03 & 17,29 & 24,53 & 34,22 & 45,80 & 60,47 & 83,11 & 145,55 & - \\
\hline & PDMA & 79,88 & 62,30 & 45,12 & 27,62 & 11,80 & 24,58 & 41,76 & 63,46 & 86,79 & 113,04 & 152,13 & - \\
\hline \multirow[t]{3}{*}{ SPI } & DM & $-12,01$ & $-9,90$ & $-7,66$ & $-5,29$ & $-2,69$ & 0,08 & 3,12 & 6,48 & 10,31 & 14,76 & 20,21 & - \\
\hline & DMA & 14,67 & 12,66 & 10,91 & 9,07 & 7,49 & 6,33 & 5,44 & 7,01 & 11,43 & 17,27 & 24,75 & - \\
\hline & PDMA & 49,93 & 44,39 & 38,30 & 31,39 & 24,15 & 16,55 & 13,01 & 17,49 & 32,91 & 57,98 & 94,39 & - \\
\hline \multirow[t]{3}{*}{$\Delta C S$} & $\mathrm{DM}$ & $-16,63$ & $-15,67$ & $-14,29$ & $-12,67$ & $-11,12$ & $-9,77$ & $-9,16$ & $-10,01$ & $-14,06$ & $-26,41$ & $-76,27$ & - \\
\hline & DMA & 39,32 & 31,75 & 23,20 & 13,95 & 9,80 & 18,19 & 28,78 & 38,79 & 49,04 & 65,84 & 120,80 & - \\
\hline & PDMA & 29,95 & 17,91 & 6,82 & $-3,77$ & $-12,35$ & 8,03 & 28,74 & 45,98 & 53,88 & 55,06 & 57,74 & - \\
\hline
\end{tabular}


Tabela 8.10: Constantes de acoplamento B98 com base aug-pcJ-2.

\begin{tabular}{|c|c|c|c|c|c|c|c|c|c|c|c|c|c|}
\hline & $\% E_{X}^{\mathrm{HF}}$ & $0 \%$ & $10 \%$ & $20 \%$ & $30 \%$ & $40 \%$ & $50 \%$ & $60 \%$ & $70 \%$ & $80 \%$ & $90 \%$ & $100 \%$ & Exp. \\
\hline $\mathrm{HF}$ & ${ }^{1} J_{\mathrm{HF}}$ & 411,6 & 428,1 & 445,8 & 464,6 & 484,6 & 505,9 & 528,5 & 552,5 & 577,9 & 604,8 & 633,1 & 500 \\
\hline $\mathrm{CO}$ & ${ }^{1} J_{\mathrm{CO}}$ & 16,6 & 15,5 & 14,2 & 12,8 & 11,2 & 9,5 & 7,7 & 5,6 & 3,4 & 1,0 & $-1,4$ & 16,4 \\
\hline $\mathrm{H}_{2} \mathrm{O}$ & ${ }^{1} J_{\mathrm{OH}}$ & $-66,0$ & $-68,2$ & $-70,5$ & $-73,0$ & $-75,6$ & $-78,4$ & $-81,4$ & $-84,6$ & $-88,1$ & $-91,7$ & $-95,6$ & $-80,6$ \\
\hline $\mathrm{H}_{2} \mathrm{O}$ & ${ }^{2} J_{\mathrm{HH}}$ & $-0,7$ & $-1,7$ & $-2,7$ & $-3,9$ & $-5,1$ & $-6,4$ & $-7,9$ & $-9,4$ & $-11,0$ & $-12,7$ & $-14,6$ & $-7,3$ \\
\hline $\mathrm{NH}_{3}$ & ${ }^{1} J_{\mathrm{NH}}$ & 37,0 & 38,1 & 39,2 & 40,4 & 41,7 & 43,1 & 44,6 & 46,1 & 47,8 & 49,6 & 51,5 & 43,8 \\
\hline $\mathrm{NH}_{3}$ & ${ }^{2} J_{\mathrm{HH}}$ & $-3,5$ & $-4,4$ & $-5,4$ & $-6,4$ & $-7,6$ & $-8,8$ & $-10,2$ & $-11,6$ & $-13,2$ & $-14,9$ & $-16,8$ & $-9,6$ \\
\hline $\mathrm{PH}_{3}$ & ${ }^{1} J_{\mathrm{PH}}$ & 165,9 & 172,2 & 179,0 & 186,1 & 193,7 & 201,7 & 210,1 & 218,9 & 228,1 & 237,8 & 247,9 & 188,2 \\
\hline $\mathrm{PF}_{3}$ & ${ }^{1} J_{\mathrm{PF}}$ & $-1622,6$ & $-1617,6$ & $-1607,1$ & $-1591,6$ & $-1572,1$ & $-1549,1$ & $-1523,4$ & $-1495,6$ & $-1466,2$ & $-1435,7$ & $-1404,5$ & -1441 \\
\hline $\mathrm{BHF}_{2}$ & ${ }^{1} J_{\mathrm{BF}}$ & $-150,1$ & $-135,5$ & $-120,6$ & $-105,2$ & $-89,6$ & $-73,8$ & $-57,8$ & $-41,8$ & $-25,7$ & $-9,6$ & 6,2 & -84 \\
\hline $\mathrm{BF}_{3}$ & ${ }^{1} J_{\mathrm{BF}}$ & $-61,5$ & $-44,7$ & $-27,7$ & $-10,4$ & 7,0 & 24,5 & 42,2 & 60,0 & 77,9 & 95,8 & 113,8 & 15 \\
\hline $\mathrm{F}_{2} \mathrm{O}$ & ${ }^{1} J_{\mathrm{OF}}$ & $-196,5$ & $-228,9$ & $-262,8$ & $-298,9$ & $-338,2$ & $-383,0$ & $-437,3$ & $-509,0$ & $-617,4$ & $-823,5$ & $-1507,1$ & -300 \\
\hline $\mathrm{CH}_{4}$ & ${ }^{1} J_{\mathrm{CH}}$ & 101,1 & 104,7 & 108,5 & 112,6 & 116,9 & 121,5 & 126,5 & 131,7 & 137,3 & 143,2 & 149,5 & 125,3 \\
\hline $\mathrm{CH}_{4}$ & ${ }^{2} J_{\mathrm{HH}}$ & $-5,9$ & $-6,8$ & $-7,7$ & $-8,7$ & $-9,8$ & $-11,0$ & $-12,2$ & $-13,5$ & $-15,0$ & $-16,5$ & $-18,1$ & $-12,8$ \\
\hline $\mathrm{C}_{2} \mathrm{H}_{2}$ & ${ }^{1} J_{\mathrm{CC}}$ & 184,5 & 188,8 & 193,5 & 198,9 & 205,0 & 212,2 & 220,6 & 230,9 & 243,6 & 260,0 & 282,1 & 174,8 \\
\hline $\mathrm{C}_{2} \mathrm{H}_{2}$ & ${ }^{1} J_{\mathrm{CH}}$ & 198,0 & 205,3 & 212,9 & 221,1 & 229,7 & 239,0 & 249,0 & 260,0 & 272,3 & 286,5 & 303,3 & 247,6 \\
\hline $\mathrm{C}_{2} \mathrm{H}_{2}$ & ${ }^{2} J_{\mathrm{CH}}$ & 50,6 & 51,5 & 52,3 & 52,9 & 53,2 & 53,2 & 52,6 & 51,4 & 49,2 & 45,4 & 39,3 & 50,1 \\
\hline $\mathrm{C}_{2} \mathrm{H}_{2}$ & ${ }^{3} J_{\mathrm{HH}}$ & 6,1 & 6,5 & 7,0 & 7,6 & 8,4 & 9,4 & 10,6 & 12,3 & 14,5 & 17,5 & 21,7 & 9,6 \\
\hline $\mathrm{C}_{2} \mathrm{H}_{4}$ & ${ }^{1} J_{\mathrm{CC}}$ & 62,2 & 65,2 & 68,5 & 72,2 & 76,4 & 81,3 & 87,2 & 94,5 & 104,0 & 117,4 & 138,3 & 67,6 \\
\hline $\mathrm{C}_{2} \mathrm{H}_{4}$ & ${ }^{1} J_{\mathrm{CH}}$ & 124,4 & 129,2 & 134,3 & 139,8 & 145,7 & 152,0 & 158,9 & 166,6 & 175,4 & 185,9 & 199,6 & 156,3 \\
\hline $\mathrm{C}_{2} \mathrm{H}_{4}$ & ${ }^{2} J_{\mathrm{CH}}$ & 2,5 & 1,8 & 1,0 & 0,1 & $-0,8$ & $-2,1$ & $-3,8$ & $-6,0$ & $-9,0$ & $-13,5$ & $-20,9$ & $-2,4$ \\
\hline $\mathrm{C}_{2} \mathrm{H}_{4}$ & ${ }^{2} J_{\mathrm{HH}}$ & 5,7 & 5,4 & 5,0 & 4,5 & 3,9 & 3,2 & 2,3 & 1,2 & $-0,3$ & $-2,5$ & $-6,2$ & 2,3 \\
\hline $\mathrm{C}_{2} \mathrm{H}_{4}$ & ${ }^{3} J_{\mathrm{HH}_{\mathrm{c}}}$ & 9,3 & 9,5 & 9,8 & 10,2 & 10,6 & 11,1 & 11,8 & 12,7 & 13,9 & 15,9 & 19,2 & 11,7 \\
\hline $\mathrm{C}_{2} \mathrm{H}_{4}$ & ${ }^{3} J_{\mathrm{HH}_{\mathrm{t}}}$ & 13,1 & 13,6 & 14,2 & 14,9 & 15,6 & 16,5 & 17,6 & 18,9 & 20,8 & 23,3 & 27,5 & 19 \\
\hline $\mathrm{C}_{2} \mathrm{H}_{6}$ & ${ }^{1} J_{\mathrm{CC}}$ & 24,5 & 26,9 & 29,5 & 32,2 & 35,1 & 38,2 & 41,5 & 45,0 & 48,8 & 52,8 & 57,1 & 34,5 \\
\hline $\mathrm{C}_{2} \mathrm{H}_{6}$ & ${ }^{1} J_{\mathrm{CH}}$ & 99,8 & 103,7 & 107,8 & 112,1 & 116,8 & 121,7 & 127,0 & 132,5 & 138,4 & 144,7 & 151,4 & 125,2 \\
\hline $\mathrm{C}_{2} \mathrm{H}_{6}$ & ${ }^{2} J_{\mathrm{CH}}$ & $-0,7$ & $-1,2$ & $-1,7$ & $-2,3$ & $-2,9$ & $-3,6$ & $-4,3$ & $-5,1$ & $-5,9$ & $-6,9$ & $-7,9$ & $-4,7$ \\
\hline \multirow[t]{3}{*}{ Total } & DM & $-16,91$ & $-14,92$ & $-12,64$ & $-10,09$ & $-7,35$ & $-4,51$ & $-1,72$ & 0,74 & 2,17 & 0,35 & $-19,10$ & - \\
\hline & DMA & 29,25 & 24,65 & 19,73 & 14,55 & 12,38 & 12,58 & 16,22 & 22,92 & 31,70 & 45,52 & 80,95 & - \\
\hline & PDMA & 59,87 & 49,92 & 39,57 & 28,67 & 18,65 & 14,08 & 20,27 & 36,64 & 57,99 & 86,02 & 129,89 & - \\
\hline \multirow[t]{3}{*}{ CPI } & DM & $-28,25$ & $-26,18$ & $-23,59$ & $-20,58$ & $-17,35$ & $-14,15$ & $-11,44$ & $-9,98$ & $-11,58$ & $-21,82$ & $-75,31$ & - \\
\hline & DMA & 52,06 & 43,33 & 33,79 & 23,36 & 20,03 & 21,97 & 30,45 & 41,38 & 55,76 & 80,13 & 152,76 & - \\
\hline & PDMA & 77,65 & 62,08 & 46,46 & 30,24 & 16,50 & 16,91 & 31,97 & 52,38 & 74,45 & 99,96 & 140,82 & - \\
\hline \multirow[t]{3}{*}{ SPI } & DM & $-8,59$ & $-6,67$ & $-4,61$ & $-2,40$ & $-0,02$ & 2,57 & 5,41 & 8,60 & 12,26 & 16,61 & 22,12 & - \\
\hline & DMA & 12,51 & 10,96 & 9,41 & 8,09 & 6,78 & 5,70 & 5,79 & 9,39 & 14,06 & 20,14 & 28,29 & - \\
\hline & PDMA & 46,84 & 41,00 & 34,51 & 27,52 & 20,23 & 12,01 & 11,68 & 25,10 & 45,92 & 75,81 & 121,88 & - \\
\hline \multirow[t]{3}{*}{$\Delta \mathrm{CS}$} & $\mathrm{DM}$ & $-19,65$ & $-19,52$ & $-18,98$ & $-18,18$ & $-17,33$ & $-16,72$ & $-16,85$ & $-18,58$ & $-23,84$ & $-38,42$ & $-97,43$ & - \\
\hline & DMA & 39,55 & 32,37 & 24,38 & 15,27 & 13,25 & 16,27 & 24,67 & 32,00 & 41,70 & 59,99 & 124,47 & - \\
\hline & PDMA & 30,81 & 21,08 & 11,96 & 2,72 & $-3,73$ & 4,91 & 20,29 & 27,28 & 28,53 & 24,15 & 18,94 & - \\
\hline
\end{tabular}


Tabela 8.11: Constantes de acoplamento BHandH com base aug-pcJ-2.

\begin{tabular}{|c|c|c|c|c|c|c|c|c|c|c|c|c|c|}
\hline & $\% E_{X}^{\mathrm{HF}}$ & $0 \%$ & $10 \%$ & $20 \%$ & $30 \%$ & $40 \%$ & $50 \%$ & $60 \%$ & $70 \%$ & $80 \%$ & $90 \%$ & $100 \%$ & Exp. \\
\hline $\mathrm{HF}$ & ${ }^{1} J_{\mathrm{HF}}$ & 420,6 & 441,1 & 462,4 & 484,4 & 507,2 & 530,8 & 555,3 & 580,6 & 606,9 & 634,2 & 662,5 & 500 \\
\hline $\mathrm{CO}$ & ${ }^{1} J_{\mathrm{CO}}$ & 24,8 & 22,9 & 20,9 & 18,7 & 16,3 & 13,7 & 11,0 & 8,0 & 4,9 & 1,6 & $-1,9$ & 16,4 \\
\hline $\mathrm{H}_{2} \mathrm{O}$ & ${ }^{1} J_{\mathrm{OH}}$ & $-69,9$ & $-72,4$ & $-75,1$ & $-77,8$ & $-80,7$ & $-83,7$ & $-86,9$ & $-90,2$ & $-93,7$ & $-97,3$ & $-101,1$ & $-80,6$ \\
\hline $\mathrm{H}_{2} \mathrm{O}$ & ${ }^{2} J_{\mathrm{HH}}$ & $-3,3$ & $-4,4$ & $-5,5$ & $-6,8$ & $-8,0$ & $-9,4$ & $-10,8$ & $-12,3$ & $-13,9$ & $-15,6$ & $-17,3$ & $-7,3$ \\
\hline $\mathrm{NH}_{3}$ & ${ }^{1} J_{\mathrm{NH}}$ & 39,4 & 40,5 & 41,7 & 42,9 & 44,2 & 45,5 & 47,0 & 48,5 & 50,0 & 51,7 & 53,4 & 43,8 \\
\hline $\mathrm{NH}_{3}$ & ${ }^{2} J_{\mathrm{HH}}$ & $-5,4$ & $-6,5$ & $-7,5$ & $-8,7$ & $-9,9$ & $-11,1$ & $-12,5$ & $-13,9$ & $-15,4$ & $-17,0$ & $-18,7$ & $-9,6$ \\
\hline $\mathrm{PH}_{3}$ & ${ }^{1} J_{\mathrm{PH}}$ & 135,5 & 144,3 & 153,5 & 163,0 & 172,9 & 183,1 & 193,7 & 204,6 & 215,9 & 227,4 & 239,2 & 188,2 \\
\hline $\mathrm{PF}_{3}$ & ${ }^{1} J_{\mathrm{PF}}$ & $-1814,4$ & $-1797,1$ & $-1773,1$ & $-1743,5$ & $-1709,0$ & $-1670,4$ & $-1628,3$ & $-1583,4$ & $-1536,2$ & $-1487,3$ & $-1437,0$ & -1441 \\
\hline $\mathrm{BHF}_{2}$ & ${ }^{1} J_{\mathrm{BF}}$ & $-187,4$ & $-169,5$ & $-151,2$ & $-132,8$ & $-114,0$ & $-95,2$ & $-76,1$ & $-57,0$ & $-37,8$ & $-18,6$ & 0,6 & -84 \\
\hline $\mathrm{BF}_{3}$ & ${ }^{1} J_{\mathrm{BF}}$ & $-79,8$ & $-61,1$ & $-42,3$ & $-23,3$ & $-4,1$ & 15,1 & 34,6 & 54,2 & 73,9 & 93,8 & 113,8 & 15 \\
\hline $\mathrm{F}_{2} \mathrm{O}$ & ${ }^{1} J_{\mathrm{OF}}$ & $-272,1$ & $-308,2$ & $-344,0$ & $-380,5$ & $-419,8$ & $-465,0$ & $-521,4$ & $-600,0$ & $-727,9$ & $-1000,8$ & $-2253,8$ & -300 \\
\hline $\mathrm{CH}_{4}$ & ${ }^{1} J_{\mathrm{CH}}$ & 106,0 & 109,4 & 113,0 & 116,8 & 120,7 & 124,9 & 129,4 & 134,0 & 138,9 & 144,0 & 149,4 & 125,3 \\
\hline $\mathrm{CH}_{4}$ & ${ }^{2} J_{\mathrm{HH}}$ & $-7,9$ & $-8,9$ & $-9,9$ & $-11,0$ & $-12,1$ & $-13,3$ & $-14,5$ & $-15,7$ & $-17,0$ & $-18,4$ & $-19,7$ & $-12,8$ \\
\hline $\mathrm{C}_{2} \mathrm{H}_{2}$ & ${ }^{1} J_{\mathrm{CC}}$ & 175,5 & 179,6 & 184,2 & 189,4 & 195,4 & 202,4 & 210,6 & 220,6 & 232,8 & 248,3 & 268,4 & 174,8 \\
\hline $\mathrm{C}_{2} \mathrm{H}_{2}$ & ${ }^{1} J_{\mathrm{CH}}$ & 226,4 & 232,3 & 238,4 & 245,0 & 252,0 & 259,5 & 267,8 & 276,9 & 287,3 & 299,2 & 313,5 & 247,6 \\
\hline $\mathrm{C}_{2} \mathrm{H}_{2}$ & ${ }^{2} J_{\mathrm{CH}}$ & 51,2 & 52,1 & 52,7 & 53,2 & 53,3 & 53,0 & 52,2 & 50,7 & 48,2 & 44,2 & 38,1 & 50,1 \\
\hline $\mathrm{C}_{2} \mathrm{H}_{2}$ & ${ }^{3} J_{\mathrm{HH}}$ & 7,2 & 7,8 & 8,5 & 9,4 & 10,5 & 11,8 & 13,4 & 15,5 & 18,1 & 21,5 & 26,0 & 9,6 \\
\hline $\mathrm{C}_{2} \mathrm{H}_{4}$ & ${ }^{1} J_{\mathrm{CC}}$ & 50,4 & 53,8 & 57,6 & 61,8 & 66,7 & 72,3 & 78,9 & 87,3 & 98,2 & 113,8 & 139,0 & 67,6 \\
\hline $\mathrm{C}_{2} \mathrm{H}_{4}$ & ${ }^{1} J_{\mathrm{CH}}$ & 136,2 & 140,5 & 145,0 & 149,9 & 155,0 & 160,6 & 166,8 & 173,7 & 181,8 & 191,8 & 205,7 & 156,3 \\
\hline $\mathrm{C}_{2} \mathrm{H}_{4}$ & ${ }^{2} J_{\mathrm{CH}}$ & 0,9 & 0,2 & $-0,4$ & $-1,3$ & $-2,4$ & $-3,8$ & $-5,6$ & $-8,0$ & $-11,4$ & $-16,5$ & $-25,4$ & $-2,4$ \\
\hline $\mathrm{C}_{2} \mathrm{H}_{4}$ & ${ }^{2} J_{\mathrm{HH}}$ & 5,5 & 5,0 & 4,4 & 3,8 & 3,1 & 2,2 & 1,1 & $-0,1$ & $-2,0$ & $-4,7$ & $-9,3$ & 2,3 \\
\hline $\mathrm{C}_{2} \mathrm{H}_{4}$ & ${ }^{3} J_{\mathrm{HH}_{\mathrm{c}}}$ & 11,2 & 11,5 & 11,8 & 12,2 & 12,7 & 13,3 & 14,1 & 15,2 & 16,8 & 19,3 & 23,7 & 11,7 \\
\hline $\mathrm{C}_{2} \mathrm{H}_{4}$ & ${ }^{3} J_{\mathrm{HH}_{\mathrm{t}}}$ & 16,3 & 16,7 & 17,3 & 17,9 & 18,7 & 19,6 & 20,8 & 22,4 & 24,5 & 27,6 & 32,9 & 19 \\
\hline $\mathrm{C}_{2} \mathrm{H}_{6}$ & ${ }^{1} J_{\mathrm{CC}}$ & 18,7 & 21,3 & 24,0 & 26,9 & 30,0 & 33,3 & 36,7 & 40,4 & 44,3 & 48,4 & 52,7 & 34,5 \\
\hline $\mathrm{C}_{2} \mathrm{H}_{6}$ & ${ }^{1} J_{\mathrm{CH}}$ & 106,1 & 109,7 & 113,4 & 117,3 & 121,5 & 125,8 & 130,4 & 135,2 & 140,2 & 145,4 & 150,9 & 125,2 \\
\hline $\mathrm{C}_{2} \mathrm{H}_{6}$ & ${ }^{2} J_{\mathrm{CH}}$ & $-1,7$ & $-2,1$ & $-2,6$ & $-3,1$ & $-3,7$ & $-4,3$ & $-4,9$ & $-5,6$ & $-6,3$ & $-7,0$ & $-7,8$ & $-4,7$ \\
\hline \multirow[t]{3}{*}{ Total } & $\mathrm{DM}$ & $-29,04$ & $-26,40$ & $-23,38$ & $-20,05$ & $-16,48$ & $-12,86$ & $-9,32$ & $-6,28$ & $-4,77$ & $-8,31$ & $-48,74$ & - \\
\hline & DMA & 34,53 & 29,43 & 26,08 & 22,41 & 19,57 & 19,73 & 24,00 & 30,75 & 39,93 & 55,48 & 110,36 & - \\
\hline & PDMA & 59,82 & 48,15 & 36,94 & 24,93 & 14,17 & 12,21 & 27,30 & 46,76 & 70,77 & 102,43 & 158,62 & - \\
\hline \multirow[t]{3}{*}{ CPI } & $\mathrm{DM}$ & $-59,35$ & $-55,57$ & $-51,01$ & $-45,94$ & $-40,53$ & $-35,23$ & $-30,48$ & $-27,44$ & $-28,56$ & $-42,62$ & $-145,56$ & - \\
\hline & DMA & 69,39 & 59,34 & 53,54 & 47,12 & 41,91 & 41,15 & 47,12 & 57,96 & 73,27 & 101,80 & 220,20 & - \\
\hline & PDMA & 91,57 & 72,82 & 55,57 & 37,59 & 22,32 & 14,76 & 33,37 & 55,94 & 80,40 & 109,77 & 169,20 & - \\
\hline \multirow[t]{3}{*}{ SPI } & DM & $-6,81$ & $-5,01$ & $-3,11$ & $-1,06$ & 1,15 & 3,55 & 6,21 & 9,23 & 12,69 & 16,85 & 22,27 & - \\
\hline & DMA & 8,97 & 7,49 & 5,94 & 4,29 & 3,19 & 4,03 & 7,05 & 10,80 & 15,49 & 21,51 & 29,81 & - \\
\hline & PDMA & 36,54 & 30,06 & 23,28 & 15,65 & 8,19 & 10,35 & 22,85 & 40,02 & 63,71 & 97,05 & 150,86 & - \\
\hline \multirow[t]{3}{*}{$\Delta \mathrm{CS}$} & DM & $-52,55$ & $-50,56$ & $-47,90$ & $-44,88$ & $-41,68$ & $-38,77$ & $-36,69$ & $-36,66$ & $-41,25$ & $-59,47$ & $-167,83$ & - \\
\hline & DMA & 60,42 & 51,84 & 47,60 & 42,83 & 38,72 & 37,13 & 40,07 & 47,16 & 57,79 & 80,29 & 190,39 & - \\
\hline & PDMA & 55,03 & 42,76 & 32,29 & 21,95 & 14,13 & 4,41 & 10,52 & 15,92 & 16,68 & 12,72 & 18,34 & - \\
\hline
\end{tabular}


Tabela 8.12: Constantes de acoplamento BMK com base aug-pcJ-2.

\begin{tabular}{|c|c|c|c|c|c|c|c|c|c|c|c|c|c|}
\hline & $\% E_{X}^{\mathrm{HF}}$ & $0 \%$ & $10 \%$ & $20 \%$ & $30 \%$ & $40 \%$ & $50 \%$ & $60 \%$ & $70 \%$ & $80 \%$ & $90 \%$ & $100 \%$ & Exp. \\
\hline $\mathrm{HF}$ & ${ }^{1} J_{\mathrm{HF}}$ & 491,4 & 502,8 & 515,2 & 528,7 & 543,5 & 559,7 & 577,4 & 597,0 & 618,7 & 642,5 & 669,0 & 500 \\
\hline $\mathrm{CO}$ & ${ }^{1} J_{\mathrm{CO}}$ & 13,8 & 14,3 & 14,6 & 14,8 & 14,8 & 14,6 & 14,1 & 13,3 & 12,0 & 10,2 & 7,7 & 16,4 \\
\hline $\mathrm{H}_{2} \mathrm{O}$ & ${ }^{1} J_{\mathrm{OH}}$ & $-72,3$ & $-72,8$ & $-73,4$ & $-74,1$ & $-74,9$ & $-75,9$ & $-77,0$ & $-78,3$ & $-79,8$ & $-81,4$ & $-83,3$ & $-80,6$ \\
\hline $\mathrm{H}_{2} \mathrm{O}$ & ${ }^{2} J_{\mathrm{HH}}$ & 2,8 & 1,8 & 0,6 & $-0,5$ & $-1,8$ & $-3,2$ & $-4,7$ & $-6,4$ & $-8,1$ & $-10,0$ & $-12,0$ & $-7,3$ \\
\hline $\mathrm{NH}_{3}$ & ${ }^{1} J_{\mathrm{NH}}$ & 36,5 & 36,6 & 36,7 & 36,8 & 37,1 & 37,4 & 37,7 & 38,2 & 38,7 & 39,3 & 40,0 & 43,8 \\
\hline $\mathrm{NH}_{3}$ & ${ }^{2} J_{\mathrm{HH}}$ & $-0,7$ & $-1,6$ & $-2,5$ & $-3,5$ & $-4,7$ & $-5,9$ & $-7,2$ & $-8,7$ & $-10,3$ & $-12,0$ & $-13,9$ & $-9,6$ \\
\hline $\mathrm{PH}_{3}$ & ${ }^{1} J_{\mathrm{PH}}$ & 125,8 & 125,4 & 125,4 & 126,0 & 127,0 & 128,5 & 130,5 & 133,0 & 136,1 & 139,7 & 144,0 & 188,2 \\
\hline $\mathrm{PF}_{3}$ & ${ }^{1} J_{\mathrm{PF}}$ & $-1529,4$ & $-1527,6$ & $-1517,9$ & $-1500,7$ & $-1476,3$ & $-1445,2$ & $-1408,2$ & $-1365,9$ & $-1319,0$ & $-1268,4$ & $-1214,4$ & -1441 \\
\hline $\mathrm{BHF}_{2}$ & ${ }^{1} J_{\mathrm{BF}}$ & $-143,1$ & $-131,7$ & $-118,2$ & $-102,8$ & $-85,4$ & $-66,1$ & $-44,9$ & $-21,9$ & 2,7 & 29,1 & 56,9 & -84 \\
\hline $\mathrm{BF}_{3}$ & ${ }^{1} J_{\mathrm{BF}}$ & $-51,1$ & $-37,2$ & $-21,4$ & $-3,8$ & 15,4 & 36,6 & 59,4 & 84,1 & 110,4 & 138,4 & 167,9 & 15 \\
\hline $\mathrm{F}_{2} \mathrm{O}$ & ${ }^{1} J_{\mathrm{OF}}$ & $-147,5$ & $-173,9$ & $-201,0$ & $-228,4$ & $-256,0$ & $-284,4$ & $-314,8$ & $-349,2$ & $-392,3$ & $-454,2$ & $-567,5$ & -300 \\
\hline $\mathrm{CH}_{4}$ & ${ }^{1} J_{\mathrm{CH}}$ & 103,1 & 104,7 & 106,5 & 108,7 & 111,2 & 114,2 & 117,5 & 121,3 & 125,7 & 130,7 & 136,4 & 125,3 \\
\hline $\mathrm{CH}_{4}$ & ${ }^{2} J_{\mathrm{HH}}$ & $-3,0$ & $-4,0$ & $-5,1$ & $-6,4$ & $-7,7$ & $-9,2$ & $-10,9$ & $-12,8$ & $-14,9$ & $-17,3$ & $-20,0$ & $-12,8$ \\
\hline $\mathrm{C}_{2} \mathrm{H}_{2}$ & ${ }^{1} J_{\mathrm{CC}}$ & 244,5 & 249,2 & 254,4 & 260,5 & 267,6 & 276,3 & 287,2 & 301,5 & 321,1 & 349,5 & 394,6 & 174,8 \\
\hline $\mathrm{C}_{2} \mathrm{H}_{2}$ & ${ }^{1} J_{\mathrm{CH}}$ & 177,9 & 184,0 & 190,5 & 197,6 & 205,4 & 214,0 & 223,8 & 235,3 & 249,0 & 266,5 & 290,8 & 247,6 \\
\hline $\mathrm{C}_{2} \mathrm{H}_{2}$ & ${ }^{2} J_{\mathrm{CH}}$ & 54,4 & 55,3 & 56,0 & 56,5 & 56,6 & 56,3 & 55,2 & 53,0 & 49,0 & 41,7 & 28,3 & 50,1 \\
\hline $\mathrm{C}_{2} \mathrm{H}_{2}$ & ${ }^{3} J_{\mathrm{HH}}$ & 5,3 & 5,6 & 6,0 & 6,5 & 7,2 & 8,2 & 9,5 & 11,3 & 13,9 & 17,8 & 24,2 & 9,6 \\
\hline $\mathrm{C}_{2} \mathrm{H}_{4}$ & ${ }^{1} J_{\mathrm{CC}}$ & 89,5 & 91,0 & 92,9 & 95,3 & 98,2 & 101,8 & 106,6 & 112,8 & 121,5 & 134,4 & 155,3 & 67,6 \\
\hline $\mathrm{C}_{2} \mathrm{H}_{4}$ & ${ }^{1} J_{\mathrm{CH}}$ & 120,5 & 123,6 & 127,2 & 131,1 & 135,5 & 140,5 & 146,3 & 153,0 & 161,2 & 171,5 & 185,9 & 156,3 \\
\hline $\mathrm{C}_{2} \mathrm{H}_{4}$ & ${ }^{2} J_{\mathrm{CH}}$ & 4,5 & 3,6 & 2,6 & 1,5 & 0,1 & $-1,4$ & $-3,4$ & $-6,0$ & $-9,7$ & $-15,1$ & $-24,0$ & $-2,4$ \\
\hline $\mathrm{C}_{2} \mathrm{H}_{4}$ & ${ }^{2} J_{\mathrm{HH}}$ & 7,7 & 7,2 & 6,6 & 5,8 & 4,9 & 3,8 & 2,5 & 0,7 & $-1,4$ & $-4,6$ & $-9,6$ & 2,3 \\
\hline $\mathrm{C}_{2} \mathrm{H}_{4}$ & ${ }^{3} J_{\mathrm{HH}_{\mathrm{c}}}$ & 9,2 & 9,3 & 9,4 & 9,6 & 9,8 & 10,2 & 10,7 & 11,5 & 12,8 & 14,9 & 18,6 & 11,7 \\
\hline $\mathrm{C}_{2} \mathrm{H}_{4}$ & ${ }^{3} J_{\mathrm{HH}_{\mathrm{t}}}$ & 11,3 & 11,8 & 12,3 & 12,9 & 13,5 & 14,3 & 15,3 & 16,6 & 18,4 & 21,1 & 25,6 & 19 \\
\hline $\mathrm{C}_{2} \mathrm{H}_{6}$ & ${ }^{1} J_{\mathrm{CC}}$ & 30,1 & 31,0 & 32,1 & 33,3 & 34,8 & 36,5 & 38,5 & 40,7 & 43,3 & 46,4 & 49,9 & 34,5 \\
\hline $\mathrm{C}_{2} \mathrm{H}_{6}$ & ${ }^{1} J_{\mathrm{CH}}$ & 101,4 & 103,3 & 105,6 & 108,2 & 111,1 & 114,4 & 118,2 & 122,5 & 127,3 & 132,8 & 139,1 & 125,2 \\
\hline $\mathrm{C}_{2} \mathrm{H}_{6}$ & ${ }^{2} J_{\mathrm{CH}}$ & 0,6 & 0,0 & $-0,8$ & $-1,5$ & $-2,4$ & $-3,3$ & $-4,3$ & $-5,4$ & $-6,7$ & $-8,1$ & $-9,7$ & $-4,7$ \\
\hline \multirow[t]{3}{*}{ Total } & DM & $-6,22$ & $-5,13$ & $-3,49$ & $-1,27$ & 1,52 & 4,91 & 8,85 & 13,32 & 18,25 & 23,48 & 28,26 & - \\
\hline & DMA & 29,54 & 26,76 & 24,11 & 21,00 & 17,46 & 16,53 & 19,25 & 24,38 & 31,50 & 43,11 & 59,29 & - \\
\hline & PDMA & 72,17 & 63,22 & 53,13 & 41,90 & 29,32 & 27,90 & 29,36 & 42,43 & 64,07 & 97,09 & 144,20 & - \\
\hline \multirow[t]{3}{*}{ CPI } & DM & $-10,43$ & $-9,53$ & $-7,53$ & $-4,40$ & $-0,20$ & 5,02 & 11,04 & 17,66 & 24,38 & 30,21 & 32,14 & - \\
\hline & DMA & 43,12 & 37,49 & 32,33 & 26,16 & 19,11 & 18,13 & 25,75 & 38,23 & 52,64 & 70,08 & 93,21 & - \\
\hline & PDMA & 79,70 & 66,70 & 52,40 & 36,82 & 20,11 & 30,96 & 44,45 & 60,11 & 80,69 & 107,82 & 138,50 & - \\
\hline \multirow[t]{3}{*}{ SPI } & DM & $-3,14$ & $-1,90$ & $-0,53$ & 1,03 & 2,78 & 4,83 & 7,24 & 10,13 & 13,76 & 18,54 & 25,42 & - \\
\hline & DMA & 19,58 & 18,89 & 18,09 & 17,21 & 16,25 & 15,35 & 14,49 & 14,23 & 16,00 & 23,33 & 34,42 & - \\
\hline & PDMA & 66,65 & 60,67 & 53,66 & 45,63 & 36,08 & 25,66 & 18,29 & 29,47 & 51,88 & 89,22 & 148,39 & - \\
\hline \multirow[t]{3}{*}{$\Delta \mathrm{CS}$} & DM & $-7,29$ & $-7,63$ & $-7,00$ & $-5,43$ & $-2,98$ & 0,18 & 3,80 & 7,54 & 10,62 & 11,67 & 6,72 & - \\
\hline & DMA & 23,54 & 18,60 & 14,24 & 8,96 & 2,86 & 2,77 & 11,25 & 23,99 & 36,64 & 46,76 & 58,79 & - \\
\hline & PDMA & 13,06 & 6,02 & $-1,26$ & $-8,81$ & $-15,98$ & 5,30 & 26,16 & 30,64 & 28,81 & 18,60 & $-9,89$ & - \\
\hline
\end{tabular}


Tabela 8.13: Constantes de acoplamento BP86 com base aug-pcJ-2.

\begin{tabular}{|c|c|c|c|c|c|c|c|c|c|c|c|c|c|}
\hline & $\% E_{X}^{\mathrm{HF}}$ & $0 \%$ & $10 \%$ & $20 \%$ & $30 \%$ & $40 \%$ & $50 \%$ & $60 \%$ & $70 \%$ & $80 \%$ & $90 \%$ & $100 \%$ & Exp. \\
\hline $\mathrm{HF}$ & ${ }^{1} J_{\mathrm{HF}}$ & 355,3 & 378,9 & 402,8 & 426,9 & 451,3 & 475,8 & 500,7 & 525,7 & 551,0 & 576,5 & 602,2 & 500 \\
\hline $\mathrm{CO}$ & ${ }^{1} J_{\mathrm{CO}}$ & 24,9 & 23,2 & 21,5 & 19,7 & 17,7 & 15,8 & 13,7 & 11,6 & 9,4 & 7,1 & 4,8 & 16,4 \\
\hline $\mathrm{H}_{2} \mathrm{O}$ & ${ }^{1} J_{\mathrm{OH}}$ & $-64,8$ & $-67,3$ & $-69,8$ & $-72,4$ & $-75,0$ & $-77,6$ & $-80,2$ & $-82,9$ & $-85,5$ & $-88,3$ & $-91,0$ & $-80,6$ \\
\hline $\mathrm{H}_{2} \mathrm{O}$ & ${ }^{2} J_{\mathrm{HH}}$ & $-4,6$ & $-5,5$ & $-6,5$ & $-7,5$ & $-8,5$ & $-9,6$ & $-10,6$ & $-11,7$ & $-12,8$ & $-13,9$ & $-15,1$ & $-7,3$ \\
\hline $\mathrm{NH}_{3}$ & ${ }^{1} J_{\mathrm{NH}}$ & 40,0 & 40,7 & 41,5 & 42,2 & 43,0 & 43,8 & 44,6 & 45,4 & 46,2 & 47,0 & 47,8 & 43,8 \\
\hline $\mathrm{NH}_{3}$ & ${ }^{2} J_{\mathrm{HH}}$ & $-7,8$ & $-8,6$ & $-9,5$ & $-10,4$ & $-11,2$ & $-12,1$ & $-13,0$ & $-13,9$ & $-14,9$ & $-15,8$ & $-16,8$ & $-9,6$ \\
\hline $\mathrm{PH}_{3}$ & ${ }^{1} J_{\mathrm{PH}}$ & 136,9 & 144,9 & 152,8 & 160,7 & 168,4 & 176,0 & 183,5 & 190,8 & 198,1 & 205,1 & 212,1 & 188,2 \\
\hline $\mathrm{PF}_{3}$ & ${ }^{1} J_{\mathrm{PF}}$ & $-1802,5$ & $-1777,4$ & $-1747,9$ & $-1714,7$ & $-1678,5$ & $-1639,9$ & $-1599,5$ & $-1557,7$ & $-1514,9$ & $-1471,4$ & $-1427,5$ & -1441 \\
\hline $\mathrm{BHF}_{2}$ & ${ }^{1} J_{\mathrm{BF}}$ & $-177,9$ & $-160,9$ & $-144,0$ & $-127,2$ & $-110,6$ & $-94,0$ & $-77,7$ & $-61,5$ & $-45,5$ & $-29,7$ & $-14,1$ & -84 \\
\hline $\mathrm{BF}_{3}$ & ${ }^{1} J_{\mathrm{BF}}$ & $-83,3$ & $-64,6$ & $-46,2$ & $-27,9$ & $-9,8$ & 8,0 & 25,7 & 43,3 & 60,6 & 77,8 & 94,8 & 15 \\
\hline $\mathrm{F}_{2} \mathrm{O}$ & ${ }^{1} J_{\mathrm{OF}}$ & $-290,1$ & $-327,4$ & $-365,0$ & $-404,4$ & $-447,8$ & $-498,7$ & $-562,6$ & $-651,0$ & $-790,4$ & $-1064,3$ & $-1973,1$ & -300 \\
\hline $\mathrm{CH}_{4}$ & ${ }^{1} J_{\mathrm{CH}}$ & 117,5 & 118,9 & 120,4 & 121,9 & 123,4 & 124,9 & 126,5 & 128,1 & 129,7 & 131,4 & 133,0 & 125,3 \\
\hline $\mathrm{CH}_{4}$ & ${ }^{2} J_{\mathrm{HH}}$ & $-11,8$ & $-12,5$ & $-13,2$ & $-13,9$ & $-14,6$ & $-15,3$ & $-16,1$ & $-16,8$ & $-17,5$ & $-18,1$ & $-18,8$ & $-12,8$ \\
\hline $\mathrm{C}_{2} \mathrm{H}_{2}$ & ${ }^{1} J_{\mathrm{CC}}$ & 187,3 & 189,9 & 193,0 & 196,5 & 200,6 & 205,4 & 211,1 & 218,0 & 226,4 & 236,9 & 250,2 & 174,8 \\
\hline $\mathrm{C}_{2} \mathrm{H}_{2}$ & ${ }^{1} J_{\mathrm{CH}}$ & 247,4 & 249,7 & 252,1 & 254,7 & 257,5 & 260,6 & 264,1 & 268,1 & 272,8 & 278,4 & 285,3 & 247,6 \\
\hline $\mathrm{C}_{2} \mathrm{H}_{2}$ & ${ }^{2} J_{\mathrm{CH}}$ & 54,6 & 54,6 & 54,4 & 53,9 & 53,1 & 51,9 & 50,3 & 48,1 & 45,2 & 41,3 & 35,9 & 50,1 \\
\hline $\mathrm{C}_{2} \mathrm{H}_{2}$ & ${ }^{3} J_{\mathrm{HH}}$ & 10,2 & 10,9 & 11,6 & 12,5 & 13,5 & 14,8 & 16,4 & 18,2 & 20,5 & 23,3 & 26,9 & 9,6 \\
\hline $\mathrm{C}_{2} \mathrm{H}_{4}$ & ${ }^{1} J_{\mathrm{CC}}$ & 59,5 & 62,2 & 65,2 & 68,5 & 72,4 & 76,9 & 82,4 & 89,4 & 98,7 & 112,2 & 133,8 & 67,6 \\
\hline $\mathrm{C}_{2} \mathrm{H}_{4}$ & ${ }^{1} J_{\mathrm{CH}}$ & 149,7 & 151,8 & 154,0 & 156,3 & 158,8 & 161,6 & 164,7 & 168,5 & 173,2 & 179,6 & 189,3 & 156,3 \\
\hline $\mathrm{C}_{2} \mathrm{H}_{4}$ & ${ }^{2} J_{\mathrm{CH}}$ & 0,0 & $-0,8$ & $-1,7$ & $-2,9$ & $-4,2$ & $-5,7$ & $-7,7$ & $-10,3$ & $-13,9$ & $-19,1$ & $-27,6$ & $-2,4$ \\
\hline $\mathrm{C}_{2} \mathrm{H}_{4}$ & ${ }^{2} J_{\mathrm{HH}}$ & 4,6 & 3,9 & 3,1 & 2,2 & 1,2 & 0,0 & $-1,2$ & $-2,9$ & $-5,2$ & $-8,4$ & $-13,5$ & 2,3 \\
\hline $\mathrm{C}_{2} \mathrm{H}_{4}$ & ${ }^{3} J_{\mathrm{HH}_{\mathrm{c}}}$ & 11,6 & 11,9 & 12,3 & 12,7 & 13,3 & 14,0 & 15,0 & 16,3 & 18,1 & 21,0 & 25,7 & 11,7 \\
\hline $\mathrm{C}_{2} \mathrm{H}_{4}$ & ${ }^{3} J_{\mathrm{HH}_{\mathrm{t}}}{ }^{c}$ & 18,5 & 18,9 & 19,3 & 19,8 & 20,4 & 21,3 & 22,4 & 23,9 & 26,1 & 29,3 & 34,7 & 19 \\
\hline $\mathrm{C}_{2} \mathrm{H}_{6}$ & ${ }^{1} J_{\mathrm{CC}}$ & 24,2 & 26,2 & 28,2 & 30,2 & 32,3 & 34,4 & 36,5 & 38,7 & 40,9 & 43,2 & 45,4 & 34,5 \\
\hline $\mathrm{C}_{2} \mathrm{H}_{6}$ & ${ }^{1} J_{\mathrm{CH}}$ & 117,6 & 119,2 & 120,9 & 122,6 & 124,3 & 126,0 & 127,8 & 129,6 & 131,3 & 133,2 & 135,0 & 125,2 \\
\hline $\mathrm{C}_{2} \mathrm{H}_{6}$ & ${ }^{2} J_{\mathrm{CH}}$ & $-2,7$ & $-3,1$ & $-3,6$ & $-4,1$ & $-4,5$ & $-5,0$ & $-5,5$ & $-6,0$ & $-6,5$ & $-7,1$ & $-7,6$ & $-4,7$ \\
\hline \multirow[t]{3}{*}{ Total } & DM & $-28,10$ & $-25,67$ & $-23,05$ & $-20,35$ & $-17,63$ & $-15,07$ & $-12,83$ & $-11,38$ & $-11,69$ & $-16,84$ & $-45,89$ & - \\
\hline & DMA & 33,03 & 29,60 & 26,84 & 24,22 & 22,25 & 20,73 & 21,63 & 27,38 & 35,80 & 49,96 & 90,58 & - \\
\hline & PDMA & 50,85 & 40,53 & 30,46 & 22,94 & 22,22 & 23,42 & 33,70 & 51,99 & 74,53 & 104,07 & 152,34 & - \\
\hline \multirow[t]{3}{*}{ CPI } & DM & $-64,98$ & $-60,45$ & $-55,56$ & $-50,54$ & $-45,63$ & $-41,22$ & $-37,85$ & $-36,62$ & $-39,96$ & $-55,53$ & $-128,80$ & - \\
\hline & DMA & 72,02 & 64,61 & 58,62 & 52,63 & 46,88 & 41,76 & 41,28 & 51,29 & 66,76 & 94,38 & 182,13 & - \\
\hline & PDMA & 89,78 & 72,91 & 56,58 & 42,32 & 30,26 & 19,53 & 25,40 & 44,36 & 65,33 & 90,28 & 134,69 & - \\
\hline \multirow[t]{3}{*}{ SPI } & $\mathrm{DM}$ & $-1,06$ & $-0,16$ & 0,79 & 1,79 & 2,89 & 4,11 & 5,51 & 7,12 & 9,05 & 11,53 & 14,91 & - \\
\hline & DMA & 4,43 & 3,93 & 3,54 & 3,39 & 4,19 & 5,30 & 7,23 & 9,84 & 13,10 & 17,39 & 23,45 & - \\
\hline & PDMA & 22,31 & 16,78 & 11,30 & 8,73 & 16,32 & 26,27 & 39,78 & 57,59 & 81,27 & 114,19 & 165,29 & - \\
\hline \multirow[t]{3}{*}{$\Delta \mathrm{CS}$} & $\mathrm{DM}$ & $-63,92$ & $-60,29$ & $-56,36$ & $-52,32$ & $-48,52$ & $-45,33$ & $-43,35$ & $-43,74$ & $-49,01$ & $-67,06$ & $-143,71$ & - \\
\hline & DMA & 67,58 & 60,68 & 55,08 & 49,24 & 42,70 & 36,46 & 34,06 & 41,45 & 53,66 & 77,00 & 158,67 & - \\
\hline & PDMA & 67,47 & 56,13 & 45,28 & 33,59 & 13,93 & $-6,74$ & $-14,38$ & $-13,23$ & $-15,94$ & $-23,91$ & $-30,60$ & - \\
\hline
\end{tabular}


Tabela 8.14: Constantes de acoplamento BPW91 com base aug-pcJ-2.

\begin{tabular}{|c|c|c|c|c|c|c|c|c|c|c|c|c|c|}
\hline & $\% E_{X}^{\mathrm{HF}}$ & $0 \%$ & $10 \%$ & $20 \%$ & $30 \%$ & $40 \%$ & $50 \%$ & $60 \%$ & $70 \%$ & $80 \%$ & $90 \%$ & $100 \%$ & Exp. \\
\hline $\mathrm{HF}$ & ${ }^{1} J_{\mathrm{HF}}$ & 353,3 & 377,4 & 401,9 & 426,6 & 451,5 & 476,7 & 502,2 & 527,9 & 553,8 & 579,9 & 606,3 & 500 \\
\hline $\mathrm{CO}$ & ${ }^{1} J_{\mathrm{CO}}$ & 25,2 & 23,6 & 21,8 & 20,0 & 18,1 & 16,1 & 14,0 & 11,8 & 9,6 & 7,3 & 4,9 & 16,4 \\
\hline $\mathrm{H}_{2} \mathrm{O}$ & ${ }^{1} J_{\mathrm{OH}}$ & $-64,9$ & $-67,5$ & $-70,1$ & $-72,7$ & $-75,4$ & $-78,1$ & $-80,8$ & $-83,5$ & $-86,3$ & $-89,1$ & $-91,9$ & $-80,6$ \\
\hline $\mathrm{H}_{2} \mathrm{O}$ & ${ }^{2} J_{\mathrm{HH}}$ & $-5,1$ & $-6,1$ & $-7,1$ & $-8,1$ & $-9,2$ & $-10,2$ & $-11,3$ & $-12,5$ & $-13,6$ & $-14,8$ & $-16,0$ & $-7,3$ \\
\hline $\mathrm{NH}_{3}$ & ${ }^{1} J_{\mathrm{NH}}$ & 40,2 & 41,0 & 41,8 & 42,6 & 43,4 & 44,2 & 45,0 & 45,8 & 46,7 & 47,5 & 48,4 & 43,8 \\
\hline $\mathrm{NH}_{3}$ & ${ }^{2} J_{\mathrm{HH}}$ & $-8,3$ & $-9,2$ & $-10,1$ & $-11,0$ & $-11,9$ & $-12,9$ & $-13,8$ & $-14,7$ & $-15,7$ & $-16,7$ & $-17,7$ & $-9,6$ \\
\hline $\mathrm{PH}_{3}$ & ${ }^{1} J_{\mathrm{PH}}$ & 137,3 & 145,6 & 153,9 & 162,0 & 170,1 & 178,0 & 185,8 & 193,4 & 200,9 & 208,3 & 215,5 & 188,2 \\
\hline $\mathrm{PF}_{3}$ & ${ }^{1} J_{\mathrm{PF}}$ & $-1810,6$ & $-1784,5$ & $-1754,1$ & $-1720,0$ & $-1683,1$ & $-1643,8$ & $-1602,7$ & $-1560,3$ & $-1516,9$ & $-1472,9$ & $-1428,5$ & -1441 \\
\hline $\mathrm{BHF}_{2}$ & ${ }^{1} J_{\mathrm{BF}}$ & $-178,0$ & $-160,8$ & $-143,8$ & $-126,8$ & $-110,0$ & $-93,3$ & $-76,8$ & $-60,4$ & $-44,3$ & $-28,3$ & $-12,5$ & -84 \\
\hline $\mathrm{BF}_{3}$ & ${ }^{1} J_{\mathrm{BF}}$ & $-83,3$ & $-64,5$ & $-45,8$ & $-27,4$ & $-9,1$ & 8,9 & 26,7 & 44,5 & 62,0 & 79,4 & 96,6 & 15 \\
\hline $\mathrm{F}_{2} \mathrm{O}$ & ${ }^{1} J_{\mathrm{OF}}$ & $-291,7$ & $-329,9$ & $-368,6$ & $-409,2$ & $-454,4$ & $-507,7$ & $-575,7$ & $-671,4$ & $-827,4$ & $-1153,6$ & $-2525,8$ & -300 \\
\hline $\mathrm{CH}_{4}$ & ${ }^{1} J_{\mathrm{CH}}$ & 118,9 & 120,4 & 121,9 & 123,5 & 125,1 & 126,7 & 128,4 & 130,0 & 131,7 & 133,4 & 135,2 & 125,3 \\
\hline $\mathrm{CH}_{4}$ & ${ }^{2} J_{\mathrm{HH}}$ & $-12,5$ & $-13,3$ & $-14,0$ & $-14,7$ & $-15,5$ & $-16,2$ & $-17,0$ & $-17,7$ & $-18,4$ & $-19,1$ & $-19,9$ & $-12,8$ \\
\hline $\mathrm{C}_{2} \mathrm{H}_{2}$ & ${ }^{1} J_{\mathrm{CC}}$ & 187,9 & 190,7 & 193,9 & 197,7 & 202,2 & 207,5 & 213,8 & 221,6 & 231,2 & 243,3 & 259,0 & 174,8 \\
\hline $\mathrm{C}_{2} \mathrm{H}_{2}$ & ${ }^{1} J_{\mathrm{CH}}$ & 251,1 & 253,6 & 256,2 & 259,1 & 262,1 & 265,6 & 269,5 & 274,1 & 279,5 & 286,1 & 294,6 & 247,6 \\
\hline $\mathrm{C}_{2} \mathrm{H}_{2}$ & ${ }^{2} J_{\mathrm{CH}}$ & 54,7 & 54,6 & 54,2 & 53,6 & 52,6 & 51,1 & 49,1 & 46,5 & 42,8 & 37,9 & 31,2 & 50,1 \\
\hline $\mathrm{C}_{2} \mathrm{H}_{2}$ & ${ }^{3} J_{\mathrm{HH}}$ & 10,8 & 11,5 & 12,4 & 13,4 & 14,6 & 16,1 & 17,9 & 20,1 & 22,8 & 26,3 & 30,7 & 9,6 \\
\hline $\mathrm{C}_{2} \mathrm{H}_{4}$ & ${ }^{1} J_{\mathrm{CC}}$ & 59,9 & 62,7 & 65,9 & 69,5 & 73,7 & 78,7 & 84,9 & 93,0 & 104,3 & 121,5 & 152,0 & 67,6 \\
\hline $\mathrm{C}_{2} \mathrm{H}_{4}$ & ${ }^{1} J_{\mathrm{CH}}$ & 151,9 & 154,1 & 156,4 & 158,9 & 161,6 & 164,7 & 168,3 & 172,6 & 178,2 & 186,4 & 200,0 & 156,3 \\
\hline $\mathrm{C}_{2} \mathrm{H}_{4}$ & ${ }^{2} J_{\mathrm{CH}}$ & $-0,4$ & $-1,4$ & $-2,4$ & $-3,6$ & $-5,1$ & $-6,9$ & $-9,2$ & $-12,4$ & $-16,8$ & $-23,7$ & $-36,2$ & $-2,4$ \\
\hline $\mathrm{C}_{2} \mathrm{H}_{4}$ & ${ }^{2} J_{\mathrm{HH}}$ & 4,2 & 3,3 & 2,5 & 1,5 & 0,4 & $-0,8$ & $-2,4$ & $-4,5$ & $-7,4$ & $-11,7$ & $-19,2$ & 2,3 \\
\hline $\mathrm{C}_{2} \mathrm{H}_{4}$ & ${ }^{3} J_{\mathrm{HH}_{\mathrm{c}}}$ & 12,0 & 12,3 & 12,7 & 13,3 & 14,0 & 14,8 & 16,0 & 17,7 & 20,1 & 24,0 & 31,2 & 11,7 \\
\hline $\mathrm{C}_{2} \mathrm{H}_{4}$ & ${ }^{3} J_{\mathrm{HH}_{\mathrm{t}}}$ & 19,1 & 19,5 & 20,0 & 20,6 & 21,4 & 22,4 & 23,7 & 25,6 & 28,4 & 32,8 & 40,9 & 19 \\
\hline $\mathrm{C}_{2} \mathrm{H}_{6}$ & ${ }^{1} J_{\mathrm{CC}}$ & 24,5 & 26,5 & 28,5 & 30,6 & 32,7 & 34,8 & 37,0 & 39,2 & 41,5 & 43,8 & 46,1 & 34,5 \\
\hline $\mathrm{C}_{2} \mathrm{H}_{6}$ & ${ }^{1} J_{\mathrm{CH}}$ & 119,2 & 120,9 & 122,6 & 124,4 & 126,2 & 128,0 & 129,8 & 131,7 & 133,5 & 135,4 & 137,3 & 125,2 \\
\hline $\mathrm{C}_{2} \mathrm{H}_{6}$ & ${ }^{2} J_{\mathrm{CH}}$ & $-3,0$ & $-3,5$ & $-3,9$ & $-4,4$ & $-4,9$ & $-5,4$ & $-6,0$ & $-6,5$ & $-7,0$ & $-7,5$ & $-8,1$ & $-4,7$ \\
\hline \multirow[t]{3}{*}{ Total } & DM & $-28,18$ & $-25,69$ & $-23,01$ & $-20,22$ & $-17,46$ & $-14,85$ & $-12,64$ & $-11,28$ & $-11,99$ & $-18,81$ & $-65,03$ & - \\
\hline & DMA & 33,18 & 29,88 & 27,15 & 24,92 & 23,10 & 21,89 & 23,41 & 29,92 & 39,35 & 56,13 & 115,74 & - \\
\hline & PDMA & 48,78 & 38,13 & 28,57 & 26,47 & 26,80 & 29,03 & 41,67 & 62,51 & 88,36 & 124,48 & 191,82 & - \\
\hline \multirow[t]{3}{*}{ CPI } & DM & $-66,07$ & $-61,44$ & $-56,46$ & $-51,35$ & $-46,45$ & $-42,09$ & $-38,94$ & $-38,21$ & $-42,92$ & $-63,08$ & $-178,33$ & - \\
\hline & DMA & 72,67 & 65,42 & 59,39 & 53,45 & 47,70 & 42,62 & 42,99 & 54,25 & 71,30 & 103,77 & 233,56 & - \\
\hline & PDMA & 88,82 & 71,78 & 56,13 & 43,46 & 31,54 & 20,46 & 27,96 & 47,80 & 69,47 & 96,38 & 155,08 & - \\
\hline \multirow[t]{3}{*}{ SPI } & DM & $-0,39$ & 0,52 & 1,52 & 2,62 & 3,80 & 5,13 & 6,65 & 8,46 & 10,69 & 13,65 & 18,05 & - \\
\hline & DMA & 4,21 & 3,83 & 3,51 & 4,01 & 5,07 & 6,69 & 9,05 & 12,07 & 15,93 & 21,20 & 29,34 & - \\
\hline & PDMA & 19,42 & 13,46 & 8,36 & 14,02 & 23,33 & 35,32 & 51,73 & 73,30 & 102,22 & 145,09 & 218,77 & - \\
\hline \multirow[t]{3}{*}{$\Delta \mathrm{CS}$} & $\mathrm{DM}$ & $-65,69$ & $-61,96$ & $-57,98$ & $-53,97$ & $-50,25$ & $-47,22$ & $-45,58$ & $-46,67$ & $-53,60$ & $-76,74$ & $-196,37$ & - \\
\hline & DMA & 68,46 & 61,59 & 55,88 & 49,44 & 42,63 & 35,92 & 33,94 & 42,17 & 55,37 & 82,57 & 204,22 & - \\
\hline & PDMA & 69,41 & 58,32 & 47,77 & 29,44 & 8,21 & $-14,86$ & $-23,77$ & $-25,51$ & $-32,75$ & $-48,71$ & $-63,69$ & - \\
\hline
\end{tabular}


8.2. VARIAÇÃO DA PORCENTAGEM DE E HF PARA OS FUNCIONAIS

HİBRIDOS

Tabela 8.15: Constantes de acoplamento M05 com base aug-pcJ-2.

\begin{tabular}{|c|c|c|c|c|c|c|c|c|c|c|c|c|c|}
\hline & $\% E_{X}^{\mathrm{HF}}$ & $0 \%$ & $10 \%$ & $20 \%$ & $30 \%$ & $40 \%$ & $50 \%$ & $60 \%$ & $70 \%$ & $80 \%$ & $90 \%$ & $100 \%$ & Exp. \\
\hline $\mathrm{HF}$ & ${ }^{1} J_{\mathrm{HF}}$ & 847,0 & 840,1 & 833,5 & 827,3 & 821,4 & 815,9 & 810,8 & 805,8 & 801,1 & 796,4 & 791,7 & 500 \\
\hline $\mathrm{CO}$ & ${ }^{1} J_{\mathrm{CO}}$ & 15,8 & 13,7 & 11,3 & 8,5 & 5,3 & 1,7 & $-2,1$ & $-6,2$ & $-10,7$ & $-15,5$ & $-20,5$ & 16,4 \\
\hline $\mathrm{H}_{2} \mathrm{O}$ & ${ }^{1} J_{\mathrm{OH}}$ & $-108,9$ & $-108,7$ & $-108,5$ & $-108,3$ & $-108,2$ & $-108,0$ & $-108,0$ & $-108,0$ & $-108,0$ & $-108,1$ & $-108,2$ & $-80,6$ \\
\hline $\mathrm{H}_{2} \mathrm{O}$ & ${ }^{2} J_{\mathrm{HH}}$ & $-18,6$ & $-18,7$ & $-18,7$ & $-18,6$ & $-18,3$ & $-17,9$ & $-17,4$ & $-16,7$ & $-15,9$ & $-15,0$ & $-13,9$ & $-7,3$ \\
\hline $\mathrm{NH}_{3}$ & ${ }^{1} J_{\mathrm{NH}}$ & 41,1 & 42,3 & 43,4 & 44,5 & 45,6 & 46,7 & 47,8 & 48,8 & 49,8 & 50,8 & 51,7 & 43,8 \\
\hline $\mathrm{NH}_{3}$ & ${ }^{2} J_{\mathrm{HH}}$ & $-13,5$ & $-14,4$ & $-15,2$ & $-15,9$ & $-16,4$ & $-16,7$ & $-16,9$ & $-16,8$ & $-16,5$ & $-15,9$ & $-15,2$ & $-9,6$ \\
\hline $\mathrm{PH}_{3}$ & ${ }^{1} J_{\mathrm{PH}}$ & 168,5 & 166,8 & 168,2 & 173,0 & 180,3 & 188,9 & 198,1 & 207,2 & 215,9 & 224,1 & 231,8 & 188,2 \\
\hline $\mathrm{PF}_{3}$ & ${ }^{1} J_{\mathrm{PF}}$ & $-1357,6$ & $-1376,0$ & $-1386,5$ & $-1388,9$ & $-1383,6$ & $-1372,0$ & $-1355,3$ & $-1334,8$ & $-1311,8$ & $-1287,0$ & $-1261,2$ & -1441 \\
\hline $\mathrm{BHF}_{2}$ & ${ }^{1} J_{\mathrm{BF}}$ & 2,2 & 8,2 & 14,9 & 22,3 & 30,5 & 39,5 & 49,5 & 60,5 & 72,8 & 86,3 & 101,3 & -84 \\
\hline $\mathrm{BF}_{3}$ & ${ }^{1} J_{\mathrm{BF}}$ & 102,9 & 111,1 & 119,8 & 129,1 & 139,0 & 149,8 & 161,4 & 174,1 & 187,8 & 202,7 & 218,9 & 15 \\
\hline $\mathrm{F}_{2} \mathrm{O}$ & ${ }^{1} J_{\mathrm{OF}}$ & $-218,9$ & $-253,7$ & $-282,8$ & $-307,6$ & $-330,0$ & $-351,6$ & $-374,7$ & $-402,2$ & $-439,1$ & $-494,9$ & $-592,4$ & -300 \\
\hline $\mathrm{CH}_{4}$ & ${ }^{1} J_{\mathrm{CH}}$ & 80,9 & 87,2 & 93,5 & 99,8 & 106,1 & 112,4 & 118,7 & 125,0 & 131,1 & 137,1 & 142,9 & 125,3 \\
\hline $\mathrm{CH}_{4}$ & ${ }^{2} J_{\mathrm{HH}}$ & $-20,8$ & $-21,1$ & $-21,2$ & $-21,2$ & $-21,0$ & $-20,8$ & $-20,4$ & $-19,8$ & $-19,2$ & $-18,5$ & $-17,9$ & $-12,8$ \\
\hline $\mathrm{C}_{2} \mathrm{H}_{2}$ & ${ }^{1} J_{\mathrm{CC}}$ & 182,9 & 192,0 & 201,6 & 211,8 & 222,6 & 234,0 & 246,1 & 258,8 & 272,4 & 286,7 & 302,0 & 174,8 \\
\hline $\mathrm{C}_{2} \mathrm{H}_{2}$ & ${ }^{1} J_{\mathrm{CH}}$ & 223,0 & 232,1 & 240,9 & 249,5 & 257,6 & 265,4 & 272,7 & 279,3 & 285,2 & 290,2 & 294,4 & 247,6 \\
\hline $\mathrm{C}_{2} \mathrm{H}_{2}$ & ${ }^{2} J_{\mathrm{CH}}$ & 35,8 & 36,1 & 36,4 & 36,6 & 36,7 & 36,7 & 36,8 & 36,7 & 36,4 & 35,9 & 34,9 & 50,1 \\
\hline $\mathrm{C}_{2} \mathrm{H}_{2}$ & ${ }^{3} J_{\mathrm{HH}}$ & 19,6 & 20,1 & 20,4 & 20,6 & 20,7 & 20,7 & 20,6 & 20,4 & 20,2 & 20,1 & 20,2 & 9,6 \\
\hline $\mathrm{C}_{2} \mathrm{H}_{4}$ & ${ }^{1} J_{\mathrm{CC}}$ & 57,9 & 64,1 & 70,7 & 77,9 & 85,7 & 94,1 & 103,3 & 113,2 & 123,9 & 135,6 & 148,4 & 67,6 \\
\hline $\mathrm{C}_{2} \mathrm{H}_{4}$ & ${ }^{1} J_{\mathrm{CH}}$ & 119,8 & 127,7 & 135,5 & 143,2 & 150,8 & 158,4 & 165,8 & 173,1 & 180,1 & 187,0 & 193,6 & 156,3 \\
\hline $\mathrm{C}_{2} \mathrm{H}_{4}$ & ${ }^{2} J_{\mathrm{CH}}$ & $-11,4$ & $-12,2$ & $-13,1$ & $-14,1$ & $-15,1$ & $-16,2$ & $-17,3$ & $-18,4$ & $-19,6$ & $-20,9$ & $-22,4$ & $-2,4$ \\
\hline $\mathrm{C}_{2} \mathrm{H}_{4}$ & ${ }^{2} J_{\mathrm{HH}}$ & $-16,0$ & $-15,7$ & $-15,1$ & $-14,4$ & $-13,6$ & $-12,6$ & $-11,4$ & $-10,1$ & $-8,8$ & $-7,5$ & $-6,4$ & 2,3 \\
\hline $\mathrm{C}_{2} \mathrm{H}_{4}$ & ${ }^{3} J_{\mathrm{HH}_{\mathrm{c}}}$ & 14,5 & 15,2 & 15,8 & 16,3 & 16,7 & 17,0 & 17,2 & 17,3 & 17,3 & 17,3 & 17,3 & 11,7 \\
\hline $\mathrm{C}_{2} \mathrm{H}_{4}$ & ${ }^{3} J_{\mathrm{HH}_{\mathrm{t}}}$ & 15,6 & 17,0 & 18,2 & 19,4 & 20,5 & 21,4 & 22,2 & 22,9 & 23,4 & 23,9 & 24,4 & 19 \\
\hline $\mathrm{C}_{2} \mathrm{H}_{6}$ & ${ }^{1} J_{\mathrm{CC}}$ & 15,2 & 18,5 & 21,9 & 25,6 & 29,4 & 33,3 & 37,5 & 41,9 & 46,4 & 51,2 & 56,2 & 34,5 \\
\hline $\mathrm{C}_{2} \mathrm{H}_{6}$ & ${ }^{1} J_{\mathrm{CH}}$ & 80,1 & 86,6 & 93,0 & 99,5 & 106,0 & 112,6 & 119,1 & 125,6 & 132,0 & 138,4 & 144,6 & 125,2 \\
\hline $\mathrm{C}_{2} \mathrm{H}_{6}$ & ${ }^{2} J_{\mathrm{CH}}$ & $-3,2$ & $-3,7$ & $-4,2$ & $-4,7$ & $-5,2$ & $-5,7$ & $-6,1$ & $-6,6$ & $-7,0$ & $-7,5$ & $-8,0$ & $-4,7$ \\
\hline \multirow[t]{3}{*}{ Total } & $\mathrm{DM}$ & 15,73 & 15,75 & 16,49 & 17,93 & 19,94 & 22,38 & 25,12 & 27,92 & 30,55 & 32,61 & 33,20 & - \\
\hline & DMA & 38,73 & 35,93 & 33,83 & 33,28 & 34,87 & 36,94 & 40,62 & 44,83 & 50,53 & 57,17 & 65,62 & - \\
\hline & PDMA & 102,34 & 104,33 & 106,37 & 109,46 & 114,16 & 118,96 & 124,72 & 130,85 & 138,18 & 146,39 & 156,29 & - \\
\hline \multirow[t]{3}{*}{ CPI } & DM & 56,28 & 51,80 & 48,95 & 47,68 & 47,70 & 48,67 & 50,21 & 51,89 & 53,14 & 53,00 & 49,37 & - \\
\hline & DMA & 68,37 & 64,51 & 61,75 & 61,50 & 64,86 & 68,93 & 75,30 & 82,58 & 91,15 & 101,78 & 116,48 & - \\
\hline & PDMA & 94,70 & 100,97 & 107,67 & 115,59 & 124,82 & 134,60 & 145,78 & 157,49 & 170,14 & 183,98 & 199,76 & - \\
\hline \multirow[t]{3}{*}{ SPI } & DM & $-14,01$ & $-10,68$ & $-7,32$ & $-3,89$ & $-0,41$ & 3,11 & 6,71 & 10,35 & 13,98 & 17,66 & 21,34 & - \\
\hline & DMA & 17,00 & 14,97 & 13,36 & 12,58 & 12,88 & 13,48 & 15,19 & 17,15 & 20,74 & 24,46 & 28,31 & - \\
\hline & PDMA & 107,95 & 106,80 & 105,42 & 104,96 & 106,35 & 107,49 & 109,29 & 111,31 & 114,74 & 118,81 & 124,41 & - \\
\hline \multirow[t]{3}{*}{$\Delta \mathrm{CS}$} & $\mathrm{DM}$ & 70,30 & 62,48 & 56,27 & 51,57 & 48,11 & 45,57 & 43,50 & 41,54 & 39,16 & 35,34 & 28,03 & - \\
\hline & DMA & 51,37 & 49,54 & 48,39 & 48,92 & 51,98 & 55,45 & 60,11 & 65,44 & 70,41 & 77,32 & 88,17 & - \\
\hline & PDMA & $-13,26$ & $-5,83$ & 2,25 & 10,63 & 18,46 & 27,11 & 36,49 & 46,18 & 55,40 & 65,17 & 75,35 & - \\
\hline
\end{tabular}


Tabela 8.16: Constantes de acoplamento M06 com base aug-pcJ-2.

\begin{tabular}{|c|c|c|c|c|c|c|c|c|c|c|c|c|c|}
\hline & $\% E_{X}^{\mathrm{HF}}$ & $0 \%$ & $10 \%$ & $20 \%$ & $30 \%$ & $40 \%$ & $50 \%$ & $60 \%$ & $70 \%$ & $80 \%$ & $90 \%$ & $100 \%$ & Exp. \\
\hline $\mathrm{HF}$ & ${ }^{1} J_{\mathrm{HF}}$ & 591,8 & 620,1 & 652,6 & 690,1 & 733,4 & 782,9 & 838,6 & 900,5 & 967,8 & 1039,5 & 1113,9 & 500 \\
\hline $\mathrm{CO}$ & ${ }^{1} J_{\mathrm{CO}}$ & 16,9 & 17,6 & 17,9 & 17,8 & 17,0 & 15,4 & 13,0 & 9,5 & 5,0 & $-0,8$ & $-7,9$ & 16,4 \\
\hline $\mathrm{H}_{2} \mathrm{O}$ & ${ }^{1} J_{\mathrm{OH}}$ & $-86,0$ & $-90,6$ & $-96,1$ & $-102,7$ & $-110,6$ & $-120,0$ & $-131,2$ & $-144,5$ & $-160,2$ & $-178,9$ & $-201,1$ & $-80,6$ \\
\hline $\mathrm{H}_{2} \mathrm{O}$ & ${ }^{2} J_{\mathrm{HH}}$ & $-5,7$ & $-9,1$ & $-13,3$ & $-18,4$ & $-24,8$ & $-32,8$ & $-42,7$ & $-54,9$ & $-70,2$ & $-89,3$ & $-113,0$ & $-7,3$ \\
\hline $\mathrm{NH}_{3}$ & ${ }^{1} J_{\mathrm{NH}}$ & 43,2 & 46,1 & 49,6 & 53,7 & 58,6 & 64,4 & 71,6 & 80,3 & 91,1 & 104,7 & 122,2 & 43,8 \\
\hline $\mathrm{NH}_{3}$ & ${ }^{2} J_{\mathrm{HH}}$ & $-7,6$ & $-10,7$ & $-14,6$ & $-19,7$ & $-26,3$ & $-35,0$ & $-46,5$ & $-62,0$ & $-83,1$ & $-112,3$ & $-153,9$ & $-9,6$ \\
\hline $\mathrm{PH}_{3}$ & ${ }^{1} J_{\mathrm{PH}}$ & 199,3 & 214,4 & 232,5 & 254,5 & 281,6 & 315,1 & 357,5 & 411,8 & 483,2 & 577,7 & 701,3 & 188,2 \\
\hline $\mathrm{PF}_{3}$ & ${ }^{1} J_{\mathrm{PF}}$ & $-1437,2$ & $-1476,6$ & $-1508,9$ & $-1533,6$ & $-1552,2$ & $-1567,1$ & $-1579,5$ & $-1588,2$ & $-1591,0$ & $-1586,1$ & $-1573,4$ & -1441 \\
\hline $\mathrm{BHF}_{2}$ & ${ }^{1} J_{\mathrm{BF}}$ & $-67,3$ & $-57,9$ & $-46,0$ & $-31,5$ & $-14,7$ & 3,7 & 22,9 & 41,7 & 58,7 & 71,6 & 75,6 & -84 \\
\hline $\mathrm{BF}_{3}$ & ${ }^{1} J_{\mathrm{BF}}$ & 27,0 & 39,1 & 53,4 & 70,2 & 89,7 & 111,5 & 135,2 & 160,1 & 185,6 & 211,4 & 237,7 & 15 \\
\hline $\mathrm{F}_{2} \mathrm{O}$ & ${ }^{1} J_{\mathrm{OF}}$ & $-161,1$ & $-211,1$ & $-265,9$ & $-328,2$ & $-406,1$ & $-530,0$ & $-975,7$ & 4267,8 & $-15,5$ & $-222,3$ & $-320,8$ & -300 \\
\hline $\mathrm{CH}_{4}$ & ${ }^{1} J_{\mathrm{CH}}$ & 103,3 & 114,7 & 128,4 & 144,8 & 164,8 & 189,3 & 219,9 & 258,9 & 309,9 & 379,0 & 477,4 & 125,3 \\
\hline $\mathrm{CH}_{4}$ & ${ }^{2} J_{\mathrm{HH}}$ & $-12,6$ & $-16,6$ & $-21,5$ & $-27,9$ & $-36,3$ & $-47,3$ & $-62,2$ & $-82,8$ & $-112,3$ & $-156,2$ & $-225,1$ & $-12,8$ \\
\hline $\mathrm{C}_{2} \mathrm{H}_{2}$ & ${ }^{1} J_{\mathrm{CC}}$ & 161,7 & 170,7 & 182,5 & 199,5 & 227,4 & 285,4 & 502,3 & $-632,7$ & $-14,0$ & 128,2 & 5815,3 & 174,8 \\
\hline $\mathrm{C}_{2} \mathrm{H}_{2}$ & ${ }^{1} J_{\mathrm{CH}}$ & 208,8 & 237,3 & 271,3 & 313,1 & 367,7 & 450,4 & 661,2 & $-166,8$ & 360,7 & 495,3 & $-161,9$ & 247,6 \\
\hline $\mathrm{C}_{2} \mathrm{H}_{2}$ & ${ }^{2} J_{\mathrm{CH}}$ & 49,7 & 51,3 & 51,6 & 49,0 & 39,6 & 9,0 & $-141,1$ & 758,3 & 315,4 & 282,8 & 1065,0 & 50,1 \\
\hline $\mathrm{C}_{2} \mathrm{H}_{2}$ & ${ }^{3} J_{\mathrm{HH}}$ & 7,6 & 9,7 & 13,2 & 19,3 & 31,2 & 60,3 & 184,0 & $-514,8$ & $-158,3$ & $-117,3$ & $-2,3$ & 9,6 \\
\hline $\mathrm{C}_{2} \mathrm{H}_{4}$ & ${ }^{1} J_{\mathrm{CC}}$ & 51,1 & 54,6 & 59,6 & 67,7 & 83,1 & 126,0 & 1247,1 & $-64,0$ & $-10,1$ & 6,5 & 13,8 & 67,6 \\
\hline $\mathrm{C}_{2} \mathrm{H}_{4}$ & ${ }^{1} J_{\mathrm{CH}}$ & 130,3 & 146,9 & 166,9 & 191,8 & 225,2 & 282,2 & 1104,7 & 218,8 & 304,5 & 376,2 & 458,4 & 156,3 \\
\hline $\mathrm{C}_{2} \mathrm{H}_{4}$ & $J_{\mathrm{CH}}$ & 0,7 & $-0,9$ & $-3,5$ & $-8,1$ & $-17,7$ & $-46,3$ & $-834,9$ & 91,9 & 56,9 & 48,8 & 48,6 & $-2,4$ \\
\hline $\mathrm{C}_{2} \mathrm{H}_{4}$ & ${ }^{2} J_{\mathrm{HH}}$ & $-3,4$ & $-5,9$ & $-9,6$ & $-15,6$ & $-26,7$ & $-56,4$ & $-792,0$ & 61,8 & 21,0 & 1,6 & $-16,5$ & 2,3 \\
\hline $\mathrm{C}_{2} \mathrm{H}_{4}$ & ${ }^{3} J_{\mathrm{HH}_{\mathrm{C}}}$ & 11,0 & 12,5 & 14,7 & 18,6 & 26,8 & 52,5 & 782,6 & $-78,9$ & $-49,1$ & $-45,4$ & $-50,8$ & 11,7 \\
\hline $\mathrm{C}_{2} \mathrm{H}_{4}$ & ${ }^{3} J_{\mathrm{HH}_{\mathrm{t}}}$ & 12,1 & 14,6 & 18,1 & 23,5 & 33,7 & 62,4 & 821,1 & $-67,9$ & $-32,7$ & $-23,3$ & $-21,2$ & 19 \\
\hline $\mathrm{C}_{2} \mathrm{H}_{6}$ & ${ }^{1} J_{\mathrm{CC}}$ & 20,1 & 22,9 & 26,4 & 30,8 & 36,4 & 43,5 & 52,9 & 65,7 & 83,6 & 110,1 & 152,2 & 34,5 \\
\hline $\mathrm{C}_{2} \mathrm{H}_{6}$ & ${ }^{1} J_{\mathrm{CH}}$ & 101,2 & 113,2 & 127,4 & 144,5 & 165,3 & 190,7 & 222,4 & 262,9 & 316,0 & 388,7 & 493,8 & 125,2 \\
\hline $\mathrm{C}_{2} \mathrm{H}_{6}$ & ${ }^{2} J_{\mathrm{CH}}$ & $-1,4$ & $-2,6$ & $-4,2$ & $-6,2$ & $-8,8$ & $-12,3$ & $-17,2$ & $-24,3$ & $-34,8$ & $-51,6$ & $-80,4$ & $-4,7$ \\
\hline \multirow[t]{3}{*}{ Total } & $\mathrm{DM}$ & 4,17 & 6,10 & 9,13 & 13,54 & 19,70 & 28,94 & 106,50 & 163,97 & 53,20 & 68,98 & 307,77 & - \\
\hline & DMA & 17,75 & 16,56 & 19,37 & 29,62 & 47,70 & 77,65 & 323,45 & 353,43 & 134,27 & 143,62 & 417,97 & - \\
\hline & PDMA & 33,84 & 35,89 & 50,78 & 88,16 & 155,56 & 312,10 & 3389,72 & 808,08 & 467,07 & 468,20 & 738,57 & - \\
\hline \multirow[t]{3}{*}{ CPI } & DM & 24,76 & 21,85 & 20,03 & 19,21 & 18,61 & 15,20 & $-16,15$ & 471,02 & 93,68 & 88,57 & 94,52 & - \\
\hline & DMA & 25,85 & 30,67 & 37,19 & 49,05 & 69,79 & 96,55 & 154,85 & 528,84 & 162,30 & 169,54 & 194,15 & - \\
\hline & PDMA & 20,42 & 29,35 & 49,75 & 75,95 & 109,84 & 152,10 & 212,49 & 386,48 & 324,21 & 400,40 & 501,27 & - \\
\hline \multirow[t]{3}{*}{ SPI } & $\mathrm{DM}$ & $-10,93$ & $-5,45$ & 1,15 & 9,38 & 20,51 & 39,02 & 196,45 & $-61,20$ & 23,51 & 54,62 & 464,15 & - \\
\hline & DMA & 11,81 & 6,21 & 6,31 & 15,38 & 31,49 & 63,79 & 447,10 & 224,80 & 113,71 & 124,62 & 582,11 & - \\
\hline & PDMA & 43,69 & 40,68 & 51,53 & 97,11 & 189,08 & 429,43 & 5719,69 & 1117,26 & 571,83 & 517,92 & 912,58 & - \\
\hline \multirow[t]{3}{*}{$\Delta \mathrm{CS}$} & $\mathrm{DM}$ & 35,69 & 27,30 & 18,88 & 9,83 & $-1,90$ & $-23,82$ & $-212,60$ & 532,22 & 70,18 & 33,95 & $-369,63$ & - \\
\hline & DMA & 14,05 & 24,47 & 30,88 & 33,67 & 38,30 & 32,75 & $-292,25$ & 304,04 & 48,59 & 44,92 & $-387,95$ & - \\
\hline & PDMA & $-23,28$ & $-11,33$ & $-1,78$ & $-21,17$ & $-79,24$ & $-277,33$ & $-5507,20$ & $-730,78$ & $-247,62$ & $-117,52$ & $-411,32$ & - \\
\hline
\end{tabular}


Tabela 8.17: Constantes de acoplamento M062X com base aug-pcJ-2.

\begin{tabular}{|c|c|c|c|c|c|c|c|c|c|c|c|c|c|}
\hline & $\% E_{X}^{\mathrm{HF}}$ & $0 \%$ & $10 \%$ & $20 \%$ & $30 \%$ & $40 \%$ & $50 \%$ & $60 \%$ & $70 \%$ & $80 \%$ & $90 \%$ & $100 \%$ & Exp. \\
\hline $\mathrm{HF}$ & ${ }^{1} J_{\mathrm{HF}}$ & 445,9 & 449,4 & 453,4 & 459,1 & 467,4 & 479,5 & 496,4 & 519,2 & 548,9 & 586,4 & 632,6 & 500 \\
\hline $\mathrm{CO}$ & ${ }^{1} J_{\mathrm{CO}}$ & 3,7 & 4,7 & 5,7 & 6,6 & 7,2 & 7,4 & 7,1 & 6,0 & 3,7 & $-0,2$ & $-6,8$ & 16,4 \\
\hline $\mathrm{H}_{2} \mathrm{O}$ & ${ }^{1} J_{\mathrm{OH}}$ & $-73,4$ & $-75,6$ & $-78,2$ & $-81,3$ & $-85,0$ & $-89,5$ & $-95,0$ & $-101,7$ & $-109,8$ & $-119,5$ & $-131,3$ & $-80,6$ \\
\hline $\mathrm{H}_{2} \mathrm{O}$ & ${ }^{2} J_{\mathrm{HH}}$ & 4,2 & 3,0 & 1,5 & $-0,3$ & $-2,7$ & $-5,7$ & $-9,5$ & $-14,4$ & $-20,5$ & $-28,2$ & $-38,1$ & $-7,3$ \\
\hline $\mathrm{NH}_{3}$ & ${ }^{1} J_{\mathrm{NH}}$ & 38,2 & 40,2 & 42,4 & 45,0 & 48,0 & 51,6 & 55,9 & 60,9 & 66,9 & 74,2 & 83,1 & 43,8 \\
\hline $\mathrm{NH}_{3}$ & ${ }^{2} J_{\mathrm{HH}}$ & 0,2 & $-0,7$ & $-2,1$ & $-4,0$ & $-6,4$ & $-9,5$ & $-13,6$ & $-18,9$ & $-25,9$ & $-35,2$ & $-47,6$ & $-9,6$ \\
\hline $\mathrm{PH}_{3}$ & ${ }^{1} J_{\mathrm{PH}}$ & 133,0 & 134,2 & 137,3 & 142,7 & 150,6 & 161,6 & 176,1 & 195,1 & 219,2 & 250,0 & 289,5 & 188,2 \\
\hline $\mathrm{PF}_{3}$ & ${ }^{1} J_{\mathrm{PF}}$ & $-1442,3$ & $-1488,8$ & $-1533,3$ & $-1573,0$ & $-1603,7$ & $-1622,0$ & $-1627,6$ & $-1623,0$ & $-1612,8$ & $-1602,7$ & $-1596,7$ & -1441 \\
\hline $\mathrm{BHF}_{2}$ & ${ }^{1} J_{\mathrm{BF}}$ & $-166,8$ & $-163,3$ & $-156,4$ & $-146,7$ & $-135,1$ & $-122,1$ & $-107,7$ & $-92,3$ & $-75,9$ & $-58,8$ & $-41,4$ & -84 \\
\hline $\mathrm{BF}_{3}$ & ${ }^{1} J_{\mathrm{BF}}$ & $-89,3$ & $-80,2$ & $-68,9$ & $-56,0$ & $-41,7$ & $-26,4$ & $-10,0$ & 7,5 & 26,7 & 47,8 & 70,9 & 15 \\
\hline $\mathrm{F}_{2} \mathrm{O}$ & ${ }^{1} J_{\mathrm{OF}}$ & $-156,6$ & $-199,7$ & $-246,2$ & $-295,8$ & $-348,4$ & $-404,9$ & $-468,8$ & $-550,1$ & $-685,1$ & $-1305,2$ & $-2162,3$ & -300 \\
\hline $\mathrm{CH}_{4}$ & ${ }^{1} J_{\mathrm{CH}}$ & 86,4 & 93,7 & 102,1 & 112,1 & 123,7 & 137,5 & 153,9 & 173,6 & 197,4 & 226,6 & 262,9 & 125,3 \\
\hline $\mathrm{CH}_{4}$ & ${ }^{2} J_{\mathrm{HH}}$ & $-0,2$ & $-1,3$ & $-2,8$ & $-4,8$ & $-7,3$ & $-10,5$ & $-14,7$ & $-20,1$ & $-27,3$ & $-36,8$ & $-49,6$ & $-12,8$ \\
\hline $\mathrm{C}_{2} \mathrm{H}_{2}$ & ${ }^{1} J_{\mathrm{CC}}$ & 167,7 & 174,7 & 182,9 & 192,6 & 204,6 & 220,1 & 241,5 & 273,9 & 331,7 & 472,8 & 1542,1 & 174,8 \\
\hline $\mathrm{C}_{2} \mathrm{H}_{2}$ & ${ }^{1} J_{\mathrm{CH}}$ & 142,4 & 159,4 & 178,9 & 201,1 & 226,7 & 256,7 & 292,4 & 336,8 & 397,0 & 500,5 & 1037,2 & 247,6 \\
\hline $\mathrm{C}_{2} \mathrm{H}_{2}$ & ${ }^{2} J_{\mathrm{CH}}$ & 46,7 & 49,1 & 51,6 & 53,9 & 55,8 & 56,9 & 56,2 & 51,7 & 36,8 & $-14,6$ & $-491,4$ & 50,1 \\
\hline $\mathrm{C}_{2} \mathrm{H}_{2}$ & ${ }^{3} J_{\mathrm{HH}}$ & 4,3 & 4,8 & 5,3 & 6,0 & 7,0 & 8,5 & 10,9 & 15,4 & 24,8 & 51,4 & 274,4 & 9,6 \\
\hline $\mathrm{C}_{2} \mathrm{H}_{4}$ & ${ }^{1} J_{\mathrm{CC}}$ & 60,5 & 63,3 & 67,0 & 71,7 & 78,0 & 86,7 & 99,5 & 120,7 & 162,3 & 284,8 & 14163,1 & 67,6 \\
\hline $\mathrm{C}_{2} \mathrm{H}_{4}$ & ${ }^{1} J_{\mathrm{CH}}$ & 99,2 & 109,3 & 120,9 & 134,4 & 150,2 & 169,0 & 192,0 & 221,3 & 263,2 & 345,6 & 6656,1 & 156,3 \\
\hline $\mathrm{C}_{2} \mathrm{H}_{4}$ & ${ }^{2} J_{\mathrm{CH}}$ & 6,3 & 5,6 & 4,7 & 3,5 & 1,7 & $-1,0$ & $-5,4$ & $-13,2$ & $-30,1$ & $-83,1$ & $-6358,9$ & $-2,4$ \\
\hline $\mathrm{C}_{2} \mathrm{H}_{4}$ & ${ }^{2} J_{\mathrm{HH}}$ & 7,0 & 7,0 & 6,8 & 6,4 & 5,7 & 4,4 & 2,2 & $-1,8$ & $-10,4$ & $-37,0$ & $-3080,4$ & 2,3 \\
\hline $\mathrm{C}_{2} \mathrm{H}_{4}$ & ${ }^{3} J_{\mathrm{HH}_{\mathrm{c}}}$ & 9,1 & 9,5 & 9,9 & 10,5 & 11,2 & 12,3 & 14,1 & 17,4 & 24,8 & 49,5 & 3090,2 & 11,7 \\
\hline $\mathrm{C}_{2} \mathrm{H}_{4}$ & ${ }^{3} J_{\mathrm{HH}_{\mathrm{t}}}{ }^{c}$ & 9,4 & 10,7 & 12,0 & 13,6 & 15,4 & 17,7 & 20,8 & 25,9 & 35,5 & 63,8 & 3278,1 & 19 \\
\hline $\mathrm{C}_{2} \mathrm{H}_{6}$ & ${ }^{1} J_{\mathrm{CC}}$ & 27,4 & 29,9 & 33,0 & 36,6 & 41,1 & 46,4 & 53,0 & 61,2 & 71,5 & 84,8 & 102,2 & 34,5 \\
\hline $\mathrm{C}_{2} \mathrm{H}_{6}$ & ${ }^{1} J_{\mathrm{CH}}$ & 84,0 & 91,7 & 100,8 & 111,4 & 123,8 & 138,4 & 155,8 & 176,6 & 201,7 & 232,6 & 271,0 & 125,2 \\
\hline $\mathrm{C}_{2} \mathrm{H}_{6}$ & ${ }^{2} J_{\mathrm{CH}}$ & 2,2 & 1,5 & 0,7 & $-0,2$ & $-1,5$ & $-3,0$ & $-5,0$ & $-7,5$ & $-10,8$ & $-15,3$ & $-21,7$ & $-4,7$ \\
\hline \multirow[t]{3}{*}{ Total } & DM & $-15,22$ & $-15,88$ & $-16,00$ & $-15,38$ & $-13,80$ & $-10,96$ & $-6,71$ & $-0,95$ & 6,10 & 3,43 & 687,78 & - \\
\hline & DMA & 30,98 & 27,80 & 24,39 & 20,63 & 20,00 & 22,33 & 28,29 & 39,11 & 60,14 & 117,91 & 1625,87 & - \\
\hline & PDMA & 90,99 & 82,14 & 71,50 & 59,66 & 46,84 & 32,90 & 33,80 & 67,29 & 141,88 & 348,16 & 18293,03 & - \\
\hline \multirow[t]{3}{*}{ CPI } & $\mathrm{DM}$ & $-13,10$ & $-19,79$ & $-25,97$ & $-31,33$ & $-35,52$ & $-38,26$ & $-39,78$ & $-41,15$ & $-45,95$ & $-93,85$ & $-162,64$ & - \\
\hline & DMA & 44,35 & 42,43 & 39,15 & 34,60 & 37,70 & 39,99 & 41,98 & 49,00 & 68,28 & 136,86 & 230,22 & - \\
\hline & PDMA & 112,79 & 102,20 & 88,76 & 73,50 & 60,02 & 44,89 & 40,48 & 44,20 & 70,11 & 128,81 & 204,29 & - \\
\hline \multirow[t]{3}{*}{ SPI } & $\mathrm{DM}$ & $-16,78$ & $-13,01$ & $-8,69$ & $-3,69$ & 2,13 & 9,07 & 17,54 & 28,52 & 44,27 & 74,77 & 1311,41 & - \\
\hline & DMA & 21,17 & 17,07 & 13,57 & 10,39 & 7,03 & 9,39 & 18,25 & 31,85 & 54,17 & 104,01 & 2649,35 & - \\
\hline & PDMA & 75,00 & 67,42 & 58,85 & 49,52 & 37,18 & 24,10 & 28,90 & 84,22 & 194,50 & 509,01 & 31558,11 & - \\
\hline \multirow[t]{3}{*}{$\Delta \mathrm{CS}$} & $\mathrm{DM}$ & 3,68 & $-6,78$ & $-17,29$ & $-27,64$ & $-37,65$ & $-47,33$ & $-57,32$ & $-69,67$ & $-90,22$ & $-168,61$ & $-1474,05$ & - \\
\hline & DMA & 23,19 & 25,36 & 25,59 & 24,21 & 30,67 & 30,60 & 23,74 & 17,15 & 14,11 & 32,86 & $-2419,13$ & - \\
\hline & PDMA & 37,80 & 34,78 & 29,90 & 23,98 & 22,84 & 20,79 & 11,58 & $-40,03$ & $-124,40$ & $-380,20$ & $-31353,82$ & - \\
\hline
\end{tabular}


Tabela 8.18: Constantes de acoplamento OLYP com base aug-pcJ-2.

\begin{tabular}{|c|c|c|c|c|c|c|c|c|c|c|c|c|c|}
\hline & $\% E_{X}^{\mathrm{HF}}$ & $0 \%$ & $10 \%$ & $20 \%$ & $30 \%$ & $40 \%$ & $50 \%$ & $60 \%$ & $70 \%$ & $80 \%$ & $90 \%$ & $100 \%$ & Exp. \\
\hline $\mathrm{HF}$ & ${ }^{1} J_{\mathrm{HF}}$ & 363,4 & 391,6 & 420,1 & 449,1 & 478,5 & 508,2 & 538,4 & 568,9 & 599,7 & 630,9 & 662,5 & 500 \\
\hline $\mathrm{CO}$ & ${ }^{1} J_{\mathrm{CO}}$ & 24,0 & 21,8 & 19,5 & 17,1 & 14,6 & 12,0 & 9,4 & 6,6 & 3,8 & 0,9 & $-1,9$ & 16,4 \\
\hline $\mathrm{H}_{2} \mathrm{O}$ & ${ }^{1} J_{\mathrm{OH}}$ & $-66,1$ & $-69,4$ & $-72,7$ & $-76,1$ & $-79,5$ & $-83,0$ & $-86,5$ & $-90,1$ & $-93,7$ & $-97,3$ & $-101,1$ & $-80,6$ \\
\hline $\mathrm{H}_{2} \mathrm{O}$ & ${ }^{2} J_{\mathrm{HH}}$ & $-7,4$ & $-8,3$ & $-9,3$ & $-10,2$ & $-11,1$ & $-12,1$ & $-13,1$ & $-14,1$ & $-15,2$ & $-16,2$ & $-17,3$ & $-7,3$ \\
\hline $\mathrm{NH}_{3}$ & ${ }^{1} J_{\mathrm{NH}}$ & 40,2 & 41,5 & 42,7 & 44,0 & 45,3 & 46,6 & 47,9 & 49,3 & 50,6 & 52,0 & 53,4 & 43,8 \\
\hline $\mathrm{NH}_{3}$ & ${ }^{2} J_{\mathrm{HH}}$ & $-9,6$ & $-10,4$ & $-11,3$ & $-12,1$ & $-13,0$ & $-13,9$ & $-14,8$ & $-15,7$ & $-16,7$ & $-17,7$ & $-18,7$ & $-9,6$ \\
\hline $\mathrm{PH}_{3}$ & ${ }^{1} J_{\mathrm{PH}}$ & 158,8 & 167,5 & 176,1 & 184,5 & 192,8 & 201,0 & 209,0 & 216,8 & 224,5 & 231,9 & 239,2 & 188,2 \\
\hline $\mathrm{PF}_{3}$ & ${ }^{1} J_{\mathrm{PF}}$ & $-1702,2$ & $-1685,7$ & $-1665,4$ & $-1642,0$ & $-1616,2$ & $-1588,5$ & $-1559,4$ & $-1529,4$ & $-1498,8$ & $-1467,9$ & $-1437,0$ & -1441 \\
\hline $\mathrm{BHF}_{2}$ & ${ }^{1} J_{\mathrm{BF}}$ & $-181,4$ & $-160,8$ & $-140,7$ & $-121,1$ & $-102,0$ & $-83,5$ & $-65,6$ & $-48,2$ & $-31,4$ & $-15,1$ & 0,6 & -84 \\
\hline $\mathrm{BF}_{3}$ & ${ }^{1} J_{\mathrm{BF}}$ & $-90,5$ & $-67,4$ & $-45,0$ & $-23,1$ & $-1,8$ & 18,8 & 38,9 & 58,4 & 77,4 & 95,8 & 113,8 & 15 \\
\hline $\mathrm{F}_{2} \mathrm{O}$ & ${ }^{1} J_{\mathrm{OF}}$ & $-254,6$ & $-290,9$ & $-327,9$ & $-367,1$ & $-410,6$ & $-461,8$ & $-526,5$ & $-616,5$ & $-760,6$ & $-1056,6$ & $-2253,8$ & -300 \\
\hline $\mathrm{CH}_{4}$ & ${ }^{1} J_{\mathrm{CH}}$ & 118,2 & 121,1 & 124,1 & 127,1 & 130,2 & 133,3 & 136,4 & 139,6 & 142,9 & 146,1 & 149,4 & 125,3 \\
\hline $\mathrm{CH}_{4}$ & ${ }^{2} J_{\mathrm{HH}}$ & $-12,9$ & $-13,5$ & $-14,2$ & $-14,9$ & $-15,6$ & $-16,3$ & $-17,0$ & $-17,7$ & $-18,4$ & $-19,1$ & $-19,7$ & $-12,8$ \\
\hline $\mathrm{C}_{2} \mathrm{H}_{2}$ & ${ }^{1} J_{\mathrm{CC}}$ & 187,4 & 192,0 & 197,1 & 202,6 & 208,8 & 215,7 & 223,5 & 232,3 & 242,5 & 254,4 & 268,4 & 174,8 \\
\hline $\mathrm{C}_{2} \mathrm{H}_{2}$ & ${ }^{1} J_{\mathrm{CH}}$ & 253,4 & 258,1 & 263,0 & 268,0 & 273,2 & 278,7 & 284,6 & 290,9 & 297,7 & 305,1 & 313,5 & 247,6 \\
\hline $\mathrm{C}_{2} \mathrm{H}_{2}$ & ${ }^{2} J_{\mathrm{CH}}$ & 53,0 & 53,0 & 52,8 & 52,4 & 51,7 & 50,7 & 49,3 & 47,6 & 45,2 & 42,1 & 38,1 & 50,1 \\
\hline $\mathrm{C}_{2} \mathrm{H}_{2}$ & ${ }^{3} J_{\mathrm{HH}}$ & 11,6 & 12,2 & 12,9 & 13,7 & 14,7 & 15,9 & 17,3 & 18,9 & 20,9 & 23,2 & 26,0 & 9,6 \\
\hline $\mathrm{C}_{2} \mathrm{H}_{4}$ & ${ }^{1} J_{\mathrm{CC}}$ & 60,8 & 64,6 & 68,7 & 73,2 & 78,2 & 83,9 & 90,5 & 98,4 & 108,1 & 120,9 & 139,0 & 67,6 \\
\hline $\mathrm{C}_{2} \mathrm{H}_{4}$ & ${ }^{1} J_{\mathrm{CH}}$ & 152,7 & 156,5 & 160,4 & 164,4 & 168,6 & 173,1 & 177,9 & 183,2 & 189,3 & 196,5 & 205,7 & 156,3 \\
\hline $\mathrm{C}_{2} \mathrm{H}_{4}$ & ${ }^{2} J_{\mathrm{CH}}$ & $-1,1$ & $-2,0$ & $-3,1$ & $-4,3$ & $-5,6$ & $-7,2$ & $-9,2$ & $-11,6$ & $-14,8$ & $-19,1$ & $-25,4$ & $-2,4$ \\
\hline $\mathrm{C}_{2} \mathrm{H}_{4}$ & ${ }^{2} J_{\mathrm{HH}}$ & 3,4 & 2,8 & 2,2 & 1,5 & 0,8 & 0,0 & $-1,1$ & $-2,3$ & $-3,9$ & $-6,1$ & $-9,3$ & 2,3 \\
\hline $\mathrm{C}_{2} \mathrm{H}_{4}$ & ${ }^{3} J_{\mathrm{HH}_{\mathrm{c}}}$ & 12,2 & 12,6 & 13,1 & 13,6 & 14,2 & 14,9 & 15,8 & 17,0 & 18,5 & 20,6 & 23,7 & 11,7 \\
\hline $\mathrm{C}_{2} \mathrm{H}_{4}$ & ${ }^{3} J_{\mathrm{HH}_{\mathrm{t}}}$ & 19,4 & 19,8 & 20,3 & 21,0 & 21,7 & 22,6 & 23,6 & 25,0 & 26,8 & 29,3 & 32,9 & 19 \\
\hline $\mathrm{C}_{2} \mathrm{H}_{6}$ & ${ }^{1} J_{\mathrm{CC}}$ & 25,4 & 27,9 & 30,4 & 33,0 & 35,6 & 38,4 & 41,1 & 43,9 & 46,8 & 49,7 & 52,7 & 34,5 \\
\hline $\mathrm{C}_{2} \mathrm{H}_{6}$ & ${ }^{1} J_{\mathrm{CH}}$ & 118,4 & 121,5 & 124,6 & 127,8 & 131,0 & 134,2 & 137,5 & 140,8 & 144,1 & 147,5 & 150,9 & 125,2 \\
\hline $\mathrm{C}_{2} \mathrm{H}_{6}$ & ${ }^{2} J_{\mathrm{CH}}$ & $-3,3$ & $-3,7$ & $-4,1$ & $-4,5$ & $-5,0$ & $-5,4$ & $-5,9$ & $-6,4$ & $-6,8$ & $-7,3$ & $-7,8$ & $-4,7$ \\
\hline \multirow[t]{3}{*}{ Total } & DM & $-21,99$ & $-18,95$ & $-15,80$ & $-12,59$ & $-9,44$ & $-6,49$ & $-3,96$ & $-2,28$ & $-2,56$ & $-8,48$ & $-48,74$ & - \\
\hline & DMA & 29,34 & 23,77 & 20,66 & 18,92 & 18,17 & 19,40 & 25,67 & 33,10 & 42,85 & 58,80 & 110,36 & - \\
\hline & PDMA & 45,94 & 35,45 & 28,59 & 26,03 & 26,01 & 30,63 & 47,52 & 65,93 & 87,40 & 114,22 & 158,62 & - \\
\hline \multirow[t]{3}{*}{ CPI } & DM & $-51,48$ & $-46,49$ & $-41,35$ & $-36,17$ & $-31,26$ & $-27,01$ & $-23,93$ & $-23,17$ & $-27,39$ & $-45,47$ & $-145,56$ & - \\
\hline & DMA & 63,75 & 51,16 & 43,35 & 37,15 & 32,57 & 32,12 & 43,13 & 56,30 & 74,26 & 105,93 & 220,20 & - \\
\hline & PDMA & 88,13 & 69,78 & 53,74 & 38,43 & 26,58 & 22,30 & 43,33 & 64,85 & 87,83 & 114,95 & 169,20 & - \\
\hline \multirow[t]{3}{*}{ SPI } & DM & $-0,37$ & 1,25 & 2,94 & 4,70 & 6,56 & 8,56 & 10,68 & 13,03 & 15,65 & 18,65 & 22,27 & - \\
\hline & DMA & 4,10 & 3,68 & 4,02 & 5,54 & 7,60 & 10,07 & 12,87 & 16,09 & 19,81 & 24,25 & 29,81 & - \\
\hline & PDMA & 15,00 & 10,27 & 10,16 & 16,94 & 25,59 & 36,74 & 50,59 & 66,72 & 87,07 & 113,69 & 150,86 & - \\
\hline \multirow[t]{3}{*}{$\Delta \mathrm{CS}$} & $\mathrm{DM}$ & $-51,12$ & $-47,74$ & $-44,29$ & $-40,87$ & $-37,82$ & $-35,57$ & $-34,61$ & $-36,21$ & $-43,04$ & $-64,12$ & $-167,83$ & - \\
\hline & DMA & 59,65 & 47,48 & 39,33 & 31,61 & 24,97 & 22,05 & 30,26 & 40,21 & 54,45 & 81,68 & 190,39 & - \\
\hline & PDMA & 73,13 & 59,51 & 43,58 & 21,48 & 1,00 & $-14,44$ & $-7,26$ & $-1,87$ & 0,76 & 1,26 & 18,34 & - \\
\hline
\end{tabular}


Tabela 8.19: Constantes de acoplamento PBE com base aug-pcJ-2.

\begin{tabular}{|c|c|c|c|c|c|c|c|c|c|c|c|c|c|}
\hline & $\% E_{X}^{\mathrm{HF}}$ & $0 \%$ & $10 \%$ & $20 \%$ & $30 \%$ & $40 \%$ & $50 \%$ & $60 \%$ & $70 \%$ & $80 \%$ & $90 \%$ & $100 \%$ & Exp. \\
\hline $\mathrm{HF}$ & ${ }^{1} J_{\mathrm{HF}}$ & 376 & 397,8 & 419,7 & 441,9 & 464,3 & 486,9 & 509,8 & 532,8 & 556,1 & 579,6 & 603,3 & 500 \\
\hline $\mathrm{CO}$ & ${ }^{1} J_{\mathrm{CO}}$ & 24,1 & 22,5 & 20,8 & 19,1 & 17,3 & 15,4 & 13,5 & 11,5 & 9,5 & 7,4 & 5,3 & 16,4 \\
\hline $\mathrm{H}_{2} \mathrm{O}$ & ${ }^{1} J_{\mathrm{OH}}$ & $-67,2$ & $-69,5$ & $-71,8$ & $-74,2$ & $-76,6$ & -79 & $-81,4$ & $-83,9$ & $-86,4$ & $-88,9$ & $-91,5$ & $-80,6$ \\
\hline $\mathrm{H}_{2} \mathrm{O}$ & ${ }^{2} J_{\mathrm{HH}}$ & $-4,7$ & $-5,7$ & $-6,7$ & $-7,8$ & $-8,9$ & -10 & $-11,1$ & $-12,3$ & $-13,5$ & $-14,7$ & $-15,9$ & $-7,3$ \\
\hline $\mathrm{NH}_{3}$ & ${ }^{1} J_{\mathrm{NH}}$ & 40,8 & 41,5 & 42,2 & 42,9 & 43,6 & 44,3 & 45,1 & 45,8 & 46,6 & 47,4 & 48,2 & 43,8 \\
\hline $\mathrm{NH}_{3}$ & ${ }^{2} J_{\mathrm{HH}}$ & $-7,8$ & $-8,7$ & $-9,6$ & $-10,6$ & $-11,5$ & $-12,5$ & $-13,5$ & $-14,5$ & $-15,5$ & $-16,6$ & $-17,6$ & $-9,6$ \\
\hline $\mathrm{PH}_{3}$ & ${ }^{1} J_{\mathrm{PH}}$ & 133,7 & 142,1 & 150,4 & 158,7 & 166,9 & 175,1 & 183,1 & 191,1 & 198,9 & 206,7 & 214,3 & 188,2 \\
\hline $\mathrm{PF}_{3}$ & ${ }^{1} J_{\mathrm{PF}}$ & -1801 & $-1776,9$ & $-1748,1$ & $-1715,3$ & $-1679,4$ & $-1640,8$ & $-1600,3$ & $-1558,1$ & $-1514,9$ & $-1470,9$ & $-1426,5$ & -1441 \\
\hline $\mathrm{BHF}_{2}$ & ${ }^{1} J_{\mathrm{BF}}$ & $-172,8$ & $-155,9$ & $-139,2$ & $-122,7$ & $-106,5$ & $-90,4$ & $-74,6$ & -59 & $-43,7$ & $-28,6$ & $-13,8$ & -84 \\
\hline $\mathrm{BF}_{3}$ & ${ }^{1} J_{\mathrm{BF}}$ & $-75,8$ & $-57,5$ & $-39,4$ & $-21,7$ & $-4,2$ & 12,9 & 29,9 & 46,6 & 63 & 79,2 & 95,2 & 15 \\
\hline $\mathrm{F}_{2} \mathrm{O}$ & ${ }^{1} J_{\mathrm{OF}}$ & -278 & $-316,3$ & $-354,9$ & $-395,6$ & $-440,5$ & $-493,5$ & $-560,8$ & $-655,5$ & $-809,2$ & $-1129,5$ & $-2453,2$ & -300 \\
\hline $\mathrm{CH}_{4}$ & ${ }^{1} J_{\mathrm{CH}}$ & 119,3 & 120,7 & 122,1 & 123,5 & 125 & 126,5 & 128 & 129,6 & 131,2 & 132,8 & 134,4 & 125,3 \\
\hline $\mathrm{CH}_{4}$ & ${ }^{2} J_{\mathrm{HH}}$ & $-11,8$ & $-12,6$ & $-13,4$ & $-14,2$ & -15 & $-15,8$ & $-16,6$ & $-17,4$ & $-18,2$ & -19 & $-19,8$ & $-12,8$ \\
\hline $\mathrm{C}_{2} \mathrm{H}_{2}$ & ${ }^{1} J_{\mathrm{CC}}$ & 188,7 & 191,5 & 194,6 & 198,3 & 202,6 & 207,6 & 213,7 & 221 & 230,2 & 241,9 & 257,1 & 174,8 \\
\hline $\mathrm{C}_{2} \mathrm{H}_{2}$ & ${ }^{1} J_{\mathrm{CH}}$ & 249,8 & 252,2 & 254,8 & 257,6 & 260,7 & 264,1 & 268 & 272,5 & 277,9 & 284,6 & 293,3 & 247,6 \\
\hline $\mathrm{C}_{2} \mathrm{H}_{2}$ & ${ }^{2} J_{\mathrm{CH}}$ & 54,1 & 54,1 & 53,7 & 53,2 & 52,2 & 50,9 & 49 & 46,5 & 42,9 & 38,1 & 31,2 & 50,1 \\
\hline $\mathrm{C}_{2} \mathrm{H}_{2}$ & ${ }^{3} J_{\mathrm{HH}}$ & 10,4 & 11,1 & 11,9 & 12,9 & 14,1 & 15,6 & 17,4 & 19,6 & 22,5 & 26,1 & 30,9 & 9,6 \\
\hline $\mathrm{C}_{2} \mathrm{H}_{4}$ & ${ }^{1} J_{\mathrm{CC}}$ & 61,3 & 64 & 67 & 70,4 & 74,4 & 79,1 & 85 & 92,8 & 103,6 & 120,3 & 150,7 & 67,6 \\
\hline $\mathrm{C}_{2} \mathrm{H}_{4}$ & ${ }^{1} J_{\mathrm{CH}}$ & 151,8 & 153,9 & 156,1 & 158,5 & 161,1 & 164 & 167,5 & 171,6 & 177,1 & 185,2 & 199 & 156,3 \\
\hline $\mathrm{C}_{2} \mathrm{H}_{4}$ & ${ }^{2} J_{\mathrm{CH}}$ & $-0,5$ & $-1,4$ & $-2,5$ & $-3,7$ & $-5,1$ & $-6,9$ & $-9,1$ & $-12,2$ & $-16,5$ & $-23,4$ & $-36,1$ & $-2,4$ \\
\hline $\mathrm{C}_{2} \mathrm{H}_{4}$ & ${ }^{2} J_{\mathrm{HH}}$ & 4,5 & 3,7 & 2,8 & 1,8 & 0,7 & $-0,5$ & $-2,1$ & $-4,1$ & -7 & $-11,4$ & $-19,4$ & 2,3 \\
\hline $\mathrm{C}_{2} \mathrm{H}_{4}$ & ${ }^{3} J_{\mathrm{HH}_{\mathrm{c}}}$ & 11,7 & 12,1 & 12,5 & 13 & 13,6 & 14,5 & 15,7 & 17,3 & 19,7 & 23,7 & 31,3 & 11,7 \\
\hline $\mathrm{C}_{2} \mathrm{H}_{4}$ & ${ }^{3} J_{\mathrm{HH}_{\mathrm{t}}}$ & 18,7 & 19 & 19,5 & 20,1 & 20,9 & 21,9 & 23,3 & 25,2 & 28 & 32,5 & 41 & 19 \\
\hline $\mathrm{C}_{2} \mathrm{H}_{6}$ & ${ }^{1} J_{\mathrm{CC}}$ & 25,7 & 27,6 & 29,4 & 31,3 & 33,3 & 35,2 & 37,2 & 39,3 & 41,3 & 43,4 & 45,6 & 34,5 \\
\hline $\mathrm{C}_{2} \mathrm{H}_{6}$ & ${ }^{1} J_{\mathrm{CH}}$ & 119,5 & 121,1 & 122,7 & 124,3 & 126 & 127,7 & 129,4 & 131,2 & 133 & 134,8 & 136,6 & 125,2 \\
\hline $\mathrm{C}_{2} \mathrm{H}_{6}$ & ${ }^{2} J_{\mathrm{CH}}$ & $-2,9$ & $-3,4$ & $-3,9$ & $-4,3$ & $-4,9$ & $-5,4$ & $-5,9$ & $-6,4$ & -7 & $-7,5$ & $-8,1$ & $-4,7$ \\
\hline \multirow[t]{3}{*}{ Total } & DM & $-26,05$ & $-23,77$ & $-21,32$ & $-18,75$ & $-16,19$ & $-13,77$ & $-11,72$ & $-10,54$ & $-11,36$ & $-18,15$ & $-62,67$ & - \\
\hline & DMA & 31,85 & 27,68 & 25,11 & 23,12 & 21,47 & 20,50 & 23,18 & 29,22 & 38,35 & 54,68 & 112,44 & - \\
\hline & PDMA & 46,79 & 35,93 & 26,02 & 23,07 & 23,41 & 26,51 & 41,16 & 61,13 & 86,55 & 122,43 & 190,22 & - \\
\hline \multirow[t]{3}{*}{ CPI } & DM & $-61,24$ & $-57,05$ & $-52,50$ & $-47,84$ & $-43,31$ & $-39,32$ & $-36,47$ & $-36,04$ & $-40,91$ & $-60,89$ & $-172,10$ & - \\
\hline & DMA & 69,87 & 60,63 & 55,01 & 49,49 & 44,20 & 39,70 & 42,91 & 53,18 & 69,62 & 101,13 & 226,41 & - \\
\hline & PDMA & 83,81 & 66,37 & 50,34 & 37,51 & 26,29 & 16,91 & 29,77 & 48,48 & 69,25 & 95,09 & 151,26 & - \\
\hline \multirow[t]{3}{*}{ SPI } & DM & $-0,25$ & 0,63 & 1,55 & 2,57 & 3,70 & 4,96 & 6,43 & 8,16 & 10,31 & 13,20 & 17,57 & - \\
\hline & DMA & 3,96 & 3,51 & 3,19 & 3,79 & 4,79 & 6,43 & 8,72 & 11,64 & 15,41 & 20,63 & 28,87 & - \\
\hline & PDMA & 19,65 & 13,60 & 8,19 & 12,49 & 21,30 & 33,55 & 49,51 & 70,42 & 99,24 & 142,49 & 218,79 & - \\
\hline \multirow[t]{3}{*}{$\Delta \mathrm{CS}$} & $\mathrm{DM}$ & $-60,98$ & $-57,68$ & $-54,05$ & $-50,41$ & $-47,01$ & $-44,28$ & $-42,90$ & $-44,20$ & $-51,22$ & $-74,09$ & $-189,67$ & - \\
\hline & DMA & 65,91 & 57,11 & 51,82 & 45,70 & 39,41 & 33,27 & 34,19 & 41,54 & 54,20 & 80,50 & 197,54 & - \\
\hline & PDMA & 64,16 & 52,77 & 42,15 & 25,03 & 4,99 & $-16,64$ & $-19,74$ & $-21,94$ & $-29,99$ & $-47,40$ & $-67,53$ & - \\
\hline
\end{tabular}


Tabela 8.20: Constantes de acoplamento PW91 com base aug-pcJ-2.

\begin{tabular}{|c|c|c|c|c|c|c|c|c|c|c|c|c|c|}
\hline & $\% E_{X}^{\mathrm{HF}}$ & $0 \%$ & $10 \%$ & $20 \%$ & $30 \%$ & $40 \%$ & $50 \%$ & $60 \%$ & $70 \%$ & $80 \%$ & $90 \%$ & $100 \%$ & Exp. \\
\hline $\mathrm{HF}$ & ${ }^{1} J_{\mathrm{HF}}$ & 364,2 & 387,4 & 410,8 & 434,5 & 458,3 & 482,4 & 506,7 & 531,2 & 556,0 & 581,0 & 606,3 & 500 \\
\hline $\mathrm{CO}$ & ${ }^{1} J_{\mathrm{CO}}$ & 24,9 & 23,2 & 21,5 & 19,6 & 17,7 & 15,8 & 13,7 & 11,6 & 9,4 & 7,2 & 4,9 & 16,4 \\
\hline $\mathrm{H}_{2} \mathrm{O}$ & ${ }^{1} J_{\mathrm{OH}}$ & $-66,3$ & $-68,7$ & $-71,2$ & $-73,7$ & $-76,2$ & $-78,7$ & $-81,3$ & $-83,9$ & $-86,5$ & $-89,2$ & $-91,9$ & $-80,6$ \\
\hline $\mathrm{H}_{2} \mathrm{O}$ & ${ }^{2} J_{\mathrm{HH}}$ & $-4,8$ & $-5,8$ & $-6,8$ & $-7,9$ & $-9,0$ & $-10,1$ & $-11,2$ & $-12,4$ & $-13,5$ & $-14,7$ & $-16,0$ & $-7,3$ \\
\hline $\mathrm{NH}_{3}$ & ${ }^{1} J_{\mathrm{NH}}$ & 40,8 & 41,5 & 42,2 & 42,9 & 43,7 & 44,5 & 45,2 & 46,0 & 46,8 & 47,6 & 48,4 & 43,8 \\
\hline $\mathrm{NH}_{3}$ & ${ }^{2} J_{\mathrm{HH}}$ & $-8,0$ & $-8,9$ & $-9,8$ & $-10,8$ & $-11,7$ & $-12,7$ & $-13,6$ & $-14,6$ & $-15,6$ & $-16,6$ & $-17,7$ & $-9,6$ \\
\hline $\mathrm{PH}_{3}$ & ${ }^{1} J_{\mathrm{PH}}$ & 137,6 & 145,9 & 154,0 & 162,1 & 170,0 & 177,9 & 185,7 & 193,3 & 200,8 & 208,2 & 215,5 & 188,2 \\
\hline $\mathrm{PF}_{3}$ & ${ }^{1} J_{\mathrm{PF}}$ & $-1815,2$ & $-1790,1$ & $-1760,3$ & $-1726,4$ & $-1689,3$ & $-1649,5$ & $-1607,6$ & $-1564,2$ & $-1519,7$ & $-1474,3$ & $-1428,5$ & -1441 \\
\hline $\mathrm{BHF}_{2}$ & ${ }^{1} J_{\mathrm{BF}}$ & $-177,6$ & $-160,4$ & $-143,4$ & $-126,4$ & $-109,6$ & $-93,0$ & $-76,5$ & $-60,2$ & $-44,1$ & $-28,2$ & $-12,5$ & -84 \\
\hline $\mathrm{BF}_{3}$ & ${ }^{1} J_{\mathrm{BF}}$ & $-80,9$ & $-62,3$ & $-43,8$ & $-25,6$ & $-7,6$ & 10,2 & 27,8 & 45,3 & 62,5 & 79,6 & 96,6 & 15 \\
\hline $\mathrm{F}_{2} \mathrm{O}$ & ${ }^{1} J_{\mathrm{OF}}$ & $-290,5$ & $-328,8$ & $-367,5$ & $-408,1$ & $-453,0$ & $-506,0$ & $-573,5$ & $-668,7$ & $-823,8$ & $-1148,9$ & $-2525,8$ & -300 \\
\hline $\mathrm{CH}_{4}$ & ${ }^{1} J_{\mathrm{CH}}$ & 120,1 & 121,5 & 122,9 & 124,3 & 125,8 & 127,3 & 128,8 & 130,4 & 131,9 & 133,5 & 135,2 & 125,3 \\
\hline $\mathrm{CH}_{4}$ & ${ }^{2} J_{\mathrm{HH}}$ & $-12,0$ & $-12,8$ & $-13,6$ & $-14,4$ & $-15,2$ & $-15,9$ & $-16,7$ & $-17,5$ & $-18,3$ & $-19,1$ & $-19,9$ & $-12,8$ \\
\hline $\mathrm{C}_{2} \mathrm{H}_{2}$ & ${ }^{1} J_{\mathrm{CC}}$ & 188,8 & 191,6 & 194,7 & 198,5 & 202,8 & 208,0 & 214,2 & 221,8 & 231,3 & 243,3 & 259,0 & 174,8 \\
\hline $\mathrm{C}_{2} \mathrm{H}_{2}$ & ${ }^{1} J_{\mathrm{CH}}$ & 252,5 & 254,8 & 257,3 & 259,9 & 262,8 & 266,1 & 269,8 & 274,3 & 279,6 & 286,1 & 294,6 & 247,6 \\
\hline $\mathrm{C}_{2} \mathrm{H}_{2}$ & ${ }^{2} J_{\mathrm{CH}}$ & 54,6 & 54,5 & 54,1 & 53,5 & 52,6 & 51,2 & 49,2 & 46,6 & 43,0 & 38,0 & 31,2 & 50,1 \\
\hline $\mathrm{C}_{2} \mathrm{H}_{2}$ & ${ }^{3} J_{\mathrm{HH}}$ & 10,5 & 11,2 & 12,0 & 13,0 & 14,2 & 15,7 & 17,5 & 19,7 & 22,5 & 26,1 & 30,7 & 9,6 \\
\hline $\mathrm{C}_{2} \mathrm{H}_{4}$ & ${ }^{1} J_{\mathrm{CC}}$ & 60,6 & 63,3 & 66,4 & 69,9 & 74,0 & 78,9 & 85,0 & 92,9 & 104,1 & 121,2 & 152,0 & 67,6 \\
\hline $\mathrm{C}_{2} \mathrm{H}_{4}$ & ${ }^{1} J_{\mathrm{CH}}$ & 153,0 & 155,1 & 157,3 & 159,6 & 162,2 & 165,1 & 168,5 & 172,7 & 178,2 & 186,2 & 200,0 & 156,3 \\
\hline $\mathrm{C}_{2} \mathrm{H}_{4}$ & ${ }^{2} J_{\mathrm{CH}}$ & $-0,4$ & $-1,3$ & $-2,3$ & $-3,5$ & $-5,0$ & $-6,8$ & $-9,1$ & $-12,1$ & $-16,5$ & $-23,5$ & $-36,2$ & $-2,4$ \\
\hline $\mathrm{C}_{2} \mathrm{H}_{4}$ & ${ }^{2} J_{\mathrm{HH}}$ & 4,5 & 3,6 & 2,8 & 1,8 & 0,7 & $-0,5$ & $-2,1$ & $-4,2$ & $-7,1$ & $-11,4$ & $-19,2$ & 2,3 \\
\hline $\mathrm{C}_{2} \mathrm{H}_{4}$ & ${ }^{3} J_{\mathrm{HH}_{\mathrm{c}}}$ & 11,9 & 12,2 & 12,6 & 13,1 & 13,8 & 14,7 & 15,8 & 17,4 & 19,8 & 23,8 & 31,2 & 11,7 \\
\hline $\mathrm{C}_{2} \mathrm{H}_{4}$ & ${ }^{3} J_{\mathrm{HH}_{\mathrm{t}}}$ & 19,0 & 19,3 & 19,8 & 20,4 & 21,1 & 22,1 & 23,5 & 25,4 & 28,1 & 32,6 & 40,9 & 19 \\
\hline $\mathrm{C}_{2} \mathrm{H}_{6}$ & ${ }^{1} J_{\mathrm{CC}}$ & 25,1 & 27,0 & 29,0 & 31,0 & 33,1 & 35,1 & 37,3 & 39,4 & 41,6 & 43,8 & 46,1 & 34,5 \\
\hline $\mathrm{C}_{2} \mathrm{H}_{6}$ & ${ }^{1} J_{\mathrm{CH}}$ & 120,3 & 121,9 & 123,5 & 125,1 & 126,8 & 128,5 & 130,2 & 132,0 & 133,7 & 135,5 & 137,3 & 125,2 \\
\hline $\mathrm{C}_{2} \mathrm{H}_{6}$ & ${ }^{2} J_{\mathrm{CH}}$ & $-2,9$ & $-3,4$ & $-3,9$ & $-4,4$ & $-4,9$ & $-5,4$ & $-5,9$ & $-6,4$ & $-7,0$ & $-7,5$ & $-8,1$ & $-4,7$ \\
\hline \multirow[t]{3}{*}{ Total } & DM & $-27,51$ & $-25,13$ & $-22,57$ & $-19,88$ & $-17,19$ & $-14,62$ & $-12,45$ & $-11,12$ & $-11,84$ & $-18,64$ & $-65,03$ & - \\
\hline & DMA & 32,72 & 29,40 & 26,80 & 24,62 & 22,93 & 21,82 & 23,78 & 30,12 & 39,39 & 56,00 & 115,74 & - \\
\hline & PDMA & 48,56 & 37,80 & 28,07 & 24,53 & 25,00 & 27,68 & 40,94 & 61,33 & 87,16 & 123,40 & 191,82 & - \\
\hline \multirow[t]{3}{*}{ CPI } & DM & $-65,15$ & $-60,72$ & $-55,93$ & $-50,97$ & $-46,15$ & $-41,83$ & $-38,68$ & $-37,95$ & $-42,60$ & $-62,65$ & $-178,33$ & - \\
\hline & DMA & 71,77 & 64,52 & 58,65 & 52,81 & 47,18 & 42,30 & 43,85 & 54,79 & 71,51 & 103,60 & 233,56 & - \\
\hline & PDMA & 87,39 & 70,40 & 54,43 & 41,35 & 29,65 & 19,37 & 28,66 & 48,28 & 69,67 & 96,27 & 155,08 & - \\
\hline \multirow[t]{3}{*}{ SPI } & DM & 0,10 & 0,96 & 1,90 & 2,91 & 4,05 & 5,33 & 6,79 & 8,55 & 10,72 & 13,63 & 18,05 & - \\
\hline & DMA & 4,07 & 3,64 & 3,45 & 3,95 & 5,14 & 6,80 & 9,07 & 12,03 & 15,84 & 21,10 & 29,34 & - \\
\hline & PDMA & 20,09 & 13,89 & 8,73 & 12,20 & 21,60 & 33,78 & 49,95 & 70,90 & 99,98 & 143,30 & 218,77 & - \\
\hline \multirow[t]{3}{*}{$\Delta \mathrm{CS}$} & $\mathrm{DM}$ & $-65,25$ & $-61,68$ & $-57,83$ & $-53,89$ & $-50,19$ & $-47,16$ & $-45,48$ & $-46,51$ & $-53,32$ & $-76,29$ & $-196,37$ & - \\
\hline & DMA & 67,70 & 60,88 & 55,21 & 48,86 & 42,04 & 35,50 & 34,77 & 42,76 & 55,67 & 82,50 & 204,22 & - \\
\hline & PDMA & 67,30 & 56,51 & 45,70 & 29,14 & 8,05 & $-14,40$ & $-21,29$ & $-22,63$ & $-30,30$ & $-47,04$ & $-63,69$ & - \\
\hline
\end{tabular}


8.2. VARIAÇÃO DA PORCENTAGEM DE E HF PARA OS FUNCIONAIS

HIBBRIDOS

Tabela 8.21: Constantes de acoplamento TPSSh com base aug-pcJ-2.

\begin{tabular}{|c|c|c|c|c|c|c|c|c|c|c|c|c|c|}
\hline & $\% E_{X}^{\mathrm{HF}}$ & $0 \%$ & $10 \%$ & $20 \%$ & $30 \%$ & $40 \%$ & $50 \%$ & $60 \%$ & $70 \%$ & $80 \%$ & $90 \%$ & $100 \%$ & Exp. \\
\hline $\mathrm{HF}$ & ${ }^{1} J_{\mathrm{HF}}$ & 366,0 & 390,6 & 415,1 & 439,7 & 464,2 & 488,7 & 513,1 & 537,4 & 561,6 & 585,8 & 610,0 & 500 \\
\hline $\mathrm{CO}$ & ${ }^{1} J_{\mathrm{CO}}$ & 21,7 & 20,3 & 18,8 & 17,3 & 15,7 & 14,0 & 12,3 & 10,5 & 8,7 & 6,8 & 4,9 & 16,4 \\
\hline $\mathrm{H}_{2} \mathrm{O}$ & ${ }^{1} J_{\mathrm{OH}}$ & $-70,2$ & $-72,5$ & $-74,9$ & $-77,3$ & $-79,6$ & $-82,0$ & $-84,3$ & $-86,6$ & $-88,9$ & $-91,1$ & $-93,4$ & $-80,6$ \\
\hline $\mathrm{H}_{2} \mathrm{O}$ & ${ }^{2} J_{\mathrm{HH}}$ & $-4,0$ & $-5,3$ & $-6,6$ & $-7,8$ & $-9,1$ & $-10,3$ & $-11,5$ & $-12,7$ & $-13,9$ & $-15,1$ & $-16,2$ & $-7,3$ \\
\hline $\mathrm{NH}_{3}$ & ${ }^{1} J_{\mathrm{NH}}$ & 45,3 & 45,8 & 46,4 & 46,9 & 47,3 & 47,8 & 48,3 & 48,8 & 49,2 & 49,7 & 50,1 & 43,8 \\
\hline $\mathrm{NH}_{3}$ & ${ }^{2} J_{\mathrm{HH}}$ & $-6,9$ & $-8,1$ & $-9,3$ & $-10,4$ & $-11,6$ & $-12,7$ & $-13,8$ & $-14,9$ & $-15,9$ & $-17,0$ & $-17,9$ & $-9,6$ \\
\hline $\mathrm{PH}_{3}$ & ${ }^{1} J_{\mathrm{PH}}$ & 195,7 & 200,5 & 205,0 & 209,3 & 213,4 & 217,2 & 220,8 & 224,1 & 227,2 & 230,0 & 232,6 & 188,2 \\
\hline $\mathrm{PF}_{3}$ & ${ }^{1} J_{\mathrm{PF}}$ & $-1757,5$ & $-1731,7$ & $-1703,3$ & $-1673,0$ & $-1641,1$ & $-1608,0$ & $-1574,1$ & $-1539,7$ & $-1504,9$ & $-1470,0$ & $-1435,2$ & -1441 \\
\hline $\mathrm{BHF}_{2}$ & ${ }^{1} J_{\mathrm{BF}}$ & $-156,7$ & $-142,5$ & $-128,4$ & $-114,3$ & $-100,2$ & $-86,1$ & $-72,1$ & $-58,1$ & $-44,2$ & $-30,3$ & $-16,4$ & -84 \\
\hline $\mathrm{BF}_{3}$ & ${ }^{1} J_{\mathrm{BF}}$ & $-63,8$ & $-47,2$ & $-30,7$ & $-14,3$ & 1,8 & 17,8 & 33,8 & 49,6 & 65,2 & 80,8 & 96,3 & 15 \\
\hline $\mathrm{F}_{2} \mathrm{O}$ & ${ }^{1} J_{\mathrm{OF}}$ & $-282,7$ & $-320,1$ & $-359,5$ & $-402,5$ & $-451,3$ & $-510,0$ & $-585,2$ & $-690,4$ & $-857,9$ & $-1192,7$ & $-2403,5$ & -300 \\
\hline $\mathrm{CH}_{4}$ & ${ }^{1} J_{\mathrm{CH}}$ & 138,0 & 138,8 & 139,6 & 140,4 & 141,1 & 141,9 & 142,6 & 143,2 & 143,8 & 144,4 & 144,9 & 125,3 \\
\hline $\mathrm{CH}_{4}$ & ${ }^{2} J_{\mathrm{HH}}$ & $-10,2$ & $-11,3$ & $-12,4$ & $-13,4$ & $-14,5$ & $-15,5$ & $-16,5$ & $-17,4$ & $-18,4$ & $-19,3$ & $-20,2$ & $-12,8$ \\
\hline $\mathrm{C}_{2} \mathrm{H}_{2}$ & ${ }^{1} J_{\mathrm{CC}}$ & 187,5 & 190,8 & 194,6 & 198,9 & 203,9 & 209,8 & 216,7 & 225,0 & 234,9 & 247,0 & 262,1 & 174,8 \\
\hline $\mathrm{C}_{2} \mathrm{H}_{2}$ & ${ }^{1} J_{\mathrm{CH}}$ & 280,6 & 282,3 & 284,1 & 286,1 & 288,3 & 290,8 & 293,7 & 297,1 & 301,3 & 306,4 & 312,9 & 247,6 \\
\hline $\mathrm{C}_{2} \mathrm{H}_{2}$ & ${ }^{2} J_{\mathrm{CH}}$ & 58,3 & 57,7 & 56,9 & 55,8 & 54,3 & 52,4 & 50,0 & 46,9 & 43,0 & 38,0 & 31,5 & 50,1 \\
\hline $\mathrm{C}_{2} \mathrm{H}_{2}$ & ${ }^{3} J_{\mathrm{HH}}$ & 12,0 & 12,6 & 13,5 & 14,5 & 15,7 & 17,3 & 19,1 & 21,4 & 24,1 & 27,5 & 31,8 & 9,6 \\
\hline $\mathrm{C}_{2} \mathrm{H}_{4}$ & ${ }^{1} J_{\mathrm{CC}}$ & 68,8 & 71,5 & 74,5 & 78,0 & 82,1 & 87,0 & 93,1 & 100,9 & 111,6 & 127,4 & 153,5 & 67,6 \\
\hline $\mathrm{C}_{2} \mathrm{H}_{4}$ & ${ }^{1} J_{\mathrm{CH}}$ & 172,7 & 174,3 & 176,1 & 178,0 & 180,1 & 182,5 & 185,3 & 188,9 & 193,6 & 200,5 & 211,7 & 156,3 \\
\hline $\mathrm{C}_{2} \mathrm{H}_{4}$ & ${ }^{2} J_{\mathrm{CH}}$ & $-0,6$ & $-1,7$ & $-3,0$ & $-4,5$ & $-6,2$ & $-8,3$ & $-10,9$ & $-14,3$ & $-18,9$ & $-25,6$ & $-36,8$ & $-2,4$ \\
\hline $\mathrm{C}_{2} \mathrm{H}_{4}$ & ${ }^{2} J_{\mathrm{HH}}$ & 9,4 & 8,2 & 6,8 & 5,4 & 3,8 & 2,0 & 0,0 & $-2,5$ & $-5,8$ & $-10,3$ & $-17,4$ & 2,3 \\
\hline $\mathrm{C}_{2} \mathrm{H}_{4}$ & ${ }^{3} J_{\mathrm{HH}_{\mathrm{c}}}$ & 12,0 & 12,5 & 13,0 & 13,7 & 14,5 & 15,5 & 16,9 & 18,6 & 21,1 & 24,9 & 31,3 & 11,7 \\
\hline $\mathrm{C}_{2} \mathrm{H}_{4}$ & ${ }^{3} J_{\mathrm{HH}_{\mathrm{t}}}$ & 22,1 & 22,5 & 22,9 & 23,5 & 24,2 & 25,2 & 26,6 & 28,4 & 31,1 & 35,2 & 42,2 & 19 \\
\hline $\mathrm{C}_{2} \mathrm{H}_{6}$ & ${ }^{1} J_{\mathrm{CC}}$ & 32,9 & 34,4 & 35,8 & 37,2 & 38,7 & 40,1 & 41,5 & 42,9 & 44,2 & 45,6 & 46,9 & 34,5 \\
\hline $\mathrm{C}_{2} \mathrm{H}_{6}$ & ${ }^{1} J_{\mathrm{CH}}$ & 137,9 & 138,9 & 140,0 & 141,0 & 141,9 & 142,9 & 143,8 & 144,7 & 145,5 & 146,3 & 147,1 & 125,2 \\
\hline $\mathrm{C}_{2} \mathrm{H}_{6}$ & ${ }^{2} J_{\mathrm{CH}}$ & $-3,3$ & $-3,8$ & $-4,3$ & $-4,9$ & $-5,4$ & $-5,9$ & $-6,4$ & $-7,0$ & $-7,5$ & $-8,0$ & $-8,5$ & $-4,7$ \\
\hline \multirow[t]{3}{*}{ Total } & DM & $-16,92$ & $-14,90$ & $-12,86$ & $-10,83$ & $-8,96$ & $-7,34$ & $-6,24$ & $-6,16$ & $-8,28$ & $-16,47$ & $-57,72$ & - \\
\hline & DMA & 29,51 & 26,71 & 25,40 & 24,44 & 23,91 & 24,23 & 28,44 & 35,26 & 44,86 & 61,59 & 113,73 & - \\
\hline & PDMA & 51,70 & 41,22 & 32,92 & 29,32 & 28,23 & 30,82 & 48,29 & 69,59 & 95,67 & 130,80 & 191,26 & - \\
\hline \multirow[t]{3}{*}{ CPI } & $\mathrm{DM}$ & $-50,36$ & $-46,46$ & $-42,57$ & $-38,85$ & $-35,58$ & $-33,14$ & $-32,15$ & $-33,90$ & $-41,34$ & $-64,00$ & $-166,33$ & - \\
\hline & DMA & 59,09 & 51,88 & 47,75 & 44,01 & 40,98 & 39,65 & 46,85 & 59,14 & 76,97 & 110,00 & 223,67 & - \\
\hline & PDMA & 72,03 & 56,46 & 41,98 & 30,62 & 22,83 & 19,94 & 36,81 & 55,37 & 75,56 & 100,96 & 152,58 & - \\
\hline \multirow[t]{3}{*}{ SPI } & $\mathrm{DM}$ & 7,60 & 8,24 & 8,93 & 9,71 & 10,56 & 11,57 & 12,76 & 14,18 & 15,97 & 18,39 & 21,93 & - \\
\hline & DMA & 7,81 & 8,25 & 9,01 & 10,09 & 11,39 & 12,92 & 14,93 & 17,75 & 21,31 & 26,09 & 33,11 & - \\
\hline & PDMA & 36,79 & 30,05 & 26,27 & 28,37 & 32,19 & 38,80 & 56,71 & 80,01 & 110,42 & 152,68 & 219,63 & - \\
\hline \multirow[t]{3}{*}{$\Delta \mathrm{CS}$} & DM & $-57,96$ & $-54,70$ & $-51,51$ & $-48,55$ & $-46,14$ & $-44,71$ & $-44,91$ & $-48,08$ & $-57,30$ & $-82,39$ & $-188,25$ & - \\
\hline & DMA & 51,28 & 43,63 & 38,74 & 33,92 & 29,60 & 26,73 & 31,92 & 41,38 & 55,66 & 83,91 & 190,56 & - \\
\hline & PDMA & 35,25 & 26,41 & 15,71 & 2,25 & $-9,36$ & $-18,86$ & $-19,90$ & $-24,64$ & $-34,87$ & $-51,73$ & $-67,05$ & - \\
\hline
\end{tabular}


Tabela 8.22: Constantes de acoplamento X3LYP com base aug-pcJ-2.

\begin{tabular}{|c|c|c|c|c|c|c|c|c|c|c|c|c|c|}
\hline & $\% E_{X}^{\mathrm{HF}}$ & $0 \%$ & $10 \%$ & $20 \%$ & $30 \%$ & $40 \%$ & $50 \%$ & $60 \%$ & $70 \%$ & $80 \%$ & $90 \%$ & $100 \%$ & Exp. \\
\hline $\mathrm{HF}$ & ${ }^{1} J_{\mathrm{HF}}$ & 397,3 & 422,2 & 447,3 & 472,6 & 498,2 & 524,1 & 550,1 & 576,4 & 602,9 & 629,7 & 656,7 & 500 \\
\hline $\mathrm{CO}$ & ${ }^{1} J_{\mathrm{CO}}$ & 21,5 & 19,7 & 17,7 & 15,6 & 13,4 & 11,1 & 8,8 & 6,3 & 3,8 & 1,2 & $-1,4$ & 16,4 \\
\hline $\mathrm{H}_{2} \mathrm{O}$ & ${ }^{1} J_{\mathrm{OH}}$ & $-72,3$ & $-75,0$ & $-77,6$ & $-80,4$ & $-83,1$ & $-85,8$ & $-88,6$ & $-91,5$ & $-94,3$ & $-97,2$ & $-100,1$ & $-80,6$ \\
\hline $\mathrm{H}_{2} \mathrm{O}$ & ${ }^{2} J_{\mathrm{HH}}$ & $-5,3$ & $-6,4$ & $-7,5$ & $-8,6$ & $-9,7$ & $-10,9$ & $-12,1$ & $-13,3$ & $-14,5$ & $-15,7$ & $-17,0$ & $-7,3$ \\
\hline $\mathrm{NH}_{3}$ & ${ }^{1} J_{\mathrm{NH}}$ & 44,5 & 45,3 & 46,1 & 46,9 & 47,8 & 48,6 & 49,4 & 50,3 & 51,2 & 52,0 & 52,9 & 43,8 \\
\hline $\mathrm{NH}_{3}$ & ${ }^{2} J_{\mathrm{HH}}$ & $-8,4$ & $-9,3$ & $-10,3$ & $-11,2$ & $-12,2$ & $-13,2$ & $-14,2$ & $-15,2$ & $-16,3$ & $-17,3$ & $-18,4$ & $-9,6$ \\
\hline $\mathrm{PH}_{3}$ & ${ }^{1} J_{\mathrm{PH}}$ & 158,3 & 166,8 & 175,2 & 183,5 & 191,6 & 199,6 & 207,5 & 215,2 & 222,7 & 230,0 & 237,2 & 188,2 \\
\hline $\mathrm{PF}_{3}$ & ${ }^{1} J_{\mathrm{PF}}$ & $-1812,7$ & $-1787,4$ & $-1757,6$ & $-1724,0$ & $-1687,4$ & $-1648,2$ & $-1607,1$ & $-1564,6$ & $-1521,0$ & $-1476,7$ & $-1432,0$ & -1441 \\
\hline $\mathrm{BHF}_{2}$ & ${ }^{1} J_{\mathrm{BF}}$ & $-168,0$ & $-150,4$ & $-132,9$ & $-115,6$ & $-98,4$ & $-81,4$ & $-64,6$ & $-47,9$ & $-31,5$ & $-15,3$ & 0,7 & -84 \\
\hline $\mathrm{BF}_{3}$ & ${ }^{1} J_{\mathrm{BF}}$ & $-69,5$ & $-50,4$ & $-31,4$ & $-12,7$ & 5,7 & 24,0 & 42,1 & 60,0 & 77,8 & 95,3 & 112,7 & 15 \\
\hline $\mathrm{F}_{2} \mathrm{O}$ & ${ }^{1} J_{\mathrm{OF}}$ & $-280,3$ & $-317,2$ & $-354,2$ & $-392,9$ & $-435,5$ & $-485,2$ & $-547,9$ & $-635,3$ & $-775,4$ & $-1061,6$ & $-2173,7$ & -300 \\
\hline $\mathrm{CH}_{4}$ & ${ }^{1} J_{\mathrm{CH}}$ & 131,8 & 133,3 & 134,9 & 136,5 & 138,1 & 139,7 & 141,4 & 143,0 & 144,7 & 146,4 & 148,2 & 125,3 \\
\hline $\mathrm{CH}_{4}$ & ${ }^{2} J_{\mathrm{HH}}$ & $-11,8$ & $-12,6$ & $-13,4$ & $-14,2$ & $-15,0$ & $-15,7$ & $-16,5$ & $-17,3$ & $-18,0$ & $-18,7$ & $-19,5$ & $-12,8$ \\
\hline $\mathrm{C}_{2} \mathrm{H}_{2}$ & ${ }^{1} J_{\mathrm{CC}}$ & 199,6 & 202,6 & 206,0 & 210,0 & 214,5 & 219,9 & 226,1 & 233,6 & 242,6 & 253,6 & 267,3 & 174,8 \\
\hline $\mathrm{C}_{2} \mathrm{H}_{2}$ & ${ }^{1} J_{\mathrm{CH}}$ & 272,4 & 274,9 & 277,4 & 280,1 & 283,0 & 286,2 & 289,8 & 293,8 & 298,5 & 304,0 & 310,7 & 247,6 \\
\hline $\mathrm{C}_{2} \mathrm{H}_{2}$ & ${ }^{2} J_{\mathrm{CH}}$ & 57,0 & 56,9 & 56,6 & 56,1 & 55,2 & 54,0 & 52,3 & 50,1 & 47,2 & 43,4 & 38,4 & 50,1 \\
\hline $\mathrm{C}_{2} \mathrm{H}_{2}$ & ${ }^{3} J_{\mathrm{HH}}$ & 10,1 & 10,7 & 11,4 & 12,3 & 13,3 & 14,5 & 15,9 & 17,7 & 19,8 & 22,4 & 25,6 & 9,6 \\
\hline $\mathrm{C}_{2} \mathrm{H}_{4}$ & ${ }^{1} J_{\mathrm{CC}}$ & 66,9 & 69,8 & 73,1 & 76,7 & 80,8 & 85,6 & 91,3 & 98,4 & 107,5 & 119,9 & 138,1 & 67,6 \\
\hline $\mathrm{C}_{2} \mathrm{H}_{4}$ & ${ }^{1} J_{\mathrm{CH}}$ & 166,3 & 168,5 & 170,8 & 173,3 & 175,9 & 178,8 & 182,0 & 185,7 & 190,2 & 196,0 & 204,0 & 156,3 \\
\hline $\mathrm{C}_{2} \mathrm{H}_{4}$ & ${ }^{2} J_{\mathrm{CH}}$ & 0,2 & $-0,6$ & $-1,6$ & $-2,8$ & $-4,1$ & $-5,7$ & $-7,7$ & $-10,2$ & $-13,5$ & $-18,1$ & $-25,0$ & $-2,4$ \\
\hline $\mathrm{C}_{2} \mathrm{H}_{4}$ & ${ }^{2} J_{\mathrm{HH}}$ & 6,1 & 5,4 & 4,6 & 3,7 & 2,7 & 1,7 & 0,4 & $-1,0$ & $-2,9$ & $-5,5$ & $-9,2$ & 2,3 \\
\hline $\mathrm{C}_{2} \mathrm{H}_{4}$ & ${ }^{3} J_{\mathrm{HH}_{\mathrm{c}}}$ & 12,5 & 12,8 & 13,1 & 13,5 & 13,9 & 14,6 & 15,4 & 16,4 & 17,9 & 20,0 & 23,3 & 11,7 \\
\hline $\mathrm{C}_{2} \mathrm{H}_{4}$ & ${ }^{3} J_{\mathrm{HH}_{\mathrm{t}}}$ & 19,9 & 20,2 & 20,5 & 21,0 & 21,5 & 22,3 & 23,2 & 24,5 & 26,2 & 28,7 & 32,4 & 19 \\
\hline $\mathrm{C}_{2} \mathrm{H}_{6}$ & ${ }^{1} J_{\mathrm{CC}}$ & 29,4 & 31,5 & 33,7 & 35,9 & 38,1 & 40,4 & 42,7 & 45,1 & 47,5 & 49,9 & 52,4 & 34,5 \\
\hline $\mathrm{C}_{2} \mathrm{H}_{6}$ & ${ }^{1} J_{\mathrm{CH}}$ & 131,3 & 133,1 & 134,8 & 136,6 & 138,4 & 140,3 & 142,1 & 144,0 & 145,9 & 147,8 & 149,7 & 125,2 \\
\hline $\mathrm{C}_{2} \mathrm{H}_{6}$ & ${ }^{2} J_{\mathrm{CH}}$ & $-2,5$ & $-3,0$ & $-3,5$ & $-4,0$ & $-4,5$ & $-5,0$ & $-5,5$ & $-6,1$ & $-6,6$ & $-7,2$ & $-7,7$ & $-4,7$ \\
\hline \multirow[t]{3}{*}{ Total } & DM & $-21,18$ & $-18,60$ & $-15,84$ & $-12,97$ & $-10,11$ & $-7,33$ & $-4,95$ & $-3,34$ & $-3,56$ & $-9,15$ & $-46,10$ & - \\
\hline & DMA & 31,02 & 27,37 & 25,25 & 23,40 & 22,34 & 24,76 & 29,72 & 35,77 & 44,28 & 58,83 & 106,59 & - \\
\hline & PDMA & 47,32 & 37,13 & 28,16 & 22,18 & 20,18 & 27,05 & 43,16 & 61,03 & 82,52 & 110,01 & 155,13 & - \\
\hline \multirow[t]{3}{*}{ CPI } & DM & $-57,80$ & $-53,00$ & $-47,83$ & $-42,52$ & $-37,32$ & $-32,56$ & $-28,86$ & $-27,32$ & $-30,50$ & $-46,95$ & $-138,48$ & - \\
\hline & DMA & 64,53 & 55,11 & 49,03 & 43,12 & 38,66 & 42,00 & 50,95 & 62,05 & 77,79 & 106,72 & 212,34 & - \\
\hline & PDMA & 74,09 & 56,15 & 41,09 & 29,78 & 21,28 & 26,06 & 45,54 & 65,77 & 87,57 & 113,54 & 164,80 & - \\
\hline \multirow[t]{3}{*}{ SPI } & DM & 5,67 & 6,63 & 7,62 & 8,71 & 9,85 & 11,17 & 12,59 & 14,24 & 16,19 & 18,57 & 21,64 & - \\
\hline & DMA & 6,45 & 7,03 & 7,81 & 8,95 & 10,37 & 12,11 & 14,15 & 16,51 & 19,70 & 23,71 & 29,04 & - \\
\hline & PDMA & 27,68 & 23,18 & 18,67 & 16,61 & 19,37 & 27,78 & 41,41 & 57,56 & 78,82 & 107,43 & 148,03 & - \\
\hline \multirow[t]{3}{*}{$\Delta \mathrm{CS}$} & $\mathrm{DM}$ & $-63,47$ & $-59,63$ & $-55,45$ & $-51,22$ & $-47,16$ & $-43,73$ & $-41,45$ & $-41,56$ & $-46,69$ & $-65,52$ & $-160,12$ & - \\
\hline & DMA & 58,08 & 48,08 & 41,22 & 34,17 & 28,30 & 29,89 & 36,81 & 45,54 & 58,09 & 83,00 & 183,30 & - \\
\hline & PDMA & 46,41 & 32,98 & 22,42 & 13,17 & 1,90 & $-1,72$ & 4,13 & 8,20 & 8,75 & 6,11 & 16,77 & - \\
\hline
\end{tabular}

Tabela 8.23: Valores de PDMA total obtidos para a variação da porcentagem de $E_{X}^{\mathrm{HF}}$ nos funcionais com base HuzIII-su3.

\begin{tabular}{|c|c|c|c|c|c|c|c|c|c|c|c|}
\hline$E_{X}^{\mathrm{HF}}(\%)$ & $0 \%$ & $10 \%$ & $20 \%$ & $30 \%$ & $40 \%$ & $50 \%$ & $60 \%$ & $70 \%$ & $80 \%$ & $90 \%$ & $100 \%$ \\
\hline B1B95 & 53,5 & 42,0 & 31,9 & 23,0 & 15,8 & 13,9 & 22,7 & 36,8 & 52,2 & 70,3 & 92,6 \\
\hline B3LYP, BHandHLYP & 47,7 & 37,6 & 29,9 & 24,6 & 22,9 & 28,7 & 44,7 & 62,9 & 84,9 & 114,2 & 161,5 \\
\hline B3P 86 & 50,3 & 39,5 & 30,0 & 26,8 & 26,6 & 28,6 & 37,1 & 57,1 & 80,2 & 112,9 & 169,3 \\
\hline B971 & 57,6 & 47,9 & 38,1 & 27,3 & 17,4 & 13,6 & 20,8 & 36,1 & 55,9 & 81,9 & 119,3 \\
\hline B972 & 61,5 & 50,9 & 40,1 & 28,9 & 18,4 & 18,7 & 24,6 & 37,0 & 55,8 & 81,6 & 120,0 \\
\hline B98 & 59,6 & 49,2 & 39,2 & 28,4 & 18,4 & 11,1 & 20,2 & 37,0 & 58,4 & 87,2 & 131,6 \\
\hline $\mathrm{BHandH}$ & 60,2 & 48,3 & 37,0 & 25,3 & 15,8 & 14,7 & 27,2 & 46,8 & 70,9 & 104,0 & 161,5 \\
\hline BMK & 71,3 & 62,5 & 52,5 & 41,2 & 28,8 & 25,4 & 27,1 & 41,8 & 66,1 & 100,8 & 150,6 \\
\hline BP86 & 50,8 & 40,1 & 30,3 & 25,6 & 24,9 & 26,3 & 34,8 & 53,8 & 75,6 & 106,2 & 156,7 \\
\hline B3PW91 & 48,4 & 37,9 & 30,1 & 29,2 & 30,0 & 32,3 & 42,7 & 63,6 & 89,7 & 127,3 & 197,9 \\
\hline M05, M05-2X & 63,4 & 67,1 & 71,3 & 76,6 & 84,9 & 94,2 & 104,9 & 116,1 & 128,2 & 141,3 & 155,4 \\
\hline M06, M06-HF & 33,0 & 26,0 & 21,2 & 21,4 & 26,2 & 37,3 & 54,8 & 78,2 & 112,5 & 180,4 & 290,3 \\
\hline M06-2X & 33,0 & 26,0 & 21,2 & 21,4 & 26,2 & 37,3 & 54,8 & 78,2 & 112,5 & 180,4 & 290,3 \\
\hline O3LYP & 53,3 & 41,1 & 28,6 & 18,7 & 14,5 & 18,0 & 34,4 & 53,4 & 76,9 & 107,9 & 161,5 \\
\hline PBE, PBE0 & 47,1 & 35,5 & 27,0 & 25,6 & 26,5 & 29,3 & 41,7 & 62,4 & 87,7 & 125,0 & 196,2 \\
\hline PW91 & 48,9 & 37,8 & 28,9 & 27,4 & 28,1 & 30,8 & 41,6 & 63,0 & 88,4 & 126,1 & 197,9 \\
\hline TPSSh & 52,5 & 41,3 & 34,2 & 31,7 & 30,4 & 33,0 & 49,1 & 70,7 & 97,5 & 133,9 & 197,2 \\
\hline X3LYP & 47,8 & 37,5 & 29,9 & 24,6 & 22,9 & 28,6 & 44,6 & 62,9 & 84,8 & 114,0 & 161,5 \\
\hline
\end{tabular}




\subsubsection{Geometrias Otimizadas}

Tabela 8.24: Constantes de acoplamento B971 com otimização de geometrias com base aug-pcJ-2.

\begin{tabular}{|c|c|c|c|c|c|c|c|c|c|c|c|c|c|}
\hline & $\% E_{X}^{\mathrm{HF}}$ & 21,00 & 21,00 & 40,00 & 40,00 & $\begin{array}{c}21,00 / \\
40,00\end{array}$ & 50,00 & 50,00 & $\begin{array}{c}21,00 / \\
50,00\end{array}$ & 60,00 & 60,00 & $\begin{array}{c}21,00 / \\
60,00\end{array}$ & - \\
\hline & Geom. & Exp. & Otm. & Exp. & Otm. & Otm. & Exp. & Otm. & Otm. & Exp. & Otm. & Otm. & Exp. \\
\hline $\mathrm{HF}$ & ${ }^{1} J_{\mathrm{HF}}$ & 449,1 & 441,3 & 499,7 & 438,6 & 492,5 & 520,6 & 485,9 & 513,5 & 542,8 & 533,4 & 535,7 & 500,0 \\
\hline $\mathrm{CO}$ & ${ }^{1} J_{\mathrm{CO}}$ & 17,4 & 16,9 & 10,7 & 14,6 & 10,2 & 9,0 & 10,4 & 8,6 & 7,3 & 6,2 & 6,8 & 16,4 \\
\hline $\mathrm{H}_{2} \mathrm{O}$ & ${ }^{1} J_{\mathrm{OH}}$ & $-74,4$ & $-74,2$ & $-77,0$ & $-70,0$ & $-76,8$ & $-79,7$ & $-76,0$ & $-79,5$ & $-82,5$ & $-81,9$ & $-82,4$ & $-80,6$ \\
\hline $\mathrm{H}_{2} \mathrm{O}$ & ${ }^{2} J_{\mathrm{HH}}$ & $-6,5$ & $-6,2$ & $-5,1$ & $-5,1$ & $-4,8$ & $-6,4$ & $-6,1$ & $-6,1$ & $-7,7$ & $-7,1$ & $-7,4$ & $-7,3$ \\
\hline $\mathrm{NH}_{3}$ & ${ }^{1} J_{\mathrm{NH}}$ & 43,3 & 43,4 & 41,9 & 40,0 & 42,0 & 43,1 & 42,4 & 43,2 & 44,4 & 44,8 & 44,6 & 43,8 \\
\hline $\mathrm{NH}_{3}$ & ${ }^{2} J_{\mathrm{HH}}$ & $-9,1$ & $-9,0$ & $-7,4$ & $-7,4$ & $-7,2$ & $-8,6$ & $-8,3$ & $-8,4$ & $-9,9$ & $-9,3$ & $-9,7$ & $-9,6$ \\
\hline $\mathrm{PH}_{3}$ & ${ }^{1} J_{\mathrm{PH}}$ & 190,7 & 196,4 & 188,9 & 182,7 & 194,0 & 196,6 & 195,7 & 201,5 & 204,6 & 208,5 & 209,3 & 188,2 \\
\hline $\mathrm{PF}_{3}$ & ${ }^{1} J_{\mathrm{PF}}$ & $-1656,7$ & $-1547,7$ & $-1562,1$ & $-1459,7$ & $-1478,1$ & $-1539,1$ & $-1449,7$ & $-1459,4$ & $-1513,4$ & $-1429,0$ & $-1438,0$ & $-1441,0$ \\
\hline $\mathrm{BHF}_{2}$ & ${ }^{1} J_{\mathrm{BF}}$ & $-123,8$ & $-129,8$ & $-85,1$ & $-118,1$ & $-91,1$ & $-69,6$ & $-88,3$ & $-75,5$ & $-54,0$ & $-59,4$ & $-59,8$ & $-84,0$ \\
\hline $\mathrm{BF}_{3}$ & ${ }^{1} J_{\mathrm{BF}}$ & $-27,9$ & $-39,4$ & 12,4 & $-28,7$ & 1,5 & 29,7 & 5,7 & 19,0 & 47,1 & 39,2 & 36,7 & 15,0 \\
\hline $\mathrm{F}_{2} \mathrm{O}$ & ${ }^{1} J_{\mathrm{OF}}$ & $-318,8$ & $-257,2$ & $-327,7$ & $-318,6$ & $-262,4$ & $-370,4$ & $-281,7$ & $-298,6$ & $-421,2$ & $-245,8$ & $-340,0$ & $-300,0$ \\
\hline $\mathrm{CH}_{4}$ & ${ }^{1} J_{\mathrm{CH}}$ & 128,8 & 129,3 & 116,5 & 121,4 & 116,9 & 120,6 & 124,4 & 121,1 & 125,0 & 127,5 & 125,4 & 125,3 \\
\hline $\mathrm{CH}_{4}$ & ${ }^{2} J_{\mathrm{HH}}$ & $-12,0$ & $-12,0$ & $-9,6$ & $-9,3$ & $-9,5$ & $-10,7$ & $-10,5$ & $-10,6$ & $-11,8$ & $-11,7$ & $-11,8$ & $-12,8$ \\
\hline $\mathrm{C}_{2} \mathrm{H}_{2}$ & ${ }^{1} J_{\mathrm{CC}}$ & 213,8 & 213,8 & 205,0 & 207,4 & 205,1 & 211,6 & 213,6 & 211,5 & 219,4 & 220,2 & 219,1 & 174,8 \\
\hline $\mathrm{C}_{2} \mathrm{H}_{2}$ & ${ }^{1} J_{\mathrm{CH}}$ & 261,3 & 260,2 & 229,5 & 239,0 & 228,6 & 237,9 & 243,9 & 236,9 & 247,0 & 249,0 & 245,9 & 247,6 \\
\hline $\mathrm{C}_{2} \mathrm{H}_{2}$ & ${ }^{2} J_{\mathrm{CH}}$ & 53,2 & 53,3 & 53,2 & 53,3 & 53,2 & 53,0 & 53,1 & 53,1 & 52,5 & 52,6 & 52,6 & 50,1 \\
\hline $\mathrm{C}_{2} \mathrm{H}_{2}$ & ${ }^{3} J_{\mathrm{HH}}$ & 10,5 & 10,3 & 8,4 & 9,1 & 8,2 & 9,3 & 9,7 & 9,1 & 10,5 & 10,5 & 10,3 & 9,6 \\
\hline $\mathrm{C}_{2} \mathrm{H}_{4}$ & ${ }^{1} J_{\mathrm{CC}}$ & 78,1 & 80,5 & 76,4 & 78,7 & 78,8 & 80,8 & 83,5 & 83,1 & 86,2 & 88,6 & 88,1 & 67,6 \\
\hline $\mathrm{C}_{2} \mathrm{H}_{4}$ & ${ }^{1} J_{\mathrm{CH}}$ & 162,8 & 160,7 & 145,4 & 149,6 & 143,6 & 151,2 & 153,5 & 149,2 & 157,4 & 157,6 & 155,2 & 156,3 \\
\hline $\mathrm{C}_{2} \mathrm{H}_{4}$ & ${ }^{2} J_{\mathrm{CH}}$ & $-2,1$ & $-1,8$ & $-0,8$ & $-0,4$ & $-0,6$ & $-2,1$ & $-1,9$ & $-1,8$ & $-3,7$ & $-3,5$ & $-3,3$ & $-2,4$ \\
\hline $\mathrm{C}_{2} \mathrm{H}_{4}$ & ${ }^{2} J_{\mathrm{HH}}$ & 3,6 & 2,4 & 4,1 & 4,3 & 3,0 & 3,4 & 3,3 & 2,3 & 2,5 & 2,1 & 1,4 & 2,3 \\
\hline $\mathrm{C}_{2} \mathrm{H}_{4}$ & ${ }^{3} J_{\mathrm{HH}_{\mathrm{c}}}$ & 11,7 & 12,2 & 10,5 & 10,3 & 11,0 & 11,0 & 11,1 & 11,5 & 11,6 & 12,0 & 12,1 & 11,7 \\
\hline $\mathrm{C}_{2} \mathrm{H}_{4}$ & ${ }^{3} J_{\mathrm{HH}_{\mathrm{t}}}$ & 18,4 & 19,0 & 15,6 & 16,6 & 16,1 & 16,4 & 17,3 & 16,9 & 17,4 & 18,2 & 17,9 & 19,0 \\
\hline $\mathrm{C}_{2} \mathrm{H}_{6}$ & ${ }^{1} J_{\mathrm{CC}}$ & 34,9 & 36,5 & 35,1 & 36,3 & 36,7 & 37,8 & 39,4 & 39,5 & 40,8 & 42,5 & 42,4 & 34,5 \\
\hline $\mathrm{C}_{2} \mathrm{H}_{6}$ & ${ }^{1} J_{\mathrm{CH}}$ & 129,1 & 128,5 & 116,5 & 120,7 & 115,9 & 120,9 & 123,9 & 120,3 & 125,5 & 127,0 & 125,0 & 125,2 \\
\hline $\mathrm{C}_{2} \mathrm{H}_{6}$ & ${ }^{2} J_{\mathrm{CH}}$ & $-3,6$ & $-3,5$ & $-2,8$ & $-2,6$ & $-2,8$ & $-3,5$ & $-3,4$ & $-3,4$ & $-4,2$ & $-4,1$ & $-4,1$ & $-4,7$ \\
\hline \multirow[t]{3}{*}{ Total } & DM & $-10,51$ & $-4,66$ & $-5,88$ & $-5,47$ & $-0,81$ & $-3,16$ & 1,77 & 2,00 & $-0,44$ & 9,35 & 4,88 & - \\
\hline & DMA & 17,89 & 15,80 & 10,48 & 11,11 & 9,01 & 12,53 & 5,98 & 6,35 & 15,65 & 10,40 & 9,31 & - \\
\hline & PDMA & 21,89 & 24,16 & 17,34 & 29,76 & 19,53 & 16,15 & 13,54 & 11,38 & 21,45 & 18,49 & 18,05 & - \\
\hline \multirow[t]{3}{*}{ CPI } & DM & $-32,51$ & $-18,76$ & $-13,79$ & $-15,69$ & $-1,92$ & $-10,52$ & $-0,99$ & 1,58 & $-7,58$ & 14,43 & 4,99 & - \\
\hline & DMA & 34,51 & 29,60 & 15,37 & 18,42 & 11,39 & 21,59 & 6,97 & 6,45 & 29,75 & 16,52 & 14,37 & - \\
\hline & PDMA & 36,11 & 44,38 & 12,12 & 40,04 & 20,37 & 20,42 & 14,19 & 11,59 & 34,57 & 27,18 & 24,58 & - \\
\hline \multirow[t]{3}{*}{ SPI } & $\mathrm{DM}$ & 5,63 & 5,69 & $-0,07$ & 2,02 & 0,01 & 2,23 & 3,79 & 2,31 & 4,80 & 5,63 & 4,81 & - \\
\hline & DMA & 5,71 & 5,69 & 6,90 & 5,75 & 7,26 & 5,89 & 5,25 & 6,27 & 5,32 & 5,91 & 5,59 & - \\
\hline & PDMA & 11,47 & 9,33 & 21,17 & 22,22 & 18,92 & 13,02 & 13,07 & 11,22 & 11,83 & 12,12 & 13,26 & - \\
\hline \multirow[t]{3}{*}{$\Delta \mathrm{CS}$} & DM & $-38,14$ & $-24,45$ & $-13,72$ & $-17,71$ & $-1,92$ & $-12,75$ & $-4,78$ & $-0,72$ & $-12,38$ & 8,80 & 0,18 & - \\
\hline & DMA & 28,80 & 23,91 & 8,47 & 12,66 & 4,13 & 15,70 & 1,72 & 0,19 & 24,43 & 10,61 & 8,78 & - \\
\hline & PDMA & 24,64 & 35,05 & $-9,04$ & 17,83 & 1,44 & 7,39 & 1,12 & 0,37 & 22,74 & 15,05 & 11,32 & - \\
\hline
\end{tabular}


Tabela 8.25: Constantes de acoplamento B972 com otimização de geometrias com base aug-pcJ-2.

\begin{tabular}{|c|c|c|c|c|c|c|c|c|c|c|c|c|c|c|c|c|}
\hline & $\% E_{X}^{\mathrm{HF}}$ & 21,00 & 21,00 & 30,00 & 30,00 & $\begin{array}{l}21,00 \\
30,00 \\
\text { Otm. }\end{array}$ & 40,00 & 40,00 & $\begin{array}{l}21,00 \\
40,00 \\
\text { Otm. }\end{array}$ & 50,00 & 50,00 & $\begin{array}{l}21,00 \\
50,00 \\
\text { Otm. }\end{array}$ & 60,00 & 60,00 & $\begin{array}{l}21,00 \\
60,00 \\
\text { Otm. }\end{array}$ & Exp. \\
\hline $\mathrm{HF}$ & ${ }^{1} J_{\mathrm{HF}}$ & 442,8 & 447,0 & 487,2 & 401,9 & 491,1 & 512,0 & 452,6 & 515,9 & 538,2 & 503,7 & 542,0 & 565,8 & 555,5 & 569,7 & 500,0 \\
\hline $\mathrm{CO}$ & ${ }^{1} J_{\mathrm{CO}}$ & 18,3 & 17,1 & 11,5 & 17,6 & 10,2 & 9,2 & 12,9 & 8,0 & 6,8 & 8,0 & 5,6 & 4,2 & 3,0 & 3,0 & 16,4 \\
\hline $\mathrm{H}_{2} \mathrm{O}$ & ${ }^{1} J_{\mathrm{OH}}$ & $-73,5$ & $-74,4$ & $-75,6$ & $-65,7$ & $-76,4$ & $-78,9$ & $-72,4$ & $-79,7$ & $-82,3$ & $-79,0$ & $-83,2$ & $-86,0$ & $-85,6$ & $-86,9$ & $-80,6$ \\
\hline $\mathrm{H}_{2} \mathrm{O}$ & ${ }^{2} J_{\mathrm{HH}}$ & $-7,5$ & $-7,2$ & $-4,3$ & $-4,7$ & $-4,1$ & $-5,5$ & $-5,5$ & $-5,3$ & $-6,7$ & $-6,4$ & $-6,5$ & $-8,0$ & $-7,4$ & $-7,8$ & $-7,3$ \\
\hline $\mathrm{NH}_{3}$ & ${ }^{1} J_{\mathrm{NH}}$ & 41,7 & 42,0 & 40,3 & 37,6 & 40,6 & 41,8 & 40,3 & 42,1 & 43,4 & 43,0 & 43,7 & 45,1 & 45,7 & 45,4 & 43,8 \\
\hline $\mathrm{NH}_{3}$ & ${ }^{2} J_{\mathrm{HH}}$ & $-9,1$ & $-9,0$ & $-6,0$ & $-6,3$ & $-6,0$ & $-7,1$ & $-7,1$ & $-7,0$ & $-8,2$ & $-7,9$ & $-8,1$ & $-9,4$ & $-8,9$ & $-9,3$ & $-9,6$ \\
\hline $\mathrm{PH}_{3}$ & ${ }^{1} J_{\mathrm{PH}}$ & 184,0 & 191,6 & 175,0 & 158,0 & 182,2 & 183,4 & 173,7 & 190,5 & 192,2 & 189,1 & 199,2 & 201,4 & 204,8 & 208,4 & 188,2 \\
\hline $\mathrm{PF}_{3}$ & ${ }^{1} J_{\mathrm{PF}}$ & $-1661,2$ & $-1562,9$ & $-1595,3$ & $-1477,0$ & $-1516,3$ & $-1576,6$ & $-1482,9$ & $-1501,6$ & $-1555,0$ & $-1472,3$ & $-1484,0$ & $-1531,2$ & $-1451,5$ & $-1464,1$ & $-1441,0$ \\
\hline $\mathrm{BHF}_{2}$ & ${ }^{1} J_{\mathrm{BF}}$ & $-129,9$ & $-132,8$ & $-100,3$ & $-146,5$ & $-103,3$ & $-82,9$ & $-115,3$ & $-85,8$ & $-65,4$ & $-84,7$ & $-68,3$ & $-48,0$ & $-55,3$ & $-50,8$ & $-84,0$ \\
\hline $\mathrm{BF}_{3}$ & ${ }^{1} J_{\mathrm{BF}}$ & $-36,6$ & $-43,3$ & $-5,4$ & $-63,3$ & $-12,0$ & 14,1 & $-26,3$ & 7,7 & 33,8 & 9,3 & 27,6 & 53,5 & 43,6 & 47,4 & 15,0 \\
\hline $\mathrm{F}_{2} \mathrm{O}$ & ${ }^{1} J_{\mathrm{OF}}$ & $-316,0$ & $-219,7$ & $-283,7$ & $-341,6$ & $-189,4$ & $-320,6$ & $-310,4$ & $-218,4$ & $-362,5$ & $-278,7$ & $-250,3$ & $-412,9$ & $-247,5$ & $-286,6$ & $-300,0$ \\
\hline $\mathrm{CH}_{4}$ & ${ }^{1} J_{\mathrm{CH}}$ & 118,8 & 118,8 & 107,2 & 112,8 & 107,2 & 111,9 & 116,6 & 111,9 & 116,9 & 120,6 & 116,9 & 122,2 & 124,6 & 122,2 & 125,3 \\
\hline $\mathrm{CH}_{4}$ & ${ }^{2} J_{\mathrm{HH}}$ & $-11,3$ & $-11,3$ & $-7,8$ & $-7,4$ & $-7,8$ & $-8,7$ & $-8,4$ & $-8,7$ & $-9,7$ & $-9,5$ & $-9,7$ & $-10,7$ & $-10,6$ & $-10,7$ & $-12,8$ \\
\hline $\mathrm{C}_{2} \mathrm{H}_{2}$ & ${ }^{1} J_{\mathrm{CC}}$ & 197,5 & 197,6 & 188,8 & 189,7 & 189,1 & 195,6 & 197,1 & 195,7 & 203,4 & 204,9 & 203,2 & 212,5 & 213,3 & 212,0 & 174,8 \\
\hline $\mathrm{C}_{2} \mathrm{H}_{2}$ & ${ }^{1} J_{\mathrm{CH}}$ & 247,3 & 245,2 & 213,7 & 226,1 & 211,9 & 222,6 & 231,8 & 220,7 & 232,0 & 237,7 & 230,0 & 242,2 & 243,9 & 240,0 & 247,6 \\
\hline $\mathrm{C}_{2} \mathrm{H}_{2}$ & ${ }^{2} J_{\mathrm{CH}}$ & 50,7 & 50,8 & 51,4 & 51,7 & 51,5 & 51,8 & 51,9 & 51,9 & 51,9 & 51,9 & 52,0 & 51,5 & 51,7 & 51,7 & 50,1 \\
\hline $\mathrm{C}_{2} \mathrm{H}_{2}$ & ${ }^{3} J_{\mathrm{HH}}$ & 10,4 & 10,1 & 7,4 & 8,4 & 7,2 & 8,1 & 8,7 & 7,8 & 8,9 & 9,2 & 8,6 & 9,9 & 9,8 & 9,6 & 9,6 \\
\hline $\mathrm{C}_{2} \mathrm{H}_{4}$ & ${ }^{1} J_{\mathrm{CC}}$ & 68,1 & 70,6 & 66,0 & 67,6 & 68,7 & 70,8 & 73,1 & 73,3 & 76,3 & 78,9 & 78,5 & 82,9 & 85,2 & 84,7 & 67,6 \\
\hline $\mathrm{C}_{2} \mathrm{H}_{4}$ & ${ }^{1} J_{\mathrm{CH}}$ & 152,3 & 149,4 & 134,1 & 139,5 & 131,7 & 140,3 & 144,2 & 137,7 & 146,9 & 149,1 & 144,1 & 154,1 & 154,1 & 151,1 & 156,3 \\
\hline $\mathrm{C}_{2} \mathrm{H}_{4}$ & ${ }^{2} J_{\mathrm{CH}}$ & $-2,0$ & $-1,6$ & 0,5 & 1,0 & 0,7 & $-0,4$ & $-0,1$ & $-0,2$ & $-1,7$ & $-1,4$ & $-1,4$ & $-3,2$ & $-3,0$ & $-2,8$ & $-2,4$ \\
\hline $\mathrm{C}_{2} \mathrm{H}_{4}$ & ${ }^{2} J_{\mathrm{HH}}$ & 3,1 & 1,9 & 4,7 & 5,2 & 3,6 & 4,2 & 4,4 & 3,1 & 3,7 & 3,5 & 2,5 & 3,0 & 2,5 & 1,9 & 2,3 \\
\hline $\mathrm{C}_{2} \mathrm{H}_{4}$ & ${ }^{3} J_{\mathrm{HH}_{\mathrm{c}}}$ & 11,2 & 11,8 & 9,7 & 9,2 & 10,3 & 10,1 & 9,9 & 10,7 & 10,6 & 10,6 & 11,1 & 11,1 & 11,5 & 11,7 & 11,7 \\
\hline $\mathrm{C}_{2} \mathrm{H}_{4}$ & ${ }^{3} J_{\mathrm{HH}_{\mathrm{t}}}$ & 17,7 & 18,3 & 14,4 & 15,5 & 14,9 & 15,1 & 16,1 & 15,6 & 15,9 & 16,8 & 16,4 & 16,8 & 17,5 & 17,3 & 19,0 \\
\hline $\mathrm{C}_{2} \mathrm{H}_{6}$ & ${ }^{1} J_{\mathrm{CC}}{ }^{\mathrm{t}}$ & 30,6 & 32,4 & 30,2 & 31,6 & 32,1 & 33,3 & 35,0 & 35,2 & 36,6 & 38,4 & 38,5 & 40,1 & 41,9 & 42,0 & 34,5 \\
\hline $\mathrm{C}_{2} \mathrm{H}_{6}$ & ${ }^{1} J_{\mathrm{CH}}$ & 118,9 & 117,3 & 106,4 & 111,4 & 105,1 & 111,4 & 115,3 & 110,0 & 116,6 & 119,3 & 115,2 & 122,1 & 123,4 & 120,6 & 125,2 \\
\hline $\mathrm{C}_{2} \mathrm{H}_{6}$ & ${ }^{2} J_{\mathrm{CH}}$ & $-3,2$ & $-3,2$ & $-1,9$ & $-1,6$ & $-1,8$ & $-2,4$ & $-2,2$ & $-2,4$ & $-3,0$ & $-2,8$ & $-2,9$ & $-3,6$ & $-3,5$ & $-3,6$ & $-4,7$ \\
\hline \multirow[t]{3}{*}{ Total } & DM & - & - & & -14 & $-4,00$ & $-7,4$ & & $-0,6$ & & & & & & & - \\
\hline & DMA & 1 & & & & 15 , & 11,6 & & 1 & & & ,29 & & & 11,68 & - \\
\hline & PDMA & 23,84 & 25,54 & 29,79 & 47,97 & 31,03 & 18,93 & 30,62 & 20,06 & 19,95 & 14,83 & 17,38 & 25,17 & 20,37 & 21,40 & - \\
\hline \multirow[t]{3}{*}{ CPI } & $\mathrm{M}$ & & & & & & & & & & & & & & & - \\
\hline & DMA & & & & & & & & & & & & & & & - \\
\hline & PDMA & 42,37 & 47,10 & 27,62 & 68,94 & 34,70 & 11,80 & 38,76 & 17,94 & 24,58 & 12,22 & 21,13 & 41,76 & 33,08 & 35,40 & - \\
\hline \multirow[t]{3}{*}{ SPI } & DM & & & & -2 , & & & & & & & & & & & - \\
\hline & DMA & & & & & & & & & & & & & & 5,97 & - \\
\hline & PDMA & 10,24 & 9,73 & 31,39 & 32,58 & 28,35 & 24,15 & 24,64 & 21,61 & 16,55 & 16,74 & 14,63 & 13,01 & 11,05 & 11,12 & - \\
\hline \multirow[t]{3}{*}{$\Delta \mathrm{CS}$} & & & & & & & & & & & & & & & & - \\
\hline & DMA & 33,55 & 30,25 & 13,95 & 27,02 & 15,12 & 9,80 & 12,52 & 8,91 & 18,19 & 1,27 & 10,34 & 28,78 & & 13,49 & - \\
\hline & PDMA & 32,13 & 37,37 & $-3,77$ & 36,36 & 6,35 & $-12,35$ & 14,12 & $-3,68$ & 8,03 & $-4,52$ & 6,49 & 28,74 & 22,03 & 24,28 & - \\
\hline
\end{tabular}


Tabela 8.26: Constantes de acoplamento B98 com otimização de geometrias com base aug-pcJ-2.

\begin{tabular}{|c|c|c|c|c|c|c|c|c|c|c|c|c|c|}
\hline & $\% E_{X}^{\mathrm{HF}}$ & 21,98 & 21,98 & 40,00 & 40,00 & $\begin{array}{l}21,98 \\
/ \\
40,00 \\
\text { Otm. }\end{array}$ & 50,00 & 50,00 & $\begin{array}{l}21,98 \\
50,00 \\
\text { Otm. }\end{array}$ & 60,00 & 60,00 & $\begin{array}{l}21,98 \\
60,00 \\
\text { Otm. }\end{array}$ & Exp. \\
\hline $\mathrm{HF}$ & ${ }^{1} J_{\mathrm{HF}}$ & 431,2 & 425,7 & 484,6 & 417,7 & 479,5 & 505,9 & 465,8 & 500,8 & 528,5 & 514,5 & 523,5 & 500,0 \\
\hline $\mathrm{CO}$ & ${ }^{1} J_{\mathrm{CO}}$ & 18,5 & 17,6 & 11,2 & 15,5 & 10,4 & 9,5 & 11,2 & 8,7 & 7,7 & 6,9 & 6,8 & 16,4 \\
\hline $\mathrm{H}_{2} \mathrm{O}$ & ${ }^{1} J_{\mathrm{OH}}$ & $-72,5$ & $-72,6$ & $-75,6$ & $-67,9$ & $-75,7$ & $-78,4$ & $-74,2$ & $-78,5$ & $-81,4$ & $-80,4$ & $-81,5$ & $-80,6$ \\
\hline $\mathrm{H}_{2} \mathrm{O}$ & ${ }^{2} J_{\mathrm{HH}}$ & $-6,9$ & $-6,5$ & $-5,1$ & $-5,1$ & $-4,7$ & $-6,4$ & $-6,1$ & $-6,1$ & $-7,9$ & $-7,2$ & $-7,5$ & $-7,3$ \\
\hline $\mathrm{NH}_{3}$ & ${ }^{1} J_{\mathrm{NH}}$ & 42,9 & 43,1 & 41,7 & 39,6 & 41,9 & 43,1 & 42,3 & 43,3 & 44,6 & 44,8 & 44,8 & 43,8 \\
\hline $\mathrm{NH}_{3}$ & ${ }^{2} J_{\mathrm{HH}}$ & $-9,5$ & $-9,3$ & $-7,6$ & $-7,5$ & $-7,4$ & $-8,8$ & $-8,5$ & $-8,6$ & $-10,2$ & $-9,6$ & $-10,0$ & $-9,6$ \\
\hline $\mathrm{PH}_{3}$ & ${ }^{1} J_{\mathrm{PH}}$ & 196,4 & 202,7 & 193,7 & 187,2 & 199,5 & 201,7 & 200,7 & 207,3 & 210,1 & 213,9 & 215,4 & 188,2 \\
\hline $\mathrm{PF}_{3}$ & ${ }^{1} J_{\mathrm{PF}}$ & $-1666,4$ & $-1560,1$ & $-1572,1$ & $-1468,9$ & $-1489,9$ & $-1549,1$ & $-1459,9$ & $-1470,8$ & $-1523,4$ & $-1439,8$ & $-1449,0$ & $-1441,0$ \\
\hline $\mathrm{BHF}_{2}$ & ${ }^{1} J_{\mathrm{BF}}$ & $-129,1$ & $-133,2$ & $-89,6$ & $-125,3$ & $-93,7$ & $-73,8$ & $-95,5$ & $-77,8$ & $-57,8$ & $-66,4$ & $-61,8$ & $-84,0$ \\
\hline $\mathrm{BF}_{3}$ & ${ }^{1} J_{\mathrm{BF}}$ & $-34,1$ & $-43,2$ & 7,0 & $-37,6$ & $-1,5$ & 24,5 & $-3,0$ & 16,1 & 42,2 & 30,6 & 34,0 & 15,0 \\
\hline $\mathrm{F}_{2} \mathrm{O}$ & ${ }^{1} J_{\mathrm{OF}}$ & $-336,9$ & $-264,6$ & $-338,2$ & $-347,7$ & $-262,5$ & $-383,0$ & $-312,7$ & $-299,3$ & $-437,3$ & $-278,5$ & $-341,9$ & $-300,0$ \\
\hline $\mathrm{CH}_{4}$ & ${ }^{1} J_{\mathrm{CH}}$ & 128,3 & 128,7 & 116,9 & 122,0 & 117,2 & 121,5 & 125,6 & 121,9 & 126,5 & 129,3 & 126,9 & 125,3 \\
\hline $\mathrm{CH}_{4}$ & ${ }^{2} J_{\mathrm{HH}}$ & $-12,5$ & $-12,5$ & $-9,8$ & $-9,5$ & $-9,8$ & $-11,0$ & $-10,8$ & $-11,0$ & $-12,2$ & $-12,1$ & $-12,2$ & $-12,8$ \\
\hline $\mathrm{C}_{2} \mathrm{H}_{2}$ & ${ }^{1} J_{\mathrm{CC}}$ & 212,9 & 212,7 & 205,0 & 207,5 & 205,0 & 212,2 & 214,3 & 211,9 & 220,6 & 221,6 & 220,0 & 174,8 \\
\hline $\mathrm{C}_{2} \mathrm{H}_{2}$ & ${ }^{1} J_{\mathrm{CH}}$ & 261,1 & 259,6 & 229,7 & 239,7 & 228,3 & 239,0 & 245,4 & 237,5 & 249,0 & 251,5 & 247,4 & 247,6 \\
\hline $\mathrm{C}_{2} \mathrm{H}_{2}$ & ${ }^{2} J_{\mathrm{CH}}$ & 52,8 & 52,9 & 53,2 & 53,4 & 53,3 & 53,2 & 53,2 & 53,3 & 52,6 & 52,7 & 52,8 & 50,1 \\
\hline $\mathrm{C}_{2} \mathrm{H}_{2}$ & ${ }^{3} J_{\mathrm{HH}}$ & 10,7 & 10,4 & 8,4 & 9,2 & 8,2 & 9,4 & 9,8 & 9,1 & 10,6 & 10,7 & 10,4 & 9,6 \\
\hline $\mathrm{C}_{2} \mathrm{H}_{4}$ & ${ }^{1} J_{\mathrm{CC}}$ & 77,3 & 79,7 & 76,4 & 78,8 & 78,9 & 81,3 & 84,1 & 83,6 & 87,2 & 89,7 & 89,1 & 67,6 \\
\hline $\mathrm{C}_{2} \mathrm{H}_{4}$ & ${ }^{1} J_{\mathrm{CH}}$ & 162,5 & 160,1 & 145,7 & 150,2 & 143,6 & 152,0 & 154,8 & 149,8 & 158,9 & 159,5 & 156,5 & 156,3 \\
\hline $\mathrm{C}_{2} \mathrm{H}_{4}$ & ${ }^{2} J_{\mathrm{CH}}$ & $-2,4$ & $-2,1$ & $-0,8$ & $-0,5$ & $-0,6$ & $-2,1$ & $-1,9$ & $-1,9$ & $-3,8$ & $-3,6$ & $-3,4$ & $-2,4$ \\
\hline $\mathrm{C}_{2} \mathrm{H}_{4}$ & ${ }^{2} J_{\mathrm{HH}}$ & 3,1 & 1,9 & 3,9 & 4,2 & 2,8 & 3,2 & 3,1 & 2,1 & 2,3 & 1,9 & 1,2 & 2,3 \\
\hline $\mathrm{C}_{2} \mathrm{H}_{4}$ & ${ }^{3} J_{\mathrm{HH}_{\mathrm{c}}}$ & 11,8 & 12,4 & 10,6 & 10,2 & 11,1 & 11,1 & 11,1 & 11,6 & 11,8 & 12,0 & 12,2 & 11,7 \\
\hline $\mathrm{C}_{2} \mathrm{H}_{4}$ & ${ }^{3} J_{\mathrm{HH}_{\mathrm{t}}}$ & 18,5 & 19,1 & 15,6 & 16,7 & 16,2 & 16,5 & 17,5 & 17,0 & 17,6 & 18,4 & 18,1 & 19,0 \\
\hline $\mathrm{C}_{2} \mathrm{H}_{6}$ & ${ }^{1} J_{\mathrm{CC}}$ & 34,4 & 36,0 & 35,1 & 36,2 & 36,7 & 38,2 & 39,6 & 39,8 & 41,5 & 43,1 & 43,1 & 34,5 \\
\hline $\mathrm{C}_{2} \mathrm{H}_{6}$ & ${ }^{1} J_{\mathrm{CH}}$ & 128,8 & 128,1 & 116,8 & 121,4 & 116,1 & 121,7 & 125,2 & 121,1 & 127,0 & 129,0 & 126,3 & 125,2 \\
\hline $\mathrm{C}_{2} \mathrm{H}_{6}$ & ${ }^{2} J_{\mathrm{CH}}$ & $-3,8$ & $-3,7$ & $-2,9$ & $-2,6$ & $-2,9$ & $-3,6$ & $-3,4$ & $-3,5$ & $-4,3$ & $-4,2$ & $-4,3$ & $-4,7$ \\
\hline \multirow[t]{3}{*}{ Total } & DM & $-12,61$ & $-6,23$ & $-7,35$ & $-8,00$ & $-1,73$ & $-4,51$ & $-0,67$ & 1,25 & $-1,72$ & 7,05 & 4,30 & - \\
\hline & DMA & 20,22 & 16,99 & 12,38 & 13,78 & 10,38 & 12,58 & 7,63 & 6,24 & 16,22 & 7,95 & 9,24 & - \\
\hline & PDMA & 22,55 & 25,09 & 18,65 & 32,25 & 20,09 & 14,08 & 15,68 & 10,44 & 20,27 & 15,80 & 17,92 & - \\
\hline \multirow[t]{3}{*}{ CPI } & DM & $-37,03$ & $-21,94$ & $-17,35$ & $-21,90$ & $-4,09$ & $-14,15$ & $-7,35$ & $-0,53$ & $-11,44$ & 7,99 & 2,90 & - \\
\hline & DMA & 40,46 & 32,88 & 20,03 & 24,99 & 14,73 & 21,97 & 11,20 & 6,38 & 30,45 & 9,72 & 13,99 & - \\
\hline & PDMA & 41,68 & 47,47 & 16,50 & 47,05 & 23,01 & 16,91 & 20,34 & 9,53 & 31,97 & 19,14 & 23,24 & - \\
\hline \multirow[t]{3}{*}{ SPI } & $\mathrm{DM}$ & 5,29 & 5,28 & $-0,02$ & 2,19 & 0,00 & 2,57 & 4,23 & 2,55 & 5,41 & 6,36 & 5,33 & - \\
\hline & DMA & 5,37 & 5,33 & 6,78 & 5,56 & 7,20 & 5,70 & 5,01 & 6,13 & 5,79 & 6,65 & 5,76 & - \\
\hline & PDMA & 8,52 & 8,68 & 20,23 & 21,39 & 17,96 & 12,01 & 12,27 & 11,11 & 11,68 & 13,34 & 14,03 & - \\
\hline \multirow[t]{3}{*}{$\Delta \mathrm{CS}$} & $\mathrm{DM}$ & $-42,32$ & $-27,22$ & $-17,33$ & $-24,09$ & $-4,09$ & $-16,72$ & $-11,58$ & $-3,07$ & $-16,85$ & 1,63 & $-2,43$ & - \\
\hline & DMA & 35,09 & 27,55 & 13,25 & 19,43 & 7,53 & 16,27 & 6,19 & 0,25 & 24,67 & 3,06 & 8,23 & - \\
\hline & PDMA & 33,17 & 38,79 & $-3,73$ & 25,65 & 5,05 & 4,91 & 8,06 & $-1,57$ & 20,29 & 5,80 & 9,21 & - \\
\hline
\end{tabular}


Tabela 8.27: Constantes de acoplamento B1B95 com otimização de geometrias com base aug-pcJ-2.

\begin{tabular}{|c|c|c|c|c|c|c|c|c|c|c|c|c|c|}
\hline & $\% E_{X}^{\mathrm{HF}}$ & 28,00 & Otm. & 40,00 & Otm. & $\begin{array}{l}28,00 \\
40,00 \\
\text { Otm. }\end{array}$ & 50,00 & 50,00 & $\begin{array}{l}28,00 \\
50,00 \\
\text { Otm. }\end{array}$ & 60,00 & Otm. & $\begin{array}{l}28,00 \\
60,00 \\
\text { Otm. }\end{array}$ & Exp. \\
\hline $\mathrm{HF}$ & ${ }^{1} J_{\mathrm{HF}}$ & 470,4 & 470,4 & 499,3 & 515,6 & 499,3 & 523,6 & 552,4 & 523,6 & 548,0 & 588,5 & 548,0 & 500,0 \\
\hline $\mathrm{CO}$ & ${ }^{1} J_{\mathrm{CO}}$ & 18,4 & 16,5 & 16,1 & 12,6 & 14,1 & 14,0 & 9,4 & 12,1 & 11,8 & 6,2 & 9,9 & 16,4 \\
\hline $\mathrm{H}_{2} \mathrm{O}$ & ${ }^{1} J_{\mathrm{OH}}$ & $-77,3$ & $-78,4$ & $-80,4$ & $-83,5$ & $-81,4$ & $-83,0$ & $-87,4$ & $-83,9$ & $-85,6$ & $-91,2$ & $-86,5$ & $-80,6$ \\
\hline $\mathrm{H}_{2} \mathrm{O}$ & ${ }^{2} J_{\mathrm{HH}}$ & $-7,0$ & $-6,6$ & $-8,2$ & $-7,3$ & $-7,8$ & $-9,2$ & $-8,1$ & $-8,8$ & $-10,3$ & $-8,9$ & $-9,8$ & $-7,3$ \\
\hline $\mathrm{NH}_{3}$ & ${ }^{1} J_{\mathrm{NH}}$ & 44,0 & 44,6 & 44,9 & 46,1 & 45,5 & 45,6 & 47,2 & 46,2 & 46,4 & 48,2 & 46,9 & 43,8 \\
\hline $\mathrm{NH}_{3}$ & ${ }^{2} J_{\mathrm{HH}}$ & $-9,3$ & $-9,1$ & $-10,4$ & $-9,8$ & $-10,1$ & $-11,3$ & $-10,5$ & $-11,0$ & $-12,1$ & $-11,2$ & $-11,8$ & $-9,6$ \\
\hline $\mathrm{PH}_{3}$ & ${ }^{1} J_{\mathrm{PH}}$ & 167,8 & 175,8 & 176,5 & 187,5 & 184,0 & 183,6 & 196,8 & 190,8 & 190,6 & 205,6 & 197,4 & 188,2 \\
\hline $\mathrm{PF}_{3}$ & ${ }^{1} J_{\mathrm{PF}}$ & $-1645,5$ & $-1532,2$ & $-1606,4$ & $-1500,6$ & $-1500,0$ & $-1571,1$ & $-1466,8$ & $-1470,3$ & $-1533,7$ & $-1427,8$ & $-1438,6$ & $-1441,0$ \\
\hline $\mathrm{BHF}_{2}$ & ${ }^{1} J_{\mathrm{BF}}$ & $-127,6$ & $-125,7$ & $-107,5$ & $-98,9$ & $-105,8$ & $-91,0$ & $-77,2$ & $-89,3$ & $-74,6$ & $-56,0$ & $-72,9$ & $-84,0$ \\
\hline $\mathrm{BF}_{3}$ & ${ }^{1} J_{\mathrm{BF}}$ & $-27,0$ & $-28,2$ & $-5,3$ & 2,1 & $-6,4$ & 12,6 & 26,6 & 11,4 & 30,3 & 50,2 & 29,2 & 15,0 \\
\hline $\mathrm{F}_{2} \mathrm{O}$ & ${ }^{1} J_{\mathrm{OF}}$ & $-361,9$ & $-249,0$ & $-404,3$ & $-221,1$ & $-280,1$ & $-443,7$ & $-199,3$ & $-307,4$ & $-490,0$ & $-179,2$ & $-337,1$ & $-300,0$ \\
\hline $\mathrm{CH}_{4}$ & ${ }^{1} J_{\mathrm{CH}}$ & 124,4 & 124,1 & 126,1 & 125,2 & 125,8 & 127,5 & 126,0 & 127,2 & 129,0 & 126,9 & 128,6 & 125,3 \\
\hline $\mathrm{CH}_{4}$ & ${ }^{2} J_{\mathrm{HH}}$ & $-12,2$ & $-12,2$ & $-13,0$ & $-13,1$ & $-13,0$ & $-13,7$ & $-13,7$ & $-13,7$ & $-14,4$ & $-14,4$ & $-14,4$ & $-12,8$ \\
\hline $\mathrm{C}_{2} \mathrm{H}_{2}$ & ${ }^{1} J_{\mathrm{CC}}$ & 195,2 & 195,5 & 199,3 & 199,1 & 199,2 & 203,2 & 202,4 & 202,8 & 207,7 & 205,9 & 207,0 & 174,8 \\
\hline $\mathrm{C}_{2} \mathrm{H}_{2}$ & ${ }^{1} J_{\mathrm{CH}}$ & 256,2 & 253,2 & 258,8 & 253,7 & 255,8 & 261,2 & 254,3 & 258,0 & 263,7 & 254,9 & 260,4 & 247,6 \\
\hline $\mathrm{C}_{2} \mathrm{H}_{2}$ & ${ }^{2} J_{\mathrm{CH}}$ & 55,6 & 55,7 & 55,2 & 55,5 & 55,4 & 54,6 & 55,1 & 54,9 & 53,8 & 54,6 & 54,2 & 50,1 \\
\hline $\mathrm{C}_{2} \mathrm{H}_{2}$ & ${ }^{3} J_{\mathrm{HH}}$ & 10,4 & 10,0 & 11,2 & 10,5 & 10,8 & 12,0 & 11,1 & 11,5 & 13,0 & 11,7 & 12,4 & 9,6 \\
\hline $\mathrm{C}_{2} \mathrm{H}_{4}$ & ${ }^{1} J_{\mathrm{CC}}$ & 66,0 & 68,9 & 69,6 & 72,1 & 72,1 & 73,0 & 74,9 & 75,1 & 76,8 & 77,9 & 78,5 & 67,6 \\
\hline $\mathrm{C}_{2} \mathrm{H}_{4}$ & ${ }^{1} J_{\mathrm{CH}}$ & 158,8 & 155,4 & 161,3 & 156,8 & 157,7 & 163,5 & 158,0 & 159,7 & 165,9 & 159,3 & 161,9 & 156,3 \\
\hline $\mathrm{C}_{2} \mathrm{H}_{4}$ & ${ }^{2} J_{\mathrm{CH}}$ & $-1,1$ & $-0,9$ & $-2,3$ & $-2,0$ & $-2,0$ & $-3,4$ & $-3,0$ & $-3,0$ & $-4,7$ & $-4,0$ & $-4,2$ & $-2,4$ \\
\hline $\mathrm{C}_{2} \mathrm{H}_{4}$ & ${ }^{2} J_{\mathrm{HH}}$ & 4,2 & 2,8 & 3,3 & 1,9 & 1,9 & 2,5 & 1,1 & 1,1 & 1,6 & 0,3 & 0,3 & 2,3 \\
\hline $\mathrm{C}_{2} \mathrm{H}_{4}$ & ${ }^{3} J_{\mathrm{HH}_{\mathrm{c}}}$ & 12,1 & 12,9 & 12,5 & 13,4 & 13,2 & 12,8 & 13,8 & 13,6 & 13,3 & 14,2 & 14,0 & 11,7 \\
\hline $\mathrm{C}_{2} \mathrm{H}_{4}$ & ${ }^{3} J_{\mathrm{HH}_{\mathrm{t}}}$ & 19,0 & 19,6 & 19,4 & 19,9 & 20,0 & 19,9 & 20,2 & 20,4 & 20,4 & 20,6 & 20,9 & 19,0 \\
\hline $\mathrm{C}_{2} \mathrm{H}_{6}$ & ${ }^{1} J_{\mathrm{CC}}$ & 30,6 & 32,5 & 33,0 & 34,7 & 34,8 & 35,0 & 36,6 & 36,8 & 37,1 & 38,7 & 38,8 & 34,5 \\
\hline $\mathrm{C}_{2} \mathrm{H}_{6}$ & ${ }^{1} J_{\mathrm{CH}}$ & 125,0 & 123,0 & 126,9 & 124,3 & 124,9 & 128,5 & 125,2 & 126,4 & 130,1 & 126,2 & 128,0 & 125,2 \\
\hline $\mathrm{C}_{2} \mathrm{H}_{6}$ & ${ }^{2} J_{\mathrm{CH}}$ & $-3,5$ & $-3,5$ & $-4,0$ & $-4,1$ & $-4,0$ & $-4,5$ & $-4,5$ & $-4,5$ & $-5,0$ & $-5,0$ & $-5,0$ & $-4,7$ \\
\hline \multirow[t]{3}{*}{ Total } & $\mathrm{DM}$ & $-13,82$ & $-5,00$ & $-10,52$ & 1,75 & $-1,58$ & $-7,80$ & 7,52 & 1,33 & $-5,23$ & 13,35 & 4,27 & - \\
\hline & DMA & 17,61 & 12,27 & 14,84 & 9,19 & 7,04 & 15,13 & 10,91 & 5,86 & 18,06 & 15,62 & 8,88 & - \\
\hline & PDMA & 24,17 & 21,61 & 14,31 & 10,96 & 12,72 & 11,69 & 15,02 & 11,38 & 21,91 & 28,67 & 21,33 & - \\
\hline \multirow[t]{3}{*}{ CPI } & DM & $-35,99$ & $-14,80$ & $-29,69$ & 0,16 & $-8,15$ & $-24,62$ & 12,93 & $-2,50$ & $-20,01$ & 25,77 & 3,07 & - \\
\hline & DMA & 37,10 & 24,85 & 29,93 & 17,44 & 12,07 & 29,24 & 20,44 & 7,70 & 34,14 & 30,14 & 12,93 & - \\
\hline & PDMA & 37,04 & 35,77 & 21,92 & 15,62 & 19,33 & 13,99 & 19,55 & 10,17 & 27,38 & 41,83 & 22,37 & - \\
\hline \multirow[t]{3}{*}{ SPI } & DM & 2,44 & 2,19 & 3,55 & 2,92 & 3,23 & 4,53 & 3,56 & 4,15 & 5,61 & 4,25 & 5,15 & - \\
\hline & DMA & 3,32 & 3,03 & 3,77 & 3,15 & 3,35 & 4,79 & 3,92 & 4,51 & 6,27 & 4,98 & 5,91 & - \\
\hline & PDMA & 14,73 & 11,22 & 8,73 & 7,55 & 7,87 & 10,00 & 11,69 & 12,27 & 17,90 & 19,02 & 20,57 & - \\
\hline \multirow[t]{3}{*}{$\Delta \mathrm{CS}$} & $\mathrm{DM}$ & $-38,43$ & $-16,99$ & $-33,24$ & $-2,76$ & $-11,38$ & $-29,15$ & 9,37 & $-6,65$ & $-25,62$ & 21,53 & $-2,08$ & - \\
\hline & DMA & 33,78 & 21,82 & 26,15 & 14,29 & 8,72 & 24,45 & 16,52 & 3,19 & 27,87 & 25,16 & 7,01 & - \\
\hline & PDMA & 22,31 & 24,55 & 13,20 & 8,06 & 11,47 & 3,99 & 7,86 & $-2,10$ & 9,48 & 22,81 & 1,81 & - \\
\hline
\end{tabular}


Tabela 8.28: Constantes de acoplamento BHandH com otimização de geometrias com base aug-pcJ-2.

\begin{tabular}{|c|c|c|c|c|c|c|c|c|c|c|c|c|c|}
\hline & $\% E_{X}^{\mathrm{HF}}$ & 50,00 & 50,00 & 30,00 & 30,00 & $\begin{array}{l}50,00 \\
30,00 \\
\text { Otm. }\end{array}$ & 40,00 & 40,00 & $\begin{array}{l}50,00 \\
/ \\
40,00 \\
\text { Otm. }\end{array}$ & 60,00 & 60,00 & $\begin{array}{l}50,00 \\
60,00 \\
\text { Otm. }\end{array}$ & Exp. \\
\hline HF & ${ }^{1} J_{\mathrm{HF}}$ & 530,8 & 546,7 & 484,4 & 472,9 & 500,8 & 507,2 & 509,6 & 523,4 & 555,3 & 584,3 & 570,9 & 500,0 \\
\hline $\mathrm{CO}$ & ${ }^{1} J_{\mathrm{CO}}$ & 13,7 & 8,0 & 18,7 & 14,9 & 12,8 & 16,3 & 11,5 & 10,4 & 11,0 & 4,4 & 5,3 & 16,4 \\
\hline $\mathrm{H}_{2} \mathrm{O}$ & ${ }^{1} J_{\mathrm{OH}}$ & $-83,7$ & $-87,5$ & $-77,8$ & $-78,5$ & $-81,7$ & $-80,7$ & $-83,1$ & $-84,6$ & $-86,9$ & $-92,0$ & $-90,6$ & $-80,6$ \\
\hline $\mathrm{H}_{2} \mathrm{O}$ & ${ }^{2} J_{\mathrm{HH}}$ & $-9,4$ & $-7,9$ & $-6,8$ & $-5,8$ & $-5,3$ & $-8,0$ & $-6,8$ & $-6,6$ & $-10,8$ & $-9,0$ & $-9,2$ & $-7,3$ \\
\hline $\mathrm{NH}_{3}$ & ${ }^{1} J_{\mathrm{NH}}$ & 45,5 & 47,7 & 42,9 & 44,5 & 45,1 & 44,2 & 46,2 & 46,4 & 47,0 & 49,5 & 49,2 & 43,8 \\
\hline $\mathrm{NH}_{3}$ & ${ }^{2} J_{\mathrm{HH}}$ & $-11,1$ & $-9,9$ & $-8,7$ & $-7,6$ & $-7,5$ & $-9,9$ & $-8,7$ & $-8,7$ & $-12,5$ & $-11,0$ & $-11,1$ & $-9,6$ \\
\hline $\mathrm{PH}_{3}$ & ${ }^{1} J_{\mathrm{PH}}$ & 183,1 & 195,1 & 163,0 & 167,4 & 175,8 & 172,9 & 181,3 & 185,3 & 193,7 & 208,9 & 205,2 & 188,2 \\
\hline $\mathrm{PF}_{3}$ & ${ }^{1} J_{\mathrm{PF}}$ & $-1670,4$ & $-1554,5$ & $-1743,5$ & $-1622,0$ & $-1624,2$ & $-1709,0$ & $-1591,4$ & $-1591,2$ & $-1628,3$ & $-1512,0$ & $-1514,8$ & $-1441,0$ \\
\hline $\mathrm{BHF}_{2}$ & ${ }^{1} J_{\mathrm{BF}}$ & $-95,2$ & $-72,8$ & $-132,8$ & $-116,4$ & $-109,5$ & $-114,0$ & $-94,5$ & $-91,2$ & $-76,1$ & $-51,3$ & $-54,3$ & $-84,0$ \\
\hline $\mathrm{BF}_{3}$ & ${ }^{1} J_{\mathrm{BF}}$ & 15,1 & 38,8 & $-23,3$ & $-7,3$ & 1,5 & $-4,1$ & 15,8 & 20,0 & 34,6 & 61,4 & 57,6 & 15,0 \\
\hline $\mathrm{F}_{2} \mathrm{O}$ & ${ }^{1} J_{\mathrm{OF}}$ & $-465,0$ & $-165,5$ & $-380,5$ & $-173,9$ & $-123,8$ & $-419,8$ & $-169,2$ & $-144,3$ & $-521,4$ & $-163,3$ & $-188,0$ & $-300,0$ \\
\hline $\mathrm{CH}_{4}$ & ${ }^{1} J_{\mathrm{CH}}$ & 124,9 & 124,4 & 116,8 & 117,4 & 116,3 & 120,7 & 120,7 & 120,3 & 129,4 & 128,1 & 128,8 & 125,3 \\
\hline $\mathrm{CH}_{4}$ & ${ }^{2} J_{\mathrm{HH}}$ & $-13,3$ & $-13,3$ & $-11,0$ & $-11,0$ & $-11,0$ & $-12,1$ & $-12,1$ & $-12,1$ & $-14,5$ & $-14,5$ & $-14,5$ & $-12,8$ \\
\hline $\mathrm{C}_{2} \mathrm{H}_{2}$ & ${ }^{1} J_{\mathrm{CC}}$ & 202,4 & 201,9 & 189,4 & 190,4 & 190,4 & 195,4 & 195,9 & 195,8 & 210,6 & 208,6 & 209,1 & 174,8 \\
\hline $\mathrm{C}_{2} \mathrm{H}_{2}$ & ${ }^{1} J_{\mathrm{CH}}$ & 259,5 & 253,3 & 245,0 & 243,0 & 239,4 & 252,0 & 248,0 & 246,1 & 267,8 & 259,1 & 261,1 & 247,6 \\
\hline $\mathrm{C}_{2} \mathrm{H}_{2}$ & ${ }^{2} J_{\mathrm{CH}}$ & 53,0 & 53,8 & 53,2 & 53,5 & 53,5 & 53,3 & 53,8 & 53,8 & 52,2 & 53,4 & 53,3 & 50,1 \\
\hline $\mathrm{C}_{2} \mathrm{H}_{2}$ & ${ }^{3} J_{\mathrm{HH}}$ & 11,8 & 10,7 & 9,4 & 8,9 & 8,6 & 10,5 & 9,8 & 9,6 & 13,4 & 11,9 & 12,2 & 9,6 \\
\hline $\mathrm{C}_{2} \mathrm{H}_{4}$ & ${ }^{1} J_{\mathrm{CC}}$ & 72,3 & 74,8 & 61,8 & 65,7 & 65,6 & 66,7 & 70,0 & 69,9 & 78,9 & 80,2 & 80,5 & 67,6 \\
\hline $\mathrm{C}_{2} \mathrm{H}_{4}$ & ${ }^{1} J_{\mathrm{CH}}$ & 160,6 & 155,7 & 149,9 & 147,1 & 145,6 & 155,0 & 151,3 & 150,5 & 166,8 & 160,4 & 161,4 & 156,3 \\
\hline $\mathrm{C}_{2} \mathrm{H}_{4}$ & ${ }^{2} J_{\mathrm{CH}}$ & $-3,8$ & $-3,4$ & $-1,3$ & $-1,2$ & $-1,2$ & $-2,4$ & $-2,2$ & $-2,2$ & $-5,6$ & $-4,8$ & $-4,8$ & $-2,4$ \\
\hline $\mathrm{C}_{2} \mathrm{H}_{4}$ & ${ }^{2} J_{\mathrm{HH}}$ & 2,2 & 1,2 & 3,8 & 3,0 & 2,8 & 3,1 & 2,1 & 2,0 & 1,1 & 0,2 & 0,3 & 2,3 \\
\hline $\mathrm{C}_{2} \mathrm{H}_{4}$ & ${ }^{3} J_{\mathrm{HH}_{\mathrm{c}}}$ & 13,3 & 14,4 & 12,2 & 13,3 & 13,4 & 12,7 & 13,8 & 13,9 & 14,1 & 15,1 & 15,1 & 11,7 \\
\hline $\mathrm{C}_{2} \mathrm{H}_{4}$ & ${ }^{3} J_{\mathrm{HH}_{\mathrm{t}}}$ & 19,6 & 20,2 & 17,9 & 18,9 & 18,6 & 18,7 & 19,5 & 19,4 & 20,8 & 21,1 & 21,2 & 19,0 \\
\hline $\mathrm{C}_{2} \mathrm{H}_{6}$ & ${ }^{1} J_{\mathrm{CC}}$ & 33,3 & 36,2 & 26,9 & 30,6 & 30,0 & 30,0 & 33,3 & 33,0 & 36,7 & 38,9 & 39,5 & 34,5 \\
\hline $\mathrm{C}_{2} \mathrm{H}_{6}$ & ${ }^{1} J_{\mathrm{CH}}$ & 125,8 & 122,8 & 117,3 & 115,3 & 114,6 & 121,5 & 119,0 & 118,6 & 130,4 & 126,8 & 127,2 & 125,2 \\
\hline $\mathrm{C}_{2} \mathrm{H}_{6}$ & ${ }^{2} J_{\mathrm{CH}}$ & $-4,3$ & $-4,4$ & $-3,1$ & $-3,3$ & $-3,2$ & $-3,7$ & $-3,8$ & $-3,8$ & $-4,9$ & $-5,0$ & $-5,0$ & $-4,7$ \\
\hline \multirow{3}{*}{ Total } & $\mathrm{DM}$ & $-12,86$ & 5,44 & $-20,05$ & $-6,35$ & $-2,98$ & $-16,48$ & $-0,58$ & 1,10 & $-9,32$ & 11,71 & 10,02 & - \\
\hline & DMA & 19,73 & 15,92 & 22,41 & 18,52 & 18,99 & 19,57 & 14,22 & 15,80 & 24,00 & 19,71 & 18,08 & - \\
\hline & PDMA & 12,21 & 19,31 & 24,93 & 19,64 & 18,32 & 14,17 & 9,04 & 10,94 & 27,30 & 34,92 & 33,31 & - \\
\hline \multirow[t]{3}{*}{ CPI } & DM & $-35,23$ & 8,85 & $-45,94$ & $-13,88$ & $-5,17$ & $-40,53$ & $-2,75$ & 1,64 & $-30,48$ & 20,82 & 16,30 & - \\
\hline & DMA & 41,15 & 32,43 & 47,12 & 37,95 & 38,34 & 41,91 & 29,11 & 32,60 & 47,12 & 38,55 & 34,17 & - \\
\hline & PDMA & 14,76 & 28,89 & 37,59 & 28,46 & 24,92 & 22,32 & 12,01 & 16,08 & 33,37 & 51,35 & 47,19 & - \\
\hline \multirow[t]{3}{*}{ SPI } & DM & 3,55 & 2,95 & $-1,06$ & $-0,83$ & $-1,38$ & 1,15 & 1,00 & 0,71 & 6,21 & 5,03 & 5,42 & - \\
\hline & DMA & 4,03 & 3,81 & 4,29 & 4,26 & 4,81 & 3,19 & 3,29 & 3,47 & 7,05 & 5,89 & 6,27 & - \\
\hline & PDMA & 10,35 & 12,29 & 15,65 & 13,17 & 13,49 & 8,19 & 6,85 & 7,18 & 22,85 & 22,88 & 23,14 & - \\
\hline \multirow[t]{3}{*}{$\Delta \mathrm{CS}$} & $\mathrm{DM}$ & $-38,77$ & 5,90 & $-44,88$ & $-13,05$ & $-3,79$ & $-41,68$ & $-3,75$ & 0,92 & $-36,69$ & 15,79 & 10,88 & - \\
\hline & DMA & 37,13 & 28,61 & 42,83 & 33,69 & 33,53 & 38,72 & 25,82 & 29,13 & 40,07 & 32,65 & 27,90 & - \\
\hline & PDMA & 4,41 & 16,59 & 21,95 & 15,29 & 11,43 & 14,13 & 5,16 & 8,91 & 10,52 & 28,47 & 24,05 & - \\
\hline
\end{tabular}


Tabela 8.29: Constantes de acoplamento PBE0 com otimização de geometrias com base aug-pcJ-2.

\begin{tabular}{|c|c|c|c|c|c|c|c|c|c|c|c|c|c|c|c|c|}
\hline & $\% E_{X}^{\mathrm{HF}}$ & 25,00 & 25,00 & 20,00 & 20,00 & $\begin{array}{l}25,00 \\
20,00 \\
\text { Otm. }\end{array}$ & 30,00 & 30,00 & $\begin{array}{l}25,00 \\
30,00 \\
\text { Otm. }\end{array}$ & 40,00 & 40,00 & $\begin{array}{l}25,00 \\
40,00 \\
\text { Otm. }\end{array}$ & 50,00 & 50,00 & $\begin{array}{l}25,00 \\
50,00 \\
\text { Otm. }\end{array}$ & Exp. \\
\hline $\mathrm{HF}$ & ${ }^{1} J_{\mathrm{HF}}$ & 430,8 & 427,7 & 419,7 & 409,3 & 416,6 & 441,9 & 445,9 & 438,8 & 464,3 & 482,0 & 461,3 & 486,9 & 517,7 & 484 & 500,0 \\
\hline $\mathrm{CO}$ & ${ }^{1} J_{\mathrm{CO}}$ & 19,9 & 18,4 & 20,8 & 19,9 & 19,2 & 19,1 & 16,9 & 17,5 & 17,3 & 13,8 & 15,7 & 15,4 & 10,9 & 13,9 & 16,4 \\
\hline $\mathrm{H}_{2} \mathrm{O}$ & ${ }^{1} J_{\mathrm{OH}}$ & $-73,0$ & $-73,5$ & $-71,8$ & $-71,5$ & $-72,3$ & $-74,2$ & $-75,4$ & $-74,7$ & $-76,6$ & $-79,6$ & -77 & $-79,0$ & $-83,4$ & $-79,4$ & $-80,6$ \\
\hline $\mathrm{H}_{2} \mathrm{O}$ & ${ }^{2} J_{\mathrm{HH}}$ & $-7,3$ & $-6,9$ & $-6,7$ & $-6,4$ & $-6,4$ & $-7,8$ & $-7,4$ & $-7,4$ & $-8,9$ & $-8,1$ & $-8,5$ & $-10,0$ & $-9,0$ & $-9,6$ & $-7,3$ \\
\hline $\mathrm{NH}_{3}$ & ${ }^{1} J_{\mathrm{NH}}$ & 42,5 & 43,0 & 42,2 & 42,3 & 42,6 & 42,9 & 43,6 & 43,4 & 43,6 & 44,8 & 44,1 & 44,3 & 45,9 & 44,8 & 43,8 \\
\hline $\mathrm{NH}_{3}$ & ${ }^{2} J_{\mathrm{HH}}$ & $-10,1$ & $-9,8$ & $-9,6$ & $-9,5$ & $-9,4$ & $-10,6$ & $-10,3$ & $-10,3$ & $-11,5$ & $-11,0$ & $-11,3$ & $-12,5$ & $-11,8$ & $-12,2$ & $-9,6$ \\
\hline $\mathrm{PH}_{3}$ & ${ }^{1} J_{\mathrm{PH}}$ & 154,6 & 161,3 & 150,4 & 155,5 & 157,2 & 158,7 & 166,9 & 165,3 & 166,9 & 178,0 & 173,2 & 175,1 & 188,6 & 181,1 & 188,2 \\
\hline $\mathrm{PF}_{3}$ & ${ }^{1} J_{\mathrm{PF}}$ & $-1732,1$ & $-1627,0$ & $-1748,1$ & $-1634,2$ & $-1639,7$ & $-1715,3$ & $-1612,1$ & $-1613,5$ & $-1679,4$ & $-1581,4$ & $-1583,9$ & $-1640,8$ & $-1543,9$ & $-1551,5$ & $-1441, \mathrm{C}$ \\
\hline $\mathrm{BHF}_{2}$ & ${ }^{1} J_{\mathrm{BF}}$ & $-131,0$ & $-130,8$ & $-139,2$ & $-142,2$ & -139 & $-122,7$ & $-119,9$ & $-122,5$ & $-106,5$ & $-97,7$ & $-106,3$ & $-90,4$ & $-76,6$ & $-90,2$ & $-84,0$ \\
\hline $\mathrm{BF}_{3}$ & ${ }^{1} J_{\mathrm{BF}}$ & $-30,5$ & $-33,5$ & $-39,4$ & $-46,9$ & $-42,4$ & $-21,7$ & $-21,1$ & $-24,6$ & $-4,2$ & 3,6 & -7 & 12,9 & 27,3 & 10,2 & 15,0 \\
\hline $\mathrm{F}_{2} \mathrm{O}$ & ${ }^{1} J_{\mathrm{OF}}$ & $-374,9$ & $-251,0$ & $-354,9$ & $-261,4$ & $-236,3$ & $-395,6$ & $-241,6$ & -266 & $-440,5$ & $-222,0$ & $-297,4$ & $-493,5$ & $-202,0$ & $-331,8$ & $-300,0$ \\
\hline $\mathrm{CH}_{4}$ & ${ }^{1} J_{\mathrm{CH}}$ & 122,8 & 123,0 & 122,1 & 122,5 & 122,3 & 123,5 & 123,5 & 123,8 & 125,0 & 124,5 & 125,2 & 126,5 & 125,5 & 126,8 & 125,3 \\
\hline $\mathrm{CH}_{4}$ & ${ }^{2} J_{\mathrm{HH}}$ & $-13,8$ & $-13,7$ & $-13,4$ & $-13,3$ & $-13,3$ & $-14,2$ & $-14,2$ & $-14,1$ & $-15,0$ & $-15,0$ & -15 & $-15,8$ & $-15,8$ & $-15,8$ & $-12,8$ \\
\hline $\mathrm{C}_{2} \mathrm{H}_{2}$ & ${ }^{1} J_{\mathrm{CC}}$ & 196,4 & 196,6 & 194,6 & 195,0 & 195 & 198,3 & 198,3 & 198,4 & 202,6 & 202,0 & 202,4 & 207,6 & 206,0 & 207,1 & 174,8 \\
\hline $\mathrm{C}_{2} \mathrm{H}_{2}$ & ${ }^{1} J_{\mathrm{CH}}$ & 256,2 & 254,5 & 254,8 & 254,0 & 253,1 & 257,6 & 255,0 & 255,9 & 260,7 & 256,1 & 258,8 & 264,1 & 257,5 & 262,1 & 247,6 \\
\hline $\mathrm{C}_{2} \mathrm{H}_{2}$ & ${ }^{2} J_{\mathrm{CH}}$ & 53,5 & 53,7 & 53,7 & 53,9 & 53,9 & 53,2 & 53,5 & 53,4 & 52,2 & 52,8 & 52,6 & 50,9 & 52,0 & 51,4 & 50,1 \\
\hline $\mathrm{C}_{2} \mathrm{H}_{2}$ & ${ }^{3} J_{\mathrm{HH}}$ & 12,4 & 12,0 & 11,9 & 11,7 & 11,6 & 12,9 & 12,4 & 12,5 & 14,1 & 13,3 & 13,7 & 15,6 & 14,3 & 15,1 & 9,6 \\
\hline $\mathrm{C}_{2} \mathrm{H}_{4}$ & ${ }^{1} J_{\mathrm{CC}}$ & 68,7 & 71,3 & 67,0 & 69,8 & 69,8 & 70,4 & 72,9 & 72,9 & 74,4 & 76,2 & 76,5 & 79,1 & 79,9 & 80,6 & 67,6 \\
\hline $\mathrm{C}_{2} \mathrm{H}_{4}$ & ${ }^{1} J_{\mathrm{CH}}$ & 157,3 & 154,6 & 156,1 & 153,8 & 153,5 & 158,5 & 155,3 & 155,7 & 161,1 & 156,9 & 158,1 & 164,0 & 158,7 & 160,8 & 156,3 \\
\hline $\mathrm{C}_{2} \mathrm{H}_{4}$ & ${ }^{2} J_{\mathrm{CH}}$ & $-3,0$ & $-2,7$ & $-2,5$ & $-2,2$ & $-2,2$ & $-3,7$ & $-3,3$ & $-3,3$ & $-5,1$ & $-4,5$ & $-4,6$ & $-6,9$ & $-5,9$ & $-6,2$ & $-2,4$ \\
\hline $\mathrm{C}_{2} \mathrm{H}_{4}$ & ${ }^{2} J_{\mathrm{HH}}$ & 2,3 & 1,2 & 2,8 & 1,7 & 1,6 & 1,8 & 0,7 & 0,7 & 0,7 & $-0,3$ & $-0,2$ & $-0,5$ & $-1,4$ & $-1,4$ & 2,3 \\
\hline $\mathrm{C}_{2} \mathrm{H}_{4}$ & ${ }^{3} J_{\mathrm{HH}_{\mathrm{C}}}$ & 12,7 & 13,4 & 12,5 & 13,1 & 13,2 & 13,0 & 13,7 & 13,6 & 13,6 & 14,3 & 14,2 & 14,5 & 15,0 & 14,9 & 11,7 \\
\hline $\mathrm{C}_{2} \mathrm{H}_{4}$ & ${ }^{3} J_{\mathrm{HH}_{\mathrm{t}}}$ & 19,8 & 20,4 & 19,5 & 20,2 & 20,2 & 20,1 & 20,7 & 20,7 & 20,9 & 21,2 & 21,4 & 21,9 & 21,9 & 22,3 & 19,0 \\
\hline $\mathrm{C}_{2} \mathrm{H}_{6}$ & ${ }^{1} J_{\mathrm{CC}}$ & 30,4 & 32,6 & 29,4 & 31,7 & 31,7 & 31,3 & 33,5 & 33,6 & 33,3 & & & & & 37,4 & 34,5 \\
\hline $\mathrm{C}_{2} \mathrm{H}_{6}$ & ${ }^{1} J_{\mathrm{CH}}$ & 123,5 & 122,0 & 122,7 & 121,5 & 121,2 & 124,3 & 122,6 & 122,9 & 126,0 & 123,8 & 124,5 & 127,7 & 124,9 & 126,2 & 125,2 \\
\hline $\mathrm{C}_{2} \mathrm{H}_{6}$ & ${ }^{2} J_{\mathrm{CH}}$ & $-4,1$ & $-4,1$ & $-3,9$ & $-3,9$ & $-3,9$ & $-4,3$ & $-4,4$ & $-4,4$ & $-4,9$ & $-4,9$ & $-4,9$ & $-5,4$ & $-5,4$ & $-5,4$ & $-4,7$ \\
\hline \multirow[t]{3}{*}{ Total } & DM & 0,04 & - & -21 , & $-13,8$ & $-12,5$ & -18 & & -9.8 & & & & & & & - \\
\hline & DMA & 1,04 & & & 20 & 21 , & & & & & & & & & & - \\
\hline & PDMA & 23,18 & 24,36 & 26,02 & 28,02 & 26,95 & 23,07 & 22,05 & 22,98 & 23,41 & 19,92 & 22,50 & 26,51 & 27,43 & 25,43 & - \\
\hline \multirow[t]{3}{*}{ CPI } & DM & 0,18 & & & & & & & & & & & & & & - \\
\hline & DMA & & & & & & & & & & & & & & & - \\
\hline & PDMA & 43,19 & 42,49 & 50,34 & 53,92 & 50,99 & 37,51 & 32,32 & 34,65 & 26,29 & 16,54 & 22,12 & 16,91 & 20,22 & 12,93 & - \\
\hline \multirow[t]{3}{*}{ SPI } & & & & & & & & & & & & & & & & - \\
\hline & DMA & & & & & & & & & & & & & & & - \\
\hline & PDMA & 8,51 & 11,06 & 8,19 & 9,03 & 9,32 & 12,49 & 14,51 & 14,42 & 21,30 & 22,39 & 22,78 & 33,55 & 32,72 & 34,60 & - \\
\hline \multirow[t]{3}{*}{$\Delta \mathrm{CS}$} & & & & & & & & & & & & & & & & - \\
\hline & DMA & 48,81 & & & & 42,28 & & & 30 , & & & & & & & - \\
\hline & PDMA & 34,68 & 31,43 & 42,15 & 44,90 & 41,67 & 25,03 & 17,80 & 20,23 & 4,99 & $-5,85$ & $-0,66$ & $-16,64$ & $-12,50$ & $-21,67$ & - \\
\hline
\end{tabular}




\subsection{Correções vibracionais para os funcionais testados}

Tabela 8.30: Constantes de acoplamento BHandH com correção vibracional na base aug-pcJ-2.

\begin{tabular}{|c|c|c|c|c|c|c|c|c|c|}
\hline & $\% E_{X}^{\mathrm{HF}}$ & 50,00 & 50,00 & 40,00 & 40,00 & $\begin{array}{c}50,00 / \\
40,00\end{array}$ & 50,00 & 40,00 & - \\
\hline & Geom. & Exp. & Otm. & Exp. & Otm. & Otm. & Correção & Correção & Exp. \\
\hline HF & ${ }^{1} J_{\mathrm{HF}}$ & 530,8 & 546,7 & 507,2 & 509,6 & 523,4 & 514,8 & 477,2 & 500 \\
\hline $\mathrm{CO}$ & ${ }^{1} J_{\mathrm{CO}}$ & 13,7 & 8,0 & 16,3 & 11,5 & 10,4 & 8,7 & 12,3 & 16,4 \\
\hline $\mathrm{H}_{2} \mathrm{O}$ & ${ }^{1} J_{\mathrm{OH}}$ & $-83,7$ & $-87,5$ & $-80,7$ & $-83,1$ & $-84,6$ & $-86,7$ & $-82,1$ & $-80,6$ \\
\hline $\mathrm{H}_{2} \mathrm{O}$ & ${ }^{2} J_{\mathrm{HH}}$ & $-9,4$ & $-7,9$ & $-8,0$ & $-6,8$ & $-6,6$ & $-6,5$ & $-5,4$ & $-7,3$ \\
\hline $\mathrm{NH}_{3}$ & ${ }^{1} J_{\mathrm{NH}}$ & 45,5 & 47,7 & 44,2 & 46,2 & 46,4 & 48,7 & 47,1 & 43,8 \\
\hline $\mathrm{NH}_{3}$ & ${ }^{2} J_{\mathrm{HH}}$ & $-11,1$ & $-9,9$ & $-9,9$ & $-8,7$ & $-8,7$ & $-9,1$ & $-7,9$ & $-9,6$ \\
\hline $\mathrm{PH}_{3}$ & ${ }^{1} J_{\mathrm{PH}}$ & 183,1 & 195,1 & 172,9 & 181,3 & 185,3 & 188,8 & 174,4 & 188,2 \\
\hline $\mathrm{PF}_{3}$ & ${ }^{1} J_{\mathrm{PF}}$ & $-1670,4$ & $-1554,5$ & $-1709,0$ & $-1591,4$ & $-1591,2$ & $-1556,8$ & $-1592,6$ & -1441 \\
\hline $\mathrm{BHF}_{2}$ & ${ }^{1} J_{\mathrm{BF}}$ & $-95,2$ & $-72,8$ & $-114,0$ & $-94,5$ & $-91,2$ & $-76,5$ & $-99,1$ & -84 \\
\hline $\mathrm{BF}_{3}$ & ${ }^{1} J_{\mathrm{BF}}$ & 15,1 & 38,8 & $-4,1$ & 15,8 & 20,0 & 36,9 & 13,9 & 15 \\
\hline $\mathrm{F}_{2} \mathrm{O}$ & ${ }^{1} J_{\mathrm{OF}}$ & $-465,0$ & $-165,5$ & $-419,8$ & $-169,2$ & $-144,3$ & $-179,7$ & $-182,1$ & -300 \\
\hline $\mathrm{CH}_{4}$ & ${ }^{1} J_{\mathrm{CH}}$ & 124,9 & 124,4 & 120,7 & 120,7 & 120,3 & 127,3 & 123,4 & 125,3 \\
\hline $\mathrm{CH}_{4}$ & ${ }^{2} J_{\mathrm{HH}}$ & $-13,3$ & $-13,3$ & $-12,1$ & $-12,1$ & $-12,1$ & $-13,6$ & $-12,4$ & $-12,8$ \\
\hline $\mathrm{C}_{2} \mathrm{H}_{2}$ & ${ }^{1} J_{\mathrm{CC}}$ & 202,4 & 201,9 & 195,4 & 195,9 & 195,8 & 203,1 & 196,7 & 174,8 \\
\hline $\mathrm{C}_{2} \mathrm{H}_{2}$ & ${ }^{1} J_{\mathrm{CH}}$ & 259,5 & 253,3 & 252,0 & 248,0 & 246,1 & 257,3 & 251,7 & 247,6 \\
\hline $\mathrm{C}_{2} \mathrm{H}_{2}$ & ${ }^{2} J_{\mathrm{CH}}$ & 53,0 & 53,8 & 53,3 & 53,8 & 53,8 & 54,2 & 54,3 & 50,1 \\
\hline $\mathrm{C}_{2} \mathrm{H}_{2}$ & ${ }^{3} J_{\mathrm{HH}}$ & 11,8 & 10,7 & 10,5 & 9,8 & 9,6 & 11,4 & 10,3 & 9,6 \\
\hline $\mathrm{C}_{2} \mathrm{H}_{4}$ & ${ }^{1} J_{\mathrm{CC}}$ & 72,3 & 74,8 & 66,7 & 70,0 & 69,9 & 75,7 & 70,6 & 67,6 \\
\hline $\mathrm{C}_{2} \mathrm{H}_{4}$ & ${ }^{1} J_{\mathrm{CH}}$ & 160,6 & 155,7 & 155,0 & 151,3 & 150,5 & 158,1 & 153,5 & 156,3 \\
\hline $\mathrm{C}_{2} \mathrm{H}_{4}$ & ${ }^{2} J_{\mathrm{CH}}$ & $-3,8$ & $-3,4$ & $-2,4$ & $-2,2$ & $-2,2$ & $-3,8$ & $-2,5$ & $-2,4$ \\
\hline $\mathrm{C}_{2} \mathrm{H}_{4}$ & ${ }^{2} J_{\mathrm{HH}}$ & 2,2 & 1,2 & 3,1 & 2,1 & 2,0 & 1,5 & 2,4 & 2,3 \\
\hline $\mathrm{C}_{2} \mathrm{H}_{4}$ & ${ }^{3} J_{\mathrm{HH}_{\mathrm{c}}}$ & 13,3 & 14,4 & 12,7 & 13,8 & 13,9 & 14,8 & 14,2 & 11,7 \\
\hline $\mathrm{C}_{2} \mathrm{H}_{4}$ & ${ }^{3} J_{\mathrm{HH}_{\mathrm{t}}}$ & 19,6 & 20,2 & 18,7 & 19,5 & 19,4 & 20,9 & 20,1 & 19 \\
\hline $\mathrm{C}_{2} \mathrm{H}_{6}$ & ${ }^{1} J_{\mathrm{CC}}$ & 33,3 & 36,2 & 30,0 & 33,3 & 33,0 & 37,2 & 34,2 & 34,5 \\
\hline $\mathrm{C}_{2} \mathrm{H}_{6}$ & ${ }^{1} J_{\mathrm{CH}}$ & 125,8 & 122,8 & 121,5 & 119,0 & 118,6 & 125,1 & 121,1 & 125,2 \\
\hline $\mathrm{C}_{2} \mathrm{H}_{6}$ & ${ }^{2} J_{\mathrm{CH}}$ & $-4,3$ & $-4,4$ & $-3,7$ & $-3,8$ & $-3,8$ & $-4,7$ & $-4,1$ & $-4,7$ \\
\hline \multirow[t]{3}{*}{ Total } & $\mathrm{DM}$ & $-12,86$ & 5,44 & $-16,48$ & $-0,58$ & 1,10 & 3,93 & $-2,15$ & - \\
\hline & DMA & 19,73 & 15,92 & 19,57 & 14,22 & 15,80 & 14,14 & 14,72 & - \\
\hline & PDMA & 12,21 & 19,31 & 14,17 & 9,04 & 10,94 & 19,07 & 10,04 & - \\
\hline \multirow[t]{3}{*}{ CPI } & $\mathrm{DM}$ & $-35,23$ & 8,85 & $-40,53$ & $-2,75$ & 1,64 & 3,82 & $-7,76$ & - \\
\hline & DMA & 41,15 & 32,43 & 41,91 & 29,11 & 32,60 & 27,36 & 30,44 & - \\
\hline & PDMA & 14,76 & 28,89 & 22,32 & 12,01 & 16,08 & 26,25 & 15,01 & - \\
\hline \multirow[t]{3}{*}{ SPI } & $\mathrm{DM}$ & 3,55 & 2,95 & 1,15 & 1,00 & 0,71 & 4,02 & 1,97 & - \\
\hline & DMA & 4,03 & 3,81 & 3,19 & 3,29 & 3,47 & 4,45 & 3,20 & - \\
\hline & PDMA & 10,35 & 12,29 & 8,19 & 6,85 & 7,18 & 13,80 & 6,39 & - \\
\hline \multirow[t]{3}{*}{$\Delta \mathrm{CS}$} & DM & $-38,77$ & 5,90 & $-41,68$ & $-3,75$ & 0,92 & $-0,20$ & $-9,73$ & - \\
\hline & DMA & 37,13 & 28,61 & 38,72 & 25,82 & 29,13 & 22,91 & 27,24 & - \\
\hline & PDMA & 4,41 & 16,59 & 14,13 & 5,16 & 8,91 & 12,45 & 8,62 & - \\
\hline
\end{tabular}


Tabela 8.31: Constantes de acoplamento PBE0 com correção vibracional na base aug-pcJ-2.

\begin{tabular}{|c|c|c|c|c|c|c|c|c|}
\hline & $\% E_{X}^{\mathrm{HF}}$ & 25,00 & 25,00 & 40,00 & 40,00 & $\begin{array}{c}25,00 / \\
40,00\end{array}$ & 40,00 & - \\
\hline & Geom. & Exp. & Otm. & Exp. & Otm. & Otm. & Correção & Exp. \\
\hline $\mathrm{HF}$ & ${ }^{1} J_{\mathrm{HF}}$ & 430,8 & 427,7 & 464,3 & 482,0 & 461,3 & 447,9 & 500 \\
\hline $\mathrm{CO}$ & ${ }^{1} J_{\mathrm{CO}}$ & 19,9 & 18,4 & 17,3 & 13,8 & 15,7 & 14,6 & 16,4 \\
\hline $\mathrm{H}_{2} \mathrm{O}$ & ${ }^{1} J_{\mathrm{OH}}$ & $-73,0$ & $-73,5$ & $-76,6$ & $-79,6$ & $-77,0$ & $-78,3$ & $-80,6$ \\
\hline $\mathrm{H}_{2} \mathrm{O}$ & ${ }^{2} J_{\mathrm{HH}}$ & $-7,3$ & $-6,9$ & $-8,9$ & $-8,1$ & $-8,5$ & $-6,7$ & $-7,3$ \\
\hline $\mathrm{NH}_{3}$ & ${ }^{1} J_{\mathrm{NH}}$ & 42,5 & 43,0 & 43,6 & 44,8 & 44,1 & 45,4 & 43,8 \\
\hline $\mathrm{NH}_{3}$ & ${ }^{2} J_{\mathrm{HH}}$ & $-10,1$ & $-9,8$ & $-11,5$ & $-11,0$ & $-11,3$ & $-10,2$ & $-9,6$ \\
\hline $\mathrm{PH}_{3}$ & ${ }^{1} J_{\mathrm{PH}}$ & 154,6 & 161,3 & 166,9 & 178,0 & 173,2 & 170,9 & 188,2 \\
\hline $\mathrm{PF}_{3}$ & ${ }^{1} J_{\mathrm{PF}}$ & $-1732,1$ & $-1627,0$ & $-1679,4$ & $-1581,4$ & $-1583,9$ & $-1582,2$ & -1441 \\
\hline $\mathrm{BHF}_{2}$ & ${ }^{1} J_{\mathrm{BF}}$ & $-131,0$ & $-130,8$ & $-106,5$ & $-97,7$ & $-106,3$ & $-102,3$ & -84 \\
\hline $\mathrm{BF}_{3}$ & ${ }^{1} J_{\mathrm{BF}}$ & $-30,5$ & $-33,5$ & $-4,2$ & 3,6 & $-7,0$ & 1,6 & 15 \\
\hline $\mathrm{F}_{2} \mathrm{O}$ & ${ }^{1} J_{\mathrm{OF}}$ & $-374,9$ & $-251,0$ & $-440,5$ & $-222,0$ & $-297,4$ & $-237,3$ & -300 \\
\hline $\mathrm{CH}_{4}$ & ${ }^{1} J_{\mathrm{CH}}$ & 122,8 & 123,0 & 125,0 & 124,5 & 125,2 & 127,2 & 125,3 \\
\hline $\mathrm{CH}_{4}$ & ${ }^{2} J_{\mathrm{HH}}$ & $-13,8$ & $-13,7$ & $-15,0$ & $-15,0$ & $-15,0$ & $-15,4$ & $-12,8$ \\
\hline $\mathrm{C}_{2} \mathrm{H}_{2}$ & ${ }^{1} J_{\mathrm{CC}}$ & 196,4 & 196,6 & 202,6 & 202,0 & 202,4 & 203,4 & 174,8 \\
\hline $\mathrm{C}_{2} \mathrm{H}_{2}$ & ${ }^{1} J_{\mathrm{CH}}$ & 256,2 & 254,5 & 260,7 & 256,1 & 258,8 & 260,0 & 247,6 \\
\hline $\mathrm{C}_{2} \mathrm{H}_{2}$ & ${ }^{2} J_{\mathrm{CH}}$ & 53,5 & 53,7 & 52,2 & 52,8 & 52,6 & 53,2 & 50,1 \\
\hline $\mathrm{C}_{2} \mathrm{H}_{2}$ & ${ }^{3} J_{\mathrm{HH}}$ & 12,4 & 12,0 & 14,1 & 13,3 & 13,7 & 14,0 & 9,6 \\
\hline $\mathrm{C}_{2} \mathrm{H}_{4}$ & ${ }^{1} J_{\mathrm{CC}}$ & 68,7 & 71,3 & 74,4 & 76,2 & 76,5 & 77,4 & 67,6 \\
\hline $\mathrm{C}_{2} \mathrm{H}_{4}$ & ${ }^{1} J_{\mathrm{CH}}$ & 157,3 & 154,6 & 161,1 & 156,9 & 158,1 & 159,3 & 156,3 \\
\hline $\mathrm{C}_{2} \mathrm{H}_{4}$ & ${ }^{2} J_{\mathrm{CH}}$ & $-3,0$ & $-2,7$ & $-5,1$ & $-4,5$ & $-4,6$ & $-5,1$ & $-2,4$ \\
\hline $\mathrm{C}_{2} \mathrm{H}_{4}$ & ${ }^{2} J_{\mathrm{HH}}$ & 2,3 & 1,2 & 0,7 & $-0,3$ & $-0,2$ & $-0,1$ & 2,3 \\
\hline $\mathrm{C}_{2} \mathrm{H}_{4}$ & ${ }^{3} J_{\mathrm{HH}_{\mathrm{c}}}$ & 12,7 & 13,4 & 13,6 & 14,3 & 14,2 & 14,8 & 11,7 \\
\hline $\mathrm{C}_{2} \mathrm{H}_{4}$ & ${ }^{3} J_{\mathrm{HH}_{\mathrm{t}}}$ & 19,8 & 20,4 & 20,9 & 21,2 & 21,4 & 22,0 & 19 \\
\hline $\mathrm{C}_{2} \mathrm{H}_{6}$ & ${ }^{1} J_{\mathrm{CC}}{ }^{\tau}$ & 30,4 & 32,6 & 33,3 & 35,3 & 35,5 & 36,3 & 34,5 \\
\hline $\mathrm{C}_{2} \mathrm{H}_{6}$ & ${ }^{1} J_{\mathrm{CH}}$ & 123,5 & 122,0 & 126,0 & 123,8 & 124,5 & 125,9 & 125,2 \\
\hline $\mathrm{C}_{2} \mathrm{H}_{6}$ & ${ }^{2} J_{\mathrm{CH}}$ & $-4,1$ & $-4,1$ & $-4,9$ & $-4,9$ & $-4,9$ & $-5,2$ & $-4,7$ \\
\hline \multirow[t]{3}{*}{ Total } & DM & $-20,04$ & $-11,24$ & $-16,19$ & $-2,73$ & $-7,07$ & $-4,38$ & - \\
\hline & DMA & 24,04 & 18,98 & 21,47 & 13,26 & 12,34 & 15,08 & - \\
\hline & PDMA & 23,18 & 24,36 & 23,41 & 19,92 & 22,50 & 22,34 & - \\
\hline \multirow[t]{3}{*}{ CPI } & $\mathrm{DM}$ & $-50,18$ & $-29,36$ & $-43,31$ & $-10,77$ & $-21,64$ & $-16,15$ & - \\
\hline & DMA & 52,20 & 40,00 & 44,20 & 25,32 & 22,82 & 28,37 & - \\
\hline & PDMA & 43,19 & 42,49 & 26,29 & 16,54 & 22,12 & 17,66 & - \\
\hline \multirow[t]{3}{*}{ SPI } & $\mathrm{DM}$ & 2,07 & 2,05 & 3,70 & 3,17 & 3,61 & 4,26 & - \\
\hline & DMA & 3,39 & 3,57 & 4,79 & 4,41 & 4,66 & 5,34 & - \\
\hline & PDMA & 8,51 & 11,06 & 21,30 & 22,39 & 22,78 & 25,78 & - \\
\hline \multirow[t]{3}{*}{$\Delta \mathrm{CS}$} & $\mathrm{DM}$ & $-52,25$ & $-31,41$ & $-47,01$ & $-13,95$ & $-25,24$ & $-20,41$ & - \\
\hline & DMA & 48,81 & 36,43 & 39,41 & 20,90 & 18,16 & 23,02 & - \\
\hline & PDMA & 34,68 & 31,43 & 4,99 & $-5,85$ & $-0,66$ & $-8,11$ & - \\
\hline
\end{tabular}

Tabela 8.32: Constantes de acoplamento empíricas obtidas com as correções vibracionais de BHandH e PBE0 na base aug-pcJ-2.

\begin{tabular}{|c|c|c|c|c|c|}
\hline & & Exp. & $\begin{array}{l}\text { Emp. } \\
\text { BHH }\end{array}$ & $\begin{array}{l}\text { Emp. } \\
\text { BHH }\end{array}$ & $\begin{array}{l}\text { Emp. } \\
\text { PBE0 }\end{array}$ \\
\hline & $\% E_{X}^{\mathrm{HF}}$ & 一 & $50,00 \%$ & $40,00 \%$ & $40,00 \%$ \\
\hline $\mathrm{HF}$ & ${ }^{1} J_{\mathrm{HF}}$ & 500 & 532,8 & 533,2 & 534,8 \\
\hline $\mathrm{CO}$ & ${ }^{1} J_{\mathrm{CO}}$ & 16,4 & 15,7 & 15,6 & 15,7 \\
\hline $\mathrm{H}_{2} \mathrm{O}$ & ${ }^{1} J_{\mathrm{OH}}$ & $-80,6$ & $-81,7$ & $-81,8$ & $-82,0$ \\
\hline $\mathrm{H}_{2} \mathrm{O}$ & ${ }^{2} J_{\mathrm{HH}}$ & $-7,3$ & $-8,8$ & $-8,7$ & $-8,8$ \\
\hline $\mathrm{NH}_{3}$ & ${ }^{1} J_{\mathrm{NH}}$ & 43,8 & 43,0 & 43,1 & 43,3 \\
\hline $\mathrm{NH}_{3}$ & ${ }^{2} J_{\mathrm{HH}}$ & $-9,6$ & $-10,5$ & $-10,5$ & $-10,4$ \\
\hline $\mathrm{PH}_{3}$ & ${ }^{1} J_{\mathrm{PH}}$ & 188,2 & 195,0 & 195,5 & 195,7 \\
\hline $\mathrm{PF}_{3}$ & ${ }^{1} J_{\mathrm{PF}}$ & -1441 & $-1.441,7$ & $-1.442,8$ & $-1.443,2$ \\
\hline $\mathrm{BHF}_{2}$ & ${ }^{1} J_{\mathrm{BF}}$ & -84 & $-79,7$ & $-79,5$ & $-79,6$ \\
\hline $\mathrm{BF}_{3}$ & ${ }^{1} J_{\mathrm{BF}}$ & 15 & 17,1 & 17,2 & 17,2 \\
\hline $\mathrm{F}_{2} \mathrm{O}$ & ${ }^{1} J_{\mathrm{OF}}$ & -300 & $-285,7$ & $-286,9$ & $-284,7$ \\
\hline $\mathrm{CH}_{4}$ & ${ }^{1} J_{\mathrm{CH}}$ & 125,3 & 122,8 & 123,0 & 122,9 \\
\hline $\mathrm{CH}_{4}$ & ${ }^{2} J_{\mathrm{HH}}$ & $-12,8$ & $-12,5$ & $-12,5$ & $-12,5$ \\
\hline $\mathrm{C}_{2} \mathrm{H}_{2}$ & ${ }^{1} J_{\mathrm{CC}}$ & 174,8 & 174,1 & 174,4 & 173,9 \\
\hline $\mathrm{C}_{2} \mathrm{H}_{2}$ & ${ }^{1} J_{\mathrm{CH}}$ & 247,6 & 244,3 & 244,5 & 244,4 \\
\hline $\mathrm{C}_{2} \mathrm{H}_{2}$ & ${ }^{2} J_{\mathrm{CH}}$ & 50,1 & 49,8 & 49,7 & 49,9 \\
\hline $\mathrm{C}_{2} \mathrm{H}_{2}$ & ${ }^{3} J_{\mathrm{HH}}$ & 9,6 & 9,0 & 9,1 & 8,9 \\
\hline $\mathrm{C}_{2} \mathrm{H}_{4}$ & ${ }^{1} J_{\mathrm{CC}}$ & 67,6 & 66,9 & 67,2 & 66,6 \\
\hline $\mathrm{C}_{2} \mathrm{H}_{4}$ & ${ }^{1} J_{\mathrm{CH}}$ & 156,3 & 154,4 & 154,5 & 154,3 \\
\hline $\mathrm{C}_{2} \mathrm{H}_{4}$ & ${ }^{2} J_{\mathrm{CH}}$ & $-2,4$ & $-2,0$ & $-2,1$ & $-1,9$ \\
\hline $\mathrm{C}_{2} \mathrm{H}_{4}$ & ${ }^{2} J_{\mathrm{HH}}$ & 2,3 & 2,1 & 2,0 & 2,1 \\
\hline $\mathrm{C}_{2} \mathrm{H}_{4}$ & ${ }^{3} J_{\mathrm{HH}_{\mathrm{c}}}$ & 11,7 & 11,4 & 11,4 & 11,3 \\
\hline $\mathrm{C}_{2} \mathrm{H}_{4}$ & ${ }^{3} J_{\mathrm{HH}_{\mathrm{t}}}$ & 19 & 18,4 & 18,5 & 18,3 \\
\hline $\mathrm{C}_{2} \mathrm{H}_{6}$ & ${ }^{1} J_{\mathrm{CC}}$ & 34,5 & 33,6 & 33,7 & 33,6 \\
\hline $\mathrm{C}_{2} \mathrm{H}_{6}$ & ${ }^{1} J_{\mathrm{CH}}$ & 125,2 & 123,3 & 123,4 & 123,4 \\
\hline $\mathrm{C}_{2} \mathrm{H}_{6}$ & ${ }^{2} J_{\mathrm{CH}}$ & $-4,7$ & $-4,5$ & $-4,5$ & $-4,5$ \\
\hline
\end{tabular}




\subsubsection{Correções vibracionais das CAISS calculadas}

\subsubsection{Precisão dos funcionais da literatura}

Tabela 8.33: Constantes de acoplamento utilizando funcionais da literatura (0 a $21 \% E_{X}^{\mathrm{HF}}$ ) com correção vibracional no nível BHandH $\left(50 \% E_{X}^{\mathrm{HF}}\right)$ e base aug-pcJ-2.

\begin{tabular}{|c|c|c|c|c|c|c|c|c|c|c|c|c|c|c|c|}
\hline & $\begin{array}{l}\text { Func. } \\
\sigma F^{\mathrm{HF}}\end{array}$ & PBE & PW91 & BP86 & $\omega \mathrm{B} 97$ & TPSSh & O3LYP & $\omega \mathrm{B} 97 \mathrm{X}$ & CAMB3 & B3P86 & B3LYP & B3W91 & B971 & B972 & Exp. \\
\hline & & & & 0,00 & 0,00 & 10,00 & 11,61 & 15,77 & 19,00 & 20,00 & 20,00 & 20,00 & 21,00 & & \\
\hline $\mathrm{HF}$ & ${ }^{1} J_{\mathrm{HF}}$ & 343,2 & 331,4 & 322,5 & 422,8 & 357,8 & 363,6 & 465,1 & 422,8 & 374,5 & 412,6 & 376,1 & 416,3 & 410,0 & 500 \\
\hline $\mathrm{CO}$ & ${ }^{1} J_{\mathrm{CO}}$ & 24,8 & 25,6 & 25,6 & 24,6 & 21,0 & 22,6 & 19,8 & 19,0 & 22,3 & 18,9 & 22,3 & 18,1 & 19,0 & 16,4 \\
\hline $\mathrm{H}_{2} \mathrm{O}$ & ${ }^{1} J_{\mathrm{OH}}$ & $-66,1$ & $-65,2$ & $-63,7$ & $-70,7$ & $-71,4$ & $-68,3$ & $-75,4$ & $-76,6$ & $-69,0$ & $-75,7$ & $-69,5$ & $-73,3$ & $-72,4$ & $-80,6$ \\
\hline $\mathrm{H}_{2} \mathrm{O}$ & ${ }^{2} J_{\mathrm{HH}}$ & $-3,2$ & $-3,3$ & $-3,1$ & $-5,1$ & $-3,8$ & $-6,5$ & $-4,9$ & $-5,9$ & $-4,8$ & $-5,7$ & $-5,3$ & $-5,0$ & $-6,0$ & $-7,3$ \\
\hline $\mathrm{NH}_{3}$ & ${ }^{1} J_{\mathrm{NH}}$ & 41,6 & 41,6 & 40,8 & 39,8 & 46,6 & 41,9 & 42,3 & 46,0 & 42,2 & 46,1 & 42,5 & 44,1 & 42,5 & 43,8 \\
\hline $\mathrm{NH}_{3}$ & ${ }^{2} J_{\mathrm{HH}}$ & $-6,9$ & $-7,1$ & $-6,9$ & $-7,6$ & $-7,2$ & $-9,2$ & $-7,8$ & $-9,3$ & $-8,4$ & $-9,0$ & $-8,9$ & $-8,2$ & $-8,2$ & $-9,6$ \\
\hline $\mathrm{PH}_{3}$ & ${ }^{1} J_{\mathrm{PH}}$ & 126,9 & 130,8 & 130,1 & 152,5 & 193,7 & 158,7 & 158,2 & 155,5 & 145,5 & 165,1 & 147,8 & 183,9 & 177,2 & 188,2 \\
\hline $\mathrm{PF}_{3}$ & ${ }^{1} J_{\mathrm{PF}}$ & $-1800,3$ & $-1814,5$ & $-1801,8$ & $-1662,3$ & $-1731,0$ & $-1687,1$ & $-1642,3$ & $-1748,4$ & $-1748,7$ & $-1755,2$ & $-1750,7$ & $-1656,0$ & $-1660,5$ & -1441 \\
\hline $\mathrm{BHF}_{2}$ & ${ }^{1} J_{\mathrm{BF}}$ & $-177,1$ & $-181,9$ & $-182,2$ & $-116,1$ & $-146,8$ & $-161,7$ & $-101,8$ & $-130,0$ & $-147,5$ & $-138,8$ & $-146,9$ & $-128,1$ & $-134,2$ & -84 \\
\hline $\mathrm{BF}_{3}$ & ${ }^{1} J_{\mathrm{BF}}$ & $-77,9$ & $-83,0$ & $-85,4$ & $-16,9$ & $-49,3$ & $-65,8$ & 1,2 & $-24,5$ & $-47,3$ & $-35,3$ & $-46,6$ & $-30,0$ & $-38,7$ & 15 \\
\hline $\mathrm{F}_{2} \mathrm{O}$ & ${ }^{1} J_{\mathrm{OF}}$ & $-292,3$ & $-304,8$ & $-304,4$ & $-325,0$ & $-334,4$ & $-311,6$ & $-340,8$ & $-400,9$ & $-374,9$ & $-366,3$ & $-377,2$ & $-333,1$ & $-330,3$ & -300 \\
\hline $\mathrm{CH}_{4}$ & ${ }^{1} J_{\mathrm{CH}}$ & 121,8 & 122,6 & 120,0 & 111,9 & 141,3 & 122,0 & 115,0 & 131,4 & 122,5 & 134,2 & 123,5 & 131,3 & 121,3 & 125,3 \\
\hline $\mathrm{CH}_{4}$ & ${ }^{2} J_{\mathrm{HH}}$ & $-12,1$ & $-12,3$ & $-12,1$ & $-11,5$ & $-11,6$ & $-13,5$ & $-11,6$ & $-13,5$ & $-13,2$ & $-13,3$ & $-13,7$ & $-12,3$ & $-11,6$ & $-12,8$ \\
\hline $\mathrm{C}_{2} \mathrm{H}_{2}$ & ${ }^{1} J_{\mathrm{CC}}$ & 189,4 & 189,5 & 188,0 & 194,9 & 191,5 & 192,2 & 193,7 & 202,7 & 194,1 & 204,0 & 194,5 & 214,5 & 198,2 & 174,8 \\
\hline $\mathrm{C}_{2} \mathrm{H}_{2}$ & ${ }^{1} J_{\mathrm{CH}}$ & 253,1 & 255,8 & 250,7 & 239,6 & 285,6 & 257,8 & 243,5 & 270,2 & 255,2 & 275,1 & 257,3 & 264,6 & 250,6 & 247,6 \\
\hline $\mathrm{C}_{2} \mathrm{H}_{2}$ & ${ }^{2} J_{\mathrm{CH}}$ & 54,4 & 54,9 & 54,9 & 52,1 & 58,0 & 52,9 & 53,7 & 57,3 & 54,3 & 56,4 & 54,3 & 53,5 & 51,0 & 50,1 \\
\hline $\mathrm{C}_{2} \mathrm{H}_{2}$ & ${ }^{3} J_{\mathrm{HH}}$ & 11,0 & 11,1 & 10,8 & 11,0 & 13,2 & 12,4 & 10,6 & 11,7 & 11,8 & 11,7 & 12,3 & 11,1 & 11,0 & 9,6 \\
\hline $\mathrm{C}_{2} \mathrm{H}_{4}$ & ${ }^{1} J_{\mathrm{CC}}$ & 62,0 & 61,3 & 60,2 & 66,3 & 72,2 & 64,6 & 65,2 & 71,3 & 65,4 & 71,7 & 66,0 & 78,8 & 68,8 & 67,6 \\
\hline $\mathrm{C}_{2} \mathrm{H}_{4}$ & ${ }^{1} J_{\mathrm{CH}}$ & 153,7 & 154,9 & 151,6 & 144,6 & 176,2 & 156,3 & 147,3 & 166,3 & 155,6 & 169,0 & 157,0 & 164,7 & 154,2 & 156,3 \\
\hline $\mathrm{C}_{2} \mathrm{H}_{4}$ & ${ }^{2} J_{\mathrm{CH}}$ & $-0,9$ & $-0,8$ & $-0,4$ & $-2,6$ & $-2,1$ & $-2,3$ & $-1,7$ & $-2,1$ & $-2,0$ & $-1,8$ & $-2,4$ & $-2,5$ & $-2,4$ & $-2,4$ \\
\hline $\mathrm{C}_{2} \mathrm{H}_{4}$ & ${ }^{2} J_{\mathrm{HH}}$ & 4,7 & 4,7 & 4,8 & 2,5 & 8,4 & 3,0 & 3,1 & 4,2 & 3,4 & 4,7 & 3,0 & 3,8 & 3,3 & 2,3 \\
\hline $\mathrm{C}_{2} \mathrm{H}_{4}$ & ${ }^{3} J_{\mathrm{HH}_{\mathrm{c}}}$ & 12,0 & 12,2 & 11,9 & 11,8 & 12,8 & 12,6 & 11,8 & 13,6 & 12,4 & 13,1 & 12,7 & 12,0 & 11,5 & 11,7 \\
\hline $\mathrm{C}_{2} \mathrm{H}_{4}$ & ${ }^{3} J_{\mathrm{HH}_{\mathrm{t}}}$ & 19,3 & 19,6 & 19,1 & 17,6 & 23,1 & 19,9 & 17,8 & 20,6 & 19,6 & 20,6 & 20,0 & 19,0 & 18,3 & 19 \\
\hline $\mathrm{C}_{2} \mathrm{H}_{6}$ & ${ }^{1} J_{\mathrm{CC}}$ & 26,6 & 26,0 & 25,1 & 29,4 & 35,3 & 28,4 & 30,0 & 33,4 & 28,9 & 33,3 & 29,2 & 35,8 & 31,5 & 34,5 \\
\hline $\mathrm{C}_{2} \mathrm{H}_{6}$ & ${ }^{1} J_{\mathrm{CH}}$ & 121,4 & 122,2 & 119,5 & 110,9 & 140,8 & 121,8 & 114,3 & 131,0 & 122,5 & 133,6 & 123,5 & 131,0 & 120,8 & 125,2 \\
\hline $\mathrm{C}_{2} \mathrm{H}_{6}$ & ${ }^{2} J_{\mathrm{CH}}$ & $-3,1$ & $-3,1$ & $-2,9$ & $-3,4$ & $-4,0$ & $-3,8$ & $-3,4$ & $-3,8$ & $-3,7$ & $-3,6$ & $-3,9$ & $-3,8$ & $-3,4$ & $-4,7$ \\
\hline \multirow[t]{3}{*}{ Total } & DM & $-27,65$ & $-29,11$ & $-29,70$ & $-16,69$ & $-16,50$ & $-20,93$ & $-13,16$ & $-19,35$ & $-24,40$ & $-18,45$ & $-24,16$ & $-12,11$ & $-16,29$ & - \\
\hline & DMA & 33,04 & 34,30 & 34,52 & 20,43 & 29,17 & 25,27 & 16,27 & 27,23 & 28,88 & 27,54 & 28,79 & 20,61 & 19,90 & - \\
\hline & PDMA & 48,58 & 50,59 & 52,60 & 22,08 & 43,98 & 35,21 & 16,29 & 26,32 & 32,83 & 30,76 & 31,05 & 24,84 & 25,53 & - \\
\hline \multirow[t]{3}{*}{ CPI } & $\mathrm{DM}$ & $-66,20$ & $-70,12$ & $-69,95$ & $-36,81$ & $-51,43$ & $-51,30$ & $-29,75$ & $-53,93$ & $-59,73$ & $-53,11$ & $-59,75$ & $-37,47$ & $-40,23$ & - \\
\hline & DMA & 73,00 & 75,77 & 75,95 & 40,86 & 56,52 & 54,88 & 32,08 & 55,84 & 63,58 & 55,27 & 63,34 & 39,84 & 42,68 & - \\
\hline & PDMA & 89,10 & 92,97 & 95,34 & 39,22 & 62,29 & 69,78 & 22,36 & 41,27 & 62,35 & 48,09 & 60,58 & 42,15 & 48,03 & - \\
\hline \multirow[t]{3}{*}{ SPI } & $\mathrm{DM}$ & 0,61 & 0,97 & $-0,19$ & $-1,93$ & 9,11 & 1,35 & $-0,99$ & 6,01 & 1,51 & 6,97 & 1,95 & 6,49 & 1,27 & - \\
\hline & DMA & 3,73 & 3,89 & 4,14 & 5,45 & 9,11 & 3,55 & 4,67 & 6,25 & 3,43 & 7,20 & 3,45 & 6,51 & 3,19 & - \\
\hline & PDMA & 18,86 & 19,52 & 21,26 & 9,51 & 30,55 & 9,86 & 11,83 & 15,35 & 11,18 & 18,05 & 9,40 & 12,14 & 9,03 & - \\
\hline \multirow[t]{3}{*}{$\Delta \mathrm{CS}$} & $\mathrm{DM}$ & $-66,81$ & $-71,08$ & $-69,75$ & $-34,88$ & $-60,53$ & $-52,65$ & $-28,77$ & $-59,94$ & $-61,24$ & $-60,08$ & $-61,70$ & $-43,97$ & $-41,49$ & - \\
\hline & DMA & 69,27 & 71,89 & 71,81 & 35,41 & 47,41 & 51,34 & 27,42 & 49,58 & 60,15 & 48,07 & 59,88 & 33,33 & 39,50 & - \\
\hline & PDMA & 70,24 & 73,46 & 74,08 & 29,70 & 31,74 & 59,92 & 10,52 & 25,92 & 51,16 & 30,04 & 51,19 & 30,01 & 39,00 & - \\
\hline
\end{tabular}


Tabela 8.34: Constantes de acoplamento utilizando funcionais da literatura (21 a 100\% $\left.E_{X}^{\mathrm{HF}}\right)$ com correção vibracional no nível BHandH $\left(50 \% E_{X}^{\mathrm{HF}}\right)$ e base aug-pcJ-2.

\begin{tabular}{|c|c|c|c|c|c|c|c|c|c|c|c|c|c|c|c|}
\hline & Func. & X3LYP & B98 & $\omega 97 \mathrm{XD}$ & PBE0 & M06 & B1B95 & M05 & BMK & $\mathrm{BHH}$ & BHLYP & M062X & M052X & M06HF & Exp. \\
\hline & $\% E_{X}^{\mathrm{HF}}$ & 21,80 & 21,98 & 22,20 & 25,00 & 27,00 & 28,00 & 28,00 & 42,00 & 50,00 & 50,00 & 54,00 & 56,00 & 100,00 & - \\
\hline HF & ${ }^{1} J_{\mathrm{HF}}$ & 420,4 & 398,4 & 451,4 & 398,0 & 645,5 & 437,6 & 795,7 & 518,0 & 498,0 & 494,0 & 452,8 & 550,5 & 144,9 & 500 \\
\hline $\mathrm{CO}$ & ${ }^{1} J_{\mathrm{CO}}$ & 18,4 & 19,2 & 20,3 & 20,6 & 18,6 & 19,1 & 9,8 & 19,4 & 14,4 & 11,6 & 8,1 & 4,6 & 5,1 & 16,4 \\
\hline $\mathrm{H}_{2} \mathrm{O}$ & ${ }^{1} J_{\mathrm{OH}}$ & $-76,7$ & $-71,4$ & $-73,6$ & $-71,9$ & $-99,5$ & $-76,2$ & $-107,2$ & $-85,8$ & $-82,6$ & $-85,4$ & $-90,5$ & $-88,2$ & $-53,7$ & $-80,6$ \\
\hline $\mathrm{H}_{2} \mathrm{O}$ & ${ }^{2} J_{\mathrm{HH}}$ & $-6,0$ & $-5,4$ & $-4,9$ & $-5,8$ & $-15,3$ & $-5,5$ & $-17,1$ & $-5,2$ & $-7,9$ & $-9,7$ & $-5,6$ & $-3,1$ & 10,3 & $-7,3$ \\
\hline $\mathrm{NH}_{3}$ & ${ }^{1} J_{\mathrm{NH}}$ & 46,6 & 43,7 & 42,7 & 43,3 & 53,2 & 44,8 & 45,1 & 48,6 & 46,3 & 49,8 & 54,0 & 44,6 & 38,5 & 43,8 \\
\hline $\mathrm{NH}_{3}$ & ${ }^{2} J_{\mathrm{HH}}$ & $-9,3$ & $-8,6$ & $-8,1$ & $-9,2$ & $-17,1$ & $-8,4$ & $-14,9$ & $-9,3$ & $-10,2$ & $-12,6$ & $-10,1$ & $-5,4$ & $-4,5$ & $-9,6$ \\
\hline $\mathrm{PH}_{3}$ & ${ }^{1} J_{\mathrm{PH}}$ & 167,5 & 189,6 & 169,9 & 147,8 & 240,7 & 161,0 & 165,0 & 131,1 & 176,3 & 194,5 & 160,1 & 111,5 & 152,5 & 188,2 \\
\hline $\mathrm{PF}_{3}$ & ${ }^{1} J_{\mathrm{PF}}$ & $-1752,3$ & $-1665,7$ & $-1637,1$ & $-1731,4$ & $-1526,2$ & $-1644,8$ & $-1388,3$ & $-1645,4$ & $-1669,7$ & $-1650,8$ & $-1625,0$ & $-1704,7$ & $-1875,9$ & -1441 \\
\hline $\mathrm{BHF}_{2}$ & ${ }^{1} J_{\mathrm{BF}}$ & $-135,8$ & $-133,4$ & $-107,4$ & $-135,3$ & $-40,4$ & $-131,9$ & 16,5 & $-108,3$ & $-99,5$ & $-86,2$ & $-120,8$ & $-109,5$ & $-279,3$ & -84 \\
\hline $\mathrm{BF}_{3}$ & ${ }^{1} J_{\mathrm{BF}}$ & $-31,2$ & $-36,2$ & $-5,1$ & $-32,6$ & 62,8 & $-29,1$ & 125,0 & 3,0 & 13,0 & 22,2 & $-22,1$ & $-5,6$ & $-198,8$ & 15 \\
\hline $\mathrm{F}_{2} \mathrm{O}$ & ${ }^{1} J_{\mathrm{OF}}$ & $-373,7$ & $-351,2$ & $-347,7$ & $-389,2$ & $-322,7$ & $-376,2$ & $-317,2$ & $-391,6$ & $-479,3$ & $-502,3$ & $-443,5$ & $-535,1$ & $-1517,8$ & -300 \\
\hline $\mathrm{CH}_{4}$ & ${ }^{1} J_{\mathrm{CH}}$ & 135,4 & 130,8 & 117,2 & 125,3 & 142,1 & 126,9 & 101,0 & 161,7 & 127,4 & 143,2 & 146,2 & 117,8 & 70,0 & 125,3 \\
\hline $\mathrm{CH}_{4}$ & ${ }^{2} J_{\mathrm{HH}}$ & $-13,5$ & $-12,8$ & $-12,1$ & $-14,1$ & $-26,2$ & $-12,5$ & $-21,5$ & $-14,6$ & $-13,6$ & $-16,3$ & $-12,4$ & $-6,9$ & $-15,8$ & $-12,8$ \\
\hline $\mathrm{C}_{2} \mathrm{H}_{2}$ & ${ }^{1} J_{\mathrm{CC}}$ & 205,1 & 213,6 & 192,0 & 197,1 & 194,3 & 195,9 & 210,4 & 343,4 & 203,1 & 220,8 & 228,5 & 225,4 & 252,0 & 174,8 \\
\hline $\mathrm{C}_{2} \mathrm{H}_{2}$ & ${ }^{1} J_{\mathrm{CH}}$ & 277,1 & 264,4 & 248,9 & 259,5 & 302,8 & 259,5 & 251,1 & 299,3 & 262,8 & 291,8 & 273,5 & 212,0 & 93,9 & 247,6 \\
\hline $\mathrm{C}_{2} \mathrm{H}_{2}$ & ${ }^{2} J_{\mathrm{CH}}$ & 56,5 & 53,1 & 54,0 & 53,8 & 50,6 & 55,9 & 36,8 & 62,3 & 53,3 & 54,4 & 57,2 & 49,9 & 45,6 & 50,1 \\
\hline $\mathrm{C}_{2} \mathrm{H}_{2}$ & ${ }^{3} J_{\mathrm{HH}}$ & 11,8 & 11,3 & 10,7 & 13,0 & 17,7 & 11,0 & 21,2 & 12,6 & 12,4 & 15,4 & 9,9 & 8,0 & 5,8 & 9,6 \\
\hline $\mathrm{C}_{2} \mathrm{H}_{4}$ & ${ }^{1} J_{\mathrm{CC}}$ & 72,7 & 78,0 & 64,4 & 69,4 & 65,5 & 66,7 & 77,1 & 128,0 & 73,0 & 86,7 & 91,9 & 85,8 & 86,6 & 67,6 \\
\hline $\mathrm{C}_{2} \mathrm{H}_{4}$ & ${ }^{1} J_{\mathrm{CH}}$ & 170,5 & 164,4 & 150,0 & 159,2 & 185,6 & 160,7 & 143,5 & 197,5 & 162,5 & 182,0 & 179,5 & 143,7 & $-59,4$ & 156,3 \\
\hline $\mathrm{C}_{2} \mathrm{H}_{4}$ & ${ }^{2} J_{\mathrm{CH}}$ & $-2,0$ & $-2,8$ & $-1,4$ & $-3,4$ & $-6,8$ & $-1,5$ & $-14,3$ & $-5,1$ & $-4,2$ & $-6,4$ & $-2,9$ & $-2,0$ & 12,6 & $-2,4$ \\
\hline $\mathrm{C}_{2} \mathrm{H}_{4}$ & ${ }^{2} J_{\mathrm{HH}}$ & 4,6 & 3,3 & 3,2 & 2,5 & $-13,2$ & 4,4 & $-14,4$ & 5,4 & 2,4 & 1,8 & 3,9 & 6,3 & 4,3 & 2,3 \\
\hline $\mathrm{C}_{2} \mathrm{H}_{4}$ & ${ }^{3} J_{\mathrm{HH}_{\mathrm{c}}}$ & 13,3 & 12,1 & 11,8 & 13,0 & 17,4 & 12,4 & 16,5 & 13,8 & 13,6 & 15,2 & 13,2 & 9,8 & 4,8 & 11,7 \\
\hline $\mathrm{C}_{2} \mathrm{H}_{4}$ & ${ }^{3} J_{\mathrm{HH}_{\mathrm{t}}}$ & 20,8 & 19,1 & 18,1 & 20,4 & 22,2 & 19,6 & 19,8 & 21,7 & 20,2 & 23,3 & 19,4 & 15,5 & 6,4 & 19 \\
\hline $\mathrm{C}_{2} \mathrm{H}_{6}$ & ${ }^{1} J_{\mathrm{CC}}{ }^{2}$ & 34,0 & 35,3 & 29,9 & 31,3 & 30,3 & 31,5 & 25,7 & 49,6 & 34,2 & 41,5 & 49,8 & 41,8 & 47,7 & 34,5 \\
\hline $\mathrm{C}_{2} \mathrm{H}_{6}$ & ${ }^{1} J_{\mathrm{CH}}$ & 134,8 & 130,7 & 117,1 & 125,4 & 141,0 & 126,9 & 100,1 & 162,1 & 127,7 & 143,2 & 146,9 & 119,3 & 83,0 & 125,2 \\
\hline $\mathrm{C}_{2} \mathrm{H}_{6}$ & ${ }^{2} J_{\mathrm{CH}}$ & $-3,7$ & $-4,0$ & $-3,5$ & $-4,3$ & $-5,7$ & $-3,7$ & $-4,8$ & $-5,3$ & $-4,5$ & $-5,3$ & $-3,9$ & $-2,9$ & $-3,5$ & $-4,7$ \\
\hline \multirow[t]{3}{*}{ Total } & DM & $-17,68$ & $-14,21$ & $-13,24$ & $-21,64$ & 10,47 & $-15,42$ & 15,98 & 2,38 & $-14,46$ & $-8,79$ & $-11,03$ & $-21,61$ & $-107,30$ & - \\
\hline & DMA & 27,28 & 22,60 & 16,49 & 26,58 & 24,54 & 20,39 & 32,17 & 33,13 & 19,97 & 25,35 & 27,11 & 32,99 & 120,93 & - \\
\hline & PDMA & 28,94 & 26,24 & 18,32 & 26,70 & 73,64 & 26,88 & 107,43 & 36,63 & 12,91 & 28,39 & 30,92 & 36,02 & 150,61 & - \\
\hline \multirow[t]{3}{*}{ CPI } & $\mathrm{DM}$ & $-52,09$ & $-41,99$ & $-30,95$ & $-55,15$ & 14,43 & $-40,95$ & 42,86 & $-33,31$ & $-40,19$ & $-37,80$ & $-43,95$ & $-52,85$ & $-219,96$ & - \\
\hline & DMA & 53,96 & 44,95 & 33,65 & 57,84 & 40,30 & 42,97 & 58,99 & 38,44 & 40,65 & 41,35 & 46,12 & 63,70 & 228,98 & - \\
\hline & PDMA & 44,28 & 47,18 & 26,75 & 48,40 & 62,46 & 43,53 & 109,05 & 23,20 & 13,55 & 22,75 & 44,62 & 45,43 & 235,68 & - \\
\hline \multirow[t]{3}{*}{ SPI } & $\mathrm{DM}$ & 7,55 & 6,16 & $-0,25$ & 2,93 & 7,57 & 3,31 & $-3,73$ & 28,55 & 4,41 & 12,48 & 13,11 & 1,29 & $-24,67$ & - \\
\hline & DMA & 7,71 & 6,21 & 3,91 & 3,67 & 12,98 & 3,83 & 12,50 & 29,23 & 4,80 & 13,63 & 13,17 & 10,47 & 41,69 & - \\
\hline & PDMA & 17,69 & 10,89 & 12,14 & 10,79 & 81,84 & 14,67 & 106,24 & 46,48 & 12,45 & 32,53 & 20,87 & 29,12 & 88,22 & - \\
\hline \multirow[t]{3}{*}{$\Delta \mathrm{CS}$} & DM & $-59,64$ & $-48,15$ & $-30,70$ & $-58,08$ & 6,86 & $-44,26$ & 46,59 & $-61,86$ & $-44,60$ & $-50,28$ & $-57,06$ & $-54,14$ & $-195,29$ & - \\
\hline & DMA & 46,25 & 38,74 & 29,74 & 54,17 & 27,32 & 39,15 & 46,49 & 9,20 & 35,85 & 27,72 & 32,94 & 53,23 & 187,30 & - \\
\hline & PDMA & 26,60 & 36,30 & 14,62 & 37,61 & $-19,38$ & 28,86 & 2,81 & $-23,28$ & 1,09 & $-9,78$ & 23,74 & 16,30 & 147,47 & - \\
\hline
\end{tabular}


Tabela 8.35: Constantes de acoplamento utilizando funcionais da literatura ( 0 a $\left.21 \% E_{X}^{\mathrm{HF}}\right)$ com correção vibracional no nível BHandH $40 \% E_{X}^{\mathrm{HF}}$ e base aug-pcJ-2.

\begin{tabular}{|c|c|c|c|c|c|c|c|c|c|c|c|c|c|c|c|}
\hline & Func. & $\mathrm{PBE}$ & PW91 & BP86 & $\omega \mathrm{B} 97$ & TPSSh & O3LYP & $\omega \mathrm{B} 97 \mathrm{X}$ & CAMB3 & B3P86 & B3LYP & B3W91 & B971 & B972 & Exp. \\
\hline & $\% E_{X}^{\mathrm{HF}}$ & 0,00 & 0,00 & 0,00 & 0,00 & 10,00 & 11,61 & 15,77 & 19,00 & 20,00 & 20,00 & 20,00 & 21,00 & 21,00 & - \\
\hline $\mathrm{HF}$ & ${ }^{1} J_{\mathrm{HF}}$ & 342,8 & 331,0 & 322,1 & 422,4 & 357,4 & 363,2 & 464,7 & 422,4 & 374,1 & 412,2 & 375,7 & 415,9 & 409,6 & 500 \\
\hline $\mathrm{CO}$ & ${ }^{1} J_{\mathrm{CO}}$ & 24,9 & 25,7 & 25,7 & 24,7 & 21,1 & 22,7 & 19,9 & 19,1 & 22,4 & 19,0 & 22,4 & 18,2 & 19,1 & 16,4 \\
\hline $\mathrm{H}_{2} \mathrm{O}$ & ${ }^{1} J_{\mathrm{OH}}$ & $-66,0$ & $-65,1$ & $-63,6$ & $-70,6$ & $-71,3$ & $-68,2$ & $-75,3$ & $-76,5$ & $-68,9$ & $-75,6$ & $-69,4$ & $-73,2$ & $-72,3$ & $-80,6$ \\
\hline $\mathrm{H}_{2} \mathrm{O}$ & ${ }^{2} J_{\mathrm{HH}}$ & $-3,3$ & $-3,4$ & $-3,2$ & $-5,2$ & $-3,9$ & $-6,6$ & $-5,0$ & $-6,0$ & $-4,9$ & $-5,8$ & $-5,4$ & $-5,1$ & $-6,1$ & $-7,3$ \\
\hline $\mathrm{NH}_{3}$ & ${ }^{1} J_{\mathrm{NH}}$ & 41,5 & 41,5 & 40,7 & 39,7 & 46,5 & 41,8 & 42,2 & 45,9 & 42,1 & 46,0 & 42,4 & 44,0 & 42,4 & 43,8 \\
\hline $\mathrm{NH}_{3}$ & ${ }^{2} J_{\mathrm{HH}}$ & $-6,9$ & $-7,1$ & $-6,9$ & $-7,6$ & $-7,2$ & $-9,2$ & $-7,8$ & $-9,3$ & $-8,4$ & $-9,0$ & $-8,9$ & $-8,2$ & $-8,2$ & $-9,6$ \\
\hline $\mathrm{PH}_{3}$ & ${ }^{1} J_{\mathrm{PH}}$ & 126,4 & 130,3 & 129,6 & 152,0 & 193,2 & 158,2 & 157,7 & 155,0 & 145,0 & 164,6 & 147,3 & 183,4 & 176,7 & 188,2 \\
\hline $\mathrm{PF}_{3}$ & ${ }^{1} J_{\mathrm{PF}}$ & $-1799,2$ & $-1813,4$ & $-1800,7$ & $-1661,2$ & $-1729,9$ & $-1686,0$ & $-1641,2$ & $-1747,3$ & $-1747,6$ & $-1754,1$ & $-1749,6$ & $-1654,9$ & $-1659,4$ & -1441 \\
\hline $\mathrm{BHF}_{2}$ & ${ }^{1} J_{\mathrm{BF}}$ & $-177,3$ & $-182,1$ & $-182,4$ & $-116,3$ & $-147,0$ & $-161,9$ & $-102,0$ & $-130,2$ & $-147,7$ & $-139,0$ & $-147,1$ & $-128,3$ & $-134,4$ & -84 \\
\hline $\mathrm{BF}_{3}$ & ${ }^{1} J_{\mathrm{BF}}$ & $-78,0$ & $-83,1$ & $-85,5$ & $-17,0$ & $-49,4$ & $-65,9$ & 1,1 & $-24,6$ & $-47,4$ & $-35,4$ & $-46,7$ & $-30,1$ & $-38,8$ & 15 \\
\hline $\mathrm{F}_{2} \mathrm{O}$ & ${ }^{1} J_{\mathrm{OF}}$ & $-291,1$ & $-303,6$ & $-303,2$ & $-323,8$ & $-333,2$ & $-310,4$ & $-339,6$ & $-399,7$ & $-373,7$ & $-365,1$ & $-376,0$ & $-331,9$ & $-329,1$ & -300 \\
\hline $\mathrm{CH}_{4}$ & ${ }^{1} J_{\mathrm{CH}}$ & 121,6 & 122,4 & 119,8 & 111,7 & 141,1 & 121,8 & 114,8 & 131,2 & 122,3 & 134,0 & 123,3 & 131,1 & 121,1 & 125,3 \\
\hline $\mathrm{CH}_{4}$ & ${ }^{2} J_{\mathrm{HH}}$ & $-12,1$ & $-12,3$ & $-12,1$ & $-11,5$ & $-11,6$ & $-13,5$ & $-11,6$ & $-13,5$ & $-13,2$ & $-13,3$ & $-13,7$ & $-12,3$ & $-11,6$ & $-12,8$ \\
\hline $\mathrm{C}_{2} \mathrm{H}_{2}$ & ${ }^{1} J_{\mathrm{CC}}$ & 189,1 & 189,2 & 187,7 & 194,6 & 191,2 & 191,9 & 193,4 & 202,4 & 193,8 & 203,7 & 194,2 & 214,2 & 197,9 & 174,8 \\
\hline $\mathrm{C}_{2} \mathrm{H}_{2}$ & ${ }^{1} J_{\mathrm{CH}}$ & 252,9 & 255,6 & 250,5 & 239,4 & 285,4 & 257,6 & 243,3 & 270,0 & 255,0 & 274,9 & 257,1 & 264,4 & 250,4 & 247,6 \\
\hline $\mathrm{C}_{2} \mathrm{H}_{2}$ & ${ }^{2} J_{\mathrm{CH}}$ & 54,5 & 55,0 & 55,0 & 52,2 & 58,1 & 53,0 & 53,8 & 57,4 & 54,4 & 56,5 & 54,4 & 53,6 & 51,1 & 50,1 \\
\hline $\mathrm{C}_{2} \mathrm{H}_{2}$ & ${ }^{3} J_{\mathrm{HH}}$ & 10,9 & 11,0 & 10,7 & 10,9 & 13,1 & 12,3 & 10,5 & 11,6 & 11,7 & 11,6 & 12,2 & 11,0 & 10,9 & 9,6 \\
\hline $\mathrm{C}_{2} \mathrm{H}_{4}$ & ${ }^{1} J_{\mathrm{CC}}$ & 61,7 & 61,0 & 59,9 & 66,0 & 71,9 & 64,3 & 64,9 & 71,0 & 65,1 & 71,4 & 65,7 & 78,5 & 68,5 & 67,6 \\
\hline $\mathrm{C}_{2} \mathrm{H}_{4}$ & ${ }^{1} J_{\mathrm{CH}}$ & 153,6 & 154,8 & 151,5 & 144,5 & 176,1 & 156,2 & 147,2 & 166,2 & 155,5 & 168,9 & 156,9 & 164,6 & 154,1 & 156,3 \\
\hline $\mathrm{C}_{2} \mathrm{H}_{4}$ & ${ }^{2} J_{\mathrm{CH}}$ & $-0,8$ & $-0,7$ & $-0,3$ & $-2,5$ & $-2,0$ & $-2,2$ & $-1,6$ & $-2,0$ & $-1,9$ & $-1,7$ & $-2,3$ & $-2,4$ & $-2,3$ & $-2,4$ \\
\hline $\mathrm{C}_{2} \mathrm{H}_{4}$ & ${ }^{2} J_{\mathrm{HH}}$ & 4,8 & 4,8 & 4,9 & 2,6 & 8,5 & 3,1 & 3,2 & 4,3 & 3,5 & 4,8 & 3,1 & 3,9 & 3,4 & 2,3 \\
\hline $\mathrm{C}_{2} \mathrm{H}_{4}$ & ${ }^{3} J_{\mathrm{HH}}$ & 12,0 & 12,2 & 11,9 & 11,8 & 12,8 & 12,6 & 11,8 & 13,6 & 12,4 & 13,1 & 12,7 & 12,0 & 11,5 & 11,7 \\
\hline $\mathrm{C}_{2} \mathrm{H}_{4}$ & ${ }^{3} J_{\mathrm{HH}_{\mathrm{t}}}{ }^{c}$ & 19,2 & 19,5 & 19,0 & 17,5 & 23,0 & 19,8 & 17,7 & 20,5 & 19,5 & 20,5 & 19,9 & 18,9 & 18,2 & 19 \\
\hline $\mathrm{C}_{2} \mathrm{H}_{6}$ & ${ }^{1} J_{\mathrm{CC}}$ & 26,5 & 25,9 & 25,0 & 29,3 & 35,2 & 28,3 & 29,9 & 33,3 & 28,8 & 33,2 & 29,1 & 35,7 & 31,4 & 34,5 \\
\hline $\mathrm{C}_{2} \mathrm{H}_{6}$ & ${ }^{1} J_{\mathrm{CH}}$ & 121,3 & 122,1 & 119,4 & 110,8 & 140,7 & 121,7 & 114,2 & 130,9 & 122,4 & 133,5 & 123,4 & 130,9 & 120,7 & 125,2 \\
\hline $\mathrm{C}_{2} \mathrm{H}_{6}$ & ${ }^{2} J_{\mathrm{CH}}$ & $-3,1$ & $-3,1$ & $-2,9$ & $-3,4$ & $-4,0$ & $-3,8$ & $-3,4$ & $-3,8$ & $-3,7$ & $-3,6$ & $-3,9$ & $-3,8$ & $-3,4$ & $-4,7$ \\
\hline \multirow[t]{3}{*}{ Total } & $\mathrm{DM}$ & $-27,66$ & $-29,11$ & $-29,71$ & $-16,69$ & $-16,51$ & $-20,93$ & $-13,16$ & $-19,35$ & $-24,40$ & $-18,45$ & $-24,16$ & $-12,11$ & $-16,29$ & - \\
\hline & DMA & 33,11 & 34,28 & 34,50 & 20,43 & 29,04 & 25,25 & 16,27 & 27,15 & 28,86 & 27,46 & 28,76 & 20,52 & 19,86 & - \\
\hline & PDMA & 48,93 & 50,91 & 52,92 & 22,12 & 44,18 & 35,53 & 16,65 & 26,56 & 33,15 & 31,00 & 31,37 & 24,78 & 25,85 & - \\
\hline \multirow[t]{3}{*}{ CPI } & DM & $-66,10$ & $-70,02$ & $-69,85$ & $-36,71$ & $-51,33$ & $-51,20$ & $-29,65$ & $-53,83$ & $-59,63$ & $-53,01$ & $-59,65$ & $-37,37$ & $-40,13$ & - \\
\hline & DMA & 73,14 & 75,69 & 75,86 & 40,78 & 56,33 & 54,80 & 32,00 & 55,74 & 63,50 & 55,17 & 63,25 & 39,74 & 42,60 & - \\
\hline & PDMA & 89,21 & 93,00 & 95,37 & 39,25 & 62,23 & 69,81 & 22,39 & 41,27 & 62,38 & 48,08 & 60,62 & 42,14 & 48,06 & - \\
\hline \multirow[t]{3}{*}{ SPI } & $\mathrm{DM}$ & 0,53 & 0,89 & $-0,27$ & $-2,01$ & 9,03 & 1,27 & $-1,07$ & 5,93 & 1,43 & 6,89 & 1,87 & 6,41 & 1,19 & - \\
\hline & DMA & 3,76 & 3,91 & 4,17 & 5,51 & 9,03 & 3,57 & 4,73 & 6,19 & 3,46 & 7,13 & 3,47 & 6,43 & 3,19 & - \\
\hline & PDMA & 19,39 & 20,04 & 21,79 & 9,57 & 30,94 & 10,39 & 12,44 & 15,78 & 11,71 & 18,48 & 9,92 & 12,05 & 9,57 & - \\
\hline \multirow[t]{3}{*}{$\Delta \mathrm{CS}$} & $\mathrm{DM}$ & $-66,63$ & $-70,90$ & $-69,57$ & $-34,70$ & $-60,35$ & $-52,47$ & $-28,59$ & $-59,76$ & $-61,06$ & $-59,90$ & $-61,52$ & $-43,79$ & $-41,31$ & - \\
\hline & DMA & 69,38 & 71,78 & 71,70 & 35,28 & 47,30 & 51,23 & 27,27 & 49,55 & 60,04 & 48,04 & 59,79 & 33,31 & 39,41 & - \\
\hline & PDMA & 69,82 & 72,96 & 73,58 & 29,68 & 31,29 & 59,42 & 9,95 & 25,48 & 50,67 & 29,60 & 50,70 & 30,10 & 38,50 & \\
\hline
\end{tabular}


Tabela 8.36: Constantes de acoplamento utilizando funcionais da literatura (21 a 100\% $\left.E_{X}^{\mathrm{HF}}\right)$ com correção vibracional no nível BHandH $40 \% E_{X}^{\mathrm{HF}}$ e base aug-pcJ-2.

\begin{tabular}{|c|c|c|c|c|c|c|c|c|c|c|c|c|c|c|c|}
\hline & $\begin{array}{l}\text { Func. } \\
\% E_{X}^{\mathrm{HF}}\end{array}$ & $\begin{array}{l}\text { X3LYP } \\
21,80\end{array}$ & $\begin{array}{c}\text { B98 } \\
21,98\end{array}$ & $\begin{array}{l}\omega 97 \mathrm{XD} \\
22,20\end{array}$ & $\begin{array}{l}\text { PBE0 } \\
25,00\end{array}$ & $\begin{array}{c}\text { M06 } \\
27,00\end{array}$ & $\begin{array}{l}\text { B1B95 } \\
28,00\end{array}$ & $\begin{array}{c}\text { M05 } \\
28,00\end{array}$ & $\begin{array}{l}\text { BMK } \\
42,00\end{array}$ & $\begin{array}{l}\mathrm{BHH} \\
50,00\end{array}$ & $\begin{array}{l}\text { BHLYP } \\
50,00\end{array}$ & $\begin{array}{l}\text { M062X } \\
54,00\end{array}$ & $\begin{array}{l}\text { M052X } \\
56,00\end{array}$ & $\begin{array}{l}\text { M06HF } \\
100,00\end{array}$ & $\begin{array}{c}\text { Exp. } \\
-\end{array}$ \\
\hline $\mathrm{HF}$ & ${ }^{1} J_{\mathrm{HF}}$ & 420,0 & 398,0 & 451,0 & 397,6 & 645,1 & 437,2 & 795,3 & 517,6 & 497,6 & 493,6 & 452,4 & 550,1 & 144,5 & 500 \\
\hline $\mathrm{CO}$ & ${ }^{1} J_{\mathrm{CO}}$ & 18,5 & 19,3 & 20,4 & 20,7 & 18,7 & 19,2 & 9,9 & 19,5 & 14,5 & 11,7 & 8,2 & 4,7 & 5,2 & 16,4 \\
\hline $\mathrm{H}_{2} \mathrm{O}$ & ${ }^{1} J_{\mathrm{OH}}$ & $-76,6$ & $-71,3$ & $-73,5$ & $-71,8$ & $-99,4$ & $-76,1$ & $-107,1$ & $-85,7$ & $-82,5$ & $-85,3$ & $-90,4$ & $-88,1$ & $-53,6$ & $-80,6$ \\
\hline $\mathrm{H}_{2} \mathrm{O}$ & ${ }^{2} J_{\mathrm{HH}}$ & $-6,1$ & $-5,5$ & $-5,0$ & $-5,9$ & $-15,4$ & $-5,6$ & $-17,2$ & $-5,3$ & $-8,0$ & $-9,8$ & $-5,7$ & $-3,2$ & 10,2 & $-7,3$ \\
\hline $\mathrm{NH}_{3}$ & ${ }^{1} J_{\mathrm{NH}}$ & 46,5 & 43,6 & 42,6 & 43,2 & 53,1 & 44,7 & 45,0 & 48,5 & 46,2 & 49,7 & 53,9 & 44,5 & 38,4 & 43,8 \\
\hline $\mathrm{NH}_{3}$ & ${ }^{2} J_{\mathrm{HH}}$ & $-9,3$ & $-8,6$ & $-8,1$ & $-9,2$ & $-17,1$ & $-8,4$ & $-14,9$ & $-9,3$ & $-10,2$ & $-12,6$ & $-10,1$ & $-5,4$ & $-4,5$ & $-9,6$ \\
\hline $\mathrm{PH}_{3}$ & ${ }^{1} J_{\mathrm{PH}}$ & 167,0 & 189,1 & 169,4 & 147,3 & 240,2 & 160,5 & 164,5 & 130,6 & 175,8 & 194,0 & 159,6 & 111,0 & 152,0 & 188,2 \\
\hline $\mathrm{PF}_{3}$ & ${ }^{1} J_{\mathrm{PF}}$ & $-1751,2$ & $-1664,6$ & $-1636,0$ & $-1730,3$ & $-1525,1$ & $-1643,7$ & $-1387,2$ & $-1644,3$ & $-1668,6$ & $-1649,7$ & $-1623,9$ & $-1703,6$ & $-1874,8$ & -1441 \\
\hline $\mathrm{BHF}_{2}$ & ${ }^{1} J_{\mathrm{BF}}$ & $-136,0$ & $-133,6$ & $-107,6$ & $-135,5$ & $-40,6$ & $-132,1$ & 16,3 & $-108,5$ & $-99,7$ & $-86,4$ & $-121,0$ & $-109,7$ & $-279,5$ & -84 \\
\hline $\mathrm{BF}_{3}$ & ${ }^{1} J_{\mathrm{BF}}$ & $-31,3$ & $-36,3$ & $-5,2$ & $-32,7$ & 62,7 & $-29,2$ & 124,9 & 2,9 & 12,9 & 22,1 & $-22,2$ & $-5,7$ & $-198,9$ & 15 \\
\hline $\mathrm{F}_{2} \mathrm{O}$ & ${ }^{1} J_{\mathrm{OF}}$ & $-372,5$ & $-350,0$ & $-346,5$ & $-388,0$ & $-321,5$ & $-375,0$ & $-316,0$ & $-390,4$ & $-478,1$ & $-501,1$ & $-442,3$ & $-533,9$ & $-1516,6$ & -300 \\
\hline $\mathrm{CH}_{4}$ & ${ }^{1} J_{\mathrm{CH}}$ & 135,2 & 130,6 & 117,0 & 125,1 & 141,9 & 126,7 & 100,8 & 161,5 & 127,2 & 143,0 & 146,0 & 117,6 & 69,8 & 125,3 \\
\hline $\mathrm{CH}_{4}$ & ${ }^{2} J_{\mathrm{HH}}$ & $-13,5$ & $-12,8$ & $-12,1$ & $-14,1$ & $-26,2$ & $-12,5$ & $-21,5$ & $-14,6$ & $-13,6$ & $-16,3$ & $-12,4$ & $-6,9$ & $-15,8$ & $-12,8$ \\
\hline $\mathrm{C}_{2} \mathrm{H}_{2}$ & ${ }^{1} J_{\mathrm{CC}}$ & 204,8 & 213,3 & 191,7 & 196,8 & 194,0 & 195,6 & 210,1 & 343,1 & 202,8 & 220,5 & 228,2 & 225,1 & 251,7 & 174,8 \\
\hline $\mathrm{C}_{2} \mathrm{H}_{2}$ & ${ }^{1} J_{\mathrm{CH}}$ & 276,9 & 264,2 & 248,7 & 259,3 & 302,6 & 259,3 & 250,9 & 299,1 & 262,6 & 291,6 & 273,3 & 211,8 & 93,7 & 247,6 \\
\hline $\mathrm{C}_{2} \mathrm{H}_{2}$ & ${ }^{2} J_{\mathrm{CH}}$ & 56,6 & 53,2 & 54,1 & 53,9 & 50,7 & 56,0 & 36,9 & 62,4 & 53,4 & 54,5 & 57,3 & 50,0 & 45,7 & 50,1 \\
\hline $\mathrm{C}_{2} \mathrm{H}_{2}$ & ${ }^{3} J_{\mathrm{HH}}$ & 11,7 & 11,2 & 10,6 & 12,9 & 17,6 & 10,9 & 21,1 & 12,5 & 12,3 & 15,3 & 9,8 & 7,9 & 5,7 & 9,6 \\
\hline $\mathrm{C}_{2} \mathrm{H}_{4}$ & ${ }^{1} J_{\mathrm{CC}}$ & 72,4 & 77,7 & 64,1 & 69,1 & 65,2 & 66,4 & 76,8 & 127,7 & 72,7 & 86,4 & 91,6 & 85,5 & 86,3 & 67,6 \\
\hline $\mathrm{C}_{2} \mathrm{H}_{4}$ & ${ }^{1} J_{\mathrm{CH}}$ & 170,4 & 164,3 & 149,9 & 159,1 & 185,5 & 160,6 & 143,4 & 197,4 & 162,4 & 181,9 & 179,4 & 143,6 & $-59,5$ & 156,3 \\
\hline $\mathrm{C}_{2} \mathrm{H}_{4}$ & ${ }^{2} J_{\mathrm{CH}}$ & $-1,9$ & $-2,7$ & $-1,3$ & $-3,3$ & $-6,7$ & $-1,4$ & $-14,2$ & $-5,0$ & $-4,1$ & $-6,3$ & $-2,8$ & $-1,9$ & 12,7 & $-2,4$ \\
\hline $\mathrm{C}_{2} \mathrm{H}_{4}$ & ${ }^{2} J_{\mathrm{HH}}$ & 4,7 & 3,4 & 3,3 & 2,6 & $-13,1$ & 4,5 & $-14,3$ & 5,5 & 2,5 & 1,9 & 4,0 & 6,4 & 4,4 & 2,3 \\
\hline $\mathrm{C}_{2} \mathrm{H}_{4}$ & ${ }^{3} J_{\mathrm{HH}_{\mathrm{c}}}$ & 13,3 & 12,1 & 11,8 & 13,0 & 17,4 & 12,4 & 16,5 & 13,8 & 13,6 & 15,2 & 13,2 & 9,8 & 4,8 & 11,7 \\
\hline $\mathrm{C}_{2} \mathrm{H}_{4}$ & ${ }^{3} J_{\mathrm{HH}_{\mathrm{t}}}$ & 20,7 & 19,0 & 18,0 & 20,3 & 22,1 & 19,5 & 19,7 & 21,6 & 20,1 & 23,2 & 19,3 & 15,4 & 6,3 & 19 \\
\hline $\mathrm{C}_{2} \mathrm{H}_{6}$ & ${ }^{1} J_{\mathrm{CC}}$ & 33,9 & 35,2 & 29,8 & 31,2 & 30,2 & 31,4 & 25,6 & 49,5 & 34,1 & 41,4 & 49,7 & 41,7 & 47,6 & 34,5 \\
\hline $\mathrm{C}_{2} \mathrm{H}_{6}$ & ${ }^{1} J_{\mathrm{CH}}$ & 134,7 & 130,6 & 117,0 & 125,3 & 140,9 & 126,8 & 100,0 & 162,0 & 127,6 & 143,1 & 146,8 & 119,2 & 82,9 & 125,2 \\
\hline $\mathrm{C}_{2} \mathrm{H}_{6}$ & ${ }^{2} J_{\mathrm{CH}}$ & $-3,7$ & $-4,0$ & $-3,5$ & $-4,3$ & $-5,7$ & $-3,7$ & $-4,8$ & $-5,3$ & $-4,5$ & $-5,3$ & $-3,9$ & $-2,9$ & $-3,5$ & $-4,7$ \\
\hline \multirow[t]{3}{*}{ Total } & $\mathrm{DM}$ & $-17,68$ & $-14,22$ & $-13,25$ & $-21,64$ & 10,47 & $-15,42$ & 15,98 & 2,38 & $-14,46$ & $-8,80$ & $-11,04$ & $-21,62$ & $-107,30$ & - \\
\hline & DMA & 27,20 & 22,48 & 16,48 & 26,52 & 24,37 & 20,33 & 32,12 & 32,99 & 19,87 & 25,20 & 27,00 & 32,91 & 120,89 & - \\
\hline & PDMA & 29,18 & 26,14 & 18,68 & 26,66 & 73,27 & 27,16 & 107,00 & 36,52 & 12,89 & 27,93 & 30,76 & 36,32 & 150,93 & - \\
\hline \multirow[t]{3}{*}{ CPI } & $\mathrm{DM}$ & $-51,99$ & $-41,89$ & $-30,85$ & $-55,05$ & 14,53 & $-40,85$ & 42,96 & $-33,21$ & $-40,09$ & $-37,70$ & $-43,85$ & $-52,75$ & $-219,86$ & - \\
\hline & DMA & 53,86 & 44,78 & 33,56 & 57,75 & 39,98 & 42,87 & 58,95 & 38,25 & 40,53 & 41,12 & 45,98 & 63,49 & 228,88 & - \\
\hline & PDMA & 44,27 & 47,17 & 26,79 & 48,43 & 62,45 & 43,52 & 108,99 & 23,15 & 13,65 & 22,68 & 44,48 & 45,27 & 235,61 & - \\
\hline \multirow[t]{3}{*}{ SPI } & DM & 7,47 & 6,08 & $-0,33$ & 2,85 & 7,49 & 3,23 & $-3,81$ & 28,47 & 4,33 & 12,40 & 13,03 & 1,21 & $-24,75$ & - \\
\hline & DMA & 7,65 & 6,12 & 3,95 & 3,61 & 12,93 & 3,80 & 12,45 & 29,14 & 4,72 & 13,52 & 13,08 & 10,48 & 41,70 & - \\
\hline & PDMA & 18,12 & 10,72 & 12,73 & 10,68 & 81,20 & 15,16 & 105,55 & 46,32 & 12,33 & 31,78 & 20,71 & 29,75 & 88,84 & - \\
\hline \multirow[t]{3}{*}{$\Delta \mathrm{CS}$} & DM & $-59,46$ & $-47,97$ & $-30,52$ & $-57,90$ & 7,04 & $-44,08$ & 46,77 & $-61,68$ & $-44,42$ & $-50,10$ & $-56,88$ & $-53,96$ & $-195,11$ & - \\
\hline & DMA & 46,22 & 38,66 & 29,62 & 54,14 & 27,06 & 39,07 & 46,50 & 9,11 & 35,81 & 27,60 & 32,90 & 53,01 & 187,18 & - \\
\hline & PDMA & 26,16 & 36,45 & 14,05 & 37,75 & $-18,74$ & 28,36 & 3,44 & $-23,16$ & 1,33 & $-9,10$ & 23,77 & 15,52 & 146,77 & \\
\hline
\end{tabular}


Tabela 8.37: Constantes de acoplamento utilizando funcionais da literatura ( 0 a $21 \% E_{X}^{\mathrm{HF}}$ ) com correção vibracional no nível PBE0 $40 \% E_{X}^{\mathrm{HF}}$ e base aug-pcJ-2.

\begin{tabular}{|c|c|c|c|c|c|c|c|c|c|c|c|c|c|c|c|}
\hline & Func. & PBE & PW91 & BP86 & $\omega \mathrm{B} 97$ & TPSSh & O3LYP & $\omega \mathrm{B} 97 \mathrm{X}$ & CAMB3 & B3P86 & B3LYP & B3W91 & B971 & B972 & Exp. \\
\hline & $\% E_{X}^{\mathrm{HF}}$ & 0,00 & 0,00 & 0,00 & 0,00 & 10,00 & 11,61 & 15,77 & 19,00 & 20,00 & 20,00 & 20,00 & 21,00 & 21,00 & - \\
\hline $\mathrm{HF}$ & ${ }^{1} J_{\mathrm{HF}}$ & 341,2 & 329,4 & 320,5 & 420,8 & 355,8 & 361,6 & 463,1 & 420,8 & 372,5 & 410,6 & 374,1 & 414,3 & 408,0 & 500 \\
\hline $\mathrm{CO}$ & ${ }^{1} J_{\mathrm{CO}}$ & 24,8 & 25,6 & 25,6 & 24,6 & 21,0 & 22,6 & 19,8 & 19,0 & 22,3 & 18,9 & 22,3 & 18,1 & 19,0 & 16,4 \\
\hline $\mathrm{H}_{2} \mathrm{O}$ & ${ }^{1} J_{\mathrm{OH}}$ & $-65,8$ & $-64,9$ & $-63,4$ & $-70,4$ & $-71,1$ & $-68,0$ & $-75,1$ & $-76,3$ & $-68,7$ & $-75,4$ & $-69,2$ & $-73,0$ & $-72,1$ & $-80,6$ \\
\hline $\mathrm{H}_{2} \mathrm{O}$ & ${ }^{2} J_{\mathrm{HH}}$ & $-3,2$ & $-3,3$ & $-3,1$ & $-5,1$ & $-3,8$ & $-6,5$ & $-4,9$ & $-5,9$ & $-4,8$ & $-5,7$ & $-5,3$ & $-5,0$ & $-6,0$ & $-7,3$ \\
\hline $\mathrm{NH}_{3}$ & ${ }^{1} J_{\mathrm{NH}}$ & 41,3 & 41,3 & 40,5 & 39,5 & 46,3 & 41,6 & 42,0 & 45,7 & 41,9 & 45,8 & 42,2 & 43,8 & 42,2 & 43,8 \\
\hline $\mathrm{NH}_{3}$ & ${ }^{2} J_{\mathrm{HH}}$ & $-7,0$ & $-7,2$ & $-7,0$ & $-7,7$ & $-7,3$ & $-9,3$ & $-7,9$ & $-9,4$ & $-8,5$ & $-9,1$ & $-9,0$ & $-8,3$ & $-8,3$ & $-9,6$ \\
\hline $\mathrm{PH}_{3}$ & ${ }^{1} J_{\mathrm{PH}}$ & 126,2 & 130,1 & 129,4 & 151,8 & 193,0 & 158,0 & 157,5 & 154,8 & 144,8 & 164,4 & 147,1 & 183,2 & 176,5 & 188,2 \\
\hline $\mathrm{PF}_{3}$ & ${ }^{1} J_{\mathrm{PF}}$ & $-1798,8$ & $-1813,0$ & $-1800,3$ & $-1660,8$ & $-1729,5$ & $-1685,6$ & $-1640,8$ & $-1746,9$ & $-1747,2$ & $-1753,7$ & $-1749,2$ & $-1654,5$ & $-1659,0$ & -1441 \\
\hline $\mathrm{BHF}_{2}$ & ${ }^{1} J_{\mathrm{BF}}$ & $-177,2$ & $-182,0$ & $-182,3$ & $-116,2$ & $-146,9$ & $-161,8$ & $-101,9$ & $-130,1$ & $-147,6$ & $-138,9$ & $-147,0$ & $-128,2$ & $-134,3$ & -84 \\
\hline $\mathrm{BF}_{3}$ & ${ }^{1} J_{\mathrm{BF}}$ & $-78,0$ & $-83,1$ & $-85,5$ & $-17,0$ & $-49,4$ & $-65,9$ & 1,1 & $-24,6$ & $-47,4$ & $-35,4$ & $-46,7$ & $-30,1$ & $-38,8$ & 15 \\
\hline $\mathrm{F}_{2} \mathrm{O}$ & ${ }^{1} J_{\mathrm{OF}}$ & $-293,3$ & $-305,8$ & $-305,4$ & $-326,0$ & $-335,4$ & $-312,6$ & $-341,8$ & $-401,9$ & $-375,9$ & $-367,3$ & $-378,2$ & $-334,1$ & $-331,3$ & -300 \\
\hline $\mathrm{CH}_{4}$ & ${ }^{1} J_{\mathrm{CH}}$ & 121,7 & 122,5 & 119,9 & 111,8 & 141,2 & 121,9 & 114,9 & 131,3 & 122,4 & 134,1 & 123,4 & 131,2 & 121,2 & 125,3 \\
\hline $\mathrm{CH}_{4}$ & ${ }^{2} J_{\mathrm{HH}}$ & $-12,1$ & $-12,3$ & $-12,1$ & $-11,5$ & $-11,6$ & $-13,5$ & $-11,6$ & $-13,5$ & $-13,2$ & $-13,3$ & $-13,7$ & $-12,3$ & $-11,6$ & $-12,8$ \\
\hline $\mathrm{C}_{2} \mathrm{H}_{2}$ & ${ }^{1} J_{\mathrm{CC}}$ & 189,6 & 189,7 & 188,2 & 195,1 & 191,7 & 192,4 & 193,9 & 202,9 & 194,3 & 204,2 & 194,7 & 214,7 & 198,4 & 174,8 \\
\hline $\mathrm{C}_{2} \mathrm{H}_{2}$ & ${ }^{1} J_{\mathrm{CH}}$ & 253,0 & 255,7 & 250,6 & 239,5 & 285,5 & 257,7 & 243,4 & 270,1 & 255,1 & 275,0 & 257,2 & 264,5 & 250,5 & 247,6 \\
\hline $\mathrm{C}_{2} \mathrm{H}_{2}$ & ${ }^{2} J_{\mathrm{CH}}$ & 54,3 & 54,8 & 54,8 & 52,0 & 57,9 & 52,8 & 53,6 & 57,2 & 54,2 & 56,3 & 54,2 & 53,4 & 50,9 & 50,1 \\
\hline $\mathrm{C}_{2} \mathrm{H}_{2}$ & ${ }^{3} J_{\mathrm{HH}}$ & 11,1 & 11,2 & 10,9 & 11,1 & 13,3 & 12,5 & 10,7 & 11,8 & 11,9 & 11,8 & 12,4 & 11,2 & 11,1 & 9,6 \\
\hline $\mathrm{C}_{2} \mathrm{H}_{4}$ & ${ }^{1} J_{\mathrm{CC}}$ & 62,3 & 61,6 & 60,5 & 66,6 & 72,5 & 64,9 & 65,5 & 71,6 & 65,7 & 72,0 & 66,3 & 79,1 & 69,1 & 67,6 \\
\hline $\mathrm{C}_{2} \mathrm{H}_{4}$ & ${ }^{1} J_{\mathrm{CH}}$ & 153,8 & 155,0 & 151,7 & 144,7 & 176,3 & 156,4 & 147,4 & 166,4 & 155,7 & 169,1 & 157,1 & 164,8 & 154,3 & 156,3 \\
\hline $\mathrm{C}_{2} \mathrm{H}_{4}$ & ${ }^{2} J_{\mathrm{CH}}$ & $-1,0$ & $-0,9$ & $-0,5$ & $-2,7$ & $-2,2$ & $-2,4$ & $-1,8$ & $-2,2$ & $-2,1$ & $-1,9$ & $-2,5$ & $-2,6$ & $-2,5$ & $-2,4$ \\
\hline $\mathrm{C}_{2} \mathrm{H}_{4}$ & ${ }^{2} J_{\mathrm{HH}}$ & 4,7 & 4,7 & 4,8 & 2,5 & 8,4 & 3,0 & 3,1 & 4,2 & 3,4 & 4,7 & 3,0 & 3,8 & 3,3 & 2,3 \\
\hline $\mathrm{C}_{2} \mathrm{H}_{4}$ & ${ }^{3} J_{\mathrm{HH}_{\mathrm{c}}}$ & 12,1 & 12,3 & 12,0 & 11,9 & 12,9 & 12,7 & 11,9 & 13,7 & 12,5 & 13,2 & 12,8 & 12,1 & 11,6 & 11,7 \\
\hline $\mathrm{C}_{2} \mathrm{H}_{4}$ & ${ }^{3} J_{\mathrm{HH}_{\mathrm{t}}}$ & 19,4 & 19,7 & 19,2 & 17,7 & 23,2 & 20,0 & 17,9 & 20,7 & 19,7 & 20,7 & 20,1 & 19,1 & 18,4 & 19 \\
\hline $\mathrm{C}_{2} \mathrm{H}_{6}$ & ${ }^{1} J_{\mathrm{CC}}$ & 26,6 & 26,0 & 25,1 & 29,4 & 35,3 & 28,4 & 30,0 & 33,4 & 28,9 & 33,3 & 29,2 & 35,8 & 31,5 & 34,5 \\
\hline $\mathrm{C}_{2} \mathrm{H}_{6}$ & ${ }^{1} J_{\mathrm{CH}}$ & 121,3 & 122,1 & 119,4 & 110,8 & 140,7 & 121,7 & 114,2 & 130,9 & 122,4 & 133,5 & 123,4 & 130,9 & 120,7 & 125,2 \\
\hline $\mathrm{C}_{2} \mathrm{H}_{6}$ & ${ }^{2} J_{\mathrm{CH}}$ & $-3,1$ & $-3,1$ & $-2,9$ & $-3,4$ & $-4,0$ & $-3,8$ & $-3,4$ & $-3,8$ & $-3,7$ & $-3,6$ & $-3,9$ & $-3,8$ & $-3,4$ & $-4,7$ \\
\hline \multirow[t]{3}{*}{ Total } & $\mathrm{DM}$ & $-27,73$ & $-29,19$ & $-29,78$ & $-16,77$ & $-16,58$ & $-21,01$ & $-13,24$ & $-19,43$ & $-24,48$ & $-18,53$ & $-24,24$ & $-12,19$ & $-16,37$ & - \\
\hline & DMA & 33,07 & 34,41 & 34,63 & 20,55 & 29,22 & 25,38 & 16,38 & 27,33 & 28,99 & 27,64 & 28,92 & 20,72 & 20,02 & - \\
\hline & PDMA & 48,54 & 50,58 & 52,58 & 22,35 & 43,91 & 35,20 & 16,23 & 26,28 & 32,81 & 30,72 & 31,36 & 25,12 & 25,76 & - \\
\hline \multirow[t]{3}{*}{ CPI } & DM & $-66,43$ & $-70,35$ & $-70,17$ & $-37,04$ & $-51,65$ & $-51,53$ & $-29,98$ & $-54,15$ & $-59,95$ & $-53,34$ & $-59,98$ & $-37,70$ & $-40,45$ & - \\
\hline & DMA & 73,08 & 76,04 & 76,21 & 41,13 & 56,60 & 55,15 & 32,35 & 56,05 & 63,85 & 55,48 & 63,60 & 40,05 & 42,95 & - \\
\hline & PDMA & 89,21 & 93,14 & 95,50 & 39,38 & 62,26 & 69,95 & 22,52 & 41,31 & 62,51 & 48,13 & 60,75 & 42,19 & 48,19 & - \\
\hline \multirow[t]{3}{*}{ SPI } & DM & 0,64 & 0,99 & $-0,17$ & $-1,91$ & 9,13 & 1,37 & $-0,96$ & 6,04 & 1,54 & 7,00 & 1,97 & 6,52 & 1,29 & - \\
\hline & DMA & 3,73 & 3,89 & 4,14 & 5,47 & 9,13 & 3,56 & 4,67 & 6,28 & 3,43 & 7,23 & 3,48 & 6,55 & 3,21 & - \\
\hline & PDMA & 18,71 & 19,37 & 21,11 & 9,85 & 30,45 & 9,72 & 11,62 & 15,25 & 11,04 & 17,95 & 9,81 & 12,60 & 9,31 & - \\
\hline \multirow[t]{3}{*}{$\Delta \mathrm{CS}$} & DM & $-67,07$ & $-71,34$ & $-70,01$ & $-35,13$ & $-60,79$ & $-52,90$ & $-29,02$ & $-60,19$ & $-61,49$ & $-60,34$ & $-61,96$ & $-44,22$ & $-41,75$ & - \\
\hline & DMA & 69,35 & 72,15 & 72,07 & 35,66 & 47,47 & 51,59 & 27,68 & 49,77 & 60,41 & 48,26 & 60,12 & 33,50 & 39,73 & - \\
\hline & PDMA & 70,49 & 73,77 & 74,39 & 29,52 & 31,81 & 60,22 & 10,90 & 26,06 & 51,47 & 30,18 & 50,93 & 29,60 & 38,88 & - \\
\hline
\end{tabular}


Tabela 8.38: Constantes de acoplamento utilizando funcionais da literatura (21 a 100\% $\left.E_{X}^{\mathrm{HF}}\right)$ com correção vibracional no nível PBE0 $40 \% E_{X}^{\mathrm{HF}}$ e base aug-pcJ-2.

\begin{tabular}{|c|c|c|c|c|c|c|c|c|c|c|c|c|c|c|c|}
\hline & Func. & X3LYP & B98 & $\omega 97 \mathrm{XD}$ & PBE0 & M06 & B1B95 & M05 & BMK & $\mathrm{BHH}$ & BHLYP & M062X & M052X & M06HF & Exp. \\
\hline & $\% E_{X}^{\mathrm{HF}}$ & 21,80 & 21,98 & 22,20 & 25,00 & 27,00 & 28,00 & 28,00 & 42,00 & 50,00 & 50,00 & 54,00 & 56,00 & 100,00 & - \\
\hline HF & ${ }^{1} J_{\mathrm{HF}}$ & 418,4 & 396,4 & 449,4 & 396,0 & 643,5 & 435,6 & 793,7 & 516,0 & 496,0 & 492,0 & 450,8 & 548,5 & 142,9 & 500 \\
\hline $\mathrm{CO}$ & ${ }^{1} J_{\mathrm{CO}}$ & 18,4 & 19,2 & 20,3 & 20,6 & 18,6 & 19,1 & 9,8 & 19,4 & 14,4 & 11,6 & 8,1 & 4,6 & 5,1 & 16,4 \\
\hline $\mathrm{H}_{2} \mathrm{O}$ & ${ }^{1} J_{\mathrm{OH}}$ & $-76,4$ & $-71,1$ & $-73,3$ & $-71,6$ & $-99,2$ & $-75,9$ & $-106,9$ & $-85,5$ & $-82,3$ & $-85,1$ & $-90,2$ & $-87,9$ & $-53,4$ & $-80,6$ \\
\hline $\mathrm{H}_{2} \mathrm{O}$ & ${ }^{2} J_{\mathrm{HH}}$ & $-6,0$ & $-5,4$ & $-4,9$ & $-5,8$ & $-15,3$ & $-5,5$ & $-17,1$ & $-5,2$ & $-7,9$ & $-9,7$ & $-5,6$ & $-3,1$ & 10,3 & $-7,3$ \\
\hline $\mathrm{NH}_{3}$ & ${ }^{1} J_{\mathrm{NH}}$ & 46,3 & 43,4 & 42,4 & 43,0 & 52,9 & 44,5 & 44,8 & 48,3 & 46,0 & 49,5 & 53,7 & 44,3 & 38,2 & 43,8 \\
\hline $\mathrm{NH}_{3}$ & ${ }^{2} J_{\mathrm{HH}}$ & $-9,4$ & $-8,7$ & $-8,2$ & $-9,3$ & $-17,2$ & $-8,5$ & $-15,0$ & $-9,4$ & $-10,3$ & $-12,7$ & $-10,2$ & $-5,5$ & $-4,6$ & $-9,6$ \\
\hline $\mathrm{PH}_{3}$ & ${ }^{1} J_{\mathrm{PH}}$ & 166,8 & 188,9 & 169,2 & 147,1 & 240,0 & 160,3 & 164,3 & 130,4 & 175,6 & 193,8 & 159,4 & 110,8 & 151,8 & 188,2 \\
\hline $\mathrm{PF}_{3}$ & ${ }^{1} J_{\mathrm{PF}}$ & $-1750,8$ & $-1664,2$ & $-1635,6$ & $-1729,9$ & $-1524,7$ & $-1643,3$ & $-1386,8$ & $-1643,9$ & $-1668,2$ & $-1649,3$ & $-1623,5$ & $-1703,2$ & $-1874,4$ & -1441 \\
\hline $\mathrm{BHF}_{2}$ & ${ }^{1} J_{\mathrm{BF}}$ & $-135,9$ & $-133,5$ & $-107,5$ & $-135,4$ & $-40,5$ & $-132,0$ & 16,4 & $-108,4$ & $-99,6$ & $-86,3$ & $-120,9$ & $-109,6$ & $-279,4$ & -84 \\
\hline $\mathrm{BF}_{3}$ & ${ }^{1} J_{\mathrm{BF}}$ & $-31,3$ & $-36,3$ & $-5,2$ & $-32,7$ & 62,7 & $-29,2$ & 124,9 & 2,9 & 12,9 & 22,1 & $-22,2$ & $-5,7$ & $-198,9$ & 15 \\
\hline $\mathrm{F}_{2} \mathrm{O}$ & ${ }^{1} J_{\mathrm{OF}}$ & $-374,7$ & $-352,2$ & $-348,7$ & $-390,2$ & $-323,7$ & $-377,2$ & $-318,2$ & $-392,6$ & $-480,3$ & $-503,3$ & $-444,5$ & $-536,1$ & $-1518,8$ & -300 \\
\hline $\mathrm{CH}_{4}$ & ${ }^{1} J_{\mathrm{CH}}$ & 135,3 & 130,7 & 117,1 & 125,2 & 142,0 & 126,8 & 100,9 & 161,6 & 127,3 & 143,1 & 146,1 & 117,7 & 69,9 & 125,3 \\
\hline $\mathrm{CH}_{4}$ & ${ }^{2} J_{\mathrm{HH}}$ & $-13,5$ & $-12,8$ & $-12,1$ & $-14,1$ & $-26,2$ & $-12,5$ & $-21,5$ & $-14,6$ & $-13,6$ & $-16,3$ & $-12,4$ & $-6,9$ & $-15,8$ & $-12,8$ \\
\hline $\mathrm{C}_{2} \mathrm{H}_{2}$ & ${ }^{1} J_{\mathrm{CC}}$ & 205,3 & 213,8 & 192,2 & 197,3 & 194,5 & 196,1 & 210,6 & 343,6 & 203,3 & 221,0 & 228,7 & 225,6 & 252,2 & 174,8 \\
\hline $\mathrm{C}_{2} \mathrm{H}_{2}$ & ${ }^{1} J_{\mathrm{CH}}$ & 277,0 & 264,3 & 248,8 & 259,4 & 302,7 & 259,4 & 251,0 & 299,2 & 262,7 & 291,7 & 273,4 & 211,9 & 93,8 & 247,6 \\
\hline $\mathrm{C}_{2} \mathrm{H}_{2}$ & ${ }^{2} J_{\mathrm{CH}}$ & 56,4 & 53,0 & 53,9 & 53,7 & 50,5 & 55,8 & 36,7 & 62,2 & 53,2 & 54,3 & 57,1 & 49,8 & 45,5 & 50,1 \\
\hline $\mathrm{C}_{2} \mathrm{H}_{2}$ & ${ }^{3} J_{\mathrm{HH}}$ & 11,9 & 11,4 & 10,8 & 13,1 & 17,8 & 11,1 & 21,3 & 12,7 & 12,5 & 15,5 & 10,0 & 8,1 & 5,9 & 9,6 \\
\hline $\mathrm{C}_{2} \mathrm{H}_{4}$ & ${ }^{1} J_{\mathrm{CC}}$ & 73,0 & 78,3 & 64,7 & 69,7 & 65,8 & 67,0 & 77,4 & 128,3 & 73,3 & 87,0 & 92,2 & 86,1 & 86,9 & 67,6 \\
\hline $\mathrm{C}_{2} \mathrm{H}_{4}$ & ${ }^{1} J_{\mathrm{CH}}$ & 170,6 & 164,5 & 150,1 & 159,3 & 185,7 & 160,8 & 143,6 & 197,6 & 162,6 & 182,1 & 179,6 & 143,8 & $-59,3$ & 156,3 \\
\hline $\mathrm{C}_{2} \mathrm{H}_{4}$ & ${ }^{2} J_{\mathrm{CH}}$ & $-2,1$ & $-2,9$ & $-1,5$ & $-3,5$ & $-6,9$ & $-1,6$ & $-14,4$ & $-5,2$ & $-4,3$ & $-6,5$ & $-3,0$ & $-2,1$ & 12,5 & $-2,4$ \\
\hline $\mathrm{C}_{2} \mathrm{H}_{4}$ & ${ }^{2} J_{\mathrm{HH}}$ & 4,6 & 3,3 & 3,2 & 2,5 & $-13,2$ & 4,4 & $-14,4$ & 5,4 & 2,4 & 1,8 & 3,9 & 6,3 & 4,3 & 2,3 \\
\hline $\mathrm{C}_{2} \mathrm{H}_{4}$ & ${ }^{3} J_{\mathrm{HH}_{\mathrm{c}}}$ & 13,4 & 12,2 & 11,9 & 13,1 & 17,5 & 12,5 & 16,6 & 13,9 & 13,7 & 15,3 & 13,3 & 9,9 & 4,9 & 11,7 \\
\hline $\mathrm{C}_{2} \mathrm{H}_{4}$ & ${ }^{3} J_{\mathrm{HH}_{\mathrm{t}}}$ & 20,9 & 19,2 & 18,2 & 20,5 & 22,3 & 19,7 & 19,9 & 21,8 & 20,3 & 23,4 & 19,5 & 15,6 & 6,5 & 19 \\
\hline $\mathrm{C}_{2} \mathrm{H}_{6}$ & ${ }^{1} J_{\mathrm{CC}}{ }^{2}$ & 34,0 & 35,3 & 29,9 & 31,3 & 30,3 & 31,5 & 25,7 & 49,6 & 34,2 & 41,5 & 49,8 & 41,8 & 47,7 & 34,5 \\
\hline $\mathrm{C}_{2} \mathrm{H}_{6}$ & ${ }^{1} J_{\mathrm{CH}}$ & 134,7 & 130,6 & 117,0 & 125,3 & 140,9 & 126,8 & 100,0 & 162,0 & 127,6 & 143,1 & 146,8 & 119,2 & 82,9 & 125,2 \\
\hline $\mathrm{C}_{2} \mathrm{H}_{6}$ & ${ }^{2} J_{\mathrm{CH}}$ & $-3,7$ & $-4,0$ & $-3,5$ & $-4,3$ & $-5,7$ & $-3,7$ & $-4,8$ & $-5,3$ & $-4,5$ & $-5,3$ & $-3,9$ & $-2,9$ & $-3,5$ & $-4,7$ \\
\hline \multirow[t]{3}{*}{ Total } & DM & $-17,76$ & $-14,29$ & $-13,32$ & $-21,72$ & 10,39 & $-15,50$ & 15,90 & 2,30 & $-14,54$ & $-8,87$ & $-11,12$ & $-21,69$ & $-107,38$ & - \\
\hline & DMA & 27,38 & 22,68 & 16,59 & 26,73 & 24,39 & 20,47 & 32,23 & 33,06 & 20,06 & 25,39 & 27,21 & 32,92 & 121,05 & - \\
\hline & PDMA & 28,90 & 26,55 & 18,26 & 27,04 & 73,82 & 26,81 & 107,70 & 36,85 & 13,25 & 28,64 & 31,25 & 35,76 & 150,46 & - \\
\hline \multirow[t]{3}{*}{ CPI } & $\mathrm{DM}$ & $-52,32$ & $-42,22$ & $-31,18$ & $-55,37$ & 14,20 & $-41,18$ & 42,64 & $-33,54$ & $-40,42$ & $-38,03$ & $-44,18$ & $-53,07$ & $-220,19$ & - \\
\hline & DMA & 54,17 & 45,09 & 33,91 & 58,10 & 39,95 & 43,18 & 59,04 & 38,23 & 40,82 & 41,37 & 46,29 & 63,49 & 229,25 & - \\
\hline & PDMA & 44,32 & 47,28 & 26,92 & 48,57 & 62,34 & 43,57 & 109,01 & 23,10 & 13,71 & 22,72 & 44,78 & 45,33 & 235,85 & - \\
\hline \multirow[t]{3}{*}{ SPI } & $\mathrm{DM}$ & 7,58 & 6,19 & $-0,23$ & 2,96 & 7,59 & 3,33 & $-3,70$ & 28,58 & 4,44 & 12,51 & 13,13 & 1,32 & $-24,65$ & - \\
\hline & DMA & 7,74 & 6,25 & 3,89 & 3,72 & 12,98 & 3,81 & 12,57 & 29,27 & 4,84 & 13,67 & 13,21 & 10,49 & 41,71 & - \\
\hline & PDMA & 17,59 & 11,34 & 11,92 & 11,25 & 82,24 & 14,51 & 106,73 & 46,93 & 12,91 & 32,98 & 21,33 & 28,74 & 87,84 & - \\
\hline \multirow[t]{3}{*}{$\Delta \mathrm{CS}$} & DM & $-59,90$ & $-48,40$ & $-30,96$ & $-58,33$ & 6,61 & $-44,52$ & 46,34 & $-62,12$ & $-44,86$ & $-50,53$ & $-57,32$ & $-54,39$ & $-195,54$ & - \\
\hline & DMA & 46,43 & 38,84 & 30,02 & 54,38 & 26,97 & 39,37 & 46,47 & 8,95 & 35,98 & 27,71 & 33,08 & 53,00 & 187,53 & - \\
\hline & PDMA & 26,74 & 35,94 & 15,00 & 37,31 & $-19,90$ & 29,06 & 2,28 & $-23,84$ & 0,80 & $-10,26$ & 23,45 & 16,58 & 148,01 & - \\
\hline
\end{tabular}




\subsubsection{Variação da porcentagem de $E_{X}^{\mathrm{HF}}$ para os funcionais híbridos - Geo- metrias Experimentais}

Tabela 8.39: Constantes de acoplamento B1B95 com correção vibracional no nível BHandH $\left(50 \% E_{X}^{\mathrm{HF}}\right)$ e base aug-pcJ-2.

\begin{tabular}{|c|c|c|c|c|c|c|c|c|c|c|c|c|c|}
\hline & $\% E_{X}^{\mathrm{HF}}$ & $0 \%$ & $10 \%$ & $20 \%$ & $30 \%$ & $40 \%$ & $50 \%$ & $60 \%$ & $70 \%$ & $80 \%$ & $90 \%$ & $100 \%$ & Exp. \\
\hline $\mathrm{HF}$ & ${ }^{1} J_{\mathrm{HF}}$ & 371,1 & 394,7 & 418,4 & 442,4 & 466,5 & 490,8 & 515,2 & 539,8 & 564,6 & 589,5 & 614,6 & 500 \\
\hline $\mathrm{CO}$ & ${ }^{1} J_{\mathrm{CO}}$ & 24,1 & 22,4 & 20,6 & 18,8 & 16,8 & 14,7 & 12,5 & 10,3 & 8,0 & 5,6 & 3,1 & 16,4 \\
\hline $\mathrm{H}_{2} \mathrm{O}$ & ${ }^{1} J_{\mathrm{OH}}$ & $-69,2$ & $-71,7$ & $-74,2$ & $-76,8$ & $-79,3$ & $-81,9$ & $-84,5$ & $-87,1$ & $-89,7$ & $-92,4$ & $-95,1$ & $-80,6$ \\
\hline $\mathrm{H}_{2} \mathrm{O}$ & ${ }^{2} J_{\mathrm{HH}}$ & $-2,7$ & $-3,7$ & $-4,7$ & $-5,7$ & $-6,7$ & $-7,7$ & $-8,8$ & $-9,8$ & $-10,9$ & $-12,0$ & $-13,2$ & $-7,3$ \\
\hline $\mathrm{NH}_{3}$ & ${ }^{1} J_{\mathrm{NH}}$ & 42,7 & 43,5 & 44,2 & 44,9 & 45,7 & 46,4 & 47,2 & 48,0 & 48,7 & 49,5 & 50,3 & 43,8 \\
\hline $\mathrm{NH}_{3}$ & ${ }^{2} J_{\mathrm{HH}}$ & $-6,1$ & $-6,9$ & $-7,8$ & $-8,6$ & $-9,5$ & $-10,4$ & $-11,2$ & $-12,1$ & $-13,0$ & $-13,9$ & $-14,9$ & $-9,6$ \\
\hline $\mathrm{PH}_{3}$ & ${ }^{1} J_{\mathrm{PH}}$ & 139,9 & 147,6 & 155,0 & 162,4 & 169,7 & 176,8 & 183,8 & 190,6 & 197,3 & 203,9 & 210,2 & 188,2 \\
\hline $\mathrm{PF}_{3}$ & ${ }^{1} J_{\mathrm{PF}}$ & $-1715,9$ & $-1694,3$ & $-1668,3$ & $-1638,5$ & $-1605,7$ & $-1570,4$ & $-1533,0$ & $-1494,2$ & $-1454,2$ & $-1413,4$ & $-1372,1$ & -1441 \\
\hline $\mathrm{BHF}_{2}$ & ${ }^{1} J_{\mathrm{BF}}$ & $-179,0$ & $-162,1$ & $-145,3$ & $-128,5$ & $-111,8$ & $-95,3$ & $-78,9$ & $-62,6$ & $-46,5$ & $-30,6$ & $-14,8$ & -84 \\
\hline $\mathrm{BF}_{3}$ & ${ }^{1} J_{\mathrm{BF}}$ & $-80,8$ & $-62,2$ & $-43,8$ & $-25,5$ & $-7,4$ & 10,5 & 28,2 & 45,8 & 63,2 & 80,5 & 97,6 & 15 \\
\hline $\mathrm{F}_{2} \mathrm{O}$ & ${ }^{1} J_{\mathrm{OF}}$ & $-281,2$ & $-315,6$ & $-349,2$ & $-383,0$ & $-418,6$ & $-458,0$ & $-504,3$ & $-563,1$ & $-645,5$ & $-779,4$ & $-1062,8$ & -300 \\
\hline $\mathrm{CH}_{4}$ & ${ }^{1} J_{\mathrm{CH}}$ & 123,2 & 124,5 & 125,8 & 127,2 & 128,6 & 130,0 & 131,5 & 132,9 & 134,4 & 135,9 & 137,4 & 125,3 \\
\hline $\mathrm{CH}_{4}$ & ${ }^{2} J_{\mathrm{HH}}$ & $-10,6$ & $-11,3$ & $-12,0$ & $-12,7$ & $-13,3$ & $-14,0$ & $-14,7$ & $-15,3$ & $-16,0$ & $-16,7$ & $-17,3$ & $-12,8$ \\
\hline $\mathrm{C}_{2} \mathrm{H}_{2}$ & ${ }^{1} J_{\mathrm{CC}}$ & 188,6 & 190,9 & 193,6 & 196,5 & 200,0 & 203,9 & 208,4 & 213,7 & 219,9 & 227,3 & 236,2 & 174,8 \\
\hline $\mathrm{C}_{2} \mathrm{H}_{2}$ & ${ }^{1} J_{\mathrm{CH}}$ & 253,9 & 255,8 & 257,8 & 259,9 & 262,1 & 264,5 & 267,0 & 269,8 & 272,9 & 276,5 & 280,6 & 247,6 \\
\hline $\mathrm{C}_{2} \mathrm{H}_{2}$ & ${ }^{2} J_{\mathrm{CH}}$ & 55,8 & 56,0 & 56,0 & 55,8 & 55,5 & 54,9 & 54,1 & 52,9 & 51,4 & 49,4 & 46,7 & 50,1 \\
\hline $\mathrm{C}_{2} \mathrm{H}_{2}$ & ${ }^{3} J_{\mathrm{HH}}$ & 9,7 & 10,1 & 10,6 & 11,2 & 11,8 & 12,6 & 13,6 & 14,7 & 16,0 & 17,6 & 19,5 & 9,6 \\
\hline $\mathrm{C}_{2} \mathrm{H}_{4}$ & ${ }^{1} J_{\mathrm{CC}}$ & 59,6 & 61,9 & 64,5 & 67,2 & 70,3 & 73,7 & 77,5 & 81,9 & 87,2 & 93,5 & 101,5 & 67,6 \\
\hline $\mathrm{C}_{2} \mathrm{H}_{4}$ & ${ }^{1} J_{\mathrm{CH}}$ & 155,3 & 157,2 & 159,1 & 161,1 & 163,2 & 165,4 & 167,8 & 170,4 & 173,3 & 176,6 & 180,6 & 156,3 \\
\hline $\mathrm{C}_{2} \mathrm{H}_{4}$ & ${ }^{2} J_{\mathrm{CH}}$ & 0,6 & $-0,1$ & $-0,8$ & $-1,7$ & $-2,7$ & $-3,8$ & $-5,1$ & $-6,7$ & $-8,5$ & $-10,8$ & $-13,8$ & $-2,4$ \\
\hline $\mathrm{C}_{2} \mathrm{H}_{4}$ & ${ }^{2} J_{\mathrm{HH}}$ & 6,2 & 5,6 & 4,9 & 4,2 & 3,5 & 2,7 & 1,8 & 0,8 & $-0,3$ & $-1,7$ & $-3,3$ & 2,3 \\
\hline $\mathrm{C}_{2} \mathrm{H}_{4}$ & ${ }^{3} J_{\mathrm{HH}_{\mathrm{c}}}$ & 11,8 & 12,0 & 12,2 & 12,5 & 12,8 & 13,1 & 13,6 & 14,2 & 15,0 & 15,9 & 17,2 & 11,7 \\
\hline $\mathrm{C}_{2} \mathrm{H}_{4}$ & ${ }^{3} J_{\mathrm{HH}_{\mathrm{t}}}$ & 18,9 & 19,1 & 19,4 & 19,6 & 20,0 & 20,5 & 21,0 & 21,7 & 22,6 & 23,8 & 25,3 & 19 \\
\hline $\mathrm{C}_{2} \mathrm{H}_{6}$ & ${ }^{1} J_{\mathrm{CC}}$ & 26,0 & 28,0 & 29,9 & 31,9 & 33,9 & 35,9 & 38,0 & 40,1 & 42,2 & 44,4 & 46,6 & 34,5 \\
\hline $\mathrm{C}_{2} \mathrm{H}_{6}$ & ${ }^{1} J_{\mathrm{CH}}$ & 122,5 & 124,1 & 125,6 & 127,2 & 128,8 & 130,4 & 132,0 & 133,7 & 135,3 & 136,9 & 138,6 & 125,2 \\
\hline $\mathrm{C}_{2} \mathrm{H}_{6}$ & ${ }^{2} J_{\mathrm{CH}}$ & $-2,4$ & $-2,9$ & $-3,3$ & $-3,8$ & $-4,2$ & $-4,7$ & $-5,2$ & $-5,6$ & $-6,1$ & $-6,6$ & $-7,1$ & $-4,7$ \\
\hline \multirow[t]{3}{*}{ Total } & DM & $-22,42$ & $-20,09$ & $-17,57$ & $-14,88$ & $-12,12$ & $-9,40$ & $-6,83$ & $-4,62$ & $-3,22$ & $-3,68$ & $-9,75$ & - \\
\hline & DMA & 28,84 & 24,87 & 22,36 & 19,88 & 17,65 & 16,03 & 17,57 & 21,77 & 27,28 & 37,08 & 54,03 & - \\
\hline & PDMA & 54,52 & 44,23 & 34,60 & 24,82 & 16,58 & 13,11 & 21,28 & 35,17 & 50,39 & 68,12 & 90,04 & - \\
\hline \multirow[t]{3}{*}{ CPI } & $\mathrm{DM}$ & $-54,36$ & $-49,93$ & $-45,09$ & $-39,91$ & $-34,65$ & $-29,58$ & $-24,97$ & $-21,39$ & $-19,90$ & $-23,05$ & $-39,82$ & - \\
\hline & DMA & 62,73 & 53,78 & 47,89 & 41,71 & 35,44 & 30,05 & 31,68 & 39,32 & 49,77 & 69,85 & 105,96 & - \\
\hline & PDMA & 90,15 & 72,62 & 56,36 & 40,34 & 24,32 & 13,16 & 22,50 & 40,60 & 59,84 & 80,99 & 106,97 & - \\
\hline \multirow[t]{3}{*}{ SPI } & DM & 1,00 & 1,79 & 2,61 & 3,47 & 4,41 & 5,40 & 6,48 & 7,67 & 9,01 & 10,53 & 12,31 & - \\
\hline & DMA & 3,99 & 3,67 & 3,64 & 3,87 & 4,60 & 5,75 & 7,23 & 8,90 & 10,79 & 13,05 & 15,95 & - \\
\hline & PDMA & 28,39 & 23,42 & 18,64 & 13,43 & 10,90 & 13,07 & 20,38 & 31,19 & 43,46 & 58,68 & 77,62 & - \\
\hline \multirow[t]{3}{*}{$\Delta \mathrm{CS}$} & DM & $-55,36$ & $-51,71$ & $-47,70$ & $-43,38$ & $-39,07$ & $-34,98$ & $-31,45$ & $-29,06$ & $-28,91$ & $-33,58$ & $-52,12$ & - \\
\hline & DMA & 58,74 & 50,12 & 44,25 & 37,84 & 30,84 & 24,31 & 24,46 & 30,42 & 38,99 & 56,81 & 90,02 & - \\
\hline & PDMA & 61,76 & 49,20 & 37,72 & 26,91 & 13,42 & 0,09 & 2,12 & 9,41 & 16,38 & 22,31 & 29,35 & - \\
\hline
\end{tabular}


Tabela 8.40: Constantes de acoplamento B3LYP com correção vibracional no nível BHandH $\left(50 \% E_{X}^{\mathrm{HF}}\right)$ e base aug-pcJ-2.

\begin{tabular}{|c|c|c|c|c|c|c|c|c|c|c|c|c|c|}
\hline & $\% E_{X}^{\mathrm{HF}}$ & $0 \%$ & $10 \%$ & $20 \%$ & $30 \%$ & $40 \%$ & $50 \%$ & $60 \%$ & $70 \%$ & $80 \%$ & $90 \%$ & $100 \%$ & Exp. \\
\hline $\mathrm{HF}$ & ${ }^{1} J_{\mathrm{HF}}$ & 360,6 & 385,6 & 410,8 & 436,3 & 462,0 & 488,0 & 514,2 & 540,6 & 567,2 & 594,1 & 621,2 & 500 \\
\hline $\mathrm{CO}$ & ${ }^{1} J_{\mathrm{CO}}$ & 22,4 & 20,6 & 18,6 & 16,5 & 14,3 & 12,1 & 9,7 & 7,2 & 4,7 & 2,1 & $-0,5$ & 16,4 \\
\hline $\mathrm{H}_{2} \mathrm{O}$ & ${ }^{1} J_{\mathrm{OH}}$ & $-70,6$ & $-73,3$ & $-76,0$ & $-78,7$ & $-81,4$ & $-84,2$ & $-87,0$ & $-89,9$ & $-92,7$ & $-95,6$ & $-98,5$ & $-80,6$ \\
\hline $\mathrm{H}_{2} \mathrm{O}$ & ${ }^{2} J_{\mathrm{HH}}$ & $-3,8$ & $-4,9$ & $-6,0$ & $-7,1$ & $-8,2$ & $-9,3$ & $-10,5$ & $-11,7$ & $-12,9$ & $-14,1$ & $-15,3$ & $-7,3$ \\
\hline $\mathrm{NH}_{3}$ & ${ }^{1} J_{\mathrm{NH}}$ & 45,0 & 45,8 & 46,6 & 47,4 & 48,3 & 49,1 & 50,0 & 50,8 & 51,7 & 52,6 & 53,5 & 43,8 \\
\hline $\mathrm{NH}_{3}$ & ${ }^{2} J_{\mathrm{HH}}$ & $-7,5$ & $-8,4$ & $-9,4$ & $-10,3$ & $-11,3$ & $-12,3$ & $-13,3$ & $-14,3$ & $-15,3$ & $-16,3$ & $-17,3$ & $-9,6$ \\
\hline $\mathrm{PH}_{3}$ & ${ }^{1} J_{\mathrm{PH}}$ & 150,8 & 159,3 & 167,7 & 175,9 & 184,1 & 192,0 & 199,9 & 207,5 & 215,0 & 222,4 & 229,5 & 188,2 \\
\hline $\mathrm{PF}_{3}$ & ${ }^{1} J_{\mathrm{PF}}$ & $-1809,6$ & $-1783,9$ & $-1753,8$ & $-1720,1$ & $-1683,3$ & $-1644,1$ & $-1603,1$ & $-1560,7$ & $-1517,4$ & $-1473,3$ & $-1428,9$ & -1441 \\
\hline $\mathrm{BHF}_{2}$ & ${ }^{1} J_{\mathrm{BF}}$ & $-172,0$ & $-154,5$ & $-137,0$ & $-119,7$ & $-102,5$ & $-85,5$ & $-68,7$ & $-52,1$ & $-35,7$ & $-19,5$ & $-3,6$ & -84 \\
\hline $\mathrm{BF}_{3}$ & ${ }^{1} J_{\mathrm{BF}}$ & $-72,3$ & $-53,1$ & $-34,2$ & $-15,4$ & 3,0 & 21,3 & 39,4 & 57,4 & 75,1 & 92,7 & 110,1 & 15 \\
\hline $\mathrm{F}_{2} \mathrm{O}$ & ${ }^{1} J_{\mathrm{OF}}$ & $-294,3$ & $-331,1$ & $-368,0$ & $-406,6$ & $-449,1$ & $-498,7$ & $-561,3$ & $-648,3$ & $-787,6$ & $-1071,0$ & $-2152,6$ & -300 \\
\hline $\mathrm{CH}_{4}$ & ${ }^{1} J_{\mathrm{CH}}$ & 133,5 & 135,1 & 136,6 & 138,2 & 139,9 & 141,5 & 143,2 & 144,9 & 146,6 & 148,4 & 150,1 & 125,3 \\
\hline $\mathrm{CH}_{4}$ & ${ }^{2} J_{\mathrm{HH}}$ & $-12,2$ & $-13,0$ & $-13,7$ & $-14,5$ & $-15,2$ & $-16,0$ & $-16,7$ & $-17,5$ & $-18,2$ & $-18,9$ & $-19,7$ & $-12,8$ \\
\hline $\mathrm{C}_{2} \mathrm{H}_{2}$ & ${ }^{1} J_{\mathrm{CC}}$ & 200,0 & 203,0 & 206,5 & 210,4 & 215,0 & 220,3 & 226,5 & 234,0 & 243,0 & 253,9 & 267,5 & 174,8 \\
\hline $\mathrm{C}_{2} \mathrm{H}_{2}$ & ${ }^{1} J_{\mathrm{CH}}$ & 274,4 & 276,8 & 279,4 & 282,2 & 285,1 & 288,3 & 291,9 & 295,9 & 300,6 & 306,0 & 312,7 & 247,6 \\
\hline $\mathrm{C}_{2} \mathrm{H}_{2}$ & ${ }^{2} J_{\mathrm{CH}}$ & 57,2 & 57,1 & 56,8 & 56,3 & 55,4 & 54,2 & 52,6 & 50,4 & 47,5 & 43,8 & 38,8 & 50,1 \\
\hline $\mathrm{C}_{2} \mathrm{H}_{2}$ & ${ }^{3} J_{\mathrm{HH}}$ & 10,8 & 11,3 & 12,0 & 12,9 & 13,9 & 15,1 & 16,5 & 18,2 & 20,3 & 22,8 & 26,0 & 9,6 \\
\hline $\mathrm{C}_{2} \mathrm{H}_{4}$ & ${ }^{1} J_{\mathrm{CC}}$ & 67,3 & 70,2 & 73,5 & 77,1 & 81,2 & 86,0 & 91,8 & 98,8 & 107,9 & 120,3 & 138,4 & 67,6 \\
\hline $\mathrm{C}_{2} \mathrm{H}_{4}$ & ${ }^{1} J_{\mathrm{CH}}$ & 167,3 & 169,6 & 171,9 & 174,4 & 177,0 & 179,9 & 183,1 & 186,9 & 191,4 & 197,1 & 205,2 & 156,3 \\
\hline $\mathrm{C}_{2} \mathrm{H}_{4}$ & ${ }^{2} J_{\mathrm{CH}}$ & $-0,1$ & $-0,9$ & $-2,0$ & $-3,1$ & $-4,5$ & $-6,1$ & $-8,1$ & $-10,5$ & $-13,8$ & $-18,4$ & $-25,2$ & $-2,4$ \\
\hline $\mathrm{C}_{2} \mathrm{H}_{4}$ & ${ }^{2} J_{\mathrm{HH}}$ & 6,2 & 5,5 & 4,7 & 3,8 & 2,9 & 1,8 & 0,6 & $-0,8$ & $-2,7$ & $-5,3$ & $-9,0$ & 2,3 \\
\hline $\mathrm{C}_{2} \mathrm{H}_{4}$ & ${ }^{3} J_{\mathrm{HH}_{\mathrm{c}}}$ & 12,7 & 13,0 & 13,3 & 13,7 & 14,1 & 14,8 & 15,6 & 16,6 & 18,1 & 20,2 & 23,5 & 11,7 \\
\hline $\mathrm{C}_{2} \mathrm{H}_{4}$ & ${ }^{3} J_{\mathrm{HH}_{\mathrm{t}}}$ & 20,4 & 20,6 & 21,0 & 21,4 & 22,0 & 22,8 & 23,7 & 25,0 & 26,7 & 29,1 & 32,9 & 19 \\
\hline $\mathrm{C}_{2} \mathrm{H}_{6}$ & ${ }^{1} J_{\mathrm{CC}}$ & 30,1 & 32,2 & 34,4 & 36,6 & 38,8 & 41,1 & 43,5 & 45,8 & 48,2 & 50,7 & 53,1 & 34,5 \\
\hline $\mathrm{C}_{2} \mathrm{H}_{6}$ & ${ }^{1} J_{\mathrm{CH}}$ & 132,4 & 134,2 & 136,0 & 137,8 & 139,6 & 141,5 & 143,4 & 145,2 & 147,1 & 149,1 & 151,0 & 125,2 \\
\hline $\mathrm{C}_{2} \mathrm{H}_{6}$ & ${ }^{2} J_{\mathrm{CH}}$ & $-2,7$ & $-3,2$ & $-3,6$ & $-4,1$ & $-4,7$ & $-5,2$ & $-5,7$ & $-6,2$ & $-6,8$ & $-7,3$ & $-7,9$ & $-4,7$ \\
\hline \multirow[t]{3}{*}{ Total } & $\mathrm{DM}$ & $-23,04$ & $-20,44$ & $-17,65$ & $-14,76$ & $-11,87$ & $-9,10$ & $-6,68$ & $-5,07$ & $-5,27$ & $-10,75$ & $-46,54$ & - \\
\hline & DMA & 32,76 & 30,21 & 28,02 & 26,08 & 24,59 & 24,42 & 28,37 & 34,39 & 42,85 & 57,31 & 104,12 & - \\
\hline & PDMA & 49,87 & 40,12 & 30,43 & 24,00 & 21,68 & 26,16 & 41,81 & 59,40 & 80,85 & 108,20 & 152,76 & - \\
\hline \multirow[t]{3}{*}{ CPI } & $\mathrm{DM}$ & $-62,93$ & $-58,07$ & $-52,87$ & $-47,52$ & $-42,27$ & $-37,50$ & $-33,78$ & $-32,22$ & $-35,35$ & $-51,53$ & $-140,30$ & - \\
\hline & DMA & 68,11 & 61,18 & 54,89 & 48,57 & 43,09 & 40,30 & 46,84 & 57,89 & 73,58 & 102,31 & 205,72 & - \\
\hline & PDMA & 80,32 & 63,18 & 46,33 & 30,96 & 21,13 & 20,62 & 39,42 & 59,66 & 81,29 & 107,26 & 157,41 & - \\
\hline \multirow[t]{3}{*}{ SPI } & $\mathrm{DM}$ & 6,21 & 7,16 & 8,18 & 9,27 & 10,43 & 11,73 & 13,19 & 14,84 & 16,79 & 19,16 & 22,22 & - \\
\hline & DMA & 6,84 & 7,49 & 8,31 & 9,59 & 11,03 & 12,78 & 14,83 & 17,16 & 20,32 & 24,31 & 29,62 & - \\
\hline & PDMA & 27,53 & 23,22 & 18,78 & 18,89 & 22,08 & 30,23 & 43,56 & 59,20 & 80,52 & 108,89 & 149,36 & - \\
\hline \multirow[t]{3}{*}{$\Delta \mathrm{CS}$} & $\mathrm{DM}$ & $-69,14$ & $-65,23$ & $-61,05$ & $-56,78$ & $-52,70$ & $-49,23$ & $-46,97$ & $-47,06$ & $-52,13$ & $-70,69$ & $-162,52$ & - \\
\hline & DMA & 61,27 & 53,69 & 46,58 & 38,99 & 32,06 & 27,52 & 32,01 & 40,73 & 53,26 & 78,00 & 176,10 & - \\
\hline & PDMA & 52,79 & 39,96 & 27,55 & 12,07 & $-0,95$ & $-9,60$ & $-4,14$ & 0,46 & 0,77 & $-1,63$ & 8,05 & - \\
\hline
\end{tabular}


Tabela 8.41: Constantes de acoplamento B3P86 com correção vibracional no nível BHandH $\left(50 \% E_{X}^{\mathrm{HF}}\right)$ e base aug-pcJ-2.

\begin{tabular}{|c|c|c|c|c|c|c|c|c|c|c|c|c|c|}
\hline & $\% E_{X}^{\mathrm{HF}}$ & $0 \%$ & $10 \%$ & $20 \%$ & $30 \%$ & $40 \%$ & $50 \%$ & $60 \%$ & $70 \%$ & $80 \%$ & $90 \%$ & $100 \%$ & Exp. \\
\hline $\mathrm{HF}$ & ${ }^{1} J_{\mathrm{HF}}$ & 324,9 & 348,6 & 372,6 & 396,7 & 421,2 & 445,8 & 470,7 & 495,7 & 521,0 & 546,5 & 572,2 & 500 \\
\hline $\mathrm{CO}$ & ${ }^{1} J_{\mathrm{CO}}$ & 25,4 & 23,8 & 22,0 & 20,2 & 18,2 & 16,2 & 14,1 & 12,0 & 9,8 & 7,5 & 5,1 & 16,4 \\
\hline $\mathrm{H}_{2} \mathrm{O}$ & ${ }^{1} J_{\mathrm{OH}}$ & $-64,1$ & $-66,7$ & $-69,2$ & $-71,8$ & $-74,4$ & $-77,0$ & $-79,7$ & $-82,3$ & $-85,0$ & $-87,8$ & $-90,5$ & $-80,6$ \\
\hline $\mathrm{H}_{2} \mathrm{O}$ & ${ }^{2} J_{\mathrm{HH}}$ & $-3,1$ & $-4,1$ & $-5,0$ & $-6,1$ & $-7,1$ & $-8,1$ & $-9,2$ & $-10,3$ & $-11,4$ & $-12,5$ & $-13,7$ & $-7,3$ \\
\hline $\mathrm{NH}_{3}$ & ${ }^{1} J_{\mathrm{NH}}$ & 41,1 & 41,9 & 42,6 & 43,4 & 44,2 & 45,0 & 45,8 & 46,6 & 47,4 & 48,3 & 49,1 & 43,8 \\
\hline $\mathrm{NH}_{3}$ & ${ }^{2} J_{\mathrm{HH}}$ & $-6,9$ & $-7,8$ & $-8,6$ & $-9,5$ & $-10,4$ & $-11,3$ & $-12,2$ & $-13,2$ & $-14,1$ & $-15,0$ & $-16,0$ & $-9,6$ \\
\hline $\mathrm{PH}_{3}$ & ${ }^{1} J_{\mathrm{PH}}$ & 131,6 & 139,8 & 147,8 & 155,8 & 163,7 & 171,4 & 179,0 & 186,5 & 193,8 & 201,0 & 208,0 & 188,2 \\
\hline $\mathrm{PF}_{3}$ & ${ }^{1} J_{\mathrm{PF}}$ & $-1803,3$ & $-1777,6$ & $-1747,4$ & $-1713,7$ & $-1677,1$ & $-1638,1$ & $-1597,3$ & $-1555,2$ & $-1512,1$ & $-1468,4$ & $-1424,3$ & -1441 \\
\hline $\mathrm{BHF}_{2}$ & ${ }^{1} J_{\mathrm{BF}}$ & $-179,8$ & $-162,7$ & $-145,7$ & $-128,9$ & $-112,2$ & $-95,6$ & $-79,2$ & $-63,0$ & $-47,0$ & $-31,2$ & $-15,6$ & -84 \\
\hline $\mathrm{BF}_{3}$ & ${ }^{1} J_{\mathrm{BF}}$ & $-83,5$ & $-64,7$ & $-46,2$ & $-27,9$ & $-9,8$ & 8,0 & 25,7 & 43,2 & 60,6 & 77,8 & 94,8 & 15 \\
\hline $\mathrm{F}_{2} \mathrm{O}$ & ${ }^{1} J_{\mathrm{OF}}$ & $-302,1$ & $-339,2$ & $-376,6$ & $-415,7$ & $-458,9$ & $-509,4$ & $-573,0$ & $-661,2$ & $-800,7$ & $-1076,2$ & $-2007,4$ & -300 \\
\hline $\mathrm{CH}_{4}$ & ${ }^{1} J_{\mathrm{CH}}$ & 121,8 & 123,3 & 124,8 & 126,3 & 127,9 & 129,5 & 131,1 & 132,7 & 134,3 & 136,0 & 137,7 & 125,3 \\
\hline $\mathrm{CH}_{4}$ & ${ }^{2} J_{\mathrm{HH}}$ & $-12,1$ & $-12,8$ & $-13,6$ & $-14,3$ & $-15,0$ & $-15,7$ & $-16,4$ & $-17,1$ & $-17,8$ & $-18,5$ & $-19,2$ & $-12,8$ \\
\hline $\mathrm{C}_{2} \mathrm{H}_{2}$ & ${ }^{1} J_{\mathrm{CC}}$ & 190,5 & 193,2 & 196,4 & 200,0 & 204,2 & 209,2 & 215,1 & 222,2 & 230,9 & 241,7 & 255,5 & 174,8 \\
\hline $\mathrm{C}_{2} \mathrm{H}_{2}$ & ${ }^{1} J_{\mathrm{CH}}$ & 254,3 & 256,7 & 259,1 & 261,8 & 264,7 & 267,8 & 271,4 & 275,5 & 280,2 & 286,0 & 293,1 & 247,6 \\
\hline $\mathrm{C}_{2} \mathrm{H}_{2}$ & ${ }^{2} J_{\mathrm{CH}}$ & 55,0 & 54,9 & 54,7 & 54,2 & 53,3 & 52,1 & 50,5 & 48,2 & 45,2 & 41,2 & 35,7 & 50,1 \\
\hline $\mathrm{C}_{2} \mathrm{H}_{2}$ & ${ }^{3} J_{\mathrm{HH}}$ & 10,8 & 11,5 & 12,2 & 13,1 & 14,2 & 15,5 & 17,0 & 18,9 & 21,2 & 24,1 & 27,7 & 9,6 \\
\hline $\mathrm{C}_{2} \mathrm{H}_{4}$ & ${ }^{1} J_{\mathrm{CC}}$ & 61,3 & 64,1 & 67,1 & 70,6 & 74,5 & 79,2 & 84,9 & 92,2 & 101,9 & 116,0 & 138,9 & 67,6 \\
\hline $\mathrm{C}_{2} \mathrm{H}_{4}$ & ${ }^{1} J_{\mathrm{CH}}$ & 153,9 & 156,0 & 158,3 & 160,7 & 163,2 & 166,1 & 169,4 & 173,2 & 178,1 & 184,7 & 194,9 & 156,3 \\
\hline $\mathrm{C}_{2} \mathrm{H}_{4}$ & ${ }^{2} J_{\mathrm{CH}}$ & $-0,4$ & $-1,2$ & $-2,2$ & $-3,3$ & $-4,6$ & $-6,3$ & $-8,3$ & $-11,0$ & $-14,7$ & $-20,1$ & $-29,1$ & $-2,4$ \\
\hline $\mathrm{C}_{2} \mathrm{H}_{4}$ & ${ }^{2} J_{\mathrm{HH}}$ & 4,9 & 4,2 & 3,4 & 2,5 & 1,5 & 0,3 & $-1,0$ & $-2,7$ & $-5,0$ & $-8,3$ & $-13,6$ & 2,3 \\
\hline $\mathrm{C}_{2} \mathrm{H}_{4}$ & ${ }^{3} J_{\mathrm{HH}_{\mathrm{c}}}$ & 11,9 & 12,2 & 12,6 & 13,0 & 13,6 & 14,3 & 15,3 & 16,6 & 18,5 & 21,4 & 26,4 & 11,7 \\
\hline $\mathrm{C}_{2} \mathrm{H}_{4}$ & ${ }^{3} J_{\mathrm{HH}_{\mathrm{t}}}$ & 19,2 & 19,5 & 19,9 & 20,5 & 21,1 & 22,0 & 23,1 & 24,7 & 26,9 & 30,2 & 35,8 & 19 \\
\hline $\mathrm{C}_{2} \mathrm{H}_{6}$ & ${ }^{1} J_{\mathrm{CC}}$ & 25,9 & 27,9 & 29,9 & 32,0 & 34,1 & 36,2 & 38,4 & 40,6 & 42,8 & 45,1 & 47,4 & 34,5 \\
\hline $\mathrm{C}_{2} \mathrm{H}_{6}$ & ${ }^{1} J_{\mathrm{CH}}$ & 121,3 & 123,0 & 124,7 & 126,4 & 128,1 & 129,9 & 131,7 & 133,5 & 135,3 & 137,2 & 139,0 & 125,2 \\
\hline $\mathrm{C}_{2} \mathrm{H}_{6}$ & ${ }^{2} J_{\mathrm{CH}}$ & $-2,9$ & $-3,3$ & $-3,8$ & $-4,3$ & $-4,7$ & $-5,2$ & $-5,7$ & $-6,2$ & $-6,8$ & $-7,3$ & $-7,8$ & $-4,7$ \\
\hline \multirow[t]{3}{*}{ Total } & $\mathrm{DM}$ & $-28,82$ & $-26,33$ & $-23,66$ & $-20,90$ & $-18,13$ & $-15,51$ & $-13,22$ & $-11,73$ & $-11,99$ & $-17,14$ & $-46,96$ & - \\
\hline & DMA & 34,08 & 31,40 & 28,78 & 26,58 & 24,77 & 23,58 & 24,35 & 27,92 & 35,93 & 50,23 & 92,11 & - \\
\hline & PDMA & 51,82 & 41,83 & 31,98 & 25,15 & 22,95 & 25,01 & 35,35 & 53,33 & 76,05 & 106,17 & 156,17 & - \\
\hline \multirow[t]{3}{*}{ CPI } & $\mathrm{DM}$ & $-69,15$ & $-64,51$ & $-59,51$ & $-54,40$ & $-49,41$ & $-44,91$ & $-41,47$ & $-40,19$ & $-43,51$ & $-59,17$ & $-134,47$ & - \\
\hline & DMA & 75,05 & 69,29 & 63,20 & 56,93 & 50,97 & 45,78 & 44,82 & 49,65 & 64,02 & 91,79 & 182,15 & - \\
\hline & PDMA & 93,53 & 76,98 & 60,74 & 44,30 & 29,79 & 18,26 & 23,86 & 41,55 & 62,18 & 87,20 & 132,39 & - \\
\hline \multirow[t]{3}{*}{ SPI } & $\mathrm{DM}$ & 0,75 & 1,67 & 2,63 & 3,67 & 4,80 & 6,05 & 7,49 & 9,15 & 11,13 & 13,69 & 17,22 & - \\
\hline & DMA & 4,05 & 3,62 & 3,55 & 4,33 & 5,55 & 7,29 & 9,33 & 11,99 & 15,34 & 19,75 & 26,09 & - \\
\hline & PDMA & 21,24 & 16,05 & 10,89 & 11,10 & 17,94 & 29,97 & 43,78 & 61,97 & 86,21 & 120,09 & 173,61 & - \\
\hline \multirow[t]{3}{*}{$\Delta \mathrm{CS}$} & $\mathrm{DM}$ & $-69,91$ & $-66,18$ & $-62,14$ & $-58,07$ & $-54,21$ & $-50,96$ & $-48,97$ & $-49,34$ & $-54,64$ & $-72,86$ & $-151,69$ & - \\
\hline & DMA & 71,00 & 65,67 & 59,65 & 52,60 & 45,43 & 38,49 & 35,48 & 37,66 & 48,68 & 72,04 & 156,06 & - \\
\hline & PDMA & 72,29 & 60,93 & 49,85 & 33,20 & 11,85 & $-11,71$ & $-19,92$ & $-20,43$ & $-24,03$ & $-32,88$ & $-41,22$ & - \\
\hline
\end{tabular}


Tabela 8.42: Constantes de acoplamento B971 com correção vibracional no nível BHandH $\left(50 \% E_{X}^{\mathrm{HF}}\right)$ e base aug-pcJ-2.

\begin{tabular}{|c|c|c|c|c|c|c|c|c|c|c|c|c|c|}
\hline & $\% E_{X}^{\mathrm{HF}}$ & $0 \%$ & $10 \%$ & $20 \%$ & $30 \%$ & $40 \%$ & $50 \%$ & $60 \%$ & $70 \%$ & $80 \%$ & $90 \%$ & $100 \%$ & Exp. \\
\hline $\mathrm{HF}$ & ${ }^{1} J_{\mathrm{HF}}$ & 394,5 & 411,1 & 428,6 & 447,2 & 466,9 & 487,8 & 510,0 & 533,3 & 558,0 & 583,9 & 611,1 & 500 \\
\hline $\mathrm{CO}$ & ${ }^{1} J_{\mathrm{CO}}$ & 16,5 & 15,4 & 14,2 & 12,9 & 11,4 & 9,7 & 8,0 & 6,0 & 3,9 & 1,7 & $-0,6$ & 16,4 \\
\hline $\mathrm{H}_{2} \mathrm{O}$ & ${ }^{1} J_{\mathrm{OH}}$ & $-66,6$ & $-68,7$ & $-71,0$ & $-73,4$ & $-75,9$ & $-78,6$ & $-81,4$ & $-84,4$ & $-87,7$ & $-91,1$ & $-94,6$ & $-80,6$ \\
\hline $\mathrm{H}_{2} \mathrm{O}$ & ${ }^{2} J_{\mathrm{HH}}$ & 0,9 & $-0,1$ & $-1,2$ & $-2,3$ & $-3,6$ & $-4,9$ & $-6,2$ & $-7,7$ & $-9,3$ & $-11,0$ & $-12,8$ & $-7,3$ \\
\hline $\mathrm{NH}_{3}$ & ${ }^{1} J_{\mathrm{NH}}$ & 38,4 & 39,4 & 40,4 & 41,5 & 42,7 & 43,9 & 45,2 & 46,7 & 48,1 & 49,7 & 51,4 & 43,8 \\
\hline $\mathrm{NH}_{3}$ & ${ }^{2} J_{\mathrm{HH}}$ & $-2,5$ & $-3,4$ & $-4,3$ & $-5,4$ & $-6,5$ & $-7,7$ & $-9,0$ & $-10,3$ & $-11,8$ & $-13,4$ & $-15,2$ & $-9,6$ \\
\hline $\mathrm{PH}_{3}$ & ${ }^{1} J_{\mathrm{PH}}$ & 155,1 & 161,3 & 167,9 & 174,8 & 182,1 & 189,8 & 197,8 & 206,3 & 215,1 & 224,3 & 233,9 & 188,2 \\
\hline $\mathrm{PF}_{3}$ & ${ }^{1} J_{\mathrm{PF}}$ & $-1612,9$ & $-1607,6$ & $-1596,7$ & $-1581,1$ & $-1561,4$ & $-1538,4$ & $-1512,7$ & $-1484,9$ & $-1455,5$ & $-1425,1$ & $-1394,1$ & -1441 \\
\hline $\mathrm{BHF}_{2}$ & ${ }^{1} J_{\mathrm{BF}}$ & $-149,3$ & $-134,8$ & $-119,9$ & $-104,8$ & $-89,4$ & $-73,9$ & $-58,3$ & $-42,7$ & $-27,1$ & $-11,5$ & 3,8 & -84 \\
\hline $\mathrm{BF}_{3}$ & ${ }^{1} J_{\mathrm{BF}}$ & $-57,8$ & $-41,0$ & $-24,0$ & $-6,8$ & 10,3 & 27,6 & 45,0 & 62,4 & 79,8 & 97,2 & 114,7 & 15 \\
\hline $\mathrm{F}_{2} \mathrm{O}$ & ${ }^{1} J_{\mathrm{OF}}$ & $-204,1$ & $-235,9$ & $-269,1$ & $-304,1$ & $-342,0$ & $-384,7$ & $-435,5$ & $-501,2$ & $-596,8$ & $-767,1$ & $-1235,6$ & -300 \\
\hline $\mathrm{CH}_{4}$ & ${ }^{1} J_{\mathrm{CH}}$ & 105,0 & 108,2 & 111,6 & 115,2 & 119,0 & 123,1 & 127,5 & 132,1 & 136,9 & 142,1 & 147,6 & 125,3 \\
\hline $\mathrm{CH}_{4}$ & ${ }^{2} J_{\mathrm{HH}}$ & $-6,1$ & $-7,0$ & $-7,9$ & $-8,8$ & $-9,9$ & $-11,0$ & $-12,1$ & $-13,4$ & $-14,7$ & $-16,1$ & $-17,6$ & $-12,8$ \\
\hline $\mathrm{C}_{2} \mathrm{H}_{2}$ & ${ }^{1} J_{\mathrm{CC}}$ & 186,8 & 190,8 & 195,1 & 200,1 & 205,7 & 212,3 & 220,1 & 229,5 & 241,2 & 256,1 & 275,8 & 174,8 \\
\hline $\mathrm{C}_{2} \mathrm{H}_{2}$ & ${ }^{1} J_{\mathrm{CH}}$ & 203,9 & 210,6 & 217,6 & 225,0 & 232,8 & 241,2 & 250,3 & 260,2 & 271,3 & 283,9 & 298,8 & 247,6 \\
\hline $\mathrm{C}_{2} \mathrm{H}_{2}$ & ${ }^{2} J_{\mathrm{CH}}$ & 51,3 & 52,2 & 52,8 & 53,3 & 53,5 & 53,3 & 52,8 & 51,5 & 49,4 & 45,9 & 40,4 & 50,1 \\
\hline $\mathrm{C}_{2} \mathrm{H}_{2}$ & ${ }^{3} J_{\mathrm{HH}}$ & 6,8 & 7,2 & 7,7 & 8,2 & 9,0 & 9,9 & 11,1 & 12,6 & 14,6 & 17,3 & 21,1 & 9,6 \\
\hline $\mathrm{C}_{2} \mathrm{H}_{4}$ & ${ }^{1} J_{\mathrm{CC}}$ & 64,1 & 66,8 & 69,8 & 73,2 & 77,1 & 81,5 & 86,9 & 93,5 & 101,9 & 113,6 & 131,2 & 67,6 \\
\hline $\mathrm{C}_{2} \mathrm{H}_{4}$ & ${ }^{1} J_{\mathrm{CH}}$ & 128,0 & 132,4 & 137,1 & 142,0 & 147,3 & 153,1 & 159,3 & 166,2 & 174,0 & 183,2 & 194,9 & 156,3 \\
\hline $\mathrm{C}_{2} \mathrm{H}_{4}$ & ${ }^{2} J_{\mathrm{CH}}$ & 2,1 & 1,5 & 0,7 & $-0,2$ & $-1,2$ & $-2,5$ & $-4,1$ & $-6,2$ & $-8,9$ & $-12,9$ & $-19,2$ & $-2,4$ \\
\hline $\mathrm{C}_{2} \mathrm{H}_{4}$ & ${ }^{2} J_{\mathrm{HH}}$ & 6,2 & 5,8 & 5,4 & 4,9 & 4,3 & 3,6 & 2,7 & 1,6 & 0,2 & $-1,8$ & $-4,9$ & 2,3 \\
\hline $\mathrm{C}_{2} \mathrm{H}_{4}$ & ${ }^{3} J_{\mathrm{HH}_{\mathrm{c}}}$ & 9,6 & 9,9 & 10,1 & 10,5 & 10,8 & 11,3 & 11,9 & 12,7 & 13,9 & 15,6 & 18,3 & 11,7 \\
\hline $\mathrm{C}_{2} \mathrm{H}_{4}$ & ${ }^{3} J_{\mathrm{HH}_{\mathrm{t}}}$ & 13,9 & 14,4 & 14,9 & 15,5 & 16,2 & 17,0 & 18,0 & 19,2 & 20,8 & 23,1 & 26,5 & 19 \\
\hline $\mathrm{C}_{2} \mathrm{H}_{6}$ & ${ }^{1} J_{\mathrm{CC}}$ & 26,3 & 28,5 & 30,9 & 33,3 & 36,0 & 38,7 & 41,7 & 44,8 & 48,1 & 51,6 & 55,3 & 34,5 \\
\hline $\mathrm{C}_{2} \mathrm{H}_{6}$ & ${ }^{1} J_{\mathrm{CH}}$ & 103,1 & 106,6 & 110,3 & 114,2 & 118,4 & 122,8 & 127,4 & 132,3 & 137,5 & 143,1 & 148,9 & 125,2 \\
\hline $\mathrm{C}_{2} \mathrm{H}_{6}$ & ${ }^{2} J_{\mathrm{CH}}$ & $-0,8$ & $-1,3$ & $-1,9$ & $-2,4$ & $-3,0$ & $-3,7$ & $-4,4$ & $-5,1$ & $-5,9$ & $-6,8$ & $-7,7$ & $-4,7$ \\
\hline \multirow[t]{3}{*}{ Total } & $\mathrm{DM}$ & $-16,64$ & $-14,72$ & $-12,53$ & $-10,10$ & $-7,48$ & $-4,76$ & $-2,04$ & 0,38 & 2,00 & 1,17 & $-10,52$ & - \\
\hline & DMA & 28,75 & 24,27 & 19,53 & 14,83 & 12,45 & 11,98 & 14,82 & 20,84 & 28,73 & 41,48 & 67,88 & - \\
\hline & PDMA & 59,09 & 49,25 & 39,06 & 28,56 & 18,51 & 15,87 & 22,10 & 34,87 & 54,74 & 80,27 & 117,17 & - \\
\hline \multirow[t]{3}{*}{ CPI } & $\mathrm{DM}$ & $-29,88$ & $-27,75$ & $-25,09$ & $-22,04$ & $-18,75$ & $-15,48$ & $-12,55$ & $-10,67$ & $-11,29$ & $-18,48$ & $-52,63$ & - \\
\hline & DMA & 52,66 & 44,00 & 34,53 & 25,02 & 20,85 & 21,06 & 26,80 & 36,67 & 49,64 & 72,39 & 125,14 & - \\
\hline & PDMA & 78,39 & 62,99 & 47,34 & 31,51 & 17,44 & 20,96 & 33,14 & 49,01 & 70,07 & 93,95 & 127,53 & - \\
\hline \multirow[t]{3}{*}{ SPI } & $\mathrm{DM}$ & $-6,93$ & $-5,17$ & $-3,33$ & $-1,34$ & 0,79 & 3,10 & 5,67 & 8,49 & 11,75 & 15,59 & 20,35 & - \\
\hline & DMA & 11,22 & 9,79 & 8,54 & 7,37 & 6,29 & 5,33 & 6,03 & 9,23 & 13,40 & 18,81 & 25,89 & - \\
\hline & PDMA & 44,94 & 39,17 & 32,99 & 26,39 & 19,30 & 12,13 & 13,99 & 24,51 & 43,49 & 70,23 & 109,58 & - \\
\hline \multirow[t]{3}{*}{$\Delta \mathrm{CS}$} & $\mathrm{DM}$ & $-22,96$ & $-22,58$ & $-21,76$ & $-20,70$ & $-19,55$ & $-18,58$ & $-18,21$ & $-19,17$ & $-23,04$ & $-34,07$ & $-72,98$ & - \\
\hline & DMA & 41,44 & 34,21 & 25,99 & 17,65 & 14,56 & 15,74 & 20,77 & 27,45 & 36,24 & 53,58 & 99,25 & - \\
\hline & PDMA & 33,44 & 23,82 & 14,36 & 5,12 & $-1,87$ & 8,83 & 19,15 & 24,50 & 26,57 & 23,72 & 17,96 & - \\
\hline
\end{tabular}


Tabela 8.43: Constantes de acoplamento B972 com correção vibracional no nível BHandH $\left(50 \% E_{X}^{\mathrm{HF}}\right)$ e base aug-pcJ-2.

\begin{tabular}{|c|c|c|c|c|c|c|c|c|c|c|c|c|c|}
\hline & $\% E_{X}^{\mathrm{HF}}$ & $0 \%$ & $10 \%$ & $20 \%$ & $30 \%$ & $40 \%$ & $50 \%$ & $60 \%$ & $70 \%$ & $80 \%$ & $90 \%$ & $100 \%$ & Exp. \\
\hline $\mathrm{HF}$ & ${ }^{1} J_{\mathrm{HF}}$ & 387,8 & 408,7 & 430,9 & 454,4 & 479,2 & 505,4 & 533,0 & 562,2 & 592,8 & 625,0 & 658,8 & 500 \\
\hline $\mathrm{CO}$ & ${ }^{1} J_{\mathrm{CO}}$ & 17,6 & 16,0 & 14,2 & 12,2 & 9,9 & 7,5 & 4,9 & 2,1 & $-0,9$ & $-4,1$ & $-7,6$ & 16,4 \\
\hline $\mathrm{H}_{2} \mathrm{O}$ & ${ }^{1} J_{\mathrm{OH}}$ & $-65,7$ & $-68,5$ & $-71,4$ & $-74,5$ & $-77,8$ & $-81,2$ & $-84,9$ & $-88,9$ & $-93,0$ & $-97,4$ & $-102,0$ & $-80,6$ \\
\hline $\mathrm{H}_{2} \mathrm{O}$ & ${ }^{2} J_{\mathrm{HH}}$ & 0,3 & $-0,7$ & $-1,7$ & $-2,8$ & $-4,0$ & $-5,2$ & $-6,5$ & $-8,0$ & $-9,5$ & $-11,1$ & $-12,8$ & $-7,3$ \\
\hline $\mathrm{NH}_{3}$ & ${ }^{1} J_{\mathrm{NH}}$ & 37,1 & 38,3 & 39,7 & 41,1 & 42,6 & 44,2 & 45,9 & 47,8 & 49,7 & 51,7 & 53,9 & 43,8 \\
\hline $\mathrm{NH}_{3}$ & ${ }^{2} J_{\mathrm{HH}}$ & $-2,4$ & $-3,3$ & $-4,2$ & $-5,1$ & $-6,2$ & $-7,3$ & $-8,5$ & $-9,8$ & $-11,2$ & $-12,7$ & $-14,3$ & $-9,6$ \\
\hline $\mathrm{PH}_{3}$ & ${ }^{1} J_{\mathrm{PH}}$ & 145,6 & 152,7 & 160,2 & 168,2 & 176,6 & 185,4 & 194,6 & 204,3 & 214,4 & 224,8 & 235,7 & 188,2 \\
\hline $\mathrm{PF}_{3}$ & ${ }^{1} J_{\mathrm{PF}}$ & $-1625,7$ & $-1620,3$ & $-1609,7$ & $-1594,6$ & $-1575,9$ & $-1554,3$ & $-1530,5$ & $-1505,0$ & $-1478,4$ & $-1451,4$ & $-1424,2$ & -1441 \\
\hline $\mathrm{BHF}_{2}$ & ${ }^{1} J_{\mathrm{BF}}$ & $-155,7$ & $-139,0$ & $-121,9$ & $-104,6$ & $-87,2$ & $-69,7$ & $-52,3$ & $-35,0$ & $-17,7$ & $-0,8$ & 16,0 & -84 \\
\hline $\mathrm{BF}_{3}$ & ${ }^{1} J_{\mathrm{BF}}$ & $-66,1$ & $-46,7$ & $-27,2$ & $-7,5$ & 12,0 & 31,7 & 51,4 & 71,0 & 90,6 & 110,1 & 129,5 & 15 \\
\hline $\mathrm{F}_{2} \mathrm{O}$ & ${ }^{1} J_{\mathrm{OF}}$ & $-201,6$ & $-232,2$ & $-264,1$ & $-298,0$ & $-334,9$ & $-376,8$ & $-427,2$ & $-493,2$ & $-591,7$ & $-776,0$ & $-1363,3$ & -300 \\
\hline $\mathrm{CH}_{4}$ & ${ }^{1} J_{\mathrm{CH}}$ & 97,1 & 101,1 & 105,3 & 109,7 & 114,4 & 119,4 & 124,7 & 130,3 & 136,2 & 142,4 & 149,0 & 125,3 \\
\hline $\mathrm{CH}_{4}$ & ${ }^{2} J_{\mathrm{HH}}$ & $-5,7$ & $-6,4$ & $-7,2$ & $-8,1$ & $-9,0$ & $-10,0$ & $-11,0$ & $-12,2$ & $-13,3$ & $-14,6$ & $-15,9$ & $-12,8$ \\
\hline $\mathrm{C}_{2} \mathrm{H}_{2}$ & ${ }^{1} J_{\mathrm{CC}}$ & 173,4 & 178,2 & 183,5 & 189,5 & 196,3 & 204,1 & 213,2 & 224,1 & 237,3 & 253,8 & 275,0 & 174,8 \\
\hline $\mathrm{C}_{2} \mathrm{H}_{2}$ & ${ }^{1} J_{\mathrm{CH}}$ & 193,2 & 200,7 & 208,7 & 217,0 & 225,9 & 235,3 & 245,5 & 256,4 & 268,5 & 281,9 & 297,4 & 247,6 \\
\hline $\mathrm{C}_{2} \mathrm{H}_{2}$ & ${ }^{2} J_{\mathrm{CH}}$ & 49,4 & 50,3 & 51,1 & 51,7 & 52,1 & 52,2 & 51,8 & 50,9 & 49,2 & 46,4 & 41,9 & 50,1 \\
\hline $\mathrm{C}_{2} \mathrm{H}_{2}$ & ${ }^{3} J_{\mathrm{HH}}$ & 6,7 & 7,1 & 7,5 & 8,0 & 8,7 & 9,5 & 10,5 & 11,8 & 13,5 & 15,7 & 18,6 & 9,6 \\
\hline $\mathrm{C}_{2} \mathrm{H}_{4}$ & ${ }^{1} J_{\mathrm{CC}}$ & 55,3 & 58,7 & 62,4 & 66,7 & 71,5 & 77,0 & 83,6 & 91,7 & 102,1 & 116,4 & 137,7 & 67,6 \\
\hline $\mathrm{C}_{2} \mathrm{H}_{4}$ & ${ }^{1} J_{\mathrm{CH}}$ & 119,7 & 124,8 & 130,3 & 136,0 & 142,2 & 148,8 & 156,0 & 163,8 & 172,7 & 183,0 & 195,9 & 156,3 \\
\hline $\mathrm{C}_{2} \mathrm{H}_{4}$ & ${ }^{2} J_{\mathrm{CH}}$ & 2,2 & 1,6 & 0,9 & 0,1 & $-0,8$ & $-2,1$ & $-3,6$ & $-5,6$ & $-8,4$ & $-12,3$ & $-18,5$ & $-2,4$ \\
\hline $\mathrm{C}_{2} \mathrm{H}_{4}$ & ${ }^{2} J_{\mathrm{HH}}$ & 5,8 & 5,6 & 5,3 & 4,9 & 4,4 & 3,9 & 3,2 & 2,4 & 1,3 & $-0,3$ & $-2,7$ & 2,3 \\
\hline $\mathrm{C}_{2} \mathrm{H}_{4}$ & ${ }^{3} J_{\mathrm{HH}_{\mathrm{c}}}$ & 9,2 & 9,4 & 9,7 & 10,0 & 10,4 & 10,9 & 11,4 & 12,1 & 13,1 & 14,6 & 16,9 & 11,7 \\
\hline $\mathrm{C}_{2} \mathrm{H}_{4}$ & ${ }^{3} J_{\mathrm{HH}_{\mathrm{t}}}$ & 13,4 & 13,9 & 14,4 & 15,0 & 15,7 & 16,5 & 17,4 & 18,5 & 20,0 & 22,0 & 25,0 & 19 \\
\hline $\mathrm{C}_{2} \mathrm{H}_{6}$ & ${ }^{1} J_{\mathrm{CC}}$ & 22,8 & 25,4 & 28,2 & 31,1 & 34,2 & 37,5 & 41,0 & 44,7 & 48,7 & 52,9 & 57,3 & 34,5 \\
\hline $\mathrm{C}_{2} \mathrm{H}_{6}$ & ${ }^{1} J_{\mathrm{CH}}$ & 95,1 & 99,3 & 103,7 & 108,3 & 113,3 & 118,5 & 124,0 & 129,8 & 136,0 & 142,5 & 149,4 & 125,2 \\
\hline $\mathrm{C}_{2} \mathrm{H}_{6}$ & ${ }^{2} J_{\mathrm{CH}}$ & $-0,7$ & $-1,1$ & $-1,6$ & $-2,1$ & $-2,6$ & $-3,2$ & $-3,8$ & $-4,4$ & $-5,1$ & $-5,9$ & $-6,7$ & $-4,7$ \\
\hline \multirow[t]{3}{*}{ Total } & $\mathrm{DM}$ & $-20,65$ & $-18,13$ & $-15,31$ & $-12,25$ & $-9,00$ & $-5,65$ & $-2,35$ & 0,65 & 2,77 & 1,98 & $-13,65$ & - \\
\hline & DMA & 32,07 & 26,88 & 21,52 & 15,77 & 12,58 & 12,67 & 16,09 & 22,52 & 31,33 & 44,28 & 75,06 & - \\
\hline & PDMA & 63,41 & 52,51 & 41,74 & 30,35 & 19,64 & 18,97 & 25,18 & 35,71 & 54,85 & 80,42 & 117,97 & - \\
\hline \multirow[t]{3}{*}{ CPI } & $\mathrm{DM}$ & $-33,61$ & $-30,54$ & $-26,92$ & $-22,92$ & $-18,78$ & $-14,65$ & $-11,00$ & $-8,49$ & $-8,71$ & $-16,62$ & $-61,02$ & - \\
\hline & DMA & 57,12 & 47,41 & 37,12 & 26,03 & 20,51 & 22,15 & 31,27 & 42,55 & 57,22 & 79,85 & 142,42 & - \\
\hline & PDMA & 85,18 & 66,82 & 49,63 & 32,13 & 16,51 & 24,82 & 40,15 & 58,16 & 81,49 & 107,74 & 146,84 & - \\
\hline \multirow[t]{3}{*}{ SPI } & $\mathrm{DM}$ & $-11,15$ & $-9,03$ & $-6,79$ & $-4,42$ & $-1,83$ & 0,95 & 3,99 & 7,35 & 11,18 & 15,63 & 21,08 & - \\
\hline & DMA & 13,71 & 11,82 & 10,09 & 8,25 & 6,76 & 5,72 & 4,96 & 7,84 & 12,35 & 18,19 & 25,67 & - \\
\hline & PDMA & 47,45 & 42,02 & 35,95 & 29,04 & 21,94 & 14,68 & 14,20 & 19,25 & 35,32 & 60,38 & 96,80 & - \\
\hline \multirow[t]{3}{*}{$\Delta \mathrm{CS}$} & $\mathrm{DM}$ & $-22,46$ & $-21,50$ & $-20,12$ & $-18,50$ & $-16,96$ & $-15,60$ & $-14,99$ & $-15,84$ & $-19,89$ & $-32,24$ & $-82,10$ & - \\
\hline & DMA & 43,41 & 35,59 & 27,03 & 17,78 & 13,75 & 16,43 & 26,31 & 34,71 & 44,86 & 61,67 & 116,75 & - \\
\hline & PDMA & 37,73 & 24,80 & 13,69 & 3,09 & $-5,43$ & 10,14 & 25,95 & 38,91 & 46,17 & 47,35 & 50,04 & - \\
\hline
\end{tabular}


Tabela 8.44: Constantes de acoplamento B98 com correção vibracional no nível BHandH $\left(50 \% E_{X}^{\mathrm{HF}}\right)$ e base aug-pcJ-2.

\begin{tabular}{|c|c|c|c|c|c|c|c|c|c|c|c|c|c|}
\hline & $\% E_{X}^{\mathrm{HF}}$ & $0 \%$ & $10 \%$ & $20 \%$ & $30 \%$ & $40 \%$ & $50 \%$ & $60 \%$ & $70 \%$ & $80 \%$ & $90 \%$ & $100 \%$ & Exp. \\
\hline $\mathrm{HF}$ & ${ }^{1} J_{\mathrm{HF}}$ & 378,8 & 395,3 & 413,0 & 431,8 & 451,8 & 473,1 & 495,7 & 519,7 & 545,1 & 572,0 & 600,3 & 500 \\
\hline $\mathrm{CO}$ & ${ }^{1} J_{\mathrm{CO}}$ & 17,3 & 16,2 & 14,9 & 13,5 & 11,9 & 10,2 & 8,4 & 6,3 & 4,1 & 1,7 & $-0,7$ & 16,4 \\
\hline $\mathrm{H}_{2} \mathrm{O}$ & ${ }^{1} J_{\mathrm{OH}}$ & $-64,9$ & $-67,1$ & $-69,4$ & $-71,9$ & $-74,5$ & $-77,3$ & $-80,3$ & $-83,5$ & $-87,0$ & $-90,6$ & $-94,5$ & $-80,6$ \\
\hline $\mathrm{H}_{2} \mathrm{O}$ & ${ }^{2} J_{\mathrm{HH}}$ & 0,8 & $-0,2$ & $-1,2$ & $-2,4$ & $-3,6$ & $-4,9$ & $-6,4$ & $-7,9$ & $-9,5$ & $-11,2$ & $-13,1$ & $-7,3$ \\
\hline $\mathrm{NH}_{3}$ & ${ }^{1} J_{\mathrm{NH}}$ & 37,8 & 38,9 & 40,0 & 41,2 & 42,5 & 43,9 & 45,4 & 46,9 & 48,6 & 50,4 & 52,3 & 43,8 \\
\hline $\mathrm{NH}_{3}$ & ${ }^{2} J_{\mathrm{HH}}$ & $-2,6$ & $-3,5$ & $-4,5$ & $-5,5$ & $-6,7$ & $-7,9$ & $-9,3$ & $-10,7$ & $-12,3$ & $-14,0$ & $-15,9$ & $-9,6$ \\
\hline $\mathrm{PH}_{3}$ & ${ }^{1} J_{\mathrm{PH}}$ & 159,1 & 165,4 & 172,2 & 179,3 & 186,9 & 194,9 & 203,3 & 212,1 & 221,3 & 231,0 & 241,1 & 188,2 \\
\hline $\mathrm{PF}_{3}$ & ${ }^{1} J_{\mathrm{PF}}$ & $-1621,9$ & $-1616,9$ & $-1606,4$ & $-1590,9$ & $-1571,4$ & $-1548,4$ & $-1522,7$ & $-1494,9$ & $-1465,5$ & $-1435,0$ & $-1403,8$ & -1441 \\
\hline $\mathrm{BHF}_{2}$ & ${ }^{1} J_{\mathrm{BF}}$ & $-154,4$ & $-139,8$ & $-124,9$ & $-109,5$ & $-93,9$ & $-78,1$ & $-62,1$ & $-46,1$ & $-30,0$ & $-13,9$ & 1,9 & -84 \\
\hline $\mathrm{BF}_{3}$ & ${ }^{1} J_{\mathrm{BF}}$ & $-63,6$ & $-46,8$ & $-29,8$ & $-12,5$ & 4,9 & 22,4 & 40,1 & 57,9 & 75,8 & 93,7 & 111,7 & 15 \\
\hline $\mathrm{F}_{2} \mathrm{O}$ & ${ }^{1} J_{\mathrm{OF}}$ & $-210,8$ & $-243,2$ & $-277,1$ & $-313,2$ & $-352,5$ & $-397,3$ & $-451,6$ & $-523,3$ & $-631,7$ & $-837,8$ & $-1521,4$ & -300 \\
\hline $\mathrm{CH}_{4}$ & ${ }^{1} J_{\mathrm{CH}}$ & 103,6 & 107,2 & 111,0 & 115,1 & 119,4 & 124,0 & 129,0 & 134,2 & 139,8 & 145,7 & 152,0 & 125,3 \\
\hline $\mathrm{CH}_{4}$ & ${ }^{2} J_{\mathrm{HH}}$ & $-6,2$ & $-7,1$ & $-8,0$ & $-9,0$ & $-10,1$ & $-11,3$ & $-12,5$ & $-13,8$ & $-15,3$ & $-16,8$ & $-18,4$ & $-12,8$ \\
\hline $\mathrm{C}_{2} \mathrm{H}_{2}$ & ${ }^{1} J_{\mathrm{CC}}$ & 185,2 & 189,5 & 194,2 & 199,6 & 205,7 & 212,9 & 221,3 & 231,6 & 244,3 & 260,7 & 282,8 & 174,8 \\
\hline $\mathrm{C}_{2} \mathrm{H}_{2}$ & ${ }^{1} J_{\mathrm{CH}}$ & 201,3 & 208,6 & 216,2 & 224,4 & 233,0 & 242,3 & 252,3 & 263,3 & 275,6 & 289,8 & 306,6 & 247,6 \\
\hline $\mathrm{C}_{2} \mathrm{H}_{2}$ & ${ }^{2} J_{\mathrm{CH}}$ & 50,9 & 51,8 & 52,6 & 53,2 & 53,5 & 53,5 & 52,9 & 51,7 & 49,5 & 45,7 & 39,6 & 50,1 \\
\hline $\mathrm{C}_{2} \mathrm{H}_{2}$ & ${ }^{3} J_{\mathrm{HH}}$ & 6,7 & 7,1 & 7,6 & 8,2 & 9,0 & 10,0 & 11,2 & 12,9 & 15,1 & 18,1 & 22,3 & 9,6 \\
\hline $\mathrm{C}_{2} \mathrm{H}_{4}$ & ${ }^{1} J_{\mathrm{CC}}$ & 62,9 & 65,9 & 69,2 & 72,9 & 77,1 & 82,0 & 87,9 & 95,2 & 104,7 & 118,1 & 139,0 & 67,6 \\
\hline $\mathrm{C}_{2} \mathrm{H}_{4}$ & ${ }^{1} J_{\mathrm{CH}}$ & 126,3 & 131,1 & 136,2 & 141,7 & 147,6 & 153,9 & 160,8 & 168,5 & 177,3 & 187,8 & 201,5 & 156,3 \\
\hline $\mathrm{C}_{2} \mathrm{H}_{4}$ & ${ }^{2} J_{\mathrm{CH}}$ & 2,1 & 1,4 & 0,6 & $-0,3$ & $-1,2$ & $-2,5$ & $-4,2$ & $-6,4$ & $-9,4$ & $-13,9$ & $-21,3$ & $-2,4$ \\
\hline $\mathrm{C}_{2} \mathrm{H}_{4}$ & ${ }^{2} J_{\mathrm{HH}}$ & 5,9 & 5,6 & 5,2 & 4,7 & 4,1 & 3,4 & 2,5 & 1,4 & $-0,1$ & $-2,3$ & $-6,0$ & 2,3 \\
\hline $\mathrm{C}_{2} \mathrm{H}_{4}$ & ${ }^{3} J_{\mathrm{HH}_{\mathrm{c}}}$ & 9,6 & 9,8 & 10,1 & 10,5 & 10,9 & 11,4 & 12,1 & 13,0 & 14,2 & 16,2 & 19,5 & 11,7 \\
\hline $\mathrm{C}_{2} \mathrm{H}_{4}$ & ${ }^{3} J_{\mathrm{HH}_{\mathrm{t}}}$ & 13,7 & 14,2 & 14,8 & 15,5 & 16,2 & 17,1 & 18,2 & 19,5 & 21,4 & 23,9 & 28,1 & 19 \\
\hline $\mathrm{C}_{2} \mathrm{H}_{6}$ & ${ }^{1} J_{\mathrm{CC}}$ & 25,4 & 27,8 & 30,4 & 33,1 & 36,0 & 39,1 & 42,4 & 45,9 & 49,7 & 53,7 & 58,0 & 34,5 \\
\hline $\mathrm{C}_{2} \mathrm{H}_{6}$ & ${ }^{1} J_{\mathrm{CH}}$ & 101,7 & 105,6 & 109,7 & 114,0 & 118,7 & 123,6 & 128,9 & 134,4 & 140,3 & 146,6 & 153,3 & 125,2 \\
\hline $\mathrm{C}_{2} \mathrm{H}_{6}$ & ${ }^{2} J_{\mathrm{CH}}$ & $-0,9$ & $-1,4$ & $-1,9$ & $-2,5$ & $-3,1$ & $-3,8$ & $-4,5$ & $-5,3$ & $-6,1$ & $-7,1$ & $-8,1$ & $-4,7$ \\
\hline \multirow[t]{3}{*}{ Total } & $\mathrm{DM}$ & $-18,51$ & $-16,52$ & $-14,24$ & $-11,69$ & $-8,95$ & $-6,11$ & $-3,32$ & $-0,86$ & 0,57 & $-1,25$ & $-20,70$ & - \\
\hline & DMA & 30,09 & 25,45 & 20,57 & 16,42 & 13,98 & 13,18 & 15,78 & 22,09 & 30,86 & 44,73 & 80,16 & - \\
\hline & PDMA & 60,76 & 50,48 & 40,20 & 29,65 & 19,63 & 14,10 & 20,66 & 35,79 & 57,14 & 85,17 & 129,04 & - \\
\hline \multirow[t]{3}{*}{ CPI } & $\mathrm{DM}$ & $-33,21$ & $-31,15$ & $-28,55$ & $-25,55$ & $-22,32$ & $-19,12$ & $-16,40$ & $-14,95$ & $-16,55$ & $-26,78$ & $-80,27$ & - \\
\hline & DMA & 55,19 & 46,33 & 36,79 & 28,76 & 24,63 & 24,12 & 28,25 & 38,13 & 52,51 & 77,00 & 149,64 & - \\
\hline & PDMA & 82,94 & 66,60 & 50,98 & 35,56 & 21,35 & 17,99 & 29,70 & 47,08 & 69,15 & 94,66 & 135,53 & - \\
\hline \multirow[t]{3}{*}{ SPI } & $\mathrm{DM}$ & $-7,73$ & $-5,80$ & $-3,75$ & $-1,53$ & 0,85 & 3,43 & 6,28 & 9,47 & 13,13 & 17,47 & 22,99 & - \\
\hline & DMA & 11,69 & 10,13 & 8,68 & 7,36 & 6,17 & 5,15 & 6,63 & 10,33 & 14,98 & 21,06 & 29,21 & - \\
\hline & PDMA & 44,49 & 38,65 & 32,30 & 25,31 & 18,36 & 11,25 & 14,03 & 27,51 & 48,33 & 78,21 & 124,29 & - \\
\hline \multirow[t]{3}{*}{$\Delta \mathrm{CS}$} & $\mathrm{DM}$ & $-25,48$ & $-25,35$ & $-24,81$ & $-24,01$ & $-23,16$ & $-22,55$ & $-22,68$ & $-24,41$ & $-29,67$ & $-44,26$ & $-103,26$ & - \\
\hline & DMA & 43,50 & 36,19 & 28,11 & 21,40 & 18,46 & 18,96 & 21,63 & 27,79 & 37,53 & 55,94 & 120,42 & - \\
\hline & PDMA & 38,45 & 27,94 & 18,68 & 10,24 & 2,99 & 6,74 & 15,68 & 19,57 & 20,82 & 16,46 & 11,24 & - \\
\hline
\end{tabular}


Tabela 8.45: Constantes de acoplamento BHandH com correção vibracional no nível BHandH $\left(50 \% E_{X}^{\mathrm{HF}}\right)$ e base aug-pcJ-2.

\begin{tabular}{|c|c|c|c|c|c|c|c|c|c|c|c|c|c|}
\hline & $\% E_{X}^{\mathrm{HF}}$ & $0 \%$ & $10 \%$ & $20 \%$ & $30 \%$ & $40 \%$ & $50 \%$ & $60 \%$ & $70 \%$ & $80 \%$ & $90 \%$ & $100 \%$ & Exp. \\
\hline $\mathrm{HF}$ & ${ }^{1} J_{\mathrm{HF}}$ & 387,8 & 408,3 & 429,6 & 451,6 & 474,4 & 498,0 & 522,5 & 547,8 & 574,1 & 601,4 & 629,7 & 500 \\
\hline $\mathrm{CO}$ & ${ }^{1} J_{\mathrm{CO}}$ & 25,5 & 23,6 & 21,6 & 19,4 & 17,0 & 14,4 & 11,7 & 8,7 & 5,6 & 2,3 & $-1,2$ & 16,4 \\
\hline $\mathrm{H}_{2} \mathrm{O}$ & ${ }^{1} J_{\mathrm{OH}}$ & $-68,8$ & $-71,3$ & $-74,0$ & $-76,7$ & $-79,6$ & $-82,6$ & $-85,8$ & $-89,1$ & $-92,6$ & $-96,2$ & $-100,0$ & $-80,6$ \\
\hline $\mathrm{H}_{2} \mathrm{O}$ & ${ }^{2} J_{\mathrm{HH}}$ & $-1,8$ & $-2,9$ & $-4,0$ & $-5,3$ & $-6,5$ & $-7,9$ & $-9,3$ & $-10,8$ & $-12,4$ & $-14,1$ & $-15,8$ & $-7,3$ \\
\hline $\mathrm{NH}_{3}$ & ${ }^{1} J_{\mathrm{NH}}$ & 40,2 & 41,3 & 42,5 & 43,7 & 45,0 & 46,3 & 47,8 & 49,3 & 50,8 & 52,5 & 54,2 & 43,8 \\
\hline $\mathrm{NH}_{3}$ & ${ }^{2} J_{\mathrm{HH}}$ & $-4,5$ & $-5,6$ & $-6,6$ & $-7,8$ & $-9,0$ & $-10,2$ & $-11,6$ & $-13,0$ & $-14,5$ & $-16,1$ & $-17,8$ & $-9,6$ \\
\hline $\mathrm{PH}_{3}$ & ${ }^{1} J_{\mathrm{PH}}$ & 128,7 & 137,5 & 146,7 & 156,2 & 166,1 & 176,3 & 186,9 & 197,8 & 209,1 & 220,6 & 232,4 & 188,2 \\
\hline $\mathrm{PF}_{3}$ & ${ }^{1} J_{\mathrm{PF}}$ & $-1813,7$ & $-1796,4$ & $-1772,4$ & $-1742,8$ & $-1708,3$ & $-1669,7$ & $-1627,6$ & $-1582,7$ & $-1535,5$ & $-1486,6$ & $-1436,3$ & -1441 \\
\hline $\mathrm{BHF}_{2}$ & ${ }^{1} J_{\mathrm{BF}}$ & $-191,7$ & $-173,8$ & $-155,5$ & $-137,1$ & $-118,3$ & $-99,5$ & $-80,4$ & $-61,3$ & $-42,1$ & $-22,9$ & $-3,7$ & -84 \\
\hline $\mathrm{BF}_{3}$ & ${ }^{1} J_{\mathrm{BF}}$ & $-81,9$ & $-63,2$ & $-44,4$ & $-25,4$ & $-6,2$ & 13,0 & 32,5 & 52,1 & 71,8 & 91,7 & 111,7 & 15 \\
\hline $\mathrm{F}_{2} \mathrm{O}$ & ${ }^{1} J_{\mathrm{OF}}$ & $-286,4$ & $-322,5$ & $-358,3$ & $-394,8$ & $-434,1$ & $-479,3$ & $-535,7$ & $-614,3$ & $-742,2$ & $-1015,1$ & $-2268,1$ & -300 \\
\hline $\mathrm{CH}_{4}$ & ${ }^{1} J_{\mathrm{CH}}$ & 108,5 & 111,9 & 115,5 & 119,3 & 123,2 & 127,4 & 131,9 & 136,5 & 141,4 & 146,5 & 151,9 & 125,3 \\
\hline $\mathrm{CH}_{4}$ & ${ }^{2} J_{\mathrm{HH}}$ & $-8,2$ & $-9,2$ & $-10,2$ & $-11,3$ & $-12,4$ & $-13,6$ & $-14,8$ & $-16,0$ & $-17,3$ & $-18,7$ & $-20,0$ & $-12,8$ \\
\hline $\mathrm{C}_{2} \mathrm{H}_{2}$ & ${ }^{1} J_{\mathrm{CC}}$ & 176,2 & 180,3 & 184,9 & 190,1 & 196,1 & 203,1 & 211,3 & 221,3 & 233,5 & 249,0 & 269,1 & 174,8 \\
\hline $\mathrm{C}_{2} \mathrm{H}_{2}$ & ${ }^{1} J_{\mathrm{CH}}$ & 229,7 & 235,6 & 241,7 & 248,3 & 255,3 & 262,8 & 271,1 & 280,2 & 290,6 & 302,5 & 316,8 & 247,6 \\
\hline $\mathrm{C}_{2} \mathrm{H}_{2}$ & ${ }^{2} J_{\mathrm{CH}}$ & 51,5 & 52,4 & 53,0 & 53,5 & 53,6 & 53,3 & 52,5 & 51,0 & 48,5 & 44,5 & 38,4 & 50,1 \\
\hline $\mathrm{C}_{2} \mathrm{H}_{2}$ & ${ }^{3} J_{\mathrm{HH}}$ & 7,8 & 8,4 & 9,1 & 10,0 & 11,1 & 12,4 & 14,0 & 16,1 & 18,7 & 22,1 & 26,6 & 9,6 \\
\hline $\mathrm{C}_{2} \mathrm{H}_{4}$ & ${ }^{1} J_{\mathrm{CC}}$ & 51,1 & 54,5 & 58,3 & 62,5 & 67,4 & 73,0 & 79,6 & 88,0 & 98,9 & 114,5 & 139,7 & 67,6 \\
\hline $\mathrm{C}_{2} \mathrm{H}_{4}$ & ${ }^{1} J_{\mathrm{CH}}$ & 138,1 & 142,4 & 146,9 & 151,8 & 156,9 & 162,5 & 168,7 & 175,6 & 183,7 & 193,7 & 207,6 & 156,3 \\
\hline $\mathrm{C}_{2} \mathrm{H}_{4}$ & ${ }^{2} J_{\mathrm{CH}}$ & 0,5 & $-0,2$ & $-0,8$ & $-1,7$ & $-2,8$ & $-4,2$ & $-6,0$ & $-8,4$ & $-11,8$ & $-16,9$ & $-25,8$ & $-2,4$ \\
\hline $\mathrm{C}_{2} \mathrm{H}_{4}$ & ${ }^{2} J_{\mathrm{HH}}$ & 5,7 & 5,2 & 4,6 & 4,0 & 3,3 & 2,4 & 1,3 & 0,1 & $-1,8$ & $-4,5$ & $-9,1$ & 2,3 \\
\hline $\mathrm{C}_{2} \mathrm{H}_{4}$ & ${ }^{3} J_{\mathrm{HH}_{\mathrm{c}}}$ & 11,5 & 11,8 & 12,1 & 12,5 & 13,0 & 13,6 & 14,4 & 15,5 & 17,1 & 19,6 & 24,0 & 11,7 \\
\hline $\mathrm{C}_{2} \mathrm{H}_{4}$ & ${ }^{3} J_{\mathrm{HH}_{\mathrm{t}}}$ & 16,9 & 17,3 & 17,9 & 18,5 & 19,3 & 20,2 & 21,4 & 23,0 & 25,1 & 28,2 & 33,5 & 19 \\
\hline $\mathrm{C}_{2} \mathrm{H}_{6}$ & ${ }^{1} J_{\mathrm{CC}}$ & 19,6 & 22,2 & 24,9 & 27,8 & 30,9 & 34,2 & 37,6 & 41,3 & 45,2 & 49,3 & 53,6 & 34,5 \\
\hline $\mathrm{C}_{2} \mathrm{H}_{6}$ & ${ }^{1} J_{\mathrm{CH}}$ & 108,0 & 111,6 & 115,3 & 119,2 & 123,4 & 127,7 & 132,3 & 137,1 & 142,1 & 147,3 & 152,8 & 125,2 \\
\hline $\mathrm{C}_{2} \mathrm{H}_{6}$ & ${ }^{2} J_{\mathrm{CH}}$ & $-1,9$ & $-2,3$ & $-2,8$ & $-3,3$ & $-3,9$ & $-4,5$ & $-5,1$ & $-5,8$ & $-6,5$ & $-7,2$ & $-8,0$ & $-4,7$ \\
\hline \multirow[t]{3}{*}{ Total } & $\mathrm{DM}$ & $-30,64$ & $-28,00$ & $-24,98$ & $-21,65$ & $-18,08$ & $-14,46$ & $-10,92$ & $-7,88$ & $-6,37$ & $-9,91$ & $-50,34$ & - \\
\hline & DMA & 35,38 & 31,38 & 28,05 & 24,46 & 21,36 & 19,97 & 23,28 & 29,93 & 39,09 & 54,63 & 109,57 & - \\
\hline & PDMA & 60,71 & 49,46 & 38,39 & 26,72 & 16,62 & 12,91 & 26,54 & 45,95 & 69,92 & 101,58 & 157,77 & - \\
\hline \multirow[t]{3}{*}{ CPI } & $\mathrm{DM}$ & $-64,32$ & $-60,54$ & $-55,97$ & $-50,90$ & $-45,49$ & $-40,19$ & $-35,45$ & $-32,40$ & $-33,53$ & $-47,58$ & $-150,53$ & - \\
\hline & DMA & 72,52 & 65,06 & 59,26 & 52,85 & 46,25 & 40,65 & 44,10 & 54,71 & 70,02 & 98,55 & 217,07 & - \\
\hline & PDMA & 96,86 & 78,98 & 61,73 & 43,75 & 26,10 & 13,55 & 28,19 & 50,64 & 75,10 & 104,47 & 163,91 & - \\
\hline \multirow[t]{3}{*}{ SPI } & $\mathrm{DM}$ & $-5,94$ & $-4,15$ & $-2,25$ & $-0,19$ & 2,02 & 4,41 & 7,07 & 10,09 & 13,55 & 17,72 & 23,13 & - \\
\hline & DMA & 8,14 & 6,68 & 5,15 & 3,65 & 3,10 & 4,80 & 8,01 & 11,76 & 16,41 & 22,43 & 30,73 & - \\
\hline & PDMA & 34,19 & 27,82 & 21,27 & 14,23 & 9,67 & 12,45 & 25,33 & 42,50 & 66,12 & 99,46 & 153,27 & - \\
\hline \multirow[t]{3}{*}{$\Delta \mathrm{CS}$} & $\mathrm{DM}$ & $-58,38$ & $-56,39$ & $-53,73$ & $-50,71$ & $-47,51$ & $-44,60$ & $-42,52$ & $-42,49$ & $-47,08$ & $-65,30$ & $-173,66$ & - \\
\hline & DMA & 64,38 & 58,38 & 54,11 & 49,20 & 43,15 & 35,85 & 36,09 & 42,95 & 53,61 & 76,12 & 186,34 & - \\
\hline & PDMA & 62,67 & 51,16 & 40,45 & 29,52 & 16,43 & 1,09 & 2,87 & 8,14 & 8,98 & 5,01 & 10,65 & - \\
\hline
\end{tabular}


Tabela 8.46: Constantes de acoplamento BMK com correção vibracional no nível BHandH $\left(50 \% E_{X}^{\mathrm{HF}}\right)$ e base aug-pcJ-2.

\begin{tabular}{|c|c|c|c|c|c|c|c|c|c|c|c|c|c|}
\hline & $\% E_{X}^{\mathrm{HF}}$ & $0 \%$ & $10 \%$ & $20 \%$ & $30 \%$ & $40 \%$ & $50 \%$ & $60 \%$ & $70 \%$ & $80 \%$ & $90 \%$ & $100 \%$ & Exp. \\
\hline $\mathrm{HF}$ & ${ }^{1} J_{\mathrm{HF}}$ & 458,6 & 470,0 & 482,4 & 495,9 & 510,7 & 526,9 & 544,6 & 564,2 & 585,9 & 609,7 & 636,2 & 500 \\
\hline $\mathrm{CO}$ & ${ }^{1} J_{\mathrm{CO}}$ & 14,5 & 15,0 & 15,3 & 15,5 & 15,5 & 15,3 & 14,8 & 14,0 & 12,7 & 10,9 & 8,4 & 16,4 \\
\hline $\mathrm{H}_{2} \mathrm{O}$ & ${ }^{1} J_{\mathrm{OH}}$ & $-71,2$ & $-71,7$ & $-72,3$ & $-73,0$ & $-73,8$ & $-74,8$ & $-75,9$ & $-77,2$ & $-78,7$ & $-80,3$ & $-82,2$ & $-80,6$ \\
\hline $\mathrm{H}_{2} \mathrm{O}$ & ${ }^{2} J_{\mathrm{HH}}$ & 4,3 & 3,3 & 2,1 & 1,0 & $-0,3$ & $-1,7$ & $-3,2$ & $-4,9$ & $-6,6$ & $-8,5$ & $-10,5$ & $-7,3$ \\
\hline $\mathrm{NH}_{3}$ & ${ }^{1} J_{\mathrm{NH}}$ & 37,3 & 37,4 & 37,5 & 37,6 & 37,9 & 38,2 & 38,5 & 39,0 & 39,5 & 40,1 & 40,8 & 43,8 \\
\hline $\mathrm{NH}_{3}$ & ${ }^{2} J_{\mathrm{HH}}$ & 0,2 & $-0,7$ & $-1,6$ & $-2,6$ & $-3,8$ & $-5,0$ & $-6,3$ & $-7,8$ & $-9,4$ & $-11,1$ & $-13,0$ & $-9,6$ \\
\hline $\mathrm{PH}_{3}$ & ${ }^{1} J_{\mathrm{PH}}$ & 119,0 & 118,6 & 118,6 & 119,2 & 120,2 & 121,7 & 123,7 & 126,2 & 129,3 & 132,9 & 137,2 & 188,2 \\
\hline $\mathrm{PF}_{3}$ & ${ }^{1} J_{\mathrm{PF}}$ & $-1528,7$ & $-1526,9$ & $-1517,2$ & $-1500,0$ & $-1475,6$ & $-1444,5$ & $-1407,5$ & $-1365,2$ & $-1318,3$ & $-1267,7$ & $-1213,7$ & -1441 \\
\hline $\mathrm{BHF}_{2}$ & ${ }^{1} J_{\mathrm{BF}}$ & $-147,4$ & $-136,0$ & $-122,5$ & $-107,1$ & $-89,7$ & $-70,4$ & $-49,2$ & $-26,2$ & $-1,6$ & 24,8 & 52,6 & -84 \\
\hline $\mathrm{BF}_{3}$ & ${ }^{1} J_{\mathrm{BF}}$ & $-53,2$ & $-39,3$ & $-23,5$ & $-5,9$ & 13,3 & 34,5 & 57,3 & 82,0 & 108,3 & 136,3 & 165,8 & 15 \\
\hline $\mathrm{F}_{2} \mathrm{O}$ & ${ }^{1} J_{\mathrm{OF}}$ & $-161,8$ & $-188,2$ & $-215,3$ & $-242,7$ & $-270,3$ & $-298,7$ & $-329,1$ & $-363,5$ & $-406,6$ & $-468,5$ & $-581,8$ & -300 \\
\hline $\mathrm{CH}_{4}$ & ${ }^{1} J_{\mathrm{CH}}$ & 105,6 & 107,2 & 109,0 & 111,2 & 113,7 & 116,7 & 120,0 & 123,8 & 128,2 & 133,2 & 138,9 & 125,3 \\
\hline $\mathrm{CH}_{4}$ & ${ }^{2} J_{\mathrm{HH}}$ & $-3,3$ & $-4,3$ & $-5,4$ & $-6,7$ & $-8,0$ & $-9,5$ & $-11,2$ & $-13,1$ & $-15,2$ & $-17,6$ & $-20,3$ & $-12,8$ \\
\hline $\mathrm{C}_{2} \mathrm{H}_{2}$ & ${ }^{1} J_{\mathrm{CC}}$ & 245,2 & 249,9 & 255,1 & 261,2 & 268,3 & 277,0 & 287,9 & 302,2 & 321,8 & 350,2 & 395,3 & 174,8 \\
\hline $\mathrm{C}_{2} \mathrm{H}_{2}$ & ${ }^{1} J_{\mathrm{CH}}$ & 181,2 & 187,3 & 193,8 & 200,9 & 208,7 & 217,3 & 227,1 & 238,6 & 252,3 & 269,8 & 294,1 & 247,6 \\
\hline $\mathrm{C}_{2} \mathrm{H}_{2}$ & ${ }^{2} J_{\mathrm{CH}}$ & 54,7 & 55,6 & 56,3 & 56,8 & 56,9 & 56,6 & 55,5 & 53,3 & 49,3 & 42,0 & 28,6 & 50,1 \\
\hline $\mathrm{C}_{2} \mathrm{H}_{2}$ & ${ }^{3} J_{\mathrm{HH}}$ & 5,9 & 6,2 & 6,6 & 7,1 & 7,8 & 8,8 & 10,1 & 11,9 & 14,5 & 18,4 & 24,8 & 9,6 \\
\hline $\mathrm{C}_{2} \mathrm{H}_{4}$ & ${ }^{1} J_{\mathrm{CC}}$ & 90,2 & 91,7 & 93,6 & 96,0 & 98,9 & 102,5 & 107,3 & 113,5 & 122,2 & 135,1 & 156,0 & 67,6 \\
\hline $\mathrm{C}_{2} \mathrm{H}_{4}$ & ${ }^{1} J_{\mathrm{CH}}$ & 122,4 & 125,5 & 129,1 & 133,0 & 137,4 & 142,4 & 148,2 & 154,9 & 163,1 & 173,4 & 187,8 & 156,3 \\
\hline $\mathrm{C}_{2} \mathrm{H}_{4}$ & ${ }^{2} J_{\mathrm{CH}}$ & 4,1 & 3,2 & 2,2 & 1,1 & $-0,3$ & $-1,8$ & $-3,8$ & $-6,4$ & $-10,1$ & $-15,5$ & $-24,4$ & $-2,4$ \\
\hline $\mathrm{C}_{2} \mathrm{H}_{4}$ & ${ }^{2} J_{\mathrm{HH}}$ & 7,9 & 7,4 & 6,8 & 6,0 & 5,1 & 4,0 & 2,7 & 0,9 & $-1,2$ & $-4,4$ & $-9,4$ & 2,3 \\
\hline $\mathrm{C}_{2} \mathrm{H}_{4}$ & ${ }^{3} J_{\mathrm{HH}_{\mathrm{c}}}$ & 9,5 & 9,6 & 9,7 & 9,9 & 10,1 & 10,5 & 11,0 & 11,8 & 13,1 & 15,2 & 18,9 & 11,7 \\
\hline $\mathrm{C}_{2} \mathrm{H}_{4}$ & ${ }^{3} J_{\mathrm{HH}_{\mathrm{t}}}{ }^{\mathrm{C}}$ & 11,9 & 12,4 & 12,9 & 13,5 & 14,1 & 14,9 & 15,9 & 17,2 & 19,0 & 21,7 & 26,2 & 19 \\
\hline $\mathrm{C}_{2} \mathrm{H}_{6}$ & ${ }^{1} J_{\mathrm{CC}}$ & 31,0 & 31,9 & 33,0 & 34,2 & 35,7 & 37,4 & 39,4 & 41,6 & 44,2 & 47,3 & 50,8 & 34,5 \\
\hline $\mathrm{C}_{2} \mathrm{H}_{6}$ & ${ }^{1} J_{\mathrm{CH}}$ & 103,3 & 105,2 & 107,5 & 110,1 & 113,0 & 116,3 & 120,1 & 124,4 & 129,2 & 134,7 & 141,0 & 125,2 \\
\hline $\mathrm{C}_{2} \mathrm{H}_{6}$ & ${ }^{2} J_{\mathrm{CH}}$ & 0,4 & $-0,2$ & $-1,0$ & $-1,7$ & $-2,6$ & $-3,5$ & $-4,5$ & $-5,6$ & $-6,9$ & $-8,3$ & $-9,9$ & $-4,7$ \\
\hline \multirow[t]{3}{*}{ Total } & $\mathrm{DM}$ & $-7,82$ & $-6,73$ & $-5,09$ & $-2,87$ & $-0,08$ & 3,31 & 7,25 & 11,72 & 16,65 & 21,88 & 26,66 & - \\
\hline & DMA & 30,38 & 27,39 & 23,79 & 19,63 & 15,82 & 14,43 & 18,38 & 23,55 & 31,28 & 42,80 & 58,96 & - \\
\hline & PDMA & 72,80 & 63,81 & 53,53 & 42,10 & 29,45 & 26,76 & 30,27 & 43,33 & 64,11 & 96,40 & 143,49 & - \\
\hline \multirow[t]{3}{*}{ CPI } & DM & $-15,39$ & $-14,49$ & $-12,49$ & $-9,36$ & $-5,16$ & 0,05 & 6,07 & 12,70 & 19,42 & 25,25 & 27,17 & - \\
\hline & DMA & 46,12 & 39,98 & 32,56 & 23,95 & 16,07 & 14,00 & 24,35 & 36,83 & 50,96 & 68,10 & 91,17 & - \\
\hline & PDMA & 84,22 & 71,11 & 56,36 & 40,29 & 22,94 & 30,81 & 45,17 & 60,83 & 78,09 & 102,92 & 133,53 & - \\
\hline \multirow[t]{3}{*}{ SPI } & $\mathrm{DM}$ & $-2,27$ & $-1,03$ & 0,34 & 1,90 & 3,65 & 5,70 & 8,11 & 10,99 & 14,63 & 19,41 & 26,29 & - \\
\hline & DMA & 18,85 & 18,15 & 17,35 & 16,47 & 15,63 & 14,74 & 14,00 & 13,81 & 16,84 & 24,25 & 35,34 & - \\
\hline & PDMA & 64,43 & 58,46 & 51,45 & 43,42 & 34,22 & 23,80 & 19,34 & 30,50 & 53,86 & 91,62 & 150,79 & - \\
\hline \multirow[t]{3}{*}{$\Delta \mathrm{CS}$} & $\mathrm{DM}$ & $-13,12$ & $-13,46$ & $-12,83$ & $-11,26$ & $-8,81$ & $-5,65$ & $-2,03$ & 1,71 & 4,79 & 5,84 & 0,89 & - \\
\hline & DMA & 27,27 & 21,83 & 15,21 & 7,47 & 0,44 & $-0,74$ & 10,35 & 23,02 & 34,12 & 43,85 & 55,83 & - \\
\hline & PDMA & 19,79 & 12,65 & 4,92 & $-3,13$ & $-11,27$ & 7,01 & 25,83 & 30,33 & 24,23 & 11,30 & $-17,26$ & - \\
\hline
\end{tabular}


Tabela 8.47: Constantes de acoplamento BP86 com correção vibracional no nível BHandH $\left(50 \% E_{X}^{\mathrm{HF}}\right)$ e base aug-pcJ-2.

\begin{tabular}{|c|c|c|c|c|c|c|c|c|c|c|c|c|c|}
\hline & $\% E_{X}^{\mathrm{HF}}$ & $0 \%$ & $10 \%$ & $20 \%$ & $30 \%$ & $40 \%$ & $50 \%$ & $60 \%$ & $70 \%$ & $80 \%$ & $90 \%$ & $100 \%$ & Exp. \\
\hline $\mathrm{HF}$ & ${ }^{1} J_{\mathrm{HF}}$ & 322,5 & 346,1 & 370,0 & 394,1 & 418,5 & 443,0 & 467,9 & 492,9 & 518,2 & 543,7 & 569,4 & 500 \\
\hline $\mathrm{CO}$ & ${ }^{1} J_{\mathrm{CO}}$ & 25,6 & 23,9 & 22,2 & 20,4 & 18,4 & 16,5 & 14,4 & 12,3 & 10,1 & 7,8 & 5,5 & 16,4 \\
\hline $\mathrm{H}_{2} \mathrm{O}$ & ${ }^{1} J_{\mathrm{OH}}$ & $-63,7$ & $-66,2$ & $-68,7$ & $-71,3$ & $-73,9$ & $-76,5$ & $-79,1$ & $-81,8$ & $-84,4$ & $-87,2$ & $-89,9$ & $-80,6$ \\
\hline $\mathrm{H}_{2} \mathrm{O}$ & ${ }^{2} J_{\mathrm{HH}}$ & $-3,1$ & $-4,0$ & $-5,0$ & $-6,0$ & $-7,0$ & $-8,1$ & $-9,1$ & $-10,2$ & $-11,3$ & $-12,4$ & $-13,6$ & $-7,3$ \\
\hline $\mathrm{NH}_{3}$ & ${ }^{1} J_{\mathrm{NH}}$ & 40,8 & 41,5 & 42,3 & 43,0 & 43,8 & 44,6 & 45,4 & 46,2 & 47,0 & 47,8 & 48,6 & 43,8 \\
\hline $\mathrm{NH}_{3}$ & ${ }^{2} J_{\mathrm{HH}}$ & $-6,9$ & $-7,7$ & $-8,6$ & $-9,5$ & $-10,3$ & $-11,2$ & $-12,1$ & $-13,0$ & $-14,0$ & $-14,9$ & $-15,9$ & $-9,6$ \\
\hline $\mathrm{PH}_{3}$ & ${ }^{1} J_{\mathrm{PH}}$ & 130,1 & 138,1 & 146,0 & 153,9 & 161,6 & 169,2 & 176,7 & 184,0 & 191,3 & 198,3 & 205,3 & 188,2 \\
\hline $\mathrm{PF}_{3}$ & ${ }^{1} J_{\mathrm{PF}}$ & $-1801,8$ & $-1776,7$ & $-1747,2$ & $-1714,0$ & $-1677,8$ & $-1639,2$ & $-1598,8$ & $-1557,0$ & $-1514,2$ & $-1470,7$ & $-1426,8$ & -1441 \\
\hline $\mathrm{BHF}_{2}$ & ${ }^{1} J_{\mathrm{BF}}$ & $-182,2$ & $-165,2$ & $-148,3$ & $-131,5$ & $-114,9$ & $-98,3$ & $-82,0$ & $-65,8$ & $-49,8$ & $-34,0$ & $-18,4$ & -84 \\
\hline $\mathrm{BF}_{3}$ & ${ }^{1} J_{\mathrm{BF}}$ & $-85,4$ & $-66,7$ & $-48,3$ & $-30,0$ & $-11,9$ & 5,9 & 23,6 & 41,2 & 58,5 & 75,7 & 92,7 & 15 \\
\hline $\mathrm{F}_{2} \mathrm{O}$ & ${ }^{1} J_{\mathrm{OF}}$ & $-304,4$ & $-341,7$ & $-379,3$ & $-418,7$ & $-462,1$ & $-513,0$ & $-576,9$ & $-665,3$ & $-804,7$ & $-1078,6$ & $-1987,4$ & -300 \\
\hline $\mathrm{CH}_{4}$ & ${ }^{1} J_{\mathrm{CH}}$ & 120,0 & 121,4 & 122,9 & 124,4 & 125,9 & 127,4 & 129,0 & 130,6 & 132,2 & 133,9 & 135,5 & 125,3 \\
\hline $\mathrm{CH}_{4}$ & ${ }^{2} J_{\mathrm{HH}}$ & $-12,1$ & $-12,8$ & $-13,5$ & $-14,2$ & $-14,9$ & $-15,6$ & $-16,4$ & $-17,1$ & $-17,8$ & $-18,4$ & $-19,1$ & $-12,8$ \\
\hline $\mathrm{C}_{2} \mathrm{H}_{2}$ & ${ }^{1} J_{\mathrm{CC}}$ & 188,0 & 190,6 & 193,7 & 197,2 & 201,3 & 206,1 & 211,8 & 218,7 & 227,1 & 237,6 & 250,9 & 174,8 \\
\hline $\mathrm{C}_{2} \mathrm{H}_{2}$ & ${ }^{1} J_{\mathrm{CH}}$ & 250,7 & 253,0 & 255,4 & 258,0 & 260,8 & 263,9 & 267,4 & 271,4 & 276,1 & 281,7 & 288,6 & 247,6 \\
\hline $\mathrm{C}_{2} \mathrm{H}_{2}$ & ${ }^{2} J_{\mathrm{CH}}$ & 54,9 & 54,9 & 54,7 & 54,2 & 53,4 & 52,2 & 50,6 & 48,4 & 45,5 & 41,6 & 36,2 & 50,1 \\
\hline $\mathrm{C}_{2} \mathrm{H}_{2}$ & ${ }^{3} J_{\mathrm{HH}}$ & 10,8 & 11,5 & 12,2 & 13,1 & 14,1 & 15,4 & 17,0 & 18,8 & 21,1 & 23,9 & 27,5 & 9,6 \\
\hline $\mathrm{C}_{2} \mathrm{H}_{4}$ & ${ }^{1} J_{\mathrm{CC}}$ & 60,2 & 62,9 & 65,9 & 69,2 & 73,1 & 77,6 & 83,1 & 90,1 & 99,4 & 112,9 & 134,5 & 67,6 \\
\hline $\mathrm{C}_{2} \mathrm{H}_{4}$ & ${ }^{1} J_{\mathrm{CH}}$ & 151,6 & 153,7 & 155,9 & 158,2 & 160,7 & 163,5 & 166,6 & 170,4 & 175,1 & 181,5 & 191,2 & 156,3 \\
\hline $\mathrm{C}_{2} \mathrm{H}_{4}$ & ${ }^{2} J_{\mathrm{CH}}$ & $-0,4$ & $-1,2$ & $-2,1$ & $-3,3$ & $-4,6$ & $-6,1$ & $-8,1$ & $-10,7$ & $-14,3$ & $-19,5$ & $-28,0$ & $-2,4$ \\
\hline $\mathrm{C}_{2} \mathrm{H}_{4}$ & ${ }^{2} J_{\mathrm{HH}}$ & 4,8 & 4,1 & 3,3 & 2,4 & 1,4 & 0,2 & $-1,0$ & $-2,7$ & $-5,0$ & $-8,2$ & $-13,3$ & 2,3 \\
\hline $\mathrm{C}_{2} \mathrm{H}_{4}$ & ${ }^{3} J_{\mathrm{HH}_{\mathrm{c}}}$ & 11,9 & 12,2 & 12,6 & 13,0 & 13,6 & 14,3 & 15,3 & 16,6 & 18,4 & 21,3 & 26,0 & 11,7 \\
\hline $\mathrm{C}_{2} \mathrm{H}_{4}$ & ${ }^{3} J_{\mathrm{HH}_{\mathrm{t}}}$ & 19,1 & 19,5 & 19,9 & 20,4 & 21,0 & 21,9 & 23,0 & 24,5 & 26,7 & 29,9 & 35,3 & 19 \\
\hline $\mathrm{C}_{2} \mathrm{H}_{6}$ & ${ }^{1} J_{\mathrm{CC}}$ & 25,1 & 27,1 & 29,1 & 31,1 & 33,2 & 35,3 & 37,4 & 39,6 & 41,8 & 44,1 & 46,3 & 34,5 \\
\hline $\mathrm{C}_{2} \mathrm{H}_{6}$ & ${ }^{1} J_{\mathrm{CH}}$ & 119,5 & 121,1 & 122,8 & 124,5 & 126,2 & 127,9 & 129,7 & 131,5 & 133,2 & 135,1 & 136,9 & 125,2 \\
\hline $\mathrm{C}_{2} \mathrm{H}_{6}$ & ${ }^{2} J_{\mathrm{CH}}$ & $-2,9$ & $-3,3$ & $-3,8$ & $-4,3$ & $-4,7$ & $-5,2$ & $-5,7$ & $-6,2$ & $-6,7$ & $-7,3$ & $-7,8$ & $-4,7$ \\
\hline \multirow[t]{3}{*}{ Total } & $\mathrm{DM}$ & $-29,70$ & $-27,27$ & $-24,65$ & $-21,95$ & $-19,23$ & $-16,67$ & $-14,43$ & $-12,98$ & $-13,29$ & $-18,44$ & $-47,49$ & - \\
\hline & DMA & 34,52 & 31,91 & 29,18 & 26,70 & 24,77 & 23,50 & 23,89 & 27,40 & 34,96 & 49,12 & 89,79 & - \\
\hline & PDMA & 52,60 & 42,76 & 32,91 & 25,66 & 23,57 & 24,97 & 33,76 & 51,41 & 73,67 & 103,21 & 151,49 & - \\
\hline \multirow[t]{3}{*}{ CPI } & $\mathrm{DM}$ & $-69,95$ & $-65,41$ & $-60,53$ & $-55,50$ & $-50,59$ & $-46,18$ & $-42,81$ & $-41,58$ & $-44,93$ & $-60,49$ & $-133,76$ & - \\
\hline & DMA & 75,95 & 70,34 & 64,35 & 58,17 & 52,23 & 47,09 & 45,30 & 50,09 & 63,51 & 91,13 & 179,00 & - \\
\hline & PDMA & 95,34 & 79,07 & 62,74 & 46,46 & 31,72 & 19,92 & 22,17 & 39,72 & 60,03 & 84,97 & 129,40 & - \\
\hline \multirow[t]{3}{*}{ SPI } & $\mathrm{DM}$ & $-0,19$ & 0,71 & 1,66 & 2,65 & 3,76 & 4,98 & 6,37 & 7,99 & 9,91 & 12,40 & 15,77 & - \\
\hline & DMA & 4,14 & 3,73 & 3,39 & 3,63 & 4,63 & 6,19 & 8,19 & 10,76 & 14,02 & 18,31 & 24,37 & - \\
\hline & PDMA & 21,26 & 16,13 & 11,03 & 10,41 & 17,59 & 28,67 & 42,26 & 59,99 & 83,68 & 116,59 & 167,69 & - \\
\hline \multirow[t]{3}{*}{$\Delta \mathrm{CS}$} & $\mathrm{DM}$ & $-69,75$ & $-66,12$ & $-62,19$ & $-58,15$ & $-54,35$ & $-51,16$ & $-49,18$ & $-49,57$ & $-54,84$ & $-72,89$ & $-149,54$ & - \\
\hline & DMA & 71,81 & 66,60 & 60,95 & 54,55 & 47,60 & 40,90 & 37,11 & 39,33 & 49,49 & 72,82 & 154,63 & - \\
\hline & PDMA & 74,08 & 62,94 & 51,71 & 36,05 & 14,13 & $-8,76$ & $-20,09$ & $-20,27$ & $-23,64$ & $-31,62$ & $-38,29$ & - \\
\hline
\end{tabular}


Tabela 8.48: Constantes de acoplamento BPW91 com correção vibracional no nível BHandH $\left(50 \% E_{X}^{\mathrm{HF}}\right)$ e base aug-pcJ-2.

\begin{tabular}{|c|c|c|c|c|c|c|c|c|c|c|c|c|c|}
\hline & $\% E_{X}^{\mathrm{HF}}$ & $0 \%$ & $10 \%$ & $20 \%$ & $30 \%$ & $40 \%$ & $50 \%$ & $60 \%$ & $70 \%$ & $80 \%$ & $90 \%$ & $100 \%$ & Exp. \\
\hline $\mathrm{HF}$ & ${ }^{1} J_{\mathrm{HF}}$ & 320,5 & 344,6 & 369,1 & 393,8 & 418,7 & 443,9 & 469,4 & 495,1 & 521,0 & 547,1 & 573,5 & 500 \\
\hline $\mathrm{CO}$ & ${ }^{1} J_{\mathrm{CO}}$ & 25,9 & 24,3 & 22,5 & 20,7 & 18,8 & 16,8 & 14,7 & 12,5 & 10,3 & 8,0 & 5,6 & 16,4 \\
\hline $\mathrm{H}_{2} \mathrm{O}$ & ${ }^{1} J_{\mathrm{OH}}$ & $-63,8$ & $-66,4$ & $-69,0$ & $-71,6$ & $-74,3$ & $-77,0$ & $-79,7$ & $-82,4$ & $-85,2$ & $-88,0$ & $-90,8$ & $-80,6$ \\
\hline $\mathrm{H}_{2} \mathrm{O}$ & ${ }^{2} J_{\mathrm{HH}}$ & $-3,6$ & $-4,6$ & $-5,6$ & $-6,6$ & $-7,7$ & $-8,7$ & $-9,8$ & $-11,0$ & $-12,1$ & $-13,3$ & $-14,5$ & $-7,3$ \\
\hline $\mathrm{NH}_{3}$ & ${ }^{1} J_{\mathrm{NH}}$ & 41,0 & 41,8 & 42,6 & 43,4 & 44,2 & 45,0 & 45,8 & 46,6 & 47,5 & 48,3 & 49,2 & 43,8 \\
\hline $\mathrm{NH}_{3}$ & ${ }^{2} J_{\mathrm{HH}}$ & $-7,4$ & $-8,3$ & $-9,2$ & $-10,1$ & $-11,0$ & $-12,0$ & $-12,9$ & $-13,8$ & $-14,8$ & $-15,8$ & $-16,8$ & $-9,6$ \\
\hline $\mathrm{PH}_{3}$ & ${ }^{1} J_{\mathrm{PH}}$ & 130,5 & 138,8 & 147,1 & 155,2 & 163,3 & 171,2 & 179,0 & 186,6 & 194,1 & 201,5 & 208,7 & 188,2 \\
\hline $\mathrm{PF}_{3}$ & ${ }^{1} J_{\mathrm{PF}}$ & $-1809,9$ & $-1783,8$ & $-1753,4$ & $-1719,3$ & $-1682,4$ & $-1643,1$ & $-1602,0$ & $-1559,6$ & $-1516,2$ & $-1472,2$ & $-1427,8$ & -1441 \\
\hline $\mathrm{BHF}_{2}$ & ${ }^{1} J_{\mathrm{BF}}$ & $-182,3$ & $-165,1$ & $-148,1$ & $-131,1$ & $-114,3$ & $-97,6$ & $-81,1$ & $-64,7$ & $-48,6$ & $-32,6$ & $-16,8$ & -84 \\
\hline $\mathrm{BF}_{3}$ & ${ }^{1} J_{\mathrm{BF}}$ & $-85,4$ & $-66,6$ & $-47,9$ & $-29,5$ & $-11,2$ & 6,8 & 24,6 & 42,4 & 59,9 & 77,3 & 94,5 & 15 \\
\hline $\mathrm{F}_{2} \mathrm{O}$ & ${ }^{1} J_{\mathrm{OF}}$ & $-306,0$ & $-344,2$ & $-382,9$ & $-423,5$ & $-468,7$ & $-522,0$ & $-590,0$ & $-685,7$ & $-841,7$ & $-1167,9$ & $-2540,1$ & -300 \\
\hline $\mathrm{CH}_{4}$ & ${ }^{1} J_{\mathrm{CH}}$ & 121,4 & 122,9 & 124,4 & 126,0 & 127,6 & 129,2 & 130,9 & 132,5 & 134,2 & 135,9 & 137,7 & 125,3 \\
\hline $\mathrm{CH}_{4}$ & ${ }^{2} J_{\mathrm{HH}}$ & $-12,8$ & $-13,6$ & $-14,3$ & $-15,0$ & $-15,8$ & $-16,5$ & $-17,3$ & $-18,0$ & $-18,7$ & $-19,4$ & $-20,2$ & $-12,8$ \\
\hline $\mathrm{C}_{2} \mathrm{H}_{2}$ & ${ }^{1} J_{\mathrm{CC}}$ & 188,6 & 191,4 & 194,6 & 198,4 & 202,9 & 208,2 & 214,5 & 222,3 & 231,9 & 244,0 & 259,7 & 174,8 \\
\hline $\mathrm{C}_{2} \mathrm{H}_{2}$ & ${ }^{1} J_{\mathrm{CH}}$ & 254,4 & 256,9 & 259,5 & 262,4 & 265,4 & 268,9 & 272,8 & 277,4 & 282,8 & 289,4 & 297,9 & 247,6 \\
\hline $\mathrm{C}_{2} \mathrm{H}_{2}$ & ${ }^{2} J_{\mathrm{CH}}$ & 55,0 & 54,9 & 54,5 & 53,9 & 52,9 & 51,4 & 49,4 & 46,8 & 43,1 & 38,2 & 31,5 & 50,1 \\
\hline $\mathrm{C}_{2} \mathrm{H}_{2}$ & ${ }^{3} J_{\mathrm{HH}}$ & 11,4 & 12,1 & 13,0 & 14,0 & 15,2 & 16,7 & 18,5 & 20,7 & 23,4 & 26,9 & 31,3 & 9,6 \\
\hline $\mathrm{C}_{2} \mathrm{H}_{4}$ & ${ }^{1} J_{\mathrm{CC}}$ & 60,6 & 63,4 & 66,6 & 70,2 & 74,4 & 79,4 & 85,6 & 93,7 & 105,0 & 122,2 & 152,7 & 67,6 \\
\hline $\mathrm{C}_{2} \mathrm{H}_{4}$ & ${ }^{1} J_{\mathrm{CH}}$ & 153,8 & 156,0 & 158,3 & 160,8 & 163,5 & 166,6 & 170,2 & 174,5 & 180,1 & 188,3 & 201,9 & 156,3 \\
\hline $\mathrm{C}_{2} \mathrm{H}_{4}$ & ${ }^{2} J_{\mathrm{CH}}$ & $-0,8$ & $-1,8$ & $-2,8$ & $-4,0$ & $-5,5$ & $-7,3$ & $-9,6$ & $-12,8$ & $-17,2$ & $-24,1$ & $-36,6$ & $-2,4$ \\
\hline $\mathrm{C}_{2} \mathrm{H}_{4}$ & ${ }^{2} J_{\mathrm{HH}}$ & 4,4 & 3,5 & 2,7 & 1,7 & 0,6 & $-0,6$ & $-2,2$ & $-4,3$ & $-7,2$ & $-11,5$ & $-19,0$ & 2,3 \\
\hline $\mathrm{C}_{2} \mathrm{H}_{4}$ & ${ }^{3} J_{\mathrm{HH}_{\mathrm{c}}}$ & 12,3 & 12,6 & 13,0 & 13,6 & 14,3 & 15,1 & 16,3 & 18,0 & 20,4 & 24,3 & 31,5 & 11,7 \\
\hline $\mathrm{C}_{2} \mathrm{H}_{4}$ & ${ }^{3} J_{\mathrm{HH}_{\mathrm{t}}}{ }^{\mathrm{C}}$ & 19,7 & 20,1 & 20,6 & 21,2 & 22,0 & 23,0 & 24,3 & 26,2 & 29,0 & 33,4 & 41,5 & 19 \\
\hline $\mathrm{C}_{2} \mathrm{H}_{6}$ & ${ }^{1} J_{\mathrm{CC}}$ & 25,4 & 27,4 & 29,4 & 31,5 & 33,6 & 35,7 & 37,9 & 40,1 & 42,4 & 44,7 & 47,0 & 34,5 \\
\hline $\mathrm{C}_{2} \mathrm{H}_{6}$ & ${ }^{1} J_{\mathrm{CH}}$ & 121,1 & 122,8 & 124,5 & 126,3 & 128,1 & 129,9 & 131,7 & 133,6 & 135,4 & 137,3 & 139,2 & 125,2 \\
\hline $\mathrm{C}_{2} \mathrm{H}_{6}$ & ${ }^{2} J_{\mathrm{CH}}$ & $-3,2$ & $-3,7$ & $-4,1$ & $-4,6$ & $-5,1$ & $-5,6$ & $-6,2$ & $-6,7$ & $-7,2$ & $-7,7$ & $-8,3$ & $-4,7$ \\
\hline \multirow[t]{3}{*}{ Total } & DM & $-29,78$ & $-27,29$ & $-24,61$ & $-21,82$ & $-19,06$ & $-16,45$ & $-14,24$ & $-12,88$ & $-13,59$ & $-20,41$ & $-66,63$ & - \\
\hline & DMA & 34,85 & 32,22 & 29,63 & 27,48 & 25,84 & 24,72 & 25,51 & 29,57 & 38,51 & 55,29 & 114,95 & - \\
\hline & PDMA & 50,84 & 40,58 & 32,00 & 28,26 & 28,40 & 30,77 & 41,65 & 61,80 & 87,51 & 123,63 & 190,97 & - \\
\hline \multirow{3}{*}{ CPI } & DM & $-71,04$ & $-66,40$ & $-61,43$ & $-56,32$ & $-51,41$ & $-47,05$ & $-43,90$ & $-43,17$ & $-47,88$ & $-68,05$ & $-183,29$ & - \\
\hline & DMA & 76,89 & 71,15 & 65,03 & 58,86 & 53,06 & 48,00 & 46,70 & 52,17 & 68,05 & 100,52 & 230,44 & - \\
\hline & PDMA & 94,48 & 77,93 & 61,34 & 45,92 & 32,42 & 21,18 & 24,63 & 42,83 & 64,17 & 91,08 & 149,79 & - \\
\hline \multirow[t]{3}{*}{ SPI } & $\mathrm{DM}$ & 0,48 & 1,39 & 2,39 & 3,49 & 4,67 & 6,00 & 7,51 & 9,33 & 11,55 & 14,52 & 18,91 & - \\
\hline & DMA & 4,03 & 3,68 & 3,67 & 4,47 & 5,88 & 7,65 & 9,97 & 12,99 & 16,85 & 22,12 & 30,26 & - \\
\hline & PDMA & 18,84 & 13,19 & 10,48 & 15,31 & 25,44 & 37,80 & 54,13 & 75,70 & 104,62 & 147,49 & 221,17 & - \\
\hline \multirow[t]{3}{*}{$\Delta \mathrm{CS}$} & $\mathrm{DM}$ & $-71,52$ & $-67,79$ & $-63,81$ & $-59,80$ & $-56,08$ & $-53,05$ & $-51,41$ & $-52,50$ & $-59,44$ & $-82,57$ & $-202,20$ & - \\
\hline & DMA & 72,86 & 67,47 & 61,36 & 54,39 & 47,18 & 40,35 & 36,73 & 39,18 & 51,20 & 78,40 & 200,18 & - \\
\hline & PDMA & 75,64 & 64,74 & 50,86 & 30,61 & 6,98 & $-16,63$ & $-29,50$ & $-32,88$ & $-40,45$ & $-56,41$ & $-71,38$ & - \\
\hline
\end{tabular}


Tabela 8.49: Constantes de acoplamento M05 com correção vibracional no nível BHandH $\left(50 \% E_{X}^{\mathrm{HF}}\right)$ e base aug-pcJ-2.

\begin{tabular}{|c|c|c|c|c|c|c|c|c|c|c|c|c|c|}
\hline & $\% E_{X}^{\mathrm{HF}}$ & $0 \%$ & $10 \%$ & $20 \%$ & $30 \%$ & $40 \%$ & $50 \%$ & $60 \%$ & $70 \%$ & $80 \%$ & $90 \%$ & $100 \%$ & Exp. \\
\hline $\mathrm{HF}$ & ${ }^{1} J_{\mathrm{HF}}$ & 814,2 & 807,3 & 800,7 & 794,5 & 788,6 & 783,1 & 778,0 & 773,0 & 768,3 & 763,6 & 758,9 & 500 \\
\hline $\mathrm{CO}$ & ${ }^{1} J_{\mathrm{CO}}$ & 16,5 & 14,4 & 12,0 & 9,2 & 6,0 & 2,4 & $-1,4$ & $-5,5$ & $-10,0$ & $-14,8$ & $-19,8$ & 16,4 \\
\hline $\mathrm{H}_{2} \mathrm{O}$ & ${ }^{1} J_{\mathrm{OH}}$ & $-107,8$ & $-107,6$ & $-107,4$ & $-107,2$ & $-107,1$ & $-106,9$ & $-106,9$ & $-106,9$ & $-106,9$ & $-107,0$ & $-107,1$ & $-80,6$ \\
\hline $\mathrm{H}_{2} \mathrm{O}$ & ${ }^{2} J_{\mathrm{HH}}$ & $-17,1$ & $-17,2$ & $-17,2$ & $-17,1$ & $-16,8$ & $-16,4$ & $-15,9$ & $-15,2$ & $-14,4$ & $-13,5$ & $-12,4$ & $-7,3$ \\
\hline $\mathrm{NH}_{3}$ & ${ }^{1} J_{\mathrm{NH}}$ & 41,9 & 43,1 & 44,2 & 45,3 & 46,4 & 47,5 & 48,6 & 49,6 & 50,6 & 51,6 & 52,5 & 43,8 \\
\hline $\mathrm{NH}_{3}$ & ${ }^{2} J_{\mathrm{HH}}$ & $-12,6$ & $-13,5$ & $-14,3$ & $-15,0$ & $-15,5$ & $-15,8$ & $-16,0$ & $-15,9$ & $-15,6$ & $-15,0$ & $-14,3$ & $-9,6$ \\
\hline $\mathrm{PH}_{3}$ & ${ }^{1} J_{\mathrm{PH}}$ & 161,7 & 160,0 & 161,4 & 166,2 & 173,5 & 182,1 & 191,3 & 200,4 & 209,1 & 217,3 & 225,0 & 188,2 \\
\hline $\mathrm{PF}_{3}$ & ${ }^{1} J_{\mathrm{PF}}$ & $-1356,9$ & $-1375,3$ & $-1385,8$ & $-1388,2$ & $-1382,9$ & $-1371,3$ & $-1354,6$ & $-1334,1$ & $-1311,1$ & $-1286,3$ & $-1260,5$ & -1441 \\
\hline $\mathrm{BHF}_{2}$ & ${ }^{1} J_{\mathrm{BF}}$ & $-2,1$ & 3,9 & 10,6 & 18,0 & 26,2 & 35,2 & 45,2 & 56,2 & 68,5 & 82,0 & 97,0 & -84 \\
\hline $\mathrm{BF}_{3}$ & ${ }^{1} J_{\mathrm{BF}}$ & 100,8 & 109,0 & 117,7 & 127,0 & 136,9 & 147,7 & 159,3 & 172,0 & 185,7 & 200,6 & 216,8 & 15 \\
\hline $\mathrm{F}_{2} \mathrm{O}$ & ${ }^{1} J_{\mathrm{OF}}$ & $-233,2$ & $-268,0$ & $-297,1$ & $-321,9$ & $-344,3$ & $-365,9$ & $-389,0$ & $-416,5$ & $-453,4$ & $-509,2$ & $-606,7$ & -300 \\
\hline $\mathrm{CH}_{4}$ & ${ }^{1} J_{\mathrm{CH}}$ & 83,4 & 89,7 & 96,0 & 102,3 & 108,6 & 114,9 & 121,2 & 127,5 & 133,6 & 139,6 & 145,4 & 125,3 \\
\hline $\mathrm{CH}_{4}$ & ${ }^{2} J_{\mathrm{HH}}$ & $-21,1$ & $-21,4$ & $-21,5$ & $-21,5$ & $-21,3$ & $-21,1$ & $-20,7$ & $-20,1$ & $-19,5$ & $-18,8$ & $-18,2$ & $-12,8$ \\
\hline $\mathrm{C}_{2} \mathrm{H}_{2}$ & ${ }^{1} J_{\mathrm{CC}}$ & 183,6 & 192,7 & 202,3 & 212,5 & 223,3 & 234,7 & 246,8 & 259,5 & 273,1 & 287,4 & 302,7 & 174,8 \\
\hline $\mathrm{C}_{2} \mathrm{H}_{2}$ & ${ }^{1} J_{\mathrm{CH}}$ & 226,3 & 235,4 & 244,2 & 252,8 & 260,9 & 268,7 & 276,0 & 282,6 & 288,5 & 293,5 & 297,7 & 247,6 \\
\hline $\mathrm{C}_{2} \mathrm{H}_{2}$ & ${ }^{2} J_{\mathrm{CH}}$ & 36,1 & 36,4 & 36,7 & 36,9 & 37,0 & 37,0 & 37,1 & 37,0 & 36,7 & 36,2 & 35,2 & 50,1 \\
\hline $\mathrm{C}_{2} \mathrm{H}_{2}$ & ${ }^{3} J_{\mathrm{HH}}$ & 20,2 & 20,7 & 21,0 & 21,2 & 21,3 & 21,3 & 21,2 & 21,0 & 20,8 & 20,7 & 20,8 & 9,6 \\
\hline $\mathrm{C}_{2} \mathrm{H}_{4}$ & ${ }^{1} J_{\mathrm{CC}}$ & 58,6 & 64,8 & 71,4 & 78,6 & 86,4 & 94,8 & 104,0 & 113,9 & 124,6 & 136,3 & 149,1 & 67,6 \\
\hline $\mathrm{C}_{2} \mathrm{H}_{4}$ & ${ }^{1} J_{\mathrm{CH}}$ & 121,7 & 129,6 & 137,4 & 145,1 & 152,7 & 160,3 & 167,7 & 175,0 & 182,0 & 188,9 & 195,5 & 156,3 \\
\hline $\mathrm{C}_{2} \mathrm{H}_{4}$ & ${ }^{2} J_{\mathrm{CH}}$ & $-11,8$ & $-12,6$ & $-13,5$ & $-14,5$ & $-15,5$ & $-16,6$ & $-17,7$ & $-18,8$ & $-20,0$ & $-21,3$ & $-22,8$ & $-2,4$ \\
\hline $\mathrm{C}_{2} \mathrm{H}_{4}$ & ${ }^{2} J_{\mathrm{HH}}$ & $-15,8$ & $-15,5$ & $-14,9$ & $-14,2$ & $-13,4$ & $-12,4$ & $-11,2$ & $-9,9$ & $-8,6$ & $-7,3$ & $-6,2$ & 2,3 \\
\hline $\mathrm{C}_{2} \mathrm{H}_{4}$ & ${ }^{3} J_{\mathrm{HH}_{\mathrm{c}}}$ & 14,8 & 15,5 & 16,1 & 16,6 & 17,0 & 17,3 & 17,5 & 17,6 & 17,6 & 17,6 & 17,6 & 11,7 \\
\hline $\mathrm{C}_{2} \mathrm{H}_{4}$ & ${ }^{3} J_{\mathrm{HH}_{\mathrm{t}}}$ & 16,2 & 17,6 & 18,8 & 20,0 & 21,1 & 22,0 & 22,8 & 23,5 & 24,0 & 24,5 & 25,0 & 19 \\
\hline $\mathrm{C}_{2} \mathrm{H}_{6}$ & ${ }^{1} J_{\mathrm{CC}}$ & 16,1 & 19,4 & 22,8 & 26,5 & 30,3 & 34,2 & 38,4 & 42,8 & 47,3 & 52,1 & 57,1 & 34,5 \\
\hline $\mathrm{C}_{2} \mathrm{H}_{6}$ & ${ }^{1} J_{\mathrm{CH}}$ & 82,0 & 88,5 & 94,9 & 101,4 & 107,9 & 114,5 & 121,0 & 127,5 & 133,9 & 140,3 & 146,5 & 125,2 \\
\hline $\mathrm{C}_{2} \mathrm{H}_{6}$ & ${ }^{2} J_{\mathrm{CH}}$ & $-3,4$ & $-3,9$ & $-4,4$ & $-4,9$ & $-5,4$ & $-5,9$ & $-6,3$ & $-6,8$ & $-7,2$ & $-7,7$ & $-8,2$ & $-4,7$ \\
\hline \multirow[t]{3}{*}{ Total } & $\mathrm{DM}$ & 14,13 & 14,15 & 14,89 & 16,33 & 18,34 & 20,78 & 23,52 & 26,32 & 28,95 & 31,01 & 31,60 & - \\
\hline & DMA & 36,39 & 33,58 & 31,57 & 32,45 & 34,05 & 36,21 & 39,49 & 44,02 & 49,74 & 56,38 & 64,82 & - \\
\hline & PDMA & 99,99 & 101,94 & 104,12 & 108,32 & 113,03 & 117,89 & 123,60 & 129,97 & 137,33 & 145,53 & 155,44 & - \\
\hline \multirow[t]{3}{*}{ CPI } & $\mathrm{DM}$ & 51,32 & 46,84 & 43,99 & 42,72 & 42,74 & 43,71 & 45,25 & 46,93 & 48,17 & 48,04 & 44,41 & - \\
\hline & DMA & 63,75 & 59,87 & 57,19 & 59,61 & 62,97 & 66,91 & 72,17 & 79,45 & 88,03 & 98,65 & 113,35 & - \\
\hline & PDMA & 88,97 & 95,14 & 102,00 & 110,95 & 120,18 & 129,90 & 140,48 & 152,20 & 164,85 & 178,69 & 194,47 & - \\
\hline \multirow[t]{3}{*}{ SPI } & $\mathrm{DM}$ & $-13,15$ & $-9,81$ & $-6,45$ & $-3,02$ & 0,45 & 3,97 & 7,58 & 11,21 & 14,85 & 18,53 & 22,21 & - \\
\hline & DMA & 16,32 & 14,29 & 12,77 & 12,54 & 12,84 & 13,69 & 15,53 & 18,03 & 21,66 & 25,38 & 29,23 & - \\
\hline & PDMA & 108,07 & 106,92 & 105,68 & 106,38 & 107,78 & 109,08 & 111,22 & 113,68 & 117,14 & 121,22 & 126,82 & - \\
\hline \multirow[t]{3}{*}{$\Delta \mathrm{CS}$} & $\mathrm{DM}$ & 64,46 & 56,65 & 50,44 & 45,74 & 42,28 & 39,74 & 37,67 & 35,71 & 33,33 & 29,51 & 22,20 & - \\
\hline & DMA & 47,43 & 45,58 & 44,42 & 47,07 & 50,13 & 53,22 & 56,65 & 61,43 & 66,37 & 73,27 & 84,12 & - \\
\hline & PDMA & $-19,10$ & $-11,78$ & $-3,67$ & 4,57 & 12,40 & 20,83 & 29,26 & 38,52 & 47,71 & 57,47 & 67,66 & - \\
\hline
\end{tabular}


Tabela 8.50: Constantes de acoplamento M06 com correção vibracional no nível BHandH $\left(50 \% E_{X}^{\mathrm{HF}}\right)$ e base aug-pcJ-2.

\begin{tabular}{|c|c|c|c|c|c|c|c|c|c|c|c|c|c|}
\hline & $\% E_{X}^{\mathrm{HF}}$ & $0 \%$ & $10 \%$ & $20 \%$ & $30 \%$ & $40 \%$ & $50 \%$ & $60 \%$ & $70 \%$ & $80 \%$ & $90 \%$ & $100 \%$ & Exp. \\
\hline $\mathrm{HF}$ & ${ }^{1} J_{\mathrm{HF}}$ & 559,0 & 587,3 & 619,8 & 657,3 & 700,6 & 750,1 & 805,8 & 867,7 & 935,0 & 1006,7 & 1081,1 & 500 \\
\hline $\mathrm{CO}$ & ${ }^{1} J_{\mathrm{CO}}$ & 17,6 & 18,3 & 18,6 & 18,5 & 17,7 & 16,1 & 13,7 & 10,2 & 5,7 & $-0,1$ & $-7,2$ & 16,4 \\
\hline $\mathrm{H}_{2} \mathrm{O}$ & ${ }^{1} J_{\mathrm{OH}}$ & $-84,9$ & $-89,5$ & $-95,0$ & $-101,6$ & $-109,5$ & $-118,9$ & $-130,1$ & $-143,4$ & $-159,1$ & $-177,8$ & $-200,0$ & $-80,6$ \\
\hline $\mathrm{H}_{2} \mathrm{O}$ & ${ }^{2} J_{\mathrm{HH}}$ & $-4,2$ & $-7,6$ & $-11,8$ & $-16,9$ & $-23,3$ & $-31,3$ & $-41,2$ & $-53,4$ & $-68,7$ & $-87,8$ & $-111,5$ & $-7,3$ \\
\hline $\mathrm{NH}_{3}$ & ${ }^{1} J_{\mathrm{NH}}$ & 44,0 & 46,9 & 50,4 & 54,5 & 59,4 & 65,2 & 72,4 & 81,1 & 91,9 & 105,5 & 123,0 & 43,8 \\
\hline $\mathrm{NH}_{3}$ & ${ }^{2} J_{\mathrm{HH}}$ & $-6,7$ & $-9,8$ & $-13,7$ & $-18,8$ & $-25,4$ & $-34,1$ & $-45,6$ & $-61,1$ & $-82,2$ & $-111,4$ & $-153,0$ & $-9,6$ \\
\hline $\mathrm{PH}_{3}$ & ${ }^{1} J_{\mathrm{PH}}$ & 192,5 & 207,6 & 225,7 & 247,7 & 274,8 & 308,3 & 350,7 & 405,0 & 476,4 & 570,9 & 694,5 & 188,2 \\
\hline $\mathrm{PF}_{3}$ & ${ }^{1} J_{\mathrm{PF}}$ & $-1436,5$ & $-1475,9$ & $-1508,2$ & $-1532,9$ & $-1551,5$ & $-1566,4$ & $-1578,8$ & $-1587,5$ & $-1590,3$ & $-1585,4$ & $-1572,7$ & -1441 \\
\hline $\mathrm{BHF}_{2}$ & ${ }^{1} J_{\mathrm{BF}}$ & $-71,6$ & $-62,2$ & $-50,3$ & $-35,8$ & $-19,0$ & $-0,6$ & 18,6 & 37,4 & 54,4 & 67,3 & 71,3 & -84 \\
\hline $\mathrm{BF}_{3}$ & ${ }^{1} J_{\mathrm{BF}}$ & 24,9 & 37,0 & 51,3 & 68,1 & 87,6 & 109,4 & 133,1 & 158,0 & 183,5 & 209,3 & 235,6 & 15 \\
\hline $\mathrm{F}_{2} \mathrm{O}$ & ${ }^{1} J_{\mathrm{OF}}$ & $-175,4$ & $-225,4$ & $-280,2$ & $-342,5$ & $-420,4$ & $-544,3$ & $-990,0$ & 4253,5 & $-29,8$ & $-236,6$ & $-335,1$ & -300 \\
\hline $\mathrm{CH}_{4}$ & ${ }^{1} J_{\mathrm{CH}}$ & 105,8 & 117,2 & 130,9 & 147,3 & 167,3 & 191,8 & 222,4 & 261,4 & 312,4 & 381,5 & 479,9 & 125,3 \\
\hline $\mathrm{CH}_{4}$ & ${ }^{2} J_{\mathrm{HH}}$ & $-12,9$ & $-16,9$ & $-21,8$ & $-28,2$ & $-36,6$ & $-47,6$ & $-62,5$ & $-83,1$ & $-112,6$ & $-156,5$ & $-225,4$ & $-12,8$ \\
\hline $\mathrm{C}_{2} \mathrm{H}_{2}$ & ${ }^{1} J_{\mathrm{CC}}$ & 162,4 & 171,4 & 183,2 & 200,2 & 228,1 & 286,1 & 503,0 & $-632,0$ & $-13,3$ & 128,9 & 5816,0 & 174,8 \\
\hline $\mathrm{C}_{2} \mathrm{H}_{2}$ & ${ }^{1} J_{\mathrm{CH}}$ & 212,1 & 240,6 & 274,6 & 316,4 & 371,0 & 453,7 & 664,5 & $-163,5$ & 364,0 & 498,6 & $-158,6$ & 247,6 \\
\hline $\mathrm{C}_{2} \mathrm{H}_{2}$ & ${ }^{2} J_{\mathrm{CH}}$ & 50,0 & 51,6 & 51,9 & 49,3 & 39,9 & 9,3 & $-140,8$ & 758,6 & 315,7 & 283,1 & 1065,3 & 50,1 \\
\hline $\mathrm{C}_{2} \mathrm{H}_{2}$ & ${ }^{3} J_{\mathrm{HH}}$ & 8,2 & 10,3 & 13,8 & 19,9 & 31,8 & 60,9 & 184,6 & $-514,2$ & $-157,7$ & $-116,7$ & $-1,7$ & 9,6 \\
\hline $\mathrm{C}_{2} \mathrm{H}_{4}$ & ${ }^{1} J_{\mathrm{CC}}$ & 51,8 & 55,3 & 60,3 & 68,4 & 83,8 & 126,7 & 1247,8 & $-63,3$ & $-9,4$ & 7,2 & 14,5 & 67,6 \\
\hline $\mathrm{C}_{2} \mathrm{H}_{4}$ & ${ }^{1} J_{\mathrm{CH}}$ & 132,2 & 148,8 & 168,8 & 193,7 & 227,1 & 284,1 & 1106,6 & 220,7 & 306,4 & 378,1 & 460,3 & 156,3 \\
\hline $\mathrm{C}_{2} \mathrm{H}_{4}$ & ${ }^{2} J_{\mathrm{CH}}$ & 0,3 & $-1,3$ & $-3,9$ & $-8,5$ & $-18,1$ & $-46,7$ & $-835,3$ & 91,5 & 56,5 & 48,4 & 48,2 & $-2,4$ \\
\hline $\mathrm{C}_{2} \mathrm{H}_{4}$ & ${ }^{2} J_{\mathrm{HH}}$ & $-3,2$ & $-5,7$ & $-9,4$ & $-15,4$ & $-26,5$ & $-56,2$ & $-791,8$ & 62,0 & 21,2 & 1,8 & $-16,3$ & 2,3 \\
\hline $\mathrm{C}_{2} \mathrm{H}_{4}$ & ${ }^{3} J_{\mathrm{HH}_{\mathrm{C}}}$ & 11,3 & 12,8 & 15,0 & 18,9 & 27,1 & 52,8 & 782,9 & $-78,6$ & $-48,8$ & $-45,1$ & $-50,5$ & 11,7 \\
\hline $\mathrm{C}_{2} \mathrm{H}_{4}$ & ${ }^{3} J_{\mathrm{HH}_{\mathrm{t}}}$ & 12,7 & 15,2 & 18,7 & 24,1 & 34,3 & 63,0 & 821,7 & $-67,3$ & $-32,1$ & $-22,7$ & $-20,6$ & 19 \\
\hline $\mathrm{C}_{2} \mathrm{H}_{6}$ & ${ }^{1} J_{\mathrm{CC}}$ & 21,0 & 23,8 & 27,3 & 31,7 & 37,3 & 44,4 & 53,8 & 66,6 & 84,5 & 111,0 & 153,1 & 34,5 \\
\hline $\mathrm{C}_{2} \mathrm{H}_{6}$ & ${ }^{1} J_{\mathrm{CH}}$ & 103,1 & 115,1 & 129,3 & 146,4 & 167,2 & 192,6 & 224,3 & 264,8 & 317,9 & 390,6 & 495,7 & 125,2 \\
\hline $\mathrm{C}_{2} \mathrm{H}_{6}$ & ${ }^{2} J_{\mathrm{CH}}$ & $-1,6$ & $-2,8$ & $-4,4$ & $-6,4$ & $-9,0$ & $-12,5$ & $-17,4$ & $-24,5$ & $-35,0$ & $-51,8$ & $-80,6$ & $-4,7$ \\
\hline \multirow[t]{3}{*}{ Total } & DM & 2,57 & 4,50 & 7,53 & 11,94 & 18,10 & 27,34 & 104,90 & 162,37 & 51,60 & 67,38 & 306,17 & - \\
\hline & DMA & 14,96 & 13,68 & 17,32 & 28,76 & 46,90 & 76,80 & 322,61 & 351,02 & 132,10 & 141,45 & 416,70 & - \\
\hline & PDMA & 31,72 & 32,41 & 49,08 & 87,43 & 155,03 & 311,24 & 3388,87 & 805,16 & 464,24 & 464,71 & 735,37 & - \\
\hline \multirow{3}{*}{ CPI } & DM & 19,80 & 16,89 & 15,06 & 14,25 & 13,65 & 10,24 & $-21,12$ & 466,05 & 88,72 & 83,61 & 89,55 & - \\
\hline & DMA & 20,58 & 24,95 & 31,46 & 45,92 & 66,66 & 93,29 & 151,59 & 522,98 & 156,45 & 163,68 & 190,90 & - \\
\hline & PDMA & 20,23 & 23,96 & 44,36 & 71,42 & 105,32 & 146,80 & 207,19 & 380,31 & 318,04 & 394,23 & 495,97 & - \\
\hline \multirow[t]{3}{*}{ SPI } & DM & $-10,06$ & $-4,58$ & 2,01 & 10,25 & 21,37 & 39,89 & 197,31 & $-60,33$ & 24,37 & 55,49 & 465,01 & - \\
\hline & DMA & 10,83 & 5,42 & 6,95 & 16,18 & 32,41 & 64,71 & 448,02 & 224,91 & 114,25 & 125,14 & 582,28 & - \\
\hline & PDMA & 40,15 & 38,61 & 52,54 & 99,17 & 191,49 & 431,83 & 5722,10 & 1116,71 & 571,46 & 516,39 & 910,93 & - \\
\hline \multirow[t]{3}{*}{$\Delta \mathrm{CS}$} & DM & 29,86 & 21,47 & 13,05 & 4,00 & $-7,73$ & $-29,65$ & $-218,43$ & 526,39 & 64,34 & 28,12 & $-375,46$ & - \\
\hline & DMA & 9,75 & 19,53 & 24,52 & 29,74 & 34,25 & 28,58 & $-296,43$ & 298,08 & 42,19 & 38,54 & $-391,38$ & - \\
\hline & PDMA & $-19,93$ & $-14,65$ & $-8,18$ & $-27,75$ & $-86,17$ & $-285,04$ & $-5514,91$ & $-736,40$ & $-253,42$ & $-122,16$ & $-414,97$ & - \\
\hline
\end{tabular}


Tabela 8.51: Constantes de acoplamento M062X com correção vibracional no nível BHandH $\left(50 \% E_{X}^{\mathrm{HF}}\right)$ e base aug-pcJ-2.

\begin{tabular}{|c|c|c|c|c|c|c|c|c|c|c|c|c|c|}
\hline & $\% E_{X}^{\mathrm{HF}}$ & $0 \%$ & $10 \%$ & $20 \%$ & $30 \%$ & $40 \%$ & $50 \%$ & $60 \%$ & $70 \%$ & $80 \%$ & $90 \%$ & $100 \%$ & Exp. \\
\hline $\mathrm{HF}$ & ${ }^{1} J_{\mathrm{HF}}$ & 413,1 & 416,6 & 420,6 & 426,3 & 434,6 & 446,7 & 463,6 & 486,4 & 516,1 & 553,6 & 599,8 & 500 \\
\hline $\mathrm{CO}$ & ${ }^{1} J_{\mathrm{CO}}$ & 4,4 & 5,4 & 6,4 & 7,3 & 7,9 & 8,1 & 7,8 & 6,7 & 4,4 & 0,5 & $-6,1$ & 16,4 \\
\hline $\mathrm{H}_{2} \mathrm{O}$ & ${ }^{1} J_{\mathrm{OH}}$ & $-72,3$ & $-74,5$ & $-77,1$ & $-80,2$ & $-83,9$ & $-88,4$ & $-93,9$ & $-100,6$ & $-108,7$ & $-118,4$ & $-130,2$ & $-80,6$ \\
\hline $\mathrm{H}_{2} \mathrm{O}$ & ${ }^{2} J_{\mathrm{HH}}$ & 5,7 & 4,5 & 3,0 & 1,2 & $-1,2$ & $-4,2$ & $-8,0$ & $-12,9$ & $-19,0$ & $-26,7$ & $-36,6$ & $-7,3$ \\
\hline $\mathrm{NH}_{3}$ & ${ }^{1} J_{\mathrm{NH}}$ & 39,0 & 41,0 & 43,2 & 45,8 & 48,8 & 52,4 & 56,7 & 61,7 & 67,7 & 75,0 & 83,9 & 43,8 \\
\hline $\mathrm{NH}_{3}$ & ${ }^{2} J_{\mathrm{HH}}$ & 1,1 & 0,2 & $-1,2$ & $-3,1$ & $-5,5$ & $-8,6$ & $-12,7$ & $-18,0$ & $-25,0$ & $-34,3$ & $-46,7$ & $-9,6$ \\
\hline $\mathrm{PH}_{3}$ & ${ }^{1} J_{\mathrm{PH}}$ & 126,2 & 127,4 & 130,5 & 135,9 & 143,8 & 154,8 & 169,3 & 188,3 & 212,4 & 243,2 & 282,7 & 188,2 \\
\hline $\mathrm{PF}_{3}$ & ${ }^{1} J_{\mathrm{PF}}$ & $-1441,6$ & $-1488,1$ & $-1532,6$ & $-1572,3$ & $-1603,0$ & $-1621,3$ & $-1626,9$ & $-1622,3$ & $-1612,1$ & $-1602,0$ & $-1596,0$ & -1441 \\
\hline $\mathrm{BHF}_{2}$ & ${ }^{1} J_{\mathrm{BF}}$ & $-171,1$ & $-167,6$ & $-160,7$ & $-151,0$ & $-139,4$ & $-126,4$ & $-112,0$ & $-96,6$ & $-80,2$ & $-63,1$ & $-45,7$ & -84 \\
\hline $\mathrm{BF}_{3}$ & ${ }^{1} J_{\mathrm{BF}}$ & $-91,4$ & $-82,3$ & $-71,0$ & $-58,1$ & $-43,8$ & $-28,5$ & $-12,1$ & 5,4 & 24,6 & 45,7 & 68,8 & 15 \\
\hline $\mathrm{F}_{2} \mathrm{O}$ & ${ }^{1} J_{\mathrm{OF}}$ & $-170,9$ & $-214,0$ & $-260,5$ & $-310,1$ & $-362,7$ & $-419,2$ & $-483,1$ & $-564,4$ & $-699,4$ & $-1319,5$ & $-2176,6$ & -300 \\
\hline $\mathrm{CH}_{4}$ & ${ }^{1} J_{\mathrm{CH}}$ & 88,9 & 96,2 & 104,6 & 114,6 & 126,2 & 140,0 & 156,4 & 176,1 & 199,9 & 229,1 & 265,4 & 125,3 \\
\hline $\mathrm{CH}_{4}$ & ${ }^{2} J_{\mathrm{HH}}$ & $-0,5$ & $-1,6$ & $-3,1$ & $-5,1$ & $-7,6$ & $-10,8$ & $-15,0$ & $-20,4$ & $-27,6$ & $-37,1$ & $-49,9$ & $-12,8$ \\
\hline $\mathrm{C}_{2} \mathrm{H}_{2}$ & ${ }^{1} J_{\mathrm{CC}}$ & 168,4 & 175,4 & 183,6 & 193,3 & 205,3 & 220,8 & 242,2 & 274,6 & 332,4 & 473,5 & 1542,8 & 174,8 \\
\hline $\mathrm{C}_{2} \mathrm{H}_{2}$ & ${ }^{1} J_{\mathrm{CH}}$ & 145,7 & 162,7 & 182,2 & 204,4 & 230,0 & 260,0 & 295,7 & 340,1 & 400,3 & 503,8 & 1040,5 & 247,6 \\
\hline $\mathrm{C}_{2} \mathrm{H}_{2}$ & ${ }^{2} J_{\mathrm{CH}}$ & 47,0 & 49,4 & 51,9 & 54,2 & 56,1 & 57,2 & 56,5 & 52,0 & 37,1 & $-14,3$ & $-491,1$ & 50,1 \\
\hline $\mathrm{C}_{2} \mathrm{H}_{2}$ & ${ }^{3} J_{\mathrm{HH}}$ & 4,9 & 5,4 & 5,9 & 6,6 & 7,6 & 9,1 & 11,5 & 16,0 & 25,4 & 52,0 & 275,0 & 9,6 \\
\hline $\mathrm{C}_{2} \mathrm{H}_{4}$ & ${ }^{1} J_{\mathrm{CC}}$ & 61,2 & 64,0 & 67,7 & 72,4 & 78,7 & 87,4 & 100,2 & 121,4 & 163,0 & 285,5 & 14163,8 & 67,6 \\
\hline $\mathrm{C}_{2} \mathrm{H}_{4}$ & ${ }^{1} J_{\mathrm{CH}}$ & 101,1 & 111,2 & 122,8 & 136,3 & 152,1 & 170,9 & 193,9 & 223,2 & 265,1 & 347,5 & 6658,0 & 156,3 \\
\hline $\mathrm{C}_{2} \mathrm{H}_{4}$ & ${ }^{2} J_{\mathrm{CH}}$ & 5,9 & 5,2 & 4,3 & 3,1 & 1,3 & $-1,4$ & $-5,8$ & $-13,6$ & $-30,5$ & $-83,5$ & $-6359,3$ & $-2,4$ \\
\hline $\mathrm{C}_{2} \mathrm{H}_{4}$ & ${ }^{2} J_{\mathrm{HH}}$ & 7,2 & 7,2 & 7,0 & 6,6 & 5,9 & 4,6 & 2,4 & $-1,6$ & $-10,2$ & $-36,8$ & $-3080,2$ & 2,3 \\
\hline $\mathrm{C}_{2} \mathrm{H}_{4}$ & ${ }^{3} J_{\mathrm{HH}_{\mathrm{c}}}$ & 9,4 & 9,8 & 10,2 & 10,8 & 11,5 & 12,6 & 14,4 & 17,7 & 25,1 & 49,8 & 3090,5 & 11,7 \\
\hline $\mathrm{C}_{2} \mathrm{H}_{4}$ & ${ }^{3} J_{\mathrm{HH}_{\mathrm{t}}}$ & 10,0 & 11,3 & 12,6 & 14,2 & 16,0 & 18,3 & 21,4 & 26,5 & 36,1 & 64,4 & 3278,7 & 19 \\
\hline $\mathrm{C}_{2} \mathrm{H}_{6}$ & ${ }^{1} J_{\mathrm{CC}}$ & 28,3 & 30,8 & 33,9 & 37,5 & 42,0 & 47,3 & 53,9 & 62,1 & 72,4 & 85,7 & 103,1 & 34,5 \\
\hline $\mathrm{C}_{2} \mathrm{H}_{6}$ & ${ }^{1} J_{\mathrm{CH}}$ & 85,9 & 93,6 & 102,7 & 113,3 & 125,7 & 140,3 & 157,7 & 178,5 & 203,6 & 234,5 & 272,9 & 125,2 \\
\hline $\mathrm{C}_{2} \mathrm{H}_{6}$ & ${ }^{2} J_{\mathrm{CH}}$ & 2,0 & 1,3 & 0,5 & $-0,4$ & $-1,7$ & $-3,2$ & $-5,2$ & $-7,7$ & $-11,0$ & $-15,5$ & $-21,9$ & $-4,7$ \\
\hline \multirow[t]{3}{*}{ Total } & $\mathrm{DM}$ & $-16,82$ & $-17,48$ & $-17,60$ & $-16,98$ & $-15,40$ & $-12,56$ & $-8,31$ & $-2,55$ & 4,50 & 1,83 & 686,18 & - \\
\hline & DMA & 31,69 & 28,56 & 25,19 & 22,33 & 22,10 & 25,09 & 31,01 & 39,82 & 59,30 & 117,06 & 1625,02 & - \\
\hline & PDMA & 91,47 & 82,64 & 72,07 & 60,83 & 48,17 & 34,80 & 35,57 & 68,16 & 141,02 & 347,30 & 18292,17 & - \\
\hline \multirow[t]{3}{*}{ CPI } & $\mathrm{DM}$ & $-18,06$ & $-24,75$ & $-30,94$ & $-36,29$ & $-40,48$ & $-43,23$ & $-44,75$ & $-46,11$ & $-50,92$ & $-98,81$ & $-167,60$ & - \\
\hline & DMA & 47,35 & 45,43 & 42,15 & 39,45 & 43,25 & 45,54 & 47,09 & 49,38 & 65,03 & 133,61 & 226,96 & - \\
\hline & PDMA & 117,31 & 106,72 & 93,27 & 78,80 & 65,49 & 50,36 & 40,50 & 42,87 & 64,81 & 123,51 & 198,99 & - \\
\hline \multirow[t]{3}{*}{ SPI } & $\mathrm{DM}$ & $-15,91$ & $-12,15$ & $-7,82$ & $-2,82$ & 3,00 & 9,93 & 18,41 & 29,39 & 45,13 & 75,63 & 1312,28 & - \\
\hline & DMA & 20,21 & 16,19 & 12,75 & 9,78 & 6,60 & 10,09 & 19,22 & 32,81 & 55,09 & 104,93 & 2650,27 & - \\
\hline & PDMA & 72,51 & 64,99 & 56,52 & 47,66 & 35,46 & 23,39 & 31,96 & 86,71 & 196,91 & 511,41 & 31560,51 & - \\
\hline \multirow[t]{3}{*}{$\Delta \mathrm{CS}$} & $\mathrm{DM}$ & $-2,15$ & $-12,61$ & $-23,12$ & $-33,47$ & $-43,48$ & $-53,16$ & $-63,15$ & $-75,50$ & $-96,05$ & $-174,44$ & $-1479,88$ & - \\
\hline & DMA & 27,15 & 29,24 & 29,40 & 29,67 & 36,65 & 35,44 & 27,87 & 16,57 & 9,93 & 28,68 & $-2423,30$ & - \\
\hline & PDMA & 44,79 & 41,73 & 36,75 & 31,14 & 30,02 & 26,97 & 8,54 & $-43,84$ & $-132,10$ & $-387,90$ & $-31361,52$ & - \\
\hline
\end{tabular}


Tabela 8.52: Constantes de acoplamento OLYP com correção vibracional no nível BHandH $\left(50 \% E_{X}^{\mathrm{HF}}\right)$ e base aug-pcJ-2.

\begin{tabular}{|c|c|c|c|c|c|c|c|c|c|c|c|c|c|}
\hline & $\% E_{X}^{\mathrm{HF}}$ & $0 \%$ & $10 \%$ & $20 \%$ & $30 \%$ & $40 \%$ & $50 \%$ & $60 \%$ & $70 \%$ & $80 \%$ & $90 \%$ & $100 \%$ & Exp. \\
\hline $\mathrm{HF}$ & ${ }^{1} J_{\mathrm{HF}}$ & 330,6 & 358,8 & 387,3 & 416,3 & 445,7 & 475,4 & 505,6 & 536,1 & 566,9 & 598,1 & 629,7 & 500 \\
\hline $\mathrm{CO}$ & ${ }^{1} J_{\mathrm{CO}}$ & 24,7 & 22,5 & 20,2 & 17,8 & 15,3 & 12,7 & 10,1 & 7,3 & 4,5 & 1,6 & $-1,2$ & 16,4 \\
\hline $\mathrm{H}_{2} \mathrm{O}$ & ${ }^{1} J_{\mathrm{OH}}$ & $-65,0$ & $-68,3$ & $-71,6$ & $-75,0$ & $-78,4$ & $-81,9$ & $-85,4$ & $-89,0$ & $-92,6$ & $-96,2$ & $-100,0$ & $-80,6$ \\
\hline $\mathrm{H}_{2} \mathrm{O}$ & ${ }^{2} J_{\mathrm{HH}}$ & $-5,9$ & $-6,8$ & $-7,8$ & $-8,7$ & $-9,6$ & $-10,6$ & $-11,6$ & $-12,6$ & $-13,7$ & $-14,7$ & $-15,8$ & $-7,3$ \\
\hline $\mathrm{NH}_{3}$ & ${ }^{1} J_{\mathrm{NH}}$ & 41,0 & 42,3 & 43,5 & 44,8 & 46,1 & 47,4 & 48,7 & 50,1 & 51,4 & 52,8 & 54,2 & 43,8 \\
\hline $\mathrm{NH}_{3}$ & ${ }^{2} J_{\mathrm{HH}}$ & $-8,7$ & $-9,5$ & $-10,4$ & $-11,2$ & $-12,1$ & $-13,0$ & $-13,9$ & $-14,8$ & $-15,8$ & $-16,8$ & $-17,8$ & $-9,6$ \\
\hline $\mathrm{PH}_{3}$ & ${ }^{1} J_{\mathrm{PH}}$ & 152,0 & 160,7 & 169,3 & 177,7 & 186,0 & 194,2 & 202,2 & 210,0 & 217,7 & 225,1 & 232,4 & 188,2 \\
\hline $\mathrm{PF}_{3}$ & ${ }^{1} J_{\mathrm{PF}}$ & $-1701,5$ & $-1685,0$ & $-1664,7$ & $-1641,3$ & $-1615,5$ & $-1587,8$ & $-1558,7$ & $-1528,7$ & $-1498,1$ & $-1467,2$ & $-1436,3$ & -1441 \\
\hline $\mathrm{BHF}_{2}$ & ${ }^{1} J_{\mathrm{BF}}$ & $-185,7$ & $-165,1$ & $-145,0$ & $-125,4$ & $-106,3$ & $-87,8$ & $-69,9$ & $-52,5$ & $-35,7$ & $-19,4$ & $-3,7$ & -84 \\
\hline $\mathrm{BF}_{3}$ & ${ }^{1} J_{\mathrm{BF}}$ & $-92,6$ & $-69,5$ & $-47,1$ & $-25,2$ & $-3,9$ & 16,7 & 36,8 & 56,3 & 75,3 & 93,7 & 111,7 & 15 \\
\hline $\mathrm{F}_{2} \mathrm{O}$ & ${ }^{1} J_{\mathrm{OF}}$ & $-268,9$ & $-305,2$ & $-342,2$ & $-381,4$ & $-424,9$ & $-476,1$ & $-540,8$ & $-630,8$ & $-774,9$ & $-1070,9$ & $-2268,1$ & -300 \\
\hline $\mathrm{CH}_{4}$ & ${ }^{1} J_{\mathrm{CH}}$ & 120,7 & 123,6 & 126,6 & 129,6 & 132,7 & 135,8 & 138,9 & 142,1 & 145,4 & 148,6 & 151,9 & 125,3 \\
\hline $\mathrm{CH}_{4}$ & ${ }^{2} J_{\mathrm{HH}}$ & $-13,2$ & $-13,8$ & $-14,5$ & $-15,2$ & $-15,9$ & $-16,6$ & $-17,3$ & $-18,0$ & $-18,7$ & $-19,4$ & $-20,0$ & $-12,8$ \\
\hline $\mathrm{C}_{2} \mathrm{H}_{2}$ & ${ }^{1} J_{\mathrm{CC}}$ & 188,1 & 192,7 & 197,8 & 203,3 & 209,5 & 216,4 & 224,2 & 233,0 & 243,2 & 255,1 & 269,1 & 174,8 \\
\hline $\mathrm{C}_{2} \mathrm{H}_{2}$ & ${ }^{1} J_{\mathrm{CH}}$ & 256,7 & 261,4 & 266,3 & 271,3 & 276,5 & 282,0 & 287,9 & 294,2 & 301,0 & 308,4 & 316,8 & 247,6 \\
\hline $\mathrm{C}_{2} \mathrm{H}_{2}$ & ${ }^{2} J_{\mathrm{CH}}$ & 53,3 & 53,3 & 53,1 & 52,7 & 52,0 & 51,0 & 49,6 & 47,9 & 45,5 & 42,4 & 38,4 & 50,1 \\
\hline $\mathrm{C}_{2} \mathrm{H}_{2}$ & ${ }^{3} J_{\mathrm{HH}}$ & 12,2 & 12,8 & 13,5 & 14,3 & 15,3 & 16,5 & 17,9 & 19,5 & 21,5 & 23,8 & 26,6 & 9,6 \\
\hline $\mathrm{C}_{2} \mathrm{H}_{4}$ & ${ }^{1} J_{\mathrm{CC}}$ & 61,5 & 65,3 & 69,4 & 73,9 & 78,9 & 84,6 & 91,2 & 99,1 & 108,8 & 121,6 & 139,7 & 67,6 \\
\hline $\mathrm{C}_{2} \mathrm{H}_{4}$ & ${ }^{1} J_{\mathrm{CH}}$ & 154,6 & 158,4 & 162,3 & 166,3 & 170,5 & 175,0 & 179,8 & 185,1 & 191,2 & 198,4 & 207,6 & 156,3 \\
\hline $\mathrm{C}_{2} \mathrm{H}_{4}$ & ${ }^{2} J_{\mathrm{CH}}$ & $-1,5$ & $-2,4$ & $-3,5$ & $-4,7$ & $-6,0$ & $-7,6$ & $-9,6$ & $-12,0$ & $-15,2$ & $-19,5$ & $-25,8$ & $-2,4$ \\
\hline $\mathrm{C}_{2} \mathrm{H}_{4}$ & ${ }^{2} J_{\mathrm{HH}}$ & 3,6 & 3,0 & 2,4 & 1,7 & 1,0 & 0,2 & $-0,9$ & $-2,1$ & $-3,7$ & $-5,9$ & $-9,1$ & 2,3 \\
\hline $\mathrm{C}_{2} \mathrm{H}_{4}$ & ${ }^{3} J_{\mathrm{HH}_{\mathrm{c}}}$ & 12,5 & 12,9 & 13,4 & 13,9 & 14,5 & 15,2 & 16,1 & 17,3 & 18,8 & 20,9 & 24,0 & 11,7 \\
\hline $\mathrm{C}_{2} \mathrm{H}_{4}$ & ${ }^{3} J_{\mathrm{HH}_{\mathrm{t}}}$ & 20,0 & 20,4 & 20,9 & 21,6 & 22,3 & 23,2 & 24,2 & 25,6 & 27,4 & 29,9 & 33,5 & 19 \\
\hline $\mathrm{C}_{2} \mathrm{H}_{6}$ & ${ }^{1} J_{\mathrm{CC}}$ & 26,3 & 28,8 & 31,3 & 33,9 & 36,5 & 39,3 & 42,0 & 44,8 & 47,7 & 50,6 & 53,6 & 34,5 \\
\hline $\mathrm{C}_{2} \mathrm{H}_{6}$ & ${ }^{1} J_{\mathrm{CH}}$ & 120,3 & 123,4 & 126,5 & 129,7 & 132,9 & 136,1 & 139,4 & 142,7 & 146,0 & 149,4 & 152,8 & 125,2 \\
\hline $\mathrm{C}_{2} \mathrm{H}_{6}$ & ${ }^{2} J_{\mathrm{CH}}$ & $-3,5$ & $-3,9$ & $-4,3$ & $-4,7$ & $-5,2$ & $-5,6$ & $-6,1$ & $-6,6$ & $-7,0$ & $-7,5$ & $-8,0$ & $-4,7$ \\
\hline \multirow[t]{3}{*}{ Total } & $\mathrm{DM}$ & $-23,59$ & $-20,55$ & $-17,40$ & $-14,19$ & $-11,04$ & $-8,09$ & $-5,56$ & $-3,88$ & $-4,16$ & $-10,08$ & $-50,34$ & - \\
\hline & DMA & 30,57 & 25,42 & 23,23 & 21,68 & 20,61 & 20,76 & 24,82 & 32,25 & 42,00 & 57,96 & 109,57 & - \\
\hline & PDMA & 47,92 & 36,06 & 30,03 & 27,38 & 27,37 & 30,54 & 46,66 & 65,07 & 86,54 & 113,36 & 157,77 & - \\
\hline \multirow[t]{3}{*}{ CPI } & $\mathrm{DM}$ & $-56,45$ & $-51,45$ & $-46,31$ & $-41,14$ & $-36,23$ & $-31,97$ & $-28,89$ & $-28,14$ & $-32,35$ & $-50,44$ & $-150,53$ & - \\
\hline & DMA & 66,86 & 54,91 & 48,64 & 42,59 & 37,05 & 34,03 & 39,87 & 53,05 & 71,01 & 102,67 & 217,07 & - \\
\hline & PDMA & 93,17 & 71,38 & 54,45 & 39,48 & 26,41 & 18,72 & 38,03 & 59,55 & 82,53 & 109,65 & 163,91 & - \\
\hline \multirow[t]{3}{*}{ SPI } & $\mathrm{DM}$ & 0,50 & 2,12 & 3,81 & 5,57 & 7,43 & 9,43 & 11,55 & 13,90 & 16,52 & 19,51 & 23,13 & - \\
\hline & DMA & 3,95 & 3,79 & 4,61 & 6,35 & 8,56 & 11,03 & 13,79 & 17,01 & 20,73 & 25,17 & 30,73 & - \\
\hline & PDMA & 14,73 & 10,17 & 12,11 & 18,51 & 28,07 & 39,22 & 52,99 & 69,12 & 89,48 & 116,09 & 153,27 & - \\
\hline \multirow[t]{3}{*}{$\Delta \mathrm{CS}$} & $\mathrm{DM}$ & $-56,95$ & $-53,57$ & $-50,12$ & $-46,70$ & $-43,65$ & $-41,40$ & $-40,44$ & $-42,04$ & $-48,87$ & $-69,95$ & $-173,66$ & - \\
\hline & DMA & 62,91 & 51,12 & 44,03 & 36,24 & 28,49 & 23,00 & 26,09 & 36,04 & 50,28 & 77,51 & 186,34 & - \\
\hline & PDMA & 78,44 & 61,21 & 42,34 & 20,97 & $-1,65$ & $-20,50$ & $-14,96$ & $-9,57$ & $-6,94$ & $-6,44$ & 10,65 & - \\
\hline
\end{tabular}


Tabela 8.53: Constantes de acoplamento PBE com correção vibracional no nível BHandH $\left(50 \% E_{X}^{\mathrm{HF}}\right)$ e base aug-pcJ-2.

\begin{tabular}{|c|c|c|c|c|c|c|c|c|c|c|c|c|c|}
\hline & $\% E_{X}^{\mathrm{HF}}$ & $0 \%$ & $10 \%$ & $20 \%$ & $30 \%$ & $40 \%$ & $50 \%$ & $60 \%$ & $70 \%$ & $80 \%$ & $90 \%$ & $100 \%$ & Exp. \\
\hline $\mathrm{HF}$ & ${ }^{1} J_{\mathrm{HF}}$ & 343,2 & 365,0 & 386,9 & 409,1 & 431,5 & 454,1 & 477,0 & 500,0 & 523,3 & 546,8 & 570,5 & 500 \\
\hline $\mathrm{CO}$ & ${ }^{1} J_{\mathrm{CO}}$ & 24,8 & 23,2 & 21,5 & 19,8 & 18,0 & 16,1 & 14,2 & 12,2 & 10,2 & 8,1 & 6,0 & 16,4 \\
\hline $\mathrm{H}_{2} \mathrm{O}$ & ${ }^{1} J_{\mathrm{OH}}$ & $-66,1$ & $-68,4$ & $-70,7$ & $-73,1$ & $-75,5$ & $-77,9$ & $-80,3$ & $-82,8$ & $-85,3$ & $-87,8$ & $-90,4$ & $-80,6$ \\
\hline $\mathrm{H}_{2} \mathrm{O}$ & ${ }^{2} J_{\mathrm{HH}}$ & $-3,2$ & $-4,2$ & $-5,2$ & $-6,3$ & $-7,4$ & $-8,5$ & $-9,6$ & $-10,8$ & $-12,0$ & $-13,2$ & $-14,4$ & $-7,3$ \\
\hline $\mathrm{NH}_{3}$ & ${ }^{1} J_{\mathrm{NH}}$ & 41,6 & 42,3 & 43,0 & 43,7 & 44,4 & 45,1 & 45,9 & 46,6 & 47,4 & 48,2 & 49,0 & 43,8 \\
\hline $\mathrm{NH}_{3}$ & ${ }^{2} J_{\mathrm{HH}}$ & $-6,9$ & $-7,8$ & $-8,7$ & $-9,7$ & $-10,6$ & $-11,6$ & $-12,6$ & $-13,6$ & $-14,6$ & $-15,7$ & $-16,7$ & $-9,6$ \\
\hline $\mathrm{PH}_{3}$ & ${ }^{1} J_{\mathrm{PH}}$ & 126,9 & 135,3 & 143,6 & 151,9 & 160,1 & 168,3 & 176,3 & 184,3 & 192,1 & 199,9 & 207,5 & 188,2 \\
\hline $\mathrm{PF}_{3}$ & ${ }^{1} J_{\mathrm{PF}}$ & $-1800,3$ & $-1776,2$ & $-1747,4$ & $-1714,6$ & $-1678,7$ & $-1640,1$ & $-1599,6$ & $-1557,4$ & $-1514,2$ & $-1470,2$ & $-1425,8$ & -1441 \\
\hline $\mathrm{BHF}_{2}$ & ${ }^{1} J_{\mathrm{BF}}$ & $-177,1$ & $-160,2$ & $-143,5$ & $-127,0$ & $-110,8$ & $-94,7$ & $-78,9$ & $-63,3$ & $-48,0$ & $-32,9$ & $-18,1$ & -84 \\
\hline $\mathrm{BF}_{3}$ & ${ }^{1} J_{\mathrm{BF}}$ & $-77,9$ & $-59,6$ & $-41,5$ & $-23,8$ & $-6,3$ & 10,8 & 27,8 & 44,5 & 60,9 & 77,1 & 93,1 & 15 \\
\hline $\mathrm{F}_{2} \mathrm{O}$ & ${ }^{1} J_{\mathrm{OF}}$ & $-292,3$ & $-330,6$ & $-369,2$ & $-409,9$ & $-454,8$ & $-507,8$ & $-575,1$ & $-669,8$ & $-823,5$ & $-1143,8$ & $-2467,5$ & -300 \\
\hline $\mathrm{CH}_{4}$ & ${ }^{1} J_{\mathrm{CH}}$ & 121,8 & 123,2 & 124,6 & 126,0 & 127,5 & 129,0 & 130,5 & 132,1 & 133,7 & 135,3 & 136,9 & 125,3 \\
\hline $\mathrm{CH}_{4}$ & ${ }^{2} J_{\mathrm{HH}}$ & $-12,1$ & $-12,9$ & $-13,7$ & $-14,5$ & $-15,3$ & $-16,1$ & $-16,9$ & $-17,7$ & $-18,5$ & $-19,3$ & $-20,1$ & $-12,8$ \\
\hline $\mathrm{C}_{2} \mathrm{H}_{2}$ & ${ }^{1} J_{\mathrm{CC}}$ & 189,4 & 192,2 & 195,3 & 199,0 & 203,3 & 208,3 & 214,4 & 221,7 & 230,9 & 242,6 & 257,8 & 174,8 \\
\hline $\mathrm{C}_{2} \mathrm{H}_{2}$ & ${ }^{1} J_{\mathrm{CH}}$ & 253,1 & 255,5 & 258,1 & 260,9 & 264,0 & 267,4 & 271,3 & 275,8 & 281,2 & 287,9 & 296,6 & 247,6 \\
\hline $\mathrm{C}_{2} \mathrm{H}_{2}$ & ${ }^{2} J_{\mathrm{CH}}$ & 54,4 & 54,4 & 54,0 & 53,5 & 52,5 & 51,2 & 49,3 & 46,8 & 43,2 & 38,4 & 31,5 & 50,1 \\
\hline $\mathrm{C}_{2} \mathrm{H}_{2}$ & ${ }^{3} J_{\mathrm{HH}}$ & 11,0 & 11,7 & 12,5 & 13,5 & 14,7 & 16,2 & 18,0 & 20,2 & 23,1 & 26,7 & 31,5 & 9,6 \\
\hline $\mathrm{C}_{2} \mathrm{H}_{4}$ & ${ }^{1} J_{\mathrm{CC}}$ & 62,0 & 64,7 & 67,7 & 71,1 & 75,1 & 79,8 & 85,7 & 93,5 & 104,3 & 121,0 & 151,4 & 67,6 \\
\hline $\mathrm{C}_{2} \mathrm{H}_{4}$ & ${ }^{1} J_{\mathrm{CH}}$ & 153,7 & 155,8 & 158,0 & 160,4 & 163,0 & 165,9 & 169,4 & 173,5 & 179,0 & 187,1 & 200,9 & 156,3 \\
\hline $\mathrm{C}_{2} \mathrm{H}_{4}$ & ${ }^{2} J_{\mathrm{CH}}$ & $-0,9$ & $-1,8$ & $-2,9$ & $-4,1$ & $-5,5$ & $-7,3$ & $-9,5$ & $-12,6$ & $-16,9$ & $-23,8$ & $-36,5$ & $-2,4$ \\
\hline $\mathrm{C}_{2} \mathrm{H}_{4}$ & ${ }^{2} J_{\mathrm{HH}}$ & 4,7 & 3,9 & 3,0 & 2,0 & 0,9 & $-0,3$ & $-1,9$ & $-3,9$ & $-6,8$ & $-11,2$ & $-19,2$ & 2,3 \\
\hline $\mathrm{C}_{2} \mathrm{H}_{4}$ & ${ }^{3} J_{\mathrm{HH}_{\mathrm{c}}}$ & 12,0 & 12,4 & 12,8 & 13,3 & 13,9 & 14,8 & 16,0 & 17,6 & 20,0 & 24,0 & 31,6 & 11,7 \\
\hline $\mathrm{C}_{2} \mathrm{H}_{4}$ & ${ }^{3} J_{\mathrm{HH}_{\mathrm{t}}}$ & 19,3 & 19,6 & 20,1 & 20,7 & 21,5 & 22,5 & 23,9 & 25,8 & 28,6 & 33,1 & 41,6 & 19 \\
\hline $\mathrm{C}_{2} \mathrm{H}_{6}$ & ${ }^{1} J_{\mathrm{CC}}$ & 26,6 & 28,5 & 30,3 & 32,2 & 34,2 & 36,1 & 38,1 & 40,2 & 42,2 & 44,3 & 46,5 & 34,5 \\
\hline $\mathrm{C}_{2} \mathrm{H}_{6}$ & ${ }^{1} J_{\mathrm{CH}}$ & 121,4 & 123,0 & 124,6 & 126,2 & 127,9 & 129,6 & 131,3 & 133,1 & 134,9 & 136,7 & 138,5 & 125,2 \\
\hline $\mathrm{C}_{2} \mathrm{H}_{6}$ & ${ }^{2} J_{\mathrm{CH}}$ & $-3,1$ & $-3,6$ & $-4,1$ & $-4,5$ & $-5,1$ & $-5,6$ & $-6,1$ & $-6,6$ & $-7,2$ & $-7,7$ & $-8,3$ & $-4,7$ \\
\hline \multirow[t]{3}{*}{ Total } & $\mathrm{DM}$ & $-27,65$ & $-25,37$ & $-22,92$ & $-20,35$ & $-17,79$ & $-15,37$ & $-13,32$ & $-12,14$ & $-12,96$ & $-19,75$ & $-64,27$ & - \\
\hline & DMA & 33,04 & 30,00 & 27,62 & 25,70 & 24,21 & 23,30 & 24,65 & 28,67 & 37,50 & 53,84 & 111,65 & - \\
\hline & PDMA & 48,58 & 38,26 & 29,85 & 25,17 & 25,04 & 28,06 & 40,97 & 60,44 & 85,70 & 121,58 & 189,37 & - \\
\hline \multirow[t]{3}{*}{ CPI } & $\mathrm{DM}$ & $-66,20$ & $-62,01$ & $-57,46$ & $-52,80$ & $-48,27$ & $-44,28$ & $-41,44$ & $-41,00$ & $-45,87$ & $-65,85$ & $-177,06$ & - \\
\hline & DMA & 73,00 & 66,35 & 60,74 & 54,96 & 49,60 & 45,01 & 45,13 & 50,64 & 66,36 & 97,87 & 223,28 & - \\
\hline & PDMA & 89,10 & 72,53 & 56,50 & 40,72 & 27,26 & 17,18 & 26,03 & 43,55 & 63,95 & 89,79 & 145,97 & - \\
\hline \multirow[t]{3}{*}{ SPI } & $\mathrm{DM}$ & 0,61 & 1,50 & 2,41 & 3,44 & 4,57 & 5,83 & 7,29 & 9,03 & 11,17 & 14,07 & 18,44 & - \\
\hline & DMA & 3,73 & 3,34 & 3,33 & 4,24 & 5,59 & 7,39 & 9,64 & 12,56 & 16,33 & 21,55 & 29,79 & - \\
\hline & PDMA & 18,86 & 13,13 & 10,31 & 13,77 & 23,40 & 36,03 & 51,92 & 72,82 & 101,64 & 144,89 & 221,20 & - \\
\hline \multirow[t]{3}{*}{$\Delta \mathrm{CS}$} & $\mathrm{DM}$ & $-66,81$ & $-63,51$ & $-59,88$ & $-56,24$ & $-52,84$ & $-50,11$ & $-48,73$ & $-50,03$ & $-57,05$ & $-79,92$ & $-195,50$ & - \\
\hline & DMA & 69,27 & 63,01 & 57,40 & 50,72 & 44,01 & 37,62 & 35,49 & 38,08 & 50,03 & 76,33 & 193,50 & - \\
\hline & PDMA & 70,24 & 59,40 & 46,19 & 26,96 & 3,86 & $-18,85$ & $-25,88$ & $-29,27$ & $-37,69$ & $-55,11$ & $-75,23$ & - \\
\hline
\end{tabular}


Tabela 8.54: Constantes de acoplamento PW91 com correção vibracional no nível BHandH $\left(50 \% E_{X}^{\mathrm{HF}}\right)$ e base aug-pcJ-2.

\begin{tabular}{|c|c|c|c|c|c|c|c|c|c|c|c|c|c|}
\hline & $\% E_{X}^{\mathrm{HF}}$ & $0 \%$ & $10 \%$ & $20 \%$ & $30 \%$ & $40 \%$ & $50 \%$ & $60 \%$ & $70 \%$ & $80 \%$ & $90 \%$ & $100 \%$ & Exp. \\
\hline $\mathrm{HF}$ & ${ }^{1} J_{\mathrm{HF}}$ & 331,4 & 354,6 & 378,0 & 401,7 & 425,5 & 449,6 & 473,9 & 498,4 & 523,2 & 548,2 & 573,5 & 500 \\
\hline $\mathrm{CO}$ & ${ }^{1} J_{\mathrm{CO}}$ & 25,6 & 23,9 & 22,2 & 20,3 & 18,4 & 16,5 & 14,4 & 12,3 & 10,1 & 7,9 & 5,6 & 16,4 \\
\hline $\mathrm{H}_{2} \mathrm{O}$ & ${ }^{1} J_{\mathrm{OH}}$ & $-65,2$ & $-67,6$ & $-70,1$ & $-72,6$ & $-75,1$ & $-77,6$ & $-80,2$ & $-82,8$ & $-85,4$ & $-88,1$ & $-90,8$ & $-80,6$ \\
\hline $\mathrm{H}_{2} \mathrm{O}$ & ${ }^{2} J_{\mathrm{HH}}$ & $-3,3$ & $-4,3$ & $-5,3$ & $-6,4$ & $-7,5$ & $-8,6$ & $-9,7$ & $-10,9$ & $-12,0$ & $-13,2$ & $-14,5$ & $-7,3$ \\
\hline $\mathrm{NH}_{3}$ & ${ }^{1} J_{\mathrm{NH}}$ & 41,6 & 42,3 & 43,0 & 43,7 & 44,5 & 45,3 & 46,0 & 46,8 & 47,6 & 48,4 & 49,2 & 43,8 \\
\hline $\mathrm{NH}_{3}$ & ${ }^{2} J_{\mathrm{HH}}$ & $-7,1$ & $-8,0$ & $-8,9$ & $-9,9$ & $-10,8$ & $-11,8$ & $-12,7$ & $-13,7$ & $-14,7$ & $-15,7$ & $-16,8$ & $-9,6$ \\
\hline $\mathrm{PH}_{3}$ & ${ }^{1} J_{\mathrm{PH}}$ & 130,8 & 139,1 & 147,2 & 155,3 & 163,2 & 171,1 & 178,9 & 186,5 & 194,0 & 201,4 & 208,7 & 188,2 \\
\hline $\mathrm{PF}_{3}$ & ${ }^{1} J_{\mathrm{PF}}$ & $-1814,5$ & $-1789,4$ & $-1759,6$ & $-1725,7$ & $-1688,6$ & $-1648,8$ & $-1606,9$ & $-1563,5$ & $-1519,0$ & $-1473,6$ & $-1427,8$ & -1441 \\
\hline $\mathrm{BHF}_{2}$ & ${ }^{1} J_{\mathrm{BF}}$ & $-181,9$ & $-164,7$ & $-147,7$ & $-130,7$ & $-113,9$ & $-97,3$ & $-80,8$ & $-64,5$ & $-48,4$ & $-32,5$ & $-16,8$ & -84 \\
\hline $\mathrm{BF}_{3}$ & ${ }^{1} J_{\mathrm{BF}}$ & $-83,0$ & $-64,4$ & $-45,9$ & $-27,7$ & $-9,7$ & 8,1 & 25,7 & 43,2 & 60,4 & 77,5 & 94,5 & 15 \\
\hline $\mathrm{F}_{2} \mathrm{O}$ & ${ }^{1} J_{\mathrm{OF}}$ & $-304,8$ & $-343,1$ & $-381,8$ & $-422,4$ & $-467,3$ & $-520,3$ & $-587,8$ & $-683,0$ & $-838,1$ & $-1163,2$ & $-2540,1$ & -300 \\
\hline $\mathrm{CH}_{4}$ & ${ }^{1} J_{\mathrm{CH}}$ & 122,6 & 124,0 & 125,4 & 126,8 & 128,3 & 129,8 & 131,3 & 132,9 & 134,4 & 136,0 & 137,7 & 125,3 \\
\hline $\mathrm{CH}_{4}$ & ${ }^{2} J_{\mathrm{HH}}$ & $-12,3$ & $-13,1$ & $-13,9$ & $-14,7$ & $-15,5$ & $-16,2$ & $-17,0$ & $-17,8$ & $-18,6$ & $-19,4$ & $-20,2$ & $-12,8$ \\
\hline $\mathrm{C}_{2} \mathrm{H}_{2}$ & ${ }^{1} J_{\mathrm{CC}}$ & 189,5 & 192,3 & 195,4 & 199,2 & 203,5 & 208,7 & 214,9 & 222,5 & 232,0 & 244,0 & 259,7 & 174,8 \\
\hline $\mathrm{C}_{2} \mathrm{H}_{2}$ & ${ }^{1} J_{\mathrm{CH}}$ & 255,8 & 258,1 & 260,6 & 263,2 & 266,1 & 269,4 & 273,1 & 277,6 & 282,9 & 289,4 & 297,9 & 247,6 \\
\hline $\mathrm{C}_{2} \mathrm{H}_{2}$ & ${ }^{2} J_{\mathrm{CH}}$ & 54,9 & 54,8 & 54,4 & 53,8 & 52,9 & 51,5 & 49,5 & 46,9 & 43,3 & 38,3 & 31,5 & 50,1 \\
\hline $\mathrm{C}_{2} \mathrm{H}_{2}$ & ${ }^{3} J_{\mathrm{HH}}$ & 11,1 & 11,8 & 12,6 & 13,6 & 14,8 & 16,3 & 18,1 & 20,3 & 23,1 & 26,7 & 31,3 & 9,6 \\
\hline $\mathrm{C}_{2} \mathrm{H}_{4}$ & ${ }^{1} J_{\mathrm{CC}}$ & 61,3 & 64,0 & 67,1 & 70,6 & 74,7 & 79,6 & 85,7 & 93,6 & 104,8 & 121,9 & 152,7 & 67,6 \\
\hline $\mathrm{C}_{2} \mathrm{H}_{4}$ & ${ }^{1} J_{\mathrm{CH}}$ & 154,9 & 157,0 & 159,2 & 161,5 & 164,1 & 167,0 & 170,4 & 174,6 & 180,1 & 188,1 & 201,9 & 156,3 \\
\hline $\mathrm{C}_{2} \mathrm{H}_{4}$ & ${ }^{2} J_{\mathrm{CH}}$ & $-0,8$ & $-1,7$ & $-2,7$ & $-3,9$ & $-5,4$ & $-7,2$ & $-9,5$ & $-12,5$ & $-16,9$ & $-23,9$ & $-36,6$ & $-2,4$ \\
\hline $\mathrm{C}_{2} \mathrm{H}_{4}$ & ${ }^{2} J_{\mathrm{HH}}$ & 4,7 & 3,8 & 3,0 & 2,0 & 0,9 & $-0,3$ & $-1,9$ & $-4,0$ & $-6,9$ & $-11,2$ & $-19,0$ & 2,3 \\
\hline $\mathrm{C}_{2} \mathrm{H}_{4}$ & ${ }^{3} J_{\mathrm{HH}_{\mathrm{c}}}$ & 12,2 & 12,5 & 12,9 & 13,4 & 14,1 & 15,0 & 16,1 & 17,7 & 20,1 & 24,1 & 31,5 & 11,7 \\
\hline $\mathrm{C}_{2} \mathrm{H}_{4}$ & ${ }^{3} J_{\mathrm{HH}_{\mathrm{t}}}$ & 19,6 & 19,9 & 20,4 & 21,0 & 21,7 & 22,7 & 24,1 & 26,0 & 28,7 & 33,2 & 41,5 & 19 \\
\hline $\mathrm{C}_{2} \mathrm{H}_{6}$ & ${ }^{1} J_{\mathrm{CC}}$ & 26,0 & 27,9 & 29,9 & 31,9 & 34,0 & 36,0 & 38,2 & 40,3 & 42,5 & 44,7 & 47,0 & 34,5 \\
\hline $\mathrm{C}_{2} \mathrm{H}_{6}$ & ${ }^{1} J_{\mathrm{CH}}$ & 122,2 & 123,8 & 125,4 & 127,0 & 128,7 & 130,4 & 132,1 & 133,9 & 135,6 & 137,4 & 139,2 & 125,2 \\
\hline $\mathrm{C}_{2} \mathrm{H}_{6}$ & ${ }^{2} J_{\mathrm{CH}}$ & $-3,1$ & $-3,6$ & $-4,1$ & $-4,6$ & $-5,1$ & $-5,6$ & $-6,1$ & $-6,6$ & $-7,2$ & $-7,7$ & $-8,3$ & $-4,7$ \\
\hline \multirow[t]{3}{*}{ Total } & $\mathrm{DM}$ & $-29,11$ & $-26,73$ & $-24,17$ & $-21,48$ & $-18,79$ & $-16,22$ & $-14,05$ & $-12,72$ & $-13,44$ & $-20,24$ & $-66,63$ & - \\
\hline & DMA & 34,30 & 31,79 & 29,32 & 27,32 & 25,70 & 24,63 & 25,50 & 29,53 & 38,55 & 55,16 & 114,95 & - \\
\hline & PDMA & 50,59 & 40,29 & 31,43 & 26,62 & 26,66 & 29,28 & 40,80 & 60,57 & 86,30 & 122,55 & 190,97 & - \\
\hline \multirow[t]{3}{*}{ CPI } & $\mathrm{DM}$ & $-70,12$ & $-65,68$ & $-60,89$ & $-55,94$ & $-51,11$ & $-46,79$ & $-43,65$ & $-42,92$ & $-47,56$ & $-67,62$ & $-183,29$ & - \\
\hline & DMA & 75,77 & 70,25 & 64,35 & 58,26 & 52,60 & 47,63 & 46,65 & 52,14 & 68,25 & 100,35 & 230,44 & - \\
\hline & PDMA & 92,97 & 76,56 & 60,21 & 44,30 & 30,66 & 19,76 & 25,06 & 43,20 & 64,37 & 90,97 & 149,79 & - \\
\hline \multirow[t]{3}{*}{ SPI } & $\mathrm{DM}$ & 0,97 & 1,83 & 2,77 & 3,78 & 4,91 & 6,20 & 7,66 & 9,42 & 11,59 & 14,50 & 18,91 & - \\
\hline & DMA & 3,89 & 3,59 & 3,63 & 4,62 & 5,98 & 7,76 & 9,99 & 12,95 & 16,76 & 22,02 & 30,26 & - \\
\hline & PDMA & 19,52 & 13,69 & 10,33 & 13,65 & 23,73 & 36,26 & 52,35 & 73,31 & 102,38 & 145,70 & 221,17 & - \\
\hline \multirow[t]{3}{*}{$\Delta \mathrm{CS}$} & $\mathrm{DM}$ & $-71,08$ & $-67,51$ & $-63,66$ & $-59,72$ & $-56,02$ & $-52,99$ & $-51,31$ & $-52,34$ & $-59,15$ & $-82,12$ & $-202,20$ & - \\
\hline & DMA & 71,89 & 66,66 & 60,71 & 53,64 & 46,62 & 39,87 & 36,65 & 39,18 & 51,49 & 78,33 & 200,18 & - \\
\hline & PDMA & 73,46 & 62,87 & 49,88 & 30,65 & 6,93 & $-16,50$ & $-27,30$ & $-30,11$ & $-38,01$ & $-54,74$ & $-71,38$ & - \\
\hline
\end{tabular}


Tabela 8.55: Constantes de acoplamento TPSSh com correção vibracional no nível BHandH $\left(50 \% E_{X}^{\mathrm{HF}}\right)$ e base aug-pcJ-2.

\begin{tabular}{|c|c|c|c|c|c|c|c|c|c|c|c|c|c|}
\hline & $\% E_{X}^{\mathrm{HF}}$ & $0 \%$ & $10 \%$ & $20 \%$ & $30 \%$ & $40 \%$ & $50 \%$ & $60 \%$ & $70 \%$ & $80 \%$ & $90 \%$ & $100 \%$ & Exp. \\
\hline $\mathrm{HF}$ & ${ }^{1} J_{\mathrm{HF}}$ & 333,2 & 357,8 & 382,3 & 406,9 & 431,4 & 455,9 & 480,3 & 504,6 & 528,8 & 553,0 & 577,2 & 500 \\
\hline $\mathrm{CO}$ & ${ }^{1} J_{\mathrm{CO}}$ & 22,4 & 21,0 & 19,5 & 18,0 & 16,4 & 14,7 & 13,0 & 11,2 & 9,4 & 7,5 & 5,6 & 16,4 \\
\hline $\mathrm{H}_{2} \mathrm{O}$ & ${ }^{1} J_{\mathrm{OH}}$ & $-69,1$ & $-71,4$ & $-73,8$ & $-76,2$ & $-78,5$ & $-80,9$ & $-83,2$ & $-85,5$ & $-87,8$ & $-90,0$ & $-92,3$ & $-80,6$ \\
\hline $\mathrm{H}_{2} \mathrm{O}$ & ${ }^{2} J_{\mathrm{HH}}$ & $-2,5$ & $-3,8$ & $-5,1$ & $-6,3$ & $-7,6$ & $-8,8$ & $-10,0$ & $-11,2$ & $-12,4$ & $-13,6$ & $-14,7$ & $-7,3$ \\
\hline $\mathrm{NH}_{3}$ & ${ }^{1} J_{\mathrm{NH}}$ & 46,1 & 46,6 & 47,2 & 47,7 & 48,1 & 48,6 & 49,1 & 49,6 & 50,0 & 50,5 & 50,9 & 43,8 \\
\hline $\mathrm{NH}_{3}$ & ${ }^{2} J_{\mathrm{HH}}$ & $-6,0$ & $-7,2$ & $-8,4$ & $-9,5$ & $-10,7$ & $-11,8$ & $-12,9$ & $-14,0$ & $-15,0$ & $-16,1$ & $-17,0$ & $-9,6$ \\
\hline $\mathrm{PH}_{3}$ & ${ }^{1} J_{\mathrm{PH}}$ & 188,9 & 193,7 & 198,2 & 202,5 & 206,6 & 210,4 & 214,0 & 217,3 & 220,4 & 223,2 & 225,8 & 188,2 \\
\hline $\mathrm{PF}_{3}$ & ${ }^{1} J_{\mathrm{PF}}$ & $-1756,8$ & $-1731,0$ & $-1702,6$ & $-1672,3$ & $-1640,4$ & $-1607,3$ & $-1573,4$ & $-1539,0$ & $-1504,2$ & $-1469,3$ & $-1434,5$ & -1441 \\
\hline $\mathrm{BHF}_{2}$ & ${ }^{1} J_{\mathrm{BF}}$ & $-161,0$ & $-146,8$ & $-132,7$ & $-118,6$ & $-104,5$ & $-90,4$ & $-76,4$ & $-62,4$ & $-48,5$ & $-34,6$ & $-20,7$ & -84 \\
\hline $\mathrm{BF}_{3}$ & ${ }^{1} J_{\mathrm{BF}}$ & $-65,9$ & $-49,3$ & $-32,8$ & $-16,4$ & $-0,3$ & 15,7 & 31,7 & 47,5 & 63,1 & 78,7 & 94,2 & 15 \\
\hline $\mathrm{F}_{2} \mathrm{O}$ & ${ }^{1} J_{\mathrm{OF}}$ & $-297,0$ & $-334,4$ & $-373,8$ & $-416,8$ & $-465,6$ & $-524,3$ & $-599,5$ & $-704,7$ & $-872,2$ & $-1207,0$ & $-2417,8$ & -300 \\
\hline $\mathrm{CH}_{4}$ & ${ }^{1} J_{\mathrm{CH}}$ & 140,5 & 141,3 & 142,1 & 142,9 & 143,6 & 144,4 & 145,1 & 145,7 & 146,3 & 146,9 & 147,4 & 125,3 \\
\hline $\mathrm{CH}_{4}$ & ${ }^{2} J_{\mathrm{HH}}$ & $-10,5$ & $-11,6$ & $-12,7$ & $-13,7$ & $-14,8$ & $-15,8$ & $-16,8$ & $-17,7$ & $-18,7$ & $-19,6$ & $-20,5$ & $-12,8$ \\
\hline $\mathrm{C}_{2} \mathrm{H}_{2}$ & ${ }^{1} J_{\mathrm{CC}}$ & 188,2 & 191,5 & 195,3 & 199,6 & 204,6 & 210,5 & 217,4 & 225,7 & 235,6 & 247,7 & 262,8 & 174,8 \\
\hline $\mathrm{C}_{2} \mathrm{H}_{2}$ & ${ }^{1} J_{\mathrm{CH}}$ & 283,9 & 285,6 & 287,4 & 289,4 & 291,6 & 294,1 & 297,0 & 300,4 & 304,6 & 309,7 & 316,2 & 247,6 \\
\hline $\mathrm{C}_{2} \mathrm{H}_{2}$ & ${ }^{2} J_{\mathrm{CH}}$ & 58,6 & 58,0 & 57,2 & 56,1 & 54,6 & 52,7 & 50,3 & 47,2 & 43,3 & 38,3 & 31,8 & 50,1 \\
\hline $\mathrm{C}_{2} \mathrm{H}_{2}$ & ${ }^{3} J_{\mathrm{HH}}$ & 12,6 & 13,2 & 14,1 & 15,1 & 16,3 & 17,9 & 19,7 & 22,0 & 24,7 & 28,1 & 32,4 & 9,6 \\
\hline $\mathrm{C}_{2} \mathrm{H}_{4}$ & ${ }^{1} J_{\mathrm{CC}}$ & 69,5 & 72,2 & 75,2 & 78,7 & 82,8 & 87,7 & 93,8 & 101,6 & 112,3 & 128,1 & 154,2 & 67,6 \\
\hline $\mathrm{C}_{2} \mathrm{H}_{4}$ & ${ }^{1} J_{\mathrm{CH}}$ & 174,6 & 176,2 & 178,0 & 179,9 & 182,0 & 184,4 & 187,2 & 190,8 & 195,5 & 202,4 & 213,6 & 156,3 \\
\hline $\mathrm{C}_{2} \mathrm{H}_{4}$ & ${ }^{2} J_{\mathrm{CH}}$ & $-1,0$ & $-2,1$ & $-3,4$ & $-4,9$ & $-6,6$ & $-8,7$ & $-11,3$ & $-14,7$ & $-19,3$ & $-26,0$ & $-37,2$ & $-2,4$ \\
\hline $\mathrm{C}_{2} \mathrm{H}_{4}$ & ${ }^{2} J_{\mathrm{HH}}$ & 9,6 & 8,4 & 7,0 & 5,6 & 4,0 & 2,2 & 0,2 & $-2,3$ & $-5,6$ & $-10,1$ & $-17,2$ & 2,3 \\
\hline $\mathrm{C}_{2} \mathrm{H}_{4}$ & ${ }^{3} J_{\mathrm{HH}_{\mathrm{c}}}$ & 12,3 & 12,8 & 13,3 & 14,0 & 14,8 & 15,8 & 17,2 & 18,9 & 21,4 & 25,2 & 31,6 & 11,7 \\
\hline $\mathrm{C}_{2} \mathrm{H}_{4}$ & ${ }^{3} J_{\mathrm{HH}_{\mathrm{t}}}$ & 22,7 & 23,1 & 23,5 & 24,1 & 24,8 & 25,8 & 27,2 & 29,0 & 31,7 & 35,8 & 42,8 & 19 \\
\hline $\mathrm{C}_{2} \mathrm{H}_{6}$ & ${ }^{1} J_{\mathrm{CC}}$ & 33,8 & 35,3 & 36,7 & 38,1 & 39,6 & 41,0 & 42,4 & 43,8 & 45,1 & 46,5 & 47,8 & 34,5 \\
\hline $\mathrm{C}_{2} \mathrm{H}_{6}$ & ${ }^{1} J_{\mathrm{CH}}$ & 139,8 & 140,8 & 141,9 & 142,9 & 143,8 & 144,8 & 145,7 & 146,6 & 147,4 & 148,2 & 149,0 & 125,2 \\
\hline $\mathrm{C}_{2} \mathrm{H}_{6}$ & ${ }^{2} J_{\mathrm{CH}}$ & $-3,5$ & $-4,0$ & $-4,5$ & $-5,1$ & $-5,6$ & $-6,1$ & $-6,6$ & $-7,2$ & $-7,7$ & $-8,2$ & $-8,7$ & $-4,7$ \\
\hline \multirow[t]{3}{*}{ Total } & $\mathrm{DM}$ & $-18,52$ & $-16,50$ & $-14,46$ & $-12,43$ & $-10,56$ & $-8,94$ & $-7,84$ & $-7,76$ & $-9,88$ & $-18,07$ & $-59,32$ & - \\
\hline & DMA & 30,80 & 29,17 & 27,90 & 26,87 & 26,20 & 26,26 & 29,12 & 34,42 & 44,02 & 60,74 & 112,94 & - \\
\hline & PDMA & 53,91 & 43,98 & 36,98 & 32,72 & 30,17 & 30,91 & 47,77 & 68,73 & 94,82 & 129,94 & 190,41 & - \\
\hline \multirow[t]{3}{*}{ CPI } & $\mathrm{DM}$ & $-55,33$ & $-51,43$ & $-47,54$ & $-43,81$ & $-40,55$ & $-38,10$ & $-37,11$ & $-38,86$ & $-46,30$ & $-68,96$ & $-171,29$ & - \\
\hline & DMA & 61,13 & 56,52 & 52,39 & 48,41 & 45,05 & 43,14 & 47,18 & 55,88 & 73,72 & 106,75 & 220,55 & - \\
\hline & PDMA & 77,00 & 62,29 & 47,82 & 33,69 & 22,45 & 16,76 & 32,22 & 50,07 & 70,25 & 95,66 & 147,29 & - \\
\hline \multirow[t]{3}{*}{ SPI } & $\mathrm{DM}$ & 8,47 & 9,11 & 9,80 & 10,57 & 11,43 & 12,44 & 13,63 & 15,05 & 16,83 & 19,26 & 22,79 & - \\
\hline & DMA & 8,56 & 9,11 & 9,93 & 11,08 & 12,37 & 13,88 & 15,88 & 18,67 & 22,23 & 27,01 & 34,03 & - \\
\hline & PDMA & 36,98 & 30,55 & 29,03 & 32,01 & 35,83 & 41,28 & 59,17 & 82,42 & 112,83 & 155,09 & 222,03 & - \\
\hline \multirow[t]{3}{*}{$\Delta \mathrm{CS}$} & $\mathrm{DM}$ & $-63,79$ & $-60,53$ & $-57,34$ & $-54,38$ & $-51,97$ & $-50,54$ & $-50,74$ & $-53,91$ & $-63,13$ & $-88,22$ & $-194,08$ & - \\
\hline & DMA & 52,57 & 47,41 & 42,46 & 37,33 & 32,68 & 29,26 & 31,30 & 37,21 & 51,48 & 79,74 & 186,51 & - \\
\hline & PDMA & 40,02 & 31,74 & 18,78 & 1,68 & $-13,38$ & $-24,52$ & $-26,94$ & $-32,35$ & $-42,57$ & $-59,43$ & $-74,74$ & - \\
\hline
\end{tabular}


Tabela 8.56: Constantes de acoplamento X3LYP com correção vibracional no nível BHandH $\left(50 \% E_{X}^{\mathrm{HF}}\right)$ e base aug-pcJ-2.

\begin{tabular}{|c|c|c|c|c|c|c|c|c|c|c|c|c|c|}
\hline & $\% E_{X}^{\mathrm{HF}}$ & $0 \%$ & $10 \%$ & $20 \%$ & $30 \%$ & $40 \%$ & $50 \%$ & $60 \%$ & $70 \%$ & $80 \%$ & $90 \%$ & $100 \%$ & Exp. \\
\hline $\mathrm{HF}$ & ${ }^{1} J_{\mathrm{HF}}$ & 364,5 & 389,4 & 414,5 & 439,8 & 465,4 & 491,3 & 517,3 & 543,6 & 570,1 & 596,9 & 623,9 & 500 \\
\hline $\mathrm{CO}$ & ${ }^{1} J_{\mathrm{CO}}$ & 22,2 & 20,4 & 18,4 & 16,3 & 14,1 & 11,8 & 9,5 & 7,0 & 4,5 & 1,9 & $-0,7$ & 16,4 \\
\hline $\mathrm{H}_{2} \mathrm{O}$ & ${ }^{1} J_{\mathrm{OH}}$ & $-71,2$ & $-73,9$ & $-76,5$ & $-79,3$ & $-82,0$ & $-84,7$ & $-87,5$ & $-90,4$ & $-93,2$ & $-96,1$ & $-99,0$ & $-80,6$ \\
\hline $\mathrm{H}_{2} \mathrm{O}$ & ${ }^{2} J_{\mathrm{HH}}$ & $-3,8$ & $-4,9$ & $-6,0$ & $-7,1$ & $-8,2$ & $-9,4$ & $-10,6$ & $-11,8$ & $-13,0$ & $-14,2$ & $-15,5$ & $-7,3$ \\
\hline $\mathrm{NH}_{3}$ & ${ }^{1} J_{\mathrm{NH}}$ & 45,3 & 46,1 & 46,9 & 47,7 & 48,6 & 49,4 & 50,2 & 51,1 & 52,0 & 52,8 & 53,7 & 43,8 \\
\hline $\mathrm{NH}_{3}$ & ${ }^{2} J_{\mathrm{HH}}$ & $-7,5$ & $-8,4$ & $-9,4$ & $-10,3$ & $-11,3$ & $-12,3$ & $-13,3$ & $-14,3$ & $-15,4$ & $-16,4$ & $-17,5$ & $-9,6$ \\
\hline $\mathrm{PH}_{3}$ & ${ }^{1} J_{\mathrm{PH}}$ & 151,5 & 160,0 & 168,4 & 176,7 & 184,8 & 192,8 & 200,7 & 208,4 & 215,9 & 223,2 & 230,4 & 188,2 \\
\hline $\mathrm{PF}_{3}$ & ${ }^{1} J_{\mathrm{PF}}$ & $-1812,0$ & $-1786,7$ & $-1756,9$ & $-1723,3$ & $-1686,7$ & $-1647,5$ & $-1606,4$ & $-1563,9$ & $-1520,3$ & $-1476,0$ & $-1431,3$ & -1441 \\
\hline $\mathrm{BHF}_{2}$ & ${ }^{1} J_{\mathrm{BF}}$ & $-172,3$ & $-154,7$ & $-137,2$ & $-119,9$ & $-102,7$ & $-85,7$ & $-68,9$ & $-52,2$ & $-35,8$ & $-19,6$ & $-3,6$ & -84 \\
\hline $\mathrm{BF}_{3}$ & ${ }^{1} J_{\mathrm{BF}}$ & $-71,6$ & $-52,5$ & $-33,5$ & $-14,8$ & 3,6 & 21,9 & 40,0 & 57,9 & 75,7 & 93,2 & 110,6 & 15 \\
\hline $\mathrm{F}_{2} \mathrm{O}$ & ${ }^{1} J_{\mathrm{OF}}$ & $-294,6$ & $-331,5$ & $-368,5$ & $-407,2$ & $-449,8$ & $-499,5$ & $-562,2$ & $-649,6$ & $-789,7$ & $-1075,9$ & $-2188,0$ & -300 \\
\hline $\mathrm{CH}_{4}$ & ${ }^{1} J_{\mathrm{CH}}$ & 134,3 & 135,8 & 137,4 & 139,0 & 140,6 & 142,2 & 143,9 & 145,5 & 147,2 & 148,9 & 150,7 & 125,3 \\
\hline $\mathrm{CH}_{4}$ & ${ }^{2} J_{\mathrm{HH}}$ & $-12,1$ & $-12,9$ & $-13,7$ & $-14,5$ & $-15,3$ & $-16,0$ & $-16,8$ & $-17,6$ & $-18,3$ & $-19,0$ & $-19,8$ & $-12,8$ \\
\hline $\mathrm{C}_{2} \mathrm{H}_{2}$ & ${ }^{1} J_{\mathrm{CC}}$ & 200,3 & 203,3 & 206,7 & 210,7 & 215,2 & 220,6 & 226,8 & 234,3 & 243,3 & 254,3 & 268,0 & 174,8 \\
\hline $\mathrm{C}_{2} \mathrm{H}_{2}$ & ${ }^{1} J_{\mathrm{CH}}$ & 275,7 & 278,2 & 280,7 & 283,4 & 286,3 & 289,5 & 293,1 & 297,1 & 301,8 & 307,3 & 314,0 & 247,6 \\
\hline $\mathrm{C}_{2} \mathrm{H}_{2}$ & ${ }^{2} J_{\mathrm{CH}}$ & 57,3 & 57,2 & 56,9 & 56,4 & 55,5 & 54,3 & 52,6 & 50,4 & 47,5 & 43,7 & 38,7 & 50,1 \\
\hline $\mathrm{C}_{2} \mathrm{H}_{2}$ & ${ }^{3} J_{\mathrm{HH}}$ & 10,7 & 11,3 & 12,0 & 12,9 & 13,9 & 15,1 & 16,5 & 18,3 & 20,4 & 23,0 & 26,2 & 9,6 \\
\hline $\mathrm{C}_{2} \mathrm{H}_{4}$ & ${ }^{1} J_{\mathrm{CC}}$ & 67,6 & 70,5 & 73,8 & 77,4 & 81,5 & 86,3 & 92,0 & 99,1 & 108,2 & 120,6 & 138,8 & 67,6 \\
\hline $\mathrm{C}_{2} \mathrm{H}_{4}$ & ${ }^{1} J_{\mathrm{CH}}$ & 168,2 & 170,4 & 172,7 & 175,2 & 177,8 & 180,7 & 183,9 & 187,6 & 192,1 & 197,9 & 205,9 & 156,3 \\
\hline $\mathrm{C}_{2} \mathrm{H}_{4}$ & ${ }^{2} J_{\mathrm{CH}}$ & $-0,2$ & $-1,0$ & $-2,0$ & $-3,2$ & $-4,5$ & $-6,1$ & $-8,1$ & $-10,6$ & $-13,9$ & $-18,5$ & $-25,4$ & $-2,4$ \\
\hline $\mathrm{C}_{2} \mathrm{H}_{4}$ & ${ }^{2} J_{\mathrm{HH}}$ & 6,3 & 5,6 & 4,8 & 3,9 & 2,9 & 1,9 & 0,6 & $-0,8$ & $-2,7$ & $-5,3$ & $-9,0$ & 2,3 \\
\hline $\mathrm{C}_{2} \mathrm{H}_{4}$ & ${ }^{3} J_{\mathrm{HH}_{\mathrm{c}}}$ & 12,8 & 13,1 & 13,4 & 13,8 & 14,2 & 14,9 & 15,7 & 16,7 & 18,2 & 20,3 & 23,6 & 11,7 \\
\hline $\mathrm{C}_{2} \mathrm{H}_{4}$ & ${ }^{3} J_{\mathrm{HH}_{\mathrm{t}}}{ }^{\mathrm{C}}$ & 20,5 & 20,8 & 21,1 & 21,6 & 22,1 & 22,9 & 23,8 & 25,1 & 26,8 & 29,3 & 33,0 & 19 \\
\hline $\mathrm{C}_{2} \mathrm{H}_{6}$ & ${ }^{1} J_{\mathrm{CC}}$ & 30,3 & 32,4 & 34,6 & 36,8 & 39,0 & 41,3 & 43,6 & 46,0 & 48,4 & 50,8 & 53,3 & 34,5 \\
\hline $\mathrm{C}_{2} \mathrm{H}_{6}$ & ${ }^{1} J_{\mathrm{CH}}$ & 133,2 & 135,0 & 136,7 & 138,5 & 140,3 & 142,2 & 144,0 & 145,9 & 147,8 & 149,7 & 151,6 & 125,2 \\
\hline $\mathrm{C}_{2} \mathrm{H}_{6}$ & ${ }^{2} J_{\mathrm{CH}}$ & $-2,7$ & $-3,2$ & $-3,7$ & $-4,2$ & $-4,7$ & $-5,2$ & $-5,7$ & $-6,3$ & $-6,8$ & $-7,4$ & $-7,9$ & $-4,7$ \\
\hline \multirow[t]{3}{*}{ Total } & DM & $-22,78$ & $-20,20$ & $-17,44$ & $-14,57$ & $-11,71$ & $-8,93$ & $-6,55$ & $-4,94$ & $-5,16$ & $-10,75$ & $-47,70$ & - \\
\hline & DMA & 32,78 & 30,29 & 28,12 & 26,22 & 24,79 & 24,73 & 28,90 & 34,95 & 43,43 & 57,98 & 105,80 & - \\
\hline & PDMA & 49,73 & 40,05 & 30,44 & 24,28 & 21,83 & 26,53 & 42,35 & 60,22 & 81,67 & 109,16 & 154,27 & - \\
\hline \multirow[t]{3}{*}{ CPI } & DM & $-62,76$ & $-57,96$ & $-52,79$ & $-47,48$ & $-42,28$ & $-37,53$ & $-33,83$ & $-32,28$ & $-35,46$ & $-51,92$ & $-143,45$ & - \\
\hline & DMA & 67,80 & 60,98 & 54,74 & 48,46 & 43,15 & 40,64 & 47,70 & 58,79 & 74,54 & 103,46 & 209,21 & - \\
\hline & PDMA & 79,72 & 62,64 & 45,75 & 30,55 & 20,98 & 21,44 & 40,24 & 60,47 & 82,27 & 108,24 & 159,51 & - \\
\hline \multirow[t]{3}{*}{ SPI } & $\mathrm{DM}$ & 6,54 & 7,49 & 8,49 & 9,57 & 10,71 & 12,03 & 13,45 & 15,11 & 17,06 & 19,43 & 22,51 & - \\
\hline & DMA & 7,10 & 7,79 & 8,61 & 9,91 & 11,33 & 13,07 & 15,11 & 17,47 & 20,62 & 24,63 & 29,96 & - \\
\hline & PDMA & 27,73 & 23,47 & 19,22 & 19,68 & 22,45 & 30,26 & 43,89 & 60,05 & 81,22 & 109,83 & 150,43 & - \\
\hline \multirow[t]{3}{*}{$\Delta \mathrm{CS}$} & $\mathrm{DM}$ & $-69,30$ & $-65,46$ & $-61,28$ & $-57,06$ & $-53,00$ & $-49,56$ & $-47,28$ & $-47,39$ & $-52,52$ & $-71,35$ & $-165,95$ & - \\
\hline & DMA & 60,70 & 53,20 & 46,13 & 38,56 & 31,83 & 27,56 & 32,59 & 41,32 & 53,92 & 78,83 & 179,25 & - \\
\hline & PDMA & 51,98 & 39,17 & 26,54 & 10,87 & $-1,47$ & $-8,82$ & $-3,65$ & 0,42 & 1,04 & $-1,60$ & 9,07 & - \\
\hline
\end{tabular}


Tabela 8.57: Constantes de acoplamento B1B95 com correção vibracional no nível BHandH $40 \% E_{X}^{\mathrm{HF}}$ e base aug-pcJ-2.

\begin{tabular}{|c|c|c|c|c|c|c|c|c|c|c|c|c|c|}
\hline & $\% E_{X}^{\mathrm{HF}}$ & $0 \%$ & $10 \%$ & $20 \%$ & $30 \%$ & $40 \%$ & $50 \%$ & $60 \%$ & $70 \%$ & $80 \%$ & $90 \%$ & $100 \%$ & Exp. \\
\hline $\mathrm{HF}$ & ${ }^{1} J_{\mathrm{HF}}$ & 370,7 & 394,3 & 418,0 & 442,0 & 466,1 & 490,4 & 514,8 & 539,4 & 564,2 & 589,1 & 614,2 & 500 \\
\hline $\mathrm{CO}$ & ${ }^{1} J_{\mathrm{CO}}$ & 24,2 & 22,5 & 20,7 & 18,9 & 16,9 & 14,8 & 12,6 & 10,4 & 8,1 & 5,7 & 3,2 & 16,4 \\
\hline $\mathrm{H}_{2} \mathrm{O}$ & ${ }^{1} J_{\mathrm{OH}}$ & $-69,1$ & $-71,6$ & $-74,1$ & $-76,7$ & $-79,2$ & $-81,8$ & $-84,4$ & $-87,0$ & $-89,6$ & $-92,3$ & $-95,0$ & $-80,6$ \\
\hline $\mathrm{H}_{2} \mathrm{O}$ & ${ }^{2} J_{\mathrm{HH}}$ & $-2,8$ & $-3,8$ & $-4,8$ & $-5,8$ & $-6,8$ & $-7,8$ & $-8,9$ & $-9,9$ & $-11,0$ & $-12,1$ & $-13,3$ & $-7,3$ \\
\hline $\mathrm{NH}_{3}$ & ${ }^{1} J_{\mathrm{NH}}$ & 42,6 & 43,4 & 44,1 & 44,8 & 45,6 & 46,3 & 47,1 & 47,9 & 48,6 & 49,4 & 50,2 & 43,8 \\
\hline $\mathrm{NH}_{3}$ & ${ }^{2} J_{\mathrm{HH}}$ & $-6,1$ & $-6,9$ & $-7,8$ & $-8,6$ & $-9,5$ & $-10,4$ & $-11,2$ & $-12,1$ & $-13,0$ & $-13,9$ & $-14,9$ & $-9,6$ \\
\hline $\mathrm{PH}_{3}$ & ${ }^{1} J_{\mathrm{PH}}$ & 139,4 & 147,1 & 154,5 & 161,9 & 169,2 & 176,3 & 183,3 & 190,1 & 196,8 & 203,4 & 209,7 & 188,2 \\
\hline $\mathrm{PF}_{3}$ & ${ }^{1} J_{\mathrm{PF}}$ & $-1714,8$ & $-1693,2$ & $-1667,2$ & $-1637,4$ & $-1604,6$ & $-1569,3$ & $-1531,9$ & $-1493,1$ & $-1453,1$ & $-1412,3$ & $-1371,0$ & -1441 \\
\hline $\mathrm{BHF}_{2}$ & ${ }^{1} J_{\mathrm{BF}}$ & $-179,2$ & $-162,3$ & $-145,5$ & $-128,7$ & $-112,0$ & $-95,5$ & $-79,1$ & $-62,8$ & $-46,7$ & $-30,8$ & $-15,0$ & -84 \\
\hline $\mathrm{BF}_{3}$ & ${ }^{1} J_{\mathrm{BF}}$ & $-80,9$ & $-62,3$ & $-43,9$ & $-25,6$ & $-7,5$ & 10,4 & 28,1 & 45,7 & 63,1 & 80,4 & 97,5 & 15 \\
\hline $\mathrm{F}_{2} \mathrm{O}$ & ${ }^{1} J_{\mathrm{OF}}$ & $-280,0$ & $-314,4$ & $-348,0$ & $-381,8$ & $-417,4$ & $-456,8$ & $-503,1$ & $-561,9$ & $-644,3$ & $-778,2$ & $-1061,6$ & -300 \\
\hline $\mathrm{CH}_{4}$ & ${ }^{1} J_{\mathrm{CH}}$ & 123,0 & 124,3 & 125,6 & 127,0 & 128,4 & 129,8 & 131,3 & 132,7 & 134,2 & 135,7 & 137,2 & 125,3 \\
\hline $\mathrm{CH}_{4}$ & ${ }^{2} J_{\mathrm{HH}}$ & $-10,6$ & $-11,3$ & $-12,0$ & $-12,7$ & $-13,3$ & $-14,0$ & $-14,7$ & $-15,3$ & $-16,0$ & $-16,7$ & $-17,3$ & $-12,8$ \\
\hline $\mathrm{C}_{2} \mathrm{H}_{2}$ & ${ }^{1} J_{\mathrm{CC}}$ & 188,3 & 190,6 & 193,3 & 196,2 & 199,7 & 203,6 & 208,1 & 213,4 & 219,6 & 227,0 & 235,9 & 174,8 \\
\hline $\mathrm{C}_{2} \mathrm{H}_{2}$ & ${ }^{1} J_{\mathrm{CH}}$ & 253,7 & 255,6 & 257,6 & 259,7 & 261,9 & 264,3 & 266,8 & 269,6 & 272,7 & 276,3 & 280,4 & 247,6 \\
\hline $\mathrm{C}_{2} \mathrm{H}_{2}$ & ${ }^{2} J_{\mathrm{CH}}$ & 55,9 & 56,1 & 56,1 & 55,9 & 55,6 & 55,0 & 54,2 & 53,0 & 51,5 & 49,5 & 46,8 & 50,1 \\
\hline $\mathrm{C}_{2} \mathrm{H}_{2}$ & ${ }^{3} J_{\mathrm{HH}}$ & 9,6 & 10,0 & 10,5 & 11,1 & 11,7 & 12,5 & 13,5 & 14,6 & 15,9 & 17,5 & 19,4 & 9,6 \\
\hline $\mathrm{C}_{2} \mathrm{H}_{4}$ & ${ }^{1} J_{\mathrm{CC}}$ & 59,3 & 61,6 & 64,2 & 66,9 & 70,0 & 73,4 & 77,2 & 81,6 & 86,9 & 93,2 & 101,2 & 67,6 \\
\hline $\mathrm{C}_{2} \mathrm{H}_{4}$ & ${ }^{1} J_{\mathrm{CH}}$ & 155,2 & 157,1 & 159,0 & 161,0 & 163,1 & 165,3 & 167,7 & 170,3 & 173,2 & 176,5 & 180,5 & 156,3 \\
\hline $\mathrm{C}_{2} \mathrm{H}_{4}$ & ${ }^{2} J_{\mathrm{CH}}$ & 0,7 & 0,0 & $-0,7$ & $-1,6$ & $-2,6$ & $-3,7$ & $-5,0$ & $-6,6$ & $-8,4$ & $-10,7$ & $-13,7$ & $-2,4$ \\
\hline $\mathrm{C}_{2} \mathrm{H}_{4}$ & ${ }^{2} J_{\mathrm{HH}}$ & 6,3 & 5,7 & 5,0 & 4,3 & 3,6 & 2,8 & 1,9 & 0,9 & $-0,2$ & $-1,6$ & $-3,2$ & 2,3 \\
\hline $\mathrm{C}_{2} \mathrm{H}_{4}$ & ${ }^{3} J_{\mathrm{HH}_{\mathrm{c}}}$ & 11,8 & 12,0 & 12,2 & 12,5 & 12,8 & 13,1 & 13,6 & 14,2 & 15,0 & 15,9 & 17,2 & 11,7 \\
\hline $\mathrm{C}_{2} \mathrm{H}_{4}$ & ${ }^{3} J_{\mathrm{HH}_{\mathrm{t}}}$ & 18,8 & 19,0 & 19,3 & 19,5 & 19,9 & 20,4 & 20,9 & 21,6 & 22,5 & 23,7 & 25,2 & 19 \\
\hline $\mathrm{C}_{2} \mathrm{H}_{6}$ & ${ }^{1} J_{\mathrm{CC}}$ & 25,9 & 27,9 & 29,8 & 31,8 & 33,8 & 35,8 & 37,9 & 40,0 & 42,1 & 44,3 & 46,5 & 34,5 \\
\hline $\mathrm{C}_{2} \mathrm{H}_{6}$ & ${ }^{1} J_{\mathrm{CH}}$ & 122,4 & 124,0 & 125,5 & 127,1 & 128,7 & 130,3 & 131,9 & 133,6 & 135,2 & 136,8 & 138,5 & 125,2 \\
\hline $\mathrm{C}_{2} \mathrm{H}_{6}$ & ${ }^{2} J_{\mathrm{CH}}$ & $-2,4$ & $-2,9$ & $-3,3$ & $-3,8$ & $-4,2$ & $-4,7$ & $-5,2$ & $-5,6$ & $-6,1$ & $-6,6$ & $-7,1$ & $-4,7$ \\
\hline \multirow[t]{3}{*}{ Total } & $\mathrm{DM}$ & $-22,43$ & $-20,10$ & $-17,57$ & $-14,89$ & $-12,12$ & $-9,40$ & $-6,83$ & $-4,63$ & $-3,22$ & $-3,68$ & $-9,75$ & - \\
\hline & DMA & 28,92 & 24,84 & 22,30 & 19,82 & 17,56 & 15,93 & 17,41 & 21,57 & 27,08 & 36,95 & 53,90 & - \\
\hline & PDMA & 54,91 & 44,55 & 34,88 & 25,09 & 16,50 & 13,06 & 20,82 & 34,69 & 49,91 & 67,63 & 89,55 & - \\
\hline \multirow[t]{3}{*}{ CPI } & $\mathrm{DM}$ & $-54,26$ & $-49,83$ & $-44,99$ & $-39,81$ & $-34,55$ & $-29,48$ & $-24,87$ & $-21,29$ & $-19,80$ & $-22,95$ & $-39,72$ & - \\
\hline & DMA & 62,86 & 53,70 & 47,79 & 41,61 & 35,34 & 29,94 & 31,44 & 38,98 & 49,44 & 69,72 & 105,83 & - \\
\hline & PDMA & 90,25 & 72,65 & 56,35 & 40,33 & 24,32 & 13,26 & 22,43 & 40,48 & 59,72 & 80,88 & 106,86 & - \\
\hline \multirow[t]{3}{*}{ SPI } & $\mathrm{DM}$ & 0,92 & 1,71 & 2,53 & 3,39 & 4,33 & 5,32 & 6,40 & 7,59 & 8,93 & 10,45 & 12,23 & - \\
\hline & DMA & 4,03 & 3,68 & 3,61 & 3,84 & 4,52 & 5,65 & 7,12 & 8,79 & 10,68 & 12,93 & 15,83 & - \\
\hline & PDMA & 28,99 & 23,94 & 19,13 & 13,92 & 10,77 & 12,91 & 19,64 & 30,44 & 42,72 & 57,91 & 76,85 & - \\
\hline \multirow[t]{3}{*}{$\Delta \mathrm{CS}$} & $\mathrm{DM}$ & $-55,18$ & $-51,53$ & $-47,52$ & $-43,20$ & $-38,89$ & $-34,80$ & $-31,27$ & $-28,88$ & $-28,73$ & $-33,40$ & $-51,94$ & - \\
\hline & DMA & 58,84 & 50,02 & 44,18 & 37,77 & 30,82 & 24,28 & 24,32 & 30,19 & 38,76 & 56,79 & 90,00 & - \\
\hline & PDMA & 61,26 & 48,71 & 37,22 & 26,42 & 13,54 & 0,36 & 2,79 & 10,03 & 17,00 & 22,97 & 30,01 & - \\
\hline
\end{tabular}


Tabela 8.58: Constantes de acoplamento B3LYP com correção vibracional no nível BHandH $40 \% E_{X}^{\mathrm{HF}}$ e base aug-pcJ-2.

\begin{tabular}{|c|c|c|c|c|c|c|c|c|c|c|c|c|c|}
\hline & $\% E_{X}^{\mathrm{HF}}$ & $0 \%$ & $10 \%$ & $20 \%$ & $30 \%$ & $40 \%$ & $50 \%$ & $60 \%$ & $70 \%$ & $80 \%$ & $90 \%$ & $100 \%$ & Exp. \\
\hline $\mathrm{HF}$ & ${ }^{1} J_{\mathrm{HF}}$ & 360,2 & 385,2 & 410,4 & 435,9 & 461,6 & 487,6 & 513,8 & 540,2 & 566,8 & 593,7 & 620,8 & 500 \\
\hline $\mathrm{CO}$ & ${ }^{1} J_{\mathrm{CO}}$ & 22,5 & 20,7 & 18,7 & 16,6 & 14,4 & 12,2 & 9,8 & 7,3 & 4,8 & 2,2 & $-0,4$ & 16,4 \\
\hline $\mathrm{H}_{2} \mathrm{O}$ & ${ }^{1} J_{\mathrm{OH}}$ & $-70,5$ & $-73,2$ & $-75,9$ & $-78,6$ & $-81,3$ & $-84,1$ & $-86,9$ & $-89,8$ & $-92,6$ & $-95,5$ & $-98,4$ & $-80,6$ \\
\hline $\mathrm{H}_{2} \mathrm{O}$ & ${ }^{2} J_{\mathrm{HH}}$ & $-3,9$ & $-5,0$ & $-6,1$ & $-7,2$ & $-8,3$ & $-9,4$ & $-10,6$ & $-11,8$ & $-13,0$ & $-14,2$ & $-15,4$ & $-7,3$ \\
\hline $\mathrm{NH}_{3}$ & ${ }^{1} J_{\mathrm{NH}}$ & 44,9 & 45,7 & 46,5 & 47,3 & 48,2 & 49,0 & 49,9 & 50,7 & 51,6 & 52,5 & 53,4 & 43,8 \\
\hline $\mathrm{NH}_{3}$ & ${ }^{2} J_{\mathrm{HH}}$ & $-7,5$ & $-8,4$ & $-9,4$ & $-10,3$ & $-11,3$ & $-12,3$ & $-13,3$ & $-14,3$ & $-15,3$ & $-16,3$ & $-17,3$ & $-9,6$ \\
\hline $\mathrm{PH}_{3}$ & ${ }^{1} J_{\mathrm{PH}}$ & 150,3 & 158,8 & 167,2 & 175,4 & 183,6 & 191,5 & 199,4 & 207,0 & 214,5 & 221,9 & 229,0 & 188,2 \\
\hline $\mathrm{PF}_{3}$ & ${ }^{1} J_{\mathrm{PF}}$ & $-1808,5$ & $-1782,8$ & $-1752,7$ & $-1719,0$ & $-1682,2$ & $-1643,0$ & $-1602,0$ & $-1559,6$ & $-1516,3$ & $-1472,2$ & $-1427,8$ & -1441 \\
\hline $\mathrm{BHF}_{2}$ & ${ }^{1} J_{\mathrm{BF}}$ & $-172,2$ & $-154,7$ & $-137,2$ & $-119,9$ & $-102,7$ & $-85,7$ & $-68,9$ & $-52,3$ & $-35,9$ & $-19,7$ & $-3,8$ & -84 \\
\hline $\mathrm{BF}_{3}$ & ${ }^{1} J_{\mathrm{BF}}$ & $-72,4$ & $-53,2$ & $-34,3$ & $-15,5$ & 2,9 & 21,2 & 39,3 & 57,3 & 75,0 & 92,6 & 110,0 & 15 \\
\hline $\mathrm{F}_{2} \mathrm{O}$ & ${ }^{1} J_{\mathrm{OF}}$ & $-293,1$ & $-329,9$ & $-366,8$ & $-405,4$ & $-447,9$ & $-497,5$ & $-560,1$ & $-647,1$ & $-786,4$ & $-1069,8$ & $-2151,4$ & -300 \\
\hline $\mathrm{CH}_{4}$ & ${ }^{1} J_{\mathrm{CH}}$ & 133,3 & 134,9 & 136,4 & 138,0 & 139,7 & 141,3 & 143,0 & 144,7 & 146,4 & 148,2 & 149,9 & 125,3 \\
\hline $\mathrm{CH}_{4}$ & ${ }^{2} J_{\mathrm{HH}}$ & $-12,2$ & $-13,0$ & $-13,7$ & $-14,5$ & $-15,2$ & $-16,0$ & $-16,7$ & $-17,5$ & $-18,2$ & $-18,9$ & $-19,7$ & $-12,8$ \\
\hline $\mathrm{C}_{2} \mathrm{H}_{2}$ & ${ }^{1} J_{\mathrm{CC}}$ & 199,7 & 202,7 & 206,2 & 210,1 & 214,7 & 220,0 & 226,2 & 233,7 & 242,7 & 253,6 & 267,2 & 174,8 \\
\hline $\mathrm{C}_{2} \mathrm{H}_{2}$ & ${ }^{1} J_{\mathrm{CH}}$ & 274,2 & 276,6 & 279,2 & 282,0 & 284,9 & 288,1 & 291,7 & 295,7 & 300,4 & 305,8 & 312,5 & 247,6 \\
\hline $\mathrm{C}_{2} \mathrm{H}_{2}$ & ${ }^{2} J_{\mathrm{CH}}$ & 57,3 & 57,2 & 56,9 & 56,4 & 55,5 & 54,3 & 52,7 & 50,5 & 47,6 & 43,9 & 38,9 & 50,1 \\
\hline $\mathrm{C}_{2} \mathrm{H}_{2}$ & ${ }^{3} J_{\mathrm{HH}}$ & 10,7 & 11,2 & 11,9 & 12,8 & 13,8 & 15,0 & 16,4 & 18,1 & 20,2 & 22,7 & 25,9 & 9,6 \\
\hline $\mathrm{C}_{2} \mathrm{H}_{4}$ & ${ }^{1} J_{\mathrm{CC}}$ & 67,0 & 69,9 & 73,2 & 76,8 & 80,9 & 85,7 & 91,5 & 98,5 & 107,6 & 120,0 & 138,1 & 67,6 \\
\hline $\mathrm{C}_{2} \mathrm{H}_{4}$ & ${ }^{1} J_{\mathrm{CH}}$ & 167,2 & 169,5 & 171,8 & 174,3 & 176,9 & 179,8 & 183,0 & 186,8 & 191,3 & 197,0 & 205,1 & 156,3 \\
\hline $\mathrm{C}_{2} \mathrm{H}_{4}$ & ${ }^{2} J_{\mathrm{CH}}$ & 0,0 & $-0,8$ & $-1,9$ & $-3,0$ & $-4,4$ & $-6,0$ & $-8,0$ & $-10,4$ & $-13,7$ & $-18,3$ & $-25,1$ & $-2,4$ \\
\hline $\mathrm{C}_{2} \mathrm{H}_{4}$ & ${ }^{2} J_{\mathrm{HH}}$ & 6,3 & 5,6 & 4,8 & 3,9 & 3,0 & 1,9 & 0,7 & $-0,7$ & $-2,6$ & $-5,2$ & $-8,9$ & 2,3 \\
\hline $\mathrm{C}_{2} \mathrm{H}_{4}$ & ${ }^{3} J_{\mathrm{HH}_{\mathrm{c}}}$ & 12,7 & 13,0 & 13,3 & 13,7 & 14,1 & 14,8 & 15,6 & 16,6 & 18,1 & 20,2 & 23,5 & 11,7 \\
\hline $\mathrm{C}_{2} \mathrm{H}_{4}$ & ${ }^{3} J_{\mathrm{HH}_{\mathrm{t}}}$ & 20,3 & 20,5 & 20,9 & 21,3 & 21,9 & 22,7 & 23,6 & 24,9 & 26,6 & 29,0 & 32,8 & 19 \\
\hline $\mathrm{C}_{2} \mathrm{H}_{6}$ & ${ }^{1} J_{\mathrm{CC}}$ & 30,0 & 32,1 & 34,3 & 36,5 & 38,7 & 41,0 & 43,4 & 45,7 & 48,1 & 50,6 & 53,0 & 34,5 \\
\hline $\mathrm{C}_{2} \mathrm{H}_{6}$ & ${ }^{1} J_{\mathrm{CH}}$ & 132,3 & 134,1 & 135,9 & 137,7 & 139,5 & 141,4 & 143,3 & 145,1 & 147,0 & 149,0 & 150,9 & 125,2 \\
\hline $\mathrm{C}_{2} \mathrm{H}_{6}$ & ${ }^{2} J_{\mathrm{CH}}$ & $-2,7$ & $-3,2$ & $-3,6$ & $-4,1$ & $-4,7$ & $-5,2$ & $-5,7$ & $-6,2$ & $-6,8$ & $-7,3$ & $-7,9$ & $-4,7$ \\
\hline \multirow[t]{3}{*}{ Total } & $\mathrm{DM}$ & $-23,04$ & $-20,44$ & $-17,65$ & $-14,76$ & $-11,87$ & $-9,10$ & $-6,69$ & $-5,07$ & $-5,27$ & $-10,75$ & $-46,54$ & - \\
\hline & DMA & 32,80 & 30,13 & 27,94 & 25,98 & 24,49 & 24,27 & 28,17 & 34,19 & 42,64 & 57,10 & 104,00 & - \\
\hline & PDMA & 50,18 & 40,37 & 30,68 & 23,90 & 21,63 & 25,71 & 41,33 & 58,92 & 80,35 & 107,70 & 152,27 & - \\
\hline \multirow[t]{3}{*}{ CPI } & $\mathrm{DM}$ & $-62,83$ & $-57,97$ & $-52,77$ & $-47,42$ & $-42,17$ & $-37,40$ & $-33,68$ & $-32,12$ & $-35,25$ & $-51,43$ & $-140,20$ & - \\
\hline & DMA & 68,23 & 61,08 & 54,79 & 48,47 & 42,97 & 40,07 & 46,50 & 57,55 & 73,25 & 101,97 & 205,58 & - \\
\hline & PDMA & 80,39 & 63,17 & 46,32 & 30,95 & 21,24 & 20,56 & 39,30 & 59,54 & 81,17 & 107,14 & 157,30 & - \\
\hline \multirow[t]{3}{*}{ SPI } & $\mathrm{DM}$ & 6,13 & 7,08 & 8,10 & 9,19 & 10,35 & 11,65 & 13,11 & 14,76 & 16,71 & 19,08 & 22,14 & - \\
\hline & DMA & 6,81 & 7,43 & 8,25 & 9,49 & 10,93 & 12,67 & 14,72 & 17,05 & 20,20 & 24,19 & 29,50 & - \\
\hline & PDMA & 28,02 & 23,65 & 19,21 & 18,72 & 21,91 & 29,48 & 42,82 & 58,46 & 79,75 & 108,12 & 148,59 & - \\
\hline \multirow[t]{3}{*}{$\Delta \mathrm{CS}$} & $\mathrm{DM}$ & $-68,96$ & $-65,05$ & $-60,87$ & $-56,60$ & $-52,52$ & $-49,05$ & $-46,79$ & $-46,88$ & $-51,95$ & $-70,51$ & $-162,34$ & - \\
\hline & DMA & 61,41 & 53,66 & 46,54 & 38,98 & 32,04 & 27,40 & 31,78 & 40,50 & 53,05 & 77,79 & 176,08 & - \\
\hline & PDMA & 52,37 & 39,52 & 27,11 & 12,23 & $-0,67$ & $-8,92$ & $-3,52$ & 1,08 & 1,42 & $-0,98$ & 8,72 & - \\
\hline
\end{tabular}


Tabela 8.59: Constantes de acoplamento B3P86 com correção vibracional no nível BHandH $40 \% E_{X}^{\mathrm{HF}}$ e base aug-pcJ-2.

\begin{tabular}{|c|c|c|c|c|c|c|c|c|c|c|c|c|c|}
\hline & $\% E_{X}^{\mathrm{HF}}$ & $0 \%$ & $10 \%$ & $20 \%$ & $30 \%$ & $40 \%$ & $50 \%$ & $60 \%$ & $70 \%$ & $80 \%$ & $90 \%$ & $100 \%$ & Exp. \\
\hline $\mathrm{HF}$ & ${ }^{1} J_{\mathrm{HF}}$ & 324,5 & 348,2 & 372,2 & 396,3 & 420,8 & 445,4 & 470,3 & 495,3 & 520,6 & 546,1 & 571,8 & 500 \\
\hline $\mathrm{CO}$ & ${ }^{1} J_{\mathrm{CO}}$ & 25,5 & 23,9 & 22,1 & 20,3 & 18,3 & 16,3 & 14,2 & 12,1 & 9,9 & 7,6 & 5,2 & 16,4 \\
\hline $\mathrm{H}_{2} \mathrm{O}$ & ${ }^{1} J_{\mathrm{OH}}$ & $-64,0$ & $-66,6$ & $-69,1$ & $-71,7$ & $-74,3$ & $-76,9$ & $-79,6$ & $-82,2$ & $-84,9$ & $-87,7$ & $-90,4$ & $-80,6$ \\
\hline $\mathrm{H}_{2} \mathrm{O}$ & ${ }^{2} J_{\mathrm{HH}}$ & $-3,2$ & $-4,2$ & $-5,1$ & $-6,2$ & $-7,2$ & $-8,2$ & $-9,3$ & $-10,4$ & $-11,5$ & $-12,6$ & $-13,8$ & $-7,3$ \\
\hline $\mathrm{NH}_{3}$ & ${ }^{1} J_{\mathrm{NH}}$ & 41,0 & 41,8 & 42,5 & 43,3 & 44,1 & 44,9 & 45,7 & 46,5 & 47,3 & 48,2 & 49,0 & 43,8 \\
\hline $\mathrm{NH}_{3}$ & ${ }^{2} J_{\mathrm{HH}}$ & $-6,9$ & $-7,8$ & $-8,6$ & $-9,5$ & $-10,4$ & $-11,3$ & $-12,2$ & $-13,2$ & $-14,1$ & $-15,0$ & $-16,0$ & $-9,6$ \\
\hline $\mathrm{PH}_{3}$ & ${ }^{1} J_{\mathrm{PH}}$ & 131,1 & 139,3 & 147,3 & 155,3 & 163,2 & 170,9 & 178,5 & 186,0 & 193,3 & 200,5 & 207,5 & 188,2 \\
\hline $\mathrm{PF}_{3}$ & ${ }^{1} J_{\mathrm{PF}}$ & $-1802,2$ & $-1776,5$ & $-1746,3$ & $-1712,6$ & $-1676,0$ & $-1637,0$ & $-1596,2$ & $-1554,1$ & $-1511,0$ & $-1467,3$ & $-1423,2$ & -1441 \\
\hline $\mathrm{BHF}_{2}$ & ${ }^{1} J_{\mathrm{BF}}$ & $-180,0$ & $-162,9$ & $-145,9$ & $-129,1$ & $-112,4$ & $-95,8$ & $-79,4$ & $-63,2$ & $-47,2$ & $-31,4$ & $-15,8$ & -84 \\
\hline $\mathrm{BF}_{3}$ & ${ }^{1} J_{\mathrm{BF}}$ & $-83,6$ & $-64,8$ & $-46,3$ & $-28,0$ & $-9,9$ & 7,9 & 25,6 & 43,1 & 60,5 & 77,7 & 94,7 & 15 \\
\hline $\mathrm{F}_{2} \mathrm{O}$ & ${ }^{1} J_{\mathrm{OF}}$ & $-300,9$ & $-338,0$ & $-375,4$ & $-414,5$ & $-457,7$ & $-508,2$ & $-571,8$ & $-660,0$ & $-799,5$ & $-1075,0$ & $-2006,2$ & -300 \\
\hline $\mathrm{CH}_{4}$ & ${ }^{1} J_{\mathrm{CH}}$ & 121,6 & 123,1 & 124,6 & 126,1 & 127,7 & 129,3 & 130,9 & 132,5 & 134,1 & 135,8 & 137,5 & 125,3 \\
\hline $\mathrm{CH}_{4}$ & ${ }^{2} J_{\mathrm{HH}}$ & $-12,1$ & $-12,8$ & $-13,6$ & $-14,3$ & $-15,0$ & $-15,7$ & $-16,4$ & $-17,1$ & $-17,8$ & $-18,5$ & $-19,2$ & $-12,8$ \\
\hline $\mathrm{C}_{2} \mathrm{H}_{2}$ & ${ }^{1} J_{\mathrm{CC}}$ & 190,2 & 192,9 & 196,1 & 199,7 & 203,9 & 208,9 & 214,8 & 221,9 & 230,6 & 241,4 & 255,2 & 174,8 \\
\hline $\mathrm{C}_{2} \mathrm{H}_{2}$ & ${ }^{1} J_{\mathrm{CH}}$ & 254,1 & 256,5 & 258,9 & 261,6 & 264,5 & 267,6 & 271,2 & 275,3 & 280,0 & 285,8 & 292,9 & 247,6 \\
\hline $\mathrm{C}_{2} \mathrm{H}_{2}$ & ${ }^{2} J_{\mathrm{CH}}$ & 55,1 & 55,0 & 54,8 & 54,3 & 53,4 & 52,2 & 50,6 & 48,3 & 45,3 & 41,3 & 35,8 & 50,1 \\
\hline $\mathrm{C}_{2} \mathrm{H}_{2}$ & ${ }^{3} J_{\mathrm{HH}}$ & 10,7 & 11,4 & 12,1 & 13,0 & 14,1 & 15,4 & 16,9 & 18,8 & 21,1 & 24,0 & 27,6 & 9,6 \\
\hline $\mathrm{C}_{2} \mathrm{H}_{4}$ & ${ }^{1} J_{\mathrm{CC}}$ & 61,0 & 63,8 & 66,8 & 70,3 & 74,2 & 78,9 & 84,6 & 91,9 & 101,6 & 115,7 & 138,6 & 67,6 \\
\hline $\mathrm{C}_{2} \mathrm{H}_{4}$ & ${ }^{1} J_{\mathrm{CH}}$ & 153,8 & 155,9 & 158,2 & 160,6 & 163,1 & 166,0 & 169,3 & 173,1 & 178,0 & 184,6 & 194,8 & 156,3 \\
\hline $\mathrm{C}_{2} \mathrm{H}_{4}$ & ${ }^{2} J_{\mathrm{CH}}$ & $-0,3$ & $-1,1$ & $-2,1$ & $-3,2$ & $-4,5$ & $-6,2$ & $-8,2$ & $-10,9$ & $-14,6$ & $-20,0$ & $-29,0$ & $-2,4$ \\
\hline $\mathrm{C}_{2} \mathrm{H}_{4}$ & ${ }^{2} J_{\mathrm{HH}}$ & 5,0 & 4,3 & 3,5 & 2,6 & 1,6 & 0,4 & $-0,9$ & $-2,6$ & $-4,9$ & $-8,2$ & $-13,5$ & 2,3 \\
\hline $\mathrm{C}_{2} \mathrm{H}_{4}$ & ${ }^{3} J_{\mathrm{HH}_{\mathrm{c}}}$ & 11,9 & 12,2 & 12,6 & 13,0 & 13,6 & 14,3 & 15,3 & 16,6 & 18,5 & 21,4 & 26,4 & 11,7 \\
\hline $\mathrm{C}_{2} \mathrm{H}_{4}$ & ${ }^{3} J_{\mathrm{HH}_{\mathrm{t}}}$ & 19,1 & 19,4 & 19,8 & 20,4 & 21,0 & 21,9 & 23,0 & 24,6 & 26,8 & 30,1 & 35,7 & 19 \\
\hline $\mathrm{C}_{2} \mathrm{H}_{6}$ & ${ }^{1} J_{\mathrm{CC}}$ & 25,8 & 27,8 & 29,8 & 31,9 & 34,0 & 36,1 & 38,3 & 40,5 & 42,7 & 45,0 & 47,3 & 34,5 \\
\hline $\mathrm{C}_{2} \mathrm{H}_{6}$ & ${ }^{1} J_{\mathrm{CH}}$ & 121,2 & 122,9 & 124,6 & 126,3 & 128,0 & 129,8 & 131,6 & 133,4 & 135,2 & 137,1 & 138,9 & 125,2 \\
\hline $\mathrm{C}_{2} \mathrm{H}_{6}$ & ${ }^{2} J_{\mathrm{CH}}$ & $-2,9$ & $-3,3$ & $-3,8$ & $-4,3$ & $-4,7$ & $-5,2$ & $-5,7$ & $-6,2$ & $-6,8$ & $-7,3$ & $-7,8$ & $-4,7$ \\
\hline \multirow[t]{3}{*}{ Total } & $\mathrm{DM}$ & $-28,83$ & $-26,33$ & $-23,67$ & $-20,90$ & $-18,14$ & $-15,51$ & $-13,23$ & $-11,73$ & $-11,99$ & $-17,14$ & $-46,96$ & - \\
\hline & DMA & 34,07 & 31,38 & 28,76 & 26,50 & 24,67 & 23,47 & 24,22 & 27,78 & 35,72 & 50,02 & 91,98 & - \\
\hline & PDMA & 52,14 & 42,14 & 32,30 & 25,09 & 22,54 & 24,64 & 34,91 & 52,86 & 75,55 & 105,68 & 155,68 & - \\
\hline \multirow[t]{3}{*}{ CPI } & $\mathrm{DM}$ & $-69,05$ & $-64,41$ & $-59,41$ & $-54,30$ & $-49,31$ & $-44,81$ & $-41,37$ & $-40,09$ & $-43,41$ & $-59,07$ & $-134,37$ & - \\
\hline & DMA & 74,96 & 69,21 & 63,12 & 56,85 & 50,87 & 45,68 & 44,66 & 49,47 & 63,68 & 91,45 & 182,01 & - \\
\hline & PDMA & 93,56 & 77,01 & 60,77 & 44,33 & 29,78 & 18,39 & 23,83 & 41,49 & 62,06 & 87,08 & 132,29 & - \\
\hline \multirow[t]{3}{*}{ SPI } & $\mathrm{DM}$ & 0,67 & 1,59 & 2,55 & 3,59 & 4,72 & 5,97 & 7,41 & 9,07 & 11,05 & 13,61 & 17,14 & - \\
\hline & DMA & 4,07 & 3,65 & 3,56 & 4,25 & 5,45 & 7,19 & 9,23 & 11,87 & 15,22 & 19,63 & 25,97 & - \\
\hline & PDMA & 21,77 & 16,58 & 11,41 & 10,97 & 17,24 & 29,22 & 43,04 & 61,20 & 85,44 & 119,31 & 172,84 & - \\
\hline \multirow[t]{3}{*}{$\Delta \mathrm{CS}$} & $\mathrm{DM}$ & $-69,73$ & $-66,00$ & $-61,96$ & $-57,89$ & $-54,03$ & $-50,78$ & $-48,79$ & $-49,16$ & $-54,46$ & $-72,68$ & $-151,51$ & - \\
\hline & DMA & 70,89 & 65,56 & 59,56 & 52,60 & 45,42 & 38,50 & 35,44 & 37,61 & 48,46 & 71,82 & 156,04 & - \\
\hline & PDMA & 71,80 & 60,43 & 49,36 & 33,36 & 12,55 & $-10,84$ & $-19,21$ & $-19,71$ & $-23,38$ & $-32,23$ & $-40,55$ & - \\
\hline
\end{tabular}


Tabela 8.60: Constantes de acoplamento B971 com correção vibracional no nível BHandH $40 \% E_{X}^{\mathrm{HF}}$ e base aug-pcJ-2.

\begin{tabular}{|c|c|c|c|c|c|c|c|c|c|c|c|c|c|}
\hline & $\% E_{X}^{\mathrm{HF}}$ & $0 \%$ & $10 \%$ & $20 \%$ & $30 \%$ & $40 \%$ & $50 \%$ & $60 \%$ & $70 \%$ & $80 \%$ & $90 \%$ & $100 \%$ & Exp. \\
\hline $\mathrm{HF}$ & ${ }^{1} J_{\mathrm{HF}}$ & 394,1 & 410,7 & 428,2 & 446,8 & 466,5 & 487,4 & 509,6 & 532,9 & 557,6 & 583,5 & 610,7 & 500 \\
\hline $\mathrm{CO}$ & ${ }^{1} J_{\mathrm{CO}}$ & 16,6 & 15,5 & 14,3 & 13,0 & 11,5 & 9,8 & 8,1 & 6,1 & 4,0 & 1,8 & $-0,5$ & 16,4 \\
\hline $\mathrm{H}_{2} \mathrm{O}$ & ${ }^{1} J_{\mathrm{OH}}$ & $-66,5$ & $-68,6$ & $-70,9$ & $-73,3$ & $-75,8$ & $-78,5$ & $-81,3$ & $-84,3$ & $-87,6$ & $-91,0$ & $-94,5$ & $-80,6$ \\
\hline $\mathrm{H}_{2} \mathrm{O}$ & ${ }^{2} J_{\mathrm{HH}}$ & 0,8 & $-0,2$ & $-1,3$ & $-2,4$ & $-3,7$ & $-5,0$ & $-6,3$ & $-7,8$ & $-9,4$ & $-11,1$ & $-12,9$ & $-7,3$ \\
\hline $\mathrm{NH}_{3}$ & ${ }^{1} J_{\mathrm{NH}}$ & 38,3 & 39,3 & 40,3 & 41,4 & 42,6 & 43,8 & 45,1 & 46,6 & 48,0 & 49,6 & 51,3 & 43,8 \\
\hline $\mathrm{NH}_{3}$ & ${ }^{2} J_{\mathrm{HH}}$ & $-2,5$ & $-3,4$ & $-4,3$ & $-5,4$ & $-6,5$ & $-7,7$ & $-9,0$ & $-10,3$ & $-11,8$ & $-13,4$ & $-15,2$ & $-9,6$ \\
\hline $\mathrm{PH}_{3}$ & ${ }^{1} J_{\mathrm{PH}}$ & 154,6 & 160,8 & 167,4 & 174,3 & 181,6 & 189,3 & 197,3 & 205,8 & 214,6 & 223,8 & 233,4 & 188,2 \\
\hline $\mathrm{PF}_{3}$ & ${ }^{1} J_{\mathrm{PF}}$ & $-1611,8$ & $-1606,5$ & $-1595,6$ & $-1580,0$ & $-1560,3$ & $-1537,3$ & $-1511,6$ & $-1483,8$ & $-1454,4$ & $-1424,0$ & $-1393,0$ & -1441 \\
\hline $\mathrm{BHF}_{2}$ & ${ }^{1} J_{\mathrm{BF}}$ & $-149,5$ & $-135,0$ & $-120,1$ & $-105,0$ & $-89,6$ & $-74,1$ & $-58,5$ & $-42,9$ & $-27,3$ & $-11,7$ & 3,6 & -84 \\
\hline $\mathrm{BF}_{3}$ & ${ }^{1} J_{\mathrm{BF}}$ & $-57,9$ & $-41,1$ & $-24,1$ & $-6,9$ & 10,2 & 27,5 & 44,9 & 62,3 & 79,7 & 97,1 & 114,6 & 15 \\
\hline $\mathrm{F}_{2} \mathrm{O}$ & ${ }^{1} J_{\mathrm{OF}}$ & $-202,9$ & $-234,7$ & $-267,9$ & $-302,9$ & $-340,8$ & $-383,5$ & $-434,3$ & $-500,0$ & $-595,6$ & $-765,9$ & $-1234,4$ & -300 \\
\hline $\mathrm{CH}_{4}$ & ${ }^{1} J_{\mathrm{CH}}$ & 104,8 & 108,0 & 111,4 & 115,0 & 118,8 & 122,9 & 127,3 & 131,9 & 136,7 & 141,9 & 147,4 & 125,3 \\
\hline $\mathrm{CH}_{4}$ & ${ }^{2} J_{\mathrm{HH}}$ & $-6,1$ & $-7,0$ & $-7,9$ & $-8,8$ & $-9,9$ & $-11,0$ & $-12,1$ & $-13,4$ & $-14,7$ & $-16,1$ & $-17,6$ & $-12,8$ \\
\hline $\mathrm{C}_{2} \mathrm{H}_{2}$ & ${ }^{1} J_{\mathrm{CC}}$ & 186,5 & 190,5 & 194,8 & 199,8 & 205,4 & 212,0 & 219,8 & 229,2 & 240,9 & 255,8 & 275,5 & 174,8 \\
\hline $\mathrm{C}_{2} \mathrm{H}_{2}$ & ${ }^{1} J_{\mathrm{CH}}$ & 203,7 & 210,4 & 217,4 & 224,8 & 232,6 & 241,0 & 250,1 & 260,0 & 271,1 & 283,7 & 298,6 & 247,6 \\
\hline $\mathrm{C}_{2} \mathrm{H}_{2}$ & ${ }^{2} J_{\mathrm{CH}}$ & 51,4 & 52,3 & 52,9 & 53,4 & 53,6 & 53,4 & 52,9 & 51,6 & 49,5 & 46,0 & 40,5 & 50,1 \\
\hline $\mathrm{C}_{2} \mathrm{H}_{2}$ & ${ }^{3} J_{\mathrm{HH}}$ & 6,7 & 7,1 & 7,6 & 8,1 & 8,9 & 9,8 & 11,0 & 12,5 & 14,5 & 17,2 & 21,0 & 9,6 \\
\hline $\mathrm{C}_{2} \mathrm{H}_{4}$ & ${ }^{1} J_{\mathrm{CC}}$ & 63,8 & 66,5 & 69,5 & 72,9 & 76,8 & 81,2 & 86,6 & 93,2 & 101,6 & 113,3 & 130,9 & 67,6 \\
\hline $\mathrm{C}_{2} \mathrm{H}_{4}$ & ${ }^{1} J_{\mathrm{CH}}$ & 127,9 & 132,3 & 137,0 & 141,9 & 147,2 & 153,0 & 159,2 & 166,1 & 173,9 & 183,1 & 194,8 & 156,3 \\
\hline $\mathrm{C}_{2} \mathrm{H}_{4}$ & ${ }^{2} J_{\mathrm{CH}}$ & 2,2 & 1,6 & 0,8 & $-0,1$ & $-1,1$ & $-2,4$ & $-4,0$ & $-6,1$ & $-8,8$ & $-12,8$ & $-19,1$ & $-2,4$ \\
\hline $\mathrm{C}_{2} \mathrm{H}_{4}$ & ${ }^{2} J_{\mathrm{HH}}$ & 6,3 & 5,9 & 5,5 & 5,0 & 4,4 & 3,7 & 2,8 & 1,7 & 0,3 & $-1,7$ & $-4,8$ & 2,3 \\
\hline $\mathrm{C}_{2} \mathrm{H}_{4}$ & ${ }^{3} J_{\mathrm{HH}_{\mathrm{c}}}$ & 9,6 & 9,9 & 10,1 & 10,5 & 10,8 & 11,3 & 11,9 & 12,7 & 13,9 & 15,6 & 18,3 & 11,7 \\
\hline $\mathrm{C}_{2} \mathrm{H}_{4}$ & ${ }^{3} J_{\mathrm{HH}_{\mathrm{t}}}$ & 13,8 & 14,3 & 14,8 & 15,4 & 16,1 & 16,9 & 17,9 & 19,1 & 20,7 & 23,0 & 26,4 & 19 \\
\hline $\mathrm{C}_{2} \mathrm{H}_{6}$ & ${ }^{1} J_{\mathrm{CC}}$ & 26,2 & 28,4 & 30,8 & 33,2 & 35,9 & 38,6 & 41,6 & 44,7 & 48,0 & 51,5 & 55,2 & 34,5 \\
\hline $\mathrm{C}_{2} \mathrm{H}_{6}$ & ${ }^{1} J_{\mathrm{CH}}$ & 103,0 & 106,5 & 110,2 & 114,1 & 118,3 & 122,7 & 127,3 & 132,2 & 137,4 & 143,0 & 148,8 & 125,2 \\
\hline $\mathrm{C}_{2} \mathrm{H}_{6}$ & ${ }^{2} J_{\mathrm{CH}}$ & $-0,8$ & $-1,3$ & $-1,9$ & $-2,4$ & $-3,0$ & $-3,7$ & $-4,4$ & $-5,1$ & $-5,9$ & $-6,8$ & $-7,7$ & $-4,7$ \\
\hline \multirow[t]{3}{*}{ Total } & $\mathrm{DM}$ & $-16,64$ & $-14,72$ & $-12,54$ & $-10,10$ & $-7,48$ & $-4,77$ & $-2,04$ & 0,38 & 2,00 & 1,17 & $-10,53$ & - \\
\hline & DMA & 28,86 & 24,36 & 19,61 & 14,82 & 12,42 & 11,87 & 14,62 & 20,63 & 28,52 & 41,35 & 67,75 & - \\
\hline & PDMA & 59,57 & 49,68 & 39,46 & 28,92 & 18,85 & 15,70 & 21,88 & 34,39 & 54,24 & 79,78 & 116,68 & - \\
\hline \multirow[t]{3}{*}{ CPI } & $\mathrm{DM}$ & $-29,78$ & $-27,65$ & $-24,99$ & $-21,94$ & $-18,65$ & $-15,38$ & $-12,45$ & $-10,57$ & $-11,19$ & $-18,38$ & $-52,53$ & - \\
\hline & DMA & 52,80 & 44,12 & 34,65 & 24,92 & 20,75 & 20,80 & 26,45 & 36,34 & 49,30 & 72,25 & 125,00 & - \\
\hline & PDMA & 78,49 & 62,99 & 47,34 & 31,43 & 17,36 & 20,63 & 32,77 & 48,89 & 69,95 & 93,85 & 127,43 & - \\
\hline \multirow[t]{3}{*}{ SPI } & DM & $-7,01$ & $-5,25$ & $-3,41$ & $-1,42$ & 0,71 & 3,02 & 5,59 & 8,41 & 11,67 & 15,51 & 20,27 & - \\
\hline & DMA & 11,30 & 9,87 & 8,58 & 7,41 & 6,31 & 5,33 & 5,95 & 9,12 & 13,28 & 18,69 & 25,77 & - \\
\hline & PDMA & 45,69 & 39,92 & 33,67 & 27,08 & 19,95 & 12,09 & 13,90 & 23,76 & 42,72 & 69,46 & 108,81 & - \\
\hline \multirow[t]{3}{*}{$\Delta \mathrm{CS}$} & $\mathrm{DM}$ & $-22,78$ & $-22,40$ & $-21,58$ & $-20,52$ & $-19,37$ & $-18,40$ & $-18,03$ & $-18,99$ & $-22,86$ & $-33,89$ & $-72,80$ & - \\
\hline & DMA & 41,50 & 34,24 & 26,07 & 17,51 & 14,43 & 15,47 & 20,50 & 27,22 & 36,02 & 53,56 & 99,23 & - \\
\hline & PDMA & 32,80 & 23,07 & 13,66 & 4,35 & $-2,59$ & 8,54 & 18,87 & 25,13 & 27,22 & 24,39 & 18,62 & - \\
\hline
\end{tabular}


Tabela 8.61: Constantes de acoplamento B972 com correção vibracional no nível BHandH $40 \% E_{X}^{\mathrm{HF}}$ e base aug-pcJ-2.

\begin{tabular}{|c|c|c|c|c|c|c|c|c|c|c|c|c|c|}
\hline & $\% E_{X}^{\mathrm{HF}}$ & $0 \%$ & $10 \%$ & $20 \%$ & $30 \%$ & $40 \%$ & $50 \%$ & $60 \%$ & $70 \%$ & $80 \%$ & $90 \%$ & $100 \%$ & Exp. \\
\hline $\mathrm{HF}$ & ${ }^{1} J_{\mathrm{HF}}$ & 387,4 & 408,3 & 430,5 & 454,0 & 478,8 & 505,0 & 532,6 & 561,8 & 592,4 & 624,6 & 658,4 & 500 \\
\hline $\mathrm{CO}$ & ${ }^{1} J_{\mathrm{CO}}$ & 17,7 & 16,1 & 14,3 & 12,3 & 10,0 & 7,6 & 5,0 & 2,2 & $-0,8$ & $-4,0$ & $-7,5$ & 16,4 \\
\hline $\mathrm{H}_{2} \mathrm{O}$ & ${ }^{1} J_{\mathrm{OH}}$ & $-65,6$ & $-68,4$ & $-71,3$ & $-74,4$ & $-77,7$ & $-81,1$ & $-84,8$ & $-88,8$ & $-92,9$ & $-97,3$ & $-101,9$ & $-80,6$ \\
\hline $\mathrm{H}_{2} \mathrm{O}$ & ${ }^{2} J_{\mathrm{HH}}$ & 0,2 & $-0,8$ & $-1,8$ & $-2,9$ & $-4,1$ & $-5,3$ & $-6,6$ & $-8,1$ & $-9,6$ & $-11,2$ & $-12,9$ & $-7,3$ \\
\hline $\mathrm{NH}_{3}$ & ${ }^{1} J_{\mathrm{NH}}$ & 37,0 & 38,2 & 39,6 & 41,0 & 42,5 & 44,1 & 45,8 & 47,7 & 49,6 & 51,6 & 53,8 & 43,8 \\
\hline $\mathrm{NH}_{3}$ & ${ }^{2} J_{\mathrm{HH}}$ & $-2,4$ & $-3,3$ & $-4,2$ & $-5,1$ & $-6,2$ & $-7,3$ & $-8,5$ & $-9,8$ & $-11,2$ & $-12,7$ & $-14,3$ & $-9,6$ \\
\hline $\mathrm{PH}_{3}$ & ${ }^{1} J_{\mathrm{PH}}$ & 145,1 & 152,2 & 159,7 & 167,7 & 176,1 & 184,9 & 194,1 & 203,8 & 213,9 & 224,3 & 235,2 & 188,2 \\
\hline $\mathrm{PF}_{3}$ & ${ }^{1} J_{\mathrm{PF}}$ & $-1624,6$ & $-1619,2$ & $-1608,6$ & $-1593,5$ & $-1574,8$ & $-1553,2$ & $-1529,4$ & $-1503,9$ & $-1477,3$ & $-1450,3$ & $-1423,1$ & -1441 \\
\hline $\mathrm{BHF}_{2}$ & ${ }^{1} J_{\mathrm{BF}}$ & $-155,9$ & $-139,2$ & $-122,1$ & $-104,8$ & $-87,4$ & $-69,9$ & $-52,5$ & $-35,2$ & $-17,9$ & $-1,0$ & 15,8 & -84 \\
\hline $\mathrm{BF}_{3}$ & ${ }^{1} J_{\mathrm{BF}}$ & $-66,2$ & $-46,8$ & $-27,3$ & $-7,6$ & 11,9 & 31,6 & 51,3 & 70,9 & 90,5 & 110,0 & 129,4 & 15 \\
\hline $\mathrm{F}_{2} \mathrm{O}$ & ${ }^{1} J_{\mathrm{OF}}$ & $-200,4$ & $-231,0$ & $-262,9$ & $-296,8$ & $-333,7$ & $-375,6$ & $-426,0$ & $-492,0$ & $-590,5$ & $-774,8$ & $-1362,1$ & -300 \\
\hline $\mathrm{CH}_{4}$ & ${ }^{1} J_{\mathrm{CH}}$ & 96,9 & 100,9 & 105,1 & 109,5 & 114,2 & 119,2 & 124,5 & 130,1 & 136,0 & 142,2 & 148,8 & 125,3 \\
\hline $\mathrm{CH}_{4}$ & ${ }^{2} J_{\mathrm{HH}}$ & $-5,7$ & $-6,4$ & $-7,2$ & $-8,1$ & $-9,0$ & $-10,0$ & $-11,0$ & $-12,2$ & $-13,3$ & $-14,6$ & $-15,9$ & $-12,8$ \\
\hline $\mathrm{C}_{2} \mathrm{H}_{2}$ & ${ }^{1} J_{\mathrm{CC}}$ & 173,1 & 177,9 & 183,2 & 189,2 & 196,0 & 203,8 & 212,9 & 223,8 & 237,0 & 253,5 & 274,7 & 174,8 \\
\hline $\mathrm{C}_{2} \mathrm{H}_{2}$ & ${ }^{1} J_{\mathrm{CH}}$ & 193,0 & 200,5 & 208,5 & 216,8 & 225,7 & 235,1 & 245,3 & 256,2 & 268,3 & 281,7 & 297,2 & 247,6 \\
\hline $\mathrm{C}_{2} \mathrm{H}_{2}$ & ${ }^{2} J_{\mathrm{CH}}$ & 49,5 & 50,4 & 51,2 & 51,8 & 52,2 & 52,3 & 51,9 & 51,0 & 49,3 & 46,5 & 42,0 & 50,1 \\
\hline $\mathrm{C}_{2} \mathrm{H}_{2}$ & ${ }^{3} J_{\mathrm{HH}}$ & 6,6 & 7,0 & 7,4 & 7,9 & 8,6 & 9,4 & 10,4 & 11,7 & 13,4 & 15,6 & 18,5 & 9,6 \\
\hline $\mathrm{C}_{2} \mathrm{H}_{4}$ & ${ }^{1} J_{\mathrm{CC}}$ & 55,0 & 58,4 & 62,1 & 66,4 & 71,2 & 76,7 & 83,3 & 91,4 & 101,8 & 116,1 & 137,4 & 67,6 \\
\hline $\mathrm{C}_{2} \mathrm{H}_{4}$ & ${ }^{1} J_{\mathrm{CH}}$ & 119,6 & 124,7 & 130,2 & 135,9 & 142,1 & 148,7 & 155,9 & 163,7 & 172,6 & 182,9 & 195,8 & 156,3 \\
\hline $\mathrm{C}_{2} \mathrm{H}_{4}$ & ${ }^{2} J_{\mathrm{CH}}$ & 2,3 & 1,7 & 1,0 & 0,2 & $-0,7$ & $-2,0$ & $-3,5$ & $-5,5$ & $-8,3$ & $-12,2$ & $-18,4$ & $-2,4$ \\
\hline $\mathrm{C}_{2} \mathrm{H}_{4}$ & ${ }^{2} J_{\mathrm{HH}}$ & 5,9 & 5,7 & 5,4 & 5,0 & 4,5 & 4,0 & 3,3 & 2,5 & 1,4 & $-0,2$ & $-2,6$ & 2,3 \\
\hline $\mathrm{C}_{2} \mathrm{H}_{4}$ & ${ }^{3} J_{\mathrm{HH}_{\mathrm{c}}}$ & 9,2 & 9,4 & 9,7 & 10,0 & 10,4 & 10,9 & 11,4 & 12,1 & 13,1 & 14,6 & 16,9 & 11,7 \\
\hline $\mathrm{C}_{2} \mathrm{H}_{4}$ & ${ }^{3} J_{\mathrm{HH}_{\mathrm{t}}}$ & 13,3 & 13,8 & 14,3 & 14,9 & 15,6 & 16,4 & 17,3 & 18,4 & 19,9 & 21,9 & 24,9 & 19 \\
\hline $\mathrm{C}_{2} \mathrm{H}_{6}$ & ${ }^{1} J_{\mathrm{CC}}$ & 22,7 & 25,3 & 28,1 & 31,0 & 34,1 & 37,4 & 40,9 & 44,6 & 48,6 & 52,8 & 57,2 & 34,5 \\
\hline $\mathrm{C}_{2} \mathrm{H}_{6}$ & ${ }^{1} J_{\mathrm{CH}}$ & 95,0 & 99,2 & 103,6 & 108,2 & 113,2 & 118,4 & 123,9 & 129,7 & 135,9 & 142,4 & 149,3 & 125,2 \\
\hline $\mathrm{C}_{2} \mathrm{H}_{6}$ & ${ }^{2} J_{\mathrm{CH}}$ & $-0,7$ & $-1,1$ & $-1,6$ & $-2,1$ & $-2,6$ & $-3,2$ & $-3,8$ & $-4,4$ & $-5,1$ & $-5,9$ & $-6,7$ & $-4,7$ \\
\hline \multirow[t]{3}{*}{ Total } & $\mathrm{DM}$ & $-20,65$ & $-18,13$ & $-15,31$ & $-12,25$ & $-9,00$ & $-5,66$ & $-2,36$ & 0,64 & 2,76 & 1,98 & $-13,66$ & - \\
\hline & DMA & 32,19 & 26,97 & 21,62 & 15,87 & 12,56 & 12,57 & 15,94 & 22,33 & 31,12 & 44,07 & 74,93 & - \\
\hline & PDMA & 63,88 & 52,94 & 42,17 & 30,78 & 20,01 & 19,21 & 25,00 & 35,61 & 54,36 & 79,92 & 117,48 & - \\
\hline \multirow[t]{3}{*}{ CPI } & DM & $-33,51$ & $-30,44$ & $-26,82$ & $-22,82$ & $-18,68$ & $-14,55$ & $-10,90$ & $-8,39$ & $-8,61$ & $-16,52$ & $-60,92$ & - \\
\hline & DMA & 57,25 & 47,53 & 37,24 & 26,15 & 20,41 & 21,88 & 30,92 & 42,21 & 56,88 & 79,52 & 142,28 & - \\
\hline & PDMA & 85,28 & 66,82 & 49,63 & 32,13 & 16,43 & 24,50 & 39,78 & 58,04 & 81,37 & 107,62 & 146,73 & - \\
\hline \multirow[t]{3}{*}{ SPI } & $\mathrm{DM}$ & $-11,23$ & $-9,11$ & $-6,87$ & $-4,50$ & $-1,91$ & 0,87 & 3,91 & 7,27 & 11,10 & 15,55 & 21,00 & - \\
\hline & DMA & 13,81 & 11,90 & 10,17 & 8,33 & 6,80 & 5,75 & 4,96 & 7,76 & 12,23 & 18,07 & 25,55 & - \\
\hline & PDMA & 48,19 & 42,77 & 36,70 & 29,79 & 22,63 & 15,34 & 14,16 & 19,16 & 34,55 & 59,61 & 96,02 & - \\
\hline \multirow[t]{3}{*}{$\Delta \mathrm{CS}$} & DM & $-22,28$ & $-21,32$ & $-19,94$ & $-18,32$ & $-16,78$ & $-15,42$ & $-14,81$ & $-15,66$ & $-19,71$ & $-32,06$ & $-81,92$ & - \\
\hline & DMA & 43,44 & 35,63 & 27,07 & 17,82 & 13,61 & 16,14 & 25,96 & 34,45 & 44,65 & 61,45 & 116,74 & - \\
\hline & PDMA & 37,09 & 24,05 & 12,93 & 2,34 & $-6,20$ & 9,17 & 25,62 & 38,89 & 46,82 & 48,00 & 50,71 & - \\
\hline
\end{tabular}


Tabela 8.62: Constantes de acoplamento B98 com correção vibracional no nível BHandH $40 \% E_{X}^{\mathrm{HF}}$ e base aug-pcJ-2.

\begin{tabular}{|c|c|c|c|c|c|c|c|c|c|c|c|c|c|}
\hline & $\% E_{X}^{\mathrm{HF}}$ & $0 \%$ & $10 \%$ & $20 \%$ & $30 \%$ & $40 \%$ & $50 \%$ & $60 \%$ & $70 \%$ & $80 \%$ & $90 \%$ & $100 \%$ & Exp. \\
\hline $\mathrm{HF}$ & ${ }^{1} J_{\mathrm{HF}}$ & 378,4 & 394,9 & 412,6 & 431,4 & 451,4 & 472,7 & 495,3 & 519,3 & 544,7 & 571,6 & 599,9 & 500 \\
\hline $\mathrm{CO}$ & ${ }^{1} J_{\mathrm{CO}}$ & 17,4 & 16,3 & 15,0 & 13,6 & 12,0 & 10,3 & 8,5 & 6,4 & 4,2 & 1,8 & $-0,6$ & 16,4 \\
\hline $\mathrm{H}_{2} \mathrm{O}$ & ${ }^{1} J_{\mathrm{OH}}$ & $-64,8$ & $-67,0$ & $-69,3$ & $-71,8$ & $-74,4$ & $-77,2$ & $-80,2$ & $-83,4$ & $-86,9$ & $-90,5$ & $-94,4$ & $-80,6$ \\
\hline $\mathrm{H}_{2} \mathrm{O}$ & ${ }^{2} J_{\mathrm{HH}}$ & 0,7 & $-0,3$ & $-1,3$ & $-2,5$ & $-3,7$ & $-5,0$ & $-6,5$ & $-8,0$ & $-9,6$ & $-11,3$ & $-13,2$ & $-7,3$ \\
\hline $\mathrm{NH}_{3}$ & ${ }^{1} J_{\mathrm{NH}}$ & 37,7 & 38,8 & 39,9 & 41,1 & 42,4 & 43,8 & 45,3 & 46,8 & 48,5 & 50,3 & 52,2 & 43,8 \\
\hline $\mathrm{NH}_{3}$ & ${ }^{2} J_{\mathrm{HH}}$ & $-2,6$ & $-3,5$ & $-4,5$ & $-5,5$ & $-6,7$ & $-7,9$ & $-9,3$ & $-10,7$ & $-12,3$ & $-14,0$ & $-15,9$ & $-9,6$ \\
\hline $\mathrm{PH}_{3}$ & ${ }^{1} J_{\mathrm{PH}}$ & 158,6 & 164,9 & 171,7 & 178,8 & 186,4 & 194,4 & 202,8 & 211,6 & 220,8 & 230,5 & 240,6 & 188,2 \\
\hline $\mathrm{PF}_{3}$ & ${ }^{1} J_{\mathrm{PF}}$ & $-1620,8$ & $-1615,8$ & $-1605,3$ & $-1589,8$ & $-1570,3$ & $-1547,3$ & $-1521,6$ & $-1493,8$ & $-1464,4$ & $-1433,9$ & $-1402,7$ & -1441 \\
\hline $\mathrm{BHF}_{2}$ & ${ }^{1} J_{\mathrm{BF}}$ & $-154,6$ & $-140,0$ & $-125,1$ & $-109,7$ & $-94,1$ & $-78,3$ & $-62,3$ & $-46,3$ & $-30,2$ & $-14,1$ & 1,7 & -84 \\
\hline $\mathrm{BF}_{3}$ & ${ }^{1} J_{\mathrm{BF}}$ & $-63,7$ & $-46,9$ & $-29,9$ & $-12,6$ & 4,8 & 22,3 & 40,0 & 57,8 & 75,7 & 93,6 & 111,6 & 15 \\
\hline $\mathrm{F}_{2} \mathrm{O}$ & ${ }^{1} J_{\mathrm{OF}}$ & $-209,6$ & $-242,0$ & $-275,9$ & $-312,0$ & $-351,3$ & $-396,1$ & $-450,4$ & $-522,1$ & $-630,5$ & $-836,6$ & $-1520,2$ & -300 \\
\hline $\mathrm{CH}_{4}$ & ${ }^{1} J_{\mathrm{CH}}$ & 103,4 & 107,0 & 110,8 & 114,9 & 119,2 & 123,8 & 128,8 & 134,0 & 139,6 & 145,5 & 151,8 & 125,3 \\
\hline $\mathrm{CH}_{4}$ & ${ }^{2} J_{\mathrm{HH}}$ & $-6,2$ & $-7,1$ & $-8,0$ & $-9,0$ & $-10,1$ & $-11,3$ & $-12,5$ & $-13,8$ & $-15,3$ & $-16,8$ & $-18,4$ & $-12,8$ \\
\hline $\mathrm{C}_{2} \mathrm{H}_{2}$ & ${ }^{1} J_{\mathrm{CC}}$ & 184,9 & 189,2 & 193,9 & 199,3 & 205,4 & 212,6 & 221,0 & 231,3 & 244,0 & 260,4 & 282,5 & 174,8 \\
\hline $\mathrm{C}_{2} \mathrm{H}_{2}$ & ${ }^{1} J_{\mathrm{CH}}$ & 201,1 & 208,4 & 216,0 & 224,2 & 232,8 & 242,1 & 252,1 & 263,1 & 275,4 & 289,6 & 306,4 & 247,6 \\
\hline $\mathrm{C}_{2} \mathrm{H}_{2}$ & ${ }^{2} J_{\mathrm{CH}}$ & 51,0 & 51,9 & 52,7 & 53,3 & 53,6 & 53,6 & 53,0 & 51,8 & 49,6 & 45,8 & 39,7 & 50,1 \\
\hline $\mathrm{C}_{2} \mathrm{H}_{2}$ & ${ }^{3} J_{\mathrm{HH}}$ & 6,6 & 7,0 & 7,5 & 8,1 & 8,9 & 9,9 & 11,1 & 12,8 & 15,0 & 18,0 & 22,2 & 9,6 \\
\hline $\mathrm{C}_{2} \mathrm{H}_{4}$ & ${ }^{1} J_{\mathrm{CC}}$ & 62,6 & 65,6 & 68,9 & 72,6 & 76,8 & 81,7 & 87,6 & 94,9 & 104,4 & 117,8 & 138,7 & 67,6 \\
\hline $\mathrm{C}_{2} \mathrm{H}_{4}$ & ${ }^{1} J_{\mathrm{CH}}$ & 126,2 & 131,0 & 136,1 & 141,6 & 147,5 & 153,8 & 160,7 & 168,4 & 177,2 & 187,7 & 201,4 & 156,3 \\
\hline $\mathrm{C}_{2} \mathrm{H}_{4}$ & ${ }^{2} J_{\mathrm{CH}}$ & 2,2 & 1,5 & 0,7 & $-0,2$ & $-1,1$ & $-2,4$ & $-4,1$ & $-6,3$ & $-9,3$ & $-13,8$ & $-21,2$ & $-2,4$ \\
\hline $\mathrm{C}_{2} \mathrm{H}_{4}$ & ${ }^{2} J_{\mathrm{HH}}$ & 6,0 & 5,7 & 5,3 & 4,8 & 4,2 & 3,5 & 2,6 & 1,5 & 0,0 & $-2,2$ & $-5,9$ & 2,3 \\
\hline $\mathrm{C}_{2} \mathrm{H}_{4}$ & ${ }^{3} J_{\mathrm{HH}_{\mathrm{c}}}$ & 9,6 & 9,8 & 10,1 & 10,5 & 10,9 & 11,4 & 12,1 & 13,0 & 14,2 & 16,2 & 19,5 & 11,7 \\
\hline $\mathrm{C}_{2} \mathrm{H}_{4}$ & ${ }^{3} J_{\mathrm{HH}_{\mathrm{t}}}$ & 13,6 & 14,1 & 14,7 & 15,4 & 16,1 & 17,0 & 18,1 & 19,4 & 21,3 & 23,8 & 28,0 & 19 \\
\hline $\mathrm{C}_{2} \mathrm{H}_{6}$ & ${ }^{1} J_{\mathrm{CC}}$ & 25,3 & 27,7 & 30,3 & 33,0 & 35,9 & 39,0 & 42,3 & 45,8 & 49,6 & 53,6 & 57,9 & 34,5 \\
\hline $\mathrm{C}_{2} \mathrm{H}_{6}$ & ${ }^{1} J_{\mathrm{CH}}$ & 101,6 & 105,5 & 109,6 & 113,9 & 118,6 & 123,5 & 128,8 & 134,3 & 140,2 & 146,5 & 153,2 & 125,2 \\
\hline $\mathrm{C}_{2} \mathrm{H}_{6}$ & ${ }^{2} J_{\mathrm{CH}}$ & $-0,9$ & $-1,4$ & $-1,9$ & $-2,5$ & $-3,1$ & $-3,8$ & $-4,5$ & $-5,3$ & $-6,1$ & $-7,1$ & $-8,1$ & $-4,7$ \\
\hline \multirow[t]{3}{*}{ Total } & $\mathrm{DM}$ & $-18,51$ & $-16,53$ & $-14,25$ & $-11,70$ & $-8,96$ & $-6,11$ & $-3,32$ & $-0,87$ & 0,57 & $-1,25$ & $-20,70$ & - \\
\hline & DMA & 30,20 & 25,54 & 20,65 & 16,40 & 13,95 & 13,07 & 15,62 & 21,89 & 30,65 & 44,60 & 80,03 & - \\
\hline & PDMA & 61,23 & 50,91 & 40,60 & 30,01 & 19,97 & 13,94 & 20,46 & 35,31 & 56,64 & 84,68 & 128,55 & - \\
\hline \multirow[t]{3}{*}{ CPI } & $\mathrm{DM}$ & $-33,11$ & $-31,05$ & $-28,45$ & $-25,45$ & $-22,22$ & $-19,02$ & $-16,30$ & $-14,85$ & $-16,45$ & $-26,68$ & $-80,17$ & - \\
\hline & DMA & 55,33 & 46,45 & 36,91 & 28,66 & 24,53 & 23,85 & 27,99 & 37,79 & 52,17 & 76,86 & 149,50 & - \\
\hline & PDMA & 83,05 & 66,59 & 50,97 & 35,48 & 21,27 & 17,66 & 29,37 & 46,96 & 69,03 & 94,56 & 135,42 & - \\
\hline \multirow[t]{3}{*}{ SPI } & $\mathrm{DM}$ & $-7,81$ & $-5,88$ & $-3,83$ & $-1,61$ & 0,77 & 3,35 & 6,20 & 9,39 & 13,05 & 17,39 & 22,91 & - \\
\hline & DMA & 11,77 & 10,21 & 8,72 & 7,40 & 6,19 & 5,15 & 6,55 & 10,23 & 14,86 & 20,94 & 29,09 & - \\
\hline & PDMA & 45,24 & 39,40 & 32,99 & 26,00 & 19,01 & 11,21 & 13,93 & 26,77 & 47,56 & 77,44 & 123,51 & - \\
\hline \multirow[t]{3}{*}{$\Delta \mathrm{CS}$} & $\mathrm{DM}$ & $-25,30$ & $-25,17$ & $-24,63$ & $-23,83$ & $-22,98$ & $-22,37$ & $-22,50$ & $-24,23$ & $-29,49$ & $-44,08$ & $-103,08$ & - \\
\hline & DMA & 43,56 & 36,23 & 28,19 & 21,26 & 18,33 & 18,70 & 21,44 & 27,56 & 37,31 & 55,92 & 120,41 & - \\
\hline & PDMA & 37,81 & 27,19 & 17,99 & 9,48 & 2,26 & 6,45 & 15,44 & 20,19 & 21,48 & 17,12 & 11,91 & - \\
\hline
\end{tabular}


Tabela 8.63: Constantes de acoplamento BHandH com correção vibracional no nível BHandH $40 \% E_{X}^{\mathrm{HF}}$ e base aug-pcJ-2.

\begin{tabular}{|c|c|c|c|c|c|c|c|c|c|c|c|c|c|}
\hline & $\% E_{X}^{\mathrm{HF}}$ & $0 \%$ & $10 \%$ & $20 \%$ & $30 \%$ & $40 \%$ & $50 \%$ & $60 \%$ & $70 \%$ & $80 \%$ & $90 \%$ & $100 \%$ & Exp. \\
\hline $\mathrm{HF}$ & ${ }^{1} J_{\mathrm{HF}}$ & 387,4 & 407,9 & 429,2 & 451,2 & 474,0 & 497,6 & 522,1 & 547,4 & 573,7 & 601,0 & 629,3 & 500 \\
\hline $\mathrm{CO}$ & ${ }^{1} J_{\mathrm{CO}}$ & 25,6 & 23,7 & 21,7 & 19,5 & 17,1 & 14,5 & 11,8 & 8,8 & 5,7 & 2,4 & $-1,1$ & 16,4 \\
\hline $\mathrm{H}_{2} \mathrm{O}$ & ${ }^{1} J_{\mathrm{OH}}$ & $-68,7$ & $-71,2$ & $-73,9$ & $-76,6$ & $-79,5$ & $-82,5$ & $-85,7$ & $-89,0$ & $-92,5$ & $-96,1$ & $-99,9$ & $-80,6$ \\
\hline $\mathrm{H}_{2} \mathrm{O}$ & ${ }^{2} J_{\mathrm{HH}}$ & $-1,9$ & $-3,0$ & $-4,1$ & $-5,4$ & $-6,6$ & $-8,0$ & $-9,4$ & $-10,9$ & $-12,5$ & $-14,2$ & $-15,9$ & $-7,3$ \\
\hline $\mathrm{NH}_{3}$ & ${ }^{1} J_{\mathrm{NH}}$ & 40,1 & 41,2 & 42,4 & 43,6 & 44,9 & 46,2 & 47,7 & 49,2 & 50,7 & 52,4 & 54,1 & 43,8 \\
\hline $\mathrm{NH}_{3}$ & ${ }^{2} J_{\mathrm{HH}}$ & $-4,5$ & $-5,6$ & $-6,6$ & $-7,8$ & $-9,0$ & $-10,2$ & $-11,6$ & $-13,0$ & $-14,5$ & $-16,1$ & $-17,8$ & $-9,6$ \\
\hline $\mathrm{PH}_{3}$ & ${ }^{1} J_{\mathrm{PH}}$ & 128,2 & 137,0 & 146,2 & 155,7 & 165,6 & 175,8 & 186,4 & 197,3 & 208,6 & 220,1 & 231,9 & 188,2 \\
\hline $\mathrm{PF}_{3}$ & ${ }^{1} J_{\mathrm{PF}}$ & $-1812,6$ & $-1795,3$ & $-1771,3$ & $-1741,7$ & $-1707,2$ & $-1668,6$ & $-1626,5$ & $-1581,6$ & $-1534,4$ & $-1485,5$ & $-1435,2$ & -1441 \\
\hline $\mathrm{BHF}_{2}$ & ${ }^{1} J_{\mathrm{BF}}$ & $-191,9$ & $-174,0$ & $-155,7$ & $-137,3$ & $-118,5$ & $-99,7$ & $-80,6$ & $-61,5$ & $-42,3$ & $-23,1$ & $-3,9$ & -84 \\
\hline $\mathrm{BF}_{3}$ & ${ }^{1} J_{\mathrm{BF}}$ & $-82,0$ & $-63,3$ & $-44,5$ & $-25,5$ & $-6,3$ & 12,9 & 32,4 & 52,0 & 71,7 & 91,6 & 111,6 & 15 \\
\hline $\mathrm{F}_{2} \mathrm{O}$ & ${ }^{1} J_{\mathrm{OF}}$ & $-285,2$ & $-321,3$ & $-357,1$ & $-393,6$ & $-432,9$ & $-478,1$ & $-534,5$ & $-613,1$ & $-741,0$ & $-1013,9$ & $-2266,9$ & -300 \\
\hline $\mathrm{CH}_{4}$ & ${ }^{1} J_{\mathrm{CH}}$ & 108,3 & 111,7 & 115,3 & 119,1 & 123,0 & 127,2 & 131,7 & 136,3 & 141,2 & 146,3 & 151,7 & 125,3 \\
\hline $\mathrm{CH}_{4}$ & ${ }^{2} J_{\mathrm{HH}}$ & $-8,2$ & $-9,2$ & $-10,2$ & $-11,3$ & $-12,4$ & $-13,6$ & $-14,8$ & $-16,0$ & $-17,3$ & $-18,7$ & $-20,0$ & $-12,8$ \\
\hline $\mathrm{C}_{2} \mathrm{H}_{2}$ & ${ }^{1} J_{\mathrm{CC}}$ & 175,9 & 180,0 & 184,6 & 189,8 & 195,8 & 202,8 & 211,0 & 221,0 & 233,2 & 248,7 & 268,8 & 174,8 \\
\hline $\mathrm{C}_{2} \mathrm{H}_{2}$ & ${ }^{1} J_{\mathrm{CH}}$ & 229,5 & 235,4 & 241,5 & 248,1 & 255,1 & 262,6 & 270,9 & 280,0 & 290,4 & 302,3 & 316,6 & 247,6 \\
\hline $\mathrm{C}_{2} \mathrm{H}_{2}$ & ${ }^{2} J_{\mathrm{CH}}$ & 51,6 & 52,5 & 53,1 & 53,6 & 53,7 & 53,4 & 52,6 & 51,1 & 48,6 & 44,6 & 38,5 & 50,1 \\
\hline $\mathrm{C}_{2} \mathrm{H}_{2}$ & ${ }^{3} J_{\mathrm{HH}}$ & 7,7 & 8,3 & 9,0 & 9,9 & 11,0 & 12,3 & 13,9 & 16,0 & 18,6 & 22,0 & 26,5 & 9,6 \\
\hline $\mathrm{C}_{2} \mathrm{H}_{4}$ & ${ }^{1} J_{\mathrm{CC}}$ & 50,8 & 54,2 & 58,0 & 62,2 & 67,1 & 72,7 & 79,3 & 87,7 & 98,6 & 114,2 & 139,4 & 67,6 \\
\hline $\mathrm{C}_{2} \mathrm{H}_{4}$ & ${ }^{1} J_{\mathrm{CH}}$ & 138,0 & 142,3 & 146,8 & 151,7 & 156,8 & 162,4 & 168,6 & 175,5 & 183,6 & 193,6 & 207,5 & 156,3 \\
\hline $\mathrm{C}_{2} \mathrm{H}_{4}$ & ${ }^{2} J_{\mathrm{CH}}$ & 0,6 & $-0,1$ & $-0,7$ & $-1,6$ & $-2,7$ & $-4,1$ & $-5,9$ & $-8,3$ & $-11,7$ & $-16,8$ & $-25,7$ & $-2,4$ \\
\hline $\mathrm{C}_{2} \mathrm{H}_{4}$ & ${ }^{2} J_{\mathrm{HH}}$ & 5,8 & 5,3 & 4,7 & 4,1 & 3,4 & 2,5 & 1,4 & 0,2 & $-1,7$ & $-4,4$ & $-9,0$ & 2,3 \\
\hline $\mathrm{C}_{2} \mathrm{H}_{4}$ & ${ }^{3} J_{\mathrm{HH}_{\mathrm{c}}}$ & 11,5 & 11,8 & 12,1 & 12,5 & 13,0 & 13,6 & 14,4 & 15,5 & 17,1 & 19,6 & 24,0 & 11,7 \\
\hline $\mathrm{C}_{2} \mathrm{H}_{4}$ & ${ }^{3} J_{\mathrm{HH}_{\mathrm{t}}}{ }^{\mathrm{C}}$ & 16,8 & 17,2 & 17,8 & 18,4 & 19,2 & 20,1 & 21,3 & 22,9 & 25,0 & 28,1 & 33,4 & 19 \\
\hline $\mathrm{C}_{2} \mathrm{H}_{6}$ & ${ }^{1} J_{\mathrm{CC}}$ & 19,5 & 22,1 & 24,8 & 27,7 & 30,8 & 34,1 & 37,5 & 41,2 & 45,1 & 49,2 & 53,5 & 34,5 \\
\hline $\mathrm{C}_{2} \mathrm{H}_{6}$ & ${ }^{1} J_{\mathrm{CH}}$ & 107,9 & 111,5 & 115,2 & 119,1 & 123,3 & 127,6 & 132,2 & 137,0 & 142,0 & 147,2 & 152,7 & 125,2 \\
\hline $\mathrm{C}_{2} \mathrm{H}_{6}$ & ${ }^{2} J_{\mathrm{CH}}$ & $-1,9$ & $-2,3$ & $-2,8$ & $-3,3$ & $-3,9$ & $-4,5$ & $-5,1$ & $-5,8$ & $-6,5$ & $-7,2$ & $-8,0$ & $-4,7$ \\
\hline \multirow[t]{3}{*}{ Total } & $\mathrm{DM}$ & $-30,64$ & $-28,01$ & $-24,98$ & $-21,65$ & $-18,08$ & $-14,46$ & $-10,92$ & $-7,89$ & $-6,37$ & $-9,91$ & $-50,34$ & - \\
\hline & DMA & 35,48 & 31,39 & 28,06 & 24,45 & 21,32 & 19,87 & 23,11 & 29,73 & 38,88 & 54,42 & 109,44 & - \\
\hline & PDMA & 61,18 & 49,91 & 38,83 & 27,08 & 16,60 & 12,89 & 26,08 & 45,46 & 69,42 & 101,08 & 157,28 & - \\
\hline \multirow[t]{3}{*}{ CPI } & $\mathrm{DM}$ & $-64,22$ & $-60,44$ & $-55,87$ & $-50,80$ & $-45,39$ & $-40,09$ & $-35,35$ & $-32,30$ & $-33,43$ & $-47,48$ & $-150,43$ & - \\
\hline & DMA & 72,65 & 64,98 & 59,18 & 52,76 & 46,15 & 40,53 & 43,85 & 54,37 & 69,68 & 98,21 & 216,94 & - \\
\hline & PDMA & 96,97 & 79,01 & 61,76 & 43,79 & 26,09 & 13,65 & 28,12 & 50,52 & 74,98 & 104,35 & 163,81 & - \\
\hline \multirow[t]{3}{*}{ SPI } & $\mathrm{DM}$ & $-6,02$ & $-4,23$ & $-2,33$ & $-0,27$ & 1,94 & 4,33 & 6,99 & 10,01 & 13,47 & 17,64 & 23,05 & - \\
\hline & DMA & 8,22 & 6,76 & 5,23 & 3,69 & 3,10 & 4,72 & 7,90 & 11,65 & 16,29 & 22,31 & 30,61 & - \\
\hline & PDMA & 34,94 & 28,57 & 22,02 & 14,83 & 9,64 & 12,33 & 24,58 & 41,76 & 65,35 & 98,68 & 152,50 & - \\
\hline \multirow[t]{3}{*}{$\Delta \mathrm{CS}$} & $\mathrm{DM}$ & $-58,20$ & $-56,21$ & $-53,55$ & $-50,53$ & $-47,33$ & $-44,42$ & $-42,34$ & $-42,31$ & $-46,90$ & $-65,12$ & $-173,48$ & - \\
\hline & DMA & 64,43 & 58,22 & 53,95 & 49,08 & 43,05 & 35,81 & 35,95 & 42,72 & 53,40 & 75,90 & 186,32 & - \\
\hline & PDMA & 62,03 & 50,44 & 39,74 & 28,96 & 16,46 & 1,33 & 3,54 & 8,76 & 9,63 & 5,66 & 11,31 & - \\
\hline
\end{tabular}


Tabela 8.64: Constantes de acoplamento BMK com correção vibracional no nível BHandH $40 \% E_{X}^{\mathrm{HF}}$ e base aug-pcJ-2.

\begin{tabular}{|c|c|c|c|c|c|c|c|c|c|c|c|c|c|}
\hline & $\% E_{X}^{\mathrm{HF}}$ & $0 \%$ & $10 \%$ & $20 \%$ & $30 \%$ & $40 \%$ & $50 \%$ & $60 \%$ & $70 \%$ & $80 \%$ & $90 \%$ & $100 \%$ & Exp. \\
\hline $\mathrm{HF}$ & ${ }^{1} J_{\mathrm{HF}}$ & 458,2 & 469,6 & 482,0 & 495,5 & 510,3 & 526,5 & 544,2 & 563,8 & 585,5 & 609,3 & 635,8 & 500 \\
\hline $\mathrm{CO}$ & ${ }^{1} J_{\mathrm{CO}}$ & 14,6 & 15,1 & 15,4 & 15,6 & 15,6 & 15,4 & 14,9 & 14,1 & 12,8 & 11,0 & 8,5 & 16,4 \\
\hline $\mathrm{H}_{2} \mathrm{O}$ & ${ }^{1} J_{\mathrm{OH}}$ & $-71,1$ & $-71,6$ & $-72,2$ & $-72,9$ & $-73,7$ & $-74,7$ & $-75,8$ & $-77,1$ & $-78,6$ & $-80,2$ & $-82,1$ & $-80,6$ \\
\hline $\mathrm{H}_{2} \mathrm{O}$ & ${ }^{2} J_{\mathrm{HH}}$ & 4,2 & 3,2 & 2,0 & 0,9 & $-0,4$ & $-1,8$ & $-3,3$ & $-5,0$ & $-6,7$ & $-8,6$ & $-10,6$ & $-7,3$ \\
\hline $\mathrm{NH}_{3}$ & ${ }^{1} J_{\mathrm{NH}}$ & 37,2 & 37,3 & 37,4 & 37,5 & 37,8 & 38,1 & 38,4 & 38,9 & 39,4 & 40,0 & 40,7 & 43,8 \\
\hline $\mathrm{NH}_{3}$ & ${ }^{2} J_{\mathrm{HH}}$ & 0,2 & $-0,7$ & $-1,6$ & $-2,6$ & $-3,8$ & $-5,0$ & $-6,3$ & $-7,8$ & $-9,4$ & $-11,1$ & $-13,0$ & $-9,6$ \\
\hline $\mathrm{PH}_{3}$ & ${ }^{1} J_{\mathrm{PH}}$ & 118,5 & 118,1 & 118,1 & 118,7 & 119,7 & 121,2 & 123,2 & 125,7 & 128,8 & 132,4 & 136,7 & 188,2 \\
\hline $\mathrm{PF}_{3}$ & ${ }^{1} J_{\mathrm{PF}}$ & $-1527,6$ & $-1525,8$ & $-1516,1$ & $-1498,9$ & $-1474,5$ & $-1443,4$ & $-1406,4$ & $-1364,1$ & $-1317,2$ & $-1266,6$ & $-1212,6$ & -1441 \\
\hline $\mathrm{BHF}_{2}$ & ${ }^{1} J_{\mathrm{BF}}$ & $-147,6$ & $-136,2$ & $-122,7$ & $-107,3$ & $-89,9$ & $-70,6$ & $-49,4$ & $-26,4$ & $-1,8$ & 24,6 & 52,4 & -84 \\
\hline $\mathrm{BF}_{3}$ & ${ }^{1} J_{\mathrm{BF}}$ & $-53,3$ & $-39,4$ & $-23,6$ & $-6,0$ & 13,2 & 34,4 & 57,2 & 81,9 & 108,2 & 136,2 & 165,7 & 15 \\
\hline $\mathrm{F}_{2} \mathrm{O}$ & ${ }^{1} J_{\mathrm{OF}}$ & $-160,6$ & $-187,0$ & $-214,1$ & $-241,5$ & $-269,1$ & $-297,5$ & $-327,9$ & $-362,3$ & $-405,4$ & $-467,3$ & $-580,6$ & -300 \\
\hline $\mathrm{CH}_{4}$ & ${ }^{1} J_{\mathrm{CH}}$ & 105,4 & 107,0 & 108,8 & 111,0 & 113,5 & 116,5 & 119,8 & 123,6 & 128,0 & 133,0 & 138,7 & 125,3 \\
\hline $\mathrm{CH}_{4}$ & ${ }^{2} J_{\mathrm{HH}}$ & $-3,3$ & $-4,3$ & $-5,4$ & $-6,7$ & $-8,0$ & $-9,5$ & $-11,2$ & $-13,1$ & $-15,2$ & $-17,6$ & $-20,3$ & $-12,8$ \\
\hline $\mathrm{C}_{2} \mathrm{H}_{2}$ & ${ }^{1} J_{\mathrm{CC}}$ & 244,9 & 249,6 & 254,8 & 260,9 & 268,0 & 276,7 & 287,6 & 301,9 & 321,5 & 349,9 & 395,0 & 174,8 \\
\hline $\mathrm{C}_{2} \mathrm{H}_{2}$ & ${ }^{1} J_{\mathrm{CH}}$ & 181,0 & 187,1 & 193,6 & 200,7 & 208,5 & 217,1 & 226,9 & 238,4 & 252,1 & 269,6 & 293,9 & 247,6 \\
\hline $\mathrm{C}_{2} \mathrm{H}_{2}$ & ${ }^{2} J_{\mathrm{CH}}$ & 54,8 & 55,7 & 56,4 & 56,9 & 57,0 & 56,7 & 55,6 & 53,4 & 49,4 & 42,1 & 28,7 & 50,1 \\
\hline $\mathrm{C}_{2} \mathrm{H}_{2}$ & ${ }^{3} J_{\mathrm{HH}}$ & 5,8 & 6,1 & 6,5 & 7,0 & 7,7 & 8,7 & 10,0 & 11,8 & 14,4 & 18,3 & 24,7 & 9,6 \\
\hline $\mathrm{C}_{2} \mathrm{H}_{4}$ & ${ }^{1} J_{\mathrm{CC}}$ & 89,9 & 91,4 & 93,3 & 95,7 & 98,6 & 102,2 & 107,0 & 113,2 & 121,9 & 134,8 & 155,7 & 67,6 \\
\hline $\mathrm{C}_{2} \mathrm{H}_{4}$ & ${ }^{1} J_{\mathrm{CH}}$ & 122,3 & 125,4 & 129,0 & 132,9 & 137,3 & 142,3 & 148,1 & 154,8 & 163,0 & 173,3 & 187,7 & 156,3 \\
\hline $\mathrm{C}_{2} \mathrm{H}_{4}$ & ${ }^{2} J_{\mathrm{CH}}$ & 4,2 & 3,3 & 2,3 & 1,2 & $-0,2$ & $-1,7$ & $-3,7$ & $-6,3$ & $-10,0$ & $-15,4$ & $-24,3$ & $-2,4$ \\
\hline $\mathrm{C}_{2} \mathrm{H}_{4}$ & ${ }^{2} J_{\mathrm{HH}}$ & 8,0 & 7,5 & 6,9 & 6,1 & 5,2 & 4,1 & 2,8 & 1,0 & $-1,1$ & $-4,3$ & $-9,3$ & 2,3 \\
\hline $\mathrm{C}_{2} \mathrm{H}_{4}$ & ${ }^{3} J_{\mathrm{HH}_{\mathrm{c}}}$ & 9,5 & 9,6 & 9,7 & 9,9 & 10,1 & 10,5 & 11,0 & 11,8 & 13,1 & 15,2 & 18,9 & 11,7 \\
\hline $\mathrm{C}_{2} \mathrm{H}_{4}$ & ${ }^{3} J_{\mathrm{HH}_{\mathrm{t}}}{ }^{\mathrm{C}}$ & 11,8 & 12,3 & 12,8 & 13,4 & 14,0 & 14,8 & 15,8 & 17,1 & 18,9 & 21,6 & 26,1 & 19 \\
\hline $\mathrm{C}_{2} \mathrm{H}_{6}$ & ${ }^{1} J_{\mathrm{CC}}$ & 30,9 & 31,8 & 32,9 & 34,1 & 35,6 & 37,3 & 39,3 & 41,5 & 44,1 & 47,2 & 50,7 & 34,5 \\
\hline $\mathrm{C}_{2} \mathrm{H}_{6}$ & ${ }^{1} J_{\mathrm{CH}}$ & 103,2 & 105,1 & 107,4 & 110,0 & 112,9 & 116,2 & 120,0 & 124,3 & 129,1 & 134,6 & 140,9 & 125,2 \\
\hline $\mathrm{C}_{2} \mathrm{H}_{6}$ & ${ }^{2} J_{\mathrm{CH}}$ & 0,4 & $-0,2$ & $-1,0$ & $-1,7$ & $-2,6$ & $-3,5$ & $-4,5$ & $-5,6$ & $-6,9$ & $-8,3$ & $-9,9$ & $-4,7$ \\
\hline \multirow[t]{3}{*}{ Total } & $\mathrm{DM}$ & $-7,83$ & $-6,73$ & $-5,09$ & $-2,87$ & $-0,08$ & 3,31 & 7,24 & 11,71 & 16,65 & 21,87 & 26,66 & - \\
\hline & DMA & 30,46 & 27,46 & 23,86 & 19,71 & 15,85 & 14,44 & 18,37 & 23,53 & 31,20 & 42,73 & 58,88 & - \\
\hline & PDMA & 73,20 & 64,21 & 53,92 & 42,49 & 29,82 & 27,06 & 30,14 & 42,87 & 63,61 & 95,96 & 143,04 & - \\
\hline \multirow[t]{3}{*}{ CPI } & DM & $-15,29$ & $-14,39$ & $-12,39$ & $-9,26$ & $-5,06$ & 0,15 & 6,17 & 12,80 & 19,52 & 25,35 & 27,27 & - \\
\hline & DMA & 46,24 & 40,10 & 32,68 & 24,06 & 16,12 & 13,99 & 24,32 & 36,80 & 50,94 & 68,09 & 91,15 & - \\
\hline & PDMA & 84,22 & 71,11 & 56,36 & 40,29 & 22,93 & 30,63 & 44,93 & 60,59 & 77,85 & 102,93 & 133,52 & - \\
\hline \multirow[t]{3}{*}{ SPI } & $\mathrm{DM}$ & $-2,35$ & $-1,11$ & 0,26 & 1,82 & 3,57 & 5,62 & 8,03 & 10,91 & 14,55 & 19,33 & 26,21 & - \\
\hline & DMA & 18,89 & 18,19 & 17,39 & 16,51 & 15,66 & 14,77 & 14,00 & 13,79 & 16,73 & 24,13 & 35,22 & - \\
\hline & PDMA & 65,12 & 59,15 & 52,14 & 44,11 & 34,87 & 24,45 & 19,30 & 29,87 & 53,16 & 90,85 & 150,02 & - \\
\hline \multirow[t]{3}{*}{$\Delta \mathrm{CS}$} & $\mathrm{DM}$ & $-12,94$ & $-13,28$ & $-12,65$ & $-11,08$ & $-8,63$ & $-5,47$ & $-1,85$ & 1,89 & 4,97 & 6,02 & 1,07 & - \\
\hline & DMA & 27,35 & 21,91 & 15,29 & 7,55 & 0,46 & $-0,78$ & 10,32 & 23,01 & 34,20 & 43,96 & 55,93 & - \\
\hline & PDMA & 19,09 & 11,95 & 4,22 & $-3,83$ & $-11,94$ & 6,18 & 25,63 & 30,71 & 24,69 & 12,08 & $-16,50$ & - \\
\hline
\end{tabular}


Tabela 8.65: Constantes de acoplamento BP86 com correção vibracional no nível BHandH $40 \% E_{X}^{\mathrm{HF}}$ e base aug-pcJ-2.

\begin{tabular}{|c|c|c|c|c|c|c|c|c|c|c|c|c|c|}
\hline & $\% E_{X}^{\mathrm{HF}}$ & $0 \%$ & $10 \%$ & $20 \%$ & $30 \%$ & $40 \%$ & $50 \%$ & $60 \%$ & $70 \%$ & $80 \%$ & $90 \%$ & $100 \%$ & Exp. \\
\hline $\mathrm{HF}$ & ${ }^{1} J_{\mathrm{HF}}$ & 322,1 & 345,7 & 369,6 & 393,7 & 418,1 & 442,6 & 467,5 & 492,5 & 517,8 & 543,3 & 569,0 & 500 \\
\hline $\mathrm{CO}$ & ${ }^{1} J_{\mathrm{CO}}$ & 25,7 & 24,0 & 22,3 & 20,5 & 18,5 & 16,6 & 14,5 & 12,4 & 10,2 & 7,9 & 5,6 & 16,4 \\
\hline $\mathrm{H}_{2} \mathrm{O}$ & ${ }^{1} J_{\mathrm{OH}}$ & $-63,6$ & $-66,1$ & $-68,6$ & $-71,2$ & $-73,8$ & $-76,4$ & $-79,0$ & $-81,7$ & $-84,3$ & $-87,1$ & $-89,8$ & $-80,6$ \\
\hline $\mathrm{H}_{2} \mathrm{O}$ & ${ }^{2} J_{\mathrm{HH}}$ & $-3,2$ & $-4,1$ & $-5,1$ & $-6,1$ & $-7,1$ & $-8,2$ & $-9,2$ & $-10,3$ & $-11,4$ & $-12,5$ & $-13,7$ & $-7,3$ \\
\hline $\mathrm{NH}_{3}$ & ${ }^{1} J_{\mathrm{NH}}$ & 40,7 & 41,4 & 42,2 & 42,9 & 43,7 & 44,5 & 45,3 & 46,1 & 46,9 & 47,7 & 48,5 & 43,8 \\
\hline $\mathrm{NH}_{3}$ & ${ }^{2} J_{\mathrm{HH}}$ & $-6,9$ & $-7,7$ & $-8,6$ & $-9,5$ & $-10,3$ & $-11,2$ & $-12,1$ & $-13,0$ & $-14,0$ & $-14,9$ & $-15,9$ & $-9,6$ \\
\hline $\mathrm{PH}_{3}$ & ${ }^{1} J_{\mathrm{PH}}$ & 129,6 & 137,6 & 145,5 & 153,4 & 161,1 & 168,7 & 176,2 & 183,5 & 190,8 & 197,8 & 204,8 & 188,2 \\
\hline $\mathrm{PF}_{3}$ & ${ }^{1} J_{\mathrm{PF}}$ & $-1800,7$ & $-1775,6$ & $-1746,1$ & $-1712,9$ & $-1676,7$ & $-1638,1$ & $-1597,7$ & $-1555,9$ & $-1513,1$ & $-1469,6$ & $-1425,7$ & -1441 \\
\hline $\mathrm{BHF}_{2}$ & ${ }^{1} J_{\mathrm{BF}}$ & $-182,4$ & $-165,4$ & $-148,5$ & $-131,7$ & $-115,1$ & $-98,5$ & $-82,2$ & $-66,0$ & $-50,0$ & $-34,2$ & $-18,6$ & -84 \\
\hline $\mathrm{BF}_{3}$ & ${ }^{1} J_{\mathrm{BF}}$ & $-85,5$ & $-66,8$ & $-48,4$ & $-30,1$ & $-12,0$ & 5,8 & 23,5 & 41,1 & 58,4 & 75,6 & 92,6 & 15 \\
\hline $\mathrm{F}_{2} \mathrm{O}$ & ${ }^{1} J_{\mathrm{OF}}$ & $-303,2$ & $-340,5$ & $-378,1$ & $-417,5$ & $-460,9$ & $-511,8$ & $-575,7$ & $-664,1$ & $-803,5$ & $-1077,4$ & $-1986,2$ & -300 \\
\hline $\mathrm{CH}_{4}$ & ${ }^{1} J_{\mathrm{CH}}$ & 119,8 & 121,2 & 122,7 & 124,2 & 125,7 & 127,2 & 128,8 & 130,4 & 132,0 & 133,7 & 135,3 & 125,3 \\
\hline $\mathrm{CH}_{4}$ & ${ }^{2} J_{\mathrm{HH}}$ & $-12,1$ & $-12,8$ & $-13,5$ & $-14,2$ & $-14,9$ & $-15,6$ & $-16,4$ & $-17,1$ & $-17,8$ & $-18,4$ & $-19,1$ & $-12,8$ \\
\hline $\mathrm{C}_{2} \mathrm{H}_{2}$ & ${ }^{1} J_{\mathrm{CC}}$ & 187,7 & 190,3 & 193,4 & 196,9 & 201,0 & 205,8 & 211,5 & 218,4 & 226,8 & 237,3 & 250,6 & 174,8 \\
\hline $\mathrm{C}_{2} \mathrm{H}_{2}$ & ${ }^{1} J_{\mathrm{CH}}$ & 250,5 & 252,8 & 255,2 & 257,8 & 260,6 & 263,7 & 267,2 & 271,2 & 275,9 & 281,5 & 288,4 & 247,6 \\
\hline $\mathrm{C}_{2} \mathrm{H}_{2}$ & ${ }^{2} J_{\mathrm{CH}}$ & 55,0 & 55,0 & 54,8 & 54,3 & 53,5 & 52,3 & 50,7 & 48,5 & 45,6 & 41,7 & 36,3 & 50,1 \\
\hline $\mathrm{C}_{2} \mathrm{H}_{2}$ & ${ }^{3} J_{\mathrm{HH}}$ & 10,7 & 11,4 & 12,1 & 13,0 & 14,0 & 15,3 & 16,9 & 18,7 & 21,0 & 23,8 & 27,4 & 9,6 \\
\hline $\mathrm{C}_{2} \mathrm{H}_{4}$ & ${ }^{1} J_{\mathrm{CC}}$ & 59,9 & 62,6 & 65,6 & 68,9 & 72,8 & 77,3 & 82,8 & 89,8 & 99,1 & 112,6 & 134,2 & 67,6 \\
\hline $\mathrm{C}_{2} \mathrm{H}_{4}$ & ${ }^{1} J_{\mathrm{CH}}$ & 151,5 & 153,6 & 155,8 & 158,1 & 160,6 & 163,4 & 166,5 & 170,3 & 175,0 & 181,4 & 191,1 & 156,3 \\
\hline $\mathrm{C}_{2} \mathrm{H}_{4}$ & ${ }^{2} J_{\mathrm{CH}}$ & $-0,3$ & $-1,1$ & $-2,0$ & $-3,2$ & $-4,5$ & $-6,0$ & $-8,0$ & $-10,6$ & $-14,2$ & $-19,4$ & $-27,9$ & $-2,4$ \\
\hline $\mathrm{C}_{2} \mathrm{H}_{4}$ & ${ }^{2} J_{\mathrm{HH}}$ & 4,9 & 4,2 & 3,4 & 2,5 & 1,5 & 0,3 & $-0,9$ & $-2,6$ & $-4,9$ & $-8,1$ & $-13,2$ & 2,3 \\
\hline $\mathrm{C}_{2} \mathrm{H}_{4}$ & ${ }^{3} J_{\mathrm{HH}_{\mathrm{c}}}$ & 11,9 & 12,2 & 12,6 & 13,0 & 13,6 & 14,3 & 15,3 & 16,6 & 18,4 & 21,3 & 26,0 & 11,7 \\
\hline $\mathrm{C}_{2} \mathrm{H}_{4}$ & ${ }^{3} J_{\mathrm{HH}_{\mathrm{t}}}{ }^{\mathrm{C}}$ & 19,0 & 19,4 & 19,8 & 20,3 & 20,9 & 21,8 & 22,9 & 24,4 & 26,6 & 29,8 & 35,2 & 19 \\
\hline $\mathrm{C}_{2} \mathrm{H}_{6}$ & ${ }^{1} J_{\mathrm{CC}}$ & 25,0 & 27,0 & 29,0 & 31,0 & 33,1 & 35,2 & 37,3 & 39,5 & 41,7 & 44,0 & 46,2 & 34,5 \\
\hline $\mathrm{C}_{2} \mathrm{H}_{6}$ & ${ }^{1} J_{\mathrm{CH}}$ & 119,4 & 121,0 & 122,7 & 124,4 & 126,1 & 127,8 & 129,6 & 131,4 & 133,1 & 135,0 & 136,8 & 125,2 \\
\hline $\mathrm{C}_{2} \mathrm{H}_{6}$ & ${ }^{2} J_{\mathrm{CH}}$ & $-2,9$ & $-3,3$ & $-3,8$ & $-4,3$ & $-4,7$ & $-5,2$ & $-5,7$ & $-6,2$ & $-6,7$ & $-7,3$ & $-7,8$ & $-4,7$ \\
\hline \multirow[t]{3}{*}{ Total } & $\mathrm{DM}$ & $-29,71$ & $-27,27$ & $-24,65$ & $-21,95$ & $-19,24$ & $-16,67$ & $-14,44$ & $-12,99$ & $-13,29$ & $-18,44$ & $-47,50$ & - \\
\hline & DMA & 34,50 & 31,89 & 29,16 & 26,65 & 24,68 & 23,40 & 23,76 & 27,26 & 34,75 & 48,90 & 89,67 & - \\
\hline & PDMA & 52,92 & 43,08 & 33,23 & 25,62 & 23,18 & 24,64 & 33,32 & 50,95 & 73,18 & 102,72 & 151,00 & - \\
\hline \multirow[t]{3}{*}{ CPI } & $\mathrm{DM}$ & $-69,85$ & $-65,31$ & $-60,43$ & $-55,40$ & $-50,49$ & $-46,08$ & $-42,71$ & $-41,48$ & $-44,83$ & $-60,39$ & $-133,66$ & - \\
\hline & DMA & 75,86 & 70,25 & 64,26 & 58,09 & 52,15 & 47,01 & 45,15 & 49,92 & 63,17 & 90,79 & 178,86 & - \\
\hline & PDMA & 95,37 & 79,10 & 62,77 & 46,49 & 31,75 & 20,16 & 22,14 & 39,66 & 59,91 & 84,85 & 129,29 & - \\
\hline \multirow[t]{3}{*}{ SPI } & $\mathrm{DM}$ & $-0,27$ & 0,63 & 1,58 & 2,57 & 3,68 & 4,90 & 6,29 & 7,91 & 9,83 & 12,32 & 15,69 & - \\
\hline & DMA & 4,17 & 3,76 & 3,42 & 3,59 & 4,53 & 6,09 & 8,08 & 10,64 & 13,90 & 18,19 & 24,25 & - \\
\hline & PDMA & 21,79 & 16,66 & 11,56 & 10,32 & 16,89 & 27,93 & 41,52 & 59,22 & 82,91 & 115,82 & 166,92 & - \\
\hline \multirow[t]{3}{*}{$\Delta \mathrm{CS}$} & $\mathrm{DM}$ & $-69,57$ & $-65,94$ & $-62,01$ & $-57,97$ & $-54,17$ & $-50,98$ & $-49,00$ & $-49,39$ & $-54,66$ & $-72,71$ & $-149,36$ & - \\
\hline & DMA & 71,70 & 66,49 & 60,84 & 54,50 & 47,61 & 40,92 & 37,07 & 39,28 & 49,27 & 72,60 & 154,61 & - \\
\hline & PDMA & 73,58 & 62,44 & 51,21 & 36,18 & 14,87 & $-7,77$ & $-19,38$ & $-19,56$ & $-22,99$ & $-30,96$ & $-37,63$ & - \\
\hline
\end{tabular}


Tabela 8.66: Constantes de acoplamento BPW91 com correção vibracional no nível BHandH $40 \% E_{X}^{\mathrm{HF}}$ e base aug-pcJ-2.

\begin{tabular}{|c|c|c|c|c|c|c|c|c|c|c|c|c|c|}
\hline & $\% E_{X}^{\mathrm{HF}}$ & $0 \%$ & $10 \%$ & $20 \%$ & $30 \%$ & $40 \%$ & $50 \%$ & $60 \%$ & $70 \%$ & $80 \%$ & $90 \%$ & $100 \%$ & Exp. \\
\hline $\mathrm{HF}$ & ${ }^{1} J_{\mathrm{HF}}$ & 320,1 & 344,2 & 368,7 & 393,4 & 418,3 & 443,5 & 469,0 & 494,7 & 520,6 & 546,7 & 573,1 & 500 \\
\hline $\mathrm{CO}$ & ${ }^{1} J_{\mathrm{CO}}$ & 26,0 & 24,4 & 22,6 & 20,8 & 18,9 & 16,9 & 14,8 & 12,6 & 10,4 & 8,1 & 5,7 & 16,4 \\
\hline $\mathrm{H}_{2} \mathrm{O}$ & ${ }^{1} J_{\mathrm{OH}}$ & $-63,7$ & $-66,3$ & $-68,9$ & $-71,5$ & $-74,2$ & $-76,9$ & $-79,6$ & $-82,3$ & $-85,1$ & $-87,9$ & $-90,7$ & $-80,6$ \\
\hline $\mathrm{H}_{2} \mathrm{O}$ & ${ }^{2} J_{\mathrm{HH}}$ & $-3,7$ & $-4,7$ & $-5,7$ & $-6,7$ & $-7,8$ & $-8,8$ & $-9,9$ & $-11,1$ & $-12,2$ & $-13,4$ & $-14,6$ & $-7,3$ \\
\hline $\mathrm{NH}_{3}$ & ${ }^{1} J_{\mathrm{NH}}$ & 40,9 & 41,7 & 42,5 & 43,3 & 44,1 & 44,9 & 45,7 & 46,5 & 47,4 & 48,2 & 49,1 & 43,8 \\
\hline $\mathrm{NH}_{3}$ & ${ }^{2} J_{\mathrm{HH}}$ & $-7,4$ & $-8,3$ & $-9,2$ & $-10,1$ & $-11,0$ & $-12,0$ & $-12,9$ & $-13,8$ & $-14,8$ & $-15,8$ & $-16,8$ & $-9,6$ \\
\hline $\mathrm{PH}_{3}$ & ${ }^{1} J_{\mathrm{PH}}$ & 130,0 & 138,3 & 146,6 & 154,7 & 162,8 & 170,7 & 178,5 & 186,1 & 193,6 & 201,0 & 208,2 & 188,2 \\
\hline $\mathrm{PF}_{3}$ & ${ }^{1} J_{\mathrm{PF}}$ & $-1808,8$ & $-1782,7$ & $-1752,3$ & $-1718,2$ & $-1681,3$ & $-1642,0$ & $-1600,9$ & $-1558,5$ & $-1515,1$ & $-1471,1$ & $-1426,7$ & -1441 \\
\hline $\mathrm{BHF}_{2}$ & ${ }^{1} J_{\mathrm{BF}}$ & $-182,5$ & $-165,3$ & $-148,3$ & $-131,3$ & $-114,5$ & $-97,8$ & $-81,3$ & $-64,9$ & $-48,8$ & $-32,8$ & $-17,0$ & -84 \\
\hline $\mathrm{BF}_{3}$ & ${ }^{1} J_{\mathrm{BF}}$ & $-85,5$ & $-66,7$ & $-48,0$ & $-29,6$ & $-11,3$ & 6,7 & 24,5 & 42,3 & 59,8 & 77,2 & 94,4 & 15 \\
\hline $\mathrm{F}_{2} \mathrm{O}$ & ${ }^{1} J_{\mathrm{OF}}$ & $-304,8$ & $-343,0$ & $-381,7$ & $-422,3$ & $-467,5$ & $-520,8$ & $-588,8$ & $-684,5$ & $-840,5$ & $-1166,7$ & $-2538,9$ & -300 \\
\hline $\mathrm{CH}_{4}$ & ${ }^{1} J_{\mathrm{CH}}$ & 121,2 & 122,7 & 124,2 & 125,8 & 127,4 & 129,0 & 130,7 & 132,3 & 134,0 & 135,7 & 137,5 & 125,3 \\
\hline $\mathrm{CH}_{4}$ & ${ }^{2} J_{\mathrm{HH}}$ & $-12,8$ & $-13,6$ & $-14,3$ & $-15,0$ & $-15,8$ & $-16,5$ & $-17,3$ & $-18,0$ & $-18,7$ & $-19,4$ & $-20,2$ & $-12,8$ \\
\hline $\mathrm{C}_{2} \mathrm{H}_{2}$ & ${ }^{1} J_{\mathrm{CC}}$ & 188,3 & 191,1 & 194,3 & 198,1 & 202,6 & 207,9 & 214,2 & 222,0 & 231,6 & 243,7 & 259,4 & 174,8 \\
\hline $\mathrm{C}_{2} \mathrm{H}_{2}$ & ${ }^{1} J_{\mathrm{CH}}$ & 254,2 & 256,7 & 259,3 & 262,2 & 265,2 & 268,7 & 272,6 & 277,2 & 282,6 & 289,2 & 297,7 & 247,6 \\
\hline $\mathrm{C}_{2} \mathrm{H}_{2}$ & ${ }^{2} J_{\mathrm{CH}}$ & 55,1 & 55,0 & 54,6 & 54,0 & 53,0 & 51,5 & 49,5 & 46,9 & 43,2 & 38,3 & 31,6 & 50,1 \\
\hline $\mathrm{C}_{2} \mathrm{H}_{2}$ & ${ }^{3} J_{\mathrm{HH}}$ & 11,3 & 12,0 & 12,9 & 13,9 & 15,1 & 16,6 & 18,4 & 20,6 & 23,3 & 26,8 & 31,2 & 9,6 \\
\hline $\mathrm{C}_{2} \mathrm{H}_{4}$ & ${ }^{1} J_{\mathrm{CC}}$ & 60,3 & 63,1 & 66,3 & 69,9 & 74,1 & 79,1 & 85,3 & 93,4 & 104,7 & 121,9 & 152,4 & 67,6 \\
\hline $\mathrm{C}_{2} \mathrm{H}_{4}$ & ${ }^{1} J_{\mathrm{CH}}$ & 153,7 & 155,9 & 158,2 & 160,7 & 163,4 & 166,5 & 170,1 & 174,4 & 180,0 & 188,2 & 201,8 & 156,3 \\
\hline $\mathrm{C}_{2} \mathrm{H}_{4}$ & ${ }^{2} J_{\mathrm{CH}}$ & $-0,7$ & $-1,7$ & $-2,7$ & $-3,9$ & $-5,4$ & $-7,2$ & $-9,5$ & $-12,7$ & $-17,1$ & $-24,0$ & $-36,5$ & $-2,4$ \\
\hline $\mathrm{C}_{2} \mathrm{H}_{4}$ & ${ }^{2} J_{\mathrm{HH}}$ & 4,5 & 3,6 & 2,8 & 1,8 & 0,7 & $-0,5$ & $-2,1$ & $-4,2$ & $-7,1$ & $-11,4$ & $-18,9$ & 2,3 \\
\hline $\mathrm{C}_{2} \mathrm{H}_{4}$ & ${ }^{3} J_{\mathrm{HH}_{\mathrm{c}}}$ & 12,3 & 12,6 & 13,0 & 13,6 & 14,3 & 15,1 & 16,3 & 18,0 & 20,4 & 24,3 & 31,5 & 11,7 \\
\hline $\mathrm{C}_{2} \mathrm{H}_{4}$ & ${ }^{3} J_{\mathrm{HH}_{\mathrm{t}}}$ & 19,6 & 20,0 & 20,5 & 21,1 & 21,9 & 22,9 & 24,2 & 26,1 & 28,9 & 33,3 & 41,4 & 19 \\
\hline $\mathrm{C}_{2} \mathrm{H}_{6}$ & ${ }^{1} J_{\mathrm{CC}}$ & 25,3 & 27,3 & 29,3 & 31,4 & 33,5 & 35,6 & 37,8 & 40,0 & 42,3 & 44,6 & 46,9 & 34,5 \\
\hline $\mathrm{C}_{2} \mathrm{H}_{6}$ & ${ }^{1} J_{\mathrm{CH}}$ & 121,0 & 122,7 & 124,4 & 126,2 & 128,0 & 129,8 & 131,6 & 133,5 & 135,3 & 137,2 & 139,1 & 125,2 \\
\hline $\mathrm{C}_{2} \mathrm{H}_{6}$ & ${ }^{2} J_{\mathrm{CH}}$ & $-3,2$ & $-3,7$ & $-4,1$ & $-4,6$ & $-5,1$ & $-5,6$ & $-6,2$ & $-6,7$ & $-7,2$ & $-7,7$ & $-8,3$ & $-4,7$ \\
\hline \multirow[t]{3}{*}{ Total } & $\mathrm{DM}$ & $-29,78$ & $-27,30$ & $-24,62$ & $-21,82$ & $-19,06$ & $-16,45$ & $-14,24$ & $-12,89$ & $-13,60$ & $-20,42$ & $-66,64$ & - \\
\hline & DMA & 34,83 & 32,20 & 29,59 & 27,40 & 25,75 & 24,63 & 25,37 & 29,43 & 38,30 & 55,08 & 114,82 & - \\
\hline & PDMA & 51,16 & 40,90 & 31,99 & 27,87 & 28,09 & 30,44 & 41,19 & 61,33 & 87,01 & 123,13 & 190,48 & - \\
\hline \multirow[t]{3}{*}{ CPI } & $\mathrm{DM}$ & $-70,94$ & $-66,30$ & $-61,33$ & $-56,22$ & $-51,31$ & $-46,95$ & $-43,80$ & $-43,07$ & $-47,78$ & $-67,95$ & $-183,19$ & - \\
\hline & DMA & 76,81 & 71,06 & 64,95 & 58,78 & 52,98 & 47,92 & 46,55 & 52,00 & 67,71 & 100,18 & 230,30 & - \\
\hline & PDMA & 94,51 & 77,97 & 61,37 & 45,95 & 32,66 & 21,42 & 24,60 & 42,77 & 64,05 & 90,96 & 149,68 & - \\
\hline \multirow[t]{3}{*}{ SPI } & $\mathrm{DM}$ & 0,40 & 1,31 & 2,31 & 3,41 & 4,59 & 5,92 & 7,43 & 9,25 & 11,47 & 14,44 & 18,83 & - \\
\hline & DMA & 4,05 & 3,71 & 3,67 & 4,38 & 5,79 & 7,55 & 9,85 & 12,87 & 16,73 & 22,00 & 30,14 & - \\
\hline & PDMA & 19,37 & 13,72 & 10,45 & 14,60 & 24,74 & 37,06 & 53,36 & 74,93 & 103,85 & 146,72 & 220,40 & - \\
\hline \multirow[t]{3}{*}{$\Delta \mathrm{CS}$} & $\mathrm{DM}$ & $-71,34$ & $-67,61$ & $-63,63$ & $-59,62$ & $-55,90$ & $-52,87$ & $-51,23$ & $-52,32$ & $-59,26$ & $-82,39$ & $-202,02$ & - \\
\hline & DMA & 72,76 & 67,36 & 61,28 & 54,40 & 47,20 & 40,37 & 36,70 & 39,13 & 50,98 & 78,18 & 200,16 & - \\
\hline & PDMA & 75,15 & 64,25 & 50,93 & 31,35 & 7,93 & $-15,64$ & $-28,76$ & $-32,16$ & $-39,80$ & $-55,76$ & $-70,72$ & - \\
\hline
\end{tabular}


Tabela 8.67: Constantes de acoplamento M05 com correção vibracional no nível BHandH $40 \% E_{X}^{\mathrm{HF}}$ e base aug-pcJ-2.

\begin{tabular}{|c|c|c|c|c|c|c|c|c|c|c|c|c|c|}
\hline & $\% E_{X}^{\mathrm{HF}}$ & $0 \%$ & $10 \%$ & $20 \%$ & $30 \%$ & $40 \%$ & $50 \%$ & $60 \%$ & $70 \%$ & $80 \%$ & $90 \%$ & $100 \%$ & Exp. \\
\hline $\mathrm{HF}$ & ${ }^{1} J_{\mathrm{HF}}$ & 813,8 & 806,9 & 800,3 & 794,1 & 788,2 & 782,7 & 777,6 & 772,6 & 767,9 & 763,2 & 758,5 & 500 \\
\hline $\mathrm{CO}$ & ${ }^{1} J_{\mathrm{CO}}$ & 16,6 & 14,5 & 12,1 & 9,3 & 6,1 & 2,5 & $-1,3$ & $-5,4$ & $-9,9$ & $-14,7$ & $-19,7$ & 16,4 \\
\hline $\mathrm{H}_{2} \mathrm{O}$ & ${ }^{1} J_{\mathrm{OH}}$ & $-107,7$ & $-107,5$ & $-107,3$ & $-107,1$ & $-107,0$ & $-106,8$ & $-106,8$ & $-106,8$ & $-106,8$ & $-106,9$ & $-107,0$ & $-80,6$ \\
\hline $\mathrm{H}_{2} \mathrm{O}$ & ${ }^{2} J_{\mathrm{HH}}$ & $-17,2$ & $-17,3$ & $-17,3$ & $-17,2$ & $-16,9$ & $-16,5$ & $-16,0$ & $-15,3$ & $-14,5$ & $-13,6$ & $-12,5$ & $-7,3$ \\
\hline $\mathrm{NH}_{3}$ & ${ }^{1} J_{\mathrm{NH}}$ & 41,8 & 43,0 & 44,1 & 45,2 & 46,3 & 47,4 & 48,5 & 49,5 & 50,5 & 51,5 & 52,4 & 43,8 \\
\hline $\mathrm{NH}_{3}$ & ${ }^{2} J_{\mathrm{HH}}$ & $-12,6$ & $-13,5$ & $-14,3$ & $-15,0$ & $-15,5$ & $-15,8$ & $-16,0$ & $-15,9$ & $-15,6$ & $-15,0$ & $-14,3$ & $-9,6$ \\
\hline $\mathrm{PH}_{3}$ & ${ }^{1} J_{\mathrm{PH}}$ & 161,2 & 159,5 & 160,9 & 165,7 & 173,0 & 181,6 & 190,8 & 199,9 & 208,6 & 216,8 & 224,5 & 188,2 \\
\hline $\mathrm{PF}_{3}$ & ${ }^{1} J_{\mathrm{PF}}$ & $-1355,8$ & $-1374,2$ & $-1384,7$ & $-1387,1$ & $-1381,8$ & $-1370,2$ & $-1353,5$ & $-1333,0$ & $-1310,0$ & $-1285,2$ & $-1259,4$ & -1441 \\
\hline $\mathrm{BHF}_{2}$ & ${ }^{1} J_{\mathrm{BF}}$ & $-2,3$ & 3,7 & 10,4 & 17,8 & 26,0 & 35,0 & 45,0 & 56,0 & 68,3 & 81,8 & 96,8 & -84 \\
\hline $\mathrm{BF}_{3}$ & ${ }^{1} J_{\mathrm{BF}}$ & 100,7 & 108,9 & 117,6 & 126,9 & 136,8 & 147,6 & 159,2 & 171,9 & 185,6 & 200,5 & 216,7 & 15 \\
\hline $\mathrm{F}_{2} \mathrm{O}$ & ${ }^{1} J_{\mathrm{OF}}$ & $-232,0$ & $-266,8$ & $-295,9$ & $-320,7$ & $-343,1$ & $-364,7$ & $-387,8$ & $-415,3$ & $-452,2$ & $-508,0$ & $-605,5$ & -300 \\
\hline $\mathrm{CH}_{4}$ & ${ }^{1} J_{\mathrm{CH}}$ & 83,2 & 89,5 & 95,8 & 102,1 & 108,4 & 114,7 & 121,0 & 127,3 & 133,4 & 139,4 & 145,2 & 125,3 \\
\hline $\mathrm{CH}_{4}$ & ${ }^{2} J_{\mathrm{HH}}$ & $-21,1$ & $-21,4$ & $-21,5$ & $-21,5$ & $-21,3$ & $-21,1$ & $-20,7$ & $-20,1$ & $-19,5$ & $-18,8$ & $-18,2$ & $-12,8$ \\
\hline $\mathrm{C}_{2} \mathrm{H}_{2}$ & ${ }^{1} J_{\mathrm{CC}}$ & 183,3 & 192,4 & 202,0 & 212,2 & 223,0 & 234,4 & 246,5 & 259,2 & 272,8 & 287,1 & 302,4 & 174,8 \\
\hline $\mathrm{C}_{2} \mathrm{H}_{2}$ & ${ }^{1} J_{\mathrm{CH}}$ & 226,1 & 235,2 & 244,0 & 252,6 & 260,7 & 268,5 & 275,8 & 282,4 & 288,3 & 293,3 & 297,5 & 247,6 \\
\hline $\mathrm{C}_{2} \mathrm{H}_{2}$ & ${ }^{2} J_{\mathrm{CH}}$ & 36,2 & 36,5 & 36,8 & 37,0 & 37,1 & 37,1 & 37,2 & 37,1 & 36,8 & 36,3 & 35,3 & 50,1 \\
\hline $\mathrm{C}_{2} \mathrm{H}_{2}$ & ${ }^{3} J_{\mathrm{HH}}$ & 20,1 & 20,6 & 20,9 & 21,1 & 21,2 & 21,2 & 21,1 & 20,9 & 20,7 & 20,6 & 20,7 & 9,6 \\
\hline $\mathrm{C}_{2} \mathrm{H}_{4}$ & ${ }^{1} J_{\mathrm{CC}}$ & 58,3 & 64,5 & 71,1 & 78,3 & 86,1 & 94,5 & 103,7 & 113,6 & 124,3 & 136,0 & 148,8 & 67,6 \\
\hline $\mathrm{C}_{2} \mathrm{H}_{4}$ & ${ }^{1} J_{\mathrm{CH}}$ & 121,6 & 129,5 & 137,3 & 145,0 & 152,6 & 160,2 & 167,6 & 174,9 & 181,9 & 188,8 & 195,4 & 156,3 \\
\hline $\mathrm{C}_{2} \mathrm{H}_{4}$ & ${ }^{2} J_{\mathrm{CH}}$ & $-11,7$ & $-12,5$ & $-13,4$ & $-14,4$ & $-15,4$ & $-16,5$ & $-17,6$ & $-18,7$ & $-19,9$ & $-21,2$ & $-22,7$ & $-2,4$ \\
\hline $\mathrm{C}_{2} \mathrm{H}_{4}$ & ${ }^{2} J_{\mathrm{HH}}$ & $-15,7$ & $-15,4$ & $-14,8$ & $-14,1$ & $-13,3$ & $-12,3$ & $-11,1$ & $-9,8$ & $-8,5$ & $-7,2$ & $-6,1$ & 2,3 \\
\hline $\mathrm{C}_{2} \mathrm{H}_{4}$ & ${ }^{3} J_{\mathrm{HH}_{\mathrm{c}}}$ & 14,8 & 15,5 & 16,1 & 16,6 & 17,0 & 17,3 & 17,5 & 17,6 & 17,6 & 17,6 & 17,6 & 11,7 \\
\hline $\mathrm{C}_{2} \mathrm{H}_{4}$ & ${ }^{3} J_{\mathrm{HH}_{\mathrm{t}}}{ }^{\mathrm{C}}$ & 16,1 & 17,5 & 18,7 & 19,9 & 21,0 & 21,9 & 22,7 & 23,4 & 23,9 & 24,4 & 24,9 & 19 \\
\hline $\mathrm{C}_{2} \mathrm{H}_{6}$ & ${ }^{1} J_{\mathrm{CC}}$ & 16,0 & 19,3 & 22,7 & 26,4 & 30,2 & 34,1 & 38,3 & 42,7 & 47,2 & 52,0 & 57,0 & 34,5 \\
\hline $\mathrm{C}_{2} \mathrm{H}_{6}$ & ${ }^{1} J_{\mathrm{CH}}$ & 81,9 & 88,4 & 94,8 & 101,3 & 107,8 & 114,4 & 120,9 & 127,4 & 133,8 & 140,2 & 146,4 & 125,2 \\
\hline $\mathrm{C}_{2} \mathrm{H}_{6}$ & ${ }^{2} J_{\mathrm{CH}}$ & $-3,4$ & $-3,9$ & $-4,4$ & $-4,9$ & $-5,4$ & $-5,9$ & $-6,3$ & $-6,8$ & $-7,2$ & $-7,7$ & $-8,2$ & $-4,7$ \\
\hline \multirow[t]{3}{*}{ Total } & $\mathrm{DM}$ & 14,12 & 14,15 & 14,88 & 16,33 & 18,34 & 20,78 & 23,51 & 26,32 & 28,94 & 31,01 & 31,60 & - \\
\hline & DMA & 36,49 & 33,67 & 31,63 & 32,40 & 34,00 & 36,15 & 39,39 & 43,89 & 49,61 & 56,25 & 64,70 & - \\
\hline & PDMA & 99,74 & 101,64 & 103,78 & 107,89 & 112,60 & 117,46 & 123,13 & 129,48 & 136,84 & 145,04 & 154,95 & - \\
\hline \multirow[t]{3}{*}{ CPI } & $\mathrm{DM}$ & 51,42 & 46,94 & 44,09 & 42,82 & 42,84 & 43,81 & 45,35 & 47,03 & 48,27 & 48,14 & 44,51 & - \\
\hline & DMA & 63,96 & 60,06 & 57,36 & 59,56 & 62,93 & 66,86 & 72,04 & 79,32 & 87,89 & 98,52 & 113,22 & - \\
\hline & PDMA & 89,14 & 95,19 & 102,02 & 110,89 & 120,13 & 129,84 & 140,38 & 152,09 & 164,74 & 178,58 & 194,37 & - \\
\hline \multirow[t]{3}{*}{ SPI } & $\mathrm{DM}$ & $-13,23$ & $-9,89$ & $-6,53$ & $-3,10$ & 0,37 & 3,89 & 7,50 & 11,13 & 14,77 & 18,45 & 22,13 & - \\
\hline & DMA & 16,35 & 14,32 & 12,76 & 12,49 & 12,79 & 13,63 & 15,45 & 17,91 & 21,54 & 25,26 & 29,11 & - \\
\hline & PDMA & 107,52 & 106,37 & 105,07 & 105,69 & 107,09 & 108,38 & 110,48 & 112,91 & 116,37 & 120,45 & 126,04 & - \\
\hline \multirow[t]{3}{*}{$\Delta \mathrm{CS}$} & $\mathrm{DM}$ & 64,64 & 56,83 & 50,62 & 45,92 & 42,46 & 39,92 & 37,85 & 35,89 & 33,51 & 29,69 & 22,38 & - \\
\hline & DMA & 47,62 & 45,74 & 44,60 & 47,08 & 50,14 & 53,24 & 56,59 & 61,41 & 66,35 & 73,26 & 84,10 & - \\
\hline & PDMA & $-18,38$ & $-11,18$ & $-3,05$ & 5,20 & 13,04 & 21,47 & 29,90 & 39,18 & 48,37 & 58,14 & 68,32 & - \\
\hline
\end{tabular}


Tabela 8.68: Constantes de acoplamento M06 com correção vibracional no nível BHandH $40 \% E_{X}^{\mathrm{HF}}$ e base aug-pcJ-2.

\begin{tabular}{|c|c|c|c|c|c|c|c|c|c|c|c|c|c|}
\hline & $\% E_{X}^{\mathrm{HF}}$ & $0 \%$ & $10 \%$ & $20 \%$ & $30 \%$ & $40 \%$ & $50 \%$ & $60 \%$ & $70 \%$ & $80 \%$ & $90 \%$ & $100 \%$ & Exp. \\
\hline $\mathrm{HF}$ & ${ }^{1} J_{\mathrm{HF}}$ & 558,6 & 586,9 & 619,4 & 656,9 & 700,2 & 749,7 & 805,4 & 867,3 & 934,6 & 1006,3 & 1080,7 & 500 \\
\hline $\mathrm{CO}$ & ${ }^{1} J_{\mathrm{CO}}$ & 17,7 & 18,4 & 18,7 & 18,6 & 17,8 & 16,2 & 13,8 & 10,3 & 5,8 & 0,0 & $-7,1$ & 16,4 \\
\hline $\mathrm{H}_{2} \mathrm{O}$ & ${ }^{1} J_{\mathrm{OH}}$ & $-84,8$ & $-89,4$ & $-94,9$ & $-101,5$ & $-109,4$ & $-118,8$ & $-130,0$ & $-143,3$ & $-159,0$ & $-177,7$ & $-199,9$ & $-80,6$ \\
\hline $\mathrm{H}_{2} \mathrm{O}$ & ${ }^{2} J_{\mathrm{HH}}$ & $-4,3$ & $-7,7$ & $-11,9$ & $-17,0$ & $-23,4$ & $-31,4$ & $-41,3$ & $-53,5$ & $-68,8$ & $-87,9$ & $-111,6$ & $-7,3$ \\
\hline $\mathrm{NH}_{3}$ & ${ }^{1} J_{\mathrm{NH}}$ & 43,9 & 46,8 & 50,3 & 54,4 & 59,3 & 65,1 & 72,3 & 81,0 & 91,8 & 105,4 & 122,9 & 43,8 \\
\hline $\mathrm{NH}_{3}$ & ${ }^{2} J_{\mathrm{HH}}$ & $-6,7$ & $-9,8$ & $-13,7$ & $-18,8$ & $-25,4$ & $-34,1$ & $-45,6$ & $-61,1$ & $-82,2$ & $-111,4$ & $-153,0$ & $-9,6$ \\
\hline $\mathrm{PH}_{3}$ & ${ }^{1} J_{\mathrm{PH}}$ & 192,0 & 207,1 & 225,2 & 247,2 & 274,3 & 307,8 & 350,2 & 404,5 & 475,9 & 570,4 & 694,0 & 188,2 \\
\hline $\mathrm{PF}_{3}$ & ${ }^{1} J_{\mathrm{PF}}$ & $-1435,4$ & $-1474,8$ & $-1507,1$ & $-1531,8$ & $-1550,4$ & $-1565,3$ & $-1577,7$ & $-1586,4$ & $-1589,2$ & $-1584,3$ & $-1571,6$ & -1441 \\
\hline $\mathrm{BHF}_{2}$ & ${ }^{1} J_{\mathrm{BF}}$ & $-71,8$ & $-62,4$ & $-50,5$ & $-36,0$ & $-19,2$ & $-0,8$ & 18,4 & 37,2 & 54,2 & 67,1 & 71,1 & -84 \\
\hline $\mathrm{BF}_{3}$ & ${ }^{1} J_{\mathrm{BF}}$ & 24,8 & 36,9 & 51,2 & 68,0 & 87,5 & 109,3 & 133,0 & 157,9 & 183,4 & 209,2 & 235,5 & 15 \\
\hline $\mathrm{F}_{2} \mathrm{O}$ & ${ }^{1} J_{\mathrm{OF}}$ & $-174,2$ & $-224,2$ & $-279,0$ & $-341,3$ & $-419,2$ & $-543,1$ & $-988,8$ & 4254,7 & $-28,6$ & $-235,4$ & $-333,9$ & -300 \\
\hline $\mathrm{CH}_{4}$ & ${ }^{1} J_{\mathrm{CH}}$ & 105,6 & 117,0 & 130,7 & 147,1 & 167,1 & 191,6 & 222,2 & 261,2 & 312,2 & 381,3 & 479,7 & 125,3 \\
\hline $\mathrm{CH}_{4}$ & ${ }^{2} J_{\mathrm{HH}}$ & $-12,9$ & $-16,9$ & $-21,8$ & $-28,2$ & $-36,6$ & $-47,6$ & $-62,5$ & $-83,1$ & $-112,6$ & $-156,5$ & $-225,4$ & $-12,8$ \\
\hline $\mathrm{C}_{2} \mathrm{H}_{2}$ & ${ }^{1} J_{\mathrm{CC}}$ & 162,1 & 171,1 & 182,9 & 199,9 & 227,8 & 285,8 & 502,7 & $-632,3$ & $-13,6$ & 128,6 & 5815,7 & 174,8 \\
\hline $\mathrm{C}_{2} \mathrm{H}_{2}$ & ${ }^{1} J_{\mathrm{CH}}$ & 211,9 & 240,4 & 274,4 & 316,2 & 370,8 & 453,5 & 664,3 & $-163,7$ & 363,8 & 498,4 & $-158,8$ & 247,6 \\
\hline $\mathrm{C}_{2} \mathrm{H}_{2}$ & ${ }^{2} J_{\mathrm{CH}}$ & 50,1 & 51,7 & 52,0 & 49,4 & 40,0 & 9,4 & $-140,7$ & 758,7 & 315,8 & 283,2 & 1065,4 & 50,1 \\
\hline $\mathrm{C}_{2} \mathrm{H}_{2}$ & ${ }^{3} J_{\mathrm{HH}}$ & 8,1 & 10,2 & 13,7 & 19,8 & 31,7 & 60,8 & 184,5 & $-514,3$ & $-157,8$ & $-116,8$ & $-1,8$ & 9,6 \\
\hline $\mathrm{C}_{2} \mathrm{H}_{4}$ & ${ }^{1} J_{\mathrm{CC}}$ & 51,5 & 55,0 & 60,0 & 68,1 & 83,5 & 126,4 & 1247,5 & $-63,6$ & $-9,7$ & 6,9 & 14,2 & 67,6 \\
\hline $\mathrm{C}_{2} \mathrm{H}_{4}$ & ${ }^{1} J_{\mathrm{CH}}$ & 132,1 & 148,7 & 168,7 & 193,6 & 227,0 & 284,0 & 1106,5 & 220,6 & 306,3 & 378,0 & 460,2 & 156,3 \\
\hline $\mathrm{C}_{2} \mathrm{H}_{4}$ & ${ }^{2} J_{\mathrm{CH}}$ & 0,4 & $-1,2$ & $-3,8$ & $-8,4$ & $-18,0$ & $-46,6$ & $-835,2$ & 91,6 & 56,6 & 48,5 & 48,3 & $-2,4$ \\
\hline $\mathrm{C}_{2} \mathrm{H}_{4}$ & ${ }^{2} J_{\mathrm{HH}}$ & $-3,1$ & $-5,6$ & $-9,3$ & $-15,3$ & $-26,4$ & $-56,1$ & $-791,7$ & 62,1 & 21,3 & 1,9 & $-16,2$ & 2,3 \\
\hline $\mathrm{C}_{2} \mathrm{H}_{4}$ & ${ }^{3} J_{\mathrm{HH}_{\mathrm{C}}}$ & 11,3 & 12,8 & 15,0 & 18,9 & 27,1 & 52,8 & 782,9 & $-78,6$ & $-48,8$ & $-45,1$ & $-50,5$ & 11,7 \\
\hline $\mathrm{C}_{2} \mathrm{H}_{4}$ & ${ }^{3} J_{\mathrm{HH}_{\mathrm{t}}}$ & 12,6 & 15,1 & 18,6 & 24,0 & 34,2 & 62,9 & 821,6 & $-67,4$ & $-32,2$ & $-22,8$ & $-20,7$ & 19 \\
\hline $\mathrm{C}_{2} \mathrm{H}_{6}$ & ${ }^{1} J_{\mathrm{CC}}$ & 20,9 & 23,7 & 27,2 & 31,6 & 37,2 & 44,3 & 53,7 & 66,5 & 84,4 & 110,9 & 153,0 & 34,5 \\
\hline $\mathrm{C}_{2} \mathrm{H}_{6}$ & ${ }^{1} J_{\mathrm{CH}}$ & 103,0 & 115,0 & 129,2 & 146,3 & 167,1 & 192,5 & 224,2 & 264,7 & 317,8 & 390,5 & 495,6 & 125,2 \\
\hline $\mathrm{C}_{2} \mathrm{H}_{6}$ & ${ }^{2} J_{\mathrm{CH}}$ & $-1,6$ & $-2,8$ & $-4,4$ & $-6,4$ & $-9,0$ & $-12,5$ & $-17,4$ & $-24,5$ & $-35,0$ & $-51,8$ & $-80,6$ & $-4,7$ \\
\hline \multirow[t]{3}{*}{ Total } & $\mathrm{DM}$ & 2,57 & 4,50 & 7,53 & 11,93 & 18,10 & 27,34 & 104,90 & 162,37 & 51,59 & 67,38 & 306,16 & - \\
\hline & DMA & 15,05 & 13,69 & 17,25 & 28,57 & 46,70 & 76,59 & 322,40 & 351,00 & 132,07 & 141,40 & 416,55 & - \\
\hline & PDMA & 31,74 & 32,47 & 48,78 & 87,00 & 154,58 & 310,75 & 3388,37 & 805,54 & 464,62 & 464,75 & 735,37 & - \\
\hline \multirow[t]{3}{*}{ CPI } & DM & 19,90 & 16,99 & 15,16 & 14,35 & 13,75 & 10,34 & $-21,02$ & 466,15 & 88,82 & 83,71 & 89,65 & - \\
\hline & DMA & 20,66 & 24,85 & 31,36 & 45,60 & 66,35 & 92,95 & 151,25 & 522,86 & 156,33 & 163,56 & 190,56 & - \\
\hline & PDMA & 20,05 & 24,02 & 44,42 & 71,41 & 105,31 & 146,68 & 207,07 & 380,27 & 317,99 & 394,18 & 495,85 & - \\
\hline \multirow[t]{3}{*}{ SPI } & $\mathrm{DM}$ & $-10,14$ & $-4,66$ & 1,93 & 10,17 & 21,29 & 39,81 & 197,23 & $-60,41$ & 24,29 & 55,41 & 464,93 & - \\
\hline & DMA & 10,93 & 5,51 & 6,91 & 16,07 & 32,29 & 64,59 & 447,90 & 224,96 & 114,28 & 125,15 & 582,28 & - \\
\hline & PDMA & 40,32 & 38,66 & 51,97 & 98,44 & 190,72 & 431,06 & 5721,33 & 1117,40 & 572,14 & 516,50 & 911,02 & - \\
\hline \multirow[t]{3}{*}{$\Delta \mathrm{CS}$} & $\mathrm{DM}$ & 30,04 & 21,65 & 13,23 & 4,18 & $-7,55$ & $-29,47$ & $-218,25$ & 526,57 & 64,52 & 28,30 & $-375,28$ & - \\
\hline & DMA & 9,74 & 19,33 & 24,46 & 29,53 & 34,05 & 28,36 & $-296,65$ & 297,90 & 42,05 & 38,41 & $-391,72$ & - \\
\hline & PDMA & $-20,26$ & $-14,64$ & $-7,54$ & $-27,02$ & $-85,41$ & $-284,39$ & $-5514,26$ & $-737,14$ & $-254,15$ & $-122,31$ & $-415,18$ & - \\
\hline
\end{tabular}


Tabela 8.69: Constantes de acoplamento M062X com correção vibracional no nível BHandH $40 \% E_{X}^{\mathrm{HF}}$ e base aug-pcJ-2.

\begin{tabular}{|c|c|c|c|c|c|c|c|c|c|c|c|c|c|}
\hline & $\% E_{X}^{\mathrm{HF}}$ & $0 \%$ & $10 \%$ & $20 \%$ & $30 \%$ & $40 \%$ & $50 \%$ & $60 \%$ & $70 \%$ & $80 \%$ & $90 \%$ & $100 \%$ & Exp. \\
\hline $\mathrm{HF}$ & ${ }^{1} J_{\mathrm{HF}}$ & 412,7 & 416,2 & 420,2 & 425,9 & 434,2 & 446,3 & 463,2 & 486,0 & 515,7 & 553,2 & 599,4 & 500 \\
\hline $\mathrm{CO}$ & ${ }^{1} J_{\mathrm{CO}}$ & 4,5 & 5,5 & 6,5 & 7,4 & 8,0 & 8,2 & 7,9 & 6,8 & 4,5 & 0,6 & $-6,0$ & 16,4 \\
\hline $\mathrm{H}_{2} \mathrm{O}$ & ${ }^{1} J_{\mathrm{OH}}$ & $-72,2$ & $-74,4$ & $-77,0$ & $-80,1$ & $-83,8$ & $-88,3$ & $-93,8$ & $-100,5$ & $-108,6$ & $-118,3$ & $-130,1$ & $-80,6$ \\
\hline $\mathrm{H}_{2} \mathrm{O}$ & ${ }^{2} J_{\mathrm{HH}}$ & 5,6 & 4,4 & 2,9 & 1,1 & $-1,3$ & $-4,3$ & $-8,1$ & $-13,0$ & $-19,1$ & $-26,8$ & $-36,7$ & $-7,3$ \\
\hline $\mathrm{NH}_{3}$ & ${ }^{1} J_{\mathrm{NH}}$ & 38,9 & 40,9 & 43,1 & 45,7 & 48,7 & 52,3 & 56,6 & 61,6 & 67,6 & 74,9 & 83,8 & 43,8 \\
\hline $\mathrm{NH}_{3}$ & ${ }^{2} J_{\mathrm{HH}}$ & 1,1 & 0,2 & $-1,2$ & $-3,1$ & $-5,5$ & $-8,6$ & $-12,7$ & $-18,0$ & $-25,0$ & $-34,3$ & $-46,7$ & $-9,6$ \\
\hline $\mathrm{PH}_{3}$ & ${ }^{1} J_{\mathrm{PH}}$ & 125,7 & 126,9 & 130,0 & 135,4 & 143,3 & 154,3 & 168,8 & 187,8 & 211,9 & 242,7 & 282,2 & 188,2 \\
\hline $\mathrm{PF}_{3}$ & ${ }^{1} J_{\mathrm{PF}}$ & $-1440,5$ & $-1487,0$ & $-1531,5$ & $-1571,2$ & $-1601,9$ & $-1620,2$ & $-1625,8$ & $-1621,2$ & $-1611,0$ & $-1600,9$ & $-1594,9$ & -1441 \\
\hline $\mathrm{BHF}_{2}$ & ${ }^{1} J_{\mathrm{BF}}$ & $-171,3$ & $-167,8$ & $-160,9$ & $-151,2$ & $-139,6$ & $-126,6$ & $-112,2$ & $-96,8$ & $-80,4$ & $-63,3$ & $-45,9$ & -84 \\
\hline $\mathrm{BF}_{3}$ & ${ }^{1} J_{\mathrm{BF}}$ & $-91,5$ & $-82,4$ & $-71,1$ & $-58,2$ & $-43,9$ & $-28,6$ & $-12,2$ & 5,3 & 24,5 & 45,6 & 68,7 & 15 \\
\hline $\mathrm{F}_{2} \mathrm{O}$ & ${ }^{1} J_{\mathrm{OF}}$ & $-169,7$ & $-212,8$ & $-259,3$ & $-308,9$ & $-361,5$ & $-418,0$ & $-481,9$ & $-563,2$ & $-698,2$ & $-1318,3$ & $-2175,4$ & -300 \\
\hline $\mathrm{CH}_{4}$ & ${ }^{1} J_{\mathrm{CH}}$ & 88,7 & 96,0 & 104,4 & 114,4 & 126,0 & 139,8 & 156,2 & 175,9 & 199,7 & 228,9 & 265,2 & 125,3 \\
\hline $\mathrm{CH}_{4}$ & ${ }^{2} J_{\mathrm{HH}}$ & $-0,5$ & $-1,6$ & $-3,1$ & $-5,1$ & $-7,6$ & $-10,8$ & $-15,0$ & $-20,4$ & $-27,6$ & $-37,1$ & $-49,9$ & $-12,8$ \\
\hline $\mathrm{C}_{2} \mathrm{H}_{2}$ & ${ }^{1} J_{\mathrm{CC}}$ & 168,1 & 175,1 & 183,3 & 193,0 & 205,0 & 220,5 & 241,9 & 274,3 & 332,1 & 473,2 & 1542,5 & 174,8 \\
\hline $\mathrm{C}_{2} \mathrm{H}_{2}$ & ${ }^{1} J_{\mathrm{CH}}$ & 145,5 & 162,5 & 182,0 & 204,2 & 229,8 & 259,8 & 295,5 & 339,9 & 400,1 & 503,6 & 1040,3 & 247,6 \\
\hline $\mathrm{C}_{2} \mathrm{H}_{2}$ & ${ }^{2} J_{\mathrm{CH}}$ & 47,1 & 49,5 & 52,0 & 54,3 & 56,2 & 57,3 & 56,6 & 52,1 & 37,2 & $-14,2$ & $-491,0$ & 50,1 \\
\hline $\mathrm{C}_{2} \mathrm{H}_{2}$ & ${ }^{3} J_{\mathrm{HH}}$ & 4,8 & 5,3 & 5,8 & 6,5 & 7,5 & 9,0 & 11,4 & 15,9 & 25,3 & 51,9 & 274,9 & 9,6 \\
\hline $\mathrm{C}_{2} \mathrm{H}_{4}$ & ${ }^{1} J_{\mathrm{CC}}$ & 60,9 & 63,7 & 67,4 & 72,1 & 78,4 & 87,1 & 99,9 & 121,1 & 162,7 & 285,2 & 14163,5 & 67,6 \\
\hline $\mathrm{C}_{2} \mathrm{H}_{4}$ & ${ }^{1} J_{\mathrm{CH}}$ & 101,0 & 111,1 & 122,7 & 136,2 & 152,0 & 170,8 & 193,8 & 223,1 & 265,0 & 347,4 & 6657,9 & 156,3 \\
\hline $\mathrm{C}_{2} \mathrm{H}_{4}$ & ${ }^{2} J_{\mathrm{CH}}$ & 6,0 & 5,3 & 4,4 & 3,2 & 1,4 & $-1,3$ & $-5,7$ & $-13,5$ & $-30,4$ & $-83,4$ & $-6359,2$ & $-2,4$ \\
\hline $\mathrm{C}_{2} \mathrm{H}_{4}$ & ${ }^{2} J_{\mathrm{HH}}$ & 7,3 & 7,3 & 7,1 & 6,7 & 6,0 & 4,7 & 2,5 & $-1,5$ & $-10,1$ & $-36,7$ & $-3080,1$ & 2,3 \\
\hline $\mathrm{C}_{2} \mathrm{H}_{4}$ & ${ }^{3} J_{\mathrm{HH}_{\mathrm{c}}}$ & 9,4 & 9,8 & 10,2 & 10,8 & 11,5 & 12,6 & 14,4 & 17,7 & 25,1 & 49,8 & 3090,5 & 11,7 \\
\hline $\mathrm{C}_{2} \mathrm{H}_{4}$ & ${ }^{3} J_{\mathrm{HH}_{\mathrm{t}}}{ }^{\mathrm{C}}$ & 9,9 & 11,2 & 12,5 & 14,1 & 15,9 & 18,2 & 21,3 & 26,4 & 36,0 & 64,3 & 3278,6 & 19 \\
\hline $\mathrm{C}_{2} \mathrm{H}_{6}$ & ${ }^{1} J_{\mathrm{CC}}$ & 28,2 & 30,7 & 33,8 & 37,4 & 41,9 & 47,2 & 53,8 & 62,0 & 72,3 & 85,6 & 103,0 & 34,5 \\
\hline $\mathrm{C}_{2} \mathrm{H}_{6}$ & ${ }^{1} J_{\mathrm{CH}}$ & 85,8 & 93,5 & 102,6 & 113,2 & 125,6 & 140,2 & 157,6 & 178,4 & 203,5 & 234,4 & 272,8 & 125,2 \\
\hline $\mathrm{C}_{2} \mathrm{H}_{6}$ & ${ }^{2} J_{\mathrm{CH}}$ & 2,0 & 1,3 & 0,5 & $-0,4$ & $-1,7$ & $-3,2$ & $-5,2$ & $-7,7$ & $-11,0$ & $-15,5$ & $-21,9$ & $-4,7$ \\
\hline \multirow[t]{3}{*}{ Total } & $\mathrm{DM}$ & $-16,83$ & $-17,48$ & $-17,60$ & $-16,98$ & $-15,40$ & $-12,56$ & $-8,32$ & $-2,56$ & 4,49 & 1,83 & 686,17 & - \\
\hline & DMA & 31,84 & 28,65 & 25,28 & 22,30 & 22,04 & 25,00 & 30,91 & 39,70 & 59,08 & 116,85 & 1624,81 & - \\
\hline & PDMA & 91,90 & 83,06 & 72,49 & 61,16 & 48,46 & 35,08 & 35,52 & 67,77 & 140,52 & 346,80 & 18291,68 & - \\
\hline \multirow[t]{3}{*}{ CPI } & $\mathrm{DM}$ & $-17,96$ & $-24,65$ & $-30,84$ & $-36,19$ & $-40,38$ & $-43,13$ & $-44,65$ & $-46,01$ & $-50,82$ & $-98,71$ & $-167,50$ & - \\
\hline & DMA & 47,56 & 45,55 & 42,27 & 39,34 & 43,11 & 45,40 & 46,97 & 49,25 & 64,69 & 133,27 & 226,63 & - \\
\hline & PDMA & 117,31 & 106,71 & 93,27 & 78,68 & 65,35 & 50,22 & 40,61 & 42,96 & 64,69 & 123,39 & 198,87 & - \\
\hline \multirow[t]{3}{*}{ SPI } & $\mathrm{DM}$ & $-15,99$ & $-12,23$ & $-7,90$ & $-2,90$ & 2,92 & 9,85 & 18,33 & 29,31 & 45,05 & 75,55 & 1312,20 & - \\
\hline & DMA & 20,31 & 16,25 & 12,82 & 9,81 & 6,59 & 10,04 & 19,13 & 32,71 & 54,97 & 104,81 & 2650,15 & - \\
\hline & PDMA & 73,26 & 65,71 & 57,25 & 48,31 & 36,08 & 23,99 & 31,79 & 85,96 & 196,14 & 510,64 & 31559,74 & - \\
\hline \multirow[t]{3}{*}{$\Delta \mathrm{CS}$} & $\mathrm{DM}$ & $-1,97$ & $-12,43$ & $-22,94$ & $-33,29$ & $-43,30$ & $-52,98$ & $-62,97$ & $-75,32$ & $-95,87$ & $-174,26$ & $-1479,70$ & - \\
\hline & DMA & 27,25 & 29,29 & 29,45 & 29,53 & 36,52 & 35,36 & 27,85 & 16,54 & 9,72 & 28,47 & $-2423,52$ & - \\
\hline & PDMA & 44,05 & 41,00 & 36,02 & 30,38 & 29,26 & 26,23 & 8,82 & $-43,00$ & $-131,45$ & $-387,25$ & $-31360,87$ & - \\
\hline
\end{tabular}


Tabela 8.70: Constantes de acoplamento OLYP com correção vibracional no nível BHandH $40 \% E_{X}^{\mathrm{HF}}$ e base aug-pcJ-2.

\begin{tabular}{|c|c|c|c|c|c|c|c|c|c|c|c|c|c|}
\hline & $\% E_{X}^{\mathrm{HF}}$ & $0 \%$ & $10 \%$ & $20 \%$ & $30 \%$ & $40 \%$ & $50 \%$ & $60 \%$ & $70 \%$ & $80 \%$ & $90 \%$ & $100 \%$ & Exp. \\
\hline $\mathrm{HF}$ & ${ }^{1} J_{\mathrm{HF}}$ & 330,2 & 358,4 & 386,9 & 415,9 & 445,3 & 475,0 & 505,2 & 535,7 & 566,5 & 597,7 & 629,3 & 500 \\
\hline $\mathrm{CO}$ & ${ }^{1} J_{\mathrm{CO}}$ & 24,8 & 22,6 & 20,3 & 17,9 & 15,4 & 12,8 & 10,2 & 7,4 & 4,6 & 1,7 & $-1,1$ & 16,4 \\
\hline $\mathrm{H}_{2} \mathrm{O}$ & ${ }^{1} J_{\mathrm{OH}}$ & $-64,9$ & $-68,2$ & $-71,5$ & $-74,9$ & $-78,3$ & $-81,8$ & $-85,3$ & $-88,9$ & $-92,5$ & $-96,1$ & $-99,9$ & $-80,6$ \\
\hline $\mathrm{H}_{2} \mathrm{O}$ & ${ }^{2} J_{\mathrm{HH}}$ & $-6,0$ & $-6,9$ & $-7,9$ & $-8,8$ & $-9,7$ & $-10,7$ & $-11,7$ & $-12,7$ & $-13,8$ & $-14,8$ & $-15,9$ & $-7,3$ \\
\hline $\mathrm{NH}_{3}$ & ${ }^{1} J_{\mathrm{NH}}$ & 40,9 & 42,2 & 43,4 & 44,7 & 46,0 & 47,3 & 48,6 & 50,0 & 51,3 & 52,7 & 54,1 & 43,8 \\
\hline $\mathrm{NH}_{3}$ & ${ }^{2} J_{\mathrm{HH}}$ & $-8,7$ & $-9,5$ & $-10,4$ & $-11,2$ & $-12,1$ & $-13,0$ & $-13,9$ & $-14,8$ & $-15,8$ & $-16,8$ & $-17,8$ & $-9,6$ \\
\hline $\mathrm{PH}_{3}$ & ${ }^{1} J_{\mathrm{PH}}$ & 151,5 & 160,2 & 168,8 & 177,2 & 185,5 & 193,7 & 201,7 & 209,5 & 217,2 & 224,6 & 231,9 & 188,2 \\
\hline $\mathrm{PF}_{3}$ & ${ }^{1} J_{\mathrm{PF}}$ & $-1700,4$ & $-1683,9$ & $-1663,6$ & $-1640,2$ & $-1614,4$ & $-1586,7$ & $-1557,6$ & $-1527,6$ & $-1497,0$ & $-1466,1$ & $-1435,2$ & -1441 \\
\hline $\mathrm{BHF}_{2}$ & ${ }^{1} J_{\mathrm{BF}}$ & $-185,9$ & $-165,3$ & $-145,2$ & $-125,6$ & $-106,5$ & $-88,0$ & $-70,1$ & $-52,7$ & $-35,9$ & $-19,6$ & $-3,9$ & -84 \\
\hline $\mathrm{BF}_{3}$ & ${ }^{1} J_{\mathrm{BF}}$ & $-92,7$ & $-69,6$ & $-47,2$ & $-25,3$ & $-4,0$ & 16,6 & 36,7 & 56,2 & 75,2 & 93,6 & 111,6 & 15 \\
\hline $\mathrm{F}_{2} \mathrm{O}$ & ${ }^{1} J_{\mathrm{OF}}$ & $-267,7$ & $-304,0$ & $-341,0$ & $-380,2$ & $-423,7$ & $-474,9$ & $-539,6$ & $-629,6$ & $-773,7$ & $-1069,7$ & $-2266,9$ & -300 \\
\hline $\mathrm{CH}_{4}$ & ${ }^{1} J_{\mathrm{CH}}$ & 120,5 & 123,4 & 126,4 & 129,4 & 132,5 & 135,6 & 138,7 & 141,9 & 145,2 & 148,4 & 151,7 & 125,3 \\
\hline $\mathrm{CH}_{4}$ & ${ }^{2} J_{\mathrm{HH}}$ & $-13,2$ & $-13,8$ & $-14,5$ & $-15,2$ & $-15,9$ & $-16,6$ & $-17,3$ & $-18,0$ & $-18,7$ & $-19,4$ & $-20,0$ & $-12,8$ \\
\hline $\mathrm{C}_{2} \mathrm{H}_{2}$ & ${ }^{1} J_{\mathrm{CC}}$ & 187,8 & 192,4 & 197,5 & 203,0 & 209,2 & 216,1 & 223,9 & 232,7 & 242,9 & 254,8 & 268,8 & 174,8 \\
\hline $\mathrm{C}_{2} \mathrm{H}_{2}$ & ${ }^{1} J_{\mathrm{CH}}$ & 256,5 & 261,2 & 266,1 & 271,1 & 276,3 & 281,8 & 287,7 & 294,0 & 300,8 & 308,2 & 316,6 & 247,6 \\
\hline $\mathrm{C}_{2} \mathrm{H}_{2}$ & ${ }^{2} J_{\mathrm{CH}}$ & 53,4 & 53,4 & 53,2 & 52,8 & 52,1 & 51,1 & 49,7 & 48,0 & 45,6 & 42,5 & 38,5 & 50,1 \\
\hline $\mathrm{C}_{2} \mathrm{H}_{2}$ & ${ }^{3} J_{\mathrm{HH}}$ & 12,1 & 12,7 & 13,4 & 14,2 & 15,2 & 16,4 & 17,8 & 19,4 & 21,4 & 23,7 & 26,5 & 9,6 \\
\hline $\mathrm{C}_{2} \mathrm{H}_{4}$ & ${ }^{1} J_{\mathrm{CC}}$ & 61,2 & 65,0 & 69,1 & 73,6 & 78,6 & 84,3 & 90,9 & 98,8 & 108,5 & 121,3 & 139,4 & 67,6 \\
\hline $\mathrm{C}_{2} \mathrm{H}_{4}$ & ${ }^{1} J_{\mathrm{CH}}$ & 154,5 & 158,3 & 162,2 & 166,2 & 170,4 & 174,9 & 179,7 & 185,0 & 191,1 & 198,3 & 207,5 & 156,3 \\
\hline $\mathrm{C}_{2} \mathrm{H}_{4}$ & ${ }^{2} J_{\mathrm{CH}}$ & $-1,4$ & $-2,3$ & $-3,4$ & $-4,6$ & $-5,9$ & $-7,5$ & $-9,5$ & $-11,9$ & $-15,1$ & $-19,4$ & $-25,7$ & $-2,4$ \\
\hline $\mathrm{C}_{2} \mathrm{H}_{4}$ & ${ }^{2} J_{\mathrm{HH}}$ & 3,7 & 3,1 & 2,5 & 1,8 & 1,1 & 0,3 & $-0,8$ & $-2,0$ & $-3,6$ & $-5,8$ & $-9,0$ & 2,3 \\
\hline $\mathrm{C}_{2} \mathrm{H}_{4}$ & ${ }^{3} J_{\mathrm{HH}_{\mathrm{c}}}$ & 12,5 & 12,9 & 13,4 & 13,9 & 14,5 & 15,2 & 16,1 & 17,3 & 18,8 & 20,9 & 24,0 & 11,7 \\
\hline $\mathrm{C}_{2} \mathrm{H}_{4}$ & ${ }^{3} J_{\mathrm{HH}_{\mathrm{t}}}$ & 19,9 & 20,3 & 20,8 & 21,5 & 22,2 & 23,1 & 24,1 & 25,5 & 27,3 & 29,8 & 33,4 & 19 \\
\hline $\mathrm{C}_{2} \mathrm{H}_{6}$ & ${ }^{1} J_{\mathrm{CC}}$ & 26,2 & 28,7 & 31,2 & 33,8 & 36,4 & 39,2 & 41,9 & 44,7 & 47,6 & 50,5 & 53,5 & 34,5 \\
\hline $\mathrm{C}_{2} \mathrm{H}_{6}$ & ${ }^{1} J_{\mathrm{CH}}$ & 120,2 & 123,3 & 126,4 & 129,6 & 132,8 & 136,0 & 139,3 & 142,6 & 145,9 & 149,3 & 152,7 & 125,2 \\
\hline $\mathrm{C}_{2} \mathrm{H}_{6}$ & ${ }^{2} J_{\mathrm{CH}}$ & $-3,5$ & $-3,9$ & $-4,3$ & $-4,7$ & $-5,2$ & $-5,6$ & $-6,1$ & $-6,6$ & $-7,0$ & $-7,5$ & $-8,0$ & $-4,7$ \\
\hline \multirow[t]{3}{*}{ Total } & $\mathrm{DM}$ & $-23,60$ & $-20,55$ & $-17,40$ & $-14,20$ & $-11,05$ & $-8,09$ & $-5,57$ & $-3,89$ & $-4,16$ & $-10,08$ & $-50,34$ & - \\
\hline & DMA & 30,64 & 25,39 & 23,16 & 21,60 & 20,51 & 20,60 & 24,61 & 32,04 & 41,79 & 57,75 & 109,44 & - \\
\hline & PDMA & 48,27 & 36,38 & 30,07 & 27,08 & 26,99 & 30,09 & 46,17 & 64,58 & 86,04 & 112,87 & 157,28 & - \\
\hline \multirow[t]{3}{*}{ CPI } & $\mathrm{DM}$ & $-56,35$ & $-51,35$ & $-46,21$ & $-41,04$ & $-36,13$ & $-31,87$ & $-28,79$ & $-28,04$ & $-32,25$ & $-50,34$ & $-150,43$ & - \\
\hline & DMA & 67,00 & 54,83 & 48,57 & 42,51 & 36,95 & 33,80 & 39,54 & 52,71 & 70,67 & 102,34 & 216,94 & - \\
\hline & PDMA & 93,28 & 71,41 & 54,74 & 39,72 & 26,54 & 18,65 & 37,91 & 59,43 & 82,41 & 109,53 & 163,81 & - \\
\hline \multirow[t]{3}{*}{ SPI } & $\mathrm{DM}$ & 0,42 & 2,04 & 3,73 & 5,49 & 7,35 & 9,35 & 11,47 & 13,82 & 16,44 & 19,43 & 23,05 & - \\
\hline & DMA & 3,98 & 3,80 & 4,53 & 6,26 & 8,45 & 10,92 & 13,67 & 16,89 & 20,61 & 25,05 & 30,61 & - \\
\hline & PDMA & 15,26 & 10,69 & 11,99 & 17,80 & 27,32 & 38,48 & 52,22 & 68,35 & 88,71 & 115,32 & 152,50 & - \\
\hline \multirow[t]{3}{*}{$\Delta \mathrm{CS}$} & $\mathrm{DM}$ & $-56,77$ & $-53,39$ & $-49,94$ & $-46,52$ & $-43,47$ & $-41,22$ & $-40,26$ & $-41,86$ & $-48,69$ & $-69,77$ & $-173,48$ & - \\
\hline & DMA & 63,02 & 51,03 & 44,05 & 36,25 & 28,49 & 22,88 & 25,87 & 35,82 & 50,06 & 77,29 & 186,32 & - \\
\hline & PDMA & 78,01 & 60,73 & 42,75 & 21,91 & $-0,78$ & $-19,82$ & $-14,31$ & $-8,92$ & $-6,29$ & $-5,79$ & 11,31 & - \\
\hline
\end{tabular}


Tabela 8.71: Constantes de acoplamento PBE com correção vibracional no nível BHandH $40 \% E_{X}^{\mathrm{HF}}$ e base aug-pcJ-2.

\begin{tabular}{|c|c|c|c|c|c|c|c|c|c|c|c|c|c|}
\hline & $\% E_{X}^{\mathrm{HF}}$ & $0 \%$ & $10 \%$ & $20 \%$ & $30 \%$ & $40 \%$ & $50 \%$ & $60 \%$ & $70 \%$ & $80 \%$ & $90 \%$ & $100 \%$ & Exp. \\
\hline $\mathrm{HF}$ & ${ }^{1} J_{\mathrm{HF}}$ & 342,8 & 364,6 & 386,5 & 408,7 & 431,1 & 453,7 & 476,6 & 499,6 & 522,9 & 546,4 & 570,1 & 500 \\
\hline $\mathrm{CO}$ & ${ }^{1} J_{\mathrm{CO}}$ & 24,9 & 23,3 & 21,6 & 19,9 & 18,1 & 16,2 & 14,3 & 12,3 & 10,3 & 8,2 & 6,1 & 16,4 \\
\hline $\mathrm{H}_{2} \mathrm{O}$ & ${ }^{1} J_{\mathrm{OH}}$ & $-66,0$ & $-68,3$ & $-70,6$ & $-73,0$ & $-75,4$ & $-77,8$ & $-80,2$ & $-82,7$ & $-85,2$ & $-87,7$ & $-90,3$ & $-80,6$ \\
\hline $\mathrm{H}_{2} \mathrm{O}$ & ${ }^{2} J_{\mathrm{HH}}$ & $-3,3$ & $-4,3$ & $-5,3$ & $-6,4$ & $-7,5$ & $-8,6$ & $-9,7$ & $-10,9$ & $-12,1$ & $-13,3$ & $-14,5$ & $-7,3$ \\
\hline $\mathrm{NH}_{3}$ & ${ }^{1} J_{\mathrm{NH}}$ & 41,5 & 42,2 & 42,9 & 43,6 & 44,3 & 45,0 & 45,8 & 46,5 & 47,3 & 48,1 & 48,9 & 43,8 \\
\hline $\mathrm{NH}_{3}$ & ${ }^{2} J_{\mathrm{HH}}$ & $-6,9$ & $-7,8$ & $-8,7$ & $-9,7$ & $-10,6$ & $-11,6$ & $-12,6$ & $-13,6$ & $-14,6$ & $-15,7$ & $-16,7$ & $-9,6$ \\
\hline $\mathrm{PH}_{3}$ & ${ }^{1} J_{\mathrm{PH}}$ & 126,4 & 134,8 & 143,1 & 151,4 & 159,6 & 167,8 & 175,8 & 183,8 & 191,6 & 199,4 & 207,0 & 188,2 \\
\hline $\mathrm{PF}_{3}$ & ${ }^{1} J_{\mathrm{PF}}$ & $-1799,2$ & $-1775,1$ & $-1746,3$ & $-1713,5$ & $-1677,6$ & $-1639,0$ & $-1598,5$ & $-1556,3$ & $-1513,1$ & $-1469,1$ & $-1424,7$ & -1441 \\
\hline $\mathrm{BHF}_{2}$ & ${ }^{1} J_{\mathrm{BF}}$ & $-177,3$ & $-160,4$ & $-143,7$ & $-127,2$ & $-111,0$ & $-94,9$ & $-79,1$ & $-63,5$ & $-48,2$ & $-33,1$ & $-18,3$ & -84 \\
\hline $\mathrm{BF}_{3}$ & ${ }^{1} J_{\mathrm{BF}}$ & $-78,0$ & $-59,7$ & $-41,6$ & $-23,9$ & $-6,4$ & 10,7 & 27,7 & 44,4 & 60,8 & 77,0 & 93,0 & 15 \\
\hline $\mathrm{F}_{2} \mathrm{O}$ & ${ }^{1} J_{\mathrm{OF}}$ & $-291,1$ & $-329,4$ & $-368,0$ & $-408,7$ & $-453,6$ & $-506,6$ & $-573,9$ & $-668,6$ & $-822,3$ & $-1142,6$ & $-2466,3$ & -300 \\
\hline $\mathrm{CH}_{4}$ & ${ }^{1} J_{\mathrm{CH}}$ & 121,6 & 123,0 & 124,4 & 125,8 & 127,3 & 128,8 & 130,3 & 131,9 & 133,5 & 135,1 & 136,7 & 125,3 \\
\hline $\mathrm{CH}_{4}$ & ${ }^{2} J_{\mathrm{HH}}$ & $-12,1$ & $-12,9$ & $-13,7$ & $-14,5$ & $-15,3$ & $-16,1$ & $-16,9$ & $-17,7$ & $-18,5$ & $-19,3$ & $-20,1$ & $-12,8$ \\
\hline $\mathrm{C}_{2} \mathrm{H}_{2}$ & ${ }^{1} J_{\mathrm{CC}}$ & 189,1 & 191,9 & 195,0 & 198,7 & 203,0 & 208,0 & 214,1 & 221,4 & 230,6 & 242,3 & 257,5 & 174,8 \\
\hline $\mathrm{C}_{2} \mathrm{H}_{2}$ & ${ }^{1} J_{\mathrm{CH}}$ & 252,9 & 255,3 & 257,9 & 260,7 & 263,8 & 267,2 & 271,1 & 275,6 & 281,0 & 287,7 & 296,4 & 247,6 \\
\hline $\mathrm{C}_{2} \mathrm{H}_{2}$ & ${ }^{2} J_{\mathrm{CH}}$ & 54,5 & 54,5 & 54,1 & 53,6 & 52,6 & 51,3 & 49,4 & 46,9 & 43,3 & 38,5 & 31,6 & 50,1 \\
\hline $\mathrm{C}_{2} \mathrm{H}_{2}$ & ${ }^{3} J_{\mathrm{HH}}$ & 10,9 & 11,6 & 12,4 & 13,4 & 14,6 & 16,1 & 17,9 & 20,1 & 23,0 & 26,6 & 31,4 & 9,6 \\
\hline $\mathrm{C}_{2} \mathrm{H}_{4}$ & ${ }^{1} J_{\mathrm{CC}}$ & 61,7 & 64,4 & 67,4 & 70,8 & 74,8 & 79,5 & 85,4 & 93,2 & 104,0 & 120,7 & 151,1 & 67,6 \\
\hline $\mathrm{C}_{2} \mathrm{H}_{4}$ & ${ }^{1} J_{\mathrm{CH}}$ & 153,6 & 155,7 & 157,9 & 160,3 & 162,9 & 165,8 & 169,3 & 173,4 & 178,9 & 187,0 & 200,8 & 156,3 \\
\hline $\mathrm{C}_{2} \mathrm{H}_{4}$ & ${ }^{2} J_{\mathrm{CH}}$ & $-0,8$ & $-1,7$ & $-2,8$ & $-4,0$ & $-5,4$ & $-7,2$ & $-9,4$ & $-12,5$ & $-16,8$ & $-23,7$ & $-36,4$ & $-2,4$ \\
\hline $\mathrm{C}_{2} \mathrm{H}_{4}$ & ${ }^{2} J_{\mathrm{HH}}$ & 4,8 & 4,0 & 3,1 & 2,1 & 1,0 & $-0,2$ & $-1,8$ & $-3,8$ & $-6,7$ & $-11,1$ & $-19,1$ & 2,3 \\
\hline $\mathrm{C}_{2} \mathrm{H}_{4}$ & ${ }^{3} J_{\mathrm{HH}_{\mathrm{c}}}$ & 12,0 & 12,4 & 12,8 & 13,3 & 13,9 & 14,8 & 16,0 & 17,6 & 20,0 & 24,0 & 31,6 & 11,7 \\
\hline $\mathrm{C}_{2} \mathrm{H}_{4}$ & ${ }^{3} J_{\mathrm{HH}_{\mathrm{t}}}$ & 19,2 & 19,5 & 20,0 & 20,6 & 21,4 & 22,4 & 23,8 & 25,7 & 28,5 & 33,0 & 41,5 & 19 \\
\hline $\mathrm{C}_{2} \mathrm{H}_{6}$ & ${ }^{1} J_{\mathrm{CC}}$ & 26,5 & 28,4 & 30,2 & 32,1 & 34,1 & 36,0 & 38,0 & 40,1 & 42,1 & 44,2 & 46,4 & 34,5 \\
\hline $\mathrm{C}_{2} \mathrm{H}_{6}$ & ${ }^{1} J_{\mathrm{CH}}$ & 121,3 & 122,9 & 124,5 & 126,1 & 127,8 & 129,5 & 131,2 & 133,0 & 134,8 & 136,6 & 138,4 & 125,2 \\
\hline $\mathrm{C}_{2} \mathrm{H}_{6}$ & ${ }^{2} J_{\mathrm{CH}}$ & $-3,1$ & $-3,6$ & $-4,1$ & $-4,5$ & $-5,1$ & $-5,6$ & $-6,1$ & $-6,6$ & $-7,2$ & $-7,7$ & $-8,3$ & $-4,7$ \\
\hline \multirow[t]{3}{*}{ Total } & $\mathrm{DM}$ & $-27,66$ & $-25,37$ & $-22,92$ & $-20,36$ & $-17,79$ & $-15,38$ & $-13,33$ & $-12,14$ & $-12,97$ & $-19,75$ & $-64,28$ & - \\
\hline & DMA & 33,11 & 29,98 & 27,58 & 25,61 & 24,12 & 23,20 & 24,52 & 28,53 & 37,29 & 53,63 & 111,52 & - \\
\hline & PDMA & 48,93 & 38,58 & 29,83 & 24,78 & 24,73 & 27,68 & 40,51 & 59,97 & 85,20 & 121,08 & 188,88 & - \\
\hline \multirow[t]{3}{*}{ CPI } & $\mathrm{DM}$ & $-66,10$ & $-61,91$ & $-57,36$ & $-52,70$ & $-48,17$ & $-44,18$ & $-41,34$ & $-40,90$ & $-45,77$ & $-65,75$ & $-176,96$ & - \\
\hline & DMA & 73,14 & 66,27 & 60,65 & 54,88 & 49,52 & 44,91 & 44,97 & 50,46 & 66,03 & 97,54 & 223,15 & - \\
\hline & PDMA & 89,21 & 72,57 & 56,53 & 40,76 & 27,50 & 17,31 & 26,00 & 43,49 & 63,83 & 89,67 & 145,87 & - \\
\hline \multirow[t]{3}{*}{ SPI } & $\mathrm{DM}$ & 0,53 & 1,42 & 2,33 & 3,36 & 4,49 & 5,75 & 7,21 & 8,95 & 11,09 & 13,99 & 18,36 & - \\
\hline & DMA & 3,76 & 3,37 & 3,32 & 4,15 & 5,50 & 7,28 & 9,52 & 12,44 & 16,21 & 21,43 & 29,67 & - \\
\hline & PDMA & 19,39 & 13,66 & 10,26 & 13,06 & 22,70 & 35,29 & 51,14 & 72,05 & 100,87 & 144,12 & 220,43 & - \\
\hline \multirow[t]{3}{*}{$\Delta \mathrm{CS}$} & $\mathrm{DM}$ & $-66,63$ & $-63,33$ & $-59,70$ & $-56,06$ & $-52,66$ & $-49,93$ & $-48,55$ & $-49,85$ & $-56,87$ & $-79,74$ & $-195,32$ & - \\
\hline & DMA & 69,38 & 62,91 & 57,33 & 50,74 & 44,02 & 37,63 & 35,45 & 38,02 & 49,81 & 76,11 & 193,48 & - \\
\hline & PDMA & 69,82 & 58,91 & 46,28 & 27,70 & 4,80 & $-17,97$ & $-25,15$ & $-28,55$ & $-37,04$ & $-54,45$ & $-74,56$ & - \\
\hline
\end{tabular}


Tabela 8.72: Constantes de acoplamento PW91 com correção vibracional no nível BHandH $40 \% E_{X}^{\mathrm{HF}}$ e base aug-pcJ-2.

\begin{tabular}{|c|c|c|c|c|c|c|c|c|c|c|c|c|c|}
\hline & $\% E_{X}^{\mathrm{HF}}$ & $0 \%$ & $10 \%$ & $20 \%$ & $30 \%$ & $40 \%$ & $50 \%$ & $60 \%$ & $70 \%$ & $80 \%$ & $90 \%$ & $100 \%$ & Exp. \\
\hline $\mathrm{HF}$ & ${ }^{1} J_{\mathrm{HF}}$ & 331,0 & 354,2 & 377,6 & 401,3 & 425,1 & 449,2 & 473,5 & 498,0 & 522,8 & 547,8 & 573,1 & 500 \\
\hline $\mathrm{CO}$ & ${ }^{1} J_{\mathrm{CO}}$ & 25,7 & 24,0 & 22,3 & 20,4 & 18,5 & 16,6 & 14,5 & 12,4 & 10,2 & 8,0 & 5,7 & 16,4 \\
\hline $\mathrm{H}_{2} \mathrm{O}$ & ${ }^{1} J_{\mathrm{OH}}$ & $-65,1$ & $-67,5$ & $-70,0$ & $-72,5$ & $-75,0$ & $-77,5$ & $-80,1$ & $-82,7$ & $-85,3$ & $-88,0$ & $-90,7$ & $-80,6$ \\
\hline $\mathrm{H}_{2} \mathrm{O}$ & ${ }^{2} J_{\mathrm{HH}}$ & $-3,4$ & $-4,4$ & $-5,4$ & $-6,5$ & $-7,6$ & $-8,7$ & $-9,8$ & $-11,0$ & $-12,1$ & $-13,3$ & $-14,6$ & $-7,3$ \\
\hline $\mathrm{NH}_{3}$ & ${ }^{1} J_{\mathrm{NH}}$ & 41,5 & 42,2 & 42,9 & 43,6 & 44,4 & 45,2 & 45,9 & 46,7 & 47,5 & 48,3 & 49,1 & 43,8 \\
\hline $\mathrm{NH}_{3}$ & ${ }^{2} J_{\mathrm{HH}}$ & $-7,1$ & $-8,0$ & $-8,9$ & $-9,9$ & $-10,8$ & $-11,8$ & $-12,7$ & $-13,7$ & $-14,7$ & $-15,7$ & $-16,8$ & $-9,6$ \\
\hline $\mathrm{PH}_{3}$ & ${ }^{1} J_{\mathrm{PH}}$ & 130,3 & 138,6 & 146,7 & 154,8 & 162,7 & 170,6 & 178,4 & 186,0 & 193,5 & 200,9 & 208,2 & 188,2 \\
\hline $\mathrm{PF}_{3}$ & ${ }^{1} J_{\mathrm{PF}}$ & $-1813,4$ & $-1788,3$ & $-1758,5$ & $-1724,6$ & $-1687,5$ & $-1647,7$ & $-1605,8$ & $-1562,4$ & $-1517,9$ & $-1472,5$ & $-1426,7$ & -1441 \\
\hline $\mathrm{BHF}_{2}$ & ${ }^{1} J_{\mathrm{BF}}$ & $-182,1$ & $-164,9$ & $-147,9$ & $-130,9$ & $-114,1$ & $-97,5$ & $-81,0$ & $-64,7$ & $-48,6$ & $-32,7$ & $-17,0$ & -84 \\
\hline $\mathrm{BF}_{3}$ & ${ }^{1} J_{\mathrm{BF}}$ & $-83,1$ & $-64,5$ & $-46,0$ & $-27,8$ & $-9,8$ & 8,0 & 25,6 & 43,1 & 60,3 & 77,4 & 94,4 & 15 \\
\hline $\mathrm{F}_{2} \mathrm{O}$ & ${ }^{1} J_{\mathrm{OF}}$ & $-303,6$ & $-341,9$ & $-380,6$ & $-421,2$ & $-466,1$ & $-519,1$ & $-586,6$ & $-681,8$ & $-836,9$ & $-1162,0$ & $-2538,9$ & -300 \\
\hline $\mathrm{CH}_{4}$ & ${ }^{1} J_{\mathrm{CH}}$ & 122,4 & 123,8 & 125,2 & 126,6 & 128,1 & 129,6 & 131,1 & 132,7 & 134,2 & 135,8 & 137,5 & 125,3 \\
\hline $\mathrm{CH}_{4}$ & ${ }^{2} J_{\mathrm{HH}}$ & $-12,3$ & $-13,1$ & $-13,9$ & $-14,7$ & $-15,5$ & $-16,2$ & $-17,0$ & $-17,8$ & $-18,6$ & $-19,4$ & $-20,2$ & $-12,8$ \\
\hline $\mathrm{C}_{2} \mathrm{H}_{2}$ & ${ }^{1} J_{\mathrm{CC}}$ & 189,2 & 192,0 & 195,1 & 198,9 & 203,2 & 208,4 & 214,6 & 222,2 & 231,7 & 243,7 & 259,4 & 174,8 \\
\hline $\mathrm{C}_{2} \mathrm{H}_{2}$ & ${ }^{1} J_{\mathrm{CH}}$ & 255,6 & 257,9 & 260,4 & 263,0 & 265,9 & 269,2 & 272,9 & 277,4 & 282,7 & 289,2 & 297,7 & 247,6 \\
\hline $\mathrm{C}_{2} \mathrm{H}_{2}$ & ${ }^{2} J_{\mathrm{CH}}$ & 55,0 & 54,9 & 54,5 & 53,9 & 53,0 & 51,6 & 49,6 & 47,0 & 43,4 & 38,4 & 31,6 & 50,1 \\
\hline $\mathrm{C}_{2} \mathrm{H}_{2}$ & ${ }^{3} J_{\mathrm{HH}}$ & 11,0 & 11,7 & 12,5 & 13,5 & 14,7 & 16,2 & 18,0 & 20,2 & 23,0 & 26,6 & 31,2 & 9,6 \\
\hline $\mathrm{C}_{2} \mathrm{H}_{4}$ & ${ }^{1} J_{\mathrm{CC}}$ & 61,0 & 63,7 & 66,8 & 70,3 & 74,4 & 79,3 & 85,4 & 93,3 & 104,5 & 121,6 & 152,4 & 67,6 \\
\hline $\mathrm{C}_{2} \mathrm{H}_{4}$ & ${ }^{1} J_{\mathrm{CH}}$ & 154,8 & 156,9 & 159,1 & 161,4 & 164,0 & 166,9 & 170,3 & 174,5 & 180,0 & 188,0 & 201,8 & 156,3 \\
\hline $\mathrm{C}_{2} \mathrm{H}_{4}$ & ${ }^{2} J_{\mathrm{CH}}$ & $-0,7$ & $-1,6$ & $-2,6$ & $-3,8$ & $-5,3$ & $-7,1$ & $-9,4$ & $-12,4$ & $-16,8$ & $-23,8$ & $-36,5$ & $-2,4$ \\
\hline $\mathrm{C}_{2} \mathrm{H}_{4}$ & ${ }^{2} J_{\mathrm{HH}}$ & 4,8 & 3,9 & 3,1 & 2,1 & 1,0 & $-0,2$ & $-1,8$ & $-3,9$ & $-6,8$ & $-11,1$ & $-18,9$ & 2,3 \\
\hline $\mathrm{C}_{2} \mathrm{H}_{4}$ & ${ }^{3} J_{\mathrm{HH}_{\mathrm{c}}}$ & 12,2 & 12,5 & 12,9 & 13,4 & 14,1 & 15,0 & 16,1 & 17,7 & 20,1 & 24,1 & 31,5 & 11,7 \\
\hline $\mathrm{C}_{2} \mathrm{H}_{4}$ & ${ }^{3} J_{\mathrm{HH}_{\mathrm{t}}}$ & 19,5 & 19,8 & 20,3 & 20,9 & 21,6 & 22,6 & 24,0 & 25,9 & 28,6 & 33,1 & 41,4 & 19 \\
\hline $\mathrm{C}_{2} \mathrm{H}_{6}$ & ${ }^{1} J_{\mathrm{CC}}$ & 25,9 & 27,8 & 29,8 & 31,8 & 33,9 & 35,9 & 38,1 & 40,2 & 42,4 & 44,6 & 46,9 & 34,5 \\
\hline $\mathrm{C}_{2} \mathrm{H}_{6}$ & ${ }^{1} J_{\mathrm{CH}}$ & 122,1 & 123,7 & 125,3 & 126,9 & 128,6 & 130,3 & 132,0 & 133,8 & 135,5 & 137,3 & 139,1 & 125,2 \\
\hline $\mathrm{C}_{2} \mathrm{H}_{6}$ & ${ }^{2} J_{\mathrm{CH}}$ & $-3,1$ & $-3,6$ & $-4,1$ & $-4,6$ & $-5,1$ & $-5,6$ & $-6,1$ & $-6,6$ & $-7,2$ & $-7,7$ & $-8,3$ & $-4,7$ \\
\hline \multirow[t]{3}{*}{ Total } & $\mathrm{DM}$ & $-29,11$ & $-26,74$ & $-24,17$ & $-21,49$ & $-18,79$ & $-16,22$ & $-14,05$ & $-12,73$ & $-13,44$ & $-20,25$ & $-66,64$ & - \\
\hline & DMA & 34,28 & 31,76 & 29,27 & 27,23 & 25,62 & 24,53 & 25,37 & 29,39 & 38,33 & 54,95 & 114,82 & - \\
\hline & PDMA & 50,91 & 40,60 & 31,41 & 26,23 & 26,36 & 28,95 & 40,35 & 60,10 & 85,80 & 122,05 & 190,48 & - \\
\hline \multirow[t]{3}{*}{ CPI } & $\mathrm{DM}$ & $-70,02$ & $-65,58$ & $-60,79$ & $-55,84$ & $-51,01$ & $-46,69$ & $-43,55$ & $-42,82$ & $-47,46$ & $-67,52$ & $-183,19$ & - \\
\hline & DMA & 75,69 & 70,16 & 64,26 & 58,18 & 52,52 & 47,55 & 46,49 & 51,96 & 67,92 & 100,01 & 230,30 & - \\
\hline & PDMA & 93,00 & 76,59 & 60,24 & 44,34 & 30,90 & 20,00 & 25,02 & 43,14 & 64,25 & 90,85 & 149,68 & - \\
\hline \multirow[t]{3}{*}{ SPI } & $\mathrm{DM}$ & 0,89 & 1,75 & 2,69 & 3,70 & 4,83 & 6,12 & 7,58 & 9,34 & 11,51 & 14,42 & 18,83 & - \\
\hline & DMA & 3,91 & 3,60 & 3,61 & 4,53 & 5,89 & 7,65 & 9,87 & 12,83 & 16,64 & 21,90 & 30,14 & - \\
\hline & PDMA & 20,04 & 14,21 & 10,27 & 12,95 & 23,03 & 35,52 & 51,58 & 72,54 & 101,61 & 144,93 & 220,40 & - \\
\hline \multirow[t]{3}{*}{$\Delta \mathrm{CS}$} & $\mathrm{DM}$ & $-70,90$ & $-67,33$ & $-63,48$ & $-59,54$ & $-55,84$ & $-52,81$ & $-51,13$ & $-52,16$ & $-58,97$ & $-81,94$ & $-202,02$ & - \\
\hline & DMA & 71,78 & 66,56 & 60,66 & 53,66 & 46,63 & 39,89 & 36,62 & 39,13 & 51,28 & 78,11 & 200,16 & - \\
\hline & PDMA & 72,96 & 62,39 & 49,97 & 31,39 & 7,87 & $-15,52$ & $-26,56$ & $-29,39$ & $-37,36$ & $-54,09$ & $-70,72$ & - \\
\hline
\end{tabular}


Tabela 8.73: Constantes de acoplamento TPSSh com correção vibracional no nível BHandH $40 \% E_{X}^{\mathrm{HF}}$ e base aug-pcJ-2.

\begin{tabular}{|c|c|c|c|c|c|c|c|c|c|c|c|c|c|}
\hline & $\% E_{X}^{\mathrm{HF}}$ & $0 \%$ & $10 \%$ & $20 \%$ & $30 \%$ & $40 \%$ & $50 \%$ & $60 \%$ & $70 \%$ & $80 \%$ & $90 \%$ & $100 \%$ & Exp. \\
\hline $\mathrm{HF}$ & ${ }^{1} J_{\mathrm{HF}}$ & 332,8 & 357,4 & 381,9 & 406,5 & 431,0 & 455,5 & 479,9 & 504,2 & 528,4 & 552,6 & 576,8 & 500 \\
\hline $\mathrm{CO}$ & ${ }^{1} J_{\mathrm{CO}}$ & 22,5 & 21,1 & 19,6 & 18,1 & 16,5 & 14,8 & 13,1 & 11,3 & 9,5 & 7,6 & 5,7 & 16,4 \\
\hline $\mathrm{H}_{2} \mathrm{O}$ & ${ }^{1} J_{\mathrm{OH}}$ & $-69,0$ & $-71,3$ & $-73,7$ & $-76,1$ & $-78,4$ & $-80,8$ & $-83,1$ & $-85,4$ & $-87,7$ & $-89,9$ & $-92,2$ & $-80,6$ \\
\hline $\mathrm{H}_{2} \mathrm{O}$ & ${ }^{2} J_{\mathrm{HH}}$ & $-2,6$ & $-3,9$ & $-5,2$ & $-6,4$ & $-7,7$ & $-8,9$ & $-10,1$ & $-11,3$ & $-12,5$ & $-13,7$ & $-14,8$ & $-7,3$ \\
\hline $\mathrm{NH}_{3}$ & ${ }^{1} J_{\mathrm{NH}}$ & 46,0 & 46,5 & 47,1 & 47,6 & 48,0 & 48,5 & 49,0 & 49,5 & 49,9 & 50,4 & 50,8 & 43,8 \\
\hline $\mathrm{NH}_{3}$ & ${ }^{2} J_{\mathrm{HH}}$ & $-6,0$ & $-7,2$ & $-8,4$ & $-9,5$ & $-10,7$ & $-11,8$ & $-12,9$ & $-14,0$ & $-15,0$ & $-16,1$ & $-17,0$ & $-9,6$ \\
\hline $\mathrm{PH}_{3}$ & ${ }^{1} J_{\mathrm{PH}}$ & 188,4 & 193,2 & 197,7 & 202,0 & 206,1 & 209,9 & 213,5 & 216,8 & 219,9 & 222,7 & 225,3 & 188,2 \\
\hline $\mathrm{PF}_{3}$ & ${ }^{1} J_{\mathrm{PF}}$ & $-1755,7$ & $-1729,9$ & $-1701,5$ & $-1671,2$ & $-1639,3$ & $-1606,2$ & $-1572,3$ & $-1537,9$ & $-1503,1$ & $-1468,2$ & $-1433,4$ & -1441 \\
\hline $\mathrm{BHF}_{2}$ & ${ }^{1} J_{\mathrm{BF}}$ & $-161,2$ & $-147,0$ & $-132,9$ & $-118,8$ & $-104,7$ & $-90,6$ & $-76,6$ & $-62,6$ & $-48,7$ & $-34,8$ & $-20,9$ & -84 \\
\hline $\mathrm{BF}_{3}$ & ${ }^{1} J_{\mathrm{BF}}$ & $-66,0$ & $-49,4$ & $-32,9$ & $-16,5$ & $-0,4$ & 15,6 & 31,6 & 47,4 & 63,0 & 78,6 & 94,1 & 15 \\
\hline $\mathrm{F}_{2} \mathrm{O}$ & ${ }^{1} J_{\mathrm{OF}}$ & $-295,8$ & $-333,2$ & $-372,6$ & $-415,6$ & $-464,4$ & $-523,1$ & $-598,3$ & $-703,5$ & $-871,0$ & $-1205,8$ & $-2416,6$ & -300 \\
\hline $\mathrm{CH}_{4}$ & ${ }^{1} J_{\mathrm{CH}}$ & 140,3 & 141,1 & 141,9 & 142,7 & 143,4 & 144,2 & 144,9 & 145,5 & 146,1 & 146,7 & 147,2 & 125,3 \\
\hline $\mathrm{CH}_{4}$ & ${ }^{2} J_{\mathrm{HH}}$ & $-10,5$ & $-11,6$ & $-12,7$ & $-13,7$ & $-14,8$ & $-15,8$ & $-16,8$ & $-17,7$ & $-18,7$ & $-19,6$ & $-20,5$ & $-12,8$ \\
\hline $\mathrm{C}_{2} \mathrm{H}_{2}$ & ${ }^{1} J_{\mathrm{CC}}$ & 187,9 & 191,2 & 195,0 & 199,3 & 204,3 & 210,2 & 217,1 & 225,4 & 235,3 & 247,4 & 262,5 & 174,8 \\
\hline $\mathrm{C}_{2} \mathrm{H}_{2}$ & ${ }^{1} J_{\mathrm{CH}}$ & 283,7 & 285,4 & 287,2 & 289,2 & 291,4 & 293,9 & 296,8 & 300,2 & 304,4 & 309,5 & 316,0 & 247,6 \\
\hline $\mathrm{C}_{2} \mathrm{H}_{2}$ & ${ }^{2} J_{\mathrm{CH}}$ & 58,7 & 58,1 & 57,3 & 56,2 & 54,7 & 52,8 & 50,4 & 47,3 & 43,4 & 38,4 & 31,9 & 50,1 \\
\hline $\mathrm{C}_{2} \mathrm{H}_{2}$ & ${ }^{3} J_{\mathrm{HH}}$ & 12,5 & 13,1 & 14,0 & 15,0 & 16,2 & 17,8 & 19,6 & 21,9 & 24,6 & 28,0 & 32,3 & 9,6 \\
\hline $\mathrm{C}_{2} \mathrm{H}_{4}$ & ${ }^{1} J_{\mathrm{CC}}$ & 69,2 & 71,9 & 74,9 & 78,4 & 82,5 & 87,4 & 93,5 & 101,3 & 112,0 & 127,8 & 153,9 & 67,6 \\
\hline $\mathrm{C}_{2} \mathrm{H}_{4}$ & ${ }^{1} J_{\mathrm{CH}}$ & 174,5 & 176,1 & 177,9 & 179,8 & 181,9 & 184,3 & 187,1 & 190,7 & 195,4 & 202,3 & 213,5 & 156,3 \\
\hline $\mathrm{C}_{2} \mathrm{H}_{4}$ & ${ }^{2} J_{\mathrm{CH}}$ & $-0,9$ & $-2,0$ & $-3,3$ & $-4,8$ & $-6,5$ & $-8,6$ & $-11,2$ & $-14,6$ & $-19,2$ & $-25,9$ & $-37,1$ & $-2,4$ \\
\hline $\mathrm{C}_{2} \mathrm{H}_{4}$ & ${ }^{2} J_{\mathrm{HH}}$ & 9,7 & 8,5 & 7,1 & 5,7 & 4,1 & 2,3 & 0,3 & $-2,2$ & $-5,5$ & $-10,0$ & $-17,1$ & 2,3 \\
\hline $\mathrm{C}_{2} \mathrm{H}_{4}$ & ${ }^{3} J_{\mathrm{HH}_{\mathrm{c}}}$ & 12,3 & 12,8 & 13,3 & 14,0 & 14,8 & 15,8 & 17,2 & 18,9 & 21,4 & 25,2 & 31,6 & 11,7 \\
\hline $\mathrm{C}_{2} \mathrm{H}_{4}$ & ${ }^{3} J_{\mathrm{HH}_{\mathrm{t}}}$ & 22,6 & 23,0 & 23,4 & 24,0 & 24,7 & 25,7 & 27,1 & 28,9 & 31,6 & 35,7 & 42,7 & 19 \\
\hline $\mathrm{C}_{2} \mathrm{H}_{6}$ & ${ }^{1} J_{\mathrm{CC}}$ & 33,7 & 35,2 & 36,6 & 38,0 & 39,5 & 40,9 & 42,3 & 43,7 & 45,0 & 46,4 & 47,7 & 34,5 \\
\hline $\mathrm{C}_{2} \mathrm{H}_{6}$ & ${ }^{1} J_{\mathrm{CH}}$ & 139,7 & 140,7 & 141,8 & 142,8 & 143,7 & 144,7 & 145,6 & 146,5 & 147,3 & 148,1 & 148,9 & 125,2 \\
\hline $\mathrm{C}_{2} \mathrm{H}_{6}$ & ${ }^{2} J_{\mathrm{CH}}$ & $-3,5$ & $-4,0$ & $-4,5$ & $-5,1$ & $-5,6$ & $-6,1$ & $-6,6$ & $-7,2$ & $-7,7$ & $-8,2$ & $-8,7$ & $-4,7$ \\
\hline \multirow[t]{3}{*}{ Total } & $\mathrm{DM}$ & $-18,53$ & $-16,51$ & $-14,46$ & $-12,44$ & $-10,57$ & $-8,95$ & $-7,84$ & $-7,77$ & $-9,88$ & $-18,07$ & $-59,32$ & - \\
\hline & DMA & 30,77 & 29,04 & 27,76 & 26,74 & 26,07 & 26,10 & 28,95 & 34,20 & 43,80 & 60,53 & 112,82 & - \\
\hline & PDMA & 54,17 & 44,18 & 36,86 & 32,60 & 30,16 & 30,45 & 47,29 & 68,23 & 94,32 & 129,45 & 189,92 & - \\
\hline \multirow[t]{3}{*}{ CPI } & $\mathrm{DM}$ & $-55,23$ & $-51,33$ & $-47,44$ & $-43,71$ & $-40,45$ & $-38,00$ & $-37,01$ & $-38,76$ & $-46,20$ & $-68,86$ & $-171,19$ & - \\
\hline & DMA & 61,15 & 56,33 & 52,20 & 48,22 & 44,88 & 42,91 & 46,92 & 55,55 & 73,38 & 106,41 & 220,41 & - \\
\hline & PDMA & 77,02 & 62,23 & 47,76 & 33,63 & 22,64 & 16,70 & 32,12 & 49,95 & 70,13 & 95,54 & 147,18 & - \\
\hline \multirow[t]{3}{*}{ SPI } & $\mathrm{DM}$ & 8,39 & 9,03 & 9,72 & 10,49 & 11,35 & 12,36 & 13,55 & 14,97 & 16,75 & 19,18 & 22,71 & - \\
\hline & DMA & 8,49 & 9,03 & 9,84 & 10,99 & 12,28 & 13,77 & 15,77 & 18,55 & 22,11 & 26,89 & 33,91 & - \\
\hline & PDMA & 37,41 & 30,94 & 28,87 & 31,85 & 35,67 & 40,54 & 58,42 & 81,64 & 112,06 & 154,31 & 221,26 & - \\
\hline \multirow[t]{3}{*}{$\Delta \mathrm{CS}$} & $\mathrm{DM}$ & $-63,61$ & $-60,35$ & $-57,16$ & $-54,20$ & $-51,79$ & $-50,36$ & $-50,56$ & $-53,73$ & $-62,95$ & $-88,04$ & $-193,90$ & - \\
\hline & DMA & 52,66 & 47,30 & 42,36 & 37,23 & 32,60 & 29,14 & 31,14 & 36,99 & 51,27 & 79,52 & 186,50 & - \\
\hline & PDMA & 39,61 & 31,29 & 18,89 & 1,79 & $-13,03$ & $-23,84$ & $-26,30$ & $-31,70$ & $-41,92$ & $-58,78$ & $-74,08$ & - \\
\hline
\end{tabular}


Tabela 8.74: Constantes de acoplamento X3LYP com correção vibracional no nível BHandH $40 \% E_{X}^{\mathrm{HF}}$ e base aug-pcJ-2.

\begin{tabular}{|c|c|c|c|c|c|c|c|c|c|c|c|c|c|}
\hline & $\% E_{X}^{\mathrm{HF}}$ & $0 \%$ & $10 \%$ & $20 \%$ & $30 \%$ & $40 \%$ & $50 \%$ & $60 \%$ & $70 \%$ & $80 \%$ & $90 \%$ & $100 \%$ & Exp. \\
\hline $\mathrm{HF}$ & ${ }^{1} J_{\mathrm{HF}}$ & 364,1 & 389,0 & 414,1 & 439,4 & 465,0 & 490,9 & 516,9 & 543,2 & 569,7 & 596,5 & 623,5 & 500 \\
\hline $\mathrm{CO}$ & ${ }^{1} J_{\mathrm{CO}}$ & 22,3 & 20,5 & 18,5 & 16,4 & 14,2 & 11,9 & 9,6 & 7,1 & 4,6 & 2,0 & $-0,6$ & 16,4 \\
\hline $\mathrm{H}_{2} \mathrm{O}$ & ${ }^{1} J_{\mathrm{OH}}$ & $-71,1$ & $-73,8$ & $-76,4$ & $-79,2$ & $-81,9$ & $-84,6$ & $-87,4$ & $-90,3$ & $-93,1$ & $-96,0$ & $-98,9$ & $-80,6$ \\
\hline $\mathrm{H}_{2} \mathrm{O}$ & ${ }^{2} J_{\mathrm{HH}}$ & $-3,9$ & $-5,0$ & $-6,1$ & $-7,2$ & $-8,3$ & $-9,5$ & $-10,7$ & $-11,9$ & $-13,1$ & $-14,3$ & $-15,6$ & $-7,3$ \\
\hline $\mathrm{NH}_{3}$ & ${ }^{1} J_{\mathrm{NH}}$ & 45,2 & 46,0 & 46,8 & 47,6 & 48,5 & 49,3 & 50,1 & 51,0 & 51,9 & 52,7 & 53,6 & 43,8 \\
\hline $\mathrm{NH}_{3}$ & ${ }^{2} J_{\mathrm{HH}}$ & $-7,5$ & $-8,4$ & $-9,4$ & $-10,3$ & $-11,3$ & $-12,3$ & $-13,3$ & $-14,3$ & $-15,4$ & $-16,4$ & $-17,5$ & $-9,6$ \\
\hline $\mathrm{PH}_{3}$ & ${ }^{1} J_{\mathrm{PH}}$ & 151,0 & 159,5 & 167,9 & 176,2 & 184,3 & 192,3 & 200,2 & 207,9 & 215,4 & 222,7 & 229,9 & 188,2 \\
\hline $\mathrm{PF}_{3}$ & ${ }^{1} J_{\mathrm{PF}}$ & $-1810,9$ & $-1785,6$ & $-1755,8$ & $-1722,2$ & $-1685,6$ & $-1646,4$ & $-1605,3$ & $-1562,8$ & $-1519,2$ & $-1474,9$ & $-1430,2$ & -1441 \\
\hline $\mathrm{BHF}_{2}$ & ${ }^{1} J_{\mathrm{BF}}$ & $-172,5$ & $-154,9$ & $-137,4$ & $-120,1$ & $-102,9$ & $-85,9$ & $-69,1$ & $-52,4$ & $-36,0$ & $-19,8$ & $-3,8$ & -84 \\
\hline $\mathrm{BF}_{3}$ & ${ }^{1} J_{\mathrm{BF}}$ & $-71,7$ & $-52,6$ & $-33,6$ & $-14,9$ & 3,5 & 21,8 & 39,9 & 57,8 & 75,6 & 93,1 & 110,5 & 15 \\
\hline $\mathrm{F}_{2} \mathrm{O}$ & ${ }^{1} J_{\mathrm{OF}}$ & $-293,4$ & $-330,3$ & $-367,3$ & $-406,0$ & $-448,6$ & $-498,3$ & $-561,0$ & $-648,4$ & $-788,5$ & $-1074,7$ & $-2186,8$ & -300 \\
\hline $\mathrm{CH}_{4}$ & ${ }^{1} J_{\mathrm{CH}}$ & 134,1 & 135,6 & 137,2 & 138,8 & 140,4 & 142,0 & 143,7 & 145,3 & 147,0 & 148,7 & 150,5 & 125,3 \\
\hline $\mathrm{CH}_{4}$ & ${ }^{2} J_{\mathrm{HH}}$ & $-12,1$ & $-12,9$ & $-13,7$ & $-14,5$ & $-15,3$ & $-16,0$ & $-16,8$ & $-17,6$ & $-18,3$ & $-19,0$ & $-19,8$ & $-12,8$ \\
\hline $\mathrm{C}_{2} \mathrm{H}_{2}$ & ${ }^{1} J_{\mathrm{CC}}$ & 200,0 & 203,0 & 206,4 & 210,4 & 214,9 & 220,3 & 226,5 & 234,0 & 243,0 & 254,0 & 267,7 & 174,8 \\
\hline $\mathrm{C}_{2} \mathrm{H}_{2}$ & ${ }^{1} J_{\mathrm{CH}}$ & 275,5 & 278,0 & 280,5 & 283,2 & 286,1 & 289,3 & 292,9 & 296,9 & 301,6 & 307,1 & 313,8 & 247,6 \\
\hline $\mathrm{C}_{2} \mathrm{H}_{2}$ & ${ }^{2} J_{\mathrm{CH}}$ & 57,4 & 57,3 & 57,0 & 56,5 & 55,6 & 54,4 & 52,7 & 50,5 & 47,6 & 43,8 & 38,8 & 50,1 \\
\hline $\mathrm{C}_{2} \mathrm{H}_{2}$ & ${ }^{3} J_{\mathrm{HH}}$ & 10,6 & 11,2 & 11,9 & 12,8 & 13,8 & 15,0 & 16,4 & 18,2 & 20,3 & 22,9 & 26,1 & 9,6 \\
\hline $\mathrm{C}_{2} \mathrm{H}_{4}$ & ${ }^{1} J_{\mathrm{CC}}$ & 67,3 & 70,2 & 73,5 & 77,1 & 81,2 & 86,0 & 91,7 & 98,8 & 107,9 & 120,3 & 138,5 & 67,6 \\
\hline $\mathrm{C}_{2} \mathrm{H}_{4}$ & ${ }^{1} J_{\mathrm{CH}}$ & 168,1 & 170,3 & 172,6 & 175,1 & 177,7 & 180,6 & 183,8 & 187,5 & 192,0 & 197,8 & 205,8 & 156,3 \\
\hline $\mathrm{C}_{2} \mathrm{H}_{4}$ & ${ }^{2} J_{\mathrm{CH}}$ & $-0,1$ & $-0,9$ & $-1,9$ & $-3,1$ & $-4,4$ & $-6,0$ & $-8,0$ & $-10,5$ & $-13,8$ & $-18,4$ & $-25,3$ & $-2,4$ \\
\hline $\mathrm{C}_{2} \mathrm{H}_{4}$ & ${ }^{2} J_{\mathrm{HH}}$ & 6,4 & 5,7 & 4,9 & 4,0 & 3,0 & 2,0 & 0,7 & $-0,7$ & $-2,6$ & $-5,2$ & $-8,9$ & 2,3 \\
\hline $\mathrm{C}_{2} \mathrm{H}_{4}$ & ${ }^{3} J_{\mathrm{HH}_{\mathrm{c}}}$ & 12,8 & 13,1 & 13,4 & 13,8 & 14,2 & 14,9 & 15,7 & 16,7 & 18,2 & 20,3 & 23,6 & 11,7 \\
\hline $\mathrm{C}_{2} \mathrm{H}_{4}$ & ${ }^{3} J_{\mathrm{HH}_{\mathrm{t}}}$ & 20,4 & 20,7 & 21,0 & 21,5 & 22,0 & 22,8 & 23,7 & 25,0 & 26,7 & 29,2 & 32,9 & 19 \\
\hline $\mathrm{C}_{2} \mathrm{H}_{6}$ & ${ }^{1} J_{\mathrm{CC}}$ & 30,2 & 32,3 & 34,5 & 36,7 & 38,9 & 41,2 & 43,5 & 45,9 & 48,3 & 50,7 & 53,2 & 34,5 \\
\hline $\mathrm{C}_{2} \mathrm{H}_{6}$ & ${ }^{1} J_{\mathrm{CH}}$ & 133,1 & 134,9 & 136,6 & 138,4 & 140,2 & 142,1 & 143,9 & 145,8 & 147,7 & 149,6 & 151,5 & 125,2 \\
\hline $\mathrm{C}_{2} \mathrm{H}_{6}$ & ${ }^{2} J_{\mathrm{CH}}$ & $-2,7$ & $-3,2$ & $-3,7$ & $-4,2$ & $-4,7$ & $-5,2$ & $-5,7$ & $-6,3$ & $-6,8$ & $-7,4$ & $-7,9$ & $-4,7$ \\
\hline \multirow[t]{3}{*}{ Total } & $\mathrm{DM}$ & $-22,78$ & $-20,20$ & $-17,44$ & $-14,57$ & $-11,71$ & $-8,94$ & $-6,55$ & $-4,95$ & $-5,17$ & $-10,76$ & $-47,71$ & - \\
\hline & DMA & 32,82 & 30,21 & 28,03 & 26,12 & 24,69 & 24,58 & 28,69 & 34,75 & 43,22 & 57,77 & 105,67 & - \\
\hline & PDMA & 50,04 & 40,29 & 30,67 & 24,13 & 21,78 & 26,07 & 41,87 & 59,74 & 81,17 & 108,66 & 153,78 & - \\
\hline \multirow[t]{3}{*}{ CPI } & $\mathrm{DM}$ & $-62,66$ & $-57,86$ & $-52,69$ & $-47,38$ & $-42,18$ & $-37,43$ & $-33,73$ & $-32,18$ & $-35,36$ & $-51,82$ & $-143,35$ & - \\
\hline & DMA & 67,92 & 60,88 & 54,64 & 48,35 & 43,04 & 40,41 & 47,36 & 58,45 & 74,20 & 103,13 & 209,07 & - \\
\hline & PDMA & 79,78 & 62,64 & 45,75 & 30,43 & 21,08 & 21,38 & 40,12 & 60,35 & 82,15 & 108,12 & 159,40 & - \\
\hline \multirow[t]{3}{*}{ SPI } & $\mathrm{DM}$ & 6,46 & 7,41 & 8,41 & 9,49 & 10,63 & 11,95 & 13,37 & 15,03 & 16,98 & 19,35 & 22,43 & - \\
\hline & DMA & 7,07 & 7,72 & 8,53 & 9,81 & 11,23 & 12,97 & 15,00 & 17,36 & 20,50 & 24,51 & 29,84 & - \\
\hline & PDMA & 28,22 & 23,90 & 19,61 & 19,52 & 22,28 & 29,52 & 43,15 & 59,30 & 80,45 & 109,06 & 149,66 & - \\
\hline \multirow[t]{3}{*}{$\Delta \mathrm{CS}$} & $\mathrm{DM}$ & $-69,12$ & $-65,28$ & $-61,10$ & $-56,88$ & $-52,82$ & $-49,38$ & $-47,10$ & $-47,21$ & $-52,34$ & $-71,17$ & $-165,77$ & - \\
\hline & DMA & 60,84 & 53,16 & 46,11 & 38,53 & 31,80 & 27,44 & 32,36 & 41,09 & 53,70 & 78,61 & 179,23 & - \\
\hline & PDMA & 51,56 & 38,73 & 26,14 & 10,91 & $-1,20$ & $-8,14$ & $-3,03$ & 1,04 & 1,69 & $-0,95$ & 9,74 & - \\
\hline
\end{tabular}


Tabela 8.75: Constantes de acoplamento B1B95 com correção vibracional no nível PBE0 $40 \% E_{X}^{\mathrm{HF}}$ e base aug-pcJ-2.

\begin{tabular}{|c|c|c|c|c|c|c|c|c|c|c|c|c|c|}
\hline & $\% E_{X}^{\mathrm{HF}}$ & $0 \%$ & $10 \%$ & $20 \%$ & $30 \%$ & $40 \%$ & $50 \%$ & $60 \%$ & $70 \%$ & $80 \%$ & $90 \%$ & $100 \%$ & Exp. \\
\hline $\mathrm{HF}$ & ${ }^{1} J_{\mathrm{HF}}$ & 369,1 & 392,7 & 416,4 & 440,4 & 464,5 & 488,8 & 513,2 & 537,8 & 562,6 & 587,5 & 612,6 & 500 \\
\hline $\mathrm{CO}$ & ${ }^{1} J_{\mathrm{CO}}$ & 24,1 & 22,4 & 20,6 & 18,8 & 16,8 & 14,7 & 12,5 & 10,3 & 8,0 & 5,6 & 3,1 & 16,4 \\
\hline $\mathrm{H}_{2} \mathrm{O}$ & ${ }^{1} J_{\mathrm{OH}}$ & $-68,9$ & $-71,4$ & $-73,9$ & $-76,5$ & $-79,0$ & $-81,6$ & $-84,2$ & $-86,8$ & $-89,4$ & $-92,1$ & $-94,8$ & $-80,6$ \\
\hline $\mathrm{H}_{2} \mathrm{O}$ & ${ }^{2} J_{\mathrm{HH}}$ & $-2,7$ & $-3,7$ & $-4,7$ & $-5,7$ & $-6,7$ & $-7,7$ & $-8,8$ & $-9,8$ & $-10,9$ & $-12,0$ & $-13,2$ & $-7,3$ \\
\hline $\mathrm{NH}_{3}$ & ${ }^{1} J_{\mathrm{NH}}$ & 42,4 & 43,2 & 43,9 & 44,6 & 45,4 & 46,1 & 46,9 & 47,7 & 48,4 & 49,2 & 50,0 & 43,8 \\
\hline $\mathrm{NH}_{3}$ & ${ }^{2} J_{\mathrm{HH}}$ & $-6,2$ & $-7,0$ & $-7,9$ & $-8,7$ & $-9,6$ & $-10,5$ & $-11,3$ & $-12,2$ & $-13,1$ & $-14,0$ & $-15,0$ & $-9,6$ \\
\hline $\mathrm{PH}_{3}$ & ${ }^{1} J_{\mathrm{PH}}$ & 139,2 & 146,9 & 154,3 & 161,7 & 169,0 & 176,1 & 183,1 & 189,9 & 196,6 & 203,2 & 209,5 & 188,2 \\
\hline $\mathrm{PF}_{3}$ & ${ }^{1} J_{\mathrm{PF}}$ & $-1714,4$ & $-1692,8$ & $-1666,8$ & $-1637,0$ & $-1604,2$ & $-1568,9$ & $-1531,5$ & $-1492,7$ & $-1452,7$ & $-1411,9$ & $-1370,6$ & -1441 \\
\hline $\mathrm{BHF}_{2}$ & ${ }^{1} J_{\mathrm{BF}}$ & $-179,1$ & $-162,2$ & $-145,4$ & $-128,6$ & $-111,9$ & $-95,4$ & $-79,0$ & $-62,7$ & $-46,6$ & $-30,7$ & $-14,9$ & -84 \\
\hline $\mathrm{BF}_{3}$ & ${ }^{1} J_{\mathrm{BF}}$ & $-80,9$ & $-62,3$ & $-43,9$ & $-25,6$ & $-7,5$ & 10,4 & 28,1 & 45,7 & 63,1 & 80,4 & 97,5 & 15 \\
\hline $\mathrm{F}_{2} \mathrm{O}$ & ${ }^{1} J_{\mathrm{OF}}$ & $-282,2$ & $-316,6$ & $-350,2$ & $-384,0$ & $-419,6$ & $-459,0$ & $-505,3$ & $-564,1$ & $-646,5$ & $-780,4$ & $-1063,8$ & -300 \\
\hline $\mathrm{CH}_{4}$ & ${ }^{1} J_{\mathrm{CH}}$ & 123,1 & 124,4 & 125,7 & 127,1 & 128,5 & 129,9 & 131,4 & 132,8 & 134,3 & 135,8 & 137,3 & 125,3 \\
\hline $\mathrm{CH}_{4}$ & ${ }^{2} J_{\mathrm{HH}}$ & $-10,6$ & $-11,3$ & $-12,0$ & $-12,7$ & $-13,3$ & $-14,0$ & $-14,7$ & $-15,3$ & $-16,0$ & $-16,7$ & $-17,3$ & $-12,8$ \\
\hline $\mathrm{C}_{2} \mathrm{H}_{2}$ & ${ }^{1} J_{\mathrm{CC}}$ & 188,8 & 191,1 & 193,8 & 196,7 & 200,2 & 204,1 & 208,6 & 213,9 & 220,1 & 227,5 & 236,4 & 174,8 \\
\hline $\mathrm{C}_{2} \mathrm{H}_{2}$ & ${ }^{1} J_{\mathrm{CH}}$ & 253,8 & 255,7 & 257,7 & 259,8 & 262,0 & 264,4 & 266,9 & 269,7 & 272,8 & 276,4 & 280,5 & 247,6 \\
\hline $\mathrm{C}_{2} \mathrm{H}_{2}$ & ${ }^{2} J_{\mathrm{CH}}$ & 55,7 & 55,9 & 55,9 & 55,7 & 55,4 & 54,8 & 54,0 & 52,8 & 51,3 & 49,3 & 46,6 & 50,1 \\
\hline $\mathrm{C}_{2} \mathrm{H}_{2}$ & ${ }^{3} J_{\mathrm{HH}}$ & 9,8 & 10,2 & 10,7 & 11,3 & 11,9 & 12,7 & 13,7 & 14,8 & 16,1 & 17,7 & 19,6 & 9,6 \\
\hline $\mathrm{C}_{2} \mathrm{H}_{4}$ & ${ }^{1} J_{\mathrm{CC}}$ & 59,9 & 62,2 & 64,8 & 67,5 & 70,6 & 74,0 & 77,8 & 82,2 & 87,5 & 93,8 & 101,8 & 67,6 \\
\hline $\mathrm{C}_{2} \mathrm{H}_{4}$ & ${ }^{1} J_{\mathrm{CH}}$ & 155,4 & 157,3 & 159,2 & 161,2 & 163,3 & 165,5 & 167,9 & 170,5 & 173,4 & 176,7 & 180,7 & 156,3 \\
\hline $\mathrm{C}_{2} \mathrm{H}_{4}$ & ${ }^{2} J_{\mathrm{CH}}$ & 0,5 & $-0,2$ & $-0,9$ & $-1,8$ & $-2,8$ & $-3,9$ & $-5,2$ & $-6,8$ & $-8,6$ & $-10,9$ & $-13,9$ & $-2,4$ \\
\hline $\mathrm{C}_{2} \mathrm{H}_{4}$ & ${ }^{2} J_{\mathrm{HH}}$ & 6,2 & 5,6 & 4,9 & 4,2 & 3,5 & 2,7 & 1,8 & 0,8 & $-0,3$ & $-1,7$ & $-3,3$ & 2,3 \\
\hline $\mathrm{C}_{2} \mathrm{H}_{4}$ & ${ }^{3} J_{\mathrm{HH}_{\mathrm{c}}}$ & 11,9 & 12,1 & 12,3 & 12,6 & 12,9 & 13,2 & 13,7 & 14,3 & 15,1 & 16,0 & 17,3 & 11,7 \\
\hline $\mathrm{C}_{2} \mathrm{H}_{4}$ & ${ }^{3} J_{\mathrm{HH}_{\mathrm{t}}}$ & 19,0 & 19,2 & 19,5 & 19,7 & 20,1 & 20,6 & 21,1 & 21,8 & 22,7 & 23,9 & 25,4 & 19 \\
\hline $\mathrm{C}_{2} \mathrm{H}_{6}$ & ${ }^{1} J_{\mathrm{CC}}$ & 26,0 & 28,0 & 29,9 & 31,9 & 33,9 & 35,9 & 38,0 & 40,1 & 42,2 & 44,4 & 46,6 & 34,5 \\
\hline $\mathrm{C}_{2} \mathrm{H}_{6}$ & ${ }^{1} J_{\mathrm{CH}}$ & 122,4 & 124,0 & 125,5 & 127,1 & 128,7 & 130,3 & 131,9 & 133,6 & 135,2 & 136,8 & 138,5 & 125,2 \\
\hline $\mathrm{C}_{2} \mathrm{H}_{6}$ & ${ }^{2} J_{\mathrm{CH}}$ & $-2,4$ & $-2,9$ & $-3,3$ & $-3,8$ & $-4,2$ & $-4,7$ & $-5,2$ & $-5,6$ & $-6,1$ & $-6,6$ & $-7,1$ & $-4,7$ \\
\hline \multirow[t]{3}{*}{ Total } & $\mathrm{DM}$ & $-22,50$ & $-20,17$ & $-17,65$ & $-14,97$ & $-12,20$ & $-9,48$ & $-6,91$ & $-4,70$ & $-3,30$ & $-3,76$ & $-9,83$ & - \\
\hline & DMA & 28,87 & 24,99 & 22,44 & 19,96 & 17,76 & 16,13 & 17,50 & 21,64 & 27,15 & 37,08 & 54,03 & - \\
\hline & PDMA & 54,44 & 44,22 & 34,52 & 24,74 & 16,86 & 13,44 & 21,52 & 35,38 & 50,60 & 68,35 & 90,27 & - \\
\hline \multirow[t]{3}{*}{ CPI } & $\mathrm{DM}$ & $-54,59$ & $-50,15$ & $-45,32$ & $-40,14$ & $-34,88$ & $-29,81$ & $-25,20$ & $-21,62$ & $-20,13$ & $-23,28$ & $-40,05$ & - \\
\hline & DMA & 62,81 & 54,05 & 48,10 & 41,92 & 35,65 & 30,23 & 31,45 & 38,96 & 49,42 & 69,77 & 105,88 & - \\
\hline & PDMA & 90,25 & 72,78 & 56,40 & 40,38 & 24,36 & 13,32 & 22,45 & 40,48 & 59,72 & 80,89 & 106,87 & - \\
\hline \multirow[t]{3}{*}{ SPI } & $\mathrm{DM}$ & 1,03 & 1,81 & 2,64 & 3,49 & 4,44 & 5,43 & 6,51 & 7,70 & 9,04 & 10,55 & 12,33 & - \\
\hline & DMA & 3,97 & 3,68 & 3,63 & 3,85 & 4,64 & 5,79 & 7,27 & 8,94 & 10,83 & 13,10 & 16,00 & - \\
\hline & PDMA & 28,17 & 23,28 & 18,48 & 13,27 & 11,35 & 13,53 & 20,84 & 31,64 & 43,92 & 59,16 & 78,10 & - \\
\hline \multirow[t]{3}{*}{$\Delta \mathrm{CS}$} & $\mathrm{DM}$ & $-55,62$ & $-51,97$ & $-47,96$ & $-43,63$ & $-39,32$ & $-35,24$ & $-31,71$ & $-29,32$ & $-29,17$ & $-33,84$ & $-52,38$ & - \\
\hline & DMA & 58,84 & 50,37 & 44,47 & 38,06 & 31,01 & 24,44 & 24,19 & 30,02 & 38,59 & 56,67 & 89,88 & - \\
\hline & PDMA & 62,08 & 49,50 & 37,92 & 27,11 & 13,01 & $-0,21$ & 1,61 & 8,83 & 15,80 & 21,72 & 28,76 & - \\
\hline
\end{tabular}


Tabela 8.76: Constantes de acoplamento B3LYP com correção vibracional no nível PBE0 $40 \% E_{X}^{\mathrm{HF}}$ e base aug-pcJ-2.

\begin{tabular}{|c|c|c|c|c|c|c|c|c|c|c|c|c|c|}
\hline & $\% E_{X}^{\mathrm{HF}}$ & $0 \%$ & $10 \%$ & $20 \%$ & $30 \%$ & $40 \%$ & $50 \%$ & $60 \%$ & $70 \%$ & $80 \%$ & $90 \%$ & $100 \%$ & Exp. \\
\hline $\mathrm{HF}$ & ${ }^{1} J_{\mathrm{HF}}$ & 358,6 & 383,6 & 408,8 & 434,3 & 460,0 & 486,0 & 512,2 & 538,6 & 565,2 & 592,1 & 619,2 & 500 \\
\hline $\mathrm{CO}$ & ${ }^{1} J_{\mathrm{CO}}$ & 22,4 & 20,6 & 18,6 & 16,5 & 14,3 & 12,1 & 9,7 & 7,2 & 4,7 & 2,1 & $-0,5$ & 16,4 \\
\hline $\mathrm{H}_{2} \mathrm{O}$ & ${ }^{1} J_{\mathrm{OH}}$ & $-70,3$ & $-73,0$ & $-75,7$ & $-78,4$ & $-81,1$ & $-83,9$ & $-86,7$ & $-89,6$ & $-92,4$ & $-95,3$ & $-98,2$ & $-80,6$ \\
\hline $\mathrm{H}_{2} \mathrm{O}$ & ${ }^{2} J_{\mathrm{HH}}$ & $-3,8$ & $-4,9$ & $-6,0$ & $-7,1$ & $-8,2$ & $-9,3$ & $-10,5$ & $-11,7$ & $-12,9$ & $-14,1$ & $-15,3$ & $-7,3$ \\
\hline $\mathrm{NH}_{3}$ & ${ }^{1} J_{\mathrm{NH}}$ & 44,7 & 45,5 & 46,3 & 47,1 & 48,0 & 48,8 & 49,7 & 50,5 & 51,4 & 52,3 & 53,2 & 43,8 \\
\hline $\mathrm{NH}_{3}$ & ${ }^{2} J_{\mathrm{HH}}$ & $-7,6$ & $-8,5$ & $-9,5$ & $-10,4$ & $-11,4$ & $-12,4$ & $-13,4$ & $-14,4$ & $-15,4$ & $-16,4$ & $-17,4$ & $-9,6$ \\
\hline $\mathrm{PH}_{3}$ & ${ }^{1} J_{\mathrm{PH}}$ & 150,1 & 158,6 & 167,0 & 175,2 & 183,4 & 191,3 & 199,2 & 206,8 & 214,3 & 221,7 & 228,8 & 188,2 \\
\hline $\mathrm{PF}_{3}$ & ${ }^{1} J_{\mathrm{PF}}$ & $-1808,1$ & $-1782,4$ & $-1752,3$ & $-1718,6$ & $-1681,8$ & $-1642,6$ & $-1601,6$ & $-1559,2$ & $-1515,9$ & $-1471,8$ & $-1427,4$ & -1441 \\
\hline $\mathrm{BHF}_{2}$ & ${ }^{1} J_{\mathrm{BF}}$ & $-172,1$ & $-154,6$ & $-137,1$ & $-119,8$ & $-102,6$ & $-85,6$ & $-68,8$ & $-52,2$ & $-35,8$ & $-19,6$ & $-3,7$ & -84 \\
\hline $\mathrm{BF}_{3}$ & ${ }^{1} J_{\mathrm{BF}}$ & $-72,4$ & $-53,2$ & $-34,3$ & $-15,5$ & 2,9 & 21,2 & 39,3 & 57,3 & 75,0 & 92,6 & 110,0 & 15 \\
\hline $\mathrm{F}_{2} \mathrm{O}$ & ${ }^{1} J_{\mathrm{OF}}$ & $-295,3$ & $-332,1$ & $-369,0$ & $-407,6$ & $-450,1$ & $-499,7$ & $-562,3$ & $-649,3$ & $-788,6$ & $-1072,0$ & $-2153,6$ & -300 \\
\hline $\mathrm{CH}_{4}$ & ${ }^{1} J_{\mathrm{CH}}$ & 133,4 & 135,0 & 136,5 & 138,1 & 139,8 & 141,4 & 143,1 & 144,8 & 146,5 & 148,3 & 150,0 & 125,3 \\
\hline $\mathrm{CH}_{4}$ & ${ }^{2} J_{\mathrm{HH}}$ & $-12,2$ & $-13,0$ & $-13,7$ & $-14,5$ & $-15,2$ & $-16,0$ & $-16,7$ & $-17,5$ & $-18,2$ & $-18,9$ & $-19,7$ & $-12,8$ \\
\hline $\mathrm{C}_{2} \mathrm{H}_{2}$ & ${ }^{1} J_{\mathrm{CC}}$ & 200,2 & 203,2 & 206,7 & 210,6 & 215,2 & 220,5 & 226,7 & 234,2 & 243,2 & 254,1 & 267,7 & 174,8 \\
\hline $\mathrm{C}_{2} \mathrm{H}_{2}$ & ${ }^{1} J_{\mathrm{CH}}$ & 274,3 & 276,7 & 279,3 & 282,1 & 285,0 & 288,2 & 291,8 & 295,8 & 300,5 & 305,9 & 312,6 & 247,6 \\
\hline $\mathrm{C}_{2} \mathrm{H}_{2}$ & ${ }^{2} J_{\mathrm{CH}}$ & 57,1 & 57,0 & 56,7 & 56,2 & 55,3 & 54,1 & 52,5 & 50,3 & 47,4 & 43,7 & 38,7 & 50,1 \\
\hline $\mathrm{C}_{2} \mathrm{H}_{2}$ & ${ }^{3} J_{\mathrm{HH}}$ & 10,9 & 11,4 & 12,1 & 13,0 & 14,0 & 15,2 & 16,6 & 18,3 & 20,4 & 22,9 & 26,1 & 9,6 \\
\hline $\mathrm{C}_{2} \mathrm{H}_{4}$ & ${ }^{1} J_{\mathrm{CC}}$ & 67,6 & 70,5 & 73,8 & 77,4 & 81,5 & 86,3 & 92,1 & 99,1 & 108,2 & 120,6 & 138,7 & 67,6 \\
\hline $\mathrm{C}_{2} \mathrm{H}_{4}$ & ${ }^{1} J_{\mathrm{CH}}$ & 167,4 & 169,7 & 172,0 & 174,5 & 177,1 & 180,0 & 183,2 & 187,0 & 191,5 & 197,2 & 205,3 & 156,3 \\
\hline $\mathrm{C}_{2} \mathrm{H}_{4}$ & ${ }^{2} J_{\mathrm{CH}}$ & $-0,2$ & $-1,0$ & $-2,1$ & $-3,2$ & $-4,6$ & $-6,2$ & $-8,2$ & $-10,6$ & $-13,9$ & $-18,5$ & $-25,3$ & $-2,4$ \\
\hline $\mathrm{C}_{2} \mathrm{H}_{4}$ & ${ }^{2} J_{\mathrm{HH}}$ & 6,2 & 5,5 & 4,7 & 3,8 & 2,9 & 1,8 & 0,6 & $-0,8$ & $-2,7$ & $-5,3$ & $-9,0$ & 2,3 \\
\hline $\mathrm{C}_{2} \mathrm{H}_{4}$ & ${ }^{3} J_{\mathrm{HH}_{\mathrm{c}}}$ & 12,8 & 13,1 & 13,4 & 13,8 & 14,2 & 14,9 & 15,7 & 16,7 & 18,2 & 20,3 & 23,6 & 11,7 \\
\hline $\mathrm{C}_{2} \mathrm{H}_{4}$ & ${ }^{3} J_{\mathrm{HH}_{\mathrm{t}}}$ & 20,5 & 20,7 & 21,1 & 21,5 & 22,1 & 22,9 & 23,8 & 25,1 & 26,8 & 29,2 & 33,0 & 19 \\
\hline $\mathrm{C}_{2} \mathrm{H}_{6}$ & ${ }^{1} J_{\mathrm{CC}}$ & 30,1 & 32,2 & 34,4 & 36,6 & 38,8 & 41,1 & 43,5 & 45,8 & 48,2 & 50,7 & 53,1 & 34,5 \\
\hline $\mathrm{C}_{2} \mathrm{H}_{6}$ & ${ }^{1} J_{\mathrm{CH}}$ & 132,3 & 134,1 & 135,9 & 137,7 & 139,5 & 141,4 & 143,3 & 145,1 & 147,0 & 149,0 & 150,9 & 125,2 \\
\hline $\mathrm{C}_{2} \mathrm{H}_{6}$ & ${ }^{2} J_{\mathrm{CH}}$ & $-2,7$ & $-3,2$ & $-3,6$ & $-4,1$ & $-4,7$ & $-5,2$ & $-5,7$ & $-6,2$ & $-6,8$ & $-7,3$ & $-7,9$ & $-4,7$ \\
\hline \multirow[t]{3}{*}{ Total } & $\mathrm{DM}$ & $-23,12$ & $-20,52$ & $-17,73$ & $-14,84$ & $-11,95$ & $-9,18$ & $-6,77$ & $-5,15$ & $-5,35$ & $-10,83$ & $-46,62$ & - \\
\hline & DMA & 32,77 & 30,31 & 28,12 & 26,20 & 24,69 & 24,46 & 28,24 & 34,27 & 42,73 & 57,19 & 104,12 & - \\
\hline & PDMA & 49,77 & 40,08 & 30,39 & 24,35 & 22,01 & 26,41 & 42,02 & 59,61 & 81,07 & 108,43 & 153,00 & - \\
\hline \multirow[t]{3}{*}{ CPI } & $\mathrm{DM}$ & $-63,15$ & $-58,30$ & $-53,10$ & $-47,75$ & $-42,50$ & $-37,73$ & $-34,01$ & $-32,45$ & $-35,57$ & $-51,75$ & $-140,53$ & - \\
\hline & DMA & 68,14 & 61,39 & 55,10 & 48,80 & 43,26 & 40,33 & 46,48 & 57,54 & 73,23 & 101,95 & 205,64 & - \\
\hline & PDMA & 80,30 & 63,22 & 46,37 & 31,19 & 21,29 & 20,59 & 39,30 & 59,54 & 81,17 & 107,14 & 157,30 & - \\
\hline \multirow[t]{3}{*}{ SPI } & $\mathrm{DM}$ & 6,24 & 7,19 & 8,21 & 9,29 & 10,45 & 11,75 & 13,21 & 14,87 & 16,81 & 19,19 & 22,25 & - \\
\hline & DMA & 6,83 & 7,52 & 8,34 & 9,63 & 11,07 & 12,82 & 14,87 & 17,20 & 20,37 & 24,36 & 29,67 & - \\
\hline & PDMA & 27,37 & 23,12 & 18,67 & 19,34 & 22,53 & 30,68 & 44,02 & 59,66 & 81,00 & 109,37 & 149,84 & - \\
\hline \multirow[t]{3}{*}{$\Delta \mathrm{CS}$} & $\mathrm{DM}$ & $-69,39$ & $-65,49$ & $-61,31$ & $-57,04$ & $-52,95$ & $-49,48$ & $-47,22$ & $-47,31$ & $-52,39$ & $-70,94$ & $-162,77$ & - \\
\hline & DMA & 61,31 & 53,87 & 46,76 & 39,17 & 32,20 & 27,51 & 31,62 & 40,34 & 52,85 & 77,59 & 175,96 & - \\
\hline & PDMA & 52,93 & 40,10 & 27,69 & 11,85 & $-1,24$ & $-10,09$ & $-4,72$ & $-0,12$ & 0,16 & $-2,23$ & 7,47 & - \\
\hline
\end{tabular}


Tabela 8.77: Constantes de acoplamento B3P86 com correção vibracional no nível PBE0 $40 \% E_{X}^{\mathrm{HF}}$ e base aug-pcJ-2.

\begin{tabular}{|c|c|c|c|c|c|c|c|c|c|c|c|c|c|}
\hline & $\% E_{X}^{\mathrm{HF}}$ & $0 \%$ & $10 \%$ & $20 \%$ & $30 \%$ & $40 \%$ & $50 \%$ & $60 \%$ & $70 \%$ & $80 \%$ & $90 \%$ & $100 \%$ & Exp. \\
\hline $\mathrm{HF}$ & ${ }^{1} J_{\mathrm{HF}}$ & 322,9 & 346,6 & 370,6 & 394,7 & 419,2 & 443,8 & 468,7 & 493,7 & 519,0 & 544,5 & 570,2 & 500 \\
\hline $\mathrm{CO}$ & ${ }^{1} J_{\mathrm{CO}}$ & 25,4 & 23,8 & 22,0 & 20,2 & 18,2 & 16,2 & 14,1 & 12,0 & 9,8 & 7,5 & 5,1 & 16,4 \\
\hline $\mathrm{H}_{2} \mathrm{O}$ & ${ }^{1} J_{\mathrm{OH}}$ & $-63,8$ & $-66,4$ & $-68,9$ & $-71,5$ & $-74,1$ & $-76,7$ & $-79,4$ & $-82,0$ & $-84,7$ & $-87,5$ & $-90,2$ & $-80,6$ \\
\hline $\mathrm{H}_{2} \mathrm{O}$ & ${ }^{2} J_{\mathrm{HH}}$ & $-3,1$ & $-4,1$ & $-5,0$ & $-6,1$ & $-7,1$ & $-8,1$ & $-9,2$ & $-10,3$ & $-11,4$ & $-12,5$ & $-13,7$ & $-7,3$ \\
\hline $\mathrm{NH}_{3}$ & ${ }^{1} J_{\mathrm{NH}}$ & 40,8 & 41,6 & 42,3 & 43,1 & 43,9 & 44,7 & 45,5 & 46,3 & 47,1 & 48,0 & 48,8 & 43,8 \\
\hline $\mathrm{NH}_{3}$ & ${ }^{2} J_{\mathrm{HH}}$ & $-7,0$ & $-7,9$ & $-8,7$ & $-9,6$ & $-10,5$ & $-11,4$ & $-12,3$ & $-13,3$ & $-14,2$ & $-15,1$ & $-16,1$ & $-9,6$ \\
\hline $\mathrm{PH}_{3}$ & ${ }^{1} J_{\mathrm{PH}}$ & 130,9 & 139,1 & 147,1 & 155,1 & 163,0 & 170,7 & 178,3 & 185,8 & 193,1 & 200,3 & 207,3 & 188,2 \\
\hline $\mathrm{PF}_{3}$ & ${ }^{1} J_{\mathrm{PF}}$ & $-1801,8$ & $-1776,1$ & $-1745,9$ & $-1712,2$ & $-1675,6$ & $-1636,6$ & $-1595,8$ & $-1553,7$ & $-1510,6$ & $-1466,9$ & $-1422,8$ & -1441 \\
\hline $\mathrm{BHF}_{2}$ & ${ }^{1} J_{\mathrm{BF}}$ & $-179,9$ & $-162,8$ & $-145,8$ & $-129,0$ & $-112,3$ & $-95,7$ & $-79,3$ & $-63,1$ & $-47,1$ & $-31,3$ & $-15,7$ & -84 \\
\hline $\mathrm{BF}_{3}$ & ${ }^{1} J_{\mathrm{BF}}$ & $-83,6$ & $-64,8$ & $-46,3$ & $-28,0$ & $-9,9$ & 7,9 & 25,6 & 43,1 & 60,5 & 77,7 & 94,7 & 15 \\
\hline $\mathrm{F}_{2} \mathrm{O}$ & ${ }^{1} J_{\mathrm{OF}}$ & $-303,1$ & $-340,2$ & $-377,6$ & $-416,7$ & $-459,9$ & $-510,4$ & $-574,0$ & $-662,2$ & $-801,7$ & $-1077,2$ & $-2008,4$ & -300 \\
\hline $\mathrm{CH}_{4}$ & ${ }^{1} J_{\mathrm{CH}}$ & 121,7 & 123,2 & 124,7 & 126,2 & 127,8 & 129,4 & 131,0 & 132,6 & 134,2 & 135,9 & 137,6 & 125,3 \\
\hline $\mathrm{CH}_{4}$ & ${ }^{2} J_{\mathrm{HH}}$ & $-12,1$ & $-12,8$ & $-13,6$ & $-14,3$ & $-15,0$ & $-15,7$ & $-16,4$ & $-17,1$ & $-17,8$ & $-18,5$ & $-19,2$ & $-12,8$ \\
\hline $\mathrm{C}_{2} \mathrm{H}_{2}$ & ${ }^{1} J_{\mathrm{CC}}$ & 190,7 & 193,4 & 196,6 & 200,2 & 204,4 & 209,4 & 215,3 & 222,4 & 231,1 & 241,9 & 255,7 & 174,8 \\
\hline $\mathrm{C}_{2} \mathrm{H}_{2}$ & ${ }^{1} J_{\mathrm{CH}}$ & 254,2 & 256,6 & 259,0 & 261,7 & 264,6 & 267,7 & 271,3 & 275,4 & 280,1 & 285,9 & 293,0 & 247,6 \\
\hline $\mathrm{C}_{2} \mathrm{H}_{2}$ & ${ }^{2} J_{\mathrm{CH}}$ & 54,9 & 54,8 & 54,6 & 54,1 & 53,2 & 52,0 & 50,4 & 48,1 & 45,1 & 41,1 & 35,6 & 50,1 \\
\hline $\mathrm{C}_{2} \mathrm{H}_{2}$ & ${ }^{3} J_{\mathrm{HH}}$ & 10,9 & 11,6 & 12,3 & 13,2 & 14,3 & 15,6 & 17,1 & 19,0 & 21,3 & 24,2 & 27,8 & 9,6 \\
\hline $\mathrm{C}_{2} \mathrm{H}_{4}$ & ${ }^{1} J_{\mathrm{CC}}$ & 61,6 & 64,4 & 67,4 & 70,9 & 74,8 & 79,5 & 85,2 & 92,5 & 102,2 & 116,3 & 139,2 & 67,6 \\
\hline $\mathrm{C}_{2} \mathrm{H}_{4}$ & ${ }^{1} J_{\mathrm{CH}}$ & 154,0 & 156,1 & 158,4 & 160,8 & 163,3 & 166,2 & 169,5 & 173,3 & 178,2 & 184,8 & 195,0 & 156,3 \\
\hline $\mathrm{C}_{2} \mathrm{H}_{4}$ & ${ }^{2} J_{\mathrm{CH}}$ & $-0,5$ & $-1,3$ & $-2,3$ & $-3,4$ & $-4,7$ & $-6,4$ & $-8,4$ & $-11,1$ & $-14,8$ & $-20,2$ & $-29,2$ & $-2,4$ \\
\hline $\mathrm{C}_{2} \mathrm{H}_{4}$ & ${ }^{2} J_{\mathrm{HH}}$ & 4,9 & 4,2 & 3,4 & 2,5 & 1,5 & 0,3 & $-1,0$ & $-2,7$ & $-5,0$ & $-8,3$ & $-13,6$ & 2,3 \\
\hline $\mathrm{C}_{2} \mathrm{H}_{4}$ & ${ }^{3} J_{\mathrm{HH}_{\mathrm{c}}}$ & 12,0 & 12,3 & 12,7 & 13,1 & 13,7 & 14,4 & 15,4 & 16,7 & 18,6 & 21,5 & 26,5 & 11,7 \\
\hline $\mathrm{C}_{2} \mathrm{H}_{4}$ & ${ }^{3} J_{\mathrm{HH}_{\mathrm{t}}}$ & 19,3 & 19,6 & 20,0 & 20,6 & 21,2 & 22,1 & 23,2 & 24,8 & 27,0 & 30,3 & 35,9 & 19 \\
\hline $\mathrm{C}_{2} \mathrm{H}_{6}$ & ${ }^{1} J_{\mathrm{CC}}$ & 25,9 & 27,9 & 29,9 & 32,0 & 34,1 & 36,2 & 38,4 & 40,6 & 42,8 & 45,1 & 47,4 & 34,5 \\
\hline $\mathrm{C}_{2} \mathrm{H}_{6}$ & ${ }^{1} J_{\mathrm{CH}}$ & 121,2 & 122,9 & 124,6 & 126,3 & 128,0 & 129,8 & 131,6 & 133,4 & 135,2 & 137,1 & 138,9 & 125,2 \\
\hline $\mathrm{C}_{2} \mathrm{H}_{6}$ & ${ }^{2} J_{\mathrm{CH}}$ & $-2,9$ & $-3,3$ & $-3,8$ & $-4,3$ & $-4,7$ & $-5,2$ & $-5,7$ & $-6,2$ & $-6,8$ & $-7,3$ & $-7,8$ & $-4,7$ \\
\hline \multirow[t]{3}{*}{ Total } & $\mathrm{DM}$ & $-28,90$ & $-26,41$ & $-23,74$ & $-20,98$ & $-18,22$ & $-15,59$ & $-13,30$ & $-11,81$ & $-12,07$ & $-17,22$ & $-47,04$ & - \\
\hline & DMA & 34,20 & 31,52 & 28,90 & 26,72 & 24,88 & 23,70 & 24,45 & 28,01 & 35,82 & 50,11 & 92,11 & - \\
\hline & PDMA & 51,81 & 41,81 & 31,97 & 25,48 & 23,31 & 25,37 & 35,65 & 53,62 & 76,27 & 106,40 & 156,40 & - \\
\hline \multirow[t]{3}{*}{ CPI } & $\mathrm{DM}$ & $-69,38$ & $-64,74$ & $-59,74$ & $-54,63$ & $-49,64$ & $-45,14$ & $-41,70$ & $-40,42$ & $-43,74$ & $-59,40$ & $-134,70$ & - \\
\hline & DMA & 75,31 & 69,55 & 63,46 & 57,19 & 51,20 & 46,01 & 45,01 & 49,78 & 63,66 & 91,44 & 182,06 & - \\
\hline & PDMA & 93,69 & 77,14 & 60,90 & 44,46 & 30,02 & 18,48 & 23,95 & 41,57 & 62,06 & 87,08 & 132,29 & - \\
\hline \multirow[t]{3}{*}{ SPI } & $\mathrm{DM}$ & 0,78 & 1,70 & 2,65 & 3,70 & 4,83 & 6,08 & 7,52 & 9,17 & 11,15 & 13,71 & 17,25 & - \\
\hline & DMA & 4,05 & 3,62 & 3,56 & 4,37 & 5,59 & 7,33 & 9,37 & 12,04 & 15,39 & 19,81 & 26,14 & - \\
\hline & PDMA & 21,09 & 15,90 & 10,75 & 11,55 & 18,40 & 30,42 & 44,23 & 62,45 & 86,69 & 120,57 & 174,09 & - \\
\hline \multirow[t]{3}{*}{$\Delta \mathrm{CS}$} & $\mathrm{DM}$ & $-70,16$ & $-66,44$ & $-62,39$ & $-58,33$ & $-54,46$ & $-51,22$ & $-49,22$ & $-49,59$ & $-54,89$ & $-73,11$ & $-151,95$ & - \\
\hline & DMA & 71,26 & 65,93 & 59,90 & 52,82 & 45,61 & 38,68 & 35,64 & 37,74 & 48,27 & 71,63 & 155,92 & - \\
\hline & PDMA & 72,60 & 61,24 & 50,15 & 32,91 & 11,62 & $-11,94$ & $-20,29$ & $-20,89$ & $-24,63$ & $-33,49$ & $-41,80$ & - \\
\hline
\end{tabular}


Tabela 8.78: Constantes de acoplamento B971 com correção vibracional no nível PBE0 $40 \% E_{X}^{\mathrm{HF}}$ e base aug-pcJ-2.

\begin{tabular}{|c|c|c|c|c|c|c|c|c|c|c|c|c|c|}
\hline & $\% E_{X}^{\mathrm{HF}}$ & $0 \%$ & $10 \%$ & $20 \%$ & $30 \%$ & $40 \%$ & $50 \%$ & $60 \%$ & $70 \%$ & $80 \%$ & $90 \%$ & $100 \%$ & Exp. \\
\hline $\mathrm{HF}$ & ${ }^{1} J_{\mathrm{HF}}$ & 392,5 & 409,1 & 426,6 & 445,2 & 464,9 & 485,8 & 508,0 & 531,3 & 556,0 & 581,9 & 609,1 & 500 \\
\hline $\mathrm{CO}$ & ${ }^{1} J_{\mathrm{CO}}$ & 16,5 & 15,4 & 14,2 & 12,9 & 11,4 & 9,7 & 8,0 & 6,0 & 3,9 & 1,7 & $-0,6$ & 16,4 \\
\hline $\mathrm{H}_{2} \mathrm{O}$ & ${ }^{1} J_{\mathrm{OH}}$ & $-66,3$ & $-68,4$ & $-70,7$ & $-73,1$ & $-75,6$ & $-78,3$ & $-81,1$ & $-84,1$ & $-87,4$ & $-90,8$ & $-94,3$ & $-80,6$ \\
\hline $\mathrm{H}_{2} \mathrm{O}$ & ${ }^{2} J_{\mathrm{HH}}$ & 0,9 & $-0,1$ & $-1,2$ & $-2,3$ & $-3,6$ & $-4,9$ & $-6,2$ & $-7,7$ & $-9,3$ & $-11,0$ & $-12,8$ & $-7,3$ \\
\hline $\mathrm{NH}_{3}$ & ${ }^{1} J_{\mathrm{NH}}$ & 38,1 & 39,1 & 40,1 & 41,2 & 42,4 & 43,6 & 44,9 & 46,4 & 47,8 & 49,4 & 51,1 & 43,8 \\
\hline $\mathrm{NH}_{3}$ & ${ }^{2} J_{\mathrm{HH}}$ & $-2,6$ & $-3,5$ & $-4,4$ & $-5,5$ & $-6,6$ & $-7,8$ & $-9,1$ & $-10,4$ & $-11,9$ & $-13,5$ & $-15,3$ & $-9,6$ \\
\hline $\mathrm{PH}_{3}$ & ${ }^{1} J_{\mathrm{PH}}$ & 154,4 & 160,6 & 167,2 & 174,1 & 181,4 & 189,1 & 197,1 & 205,6 & 214,4 & 223,6 & 233,2 & 188,2 \\
\hline $\mathrm{PF}_{3}$ & ${ }^{1} J_{\mathrm{PF}}$ & $-1611,4$ & $-1606,1$ & $-1595,2$ & $-1579,6$ & $-1559,9$ & $-1536,9$ & $-1511,2$ & $-1483,4$ & $-1454,0$ & $-1423,6$ & $-1392,6$ & -1441 \\
\hline $\mathrm{BHF}_{2}$ & ${ }^{1} J_{\mathrm{BF}}$ & $-149,4$ & $-134,9$ & $-120,0$ & $-104,9$ & $-89,5$ & $-74,0$ & $-58,4$ & $-42,8$ & $-27,2$ & $-11,6$ & 3,7 & -84 \\
\hline $\mathrm{BF}_{3}$ & ${ }^{1} J_{\mathrm{BF}}$ & $-57,9$ & $-41,1$ & $-24,1$ & $-6,9$ & 10,2 & 27,5 & 44,9 & 62,3 & 79,7 & 97,1 & 114,6 & 15 \\
\hline $\mathrm{F}_{2} \mathrm{O}$ & ${ }^{1} J_{\mathrm{OF}}$ & $-205,1$ & $-236,9$ & $-270,1$ & $-305,1$ & $-343,0$ & $-385,7$ & $-436,5$ & $-502,2$ & $-597,8$ & $-768,1$ & $-1236,6$ & -300 \\
\hline $\mathrm{CH}_{4}$ & ${ }^{1} J_{\mathrm{CH}}$ & 104,9 & 108,1 & 111,5 & 115,1 & 118,9 & 123,0 & 127,4 & 132,0 & 136,8 & 142,0 & 147,5 & 125,3 \\
\hline $\mathrm{CH}_{4}$ & ${ }^{2} J_{\mathrm{HH}}$ & $-6,1$ & $-7,0$ & $-7,9$ & $-8,8$ & $-9,9$ & $-11,0$ & $-12,1$ & $-13,4$ & $-14,7$ & $-16,1$ & $-17,6$ & $-12,8$ \\
\hline $\mathrm{C}_{2} \mathrm{H}_{2}$ & ${ }^{1} J_{\mathrm{CC}}$ & 187,0 & 191,0 & 195,3 & 200,3 & 205,9 & 212,5 & 220,3 & 229,7 & 241,4 & 256,3 & 276,0 & 174,8 \\
\hline $\mathrm{C}_{2} \mathrm{H}_{2}$ & ${ }^{1} J_{\mathrm{CH}}$ & 203,8 & 210,5 & 217,5 & 224,9 & 232,7 & 241,1 & 250,2 & 260,1 & 271,2 & 283,8 & 298,7 & 247,6 \\
\hline $\mathrm{C}_{2} \mathrm{H}_{2}$ & ${ }^{2} J_{\mathrm{CH}}$ & 51,2 & 52,1 & 52,7 & 53,2 & 53,4 & 53,2 & 52,7 & 51,4 & 49,3 & 45,8 & 40,3 & 50,1 \\
\hline $\mathrm{C}_{2} \mathrm{H}_{2}$ & ${ }^{3} J_{\mathrm{HH}}$ & 6,9 & 7,3 & 7,8 & 8,3 & 9,1 & 10,0 & 11,2 & 12,7 & 14,7 & 17,4 & 21,2 & 9,6 \\
\hline $\mathrm{C}_{2} \mathrm{H}_{4}$ & ${ }^{1} J_{\mathrm{CC}}$ & 64,4 & 67,1 & 70,1 & 73,5 & 77,4 & 81,8 & 87,2 & 93,8 & 102,2 & 113,9 & 131,5 & 67,6 \\
\hline $\mathrm{C}_{2} \mathrm{H}_{4}$ & ${ }^{1} J_{\mathrm{CH}}$ & 128,1 & 132,5 & 137,2 & 142,1 & 147,4 & 153,2 & 159,4 & 166,3 & 174,1 & 183,3 & 195,0 & 156,3 \\
\hline $\mathrm{C}_{2} \mathrm{H}_{4}$ & ${ }^{2} J_{\mathrm{CH}}$ & 2,0 & 1,4 & 0,6 & $-0,3$ & $-1,3$ & $-2,6$ & $-4,2$ & $-6,3$ & $-9,0$ & $-13,0$ & $-19,3$ & $-2,4$ \\
\hline $\mathrm{C}_{2} \mathrm{H}_{4}$ & ${ }^{2} J_{\mathrm{HH}}$ & 6,2 & 5,8 & 5,4 & 4,9 & 4,3 & 3,6 & 2,7 & 1,6 & 0,2 & $-1,8$ & $-4,9$ & 2,3 \\
\hline $\mathrm{C}_{2} \mathrm{H}_{4}$ & ${ }^{3} J_{\mathrm{HH}_{\mathrm{c}}}$ & 9,7 & 10,0 & 10,2 & 10,6 & 10,9 & 11,4 & 12,0 & 12,8 & 14,0 & 15,7 & 18,4 & 11,7 \\
\hline $\mathrm{C}_{2} \mathrm{H}_{4}$ & ${ }^{3} J_{\mathrm{HH}_{\mathrm{t}}}$ & 14,0 & 14,5 & 15,0 & 15,6 & 16,3 & 17,1 & 18,1 & 19,3 & 20,9 & 23,2 & 26,6 & 19 \\
\hline $\mathrm{C}_{2} \mathrm{H}_{6}$ & ${ }^{1} J_{\mathrm{CC}}$ & 26,3 & 28,5 & 30,9 & 33,3 & 36,0 & 38,7 & 41,7 & 44,8 & 48,1 & 51,6 & 55,3 & 34,5 \\
\hline $\mathrm{C}_{2} \mathrm{H}_{6}$ & ${ }^{1} J_{\mathrm{CH}}$ & 103,0 & 106,5 & 110,2 & 114,1 & 118,3 & 122,7 & 127,3 & 132,2 & 137,4 & 143,0 & 148,8 & 125,2 \\
\hline $\mathrm{C}_{2} \mathrm{H}_{6}$ & ${ }^{2} J_{\mathrm{CH}}$ & $-0,8$ & $-1,3$ & $-1,9$ & $-2,4$ & $-3,0$ & $-3,7$ & $-4,4$ & $-5,1$ & $-5,9$ & $-6,8$ & $-7,7$ & $-4,7$ \\
\hline \multirow[t]{3}{*}{ Total } & $\mathrm{DM}$ & $-16,72$ & $-14,80$ & $-12,62$ & $-10,18$ & $-7,56$ & $-4,84$ & $-2,12$ & 0,30 & 1,92 & 1,09 & $-10,60$ & - \\
\hline & DMA & 28,77 & 24,28 & 19,58 & 14,95 & 12,57 & 12,04 & 14,67 & 20,71 & 28,61 & 41,48 & 67,87 & - \\
\hline & PDMA & 58,87 & 49,03 & 38,87 & 28,39 & 18,35 & 15,99 & 22,19 & 35,08 & 54,96 & 80,50 & 117,41 & - \\
\hline \multirow[t]{3}{*}{ CPI } & $\mathrm{DM}$ & $-30,11$ & $-27,97$ & $-25,32$ & $-22,26$ & $-18,98$ & $-15,71$ & $-12,77$ & $-10,90$ & $-11,52$ & $-18,71$ & $-52,85$ & - \\
\hline & DMA & 52,75 & 44,08 & 34,61 & 25,28 & 21,11 & 21,15 & 26,43 & 36,32 & 49,28 & 72,31 & 125,05 & - \\
\hline & PDMA & 78,49 & 63,10 & 47,45 & 31,68 & 17,60 & 20,87 & 32,83 & 48,88 & 69,94 & 93,85 & 127,43 & - \\
\hline \multirow[t]{3}{*}{ SPI } & $\mathrm{DM}$ & $-6,90$ & $-5,14$ & $-3,30$ & $-1,31$ & 0,82 & 3,13 & 5,69 & 8,52 & 11,77 & 15,61 & 20,38 & - \\
\hline & DMA & 11,19 & 9,77 & 8,55 & 7,38 & 6,30 & 5,37 & 6,05 & 9,27 & 13,45 & 18,87 & 25,94 & - \\
\hline & PDMA & 44,48 & 38,71 & 32,58 & 25,99 & 18,90 & 12,42 & 14,38 & 24,96 & 43,97 & 70,71 & 110,06 & - \\
\hline \multirow[t]{3}{*}{$\Delta \mathrm{CS}$} & $\mathrm{DM}$ & $-23,21$ & $-22,83$ & $-22,02$ & $-20,95$ & $-19,80$ & $-18,84$ & $-18,47$ & $-19,42$ & $-23,29$ & $-34,32$ & $-73,23$ & - \\
\hline & DMA & 41,55 & 34,32 & 26,06 & 17,90 & 14,81 & 15,78 & 20,37 & 27,05 & 35,83 & 53,44 & 99,11 & - \\
\hline & PDMA & 34,01 & 24,39 & 14,87 & 5,69 & $-1,30$ & 8,45 & 18,45 & 23,92 & 25,97 & 23,14 & 17,37 & - \\
\hline
\end{tabular}


Tabela 8.79: Constantes de acoplamento B972 com correção vibracional no nível PBE0 $40 \% E_{X}^{\mathrm{HF}}$ e base aug-pcJ-2.

\begin{tabular}{|c|c|c|c|c|c|c|c|c|c|c|c|c|c|}
\hline & $\% E_{X}^{\mathrm{HF}}$ & $0 \%$ & $10 \%$ & $20 \%$ & $30 \%$ & $40 \%$ & $50 \%$ & $60 \%$ & $70 \%$ & $80 \%$ & $90 \%$ & $100 \%$ & Exp. \\
\hline $\mathrm{HF}$ & ${ }^{1} J_{\mathrm{HF}}$ & 385,8 & 406,7 & 428,9 & 452,4 & 477,2 & 503,4 & 531,0 & 560,2 & 590,8 & 623,0 & 656,8 & 500 \\
\hline $\mathrm{CO}$ & ${ }^{1} J_{\mathrm{CO}}$ & 17,6 & 16,0 & 14,2 & 12,2 & 9,9 & 7,5 & 4,9 & 2,1 & $-0,9$ & $-4,1$ & $-7,6$ & 16,4 \\
\hline $\mathrm{H}_{2} \mathrm{O}$ & ${ }^{1} J_{\mathrm{OH}}$ & $-65,4$ & $-68,2$ & $-71,1$ & $-74,2$ & $-77,5$ & $-80,9$ & $-84,6$ & $-88,6$ & $-92,7$ & $-97,1$ & $-101,7$ & $-80,6$ \\
\hline $\mathrm{H}_{2} \mathrm{O}$ & ${ }^{2} J_{\mathrm{HH}}$ & 0,3 & $-0,7$ & $-1,7$ & $-2,8$ & $-4,0$ & $-5,2$ & $-6,5$ & $-8,0$ & $-9,5$ & $-11,1$ & $-12,8$ & $-7,3$ \\
\hline $\mathrm{NH}_{3}$ & ${ }^{1} J_{\mathrm{NH}}$ & 36,8 & 38,0 & 39,4 & 40,8 & 42,3 & 43,9 & 45,6 & 47,5 & 49,4 & 51,4 & 53,6 & 43,8 \\
\hline $\mathrm{NH}_{3}$ & ${ }^{2} J_{\mathrm{HH}}$ & $-2,5$ & $-3,4$ & $-4,3$ & $-5,2$ & $-6,3$ & $-7,4$ & $-8,6$ & $-9,9$ & $-11,3$ & $-12,8$ & $-14,4$ & $-9,6$ \\
\hline $\mathrm{PH}_{3}$ & ${ }^{1} J_{\mathrm{PH}}$ & 144,9 & 152,0 & 159,5 & 167,5 & 175,9 & 184,7 & 193,9 & 203,6 & 213,7 & 224,1 & 235,0 & 188,2 \\
\hline $\mathrm{PF}_{3}$ & ${ }^{1} J_{\mathrm{PF}}$ & $-1624,2$ & $-1618,8$ & $-1608,2$ & $-1593,1$ & $-1574,4$ & $-1552,8$ & $-1529,0$ & $-1503,5$ & $-1476,9$ & $-1449,9$ & $-1422,7$ & -1441 \\
\hline $\mathrm{BHF}_{2}$ & ${ }^{1} J_{\mathrm{BF}}$ & $-155,8$ & $-139,1$ & $-122,0$ & $-104,7$ & $-87,3$ & $-69,8$ & $-52,4$ & $-35,1$ & $-17,8$ & $-0,9$ & 15,9 & -84 \\
\hline $\mathrm{BF}_{3}$ & ${ }^{1} J_{\mathrm{BF}}$ & $-66,2$ & $-46,8$ & $-27,3$ & $-7,6$ & 11,9 & 31,6 & 51,3 & 70,9 & 90,5 & 110,0 & 129,4 & 15 \\
\hline $\mathrm{F}_{2} \mathrm{O}$ & ${ }^{1} J_{\mathrm{OF}}$ & $-202,6$ & $-233,2$ & $-265,1$ & $-299,0$ & $-335,9$ & $-377,8$ & $-428,2$ & $-494,2$ & $-592,7$ & $-777,0$ & $-1364,3$ & -300 \\
\hline $\mathrm{CH}_{4}$ & ${ }^{1} J_{\mathrm{CH}}$ & 97,0 & 101,0 & 105,2 & 109,6 & 114,3 & 119,3 & 124,6 & 130,2 & 136,1 & 142,3 & 148,9 & 125,3 \\
\hline $\mathrm{CH}_{4}$ & ${ }^{2} J_{\mathrm{HH}}$ & $-5,7$ & $-6,4$ & $-7,2$ & $-8,1$ & $-9,0$ & $-10,0$ & $-11,0$ & $-12,2$ & $-13,3$ & $-14,6$ & $-15,9$ & $-12,8$ \\
\hline $\mathrm{C}_{2} \mathrm{H}_{2}$ & ${ }^{1} J_{\mathrm{CC}}$ & 173,6 & 178,4 & 183,7 & 189,7 & 196,5 & 204,3 & 213,4 & 224,3 & 237,5 & 254,0 & 275,2 & 174,8 \\
\hline $\mathrm{C}_{2} \mathrm{H}_{2}$ & ${ }^{1} J_{\mathrm{CH}}$ & 193,1 & 200,6 & 208,6 & 216,9 & 225,8 & 235,2 & 245,4 & 256,3 & 268,4 & 281,8 & 297,3 & 247,6 \\
\hline $\mathrm{C}_{2} \mathrm{H}_{2}$ & ${ }^{2} J_{\mathrm{CH}}$ & 49,3 & 50,2 & 51,0 & 51,6 & 52,0 & 52,1 & 51,7 & 50,8 & 49,1 & 46,3 & 41,8 & 50,1 \\
\hline $\mathrm{C}_{2} \mathrm{H}_{2}$ & ${ }^{3} J_{\mathrm{HH}}$ & 6,8 & 7,2 & 7,6 & 8,1 & 8,8 & 9,6 & 10,6 & 11,9 & 13,6 & 15,8 & 18,7 & 9,6 \\
\hline $\mathrm{C}_{2} \mathrm{H}_{4}$ & ${ }^{1} J_{\mathrm{CC}}$ & 55,6 & 59,0 & 62,7 & 67,0 & 71,8 & 77,3 & 83,9 & 92,0 & 102,4 & 116,7 & 138,0 & 67,6 \\
\hline $\mathrm{C}_{2} \mathrm{H}_{4}$ & ${ }^{1} J_{\mathrm{CH}}$ & 119,8 & 124,9 & 130,4 & 136,1 & 142,3 & 148,9 & 156,1 & 163,9 & 172,8 & 183,1 & 196,0 & 156,3 \\
\hline $\mathrm{C}_{2} \mathrm{H}_{4}$ & ${ }^{2} J_{\mathrm{CH}}$ & 2,1 & 1,5 & 0,8 & 0,0 & $-0,9$ & $-2,2$ & $-3,7$ & $-5,7$ & $-8,5$ & $-12,4$ & $-18,6$ & $-2,4$ \\
\hline $\mathrm{C}_{2} \mathrm{H}_{4}$ & ${ }^{2} J_{\mathrm{HH}}$ & 5,8 & 5,6 & 5,3 & 4,9 & 4,4 & 3,9 & 3,2 & 2,4 & 1,3 & $-0,3$ & $-2,7$ & 2,3 \\
\hline $\mathrm{C}_{2} \mathrm{H}_{4}$ & ${ }^{3} J_{\mathrm{HH}_{\mathrm{c}}}$ & 9,3 & 9,5 & 9,8 & 10,1 & 10,5 & 11,0 & 11,5 & 12,2 & 13,2 & 14,7 & 17,0 & 11,7 \\
\hline $\mathrm{C}_{2} \mathrm{H}_{4}$ & ${ }^{3} J_{\mathrm{HH}_{\mathrm{t}}}$ & 13,5 & 14,0 & 14,5 & 15,1 & 15,8 & 16,6 & 17,5 & 18,6 & 20,1 & 22,1 & 25,1 & 19 \\
\hline $\mathrm{C}_{2} \mathrm{H}_{6}$ & ${ }^{1} J_{\mathrm{CC}}$ & 22,8 & 25,4 & 28,2 & 31,1 & 34,2 & 37,5 & 41,0 & 44,7 & 48,7 & 52,9 & 57,3 & 34,5 \\
\hline $\mathrm{C}_{2} \mathrm{H}_{6}$ & ${ }^{1} J_{\mathrm{CH}}$ & 95,0 & 99,2 & 103,6 & 108,2 & 113,2 & 118,4 & 123,9 & 129,7 & 135,9 & 142,4 & 149,3 & 125,2 \\
\hline $\mathrm{C}_{2} \mathrm{H}_{6}$ & ${ }^{2} J_{\mathrm{CH}}$ & $-0,7$ & $-1,1$ & $-1,6$ & $-2,1$ & $-2,6$ & $-3,2$ & $-3,8$ & $-4,4$ & $-5,1$ & $-5,9$ & $-6,7$ & $-4,7$ \\
\hline \multirow[t]{3}{*}{ Total } & $\mathrm{DM}$ & $-20,73$ & $-18,21$ & $-15,39$ & $-12,33$ & $-9,08$ & $-5,73$ & $-2,43$ & 0,57 & 2,68 & 1,90 & $-13,73$ & - \\
\hline & DMA & 32,08 & 26,90 & 21,54 & 15,79 & 12,70 & 12,57 & 15,96 & 22,39 & 31,22 & 44,16 & 75,06 & - \\
\hline & PDMA & 63,19 & 52,29 & 41,51 & 30,12 & 19,48 & 18,64 & 25,22 & 35,88 & 55,08 & 80,64 & 118,20 & - \\
\hline \multirow[t]{3}{*}{ CPI } & $\mathrm{DM}$ & $-33,84$ & $-30,76$ & $-27,15$ & $-23,15$ & $-19,01$ & $-14,88$ & $-11,23$ & $-8,72$ & $-8,94$ & $-16,85$ & $-61,25$ & - \\
\hline & DMA & 57,20 & 47,49 & 37,20 & 26,11 & 20,77 & 21,90 & 30,90 & 42,19 & 56,86 & 79,50 & 142,34 & - \\
\hline & PDMA & 85,28 & 66,92 & 49,74 & 32,24 & 16,67 & 24,58 & 39,84 & 58,04 & 81,37 & 107,62 & 146,74 & - \\
\hline \multirow[t]{3}{*}{ SPI } & $\mathrm{DM}$ & $-11,12$ & $-9,01$ & $-6,77$ & $-4,39$ & $-1,80$ & 0,97 & 4,01 & 7,37 & 11,21 & 15,65 & 21,11 & - \\
\hline & DMA & 13,67 & 11,79 & 10,06 & 8,22 & 6,77 & 5,73 & 5,00 & 7,87 & 12,41 & 18,24 & 25,72 & - \\
\hline & PDMA & 46,99 & 41,55 & 35,48 & 28,57 & 21,53 & 14,28 & 14,49 & 19,63 & 35,80 & 60,86 & 97,28 & - \\
\hline \multirow[t]{3}{*}{$\Delta \mathrm{CS}$} & $\mathrm{DM}$ & $-22,72$ & $-21,76$ & $-20,38$ & $-18,75$ & $-17,21$ & $-15,86$ & $-15,24$ & $-16,09$ & $-20,14$ & $-32,50$ & $-82,35$ & - \\
\hline & DMA & 43,53 & 35,70 & 27,14 & 17,89 & 14,00 & 16,17 & 25,90 & 34,32 & 44,46 & 61,26 & 116,62 & - \\
\hline & PDMA & 38,29 & 25,37 & 14,25 & 3,66 & $-4,86$ & 10,30 & 25,35 & 38,41 & 45,57 & 46,75 & 49,46 & - \\
\hline
\end{tabular}


Tabela 8.80: Constantes de acoplamento B98 com correção vibracional no nível PBE0 $40 \% E_{X}^{\mathrm{HF}}$ e base aug-pcJ-2.

\begin{tabular}{|c|c|c|c|c|c|c|c|c|c|c|c|c|c|}
\hline & $\% E_{X}^{\mathrm{HF}}$ & $0 \%$ & $10 \%$ & $20 \%$ & $30 \%$ & $40 \%$ & $50 \%$ & $60 \%$ & $70 \%$ & $80 \%$ & $90 \%$ & $100 \%$ & Exp. \\
\hline $\mathrm{HF}$ & ${ }^{1} J_{\mathrm{HF}}$ & 376,8 & 393,3 & 411,0 & 429,8 & 449,8 & 471,1 & 493,7 & 517,7 & 543,1 & 570,0 & 598,3 & 500 \\
\hline $\mathrm{CO}$ & ${ }^{1} J_{\mathrm{CO}}$ & 17,3 & 16,2 & 14,9 & 13,5 & 11,9 & 10,2 & 8,4 & 6,3 & 4,1 & 1,7 & $-0,7$ & 16,4 \\
\hline $\mathrm{H}_{2} \mathrm{O}$ & ${ }^{1} J_{\mathrm{OH}}$ & $-64,6$ & $-66,8$ & $-69,1$ & $-71,6$ & $-74,2$ & $-77,0$ & $-80,0$ & $-83,2$ & $-86,7$ & $-90,3$ & $-94,2$ & $-80,6$ \\
\hline $\mathrm{H}_{2} \mathrm{O}$ & ${ }^{2} J_{\mathrm{HH}}$ & 0,8 & $-0,2$ & $-1,2$ & $-2,4$ & $-3,6$ & $-4,9$ & $-6,4$ & $-7,9$ & $-9,5$ & $-11,2$ & $-13,1$ & $-7,3$ \\
\hline $\mathrm{NH}_{3}$ & ${ }^{1} J_{\mathrm{NH}}$ & 37,5 & 38,6 & 39,7 & 40,9 & 42,2 & 43,6 & 45,1 & 46,6 & 48,3 & 50,1 & 52,0 & 43,8 \\
\hline $\mathrm{NH}_{3}$ & ${ }^{2} J_{\mathrm{HH}}$ & $-2,7$ & $-3,6$ & $-4,6$ & $-5,6$ & $-6,8$ & $-8,0$ & $-9,4$ & $-10,8$ & $-12,4$ & $-14,1$ & $-16,0$ & $-9,6$ \\
\hline $\mathrm{PH}_{3}$ & ${ }^{1} J_{\mathrm{PH}}$ & 158,4 & 164,7 & 171,5 & 178,6 & 186,2 & 194,2 & 202,6 & 211,4 & 220,6 & 230,3 & 240,4 & 188,2 \\
\hline $\mathrm{PF}_{3}$ & ${ }^{1} J_{\mathrm{PF}}$ & $-1620,4$ & $-1615,4$ & $-1604,9$ & $-1589,4$ & $-1569,9$ & $-1546,9$ & $-1521,2$ & $-1493,4$ & $-1464,0$ & $-1433,5$ & $-1402,3$ & -1441 \\
\hline $\mathrm{BHF}_{2}$ & ${ }^{1} J_{\mathrm{BF}}$ & $-154,5$ & $-139,9$ & $-125,0$ & $-109,6$ & $-94,0$ & $-78,2$ & $-62,2$ & $-46,2$ & $-30,1$ & $-14,0$ & 1,8 & -84 \\
\hline $\mathrm{BF}_{3}$ & ${ }^{1} J_{\mathrm{BF}}$ & $-63,7$ & $-46,9$ & $-29,9$ & $-12,6$ & 4,8 & 22,3 & 40,0 & 57,8 & 75,7 & 93,6 & 111,6 & 15 \\
\hline $\mathrm{F}_{2} \mathrm{O}$ & ${ }^{1} J_{\mathrm{OF}}$ & $-211,8$ & $-244,2$ & $-278,1$ & $-314,2$ & $-353,5$ & $-398,3$ & $-452,6$ & $-524,3$ & $-632,7$ & $-838,8$ & $-1522,4$ & -300 \\
\hline $\mathrm{CH}_{4}$ & ${ }^{1} J_{\mathrm{CH}}$ & 103,5 & 107,1 & 110,9 & 115,0 & 119,3 & 123,9 & 128,9 & 134,1 & 139,7 & 145,6 & 151,9 & 125,3 \\
\hline $\mathrm{CH}_{4}$ & ${ }^{2} J_{\mathrm{HH}}$ & $-6,2$ & $-7,1$ & $-8,0$ & $-9,0$ & $-10,1$ & $-11,3$ & $-12,5$ & $-13,8$ & $-15,3$ & $-16,8$ & $-18,4$ & $-12,8$ \\
\hline $\mathrm{C}_{2} \mathrm{H}_{2}$ & ${ }^{1} J_{\mathrm{CC}}$ & 185,4 & 189,7 & 194,4 & 199,8 & 205,9 & 213,1 & 221,5 & 231,8 & 244,5 & 260,9 & 283,0 & 174,8 \\
\hline $\mathrm{C}_{2} \mathrm{H}_{2}$ & ${ }^{1} J_{\mathrm{CH}}$ & 201,2 & 208,5 & 216,1 & 224,3 & 232,9 & 242,2 & 252,2 & 263,2 & 275,5 & 289,7 & 306,5 & 247,6 \\
\hline $\mathrm{C}_{2} \mathrm{H}_{2}$ & ${ }^{2} J_{\mathrm{CH}}$ & 50,8 & 51,7 & 52,5 & 53,1 & 53,4 & 53,4 & 52,8 & 51,6 & 49,4 & 45,6 & 39,5 & 50,1 \\
\hline $\mathrm{C}_{2} \mathrm{H}_{2}$ & ${ }^{3} J_{\mathrm{HH}}$ & 6,8 & 7,2 & 7,7 & 8,3 & 9,1 & 10,1 & 11,3 & 13,0 & 15,2 & 18,2 & 22,4 & 9,6 \\
\hline $\mathrm{C}_{2} \mathrm{H}_{4}$ & ${ }^{1} J_{\mathrm{CC}}$ & 63,2 & 66,2 & 69,5 & 73,2 & 77,4 & 82,3 & 88,2 & 95,5 & 105,0 & 118,4 & 139,3 & 67,6 \\
\hline $\mathrm{C}_{2} \mathrm{H}_{4}$ & ${ }^{1} J_{\mathrm{CH}}$ & 126,4 & 131,2 & 136,3 & 141,8 & 147,7 & 154,0 & 160,9 & 168,6 & 177,4 & 187,9 & 201,6 & 156,3 \\
\hline $\mathrm{C}_{2} \mathrm{H}_{4}$ & ${ }^{2} J_{\mathrm{CH}}$ & 2,0 & 1,3 & 0,5 & $-0,4$ & $-1,3$ & $-2,6$ & $-4,3$ & $-6,5$ & $-9,5$ & $-14,0$ & $-21,4$ & $-2,4$ \\
\hline $\mathrm{C}_{2} \mathrm{H}_{4}$ & ${ }^{2} J_{\mathrm{HH}}$ & 5,9 & 5,6 & 5,2 & 4,7 & 4,1 & 3,4 & 2,5 & 1,4 & $-0,1$ & $-2,3$ & $-6,0$ & 2,3 \\
\hline $\mathrm{C}_{2} \mathrm{H}_{4}$ & ${ }^{3} J_{\mathrm{HH}_{\mathrm{c}}}$ & 9,7 & 9,9 & 10,2 & 10,6 & 11,0 & 11,5 & 12,2 & 13,1 & 14,3 & 16,3 & 19,6 & 11,7 \\
\hline $\mathrm{C}_{2} \mathrm{H}_{4}$ & ${ }^{3} J_{\mathrm{HH}_{\mathrm{t}}}$ & 13,8 & 14,3 & 14,9 & 15,6 & 16,3 & 17,2 & 18,3 & 19,6 & 21,5 & 24,0 & 28,2 & 19 \\
\hline $\mathrm{C}_{2} \mathrm{H}_{6}$ & ${ }^{1} J_{\mathrm{CC}}$ & 25,4 & 27,8 & 30,4 & 33,1 & 36,0 & 39,1 & 42,4 & 45,9 & 49,7 & 53,7 & 58,0 & 34,5 \\
\hline $\mathrm{C}_{2} \mathrm{H}_{6}$ & ${ }^{1} J_{\mathrm{CH}}$ & 101,6 & 105,5 & 109,6 & 113,9 & 118,6 & 123,5 & 128,8 & 134,3 & 140,2 & 146,5 & 153,2 & 125,2 \\
\hline $\mathrm{C}_{2} \mathrm{H}_{6}$ & ${ }^{2} J_{\mathrm{CH}}$ & $-0,9$ & $-1,4$ & $-1,9$ & $-2,5$ & $-3,1$ & $-3,8$ & $-4,5$ & $-5,3$ & $-6,1$ & $-7,1$ & $-8,1$ & $-4,7$ \\
\hline \multirow[t]{3}{*}{ Total } & $\mathrm{DM}$ & $-18,59$ & $-16,60$ & $-14,32$ & $-11,77$ & $-9,03$ & $-6,19$ & $-3,40$ & $-0,94$ & 0,49 & $-1,33$ & $-20,78$ & - \\
\hline & DMA & 30,11 & 25,47 & 20,62 & 16,53 & 14,10 & 13,23 & 15,81 & 21,97 & 30,74 & 44,72 & 80,16 & - \\
\hline & PDMA & 60,53 & 50,25 & 40,01 & 29,48 & 19,46 & 14,23 & 20,81 & 36,00 & 57,36 & 85,40 & 129,28 & - \\
\hline \multirow[t]{3}{*}{ CPI } & $\mathrm{DM}$ & $-33,44$ & $-31,37$ & $-28,78$ & $-25,77$ & $-22,55$ & $-19,35$ & $-16,63$ & $-15,17$ & $-16,77$ & $-27,01$ & $-80,50$ & - \\
\hline & DMA & 55,27 & 46,41 & 36,87 & 29,03 & 24,89 & 24,20 & 28,30 & 37,77 & 52,15 & 76,92 & 149,55 & - \\
\hline & PDMA & 83,04 & 66,70 & 51,08 & 35,72 & 21,52 & 17,90 & 29,53 & 46,96 & 69,03 & 94,56 & 135,42 & - \\
\hline \multirow[t]{3}{*}{ SPI } & $\mathrm{DM}$ & $-7,70$ & $-5,77$ & $-3,72$ & $-1,51$ & 0,87 & 3,46 & 6,31 & 9,49 & 13,15 & 17,50 & 23,01 & - \\
\hline & DMA & 11,66 & 10,11 & 8,69 & 7,37 & 6,18 & 5,19 & 6,65 & 10,37 & 15,03 & 21,11 & 29,27 & - \\
\hline & PDMA & 44,02 & 38,19 & 31,89 & 24,91 & 17,96 & 11,54 & 14,41 & 27,96 & 48,81 & 78,69 & 124,77 & - \\
\hline \multirow[t]{3}{*}{$\Delta \mathrm{CS}$} & $\mathrm{DM}$ & $-25,74$ & $-25,60$ & $-25,06$ & $-24,27$ & $-23,42$ & $-22,81$ & $-22,93$ & $-24,67$ & $-29,93$ & $-44,51$ & $-103,51$ & - \\
\hline & DMA & 43,61 & 36,30 & 28,18 & 21,65 & 18,71 & 19,01 & 21,65 & 27,40 & 37,12 & 55,80 & 120,29 & - \\
\hline & PDMA & 39,02 & 28,51 & 19,19 & 10,81 & 3,56 & 6,36 & 15,12 & 18,99 & 20,22 & 15,87 & 10,66 & - \\
\hline
\end{tabular}


Tabela 8.81: Constantes de acoplamento BHandH com correção vibracional no nível PBE0 $40 \% E_{X}^{\mathrm{HF}}$ e base aug-pcJ-2.

\begin{tabular}{|c|c|c|c|c|c|c|c|c|c|c|c|c|c|}
\hline & $\% E_{X}^{\mathrm{HF}}$ & $0 \%$ & $10 \%$ & $20 \%$ & $30 \%$ & $40 \%$ & $50 \%$ & $60 \%$ & $70 \%$ & $80 \%$ & $90 \%$ & $100 \%$ & Exp. \\
\hline $\mathrm{HF}$ & ${ }^{1} J_{\mathrm{HF}}$ & 385,8 & 406,3 & 427,6 & 449,6 & 472,4 & 496,0 & 520,5 & 545,8 & 572,1 & 599,4 & 627,7 & 500 \\
\hline $\mathrm{CO}$ & ${ }^{1} J_{\mathrm{CO}}$ & 25,5 & 23,6 & 21,6 & 19,4 & 17,0 & 14,4 & 11,7 & 8,7 & 5,6 & 2,3 & $-1,2$ & 16,4 \\
\hline $\mathrm{H}_{2} \mathrm{O}$ & ${ }^{1} J_{\mathrm{OH}}$ & $-68,5$ & $-71,0$ & $-73,7$ & $-76,4$ & $-79,3$ & $-82,3$ & $-85,5$ & $-88,8$ & $-92,3$ & $-95,9$ & $-99,7$ & $-80,6$ \\
\hline $\mathrm{H}_{2} \mathrm{O}$ & ${ }^{2} J_{\mathrm{HH}}$ & $-1,8$ & $-2,9$ & $-4,0$ & $-5,3$ & $-6,5$ & $-7,9$ & $-9,3$ & $-10,8$ & $-12,4$ & $-14,1$ & $-15,8$ & $-7,3$ \\
\hline $\mathrm{NH}_{3}$ & ${ }^{1} J_{\mathrm{NH}}$ & 39,9 & 41,0 & 42,2 & 43,4 & 44,7 & 46,0 & 47,5 & 49,0 & 50,5 & 52,2 & 53,9 & 43,8 \\
\hline $\mathrm{NH}_{3}$ & ${ }^{2} J_{\mathrm{HH}}$ & $-4,6$ & $-5,7$ & $-6,7$ & $-7,9$ & $-9,1$ & $-10,3$ & $-11,7$ & $-13,1$ & $-14,6$ & $-16,2$ & $-17,9$ & $-9,6$ \\
\hline $\mathrm{PH}_{3}$ & ${ }^{1} J_{\mathrm{PH}}$ & 128,0 & 136,8 & 146,0 & 155,5 & 165,4 & 175,6 & 186,2 & 197,1 & 208,4 & 219,9 & 231,7 & 188,2 \\
\hline $\mathrm{PF}_{3}$ & ${ }^{1} J_{\mathrm{PF}}$ & $-1812,2$ & $-1794,9$ & $-1770,9$ & $-1741,3$ & $-1706,8$ & $-1668,2$ & $-1626,1$ & $-1581,2$ & $-1534,0$ & $-1485,1$ & $-1434,8$ & -1441 \\
\hline $\mathrm{BHF}_{2}$ & ${ }^{1} J_{\mathrm{BF}}$ & $-191,8$ & $-173,9$ & $-155,6$ & $-137,2$ & $-118,4$ & $-99,6$ & $-80,5$ & $-61,4$ & $-42,2$ & $-23,0$ & $-3,8$ & -84 \\
\hline $\mathrm{BF}_{3}$ & ${ }^{1} J_{\mathrm{BF}}$ & $-82,0$ & $-63,3$ & $-44,5$ & $-25,5$ & $-6,3$ & 12,9 & 32,4 & 52,0 & 71,7 & 91,6 & 111,6 & 15 \\
\hline $\mathrm{F}_{2} \mathrm{O}$ & ${ }^{1} J_{\mathrm{OF}}$ & $-287,4$ & $-323,5$ & $-359,3$ & $-395,8$ & $-435,1$ & $-480,3$ & $-536,7$ & $-615,3$ & $-743,2$ & $-1016,1$ & $-2269,1$ & -300 \\
\hline $\mathrm{CH}_{4}$ & ${ }^{1} J_{\mathrm{CH}}$ & 108,4 & 111,8 & 115,4 & 119,2 & 123,1 & 127,3 & 131,8 & 136,4 & 141,3 & 146,4 & 151,8 & 125,3 \\
\hline $\mathrm{CH}_{4}$ & ${ }^{2} J_{\mathrm{HH}}$ & $-8,2$ & $-9,2$ & $-10,2$ & $-11,3$ & $-12,4$ & $-13,6$ & $-14,8$ & $-16,0$ & $-17,3$ & $-18,7$ & $-20,0$ & $-12,8$ \\
\hline $\mathrm{C}_{2} \mathrm{H}_{2}$ & ${ }^{1} J_{\mathrm{CC}}$ & 176,4 & 180,5 & 185,1 & 190,3 & 196,3 & 203,3 & 211,5 & 221,5 & 233,7 & 249,2 & 269,3 & 174,8 \\
\hline $\mathrm{C}_{2} \mathrm{H}_{2}$ & ${ }^{1} J_{\mathrm{CH}}$ & 229,6 & 235,5 & 241,6 & 248,2 & 255,2 & 262,7 & 271,0 & 280,1 & 290,5 & 302,4 & 316,7 & 247,6 \\
\hline $\mathrm{C}_{2} \mathrm{H}_{2}$ & ${ }^{2} J_{\mathrm{CH}}$ & 51,4 & 52,3 & 52,9 & 53,4 & 53,5 & 53,2 & 52,4 & 50,9 & 48,4 & 44,4 & 38,3 & 50,1 \\
\hline $\mathrm{C}_{2} \mathrm{H}_{2}$ & ${ }^{3} J_{\mathrm{HH}}$ & 7,9 & 8,5 & 9,2 & 10,1 & 11,2 & 12,5 & 14,1 & 16,2 & 18,8 & 22,2 & 26,7 & 9,6 \\
\hline $\mathrm{C}_{2} \mathrm{H}_{4}$ & ${ }^{1} J_{\mathrm{CC}}$ & 51,4 & 54,8 & 58,6 & 62,8 & 67,7 & 73,3 & 79,9 & 88,3 & 99,2 & 114,8 & 140,0 & 67,6 \\
\hline $\mathrm{C}_{2} \mathrm{H}_{4}$ & ${ }^{1} J_{\mathrm{CH}}$ & 138,2 & 142,5 & 147,0 & 151,9 & 157,0 & 162,6 & 168,8 & 175,7 & 183,8 & 193,8 & 207,7 & 156,3 \\
\hline $\mathrm{C}_{2} \mathrm{H}_{4}$ & ${ }^{2} J_{\mathrm{CH}}$ & 0,4 & $-0,3$ & $-0,9$ & $-1,8$ & $-2,9$ & $-4,3$ & $-6,1$ & $-8,5$ & $-11,9$ & $-17,0$ & $-25,9$ & $-2,4$ \\
\hline $\mathrm{C}_{2} \mathrm{H}_{4}$ & ${ }^{2} J_{\mathrm{HH}}$ & 5,7 & 5,2 & 4,6 & 4,0 & 3,3 & 2,4 & 1,3 & 0,1 & $-1,8$ & $-4,5$ & $-9,1$ & 2,3 \\
\hline $\mathrm{C}_{2} \mathrm{H}_{4}$ & ${ }^{3} J_{\mathrm{HH}_{\mathrm{c}}}$ & 11,6 & 11,9 & 12,2 & 12,6 & 13,1 & 13,7 & 14,5 & 15,6 & 17,2 & 19,7 & 24,1 & 11,7 \\
\hline $\mathrm{C}_{2} \mathrm{H}_{4}$ & ${ }^{3} J_{\mathrm{HH}_{\mathrm{t}}}{ }^{\mathrm{C}}$ & 17,0 & 17,4 & 18,0 & 18,6 & 19,4 & 20,3 & 21,5 & 23,1 & 25,2 & 28,3 & 33,6 & 19 \\
\hline $\mathrm{C}_{2} \mathrm{H}_{6}$ & ${ }^{1} J_{\mathrm{CC}}$ & 19,6 & 22,2 & 24,9 & 27,8 & 30,9 & 34,2 & 37,6 & 41,3 & 45,2 & 49,3 & 53,6 & 34,5 \\
\hline $\mathrm{C}_{2} \mathrm{H}_{6}$ & ${ }^{1} J_{\mathrm{CH}}$ & 107,9 & 111,5 & 115,2 & 119,1 & 123,3 & 127,6 & 132,2 & 137,0 & 142,0 & 147,2 & 152,7 & 125,2 \\
\hline $\mathrm{C}_{2} \mathrm{H}_{6}$ & ${ }^{2} J_{\mathrm{CH}}$ & $-1,9$ & $-2,3$ & $-2,8$ & $-3,3$ & $-3,9$ & $-4,5$ & $-5,1$ & $-5,8$ & $-6,5$ & $-7,2$ & $-8,0$ & $-4,7$ \\
\hline \multirow[t]{3}{*}{ Total } & DM & $-30,72$ & $-28,08$ & $-25,06$ & $-21,73$ & $-18,16$ & $-14,54$ & $-11,00$ & $-7,97$ & $-6,45$ & $-9,99$ & $-50,42$ & - \\
\hline & DMA & 35,40 & 31,48 & 28,15 & 24,57 & 21,47 & 20,06 & 23,20 & 29,80 & 38,97 & 54,51 & 109,57 & - \\
\hline & PDMA & 60,48 & 49,33 & 38,25 & 26,66 & 16,89 & 13,25 & 26,78 & 46,16 & 70,14 & 101,80 & 158,00 & - \\
\hline \multirow[t]{3}{*}{ CPI } & $\mathrm{DM}$ & $-64,55$ & $-60,76$ & $-56,20$ & $-51,13$ & $-45,72$ & $-40,42$ & $-35,67$ & $-32,63$ & $-33,75$ & $-47,81$ & $-150,75$ & - \\
\hline & DMA & 72,60 & 65,33 & 59,53 & 53,11 & 46,46 & 40,82 & 43,87 & 54,35 & 69,66 & 98,19 & 216,99 & - \\
\hline & PDMA & 96,97 & 79,14 & 61,89 & 43,92 & 26,14 & 13,71 & 28,14 & 50,52 & 74,97 & 104,35 & 163,81 & - \\
\hline \multirow[t]{3}{*}{ SPI } & $\mathrm{DM}$ & $-5,91$ & $-4,12$ & $-2,22$ & $-0,17$ & 2,05 & 4,44 & 7,10 & 10,12 & 13,58 & 17,75 & 23,16 & - \\
\hline & DMA & 8,11 & 6,67 & 5,14 & 3,63 & 3,14 & 4,84 & 8,05 & 11,80 & 16,46 & 22,48 & 30,79 & - \\
\hline & PDMA & 33,73 & 27,47 & 20,92 & 14,01 & 10,11 & 12,91 & 25,78 & 42,96 & 66,60 & 99,94 & 153,75 & - \\
\hline \multirow[t]{3}{*}{$\Delta \mathrm{CS}$} & $\mathrm{DM}$ & $-58,63$ & $-56,64$ & $-53,98$ & $-50,96$ & $-47,76$ & $-44,86$ & $-42,77$ & $-42,75$ & $-47,33$ & $-65,56$ & $-173,91$ & - \\
\hline & DMA & 64,49 & 58,66 & 54,39 & 49,48 & 43,32 & 35,98 & 35,83 & 42,55 & 53,20 & 75,71 & 186,20 & - \\
\hline & PDMA & 63,24 & 51,67 & 40,97 & 29,90 & 16,03 & 0,80 & 2,36 & 7,56 & 8,38 & 4,41 & 10,06 & - \\
\hline
\end{tabular}


Tabela 8.82: Constantes de acoplamento BMK com correção vibracional no nível PBE0 $40 \% E_{X}^{\mathrm{HF}}$ e base aug-pcJ-2.

\begin{tabular}{|c|c|c|c|c|c|c|c|c|c|c|c|c|c|}
\hline & $\% E_{X}^{\mathrm{HF}}$ & $0 \%$ & $10 \%$ & $20 \%$ & $30 \%$ & $40 \%$ & $50 \%$ & $60 \%$ & $70 \%$ & $80 \%$ & $90 \%$ & $100 \%$ & Exp. \\
\hline $\mathrm{HF}$ & ${ }^{1} J_{\mathrm{HF}}$ & 456,6 & 468,0 & 480,4 & 493,9 & 508,7 & 524,9 & 542,6 & 562,2 & 583,9 & 607,7 & 634,2 & 500 \\
\hline $\mathrm{CO}$ & ${ }^{1} J_{\mathrm{CO}}$ & 14,5 & 15,0 & 15,3 & 15,5 & 15,5 & 15,3 & 14,8 & 14,0 & 12,7 & 10,9 & 8,4 & 16,4 \\
\hline $\mathrm{H}_{2} \mathrm{O}$ & ${ }^{1} J_{\mathrm{OH}}$ & $-70,9$ & $-71,4$ & $-72,0$ & $-72,7$ & $-73,5$ & $-74,5$ & $-75,6$ & $-76,9$ & $-78,4$ & $-80,0$ & $-81,9$ & $-80,6$ \\
\hline $\mathrm{H}_{2} \mathrm{O}$ & ${ }^{2} J_{\mathrm{HH}}$ & 4,3 & 3,3 & 2,1 & 1,0 & $-0,3$ & $-1,7$ & $-3,2$ & $-4,9$ & $-6,6$ & $-8,5$ & $-10,5$ & $-7,3$ \\
\hline $\mathrm{NH}_{3}$ & ${ }^{1} J_{\mathrm{NH}}$ & 37,0 & 37,1 & 37,2 & 37,3 & 37,6 & 37,9 & 38,2 & 38,7 & 39,2 & 39,8 & 40,5 & 43,8 \\
\hline $\mathrm{NH}_{3}$ & ${ }^{2} J_{\mathrm{HH}}$ & 0,1 & $-0,8$ & $-1,7$ & $-2,7$ & $-3,9$ & $-5,1$ & $-6,4$ & $-7,9$ & $-9,5$ & $-11,2$ & $-13,1$ & $-9,6$ \\
\hline $\mathrm{PH}_{3}$ & ${ }^{1} J_{\mathrm{PH}}$ & 118,3 & 117,9 & 117,9 & 118,5 & 119,5 & 121,0 & 123,0 & 125,5 & 128,6 & 132,2 & 136,5 & 188,2 \\
\hline $\mathrm{PF}_{3}$ & ${ }^{1} J_{\mathrm{PF}}$ & $-1527,2$ & $-1525,4$ & $-1515,7$ & $-1498,5$ & $-1474,1$ & $-1443,0$ & $-1406,0$ & $-1363,7$ & $-1316,8$ & $-1266,2$ & $-1212,2$ & -1441 \\
\hline $\mathrm{BHF}_{2}$ & ${ }^{1} J_{\mathrm{BF}}$ & $-147,5$ & $-136,1$ & $-122,6$ & $-107,2$ & $-89,8$ & $-70,5$ & $-49,3$ & $-26,3$ & $-1,7$ & 24,7 & 52,5 & -84 \\
\hline $\mathrm{BF}_{3}$ & ${ }^{1} J_{\mathrm{BF}}$ & $-53,3$ & $-39,4$ & $-23,6$ & $-6,0$ & 13,2 & 34,4 & 57,2 & 81,9 & 108,2 & 136,2 & 165,7 & 15 \\
\hline $\mathrm{F}_{2} \mathrm{O}$ & ${ }^{1} J_{\mathrm{OF}}$ & $-162,8$ & $-189,2$ & $-216,3$ & $-243,7$ & $-271,3$ & $-299,7$ & $-330,1$ & $-364,5$ & $-407,6$ & $-469,5$ & $-582,8$ & -300 \\
\hline $\mathrm{CH}_{4}$ & ${ }^{1} J_{\mathrm{CH}}$ & 105,5 & 107,1 & 108,9 & 111,1 & 113,6 & 116,6 & 119,9 & 123,7 & 128,1 & 133,1 & 138,8 & 125,3 \\
\hline $\mathrm{CH}_{4}$ & ${ }^{2} J_{\mathrm{HH}}$ & $-3,3$ & $-4,3$ & $-5,4$ & $-6,7$ & $-8,0$ & $-9,5$ & $-11,2$ & $-13,1$ & $-15,2$ & $-17,6$ & $-20,3$ & $-12,8$ \\
\hline $\mathrm{C}_{2} \mathrm{H}_{2}$ & ${ }^{1} J_{\mathrm{CC}}$ & 245,4 & 250,1 & 255,3 & 261,4 & 268,5 & 277,2 & 288,1 & 302,4 & 322,0 & 350,4 & 395,5 & 174,8 \\
\hline $\mathrm{C}_{2} \mathrm{H}_{2}$ & ${ }^{1} J_{\mathrm{CH}}$ & 181,1 & 187,2 & 193,7 & 200,8 & 208,6 & 217,2 & 227,0 & 238,5 & 252,2 & 269,7 & 294,0 & 247,6 \\
\hline $\mathrm{C}_{2} \mathrm{H}_{2}$ & ${ }^{2} J_{\mathrm{CH}}$ & 54,6 & 55,5 & 56,2 & 56,7 & 56,8 & 56,5 & 55,4 & 53,2 & 49,2 & 41,9 & 28,5 & 50,1 \\
\hline $\mathrm{C}_{2} \mathrm{H}_{2}$ & ${ }^{3} J_{\mathrm{HH}}$ & 6,0 & 6,3 & 6,7 & 7,2 & 7,9 & 8,9 & 10,2 & 12,0 & 14,6 & 18,5 & 24,9 & 9,6 \\
\hline $\mathrm{C}_{2} \mathrm{H}_{4}$ & ${ }^{1} J_{\mathrm{CC}}$ & 90,5 & 92,0 & 93,9 & 96,3 & 99,2 & 102,8 & 107,6 & 113,8 & 122,5 & 135,4 & 156,3 & 67,6 \\
\hline $\mathrm{C}_{2} \mathrm{H}_{4}$ & ${ }^{1} J_{\mathrm{CH}}$ & 122,5 & 125,6 & 129,2 & 133,1 & 137,5 & 142,5 & 148,3 & 155,0 & 163,2 & 173,5 & 187,9 & 156,3 \\
\hline $\mathrm{C}_{2} \mathrm{H}_{4}$ & ${ }^{2} J_{\mathrm{CH}}$ & 4,0 & 3,1 & 2,1 & 1,0 & $-0,4$ & $-1,9$ & $-3,9$ & $-6,5$ & $-10,2$ & $-15,6$ & $-24,5$ & $-2,4$ \\
\hline $\mathrm{C}_{2} \mathrm{H}_{4}$ & ${ }^{2} J_{\mathrm{HH}}$ & 7,9 & 7,4 & 6,8 & 6,0 & 5,1 & 4,0 & 2,7 & 0,9 & $-1,2$ & $-4,4$ & $-9,4$ & 2,3 \\
\hline $\mathrm{C}_{2} \mathrm{H}_{4}$ & ${ }^{3} J_{\mathrm{HH}_{\mathrm{c}}}$ & 9,6 & 9,7 & 9,8 & 10,0 & 10,2 & 10,6 & 11,1 & 11,9 & 13,2 & 15,3 & 19,0 & 11,7 \\
\hline $\mathrm{C}_{2} \mathrm{H}_{4}$ & ${ }^{3} J_{\mathrm{HH}_{\mathrm{t}}}{ }^{\mathrm{C}}$ & 12,0 & 12,5 & 13,0 & 13,6 & 14,2 & 15,0 & 16,0 & 17,3 & 19,1 & 21,8 & 26,3 & 19 \\
\hline $\mathrm{C}_{2} \mathrm{H}_{6}$ & ${ }^{1} J_{\mathrm{CC}}$ & 31,0 & 31,9 & 33,0 & 34,2 & 35,7 & 37,4 & 39,4 & 41,6 & 44,2 & 47,3 & 50,8 & 34,5 \\
\hline $\mathrm{C}_{2} \mathrm{H}_{6}$ & ${ }^{1} J_{\mathrm{CH}}$ & 103,2 & 105,1 & 107,4 & 110,0 & 112,9 & 116,2 & 120,0 & 124,3 & 129,1 & 134,6 & 140,9 & 125,2 \\
\hline $\mathrm{C}_{2} \mathrm{H}_{6}$ & ${ }^{2} J_{\mathrm{CH}}$ & 0,4 & $-0,2$ & $-1,0$ & $-1,7$ & $-2,6$ & $-3,5$ & $-4,5$ & $-5,6$ & $-6,9$ & $-8,3$ & $-9,9$ & $-4,7$ \\
\hline \multirow[t]{3}{*}{ Total } & $\mathrm{DM}$ & $-7,90$ & $-6,81$ & $-5,17$ & $-2,95$ & $-0,16$ & 3,23 & 7,17 & 11,63 & 16,57 & 21,80 & 26,58 & - \\
\hline & DMA & 30,43 & 27,43 & 23,83 & 19,68 & 15,71 & 14,30 & 18,46 & 23,63 & 31,37 & 42,90 & 59,03 & - \\
\hline & PDMA & 72,61 & 63,62 & 53,34 & 41,91 & 29,23 & 26,48 & 30,42 & 43,55 & 64,38 & 96,74 & 143,80 & - \\
\hline \multirow[t]{3}{*}{ CPI } & DM & $-15,62$ & $-14,72$ & $-12,72$ & $-9,59$ & $-5,39$ & $-0,17$ & 5,85 & 12,47 & 19,19 & 25,02 & 26,95 & - \\
\hline & DMA & 46,20 & 40,06 & 32,65 & 24,03 & 15,79 & 13,68 & 24,48 & 36,96 & 51,10 & 68,25 & 91,27 & - \\
\hline & PDMA & 84,32 & 71,21 & 56,47 & 40,39 & 22,98 & 30,70 & 45,14 & 60,80 & 78,06 & 103,08 & 133,62 & - \\
\hline \multirow[t]{3}{*}{ SPI } & $\mathrm{DM}$ & $-2,25$ & $-1,01$ & 0,37 & 1,93 & 3,67 & 5,73 & 8,13 & 11,02 & 14,65 & 19,43 & 26,31 & - \\
\hline & DMA & 18,86 & 18,17 & 17,37 & 16,49 & 15,65 & 14,75 & 14,04 & 13,86 & 16,89 & 24,30 & 35,39 & - \\
\hline & PDMA & 64,03 & 58,06 & 51,04 & 43,02 & 33,81 & 23,39 & 19,63 & 30,90 & 54,34 & 92,10 & 151,27 & - \\
\hline \multirow[t]{3}{*}{$\Delta \mathrm{CS}$} & $\mathrm{DM}$ & $-13,37$ & $-13,71$ & $-13,08$ & $-11,52$ & $-9,06$ & $-5,90$ & $-2,29$ & 1,45 & 4,54 & 5,58 & 0,63 & - \\
\hline & DMA & 27,34 & 21,90 & 15,28 & 7,54 & 0,14 & $-1,07$ & 10,44 & 23,10 & 34,21 & 43,95 & 55,88 & - \\
\hline & PDMA & 20,30 & 13,16 & 5,43 & $-2,62$ & $-10,84$ & 7,30 & 25,51 & 29,90 & 23,72 & 10,98 & $-17,65$ & - \\
\hline
\end{tabular}


Tabela 8.83: Constantes de acoplamento BP86 com correção vibracional no nível PBE0 $40 \% E_{X}^{\mathrm{HF}}$ e base aug-pcJ-2.

\begin{tabular}{|c|c|c|c|c|c|c|c|c|c|c|c|c|c|}
\hline & $\% E_{X}^{\mathrm{HF}}$ & $0 \%$ & $10 \%$ & $20 \%$ & $30 \%$ & $40 \%$ & $50 \%$ & $60 \%$ & $70 \%$ & $80 \%$ & $90 \%$ & $100 \%$ & Exp. \\
\hline $\mathrm{HF}$ & ${ }^{1} J_{\mathrm{HF}}$ & 320,5 & 344,1 & 368,0 & 392,1 & 416,5 & 441,0 & 465,9 & 490,9 & 516,2 & 541,7 & 567,4 & 500 \\
\hline $\mathrm{CO}$ & ${ }^{1} J_{\mathrm{CO}}$ & 25,6 & 23,9 & 22,2 & 20,4 & 18,4 & 16,5 & 14,4 & 12,3 & 10,1 & 7,8 & 5,5 & 16,4 \\
\hline $\mathrm{H}_{2} \mathrm{O}$ & ${ }^{1} J_{\mathrm{OH}}$ & $-63,4$ & $-65,9$ & $-68,4$ & $-71,0$ & $-73,6$ & $-76,2$ & $-78,8$ & $-81,5$ & $-84,1$ & $-86,9$ & $-89,6$ & $-80,6$ \\
\hline $\mathrm{H}_{2} \mathrm{O}$ & ${ }^{2} J_{\mathrm{HH}}$ & $-3,1$ & $-4,0$ & $-5,0$ & $-6,0$ & $-7,0$ & $-8,1$ & $-9,1$ & $-10,2$ & $-11,3$ & $-12,4$ & $-13,6$ & $-7,3$ \\
\hline $\mathrm{NH}_{3}$ & ${ }^{1} J_{\mathrm{NH}}$ & 40,5 & 41,2 & 42,0 & 42,7 & 43,5 & 44,3 & 45,1 & 45,9 & 46,7 & 47,5 & 48,3 & 43,8 \\
\hline $\mathrm{NH}_{3}$ & ${ }^{2} J_{\mathrm{HH}}$ & $-7,0$ & $-7,8$ & $-8,7$ & $-9,6$ & $-10,4$ & $-11,3$ & $-12,2$ & $-13,1$ & $-14,1$ & $-15,0$ & $-16,0$ & $-9,6$ \\
\hline $\mathrm{PH}_{3}$ & ${ }^{1} J_{\mathrm{PH}}$ & 129,4 & 137,4 & 145,3 & 153,2 & 160,9 & 168,5 & 176,0 & 183,3 & 190,6 & 197,6 & 204,6 & 188,2 \\
\hline $\mathrm{PF}_{3}$ & ${ }^{1} J_{\mathrm{PF}}$ & $-1800,3$ & $-1775,2$ & $-1745,7$ & $-1712,5$ & $-1676,3$ & $-1637,7$ & $-1597,3$ & $-1555,5$ & $-1512,7$ & $-1469,2$ & $-1425,3$ & -1441 \\
\hline $\mathrm{BHF}_{2}$ & ${ }^{1} J_{\mathrm{BF}}$ & $-182,3$ & $-165,3$ & $-148,4$ & $-131,6$ & $-115,0$ & $-98,4$ & $-82,1$ & $-65,9$ & $-49,9$ & $-34,1$ & $-18,5$ & -84 \\
\hline $\mathrm{BF}_{3}$ & ${ }^{1} J_{\mathrm{BF}}$ & $-85,5$ & $-66,8$ & $-48,4$ & $-30,1$ & $-12,0$ & 5,8 & 23,5 & 41,1 & 58,4 & 75,6 & 92,6 & 15 \\
\hline $\mathrm{F}_{2} \mathrm{O}$ & ${ }^{1} J_{\mathrm{OF}}$ & $-305,4$ & $-342,7$ & $-380,3$ & $-419,7$ & $-463,1$ & $-514,0$ & $-577,9$ & $-666,3$ & $-805,7$ & $-1079,6$ & $-1988,4$ & -300 \\
\hline $\mathrm{CH}_{4}$ & ${ }^{1} J_{\mathrm{CH}}$ & 119,9 & 121,3 & 122,8 & 124,3 & 125,8 & 127,3 & 128,9 & 130,5 & 132,1 & 133,8 & 135,4 & 125,3 \\
\hline $\mathrm{CH}_{4}$ & ${ }^{2} J_{\mathrm{HH}}$ & $-12,1$ & $-12,8$ & $-13,5$ & $-14,2$ & $-14,9$ & $-15,6$ & $-16,4$ & $-17,1$ & $-17,8$ & $-18,4$ & $-19,1$ & $-12,8$ \\
\hline $\mathrm{C}_{2} \mathrm{H}_{2}$ & ${ }^{1} J_{\mathrm{CC}}$ & 188,2 & 190,8 & 193,9 & 197,4 & 201,5 & 206,3 & 212,0 & 218,9 & 227,3 & 237,8 & 251,1 & 174,8 \\
\hline $\mathrm{C}_{2} \mathrm{H}_{2}$ & ${ }^{1} J_{\mathrm{CH}}$ & 250,6 & 252,9 & 255,3 & 257,9 & 260,7 & 263,8 & 267,3 & 271,3 & 276,0 & 281,6 & 288,5 & 247,6 \\
\hline $\mathrm{C}_{2} \mathrm{H}_{2}$ & ${ }^{2} J_{\mathrm{CH}}$ & 54,8 & 54,8 & 54,6 & 54,1 & 53,3 & 52,1 & 50,5 & 48,3 & 45,4 & 41,5 & 36,1 & 50,1 \\
\hline $\mathrm{C}_{2} \mathrm{H}_{2}$ & ${ }^{3} J_{\mathrm{HH}}$ & 10,9 & 11,6 & 12,3 & 13,2 & 14,2 & 15,5 & 17,1 & 18,9 & 21,2 & 24,0 & 27,6 & 9,6 \\
\hline $\mathrm{C}_{2} \mathrm{H}_{4}$ & ${ }^{1} J_{\mathrm{CC}}$ & 60,5 & 63,2 & 66,2 & 69,5 & 73,4 & 77,9 & 83,4 & 90,4 & 99,7 & 113,2 & 134,8 & 67,6 \\
\hline $\mathrm{C}_{2} \mathrm{H}_{4}$ & ${ }^{1} J_{\mathrm{CH}}$ & 151,7 & 153,8 & 156,0 & 158,3 & 160,8 & 163,6 & 166,7 & 170,5 & 175,2 & 181,6 & 191,3 & 156,3 \\
\hline $\mathrm{C}_{2} \mathrm{H}_{4}$ & ${ }^{2} J_{\mathrm{CH}}$ & $-0,5$ & $-1,3$ & $-2,2$ & $-3,4$ & $-4,7$ & $-6,2$ & $-8,2$ & $-10,8$ & $-14,4$ & $-19,6$ & $-28,1$ & $-2,4$ \\
\hline $\mathrm{C}_{2} \mathrm{H}_{4}$ & ${ }^{2} J_{\mathrm{HH}}$ & 4,8 & 4,1 & 3,3 & 2,4 & 1,4 & 0,2 & $-1,0$ & $-2,7$ & $-5,0$ & $-8,2$ & $-13,3$ & 2,3 \\
\hline $\mathrm{C}_{2} \mathrm{H}_{4}$ & ${ }^{3} J_{\mathrm{HH}_{\mathrm{c}}}$ & 12,0 & 12,3 & 12,7 & 13,1 & 13,7 & 14,4 & 15,4 & 16,7 & 18,5 & 21,4 & 26,1 & 11,7 \\
\hline $\mathrm{C}_{2} \mathrm{H}_{4}$ & ${ }^{3} J_{\mathrm{HH}_{\mathrm{t}}}$ & 19,2 & 19,6 & 20,0 & 20,5 & 21,1 & 22,0 & 23,1 & 24,6 & 26,8 & 30,0 & 35,4 & 19 \\
\hline $\mathrm{C}_{2} \mathrm{H}_{6}$ & ${ }^{1} J_{\mathrm{CC}}$ & 25,1 & 27,1 & 29,1 & 31,1 & 33,2 & 35,3 & 37,4 & 39,6 & 41,8 & 44,1 & 46,3 & 34,5 \\
\hline $\mathrm{C}_{2} \mathrm{H}_{6}$ & ${ }^{1} J_{\mathrm{CH}}$ & 119,4 & 121,0 & 122,7 & 124,4 & 126,1 & 127,8 & 129,6 & 131,4 & 133,1 & 135,0 & 136,8 & 125,2 \\
\hline $\mathrm{C}_{2} \mathrm{H}_{6}$ & ${ }^{2} J_{\mathrm{CH}}$ & $-2,9$ & $-3,3$ & $-3,8$ & $-4,3$ & $-4,7$ & $-5,2$ & $-5,7$ & $-6,2$ & $-6,7$ & $-7,3$ & $-7,8$ & $-4,7$ \\
\hline \multirow[t]{3}{*}{ Total } & $\mathrm{DM}$ & $-29,78$ & $-27,35$ & $-24,73$ & $-22,03$ & $-19,32$ & $-16,75$ & $-14,52$ & $-13,07$ & $-13,37$ & $-18,52$ & $-47,57$ & - \\
\hline & DMA & 34,63 & 32,02 & 29,29 & 26,85 & 24,91 & 23,62 & 23,99 & 27,49 & 34,84 & 49,00 & 89,79 & - \\
\hline & PDMA & 52,58 & 42,74 & 32,89 & 26,01 & 23,98 & 25,33 & 34,06 & 51,70 & 73,90 & 103,44 & 151,73 & - \\
\hline \multirow[t]{3}{*}{ CPI } & $\mathrm{DM}$ & $-70,17$ & $-65,64$ & $-60,75$ & $-55,73$ & $-50,82$ & $-46,41$ & $-43,04$ & $-41,81$ & $-45,15$ & $-60,72$ & $-133,99$ & - \\
\hline & DMA & 76,21 & 70,60 & 64,61 & 58,44 & 52,51 & 47,32 & 45,49 & 50,23 & 63,15 & 90,77 & 178,92 & - \\
\hline & PDMA & 95,50 & 79,23 & 62,90 & 46,62 & 32,07 & 20,15 & 22,26 & 39,74 & 59,91 & 84,85 & 129,30 & - \\
\hline \multirow[t]{3}{*}{ SPI } & $\mathrm{DM}$ & $-0,17$ & 0,73 & 1,69 & 2,68 & 3,79 & 5,01 & 6,40 & 8,01 & 9,94 & 12,43 & 15,80 & - \\
\hline & DMA & 4,14 & 3,73 & 3,39 & 3,69 & 4,67 & 6,23 & 8,23 & 10,81 & 14,07 & 18,36 & 24,43 & - \\
\hline & PDMA & 21,11 & 15,99 & 10,89 & 10,89 & 18,05 & 29,13 & 42,72 & 60,47 & 84,16 & 117,07 & 168,17 & - \\
\hline \multirow[t]{3}{*}{$\Delta \mathrm{CS}$} & $\mathrm{DM}$ & $-70,01$ & $-66,37$ & $-62,44$ & $-58,41$ & $-54,60$ & $-51,42$ & $-49,44$ & $-49,82$ & $-55,09$ & $-73,14$ & $-149,79$ & - \\
\hline & DMA & 72,07 & 66,87 & 61,22 & 54,74 & 47,84 & 41,08 & 37,26 & 39,41 & 49,08 & 72,41 & 154,49 & - \\
\hline & PDMA & 74,39 & 63,25 & 52,02 & 35,74 & 14,03 & $-8,98$ & $-20,46$ & $-20,73$ & $-24,25$ & $-32,22$ & $-38,88$ & - \\
\hline
\end{tabular}


Tabela 8.84: Constantes de acoplamento BPW91 com correção vibracional no nível PBE0 $40 \% E_{X}^{\mathrm{HF}}$ e base aug-pcJ-2.

\begin{tabular}{|c|c|c|c|c|c|c|c|c|c|c|c|c|c|}
\hline & $\% E_{X}^{\mathrm{HF}}$ & $0 \%$ & $10 \%$ & $20 \%$ & $30 \%$ & $40 \%$ & $50 \%$ & $60 \%$ & $70 \%$ & $80 \%$ & $90 \%$ & $100 \%$ & Exp. \\
\hline $\mathrm{HF}$ & ${ }^{1} J_{\mathrm{HF}}$ & 318,5 & 342,6 & 367,1 & 391,8 & 416,7 & 441,9 & 467,4 & 493,1 & 519,0 & 545,1 & 571,5 & 500 \\
\hline $\mathrm{CO}$ & ${ }^{1} J_{\mathrm{CO}}$ & 25,9 & 24,3 & 22,5 & 20,7 & 18,8 & 16,8 & 14,7 & 12,5 & 10,3 & 8,0 & 5,6 & 16,4 \\
\hline $\mathrm{H}_{2} \mathrm{O}$ & ${ }^{1} J_{\mathrm{OH}}$ & $-63,5$ & $-66,1$ & $-68,7$ & $-71,3$ & $-74,0$ & $-76,7$ & $-79,4$ & $-82,1$ & $-84,9$ & $-87,7$ & $-90,5$ & $-80,6$ \\
\hline $\mathrm{H}_{2} \mathrm{O}$ & ${ }^{2} J_{\mathrm{HH}}$ & $-3,6$ & $-4,6$ & $-5,6$ & $-6,6$ & $-7,7$ & $-8,7$ & $-9,8$ & $-11,0$ & $-12,1$ & $-13,3$ & $-14,5$ & $-7,3$ \\
\hline $\mathrm{NH}_{3}$ & ${ }^{1} J_{\mathrm{NH}}$ & 40,7 & 41,5 & 42,3 & 43,1 & 43,9 & 44,7 & 45,5 & 46,3 & 47,2 & 48,0 & 48,9 & 43,8 \\
\hline $\mathrm{NH}_{3}$ & ${ }^{2} J_{\mathrm{HH}}$ & $-7,5$ & $-8,4$ & $-9,3$ & $-10,2$ & $-11,1$ & $-12,1$ & $-13,0$ & $-13,9$ & $-14,9$ & $-15,9$ & $-16,9$ & $-9,6$ \\
\hline $\mathrm{PH}_{3}$ & ${ }^{1} J_{\mathrm{PH}}$ & 129,8 & 138,1 & 146,4 & 154,5 & 162,6 & 170,5 & 178,3 & 185,9 & 193,4 & 200,8 & 208,0 & 188,2 \\
\hline $\mathrm{PF}_{3}$ & ${ }^{1} J_{\mathrm{PF}}$ & $-1808,4$ & $-1782,3$ & $-1751,9$ & $-1717,8$ & $-1680,9$ & $-1641,6$ & $-1600,5$ & $-1558,1$ & $-1514,7$ & $-1470,7$ & $-1426,3$ & -1441 \\
\hline $\mathrm{BHF}_{2}$ & ${ }^{1} J_{\mathrm{BF}}$ & $-182,4$ & $-165,2$ & $-148,2$ & $-131,2$ & $-114,4$ & $-97,7$ & $-81,2$ & $-64,8$ & $-48,7$ & $-32,7$ & $-16,9$ & -84 \\
\hline $\mathrm{BF}_{3}$ & ${ }^{1} J_{\mathrm{BF}}$ & $-85,5$ & $-66,7$ & $-48,0$ & $-29,6$ & $-11,3$ & 6,7 & 24,5 & 42,3 & 59,8 & 77,2 & 94,4 & 15 \\
\hline $\mathrm{F}_{2} \mathrm{O}$ & ${ }^{1} J_{\mathrm{OF}}$ & $-307,0$ & $-345,2$ & $-383,9$ & $-424,5$ & $-469,7$ & $-523,0$ & $-591,0$ & $-686,7$ & $-842,7$ & $-1168,9$ & $-2541,1$ & -300 \\
\hline $\mathrm{CH}_{4}$ & ${ }^{1} J_{\mathrm{CH}}$ & 121,3 & 122,8 & 124,3 & 125,9 & 127,5 & 129,1 & 130,8 & 132,4 & 134,1 & 135,8 & 137,6 & 125,3 \\
\hline $\mathrm{CH}_{4}$ & ${ }^{2} J_{\mathrm{HH}}$ & $-12,8$ & $-13,6$ & $-14,3$ & $-15,0$ & $-15,8$ & $-16,5$ & $-17,3$ & $-18,0$ & $-18,7$ & $-19,4$ & $-20,2$ & $-12,8$ \\
\hline $\mathrm{C}_{2} \mathrm{H}_{2}$ & ${ }^{1} J_{\mathrm{CC}}$ & 188,8 & 191,6 & 194,8 & 198,6 & 203,1 & 208,4 & 214,7 & 222,5 & 232,1 & 244,2 & 259,9 & 174,8 \\
\hline $\mathrm{C}_{2} \mathrm{H}_{2}$ & ${ }^{1} J_{\mathrm{CH}}$ & 254,3 & 256,8 & 259,4 & 262,3 & 265,3 & 268,8 & 272,7 & 277,3 & 282,7 & 289,3 & 297,8 & 247,6 \\
\hline $\mathrm{C}_{2} \mathrm{H}_{2}$ & ${ }^{2} J_{\mathrm{CH}}$ & 54,9 & 54,8 & 54,4 & 53,8 & 52,8 & 51,3 & 49,3 & 46,7 & 43,0 & 38,1 & 31,4 & 50,1 \\
\hline $\mathrm{C}_{2} \mathrm{H}_{2}$ & ${ }^{3} J_{\mathrm{HH}}$ & 11,5 & 12,2 & 13,1 & 14,1 & 15,3 & 16,8 & 18,6 & 20,8 & 23,5 & 27,0 & 31,4 & 9,6 \\
\hline $\mathrm{C}_{2} \mathrm{H}_{4}$ & ${ }^{1} J_{\mathrm{CC}}$ & 60,9 & 63,7 & 66,9 & 70,5 & 74,7 & 79,7 & 85,9 & 94,0 & 105,3 & 122,5 & 153,0 & 67,6 \\
\hline $\mathrm{C}_{2} \mathrm{H}_{4}$ & ${ }^{1} J_{\mathrm{CH}}$ & 153,9 & 156,1 & 158,4 & 160,9 & 163,6 & 166,7 & 170,3 & 174,6 & 180,2 & 188,4 & 202,0 & 156,3 \\
\hline $\mathrm{C}_{2} \mathrm{H}_{4}$ & ${ }^{2} J_{\mathrm{CH}}$ & $-0,9$ & $-1,9$ & $-2,9$ & $-4,1$ & $-5,6$ & $-7,4$ & $-9,7$ & $-12,9$ & $-17,3$ & $-24,2$ & $-36,7$ & $-2,4$ \\
\hline $\mathrm{C}_{2} \mathrm{H}_{4}$ & ${ }^{2} J_{\mathrm{HH}}$ & 4,4 & 3,5 & 2,7 & 1,7 & 0,6 & $-0,6$ & $-2,2$ & $-4,3$ & $-7,2$ & $-11,5$ & $-19,0$ & 2,3 \\
\hline $\mathrm{C}_{2} \mathrm{H}_{4}$ & ${ }^{3} J_{\mathrm{HH}_{\mathrm{c}}}$ & 12,4 & 12,7 & 13,1 & 13,7 & 14,4 & 15,2 & 16,4 & 18,1 & 20,5 & 24,4 & 31,6 & 11,7 \\
\hline $\mathrm{C}_{2} \mathrm{H}_{4}$ & ${ }^{3} J_{\mathrm{HH}_{\mathrm{t}}}$ & 19,8 & 20,2 & 20,7 & 21,3 & 22,1 & 23,1 & 24,4 & 26,3 & 29,1 & 33,5 & 41,6 & 19 \\
\hline $\mathrm{C}_{2} \mathrm{H}_{6}$ & ${ }^{1} J_{\mathrm{CC}}$ & 25,4 & 27,4 & 29,4 & 31,5 & 33,6 & 35,7 & 37,9 & 40,1 & 42,4 & 44,7 & 47,0 & 34,5 \\
\hline $\mathrm{C}_{2} \mathrm{H}_{6}$ & ${ }^{1} J_{\mathrm{CH}}$ & 121,0 & 122,7 & 124,4 & 126,2 & 128,0 & 129,8 & 131,6 & 133,5 & 135,3 & 137,2 & 139,1 & 125,2 \\
\hline $\mathrm{C}_{2} \mathrm{H}_{6}$ & ${ }^{2} J_{\mathrm{CH}}$ & $-3,2$ & $-3,7$ & $-4,1$ & $-4,6$ & $-5,1$ & $-5,6$ & $-6,2$ & $-6,7$ & $-7,2$ & $-7,7$ & $-8,3$ & $-4,7$ \\
\hline \multirow[t]{3}{*}{ Total } & $\mathrm{DM}$ & $-29,86$ & $-27,37$ & $-24,69$ & $-21,90$ & $-19,14$ & $-16,53$ & $-14,32$ & $-12,97$ & $-13,67$ & $-20,49$ & $-66,72$ & - \\
\hline & DMA & 34,97 & 32,33 & 29,75 & 27,63 & 25,96 & 24,84 & 25,62 & 29,66 & 38,39 & 55,17 & 114,95 & - \\
\hline & PDMA & 50,83 & 40,57 & 32,31 & 28,67 & 28,75 & 31,13 & 41,97 & 62,08 & 87,73 & 123,85 & 191,20 & - \\
\hline \multirow[t]{3}{*}{ CPI } & $\mathrm{DM}$ & $-71,26$ & $-66,63$ & $-61,65$ & $-56,55$ & $-51,64$ & $-47,28$ & $-44,13$ & $-43,40$ & $-48,11$ & $-68,27$ & $-183,52$ & - \\
\hline & DMA & 77,15 & 71,41 & 65,29 & 59,15 & 53,29 & 48,23 & 46,89 & 52,31 & 67,69 & 100,16 & 230,35 & - \\
\hline & PDMA & 94,64 & 78,10 & 61,51 & 46,27 & 32,65 & 21,41 & 24,72 & 42,85 & 64,05 & 90,96 & 149,69 & - \\
\hline \multirow[t]{3}{*}{ SPI } & $\mathrm{DM}$ & 0,51 & 1,41 & 2,41 & 3,51 & 4,69 & 6,03 & 7,54 & 9,35 & 11,58 & 14,55 & 18,94 & - \\
\hline & DMA & 4,03 & 3,68 & 3,69 & 4,51 & 5,92 & 7,69 & 10,02 & 13,05 & 16,90 & 22,17 & 30,31 & - \\
\hline & PDMA & 18,69 & 13,04 & 10,90 & 15,76 & 25,90 & 38,26 & 54,61 & 76,19 & 105,10 & 147,97 & 221,65 & - \\
\hline \multirow[t]{3}{*}{$\Delta \mathrm{CS}$} & $\mathrm{DM}$ & $-71,77$ & $-68,04$ & $-64,07$ & $-60,06$ & $-56,33$ & $-53,31$ & $-51,67$ & $-52,75$ & $-59,69$ & $-82,82$ & $-202,46$ & - \\
\hline & DMA & 73,13 & 67,73 & 61,60 & 54,63 & 47,37 & 40,53 & 36,87 & 39,26 & 50,79 & 77,99 & 200,04 & - \\
\hline & PDMA & 75,95 & 65,05 & 50,61 & 30,51 & 6,75 & $-16,85$ & $-29,89$ & $-33,34$ & $-41,05$ & $-57,01$ & $-71,97$ & - \\
\hline
\end{tabular}


Tabela 8.85: Constantes de acoplamento M05 com correção vibracional no nível PBE0 $40 \% E_{X}^{\mathrm{HF}}$ e base aug-pcJ-2.

\begin{tabular}{|c|c|c|c|c|c|c|c|c|c|c|c|c|c|}
\hline & $\% E_{X}^{\mathrm{HF}}$ & $0 \%$ & $10 \%$ & $20 \%$ & $30 \%$ & $40 \%$ & $50 \%$ & $60 \%$ & $70 \%$ & $80 \%$ & $90 \%$ & $100 \%$ & Exp. \\
\hline $\mathrm{HF}$ & ${ }^{1} J_{\mathrm{HF}}$ & 812,2 & 805,3 & 798,7 & 792,5 & 786,6 & 781,1 & 776,0 & 771,0 & 766,3 & 761,6 & 756,9 & 500 \\
\hline $\mathrm{CO}$ & ${ }^{1} J_{\mathrm{CO}}$ & 16,5 & 14,4 & 12,0 & 9,2 & 6,0 & 2,4 & $-1,4$ & $-5,5$ & $-10,0$ & $-14,8$ & $-19,8$ & 16,4 \\
\hline $\mathrm{H}_{2} \mathrm{O}$ & ${ }^{1} J_{\mathrm{OH}}$ & $-107,5$ & $-107,3$ & $-107,1$ & $-106,9$ & $-106,8$ & $-106,6$ & $-106,6$ & $-106,6$ & $-106,6$ & $-106,7$ & $-106,8$ & $-80,6$ \\
\hline $\mathrm{H}_{2} \mathrm{O}$ & ${ }^{2} J_{\mathrm{HH}}$ & $-17,1$ & $-17,2$ & $-17,2$ & $-17,1$ & $-16,8$ & $-16,4$ & $-15,9$ & $-15,2$ & $-14,4$ & $-13,5$ & $-12,4$ & $-7,3$ \\
\hline $\mathrm{NH}_{3}$ & ${ }^{1} J_{\mathrm{NH}}$ & 41,6 & 42,8 & 43,9 & 45,0 & 46,1 & 47,2 & 48,3 & 49,3 & 50,3 & 51,3 & 52,2 & 43,8 \\
\hline $\mathrm{NH}_{3}$ & ${ }^{2} J_{\mathrm{HH}}$ & $-12,7$ & $-13,6$ & $-14,4$ & $-15,1$ & $-15,6$ & $-15,9$ & $-16,1$ & $-16,0$ & $-15,7$ & $-15,1$ & $-14,4$ & $-9,6$ \\
\hline $\mathrm{PH}_{3}$ & ${ }^{1} J_{\mathrm{PH}}$ & 161,0 & 159,3 & 160,7 & 165,5 & 172,8 & 181,4 & 190,6 & 199,7 & 208,4 & 216,6 & 224,3 & 188,2 \\
\hline $\mathrm{PF}_{3}$ & ${ }^{1} J_{\mathrm{PF}}$ & $-1355,4$ & $-1373,8$ & $-1384,3$ & $-1386,7$ & $-1381,4$ & $-1369,8$ & $-1353,1$ & $-1332,6$ & $-1309,6$ & $-1284,8$ & $-1259,0$ & -1441 \\
\hline $\mathrm{BHF}_{2}$ & ${ }^{1} J_{\mathrm{BF}}$ & $-2,2$ & 3,8 & 10,5 & 17,9 & 26,1 & 35,1 & 45,1 & 56,1 & 68,4 & 81,9 & 96,9 & -84 \\
\hline $\mathrm{BF}_{3}$ & ${ }^{1} J_{\mathrm{BF}}$ & 100,7 & 108,9 & 117,6 & 126,9 & 136,8 & 147,6 & 159,2 & 171,9 & 185,6 & 200,5 & 216,7 & 15 \\
\hline $\mathrm{F}_{2} \mathrm{O}$ & ${ }^{1} J_{\mathrm{OF}}$ & $-234,2$ & $-269,0$ & $-298,1$ & $-322,9$ & $-345,3$ & $-366,9$ & $-390,0$ & $-417,5$ & $-454,4$ & $-510,2$ & $-607,7$ & -300 \\
\hline $\mathrm{CH}_{4}$ & ${ }^{1} J_{\mathrm{CH}}$ & 83,3 & 89,6 & 95,9 & 102,2 & 108,5 & 114,8 & 121,1 & 127,4 & 133,5 & 139,5 & 145,3 & 125,3 \\
\hline $\mathrm{CH}_{4}$ & ${ }^{2} J_{\mathrm{HH}}$ & $-21,1$ & $-21,4$ & $-21,5$ & $-21,5$ & $-21,3$ & $-21,1$ & $-20,7$ & $-20,1$ & $-19,5$ & $-18,8$ & $-18,2$ & $-12,8$ \\
\hline $\mathrm{C}_{2} \mathrm{H}_{2}$ & ${ }^{1} J_{\mathrm{CC}}$ & 183,8 & 192,9 & 202,5 & 212,7 & 223,5 & 234,9 & 247,0 & 259,7 & 273,3 & 287,6 & 302,9 & 174,8 \\
\hline $\mathrm{C}_{2} \mathrm{H}_{2}$ & ${ }^{1} J_{\mathrm{CH}}$ & 226,2 & 235,3 & 244,1 & 252,7 & 260,8 & 268,6 & 275,9 & 282,5 & 288,4 & 293,4 & 297,6 & 247,6 \\
\hline $\mathrm{C}_{2} \mathrm{H}_{2}$ & ${ }^{2} J_{\mathrm{CH}}$ & 36,0 & 36,3 & 36,6 & 36,8 & 36,9 & 36,9 & 37,0 & 36,9 & 36,6 & 36,1 & 35,1 & 50,1 \\
\hline $\mathrm{C}_{2} \mathrm{H}_{2}$ & ${ }^{3} J_{\mathrm{HH}}$ & 20,3 & 20,8 & 21,1 & 21,3 & 21,4 & 21,4 & 21,3 & 21,1 & 20,9 & 20,8 & 20,9 & 9,6 \\
\hline $\mathrm{C}_{2} \mathrm{H}_{4}$ & ${ }^{1} J_{\mathrm{CC}}$ & 58,9 & 65,1 & 71,7 & 78,9 & 86,7 & 95,1 & 104,3 & 114,2 & 124,9 & 136,6 & 149,4 & 67,6 \\
\hline $\mathrm{C}_{2} \mathrm{H}_{4}$ & ${ }^{1} J_{\mathrm{CH}}$ & 121,8 & 129,7 & 137,5 & 145,2 & 152,8 & 160,4 & 167,8 & 175,1 & 182,1 & 189,0 & 195,6 & 156,3 \\
\hline $\mathrm{C}_{2} \mathrm{H}_{4}$ & ${ }^{2} J_{\mathrm{CH}}$ & $-11,9$ & $-12,7$ & $-13,6$ & $-14,6$ & $-15,6$ & $-16,7$ & $-17,8$ & $-18,9$ & $-20,1$ & $-21,4$ & $-22,9$ & $-2,4$ \\
\hline $\mathrm{C}_{2} \mathrm{H}_{4}$ & ${ }^{2} J_{\mathrm{HH}}$ & $-15,8$ & $-15,5$ & $-14,9$ & $-14,2$ & $-13,4$ & $-12,4$ & $-11,2$ & $-9,9$ & $-8,6$ & $-7,3$ & $-6,2$ & 2,3 \\
\hline $\mathrm{C}_{2} \mathrm{H}_{4}$ & ${ }^{3} J_{\mathrm{HH}_{\mathrm{c}}}$ & 14,9 & 15,6 & 16,2 & 16,7 & 17,1 & 17,4 & 17,6 & 17,7 & 17,7 & 17,7 & 17,7 & 11,7 \\
\hline $\mathrm{C}_{2} \mathrm{H}_{4}$ & ${ }^{3} J_{\mathrm{HH}_{\mathrm{t}}}$ & 16,3 & 17,7 & 18,9 & 20,1 & 21,2 & 22,1 & 22,9 & 23,6 & 24,1 & 24,6 & 25,1 & 19 \\
\hline $\mathrm{C}_{2} \mathrm{H}_{6}$ & ${ }^{1} J_{\mathrm{CC}}$ & 16,1 & 19,4 & 22,8 & 26,5 & 30,3 & 34,2 & 38,4 & 42,8 & 47,3 & 52,1 & 57,1 & 34,5 \\
\hline $\mathrm{C}_{2} \mathrm{H}_{6}$ & ${ }^{1} J_{\mathrm{CH}}$ & 81,9 & 88,4 & 94,8 & 101,3 & 107,8 & 114,4 & 120,9 & 127,4 & 133,8 & 140,2 & 146,4 & 125,2 \\
\hline $\mathrm{C}_{2} \mathrm{H}_{6}$ & ${ }^{2} J_{\mathrm{CH}}$ & $-3,4$ & $-3,9$ & $-4,4$ & $-4,9$ & $-5,4$ & $-5,9$ & $-6,3$ & $-6,8$ & $-7,2$ & $-7,7$ & $-8,2$ & $-4,7$ \\
\hline \multirow[t]{3}{*}{ Total } & $\mathrm{DM}$ & 14,05 & 14,07 & 14,81 & 16,25 & 18,26 & 20,70 & 23,43 & 26,24 & 28,87 & 30,93 & 31,52 & - \\
\hline & DMA & 36,37 & 33,56 & 31,55 & 32,51 & 34,11 & 36,27 & 39,50 & 44,01 & 49,73 & 56,38 & 64,82 & - \\
\hline & PDMA & 100,22 & 102,16 & 104,33 & 108,59 & 113,30 & 118,16 & 123,85 & 130,21 & 137,56 & 145,77 & 155,67 & - \\
\hline \multirow[t]{3}{*}{ CPI } & DM & 51,09 & 46,61 & 43,76 & 42,49 & 42,51 & 43,48 & 45,02 & 46,70 & 47,95 & 47,81 & 44,18 & - \\
\hline & DMA & 63,67 & 59,79 & 57,05 & 59,65 & 63,02 & 66,95 & 72,09 & 79,37 & 87,95 & 98,57 & 113,27 & - \\
\hline & PDMA & 89,00 & 95,17 & 101,91 & 110,92 & 120,15 & 129,87 & 140,38 & 152,09 & 164,75 & 178,59 & 194,37 & - \\
\hline \multirow[t]{3}{*}{ SPI } & $\mathrm{DM}$ & $-13,12$ & $-9,79$ & $-6,43$ & $-2,99$ & 0,48 & 4,00 & 7,61 & 11,24 & 14,87 & 18,55 & 22,23 & - \\
\hline & DMA & 16,35 & 14,32 & 12,84 & 12,61 & 12,91 & 13,77 & 15,61 & 18,08 & 21,71 & 25,43 & 29,29 & - \\
\hline & PDMA & 108,44 & 107,29 & 106,11 & 106,88 & 108,27 & 109,58 & 111,72 & 114,16 & 117,62 & 121,70 & 127,30 & - \\
\hline \multirow[t]{3}{*}{$\Delta \mathrm{CS}$} & $\mathrm{DM}$ & 64,21 & 56,40 & 50,19 & 45,48 & 42,03 & 39,48 & 37,41 & 35,46 & 33,07 & 29,26 & 21,95 & - \\
\hline & DMA & 47,33 & 45,47 & 44,21 & 47,05 & 50,11 & 53,18 & 56,48 & 61,29 & 66,23 & 73,14 & 83,99 & - \\
\hline & PDMA & $-19,44$ & $-12,13$ & $-4,20$ & 4,04 & 11,88 & 20,29 & 28,66 & 37,93 & 47,12 & 56,89 & 67,07 & - \\
\hline
\end{tabular}


Tabela 8.86: Constantes de acoplamento M06 com correção vibracionals no nível PBE0 $40 \% E_{X}^{\mathrm{HF}}$ e base aug-pcJ-2.

\begin{tabular}{|c|c|c|c|c|c|c|c|c|c|c|c|c|c|}
\hline & $\% E_{X}^{\mathrm{HF}}$ & $0 \%$ & $10 \%$ & $20 \%$ & $30 \%$ & $40 \%$ & $50 \%$ & $60 \%$ & $70 \%$ & $80 \%$ & $90 \%$ & $100 \%$ & Exp. \\
\hline $\mathrm{HF}$ & ${ }^{1} J_{\mathrm{HF}}$ & 557,0 & 585,3 & 617,8 & 655,3 & 698,6 & 748,1 & 803,8 & 865,7 & 933,0 & 1004,7 & 1079,1 & 500 \\
\hline $\mathrm{CO}$ & ${ }^{1} J_{\mathrm{CO}}$ & 17,6 & 18,3 & 18,6 & 18,5 & 17,7 & 16,1 & 13,7 & 10,2 & 5,7 & $-0,1$ & $-7,2$ & 16,4 \\
\hline $\mathrm{H}_{2} \mathrm{O}$ & ${ }^{1} J_{\mathrm{OH}}$ & $-84,6$ & $-89,2$ & $-94,7$ & $-101,3$ & $-109,2$ & $-118,6$ & $-129,8$ & $-143,1$ & $-158,8$ & $-177,5$ & $-199,7$ & $-80,6$ \\
\hline $\mathrm{H}_{2} \mathrm{O}$ & ${ }^{2} J_{\mathrm{HH}}$ & $-4,2$ & $-7,6$ & $-11,8$ & $-16,9$ & $-23,3$ & $-31,3$ & $-41,2$ & $-53,4$ & $-68,7$ & $-87,8$ & $-111,5$ & $-7,3$ \\
\hline $\mathrm{NH}_{3}$ & ${ }^{1} J_{\mathrm{NH}}$ & 43,7 & 46,6 & 50,1 & 54,2 & 59,1 & 64,9 & 72,1 & 80,8 & 91,6 & 105,2 & 122,7 & 43,8 \\
\hline $\mathrm{NH}_{3}$ & ${ }^{2} J_{\mathrm{HH}}$ & $-6,8$ & $-9,9$ & $-13,8$ & $-18,9$ & $-25,5$ & $-34,2$ & $-45,7$ & $-61,2$ & $-82,3$ & $-111,5$ & $-153,1$ & $-9,6$ \\
\hline $\mathrm{PH}_{3}$ & ${ }^{1} J_{\mathrm{PH}}$ & 191,8 & 206,9 & 225,0 & 247,0 & 274,1 & 307,6 & 350,0 & 404,3 & 475,7 & 570,2 & 693,8 & 188,2 \\
\hline $\mathrm{PF}_{3}$ & ${ }^{1} J_{\mathrm{PF}}$ & $-1435,0$ & $-1474,4$ & $-1506,7$ & $-1531,4$ & $-1550,0$ & $-1564,9$ & $-1577,3$ & $-1586,0$ & $-1588,8$ & $-1583,9$ & $-1571,2$ & -1441 \\
\hline $\mathrm{BHF}_{2}$ & ${ }^{1} J_{\mathrm{BF}}$ & $-71,7$ & $-62,3$ & $-50,4$ & $-35,9$ & $-19,1$ & $-0,7$ & 18,5 & 37,3 & 54,3 & 67,2 & 71,2 & -84 \\
\hline $\mathrm{BF}_{3}$ & ${ }^{1} J_{\mathrm{BF}}$ & 24,8 & 36,9 & 51,2 & 68,0 & 87,5 & 109,3 & 133,0 & 157,9 & 183,4 & 209,2 & 235,5 & 15 \\
\hline $\mathrm{F}_{2} \mathrm{O}$ & ${ }^{1} J_{\mathrm{OF}}$ & $-176,4$ & $-226,4$ & $-281,2$ & $-343,5$ & $-421,4$ & $-545,3$ & $-991,0$ & 4252,5 & $-30,8$ & $-237,6$ & $-336,1$ & -300 \\
\hline $\mathrm{CH}_{4}$ & ${ }^{1} J_{\mathrm{CH}}$ & 105,7 & 117,1 & 130,8 & 147,2 & 167,2 & 191,7 & 222,3 & 261,3 & 312,3 & 381,4 & 479,8 & 125,3 \\
\hline $\mathrm{CH}_{4}$ & ${ }^{2} J_{\mathrm{HH}}$ & $-12,9$ & $-16,9$ & $-21,8$ & $-28,2$ & $-36,6$ & $-47,6$ & $-62,5$ & $-83,1$ & $-112,6$ & $-156,5$ & $-225,4$ & $-12,8$ \\
\hline $\mathrm{C}_{2} \mathrm{H}_{2}$ & ${ }^{1} J_{\mathrm{CC}}$ & 162,6 & 171,6 & 183,4 & 200,4 & 228,3 & 286,3 & 503,2 & $-631,8$ & $-13,1$ & 129,1 & 5816,2 & 174,8 \\
\hline $\mathrm{C}_{2} \mathrm{H}_{2}$ & ${ }^{1} J_{\mathrm{CH}}$ & 212,0 & 240,5 & 274,5 & 316,3 & 370,9 & 453,6 & 664,4 & $-163,6$ & 363,9 & 498,5 & $-158,7$ & 247,6 \\
\hline $\mathrm{C}_{2} \mathrm{H}_{2}$ & ${ }^{2} J_{\mathrm{CH}}$ & 49,9 & 51,5 & 51,8 & 49,2 & 39,8 & 9,2 & $-140,9$ & 758,5 & 315,6 & 283,0 & 1065,2 & 50,1 \\
\hline $\mathrm{C}_{2} \mathrm{H}_{2}$ & ${ }^{3} J_{\mathrm{HH}}$ & 8,3 & 10,4 & 13,9 & 20,0 & 31,9 & 61,0 & 184,7 & $-514,1$ & $-157,6$ & $-116,6$ & $-1,6$ & 9,6 \\
\hline $\mathrm{C}_{2} \mathrm{H}_{4}$ & ${ }^{1} J_{\mathrm{CC}}$ & 52,1 & 55,6 & 60,6 & 68,7 & 84,1 & 127,0 & 1248,1 & $-63,0$ & $-9,1$ & 7,5 & 14,8 & 67,6 \\
\hline $\mathrm{C}_{2} \mathrm{H}_{4}$ & ${ }^{1} J_{\mathrm{CH}}$ & 132,3 & 148,9 & 168,9 & 193,8 & 227,2 & 284,2 & 1106,7 & 220,8 & 306,5 & 378,2 & 460,4 & 156,3 \\
\hline $\mathrm{C}_{2} \mathrm{H}_{4}$ & ${ }^{2} J_{\mathrm{CH}}$ & 0,2 & $-1,4$ & $-4,0$ & $-8,6$ & $-18,2$ & $-46,8$ & $-835,4$ & 91,4 & 56,4 & 48,3 & 48,1 & $-2,4$ \\
\hline $\mathrm{C}_{2} \mathrm{H}_{4}$ & ${ }^{2} J_{\mathrm{HH}}$ & $-3,2$ & $-5,7$ & $-9,4$ & $-15,4$ & $-26,5$ & $-56,2$ & $-791,8$ & 62,0 & 21,2 & 1,8 & $-16,3$ & 2,3 \\
\hline $\mathrm{C}_{2} \mathrm{H}_{4}$ & ${ }^{3} J_{\mathrm{HH}_{\mathrm{C}}}$ & 11,4 & 12,9 & 15,1 & 19,0 & 27,2 & 52,9 & 783,0 & $-78,5$ & $-48,7$ & $-45,0$ & $-50,4$ & 11,7 \\
\hline $\mathrm{C}_{2} \mathrm{H}_{4}$ & ${ }^{3} J_{\mathrm{HH}_{\mathrm{t}}}$ & 12,8 & 15,3 & 18,8 & 24,2 & 34,4 & 63,1 & 821,8 & $-67,2$ & $-32,0$ & $-22,6$ & $-20,5$ & 19 \\
\hline $\mathrm{C}_{2} \mathrm{H}_{6}$ & ${ }^{1} J_{\mathrm{CC}}$ & 21,0 & 23,8 & 27,3 & 31,7 & 37,3 & 44,4 & 53,8 & 66,6 & 84,5 & 111,0 & 153,1 & 34,5 \\
\hline $\mathrm{C}_{2} \mathrm{H}_{6}$ & ${ }^{1} J_{\mathrm{CH}}$ & 103,0 & 115,0 & 129,2 & 146,3 & 167,1 & 192,5 & 224,2 & 264,7 & 317,8 & 390,5 & 495,6 & 125,2 \\
\hline $\mathrm{C}_{2} \mathrm{H}_{6}$ & ${ }^{2} J_{\mathrm{CH}}$ & $-1,6$ & $-2,8$ & $-4,4$ & $-6,4$ & $-9,0$ & $-12,5$ & $-17,4$ & $-24,5$ & $-35,0$ & $-51,8$ & $-80,6$ & $-4,7$ \\
\hline \multirow[t]{3}{*}{ Total } & $\mathrm{DM}$ & 2,49 & 4,42 & 7,45 & 11,86 & 18,02 & 27,26 & 104,82 & 162,29 & 51,52 & 67,30 & 306,08 & - \\
\hline & DMA & 14,82 & 13,44 & 17,08 & 28,64 & 46,78 & 76,68 & 322,49 & 350,75 & 131,83 & 141,17 & 416,52 & - \\
\hline & PDMA & 31,33 & 32,20 & 49,19 & 87,65 & 155,26 & 311,47 & 3389,09 & 804,80 & 463,88 & 464,34 & 735,04 & - \\
\hline \multirow[t]{3}{*}{ CPI } & DM & 19,57 & 16,66 & 14,84 & 14,02 & 13,42 & 10,01 & $-21,35$ & 465,83 & 88,49 & 83,38 & 89,33 & - \\
\hline & DMA & 20,32 & 24,41 & 30,93 & 45,56 & 66,31 & 92,94 & 151,24 & 522,45 & 155,91 & 163,15 & 190,55 & - \\
\hline & PDMA & 19,91 & 23,78 & 44,18 & 71,30 & 105,19 & 146,68 & 207,07 & 380,13 & 317,86 & 394,05 & 495,85 & - \\
\hline \multirow[t]{3}{*}{ SPI } & $\mathrm{DM}$ & $-10,03$ & $-4,55$ & 2,04 & 10,27 & 21,40 & 39,91 & 197,34 & $-60,31$ & 24,40 & 55,51 & 465,04 & - \\
\hline & DMA & 10,79 & 5,39 & 6,93 & 16,23 & 32,47 & 64,77 & 448,07 & 224,84 & 114,17 & 125,06 & 582,24 & - \\
\hline & PDMA & 39,70 & 38,38 & 52,87 & 99,65 & 191,97 & 432,32 & 5722,58 & 1116,22 & 570,96 & 515,89 & 910,45 & - \\
\hline \multirow[t]{3}{*}{$\Delta \mathrm{CS}$} & $\mathrm{DM}$ & 29,61 & 21,22 & 12,80 & 3,74 & $-7,98$ & $-29,90$ & $-218,69$ & 526,13 & 64,09 & 27,87 & $-375,71$ & - \\
\hline & DMA & 9,52 & 19,02 & 23,99 & 29,33 & 33,84 & 28,17 & $-296,84$ & 297,61 & 41,74 & 38,09 & $-391,69$ & - \\
\hline & PDMA & $-19,79$ & $-14,60$ & $-8,69$ & $-28,35$ & $-86,77$ & $-285,64$ & $-5515,51$ & $-736,09$ & $-253,10$ & $-121,85$ & $-414,61$ & - \\
\hline
\end{tabular}


Tabela 8.87: Constantes de acoplamento M062X com correção vibracional no nível PBE0 $40 \% E_{X}^{\mathrm{HF}}$ e base aug-pcJ-2.

\begin{tabular}{|c|c|c|c|c|c|c|c|c|c|c|c|c|c|}
\hline & $\% E_{X}^{\mathrm{HF}}$ & $0 \%$ & $10 \%$ & $20 \%$ & $30 \%$ & $40 \%$ & $50 \%$ & $60 \%$ & $70 \%$ & $80 \%$ & $90 \%$ & $100 \%$ & Exp. \\
\hline $\mathrm{HF}$ & ${ }^{1} J_{\mathrm{HF}}$ & 411,1 & 414,6 & 418,6 & 424,3 & 432,6 & 444,7 & 461,6 & 484,4 & 514,1 & 551,6 & 597,8 & 500 \\
\hline $\mathrm{CO}$ & ${ }^{1} J_{\mathrm{CO}}$ & 4,4 & 5,4 & 6,4 & 7,3 & 7,9 & 8,1 & 7,8 & 6,7 & 4,4 & 0,5 & $-6,1$ & 16,4 \\
\hline $\mathrm{H}_{2} \mathrm{O}$ & ${ }^{1} J_{\mathrm{OH}}$ & $-72,0$ & $-74,2$ & $-76,8$ & $-79,9$ & $-83,6$ & $-88,1$ & $-93,6$ & $-100,3$ & $-108,4$ & $-118,1$ & $-129,9$ & $-80,6$ \\
\hline $\mathrm{H}_{2} \mathrm{O}$ & ${ }^{2} J_{\mathrm{HH}}$ & 5,7 & 4,5 & 3,0 & 1,2 & $-1,2$ & $-4,2$ & $-8,0$ & $-12,9$ & $-19,0$ & $-26,7$ & $-36,6$ & $-7,3$ \\
\hline $\mathrm{NH}_{3}$ & ${ }^{1} J_{\mathrm{NH}}$ & 38,7 & 40,7 & 42,9 & 45,5 & 48,5 & 52,1 & 56,4 & 61,4 & 67,4 & 74,7 & 83,6 & 43,8 \\
\hline $\mathrm{NH}_{3}$ & ${ }^{2} J_{\mathrm{HH}}$ & 1,0 & 0,1 & $-1,3$ & $-3,2$ & $-5,6$ & $-8,7$ & $-12,8$ & $-18,1$ & $-25,1$ & $-34,4$ & $-46,8$ & $-9,6$ \\
\hline $\mathrm{PH}_{3}$ & ${ }^{1} J_{\mathrm{PH}}$ & 125,5 & 126,7 & 129,8 & 135,2 & 143,1 & 154,1 & 168,6 & 187,6 & 211,7 & 242,5 & 282,0 & 188,2 \\
\hline $\mathrm{PF}_{3}$ & ${ }^{1} J_{\mathrm{PF}}$ & $-1440,1$ & $-1486,6$ & $-1531,1$ & $-1570,8$ & $-1601,5$ & $-1619,8$ & $-1625,4$ & $-1620,8$ & $-1610,6$ & $-1600,5$ & $-1594,5$ & -1441 \\
\hline $\mathrm{BHF}_{2}$ & ${ }^{1} J_{\mathrm{BF}}$ & $-171,2$ & $-167,7$ & $-160,8$ & $-151,1$ & $-139,5$ & $-126,5$ & $-112,1$ & $-96,7$ & $-80,3$ & $-63,2$ & $-45,8$ & -84 \\
\hline $\mathrm{BF}_{3}$ & ${ }^{1} J_{\mathrm{BF}}$ & $-91,5$ & $-82,4$ & $-71,1$ & $-58,2$ & $-43,9$ & $-28,6$ & $-12,2$ & 5,3 & 24,5 & 45,6 & 68,7 & 15 \\
\hline $\mathrm{F}_{2} \mathrm{O}$ & ${ }^{1} J_{\mathrm{OF}}$ & $-171,9$ & $-215,0$ & $-261,5$ & $-311,1$ & $-363,7$ & $-420,2$ & $-484,1$ & $-565,4$ & $-700,4$ & $-1320,5$ & $-2177,6$ & -300 \\
\hline $\mathrm{CH}_{4}$ & ${ }^{1} J_{\mathrm{CH}}$ & 88,8 & 96,1 & 104,5 & 114,5 & 126,1 & 139,9 & 156,3 & 176,0 & 199,8 & 229,0 & 265,3 & 125,3 \\
\hline $\mathrm{CH}_{4}$ & ${ }^{2} J_{\mathrm{HH}}$ & $-0,5$ & $-1,6$ & $-3,1$ & $-5,1$ & $-7,6$ & $-10,8$ & $-15,0$ & $-20,4$ & $-27,6$ & $-37,1$ & $-49,9$ & $-12,8$ \\
\hline $\mathrm{C}_{2} \mathrm{H}_{2}$ & ${ }^{1} J_{\mathrm{CC}}$ & 168,6 & 175,6 & 183,8 & 193,5 & 205,5 & 221,0 & 242,4 & 274,8 & 332,6 & 473,7 & 1543,0 & 174,8 \\
\hline $\mathrm{C}_{2} \mathrm{H}_{2}$ & ${ }^{1} J_{\mathrm{CH}}$ & 145,6 & 162,6 & 182,1 & 204,3 & 229,9 & 259,9 & 295,6 & 340,0 & 400,2 & 503,7 & 1040,4 & 247,6 \\
\hline $\mathrm{C}_{2} \mathrm{H}_{2}$ & ${ }^{2} J_{\mathrm{CH}}$ & 46,9 & 49,3 & 51,8 & 54,1 & 56,0 & 57,1 & 56,4 & 51,9 & 37,0 & $-14,4$ & $-491,2$ & 50,1 \\
\hline $\mathrm{C}_{2} \mathrm{H}_{2}$ & ${ }^{3} J_{\mathrm{HH}}$ & 5,0 & 5,5 & 6,0 & 6,7 & 7,7 & 9,2 & 11,6 & 16,1 & 25,5 & 52,1 & 275,1 & 9,6 \\
\hline $\mathrm{C}_{2} \mathrm{H}_{4}$ & ${ }^{1} J_{\mathrm{CC}}$ & 61,5 & 64,3 & 68,0 & 72,7 & 79,0 & 87,7 & 100,5 & 121,7 & 163,3 & 285,8 & 14164,1 & 67,6 \\
\hline $\mathrm{C}_{2} \mathrm{H}_{4}$ & ${ }^{1} J_{\mathrm{CH}}$ & 101,2 & 111,3 & 122,9 & 136,4 & 152,2 & 171,0 & 194,0 & 223,3 & 265,2 & 347,6 & 6658,1 & 156,3 \\
\hline $\mathrm{C}_{2} \mathrm{H}_{4}$ & ${ }^{2} J_{\mathrm{CH}}$ & 5,8 & 5,1 & 4,2 & 3,0 & 1,2 & $-1,5$ & $-5,9$ & $-13,7$ & $-30,6$ & $-83,6$ & $-6359,4$ & $-2,4$ \\
\hline $\mathrm{C}_{2} \mathrm{H}_{4}$ & ${ }^{2} J_{\mathrm{HH}}$ & 7,2 & 7,2 & 7,0 & 6,6 & 5,9 & 4,6 & 2,4 & $-1,6$ & $-10,2$ & $-36,8$ & $-3080,2$ & 2,3 \\
\hline $\mathrm{C}_{2} \mathrm{H}_{4}$ & ${ }^{3} J_{\mathrm{HH}_{\mathrm{c}}}$ & 9,5 & 9,9 & 10,3 & 10,9 & 11,6 & 12,7 & 14,5 & 17,8 & 25,2 & 49,9 & 3090,6 & 11,7 \\
\hline $\mathrm{C}_{2} \mathrm{H}_{4}$ & ${ }^{3} J_{\mathrm{HH}_{\mathrm{t}}}$ & 10,1 & 11,4 & 12,7 & 14,3 & 16,1 & 18,4 & 21,5 & 26,6 & 36,2 & 64,5 & 3278,8 & 19 \\
\hline $\mathrm{C}_{2} \mathrm{H}_{6}$ & ${ }^{1} J_{\mathrm{CC}}$ & 28,3 & 30,8 & 33,9 & 37,5 & 42,0 & 47,3 & 53,9 & 62,1 & 72,4 & 85,7 & 103,1 & 34,5 \\
\hline $\mathrm{C}_{2} \mathrm{H}_{6}$ & ${ }^{1} J_{\mathrm{CH}}$ & 85,8 & 93,5 & 102,6 & 113,2 & 125,6 & 140,2 & 157,6 & 178,4 & 203,5 & 234,4 & 272,8 & 125,2 \\
\hline $\mathrm{C}_{2} \mathrm{H}_{6}$ & ${ }^{2} J_{\mathrm{CH}}$ & 2,0 & 1,3 & 0,5 & $-0,4$ & $-1,7$ & $-3,2$ & $-5,2$ & $-7,7$ & $-11,0$ & $-15,5$ & $-21,9$ & $-4,7$ \\
\hline \multirow[t]{3}{*}{ Total } & $\mathrm{DM}$ & $-16,90$ & $-17,56$ & $-17,68$ & $-17,06$ & $-15,48$ & $-12,64$ & $-8,39$ & $-2,63$ & 4,42 & 1,75 & 686,10 & - \\
\hline & DMA & 31,77 & 28,58 & 25,23 & 22,43 & 22,16 & 25,15 & 31,11 & 39,91 & 59,18 & 116,94 & 1624,90 & - \\
\hline & PDMA & 91,25 & 82,43 & 71,88 & 60,61 & 47,91 & 34,61 & 35,90 & 68,49 & 141,25 & 347,53 & 18292,40 & - \\
\hline \multirow[t]{3}{*}{ CPI } & $\mathrm{DM}$ & $-18,29$ & $-24,98$ & $-31,16$ & $-36,52$ & $-40,71$ & $-43,45$ & $-44,97$ & $-46,34$ & $-51,15$ & $-99,04$ & $-167,83$ & - \\
\hline & DMA & 47,60 & 45,51 & 42,24 & 39,66 & 43,40 & 45,69 & 47,26 & 49,54 & 64,67 & 133,25 & 226,61 & - \\
\hline & PDMA & 117,42 & 106,82 & 93,37 & 78,84 & 65,46 & 50,33 & 40,66 & 43,02 & 64,69 & 123,39 & 198,86 & - \\
\hline \multirow[t]{3}{*}{ SPI } & $\mathrm{DM}$ & $-15,89$ & $-12,12$ & $-7,79$ & $-2,79$ & 3,03 & 9,96 & 18,43 & 29,41 & 45,16 & 75,66 & 1312,31 & - \\
\hline & DMA & 20,17 & 16,17 & 12,77 & 9,79 & 6,59 & 10,09 & 19,26 & 32,85 & 55,15 & 104,98 & 2650,32 & - \\
\hline & PDMA & 72,06 & 64,55 & 56,12 & 47,25 & 35,04 & 23,08 & 32,41 & 87,16 & 197,39 & 511,89 & 31560,99 & - \\
\hline \multirow[t]{3}{*}{$\Delta \mathrm{CS}$} & $\mathrm{DM}$ & $-2,40$ & $-12,86$ & $-23,37$ & $-33,72$ & $-43,74$ & $-53,41$ & $-63,41$ & $-75,75$ & $-96,31$ & $-174,70$ & $-1480,13$ & - \\
\hline & DMA & 27,43 & 29,34 & 29,47 & 29,87 & 36,81 & 35,60 & 28,00 & 16,68 & 9,53 & 28,27 & $-2423,71$ & - \\
\hline & PDMA & 45,36 & 42,27 & 37,26 & 31,59 & 30,42 & 27,25 & 8,25 & $-44,14$ & $-132,70$ & $-388,50$ & $-31362,13$ & - \\
\hline
\end{tabular}


Tabela 8.88: Constantes de acoplamento OLYP com correção vibracional no nível PBE0 $40 \% E_{X}^{\mathrm{HF}}$ e base aug-pcJ-2.

\begin{tabular}{|c|c|c|c|c|c|c|c|c|c|c|c|c|c|}
\hline & $\% E_{X}^{\mathrm{HF}}$ & $0 \%$ & $10 \%$ & $20 \%$ & $30 \%$ & $40 \%$ & $50 \%$ & $60 \%$ & $70 \%$ & $80 \%$ & $90 \%$ & $100 \%$ & Exp. \\
\hline $\mathrm{HF}$ & ${ }^{1} J_{\mathrm{HF}}$ & 328,6 & 356,8 & 385,3 & 414,3 & 443,7 & 473,4 & 503,6 & 534,1 & 564,9 & 596,1 & 627,7 & 500 \\
\hline $\mathrm{CO}$ & ${ }^{1} J_{\mathrm{CO}}$ & 24,7 & 22,5 & 20,2 & 17,8 & 15,3 & 12,7 & 10,1 & 7,3 & 4,5 & 1,6 & $-1,2$ & 16,4 \\
\hline $\mathrm{H}_{2} \mathrm{O}$ & ${ }^{1} J_{\mathrm{OH}}$ & $-64,7$ & $-68,0$ & $-71,3$ & $-74,7$ & $-78,1$ & $-81,6$ & $-85,1$ & $-88,7$ & $-92,3$ & $-95,9$ & $-99,7$ & $-80,6$ \\
\hline $\mathrm{H}_{2} \mathrm{O}$ & ${ }^{2} J_{\mathrm{HH}}$ & $-5,9$ & $-6,8$ & $-7,8$ & $-8,7$ & $-9,6$ & $-10,6$ & $-11,6$ & $-12,6$ & $-13,7$ & $-14,7$ & $-15,8$ & $-7,3$ \\
\hline $\mathrm{NH}_{3}$ & ${ }^{1} J_{\mathrm{NH}}$ & 40,7 & 42,0 & 43,2 & 44,5 & 45,8 & 47,1 & 48,4 & 49,8 & 51,1 & 52,5 & 53,9 & 43,8 \\
\hline $\mathrm{NH}_{3}$ & ${ }^{2} J_{\mathrm{HH}}$ & $-8,8$ & $-9,6$ & $-10,5$ & $-11,3$ & $-12,2$ & $-13,1$ & $-14,0$ & $-14,9$ & $-15,9$ & $-16,9$ & $-17,9$ & $-9,6$ \\
\hline $\mathrm{PH}_{3}$ & ${ }^{1} J_{\mathrm{PH}}$ & 151,3 & 160,0 & 168,6 & 177,0 & 185,3 & 193,5 & 201,5 & 209,3 & 217,0 & 224,4 & 231,7 & 188,2 \\
\hline $\mathrm{PF}_{3}$ & ${ }^{1} J_{\mathrm{PF}}$ & $-1700,0$ & $-1683,5$ & $-1663,2$ & $-1639,8$ & $-1614,0$ & $-1586,3$ & $-1557,2$ & $-1527,2$ & $-1496,6$ & $-1465,7$ & $-1434,8$ & -1441 \\
\hline $\mathrm{BHF}_{2}$ & ${ }^{1} J_{\mathrm{BF}}$ & $-185,8$ & $-165,2$ & $-145,1$ & $-125,5$ & $-106,4$ & $-87,9$ & $-70,0$ & $-52,6$ & $-35,8$ & $-19,5$ & $-3,8$ & -84 \\
\hline $\mathrm{BF}_{3}$ & ${ }^{1} J_{\mathrm{BF}}$ & $-92,7$ & $-69,6$ & $-47,2$ & $-25,3$ & $-4,0$ & 16,6 & 36,7 & 56,2 & 75,2 & 93,6 & 111,6 & 15 \\
\hline $\mathrm{F}_{2} \mathrm{O}$ & ${ }^{1} J_{\mathrm{OF}}$ & $-269,9$ & $-306,2$ & $-343,2$ & $-382,4$ & $-425,9$ & $-477,1$ & $-541,8$ & $-631,8$ & $-775,9$ & $-1071,9$ & $-2269,1$ & -300 \\
\hline $\mathrm{CH}_{4}$ & ${ }^{1} J_{\mathrm{CH}}$ & 120,6 & 123,5 & 126,5 & 129,5 & 132,6 & 135,7 & 138,8 & 142,0 & 145,3 & 148,5 & 151,8 & 125,3 \\
\hline $\mathrm{CH}_{4}$ & ${ }^{2} J_{\mathrm{HH}}$ & $-13,2$ & $-13,8$ & $-14,5$ & $-15,2$ & $-15,9$ & $-16,6$ & $-17,3$ & $-18,0$ & $-18,7$ & $-19,4$ & $-20,0$ & $-12,8$ \\
\hline $\mathrm{C}_{2} \mathrm{H}_{2}$ & ${ }^{1} J_{\mathrm{CC}}$ & 188,3 & 192,9 & 198,0 & 203,5 & 209,7 & 216,6 & 224,4 & 233,2 & 243,4 & 255,3 & 269,3 & 174,8 \\
\hline $\mathrm{C}_{2} \mathrm{H}_{2}$ & ${ }^{1} J_{\mathrm{CH}}$ & 256,6 & 261,3 & 266,2 & 271,2 & 276,4 & 281,9 & 287,8 & 294,1 & 300,9 & 308,3 & 316,7 & 247,6 \\
\hline $\mathrm{C}_{2} \mathrm{H}_{2}$ & ${ }^{2} J_{\mathrm{CH}}$ & 53,2 & 53,2 & 53,0 & 52,6 & 51,9 & 50,9 & 49,5 & 47,8 & 45,4 & 42,3 & 38,3 & 50,1 \\
\hline $\mathrm{C}_{2} \mathrm{H}_{2}$ & ${ }^{3} J_{\mathrm{HH}}$ & 12,3 & 12,9 & 13,6 & 14,4 & 15,4 & 16,6 & 18,0 & 19,6 & 21,6 & 23,9 & 26,7 & 9,6 \\
\hline $\mathrm{C}_{2} \mathrm{H}_{4}$ & ${ }^{1} J_{\mathrm{CC}}$ & 61,8 & 65,6 & 69,7 & 74,2 & 79,2 & 84,9 & 91,5 & 99,4 & 109,1 & 121,9 & 140,0 & 67,6 \\
\hline $\mathrm{C}_{2} \mathrm{H}_{4}$ & ${ }^{1} J_{\mathrm{CH}}$ & 154,7 & 158,5 & 162,4 & 166,4 & 170,6 & 175,1 & 179,9 & 185,2 & 191,3 & 198,5 & 207,7 & 156,3 \\
\hline $\mathrm{C}_{2} \mathrm{H}_{4}$ & ${ }^{2} J_{\mathrm{CH}}$ & $-1,6$ & $-2,5$ & $-3,6$ & $-4,8$ & $-6,1$ & $-7,7$ & $-9,7$ & $-12,1$ & $-15,3$ & $-19,6$ & $-25,9$ & $-2,4$ \\
\hline $\mathrm{C}_{2} \mathrm{H}_{4}$ & ${ }^{2} J_{\mathrm{HH}}$ & 3,6 & 3,0 & 2,4 & 1,7 & 1,0 & 0,2 & $-0,9$ & $-2,1$ & $-3,7$ & $-5,9$ & $-9,1$ & 2,3 \\
\hline $\mathrm{C}_{2} \mathrm{H}_{4}$ & ${ }^{3} J_{\mathrm{HH}_{\mathrm{c}}}$ & 12,6 & 13,0 & 13,5 & 14,0 & 14,6 & 15,3 & 16,2 & 17,4 & 18,9 & 21,0 & 24,1 & 11,7 \\
\hline $\mathrm{C}_{2} \mathrm{H}_{4}$ & ${ }^{3} J_{\mathrm{HH}_{\mathrm{t}}}$ & 20,1 & 20,5 & 21,0 & 21,7 & 22,4 & 23,3 & 24,3 & 25,7 & 27,5 & 30,0 & 33,6 & 19 \\
\hline $\mathrm{C}_{2} \mathrm{H}_{6}$ & ${ }^{1} J_{\mathrm{CC}}$ & 26,3 & 28,8 & 31,3 & 33,9 & 36,5 & 39,3 & 42,0 & 44,8 & 47,7 & 50,6 & 53,6 & 34,5 \\
\hline $\mathrm{C}_{2} \mathrm{H}_{6}$ & ${ }^{1} J_{\mathrm{CH}}$ & 120,2 & 123,3 & 126,4 & 129,6 & 132,8 & 136,0 & 139,3 & 142,6 & 145,9 & 149,3 & 152,7 & 125,2 \\
\hline $\mathrm{C}_{2} \mathrm{H}_{6}$ & ${ }^{2} J_{\mathrm{CH}}$ & $-3,5$ & $-3,9$ & $-4,3$ & $-4,7$ & $-5,2$ & $-5,6$ & $-6,1$ & $-6,6$ & $-7,0$ & $-7,5$ & $-8,0$ & $-4,7$ \\
\hline \multirow[t]{3}{*}{ Total } & $\mathrm{DM}$ & $-23,67$ & $-20,63$ & $-17,48$ & $-14,27$ & $-11,12$ & $-8,17$ & $-5,64$ & $-3,97$ & $-4,24$ & $-10,16$ & $-50,42$ & - \\
\hline & DMA & 30,60 & 25,54 & 23,38 & 21,80 & 20,73 & 20,79 & 24,70 & 32,13 & 41,88 & 57,84 & 109,57 & - \\
\hline & PDMA & 47,88 & 36,37 & 30,44 & 27,74 & 27,73 & 30,80 & 46,89 & 65,30 & 86,77 & 113,59 & 158,00 & - \\
\hline \multirow[t]{3}{*}{ CPI } & $\mathrm{DM}$ & $-56,67$ & $-51,68$ & $-46,54$ & $-41,36$ & $-36,45$ & $-32,20$ & $-29,12$ & $-28,36$ & $-32,58$ & $-50,66$ & $-150,75$ & - \\
\hline & DMA & 66,95 & 55,17 & 48,92 & 42,82 & 37,27 & 34,05 & 39,52 & 52,69 & 70,65 & 102,32 & 216,99 & - \\
\hline & PDMA & 93,27 & 71,54 & 54,81 & 39,71 & 26,64 & 18,69 & 37,91 & 59,43 & 82,41 & 109,52 & 163,81 & - \\
\hline \multirow[t]{3}{*}{ SPI } & $\mathrm{DM}$ & 0,53 & 2,15 & 3,83 & 5,59 & 7,45 & 9,45 & 11,57 & 13,93 & 16,55 & 19,54 & 23,16 & - \\
\hline & DMA & 3,95 & 3,81 & 4,65 & 6,39 & 8,60 & 11,07 & 13,84 & 17,06 & 20,79 & 25,22 & 30,79 & - \\
\hline & PDMA & 14,59 & 10,58 & 12,57 & 18,97 & 28,52 & 39,67 & 53,48 & 69,60 & 89,96 & 116,57 & 153,75 & - \\
\hline \multirow[t]{3}{*}{$\Delta \mathrm{CS}$} & $\mathrm{DM}$ & $-57,20$ & $-53,83$ & $-50,37$ & $-46,96$ & $-43,91$ & $-41,65$ & $-40,69$ & $-42,29$ & $-49,13$ & $-70,20$ & $-173,91$ & - \\
\hline & DMA & 62,99 & 51,36 & 44,27 & 36,42 & 28,67 & 22,99 & 25,68 & 35,63 & 49,87 & 77,10 & 186,20 & - \\
\hline & PDMA & 78,69 & 60,96 & 42,24 & 20,74 & $-1,88$ & $-20,99$ & $-15,56$ & $-10,18$ & $-7,55$ & $-7,05$ & 10,06 & - \\
\hline
\end{tabular}


Tabela 8.89: Constantes de acoplamento PBE com correção vibracional no nível PBE0 $40 \% E_{X}^{\mathrm{HF}}$ e base aug-pcJ-2.

\begin{tabular}{|c|c|c|c|c|c|c|c|c|c|c|c|c|c|}
\hline & $\% E_{X}^{\mathrm{HF}}$ & $0 \%$ & $10 \%$ & $20 \%$ & $30 \%$ & $40 \%$ & $50 \%$ & $60 \%$ & $70 \%$ & $80 \%$ & $90 \%$ & $100 \%$ & Exp. \\
\hline $\mathrm{HF}$ & ${ }^{1} J_{\mathrm{HF}}$ & 341,2 & 363,0 & 384,9 & 407,1 & 429,5 & 452,1 & 475,0 & 498,0 & 521,3 & 544,8 & 568,5 & 500 \\
\hline $\mathrm{CO}$ & ${ }^{1} J_{\mathrm{CO}}$ & 24,8 & 23,2 & 21,5 & 19,8 & 18,0 & 16,1 & 14,2 & 12,2 & 10,2 & 8,1 & 6,0 & 16,4 \\
\hline $\mathrm{H}_{2} \mathrm{O}$ & ${ }^{1} J_{\mathrm{OH}}$ & $-65,8$ & $-68,1$ & $-70,4$ & $-72,8$ & $-75,2$ & $-77,6$ & $-80,0$ & $-82,5$ & $-85,0$ & $-87,5$ & $-90,1$ & $-80,6$ \\
\hline $\mathrm{H}_{2} \mathrm{O}$ & ${ }^{2} J_{\mathrm{HH}}$ & $-3,2$ & $-4,2$ & $-5,2$ & $-6,3$ & $-7,4$ & $-8,5$ & $-9,6$ & $-10,8$ & $-12,0$ & $-13,2$ & $-14,4$ & $-7,3$ \\
\hline $\mathrm{NH}_{3}$ & ${ }^{1} J_{\mathrm{NH}}$ & 41,3 & 42,0 & 42,7 & 43,4 & 44,1 & 44,8 & 45,6 & 46,3 & 47,1 & 47,9 & 48,7 & 43,8 \\
\hline $\mathrm{NH}_{3}$ & ${ }^{2} J_{\mathrm{HH}}$ & $-7,0$ & $-7,9$ & $-8,8$ & $-9,8$ & $-10,7$ & $-11,7$ & $-12,7$ & $-13,7$ & $-14,7$ & $-15,8$ & $-16,8$ & $-9,6$ \\
\hline $\mathrm{PH}_{3}$ & ${ }^{1} J_{\mathrm{PH}}$ & 126,2 & 134,6 & 142,9 & 151,2 & 159,4 & 167,6 & 175,6 & 183,6 & 191,4 & 199,2 & 206,8 & 188,2 \\
\hline $\mathrm{PF}_{3}$ & ${ }^{1} J_{\mathrm{PF}}$ & $-1798,8$ & $-1774,7$ & $-1745,9$ & $-1713,1$ & $-1677,2$ & $-1638,6$ & $-1598,1$ & $-1555,9$ & $-1512,7$ & $-1468,7$ & $-1424,3$ & -1441 \\
\hline $\mathrm{BHF}_{2}$ & ${ }^{1} J_{\mathrm{BF}}$ & $-177,2$ & $-160,3$ & $-143,6$ & $-127,1$ & $-110,9$ & $-94,8$ & $-79,0$ & $-63,4$ & $-48,1$ & $-33,0$ & $-18,2$ & -84 \\
\hline $\mathrm{BF}_{3}$ & ${ }^{1} J_{\mathrm{BF}}$ & $-78,0$ & $-59,7$ & $-41,6$ & $-23,9$ & $-6,4$ & 10,7 & 27,7 & 44,4 & 60,8 & 77,0 & 93,0 & 15 \\
\hline $\mathrm{F}_{2} \mathrm{O}$ & ${ }^{1} J_{\mathrm{OF}}$ & $-293,3$ & $-331,6$ & $-370,2$ & $-410,9$ & $-455,8$ & $-508,8$ & $-576,1$ & $-670,8$ & $-824,5$ & $-1144,8$ & $-2468,5$ & -300 \\
\hline $\mathrm{CH}_{4}$ & ${ }^{1} J_{\mathrm{CH}}$ & 121,7 & 123,1 & 124,5 & 125,9 & 127,4 & 128,9 & 130,4 & 132,0 & 133,6 & 135,2 & 136,8 & 125,3 \\
\hline $\mathrm{CH}_{4}$ & ${ }^{2} J_{\mathrm{HH}}$ & $-12,1$ & $-12,9$ & $-13,7$ & $-14,5$ & $-15,3$ & $-16,1$ & $-16,9$ & $-17,7$ & $-18,5$ & $-19,3$ & $-20,1$ & $-12,8$ \\
\hline $\mathrm{C}_{2} \mathrm{H}_{2}$ & ${ }^{1} J_{\mathrm{CC}}$ & 189,6 & 192,4 & 195,5 & 199,2 & 203,5 & 208,5 & 214,6 & 221,9 & 231,1 & 242,8 & 258,0 & 174,8 \\
\hline $\mathrm{C}_{2} \mathrm{H}_{2}$ & ${ }^{1} J_{\mathrm{CH}}$ & 253,0 & 255,4 & 258,0 & 260,8 & 263,9 & 267,3 & 271,2 & 275,7 & 281,1 & 287,8 & 296,5 & 247,6 \\
\hline $\mathrm{C}_{2} \mathrm{H}_{2}$ & ${ }^{2} J_{\mathrm{CH}}$ & 54,3 & 54,3 & 53,9 & 53,4 & 52,4 & 51,1 & 49,2 & 46,7 & 43,1 & 38,3 & 31,4 & 50,1 \\
\hline $\mathrm{C}_{2} \mathrm{H}_{2}$ & ${ }^{3} J_{\mathrm{HH}}$ & 11,1 & 11,8 & 12,6 & 13,6 & 14,8 & 16,3 & 18,1 & 20,3 & 23,2 & 26,8 & 31,6 & 9,6 \\
\hline $\mathrm{C}_{2} \mathrm{H}_{4}$ & ${ }^{1} J_{\mathrm{CC}}$ & 62,3 & 65,0 & 68,0 & 71,4 & 75,4 & 80,1 & 86,0 & 93,8 & 104,6 & 121,3 & 151,7 & 67,6 \\
\hline $\mathrm{C}_{2} \mathrm{H}_{4}$ & ${ }^{1} J_{\mathrm{CH}}$ & 153,8 & 155,9 & 158,1 & 160,5 & 163,1 & 166,0 & 169,5 & 173,6 & 179,1 & 187,2 & 201,0 & 156,3 \\
\hline $\mathrm{C}_{2} \mathrm{H}_{4}$ & ${ }^{2} J_{\mathrm{CH}}$ & $-1,0$ & $-1,9$ & $-3,0$ & $-4,2$ & $-5,6$ & $-7,4$ & $-9,6$ & $-12,7$ & $-17,0$ & $-23,9$ & $-36,6$ & $-2,4$ \\
\hline $\mathrm{C}_{2} \mathrm{H}_{4}$ & ${ }^{2} J_{\mathrm{HH}}$ & 4,7 & 3,9 & 3,0 & 2,0 & 0,9 & $-0,3$ & $-1,9$ & $-3,9$ & $-6,8$ & $-11,2$ & $-19,2$ & 2,3 \\
\hline $\mathrm{C}_{2} \mathrm{H}_{4}$ & ${ }^{3} J_{\mathrm{HH}_{\mathrm{c}}}$ & 12,1 & 12,5 & 12,9 & 13,4 & 14,0 & 14,9 & 16,1 & 17,7 & 20,1 & 24,1 & 31,7 & 11,7 \\
\hline $\mathrm{C}_{2} \mathrm{H}_{4}$ & ${ }^{3} J_{\mathrm{HH}_{\mathrm{t}}}$ & 19,4 & 19,7 & 20,2 & 20,8 & 21,6 & 22,6 & 24,0 & 25,9 & 28,7 & 33,2 & 41,7 & 19 \\
\hline $\mathrm{C}_{2} \mathrm{H}_{6}$ & ${ }^{1} J_{\mathrm{CC}}$ & 26,6 & 28,5 & 30,3 & 32,2 & 34,2 & 36,1 & 38,1 & 40,2 & 42,2 & 44,3 & 46,5 & 34,5 \\
\hline $\mathrm{C}_{2} \mathrm{H}_{6}$ & ${ }^{1} J_{\mathrm{CH}}$ & 121,3 & 122,9 & 124,5 & 126,1 & 127,8 & 129,5 & 131,2 & 133,0 & 134,8 & 136,6 & 138,4 & 125,2 \\
\hline $\mathrm{C}_{2} \mathrm{H}_{6}$ & ${ }^{2} J_{\mathrm{CH}}$ & $-3,1$ & $-3,6$ & $-4,1$ & $-4,5$ & $-5,1$ & $-5,6$ & $-6,1$ & $-6,6$ & $-7,2$ & $-7,7$ & $-8,3$ & $-4,7$ \\
\hline \multirow[t]{3}{*}{ Total } & $\mathrm{DM}$ & $-27,73$ & $-25,45$ & $-23,00$ & $-20,43$ & $-17,87$ & $-15,45$ & $-13,40$ & $-12,22$ & $-13,04$ & $-19,83$ & $-64,35$ & - \\
\hline & DMA & 33,07 & 30,11 & 27,77 & 25,84 & 24,33 & 23,42 & 24,77 & 28,76 & 37,38 & 53,72 & 111,65 & - \\
\hline & PDMA & 48,54 & 38,25 & 30,20 & 25,58 & 25,39 & 28,41 & 41,28 & 60,72 & 85,92 & 121,80 & 189,61 & - \\
\hline \multirow[t]{3}{*}{ CPI } & $\mathrm{DM}$ & $-66,43$ & $-62,24$ & $-57,69$ & $-53,03$ & $-48,50$ & $-44,51$ & $-41,66$ & $-41,23$ & $-46,10$ & $-66,08$ & $-177,29$ & - \\
\hline & DMA & 73,08 & 66,62 & 61,00 & 55,25 & 49,83 & 45,24 & 45,32 & 50,77 & 66,01 & 97,52 & 223,20 & - \\
\hline & PDMA & 89,21 & 72,70 & 56,66 & 41,08 & 27,49 & 17,41 & 26,12 & 43,57 & 63,83 & 89,66 & 145,87 & - \\
\hline \multirow[t]{3}{*}{ SPI } & $\mathrm{DM}$ & 0,64 & 1,53 & 2,44 & 3,47 & 4,59 & 5,85 & 7,32 & 9,05 & 11,20 & 14,09 & 18,47 & - \\
\hline & DMA & 3,73 & 3,34 & 3,40 & 4,28 & 5,63 & 7,43 & 9,69 & 12,61 & 16,39 & 21,60 & 29,84 & - \\
\hline & PDMA & 18,71 & 12,98 & 10,79 & 14,22 & 23,86 & 36,48 & 52,40 & 73,30 & 102,12 & 145,37 & 221,68 & - \\
\hline \multirow[t]{3}{*}{$\Delta \mathrm{CS}$} & $\mathrm{DM}$ & $-67,07$ & $-63,76$ & $-60,13$ & $-56,49$ & $-53,09$ & $-50,36$ & $-48,98$ & $-50,28$ & $-57,30$ & $-80,18$ & $-195,76$ & - \\
\hline & DMA & 69,35 & 63,28 & 57,60 & 50,97 & 44,19 & 37,81 & 35,62 & 38,16 & 49,62 & 75,92 & 193,36 & - \\
\hline & PDMA & 70,49 & 59,72 & 45,88 & 26,86 & 3,63 & $-19,07$ & $-26,28$ & $-29,73$ & $-38,29$ & $-55,71$ & $-75,81$ & - \\
\hline
\end{tabular}


Tabela 8.90: Constantes de acoplamento PW91 com correção vibracional no nível PBE0 $40 \% E_{X}^{\mathrm{HF}}$ e base aug-pcJ-2.

\begin{tabular}{|c|c|c|c|c|c|c|c|c|c|c|c|c|c|}
\hline & $\% E_{X}^{\mathrm{HF}}$ & $0 \%$ & $10 \%$ & $20 \%$ & $30 \%$ & $40 \%$ & $50 \%$ & $60 \%$ & $70 \%$ & $80 \%$ & $90 \%$ & $100 \%$ & Exp. \\
\hline $\mathrm{HF}$ & ${ }^{1} J_{\mathrm{HF}}$ & 329,4 & 352,6 & 376,0 & 399,7 & 423,5 & 447,6 & 471,9 & 496,4 & 521,2 & 546,2 & 571,5 & 500 \\
\hline $\mathrm{CO}$ & ${ }^{1} J_{\mathrm{CO}}$ & 25,6 & 23,9 & 22,2 & 20,3 & 18,4 & 16,5 & 14,4 & 12,3 & 10,1 & 7,9 & 5,6 & 16,4 \\
\hline $\mathrm{H}_{2} \mathrm{O}$ & ${ }^{1} J_{\mathrm{OH}}$ & $-64,9$ & $-67,3$ & $-69,8$ & $-72,3$ & $-74,8$ & $-77,3$ & $-79,9$ & $-82,5$ & $-85,1$ & $-87,8$ & $-90,5$ & $-80,6$ \\
\hline $\mathrm{H}_{2} \mathrm{O}$ & ${ }^{2} J_{\mathrm{HH}}$ & $-3,3$ & $-4,3$ & $-5,3$ & $-6,4$ & $-7,5$ & $-8,6$ & $-9,7$ & $-10,9$ & $-12,0$ & $-13,2$ & $-14,5$ & $-7,3$ \\
\hline $\mathrm{NH}_{3}$ & ${ }^{1} J_{\mathrm{NH}}$ & 41,3 & 42,0 & 42,7 & 43,4 & 44,2 & 45,0 & 45,7 & 46,5 & 47,3 & 48,1 & 48,9 & 43,8 \\
\hline $\mathrm{NH}_{3}$ & ${ }^{2} J_{\mathrm{HH}}$ & $-7,2$ & $-8,1$ & $-9,0$ & $-10,0$ & $-10,9$ & $-11,9$ & $-12,8$ & $-13,8$ & $-14,8$ & $-15,8$ & $-16,9$ & $-9,6$ \\
\hline $\mathrm{PH}_{3}$ & ${ }^{1} J_{\mathrm{PH}}$ & 130,1 & 138,4 & 146,5 & 154,6 & 162,5 & 170,4 & 178,2 & 185,8 & 193,3 & 200,7 & 208,0 & 188,2 \\
\hline $\mathrm{PF}_{3}$ & ${ }^{1} J_{\mathrm{PF}}$ & $-1813,0$ & $-1787,9$ & $-1758,1$ & $-1724,2$ & $-1687,1$ & $-1647,3$ & $-1605,4$ & $-1562,0$ & $-1517,5$ & $-1472,1$ & $-1426,3$ & -1441 \\
\hline $\mathrm{BHF}_{2}$ & ${ }^{1} J_{\mathrm{BF}}$ & $-182,0$ & $-164,8$ & $-147,8$ & $-130,8$ & $-114,0$ & $-97,4$ & $-80,9$ & $-64,6$ & $-48,5$ & $-32,6$ & $-16,9$ & -84 \\
\hline $\mathrm{BF}_{3}$ & ${ }^{1} J_{\mathrm{BF}}$ & $-83,1$ & $-64,5$ & $-46,0$ & $-27,8$ & $-9,8$ & 8,0 & 25,6 & 43,1 & 60,3 & 77,4 & 94,4 & 15 \\
\hline $\mathrm{F}_{2} \mathrm{O}$ & ${ }^{1} J_{\mathrm{OF}}$ & $-305,8$ & $-344,1$ & $-382,8$ & $-423,4$ & $-468,3$ & $-521,3$ & $-588,8$ & $-684,0$ & $-839,1$ & $-1164,2$ & $-2541,1$ & -300 \\
\hline $\mathrm{CH}_{4}$ & ${ }^{1} J_{\mathrm{CH}}$ & 122,5 & 123,9 & 125,3 & 126,7 & 128,2 & 129,7 & 131,2 & 132,8 & 134,3 & 135,9 & 137,6 & 125,3 \\
\hline $\mathrm{CH}_{4}$ & ${ }^{2} J_{\mathrm{HH}}$ & $-12,3$ & $-13,1$ & $-13,9$ & $-14,7$ & $-15,5$ & $-16,2$ & $-17,0$ & $-17,8$ & $-18,6$ & $-19,4$ & $-20,2$ & $-12,8$ \\
\hline $\mathrm{C}_{2} \mathrm{H}_{2}$ & ${ }^{1} J_{\mathrm{CC}}$ & 189,7 & 192,5 & 195,6 & 199,4 & 203,7 & 208,9 & 215,1 & 222,7 & 232,2 & 244,2 & 259,9 & 174,8 \\
\hline $\mathrm{C}_{2} \mathrm{H}_{2}$ & ${ }^{1} J_{\mathrm{CH}}$ & 255,7 & 258,0 & 260,5 & 263,1 & 266,0 & 269,3 & 273,0 & 277,5 & 282,8 & 289,3 & 297,8 & 247,6 \\
\hline $\mathrm{C}_{2} \mathrm{H}_{2}$ & ${ }^{2} J_{\mathrm{CH}}$ & 54,8 & 54,7 & 54,3 & 53,7 & 52,8 & 51,4 & 49,4 & 46,8 & 43,2 & 38,2 & 31,4 & 50,1 \\
\hline $\mathrm{C}_{2} \mathrm{H}_{2}$ & ${ }^{3} J_{\mathrm{HH}}$ & 11,2 & 11,9 & 12,7 & 13,7 & 14,9 & 16,4 & 18,2 & 20,4 & 23,2 & 26,8 & 31,4 & 9,6 \\
\hline $\mathrm{C}_{2} \mathrm{H}_{4}$ & ${ }^{1} J_{\mathrm{CC}}$ & 61,6 & 64,3 & 67,4 & 70,9 & 75,0 & 79,9 & 86,0 & 93,9 & 105,1 & 122,2 & 153,0 & 67,6 \\
\hline $\mathrm{C}_{2} \mathrm{H}_{4}$ & ${ }^{1} J_{\mathrm{CH}}$ & 155,0 & 157,1 & 159,3 & 161,6 & 164,2 & 167,1 & 170,5 & 174,7 & 180,2 & 188,2 & 202,0 & 156,3 \\
\hline $\mathrm{C}_{2} \mathrm{H}_{4}$ & ${ }^{2} J_{\mathrm{CH}}$ & $-0,9$ & $-1,8$ & $-2,8$ & $-4,0$ & $-5,5$ & $-7,3$ & $-9,6$ & $-12,6$ & $-17,0$ & $-24,0$ & $-36,7$ & $-2,4$ \\
\hline $\mathrm{C}_{2} \mathrm{H}_{4}$ & ${ }^{2} J_{\mathrm{HH}}$ & 4,7 & 3,8 & 3,0 & 2,0 & 0,9 & $-0,3$ & $-1,9$ & $-4,0$ & $-6,9$ & $-11,2$ & $-19,0$ & 2,3 \\
\hline $\mathrm{C}_{2} \mathrm{H}_{4}$ & ${ }^{3} J_{\mathrm{HH}_{\mathrm{c}}}$ & 12,3 & 12,6 & 13,0 & 13,5 & 14,2 & 15,1 & 16,2 & 17,8 & 20,2 & 24,2 & 31,6 & 11,7 \\
\hline $\mathrm{C}_{2} \mathrm{H}_{4}$ & ${ }^{3} J_{\mathrm{HH}_{\mathrm{t}}}$ & 19,7 & 20,0 & 20,5 & 21,1 & 21,8 & 22,8 & 24,2 & 26,1 & 28,8 & 33,3 & 41,6 & 19 \\
\hline $\mathrm{C}_{2} \mathrm{H}_{6}$ & ${ }^{1} J_{\mathrm{CC}}$ & 26,0 & 27,9 & 29,9 & 31,9 & 34,0 & 36,0 & 38,2 & 40,3 & 42,5 & 44,7 & 47,0 & 34,5 \\
\hline $\mathrm{C}_{2} \mathrm{H}_{6}$ & ${ }^{1} J_{\mathrm{CH}}$ & 122,1 & 123,7 & 125,3 & 126,9 & 128,6 & 130,3 & 132,0 & 133,8 & 135,5 & 137,3 & 139,1 & 125,2 \\
\hline $\mathrm{C}_{2} \mathrm{H}_{6}$ & ${ }^{2} J_{\mathrm{CH}}$ & $-3,1$ & $-3,6$ & $-4,1$ & $-4,6$ & $-5,1$ & $-5,6$ & $-6,1$ & $-6,6$ & $-7,2$ & $-7,7$ & $-8,3$ & $-4,7$ \\
\hline \multirow[t]{3}{*}{ Total } & $\mathrm{DM}$ & $-29,19$ & $-26,82$ & $-24,25$ & $-21,57$ & $-18,87$ & $-16,30$ & $-14,13$ & $-12,80$ & $-13,52$ & $-20,32$ & $-66,72$ & - \\
\hline & DMA & 34,41 & 31,91 & 29,43 & 27,46 & 25,82 & 24,75 & 25,61 & 29,62 & 38,43 & 55,04 & 114,95 & - \\
\hline & PDMA & 50,58 & 40,28 & 31,73 & 27,03 & 27,02 & 29,64 & 41,12 & 60,85 & 86,53 & 122,77 & 191,20 & - \\
\hline \multirow[t]{3}{*}{ CPI } & $\mathrm{DM}$ & $-70,35$ & $-65,91$ & $-61,12$ & $-56,16$ & $-51,34$ & $-47,02$ & $-43,87$ & $-43,15$ & $-47,79$ & $-67,85$ & $-183,52$ & - \\
\hline & DMA & 76,04 & 70,51 & 64,61 & 58,55 & 52,83 & 47,85 & 46,84 & 52,27 & 67,90 & 99,99 & 230,35 & - \\
\hline & PDMA & 93,14 & 76,72 & 60,37 & 44,66 & 30,89 & 19,99 & 25,14 & 43,22 & 64,25 & 90,84 & 149,69 & - \\
\hline \multirow[t]{3}{*}{ SPI } & $\mathrm{DM}$ & 0,99 & 1,85 & 2,79 & 3,81 & 4,94 & 6,23 & 7,69 & 9,45 & 11,61 & 14,53 & 18,94 & - \\
\hline & DMA & 3,89 & 3,60 & 3,63 & 4,66 & 6,02 & 7,80 & 10,05 & 13,01 & 16,81 & 22,07 & 30,31 & - \\
\hline & PDMA & 19,37 & 13,55 & 10,73 & 14,11 & 24,19 & 36,71 & 52,83 & 73,79 & 102,86 & 146,19 & 221,65 & - \\
\hline \multirow[t]{3}{*}{$\Delta \mathrm{CS}$} & $\mathrm{DM}$ & $-71,34$ & $-67,76$ & $-63,91$ & $-59,97$ & $-56,28$ & $-53,24$ & $-51,56$ & $-52,59$ & $-59,40$ & $-82,37$ & $-202,46$ & - \\
\hline & DMA & 72,15 & 66,91 & 60,98 & 53,89 & 46,81 & 40,05 & 36,79 & 39,27 & 51,09 & 77,92 & 200,04 & - \\
\hline & PDMA & 73,77 & 63,18 & 49,65 & 30,55 & 6,70 & $-16,73$ & $-27,69$ & $-30,57$ & $-38,61$ & $-55,34$ & $-71,97$ & - \\
\hline
\end{tabular}


Tabela 8.91: Constantes de acoplamento TPSSh com correção vibracional no nível PBE0 $40 \% E_{X}^{\mathrm{HF}}$ e base aug-pcJ-2.

\begin{tabular}{|c|c|c|c|c|c|c|c|c|c|c|c|c|c|}
\hline & $\% E_{X}^{\mathrm{HF}}$ & $0 \%$ & $10 \%$ & $20 \%$ & $30 \%$ & $40 \%$ & $50 \%$ & $60 \%$ & $70 \%$ & $80 \%$ & $90 \%$ & $100 \%$ & Exp. \\
\hline $\mathrm{HF}$ & ${ }^{1} J_{\mathrm{HF}}$ & 331,2 & 355,8 & 380,3 & 404,9 & 429,4 & 453,9 & 478,3 & 502,6 & 526,8 & 551,0 & 575,2 & 500 \\
\hline $\mathrm{CO}$ & ${ }^{1} J_{\mathrm{CO}}$ & 22,4 & 21,0 & 19,5 & 18,0 & 16,4 & 14,7 & 13,0 & 11,2 & 9,4 & 7,5 & 5,6 & 16,4 \\
\hline $\mathrm{H}_{2} \mathrm{O}$ & ${ }^{1} J_{\mathrm{OH}}$ & $-68,8$ & $-71,1$ & $-73,5$ & $-75,9$ & $-78,2$ & $-80,6$ & $-82,9$ & $-85,2$ & $-87,5$ & $-89,7$ & $-92,0$ & $-80,6$ \\
\hline $\mathrm{H}_{2} \mathrm{O}$ & ${ }^{2} J_{\mathrm{HH}}$ & $-2,5$ & $-3,8$ & $-5,1$ & $-6,3$ & $-7,6$ & $-8,8$ & $-10,0$ & $-11,2$ & $-12,4$ & $-13,6$ & $-14,7$ & $-7,3$ \\
\hline $\mathrm{NH}_{3}$ & ${ }^{1} J_{\mathrm{NH}}$ & 45,8 & 46,3 & 46,9 & 47,4 & 47,8 & 48,3 & 48,8 & 49,3 & 49,7 & 50,2 & 50,6 & 43,8 \\
\hline $\mathrm{NH}_{3}$ & ${ }^{2} J_{\mathrm{HH}}$ & $-6,1$ & $-7,3$ & $-8,5$ & $-9,6$ & $-10,8$ & $-11,9$ & $-13,0$ & $-14,1$ & $-15,1$ & $-16,2$ & $-17,1$ & $-9,6$ \\
\hline $\mathrm{PH}_{3}$ & ${ }^{1} J_{\mathrm{PH}}$ & 188,2 & 193,0 & 197,5 & 201,8 & 205,9 & 209,7 & 213,3 & 216,6 & 219,7 & 222,5 & 225,1 & 188,2 \\
\hline $\mathrm{PF}_{3}$ & ${ }^{1} J_{\mathrm{PF}}$ & $-1755,3$ & $-1729,5$ & $-1701,1$ & $-1670,8$ & $-1638,9$ & $-1605,8$ & $-1571,9$ & $-1537,5$ & $-1502,7$ & $-1467,8$ & $-1433,0$ & -1441 \\
\hline $\mathrm{BHF}_{2}$ & ${ }^{1} J_{\mathrm{BF}}$ & $-161,1$ & $-146,9$ & $-132,8$ & $-118,7$ & $-104,6$ & $-90,5$ & $-76,5$ & $-62,5$ & $-48,6$ & $-34,7$ & $-20,8$ & -84 \\
\hline $\mathrm{BF}_{3}$ & ${ }^{1} J_{\mathrm{BF}}$ & $-66,0$ & $-49,4$ & $-32,9$ & $-16,5$ & $-0,4$ & 15,6 & 31,6 & 47,4 & 63,0 & 78,6 & 94,1 & 15 \\
\hline $\mathrm{F}_{2} \mathrm{O}$ & ${ }^{1} J_{\mathrm{OF}}$ & $-298,0$ & $-335,4$ & $-374,8$ & $-417,8$ & $-466,6$ & $-525,3$ & $-600,5$ & $-705,7$ & $-873,2$ & $-1208,0$ & $-2418,8$ & -300 \\
\hline $\mathrm{CH}_{4}$ & ${ }^{1} J_{\mathrm{CH}}$ & 140,4 & 141,2 & 142,0 & 142,8 & 143,5 & 144,3 & 145,0 & 145,6 & 146,2 & 146,8 & 147,3 & 125,3 \\
\hline $\mathrm{CH}_{4}$ & ${ }^{2} J_{\mathrm{HH}}$ & $-10,5$ & $-11,6$ & $-12,7$ & $-13,7$ & $-14,8$ & $-15,8$ & $-16,8$ & $-17,7$ & $-18,7$ & $-19,6$ & $-20,5$ & $-12,8$ \\
\hline $\mathrm{C}_{2} \mathrm{H}_{2}$ & ${ }^{1} J_{\mathrm{CC}}$ & 188,4 & 191,7 & 195,5 & 199,8 & 204,8 & 210,7 & 217,6 & 225,9 & 235,8 & 247,9 & 263,0 & 174,8 \\
\hline $\mathrm{C}_{2} \mathrm{H}_{2}$ & ${ }^{1} J_{\mathrm{CH}}$ & 283,8 & 285,5 & 287,3 & 289,3 & 291,5 & 294,0 & 296,9 & 300,3 & 304,5 & 309,6 & 316,1 & 247,6 \\
\hline $\mathrm{C}_{2} \mathrm{H}_{2}$ & ${ }^{2} J_{\mathrm{CH}}$ & 58,5 & 57,9 & 57,1 & 56,0 & 54,5 & 52,6 & 50,2 & 47,1 & 43,2 & 38,2 & 31,7 & 50,1 \\
\hline $\mathrm{C}_{2} \mathrm{H}_{2}$ & ${ }^{3} J_{\mathrm{HH}}$ & 12,7 & 13,3 & 14,2 & 15,2 & 16,4 & 18,0 & 19,8 & 22,1 & 24,8 & 28,2 & 32,5 & 9,6 \\
\hline $\mathrm{C}_{2} \mathrm{H}_{4}$ & ${ }^{1} J_{\mathrm{CC}}$ & 69,8 & 72,5 & 75,5 & 79,0 & 83,1 & 88,0 & 94,1 & 101,9 & 112,6 & 128,4 & 154,5 & 67,6 \\
\hline $\mathrm{C}_{2} \mathrm{H}_{4}$ & ${ }^{1} J_{\mathrm{CH}}$ & 174,7 & 176,3 & 178,1 & 180,0 & 182,1 & 184,5 & 187,3 & 190,9 & 195,6 & 202,5 & 213,7 & 156,3 \\
\hline $\mathrm{C}_{2} \mathrm{H}_{4}$ & ${ }^{2} J_{\mathrm{CH}}$ & $-1,1$ & $-2,2$ & $-3,5$ & $-5,0$ & $-6,7$ & $-8,8$ & $-11,4$ & $-14,8$ & $-19,4$ & $-26,1$ & $-37,3$ & $-2,4$ \\
\hline $\mathrm{C}_{2} \mathrm{H}_{4}$ & ${ }^{2} J_{\mathrm{HH}}$ & 9,6 & 8,4 & 7,0 & 5,6 & 4,0 & 2,2 & 0,2 & $-2,3$ & $-5,6$ & $-10,1$ & $-17,2$ & 2,3 \\
\hline $\mathrm{C}_{2} \mathrm{H}_{4}$ & ${ }^{3} J_{\mathrm{HH}_{\mathrm{c}}}$ & 12,4 & 12,9 & 13,4 & 14,1 & 14,9 & 15,9 & 17,3 & 19,0 & 21,5 & 25,3 & 31,7 & 11,7 \\
\hline $\mathrm{C}_{2} \mathrm{H}_{4}$ & ${ }^{3} J_{\mathrm{HH}_{\mathrm{t}}}$ & 22,8 & 23,2 & 23,6 & 24,2 & 24,9 & 25,9 & 27,3 & 29,1 & 31,8 & 35,9 & 42,9 & 19 \\
\hline $\mathrm{C}_{2} \mathrm{H}_{6}$ & ${ }^{1} J_{\mathrm{CC}}$ & 33,8 & 35,3 & 36,7 & 38,1 & 39,6 & 41,0 & 42,4 & 43,8 & 45,1 & 46,5 & 47,8 & 34,5 \\
\hline $\mathrm{C}_{2} \mathrm{H}_{6}$ & ${ }^{1} J_{\mathrm{CH}}$ & 139,7 & 140,7 & 141,8 & 142,8 & 143,7 & 144,7 & 145,6 & 146,5 & 147,3 & 148,1 & 148,9 & 125,2 \\
\hline $\mathrm{C}_{2} \mathrm{H}_{6}$ & ${ }^{2} J_{\mathrm{CH}}$ & $-3,5$ & $-4,0$ & $-4,5$ & $-5,1$ & $-5,6$ & $-6,1$ & $-6,6$ & $-7,2$ & $-7,7$ & $-8,2$ & $-8,7$ & $-4,7$ \\
\hline \multirow[t]{3}{*}{ Total } & $\mathrm{DM}$ & $-18,60$ & $-16,58$ & $-14,54$ & $-12,52$ & $-10,64$ & $-9,02$ & $-7,92$ & $-7,84$ & $-9,96$ & $-18,15$ & $-59,40$ & - \\
\hline & DMA & 30,77 & 29,22 & 27,95 & 26,93 & 26,27 & 26,29 & 29,15 & 34,30 & 43,90 & 60,62 & 112,94 & - \\
\hline & PDMA & 53,82 & 43,91 & 37,23 & 32,97 & 30,50 & 31,16 & 48,01 & 68,96 & 95,04 & 130,17 & 190,64 & - \\
\hline \multirow[t]{3}{*}{ CPI } & $\mathrm{DM}$ & $-55,55$ & $-51,65$ & $-47,76$ & $-44,04$ & $-40,77$ & $-38,33$ & $-37,34$ & $-39,09$ & $-46,53$ & $-69,19$ & $-171,52$ & - \\
\hline & DMA & 61,03 & 56,60 & 52,47 & 48,49 & 45,15 & 43,16 & 47,19 & 55,53 & 73,36 & 106,39 & 220,46 & - \\
\hline & PDMA & 76,91 & 62,26 & 47,79 & 33,66 & 22,61 & 16,73 & 32,18 & 49,95 & 70,13 & 95,53 & 147,19 & - \\
\hline \multirow[t]{3}{*}{ SPI } & $\mathrm{DM}$ & 8,49 & 9,13 & 9,83 & 10,60 & 11,45 & 12,47 & 13,65 & 15,07 & 16,86 & 19,29 & 22,82 & - \\
\hline & DMA & 8,59 & 9,13 & 9,97 & 11,12 & 12,41 & 13,92 & 15,92 & 18,73 & 22,29 & 27,06 & 34,09 & - \\
\hline & PDMA & 36,88 & 30,45 & 29,49 & 32,46 & 36,29 & 41,73 & 59,62 & 82,90 & 113,31 & 155,57 & 222,51 & - \\
\hline \multirow[t]{3}{*}{$\Delta \mathrm{CS}$} & $\mathrm{DM}$ & $-64,05$ & $-60,79$ & $-57,59$ & $-54,64$ & $-52,23$ & $-50,79$ & $-50,99$ & $-54,16$ & $-63,39$ & $-88,48$ & $-194,34$ & - \\
\hline & DMA & 52,44 & 47,47 & 42,50 & 37,37 & 32,74 & 29,24 & 31,27 & 36,80 & 51,08 & 79,33 & 186,38 & - \\
\hline & PDMA & 40,03 & 31,81 & 18,30 & 1,20 & $-13,68$ & $-25,00$ & $-27,45$ & $-32,95$ & $-43,18$ & $-60,03$ & $-75,33$ & - \\
\hline
\end{tabular}


Tabela 8.92: Constantes de acoplamento X3LYP com correção vibracional no nível PBE0 $40 \% E_{X}^{\mathrm{HF}}$ e base aug-pcJ-2.

\begin{tabular}{|c|c|c|c|c|c|c|c|c|c|c|c|c|c|}
\hline & $\% E_{X}^{\mathrm{HF}}$ & $0 \%$ & $10 \%$ & $20 \%$ & $30 \%$ & $40 \%$ & $50 \%$ & $60 \%$ & $70 \%$ & $80 \%$ & $90 \%$ & $100 \%$ & Exp. \\
\hline $\mathrm{HF}$ & ${ }^{1} J_{\mathrm{HF}}$ & 362,5 & 387,4 & 412,5 & 437,8 & 463,4 & 489,3 & 515,3 & 541,6 & 568,1 & 594,9 & 621,9 & 500 \\
\hline $\mathrm{CO}$ & ${ }^{1} J_{\mathrm{CO}}$ & 22,2 & 20,4 & 18,4 & 16,3 & 14,1 & 11,8 & 9,5 & 7,0 & 4,5 & 1,9 & $-0,7$ & 16,4 \\
\hline $\mathrm{H}_{2} \mathrm{O}$ & ${ }^{1} J_{\mathrm{OH}}$ & $-70,9$ & $-73,6$ & $-76,2$ & $-79,0$ & $-81,7$ & $-84,4$ & $-87,2$ & $-90,1$ & $-92,9$ & $-95,8$ & $-98,7$ & $-80,6$ \\
\hline $\mathrm{H}_{2} \mathrm{O}$ & ${ }^{2} J_{\mathrm{HH}}$ & $-3,8$ & $-4,9$ & $-6,0$ & $-7,1$ & $-8,2$ & $-9,4$ & $-10,6$ & $-11,8$ & $-13,0$ & $-14,2$ & $-15,5$ & $-7,3$ \\
\hline $\mathrm{NH}_{3}$ & ${ }^{1} J_{\mathrm{NH}}$ & 45,0 & 45,8 & 46,6 & 47,4 & 48,3 & 49,1 & 49,9 & 50,8 & 51,7 & 52,5 & 53,4 & 43,8 \\
\hline $\mathrm{NH}_{3}$ & ${ }^{2} J_{\mathrm{HH}}$ & $-7,6$ & $-8,5$ & $-9,5$ & $-10,4$ & $-11,4$ & $-12,4$ & $-13,4$ & $-14,4$ & $-15,5$ & $-16,5$ & $-17,6$ & $-9,6$ \\
\hline $\mathrm{PH}_{3}$ & ${ }^{1} J_{\mathrm{PH}}$ & 150,8 & 159,3 & 167,7 & 176,0 & 184,1 & 192,1 & 200,0 & 207,7 & 215,2 & 222,5 & 229,7 & 188,2 \\
\hline $\mathrm{PF}_{3}$ & ${ }^{1} J_{\mathrm{PF}}$ & $-1810,5$ & $-1785,2$ & $-1755,4$ & $-1721,8$ & $-1685,2$ & $-1646,0$ & $-1604,9$ & $-1562,4$ & $-1518,8$ & $-1474,5$ & $-1429,8$ & -1441 \\
\hline $\mathrm{BHF}_{2}$ & ${ }^{1} J_{\mathrm{BF}}$ & $-172,4$ & $-154,8$ & $-137,3$ & $-120,0$ & $-102,8$ & $-85,8$ & $-69,0$ & $-52,3$ & $-35,9$ & $-19,7$ & $-3,7$ & -84 \\
\hline $\mathrm{BF}_{3}$ & ${ }^{1} J_{\mathrm{BF}}$ & $-71,7$ & $-52,6$ & $-33,6$ & $-14,9$ & 3,5 & 21,8 & 39,9 & 57,8 & 75,6 & 93,1 & 110,5 & 15 \\
\hline $\mathrm{F}_{2} \mathrm{O}$ & ${ }^{1} J_{\mathrm{OF}}$ & $-295,6$ & $-332,5$ & $-369,5$ & $-408,2$ & $-450,8$ & $-500,5$ & $-563,2$ & $-650,6$ & $-790,7$ & $-1076,9$ & $-2189,0$ & -300 \\
\hline $\mathrm{CH}_{4}$ & ${ }^{1} J_{\mathrm{CH}}$ & 134,2 & 135,7 & 137,3 & 138,9 & 140,5 & 142,1 & 143,8 & 145,4 & 147,1 & 148,8 & 150,6 & 125,3 \\
\hline $\mathrm{CH}_{4}$ & ${ }^{2} J_{\mathrm{HH}}$ & $-12,1$ & $-12,9$ & $-13,7$ & $-14,5$ & $-15,3$ & $-16,0$ & $-16,8$ & $-17,6$ & $-18,3$ & $-19,0$ & $-19,8$ & $-12,8$ \\
\hline $\mathrm{C}_{2} \mathrm{H}_{2}$ & ${ }^{1} J_{\mathrm{CC}}$ & 200,5 & 203,5 & 206,9 & 210,9 & 215,4 & 220,8 & 227,0 & 234,5 & 243,5 & 254,5 & 268,2 & 174,8 \\
\hline $\mathrm{C}_{2} \mathrm{H}_{2}$ & ${ }^{1} J_{\mathrm{CH}}$ & 275,6 & 278,1 & 280,6 & 283,3 & 286,2 & 289,4 & 293,0 & 297,0 & 301,7 & 307,2 & 313,9 & 247,6 \\
\hline $\mathrm{C}_{2} \mathrm{H}_{2}$ & ${ }^{2} J_{\mathrm{CH}}$ & 57,2 & 57,1 & 56,8 & 56,3 & 55,4 & 54,2 & 52,5 & 50,3 & 47,4 & 43,6 & 38,6 & 50,1 \\
\hline $\mathrm{C}_{2} \mathrm{H}_{2}$ & ${ }^{3} J_{\mathrm{HH}}$ & 10,8 & 11,4 & 12,1 & 13,0 & 14,0 & 15,2 & 16,6 & 18,4 & 20,5 & 23,1 & 26,3 & 9,6 \\
\hline $\mathrm{C}_{2} \mathrm{H}_{4}$ & ${ }^{1} J_{\mathrm{CC}}$ & 67,9 & 70,8 & 74,1 & 77,7 & 81,8 & 86,6 & 92,3 & 99,4 & 108,5 & 120,9 & 139,1 & 67,6 \\
\hline $\mathrm{C}_{2} \mathrm{H}_{4}$ & ${ }^{1} J_{\mathrm{CH}}$ & 168,3 & 170,5 & 172,8 & 175,3 & 177,9 & 180,8 & 184,0 & 187,7 & 192,2 & 198,0 & 206,0 & 156,3 \\
\hline $\mathrm{C}_{2} \mathrm{H}_{4}$ & ${ }^{2} J_{\mathrm{CH}}$ & $-0,3$ & $-1,1$ & $-2,1$ & $-3,3$ & $-4,6$ & $-6,2$ & $-8,2$ & $-10,7$ & $-14,0$ & $-18,6$ & $-25,5$ & $-2,4$ \\
\hline $\mathrm{C}_{2} \mathrm{H}_{4}$ & ${ }^{2} J_{\mathrm{HH}}$ & 6,3 & 5,6 & 4,8 & 3,9 & 2,9 & 1,9 & 0,6 & $-0,8$ & $-2,7$ & $-5,3$ & $-9,0$ & 2,3 \\
\hline $\mathrm{C}_{2} \mathrm{H}_{4}$ & ${ }^{3} J_{\mathrm{HH}_{\mathrm{c}}}$ & 12,9 & 13,2 & 13,5 & 13,9 & 14,3 & 15,0 & 15,8 & 16,8 & 18,3 & 20,4 & 23,7 & 11,7 \\
\hline $\mathrm{C}_{2} \mathrm{H}_{4}$ & ${ }^{3} J_{\mathrm{HH}_{\mathrm{t}}}$ & 20,6 & 20,9 & 21,2 & 21,7 & 22,2 & 23,0 & 23,9 & 25,2 & 26,9 & 29,4 & 33,1 & 19 \\
\hline $\mathrm{C}_{2} \mathrm{H}_{6}$ & ${ }^{1} J_{\mathrm{CC}}$ & 30,3 & 32,4 & 34,6 & 36,8 & 39,0 & 41,3 & 43,6 & 46,0 & 48,4 & 50,8 & 53,3 & 34,5 \\
\hline $\mathrm{C}_{2} \mathrm{H}_{6}$ & ${ }^{1} J_{\mathrm{CH}}$ & 133,1 & 134,9 & 136,6 & 138,4 & 140,2 & 142,1 & 143,9 & 145,8 & 147,7 & 149,6 & 151,5 & 125,2 \\
\hline $\mathrm{C}_{2} \mathrm{H}_{6}$ & ${ }^{2} J_{\mathrm{CH}}$ & $-2,7$ & $-3,2$ & $-3,7$ & $-4,2$ & $-4,7$ & $-5,2$ & $-5,7$ & $-6,3$ & $-6,8$ & $-7,4$ & $-7,9$ & $-4,7$ \\
\hline \multirow[t]{3}{*}{ Total } & $\mathrm{DM}$ & $-22,86$ & $-20,28$ & $-17,52$ & $-14,65$ & $-11,79$ & $-9,02$ & $-6,63$ & $-5,02$ & $-5,24$ & $-10,83$ & $-47,78$ & - \\
\hline & DMA & 32,81 & 30,40 & 28,23 & 26,34 & 24,89 & 24,77 & 28,77 & 34,82 & 43,31 & 57,87 & 105,79 & - \\
\hline & PDMA & 49,66 & 40,00 & 30,40 & 24,64 & 22,16 & 26,78 & 42,56 & 60,43 & 81,89 & 109,38 & 154,51 & - \\
\hline \multirow[t]{3}{*}{ CPI } & $\mathrm{DM}$ & $-62,99$ & $-58,19$ & $-53,02$ & $-47,71$ & $-42,51$ & $-37,75$ & $-34,05$ & $-32,51$ & $-35,69$ & $-52,15$ & $-143,67$ & - \\
\hline & DMA & 67,83 & 61,19 & 54,95 & 48,69 & 43,33 & 40,66 & 47,35 & 58,44 & 74,18 & 103,11 & 209,13 & - \\
\hline & PDMA & 79,69 & 62,68 & 45,79 & 30,78 & 21,14 & 21,41 & 40,12 & 60,34 & 82,14 & 108,11 & 159,40 & - \\
\hline \multirow[t]{3}{*}{ SPI } & $\mathrm{DM}$ & 6,57 & 7,52 & 8,51 & 9,60 & 10,74 & 12,06 & 13,48 & 15,13 & 17,09 & 19,46 & 22,53 & - \\
\hline & DMA & 7,13 & 7,81 & 8,63 & 9,95 & 11,37 & 13,11 & 15,15 & 17,51 & 20,67 & 24,69 & 30,01 & - \\
\hline & PDMA & 27,63 & 23,37 & 19,11 & 20,13 & 22,90 & 30,72 & 44,35 & 60,50 & 81,71 & 110,31 & 150,92 & - \\
\hline \multirow[t]{3}{*}{$\Delta \mathrm{CS}$} & $\mathrm{DM}$ & $-69,56$ & $-65,71$ & $-61,53$ & $-57,31$ & $-53,25$ & $-49,81$ & $-47,53$ & $-47,64$ & $-52,78$ & $-71,61$ & $-166,21$ & - \\
\hline & DMA & 60,70 & 53,38 & 46,31 & 38,74 & 31,96 & 27,55 & 32,20 & 40,93 & 53,51 & 78,42 & 179,11 & - \\
\hline & PDMA & 52,06 & 39,31 & 26,68 & 10,64 & $-1,77$ & $-9,30$ & $-4,23$ & $-0,16$ & 0,44 & $-2,20$ & 8,49 & - \\
\hline
\end{tabular}




\subsubsection{Variação da porcentagem de $E_{X}^{\mathrm{HF}}$ para os funcionais híbridos - Geo- metrias Otimizadas}

Tabela 8.93: Constantes de acoplamento B971 com otimização de geometrias com correção vibracional no nível BHandH $\left(50 \% E_{X}^{\mathrm{HF}}\right)$ e base aug-pcJ-2.

\begin{tabular}{|c|c|c|c|c|c|c|c|c|c|c|c|c|c|}
\hline & $\% E_{X}^{\mathrm{HF}}$ & 21,00 & 21,00 & 40,00 & 40,00 & $\begin{array}{l}21,00 \\
40,00 \\
\text { Otm. }\end{array}$ & 50,00 & 50,00 & $\begin{array}{l}21,00 \\
50,00 \\
\text { Otm. }\end{array}$ & 60,00 & 60,00 & $\begin{array}{l}21,00 \\
60,00 \\
\text { Otm. }\end{array}$ & Exp. \\
\hline $\mathrm{HF}$ & ${ }^{1} J_{\mathrm{HF}}$ & 416,3 & 408,5 & 466,9 & 405,8 & 459,7 & 487,8 & 453,1 & 480,7 & 510,0 & 500,6 & 502,9 & 500,0 \\
\hline $\mathrm{CO}$ & ${ }^{1} J_{\mathrm{CO}}$ & 18,1 & 17,6 & 11,4 & 15,3 & 10,9 & 9,7 & 11,1 & 9,3 & 8,0 & 6,9 & 7,5 & 16,4 \\
\hline $\mathrm{H}_{2} \mathrm{O}$ & ${ }^{1} J_{\mathrm{OH}}$ & $-73,3$ & $-73,1$ & $-75,9$ & $-68,9$ & $-75,7$ & $-78,6$ & $-74,9$ & $-78,4$ & $-81,4$ & $-80,8$ & $-81,3$ & $-80,6$ \\
\hline $\mathrm{H}_{2} \mathrm{O}$ & ${ }^{2} J_{\mathrm{HH}}$ & $-5,0$ & $-4,7$ & $-3,6$ & $-3,6$ & $-3,3$ & $-4,9$ & $-4,6$ & $-4,6$ & $-6,2$ & $-5,6$ & $-5,9$ & $-7,3$ \\
\hline $\mathrm{NH}_{3}$ & ${ }^{1} J_{\mathrm{NH}}$ & 44,1 & 44,2 & 42,7 & 40,8 & 42,8 & 43,9 & 43,2 & 44,0 & 45,2 & 45,6 & 45,4 & 43,8 \\
\hline $\mathrm{NH}_{3}$ & ${ }^{2} J_{\mathrm{HH}}$ & $-8,2$ & $-8,1$ & $-6,5$ & $-6,5$ & $-6,3$ & $-7,7$ & $-7,4$ & $-7,5$ & $-9,0$ & $-8,4$ & $-8,8$ & $-9,6$ \\
\hline $\mathrm{PH}_{3}$ & ${ }^{1} J_{\mathrm{PH}}$ & 183,9 & 189,6 & 182,1 & 175,9 & 187,2 & 189,8 & 188,9 & 194,7 & 197,8 & 201,7 & 202,5 & 188,2 \\
\hline $\mathrm{PF}_{3}$ & ${ }^{1} J_{\mathrm{PF}}$ & $-1656,0$ & $-1547,0$ & $-1561,4$ & $-1459,0$ & $-1477,4$ & $-1538,4$ & $-1449,0$ & $-1458,7$ & $-1512,7$ & $-1428,3$ & $-1437,3$ & $-1441,0$ \\
\hline $\mathrm{BHF}_{2}$ & ${ }^{1} J_{\mathrm{BF}}$ & $-128,1$ & $-134,1$ & $-89,4$ & $-122,4$ & $-95,4$ & $-73,9$ & $-92,6$ & $-79,8$ & $-58,3$ & $-63,7$ & $-64,1$ & $-84,0$ \\
\hline $\mathrm{BF}_{3}$ & ${ }^{1} J_{\mathrm{BF}}$ & $-30,0$ & $-41,5$ & 10,3 & $-30,8$ & $-0,6$ & 27,6 & 3,6 & 16,9 & 45,0 & 37,1 & 34,6 & 15,0 \\
\hline $\mathrm{F}_{2} \mathrm{O}$ & ${ }^{1} J_{\mathrm{OF}}$ & $-333,1$ & $-271,5$ & $-342,0$ & $-332,9$ & $-276,7$ & $-384,7$ & $-296,0$ & $-312,9$ & $-435,5$ & $-260,1$ & $-354,3$ & $-300,0$ \\
\hline $\mathrm{CH}_{4}$ & ${ }^{1} J_{\mathrm{CH}}$ & 131,3 & 131,8 & 119,0 & 123,9 & 119,4 & 123,1 & 126,9 & 123,6 & 127,5 & 130,0 & 127,9 & 125,3 \\
\hline $\mathrm{CH}_{4}$ & ${ }^{2} J_{\mathrm{HH}}$ & $-12,3$ & $-12,3$ & $-9,9$ & $-9,6$ & $-9,8$ & $-11,0$ & $-10,8$ & $-10,9$ & $-12,1$ & $-12,0$ & $-12,1$ & $-12,8$ \\
\hline $\mathrm{C}_{2} \mathrm{H}_{2}$ & ${ }^{1} J_{\mathrm{CC}}$ & 214,5 & 214,5 & 205,7 & 208,1 & 205,8 & 212,3 & 214,3 & 212,2 & 220,1 & 220,9 & 219,8 & 174,8 \\
\hline $\mathrm{C}_{2} \mathrm{H}_{2}$ & ${ }^{1} J_{\mathrm{CH}}$ & 264,6 & 263,5 & 232,8 & 242,3 & 231,9 & 241,2 & 247,2 & 240,2 & 250,3 & 252,3 & 249,2 & 247,6 \\
\hline $\mathrm{C}_{2} \mathrm{H}_{2}$ & ${ }^{2} J_{\mathrm{CH}}$ & 53,5 & 53,6 & 53,5 & 53,6 & 53,5 & 53,3 & 53,4 & 53,4 & 52,8 & 52,9 & 52,9 & 50,1 \\
\hline $\mathrm{C}_{2} \mathrm{H}_{2}$ & ${ }^{3} J_{\mathrm{HH}}$ & 11,1 & 10,9 & 9,0 & 9,7 & 8,8 & 9,9 & 10,3 & 9,7 & 11,1 & 11,1 & 10,9 & 9,6 \\
\hline $\mathrm{C}_{2} \mathrm{H}_{4}$ & ${ }^{1} J_{\mathrm{CC}}$ & 78,8 & 81,2 & 77,1 & 79,4 & 79,5 & 81,5 & 84,2 & 83,8 & 86,9 & 89,3 & 88,8 & 67,6 \\
\hline $\mathrm{C}_{2} \mathrm{H}_{4}$ & ${ }^{1} J_{\mathrm{CH}}$ & 164,7 & 162,6 & 147,3 & 151,5 & 145,5 & 153,1 & 155,4 & 151,1 & 159,3 & 159,5 & 157,1 & 156,3 \\
\hline $\mathrm{C}_{2} \mathrm{H}_{4}$ & ${ }^{2} J_{\mathrm{CH}}$ & $-2,5$ & $-2,2$ & $-1,2$ & $-0,8$ & $-1,0$ & $-2,5$ & $-2,3$ & $-2,2$ & $-4,1$ & $-3,9$ & $-3,7$ & $-2,4$ \\
\hline $\mathrm{C}_{2} \mathrm{H}_{4}$ & ${ }^{2} J_{\mathrm{HH}}$ & 3,8 & 2,6 & 4,3 & 4,5 & 3,2 & 3,6 & 3,5 & 2,5 & 2,7 & 2,3 & 1,6 & 2,3 \\
\hline $\mathrm{C}_{2} \mathrm{H}_{4}$ & ${ }^{3} J_{\mathrm{HH}_{\mathrm{c}}}$ & 12,0 & 12,5 & 10,8 & 10,6 & 11,3 & 11,3 & 11,4 & 11,8 & 11,9 & 12,3 & 12,4 & 11,7 \\
\hline $\mathrm{C}_{2} \mathrm{H}_{4}$ & ${ }^{3} J_{\mathrm{HH}_{\mathrm{t}}}$ & 19,0 & 19,6 & 16,2 & 17,2 & 16,7 & 17,0 & 17,9 & 17,5 & 18,0 & 18,8 & 18,5 & 19,0 \\
\hline $\mathrm{C}_{2} \mathrm{H}_{6}$ & ${ }^{1} J_{\mathrm{CC}}$ & 35,8 & 37,4 & 36,0 & 37,2 & 37,6 & 38,7 & 40,3 & 40,4 & 41,7 & 43,4 & 43,3 & 34,5 \\
\hline $\mathrm{C}_{2} \mathrm{H}_{6}$ & ${ }^{1} J_{\mathrm{CH}}$ & 131,0 & 130,4 & 118,4 & 122,6 & 117,8 & 122,8 & 125,8 & 122,2 & 127,4 & 128,9 & 126,9 & 125,2 \\
\hline $\mathrm{C}_{2} \mathrm{H}_{6}$ & ${ }^{2} J_{\mathrm{CH}}$ & $-3,8$ & $-3,7$ & $-3,0$ & $-2,8$ & $-3,0$ & $-3,7$ & $-3,6$ & $-3,6$ & $-4,4$ & $-4,3$ & $-4,3$ & $-4,7$ \\
\hline \multirow[t]{3}{*}{ Total } & $\mathrm{DM}$ & $-12,11$ & $-6,26$ & $-7,48$ & $-7,07$ & $-2,41$ & $-4,76$ & 0,17 & 0,40 & $-2,04$ & 7,75 & 3,28 & - \\
\hline & DMA & 20,61 & 17,13 & 12,45 & 13,13 & 9,48 & 11,98 & 6,59 & 6,23 & 14,82 & 8,63 & 8,39 & - \\
\hline & PDMA & 24,84 & 26,50 & 18,51 & 31,04 & 20,13 & 15,87 & 14,72 & 10,77 & 22,10 & 18,87 & 18,49 & - \\
\hline \multirow[t]{3}{*}{ CPI } & $\mathrm{DM}$ & $-37,47$ & $-23,73$ & $-18,75$ & $-20,65$ & $-6,88$ & $-15,48$ & $-5,95$ & $-3,38$ & $-12,55$ & 9,46 & 0,03 & - \\
\hline & DMA & 39,84 & 31,56 & 20,85 & 24,02 & 13,34 & 21,06 & 8,74 & 6,98 & 26,80 & 11,23 & 11,65 & - \\
\hline & PDMA & 42,15 & 49,18 & 17,44 & 45,43 & 24,32 & 20,96 & 18,05 & 12,35 & 33,14 & 26,46 & 24,29 & - \\
\hline \multirow[t]{3}{*}{ SPI } & $\mathrm{DM}$ & 6,49 & 6,55 & 0,79 & 2,89 & 0,87 & 3,10 & 4,65 & 3,17 & 5,67 & 6,49 & 5,67 & - \\
\hline & DMA & 6,51 & 6,55 & 6,29 & 5,15 & 6,65 & 5,33 & 5,01 & 5,68 & 6,03 & 6,72 & 6,01 & - \\
\hline & PDMA & 12,14 & 9,87 & 19,30 & 20,49 & 17,06 & 12,13 & 12,27 & 9,61 & 13,99 & 13,31 & 14,24 & - \\
\hline \multirow[t]{3}{*}{$\Delta \mathrm{CS}$} & $\mathrm{DM}$ & $-43,97$ & $-30,28$ & $-19,55$ & $-23,54$ & $-7,76$ & $-18,58$ & $-10,61$ & $-6,56$ & $-18,21$ & 2,97 & $-5,65$ & - \\
\hline & DMA & 33,33 & 25,01 & 14,56 & 18,86 & 6,69 & 15,74 & 3,72 & 1,30 & 20,77 & 4,51 & 5,64 & - \\
\hline & PDMA & 30,01 & 39,31 & $-1,87$ & 24,93 & 7,26 & 8,83 & 5,78 & 2,74 & 19,15 & 13,15 & 10,06 & - \\
\hline
\end{tabular}


Tabela 8.94: Constantes de acoplamento B972 com otimização de geometrias com correção vibracional no nível BHandH $\left(50 \% E_{X}^{\mathrm{HF}}\right)$ e base aug-pcJ-2.

\begin{tabular}{|c|c|c|c|c|c|c|c|c|c|c|c|c|c|c|c|c|}
\hline & $\% E_{X}^{\mathrm{HF}}$ & 21,00 & 21,00 & 30,00 & 30,00 & $\begin{array}{l}21,00 \\
30,00 \\
\text { Otm. }\end{array}$ & 40,00 & 40,00 & $\begin{array}{l}21,00 \\
40,00 \\
\text { Otm. }\end{array}$ & 50,00 & 50,00 & $\begin{array}{l}21,00 \\
50,00 \\
\text { Otm. }\end{array}$ & 60,00 & 60,00 & $\begin{array}{l}21,00 \\
60,00 \\
\text { Otm. }\end{array}$ & Exp. \\
\hline HF & ${ }^{1} J_{\mathrm{HF}}$ & 410,0 & 414,2 & 454,4 & 369,1 & 458,3 & 479,2 & 419,8 & 483,1 & 505,4 & 470,9 & 509,2 & 533,0 & 522,7 & 536,9 & 500,0 \\
\hline $\mathrm{CO}$ & ${ }^{1} J_{\mathrm{CO}}$ & 19,0 & 17,8 & 12,2 & 18,3 & 10,9 & 9,9 & 13,6 & 8,7 & 7,5 & 8,7 & 6,3 & 4,9 & 3,7 & 3,7 & 16,4 \\
\hline $\mathrm{H}_{2} \mathrm{O}$ & ${ }^{1} J_{\mathrm{OH}}$ & $-72,4$ & $-73,3$ & $-74,5$ & $-64,6$ & $-75,3$ & $-77,8$ & $-71,3$ & $-78,6$ & $-81,2$ & $-77,9$ & $-82,1$ & $-84,9$ & $-84,5$ & $-85,8$ & $-80,6$ \\
\hline $\mathrm{H}_{2} \mathrm{O}$ & ${ }^{2} J_{\mathrm{HH}}$ & $-6,0$ & $-5,7$ & $-2,8$ & $-3,2$ & $-2,6$ & $-4,0$ & $-4,0$ & $-3,8$ & $-5,2$ & $-4,9$ & $-5,0$ & $-6,5$ & $-5,9$ & $-6,3$ & $-7,3$ \\
\hline $\mathrm{NH}_{3}$ & ${ }^{1} J_{\mathrm{NH}}$ & 42,5 & 42,8 & 41,1 & 38,4 & 41,4 & 42,6 & 41,1 & 42,9 & 44,2 & 43,8 & 44,5 & 45,9 & 46,5 & 46,2 & 43,8 \\
\hline $\mathrm{NH}_{3}$ & ${ }^{2} J_{\mathrm{HH}}$ & $-8,2$ & $-8,1$ & $-5,1$ & $-5,4$ & $-5,1$ & $-6,2$ & $-6,2$ & $-6,1$ & $-7,3$ & $-7,0$ & $-7,2$ & $-8,5$ & $-8,0$ & $-8,4$ & $-9,6$ \\
\hline $\mathrm{PH}_{3}$ & ${ }^{1} J_{\mathrm{PH}}$ & 177,2 & 184,8 & 168,2 & 151,2 & 175,4 & 176,6 & 166,9 & 183,7 & 185,4 & 182,3 & 192,4 & 194,6 & 198,0 & 201,6 & 188,2 \\
\hline $\mathrm{PF}_{3}$ & ${ }^{1} J_{\mathrm{PF}}$ & $-1660,5$ & $-1562,2$ & $-1594,6$ & $-1476,3$ & $-1515,6$ & $-1575,9$ & $-1482,2$ & $-1500,9$ & $-1554,3$ & $-1471,6$ & $-1483,3$ & $-1530,5$ & $-1450,8$ & $-1463,4$ & $-1441,0$ \\
\hline $\mathrm{BHF}_{2}$ & ${ }^{1} J_{\mathrm{BF}}$ & $-134,2$ & $-137,1$ & $-104,6$ & $-150,8$ & $-107,6$ & $-87,2$ & $-119,6$ & $-90,1$ & $-69,7$ & $-89,0$ & $-72,6$ & $-52,3$ & $-59,6$ & $-55,1$ & $-84,0$ \\
\hline $\mathrm{BF}_{3}$ & ${ }^{1} J_{\mathrm{BF}}$ & $-38,7$ & $-45,4$ & $-7,5$ & $-65,4$ & $-14,1$ & 12,0 & $-28,4$ & 5,6 & 31,7 & 7,2 & 25,5 & 51,4 & 41,5 & 45,3 & 15,0 \\
\hline $\mathrm{F}_{2} \mathrm{O}$ & ${ }^{1} J_{\mathrm{OF}}$ & $-330,3$ & $-234,0$ & $-298,0$ & $-355,9$ & $-203,7$ & $-334,9$ & $-324,7$ & $-232,7$ & $-376,8$ & $-293,0$ & $-264,6$ & $-427,2$ & $-261,8$ & $-300,9$ & $-300,0$ \\
\hline $\mathrm{CH}_{4}$ & ${ }^{1} J_{\mathrm{CH}}$ & 121,3 & 121,3 & 109,7 & 115,3 & 109,7 & 114,4 & 119,1 & 114,4 & 119,4 & 123,1 & 119,4 & 124,7 & 127,1 & 124,7 & 125,3 \\
\hline $\mathrm{CH}_{4}$ & ${ }^{2} J_{\mathrm{HH}}$ & $-11,6$ & $-11,6$ & $-8,1$ & $-7,7$ & $-8,1$ & $-9,0$ & $-8,7$ & $-9,0$ & $-10,0$ & $-9,8$ & $-10,0$ & $-11,0$ & $-10,9$ & $-11,0$ & $-12,8$ \\
\hline $\mathrm{C}_{2} \mathrm{H}_{2}$ & ${ }^{1} J_{\mathrm{CC}}$ & 198,2 & 198,3 & 189,5 & 190,4 & 189,8 & 196,3 & 197,8 & 196,4 & 204,1 & 205,6 & 203,9 & 213,2 & 214,0 & 212,7 & 174,8 \\
\hline $\mathrm{C}_{2} \mathrm{H}_{2}$ & ${ }^{1} J_{\mathrm{CH}}$ & 250,6 & 248,5 & 217,0 & 229,4 & 215,2 & 225,9 & 235,1 & 224,0 & 235,3 & 241,0 & 233,3 & 245,5 & 247,2 & 243,3 & 247,6 \\
\hline $\mathrm{C}_{2} \mathrm{H}_{2}$ & ${ }^{2} J_{\mathrm{CH}}$ & 51,0 & 51,1 & 51,7 & 52,0 & 51,8 & 52,1 & 52,2 & 52,2 & 52,2 & 52,2 & 52,3 & 51,8 & 52,0 & 52,0 & 50,1 \\
\hline $\mathrm{C}_{2} \mathrm{H}_{2}$ & ${ }^{3} J_{\mathrm{HH}}$ & 11,0 & 10,7 & 8,0 & 9,0 & 7,8 & 8,7 & 9,3 & 8,4 & 9,5 & 9,8 & 9,2 & 10,5 & 10,4 & 10,2 & 9,6 \\
\hline $\mathrm{C}_{2} \mathrm{H}_{4}$ & ${ }^{1} J_{\mathrm{CC}}$ & 68,8 & 71,3 & 66,7 & 68,3 & 69,4 & 71,5 & 73,8 & 74,0 & 77,0 & 79,6 & 79,2 & 83,6 & 85,9 & 85,4 & 67,6 \\
\hline $\mathrm{C}_{2} \mathrm{H}_{4}$ & ${ }^{1} J_{\mathrm{CH}}$ & 154,2 & 151,3 & 136,0 & 141,4 & 133,6 & 142,2 & 146,1 & 139,6 & 148,8 & 151,0 & 146,0 & 156,0 & 156,0 & 153,0 & 156,3 \\
\hline $\mathrm{C}_{2} \mathrm{H}_{4}$ & ${ }^{2} J_{\mathrm{CH}}$ & $-2,4$ & $-2,0$ & 0,1 & 0,6 & 0,3 & $-0,8$ & $-0,5$ & $-0,6$ & $-2,1$ & $-1,8$ & $-1,8$ & $-3,6$ & $-3,4$ & $-3,2$ & $-2,4$ \\
\hline $\mathrm{C}_{2} \mathrm{H}_{4}$ & ${ }^{2} J_{\mathrm{HH}}$ & 3,3 & 2,1 & 4,9 & 5,4 & 3,8 & 4,4 & 4,6 & 3,3 & 3,9 & 3,7 & 2,7 & 3,2 & 2,7 & 2,1 & 2,3 \\
\hline $\mathrm{C}_{2} \mathrm{H}_{4}$ & ${ }^{3} J_{\mathrm{HH}_{\mathrm{c}}}$ & 11,5 & 12,1 & 10,0 & 9,5 & 10,6 & 10,4 & 10,2 & 11,0 & 10,9 & 10,9 & 11,4 & 11,4 & 11,8 & 12,0 & 11,7 \\
\hline $\mathrm{C}_{2} \mathrm{H}_{4}$ & ${ }^{3} J_{\mathrm{HH}_{\mathrm{t}}}$ & 18,3 & 18,9 & 15,0 & 16,1 & 15,5 & 15,7 & 16,7 & 16,2 & 16,5 & 17,4 & 17,0 & 17,4 & 18,1 & 17,9 & 19,0 \\
\hline $\mathrm{C}_{2} \mathrm{H}_{6}$ & ${ }^{1} J_{\mathrm{CC}}$ & 31,5 & 33,3 & 31,1 & 32,5 & 33,0 & 34,2 & 35,9 & 36,1 & 37,5 & 39,3 & 39,4 & 41,0 & 42,8 & 42,9 & 34,5 \\
\hline $\mathrm{C}_{2} \mathrm{H}_{6}$ & ${ }^{1} J_{\mathrm{CH}}$ & 120,8 & 119,2 & 108,3 & 113,3 & 107,0 & 113,3 & 117,2 & 111,9 & 118,5 & 121,2 & 117,1 & 124,0 & 125,3 & 122,5 & 125,2 \\
\hline $\mathrm{C}_{2} \mathrm{H}_{6}$ & ${ }^{2} J_{\mathrm{CH}}$ & $-3,4$ & $-3,4$ & $-2,1$ & $-1,8$ & $-2,0$ & $-2,6$ & $-2,4$ & $-2,6$ & $-3,2$ & $-3,0$ & $-3,1$ & $-3,8$ & $-3,7$ & $-3,8$ & $-4,7$ \\
\hline \multirow[t]{3}{*}{ Total } & DM & $-16,29$ & $-8,85$ & $-12,25$ & $-16,00$ & $-5,60$ & $-9,00$ & $-8,98$ & $-2,23$ & $-5,65$ & $-1,36$ & 1,31 & $-2,35$ & 6,62 & 4,98 & - \\
\hline & DMA & 19,90 & 17,41 & 15,77 & 20,50 & 16,44 & 12,58 & 13,55 & 11,20 & 12,67 & 6,84 & 8,63 & 16,09 & 8,85 & 9,15 & - \\
\hline & PDMA & 25,53 & 26,40 & 30,35 & 49,30 & 31,67 & 19,64 & 31,82 & 20,56 & 18,97 & 15,73 & 15,98 & 25,18 & 20,83 & 20,80 & - \\
\hline \multirow[t]{3}{*}{ CPI } & DM & $-40,23$ & $-22,46$ & $-22,92$ & $-35,05$ & $-7,17$ & $-18,78$ & $-21,45$ & $-2,65$ & $-14,65$ & $-6,49$ & 2,02 & -11 & 9,1 & 6,63 & - \\
\hline & DMA & 42,68 & 36,61 & 26,03 & 39,81 & 27,32 & 20,51 & 24,35 & 16,52 & 22,15 & 9,16 & 11,82 & 31,27 & & 14,12 & - \\
\hline & PDMA & 48,03 & 52,06 & 32,13 & 75,10 & 39,21 & 16,51 & 44,14 & 21,65 & 24,82 & 16,51 & 20,36 & 40,15 & 32,11 & 33,48 & - \\
\hline \multirow[t]{3}{*}{ SPI } & $\mathrm{DM}$ & 1,27 & 1,13 & $-4,42$ & $-2,03$ & $-4,45$ & $-1,83$ & 0,1 & $-1,9$ & 0,9 & 2,4 & 0,7 & 3,9 & 4,7 & 3,7 & - \\
\hline & DMA & 3,19 & 3,33 & 8,25 & 6,33 & 8,46 & 6,76 & 5,62 & 7,31 & & & 6,30 & 4,96 & 5,09 & 5,51 & - \\
\hline & PDMA & 9,03 & 7,58 & 29,04 & 30,37 & 26,14 & 21,94 & 22,78 & 19,75 & 14,68 & 15,15 & 12,77 & 14,20 & 12,55 & 11,50 & - \\
\hline \multirow[t]{3}{*}{$\Delta \mathrm{CS}$} & DM & $-41,49$ & $-23,60$ & $-18,50$ & $-33,02$ & $-2,73$ & $-16,96$ & -21 & $-0,73$ & -15 & -8 & 1,2 & & 4, & 2,85 & - \\
\hline & DMA & 39,50 & 33,28 & 17,78 & 33,48 & 18,86 & 13,75 & 18,73 & 9,21 & 16,43 & 4,02 & 5,52 & 26,31 & 8,88 & 8,61 & - \\
\hline & PDMA & 39,00 & 44,48 & 3,09 & 44,73 & 13,08 & $-5,43$ & 21,36 & 1,90 & 10,14 & 1,36 & 7,59 & 25,95 & 19,55 & 21,99 & - \\
\hline
\end{tabular}


Tabela 8.95: Constantes de acoplamento B98 com otimização de geometrias com correção vibracional no nível BHandH $\left(50 \% E_{X}^{\mathrm{HF}}\right)$ e base aug-pcJ-2.

\begin{tabular}{|c|c|c|c|c|c|c|c|c|c|c|c|c|c|}
\hline & $\% E_{X}^{\mathrm{HF}}$ & 21,98 & 21,98 & 40,00 & 40,00 & $\begin{array}{l}21,98 \\
40,00 \\
\text { Otm. }\end{array}$ & 50,00 & 50,00 & $\begin{array}{l}21,98 \\
50,00 \\
\text { Otm. }\end{array}$ & 60,00 & 60,00 & $\begin{array}{l}21,98 \\
60,00 \\
\text { Otm. }\end{array}$ & Exp. \\
\hline HF & ${ }^{1} J_{\mathrm{HF}}$ & 398,4 & 392,9 & 451,8 & 384,9 & 446,7 & 473,1 & 433,0 & 468,0 & 495,7 & 481,7 & 490,7 & 500,0 \\
\hline $\mathrm{CO}$ & ${ }^{1} J_{\mathrm{CO}}$ & 19,2 & 18,3 & 11,9 & 16,2 & 11,1 & 10,2 & 11,9 & 9,4 & 8,4 & 7,6 & 7,5 & 16,4 \\
\hline $\mathrm{H}_{2} \mathrm{O}$ & ${ }^{1} J_{\mathrm{OH}}$ & $-71,4$ & $-71,5$ & $-74,5$ & $-66,8$ & $-74,6$ & $-77,3$ & $-73,1$ & $-77,4$ & $-80,3$ & $-79,3$ & $-80,4$ & $-80,6$ \\
\hline $\mathrm{H}_{2} \mathrm{O}$ & ${ }^{2} J_{\mathrm{HH}}$ & $-5,4$ & $-5,0$ & $-3,6$ & $-3,6$ & $-3,2$ & $-4,9$ & $-4,6$ & $-4,6$ & $-6,4$ & $-5,7$ & $-6,0$ & $-7,3$ \\
\hline $\mathrm{NH}_{3}$ & ${ }^{1} J_{\mathrm{NH}}$ & 43,7 & 43,9 & 42,5 & 40,4 & 42,7 & 43,9 & 43,1 & 44,1 & 45,4 & 45,6 & 45,6 & 43,8 \\
\hline $\mathrm{NH}_{3}$ & ${ }^{2} J_{\mathrm{HH}}$ & $-8,6$ & $-8,4$ & $-6,7$ & $-6,6$ & $-6,5$ & $-7,9$ & $-7,6$ & $-7,7$ & $-9,3$ & $-8,7$ & $-9,1$ & $-9,6$ \\
\hline $\mathrm{PH}_{3}$ & ${ }^{1} J_{\mathrm{PH}}$ & 189,6 & 195,9 & 186,9 & 180,4 & 192,7 & 194,9 & 193,9 & 200,5 & 203,3 & 207,1 & 208,6 & 188,2 \\
\hline $\mathrm{PF}_{3}$ & ${ }^{1} J_{\mathrm{PF}}$ & $-1665,7$ & $-1559,4$ & $-1571,4$ & $-1468,2$ & $-1489,2$ & $-1548,4$ & $-1459,2$ & $-1470,1$ & $-1522,7$ & $-1439,1$ & $-1448,3$ & $-1441,0$ \\
\hline $\mathrm{BHF}_{2}$ & ${ }^{1} J_{\mathrm{BF}}$ & $-133,4$ & $-137,5$ & $-93,9$ & $-129,6$ & $-98,0$ & $-78,1$ & $-99,8$ & $-82,1$ & $-62,1$ & $-70,7$ & $-66,1$ & $-84,0$ \\
\hline $\mathrm{BF}_{3}$ & ${ }^{1} J_{\mathrm{BF}}$ & $-36,2$ & $-45,3$ & 4,9 & $-39,7$ & $-3,6$ & 22,4 & $-5,1$ & 14,0 & 40,1 & 28,5 & 31,9 & 15,0 \\
\hline $\mathrm{F}_{2} \mathrm{O}$ & ${ }^{1} J_{\mathrm{OF}}$ & $-351,2$ & $-278,9$ & $-352,5$ & $-362,0$ & $-276,8$ & $-397,3$ & $-327,0$ & $-313,6$ & $-451,6$ & $-292,8$ & $-356,2$ & $-300,0$ \\
\hline $\mathrm{CH}_{4}$ & ${ }^{1} J_{\mathrm{CH}}$ & 130,8 & 131,2 & 119,4 & 124,5 & 119,7 & 124,0 & 128,1 & 124,4 & 129,0 & 131,8 & 129,4 & 125,3 \\
\hline $\mathrm{CH}_{4}$ & ${ }^{2} J_{\mathrm{HH}}$ & $-12,8$ & $-12,8$ & $-10,1$ & $-9,8$ & $-10,1$ & $-11,3$ & $-11,1$ & $-11,3$ & $-12,5$ & $-12,4$ & $-12,5$ & $-12,8$ \\
\hline $\mathrm{C}_{2} \mathrm{H}_{2}$ & ${ }^{1} J_{\mathrm{CC}}$ & 213,6 & 213,4 & 205,7 & 208,2 & 205,7 & 212,9 & 215,0 & 212,6 & 221,3 & 222,3 & 220,7 & 174,8 \\
\hline $\mathrm{C}_{2} \mathrm{H}_{2}$ & ${ }^{1} J_{\mathrm{CH}}$ & 264,4 & 262,9 & 233,0 & 243,0 & 231,6 & 242,3 & 248,7 & 240,8 & 252,3 & 254,8 & 250,7 & 247,6 \\
\hline $\mathrm{C}_{2} \mathrm{H}_{2}$ & ${ }^{2} J_{\mathrm{CH}}$ & 53,1 & 53,2 & 53,5 & 53,7 & 53,6 & 53,5 & 53,5 & 53,6 & 52,9 & 53,0 & 53,1 & 50,1 \\
\hline $\mathrm{C}_{2} \mathrm{H}_{2}$ & ${ }^{3} J_{\mathrm{HH}}$ & 11,3 & 11,0 & 9,0 & 9,8 & 8,8 & 10,0 & 10,4 & 9,7 & 11,2 & 11,3 & 11,0 & 9,6 \\
\hline $\mathrm{C}_{2} \mathrm{H}_{4}$ & ${ }^{1} J_{\mathrm{CC}}$ & 78,0 & 80,4 & 77,1 & 79,5 & 79,6 & 82,0 & 84,8 & 84,3 & 87,9 & 90,4 & 89,8 & 67,6 \\
\hline $\mathrm{C}_{2} \mathrm{H}_{4}$ & ${ }^{1} J_{\mathrm{CH}}$ & 164,4 & 162,0 & 147,6 & 152,1 & 145,5 & 153,9 & 156,7 & 151,7 & 160,8 & 161,4 & 158,4 & 156,3 \\
\hline $\mathrm{C}_{2} \mathrm{H}_{4}$ & ${ }^{2} J_{\mathrm{CH}}$ & $-2,8$ & $-2,5$ & $-1,2$ & $-0,9$ & $-1,0$ & $-2,5$ & $-2,3$ & $-2,3$ & $-4,2$ & $-4,0$ & $-3,8$ & $-2,4$ \\
\hline $\mathrm{C}_{2} \mathrm{H}_{4}$ & ${ }^{2} J_{\mathrm{HH}}$ & 3,3 & 2,1 & 4,1 & 4,4 & 3,0 & 3,4 & 3,3 & 2,3 & 2,5 & 2,1 & 1,4 & 2,3 \\
\hline $\mathrm{C}_{2} \mathrm{H}_{4}$ & ${ }^{3} J_{\mathrm{HH}_{\mathrm{c}}}$ & 12,1 & 12,7 & 10,9 & 10,5 & 11,4 & 11,4 & 11,4 & 11,9 & 12,1 & 12,3 & 12,5 & 11,7 \\
\hline $\mathrm{C}_{2} \mathrm{H}_{4}$ & ${ }^{3} J_{\mathrm{HH}_{\mathrm{t}}}$ & 19,1 & 19,7 & 16,2 & 17,3 & 16,8 & 17,1 & 18,1 & 17,6 & 18,2 & 19,0 & 18,7 & 19,0 \\
\hline $\mathrm{C}_{2} \mathrm{H}_{6}$ & ${ }^{1} J_{\mathrm{CC}}$ & 35,3 & 36,9 & 36,0 & 37,1 & 37,6 & 39,1 & 40,5 & 40,7 & 42,4 & 44,0 & 44,0 & 34,5 \\
\hline $\mathrm{C}_{2} \mathrm{H}_{6}$ & ${ }^{1} J_{\mathrm{CH}}$ & 130,7 & 130,0 & 118,7 & 123,3 & 118,0 & 123,6 & 127,1 & 123,0 & 128,9 & 130,9 & 128,2 & 125,2 \\
\hline $\mathrm{C}_{2} \mathrm{H}_{6}$ & ${ }^{2} J_{\mathrm{CH}}$ & $-4,0$ & $-3,9$ & $-3,1$ & $-2,8$ & $-3,1$ & $-3,8$ & $-3,6$ & $-3,7$ & $-4,5$ & $-4,4$ & $-4,5$ & $-4,7$ \\
\hline \multirow[t]{3}{*}{ Total } & $\mathrm{DM}$ & $-14,21$ & $-7,83$ & $-8,95$ & $-9,60$ & $-3,33$ & $-6,11$ & $-2,27$ & $-0,35$ & $-3,32$ & 5,45 & 2,70 & - \\
\hline & DMA & 22,60 & 18,29 & 13,98 & 15,81 & 10,78 & 13,18 & 9,62 & 7,23 & 15,78 & 7,67 & 9,19 & - \\
\hline & PDMA & 26,24 & 27,03 & 19,63 & 33,61 & 20,65 & 14,10 & 17,41 & 9,97 & 20,66 & 16,56 & 18,29 & - \\
\hline \multirow[t]{3}{*}{ CPI } & $\mathrm{DM}$ & $-41,99$ & $-26,90$ & $-22,32$ & $-26,86$ & $-9,05$ & $-19,12$ & $-12,31$ & $-5,49$ & $-16,40$ & 3,03 & $-2,06$ & - \\
\hline & DMA & 44,95 & 34,79 & 24,63 & 30,59 & 16,49 & 24,12 & 15,56 & 9,55 & 28,25 & 7,95 & 12,79 & - \\
\hline & PDMA & 47,18 & 52,14 & 21,35 & 52,43 & 26,87 & 17,99 & 25,06 & 12,05 & 29,70 & 19,34 & 22,51 & - \\
\hline \multirow[t]{3}{*}{ SPI } & $\mathrm{DM}$ & 6,16 & 6,15 & 0,85 & 3,05 & 0,87 & 3,43 & 5,10 & 3,41 & 6,28 & 7,23 & 6,20 & - \\
\hline & DMA & 6,21 & 6,19 & 6,17 & 4,97 & 6,59 & 5,15 & 5,26 & 5,53 & 6,63 & 7,47 & 6,55 & - \\
\hline & PDMA & 10,89 & 8,62 & 18,36 & 19,81 & 16,09 & 11,25 & 11,80 & 8,45 & 14,03 & 14,52 & 15,20 & - \\
\hline \multirow[t]{3}{*}{$\Delta \mathrm{CS}$} & DM & $-48,15$ & $-33,05$ & $-23,16$ & $-29,92$ & $-9,92$ & $-22,55$ & $-17,41$ & $-8,90$ & $-22,68$ & $-4,20$ & $-8,26$ & - \\
\hline & DMA & 38,74 & 28,60 & 18,46 & 25,62 & 9,90 & 18,96 & 10,30 & 4,01 & 21,63 & 0,49 & 6,24 & - \\
\hline & PDMA & 36,30 & 43,53 & 2,99 & 32,62 & 10,77 & 6,74 & 13,26 & 3,60 & 15,68 & 4,82 & 7,31 & - \\
\hline
\end{tabular}


Tabela 8.96: Constantes de acoplamento B1B95 com otimização de geometrias com correção vibracional no nível BHandH $\left(50 \% E_{X}^{\mathrm{HF}}\right)$ e base aug-pcJ-2.

\begin{tabular}{|c|c|c|c|c|c|c|c|c|c|c|c|c|c|}
\hline & $\% E_{X}^{\mathrm{HF}}$ & 28,00 & 28,00 & 40,00 & 40,00 & $\begin{array}{l}28,00 \\
40,00 \\
\text { Otm. }\end{array}$ & 50,00 & 50,00 & $\begin{array}{l}28,00 \\
50,00 \\
\text { Otm. }\end{array}$ & 60,00 & 60,00 & $\begin{array}{c}28,00 \\
60,00 \\
\text { Otm. }\end{array}$ & Exp. \\
\hline $\mathrm{HF}$ & ${ }^{1} J_{\mathrm{HF}}$ & 437,6 & 437,6 & 466,5 & 482,8 & 466,5 & 490,8 & 519,6 & 490,8 & 515,2 & 555,7 & 515,2 & 500,0 \\
\hline $\mathrm{CO}$ & ${ }^{1} J_{\mathrm{CO}}$ & 19,1 & 17,2 & 16,8 & 13,3 & 14,8 & 14,7 & 10,1 & 12,8 & 12,5 & 6,9 & 10,6 & 16,4 \\
\hline $\mathrm{H}_{2} \mathrm{O}$ & ${ }^{1} J_{\mathrm{OH}}$ & $-76,2$ & $-77,3$ & $-79,3$ & $-82,4$ & $-80,3$ & $-81,9$ & $-86,3$ & $-82,8$ & $-84,5$ & $-90,1$ & $-85,4$ & $-80,6$ \\
\hline $\mathrm{H}_{2} \mathrm{O}$ & ${ }^{2} J_{\mathrm{HH}}$ & $-5,5$ & $-5,1$ & $-6,7$ & $-5,8$ & $-6,3$ & $-7,7$ & $-6,6$ & $-7,3$ & $-8,8$ & $-7,4$ & $-8,3$ & $-7,3$ \\
\hline $\mathrm{NH}_{3}$ & ${ }^{1} J_{\mathrm{NH}}$ & 44,8 & 45,4 & 45,7 & 46,9 & 46,3 & 46,4 & 48,0 & 47,0 & 47,2 & 49,0 & 47,7 & 43,8 \\
\hline $\mathrm{NH}_{3}$ & ${ }^{2} J_{\mathrm{HH}}$ & $-8,4$ & $-8,2$ & $-9,5$ & $-8,9$ & $-9,2$ & $-10,4$ & $-9,6$ & $-10,1$ & $-11,2$ & $-10,3$ & $-10,9$ & $-9,6$ \\
\hline $\mathrm{PH}_{3}$ & ${ }^{1} J_{\mathrm{PH}}$ & 161,0 & 169,0 & 169,7 & 180,7 & 177,2 & 176,8 & 190,0 & 184,0 & 183,8 & 198,8 & 190,6 & 188,2 \\
\hline $\mathrm{PF}_{3}$ & ${ }^{1} J_{\mathrm{PF}}$ & $-1644,8$ & $-1531,5$ & $-1605,7$ & $-1499,9$ & $-1499,3$ & $-1570,4$ & $-1466,1$ & $-1469,6$ & $-1533,0$ & $-1427,1$ & $-1437,9$ & $-1441,0$ \\
\hline $\mathrm{BHF}_{2}$ & ${ }^{1} J_{\mathrm{BF}}$ & $-131,9$ & $-130,0$ & $-111,8$ & $-103,2$ & $-110,1$ & $-95,3$ & $-81,5$ & $-93,6$ & $-78,9$ & $-60,3$ & $-77,2$ & $-84,0$ \\
\hline $\mathrm{BF}_{3}$ & ${ }^{1} J_{\mathrm{BF}}$ & $-29,1$ & $-30,3$ & $-7,4$ & 0,0 & $-8,5$ & 10,5 & 24,5 & 9,3 & 28,2 & 48,1 & 27,1 & 15,0 \\
\hline $\mathrm{F}_{2} \mathrm{O}$ & ${ }^{1} J_{\mathrm{OF}}$ & $-376,2$ & $-263,3$ & $-418,6$ & $-235,4$ & $-294,4$ & $-458,0$ & $-213,6$ & $-321,7$ & $-504,3$ & $-193,5$ & $-351,4$ & $-300,0$ \\
\hline $\mathrm{CH}_{4}$ & ${ }^{1} J_{\mathrm{CH}}$ & 126,9 & 126,6 & 128,6 & 127,7 & 128,3 & 130,0 & 128,5 & 129,7 & 131,5 & 129,4 & 131,1 & 125,3 \\
\hline $\mathrm{CH}_{4}$ & ${ }^{2} J_{\mathrm{HH}}$ & $-12,5$ & $-12,5$ & $-13,3$ & $-13,4$ & $-13,3$ & $-14,0$ & $-14,0$ & $-14,0$ & $-14,7$ & $-14,7$ & $-14,7$ & $-12,8$ \\
\hline $\mathrm{C}_{2} \mathrm{H}_{2}$ & ${ }^{1} J_{\mathrm{CC}}$ & 195,9 & 196,2 & 200,0 & 199,8 & 199,9 & 203,9 & 203,1 & 203,5 & 208,4 & 206,6 & 207,7 & 174,8 \\
\hline $\mathrm{C}_{2} \mathrm{H}_{2}$ & ${ }^{1} J_{\mathrm{CH}}$ & 259,5 & 256,5 & 262,1 & 257,0 & 259,1 & 264,5 & 257,6 & 261,3 & 267,0 & 258,2 & 263,7 & 247,6 \\
\hline $\mathrm{C}_{2} \mathrm{H}_{2}$ & ${ }^{2} J_{\mathrm{CH}}$ & 55,9 & 56,0 & 55,5 & 55,8 & 55,7 & 54,9 & 55,4 & 55,2 & 54,1 & 54,9 & 54,5 & 50,1 \\
\hline $\mathrm{C}_{2} \mathrm{H}_{2}$ & ${ }^{3} J_{\mathrm{HH}}$ & 11,0 & 10,6 & 11,8 & 11,1 & 11,4 & 12,6 & 11,7 & 12,1 & 13,6 & 12,3 & 13,0 & 9,6 \\
\hline $\mathrm{C}_{2} \mathrm{H}_{4}$ & ${ }^{1} J_{\mathrm{CC}}$ & 66,7 & 69,6 & 70,3 & 72,8 & 72,8 & 73,7 & 75,6 & 75,8 & 77,5 & 78,6 & 79,2 & 67,6 \\
\hline $\mathrm{C}_{2} \mathrm{H}_{4}$ & ${ }^{1} J_{\mathrm{CH}}$ & 160,7 & 157,3 & 163,2 & 158,7 & 159,6 & 165,4 & 159,9 & 161,6 & 167,8 & 161,2 & 163,8 & 156,3 \\
\hline $\mathrm{C}_{2} \mathrm{H}_{4}$ & ${ }^{2} J_{\mathrm{CH}}$ & $-1,5$ & $-1,3$ & $-2,7$ & $-2,4$ & $-2,4$ & $-3,8$ & $-3,4$ & $-3,4$ & $-5,1$ & $-4,4$ & $-4,6$ & $-2,4$ \\
\hline $\mathrm{C}_{2} \mathrm{H}_{4}$ & ${ }^{2} J_{\mathrm{HH}}$ & 4,4 & 3,0 & 3,5 & 2,1 & 2,1 & 2,7 & 1,3 & 1,3 & 1,8 & 0,5 & 0,5 & 2,3 \\
\hline $\mathrm{C}_{2} \mathrm{H}_{4}$ & ${ }^{3} J_{\mathrm{HH}_{\mathrm{c}}}$ & 12,4 & 13,2 & 12,8 & 13,7 & 13,5 & 13,1 & 14,1 & 13,9 & 13,6 & 14,5 & 14,3 & 11,7 \\
\hline $\mathrm{C}_{2} \mathrm{H}_{4}$ & ${ }^{3} J_{\mathrm{HH}_{\mathrm{t}}}$ & 19,6 & 20,2 & 20,0 & 20,5 & 20,6 & 20,5 & 20,8 & 21,0 & 21,0 & 21,2 & 21,5 & 19,0 \\
\hline $\mathrm{C}_{2} \mathrm{H}_{6}$ & ${ }^{1} J_{\mathrm{CC}}$ & 31,5 & 33,4 & 33,9 & 35,6 & 35,7 & 35,9 & 37,5 & 37,7 & 38,0 & 39,6 & 39,7 & 34,5 \\
\hline $\mathrm{C}_{2} \mathrm{H}_{6}$ & ${ }^{1} J_{\mathrm{CH}}$ & 126,9 & 124,9 & 128,8 & 126,2 & 126,8 & 130,4 & 127,1 & 128,3 & 132,0 & 128,1 & 129,9 & 125,2 \\
\hline $\mathrm{C}_{2} \mathrm{H}_{6}$ & ${ }^{2} J_{\mathrm{CH}}$ & $-3,7$ & $-3,7$ & $-4,2$ & $-4,3$ & $-4,2$ & $-4,7$ & $-4,7$ & $-4,7$ & $-5,2$ & $-5,2$ & $-5,2$ & $-4,7$ \\
\hline \multirow[t]{3}{*}{ Total } & DM & $-15,42$ & $-6,60$ & $-12,12$ & 0,15 & $-3,18$ & $-9,40$ & 5,92 & $-0,27$ & $-6,83$ & 11,75 & 2,67 & - \\
\hline & DMA & 20,39 & 13,77 & 17,65 & 9,65 & 8,72 & 16,03 & 9,02 & 6,54 & 17,57 & 13,75 & 8,11 & - \\
\hline & PDMA & 26,88 & 23,86 & 16,58 & 12,27 & 13,57 & 13,11 & 14,25 & 12,03 & 21,28 & 27,50 & 20,52 & - \\
\hline \multirow[t]{3}{*}{ CPI } & DM & $-40,95$ & $-19,76$ & $-34,65$ & $-4,80$ & $-13,11$ & $-29,58$ & 7,96 & $-7,46$ & $-24,97$ & 20,81 & $-1,89$ & - \\
\hline & DMA & 42,97 & 28,13 & 35,44 & 17,51 & 14,89 & 30,05 & 14,71 & 8,05 & 31,68 & 24,41 & 9,80 & - \\
\hline & PDMA & 43,53 & 41,39 & 24,32 & 19,27 & 21,81 & 13,16 & 15,13 & 9,08 & 22,50 & 35,67 & 17,08 & - \\
\hline \multirow[t]{3}{*}{ SPI } & DM & 3,31 & 3,06 & 4,41 & 3,79 & 4,10 & 5,40 & 4,43 & 5,01 & 6,48 & 5,11 & 6,02 & - \\
\hline & DMA & 3,83 & 3,25 & 4,60 & 3,89 & 4,19 & 5,75 & 4,85 & 5,44 & 7,23 & 5,94 & 6,87 & - \\
\hline & PDMA & 14,67 & 11,01 & 10,90 & 7,14 & 7,53 & 13,07 & 13,61 & 14,19 & 20,38 & 21,50 & 23,05 & - \\
\hline \multirow[t]{3}{*}{$\Delta \mathrm{CS}$} & DM & $-44,26$ & $-22,82$ & $-39,07$ & $-8,59$ & $-17,21$ & $-34,98$ & 3,54 & $-12,48$ & $-31,45$ & 15,70 & $-7,91$ & - \\
\hline & DMA & 39,15 & 24,88 & 30,84 & 13,62 & 10,70 & 24,31 & 9,86 & 2,61 & 24,46 & 18,47 & 2,93 & - \\
\hline & PDMA & 28,86 & 30,38 & 13,42 & 12,13 & 14,28 & 0,09 & 1,52 & $-5,10$ & 2,12 & 14,17 & $-5,97$ & - \\
\hline
\end{tabular}


Tabela 8.97: Constantes de acoplamento BHandH com otimização de geometrias com correção vibracional no nível BHandH $\left(50 \% E_{X}^{\mathrm{HF}}\right)$ e base aug-pcJ-2.

\begin{tabular}{|c|c|c|c|c|c|c|c|c|c|c|c|c|c|}
\hline & $\% E_{X}^{\mathrm{HF}}$ & 50,00 & 50,00 & 30,00 & 30,00 & $\begin{array}{l}50,00 \\
30,00 \\
\text { Otm. }\end{array}$ & 40,00 & 40,00 & $\begin{array}{l}50,00 \\
40,00 \\
\text { Otm. }\end{array}$ & 60,00 & 60,00 & $\begin{array}{l}50,00 \\
60,00 \\
\text { Otm. }\end{array}$ & Exp. \\
\hline $\mathrm{HF}$ & ${ }^{1} J_{\mathrm{HF}}$ & 498,0 & 513,9 & 451,6 & 440,1 & 468,0 & 474,4 & 476,8 & 490,6 & 522,5 & 551,5 & 538,1 & 500,0 \\
\hline $\mathrm{CO}$ & ${ }^{1} J_{\mathrm{CO}}$ & 14,4 & 8,7 & 19,4 & 15,6 & 13,5 & 17,0 & 12,2 & 11,1 & 11,7 & 5,1 & 6,0 & 16,4 \\
\hline $\mathrm{H}_{2} \mathrm{O}$ & ${ }^{1} J_{\mathrm{OH}}$ & $-82,6$ & $-86,4$ & $-76,7$ & $-77,4$ & $-80,6$ & $-79,6$ & $-82,0$ & $-83,5$ & $-85,8$ & $-90,9$ & $-89,5$ & $-80,6$ \\
\hline $\mathrm{H}_{2} \mathrm{O}$ & ${ }^{2} J_{\mathrm{HH}}$ & $-7,9$ & $-6,4$ & $-5,3$ & $-4,3$ & $-3,8$ & $-6,5$ & $-5,3$ & $-5,1$ & $-9,3$ & $-7,5$ & $-7,7$ & $-7,3$ \\
\hline $\mathrm{NH}_{3}$ & ${ }^{1} J_{\mathrm{NH}}$ & 46,3 & 48,5 & 43,7 & 45,3 & 45,9 & 45,0 & 47,0 & 47,2 & 47,8 & 50,3 & 50,0 & 43,8 \\
\hline $\mathrm{NH}_{3}$ & ${ }^{2} J_{\mathrm{HH}}$ & $-10,2$ & $-9,0$ & $-7,8$ & $-6,7$ & $-6,6$ & $-9,0$ & $-7,8$ & $-7,8$ & $-11,6$ & $-10,1$ & $-10,2$ & $-9,6$ \\
\hline $\mathrm{PH}_{3}$ & ${ }^{1} J_{\mathrm{PH}}$ & 176,3 & 188,3 & 156,2 & 160,6 & 169,0 & 166,1 & 174,5 & 178,5 & 186,9 & 202,1 & 198,4 & 188,2 \\
\hline $\mathrm{PF}_{3}$ & ${ }^{1} J_{\mathrm{PF}}$ & $-1669,7$ & $-1553,8$ & $-1742,8$ & $-1621,3$ & $-1623,5$ & $-1708,3$ & $-1590,7$ & $-1590,5$ & $-1627,6$ & $-1511,3$ & $-1514,1$ & $-1441,0$ \\
\hline $\mathrm{BHF}_{2}$ & ${ }^{1} J_{\mathrm{BF}}$ & $-99,5$ & $-77,1$ & $-137,1$ & $-120,7$ & $-113,8$ & $-118,3$ & $-98,8$ & $-95,5$ & $-80,4$ & $-55,6$ & $-58,6$ & $-84,0$ \\
\hline $\mathrm{BF}_{3}$ & ${ }^{1} J_{\mathrm{BF}}$ & 13,0 & 36,7 & $-25,4$ & $-9,4$ & $-0,6$ & $-6,2$ & 13,7 & 17,9 & 32,5 & 59,3 & 55,5 & 15,0 \\
\hline $\mathrm{F}_{2} \mathrm{O}$ & ${ }^{1} J_{\mathrm{OF}}$ & $-479,3$ & $-179,8$ & $-394,8$ & $-188,2$ & $-138,1$ & $-434,1$ & $-183,5$ & $-158,6$ & $-535,7$ & $-177,6$ & $-202,3$ & $-300,0$ \\
\hline $\mathrm{CH}_{4}$ & ${ }^{1} J_{\mathrm{CH}}$ & 127,4 & 126,9 & 119,3 & 119,9 & 118,8 & 123,2 & 123,2 & 122,8 & 131,9 & 130,6 & 131,3 & 125,3 \\
\hline $\mathrm{CH}_{4}$ & ${ }^{2} J_{\mathrm{HH}}$ & $-13,6$ & $-13,6$ & $-11,3$ & $-11,3$ & $-11,3$ & $-12,4$ & $-12,4$ & $-12,4$ & $-14,8$ & $-14,8$ & $-14,8$ & $-12,8$ \\
\hline $\mathrm{C}_{2} \mathrm{H}_{2}$ & ${ }^{1} J_{\mathrm{CC}}$ & 203,1 & 202,6 & 190,1 & 191,1 & 191,1 & 196,1 & 196,6 & 196,5 & 211,3 & 209,3 & 209,8 & 174,8 \\
\hline $\mathrm{C}_{2} \mathrm{H}_{2}$ & ${ }^{1} J_{\mathrm{CH}}$ & 262,8 & 256,6 & 248,3 & 246,3 & 242,7 & 255,3 & 251,3 & 249,4 & 271,1 & 262,4 & 264,4 & 247,6 \\
\hline $\mathrm{C}_{2} \mathrm{H}_{2}$ & ${ }^{2} J_{\mathrm{CH}}$ & 53,3 & 54,1 & 53,5 & 53,8 & 53,8 & 53,6 & 54,1 & 54,1 & 52,5 & 53,7 & 53,6 & 50,1 \\
\hline $\mathrm{C}_{2} \mathrm{H}_{2}$ & ${ }^{3} J_{\mathrm{HH}}$ & 12,4 & 11,3 & 10,0 & 9,5 & 9,2 & 11,1 & 10,4 & 10,2 & 14,0 & 12,5 & 12,8 & 9,6 \\
\hline $\mathrm{C}_{2} \mathrm{H}_{4}$ & ${ }^{1} J_{\mathrm{CC}}$ & 73,0 & 75,5 & 62,5 & 66,4 & 66,3 & 67,4 & 70,7 & 70,6 & 79,6 & 80,9 & 81,2 & 67,6 \\
\hline $\mathrm{C}_{2} \mathrm{H}_{4}$ & ${ }^{1} J_{\mathrm{CH}}$ & 162,5 & 157,6 & 151,8 & 149,0 & 147,5 & 156,9 & 153,2 & 152,4 & 168,7 & 162,3 & 163,3 & 156,3 \\
\hline $\mathrm{C}_{2} \mathrm{H}_{4}$ & ${ }^{2} J_{\mathrm{CH}}$ & $-4,2$ & $-3,8$ & $-1,7$ & $-1,6$ & $-1,6$ & $-2,8$ & $-2,6$ & $-2,6$ & $-6,0$ & $-5,2$ & $-5,2$ & $-2,4$ \\
\hline $\mathrm{C}_{2} \mathrm{H}_{4}$ & ${ }^{2} J_{\mathrm{HH}}$ & 2,4 & 1,4 & 4,0 & 3,2 & 3,0 & 3,3 & 2,3 & 2,2 & 1,3 & 0,4 & 0,5 & 2,3 \\
\hline $\mathrm{C}_{2} \mathrm{H}_{4}$ & ${ }^{3} J_{\mathrm{HH}_{\mathrm{C}}}$ & 13,6 & 14,7 & 12,5 & 13,6 & 13,7 & 13,0 & 14,1 & 14,2 & 14,4 & 15,4 & 15,4 & 11,7 \\
\hline $\mathrm{C}_{2} \mathrm{H}_{4}$ & ${ }^{3} J_{\mathrm{HH}_{\mathrm{t}}}$ & 20,2 & 20,8 & 18,5 & 19,5 & 19,2 & 19,3 & 20,1 & 20,0 & 21,4 & 21,7 & 21,8 & 19,0 \\
\hline $\mathrm{C}_{2} \mathrm{H}_{6}$ & ${ }^{1} J_{\mathrm{CC}}$ & 34,2 & 37,1 & 27,8 & 31,5 & 30,9 & 30,9 & 34,2 & 33,9 & 37,6 & 39,8 & 40,4 & 34,5 \\
\hline $\mathrm{C}_{2} \mathrm{H}_{6}$ & ${ }^{1} J_{\mathrm{CH}}$ & 127,7 & 124,7 & 119,2 & 117,2 & 116,5 & 123,4 & 120,9 & 120,5 & 132,3 & 128,7 & 129,1 & 125,2 \\
\hline $\mathrm{C}_{2} \mathrm{H}_{6}$ & ${ }^{2} J_{\mathrm{CH}}$ & $-4,5$ & $-4,6$ & $-3,3$ & $-3,5$ & $-3,4$ & $-3,9$ & $-4,0$ & $-4,0$ & $-5,1$ & $-5,2$ & $-5,2$ & $-4,7$ \\
\hline \multirow[t]{3}{*}{ Total } & $\mathrm{DM}$ & $-14,46$ & 3,84 & $-21,65$ & $-7,95$ & $-4,58$ & $-18,08$ & $-2,18$ & $-0,50$ & $-10,92$ & 10,11 & 8,42 & - \\
\hline & DMA & 19,97 & 13,83 & 24,46 & 19,43 & 19,74 & 21,36 & 14,61 & 14,91 & 23,28 & 17,78 & 16,15 & - \\
\hline & PDMA & 12,91 & 19,04 & 26,72 & 20,73 & 19,18 & 16,62 & 10,14 & 11,13 & 26,54 & 33,74 & 32,14 & - \\
\hline \multirow[t]{3}{*}{ CPI } & $\mathrm{DM}$ & $-40,19$ & 3,88 & $-50,90$ & $-18,85$ & $-10,14$ & $-45,49$ & $-7,71$ & $-3,33$ & $-35,45$ & 15,85 & 11,34 & - \\
\hline & DMA & 40,65 & 26,85 & 52,85 & 41,10 & 41,14 & 46,25 & 30,16 & 30,91 & 44,10 & 32,69 & 28,32 & - \\
\hline & PDMA & 13,55 & 26,10 & 43,75 & 33,31 & 29,49 & 26,10 & 15,29 & 17,28 & 28,19 & 45,18 & 41,02 & - \\
\hline \multirow[t]{3}{*}{ SPI } & DM & 4,41 & 3,81 & $-0,19$ & 0,03 & $-0,51$ & 2,02 & 1,87 & 1,58 & 7,07 & 5,89 & 6,29 & - \\
\hline & DMA & 4,80 & 4,29 & 3,65 & 3,54 & 4,05 & 3,10 & 3,20 & 3,18 & 8,01 & 6,85 & 7,23 & - \\
\hline & PDMA & 12,45 & 13,86 & 14,23 & 11,51 & 11,62 & 9,67 & 6,37 & 6,61 & 25,33 & 25,36 & 25,62 & - \\
\hline \multirow[t]{3}{*}{$\Delta \mathrm{CS}$} & $\mathrm{DM}$ & $-44,60$ & 0,07 & $-50,71$ & $-18,88$ & $-9,62$ & $-47,51$ & $-9,58$ & $-4,91$ & $-42,52$ & 9,96 & 5,05 & - \\
\hline & DMA & 35,85 & 22,55 & 49,20 & 37,56 & 37,09 & 43,15 & 26,96 & 27,73 & 36,09 & 25,84 & 21,08 & - \\
\hline & PDMA & 1,09 & 12,24 & 29,52 & 21,79 & 17,87 & 16,43 & 8,93 & 10,68 & 2,87 & 19,82 & 15,40 & - \\
\hline
\end{tabular}


Tabela 8.98: Constantes de acoplamento PBE0 com otimização de geometrias com correção vibracional no nível BHandH $\left(50 \% E_{X}^{\mathrm{HF}}\right)$ e base aug-pcJ-2.

\begin{tabular}{|c|c|c|c|c|c|c|c|c|c|c|c|c|c|c|c|c|}
\hline & $\% E_{X}^{\mathrm{HF}}$ & 25,00 & 25,00 & 20,00 & 20,00 & $\begin{array}{l}25,00 \\
20,00 \\
\text { Otm. }\end{array}$ & 30,00 & 30,00 & $\begin{array}{l}25,00 \\
30,00 \\
\text { Otm. }\end{array}$ & 40,00 & 40,00 & $\begin{array}{l}25,00 \\
40,00 \\
\text { Otm. }\end{array}$ & 50,00 & 50,00 & $\begin{array}{l}25,00 \\
50,00 \\
\text { Otm. }\end{array}$ & Exp. \\
\hline HF & ${ }^{1} J_{\mathrm{HF}}$ & 398,0 & 394,9 & 386,9 & 376,5 & 383,8 & 409,1 & 413,1 & 406,0 & 431,5 & 449,2 & 428,5 & 454,1 & 484,9 & 451,2 & 500,0 \\
\hline $\mathrm{CO}$ & ${ }^{1} J_{\mathrm{CO}}$ & 20,6 & 19,1 & 21,5 & 20,6 & 19,9 & 19,8 & 17,6 & 18,2 & 18,0 & 14,5 & 16,4 & 16,1 & 11,6 & 14,6 & 16,4 \\
\hline $\mathrm{H}_{2} \mathrm{O}$ & ${ }^{1} J_{\mathrm{OH}}$ & $-71,9$ & $-72,4$ & $-70,7$ & $-70,4$ & $-71,2$ & $-73,1$ & $-74,3$ & $-73,6$ & $-75,5$ & $-78,5$ & $-75,9$ & $-77,9$ & $-82,3$ & $-78,3$ & $-80,6$ \\
\hline $\mathrm{H}_{2} \mathrm{O}$ & ${ }^{2} J_{\mathrm{HH}}$ & $-5,8$ & $-5,4$ & $-5,2$ & $-4,9$ & $-4,9$ & $-6,3$ & $-5,9$ & $-5,9$ & $-7,4$ & $-6,6$ & $-7,0$ & $-8,5$ & $-7,5$ & $-8,1$ & $-7,3$ \\
\hline $\mathrm{NH}_{3}$ & ${ }^{1} J_{\mathrm{NH}}$ & 43,3 & 43,8 & 43,0 & 43,1 & 43,4 & 43,7 & 44,4 & 44,2 & 44,4 & 45,6 & 44,9 & 45,1 & 46,7 & 45,6 & 43,8 \\
\hline $\mathrm{NH}_{3}$ & ${ }^{2} J_{\mathrm{HH}}$ & $-9,2$ & $-8,9$ & $-8,7$ & $-8,6$ & $-8,5$ & $-9,7$ & $-9,4$ & $-9,4$ & $-10,6$ & $-10,1$ & $-10,4$ & $-11,6$ & $-10,9$ & $-11,3$ & $-9,6$ \\
\hline $\mathrm{PH}_{3}$ & ${ }^{1} J_{\mathrm{PH}}$ & 147,8 & 154,5 & 143,6 & 148,7 & 150,4 & 151,9 & 160,1 & 158,5 & 160,1 & 171,2 & 166,4 & 168,3 & 181,8 & 174,3 & 188,2 \\
\hline $\mathrm{PF}_{3}$ & ${ }^{1} J_{\mathrm{PF}}$ & $-1731,4$ & $-1626,3$ & $-1747,4$ & $-1633,5$ & $-1639,0$ & $-1714,6$ & $-1611,4$ & $-1612,8$ & $-1678,7$ & $-1580,7$ & $-1583,2$ & $-1640,1$ & $-1543,2$ & $-1550,8$ & $-1441, \mathrm{C}$ \\
\hline $\mathrm{BHF}_{2}$ & ${ }^{1} J_{\mathrm{BF}}$ & $-135,3$ & $-135,1$ & $-143,5$ & $-146,5$ & $-143,3$ & $-127,0$ & $-124,2$ & $-126,8$ & $-110,8$ & $-102,0$ & $-110,6$ & $-94,7$ & $-80,9$ & $-94,5$ & $-84,0$ \\
\hline $\mathrm{BF}_{3}$ & ${ }^{1} J_{\mathrm{BF}}$ & $-32,6$ & $-35,6$ & $-41,5$ & $-49,0$ & $-44,5$ & $-23,8$ & $-23,2$ & $-26,7$ & $-6,3$ & 1,5 & $-9,1$ & 10,8 & 25,2 & 8,1 & 15,0 \\
\hline $\mathrm{F}_{2} \mathrm{O}$ & ${ }^{1} J_{\mathrm{OF}}$ & $-389,2$ & $-265,3$ & $-369,2$ & $-275,7$ & $-250,6$ & $-409,9$ & $-255,9$ & $-280,3$ & $-454,8$ & $-236,3$ & $-311,7$ & $-507,8$ & $-216,3$ & $-346,1$ & $-300,0$ \\
\hline $\mathrm{CH}_{4}$ & ${ }^{1} J_{\mathrm{CH}}$ & 125,3 & 125,5 & 124,6 & 125,0 & 124,8 & 126,0 & 126,0 & 126,3 & 127,5 & 127,0 & 127,7 & 129 & 128,0 & 129,3 & 125,3 \\
\hline $\mathrm{CH}_{4}$ & ${ }^{2} J_{\mathrm{HH}}$ & $-14,1$ & $-14,0$ & $-13,7$ & $-13,6$ & $-13,6$ & $-14,5$ & $-14,5$ & $-14,4$ & $-15,3$ & $-15,3$ & $-15,3$ & -16 & $-16,1$ & $-16,1$ & $-12,8$ \\
\hline $\mathrm{C}_{2} \mathrm{H}_{2}$ & ${ }^{1} J_{\mathrm{CC}}$ & 197,1 & 197,3 & 195,3 & 195,7 & 195,7 & 199,0 & 199,0 & 199,1 & 203,3 & 202,7 & 203,1 & 208,3 & 206,7 & 207,8 & 174,8 \\
\hline $\mathrm{C}_{2} \mathrm{H}_{2}$ & ${ }^{1} J_{\mathrm{CH}}$ & 259,5 & 257,8 & 258,1 & 257,3 & 256,4 & 260,9 & 258,3 & 259,2 & 264,0 & 259,4 & 262,1 & 267,4 & 260,8 & 265,4 & 247,6 \\
\hline $\mathrm{C}_{2} \mathrm{H}_{2}$ & ${ }^{2} J_{\mathrm{CH}}$ & 53,8 & 54,0 & 54,0 & 54,2 & 54,2 & 53,5 & 53,8 & 53,7 & 52,5 & 53,1 & 52,9 & 51 & 52, & 51,7 & 50,1 \\
\hline $\mathrm{C}_{2} \mathrm{H}_{2}$ & ${ }^{3} J_{\mathrm{HH}}$ & 13,0 & 12,6 & 12,5 & 12,3 & 12,2 & 13,5 & 13,0 & 13,1 & 14,7 & 13 & 14,3 & 16,2 & 14,9 & 15,7 & 9,6 \\
\hline $\mathrm{C}_{2} \mathrm{H}_{4}$ & ${ }^{1} J_{\mathrm{CC}}$ & 69,4 & 72,0 & 67,7 & 70,5 & 70,5 & 71 & 73,6 & 73,6 & 75,1 & 76 & 77,2 & 79,8 & 80,6 & 81,3 & 67,6 \\
\hline $\mathrm{C}_{2} \mathrm{H}_{4}$ & ${ }^{1} J_{\mathrm{CH}}$ & 159,2 & 156,5 & 158,0 & 155,7 & 155,4 & 160,4 & 157,2 & 157,6 & 163,0 & 158,8 & 160,0 & 165 & 160,6 & 162,7 & 156,3 \\
\hline $\mathrm{C}_{2} \mathrm{H}_{4}$ & ${ }^{2} J_{\mathrm{CH}}$ & $-3,4$ & $-3,1$ & $-2,9$ & $-2,6$ & $-2,6$ & $-4,1$ & $-3,7$ & $-3,7$ & $-5,5$ & $-4,9$ & $-5,0$ & $-7,3$ & $-6,3$ & $-6,6$ & $-2,4$ \\
\hline $\mathrm{C}_{2} \mathrm{H}_{4}$ & ${ }^{2} J_{\mathrm{HH}}$ & 2,5 & 1,4 & 3,0 & 1,9 & 1,8 & 2,0 & 0,9 & 0,9 & 0,9 & $-0,1$ & 0,0 & $-0,3$ & $-1,2$ & $-1,2$ & 2,3 \\
\hline $\mathrm{C}_{2} \mathrm{H}_{4}$ & ${ }^{3} J_{\mathrm{HH}_{\mathrm{c}}}$ & 13,0 & 13,7 & 12,8 & 13,4 & 13,5 & 13,3 & 14,0 & 13,9 & 13,9 & 14,6 & 14,5 & 14,8 & 15,3 & 15,2 & 11,7 \\
\hline $\mathrm{C}_{2} \mathrm{H}_{4}$ & ${ }^{3} J_{\mathrm{HH}_{\mathrm{t}}}$ & 20,4 & 21,0 & 20,1 & 20,8 & 20,8 & 20,7 & 21,3 & 21,3 & 21,5 & 21,8 & 22,0 & 22,5 & 22,5 & 22,9 & 19,0 \\
\hline $\mathrm{C}_{2} \mathrm{H}_{6}$ & ${ }^{1} J_{\mathrm{CC}}$ & 31,3 & 33,5 & 30,3 & 32,6 & 32,6 & 32,2 & & 34,5 & 34,2 & 36,2 & 36,4 & & 38,0 & 38,3 & 34,5 \\
\hline $\mathrm{C}_{2} \mathrm{H}_{6}$ & ${ }^{1} J_{\mathrm{CH}}$ & 125,4 & 123,9 & 124,6 & 123,4 & 123,1 & 126,2 & 124,5 & 124,8 & 127,9 & 125,7 & 126,4 & 129,6 & 126,8 & 128,1 & 125,2 \\
\hline $\mathrm{C}_{2} \mathrm{H}_{6}$ & ${ }^{2} J_{\mathrm{CH}}$ & $-4,3$ & $-4,3$ & $-4,1$ & $-4,1$ & $-4,1$ & $-4,5$ & $-4,6$ & $-4,6$ & $-5,1$ & $-5,1$ & $-5,1$ & $-5,6$ & $-5,6$ & $-5,6$ & $-4,7$ \\
\hline \multirow[t]{3}{*}{ Total } & DM & 1 & 128 & - & & & & & & & & & & & $-5,8$ & - \\
\hline & DMA & & & & & & & & & & & & & & & - \\
\hline & PDMA & 26,70 & 27,00 & 29,85 & 30,16 & 29,09 & 25,17 & 24,35 & 25,29 & 25,04 & 21,70 & 24,25 & 28,06 & 26,73 & 26,98 & - \\
\hline \multirow[t]{3}{*}{ CPI } & $\mathrm{DM}$ & & & & & & & & & & & & & & & - \\
\hline & DMA & & & & & & & & & & & & & & & - \\
\hline & PDMA & 48,40 & 47,41 & 56,50 & 59,22 & 56,28 & 40,72 & 36,28 & 38,53 & 27,26 & 17,70 & 22,98 & 17,18 & 15,22 & 13,20 & - \\
\hline \multirow[t]{3}{*}{ SPI } & & & & & & & & & & & & & & & & - \\
\hline & DMA & & & & & & & & & & & & & & & - \\
\hline & PDMA & 10,79 & 12,04 & 10,31 & 8,85 & 9,14 & 13,77 & 15,60 & 15,58 & 23,40 & 24,64 & 25,18 & 36,03 & 35,17 & 37,08 & - \\
\hline \multirow[t]{3}{*}{$\Delta \mathrm{CS}$} & & & & & & & & & & & & & & & & - \\
\hline & & & & & & & & & & & & & & & & - \\
\hline & PDMA & 37,61 & 35,37 & 46,19 & 50,36 & 47,13 & 26,96 & 20,68 & 22,96 & 3,86 & $-6,95$ & $-2,20$ & $-18,85$ & $-19,95$ & $-23,88$ & - \\
\hline
\end{tabular}


Tabela 8.99: Constantes de acoplamento B971 com otimização de geometrias com correção vibracional no nível BHandH $40 \% E_{X}^{\mathrm{HF}}$ e base aug-pcJ-2.

\begin{tabular}{|c|c|c|c|c|c|c|c|c|c|c|c|c|c|}
\hline & $\% E_{X}^{\mathrm{HF}}$ & 21,00 & 21,00 & 40,00 & 40,00 & $\begin{array}{l}21,00 \\
40,00 \\
\text { Otm. }\end{array}$ & 50,00 & 50,00 & $\begin{array}{l}21,00 \\
50,00 \\
\text { Otm. }\end{array}$ & 60,00 & 60,00 & $\begin{array}{l}21,00 \\
60,00 \\
\text { Otm. }\end{array}$ & Exp. \\
\hline $\mathrm{HF}$ & ${ }^{1} J_{\mathrm{HF}}$ & 415,9 & 408,1 & 466,5 & 405,4 & 459,3 & 487,4 & 452,7 & 480,3 & 509,6 & 500,2 & 502,5 & 500,0 \\
\hline $\mathrm{CO}$ & ${ }^{1} J_{\mathrm{CO}}$ & 18,2 & 17,7 & 11,5 & 15,4 & 11,0 & 9,8 & 11,2 & 9,4 & 8,1 & 7,0 & 7,6 & 16,4 \\
\hline $\mathrm{H}_{2} \mathrm{O}$ & ${ }^{1} J_{\mathrm{OH}}$ & $-73,2$ & $-73,0$ & $-75,8$ & $-68,8$ & $-75,6$ & $-78,5$ & $-74,8$ & $-78,3$ & $-81,3$ & $-80,7$ & $-81,2$ & $-80,6$ \\
\hline $\mathrm{H}_{2} \mathrm{O}$ & ${ }^{2} J_{\mathrm{HH}}$ & $-5,1$ & $-4,8$ & $-3,7$ & $-3,7$ & $-3,4$ & $-5,0$ & $-4,7$ & $-4,7$ & $-6,3$ & $-5,7$ & $-6,0$ & $-7,3$ \\
\hline $\mathrm{NH}_{3}$ & ${ }^{1} J_{\mathrm{NH}}$ & 44,0 & 44,1 & 42,6 & 40,7 & 42,7 & 43,8 & 43,1 & 43,9 & 45,1 & 45,5 & 45,3 & 43,8 \\
\hline $\mathrm{NH}_{3}$ & ${ }^{2} J_{\mathrm{HH}}$ & $-8,2$ & $-8,1$ & $-6,5$ & $-6,5$ & $-6,3$ & $-7,7$ & $-7,4$ & $-7,5$ & $-9,0$ & $-8,4$ & $-8,8$ & $-9,6$ \\
\hline $\mathrm{PH}_{3}$ & ${ }^{1} J_{\mathrm{PH}}$ & 183,4 & 189,1 & 181,6 & 175,4 & 186,7 & 189,3 & 188,4 & 194,2 & 197,3 & 201,2 & 202,0 & 188,2 \\
\hline $\mathrm{PF}_{3}$ & ${ }^{1} J_{\mathrm{PF}}$ & $-1654,9$ & $-1545,9$ & $-1560,3$ & $-1457,9$ & $-1476,3$ & $-1537,3$ & $-1447,9$ & $-1457,6$ & $-1511,6$ & $-1427,2$ & $-1436,2$ & $-1441,0$ \\
\hline $\mathrm{BHF}_{2}$ & ${ }^{1} J_{\mathrm{BF}}$ & $-128,3$ & $-134,3$ & $-89,6$ & $-122,6$ & $-95,6$ & $-74,1$ & $-92,8$ & $-80,0$ & $-58,5$ & $-63,9$ & $-64,3$ & $-84,0$ \\
\hline $\mathrm{BF}_{3}$ & ${ }^{1} J_{\mathrm{BF}}$ & $-30,1$ & $-41,6$ & 10,2 & $-30,9$ & $-0,7$ & 27,5 & 3,5 & 16,8 & 44,9 & 37,0 & 34,5 & 15,0 \\
\hline $\mathrm{F}_{2} \mathrm{O}$ & ${ }^{1} J_{\mathrm{OF}}$ & $-331,9$ & $-270,3$ & $-340,8$ & $-331,7$ & $-275,5$ & $-383,5$ & $-294,8$ & $-311,7$ & $-434,3$ & $-258,9$ & $-353,1$ & $-300,0$ \\
\hline $\mathrm{CH}_{4}$ & ${ }^{1} J_{\mathrm{CH}}$ & 131,1 & 131,6 & 118,8 & 123,7 & 119,2 & 122,9 & 126,7 & 123,4 & 127,3 & 129,8 & 127,7 & 125,3 \\
\hline $\mathrm{CH}_{4}$ & ${ }^{2} J_{\mathrm{HH}}$ & $-12,3$ & $-12,3$ & $-9,9$ & $-9,6$ & $-9,8$ & $-11,0$ & $-10,8$ & $-10,9$ & $-12,1$ & $-12,0$ & $-12,1$ & $-12,8$ \\
\hline $\mathrm{C}_{2} \mathrm{H}_{2}$ & ${ }^{1} J_{\mathrm{CC}}$ & 214,2 & 214,2 & 205,4 & 207,8 & 205,5 & 212,0 & 214,0 & 211,9 & 219,8 & 220,6 & 219,5 & 174,8 \\
\hline $\mathrm{C}_{2} \mathrm{H}_{2}$ & ${ }^{1} J_{\mathrm{CH}}$ & 264,4 & 263,3 & 232,6 & 242,1 & 231,7 & 241,0 & 247,0 & 240,0 & 250,1 & 252,1 & 249,0 & 247,6 \\
\hline $\mathrm{C}_{2} \mathrm{H}_{2}$ & ${ }^{2} J_{\mathrm{CH}}$ & 53,6 & 53,7 & 53,6 & 53,7 & 53,6 & 53,4 & 53,5 & 53,5 & 52,9 & 53,0 & 53,0 & 50,1 \\
\hline $\mathrm{C}_{2} \mathrm{H}_{2}$ & ${ }^{3} J_{\mathrm{HH}}$ & 11,0 & 10,8 & 8,9 & 9,6 & 8,7 & 9,8 & 10,2 & 9,6 & 11,0 & 11,0 & 10,8 & 9,6 \\
\hline $\mathrm{C}_{2} \mathrm{H}_{4}$ & ${ }^{1} J_{\mathrm{CC}}$ & 78,5 & 80,9 & 76,8 & 79,1 & 79,2 & 81,2 & 83,9 & 83,5 & 86,6 & 89,0 & 88,5 & 67,6 \\
\hline $\mathrm{C}_{2} \mathrm{H}_{4}$ & ${ }^{1} J_{\mathrm{CH}}$ & 164,6 & 162,5 & 147,2 & 151,4 & 145,4 & 153,0 & 155,3 & 151,0 & 159,2 & 159,4 & 157,0 & 156,3 \\
\hline $\mathrm{C}_{2} \mathrm{H}_{4}$ & ${ }^{2} J_{\mathrm{CH}}$ & $-2,4$ & $-2,1$ & $-1,1$ & $-0,7$ & $-0,9$ & $-2,4$ & $-2,2$ & $-2,1$ & $-4,0$ & $-3,8$ & $-3,6$ & $-2,4$ \\
\hline $\mathrm{C}_{2} \mathrm{H}_{4}$ & ${ }^{2} J_{\mathrm{HH}}$ & 3,9 & 2,7 & 4,4 & 4,6 & 3,3 & 3,7 & 3,6 & 2,6 & 2,8 & 2,4 & 1,7 & 2,3 \\
\hline $\mathrm{C}_{2} \mathrm{H}_{4}$ & ${ }^{3} J_{\mathrm{HH}_{\mathrm{c}}}$ & 12,0 & 12,5 & 10,8 & 10,6 & 11,3 & 11,3 & 11,4 & 11,8 & 11,9 & 12,3 & 12,4 & 11,7 \\
\hline $\mathrm{C}_{2} \mathrm{H}_{4}$ & ${ }^{3} J_{\mathrm{HH}_{\mathrm{t}}}$ & 18,9 & 19,5 & 16,1 & 17,1 & 16,6 & 16,9 & 17,8 & 17,4 & 17,9 & 18,7 & 18,4 & 19,0 \\
\hline $\mathrm{C}_{2} \mathrm{H}_{6}$ & ${ }^{1} J_{\mathrm{CC}}$ & 35,7 & 37,3 & 35,9 & 37,1 & 37,5 & 38,6 & 40,2 & 40,3 & 41,6 & 43,3 & 43,2 & 34,5 \\
\hline $\mathrm{C}_{2} \mathrm{H}_{6}$ & ${ }^{1} J_{\mathrm{CH}}$ & 130,9 & 130,3 & 118,3 & 122,5 & 117,7 & 122,7 & 125,7 & 122,1 & 127,3 & 128,8 & 126,8 & 125,2 \\
\hline $\mathrm{C}_{2} \mathrm{H}_{6}$ & ${ }^{2} J_{\mathrm{CH}}$ & $-3,8$ & $-3,7$ & $-3,0$ & $-2,8$ & $-3,0$ & $-3,7$ & $-3,6$ & $-3,6$ & $-4,4$ & $-4,3$ & $-4,3$ & $-4,7$ \\
\hline \multirow[t]{3}{*}{ Total } & $\mathrm{DM}$ & $-12,11$ & $-6,26$ & $-7,48$ & $-7,08$ & $-2,41$ & $-4,77$ & 0,16 & 0,40 & $-2,04$ & 7,75 & 3,28 & - \\
\hline & DMA & 20,52 & 17,10 & 12,42 & 13,10 & 9,54 & 11,87 & 6,58 & 6,13 & 14,62 & 8,61 & 8,27 & - \\
\hline & PDMA & 24,78 & 26,74 & 18,85 & 31,30 & 20,51 & 15,70 & 14,97 & 10,93 & 21,88 & 18,70 & 17,95 & - \\
\hline \multirow[t]{3}{*}{ CPI } & DM & $-37,37$ & $-23,63$ & $-18,65$ & $-20,55$ & $-6,78$ & $-15,38$ & $-5,85$ & $-3,28$ & $-12,45$ & 9,56 & 0,13 & - \\
\hline & DMA & 39,74 & 31,59 & 20,75 & 23,92 & 13,45 & 20,80 & 8,76 & 6,72 & 26,45 & 11,29 & 11,49 & - \\
\hline & PDMA & 42,14 & 49,20 & 17,36 & 45,35 & 24,32 & 20,63 & 18,00 & 12,02 & 32,77 & 26,18 & 23,94 & - \\
\hline \multirow[t]{3}{*}{ SPI } & $\mathrm{DM}$ & 6,41 & 6,47 & 0,71 & 2,81 & 0,79 & 3,02 & 4,57 & 3,09 & 5,59 & 6,41 & 5,59 & - \\
\hline & DMA & 6,43 & 6,47 & 6,31 & 5,17 & 6,67 & 5,33 & 4,99 & 5,69 & 5,95 & 6,64 & 5,91 & - \\
\hline & PDMA & 12,05 & 10,26 & 19,95 & 21,00 & 17,71 & 12,09 & 12,75 & 10,12 & 13,90 & 13,21 & 13,56 & - \\
\hline \multirow[t]{3}{*}{$\Delta \mathrm{CS}$} & DM & $-43,79$ & $-30,10$ & $-19,37$ & $-23,36$ & $-7,58$ & $-18,40$ & $-10,43$ & $-6,38$ & $-18,03$ & 3,15 & $-5,47$ & - \\
\hline & DMA & 33,31 & 25,12 & 14,43 & 18,75 & 6,78 & 15,47 & 3,78 & 1,02 & 20,50 & 4,65 & 5,58 & - \\
\hline & PDMA & 30,10 & 38,93 & $-2,59$ & 24,34 & 6,60 & 8,54 & 5,25 & 1,89 & 18,87 & 12,97 & 10,37 & - \\
\hline
\end{tabular}


Tabela 8.100: Constantes de acoplamento B972 com otimização de geometrias com correção vibracional no nível BHandH $40 \% E_{X}^{\mathrm{HF}}$ e base aug-pcJ-2.

\begin{tabular}{|c|c|c|c|c|c|c|c|c|c|c|c|c|c|c|c|c|}
\hline & $\% E_{X}^{\mathrm{HF}}$ & 21,00 & 21,00 & 30,00 & 30,00 & $\begin{array}{l}21,00 \\
30,00 \\
\text { Otm. }\end{array}$ & 40,00 & 40,00 & $\begin{array}{l}21,00 \\
40,00 \\
\text { Otm. }\end{array}$ & 50,00 & 50,00 & $\begin{array}{l}21,00 \\
\text { 50,00 } \\
\text { Otm. }\end{array}$ & 60,00 & 60,00 & $\begin{array}{l}21,00 \\
60,00 \\
\text { Otm. }\end{array}$ & Exp. \\
\hline $\mathrm{HF}$ & ${ }^{1} J_{\mathrm{HF}}$ & 409,6 & 413,8 & 454,0 & 368,7 & 457,9 & 478,8 & 419,4 & 482,7 & 505,0 & 470,5 & 508,8 & 532,6 & 522,3 & 536,5 & 500,0 \\
\hline $\mathrm{CO}$ & ${ }^{1} J_{\mathrm{CO}}$ & 19,1 & 17,9 & 12,3 & 18,4 & 11,0 & 10,0 & 13,7 & 8,8 & 7,6 & 8,8 & 6,4 & 5,0 & 3,8 & 3,8 & 16,4 \\
\hline $\mathrm{H}_{2} \mathrm{O}$ & ${ }^{1} J_{\mathrm{OH}}$ & $-72,3$ & $-73,2$ & $-74,4$ & $-64,5$ & $-75,2$ & $-77,7$ & $-71,2$ & $-78,5$ & $-81,1$ & $-77,8$ & $-82,0$ & $-84,8$ & $-84,4$ & $-85,7$ & $-80,6$ \\
\hline $\mathrm{H}_{2} \mathrm{O}$ & ${ }^{2} J_{\mathrm{HH}}$ & $-6,1$ & $-5,8$ & $-2,9$ & $-3,3$ & $-2,7$ & $-4,1$ & $-4,1$ & $-3,9$ & $-5,3$ & $-5,0$ & $-5,1$ & $-6,6$ & $-6,0$ & $-6,4$ & $-7,3$ \\
\hline $\mathrm{NH}_{3}$ & ${ }^{1} J_{\mathrm{NH}}$ & 42,4 & 42,7 & 41,0 & 38,3 & 41,3 & 42,5 & 41,0 & 42,8 & 44,1 & 43,7 & 44,4 & 45,8 & 46,4 & 46,1 & 43,8 \\
\hline $\mathrm{NH}_{3}$ & ${ }^{2} J_{\mathrm{HH}}$ & $-8,2$ & $-8,1$ & $-5,1$ & $-5,4$ & $-5,1$ & $-6,2$ & $-6,2$ & $-6,1$ & $-7,3$ & $-7,0$ & $-7,2$ & $-8,5$ & $-8,0$ & $-8,4$ & $-9,6$ \\
\hline $\mathrm{PH}_{3}$ & ${ }^{1} J_{\mathrm{PH}}$ & 176,7 & 184,3 & 167,7 & 150,7 & 174,9 & 176,1 & 166,4 & 183,2 & 184,9 & 181,8 & 191,9 & 194,1 & 197,5 & 201,1 & 188,2 \\
\hline $\mathrm{PF}_{3}$ & ${ }^{1} J_{\mathrm{PF}}$ & $-1659,4$ & $-1561,1$ & $-1593,5$ & $-1475,2$ & $-1514,5$ & $-1574,8$ & $-1481,1$ & $-1499,8$ & $-1553,2$ & $-1470,5$ & $-1482,2$ & $-1529,4$ & $-1449,7$ & $-1462,3$ & $-1441,0$ \\
\hline $\mathrm{BHF}_{2}$ & ${ }^{1} J_{\mathrm{BF}}$ & $-134,4$ & $-137,3$ & $-104,8$ & $-151,0$ & $-107,8$ & $-87,4$ & $-119,8$ & $-90,3$ & $-69,9$ & $-89,2$ & $-72,8$ & $-52,5$ & $-59,8$ & $-55,3$ & $-84,0$ \\
\hline $\mathrm{BF}_{3}$ & ${ }^{1} J_{\mathrm{BF}}$ & $-38,8$ & $-45,5$ & $-7,6$ & $-65,5$ & $-14,2$ & 11,9 & $-28,5$ & 5,5 & 31,6 & 7,1 & 25,4 & 51,3 & 41,4 & 45,2 & 15,0 \\
\hline $\mathrm{F}_{2} \mathrm{O}$ & ${ }^{1} J_{\mathrm{OF}}$ & $-329,1$ & $-232,8$ & $-296,8$ & $-354,7$ & $-202,5$ & $-333,7$ & $-323,5$ & $-231,5$ & $-375,6$ & $-291,8$ & $-263,4$ & $-426,0$ & $-260,6$ & $-299,7$ & $-300,0$ \\
\hline $\mathrm{CH}_{4}$ & ${ }^{1} J_{\mathrm{CH}}$ & 121,1 & 121,1 & 109,5 & 115,1 & 109,5 & 114,2 & 118,9 & 114,2 & 119,2 & 122,9 & 119,2 & 124,5 & 126,9 & 124,5 & 125,3 \\
\hline $\mathrm{CH}_{4}$ & ${ }^{2} J_{\mathrm{HH}}$ & $-11,6$ & $-11,6$ & $-8,1$ & $-7,7$ & $-8,1$ & $-9,0$ & $-8,7$ & $-9,0$ & $-10,0$ & $-9,8$ & $-10,0$ & $-11,0$ & $-10,9$ & $-11,0$ & $-12,8$ \\
\hline $\mathrm{C}_{2} \mathrm{H}_{2}$ & ${ }^{1} J_{\mathrm{CC}}$ & 197,9 & 198,0 & 189,2 & 190,1 & 189,5 & 196,0 & 197,5 & 196,1 & 203,8 & 205,3 & 203,6 & 212,9 & 213,7 & 212,4 & 174,8 \\
\hline $\mathrm{C}_{2} \mathrm{H}_{2}$ & $J_{\mathrm{CH}}$ & 250,4 & 248,3 & 216,8 & 229,2 & 215,0 & 225,7 & 234,9 & 223,8 & 235,1 & 240,8 & 233,1 & 245,3 & 247,0 & 243,1 & 247,6 \\
\hline $\mathrm{C}_{2} \mathrm{H}_{2}$ & ${ }^{2} J_{\mathrm{CH}}$ & 51,1 & 51,2 & 51,8 & 52,1 & 51,9 & 52,2 & 52,3 & 52,3 & 52,3 & 52,3 & 52,4 & 51,9 & 52,1 & 52,1 & 50,1 \\
\hline $\mathrm{C}_{2} \mathrm{H}_{2}$ & ${ }^{3} J_{\mathrm{HH}}$ & 10,9 & 10,6 & 7,9 & 8,9 & 7,7 & 8,6 & 9,2 & 8,3 & 9,4 & 9,7 & 9,1 & 10,4 & 10,3 & 10,1 & 9,6 \\
\hline $\mathrm{C}_{2} \mathrm{H}_{4}$ & ${ }^{1} J_{\mathrm{CC}}$ & 68,5 & 71,0 & 66,4 & 68,0 & 69,1 & 71,2 & 73 & 73,7 & 76 & 79 & 78,9 & 83 & 85 & 85,1 & 67,6 \\
\hline $\mathrm{C}_{2} \mathrm{H}_{4}$ & ${ }^{1} J_{\mathrm{CH}}$ & 154,1 & 151,2 & 135,9 & 141,3 & 133,5 & 142,1 & 146,0 & 139,5 & 148,7 & 150,9 & 145,9 & 155,9 & 155,9 & 152,9 & 156,3 \\
\hline $\mathrm{C}_{2} \mathrm{H}_{4}$ & ${ }^{2} J_{\mathrm{CH}}$ & $-2,3$ & $-1,9$ & 0,2 & 0,7 & 0,4 & $-0,7$ & $-0,4$ & $-0,5$ & $-2,0$ & $-1,7$ & $-1,7$ & $-3,5$ & $-3,3$ & $-3,1$ & $-2,4$ \\
\hline $\mathrm{C}_{2} \mathrm{H}_{4}$ & ${ }^{2} J_{\mathrm{HH}}$ & 3,4 & 2,2 & 5,0 & 5,5 & 3,9 & 4,5 & 4,7 & 3,4 & 4,0 & 3,8 & 2,8 & 3,3 & 2,8 & 2,2 & 2,3 \\
\hline $\mathrm{C}_{2} \mathrm{H}_{4}$ & ${ }^{3} J_{\mathrm{HH}_{\mathrm{c}}}$ & 11,5 & 12,1 & 10,0 & 9,5 & 10,6 & 10,4 & 10,2 & 11,0 & 10,9 & 10,9 & 11,4 & 11,4 & 11,8 & 12,0 & 11,7 \\
\hline $\mathrm{C}_{2} \mathrm{H}_{4}$ & ${ }^{3} J_{\mathrm{HH}_{\mathrm{t}}}$ & 18,2 & 18,8 & 14,9 & 16,0 & 15,4 & 15,6 & 16,6 & 16,1 & 16,4 & 17,3 & 16,9 & 17,3 & 18,0 & 17,8 & 19,0 \\
\hline $\mathrm{C}_{2} \mathrm{H}_{6}$ & ${ }^{1} J_{\mathrm{CC}}$ & 31,4 & 33,2 & 31,0 & 32,4 & 32,9 & 34,1 & 35,8 & 36,0 & 37,4 & 2 & 39,3 & 40,9 & 42,7 & 42,8 & 34,5 \\
\hline $\mathrm{C}_{2} \mathrm{H}_{6}$ & ${ }^{1} J_{\mathrm{CH}}$ & 120,7 & 119,1 & 108,2 & 113,2 & 106,9 & 113,2 & 117,1 & 111,8 & 118,4 & 121,1 & 117,0 & 123,9 & 125,2 & 122,4 & 125,2 \\
\hline $\mathrm{C}_{2} \mathrm{H}_{6}$ & ${ }^{2} J_{\mathrm{CH}}$ & $-3,4$ & $-3,4$ & $-2,1$ & $-1,8$ & $-2,0$ & $-2,6$ & $-2,4$ & $-2,6$ & $-3,2$ & $-3,0$ & $-3,1$ & $-3,8$ & $-3,7$ & $-3,8$ & $-4,7$ \\
\hline \multirow[t]{3}{*}{ Total } & & - & & & -16 & $-5,60$ & & & & & & & & & 4, & - \\
\hline & DMA & 9,86 & 17,46 & & 20,48 & 16,51 & & & 11,27 & & & & & & 9,02 & - \\
\hline & PDMA & 25,85 & 26,42 & 30,78 & 49,71 & 32,06 & 20,01 & 32,16 & 20,93 & 19,21 & 16,02 & 16,23 & 25,00 & 20,66 & 20,29 & - \\
\hline \multirow[t]{3}{*}{ CPI } & DM & $-40,13$ & $-22,36$ & $-22,82$ & $-34,95$ & $-7,07$ & $-18,68$ & -21 , & $-2,55$ & & & & & & & - \\
\hline & DMA & 42,60 & 3 & & & 27,44 & & & & & & & & & & - \\
\hline & PDMA & 48,06 & 52,17 & 32,13 & 75,14 & 39,21 & 16,43 & 44,06 & 21,65 & 24,50 & 16,51 & 20,06 & 39,78 & 31,81 & 33,13 & - \\
\hline \multirow[t]{3}{*}{ SPI } & & & & & & & & & & & & & & & & - \\
\hline & DMA & 3,19 & 3,32 & & 6,37 & 8,50 & 6,80 & & 7,33 & & & & 4,96 & & 5,49 & - \\
\hline & PDMA & 9,57 & 7,54 & 29,79 & 31,06 & 26,83 & 22,63 & 23,43 & 20,40 & 15,34 & 15,67 & 13,42 & 14,16 & 12,48 & 10,88 & - \\
\hline \multirow[t]{3}{*}{$\Delta \mathrm{CS}$} & DM & $-41,31$ & 23,42 & $-18,3$ & -32 , & $-2,5$ & 8 & & $-0,5$ & & -8 & 1,4 & & 4 , & 3, & - \\
\hline & DNDA & & & & & & & & & & & & & & & - \\
\hline & PDMA & 38,50 & 44,63 & 2,34 & 44,08 & 12,38 & $-6,20$ & 20,64 & 1,25 & 9,17 & 0,84 & 6,64 & 25,62 & 19,33 & 22,26 & - \\
\hline
\end{tabular}


Tabela 8.101: Constantes de acoplamento B98 com otimização de geometrias com correção vibracional no nível BHandH $40 \% E_{X}^{\mathrm{HF}}$ e base aug-pcJ-2.

\begin{tabular}{|c|c|c|c|c|c|c|c|c|c|c|c|c|c|}
\hline & $\% E_{X}^{\mathrm{HF}}$ & 21,98 & 21,98 & 40,00 & 40,00 & $\begin{array}{l}21,98 \\
40,00 \\
\text { Otm. }\end{array}$ & 50,00 & 50,00 & $\begin{array}{l}21,98 \\
50,00 \\
\text { Otm. }\end{array}$ & 60,00 & 60,00 & $\begin{array}{l}21,98 \\
60,00 \\
\text { Otm. }\end{array}$ & Exp. \\
\hline $\mathrm{HF}$ & ${ }^{1} J_{\mathrm{HF}}$ & 398,0 & 392,5 & 451,4 & 384,5 & 446,3 & 472,7 & 432,6 & 467,6 & 495,3 & 481,3 & 490,3 & 500,0 \\
\hline $\mathrm{CO}$ & ${ }^{1} J_{\mathrm{CO}}$ & 19,3 & 18,4 & 12,0 & 16,3 & 11,2 & 10,3 & 12,0 & 9,5 & 8,5 & 7,7 & 7,6 & 16,4 \\
\hline $\mathrm{H}_{2} \mathrm{O}$ & ${ }^{1} J_{\mathrm{OH}}$ & $-71,3$ & $-71,4$ & $-74,4$ & $-66,7$ & $-74,5$ & $-77,2$ & $-73,0$ & $-77,3$ & $-80,2$ & $-79,2$ & $-80,3$ & $-80,6$ \\
\hline $\mathrm{H}_{2} \mathrm{O}$ & ${ }^{2} J_{\mathrm{HH}}$ & $-5,5$ & $-5,1$ & $-3,7$ & $-3,7$ & $-3,3$ & $-5,0$ & $-4,7$ & $-4,7$ & $-6,5$ & $-5,8$ & $-6,1$ & $-7,3$ \\
\hline $\mathrm{NH}_{3}$ & ${ }^{1} J_{\mathrm{NH}}$ & 43,6 & 43,8 & 42,4 & 40,3 & 42,6 & 43,8 & 43,0 & 44,0 & 45,3 & 45,5 & 45,5 & 43,8 \\
\hline $\mathrm{NH}_{3}$ & ${ }^{2} J_{\mathrm{HH}}$ & $-8,6$ & $-8,4$ & $-6,7$ & $-6,6$ & $-6,5$ & $-7,9$ & $-7,6$ & $-7,7$ & $-9,3$ & $-8,7$ & $-9,1$ & $-9,6$ \\
\hline $\mathrm{PH}_{3}$ & ${ }^{1} J_{\mathrm{PH}}$ & 189,1 & 195,4 & 186,4 & 179,9 & 192,2 & 194,4 & 193,4 & 200,0 & 202,8 & 206,6 & 208,1 & 188,2 \\
\hline $\mathrm{PF}_{3}$ & ${ }^{1} J_{\mathrm{PF}}$ & $-1664,6$ & $-1558,3$ & $-1570,3$ & $-1467,1$ & $-1488,1$ & $-1547,3$ & $-1458,1$ & $-1469,0$ & $-1521,6$ & $-1438,0$ & $-1447,2$ & $-1441,0$ \\
\hline $\mathrm{BHF}_{2}$ & ${ }^{1} J_{\mathrm{BF}}$ & $-133,6$ & $-137,7$ & $-94,1$ & $-129,8$ & $-98,2$ & $-78,3$ & $-100,0$ & $-82,3$ & $-62,3$ & $-70,9$ & $-66,3$ & $-84,0$ \\
\hline $\mathrm{BF}_{3}$ & ${ }^{1} J_{\mathrm{BF}}$ & $-36,3$ & $-45,4$ & 4,8 & $-39,8$ & $-3,7$ & 22,3 & $-5,2$ & 13,9 & 40,0 & 28,4 & 31,8 & 15,0 \\
\hline $\mathrm{F}_{2} \mathrm{O}$ & ${ }^{1} J_{\mathrm{OF}}$ & $-350,0$ & $-277,7$ & $-351,3$ & $-360,8$ & $-275,6$ & $-396,1$ & $-325,8$ & $-312,4$ & $-450,4$ & $-291,6$ & $-355,0$ & $-300,0$ \\
\hline $\mathrm{CH}_{4}$ & ${ }^{1} J_{\mathrm{CH}}$ & 130,6 & 131,0 & 119,2 & 124,3 & 119,5 & 123,8 & 127,9 & 124,2 & 128,8 & 131,6 & 129,2 & 125,3 \\
\hline $\mathrm{CH}_{4}$ & ${ }^{2} J_{\mathrm{HH}}$ & $-12,8$ & $-12,8$ & $-10,1$ & $-9,8$ & $-10,1$ & $-11,3$ & $-11,1$ & $-11,3$ & $-12,5$ & $-12,4$ & $-12,5$ & $-12,8$ \\
\hline $\mathrm{C}_{2} \mathrm{H}_{2}$ & ${ }^{1} J_{\mathrm{CC}}$ & 213,3 & 213,1 & 205,4 & 207,9 & 205,4 & 212,6 & 214,7 & 212,3 & 221,0 & 222,0 & 220,4 & 174,8 \\
\hline $\mathrm{C}_{2} \mathrm{H}_{2}$ & ${ }^{1} J_{\mathrm{CH}}$ & 264,2 & 262,7 & 232,8 & 242,8 & 231,4 & 242,1 & 248,5 & 240,6 & 252,1 & 254,6 & 250,5 & 247,6 \\
\hline $\mathrm{C}_{2} \mathrm{H}_{2}$ & ${ }^{2} J_{\mathrm{CH}}$ & 53,2 & 53,3 & 53,6 & 53,8 & 53,7 & 53,6 & 53,6 & 53,7 & 53,0 & 53,1 & 53,2 & 50,1 \\
\hline $\mathrm{C}_{2} \mathrm{H}_{2}$ & ${ }^{3} J_{\mathrm{HH}}$ & 11,2 & 10,9 & 8,9 & 9,7 & 8,7 & 9,9 & 10,3 & 9,6 & 11,1 & 11,2 & 10,9 & 9,6 \\
\hline $\mathrm{C}_{2} \mathrm{H}_{4}$ & ${ }^{1} J_{\mathrm{CC}}$ & 77,7 & 80,1 & 76,8 & 79,2 & 79,3 & 81,7 & 84,5 & 84,0 & 87,6 & 90,1 & 89,5 & 67,6 \\
\hline $\mathrm{C}_{2} \mathrm{H}_{4}$ & ${ }^{1} J_{\mathrm{CH}}$ & 164,3 & 161,9 & 147,5 & 152,0 & 145,4 & 153,8 & 156,6 & 151,6 & 160,7 & 161,3 & 158,3 & 156,3 \\
\hline $\mathrm{C}_{2} \mathrm{H}_{4}$ & ${ }^{2} J_{\mathrm{CH}}$ & $-2,7$ & $-2,4$ & $-1,1$ & $-0,8$ & $-0,9$ & $-2,4$ & $-2,2$ & $-2,2$ & $-4,1$ & $-3,9$ & $-3,7$ & $-2,4$ \\
\hline $\mathrm{C}_{2} \mathrm{H}_{4}$ & ${ }^{2} J_{\mathrm{HH}}$ & 3,4 & 2,2 & 4,2 & 4,5 & 3,1 & 3,5 & 3,4 & 2,4 & 2,6 & 2,2 & 1,5 & 2,3 \\
\hline $\mathrm{C}_{2} \mathrm{H}_{4}$ & ${ }^{3} J_{\mathrm{HH}_{\mathrm{c}}}$ & 12,1 & 12,7 & 10,9 & 10,5 & 11,4 & 11,4 & 11,4 & 11,9 & 12,1 & 12,3 & 12,5 & 11,7 \\
\hline $\mathrm{C}_{2} \mathrm{H}_{4}$ & ${ }^{3} J_{\mathrm{HH}_{\mathrm{t}}}$ & 19,0 & 19,6 & 16,1 & 17,2 & 16,7 & 17,0 & 18,0 & 17,5 & 18,1 & 18,9 & 18,6 & 19,0 \\
\hline $\mathrm{C}_{2} \mathrm{H}_{6}$ & ${ }^{1} J_{\mathrm{CC}}$ & 35,2 & 36,8 & 35,9 & 37,0 & 37,5 & 39,0 & 40,4 & 40,6 & 42,3 & 43,9 & 43,9 & 34,5 \\
\hline $\mathrm{C}_{2} \mathrm{H}_{6}$ & ${ }^{1} J_{\mathrm{CH}}$ & 130,6 & 129,9 & 118,6 & 123,2 & 117,9 & 123,5 & 127,0 & 122,9 & 128,8 & 130,8 & 128,1 & 125,2 \\
\hline $\mathrm{C}_{2} \mathrm{H}_{6}$ & ${ }^{2} J_{\mathrm{CH}}$ & $-4,0$ & $-3,9$ & $-3,1$ & $-2,8$ & $-3,1$ & $-3,8$ & $-3,6$ & $-3,7$ & $-4,5$ & $-4,4$ & $-4,5$ & $-4,7$ \\
\hline \multirow[t]{3}{*}{ Total } & $\mathrm{DM}$ & $-14,22$ & $-7,84$ & $-8,96$ & $-9,61$ & $-3,33$ & $-6,11$ & $-2,27$ & $-0,36$ & $-3,32$ & 5,45 & 2,70 & - \\
\hline & DMA & 22,48 & 18,24 & 13,95 & 15,78 & 10,80 & 13,07 & 9,50 & 7,13 & 15,62 & 7,68 & 9,02 & - \\
\hline & PDMA & 26,14 & 26,61 & 19,97 & 33,87 & 21,00 & 13,94 & 17,62 & 10,18 & 20,46 & 16,07 & 17,76 & - \\
\hline \multirow[t]{3}{*}{ CPI } & DM & $-41,89$ & $-26,80$ & $-22,22$ & $-26,76$ & $-8,95$ & $-19,02$ & $-12,21$ & $-5,39$ & $-16,30$ & 3,13 & $-1,96$ & - \\
\hline & DMA & 44,78 & 34,82 & 24,53 & 30,49 & 16,52 & 23,85 & 15,37 & 9,30 & 27,99 & 8,11 & 12,53 & - \\
\hline & PDMA & 47,17 & 52,16 & 21,27 & 52,35 & 26,81 & 17,66 & 24,93 & 11,84 & 29,37 & 19,09 & 22,17 & - \\
\hline \multirow[t]{3}{*}{ SPI } & $\mathrm{DM}$ & 6,08 & 6,07 & 0,77 & 2,97 & 0,79 & 3,35 & 5,02 & 3,33 & 6,20 & 7,15 & 6,12 & - \\
\hline & DMA & 6,12 & 6,08 & 6,19 & 4,99 & 6,61 & 5,15 & 5,19 & 5,55 & 6,55 & 7,37 & 6,45 & - \\
\hline & PDMA & 10,72 & 7,87 & 19,01 & 20,32 & 16,74 & 11,21 & 12,26 & 8,96 & 13,93 & 13,85 & 14,52 & - \\
\hline \multirow[t]{3}{*}{$\Delta \mathrm{CS}$} & DM & $-47,97$ & $-32,87$ & $-22,98$ & $-29,74$ & $-9,74$ & $-22,37$ & $-17,23$ & $-8,72$ & $-22,50$ & $-4,02$ & $-8,08$ & - \\
\hline & DMA & 38,66 & 28,74 & 18,33 & 25,50 & 9,90 & 18,70 & 10,18 & 3,75 & 21,44 & 0,74 & 6,07 & - \\
\hline & PDMA & 36,45 & 44,29 & 2,26 & 32,03 & 10,07 & 6,45 & 12,67 & 2,88 & 15,44 & 5,25 & 7,65 & - \\
\hline
\end{tabular}


Tabela 8.102: Constantes de acoplamento B1B95 com otimização de geometrias com correção vibracional no nível BHandH $40 \% E_{X}^{\mathrm{HF}}$ e base aug-pcJ-2.

\begin{tabular}{|c|c|c|c|c|c|c|c|c|c|c|c|c|c|}
\hline & $\% E_{X}^{\mathrm{HF}}$ & 28,00 & 28,00 & 40,00 & 40,00 & $\begin{array}{l}28,00 \\
40,00 \\
\text { Otm. }\end{array}$ & 50,00 & 50,00 & $\begin{array}{l}28,00 \\
50,00 \\
\text { Otm. }\end{array}$ & 60,00 & 60,00 & $\begin{array}{c}28,00 \\
60,00 \\
\text { Otm. }\end{array}$ & Exp. \\
\hline HF & ${ }^{1} J_{\mathrm{HF}}$ & 437,2 & 437,2 & 466,1 & 482,4 & 466,1 & 490,4 & 519,2 & 490,4 & 514,8 & 555,3 & 514,8 & 500,0 \\
\hline $\mathrm{CO}$ & ${ }^{1} J_{\mathrm{CO}}$ & 19,2 & 17,3 & 16,9 & 13,4 & 14,9 & 14,8 & 10,2 & 12,9 & 12,6 & 7,0 & 10,7 & 16,4 \\
\hline $\mathrm{H}_{2} \mathrm{O}$ & ${ }^{1} J_{\mathrm{OH}}$ & $-76,1$ & $-77,2$ & $-79,2$ & $-82,3$ & $-80,2$ & $-81,8$ & $-86,2$ & $-82,7$ & $-84,4$ & $-90,0$ & $-85,3$ & $-80,6$ \\
\hline $\mathrm{H}_{2} \mathrm{O}$ & ${ }^{2} J_{\mathrm{HH}}$ & $-5,6$ & $-5,2$ & $-6,8$ & $-5,9$ & $-6,4$ & $-7,8$ & $-6,7$ & $-7,4$ & $-8,9$ & $-7,5$ & $-8,4$ & $-7,3$ \\
\hline $\mathrm{NH}_{3}$ & ${ }^{1} J_{\mathrm{NH}}$ & 44,7 & 45,3 & 45,6 & 46,8 & 46,2 & 46,3 & 47,9 & 46,9 & 47,1 & 48,9 & 47,6 & 43,8 \\
\hline $\mathrm{NH}_{3}$ & ${ }^{2} J_{\mathrm{HH}}$ & $-8,4$ & $-8,2$ & $-9,5$ & $-8,9$ & $-9,2$ & $-10,4$ & $-9,6$ & $-10,1$ & $-11,2$ & $-10,3$ & $-10,9$ & $-9,6$ \\
\hline $\mathrm{PH}_{3}$ & ${ }^{1} J_{\mathrm{PH}}$ & 160,5 & 168,5 & 169,2 & 180,2 & 176,7 & 176,3 & 189,5 & 183,5 & 183,3 & 198,3 & 190,1 & 188,2 \\
\hline $\mathrm{PF}_{3}$ & ${ }^{1} J_{\mathrm{PF}}$ & $-1643,7$ & $-1530,4$ & $-1604,6$ & $-1498,8$ & $-1498,2$ & $-1569,3$ & $-1465,0$ & $-1468,5$ & $-1531,9$ & $-1426,0$ & $-1436,8$ & $-1441,0$ \\
\hline $\mathrm{BHF}_{2}$ & ${ }^{1} J_{\mathrm{BF}}$ & $-132,1$ & $-130,2$ & $-112,0$ & $-103,4$ & $-110,3$ & $-95,5$ & $-81,7$ & $-93,8$ & $-79,1$ & $-60,5$ & $-77,4$ & $-84,0$ \\
\hline $\mathrm{BF}_{3}$ & ${ }^{1} J_{\mathrm{BF}}$ & $-29,2$ & $-30,4$ & $-7,5$ & $-0,1$ & $-8,6$ & 10,4 & 24,4 & 9,2 & 28,1 & 48,0 & 27,0 & 15,0 \\
\hline $\mathrm{F}_{2} \mathrm{O}$ & ${ }^{1} J_{\mathrm{OF}}$ & $-375,0$ & $-262,1$ & $-417,4$ & $-234,2$ & $-293,2$ & $-456,8$ & $-212,4$ & $-320,5$ & $-503,1$ & $-192,3$ & $-350,2$ & $-300,0$ \\
\hline $\mathrm{CH}_{4}$ & ${ }^{1} J_{\mathrm{CH}}$ & 126,7 & 126,4 & 128,4 & 127,5 & 128,1 & 129,8 & 128,3 & 129,5 & 131,3 & 129,2 & 130,9 & 125,3 \\
\hline $\mathrm{CH}_{4}$ & ${ }^{2} J_{\mathrm{HH}}$ & $-12,5$ & $-12,5$ & $-13,3$ & $-13,4$ & $-13,3$ & $-14,0$ & $-14,0$ & $-14,0$ & $-14,7$ & $-14,7$ & $-14,7$ & $-12,8$ \\
\hline $\mathrm{C}_{2} \mathrm{H}_{2}$ & ${ }^{1} J_{\mathrm{CC}}$ & 195,6 & 195,9 & 199,7 & 199,5 & 199,6 & 203,6 & 202,8 & 203,2 & 208,1 & 206,3 & 207,4 & 174,8 \\
\hline $\mathrm{C}_{2} \mathrm{H}_{2}$ & ${ }^{1} J_{\mathrm{CH}}$ & 259,3 & 256,3 & 261,9 & 256,8 & 258,9 & 264,3 & 257,4 & 261,1 & 266,8 & 258,0 & 263,5 & 247,6 \\
\hline $\mathrm{C}_{2} \mathrm{H}_{2}$ & ${ }^{2} J_{\mathrm{CH}}$ & 56,0 & 56,1 & 55,6 & 55,9 & 55,8 & 55,0 & 55,5 & 55,3 & 54,2 & 55,0 & 54,6 & 50,1 \\
\hline $\mathrm{C}_{2} \mathrm{H}_{2}$ & ${ }^{3} J_{\mathrm{HH}}$ & 10,9 & 10,5 & 11,7 & 11,0 & 11,3 & 12,5 & 11,6 & 12,0 & 13,5 & 12,2 & 12,9 & 9,6 \\
\hline $\mathrm{C}_{2} \mathrm{H}_{4}$ & ${ }^{1} J_{\mathrm{CC}}$ & 66,4 & 69,3 & 70,0 & 72,5 & 72,5 & 73,4 & 75,3 & 75,5 & 77,2 & 78,3 & 78,9 & 67,6 \\
\hline $\mathrm{C}_{2} \mathrm{H}_{4}$ & ${ }^{1} J_{\mathrm{CH}}$ & 160,6 & 157,2 & 163,1 & 158,6 & 159,5 & 165,3 & 159,8 & 161,5 & 167,7 & 161,1 & 163,7 & 156,3 \\
\hline $\mathrm{C}_{2} \mathrm{H}_{4}$ & ${ }^{2} J_{\mathrm{CH}}$ & $-1,4$ & $-1,2$ & $-2,6$ & $-2,3$ & $-2,3$ & $-3,7$ & $-3,3$ & $-3,3$ & $-5,0$ & $-4,3$ & $-4,5$ & $-2,4$ \\
\hline $\mathrm{C}_{2} \mathrm{H}_{4}$ & ${ }^{2} J_{\mathrm{HH}}$ & 4,5 & 3,1 & 3,6 & 2,2 & 2,2 & 2,8 & 1,4 & 1,4 & 1,9 & 0,6 & 0,6 & 2,3 \\
\hline $\mathrm{C}_{2} \mathrm{H}_{4}$ & ${ }^{3} J_{\mathrm{HH}_{\mathrm{c}}}$ & 12,4 & 13,2 & 12,8 & 13,7 & 13,5 & 13,1 & 14,1 & 13,9 & 13,6 & 14,5 & 14,3 & 11,7 \\
\hline $\mathrm{C}_{2} \mathrm{H}_{4}$ & ${ }^{3} J_{\mathrm{HH}_{\mathrm{t}}}$ & 19,5 & 20,1 & 19,9 & 20,4 & 20,5 & 20,4 & 20,7 & 20,9 & 20,9 & 21,1 & 21,4 & 19,0 \\
\hline $\mathrm{C}_{2} \mathrm{H}_{6}$ & ${ }^{1} J_{\mathrm{CC}}$ & 31,4 & 33,3 & 33,8 & 35,5 & 35,6 & 35,8 & 37,4 & 37,6 & 37,9 & 39,5 & 39,6 & 34,5 \\
\hline $\mathrm{C}_{2} \mathrm{H}_{6}$ & ${ }^{1} J_{\mathrm{CH}}$ & 126,8 & 124,8 & 128,7 & 126,1 & 126,7 & 130,3 & 127,0 & 128,2 & 131,9 & 128,0 & 129,8 & 125,2 \\
\hline $\mathrm{C}_{2} \mathrm{H}_{6}$ & ${ }^{2} J_{\mathrm{CH}}$ & $-3,7$ & $-3,7$ & $-4,2$ & $-4,3$ & $-4,2$ & $-4,7$ & $-4,7$ & $-4,7$ & $-5,2$ & $-5,2$ & $-5,2$ & $-4,7$ \\
\hline \multirow[t]{3}{*}{ Total } & DM & $-15,42$ & $-6,60$ & $-12,12$ & 0,15 & $-3,18$ & $-9,40$ & 5,92 & $-0,27$ & $-6,83$ & 11,75 & 2,67 & - \\
\hline & DMA & 20,33 & 13,79 & 17,56 & 9,63 & 8,71 & 15,93 & 8,90 & 6,43 & 17,41 & 13,73 & 7,99 & - \\
\hline & PDMA & 27,16 & 24,14 & 16,50 & 12,13 & 13,44 & 13,06 & 13,69 & 11,64 & 20,82 & 27,05 & 20,05 & - \\
\hline \multirow[t]{3}{*}{ CPI } & DM & $-40,85$ & $-19,66$ & $-34,55$ & $-4,70$ & $-13,01$ & $-29,48$ & 8,06 & $-7,36$ & $-24,87$ & 20,91 & $-1,79$ & - \\
\hline & DMA & 42,87 & 28,25 & 35,34 & 17,59 & 14,99 & 29,94 & 14,57 & 7,93 & 31,44 & 24,49 & 9,66 & - \\
\hline & PDMA & 43,52 & 41,46 & 24,32 & 19,20 & 21,76 & 13,26 & 14,83 & 9,19 & 22,43 & 35,64 & 16,97 & - \\
\hline \multirow[t]{3}{*}{ SPI } & DM & 3,23 & 2,98 & 4,33 & 3,71 & 4,02 & 5,32 & 4,35 & 4,93 & 6,40 & 5,03 & 5,94 & - \\
\hline & DMA & 3,80 & 3,19 & 4,52 & 3,80 & 4,10 & 5,65 & 4,75 & 5,33 & 7,12 & 5,83 & 6,77 & - \\
\hline & PDMA & 15,16 & 11,45 & 10,77 & 6,95 & 7,34 & 12,91 & 12,86 & 13,44 & 19,64 & 20,76 & 22,30 & - \\
\hline \multirow[t]{3}{*}{$\Delta \mathrm{CS}$} & DM & $-44,08$ & $-22,64$ & $-38,89$ & $-8,41$ & $-17,03$ & $-34,80$ & 3,72 & $-12,30$ & $-31,27$ & 15,88 & $-7,73$ & - \\
\hline & DMA & 39,07 & 25,05 & 30,82 & 13,79 & 10,89 & 24,28 & 9,83 & 2,59 & 24,32 & 18,66 & 2,90 & - \\
\hline & PDMA & 28,36 & 30,01 & 13,54 & 12,25 & 14,42 & 0,36 & 1,97 & $-4,25$ & 2,79 & 14,88 & $-5,33$ & - \\
\hline
\end{tabular}


Tabela 8.103: Constantes de acoplamento BHandH com otimização de geometrias com correção vibracional no nível BHandH $40 \% E_{X}^{\mathrm{HF}}$ e base aug-pcJ-2.

\begin{tabular}{|c|c|c|c|c|c|c|c|c|c|c|c|c|c|}
\hline & $\% E_{X}^{\mathrm{HF}}$ & 50,00 & 50,00 & 30,00 & 30,00 & $\begin{array}{l}50,00 \\
30,00 \\
\text { Otm. }\end{array}$ & 40,00 & 40,00 & $\begin{array}{l}50,00 \\
40,00 \\
\text { Otm. }\end{array}$ & 60,00 & 60,00 & $\begin{array}{l}50,00 \\
60,00 \\
\text { Otm. }\end{array}$ & Exp. \\
\hline $\mathrm{HF}$ & ${ }^{1} J_{\mathrm{HF}}$ & 497,6 & 513,5 & 451,2 & 439,7 & 467,6 & 474,0 & 476,4 & 490,2 & 522,1 & 551,1 & 537,7 & 500,0 \\
\hline $\mathrm{CO}$ & ${ }^{1} J_{\mathrm{CO}}$ & 14,5 & 8,8 & 19,5 & 15,7 & 13,6 & 17,1 & 12,3 & 11,2 & 11,8 & 5,2 & 6,1 & 16,4 \\
\hline $\mathrm{H}_{2} \mathrm{O}$ & ${ }^{1} J_{\mathrm{OH}}$ & $-82,5$ & $-86,3$ & $-76,6$ & $-77,3$ & $-80,5$ & $-79,5$ & $-81,9$ & $-83,4$ & $-85,7$ & $-90,8$ & $-89,4$ & $-80,6$ \\
\hline $\mathrm{H}_{2} \mathrm{O}$ & ${ }^{2} J_{\mathrm{HH}}$ & $-8,0$ & $-6,5$ & $-5,4$ & $-4,4$ & $-3,9$ & $-6,6$ & $-5,4$ & $-5,2$ & $-9,4$ & $-7,6$ & $-7,8$ & $-7,3$ \\
\hline $\mathrm{NH}_{3}$ & ${ }^{1} J_{\mathrm{NH}}$ & 46,2 & 48,4 & 43,6 & 45,2 & 45,8 & 44,9 & 46,9 & 47,1 & 47,7 & 50,2 & 49,9 & 43,8 \\
\hline $\mathrm{NH}_{3}$ & ${ }^{2} J_{\mathrm{HH}}$ & $-10,2$ & $-9,0$ & $-7,8$ & $-6,7$ & $-6,6$ & $-9,0$ & $-7,8$ & $-7,8$ & $-11,6$ & $-10,1$ & $-10,2$ & $-9,6$ \\
\hline $\mathrm{PH}_{3}$ & ${ }^{1} J_{\mathrm{PH}}$ & 175,8 & 187,8 & 155,7 & 160,1 & 168,5 & 165,6 & 174,0 & 178,0 & 186,4 & 201,6 & 197,9 & 188,2 \\
\hline $\mathrm{PF}_{3}$ & ${ }^{1} J_{\mathrm{PF}}$ & $-1668,6$ & $-1552,7$ & $-1741,7$ & $-1620,2$ & $-1622,4$ & $-1707,2$ & $-1589,6$ & $-1589,4$ & $-1626,5$ & $-1510,2$ & $-1513,0$ & $-1441,0$ \\
\hline $\mathrm{BHF}_{2}$ & ${ }^{1} J_{\mathrm{BF}}$ & $-99,7$ & $-77,3$ & $-137,3$ & $-120,9$ & $-114,0$ & $-118,5$ & $-99,0$ & $-95,7$ & $-80,6$ & $-55,8$ & $-58,8$ & $-84,0$ \\
\hline $\mathrm{BF}_{3}$ & ${ }^{1} J_{\mathrm{BF}}$ & 12,9 & 36,6 & $-25,5$ & $-9,5$ & $-0,7$ & $-6,3$ & 13,6 & 17,8 & 32,4 & 59,2 & 55,4 & 15,0 \\
\hline $\mathrm{F}_{2} \mathrm{O}$ & ${ }^{1} J_{\mathrm{OF}}$ & $-478,1$ & $-178,6$ & $-393,6$ & $-187,0$ & $-136,9$ & $-432,9$ & $-182,3$ & $-157,4$ & $-534,5$ & $-176,4$ & $-201,1$ & $-300,0$ \\
\hline $\mathrm{CH}_{4}$ & ${ }^{1} J_{\mathrm{CH}}$ & 127,2 & 126,7 & 119,1 & 119,7 & 118,6 & 123,0 & 123,0 & 122,6 & 131,7 & 130,4 & 131,1 & 125,3 \\
\hline $\mathrm{CH}_{4}$ & ${ }^{2} J_{\mathrm{HH}}$ & $-13,6$ & $-13,6$ & $-11,3$ & $-11,3$ & $-11,3$ & $-12,4$ & $-12,4$ & $-12,4$ & $-14,8$ & $-14,8$ & $-14,8$ & $-12,8$ \\
\hline $\mathrm{C}_{2} \mathrm{H}_{2}$ & ${ }^{1} J_{\mathrm{CC}}$ & 202,8 & 202,3 & 189,8 & 190,8 & 190,8 & 195,8 & 196,3 & 196,2 & 211,0 & 209,0 & 209,5 & 174,8 \\
\hline $\mathrm{C}_{2} \mathrm{H}_{2}$ & ${ }^{1} J_{\mathrm{CH}}$ & 262,6 & 256,4 & 248,1 & 246,1 & 242,5 & 255,1 & 251,1 & 249,2 & 270,9 & 262,2 & 264,2 & 247,6 \\
\hline $\mathrm{C}_{2} \mathrm{H}_{2}$ & ${ }^{2} J_{\mathrm{CH}}$ & 53,4 & 54,2 & 53,6 & 53,9 & 53,9 & 53,7 & 54,2 & 54,2 & 52,6 & 53,8 & 53,7 & 50,1 \\
\hline $\mathrm{C}_{2} \mathrm{H}_{2}$ & ${ }^{3} J_{\mathrm{HH}}$ & 12,3 & 11,2 & 9,9 & 9,4 & 9,1 & 11,0 & 10,3 & 10,1 & 13,9 & 12,4 & 12,7 & 9,6 \\
\hline $\mathrm{C}_{2} \mathrm{H}_{4}$ & ${ }^{1} J_{\mathrm{CC}}$ & 72,7 & 75,2 & 62,2 & 66,1 & 66,0 & 67,1 & 70,4 & 70,3 & 79,3 & 80,6 & 80,9 & 67,6 \\
\hline $\mathrm{C}_{2} \mathrm{H}_{4}$ & ${ }^{1} J_{\mathrm{CH}}$ & 162,4 & 157,5 & 151,7 & 148,9 & 147,4 & 156,8 & 153,1 & 152,3 & 168,6 & 162,2 & 163,2 & 156,3 \\
\hline $\mathrm{C}_{2} \mathrm{H}_{4}$ & ${ }^{2} J_{\mathrm{CH}}$ & $-4,1$ & $-3,7$ & $-1,6$ & $-1,5$ & $-1,5$ & $-2,7$ & $-2,5$ & $-2,5$ & $-5,9$ & $-5,1$ & $-5,1$ & $-2,4$ \\
\hline $\mathrm{C}_{2} \mathrm{H}_{4}$ & ${ }^{2} J_{\mathrm{HH}}$ & 2,5 & 1,5 & 4,1 & 3,3 & 3,1 & 3,4 & 2,4 & 2,3 & 1,4 & 0,5 & 0,6 & 2,3 \\
\hline $\mathrm{C}_{2} \mathrm{H}_{4}$ & ${ }^{3} J_{\mathrm{HH}_{\mathrm{C}}}$ & 13,6 & 14,7 & 12,5 & 13,6 & 13,7 & 13,0 & 14,1 & 14,2 & 14,4 & 15,4 & 15,4 & 11,7 \\
\hline $\mathrm{C}_{2} \mathrm{H}_{4}$ & ${ }^{3} J_{\mathrm{HH}_{\mathrm{t}}}$ & 20,1 & 20,7 & 18,4 & 19,4 & 19,1 & 19,2 & 20,0 & 19,9 & 21,3 & 21,6 & 21,7 & 19,0 \\
\hline $\mathrm{C}_{2} \mathrm{H}_{6}$ & ${ }^{1} J_{\mathrm{CC}}$ & 34,1 & 37,0 & 27,7 & 31,4 & 30,8 & 30,8 & 34,1 & 33,8 & 37,5 & 39,7 & 40,3 & 34,5 \\
\hline $\mathrm{C}_{2} \mathrm{H}_{6}$ & ${ }^{1} J_{\mathrm{CH}}$ & 127,6 & 124,6 & 119,1 & 117,1 & 116,4 & 123,3 & 120,8 & 120,4 & 132,2 & 128,6 & 129,0 & 125,2 \\
\hline $\mathrm{C}_{2} \mathrm{H}_{6}$ & ${ }^{2} J_{\mathrm{CH}}$ & $-4,5$ & $-4,6$ & $-3,3$ & $-3,5$ & $-3,4$ & $-3,9$ & $-4,0$ & $-4,0$ & $-5,1$ & $-5,2$ & $-5,2$ & $-4,7$ \\
\hline \multirow[t]{3}{*}{ Total } & $\mathrm{DM}$ & $-14,46$ & 3,84 & $-21,65$ & $-7,96$ & $-4,59$ & $-18,08$ & $-2,19$ & $-0,50$ & $-10,92$ & 10,10 & 8,42 & - \\
\hline & DMA & 19,87 & 13,75 & 24,45 & 19,51 & 19,82 & 21,32 & 14,63 & 14,92 & 23,11 & 17,67 & 16,04 & - \\
\hline & PDMA & 12,89 & 18,51 & 27,08 & 21,10 & 19,55 & 16,60 & 10,06 & 10,66 & 26,08 & 33,29 & 31,69 & - \\
\hline \multirow[t]{3}{*}{ CPI } & $\mathrm{DM}$ & $-40,09$ & 3,98 & $-50,80$ & $-18,75$ & $-10,04$ & $-45,39$ & $-7,61$ & $-3,23$ & $-35,35$ & 15,95 & 11,44 & - \\
\hline & DMA & 40,53 & 26,78 & 52,76 & 41,20 & 41,24 & 46,15 & 30,25 & 30,97 & 43,85 & 32,57 & 28,20 & - \\
\hline & PDMA & 13,65 & 25,84 & 43,79 & 33,26 & 29,44 & 26,09 & 15,22 & 17,09 & 28,12 & 45,13 & 40,98 & - \\
\hline \multirow[t]{3}{*}{ SPI } & $\mathrm{DM}$ & 4,33 & 3,73 & $-0,27$ & $-0,05$ & $-0,59$ & 1,94 & 1,79 & 1,50 & 6,99 & 5,81 & 6,21 & - \\
\hline & DMA & 4,72 & 4,20 & 3,69 & 3,61 & 4,11 & 3,10 & 3,17 & 3,14 & 7,90 & 6,75 & 7,13 & - \\
\hline & PDMA & 12,33 & 13,13 & 14,83 & 12,19 & 12,30 & 9,64 & 6,28 & 5,94 & 24,58 & 24,61 & 24,87 & - \\
\hline \multirow[t]{3}{*}{$\Delta \mathrm{CS}$} & $\mathrm{DM}$ & $-44,42$ & 0,25 & $-50,53$ & $-18,70$ & $-9,44$ & $-47,33$ & $-9,40$ & $-4,73$ & $-42,34$ & 10,14 & 5,23 & - \\
\hline & DMA & 35,81 & 22,58 & 49,08 & 37,59 & 37,12 & 43,05 & 27,07 & 27,83 & 35,95 & 25,83 & 21,07 & - \\
\hline & PDMA & 1,33 & 12,71 & 28,96 & 21,07 & 17,15 & 16,46 & 8,94 & 11,15 & 3,54 & 20,52 & 16,10 & - \\
\hline
\end{tabular}


Tabela 8.104: Constantes de acoplamento PBE0 com otimização de geometrias com correção vibracional no nível BHandH $40 \% E_{X}^{\mathrm{HF}}$ e base aug-pcJ-2.

\begin{tabular}{|c|c|c|c|c|c|c|c|c|c|c|c|c|c|c|c|c|}
\hline & $\% E_{X}^{\mathrm{HF}}$ & 25,00 & 25,00 & 20,00 & 20,00 & $\begin{array}{l}25,00 \\
20,00 \\
\text { Otm. }\end{array}$ & 30,00 & 30,00 & $\begin{array}{l}25,00 \\
30,00 \\
\text { Otm. }\end{array}$ & 40,00 & 40,00 & $\begin{array}{l}25,00 \\
40,00 \\
\text { Otm. }\end{array}$ & 50,00 & 50,00 & $\begin{array}{l}25,00 \\
50,00 \\
\text { Otm. }\end{array}$ & Exp. \\
\hline $\mathrm{HF}$ & ${ }^{1} J_{\mathrm{HF}}$ & 397,6 & 394,5 & 386,5 & 376,1 & 383,4 & 408,7 & 412,7 & 405,6 & 431,1 & 448,8 & 428,1 & 453,7 & 484,5 & 450,8 & 500,0 \\
\hline $\mathrm{CO}$ & ${ }^{1} J_{\mathrm{CO}}$ & 20,7 & 19,2 & 21,6 & 20,7 & 20,0 & 19,9 & 17,7 & 18,3 & 18,1 & 14,6 & 16,5 & 16,2 & 11,7 & 14,7 & 16,4 \\
\hline $\mathrm{H}_{2} \mathrm{O}$ & ${ }^{1} J_{\mathrm{OH}}$ & $-71,8$ & $-72,3$ & $-70,6$ & $-70,3$ & $-71,1$ & $-73,0$ & $-74,2$ & $-73,5$ & $-75,4$ & $-78,4$ & $-75,8$ & $-77,8$ & $-82,2$ & $-78,2$ & $-80,6$ \\
\hline $\mathrm{H}_{2} \mathrm{O}$ & ${ }^{2} J_{\mathrm{HH}}$ & $-5,9$ & $-5,5$ & $-5,3$ & $-5,0$ & $-5,0$ & $-6,4$ & $-6,0$ & $-6,0$ & $-7,5$ & $-6,7$ & $-7,1$ & $-8,6$ & $-7,6$ & $-8,2$ & $-7,3$ \\
\hline $\mathrm{NH}_{3}$ & ${ }^{1} J_{\mathrm{NH}}$ & 43,2 & 43,7 & 42,9 & 43,0 & 43,3 & 43,6 & 44,3 & 44,1 & 44,3 & 45,5 & 44,8 & 45,0 & 46,6 & 45,5 & 43,8 \\
\hline $\mathrm{NH}_{3}$ & ${ }^{2} J_{\mathrm{HH}}$ & $-9,2$ & $-8,9$ & $-8,7$ & $-8,6$ & $-8,5$ & $-9,7$ & $-9,4$ & $-9,4$ & $-10,6$ & $-10,1$ & $-10,4$ & $-11,6$ & $-10,9$ & $-11,3$ & $-9,6$ \\
\hline $\mathrm{PH}_{3}$ & ${ }^{1} J_{\mathrm{PH}}$ & 147,3 & 154,0 & 143,1 & 148,2 & 149,9 & 151,4 & 159,6 & 158,0 & 159,6 & 170,7 & 165,9 & 167,8 & 181,3 & 173,8 & 188,2 \\
\hline $\mathrm{PF}_{3}$ & ${ }^{1} J_{\mathrm{PF}}$ & $-1730,3$ & $-1625,2$ & $-1746,3$ & $-1632,4$ & $-1637,9$ & $-1713,5$ & $-1610,3$ & $-1611,7$ & $-1677,6$ & $-1579,6$ & $-1582,1$ & $-1639,0$ & $-1542,1$ & $-1549,7$ & $-1441,0$ \\
\hline $\mathrm{BHF}_{2}$ & ${ }^{1} J_{\mathrm{BF}}$ & $-135,5$ & $-135,3$ & $-143,7$ & $-146,7$ & $-143,5$ & $-127,2$ & $-124,4$ & $-127,0$ & $-111,0$ & $-102,2$ & $-110,8$ & $-94,9$ & $-81,1$ & $-94,7$ & $-84,0$ \\
\hline $\mathrm{BF}_{3}$ & ${ }^{1} J_{\mathrm{BF}}$ & $-32,7$ & $-35,7$ & $-41,6$ & $-49,1$ & $-44,6$ & $-23,9$ & $-23,3$ & $-26,8$ & $-6,4$ & 1,4 & $-9,2$ & 10,7 & 25,1 & 8,0 & 15,0 \\
\hline $\mathrm{F}_{2} \mathrm{O}$ & ${ }^{1} J_{\mathrm{OF}}$ & $-388,0$ & $-264,1$ & $-368,0$ & $-274,5$ & $-249,4$ & $-408,7$ & $-254,7$ & $-279,1$ & $-453,6$ & $-235,1$ & $-310,5$ & $-506,6$ & $-215,1$ & $-344,9$ & $-300,0$ \\
\hline $\mathrm{CH}_{4}$ & ${ }^{1} J_{\mathrm{CH}}$ & 125,1 & 125,3 & 124,4 & 124,8 & 124,6 & 125,8 & 125,8 & 126,1 & 127,3 & 126,8 & 127,5 & 128,8 & 127,8 & 129,1 & 125,3 \\
\hline $\mathrm{CH}_{4}$ & ${ }^{2} J_{\mathrm{HH}}$ & $-14,1$ & $-14,0$ & $-13,7$ & $-13,6$ & $-13,6$ & $-14,5$ & $-14,5$ & $-14,4$ & $-15,3$ & $-15,3$ & $-15,3$ & $-16,1$ & $-16,1$ & $-16,1$ & $-12,8$ \\
\hline $\mathrm{C}_{2} \mathrm{H}_{2}$ & $J_{\mathrm{CC}}$ & 196,8 & 197,0 & 195,0 & 195,4 & 195,4 & 198,7 & 198,7 & 198,8 & 203,0 & 202,4 & 202,8 & 208,0 & 206,4 & 207,5 & 174,8 \\
\hline $\mathrm{C}_{2} \mathrm{H}_{2}$ & $J_{\mathrm{CH}}$ & 259,3 & 257,6 & 257,9 & 257,1 & 256,2 & 260,7 & 258,1 & 259,0 & 263,8 & 259,2 & 261,9 & 267,2 & 260,6 & 265,2 & 247,6 \\
\hline $\mathrm{C}_{2} \mathrm{H}_{2}$ & ${ }^{2} J_{\mathrm{CH}}$ & 53,9 & 54,1 & 54,1 & 54,3 & 54,3 & 53,6 & 53,9 & 53,8 & 52,6 & 53,2 & 53,0 & 51,3 & 52,4 & 51,8 & 50,1 \\
\hline $\mathrm{C}_{2} \mathrm{H}_{2}$ & ${ }^{3} J_{\mathrm{HH}}$ & 12,9 & 12,5 & 12,4 & 12,2 & 12,1 & 13,4 & 12,9 & 13,0 & 14,6 & 13,8 & 14,2 & 16,1 & 14,8 & 15,6 & 9,6 \\
\hline $\mathrm{C}_{2} \mathrm{H}_{4}$ & ${ }^{1} J_{\mathrm{CC}}$ & 69,1 & 71,7 & 7,4 & 70,2 & 70,2 & 70,8 & 73,3 & 73,3 & 74,8 & 76,6 & 76,9 & 79,5 & 80,3 & 81,0 & 67,6 \\
\hline $\mathrm{C}_{2} \mathrm{H}_{4}$ & ${ }^{1} J_{\mathrm{CH}}$ & 159,1 & 156,4 & 157,9 & 155,6 & 155,3 & 160,3 & 157,1 & 157,5 & 162,9 & 158,7 & 159,9 & 165,8 & 160,5 & 162,6 & 156,3 \\
\hline $\mathrm{C}_{2} \mathrm{H}_{4}$ & ${ }^{2} J_{\mathrm{CH}}$ & $-3,3$ & $-3,0$ & $-2,8$ & $-2,5$ & $-2,5$ & $-4,0$ & $-3,6$ & $-3,6$ & $-5,4$ & $-4,8$ & $-4,9$ & $-7,2$ & $-6,2$ & $-6,5$ & $-2,4$ \\
\hline $\mathrm{C}_{2} \mathrm{H}_{4}$ & ${ }^{2} J_{\mathrm{HH}}$ & 2,6 & 1,5 & 3,1 & 2,0 & 1,9 & 2,1 & 1,0 & 1,0 & 1,0 & 0,0 & 0,1 & $-0,2$ & $-1,1$ & $-1,1$ & 2,3 \\
\hline $\mathrm{C}_{2} \mathrm{H}_{4}$ & ${ }^{3} J_{\mathrm{HH}_{\mathrm{c}}}$ & 13,0 & 13,7 & 12,8 & 13,4 & 13,5 & 13,3 & 14,0 & 13,9 & 13,9 & 14,6 & 14,5 & 14,8 & 15,3 & 15,2 & 11,7 \\
\hline $\mathrm{C}_{2} \mathrm{H}_{4}$ & ${ }^{3} J_{\mathrm{HH}_{\mathrm{t}}}$ & 20,3 & 20,9 & 20,0 & 20,7 & 20,7 & 20,6 & 21,2 & 21,2 & 21,4 & 21,7 & 21,9 & 22,4 & 22,4 & 22,8 & 19,0 \\
\hline $\mathrm{C}_{2} \mathrm{H}_{6}$ & ${ }^{1} J_{\mathrm{CC}}$ & 31,2 & 33,4 & 30 , & 32 , & 32,5 & 32,1 & & 34 & 34,1 & & 36,3 & 36,0 & & 38,2 & 34,5 \\
\hline $\mathrm{C}_{2} \mathrm{H}_{6}$ & ${ }^{1} J_{\mathrm{CH}}$ & 125,3 & 123,8 & 124,5 & 123,3 & 123,0 & 126,1 & 124,4 & 124,7 & 127,8 & 125,6 & 126,3 & 129,5 & 126,7 & 128,0 & 125,2 \\
\hline $\mathrm{C}_{2} \mathrm{H}_{6}$ & ${ }^{2} J_{\mathrm{CH}}$ & $-4,3$ & $-4,3$ & $-4,1$ & $-4,1$ & $-4,1$ & $-4,5$ & $-4,6$ & $-4,6$ & $-5,1$ & $-5,1$ & $-5,1$ & $-5,6$ & $-5,6$ & $-5,6$ & $-4,7$ \\
\hline \multirow[t]{3}{*}{ Total } & & - & & & & & & & & & & & & & & - \\
\hline & DMA & 26,52 & 0,32 & 27,58 & 22,16 & 22,63 & & & & & & & & & 13,47 & - \\
\hline & PDMA & 26,66 & 26,65 & 29,83 & 29,82 & 28,75 & 24,78 & 23,98 & 24,91 & 24,73 & 21,25 & 23,81 & 27,68 & 26,30 & 26,60 & - \\
\hline \multirow[t]{3}{*}{ CPI } & DM & $-55,05$ & $-34,23$ & $-57,36$ & $-39,95$ & $-36,75$ & & & $-31,67$ & & & & & & & - \\
\hline & MA & 57,75 & & & & & & & & & & & & & & - \\
\hline & PDMA & 48,43 & 47,51 & 56,53 & 59,32 & 56,38 & 40,76 & 36,35 & 38,60 & 27,50 & 17,65 & 22,97 & 17,31 & 15,23 & 13,33 & - \\
\hline \multirow[t]{3}{*}{ SPI } & & & & & & & & & & & & & & & & - \\
\hline & DMA & 3,61 & & & 3,32 & 3,32 & & & 3,96 & & & 5,41 & 7,28 & & 7,13 & - \\
\hline & PDMA & 10,68 & 11,34 & 10,26 & 8,19 & 8,48 & 13,06 & 14,91 & 14,88 & 22,70 & 23,90 & 24,43 & 35,29 & 34,42 & 36,34 & - \\
\hline \multirow[t]{3}{*}{$\Delta \mathrm{CS}$} & DM & $-57,90$ & 6 & & & -39 & & & & & & & & & & - \\
\hline & $\operatorname{lvin}$ & 54,14 & & & & & & & & & & & & & & - \\
\hline & PDMA & 37,75 & 36,17 & 46,28 & 51,14 & 47,90 & 27,70 & 21,44 & 23,72 & 4,80 & $-6,25$ & $-1,46$ & $-17,97$ & $-19,19$ & $-23,00$ & - \\
\hline
\end{tabular}


Tabela 8.105: Constantes de acoplamento B971 com otimização de geometrias com correção vibracional no nível PBE0 $40 \% E_{X}^{\mathrm{HF}}$ e base aug-pcJ-2.

\begin{tabular}{|c|c|c|c|c|c|c|c|c|c|c|c|c|c|}
\hline & $\% E_{X}^{\mathrm{HF}}$ & 21,00 & 21,00 & 40,00 & 40,00 & $\begin{array}{l}21,00 \\
40,00 \\
\text { Otm. }\end{array}$ & 50,00 & 50,00 & $\begin{array}{l}21,00 \\
50,00 \\
\text { Otm. }\end{array}$ & 60,00 & 60,00 & $\begin{array}{l}21,00 \\
60,00 \\
\text { Otm. }\end{array}$ & Exp. \\
\hline $\mathrm{HF}$ & ${ }^{1} J_{\mathrm{HF}}$ & 414,3 & 406,5 & 464,9 & 403,8 & 457,7 & 485,8 & 451,1 & 478,7 & 508,0 & 498,6 & 500,9 & 500,0 \\
\hline $\mathrm{CO}$ & ${ }^{1} J_{\mathrm{CO}}$ & 18,1 & 17,6 & 11,4 & 15,3 & 10,9 & 9,7 & 11,1 & 9,3 & 8,0 & 6,9 & 7,5 & 16,4 \\
\hline $\mathrm{H}_{2} \mathrm{O}$ & ${ }^{1} J_{\mathrm{OH}}$ & $-73,0$ & $-72,8$ & $-75,6$ & $-68,6$ & $-75,4$ & $-78,3$ & $-74,6$ & $-78,1$ & $-81,1$ & $-80,5$ & $-81,0$ & $-80,6$ \\
\hline $\mathrm{H}_{2} \mathrm{O}$ & ${ }^{2} J_{\mathrm{HH}}$ & $-5,0$ & $-4,7$ & $-3,6$ & $-3,6$ & $-3,3$ & $-4,9$ & $-4,6$ & $-4,6$ & $-6,2$ & $-5,6$ & $-5,9$ & $-7,3$ \\
\hline $\mathrm{NH}_{3}$ & ${ }^{1} J_{\mathrm{NH}}$ & 43,8 & 43,9 & 42,4 & 40,5 & 42,5 & 43,6 & 42,9 & 43,7 & 44,9 & 45,3 & 45,1 & 43,8 \\
\hline $\mathrm{NH}_{3}$ & ${ }^{2} J_{\mathrm{HH}}$ & $-8,3$ & $-8,2$ & $-6,6$ & $-6,6$ & $-6,4$ & $-7,8$ & $-7,5$ & $-7,6$ & $-9,1$ & $-8,5$ & $-8,9$ & $-9,6$ \\
\hline $\mathrm{PH}_{3}$ & ${ }^{1} J_{\mathrm{PH}}$ & 183,2 & 188,9 & 181,4 & 175,2 & 186,5 & 189,1 & 188,2 & 194,0 & 197,1 & 201,0 & 201,8 & 188,2 \\
\hline $\mathrm{PF}_{3}$ & ${ }^{1} J_{\mathrm{PF}}$ & $-1654,5$ & $-1545,5$ & $-1559,9$ & $-1457,5$ & $-1475,9$ & $-1536,9$ & $-1447,5$ & $-1457,2$ & $-1511,2$ & $-1426,8$ & $-1435,8$ & $-1441,0$ \\
\hline $\mathrm{BHF}_{2}$ & ${ }^{1} J_{\mathrm{BF}}$ & $-128,2$ & $-134,2$ & $-89,5$ & $-122,5$ & $-95,5$ & $-74,0$ & $-92,7$ & $-79,9$ & $-58,4$ & $-63,8$ & $-64,2$ & $-84,0$ \\
\hline $\mathrm{BF}_{3}$ & ${ }^{1} J_{\mathrm{BF}}$ & $-30,1$ & $-41,6$ & 10,2 & $-30,9$ & $-0,7$ & 27,5 & 3,5 & 16,8 & 44,9 & 37,0 & 34,5 & 15,0 \\
\hline $\mathrm{F}_{2} \mathrm{O}$ & ${ }^{1} J_{\mathrm{OF}}$ & $-334,1$ & $-272,5$ & $-343,0$ & $-333,9$ & $-277,7$ & $-385,7$ & $-297,0$ & $-313,9$ & $-436,5$ & $-261,1$ & $-355,3$ & $-300,0$ \\
\hline $\mathrm{CH}_{4}$ & ${ }^{1} J_{\mathrm{CH}}$ & 131,2 & 131,7 & 118,9 & 123,8 & 119,3 & 123,0 & 126,8 & 123,5 & 127,4 & 129,9 & 127,8 & 125,3 \\
\hline $\mathrm{CH}_{4}$ & ${ }^{2} J_{\mathrm{HH}}$ & $-12,3$ & $-12,3$ & $-9,9$ & $-9,6$ & $-9,8$ & $-11,0$ & $-10,8$ & $-10,9$ & $-12,1$ & $-12,0$ & $-12,1$ & $-12,8$ \\
\hline $\mathrm{C}_{2} \mathrm{H}_{2}$ & ${ }^{1} J_{\mathrm{CC}}$ & 214,7 & 214,7 & 205,9 & 208,3 & 206,0 & 212,5 & 214,5 & 212,4 & 220,3 & 221,1 & 220,0 & 174,8 \\
\hline $\mathrm{C}_{2} \mathrm{H}_{2}$ & ${ }^{1} J_{\mathrm{CH}}$ & 264,5 & 263,4 & 232,7 & 242,2 & 231,8 & 241,1 & 247,1 & 240,1 & 250,2 & 252,2 & 249,1 & 247,6 \\
\hline $\mathrm{C}_{2} \mathrm{H}_{2}$ & ${ }^{2} J_{\mathrm{CH}}$ & 53,4 & 53,5 & 53,4 & 53,5 & 53,4 & 53,2 & 53,3 & 53,3 & 52,7 & 52,8 & 52,8 & 50,1 \\
\hline $\mathrm{C}_{2} \mathrm{H}_{2}$ & ${ }^{3} J_{\mathrm{HH}}$ & 11,2 & 11,0 & 9,1 & 9,8 & 8,9 & 10,0 & 10,4 & 9,8 & 11,2 & 11,2 & 11,0 & 9,6 \\
\hline $\mathrm{C}_{2} \mathrm{H}_{4}$ & ${ }^{1} J_{\mathrm{CC}}$ & 79,1 & 81,5 & 77,4 & 79,7 & 79,8 & 81,8 & 84,5 & 84,1 & 87,2 & 89,6 & 89,1 & 67,6 \\
\hline $\mathrm{C}_{2} \mathrm{H}_{4}$ & ${ }^{1} J_{\mathrm{CH}}$ & 164,8 & 162,7 & 147,4 & 151,6 & 145,6 & 153,2 & 155,5 & 151,2 & 159,4 & 159,6 & 157,2 & 156,3 \\
\hline $\mathrm{C}_{2} \mathrm{H}_{4}$ & ${ }^{2} J_{\mathrm{CH}}$ & $-2,6$ & $-2,3$ & $-1,3$ & $-0,9$ & $-1,1$ & $-2,6$ & $-2,4$ & $-2,3$ & $-4,2$ & $-4,0$ & $-3,8$ & $-2,4$ \\
\hline $\mathrm{C}_{2} \mathrm{H}_{4}$ & ${ }^{2} J_{\mathrm{HH}}$ & 3,8 & 2,6 & 4,3 & 4,5 & 3,2 & 3,6 & 3,5 & 2,5 & 2,7 & 2,3 & 1,6 & 2,3 \\
\hline $\mathrm{C}_{2} \mathrm{H}_{4}$ & ${ }^{3} J_{\mathrm{HH}_{\mathrm{c}}}$ & 12,1 & 12,6 & 10,9 & 10,7 & 11,4 & 11,4 & 11,5 & 11,9 & 12,0 & 12,4 & 12,5 & 11,7 \\
\hline $\mathrm{C}_{2} \mathrm{H}_{4}$ & ${ }^{3} J_{\mathrm{HH}_{\mathrm{t}}}$ & 19,1 & 19,7 & 16,3 & 17,3 & 16,8 & 17,1 & 18,0 & 17,6 & 18,1 & 18,9 & 18,6 & 19,0 \\
\hline $\mathrm{C}_{2} \mathrm{H}_{6}$ & ${ }^{1} J_{\mathrm{CC}}$ & 35,8 & 37,4 & 36,0 & 37,2 & 37,6 & 38,7 & 40,3 & 40,4 & 41,7 & 43,4 & 43,3 & 34,5 \\
\hline $\mathrm{C}_{2} \mathrm{H}_{6}$ & ${ }^{1} J_{\mathrm{CH}}$ & 130,9 & 130,3 & 118,3 & 122,5 & 117,7 & 122,7 & 125,7 & 122,1 & 127,3 & 128,8 & 126,8 & 125,2 \\
\hline $\mathrm{C}_{2} \mathrm{H}_{6}$ & ${ }^{2} J_{\mathrm{CH}}$ & $-3,8$ & $-3,7$ & $-3,0$ & $-2,8$ & $-3,0$ & $-3,7$ & $-3,6$ & $-3,6$ & $-4,4$ & $-4,3$ & $-4,3$ & $-4,7$ \\
\hline \multirow[t]{3}{*}{ Total } & DM & $-12,19$ & $-6,34$ & $-7,56$ & $-7,15$ & $-2,49$ & $-4,84$ & 0,08 & 0,32 & $-2,12$ & 7,67 & 3,20 & - \\
\hline & DMA & 20,72 & 17,11 & 12,57 & 13,26 & 9,52 & 12,04 & 6,57 & 6,28 & 14,67 & 8,64 & 8,37 & - \\
\hline & PDMA & 25,12 & 26,41 & 18,35 & 30,96 & 19,94 & 15,99 & 14,56 & 10,63 & 22,19 & 18,97 & 18,59 & - \\
\hline \multirow[t]{3}{*}{ CPI } & $\mathrm{DM}$ & $-37,70$ & $-23,95$ & $-18,98$ & $-20,88$ & $-7,11$ & $-15,71$ & $-6,18$ & $-3,61$ & $-12,77$ & 9,24 & $-0,20$ & - \\
\hline & DMA & 40,05 & 31,46 & 21,11 & 24,28 & 13,42 & 21,15 & 8,69 & 7,05 & 26,43 & 11,22 & 11,55 & - \\
\hline & PDMA & 42,19 & 49,09 & 17,60 & 45,59 & 24,42 & 20,87 & 18,08 & 12,22 & 32,83 & 26,18 & 24,00 & - \\
\hline \multirow[t]{3}{*}{ SPI } & $\mathrm{DM}$ & 6,52 & 6,58 & 0,82 & 2,91 & 0,90 & 3,13 & 4,68 & 3,20 & 5,69 & 6,52 & 5,70 & - \\
\hline & DMA & 6,55 & 6,58 & 6,30 & 5,18 & 6,66 & 5,37 & 5,01 & 5,72 & 6,05 & 6,75 & 6,03 & - \\
\hline & PDMA & 12,60 & 9,77 & 18,90 & 20,22 & 16,65 & 12,42 & 11,98 & 9,46 & 14,38 & 13,69 & 14,62 & - \\
\hline \multirow[t]{3}{*}{$\Delta \mathrm{CS}$} & $\mathrm{DM}$ & $-44,22$ & $-30,53$ & $-19,80$ & $-23,80$ & $-8,01$ & $-18,84$ & $-10,86$ & $-6,81$ & $-18,47$ & 2,72 & $-5,90$ & - \\
\hline & DMA & 33,50 & 24,88 & 14,81 & 19,10 & 6,76 & 15,78 & 3,68 & 1,33 & 20,37 & 4,47 & 5,51 & - \\
\hline & PDMA & 29,60 & 39,32 & $-1,30$ & 25,37 & 7,77 & 8,45 & 6,10 & 2,76 & 18,45 & 12,49 & 9,38 & - \\
\hline
\end{tabular}


Tabela 8.106: Constantes de acoplamento B972 com otimização de geometrias com correção vibracional no nível PBE0 $40 \% E_{X}^{\mathrm{HF}}$ e base aug-pcJ-2.

\begin{tabular}{|c|c|c|c|c|c|c|c|c|c|c|c|c|c|c|c|c|}
\hline & $\% E_{X}^{\mathrm{HF}}$ & 21,00 & 21,00 & 30,00 & 30,00 & $\begin{array}{l}21,00 \\
30,00 \\
\text { Otm. }\end{array}$ & 40,00 & 40,00 & $\begin{array}{l}21,00 \\
40,00 \\
\text { Otm. }\end{array}$ & 50,00 & 50,00 & $\begin{array}{l}21,00 \\
50,00 \\
\text { Otm. }\end{array}$ & 60,00 & 60,00 & $\begin{array}{l}21,00 \\
60,00 \\
\text { Otm. }\end{array}$ & Exp. \\
\hline $\mathrm{HF}$ & ${ }^{1} J_{\mathrm{HF}}$ & 408,0 & 412,2 & 452,4 & 367,1 & 456,3 & 477,2 & 417,8 & 481,1 & 503,4 & 468,9 & 507,2 & 531,0 & 520,7 & 534,9 & 500,0 \\
\hline $\mathrm{CO}$ & ${ }^{1} J_{\mathrm{CO}}$ & 19,0 & 17,8 & 12,2 & 18,3 & 10,9 & 9,9 & 13,6 & 8,7 & 7,5 & 8,7 & 6,3 & 4,9 & 3,7 & 3,7 & 16,4 \\
\hline $\mathrm{H}_{2} \mathrm{O}$ & ${ }^{1} J_{\mathrm{OH}}$ & $-72,1$ & $-73,0$ & $-74,2$ & $-64,3$ & $-75,0$ & $-77,5$ & $-71,0$ & $-78,3$ & $-80,9$ & $-77,6$ & $-81,8$ & $-84,6$ & $-84,2$ & $-85,5$ & $-80,6$ \\
\hline $\mathrm{H}_{2} \mathrm{O}$ & ${ }^{2} J_{\mathrm{HH}}$ & $-6,0$ & $-5,7$ & $-2,8$ & $-3,2$ & $-2,6$ & $-4,0$ & $-4,0$ & $-3,8$ & $-5,2$ & $-4,9$ & $-5,0$ & $-6,5$ & $-5,9$ & $-6,3$ & $-7,3$ \\
\hline $\mathrm{NH}_{3}$ & ${ }^{1} J_{\mathrm{NH}}$ & 42,2 & 42,5 & 40,8 & 38,1 & 41,1 & 42,3 & 40,8 & 42,6 & 43,9 & 43,5 & 44,2 & 45,6 & 46,2 & 45,9 & 43,8 \\
\hline $\mathrm{NH}_{3}$ & ${ }^{2} J_{\mathrm{HH}}$ & $-8,3$ & $-8,2$ & $-5,2$ & $-5,5$ & $-5,2$ & $-6,3$ & $-6,3$ & $-6,2$ & $-7,4$ & $-7,1$ & $-7,3$ & $-8,6$ & $-8,1$ & $-8,5$ & $-9,6$ \\
\hline $\mathrm{PH}_{3}$ & ${ }^{1} J_{\mathrm{PH}}$ & 176,5 & 184,1 & 167,5 & 150,5 & 174,7 & 175,9 & 166,2 & 183,0 & 184,7 & 181,6 & 191,7 & 193,9 & 197,3 & 200,9 & 188,2 \\
\hline $\mathrm{PF}_{3}$ & ${ }^{1} J_{\mathrm{PF}}$ & $-1659,0$ & $-1560,7$ & $-1593,1$ & $-1474,8$ & $-1514,1$ & $-1574,4$ & $-1480,7$ & $-1499,4$ & $-1552,8$ & $-1470,1$ & $-1481,8$ & $-1529,0$ & $-1449,3$ & $-1461,9$ & $-1441,0$ \\
\hline $\mathrm{BHF}_{2}$ & ${ }^{1} J_{\mathrm{BF}}$ & $-134,3$ & $-137,2$ & $-104,7$ & $-150,9$ & $-107,7$ & $-87,3$ & $-119,7$ & $-90,2$ & $-69,8$ & $-89,1$ & $-72,7$ & $-52,4$ & $-59,7$ & $-55,2$ & $-84,0$ \\
\hline $\mathrm{BF}_{3}$ & ${ }^{1} J_{\mathrm{BF}}$ & $-38,8$ & $-45,5$ & $-7,6$ & $-65,5$ & $-14,2$ & 11,9 & $-28,5$ & 5,5 & 31,6 & 7,1 & 25,4 & 51,3 & 41,4 & 45,2 & 15,0 \\
\hline $\mathrm{F}_{2} \mathrm{O}$ & ${ }^{1} J_{\mathrm{OF}}$ & $-331,3$ & $-235,0$ & $-299,0$ & $-356,9$ & $-204,7$ & $-335,9$ & $-325,7$ & $-233,7$ & $-377,8$ & $-294,0$ & $-265,6$ & $-428,2$ & $-262,8$ & $-301,9$ & $-300,0$ \\
\hline $\mathrm{CH}_{4}$ & ${ }^{1} J_{\mathrm{CH}}$ & 121,2 & 121,2 & 109,6 & 115,2 & 109,6 & 114,3 & 119,0 & 114,3 & 119,3 & 123,0 & 119,3 & 124,6 & 127,0 & 124,6 & 125,3 \\
\hline $\mathrm{CH}_{4}$ & ${ }^{2} J_{\mathrm{HH}}$ & $-11,6$ & $-11,6$ & $-8,1$ & $-7,7$ & $-8,1$ & $-9,0$ & $-8,7$ & $-9,0$ & $-10,0$ & $-9,8$ & $-10,0$ & $-11,0$ & $-10,9$ & $-11,0$ & $-12,8$ \\
\hline $\mathrm{C}_{2} \mathrm{H}_{2}$ & ${ }^{1} J_{\mathrm{CC}}$ & 198,4 & 198,5 & 189,7 & 190,6 & 190,0 & 196,5 & 198,0 & 196,6 & 204,3 & 205,8 & 204,1 & 213,4 & 214,2 & 212,9 & 174,8 \\
\hline $\mathrm{C}_{2} \mathrm{H}_{2}$ & ${ }^{1} J_{\mathrm{CH}}$ & 250,5 & 248,4 & 216,9 & 229,3 & 215,1 & 225,8 & 235,0 & 223,9 & 235,2 & 240,9 & 233,2 & 245,4 & 247,1 & 243,2 & 247,6 \\
\hline $\mathrm{C}_{2} \mathrm{H}_{2}$ & ${ }^{2} J_{\mathrm{CH}}$ & 50,9 & 51,0 & 51,6 & 51,9 & 51,7 & 52,0 & 52,1 & 52,1 & 52,1 & 52,1 & 52,2 & 51,7 & 51,9 & 51,9 & 50,1 \\
\hline $\mathrm{C}_{2} \mathrm{H}_{2}$ & ${ }^{3} J_{\mathrm{HH}}$ & 11,1 & 10,8 & 8,1 & 9,1 & 7,9 & 8,8 & 9,4 & 8,5 & 9,6 & 9,9 & 9,3 & 10,6 & 10,5 & 10,3 & 9,6 \\
\hline $\mathrm{C}_{2} \mathrm{H}_{4}$ & ${ }^{1} J_{\mathrm{CC}}$ & 69,1 & 71,6 & 67,0 & 68,6 & 69,7 & 71,8 & 74,1 & 74,3 & 77,3 & 79,9 & 79,5 & 83,9 & 86,2 & 85,7 & 67,6 \\
\hline $\mathrm{C}_{2} \mathrm{H}_{4}$ & ${ }^{1} J_{\mathrm{CH}}$ & 154,3 & 151,4 & 136,1 & 141,5 & 133,7 & 142,3 & 146,2 & 139,7 & 148,9 & 151,1 & 146,1 & 156,1 & 156,1 & 153,1 & 156,3 \\
\hline $\mathrm{C}_{2} \mathrm{H}_{4}$ & ${ }^{2} J_{\mathrm{CH}}$ & $-2,5$ & $-2,1$ & 0,0 & 0,5 & 0,2 & $-0,9$ & $-0,6$ & $-0,7$ & $-2,2$ & $-1,9$ & $-1,9$ & $-3,7$ & $-3,5$ & $-3,3$ & $-2,4$ \\
\hline $\mathrm{C}_{2} \mathrm{H}_{4}$ & ${ }^{2} J_{\mathrm{HH}}$ & 3,3 & 2,1 & 4,9 & 5,4 & 3,8 & 4,4 & 4,6 & 3,3 & 3,9 & 3,7 & 2,7 & 3,2 & 2,7 & 2,1 & 2,3 \\
\hline $\mathrm{C}_{2} \mathrm{H}_{4}$ & ${ }^{3} J_{\mathrm{HH}_{\mathrm{c}}}$ & 11,6 & 12,2 & 10,1 & 9,6 & 10,7 & 10,5 & 10,3 & 11,1 & 11,0 & 11,0 & 11,5 & 11,5 & 11,9 & 12,1 & 11,7 \\
\hline $\mathrm{C}_{2} \mathrm{H}_{4}$ & ${ }^{3} J_{\mathrm{HH}_{\mathrm{t}}}$ & 18,4 & 19,0 & 15,1 & 16,2 & 15,6 & 15,8 & 16,8 & 16,3 & 16,6 & 17,5 & 17,1 & 17,5 & 18,2 & 18,0 & 19,0 \\
\hline $\mathrm{C}_{2} \mathrm{H}_{6}$ & ${ }^{1} J_{\mathrm{CC}}$ & 31,5 & 33,3 & 31,1 & 32,5 & 33,0 & 34,2 & 35,9 & 36,1 & & & 39,4 & 41,0 & & 42,9 & 34,5 \\
\hline $\mathrm{C}_{2} \mathrm{H}_{6}$ & ${ }^{1} J_{\mathrm{CH}}$ & 120,7 & 119,1 & 108,2 & 113,2 & 106,9 & 113,2 & 117,1 & 111,8 & 118,4 & 121,1 & 117,0 & 123,9 & 125,2 & 122,4 & 125,2 \\
\hline $\mathrm{C}_{2} \mathrm{H}_{6}$ & ${ }^{2} J_{\mathrm{CH}}$ & $-3,4$ & $-3,4$ & $-2,1$ & $-1,8$ & $-2,0$ & $-2,6$ & $-2,4$ & $-2,6$ & $-3,2$ & $-3,0$ & $-3,1$ & $-3,8$ & $-3,7$ & $-3,8$ & $-4,7$ \\
\hline \multirow[t]{3}{*}{ Total } & DM & - & 39 & -12 , & $-16,08$ & $-5,68$ & & 0 & -2, & -5 & & 1. & & & 4, & - \\
\hline & DMA & 20,02 & 1 & & & 16,48 & & & & & & & & & 9,0 & - \\
\hline & PDMA & 25,76 & 26,35 & 30,12 & 49,13 & 31,48 & 19,48 & 31,65 & 20,36 & 18,64 & 15,62 & 15,59 & 25,22 & 20,89 & 20,90 & - \\
\hline \multirow[t]{3}{*}{ CPI } & $\mathrm{DM}$ & 40, & -22 & & & -7, & & & -2 , & & & & & & & - \\
\hline & DMA & 42,95 & & & & & & & & & & & & & & - \\
\hline & PDMA & 48,19 & 52,16 & 32,24 & 75,27 & 39,32 & 16,67 & 44,31 & 21,76 & 24,58 & 16,61 & 19,99 & 39,84 & 31,73 & 33,17 & - \\
\hline \multirow[t]{3}{*}{ SPI } & M & 1,2 & & & -2, & $-4,42$ & & & & & & & & & & - \\
\hline & DMA & 3,2 & & & & & & & & & & & & & 5,56 & - \\
\hline & PDMA & 9,31 & 7,42 & 28,57 & 29,96 & 25,73 & 21,53 & 22,37 & 19,34 & 14,28 & 14,89 & 12,36 & 14,49 & 12,94 & 11,90 & - \\
\hline \multirow[t]{3}{*}{$\Delta \mathrm{CS}$} & & -41 & & & & -2 , & & & -0 , & & & & & & & - \\
\hline & DMA & 9,73 & & 17 & 33, & & & & 9,2 & & & & & & 8,19 & - \\
\hline & PDMA & 38,88 & 44,74 & 3,66 & 45,30 & 13,59 & $-4,86$ & 21,93 & 2,41 & 10,30 & 1,73 & 7,62 & 25,35 & 18,80 & 21,27 & - \\
\hline
\end{tabular}


Tabela 8.107: Constantes de acoplamento B98 com otimização de geometrias com correção vibracional no nível PBE0 $40 \% E_{X}^{\mathrm{HF}}$ e base aug-pcJ-2.

\begin{tabular}{|c|c|c|c|c|c|c|c|c|c|c|c|c|c|}
\hline & $\% E_{X}^{\mathrm{HF}}$ & 21,98 & 21,98 & 40,00 & 40,00 & $\begin{array}{l}21,98 \\
40,00 \\
\text { Otm. }\end{array}$ & 50,00 & 50,00 & $\begin{array}{l}21,98 \\
50,00 \\
\text { Otm. }\end{array}$ & 60,00 & 60,00 & $\begin{array}{l}21,98 \\
60,00 \\
\text { Otm. }\end{array}$ & Exp. \\
\hline $\mathrm{HF}$ & ${ }^{1} J_{\mathrm{HF}}$ & 396,4 & 390,9 & 449,8 & 382,9 & 444,7 & 471,1 & 431,0 & 466,0 & 493,7 & 479,7 & 488,7 & 500,0 \\
\hline $\mathrm{CO}$ & ${ }^{1} J_{\mathrm{CO}}$ & 19,2 & 18,3 & 11,9 & 16,2 & 11,1 & 10,2 & 11,9 & 9,4 & 8,4 & 7,6 & 7,5 & 16,4 \\
\hline $\mathrm{H}_{2} \mathrm{O}$ & ${ }^{1} J_{\mathrm{OH}}$ & $-71,1$ & $-71,2$ & $-74,2$ & $-66,5$ & $-74,3$ & $-77,0$ & $-72,8$ & $-77,1$ & $-80,0$ & $-79,0$ & $-80,1$ & $-80,6$ \\
\hline $\mathrm{H}_{2} \mathrm{O}$ & ${ }^{2} J_{\mathrm{HH}}$ & $-5,4$ & $-5,0$ & $-3,6$ & $-3,6$ & $-3,2$ & $-4,9$ & $-4,6$ & $-4,6$ & $-6,4$ & $-5,7$ & $-6,0$ & $-7,3$ \\
\hline $\mathrm{NH}_{3}$ & ${ }^{1} J_{\mathrm{NH}}$ & 43,4 & 43,6 & 42,2 & 40,1 & 42,4 & 43,6 & 42,8 & 43,8 & 45,1 & 45,3 & 45,3 & 43,8 \\
\hline $\mathrm{NH}_{3}$ & ${ }^{2} J_{\mathrm{HH}}$ & $-8,7$ & $-8,5$ & $-6,8$ & $-6,7$ & $-6,6$ & $-8,0$ & $-7,7$ & $-7,8$ & $-9,4$ & $-8,8$ & $-9,2$ & $-9,6$ \\
\hline $\mathrm{PH}_{3}$ & ${ }^{1} J_{\mathrm{PH}}$ & 188,9 & 195,2 & 186,2 & 179,7 & 192,0 & 194,2 & 193,2 & 199,8 & 202,6 & 206,4 & 207,9 & 188,2 \\
\hline $\mathrm{PF}_{3}$ & ${ }^{1} J_{\mathrm{PF}}$ & $-1664,2$ & $-1557,9$ & $-1569,9$ & $-1466,7$ & $-1487,7$ & $-1546,9$ & $-1457,7$ & $-1468,6$ & $-1521,2$ & $-1437,6$ & $-1446,8$ & $-1441,0$ \\
\hline $\mathrm{BHF}_{2}$ & ${ }^{1} J_{\mathrm{BF}}$ & $-133,5$ & $-137,6$ & $-94,0$ & $-129,7$ & $-98,1$ & $-78,2$ & $-99,9$ & $-82,2$ & $-62,2$ & $-70,8$ & $-66,2$ & $-84,0$ \\
\hline $\mathrm{BF}_{3}$ & ${ }^{1} J_{\mathrm{BF}}$ & $-36,3$ & $-45,4$ & 4,8 & $-39,8$ & $-3,7$ & 22,3 & $-5,2$ & 13,9 & 40,0 & 28,4 & 31,8 & 15,0 \\
\hline $\mathrm{F}_{2} \mathrm{O}$ & ${ }^{1} J_{\mathrm{OF}}$ & $-352,2$ & $-279,9$ & $-353,5$ & $-363,0$ & $-277,8$ & $-398,3$ & $-328,0$ & $-314,6$ & $-452,6$ & $-293,8$ & $-357,2$ & $-300,0$ \\
\hline $\mathrm{CH}_{4}$ & ${ }^{1} J_{\mathrm{CH}}$ & 130,7 & 131,1 & 119,3 & 124,4 & 119,6 & 123,9 & 128,0 & 124,3 & 128,9 & 131,7 & 129,3 & 125,3 \\
\hline $\mathrm{CH}_{4}$ & ${ }^{2} J_{\mathrm{HH}}$ & $-12,8$ & $-12,8$ & $-10,1$ & $-9,8$ & $-10,1$ & $-11,3$ & $-11,1$ & $-11,3$ & $-12,5$ & $-12,4$ & $-12,5$ & $-12,8$ \\
\hline $\mathrm{C}_{2} \mathrm{H}_{2}$ & ${ }^{1} J_{\mathrm{CC}}$ & 213,8 & 213,6 & 205,9 & 208,4 & 205,9 & 213,1 & 215,2 & 212,8 & 221,5 & 222,5 & 220,9 & 174,8 \\
\hline $\mathrm{C}_{2} \mathrm{H}_{2}$ & ${ }^{1} J_{\mathrm{CH}}$ & 264,3 & 262,8 & 232,9 & 242,9 & 231,5 & 242,2 & 248,6 & 240,7 & 252,2 & 254,7 & 250,6 & 247,6 \\
\hline $\mathrm{C}_{2} \mathrm{H}_{2}$ & ${ }^{2} J_{\mathrm{CH}}$ & 53,0 & 53,1 & 53,4 & 53,6 & 53,5 & 53,4 & 53,4 & 53,5 & 52,8 & 52,9 & 53,0 & 50,1 \\
\hline $\mathrm{C}_{2} \mathrm{H}_{2}$ & ${ }^{3} J_{\mathrm{HH}}$ & 11,4 & 11,1 & 9,1 & 9,9 & 8,9 & 10,1 & 10,5 & 9,8 & 11,3 & 11,4 & 11,1 & 9,6 \\
\hline $\mathrm{C}_{2} \mathrm{H}_{4}$ & ${ }^{1} J_{\mathrm{CC}}$ & 78,3 & 80,7 & 77,4 & 79,8 & 79,9 & 82,3 & 85,1 & 84,6 & 88,2 & 90,7 & 90,1 & 67,6 \\
\hline $\mathrm{C}_{2} \mathrm{H}_{4}$ & ${ }^{1} J_{\mathrm{CH}}$ & 164,5 & 162,1 & 147,7 & 152,2 & 145,6 & 154,0 & 156,8 & 151,8 & 160,9 & 161,5 & 158,5 & 156,3 \\
\hline $\mathrm{C}_{2} \mathrm{H}_{4}$ & ${ }^{2} J_{\mathrm{CH}}$ & $-2,9$ & $-2,6$ & $-1,3$ & $-1,0$ & $-1,1$ & $-2,6$ & $-2,4$ & $-2,4$ & $-4,3$ & $-4,1$ & $-3,9$ & $-2,4$ \\
\hline $\mathrm{C}_{2} \mathrm{H}_{4}$ & ${ }^{2} J_{\mathrm{HH}}$ & 3,3 & 2,1 & 4,1 & 4,4 & 3,0 & 3,4 & 3,3 & 2,3 & 2,5 & 2,1 & 1,4 & 2,3 \\
\hline $\mathrm{C}_{2} \mathrm{H}_{4}$ & ${ }^{3} J_{\mathrm{HH}_{\mathrm{c}}}$ & 12,2 & 12,8 & 11,0 & 10,6 & 11,5 & 11,5 & 11,5 & 12,0 & 12,2 & 12,4 & 12,6 & 11,7 \\
\hline $\mathrm{C}_{2} \mathrm{H}_{4}$ & ${ }^{3} J_{\mathrm{HH}_{\mathrm{t}}}$ & 19,2 & 19,8 & 16,3 & 17,4 & 16,9 & 17,2 & 18,2 & 17,7 & 18,3 & 19,1 & 18,8 & 19,0 \\
\hline $\mathrm{C}_{2} \mathrm{H}_{6}$ & ${ }^{1} J_{\mathrm{CC}}$ & 35,3 & 36,9 & 36,0 & 37,1 & 37,6 & 39,1 & 40,5 & 40,7 & 42,4 & 44,0 & 44,0 & 34,5 \\
\hline $\mathrm{C}_{2} \mathrm{H}_{6}$ & ${ }^{1} J_{\mathrm{CH}}$ & 130,6 & 129,9 & 118,6 & 123,2 & 117,9 & 123,5 & 127,0 & 122,9 & 128,8 & 130,8 & 128,1 & 125,2 \\
\hline $\mathrm{C}_{2} \mathrm{H}_{6}$ & ${ }^{2} J_{\mathrm{CH}}$ & $-4,0$ & $-3,9$ & $-3,1$ & $-2,8$ & $-3,1$ & $-3,8$ & $-3,6$ & $-3,7$ & $-4,5$ & $-4,4$ & $-4,5$ & $-4,7$ \\
\hline \multirow[t]{3}{*}{ Total } & $\mathrm{DM}$ & $-14,29$ & $-7,92$ & $-9,03$ & $-9,68$ & $-3,41$ & $-6,19$ & $-2,35$ & $-0,43$ & $-3,40$ & 5,37 & 2,62 & - \\
\hline & DMA & 22,68 & 18,28 & 14,10 & 15,94 & 10,77 & 13,23 & 9,68 & 7,28 & 15,81 & 7,75 & 9,22 & - \\
\hline & PDMA & 26,55 & 27,29 & 19,46 & 33,52 & 20,43 & 14,23 & 17,29 & 9,86 & 20,81 & 16,73 & 18,44 & - \\
\hline \multirow[t]{3}{*}{ CPI } & DM & $-42,22$ & $-27,13$ & $-22,55$ & $-27,09$ & $-9,28$ & $-19,35$ & $-12,54$ & $-5,72$ & $-16,63$ & 2,80 & $-2,29$ & - \\
\hline & DMA & 45,09 & 34,73 & 24,89 & 30,85 & 16,45 & 24,20 & 15,70 & 9,61 & 28,30 & 8,09 & 12,84 & - \\
\hline & PDMA & 47,28 & 52,14 & 21,52 & 52,59 & 26,90 & 17,90 & 25,16 & 12,00 & 29,53 & 19,13 & 22,33 & - \\
\hline \multirow[t]{3}{*}{ SPI } & $\mathrm{DM}$ & 6,19 & 6,17 & 0,87 & 3,08 & 0,89 & 3,46 & 5,13 & 3,44 & 6,31 & 7,25 & 6,23 & - \\
\hline & DMA & 6,25 & 6,23 & 6,18 & 5,00 & 6,60 & 5,19 & 5,26 & 5,57 & 6,65 & 7,51 & 6,57 & - \\
\hline & PDMA & 11,34 & 9,07 & 17,96 & 19,54 & 15,69 & 11,54 & 11,52 & 8,30 & 14,41 & 14,98 & 15,58 & - \\
\hline \multirow[t]{3}{*}{$\Delta \mathrm{CS}$} & DM & $-48,40$ & $-33,30$ & $-23,42$ & $-30,17$ & $-10,18$ & $-22,81$ & $-17,66$ & $-9,16$ & $-22,93$ & $-4,45$ & $-8,52$ & - \\
\hline & DMA & 38,84 & 28,50 & 18,71 & 25,85 & 9,85 & 19,01 & 10,44 & 4,04 & 21,65 & 0,58 & 6,26 & - \\
\hline & PDMA & 35,94 & 43,07 & 3,56 & 33,05 & 11,22 & 6,36 & 13,64 & 3,70 & 15,12 & 4,15 & 6,75 & - \\
\hline
\end{tabular}


Tabela 8.108: Constantes de acoplamento B1B95 com otimização de geometrias com correção vibracional no nível PBE0 $40 \% E_{X}^{\mathrm{HF}}$ e base aug-pcJ-2.

\begin{tabular}{|c|c|c|c|c|c|c|c|c|c|c|c|c|c|}
\hline & $\% E_{X}^{\mathrm{HF}}$ & 28,00 & 28,00 & 40,00 & 40,00 & $\begin{array}{l}28,00 \\
40,00 \\
\text { Otm. }\end{array}$ & 50,00 & 50,00 & $\begin{array}{l}28,00 \\
50,00 \\
\text { Otm. }\end{array}$ & 60,00 & 60,00 & $\begin{array}{c}28,00 \\
60,00 \\
\text { Otm. }\end{array}$ & Exp. \\
\hline HF & ${ }^{1} J_{\mathrm{HF}}$ & 435,6 & 435,6 & 464,5 & 480,8 & 464,5 & 488,8 & 517,6 & 488,8 & 513,2 & 553,7 & 513,2 & 500,0 \\
\hline $\mathrm{CO}$ & ${ }^{1} J_{\mathrm{CO}}$ & 19,1 & 17,2 & 16,8 & 13,3 & 14,8 & 14,7 & 10,1 & 12,8 & 12,5 & 6,9 & 10,6 & 16,4 \\
\hline $\mathrm{H}_{2} \mathrm{O}$ & ${ }^{1} J_{\mathrm{OH}}$ & $-75,9$ & $-77,0$ & $-79,0$ & $-82,1$ & $-80,0$ & $-81,6$ & $-86,0$ & $-82,5$ & $-84,2$ & $-89,8$ & $-85,1$ & $-80,6$ \\
\hline $\mathrm{H}_{2} \mathrm{O}$ & ${ }^{2} J_{\mathrm{HH}}$ & $-5,5$ & $-5,1$ & $-6,7$ & $-5,8$ & $-6,3$ & $-7,7$ & $-6,6$ & $-7,3$ & $-8,8$ & $-7,4$ & $-8,3$ & $-7,3$ \\
\hline $\mathrm{NH}_{3}$ & ${ }^{1} J_{\mathrm{NH}}$ & 44,5 & 45,1 & 45,4 & 46,6 & 46,0 & 46,1 & 47,7 & 46,7 & 46,9 & 48,7 & 47,4 & 43,8 \\
\hline $\mathrm{NH}_{3}$ & ${ }^{2} J_{\mathrm{HH}}$ & $-8,5$ & $-8,3$ & $-9,6$ & $-9,0$ & $-9,3$ & $-10,5$ & $-9,7$ & $-10,2$ & $-11,3$ & $-10,4$ & $-11,0$ & $-9,6$ \\
\hline $\mathrm{PH}_{3}$ & ${ }^{1} J_{\mathrm{PH}}$ & 160,3 & 168,3 & 169,0 & 180,0 & 176,5 & 176,1 & 189,3 & 183,3 & 183,1 & 198,1 & 189,9 & 188,2 \\
\hline $\mathrm{PF}_{3}$ & ${ }^{1} J_{\mathrm{PF}}$ & $-1643,3$ & $-1530,0$ & $-1604,2$ & $-1498,4$ & $-1497,8$ & $-1568,9$ & $-1464,6$ & $-1468,1$ & $-1531,5$ & $-1425,6$ & $-1436,4$ & $-1441,0$ \\
\hline $\mathrm{BHF}_{2}$ & ${ }^{1} J_{\mathrm{BF}}$ & $-132,0$ & $-130,1$ & $-111,9$ & $-103,3$ & $-110,2$ & $-95,4$ & $-81,6$ & $-93,7$ & $-79,0$ & $-60,4$ & $-77,3$ & $-84,0$ \\
\hline $\mathrm{BF}_{3}$ & ${ }^{1} J_{\mathrm{BF}}$ & $-29,2$ & $-30,4$ & $-7,5$ & $-0,1$ & $-8,6$ & 10,4 & 24,4 & 9,2 & 28,1 & 48,0 & 27,0 & 15,0 \\
\hline $\mathrm{F}_{2} \mathrm{O}$ & ${ }^{1} J_{\mathrm{OF}}$ & $-377,2$ & $-264,3$ & $-419,6$ & $-236,4$ & $-295,4$ & $-459,0$ & $-214,6$ & $-322,7$ & $-505,3$ & $-194,5$ & $-352,4$ & $-300,0$ \\
\hline $\mathrm{CH}_{4}$ & ${ }^{1} J_{\mathrm{CH}}$ & 126,8 & 126,5 & 128,5 & 127,6 & 128,2 & 129,9 & 128,4 & 129,6 & 131,4 & 129,3 & 131,0 & 125,3 \\
\hline $\mathrm{CH}_{4}$ & ${ }^{2} J_{\mathrm{HH}}$ & $-12,5$ & $-12,5$ & $-13,3$ & $-13,4$ & $-13,3$ & $-14,0$ & $-14,0$ & $-14,0$ & $-14,7$ & $-14,7$ & $-14,7$ & $-12,8$ \\
\hline $\mathrm{C}_{2} \mathrm{H}_{2}$ & ${ }^{1} J_{\mathrm{CC}}$ & 196,1 & 196,4 & 200,2 & 200,0 & 200,1 & 204,1 & 203,3 & 203,7 & 208,6 & 206,8 & 207,9 & 174,8 \\
\hline $\mathrm{C}_{2} \mathrm{H}_{2}$ & ${ }^{1} J_{\mathrm{CH}}$ & 259,4 & 256,4 & 262,0 & 256,9 & 259,0 & 264,4 & 257,5 & 261,2 & 266,9 & 258,1 & 263,6 & 247,6 \\
\hline $\mathrm{C}_{2} \mathrm{H}_{2}$ & ${ }^{2} J_{\mathrm{CH}}$ & 55,8 & 55,9 & 55,4 & 55,7 & 55,6 & 54,8 & 55,3 & 55,1 & 54,0 & 54,8 & 54,4 & 50,1 \\
\hline $\mathrm{C}_{2} \mathrm{H}_{2}$ & ${ }^{3} J_{\mathrm{HH}}$ & 11,1 & 10,7 & 11,9 & 11,2 & 11,5 & 12,7 & 11,8 & 12,2 & 13,7 & 12,4 & 13,1 & 9,6 \\
\hline $\mathrm{C}_{2} \mathrm{H}_{4}$ & ${ }^{1} J_{\mathrm{CC}}$ & 67,0 & 69,9 & 70,6 & 73,1 & 73,1 & 74,0 & 75,9 & 76,1 & 77,8 & 78,9 & 79,5 & 67,6 \\
\hline $\mathrm{C}_{2} \mathrm{H}_{4}$ & ${ }^{1} J_{\mathrm{CH}}$ & 160,8 & 157,4 & 163,3 & 158,8 & 159,7 & 165,5 & 160,0 & 161,7 & 167,9 & 161,3 & 163,9 & 156,3 \\
\hline $\mathrm{C}_{2} \mathrm{H}_{4}$ & ${ }^{2} J_{\mathrm{CH}}$ & $-1,6$ & $-1,4$ & $-2,8$ & $-2,5$ & $-2,5$ & $-3,9$ & $-3,5$ & $-3,5$ & $-5,2$ & $-4,5$ & $-4,7$ & $-2,4$ \\
\hline $\mathrm{C}_{2} \mathrm{H}_{4}$ & ${ }^{2} J_{\mathrm{HH}}$ & 4,4 & 3,0 & 3,5 & 2,1 & 2,1 & 2,7 & 1,3 & 1,3 & 1,8 & 0,5 & 0,5 & 2,3 \\
\hline $\mathrm{C}_{2} \mathrm{H}_{4}$ & ${ }^{3} J_{\mathrm{HH}_{\mathrm{c}}}$ & 12,5 & 13,3 & 12,9 & 13,8 & 13,6 & 13,2 & 14,2 & 14,0 & 13,7 & 14,6 & 14,4 & 11,7 \\
\hline $\mathrm{C}_{2} \mathrm{H}_{4}$ & ${ }^{3} J_{\mathrm{HH}_{\mathrm{t}}}$ & 19,7 & 20,3 & 20,1 & 20,6 & 20,7 & 20,6 & 20,9 & 21,1 & 21,1 & 21,3 & 21,6 & 19,0 \\
\hline $\mathrm{C}_{2} \mathrm{H}_{6}$ & ${ }^{1} J_{\mathrm{CC}}$ & 31,5 & 33,4 & 33,9 & 35,6 & 35,7 & 35,9 & 37,5 & 37,7 & 38,0 & 39,6 & 39,7 & 34,5 \\
\hline $\mathrm{C}_{2} \mathrm{H}_{6}$ & ${ }^{1} J_{\mathrm{CH}}$ & 126,8 & 124,8 & 128,7 & 126,1 & 126,7 & 130,3 & 127,0 & 128,2 & 131,9 & 128,0 & 129,8 & 125,2 \\
\hline $\mathrm{C}_{2} \mathrm{H}_{6}$ & ${ }^{2} J_{\mathrm{CH}}$ & $-3,7$ & $-3,7$ & $-4,2$ & $-4,3$ & $-4,2$ & $-4,7$ & $-4,7$ & $-4,7$ & $-5,2$ & $-5,2$ & $-5,2$ & $-4,7$ \\
\hline \multirow[t]{3}{*}{ Total } & DM & $-15,50$ & $-6,68$ & $-12,20$ & 0,07 & $-3,26$ & $-9,48$ & 5,84 & $-0,35$ & $-6,91$ & 11,67 & 2,59 & - \\
\hline & DMA & 20,47 & 13,81 & 17,76 & 9,67 & 8,75 & 16,13 & 8,82 & 6,64 & 17,50 & 13,67 & 8,10 & - \\
\hline & PDMA & 26,81 & 23,80 & 16,86 & 12,50 & 13,82 & 13,44 & 14,43 & 12,36 & 21,52 & 27,69 & 20,74 & - \\
\hline \multirow[t]{3}{*}{ CPI } & DM & $-41,18$ & $-19,99$ & $-34,88$ & $-5,03$ & $-13,34$ & $-29,81$ & 7,74 & $-7,69$ & $-25,20$ & 20,58 & $-2,12$ & - \\
\hline & DMA & 43,18 & 28,15 & 35,65 & 17,48 & 14,92 & 30,23 & 14,17 & 8,22 & 31,45 & 24,15 & 9,72 & - \\
\hline & PDMA & 43,57 & 41,37 & 24,36 & 19,18 & 21,79 & 13,32 & 14,94 & 9,24 & 22,45 & 35,51 & 16,98 & - \\
\hline \multirow[t]{3}{*}{ SPI } & DM & 3,33 & 3,09 & 4,44 & 3,81 & 4,13 & 5,43 & 4,45 & 5,04 & 6,51 & 5,14 & 6,05 & - \\
\hline & DMA & 3,81 & 3,29 & 4,64 & 3,93 & 4,23 & 5,79 & 4,89 & 5,48 & 7,27 & 5,98 & 6,91 & - \\
\hline & PDMA & 14,51 & 10,92 & 11,35 & 7,60 & 7,98 & 13,53 & 14,06 & 14,64 & 20,84 & 21,96 & 23,50 & - \\
\hline \multirow[t]{3}{*}{$\Delta \mathrm{CS}$} & DM & $-44,52$ & $-23,08$ & $-39,32$ & $-8,84$ & $-17,46$ & $-35,24$ & 3,28 & $-12,73$ & $-31,71$ & 15,44 & $-8,16$ & - \\
\hline & DMA & 39,37 & 24,87 & 31,01 & 13,55 & 10,68 & 24,44 & 9,28 & 2,74 & 24,19 & 18,17 & 2,80 & - \\
\hline & PDMA & 29,06 & 30,45 & 13,01 & 11,58 & 13,80 & $-0,21$ & 0,88 & $-5,40$ & 1,61 & 13,55 & $-6,52$ & - \\
\hline
\end{tabular}


Tabela 8.109: Constantes de acoplamento BHandH com otimização de geometrias com correção vibracional no nível PBE0 $40 \% E_{X}^{\mathrm{HF}}$ e base aug-pcJ-2.

\begin{tabular}{|c|c|c|c|c|c|c|c|c|c|c|c|c|c|}
\hline & $\% E_{X}^{\mathrm{HF}}$ & 50,00 & 50,00 & 30,00 & 30,00 & $\begin{array}{l}50,00 \\
30,00 \\
\text { Otm. }\end{array}$ & 40,00 & 40,00 & $\begin{array}{l}50,00 \\
40,00 \\
\text { Otm. }\end{array}$ & 60,00 & 60,00 & $\begin{array}{l}50,00 \\
60,00 \\
\text { Otm. }\end{array}$ & Exp. \\
\hline $\mathrm{HF}$ & ${ }^{1} J_{\mathrm{HF}}$ & 496,0 & 511,9 & 449,6 & 438,1 & 466,0 & 472,4 & 474,8 & 488,6 & 520,5 & 549,5 & 536,1 & 500,0 \\
\hline $\mathrm{CO}$ & ${ }^{1} J_{\mathrm{CO}}$ & 14,4 & 8,7 & 19,4 & 15,6 & 13,5 & 17,0 & 12,2 & 11,1 & 11,7 & 5,1 & 6,0 & 16,4 \\
\hline $\mathrm{H}_{2} \mathrm{O}$ & ${ }^{1} J_{\mathrm{OH}}$ & $-82,3$ & $-86,1$ & $-76,4$ & $-77,1$ & $-80,3$ & $-79,3$ & $-81,7$ & $-83,2$ & $-85,5$ & $-90,6$ & $-89,2$ & $-80,6$ \\
\hline $\mathrm{H}_{2} \mathrm{O}$ & ${ }^{2} J_{\mathrm{HH}}$ & $-7,9$ & $-6,4$ & $-5,3$ & $-4,3$ & $-3,8$ & $-6,5$ & $-5,3$ & $-5,1$ & $-9,3$ & $-7,5$ & $-7,7$ & $-7,3$ \\
\hline $\mathrm{NH}_{3}$ & ${ }^{1} J_{\mathrm{NH}}$ & 46,0 & 48,2 & 43,4 & 45,0 & 45,6 & 44,7 & 46,7 & 46,9 & 47,5 & 50,0 & 49,7 & 43,8 \\
\hline $\mathrm{NH}_{3}$ & ${ }^{2} J_{\mathrm{HH}}$ & $-10,3$ & $-9,1$ & $-7,9$ & $-6,8$ & $-6,7$ & $-9,1$ & $-7,9$ & $-7,9$ & $-11,7$ & $-10,2$ & $-10,3$ & $-9,6$ \\
\hline $\mathrm{PH}_{3}$ & ${ }^{1} J_{\mathrm{PH}}$ & 175,6 & 187,6 & 155,5 & 159,9 & 168,3 & 165,4 & 173,8 & 177,8 & 186,2 & 201,4 & 197,7 & 188,2 \\
\hline $\mathrm{PF}_{3}$ & ${ }^{1} J_{\mathrm{PF}}$ & $-1668,2$ & $-1552,3$ & $-1741,3$ & $-1619,8$ & $-1622,0$ & $-1706,8$ & $-1589,2$ & $-1589,0$ & $-1626,1$ & $-1509,8$ & $-1512,6$ & $-1441,0$ \\
\hline $\mathrm{BHF}_{2}$ & ${ }^{1} J_{\mathrm{BF}}$ & $-99,6$ & $-77,2$ & $-137,2$ & $-120,8$ & $-113,9$ & $-118,4$ & $-98,9$ & $-95,6$ & $-80,5$ & $-55,7$ & $-58,7$ & $-84,0$ \\
\hline $\mathrm{BF}_{3}$ & ${ }^{1} J_{\mathrm{BF}}$ & 12,9 & 36,6 & $-25,5$ & $-9,5$ & $-0,7$ & $-6,3$ & 13,6 & 17,8 & 32,4 & 59,2 & 55,4 & 15,0 \\
\hline $\mathrm{F}_{2} \mathrm{O}$ & ${ }^{1} J_{\mathrm{OF}}$ & $-480,3$ & $-180,8$ & $-395,8$ & $-189,2$ & $-139,1$ & $-435,1$ & $-184,5$ & $-159,6$ & $-536,7$ & $-178,6$ & $-203,3$ & $-300,0$ \\
\hline $\mathrm{CH}_{4}$ & ${ }^{1} J_{\mathrm{CH}}$ & 127,3 & 126,8 & 119,2 & 119,8 & 118,7 & 123,1 & 123,1 & 122,7 & 131,8 & 130,5 & 131,2 & 125,3 \\
\hline $\mathrm{CH}_{4}$ & ${ }^{2} J_{\mathrm{HH}}$ & $-13,6$ & $-13,6$ & $-11,3$ & $-11,3$ & $-11,3$ & $-12,4$ & $-12,4$ & $-12,4$ & $-14,8$ & $-14,8$ & $-14,8$ & $-12,8$ \\
\hline $\mathrm{C}_{2} \mathrm{H}_{2}$ & ${ }^{1} J_{\mathrm{CC}}$ & 203,3 & 202,8 & 190,3 & 191,3 & 191,3 & 196,3 & 196,8 & 196,7 & 211,5 & 209,5 & 210,0 & 174,8 \\
\hline $\mathrm{C}_{2} \mathrm{H}_{2}$ & ${ }^{1} J_{\mathrm{CH}}$ & 262,7 & 256,5 & 248,2 & 246,2 & 242,6 & 255,2 & 251,2 & 249,3 & 271,0 & 262,3 & 264,3 & 247,6 \\
\hline $\mathrm{C}_{2} \mathrm{H}_{2}$ & ${ }^{2} J_{\mathrm{CH}}$ & 53,2 & 54,0 & 53,4 & 53,7 & 53,7 & 53,5 & 54,0 & 54,0 & 52,4 & 53,6 & 53,5 & 50,1 \\
\hline $\mathrm{C}_{2} \mathrm{H}_{2}$ & ${ }^{3} J_{\mathrm{HH}}$ & 12,5 & 11,4 & 10,1 & 9,6 & 9,3 & 11,2 & 10,5 & 10,3 & 14,1 & 12,6 & 12,9 & 9,6 \\
\hline $\mathrm{C}_{2} \mathrm{H}_{4}$ & ${ }^{1} J_{\mathrm{CC}}$ & 73,3 & 75,8 & 62,8 & 66,7 & 66,6 & 67,7 & 71,0 & 70,9 & 79,9 & 81,2 & 81,5 & 67,6 \\
\hline $\mathrm{C}_{2} \mathrm{H}_{4}$ & ${ }^{1} J_{\mathrm{CH}}$ & 162,6 & 157,7 & 151,9 & 149,1 & 147,6 & 157,0 & 153,3 & 152,5 & 168,8 & 162,4 & 163,4 & 156,3 \\
\hline $\mathrm{C}_{2} \mathrm{H}_{4}$ & ${ }^{2} J_{\mathrm{CH}}$ & $-4,3$ & $-3,9$ & $-1,8$ & $-1,7$ & $-1,7$ & $-2,9$ & $-2,7$ & $-2,7$ & $-6,1$ & $-5,3$ & $-5,3$ & $-2,4$ \\
\hline $\mathrm{C}_{2} \mathrm{H}_{4}$ & ${ }^{2} J_{\mathrm{HH}}$ & 2,4 & 1,4 & 4,0 & 3,2 & 3,0 & 3,3 & 2,3 & 2,2 & 1,3 & 0,4 & 0,5 & 2,3 \\
\hline $\mathrm{C}_{2} \mathrm{H}_{4}$ & ${ }^{3} J_{\mathrm{HH}_{\mathrm{c}}}$ & 13,7 & 14,8 & 12,6 & 13,7 & 13,8 & 13,1 & 14,2 & 14,3 & 14,5 & 15,5 & 15,5 & 11,7 \\
\hline $\mathrm{C}_{2} \mathrm{H}_{4}$ & ${ }^{3} J_{\mathrm{HH}_{\mathrm{t}}}$ & 20,3 & 20,9 & 18,6 & 19,6 & 19,3 & 19,4 & 20,2 & 20,1 & 21,5 & 21,8 & 21,9 & 19,0 \\
\hline $\mathrm{C}_{2} \mathrm{H}_{6}$ & ${ }^{1} J_{\mathrm{CC}}$ & 34,2 & 37,1 & 27,8 & 31,5 & 30,9 & 30,9 & 34,2 & 33,9 & 37,6 & 39,8 & 40,4 & 34,5 \\
\hline $\mathrm{C}_{2} \mathrm{H}_{6}$ & ${ }^{1} J_{\mathrm{CH}}$ & 127,6 & 124,6 & 119,1 & 117,1 & 116,4 & 123,3 & 120,8 & 120,4 & 132,2 & 128,6 & 129,0 & 125,2 \\
\hline $\mathrm{C}_{2} \mathrm{H}_{6}$ & ${ }^{2} J_{\mathrm{CH}}$ & $-4,5$ & $-4,6$ & $-3,3$ & $-3,5$ & $-3,4$ & $-3,9$ & $-4,0$ & $-4,0$ & $-5,1$ & $-5,2$ & $-5,2$ & $-4,7$ \\
\hline \multirow[t]{3}{*}{ Total } & $\mathrm{DM}$ & $-14,54$ & 3,76 & $-21,73$ & $-8,03$ & $-4,67$ & $-18,16$ & $-2,27$ & $-0,58$ & $-11,00$ & 10,03 & 8,34 & - \\
\hline & DMA & 20,06 & 13,68 & 24,57 & 19,44 & 19,75 & 21,47 & 14,63 & 14,92 & 23,20 & 17,58 & 15,95 & - \\
\hline & PDMA & 13,25 & 19,17 & 26,66 & 20,56 & 19,01 & 16,89 & 10,37 & 11,31 & 26,78 & 33,93 & 32,32 & - \\
\hline \multirow[t]{3}{*}{ CPI } & $\mathrm{DM}$ & $-40,42$ & 3,65 & $-51,13$ & $-19,07$ & $-10,36$ & $-45,72$ & $-7,94$ & $-3,55$ & $-35,67$ & 15,63 & 11,11 & - \\
\hline & DMA & 40,82 & 26,40 & 53,11 & 41,13 & 41,16 & 46,46 & 30,14 & 30,86 & 43,87 & 32,15 & 27,78 & - \\
\hline & PDMA & 13,71 & 25,78 & 43,92 & 33,28 & 29,47 & 26,14 & 15,20 & 17,07 & 28,14 & 45,00 & 40,84 & - \\
\hline \multirow[t]{3}{*}{ SPI } & DM & 4,44 & 3,84 & $-0,17$ & 0,06 & $-0,49$ & 2,05 & 1,89 & 1,61 & 7,10 & 5,92 & 6,31 & - \\
\hline & DMA & 4,84 & 4,35 & 3,63 & 3,54 & 4,05 & 3,14 & 3,25 & 3,23 & 8,05 & 6,89 & 7,27 & - \\
\hline & PDMA & 12,91 & 14,33 & 14,01 & 11,23 & 11,34 & 10,11 & 6,83 & 7,08 & 25,78 & 25,81 & 26,07 & - \\
\hline \multirow[t]{3}{*}{$\Delta \mathrm{CS}$} & $\mathrm{DM}$ & $-44,86$ & $-0,19$ & $-50,96$ & $-19,13$ & $-9,88$ & $-47,76$ & $-9,83$ & $-5,16$ & $-42,77$ & 9,71 & 4,80 & - \\
\hline & DMA & 35,98 & 22,05 & 49,48 & 37,59 & 37,12 & 43,32 & 26,88 & 27,63 & 35,83 & 25,26 & 20,51 & - \\
\hline & PDMA & 0,80 & 11,46 & 29,90 & 22,05 & 18,13 & 16,03 & 8,37 & 10,00 & 2,36 & 19,18 & 14,77 & - \\
\hline
\end{tabular}


Tabela 8.110: Constantes de acoplamento PBE0 com otimização de geometrias com correção vibracional no nível PBE0 $40 \% E_{X}^{\mathrm{HF}}$ e base aug-pcJ-2.

\begin{tabular}{|c|c|c|c|c|c|c|c|c|c|c|c|c|c|c|c|c|}
\hline & $\% E_{X}^{\mathrm{HF}}$ & 25,00 & 25,00 & 20,00 & 20,00 & $\begin{array}{l}25,00 \\
20,00 \\
\text { Otm. }\end{array}$ & 30,00 & 30,00 & $\begin{array}{l}25,00 \\
30,00 \\
\text { Otm. }\end{array}$ & 40,00 & 40,00 & $\begin{array}{l}25,00 \\
40,00 \\
\text { Otm. }\end{array}$ & 50,00 & 50,00 & $\begin{array}{l}25,00 \\
50,00 \\
\text { Otm. }\end{array}$ & Exp. \\
\hline $\mathrm{HF}$ & ${ }^{1} J_{\mathrm{HF}}$ & 396,0 & 392,9 & 384,9 & 374,5 & 381,8 & 407,1 & 411,1 & 404,0 & 429,5 & 447,2 & 426,5 & 452,1 & 482,9 & 449,2 & 500,0 \\
\hline $\mathrm{CO}$ & ${ }^{1} J_{\mathrm{CO}}$ & 20,6 & 19,1 & 21,5 & 20,6 & 19,9 & 19,8 & 17,6 & 18,2 & 18,0 & 14,5 & 16,4 & 16,1 & 11,6 & 14,6 & 16,4 \\
\hline $\mathrm{H}_{2} \mathrm{O}$ & ${ }^{1} J_{\mathrm{OH}}$ & $-71,6$ & $-72,1$ & $-70,4$ & $-70,1$ & $-70,9$ & $-72,8$ & $-74,0$ & $-73,3$ & $-75,2$ & $-78,2$ & $-75,6$ & $-77,6$ & $-82,0$ & $-78,0$ & $-80,6$ \\
\hline $\mathrm{H}_{2} \mathrm{O}$ & ${ }^{2} J_{\mathrm{HH}}$ & $-5,8$ & $-5,4$ & $-5,2$ & $-4,9$ & $-4,9$ & $-6,3$ & $-5,9$ & $-5,9$ & $-7,4$ & $-6,6$ & $-7,0$ & $-8,5$ & $-7,5$ & $-8,1$ & $-7,3$ \\
\hline $\mathrm{NH}_{3}$ & ${ }^{1} J_{\mathrm{NH}}$ & 43,0 & 43,5 & 42,7 & 42,8 & 43,1 & 43,4 & 44,1 & 43,9 & 44,1 & 45,3 & 44,6 & 44,8 & 46,4 & 45,3 & 43,8 \\
\hline $\mathrm{NH}_{3}$ & ${ }^{2} J_{\mathrm{HH}}$ & $-9,3$ & $-9,0$ & $-8,8$ & $-8,7$ & $-8,6$ & $-9,8$ & $-9,5$ & $-9,5$ & $-10,7$ & $-10,2$ & $-10,5$ & $-11,7$ & $-11,0$ & $-11,4$ & $-9,6$ \\
\hline $\mathrm{PH}_{3}$ & ${ }^{1} J_{\mathrm{PH}}$ & 147,1 & 153,8 & 142,9 & 148,0 & 149,7 & 151,2 & 159,4 & 157,8 & 159,4 & 170,5 & 165,7 & 167,6 & 181,1 & 173,6 & 188,2 \\
\hline $\mathrm{PF}_{3}$ & ${ }^{1} J_{\mathrm{PF}}$ & $-1729,9$ & $-1624,8$ & $-1745,9$ & $-1632,0$ & $-1637,5$ & $-1713,1$ & $-1609,9$ & $-1611,3$ & $-1677,2$ & $-1579,2$ & $-1581,7$ & $-1638,6$ & $-1541,7$ & $-1549,3$ & $-1441,0$ \\
\hline $\mathrm{BHF}_{2}$ & ${ }^{1} J_{\mathrm{BF}}$ & $-135,4$ & $-135,2$ & $-143,6$ & $-146,6$ & $-143,4$ & $-127,1$ & $-124,3$ & $-126,9$ & $-110,9$ & $-102,1$ & $-110,7$ & $-94,8$ & $-81,0$ & $-94,6$ & $-84,0$ \\
\hline $\mathrm{BF}_{3}$ & ${ }^{1} J_{\mathrm{BF}}$ & $-32,7$ & $-35,7$ & $-41,6$ & $-49,1$ & $-44,6$ & $-23,9$ & $-23,3$ & $-26,8$ & $-6,4$ & 1,4 & $-9,2$ & 10,7 & 25,1 & 8,0 & 15,0 \\
\hline $\mathrm{F}_{2} \mathrm{O}$ & ${ }^{1} J_{\mathrm{OF}}$ & $-390,2$ & $-266,3$ & $-370,2$ & $-276,7$ & $-251,6$ & $-410,9$ & $-256,9$ & $-281,3$ & $-455,8$ & $-237,3$ & $-312,7$ & $-508,8$ & $-217,3$ & $-347,1$ & $-300,0$ \\
\hline $\mathrm{CH}_{4}$ & ${ }^{1} J_{\mathrm{CH}}$ & 125,2 & 125,4 & 124,5 & 124,9 & 124,7 & 125,9 & 125,9 & 126,2 & 127,4 & 126,9 & 127,6 & 128,9 & 127,9 & 129,2 & 125,3 \\
\hline $\mathrm{CH}_{4}$ & ${ }^{2} J_{\mathrm{HH}}$ & $-14,1$ & $-14,0$ & $-13,7$ & $-13,6$ & $-13,6$ & $-14,5$ & $-14,5$ & $-14,4$ & $-15,3$ & $-15,3$ & $-15,3$ & $-16,1$ & $-16,1$ & $-16,1$ & $-12,8$ \\
\hline $\mathrm{C}_{2} \mathrm{H}_{2}$ & ${ }^{1} J_{\mathrm{CC}}$ & 197,3 & 197,5 & 195,5 & 195,9 & 195,9 & 199,2 & 199,2 & 199,3 & 203,5 & 202,9 & 203,3 & 208,5 & 206,9 & 208,0 & 174,8 \\
\hline $\mathrm{C}_{2} \mathrm{H}_{2}$ & ${ }^{1} J_{\mathrm{CH}}$ & 259,4 & 257,7 & 258,0 & 257,2 & 256,3 & 260,8 & 258,2 & 259,1 & 263,9 & 259,3 & 262,0 & 267,3 & 260,7 & 265,3 & 247,6 \\
\hline $\mathrm{C}_{2} \mathrm{H}_{2}$ & ${ }^{2} J_{\mathrm{CH}}$ & 53,7 & 53,9 & 53,9 & 54,1 & 54,1 & 53,4 & 53,7 & 53,6 & 52,4 & 53,0 & 52,8 & 51,1 & 52,2 & 51,6 & 50,1 \\
\hline $\mathrm{C}_{2} \mathrm{H}_{2}$ & ${ }^{3} J_{\mathrm{HH}}$ & 13,1 & 12,7 & 12,6 & 12,4 & 12,3 & 13,6 & 13,1 & 13,2 & 14,8 & 14,0 & 14,4 & 16,3 & 15,0 & 15,8 & 9,6 \\
\hline $\mathrm{C}_{2} \mathrm{H}_{4}$ & ${ }^{1} J_{\mathrm{CC}}$ & 69,7 & 72,3 & 68,0 & 70,8 & 70,8 & 71,4 & 73,9 & 73,9 & 75,4 & 77,2 & 77,5 & 80,1 & 80,9 & 81,6 & 67,6 \\
\hline $\mathrm{C}_{2} \mathrm{H}_{4}$ & ${ }^{1} J_{\mathrm{CH}}$ & 159,3 & 156,6 & 158,1 & 155,8 & 155,5 & 160,5 & 157,3 & 157,7 & 163,1 & 158,9 & 160,1 & 166,0 & 160,7 & 162,8 & 156,3 \\
\hline $\mathrm{C}_{2} \mathrm{H}_{4}$ & ${ }^{2} J_{\mathrm{CH}}$ & $-3,5$ & $-3,2$ & $-3,0$ & $-2,7$ & $-2,7$ & $-4,2$ & $-3,8$ & $-3,8$ & $-5,6$ & $-5,0$ & $-5,1$ & $-7,4$ & $-6,4$ & $-6,7$ & $-2,4$ \\
\hline $\mathrm{C}_{2} \mathrm{H}_{4}$ & ${ }^{2} J_{\mathrm{HH}}$ & 2,5 & 1,4 & 3,0 & 1,9 & 1,8 & 2,0 & 0,9 & 0,9 & 0,9 & $-0,1$ & 0,0 & $-0,3$ & $-1,2$ & $-1,2$ & 2,3 \\
\hline $\mathrm{C}_{2} \mathrm{H}_{4}$ & ${ }^{3} J_{\mathrm{HH}_{\mathrm{C}}}$ & 13,1 & 13,8 & 12,9 & 13,5 & 13,6 & 13,4 & 14,1 & 14,0 & 14,0 & 14,7 & 14,6 & 14,9 & 15,4 & 15,3 & 11,7 \\
\hline $\mathrm{C}_{2} \mathrm{H}_{4}$ & ${ }^{3} J_{\mathrm{HH}_{\mathrm{t}}}$ & 20,5 & 21,1 & 20,2 & 20,9 & 20,9 & 20,8 & 21,4 & 21,4 & 21,6 & 21,9 & 22,1 & 22,6 & 22,6 & 23,0 & 19,0 \\
\hline $\mathrm{C}_{2} \mathrm{H}_{6}$ & ${ }^{1} J_{\mathrm{CC}}{ }^{l}$ & 31,3 & 33,5 & 30,3 & 32,6 & 32,6 & 32,2 & 34,4 & 34,5 & 34,2 & 36,2 & 36,4 & 36,1 & 38,0 & 38,3 & 34,5 \\
\hline $\mathrm{C}_{2} \mathrm{H}_{6}$ & ${ }^{1} J_{\mathrm{CH}}$ & 125,3 & 123,8 & 124,5 & 123,3 & 123,0 & 126,1 & 124,4 & 124,7 & 127,8 & 125,6 & 126,3 & 129,5 & 126,7 & 128,0 & 125,2 \\
\hline $\mathrm{C}_{2} \mathrm{H}_{6}$ & ${ }^{2} J_{\mathrm{CH}}$ & $-4,3$ & $-4,3$ & $-4,1$ & $-4,1$ & $-4,1$ & $-4,5$ & $-4,6$ & $-4,6$ & $-5,1$ & $-5,1$ & $-5,1$ & $-5,6$ & $-5,6$ & $-5,6$ & $-4,7$ \\
\hline \multirow[t]{3}{*}{ Total } & DM & $-21,72$ & $-12,92$ & $-23,00$ & $-15,55$ & $-14,27$ & $-20,43$ & $-10,12$ & $-11,55$ & $-17,87$ & $-4,41$ & $-8,75$ & $-15,45$ & 1,5 & $-5,90$ & - \\
\hline & DMA & 26,73 & 20,37 & 27,77 & 22,19 & 22,66 & 25,84 & 18,39 & 18,16 & 24,33 & 14,88 & 15,02 & 23,42 & 12,62 & 13,70 & - \\
\hline & PDMA & 27,04 & 27,31 & 30,20 & 30,47 & 29,40 & 25,58 & 24,61 & 25,55 & 25,39 & 22,04 & 24,61 & 28,41 & 26,97 & 27,34 & - \\
\hline \multirow[t]{3}{*}{ CPI } & DM & $-55,37$ & $-34,55$ & $-57,69$ & $-40,28$ & $-37,08$ & $-53,03$ & $-28,41$ & $-32,00$ & $-48,50$ & $-15,96$ & $-26,83$ & $-44,51$ & $-3,12$ & & - \\
\hline & DMA & 58,10 & 43,17 & 61,00 & 47,79 & 48,90 & 55,25 & 37,99 & 37,35 & 49,83 & 28,20 & 27,94 & 45,24 & & 22,45 & - \\
\hline & PDMA & 48,57 & 47,51 & 56,66 & 59,32 & 56,38 & 41,08 & 36,26 & 38,51 & 27,49 & 17,86 & 23,21 & 17,41 & 15,17 & 13,43 & - \\
\hline \multirow[t]{3}{*}{ SPI } & DM & 2,96 & 2,94 & & 2,59 & 2,47 & 3,47 & 3,30 & 3,44 & 4,5 & 4,07 & 4,50 & 5,85 & 4, & 5,68 & - \\
\hline & DMA & 3,72 & 3,65 & 3,40 & 3,41 & 3,41 & 4,28 & 4,02 & 4,09 & 5,63 & 5,12 & 5,55 & 7,43 & 6,47 & 7,28 & - \\
\hline & PDMA & 11,25 & 12,50 & 10,79 & 9,32 & 9,61 & 14,22 & 16,07 & 16,04 & 23,86 & 25,10 & 25,63 & 36,48 & 35,62 & 37,54 & - \\
\hline \multirow[t]{3}{*}{$\Delta \mathrm{CS}$} & DM & $-58,33$ & $-37,49$ & $-60,13$ & $-42,87$ & $-39,55$ & $-56,49$ & $-31,71$ & $-35,44$ & $-53,09$ & $-20,03$ & $-31,33$ & $-50,36$ & $-8,02$ & $-27,38$ & - \\
\hline & DMA & 54,38 & 39,53 & & 44,38 & 45,49 & 50,97 & & 33,25 & 44,19 & & 22,38 & & & 15,17 & - \\
\hline & PDMA & 37,31 & 35,01 & 45,88 & 50,00 & 46,77 & 26,86 & 20,20 & 22,47 & 3,63 & $-7,23$ & $-2,42$ & $-19,07$ & $-20,45$ & $-24,10$ & - \\
\hline
\end{tabular}




\subsubsection{Utilização de CAISS empíricas}

\subsubsection{Precisão dos funcionais da literatura}

Tabela 8.111: Constantes de acoplamento utilizando funcionais da literatura (0 a $21 \%$ $\left.E_{X}^{\mathrm{HF}}\right)$ e constantes empíricas no nível BHandH $\left(50 \% E_{X}^{\mathrm{HF}}\right)$ e base aug-pcJ-2.

\begin{tabular}{|c|c|c|c|c|c|c|c|c|c|c|c|c|c|c|c|}
\hline & Func. & PBE & PW91 & BP86 & $\omega \mathrm{B} 97$ & TPSSh & O3LYP & $\omega \mathrm{B} 97 \mathrm{X}$ & CAMB3 & B3P86 & B3LYP & B3W91 & B971 & B972 & Emp. \\
\hline & $\% E_{X}^{\mathrm{HF}}$ & 0,00 & 0,00 & 0,00 & 0,00 & 10,00 & 11,61 & 15,77 & 19,00 & 20,00 & 20,00 & 20,00 & 21,00 & 21,00 & - \\
\hline $\mathrm{HF}$ & ${ }^{1} J_{\mathrm{HF}}$ & 376,0 & 364,2 & 355,3 & 455,6 & 390,6 & 396,4 & 497,9 & 455,6 & 407,3 & 445,4 & 408,9 & 449,1 & 442,8 & 532,8 \\
\hline $\mathrm{CO}$ & ${ }^{1} J_{\mathrm{CO}}$ & 24,1 & 24,9 & 24,9 & 23,9 & 20,3 & 21,9 & 19,1 & 18,3 & 21,6 & 18,2 & 21,6 & 17,4 & 18,3 & 15,7 \\
\hline $\mathrm{H}_{2} \mathrm{O}$ & ${ }^{1} J_{\mathrm{OH}}$ & $-67,2$ & $-66,3$ & $-64,8$ & $-71,8$ & $-72,5$ & $-69,4$ & $-76,5$ & $-77,7$ & $-70,1$ & $-76,8$ & $-70,6$ & $-74,4$ & $-73,5$ & $-81,7$ \\
\hline $\mathrm{H}_{2} \mathrm{O}$ & ${ }^{2} J_{\mathrm{HH}}$ & $-4,7$ & $-4,8$ & $-4,6$ & $-6,6$ & $-5,3$ & $-8,0$ & $-6,4$ & $-7,4$ & $-6,3$ & $-7,2$ & $-6,8$ & $-6,5$ & $-7,5$ & $-8,8$ \\
\hline $\mathrm{NH}_{3}$ & ${ }^{1} J_{\mathrm{NH}}$ & 40,8 & 40,8 & 40,0 & 39,0 & 45,8 & 41,1 & 41,5 & 45,2 & 41,4 & 45,3 & 41,7 & 43,3 & 41,7 & 43,0 \\
\hline $\mathrm{NH}_{3}$ & ${ }^{2} J_{\mathrm{HH}}$ & $-7,8$ & $-8,0$ & $-7,8$ & $-8,5$ & $-8,1$ & $-10,1$ & $-8,7$ & $-10,2$ & $-9,3$ & $-9,9$ & $-9,8$ & $-9,1$ & $-9,1$ & $-10,5$ \\
\hline $\mathrm{PH}_{3}$ & ${ }^{1} J_{\mathrm{PH}}$ & 133,7 & 137,6 & 136,9 & 159,3 & 200,5 & 165,5 & 165,0 & 162,3 & 152,3 & 171,9 & 154,6 & 190,7 & 184,0 & 195,0 \\
\hline $\mathrm{PF}_{3}$ & ${ }^{1} J_{\mathrm{PF}}$ & $-1801,0$ & $-1815,2$ & $-1802,5$ & $-1663,0$ & $-1731,7$ & $-1687,8$ & $-1643,0$ & $-1749,1$ & $-1749,4$ & $-1755,9$ & $-1751,4$ & $-1656,7$ & $-1661,2$ & $-1441,7$ \\
\hline $\mathrm{BHF}_{2}$ & ${ }^{1} J_{\mathrm{BF}}$ & $-172,8$ & $-177,6$ & $-177,9$ & $-111,8$ & $-142,5$ & $-157,4$ & $-97,5$ & $-125,7$ & $-143,2$ & $-134,5$ & $-142,6$ & $-123,8$ & $-129,9$ & $-79,7$ \\
\hline $\mathrm{BF}_{3}$ & ${ }^{1} J_{\mathrm{BF}}$ & $-75,8$ & $-80,9$ & $-83,3$ & $-14,8$ & $-47,2$ & $-63,7$ & 3,3 & $-22,4$ & $-45,2$ & $-33,2$ & $-44,5$ & $-27,9$ & $-36,6$ & 17,1 \\
\hline $\mathrm{F}_{2} \mathrm{O}$ & ${ }^{1} J_{\mathrm{OF}}$ & $-278,0$ & $-290,5$ & $-290,1$ & $-310,7$ & $-320,1$ & $-297,3$ & $-326,5$ & $-386,6$ & $-360,6$ & $-352,0$ & $-362,9$ & $-318,8$ & $-316,0$ & $-285,7$ \\
\hline $\mathrm{CH}_{4}$ & ${ }^{1} J_{\mathrm{CH}}$ & 119,3 & 120,1 & 117,5 & 109,4 & 138,8 & 119,5 & 112,5 & 128,9 & 120,0 & 131,7 & 121,0 & 128,8 & 118,8 & 122,8 \\
\hline $\mathrm{CH}_{4}$ & ${ }^{2} J_{\mathrm{HH}}$ & $-11,8$ & $-12,0$ & $-11,8$ & $-11,2$ & $-11,3$ & $-13,2$ & $-11,3$ & $-13,2$ & $-12,9$ & $-13,0$ & $-13,4$ & $-12,0$ & $-11,3$ & $-12,5$ \\
\hline $\mathrm{C}_{2} \mathrm{H}_{2}$ & ${ }^{1} J_{\mathrm{CC}}$ & 188,7 & 188,8 & 187,3 & 194,2 & 190,8 & 191,5 & 193,0 & 202,0 & 193,4 & 203,3 & 193,8 & 213,8 & 197,5 & 174,1 \\
\hline $\mathrm{C}_{2} \mathrm{H}_{2}$ & ${ }^{1} J_{\mathrm{CH}}$ & 249,8 & 252,5 & 247,4 & 236,3 & 282,3 & 254,5 & 240,2 & 266,9 & 251,9 & 271,8 & 254,0 & 261,3 & 247,3 & 244,3 \\
\hline $\mathrm{C}_{2} \mathrm{H}_{2}$ & ${ }^{2} J_{\mathrm{CH}}$ & 54,1 & 54,6 & 54,6 & 51,8 & 57,7 & 52,6 & 53,4 & 57,0 & 54,0 & 56,1 & 54,0 & 53,2 & 50,7 & 49,8 \\
\hline $\mathrm{C}_{2} \mathrm{H}_{2}$ & ${ }^{3} J_{\mathrm{HH}}$ & 10,4 & 10,5 & 10,2 & 10,4 & 12,6 & 11,8 & 10,0 & 11,1 & 11,2 & 11,1 & 11,7 & 10,5 & 10,4 & 9,0 \\
\hline $\mathrm{C}_{2} \mathrm{H}_{4}$ & ${ }^{1} J_{\mathrm{CC}}$ & 61,3 & 60,6 & 59,5 & 65,6 & 71,5 & 63,9 & 64,5 & 70,6 & 64,7 & 71,0 & 65,3 & 78,1 & 68,1 & 66,9 \\
\hline $\mathrm{C}_{2} \mathrm{H}_{4}$ & ${ }^{1} J_{\mathrm{CH}}$ & 151,8 & 153,0 & 149,7 & 142,7 & 174,3 & 154,4 & 145,4 & 164,4 & 153,7 & 167,1 & 155,1 & 162,8 & 152,3 & 154,4 \\
\hline $\mathrm{C}_{2} \mathrm{H}_{4}$ & ${ }^{2} J_{\mathrm{CH}}$ & $-0,5$ & $-0,4$ & 0,0 & $-2,2$ & $-1,7$ & $-1,9$ & $-1,3$ & $-1,7$ & $-1,6$ & $-1,4$ & $-2,0$ & $-2,1$ & $-2,0$ & $-2,0$ \\
\hline $\mathrm{C}_{2} \mathrm{H}_{4}$ & ${ }^{2} J_{\mathrm{HH}}$ & 4,5 & 4,5 & 4,6 & 2,3 & 8,2 & 2,8 & 2,9 & 4,0 & 3,2 & 4,5 & 2,8 & 3,6 & 3,1 & 2,1 \\
\hline $\mathrm{C}_{2} \mathrm{H}_{4}$ & ${ }^{3} J_{\mathrm{HH}_{\mathrm{c}}}$ & 11,7 & 11,9 & 11,6 & 11,5 & 12,5 & 12,3 & 11,5 & 13,3 & 12,1 & 12,8 & 12,4 & 11,7 & 11,2 & 11,4 \\
\hline $\mathrm{C}_{2} \mathrm{H}_{4}$ & ${ }^{3} J_{\mathrm{HH}_{\mathrm{t}}}$ & 18,7 & 19,0 & 18,5 & 17,0 & 22,5 & 19,3 & 17,2 & 20,0 & 19,0 & 20,0 & 19,4 & 18,4 & 17,7 & 18,4 \\
\hline $\mathrm{C}_{2} \mathrm{H}_{6}$ & ${ }^{1} J_{\mathrm{CC}}$ & 25,7 & 25,1 & 24,2 & 28,5 & 34,4 & 27,5 & 29,1 & 32,5 & 28,0 & 32,4 & 28,3 & 34,9 & 30,6 & 33,6 \\
\hline $\mathrm{C}_{2} \mathrm{H}_{6}$ & ${ }^{1} J_{\mathrm{CH}}$ & 119,5 & 120,3 & 117,6 & 109,0 & 138,9 & 119,9 & 112,4 & 129,1 & 120,6 & 131,7 & 121,6 & 129,1 & 118,9 & 123,3 \\
\hline $\mathrm{C}_{2} \mathrm{H}_{6}$ & ${ }^{2} J_{\mathrm{CH}}$ & $-2,9$ & $-2,9$ & $-2,7$ & $-3,2$ & $-3,8$ & $-3,6$ & $-3,2$ & $-3,6$ & $-3,5$ & $-3,4$ & $-3,7$ & $-3,6$ & $-3,2$ & $-4,5$ \\
\hline \multirow[t]{3}{*}{ Total } & $\mathrm{DM}$ & $-27,65$ & $-29,11$ & $-29,70$ & $-16,69$ & $-16,50$ & $-20,93$ & $-13,16$ & $-19,35$ & $-24,40$ & $-18,45$ & $-24,16$ & $-12,11$ & $-16,29$ & - \\
\hline & DMA & 33,04 & 34,30 & 34,52 & 20,43 & 29,17 & 25,27 & 16,27 & 27,23 & 28,88 & 27,54 & 28,79 & 20,61 & 19,90 & - \\
\hline & PDMA & 46,40 & 48,32 & 50,37 & 21,17 & 42,98 & 33,06 & 16,12 & 25,63 & 31,21 & 29,89 & 29,34 & 23,65 & 24,07 & - \\
\hline \multirow[t]{3}{*}{ CPI } & $\mathrm{DM}$ & $-66,20$ & $-70,12$ & $-69,95$ & $-36,81$ & $-51,43$ & $-51,30$ & $-29,75$ & $-53,93$ & $-59,73$ & $-53,11$ & $-59,75$ & $-37,47$ & $-40,23$ & - \\
\hline & DMA & 73,00 & 75,77 & 75,95 & 40,86 & 56,52 & 54,88 & 32,08 & 55,84 & 63,58 & 55,27 & 63,34 & 39,84 & 42,68 & - \\
\hline & PDMA & 81,57 & 85,13 & 87,25 & 36,49 & 56,93 & 63,98 & 20,83 & 38,36 & 57,49 & 44,30 & 55,93 & 38,44 & 43,92 & - \\
\hline \multirow[t]{3}{*}{ SPI } & DM & 0,61 & 0,97 & $-0,19$ & $-1,93$ & 9,11 & 1,35 & $-0,99$ & 6,01 & 1,51 & 6,97 & $1, \mathrm{~s}$ & 6,49 & 1,27 & - \\
\hline & DMA & 3,73 & 3,89 & 4,14 & 5,45 & 9,11 & 3,55 & 4,67 & 6,25 & 3,43 & 7,20 & 3,45 & 6,51 & 3,19 & - \\
\hline & PDMA & 20,60 & 21,32 & 23,32 & 9,93 & 32,76 & 10,38 & 12,66 & 16,30 & 11,94 & 19,31 & 9,85 & 12,80 & 9,51 & - \\
\hline \multirow[t]{3}{*}{$\Delta \mathrm{CS}$} & DM & $-66,81$ & $-71,08$ & $-69,75$ & $-34,88$ & $-60,53$ & $-52,65$ & $-28,77$ & $-59,94$ & $-61,24$ & $-60,08$ & $-61,70$ & $-43,97$ & $-41,49$ & - \\
\hline & DMA & 69,27 & 71,89 & 71,81 & 35,41 & 47,41 & 51,34 & 27,42 & 49,58 & 60,15 & 48,07 & 59,88 & 33,33 & 39,50 & - \\
\hline & PDMA & 60,97 & 63,81 & 63,93 & 26,57 & 24,17 & 53,59 & 8,17 & 22,06 & 45,54 & 24,99 & 46,08 & 25,64 & 34,41 & - \\
\hline
\end{tabular}


Tabela 8.112: Constantes de acoplamento utilizando funcionais da literatura (21 a 100\% $\left.E_{X}^{\mathrm{HF}}\right)$ e constantes empíricas no nível BHandH $\left(50 \% E_{X}^{\mathrm{HF}}\right)$ e base aug-pcJ-2.

\begin{tabular}{|c|c|c|c|c|c|c|c|c|c|c|c|c|c|c|c|}
\hline & Func. & X3LYP & B98 & $\omega 97 X D$ & PBE0 & M06 & B1B95 & M05 & BMK & $\mathrm{BHH}$ & BHLYP & M062X & M052X & M06HF & Emp. \\
\hline & $\% E_{X}^{\mathrm{HF}}$ & 21,80 & 21,98 & 22,20 & 25,00 & 27,00 & 28,00 & 28,00 & 42,00 & 50,00 & 50,00 & 54,00 & 56,00 & 100,00 & - \\
\hline $\mathrm{HF}$ & ${ }^{1} J_{\mathrm{HF}} \mathrm{A}$ & 453,2 & 431,2 & 484,2 & 430,8 & 678,3 & 470,4 & 828,5 & 550,8 & 530,8 & 526,8 & 485,6 & 583,3 & 177,7 & 532,8 \\
\hline $\mathrm{CO}$ & ${ }^{1} J_{\mathrm{CO}}$ & 17,7 & 18,5 & 19,6 & 19,9 & 17,9 & 18,4 & 9,1 & 18,7 & 13,7 & 10,9 & 7,4 & 3,9 & 4,4 & 15,7 \\
\hline $\mathrm{H}_{2} \mathrm{O}$ & ${ }^{1} J_{\mathrm{OH}}$ & $-77,8$ & $-72,5$ & $-74,7$ & $-73,0$ & $-100,6$ & $-77,3$ & $-108,3$ & $-86,9$ & $-83,7$ & $-86,5$ & $-91,6$ & $-89,3$ & $-54,8$ & $-81,7$ \\
\hline $\mathrm{H}_{2} \mathrm{O}$ & ${ }^{2} J_{\mathrm{HH}}$ & $-7,5$ & $-6,9$ & $-6,4$ & $-7,3$ & $-16,8$ & $-7,0$ & $-18,6$ & $-6,7$ & $-9,4$ & $-11,2$ & $-7,1$ & $-4,6$ & 8,8 & $-8,8$ \\
\hline $\mathrm{NH}_{3}$ & ${ }^{1} J_{\mathrm{NH}}$ & 45,8 & 42,9 & 41,9 & 42,5 & 52,4 & 44,0 & 44,3 & 47,8 & 45,5 & 49,0 & 53,2 & 43,8 & 37,7 & 43,0 \\
\hline $\mathrm{NH}_{3}$ & ${ }^{2} J_{\mathrm{HH}}$ & $-10,2$ & $-9,5$ & $-9,0$ & $-10,1$ & $-18,0$ & $-9,3$ & $-15,8$ & $-10,2$ & $-11,1$ & $-13,5$ & $-11,0$ & $-6,3$ & $-5,4$ & $-10,5$ \\
\hline $\mathrm{PH}_{3}$ & ${ }^{1} J_{\mathrm{PH}}$ & 174,3 & 196,4 & 176,7 & 154,6 & 247,5 & 167,8 & 171,8 & 137,9 & 183,1 & 201,3 & 166,9 & 118,3 & 159,3 & 195,0 \\
\hline $\mathrm{PF}_{3}$ & ${ }^{1} J_{\mathrm{PF}}$ & $-1753,0$ & $-1666,4$ & $-1637,8$ & $-1732,1$ & $-1526,9$ & $-1645,5$ & $-1389,0$ & $-1646,1$ & $-1670,4$ & $-1651,5$ & $-1625,7$ & $-1705,4$ & $-1876,6$ & $-1441,7$ \\
\hline $\mathrm{BHF}_{2}$ & ${ }^{1} J_{\mathrm{BF}}$ & $-131,5$ & $-129,1$ & $-103,1$ & $-131,0$ & $-36,1$ & $-127,6$ & 20,8 & $-104,0$ & $-95,2$ & $-81,9$ & $-116,5$ & $-105,2$ & $-275,0$ & $-79,7$ \\
\hline $\mathrm{BF}_{3}$ & ${ }^{1} J_{\mathrm{BF}}$ & $-29,1$ & $-34,1$ & $-3,0$ & $-30,5$ & 64,9 & $-27,0$ & 127,1 & 5,1 & 15,1 & 24,3 & $-20,0$ & $-3,5$ & $-196,7$ & 17,1 \\
\hline $\mathrm{F}_{2} \mathrm{O}$ & ${ }^{1} J_{\mathrm{OF}}$ & $-359,4$ & $-336,9$ & $-333,4$ & $-374,9$ & $-308,4$ & $-361,9$ & $-302,9$ & $-377,3$ & $-465,0$ & $-488,0$ & $-429,2$ & $-520,8$ & $-1503,5$ & $-285,7$ \\
\hline $\mathrm{CH}_{4}$ & ${ }^{1} J_{\mathrm{CH}}$ & 132,9 & 128,3 & 114,7 & 122,8 & 139,6 & 124,4 & 98,5 & 159,2 & 124,9 & 140,7 & 143,7 & 115,3 & 67,5 & 122,8 \\
\hline $\mathrm{CH}_{4}$ & ${ }^{2} J_{\mathrm{HH}}$ & $-13,2$ & $-12,5$ & $-11,8$ & $-13,8$ & $-25,9$ & $-12,2$ & $-21,2$ & $-14,3$ & $-13,3$ & $-16,0$ & $-12,1$ & $-6,6$ & $-15,5$ & $-12,5$ \\
\hline $\mathrm{C}_{2} \mathrm{H}_{2}$ & ${ }^{1} J_{\mathrm{CC}}$ & 204,4 & 212,9 & 191,3 & 196,4 & 193,6 & 195,2 & 209,7 & 342,7 & 202,4 & 220,1 & 227,8 & 224,7 & 251,3 & 174,1 \\
\hline $\mathrm{C}_{2} \mathrm{H}_{2}$ & ${ }^{1} J_{\mathrm{CH}}$ & 273,8 & 261,1 & 245,6 & 256,2 & 299,5 & 256,2 & 247,8 & 296,0 & 259,5 & 288,5 & 270,2 & 208,7 & 90,6 & 244,3 \\
\hline $\mathrm{C}_{2} \mathrm{H}_{2}$ & ${ }^{2} J_{\mathrm{CH}}$ & 56,2 & 52,8 & 53,7 & 53,5 & 50,3 & 55,6 & 36,5 & 62,0 & 53,0 & 54,1 & 56,9 & 49,6 & 45,3 & 49,8 \\
\hline $\mathrm{C}_{2} \mathrm{H}_{2}$ & ${ }^{3} J_{\mathrm{HH}}$ & 11,2 & 10,7 & 10,1 & 12,4 & 17,1 & 10,4 & 20,6 & 12,0 & 11,8 & 14,8 & 9,3 & 7,4 & 5,2 & 9,0 \\
\hline $\mathrm{C}_{2} \mathrm{H}_{4}$ & ${ }^{1} J_{\mathrm{CC}}$ & 72,0 & 77,3 & 63,7 & 68,7 & 64,8 & 66,0 & 76,4 & 127,3 & 72,3 & 86,0 & 91,2 & 85,1 & 85,9 & 66,9 \\
\hline $\mathrm{C}_{2} \mathrm{H}_{4}$ & ${ }^{1} J_{\mathrm{CH}}$ & 168,6 & 162,5 & 148,1 & 157,3 & 183,7 & 158,8 & 141,6 & 195,6 & 160,6 & 180,1 & 177,6 & 141,8 & $-61,3$ & 154,4 \\
\hline $\mathrm{C}_{2} \mathrm{H}_{4}$ & ${ }^{2} J_{\mathrm{CH}}$ & $-1,6$ & $-2,4$ & $-1,0$ & $-3,0$ & $-6,4$ & $-1,1$ & $-13,9$ & $-4,7$ & $-3,8$ & $-6,0$ & $-2,5$ & $-1,6$ & 13,0 & $-2,0$ \\
\hline $\mathrm{C}_{2} \mathrm{H}_{4}$ & ${ }^{2} J_{\mathrm{HH}}$ & 4,4 & 3,1 & 3,0 & 2,3 & $-13,4$ & 4,2 & $-14,6$ & 5,2 & 2,2 & 1,6 & 3,7 & 6,1 & 4,1 & 2,1 \\
\hline $\mathrm{C}_{2} \mathrm{H}_{4}$ & ${ }^{3} J_{\mathrm{HH}_{\mathrm{c}}}$ & 13,0 & 11,8 & 11,5 & 12,7 & 17,1 & 12,1 & 16,2 & 13,5 & 13,3 & 14,9 & 12,9 & 9,5 & 4,5 & 11,4 \\
\hline $\mathrm{C}_{2} \mathrm{H}_{4}$ & ${ }^{3} J_{\mathrm{HH}_{\mathrm{t}}}$ & 20,2 & 18,5 & 17,5 & 19,8 & 21,6 & 19,0 & 19,2 & 21,1 & 19,6 & 22,7 & 18,8 & 14,9 & 5,8 & 18,4 \\
\hline $\mathrm{C}_{2} \mathrm{H}_{6}$ & ${ }^{1} J_{\mathrm{CC}}$ & 33,1 & 34,4 & 29,0 & 30,4 & 29,4 & 30,6 & 24,8 & 48,7 & 33,3 & 40,6 & 48,9 & 40,9 & 46,8 & 33,6 \\
\hline $\mathrm{C}_{2} \mathrm{H}_{6}$ & ${ }^{1} J_{\mathrm{CH}}$ & 132,9 & 128,8 & 115,2 & 123,5 & 139,1 & 125,0 & 98,2 & 160,2 & 125,8 & 141,3 & 145,0 & 117,4 & 81,1 & 123,3 \\
\hline $\mathrm{C}_{2} \mathrm{H}_{6}$ & ${ }^{2} J_{\mathrm{CH}}$ & $-3,5$ & $-3,8$ & $-3,3$ & $-4,1$ & $-5,5$ & $-3,5$ & $-4,6$ & $-5,1$ & $-4,3$ & $-5,1$ & $-3,7$ & $-2,7$ & $-3,3$ & $-4,5$ \\
\hline \multirow[t]{3}{*}{ Total } & DM & 7,6 & 4,2 & -13 & $-21,64$ & 10,4 & -15 & 15,9 & 2,3 & $-14,46$ & $-8,7$ & & & & - \\
\hline & DMA & 27,28 & 22,60 & ,49 & 26,58 & 24,5 & 20,39 & 32,1 & 33,13 & 19,97 & 5 & 27,11 & 32,99 & 120,93 & - \\
\hline & PDMA & 28,15 & 24,94 & 18,09 & 25,71 & 75,56 & 26,16 & 110,03 & 37,83 & 13,67 & 29,72 & 30,39 & 36,12 & 148,95 & - \\
\hline \multirow[t]{3}{*}{ CPI } & DM & 2,09 & $-41,99$ & $-30,95$ & $-55,15$ & 14,4 & $-40,95$ & 42,86 & $-33,31$ & $-40,19$ & $-37,80$ & $-43,95$ & -52 & $-219,96$ & - \\
\hline & DMA & 3,96 & 44,95 & 33,65 & 57,84 & 40,3 & 42,97 & 58,99 & 38,44 & 40,65 & 41,35 & 46,12 & 63,70 & 228,98 & - \\
\hline & PDMA & 40,89 & 43,19 & 24,84 & 44,85 & 56,70 & 40,11 & 98,72 & 22,08 & 13,62 & 21,89 & 42,02 & 43,26 & 218,41 & - \\
\hline \multirow[t]{3}{*}{ SPI } & DM & 7,55 & 6,1 & $-c$ & 2,9 & & 3,3 & -3 & & 4,4 & & & 1, & & - \\
\hline & MA & 7,71 & & & & & & & & & & & & & - \\
\hline & PDMA & 18,82 & 11,56 & 13,14 & 11,66 & 89,39 & 15,93 & 118,32 & 49,38 & 13,70 & 35,47 & 21,87 & 30,88 & 98,00 & - \\
\hline \multirow[t]{3}{*}{$\Delta \mathrm{CS}$} & DM & & -48 & & $-58,08$ & & & & -61 & & & & & -19 & - \\
\hline & DMA & 25 & 38 & & 54,17 & 27,3 & & & 9,2 & & & & 53,2 & 187,30 & - \\
\hline & PDM & 22,07 & 31,63 & 11,70 & 33,19 & $-32,69$ & 24,18 & $-19,60$ & $-27,30$ & $-0,09$ & $-13,57$ & 20,15 & 12,39 & 120,40 & 一 \\
\hline
\end{tabular}


Tabela 8.113: Constantes de acoplamento utilizando funcionais da literatura (0 a 21\% $\left.E_{X}^{\mathrm{HF}}\right)$ e constantes empíricas no nível BHandH $40 \% E_{X}^{\mathrm{HF}}$ e base aug-pcJ-2.

\begin{tabular}{|c|c|c|c|c|c|c|c|c|c|c|c|c|c|c|c|}
\hline & Func. & PBE & PW91 & BP86 & $\omega \mathrm{B} 97$ & TPSSh & O3LYP & $\omega \mathrm{B} 97 \mathrm{X}$ & CAMB3 & B3P86 & B3LYP & B3W91 & B971 & B972 & Emp. \\
\hline & $\% E_{X}^{\mathrm{HF}}$ & 0,00 & 0,00 & 0,00 & 0,00 & 10,00 & 11,61 & 15,77 & 19,00 & 20,00 & 20,00 & 20,00 & 21,00 & 21,00 & _- \\
\hline $\mathrm{HF}$ & ${ }^{1} J_{\mathrm{HF}}{ }^{A}$ & 376,0 & 364,2 & 355,3 & 455,6 & 390,6 & 396,4 & 497,9 & 455,6 & 407,3 & 445,4 & 408,9 & 449,1 & 442,8 & 533,2 \\
\hline $\mathrm{CO}$ & ${ }^{1} J_{\mathrm{CO}}$ & 24,1 & 24,9 & 24,9 & 23,9 & 20,3 & 21,9 & 19,1 & 18,3 & 21,6 & 18,2 & 21,6 & 17,4 & 18,3 & 15,6 \\
\hline $\mathrm{H}_{2} \mathrm{O}$ & ${ }^{1} J_{\mathrm{OH}}$ & $-67,2$ & $-66,3$ & $-64,8$ & $-71,8$ & $-72,5$ & $-69,4$ & $-76,5$ & $-77,7$ & $-70,1$ & $-76,8$ & $-70,6$ & $-74,4$ & $-73,5$ & $-81,8$ \\
\hline $\mathrm{H}_{2} \mathrm{O}$ & ${ }^{2} J_{\mathrm{HH}}$ & $-4,7$ & $-4,8$ & $-4,6$ & $-6,6$ & $-5,3$ & $-8,0$ & $-6,4$ & $-7,4$ & $-6,3$ & $-7,2$ & $-6,8$ & $-6,5$ & $-7,5$ & $-8,7$ \\
\hline $\mathrm{NH}_{3}$ & ${ }^{1} J_{\mathrm{NH}}$ & 40,8 & 40,8 & 40,0 & 39,0 & 45,8 & 41,1 & 41,5 & 45,2 & 41,4 & 45,3 & 41,7 & 43,3 & 41,7 & 43,1 \\
\hline $\mathrm{NH}_{3}$ & ${ }^{2} J_{\mathrm{HH}}$ & $-7,8$ & $-8,0$ & $-7,8$ & $-8,5$ & $-8,1$ & $-10,1$ & $-8,7$ & $-10,2$ & $-9,3$ & $-9,9$ & $-9,8$ & $-9,1$ & $-9,1$ & $-10,5$ \\
\hline $\mathrm{PH}_{3}$ & ${ }^{1} J_{\mathrm{PH}}$ & 133,7 & 137,6 & 136,9 & 159,3 & 200,5 & 165,5 & 165,0 & 162,3 & 152,3 & 171,9 & 154,6 & 190,7 & 184,0 & 195,5 \\
\hline $\mathrm{PF}_{3}$ & ${ }^{1} J_{\mathrm{PF}}$ & $-1801,0$ & $-1815,2$ & $-1802,5$ & $-1663,0$ & $-1731,7$ & $-1687,8$ & $-1643,0$ & $-1749,1$ & $-1749,4$ & $-1755,9$ & $-1751,4$ & $-1656,7$ & $-1661,2$ & $-1442,8$ \\
\hline $\mathrm{BHF}_{2}$ & ${ }^{1} J_{\mathrm{BF}}$ & $-172,8$ & $-177,6$ & $-177,9$ & $-111,8$ & $-142,5$ & $-157,4$ & $-97,5$ & $-125,7$ & $-143,2$ & $-134,5$ & $-142,6$ & $-123,8$ & $-129,9$ & $-79,5$ \\
\hline $\mathrm{BF}_{3}$ & ${ }^{1} J_{\mathrm{BF}}$ & $-75,8$ & $-80,9$ & $-83,3$ & $-14,8$ & $-47,2$ & $-63,7$ & 3,3 & $-22,4$ & $-45,2$ & $-33,2$ & $-44,5$ & $-27,9$ & $-36,6$ & 17,2 \\
\hline $\mathrm{F}_{2} \mathrm{O}$ & ${ }^{1} J_{\mathrm{OF}}$ & $-278,0$ & $-290,5$ & $-290,1$ & $-310,7$ & $-320,1$ & $-297,3$ & $-326,5$ & $-386,6$ & $-360,6$ & $-352,0$ & $-362,9$ & $-318,8$ & $-316,0$ & $-286,9$ \\
\hline $\mathrm{CH}_{4}$ & ${ }^{1} J_{\mathrm{CH}}$ & 119,3 & 120,1 & 117,5 & 109,4 & 138,8 & 119,5 & 112,5 & 128,9 & 120,0 & 131,7 & 121,0 & 128,8 & 118,8 & 123,0 \\
\hline $\mathrm{CH}_{4}$ & ${ }^{2} J_{\mathrm{HH}}$ & $-11,8$ & $-12,0$ & $-11,8$ & $-11,2$ & $-11,3$ & $-13,2$ & $-11,3$ & $-13,2$ & $-12,9$ & $-13,0$ & $-13,4$ & $-12,0$ & $-11,3$ & $-12,5$ \\
\hline $\mathrm{C}_{2} \mathrm{H}_{2}$ & ${ }^{1} J_{\mathrm{CC}}$ & 188,7 & 188,8 & 187,3 & 194,2 & 190,8 & 191,5 & 193,0 & 202,0 & 193,4 & 203,3 & 193,8 & 213,8 & 197,5 & 174,4 \\
\hline $\mathrm{C}_{2} \mathrm{H}_{2}$ & ${ }^{1} J_{\mathrm{CH}}$ & 249,8 & 252,5 & 247,4 & 236,3 & 282,3 & 254,5 & 240,2 & 266,9 & 251,9 & 271,8 & 254,0 & 261,3 & 247,3 & 244,5 \\
\hline $\mathrm{C}_{2} \mathrm{H}_{2}$ & ${ }^{2} J_{\mathrm{CH}}$ & 54,1 & 54,6 & 54,6 & 51,8 & 57,7 & 52,6 & 53,4 & 57,0 & 54,0 & 56,1 & 54,0 & 53,2 & 50,7 & 49,7 \\
\hline $\mathrm{C}_{2} \mathrm{H}_{2}$ & ${ }^{3} J_{\mathrm{HH}}$ & 10,4 & 10,5 & 10,2 & 10,4 & 12,6 & 11,8 & 10,0 & 11,1 & 11,2 & 11,1 & 11,7 & 10,5 & 10,4 & 9,1 \\
\hline $\mathrm{C}_{2} \mathrm{H}_{4}$ & ${ }^{1} J_{\mathrm{CC}}$ & 61,3 & 60,6 & 59,5 & 65,6 & 71,5 & 63,9 & 64,5 & 70,6 & 64,7 & 71,0 & 65,3 & 78,1 & 68,1 & 67,2 \\
\hline $\mathrm{C}_{2} \mathrm{H}_{4}$ & ${ }^{1} J_{\mathrm{CH}}$ & 151,8 & 153,0 & 149,7 & 142,7 & 174,3 & 154,4 & 145,4 & 164,4 & 153,7 & 167,1 & 155,1 & 162,8 & 152,3 & 154,5 \\
\hline $\mathrm{C}_{2} \mathrm{H}_{4}$ & ${ }^{2} J_{\mathrm{CH}}$ & $-0,5$ & $-0,4$ & 0,0 & $-2,2$ & $-1,7$ & $-1,9$ & $-1,3$ & $-1,7$ & $-1,6$ & $-1,4$ & $-2,0$ & $-2,1$ & $-2,0$ & $-2,1$ \\
\hline $\mathrm{C}_{2} \mathrm{H}_{4}$ & ${ }^{2} J_{\mathrm{HH}}$ & 4,5 & 4,5 & 4,6 & 2,3 & 8,2 & 2,8 & 2,9 & 4,0 & 3,2 & 4,5 & 2,8 & 3,6 & 3,1 & 2,0 \\
\hline $\mathrm{C}_{2} \mathrm{H}_{4}$ & ${ }^{3} J_{\mathrm{HH}_{\mathrm{c}}}$ & 11,7 & 11,9 & 11,6 & 11,5 & 12,5 & 12,3 & 11,5 & 13,3 & 12,1 & 12,8 & 12,4 & 11,7 & 11,2 & 11,4 \\
\hline $\mathrm{C}_{2} \mathrm{H}_{4}$ & ${ }^{3} J_{\mathrm{HH}_{\mathrm{t}}}$ & 18,7 & 19,0 & 18,5 & 17,0 & 22,5 & 19,3 & 17,2 & 20,0 & 19,0 & 20,0 & 19,4 & 18,4 & 17,7 & 18,5 \\
\hline $\mathrm{C}_{2} \mathrm{H}_{6}$ & ${ }^{1} J_{\mathrm{CC}}$ & 25,7 & 25,1 & 24,2 & 28,5 & 34,4 & 27,5 & 29,1 & 32,5 & 28,0 & 32,4 & 28,3 & 34,9 & 30,6 & 33,7 \\
\hline $\mathrm{C}_{2} \mathrm{H}_{6}$ & ${ }^{1} J_{\mathrm{CH}}$ & 119,5 & 120,3 & 117,6 & 109,0 & 138,9 & 119,9 & 112,4 & 129,1 & 120,6 & 131,7 & 121,6 & 129,1 & 118,9 & 123,4 \\
\hline $\mathrm{C}_{2} \mathrm{H}_{6}$ & ${ }^{2} J_{\mathrm{CH}}$ & $-2,9$ & $-2,9$ & $-2,7$ & $-3,2$ & $-3,8$ & $-3,6$ & $-3,2$ & $-3,6$ & $-3,5$ & $-3,4$ & $-3,7$ & $-3,6$ & $-3,2$ & $-4,5$ \\
\hline \multirow[t]{3}{*}{ Total } & $\mathrm{DM}$ & $-27,66$ & 29,11 & $-29,71$ & $-16,69$ & $-16,51$ & $-20,93$ & $-13,16$ & $-19,35$ & $-24,40$ & $-18,45$ & $-24,16$ & $-12,11$ & $-16,29$ & - \\
\hline & DMA & 33,11 & 34,28 & 34,50 & 20,43 & 29,04 & 25,25 & 16,27 & 27,15 & 28,86 & 27,46 & 28,76 & 20,52 & 19,86 & - \\
\hline & PDMA & 46,79 & 48,66 & 50,68 & 21,19 & 43,69 & 33,38 & 16,53 & 26,01 & 31,57 & 30,28 & 29,69 & 23,67 & 24,47 & - \\
\hline \multirow[t]{3}{*}{ CPI } & DM & $-66,10$ & $-70,02$ & $-69,85$ & $-36,71$ & $-51,33$ & $-51,20$ & $-29,65$ & $-53,83$ & $-59,63$ & $-53,01$ & $-59,65$ & $-37,37$ & $-40,13$ & - \\
\hline & DMA & 73,14 & 75,69 & 75,86 & 40,78 & 56,33 & 54,80 & 32,00 & 55,74 & 63,50 & 55,17 & 63,25 & 39,74 & 42,60 & - \\
\hline & PDMA & 81,49 & 84,97 & 87,08 & 36,49 & 56,75 & 63,82 & 20,87 & 38,26 & 57,39 & 44,18 & 55,83 & 38,34 & 43,83 & - \\
\hline \multirow[t]{3}{*}{ SPI } & DM & 0,53 & 0,89 & $-0,27$ & $-2,01$ & 9,03 & 1,27 & $-1,07$ & 5,93 & 1,43 & 6,89 & 1,87 & 6,41 & 1,19 & - \\
\hline & DMA & 3,76 & 3,91 & 4,17 & 5,51 & 9,03 & 3,57 & 4,73 & 6,19 & 3,46 & 7,13 & 3,47 & 6,43 & 3,19 & - \\
\hline & PDMA & 21,33 & 22,04 & 23,99 & 9,96 & 34,11 & 11,05 & 13,35 & 17,03 & 12,64 & 20,08 & 10,53 & 12,90 & 10,27 & - \\
\hline \multirow[t]{3}{*}{$\Delta \mathrm{CS}$} & $\mathrm{DM}$ & $-66,63$ & $-70,90$ & $-69,57$ & $-34,70$ & $-60,35$ & $-52,47$ & $-28,59$ & $-59,76$ & $-61,06$ & $-59,90$ & $-61,52$ & $-43,79$ & $-41,31$ & - \\
\hline & DMA & 69,38 & 71,78 & 71,70 & 35,28 & 47,30 & 51,23 & 27,27 & 49,55 & 60,04 & 48,04 & 59,79 & 33,31 & 39,41 & - \\
\hline & PDMA & 60,16 & 62,93 & 63,09 & 26,53 & 22,64 & 52,76 & 7,52 & 21,22 & 44,75 & 24,10 & 45,30 & 25,44 & 33,56 & - \\
\hline
\end{tabular}


Tabela 8.114: Constantes de acoplamento utilizando funcionais da literatura (21 a 100\% $\left.E_{X}^{\mathrm{HF}}\right)$ e constantes empíricas no nível BHandH $40 \% E_{X}^{\mathrm{HF}}$ e base aug-pcJ-2.

\begin{tabular}{|c|c|c|c|c|c|c|c|c|c|c|c|c|c|c|c|}
\hline & Func. & X3LYP & B98 & $\omega 97 X D$ & PBE0 & M06 & B1B95 & M05 & BMK & $\mathrm{BHH}$ & BHLYP & M062X & M052X & M06HF & Emp. \\
\hline & $\% E_{X}^{\mathrm{HF}}$ & 21,80 & 21,98 & 22,20 & 25,00 & 27,00 & 28,00 & 28,00 & 42,00 & 50,00 & 50,00 & 54,00 & 56,00 & 100,00 & - \\
\hline $\mathrm{HF}$ & ${ }^{1} J_{\mathrm{HF}} \mathrm{A}$ & 453,2 & 431,2 & 484,2 & 430,8 & 678,3 & 470,4 & 828,5 & 550,8 & 530,8 & 526,8 & 485,6 & 583,3 & 177,7 & 533,2 \\
\hline $\mathrm{CO}$ & ${ }^{1} J_{\mathrm{CO}}$ & 17,7 & 18,5 & 19,6 & 19,9 & 17,9 & 18,4 & 9,1 & 18,7 & 13,7 & 10,9 & 7,4 & 3,9 & 4,4 & 15,6 \\
\hline $\mathrm{H}_{2} \mathrm{O}$ & ${ }^{1} J_{\mathrm{OH}}$ & $-77,8$ & $-72,5$ & $-74,7$ & $-73,0$ & $-100,6$ & $-77,3$ & $-108,3$ & $-86,9$ & $-83,7$ & $-86,5$ & $-91,6$ & $-89,3$ & $-54,8$ & $-81,8$ \\
\hline $\mathrm{H}_{2} \mathrm{O}$ & ${ }^{2} J_{\mathrm{HH}}$ & $-7,5$ & $-6,9$ & $-6,4$ & $-7,3$ & $-16,8$ & $-7,0$ & $-18,6$ & $-6,7$ & $-9,4$ & $-11,2$ & $-7,1$ & $-4,6$ & 8,8 & $-8,7$ \\
\hline $\mathrm{NH}_{3}$ & ${ }^{1} J_{\mathrm{NH}}$ & 45,8 & 42,9 & 41,9 & 42,5 & 52,4 & 44,0 & 44,3 & 47,8 & 45,5 & 49,0 & 53,2 & 43,8 & 37,7 & 43,1 \\
\hline $\mathrm{NH}_{3}$ & ${ }^{2} J_{\mathrm{HH}}$ & $-10,2$ & $-9,5$ & $-9,0$ & $-10,1$ & $-18,0$ & $-9,3$ & $-15,8$ & $-10,2$ & $-11,1$ & $-13,5$ & $-11,0$ & $-6,3$ & $-5,4$ & $-10,5$ \\
\hline $\mathrm{PH}_{3}$ & ${ }^{1} J_{\mathrm{PH}}$ & 174,3 & 196,4 & 176,7 & 154,6 & 247,5 & 167,8 & 171,8 & 137,9 & 183,1 & 201,3 & 166,9 & 118,3 & 159,3 & 195,5 \\
\hline $\mathrm{PF}_{3}$ & ${ }^{1} J_{\mathrm{PF}}$ & $-1753,0$ & $-1666,4$ & $-1637,8$ & $-1732,1$ & $-1526,9$ & $-1645,5$ & $-1389,0$ & $-1646,1$ & $-1670,4$ & $-1651,5$ & $-1625,7$ & $-1705,4$ & $-1876,6$ & $-1442,8$ \\
\hline $\mathrm{BHF}_{2}$ & ${ }^{1} J_{\mathrm{BF}}$ & $-131,5$ & $-129,1$ & $-103,1$ & $-131,0$ & $-36,1$ & $-127,6$ & 20,8 & $-104,0$ & $-95,2$ & $-81,9$ & $-116,5$ & $-105,2$ & $-275,0$ & $-79,5$ \\
\hline $\mathrm{BF}_{3}$ & ${ }^{1} J_{\mathrm{BF}}$ & $-29,1$ & $-34,1$ & $-3,0$ & $-30,5$ & 64,9 & $-27,0$ & 127,1 & 5,1 & 15,1 & 24,3 & $-20,0$ & $-3,5$ & $-196,7$ & 17,2 \\
\hline $\mathrm{F}_{2} \mathrm{O}$ & ${ }^{1} J_{\mathrm{OF}}$ & $-359,4$ & $-336,9$ & $-333,4$ & $-374,9$ & $-308,4$ & $-361,9$ & $-302,9$ & $-377,3$ & $-465,0$ & $-488,0$ & $-429,2$ & $-520,8$ & $-1503,5$ & $-286,9$ \\
\hline $\mathrm{CH}_{4}$ & ${ }^{1} J_{\mathrm{CH}}$ & 132,9 & 128,3 & 114,7 & 122,8 & 139,6 & 124,4 & 98,5 & 159,2 & 124,9 & 140,7 & 143,7 & 115,3 & 67,5 & 123,0 \\
\hline $\mathrm{CH}_{4}$ & ${ }^{2} J_{\mathrm{HH}}$ & $-13,2$ & $-12,5$ & $-11,8$ & $-13,8$ & $-25,9$ & $-12,2$ & $-21,2$ & $-14,3$ & $-13,3$ & $-16,0$ & $-12,1$ & $-6,6$ & $-15,5$ & $-12,5$ \\
\hline $\mathrm{C}_{2} \mathrm{H}_{2}$ & ${ }^{1} J_{\mathrm{CC}}$ & 204,4 & 212,9 & 191,3 & 196,4 & 193,6 & 195,2 & 209,7 & 342,7 & 202,4 & 220,1 & 227,8 & 224,7 & 251,3 & 174,4 \\
\hline $\mathrm{C}_{2} \mathrm{H}_{2}$ & ${ }^{1} J_{\mathrm{CH}}$ & 273,8 & 261,1 & 245,6 & 256,2 & 299,5 & 256,2 & 247,8 & 296,0 & 259,5 & 288,5 & 270,2 & 208,7 & 90,6 & 244,5 \\
\hline $\mathrm{C}_{2} \mathrm{H}_{2}$ & ${ }^{2} J_{\mathrm{CH}}$ & 56,2 & 52,8 & 53,7 & 53,5 & 50,3 & 55,6 & 36,5 & 62,0 & 53,0 & 54,1 & 56,9 & 49,6 & 45,3 & 49,7 \\
\hline $\mathrm{C}_{2} \mathrm{H}_{2}$ & ${ }^{3} J_{\mathrm{HH}}$ & 11,2 & 10,7 & 10,1 & 12,4 & 17,1 & 10,4 & 20,6 & 12,0 & 11,8 & 14,8 & 9,3 & 7,4 & 5,2 & 9,1 \\
\hline $\mathrm{C}_{2} \mathrm{H}_{4}$ & ${ }^{1} J_{\mathrm{CC}}$ & 72,0 & 77,3 & 63,7 & 68,7 & 64,8 & 66,0 & 76,4 & 127,3 & 72,3 & 86,0 & 91,2 & 85,1 & 85,9 & 67,2 \\
\hline $\mathrm{C}_{2} \mathrm{H}_{4}$ & ${ }^{1} J_{\mathrm{CH}}$ & 168,6 & 162,5 & 148,1 & 157,3 & 183,7 & 158,8 & 141,6 & 195,6 & 160,6 & 180,1 & 177,6 & 141,8 & $-61,3$ & 154,5 \\
\hline $\mathrm{C}_{2} \mathrm{H}_{4}$ & ${ }^{2} J_{\mathrm{CH}}$ & $-1,6$ & $-2,4$ & $-1,0$ & $-3,0$ & $-6,4$ & $-1,1$ & $-13,9$ & $-4,7$ & $-3,8$ & $-6,0$ & $-2,5$ & $-1,6$ & 13,0 & $-2,1$ \\
\hline $\mathrm{C}_{2} \mathrm{H}_{4}$ & ${ }^{2} J_{\mathrm{HH}}$ & 4,4 & 3,1 & 3,0 & 2,3 & $-13,4$ & 4,2 & $-14,6$ & 5,2 & 2,2 & 1,6 & 3,7 & 6,1 & 4,1 & 2,0 \\
\hline $\mathrm{C}_{2} \mathrm{H}_{4}$ & ${ }^{3} J_{\mathrm{HH}_{\mathrm{c}}}$ & 13,0 & 11,8 & 11,5 & 12,7 & 17,1 & 12,1 & 16,2 & 13,5 & 13,3 & 14,9 & 12,9 & 9,5 & 4,5 & 11,4 \\
\hline $\mathrm{C}_{2} \mathrm{H}_{4}$ & ${ }^{3} J_{\mathrm{HH}_{\mathrm{t}}}$ & 20,2 & 18,5 & 17,5 & 19,8 & 21,6 & 19,0 & 19,2 & 21,1 & 19,6 & 22,7 & 18,8 & 14,9 & 5,8 & 18,5 \\
\hline $\mathrm{C}_{2} \mathrm{H}_{6}$ & ${ }^{1} J_{\mathrm{CC}}$ & 33,1 & 34,4 & 29,0 & 30,4 & 29,4 & 30,6 & 24,8 & 48,7 & 33,3 & 40,6 & 48,9 & 40,9 & 46,8 & 33,7 \\
\hline $\mathrm{C}_{2} \mathrm{H}_{6}$ & ${ }^{1} J_{\mathrm{CH}}$ & 132,9 & 128,8 & 115,2 & 123,5 & 139,1 & 125,0 & 98,2 & 160,2 & 125,8 & 141,3 & 145,0 & 117,4 & 81,1 & 123,4 \\
\hline $\mathrm{C}_{2} \mathrm{H}_{6}$ & ${ }^{2} J_{\mathrm{CH}}$ & $-3,5$ & $-3,8$ & $-3,3$ & $-4,1$ & $-5,5$ & $-3,5$ & $-4,6$ & $-5,1$ & $-4,3$ & $-5,1$ & $-3,7$ & $-2,7$ & $-3,3$ & $-4,5$ \\
\hline \multirow[t]{3}{*}{ Total } & DM & 7,6 & 4,22 & -13 & $-21,64$ & 10,4 & -15, & 15,9 & 2,3 & $-14,46$ & $-8,8$ & & & & - \\
\hline & DMA & 27,20 & 22,48 & 16,48 & 26,52 & 24,3 & 20,33 & 32,1 & 32,99 & 19,87 & 25,20 & 27,00 & 32,91 & 120,89 & - \\
\hline & PDMA & 28,56 & 24,84 & 18,47 & 25,52 & 76,07 & 26,55 & 109,85 & 37,71 & 13,44 & 28,84 & 30,29 & 36,77 & 147,86 & - \\
\hline \multirow[t]{3}{*}{ CPI } & DM & 1,99 & $-41,89$ & $-30,85$ & $-55,05$ & 14,5 & $-40,85$ & 42,96 & $-33,21$ & $-40,09$ & $-37,70$ & $-43,85$ & $-52,75$ & $-219,86$ & - \\
\hline & DMA & 3,86 & 44,78 & 33,56 & 57,75 & 39,98 & 42,87 & 58,95 & 38,25 & 40,53 & 41,12 & $45, \mathrm{~s}$ & 63,49 & 228,88 & - \\
\hline & PDMA & 40,77 & 43,07 & 24,86 & 44,78 & 56,63 & 40,01 & 98,46 & 22,04 & 13,68 & 21,81 & 41,80 & 43,11 & 217,81 & - \\
\hline \multirow[t]{3}{*}{ SPI } & DM & 7,47 & 6,0 & $-c$ & 2,8 & & 3,2 & $-3,8$ & & 4,3 & & & 1, & -24 & - \\
\hline & MA & & & & 3,61 & & & & & & & & & & - \\
\hline & PDMA & 19,60 & 11,47 & 13,79 & 11,40 & 90,33 & 16,68 & 118,20 & 49,20 & 13,27 & 34,00 & 21,85 & 32,12 & 96,56 & - \\
\hline \multirow[t]{3}{*}{$\Delta \mathrm{CS}$} & DM & & -47 & & $-57, \mathrm{~s}$ & 7,0 & -44 & & -61 & & & & & 5,11 & - \\
\hline & DMA & ,22 & 38 & & 54,14 & 27,0 & & & 9,1 & 35 , & & & 53, & 187,18 & - \\
\hline & PDM & 21,17 & 31,61 & 11,08 & 33,38 & $-33,71$ & 23,33 & $-19,74$ & $-27,16$ & 0,40 & $-12,20$ & 19,95 & 10,99 & 121,25 & - \\
\hline
\end{tabular}


Tabela 8.115: Constantes de acoplamento utilizando funcionais da literatura (0 a 21\% $\left.E_{X}^{\mathrm{HF}}\right)$ e constantes empíricas no nível PBE0 $40 \% E_{X}^{\mathrm{HF}}$ e base aug-pcJ-2.

\begin{tabular}{|c|c|c|c|c|c|c|c|c|c|c|c|c|c|c|c|}
\hline & Func. & PBE & PW91 & BP86 & $\omega \mathrm{B} 97$ & TPSSh & O3LYP & $\omega \mathrm{B} 97 \mathrm{X}$ & CAMB3 & B3P86 & B3LYP & B3W91 & B971 & B972 & Emp. \\
\hline & $\% E_{X}^{\mathrm{HF}}$ & 0,00 & 0,00 & 0,00 & 0,00 & 10,00 & 11,61 & 15,77 & 19,00 & 20,00 & 20,00 & 20,00 & 21,00 & 21,00 & - \\
\hline $\mathrm{HF}$ & ${ }^{1} J_{\mathrm{HF}} \mathrm{A}$ & 376,0 & 364,2 & 355,3 & 455,6 & 390,6 & 396,4 & 497,9 & 455,6 & 407,3 & 445,4 & 408,9 & 449,1 & 442,8 & 534,8 \\
\hline $\mathrm{CO}$ & ${ }^{1} J_{\mathrm{CO}}$ & 24,1 & 24,9 & 24,9 & 23,9 & 20,3 & 21,9 & 19,1 & 18,3 & 21,6 & 18,2 & 21,6 & 17,4 & 18,3 & 15,7 \\
\hline $\mathrm{H}_{2} \mathrm{O}$ & ${ }^{1} J_{\mathrm{OH}}$ & $-67,2$ & $-66,3$ & $-64,8$ & $-71,8$ & $-72,5$ & $-69,4$ & $-76,5$ & $-77,7$ & $-70,1$ & $-76,8$ & $-70,6$ & $-74,4$ & $-73,5$ & $-82,0$ \\
\hline $\mathrm{H}_{2} \mathrm{O}$ & ${ }^{2} J_{\mathrm{HH}}$ & $-4,7$ & $-4,8$ & $-4,6$ & $-6,6$ & $-5,3$ & $-8,0$ & $-6,4$ & $-7,4$ & $-6,3$ & $-7,2$ & $-6,8$ & $-6,5$ & $-7,5$ & $-8,8$ \\
\hline $\mathrm{NH}_{3}$ & ${ }^{1} J_{\mathrm{NH}}$ & 40,8 & 40,8 & 40,0 & 39,0 & 45,8 & 41,1 & 41,5 & 45,2 & 41,4 & 45,3 & 41,7 & 43,3 & 41,7 & 43,3 \\
\hline $\mathrm{NH}_{3}$ & ${ }^{2} J_{\mathrm{HH}}$ & $-7,8$ & $-8,0$ & $-7,8$ & $-8,5$ & $-8,1$ & $-10,1$ & $-8,7$ & $-10,2$ & $-9,3$ & $-9,9$ & $-9,8$ & $-9,1$ & $-9,1$ & $-10,4$ \\
\hline $\mathrm{PH}_{3}$ & ${ }^{1} J_{\mathrm{PH}}$ & 133,7 & 137,6 & 136,9 & 159,3 & 200,5 & 165,5 & 165,0 & 162,3 & 152,3 & 171,9 & 154,6 & 190,7 & 184,0 & 195,7 \\
\hline $\mathrm{PF}_{3}$ & ${ }^{1} J_{\mathrm{PF}}$ & $-1801,0$ & $-1815,2$ & $-1802,5$ & $-1663,0$ & $-1731,7$ & $-1687,8$ & $-1643,0$ & $-1749,1$ & $-1749,4$ & $-1755,9$ & $-1751,4$ & $-1656,7$ & $-1661,2$ & $-1.443,2$ \\
\hline $\mathrm{BHF}_{2}$ & ${ }^{1} J_{\mathrm{BF}}$ & $-172,8$ & $-177,6$ & $-177,9$ & $-111,8$ & $-142,5$ & $-157,4$ & $-97,5$ & $-125,7$ & $-143,2$ & $-134,5$ & $-142,6$ & $-123,8$ & $-129,9$ & $-79,6$ \\
\hline $\mathrm{BF}_{3}$ & ${ }^{1} J_{\mathrm{BF}}$ & $-75,8$ & $-80,9$ & $-83,3$ & $-14,8$ & $-47,2$ & $-63,7$ & 3,3 & $-22,4$ & $-45,2$ & $-33,2$ & $-44,5$ & $-27,9$ & $-36,6$ & 17,2 \\
\hline $\mathrm{F}_{2} \mathrm{O}$ & ${ }^{1} J_{\mathrm{OF}}$ & $-278,0$ & $-290,5$ & $-290,1$ & $-310,7$ & $-320,1$ & $-297,3$ & $-326,5$ & $-386,6$ & $-360,6$ & $-352,0$ & $-362,9$ & $-318,8$ & $-316,0$ & $-284,7$ \\
\hline $\mathrm{CH}_{4}$ & ${ }^{1} J_{\mathrm{CH}}$ & 119,3 & 120,1 & 117,5 & 109,4 & 138,8 & 119,5 & 112,5 & 128,9 & 120,0 & 131,7 & 121,0 & 128,8 & 118,8 & 122,9 \\
\hline $\mathrm{CH}_{4}$ & ${ }^{2} J_{\mathrm{HH}}$ & $-11,8$ & $-12,0$ & $-11,8$ & $-11,2$ & $-11,3$ & $-13,2$ & $-11,3$ & $-13,2$ & $-12,9$ & $-13,0$ & $-13,4$ & $-12,0$ & $-11,3$ & $-12,5$ \\
\hline $\mathrm{C}_{2} \mathrm{H}_{2}$ & ${ }^{1} J_{\mathrm{CC}}$ & 188,7 & 188,8 & 187,3 & 194,2 & 190,8 & 191,5 & 193,0 & 202,0 & 193,4 & 203,3 & 193,8 & 213,8 & 197,5 & 173,9 \\
\hline $\mathrm{C}_{2} \mathrm{H}_{2}$ & ${ }^{1} J_{\mathrm{CH}}$ & 249,8 & 252,5 & 247,4 & 236,3 & 282,3 & 254,5 & 240,2 & 266,9 & 251,9 & 271,8 & 254,0 & 261,3 & 247,3 & 244,4 \\
\hline $\mathrm{C}_{2} \mathrm{H}_{2}$ & ${ }^{2} J_{\mathrm{CH}}$ & 54,1 & 54,6 & 54,6 & 51,8 & 57,7 & 52,6 & 53,4 & 57,0 & 54,0 & 56,1 & 54,0 & 53,2 & 50,7 & 49,9 \\
\hline $\mathrm{C}_{2} \mathrm{H}_{2}$ & ${ }^{3} J_{\mathrm{HH}}$ & 10,4 & 10,5 & 10,2 & 10,4 & 12,6 & 11,8 & 10,0 & 11,1 & 11,2 & 11,1 & 11,7 & 10,5 & 10,4 & 8,9 \\
\hline $\mathrm{C}_{2} \mathrm{H}_{4}$ & ${ }^{1} J_{\mathrm{CC}}$ & 61,3 & 60,6 & 59,5 & 65,6 & 71,5 & 63,9 & 64,5 & 70,6 & 64,7 & 71,0 & 65,3 & 78,1 & 68,1 & 66,6 \\
\hline $\mathrm{C}_{2} \mathrm{H}_{4}$ & ${ }^{1} J_{\mathrm{CH}}$ & 151,8 & 153,0 & 149,7 & 142,7 & 174,3 & 154,4 & 145,4 & 164,4 & 153,7 & 167,1 & 155,1 & 162,8 & 152,3 & 154,3 \\
\hline $\mathrm{C}_{2} \mathrm{H}_{4}$ & ${ }^{2} J_{\mathrm{CH}}$ & $-0,5$ & $-0,4$ & 0,0 & $-2,2$ & $-1,7$ & $-1,9$ & $-1,3$ & $-1,7$ & $-1,6$ & $-1,4$ & $-2,0$ & $-2,1$ & $-2,0$ & $-1,9$ \\
\hline $\mathrm{C}_{2} \mathrm{H}_{4}$ & ${ }^{2} J_{\mathrm{HH}}$ & 4,5 & 4,5 & 4,6 & 2,3 & 8,2 & 2,8 & 2,9 & 4,0 & 3,2 & 4,5 & 2,8 & 3,6 & 3,1 & 2,1 \\
\hline $\mathrm{C}_{2} \mathrm{H}_{4}$ & ${ }^{3} J_{\mathrm{HH}_{\mathrm{c}}}$ & 11,7 & 11,9 & 11,6 & 11,5 & 12,5 & 12,3 & 11,5 & 13,3 & 12,1 & 12,8 & 12,4 & 11,7 & 11,2 & 11,3 \\
\hline $\mathrm{C}_{2} \mathrm{H}_{4}$ & ${ }^{3} J_{\mathrm{HH}_{\mathrm{t}}}$ & 18,7 & 19,0 & 18,5 & 17,0 & 22,5 & 19,3 & 17,2 & 20,0 & 19,0 & 20,0 & 19,4 & 18,4 & 17,7 & 18,3 \\
\hline $\mathrm{C}_{2} \mathrm{H}_{6}$ & ${ }^{1} J_{\mathrm{CC}}$ & 25,7 & 25,1 & 24,2 & 28,5 & 34,4 & 27,5 & 29,1 & 32,5 & 28,0 & 32,4 & 28,3 & 34,9 & 30,6 & 33,6 \\
\hline $\mathrm{C}_{2} \mathrm{H}_{6}$ & ${ }^{1} J_{\mathrm{CH}}$ & 119,5 & 120,3 & 117,6 & 109,0 & 138,9 & 119,9 & 112,4 & 129,1 & 120,6 & 131,7 & 121,6 & 129,1 & 118,9 & 123,4 \\
\hline $\mathrm{C}_{2} \mathrm{H}_{6}$ & ${ }^{2} J_{\mathrm{CH}}$ & $-2,9$ & $-2,9$ & $-2,7$ & $-3,2$ & $-3,8$ & $-3,6$ & $-3,2$ & $-3,6$ & $-3,5$ & $-3,4$ & $-3,7$ & $-3,6$ & $-3,2$ & $-4,5$ \\
\hline \multirow[t]{3}{*}{ Total } & DM & $-27,73$ & $-29,19$ & $-29,78$ & $-16,77$ & $-16,58$ & $-21,01$ & $-13,24$ & $-19,43$ & $-24,48$ & $-18,53$ & $-24,24$ & $-12,19$ & $-16,37$ & - \\
\hline & DMA & 33,07 & 34,41 & 34,63 & 20,55 & 29,22 & 25,38 & 16,38 & 27,33 & 28,99 & 27,64 & 28,92 & 20,72 & 20,02 & - \\
\hline & PDMA & 46,36 & 48,31 & 50,39 & 21,47 & 42,85 & 32,93 & 16,09 & 25,55 & 31,13 & 29,82 & 29,64 & 23,94 & 24,28 & - \\
\hline \multirow[t]{3}{*}{ CPI } & DM & $-66,43$ & $-70,35$ & $-70,17$ & $-37,04$ & $-51,65$ & $-51,53$ & $-29,98$ & $-54,15$ & $-59,95$ & $-53,34$ & $-59,98$ & $-37,70$ & $-40,45$ & - \\
\hline & DMA & 73,08 & 76,04 & 76,21 & 41,13 & 56,60 & 55,15 & 32,35 & 56,05 & 63,85 & 55,48 & 63,60 & 40,05 & 42,95 & - \\
\hline & PDMA & 81,38 & 84,99 & 87,10 & 36,56 & 56,71 & 63,88 & 20,96 & 38,28 & 57,46 & 44,19 & 55,90 & 38,35 & 43,92 & - \\
\hline \multirow[t]{3}{*}{ SPI } & DM & 0,64 & 0,99 & $-0,17$ & $-1,91$ & 9,13 & 1,37 & $-0,96$ & 6,04 & 1,54 & 7,00 & 1,97 & 6,52 & 1,29 & - \\
\hline & DMA & 3,73 & 3,89 & 4,14 & 5,47 & 9,13 & 3,56 & 4,67 & 6,28 & 3,43 & 7,23 & 3,48 & 6,55 & 3,21 & - \\
\hline & PDMA & 20,67 & 21,41 & 23,47 & 10,40 & 32,69 & 10,22 & 12,51 & 16,22 & 11,83 & 19,28 & 10,37 & 13,37 & 9,88 & - \\
\hline \multirow[t]{3}{*}{$\Delta \mathrm{CS}$} & $\mathrm{DM}$ & $-67,07$ & $-71,34$ & $-70,01$ & $-35,13$ & $-60,79$ & $-52,90$ & $-29,02$ & $-60,19$ & $-61,49$ & $-60,34$ & $-61,96$ & $-44,22$ & $-41,75$ & - \\
\hline & DMA & 69,35 & 72,15 & 72,07 & 35,66 & 47,47 & 51,59 & 27,68 & 49,77 & 60,41 & 48,26 & 60,12 & 33,50 & 39,73 & - \\
\hline & PDMA & 60,72 & 63,58 & 63,63 & 26,16 & 24,02 & 53,66 & 8,45 & 22,06 & 45,63 & 24,90 & 45,53 & 24,98 & 34,04 & - \\
\hline
\end{tabular}


Tabela 8.116: Constantes de acoplamento utilizando funcionais da literatura (21 a 100\% $\left.E_{X}^{\mathrm{HF}}\right)$ e constantes empíricas no nível PBE0 $40 \% E_{X}^{\mathrm{HF}}$ e base aug-pcJ-2.

\begin{tabular}{|c|c|c|c|c|c|c|c|c|c|c|c|c|c|c|c|}
\hline & Func. & X3LYP & B98 & $\omega 97 \mathrm{XD}$ & PBE0 & M06 & B1B95 & M05 & BMK & $\mathrm{BHH}$ & BHLYP & M062X & M052X & $\mathrm{M} 06 \mathrm{HF}$ & Emp. \\
\hline & $\% E_{X}^{\mathrm{HF}}$ & 21,80 & 21,98 & 22,20 & 25,00 & 27,00 & 28,00 & 28,00 & 42,00 & 50,00 & 50,00 & 54,00 & 56,00 & 100,00 & - \\
\hline $\mathrm{HF}$ & ${ }^{1} J_{\mathrm{HF}}$ & 453,2 & 431,2 & 484,2 & 430,8 & 678,3 & 470,4 & 828,5 & 550,8 & 530,8 & 526,8 & 485,6 & 583,3 & 177,7 & 534,8 \\
\hline $\mathrm{CO}$ & ${ }^{1} J_{\mathrm{CO}}$ & 17,7 & 18,5 & 19,6 & 19,9 & 17,9 & 18,4 & 9,1 & 18,7 & 13,7 & 10,9 & 7,4 & 3,9 & 4,4 & 15,7 \\
\hline $\mathrm{H}_{2} \mathrm{O}$ & ${ }^{1} J_{\mathrm{OH}}$ & $-77,8$ & $-72,5$ & $-74,7$ & $-73,0$ & $-100,6$ & $-77,3$ & $-108,3$ & $-86,9$ & $-83,7$ & $-86,5$ & $-91,6$ & $-89,3$ & $-54,8$ & $-82,0$ \\
\hline $\mathrm{H}_{2} \mathrm{O}$ & ${ }^{2} J_{\mathrm{HH}}$ & $-7,5$ & $-6,9$ & $-6,4$ & $-7,3$ & $-16,8$ & $-7,0$ & $-18,6$ & $-6,7$ & $-9,4$ & $-11,2$ & $-7,1$ & $-4,6$ & 8,8 & $-8,8$ \\
\hline $\mathrm{NH}_{3}$ & ${ }^{1} J_{\mathrm{NH}}$ & 45,8 & 42,9 & 41,9 & 42,5 & 52,4 & 44,0 & 44,3 & 47,8 & 45,5 & 49,0 & 53,2 & 43,8 & 37,7 & 43,3 \\
\hline $\mathrm{NH}_{3}$ & ${ }^{2} J_{\mathrm{HH}}$ & $-10,2$ & $-9,5$ & $-9,0$ & $-10,1$ & $-18,0$ & $-9,3$ & $-15,8$ & $-10,2$ & $-11,1$ & $-13,5$ & $-11,0$ & $-6,3$ & $-5,4$ & $-10,4$ \\
\hline $\mathrm{PH}_{3}$ & ${ }^{1} J_{\mathrm{PH}}$ & 174,3 & 196,4 & 176,7 & 154,6 & 247,5 & 167,8 & 171,8 & 137,9 & 183,1 & 201,3 & 166,9 & 118,3 & 159,3 & 195,7 \\
\hline $\mathrm{PF}_{3}$ & ${ }^{1} J_{\mathrm{PF}}$ & $-1753,0$ & $-1666,4$ & $-1637,8$ & $-1732,1$ & $-1526,9$ & $-1645,5$ & $-1389,0$ & $-1646,1$ & $-1670,4$ & $-1651,5$ & $-1625,7$ & $-1705,4$ & $-1876,6$ & $-1.443,2$ \\
\hline $\mathrm{BHF}_{2}$ & ${ }^{1} J_{\mathrm{BF}}$ & $-131,5$ & $-129,1$ & $-103,1$ & $-131,0$ & $-36,1$ & $-127,6$ & 20,8 & $-104,0$ & $-95,2$ & $-81,9$ & $-116,5$ & $-105,2$ & $-275,0$ & $-79,6$ \\
\hline $\mathrm{BF}_{3}$ & ${ }^{1} J_{\mathrm{BF}}$ & $-29,1$ & $-34,1$ & $-3,0$ & $-30,5$ & 64,9 & $-27,0$ & 127,1 & 5,1 & 15,1 & 24,3 & $-20,0$ & $-3,5$ & $-196,7$ & 17,2 \\
\hline $\mathrm{F}_{2} \mathrm{O}$ & ${ }^{1} J_{\mathrm{OF}}$ & $-359,4$ & $-336,9$ & $-333,4$ & $-374,9$ & $-308,4$ & $-361,9$ & $-302,9$ & $-377,3$ & $-465,0$ & $-488,0$ & $-429,2$ & $-520,8$ & $-1503,5$ & $-284,7$ \\
\hline $\mathrm{CH}_{4}$ & ${ }^{1} J_{\mathrm{CH}}$ & 132,9 & 128,3 & 114,7 & 122,8 & 139,6 & 124,4 & 98,5 & 159,2 & 124,9 & 140,7 & 143,7 & 115,3 & 67,5 & 122,9 \\
\hline $\mathrm{CH}_{4}$ & ${ }^{2} J_{\mathrm{HH}}$ & $-13,2$ & $-12,5$ & $-11,8$ & $-13,8$ & $-25,9$ & $-12,2$ & $-21,2$ & $-14,3$ & $-13,3$ & $-16,0$ & $-12,1$ & $-6,6$ & $-15,5$ & $-12,5$ \\
\hline $\mathrm{C}_{2} \mathrm{H}_{2}$ & ${ }^{1} J_{\mathrm{CC}}$ & 204,4 & 212,9 & 191,3 & 196,4 & 193,6 & 195,2 & 209,7 & 342,7 & 202,4 & 220,1 & 227,8 & 224,7 & 251,3 & 173,9 \\
\hline $\mathrm{C}_{2} \mathrm{H}_{2}$ & ${ }^{1} J_{\mathrm{CH}}$ & 273,8 & 261,1 & 245,6 & 256,2 & 299,5 & 256,2 & 247,8 & 296,0 & 259,5 & 288,5 & 270,2 & 208,7 & 90,6 & 244,4 \\
\hline $\mathrm{C}_{2} \mathrm{H}_{2}$ & ${ }^{2} J_{\mathrm{CH}}$ & 56,2 & 52,8 & 53,7 & 53,5 & 50,3 & 55,6 & 36,5 & 62,0 & 53,0 & 54,1 & 56,9 & 49,6 & 45,3 & 49,9 \\
\hline $\mathrm{C}_{2} \mathrm{H}_{2}$ & ${ }^{3} J_{\mathrm{HH}}$ & 11,2 & 10,7 & 10,1 & 12,4 & 17,1 & 10,4 & 20,6 & 12,0 & 11,8 & 14,8 & 9,3 & 7,4 & 5,2 & 8,9 \\
\hline $\mathrm{C}_{2} \mathrm{H}_{4}$ & ${ }^{1} J_{\mathrm{CC}}$ & 72,0 & 77,3 & 63,7 & 68,7 & 64,8 & 66,0 & 76,4 & 127,3 & 72,3 & 86,0 & 91,2 & 85,1 & 85,9 & 66,6 \\
\hline $\mathrm{C}_{2} \mathrm{H}_{4}$ & ${ }^{1} J_{\mathrm{CH}}$ & 168,6 & 162,5 & 148,1 & 157,3 & 183,7 & 158,8 & 141,6 & 195,6 & 160,6 & 180,1 & 177,6 & 141,8 & $-61,3$ & 154,3 \\
\hline $\mathrm{C}_{2} \mathrm{H}_{4}$ & ${ }^{2} J_{\mathrm{CH}}$ & $-1,6$ & $-2,4$ & $-1,0$ & $-3,0$ & $-6,4$ & $-1,1$ & $-13,9$ & $-4,7$ & $-3,8$ & $-6,0$ & $-2,5$ & $-1,6$ & 13,0 & $-1,9$ \\
\hline $\mathrm{C}_{2} \mathrm{H}_{4}$ & ${ }^{2} J_{\mathrm{HH}}$ & 4,4 & 3,1 & 3,0 & 2,3 & $-13,4$ & 4,2 & $-14,6$ & 5,2 & 2,2 & 1,6 & 3,7 & 6,1 & 4,1 & 2,1 \\
\hline $\mathrm{C}_{2} \mathrm{H}_{4}$ & ${ }^{3} J_{\mathrm{HH}_{\mathrm{c}}}$ & 13,0 & 11,8 & 11,5 & 12,7 & 17,1 & 12,1 & 16,2 & 13,5 & 13,3 & 14,9 & 12,9 & 9,5 & 4,5 & 11,3 \\
\hline $\mathrm{C}_{2} \mathrm{H}_{4}$ & ${ }^{3} J_{\mathrm{HH}_{\mathrm{t}}}$ & 20,2 & 18,5 & 17,5 & 19,8 & 21,6 & 19,0 & 19,2 & 21,1 & 19,6 & 22,7 & 18,8 & 14,9 & 5,8 & 18,3 \\
\hline $\mathrm{C}_{2} \mathrm{H}_{6}$ & ${ }^{1} J_{\mathrm{CC}}$ & 33,1 & 34,4 & 29,0 & 30,4 & 29,4 & 30,6 & 24,8 & 48,7 & 33,3 & 40,6 & 48,9 & 40,9 & 46,8 & 33,6 \\
\hline $\mathrm{C}_{2} \mathrm{H}_{6}$ & ${ }^{1} J_{\mathrm{CH}}$ & 132,9 & 128,8 & 115,2 & 123,5 & 139,1 & 125,0 & 98,2 & 160,2 & 125,8 & 141,3 & 145,0 & 117,4 & 81,1 & 123,4 \\
\hline $\mathrm{C}_{2} \mathrm{H}_{6}$ & ${ }^{2} J_{\mathrm{CH}}$ & $-3,5$ & $-3,8$ & $-3,3$ & $-4,1$ & $-5,5$ & $-3,5$ & $-4,6$ & $-5,1$ & $-4,3$ & $-5,1$ & $-3,7$ & $-2,7$ & $-3,3$ & $-4,5$ \\
\hline \multirow[t]{3}{*}{ Total } & DM & 7,76 & $-14,29$ & $-13,32$ & $-21,72$ & 10,39 & & 15,90 & 2,30 & $-14,54$ & $-8,8$ & $-11,12$ & & $-107,38$ & - \\
\hline & DMA & 7,38 & 22,68 & & 26,73 & 24,3 & & 32,2 & 33,06 & & & & & & - \\
\hline & PDMA & 28,07 & 25,28 & 18,08 & 26,15 & 76,24 & 26,10 & 111,49 & 38,40 & 14,25 & 30,48 & 30,78 & 35,87 & 150,11 & - \\
\hline \multirow[t]{3}{*}{ CPI } & $\mathrm{DM}$ & $-52,32$ & $-42,22$ & $-31,1$ & $-55,37$ & 14,2 & -41 & 42,6 & -33 & $-40,42$ & -38 & -44, & & -220 & - \\
\hline & DMA & 54,17 & 45,09 & 33,9 & 58,1 & 39,95 & 43,1 & 59,04 & 38,23 & 40,8 & 41,3 & 46,29 & 63,4 & 229,2 & - \\
\hline & PDMA & 40,78 & 43,14 & 24,95 & 44,87 & 56,46 & 40,03 & 98,37 & 21,94 & 13,77 & 21,88 & 42,04 & 43,14 & 218,07 & - \\
\hline \multirow[t]{3}{*}{ SPI } & DM & 7,58 & 6 , & & 2,9 & & & & & & & & & & - \\
\hline & MA & 7,74 & & & 3,72 & & & & & & & & & & - \\
\hline & PDMA & 18,75 & 12,19 & 13,04 & 12,43 & 90,74 & 15,88 & 121,11 & 50,46 & 14,59 & 36,79 & 22,51 & 30,53 & 100,28 & - \\
\hline \multirow[t]{3}{*}{$\Delta \mathrm{CS}$} & DM & & & & & & & & -62 & & & & & & - \\
\hline & DMA & & & & 54,38 & 26,97 & & & & & & & & 187,53 & - \\
\hline & PDMA & 22,03 & 30,95 & 11,91 & 32,44 & $-34,28$ & 24,14 & $-22,74$ & $-28,52$ & $-0,82$ & $-14,91$ & 19,53 & 12,62 & 117,79 & - \\
\hline
\end{tabular}




\subsubsection{Variação da porcentagem de $E_{X}^{\mathrm{HF}}$ para os funcionais híbridos - Geo- metrias Experimentais}

Tabela 8.117: Constantes de acoplamento B1B95 e constantes empíricas no nível BHandH $\left(50 \% E_{X}^{\mathrm{HF}}\right)$ e base aug-pcJ-2.

\begin{tabular}{|c|c|c|c|c|c|c|c|c|c|c|c|c|c|}
\hline & $\% E_{X}^{\mathrm{HF}}$ & $0 \%$ & $10 \%$ & $20 \%$ & $30 \%$ & $40 \%$ & $50 \%$ & $60 \%$ & $70 \%$ & $80 \%$ & $90 \%$ & $100 \%$ & Emp. \\
\hline $\mathrm{HF}$ & ${ }^{1} J_{\mathrm{HF}}$ & 403,9 & 427,5 & 451,2 & 475,2 & 499,3 & 523,6 & 548,0 & 572,6 & 597,4 & 622,3 & 647,4 & 532,8 \\
\hline $\mathrm{CO}$ & ${ }^{1} J_{\mathrm{CO}}$ & 23,4 & 21,7 & 19,9 & 18,1 & 16,1 & 14,0 & 11,8 & 9,6 & 7,3 & 4,9 & 2,4 & 15,7 \\
\hline $\mathrm{H}_{2} \mathrm{O}$ & ${ }^{1} J_{\mathrm{OH}}$ & $-70,3$ & $-72,8$ & $-75,3$ & $-77,9$ & $-80,4$ & $-83,0$ & $-85,6$ & $-88,2$ & $-90,8$ & $-93,5$ & $-96,2$ & $-81,7$ \\
\hline $\mathrm{H}_{2} \mathrm{O}$ & ${ }^{2} J_{\mathrm{HH}}$ & $-4,2$ & $-5,2$ & $-6,2$ & $-7,2$ & $-8,2$ & $-9,2$ & $-10,3$ & $-11,3$ & $-12,4$ & $-13,5$ & $-14,7$ & $-8,8$ \\
\hline $\mathrm{NH}_{3}$ & ${ }^{1} J_{\mathrm{NH}}$ & 41,9 & 42,7 & 43,4 & 44,1 & 44,9 & 45,6 & 46,4 & 47,2 & 47,9 & 48,7 & 49,5 & 43,0 \\
\hline $\mathrm{NH}_{3}$ & ${ }^{2} J_{\mathrm{HH}}$ & $-7,0$ & $-7,8$ & $-8,7$ & $-9,5$ & $-10,4$ & $-11,3$ & $-12,1$ & $-13,0$ & $-13,9$ & $-14,8$ & $-15,8$ & $-10,5$ \\
\hline $\mathrm{PH}_{3}$ & ${ }^{1} J_{\mathrm{PH}}$ & 146,7 & 154,4 & 161,8 & 169,2 & 176,5 & 183,6 & 190,6 & 197,4 & 204,1 & 210,7 & 217,0 & 195,0 \\
\hline $\mathrm{PF}_{3}$ & ${ }^{1} J_{\mathrm{PF}}$ & $-1716,6$ & $-1695,0$ & $-1669,0$ & $-1639,2$ & $-1606,4$ & $-1571,1$ & $-1533,7$ & $-1494,9$ & $-1454,9$ & $-1414,1$ & $-1372,8$ & $-1441,7$ \\
\hline $\mathrm{BHF}_{2}$ & ${ }^{1} J_{\mathrm{BF}}$ & $-174,7$ & $-157,8$ & $-141,0$ & $-124,2$ & $-107,5$ & $-91,0$ & $-74,6$ & $-58,3$ & $-42,2$ & $-26,3$ & $-10,5$ & $-79,7$ \\
\hline $\mathrm{BF}_{3}$ & ${ }^{1} J_{\mathrm{BF}}$ & $-78,7$ & $-60,1$ & $-41,7$ & $-23,4$ & $-5,3$ & 12,6 & 30,3 & 47,9 & 65,3 & 82,6 & 99,7 & 17,1 \\
\hline $\mathrm{F}_{2} \mathrm{O}$ & ${ }^{1} J_{\mathrm{OF}}$ & $-266,9$ & $-301,3$ & $-334,9$ & $-368,7$ & $-404,3$ & $-443,7$ & $-490,0$ & $-548,8$ & $-631,2$ & $-765,1$ & $-1048,5$ & $-285,7$ \\
\hline $\mathrm{CH}_{4}$ & ${ }^{1} J_{\mathrm{CH}}$ & 120,7 & 122,0 & 123,3 & 124,7 & 126,1 & 127,5 & 129,0 & 130,4 & 131,9 & 133,4 & 134,9 & 122,8 \\
\hline $\mathrm{CH}_{4}$ & ${ }^{2} J_{\mathrm{HH}}$ & $-10,3$ & $-11,0$ & $-11,7$ & $-12,4$ & $-13,0$ & $-13,7$ & $-14,4$ & $-15,0$ & $-15,7$ & $-16,4$ & $-17,0$ & $-12,5$ \\
\hline $\mathrm{C}_{2} \mathrm{H}_{2}$ & ${ }^{1} J_{\mathrm{CC}}$ & 187,9 & 190,2 & 192,9 & 195,8 & 199,3 & 203,2 & 207,7 & 213,0 & 219,2 & 226,6 & 235,5 & 174,1 \\
\hline $\mathrm{C}_{2} \mathrm{H}_{2}$ & ${ }^{1} J_{\mathrm{CH}}$ & 250,6 & 252,5 & 254,5 & 256,6 & 258,8 & 261,2 & 263,7 & 266,5 & 269,6 & 273,2 & 277,3 & 244,3 \\
\hline $\mathrm{C}_{2} \mathrm{H}_{2}$ & ${ }^{2} J_{\mathrm{CH}}$ & 55,5 & 55,7 & 55,7 & 55,5 & 55,2 & 54,6 & 53,8 & 52,6 & 51,1 & 49,1 & 46,4 & 49,8 \\
\hline $\mathrm{C}_{2} \mathrm{H}_{2}$ & ${ }^{3} J_{\mathrm{HH}}$ & 9,1 & 9,5 & 10,0 & 10,6 & 11,2 & 12,0 & 13,0 & 14,1 & 15,4 & 17,0 & 18,9 & 9,0 \\
\hline $\mathrm{C}_{2} \mathrm{H}_{4}$ & ${ }^{1} J_{\mathrm{CC}}$ & 58,9 & 61,2 & 63,8 & 66,5 & 69,6 & 73,0 & 76,8 & 81,2 & 86,5 & 92,8 & 100,8 & 66,9 \\
\hline $\mathrm{C}_{2} \mathrm{H}_{4}$ & ${ }^{1} J_{\mathrm{CH}}$ & 153,4 & 155,3 & 157,2 & 159,2 & 161,3 & 163,5 & 165,9 & 168,5 & 171,4 & 174,7 & 178,7 & 154,4 \\
\hline $\mathrm{C}_{2} \mathrm{H}_{4}$ & ${ }^{2} J_{\mathrm{CH}}$ & 1,0 & 0,3 & $-0,4$ & $-1,3$ & $-2,3$ & $-3,4$ & $-4,7$ & $-6,3$ & $-8,1$ & $-10,4$ & $-13,4$ & $-2,0$ \\
\hline $\mathrm{C}_{2} \mathrm{H}_{4}$ & ${ }^{2} J_{\mathrm{HH}}$ & 6,0 & 5,4 & 4,7 & 4,0 & 3,3 & 2,5 & 1,6 & 0,6 & $-0,5$ & $-1,9$ & $-3,5$ & 2,1 \\
\hline $\mathrm{C}_{2} \mathrm{H}_{4}$ & ${ }^{3} J_{\mathrm{HH}_{\mathrm{c}}}$ & 11,5 & 11,7 & 11,9 & 12,2 & 12,5 & 12,8 & 13,3 & 13,9 & 14,7 & 15,6 & 16,9 & 11,4 \\
\hline $\mathrm{C}_{2} \mathrm{H}_{4}$ & ${ }^{3} J_{\mathrm{HH}_{\mathrm{t}}}$ & 18,3 & 18,5 & 18,8 & 19,0 & 19,4 & 19,9 & 20,4 & 21,1 & 22,0 & 23,2 & 24,7 & 18,4 \\
\hline $\mathrm{C}_{2} \mathrm{H}_{6}$ & ${ }^{1} J_{\mathrm{CC}}$ & 25,1 & 27,1 & 29,0 & 31,0 & 33,0 & 35,0 & 37,1 & 39,2 & 41,3 & 43,5 & 45,7 & 33,6 \\
\hline $\mathrm{C}_{2} \mathrm{H}_{6}$ & ${ }^{1} J_{\mathrm{CH}}$ & 120,6 & 122,2 & 123,7 & 125,3 & 126,9 & 128,5 & 130,1 & 131,8 & 133,4 & 135,0 & 136,7 & 123,3 \\
\hline $\mathrm{C}_{2} \mathrm{H}_{6}$ & ${ }^{2} J_{\mathrm{CH}}$ & $-2,2$ & $-2,7$ & $-3,1$ & $-3,6$ & $-4,0$ & $-4,5$ & $-5,0$ & $-5,4$ & $-5,9$ & $-6,4$ & $-6,9$ & $-4,5$ \\
\hline \multirow[t]{3}{*}{ Total } & $\mathrm{DM}$ & $-22,42$ & $-20,09$ & $-17,57$ & $-14,88$ & $-12,12$ & $-9,40$ & $-6,83$ & $-4,62$ & $-3,22$ & $-3,68$ & $-9,75$ & - \\
\hline & DMA & 28,84 & 24,87 & 22,36 & 19,88 & 17,65 & 16,03 & 17,57 & 21,77 & 27,28 & 37,08 & 54,03 & - \\
\hline & PDMA & 52,92 & 42,95 & 33,65 & 24,14 & 16,34 & 13,69 & 22,00 & 36,05 & 51,53 & 69,77 & 92,57 & - \\
\hline \multirow[t]{3}{*}{ CPI } & $\mathrm{DM}$ & $-54,36$ & $-49,93$ & $-45,09$ & $-39,91$ & $-34,65$ & $-29,58$ & $-24,97$ & $-21,39$ & $-19,90$ & $-23,05$ & $-39,82$ & - \\
\hline & DMA & 62,73 & 53,78 & 47,89 & 41,71 & 35,44 & 30,05 & 31,68 & 39,32 & 49,77 & 69,85 & 105,96 & - \\
\hline & PDMA & 82,29 & 66,32 & 51,66 & 37,24 & 22,81 & 13,00 & 21,49 & 38,20 & 56,08 & 75,95 & 100,87 & - \\
\hline \multirow[t]{3}{*}{ SPI } & $\mathrm{DM}$ & 1,00 & 1,79 & 2,61 & 3,47 & 4,41 & 5,40 & 6,48 & 7,67 & 9,01 & 10,53 & 12,31 & - \\
\hline & DMA & 3,99 & 3,67 & 3,64 & 3,87 & 4,60 & 5,75 & 7,23 & 8,90 & 10,79 & 13,05 & 15,95 & - \\
\hline & PDMA & 31,38 & 25,82 & 20,45 & 14,53 & 11,60 & 14,19 & 22,37 & 34,47 & 48,19 & 65,24 & 86,48 & - \\
\hline \multirow[t]{3}{*}{$\Delta \mathrm{CS}$} & DM & $-55,36$ & $-51,71$ & $-47,70$ & $-43,38$ & $-39,07$ & $-34,98$ & $-31,45$ & $-29,06$ & $-28,91$ & $-33,58$ & $-52,12$ & - \\
\hline & DMA & 58,74 & 50,12 & 44,25 & 37,84 & 30,84 & 24,31 & 24,46 & 30,42 & 38,99 & 56,81 & 90,02 & - \\
\hline & PDMA & 50,91 & 40,50 & 31,22 & 22,72 & 11,21 & $-1,20$ & $-0,88$ & 3,74 & 7,89 & 10,71 & 14,38 & - \\
\hline
\end{tabular}


Tabela 8.118: Constantes de acoplamento B3LYP e constantes empíricas no nível BHandH $\left(50 \% E_{X}^{\mathrm{HF}}\right)$ e base aug-pcJ-2.

\begin{tabular}{|c|c|c|c|c|c|c|c|c|c|c|c|c|c|}
\hline & $\% E_{X}^{\mathrm{HF}}$ & $0 \%$ & $10 \%$ & $20 \%$ & $30 \%$ & $40 \%$ & $50 \%$ & $60 \%$ & $70 \%$ & $80 \%$ & $90 \%$ & $100 \%$ & Emp. \\
\hline $\mathrm{HF}$ & ${ }^{1} J_{\mathrm{HF}}$ & 393,4 & 418,4 & 443,6 & 469,1 & 494,8 & 520,8 & 547,0 & 573,4 & 600,0 & 626,9 & 654,0 & 532,8 \\
\hline $\mathrm{CO}$ & ${ }^{1} J_{\mathrm{CO}}$ & 21,7 & 19,9 & 17,9 & 15,8 & 13,6 & 11,4 & 9,0 & 6,5 & 4,0 & 1,4 & $-1,2$ & 15,7 \\
\hline $\mathrm{H}_{2} \mathrm{O}$ & ${ }^{1} J_{\mathrm{OH}}$ & $-71,7$ & $-74,4$ & $-77,1$ & $-79,8$ & $-82,5$ & $-85,3$ & $-88,1$ & $-91,0$ & $-93,8$ & $-96,7$ & $-99,6$ & $-81,7$ \\
\hline $\mathrm{H}_{2} \mathrm{O}$ & ${ }^{2} J_{\mathrm{HH}}$ & $-5,3$ & $-6,4$ & $-7,5$ & $-8,6$ & $-9,7$ & $-10,8$ & $-12,0$ & $-13,2$ & $-14,4$ & $-15,6$ & $-16,8$ & $-8,8$ \\
\hline $\mathrm{NH}_{3}$ & ${ }^{1} J_{\mathrm{NH}}$ & 44,2 & 45,0 & 45,8 & 46,6 & 47,5 & 48,3 & 49,2 & 50,0 & 50,9 & 51,8 & 52,7 & 43,0 \\
\hline $\mathrm{NH}_{3}$ & ${ }^{2} J_{\mathrm{HH}}$ & $-8,4$ & $-9,3$ & $-10,3$ & $-11,2$ & $-12,2$ & $-13,2$ & $-14,2$ & $-15,2$ & $-16,2$ & $-17,2$ & $-18,2$ & $-10,5$ \\
\hline $\mathrm{PH}_{3}$ & ${ }^{1} J_{\mathrm{PH}}$ & 157,6 & 166,1 & 174,5 & 182,7 & 190,9 & 198,8 & 206,7 & 214,3 & 221,8 & 229,2 & 236,3 & 195,0 \\
\hline $\mathrm{PF}_{3}$ & ${ }^{1} J_{\mathrm{PF}}$ & $-1810,3$ & $-1784,6$ & $-1754,5$ & $-1720,8$ & $-1684,0$ & $-1644,8$ & $-1603,8$ & $-1561,4$ & $-1518,1$ & $-1474,0$ & $-1429,6$ & $-1441,7$ \\
\hline $\mathrm{BHF}_{2}$ & ${ }^{1} J_{\mathrm{BF}}$ & $-167,7$ & $-150,2$ & $-132,7$ & $-115,4$ & $-98,2$ & $-81,2$ & $-64,4$ & $-47,8$ & $-31,4$ & $-15,2$ & 0,7 & $-79,7$ \\
\hline $\mathrm{BF}_{3}$ & ${ }^{1} J_{\mathrm{BF}}$ & $-70,2$ & $-51,0$ & $-32,1$ & $-13,3$ & 5,1 & 23,4 & 41,5 & 59,5 & 77,2 & 94,8 & 112,2 & 17,1 \\
\hline $\mathrm{F}_{2} \mathrm{O}$ & ${ }^{1} J_{\mathrm{OF}}$ & $-280,0$ & $-316,8$ & $-353,7$ & $-392,3$ & $-434,8$ & $-484,4$ & $-547,0$ & $-634,0$ & $-773,3$ & $-1056,7$ & $-2138,3$ & $-285,7$ \\
\hline $\mathrm{CH}_{4}$ & ${ }^{1} J_{\mathrm{CH}}$ & 131,0 & 132,6 & 134,1 & 135,7 & 137,4 & 139,0 & 140,7 & 142,4 & 144,1 & 145,9 & 147,6 & 122,8 \\
\hline $\mathrm{CH}_{4}$ & ${ }^{2} J_{\mathrm{HH}}$ & $-11,9$ & $-12,7$ & $-13,4$ & $-14,2$ & $-14,9$ & $-15,7$ & $-16,4$ & $-17,2$ & $-17,9$ & $-18,6$ & $-19,4$ & $-12,5$ \\
\hline $\mathrm{C}_{2} \mathrm{H}_{2}$ & ${ }^{1} J_{\mathrm{CC}}$ & 199,3 & 202,3 & 205,8 & 209,7 & 214,3 & 219,6 & 225,8 & 233,3 & 242,3 & 253,2 & 266,8 & 174,1 \\
\hline $\mathrm{C}_{2} \mathrm{H}_{2}$ & ${ }^{1} J_{\mathrm{CH}}$ & 271,1 & 273,5 & 276,1 & 278,9 & 281,8 & 285,0 & 288,6 & 292,6 & 297,3 & 302,7 & 309,4 & 244,3 \\
\hline $\mathrm{C}_{2} \mathrm{H}_{2}$ & ${ }^{2} J_{\mathrm{CH}}$ & 56,9 & 56,8 & 56,5 & 56,0 & 55,1 & 53,9 & 52,3 & 50,1 & 47,2 & 43,5 & 38,5 & 49,8 \\
\hline $\mathrm{C}_{2} \mathrm{H}_{2}$ & ${ }^{3} J_{\mathrm{HH}}$ & 10,2 & 10,7 & 11,4 & 12,3 & 13,3 & 14,5 & 15,9 & 17,6 & 19,7 & 22,2 & 25,4 & 9,0 \\
\hline $\mathrm{C}_{2} \mathrm{H}_{4}$ & ${ }^{1} J_{\mathrm{CC}}$ & 66,6 & 69,5 & 72,8 & 76,4 & 80,5 & 85,3 & 91,1 & 98,1 & 107,2 & 119,6 & 137,7 & 66,9 \\
\hline $\mathrm{C}_{2} \mathrm{H}_{4}$ & ${ }^{1} J_{\mathrm{CH}}$ & 165,4 & 167,7 & 170,0 & 172,5 & 175,1 & 178,0 & 181,2 & 185,0 & 189,5 & 195,2 & 203,3 & 154,4 \\
\hline $\mathrm{C}_{2} \mathrm{H}_{4}$ & ${ }^{2} J_{\mathrm{CH}}$ & 0,3 & $-0,5$ & $-1,6$ & $-2,7$ & $-4,1$ & $-5,7$ & $-7,7$ & $-10,1$ & $-13,4$ & $-18,0$ & $-24,8$ & $-2,0$ \\
\hline $\mathrm{C}_{2} \mathrm{H}_{4}$ & ${ }^{2} J_{\mathrm{HH}}$ & 6,0 & 5,3 & 4,5 & 3,6 & 2,7 & 1,6 & 0,4 & $-1,0$ & $-2,9$ & $-5,5$ & $-9,2$ & 2,1 \\
\hline $\mathrm{C}_{2} \mathrm{H}_{4}$ & ${ }^{3} J_{\mathrm{HH}_{\mathrm{c}}}$ & 12,4 & 12,7 & 13,0 & 13,4 & 13,8 & 14,5 & 15,3 & 16,3 & 17,8 & 19,9 & 23,2 & 11,4 \\
\hline $\mathrm{C}_{2} \mathrm{H}_{4}$ & ${ }^{3} J_{\mathrm{HH}_{\mathrm{t}}}$ & 19,8 & 20,0 & 20,4 & 20,8 & 21,4 & 22,2 & 23,1 & 24,4 & 26,1 & 28,5 & 32,3 & 18,4 \\
\hline $\mathrm{C}_{2} \mathrm{H}_{6}$ & ${ }^{1} J_{\mathrm{CC}}$ & 29,2 & 31,3 & 33,5 & 35,7 & 37,9 & 40,2 & 42,6 & 44,9 & 47,3 & 49,8 & 52,2 & 33,6 \\
\hline $\mathrm{C}_{2} \mathrm{H}_{6}$ & ${ }^{1} J_{\mathrm{CH}}$ & 130,5 & 132,3 & 134,1 & 135,9 & 137,7 & 139,6 & 141,5 & 143,3 & 145,2 & 147,2 & 149,1 & 123,3 \\
\hline $\mathrm{C}_{2} \mathrm{H}_{6}$ & ${ }^{2} J_{\mathrm{CH}}$ & $-2,5$ & $-3,0$ & $-3,4$ & $-3,9$ & $-4,5$ & $-5,0$ & $-5,5$ & $-6,0$ & $-6,6$ & $-7,1$ & $-7,7$ & $-4,5$ \\
\hline \multirow[t]{3}{*}{ Total } & $\mathrm{DM}$ & $-23,04$ & $-20,44$ & $-17,65$ & $-14,76$ & $-11,87$ & $-9,10$ & $-6,68$ & $-5,07$ & $-5,27$ & $-10,75$ & $-46,54$ & - \\
\hline & DMA & 32,76 & 30,21 & 28,02 & 26,08 & 24,59 & 24,42 & 28,37 & 34,39 & 42,85 & 57,31 & 104,12 & - \\
\hline & PDMA & 48,44 & 39,03 & 29,58 & 23,78 & 22,31 & 27,44 & 43,39 & 61,46 & 83,84 & 112,76 & 160,34 & - \\
\hline \multirow[t]{3}{*}{ CPI } & $\mathrm{DM}$ & $-62,93$ & $-58,07$ & $-52,87$ & $-47,52$ & $-42,27$ & $-37,50$ & $-33,78$ & $-32,22$ & $-35,35$ & $-51,53$ & $-140,30$ & - \\
\hline & DMA & 68,11 & 61,18 & 54,89 & 48,57 & 43,09 & 40,30 & 46,84 & 57,89 & 73,58 & 102,31 & 205,72 & - \\
\hline & PDMA & 73,35 & 57,88 & 42,71 & 28,89 & 20,26 & 19,92 & 37,25 & 56,07 & 76,37 & 101,24 & 151,51 & - \\
\hline \multirow[t]{3}{*}{ SPI } & $\mathrm{DM}$ & 6,21 & 7,16 & 8,18 & 9,27 & 10,43 & 11,73 & 13,19 & 14,84 & 16,79 & 19,16 & 22,22 & - \\
\hline & DMA & 6,84 & 7,49 & 8,31 & 9,59 & 11,03 & 12,78 & 14,83 & 17,16 & 20,32 & 24,31 & 29,62 & - \\
\hline & PDMA & 30,17 & 25,21 & 19,96 & 20,04 & 23,81 & 32,96 & 47,89 & 65,42 & 89,32 & 121,21 & 166,82 & - \\
\hline \multirow[t]{3}{*}{$\Delta \mathrm{CS}$} & $\mathrm{DM}$ & $-69,14$ & $-65,23$ & $-61,05$ & $-56,78$ & $-52,70$ & $-49,23$ & $-46,97$ & $-47,06$ & $-52,13$ & $-70,69$ & $-162,52$ & - \\
\hline & DMA & 61,27 & 53,69 & 46,58 & 38,99 & 32,06 & 27,52 & 32,01 & 40,73 & 53,26 & 78,00 & 176,10 & - \\
\hline & PDMA & 43,18 & 32,67 & 22,75 & 8,85 & $-3,55$ & $-13,04$ & $-10,63$ & $-9,36$ & $-12,95$ & $-19,98$ & $-15,31$ & - \\
\hline
\end{tabular}


Tabela 8.119: Constantes de acoplamento B3P86 e constantes empíricas no nível BHandH $\left(50 \% E_{X}^{\mathrm{HF}}\right)$ e base aug-pcJ-2.

\begin{tabular}{|c|c|c|c|c|c|c|c|c|c|c|c|c|c|}
\hline & $\% E_{X}^{\mathrm{HF}}$ & $0 \%$ & $10 \%$ & $20 \%$ & $30 \%$ & $40 \%$ & $50 \%$ & $60 \%$ & $70 \%$ & $80 \%$ & $90 \%$ & $100 \%$ & Emp. \\
\hline $\mathrm{HF}$ & ${ }^{1} J_{\mathrm{HF}}$ & 357,7 & 381,4 & 405,4 & 429,5 & 454,0 & 478,6 & 503,5 & 528,5 & 553,8 & 579,3 & 605,0 & 532,8 \\
\hline $\mathrm{CO}$ & ${ }^{1} J_{\mathrm{CO}}$ & 24,7 & 23,1 & 21,3 & 19,5 & 17,5 & 15,5 & 13,4 & 11,3 & 9,1 & 6,8 & 4,4 & 15,7 \\
\hline $\mathrm{H}_{2} \mathrm{O}$ & ${ }^{1} J_{\mathrm{OH}}$ & $-65,2$ & $-67,8$ & $-70,3$ & $-72,9$ & $-75,5$ & $-78,1$ & $-80,8$ & $-83,4$ & $-86,1$ & $-88,9$ & $-91,6$ & $-81,7$ \\
\hline $\mathrm{H}_{2} \mathrm{O}$ & ${ }^{2} J_{\mathrm{HH}}$ & $-4,6$ & $-5,6$ & $-6,5$ & $-7,6$ & $-8,6$ & $-9,6$ & $-10,7$ & $-11,8$ & $-12,9$ & $-14,0$ & $-15,2$ & $-8,8$ \\
\hline $\mathrm{NH}_{3}$ & ${ }^{1} J_{\mathrm{NH}}$ & 40,3 & 41,1 & 41,8 & 42,6 & 43,4 & 44,2 & 45,0 & 45,8 & 46,6 & 47,5 & 48,3 & 43,0 \\
\hline $\mathrm{NH}_{3}$ & ${ }^{2} J_{\mathrm{HH}}$ & $-7,8$ & $-8,7$ & $-9,5$ & $-10,4$ & $-11,3$ & $-12,2$ & $-13,1$ & $-14,1$ & $-15,0$ & $-15,9$ & $-16,9$ & $-10,5$ \\
\hline $\mathrm{PH}_{3}$ & ${ }^{1} J_{\mathrm{PH}}$ & 138,4 & 146,6 & 154,6 & 162,6 & 170,5 & 178,2 & 185,8 & 193,3 & 200,6 & 207,8 & 214,8 & 195,0 \\
\hline $\mathrm{PF}_{3}$ & ${ }^{1} J_{\mathrm{PF}}$ & $-1804,0$ & $-1778,3$ & $-1748,1$ & $-1714,4$ & $-1677,8$ & $-1638,8$ & $-1598,0$ & $-1555,9$ & $-1512,8$ & $-1469,1$ & $-1425,0$ & $-1441,7$ \\
\hline $\mathrm{BHF}_{2}$ & ${ }^{1} J_{\mathrm{BF}}$ & $-175,5$ & $-158,4$ & $-141,4$ & $-124,6$ & $-107,9$ & $-91,3$ & $-74,9$ & $-58,7$ & $-42,7$ & $-26,9$ & $-11,3$ & $-79,7$ \\
\hline $\mathrm{BF}_{3}$ & ${ }^{1} J_{\mathrm{BF}}$ & $-81,4$ & $-62,6$ & $-44,1$ & $-25,8$ & $-7,7$ & 10,1 & 27,8 & 45,3 & 62,7 & 79,9 & 96,9 & 17,1 \\
\hline $\mathrm{F}_{2} \mathrm{O}$ & ${ }^{1} J_{\mathrm{OF}}$ & $-287,8$ & $-324,9$ & $-362,3$ & $-401,4$ & $-444,6$ & $-495,1$ & $-558,7$ & $-646,9$ & $-786,4$ & $-1061,9$ & $-1993,1$ & $-285,7$ \\
\hline $\mathrm{CH}_{4}$ & ${ }^{1} J_{\mathrm{CH}}$ & 119,3 & 120,8 & 122,3 & 123,8 & 125,4 & 127,0 & 128,6 & 130,2 & 131,8 & 133,5 & 135,2 & 122,8 \\
\hline $\mathrm{CH}_{4}$ & ${ }^{2} J_{\mathrm{HH}}$ & $-11,8$ & $-12,5$ & $-13,3$ & $-14,0$ & $-14,7$ & $-15,4$ & $-16,1$ & $-16,8$ & $-17,5$ & $-18,2$ & $-18,9$ & $-12,5$ \\
\hline $\mathrm{C}_{2} \mathrm{H}_{2}$ & ${ }^{1} J_{\mathrm{CC}}$ & 189,8 & 192,5 & 195,7 & 199,3 & 203,5 & 208,5 & 214,4 & 221,5 & 230,2 & 241,0 & 254,8 & 174,1 \\
\hline $\mathrm{C}_{2} \mathrm{H}_{2}$ & ${ }^{1} J_{\mathrm{CH}}$ & 251,0 & 253,4 & 255,8 & 258,5 & 261,4 & 264,5 & 268,1 & 272,2 & 276,9 & 282,7 & 289,8 & 244,3 \\
\hline $\mathrm{C}_{2} \mathrm{H}_{2}$ & ${ }^{2} J_{\mathrm{CH}}$ & 54,7 & 54,6 & 54,4 & 53,9 & 53,0 & 51,8 & 50,2 & 47,9 & 44,9 & 40,9 & 35,4 & 49,8 \\
\hline $\mathrm{C}_{2} \mathrm{H}_{2}$ & ${ }^{3} J_{\mathrm{HH}}$ & 10,2 & 10,9 & 11,6 & 12,5 & 13,6 & 14,9 & 16,4 & 18,3 & 20,6 & 23,5 & 27,1 & 9,0 \\
\hline $\mathrm{C}_{2} \mathrm{H}_{4}$ & ${ }^{1} J_{\mathrm{CC}}$ & 60,6 & 63,4 & 66,4 & 69,9 & 73,8 & 78,5 & 84,2 & 91,5 & 101,2 & 115,3 & 138,2 & 66,9 \\
\hline $\mathrm{C}_{2} \mathrm{H}_{4}$ & ${ }^{1} J_{\mathrm{CH}}$ & 152,0 & 154,1 & 156,4 & 158,8 & 161,3 & 164,2 & 167,5 & 171,3 & 176,2 & 182,8 & 193,0 & 154,4 \\
\hline $\mathrm{C}_{2} \mathrm{H}_{4}$ & ${ }^{2} J_{\mathrm{CH}}$ & 0,0 & $-0,8$ & $-1,8$ & $-2,9$ & $-4,2$ & $-5,9$ & $-7,9$ & $-10,6$ & $-14,3$ & $-19,7$ & $-28,7$ & $-2,0$ \\
\hline $\mathrm{C}_{2} \mathrm{H}_{4}$ & ${ }^{2} J_{\mathrm{HH}}$ & 4,7 & 4,0 & 3,2 & 2,3 & 1,3 & 0,1 & $-1,2$ & $-2,9$ & $-5,2$ & $-8,5$ & $-13,8$ & 2,1 \\
\hline $\mathrm{C}_{2} \mathrm{H}_{4}$ & ${ }^{3} J_{\mathrm{HH}_{\mathrm{c}}}$ & 11,6 & 11,9 & 12,3 & 12,7 & 13,3 & 14,0 & 15,0 & 16,3 & 18,2 & 21,1 & 26,1 & 11,4 \\
\hline $\mathrm{C}_{2} \mathrm{H}_{4}$ & ${ }^{3} J_{\mathrm{HH}_{\mathrm{t}}}{ }^{\mathrm{C}}$ & 18,6 & 18,9 & 19,3 & 19,9 & 20,5 & 21,4 & 22,5 & 24,1 & 26,3 & 29,6 & 35,2 & 18,4 \\
\hline $\mathrm{C}_{2} \mathrm{H}_{6}$ & ${ }^{1} J_{\mathrm{CC}}$ & 25,0 & 27,0 & 29,0 & 31,1 & 33,2 & 35,3 & 37,5 & 39,7 & 41,9 & 44,2 & 46,5 & 33,6 \\
\hline $\mathrm{C}_{2} \mathrm{H}_{6}$ & ${ }^{1} J_{\mathrm{CH}}$ & 119,4 & 121,1 & 122,8 & 124,5 & 126,2 & 128,0 & 129,8 & 131,6 & 133,4 & 135,3 & 137,1 & 123,3 \\
\hline $\mathrm{C}_{2} \mathrm{H}_{6}$ & ${ }^{2} J_{\mathrm{CH}}$ & $-2,7$ & $-3,1$ & $-3,6$ & $-4,1$ & $-4,5$ & $-5,0$ & $-5,5$ & $-6,0$ & $-6,6$ & $-7,1$ & $-7,6$ & $-4,5$ \\
\hline \multirow[t]{3}{*}{ Total } & $\mathrm{DM}$ & $-28,82$ & $-26,33$ & $-23,66$ & $-20,90$ & $-18,13$ & $-15,51$ & $-13,22$ & $-11,73$ & $-11,99$ & $-17,14$ & $-46,96$ & - \\
\hline & DMA & 34,08 & 31,40 & 28,78 & 26,58 & 24,77 & 23,58 & 24,35 & 27,92 & 35,93 & 50,23 & 92,11 & - \\
\hline & PDMA & 49,65 & 39,98 & 30,36 & 24,31 & 23,28 & 26,62 & 37,73 & 56,40 & 80,27 & 112,38 & 166,30 & - \\
\hline \multirow[t]{3}{*}{ CPI } & $\mathrm{DM}$ & $-69,15$ & $-64,51$ & $-59,51$ & $-54,40$ & $-49,41$ & $-44,91$ & $-41,47$ & $-40,19$ & $-43,51$ & $-59,17$ & $-134,47$ & - \\
\hline & DMA & 75,05 & 69,29 & 63,20 & 56,93 & 50,97 & 45,78 & 44,82 & 49,65 & 64,02 & 91,79 & 182,15 & - \\
\hline & PDMA & 85,57 & 70,65 & 56,01 & 41,19 & 28,15 & 17,73 & 22,91 & 39,30 & 58,67 & 82,62 & 127,73 & - \\
\hline \multirow[t]{3}{*}{ SPI } & DM & 0,75 & 1,67 & 2,63 & 3,67 & 4,80 & 6,05 & 7,49 & 9,15 & 11,13 & 13,69 & 17,22 & - \\
\hline & DMA & 4,05 & 3,62 & 3,55 & 4,33 & 5,55 & 7,29 & 9,33 & 11,99 & 15,34 & 19,75 & 26,09 & - \\
\hline & PDMA & 23,32 & 17,48 & 11,56 & 11,93 & 19,71 & 33,15 & 48,59 & 68,95 & 96,12 & 134,20 & 194,58 & - \\
\hline \multirow[t]{3}{*}{$\Delta \mathrm{CS}$} & $\mathrm{DM}$ & $-69,91$ & $-66,18$ & $-62,14$ & $-58,07$ & $-54,21$ & $-50,96$ & $-48,97$ & $-49,34$ & $-54,64$ & $-72,86$ & $-151,69$ & - \\
\hline & DMA & 71,00 & 65,67 & 59,65 & 52,60 & 45,43 & 38,49 & 35,48 & 37,66 & 48,68 & 72,04 & 156,06 & - \\
\hline & PDMA & 62,25 & 53,17 & 44,45 & 29,26 & 8,44 & $-15,42$ & $-25,69$ & $-29,65$ & $-37,45$ & $-51,57$ & $-66,85$ & - \\
\hline
\end{tabular}


Tabela 8.120: Constantes de acoplamento B971 e constantes empíricas no nível BHandH $\left(50 \% E_{X}^{\mathrm{HF}}\right)$ e base aug-pcJ-2.

\begin{tabular}{|c|c|c|c|c|c|c|c|c|c|c|c|c|c|}
\hline & $\% E_{X}^{\mathrm{HF}}$ & $0 \%$ & $10 \%$ & $20 \%$ & $30 \%$ & $40 \%$ & $50 \%$ & $60 \%$ & $70 \%$ & $80 \%$ & $90 \%$ & $100 \%$ & Emp. \\
\hline $\mathrm{HF}$ & ${ }^{1} J_{\mathrm{HF}}$ & 427,3 & 443,9 & 461,4 & 480,0 & 499,7 & 520,6 & 542,8 & 566,1 & 590,8 & 616,7 & 643,9 & 532,8 \\
\hline $\mathrm{CO}$ & ${ }^{1} J_{\mathrm{CO}}$ & 15,8 & 14,7 & 13,5 & 12,2 & 10,7 & 9,0 & 7,3 & 5,3 & 3,2 & 1,0 & $-1,3$ & 15,7 \\
\hline $\mathrm{H}_{2} \mathrm{O}$ & ${ }^{1} J_{\mathrm{OH}}$ & $-67,7$ & $-69,8$ & $-72,1$ & $-74,5$ & $-77,0$ & $-79,7$ & $-82,5$ & $-85,5$ & $-88,8$ & $-92,2$ & $-95,7$ & $-81,7$ \\
\hline $\mathrm{H}_{2} \mathrm{O}$ & ${ }^{2} J_{\mathrm{HH}}$ & $-0,6$ & $-1,6$ & $-2,7$ & $-3,8$ & $-5,1$ & $-6,4$ & $-7,7$ & $-9,2$ & $-10,8$ & $-12,5$ & $-14,3$ & $-8,8$ \\
\hline $\mathrm{NH}_{3}$ & ${ }^{1} J_{\mathrm{NH}}$ & 37,6 & 38,6 & 39,6 & 40,7 & 41,9 & 43,1 & 44,4 & 45,9 & 47,3 & 48,9 & 50,6 & 43,0 \\
\hline $\mathrm{NH}_{3}$ & ${ }^{2} J_{\mathrm{HH}}$ & $-3,4$ & $-4,3$ & $-5,2$ & $-6,3$ & $-7,4$ & $-8,6$ & $-9,9$ & $-11,2$ & $-12,7$ & $-14,3$ & $-16,1$ & $-10,5$ \\
\hline $\mathrm{PH}_{3}$ & ${ }^{1} J_{\mathrm{PH}}$ & 161,9 & 168,1 & 174,7 & 181,6 & 188,9 & 196,6 & 204,6 & 213,1 & 221,9 & 231,1 & 240,7 & 195,0 \\
\hline $\mathrm{PF}_{3}$ & ${ }^{1} J_{\mathrm{PF}}$ & $-1613,6$ & $-1608,3$ & $-1597,4$ & $-1581,8$ & $-1562,1$ & $-1539,1$ & $-1513,4$ & $-1485,6$ & $-1456,2$ & $-1425,8$ & $-1394,8$ & $-1441,7$ \\
\hline $\mathrm{BHF}_{2}$ & ${ }^{1} J_{\mathrm{BF}}$ & $-145,0$ & $-130,5$ & $-115,6$ & $-100,5$ & $-85,1$ & $-69,6$ & $-54,0$ & $-38,4$ & $-22,8$ & $-7,2$ & 8,1 & $-79,7$ \\
\hline $\mathrm{BF}_{3}$ & ${ }^{1} J_{\mathrm{BF}}$ & $-55,7$ & $-38,9$ & $-21,9$ & $-4,7$ & 12,4 & 29,7 & 47,1 & 64,5 & 81,9 & 99,3 & 116,8 & 17,1 \\
\hline $\mathrm{F}_{2} \mathrm{O}$ & ${ }^{1} J_{\mathrm{OF}}$ & $-189,8$ & $-221,6$ & $-254,8$ & $-289,8$ & $-327,7$ & $-370,4$ & $-421,2$ & $-486,9$ & $-582,5$ & $-752,8$ & $-1221,3$ & $-285,7$ \\
\hline $\mathrm{CH}_{4}$ & ${ }^{1} J_{\mathrm{CH}}$ & 102,5 & 105,7 & 109,1 & 112,7 & 116,5 & 120,6 & 125,0 & 129,6 & 134,4 & 139,6 & 145,1 & 122,8 \\
\hline $\mathrm{CH}_{4}$ & ${ }^{2} J_{\mathrm{HH}}$ & $-5,8$ & $-6,7$ & $-7,6$ & $-8,5$ & $-9,6$ & $-10,7$ & $-11,8$ & $-13,1$ & $-14,4$ & $-15,8$ & $-17,3$ & $-12,5$ \\
\hline $\mathrm{C}_{2} \mathrm{H}_{2}$ & ${ }^{1} J_{\mathrm{CC}}$ & 186,1 & 190,1 & 194,4 & 199,4 & 205,0 & 211,6 & 219,4 & 228,8 & 240,5 & 255,4 & 275,1 & 174,1 \\
\hline $\mathrm{C}_{2} \mathrm{H}_{2}$ & ${ }^{1} J_{\mathrm{CH}}$ & 200,6 & 207,3 & 214,3 & 221,7 & 229,5 & 237,9 & 247,0 & 256,9 & 268,0 & 280,6 & 295,5 & 244,3 \\
\hline $\mathrm{C}_{2} \mathrm{H}_{2}$ & ${ }^{2} J_{\mathrm{CH}}$ & 51,0 & 51,9 & 52,5 & 53,0 & 53,2 & 53,0 & 52,5 & 51,2 & 49,1 & 45,6 & 40,1 & 49,8 \\
\hline $\mathrm{C}_{2} \mathrm{H}_{2}$ & ${ }^{3} J_{\mathrm{HH}}$ & 6,2 & 6,6 & 7,1 & 7,6 & 8,4 & 9,3 & 10,5 & 12,0 & 14,0 & 16,7 & 20,5 & 9,0 \\
\hline $\mathrm{C}_{2} \mathrm{H}_{4}$ & ${ }^{1} J_{\mathrm{CC}}$ & 63,4 & 66,1 & 69,1 & 72,5 & 76,4 & 80,8 & 86,2 & 92,8 & 101,2 & 112,9 & 130,5 & 66,9 \\
\hline $\mathrm{C}_{2} \mathrm{H}_{4}$ & ${ }^{1} J_{\mathrm{CH}}$ & 126,1 & 130,5 & 135,2 & 140,1 & 145,4 & 151,2 & 157,4 & 164,3 & 172,1 & 181,3 & 193,0 & 154,4 \\
\hline $\mathrm{C}_{2} \mathrm{H}_{4}$ & ${ }^{2} J_{\mathrm{CH}}$ & 2,5 & 1,9 & 1,1 & 0,2 & $-0,8$ & $-2,1$ & $-3,7$ & $-5,8$ & $-8,5$ & $-12,5$ & $-18,8$ & $-2,0$ \\
\hline $\mathrm{C}_{2} \mathrm{H}_{4}$ & ${ }^{2} J_{\mathrm{HH}}$ & 6,0 & 5,6 & 5,2 & 4,7 & 4,1 & 3,4 & 2,5 & 1,4 & 0,0 & $-2,0$ & $-5,1$ & 2,1 \\
\hline $\mathrm{C}_{2} \mathrm{H}_{4}$ & ${ }^{3} J_{\mathrm{HH}_{\mathrm{C}}}$ & 9,3 & 9,6 & 9,8 & 10,2 & 10,5 & 11,0 & 11,6 & 12,4 & 13,6 & 15,3 & 18,0 & 11,4 \\
\hline $\mathrm{C}_{2} \mathrm{H}_{4}$ & ${ }^{3} J_{\mathrm{HH}_{\mathrm{t}}}$ & 13,3 & 13,8 & 14,3 & 14,9 & 15,6 & 16,4 & 17,4 & 18,6 & 20,2 & 22,5 & 25,9 & 18,4 \\
\hline $\mathrm{C}_{2} \mathrm{H}_{6}$ & ${ }^{1} J_{\mathrm{CC}}$ & 25,4 & 27,6 & 30,0 & 32,4 & 35,1 & 37,8 & 40,8 & 43,9 & 47,2 & 50,7 & 54,4 & 33,6 \\
\hline $\mathrm{C}_{2} \mathrm{H}_{6}$ & ${ }^{1} J_{\mathrm{CH}}$ & 101,2 & 104,7 & 108,4 & 112,3 & 116,5 & 120,9 & 125,5 & 130,4 & 135,6 & 141,2 & 147,0 & 123,3 \\
\hline $\mathrm{C}_{2} \mathrm{H}_{6}$ & ${ }^{2} J_{\mathrm{CH}}$ & $-0,6$ & $-1,1$ & $-1,7$ & $-2,2$ & $-2,8$ & $-3,5$ & $-4,2$ & $-4,9$ & $-5,7$ & $-6,6$ & $-7,5$ & $-4,5$ \\
\hline \multirow[t]{3}{*}{ Total } & DM & $-16,64$ & $-14,72$ & $-12,53$ & $-10,10$ & $-7,48$ & $-4,76$ & $-2,04$ & 0,38 & 2,00 & 1,17 & $-10,52$ & - \\
\hline & DMA & 28,75 & 24,27 & 19,53 & 14,83 & 12,45 & 11,98 & 14,82 & 20,84 & 28,73 & 41,48 & 67,88 & - \\
\hline & PDMA & 58,42 & 48,88 & 38,94 & 28,67 & 18,85 & 15,67 & 21,98 & 35,14 & 55,59 & 82,29 & 121,51 & - \\
\hline \multirow[t]{3}{*}{ CPI } & $\mathrm{DM}$ & $-29,88$ & $-27,75$ & $-25,09$ & $-22,04$ & $-18,75$ & $-15,48$ & $-12,55$ & $-10,67$ & $-11,29$ & $-18,48$ & $-52,63$ & - \\
\hline & DMA & 52,66 & 44,00 & 34,53 & 25,02 & 20,85 & 21,06 & 26,80 & 36,67 & 49,64 & 72,39 & 125,14 & - \\
\hline & PDMA & 71,01 & 57,07 & 42,91 & 28,62 & 16,22 & 19,69 & 31,17 & 46,08 & 65,63 & 88,09 & 120,65 & - \\
\hline \multirow[t]{3}{*}{ SPI } & $\mathrm{DM}$ & $-6,93$ & $-5,17$ & $-3,33$ & $-1,34$ & 0,79 & 3,10 & 5,67 & 8,49 & 11,75 & 15,59 & 20,35 & - \\
\hline & DMA & 11,22 & 9,79 & 8,54 & 7,37 & 6,29 & 5,33 & 6,03 & 9,23 & 13,40 & 18,81 & 25,89 & - \\
\hline & PDMA & 49,19 & 42,88 & 36,03 & 28,71 & 20,78 & 12,73 & 15,23 & 27,11 & 48,23 & 78,04 & 122,14 & - \\
\hline \multirow[t]{3}{*}{$\Delta \mathrm{CS}$} & DM & $-22,96$ & $-22,58$ & $-21,76$ & $-20,70$ & $-19,55$ & $-18,58$ & $-18,21$ & $-19,17$ & $-23,04$ & $-34,07$ & $-72,98$ & - \\
\hline & DMA & 41,44 & 34,21 & 25,99 & 17,65 & 14,56 & 15,74 & 20,77 & 27,45 & 36,24 & 53,58 & 99,25 & - \\
\hline & PDMA & 21,82 & 14,19 & 6,88 & $-0,09$ & $-4,57$ & 6,96 & 15,93 & 18,97 & 17,40 & 10,05 & $-1,49$ & - \\
\hline
\end{tabular}


Tabela 8.121: Constantes de acoplamento B972 e constantes empíricas no nível BHandH $\left(50 \% E_{X}^{\mathrm{HF}}\right)$ e base aug-pcJ-2.

\begin{tabular}{|c|c|c|c|c|c|c|c|c|c|c|c|c|c|}
\hline & $\% E_{X}^{\mathrm{HF}}$ & $0 \%$ & $10 \%$ & $20 \%$ & $30 \%$ & $40 \%$ & $50 \%$ & $60 \%$ & $70 \%$ & $80 \%$ & $90 \%$ & $100 \%$ & Emp. \\
\hline $\mathrm{HF}$ & ${ }^{1} J_{\mathrm{HF}}$ & 420,6 & 441,5 & 463,7 & 487,2 & 512,0 & 538,2 & 565,8 & 595,0 & 625,6 & 657,8 & 691,6 & 532,8 \\
\hline $\mathrm{CO}$ & ${ }^{1} J_{\mathrm{CO}}$ & 16,9 & 15,3 & 13,5 & 11,5 & 9,2 & 6,8 & 4,2 & 1,4 & $-1,6$ & $-4,8$ & $-8,3$ & 15,7 \\
\hline $\mathrm{H}_{2} \mathrm{O}$ & ${ }^{1} J_{\mathrm{OH}}$ & $-66,8$ & $-69,6$ & $-72,5$ & $-75,6$ & $-78,9$ & $-82,3$ & $-86,0$ & $-90,0$ & $-94,1$ & $-98,5$ & $-103,1$ & $-81,7$ \\
\hline $\mathrm{H}_{2} \mathrm{O}$ & ${ }^{2} J_{\mathrm{HH}}$ & $-1,2$ & $-2,2$ & $-3,2$ & $-4,3$ & $-5,5$ & $-6,7$ & $-8,0$ & $-9,5$ & $-11,0$ & $-12,6$ & $-14,3$ & $-8,8$ \\
\hline $\mathrm{NH}_{3}$ & ${ }^{1} J_{\mathrm{NH}}$ & 36,3 & 37,5 & 38,9 & 40,3 & 41,8 & 43,4 & 45,1 & 47,0 & 48,9 & 50,9 & 53,1 & 43,0 \\
\hline $\mathrm{NH}_{3}$ & ${ }^{2} J_{\mathrm{HH}}$ & $-3,3$ & $-4,2$ & $-5,1$ & $-6,0$ & $-7,1$ & $-8,2$ & $-9,4$ & $-10,7$ & $-12,1$ & $-13,6$ & $-15,2$ & $-10,5$ \\
\hline $\mathrm{PH}_{3}$ & ${ }^{1} J_{\mathrm{PH}}$ & 152,4 & 159,5 & 167,0 & 175,0 & 183,4 & 192,2 & 201,4 & 211,1 & 221,2 & 231,6 & 242,5 & 195,0 \\
\hline $\mathrm{PF}_{3}$ & ${ }^{1} J_{\mathrm{PF}}$ & $-1626,4$ & $-1621,0$ & $-1610,4$ & $-1595,3$ & $-1576,6$ & $-1555,0$ & $-1531,2$ & $-1505,7$ & $-1479,1$ & $-1452,1$ & $-1424,9$ & $-1441,7$ \\
\hline $\mathrm{BHF}_{2}$ & ${ }^{1} J_{\mathrm{BF}}$ & $-151,4$ & $-134,7$ & $-117,6$ & $-100,3$ & $-82,9$ & $-65,4$ & $-48,0$ & $-30,7$ & $-13,4$ & 3,5 & 20,3 & $-79,7$ \\
\hline $\mathrm{BF}_{3}$ & ${ }^{1} J_{\mathrm{BF}}$ & $-64,0$ & $-44,6$ & $-25,1$ & $-5,4$ & 14,1 & 33,8 & 53,5 & 73,1 & 92,7 & 112,2 & 131,6 & 17,1 \\
\hline $\mathrm{F}_{2} \mathrm{O}$ & ${ }^{1} J_{\mathrm{OF}}$ & $-187,3$ & $-217,9$ & $-249,8$ & $-283,7$ & $-320,6$ & $-362,5$ & $-412,9$ & $-478,9$ & $-577,4$ & $-761,7$ & $-1349,0$ & $-285,7$ \\
\hline $\mathrm{CH}_{4}$ & ${ }^{1} J_{\mathrm{CH}}$ & 94,6 & 98,6 & 102,8 & 107,2 & 111,9 & 116,9 & 122,2 & 127,8 & 133,7 & 139,9 & 146,5 & 122,8 \\
\hline $\mathrm{CH}_{4}$ & ${ }^{2} J_{\mathrm{HH}}$ & $-5,4$ & $-6,1$ & $-6,9$ & $-7,8$ & $-8,7$ & $-9,7$ & $-10,7$ & $-11,9$ & $-13,0$ & $-14,3$ & $-15,6$ & $-12,5$ \\
\hline $\mathrm{C}_{2} \mathrm{H}_{2}$ & ${ }^{1} J_{\mathrm{CC}}$ & 172,7 & 177,5 & 182,8 & 188,8 & 195,6 & 203,4 & 212,5 & 223,4 & 236,6 & 253,1 & 274,3 & 174,1 \\
\hline $\mathrm{C}_{2} \mathrm{H}_{2}$ & ${ }^{1} J_{\mathrm{CH}}$ & 189,9 & 197,4 & 205,4 & 213,7 & 222,6 & 232,0 & 242,2 & 253,1 & 265,2 & 278,6 & 294,1 & 244,3 \\
\hline $\mathrm{C}_{2} \mathrm{H}_{2}$ & ${ }^{2} J_{\mathrm{CH}}$ & 49,1 & 50,0 & 50,8 & 51,4 & 51,8 & 51,9 & 51,5 & 50,6 & 48,9 & 46,1 & 41,6 & 49,8 \\
\hline $\mathrm{C}_{2} \mathrm{H}_{2}$ & ${ }^{3} J_{\mathrm{HH}}$ & 6,1 & 6,5 & 6,9 & 7,4 & 8,1 & 8,9 & 9,9 & 11,2 & 12,9 & 15,1 & 18,0 & 9,0 \\
\hline $\mathrm{C}_{2} \mathrm{H}_{4}$ & ${ }^{1} J_{\mathrm{CC}}$ & 54,6 & 58,0 & 61,7 & 66,0 & 70,8 & 76,3 & 82,9 & 91,0 & 101,4 & 115,7 & 137,0 & 66,9 \\
\hline $\mathrm{C}_{2} \mathrm{H}_{4}$ & ${ }^{1} J_{\mathrm{CH}}$ & 117,8 & 122,9 & 128,4 & 134,1 & 140,3 & 146,9 & 154,1 & 161,9 & 170,8 & 181,1 & 194,0 & 154,4 \\
\hline $\mathrm{C}_{2} \mathrm{H}_{4}$ & ${ }^{2} J_{\mathrm{CH}}$ & 2,6 & 2,0 & 1,3 & 0,5 & $-0,4$ & $-1,7$ & $-3,2$ & $-5,2$ & $-8,0$ & $-11,9$ & $-18,1$ & $-2,0$ \\
\hline $\mathrm{C}_{2} \mathrm{H}_{4}$ & ${ }^{2} J_{\mathrm{HH}}$ & 5,6 & 5,4 & 5,1 & 4,7 & 4,2 & 3,7 & 3,0 & 2,2 & 1,1 & $-0,5$ & $-2,9$ & 2,1 \\
\hline $\mathrm{C}_{2} \mathrm{H}_{4}$ & ${ }^{3} J_{\mathrm{HH}_{\mathrm{c}}}$ & 8,9 & 9,1 & 9,4 & 9,7 & 10,1 & 10,6 & 11,1 & 11,8 & 12,8 & 14,3 & 16,6 & 11,4 \\
\hline $\mathrm{C}_{2} \mathrm{H}_{4}$ & ${ }^{3} J_{\mathrm{HH}_{\mathrm{t}}}$ & 12,8 & 13,3 & 13,8 & 14,4 & 15,1 & 15,9 & 16,8 & 17,9 & 19,4 & 21,4 & 24,4 & 18,4 \\
\hline $\mathrm{C}_{2} \mathrm{H}_{6}$ & ${ }^{1} J_{\mathrm{CC}}$ & 21,9 & 24,5 & 27,3 & 30,2 & 33,3 & 36,6 & 40,1 & 43,8 & 47,8 & 52,0 & 56,4 & 33,6 \\
\hline $\mathrm{C}_{2} \mathrm{H}_{6}$ & ${ }^{1} J_{\mathrm{CH}}$ & 93,2 & 97,4 & 101,8 & 106,4 & 111,4 & 116,6 & 122,1 & 127,9 & 134,1 & 140,6 & 147,5 & 123,3 \\
\hline $\mathrm{C}_{2} \mathrm{H}_{6}$ & ${ }^{2} J_{\mathrm{CH}}$ & $-0,5$ & $-0,9$ & $-1,4$ & $-1,9$ & $-2,4$ & $-3,0$ & $-3,6$ & $-4,2$ & $-4,9$ & $-5,7$ & $-6,5$ & $-4,5$ \\
\hline \multirow[t]{3}{*}{ Total } & $\mathrm{DM}$ & $-20,65$ & $-18,13$ & $-15,31$ & $-12,25$ & $-9,00$ & $-5,65$ & $-2,35$ & 0,65 & 2,77 & 1,98 & $-13,65$ & - \\
\hline & DMA & 32,07 & 26,88 & 21,52 & 15,77 & 12,58 & 12,67 & 16,09 & 22,52 & 31,33 & 44,28 & 75,06 & - \\
\hline & PDMA & 62,56 & 52,06 & 41,66 & 30,61 & 20,25 & 18,83 & 24,83 & 35,42 & 55,00 & 81,60 & 121,33 & - \\
\hline \multirow[t]{3}{*}{ CPI } & DM & $-33,61$ & $-30,54$ & $-26,92$ & $-22,92$ & $-18,78$ & $-14,65$ & $-11,00$ & $-8,49$ & $-8,71$ & $-16,62$ & $-61,02$ & - \\
\hline & DMA & 57,12 & 47,41 & 37,12 & 26,03 & 20,51 & 22,15 & 31,27 & 42,55 & 57,22 & 79,85 & 142,42 & - \\
\hline & PDMA & 77,34 & 60,59 & 45,07 & 29,28 & 15,50 & 23,36 & 37,80 & 54,67 & 76,38 & 101,12 & 139,31 & - \\
\hline \multirow[t]{3}{*}{ SPI } & DM & $-11,15$ & $-9,03$ & $-6,79$ & $-4,42$ & $-1,83$ & 0,95 & 3,99 & 7,35 & 11,18 & 15,63 & 21,08 & - \\
\hline & DMA & 13,71 & 11,82 & 10,09 & 8,25 & 6,76 & 5,72 & 4,96 & 7,84 & 12,35 & 18,19 & 25,67 & - \\
\hline & PDMA & 51,71 & 45,80 & 39,16 & 31,59 & 23,74 & 15,52 & 15,32 & 21,30 & 39,33 & 67,28 & 108,15 & - \\
\hline \multirow[t]{3}{*}{$\Delta \mathrm{CS}$} & DM & $-22,46$ & $-21,50$ & $-20,12$ & $-18,50$ & $-16,96$ & $-15,60$ & $-14,99$ & $-15,84$ & $-19,89$ & $-32,24$ & $-82,10$ & - \\
\hline & DMA & 43,41 & 35,59 & 27,03 & 17,78 & 13,75 & 16,43 & 26,31 & 34,71 & 44,86 & 61,67 & 116,75 & - \\
\hline & PDMA & 25,63 & 14,79 & 5,91 & $-2,31$ & $-8,24$ & 7,84 & 22,48 & 33,37 & 37,05 & 33,84 & 31,16 & - \\
\hline
\end{tabular}


Tabela 8.122: Constantes de acoplamento B98 e constantes empíricas no nível BHandH $\left(50 \% E_{X}^{\mathrm{HF}}\right)$ e base aug-pcJ-2.

\begin{tabular}{|c|c|c|c|c|c|c|c|c|c|c|c|c|c|}
\hline & $\% E_{X}^{\mathrm{HF}}$ & $0 \%$ & $10 \%$ & $20 \%$ & $30 \%$ & $40 \%$ & $50 \%$ & $60 \%$ & $70 \%$ & $80 \%$ & $90 \%$ & $100 \%$ & Emp. \\
\hline $\mathrm{HF}$ & ${ }^{1} J_{\mathrm{HF}}$ & 411,6 & 428,1 & 445,8 & 464,6 & 484,6 & 505,9 & 528,5 & 552,5 & 577,9 & 604,8 & 633,1 & 532,8 \\
\hline $\mathrm{CO}$ & ${ }^{1} J_{\mathrm{CO}}$ & 16,6 & 15,5 & 14,2 & 12,8 & 11,2 & 9,5 & 7,7 & 5,6 & 3,4 & 1,0 & $-1,4$ & 15,7 \\
\hline $\mathrm{H}_{2} \mathrm{O}$ & ${ }^{1} J_{\mathrm{OH}}$ & $-66,0$ & $-68,2$ & $-70,5$ & $-73,0$ & $-75,6$ & $-78,4$ & $-81,4$ & $-84,6$ & $-88,1$ & $-91,7$ & $-95,6$ & $-81,7$ \\
\hline $\mathrm{H}_{2} \mathrm{O}$ & ${ }^{2} J_{\mathrm{HH}}$ & $-0,7$ & $-1,7$ & $-2,7$ & $-3,9$ & $-5,1$ & $-6,4$ & $-7,9$ & $-9,4$ & $-11,0$ & $-12,7$ & $-14,6$ & $-8,8$ \\
\hline $\mathrm{NH}_{3}$ & ${ }^{1} J_{\mathrm{NH}}$ & 37,0 & 38,1 & 39,2 & 40,4 & 41,7 & 43,1 & 44,6 & 46,1 & 47,8 & 49,6 & 51,5 & 43,0 \\
\hline $\mathrm{NH}_{3}$ & ${ }^{2} J_{\mathrm{HH}}$ & $-3,5$ & $-4,4$ & $-5,4$ & $-6,4$ & $-7,6$ & $-8,8$ & $-10,2$ & $-11,6$ & $-13,2$ & $-14,9$ & $-16,8$ & $-10,5$ \\
\hline $\mathrm{PH}_{3}$ & ${ }^{1} J_{\mathrm{PH}}$ & 165,9 & 172,2 & 179,0 & 186,1 & 193,7 & 201,7 & 210,1 & 218,9 & 228,1 & 237,8 & 247,9 & 195,0 \\
\hline $\mathrm{PF}_{3}$ & ${ }^{1} J_{\mathrm{PF}}$ & $-1622,6$ & $-1617,6$ & $-1607,1$ & $-1591,6$ & $-1572,1$ & $-1549,1$ & $-1523,4$ & $-1495,6$ & $-1466,2$ & $-1435,7$ & $-1404,5$ & $-1441,7$ \\
\hline $\mathrm{BHF}_{2}$ & ${ }^{1} J_{\mathrm{BF}}$ & $-150,1$ & $-135,5$ & $-120,6$ & $-105,2$ & $-89,6$ & $-73,8$ & $-57,8$ & $-41,8$ & $-25,7$ & $-9,6$ & 6,2 & $-79,7$ \\
\hline $\mathrm{BF}_{3}$ & ${ }^{1} J_{\mathrm{BF}}$ & $-61,5$ & $-44,7$ & $-27,7$ & $-10,4$ & 7,0 & 24,5 & 42,2 & 60,0 & 77,9 & 95,8 & 113,8 & 17,1 \\
\hline $\mathrm{F}_{2} \mathrm{O}$ & ${ }^{1} J_{\mathrm{OF}}$ & $-196,5$ & $-228,9$ & $-262,8$ & $-298,9$ & $-338,2$ & $-383,0$ & $-437,3$ & $-509,0$ & $-617,4$ & $-823,5$ & $-1507,1$ & $-285,7$ \\
\hline $\mathrm{CH}_{4}$ & ${ }^{1} J_{\mathrm{CH}}$ & 101,1 & 104,7 & 108,5 & 112,6 & 116,9 & 121,5 & 126,5 & 131,7 & 137,3 & 143,2 & 149,5 & 122,8 \\
\hline $\mathrm{CH}_{4}$ & ${ }^{2} J_{\mathrm{HH}}$ & $-5,9$ & $-6,8$ & $-7,7$ & $-8,7$ & $-9,8$ & $-11,0$ & $-12,2$ & $-13,5$ & $-15,0$ & $-16,5$ & $-18,1$ & $-12,5$ \\
\hline $\mathrm{C}_{2} \mathrm{H}_{2}$ & ${ }^{1} J_{\mathrm{CC}}$ & 184,5 & 188,8 & 193,5 & 198,9 & 205,0 & 212,2 & 220,6 & 230,9 & 243,6 & 260,0 & 282,1 & 174,1 \\
\hline $\mathrm{C}_{2} \mathrm{H}_{2}$ & ${ }^{1} J_{\mathrm{CH}}$ & 198,0 & 205,3 & 212,9 & 221,1 & 229,7 & 239,0 & 249,0 & 260,0 & 272,3 & 286,5 & 303,3 & 244,3 \\
\hline $\mathrm{C}_{2} \mathrm{H}_{2}$ & ${ }^{2} J_{\mathrm{CH}}$ & 50,6 & 51,5 & 52,3 & 52,9 & 53,2 & 53,2 & 52,6 & 51,4 & 49,2 & 45,4 & 39,3 & 49,8 \\
\hline $\mathrm{C}_{2} \mathrm{H}_{2}$ & ${ }^{3} J_{\mathrm{HH}}$ & 6,1 & 6,5 & 7,0 & 7,6 & 8,4 & 9,4 & 10,6 & 12,3 & 14,5 & 17,5 & 21,7 & 9,0 \\
\hline $\mathrm{C}_{2} \mathrm{H}_{4}$ & ${ }^{1} J_{\mathrm{CC}}$ & 62,2 & 65,2 & 68,5 & 72,2 & 76,4 & 81,3 & 87,2 & 94,5 & 104,0 & 117,4 & 138,3 & 66,9 \\
\hline $\mathrm{C}_{2} \mathrm{H}_{4}$ & ${ }^{1} J_{\mathrm{CH}}$ & 124,4 & 129,2 & 134,3 & 139,8 & 145,7 & 152,0 & 158,9 & 166,6 & 175,4 & 185,9 & 199,6 & 154,4 \\
\hline $\mathrm{C}_{2} \mathrm{H}_{4}$ & ${ }^{2} J_{\mathrm{CH}}$ & 2,5 & 1,8 & 1,0 & 0,1 & $-0,8$ & $-2,1$ & $-3,8$ & $-6,0$ & $-9,0$ & $-13,5$ & $-20,9$ & $-2,0$ \\
\hline $\mathrm{C}_{2} \mathrm{H}_{4}$ & ${ }^{2} J_{\mathrm{HH}}$ & 5,7 & 5,4 & 5,0 & 4,5 & 3,9 & 3,2 & 2,3 & 1,2 & $-0,3$ & $-2,5$ & $-6,2$ & 2,1 \\
\hline $\mathrm{C}_{2} \mathrm{H}_{4}$ & ${ }^{3} J_{\mathrm{HH}_{\mathrm{c}}}$ & 9,3 & 9,5 & 9,8 & 10,2 & 10,6 & 11,1 & 11,8 & 12,7 & 13,9 & 15,9 & 19,2 & 11,4 \\
\hline $\mathrm{C}_{2} \mathrm{H}_{4}$ & ${ }^{3} J_{\mathrm{HH}_{\mathrm{t}}}$ & 13,1 & 13,6 & 14,2 & 14,9 & 15,6 & 16,5 & 17,6 & 18,9 & 20,8 & 23,3 & 27,5 & 18,4 \\
\hline $\mathrm{C}_{2} \mathrm{H}_{6}$ & ${ }^{1} J_{\mathrm{CC}}$ & 24,5 & 26,9 & 29,5 & 32,2 & 35,1 & 38,2 & 41,5 & 45,0 & 48,8 & 52,8 & 57,1 & 33,6 \\
\hline $\mathrm{C}_{2} \mathrm{H}_{6}$ & ${ }^{1} J_{\mathrm{CH}}$ & 99,8 & 103,7 & 107,8 & 112,1 & 116,8 & 121,7 & 127,0 & 132,5 & 138,4 & 144,7 & 151,4 & 123,3 \\
\hline $\mathrm{C}_{2} \mathrm{H}_{6}$ & ${ }^{2} J_{\mathrm{CH}}$ & $-0,7$ & $-1,2$ & $-1,7$ & $-2,3$ & $-2,9$ & $-3,6$ & $-4,3$ & $-5,1$ & $-5,9$ & $-6,9$ & $-7,9$ & $-4,5$ \\
\hline \multirow[t]{3}{*}{ Total } & $\mathrm{DM}$ & $-18,51$ & $-16,52$ & $-14,24$ & $-11,69$ & $-8,95$ & $-6,11$ & $-3,32$ & $-0,86$ & 0,57 & $-1,25$ & $-20,70$ & - \\
\hline & DMA & 30,09 & 25,45 & 20,57 & 16,42 & 13,98 & 13,18 & 15,78 & 22,09 & 30,86 & 44,73 & 80,16 & - \\
\hline & PDMA & 59,88 & 49,87 & 39,84 & 29,53 & 19,77 & 14,03 & 20,72 & 36,30 & 58,35 & 87,77 & 134,55 & - \\
\hline \multirow[t]{3}{*}{ CPI } & DM & $-33,21$ & $-31,15$ & $-28,55$ & $-25,55$ & $-22,32$ & $-19,12$ & $-16,40$ & $-14,95$ & $-16,55$ & $-26,78$ & $-80,27$ & - \\
\hline & DMA & 55,19 & 46,33 & 36,79 & 28,76 & 24,63 & 24,12 & 28,25 & 38,13 & 52,51 & 77,00 & 149,64 & - \\
\hline & PDMA & 75,19 & 60,26 & 46,12 & 32,28 & 19,77 & 17,08 & 28,15 & 44,42 & 64,96 & 89,07 & 129,18 & - \\
\hline \multirow[t]{3}{*}{ SPI } & $\mathrm{DM}$ & $-7,73$ & $-5,80$ & $-3,75$ & $-1,53$ & 0,85 & 3,43 & 6,28 & 9,47 & 13,13 & 17,47 & 22,99 & - \\
\hline & DMA & 11,69 & 10,13 & 8,68 & 7,36 & 6,17 & 5,15 & 6,63 & 10,33 & 14,98 & 21,06 & 29,21 & - \\
\hline & PDMA & 48,66 & 42,26 & 35,24 & 27,51 & 19,78 & 11,79 & 15,27 & 30,34 & 53,49 & 86,83 & 138,49 & - \\
\hline \multirow[t]{3}{*}{$\Delta \mathrm{CS}$} & DM & $-25,48$ & $-25,35$ & $-24,81$ & $-24,01$ & $-23,16$ & $-22,55$ & $-22,68$ & $-24,41$ & $-29,67$ & $-44,26$ & $-103,26$ & - \\
\hline & DMA & 43,50 & 36,19 & 28,11 & 21,40 & 18,46 & 18,96 & 21,63 & 27,79 & 37,53 & 55,94 & 120,42 & - \\
\hline & PDMA & 26,52 & 18,00 & 10,88 & 4,78 & $-0,01$ & 5,30 & 12,88 & 14,09 & 11,47 & 2,24 & $-9,31$ & - \\
\hline
\end{tabular}


Tabela 8.123: Constantes de acoplamento BHandH e constantes empíricas no nível BHandH $\left(50 \% E_{X}^{\mathrm{HF}}\right)$ e base aug-pcJ-2.

\begin{tabular}{|c|c|c|c|c|c|c|c|c|c|c|c|c|c|}
\hline & $\% E_{X}^{\mathrm{HF}}$ & $0 \%$ & $10 \%$ & $20 \%$ & $30 \%$ & $40 \%$ & $50 \%$ & $60 \%$ & $70 \%$ & $80 \%$ & $90 \%$ & $100 \%$ & Emp. \\
\hline $\mathrm{HF}$ & ${ }^{1} J_{\mathrm{HF}}$ & 420,6 & 441,1 & 462,4 & 484,4 & 507,2 & 530,8 & 555,3 & 580,6 & 606,9 & 634,2 & 662,5 & 532,8 \\
\hline $\mathrm{CO}$ & ${ }^{1} J_{\mathrm{CO}}$ & 24,8 & 22,9 & 20,9 & 18,7 & 16,3 & 13,7 & 11,0 & 8,0 & 4,9 & 1,6 & $-1,9$ & 15,7 \\
\hline $\mathrm{H}_{2} \mathrm{O}$ & ${ }^{1} J_{\mathrm{OH}}$ & $-69,9$ & $-72,4$ & $-75,1$ & $-77,8$ & $-80,7$ & $-83,7$ & $-86,9$ & $-90,2$ & $-93,7$ & $-97,3$ & $-101,1$ & $-81,7$ \\
\hline $\mathrm{H}_{2} \mathrm{O}$ & ${ }^{2} J_{\mathrm{HH}}$ & $-3,3$ & $-4,4$ & $-5,5$ & $-6,8$ & $-8,0$ & $-9,4$ & $-10,8$ & $-12,3$ & $-13,9$ & $-15,6$ & $-17,3$ & $-8,8$ \\
\hline $\mathrm{NH}_{3}$ & ${ }^{1} J_{\mathrm{NH}}$ & 39,4 & 40,5 & 41,7 & 42,9 & 44,2 & 45,5 & 47,0 & 48,5 & 50,0 & 51,7 & 53,4 & 43,0 \\
\hline $\mathrm{NH}_{3}$ & ${ }^{2} J_{\mathrm{HH}}$ & $-5,4$ & $-6,5$ & $-7,5$ & $-8,7$ & $-9,9$ & $-11,1$ & $-12,5$ & $-13,9$ & $-15,4$ & $-17,0$ & $-18,7$ & $-10,5$ \\
\hline $\mathrm{PH}_{3}$ & ${ }^{1} J_{\mathrm{PH}}$ & 135,5 & 144,3 & 153,5 & 163,0 & 172,9 & 183,1 & 193,7 & 204,6 & 215,9 & 227,4 & 239,2 & 195,0 \\
\hline $\mathrm{PF}_{3}$ & ${ }^{1} J_{\mathrm{PF}}$ & $-1814,4$ & $-1797,1$ & $-1773,1$ & $-1743,5$ & $-1709,0$ & $-1670,4$ & $-1628,3$ & $-1583,4$ & $-1536,2$ & $-1487,3$ & $-1437,0$ & $-1441,7$ \\
\hline $\mathrm{BHF}_{2}$ & ${ }^{1} J_{\mathrm{BF}}$ & $-187,4$ & $-169,5$ & $-151,2$ & $-132,8$ & $-114,0$ & $-95,2$ & $-76,1$ & $-57,0$ & $-37,8$ & $-18,6$ & 0,6 & $-79,7$ \\
\hline $\mathrm{BF}_{3}$ & ${ }^{1} J_{\mathrm{BF}}$ & $-79,8$ & $-61,1$ & $-42,3$ & $-23,3$ & $-4,1$ & 15,1 & 34,6 & 54,2 & 73,9 & 93,8 & 113,8 & 17,1 \\
\hline $\mathrm{F}_{2} \mathrm{O}$ & ${ }^{1} J_{\mathrm{OF}}$ & $-272,1$ & $-308,2$ & $-344,0$ & $-380,5$ & $-419,8$ & $-465,0$ & $-521,4$ & $-600,0$ & $-727,9$ & $-1000,8$ & $-2253,8$ & $-285,7$ \\
\hline $\mathrm{CH}_{4}$ & ${ }^{1} J_{\mathrm{CH}}$ & 106,0 & 109,4 & 113,0 & 116,8 & 120,7 & 124,9 & 129,4 & 134,0 & 138,9 & 144,0 & 149,4 & 122,8 \\
\hline $\mathrm{CH}_{4}$ & ${ }^{2} J_{\mathrm{HH}}$ & $-7,9$ & $-8,9$ & $-9,9$ & $-11,0$ & $-12,1$ & $-13,3$ & $-14,5$ & $-15,7$ & $-17,0$ & $-18,4$ & $-19,7$ & $-12,5$ \\
\hline $\mathrm{C}_{2} \mathrm{H}_{2}$ & ${ }^{1} J_{\mathrm{CC}}$ & 175,5 & 179,6 & 184,2 & 189,4 & 195,4 & 202,4 & 210,6 & 220,6 & 232,8 & 248,3 & 268,4 & 174,1 \\
\hline $\mathrm{C}_{2} \mathrm{H}_{2}$ & ${ }^{1} J_{\mathrm{CH}}$ & 226,4 & 232,3 & 238,4 & 245,0 & 252,0 & 259,5 & 267,8 & 276,9 & 287,3 & 299,2 & 313,5 & 244,3 \\
\hline $\mathrm{C}_{2} \mathrm{H}_{2}$ & ${ }^{2} J_{\mathrm{CH}}$ & 51,2 & 52,1 & 52,7 & 53,2 & 53,3 & 53,0 & 52,2 & 50,7 & 48,2 & 44,2 & 38,1 & 49,8 \\
\hline $\mathrm{C}_{2} \mathrm{H}_{2}$ & ${ }^{3} J_{\mathrm{HH}}$ & 7,2 & 7,8 & 8,5 & 9,4 & 10,5 & 11,8 & 13,4 & 15,5 & 18,1 & 21,5 & 26,0 & 9,0 \\
\hline $\mathrm{C}_{2} \mathrm{H}_{4}$ & ${ }^{1} J_{\mathrm{CC}}$ & 50,4 & 53,8 & 57,6 & 61,8 & 66,7 & 72,3 & 78,9 & 87,3 & 98,2 & 113,8 & 139,0 & 66,9 \\
\hline $\mathrm{C}_{2} \mathrm{H}_{4}$ & ${ }^{1} J_{\mathrm{CH}}$ & 136,2 & 140,5 & 145,0 & 149,9 & 155,0 & 160,6 & 166,8 & 173,7 & 181,8 & 191,8 & 205,7 & 154,4 \\
\hline $\mathrm{C}_{2} \mathrm{H}_{4}$ & ${ }^{2} J_{\mathrm{CH}}$ & 0,9 & 0,2 & $-0,4$ & $-1,3$ & $-2,4$ & $-3,8$ & $-5,6$ & $-8,0$ & $-11,4$ & $-16,5$ & $-25,4$ & $-2,0$ \\
\hline $\mathrm{C}_{2} \mathrm{H}_{4}$ & ${ }^{2} J_{\mathrm{HH}}$ & 5,5 & 5,0 & 4,4 & 3,8 & 3,1 & 2,2 & 1,1 & $-0,1$ & $-2,0$ & $-4,7$ & $-9,3$ & 2,1 \\
\hline $\mathrm{C}_{2} \mathrm{H}_{4}$ & ${ }^{3} J_{\mathrm{HH}_{\mathrm{c}}}$ & 11,2 & 11,5 & 11,8 & 12,2 & 12,7 & 13,3 & 14,1 & 15,2 & 16,8 & 19,3 & 23,7 & 11,4 \\
\hline $\mathrm{C}_{2} \mathrm{H}_{4}$ & ${ }^{3} J_{\mathrm{HH}_{\mathrm{t}}}$ & 16,3 & 16,7 & 17,3 & 17,9 & 18,7 & 19,6 & 20,8 & 22,4 & 24,5 & 27,6 & 32,9 & 18,4 \\
\hline $\mathrm{C}_{2} \mathrm{H}_{6}$ & ${ }^{1} J_{\mathrm{CC}}$ & 18,7 & 21,3 & 24,0 & 26,9 & 30,0 & 33,3 & 36,7 & 40,4 & 44,3 & 48,4 & 52,7 & 33,6 \\
\hline $\mathrm{C}_{2} \mathrm{H}_{6}$ & ${ }^{1} J_{\mathrm{CH}}$ & 106,1 & 109,7 & 113,4 & 117,3 & 121,5 & 125,8 & 130,4 & 135,2 & 140,2 & 145,4 & 150,9 & 123,3 \\
\hline $\mathrm{C}_{2} \mathrm{H}_{6}$ & ${ }^{2} J_{\mathrm{CH}}$ & $-1,7$ & $-2,1$ & $-2,6$ & $-3,1$ & $-3,7$ & $-4,3$ & $-4,9$ & $-5,6$ & $-6,3$ & $-7,0$ & $-7,8$ & $-4,5$ \\
\hline \multirow[t]{3}{*}{ Total } & $\mathrm{DM}$ & $-30,64$ & $-28,00$ & $-24,98$ & $-21,65$ & $-18,08$ & $-14,46$ & $-10,92$ & $-7,88$ & $-6,37$ & $-9,91$ & $-50,34$ & - \\
\hline & DMA & 35,38 & 31,38 & 28,05 & 24,46 & 21,36 & 19,97 & 23,28 & 29,93 & 39,09 & 54,63 & 109,57 & - \\
\hline & PDMA & 59,01 & 48,09 & 37,36 & 25,99 & 16,41 & 13,67 & 27,48 & 47,29 & 72,14 & 105,47 & 165,55 & - \\
\hline \multirow[t]{3}{*}{ CPI } & DM & $-64,32$ & $-60,54$ & $-55,97$ & $-50,90$ & $-45,49$ & $-40,19$ & $-35,45$ & $-32,40$ & $-33,53$ & $-47,58$ & $-150,53$ & - \\
\hline & DMA & 72,52 & 65,06 & 59,26 & 52,85 & 46,25 & 40,65 & 44,10 & 54,71 & 70,02 & 98,55 & 217,07 & - \\
\hline & PDMA & 88,71 & 72,44 & 56,84 & 40,59 & 24,66 & 13,62 & 26,78 & 47,60 & 70,46 & 98,42 & 157,92 & - \\
\hline \multirow[t]{3}{*}{ SPI } & $\mathrm{DM}$ & $-5,94$ & $-4,15$ & $-2,25$ & $-0,19$ & 2,02 & 4,41 & 7,07 & 10,09 & 13,55 & 17,72 & 23,13 & - \\
\hline & DMA & 8,14 & 6,68 & 5,15 & 3,65 & 3,10 & 4,80 & 8,01 & 11,76 & 16,41 & 22,43 & 30,73 & - \\
\hline & PDMA & 37,23 & 30,23 & 23,08 & 15,29 & 10,35 & 13,70 & 27,99 & 47,06 & 73,37 & 110,64 & 171,15 & - \\
\hline \multirow[t]{3}{*}{$\Delta \mathrm{CS}$} & DM & $-58,38$ & $-56,39$ & $-53,73$ & $-50,71$ & $-47,51$ & $-44,60$ & $-42,52$ & $-42,49$ & $-47,08$ & $-65,30$ & $-173,66$ & - \\
\hline & DMA & 64,38 & 58,38 & 54,11 & 49,20 & 43,15 & 35,85 & 36,09 & 42,95 & 53,61 & 76,12 & 186,34 & - \\
\hline & PDMA & 51,48 & 42,21 & 33,76 & 25,30 & 14,31 & $-0,09$ & $-1,21$ & 0,53 & $-2,91$ & $-12,22$ & $-13,23$ & - \\
\hline
\end{tabular}


Tabela 8.124: Constantes de acoplamento BMK e constantes empíricas no nível BHandH $\left(50 \% E_{X}^{\mathrm{HF}}\right)$ e base aug-pcJ-2.

\begin{tabular}{|c|c|c|c|c|c|c|c|c|c|c|c|c|c|}
\hline & $\% E_{X}^{\mathrm{HF}}$ & $0 \%$ & $10 \%$ & $20 \%$ & $30 \%$ & $40 \%$ & $50 \%$ & $60 \%$ & $70 \%$ & $80 \%$ & $90 \%$ & $100 \%$ & Emp. \\
\hline $\mathrm{HF}$ & ${ }^{1} J_{\mathrm{HF}}$ & 491,4 & 502,8 & 515,2 & 528,7 & 543,5 & 559,7 & 577,4 & 597,0 & 618,7 & 642,5 & 669,0 & 532,8 \\
\hline $\mathrm{CO}$ & ${ }^{1} J_{\mathrm{CO}}$ & 13,8 & 14,3 & 14,6 & 14,8 & 14,8 & 14,6 & 14,1 & 13,3 & 12,0 & 10,2 & 7,7 & 15,7 \\
\hline $\mathrm{H}_{2} \mathrm{O}$ & ${ }^{1} J_{\mathrm{OH}}$ & $-72,3$ & $-72,8$ & $-73,4$ & $-74,1$ & $-74,9$ & $-75,9$ & $-77,0$ & $-78,3$ & $-79,8$ & $-81,4$ & $-83,3$ & $-81,7$ \\
\hline $\mathrm{H}_{2} \mathrm{O}$ & ${ }^{2} J_{\mathrm{HH}}$ & 2,8 & 1,8 & 0,6 & $-0,5$ & $-1,8$ & $-3,2$ & $-4,7$ & $-6,4$ & $-8,1$ & $-10,0$ & $-12,0$ & $-8,8$ \\
\hline $\mathrm{NH}_{3}$ & ${ }^{1} J_{\mathrm{NH}}$ & 36,5 & 36,6 & 36,7 & 36,8 & 37,1 & 37,4 & 37,7 & 38,2 & 38,7 & 39,3 & 40,0 & 43,0 \\
\hline $\mathrm{NH}_{3}$ & ${ }^{2} J_{\mathrm{HH}}$ & $-0,7$ & $-1,6$ & $-2,5$ & $-3,5$ & $-4,7$ & $-5,9$ & $-7,2$ & $-8,7$ & $-10,3$ & $-12,0$ & $-13,9$ & $-10,5$ \\
\hline $\mathrm{PH}_{3}$ & ${ }^{1} J_{\mathrm{PH}}$ & 125,8 & 125,4 & 125,4 & 126,0 & 127,0 & 128,5 & 130,5 & 133,0 & 136,1 & 139,7 & 144,0 & 195,0 \\
\hline $\mathrm{PF}_{3}$ & ${ }^{1} J_{\mathrm{PF}}$ & $-1529,4$ & $-1527,6$ & $-1517,9$ & $-1500,7$ & $-1476,3$ & $-1445,2$ & $-1408,2$ & $-1365,9$ & $-1319,0$ & $-1268,4$ & $-1214,4$ & $-1441,7$ \\
\hline $\mathrm{BHF}_{2}$ & ${ }^{1} J_{\mathrm{BF}}$ & $-143,1$ & $-131,7$ & $-118,2$ & $-102,8$ & $-85,4$ & $-66,1$ & $-44,9$ & $-21,9$ & 2,7 & 29,1 & 56,9 & $-79,7$ \\
\hline $\mathrm{BF}_{3}$ & ${ }^{1} J_{\mathrm{BF}}$ & $-51,1$ & $-37,2$ & $-21,4$ & $-3,8$ & 15,4 & 36,6 & 59,4 & 84,1 & 110,4 & 138,4 & 167,9 & 17,1 \\
\hline $\mathrm{F}_{2} \mathrm{O}$ & ${ }^{1} J_{\mathrm{OF}}$ & $-147,5$ & $-173,9$ & $-201,0$ & $-228,4$ & $-256,0$ & $-284,4$ & $-314,8$ & $-349,2$ & $-392,3$ & $-454,2$ & $-567,5$ & $-285,7$ \\
\hline $\mathrm{CH}_{4}$ & ${ }^{1} J_{\mathrm{CH}}$ & 103,1 & 104,7 & 106,5 & 108,7 & 111,2 & 114,2 & 117,5 & 121,3 & 125,7 & 130,7 & 136,4 & 122,8 \\
\hline $\mathrm{CH}_{4}$ & ${ }^{2} J_{\mathrm{HH}}$ & $-3,0$ & $-4,0$ & $-5,1$ & $-6,4$ & $-7,7$ & $-9,2$ & $-10,9$ & $-12,8$ & $-14,9$ & $-17,3$ & $-20,0$ & $-12,5$ \\
\hline $\mathrm{C}_{2} \mathrm{H}_{2}$ & ${ }^{1} J_{\mathrm{CC}}$ & 244,5 & 249,2 & 254,4 & 260,5 & 267,6 & 276,3 & 287,2 & 301,5 & 321,1 & 349,5 & 394,6 & 174,1 \\
\hline $\mathrm{C}_{2} \mathrm{H}_{2}$ & ${ }^{1} J_{\mathrm{CH}}$ & 177,9 & 184,0 & 190,5 & 197,6 & 205,4 & 214,0 & 223,8 & 235,3 & 249,0 & 266,5 & 290,8 & 244,3 \\
\hline $\mathrm{C}_{2} \mathrm{H}_{2}$ & ${ }^{2} J_{\mathrm{CH}}$ & 54,4 & 55,3 & 56,0 & 56,5 & 56,6 & 56,3 & 55,2 & 53,0 & 49,0 & 41,7 & 28,3 & 49,8 \\
\hline $\mathrm{C}_{2} \mathrm{H}_{2}$ & ${ }^{3} J_{\mathrm{HH}}$ & 5,3 & 5,6 & 6,0 & 6,5 & 7,2 & 8,2 & 9,5 & 11,3 & 13,9 & 17,8 & 24,2 & 9,0 \\
\hline $\mathrm{C}_{2} \mathrm{H}_{4}$ & ${ }^{1} J_{\mathrm{CC}}$ & 89,5 & 91,0 & 92,9 & 95,3 & 98,2 & 101,8 & 106,6 & 112,8 & 121,5 & 134,4 & 155,3 & 66,9 \\
\hline $\mathrm{C}_{2} \mathrm{H}_{4}$ & ${ }^{1} J_{\mathrm{CH}}$ & 120,5 & 123,6 & 127,2 & 131,1 & 135,5 & 140,5 & 146,3 & 153,0 & 161,2 & 171,5 & 185,9 & 154,4 \\
\hline $\mathrm{C}_{2} \mathrm{H}_{4}$ & ${ }^{2} J_{\mathrm{CH}}$ & 4,5 & 3,6 & 2,6 & 1,5 & 0,1 & $-1,4$ & $-3,4$ & $-6,0$ & $-9,7$ & $-15,1$ & $-24,0$ & $-2,0$ \\
\hline $\mathrm{C}_{2} \mathrm{H}_{4}$ & ${ }^{2} J_{\mathrm{HH}}$ & 7,7 & 7,2 & 6,6 & 5,8 & 4,9 & 3,8 & 2,5 & 0,7 & $-1,4$ & $-4,6$ & $-9,6$ & 2,1 \\
\hline $\mathrm{C}_{2} \mathrm{H}_{4}$ & ${ }^{3} J_{\mathrm{HH}_{\mathrm{c}}}$ & 9,2 & 9,3 & 9,4 & 9,6 & 9,8 & 10,2 & 10,7 & 11,5 & 12,8 & 14,9 & 18,6 & 11,4 \\
\hline $\mathrm{C}_{2} \mathrm{H}_{4}$ & ${ }^{3} J_{\mathrm{HH}_{\mathrm{t}}}$ & 11,3 & 11,8 & 12,3 & 12,9 & 13,5 & 14,3 & 15,3 & 16,6 & 18,4 & 21,1 & 25,6 & 18,4 \\
\hline $\mathrm{C}_{2} \mathrm{H}_{6}$ & ${ }^{1} J_{\mathrm{CC}}$ & 30,1 & 31,0 & 32,1 & 33,3 & 34,8 & 36,5 & 38,5 & 40,7 & 43,3 & 46,4 & 49,9 & 33,6 \\
\hline $\mathrm{C}_{2} \mathrm{H}_{6}$ & ${ }^{1} J_{\mathrm{CH}}$ & 101,4 & 103,3 & 105,6 & 108,2 & 111,1 & 114,4 & 118,2 & 122,5 & 127,3 & 132,8 & 139,1 & 123,3 \\
\hline $\mathrm{C}_{2} \mathrm{H}_{6}$ & ${ }^{2} J_{\mathrm{CH}}$ & 0,6 & 0,0 & $-0,8$ & $-1,5$ & $-2,4$ & $-3,3$ & $-4,3$ & $-5,4$ & $-6,7$ & $-8,1$ & $-9,7$ & $-4,5$ \\
\hline \multirow[t]{3}{*}{ Total } & DM & $-7,82$ & $-6,73$ & $-5,09$ & $-2,87$ & $-0,08$ & 3,31 & 7,25 & 11,72 & 16,65 & 21,88 & 26,66 & - \\
\hline & DMA & 30,38 & 27,39 & 23,79 & 19,63 & 15,82 & 14,43 & 18,38 & 23,55 & 31,28 & 42,80 & 58,96 & - \\
\hline & PDMA & 72,95 & 64,06 & 53,89 & 42,55 & 29,95 & 26,13 & 29,15 & 42,76 & 64,69 & 98,60 & 148,68 & - \\
\hline \multirow[t]{3}{*}{ CPI } & $\mathrm{DM}$ & $-15,39$ & $-14,49$ & $-12,49$ & $-9,36$ & $-5,16$ & 0,05 & 6,07 & 12,70 & 19,42 & 25,25 & 27,17 & - \\
\hline & DMA & 46,12 & 39,98 & 32,56 & 23,95 & 16,07 & 14,00 & 24,35 & 36,83 & 50,96 & 68,10 & 91,17 & - \\
\hline & PDMA & 76,36 & 64,46 & 51,11 & 36,54 & 20,85 & 27,77 & 41,03 & 55,52 & 71,54 & 94,34 & 122,55 & - \\
\hline \multirow[t]{3}{*}{ SPI } & DM & $-2,27$ & $-1,03$ & 0,34 & 1,90 & 3,65 & 5,70 & 8,11 & 10,99 & 14,63 & 19,41 & 26,29 & - \\
\hline & DMA & 18,85 & 18,15 & 17,35 & 16,47 & 15,63 & 14,74 & 14,00 & 13,81 & 16,84 & 24,25 & 35,34 & - \\
\hline & PDMA & 70,45 & 63,76 & 55,93 & 46,97 & 36,62 & 24,93 & 20,44 & 33,41 & 59,66 & 101,73 & 167,84 & - \\
\hline \multirow[t]{3}{*}{$\Delta \mathrm{CS}$} & DM & $-13,12$ & $-13,46$ & $-12,83$ & $-11,26$ & $-8,81$ & $-5,65$ & $-2,03$ & 1,71 & 4,79 & 5,84 & 0,89 & - \\
\hline & DMA & 27,27 & 21,83 & 15,21 & 7,47 & 0,44 & $-0,74$ & 10,35 & 23,02 & 34,12 & 43,85 & 55,83 & - \\
\hline & PDMA & 5,91 & 0,70 & $-4,82$ & $-10,42$ & $-15,77$ & 2,85 & 20,58 & 22,11 & 11,87 & $-7,39$ & $-45,30$ & - \\
\hline
\end{tabular}


Tabela 8.125: Constantes de acoplamento BP86 e constantes empíricas no nível BHandH $\left(50 \% E_{X}^{\mathrm{HF}}\right)$ e base aug-pcJ-2.

\begin{tabular}{|c|c|c|c|c|c|c|c|c|c|c|c|c|c|}
\hline & $\% E_{X}^{\mathrm{HF}}$ & $0 \%$ & $10 \%$ & $20 \%$ & $30 \%$ & $40 \%$ & $50 \%$ & $60 \%$ & $70 \%$ & $80 \%$ & $90 \%$ & $100 \%$ & Emp. \\
\hline $\mathrm{HF}$ & ${ }^{1} J_{\mathrm{HF}}$ & 355,3 & 378,9 & 402,8 & 426,9 & 451,3 & 475,8 & 500,7 & 525,7 & 551,0 & 576,5 & 602,2 & 532,8 \\
\hline $\mathrm{CO}$ & ${ }^{1} J_{\mathrm{CO}}$ & 24,9 & 23,2 & 21,5 & 19,7 & 17,7 & 15,8 & 13,7 & 11,6 & 9,4 & 7,1 & 4,8 & 15,7 \\
\hline $\mathrm{H}_{2} \mathrm{O}$ & ${ }^{1} J_{\mathrm{OH}}$ & $-64,8$ & $-67,3$ & $-69,8$ & $-72,4$ & $-75,0$ & $-77,6$ & $-80,2$ & $-82,9$ & $-85,5$ & $-88,3$ & $-91,0$ & $-81,7$ \\
\hline $\mathrm{H}_{2} \mathrm{O}$ & ${ }^{2} J_{\mathrm{HH}}$ & $-4,6$ & $-5,5$ & $-6,5$ & $-7,5$ & $-8,5$ & $-9,6$ & $-10,6$ & $-11,7$ & $-12,8$ & $-13,9$ & $-15,1$ & $-8,8$ \\
\hline $\mathrm{NH}_{3}$ & ${ }^{1} J_{\mathrm{NH}}$ & 40,0 & 40,7 & 41,5 & 42,2 & 43,0 & 43,8 & 44,6 & 45,4 & 46,2 & 47,0 & 47,8 & 43,0 \\
\hline $\mathrm{NH}_{3}$ & ${ }^{2} J_{\mathrm{HH}}$ & $-7,8$ & $-8,6$ & $-9,5$ & $-10,4$ & $-11,2$ & $-12,1$ & $-13,0$ & $-13,9$ & $-14,9$ & $-15,8$ & $-16,8$ & $-10,5$ \\
\hline $\mathrm{PH}_{3}$ & ${ }^{1} J_{\mathrm{PH}}$ & 136,9 & 144,9 & 152,8 & 160,7 & 168,4 & 176,0 & 183,5 & 190,8 & 198,1 & 205,1 & 212,1 & 195,0 \\
\hline $\mathrm{PF}_{3}$ & ${ }^{1} J_{\mathrm{PF}}$ & $-1802,5$ & $-1777,4$ & $-1747,9$ & $-1714,7$ & $-1678,5$ & $-1639,9$ & $-1599,5$ & $-1557,7$ & $-1514,9$ & $-1471,4$ & $-1427,5$ & $-1441,7$ \\
\hline $\mathrm{BHF}_{2}$ & ${ }^{1} J_{\mathrm{BF}}$ & $-177,9$ & $-160,9$ & $-144,0$ & $-127,2$ & $-110,6$ & $-94,0$ & $-77,7$ & $-61,5$ & $-45,5$ & $-29,7$ & $-14,1$ & $-79,7$ \\
\hline $\mathrm{BF}_{3}$ & ${ }^{1} J_{\mathrm{BF}}$ & $-83,3$ & $-64,6$ & $-46,2$ & $-27,9$ & $-9,8$ & 8,0 & 25,7 & 43,3 & 60,6 & 77,8 & 94,8 & 17,1 \\
\hline $\mathrm{F}_{2} \mathrm{O}$ & ${ }^{1} J_{\mathrm{OF}}$ & $-290,1$ & $-327,4$ & $-365,0$ & $-404,4$ & $-447,8$ & $-498,7$ & $-562,6$ & $-651,0$ & $-790,4$ & $-1064,3$ & $-1973,1$ & $-285,7$ \\
\hline $\mathrm{CH}_{4}$ & ${ }^{1} J_{\mathrm{CH}}$ & 117,5 & 118,9 & 120,4 & 121,9 & 123,4 & 124,9 & 126,5 & 128,1 & 129,7 & 131,4 & 133,0 & 122,8 \\
\hline $\mathrm{CH}_{4}$ & ${ }^{2} J_{\mathrm{HH}}$ & $-11,8$ & $-12,5$ & $-13,2$ & $-13,9$ & $-14,6$ & $-15,3$ & $-16,1$ & $-16,8$ & $-17,5$ & $-18,1$ & $-18,8$ & $-12,5$ \\
\hline $\mathrm{C}_{2} \mathrm{H}_{2}$ & ${ }^{1} J_{\mathrm{CC}}$ & 187,3 & 189,9 & 193,0 & 196,5 & 200,6 & 205,4 & 211,1 & 218,0 & 226,4 & 236,9 & 250,2 & 174,1 \\
\hline $\mathrm{C}_{2} \mathrm{H}_{2}$ & ${ }^{1} J_{\mathrm{CH}}$ & 247,4 & 249,7 & 252,1 & 254,7 & 257,5 & 260,6 & 264,1 & 268,1 & 272,8 & 278,4 & 285,3 & 244,3 \\
\hline $\mathrm{C}_{2} \mathrm{H}_{2}$ & ${ }^{2} J_{\mathrm{CH}}$ & 54,6 & 54,6 & 54,4 & 53,9 & 53,1 & 51,9 & 50,3 & 48,1 & 45,2 & 41,3 & 35,9 & 49,8 \\
\hline $\mathrm{C}_{2} \mathrm{H}_{2}$ & ${ }^{3} J_{\mathrm{HH}}$ & 10,2 & 10,9 & 11,6 & 12,5 & 13,5 & 14,8 & 16,4 & 18,2 & 20,5 & 23,3 & 26,9 & 9,0 \\
\hline $\mathrm{C}_{2} \mathrm{H}_{4}$ & ${ }^{1} J_{\mathrm{CC}}$ & 59,5 & 62,2 & 65,2 & 68,5 & 72,4 & 76,9 & 82,4 & 89,4 & 98,7 & 112,2 & 133,8 & 66,9 \\
\hline $\mathrm{C}_{2} \mathrm{H}_{4}$ & ${ }^{1} J_{\mathrm{CH}}$ & 149,7 & 151,8 & 154,0 & 156,3 & 158,8 & 161,6 & 164,7 & 168,5 & 173,2 & 179,6 & 189,3 & 154,4 \\
\hline $\mathrm{C}_{2} \mathrm{H}_{4}$ & ${ }^{2} J_{\mathrm{CH}}$ & 0,0 & $-0,8$ & $-1,7$ & $-2,9$ & $-4,2$ & $-5,7$ & $-7,7$ & $-10,3$ & $-13,9$ & $-19,1$ & $-27,6$ & $-2,0$ \\
\hline $\mathrm{C}_{2} \mathrm{H}_{4}$ & ${ }^{2} J_{\mathrm{HH}}$ & 4,6 & 3,9 & 3,1 & 2,2 & 1,2 & 0,0 & $-1,2$ & $-2,9$ & $-5,2$ & $-8,4$ & $-13,5$ & 2,1 \\
\hline $\mathrm{C}_{2} \mathrm{H}_{4}$ & ${ }^{3} J_{\mathrm{HH}_{\mathrm{c}}}$ & 11,6 & 11,9 & 12,3 & 12,7 & 13,3 & 14,0 & 15,0 & 16,3 & 18,1 & 21,0 & 25,7 & 11,4 \\
\hline $\mathrm{C}_{2} \mathrm{H}_{4}$ & ${ }^{3} J_{\mathrm{HH}_{\mathrm{t}}}$ & 18,5 & 18,9 & 19,3 & 19,8 & 20,4 & 21,3 & 22,4 & 23,9 & 26,1 & 29,3 & 34,7 & 18,4 \\
\hline $\mathrm{C}_{2} \mathrm{H}_{6}$ & ${ }^{1} J_{\mathrm{CC}}$ & 24,2 & 26,2 & 28,2 & 30,2 & 32,3 & 34,4 & 36,5 & 38,7 & 40,9 & 43,2 & 45,4 & 33,6 \\
\hline $\mathrm{C}_{2} \mathrm{H}_{6}$ & ${ }^{1} J_{\mathrm{CH}}$ & 117,6 & 119,2 & 120,9 & 122,6 & 124,3 & 126,0 & 127,8 & 129,6 & 131,3 & 133,2 & 135,0 & 123,3 \\
\hline $\mathrm{C}_{2} \mathrm{H}_{6}$ & ${ }^{2} J_{\mathrm{CH}}$ & $-2,7$ & $-3,1$ & $-3,6$ & $-4,1$ & $-4,5$ & $-5,0$ & $-5,5$ & $-6,0$ & $-6,5$ & $-7,1$ & $-7,6$ & $-4,5$ \\
\hline \multirow[t]{3}{*}{ Total } & $\mathrm{DM}$ & $-29,70$ & $-27,27$ & $-24,65$ & $-21,95$ & $-19,23$ & $-16,67$ & $-14,43$ & $-12,98$ & $-13,29$ & $-18,44$ & $-47,49$ & - \\
\hline & DMA & 34,52 & 31,91 & 29,18 & 26,70 & 24,77 & 23,50 & 23,89 & 27,40 & 34,96 & 49,12 & 89,79 & - \\
\hline & PDMA & 50,37 & 40,83 & 31,25 & 24,74 & 23,84 & 26,46 & 36,13 & 54,45 & 77,83 & 109,27 & 161,26 & - \\
\hline \multirow[t]{3}{*}{ CPI } & DM & $-69,95$ & $-65,41$ & $-60,53$ & $-55,50$ & $-50,59$ & $-46,18$ & $-42,81$ & $-41,58$ & $-44,93$ & $-60,49$ & $-133,76$ & - \\
\hline & DMA & 75,95 & 70,34 & 64,35 & 58,17 & 52,23 & 47,09 & 45,30 & 50,09 & 63,51 & 91,13 & 179,00 & - \\
\hline & PDMA & 87,25 & 72,59 & 57,87 & 43,20 & 29,93 & 19,25 & 21,38 & 37,63 & 56,69 & 80,57 & 124,88 & - \\
\hline \multirow[t]{3}{*}{ SPI } & $\mathrm{DM}$ & $-0,19$ & 0,71 & 1,66 & 2,65 & 3,76 & 4,98 & 6,37 & 7,99 & 9,91 & 12,40 & 15,77 & - \\
\hline & DMA & 4,14 & 3,73 & 3,39 & 3,63 & 4,63 & 6,19 & 8,19 & 10,76 & 14,02 & 18,31 & 24,37 & - \\
\hline & PDMA & 23,32 & 17,55 & 11,73 & 11,21 & 19,38 & 31,75 & 46,95 & 66,78 & 93,33 & 130,31 & 187,93 & - \\
\hline \multirow[t]{3}{*}{$\Delta \mathrm{CS}$} & DM & $-69,75$ & $-66,12$ & $-62,19$ & $-58,15$ & $-54,35$ & $-51,16$ & $-49,18$ & $-49,57$ & $-54,84$ & $-72,89$ & $-149,54$ & - \\
\hline & DMA & 71,81 & 66,60 & 60,95 & 54,55 & 47,60 & 40,90 & 37,11 & 39,33 & 49,49 & 72,82 & 154,63 & - \\
\hline & PDMA & 63,93 & 55,04 & 46,14 & 31,99 & 10,55 & $-12,50$ & $-25,57$ & $-29,15$ & $-36,64$ & $-49,74$ & $-63,05$ & - \\
\hline
\end{tabular}


Tabela 8.126: Constantes de acoplamento BPW91 e constantes empíricas no nível BHandH $\left(50 \% E_{X}^{\mathrm{HF}}\right)$ e base aug-pcJ-2.

\begin{tabular}{|c|c|c|c|c|c|c|c|c|c|c|c|c|c|}
\hline & $\% E_{X}^{\mathrm{HF}}$ & $0 \%$ & $10 \%$ & $20 \%$ & $30 \%$ & $40 \%$ & $50 \%$ & $60 \%$ & $70 \%$ & $80 \%$ & $90 \%$ & $100 \%$ & Emp. \\
\hline $\mathrm{HF}$ & ${ }^{1} J_{\mathrm{HF}}$ & 353,3 & 377,4 & 401,9 & 426,6 & 451,5 & 476,7 & 502,2 & 527,9 & 553,8 & 579,9 & 606,3 & 532,8 \\
\hline $\mathrm{CO}$ & ${ }^{1} J_{\mathrm{CO}}$ & 25,2 & 23,6 & 21,8 & 20,0 & 18,1 & 16,1 & 14,0 & 11,8 & 9,6 & 7,3 & 4,9 & 15,7 \\
\hline $\mathrm{H}_{2} \mathrm{O}$ & ${ }^{1} J_{\mathrm{OH}}$ & $-64,9$ & $-67,5$ & $-70,1$ & $-72,7$ & $-75,4$ & $-78,1$ & $-80,8$ & $-83,5$ & $-86,3$ & $-89,1$ & $-91,9$ & $-81,7$ \\
\hline $\mathrm{H}_{2} \mathrm{O}$ & ${ }^{2} J_{\mathrm{HH}}$ & $-5,1$ & $-6,1$ & $-7,1$ & $-8,1$ & $-9,2$ & $-10,2$ & $-11,3$ & $-12,5$ & $-13,6$ & $-14,8$ & $-16,0$ & $-8,8$ \\
\hline $\mathrm{NH}_{3}$ & ${ }^{1} J_{\mathrm{NH}}$ & 40,2 & 41,0 & 41,8 & 42,6 & 43,4 & 44,2 & 45,0 & 45,8 & 46,7 & 47,5 & 48,4 & 43,0 \\
\hline $\mathrm{NH}_{3}$ & ${ }^{2} J_{\mathrm{HH}}$ & $-8,3$ & $-9,2$ & $-10,1$ & $-11,0$ & $-11,9$ & $-12,9$ & $-13,8$ & $-14,7$ & $-15,7$ & $-16,7$ & $-17,7$ & $-10,5$ \\
\hline $\mathrm{PH}_{3}$ & ${ }^{1} J_{\mathrm{PH}}$ & 137,3 & 145,6 & 153,9 & 162,0 & 170,1 & 178,0 & 185,8 & 193,4 & 200,9 & 208,3 & 215,5 & 195,0 \\
\hline $\mathrm{PF}_{3}$ & ${ }^{1} J_{\mathrm{PF}}$ & $-1810,6$ & $-1784,5$ & $-1754,1$ & $-1720,0$ & $-1683,1$ & $-1643,8$ & $-1602,7$ & $-1560,3$ & $-1516,9$ & $-1472,9$ & $-1428,5$ & $-1441,7$ \\
\hline $\mathrm{BHF}_{2}$ & ${ }^{1} J_{\mathrm{BF}}$ & $-178,0$ & $-160,8$ & $-143,8$ & $-126,8$ & $-110,0$ & $-93,3$ & $-76,8$ & $-60,4$ & $-44,3$ & $-28,3$ & $-12,5$ & $-79,7$ \\
\hline $\mathrm{BF}_{3}$ & ${ }^{1} J_{\mathrm{BF}}$ & $-83,3$ & $-64,5$ & $-45,8$ & $-27,4$ & $-9,1$ & 8,9 & 26,7 & 44,5 & 62,0 & 79,4 & 96,6 & 17,1 \\
\hline $\mathrm{F}_{2} \mathrm{O}$ & ${ }^{1} J_{\mathrm{OF}}$ & $-291,7$ & $-329,9$ & $-368,6$ & $-409,2$ & $-454,4$ & $-507,7$ & $-575,7$ & $-671,4$ & $-827,4$ & $-1153,6$ & $-2525,8$ & $-285,7$ \\
\hline $\mathrm{CH}_{4}$ & ${ }^{1} J_{\mathrm{CH}}$ & 118,9 & 120,4 & 121,9 & 123,5 & 125,1 & 126,7 & 128,4 & 130,0 & 131,7 & 133,4 & 135,2 & 122,8 \\
\hline $\mathrm{CH}_{4}$ & ${ }^{2} J_{\mathrm{HH}}$ & $-12,5$ & $-13,3$ & $-14,0$ & $-14,7$ & $-15,5$ & $-16,2$ & $-17,0$ & $-17,7$ & $-18,4$ & $-19,1$ & $-19,9$ & $-12,5$ \\
\hline $\mathrm{C}_{2} \mathrm{H}_{2}$ & ${ }^{1} J_{\mathrm{CC}}$ & 187,9 & 190,7 & 193,9 & 197,7 & 202,2 & 207,5 & 213,8 & 221,6 & 231,2 & 243,3 & 259,0 & 174,1 \\
\hline $\mathrm{C}_{2} \mathrm{H}_{2}$ & ${ }^{1} J_{\mathrm{CH}}$ & 251,1 & 253,6 & 256,2 & 259,1 & 262,1 & 265,6 & 269,5 & 274,1 & 279,5 & 286,1 & 294,6 & 244,3 \\
\hline $\mathrm{C}_{2} \mathrm{H}_{2}$ & ${ }^{2} J_{\mathrm{CH}}$ & 54,7 & 54,6 & 54,2 & 53,6 & 52,6 & 51,1 & 49,1 & 46,5 & 42,8 & 37,9 & 31,2 & 49,8 \\
\hline $\mathrm{C}_{2} \mathrm{H}_{2}$ & ${ }^{3} J_{\mathrm{HH}}$ & 10,8 & 11,5 & 12,4 & 13,4 & 14,6 & 16,1 & 17,9 & 20,1 & 22,8 & 26,3 & 30,7 & 9,0 \\
\hline $\mathrm{C}_{2} \mathrm{H}_{4}$ & ${ }^{1} J_{\mathrm{CC}}$ & 59,9 & 62,7 & 65,9 & 69,5 & 73,7 & 78,7 & 84,9 & 93,0 & 104,3 & 121,5 & 152,0 & 66,9 \\
\hline $\mathrm{C}_{2} \mathrm{H}_{4}$ & ${ }^{1} J_{\mathrm{CH}}$ & 151,9 & 154,1 & 156,4 & 158,9 & 161,6 & 164,7 & 168,3 & 172,6 & 178,2 & 186,4 & 200,0 & 154,4 \\
\hline $\mathrm{C}_{2} \mathrm{H}_{4}$ & ${ }^{2} J_{\mathrm{CH}}$ & $-0,4$ & $-1,4$ & $-2,4$ & $-3,6$ & $-5,1$ & $-6,9$ & $-9,2$ & $-12,4$ & $-16,8$ & $-23,7$ & $-36,2$ & $-2,0$ \\
\hline $\mathrm{C}_{2} \mathrm{H}_{4}$ & ${ }^{2} J_{\mathrm{HH}}$ & 4,2 & 3,3 & 2,5 & 1,5 & 0,4 & $-0,8$ & $-2,4$ & $-4,5$ & $-7,4$ & $-11,7$ & $-19,2$ & 2,1 \\
\hline $\mathrm{C}_{2} \mathrm{H}_{4}$ & ${ }^{3} J_{\mathrm{HH}_{\mathrm{c}}}$ & 12,0 & 12,3 & 12,7 & 13,3 & 14,0 & 14,8 & 16,0 & 17,7 & 20,1 & 24,0 & 31,2 & 11,4 \\
\hline $\mathrm{C}_{2} \mathrm{H}_{4}$ & ${ }^{3} J_{\mathrm{HH}_{\mathrm{t}}}$ & 19,1 & 19,5 & 20,0 & 20,6 & 21,4 & 22,4 & 23,7 & 25,6 & 28,4 & 32,8 & 40,9 & 18,4 \\
\hline $\mathrm{C}_{2} \mathrm{H}_{6}$ & ${ }^{1} J_{\mathrm{CC}}$ & 24,5 & 26,5 & 28,5 & 30,6 & 32,7 & 34,8 & 37,0 & 39,2 & 41,5 & 43,8 & 46,1 & 33,6 \\
\hline $\mathrm{C}_{2} \mathrm{H}_{6}$ & ${ }^{1} J_{\mathrm{CH}}$ & 119,2 & 120,9 & 122,6 & 124,4 & 126,2 & 128,0 & 129,8 & 131,7 & 133,5 & 135,4 & 137,3 & 123,3 \\
\hline $\mathrm{C}_{2} \mathrm{H}_{6}$ & ${ }^{2} J_{\mathrm{CH}}$ & $-3,0$ & $-3,5$ & $-3,9$ & $-4,4$ & $-4,9$ & $-5,4$ & $-6,0$ & $-6,5$ & $-7,0$ & $-7,5$ & $-8,1$ & $-4,5$ \\
\hline \multirow[t]{3}{*}{ Total } & DM & $-29,78$ & $-27,29$ & $-24,61$ & $-21,82$ & $-19,06$ & $-16,45$ & $-14,24$ & $-12,88$ & $-13,59$ & $-20,41$ & $-66,63$ & - \\
\hline & DMA & 34,85 & 32,22 & 29,63 & 27,48 & 25,84 & 24,72 & 25,51 & 29,57 & 38,51 & 55,29 & 114,95 & - \\
\hline & PDMA & 48,49 & 38,46 & 30,39 & 27,73 & 29,15 & 32,81 & 44,67 & 65,74 & 92,95 & 131,74 & 204,82 & - \\
\hline \multirow[t]{3}{*}{ CPI } & DM & $-71,04$ & $-66,40$ & $-61,43$ & $-56,32$ & $-51,41$ & $-47,05$ & $-43,90$ & $-43,17$ & $-47,88$ & $-68,05$ & $-183,29$ & - \\
\hline & DMA & 76,89 & 71,15 & 65,03 & 58,86 & 53,06 & 48,00 & 46,70 & 52,17 & 68,05 & 100,52 & 230,44 & - \\
\hline & PDMA & 86,55 & 71,65 & 56,69 & 42,80 & 30,62 & 20,41 & 23,58 & 40,46 & 60,54 & 86,43 & 145,70 & - \\
\hline \multirow[t]{3}{*}{ SPI } & $\mathrm{DM}$ & 0,48 & 1,39 & 2,39 & 3,49 & 4,67 & 6,00 & 7,51 & 9,33 & 11,55 & 14,52 & 18,91 & - \\
\hline & DMA & 4,03 & 3,68 & 3,67 & 4,47 & 5,88 & 7,65 & 9,97 & 12,99 & 16,85 & 22,12 & 30,26 & - \\
\hline & PDMA & 20,57 & 14,13 & 11,11 & 16,69 & 28,06 & 41,90 & 60,14 & 84,29 & 116,72 & 164,97 & 248,18 & - \\
\hline \multirow[t]{3}{*}{$\Delta \mathrm{CS}$} & $\mathrm{DM}$ & $-71,52$ & $-67,79$ & $-63,81$ & $-59,80$ & $-56,08$ & $-53,05$ & $-51,41$ & $-52,50$ & $-59,44$ & $-82,57$ & $-202,20$ & - \\
\hline & DMA & 72,86 & 67,47 & 61,36 & 54,39 & 47,18 & 40,35 & 36,73 & 39,18 & 51,20 & 78,40 & 200,18 & - \\
\hline & PDMA & 65,97 & 57,52 & 45,58 & 26,11 & 2,56 & $-21,49$ & $-36,56$ & $-43,83$ & $-56,18$ & $-78,54$ & $-102,47$ & - \\
\hline
\end{tabular}


Tabela 8.127: Constantes de acoplamento M05 e constantes empíricas no nível BHandH $\left(50 \% E_{X}^{\mathrm{HF}}\right)$ e base aug-pcJ-2.

\begin{tabular}{|c|c|c|c|c|c|c|c|c|c|c|c|c|c|}
\hline & $\% E_{X}^{\mathrm{HF}}$ & $0 \%$ & $10 \%$ & $20 \%$ & $30 \%$ & $40 \%$ & $50 \%$ & $60 \%$ & $70 \%$ & $80 \%$ & $90 \%$ & $100 \%$ & Emp. \\
\hline $\mathrm{HF}$ & ${ }^{1} J_{\mathrm{HF}}$ & 847,0 & 840,1 & 833,5 & 827,3 & 821,4 & 815,9 & 810,8 & 805,8 & 801,1 & 796,4 & 791,7 & 532,8 \\
\hline $\mathrm{CO}$ & ${ }^{1} J_{\mathrm{CO}}$ & 15,8 & 13,7 & 11,3 & 8,5 & 5,3 & 1,7 & $-2,1$ & $-6,2$ & $-10,7$ & $-15,5$ & $-20,5$ & 15,7 \\
\hline $\mathrm{H}_{2} \mathrm{O}$ & ${ }^{1} J_{\mathrm{OH}}$ & $-108,9$ & $-108,7$ & $-108,5$ & $-108,3$ & $-108,2$ & $-108,0$ & $-108,0$ & $-108,0$ & $-108,0$ & $-108,1$ & $-108,2$ & $-81,7$ \\
\hline $\mathrm{H}_{2} \mathrm{O}$ & ${ }^{2} J_{\mathrm{HH}}$ & $-18,6$ & $-18,7$ & $-18,7$ & $-18,6$ & $-18,3$ & $-17,9$ & $-17,4$ & $-16,7$ & $-15,9$ & $-15,0$ & $-13,9$ & $-8,8$ \\
\hline $\mathrm{NH}_{3}$ & ${ }^{1} J_{\mathrm{NH}}$ & 41,1 & 42,3 & 43,4 & 44,5 & 45,6 & 46,7 & 47,8 & 48,8 & 49,8 & 50,8 & 51,7 & 43,0 \\
\hline $\mathrm{NH}_{3}$ & ${ }^{2} J_{\mathrm{HH}}$ & $-13,5$ & $-14,4$ & $-15,2$ & $-15,9$ & $-16,4$ & $-16,7$ & $-16,9$ & $-16,8$ & $-16,5$ & $-15,9$ & $-15,2$ & $-10,5$ \\
\hline $\mathrm{PH}_{3}$ & ${ }^{1} J_{\mathrm{PH}}$ & 168,5 & 166,8 & 168,2 & 173,0 & 180,3 & 188,9 & 198,1 & 207,2 & 215,9 & 224,1 & 231,8 & 195,0 \\
\hline $\mathrm{PF}_{3}$ & ${ }^{1} J_{\mathrm{PF}}$ & $-1357,6$ & $-1376,0$ & $-1386,5$ & $-1388,9$ & $-1383,6$ & $-1372,0$ & $-1355,3$ & $-1334,8$ & $-1311,8$ & $-1287,0$ & $-1261,2$ & $-1441,7$ \\
\hline $\mathrm{BHF}_{2}$ & ${ }^{1} J_{\mathrm{BF}}$ & 2,2 & 8,2 & 14,9 & 22,3 & 30,5 & 39,5 & 49,5 & 60,5 & 72,8 & 86,3 & 101,3 & $-79,7$ \\
\hline $\mathrm{BF}_{3}$ & ${ }^{1} J_{\mathrm{BF}}$ & 102,9 & 111,1 & 119,8 & 129,1 & 139,0 & 149,8 & 161,4 & 174,1 & 187,8 & 202,7 & 218,9 & 17,1 \\
\hline $\mathrm{F}_{2} \mathrm{O}$ & ${ }^{1} J_{\mathrm{OF}}$ & $-218,9$ & $-253,7$ & $-282,8$ & $-307,6$ & $-330,0$ & $-351,6$ & $-374,7$ & $-402,2$ & $-439,1$ & $-494,9$ & $-592,4$ & $-285,7$ \\
\hline $\mathrm{CH}_{4}$ & ${ }^{1} J_{\mathrm{CH}}$ & 80,9 & 87,2 & 93,5 & 99,8 & 106,1 & 112,4 & 118,7 & 125,0 & 131,1 & 137,1 & 142,9 & 122,8 \\
\hline $\mathrm{CH}_{4}$ & ${ }^{2} J_{\mathrm{HH}}$ & $-20,8$ & $-21,1$ & $-21,2$ & $-21,2$ & $-21,0$ & $-20,8$ & $-20,4$ & $-19,8$ & $-19,2$ & $-18,5$ & $-17,9$ & $-12,5$ \\
\hline $\mathrm{C}_{2} \mathrm{H}_{2}$ & ${ }^{1} J_{\mathrm{CC}}$ & 182,9 & 192,0 & 201,6 & 211,8 & 222,6 & 234,0 & 246,1 & 258,8 & 272,4 & 286,7 & 302,0 & 174,1 \\
\hline $\mathrm{C}_{2} \mathrm{H}_{2}$ & ${ }^{1} J_{\mathrm{CH}}$ & 223,0 & 232,1 & 240,9 & 249,5 & 257,6 & 265,4 & 272,7 & 279,3 & 285,2 & 290,2 & 294,4 & 244,3 \\
\hline $\mathrm{C}_{2} \mathrm{H}_{2}$ & ${ }^{2} J_{\mathrm{CH}}$ & 35,8 & 36,1 & 36,4 & 36,6 & 36,7 & 36,7 & 36,8 & 36,7 & 36,4 & 35,9 & 34,9 & 49,8 \\
\hline $\mathrm{C}_{2} \mathrm{H}_{2}$ & ${ }^{3} J_{\mathrm{HH}}$ & 19,6 & 20,1 & 20,4 & 20,6 & 20,7 & 20,7 & 20,6 & 20,4 & 20,2 & 20,1 & 20,2 & 9,0 \\
\hline $\mathrm{C}_{2} \mathrm{H}_{4}$ & ${ }^{1} J_{\mathrm{CC}}$ & 57,9 & 64,1 & 70,7 & 77,9 & 85,7 & 94,1 & 103,3 & 113,2 & 123,9 & 135,6 & 148,4 & 66,9 \\
\hline $\mathrm{C}_{2} \mathrm{H}_{4}$ & ${ }^{1} J_{\mathrm{CH}}$ & 119,8 & 127,7 & 135,5 & 143,2 & 150,8 & 158,4 & 165,8 & 173,1 & 180,1 & 187,0 & 193,6 & 154,4 \\
\hline $\mathrm{C}_{2} \mathrm{H}_{4}$ & ${ }^{2} J_{\mathrm{CH}}$ & $-11,4$ & $-12,2$ & $-13,1$ & $-14,1$ & $-15,1$ & $-16,2$ & $-17,3$ & $-18,4$ & $-19,6$ & $-20,9$ & $-22,4$ & $-2,0$ \\
\hline $\mathrm{C}_{2} \mathrm{H}_{4}$ & ${ }^{2} J_{\mathrm{HH}}$ & $-16,0$ & $-15,7$ & $-15,1$ & $-14,4$ & $-13,6$ & $-12,6$ & $-11,4$ & $-10,1$ & $-8,8$ & $-7,5$ & $-6,4$ & 2,1 \\
\hline $\mathrm{C}_{2} \mathrm{H}_{4}$ & ${ }^{3} J_{\mathrm{HH}_{\mathrm{c}}}$ & 14,5 & 15,2 & 15,8 & 16,3 & 16,7 & 17,0 & 17,2 & 17,3 & 17,3 & 17,3 & 17,3 & 11,4 \\
\hline $\mathrm{C}_{2} \mathrm{H}_{4}$ & ${ }^{3} J_{\mathrm{HH}_{\mathrm{t}}}$ & 15,6 & 17,0 & 18,2 & 19,4 & 20,5 & 21,4 & 22,2 & 22,9 & 23,4 & 23,9 & 24,4 & 18,4 \\
\hline $\mathrm{C}_{2} \mathrm{H}_{6}$ & ${ }^{1} J_{\mathrm{CC}}$ & 15,2 & 18,5 & 21,9 & 25,6 & 29,4 & 33,3 & 37,5 & 41,9 & 46,4 & 51,2 & 56,2 & 33,6 \\
\hline $\mathrm{C}_{2} \mathrm{H}_{6}$ & ${ }^{1} J_{\mathrm{CH}}$ & 80,1 & 86,6 & 93,0 & 99,5 & 106,0 & 112,6 & 119,1 & 125,6 & 132,0 & 138,4 & 144,6 & 123,3 \\
\hline $\mathrm{C}_{2} \mathrm{H}_{6}$ & ${ }^{2} J_{\mathrm{CH}}$ & $-3,2$ & $-3,7$ & $-4,2$ & $-4,7$ & $-5,2$ & $-5,7$ & $-6,1$ & $-6,6$ & $-7,0$ & $-7,5$ & $-8,0$ & $-4,5$ \\
\hline \multirow[t]{3}{*}{ Total } & $\mathrm{DM}$ & 14,13 & 14,15 & 14,89 & 16,33 & 18,34 & 20,78 & 23,52 & 26,32 & 28,95 & 31,01 & 31,60 & - \\
\hline & DMA & 36,39 & 33,58 & 31,57 & 32,45 & 34,05 & 36,21 & 39,49 & 44,02 & 49,74 & 56,38 & 64,82 & - \\
\hline & PDMA & 102,83 & 104,67 & 106,74 & 110,90 & 115,60 & 120,43 & 126,10 & 132,40 & 139,72 & 147,94 & 157,96 & - \\
\hline \multirow[t]{3}{*}{ CPI } & $\mathrm{DM}$ & 51,32 & 46,84 & 43,99 & 42,72 & 42,74 & 43,71 & 45,25 & 46,93 & 48,17 & 48,04 & 44,41 & - \\
\hline & DMA & 63,75 & 59,87 & 57,19 & 59,61 & 62,97 & 66,91 & 72,17 & 79,45 & 88,03 & 98,65 & 113,35 & - \\
\hline & PDMA & 80,42 & 85,90 & 92,12 & 100,50 & 109,20 & 118,38 & 128,39 & 139,52 & 151,58 & 164,82 & 180,05 & - \\
\hline \multirow[t]{3}{*}{ SPI } & DM & $-13,15$ & $-9,81$ & $-6,45$ & $-3,02$ & 0,45 & 3,97 & 7,58 & 11,21 & 14,85 & 18,53 & 22,21 & - \\
\hline & DMA & 16,32 & 14,29 & 12,77 & 12,54 & 12,84 & 13,69 & 15,53 & 18,03 & 21,66 & 25,38 & 29,23 & - \\
\hline & PDMA & 119,27 & 118,43 & 117,46 & 118,53 & 120,28 & 121,94 & 124,42 & 127,19 & 131,03 & 135,55 & 141,77 & - \\
\hline \multirow[t]{3}{*}{$\Delta \mathrm{CS}$} & DM & 64,46 & 56,65 & 50,44 & 45,74 & 42,28 & 39,74 & 37,67 & 35,71 & 33,33 & 29,51 & 22,20 & - \\
\hline & DMA & 47,43 & 45,58 & 44,42 & 47,07 & 50,13 & 53,22 & 56,65 & 61,43 & 66,37 & 73,27 & 84,12 & - \\
\hline & PDMA & $-38,85$ & $-32,52$ & $-25,34$ & $-18,02$ & $-11,08$ & $-3,56$ & 3,97 & 12,32 & 20,55 & 29,28 & 38,28 & - \\
\hline
\end{tabular}


Tabela 8.128: Constantes de acoplamento M06 e constantes empíricas no nível BHandH $\left(50 \% E_{X}^{\mathrm{HF}}\right)$ e base aug-pcJ-2.

\begin{tabular}{|c|c|c|c|c|c|c|c|c|c|c|c|c|c|}
\hline & $\% E_{X}^{\mathrm{HF}}$ & $0 \%$ & $10 \%$ & $20 \%$ & $30 \%$ & $40 \%$ & $50 \%$ & $60 \%$ & $70 \%$ & $80 \%$ & $90 \%$ & $100 \%$ & Emp. \\
\hline $\mathrm{HF}$ & ${ }^{1} J_{\mathrm{HF}}$ & 591,8 & 620,1 & 652,6 & 690,1 & 733,4 & 782,9 & 838,6 & 900,5 & 967,8 & 1039,5 & 1113,9 & 532,8 \\
\hline $\mathrm{CO}$ & ${ }^{1} J_{\mathrm{CO}}$ & 16,9 & 17,6 & 17,9 & 17,8 & 17,0 & 15,4 & 13,0 & 9,5 & 5,0 & $-0,8$ & $-7,9$ & 15,7 \\
\hline $\mathrm{H}_{2} \mathrm{O}$ & ${ }^{1} J_{\mathrm{OH}}$ & $-86,0$ & $-90,6$ & $-96,1$ & $-102,7$ & $-110,6$ & $-120,0$ & $-131,2$ & $-144,5$ & $-160,2$ & $-178,9$ & $-201,1$ & $-81,7$ \\
\hline $\mathrm{H}_{2} \mathrm{O}$ & ${ }^{2} J_{\mathrm{HH}}$ & $-5,7$ & $-9,1$ & $-13,3$ & $-18,4$ & $-24,8$ & $-32,8$ & $-42,7$ & $-54,9$ & $-70,2$ & $-89,3$ & $-113,0$ & $-8,8$ \\
\hline $\mathrm{NH}_{3}$ & ${ }^{1} J_{\mathrm{NH}}$ & 43,2 & 46,1 & 49,6 & 53,7 & 58,6 & 64,4 & 71,6 & 80,3 & 91,1 & 104,7 & 122,2 & 43,0 \\
\hline $\mathrm{NH}_{3}$ & ${ }^{2} J_{\mathrm{HH}}$ & $-7,6$ & $-10,7$ & $-14,6$ & $-19,7$ & $-26,3$ & $-35,0$ & $-46,5$ & $-62,0$ & $-83,1$ & $-112,3$ & $-153,9$ & $-10,5$ \\
\hline $\mathrm{PH}_{3}$ & ${ }^{1} J_{\mathrm{PH}}$ & 199,3 & 214,4 & 232,5 & 254,5 & 281,6 & 315,1 & 357,5 & 411,8 & 483,2 & 577,7 & 701,3 & 195,0 \\
\hline $\mathrm{PF}_{3}$ & ${ }^{1} J_{\mathrm{PF}}$ & $-1437,2$ & $-1476,6$ & $-1508,9$ & $-1533,6$ & $-1552,2$ & $-1567,1$ & $-1579,5$ & $-1588,2$ & $-1591,0$ & $-1586,1$ & $-1573,4$ & $-1441,7$ \\
\hline $\mathrm{BHF}_{2}$ & ${ }^{1} J_{\mathrm{BF}}$ & $-67,3$ & $-57,9$ & $-46,0$ & $-31,5$ & $-14,7$ & 3,7 & 22,9 & 41,7 & 58,7 & 71,6 & 75,6 & $-79,7$ \\
\hline $\mathrm{BF}_{3}$ & ${ }^{1} J_{\mathrm{BF}}$ & 27,0 & 39,1 & 53,4 & 70,2 & 89,7 & 111,5 & 135,2 & 160,1 & 185,6 & 211,4 & 237,7 & 17,1 \\
\hline $\mathrm{F}_{2} \mathrm{O}$ & ${ }^{1} J_{\mathrm{OF}}$ & $-161,1$ & $-211,1$ & $-265,9$ & $-328,2$ & $-406,1$ & $-530,0$ & $-975,7$ & 4267,8 & $-15,5$ & $-222,3$ & $-320,8$ & $-285,7$ \\
\hline $\mathrm{CH}_{4}$ & ${ }^{1} J_{\mathrm{CH}}$ & 103,3 & 114,7 & 128,4 & 144,8 & 164,8 & 189,3 & 219,9 & 258,9 & 309,9 & 379,0 & 477,4 & 122,8 \\
\hline $\mathrm{CH}_{4}$ & ${ }^{2} J_{\mathrm{HH}}$ & $-12,6$ & $-16,6$ & $-21,5$ & $-27,9$ & $-36,3$ & $-47,3$ & $-62,2$ & $-82,8$ & $-112,3$ & $-156,2$ & $-225,1$ & $-12,5$ \\
\hline $\mathrm{C}_{2} \mathrm{H}_{2}$ & ${ }^{1} J_{\mathrm{CC}}$ & 161,7 & 170,7 & 182,5 & 199,5 & 227,4 & 285,4 & 502,3 & $-632,7$ & $-14,0$ & 128,2 & 5815,3 & 174,1 \\
\hline $\mathrm{C}_{2} \mathrm{H}_{2}$ & ${ }^{1} J_{\mathrm{CH}}$ & 208,8 & 237,3 & 271,3 & 313,1 & 367,7 & 450,4 & 661,2 & $-166,8$ & 360,7 & 495,3 & $-161,9$ & 244,3 \\
\hline $\mathrm{C}_{2} \mathrm{H}_{2}$ & ${ }^{2} J_{\mathrm{CH}}$ & 49,7 & 51,3 & 51,6 & 49,0 & 39,6 & 9,0 & $-141,1$ & 758,3 & 315,4 & 282,8 & 1065,0 & 49,8 \\
\hline $\mathrm{C}_{2} \mathrm{H}_{2}$ & ${ }^{3} J_{\mathrm{HH}}$ & 7,6 & 9,7 & 13,2 & 19,3 & 31,2 & 60,3 & 184,0 & $-514,8$ & $-158,3$ & $-117,3$ & $-2,3$ & 9,0 \\
\hline $\mathrm{C}_{2} \mathrm{H}_{4}$ & ${ }^{1} J_{\mathrm{CC}}$ & 51,1 & 54,6 & 59,6 & 67,7 & 83,1 & 126,0 & 1247,1 & $-64,0$ & $-10,1$ & 6,5 & 13,8 & 66,9 \\
\hline $\mathrm{C}_{2} \mathrm{H}_{4}$ & ${ }^{1} J_{\mathrm{CH}}$ & 130,3 & 146,9 & 166,9 & 191,8 & 225,2 & 282,2 & 1104,7 & 218,8 & 304,5 & 376,2 & 458,4 & 154,4 \\
\hline $\mathrm{C}_{2} \mathrm{H}_{4}$ & ${ }^{2} J_{\mathrm{CH}}$ & 0,7 & $-0,9$ & $-3,5$ & $-8,1$ & $-17,7$ & $-46,3$ & $-834,9$ & 91,9 & 56,9 & 48,8 & 48,6 & $-2,0$ \\
\hline $\mathrm{C}_{2} \mathrm{H}_{4}$ & ${ }^{2} J_{\mathrm{HH}}$ & $-3,4$ & $-5,9$ & $-9,6$ & $-15,6$ & $-26,7$ & $-56,4$ & $-792,0$ & 61,8 & 21,0 & 1,6 & $-16,5$ & 2,1 \\
\hline $\mathrm{C}_{2} \mathrm{H}_{4}$ & ${ }^{3} J_{\mathrm{HH}_{\mathrm{C}}}$ & 11,0 & 12,5 & 14,7 & 18,6 & 26,8 & 52,5 & 782,6 & $-78,9$ & $-49,1$ & $-45,4$ & $-50,8$ & 11,4 \\
\hline $\mathrm{C}_{2} \mathrm{H}_{4}$ & ${ }^{3} J_{\mathrm{HH}_{\mathrm{t}}}$ & 12,1 & 14,6 & 18,1 & 23,5 & 33,7 & 62,4 & 821,1 & $-67,9$ & $-32,7$ & $-23,3$ & $-21,2$ & 18,4 \\
\hline $\mathrm{C}_{2} \mathrm{H}_{6}$ & ${ }^{1} J_{\mathrm{CC}}$ & 20,1 & 22,9 & 26,4 & 30,8 & 36,4 & 43,5 & 52,9 & 65,7 & 83,6 & 110,1 & 152,2 & 33,6 \\
\hline $\mathrm{C}_{2} \mathrm{H}_{6}$ & ${ }^{1} J_{\mathrm{CH}}$ & 101,2 & 113,2 & 127,4 & 144,5 & 165,3 & 190,7 & 222,4 & 262,9 & 316,0 & 388,7 & 493,8 & 123,3 \\
\hline $\mathrm{C}_{2} \mathrm{H}_{6}$ & ${ }^{2} J_{\mathrm{CH}}$ & $-1,4$ & $-2,6$ & $-4,2$ & $-6,2$ & $-8,8$ & $-12,3$ & $-17,2$ & $-24,3$ & $-34,8$ & $-51,6$ & $-80,4$ & $-4,5$ \\
\hline \multirow[t]{3}{*}{ Total } & $\mathrm{DM}$ & 2,57 & 4,50 & 7,53 & 11,94 & 18,10 & 27,34 & 104,90 & 162,37 & 51,60 & 67,38 & 306,17 & - \\
\hline & DMA & 14,96 & 13,68 & 17,32 & 28,76 & 46,90 & 76,80 & 322,61 & 351,02 & 132,10 & 141,45 & 416,70 & - \\
\hline & PDMA & 33,15 & 33,58 & 50,03 & 90,01 & 161,76 & 331,76 & 3793,60 & 854,73 & 480,83 & 472,01 & 740,71 & - \\
\hline \multirow{3}{*}{ CPI } & DM & 19,80 & 16,89 & 15,06 & 14,25 & 13,65 & 10,24 & $-21,12$ & 466,05 & 88,72 & 83,61 & 89,55 & - \\
\hline & DMA & 20,58 & 24,95 & 31,46 & 45,92 & 66,66 & 93,29 & 151,59 & 522,98 & 156,45 & 163,68 & 190,90 & - \\
\hline & PDMA & 18,81 & 22,40 & 40,46 & 64,81 & 95,47 & 133,09 & 189,41 & 362,74 & 287,15 & 354,68 & 445,95 & - \\
\hline \multirow[t]{3}{*}{ SPI } & DM & $-10,06$ & $-4,58$ & 2,01 & 10,25 & 21,37 & 39,89 & 197,31 & $-60,33$ & 24,37 & 55,49 & 465,01 & - \\
\hline & DMA & 10,83 & 5,42 & 6,95 & 16,18 & 32,41 & 64,71 & 448,02 & 224,91 & 114,25 & 125,14 & 582,28 & - \\
\hline & PDMA & 43,66 & 41,78 & 57,06 & 108,49 & 210,37 & 477,45 & 6436,66 & 1215,51 & 622,86 & 558,05 & 956,87 & - \\
\hline \multirow[t]{3}{*}{$\Delta \mathrm{CS}$} & DM & 29,86 & 21,47 & 13,05 & 4,00 & $-7,73$ & $-29,65$ & $-218,43$ & 526,39 & 64,34 & 28,12 & $-375,46$ & - \\
\hline & DMA & 9,75 & 19,53 & 24,52 & 29,74 & 34,25 & 28,58 & $-296,43$ & 298,08 & 42,19 & 38,54 & $-391,38$ & - \\
\hline & PDMA & $-24,86$ & $-19,38$ & $-16,60$ & $-43,68$ & $-114,90$ & $-344,35$ & $-6247,25$ & $-852,77$ & $-335,71$ & $-203,37$ & $-510,92$ & - \\
\hline
\end{tabular}


Tabela 8.129: Constantes de acoplamento M062X e constantes empíricas no nível BHandH $\left(50 \% E_{X}^{\mathrm{HF}}\right)$ e base aug-pcJ-2.

\begin{tabular}{|c|c|c|c|c|c|c|c|c|c|c|c|c|c|}
\hline & $\% E_{X}^{\mathrm{HF}}$ & $0 \%$ & $10 \%$ & $20 \%$ & $30 \%$ & $40 \%$ & $50 \%$ & $60 \%$ & $70 \%$ & $80 \%$ & $90 \%$ & $100 \%$ & Emp. \\
\hline $\mathrm{HF}$ & ${ }^{1} J_{\mathrm{HF}}$ & 445,9 & 449,4 & 453,4 & 459,1 & 467,4 & 479,5 & 496,4 & 519,2 & 548,9 & 586,4 & 632,6 & 532,8 \\
\hline $\mathrm{CO}$ & ${ }^{1} J_{\mathrm{CO}}$ & 3,7 & 4,7 & 5,7 & 6,6 & 7,2 & 7,4 & 7,1 & 6,0 & 3,7 & $-0,2$ & $-6,8$ & 15,7 \\
\hline $\mathrm{H}_{2} \mathrm{O}$ & ${ }^{1} J_{\mathrm{OH}}$ & $-73,4$ & $-75,6$ & $-78,2$ & $-81,3$ & $-85,0$ & $-89,5$ & $-95,0$ & $-101,7$ & $-109,8$ & $-119,5$ & $-131,3$ & $-81,7$ \\
\hline $\mathrm{H}_{2} \mathrm{O}$ & ${ }^{2} J_{\mathrm{HH}}$ & 4,2 & 3,0 & 1,5 & $-0,3$ & $-2,7$ & $-5,7$ & $-9,5$ & $-14,4$ & $-20,5$ & $-28,2$ & $-38,1$ & $-8,8$ \\
\hline $\mathrm{NH}_{3}$ & ${ }^{1} J_{\mathrm{NH}}$ & 38,2 & 40,2 & 42,4 & 45,0 & 48,0 & 51,6 & 55,9 & 60,9 & 66,9 & 74,2 & 83,1 & 43,0 \\
\hline $\mathrm{NH}_{3}$ & ${ }^{2} J_{\mathrm{HH}}$ & 0,2 & $-0,7$ & $-2,1$ & $-4,0$ & $-6,4$ & $-9,5$ & $-13,6$ & $-18,9$ & $-25,9$ & $-35,2$ & $-47,6$ & $-10,5$ \\
\hline $\mathrm{PH}_{3}$ & ${ }^{1} J_{\mathrm{PH}}$ & 133,0 & 134,2 & 137,3 & 142,7 & 150,6 & 161,6 & 176,1 & 195,1 & 219,2 & 250,0 & 289,5 & 195,0 \\
\hline $\mathrm{PF}_{3}$ & ${ }^{1} J_{\mathrm{PF}}$ & $-1442,3$ & $-1488,8$ & $-1533,3$ & $-1573,0$ & $-1603,7$ & $-1622,0$ & $-1627,6$ & $-1623,0$ & $-1612,8$ & $-1602,7$ & $-1596,7$ & $-1441,7$ \\
\hline $\mathrm{BHF}_{2}$ & ${ }^{1} J_{\mathrm{BF}}$ & $-166,8$ & $-163,3$ & $-156,4$ & $-146,7$ & $-135,1$ & $-122,1$ & $-107,7$ & $-92,3$ & $-75,9$ & $-58,8$ & $-41,4$ & $-79,7$ \\
\hline $\mathrm{BF}_{3}$ & ${ }^{1} J_{\mathrm{BF}}$ & $-89,3$ & $-80,2$ & $-68,9$ & $-56,0$ & $-41,7$ & $-26,4$ & $-10,0$ & 7,5 & 26,7 & 47,8 & 70,9 & 17,1 \\
\hline $\mathrm{F}_{2} \mathrm{O}$ & ${ }^{1} J_{\mathrm{OF}}$ & $-156,6$ & $-199,7$ & $-246,2$ & $-295,8$ & $-348,4$ & $-404,9$ & $-468,8$ & $-550,1$ & $-685,1$ & $-1305,2$ & $-2162,3$ & $-285,7$ \\
\hline $\mathrm{CH}_{4}$ & ${ }^{1} J_{\mathrm{CH}}$ & 86,4 & 93,7 & 102,1 & 112,1 & 123,7 & 137,5 & 153,9 & 173,6 & 197,4 & 226,6 & 262,9 & 122,8 \\
\hline $\mathrm{CH}_{4}$ & ${ }^{2} J_{\mathrm{HH}}$ & $-0,2$ & $-1,3$ & $-2,8$ & $-4,8$ & $-7,3$ & $-10,5$ & $-14,7$ & $-20,1$ & $-27,3$ & $-36,8$ & $-49,6$ & $-12,5$ \\
\hline $\mathrm{C}_{2} \mathrm{H}_{2}$ & ${ }^{1} J_{\mathrm{CC}}$ & 167,7 & 174,7 & 182,9 & 192,6 & 204,6 & 220,1 & 241,5 & 273,9 & 331,7 & 472,8 & 1542,1 & 174,1 \\
\hline $\mathrm{C}_{2} \mathrm{H}_{2}$ & ${ }^{1} J_{\mathrm{CH}}$ & 142,4 & 159,4 & 178,9 & 201,1 & 226,7 & 256,7 & 292,4 & 336,8 & 397,0 & 500,5 & 1037,2 & 244,3 \\
\hline $\mathrm{C}_{2} \mathrm{H}_{2}$ & ${ }^{2} J_{\mathrm{CH}}$ & 46,7 & 49,1 & 51,6 & 53,9 & 55,8 & 56,9 & 56,2 & 51,7 & 36,8 & $-14,6$ & $-491,4$ & 49,8 \\
\hline $\mathrm{C}_{2} \mathrm{H}_{2}$ & ${ }^{3} J_{\mathrm{HH}}$ & 4,3 & 4,8 & 5,3 & 6,0 & 7,0 & 8,5 & 10,9 & 15,4 & 24,8 & 51,4 & 274,4 & 9,0 \\
\hline $\mathrm{C}_{2} \mathrm{H}_{4}$ & ${ }^{1} J_{\mathrm{CC}}$ & 60,5 & 63,3 & 67,0 & 71,7 & 78,0 & 86,7 & 99,5 & 120,7 & 162,3 & 284,8 & 14163,1 & 66,9 \\
\hline $\mathrm{C}_{2} \mathrm{H}_{4}$ & ${ }^{1} J_{\mathrm{CH}}$ & 99,2 & 109,3 & 120,9 & 134,4 & 150,2 & 169,0 & 192,0 & 221,3 & 263,2 & 345,6 & 6656,1 & 154,4 \\
\hline $\mathrm{C}_{2} \mathrm{H}_{4}$ & ${ }^{2} J_{\mathrm{CH}}$ & 6,3 & 5,6 & 4,7 & 3,5 & 1,7 & $-1,0$ & $-5,4$ & $-13,2$ & $-30,1$ & $-83,1$ & $-6358,9$ & $-2,0$ \\
\hline $\mathrm{C}_{2} \mathrm{H}_{4}$ & ${ }^{2} J_{\mathrm{HH}}$ & 7,0 & 7,0 & 6,8 & 6,4 & 5,7 & 4,4 & 2,2 & $-1,8$ & $-10,4$ & $-37,0$ & $-3080,4$ & 2,1 \\
\hline $\mathrm{C}_{2} \mathrm{H}_{4}$ & ${ }^{3} J_{\mathrm{HH}_{\mathrm{c}}}$ & 9,1 & 9,5 & 9,9 & 10,5 & 11,2 & 12,3 & 14,1 & 17,4 & 24,8 & 49,5 & 3090,2 & 11,4 \\
\hline $\mathrm{C}_{2} \mathrm{H}_{4}$ & ${ }^{3} J_{\mathrm{HH}_{\mathrm{t}}}{ }^{\mathrm{C}}$ & 9,4 & 10,7 & 12,0 & 13,6 & 15,4 & 17,7 & 20,8 & 25,9 & 35,5 & 63,8 & 3278,1 & 18,4 \\
\hline $\mathrm{C}_{2} \mathrm{H}_{6}$ & ${ }^{1} J_{\mathrm{CC}}$ & 27,4 & 29,9 & 33,0 & 36,6 & 41,1 & 46,4 & 53,0 & 61,2 & 71,5 & 84,8 & 102,2 & 33,6 \\
\hline $\mathrm{C}_{2} \mathrm{H}_{6}$ & ${ }^{1} J_{\mathrm{CH}}$ & 84,0 & 91,7 & 100,8 & 111,4 & 123,8 & 138,4 & 155,8 & 176,6 & 201,7 & 232,6 & 271,0 & 123,3 \\
\hline $\mathrm{C}_{2} \mathrm{H}_{6}$ & ${ }^{2} J_{\mathrm{CH}}$ & 2,2 & 1,5 & 0,7 & $-0,2$ & $-1,5$ & $-3,0$ & $-5,0$ & $-7,5$ & $-10,8$ & $-15,3$ & $-21,7$ & $-4,5$ \\
\hline \multirow[t]{3}{*}{ Total } & $\mathrm{DM}$ & $-16,82$ & $-17,48$ & $-17,60$ & $-16,98$ & $-15,40$ & $-12,56$ & $-8,31$ & $-2,55$ & 4,50 & 1,83 & 686,18 & - \\
\hline & DMA & 31,69 & 28,56 & 25,19 & 22,33 & 22,10 & 25,09 & 31,01 & 39,82 & 59,30 & 117,06 & 1625,02 & - \\
\hline & PDMA & 91,00 & 82,25 & 71,75 & 60,56 & 47,86 & 34,21 & 36,18 & 72,25 & 151,85 & 379,69 & 20883,81 & - \\
\hline \multirow[t]{3}{*}{ CPI } & DM & $-18,06$ & $-24,75$ & $-30,94$ & $-36,29$ & $-40,48$ & $-43,23$ & $-44,75$ & $-46,11$ & $-50,92$ & $-98,81$ & $-167,60$ & - \\
\hline & DMA & 47,35 & 45,43 & 42,15 & 39,45 & 43,25 & 45,54 & 47,09 & 49,38 & 65,03 & 133,61 & 226,96 & - \\
\hline & PDMA & 106,57 & 96,87 & 84,57 & 71,49 & 59,98 & 46,92 & 38,70 & 41,02 & 61,28 & 117,07 & 189,18 & - \\
\hline \multirow[t]{3}{*}{ SPI } & DM & $-15,91$ & $-12,15$ & $-7,82$ & $-2,82$ & 3,00 & 9,93 & 18,41 & 29,39 & 45,13 & 75,63 & 1312,28 & - \\
\hline & DMA & 20,21 & 16,19 & 12,75 & 9,78 & 6,60 & 10,09 & 19,22 & 32,81 & 55,09 & 104,93 & 2650,27 & - \\
\hline & PDMA & 79,59 & 71,53 & 62,35 & 52,55 & 38,97 & 24,88 & 34,34 & 95,14 & 218,27 & 572,28 & 36059,87 & - \\
\hline \multirow[t]{3}{*}{$\Delta \mathrm{CS}$} & DM & $-2,15$ & $-12,61$ & $-23,12$ & $-33,47$ & $-43,48$ & $-53,16$ & $-63,15$ & $-75,50$ & $-96,05$ & $-174,44$ & $-1479,88$ & - \\
\hline & DMA & 27,15 & 29,24 & 29,40 & 29,67 & 36,65 & 35,44 & 27,87 & 16,57 & 9,93 & 28,68 & $-2423,30$ & - \\
\hline & PDMA & 26,98 & 25,34 & 22,22 & 18,95 & 21,01 & 22,04 & 4,36 & $-54,13$ & $-156,99$ & $-455,21$ & $-35870,68$ & - \\
\hline
\end{tabular}


Tabela 8.130: Constantes de acoplamento OLYP e constantes empíricas no nível BHandH $\left(50 \% E_{X}^{\mathrm{HF}}\right)$ e base aug-pcJ-2.

\begin{tabular}{|c|c|c|c|c|c|c|c|c|c|c|c|c|c|}
\hline & $\% E_{X}^{\mathrm{HF}}$ & $0 \%$ & $10 \%$ & $20 \%$ & $30 \%$ & $40 \%$ & $50 \%$ & $60 \%$ & $70 \%$ & $80 \%$ & $90 \%$ & $100 \%$ & Emp. \\
\hline $\mathrm{HF}$ & ${ }^{1} J_{\mathrm{HF}}$ & 363,4 & 391,6 & 420,1 & 449,1 & 478,5 & 508,2 & 538,4 & 568,9 & 599,7 & 630,9 & 662,5 & 532,8 \\
\hline $\mathrm{CO}$ & ${ }^{1} J_{\mathrm{CO}}$ & 24,0 & 21,8 & 19,5 & 17,1 & 14,6 & 12,0 & 9,4 & 6,6 & 3,8 & 0,9 & $-1,9$ & 15,7 \\
\hline $\mathrm{H}_{2} \mathrm{O}$ & ${ }^{1} J_{\mathrm{OH}}$ & $-66,1$ & $-69,4$ & $-72,7$ & $-76,1$ & $-79,5$ & $-83,0$ & $-86,5$ & $-90,1$ & $-93,7$ & $-97,3$ & $-101,1$ & $-81,7$ \\
\hline $\mathrm{H}_{2} \mathrm{O}$ & ${ }^{2} J_{\mathrm{HH}}$ & $-7,4$ & $-8,3$ & $-9,3$ & $-10,2$ & $-11,1$ & $-12,1$ & $-13,1$ & $-14,1$ & $-15,2$ & $-16,2$ & $-17,3$ & $-8,8$ \\
\hline $\mathrm{NH}_{3}$ & ${ }^{1} J_{\mathrm{NH}}$ & 40,2 & 41,5 & 42,7 & 44,0 & 45,3 & 46,6 & 47,9 & 49,3 & 50,6 & 52,0 & 53,4 & 43,0 \\
\hline $\mathrm{NH}_{3}$ & ${ }^{2} J_{\mathrm{HH}}$ & $-9,6$ & $-10,4$ & $-11,3$ & $-12,1$ & $-13,0$ & $-13,9$ & $-14,8$ & $-15,7$ & $-16,7$ & $-17,7$ & $-18,7$ & $-10,5$ \\
\hline $\mathrm{PH}_{3}$ & ${ }^{1} J_{\mathrm{PH}}$ & 158,8 & 167,5 & 176,1 & 184,5 & 192,8 & 201,0 & 209,0 & 216,8 & 224,5 & 231,9 & 239,2 & 195,0 \\
\hline $\mathrm{PF}_{3}$ & ${ }^{1} J_{\mathrm{PF}}$ & $-1702,2$ & $-1685,7$ & $-1665,4$ & $-1642,0$ & $-1616,2$ & $-1588,5$ & $-1559,4$ & $-1529,4$ & $-1498,8$ & $-1467,9$ & $-1437,0$ & $-1441,7$ \\
\hline $\mathrm{BHF}_{2}$ & ${ }^{1} J_{\mathrm{BF}}$ & $-181,4$ & $-160,8$ & $-140,7$ & $-121,1$ & $-102,0$ & $-83,5$ & $-65,6$ & $-48,2$ & $-31,4$ & $-15,1$ & 0,6 & $-79,7$ \\
\hline $\mathrm{BF}_{3}$ & ${ }^{1} J_{\mathrm{BF}}$ & $-90,5$ & $-67,4$ & $-45,0$ & $-23,1$ & $-1,8$ & 18,8 & 38,9 & 58,4 & 77,4 & 95,8 & 113,8 & 17,1 \\
\hline $\mathrm{F}_{2} \mathrm{O}$ & ${ }^{1} J_{\mathrm{OF}}$ & $-254,6$ & $-290,9$ & $-327,9$ & $-367,1$ & $-410,6$ & $-461,8$ & $-526,5$ & $-616,5$ & $-760,6$ & $-1056,6$ & $-2253,8$ & $-285,7$ \\
\hline $\mathrm{CH}_{4}$ & ${ }^{1} J_{\mathrm{CH}}$ & 118,2 & 121,1 & 124,1 & 127,1 & 130,2 & 133,3 & 136,4 & 139,6 & 142,9 & 146,1 & 149,4 & 122,8 \\
\hline $\mathrm{CH}_{4}$ & ${ }^{2} J_{\mathrm{HH}}$ & $-12,9$ & $-13,5$ & $-14,2$ & $-14,9$ & $-15,6$ & $-16,3$ & $-17,0$ & $-17,7$ & $-18,4$ & $-19,1$ & $-19,7$ & $-12,5$ \\
\hline $\mathrm{C}_{2} \mathrm{H}_{2}$ & ${ }^{1} J_{\mathrm{CC}}$ & 187,4 & 192,0 & 197,1 & 202,6 & 208,8 & 215,7 & 223,5 & 232,3 & 242,5 & 254,4 & 268,4 & 174,1 \\
\hline $\mathrm{C}_{2} \mathrm{H}_{2}$ & ${ }^{1} J_{\mathrm{CH}}$ & 253,4 & 258,1 & 263,0 & 268,0 & 273,2 & 278,7 & 284,6 & 290,9 & 297,7 & 305,1 & 313,5 & 244,3 \\
\hline $\mathrm{C}_{2} \mathrm{H}_{2}$ & ${ }^{2} J_{\mathrm{CH}}$ & 53,0 & 53,0 & 52,8 & 52,4 & 51,7 & 50,7 & 49,3 & 47,6 & 45,2 & 42,1 & 38,1 & 49,8 \\
\hline $\mathrm{C}_{2} \mathrm{H}_{2}$ & ${ }^{3} J_{\mathrm{HH}}$ & 11,6 & 12,2 & 12,9 & 13,7 & 14,7 & 15,9 & 17,3 & 18,9 & 20,9 & 23,2 & 26,0 & 9,0 \\
\hline $\mathrm{C}_{2} \mathrm{H}_{4}$ & ${ }^{1} J_{\mathrm{CC}}$ & 60,8 & 64,6 & 68,7 & 73,2 & 78,2 & 83,9 & 90,5 & 98,4 & 108,1 & 120,9 & 139,0 & 66,9 \\
\hline $\mathrm{C}_{2} \mathrm{H}_{4}$ & ${ }^{1} J_{\mathrm{CH}}$ & 152,7 & 156,5 & 160,4 & 164,4 & 168,6 & 173,1 & 177,9 & 183,2 & 189,3 & 196,5 & 205,7 & 154,4 \\
\hline $\mathrm{C}_{2} \mathrm{H}_{4}$ & ${ }^{2} J_{\mathrm{CH}}$ & $-1,1$ & $-2,0$ & $-3,1$ & $-4,3$ & $-5,6$ & $-7,2$ & $-9,2$ & $-11,6$ & $-14,8$ & $-19,1$ & $-25,4$ & $-2,0$ \\
\hline $\mathrm{C}_{2} \mathrm{H}_{4}$ & ${ }^{2} J_{\mathrm{HH}}$ & 3,4 & 2,8 & 2,2 & 1,5 & 0,8 & 0,0 & $-1,1$ & $-2,3$ & $-3,9$ & $-6,1$ & $-9,3$ & 2,1 \\
\hline $\mathrm{C}_{2} \mathrm{H}_{4}$ & ${ }^{3} J_{\mathrm{HH}_{\mathrm{c}}}$ & 12,2 & 12,6 & 13,1 & 13,6 & 14,2 & 14,9 & 15,8 & 17,0 & 18,5 & 20,6 & 23,7 & 11,4 \\
\hline $\mathrm{C}_{2} \mathrm{H}_{4}$ & ${ }^{3} J_{\mathrm{HH}_{\mathrm{t}}}$ & 19,4 & 19,8 & 20,3 & 21,0 & 21,7 & 22,6 & 23,6 & 25,0 & 26,8 & 29,3 & 32,9 & 18,4 \\
\hline $\mathrm{C}_{2} \mathrm{H}_{6}$ & ${ }^{1} J_{\mathrm{CC}}$ & 25,4 & 27,9 & 30,4 & 33,0 & 35,6 & 38,4 & 41,1 & 43,9 & 46,8 & 49,7 & 52,7 & 33,6 \\
\hline $\mathrm{C}_{2} \mathrm{H}_{6}$ & ${ }^{1} J_{\mathrm{CH}}$ & 118,4 & 121,5 & 124,6 & 127,8 & 131,0 & 134,2 & 137,5 & 140,8 & 144,1 & 147,5 & 150,9 & 123,3 \\
\hline $\mathrm{C}_{2} \mathrm{H}_{6}$ & ${ }^{2} J_{\mathrm{CH}}$ & $-3,3$ & $-3,7$ & $-4,1$ & $-4,5$ & $-5,0$ & $-5,4$ & $-5,9$ & $-6,4$ & $-6,8$ & $-7,3$ & $-7,8$ & $-4,5$ \\
\hline \multirow[t]{3}{*}{ Total } & $\mathrm{DM}$ & $-23,59$ & $-20,55$ & $-17,40$ & $-14,19$ & $-11,04$ & $-8,09$ & $-5,56$ & $-3,88$ & $-4,16$ & $-10,08$ & $-50,34$ & - \\
\hline & DMA & 30,57 & 25,42 & 23,23 & 21,68 & 20,61 & 20,76 & 24,82 & 32,25 & 42,00 & 57,96 & 109,57 & - \\
\hline & PDMA & 45,28 & 33,81 & 28,69 & 27,09 & 28,24 & 32,59 & 48,96 & 67,81 & 90,09 & 118,32 & 165,55 & - \\
\hline \multirow[t]{3}{*}{ CPI } & DM & $-56,45$ & $-51,45$ & $-46,31$ & $-41,14$ & $-36,23$ & $-31,97$ & $-28,89$ & $-28,14$ & $-32,35$ & $-50,44$ & $-150,53$ & - \\
\hline & DMA & 66,86 & 54,91 & 48,64 & 42,59 & 37,05 & 34,03 & 39,87 & 53,05 & 71,01 & 102,67 & 217,07 & - \\
\hline & PDMA & 85,37 & 65,39 & 50,00 & 36,34 & 24,60 & 17,97 & 35,73 & 55,77 & 77,37 & 103,38 & 157,92 & - \\
\hline \multirow[t]{3}{*}{ SPI } & DM & 0,50 & 2,12 & 3,81 & 5,57 & 7,43 & 9,43 & 11,55 & 13,90 & 16,52 & 19,51 & 23,13 & - \\
\hline & DMA & 3,95 & 3,79 & 4,61 & 6,35 & 8,56 & 11,03 & 13,79 & 17,01 & 20,73 & 25,17 & 30,73 & - \\
\hline & PDMA & 15,88 & 10,65 & 13,06 & 20,30 & 30,90 & 43,31 & 58,66 & 76,64 & 99,42 & 129,28 & 171,15 & - \\
\hline \multirow[t]{3}{*}{$\Delta \mathrm{CS}$} & DM & $-56,95$ & $-53,57$ & $-50,12$ & $-46,70$ & $-43,65$ & $-41,40$ & $-40,44$ & $-42,04$ & $-48,87$ & $-69,95$ & $-173,66$ & - \\
\hline & DMA & 62,91 & 51,12 & 44,03 & 36,24 & 28,49 & 23,00 & 26,09 & 36,04 & 50,28 & 77,51 & 186,34 & - \\
\hline & PDMA & 69,49 & 54,74 & 36,94 & 16,04 & $-6,30$ & $-25,34$ & $-22,92$ & $-20,86$ & $-22,05$ & $-25,90$ & $-13,23$ & - \\
\hline
\end{tabular}


Tabela 8.131: Constantes de acoplamento PBE e constantes empíricas no nível BHandH $\left(50 \% E_{X}^{\mathrm{HF}}\right)$ e base aug-pcJ-2.

\begin{tabular}{|c|c|c|c|c|c|c|c|c|c|c|c|c|c|}
\hline & $\% E_{X}^{\mathrm{HF}}$ & $0 \%$ & $10 \%$ & $20 \%$ & $30 \%$ & $40 \%$ & $50 \%$ & $60 \%$ & $70 \%$ & $80 \%$ & $90 \%$ & $100 \%$ & Emp. \\
\hline $\mathrm{HF}$ & ${ }^{1} J_{\mathrm{HF}}$ & 376,0 & 397,8 & 419,7 & 441,9 & 464,3 & 486,9 & 509,8 & 532,8 & 556,1 & 579,6 & 603,3 & 532,8 \\
\hline $\mathrm{CO}$ & ${ }^{1} J_{\mathrm{CO}}$ & 24,1 & 22,5 & 20,8 & 19,1 & 17,3 & 15,4 & 13,5 & 11,5 & 9,5 & 7,4 & 5,3 & 15,7 \\
\hline $\mathrm{H}_{2} \mathrm{O}$ & ${ }^{1} J_{\mathrm{OH}}$ & $-67,2$ & $-69,5$ & $-71,8$ & $-74,2$ & $-76,6$ & $-79,0$ & $-81,4$ & $-83,9$ & $-86,4$ & $-88,9$ & $-91,5$ & $-81,7$ \\
\hline $\mathrm{H}_{2} \mathrm{O}$ & ${ }^{2} J_{\mathrm{HH}}$ & $-4,7$ & $-5,7$ & $-6,7$ & $-7,8$ & $-8,9$ & $-10,0$ & $-11,1$ & $-12,3$ & $-13,5$ & $-14,7$ & $-15,9$ & $-8,8$ \\
\hline $\mathrm{NH}_{3}$ & ${ }^{1} J_{\mathrm{NH}}$ & 40,8 & 41,5 & 42,2 & 42,9 & 43,6 & 44,3 & 45,1 & 45,8 & 46,6 & 47,4 & 48,2 & 43,0 \\
\hline $\mathrm{NH}_{3}$ & ${ }^{2} J_{\mathrm{HH}}$ & $-7,8$ & $-8,7$ & $-9,6$ & $-10,6$ & $-11,5$ & $-12,5$ & $-13,5$ & $-14,5$ & $-15,5$ & $-16,6$ & $-17,6$ & $-10,5$ \\
\hline $\mathrm{PH}_{3}$ & ${ }^{1} J_{\mathrm{PH}}$ & 133,7 & 142,1 & 150,4 & 158,7 & 166,9 & 175,1 & 183,1 & 191,1 & 198,9 & 206,7 & 214,3 & 195,0 \\
\hline $\mathrm{PF}_{3}$ & ${ }^{1} J_{\mathrm{PF}}$ & $-1801,0$ & $-1776,9$ & $-1748,1$ & $-1715,3$ & $-1679,4$ & $-1640,8$ & $-1600,3$ & $-1558,1$ & $-1514,9$ & $-1470,9$ & $-1426,5$ & $-1441,7$ \\
\hline $\mathrm{BHF}_{2}$ & ${ }^{1} J_{\mathrm{BF}}$ & $-172,8$ & $-155,9$ & $-139,2$ & $-122,7$ & $-106,5$ & $-90,4$ & $-74,6$ & $-59,0$ & $-43,7$ & $-28,6$ & $-13,8$ & $-79,7$ \\
\hline $\mathrm{BF}_{3}$ & ${ }^{1} J_{\mathrm{BF}}$ & $-75,8$ & $-57,5$ & $-39,4$ & $-21,7$ & $-4,2$ & 12,9 & 29,9 & 46,6 & 63,0 & 79,2 & 95,2 & 17,1 \\
\hline $\mathrm{F}_{2} \mathrm{O}$ & ${ }^{1} J_{\mathrm{OF}}$ & $-278,0$ & $-316,3$ & $-354,9$ & $-395,6$ & $-440,5$ & $-493,5$ & $-560,8$ & $-655,5$ & $-809,2$ & $-1129,5$ & $-2453,2$ & $-285,7$ \\
\hline $\mathrm{CH}_{4}$ & ${ }^{1} J_{\mathrm{CH}}$ & 119,3 & 120,7 & 122,1 & 123,5 & 125,0 & 126,5 & 128,0 & 129,6 & 131,2 & 132,8 & 134,4 & 122,8 \\
\hline $\mathrm{CH}_{4}$ & ${ }^{2} J_{\mathrm{HH}}$ & $-11,8$ & $-12,6$ & $-13,4$ & $-14,2$ & $-15,0$ & $-15,8$ & $-16,6$ & $-17,4$ & $-18,2$ & $-19,0$ & $-19,8$ & $-12,5$ \\
\hline $\mathrm{C}_{2} \mathrm{H}_{2}$ & ${ }^{1} J_{\mathrm{CC}}$ & 188,7 & 191,5 & 194,6 & 198,3 & 202,6 & 207,6 & 213,7 & 221,0 & 230,2 & 241,9 & 257,1 & 174,1 \\
\hline $\mathrm{C}_{2} \mathrm{H}_{2}$ & ${ }^{1} J_{\mathrm{CH}}$ & 249,8 & 252,2 & 254,8 & 257,6 & 260,7 & 264,1 & 268,0 & 272,5 & 277,9 & 284,6 & 293,3 & 244,3 \\
\hline $\mathrm{C}_{2} \mathrm{H}_{2}$ & ${ }^{2} J_{\mathrm{CH}}$ & 54,1 & 54,1 & 53,7 & 53,2 & 52,2 & 50,9 & 49,0 & 46,5 & 42,9 & 38,1 & 31,2 & 49,8 \\
\hline $\mathrm{C}_{2} \mathrm{H}_{2}$ & ${ }^{3} J_{\mathrm{HH}}$ & 10,4 & 11,1 & 11,9 & 12,9 & 14,1 & 15,6 & 17,4 & 19,6 & 22,5 & 26,1 & 30,9 & 9,0 \\
\hline $\mathrm{C}_{2} \mathrm{H}_{4}$ & ${ }^{1} J_{\mathrm{CC}}$ & 61,3 & 64,0 & 67,0 & 70,4 & 74,4 & 79,1 & 85,0 & 92,8 & 103,6 & 120,3 & 150,7 & 66,9 \\
\hline $\mathrm{C}_{2} \mathrm{H}_{4}$ & ${ }^{1} J_{\mathrm{CH}}$ & 151,8 & 153,9 & 156,1 & 158,5 & 161,1 & 164,0 & 167,5 & 171,6 & 177,1 & 185,2 & 199,0 & 154,4 \\
\hline $\mathrm{C}_{2} \mathrm{H}_{4}$ & ${ }^{2} J_{\mathrm{CH}}$ & $-0,5$ & $-1,4$ & $-2,5$ & $-3,7$ & $-5,1$ & $-6,9$ & $-9,1$ & $-12,2$ & $-16,5$ & $-23,4$ & $-36,1$ & $-2,0$ \\
\hline $\mathrm{C}_{2} \mathrm{H}_{4}$ & ${ }^{2} J_{\mathrm{HH}}$ & 4,5 & 3,7 & 2,8 & 1,8 & 0,7 & $-0,5$ & $-2,1$ & $-4,1$ & $-7,0$ & $-11,4$ & $-19,4$ & 2,1 \\
\hline $\mathrm{C}_{2} \mathrm{H}_{4}$ & ${ }^{3} J_{\mathrm{HH}_{\mathrm{c}}}$ & 11,7 & 12,1 & 12,5 & 13,0 & 13,6 & 14,5 & 15,7 & 17,3 & 19,7 & 23,7 & 31,3 & 11,4 \\
\hline $\mathrm{C}_{2} \mathrm{H}_{4}$ & ${ }^{3} J_{\mathrm{HH}_{\mathrm{t}}}$ & 18,7 & 19,0 & 19,5 & 20,1 & 20,9 & 21,9 & 23,3 & 25,2 & 28,0 & 32,5 & 41,0 & 18,4 \\
\hline $\mathrm{C}_{2} \mathrm{H}_{6}$ & ${ }^{1} J_{\mathrm{CC}}$ & 25,7 & 27,6 & 29,4 & 31,3 & 33,3 & 35,2 & 37,2 & 39,3 & 41,3 & 43,4 & 45,6 & 33,6 \\
\hline $\mathrm{C}_{2} \mathrm{H}_{6}$ & ${ }^{1} J_{\mathrm{CH}}$ & 119,5 & 121,1 & 122,7 & 124,3 & 126,0 & 127,7 & 129,4 & 131,2 & 133,0 & 134,8 & 136,6 & 123,3 \\
\hline $\mathrm{C}_{2} \mathrm{H}_{6}$ & ${ }^{2} J_{\mathrm{CH}}$ & $-2,9$ & $-3,4$ & $-3,9$ & $-4,3$ & $-4,9$ & $-5,4$ & $-5,9$ & $-6,4$ & $-7,0$ & $-7,5$ & $-8,1$ & $-4,5$ \\
\hline \multirow[t]{3}{*}{ Total } & $\mathrm{DM}$ & $-27,65$ & $-25,37$ & $-22,92$ & $-20,35$ & $-17,79$ & $-15,37$ & $-13,32$ & $-12,14$ & $-12,96$ & $-19,75$ & $-64,27$ & - \\
\hline & DMA & 33,04 & 30,00 & 27,62 & 25,70 & 24,21 & 23,30 & 24,65 & 28,67 & 37,50 & 53,84 & 111,65 & - \\
\hline & PDMA & 46,40 & 36,32 & 28,42 & 24,75 & 25,89 & 30,17 & 43,81 & 64,19 & 90,94 & 129,53 & 203,23 & - \\
\hline \multirow[t]{3}{*}{ CPI } & DM & $-66,20$ & $-62,01$ & $-57,46$ & $-52,80$ & $-48,27$ & $-44,28$ & $-41,44$ & $-41,00$ & $-45,87$ & $-65,85$ & $-177,06$ & - \\
\hline & DMA & 73,00 & 66,35 & 60,74 & 54,96 & 49,60 & 45,01 & 45,13 & 50,64 & 66,36 & 97,87 & 223,28 & - \\
\hline & PDMA & 81,57 & 66,58 & 52,14 & 37,94 & 25,87 & 16,75 & 24,81 & 41,07 & 60,27 & 85,13 & 141,90 & - \\
\hline \multirow[t]{3}{*}{ SPI } & $\mathrm{DM}$ & 0,61 & 1,50 & 2,41 & 3,44 & 4,57 & 5,83 & 7,29 & 9,03 & 11,17 & 14,07 & 18,44 & - \\
\hline & DMA & 3,73 & 3,34 & 3,33 & 4,24 & 5,59 & 7,39 & 9,64 & 12,56 & 16,33 & 21,55 & 29,79 & - \\
\hline & PDMA & 20,60 & 14,14 & 11,03 & 15,08 & 25,90 & 40,01 & 57,74 & 81,13 & 113,43 & 162,09 & 248,21 & - \\
\hline \multirow[t]{3}{*}{$\Delta \mathrm{CS}$} & DM & $-66,81$ & $-63,51$ & $-59,88$ & $-56,24$ & $-52,84$ & $-50,11$ & $-48,73$ & $-50,03$ & $-57,05$ & $-79,92$ & $-195,50$ & - \\
\hline & DMA & 69,27 & 63,01 & 57,40 & 50,72 & 44,01 & 37,62 & 35,49 & 38,08 & 50,03 & 76,33 & 193,50 & - \\
\hline & PDMA & 60,97 & 52,45 & 41,11 & 22,86 & $-0,02$ & $-23,26$ & $-32,93$ & $-40,06$ & $-53,17$ & $-76,96$ & $-106,31$ & - \\
\hline
\end{tabular}


Tabela 8.132: Constantes de acoplamento PW91 e constantes empíricas no nível BHandH $\left(50 \% E_{X}^{\mathrm{HF}}\right)$ e base aug-pcJ-2.

\begin{tabular}{|c|c|c|c|c|c|c|c|c|c|c|c|c|c|}
\hline & $\% E_{X}^{\mathrm{HF}}$ & $0 \%$ & $10 \%$ & $20 \%$ & $30 \%$ & $40 \%$ & $50 \%$ & $60 \%$ & $70 \%$ & $80 \%$ & $90 \%$ & $100 \%$ & Emp. \\
\hline $\mathrm{HF}$ & ${ }^{1} J_{\mathrm{HF}}$ & 364,2 & 387,4 & 410,8 & 434,5 & 458,3 & 482,4 & 506,7 & 531,2 & 556,0 & 581,0 & 606,3 & 532,8 \\
\hline $\mathrm{CO}$ & ${ }^{1} J_{\mathrm{CO}}$ & 24,9 & 23,2 & 21,5 & 19,6 & 17,7 & 15,8 & 13,7 & 11,6 & 9,4 & 7,2 & 4,9 & 15,7 \\
\hline $\mathrm{H}_{2} \mathrm{O}$ & ${ }^{1} J_{\mathrm{OH}}$ & $-66,3$ & $-68,7$ & $-71,2$ & $-73,7$ & $-76,2$ & $-78,7$ & $-81,3$ & $-83,9$ & $-86,5$ & $-89,2$ & $-91,9$ & $-81,7$ \\
\hline $\mathrm{H}_{2} \mathrm{O}$ & ${ }^{2} J_{\mathrm{HH}}$ & $-4,8$ & $-5,8$ & $-6,8$ & $-7,9$ & $-9,0$ & $-10,1$ & $-11,2$ & $-12,4$ & $-13,5$ & $-14,7$ & $-16,0$ & $-8,8$ \\
\hline $\mathrm{NH}_{3}$ & ${ }^{1} J_{\mathrm{NH}}$ & 40,8 & 41,5 & 42,2 & 42,9 & 43,7 & 44,5 & 45,2 & 46,0 & 46,8 & 47,6 & 48,4 & 43,0 \\
\hline $\mathrm{NH}_{3}$ & ${ }^{2} J_{\mathrm{HH}}$ & $-8,0$ & $-8,9$ & $-9,8$ & $-10,8$ & $-11,7$ & $-12,7$ & $-13,6$ & $-14,6$ & $-15,6$ & $-16,6$ & $-17,7$ & $-10,5$ \\
\hline $\mathrm{PH}_{3}$ & ${ }^{1} J_{\mathrm{PH}}$ & 137,6 & 145,9 & 154,0 & 162,1 & 170,0 & 177,9 & 185,7 & 193,3 & 200,8 & 208,2 & 215,5 & 195,0 \\
\hline $\mathrm{PF}_{3}$ & ${ }^{1} J_{\mathrm{PF}}$ & $-1815,2$ & $-1790,1$ & $-1760,3$ & $-1726,4$ & $-1689,3$ & $-1649,5$ & $-1607,6$ & $-1564,2$ & $-1519,7$ & $-1474,3$ & $-1428,5$ & $-1441,7$ \\
\hline $\mathrm{BHF}_{2}$ & ${ }^{1} J_{\mathrm{BF}}$ & $-177,6$ & $-160,4$ & $-143,4$ & $-126,4$ & $-109,6$ & $-93,0$ & $-76,5$ & $-60,2$ & $-44,1$ & $-28,2$ & $-12,5$ & $-79,7$ \\
\hline $\mathrm{BF}_{3}$ & ${ }^{1} J_{\mathrm{BF}}$ & $-80,9$ & $-62,3$ & $-43,8$ & $-25,6$ & $-7,6$ & 10,2 & 27,8 & 45,3 & 62,5 & 79,6 & 96,6 & 17,1 \\
\hline $\mathrm{F}_{2} \mathrm{O}$ & ${ }^{1} J_{\mathrm{OF}}$ & $-290,5$ & $-328,8$ & $-367,5$ & $-408,1$ & $-453,0$ & $-506,0$ & $-573,5$ & $-668,7$ & $-823,8$ & $-1148,9$ & $-2525,8$ & $-285,7$ \\
\hline $\mathrm{CH}_{4}$ & ${ }^{1} J_{\mathrm{CH}}$ & 120,1 & 121,5 & 122,9 & 124,3 & 125,8 & 127,3 & 128,8 & 130,4 & 131,9 & 133,5 & 135,2 & 122,8 \\
\hline $\mathrm{CH}_{4}$ & ${ }^{2} J_{\mathrm{HH}}$ & $-12,0$ & $-12,8$ & $-13,6$ & $-14,4$ & $-15,2$ & $-15,9$ & $-16,7$ & $-17,5$ & $-18,3$ & $-19,1$ & $-19,9$ & $-12,5$ \\
\hline $\mathrm{C}_{2} \mathrm{H}_{2}$ & ${ }^{1} J_{\mathrm{CC}}$ & 188,8 & 191,6 & 194,7 & 198,5 & 202,8 & 208,0 & 214,2 & 221,8 & 231,3 & 243,3 & 259,0 & 174,1 \\
\hline $\mathrm{C}_{2} \mathrm{H}_{2}$ & ${ }^{1} J_{\mathrm{CH}}$ & 252,5 & 254,8 & 257,3 & 259,9 & 262,8 & 266,1 & 269,8 & 274,3 & 279,6 & 286,1 & 294,6 & 244,3 \\
\hline $\mathrm{C}_{2} \mathrm{H}_{2}$ & ${ }^{2} J_{\mathrm{CH}}$ & 54,6 & 54,5 & 54,1 & 53,5 & 52,6 & 51,2 & 49,2 & 46,6 & 43,0 & 38,0 & 31,2 & 49,8 \\
\hline $\mathrm{C}_{2} \mathrm{H}_{2}$ & ${ }^{3} J_{\mathrm{HH}}$ & 10,5 & 11,2 & 12,0 & 13,0 & 14,2 & 15,7 & 17,5 & 19,7 & 22,5 & 26,1 & 30,7 & 9,0 \\
\hline $\mathrm{C}_{2} \mathrm{H}_{4}$ & ${ }^{1} J_{\mathrm{CC}}$ & 60,6 & 63,3 & 66,4 & 69,9 & 74,0 & 78,9 & 85,0 & 92,9 & 104,1 & 121,2 & 152,0 & 66,9 \\
\hline $\mathrm{C}_{2} \mathrm{H}_{4}$ & ${ }^{1} J_{\mathrm{CH}}$ & 153,0 & 155,1 & 157,3 & 159,6 & 162,2 & 165,1 & 168,5 & 172,7 & 178,2 & 186,2 & 200,0 & 154,4 \\
\hline $\mathrm{C}_{2} \mathrm{H}_{4}$ & ${ }^{2} J_{\mathrm{CH}}$ & $-0,4$ & $-1,3$ & $-2,3$ & $-3,5$ & $-5,0$ & $-6,8$ & $-9,1$ & $-12,1$ & $-16,5$ & $-23,5$ & $-36,2$ & $-2,0$ \\
\hline $\mathrm{C}_{2} \mathrm{H}_{4}$ & ${ }^{2} J_{\mathrm{HH}}$ & 4,5 & 3,6 & 2,8 & 1,8 & 0,7 & $-0,5$ & $-2,1$ & $-4,2$ & $-7,1$ & $-11,4$ & $-19,2$ & 2,1 \\
\hline $\mathrm{C}_{2} \mathrm{H}_{4}$ & ${ }^{3} J_{\mathrm{HH}_{\mathrm{c}}}$ & 11,9 & 12,2 & 12,6 & 13,1 & 13,8 & 14,7 & 15,8 & 17,4 & 19,8 & 23,8 & 31,2 & 11,4 \\
\hline $\mathrm{C}_{2} \mathrm{H}_{4}$ & ${ }^{3} J_{\mathrm{HH}_{\mathrm{t}}}$ & 19,0 & 19,3 & 19,8 & 20,4 & 21,1 & 22,1 & 23,5 & 25,4 & 28,1 & 32,6 & 40,9 & 18,4 \\
\hline $\mathrm{C}_{2} \mathrm{H}_{6}$ & ${ }^{1} J_{\mathrm{CC}}$ & 25,1 & 27,0 & 29,0 & 31,0 & 33,1 & 35,1 & 37,3 & 39,4 & 41,6 & 43,8 & 46,1 & 33,6 \\
\hline $\mathrm{C}_{2} \mathrm{H}_{6}$ & ${ }^{1} J_{\mathrm{CH}}$ & 120,3 & 121,9 & 123,5 & 125,1 & 126,8 & 128,5 & 130,2 & 132,0 & 133,7 & 135,5 & 137,3 & 123,3 \\
\hline $\mathrm{C}_{2} \mathrm{H}_{6}$ & ${ }^{2} J_{\mathrm{CH}}$ & $-2,9$ & $-3,4$ & $-3,9$ & $-4,4$ & $-4,9$ & $-5,4$ & $-5,9$ & $-6,4$ & $-7,0$ & $-7,5$ & $-8,1$ & $-4,5$ \\
\hline \multirow[t]{3}{*}{ Total } & $\mathrm{DM}$ & $-29,11$ & $-26,73$ & $-24,17$ & $-21,48$ & $-18,79$ & $-16,22$ & $-14,05$ & $-12,72$ & $-13,44$ & $-20,24$ & $-66,63$ & - \\
\hline & DMA & 34,30 & 31,79 & 29,32 & 27,32 & 25,70 & 24,63 & 25,50 & 29,53 & 38,55 & 55,16 & 114,95 & - \\
\hline & PDMA & 48,32 & 38,26 & 29,85 & 26,05 & 27,39 & 31,28 & 43,71 & 64,34 & 91,58 & 130,54 & 204,82 & - \\
\hline \multirow[t]{3}{*}{ CPI } & DM & $-70,12$ & $-65,68$ & $-60,89$ & $-55,94$ & $-51,11$ & $-46,79$ & $-43,65$ & $-42,92$ & $-47,56$ & $-67,62$ & $-183,29$ & - \\
\hline & DMA & 75,77 & 70,25 & 64,35 & 58,26 & 52,60 & 47,63 & 46,65 & 52,14 & 68,25 & 100,35 & 230,44 & - \\
\hline & PDMA & 85,13 & 70,35 & 55,62 & 41,29 & 29,03 & 19,12 & 23,97 & 40,80 & 60,73 & 86,32 & 145,70 & - \\
\hline \multirow[t]{3}{*}{ SPI } & DM & 0,97 & 1,83 & 2,77 & 3,78 & 4,91 & 6,20 & 7,66 & 9,42 & 11,59 & 14,50 & 18,91 & - \\
\hline & DMA & 3,89 & 3,59 & 3,63 & 4,62 & 5,98 & 7,76 & 9,99 & 12,95 & 16,76 & 22,02 & 30,26 & - \\
\hline & PDMA & 21,32 & 14,74 & 10,95 & 14,87 & 26,18 & 40,20 & 58,19 & 81,61 & 114,21 & 162,97 & 248,18 & - \\
\hline \multirow[t]{3}{*}{$\Delta \mathrm{CS}$} & DM & $-71,08$ & $-67,51$ & $-63,66$ & $-59,72$ & $-56,02$ & $-52,99$ & $-51,31$ & $-52,34$ & $-59,15$ & $-82,12$ & $-202,20$ & - \\
\hline & DMA & 71,89 & 66,66 & 60,71 & 53,64 & 46,62 & 39,87 & 36,65 & 39,18 & 51,49 & 78,33 & 200,18 & - \\
\hline & PDMA & 63,81 & 55,61 & 44,66 & 26,42 & 2,84 & $-21,08$ & $-34,22$ & $-40,80$ & $-53,47$ & $-76,65$ & $-102,47$ & - \\
\hline
\end{tabular}


Tabela 8.133: Constantes de acoplamento TPSSh e constantes empíricas no nível BHandH $\left(50 \% E_{X}^{\mathrm{HF}}\right)$ e base aug-pcJ-2.

\begin{tabular}{|c|c|c|c|c|c|c|c|c|c|c|c|c|c|}
\hline & $\% E_{X}^{\mathrm{HF}}$ & $0 \%$ & $10 \%$ & $20 \%$ & $30 \%$ & $40 \%$ & $50 \%$ & $60 \%$ & $70 \%$ & $80 \%$ & $90 \%$ & $100 \%$ & Emp. \\
\hline $\mathrm{HF}$ & ${ }^{1} J_{\mathrm{HF}}$ & 366,0 & 390,6 & 415,1 & 439,7 & 464,2 & 488,7 & 513,1 & 537,4 & 561,6 & 585,8 & 610,0 & 532,8 \\
\hline $\mathrm{CO}$ & ${ }^{1} J_{\mathrm{CO}}$ & 21,7 & 20,3 & 18,8 & 17,3 & 15,7 & 14,0 & 12,3 & 10,5 & 8,7 & 6,8 & 4,9 & 15,7 \\
\hline $\mathrm{H}_{2} \mathrm{O}$ & ${ }^{1} J_{\mathrm{OH}}$ & $-70,2$ & $-72,5$ & $-74,9$ & $-77,3$ & $-79,6$ & $-82,0$ & $-84,3$ & $-86,6$ & $-88,9$ & $-91,1$ & $-93,4$ & $-81,7$ \\
\hline $\mathrm{H}_{2} \mathrm{O}$ & ${ }^{2} J_{\mathrm{HH}}$ & $-4,0$ & $-5,3$ & $-6,6$ & $-7,8$ & $-9,1$ & $-10,3$ & $-11,5$ & $-12,7$ & $-13,9$ & $-15,1$ & $-16,2$ & $-8,8$ \\
\hline $\mathrm{NH}_{3}$ & ${ }^{1} J_{\mathrm{NH}}$ & 45,3 & 45,8 & 46,4 & 46,9 & 47,3 & 47,8 & 48,3 & 48,8 & 49,2 & 49,7 & 50,1 & 43,0 \\
\hline $\mathrm{NH}_{3}$ & ${ }^{2} J_{\mathrm{HH}}$ & $-6,9$ & $-8,1$ & $-9,3$ & $-10,4$ & $-11,6$ & $-12,7$ & $-13,8$ & $-14,9$ & $-15,9$ & $-17,0$ & $-17,9$ & $-10,5$ \\
\hline $\mathrm{PH}_{3}$ & ${ }^{1} J_{\mathrm{PH}}$ & 195,7 & 200,5 & 205,0 & 209,3 & 213,4 & 217,2 & 220,8 & 224,1 & 227,2 & 230,0 & 232,6 & 195,0 \\
\hline $\mathrm{PF}_{3}$ & ${ }^{1} J_{\mathrm{PF}}$ & $-1757,5$ & $-1731,7$ & $-1703,3$ & $-1673,0$ & $-1641,1$ & $-1608,0$ & $-1574,1$ & $-1539,7$ & $-1504,9$ & $-1470,0$ & $-1435,2$ & $-1441,7$ \\
\hline $\mathrm{BHF}_{2}$ & ${ }^{1} J_{\mathrm{BF}}$ & $-156,7$ & $-142,5$ & $-128,4$ & $-114,3$ & $-100,2$ & $-86,1$ & $-72,1$ & $-58,1$ & $-44,2$ & $-30,3$ & $-16,4$ & $-79,7$ \\
\hline $\mathrm{BF}_{3}$ & ${ }^{1} J_{\mathrm{BF}}$ & $-63,8$ & $-47,2$ & $-30,7$ & $-14,3$ & 1,8 & 17,8 & 33,8 & 49,6 & 65,2 & 80,8 & 96,3 & 17,1 \\
\hline $\mathrm{F}_{2} \mathrm{O}$ & ${ }^{1} J_{\mathrm{OF}}$ & $-282,7$ & $-320,1$ & $-359,5$ & $-402,5$ & $-451,3$ & $-510,0$ & $-585,2$ & $-690,4$ & $-857,9$ & $-1192,7$ & $-2403,5$ & $-285,7$ \\
\hline $\mathrm{CH}_{4}$ & ${ }^{1} J_{\mathrm{CH}}$ & 138,0 & 138,8 & 139,6 & 140,4 & 141,1 & 141,9 & 142,6 & 143,2 & 143,8 & 144,4 & 144,9 & 122,8 \\
\hline $\mathrm{CH}_{4}$ & ${ }^{2} J_{\mathrm{HH}}$ & $-10,2$ & $-11,3$ & $-12,4$ & $-13,4$ & $-14,5$ & $-15,5$ & $-16,5$ & $-17,4$ & $-18,4$ & $-19,3$ & $-20,2$ & $-12,5$ \\
\hline $\mathrm{C}_{2} \mathrm{H}_{2}$ & ${ }^{1} J_{\mathrm{CC}}$ & 187,5 & 190,8 & 194,6 & 198,9 & 203,9 & 209,8 & 216,7 & 225,0 & 234,9 & 247,0 & 262,1 & 174,1 \\
\hline $\mathrm{C}_{2} \mathrm{H}_{2}$ & ${ }^{1} J_{\mathrm{CH}}$ & 280,6 & 282,3 & 284,1 & 286,1 & 288,3 & 290,8 & 293,7 & 297,1 & 301,3 & 306,4 & 312,9 & 244,3 \\
\hline $\mathrm{C}_{2} \mathrm{H}_{2}$ & ${ }^{2} J_{\mathrm{CH}}$ & 58,3 & 57,7 & 56,9 & 55,8 & 54,3 & 52,4 & 50,0 & 46,9 & 43,0 & 38,0 & 31,5 & 49,8 \\
\hline $\mathrm{C}_{2} \mathrm{H}_{2}$ & ${ }^{3} J_{\mathrm{HH}}$ & 12,0 & 12,6 & 13,5 & 14,5 & 15,7 & 17,3 & 19,1 & 21,4 & 24,1 & 27,5 & 31,8 & 9,0 \\
\hline $\mathrm{C}_{2} \mathrm{H}_{4}$ & ${ }^{1} J_{\mathrm{CC}}$ & 68,8 & 71,5 & 74,5 & 78,0 & 82,1 & 87,0 & 93,1 & 100,9 & 111,6 & 127,4 & 153,5 & 66,9 \\
\hline $\mathrm{C}_{2} \mathrm{H}_{4}$ & ${ }^{1} J_{\mathrm{CH}}$ & 172,7 & 174,3 & 176,1 & 178,0 & 180,1 & 182,5 & 185,3 & 188,9 & 193,6 & 200,5 & 211,7 & 154,4 \\
\hline $\mathrm{C}_{2} \mathrm{H}_{4}$ & ${ }^{2} J_{\mathrm{CH}}$ & $-0,6$ & $-1,7$ & $-3,0$ & $-4,5$ & $-6,2$ & $-8,3$ & $-10,9$ & $-14,3$ & $-18,9$ & $-25,6$ & $-36,8$ & $-2,0$ \\
\hline $\mathrm{C}_{2} \mathrm{H}_{4}$ & ${ }^{2} J_{\mathrm{HH}}$ & 9,4 & 8,2 & 6,8 & 5,4 & 3,8 & 2,0 & 0,0 & $-2,5$ & $-5,8$ & $-10,3$ & $-17,4$ & 2,1 \\
\hline $\mathrm{C}_{2} \mathrm{H}_{4}$ & ${ }^{3} J_{\mathrm{HH}_{\mathrm{C}}}$ & 12,0 & 12,5 & 13,0 & 13,7 & 14,5 & 15,5 & 16,9 & 18,6 & 21,1 & 24,9 & 31,3 & 11,4 \\
\hline $\mathrm{C}_{2} \mathrm{H}_{4}$ & ${ }^{3} J_{\mathrm{HH}_{\mathrm{t}}}{ }^{\mathrm{C}}$ & 22,1 & 22,5 & 22,9 & 23,5 & 24,2 & 25,2 & 26,6 & 28,4 & 31,1 & 35,2 & 42,2 & 18,4 \\
\hline $\mathrm{C}_{2} \mathrm{H}_{6}$ & ${ }^{1} J_{\mathrm{CC}}$ & 32,9 & 34,4 & 35,8 & 37,2 & 38,7 & 40,1 & 41,5 & 42,9 & 44,2 & 45,6 & 46,9 & 33,6 \\
\hline $\mathrm{C}_{2} \mathrm{H}_{6}$ & ${ }^{1} J_{\mathrm{CH}}$ & 137,9 & 138,9 & 140,0 & 141,0 & 141,9 & 142,9 & 143,8 & 144,7 & 145,5 & 146,3 & 147,1 & 123,3 \\
\hline $\mathrm{C}_{2} \mathrm{H}_{6}$ & ${ }^{2} J_{\mathrm{CH}}$ & $-3,3$ & $-3,8$ & $-4,3$ & $-4,9$ & $-5,4$ & $-5,9$ & $-6,4$ & $-7,0$ & $-7,5$ & $-8,0$ & $-8,5$ & $-4,5$ \\
\hline \multirow[t]{3}{*}{ Total } & $\mathrm{DM}$ & $-18,52$ & $-16,50$ & $-14,46$ & $-12,43$ & $-10,56$ & $-8,94$ & $-7,84$ & $-7,76$ & $-9,88$ & $-18,07$ & $-59,32$ & - \\
\hline & DMA & 30,80 & 29,17 & 27,90 & 26,87 & 26,20 & 26,26 & 29,12 & 34,42 & 44,02 & 60,74 & 112,94 & - \\
\hline & PDMA & 52,80 & 42,98 & 36,67 & 33,37 & 31,71 & 33,31 & 50,85 & 72,92 & 100,67 & 138,47 & 204,13 & - \\
\hline \multirow[t]{3}{*}{ CPI } & $\mathrm{DM}$ & $-55,33$ & $-51,43$ & $-47,54$ & $-43,81$ & $-40,55$ & $-38,10$ & $-37,11$ & $-38,86$ & $-46,30$ & $-68,96$ & $-171,29$ & - \\
\hline & DMA & 61,13 & 56,52 & 52,39 & 48,41 & 45,05 & 43,14 & 47,18 & 55,88 & 73,72 & 106,75 & 220,55 & - \\
\hline & PDMA & 70,07 & 56,93 & 44,02 & 31,43 & 21,43 & 16,56 & 30,67 & 47,29 & 66,33 & 90,83 & 142,93 & - \\
\hline \multirow[t]{3}{*}{ SPI } & DM & 8,47 & 9,11 & 9,80 & 10,57 & 11,43 & 12,44 & 13,63 & 15,05 & 16,83 & 19,26 & 22,79 & - \\
\hline & DMA & 8,56 & 9,11 & 9,93 & 11,08 & 12,37 & 13,88 & 15,88 & 18,67 & 22,23 & 27,01 & 34,03 & - \\
\hline & PDMA & 40,13 & 32,76 & 31,27 & 34,79 & 39,25 & 45,59 & 65,65 & 91,70 & 125,85 & 173,41 & 249,01 & - \\
\hline \multirow[t]{3}{*}{$\Delta \mathrm{CS}$} & $\mathrm{DM}$ & $-63,79$ & $-60,53$ & $-57,34$ & $-54,38$ & $-51,97$ & $-50,54$ & $-50,74$ & $-53,91$ & $-63,13$ & $-88,22$ & $-194,08$ & - \\
\hline & DMA & 52,57 & 47,41 & 42,46 & 37,33 & 32,68 & 29,26 & 31,30 & 37,21 & 51,48 & 79,74 & 186,51 & - \\
\hline & PDMA & 29,94 & 24,17 & 12,75 & $-3,36$ & $-17,82$ & $-29,03$ & $-34,98$ & $-44,41$ & $-59,52$ & $-82,58$ & $-106,08$ & - \\
\hline
\end{tabular}


Tabela 8.134: Constantes de acoplamento X3LYP e constantes empíricas no nível BHandH $\left(50 \% E_{X}^{\mathrm{HF}}\right)$ e base aug-pcJ-2.

\begin{tabular}{|c|c|c|c|c|c|c|c|c|c|c|c|c|c|}
\hline & $\% E_{X}^{\mathrm{HF}}$ & $0 \%$ & $10 \%$ & $20 \%$ & $30 \%$ & $40 \%$ & $50 \%$ & $60 \%$ & $70 \%$ & $80 \%$ & $90 \%$ & $100 \%$ & Emp. \\
\hline $\mathrm{HF}$ & ${ }^{1} J_{\mathrm{HF}}$ & 397,3 & 422,2 & 447,3 & 472,6 & 498,2 & 524,1 & 550,1 & 576,4 & 602,9 & 629,7 & 656,7 & 532,8 \\
\hline $\mathrm{CO}$ & ${ }^{1} J_{\mathrm{CO}}$ & 21,5 & 19,7 & 17,7 & 15,6 & 13,4 & 11,1 & 8,8 & 6,3 & 3,8 & 1,2 & $-1,4$ & 15,7 \\
\hline $\mathrm{H}_{2} \mathrm{O}$ & ${ }^{1} J_{\mathrm{OH}}$ & $-72,3$ & $-75,0$ & $-77,6$ & $-80,4$ & $-83,1$ & $-85,8$ & $-88,6$ & $-91,5$ & $-94,3$ & $-97,2$ & $-100,1$ & $-81,7$ \\
\hline $\mathrm{H}_{2} \mathrm{O}$ & ${ }^{2} J_{\mathrm{HH}}$ & $-5,3$ & $-6,4$ & $-7,5$ & $-8,6$ & $-9,7$ & $-10,9$ & $-12,1$ & $-13,3$ & $-14,5$ & $-15,7$ & $-17,0$ & $-8,8$ \\
\hline $\mathrm{NH}_{3}$ & ${ }^{1} J_{\mathrm{NH}}$ & 44,5 & 45,3 & 46,1 & 46,9 & 47,8 & 48,6 & 49,4 & 50,3 & 51,2 & 52,0 & 52,9 & 43,0 \\
\hline $\mathrm{NH}_{3}$ & ${ }^{2} J_{\mathrm{HH}}$ & $-8,4$ & $-9,3$ & $-10,3$ & $-11,2$ & $-12,2$ & $-13,2$ & $-14,2$ & $-15,2$ & $-16,3$ & $-17,3$ & $-18,4$ & $-10,5$ \\
\hline $\mathrm{PH}_{3}$ & ${ }^{1} J_{\mathrm{PH}}$ & 158,3 & 166,8 & 175,2 & 183,5 & 191,6 & 199,6 & 207,5 & 215,2 & 222,7 & 230,0 & 237,2 & 195,0 \\
\hline $\mathrm{PF}_{3}$ & ${ }^{1} J_{\mathrm{PF}}$ & $-1812,7$ & $-1787,4$ & $-1757,6$ & $-1724,0$ & $-1687,4$ & $-1648,2$ & $-1607,1$ & $-1564,6$ & $-1521,0$ & $-1476,7$ & $-1432,0$ & $-1441,7$ \\
\hline $\mathrm{BHF}_{2}$ & ${ }^{1} J_{\mathrm{BF}}$ & $-168,0$ & $-150,4$ & $-132,9$ & $-115,6$ & $-98,4$ & $-81,4$ & $-64,6$ & $-47,9$ & $-31,5$ & $-15,3$ & 0,7 & $-79,7$ \\
\hline $\mathrm{BF}_{3}$ & ${ }^{1} J_{\mathrm{BF}}$ & $-69,5$ & $-50,4$ & $-31,4$ & $-12,7$ & 5,7 & 24,0 & 42,1 & 60,0 & 77,8 & 95,3 & 112,7 & 17,1 \\
\hline $\mathrm{F}_{2} \mathrm{O}$ & ${ }^{1} J_{\mathrm{OF}}$ & $-280,3$ & $-317,2$ & $-354,2$ & $-392,9$ & $-435,5$ & $-485,2$ & $-547,9$ & $-635,3$ & $-775,4$ & $-1061,6$ & $-2173,7$ & $-285,7$ \\
\hline $\mathrm{CH}_{4}$ & ${ }^{1} J_{\mathrm{CH}}$ & 131,8 & 133,3 & 134,9 & 136,5 & 138,1 & 139,7 & 141,4 & 143,0 & 144,7 & 146,4 & 148,2 & 122,8 \\
\hline $\mathrm{CH}_{4}$ & ${ }^{2} J_{\mathrm{HH}}$ & $-11,8$ & $-12,6$ & $-13,4$ & $-14,2$ & $-15,0$ & $-15,7$ & $-16,5$ & $-17,3$ & $-18,0$ & $-18,7$ & $-19,5$ & $-12,5$ \\
\hline $\mathrm{C}_{2} \mathrm{H}_{2}$ & ${ }^{1} J_{\mathrm{CC}}$ & 199,6 & 202,6 & 206,0 & 210,0 & 214,5 & 219,9 & 226,1 & 233,6 & 242,6 & 253,6 & 267,3 & 174,1 \\
\hline $\mathrm{C}_{2} \mathrm{H}_{2}$ & ${ }^{1} J_{\mathrm{CH}}$ & 272,4 & 274,9 & 277,4 & 280,1 & 283,0 & 286,2 & 289,8 & 293,8 & 298,5 & 304,0 & 310,7 & 244,3 \\
\hline $\mathrm{C}_{2} \mathrm{H}_{2}$ & ${ }^{2} J_{\mathrm{CH}}$ & 57,0 & 56,9 & 56,6 & 56,1 & 55,2 & 54,0 & 52,3 & 50,1 & 47,2 & 43,4 & 38,4 & 49,8 \\
\hline $\mathrm{C}_{2} \mathrm{H}_{2}$ & ${ }^{3} J_{\mathrm{HH}}$ & 10,1 & 10,7 & 11,4 & 12,3 & 13,3 & 14,5 & 15,9 & 17,7 & 19,8 & 22,4 & 25,6 & 9,0 \\
\hline $\mathrm{C}_{2} \mathrm{H}_{4}$ & ${ }^{1} J_{\mathrm{CC}}$ & 66,9 & 69,8 & 73,1 & 76,7 & 80,8 & 85,6 & 91,3 & 98,4 & 107,5 & 119,9 & 138,1 & 66,9 \\
\hline $\mathrm{C}_{2} \mathrm{H}_{4}$ & ${ }^{1} J_{\mathrm{CH}}$ & 166,3 & 168,5 & 170,8 & 173,3 & 175,9 & 178,8 & 182,0 & 185,7 & 190,2 & 196,0 & 204,0 & 154,4 \\
\hline $\mathrm{C}_{2} \mathrm{H}_{4}$ & ${ }^{2} J_{\mathrm{CH}}$ & 0,2 & $-0,6$ & $-1,6$ & $-2,8$ & $-4,1$ & $-5,7$ & $-7,7$ & $-10,2$ & $-13,5$ & $-18,1$ & $-25,0$ & $-2,0$ \\
\hline $\mathrm{C}_{2} \mathrm{H}_{4}$ & ${ }^{2} J_{\mathrm{HH}}$ & 6,1 & 5,4 & 4,6 & 3,7 & 2,7 & 1,7 & 0,4 & $-1,0$ & $-2,9$ & $-5,5$ & $-9,2$ & 2,1 \\
\hline $\mathrm{C}_{2} \mathrm{H}_{4}$ & ${ }^{3} J_{\mathrm{HH}_{\mathrm{C}}}$ & 12,5 & 12,8 & 13,1 & 13,5 & 13,9 & 14,6 & 15,4 & 16,4 & 17,9 & 20,0 & 23,3 & 11,4 \\
\hline $\mathrm{C}_{2} \mathrm{H}_{4}$ & ${ }^{3} J_{\mathrm{HH}_{\mathrm{t}}}$ & 19,9 & 20,2 & 20,5 & 21,0 & 21,5 & 22,3 & 23,2 & 24,5 & 26,2 & 28,7 & 32,4 & 18,4 \\
\hline $\mathrm{C}_{2} \mathrm{H}_{6}$ & ${ }^{1} J_{\mathrm{CC}}$ & 29,4 & 31,5 & 33,7 & 35,9 & 38,1 & 40,4 & 42,7 & 45,1 & 47,5 & 49,9 & 52,4 & 33,6 \\
\hline $\mathrm{C}_{2} \mathrm{H}_{6}$ & ${ }^{1} J_{\mathrm{CH}}$ & 131,3 & 133,1 & 134,8 & 136,6 & 138,4 & 140,3 & 142,1 & 144,0 & 145,9 & 147,8 & 149,7 & 123,3 \\
\hline $\mathrm{C}_{2} \mathrm{H}_{6}$ & ${ }^{2} J_{\mathrm{CH}}$ & $-2,5$ & $-3,0$ & $-3,5$ & $-4,0$ & $-4,5$ & $-5,0$ & $-5,5$ & $-6,1$ & $-6,6$ & $-7,2$ & $-7,7$ & $-4,5$ \\
\hline \multirow[t]{3}{*}{ Total } & $\mathrm{DM}$ & $-22,78$ & $-20,20$ & $-17,44$ & $-14,57$ & $-11,71$ & $-8,93$ & $-6,55$ & $-4,94$ & $-5,16$ & $-10,75$ & $-47,70$ & - \\
\hline & DMA & 32,78 & 30,29 & 28,12 & 26,22 & 24,79 & 24,73 & 28,90 & 34,95 & 43,43 & 57,98 & 105,80 & - \\
\hline & PDMA & 48,31 & 38,96 & 29,63 & 24,14 & 22,48 & 27,77 & 43,90 & 62,31 & 84,67 & 113,74 & 161,91 & - \\
\hline \multirow[t]{3}{*}{ CPI } & $\mathrm{DM}$ & $-62,76$ & $-57,96$ & $-52,79$ & $-47,48$ & $-42,28$ & $-37,53$ & $-33,83$ & $-32,28$ & $-35,46$ & $-51,92$ & $-143,45$ & - \\
\hline & DMA & 67,80 & 60,98 & 54,74 & 48,46 & 43,15 & 40,64 & 47,70 & 58,79 & 74,54 & 103,46 & 209,21 & - \\
\hline & PDMA & 72,80 & 57,40 & 42,19 & 28,53 & 20,16 & 20,69 & 38,01 & 56,81 & 77,27 & 102,15 & 153,57 & - \\
\hline \multirow[t]{3}{*}{ SPI } & DM & 6,54 & 7,49 & 8,49 & 9,57 & 10,71 & 12,03 & 13,45 & 15,11 & 17,06 & 19,43 & 22,51 & - \\
\hline & DMA & 7,10 & 7,79 & 8,61 & 9,91 & 11,33 & 13,07 & 15,11 & 17,47 & 20,62 & 24,63 & 29,96 & - \\
\hline & PDMA & 30,35 & 25,44 & 20,42 & 20,91 & 24,19 & 32,97 & 48,22 & 66,34 & 90,09 & 122,24 & 168,02 & - \\
\hline \multirow[t]{3}{*}{$\Delta \mathrm{CS}$} & $\mathrm{DM}$ & $-69,30$ & $-65,46$ & $-61,28$ & $-57,06$ & $-53,00$ & $-49,56$ & $-47,28$ & $-47,39$ & $-52,52$ & $-71,35$ & $-165,95$ & - \\
\hline & DMA & 60,70 & 53,20 & 46,13 & 38,56 & 31,83 & 27,56 & 32,59 & 41,32 & 53,92 & 78,83 & 179,25 & - \\
\hline & PDMA & 42,46 & 31,96 & 21,77 & 7,62 & $-4,03$ & $-12,29$ & $-10,22$ & $-9,53$ & $-12,81$ & $-20,08$ & $-14,46$ & - \\
\hline
\end{tabular}


Tabela 8.135: Constantes de acoplamento B1B95 e constantes empíricas no nível BHandH $40 \% E_{X}^{\mathrm{HF}}$ e base aug-pcJ-2.

\begin{tabular}{|c|c|c|c|c|c|c|c|c|c|c|c|c|c|}
\hline & $\% E_{X}^{\mathrm{HF}}$ & $0 \%$ & $10 \%$ & $20 \%$ & $30 \%$ & $40 \%$ & $50 \%$ & $60 \%$ & $70 \%$ & $80 \%$ & $90 \%$ & $100 \%$ & Emp. \\
\hline $\mathrm{HF}$ & ${ }^{1} J_{\mathrm{HF}}$ & 403,9 & 427,5 & 451,2 & 475,2 & 499,3 & 523,6 & 548,0 & 572,6 & 597,4 & 622,3 & 647,4 & 533,2 \\
\hline $\mathrm{CO}$ & ${ }^{1} J_{\mathrm{CO}}$ & 23,4 & 21,7 & 19,9 & 18,1 & 16,1 & 14,0 & 11,8 & 9,6 & 7,3 & 4,9 & 2,4 & 15,6 \\
\hline $\mathrm{H}_{2} \mathrm{O}$ & ${ }^{1} J_{\mathrm{OH}}$ & $-70,3$ & $-72,8$ & $-75,3$ & $-77,9$ & $-80,4$ & $-83,0$ & $-85,6$ & $-88,2$ & $-90,8$ & $-93,5$ & $-96,2$ & $-81,8$ \\
\hline $\mathrm{H}_{2} \mathrm{O}$ & ${ }^{2} J_{\mathrm{HH}}$ & $-4,2$ & $-5,2$ & $-6,2$ & $-7,2$ & $-8,2$ & $-9,2$ & $-10,3$ & $-11,3$ & $-12,4$ & $-13,5$ & $-14,7$ & $-8,7$ \\
\hline $\mathrm{NH}_{3}$ & ${ }^{1} J_{\mathrm{NH}}$ & 41,9 & 42,7 & 43,4 & 44,1 & 44,9 & 45,6 & 46,4 & 47,2 & 47,9 & 48,7 & 49,5 & 43,1 \\
\hline $\mathrm{NH}_{3}$ & ${ }^{2} J_{\mathrm{HH}}$ & $-7,0$ & $-7,8$ & $-8,7$ & $-9,5$ & $-10,4$ & $-11,3$ & $-12,1$ & $-13,0$ & $-13,9$ & $-14,8$ & $-15,8$ & $-10,5$ \\
\hline $\mathrm{PH}_{3}$ & ${ }^{1} J_{\mathrm{PH}}$ & 146,7 & 154,4 & 161,8 & 169,2 & 176,5 & 183,6 & 190,6 & 197,4 & 204,1 & 210,7 & 217,0 & 195,5 \\
\hline $\mathrm{PF}_{3}$ & ${ }^{1} J_{\mathrm{PF}}$ & $-1716,6$ & $-1695,0$ & $-1669,0$ & $-1639,2$ & $-1606,4$ & $-1571,1$ & $-1533,7$ & $-1494,9$ & $-1454,9$ & $-1414,1$ & $-1372,8$ & $-1.442,80$ \\
\hline $\mathrm{BHF}_{2}$ & ${ }^{1} J_{\mathrm{BF}}$ & $-174,7$ & $-157,8$ & $-141,0$ & $-124,2$ & $-107,5$ & $-91,0$ & $-74,6$ & $-58,3$ & $-42,2$ & $-26,3$ & $-10,5$ & $-79,5$ \\
\hline $\mathrm{BF}_{3}$ & ${ }^{1} J_{\mathrm{BF}}$ & $-78,7$ & $-60,1$ & $-41,7$ & $-23,4$ & $-5,3$ & 12,6 & 30,3 & 47,9 & 65,3 & 82,6 & 99,7 & 17,2 \\
\hline $\mathrm{F}_{2} \mathrm{O}$ & ${ }^{1} J_{\mathrm{OF}}$ & $-266,9$ & $-301,3$ & $-334,9$ & $-368,7$ & $-404,3$ & $-443,7$ & $-490,0$ & $-548,8$ & $-631,2$ & $-765,1$ & $-1048,5$ & $-286,9$ \\
\hline $\mathrm{CH}_{4}$ & ${ }^{1} J_{\mathrm{CH}}$ & 120,7 & 122,0 & 123,3 & 124,7 & 126,1 & 127,5 & 129,0 & 130,4 & 131,9 & 133,4 & 134,9 & 123 \\
\hline $\mathrm{CH}_{4}$ & ${ }^{2} J_{\mathrm{HH}}$ & $-10,3$ & $-11,0$ & $-11,7$ & $-12,4$ & $-13,0$ & $-13,7$ & $-14,4$ & $-15,0$ & $-15,7$ & $-16,4$ & $-17,0$ & $-12,5$ \\
\hline $\mathrm{C}_{2} \mathrm{H}_{2}$ & ${ }^{1} J_{\mathrm{CC}}$ & 187,9 & 190,2 & 192,9 & 195,8 & 199,3 & 203,2 & 207,7 & 213,0 & 219,2 & 226,6 & 235,5 & 174,4 \\
\hline $\mathrm{C}_{2} \mathrm{H}_{2}$ & ${ }^{1} J_{\mathrm{CH}}$ & 250,6 & 252,5 & 254,5 & 256,6 & 258,8 & 261,2 & 263,7 & 266,5 & 269,6 & 273,2 & 277,3 & 244,5 \\
\hline $\mathrm{C}_{2} \mathrm{H}_{2}$ & ${ }^{2} J_{\mathrm{CH}}$ & 55,5 & 55,7 & 55,7 & 55,5 & 55,2 & 54,6 & 53,8 & 52,6 & 51,1 & 49,1 & 46,4 & 49,7 \\
\hline $\mathrm{C}_{2} \mathrm{H}_{2}$ & ${ }^{3} J_{\mathrm{HH}}$ & 9,1 & 9,5 & 10,0 & 10,6 & 11,2 & 12,0 & 13,0 & 14,1 & 15,4 & 17,0 & 18,9 & 9,1 \\
\hline $\mathrm{C}_{2} \mathrm{H}_{4}$ & ${ }^{1} J_{\mathrm{CC}}$ & 58,9 & 61,2 & 63,8 & 66,5 & 69,6 & 73,0 & 76,8 & 81,2 & 86,5 & 92,8 & 100,8 & 67,2 \\
\hline $\mathrm{C}_{2} \mathrm{H}_{4}$ & ${ }^{1} J_{\mathrm{CH}}$ & 153,4 & 155,3 & 157,2 & 159,2 & 161,3 & 163,5 & 165,9 & 168,5 & 171,4 & 174,7 & 178,7 & 154,5 \\
\hline $\mathrm{C}_{2} \mathrm{H}_{4}$ & ${ }^{2} J_{\mathrm{CH}}$ & 1,0 & 0,3 & $-0,4$ & $-1,3$ & $-2,3$ & $-3,4$ & $-4,7$ & $-6,3$ & $-8,1$ & $-10,4$ & $-13,4$ & $-2,1$ \\
\hline $\mathrm{C}_{2} \mathrm{H}_{4}$ & ${ }^{2} J_{\mathrm{HH}}$ & 6,0 & 5,4 & 4,7 & 4,0 & 3,3 & 2,5 & 1,6 & 0,6 & $-0,5$ & $-1,9$ & $-3,5$ & 2 \\
\hline $\mathrm{C}_{2} \mathrm{H}_{4}$ & ${ }^{3} J_{\mathrm{HH}_{\mathrm{c}}}$ & 11,5 & 11,7 & 11,9 & 12,2 & 12,5 & 12,8 & 13,3 & 13,9 & 14,7 & 15,6 & 16,9 & 11,4 \\
\hline $\mathrm{C}_{2} \mathrm{H}_{4}$ & ${ }^{3} J_{\mathrm{HH}_{\mathrm{t}}}$ & 18,3 & 18,5 & 18,8 & 19,0 & 19,4 & 19,9 & 20,4 & 21,1 & 22,0 & 23,2 & 24,7 & 18,5 \\
\hline $\mathrm{C}_{2} \mathrm{H}_{6}$ & ${ }^{1} J_{\mathrm{CC}}$ & 25,1 & 27,1 & 29,0 & 31,0 & 33,0 & 35,0 & 37,1 & 39,2 & 41,3 & 43,5 & 45,7 & 33,7 \\
\hline $\mathrm{C}_{2} \mathrm{H}_{6}$ & ${ }^{1} J_{\mathrm{CH}}$ & 120,6 & 122,2 & 123,7 & 125,3 & 126,9 & 128,5 & 130,1 & 131,8 & 133,4 & 135,0 & 136,7 & 123,4 \\
\hline $\mathrm{C}_{2} \mathrm{H}_{6}$ & ${ }^{2} J_{\mathrm{CH}}$ & $-2,2$ & $-2,7$ & $-3,1$ & $-3,6$ & $-4,0$ & $-4,5$ & $-5,0$ & $-5,4$ & $-5,9$ & $-6,4$ & $-6,9$ & $-4,5$ \\
\hline \multirow[t]{3}{*}{ Total } & DM & $-22,43$ & $-20,10$ & $-17,57$ & $-14,89$ & $-12,12$ & $-9,40$ & $-6,83$ & $-4,63$ & $-3,22$ & $-3,68$ & $-9,75$ & - \\
\hline & DMA & 28,92 & 24,84 & 22,30 & 19,82 & 17,56 & 15,93 & 17,41 & 21,57 & 27,08 & 36,95 & 53,90 & - \\
\hline & PDMA & 53,36 & 43,34 & 34,01 & 24,52 & 16,31 & 13,50 & 21,24 & 35,19 & 50,58 & 68,69 & 91,32 & - \\
\hline \multirow[t]{3}{*}{ CPI } & DM & $-54,26$ & $-49,83$ & $-44,99$ & $-39,81$ & $-34,55$ & $-29,48$ & $-24,87$ & $-21,29$ & $-19,80$ & $-22,95$ & $-39,72$ & - \\
\hline & DMA & 62,86 & 53,70 & 47,79 & 41,61 & 35,34 & 29,94 & 31,44 & 38,98 & 49,44 & 69,72 & 105,83 & - \\
\hline & PDMA & 82,22 & 66,20 & 51,54 & 37,15 & 22,74 & 13,05 & 21,36 & 37,99 & 55,83 & 75,66 & 100,52 & - \\
\hline \multirow[t]{3}{*}{ SPI } & DM & 0,92 & 1,71 & 2,53 & 3,39 & 4,33 & 5,32 & 6,40 & 7,59 & 8,93 & 10,45 & 12,23 & - \\
\hline & DMA & 4,03 & 3,68 & 3,61 & 3,84 & 4,52 & 5,65 & 7,12 & 8,79 & 10,68 & 12,93 & 15,83 & - \\
\hline & PDMA & 32,19 & 26,57 & 21,16 & 15,27 & 11,59 & 13,84 & 21,14 & 33,13 & 46,72 & 63,58 & 84,58 & - \\
\hline \multirow[t]{3}{*}{$\Delta \mathrm{CS}$} & DM & $-55,18$ & $-51,53$ & $-47,52$ & $-43,20$ & $-38,89$ & $-34,80$ & $-31,27$ & $-28,88$ & $-28,73$ & $-33,40$ & $-51,94$ & - \\
\hline & DMA & 58,84 & 50,02 & 44,18 & 37,77 & 30,82 & 24,28 & 24,32 & 30,19 & 38,76 & 56,79 & 90,00 & - \\
\hline & PDMA & 50,02 & 39,63 & 30,38 & 21,88 & 11,15 & $-0,79$ & 0,22 & 4,86 & 9,11 & 12,08 & 15,94 & - \\
\hline
\end{tabular}


Tabela 8.136: Constantes de acoplamento B3LYP e constantes empíricas no nível BHandH $40 \% E_{X}^{\mathrm{HF}}$ e base aug-pcJ-2.

\begin{tabular}{|c|c|c|c|c|c|c|c|c|c|c|c|c|c|}
\hline & $\% E_{X}^{\mathrm{HF}}$ & $0 \%$ & $10 \%$ & $20 \%$ & $30 \%$ & $40 \%$ & $50 \%$ & $60 \%$ & $70 \%$ & $80 \%$ & $90 \%$ & $100 \%$ & Emp. \\
\hline $\mathrm{HF}$ & ${ }^{1} J_{\mathrm{HF}}$ & 393,4 & 418,4 & 443,6 & 469,1 & 494,8 & 520,8 & 547,0 & 573,4 & 600,0 & 626,9 & 654,0 & 533,2 \\
\hline $\mathrm{CO}$ & ${ }^{1} J_{\mathrm{CO}}$ & 21,7 & 19,9 & 17,9 & 15,8 & 13,6 & 11,4 & 9,0 & 6,5 & 4,0 & 1,4 & $-1,2$ & 15,6 \\
\hline $\mathrm{H}_{2} \mathrm{O}$ & ${ }^{1} J_{\mathrm{OH}}$ & $-71,7$ & $-74,4$ & $-77,1$ & $-79,8$ & $-82,5$ & $-85,3$ & $-88,1$ & $-91,0$ & $-93,8$ & $-96,7$ & $-99,6$ & $-81,8$ \\
\hline $\mathrm{H}_{2} \mathrm{O}$ & ${ }^{2} J_{\mathrm{HH}}$ & $-5,3$ & $-6,4$ & $-7,5$ & $-8,6$ & $-9,7$ & $-10,8$ & $-12,0$ & $-13,2$ & $-14,4$ & $-15,6$ & $-16,8$ & $-8,7$ \\
\hline $\mathrm{NH}_{3}$ & ${ }^{1} J_{\mathrm{NH}}$ & 44,2 & 45,0 & 45,8 & 46,6 & 47,5 & 48,3 & 49,2 & 50,0 & 50,9 & 51,8 & 52,7 & 43,1 \\
\hline $\mathrm{NH}_{3}$ & ${ }^{2} J_{\mathrm{HH}}$ & $-8,4$ & $-9,3$ & $-10,3$ & $-11,2$ & $-12,2$ & $-13,2$ & $-14,2$ & $-15,2$ & $-16,2$ & $-17,2$ & $-18,2$ & $-10,5$ \\
\hline $\mathrm{PH}_{3}$ & ${ }^{1} J_{\mathrm{PH}}$ & 157,6 & 166,1 & 174,5 & 182,7 & 190,9 & 198,8 & 206,7 & 214,3 & 221,8 & 229,2 & 236,3 & 195,5 \\
\hline $\mathrm{PF}_{3}$ & ${ }^{1} J_{\mathrm{PF}}$ & $-1810,3$ & $-1784,6$ & $-1754,5$ & $-1720,8$ & $-1684,0$ & $-1644,8$ & $-1603,8$ & $-1561,4$ & $-1518,1$ & $-1474,0$ & $-1429,6$ & $-1.442,80$ \\
\hline $\mathrm{BHF}_{2}$ & ${ }^{1} J_{\mathrm{BF}}$ & $-167,7$ & $-150,2$ & $-132,7$ & $-115,4$ & $-98,2$ & $-81,2$ & $-64,4$ & $-47,8$ & $-31,4$ & $-15,2$ & 0,7 & $-79,5$ \\
\hline $\mathrm{BF}_{3}$ & ${ }^{1} J_{\mathrm{BF}}$ & $-70,2$ & $-51,0$ & $-32,1$ & $-13,3$ & 5,1 & 23,4 & 41,5 & 59,5 & 77,2 & 94,8 & 112,2 & 17,2 \\
\hline $\mathrm{F}_{2} \mathrm{O}$ & ${ }^{1} J_{\mathrm{OF}}$ & $-280,0$ & $-316,8$ & $-353,7$ & $-392,3$ & $-434,8$ & $-484,4$ & $-547,0$ & $-634,0$ & $-773,3$ & $-1056,7$ & $-2138,3$ & $-286,9$ \\
\hline $\mathrm{CH}_{4}$ & ${ }^{1} J_{\mathrm{CH}}$ & 131,0 & 132,6 & 134,1 & 135,7 & 137,4 & 139,0 & 140,7 & 142,4 & 144,1 & 145,9 & 147,6 & 123 \\
\hline $\mathrm{CH}_{4}$ & ${ }^{2} J_{\mathrm{HH}}$ & $-11,9$ & $-12,7$ & $-13,4$ & $-14,2$ & $-14,9$ & $-15,7$ & $-16,4$ & $-17,2$ & $-17,9$ & $-18,6$ & $-19,4$ & $-12,5$ \\
\hline $\mathrm{C}_{2} \mathrm{H}_{2}$ & ${ }^{1} J_{\mathrm{CC}}$ & 199,3 & 202,3 & 205,8 & 209,7 & 214,3 & 219,6 & 225,8 & 233,3 & 242,3 & 253,2 & 266,8 & 174,4 \\
\hline $\mathrm{C}_{2} \mathrm{H}_{2}$ & ${ }^{1} J_{\mathrm{CH}}$ & 271,1 & 273,5 & 276,1 & 278,9 & 281,8 & 285,0 & 288,6 & 292,6 & 297,3 & 302,7 & 309,4 & 244,5 \\
\hline $\mathrm{C}_{2} \mathrm{H}_{2}$ & ${ }^{2} J_{\mathrm{CH}}$ & 56,9 & 56,8 & 56,5 & 56,0 & 55,1 & 53,9 & 52,3 & 50,1 & 47,2 & 43,5 & 38,5 & 49,7 \\
\hline $\mathrm{C}_{2} \mathrm{H}_{2}$ & ${ }^{3} J_{\mathrm{HH}}$ & 10,2 & 10,7 & 11,4 & 12,3 & 13,3 & 14,5 & 15,9 & 17,6 & 19,7 & 22,2 & 25,4 & 9,1 \\
\hline $\mathrm{C}_{2} \mathrm{H}_{4}$ & ${ }^{1} J_{\mathrm{CC}}$ & 66,6 & 69,5 & 72,8 & 76,4 & 80,5 & 85,3 & 91,1 & 98,1 & 107,2 & 119,6 & 137,7 & 67,2 \\
\hline $\mathrm{C}_{2} \mathrm{H}_{4}$ & ${ }^{1} J_{\mathrm{CH}}$ & 165,4 & 167,7 & 170,0 & 172,5 & 175,1 & 178,0 & 181,2 & 185,0 & 189,5 & 195,2 & 203,3 & 154,5 \\
\hline $\mathrm{C}_{2} \mathrm{H}_{4}$ & ${ }^{2} J_{\mathrm{CH}}$ & 0,3 & $-0,5$ & $-1,6$ & $-2,7$ & $-4,1$ & $-5,7$ & $-7,7$ & $-10,1$ & $-13,4$ & $-18,0$ & $-24,8$ & $-2,1$ \\
\hline $\mathrm{C}_{2} \mathrm{H}_{4}$ & ${ }^{2} J_{\mathrm{HH}}$ & 6,0 & 5,3 & 4,5 & 3,6 & 2,7 & 1,6 & 0,4 & $-1,0$ & $-2,9$ & $-5,5$ & $-9,2$ & 2 \\
\hline $\mathrm{C}_{2} \mathrm{H}_{4}$ & ${ }^{3} J_{\mathrm{HH}_{\mathrm{c}}}$ & 12,4 & 12,7 & 13,0 & 13,4 & 13,8 & 14,5 & 15,3 & 16,3 & 17,8 & 19,9 & 23,2 & 11,4 \\
\hline $\mathrm{C}_{2} \mathrm{H}_{4}$ & ${ }^{3} J_{\mathrm{HH}_{\mathrm{t}}}$ & 19,8 & 20,0 & 20,4 & 20,8 & 21,4 & 22,2 & 23,1 & 24,4 & 26,1 & 28,5 & 32,3 & 18,5 \\
\hline $\mathrm{C}_{2} \mathrm{H}_{6}$ & ${ }^{1} J_{\mathrm{CC}}$ & 29,2 & 31,3 & 33,5 & 35,7 & 37,9 & 40,2 & 42,6 & 44,9 & 47,3 & 49,8 & 52,2 & 33,7 \\
\hline $\mathrm{C}_{2} \mathrm{H}_{6}$ & ${ }^{1} J_{\mathrm{CH}}$ & 130,5 & 132,3 & 134,1 & 135,9 & 137,7 & 139,6 & 141,5 & 143,3 & 145,2 & 147,2 & 149,1 & 123,4 \\
\hline $\mathrm{C}_{2} \mathrm{H}_{6}$ & ${ }^{2} J_{\mathrm{CH}}$ & $-2,5$ & $-3,0$ & $-3,4$ & $-3,9$ & $-4,5$ & $-5,0$ & $-5,5$ & $-6,0$ & $-6,6$ & $-7,1$ & $-7,7$ & $-4,5$ \\
\hline \multirow[t]{3}{*}{ Total } & DM & $-23,04$ & $-20,44$ & $-17,65$ & $-14,76$ & $-11,87$ & $-9,10$ & $-6,69$ & $-5,07$ & $-5,27$ & $-10,75$ & $-46,54$ & - \\
\hline & DMA & 32,80 & 30,13 & 27,94 & 25,98 & 24,49 & 24,27 & 28,17 & 34,19 & 42,64 & 57,10 & 104,00 & - \\
\hline & PDMA & 48,86 & 39,40 & 29,99 & 23,70 & 22,06 & 26,59 & 42,41 & 60,37 & 82,56 & 111,26 & 158,46 & - \\
\hline \multirow[t]{3}{*}{ CPI } & DM & $-62,83$ & $-57,97$ & $-52,77$ & $-47,42$ & $-42,17$ & $-37,40$ & $-33,68$ & $-32,12$ & $-35,25$ & $-51,43$ & $-140,20$ & - \\
\hline & DMA & 68,23 & 61,08 & 54,79 & 48,47 & 42,97 & 40,07 & 46,50 & 57,55 & 73,25 & 101,97 & 205,58 & - \\
\hline & PDMA & 73,24 & 57,73 & 42,58 & 28,79 & 20,30 & 19,83 & 37,07 & 55,84 & 76,09 & 100,90 & 151,01 & - \\
\hline \multirow[t]{3}{*}{ SPI } & $\mathrm{DM}$ & 6,13 & 7,08 & 8,10 & 9,19 & 10,35 & 11,65 & 13,11 & 14,76 & 16,71 & 19,08 & 22,14 & - \\
\hline & DMA & 6,81 & 7,43 & 8,25 & 9,49 & 10,93 & 12,67 & 14,72 & 17,05 & 20,20 & 24,19 & 29,50 & - \\
\hline & PDMA & 30,97 & 25,96 & 20,75 & 19,96 & 23,35 & 31,54 & 46,33 & 63,68 & 87,31 & 118,85 & 163,92 & - \\
\hline \multirow[t]{3}{*}{$\Delta \mathrm{CS}$} & DM & $-68,96$ & $-65,05$ & $-60,87$ & $-56,60$ & $-52,52$ & $-49,05$ & $-46,79$ & $-46,88$ & $-51,95$ & $-70,51$ & $-162,34$ & - \\
\hline & DMA & 61,41 & 53,66 & 46,54 & 38,98 & 32,04 & 27,40 & 31,78 & 40,50 & 53,05 & 77,79 & 176,08 & - \\
\hline & PDMA & 42,27 & 31,76 & 21,83 & 8,84 & $-3,05$ & $-11,71$ & $-9,26$ & $-7,85$ & $-11,21$ & $-17,95$ & $-12,91$ & - \\
\hline
\end{tabular}


Tabela 8.137: Constantes de acoplamento B3P86 e constantes empíricas no nível BHandH $40 \% E_{X}^{\mathrm{HF}}$ e base aug-pcJ-2.

\begin{tabular}{|c|c|c|c|c|c|c|c|c|c|c|c|c|c|}
\hline & $\% E_{X}^{\mathrm{HF}}$ & $0 \%$ & $10 \%$ & $20 \%$ & $30 \%$ & $40 \%$ & $50 \%$ & $60 \%$ & $70 \%$ & $80 \%$ & $90 \%$ & $100 \%$ & Emp. \\
\hline $\mathrm{HF}$ & ${ }^{1} J_{\mathrm{HF}}$ & 357,7 & 381,4 & 405,4 & 429,5 & 454,0 & 478,6 & 503,5 & 528,5 & 553,8 & 579,3 & 605,0 & 533,2 \\
\hline $\mathrm{CO}$ & ${ }^{1} J_{\mathrm{CO}}$ & 24,7 & 23,1 & 21,3 & 19,5 & 17,5 & 15,5 & 13,4 & 11,3 & 9,1 & 6,8 & 4,4 & 15,6 \\
\hline $\mathrm{H}_{2} \mathrm{O}$ & ${ }^{1} J_{\mathrm{OH}}$ & $-65,2$ & $-67,8$ & $-70,3$ & $-72,9$ & $-75,5$ & $-78,1$ & $-80,8$ & $-83,4$ & $-86,1$ & $-88,9$ & $-91,6$ & $-81,8$ \\
\hline $\mathrm{H}_{2} \mathrm{O}$ & ${ }^{2} J_{\mathrm{HH}}$ & $-4,6$ & $-5,6$ & $-6,5$ & $-7,6$ & $-8,6$ & $-9,6$ & $-10,7$ & $-11,8$ & $-12,9$ & $-14,0$ & $-15,2$ & $-8,7$ \\
\hline $\mathrm{NH}_{3}$ & ${ }^{1} J_{\mathrm{NH}}$ & 40,3 & 41,1 & 41,8 & 42,6 & 43,4 & 44,2 & 45,0 & 45,8 & 46,6 & 47,5 & 48,3 & 43,1 \\
\hline $\mathrm{NH}_{3}$ & ${ }^{2} J_{\mathrm{HH}}$ & $-7,8$ & $-8,7$ & $-9,5$ & $-10,4$ & $-11,3$ & $-12,2$ & $-13,1$ & $-14,1$ & $-15,0$ & $-15,9$ & $-16,9$ & $-10,5$ \\
\hline $\mathrm{PH}_{3}$ & ${ }^{1} J_{\mathrm{PH}}$ & 138,4 & 146,6 & 154,6 & 162,6 & 170,5 & 178,2 & 185,8 & 193,3 & 200,6 & 207,8 & 214,8 & 195,5 \\
\hline $\mathrm{PF}_{3}$ & ${ }^{1} J_{\mathrm{PF}}$ & $-1804,0$ & $-1778,3$ & $-1748,1$ & $-1714,4$ & $-1677,8$ & $-1638,8$ & $-1598,0$ & $-1555,9$ & $-1512,8$ & $-1469,1$ & $-1425,0$ & $-1.442,80$ \\
\hline $\mathrm{BHF}_{2}$ & ${ }^{1} J_{\mathrm{BF}}$ & $-175,5$ & $-158,4$ & $-141,4$ & $-124,6$ & $-107,9$ & $-91,3$ & $-74,9$ & $-58,7$ & $-42,7$ & $-26,9$ & $-11,3$ & $-79,5$ \\
\hline $\mathrm{BF}_{3}$ & ${ }^{1} J_{\mathrm{BF}}$ & $-81,4$ & $-62,6$ & $-44,1$ & $-25,8$ & $-7,7$ & 10,1 & 27,8 & 45,3 & 62,7 & 79,9 & 96,9 & 17,2 \\
\hline $\mathrm{F}_{2} \mathrm{O}$ & ${ }^{1} J_{\mathrm{OF}}$ & $-287,8$ & $-324,9$ & $-362,3$ & $-401,4$ & $-444,6$ & $-495,1$ & $-558,7$ & $-646,9$ & $-786,4$ & $-1061,9$ & $-1993,1$ & $-286,9$ \\
\hline $\mathrm{CH}_{4}$ & ${ }^{1} J_{\mathrm{CH}}$ & 119,3 & 120,8 & 122,3 & 123,8 & 125,4 & 127,0 & 128,6 & 130,2 & 131,8 & 133,5 & 135,2 & 123 \\
\hline $\mathrm{CH}_{4}$ & ${ }^{2} J_{\mathrm{HH}}$ & $-11,8$ & $-12,5$ & $-13,3$ & $-14,0$ & $-14,7$ & $-15,4$ & $-16,1$ & $-16,8$ & $-17,5$ & $-18,2$ & $-18,9$ & $-12,5$ \\
\hline $\mathrm{C}_{2} \mathrm{H}_{2}$ & ${ }^{1} J_{\mathrm{CC}}$ & 189,8 & 192,5 & 195,7 & 199,3 & 203,5 & 208,5 & 214,4 & 221,5 & 230,2 & 241,0 & 254,8 & 174,4 \\
\hline $\mathrm{C}_{2} \mathrm{H}_{2}$ & ${ }^{1} J_{\mathrm{CH}}$ & 251,0 & 253,4 & 255,8 & 258,5 & 261,4 & 264,5 & 268,1 & 272,2 & 276,9 & 282,7 & 289,8 & 244,5 \\
\hline $\mathrm{C}_{2} \mathrm{H}_{2}$ & ${ }^{2} J_{\mathrm{CH}}$ & 54,7 & 54,6 & 54,4 & 53,9 & 53,0 & 51,8 & 50,2 & 47,9 & 44,9 & 40,9 & 35,4 & 49,7 \\
\hline $\mathrm{C}_{2} \mathrm{H}_{2}$ & ${ }^{3} J_{\mathrm{HH}}$ & 10,2 & 10,9 & 11,6 & 12,5 & 13,6 & 14,9 & 16,4 & 18,3 & 20,6 & 23,5 & 27,1 & 9,1 \\
\hline $\mathrm{C}_{2} \mathrm{H}_{4}$ & ${ }^{1} J_{\mathrm{CC}}$ & 60,6 & 63,4 & 66,4 & 69,9 & 73,8 & 78,5 & 84,2 & 91,5 & 101,2 & 115,3 & 138,2 & 67,2 \\
\hline $\mathrm{C}_{2} \mathrm{H}_{4}$ & ${ }^{1} J_{\mathrm{CH}}$ & 152,0 & 154,1 & 156,4 & 158,8 & 161,3 & 164,2 & 167,5 & 171,3 & 176,2 & 182,8 & 193,0 & 154,5 \\
\hline $\mathrm{C}_{2} \mathrm{H}_{4}$ & ${ }^{2} J_{\mathrm{CH}}$ & 0,0 & $-0,8$ & $-1,8$ & $-2,9$ & $-4,2$ & $-5,9$ & $-7,9$ & $-10,6$ & $-14,3$ & $-19,7$ & $-28,7$ & $-2,1$ \\
\hline $\mathrm{C}_{2} \mathrm{H}_{4}$ & ${ }^{2} J_{\mathrm{HH}}$ & 4,7 & 4,0 & 3,2 & 2,3 & 1,3 & 0,1 & $-1,2$ & $-2,9$ & $-5,2$ & $-8,5$ & $-13,8$ & 2 \\
\hline $\mathrm{C}_{2} \mathrm{H}_{4}$ & ${ }^{3} J_{\mathrm{HH}_{\mathrm{c}}}$ & 11,6 & 11,9 & 12,3 & 12,7 & 13,3 & 14,0 & 15,0 & 16,3 & 18,2 & 21,1 & 26,1 & 11,4 \\
\hline $\mathrm{C}_{2} \mathrm{H}_{4}$ & ${ }^{3} J_{\mathrm{HH}_{\mathrm{t}}}$ & 18,6 & 18,9 & 19,3 & 19,9 & 20,5 & 21,4 & 22,5 & 24,1 & 26,3 & 29,6 & 35,2 & 18,5 \\
\hline $\mathrm{C}_{2} \mathrm{H}_{6}$ & ${ }^{1} J_{\mathrm{CC}}$ & 25,0 & 27,0 & 29,0 & 31,1 & 33,2 & 35,3 & 37,5 & 39,7 & 41,9 & 44,2 & 46,5 & 33,7 \\
\hline $\mathrm{C}_{2} \mathrm{H}_{6}$ & ${ }^{1} J_{\mathrm{CH}}$ & 119,4 & 121,1 & 122,8 & 124,5 & 126,2 & 128,0 & 129,8 & 131,6 & 133,4 & 135,3 & 137,1 & 123,4 \\
\hline $\mathrm{C}_{2} \mathrm{H}_{6}$ & ${ }^{2} J_{\mathrm{CH}}$ & $-2,7$ & $-3,1$ & $-3,6$ & $-4,1$ & $-4,5$ & $-5,0$ & $-5,5$ & $-6,0$ & $-6,6$ & $-7,1$ & $-7,6$ & $-4,5$ \\
\hline \multirow[t]{3}{*}{ Total } & DM & $-28,83$ & $-26,33$ & $-23,67$ & $-20,90$ & $-18,14$ & $-15,51$ & $-13,23$ & $-11,73$ & $-11,99$ & $-17,14$ & $-46,96$ & - \\
\hline & DMA & 34,07 & 31,38 & 28,76 & 26,50 & 24,67 & 23,47 & 24,22 & 27,78 & 35,72 & 50,02 & 91,98 & - \\
\hline & PDMA & 49,98 & 40,33 & 30,73 & 24,12 & 22,63 & 25,96 & 36,92 & 55,45 & 79,13 & 110,99 & 164,49 & - \\
\hline \multirow[t]{3}{*}{ CPI } & DM & $-69,05$ & $-64,41$ & $-59,41$ & $-54,30$ & $-49,31$ & $-44,81$ & $-41,37$ & $-40,09$ & $-43,41$ & $-59,07$ & $-134,37$ & - \\
\hline & DMA & 74,96 & 69,21 & 63,12 & 56,85 & 50,87 & 45,68 & 44,66 & 49,47 & 63,68 & 91,45 & 182,01 & - \\
\hline & PDMA & 85,40 & 70,53 & 55,91 & 41,13 & 28,07 & 17,78 & 22,81 & 39,14 & 58,40 & 82,29 & 127,27 & - \\
\hline \multirow[t]{3}{*}{ SPI } & $\mathrm{DM}$ & 0,67 & 1,59 & 2,55 & 3,59 & 4,72 & 5,97 & 7,41 & 9,07 & 11,05 & 13,61 & 17,14 & - \\
\hline & DMA & 4,07 & 3,65 & 3,56 & 4,25 & 5,45 & 7,19 & 9,23 & 11,87 & 15,22 & 19,63 & 25,97 & - \\
\hline & PDMA & 24,00 & 18,18 & 12,27 & 11,66 & 18,65 & 31,95 & 47,26 & 67,41 & 94,33 & 132,04 & 191,78 & - \\
\hline \multirow[t]{3}{*}{$\Delta \mathrm{CS}$} & DM & $-69,73$ & $-66,00$ & $-61,96$ & $-57,89$ & $-54,03$ & $-50,78$ & $-48,79$ & $-49,16$ & $-54,46$ & $-72,68$ & $-151,51$ & - \\
\hline & DMA & 70,89 & 65,56 & 59,56 & 52,60 & 45,42 & 38,50 & 35,44 & 37,61 & 48,46 & 71,82 & 156,04 & - \\
\hline & PDMA & 61,40 & 52,35 & 43,64 & 29,47 & 9,42 & $-14,17$ & $-24,45$ & $-28,27$ & $-35,93$ & $-49,74$ & $-64,52$ & - \\
\hline
\end{tabular}


Tabela 8.138: Constantes de acoplamento B971 e constantes empíricas no nível BHandH $40 \% E_{X}^{\mathrm{HF}}$ e base aug-pcJ-2.

\begin{tabular}{|c|c|c|c|c|c|c|c|c|c|c|c|c|c|}
\hline & $\% E_{X}^{\mathrm{HF}}$ & $0 \%$ & $10 \%$ & $20 \%$ & $30 \%$ & $40 \%$ & $50 \%$ & $60 \%$ & $70 \%$ & $80 \%$ & $90 \%$ & $100 \%$ & Emp. \\
\hline $\mathrm{HF}$ & ${ }^{1} J_{\mathrm{HF}}$ & 427,3 & 443,9 & 461,4 & 480,0 & 499,7 & 520,6 & 542,8 & 566,1 & 590,8 & 616,7 & 643,9 & 533,2 \\
\hline $\mathrm{CO}$ & ${ }^{1} J_{\mathrm{CO}}$ & 15,8 & 14,7 & 13,5 & 12,2 & 10,7 & 9,0 & 7,3 & 5,3 & 3,2 & 1,0 & $-1,3$ & 15,6 \\
\hline $\mathrm{H}_{2} \mathrm{O}$ & ${ }^{1} J_{\mathrm{OH}}$ & $-67,7$ & $-69,8$ & $-72,1$ & $-74,5$ & $-77,0$ & $-79,7$ & $-82,5$ & $-85,5$ & $-88,8$ & $-92,2$ & $-95,7$ & $-81,8$ \\
\hline $\mathrm{H}_{2} \mathrm{O}$ & ${ }^{2} J_{\mathrm{HH}}$ & $-0,6$ & $-1,6$ & $-2,7$ & $-3,8$ & $-5,1$ & $-6,4$ & $-7,7$ & $-9,2$ & $-10,8$ & $-12,5$ & $-14,3$ & $-8,7$ \\
\hline $\mathrm{NH}_{3}$ & ${ }^{1} J_{\mathrm{NH}}$ & 37,6 & 38,6 & 39,6 & 40,7 & 41,9 & 43,1 & 44,4 & 45,9 & 47,3 & 48,9 & 50,6 & 43,1 \\
\hline $\mathrm{NH}_{3}$ & ${ }^{2} J_{\mathrm{HH}}$ & $-3,4$ & $-4,3$ & $-5,2$ & $-6,3$ & $-7,4$ & $-8,6$ & $-9,9$ & $-11,2$ & $-12,7$ & $-14,3$ & $-16,1$ & $-10,5$ \\
\hline $\mathrm{PH}_{3}$ & ${ }^{1} J_{\mathrm{PH}}$ & 161,9 & 168,1 & 174,7 & 181,6 & 188,9 & 196,6 & 204,6 & 213,1 & 221,9 & 231,1 & 240,7 & 195,5 \\
\hline $\mathrm{PF}_{3}$ & ${ }^{1} J_{\mathrm{PF}}$ & $-1613,6$ & $-1608,3$ & $-1597,4$ & $-1581,8$ & $-1562,1$ & $-1539,1$ & $-1513,4$ & $-1485,6$ & $-1456,2$ & $-1425,8$ & $-1394,8$ & $-1.442,80$ \\
\hline $\mathrm{BHF}_{2}$ & ${ }^{1} J_{\mathrm{BF}}$ & $-145,0$ & $-130,5$ & $-115,6$ & $-100,5$ & $-85,1$ & $-69,6$ & $-54,0$ & $-38,4$ & $-22,8$ & $-7,2$ & 8,1 & $-79,5$ \\
\hline $\mathrm{BF}_{3}$ & ${ }^{1} J_{\mathrm{BF}}$ & $-55,7$ & $-38,9$ & $-21,9$ & $-4,7$ & 12,4 & 29,7 & 47,1 & 64,5 & 81,9 & 99,3 & 116,8 & 17,2 \\
\hline $\mathrm{F}_{2} \mathrm{O}$ & ${ }^{1} J_{\mathrm{OF}}$ & $-189,8$ & $-221,6$ & $-254,8$ & $-289,8$ & $-327,7$ & $-370,4$ & $-421,2$ & $-486,9$ & $-582,5$ & $-752,8$ & $-1221,3$ & $-286,9$ \\
\hline $\mathrm{CH}_{4}$ & ${ }^{1} J_{\mathrm{CH}}$ & 102,5 & 105,7 & 109,1 & 112,7 & 116,5 & 120,6 & 125,0 & 129,6 & 134,4 & 139,6 & 145,1 & 123 \\
\hline $\mathrm{CH}_{4}$ & ${ }^{2} J_{\mathrm{HH}}$ & $-5,8$ & $-6,7$ & $-7,6$ & $-8,5$ & $-9,6$ & $-10,7$ & $-11,8$ & $-13,1$ & $-14,4$ & $-15,8$ & $-17,3$ & $-12,5$ \\
\hline $\mathrm{C}_{2} \mathrm{H}_{2}$ & ${ }^{1} J_{\mathrm{CC}}$ & 186,1 & 190,1 & 194,4 & 199,4 & 205,0 & 211,6 & 219,4 & 228,8 & 240,5 & 255,4 & 275,1 & 174,4 \\
\hline $\mathrm{C}_{2} \mathrm{H}_{2}$ & ${ }^{1} J_{\mathrm{CH}}$ & 200,6 & 207,3 & 214,3 & 221,7 & 229,5 & 237,9 & 247,0 & 256,9 & 268,0 & 280,6 & 295,5 & 244,5 \\
\hline $\mathrm{C}_{2} \mathrm{H}_{2}$ & ${ }^{2} J_{\mathrm{CH}}$ & 51,0 & 51,9 & 52,5 & 53,0 & 53,2 & 53,0 & 52,5 & 51,2 & 49,1 & 45,6 & 40,1 & 49,7 \\
\hline $\mathrm{C}_{2} \mathrm{H}_{2}$ & ${ }^{3} J_{\mathrm{HH}}$ & 6,2 & 6,6 & 7,1 & 7,6 & 8,4 & 9,3 & 10,5 & 12,0 & 14,0 & 16,7 & 20,5 & 9,1 \\
\hline $\mathrm{C}_{2} \mathrm{H}_{4}$ & ${ }^{1} J_{\mathrm{CC}}$ & 63,4 & 66,1 & 69,1 & 72,5 & 76,4 & 80,8 & 86,2 & 92,8 & 101,2 & 112,9 & 130,5 & 67,2 \\
\hline $\mathrm{C}_{2} \mathrm{H}_{4}$ & ${ }^{1} J_{\mathrm{CH}}$ & 126,1 & 130,5 & 135,2 & 140,1 & 145,4 & 151,2 & 157,4 & 164,3 & 172,1 & 181,3 & 193,0 & 154,5 \\
\hline $\mathrm{C}_{2} \mathrm{H}_{4}$ & ${ }^{2} J_{\mathrm{CH}}$ & 2,5 & 1,9 & 1,1 & 0,2 & $-0,8$ & $-2,1$ & $-3,7$ & $-5,8$ & $-8,5$ & $-12,5$ & $-18,8$ & $-2,1$ \\
\hline $\mathrm{C}_{2} \mathrm{H}_{4}$ & ${ }^{2} J_{\mathrm{HH}}$ & 6,0 & 5,6 & 5,2 & 4,7 & 4,1 & 3,4 & 2,5 & 1,4 & 0,0 & $-2,0$ & $-5,1$ & 2 \\
\hline $\mathrm{C}_{2} \mathrm{H}_{4}$ & ${ }^{3} J_{\mathrm{HH}_{\mathrm{c}}}$ & 9,3 & 9,6 & 9,8 & 10,2 & 10,5 & 11,0 & 11,6 & 12,4 & 13,6 & 15,3 & 18,0 & 11,4 \\
\hline $\mathrm{C}_{2} \mathrm{H}_{4}$ & ${ }^{3} J_{\mathrm{HH}_{\mathrm{t}}}$ & 13,3 & 13,8 & 14,3 & 14,9 & 15,6 & 16,4 & 17,4 & 18,6 & 20,2 & 22,5 & 25,9 & 18,5 \\
\hline $\mathrm{C}_{2} \mathrm{H}_{6}$ & ${ }^{1} J_{\mathrm{CC}}$ & 25,4 & 27,6 & 30,0 & 32,4 & 35,1 & 37,8 & 40,8 & 43,9 & 47,2 & 50,7 & 54,4 & 33,7 \\
\hline $\mathrm{C}_{2} \mathrm{H}_{6}$ & ${ }^{1} J_{\mathrm{CH}}$ & 101,2 & 104,7 & 108,4 & 112,3 & 116,5 & 120,9 & 125,5 & 130,4 & 135,6 & 141,2 & 147,0 & 123,4 \\
\hline $\mathrm{C}_{2} \mathrm{H}_{6}$ & ${ }^{2} J_{\mathrm{CH}}$ & $-0,6$ & $-1,1$ & $-1,7$ & $-2,2$ & $-2,8$ & $-3,5$ & $-4,2$ & $-4,9$ & $-5,7$ & $-6,6$ & $-7,5$ & $-4,5$ \\
\hline \multirow[t]{3}{*}{ Total } & $\mathrm{DM}$ & $-16,64$ & $-14,72$ & $-12,54$ & $-10,10$ & $-7,48$ & $-4,77$ & $-2,04$ & 0,38 & 2,00 & 1,17 & $-10,53$ & - \\
\hline & DMA & 28,86 & 24,36 & 19,61 & 14,82 & 12,42 & 11,87 & 14,62 & 20,63 & 28,52 & 41,35 & 67,75 & - \\
\hline & PDMA & 58,82 & 49,27 & 39,36 & 29,11 & 19,33 & 15,62 & 21,61 & 34,23 & 54,52 & 81,01 & 119,87 & - \\
\hline \multirow[t]{3}{*}{ CPI } & DM & $-29,78$ & $-27,65$ & $-24,99$ & $-21,94$ & $-18,65$ & $-15,38$ & $-12,45$ & $-10,57$ & $-11,19$ & $-18,38$ & $-52,53$ & - \\
\hline & DMA & 52,80 & 44,12 & 34,65 & 24,92 & 20,75 & 20,80 & 26,45 & 36,34 & 49,30 & 72,25 & 125,00 & - \\
\hline & PDMA & 71,00 & 56,99 & 42,88 & 28,55 & 16,19 & 19,39 & 30,76 & 45,82 & 65,33 & 87,76 & 120,23 & - \\
\hline \multirow[t]{3}{*}{ SPI } & $\mathrm{DM}$ & $-7,01$ & $-5,25$ & $-3,41$ & $-1,42$ & 0,71 & 3,02 & 5,59 & 8,41 & 11,67 & 15,51 & 20,27 & - \\
\hline & DMA & 11,30 & 9,87 & 8,58 & 7,41 & 6,31 & 5,33 & 5,95 & 9,12 & 13,28 & 18,69 & 25,77 & - \\
\hline & PDMA & 49,89 & 43,62 & 36,78 & 29,52 & 21,63 & 12,86 & 14,90 & 25,74 & 46,59 & 76,06 & 119,60 & - \\
\hline \multirow[t]{3}{*}{$\Delta \mathrm{CS}$} & DM & $-22,78$ & $-22,40$ & $-21,58$ & $-20,52$ & $-19,37$ & $-18,40$ & $-18,03$ & $-18,99$ & $-22,86$ & $-33,89$ & $-72,80$ & - \\
\hline & DMA & 41,50 & 34,24 & 26,07 & 17,51 & 14,43 & 15,47 & 20,50 & 27,22 & 36,02 & 53,56 & 99,23 & - \\
\hline & PDMA & 21,11 & 13,37 & 6,09 & $-0,97$ & $-5,44$ & 6,53 & 15,86 & 20,08 & 18,74 & 11,70 & 0,63 & - \\
\hline
\end{tabular}


Tabela 8.139: Constantes de acoplamento B972 e constantes empíricas no nível BHandH $40 \% E_{X}^{\mathrm{HF}}$ e base aug-pcJ-2.

\begin{tabular}{|c|c|c|c|c|c|c|c|c|c|c|c|c|c|}
\hline & $\% E_{X}^{\mathrm{HF}}$ & $0 \%$ & $10 \%$ & $20 \%$ & $30 \%$ & $40 \%$ & $50 \%$ & $60 \%$ & $70 \%$ & $80 \%$ & $90 \%$ & $100 \%$ & Emp. \\
\hline $\mathrm{HF}$ & ${ }^{1} J_{\mathrm{HF}}$ & 420,6 & 441,5 & 463,7 & 487,2 & 512,0 & 538,2 & 565,8 & 595,0 & 625,6 & 657,8 & 691,6 & 533,2 \\
\hline $\mathrm{CO}$ & ${ }^{1} J_{\mathrm{CO}}$ & 16,9 & 15,3 & 13,5 & 11,5 & 9,2 & 6,8 & 4,2 & 1,4 & $-1,6$ & $-4,8$ & $-8,3$ & 15,6 \\
\hline $\mathrm{H}_{2} \mathrm{O}$ & ${ }^{1} J_{\mathrm{OH}}$ & $-66,8$ & $-69,6$ & $-72,5$ & $-75,6$ & $-78,9$ & $-82,3$ & $-86,0$ & $-90,0$ & $-94,1$ & $-98,5$ & $-103,1$ & $-81,8$ \\
\hline $\mathrm{H}_{2} \mathrm{O}$ & ${ }^{2} J_{\mathrm{HH}}$ & $-1,2$ & $-2,2$ & $-3,2$ & $-4,3$ & $-5,5$ & $-6,7$ & $-8,0$ & $-9,5$ & $-11,0$ & $-12,6$ & $-14,3$ & $-8,7$ \\
\hline $\mathrm{NH}_{3}$ & ${ }^{1} J_{\mathrm{NH}}$ & 36,3 & 37,5 & 38,9 & 40,3 & 41,8 & 43,4 & 45,1 & 47,0 & 48,9 & 50,9 & 53,1 & 43,1 \\
\hline $\mathrm{NH}_{3}$ & ${ }^{2} J_{\mathrm{HH}}$ & $-3,3$ & $-4,2$ & $-5,1$ & $-6,0$ & $-7,1$ & $-8,2$ & $-9,4$ & $-10,7$ & $-12,1$ & $-13,6$ & $-15,2$ & $-10,5$ \\
\hline $\mathrm{PH}_{3}$ & ${ }^{1} J_{\mathrm{PH}}$ & 152,4 & 159,5 & 167,0 & 175,0 & 183,4 & 192,2 & 201,4 & 211,1 & 221,2 & 231,6 & 242,5 & 195,5 \\
\hline $\mathrm{PF}_{3}$ & ${ }^{1} J_{\mathrm{PF}}$ & $-1626,4$ & $-1621,0$ & $-1610,4$ & $-1595,3$ & $-1576,6$ & $-1555,0$ & $-1531,2$ & $-1505,7$ & $-1479,1$ & $-1452,1$ & $-1424,9$ & $-1.442,80$ \\
\hline $\mathrm{BHF}_{2}$ & ${ }^{1} J_{\mathrm{BF}}$ & $-151,4$ & $-134,7$ & $-117,6$ & $-100,3$ & $-82,9$ & $-65,4$ & $-48,0$ & $-30,7$ & $-13,4$ & 3,5 & 20,3 & $-79,5$ \\
\hline $\mathrm{BF}_{3}$ & ${ }^{1} J_{\mathrm{BF}}$ & $-64,0$ & $-44,6$ & $-25,1$ & $-5,4$ & 14,1 & 33,8 & 53,5 & 73,1 & 92,7 & 112,2 & 131,6 & 17,2 \\
\hline $\mathrm{F}_{2} \mathrm{O}$ & ${ }^{1} J_{\mathrm{OF}}$ & $-187,3$ & $-217,9$ & $-249,8$ & $-283,7$ & $-320,6$ & $-362,5$ & $-412,9$ & $-478,9$ & $-577,4$ & $-761,7$ & $-1349,0$ & $-286,9$ \\
\hline $\mathrm{CH}_{4}$ & ${ }^{1} J_{\mathrm{CH}}$ & 94,6 & 98,6 & 102,8 & 107,2 & 111,9 & 116,9 & 122,2 & 127,8 & 133,7 & 139,9 & 146,5 & 123 \\
\hline $\mathrm{CH}_{4}$ & ${ }^{2} J_{\mathrm{HH}}$ & $-5,4$ & $-6,1$ & $-6,9$ & $-7,8$ & $-8,7$ & $-9,7$ & $-10,7$ & $-11,9$ & $-13,0$ & $-14,3$ & $-15,6$ & $-12,5$ \\
\hline $\mathrm{C}_{2} \mathrm{H}_{2}$ & ${ }^{1} J_{\mathrm{CC}}$ & 172,7 & 177,5 & 182,8 & 188,8 & 195,6 & 203,4 & 212,5 & 223,4 & 236,6 & 253,1 & 274,3 & 174,4 \\
\hline $\mathrm{C}_{2} \mathrm{H}_{2}$ & ${ }^{1} J_{\mathrm{CH}}$ & 189,9 & 197,4 & 205,4 & 213,7 & 222,6 & 232,0 & 242,2 & 253,1 & 265,2 & 278,6 & 294,1 & 244,5 \\
\hline $\mathrm{C}_{2} \mathrm{H}_{2}$ & ${ }^{2} J_{\mathrm{CH}}$ & 49,1 & 50,0 & 50,8 & 51,4 & 51,8 & 51,9 & 51,5 & 50,6 & 48,9 & 46,1 & 41,6 & 49,7 \\
\hline $\mathrm{C}_{2} \mathrm{H}_{2}$ & ${ }^{3} J_{\mathrm{HH}}$ & 6,1 & 6,5 & 6,9 & 7,4 & 8,1 & 8,9 & 9,9 & 11,2 & 12,9 & 15,1 & 18,0 & 9,1 \\
\hline $\mathrm{C}_{2} \mathrm{H}_{4}$ & ${ }^{1} J_{\mathrm{CC}}$ & 54,6 & 58,0 & 61,7 & 66,0 & 70,8 & 76,3 & 82,9 & 91,0 & 101,4 & 115,7 & 137,0 & 67,2 \\
\hline $\mathrm{C}_{2} \mathrm{H}_{4}$ & ${ }^{1} J_{\mathrm{CH}}$ & 117,8 & 122,9 & 128,4 & 134,1 & 140,3 & 146,9 & 154,1 & 161,9 & 170,8 & 181,1 & 194,0 & 154,5 \\
\hline $\mathrm{C}_{2} \mathrm{H}_{4}$ & ${ }^{2} J_{\mathrm{CH}}$ & 2,6 & 2,0 & 1,3 & 0,5 & $-0,4$ & $-1,7$ & $-3,2$ & $-5,2$ & $-8,0$ & $-11,9$ & $-18,1$ & $-2,1$ \\
\hline $\mathrm{C}_{2} \mathrm{H}_{4}$ & ${ }^{2} J_{\mathrm{HH}}$ & 5,6 & 5,4 & 5,1 & 4,7 & 4,2 & 3,7 & 3,0 & 2,2 & 1,1 & $-0,5$ & $-2,9$ & 2 \\
\hline $\mathrm{C}_{2} \mathrm{H}_{4}$ & ${ }^{3} J_{\mathrm{HH}_{\mathrm{c}}}$ & 8,9 & 9,1 & 9,4 & 9,7 & 10,1 & 10,6 & 11,1 & 11,8 & 12,8 & 14,3 & 16,6 & 11,4 \\
\hline $\mathrm{C}_{2} \mathrm{H}_{4}$ & ${ }^{3} J_{\mathrm{HH}_{\mathrm{t}}}$ & 12,8 & 13,3 & 13,8 & 14,4 & 15,1 & 15,9 & 16,8 & 17,9 & 19,4 & 21,4 & 24,4 & 18,5 \\
\hline $\mathrm{C}_{2} \mathrm{H}_{6}$ & ${ }^{1} J_{\mathrm{CC}}$ & 21,9 & 24,5 & 27,3 & 30,2 & 33,3 & 36,6 & 40,1 & 43,8 & 47,8 & 52,0 & 56,4 & 33,7 \\
\hline $\mathrm{C}_{2} \mathrm{H}_{6}$ & ${ }^{1} J_{\mathrm{CH}}$ & 93,2 & 97,4 & 101,8 & 106,4 & 111,4 & 116,6 & 122,1 & 127,9 & 134,1 & 140,6 & 147,5 & 123,4 \\
\hline $\mathrm{C}_{2} \mathrm{H}_{6}$ & ${ }^{2} J_{\mathrm{CH}}$ & $-0,5$ & $-0,9$ & $-1,4$ & $-1,9$ & $-2,4$ & $-3,0$ & $-3,6$ & $-4,2$ & $-4,9$ & $-5,7$ & $-6,5$ & $-4,5$ \\
\hline \multirow[t]{3}{*}{ Total } & $\mathrm{DM}$ & $-20,65$ & $-18,13$ & $-15,31$ & $-12,25$ & $-9,00$ & $-5,66$ & $-2,36$ & 0,64 & 2,76 & 1,98 & $-13,66$ & - \\
\hline & DMA & 32,19 & 26,97 & 21,62 & 15,87 & 12,56 & 12,57 & 15,94 & 22,33 & 31,12 & 44,07 & 74,93 & - \\
\hline & PDMA & 62,89 & 52,41 & 42,08 & 31,09 & 20,72 & 19,24 & 24,59 & 34,94 & 53,88 & 80,22 & 119,54 & - \\
\hline \multirow[t]{3}{*}{ CPI } & DM & $-33,51$ & $-30,44$ & $-26,82$ & $-22,82$ & $-18,68$ & $-14,55$ & $-10,90$ & $-8,39$ & $-8,61$ & $-16,52$ & $-60,92$ & - \\
\hline & DMA & 57,25 & 47,53 & 37,24 & 26,15 & 20,41 & 21,88 & 30,92 & 42,21 & 56,88 & 79,52 & 142,28 & - \\
\hline & PDMA & 77,31 & 60,48 & 45,02 & 29,29 & 15,48 & 23,06 & 37,38 & 54,40 & 76,07 & 100,76 & 138,86 & - \\
\hline \multirow[t]{3}{*}{ SPI } & $\mathrm{DM}$ & $-11,23$ & $-9,11$ & $-6,87$ & $-4,50$ & $-1,91$ & 0,87 & 3,91 & 7,27 & 11,10 & 15,55 & 21,00 & - \\
\hline & DMA & 13,81 & 11,90 & 10,17 & 8,33 & 6,80 & 5,75 & 4,96 & 7,76 & 12,23 & 18,07 & 25,55 & - \\
\hline & PDMA & 52,32 & 46,49 & 39,92 & 32,41 & 24,57 & 16,45 & 15,21 & 20,67 & 37,61 & 65,16 & 105,38 & - \\
\hline \multirow[t]{3}{*}{$\Delta \mathrm{CS}$} & DM & $-22,28$ & $-21,32$ & $-19,94$ & $-18,32$ & $-16,78$ & $-15,42$ & $-14,81$ & $-15,66$ & $-19,71$ & $-32,06$ & $-81,92$ & - \\
\hline & DMA & 43,44 & 35,63 & 27,07 & 17,82 & 13,61 & 16,14 & 25,96 & 34,45 & 44,65 & 61,45 & 116,74 & - \\
\hline & PDMA & 24,99 & 14,00 & 5,11 & $-3,13$ & $-9,10$ & 6,61 & 22,18 & 33,73 & 38,46 & 35,59 & 33,47 & - \\
\hline
\end{tabular}


Tabela 8.140: Constantes de acoplamento B98 e constantes empíricas no nível BHandH $40 \% E_{X}^{\mathrm{HF}}$ e base aug-pcJ-2.

\begin{tabular}{|c|c|c|c|c|c|c|c|c|c|c|c|c|c|}
\hline & $\% E_{X}^{\mathrm{HF}}$ & $0 \%$ & $10 \%$ & $20 \%$ & $30 \%$ & $40 \%$ & $50 \%$ & $60 \%$ & $70 \%$ & $80 \%$ & $90 \%$ & $100 \%$ & Emp. \\
\hline $\mathrm{HF}$ & ${ }^{1} J_{\mathrm{HF}}$ & 411,6 & 428,1 & 445,8 & 464,6 & 484,6 & 505,9 & 528,5 & 552,5 & 577,9 & 604,8 & 633,1 & 533,2 \\
\hline $\mathrm{CO}$ & ${ }^{1} J_{\mathrm{CO}}$ & 16,6 & 15,5 & 14,2 & 12,8 & 11,2 & 9,5 & 7,7 & 5,6 & 3,4 & 1,0 & $-1,4$ & 15,6 \\
\hline $\mathrm{H}_{2} \mathrm{O}$ & ${ }^{1} J_{\mathrm{OH}}$ & $-66,0$ & $-68,2$ & $-70,5$ & $-73,0$ & $-75,6$ & $-78,4$ & $-81,4$ & $-84,6$ & $-88,1$ & $-91,7$ & $-95,6$ & $-81,8$ \\
\hline $\mathrm{H}_{2} \mathrm{O}$ & ${ }^{2} J_{\mathrm{HH}}$ & $-0,7$ & $-1,7$ & $-2,7$ & $-3,9$ & $-5,1$ & $-6,4$ & $-7,9$ & $-9,4$ & $-11,0$ & $-12,7$ & $-14,6$ & $-8,7$ \\
\hline $\mathrm{NH}_{3}$ & ${ }^{1} J_{\mathrm{NH}}$ & 37,0 & 38,1 & 39,2 & 40,4 & 41,7 & 43,1 & 44,6 & 46,1 & 47,8 & 49,6 & 51,5 & 43,1 \\
\hline $\mathrm{NH}_{3}$ & ${ }^{2} J_{\mathrm{HH}}$ & $-3,5$ & $-4,4$ & $-5,4$ & $-6,4$ & $-7,6$ & $-8,8$ & $-10,2$ & $-11,6$ & $-13,2$ & $-14,9$ & $-16,8$ & $-10,5$ \\
\hline $\mathrm{PH}_{3}$ & ${ }^{1} J_{\mathrm{PH}}$ & 165,9 & 172,2 & 179,0 & 186,1 & 193,7 & 201,7 & 210,1 & 218,9 & 228,1 & 237,8 & 247,9 & 195,5 \\
\hline $\mathrm{PF}_{3}$ & ${ }^{1} J_{\mathrm{PF}}$ & $-1622,6$ & $-1617,6$ & $-1607,1$ & $-1591,6$ & $-1572,1$ & $-1549,1$ & $-1523,4$ & $-1495,6$ & $-1466,2$ & $-1435,7$ & $-1404,5$ & $-1.442,80$ \\
\hline $\mathrm{BHF}_{2}$ & ${ }^{1} J_{\mathrm{BF}}$ & $-150,1$ & $-135,5$ & $-120,6$ & $-105,2$ & $-89,6$ & $-73,8$ & $-57,8$ & $-41,8$ & $-25,7$ & $-9,6$ & 6,2 & $-79,5$ \\
\hline $\mathrm{BF}_{3}$ & ${ }^{1} J_{\mathrm{BF}}$ & $-61,5$ & $-44,7$ & $-27,7$ & $-10,4$ & 7,0 & 24,5 & 42,2 & 60,0 & 77,9 & 95,8 & 113,8 & 17,2 \\
\hline $\mathrm{F}_{2} \mathrm{O}$ & ${ }^{1} J_{\mathrm{OF}}$ & $-196,5$ & $-228,9$ & $-262,8$ & $-298,9$ & $-338,2$ & $-383,0$ & $-437,3$ & $-509,0$ & $-617,4$ & $-823,5$ & $-1507,1$ & $-286,9$ \\
\hline $\mathrm{CH}_{4}$ & ${ }^{1} J_{\mathrm{CH}}$ & 101,1 & 104,7 & 108,5 & 112,6 & 116,9 & 121,5 & 126,5 & 131,7 & 137,3 & 143,2 & 149,5 & 123 \\
\hline $\mathrm{CH}_{4}$ & ${ }^{2} J_{\mathrm{HH}}$ & $-5,9$ & $-6,8$ & $-7,7$ & $-8,7$ & $-9,8$ & $-11,0$ & $-12,2$ & $-13,5$ & $-15,0$ & $-16,5$ & $-18,1$ & $-12,5$ \\
\hline $\mathrm{C}_{2} \mathrm{H}_{2}$ & ${ }^{1} J_{\mathrm{CC}}$ & 184,5 & 188,8 & 193,5 & 198,9 & 205,0 & 212,2 & 220,6 & 230,9 & 243,6 & 260,0 & 282,1 & 174,4 \\
\hline $\mathrm{C}_{2} \mathrm{H}_{2}$ & ${ }^{1} J_{\mathrm{CH}}$ & 198,0 & 205,3 & 212,9 & 221,1 & 229,7 & 239,0 & 249,0 & 260,0 & 272,3 & 286,5 & 303,3 & 244,5 \\
\hline $\mathrm{C}_{2} \mathrm{H}_{2}$ & ${ }^{2} J_{\mathrm{CH}}$ & 50,6 & 51,5 & 52,3 & 52,9 & 53,2 & 53,2 & 52,6 & 51,4 & 49,2 & 45,4 & 39,3 & 49,7 \\
\hline $\mathrm{C}_{2} \mathrm{H}_{2}$ & ${ }^{3} J_{\mathrm{HH}}$ & 6,1 & 6,5 & 7,0 & 7,6 & 8,4 & 9,4 & 10,6 & 12,3 & 14,5 & 17,5 & 21,7 & 9,1 \\
\hline $\mathrm{C}_{2} \mathrm{H}_{4}$ & ${ }^{1} J_{\mathrm{CC}}$ & 62,2 & 65,2 & 68,5 & 72,2 & 76,4 & 81,3 & 87,2 & 94,5 & 104,0 & 117,4 & 138,3 & 67,2 \\
\hline $\mathrm{C}_{2} \mathrm{H}_{4}$ & ${ }^{1} J_{\mathrm{CH}}$ & 124,4 & 129,2 & 134,3 & 139,8 & 145,7 & 152,0 & 158,9 & 166,6 & 175,4 & 185,9 & 199,6 & 154,5 \\
\hline $\mathrm{C}_{2} \mathrm{H}_{4}$ & ${ }^{2} J_{\mathrm{CH}}$ & 2,5 & 1,8 & 1,0 & 0,1 & $-0,8$ & $-2,1$ & $-3,8$ & $-6,0$ & $-9,0$ & $-13,5$ & $-20,9$ & $-2,1$ \\
\hline $\mathrm{C}_{2} \mathrm{H}_{4}$ & ${ }^{2} J_{\mathrm{HH}}$ & 5,7 & 5,4 & 5,0 & 4,5 & 3,9 & 3,2 & 2,3 & 1,2 & $-0,3$ & $-2,5$ & $-6,2$ & 2 \\
\hline $\mathrm{C}_{2} \mathrm{H}_{4}$ & ${ }^{3} J_{\mathrm{HH}_{\mathrm{c}}}$ & 9,3 & 9,5 & 9,8 & 10,2 & 10,6 & 11,1 & 11,8 & 12,7 & 13,9 & 15,9 & 19,2 & 11,4 \\
\hline $\mathrm{C}_{2} \mathrm{H}_{4}$ & ${ }^{3} J_{\mathrm{HH}_{\mathrm{t}}}$ & 13,1 & 13,6 & 14,2 & 14,9 & 15,6 & 16,5 & 17,6 & 18,9 & 20,8 & 23,3 & 27,5 & 18,5 \\
\hline $\mathrm{C}_{2} \mathrm{H}_{6}$ & ${ }^{1} J_{\mathrm{CC}}$ & 24,5 & 26,9 & 29,5 & 32,2 & 35,1 & 38,2 & 41,5 & 45,0 & 48,8 & 52,8 & 57,1 & 33,7 \\
\hline $\mathrm{C}_{2} \mathrm{H}_{6}$ & ${ }^{1} J_{\mathrm{CH}}$ & 99,8 & 103,7 & 107,8 & 112,1 & 116,8 & 121,7 & 127,0 & 132,5 & 138,4 & 144,7 & 151,4 & 123,4 \\
\hline $\mathrm{C}_{2} \mathrm{H}_{6}$ & ${ }^{2} J_{\mathrm{CH}}$ & $-0,7$ & $-1,2$ & $-1,7$ & $-2,3$ & $-2,9$ & $-3,6$ & $-4,3$ & $-5,1$ & $-5,9$ & $-6,9$ & $-7,9$ & $-4,5$ \\
\hline \multirow[t]{3}{*}{ Total } & $\mathrm{DM}$ & $-18,51$ & $-16,53$ & $-14,25$ & $-11,70$ & $-8,96$ & $-6,11$ & $-3,32$ & $-0,87$ & 0,57 & $-1,25$ & $-20,70$ & - \\
\hline & DMA & 30,20 & 25,54 & 20,65 & 16,40 & 13,95 & 13,07 & 15,62 & 21,89 & 30,65 & 44,60 & 80,03 & - \\
\hline & PDMA & 60,25 & 50,24 & 40,24 & 29,95 & 20,23 & 13,96 & 20,35 & 35,40 & 57,26 & 86,44 & 132,79 & - \\
\hline \multirow[t]{3}{*}{ CPI } & DM & $-33,11$ & $-31,05$ & $-28,45$ & $-25,45$ & $-22,22$ & $-19,02$ & $-16,30$ & $-14,85$ & $-16,45$ & $-26,68$ & $-80,17$ & - \\
\hline & DMA & 55,33 & 46,45 & 36,91 & 28,66 & 24,53 & 23,85 & 27,99 & 37,79 & 52,17 & 76,86 & 149,50 & - \\
\hline & PDMA & 75,16 & 60,16 & 46,07 & 32,20 & 19,72 & 16,79 & 27,79 & 44,18 & 64,67 & 88,74 & 128,73 & - \\
\hline \multirow[t]{3}{*}{ SPI } & $\mathrm{DM}$ & $-7,81$ & $-5,88$ & $-3,83$ & $-1,61$ & 0,77 & 3,35 & 6,20 & 9,39 & 13,05 & 17,39 & 22,91 & - \\
\hline & DMA & 11,77 & 10,21 & 8,72 & 7,40 & 6,19 & 5,15 & 6,55 & 10,23 & 14,86 & 20,94 & 29,09 & - \\
\hline & PDMA & 49,31 & 42,98 & 35,97 & 28,31 & 20,60 & 11,88 & 14,89 & 28,96 & 51,82 & 84,75 & 135,77 & - \\
\hline \multirow[t]{3}{*}{$\Delta \mathrm{CS}$} & DM & $-25,30$ & $-25,17$ & $-24,63$ & $-23,83$ & $-22,98$ & $-22,37$ & $-22,50$ & $-24,23$ & $-29,49$ & $-44,08$ & $-103,08$ & - \\
\hline & DMA & 43,56 & 36,23 & 28,19 & 21,26 & 18,33 & 18,70 & 21,44 & 27,56 & 37,31 & 55,92 & 120,41 & - \\
\hline & PDMA & 25,85 & 17,18 & 10,09 & 3,89 & $-0,88$ & 4,90 & 12,90 & 15,22 & 12,85 & 3,99 & $-7,03$ & - \\
\hline
\end{tabular}


Tabela 8.141: Constantes de acoplamento BHandH e constantes empíricas no nível BHandH $40 \% E_{X}^{\mathrm{HF}}$ e base aug-pcJ-2.

\begin{tabular}{|c|c|c|c|c|c|c|c|c|c|c|c|c|c|}
\hline & $\% E_{X}^{\mathrm{HF}}$ & $0 \%$ & $10 \%$ & $20 \%$ & $30 \%$ & $40 \%$ & $50 \%$ & $60 \%$ & $70 \%$ & $80 \%$ & $90 \%$ & $100 \%$ & Emp. \\
\hline $\mathrm{HF}$ & ${ }^{1} J_{\mathrm{HF}}$ & 420,6 & 441,1 & 462,4 & 484,4 & 507,2 & 530,8 & 555,3 & 580,6 & 606,9 & 634,2 & 662,5 & 533,2 \\
\hline $\mathrm{CO}$ & ${ }^{1} J_{\mathrm{CO}}$ & 24,8 & 22,9 & 20,9 & 18,7 & 16,3 & 13,7 & 11,0 & 8,0 & 4,9 & 1,6 & $-1,9$ & 15,6 \\
\hline $\mathrm{H}_{2} \mathrm{O}$ & ${ }^{1} J_{\mathrm{OH}}$ & $-69,9$ & $-72,4$ & $-75,1$ & $-77,8$ & $-80,7$ & $-83,7$ & $-86,9$ & $-90,2$ & $-93,7$ & $-97,3$ & $-101,1$ & $-81,8$ \\
\hline $\mathrm{H}_{2} \mathrm{O}$ & ${ }^{2} J_{\mathrm{HH}}$ & $-3,3$ & $-4,4$ & $-5,5$ & $-6,8$ & $-8,0$ & $-9,4$ & $-10,8$ & $-12,3$ & $-13,9$ & $-15,6$ & $-17,3$ & $-8,7$ \\
\hline $\mathrm{NH}_{3}$ & ${ }^{1} J_{\mathrm{NH}}$ & 39,4 & 40,5 & 41,7 & 42,9 & 44,2 & 45,5 & 47,0 & 48,5 & 50,0 & 51,7 & 53,4 & 43,1 \\
\hline $\mathrm{NH}_{3}$ & ${ }^{2} J_{\mathrm{HH}}$ & $-5,4$ & $-6,5$ & $-7,5$ & $-8,7$ & $-9,9$ & $-11,1$ & $-12,5$ & $-13,9$ & $-15,4$ & $-17,0$ & $-18,7$ & $-10,5$ \\
\hline $\mathrm{PH}_{3}$ & ${ }^{1} J_{\mathrm{PH}}$ & 135,5 & 144,3 & 153,5 & 163,0 & 172,9 & 183,1 & 193,7 & 204,6 & 215,9 & 227,4 & 239,2 & 195,5 \\
\hline $\mathrm{PF}_{3}$ & ${ }^{1} J_{\mathrm{PF}}$ & $-1814,4$ & $-1797,1$ & $-1773,1$ & $-1743,5$ & $-1709,0$ & $-1670,4$ & $-1628,3$ & $-1583,4$ & $-1536,2$ & $-1487,3$ & $-1437,0$ & $-1.442,80$ \\
\hline $\mathrm{BHF}_{2}$ & ${ }^{1} J_{\mathrm{BF}}$ & $-187,4$ & $-169,5$ & $-151,2$ & $-132,8$ & $-114,0$ & $-95,2$ & $-76,1$ & $-57,0$ & $-37,8$ & $-18,6$ & 0,6 & $-79,5$ \\
\hline $\mathrm{BF}_{3}$ & ${ }^{1} J_{\mathrm{BF}}$ & $-79,8$ & $-61,1$ & $-42,3$ & $-23,3$ & $-4,1$ & 15,1 & 34,6 & 54,2 & 73,9 & 93,8 & 113,8 & 17,2 \\
\hline $\mathrm{F}_{2} \mathrm{O}$ & ${ }^{1} J_{\mathrm{OF}}$ & $-272,1$ & $-308,2$ & $-344,0$ & $-380,5$ & $-419,8$ & $-465,0$ & $-521,4$ & $-600,0$ & $-727,9$ & $-1000,8$ & $-2253,8$ & $-286,9$ \\
\hline $\mathrm{CH}_{4}$ & ${ }^{1} J_{\mathrm{CH}}$ & 106,0 & 109,4 & 113,0 & 116,8 & 120,7 & 124,9 & 129,4 & 134,0 & 138,9 & 144,0 & 149,4 & 123 \\
\hline $\mathrm{CH}_{4}$ & ${ }^{2} J_{\mathrm{HH}}$ & $-7,9$ & $-8,9$ & $-9,9$ & $-11,0$ & $-12,1$ & $-13,3$ & $-14,5$ & $-15,7$ & $-17,0$ & $-18,4$ & $-19,7$ & $-12,5$ \\
\hline $\mathrm{C}_{2} \mathrm{H}_{2}$ & ${ }^{1} J_{\mathrm{CC}}$ & 175,5 & 179,6 & 184,2 & 189,4 & 195,4 & 202,4 & 210,6 & 220,6 & 232,8 & 248,3 & 268,4 & 174,4 \\
\hline $\mathrm{C}_{2} \mathrm{H}_{2}$ & ${ }^{1} J_{\mathrm{CH}}$ & 226,4 & 232,3 & 238,4 & 245,0 & 252,0 & 259,5 & 267,8 & 276,9 & 287,3 & 299,2 & 313,5 & 244,5 \\
\hline $\mathrm{C}_{2} \mathrm{H}_{2}$ & ${ }^{2} J_{\mathrm{CH}}$ & 51,2 & 52,1 & 52,7 & 53,2 & 53,3 & 53,0 & 52,2 & 50,7 & 48,2 & 44,2 & 38,1 & 49,7 \\
\hline $\mathrm{C}_{2} \mathrm{H}_{2}$ & ${ }^{3} J_{\mathrm{HH}}$ & 7,2 & 7,8 & 8,5 & 9,4 & 10,5 & 11,8 & 13,4 & 15,5 & 18,1 & 21,5 & 26,0 & 9,1 \\
\hline $\mathrm{C}_{2} \mathrm{H}_{4}$ & ${ }^{1} J_{\mathrm{CC}}$ & 50,4 & 53,8 & 57,6 & 61,8 & 66,7 & 72,3 & 78,9 & 87,3 & 98,2 & 113,8 & 139,0 & 67,2 \\
\hline $\mathrm{C}_{2} \mathrm{H}_{4}$ & ${ }^{1} J_{\mathrm{CH}}$ & 136,2 & 140,5 & 145,0 & 149,9 & 155,0 & 160,6 & 166,8 & 173,7 & 181,8 & 191,8 & 205,7 & 154,5 \\
\hline $\mathrm{C}_{2} \mathrm{H}_{4}$ & ${ }^{2} J_{\mathrm{CH}}$ & 0,9 & 0,2 & $-0,4$ & $-1,3$ & $-2,4$ & $-3,8$ & $-5,6$ & $-8,0$ & $-11,4$ & $-16,5$ & $-25,4$ & $-2,1$ \\
\hline $\mathrm{C}_{2} \mathrm{H}_{4}$ & ${ }^{2} J_{\mathrm{HH}}$ & 5,5 & 5,0 & 4,4 & 3,8 & 3,1 & 2,2 & 1,1 & $-0,1$ & $-2,0$ & $-4,7$ & $-9,3$ & 2 \\
\hline $\mathrm{C}_{2} \mathrm{H}_{4}$ & ${ }^{3} J_{\mathrm{HH}_{\mathrm{c}}}$ & 11,2 & 11,5 & 11,8 & 12,2 & 12,7 & 13,3 & 14,1 & 15,2 & 16,8 & 19,3 & 23,7 & 11,4 \\
\hline $\mathrm{C}_{2} \mathrm{H}_{4}$ & ${ }^{3} J_{\mathrm{HH}_{\mathrm{t}}}$ & 16,3 & 16,7 & 17,3 & 17,9 & 18,7 & 19,6 & 20,8 & 22,4 & 24,5 & 27,6 & 32,9 & 18,5 \\
\hline $\mathrm{C}_{2} \mathrm{H}_{6}$ & ${ }^{1} J_{\mathrm{CC}}$ & 18,7 & 21,3 & 24,0 & 26,9 & 30,0 & 33,3 & 36,7 & 40,4 & 44,3 & 48,4 & 52,7 & 33,7 \\
\hline $\mathrm{C}_{2} \mathrm{H}_{6}$ & ${ }^{1} J_{\mathrm{CH}}$ & 106,1 & 109,7 & 113,4 & 117,3 & 121,5 & 125,8 & 130,4 & 135,2 & 140,2 & 145,4 & 150,9 & 123,4 \\
\hline $\mathrm{C}_{2} \mathrm{H}_{6}$ & ${ }^{2} J_{\mathrm{CH}}$ & $-1,7$ & $-2,1$ & $-2,6$ & $-3,1$ & $-3,7$ & $-4,3$ & $-4,9$ & $-5,6$ & $-6,3$ & $-7,0$ & $-7,8$ & $-4,5$ \\
\hline \multirow[t]{3}{*}{ Total } & $\mathrm{DM}$ & $-30,64$ & $-28,01$ & $-24,98$ & $-21,65$ & $-18,08$ & $-14,46$ & $-10,92$ & $-7,89$ & $-6,37$ & $-9,91$ & $-50,34$ & - \\
\hline & DMA & 35,48 & 31,39 & 28,06 & 24,45 & 21,32 & 19,87 & 23,11 & 29,73 & 38,88 & 54,42 & 109,44 & - \\
\hline & PDMA & 59,49 & 48,58 & 37,87 & 26,45 & 16,40 & 13,44 & 26,67 & 46,32 & 70,98 & 104,04 & 163,62 & - \\
\hline \multirow[t]{3}{*}{ CPI } & DM & $-64,22$ & $-60,44$ & $-55,87$ & $-50,80$ & $-45,39$ & $-40,09$ & $-35,35$ & $-32,30$ & $-33,43$ & $-47,48$ & $-150,43$ & - \\
\hline & DMA & 72,65 & 64,98 & 59,18 & 52,76 & 46,15 & 40,53 & 43,85 & 54,37 & 69,68 & 98,21 & 216,94 & - \\
\hline & PDMA & 88,65 & 72,34 & 56,77 & 40,54 & 24,60 & 13,68 & 26,64 & 47,37 & 70,19 & 98,09 & 157,42 & - \\
\hline \multirow[t]{3}{*}{ SPI } & $\mathrm{DM}$ & $-6,02$ & $-4,23$ & $-2,33$ & $-0,27$ & 1,94 & 4,33 & 6,99 & 10,01 & 13,47 & 17,64 & 23,05 & - \\
\hline & DMA & 8,22 & 6,76 & 5,23 & 3,69 & 3,10 & 4,72 & 7,90 & 11,65 & 16,29 & 22,31 & 30,61 & - \\
\hline & PDMA & 38,11 & 31,15 & 24,01 & 16,12 & 10,40 & 13,27 & 26,69 & 45,55 & 71,56 & 108,40 & 168,17 & - \\
\hline \multirow[t]{3}{*}{$\Delta \mathrm{CS}$} & DM & $-58,20$ & $-56,21$ & $-53,55$ & $-50,53$ & $-47,33$ & $-44,42$ & $-42,34$ & $-42,31$ & $-46,90$ & $-65,12$ & $-173,48$ & - \\
\hline & DMA & 64,43 & 58,22 & 53,95 & 49,08 & 43,05 & 35,81 & 35,95 & 42,72 & 53,40 & 75,90 & 186,32 & - \\
\hline & PDMA & 50,54 & 41,18 & 32,76 & 24,42 & 14,20 & 0,40 & $-0,05$ & 1,83 & $-1,36$ & $-10,31$ & $-10,75$ & - \\
\hline
\end{tabular}


Tabela 8.142: Constantes de acoplamento BMK e constantes empíricas no nível BHandH $40 \% E_{X}^{\mathrm{HF}}$ e base aug-pcJ-2.

\begin{tabular}{|c|c|c|c|c|c|c|c|c|c|c|c|c|c|}
\hline & $\% E_{X}^{\mathrm{HF}}$ & $0 \%$ & $10 \%$ & $20 \%$ & $30 \%$ & $40 \%$ & $50 \%$ & $60 \%$ & $70 \%$ & $80 \%$ & $90 \%$ & $100 \%$ & Emp. \\
\hline $\mathrm{HF}$ & ${ }^{1} J_{\mathrm{HF}}$ & 491,4 & 502,8 & 515,2 & 528,7 & 543,5 & 559,7 & 577,4 & 597,0 & 618,7 & 642,5 & 669,0 & 533,2 \\
\hline $\mathrm{CO}$ & ${ }^{1} J_{\mathrm{CO}}$ & 13,8 & 14,3 & 14,6 & 14,8 & 14,8 & 14,6 & 14,1 & 13,3 & 12,0 & 10,2 & 7,7 & 15,6 \\
\hline $\mathrm{H}_{2} \mathrm{O}$ & ${ }^{1} J_{\mathrm{OH}}$ & $-72,3$ & $-72,8$ & $-73,4$ & $-74,1$ & $-74,9$ & $-75,9$ & $-77,0$ & $-78,3$ & $-79,8$ & $-81,4$ & $-83,3$ & $-81,8$ \\
\hline $\mathrm{H}_{2} \mathrm{O}$ & ${ }^{2} J_{\mathrm{HH}}$ & 2,8 & 1,8 & 0,6 & $-0,5$ & $-1,8$ & $-3,2$ & $-4,7$ & $-6,4$ & $-8,1$ & $-10,0$ & $-12,0$ & $-8,7$ \\
\hline $\mathrm{NH}_{3}$ & ${ }^{1} J_{\mathrm{NH}}$ & 36,5 & 36,6 & 36,7 & 36,8 & 37,1 & 37,4 & 37,7 & 38,2 & 38,7 & 39,3 & 40,0 & 43,1 \\
\hline $\mathrm{NH}_{3}$ & ${ }^{2} J_{\mathrm{HH}}$ & $-0,7$ & $-1,6$ & $-2,5$ & $-3,5$ & $-4,7$ & $-5,9$ & $-7,2$ & $-8,7$ & $-10,3$ & $-12,0$ & $-13,9$ & $-10,5$ \\
\hline $\mathrm{PH}_{3}$ & ${ }^{1} J_{\mathrm{PH}}$ & 125,8 & 125,4 & 125,4 & 126,0 & 127,0 & 128,5 & 130,5 & 133,0 & 136,1 & 139,7 & 144,0 & 195,5 \\
\hline $\mathrm{PF}_{3}$ & ${ }^{1} J_{\mathrm{PF}}$ & $-1529,4$ & $-1527,6$ & $-1517,9$ & $-1500,7$ & $-1476,3$ & $-1445,2$ & $-1408,2$ & $-1365,9$ & $-1319,0$ & $-1268,4$ & $-1214,4$ & $-1.442,80$ \\
\hline $\mathrm{BHF}_{2}$ & ${ }^{1} J_{\mathrm{BF}}$ & $-143,1$ & $-131,7$ & $-118,2$ & $-102,8$ & $-85,4$ & $-66,1$ & $-44,9$ & $-21,9$ & 2,7 & 29,1 & 56,9 & $-79,5$ \\
\hline $\mathrm{BF}_{3}$ & ${ }^{1} J_{\mathrm{BF}}$ & $-51,1$ & $-37,2$ & $-21,4$ & $-3,8$ & 15,4 & 36,6 & 59,4 & 84,1 & 110,4 & 138,4 & 167,9 & 17,2 \\
\hline $\mathrm{F}_{2} \mathrm{O}$ & ${ }^{1} J_{\mathrm{OF}}$ & $-147,5$ & $-173,9$ & $-201,0$ & $-228,4$ & $-256,0$ & $-284,4$ & $-314,8$ & $-349,2$ & $-392,3$ & $-454,2$ & $-567,5$ & $-286,9$ \\
\hline $\mathrm{CH}_{4}$ & ${ }^{1} J_{\mathrm{CH}}$ & 103,1 & 104,7 & 106,5 & 108,7 & 111,2 & 114,2 & 117,5 & 121,3 & 125,7 & 130,7 & 136,4 & 123 \\
\hline $\mathrm{CH}_{4}$ & ${ }^{2} J_{\mathrm{HH}}$ & $-3,0$ & $-4,0$ & $-5,1$ & $-6,4$ & $-7,7$ & $-9,2$ & $-10,9$ & $-12,8$ & $-14,9$ & $-17,3$ & $-20,0$ & $-12,5$ \\
\hline $\mathrm{C}_{2} \mathrm{H}_{2}$ & ${ }^{1} J_{\mathrm{CC}}$ & 244,5 & 249,2 & 254,4 & 260,5 & 267,6 & 276,3 & 287,2 & 301,5 & 321,1 & 349,5 & 394,6 & 174,4 \\
\hline $\mathrm{C}_{2} \mathrm{H}_{2}$ & ${ }^{1} J_{\mathrm{CH}}$ & 177,9 & 184,0 & 190,5 & 197,6 & 205,4 & 214,0 & 223,8 & 235,3 & 249,0 & 266,5 & 290,8 & 244,5 \\
\hline $\mathrm{C}_{2} \mathrm{H}_{2}$ & ${ }^{2} J_{\mathrm{CH}}$ & 54,4 & 55,3 & 56,0 & 56,5 & 56,6 & 56,3 & 55,2 & 53,0 & 49,0 & 41,7 & 28,3 & 49,7 \\
\hline $\mathrm{C}_{2} \mathrm{H}_{2}$ & ${ }^{3} J_{\mathrm{HH}}$ & 5,3 & 5,6 & 6,0 & 6,5 & 7,2 & 8,2 & 9,5 & 11,3 & 13,9 & 17,8 & 24,2 & 9,1 \\
\hline $\mathrm{C}_{2} \mathrm{H}_{4}$ & ${ }^{1} J_{\mathrm{CC}}$ & 89,5 & 91,0 & 92,9 & 95,3 & 98,2 & 101,8 & 106,6 & 112,8 & 121,5 & 134,4 & 155,3 & 67,2 \\
\hline $\mathrm{C}_{2} \mathrm{H}_{4}$ & ${ }^{1} J_{\mathrm{CH}}$ & 120,5 & 123,6 & 127,2 & 131,1 & 135,5 & 140,5 & 146,3 & 153,0 & 161,2 & 171,5 & 185,9 & 154,5 \\
\hline $\mathrm{C}_{2} \mathrm{H}_{4}$ & ${ }^{2} J_{\mathrm{CH}}$ & 4,5 & 3,6 & 2,6 & 1,5 & 0,1 & $-1,4$ & $-3,4$ & $-6,0$ & $-9,7$ & $-15,1$ & $-24,0$ & $-2,1$ \\
\hline $\mathrm{C}_{2} \mathrm{H}_{4}$ & ${ }^{2} J_{\mathrm{HH}}$ & 7,7 & 7,2 & 6,6 & 5,8 & 4,9 & 3,8 & 2,5 & 0,7 & $-1,4$ & $-4,6$ & $-9,6$ & 2 \\
\hline $\mathrm{C}_{2} \mathrm{H}_{4}$ & ${ }^{3} J_{\mathrm{HH}_{\mathrm{c}}}$ & 9,2 & 9,3 & 9,4 & 9,6 & 9,8 & 10,2 & 10,7 & 11,5 & 12,8 & 14,9 & 18,6 & 11,4 \\
\hline $\mathrm{C}_{2} \mathrm{H}_{4}$ & ${ }^{3} J_{\mathrm{HH}_{\mathrm{t}}}$ & 11,3 & 11,8 & 12,3 & 12,9 & 13,5 & 14,3 & 15,3 & 16,6 & 18,4 & 21,1 & 25,6 & 18,5 \\
\hline $\mathrm{C}_{2} \mathrm{H}_{6}$ & ${ }^{1} J_{\mathrm{CC}}$ & 30,1 & 31,0 & 32,1 & 33,3 & 34,8 & 36,5 & 38,5 & 40,7 & 43,3 & 46,4 & 49,9 & 33,7 \\
\hline $\mathrm{C}_{2} \mathrm{H}_{6}$ & ${ }^{1} J_{\mathrm{CH}}$ & 101,4 & 103,3 & 105,6 & 108,2 & 111,1 & 114,4 & 118,2 & 122,5 & 127,3 & 132,8 & 139,1 & 123,4 \\
\hline $\mathrm{C}_{2} \mathrm{H}_{6}$ & ${ }^{2} J_{\mathrm{CH}}$ & 0,6 & 0,0 & $-0,8$ & $-1,5$ & $-2,4$ & $-3,3$ & $-4,3$ & $-5,4$ & $-6,7$ & $-8,1$ & $-9,7$ & $-4,5$ \\
\hline \multirow[t]{3}{*}{ Total } & $\mathrm{DM}$ & $-7,83$ & $-6,73$ & $-5,09$ & $-2,87$ & $-0,08$ & 3,31 & 7,24 & 11,71 & 16,65 & 21,87 & 26,66 & - \\
\hline & DMA & 30,46 & 27,46 & 23,86 & 19,71 & 15,85 & 14,44 & 18,37 & 23,53 & 31,20 & 42,73 & 58,88 & - \\
\hline & PDMA & 73,25 & 64,41 & 54,29 & 43,00 & 30,44 & 26,57 & 28,89 & 41,91 & 63,59 & 97,30 & 146,94 & - \\
\hline \multirow[t]{3}{*}{ CPI } & DM & $-15,29$ & $-14,39$ & $-12,39$ & $-9,26$ & $-5,06$ & 0,15 & 6,17 & 12,80 & 19,52 & 25,35 & 27,27 & - \\
\hline & DMA & 46,24 & 40,10 & 32,68 & 24,06 & 16,12 & 13,99 & 24,32 & 36,80 & 50,94 & 68,09 & 91,15 & - \\
\hline & PDMA & 76,29 & 64,42 & 51,10 & 36,57 & 20,91 & 27,62 & 40,72 & 55,12 & 71,05 & 93,99 & 122,11 & - \\
\hline \multirow[t]{3}{*}{ SPI } & $\mathrm{DM}$ & $-2,35$ & $-1,11$ & 0,26 & 1,82 & 3,57 & 5,62 & 8,03 & 10,91 & 14,55 & 19,33 & 26,21 & - \\
\hline & DMA & 18,89 & 18,19 & 17,39 & 16,51 & 15,66 & 14,77 & 14,00 & 13,79 & 16,73 & 24,13 & 35,22 & - \\
\hline & PDMA & 71,02 & 64,40 & 56,63 & 47,72 & 37,42 & 25,80 & 20,20 & 32,23 & 58,13 & 99,72 & 165,15 & - \\
\hline \multirow[t]{3}{*}{$\Delta \mathrm{CS}$} & DM & $-12,94$ & $-13,28$ & $-12,65$ & $-11,08$ & $-8,63$ & $-5,47$ & $-1,85$ & 1,89 & 4,97 & 6,02 & 1,07 & - \\
\hline & DMA & 27,35 & 21,91 & 15,29 & 7,55 & 0,46 & $-0,78$ & 10,32 & 23,01 & 34,20 & 43,96 & 55,93 & - \\
\hline & PDMA & 5,26 & 0,02 & $-5,53$ & $-11,15$ & $-16,52$ & 1,82 & 20,52 & 22,89 & 12,92 & $-5,74$ & $-43,04$ & - \\
\hline
\end{tabular}


Tabela 8.143: Constantes de acoplamento BP86 e constantes empíricas no nível BHandH $40 \% E_{X}^{\mathrm{HF}}$ e base aug-pcJ-2.

\begin{tabular}{|c|c|c|c|c|c|c|c|c|c|c|c|c|c|}
\hline & $\% E_{X}^{\mathrm{HF}}$ & $0 \%$ & $10 \%$ & $20 \%$ & $30 \%$ & $40 \%$ & $50 \%$ & $60 \%$ & $70 \%$ & $80 \%$ & $90 \%$ & $100 \%$ & Emp. \\
\hline $\mathrm{HF}$ & ${ }^{1} J_{\mathrm{HF}}$ & 355,3 & 378,9 & 402,8 & 426,9 & 451,3 & 475,8 & 500,7 & 525,7 & 551,0 & 576,5 & 602,2 & 533,2 \\
\hline $\mathrm{CO}$ & ${ }^{1} J_{\mathrm{CO}}$ & 24,9 & 23,2 & 21,5 & 19,7 & 17,7 & 15,8 & 13,7 & 11,6 & 9,4 & 7,1 & 4,8 & 15,6 \\
\hline $\mathrm{H}_{2} \mathrm{O}$ & ${ }^{1} J_{\mathrm{OH}}$ & $-64,8$ & $-67,3$ & $-69,8$ & $-72,4$ & $-75,0$ & $-77,6$ & $-80,2$ & $-82,9$ & $-85,5$ & $-88,3$ & $-91,0$ & $-81,8$ \\
\hline $\mathrm{H}_{2} \mathrm{O}$ & ${ }^{2} J_{\mathrm{HH}}$ & $-4,6$ & $-5,5$ & $-6,5$ & $-7,5$ & $-8,5$ & $-9,6$ & $-10,6$ & $-11,7$ & $-12,8$ & $-13,9$ & $-15,1$ & $-8,7$ \\
\hline $\mathrm{NH}_{3}$ & ${ }^{1} J_{\mathrm{NH}}$ & 40,0 & 40,7 & 41,5 & 42,2 & 43,0 & 43,8 & 44,6 & 45,4 & 46,2 & 47,0 & 47,8 & 43,1 \\
\hline $\mathrm{NH}_{3}$ & ${ }^{2} J_{\mathrm{HH}}$ & $-7,8$ & $-8,6$ & $-9,5$ & $-10,4$ & $-11,2$ & $-12,1$ & $-13,0$ & $-13,9$ & $-14,9$ & $-15,8$ & $-16,8$ & $-10,5$ \\
\hline $\mathrm{PH}_{3}$ & ${ }^{1} J_{\mathrm{PH}}$ & 136,9 & 144,9 & 152,8 & 160,7 & 168,4 & 176,0 & 183,5 & 190,8 & 198,1 & 205,1 & 212,1 & 195,5 \\
\hline $\mathrm{PF}_{3}$ & ${ }^{1} J_{\mathrm{PF}}$ & $-1802,5$ & $-1777,4$ & $-1747,9$ & $-1714,7$ & $-1678,5$ & $-1639,9$ & $-1599,5$ & $-1557,7$ & $-1514,9$ & $-1471,4$ & $-1427,5$ & $-1.442,80$ \\
\hline $\mathrm{BHF}_{2}$ & ${ }^{1} J_{\mathrm{BF}}$ & $-177,9$ & $-160,9$ & $-144,0$ & $-127,2$ & $-110,6$ & $-94,0$ & $-77,7$ & $-61,5$ & $-45,5$ & $-29,7$ & $-14,1$ & $-79,5$ \\
\hline $\mathrm{BF}_{3}$ & ${ }^{1} J_{\mathrm{BF}}$ & $-83,3$ & $-64,6$ & $-46,2$ & $-27,9$ & $-9,8$ & 8,0 & 25,7 & 43,3 & 60,6 & 77,8 & 94,8 & 17,2 \\
\hline $\mathrm{F}_{2} \mathrm{O}$ & ${ }^{1} J_{\mathrm{OF}}$ & $-290,1$ & $-327,4$ & $-365,0$ & $-404,4$ & $-447,8$ & $-498,7$ & $-562,6$ & $-651,0$ & $-790,4$ & $-1064,3$ & $-1973,1$ & $-286,9$ \\
\hline $\mathrm{CH}_{4}$ & ${ }^{1} J_{\mathrm{CH}}$ & 117,5 & 118,9 & 120,4 & 121,9 & 123,4 & 124,9 & 126,5 & 128,1 & 129,7 & 131,4 & 133,0 & 123 \\
\hline $\mathrm{CH}_{4}$ & ${ }^{2} J_{\mathrm{HH}}$ & $-11,8$ & $-12,5$ & $-13,2$ & $-13,9$ & $-14,6$ & $-15,3$ & $-16,1$ & $-16,8$ & $-17,5$ & $-18,1$ & $-18,8$ & $-12,5$ \\
\hline $\mathrm{C}_{2} \mathrm{H}_{2}$ & ${ }^{1} J_{\mathrm{CC}}$ & 187,3 & 189,9 & 193,0 & 196,5 & 200,6 & 205,4 & 211,1 & 218,0 & 226,4 & 236,9 & 250,2 & 174,4 \\
\hline $\mathrm{C}_{2} \mathrm{H}_{2}$ & ${ }^{1} J_{\mathrm{CH}}$ & 247,4 & 249,7 & 252,1 & 254,7 & 257,5 & 260,6 & 264,1 & 268,1 & 272,8 & 278,4 & 285,3 & 244,5 \\
\hline $\mathrm{C}_{2} \mathrm{H}_{2}$ & ${ }^{2} J_{\mathrm{CH}}$ & 54,6 & 54,6 & 54,4 & 53,9 & 53,1 & 51,9 & 50,3 & 48,1 & 45,2 & 41,3 & 35,9 & 49,7 \\
\hline $\mathrm{C}_{2} \mathrm{H}_{2}$ & ${ }^{3} J_{\mathrm{HH}}$ & 10,2 & 10,9 & 11,6 & 12,5 & 13,5 & 14,8 & 16,4 & 18,2 & 20,5 & 23,3 & 26,9 & 9,1 \\
\hline $\mathrm{C}_{2} \mathrm{H}_{4}$ & ${ }^{1} J_{\mathrm{CC}}$ & 59,5 & 62,2 & 65,2 & 68,5 & 72,4 & 76,9 & 82,4 & 89,4 & 98,7 & 112,2 & 133,8 & 67,2 \\
\hline $\mathrm{C}_{2} \mathrm{H}_{4}$ & ${ }^{1} J_{\mathrm{CH}}$ & 149,7 & 151,8 & 154,0 & 156,3 & 158,8 & 161,6 & 164,7 & 168,5 & 173,2 & 179,6 & 189,3 & 154,5 \\
\hline $\mathrm{C}_{2} \mathrm{H}_{4}$ & ${ }^{2} J_{\mathrm{CH}}$ & 0,0 & $-0,8$ & $-1,7$ & $-2,9$ & $-4,2$ & $-5,7$ & $-7,7$ & $-10,3$ & $-13,9$ & $-19,1$ & $-27,6$ & $-2,1$ \\
\hline $\mathrm{C}_{2} \mathrm{H}_{4}$ & ${ }^{2} J_{\mathrm{HH}}$ & 4,6 & 3,9 & 3,1 & 2,2 & 1,2 & 0,0 & $-1,2$ & $-2,9$ & $-5,2$ & $-8,4$ & $-13,5$ & 2 \\
\hline $\mathrm{C}_{2} \mathrm{H}_{4}$ & ${ }^{3} J_{\mathrm{HH}_{\mathrm{c}}}$ & 11,6 & 11,9 & 12,3 & 12,7 & 13,3 & 14,0 & 15,0 & 16,3 & 18,1 & 21,0 & 25,7 & 11,4 \\
\hline $\mathrm{C}_{2} \mathrm{H}_{4}$ & ${ }^{3} J_{\mathrm{HH}_{\mathrm{t}}}$ & 18,5 & 18,9 & 19,3 & 19,8 & 20,4 & 21,3 & 22,4 & 23,9 & 26,1 & 29,3 & 34,7 & 18,5 \\
\hline $\mathrm{C}_{2} \mathrm{H}_{6}$ & ${ }^{1} J_{\mathrm{CC}}$ & 24,2 & 26,2 & 28,2 & 30,2 & 32,3 & 34,4 & 36,5 & 38,7 & 40,9 & 43,2 & 45,4 & 33,7 \\
\hline $\mathrm{C}_{2} \mathrm{H}_{6}$ & ${ }^{1} J_{\mathrm{CH}}$ & 117,6 & 119,2 & 120,9 & 122,6 & 124,3 & 126,0 & 127,8 & 129,6 & 131,3 & 133,2 & 135,0 & 123,4 \\
\hline $\mathrm{C}_{2} \mathrm{H}_{6}$ & ${ }^{2} J_{\mathrm{CH}}$ & $-2,7$ & $-3,1$ & $-3,6$ & $-4,1$ & $-4,5$ & $-5,0$ & $-5,5$ & $-6,0$ & $-6,5$ & $-7,1$ & $-7,6$ & $-4,5$ \\
\hline \multirow[t]{3}{*}{ Total } & DM & $-29,71$ & $-27,27$ & $-24,65$ & $-21,95$ & $-19,24$ & $-16,67$ & $-14,44$ & $-12,99$ & $-13,29$ & $-18,44$ & $-47,50$ & - \\
\hline & DMA & 34,50 & 31,89 & 29,16 & 26,65 & 24,68 & 23,40 & 23,76 & 27,26 & 34,75 & 48,90 & 89,67 & - \\
\hline & PDMA & 50,68 & 41,17 & 31,61 & 24,56 & 23,22 & 25,87 & 35,34 & 53,52 & 76,73 & 107,93 & 159,52 & - \\
\hline \multirow[t]{3}{*}{ CPI } & $\mathrm{DM}$ & $-69,85$ & $-65,31$ & $-60,43$ & $-55,40$ & $-50,49$ & $-46,08$ & $-42,71$ & $-41,48$ & $-44,83$ & $-60,39$ & $-133,66$ & - \\
\hline & DMA & 75,86 & 70,25 & 64,26 & 58,09 & 52,15 & 47,01 & 45,15 & 49,92 & 63,17 & 90,79 & 178,86 & - \\
\hline & PDMA & 87,08 & 72,45 & 57,77 & 43,12 & 29,88 & 19,42 & 21,29 & 37,48 & 56,43 & 80,24 & 124,42 & - \\
\hline \multirow[t]{3}{*}{ SPI } & $\mathrm{DM}$ & $-0,27$ & 0,63 & 1,58 & 2,57 & 3,68 & 4,90 & 6,29 & 7,91 & 9,83 & 12,32 & 15,69 & - \\
\hline & DMA & 4,17 & 3,76 & 3,42 & 3,59 & 4,53 & 6,09 & 8,08 & 10,64 & 13,90 & 18,19 & 24,25 & - \\
\hline & PDMA & 23,99 & 18,23 & 12,42 & 10,95 & 18,33 & 30,60 & 45,65 & 65,29 & 91,61 & 128,23 & 185,27 & - \\
\hline \multirow[t]{3}{*}{$\Delta \mathrm{CS}$} & $\mathrm{DM}$ & $-69,57$ & $-65,94$ & $-62,01$ & $-57,97$ & $-54,17$ & $-50,98$ & $-49,00$ & $-49,39$ & $-54,66$ & $-72,71$ & $-149,36$ & - \\
\hline & DMA & 71,70 & 66,49 & 60,84 & 54,50 & 47,61 & 40,92 & 37,07 & 39,28 & 49,27 & 72,60 & 154,61 & - \\
\hline & PDMA & 63,09 & 54,23 & 45,34 & 32,17 & 11,55 & $-11,19$ & $-24,37$ & $-27,81$ & $-35,18$ & $-47,99$ & $-60,85$ & - \\
\hline
\end{tabular}


Tabela 8.144: Constantes de acoplamento BPW91 e constantes empíricas no nível BHandH $40 \% E_{X}^{\mathrm{HF}}$ e base aug-pcJ-2.

\begin{tabular}{|c|c|c|c|c|c|c|c|c|c|c|c|c|c|}
\hline & $\% E_{X}^{\mathrm{HF}}$ & $0 \%$ & $10 \%$ & $20 \%$ & $30 \%$ & $40 \%$ & $50 \%$ & $60 \%$ & $70 \%$ & $80 \%$ & $90 \%$ & $100 \%$ & Emp. \\
\hline $\mathrm{HF}$ & ${ }^{1} J_{\mathrm{HF}}$ & 353,3 & 377,4 & 401,9 & 426,6 & 451,5 & 476,7 & 502,2 & 527,9 & 553,8 & 579,9 & 606,3 & 533,2 \\
\hline $\mathrm{CO}$ & ${ }^{1} J_{\mathrm{CO}}$ & 25,2 & 23,6 & 21,8 & 20,0 & 18,1 & 16,1 & 14,0 & 11,8 & 9,6 & 7,3 & 4,9 & 15,6 \\
\hline $\mathrm{H}_{2} \mathrm{O}$ & ${ }^{1} J_{\mathrm{OH}}$ & $-64,9$ & $-67,5$ & $-70,1$ & $-72,7$ & $-75,4$ & $-78,1$ & $-80,8$ & $-83,5$ & $-86,3$ & $-89,1$ & $-91,9$ & $-81,8$ \\
\hline $\mathrm{H}_{2} \mathrm{O}$ & ${ }^{2} J_{\mathrm{HH}}$ & $-5,1$ & $-6,1$ & $-7,1$ & $-8,1$ & $-9,2$ & $-10,2$ & $-11,3$ & $-12,5$ & $-13,6$ & $-14,8$ & $-16,0$ & $-8,7$ \\
\hline $\mathrm{NH}_{3}$ & ${ }^{1} J_{\mathrm{NH}}$ & 40,2 & 41,0 & 41,8 & 42,6 & 43,4 & 44,2 & 45,0 & 45,8 & 46,7 & 47,5 & 48,4 & 43,1 \\
\hline $\mathrm{NH}_{3}$ & ${ }^{2} J_{\mathrm{HH}}$ & $-8,3$ & $-9,2$ & $-10,1$ & $-11,0$ & $-11,9$ & $-12,9$ & $-13,8$ & $-14,7$ & $-15,7$ & $-16,7$ & $-17,7$ & $-10,5$ \\
\hline $\mathrm{PH}_{3}$ & ${ }^{1} J_{\mathrm{PH}}$ & 137,3 & 145,6 & 153,9 & 162,0 & 170,1 & 178,0 & 185,8 & 193,4 & 200,9 & 208,3 & 215,5 & 195,5 \\
\hline $\mathrm{PF}_{3}$ & ${ }^{1} J_{\mathrm{PF}}$ & $-1810,6$ & $-1784,5$ & $-1754,1$ & $-1720,0$ & $-1683,1$ & $-1643,8$ & $-1602,7$ & $-1560,3$ & $-1516,9$ & $-1472,9$ & $-1428,5$ & $-1.442,80$ \\
\hline $\mathrm{BHF}_{2}$ & ${ }^{1} J_{\mathrm{BF}}$ & $-178,0$ & $-160,8$ & $-143,8$ & $-126,8$ & $-110,0$ & $-93,3$ & $-76,8$ & $-60,4$ & $-44,3$ & $-28,3$ & $-12,5$ & $-79,5$ \\
\hline $\mathrm{BF}_{3}$ & ${ }^{1} J_{\mathrm{BF}}$ & $-83,3$ & $-64,5$ & $-45,8$ & $-27,4$ & $-9,1$ & 8,9 & 26,7 & 44,5 & 62,0 & 79,4 & 96,6 & 17,2 \\
\hline $\mathrm{F}_{2} \mathrm{O}$ & ${ }^{1} J_{\mathrm{OF}}$ & $-291,7$ & $-329,9$ & $-368,6$ & $-409,2$ & $-454,4$ & $-507,7$ & $-575,7$ & $-671,4$ & $-827,4$ & $-1153,6$ & $-2525,8$ & $-286,9$ \\
\hline $\mathrm{CH}_{4}$ & ${ }^{1} J_{\mathrm{CH}}$ & 118,9 & 120,4 & 121,9 & 123,5 & 125,1 & 126,7 & 128,4 & 130,0 & 131,7 & 133,4 & 135,2 & 123 \\
\hline $\mathrm{CH}_{4}$ & ${ }^{2} J_{\mathrm{HH}}$ & $-12,5$ & $-13,3$ & $-14,0$ & $-14,7$ & $-15,5$ & $-16,2$ & $-17,0$ & $-17,7$ & $-18,4$ & $-19,1$ & $-19,9$ & $-12,5$ \\
\hline $\mathrm{C}_{2} \mathrm{H}_{2}$ & ${ }^{1} J_{\mathrm{CC}}$ & 187,9 & 190,7 & 193,9 & 197,7 & 202,2 & 207,5 & 213,8 & 221,6 & 231,2 & 243,3 & 259,0 & 174,4 \\
\hline $\mathrm{C}_{2} \mathrm{H}_{2}$ & ${ }^{1} J_{\mathrm{CH}}$ & 251,1 & 253,6 & 256,2 & 259,1 & 262,1 & 265,6 & 269,5 & 274,1 & 279,5 & 286,1 & 294,6 & 244,5 \\
\hline $\mathrm{C}_{2} \mathrm{H}_{2}$ & ${ }^{2} J_{\mathrm{CH}}$ & 54,7 & 54,6 & 54,2 & 53,6 & 52,6 & 51,1 & 49,1 & 46,5 & 42,8 & 37,9 & 31,2 & 49,7 \\
\hline $\mathrm{C}_{2} \mathrm{H}_{2}$ & ${ }^{3} J_{\mathrm{HH}}$ & 10,8 & 11,5 & 12,4 & 13,4 & 14,6 & 16,1 & 17,9 & 20,1 & 22,8 & 26,3 & 30,7 & 9,1 \\
\hline $\mathrm{C}_{2} \mathrm{H}_{4}$ & ${ }^{1} J_{\mathrm{CC}}$ & 59,9 & 62,7 & 65,9 & 69,5 & 73,7 & 78,7 & 84,9 & 93,0 & 104,3 & 121,5 & 152,0 & 67,2 \\
\hline $\mathrm{C}_{2} \mathrm{H}_{4}$ & ${ }^{1} J_{\mathrm{CH}}$ & 151,9 & 154,1 & 156,4 & 158,9 & 161,6 & 164,7 & 168,3 & 172,6 & 178,2 & 186,4 & 200,0 & 154,5 \\
\hline $\mathrm{C}_{2} \mathrm{H}_{4}$ & ${ }^{2} J_{\mathrm{CH}}$ & $-0,4$ & $-1,4$ & $-2,4$ & $-3,6$ & $-5,1$ & $-6,9$ & $-9,2$ & $-12,4$ & $-16,8$ & $-23,7$ & $-36,2$ & $-2,1$ \\
\hline $\mathrm{C}_{2} \mathrm{H}_{4}$ & ${ }^{2} J_{\mathrm{HH}}$ & 4,2 & 3,3 & 2,5 & 1,5 & 0,4 & $-0,8$ & $-2,4$ & $-4,5$ & $-7,4$ & $-11,7$ & $-19,2$ & 2 \\
\hline $\mathrm{C}_{2} \mathrm{H}_{4}$ & ${ }^{3} J_{\mathrm{HH}_{\mathrm{C}}}$ & 12,0 & 12,3 & 12,7 & 13,3 & 14,0 & 14,8 & 16,0 & 17,7 & 20,1 & 24,0 & 31,2 & 11,4 \\
\hline $\mathrm{C}_{2} \mathrm{H}_{4}$ & ${ }^{3} J_{\mathrm{HH}_{\mathrm{t}}}$ & 19,1 & 19,5 & 20,0 & 20,6 & 21,4 & 22,4 & 23,7 & 25,6 & 28,4 & 32,8 & 40,9 & 18,5 \\
\hline $\mathrm{C}_{2} \mathrm{H}_{6}$ & ${ }^{1} J_{\mathrm{CC}}{ }^{2}$ & 24,5 & 26,5 & 28,5 & 30,6 & 32,7 & 34,8 & 37,0 & 39,2 & 41,5 & 43,8 & 46,1 & 33,7 \\
\hline $\mathrm{C}_{2} \mathrm{H}_{6}$ & ${ }^{1} J_{\mathrm{CH}}$ & 119,2 & 120,9 & 122,6 & 124,4 & 126,2 & 128,0 & 129,8 & 131,7 & 133,5 & 135,4 & 137,3 & 123,4 \\
\hline $\mathrm{C}_{2} \mathrm{H}_{6}$ & ${ }^{2} J_{\mathrm{CH}}$ & $-3,0$ & $-3,5$ & $-3,9$ & $-4,4$ & $-4,9$ & $-5,4$ & $-6,0$ & $-6,5$ & $-7,0$ & $-7,5$ & $-8,1$ & $-4,5$ \\
\hline \multirow[t]{3}{*}{ Total } & DM & $-29,78$ & $-27,30$ & $-24,62$ & $-21,82$ & $-19,06$ & $-16,45$ & $-14,24$ & $-12,89$ & $-13,60$ & $-20,42$ & $-66,64$ & - \\
\hline & DMA & 34,83 & 32,20 & 29,59 & 27,40 & 25,75 & 24,63 & 25,37 & 29,43 & 38,30 & 55,08 & 114,82 & - \\
\hline & PDMA & 48,80 & 38,79 & 30,31 & 27,13 & 28,58 & 32,18 & 43,83 & 64,76 & 91,77 & 130,26 & 202,77 & - \\
\hline \multirow[t]{3}{*}{ CPI } & $\mathrm{DM}$ & $-70,94$ & $-66,30$ & $-61,33$ & $-56,22$ & $-51,31$ & $-46,95$ & $-43,80$ & $-43,07$ & $-47,78$ & $-67,95$ & $-183,19$ & - \\
\hline & DMA & 76,81 & 71,06 & 64,95 & 58,78 & 52,98 & 47,92 & 46,55 & 52,00 & 67,71 & 100,18 & 230,30 & - \\
\hline & PDMA & 86,38 & 71,51 & 56,58 & 42,72 & 30,75 & 20,58 & 23,49 & 40,31 & 60,28 & 86,09 & 145,18 & - \\
\hline \multirow[t]{3}{*}{ SPI } & $\mathrm{DM}$ & 0,40 & 1,31 & 2,31 & 3,41 & 4,59 & 5,92 & 7,43 & 9,25 & 11,47 & 14,44 & 18,83 & - \\
\hline & DMA & 4,05 & 3,71 & 3,67 & 4,38 & 5,79 & 7,55 & 9,85 & 12,87 & 16,73 & 22,00 & 30,14 & - \\
\hline & PDMA & 21,24 & 14,80 & 11,04 & 15,69 & 26,99 & 40,68 & 58,75 & 82,70 & 114,86 & 162,65 & 245,00 & - \\
\hline \multirow[t]{3}{*}{$\Delta \mathrm{CS}$} & $\mathrm{DM}$ & $-71,34$ & $-67,61$ & $-63,63$ & $-59,62$ & $-55,90$ & $-52,87$ & $-51,23$ & $-52,32$ & $-59,26$ & $-82,39$ & $-202,02$ & - \\
\hline & DMA & 72,76 & 67,36 & 61,28 & 54,40 & 47,20 & 40,37 & 36,70 & 39,13 & 50,98 & 78,18 & 200,16 & - \\
\hline & PDMA & 65,14 & 56,71 & 45,54 & 27,03 & 3,76 & $-20,09$ & $-35,26$ & $-42,39$ & $-54,58$ & $-76,56$ & $-99,82$ & - \\
\hline
\end{tabular}


Tabela 8.145: Constantes de acoplamento M05 e constantes empíricas no nível BHandH $40 \% E_{X}^{\mathrm{HF}}$ e base aug-pcJ-2.

\begin{tabular}{|c|c|c|c|c|c|c|c|c|c|c|c|c|c|}
\hline & $\% E_{X}^{\mathrm{HF}}$ & $0 \%$ & $10 \%$ & $20 \%$ & $30 \%$ & $40 \%$ & $50 \%$ & $60 \%$ & $70 \%$ & $80 \%$ & $90 \%$ & $100 \%$ & Emp. \\
\hline $\mathrm{HF}$ & ${ }^{1} J_{\mathrm{HF}}^{X}$ & 847,0 & 840,1 & 833,5 & 827,3 & 821,4 & 815,9 & 810,8 & 805,8 & 801,1 & 796,4 & 791,7 & 533,2 \\
\hline $\mathrm{CO}$ & ${ }^{1} J_{\mathrm{CO}}$ & 15,8 & 13,7 & 11,3 & 8,5 & 5,3 & 1,7 & $-2,1$ & $-6,2$ & $-10,7$ & $-15,5$ & $-20,5$ & 15,6 \\
\hline $\mathrm{H}_{2} \mathrm{O}$ & ${ }^{1} J_{\mathrm{OH}}$ & $-108,9$ & $-108,7$ & $-108,5$ & $-108,3$ & $-108,2$ & $-108,0$ & $-108,0$ & $-108,0$ & $-108,0$ & $-108,1$ & $-108,2$ & $-81,8$ \\
\hline $\mathrm{H}_{2} \mathrm{O}$ & ${ }^{2} J_{\mathrm{HH}}$ & $-18,6$ & $-18,7$ & $-18,7$ & $-18,6$ & $-18,3$ & $-17,9$ & $-17,4$ & $-16,7$ & $-15,9$ & $-15,0$ & $-13,9$ & $-8,7$ \\
\hline $\mathrm{NH}_{3}$ & ${ }^{1} J_{\mathrm{NH}}$ & 41,1 & 42,3 & 43,4 & 44,5 & 45,6 & 46,7 & 47,8 & 48,8 & 49,8 & 50,8 & 51,7 & 43,1 \\
\hline $\mathrm{NH}_{3}$ & ${ }^{2} J_{\mathrm{HH}}$ & $-13,5$ & $-14,4$ & $-15,2$ & $-15,9$ & $-16,4$ & $-16,7$ & $-16,9$ & $-16,8$ & $-16,5$ & $-15,9$ & $-15,2$ & $-10,5$ \\
\hline $\mathrm{PH}_{3}$ & ${ }^{1} J_{\mathrm{PH}}$ & 168,5 & 166,8 & 168,2 & 173,0 & 180,3 & 188,9 & 198,1 & 207,2 & 215,9 & 224,1 & 231,8 & 195,5 \\
\hline $\mathrm{PF}_{3}$ & ${ }^{1} J_{\mathrm{PF}}$ & $-1357,6$ & $-1376,0$ & $-1386,5$ & $-1388,9$ & $-1383,6$ & $-1372,0$ & $-1355,3$ & $-1334,8$ & $-1311,8$ & $-1287,0$ & $-1261,2$ & $-1.442,80$ \\
\hline $\mathrm{BHF}_{2}$ & ${ }^{1} J_{\mathrm{BF}}$ & 2,2 & 8,2 & 14,9 & 22,3 & 30,5 & 39,5 & 49,5 & 60,5 & 72,8 & 86,3 & 101,3 & $-79,5$ \\
\hline $\mathrm{BF}_{3}$ & ${ }^{1} J_{\mathrm{BF}}$ & 102,9 & 111,1 & 119,8 & 129,1 & 139,0 & 149,8 & 161,4 & 174,1 & 187,8 & 202,7 & 218,9 & 17,2 \\
\hline $\mathrm{F}_{2} \mathrm{O}$ & ${ }^{1} J_{\mathrm{OF}}$ & $-218,9$ & $-253,7$ & $-282,8$ & $-307,6$ & $-330,0$ & $-351,6$ & $-374,7$ & $-402,2$ & $-439,1$ & $-494,9$ & $-592,4$ & $-286,9$ \\
\hline $\mathrm{CH}_{4}$ & ${ }^{1} J_{\mathrm{CH}}$ & 80,9 & 87,2 & 93,5 & 99,8 & 106,1 & 112,4 & 118,7 & 125,0 & 131,1 & 137,1 & 142,9 & 123 \\
\hline $\mathrm{CH}_{4}$ & ${ }^{2} J_{\mathrm{HH}}$ & $-20,8$ & $-21,1$ & $-21,2$ & $-21,2$ & $-21,0$ & $-20,8$ & $-20,4$ & $-19,8$ & $-19,2$ & $-18,5$ & $-17,9$ & $-12,5$ \\
\hline $\mathrm{C}_{2} \mathrm{H}_{2}$ & ${ }^{1} J_{\mathrm{CC}}$ & 182,9 & 192,0 & 201,6 & 211,8 & 222,6 & 234,0 & 246,1 & 258,8 & 272,4 & 286,7 & 302,0 & 174,4 \\
\hline $\mathrm{C}_{2} \mathrm{H}_{2}$ & ${ }^{1} J_{\mathrm{CH}}$ & 223,0 & 232,1 & 240,9 & 249,5 & 257,6 & 265,4 & 272,7 & 279,3 & 285,2 & 290,2 & 294,4 & 244,5 \\
\hline $\mathrm{C}_{2} \mathrm{H}_{2}$ & ${ }^{2} J_{\mathrm{CH}}$ & 35,8 & 36,1 & 36,4 & 36,6 & 36,7 & 36,7 & 36,8 & 36,7 & 36,4 & 35,9 & 34,9 & 49,7 \\
\hline $\mathrm{C}_{2} \mathrm{H}_{2}$ & ${ }^{3} J_{\mathrm{HH}}$ & 19,6 & 20,1 & 20,4 & 20,6 & 20,7 & 20,7 & 20,6 & 20,4 & 20,2 & 20,1 & 20,2 & 9,1 \\
\hline $\mathrm{C}_{2} \mathrm{H}_{4}$ & ${ }^{1} J_{\mathrm{CC}}$ & 57,9 & 64,1 & 70,7 & 77,9 & 85,7 & 94,1 & 103,3 & 113,2 & 123,9 & 135,6 & 148,4 & 67,2 \\
\hline $\mathrm{C}_{2} \mathrm{H}_{4}$ & ${ }^{1} J_{\mathrm{CH}}$ & 119,8 & 127,7 & 135,5 & 143,2 & 150,8 & 158,4 & 165,8 & 173,1 & 180,1 & 187,0 & 193,6 & 154,5 \\
\hline $\mathrm{C}_{2} \mathrm{H}_{4}$ & ${ }^{2} J_{\mathrm{CH}}$ & $-11,4$ & $-12,2$ & $-13,1$ & $-14,1$ & $-15,1$ & $-16,2$ & $-17,3$ & $-18,4$ & $-19,6$ & $-20,9$ & $-22,4$ & $-2,1$ \\
\hline $\mathrm{C}_{2} \mathrm{H}_{4}$ & ${ }^{2} J_{\mathrm{HH}}$ & $-16,0$ & $-15,7$ & $-15,1$ & $-14,4$ & $-13,6$ & $-12,6$ & $-11,4$ & $-10,1$ & $-8,8$ & $-7,5$ & $-6,4$ & 2 \\
\hline $\mathrm{C}_{2} \mathrm{H}_{4}$ & ${ }^{3} J_{\mathrm{HH}_{\mathrm{c}}}$ & 14,5 & 15,2 & 15,8 & 16,3 & 16,7 & 17,0 & 17,2 & 17,3 & 17,3 & 17,3 & 17,3 & 11,4 \\
\hline $\mathrm{C}_{2} \mathrm{H}_{4}$ & ${ }^{3} J_{\mathrm{HH}_{\mathrm{t}}}$ & 15,6 & 17,0 & 18,2 & 19,4 & 20,5 & 21,4 & 22,2 & 22,9 & 23,4 & 23,9 & 24,4 & 18,5 \\
\hline $\mathrm{C}_{2} \mathrm{H}_{6}$ & ${ }^{1} J_{\mathrm{CC}}$ & 15,2 & 18,5 & 21,9 & 25,6 & 29,4 & 33,3 & 37,5 & 41,9 & 46,4 & 51,2 & 56,2 & 33,7 \\
\hline $\mathrm{C}_{2} \mathrm{H}_{6}$ & ${ }^{1} J_{\mathrm{CH}}$ & 80,1 & 86,6 & 93,0 & 99,5 & 106,0 & 112,6 & 119,1 & 125,6 & 132,0 & 138,4 & 144,6 & 123,4 \\
\hline $\mathrm{C}_{2} \mathrm{H}_{6}$ & ${ }^{2} J_{\mathrm{CH}}$ & $-3,2$ & $-3,7$ & $-4,2$ & $-4,7$ & $-5,2$ & $-5,7$ & $-6,1$ & $-6,6$ & $-7,0$ & $-7,5$ & $-8,0$ & $-4,5$ \\
\hline \multirow[t]{3}{*}{ Total } & DM & 14,12 & 14,15 & 14,88 & 16,33 & 18,34 & 20,78 & 23,51 & 26,32 & 28,94 & 31,01 & 31,60 & - \\
\hline & DMA & 36,49 & 33,67 & 31,63 & 32,40 & 34,00 & 36,15 & 39,39 & 43,89 & 49,61 & 56,25 & 64,70 & - \\
\hline & PDMA & 103,20 & 104,89 & 106,77 & 110,68 & 115,20 & 119,83 & 125,22 & 131,27 & 138,34 & 146,29 & 156,05 & - \\
\hline \multirow[t]{3}{*}{ CPI } & DM & 51,42 & 46,94 & 44,09 & 42,82 & 42,84 & 43,81 & 45,35 & 47,03 & 48,27 & 48,14 & 44,51 & - \\
\hline & DMA & 63,96 & 60,06 & 57,36 & 59,56 & 62,93 & 66,86 & 72,04 & 79,32 & 87,89 & 98,52 & 113,22 & - \\
\hline & PDMA & 80,43 & 85,79 & 91,95 & 100,24 & 108,92 & 118,07 & 128,00 & 139,10 & 151,12 & 164,32 & 179,49 & - \\
\hline \multirow[t]{3}{*}{ SPI } & $\mathrm{DM}$ & $-13,23$ & $-9,89$ & $-6,53$ & $-3,10$ & 0,37 & 3,89 & 7,50 & 11,13 & 14,77 & 18,45 & 22,13 & - \\
\hline & DMA & 16,35 & 14,32 & 12,76 & 12,49 & 12,79 & 13,63 & 15,45 & 17,91 & 21,54 & 25,26 & 29,11 & - \\
\hline & PDMA & 119,90 & 118,89 & 117,63 & 118,34 & 119,80 & 121,12 & 123,18 & 125,53 & 128,97 & 133,06 & 138,86 & - \\
\hline \multirow[t]{3}{*}{$\Delta \mathrm{CS}$} & DM & 64,64 & 56,83 & 50,62 & 45,92 & 42,46 & 39,92 & 37,85 & 35,89 & 33,51 & 29,69 & 22,38 & - \\
\hline & DMA & 47,62 & 45,74 & 44,60 & 47,08 & 50,14 & 53,24 & 56,59 & 61,41 & 66,35 & 73,26 & 84,10 & - \\
\hline & PDMA & $-39,47$ & $-33,10$ & $-25,68$ & $-18,10$ & $-10,89$ & $-3,05$ & 4,82 & 13,56 & 22,15 & 31,26 & 40,63 & - \\
\hline
\end{tabular}


Tabela 8.146: Constantes de acoplamento M06 e constantes empíricas no nível BHandH $40 \% E_{X}^{\mathrm{HF}}$ e base aug-pcJ-2.

\begin{tabular}{|c|c|c|c|c|c|c|c|c|c|c|c|c|c|}
\hline & $\% E_{X}^{\mathrm{HF}}$ & $0 \%$ & $10 \%$ & $20 \%$ & $30 \%$ & $40 \%$ & $50 \%$ & $60 \%$ & $70 \%$ & $80 \%$ & $90 \%$ & $100 \%$ & Emp. \\
\hline $\mathrm{HF}$ & ${ }^{1} J_{\mathrm{HF}}$ & 591,8 & 620,1 & 652,6 & 690,1 & 733,4 & 782,9 & 838,6 & 900,5 & 967,8 & 1039,5 & 1113,9 & 533,2 \\
\hline $\mathrm{CO}$ & ${ }^{1} J_{\mathrm{CO}}$ & 16,9 & 17,6 & 17,9 & 17,8 & 17,0 & 15,4 & 13,0 & 9,5 & 5,0 & $-0,8$ & $-7,9$ & 15,6 \\
\hline $\mathrm{H}_{2} \mathrm{O}$ & ${ }^{1} J_{\mathrm{OH}}$ & $-86,0$ & $-90,6$ & $-96,1$ & $-102,7$ & $-110,6$ & $-120,0$ & $-131,2$ & $-144,5$ & $-160,2$ & $-178,9$ & $-201,1$ & $-81,8$ \\
\hline $\mathrm{H}_{2} \mathrm{O}$ & ${ }^{2} J_{\mathrm{HH}}$ & $-5,7$ & $-9,1$ & $-13,3$ & $-18,4$ & $-24,8$ & $-32,8$ & $-42,7$ & $-54,9$ & $-70,2$ & $-89,3$ & $-113,0$ & $-8,7$ \\
\hline $\mathrm{NH}_{3}$ & ${ }^{1} J_{\mathrm{NH}}$ & 43,2 & 46,1 & 49,6 & 53,7 & 58,6 & 64,4 & 71,6 & 80,3 & 91,1 & 104,7 & 122,2 & 43,1 \\
\hline $\mathrm{NH}_{3}$ & ${ }^{2} J_{\mathrm{HH}}$ & $-7,6$ & $-10,7$ & $-14,6$ & $-19,7$ & $-26,3$ & $-35,0$ & $-46,5$ & $-62,0$ & $-83,1$ & $-112,3$ & $-153,9$ & $-10,5$ \\
\hline $\mathrm{PH}_{3}$ & ${ }^{1} J_{\mathrm{PH}}$ & 199,3 & 214,4 & 232,5 & 254,5 & 281,6 & 315,1 & 357,5 & 411,8 & 483,2 & 577,7 & 701,3 & 195,5 \\
\hline $\mathrm{PF}_{3}$ & ${ }^{1} J_{\mathrm{PF}}$ & $-1437,2$ & $-1476,6$ & $-1508,9$ & $-1533,6$ & $-1552,2$ & $-1567,1$ & $-1579,5$ & $-1588,2$ & $-1591,0$ & $-1586,1$ & $-1573,4$ & $-1.442,80$ \\
\hline $\mathrm{BHF}_{2}$ & ${ }^{1} J_{\mathrm{BF}}$ & $-67,3$ & $-57,9$ & $-46,0$ & $-31,5$ & $-14,7$ & 3,7 & 22,9 & 41,7 & 58,7 & 71,6 & 75,6 & $-79,5$ \\
\hline $\mathrm{BF}_{3}$ & ${ }^{1} J_{\mathrm{BF}}$ & 27,0 & 39,1 & 53,4 & 70,2 & 89,7 & 111,5 & 135,2 & 160,1 & 185,6 & 211,4 & 237,7 & 17,2 \\
\hline $\mathrm{F}_{2} \mathrm{O}$ & ${ }^{1} J_{\mathrm{OF}}$ & $-161,1$ & $-211,1$ & $-265,9$ & $-328,2$ & $-406,1$ & $-530,0$ & $-975,7$ & 4267,8 & $-15,5$ & $-222,3$ & $-320,8$ & $-286,9$ \\
\hline $\mathrm{CH}_{4}$ & ${ }^{1} J_{\mathrm{CH}}$ & 103,3 & 114,7 & 128,4 & 144,8 & 164,8 & 189,3 & 219,9 & 258,9 & 309,9 & 379,0 & 477,4 & 123 \\
\hline $\mathrm{CH}_{4}$ & ${ }^{2} J_{\mathrm{HH}}$ & $-12,6$ & $-16,6$ & $-21,5$ & $-27,9$ & $-36,3$ & $-47,3$ & $-62,2$ & $-82,8$ & $-112,3$ & $-156,2$ & $-225,1$ & $-12,5$ \\
\hline $\mathrm{C}_{2} \mathrm{H}_{2}$ & ${ }^{1} J_{\mathrm{CC}}$ & 161,7 & 170,7 & 182,5 & 199,5 & 227,4 & 285,4 & 502,3 & $-632,7$ & $-14,0$ & 128,2 & 5815,3 & 174,4 \\
\hline $\mathrm{C}_{2} \mathrm{H}_{2}$ & ${ }^{1} J_{\mathrm{CH}}$ & 208,8 & 237,3 & 271,3 & 313,1 & 367,7 & 450,4 & 661,2 & $-166,8$ & 360,7 & 495,3 & $-161,9$ & 244,5 \\
\hline $\mathrm{C}_{2} \mathrm{H}_{2}$ & ${ }^{2} J_{\mathrm{CH}}$ & 49,7 & 51,3 & 51,6 & 49,0 & 39,6 & 9,0 & $-141,1$ & 758,3 & 315,4 & 282,8 & 1065,0 & 49,7 \\
\hline $\mathrm{C}_{2} \mathrm{H}_{2}$ & ${ }^{3} J_{\mathrm{HH}}$ & 7,6 & 9,7 & 13,2 & 19,3 & 31,2 & 60,3 & 184,0 & $-514,8$ & $-158,3$ & $-117,3$ & $-2,3$ & 9,1 \\
\hline $\mathrm{C}_{2} \mathrm{H}_{4}$ & ${ }^{1} J_{\mathrm{CC}}$ & 51,1 & 54,6 & 59,6 & 67,7 & 83,1 & 126,0 & 1247,1 & $-64,0$ & $-10,1$ & 6,5 & 13,8 & 67,2 \\
\hline $\mathrm{C}_{2} \mathrm{H}_{4}$ & ${ }^{1} J_{\mathrm{CH}}$ & 130,3 & 146,9 & 166,9 & 191,8 & 225,2 & 282,2 & 1104,7 & 218,8 & 304,5 & 376,2 & 458,4 & 154,5 \\
\hline $\mathrm{C}_{2} \mathrm{H}_{4}$ & ${ }^{2} J_{\mathrm{CH}}$ & 0,7 & $-0,9$ & $-3,5$ & $-8,1$ & $-17,7$ & $-46,3$ & $-834,9$ & 91,9 & 56,9 & 48,8 & 48,6 & $-2,1$ \\
\hline $\mathrm{C}_{2} \mathrm{H}_{4}$ & ${ }^{2} J_{\mathrm{HH}}$ & $-3,4$ & $-5,9$ & $-9,6$ & $-15,6$ & $-26,7$ & $-56,4$ & $-792,0$ & 61,8 & 21,0 & 1,6 & $-16,5$ & 2 \\
\hline $\mathrm{C}_{2} \mathrm{H}_{4}$ & ${ }^{3} J_{\mathrm{HH}_{\mathrm{c}}}$ & 11,0 & 12,5 & 14,7 & 18,6 & 26,8 & 52,5 & 782,6 & $-78,9$ & $-49,1$ & $-45,4$ & $-50,8$ & 11,4 \\
\hline $\mathrm{C}_{2} \mathrm{H}_{4}$ & ${ }^{3} J_{\mathrm{HH}_{\mathrm{t}}}$ & 12,1 & 14,6 & 18,1 & 23,5 & 33,7 & 62,4 & 821,1 & $-67,9$ & $-32,7$ & $-23,3$ & $-21,2$ & 18,5 \\
\hline $\mathrm{C}_{2} \mathrm{H}_{6}$ & ${ }^{1} J_{\mathrm{CC}}$ & 20,1 & 22,9 & 26,4 & 30,8 & 36,4 & 43,5 & 52,9 & 65,7 & 83,6 & 110,1 & 152,2 & 33,7 \\
\hline $\mathrm{C}_{2} \mathrm{H}_{6}$ & ${ }^{1} J_{\mathrm{CH}}$ & 101,2 & 113,2 & 127,4 & 144,5 & 165,3 & 190,7 & 222,4 & 262,9 & 316,0 & 388,7 & 493,8 & 123,4 \\
\hline $\mathrm{C}_{2} \mathrm{H}_{6}$ & ${ }^{2} J_{\mathrm{CH}}$ & $-1,4$ & $-2,6$ & $-4,2$ & $-6,2$ & $-8,8$ & $-12,3$ & $-17,2$ & $-24,3$ & $-34,8$ & $-51,6$ & $-80,4$ & $-4,5$ \\
\hline \multirow[t]{3}{*}{ Total } & DM & 2,57 & 4,50 & 7,53 & 11,93 & 18,10 & 27,34 & 104,90 & 162,37 & 51,59 & 67,38 & 306,16 & - \\
\hline & DMA & 15,05 & 13,69 & 17,25 & 28,57 & 46,70 & 76,59 & 322,40 & 351,00 & 132,07 & 141,40 & 416,55 & - \\
\hline & PDMA & 33,41 & 34,22 & 50,56 & 90,51 & 162,30 & 332,17 & 3787,41 & 849,27 & 476,79 & 466,91 & 737,77 & - \\
\hline \multirow[t]{3}{*}{ CPI } & DM & 19,90 & 16,99 & 15,16 & 14,35 & 13,75 & 10,34 & $-21,02$ & 466,15 & 88,82 & 83,71 & 89,65 & - \\
\hline & DMA & 20,66 & 24,85 & 31,36 & 45,60 & 66,35 & 92,95 & 151,25 & 522,86 & 156,33 & 163,56 & 190,56 & - \\
\hline & PDMA & 18,66 & 22,39 & 40,46 & 64,74 & 95,40 & 132,91 & 189,22 & 362,18 & 287,27 & 354,98 & 446,38 & - \\
\hline \multirow[t]{3}{*}{ SPI } & $\mathrm{DM}$ & $-10,14$ & $-4,66$ & 1,93 & 10,17 & 21,29 & 39,81 & 197,23 & $-60,41$ & 24,29 & 55,41 & 464,93 & - \\
\hline & DMA & 10,93 & 5,51 & 6,91 & 16,07 & 32,29 & 64,59 & 447,90 & 224,96 & 114,28 & 125,15 & 582,28 & - \\
\hline & PDMA & 44,23 & 42,90 & 57,97 & 109,41 & 211,36 & 478,29 & 6426,09 & 1206,46 & 615,78 & 549,00 & 951,46 & - \\
\hline \multirow[t]{3}{*}{$\Delta \mathrm{CS}$} & $\mathrm{DM}$ & 30,04 & 21,65 & 13,23 & 4,18 & $-7,55$ & $-29,47$ & $-218,25$ & 526,57 & 64,52 & 28,30 & $-375,28$ & - \\
\hline & DMA & 9,74 & 19,33 & 24,46 & 29,53 & 34,05 & 28,36 & $-296,65$ & 297,90 & 42,05 & 38,41 & $-391,72$ & - \\
\hline & PDMA & $-25,57$ & $-20,51$ & $-17,51$ & $-44,67$ & $-115,96$ & $-345,38$ & $-6236,87$ & $-844,28$ & $-328,51$ & $-194,02$ & $-505,08$ & - \\
\hline
\end{tabular}


Tabela 8.147: Constantes de acoplamento M062X e constantes empíricas no nível BHandH $40 \% E_{X}^{\mathrm{HF}}$ e base aug-pcJ-2.

\begin{tabular}{|c|c|c|c|c|c|c|c|c|c|c|c|c|c|}
\hline & $\% E_{X}^{\mathrm{HF}}$ & $0 \%$ & $10 \%$ & $20 \%$ & $30 \%$ & $40 \%$ & $50 \%$ & $60 \%$ & $70 \%$ & $80 \%$ & $90 \%$ & $100 \%$ & Emp. \\
\hline $\mathrm{HF}$ & ${ }^{1} J_{\mathrm{HF}}$ & 445,9 & 449,4 & 453,4 & 459,1 & 467,4 & 479,5 & 496,4 & 519,2 & 548,9 & 586,4 & 632,6 & 533,2 \\
\hline $\mathrm{CO}$ & ${ }^{1} J_{\mathrm{CO}}$ & 3,7 & 4,7 & 5,7 & 6,6 & 7,2 & 7,4 & 7,1 & 6,0 & 3,7 & $-0,2$ & $-6,8$ & 15,6 \\
\hline $\mathrm{H}_{2} \mathrm{O}$ & ${ }^{1} J_{\mathrm{OH}}$ & $-73,4$ & $-75,6$ & $-78,2$ & $-81,3$ & $-85,0$ & $-89,5$ & $-95,0$ & $-101,7$ & $-109,8$ & $-119,5$ & $-131,3$ & $-81,8$ \\
\hline $\mathrm{H}_{2} \mathrm{O}$ & ${ }^{2} J_{\mathrm{HH}}$ & 4,2 & 3,0 & 1,5 & $-0,3$ & $-2,7$ & $-5,7$ & $-9,5$ & $-14,4$ & $-20,5$ & $-28,2$ & $-38,1$ & $-8,7$ \\
\hline $\mathrm{NH}_{3}$ & ${ }^{1} J_{\mathrm{NH}}$ & 38,2 & 40,2 & 42,4 & 45,0 & 48,0 & 51,6 & 55,9 & 60,9 & 66,9 & 74,2 & 83,1 & 43,1 \\
\hline $\mathrm{NH}_{3}$ & ${ }^{2} J_{\mathrm{HH}}$ & 0,2 & $-0,7$ & $-2,1$ & $-4,0$ & $-6,4$ & $-9,5$ & $-13,6$ & $-18,9$ & $-25,9$ & $-35,2$ & $-47,6$ & $-10,5$ \\
\hline $\mathrm{PH}_{3}$ & ${ }^{1} J_{\mathrm{PH}}$ & 133,0 & 134,2 & 137,3 & 142,7 & 150,6 & 161,6 & 176,1 & 195,1 & 219,2 & 250,0 & 289,5 & 195,5 \\
\hline $\mathrm{PF}_{3}$ & ${ }^{1} J_{\mathrm{PF}}$ & $-1442,3$ & $-1488,8$ & $-1533,3$ & $-1573,0$ & $-1603,7$ & $-1622,0$ & $-1627,6$ & $-1623,0$ & $-1612,8$ & $-1602,7$ & $-1596,7$ & $-1.442,80$ \\
\hline $\mathrm{BHF}_{2}$ & ${ }^{1} J_{\mathrm{BF}}$ & $-166,8$ & $-163,3$ & $-156,4$ & $-146,7$ & $-135,1$ & $-122,1$ & $-107,7$ & $-92,3$ & $-75,9$ & $-58,8$ & $-41,4$ & $-79,5$ \\
\hline $\mathrm{BF}_{3}$ & ${ }^{1} J_{\mathrm{BF}}$ & $-89,3$ & $-80,2$ & $-68,9$ & $-56,0$ & $-41,7$ & $-26,4$ & $-10,0$ & 7,5 & 26,7 & 47,8 & 70,9 & 17,2 \\
\hline $\mathrm{F}_{2} \mathrm{O}$ & ${ }^{1} J_{\mathrm{OF}}$ & $-156,6$ & $-199,7$ & $-246,2$ & $-295,8$ & $-348,4$ & $-404,9$ & $-468,8$ & $-550,1$ & $-685,1$ & $-1305,2$ & $-2162,3$ & $-286,9$ \\
\hline $\mathrm{CH}_{4}$ & ${ }^{1} J_{\mathrm{CH}}$ & 86,4 & 93,7 & 102,1 & 112,1 & 123,7 & 137,5 & 153,9 & 173,6 & 197,4 & 226,6 & 262,9 & 123 \\
\hline $\mathrm{CH}_{4}$ & ${ }^{2} J_{\mathrm{HH}}$ & $-0,2$ & $-1,3$ & $-2,8$ & $-4,8$ & $-7,3$ & $-10,5$ & $-14,7$ & $-20,1$ & $-27,3$ & $-36,8$ & $-49,6$ & $-12,5$ \\
\hline $\mathrm{C}_{2} \mathrm{H}_{2}$ & ${ }^{1} J_{\mathrm{CC}}$ & 167,7 & 174,7 & 182,9 & 192,6 & 204,6 & 220,1 & 241,5 & 273,9 & 331,7 & 472,8 & 1542,1 & 174,4 \\
\hline $\mathrm{C}_{2} \mathrm{H}_{2}$ & ${ }^{1} J_{\mathrm{CH}}$ & 142,4 & 159,4 & 178,9 & 201,1 & 226,7 & 256,7 & 292,4 & 336,8 & 397,0 & 500,5 & 1037,2 & 244,5 \\
\hline $\mathrm{C}_{2} \mathrm{H}_{2}$ & ${ }^{2} J_{\mathrm{CH}}$ & 46,7 & 49,1 & 51,6 & 53,9 & 55,8 & 56,9 & 56,2 & 51,7 & 36,8 & $-14,6$ & $-491,4$ & 49,7 \\
\hline $\mathrm{C}_{2} \mathrm{H}_{2}$ & ${ }^{3} J_{\mathrm{HH}}$ & 4,3 & 4,8 & 5,3 & 6,0 & 7,0 & 8,5 & 10,9 & 15,4 & 24,8 & 51,4 & 274,4 & 9,1 \\
\hline $\mathrm{C}_{2} \mathrm{H}_{4}$ & ${ }^{1} J_{\mathrm{CC}}$ & 60,5 & 63,3 & 67,0 & 71,7 & 78,0 & 86,7 & 99,5 & 120,7 & 162,3 & 284,8 & 14163,1 & 67,2 \\
\hline $\mathrm{C}_{2} \mathrm{H}_{4}$ & ${ }^{1} J_{\mathrm{CH}}$ & 99,2 & 109,3 & 120,9 & 134,4 & 150,2 & 169,0 & 192,0 & 221,3 & 263,2 & 345,6 & 6656,1 & 154,5 \\
\hline $\mathrm{C}_{2} \mathrm{H}_{4}$ & ${ }^{2} J_{\mathrm{CH}}$ & 6,3 & 5,6 & 4,7 & 3,5 & 1,7 & $-1,0$ & $-5,4$ & $-13,2$ & $-30,1$ & $-83,1$ & $-6358,9$ & $-2,1$ \\
\hline $\mathrm{C}_{2} \mathrm{H}_{4}$ & ${ }^{2} J_{\mathrm{HH}}$ & 7,0 & 7,0 & 6,8 & 6,4 & 5,7 & 4,4 & 2,2 & $-1,8$ & $-10,4$ & $-37,0$ & $-3080,4$ & 2 \\
\hline $\mathrm{C}_{2} \mathrm{H}_{4}$ & ${ }^{3} J_{\mathrm{HH}_{\mathrm{c}}}$ & 9,1 & 9,5 & 9,9 & 10,5 & 11,2 & 12,3 & 14,1 & 17,4 & 24,8 & 49,5 & 3090,2 & 11,4 \\
\hline $\mathrm{C}_{2} \mathrm{H}_{4}$ & ${ }^{3} J_{\mathrm{HH}_{\mathrm{t}}}$ & 9,4 & 10,7 & 12,0 & 13,6 & 15,4 & 17,7 & 20,8 & 25,9 & 35,5 & 63,8 & 3278,1 & 18,5 \\
\hline $\mathrm{C}_{2} \mathrm{H}_{6}$ & ${ }^{1} J_{\mathrm{CC}}$ & 27,4 & 29,9 & 33,0 & 36,6 & 41,1 & 46,4 & 53,0 & 61,2 & 71,5 & 84,8 & 102,2 & 33,7 \\
\hline $\mathrm{C}_{2} \mathrm{H}_{6}$ & ${ }^{1} J_{\mathrm{CH}}$ & 84,0 & 91,7 & 100,8 & 111,4 & 123,8 & 138,4 & 155,8 & 176,6 & 201,7 & 232,6 & 271,0 & 123,4 \\
\hline $\mathrm{C}_{2} \mathrm{H}_{6}$ & ${ }^{2} J_{\mathrm{CH}}$ & 2,2 & 1,5 & 0,7 & $-0,2$ & $-1,5$ & $-3,0$ & $-5,0$ & $-7,5$ & $-10,8$ & $-15,3$ & $-21,7$ & $-4,5$ \\
\hline \multirow[t]{3}{*}{ Total } & DM & $-16,83$ & $-17,48$ & $-17,60$ & $-16,98$ & $-15,40$ & $-12,56$ & $-8,32$ & $-2,56$ & 4,49 & 1,83 & 686,17 & - \\
\hline & DMA & 31,84 & 28,65 & 25,28 & 22,30 & 22,04 & 25,00 & 30,91 & 39,70 & 59,08 & 116,85 & 1624,81 & - \\
\hline & PDMA & 91,08 & 82,39 & 71,97 & 60,77 & 48,15 & 34,61 & 35,75 & 71,06 & 149,76 & 374,97 & 20574,73 & - \\
\hline \multirow[t]{3}{*}{ CPI } & $\mathrm{DM}$ & $-17,96$ & $-24,65$ & $-30,84$ & $-36,19$ & $-40,38$ & $-43,13$ & $-44,65$ & $-46,01$ & $-50,82$ & $-98,71$ & $-167,50$ & - \\
\hline & DMA & 47,56 & 45,55 & 42,27 & 39,34 & 43,11 & 45,40 & 46,97 & 49,25 & 64,69 & 133,27 & 226,63 & - \\
\hline & PDMA & 106,44 & 96,76 & 84,48 & 71,30 & 59,76 & 46,70 & 38,70 & 41,11 & 61,22 & 116,97 & 189,03 & - \\
\hline \multirow[t]{3}{*}{ SPI } & $\mathrm{DM}$ & $-15,99$ & $-12,23$ & $-7,90$ & $-2,90$ & 2,92 & 9,85 & 18,33 & 29,31 & 45,05 & 75,55 & 1312,20 & - \\
\hline & DMA & 20,31 & 16,25 & 12,82 & 9,81 & 6,59 & 10,04 & 19,13 & 32,71 & 54,97 & 104,81 & 2650,15 & - \\
\hline & PDMA & 79,81 & 71,85 & 62,80 & 53,05 & 39,63 & 25,75 & 33,59 & 93,03 & 214,68 & 564,17 & 35524,24 & - \\
\hline \multirow[t]{3}{*}{$\Delta \mathrm{CS}$} & DM & $-1,97$ & $-12,43$ & $-22,94$ & $-33,29$ & $-43,30$ & $-52,98$ & $-62,97$ & $-75,32$ & $-95,87$ & $-174,26$ & $-1479,70$ & - \\
\hline & DMA & 27,25 & 29,29 & 29,45 & 29,53 & 36,52 & 35,36 & 27,85 & 16,54 & 9,72 & 28,47 & $-2423,52$ & - \\
\hline & PDMA & 26,63 & 24,91 & 21,68 & 18,25 & 20,14 & 20,95 & 5,11 & $-51,92$ & $-153,46$ & $-447,19$ & $-35335,21$ & - \\
\hline
\end{tabular}


Tabela 8.148: Constantes de acoplamento OLYP e constantes empíricas no nível BHandH $40 \% E_{X}^{\mathrm{HF}}$ e base aug-pcJ-2.

\begin{tabular}{|c|c|c|c|c|c|c|c|c|c|c|c|c|c|}
\hline & $\% E_{X}^{\mathrm{HF}}$ & $0 \%$ & $10 \%$ & $20 \%$ & $30 \%$ & $40 \%$ & $50 \%$ & $60 \%$ & $70 \%$ & $80 \%$ & $90 \%$ & $100 \%$ & Emp. \\
\hline $\mathrm{HF}$ & ${ }^{1} J_{\mathrm{HF}}$ & 363,4 & 391,6 & 420,1 & 449,1 & 478,5 & 508,2 & 538,4 & 568,9 & 599,7 & 630,9 & 662,5 & 533,2 \\
\hline $\mathrm{CO}$ & ${ }^{1} J_{\mathrm{CO}}$ & 24,0 & 21,8 & 19,5 & 17,1 & 14,6 & 12,0 & 9,4 & 6,6 & 3,8 & 0,9 & $-1,9$ & 15,6 \\
\hline $\mathrm{H}_{2} \mathrm{O}$ & ${ }^{1} J_{\mathrm{OH}}$ & $-66,1$ & $-69,4$ & $-72,7$ & $-76,1$ & $-79,5$ & $-83,0$ & $-86,5$ & $-90,1$ & $-93,7$ & $-97,3$ & $-101,1$ & $-81,8$ \\
\hline $\mathrm{H}_{2} \mathrm{O}$ & ${ }^{2} J_{\mathrm{HH}}$ & $-7,4$ & $-8,3$ & $-9,3$ & $-10,2$ & $-11,1$ & $-12,1$ & $-13,1$ & $-14,1$ & $-15,2$ & $-16,2$ & $-17,3$ & $-8,7$ \\
\hline $\mathrm{NH}_{3}$ & ${ }^{1} J_{\mathrm{NH}}$ & 40,2 & 41,5 & 42,7 & 44,0 & 45,3 & 46,6 & 47,9 & 49,3 & 50,6 & 52,0 & 53,4 & 43,1 \\
\hline $\mathrm{NH}_{3}$ & ${ }^{2} J_{\mathrm{HH}}$ & $-9,6$ & $-10,4$ & $-11,3$ & $-12,1$ & $-13,0$ & $-13,9$ & $-14,8$ & $-15,7$ & $-16,7$ & $-17,7$ & $-18,7$ & $-10,5$ \\
\hline $\mathrm{PH}_{3}$ & ${ }^{1} J_{\mathrm{PH}}$ & 158,8 & 167,5 & 176,1 & 184,5 & 192,8 & 201,0 & 209,0 & 216,8 & 224,5 & 231,9 & 239,2 & 195,5 \\
\hline $\mathrm{PF}_{3}$ & ${ }^{1} J_{\mathrm{PF}}$ & $-1702,2$ & $-1685,7$ & $-1665,4$ & $-1642,0$ & $-1616,2$ & $-1588,5$ & $-1559,4$ & $-1529,4$ & $-1498,8$ & $-1467,9$ & $-1437,0$ & $-1.442,80$ \\
\hline $\mathrm{BHF}_{2}$ & ${ }^{1} J_{\mathrm{BF}}$ & $-181,4$ & $-160,8$ & $-140,7$ & $-121,1$ & $-102,0$ & $-83,5$ & $-65,6$ & $-48,2$ & $-31,4$ & $-15,1$ & 0,6 & $-79,5$ \\
\hline $\mathrm{BF}_{3}$ & ${ }^{1} J_{\mathrm{BF}}$ & $-90,5$ & $-67,4$ & $-45,0$ & $-23,1$ & $-1,8$ & 18,8 & 38,9 & 58,4 & 77,4 & 95,8 & 113,8 & 17,2 \\
\hline $\mathrm{F}_{2} \mathrm{O}$ & ${ }^{1} J_{\mathrm{OF}}$ & $-254,6$ & $-290,9$ & $-327,9$ & $-367,1$ & $-410,6$ & $-461,8$ & $-526,5$ & $-616,5$ & $-760,6$ & $-1056,6$ & $-2253,8$ & $-286,9$ \\
\hline $\mathrm{CH}_{4}$ & ${ }^{1} J_{\mathrm{CH}}$ & 118,2 & 121,1 & 124,1 & 127,1 & 130,2 & 133,3 & 136,4 & 139,6 & 142,9 & 146,1 & 149,4 & 123 \\
\hline $\mathrm{CH}_{4}$ & ${ }^{2} J_{\mathrm{HH}}$ & $-12,9$ & $-13,5$ & $-14,2$ & $-14,9$ & $-15,6$ & $-16,3$ & $-17,0$ & $-17,7$ & $-18,4$ & $-19,1$ & $-19,7$ & $-12,5$ \\
\hline $\mathrm{C}_{2} \mathrm{H}_{2}$ & ${ }^{1} J_{\mathrm{CC}}$ & 187,4 & 192,0 & 197,1 & 202,6 & 208,8 & 215,7 & 223,5 & 232,3 & 242,5 & 254,4 & 268,4 & 174,4 \\
\hline $\mathrm{C}_{2} \mathrm{H}_{2}$ & ${ }^{1} J_{\mathrm{CH}}$ & 253,4 & 258,1 & 263,0 & 268,0 & 273,2 & 278,7 & 284,6 & 290,9 & 297,7 & 305,1 & 313,5 & 244,5 \\
\hline $\mathrm{C}_{2} \mathrm{H}_{2}$ & ${ }^{2} J_{\mathrm{CH}}$ & 53,0 & 53,0 & 52,8 & 52,4 & 51,7 & 50,7 & 49,3 & 47,6 & 45,2 & 42,1 & 38,1 & 49,7 \\
\hline $\mathrm{C}_{2} \mathrm{H}_{2}$ & ${ }^{3} J_{\mathrm{HH}}$ & 11,6 & 12,2 & 12,9 & 13,7 & 14,7 & 15,9 & 17,3 & 18,9 & 20,9 & 23,2 & 26,0 & 9,1 \\
\hline $\mathrm{C}_{2} \mathrm{H}_{4}$ & ${ }^{1} J_{\mathrm{CC}}$ & 60,8 & 64,6 & 68,7 & 73,2 & 78,2 & 83,9 & 90,5 & 98,4 & 108,1 & 120,9 & 139,0 & 67,2 \\
\hline $\mathrm{C}_{2} \mathrm{H}_{4}$ & ${ }^{1} J_{\mathrm{CH}}$ & 152,7 & 156,5 & 160,4 & 164,4 & 168,6 & 173,1 & 177,9 & 183,2 & 189,3 & 196,5 & 205,7 & 154,5 \\
\hline $\mathrm{C}_{2} \mathrm{H}_{4}$ & ${ }^{2} J_{\mathrm{CH}}$ & $-1,1$ & $-2,0$ & $-3,1$ & $-4,3$ & $-5,6$ & $-7,2$ & $-9,2$ & $-11,6$ & $-14,8$ & $-19,1$ & $-25,4$ & $-2,1$ \\
\hline $\mathrm{C}_{2} \mathrm{H}_{4}$ & ${ }^{2} J_{\mathrm{HH}}$ & 3,4 & 2,8 & 2,2 & 1,5 & 0,8 & 0,0 & $-1,1$ & $-2,3$ & $-3,9$ & $-6,1$ & $-9,3$ & 2 \\
\hline $\mathrm{C}_{2} \mathrm{H}_{4}$ & ${ }^{3} J_{\mathrm{HH}_{\mathrm{c}}}$ & 12,2 & 12,6 & 13,1 & 13,6 & 14,2 & 14,9 & 15,8 & 17,0 & 18,5 & 20,6 & 23,7 & 11,4 \\
\hline $\mathrm{C}_{2} \mathrm{H}_{4}$ & ${ }^{3} J_{\mathrm{HH}_{\mathrm{t}}}$ & 19,4 & 19,8 & 20,3 & 21,0 & 21,7 & 22,6 & 23,6 & 25,0 & 26,8 & 29,3 & 32,9 & 18,5 \\
\hline $\mathrm{C}_{2} \mathrm{H}_{6}$ & ${ }^{1} J_{\mathrm{CC}}$ & 25,4 & 27,9 & 30,4 & 33,0 & 35,6 & 38,4 & 41,1 & 43,9 & 46,8 & 49,7 & 52,7 & 33,7 \\
\hline $\mathrm{C}_{2} \mathrm{H}_{6}$ & ${ }^{1} J_{\mathrm{CH}}$ & 118,4 & 121,5 & 124,6 & 127,8 & 131,0 & 134,2 & 137,5 & 140,8 & 144,1 & 147,5 & 150,9 & 123,4 \\
\hline $\mathrm{C}_{2} \mathrm{H}_{6}$ & ${ }^{2} J_{\mathrm{CH}}$ & $-3,3$ & $-3,7$ & $-4,1$ & $-4,5$ & $-5,0$ & $-5,4$ & $-5,9$ & $-6,4$ & $-6,8$ & $-7,3$ & $-7,8$ & $-4,5$ \\
\hline \multirow[t]{3}{*}{ Total } & DM & $-23,60$ & $-20,55$ & $-17,40$ & $-14,20$ & $-11,05$ & $-8,09$ & $-5,57$ & $-3,89$ & $-4,16$ & $-10,08$ & $-50,34$ & - \\
\hline & DMA & 30,64 & 25,39 & 23,16 & 21,60 & 20,51 & 20,60 & 24,61 & 32,04 & 41,79 & 57,75 & 109,44 & - \\
\hline & PDMA & 45,59 & 34,13 & 28,54 & 26,49 & 27,53 & 31,75 & 47,97 & 66,68 & 88,77 & 116,77 & 163,62 & - \\
\hline \multirow[t]{3}{*}{ CPI } & DM & $-56,35$ & $-51,35$ & $-46,21$ & $-41,04$ & $-36,13$ & $-31,87$ & $-28,79$ & $-28,04$ & $-32,25$ & $-50,34$ & $-150,43$ & - \\
\hline & DMA & 67,00 & 54,83 & 48,57 & 42,51 & 36,95 & 33,80 & 39,54 & 52,71 & 70,67 & 102,34 & 216,94 & - \\
\hline & PDMA & 85,23 & 65,22 & 50,09 & 36,45 & 24,66 & 17,91 & 35,57 & 55,56 & 77,10 & 103,05 & 157,42 & - \\
\hline \multirow[t]{3}{*}{ SPI } & $\mathrm{DM}$ & 0,42 & 2,04 & 3,73 & 5,49 & 7,35 & 9,35 & 11,47 & 13,82 & 16,44 & 19,43 & 23,05 & - \\
\hline & DMA & 3,98 & 3,80 & 4,53 & 6,26 & 8,45 & 10,92 & 13,67 & 16,89 & 20,61 & 25,05 & 30,61 & - \\
\hline & PDMA & 16,52 & 11,33 & 12,74 & 19,19 & 29,64 & 41,90 & 57,06 & 74,83 & 97,33 & 126,83 & 168,17 & - \\
\hline \multirow[t]{3}{*}{$\Delta \mathrm{CS}$} & DM & $-56,77$ & $-53,39$ & $-49,94$ & $-46,52$ & $-43,47$ & $-41,22$ & $-40,26$ & $-41,86$ & $-48,69$ & $-69,77$ & $-173,48$ & - \\
\hline & DMA & 63,02 & 51,03 & 44,05 & 36,25 & 28,49 & 22,88 & 25,87 & 35,82 & 50,06 & 77,29 & 186,32 & - \\
\hline & PDMA & 68,70 & 53,89 & 37,36 & 17,26 & $-4,98$ & $-23,99$ & $-21,49$ & $-19,26$ & $-20,23$ & $-23,78$ & $-10,75$ & - \\
\hline
\end{tabular}


Tabela 8.149: Constantes de acoplamento PBE e constantes empíricas no nível BHandH $40 \% E_{X}^{\mathrm{HF}}$ e base aug-pcJ-2.

\begin{tabular}{|c|c|c|c|c|c|c|c|c|c|c|c|c|c|}
\hline & $\% E_{X}^{\mathrm{HF}}$ & $0 \%$ & $10 \%$ & $20 \%$ & $30 \%$ & $40 \%$ & $50 \%$ & $60 \%$ & $70 \%$ & $80 \%$ & $90 \%$ & $100 \%$ & Emp. \\
\hline $\mathrm{HF}$ & ${ }^{1} J_{\mathrm{HF}}$ & 376,0 & 397,8 & 419,7 & 441,9 & 464,3 & 486,9 & 509,8 & 532,8 & 556,1 & 579,6 & 603,3 & 533,2 \\
\hline $\mathrm{CO}$ & ${ }^{1} J_{\mathrm{CO}}$ & 24,1 & 22,5 & 20,8 & 19,1 & 17,3 & 15,4 & 13,5 & 11,5 & 9,5 & 7,4 & 5,3 & 15,6 \\
\hline $\mathrm{H}_{2} \mathrm{O}$ & ${ }^{1} J_{\mathrm{OH}}$ & $-67,2$ & $-69,5$ & $-71,8$ & $-74,2$ & $-76,6$ & $-79,0$ & $-81,4$ & $-83,9$ & $-86,4$ & $-88,9$ & $-91,5$ & $-81,8$ \\
\hline $\mathrm{H}_{2} \mathrm{O}$ & ${ }^{2} J_{\mathrm{HH}}$ & $-4,7$ & $-5,7$ & $-6,7$ & $-7,8$ & $-8,9$ & $-10,0$ & $-11,1$ & $-12,3$ & $-13,5$ & $-14,7$ & $-15,9$ & $-8,7$ \\
\hline $\mathrm{NH}_{3}$ & ${ }^{1} J_{\mathrm{NH}}$ & 40,8 & 41,5 & 42,2 & 42,9 & 43,6 & 44,3 & 45,1 & 45,8 & 46,6 & 47,4 & 48,2 & 43,1 \\
\hline $\mathrm{NH}_{3}$ & ${ }^{2} J_{\mathrm{HH}}$ & $-7,8$ & $-8,7$ & $-9,6$ & $-10,6$ & $-11,5$ & $-12,5$ & $-13,5$ & $-14,5$ & $-15,5$ & $-16,6$ & $-17,6$ & $-10,5$ \\
\hline $\mathrm{PH}_{3}$ & ${ }^{1} J_{\mathrm{PH}}$ & 133,7 & 142,1 & 150,4 & 158,7 & 166,9 & 175,1 & 183,1 & 191,1 & 198,9 & 206,7 & 214,3 & 195,5 \\
\hline $\mathrm{PF}_{3}$ & ${ }^{1} J_{\mathrm{PF}}$ & $-1801,0$ & $-1776,9$ & $-1748,1$ & $-1715,3$ & $-1679,4$ & $-1640,8$ & $-1600,3$ & $-1558,1$ & $-1514,9$ & $-1470,9$ & $-1426,5$ & $-1.442,80$ \\
\hline $\mathrm{BHF}_{2}$ & ${ }^{1} J_{\mathrm{BF}}$ & $-172,8$ & $-155,9$ & $-139,2$ & $-122,7$ & $-106,5$ & $-90,4$ & $-74,6$ & $-59,0$ & $-43,7$ & $-28,6$ & $-13,8$ & $-79,5$ \\
\hline $\mathrm{BF}_{3}$ & ${ }^{1} J_{\mathrm{BF}}$ & $-75,8$ & $-57,5$ & $-39,4$ & $-21,7$ & $-4,2$ & 12,9 & 29,9 & 46,6 & 63,0 & 79,2 & 95,2 & 17,2 \\
\hline $\mathrm{F}_{2} \mathrm{O}$ & ${ }^{1} J_{\mathrm{OF}}$ & $-278,0$ & $-316,3$ & $-354,9$ & $-395,6$ & $-440,5$ & $-493,5$ & $-560,8$ & $-655,5$ & $-809,2$ & $-1129,5$ & $-2453,2$ & $-286,9$ \\
\hline $\mathrm{CH}_{4}$ & ${ }^{1} J_{\mathrm{CH}}$ & 119,3 & 120,7 & 122,1 & 123,5 & 125,0 & 126,5 & 128,0 & 129,6 & 131,2 & 132,8 & 134,4 & 123 \\
\hline $\mathrm{CH}_{4}$ & ${ }^{2} J_{\mathrm{HH}}$ & $-11,8$ & $-12,6$ & $-13,4$ & $-14,2$ & $-15,0$ & $-15,8$ & $-16,6$ & $-17,4$ & $-18,2$ & $-19,0$ & $-19,8$ & $-12,5$ \\
\hline $\mathrm{C}_{2} \mathrm{H}_{2}$ & ${ }^{1} J_{\mathrm{CC}}$ & 188,7 & 191,5 & 194,6 & 198,3 & 202,6 & 207,6 & 213,7 & 221,0 & 230,2 & 241,9 & 257,1 & 174,4 \\
\hline $\mathrm{C}_{2} \mathrm{H}_{2}$ & ${ }^{1} J_{\mathrm{CH}}$ & 249,8 & 252,2 & 254,8 & 257,6 & 260,7 & 264,1 & 268,0 & 272,5 & 277,9 & 284,6 & 293,3 & 244,5 \\
\hline $\mathrm{C}_{2} \mathrm{H}_{2}$ & ${ }^{2} J_{\mathrm{CH}}$ & 54,1 & 54,1 & 53,7 & 53,2 & 52,2 & 50,9 & 49,0 & 46,5 & 42,9 & 38,1 & 31,2 & 49,7 \\
\hline $\mathrm{C}_{2} \mathrm{H}_{2}$ & ${ }^{3} J_{\mathrm{HH}}$ & 10,4 & 11,1 & 11,9 & 12,9 & 14,1 & 15,6 & 17,4 & 19,6 & 22,5 & 26,1 & 30,9 & 9,1 \\
\hline $\mathrm{C}_{2} \mathrm{H}_{4}$ & ${ }^{1} J_{\mathrm{CC}}$ & 61,3 & 64,0 & 67,0 & 70,4 & 74,4 & 79,1 & 85,0 & 92,8 & 103,6 & 120,3 & 150,7 & 67,2 \\
\hline $\mathrm{C}_{2} \mathrm{H}_{4}$ & ${ }^{1} J_{\mathrm{CH}}$ & 151,8 & 153,9 & 156,1 & 158,5 & 161,1 & 164,0 & 167,5 & 171,6 & 177,1 & 185,2 & 199,0 & 154,5 \\
\hline $\mathrm{C}_{2} \mathrm{H}_{4}$ & ${ }^{2} J_{\mathrm{CH}}$ & $-0,5$ & $-1,4$ & $-2,5$ & $-3,7$ & $-5,1$ & $-6,9$ & $-9,1$ & $-12,2$ & $-16,5$ & $-23,4$ & $-36,1$ & $-2,1$ \\
\hline $\mathrm{C}_{2} \mathrm{H}_{4}$ & ${ }^{2} J_{\mathrm{HH}}$ & 4,5 & 3,7 & 2,8 & 1,8 & 0,7 & $-0,5$ & $-2,1$ & $-4,1$ & $-7,0$ & $-11,4$ & $-19,4$ & 2 \\
\hline $\mathrm{C}_{2} \mathrm{H}_{4}$ & ${ }^{3} J_{\mathrm{HH}_{\mathrm{c}}}$ & 11,7 & 12,1 & 12,5 & 13,0 & 13,6 & 14,5 & 15,7 & 17,3 & 19,7 & 23,7 & 31,3 & 11,4 \\
\hline $\mathrm{C}_{2} \mathrm{H}_{4}$ & ${ }^{3} J_{\mathrm{HH}_{\mathrm{t}}}$ & 18,7 & 19,0 & 19,5 & 20,1 & 20,9 & 21,9 & 23,3 & 25,2 & 28,0 & 32,5 & 41,0 & 18,5 \\
\hline $\mathrm{C}_{2} \mathrm{H}_{6}$ & ${ }^{1} J_{\mathrm{CC}}$ & 25,7 & 27,6 & 29,4 & 31,3 & 33,3 & 35,2 & 37,2 & 39,3 & 41,3 & 43,4 & 45,6 & 33,7 \\
\hline $\mathrm{C}_{2} \mathrm{H}_{6}$ & ${ }^{1} J_{\mathrm{CH}}$ & 119,5 & 121,1 & 122,7 & 124,3 & 126,0 & 127,7 & 129,4 & 131,2 & 133,0 & 134,8 & 136,6 & 123,4 \\
\hline $\mathrm{C}_{2} \mathrm{H}_{6}$ & ${ }^{2} J_{\mathrm{CH}}$ & $-2,9$ & $-3,4$ & $-3,9$ & $-4,3$ & $-4,9$ & $-5,4$ & $-5,9$ & $-6,4$ & $-7,0$ & $-7,5$ & $-8,1$ & $-4,5$ \\
\hline \multirow[t]{3}{*}{ Total } & DM & $-27,66$ & $-25,37$ & $-22,92$ & $-20,36$ & $-17,79$ & $-15,38$ & $-13,33$ & $-12,14$ & $-12,97$ & $-19,75$ & $-64,28$ & - \\
\hline & DMA & 33,11 & 29,98 & 27,58 & 25,61 & 24,12 & 23,20 & 24,52 & 28,53 & 37,29 & 53,63 & 111,52 & - \\
\hline & PDMA & 46,79 & 36,70 & 28,35 & 24,12 & 25,30 & 29,47 & 42,95 & 63,19 & 89,75 & 128,06 & 201,20 & - \\
\hline \multirow[t]{3}{*}{ CPI } & $\mathrm{DM}$ & $-66,10$ & $-61,91$ & $-57,36$ & $-52,70$ & $-48,17$ & $-44,18$ & $-41,34$ & $-40,90$ & $-45,77$ & $-65,75$ & $-176,96$ & - \\
\hline & DMA & 73,14 & 66,27 & 60,65 & 54,88 & 49,52 & 44,91 & 44,97 & 50,46 & 66,03 & 97,54 & 223,15 & - \\
\hline & PDMA & 81,49 & 66,47 & 52,05 & 37,88 & 26,01 & 16,82 & 24,72 & 40,92 & 60,00 & 84,80 & 141,38 & - \\
\hline \multirow[t]{3}{*}{ SPI } & $\mathrm{DM}$ & 0,53 & 1,42 & 2,33 & 3,36 & 4,49 & 5,75 & 7,21 & 8,95 & 11,09 & 13,99 & 18,36 & - \\
\hline & DMA & 3,76 & 3,37 & 3,32 & 4,15 & 5,50 & 7,28 & 9,52 & 12,44 & 16,21 & 21,43 & 29,67 & - \\
\hline & PDMA & 21,33 & 14,88 & 10,98 & 14,03 & 24,78 & 38,74 & 56,33 & 79,52 & 111,56 & 159,78 & 245,08 & - \\
\hline \multirow[t]{3}{*}{$\Delta \mathrm{CS}$} & DM & $-66,63$ & $-63,33$ & $-59,70$ & $-56,06$ & $-52,66$ & $-49,93$ & $-48,55$ & $-49,85$ & $-56,87$ & $-79,74$ & $-195,32$ & - \\
\hline & DMA & 69,38 & 62,91 & 57,33 & 50,74 & 44,02 & 37,63 & 35,45 & 38,02 & 49,81 & 76,11 & 193,48 & - \\
\hline & PDMA & 60,16 & 51,59 & 41,08 & 23,86 & 1,23 & $-21,92$ & $-31,61$ & $-38,60$ & $-51,56$ & $-74,97$ & $-103,69$ & - \\
\hline
\end{tabular}


Tabela 8.150: Constantes de acoplamento PW91 e constantes empíricas no nível BHandH $40 \% E_{X}^{\mathrm{HF}}$ e base aug-pcJ-2.

\begin{tabular}{|c|c|c|c|c|c|c|c|c|c|c|c|c|c|}
\hline & $\% E_{X}^{\mathrm{HF}}$ & $0 \%$ & $10 \%$ & $20 \%$ & $30 \%$ & $40 \%$ & $50 \%$ & $60 \%$ & $70 \%$ & $80 \%$ & $90 \%$ & $100 \%$ & Emp. \\
\hline $\mathrm{HF}$ & ${ }^{1} J_{\mathrm{HF}}^{X}$ & 364,2 & 387,4 & 410,8 & 434,5 & 458,3 & 482,4 & 506,7 & 531,2 & 556,0 & 581,0 & 606,3 & 533,2 \\
\hline $\mathrm{CO}$ & ${ }^{1} J_{\mathrm{CO}}$ & 24,9 & 23,2 & 21,5 & 19,6 & 17,7 & 15,8 & 13,7 & 11,6 & 9,4 & 7,2 & 4,9 & 15,6 \\
\hline $\mathrm{H}_{2} \mathrm{O}$ & ${ }^{1} J_{\mathrm{OH}}$ & $-66,3$ & $-68,7$ & $-71,2$ & $-73,7$ & $-76,2$ & $-78,7$ & $-81,3$ & $-83,9$ & $-86,5$ & $-89,2$ & $-91,9$ & $-81,8$ \\
\hline $\mathrm{H}_{2} \mathrm{O}$ & ${ }^{2} J_{\mathrm{HH}}$ & $-4,8$ & $-5,8$ & $-6,8$ & $-7,9$ & $-9,0$ & $-10,1$ & $-11,2$ & $-12,4$ & $-13,5$ & $-14,7$ & $-16,0$ & $-8,7$ \\
\hline $\mathrm{NH}_{3}$ & ${ }^{1} J_{\mathrm{NH}}$ & 40,8 & 41,5 & 42,2 & 42,9 & 43,7 & 44,5 & 45,2 & 46,0 & 46,8 & 47,6 & 48,4 & 43,1 \\
\hline $\mathrm{NH}_{3}$ & ${ }^{2} J_{\mathrm{HH}}$ & $-8,0$ & $-8,9$ & $-9,8$ & $-10,8$ & $-11,7$ & $-12,7$ & $-13,6$ & $-14,6$ & $-15,6$ & $-16,6$ & $-17,7$ & $-10,5$ \\
\hline $\mathrm{PH}_{3}$ & ${ }^{1} J_{\mathrm{PH}}$ & 137,6 & 145,9 & 154,0 & 162,1 & 170,0 & 177,9 & 185,7 & 193,3 & 200,8 & 208,2 & 215,5 & 195,5 \\
\hline $\mathrm{PF}_{3}$ & ${ }^{1} J_{\mathrm{PF}}$ & $-1815,2$ & $-1790,1$ & $-1760,3$ & $-1726,4$ & $-1689,3$ & $-1649,5$ & $-1607,6$ & $-1564,2$ & $-1519,7$ & $-1474,3$ & $-1428,5$ & $-1.442,80$ \\
\hline $\mathrm{BHF}_{2}$ & ${ }^{1} J_{\mathrm{BF}}$ & $-177,6$ & $-160,4$ & $-143,4$ & $-126,4$ & $-109,6$ & $-93,0$ & $-76,5$ & $-60,2$ & $-44,1$ & $-28,2$ & $-12,5$ & $-79,5$ \\
\hline $\mathrm{BF}_{3}$ & ${ }^{1} J_{\mathrm{BF}}$ & $-80,9$ & $-62,3$ & $-43,8$ & $-25,6$ & $-7,6$ & 10,2 & 27,8 & 45,3 & 62,5 & 79,6 & 96,6 & 17,2 \\
\hline $\mathrm{F}_{2} \mathrm{O}$ & ${ }^{1} J_{\mathrm{OF}}$ & $-290,5$ & $-328,8$ & $-367,5$ & $-408,1$ & $-453,0$ & $-506,0$ & $-573,5$ & $-668,7$ & $-823,8$ & $-1148,9$ & $-2525,8$ & $-286,9$ \\
\hline $\mathrm{CH}_{4}$ & ${ }^{1} J_{\mathrm{CH}}$ & 120,1 & 121,5 & 122,9 & 124,3 & 125,8 & 127,3 & 128,8 & 130,4 & 131,9 & 133,5 & 135,2 & 123 \\
\hline $\mathrm{CH}_{4}$ & ${ }^{2} J_{\mathrm{HH}}$ & $-12,0$ & $-12,8$ & $-13,6$ & $-14,4$ & $-15,2$ & $-15,9$ & $-16,7$ & $-17,5$ & $-18,3$ & $-19,1$ & $-19,9$ & $-12,5$ \\
\hline $\mathrm{C}_{2} \mathrm{H}_{2}$ & ${ }^{1} J_{\mathrm{CC}}$ & 188,8 & 191,6 & 194,7 & 198,5 & 202,8 & 208,0 & 214,2 & 221,8 & 231,3 & 243,3 & 259,0 & 174,4 \\
\hline $\mathrm{C}_{2} \mathrm{H}_{2}$ & ${ }^{1} J_{\mathrm{CH}}$ & 252,5 & 254,8 & 257,3 & 259,9 & 262,8 & 266,1 & 269,8 & 274,3 & 279,6 & 286,1 & 294,6 & 244,5 \\
\hline $\mathrm{C}_{2} \mathrm{H}_{2}$ & ${ }^{2} J_{\mathrm{CH}}$ & 54,6 & 54,5 & 54,1 & 53,5 & 52,6 & 51,2 & 49,2 & 46,6 & 43,0 & 38,0 & 31,2 & 49,7 \\
\hline $\mathrm{C}_{2} \mathrm{H}_{2}$ & ${ }^{3} J_{\mathrm{HH}}$ & 10,5 & 11,2 & 12,0 & 13,0 & 14,2 & 15,7 & 17,5 & 19,7 & 22,5 & 26,1 & 30,7 & 9,1 \\
\hline $\mathrm{C}_{2} \mathrm{H}_{4}$ & ${ }^{1} J_{\mathrm{CC}}$ & 60,6 & 63,3 & 66,4 & 69,9 & 74,0 & 78,9 & 85,0 & 92,9 & 104,1 & 121,2 & 152,0 & 67,2 \\
\hline $\mathrm{C}_{2} \mathrm{H}_{4}$ & ${ }^{1} J_{\mathrm{CH}}$ & 153,0 & 155,1 & 157,3 & 159,6 & 162,2 & 165,1 & 168,5 & 172,7 & 178,2 & 186,2 & 200,0 & 154,5 \\
\hline $\mathrm{C}_{2} \mathrm{H}_{4}$ & ${ }^{2} J_{\mathrm{CH}}$ & $-0,4$ & $-1,3$ & $-2,3$ & $-3,5$ & $-5,0$ & $-6,8$ & $-9,1$ & $-12,1$ & $-16,5$ & $-23,5$ & $-36,2$ & $-2,1$ \\
\hline $\mathrm{C}_{2} \mathrm{H}_{4}$ & ${ }^{2} J_{\mathrm{HH}}$ & 4,5 & 3,6 & 2,8 & 1,8 & 0,7 & $-0,5$ & $-2,1$ & $-4,2$ & $-7,1$ & $-11,4$ & $-19,2$ & 2 \\
\hline $\mathrm{C}_{2} \mathrm{H}_{4}$ & ${ }^{3} J_{\mathrm{HH}_{\mathrm{c}}}$ & 11,9 & 12,2 & 12,6 & 13,1 & 13,8 & 14,7 & 15,8 & 17,4 & 19,8 & 23,8 & 31,2 & 11,4 \\
\hline $\mathrm{C}_{2} \mathrm{H}_{4}$ & ${ }^{3} J_{\mathrm{HH}_{\mathrm{t}}}$ & 19,0 & 19,3 & 19,8 & 20,4 & 21,1 & 22,1 & 23,5 & 25,4 & 28,1 & 32,6 & 40,9 & 18,5 \\
\hline $\mathrm{C}_{2} \mathrm{H}_{6}$ & ${ }^{1} J_{\mathrm{CC}}$ & 25,1 & 27,0 & 29,0 & 31,0 & 33,1 & 35,1 & 37,3 & 39,4 & 41,6 & 43,8 & 46,1 & 33,7 \\
\hline $\mathrm{C}_{2} \mathrm{H}_{6}$ & ${ }^{1} J_{\mathrm{CH}}$ & 120,3 & 121,9 & 123,5 & 125,1 & 126,8 & 128,5 & 130,2 & 132,0 & 133,7 & 135,5 & 137,3 & 123,4 \\
\hline $\mathrm{C}_{2} \mathrm{H}_{6}$ & ${ }^{2} J_{\mathrm{CH}}$ & $-2,9$ & $-3,4$ & $-3,9$ & $-4,4$ & $-4,9$ & $-5,4$ & $-5,9$ & $-6,4$ & $-7,0$ & $-7,5$ & $-8,1$ & $-4,5$ \\
\hline \multirow[t]{3}{*}{ Total } & $\mathrm{DM}$ & $-29,11$ & $-26,74$ & $-24,17$ & $-21,49$ & $-18,79$ & $-16,22$ & $-14,05$ & $-12,73$ & $-13,44$ & $-20,25$ & $-66,64$ & - \\
\hline & DMA & 34,28 & 31,76 & 29,27 & 27,23 & 25,62 & 24,53 & 25,37 & 29,39 & 38,33 & 54,95 & 114,82 & - \\
\hline & PDMA & 48,66 & 38,61 & 29,79 & 25,42 & 26,81 & 30,63 & 42,86 & 63,37 & 90,40 & 129,05 & 202,77 & - \\
\hline \multirow[t]{3}{*}{ CPI } & $\mathrm{DM}$ & $-70,02$ & $-65,58$ & $-60,79$ & $-55,84$ & $-51,01$ & $-46,69$ & $-43,55$ & $-42,82$ & $-47,46$ & $-67,52$ & $-183,19$ & - \\
\hline & DMA & 75,69 & 70,16 & 64,26 & 58,18 & 52,52 & 47,55 & 46,49 & 51,96 & 67,92 & 100,01 & 230,30 & - \\
\hline & PDMA & 84,97 & 70,22 & 55,52 & 41,22 & 29,15 & 19,30 & 23,87 & 40,65 & 60,47 & 85,98 & 145,18 & - \\
\hline \multirow[t]{3}{*}{ SPI } & $\mathrm{DM}$ & 0,89 & 1,75 & 2,69 & 3,70 & 4,83 & 6,12 & 7,58 & 9,34 & 11,51 & 14,42 & 18,83 & - \\
\hline & DMA & 3,91 & 3,60 & 3,61 & 4,53 & 5,89 & 7,65 & 9,87 & 12,83 & 16,64 & 21,90 & 30,14 & - \\
\hline & PDMA & 22,04 & 15,44 & 10,93 & 13,84 & 25,08 & 38,94 & 56,77 & 80,02 & 112,35 & 160,64 & 245,00 & - \\
\hline \multirow[t]{3}{*}{$\Delta \mathrm{CS}$} & $\mathrm{DM}$ & $-70,90$ & $-67,33$ & $-63,48$ & $-59,54$ & $-55,84$ & $-52,81$ & $-51,13$ & $-52,16$ & $-58,97$ & $-81,94$ & $-202,02$ & - \\
\hline & DMA & 71,78 & 66,56 & 60,66 & 53,66 & 46,63 & 39,89 & 36,62 & 39,13 & 51,28 & 78,11 & 200,16 & - \\
\hline & PDMA & 62,93 & 54,78 & 44,59 & 27,37 & 4,07 & $-19,64$ & $-32,90$ & $-39,37$ & $-51,88$ & $-74,65$ & $-99,82$ & - \\
\hline
\end{tabular}


Tabela 8.151: Constantes de acoplamento TPSSh e constantes empíricas no nível BHandH $40 \% E_{X}^{\mathrm{HF}}$ e base aug-pcJ-2.

\begin{tabular}{|c|c|c|c|c|c|c|c|c|c|c|c|c|c|}
\hline & $\% E_{X}^{\mathrm{HF}}$ & $0 \%$ & $10 \%$ & $20 \%$ & $30 \%$ & $40 \%$ & $50 \%$ & $60 \%$ & $70 \%$ & $80 \%$ & $90 \%$ & $100 \%$ & Emp. \\
\hline $\mathrm{HF}$ & ${ }^{1} J_{\mathrm{HF}}$ & 366,0 & 390,6 & 415,1 & 439,7 & 464,2 & 488,7 & 513,1 & 537,4 & 561,6 & 585,8 & 610,0 & 533,2 \\
\hline $\mathrm{CO}$ & ${ }^{1} J_{\mathrm{CO}}$ & 21,7 & 20,3 & 18,8 & 17,3 & 15,7 & 14,0 & 12,3 & 10,5 & 8,7 & 6,8 & 4,9 & 15,6 \\
\hline $\mathrm{H}_{2} \mathrm{O}$ & ${ }^{1} J_{\mathrm{OH}}$ & $-70,2$ & $-72,5$ & $-74,9$ & $-77,3$ & $-79,6$ & $-82,0$ & $-84,3$ & $-86,6$ & $-88,9$ & $-91,1$ & $-93,4$ & $-81,8$ \\
\hline $\mathrm{H}_{2} \mathrm{O}$ & ${ }^{2} J_{\mathrm{HH}}$ & $-4,0$ & $-5,3$ & $-6,6$ & $-7,8$ & $-9,1$ & $-10,3$ & $-11,5$ & $-12,7$ & $-13,9$ & $-15,1$ & $-16,2$ & $-8,7$ \\
\hline $\mathrm{NH}_{3}$ & ${ }^{1} J_{\mathrm{NH}}$ & 45,3 & 45,8 & 46,4 & 46,9 & 47,3 & 47,8 & 48,3 & 48,8 & 49,2 & 49,7 & 50,1 & 43,1 \\
\hline $\mathrm{NH}_{3}$ & ${ }^{2} J_{\mathrm{HH}}$ & $-6,9$ & $-8,1$ & $-9,3$ & $-10,4$ & $-11,6$ & $-12,7$ & $-13,8$ & $-14,9$ & $-15,9$ & $-17,0$ & $-17,9$ & $-10,5$ \\
\hline $\mathrm{PH}_{3}$ & ${ }^{1} J_{\mathrm{PH}}$ & 195,7 & 200,5 & 205,0 & 209,3 & 213,4 & 217,2 & 220,8 & 224,1 & 227,2 & 230,0 & 232,6 & 195,5 \\
\hline $\mathrm{PF}_{3}$ & ${ }^{1} J_{\mathrm{PF}}$ & $-1757,5$ & $-1731,7$ & $-1703,3$ & $-1673,0$ & $-1641,1$ & $-1608,0$ & $-1574,1$ & $-1539,7$ & $-1504,9$ & $-1470,0$ & $-1435,2$ & $-1.442,80$ \\
\hline $\mathrm{BHF}_{2}$ & ${ }^{1} J_{\mathrm{BF}}$ & $-156,7$ & $-142,5$ & $-128,4$ & $-114,3$ & $-100,2$ & $-86,1$ & $-72,1$ & $-58,1$ & $-44,2$ & $-30,3$ & $-16,4$ & $-79,5$ \\
\hline $\mathrm{BF}_{3}$ & ${ }^{1} J_{\mathrm{BF}}$ & $-63,8$ & $-47,2$ & $-30,7$ & $-14,3$ & 1,8 & 17,8 & 33,8 & 49,6 & 65,2 & 80,8 & 96,3 & 17,2 \\
\hline $\mathrm{F}_{2} \mathrm{O}$ & ${ }^{1} J_{\mathrm{OF}}$ & $-282,7$ & $-320,1$ & $-359,5$ & $-402,5$ & $-451,3$ & $-510,0$ & $-585,2$ & $-690,4$ & $-857,9$ & $-1192,7$ & $-2403,5$ & $-286,9$ \\
\hline $\mathrm{CH}_{4}$ & ${ }^{1} J_{\mathrm{CH}}$ & 138,0 & 138,8 & 139,6 & 140,4 & 141,1 & 141,9 & 142,6 & 143,2 & 143,8 & 144,4 & 144,9 & 123 \\
\hline $\mathrm{CH}_{4}$ & ${ }^{2} J_{\mathrm{HH}}$ & $-10,2$ & $-11,3$ & $-12,4$ & $-13,4$ & $-14,5$ & $-15,5$ & $-16,5$ & $-17,4$ & $-18,4$ & $-19,3$ & $-20,2$ & $-12,5$ \\
\hline $\mathrm{C}_{2} \mathrm{H}_{2}$ & ${ }^{1} J_{\mathrm{CC}}$ & 187,5 & 190,8 & 194,6 & 198,9 & 203,9 & 209,8 & 216,7 & 225,0 & 234,9 & 247,0 & 262,1 & 174,4 \\
\hline $\mathrm{C}_{2} \mathrm{H}_{2}$ & ${ }^{1} J_{\mathrm{CH}}$ & 280,6 & 282,3 & 284,1 & 286,1 & 288,3 & 290,8 & 293,7 & 297,1 & 301,3 & 306,4 & 312,9 & 244,5 \\
\hline $\mathrm{C}_{2} \mathrm{H}_{2}$ & ${ }^{2} J_{\mathrm{CH}}$ & 58,3 & 57,7 & 56,9 & 55,8 & 54,3 & 52,4 & 50,0 & 46,9 & 43,0 & 38,0 & 31,5 & 49,7 \\
\hline $\mathrm{C}_{2} \mathrm{H}_{2}$ & ${ }^{3} J_{\mathrm{HH}}$ & 12,0 & 12,6 & 13,5 & 14,5 & 15,7 & 17,3 & 19,1 & 21,4 & 24,1 & 27,5 & 31,8 & 9,1 \\
\hline $\mathrm{C}_{2} \mathrm{H}_{4}$ & ${ }^{1} J_{\mathrm{CC}}$ & 68,8 & 71,5 & 74,5 & 78,0 & 82,1 & 87,0 & 93,1 & 100,9 & 111,6 & 127,4 & 153,5 & 67,2 \\
\hline $\mathrm{C}_{2} \mathrm{H}_{4}$ & ${ }^{1} J_{\mathrm{CH}}$ & 172,7 & 174,3 & 176,1 & 178,0 & 180,1 & 182,5 & 185,3 & 188,9 & 193,6 & 200,5 & 211,7 & 154,5 \\
\hline $\mathrm{C}_{2} \mathrm{H}_{4}$ & ${ }^{2} J_{\mathrm{CH}}$ & $-0,6$ & $-1,7$ & $-3,0$ & $-4,5$ & $-6,2$ & $-8,3$ & $-10,9$ & $-14,3$ & $-18,9$ & $-25,6$ & $-36,8$ & $-2,1$ \\
\hline $\mathrm{C}_{2} \mathrm{H}_{4}$ & ${ }^{2} J_{\mathrm{HH}}$ & 9,4 & 8,2 & 6,8 & 5,4 & 3,8 & 2,0 & 0,0 & $-2,5$ & $-5,8$ & $-10,3$ & $-17,4$ & 2 \\
\hline $\mathrm{C}_{2} \mathrm{H}_{4}$ & ${ }^{3} J_{\mathrm{HH}_{\mathrm{c}}}$ & 12,0 & 12,5 & 13,0 & 13,7 & 14,5 & 15,5 & 16,9 & 18,6 & 21,1 & 24,9 & 31,3 & 11,4 \\
\hline $\mathrm{C}_{2} \mathrm{H}_{4}$ & ${ }^{3} J_{\mathrm{HH}_{\mathrm{t}}}$ & 22,1 & 22,5 & 22,9 & 23,5 & 24,2 & 25,2 & 26,6 & 28,4 & 31,1 & 35,2 & 42,2 & 18,5 \\
\hline $\mathrm{C}_{2} \mathrm{H}_{6}$ & ${ }^{1} J_{\mathrm{CC}}$ & 32,9 & 34,4 & 35,8 & 37,2 & 38,7 & 40,1 & 41,5 & 42,9 & 44,2 & 45,6 & 46,9 & 33,7 \\
\hline $\mathrm{C}_{2} \mathrm{H}_{6}$ & ${ }^{1} J_{\mathrm{CH}}$ & 137,9 & 138,9 & 140,0 & 141,0 & 141,9 & 142,9 & 143,8 & 144,7 & 145,5 & 146,3 & 147,1 & 123,4 \\
\hline $\mathrm{C}_{2} \mathrm{H}_{6}$ & ${ }^{2} J_{\mathrm{CH}}$ & $-3,3$ & $-3,8$ & $-4,3$ & $-4,9$ & $-5,4$ & $-5,9$ & $-6,4$ & $-7,0$ & $-7,5$ & $-8,0$ & $-8,5$ & $-4,5$ \\
\hline \multirow[t]{3}{*}{ Total } & DM & $-18,53$ & $-16,51$ & $-14,46$ & $-12,44$ & $-10,57$ & $-8,95$ & $-7,84$ & $-7,77$ & $-9,88$ & $-18,07$ & $-59,32$ & - \\
\hline & DMA & 30,77 & 29,04 & 27,76 & 26,74 & 26,07 & 26,10 & 28,95 & 34,20 & 43,80 & 60,53 & 112,82 & - \\
\hline & PDMA & 53,56 & 43,69 & 36,81 & 33,25 & 31,38 & 32,16 & 49,61 & 71,53 & 99,13 & 136,68 & 201,85 & - \\
\hline \multirow[t]{3}{*}{ CPI } & $\mathrm{DM}$ & $-55,23$ & $-51,33$ & $-47,44$ & $-43,71$ & $-40,45$ & $-38,00$ & $-37,01$ & $-38,76$ & $-46,20$ & $-68,86$ & $-171,19$ & - \\
\hline & DMA & 61,15 & 56,33 & 52,20 & 48,22 & 44,88 & 42,91 & 46,92 & 55,55 & 73,38 & 106,41 & 220,41 & - \\
\hline & PDMA & 69,95 & 56,75 & 43,87 & 31,30 & 21,53 & 16,47 & 30,50 & 47,07 & 66,05 & 90,48 & 142,42 & - \\
\hline \multirow[t]{3}{*}{ SPI } & $\mathrm{DM}$ & 8,39 & 9,03 & 9,72 & 10,49 & 11,35 & 12,36 & 13,55 & 14,97 & 16,75 & 19,18 & 22,71 & - \\
\hline & DMA & 8,49 & 9,03 & 9,84 & 10,99 & 12,28 & 13,77 & 15,77 & 18,55 & 22,11 & 26,89 & 33,91 & - \\
\hline & PDMA & 41,54 & 34,11 & 31,64 & 34,69 & 38,61 & 43,67 & 63,62 & 89,47 & 123,38 & 170,55 & 245,43 & - \\
\hline \multirow[t]{3}{*}{$\Delta \mathrm{CS}$} & DM & $-63,61$ & $-60,35$ & $-57,16$ & $-54,20$ & $-51,79$ & $-50,36$ & $-50,56$ & $-53,73$ & $-62,95$ & $-88,04$ & $-193,90$ & - \\
\hline & DMA & 52,66 & 47,30 & 42,36 & 37,23 & 32,60 & 29,14 & 31,14 & 36,99 & 51,27 & 79,52 & 186,50 & - \\
\hline & PDMA & 28,41 & 22,64 & 12,23 & $-3,39$ & $-17,08$ & $-27,20$ & $-33,12$ & $-42,41$ & $-57,32$ & $-80,06$ & $-103,01$ & - \\
\hline
\end{tabular}


Tabela 8.152: Constantes de acoplamento X3LYP e constantes empíricas no nível BHandH $40 \% E_{X}^{\mathrm{HF}}$ e base aug-pcJ-2.

\begin{tabular}{|c|c|c|c|c|c|c|c|c|c|c|c|c|c|}
\hline & $\% E_{X}^{\mathrm{HF}}$ & $0 \%$ & $10 \%$ & $20 \%$ & $30 \%$ & $40 \%$ & $50 \%$ & $60 \%$ & $70 \%$ & $80 \%$ & $90 \%$ & $100 \%$ & Emp. \\
\hline $\mathrm{HF}$ & ${ }^{1} J_{\mathrm{HF}}$ & 397,3 & 422,2 & 447,3 & 472,6 & 498,2 & 524,1 & 550,1 & 576,4 & 602,9 & 629,7 & 656,7 & 533,2 \\
\hline $\mathrm{CO}$ & ${ }^{1} J_{\mathrm{CO}}$ & 21,5 & 19,7 & 17,7 & 15,6 & 13,4 & 11,1 & 8,8 & 6,3 & 3,8 & 1,2 & $-1,4$ & 15,6 \\
\hline $\mathrm{H}_{2} \mathrm{O}$ & ${ }^{1} J_{\mathrm{OH}}$ & $-72,3$ & $-75,0$ & $-77,6$ & $-80,4$ & $-83,1$ & $-85,8$ & $-88,6$ & $-91,5$ & $-94,3$ & $-97,2$ & $-100,1$ & $-81,8$ \\
\hline $\mathrm{H}_{2} \mathrm{O}$ & ${ }^{2} J_{\mathrm{HH}}$ & $-5,3$ & $-6,4$ & $-7,5$ & $-8,6$ & $-9,7$ & $-10,9$ & $-12,1$ & $-13,3$ & $-14,5$ & $-15,7$ & $-17,0$ & $-8,7$ \\
\hline $\mathrm{NH}_{3}$ & ${ }^{1} J_{\mathrm{NH}}$ & 44,5 & 45,3 & 46,1 & 46,9 & 47,8 & 48,6 & 49,4 & 50,3 & 51,2 & 52,0 & 52,9 & 43,1 \\
\hline $\mathrm{NH}_{3}$ & ${ }^{2} J_{\mathrm{HH}}$ & $-8,4$ & $-9,3$ & $-10,3$ & $-11,2$ & $-12,2$ & $-13,2$ & $-14,2$ & $-15,2$ & $-16,3$ & $-17,3$ & $-18,4$ & $-10,5$ \\
\hline $\mathrm{PH}_{3}$ & ${ }^{1} J_{\mathrm{PH}}$ & 158,3 & 166,8 & 175,2 & 183,5 & 191,6 & 199,6 & 207,5 & 215,2 & 222,7 & 230,0 & 237,2 & 195,5 \\
\hline $\mathrm{PF}_{3}$ & ${ }^{1} J_{\mathrm{PF}}$ & $-1812,7$ & $-1787,4$ & $-1757,6$ & $-1724,0$ & $-1687,4$ & $-1648,2$ & $-1607,1$ & $-1564,6$ & $-1521,0$ & $-1476,7$ & $-1432,0$ & $-1.442,80$ \\
\hline $\mathrm{BHF}_{2}$ & ${ }^{1} J_{\mathrm{BF}}$ & $-168,0$ & $-150,4$ & $-132,9$ & $-115,6$ & $-98,4$ & $-81,4$ & $-64,6$ & $-47,9$ & $-31,5$ & $-15,3$ & 0,7 & $-79,5$ \\
\hline $\mathrm{BF}_{3}$ & ${ }^{1} J_{\mathrm{BF}}$ & $-69,5$ & $-50,4$ & $-31,4$ & $-12,7$ & 5,7 & 24,0 & 42,1 & 60,0 & 77,8 & 95,3 & 112,7 & 17,2 \\
\hline $\mathrm{F}_{2} \mathrm{O}$ & ${ }^{1} J_{\mathrm{OF}}$ & $-280,3$ & $-317,2$ & $-354,2$ & $-392,9$ & $-435,5$ & $-485,2$ & $-547,9$ & $-635,3$ & $-775,4$ & $-1061,6$ & $-2173,7$ & $-286,9$ \\
\hline $\mathrm{CH}_{4}$ & ${ }^{1} J_{\mathrm{CH}}$ & 131,8 & 133,3 & 134,9 & 136,5 & 138,1 & 139,7 & 141,4 & 143,0 & 144,7 & 146,4 & 148,2 & 123 \\
\hline $\mathrm{CH}_{4}$ & ${ }^{2} J_{\mathrm{HH}}$ & $-11,8$ & $-12,6$ & $-13,4$ & $-14,2$ & $-15,0$ & $-15,7$ & $-16,5$ & $-17,3$ & $-18,0$ & $-18,7$ & $-19,5$ & $-12,5$ \\
\hline $\mathrm{C}_{2} \mathrm{H}_{2}$ & ${ }^{1} J_{\mathrm{CC}}$ & 199,6 & 202,6 & 206,0 & 210,0 & 214,5 & 219,9 & 226,1 & 233,6 & 242,6 & 253,6 & 267,3 & 174,4 \\
\hline $\mathrm{C}_{2} \mathrm{H}_{2}$ & ${ }^{1} J_{\mathrm{CH}}$ & 272,4 & 274,9 & 277,4 & 280,1 & 283,0 & 286,2 & 289,8 & 293,8 & 298,5 & 304,0 & 310,7 & 244,5 \\
\hline $\mathrm{C}_{2} \mathrm{H}_{2}$ & ${ }^{2} J_{\mathrm{CH}}$ & 57,0 & 56,9 & 56,6 & 56,1 & 55,2 & 54,0 & 52,3 & 50,1 & 47,2 & 43,4 & 38,4 & 49,7 \\
\hline $\mathrm{C}_{2} \mathrm{H}_{2}$ & ${ }^{3} J_{\mathrm{HH}}$ & 10,1 & 10,7 & 11,4 & 12,3 & 13,3 & 14,5 & 15,9 & 17,7 & 19,8 & 22,4 & 25,6 & 9,1 \\
\hline $\mathrm{C}_{2} \mathrm{H}_{4}$ & ${ }^{1} J_{\mathrm{CC}}$ & 66,9 & 69,8 & 73,1 & 76,7 & 80,8 & 85,6 & 91,3 & 98,4 & 107,5 & 119,9 & 138,1 & 67,2 \\
\hline $\mathrm{C}_{2} \mathrm{H}_{4}$ & ${ }^{1} J_{\mathrm{CH}}$ & 166,3 & 168,5 & 170,8 & 173,3 & 175,9 & 178,8 & 182,0 & 185,7 & 190,2 & 196,0 & 204,0 & 154,5 \\
\hline $\mathrm{C}_{2} \mathrm{H}_{4}$ & ${ }^{2} J_{\mathrm{CH}}$ & 0,2 & $-0,6$ & $-1,6$ & $-2,8$ & $-4,1$ & $-5,7$ & $-7,7$ & $-10,2$ & $-13,5$ & $-18,1$ & $-25,0$ & $-2,1$ \\
\hline $\mathrm{C}_{2} \mathrm{H}_{4}$ & ${ }^{2} J_{\mathrm{HH}}$ & 6,1 & 5,4 & 4,6 & 3,7 & 2,7 & 1,7 & 0,4 & $-1,0$ & $-2,9$ & $-5,5$ & $-9,2$ & 2 \\
\hline $\mathrm{C}_{2} \mathrm{H}_{4}$ & ${ }^{3} J_{\mathrm{HH}_{\mathrm{c}}}$ & 12,5 & 12,8 & 13,1 & 13,5 & 13,9 & 14,6 & 15,4 & 16,4 & 17,9 & 20,0 & 23,3 & 11,4 \\
\hline $\mathrm{C}_{2} \mathrm{H}_{4}$ & ${ }^{3} J_{\mathrm{HH}_{\mathrm{t}}}$ & 19,9 & 20,2 & 20,5 & 21,0 & 21,5 & 22,3 & 23,2 & 24,5 & 26,2 & 28,7 & 32,4 & 18,5 \\
\hline $\mathrm{C}_{2} \mathrm{H}_{6}$ & ${ }^{1} J_{\mathrm{CC}}$ & 29,4 & 31,5 & 33,7 & 35,9 & 38,1 & 40,4 & 42,7 & 45,1 & 47,5 & 49,9 & 52,4 & 33,7 \\
\hline $\mathrm{C}_{2} \mathrm{H}_{6}$ & ${ }^{1} J_{\mathrm{CH}}$ & 131,3 & 133,1 & 134,8 & 136,6 & 138,4 & 140,3 & 142,1 & 144,0 & 145,9 & 147,8 & 149,7 & 123,4 \\
\hline $\mathrm{C}_{2} \mathrm{H}_{6}$ & ${ }^{2} J_{\mathrm{CH}}$ & $-2,5$ & $-3,0$ & $-3,5$ & $-4,0$ & $-4,5$ & $-5,0$ & $-5,5$ & $-6,1$ & $-6,6$ & $-7,2$ & $-7,7$ & $-4,5$ \\
\hline \multirow[t]{3}{*}{ Total } & DM & $-22,78$ & $-20,20$ & $-17,44$ & $-14,57$ & $-11,71$ & $-8,94$ & $-6,55$ & $-4,95$ & $-5,17$ & $-10,76$ & $-47,71$ & - \\
\hline & DMA & 32,82 & 30,21 & 28,03 & 26,12 & 24,69 & 24,58 & 28,69 & 34,75 & 43,22 & 57,77 & 105,67 & - \\
\hline & PDMA & 48,74 & 39,35 & 30,03 & 24,00 & 22,24 & 26,91 & 42,92 & 61,20 & 83,38 & 112,22 & 160,00 & - \\
\hline \multirow[t]{3}{*}{ CPI } & DM & $-62,66$ & $-57,86$ & $-52,69$ & $-47,38$ & $-42,18$ & $-37,43$ & $-33,73$ & $-32,18$ & $-35,36$ & $-51,82$ & $-143,35$ & - \\
\hline & DMA & 67,92 & 60,88 & 54,64 & 48,35 & 43,04 & 40,41 & 47,36 & 58,45 & 74,20 & 103,13 & 209,07 & - \\
\hline & PDMA & 72,69 & 57,25 & 42,07 & 28,32 & 20,20 & 20,60 & 37,82 & 56,59 & 77,00 & 101,81 & 153,07 & - \\
\hline \multirow[t]{3}{*}{ SPI } & $\mathrm{DM}$ & 6,46 & 7,41 & 8,41 & 9,49 & 10,63 & 11,95 & 13,37 & 15,03 & 16,98 & 19,35 & 22,43 & - \\
\hline & DMA & 7,07 & 7,72 & 8,53 & 9,81 & 11,23 & 12,97 & 15,00 & 17,36 & 20,50 & 24,51 & 29,84 & - \\
\hline & PDMA & 31,18 & 26,23 & 21,20 & 20,83 & 23,73 & 31,54 & 46,67 & 64,59 & 88,06 & 119,85 & 165,09 & - \\
\hline \multirow[t]{3}{*}{$\Delta \mathrm{CS}$} & DM & $-69,12$ & $-65,28$ & $-61,10$ & $-56,88$ & $-52,82$ & $-49,38$ & $-47,10$ & $-47,21$ & $-52,34$ & $-71,17$ & $-165,77$ & - \\
\hline & DMA & 60,84 & 53,16 & 46,11 & 38,53 & 31,80 & 27,44 & 32,36 & 41,09 & 53,70 & 78,61 & 179,23 & - \\
\hline & PDMA & 41,51 & 31,02 & 20,87 & 7,49 & $-3,53$ & $-10,95$ & $-8,85$ & $-8,00$ & $-11,06$ & $-18,04$ & $-12,02$ & - \\
\hline
\end{tabular}


Tabela 8.153: Constantes de acoplamento B1B95 e constantes empíricas no nível PBE0 $40 \% E_{X}^{\mathrm{HF}}$ e base aug-pcJ-2.

\begin{tabular}{|c|c|c|c|c|c|c|c|c|c|c|c|c|c|}
\hline & $\% E_{X}^{\mathrm{HF}}$ & $0 \%$ & $10 \%$ & $20 \%$ & $30 \%$ & $40 \%$ & $50 \%$ & $60 \%$ & $70 \%$ & $80 \%$ & $90 \%$ & $100 \%$ & Emp. \\
\hline $\mathrm{HF}$ & ${ }^{1} J_{\mathrm{HF}}$ & 403,9 & 427,5 & 451,2 & 475,2 & 499,3 & 523,6 & 548,0 & 572,6 & 597,4 & 622,3 & 647,4 & 534,8 \\
\hline $\mathrm{CO}$ & ${ }^{1} J_{\mathrm{CO}}$ & 23,4 & 21,7 & 19,9 & 18,1 & 16,1 & 14,0 & 11,8 & 9,6 & 7,3 & 4,9 & 2,4 & 15,7 \\
\hline $\mathrm{H}_{2} \mathrm{O}$ & ${ }^{1} J_{\mathrm{OH}}$ & $-70,3$ & $-72,8$ & $-75,3$ & $-77,9$ & $-80,4$ & $-83,0$ & $-85,6$ & $-88,2$ & $-90,8$ & $-93,5$ & $-96,2$ & $-82,0$ \\
\hline $\mathrm{H}_{2} \mathrm{O}$ & ${ }^{2} J_{\mathrm{HH}}$ & $-4,2$ & $-5,2$ & $-6,2$ & $-7,2$ & $-8,2$ & $-9,2$ & $-10,3$ & $-11,3$ & $-12,4$ & $-13,5$ & $-14,7$ & $-8,8$ \\
\hline $\mathrm{NH}_{3}$ & ${ }^{1} J_{\mathrm{NH}}$ & 41,9 & 42,7 & 43,4 & 44,1 & 44,9 & 45,6 & 46,4 & 47,2 & 47,9 & 48,7 & 49,5 & 43,3 \\
\hline $\mathrm{NH}_{3}$ & ${ }^{2} J_{\mathrm{HH}}$ & $-7,0$ & $-7,8$ & $-8,7$ & $-9,5$ & $-10,4$ & $-11,3$ & $-12,1$ & $-13,0$ & $-13,9$ & $-14,8$ & $-15,8$ & $-10,4$ \\
\hline $\mathrm{PH}_{3}$ & ${ }^{1} J_{\mathrm{PH}}$ & 146,7 & 154,4 & 161,8 & 169,2 & 176,5 & 183,6 & 190,6 & 197,4 & 204,1 & 210,7 & 217,0 & 195,7 \\
\hline $\mathrm{PF}_{3}$ & ${ }^{1} J_{\mathrm{PF}}$ & $-1716,6$ & $-1695,0$ & $-1669,0$ & $-1639,2$ & $-1606,4$ & $-1571,1$ & $-1533,7$ & $-1494,9$ & $-1454,9$ & $-1414,1$ & $-1372,8$ & $-1.443,2$ \\
\hline $\mathrm{BHF}_{2}$ & ${ }^{1} J_{\mathrm{BF}}$ & $-174,7$ & $-157,8$ & $-141,0$ & $-124,2$ & $-107,5$ & $-91,0$ & $-74,6$ & $-58,3$ & $-42,2$ & $-26,3$ & $-10,5$ & $-79,6$ \\
\hline $\mathrm{BF}_{3}$ & ${ }^{1} J_{\mathrm{BF}}$ & $-78,7$ & $-60,1$ & $-41,7$ & $-23,4$ & $-5,3$ & 12,6 & 30,3 & 47,9 & 65,3 & 82,6 & 99,7 & 17,2 \\
\hline $\mathrm{F}_{2} \mathrm{O}$ & ${ }^{1} J_{\mathrm{OF}}$ & $-266,9$ & $-301,3$ & $-334,9$ & $-368,7$ & $-404,3$ & $-443,7$ & $-490,0$ & $-548,8$ & $-631,2$ & $-765,1$ & $-1048,5$ & $-284,7$ \\
\hline $\mathrm{CH}_{4}$ & ${ }^{1} J_{\mathrm{CH}}$ & 120,7 & 122,0 & 123,3 & 124,7 & 126,1 & 127,5 & 129,0 & 130,4 & 131,9 & 133,4 & 134,9 & 122,9 \\
\hline $\mathrm{CH}_{4}$ & ${ }^{2} J_{\mathrm{HH}}$ & $-10,3$ & $-11,0$ & $-11,7$ & $-12,4$ & $-13,0$ & $-13,7$ & $-14,4$ & $-15,0$ & $-15,7$ & $-16,4$ & $-17,0$ & $-12,5$ \\
\hline $\mathrm{C}_{2} \mathrm{H}_{2}$ & ${ }^{1} J_{\mathrm{CC}}$ & 187,9 & 190,2 & 192,9 & 195,8 & 199,3 & 203,2 & 207,7 & 213,0 & 219,2 & 226,6 & 235,5 & 173,9 \\
\hline $\mathrm{C}_{2} \mathrm{H}_{2}$ & ${ }^{1} J_{\mathrm{CH}}$ & 250,6 & 252,5 & 254,5 & 256,6 & 258,8 & 261,2 & 263,7 & 266,5 & 269,6 & 273,2 & 277,3 & 244,4 \\
\hline $\mathrm{C}_{2} \mathrm{H}_{2}$ & ${ }^{2} J_{\mathrm{CH}}$ & 55,5 & 55,7 & 55,7 & 55,5 & 55,2 & 54,6 & 53,8 & 52,6 & 51,1 & 49,1 & 46,4 & 49,9 \\
\hline $\mathrm{C}_{2} \mathrm{H}_{2}$ & ${ }^{3} J_{\mathrm{HH}}$ & 9,1 & 9,5 & 10,0 & 10,6 & 11,2 & 12,0 & 13,0 & 14,1 & 15,4 & 17,0 & 18,9 & 8,9 \\
\hline $\mathrm{C}_{2} \mathrm{H}_{4}$ & ${ }^{1} J_{\mathrm{CC}}$ & 58,9 & 61,2 & 63,8 & 66,5 & 69,6 & 73,0 & 76,8 & 81,2 & 86,5 & 92,8 & 100,8 & 66,6 \\
\hline $\mathrm{C}_{2} \mathrm{H}_{4}$ & ${ }^{1} J_{\mathrm{CH}}$ & 153,4 & 155,3 & 157,2 & 159,2 & 161,3 & 163,5 & 165,9 & 168,5 & 171,4 & 174,7 & 178,7 & 154,3 \\
\hline $\mathrm{C}_{2} \mathrm{H}_{4}$ & ${ }^{2} J_{\mathrm{CH}}$ & 1,0 & 0,3 & $-0,4$ & $-1,3$ & $-2,3$ & $-3,4$ & $-4,7$ & $-6,3$ & $-8,1$ & $-10,4$ & $-13,4$ & $-1,9$ \\
\hline $\mathrm{C}_{2} \mathrm{H}_{4}$ & ${ }^{2} J_{\mathrm{HH}}$ & 6,0 & 5,4 & 4,7 & 4,0 & 3,3 & 2,5 & 1,6 & 0,6 & $-0,5$ & $-1,9$ & $-3,5$ & 2,1 \\
\hline $\mathrm{C}_{2} \mathrm{H}_{4}$ & ${ }^{3} J_{\mathrm{HH}_{\mathrm{c}}}$ & 11,5 & 11,7 & 11,9 & 12,2 & 12,5 & 12,8 & 13,3 & 13,9 & 14,7 & 15,6 & 16,9 & 11,3 \\
\hline $\mathrm{C}_{2} \mathrm{H}_{4}$ & ${ }^{3} J_{\mathrm{HH}_{\mathrm{t}}}$ & 18,3 & 18,5 & 18,8 & 19,0 & 19,4 & 19,9 & 20,4 & 21,1 & 22,0 & 23,2 & 24,7 & 18,3 \\
\hline $\mathrm{C}_{2} \mathrm{H}_{6}$ & ${ }^{1} J_{\mathrm{CC}}$ & 25,1 & 27,1 & 29,0 & 31,0 & 33,0 & 35,0 & 37,1 & 39,2 & 41,3 & 43,5 & 45,7 & 33,6 \\
\hline $\mathrm{C}_{2} \mathrm{H}_{6}$ & ${ }^{1} J_{\mathrm{CH}}$ & 120,6 & 122,2 & 123,7 & 125,3 & 126,9 & 128,5 & 130,1 & 131,8 & 133,4 & 135,0 & 136,7 & 123,4 \\
\hline $\mathrm{C}_{2} \mathrm{H}_{6}$ & ${ }^{2} J_{\mathrm{CH}}$ & $-2,2$ & $-2,7$ & $-3,1$ & $-3,6$ & $-4,0$ & $-4,5$ & $-5,0$ & $-5,4$ & $-5,9$ & $-6,4$ & $-6,9$ & $-4,5$ \\
\hline \multirow[t]{3}{*}{ Total } & $\mathrm{DM}$ & $-22,50$ & $-20,17$ & $-17,65$ & $-14,97$ & $-12,20$ & $-9,48$ & $-6,91$ & $-4,70$ & $-3,30$ & $-3,76$ & $-9,83$ & - \\
\hline & DMA & 28,87 & 24,99 & 22,44 & 19,96 & 17,76 & 16,13 & 17,50 & 21,64 & 27,15 & 37,08 & 54,03 & - \\
\hline & PDMA & 52,99 & 43,05 & 33,64 & 24,06 & 16,68 & 14,22 & 22,58 & 36,76 & 52,42 & 70,91 & 94,02 & - \\
\hline \multirow[t]{3}{*}{ CPI } & $\mathrm{DM}$ & $-54,59$ & $-50,15$ & $-45,32$ & $-40,14$ & $-34,88$ & $-29,81$ & $-25,20$ & $-21,62$ & $-20,13$ & $-23,28$ & $-40,05$ & - \\
\hline & DMA & 62,81 & 54,05 & 48,10 & 41,92 & 35,65 & 30,23 & 31,45 & 38,96 & 49,42 & 69,77 & 105,88 & - \\
\hline & PDMA & 82,11 & 66,26 & 51,53 & 37,17 & 22,79 & 13,15 & 21,43 & 38,03 & 55,87 & 75,73 & 100,63 & - \\
\hline \multirow[t]{3}{*}{ SPI } & $\mathrm{DM}$ & 1,03 & 1,81 & 2,64 & 3,49 & 4,44 & 5,43 & 6,51 & 7,70 & 9,04 & 10,55 & 12,33 & - \\
\hline & DMA & 3,97 & 3,68 & 3,63 & 3,85 & 4,64 & 5,79 & 7,27 & 8,94 & 10,83 & 13,10 & 16,00 & - \\
\hline & PDMA & 31,63 & 26,03 & 20,51 & 14,44 & 12,21 & 15,01 & 23,43 & 35,83 & 49,88 & 67,38 & 89,18 & - \\
\hline \multirow[t]{3}{*}{$\Delta \mathrm{CS}$} & DM & $-55,62$ & $-51,97$ & $-47,96$ & $-43,63$ & $-39,32$ & $-35,24$ & $-31,71$ & $-29,32$ & $-29,17$ & $-33,84$ & $-52,38$ & - \\
\hline & DMA & 58,84 & 50,37 & 44,47 & 38,06 & 31,01 & 24,44 & 24,19 & 30,02 & 38,59 & 56,67 & 89,88 & - \\
\hline & PDMA & 50,49 & 40,23 & 31,02 & 22,72 & 10,57 & $-1,87$ & $-2,01$ & 2,21 & 5,99 & 8,34 & 11,44 & - \\
\hline
\end{tabular}


Tabela 8.154: Constantes de acoplamento B3LYP e constantes empíricas no nível PBE0 $40 \% E_{X}^{\mathrm{HF}}$ e base aug-pcJ-2.

\begin{tabular}{|c|c|c|c|c|c|c|c|c|c|c|c|c|c|}
\hline & $\% E_{X}^{\mathrm{HF}}$ & $0 \%$ & $10 \%$ & $20 \%$ & $30 \%$ & $40 \%$ & $50 \%$ & $60 \%$ & $70 \%$ & $80 \%$ & $90 \%$ & $100 \%$ & Emp. \\
\hline $\mathrm{HF}$ & ${ }^{1} J_{\mathrm{HF}}$ & 393,4 & 418,4 & 443,6 & 469,1 & 494,8 & 520,8 & 547,0 & 573,4 & 600,0 & 626,9 & 654,0 & 534,8 \\
\hline $\mathrm{CO}$ & ${ }^{1} J_{\mathrm{CO}}$ & 21,7 & 19,9 & 17,9 & 15,8 & 13,6 & 11,4 & 9,0 & 6,5 & 4,0 & 1,4 & $-1,2$ & 15,7 \\
\hline $\mathrm{H}_{2} \mathrm{O}$ & ${ }^{1} J_{\mathrm{OH}}$ & $-71,7$ & $-74,4$ & $-77,1$ & $-79,8$ & $-82,5$ & $-85,3$ & $-88,1$ & $-91,0$ & $-93,8$ & $-96,7$ & $-99,6$ & $-82,0$ \\
\hline $\mathrm{H}_{2} \mathrm{O}$ & ${ }^{2} J_{\mathrm{HH}}$ & $-5,3$ & $-6,4$ & $-7,5$ & $-8,6$ & $-9,7$ & $-10,8$ & $-12,0$ & $-13,2$ & $-14,4$ & $-15,6$ & $-16,8$ & $-8,8$ \\
\hline $\mathrm{NH}_{3}$ & ${ }^{1} J_{\mathrm{NH}}$ & 44,2 & 45,0 & 45,8 & 46,6 & 47,5 & 48,3 & 49,2 & 50,0 & 50,9 & 51,8 & 52,7 & 43,3 \\
\hline $\mathrm{NH}_{3}$ & ${ }^{2} J_{\mathrm{HH}}$ & $-8,4$ & $-9,3$ & $-10,3$ & $-11,2$ & $-12,2$ & $-13,2$ & $-14,2$ & $-15,2$ & $-16,2$ & $-17,2$ & $-18,2$ & $-10,4$ \\
\hline $\mathrm{PH}_{3}$ & ${ }^{1} J_{\mathrm{PH}}$ & 157,6 & 166,1 & 174,5 & 182,7 & 190,9 & 198,8 & 206,7 & 214,3 & 221,8 & 229,2 & 236,3 & 195,7 \\
\hline $\mathrm{PF}_{3}$ & ${ }^{1} J_{\mathrm{PF}}$ & $-1810,3$ & $-1784,6$ & $-1754,5$ & $-1720,8$ & $-1684,0$ & $-1644,8$ & $-1603,8$ & $-1561,4$ & $-1518,1$ & $-1474,0$ & $-1429,6$ & $-1.443,2$ \\
\hline $\mathrm{BHF}_{2}$ & ${ }^{1} J_{\mathrm{BF}}$ & $-167,7$ & $-150,2$ & $-132,7$ & $-115,4$ & $-98,2$ & $-81,2$ & $-64,4$ & $-47,8$ & $-31,4$ & $-15,2$ & 0,7 & $-79,6$ \\
\hline $\mathrm{BF}_{3}$ & ${ }^{1} J_{\mathrm{BF}}$ & $-70,2$ & $-51,0$ & $-32,1$ & $-13,3$ & 5,1 & 23,4 & 41,5 & 59,5 & 77,2 & 94,8 & 112,2 & 17,2 \\
\hline $\mathrm{F}_{2} \mathrm{O}$ & ${ }^{1} J_{\mathrm{OF}}$ & $-280,0$ & $-316,8$ & $-353,7$ & $-392,3$ & $-434,8$ & $-484,4$ & $-547,0$ & $-634,0$ & $-773,3$ & $-1056,7$ & $-2138,3$ & $-284,7$ \\
\hline $\mathrm{CH}_{4}$ & ${ }^{1} J_{\mathrm{CH}}$ & 131,0 & 132,6 & 134,1 & 135,7 & 137,4 & 139,0 & 140,7 & 142,4 & 144,1 & 145,9 & 147,6 & 122,9 \\
\hline $\mathrm{CH}_{4}$ & ${ }^{2} J_{\mathrm{HH}}$ & $-11,9$ & $-12,7$ & $-13,4$ & $-14,2$ & $-14,9$ & $-15,7$ & $-16,4$ & $-17,2$ & $-17,9$ & $-18,6$ & $-19,4$ & $-12,5$ \\
\hline $\mathrm{C}_{2} \mathrm{H}_{2}$ & ${ }^{1} J_{\mathrm{CC}}$ & 199,3 & 202,3 & 205,8 & 209,7 & 214,3 & 219,6 & 225,8 & 233,3 & 242,3 & 253,2 & 266,8 & 173,9 \\
\hline $\mathrm{C}_{2} \mathrm{H}_{2}$ & ${ }^{1} J_{\mathrm{CH}}$ & 271,1 & 273,5 & 276,1 & 278,9 & 281,8 & 285,0 & 288,6 & 292,6 & 297,3 & 302,7 & 309,4 & 244,4 \\
\hline $\mathrm{C}_{2} \mathrm{H}_{2}$ & ${ }^{2} J_{\mathrm{CH}}$ & 56,9 & 56,8 & 56,5 & 56,0 & 55,1 & 53,9 & 52,3 & 50,1 & 47,2 & 43,5 & 38,5 & 49,9 \\
\hline $\mathrm{C}_{2} \mathrm{H}_{2}$ & ${ }^{3} J_{\mathrm{HH}}$ & 10,2 & 10,7 & 11,4 & 12,3 & 13,3 & 14,5 & 15,9 & 17,6 & 19,7 & 22,2 & 25,4 & 8,9 \\
\hline $\mathrm{C}_{2} \mathrm{H}_{4}$ & ${ }^{1} J_{\mathrm{CC}}$ & 66,6 & 69,5 & 72,8 & 76,4 & 80,5 & 85,3 & 91,1 & 98,1 & 107,2 & 119,6 & 137,7 & 66,6 \\
\hline $\mathrm{C}_{2} \mathrm{H}_{4}$ & ${ }^{1} J_{\mathrm{CH}}$ & 165,4 & 167,7 & 170,0 & 172,5 & 175,1 & 178,0 & 181,2 & 185,0 & 189,5 & 195,2 & 203,3 & 154,3 \\
\hline $\mathrm{C}_{2} \mathrm{H}_{4}$ & ${ }^{2} J_{\mathrm{CH}}$ & 0,3 & $-0,5$ & $-1,6$ & $-2,7$ & $-4,1$ & $-5,7$ & $-7,7$ & $-10,1$ & $-13,4$ & $-18,0$ & $-24,8$ & $-1,9$ \\
\hline $\mathrm{C}_{2} \mathrm{H}_{4}$ & ${ }^{2} J_{\mathrm{HH}}$ & 6,0 & 5,3 & 4,5 & 3,6 & 2,7 & 1,6 & 0,4 & $-1,0$ & $-2,9$ & $-5,5$ & $-9,2$ & 2,1 \\
\hline $\mathrm{C}_{2} \mathrm{H}_{4}$ & ${ }^{3} J_{\mathrm{HH}_{\mathrm{C}}}$ & 12,4 & 12,7 & 13,0 & 13,4 & 13,8 & 14,5 & 15,3 & 16,3 & 17,8 & 19,9 & 23,2 & 11,3 \\
\hline $\mathrm{C}_{2} \mathrm{H}_{4}$ & ${ }^{3} J_{\mathrm{HH}_{\mathrm{t}}}$ & 19,8 & 20,0 & 20,4 & 20,8 & 21,4 & 22,2 & 23,1 & 24,4 & 26,1 & 28,5 & 32,3 & 18,3 \\
\hline $\mathrm{C}_{2} \mathrm{H}_{6}$ & ${ }^{1} J_{\mathrm{CC}}$ & 29,2 & 31,3 & 33,5 & 35,7 & 37,9 & 40,2 & 42,6 & 44,9 & 47,3 & 49,8 & 52,2 & 33,6 \\
\hline $\mathrm{C}_{2} \mathrm{H}_{6}$ & ${ }^{1} J_{\mathrm{CH}}$ & 130,5 & 132,3 & 134,1 & 135,9 & 137,7 & 139,6 & 141,5 & 143,3 & 145,2 & 147,2 & 149,1 & 123,4 \\
\hline $\mathrm{C}_{2} \mathrm{H}_{6}$ & ${ }^{2} J_{\mathrm{CH}}$ & $-2,5$ & $-3,0$ & $-3,4$ & $-3,9$ & $-4,5$ & $-5,0$ & $-5,5$ & $-6,0$ & $-6,6$ & $-7,1$ & $-7,7$ & $-4,5$ \\
\hline \multirow[t]{3}{*}{ Total } & $\mathrm{DM}$ & $-23,12$ & $-20,52$ & $-17,73$ & $-14,84$ & $-11,95$ & $-9,18$ & $-6,77$ & $-5,15$ & $-5,35$ & $-10,83$ & $-46,62$ & - \\
\hline & DMA & 32,77 & 30,31 & 28,12 & 26,20 & 24,69 & 24,46 & 28,24 & 34,27 & 42,73 & 57,19 & 104,12 & - \\
\hline & PDMA & 48,43 & 39,03 & 29,50 & 24,24 & 22,92 & 28,16 & 44,27 & 62,59 & 85,31 & 114,72 & 163,06 & - \\
\hline \multirow[t]{3}{*}{ CPI } & $\mathrm{DM}$ & $-63,15$ & $-58,30$ & $-53,10$ & $-47,75$ & $-42,50$ & $-37,73$ & $-34,01$ & $-32,45$ & $-35,57$ & $-51,75$ & $-140,53$ & - \\
\hline & DMA & 68,14 & 61,39 & 55,10 & 48,80 & 43,26 & 40,33 & 46,48 & 57,54 & 73,23 & 101,95 & 205,64 & - \\
\hline & PDMA & 73,06 & 57,71 & 42,59 & 29,01 & 20,39 & 19,91 & 37,11 & 55,88 & 76,15 & 101,00 & 151,36 & - \\
\hline \multirow[t]{3}{*}{ SPI } & $\mathrm{DM}$ & 6,24 & 7,19 & 8,21 & 9,29 & 10,45 & 11,75 & 13,21 & 14,87 & 16,81 & 19,19 & 22,25 & - \\
\hline & DMA & 6,83 & 7,52 & 8,34 & 9,63 & 11,07 & 12,82 & 14,87 & 17,20 & 20,37 & 24,36 & 29,67 & - \\
\hline & PDMA & 30,37 & 25,33 & 19,90 & 20,74 & 24,77 & 34,22 & 49,52 & 67,50 & 92,04 & 124,78 & 171,64 & - \\
\hline \multirow[t]{3}{*}{$\Delta \mathrm{CS}$} & $\mathrm{DM}$ & $-69,39$ & $-65,49$ & $-61,31$ & $-57,04$ & $-52,95$ & $-49,48$ & $-47,22$ & $-47,31$ & $-52,39$ & $-70,94$ & $-162,77$ & - \\
\hline & DMA & 61,31 & 53,87 & 46,76 & 39,17 & 32,20 & 27,51 & 31,62 & 40,34 & 52,85 & 77,59 & 175,96 & - \\
\hline & PDMA & 42,70 & 32,38 & 22,70 & 8,27 & $-4,38$ & $-14,31$ & $-12,41$ & $-11,62$ & $-15,89$ & $-23,78$ & $-20,27$ & - \\
\hline
\end{tabular}


Tabela 8.155: Constantes de acoplamento B3P86 e constantes empíricas no nível PBE0 $40 \% E_{X}^{\mathrm{HF}}$ e base aug-pcJ-2.

\begin{tabular}{|c|c|c|c|c|c|c|c|c|c|c|c|c|c|}
\hline & $\% E_{X}^{\mathrm{HF}}$ & $0 \%$ & $10 \%$ & $20 \%$ & $30 \%$ & $40 \%$ & $50 \%$ & $60 \%$ & $70 \%$ & $80 \%$ & $90 \%$ & $100 \%$ & Emp. \\
\hline $\mathrm{HF}$ & ${ }^{1} J_{\mathrm{HF}}$ & 357,7 & 381,4 & 405,4 & 429,5 & 454,0 & 478,6 & 503,5 & 528,5 & 553,8 & 579,3 & 605,0 & 534,8 \\
\hline $\mathrm{CO}$ & ${ }^{1} J_{\mathrm{CO}}$ & 24,7 & 23,1 & 21,3 & 19,5 & 17,5 & 15,5 & 13,4 & 11,3 & 9,1 & 6,8 & 4,4 & 15,7 \\
\hline $\mathrm{H}_{2} \mathrm{O}$ & ${ }^{1} J_{\mathrm{OH}}$ & $-65,2$ & $-67,8$ & $-70,3$ & $-72,9$ & $-75,5$ & $-78,1$ & $-80,8$ & $-83,4$ & $-86,1$ & $-88,9$ & $-91,6$ & $-82,0$ \\
\hline $\mathrm{H}_{2} \mathrm{O}$ & ${ }^{2} J_{\mathrm{HH}}$ & $-4,6$ & $-5,6$ & $-6,5$ & $-7,6$ & $-8,6$ & $-9,6$ & $-10,7$ & $-11,8$ & $-12,9$ & $-14,0$ & $-15,2$ & $-8,8$ \\
\hline $\mathrm{NH}_{3}$ & ${ }^{1} J_{\mathrm{NH}}$ & 40,3 & 41,1 & 41,8 & 42,6 & 43,4 & 44,2 & 45,0 & 45,8 & 46,6 & 47,5 & 48,3 & 43,3 \\
\hline $\mathrm{NH}_{3}$ & ${ }^{2} J_{\mathrm{HH}}$ & $-7,8$ & $-8,7$ & $-9,5$ & $-10,4$ & $-11,3$ & $-12,2$ & $-13,1$ & $-14,1$ & $-15,0$ & $-15,9$ & $-16,9$ & $-10,4$ \\
\hline $\mathrm{PH}_{3}$ & ${ }^{1} J_{\mathrm{PH}}$ & 138,4 & 146,6 & 154,6 & 162,6 & 170,5 & 178,2 & 185,8 & 193,3 & 200,6 & 207,8 & 214,8 & 195,7 \\
\hline $\mathrm{PF}_{3}$ & ${ }^{1} J_{\mathrm{PF}}$ & $-1804,0$ & $-1778,3$ & $-1748,1$ & $-1714,4$ & $-1677,8$ & $-1638,8$ & $-1598,0$ & $-1555,9$ & $-1512,8$ & $-1469,1$ & $-1425,0$ & $-1.443,2$ \\
\hline $\mathrm{BHF}_{2}$ & ${ }^{1} J_{\mathrm{BF}}$ & $-175,5$ & $-158,4$ & $-141,4$ & $-124,6$ & $-107,9$ & $-91,3$ & $-74,9$ & $-58,7$ & $-42,7$ & $-26,9$ & $-11,3$ & $-79,6$ \\
\hline $\mathrm{BF}_{3}$ & ${ }^{1} J_{\mathrm{BF}}$ & $-81,4$ & $-62,6$ & $-44,1$ & $-25,8$ & $-7,7$ & 10,1 & 27,8 & 45,3 & 62,7 & 79,9 & 96,9 & 17,2 \\
\hline $\mathrm{F}_{2} \mathrm{O}$ & ${ }^{1} J_{\mathrm{OF}}$ & $-287,8$ & $-324,9$ & $-362,3$ & $-401,4$ & $-444,6$ & $-495,1$ & $-558,7$ & $-646,9$ & $-786,4$ & $-1061,9$ & $-1993,1$ & $-284,7$ \\
\hline $\mathrm{CH}_{4}$ & ${ }^{1} J_{\mathrm{CH}}$ & 119,3 & 120,8 & 122,3 & 123,8 & 125,4 & 127,0 & 128,6 & 130,2 & 131,8 & 133,5 & 135,2 & 122,9 \\
\hline $\mathrm{CH}_{4}$ & ${ }^{2} J_{\mathrm{HH}}$ & $-11,8$ & $-12,5$ & $-13,3$ & $-14,0$ & $-14,7$ & $-15,4$ & $-16,1$ & $-16,8$ & $-17,5$ & $-18,2$ & $-18,9$ & $-12,5$ \\
\hline $\mathrm{C}_{2} \mathrm{H}_{2}$ & ${ }^{1} J_{\mathrm{CC}}$ & 189,8 & 192,5 & 195,7 & 199,3 & 203,5 & 208,5 & 214,4 & 221,5 & 230,2 & 241,0 & 254,8 & 173,9 \\
\hline $\mathrm{C}_{2} \mathrm{H}_{2}$ & ${ }^{1} J_{\mathrm{CH}}$ & 251,0 & 253,4 & 255,8 & 258,5 & 261,4 & 264,5 & 268,1 & 272,2 & 276,9 & 282,7 & 289,8 & 244,4 \\
\hline $\mathrm{C}_{2} \mathrm{H}_{2}$ & ${ }^{2} J_{\mathrm{CH}}$ & 54,7 & 54,6 & 54,4 & 53,9 & 53,0 & 51,8 & 50,2 & 47,9 & 44,9 & 40,9 & 35,4 & 49,9 \\
\hline $\mathrm{C}_{2} \mathrm{H}_{2}$ & ${ }^{3} J_{\mathrm{HH}}$ & 10,2 & 10,9 & 11,6 & 12,5 & 13,6 & 14,9 & 16,4 & 18,3 & 20,6 & 23,5 & 27,1 & 8,9 \\
\hline $\mathrm{C}_{2} \mathrm{H}_{4}$ & ${ }^{1} J_{\mathrm{CC}}$ & 60,6 & 63,4 & 66,4 & 69,9 & 73,8 & 78,5 & 84,2 & 91,5 & 101,2 & 115,3 & 138,2 & 66,6 \\
\hline $\mathrm{C}_{2} \mathrm{H}_{4}$ & ${ }^{1} J_{\mathrm{CH}}$ & 152,0 & 154,1 & 156,4 & 158,8 & 161,3 & 164,2 & 167,5 & 171,3 & 176,2 & 182,8 & 193,0 & 154,3 \\
\hline $\mathrm{C}_{2} \mathrm{H}_{4}$ & ${ }^{2} J_{\mathrm{CH}}$ & 0,0 & $-0,8$ & $-1,8$ & $-2,9$ & $-4,2$ & $-5,9$ & $-7,9$ & $-10,6$ & $-14,3$ & $-19,7$ & $-28,7$ & $-1,9$ \\
\hline $\mathrm{C}_{2} \mathrm{H}_{4}$ & ${ }^{2} J_{\mathrm{HH}}$ & 4,7 & 4,0 & 3,2 & 2,3 & 1,3 & 0,1 & $-1,2$ & $-2,9$ & $-5,2$ & $-8,5$ & $-13,8$ & 2,1 \\
\hline $\mathrm{C}_{2} \mathrm{H}_{4}$ & ${ }^{3} J_{\mathrm{HH}_{\mathrm{c}}}$ & 11,6 & 11,9 & 12,3 & 12,7 & 13,3 & 14,0 & 15,0 & 16,3 & 18,2 & 21,1 & 26,1 & 11,3 \\
\hline $\mathrm{C}_{2} \mathrm{H}_{4}$ & ${ }^{3} J_{\mathrm{HH}_{\mathrm{t}}}$ & 18,6 & 18,9 & 19,3 & 19,9 & 20,5 & 21,4 & 22,5 & 24,1 & 26,3 & 29,6 & 35,2 & 18,3 \\
\hline $\mathrm{C}_{2} \mathrm{H}_{6}$ & ${ }^{1} J_{\mathrm{CC}}$ & 25,0 & 27,0 & 29,0 & 31,1 & 33,2 & 35,3 & 37,5 & 39,7 & 41,9 & 44,2 & 46,5 & 33,6 \\
\hline $\mathrm{C}_{2} \mathrm{H}_{6}$ & ${ }^{1} J_{\mathrm{CH}}$ & 119,4 & 121,1 & 122,8 & 124,5 & 126,2 & 128,0 & 129,8 & 131,6 & 133,4 & 135,3 & 137,1 & 123,4 \\
\hline $\mathrm{C}_{2} \mathrm{H}_{6}$ & ${ }^{2} J_{\mathrm{CH}}$ & $-2,7$ & $-3,1$ & $-3,6$ & $-4,1$ & $-4,5$ & $-5,0$ & $-5,5$ & $-6,0$ & $-6,6$ & $-7,1$ & $-7,6$ & $-4,5$ \\
\hline \multirow[t]{3}{*}{ Total } & DM & $-28,90$ & $-26,41$ & $-23,74$ & $-20,98$ & $-18,22$ & $-15,59$ & $-13,30$ & $-11,81$ & $-12,07$ & $-17,22$ & $-47,04$ & - \\
\hline & DMA & 34,20 & 31,52 & 28,90 & 26,72 & 24,88 & 23,70 & 24,45 & 28,01 & 35,82 & 50,11 & 92,11 & - \\
\hline & PDMA & 49,68 & 39,95 & 30,27 & 24,75 & 23,91 & 27,46 & 38,73 & 57,67 & 81,87 & 114,54 & 169,45 & - \\
\hline \multirow[t]{3}{*}{ CPI } & $\mathrm{DM}$ & $-69,38$ & $-64,74$ & $-59,74$ & $-54,63$ & $-49,64$ & $-45,14$ & $-41,70$ & $-40,42$ & $-43,74$ & $-59,40$ & $-134,70$ & - \\
\hline & DMA & 75,31 & 69,55 & 63,46 & 57,19 & 51,20 & 46,01 & 45,01 & 49,78 & 63,66 & 91,44 & 182,06 & - \\
\hline & PDMA & 85,43 & 70,57 & 55,98 & 41,22 & 28,30 & 17,94 & 23,00 & 39,29 & 58,50 & 82,44 & 127,62 & - \\
\hline \multirow[t]{3}{*}{ SPI } & $\mathrm{DM}$ & 0,78 & 1,70 & 2,65 & 3,70 & 4,83 & 6,08 & 7,52 & 9,17 & 11,15 & 13,71 & 17,25 & - \\
\hline & DMA & 4,05 & 3,62 & 3,56 & 4,37 & 5,59 & 7,33 & 9,37 & 12,04 & 15,39 & 19,81 & 26,14 & - \\
\hline & PDMA & 23,47 & 17,50 & 11,42 & 12,66 & 20,69 & 34,44 & 50,26 & 71,15 & 99,00 & 138,08 & 200,12 & - \\
\hline \multirow[t]{3}{*}{$\Delta \mathrm{CS}$} & $\mathrm{DM}$ & $-70,16$ & $-66,44$ & $-62,39$ & $-58,33$ & $-54,46$ & $-51,22$ & $-49,22$ & $-49,59$ & $-54,89$ & $-73,11$ & $-151,95$ & - \\
\hline & DMA & 71,26 & 65,93 & 59,90 & 52,82 & 45,61 & 38,68 & 35,64 & 37,74 & 48,27 & 71,63 & 155,92 & - \\
\hline & PDMA & 61,96 & 53,07 & 44,57 & 28,56 & 7,61 & $-16,50$ & $-27,26$ & $-31,85$ & $-40,51$ & $-55,64$ & $-72,50$ & - \\
\hline
\end{tabular}


Tabela 8.156: Constantes de acoplamento B971 e constantes empíricas no nível PBE0 $40 \% E_{X}^{\mathrm{HF}}$ e base aug-pcJ-2.

\begin{tabular}{|c|c|c|c|c|c|c|c|c|c|c|c|c|c|}
\hline & $\% E_{X}^{\mathrm{HF}}$ & $0 \%$ & $10 \%$ & $20 \%$ & $30 \%$ & $40 \%$ & $50 \%$ & $60 \%$ & $70 \%$ & $80 \%$ & $90 \%$ & $100 \%$ & Emp. \\
\hline $\mathrm{HF}$ & ${ }^{1} J_{\mathrm{HF}}$ & 427,3 & 443,9 & 461,4 & 480,0 & 499,7 & 520,6 & 542,8 & 566,1 & 590,8 & 616,7 & 643,9 & 534,8 \\
\hline $\mathrm{CO}$ & ${ }^{1} J_{\mathrm{CO}}$ & 15,8 & 14,7 & 13,5 & 12,2 & 10,7 & 9,0 & 7,3 & 5,3 & 3,2 & 1,0 & $-1,3$ & 15,7 \\
\hline $\mathrm{H}_{2} \mathrm{O}$ & ${ }^{1} J_{\mathrm{OH}}$ & $-67,7$ & $-69,8$ & $-72,1$ & $-74,5$ & $-77,0$ & $-79,7$ & $-82,5$ & $-85,5$ & $-88,8$ & $-92,2$ & $-95,7$ & $-82,0$ \\
\hline $\mathrm{H}_{2} \mathrm{O}$ & ${ }^{2} J_{\mathrm{HH}}$ & $-0,6$ & $-1,6$ & $-2,7$ & $-3,8$ & $-5,1$ & $-6,4$ & $-7,7$ & $-9,2$ & $-10,8$ & $-12,5$ & $-14,3$ & $-8,8$ \\
\hline $\mathrm{NH}_{3}$ & ${ }^{1} J_{\mathrm{NH}}$ & 37,6 & 38,6 & 39,6 & 40,7 & 41,9 & 43,1 & 44,4 & 45,9 & 47,3 & 48,9 & 50,6 & 43,3 \\
\hline $\mathrm{NH}_{3}$ & ${ }^{2} J_{\mathrm{HH}}$ & $-3,4$ & $-4,3$ & $-5,2$ & $-6,3$ & $-7,4$ & $-8,6$ & $-9,9$ & $-11,2$ & $-12,7$ & $-14,3$ & $-16,1$ & $-10,4$ \\
\hline $\mathrm{PH}_{3}$ & ${ }^{1} J_{\mathrm{PH}}$ & 161,9 & 168,1 & 174,7 & 181,6 & 188,9 & 196,6 & 204,6 & 213,1 & 221,9 & 231,1 & 240,7 & 195,7 \\
\hline $\mathrm{PF}_{3}$ & ${ }^{1} J_{\mathrm{PF}}$ & $-1613,6$ & $-1608,3$ & $-1597,4$ & $-1581,8$ & $-1562,1$ & $-1539,1$ & $-1513,4$ & $-1485,6$ & $-1456,2$ & $-1425,8$ & $-1394,8$ & $-1.443,2$ \\
\hline $\mathrm{BHF}_{2}$ & ${ }^{1} J_{\mathrm{BF}}$ & $-145,0$ & $-130,5$ & $-115,6$ & $-100,5$ & $-85,1$ & $-69,6$ & $-54,0$ & $-38,4$ & $-22,8$ & $-7,2$ & 8,1 & $-79,6$ \\
\hline $\mathrm{BF}_{3}$ & ${ }^{1} J_{\mathrm{BF}}$ & $-55,7$ & $-38,9$ & $-21,9$ & $-4,7$ & 12,4 & 29,7 & 47,1 & 64,5 & 81,9 & 99,3 & 116,8 & 17,2 \\
\hline $\mathrm{F}_{2} \mathrm{O}$ & ${ }^{1} J_{\mathrm{OF}}$ & $-189,8$ & $-221,6$ & $-254,8$ & $-289,8$ & $-327,7$ & $-370,4$ & $-421,2$ & $-486,9$ & $-582,5$ & $-752,8$ & $-1221,3$ & $-284,7$ \\
\hline $\mathrm{CH}_{4}$ & ${ }^{1} J_{\mathrm{CH}}$ & 102,5 & 105,7 & 109,1 & 112,7 & 116,5 & 120,6 & 125,0 & 129,6 & 134,4 & 139,6 & 145,1 & 122,9 \\
\hline $\mathrm{CH}_{4}$ & ${ }^{2} J_{\mathrm{HH}}$ & $-5,8$ & $-6,7$ & $-7,6$ & $-8,5$ & $-9,6$ & $-10,7$ & $-11,8$ & $-13,1$ & $-14,4$ & $-15,8$ & $-17,3$ & $-12,5$ \\
\hline $\mathrm{C}_{2} \mathrm{H}_{2}$ & ${ }^{1} J_{\mathrm{CC}}$ & 186,1 & 190,1 & 194,4 & 199,4 & 205,0 & 211,6 & 219,4 & 228,8 & 240,5 & 255,4 & 275,1 & 173,9 \\
\hline $\mathrm{C}_{2} \mathrm{H}_{2}$ & ${ }^{1} J_{\mathrm{CH}}$ & 200,6 & 207,3 & 214,3 & 221,7 & 229,5 & 237,9 & 247,0 & 256,9 & 268,0 & 280,6 & 295,5 & 244,4 \\
\hline $\mathrm{C}_{2} \mathrm{H}_{2}$ & ${ }^{2} J_{\mathrm{CH}}$ & 51,0 & 51,9 & 52,5 & 53,0 & 53,2 & 53,0 & 52,5 & 51,2 & 49,1 & 45,6 & 40,1 & 49,9 \\
\hline $\mathrm{C}_{2} \mathrm{H}_{2}$ & ${ }^{3} J_{\mathrm{HH}}$ & 6,2 & 6,6 & 7,1 & 7,6 & 8,4 & 9,3 & 10,5 & 12,0 & 14,0 & 16,7 & 20,5 & 8,9 \\
\hline $\mathrm{C}_{2} \mathrm{H}_{4}$ & ${ }^{1} J_{\mathrm{CC}}$ & 63,4 & 66,1 & 69,1 & 72,5 & 76,4 & 80,8 & 86,2 & 92,8 & 101,2 & 112,9 & 130,5 & 66,6 \\
\hline $\mathrm{C}_{2} \mathrm{H}_{4}$ & ${ }^{1} J_{\mathrm{CH}}$ & 126,1 & 130,5 & 135,2 & 140,1 & 145,4 & 151,2 & 157,4 & 164,3 & 172,1 & 181,3 & 193,0 & 154,3 \\
\hline $\mathrm{C}_{2} \mathrm{H}_{4}$ & ${ }^{2} J_{\mathrm{CH}}$ & 2,5 & 1,9 & 1,1 & 0,2 & $-0,8$ & $-2,1$ & $-3,7$ & $-5,8$ & $-8,5$ & $-12,5$ & $-18,8$ & $-1,9$ \\
\hline $\mathrm{C}_{2} \mathrm{H}_{4}$ & ${ }^{2} J_{\mathrm{HH}}$ & 6,0 & 5,6 & 5,2 & 4,7 & 4,1 & 3,4 & 2,5 & 1,4 & 0,0 & $-2,0$ & $-5,1$ & 2,1 \\
\hline $\mathrm{C}_{2} \mathrm{H}_{4}$ & ${ }^{3} J_{\mathrm{HH}_{\mathrm{c}}}$ & 9,3 & 9,6 & 9,8 & 10,2 & 10,5 & 11,0 & 11,6 & 12,4 & 13,6 & 15,3 & 18,0 & 11,3 \\
\hline $\mathrm{C}_{2} \mathrm{H}_{4}$ & ${ }^{3} J_{\mathrm{HH}_{\mathrm{t}}}$ & 13,3 & 13,8 & 14,3 & 14,9 & 15,6 & 16,4 & 17,4 & 18,6 & 20,2 & 22,5 & 25,9 & 18,3 \\
\hline $\mathrm{C}_{2} \mathrm{H}_{6}$ & ${ }^{1} J_{\mathrm{CC}}$ & 25,4 & 27,6 & 30,0 & 32,4 & 35,1 & 37,8 & 40,8 & 43,9 & 47,2 & 50,7 & 54,4 & 33,6 \\
\hline $\mathrm{C}_{2} \mathrm{H}_{6}$ & ${ }^{1} J_{\mathrm{CH}}$ & 101,2 & 104,7 & 108,4 & 112,3 & 116,5 & 120,9 & 125,5 & 130,4 & 135,6 & 141,2 & 147,0 & 123,4 \\
\hline $\mathrm{C}_{2} \mathrm{H}_{6}$ & ${ }^{2} J_{\mathrm{CH}}$ & $-0,6$ & $-1,1$ & $-1,7$ & $-2,2$ & $-2,8$ & $-3,5$ & $-4,2$ & $-4,9$ & $-5,7$ & $-6,6$ & $-7,5$ & $-4,5$ \\
\hline \multirow[t]{3}{*}{ Total } & $\mathrm{DM}$ & $-16,72$ & $-14,80$ & $-12,62$ & $-10,18$ & $-7,56$ & $-4,84$ & $-2,12$ & 0,30 & 1,92 & 1,09 & $-10,60$ & - \\
\hline & DMA & 28,77 & 24,28 & 19,58 & 14,95 & 12,57 & 12,04 & 14,67 & 20,71 & 28,61 & 41,48 & 67,87 & - \\
\hline & PDMA & 58,55 & 48,97 & 39,00 & 28,68 & 18,78 & 15,86 & 22,27 & 35,75 & 56,50 & 83,63 & 123,52 & - \\
\hline \multirow[t]{3}{*}{ CPI } & $\mathrm{DM}$ & $-30,11$ & $-27,97$ & $-25,32$ & $-22,26$ & $-18,98$ & $-15,71$ & $-12,77$ & $-10,90$ & $-11,52$ & $-18,71$ & $-52,85$ & - \\
\hline & DMA & 52,75 & 44,08 & 34,61 & 25,28 & 21,11 & 21,15 & 26,43 & 36,32 & 49,28 & 72,31 & 125,05 & - \\
\hline & PDMA & 70,93 & 57,04 & 42,92 & 28,74 & 16,39 & 19,60 & 30,80 & 45,84 & 65,35 & 87,81 & 120,38 & - \\
\hline \multirow[t]{3}{*}{ SPI } & $\mathrm{DM}$ & $-6,90$ & $-5,14$ & $-3,30$ & $-1,31$ & 0,82 & 3,13 & 5,69 & 8,52 & 11,77 & 15,61 & 20,38 & - \\
\hline & DMA & 11,19 & 9,77 & 8,55 & 7,38 & 6,30 & 5,37 & 6,05 & 9,27 & 13,45 & 18,87 & 25,94 & - \\
\hline & PDMA & 49,48 & 43,05 & 36,12 & 28,63 & 20,53 & 13,12 & 16,02 & 28,36 & 50,00 & 80,56 & 125,83 & - \\
\hline \multirow[t]{3}{*}{$\Delta \mathrm{CS}$} & $\mathrm{DM}$ & $-23,21$ & $-22,83$ & $-22,02$ & $-20,95$ & $-19,80$ & $-18,84$ & $-18,47$ & $-19,42$ & $-23,29$ & $-34,32$ & $-73,23$ & - \\
\hline & DMA & 41,55 & 34,32 & 26,06 & 17,90 & 14,81 & 15,78 & 20,37 & 27,05 & 35,83 & 53,44 & 99,11 & - \\
\hline & PDMA & 21,46 & 13,98 & 6,80 & 0,11 & $-4,14$ & 6,48 & 14,78 & 17,48 & 15,35 & 7,24 & $-5,45$ & - \\
\hline
\end{tabular}


Tabela 8.157: Constantes de acoplamento B972 e constantes empíricas no nível PBE0 $40 \% E_{X}^{\mathrm{HF}}$ e base aug-pcJ-2.

\begin{tabular}{|c|c|c|c|c|c|c|c|c|c|c|c|c|c|}
\hline & $\% E_{X}^{\mathrm{HF}}$ & $0 \%$ & $10 \%$ & $20 \%$ & $30 \%$ & $40 \%$ & $50 \%$ & $60 \%$ & $70 \%$ & $80 \%$ & $90 \%$ & $100 \%$ & Emp. \\
\hline $\mathrm{HF}$ & ${ }^{1} J_{\mathrm{HF}}$ & 420,6 & 441,5 & 463,7 & 487,2 & 512,0 & 538,2 & 565,8 & 595,0 & 625,6 & 657,8 & 691,6 & 534,8 \\
\hline $\mathrm{CO}$ & ${ }^{1} J_{\mathrm{CO}}$ & 16,9 & 15,3 & 13,5 & 11,5 & 9,2 & 6,8 & 4,2 & 1,4 & $-1,6$ & $-4,8$ & $-8,3$ & 15,7 \\
\hline $\mathrm{H}_{2} \mathrm{O}$ & ${ }^{1} J_{\mathrm{OH}}$ & $-66,8$ & $-69,6$ & $-72,5$ & $-75,6$ & $-78,9$ & $-82,3$ & $-86,0$ & $-90,0$ & $-94,1$ & $-98,5$ & $-103,1$ & $-82,0$ \\
\hline $\mathrm{H}_{2} \mathrm{O}$ & ${ }^{2} J_{\mathrm{HH}}$ & $-1,2$ & $-2,2$ & $-3,2$ & $-4,3$ & $-5,5$ & $-6,7$ & $-8,0$ & $-9,5$ & $-11,0$ & $-12,6$ & $-14,3$ & $-8,8$ \\
\hline $\mathrm{NH}_{3}$ & ${ }^{1} J_{\mathrm{NH}}$ & 36,3 & 37,5 & 38,9 & 40,3 & 41,8 & 43,4 & 45,1 & 47,0 & 48,9 & 50,9 & 53,1 & 43,3 \\
\hline $\mathrm{NH}_{3}$ & ${ }^{2} J_{\mathrm{HH}}$ & $-3,3$ & $-4,2$ & $-5,1$ & $-6,0$ & $-7,1$ & $-8,2$ & $-9,4$ & $-10,7$ & $-12,1$ & $-13,6$ & $-15,2$ & $-10,4$ \\
\hline $\mathrm{PH}_{3}$ & ${ }^{1} J_{\mathrm{PH}}$ & 152,4 & 159,5 & 167,0 & 175,0 & 183,4 & 192,2 & 201,4 & 211,1 & 221,2 & 231,6 & 242,5 & 195,7 \\
\hline $\mathrm{PF}_{3}$ & ${ }^{1} J_{\mathrm{PF}}$ & $-1626,4$ & $-1621,0$ & $-1610,4$ & $-1595,3$ & $-1576,6$ & $-1555,0$ & $-1531,2$ & $-1505,7$ & $-1479,1$ & $-1452,1$ & $-1424,9$ & $-1.443,2$ \\
\hline $\mathrm{BHF}_{2}$ & ${ }^{1} J_{\mathrm{BF}}$ & $-151,4$ & $-134,7$ & $-117,6$ & $-100,3$ & $-82,9$ & $-65,4$ & $-48,0$ & $-30,7$ & $-13,4$ & 3,5 & 20,3 & $-79,6$ \\
\hline $\mathrm{BF}_{3}$ & ${ }^{1} J_{\mathrm{BF}}$ & $-64,0$ & $-44,6$ & $-25,1$ & $-5,4$ & 14,1 & 33,8 & 53,5 & 73,1 & 92,7 & 112,2 & 131,6 & 17,2 \\
\hline $\mathrm{F}_{2} \mathrm{O}$ & ${ }^{1} J_{\mathrm{OF}}$ & $-187,3$ & $-217,9$ & $-249,8$ & $-283,7$ & $-320,6$ & $-362,5$ & $-412,9$ & $-478,9$ & $-577,4$ & $-761,7$ & $-1349,0$ & $-284,7$ \\
\hline $\mathrm{CH}_{4}$ & ${ }^{1} J_{\mathrm{CH}}$ & 94,6 & 98,6 & 102,8 & 107,2 & 111,9 & 116,9 & 122,2 & 127,8 & 133,7 & 139,9 & 146,5 & 122,9 \\
\hline $\mathrm{CH}_{4}$ & ${ }^{2} J_{\mathrm{HH}}$ & $-5,4$ & $-6,1$ & $-6,9$ & $-7,8$ & $-8,7$ & $-9,7$ & $-10,7$ & $-11,9$ & $-13,0$ & $-14,3$ & $-15,6$ & $-12,5$ \\
\hline $\mathrm{C}_{2} \mathrm{H}_{2}$ & ${ }^{1} J_{\mathrm{CC}}$ & 172,7 & 177,5 & 182,8 & 188,8 & 195,6 & 203,4 & 212,5 & 223,4 & 236,6 & 253,1 & 274,3 & 173,9 \\
\hline $\mathrm{C}_{2} \mathrm{H}_{2}$ & ${ }^{1} J_{\mathrm{CH}}$ & 189,9 & 197,4 & 205,4 & 213,7 & 222,6 & 232,0 & 242,2 & 253,1 & 265,2 & 278,6 & 294,1 & 244,4 \\
\hline $\mathrm{C}_{2} \mathrm{H}_{2}$ & ${ }^{2} J_{\mathrm{CH}}$ & 49,1 & 50,0 & 50,8 & 51,4 & 51,8 & 51,9 & 51,5 & 50,6 & 48,9 & 46,1 & 41,6 & 49,9 \\
\hline $\mathrm{C}_{2} \mathrm{H}_{2}$ & ${ }^{3} J_{\mathrm{HH}}$ & 6,1 & 6,5 & 6,9 & 7,4 & 8,1 & 8,9 & 9,9 & 11,2 & 12,9 & 15,1 & 18,0 & 8,9 \\
\hline $\mathrm{C}_{2} \mathrm{H}_{4}$ & ${ }^{1} J_{\mathrm{CC}}$ & 54,6 & 58,0 & 61,7 & 66,0 & 70,8 & 76,3 & 82,9 & 91,0 & 101,4 & 115,7 & 137,0 & 66,6 \\
\hline $\mathrm{C}_{2} \mathrm{H}_{4}$ & ${ }^{1} J_{\mathrm{CH}}$ & 117,8 & 122,9 & 128,4 & 134,1 & 140,3 & 146,9 & 154,1 & 161,9 & 170,8 & 181,1 & 194,0 & 154,3 \\
\hline $\mathrm{C}_{2} \mathrm{H}_{4}$ & ${ }^{2} J_{\mathrm{CH}}$ & 2,6 & 2,0 & 1,3 & 0,5 & $-0,4$ & $-1,7$ & $-3,2$ & $-5,2$ & $-8,0$ & $-11,9$ & $-18,1$ & $-1,9$ \\
\hline $\mathrm{C}_{2} \mathrm{H}_{4}$ & ${ }^{2} J_{\mathrm{HH}}$ & 5,6 & 5,4 & 5,1 & 4,7 & 4,2 & 3,7 & 3,0 & 2,2 & 1,1 & $-0,5$ & $-2,9$ & 2,1 \\
\hline $\mathrm{C}_{2} \mathrm{H}_{4}$ & ${ }^{3} J_{\mathrm{HH}_{\mathrm{c}}}$ & 8,9 & 9,1 & 9,4 & 9,7 & 10,1 & 10,6 & 11,1 & 11,8 & 12,8 & 14,3 & 16,6 & 11,3 \\
\hline $\mathrm{C}_{2} \mathrm{H}_{4}$ & ${ }^{3} J_{\mathrm{HH}_{\mathrm{t}}}$ & 12,8 & 13,3 & 13,8 & 14,4 & 15,1 & 15,9 & 16,8 & 17,9 & 19,4 & 21,4 & 24,4 & 18,3 \\
\hline $\mathrm{C}_{2} \mathrm{H}_{6}$ & ${ }^{1} J_{\mathrm{CC}}$ & 21,9 & 24,5 & 27,3 & 30,2 & 33,3 & 36,6 & 40,1 & 43,8 & 47,8 & 52,0 & 56,4 & 33,6 \\
\hline $\mathrm{C}_{2} \mathrm{H}_{6}$ & ${ }^{1} J_{\mathrm{CH}}$ & 93,2 & 97,4 & 101,8 & 106,4 & 111,4 & 116,6 & 122,1 & 127,9 & 134,1 & 140,6 & 147,5 & 123,4 \\
\hline $\mathrm{C}_{2} \mathrm{H}_{6}$ & ${ }^{2} J_{\mathrm{CH}}$ & $-0,5$ & $-0,9$ & $-1,4$ & $-1,9$ & $-2,4$ & $-3,0$ & $-3,6$ & $-4,2$ & $-4,9$ & $-5,7$ & $-6,5$ & $-4,5$ \\
\hline \multirow[t]{3}{*}{ Total } & $\mathrm{DM}$ & $-20,73$ & $-18,21$ & $-15,39$ & $-12,33$ & $-9,08$ & $-5,73$ & $-2,43$ & 0,57 & 2,68 & 1,90 & $-13,73$ & - \\
\hline & DMA & 32,08 & 26,90 & 21,54 & 15,79 & 12,70 & 12,57 & 15,96 & 22,39 & 31,22 & 44,16 & 75,06 & - \\
\hline & PDMA & 62,70 & 52,15 & 41,70 & 30,59 & 20,22 & 18,49 & 25,01 & 35,91 & 55,83 & 82,83 & 123,23 & - \\
\hline \multirow[t]{3}{*}{ CPI } & $\mathrm{DM}$ & $-33,84$ & $-30,76$ & $-27,15$ & $-23,15$ & $-19,01$ & $-14,88$ & $-11,23$ & $-8,72$ & $-8,94$ & $-16,85$ & $-61,25$ & - \\
\hline & DMA & 57,20 & 47,49 & 37,20 & 26,11 & 20,77 & 21,90 & 30,90 & 42,19 & 56,86 & 79,50 & 142,34 & - \\
\hline & PDMA & 77,24 & 60,54 & 45,08 & 29,34 & 15,68 & 23,10 & 37,42 & 54,39 & 76,06 & 100,77 & 138,99 & - \\
\hline \multirow[t]{3}{*}{ SPI } & DM & $-11,12$ & $-9,01$ & $-6,77$ & $-4,39$ & $-1,80$ & 0,97 & 4,01 & 7,37 & 11,21 & 15,65 & 21,11 & - \\
\hline & DMA & 13,67 & 11,79 & 10,06 & 8,22 & 6,77 & 5,73 & 5,00 & 7,87 & 12,41 & 18,24 & 25,72 & - \\
\hline & PDMA & 52,04 & 46,00 & 39,23 & 31,51 & 23,55 & 15,10 & 15,92 & 22,36 & 41,00 & 69,67 & 111,68 & - \\
\hline \multirow[t]{3}{*}{$\Delta \mathrm{CS}$} & DM & $-22,72$ & $-21,76$ & $-20,38$ & $-18,75$ & $-17,21$ & $-15,86$ & $-15,24$ & $-16,09$ & $-20,14$ & $-32,50$ & $-82,35$ & - \\
\hline & DMA & 43,53 & 35,70 & 27,14 & 17,89 & 14,00 & 16,17 & 25,90 & 34,32 & 44,46 & 61,26 & 116,62 & - \\
\hline & PDMA & 25,21 & 14,54 & 5,84 & $-2,17$ & $-7,87$ & 8,01 & 21,50 & 32,04 & 35,06 & 31,09 & 27,31 & - \\
\hline
\end{tabular}


Tabela 8.158: Constantes de acoplamento B98 e constantes empíricas no nível PBE0 40\% $E_{X}^{\mathrm{HF}}$ e base aug-pcJ-2.

\begin{tabular}{|c|c|c|c|c|c|c|c|c|c|c|c|c|c|}
\hline & $\% E_{X}^{\mathrm{HF}}$ & $0 \%$ & $10 \%$ & $20 \%$ & $30 \%$ & $40 \%$ & $50 \%$ & $60 \%$ & $70 \%$ & $80 \%$ & $90 \%$ & $100 \%$ & Emp. \\
\hline $\mathrm{HF}$ & ${ }^{1} J_{\mathrm{HF}}$ & 411,6 & 428,1 & 445,8 & 464,6 & 484,6 & 505,9 & 528,5 & 552,5 & 577,9 & 604,8 & 633,1 & 534,8 \\
\hline $\mathrm{CO}$ & ${ }^{1} J_{\mathrm{CO}}$ & 16,6 & 15,5 & 14,2 & 12,8 & 11,2 & 9,5 & 7,7 & 5,6 & 3,4 & 1,0 & $-1,4$ & 15,7 \\
\hline $\mathrm{H}_{2} \mathrm{O}$ & ${ }^{1} J_{\mathrm{OH}}$ & $-66,0$ & $-68,2$ & $-70,5$ & $-73,0$ & $-75,6$ & $-78,4$ & $-81,4$ & $-84,6$ & $-88,1$ & $-91,7$ & $-95,6$ & $-82,0$ \\
\hline $\mathrm{H}_{2} \mathrm{O}$ & ${ }^{2} J_{\mathrm{HH}}$ & $-0,7$ & $-1,7$ & $-2,7$ & $-3,9$ & $-5,1$ & $-6,4$ & $-7,9$ & $-9,4$ & $-11,0$ & $-12,7$ & $-14,6$ & $-8,8$ \\
\hline $\mathrm{NH}_{3}$ & ${ }^{1} J_{\mathrm{NH}}$ & 37,0 & 38,1 & 39,2 & 40,4 & 41,7 & 43,1 & 44,6 & 46,1 & 47,8 & 49,6 & 51,5 & 43,3 \\
\hline $\mathrm{NH}_{3}$ & ${ }^{2} J_{\mathrm{HH}}$ & $-3,5$ & $-4,4$ & $-5,4$ & $-6,4$ & $-7,6$ & $-8,8$ & $-10,2$ & $-11,6$ & $-13,2$ & $-14,9$ & $-16,8$ & $-10,4$ \\
\hline $\mathrm{PH}_{3}$ & ${ }^{1} J_{\mathrm{PH}}$ & 165,9 & 172,2 & 179,0 & 186,1 & 193,7 & 201,7 & 210,1 & 218,9 & 228,1 & 237,8 & 247,9 & 195,7 \\
\hline $\mathrm{PF}_{3}$ & ${ }^{1} J_{\mathrm{PF}}$ & $-1622,6$ & $-1617,6$ & $-1607,1$ & $-1591,6$ & $-1572,1$ & $-1549,1$ & $-1523,4$ & $-1495,6$ & $-1466,2$ & $-1435,7$ & $-1404,5$ & $-1.443,2$ \\
\hline $\mathrm{BHF}_{2}$ & ${ }^{1} J_{\mathrm{BF}}$ & $-150,1$ & $-135,5$ & $-120,6$ & $-105,2$ & $-89,6$ & $-73,8$ & $-57,8$ & $-41,8$ & $-25,7$ & $-9,6$ & 6,2 & $-79,6$ \\
\hline $\mathrm{BF}_{3}$ & ${ }^{1} J_{\mathrm{BF}}$ & $-61,5$ & $-44,7$ & $-27,7$ & $-10,4$ & 7,0 & 24,5 & 42,2 & 60,0 & 77,9 & 95,8 & 113,8 & 17,2 \\
\hline $\mathrm{F}_{2} \mathrm{O}$ & ${ }^{1} J_{\mathrm{OF}}$ & $-196,5$ & $-228,9$ & $-262,8$ & $-298,9$ & $-338,2$ & $-383,0$ & $-437,3$ & $-509,0$ & $-617,4$ & $-823,5$ & $-1507,1$ & $-284,7$ \\
\hline $\mathrm{CH}_{4}$ & ${ }^{1} J_{\mathrm{CH}}$ & 101,1 & 104,7 & 108,5 & 112,6 & 116,9 & 121,5 & 126,5 & 131,7 & 137,3 & 143,2 & 149,5 & 122,9 \\
\hline $\mathrm{CH}_{4}$ & ${ }^{2} J_{\mathrm{HH}}$ & $-5,9$ & $-6,8$ & $-7,7$ & $-8,7$ & $-9,8$ & $-11,0$ & $-12,2$ & $-13,5$ & $-15,0$ & $-16,5$ & $-18,1$ & $-12,5$ \\
\hline $\mathrm{C}_{2} \mathrm{H}_{2}$ & ${ }^{1} J_{\mathrm{CC}}$ & 184,5 & 188,8 & 193,5 & 198,9 & 205,0 & 212,2 & 220,6 & 230,9 & 243,6 & 260,0 & 282,1 & 173,9 \\
\hline $\mathrm{C}_{2} \mathrm{H}_{2}$ & ${ }^{1} J_{\mathrm{CH}}$ & 198,0 & 205,3 & 212,9 & 221,1 & 229,7 & 239,0 & 249,0 & 260,0 & 272,3 & 286,5 & 303,3 & 244,4 \\
\hline $\mathrm{C}_{2} \mathrm{H}_{2}$ & ${ }^{2} J_{\mathrm{CH}}$ & 50,6 & 51,5 & 52,3 & 52,9 & 53,2 & 53,2 & 52,6 & 51,4 & 49,2 & 45,4 & 39,3 & 49,9 \\
\hline $\mathrm{C}_{2} \mathrm{H}_{2}$ & ${ }^{3} J_{\mathrm{HH}}$ & 6,1 & 6,5 & 7,0 & 7,6 & 8,4 & 9,4 & 10,6 & 12,3 & 14,5 & 17,5 & 21,7 & 8,9 \\
\hline $\mathrm{C}_{2} \mathrm{H}_{4}$ & ${ }^{1} J_{\mathrm{CC}}$ & 62,2 & 65,2 & 68,5 & 72,2 & 76,4 & 81,3 & 87,2 & 94,5 & 104,0 & 117,4 & 138,3 & 66,6 \\
\hline $\mathrm{C}_{2} \mathrm{H}_{4}$ & ${ }^{1} J_{\mathrm{CH}}$ & 124,4 & 129,2 & 134,3 & 139,8 & 145,7 & 152,0 & 158,9 & 166,6 & 175,4 & 185,9 & 199,6 & 154,3 \\
\hline $\mathrm{C}_{2} \mathrm{H}_{4}$ & ${ }^{2} J_{\mathrm{CH}}$ & 2,5 & 1,8 & 1,0 & 0,1 & $-0,8$ & $-2,1$ & $-3,8$ & $-6,0$ & $-9,0$ & $-13,5$ & $-20,9$ & $-1,9$ \\
\hline $\mathrm{C}_{2} \mathrm{H}_{4}$ & ${ }^{2} J_{\mathrm{HH}}$ & 5,7 & 5,4 & 5,0 & 4,5 & 3,9 & 3,2 & 2,3 & 1,2 & $-0,3$ & $-2,5$ & $-6,2$ & 2,1 \\
\hline $\mathrm{C}_{2} \mathrm{H}_{4}$ & ${ }^{3} J_{\mathrm{HH}_{\mathrm{c}}}$ & 9,3 & 9,5 & 9,8 & 10,2 & 10,6 & 11,1 & 11,8 & 12,7 & 13,9 & 15,9 & 19,2 & 11,3 \\
\hline $\mathrm{C}_{2} \mathrm{H}_{4}$ & ${ }^{3} J_{\mathrm{HH}_{\mathrm{t}}}$ & 13,1 & 13,6 & 14,2 & 14,9 & 15,6 & 16,5 & 17,6 & 18,9 & 20,8 & 23,3 & 27,5 & 18,3 \\
\hline $\mathrm{C}_{2} \mathrm{H}_{6}$ & ${ }^{1} J_{\mathrm{CC}}$ & 24,5 & 26,9 & 29,5 & 32,2 & 35,1 & 38,2 & 41,5 & 45,0 & 48,8 & 52,8 & 57,1 & 33,6 \\
\hline $\mathrm{C}_{2} \mathrm{H}_{6}$ & ${ }^{1} J_{\mathrm{CH}}$ & 99,8 & 103,7 & 107,8 & 112,1 & 116,8 & 121,7 & 127,0 & 132,5 & 138,4 & 144,7 & 151,4 & 123,4 \\
\hline $\mathrm{C}_{2} \mathrm{H}_{6}$ & ${ }^{2} J_{\mathrm{CH}}$ & $-0,7$ & $-1,2$ & $-1,7$ & $-2,3$ & $-2,9$ & $-3,6$ & $-4,3$ & $-5,1$ & $-5,9$ & $-6,9$ & $-7,9$ & $-4,5$ \\
\hline \multirow[t]{3}{*}{ Total } & $\mathrm{DM}$ & $-18,59$ & $-16,60$ & $-14,32$ & $-11,77$ & $-9,03$ & $-6,19$ & $-3,40$ & $-0,94$ & 0,49 & $-1,33$ & $-20,78$ & - \\
\hline & DMA & 30,11 & 25,47 & 20,62 & 16,53 & 14,10 & 13,23 & 15,81 & 21,97 & 30,74 & 44,72 & 80,16 & - \\
\hline & PDMA & 60,01 & 49,94 & 39,88 & 29,52 & 19,69 & 14,22 & 21,09 & 36,95 & 59,32 & 89,23 & 136,80 & - \\
\hline \multirow[t]{3}{*}{ CPI } & $\mathrm{DM}$ & $-33,44$ & $-31,37$ & $-28,78$ & $-25,77$ & $-22,55$ & $-19,35$ & $-16,63$ & $-15,17$ & $-16,77$ & $-27,01$ & $-80,50$ & - \\
\hline & DMA & 55,27 & 46,41 & 36,87 & 29,03 & 24,89 & 24,20 & 28,30 & 37,77 & 52,15 & 76,92 & 149,55 & - \\
\hline & PDMA & 75,09 & 60,20 & 46,11 & 32,38 & 19,92 & 17,01 & 27,93 & 44,20 & 64,71 & 88,81 & 128,95 & - \\
\hline \multirow[t]{3}{*}{ SPI } & $\mathrm{DM}$ & $-7,70$ & $-5,77$ & $-3,72$ & $-1,51$ & 0,87 & 3,46 & 6,31 & 9,49 & 13,15 & 17,50 & 23,01 & - \\
\hline & DMA & 11,66 & 10,11 & 8,69 & 7,37 & 6,18 & 5,19 & 6,65 & 10,37 & 15,03 & 21,11 & 29,27 & - \\
\hline & PDMA & 48,95 & 42,42 & 35,31 & 27,41 & 19,52 & 12,18 & 16,08 & 31,62 & 55,37 & 89,53 & 142,56 & - \\
\hline \multirow[t]{3}{*}{$\Delta \mathrm{CS}$} & $\mathrm{DM}$ & $-25,74$ & $-25,60$ & $-25,06$ & $-24,27$ & $-23,42$ & $-22,81$ & $-22,93$ & $-24,67$ & $-29,93$ & $-44,51$ & $-103,51$ & - \\
\hline & DMA & 43,61 & 36,30 & 28,18 & 21,65 & 18,71 & 19,01 & 21,65 & 27,40 & 37,12 & 55,80 & 120,29 & - \\
\hline & PDMA & 26,14 & 17,79 & 10,80 & 4,97 & 0,40 & 4,82 & 11,86 & 12,58 & 9,34 & $-0,73$ & $-13,62$ & - \\
\hline
\end{tabular}


Tabela 8.159: Constantes de acoplamento BHandH e constantes empíricas no nível PBE0 $40 \% E_{X}^{\mathrm{HF}}$ e base aug-pcJ-2.

\begin{tabular}{|c|c|c|c|c|c|c|c|c|c|c|c|c|c|}
\hline & $\% E_{X}^{\mathrm{HF}}$ & $0 \%$ & $10 \%$ & $20 \%$ & $30 \%$ & $40 \%$ & $50 \%$ & $60 \%$ & $70 \%$ & $80 \%$ & $90 \%$ & $100 \%$ & Emp. \\
\hline $\mathrm{HF}$ & ${ }^{1} J_{\mathrm{HF}}$ & 420,6 & 441,1 & 462,4 & 484,4 & 507,2 & 530,8 & 555,3 & 580,6 & 606,9 & 634,2 & 662,5 & 534,8 \\
\hline $\mathrm{CO}$ & ${ }^{1} J_{\mathrm{CO}}$ & 24,8 & 22,9 & 20,9 & 18,7 & 16,3 & 13,7 & 11,0 & 8,0 & 4,9 & 1,6 & $-1,9$ & 15,7 \\
\hline $\mathrm{H}_{2} \mathrm{O}$ & ${ }^{1} J_{\mathrm{OH}}$ & $-69,9$ & $-72,4$ & $-75,1$ & $-77,8$ & $-80,7$ & $-83,7$ & $-86,9$ & $-90,2$ & $-93,7$ & $-97,3$ & $-101,1$ & $-82,0$ \\
\hline $\mathrm{H}_{2} \mathrm{O}$ & ${ }^{2} J_{\mathrm{HH}}$ & $-3,3$ & $-4,4$ & $-5,5$ & $-6,8$ & $-8,0$ & $-9,4$ & $-10,8$ & $-12,3$ & $-13,9$ & $-15,6$ & $-17,3$ & $-8,8$ \\
\hline $\mathrm{NH}_{3}$ & ${ }^{1} J_{\mathrm{NH}}$ & 39,4 & 40,5 & 41,7 & 42,9 & 44,2 & 45,5 & 47,0 & 48,5 & 50,0 & 51,7 & 53,4 & 43,3 \\
\hline $\mathrm{NH}_{3}$ & ${ }^{2} J_{\mathrm{HH}}$ & $-5,4$ & $-6,5$ & $-7,5$ & $-8,7$ & $-9,9$ & $-11,1$ & $-12,5$ & $-13,9$ & $-15,4$ & $-17,0$ & $-18,7$ & $-10,4$ \\
\hline $\mathrm{PH}_{3}$ & ${ }^{1} J_{\mathrm{PH}}$ & 135,5 & 144,3 & 153,5 & 163,0 & 172,9 & 183,1 & 193,7 & 204,6 & 215,9 & 227,4 & 239,2 & 195,7 \\
\hline $\mathrm{PF}_{3}$ & ${ }^{1} J_{\mathrm{PF}}$ & $-1814,4$ & $-1797,1$ & $-1773,1$ & $-1743,5$ & $-1709,0$ & $-1670,4$ & $-1628,3$ & $-1583,4$ & $-1536,2$ & $-1487,3$ & $-1437,0$ & $-1.443,2$ \\
\hline $\mathrm{BHF}_{2}$ & ${ }^{1} J_{\mathrm{BF}}$ & $-187,4$ & $-169,5$ & $-151,2$ & $-132,8$ & $-114,0$ & $-95,2$ & $-76,1$ & $-57,0$ & $-37,8$ & $-18,6$ & 0,6 & $-79,6$ \\
\hline $\mathrm{BF}_{3}$ & ${ }^{1} J_{\mathrm{BF}}$ & $-79,8$ & $-61,1$ & $-42,3$ & $-23,3$ & $-4,1$ & 15,1 & 34,6 & 54,2 & 73,9 & 93,8 & 113,8 & 17,2 \\
\hline $\mathrm{F}_{2} \mathrm{O}$ & ${ }^{1} J_{\mathrm{OF}}$ & $-272,1$ & $-308,2$ & $-344,0$ & $-380,5$ & $-419,8$ & $-465,0$ & $-521,4$ & $-600,0$ & $-727,9$ & $-1000,8$ & $-2253,8$ & $-284,7$ \\
\hline $\mathrm{CH}_{4}$ & ${ }^{1} J_{\mathrm{CH}}$ & 106,0 & 109,4 & 113,0 & 116,8 & 120,7 & 124,9 & 129,4 & 134,0 & 138,9 & 144,0 & 149,4 & 122,9 \\
\hline $\mathrm{CH}_{4}$ & ${ }^{2} J_{\mathrm{HH}}$ & $-7,9$ & $-8,9$ & $-9,9$ & $-11,0$ & $-12,1$ & $-13,3$ & $-14,5$ & $-15,7$ & $-17,0$ & $-18,4$ & $-19,7$ & $-12,5$ \\
\hline $\mathrm{C}_{2} \mathrm{H}_{2}$ & ${ }^{1} J_{\mathrm{CC}}$ & 175,5 & 179,6 & 184,2 & 189,4 & 195,4 & 202,4 & 210,6 & 220,6 & 232,8 & 248,3 & 268,4 & 173,9 \\
\hline $\mathrm{C}_{2} \mathrm{H}_{2}$ & ${ }^{1} J_{\mathrm{CH}}$ & 226,4 & 232,3 & 238,4 & 245,0 & 252,0 & 259,5 & 267,8 & 276,9 & 287,3 & 299,2 & 313,5 & 244,4 \\
\hline $\mathrm{C}_{2} \mathrm{H}_{2}$ & ${ }^{2} J_{\mathrm{CH}}$ & 51,2 & 52,1 & 52,7 & 53,2 & 53,3 & 53,0 & 52,2 & 50,7 & 48,2 & 44,2 & 38,1 & 49,9 \\
\hline $\mathrm{C}_{2} \mathrm{H}_{2}$ & ${ }^{3} J_{\mathrm{HH}}$ & 7,2 & 7,8 & 8,5 & 9,4 & 10,5 & 11,8 & 13,4 & 15,5 & 18,1 & 21,5 & 26,0 & 8,9 \\
\hline $\mathrm{C}_{2} \mathrm{H}_{4}$ & ${ }^{1} J_{\mathrm{CC}}$ & 50,4 & 53,8 & 57,6 & 61,8 & 66,7 & 72,3 & 78,9 & 87,3 & 98,2 & 113,8 & 139,0 & 66,6 \\
\hline $\mathrm{C}_{2} \mathrm{H}_{4}$ & ${ }^{1} J_{\mathrm{CH}}$ & 136,2 & 140,5 & 145,0 & 149,9 & 155,0 & 160,6 & 166,8 & 173,7 & 181,8 & 191,8 & 205,7 & 154,3 \\
\hline $\mathrm{C}_{2} \mathrm{H}_{4}$ & ${ }^{2} J_{\mathrm{CH}}$ & 0,9 & 0,2 & $-0,4$ & $-1,3$ & $-2,4$ & $-3,8$ & $-5,6$ & $-8,0$ & $-11,4$ & $-16,5$ & $-25,4$ & $-1,9$ \\
\hline $\mathrm{C}_{2} \mathrm{H}_{4}$ & ${ }^{2} J_{\mathrm{HH}}$ & 5,5 & 5,0 & 4,4 & 3,8 & 3,1 & 2,2 & 1,1 & $-0,1$ & $-2,0$ & $-4,7$ & $-9,3$ & 2,1 \\
\hline $\mathrm{C}_{2} \mathrm{H}_{4}$ & ${ }^{3} J_{\mathrm{HH}_{\mathrm{c}}}$ & 11,2 & 11,5 & 11,8 & 12,2 & 12,7 & 13,3 & 14,1 & 15,2 & 16,8 & 19,3 & 23,7 & 11,3 \\
\hline $\mathrm{C}_{2} \mathrm{H}_{4}$ & ${ }^{3} J_{\mathrm{HH}_{\mathrm{t}}}$ & 16,3 & 16,7 & 17,3 & 17,9 & 18,7 & 19,6 & 20,8 & 22,4 & 24,5 & 27,6 & 32,9 & 18,3 \\
\hline $\mathrm{C}_{2} \mathrm{H}_{6}$ & ${ }^{1} J_{\mathrm{CC}}$ & 18,7 & 21,3 & 24,0 & 26,9 & 30,0 & 33,3 & 36,7 & 40,4 & 44,3 & 48,4 & 52,7 & 33,6 \\
\hline $\mathrm{C}_{2} \mathrm{H}_{6}$ & ${ }^{1} J_{\mathrm{CH}}$ & 106,1 & 109,7 & 113,4 & 117,3 & 121,5 & 125,8 & 130,4 & 135,2 & 140,2 & 145,4 & 150,9 & 123,4 \\
\hline $\mathrm{C}_{2} \mathrm{H}_{6}$ & ${ }^{2} J_{\mathrm{CH}}$ & $-1,7$ & $-2,1$ & $-2,6$ & $-3,1$ & $-3,7$ & $-4,3$ & $-4,9$ & $-5,6$ & $-6,3$ & $-7,0$ & $-7,8$ & $-4,5$ \\
\hline \multirow[t]{3}{*}{ Total } & $\mathrm{DM}$ & $-30,72$ & $-28,08$ & $-25,06$ & $-21,73$ & $-18,16$ & $-14,54$ & $-11,00$ & $-7,97$ & $-6,45$ & $-9,99$ & $-50,42$ & - \\
\hline & DMA & 35,40 & 31,48 & 28,15 & 24,57 & 21,47 & 20,06 & 23,20 & 29,80 & 38,97 & 54,51 & 109,57 & - \\
\hline & PDMA & 58,93 & 48,05 & 37,29 & 25,93 & 16,75 & 14,25 & 28,16 & 48,18 & 73,40 & 107,27 & 168,34 & - \\
\hline \multirow[t]{3}{*}{ CPI } & $\mathrm{DM}$ & $-64,55$ & $-60,76$ & $-56,20$ & $-51,13$ & $-45,72$ & $-40,42$ & $-35,67$ & $-32,63$ & $-33,75$ & $-47,81$ & $-150,75$ & - \\
\hline & DMA & 72,60 & 65,33 & 59,53 & 53,11 & 46,46 & 40,82 & 43,87 & 54,35 & 69,66 & 98,19 & 216,99 & - \\
\hline & PDMA & 88,54 & 72,39 & 56,84 & 40,65 & 24,65 & 13,77 & 26,71 & 47,41 & 70,24 & 98,18 & 157,79 & - \\
\hline \multirow[t]{3}{*}{ SPI } & $\mathrm{DM}$ & $-5,91$ & $-4,12$ & $-2,22$ & $-0,17$ & 2,05 & 4,44 & 7,10 & 10,12 & 13,58 & 17,75 & 23,16 & - \\
\hline & DMA & 8,11 & 6,67 & 5,14 & 3,63 & 3,14 & 4,84 & 8,05 & 11,80 & 16,46 & 22,48 & 30,79 & - \\
\hline & PDMA & 37,22 & 30,21 & 22,94 & 15,14 & 10,96 & 14,59 & 29,22 & 48,75 & 75,72 & 113,93 & 176,08 & - \\
\hline \multirow[t]{3}{*}{$\Delta \mathrm{CS}$} & $\mathrm{DM}$ & $-58,63$ & $-56,64$ & $-53,98$ & $-50,96$ & $-47,76$ & $-44,86$ & $-42,77$ & $-42,75$ & $-47,33$ & $-65,56$ & $-173,91$ & - \\
\hline & DMA & 64,49 & 58,66 & 54,39 & 49,48 & 43,32 & 35,98 & 35,83 & 42,55 & 53,20 & 75,71 & 186,20 & - \\
\hline & PDMA & 51,32 & 42,18 & 33,90 & 25,51 & 13,69 & $-0,82$ & $-2,51$ & $-1,33$ & $-5,48$ & $-15,76$ & $-18,30$ & - \\
\hline
\end{tabular}


Tabela 8.160: Constantes de acoplamento BMK e constantes empíricas no nível PBE0 $40 \% E_{X}^{\mathrm{HF}}$ e base aug-pcJ-2.

\begin{tabular}{|c|c|c|c|c|c|c|c|c|c|c|c|c|c|}
\hline & $\% E_{X}^{\mathrm{HF}}$ & $0 \%$ & $10 \%$ & $20 \%$ & $30 \%$ & $40 \%$ & $50 \%$ & $60 \%$ & $70 \%$ & $80 \%$ & $90 \%$ & $100 \%$ & Emp. \\
\hline $\mathrm{HF}$ & ${ }^{1} J_{\mathrm{HF}}$ & 491,4 & 502,8 & 515,2 & 528,7 & 543,5 & 559,7 & 577,4 & 597,0 & 618,7 & 642,5 & 669,0 & 534,8 \\
\hline $\mathrm{CO}$ & ${ }^{1} J_{\mathrm{CO}}$ & 13,8 & 14,3 & 14,6 & 14,8 & 14,8 & 14,6 & 14,1 & 13,3 & 12,0 & 10,2 & 7,7 & 15,7 \\
\hline $\mathrm{H}_{2} \mathrm{O}$ & ${ }^{1} J_{\mathrm{OH}}$ & $-72,3$ & $-72,8$ & $-73,4$ & $-74,1$ & $-74,9$ & $-75,9$ & $-77,0$ & $-78,3$ & $-79,8$ & $-81,4$ & $-83,3$ & $-82,0$ \\
\hline $\mathrm{H}_{2} \mathrm{O}$ & ${ }^{2} J_{\mathrm{HH}}$ & 2,8 & 1,8 & 0,6 & $-0,5$ & $-1,8$ & $-3,2$ & $-4,7$ & $-6,4$ & $-8,1$ & $-10,0$ & $-12,0$ & $-8,8$ \\
\hline $\mathrm{NH}_{3}$ & ${ }^{1} J_{\mathrm{NH}}$ & 36,5 & 36,6 & 36,7 & 36,8 & 37,1 & 37,4 & 37,7 & 38,2 & 38,7 & 39,3 & 40,0 & 43,3 \\
\hline $\mathrm{NH}_{3}$ & ${ }^{2} J_{\mathrm{HH}}$ & $-0,7$ & $-1,6$ & $-2,5$ & $-3,5$ & $-4,7$ & $-5,9$ & $-7,2$ & $-8,7$ & $-10,3$ & $-12,0$ & $-13,9$ & $-10,4$ \\
\hline $\mathrm{PH}_{3}$ & ${ }^{1} J_{\mathrm{PH}}$ & 125,8 & 125,4 & 125,4 & 126,0 & 127,0 & 128,5 & 130,5 & 133,0 & 136,1 & 139,7 & 144,0 & 195,7 \\
\hline $\mathrm{PF}_{3}$ & ${ }^{1} J_{\mathrm{PF}}$ & $-1529,4$ & $-1527,6$ & $-1517,9$ & $-1500,7$ & $-1476,3$ & $-1445,2$ & $-1408,2$ & $-1365,9$ & $-1319,0$ & $-1268,4$ & $-1214,4$ & $-1.443,2$ \\
\hline $\mathrm{BHF}_{2}$ & ${ }^{1} J_{\mathrm{BF}}$ & $-143,1$ & $-131,7$ & $-118,2$ & $-102,8$ & $-85,4$ & $-66,1$ & $-44,9$ & $-21,9$ & 2,7 & 29,1 & 56,9 & $-79,6$ \\
\hline $\mathrm{BF}_{3}$ & ${ }^{1} J_{\mathrm{BF}}$ & $-51,1$ & $-37,2$ & $-21,4$ & $-3,8$ & 15,4 & 36,6 & 59,4 & 84,1 & 110,4 & 138,4 & 167,9 & 17,2 \\
\hline $\mathrm{F}_{2} \mathrm{O}$ & ${ }^{1} J_{\mathrm{OF}}$ & $-147,5$ & $-173,9$ & $-201,0$ & $-228,4$ & $-256,0$ & $-284,4$ & $-314,8$ & $-349,2$ & $-392,3$ & $-454,2$ & $-567,5$ & $-284,7$ \\
\hline $\mathrm{CH}_{4}$ & ${ }^{1} J_{\mathrm{CH}}$ & 103,1 & 104,7 & 106,5 & 108,7 & 111,2 & 114,2 & 117,5 & 121,3 & 125,7 & 130,7 & 136,4 & 122,9 \\
\hline $\mathrm{CH}_{4}$ & ${ }^{2} J_{\mathrm{HH}}$ & $-3,0$ & $-4,0$ & $-5,1$ & $-6,4$ & $-7,7$ & $-9,2$ & $-10,9$ & $-12,8$ & $-14,9$ & $-17,3$ & $-20,0$ & $-12,5$ \\
\hline $\mathrm{C}_{2} \mathrm{H}_{2}$ & ${ }^{1} J_{\mathrm{CC}}$ & 244,5 & 249,2 & 254,4 & 260,5 & 267,6 & 276,3 & 287,2 & 301,5 & 321,1 & 349,5 & 394,6 & 173,9 \\
\hline $\mathrm{C}_{2} \mathrm{H}_{2}$ & ${ }^{1} J_{\mathrm{CH}}$ & 177,9 & 184,0 & 190,5 & 197,6 & 205,4 & 214,0 & 223,8 & 235,3 & 249,0 & 266,5 & 290,8 & 244,4 \\
\hline $\mathrm{C}_{2} \mathrm{H}_{2}$ & ${ }^{2} J_{\mathrm{CH}}$ & 54,4 & 55,3 & 56,0 & 56,5 & 56,6 & 56,3 & 55,2 & 53,0 & 49,0 & 41,7 & 28,3 & 49,9 \\
\hline $\mathrm{C}_{2} \mathrm{H}_{2}$ & ${ }^{3} J_{\mathrm{HH}}$ & 5,3 & 5,6 & 6,0 & 6,5 & 7,2 & 8,2 & 9,5 & 11,3 & 13,9 & 17,8 & 24,2 & 8,9 \\
\hline $\mathrm{C}_{2} \mathrm{H}_{4}$ & ${ }^{1} J_{\mathrm{CC}}$ & 89,5 & 91,0 & 92,9 & 95,3 & 98,2 & 101,8 & 106,6 & 112,8 & 121,5 & 134,4 & 155,3 & 66,6 \\
\hline $\mathrm{C}_{2} \mathrm{H}_{4}$ & ${ }^{1} J_{\mathrm{CH}}$ & 120,5 & 123,6 & 127,2 & 131,1 & 135,5 & 140,5 & 146,3 & 153,0 & 161,2 & 171,5 & 185,9 & 154,3 \\
\hline $\mathrm{C}_{2} \mathrm{H}_{4}$ & ${ }^{2} J_{\mathrm{CH}}$ & 4,5 & 3,6 & 2,6 & 1,5 & 0,1 & $-1,4$ & $-3,4$ & $-6,0$ & $-9,7$ & $-15,1$ & $-24,0$ & $-1,9$ \\
\hline $\mathrm{C}_{2} \mathrm{H}_{4}$ & ${ }^{2} J_{\mathrm{HH}}$ & 7,7 & 7,2 & 6,6 & 5,8 & 4,9 & 3,8 & 2,5 & 0,7 & $-1,4$ & $-4,6$ & $-9,6$ & 2,1 \\
\hline $\mathrm{C}_{2} \mathrm{H}_{4}$ & ${ }^{3} J_{\mathrm{HH}_{\mathrm{c}}}$ & 9,2 & 9,3 & 9,4 & 9,6 & 9,8 & 10,2 & 10,7 & 11,5 & 12,8 & 14,9 & 18,6 & 11,3 \\
\hline $\mathrm{C}_{2} \mathrm{H}_{4}$ & ${ }^{3} J_{\mathrm{HH}_{\mathrm{t}}}{ }^{\mathrm{C}}$ & 11,3 & 11,8 & 12,3 & 12,9 & 13,5 & 14,3 & 15,3 & 16,6 & 18,4 & 21,1 & 25,6 & 18,3 \\
\hline $\mathrm{C}_{2} \mathrm{H}_{6}$ & ${ }^{1} J_{\mathrm{CC}}$ & 30,1 & 31,0 & 32,1 & 33,3 & 34,8 & 36,5 & 38,5 & 40,7 & 43,3 & 46,4 & 49,9 & 33,6 \\
\hline $\mathrm{C}_{2} \mathrm{H}_{6}$ & ${ }^{1} J_{\mathrm{CH}}$ & 101,4 & 103,3 & 105,6 & 108,2 & 111,1 & 114,4 & 118,2 & 122,5 & 127,3 & 132,8 & 139,1 & 123,4 \\
\hline $\mathrm{C}_{2} \mathrm{H}_{6}$ & ${ }^{2} J_{\mathrm{CH}}$ & 0,6 & 0,0 & $-0,8$ & $-1,5$ & $-2,4$ & $-3,3$ & $-4,3$ & $-5,4$ & $-6,7$ & $-8,1$ & $-9,7$ & $-4,5$ \\
\hline \multirow[t]{3}{*}{ Total } & $\mathrm{DM}$ & $-7,90$ & $-6,81$ & $-5,17$ & $-2,95$ & $-0,16$ & 3,23 & 7,17 & 11,63 & 16,57 & 21,80 & 26,58 & - \\
\hline & DMA & 30,43 & 27,43 & 23,83 & 19,68 & 15,71 & 14,30 & 18,46 & 23,63 & 31,37 & 42,90 & 59,03 & - \\
\hline & PDMA & 73,35 & 64,38 & 54,12 & 42,69 & 29,93 & 25,87 & 29,47 & 43,38 & 65,71 & 100,25 & 151,22 & - \\
\hline \multirow[t]{3}{*}{ CPI } & DM & $-15,62$ & $-14,72$ & $-12,72$ & $-9,59$ & $-5,39$ & $-0,17$ & 5,85 & 12,47 & 19,19 & 25,02 & 26,95 & - \\
\hline & DMA & 46,20 & 40,06 & 32,65 & 24,03 & 15,79 & 13,68 & 24,48 & 36,96 & 51,10 & 68,25 & 91,27 & - \\
\hline & PDMA & 76,33 & 64,46 & 51,14 & 36,62 & 20,90 & 27,63 & 40,89 & 55,30 & 71,23 & 94,15 & 122,23 & - \\
\hline \multirow[t]{3}{*}{ SPI } & $\mathrm{DM}$ & $-2,25$ & $-1,01$ & 0,37 & 1,93 & 3,67 & 5,73 & 8,13 & 11,02 & 14,65 & 19,43 & 26,31 & - \\
\hline & DMA & 18,86 & 18,17 & 17,37 & 16,49 & 15,65 & 14,75 & 14,04 & 13,86 & 16,89 & 24,30 & 35,39 & - \\
\hline & PDMA & 71,17 & 64,32 & 56,31 & 47,15 & 36,55 & 24,58 & 21,09 & 34,64 & 61,66 & 104,72 & 172,49 & - \\
\hline \multirow[t]{3}{*}{$\Delta \mathrm{CS}$} & $\mathrm{DM}$ & $-13,37$ & $-13,71$ & $-13,08$ & $-11,52$ & $-9,06$ & $-5,90$ & $-2,29$ & 1,45 & 4,54 & 5,58 & 0,63 & - \\
\hline & DMA & 27,34 & 21,90 & 15,28 & 7,54 & 0,14 & $-1,07$ & 10,44 & 23,10 & 34,21 & 43,95 & 55,88 & - \\
\hline & PDMA & 5,15 & 0,14 & $-5,16$ & $-10,53$ & $-15,65$ & 3,05 & 19,80 & 20,66 & 9,58 & $-10,57$ & $-50,26$ & - \\
\hline
\end{tabular}


Tabela 8.161: Constantes de acoplamento BP86 e constantes empíricas no nível PBE0 $40 \% E_{X}^{\mathrm{HF}}$ e base aug-pcJ-2.

\begin{tabular}{|c|c|c|c|c|c|c|c|c|c|c|c|c|c|}
\hline & $\% E_{X}^{\mathrm{HF}}$ & $0 \%$ & $10 \%$ & $20 \%$ & $30 \%$ & $40 \%$ & $50 \%$ & $60 \%$ & $70 \%$ & $80 \%$ & $90 \%$ & $100 \%$ & Emp. \\
\hline $\mathrm{HF}$ & ${ }^{1} J_{\mathrm{HF}}$ & 355,3 & 378,9 & 402,8 & 426,9 & 451,3 & 475,8 & 500,7 & 525,7 & 551,0 & 576,5 & 602,2 & 534,8 \\
\hline $\mathrm{CO}$ & ${ }^{1} J_{\mathrm{CO}}$ & 24,9 & 23,2 & 21,5 & 19,7 & 17,7 & 15,8 & 13,7 & 11,6 & 9,4 & 7,1 & 4,8 & 15,7 \\
\hline $\mathrm{H}_{2} \mathrm{O}$ & ${ }^{1} J_{\mathrm{OH}}$ & $-64,8$ & $-67,3$ & $-69,8$ & $-72,4$ & $-75,0$ & $-77,6$ & $-80,2$ & $-82,9$ & $-85,5$ & $-88,3$ & $-91,0$ & $-82,0$ \\
\hline $\mathrm{H}_{2} \mathrm{O}$ & ${ }^{2} J_{\mathrm{HH}}$ & $-4,6$ & $-5,5$ & $-6,5$ & $-7,5$ & $-8,5$ & $-9,6$ & $-10,6$ & $-11,7$ & $-12,8$ & $-13,9$ & $-15,1$ & $-8,8$ \\
\hline $\mathrm{NH}_{3}$ & ${ }^{1} J_{\mathrm{NH}}$ & 40,0 & 40,7 & 41,5 & 42,2 & 43,0 & 43,8 & 44,6 & 45,4 & 46,2 & 47,0 & 47,8 & 43,3 \\
\hline $\mathrm{NH}_{3}$ & ${ }^{2} J_{\mathrm{HH}}$ & $-7,8$ & $-8,6$ & $-9,5$ & $-10,4$ & $-11,2$ & $-12,1$ & $-13,0$ & $-13,9$ & $-14,9$ & $-15,8$ & $-16,8$ & $-10,4$ \\
\hline $\mathrm{PH}_{3}$ & ${ }^{1} J_{\mathrm{PH}}$ & 136,9 & 144,9 & 152,8 & 160,7 & 168,4 & 176,0 & 183,5 & 190,8 & 198,1 & 205,1 & 212,1 & 195,7 \\
\hline $\mathrm{PF}_{3}$ & ${ }^{1} J_{\mathrm{PF}}$ & $-1802,5$ & $-1777,4$ & $-1747,9$ & $-1714,7$ & $-1678,5$ & $-1639,9$ & $-1599,5$ & $-1557,7$ & $-1514,9$ & $-1471,4$ & $-1427,5$ & $-1.443,2$ \\
\hline $\mathrm{BHF}_{2}$ & ${ }^{1} J_{\mathrm{BF}}$ & $-177,9$ & $-160,9$ & $-144,0$ & $-127,2$ & $-110,6$ & $-94,0$ & $-77,7$ & $-61,5$ & $-45,5$ & $-29,7$ & $-14,1$ & $-79,6$ \\
\hline $\mathrm{BF}_{3}$ & ${ }^{1} J_{\mathrm{BF}}$ & $-83,3$ & $-64,6$ & $-46,2$ & $-27,9$ & $-9,8$ & 8,0 & 25,7 & 43,3 & 60,6 & 77,8 & 94,8 & 17,2 \\
\hline $\mathrm{F}_{2} \mathrm{O}$ & ${ }^{1} J_{\mathrm{OF}}$ & $-290,1$ & $-327,4$ & $-365,0$ & $-404,4$ & $-447,8$ & $-498,7$ & $-562,6$ & $-651,0$ & $-790,4$ & $-1064,3$ & $-1973,1$ & $-284,7$ \\
\hline $\mathrm{CH}_{4}$ & ${ }^{1} J_{\mathrm{CH}}$ & 117,5 & 118,9 & 120,4 & 121,9 & 123,4 & 124,9 & 126,5 & 128,1 & 129,7 & 131,4 & 133,0 & 122,9 \\
\hline $\mathrm{CH}_{4}$ & ${ }^{2} J_{\mathrm{HH}}$ & $-11,8$ & $-12,5$ & $-13,2$ & $-13,9$ & $-14,6$ & $-15,3$ & $-16,1$ & $-16,8$ & $-17,5$ & $-18,1$ & $-18,8$ & $-12,5$ \\
\hline $\mathrm{C}_{2} \mathrm{H}_{2}$ & ${ }^{1} J_{\mathrm{CC}}$ & 187,3 & 189,9 & 193,0 & 196,5 & 200,6 & 205,4 & 211,1 & 218,0 & 226,4 & 236,9 & 250,2 & 173,9 \\
\hline $\mathrm{C}_{2} \mathrm{H}_{2}$ & ${ }^{1} J_{\mathrm{CH}}$ & 247,4 & 249,7 & 252,1 & 254,7 & 257,5 & 260,6 & 264,1 & 268,1 & 272,8 & 278,4 & 285,3 & 244,4 \\
\hline $\mathrm{C}_{2} \mathrm{H}_{2}$ & ${ }^{2} J_{\mathrm{CH}}$ & 54,6 & 54,6 & 54,4 & 53,9 & 53,1 & 51,9 & 50,3 & 48,1 & 45,2 & 41,3 & 35,9 & 49,9 \\
\hline $\mathrm{C}_{2} \mathrm{H}_{2}$ & ${ }^{3} J_{\mathrm{HH}}$ & 10,2 & 10,9 & 11,6 & 12,5 & 13,5 & 14,8 & 16,4 & 18,2 & 20,5 & 23,3 & 26,9 & 8,9 \\
\hline $\mathrm{C}_{2} \mathrm{H}_{4}$ & ${ }^{1} J_{\mathrm{CC}}$ & 59,5 & 62,2 & 65,2 & 68,5 & 72,4 & 76,9 & 82,4 & 89,4 & 98,7 & 112,2 & 133,8 & 66,6 \\
\hline $\mathrm{C}_{2} \mathrm{H}_{4}$ & ${ }^{1} J_{\mathrm{CH}}$ & 149,7 & 151,8 & 154,0 & 156,3 & 158,8 & 161,6 & 164,7 & 168,5 & 173,2 & 179,6 & 189,3 & 154,3 \\
\hline $\mathrm{C}_{2} \mathrm{H}_{4}$ & ${ }^{2} J_{\mathrm{CH}}$ & 0,0 & $-0,8$ & $-1,7$ & $-2,9$ & $-4,2$ & $-5,7$ & $-7,7$ & $-10,3$ & $-13,9$ & $-19,1$ & $-27,6$ & $-1,9$ \\
\hline $\mathrm{C}_{2} \mathrm{H}_{4}$ & ${ }^{2} J_{\mathrm{HH}}$ & 4,6 & 3,9 & 3,1 & 2,2 & 1,2 & 0,0 & $-1,2$ & $-2,9$ & $-5,2$ & $-8,4$ & $-13,5$ & 2,1 \\
\hline $\mathrm{C}_{2} \mathrm{H}_{4}$ & ${ }^{3} J_{\mathrm{HH}_{\mathrm{C}}}$ & 11,6 & 11,9 & 12,3 & 12,7 & 13,3 & 14,0 & 15,0 & 16,3 & 18,1 & 21,0 & 25,7 & 11,3 \\
\hline $\mathrm{C}_{2} \mathrm{H}_{4}$ & ${ }^{3} J_{\mathrm{HH}_{\mathrm{t}}}{ }^{\mathrm{C}}$ & 18,5 & 18,9 & 19,3 & 19,8 & 20,4 & 21,3 & 22,4 & 23,9 & 26,1 & 29,3 & 34,7 & 18,3 \\
\hline $\mathrm{C}_{2} \mathrm{H}_{6}$ & ${ }^{1} J_{\mathrm{CC}}$ & 24,2 & 26,2 & 28,2 & 30,2 & 32,3 & 34,4 & 36,5 & 38,7 & 40,9 & 43,2 & 45,4 & 33,6 \\
\hline $\mathrm{C}_{2} \mathrm{H}_{6}$ & ${ }^{1} J_{\mathrm{CH}}$ & 117,6 & 119,2 & 120,9 & 122,6 & 124,3 & 126,0 & 127,8 & 129,6 & 131,3 & 133,2 & 135,0 & 123,4 \\
\hline $\mathrm{C}_{2} \mathrm{H}_{6}$ & ${ }^{2} J_{\mathrm{CH}}$ & $-2,7$ & $-3,1$ & $-3,6$ & $-4,1$ & $-4,5$ & $-5,0$ & $-5,5$ & $-6,0$ & $-6,5$ & $-7,1$ & $-7,6$ & $-4,5$ \\
\hline \multirow[t]{3}{*}{ Total } & $\mathrm{DM}$ & $-29,78$ & $-27,35$ & $-24,73$ & $-22,03$ & $-19,32$ & $-16,75$ & $-14,52$ & $-13,07$ & $-13,37$ & $-18,52$ & $-47,57$ & - \\
\hline & DMA & 34,63 & 32,02 & 29,29 & 26,85 & 24,91 & 23,62 & 23,99 & 27,49 & 34,84 & 49,00 & 89,79 & - \\
\hline & PDMA & 50,39 & 40,81 & 31,16 & 25,19 & 24,52 & 27,28 & 37,11 & 55,68 & 79,38 & 111,37 & 164,29 & - \\
\hline \multirow[t]{3}{*}{ CPI } & $\mathrm{DM}$ & $-70,17$ & $-65,64$ & $-60,75$ & $-55,73$ & $-50,82$ & $-46,41$ & $-43,04$ & $-41,81$ & $-45,15$ & $-60,72$ & $-133,99$ & - \\
\hline & DMA & 76,21 & 70,60 & 64,61 & 58,44 & 52,51 & 47,32 & 45,49 & 50,23 & 63,15 & 90,77 & 178,92 & - \\
\hline & PDMA & 87,10 & 72,50 & 57,84 & 43,22 & 30,20 & 19,46 & 21,48 & 37,63 & 56,53 & 80,39 & 124,77 & - \\
\hline \multirow[t]{3}{*}{ SPI } & $\mathrm{DM}$ & $-0,17$ & 0,73 & 1,69 & 2,68 & 3,79 & 5,01 & 6,40 & 8,01 & 9,94 & 12,43 & 15,80 & - \\
\hline & DMA & 4,14 & 3,73 & 3,39 & 3,69 & 4,67 & 6,23 & 8,23 & 10,81 & 14,07 & 18,36 & 24,43 & - \\
\hline & PDMA & 23,47 & 17,57 & 11,60 & 11,96 & 20,36 & 33,01 & 48,58 & 68,92 & 96,14 & 134,08 & 193,27 & - \\
\hline \multirow[t]{3}{*}{$\Delta \mathrm{CS}$} & $\mathrm{DM}$ & $-70,01$ & $-66,37$ & $-62,44$ & $-58,41$ & $-54,60$ & $-51,42$ & $-49,44$ & $-49,82$ & $-55,09$ & $-73,14$ & $-149,79$ & - \\
\hline & DMA & 72,07 & 66,87 & 61,22 & 54,74 & 47,84 & 41,08 & 37,26 & 39,41 & 49,08 & 72,41 & 154,49 & - \\
\hline & PDMA & 63,63 & 54,93 & 46,24 & 31,26 & 9,84 & $-13,55$ & $-27,10$ & $-31,29$ & $-39,61$ & $-53,69$ & $-68,50$ & - \\
\hline
\end{tabular}


Tabela 8.162: Constantes de acoplamento BPW91 e constantes empíricas no nível PBE0 $40 \% E_{X}^{\mathrm{HF}}$ e base aug-pcJ-2.

\begin{tabular}{|c|c|c|c|c|c|c|c|c|c|c|c|c|c|}
\hline & $\% E_{X}^{\mathrm{HF}}$ & $0 \%$ & $10 \%$ & $20 \%$ & $30 \%$ & $40 \%$ & $50 \%$ & $60 \%$ & $70 \%$ & $80 \%$ & $90 \%$ & $100 \%$ & Emp. \\
\hline $\mathrm{HF}$ & ${ }^{1} J_{\mathrm{HF}}$ & 353,3 & 377,4 & 401,9 & 426,6 & 451,5 & 476,7 & 502,2 & 527,9 & 553,8 & 579,9 & 606,3 & 534,8 \\
\hline $\mathrm{CO}$ & ${ }^{1} J_{\mathrm{CO}}$ & 25,2 & 23,6 & 21,8 & 20,0 & 18,1 & 16,1 & 14,0 & 11,8 & 9,6 & 7,3 & 4,9 & 15,7 \\
\hline $\mathrm{H}_{2} \mathrm{O}$ & ${ }^{1} J_{\mathrm{OH}}$ & $-64,9$ & $-67,5$ & $-70,1$ & $-72,7$ & $-75,4$ & $-78,1$ & $-80,8$ & $-83,5$ & $-86,3$ & $-89,1$ & $-91,9$ & $-82,0$ \\
\hline $\mathrm{H}_{2} \mathrm{O}$ & ${ }^{2} J_{\mathrm{HH}}$ & $-5,1$ & $-6,1$ & $-7,1$ & $-8,1$ & $-9,2$ & $-10,2$ & $-11,3$ & $-12,5$ & $-13,6$ & $-14,8$ & $-16,0$ & $-8,8$ \\
\hline $\mathrm{NH}_{3}$ & ${ }^{1} J_{\mathrm{NH}}$ & 40,2 & 41,0 & 41,8 & 42,6 & 43,4 & 44,2 & 45,0 & 45,8 & 46,7 & 47,5 & 48,4 & 43,3 \\
\hline $\mathrm{NH}_{3}$ & ${ }^{2} J_{\mathrm{HH}}$ & $-8,3$ & $-9,2$ & $-10,1$ & $-11,0$ & $-11,9$ & $-12,9$ & $-13,8$ & $-14,7$ & $-15,7$ & $-16,7$ & $-17,7$ & $-10,4$ \\
\hline $\mathrm{PH}_{3}$ & ${ }^{1} J_{\mathrm{PH}}$ & 137,3 & 145,6 & 153,9 & 162,0 & 170,1 & 178,0 & 185,8 & 193,4 & 200,9 & 208,3 & 215,5 & 195,7 \\
\hline $\mathrm{PF}_{3}$ & ${ }^{1} J_{\mathrm{PF}}$ & $-1810,6$ & $-1784,5$ & $-1754,1$ & $-1720,0$ & $-1683,1$ & $-1643,8$ & $-1602,7$ & $-1560,3$ & $-1516,9$ & $-1472,9$ & $-1428,5$ & $-1.443,2$ \\
\hline $\mathrm{BHF}_{2}$ & ${ }^{1} J_{\mathrm{BF}}$ & $-178,0$ & $-160,8$ & $-143,8$ & $-126,8$ & $-110,0$ & $-93,3$ & $-76,8$ & $-60,4$ & $-44,3$ & $-28,3$ & $-12,5$ & $-79,6$ \\
\hline $\mathrm{BF}_{3}$ & ${ }^{1} J_{\mathrm{BF}}$ & $-83,3$ & $-64,5$ & $-45,8$ & $-27,4$ & $-9,1$ & 8,9 & 26,7 & 44,5 & 62,0 & 79,4 & 96,6 & 17,2 \\
\hline $\mathrm{F}_{2} \mathrm{O}$ & ${ }^{1} J_{\mathrm{OF}}$ & $-291,7$ & $-329,9$ & $-368,6$ & $-409,2$ & $-454,4$ & $-507,7$ & $-575,7$ & $-671,4$ & $-827,4$ & $-1153,6$ & $-2525,8$ & $-284,7$ \\
\hline $\mathrm{CH}_{4}$ & ${ }^{1} J_{\mathrm{CH}}$ & 118,9 & 120,4 & 121,9 & 123,5 & 125,1 & 126,7 & 128,4 & 130,0 & 131,7 & 133,4 & 135,2 & 122,9 \\
\hline $\mathrm{CH}_{4}$ & ${ }^{2} J_{\mathrm{HH}}$ & $-12,5$ & $-13,3$ & $-14,0$ & $-14,7$ & $-15,5$ & $-16,2$ & $-17,0$ & $-17,7$ & $-18,4$ & $-19,1$ & $-19,9$ & $-12,5$ \\
\hline $\mathrm{C}_{2} \mathrm{H}_{2}$ & ${ }^{1} J_{\mathrm{CC}}$ & 187,9 & 190,7 & 193,9 & 197,7 & 202,2 & 207,5 & 213,8 & 221,6 & 231,2 & 243,3 & 259,0 & 173,9 \\
\hline $\mathrm{C}_{2} \mathrm{H}_{2}$ & ${ }^{1} J_{\mathrm{CH}}$ & 251,1 & 253,6 & 256,2 & 259,1 & 262,1 & 265,6 & 269,5 & 274,1 & 279,5 & 286,1 & 294,6 & 244,4 \\
\hline $\mathrm{C}_{2} \mathrm{H}_{2}$ & ${ }^{2} J_{\mathrm{CH}}$ & 54,7 & 54,6 & 54,2 & 53,6 & 52,6 & 51,1 & 49,1 & 46,5 & 42,8 & 37,9 & 31,2 & 49,9 \\
\hline $\mathrm{C}_{2} \mathrm{H}_{2}$ & ${ }^{3} J_{\mathrm{HH}}$ & 10,8 & 11,5 & 12,4 & 13,4 & 14,6 & 16,1 & 17,9 & 20,1 & 22,8 & 26,3 & 30,7 & 8,9 \\
\hline $\mathrm{C}_{2} \mathrm{H}_{4}$ & ${ }^{1} J_{\mathrm{CC}}$ & 59,9 & 62,7 & 65,9 & 69,5 & 73,7 & 78,7 & 84,9 & 93,0 & 104,3 & 121,5 & 152,0 & 66,6 \\
\hline $\mathrm{C}_{2} \mathrm{H}_{4}$ & ${ }^{1} J_{\mathrm{CH}}$ & 151,9 & 154,1 & 156,4 & 158,9 & 161,6 & 164,7 & 168,3 & 172,6 & 178,2 & 186,4 & 200,0 & 154,3 \\
\hline $\mathrm{C}_{2} \mathrm{H}_{4}$ & ${ }^{2} J_{\mathrm{CH}}$ & $-0,4$ & $-1,4$ & $-2,4$ & $-3,6$ & $-5,1$ & $-6,9$ & $-9,2$ & $-12,4$ & $-16,8$ & $-23,7$ & $-36,2$ & $-1,9$ \\
\hline $\mathrm{C}_{2} \mathrm{H}_{4}$ & ${ }^{2} J_{\mathrm{HH}}$ & 4,2 & 3,3 & 2,5 & 1,5 & 0,4 & $-0,8$ & $-2,4$ & $-4,5$ & $-7,4$ & $-11,7$ & $-19,2$ & 2,1 \\
\hline $\mathrm{C}_{2} \mathrm{H}_{4}$ & ${ }^{3} J_{\mathrm{HH}_{\mathrm{C}}}$ & 12,0 & 12,3 & 12,7 & 13,3 & 14,0 & 14,8 & 16,0 & 17,7 & 20,1 & 24,0 & 31,2 & 11,3 \\
\hline $\mathrm{C}_{2} \mathrm{H}_{4}$ & ${ }^{3} J_{\mathrm{HH}_{\mathrm{t}}}{ }^{\mathrm{C}}$ & 19,1 & 19,5 & 20,0 & 20,6 & 21,4 & 22,4 & 23,7 & 25,6 & 28,4 & 32,8 & 40,9 & 18,3 \\
\hline $\mathrm{C}_{2} \mathrm{H}_{6}$ & ${ }^{1} J_{\mathrm{CC}}$ & 24,5 & 26,5 & 28,5 & 30,6 & 32,7 & 34,8 & 37,0 & 39,2 & 41,5 & 43,8 & 46,1 & 33,6 \\
\hline $\mathrm{C}_{2} \mathrm{H}_{6}$ & ${ }^{1} J_{\mathrm{CH}}$ & 119,2 & 120,9 & 122,6 & 124,4 & 126,2 & 128,0 & 129,8 & 131,7 & 133,5 & 135,4 & 137,3 & 123,4 \\
\hline $\mathrm{C}_{2} \mathrm{H}_{6}$ & ${ }^{2} J_{\mathrm{CH}}$ & $-3,0$ & $-3,5$ & $-3,9$ & $-4,4$ & $-4,9$ & $-5,4$ & $-6,0$ & $-6,5$ & $-7,0$ & $-7,5$ & $-8,1$ & $-4,5$ \\
\hline \multirow[t]{3}{*}{ Total } & $\mathrm{DM}$ & $-29,86$ & $-27,37$ & $-24,69$ & $-21,90$ & $-19,14$ & $-16,53$ & $-14,32$ & $-12,97$ & $-13,67$ & $-20,49$ & $-66,72$ & - \\
\hline & DMA & 34,97 & 32,33 & 29,75 & 27,63 & 25,96 & 24,84 & 25,62 & 29,66 & 38,39 & 55,17 & 114,95 & - \\
\hline & PDMA & 48,47 & 38,38 & 30,73 & 28,32 & 29,87 & 33,76 & 45,83 & 67,21 & 94,82 & 134,34 & 208,80 & - \\
\hline \multirow[t]{3}{*}{ CPI } & $\mathrm{DM}$ & $-71,26$ & $-66,63$ & $-61,65$ & $-56,55$ & $-51,64$ & $-47,28$ & $-44,13$ & $-43,40$ & $-48,11$ & $-68,27$ & $-183,52$ & - \\
\hline & DMA & 77,15 & 71,41 & 65,29 & 59,15 & 53,29 & 48,23 & 46,89 & 52,31 & 67,69 & 100,16 & 230,35 & - \\
\hline & PDMA & 86,40 & 71,55 & 56,65 & 43,00 & 30,77 & 20,63 & 23,68 & 40,46 & 60,38 & 86,26 & 145,66 & - \\
\hline \multirow[t]{3}{*}{ SPI } & $\mathrm{DM}$ & 0,51 & 1,41 & 2,41 & 3,51 & 4,69 & 6,03 & 7,54 & 9,35 & 11,58 & 14,55 & 18,94 & - \\
\hline & DMA & 4,03 & 3,68 & 3,69 & 4,51 & 5,92 & 7,69 & 10,02 & 13,05 & 16,90 & 22,17 & 30,31 & - \\
\hline & PDMA & 20,66 & 14,05 & 11,71 & 17,56 & 29,21 & 43,39 & 62,08 & 86,83 & 120,07 & 169,60 & 255,10 & - \\
\hline \multirow[t]{3}{*}{$\Delta \mathrm{CS}$} & $\mathrm{DM}$ & $-71,77$ & $-68,04$ & $-64,07$ & $-60,06$ & $-56,33$ & $-53,31$ & $-51,67$ & $-52,75$ & $-59,69$ & $-82,82$ & $-202,46$ & - \\
\hline & DMA & 73,13 & 67,73 & 61,60 & 54,63 & 47,37 & 40,53 & 36,87 & 39,26 & 50,79 & 77,99 & 200,04 & - \\
\hline & PDMA & 65,73 & 57,51 & 44,94 & 25,44 & 1,56 & $-22,76$ & $-38,40$ & $-46,36$ & $-59,69$ & $-83,34$ & $-109,44$ & - \\
\hline
\end{tabular}


Tabela 8.163: Constantes de acoplamento M05 e constantes empíricas no nível PBE0 40\% $E_{X}^{\mathrm{HF}}$ e base aug-pcJ-2.

\begin{tabular}{|c|c|c|c|c|c|c|c|c|c|c|c|c|c|}
\hline & $\% E_{X}^{\mathrm{HF}}$ & $0 \%$ & $10 \%$ & $20 \%$ & $30 \%$ & $40 \%$ & $50 \%$ & $60 \%$ & $70 \%$ & $80 \%$ & $90 \%$ & $100 \%$ & Emp. \\
\hline $\mathrm{HF}$ & $\frac{X}{{ }^{1} J_{\mathrm{HF}}}$ & 847,0 & 840,1 & 833,5 & 827,3 & 821,4 & 815,9 & 810,8 & 805,8 & 801,1 & 796,4 & 791,7 & 534,8 \\
\hline $\mathrm{CO}$ & ${ }^{1} J_{\mathrm{CO}}$ & 15,8 & 13,7 & 11,3 & 8,5 & 5,3 & 1,7 & $-2,1$ & $-6,2$ & $-10,7$ & $-15,5$ & $-20,5$ & $\begin{array}{c}15,7 \\
\text {. }\end{array}$ \\
\hline $\mathrm{H}_{2} \mathrm{O}$ & ${ }^{1} J_{\mathrm{OH}}$ & $-108,9$ & $-108,7$ & $-108,5$ & $-108,3$ & $-108,2$ & $-108,0$ & $-108,0$ & $-108,0$ & $-108,0$ & $-108,1$ & $-108,2$ & $-82,0$ \\
\hline $\mathrm{H}_{2} \mathrm{O}$ & ${ }^{2} J_{\mathrm{HH}}$ & $-18,6$ & $-18,7$ & $-18,7$ & $-18,6$ & $-18,3$ & $-17,9$ & $-17,4$ & $-16,7$ & $-15,9$ & $-15,0$ & $-13,9$ & $-8,8$ \\
\hline $\mathrm{NH}_{3}$ & ${ }^{1} J_{\mathrm{NH}}$ & 41,1 & 42,3 & 43,4 & 44,5 & 45,6 & 46,7 & 47,8 & 48,8 & 49,8 & 50,8 & 51,7 & 43,3 \\
\hline $\mathrm{NH}_{3}$ & ${ }^{2} J_{\mathrm{HH}}$ & $-13,5$ & $-14,4$ & $-15,2$ & $-15,9$ & $-16,4$ & $-16,7$ & $-16,9$ & $-16,8$ & $-16,5$ & $-15,9$ & $-15,2$ & $-10,4$ \\
\hline $\mathrm{PH}_{3}$ & ${ }^{1} J_{\mathrm{PH}}$ & 168,5 & 166,8 & 168,2 & 173,0 & 180,3 & 188,9 & 198,1 & 207,2 & 215,9 & 224,1 & 231,8 & 195,7 \\
\hline $\mathrm{PF}_{3}$ & ${ }^{1} J_{\mathrm{PF}}$ & $-1357,6$ & $-1376,0$ & $-1386,5$ & $-1388,9$ & $-1383,6$ & $-1372,0$ & $-1355,3$ & $-1334,8$ & $-1311,8$ & $-1287,0$ & $-1261,2$ & $-1.443,2$ \\
\hline $\mathrm{BHF}_{2}$ & ${ }^{1} J_{\mathrm{BF}}$ & 2,2 & 8,2 & 14,9 & 22,3 & 30,5 & 39,5 & 49,5 & 60,5 & 72,8 & 86,3 & 101,3 & $-79,6$ \\
\hline $\mathrm{BF}_{3}$ & ${ }^{1} J_{\mathrm{BF}}$ & 102,9 & 111,1 & 119,8 & 129,1 & 139,0 & 149,8 & 161,4 & 174,1 & 187,8 & 202,7 & 218,9 & 17,2 \\
\hline $\mathrm{F}_{2} \mathrm{O}$ & ${ }^{1} J_{\mathrm{OF}}$ & $-218,9$ & $\begin{array}{l}-253,7 \\
-253\end{array}$ & $-282,8$ & $-307,6$ & $-330,0$ & $-351,6$ & $-374,7$ & $-402,2$ & $-439,1$ & $-494,9$ & $-592,4$ & $-284,7$ \\
\hline $\mathrm{CH}_{4}$ & ${ }^{1} J_{\mathrm{CH}}$ & 80,9 & 87,2 & 93,5 & 99,8 & 106,1 & 112,4 & 118,7 & 125,0 & 131,1 & 137,1 & 142,9 & 122,9 \\
\hline $\mathrm{CH}_{4}$ & ${ }^{2} J_{\mathrm{HH}}$ & $-20,8$ & $-21,1$ & $-21,2$ & $-21,2$ & $-21,0$ & $-20,8$ & $-20,4$ & $-19,8$ & $-19,2$ & $-18,5$ & $-17,9$ & $-12,5$ \\
\hline $\mathrm{C}_{2} \mathrm{H}_{2}$ & ${ }^{1} J_{\mathrm{CC}}$ & 182,9 & 192,0 & 201,6 & 211,8 & 222,6 & 234,0 & 246,1 & 258,8 & 272,4 & 286,7 & 302,0 & 173,9 \\
\hline $\mathrm{C}_{2} \mathrm{H}_{2}$ & ${ }^{1} J_{\mathrm{CH}}$ & 223,0 & 232,1 & 240,9 & 249,5 & 257,6 & 265,4 & 272,7 & 279,3 & 285,2 & 290,2 & 294,4 & 244,4 \\
\hline $\mathrm{C}_{2} \mathrm{H}_{2}$ & ${ }^{2} J_{\mathrm{CH}}$ & 35,8 & 36,1 & 36,4 & 36,6 & 36,7 & 36,7 & 36,8 & 36,7 & 36,4 & 35,9 & 34,9 & 49,9 \\
\hline $\mathrm{C}_{2} \mathrm{H}_{2}$ & ${ }^{3} J_{\mathrm{HH}}$ & 19,6 & 20,1 & 20,4 & 20,6 & 20,7 & 20,7 & 20,6 & 20,4 & 20,2 & 20,1 & 20,2 & 8,9 \\
\hline $\mathrm{C}_{2} \mathrm{H}_{4}$ & ${ }^{1} J_{\mathrm{CC}}$ & 57,9 & 64,1 & 70,7 & 77,9 & 85,7 & 94,1 & 103,3 & 113,2 & 123,9 & 135,6 & 148,4 & 66,6 \\
\hline $\mathrm{C}_{2} \mathrm{H}_{4}$ & ${ }^{1} J_{\mathrm{CH}}$ & 119,8 & 127,7 & 135,5 & 143,2 & 150,8 & 158,4 & 165,8 & 173,1 & 180,1 & 187,0 & 193,6 & 154,3 \\
\hline $\mathrm{C}_{2} \mathrm{H}_{4}$ & ${ }^{2} J_{\mathrm{CH}}$ & $-11,4$ & $-12,2$ & $-13,1$ & $-14,1$ & $-15,1$ & $-16,2$ & $-17,3$ & $-18,4$ & $-19,6$ & $-20,9$ & $-22,4$ & $-1,9$ \\
\hline $\mathrm{C}_{2} \mathrm{H}_{4}$ & ${ }^{2} J_{\mathrm{HH}}$ & $-16,0$ & $-15,7$ & $-15,1$ & $-14,4$ & $-13,6$ & $-12,6$ & $-11,4$ & $-10,1$ & $-8,8$ & $-7,5$ & $-6,4$ & 2,1 \\
\hline $\mathrm{C}_{2} \mathrm{H}_{4}$ & ${ }^{3} J_{\mathrm{HH}}$ & 14,5 & 15,2 & 15,8 & 16,3 & 16,7 & 17,0 & 17,2 & 17,3 & 17,3 & 17,3 & 17,3 & 11,3 \\
\hline $\mathrm{C}_{2} \mathrm{H}_{4}$ & ${ }^{3} J_{\mathrm{HH}}$ & 15,6 & 17,0 & 18,2 & 19,4 & 20,5 & 21,4 & 22,2 & 22,9 & 23,4 & 23,9 & 24,4 & 18,3 \\
\hline $\mathrm{C}_{2} \mathrm{H}_{6}$ & ${ }^{1} J_{\mathrm{CC}}$ & 15,2 & 18,5 & 21,9 & 25,6 & 29,4 & 33,3 & 37,5 & 41,9 & 46,4 & 51,2 & 56,2 & 33,6 \\
\hline $\mathrm{C}_{2} \mathrm{H}_{6}$ & ${ }^{1} J_{\mathrm{CH}}$ & 80,1 & 86,6 & 93,0 & 99,5 & 106,0 & 112,6 & 119,1 & 125,6 & 132,0 & 138,4 & 144,6 & 123,4 \\
\hline $\mathrm{C}_{2} \mathrm{H}_{6}$ & ${ }^{2} J_{\mathrm{CH}}$ & $-3,2$ & $-3,7$ & $-4,2$ & $-4,7$ & $-5,2$ & $-5,7$ & $-6,1$ & $-6,6$ & $-7,0$ & $-7,5$ & $-8,0$ & $-4,5$ \\
\hline \multirow[t]{3}{*}{ Total } & $\mathrm{DM}$ & 14,05 & 14,07 & 14,81 & 16,25 & 18,26 & 20,70 & 23,43 & 26,24 & 28,87 & 30,93 & 31,52 & - \\
\hline & DMA & 36,37 & 33,56 & 31,55 & 32,51 & 34,11 & 36,27 & 39,50 & 44,01 & 49,73 & 56,38 & 64,82 & - \\
\hline & PDMA & 104,01 & 105,92 & 108,06 & 112,38 & 117,17 & 122,12 & 127,86 & 134,25 & 141,68 & 150,00 & 160,17 & - \\
\hline \multirow[t]{3}{*}{ CPI } & $\mathrm{DM}$ & 51,09 & 46,61 & 43,76 & 42,49 & 42,51 & 43,48 & 45,02 & 46,70 & 47,95 & 47,81 & 44,18 & - \\
\hline & DMA & 63,67 & 59,79 & 57,05 & 59,65 & 63,02 & 66,95 & 72,09 & 79,37 & 87,95 & 98,57 & 113,27 & - \\
\hline & PDMA & 80,18 & 85,65 & 91,72 & 100,15 & 108,83 & 117,98 & 127,89 & 138,98 & 151,00 & 164,20 & 179,38 & - \\
\hline \multirow[t]{3}{*}{ SPI } & $\mathrm{DM}$ & $-13,12$ & $-9,79$ & $-6,43$ & $-2,99$ & 0,48 & 4,00 & 7,61 & 11,24 & 14,87 & 18,55 & 22,23 & - \\
\hline & DMA & 16,35 & 14,32 & 12,84 & 12,61 & 12,91 & 13,77 & 15,61 & 18,08 & 21,71 & 25,43 & 29,29 & - \\
\hline & PDMA & 121,48 & 120,78 & 120,03 & 121,35 & 123,29 & 125,16 & 127,84 & 130,79 & 134,84 & 139,59 & 146,08 & - \\
\hline \multirow[t]{3}{*}{$\Delta \mathrm{CS}$} & $\mathrm{DM}$ & 64,21 & 56,40 & 50,19 & 45,48 & 42,03 & 39,48 & 37,41 & 35,46 & 33,07 & 29,26 & 21,95 & - \\
\hline & DMA & 47,33 & 45,47 & 44,21 & 47,05 & 50,11 & 53,18 & 56,48 & 61,29 & 66,23 & 73,14 & 83,99 & - \\
\hline & PDMA & $-41,29$ & $-35,12$ & $\begin{array}{l}-28,31 \\
\end{array}$ & $-21,20$ & $-14,46$ & $-7,18$ & 0,05 & 8,19 & 16,16 & 24,61 & 33,29 & - \\
\hline
\end{tabular}


Tabela 8.164: Constantes de acoplamento M06 e constantes empíricas no nível PBE0 40\% $E_{X}^{\mathrm{HF}}$ e base aug-pcJ-2.

\begin{tabular}{|c|c|c|c|c|c|c|c|c|c|c|c|c|c|}
\hline & $\% E_{X}^{\mathrm{HF}}$ & $0 \%$ & $10 \%$ & $20 \%$ & $30 \%$ & $40 \%$ & $50 \%$ & $60 \%$ & $70 \%$ & $80 \%$ & $90 \%$ & $100 \%$ & Emp. \\
\hline $\mathrm{HF}$ & ${ }^{1} J_{\mathrm{HF}}$ & 591,8 & 620,1 & 652,6 & 690,1 & 733,4 & 782,9 & 838,6 & 900,5 & 967,8 & 1039,5 & 1113,9 & 534,8 \\
\hline $\mathrm{CO}$ & ${ }^{1} J_{\mathrm{CO}}$ & 16,9 & 17,6 & 17,9 & 17,8 & 17,0 & 15,4 & 13,0 & 9,5 & 5,0 & $-0,8$ & $-7,9$ & 15,7 \\
\hline $\mathrm{H}_{2} \mathrm{O}$ & ${ }^{1} J_{\mathrm{OH}}$ & $-86,0$ & $-90,6$ & $-96,1$ & $-102,7$ & $-110,6$ & $-120,0$ & $-131,2$ & $-144,5$ & $-160,2$ & $-178,9$ & $-201,1$ & $-82,0$ \\
\hline $\mathrm{H}_{2} \mathrm{O}$ & ${ }^{2} J_{\mathrm{HH}}$ & $-5,7$ & $-9,1$ & $-13,3$ & $-18,4$ & $-24,8$ & $-32,8$ & $-42,7$ & $-54,9$ & $-70,2$ & $-89,3$ & $-113,0$ & $-8,8$ \\
\hline $\mathrm{NH}_{3}$ & ${ }^{1} J_{\mathrm{NH}}$ & 43,2 & 46,1 & 49,6 & 53,7 & 58,6 & 64,4 & 71,6 & 80,3 & 91,1 & 104,7 & 122,2 & 43,3 \\
\hline $\mathrm{NH}_{3}$ & ${ }^{2} J_{\mathrm{HH}}$ & $-7,6$ & $-10,7$ & $-14,6$ & $-19,7$ & $-26,3$ & $-35,0$ & $-46,5$ & $-62,0$ & $-83,1$ & $-112,3$ & $-153,9$ & $-10,4$ \\
\hline $\mathrm{PH}_{3}$ & ${ }^{1} J_{\mathrm{PH}}$ & 199,3 & 214,4 & 232,5 & 254,5 & 281,6 & 315,1 & 357,5 & 411,8 & 483,2 & 577,7 & 701,3 & 195,7 \\
\hline $\mathrm{PF}_{3}$ & ${ }^{1} J_{\mathrm{PF}}$ & $-1437,2$ & $-1476,6$ & $-1508,9$ & $-1533,6$ & $-1552,2$ & $-1567,1$ & $-1579,5$ & $-1588,2$ & $-1591,0$ & $-1586,1$ & $-1573,4$ & $-1.443,2$ \\
\hline $\mathrm{BHF}_{2}$ & ${ }^{1} J_{\mathrm{BF}}$ & $-67,3$ & $-57,9$ & $-46,0$ & $-31,5$ & $-14,7$ & 3,7 & 22,9 & 41,7 & 58,7 & 71,6 & 75,6 & $-79,6$ \\
\hline $\mathrm{BF}_{3}$ & ${ }^{1} J_{\mathrm{BF}}$ & 27,0 & 39,1 & 53,4 & 70,2 & 89,7 & 111,5 & 135,2 & 160,1 & 185,6 & 211,4 & 237,7 & 17,2 \\
\hline $\mathrm{F}_{2} \mathrm{O}$ & ${ }^{1} J_{\mathrm{OF}}$ & $-161,1$ & $-211,1$ & $-265,9$ & $-328,2$ & $-406,1$ & $-530,0$ & $-975,7$ & 4267,8 & $-15,5$ & $-222,3$ & $-320,8$ & $-284,7$ \\
\hline $\mathrm{CH}_{4}$ & ${ }^{1} J_{\mathrm{CH}}$ & 103,3 & 114,7 & 128,4 & 144,8 & 164,8 & 189,3 & 219,9 & 258,9 & 309,9 & 379,0 & 477,4 & 122,9 \\
\hline $\mathrm{CH}_{4}$ & ${ }^{2} J_{\mathrm{HH}}$ & $-12,6$ & $-16,6$ & $-21,5$ & $-27,9$ & $-36,3$ & $-47,3$ & $-62,2$ & $-82,8$ & $-112,3$ & $-156,2$ & $-225,1$ & $-12,5$ \\
\hline $\mathrm{C}_{2} \mathrm{H}_{2}$ & ${ }^{1} J_{\mathrm{CC}}$ & 161,7 & 170,7 & 182,5 & 199,5 & 227,4 & 285,4 & 502,3 & $-632,7$ & $-14,0$ & 128,2 & 5815,3 & 173,9 \\
\hline $\mathrm{C}_{2} \mathrm{H}_{2}$ & ${ }^{1} J_{\mathrm{CH}}$ & 208,8 & 237,3 & 271,3 & 313,1 & 367,7 & 450,4 & 661,2 & $-166,8$ & 360,7 & 495,3 & $-161,9$ & 244,4 \\
\hline $\mathrm{C}_{2} \mathrm{H}_{2}$ & ${ }^{2} J_{\mathrm{CH}}$ & 49,7 & 51,3 & 51,6 & 49,0 & 39,6 & 9,0 & $-141,1$ & 758,3 & 315,4 & 282,8 & 1065,0 & 49,9 \\
\hline $\mathrm{C}_{2} \mathrm{H}_{2}$ & ${ }^{3} J_{\mathrm{HH}}$ & 7,6 & 9,7 & 13,2 & 19,3 & 31,2 & 60,3 & 184,0 & $-514,8$ & $-158,3$ & $-117,3$ & $-2,3$ & 8,9 \\
\hline $\mathrm{C}_{2} \mathrm{H}_{4}$ & ${ }^{1} J_{\mathrm{CC}}$ & 51,1 & 54,6 & 59,6 & 67,7 & 83,1 & 126,0 & 1247,1 & $-64,0$ & $-10,1$ & 6,5 & 13,8 & 66,6 \\
\hline $\mathrm{C}_{2} \mathrm{H}_{4}$ & ${ }^{1} J_{\mathrm{CH}}$ & 130,3 & 146,9 & 166,9 & 191,8 & 225,2 & 282,2 & 1104,7 & 218,8 & 304,5 & 376,2 & 458,4 & 154,3 \\
\hline $\mathrm{C}_{2} \mathrm{H}_{4}$ & ${ }^{2} J_{\mathrm{CH}}$ & 0,7 & $-0,9$ & $-3,5$ & $-8,1$ & $-17,7$ & $-46,3$ & $-834,9$ & 91,9 & 56,9 & 48,8 & 48,6 & $-1,9$ \\
\hline $\mathrm{C}_{2} \mathrm{H}_{4}$ & ${ }^{2} J_{\mathrm{HH}}$ & $-3,4$ & $-5,9$ & $-9,6$ & $-15,6$ & $-26,7$ & $-56,4$ & $-792,0$ & 61,8 & 21,0 & 1,6 & $-16,5$ & 2,1 \\
\hline $\mathrm{C}_{2} \mathrm{H}_{4}$ & ${ }^{3} J_{\mathrm{HH}_{\mathrm{C}}}$ & 11,0 & 12,5 & 14,7 & 18,6 & 26,8 & 52,5 & 782,6 & $-78,9$ & $-49,1$ & $-45,4$ & $-50,8$ & 11,3 \\
\hline $\mathrm{C}_{2} \mathrm{H}_{4}$ & ${ }^{3} J_{\mathrm{HH}_{\mathrm{t}}}$ & 12,1 & 14,6 & 18,1 & 23,5 & 33,7 & 62,4 & 821,1 & $-67,9$ & $-32,7$ & $-23,3$ & $-21,2$ & 18,3 \\
\hline $\mathrm{C}_{2} \mathrm{H}_{6}$ & ${ }^{1} J_{\mathrm{CC}}$ & 20,1 & 22,9 & 26,4 & 30,8 & 36,4 & 43,5 & 52,9 & 65,7 & 83,6 & 110,1 & 152,2 & 33,6 \\
\hline $\mathrm{C}_{2} \mathrm{H}_{6}$ & ${ }^{1} J_{\mathrm{CH}}$ & 101,2 & 113,2 & 127,4 & 144,5 & 165,3 & 190,7 & 222,4 & 262,9 & 316,0 & 388,7 & 493,8 & 123,4 \\
\hline $\mathrm{C}_{2} \mathrm{H}_{6}$ & ${ }^{2} J_{\mathrm{CH}}$ & $-1,4$ & $-2,6$ & $-4,2$ & $-6,2$ & $-8,8$ & $-12,3$ & $-17,2$ & $-24,3$ & $-34,8$ & $-51,6$ & $-80,4$ & $-4,5$ \\
\hline \multirow[t]{3}{*}{ Total } & $\mathrm{DM}$ & 2,49 & 4,42 & 7,45 & 11,86 & 18,02 & 27,26 & 104,82 & 162,29 & 51,52 & 67,30 & 306,08 & - \\
\hline & DMA & 14,82 & 13,44 & 17,08 & 28,64 & 46,78 & 76,68 & 322,49 & 350,75 & 131,83 & 141,17 & 416,52 & - \\
\hline & PDMA & 33,01 & 33,43 & 50,33 & 90,93 & 163,74 & 336,89 & 3882,49 & 866,80 & 487,37 & 477,55 & 745,84 & - \\
\hline \multirow[t]{3}{*}{ CPI } & $\mathrm{DM}$ & 19,57 & 16,66 & 14,84 & 14,02 & 13,42 & 10,01 & $-21,35$ & 465,83 & 88,49 & 83,38 & 89,33 & - \\
\hline & DMA & 20,32 & 24,41 & 30,93 & 45,56 & 66,31 & 92,94 & 151,24 & 522,45 & 155,91 & 163,15 & 190,55 & - \\
\hline & PDMA & 18,51 & 22,15 & 40,18 & 64,58 & 95,22 & 132,85 & 189,21 & 362,93 & 286,92 & 354,55 & 446,09 & - \\
\hline \multirow[t]{3}{*}{ SPI } & DM & $-10,03$ & $-4,55$ & 2,04 & 10,27 & 21,40 & 39,91 & 197,34 & $-60,31$ & 24,40 & 55,51 & 465,04 & - \\
\hline & DMA & 10,79 & 5,39 & 6,93 & 16,23 & 32,47 & 64,77 & 448,07 & 224,84 & 114,17 & 125,06 & 582,24 & - \\
\hline & PDMA & 43,63 & 41,71 & 57,78 & 110,26 & 213,99 & 486,53 & 6590,89 & 1236,30 & 634,37 & 567,76 & 965,66 & - \\
\hline \multirow[t]{3}{*}{$\Delta \mathrm{CS}$} & $\mathrm{DM}$ & 29,61 & 21,22 & 12,80 & 3,74 & $-7,98$ & $-29,90$ & $-218,69$ & 526,13 & 64,09 & 27,87 & $-375,71$ & - \\
\hline & DMA & 9,52 & 19,02 & 23,99 & 29,33 & 33,84 & 28,17 & $-296,84$ & 297,61 & 41,74 & 38,09 & $-391,69$ & - \\
\hline & PDMA & $-25,12$ & $-19,56$ & $-17,60$ & $-45,68$ & $-118,76$ & $-353,68$ & $-6401,68$ & $-873,36$ & $-347,45$ & $-213,21$ & $-519,57$ & - \\
\hline
\end{tabular}


Tabela 8.165: Constantes de acoplamento M062X e constantes empíricas no nível PBE0 $40 \% E_{X}^{\mathrm{HF}}$ e base aug-pcJ-2.

\begin{tabular}{|c|c|c|c|c|c|c|c|c|c|c|c|c|c|}
\hline & $\% E_{X}^{\mathrm{HF}}$ & $0 \%$ & $10 \%$ & $20 \%$ & $30 \%$ & $40 \%$ & $50 \%$ & $60 \%$ & $70 \%$ & $80 \%$ & $90 \%$ & $100 \%$ & Emp. \\
\hline $\mathrm{HF}$ & ${ }^{1} J_{\mathrm{HF}}$ & 445,9 & 449,4 & 453,4 & 459,1 & 467,4 & 479,5 & 496,4 & 519,2 & 548,9 & 586,4 & 632,6 & 534,8 \\
\hline $\mathrm{CO}$ & ${ }^{1} J_{\mathrm{CO}}$ & 3,7 & 4,7 & 5,7 & 6,6 & 7,2 & 7,4 & 7,1 & 6,0 & 3,7 & $-0,2$ & $-6,8$ & 15,7 \\
\hline $\mathrm{H}_{2} \mathrm{O}$ & ${ }^{1} J_{\mathrm{OH}}$ & $-73,4$ & $-75,6$ & $-78,2$ & $-81,3$ & $-85,0$ & $-89,5$ & $-95,0$ & $-101,7$ & $-109,8$ & $-119,5$ & $-131,3$ & $-82,0$ \\
\hline $\mathrm{H}_{2} \mathrm{O}$ & ${ }^{2} J_{\mathrm{HH}}$ & 4,2 & 3,0 & 1,5 & $-0,3$ & $-2,7$ & $-5,7$ & $-9,5$ & $-14,4$ & $-20,5$ & $-28,2$ & $-38,1$ & $-8,8$ \\
\hline $\mathrm{NH}_{3}$ & ${ }^{1} J_{\mathrm{NH}}$ & 38,2 & 40,2 & 42,4 & 45,0 & 48,0 & 51,6 & 55,9 & 60,9 & 66,9 & 74,2 & 83,1 & 43,3 \\
\hline $\mathrm{NH}_{3}$ & ${ }^{2} J_{\mathrm{HH}}$ & 0,2 & $-0,7$ & $-2,1$ & $-4,0$ & $-6,4$ & $-9,5$ & $-13,6$ & $-18,9$ & $-25,9$ & $-35,2$ & $-47,6$ & $-10,4$ \\
\hline $\mathrm{PH}_{3}$ & ${ }^{1} J_{\mathrm{PH}}$ & 133,0 & 134,2 & 137,3 & 142,7 & 150,6 & 161,6 & 176,1 & 195,1 & 219,2 & 250,0 & 289,5 & 195,7 \\
\hline $\mathrm{PF}_{3}$ & ${ }^{1} J_{\mathrm{PF}}$ & $-1442,3$ & $-1488,8$ & $-1533,3$ & $-1573,0$ & $-1603,7$ & $-1622,0$ & $-1627,6$ & $-1623,0$ & $-1612,8$ & $-1602,7$ & $-1596,7$ & $-1.443,2$ \\
\hline $\mathrm{BHF}_{2}$ & ${ }^{1} J_{\mathrm{BF}}$ & $-166,8$ & $-163,3$ & $-156,4$ & $-146,7$ & $-135,1$ & $-122,1$ & $-107,7$ & $-92,3$ & $-75,9$ & $-58,8$ & $-41,4$ & $-79,6$ \\
\hline $\mathrm{BF}_{3}$ & ${ }^{1} J_{\mathrm{BF}}$ & $-89,3$ & $-80,2$ & $-68,9$ & $-56,0$ & $-41,7$ & $-26,4$ & $-10,0$ & 7,5 & 26,7 & 47,8 & 70,9 & 17,2 \\
\hline $\mathrm{F}_{2} \mathrm{O}$ & ${ }^{1} J_{\mathrm{OF}}$ & $-156,6$ & $-199,7$ & $-246,2$ & $-295,8$ & $-348,4$ & $-404,9$ & $-468,8$ & $-550,1$ & $-685,1$ & $-1305,2$ & $-2162,3$ & $-284,7$ \\
\hline $\mathrm{CH}_{4}$ & ${ }^{1} J_{\mathrm{CH}}$ & 86,4 & 93,7 & 102,1 & 112,1 & 123,7 & 137,5 & 153,9 & 173,6 & 197,4 & 226,6 & 262,9 & 122,9 \\
\hline $\mathrm{CH}_{4}$ & ${ }^{2} J_{\mathrm{HH}}$ & $-0,2$ & $-1,3$ & $-2,8$ & $-4,8$ & $-7,3$ & $-10,5$ & $-14,7$ & $-20,1$ & $-27,3$ & $-36,8$ & $-49,6$ & $-12,5$ \\
\hline $\mathrm{C}_{2} \mathrm{H}_{2}$ & ${ }^{1} J_{\mathrm{CC}}$ & 167,7 & 174,7 & 182,9 & 192,6 & 204,6 & 220,1 & 241,5 & 273,9 & 331,7 & 472,8 & 1542,1 & 173,9 \\
\hline $\mathrm{C}_{2} \mathrm{H}_{2}$ & ${ }^{1} J_{\mathrm{CH}}$ & 142,4 & 159,4 & 178,9 & 201,1 & 226,7 & 256,7 & 292,4 & 336,8 & 397,0 & 500,5 & 1037,2 & 244,4 \\
\hline $\mathrm{C}_{2} \mathrm{H}_{2}$ & ${ }^{2} J_{\mathrm{CH}}$ & 46,7 & 49,1 & 51,6 & 53,9 & 55,8 & 56,9 & 56,2 & 51,7 & 36,8 & $-14,6$ & $-491,4$ & 49,9 \\
\hline $\mathrm{C}_{2} \mathrm{H}_{2}$ & ${ }^{3} J_{\mathrm{HH}}$ & 4,3 & 4,8 & 5,3 & 6,0 & 7,0 & 8,5 & 10,9 & 15,4 & 24,8 & 51,4 & 274,4 & 8,9 \\
\hline $\mathrm{C}_{2} \mathrm{H}_{4}$ & ${ }^{1} J_{\mathrm{CC}}$ & 60,5 & 63,3 & 67,0 & 71,7 & 78,0 & 86,7 & 99,5 & 120,7 & 162,3 & 284,8 & 14163,1 & 66,6 \\
\hline $\mathrm{C}_{2} \mathrm{H}_{4}$ & ${ }^{1} J_{\mathrm{CH}}$ & 99,2 & 109,3 & 120,9 & 134,4 & 150,2 & 169,0 & 192,0 & 221,3 & 263,2 & 345,6 & 6656,1 & 154,3 \\
\hline $\mathrm{C}_{2} \mathrm{H}_{4}$ & ${ }^{2} J_{\mathrm{CH}}$ & 6,3 & 5,6 & 4,7 & 3,5 & 1,7 & $-1,0$ & $-5,4$ & $-13,2$ & $-30,1$ & $-83,1$ & $-6358,9$ & $-1,9$ \\
\hline $\mathrm{C}_{2} \mathrm{H}_{4}$ & ${ }^{2} J_{\mathrm{HH}}$ & 7,0 & 7,0 & 6,8 & 6,4 & 5,7 & 4,4 & 2,2 & $-1,8$ & $-10,4$ & $-37,0$ & $-3080,4$ & 2,1 \\
\hline $\mathrm{C}_{2} \mathrm{H}_{4}$ & ${ }^{3} J_{\mathrm{HH}_{\mathrm{c}}}$ & 9,1 & 9,5 & 9,9 & 10,5 & 11,2 & 12,3 & 14,1 & 17,4 & 24,8 & 49,5 & 3090,2 & 11,3 \\
\hline $\mathrm{C}_{2} \mathrm{H}_{4}$ & ${ }^{3} J_{\mathrm{HH}_{\mathrm{t}}}{ }^{\mathrm{C}}$ & 9,4 & 10,7 & 12,0 & 13,6 & 15,4 & 17,7 & 20,8 & 25,9 & 35,5 & 63,8 & 3278,1 & 18,3 \\
\hline $\mathrm{C}_{2} \mathrm{H}_{6}$ & ${ }^{1} J_{\mathrm{CC}}$ & 27,4 & 29,9 & 33,0 & 36,6 & 41,1 & 46,4 & 53,0 & 61,2 & 71,5 & 84,8 & 102,2 & 33,6 \\
\hline $\mathrm{C}_{2} \mathrm{H}_{6}$ & ${ }^{1} J_{\mathrm{CH}}$ & 84,0 & 91,7 & 100,8 & 111,4 & 123,8 & 138,4 & 155,8 & 176,6 & 201,7 & 232,6 & 271,0 & 123,4 \\
\hline $\mathrm{C}_{2} \mathrm{H}_{6}$ & ${ }^{2} J_{\mathrm{CH}}$ & 2,2 & 1,5 & 0,7 & $-0,2$ & $-1,5$ & $-3,0$ & $-5,0$ & $-7,5$ & $-10,8$ & $-15,3$ & $-21,7$ & $-4,5$ \\
\hline \multirow[t]{3}{*}{ Total } & $\mathrm{DM}$ & $-16,90$ & $-17,56$ & $-17,68$ & $-17,06$ & $-15,48$ & $-12,64$ & $-8,39$ & $-2,63$ & 4,42 & 1,75 & 686,10 & - \\
\hline & DMA & 31,77 & 28,58 & 25,23 & 22,43 & 22,16 & 25,15 & 31,11 & 39,91 & 59,18 & 116,94 & 1624,90 & - \\
\hline & PDMA & 91,52 & 82,70 & 72,13 & 60,80 & 47,88 & 34,02 & 36,90 & 73,83 & 155,16 & 388,66 & 21545,49 & - \\
\hline \multirow[t]{3}{*}{ CPI } & $\mathrm{DM}$ & $-18,29$ & $-24,98$ & $-31,16$ & $-36,52$ & $-40,71$ & $-43,45$ & $-44,97$ & $-46,34$ & $-51,15$ & $-99,04$ & $-167,83$ & - \\
\hline & DMA & 47,60 & 45,51 & 42,24 & 39,66 & 43,40 & 45,69 & 47,26 & 49,54 & 64,67 & 133,25 & 226,61 & - \\
\hline & PDMA & 106,44 & 96,75 & 84,47 & 71,35 & 59,79 & 46,76 & 38,78 & 41,19 & 61,25 & 117,11 & 189,32 & - \\
\hline \multirow[t]{3}{*}{ SPI } & $\mathrm{DM}$ & $-15,89$ & $-12,12$ & $-7,79$ & $-2,79$ & 3,03 & 9,96 & 18,43 & 29,41 & 45,16 & 75,66 & 1312,31 & - \\
\hline & DMA & 20,17 & 16,17 & 12,77 & 9,79 & 6,59 & 10,09 & 19,26 & 32,85 & 55,15 & 104,98 & 2650,32 & - \\
\hline & PDMA & 80,58 & 72,40 & 63,08 & 53,06 & 39,14 & 24,69 & 35,52 & 97,77 & 224,04 & 587,80 & 37206,67 & - \\
\hline \multirow[t]{3}{*}{$\Delta \mathrm{CS}$} & $\mathrm{DM}$ & $-2,40$ & $-12,86$ & $-23,37$ & $-33,72$ & $-43,74$ & $-53,41$ & $-63,41$ & $-75,75$ & $-96,31$ & $-174,70$ & $-1480,13$ & - \\
\hline & DMA & 27,43 & 29,34 & 29,47 & 29,87 & 36,81 & 35,60 & 28,00 & 16,68 & 9,53 & 28,27 & $-2423,71$ & - \\
\hline & PDMA & 25,86 & 24,35 & 21,38 & 18,29 & 20,66 & 22,07 & 3,26 & $-56,58$ & $-162,79$ & $-470,69$ & $-37017,35$ & - \\
\hline
\end{tabular}


Tabela 8.166: Constantes de acoplamento OLYP e constantes empíricas no nível PBE0 $40 \% E_{X}^{\mathrm{HF}}$ e base aug-pcJ-2.

\begin{tabular}{|c|c|c|c|c|c|c|c|c|c|c|c|c|c|}
\hline & $\% E_{X}^{\mathrm{HF}}$ & $0 \%$ & $10 \%$ & $20 \%$ & $30 \%$ & $40 \%$ & $50 \%$ & $60 \%$ & $70 \%$ & $80 \%$ & $90 \%$ & $100 \%$ & Emp. \\
\hline $\mathrm{HF}$ & ${ }^{1} J_{\mathrm{HF}}$ & 363,4 & 391,6 & 420,1 & 449,1 & 478,5 & 508,2 & 538,4 & 568,9 & 599,7 & 630,9 & 662,5 & 534,8 \\
\hline $\mathrm{CO}$ & ${ }^{1} J_{\mathrm{CO}}$ & 24,0 & 21,8 & 19,5 & 17,1 & 14,6 & 12,0 & 9,4 & 6,6 & 3,8 & 0,9 & $-1,9$ & 15,7 \\
\hline $\mathrm{H}_{2} \mathrm{O}$ & ${ }^{1} J_{\mathrm{OH}}$ & $-66,1$ & $-69,4$ & $-72,7$ & $-76,1$ & $-79,5$ & $-83,0$ & $-86,5$ & $-90,1$ & $-93,7$ & $-97,3$ & $-101,1$ & $-82,0$ \\
\hline $\mathrm{H}_{2} \mathrm{O}$ & ${ }^{2} J_{\mathrm{HH}}$ & $-7,4$ & $-8,3$ & $-9,3$ & $-10,2$ & $-11,1$ & $-12,1$ & $-13,1$ & $-14,1$ & $-15,2$ & $-16,2$ & $-17,3$ & $-8,8$ \\
\hline $\mathrm{NH}_{3}$ & ${ }^{1} J_{\mathrm{NH}}$ & 40,2 & 41,5 & 42,7 & 44,0 & 45,3 & 46,6 & 47,9 & 49,3 & 50,6 & 52,0 & 53,4 & 43,3 \\
\hline $\mathrm{NH}_{3}$ & ${ }^{2} J_{\mathrm{HH}}$ & $-9,6$ & $-10,4$ & $-11,3$ & $-12,1$ & $-13,0$ & $-13,9$ & $-14,8$ & $-15,7$ & $-16,7$ & $-17,7$ & $-18,7$ & $-10,4$ \\
\hline $\mathrm{PH}_{3}$ & ${ }^{1} J_{\mathrm{PH}}$ & 158,8 & 167,5 & 176,1 & 184,5 & 192,8 & 201,0 & 209,0 & 216,8 & 224,5 & 231,9 & 239,2 & 195,7 \\
\hline $\mathrm{PF}_{3}$ & ${ }^{1} J_{\mathrm{PF}}$ & $-1702,2$ & $-1685,7$ & $-1665,4$ & $-1642,0$ & $-1616,2$ & $-1588,5$ & $-1559,4$ & $-1529,4$ & $-1498,8$ & $-1467,9$ & $-1437,0$ & $-1.443,2$ \\
\hline $\mathrm{BHF}_{2}$ & ${ }^{1} J_{\mathrm{BF}}$ & $-181,4$ & $-160,8$ & $-140,7$ & $-121,1$ & $-102,0$ & $-83,5$ & $-65,6$ & $-48,2$ & $-31,4$ & $-15,1$ & 0,6 & $-79,6$ \\
\hline $\mathrm{BF}_{3}$ & ${ }^{1} J_{\mathrm{BF}}$ & $-90,5$ & $-67,4$ & $-45,0$ & $-23,1$ & $-1,8$ & 18,8 & 38,9 & 58,4 & 77,4 & 95,8 & 113,8 & 17,2 \\
\hline $\mathrm{F}_{2} \mathrm{O}$ & ${ }^{1} J_{\mathrm{OF}}$ & $-254,6$ & $-290,9$ & $-327,9$ & $-367,1$ & $-410,6$ & $-461,8$ & $-526,5$ & $-616,5$ & $-760,6$ & $-1056,6$ & $-2253,8$ & $-284,7$ \\
\hline $\mathrm{CH}_{4}$ & ${ }^{1} J_{\mathrm{CH}}$ & 118,2 & 121,1 & 124,1 & 127,1 & 130,2 & 133,3 & 136,4 & 139,6 & 142,9 & 146,1 & 149,4 & 122,9 \\
\hline $\mathrm{CH}_{4}$ & ${ }^{2} J_{\mathrm{HH}}$ & $-12,9$ & $-13,5$ & $-14,2$ & $-14,9$ & $-15,6$ & $-16,3$ & $-17,0$ & $-17,7$ & $-18,4$ & $-19,1$ & $-19,7$ & $-12,5$ \\
\hline $\mathrm{C}_{2} \mathrm{H}_{2}$ & ${ }^{1} J_{\mathrm{CC}}$ & 187,4 & 192,0 & 197,1 & 202,6 & 208,8 & 215,7 & 223,5 & 232,3 & 242,5 & 254,4 & 268,4 & 173,9 \\
\hline $\mathrm{C}_{2} \mathrm{H}_{2}$ & ${ }^{1} J_{\mathrm{CH}}$ & 253,4 & 258,1 & 263,0 & 268,0 & 273,2 & 278,7 & 284,6 & 290,9 & 297,7 & 305,1 & 313,5 & 244,4 \\
\hline $\mathrm{C}_{2} \mathrm{H}_{2}$ & ${ }^{2} J_{\mathrm{CH}}$ & 53,0 & 53,0 & 52,8 & 52,4 & 51,7 & 50,7 & 49,3 & 47,6 & 45,2 & 42,1 & 38,1 & 49,9 \\
\hline $\mathrm{C}_{2} \mathrm{H}_{2}$ & ${ }^{3} J_{\mathrm{HH}}$ & 11,6 & 12,2 & 12,9 & 13,7 & 14,7 & 15,9 & 17,3 & 18,9 & 20,9 & 23,2 & 26,0 & 8,9 \\
\hline $\mathrm{C}_{2} \mathrm{H}_{4}$ & ${ }^{1} J_{\mathrm{CC}}$ & 60,8 & 64,6 & 68,7 & 73,2 & 78,2 & 83,9 & 90,5 & 98,4 & 108,1 & 120,9 & 139,0 & 66,6 \\
\hline $\mathrm{C}_{2} \mathrm{H}_{4}$ & ${ }^{1} J_{\mathrm{CH}}$ & 152,7 & 156,5 & 160,4 & 164,4 & 168,6 & 173,1 & 177,9 & 183,2 & 189,3 & 196,5 & 205,7 & 154,3 \\
\hline $\mathrm{C}_{2} \mathrm{H}_{4}$ & ${ }^{2} J_{\mathrm{CH}}$ & $-1,1$ & $-2,0$ & $-3,1$ & $-4,3$ & $-5,6$ & $-7,2$ & $-9,2$ & $-11,6$ & $-14,8$ & $-19,1$ & $-25,4$ & $-1,9$ \\
\hline $\mathrm{C}_{2} \mathrm{H}_{4}$ & ${ }^{2} J_{\mathrm{HH}}$ & 3,4 & 2,8 & 2,2 & 1,5 & 0,8 & 0,0 & $-1,1$ & $-2,3$ & $-3,9$ & $-6,1$ & $-9,3$ & 2,1 \\
\hline $\mathrm{C}_{2} \mathrm{H}_{4}$ & ${ }^{3} J_{\mathrm{HH}_{\mathrm{c}}}$ & 12,2 & 12,6 & 13,1 & 13,6 & 14,2 & 14,9 & 15,8 & 17,0 & 18,5 & 20,6 & 23,7 & 11,3 \\
\hline $\mathrm{C}_{2} \mathrm{H}_{4}$ & ${ }^{3} J_{\mathrm{HH}_{\mathrm{t}}}$ & 19,4 & 19,8 & 20,3 & 21,0 & 21,7 & 22,6 & 23,6 & 25,0 & 26,8 & 29,3 & 32,9 & 18,3 \\
\hline $\mathrm{C}_{2} \mathrm{H}_{6}$ & ${ }^{1} J_{\mathrm{CC}}$ & 25,4 & 27,9 & 30,4 & 33,0 & 35,6 & 38,4 & 41,1 & 43,9 & 46,8 & 49,7 & 52,7 & 33,6 \\
\hline $\mathrm{C}_{2} \mathrm{H}_{6}$ & ${ }^{1} J_{\mathrm{CH}}$ & 118,4 & 121,5 & 124,6 & 127,8 & 131,0 & 134,2 & 137,5 & 140,8 & 144,1 & 147,5 & 150,9 & 123,4 \\
\hline $\mathrm{C}_{2} \mathrm{H}_{6}$ & ${ }^{2} J_{\mathrm{CH}}$ & $-3,3$ & $-3,7$ & $-4,1$ & $-4,5$ & $-5,0$ & $-5,4$ & $-5,9$ & $-6,4$ & $-6,8$ & $-7,3$ & $-7,8$ & $-4,5$ \\
\hline \multirow[t]{3}{*}{ Total } & $\mathrm{DM}$ & $-23,67$ & $-20,63$ & $-17,48$ & $-14,27$ & $-11,12$ & $-8,17$ & $-5,64$ & $-3,97$ & $-4,24$ & $-10,16$ & $-50,42$ & - \\
\hline & DMA & 30,60 & 25,54 & 23,38 & 21,80 & 20,73 & 20,79 & 24,70 & 32,13 & 41,88 & 57,84 & 109,57 & - \\
\hline & PDMA & 45,17 & 34,07 & 29,20 & 27,71 & 29,03 & 33,48 & 50,02 & 69,11 & 91,72 & 120,40 & 168,34 & - \\
\hline \multirow[t]{3}{*}{ CPI } & $\mathrm{DM}$ & $-56,67$ & $-51,68$ & $-46,54$ & $-41,36$ & $-36,45$ & $-32,20$ & $-29,12$ & $-28,36$ & $-32,58$ & $-50,66$ & $-150,75$ & - \\
\hline & DMA & 66,95 & 55,17 & 48,92 & 42,82 & 37,27 & 34,05 & 39,52 & 52,69 & 70,65 & 102,32 & 216,99 & - \\
\hline & PDMA & 85,14 & 65,28 & 50,15 & 36,44 & 24,78 & 17,97 & 35,60 & 55,59 & 77,15 & 103,15 & 157,79 & - \\
\hline \multirow[t]{3}{*}{ SPI } & $\mathrm{DM}$ & 0,53 & 2,15 & 3,83 & 5,59 & 7,45 & 9,45 & 11,57 & 13,93 & 16,55 & 19,54 & 23,16 & - \\
\hline & DMA & 3,95 & 3,81 & 4,65 & 6,39 & 8,60 & 11,07 & 13,84 & 17,06 & 20,79 & 25,22 & 30,79 & - \\
\hline & PDMA & 15,86 & 11,19 & 13,84 & 21,30 & 32,14 & 44,85 & 60,60 & 79,02 & 102,40 & 133,05 & 176,08 & - \\
\hline \multirow[t]{3}{*}{$\Delta \mathrm{CS}$} & $\mathrm{DM}$ & $-57,20$ & $-53,83$ & $-50,37$ & $-46,96$ & $-43,91$ & $-41,65$ & $-40,69$ & $-42,29$ & $-49,13$ & $-70,20$ & $-173,91$ & - \\
\hline & DMA & 62,99 & 51,36 & 44,27 & 36,42 & 28,67 & 22,99 & 25,68 & 35,63 & 49,87 & 77,10 & 186,20 & - \\
\hline & PDMA & 69,28 & 54,10 & 36,32 & 15,14 & $-7,36$ & $-26,87$ & $-25,00$ & $-23,43$ & $-25,25$ & $-29,91$ & $-18,30$ & - \\
\hline
\end{tabular}


Tabela 8.167: Constantes de acoplamento PBE e constantes empíricas no nível PBE0 40\% $E_{X}^{\mathrm{HF}}$ e base aug-pcJ-2.

\begin{tabular}{|c|c|c|c|c|c|c|c|c|c|c|c|c|c|}
\hline & $\% E_{X}^{\mathrm{HF}}$ & $0 \%$ & $10 \%$ & $20 \%$ & $30 \%$ & $40 \%$ & $50 \%$ & $60 \%$ & $70 \%$ & $80 \%$ & $90 \%$ & $100 \%$ & Emp. \\
\hline $\mathrm{HF}$ & ${ }^{1} J_{\mathrm{HF}}$ & 376,0 & 397,8 & 419,7 & 441,9 & 464,3 & 486,9 & 509,8 & 532,8 & 556,1 & 579,6 & 603,3 & 534,8 \\
\hline $\mathrm{CO}$ & ${ }^{1} J_{\mathrm{CO}}$ & 24,1 & 22,5 & 20,8 & 19,1 & 17,3 & 15,4 & 13,5 & 11,5 & 9,5 & 7,4 & 5,3 & 15,7 \\
\hline $\mathrm{H}_{2} \mathrm{O}$ & ${ }^{1} J_{\mathrm{OH}}$ & $-67,2$ & $-69,5$ & $-71,8$ & $-74,2$ & $-76,6$ & $-79,0$ & $-81,4$ & $-83,9$ & $-86,4$ & $-88,9$ & $-91,5$ & $-82,0$ \\
\hline $\mathrm{H}_{2} \mathrm{O}$ & ${ }^{2} J_{\mathrm{HH}}$ & $-4,7$ & $-5,7$ & $-6,7$ & $-7,8$ & $-8,9$ & $-10,0$ & $-11,1$ & $-12,3$ & $-13,5$ & $-14,7$ & $-15,9$ & $-8,8$ \\
\hline $\mathrm{NH}_{3}$ & ${ }^{1} J_{\mathrm{NH}}$ & 40,8 & 41,5 & 42,2 & 42,9 & 43,6 & 44,3 & 45,1 & 45,8 & 46,6 & 47,4 & 48,2 & 43,3 \\
\hline $\mathrm{NH}_{3}$ & ${ }^{2} J_{\mathrm{HH}}$ & $-7,8$ & $-8,7$ & $-9,6$ & $-10,6$ & $-11,5$ & $-12,5$ & $-13,5$ & $-14,5$ & $-15,5$ & $-16,6$ & $-17,6$ & $-10,4$ \\
\hline $\mathrm{PH}_{3}$ & ${ }^{1} J_{\mathrm{PH}}$ & 133,7 & 142,1 & 150,4 & 158,7 & 166,9 & 175,1 & 183,1 & 191,1 & 198,9 & 206,7 & 214,3 & 195,7 \\
\hline $\mathrm{PF}_{3}$ & ${ }^{1} J_{\mathrm{PF}}$ & $-1801,0$ & $-1776,9$ & $-1748,1$ & $-1715,3$ & $-1679,4$ & $-1640,8$ & $-1600,3$ & $-1558,1$ & $-1514,9$ & $-1470,9$ & $-1426,5$ & $-1.443,2$ \\
\hline $\mathrm{BHF}_{2}$ & ${ }^{1} J_{\mathrm{BF}}$ & $-172,8$ & $-155,9$ & $-139,2$ & $-122,7$ & $-106,5$ & $-90,4$ & $-74,6$ & $-59,0$ & $-43,7$ & $-28,6$ & $-13,8$ & $-79,6$ \\
\hline $\mathrm{BF}_{3}$ & ${ }^{1} J_{\mathrm{BF}}$ & $-75,8$ & $-57,5$ & $-39,4$ & $-21,7$ & $-4,2$ & 12,9 & 29,9 & 46,6 & 63,0 & 79,2 & 95,2 & 17,2 \\
\hline $\mathrm{F}_{2} \mathrm{O}$ & ${ }^{1} J_{\mathrm{OF}}$ & $-278,0$ & $-316,3$ & $-354,9$ & $-395,6$ & $-440,5$ & $-493,5$ & $-560,8$ & $-655,5$ & $-809,2$ & $-1129,5$ & $-2453,2$ & $-284,7$ \\
\hline $\mathrm{CH}_{4}$ & ${ }^{1} J_{\mathrm{CH}}$ & 119,3 & 120,7 & 122,1 & 123,5 & 125,0 & 126,5 & 128,0 & 129,6 & 131,2 & 132,8 & 134,4 & 122,9 \\
\hline $\mathrm{CH}_{4}$ & ${ }^{2} J_{\mathrm{HH}}$ & $-11,8$ & $-12,6$ & $-13,4$ & $-14,2$ & $-15,0$ & $-15,8$ & $-16,6$ & $-17,4$ & $-18,2$ & $-19,0$ & $-19,8$ & $-12,5$ \\
\hline $\mathrm{C}_{2} \mathrm{H}_{2}$ & ${ }^{1} J_{\mathrm{CC}}$ & 188,7 & 191,5 & 194,6 & 198,3 & 202,6 & 207,6 & 213,7 & 221,0 & 230,2 & 241,9 & 257,1 & 173,9 \\
\hline $\mathrm{C}_{2} \mathrm{H}_{2}$ & ${ }^{1} J_{\mathrm{CH}}$ & 249,8 & 252,2 & 254,8 & 257,6 & 260,7 & 264,1 & 268,0 & 272,5 & 277,9 & 284,6 & 293,3 & 244,4 \\
\hline $\mathrm{C}_{2} \mathrm{H}_{2}$ & ${ }^{2} J_{\mathrm{CH}}$ & 54,1 & 54,1 & 53,7 & 53,2 & 52,2 & 50,9 & 49,0 & 46,5 & 42,9 & 38,1 & 31,2 & 49,9 \\
\hline $\mathrm{C}_{2} \mathrm{H}_{2}$ & ${ }^{3} J_{\mathrm{HH}}$ & 10,4 & 11,1 & 11,9 & 12,9 & 14,1 & 15,6 & 17,4 & 19,6 & 22,5 & 26,1 & 30,9 & 8,9 \\
\hline $\mathrm{C}_{2} \mathrm{H}_{4}$ & ${ }^{1} J_{\mathrm{CC}}$ & 61,3 & 64,0 & 67,0 & 70,4 & 74,4 & 79,1 & 85,0 & 92,8 & 103,6 & 120,3 & 150,7 & 66,6 \\
\hline $\mathrm{C}_{2} \mathrm{H}_{4}$ & ${ }^{1} J_{\mathrm{CH}}$ & 151,8 & 153,9 & 156,1 & 158,5 & 161,1 & 164,0 & 167,5 & 171,6 & 177,1 & 185,2 & 199,0 & 154,3 \\
\hline $\mathrm{C}_{2} \mathrm{H}_{4}$ & ${ }^{2} J_{\mathrm{CH}}$ & $-0,5$ & $-1,4$ & $-2,5$ & $-3,7$ & $-5,1$ & $-6,9$ & $-9,1$ & $-12,2$ & $-16,5$ & $-23,4$ & $-36,1$ & $-1,9$ \\
\hline $\mathrm{C}_{2} \mathrm{H}_{4}$ & ${ }^{2} J_{\mathrm{HH}}$ & 4,5 & 3,7 & 2,8 & 1,8 & 0,7 & $-0,5$ & $-2,1$ & $-4,1$ & $-7,0$ & $-11,4$ & $-19,4$ & 2,1 \\
\hline $\mathrm{C}_{2} \mathrm{H}_{4}$ & ${ }^{3} J_{\mathrm{HH}_{\mathrm{c}}}$ & 11,7 & 12,1 & 12,5 & 13,0 & 13,6 & 14,5 & 15,7 & 17,3 & 19,7 & 23,7 & 31,3 & 11,3 \\
\hline $\mathrm{C}_{2} \mathrm{H}_{4}$ & ${ }^{3} J_{\mathrm{HH}_{\mathrm{t}}}$ & 18,7 & 19,0 & 19,5 & 20,1 & 20,9 & 21,9 & 23,3 & 25,2 & 28,0 & 32,5 & 41,0 & 18,3 \\
\hline $\mathrm{C}_{2} \mathrm{H}_{6}$ & ${ }^{1} J_{\mathrm{CC}}$ & 25,7 & 27,6 & 29,4 & 31,3 & 33,3 & 35,2 & 37,2 & 39,3 & 41,3 & 43,4 & 45,6 & 33,6 \\
\hline $\mathrm{C}_{2} \mathrm{H}_{6}$ & ${ }^{1} J_{\mathrm{CH}}$ & 119,5 & 121,1 & 122,7 & 124,3 & 126,0 & 127,7 & 129,4 & 131,2 & 133,0 & 134,8 & 136,6 & 123,4 \\
\hline $\mathrm{C}_{2} \mathrm{H}_{6}$ & ${ }^{2} J_{\mathrm{CH}}$ & $-2,9$ & $-3,4$ & $-3,9$ & $-4,3$ & $-4,9$ & $-5,4$ & $-5,9$ & $-6,4$ & $-7,0$ & $-7,5$ & $-8,1$ & $-4,5$ \\
\hline \multirow[t]{3}{*}{ Total } & $\mathrm{DM}$ & $-27,73$ & $-25,45$ & $-23,00$ & $-20,43$ & $-17,87$ & $-15,45$ & $-13,40$ & $-12,22$ & $-13,04$ & $-19,83$ & $-64,35$ & - \\
\hline & DMA & 33,07 & 30,11 & 27,77 & 25,84 & 24,33 & 23,42 & 24,77 & 28,76 & 37,38 & 53,72 & 111,65 & - \\
\hline & PDMA & 46,36 & 36,25 & 28,81 & 25,35 & 26,61 & 31,12 & 44,95 & 65,63 & 92,77 & 132,10 & 207,20 & - \\
\hline \multirow[t]{3}{*}{ CPI } & $\mathrm{DM}$ & $-66,43$ & $-62,24$ & $-57,69$ & $-53,03$ & $-48,50$ & $-44,51$ & $-41,66$ & $-41,23$ & $-46,10$ & $-66,08$ & $-177,29$ & - \\
\hline & DMA & 73,08 & 66,62 & 61,00 & 55,25 & 49,83 & 45,24 & 45,32 & 50,77 & 66,01 & 97,52 & 223,20 & - \\
\hline & PDMA & 81,38 & 66,52 & 52,13 & 38,16 & 26,03 & 16,98 & 24,90 & 41,07 & 60,10 & 84,96 & 141,85 & - \\
\hline \multirow[t]{3}{*}{ SPI } & $\mathrm{DM}$ & 0,64 & 1,53 & 2,44 & 3,47 & 4,59 & 5,85 & 7,32 & 9,05 & 11,20 & 14,09 & 18,47 & - \\
\hline & DMA & 3,73 & 3,34 & 3,40 & 4,28 & 5,63 & 7,43 & 9,69 & 12,61 & 16,39 & 21,60 & 29,84 & - \\
\hline & PDMA & 20,67 & 14,05 & 11,71 & 15,96 & 27,04 & 41,49 & 59,66 & 83,63 & 116,73 & 166,67 & 255,12 & - \\
\hline \multirow[t]{3}{*}{$\Delta \mathrm{CS}$} & $\mathrm{DM}$ & $-67,07$ & $-63,76$ & $-60,13$ & $-56,49$ & $-53,09$ & $-50,36$ & $-48,98$ & $-50,28$ & $-57,30$ & $-80,18$ & $-195,76$ & - \\
\hline & DMA & 69,35 & 63,28 & 57,60 & 50,97 & 44,19 & 37,81 & 35,62 & 38,16 & 49,62 & 75,92 & 193,36 & - \\
\hline & PDMA & 60,72 & 52,46 & 40,42 & 22,20 & $-1,00$ & $-24,51$ & $-34,75$ & $-42,56$ & $-56,63$ & $-81,70$ & $-113,27$ & - \\
\hline
\end{tabular}


Tabela 8.168: Constantes de acoplamento PW91 e constantes empíricas no nível PBE0 $40 \% E_{X}^{\mathrm{HF}}$ e base aug-pcJ-2.

\begin{tabular}{|c|c|c|c|c|c|c|c|c|c|c|c|c|c|}
\hline & $\% E_{X}^{\mathrm{HF}}$ & $0 \%$ & $10 \%$ & $20 \%$ & $30 \%$ & $40 \%$ & $50 \%$ & $60 \%$ & $70 \%$ & $80 \%$ & $90 \%$ & $100 \%$ & Emp. \\
\hline $\mathrm{HF}$ & ${ }^{1} J_{\mathrm{HF}}$ & 364,2 & 387,4 & 410,8 & 434,5 & 458,3 & 482,4 & 506,7 & 531,2 & 556,0 & 581,0 & 606,3 & 534,8 \\
\hline $\mathrm{CO}$ & ${ }^{1} J_{\mathrm{CO}}$ & 24,9 & 23,2 & 21,5 & 19,6 & 17,7 & 15,8 & 13,7 & 11,6 & 9,4 & 7,2 & 4,9 & 15,7 \\
\hline $\mathrm{H}_{2} \mathrm{O}$ & ${ }^{1} J_{\mathrm{OH}}$ & $-66,3$ & $-68,7$ & $-71,2$ & $-73,7$ & $-76,2$ & $-78,7$ & $-81,3$ & $-83,9$ & $-86,5$ & $-89,2$ & $-91,9$ & $-82,0$ \\
\hline $\mathrm{H}_{2} \mathrm{O}$ & ${ }^{2} J_{\mathrm{HH}}$ & $-4,8$ & $-5,8$ & $-6,8$ & $-7,9$ & $-9,0$ & $-10,1$ & $-11,2$ & $-12,4$ & $-13,5$ & $-14,7$ & $-16,0$ & $-8,8$ \\
\hline $\mathrm{NH}_{3}$ & ${ }^{1} J_{\mathrm{NH}}$ & 40,8 & 41,5 & 42,2 & 42,9 & 43,7 & 44,5 & 45,2 & 46,0 & 46,8 & 47,6 & 48,4 & 43,3 \\
\hline $\mathrm{NH}_{3}$ & ${ }^{2} J_{\mathrm{HH}}$ & $-8,0$ & $-8,9$ & $-9,8$ & $-10,8$ & $-11,7$ & $-12,7$ & $-13,6$ & $-14,6$ & $-15,6$ & $-16,6$ & $-17,7$ & $-10,4$ \\
\hline $\mathrm{PH}_{3}$ & ${ }^{1} J_{\mathrm{PH}}$ & 137,6 & 145,9 & 154,0 & 162,1 & 170,0 & 177,9 & 185,7 & 193,3 & 200,8 & 208,2 & 215,5 & 195,7 \\
\hline $\mathrm{PF}_{3}$ & ${ }^{1} J_{\mathrm{PF}}$ & $-1815,2$ & $-1790,1$ & $-1760,3$ & $-1726,4$ & $-1689,3$ & $-1649,5$ & $-1607,6$ & $-1564,2$ & $-1519,7$ & $-1474,3$ & $-1428,5$ & $-1.443,2$ \\
\hline $\mathrm{BHF}_{2}$ & ${ }^{1} J_{\mathrm{BF}}$ & $-177,6$ & $-160,4$ & $-143,4$ & $-126,4$ & $-109,6$ & $-93,0$ & $-76,5$ & $-60,2$ & $-44,1$ & $-28,2$ & $-12,5$ & $-79,6$ \\
\hline $\mathrm{BF}_{3}$ & ${ }^{1} J_{\mathrm{BF}}$ & $-80,9$ & $-62,3$ & $-43,8$ & $-25,6$ & $-7,6$ & 10,2 & 27,8 & 45,3 & 62,5 & 79,6 & 96,6 & 17,2 \\
\hline $\mathrm{F}_{2} \mathrm{O}$ & ${ }^{1} J_{\mathrm{OF}}$ & $-290,5$ & $-328,8$ & $-367,5$ & $-408,1$ & $-453,0$ & $-506,0$ & $-573,5$ & $-668,7$ & $-823,8$ & $-1148,9$ & $-2525,8$ & $-284,7$ \\
\hline $\mathrm{CH}_{4}$ & ${ }^{1} J_{\mathrm{CH}}$ & 120,1 & 121,5 & 122,9 & 124,3 & 125,8 & 127,3 & 128,8 & 130,4 & 131,9 & 133,5 & 135,2 & 122,9 \\
\hline $\mathrm{CH}_{4}$ & ${ }^{2} J_{\mathrm{HH}}$ & $-12,0$ & $-12,8$ & $-13,6$ & $-14,4$ & $-15,2$ & $-15,9$ & $-16,7$ & $-17,5$ & $-18,3$ & $-19,1$ & $-19,9$ & $-12,5$ \\
\hline $\mathrm{C}_{2} \mathrm{H}_{2}$ & ${ }^{1} J_{\mathrm{CC}}$ & 188,8 & 191,6 & 194,7 & 198,5 & 202,8 & 208,0 & 214,2 & 221,8 & 231,3 & 243,3 & 259,0 & 173,9 \\
\hline $\mathrm{C}_{2} \mathrm{H}_{2}$ & ${ }^{1} J_{\mathrm{CH}}$ & 252,5 & 254,8 & 257,3 & 259,9 & 262,8 & 266,1 & 269,8 & 274,3 & 279,6 & 286,1 & 294,6 & 244,4 \\
\hline $\mathrm{C}_{2} \mathrm{H}_{2}$ & ${ }^{2} J_{\mathrm{CH}}$ & 54,6 & 54,5 & 54,1 & 53,5 & 52,6 & 51,2 & 49,2 & 46,6 & 43,0 & 38,0 & 31,2 & 49,9 \\
\hline $\mathrm{C}_{2} \mathrm{H}_{2}$ & ${ }^{3} J_{\mathrm{HH}}$ & 10,5 & 11,2 & 12,0 & 13,0 & 14,2 & 15,7 & 17,5 & 19,7 & 22,5 & 26,1 & 30,7 & 8,9 \\
\hline $\mathrm{C}_{2} \mathrm{H}_{4}$ & ${ }^{1} J_{\mathrm{CC}}$ & 60,6 & 63,3 & 66,4 & 69,9 & 74,0 & 78,9 & 85,0 & 92,9 & 104,1 & 121,2 & 152,0 & 66,6 \\
\hline $\mathrm{C}_{2} \mathrm{H}_{4}$ & ${ }^{1} J_{\mathrm{CH}}$ & 153,0 & 155,1 & 157,3 & 159,6 & 162,2 & 165,1 & 168,5 & 172,7 & 178,2 & 186,2 & 200,0 & 154,3 \\
\hline $\mathrm{C}_{2} \mathrm{H}_{4}$ & ${ }^{2} J_{\mathrm{CH}}$ & $-0,4$ & $-1,3$ & $-2,3$ & $-3,5$ & $-5,0$ & $-6,8$ & $-9,1$ & $-12,1$ & $-16,5$ & $-23,5$ & $-36,2$ & $-1,9$ \\
\hline $\mathrm{C}_{2} \mathrm{H}_{4}$ & ${ }^{2} J_{\mathrm{HH}}$ & 4,5 & 3,6 & 2,8 & 1,8 & 0,7 & $-0,5$ & $-2,1$ & $-4,2$ & $-7,1$ & $-11,4$ & $-19,2$ & 2,1 \\
\hline $\mathrm{C}_{2} \mathrm{H}_{4}$ & ${ }^{3} J_{\mathrm{HH}_{\mathrm{c}}}$ & 11,9 & 12,2 & 12,6 & 13,1 & 13,8 & 14,7 & 15,8 & 17,4 & 19,8 & 23,8 & 31,2 & 11,3 \\
\hline $\mathrm{C}_{2} \mathrm{H}_{4}$ & ${ }^{3} J_{\mathrm{HH}_{\mathrm{t}}}{ }^{\mathrm{C}}$ & 19,0 & 19,3 & 19,8 & 20,4 & 21,1 & 22,1 & 23,5 & 25,4 & 28,1 & 32,6 & 40,9 & 18,3 \\
\hline $\mathrm{C}_{2} \mathrm{H}_{6}$ & ${ }^{1} J_{\mathrm{CC}}$ & 25,1 & 27,0 & 29,0 & 31,0 & 33,1 & 35,1 & 37,3 & 39,4 & 41,6 & 43,8 & 46,1 & 33,6 \\
\hline $\mathrm{C}_{2} \mathrm{H}_{6}$ & ${ }^{1} J_{\mathrm{CH}}$ & 120,3 & 121,9 & 123,5 & 125,1 & 126,8 & 128,5 & 130,2 & 132,0 & 133,7 & 135,5 & 137,3 & 123,4 \\
\hline $\mathrm{C}_{2} \mathrm{H}_{6}$ & ${ }^{2} J_{\mathrm{CH}}$ & $-2,9$ & $-3,4$ & $-3,9$ & $-4,4$ & $-4,9$ & $-5,4$ & $-5,9$ & $-6,4$ & $-7,0$ & $-7,5$ & $-8,1$ & $-4,5$ \\
\hline \multirow[t]{3}{*}{ Total } & $\mathrm{DM}$ & $-29,19$ & $-26,82$ & $-24,25$ & $-21,57$ & $-18,87$ & $-16,30$ & $-14,13$ & $-12,80$ & $-13,52$ & $-20,32$ & $-66,72$ & - \\
\hline & DMA & 34,41 & 31,91 & 29,43 & 27,46 & 25,82 & 24,75 & 25,61 & 29,62 & 38,43 & 55,04 & 114,95 & - \\
\hline & PDMA & 48,31 & 38,20 & 30,16 & 26,62 & 28,10 & 32,22 & 44,86 & 65,78 & 93,42 & 133,12 & 208,80 & - \\
\hline \multirow[t]{3}{*}{ CPI } & $\mathrm{DM}$ & $-70,35$ & $-65,91$ & $-61,12$ & $-56,16$ & $-51,34$ & $-47,02$ & $-43,87$ & $-43,15$ & $-47,79$ & $-67,85$ & $-183,52$ & - \\
\hline & DMA & 76,04 & 70,51 & 64,61 & 58,55 & 52,83 & 47,85 & 46,84 & 52,27 & 67,90 & 99,99 & 230,35 & - \\
\hline & PDMA & 84,99 & 70,26 & 55,59 & 41,50 & 29,18 & 19,34 & 24,07 & 40,81 & 60,57 & 86,15 & 145,66 & - \\
\hline \multirow[t]{3}{*}{ SPI } & $\mathrm{DM}$ & 0,99 & 1,85 & 2,79 & 3,81 & 4,94 & 6,23 & 7,69 & 9,45 & 11,61 & 14,53 & 18,94 & - \\
\hline & DMA & 3,89 & 3,60 & 3,63 & 4,66 & 6,02 & 7,80 & 10,05 & 13,01 & 16,81 & 22,07 & 30,31 & - \\
\hline & PDMA & 21,41 & 14,68 & 11,51 & 15,72 & 27,31 & 41,66 & 60,11 & 84,09 & 117,50 & 167,56 & 255,10 & - \\
\hline \multirow[t]{3}{*}{$\Delta \mathrm{CS}$} & $\mathrm{DM}$ & $-71,34$ & $-67,76$ & $-63,91$ & $-59,97$ & $-56,28$ & $-53,24$ & $-51,56$ & $-52,59$ & $-59,40$ & $-82,37$ & $-202,46$ & - \\
\hline & DMA & 72,15 & 66,91 & 60,98 & 53,89 & 46,81 & 40,05 & 36,79 & 39,27 & 51,09 & 77,92 & 200,04 & - \\
\hline & PDMA & 63,58 & 55,58 & 44,08 & 25,78 & 1,87 & $-22,32$ & $-36,04$ & $-43,28$ & $-56,93$ & $-81,42$ & $-109,44$ & - \\
\hline
\end{tabular}


Tabela 8.169: Constantes de acoplamento TPSSh e constantes empíricas no nível PBE0 $40 \% E_{X}^{\mathrm{HF}}$ e base aug-pcJ-2.

\begin{tabular}{|c|c|c|c|c|c|c|c|c|c|c|c|c|c|}
\hline & $\% E_{X}^{\mathrm{HF}}$ & $0 \%$ & $10 \%$ & $20 \%$ & $30 \%$ & $40 \%$ & $50 \%$ & $60 \%$ & $70 \%$ & $80 \%$ & $90 \%$ & $100 \%$ & Emp. \\
\hline $\mathrm{HF}$ & ${ }^{1} J_{\mathrm{HF}}$ & 366,0 & 390,6 & 415,1 & 439,7 & 464,2 & 488,7 & 513,1 & 537,4 & 561,6 & 585,8 & 610,0 & 534,8 \\
\hline $\mathrm{CO}$ & ${ }^{1} J_{\mathrm{CO}}$ & 21,7 & 20,3 & 18,8 & 17,3 & 15,7 & 14,0 & 12,3 & 10,5 & 8,7 & 6,8 & 4,9 & 15,7 \\
\hline $\mathrm{H}_{2} \mathrm{O}$ & ${ }^{1} J_{\mathrm{OH}}$ & $-70,2$ & $-72,5$ & $-74,9$ & $-77,3$ & $-79,6$ & $-82,0$ & $-84,3$ & $-86,6$ & $-88,9$ & $-91,1$ & $-93,4$ & $-82,0$ \\
\hline $\mathrm{H}_{2} \mathrm{O}$ & ${ }^{2} J_{\mathrm{HH}}$ & $-4,0$ & $-5,3$ & $-6,6$ & $-7,8$ & $-9,1$ & $-10,3$ & $-11,5$ & $-12,7$ & $-13,9$ & $-15,1$ & $-16,2$ & $-8,8$ \\
\hline $\mathrm{NH}_{3}$ & ${ }^{1} J_{\mathrm{NH}}$ & 45,3 & 45,8 & 46,4 & 46,9 & 47,3 & 47,8 & 48,3 & 48,8 & 49,2 & 49,7 & 50,1 & 43,3 \\
\hline $\mathrm{NH}_{3}$ & ${ }^{2} J_{\mathrm{HH}}$ & $-6,9$ & $-8,1$ & $-9,3$ & $-10,4$ & $-11,6$ & $-12,7$ & $-13,8$ & $-14,9$ & $-15,9$ & $-17,0$ & $-17,9$ & $-10,4$ \\
\hline $\mathrm{PH}_{3}$ & ${ }^{1} J_{\mathrm{PH}}$ & 195,7 & 200,5 & 205,0 & 209,3 & 213,4 & 217,2 & 220,8 & 224,1 & 227,2 & 230,0 & 232,6 & 195,7 \\
\hline $\mathrm{PF}_{3}$ & ${ }^{1} J_{\mathrm{PF}}$ & $-1757,5$ & $-1731,7$ & $-1703,3$ & $-1673,0$ & $-1641,1$ & $-1608,0$ & $-1574,1$ & $-1539,7$ & $-1504,9$ & $-1470,0$ & $-1435,2$ & $-1.443,2$ \\
\hline $\mathrm{BHF}_{2}$ & ${ }^{1} J_{\mathrm{BF}}$ & $-156,7$ & $-142,5$ & $-128,4$ & $-114,3$ & $-100,2$ & $-86,1$ & $-72,1$ & $-58,1$ & $-44,2$ & $-30,3$ & $-16,4$ & $-79,6$ \\
\hline $\mathrm{BF}_{3}$ & ${ }^{1} J_{\mathrm{BF}}$ & $-63,8$ & $-47,2$ & $-30,7$ & $-14,3$ & 1,8 & 17,8 & 33,8 & 49,6 & 65,2 & 80,8 & 96,3 & 17,2 \\
\hline $\mathrm{F}_{2} \mathrm{O}$ & ${ }^{1} J_{\mathrm{OF}}$ & $-282,7$ & $-320,1$ & $-359,5$ & $-402,5$ & $-451,3$ & $-510,0$ & $-585,2$ & $-690,4$ & $-857,9$ & $-1192,7$ & $-2403,5$ & $-284,7$ \\
\hline $\mathrm{CH}_{4}$ & ${ }^{1} J_{\mathrm{CH}}$ & 138,0 & 138,8 & 139,6 & 140,4 & 141,1 & 141,9 & 142,6 & 143,2 & 143,8 & 144,4 & 144,9 & 122,9 \\
\hline $\mathrm{CH}_{4}$ & ${ }^{2} J_{\mathrm{HH}}$ & $-10,2$ & $-11,3$ & $-12,4$ & $-13,4$ & $-14,5$ & $-15,5$ & $-16,5$ & $-17,4$ & $-18,4$ & $-19,3$ & $-20,2$ & $-12,5$ \\
\hline $\mathrm{C}_{2} \mathrm{H}_{2}$ & ${ }^{1} J_{\mathrm{CC}}$ & 187,5 & 190,8 & 194,6 & 198,9 & 203,9 & 209,8 & 216,7 & 225,0 & 234,9 & 247,0 & 262,1 & 173,9 \\
\hline $\mathrm{C}_{2} \mathrm{H}_{2}$ & ${ }^{1} J_{\mathrm{CH}}$ & 280,6 & 282,3 & 284,1 & 286,1 & 288,3 & 290,8 & 293,7 & 297,1 & 301,3 & 306,4 & 312,9 & 244,4 \\
\hline $\mathrm{C}_{2} \mathrm{H}_{2}$ & ${ }^{2} J_{\mathrm{CH}}$ & 58,3 & 57,7 & 56,9 & 55,8 & 54,3 & 52,4 & 50,0 & 46,9 & 43,0 & 38,0 & 31,5 & 49,9 \\
\hline $\mathrm{C}_{2} \mathrm{H}_{2}$ & ${ }^{3} J_{\mathrm{HH}}$ & 12,0 & 12,6 & 13,5 & 14,5 & 15,7 & 17,3 & 19,1 & 21,4 & 24,1 & 27,5 & 31,8 & 8,9 \\
\hline $\mathrm{C}_{2} \mathrm{H}_{4}$ & ${ }^{1} J_{\mathrm{CC}}$ & 68,8 & 71,5 & 74,5 & 78,0 & 82,1 & 87,0 & 93,1 & 100,9 & 111,6 & 127,4 & 153,5 & 66,6 \\
\hline $\mathrm{C}_{2} \mathrm{H}_{4}$ & ${ }^{1} J_{\mathrm{CH}}$ & 172,7 & 174,3 & 176,1 & 178,0 & 180,1 & 182,5 & 185,3 & 188,9 & 193,6 & 200,5 & 211,7 & 154,3 \\
\hline $\mathrm{C}_{2} \mathrm{H}_{4}$ & ${ }^{2} J_{\mathrm{CH}}$ & $-0,6$ & $-1,7$ & $-3,0$ & $-4,5$ & $-6,2$ & $-8,3$ & $-10,9$ & $-14,3$ & $-18,9$ & $-25,6$ & $-36,8$ & $-1,9$ \\
\hline $\mathrm{C}_{2} \mathrm{H}_{4}$ & ${ }^{2} J_{\mathrm{HH}}$ & 9,4 & 8,2 & 6,8 & 5,4 & 3,8 & 2,0 & 0,0 & $-2,5$ & $-5,8$ & $-10,3$ & $-17,4$ & 2,1 \\
\hline $\mathrm{C}_{2} \mathrm{H}_{4}$ & ${ }^{3} J_{\mathrm{HH}_{\mathrm{c}}}$ & 12,0 & 12,5 & 13,0 & 13,7 & 14,5 & 15,5 & 16,9 & 18,6 & 21,1 & 24,9 & 31,3 & 11,3 \\
\hline $\mathrm{C}_{2} \mathrm{H}_{4}$ & ${ }^{3} J_{\mathrm{HH}_{\mathrm{t}}}$ & 22,1 & 22,5 & 22,9 & 23,5 & 24,2 & 25,2 & 26,6 & 28,4 & 31,1 & 35,2 & 42,2 & 18,3 \\
\hline $\mathrm{C}_{2} \mathrm{H}_{6}$ & ${ }^{1} J_{\mathrm{CC}}$ & 32,9 & 34,4 & 35,8 & 37,2 & 38,7 & 40,1 & 41,5 & 42,9 & 44,2 & 45,6 & 46,9 & 33,6 \\
\hline $\mathrm{C}_{2} \mathrm{H}_{6}$ & ${ }^{1} J_{\mathrm{CH}}$ & 137,9 & 138,9 & 140,0 & 141,0 & 141,9 & 142,9 & 143,8 & 144,7 & 145,5 & 146,3 & 147,1 & 123,4 \\
\hline $\mathrm{C}_{2} \mathrm{H}_{6}$ & ${ }^{2} J_{\mathrm{CH}}$ & $-3,3$ & $-3,8$ & $-4,3$ & $-4,9$ & $-5,4$ & $-5,9$ & $-6,4$ & $-7,0$ & $-7,5$ & $-8,0$ & $-8,5$ & $-4,5$ \\
\hline \multirow[t]{3}{*}{ Total } & $\mathrm{DM}$ & $-18,60$ & $-16,58$ & $-14,54$ & $-12,52$ & $-10,64$ & $-9,02$ & $-7,92$ & $-7,84$ & $-9,96$ & $-18,15$ & $-59,40$ & - \\
\hline & DMA & 30,77 & 29,22 & 27,95 & 26,93 & 26,27 & 26,29 & 29,15 & 34,30 & 43,90 & 60,62 & 112,94 & - \\
\hline & PDMA & 52,73 & 42,85 & 37,04 & 33,92 & 32,55 & 34,32 & 52,12 & 74,52 & 102,76 & 141,27 & 208,17 & - \\
\hline \multirow[t]{3}{*}{ CPI } & $\mathrm{DM}$ & $-55,55$ & $-51,65$ & $-47,76$ & $-44,04$ & $-40,77$ & $-38,33$ & $-37,34$ & $-39,09$ & $-46,53$ & $-69,19$ & $-171,52$ & - \\
\hline & DMA & 61,03 & 56,60 & 52,47 & 48,49 & 45,15 & 43,16 & 47,19 & 55,53 & 73,36 & 106,39 & 220,46 & - \\
\hline & PDMA & 69,75 & 56,71 & 43,85 & 31,31 & 21,55 & 16,56 & 30,62 & 47,14 & 66,16 & 90,65 & 142,87 & - \\
\hline \multirow[t]{3}{*}{ SPI } & $\mathrm{DM}$ & 8,49 & 9,13 & 9,83 & 10,60 & 11,45 & 12,47 & 13,65 & 15,07 & 16,86 & 19,29 & 22,82 & - \\
\hline & DMA & 8,59 & 9,13 & 9,97 & 11,12 & 12,41 & 13,92 & 15,92 & 18,73 & 22,29 & 27,06 & 34,09 & - \\
\hline & PDMA & 40,25 & 32,69 & 32,04 & 35,84 & 40,62 & 47,34 & 67,89 & 94,60 & 129,60 & 178,40 & 256,05 & - \\
\hline \multirow[t]{3}{*}{$\Delta \mathrm{CS}$} & $\mathrm{DM}$ & $-64,05$ & $-60,79$ & $-57,59$ & $-54,64$ & $-52,23$ & $-50,79$ & $-50,99$ & $-54,16$ & $-63,39$ & $-88,48$ & $-194,34$ & - \\
\hline & DMA & 52,44 & 47,47 & 42,50 & 37,37 & 32,74 & 29,24 & 31,27 & 36,80 & 51,08 & 79,33 & 186,38 & - \\
\hline & PDMA & 29,50 & 24,02 & 11,81 & $-4,53$ & $-19,07$ & $-30,78$ & $-37,27$ & $-47,46$ & $-63,44$ & $-87,75$ & $-113,18$ & - \\
\hline
\end{tabular}


Tabela 8.170: Constantes de acoplamento X3LYP e constantes empíricas no nível PBE0 $40 \% E_{X}^{\mathrm{HF}}$ e base aug-pcJ-2.

\begin{tabular}{|c|c|c|c|c|c|c|c|c|c|c|c|c|c|}
\hline & $\% E_{X}^{\mathrm{HF}}$ & $0 \%$ & $10 \%$ & $20 \%$ & $30 \%$ & $40 \%$ & $50 \%$ & $60 \%$ & $70 \%$ & $80 \%$ & $90 \%$ & $100 \%$ & Emp. \\
\hline $\mathrm{HF}$ & ${ }^{1} J_{\mathrm{HF}}$ & 397,3 & 422,2 & 447,3 & 472,6 & 498,2 & 524,1 & 550,1 & 576,4 & 602,9 & 629,7 & 656,7 & 534,8 \\
\hline $\mathrm{CO}$ & ${ }^{1} J_{\mathrm{CO}}$ & 21,5 & 19,7 & 17,7 & 15,6 & 13,4 & 11,1 & 8,8 & 6,3 & 3,8 & 1,2 & $-1,4$ & 15,7 \\
\hline $\mathrm{H}_{2} \mathrm{O}$ & ${ }^{1} J_{\mathrm{OH}}$ & $-72,3$ & $-75,0$ & $-77,6$ & $-80,4$ & $-83,1$ & $-85,8$ & $-88,6$ & $-91,5$ & $-94,3$ & $-97,2$ & $-100,1$ & $-82,0$ \\
\hline $\mathrm{H}_{2} \mathrm{O}$ & ${ }^{2} J_{\mathrm{HH}}$ & $-5,3$ & $-6,4$ & $-7,5$ & $-8,6$ & $-9,7$ & $-10,9$ & $-12,1$ & $-13,3$ & $-14,5$ & $-15,7$ & $-17,0$ & $-8,8$ \\
\hline $\mathrm{NH}_{3}$ & ${ }^{1} J_{\mathrm{NH}}$ & 44,5 & 45,3 & 46,1 & 46,9 & 47,8 & 48,6 & 49,4 & 50,3 & 51,2 & 52,0 & 52,9 & 43,3 \\
\hline $\mathrm{NH}_{3}$ & ${ }^{2} J_{\mathrm{HH}}$ & $-8,4$ & $-9,3$ & $-10,3$ & $-11,2$ & $-12,2$ & $-13,2$ & $-14,2$ & $-15,2$ & $-16,3$ & $-17,3$ & $-18,4$ & $-10,4$ \\
\hline $\mathrm{PH}_{3}$ & ${ }^{1} J_{\mathrm{PH}}$ & 158,3 & 166,8 & 175,2 & 183,5 & 191,6 & 199,6 & 207,5 & 215,2 & 222,7 & 230,0 & 237,2 & 195,7 \\
\hline $\mathrm{PF}_{3}$ & ${ }^{1} J_{\mathrm{PF}}$ & $-1812,7$ & $-1787,4$ & $-1757,6$ & $-1724,0$ & $-1687,4$ & $-1648,2$ & $-1607,1$ & $-1564,6$ & $-1521,0$ & $-1476,7$ & $-1432,0$ & $-1.443,2$ \\
\hline $\mathrm{BHF}_{2}$ & ${ }^{1} J_{\mathrm{BF}}$ & $-168,0$ & $-150,4$ & $-132,9$ & $-115,6$ & $-98,4$ & $-81,4$ & $-64,6$ & $-47,9$ & $-31,5$ & $-15,3$ & 0,7 & $-79,6$ \\
\hline $\mathrm{BF}_{3}$ & ${ }^{1} J_{\mathrm{BF}}$ & $-69,5$ & $-50,4$ & $-31,4$ & $-12,7$ & 5,7 & 24,0 & 42,1 & 60,0 & 77,8 & 95,3 & 112,7 & 17,2 \\
\hline $\mathrm{F}_{2} \mathrm{O}$ & ${ }^{1} J_{\mathrm{OF}}$ & $-280,3$ & $-317,2$ & $-354,2$ & $-392,9$ & $-435,5$ & $-485,2$ & $-547,9$ & $-635,3$ & $-775,4$ & $-1061,6$ & $-2173,7$ & $-284,7$ \\
\hline $\mathrm{CH}_{4}$ & ${ }^{1} J_{\mathrm{CH}}$ & 131,8 & 133,3 & 134,9 & 136,5 & 138,1 & 139,7 & 141,4 & 143,0 & 144,7 & 146,4 & 148,2 & 122,9 \\
\hline $\mathrm{CH}_{4}$ & ${ }^{2} J_{\mathrm{HH}}$ & $-11,8$ & $-12,6$ & $-13,4$ & $-14,2$ & $-15,0$ & $-15,7$ & $-16,5$ & $-17,3$ & $-18,0$ & $-18,7$ & $-19,5$ & $-12,5$ \\
\hline $\mathrm{C}_{2} \mathrm{H}_{2}$ & ${ }^{1} J_{\mathrm{CC}}$ & 199,6 & 202,6 & 206,0 & 210,0 & 214,5 & 219,9 & 226,1 & 233,6 & 242,6 & 253,6 & 267,3 & 173,9 \\
\hline $\mathrm{C}_{2} \mathrm{H}_{2}$ & ${ }^{1} J_{\mathrm{CH}}$ & 272,4 & 274,9 & 277,4 & 280,1 & 283,0 & 286,2 & 289,8 & 293,8 & 298,5 & 304,0 & 310,7 & 244,4 \\
\hline $\mathrm{C}_{2} \mathrm{H}_{2}$ & ${ }^{2} J_{\mathrm{CH}}$ & 57,0 & 56,9 & 56,6 & 56,1 & 55,2 & 54,0 & 52,3 & 50,1 & 47,2 & 43,4 & 38,4 & 49,9 \\
\hline $\mathrm{C}_{2} \mathrm{H}_{2}$ & ${ }^{3} J_{\mathrm{HH}}$ & 10,1 & 10,7 & 11,4 & 12,3 & 13,3 & 14,5 & 15,9 & 17,7 & 19,8 & 22,4 & 25,6 & 8,9 \\
\hline $\mathrm{C}_{2} \mathrm{H}_{4}$ & ${ }^{1} J_{\mathrm{CC}}$ & 66,9 & 69,8 & 73,1 & 76,7 & 80,8 & 85,6 & 91,3 & 98,4 & 107,5 & 119,9 & 138,1 & 66,6 \\
\hline $\mathrm{C}_{2} \mathrm{H}_{4}$ & ${ }^{1} J_{\mathrm{CH}}$ & 166,3 & 168,5 & 170,8 & 173,3 & 175,9 & 178,8 & 182,0 & 185,7 & 190,2 & 196,0 & 204,0 & 154,3 \\
\hline $\mathrm{C}_{2} \mathrm{H}_{4}$ & ${ }^{2} J_{\mathrm{CH}}$ & 0,2 & $-0,6$ & $-1,6$ & $-2,8$ & $-4,1$ & $-5,7$ & $-7,7$ & $-10,2$ & $-13,5$ & $-18,1$ & $-25,0$ & $-1,9$ \\
\hline $\mathrm{C}_{2} \mathrm{H}_{4}$ & ${ }^{2} J_{\mathrm{HH}}$ & 6,1 & 5,4 & 4,6 & 3,7 & 2,7 & 1,7 & 0,4 & $-1,0$ & $-2,9$ & $-5,5$ & $-9,2$ & 2,1 \\
\hline $\mathrm{C}_{2} \mathrm{H}_{4}$ & ${ }^{3} J_{\mathrm{HH}_{\mathrm{C}}}$ & 12,5 & 12,8 & 13,1 & 13,5 & 13,9 & 14,6 & 15,4 & 16,4 & 17,9 & 20,0 & 23,3 & 11,3 \\
\hline $\mathrm{C}_{2} \mathrm{H}_{4}$ & ${ }^{3} J_{\mathrm{HH}_{\mathrm{t}}}$ & 19,9 & 20,2 & 20,5 & 21,0 & 21,5 & 22,3 & 23,2 & 24,5 & 26,2 & 28,7 & 32,4 & 18,3 \\
\hline $\mathrm{C}_{2} \mathrm{H}_{6}$ & ${ }^{1} J_{\mathrm{CC}}$ & 29,4 & 31,5 & 33,7 & 35,9 & 38,1 & 40,4 & 42,7 & 45,1 & 47,5 & 49,9 & 52,4 & 33,6 \\
\hline $\mathrm{C}_{2} \mathrm{H}_{6}$ & ${ }^{1} J_{\mathrm{CH}}$ & 131,3 & 133,1 & 134,8 & 136,6 & 138,4 & 140,3 & 142,1 & 144,0 & 145,9 & 147,8 & 149,7 & 123,4 \\
\hline $\mathrm{C}_{2} \mathrm{H}_{6}$ & ${ }^{2} J_{\mathrm{CH}}$ & $-2,5$ & $-3,0$ & $-3,5$ & $-4,0$ & $-4,5$ & $-5,0$ & $-5,5$ & $-6,1$ & $-6,6$ & $-7,2$ & $-7,7$ & $-4,5$ \\
\hline \multirow[t]{3}{*}{ Total } & $\mathrm{DM}$ & $-22,86$ & $-20,28$ & $-17,52$ & $-14,65$ & $-11,79$ & $-9,02$ & $-6,63$ & $-5,02$ & $-5,24$ & $-10,83$ & $-47,78$ & - \\
\hline & DMA & 32,81 & 30,40 & 28,23 & 26,34 & 24,89 & 24,77 & 28,77 & 34,82 & 43,31 & 57,87 & 105,79 & - \\
\hline & PDMA & 48,32 & 38,95 & 29,55 & 24,61 & 23,10 & 28,50 & 44,78 & 63,44 & 86,15 & 115,71 & 164,65 & - \\
\hline \multirow[t]{3}{*}{ CPI } & $\mathrm{DM}$ & $-62,99$ & $-58,19$ & $-53,02$ & $-47,71$ & $-42,51$ & $-37,75$ & $-34,05$ & $-32,51$ & $-35,69$ & $-52,15$ & $-143,67$ & - \\
\hline & DMA & 67,83 & 61,19 & 54,95 & 48,69 & 43,33 & 40,66 & 47,35 & 58,44 & 74,18 & 103,11 & 209,13 & - \\
\hline & PDMA & 72,51 & 57,23 & 42,08 & 28,66 & 20,29 & 20,67 & 37,86 & 56,63 & 77,05 & 101,92 & 153,42 & - \\
\hline \multirow[t]{3}{*}{ SPI } & $\mathrm{DM}$ & 6,57 & 7,52 & 8,51 & 9,60 & 10,74 & 12,06 & 13,48 & 15,13 & 17,09 & 19,46 & 22,53 & - \\
\hline & DMA & 7,13 & 7,81 & 8,63 & 9,95 & 11,37 & 13,11 & 15,15 & 17,51 & 20,67 & 24,69 & 30,01 & - \\
\hline & PDMA & 30,58 & 25,54 & 20,36 & 21,64 & 25,15 & 34,23 & 49,86 & 68,44 & 92,83 & 125,82 & 172,88 & - \\
\hline \multirow[t]{3}{*}{$\Delta \mathrm{CS}$} & $\mathrm{DM}$ & $-69,56$ & $-65,71$ & $-61,53$ & $-57,31$ & $-53,25$ & $-49,81$ & $-47,53$ & $-47,64$ & $-52,78$ & $-71,61$ & $-166,21$ & - \\
\hline & DMA & 60,70 & 53,38 & 46,31 & 38,74 & 31,96 & 27,55 & 32,20 & 40,93 & 53,51 & 78,42 & 179,11 & - \\
\hline & PDMA & 41,93 & 31,69 & 21,72 & 7,02 & $-4,86$ & $-13,56$ & $-12,00$ & $-11,82$ & $-15,77$ & $-23,91$ & $-19,46$ & - \\
\hline
\end{tabular}




\subsubsection{Variação da porcentagem de $E_{X}^{\mathrm{HF}}$ para os funcionais híbridos - Geo- metrias Otimizadas}

Tabela 8.171: Constantes de acoplamento B971 com otimização de geometrias e constantes empíricas no nível BHandH $\left(50 \% E_{X}^{\mathrm{HF}}\right)$ e base aug-pcJ-2.

\begin{tabular}{|c|c|c|c|c|c|c|c|c|c|c|c|c|c|}
\hline & $\% E_{X}^{\mathrm{HF}}$ & 21,00 & 21,00 & 40,00 & 40,00 & $\begin{array}{l}21,00 \\
40,00 \\
\text { Otm. }\end{array}$ & 50,00 & 50,00 & $\begin{array}{l}21,00 \\
50,00 \\
\text { Otm. }\end{array}$ & 60,00 & 60,00 & $\begin{array}{l}21,00 \\
60,00 \\
\text { Otm. }\end{array}$ & Exp. \\
\hline $\mathrm{HF}$ & ${ }^{1} J_{\mathrm{HF}}$ & 449,1 & 441,3 & 499,7 & 438,6 & 492,5 & 520,6 & 485,9 & 513,5 & 542,8 & 533,4 & 535,7 & 532,8 \\
\hline $\mathrm{CO}$ & ${ }^{1} J_{\mathrm{CO}}$ & 17,4 & 16,9 & 10,7 & 14,6 & 10,2 & 9,0 & 10,4 & 8,6 & 7,3 & 6,2 & 6,8 & 15,7 \\
\hline $\mathrm{H}_{2} \mathrm{O}$ & ${ }^{1} J_{\mathrm{OH}}$ & $-74,4$ & $-74,2$ & $-77,0$ & $-70,0$ & $-76,8$ & $-79,7$ & $-76,0$ & $-79,5$ & $-82,5$ & $-81,9$ & $-82,4$ & $-81,7$ \\
\hline $\mathrm{H}_{2} \mathrm{O}$ & ${ }^{2} J_{\mathrm{HH}}$ & $-6,5$ & $-6,2$ & $-5,1$ & $-5,1$ & $-4,8$ & $-6,4$ & $-6,1$ & $-6,1$ & $-7,7$ & $-7,1$ & $-7,4$ & $-8,8$ \\
\hline $\mathrm{NH}_{3}$ & ${ }^{1} J_{\mathrm{NH}}$ & 43,3 & 43,4 & 41,9 & 40,0 & 42,0 & 43,1 & 42,4 & 43,2 & 44,4 & 44,8 & 44,6 & 43,0 \\
\hline $\mathrm{NH}_{3}$ & ${ }^{2} J_{\mathrm{HH}}$ & $-9,1$ & $-9,0$ & $-7,4$ & $-7,4$ & $-7,2$ & $-8,6$ & $-8,3$ & $-8,4$ & $-9,9$ & $-9,3$ & $-9,7$ & $-10,5$ \\
\hline $\mathrm{PH}_{3}$ & ${ }^{1} J_{\mathrm{PH}}$ & 190,7 & 196,4 & 188,9 & 182,7 & 194,0 & 196,6 & 195,7 & 201,5 & 204,6 & 208,5 & 209,3 & 195,0 \\
\hline $\mathrm{PF}_{3}$ & ${ }^{1} J_{\mathrm{PF}}$ & $-1656,7$ & $-1547,7$ & $-1562,1$ & $-1459,7$ & $-1478,1$ & $-1539,1$ & $-1449,7$ & $-1459,4$ & $-1513,4$ & $-1429,0$ & $-1438,0$ & $-1441,7$ \\
\hline $\mathrm{BHF}_{2}$ & ${ }^{1} J_{\mathrm{BF}}$ & $-123,8$ & $-129,8$ & $-85,1$ & $-118,1$ & $-91,1$ & $-69,6$ & $-88,3$ & $-75,5$ & $-54,0$ & $-59,4$ & $-59,8$ & $-79,7$ \\
\hline $\mathrm{BF}_{3}$ & ${ }^{1} J_{\mathrm{BF}}$ & $-27,9$ & $-39,4$ & 12,4 & $-28,7$ & 1,5 & 29,7 & 5,7 & 19,0 & 47,1 & 39,2 & 36,7 & 17,1 \\
\hline $\mathrm{F}_{2} \mathrm{O}$ & ${ }^{1} J_{\mathrm{OF}}$ & $-318,8$ & $-257,2$ & $-327,7$ & $-318,6$ & $-262,4$ & $-370,4$ & $-281,7$ & $-298,6$ & $-421,2$ & $-245,8$ & $-340,0$ & $-285,7$ \\
\hline $\mathrm{CH}_{4}$ & ${ }^{1} J_{\mathrm{CH}}$ & 128,8 & 129,3 & 116,5 & 121,4 & 116,9 & 120,6 & 124,4 & 121,1 & 125,0 & 127,5 & 125,4 & 122,8 \\
\hline $\mathrm{CH}_{4}$ & ${ }^{2} J_{\mathrm{HH}}$ & $-12,0$ & $-12,0$ & $-9,6$ & $-9,3$ & $-9,5$ & $-10,7$ & $-10,5$ & $-10,6$ & $-11,8$ & $-11,7$ & $-11,8$ & $-12,5$ \\
\hline $\mathrm{C}_{2} \mathrm{H}_{2}$ & ${ }^{1} J_{\mathrm{CC}}$ & 213,8 & 213,8 & 205,0 & 207,4 & 205,1 & 211,6 & 213,6 & 211,5 & 219,4 & 220,2 & 219,1 & 174,1 \\
\hline $\mathrm{C}_{2} \mathrm{H}_{2}$ & ${ }^{1} J_{\mathrm{CH}}$ & 261,3 & 260,2 & 229,5 & 239,0 & 228,6 & 237,9 & 243,9 & 236,9 & 247,0 & 249,0 & 245,9 & 244,3 \\
\hline $\mathrm{C}_{2} \mathrm{H}_{2}$ & ${ }^{2} J_{\mathrm{CH}}$ & 53,2 & 53,3 & 53,2 & 53,3 & 53,2 & 53,0 & 53,1 & 53,1 & 52,5 & 52,6 & 52,6 & 49,8 \\
\hline $\mathrm{C}_{2} \mathrm{H}_{2}$ & ${ }^{3} J_{\mathrm{HH}}$ & 10,5 & 10,3 & 8,4 & 9,1 & 8,2 & 9,3 & 9,7 & 9,1 & 10,5 & 10,5 & 10,3 & 9,0 \\
\hline $\mathrm{C}_{2} \mathrm{H}_{4}$ & ${ }^{1} J_{\mathrm{CC}}$ & 78,1 & 80,5 & 76,4 & 78,7 & 78,8 & 80,8 & 83,5 & 83,1 & 86,2 & 88,6 & 88,1 & 66,9 \\
\hline $\mathrm{C}_{2} \mathrm{H}_{4}$ & ${ }^{1} J_{\mathrm{CH}}$ & 162,8 & 160,7 & 145,4 & 149,6 & 143,6 & 151,2 & 153,5 & 149,2 & 157,4 & 157,6 & 155,2 & 154,4 \\
\hline $\mathrm{C}_{2} \mathrm{H}_{4}$ & ${ }^{2} J_{\mathrm{CH}}$ & $-2,1$ & $-1,8$ & $-0,8$ & $-0,4$ & $-0,6$ & $-2,1$ & $-1,9$ & $-1,8$ & $-3,7$ & $-3,5$ & $-3,3$ & $-2,0$ \\
\hline $\mathrm{C}_{2} \mathrm{H}_{4}$ & ${ }^{2} J_{\mathrm{HH}}$ & 3,6 & 2,4 & 4,1 & 4,3 & 3,0 & 3,4 & 3,3 & 2,3 & 2,5 & 2,1 & 1,4 & 2,1 \\
\hline $\mathrm{C}_{2} \mathrm{H}_{4}$ & ${ }^{3} J_{\mathrm{HH}_{\mathrm{C}}}$ & 11,7 & 12,2 & 10,5 & 10,3 & 11,0 & 11,0 & 11,1 & 11,5 & 11,6 & 12,0 & 12,1 & 11,4 \\
\hline $\mathrm{C}_{2} \mathrm{H}_{4}$ & ${ }^{3} J_{\mathrm{HH}_{\mathrm{t}}}$ & 18,4 & 19,0 & 15,6 & 16,6 & 16,1 & 16,4 & 17,3 & 16,9 & 17,4 & 18,2 & 17,9 & 18,4 \\
\hline $\mathrm{C}_{2} \mathrm{H}_{6}$ & ${ }^{1} J_{\mathrm{CC}}$ & 34,9 & 36,5 & 35,1 & 36,3 & 36,7 & 37,8 & 39,4 & 39,5 & 40,8 & 42,5 & 42,4 & 33,6 \\
\hline $\mathrm{C}_{2} \mathrm{H}_{6}$ & ${ }^{1} J_{\mathrm{CH}}$ & 129,1 & 128,5 & 116,5 & 120,7 & 115,9 & 120,9 & 123,9 & 120,3 & 125,5 & 127,0 & 125,0 & 123,3 \\
\hline $\mathrm{C}_{2} \mathrm{H}_{6}$ & ${ }^{2} J_{\mathrm{CH}}$ & $-3,6$ & $-3,5$ & $-2,8$ & $-2,6$ & $-2,8$ & $-3,5$ & $-3,4$ & $-3,4$ & $-4,2$ & $-4,1$ & $-4,1$ & $-4,5$ \\
\hline \multirow[t]{3}{*}{ Total } & $\mathrm{DM}$ & $-12,11$ & $-6,26$ & $-7,48$ & $-7,07$ & $-2,41$ & $-4,76$ & 0,17 & 0,40 & $-2,04$ & 7,75 & 3,28 & - \\
\hline & DMA & 20,61 & 17,13 & 12,45 & 13,13 & 9,48 & 11,98 & 6,59 & 6,23 & 14,82 & 8,63 & 8,39 & - \\
\hline & PDMA & 23,65 & 24,78 & 18,85 & 30,24 & 20,00 & 15,67 & 14,43 & 10,67 & 21,98 & 18,75 & 18,53 & - \\
\hline \multirow[t]{3}{*}{ CPI } & DM & $-37,47$ & $-23,73$ & $-18,75$ & $-20,65$ & $-6,88$ & $-15,48$ & $-5,95$ & $-3,38$ & $-12,55$ & 9,46 & 0,03 & - \\
\hline & DMA & 39,84 & 31,56 & 20,85 & 24,02 & 13,34 & 21,06 & 8,74 & 6,98 & 26,80 & 11,23 & 11,65 & - \\
\hline & PDMA & 38,44 & 44,55 & 16,22 & 41,15 & 22,23 & 19,69 & 16,58 & 11,65 & 31,17 & 24,75 & 22,87 & - \\
\hline \multirow[t]{3}{*}{ SPI } & DM & 6,49 & 6,55 & 0,79 & 2,89 & 0,87 & 3,10 & 4,65 & 3,17 & 5,67 & 6,49 & 5,67 & - \\
\hline & DMA & 6,51 & 6,55 & 6,29 & 5,15 & 6,65 & 5,33 & 5,01 & 5,68 & 6,03 & 6,72 & 6,01 & - \\
\hline & PDMA & 12,80 & 10,27 & 20,78 & 22,23 & 18,36 & 12,73 & 12,86 & 9,96 & 15,23 & 14,34 & 15,34 & - \\
\hline \multirow[t]{3}{*}{$\Delta \mathrm{CS}$} & DM & $-43,97$ & $-30,28$ & $-19,55$ & $-23,54$ & $-7,76$ & $-18,58$ & $-10,61$ & $-6,56$ & $-18,21$ & 2,97 & $-5,65$ & - \\
\hline & DMA & 33,33 & 25,01 & 14,56 & 18,86 & 6,69 & 15,74 & 3,72 & 1,30 & 20,77 & 4,51 & 5,64 & - \\
\hline & PDMA & 25,64 & 34,28 & $-4,57$ & 18,92 & 3,87 & 6,96 & 3,72 & 1,69 & 15,93 & 10,41 & 7,52 & - \\
\hline
\end{tabular}


Tabela 8.172: Constantes de acoplamento B972 com otimização de geometrias e constantes empíricas no nível BHandH $\left(50 \% E_{X}^{\mathrm{HF}}\right)$ e base aug-pcJ-2.

\begin{tabular}{|c|c|c|c|c|c|c|c|c|c|c|c|c|c|c|c|c|}
\hline & $\% E_{X}^{\mathrm{HF}}$ & 21,00 & 21,00 & 30,00 & 30,00 & $\begin{array}{l}21,00 \\
\text { 30,00 } \\
\text { Otm. }\end{array}$ & 40,00 & 40,00 & $\begin{array}{l}21,00 \\
40,00 \\
\text { Otm. }\end{array}$ & 50,00 & 50,00 & $\begin{array}{l}21,00 \\
50,00 \\
\text { Otm. }\end{array}$ & 60,00 & 60,00 & $\begin{array}{l}21,00 \\
\text { 6́,00 } \\
\text { Otm. }\end{array}$ & Exp. \\
\hline $\mathrm{HF}$ & ${ }^{1} J_{\mathrm{HF}}$ & 442,8 & 447,0 & 487,2 & 401,9 & 491,1 & 512,0 & 452,6 & 515,9 & 538,2 & 503,7 & 542,0 & 565,8 & 555,5 & 569,7 & 532,8 \\
\hline $\mathrm{CO}$ & ${ }^{1} J_{\mathrm{CO}}$ & 18,3 & 17,1 & 11,5 & 17,6 & 10,2 & 9,2 & 12,9 & 8,0 & 6,8 & 8,0 & 5,6 & 4,2 & 3,0 & 3,0 & 15,7 \\
\hline $\mathrm{H}_{2} \mathrm{O}$ & ${ }^{1} J_{\mathrm{OH}}$ & $-73,5$ & $-74,4$ & $-75,6$ & $-65,7$ & $-76,4$ & $-78,9$ & $-72,4$ & $-79,7$ & $-82,3$ & $-79,0$ & $-83,2$ & $-86,0$ & $-85,6$ & $-86,9$ & $-81,7$ \\
\hline $\mathrm{H}_{2} \mathrm{O}$ & ${ }^{2} J_{\mathrm{HH}}$ & $-7,5$ & $-7,2$ & $-4,3$ & $-4,7$ & $-4,1$ & $-5,5$ & $-5,5$ & $-5,3$ & $-6,7$ & $-6,4$ & $-6,5$ & $-8,0$ & $-7,4$ & $-7,8$ & $-8,8$ \\
\hline $\mathrm{NH}_{3}$ & ${ }^{1} J_{\mathrm{NH}}$ & 41,7 & 42,0 & 40,3 & 37,6 & 40,6 & 41,8 & 40,3 & 42,1 & 43,4 & 43,0 & 43,7 & 45,1 & 45,7 & 45,4 & 43,0 \\
\hline $\mathrm{NH}_{3}$ & ${ }^{2} J_{\mathrm{HH}}$ & $-9,1$ & $-9,0$ & $-6,0$ & $-6,3$ & $-6,0$ & $-7,1$ & $-7,1$ & $-7,0$ & $-8,2$ & $-7,9$ & $-8,1$ & $-9,4$ & $-8,9$ & $-9,3$ & $-10,5$ \\
\hline $\mathrm{PH}_{3}$ & ${ }^{1} J_{\mathrm{PH}}$ & 184,0 & 191,6 & 175,0 & 158,0 & 182,2 & 183,4 & 173,7 & 190,5 & 192,2 & 189,1 & 199,2 & 201,4 & 204,8 & 208,4 & 195,0 \\
\hline $\mathrm{PF}_{3}$ & ${ }^{1} J_{\mathrm{PF}}$ & $-1661,2$ & $-1562,9$ & $-1595,3$ & $-1477,0$ & $-1516,3$ & $-1576,6$ & $-1482,9$ & $-1501,6$ & $-1555,0$ & $-1472,3$ & $-1484,0$ & $-1531,2$ & $-1451,5$ & $-1464,1$ & $-1441,7$ \\
\hline $\mathrm{BHF}_{2}$ & ${ }^{1} J_{\mathrm{BF}}$ & $-129,9$ & $-132,8$ & $-100,3$ & $-146,5$ & $-103,3$ & $-82,9$ & $-115,3$ & $-85,8$ & $-65,4$ & $-84,7$ & $-68,3$ & $-48,0$ & $-55,3$ & $-50,8$ & $-79,7$ \\
\hline $\mathrm{BF}_{3}$ & ${ }^{1} J_{\mathrm{BF}}$ & $-36,6$ & $-43,3$ & $-5,4$ & $-63,3$ & $-12,0$ & 14,1 & $-26,3$ & 7,7 & 33,8 & 9,3 & 27,6 & 53,5 & 43,6 & 47,4 & 17,1 \\
\hline $\mathrm{F}_{2} \mathrm{O}$ & ${ }^{1} J_{\mathrm{OF}}$ & $-316,0$ & $-219,7$ & $-283,7$ & $-341,6$ & $-189,4$ & $-320,6$ & $-310,4$ & $-218,4$ & $-362,5$ & $-278,7$ & $-250,3$ & $-412,9$ & $-247,5$ & $-286,6$ & $-285,7$ \\
\hline $\mathrm{CH}_{4}$ & ${ }^{1} J_{\mathrm{CH}}$ & 118,8 & 118,8 & 107,2 & 112,8 & 107,2 & 111,9 & 116,6 & 111,9 & 116,9 & 120,6 & 116,9 & 122,2 & 124,6 & 122,2 & 122,8 \\
\hline $\mathrm{CH}_{4}$ & ${ }^{2} J_{\mathrm{HH}}$ & $-11,3$ & $-11,3$ & $-7,8$ & $-7,4$ & $-7,8$ & $-8,7$ & $-8,4$ & $-8,7$ & $-9,7$ & $-9,5$ & $-9,7$ & $-10,7$ & $-10,6$ & $-10,7$ & $-12,5$ \\
\hline $\mathrm{C}_{2} \mathrm{H}_{2}$ & ${ }^{1} J_{\mathrm{CC}}$ & 197,5 & 197,6 & 188,8 & 189,7 & 189,1 & 195,6 & 197,1 & 195,7 & 203,4 & 204,9 & 203,2 & 212,5 & 213,3 & 212,0 & 174,1 \\
\hline $\mathrm{C}_{2} \mathrm{H}_{2}$ & ${ }^{1} J_{\mathrm{CH}}$ & 247,3 & 245,2 & 213,7 & 226,1 & 211,9 & 222,6 & 231,8 & 220,7 & 232,0 & 237,7 & 230,0 & 242,2 & 243,9 & 240,0 & 244,3 \\
\hline $\mathrm{C}_{2} \mathrm{H}_{2}$ & ${ }^{2} J_{\mathrm{CH}}$ & 50,7 & 50,8 & 51,4 & 51,7 & 51,5 & 51,8 & 51,9 & 51,9 & 51,9 & 51,9 & 52,0 & 51,5 & 51,7 & 51,7 & 49,8 \\
\hline $\mathrm{C}_{2} \mathrm{H}_{2}$ & ${ }^{3} J_{\mathrm{HH}}$ & 10,4 & 10,1 & 7,4 & 8,4 & 7,2 & 8,1 & 8,7 & 7,8 & 8,9 & 9,2 & 8,6 & 9,9 & 9,8 & 9,6 & 9,0 \\
\hline $\mathrm{C}_{2} \mathrm{H}_{4}$ & ${ }^{1} J_{\mathrm{CC}}$ & 68,1 & 70,6 & 66,0 & 67,6 & 68,7 & 70,8 & 73,1 & 73,3 & 76,3 & 78,9 & 78,5 & 82,9 & 85,2 & 84,7 & 66,9 \\
\hline $\mathrm{C}_{2} \mathrm{H}_{4}$ & ${ }^{1} J_{\mathrm{CH}}$ & 152,3 & 149,4 & 134,1 & 139,5 & 131,7 & 140,3 & 144,2 & 137,7 & 146,9 & 149,1 & 144,1 & 154,1 & 154,1 & 151,1 & 154,4 \\
\hline $\mathrm{C}_{2} \mathrm{H}_{4}$ & ${ }^{2} J_{\mathrm{CH}}$ & $-2,0$ & $-1,6$ & 0,5 & 1,0 & 0,7 & $-0,4$ & $-0,1$ & $-0,2$ & $-1,7$ & $-1,4$ & $-1,4$ & $-3,2$ & $-3,0$ & $-2,8$ & $-2,0$ \\
\hline $\mathrm{C}_{2} \mathrm{H}_{4}$ & ${ }^{2} J_{\mathrm{HH}}$ & 3,1 & 1,9 & 4,7 & 5,2 & 3,6 & 4,2 & 4,4 & 3,1 & 3,7 & 3,5 & 2,5 & 3,0 & 2,5 & 1,9 & 2,1 \\
\hline $\mathrm{C}_{2} \mathrm{H}_{4}$ & ${ }^{3} J_{\mathrm{HH}_{\mathrm{C}}}$ & 11,2 & 11,8 & 9,7 & 9,2 & 10,3 & 10,1 & 9,9 & 10,7 & 10,6 & 10,6 & 11,1 & 11,1 & 11,5 & 11,7 & 11,4 \\
\hline $\mathrm{C}_{2} \mathrm{H}_{4}$ & ${ }^{3} J_{\mathrm{HH}_{\mathrm{t}}}$ & 17,7 & 18,3 & 14,4 & 15,5 & 14,9 & 15,1 & 16,1 & 15,6 & 15,9 & 16,8 & 16,4 & 16,8 & 17,5 & 17,3 & 18,4 \\
\hline $\mathrm{C}_{2} \mathrm{H}_{6}$ & ${ }^{1} J_{\mathrm{CC}}{ }^{t}$ & 30,6 & 32,4 & 30,2 & 31,6 & 32,1 & 33,3 & 35,0 & 35,2 & 36,6 & 38,4 & 38,5 & 40,1 & 41,9 & 42,0 & 33,6 \\
\hline $\mathrm{C}_{2} \mathrm{H}_{6}$ & ${ }^{1} J_{\mathrm{CH}}$ & 118,9 & 117,3 & 106,4 & 111,4 & 105,1 & 111,4 & 115,3 & 110,0 & 116,6 & 119,3 & 115,2 & 122,1 & 123,4 & 120,6 & 123,3 \\
\hline $\mathrm{C}_{2} \mathrm{H}_{6}$ & ${ }^{2} J_{\mathrm{CH}}$ & $-3,2$ & $-3,2$ & $-1,9$ & $-1,6$ & $-1,8$ & $-2,4$ & $-2,2$ & $-2,4$ & $-3,0$ & $-2,8$ & $-2,9$ & $-3,6$ & $-3,5$ & $-3,6$ & $-4,5$ \\
\hline \multirow[t]{3}{*}{ Total } & $\mathrm{DM}$ & $-16,29$ & $-8,85$ & $-12,25$ & $-16,00$ & $-5,60$ & $-9,00$ & $-8,98$ & $-2,23$ & $-5,65$ & $-1,36$ & 1,31 & $-2,35$ & 6,62 & 4,98 & - \\
\hline & DMA & 19,90 & 17,41 & 15,77 & 20,50 & 16,44 & 12,58 & 13,55 & 11,20 & 12,67 & 6,84 & 8,63 & 16,09 & 8,85 & 9,15 & - \\
\hline & PDMA & 24,07 & 24,71 & 30,61 & 48,06 & 31,68 & 20,25 & 31,26 & 20,88 & 18,83 & 15,81 & 15,91 & 24,83 & 20,52 & 20,30 & - \\
\hline \multirow[t]{3}{*}{ CPI } & DM & $-40,23$ & $-22,46$ & $-22,92$ & $-35,05$ & $-7,17$ & $-18,78$ & $-21,45$ & $-2,65$ & $-14,65$ & $-6,49$ & 2,02 & $-11,00$ & 9,1 & 6,63 & - \\
\hline & DMA & 42,68 & 36,61 & 26,03 & 39,81 & 27,32 & 20,51 & 24,35 & 16,52 & 22,15 & 9,16 & 11,82 & & 13,97 & 14,12 & - \\
\hline & PDMA & 43,92 & 47,44 & 29,28 & 68,22 & 36,04 & 15,50 & 40,12 & 20,23 & 23,36 & 15,39 & 19,25 & 37,80 & 30,18 & 31,34 & - \\
\hline \multirow[t]{3}{*}{ SPI } & DM & 1,27 & 1,13 & $-4,42$ & $-2,03$ & $-4,45$ & $-1,83$ & 0,15 & $-1,92$ & 0,95 & 2,4 & 0,79 & 3,9 & 4,7 & 3,77 & - \\
\hline & DMA & 3,19 & 3,33 & 8,25 & 6,33 & 8,46 & 6,76 & 5,62 & 7,31 & 5,72 & 5,14 & 6,30 & 4,96 & 5,09 & 5,51 & - \\
\hline & PDMA & 9,51 & 8,04 & 31,59 & 33,28 & 28,49 & 23,74 & 24,77 & 21,36 & 15,52 & 16,11 & 13,46 & 15,32 & 13,43 & 12,20 & - \\
\hline \multirow[t]{3}{*}{$\Delta \mathrm{CS}$} & DM & $-41,49$ & $-23,60$ & $-18,50$ & $-33,02$ & $-2,73$ & $-16,96$ & $-21,60$ & $-0,73$ & $-15,60$ & $-8,90$ & 1,22 & $-14,99$ & 4,43 & 2,85 & - \\
\hline & DMA & 9,50 & 33,28 & 17,78 & 33,48 & 18,86 & 13,75 & 18,73 & 9,21 & 16,43 & & 5,52 & & 8,88 & 8,61 & - \\
\hline & PDMA & 34,41 & 39,40 & $-2,31$ & 34,93 & 7,55 & $-8,24$ & 15,35 & $-1,14$ & 7,84 & $-0,72$ & 5,79 & 22,48 & 16,76 & 19,14 & - \\
\hline
\end{tabular}


Tabela 8.173: Constantes de acoplamento B98 com otimização de geometrias e constantes empíricas no nível BHandH $\left(50 \% E_{X}^{\mathrm{HF}}\right)$ e base aug-pcJ-2.

\begin{tabular}{|c|c|c|c|c|c|c|c|c|c|c|c|c|c|}
\hline & $\% E_{X}^{\mathrm{HF}}$ & 21,98 & 21,98 & 40,00 & 40,00 & $\begin{array}{l}21,98 \\
40,00 \\
\text { Otm. }\end{array}$ & 50,00 & 50,00 & $\begin{array}{l}21,98 \\
50,00 \\
\text { Otm. }\end{array}$ & 60,00 & 60,00 & $\begin{array}{l}21,98 \\
60,00 \\
\text { Otm. }\end{array}$ & Exp. \\
\hline HF & ${ }^{1} J_{\mathrm{HF}}$ & 431,2 & 425,7 & 484,6 & 417,7 & 479,5 & 505,9 & 465,8 & 500,8 & 528,5 & 514,5 & 523,5 & 532,8 \\
\hline $\mathrm{CO}$ & ${ }^{1} J_{\mathrm{CO}}$ & 18,5 & 17,6 & 11,2 & 15,5 & 10,4 & 9,5 & 11,2 & 8,7 & 7,7 & 6,9 & 6,8 & 15,7 \\
\hline $\mathrm{H}_{2} \mathrm{O}$ & ${ }^{1} J_{\mathrm{OH}}$ & $-72,5$ & $-72,6$ & $-75,6$ & $-67,9$ & $-75,7$ & $-78,4$ & $-74,2$ & $-78,5$ & $-81,4$ & $-80,4$ & $-81,5$ & $-81,7$ \\
\hline $\mathrm{H}_{2} \mathrm{O}$ & ${ }^{2} J_{\mathrm{HH}}$ & $-6,9$ & $-6,5$ & $-5,1$ & $-5,1$ & $-4,7$ & $-6,4$ & $-6,1$ & $-6,1$ & $-7,9$ & $-7,2$ & $-7,5$ & $-8,8$ \\
\hline $\mathrm{NH}_{3}$ & ${ }^{1} J_{\mathrm{NH}}$ & 42,9 & 43,1 & 41,7 & 39,6 & 41,9 & 43,1 & 42,3 & 43,3 & 44,6 & 44,8 & 44,8 & 43,0 \\
\hline $\mathrm{NH}_{3}$ & ${ }^{2} J_{\mathrm{HH}}$ & $-9,5$ & $-9,3$ & $-7,6$ & $-7,5$ & $-7,4$ & $-8,8$ & $-8,5$ & $-8,6$ & $-10,2$ & $-9,6$ & $-10,0$ & $-10,5$ \\
\hline $\mathrm{PH}_{3}$ & ${ }^{1} J_{\mathrm{PH}}$ & 196,4 & 202,7 & 193,7 & 187,2 & 199,5 & 201,7 & 200,7 & 207,3 & 210,1 & 213,9 & 215,4 & 195,0 \\
\hline $\mathrm{PF}_{3}$ & ${ }^{1} J_{\mathrm{PF}}$ & $-1666,4$ & $-1560,1$ & $-1572,1$ & $-1468,9$ & $-1489,9$ & $-1549,1$ & $-1459,9$ & $-1470,8$ & $-1523,4$ & $-1439,8$ & $-1449,0$ & $-1441,7$ \\
\hline $\mathrm{BHF}_{2}$ & ${ }^{1} J_{\mathrm{BF}}$ & $-129,1$ & $-133,2$ & $-89,6$ & $-125,3$ & $-93,7$ & $-73,8$ & $-95,5$ & $-77,8$ & $-57,8$ & $-66,4$ & $-61,8$ & $-79,7$ \\
\hline $\mathrm{BF}_{3}$ & ${ }^{1} J_{\mathrm{BF}}$ & $-34,1$ & $-43,2$ & 7,0 & $-37,6$ & $-1,5$ & 24,5 & $-3,0$ & 16,1 & 42,2 & 30,6 & 34,0 & 17,1 \\
\hline $\mathrm{F}_{2} \mathrm{O}$ & ${ }^{1} J_{\mathrm{OF}}$ & $-336,9$ & $-264,6$ & $-338,2$ & $-347,7$ & $-262,5$ & $-383,0$ & $-312,7$ & $-299,3$ & $-437,3$ & $-278,5$ & $-341,9$ & $-285,7$ \\
\hline $\mathrm{CH}_{4}$ & ${ }^{1} J_{\mathrm{CH}}$ & 128,3 & 128,7 & 116,9 & 122,0 & 117,2 & 121,5 & 125,6 & 121,9 & 126,5 & 129,3 & 126,9 & 122,8 \\
\hline $\mathrm{CH}_{4}$ & ${ }^{2} J_{\mathrm{HH}}$ & $-12,5$ & $-12,5$ & $-9,8$ & $-9,5$ & $-9,8$ & $-11,0$ & $-10,8$ & $-11,0$ & $-12,2$ & $-12,1$ & $-12,2$ & $-12,5$ \\
\hline $\mathrm{C}_{2} \mathrm{H}_{2}$ & ${ }^{1} J_{\mathrm{CC}}$ & 212,9 & 212,7 & 205,0 & 207,5 & 205,0 & 212,2 & 214,3 & 211,9 & 220,6 & 221,6 & 220,0 & 174,1 \\
\hline $\mathrm{C}_{2} \mathrm{H}_{2}$ & ${ }^{1} J_{\mathrm{CH}}$ & 261,1 & 259,6 & 229,7 & 239,7 & 228,3 & 239,0 & 245,4 & 237,5 & 249,0 & 251,5 & 247,4 & 244,3 \\
\hline $\mathrm{C}_{2} \mathrm{H}_{2}$ & ${ }^{2} J_{\mathrm{CH}}$ & 52,8 & 52,9 & 53,2 & 53,4 & 53,3 & 53,2 & 53,2 & 53,3 & 52,6 & 52,7 & 52,8 & 49,8 \\
\hline $\mathrm{C}_{2} \mathrm{H}_{2}$ & ${ }^{3} J_{\mathrm{HH}}$ & 10,7 & 10,4 & 8,4 & 9,2 & 8,2 & 9,4 & 9,8 & 9,1 & 10,6 & 10,7 & 10,4 & 9,0 \\
\hline $\mathrm{C}_{2} \mathrm{H}_{4}$ & ${ }^{1} J_{\mathrm{CC}}$ & 77,3 & 79,7 & 76,4 & 78,8 & 78,9 & 81,3 & 84,1 & 83,6 & 87,2 & 89,7 & 89,1 & 66,9 \\
\hline $\mathrm{C}_{2} \mathrm{H}_{4}$ & ${ }^{1} J_{\mathrm{CH}}$ & 162,5 & 160,1 & 145,7 & 150,2 & 143,6 & 152,0 & 154,8 & 149,8 & 158,9 & 159,5 & 156,5 & 154,4 \\
\hline $\mathrm{C}_{2} \mathrm{H}_{4}$ & ${ }^{2} J_{\mathrm{CH}}$ & $-2,4$ & $-2,1$ & $-0,8$ & $-0,5$ & $-0,6$ & $-2,1$ & $-1,9$ & $-1,9$ & $-3,8$ & $-3,6$ & $-3,4$ & $-2,0$ \\
\hline $\mathrm{C}_{2} \mathrm{H}_{4}$ & ${ }^{2} J_{\mathrm{HH}}$ & 3,1 & 1,9 & 3,9 & 4,2 & 2,8 & 3,2 & 3,1 & 2,1 & 2,3 & 1,9 & 1,2 & 2,1 \\
\hline $\mathrm{C}_{2} \mathrm{H}_{4}$ & ${ }^{3} J_{\mathrm{HH}_{\mathrm{c}}}$ & 11,8 & 12,4 & 10,6 & 10,2 & 11,1 & 11,1 & 11,1 & 11,6 & 11,8 & 12,0 & 12,2 & 11,4 \\
\hline $\mathrm{C}_{2} \mathrm{H}_{4}$ & ${ }^{3} J_{\mathrm{HH}_{\mathrm{t}}}$ & 18,5 & 19,1 & 15,6 & 16,7 & 16,2 & 16,5 & 17,5 & 17,0 & 17,6 & 18,4 & 18,1 & 18,4 \\
\hline $\mathrm{C}_{2} \mathrm{H}_{6}$ & ${ }^{1} J_{\mathrm{CC}}$ & 34,4 & 36,0 & 35,1 & 36,2 & 36,7 & 38,2 & 39,6 & 39,8 & 41,5 & 43,1 & 43,1 & 33,6 \\
\hline $\mathrm{C}_{2} \mathrm{H}_{6}$ & ${ }^{1} J_{\mathrm{CH}}$ & 128,8 & 128,1 & 116,8 & 121,4 & 116,1 & 121,7 & 125,2 & 121,1 & 127,0 & 129,0 & 126,3 & 123,3 \\
\hline $\mathrm{C}_{2} \mathrm{H}_{6}$ & ${ }^{2} J_{\mathrm{CH}}$ & $-3,8$ & $-3,7$ & $-2,9$ & $-2,6$ & $-2,9$ & $-3,6$ & $-3,4$ & $-3,5$ & $-4,3$ & $-4,2$ & $-4,3$ & $-4,5$ \\
\hline \multirow[t]{3}{*}{ Total } & $\mathrm{DM}$ & $-14,21$ & $-7,83$ & $-8,95$ & $-9,60$ & $-3,33$ & $-6,11$ & $-2,27$ & $-0,35$ & $-3,32$ & 5,45 & 2,70 & - \\
\hline & DMA & 22,60 & 18,29 & 13,98 & 15,81 & 10,78 & 13,18 & 9,62 & 7,23 & 15,78 & 7,67 & 9,19 & - \\
\hline & PDMA & 24,94 & 25,16 & 19,77 & 32,50 & 20,37 & 14,03 & 16,84 & 9,82 & 20,72 & 16,74 & 18,48 & - \\
\hline \multirow[t]{3}{*}{ CPI } & DM & $-41,99$ & $-26,90$ & $-22,32$ & $-26,86$ & $-9,05$ & $-19,12$ & $-12,31$ & $-5,49$ & $-16,40$ & 3,03 & $-2,06$ & - \\
\hline & DMA & 44,95 & 34,79 & 24,63 & 30,59 & 16,49 & 24,12 & 15,56 & 9,55 & 28,25 & 7,95 & 12,79 & - \\
\hline & PDMA & 43,19 & 47,31 & 19,77 & 47,54 & 24,54 & 17,08 & 22,98 & 11,39 & 28,15 & 18,18 & 21,30 & - \\
\hline \multirow[t]{3}{*}{ SPI } & $\mathrm{DM}$ & 6,16 & 6,15 & 0,85 & 3,05 & 0,87 & 3,43 & 5,10 & 3,41 & 6,28 & 7,23 & 6,20 & - \\
\hline & DMA & 6,21 & 6,19 & 6,17 & 4,97 & 6,59 & 5,15 & 5,26 & 5,53 & 6,63 & 7,47 & 6,55 & - \\
\hline & PDMA & 11,56 & 8,92 & 19,78 & 21,46 & 17,32 & 11,79 & 12,34 & 8,68 & 15,27 & 15,68 & 16,41 & - \\
\hline \multirow[t]{3}{*}{$\Delta \mathrm{CS}$} & DM & $-48,15$ & $-33,05$ & $-23,16$ & $-29,92$ & $-9,92$ & $-22,55$ & $-17,41$ & $-8,90$ & $-22,68$ & $-4,20$ & $-8,26$ & - \\
\hline & DMA & 38,74 & 28,60 & 18,46 & 25,62 & 9,90 & 18,96 & 10,30 & 4,01 & 21,63 & 0,49 & 6,24 & - \\
\hline & PDMA & 31,63 & 38,40 & $-0,01$ & 26,08 & 7,21 & 5,30 & 10,64 & 2,72 & 12,88 & 2,50 & 4,89 & - \\
\hline
\end{tabular}


Tabela 8.174: Constantes de acoplamento B1B95 com otimização de geometrias e constantes empíricas no nível BHandH $\left(50 \% E_{X}^{\mathrm{HF}}\right)$ e base aug-pcJ-2.

\begin{tabular}{|c|c|c|c|c|c|c|c|c|c|c|c|c|c|}
\hline & $\% E_{X}^{\mathrm{HF}}$ & 28,00 & 28,00 & 40,00 & 40,00 & $\begin{array}{l}28,00 \\
40,00 \\
\text { Otm. }\end{array}$ & 50,00 & 50,00 & $\begin{array}{l}28,00 \\
50,00 \\
\text { Otm. }\end{array}$ & 60,00 & 60,00 & $\begin{array}{c}28,00 \\
60,00 \\
\text { Otm. }\end{array}$ & Exp. \\
\hline HF & ${ }^{1} J_{\mathrm{HF}}$ & 470,4 & 470,4 & 499,3 & 515,6 & 499,3 & 523,6 & 552,4 & 523,6 & 548,0 & 588,5 & 548,0 & 532,8 \\
\hline $\mathrm{CO}$ & ${ }^{1} J_{\mathrm{CO}}$ & 18,4 & 16,5 & 16,1 & 12,6 & 14,1 & 14,0 & 9,4 & 12,1 & 11,8 & 6,2 & 9,9 & 15,7 \\
\hline $\mathrm{H}_{2} \mathrm{O}$ & ${ }^{1} J_{\mathrm{OH}}$ & $-77,3$ & $-78,4$ & $-80,4$ & $-83,5$ & $-81,4$ & $-83,0$ & $-87,4$ & $-83,9$ & $-85,6$ & $-91,2$ & $-86,5$ & $-81,7$ \\
\hline $\mathrm{H}_{2} \mathrm{O}$ & ${ }^{2} J_{\mathrm{HH}}$ & $-7,0$ & $-6,6$ & $-8,2$ & $-7,3$ & $-7,8$ & $-9,2$ & $-8,1$ & $-8,8$ & $-10,3$ & $-8,9$ & $-9,8$ & $-8,8$ \\
\hline $\mathrm{NH}_{3}$ & ${ }^{1} J_{\mathrm{NH}}$ & 44,0 & 44,6 & 44,9 & 46,1 & 45,5 & 45,6 & 47,2 & 46,2 & 46,4 & 48,2 & 46,9 & 43,0 \\
\hline $\mathrm{NH}_{3}$ & ${ }^{2} J_{\mathrm{HH}}$ & $-9,3$ & $-9,1$ & $-10,4$ & $-9,8$ & $-10,1$ & $-11,3$ & $-10,5$ & $-11,0$ & $-12,1$ & $-11,2$ & $-11,8$ & $-10,5$ \\
\hline $\mathrm{PH}_{3}$ & ${ }^{1} J_{\mathrm{PH}}$ & 167,8 & 175,8 & 176,5 & 187,5 & 184,0 & 183,6 & 196,8 & 190,8 & 190,6 & 205,6 & 197,4 & 195,0 \\
\hline $\mathrm{PF}_{3}$ & ${ }^{1} J_{\mathrm{PF}}$ & $-1645,5$ & $-1532,2$ & $-1606,4$ & $-1500,6$ & $-1500,0$ & $-1571,1$ & $-1466,8$ & $-1470,3$ & $-1533,7$ & $-1427,8$ & $-1438,6$ & $-1441,7$ \\
\hline $\mathrm{BHF}_{2}$ & ${ }^{1} J_{\mathrm{BF}}$ & $-127,6$ & $-125,7$ & $-107,5$ & $-98,9$ & $-105,8$ & $-91,0$ & $-77,2$ & $-89,3$ & $-74,6$ & $-56,0$ & $-72,9$ & $-79,7$ \\
\hline $\mathrm{BF}_{3}$ & ${ }^{1} J_{\mathrm{BF}}$ & $-27,0$ & $-28,2$ & $-5,3$ & 2,1 & $-6,4$ & 12,6 & 26,6 & 11,4 & 30,3 & 50,2 & 29,2 & 17,1 \\
\hline $\mathrm{F}_{2} \mathrm{O}$ & ${ }^{1} J_{\mathrm{OF}}$ & $-361,9$ & $-249,0$ & $-404,3$ & $-221,1$ & $-280,1$ & $-443,7$ & $-199,3$ & $-307,4$ & $-490,0$ & $-179,2$ & $-337,1$ & $-285,7$ \\
\hline $\mathrm{CH}_{4}$ & ${ }^{1} J_{\mathrm{CH}}$ & 124,4 & 124,1 & 126,1 & 125,2 & 125,8 & 127,5 & 126,0 & 127,2 & 129,0 & 126,9 & 128,6 & 122,8 \\
\hline $\mathrm{CH}_{4}$ & ${ }^{2} J_{\mathrm{HH}}$ & $-12,2$ & $-12,2$ & $-13,0$ & $-13,1$ & $-13,0$ & $-13,7$ & $-13,7$ & $-13,7$ & $-14,4$ & $-14,4$ & $-14,4$ & $-12,5$ \\
\hline $\mathrm{C}_{2} \mathrm{H}_{2}$ & ${ }^{1} J_{\mathrm{CC}}$ & 195,2 & 195,5 & 199,3 & 199,1 & 199,2 & 203,2 & 202,4 & 202,8 & 207,7 & 205,9 & 207,0 & 174,1 \\
\hline $\mathrm{C}_{2} \mathrm{H}_{2}$ & ${ }^{1} J_{\mathrm{CH}}$ & 256,2 & 253,2 & 258,8 & 253,7 & 255,8 & 261,2 & 254,3 & 258,0 & 263,7 & 254,9 & 260,4 & 244,3 \\
\hline $\mathrm{C}_{2} \mathrm{H}_{2}$ & ${ }^{2} J_{\mathrm{CH}}$ & 55,6 & 55,7 & 55,2 & 55,5 & 55,4 & 54,6 & 55,1 & 54,9 & 53,8 & 54,6 & 54,2 & 49,8 \\
\hline $\mathrm{C}_{2} \mathrm{H}_{2}$ & ${ }^{3} J_{\mathrm{HH}}$ & 10,4 & 10,0 & 11,2 & 10,5 & 10,8 & 12,0 & 11,1 & 11,5 & 13,0 & 11,7 & 12,4 & 9,0 \\
\hline $\mathrm{C}_{2} \mathrm{H}_{4}$ & ${ }^{1} J_{\mathrm{CC}}$ & 66,0 & 68,9 & 69,6 & 72,1 & 72,1 & 73,0 & 74,9 & 75,1 & 76,8 & 77,9 & 78,5 & 66,9 \\
\hline $\mathrm{C}_{2} \mathrm{H}_{4}$ & ${ }^{1} J_{\mathrm{CH}}$ & 158,8 & 155,4 & 161,3 & 156,8 & 157,7 & 163,5 & 158,0 & 159,7 & 165,9 & 159,3 & 161,9 & 154,4 \\
\hline $\mathrm{C}_{2} \mathrm{H}_{4}$ & ${ }^{2} J_{\mathrm{CH}}$ & $-1,1$ & $-0,9$ & $-2,3$ & $-2,0$ & $-2,0$ & $-3,4$ & $-3,0$ & $-3,0$ & $-4,7$ & $-4,0$ & $-4,2$ & $-2,0$ \\
\hline $\mathrm{C}_{2} \mathrm{H}_{4}$ & ${ }^{2} J_{\mathrm{HH}}$ & 4,2 & 2,8 & 3,3 & 1,9 & 1,9 & 2,5 & 1,1 & 1,1 & 1,6 & 0,3 & 0,3 & 2,1 \\
\hline $\mathrm{C}_{2} \mathrm{H}_{4}$ & ${ }^{3} J_{\mathrm{HH}_{\mathrm{c}}}$ & 12,1 & 12,9 & 12,5 & 13,4 & 13,2 & 12,8 & 13,8 & 13,6 & 13,3 & 14,2 & 14,0 & 11,4 \\
\hline $\mathrm{C}_{2} \mathrm{H}_{4}$ & ${ }^{3} J_{\mathrm{HH}_{\mathrm{t}}}$ & 19,0 & 19,6 & 19,4 & 19,9 & 20,0 & 19,9 & 20,2 & 20,4 & 20,4 & 20,6 & 20,9 & 18,4 \\
\hline $\mathrm{C}_{2} \mathrm{H}_{6}$ & ${ }^{1} J_{\mathrm{CC}}$ & 30,6 & 32,5 & 33,0 & 34,7 & 34,8 & 35,0 & 36,6 & 36,8 & 37,1 & 38,7 & 38,8 & 33,6 \\
\hline $\mathrm{C}_{2} \mathrm{H}_{6}$ & ${ }^{1} J_{\mathrm{CH}}$ & 125,0 & 123,0 & 126,9 & 124,3 & 124,9 & 128,5 & 125,2 & 126,4 & 130,1 & 126,2 & 128,0 & 123,3 \\
\hline $\mathrm{C}_{2} \mathrm{H}_{6}$ & ${ }^{2} J_{\mathrm{CH}}$ & $-3,5$ & $-3,5$ & $-4,0$ & $-4,1$ & $-4,0$ & $-4,5$ & $-4,5$ & $-4,5$ & $-5,0$ & $-5,0$ & $-5,0$ & $-4,5$ \\
\hline \multirow[t]{3}{*}{ Total } & DM & $-15,42$ & $-6,60$ & $-12,12$ & 0,15 & $-3,18$ & $-9,40$ & 5,92 & $-0,27$ & $-6,83$ & 11,75 & 2,67 & - \\
\hline & DMA & 20,39 & 13,77 & 17,65 & 9,65 & 8,72 & 16,03 & 9,02 & 6,54 & 17,57 & 13,75 & 8,11 & - \\
\hline & PDMA & 26,16 & 22,86 & 16,34 & 11,89 & 12,94 & 13,69 & 14,61 & 12,52 & 22,00 & 27,72 & 21,31 & - \\
\hline \multirow[t]{3}{*}{ CPI } & DM & $-40,95$ & $-19,76$ & $-34,65$ & $-4,80$ & $-13,11$ & $-29,58$ & 7,96 & $-7,46$ & $-24,97$ & 20,81 & $-1,89$ & - \\
\hline & DMA & 42,97 & 28,13 & 35,44 & 17,51 & 14,89 & 30,05 & 14,71 & 8,05 & 31,68 & 24,41 & 9,80 & - \\
\hline & PDMA & 40,11 & 37,68 & 22,81 & 18,04 & 19,97 & 13,00 & 14,55 & 8,79 & 21,49 & 33,59 & 16,11 & - \\
\hline \multirow[t]{3}{*}{ SPI } & DM & 3,31 & 3,06 & 4,41 & 3,79 & 4,10 & 5,40 & 4,43 & 5,01 & 6,48 & 5,11 & 6,02 & - \\
\hline & DMA & 3,83 & 3,25 & 4,60 & 3,89 & 4,19 & 5,75 & 4,85 & 5,44 & 7,23 & 5,94 & 6,87 & - \\
\hline & PDMA & 15,93 & 11,98 & 11,60 & 7,37 & 7,78 & 14,19 & 14,65 & 15,25 & 22,37 & 23,42 & 25,12 & - \\
\hline \multirow[t]{3}{*}{$\Delta \mathrm{CS}$} & DM & $-44,26$ & $-22,82$ & $-39,07$ & $-8,59$ & $-17,21$ & $-34,98$ & 3,54 & $-12,48$ & $-31,45$ & 15,70 & $-7,91$ & - \\
\hline & DMA & 39,15 & 24,88 & 30,84 & 13,62 & 10,70 & 24,31 & 9,86 & 2,61 & 24,46 & 18,47 & 2,93 & - \\
\hline & PDMA & 24,18 & 25,70 & 11,21 & 10,67 & 12,19 & $-1,20$ & $-0,09$ & $-6,47$ & $-0,88$ & 10,17 & $-9,00$ & - \\
\hline
\end{tabular}


Tabela 8.175: Constantes de acoplamento BHandH com otimização de geometrias e constantes empíricas no nível BHandH $\left(50 \% E_{X}^{\mathrm{HF}}\right)$ e base aug-pcJ-2.

\begin{tabular}{|c|c|c|c|c|c|c|c|c|c|c|c|c|c|}
\hline & $\% E_{X}^{\mathrm{HF}}$ & 50,00 & 50,00 & 30,00 & 30,00 & $\begin{array}{l}50,00 \\
30,00 \\
\text { Otm. }\end{array}$ & 40,00 & 40,00 & $\begin{array}{l}50,00 \\
/ \\
40,00 \\
\text { Otm. }\end{array}$ & 60,00 & 60,00 & $\begin{array}{l}50,00 \\
60,00 \\
\text { Otm. }\end{array}$ & Exp. \\
\hline HF & ${ }^{1} J_{\mathrm{HF}}$ & 530,8 & 546,7 & 484,4 & 472,9 & 500,8 & 507,2 & 509,6 & 523,4 & 555,3 & 584,3 & 570,9 & 532,8 \\
\hline $\mathrm{CO}$ & ${ }^{1} J_{\mathrm{CO}}$ & 13,7 & 8,0 & 18,7 & 14,9 & 12,8 & 16,3 & 11,5 & 10,4 & 11,0 & 4,4 & 5,3 & 15,7 \\
\hline $\mathrm{H}_{2} \mathrm{O}$ & ${ }^{1} J_{\mathrm{OH}}$ & $-83,7$ & $-87,5$ & $-77,8$ & $-78,5$ & $-81,7$ & $-80,7$ & $-83,1$ & $-84,6$ & $-86,9$ & $-92,0$ & $-90,6$ & $-81,7$ \\
\hline $\mathrm{H}_{2} \mathrm{O}$ & ${ }^{2} J_{\mathrm{HH}}$ & $-9,4$ & $-7,9$ & $-6,8$ & $-5,8$ & $-5,3$ & $-8,0$ & $-6,8$ & $-6,6$ & $-10,8$ & $-9,0$ & $-9,2$ & $-8,8$ \\
\hline $\mathrm{NH}_{3}$ & ${ }^{1} J_{\mathrm{NH}}$ & 45,5 & 47,7 & 42,9 & 44,5 & 45,1 & 44,2 & 46,2 & 46,4 & 47,0 & 49,5 & 49,2 & 43,0 \\
\hline $\mathrm{NH}_{3}$ & ${ }^{2} J_{\mathrm{HH}}$ & $-11,1$ & $-9,9$ & $-8,7$ & $-7,6$ & $-7,5$ & $-9,9$ & $-8,7$ & $-8,7$ & $-12,5$ & $-11,0$ & $-11,1$ & $-10,5$ \\
\hline $\mathrm{PH}_{3}$ & ${ }^{1} J_{\mathrm{PH}}$ & 183,1 & 195,1 & 163,0 & 167,4 & 175,8 & 172,9 & 181,3 & 185,3 & 193,7 & 208,9 & 205,2 & 195,0 \\
\hline $\mathrm{PF}_{3}$ & ${ }^{1} J_{\mathrm{PF}}$ & $-1670,4$ & $-1554,5$ & $-1743,5$ & $-1622,0$ & $-1624,2$ & $-1709,0$ & $-1591,4$ & $-1591,2$ & $-1628,3$ & $-1512,0$ & $-1514,8$ & $-1441,7$ \\
\hline $\mathrm{BHF}_{2}$ & ${ }^{1} J_{\mathrm{BF}}$ & $-95,2$ & $-72,8$ & $-132,8$ & $-116,4$ & $-109,5$ & $-114,0$ & $-94,5$ & $-91,2$ & $-76,1$ & $-51,3$ & $-54,3$ & $-79,7$ \\
\hline $\mathrm{BF}_{3}$ & ${ }^{1} J_{\mathrm{BF}}$ & 15,1 & 38,8 & $-23,3$ & $-7,3$ & 1,5 & $-4,1$ & 15,8 & 20,0 & 34,6 & 61,4 & 57,6 & 17,1 \\
\hline $\mathrm{F}_{2} \mathrm{O}$ & ${ }^{1} J_{\mathrm{OF}}$ & $-465,0$ & $-165,5$ & $-380,5$ & $-173,9$ & $-123,8$ & $-419,8$ & $-169,2$ & $-144,3$ & $-521,4$ & $-163,3$ & $-188,0$ & $-285,7$ \\
\hline $\mathrm{CH}_{4}$ & ${ }^{1} J_{\mathrm{CH}}$ & 124,9 & 124,4 & 116,8 & 117,4 & 116,3 & 120,7 & 120,7 & 120,3 & 129,4 & 128,1 & 128,8 & 122,8 \\
\hline $\mathrm{CH}_{4}$ & ${ }^{2} J_{\mathrm{HH}}$ & $-13,3$ & $-13,3$ & $-11,0$ & $-11,0$ & $-11,0$ & $-12,1$ & $-12,1$ & $-12,1$ & $-14,5$ & $-14,5$ & $-14,5$ & $-12,5$ \\
\hline $\mathrm{C}_{2} \mathrm{H}_{2}$ & ${ }^{1} J_{\mathrm{CC}}$ & 202,4 & 201,9 & 189,4 & 190,4 & 190,4 & 195,4 & 195,9 & 195,8 & 210,6 & 208,6 & 209,1 & 174,1 \\
\hline $\mathrm{C}_{2} \mathrm{H}_{2}$ & ${ }^{1} J_{\mathrm{CH}}$ & 259,5 & 253,3 & 245,0 & 243,0 & 239,4 & 252,0 & 248,0 & 246,1 & 267,8 & 259,1 & 261,1 & 244,3 \\
\hline $\mathrm{C}_{2} \mathrm{H}_{2}$ & ${ }^{2} J_{\mathrm{CH}}$ & 53,0 & 53,8 & 53,2 & 53,5 & 53,5 & 53,3 & 53,8 & 53,8 & 52,2 & 53,4 & 53,3 & 49,8 \\
\hline $\mathrm{C}_{2} \mathrm{H}_{2}$ & ${ }^{3} J_{\mathrm{HH}}$ & 11,8 & 10,7 & 9,4 & 8,9 & 8,6 & 10,5 & 9,8 & 9,6 & 13,4 & 11,9 & 12,2 & 9,0 \\
\hline $\mathrm{C}_{2} \mathrm{H}_{4}$ & ${ }^{1} J_{\mathrm{CC}}$ & 72,3 & 74,8 & 61,8 & 65,7 & 65,6 & 66,7 & 70,0 & 69,9 & 78,9 & 80,2 & 80,5 & 66,9 \\
\hline $\mathrm{C}_{2} \mathrm{H}_{4}$ & ${ }^{1} J_{\mathrm{CH}}$ & 160,6 & 155,7 & 149,9 & 147,1 & 145,6 & 155,0 & 151,3 & 150,5 & 166,8 & 160,4 & 161,4 & 154,4 \\
\hline $\mathrm{C}_{2} \mathrm{H}_{4}$ & ${ }^{2} J_{\mathrm{CH}}$ & $-3,8$ & $-3,4$ & $-1,3$ & $-1,2$ & $-1,2$ & $-2,4$ & $-2,2$ & $-2,2$ & $-5,6$ & $-4,8$ & $-4,8$ & $-2,0$ \\
\hline $\mathrm{C}_{2} \mathrm{H}_{4}$ & ${ }^{2} J_{\mathrm{HH}}$ & 2,2 & 1,2 & 3,8 & 3,0 & 2,8 & 3,1 & 2,1 & 2,0 & 1,1 & 0,2 & 0,3 & 2,1 \\
\hline $\mathrm{C}_{2} \mathrm{H}_{4}$ & ${ }^{3} J_{\mathrm{HH}_{\mathrm{c}}}$ & 13,3 & 14,4 & 12,2 & 13,3 & 13,4 & 12,7 & 13,8 & 13,9 & 14,1 & 15,1 & 15,1 & 11,4 \\
\hline $\mathrm{C}_{2} \mathrm{H}_{4}$ & ${ }^{3} J_{\mathrm{HH}_{\mathrm{t}}}$ & 19,6 & 20,2 & 17,9 & 18,9 & 18,6 & 18,7 & 19,5 & 19,4 & 20,8 & 21,1 & 21,2 & 18,4 \\
\hline $\mathrm{C}_{2} \mathrm{H}_{6}$ & ${ }^{1} J_{\mathrm{CC}}$ & 33,3 & 36,2 & 26,9 & 30,6 & 30,0 & 30,0 & 33,3 & 33,0 & 36,7 & 38,9 & 39,5 & 33,6 \\
\hline $\mathrm{C}_{2} \mathrm{H}_{6}$ & ${ }^{1} J_{\mathrm{CH}}$ & 125,8 & 122,8 & 117,3 & 115,3 & 114,6 & 121,5 & 119,0 & 118,6 & 130,4 & 126,8 & 127,2 & 123,3 \\
\hline $\mathrm{C}_{2} \mathrm{H}_{6}$ & ${ }^{2} J_{\mathrm{CH}}$ & $-4,3$ & $-4,4$ & $-3,1$ & $-3,3$ & $-3,2$ & $-3,7$ & $-3,8$ & $-3,8$ & $-4,9$ & $-5,0$ & $-5,0$ & $-4,5$ \\
\hline \multirow[t]{3}{*}{ Total } & $\mathrm{DM}$ & $-14,46$ & 3,84 & $-21,65$ & $-7,95$ & $-4,58$ & $-18,08$ & $-2,18$ & $-0,50$ & $-10,92$ & 10,11 & 8,42 & - \\
\hline & DMA & 19,97 & 13,83 & 24,46 & 19,43 & 19,74 & 21,36 & 14,61 & 14,91 & 23,28 & 17,78 & 16,15 & - \\
\hline & PDMA & 13,67 & 19,13 & 25,99 & 20,22 & 18,93 & 16,41 & 10,15 & 11,11 & 27,48 & 33,95 & 32,41 & - \\
\hline \multirow[t]{3}{*}{ CPI } & DM & $-40,19$ & 3,88 & $-50,90$ & $-18,85$ & $-10,14$ & $-45,49$ & $-7,71$ & $-3,33$ & $-35,45$ & 15,85 & 11,34 & - \\
\hline & DMA & 40,65 & 26,85 & 52,85 & 41,10 & 41,14 & 46,25 & 30,16 & 30,91 & 44,10 & 32,69 & 28,32 & - \\
\hline & PDMA & 13,62 & 24,65 & 40,59 & 30,91 & 27,77 & 24,66 & 14,95 & 16,85 & 26,78 & 42,36 & 38,38 & - \\
\hline \multirow[t]{3}{*}{ SPI } & DM & 4,41 & 3,81 & $-0,19$ & 0,03 & $-0,51$ & 2,02 & 1,87 & 1,58 & 7,07 & 5,89 & 6,29 & - \\
\hline & DMA & 4,80 & 4,29 & 3,65 & 3,54 & 4,05 & 3,10 & 3,20 & 3,18 & 8,01 & 6,85 & 7,23 & - \\
\hline & PDMA & 13,70 & 15,08 & 15,29 & 12,38 & 12,45 & 10,35 & 6,63 & 6,90 & 27,99 & 27,78 & 28,04 & - \\
\hline \multirow[t]{3}{*}{$\Delta \mathrm{CS}$} & DM & $-44,60$ & 0,07 & $-50,71$ & $-18,88$ & $-9,62$ & $-47,51$ & $-9,58$ & $-4,91$ & $-42,52$ & 9,96 & 5,05 & - \\
\hline & DMA & 35,85 & 22,55 & 49,20 & 37,56 & 37,09 & 43,15 & 26,96 & 27,73 & 36,09 & 25,84 & 21,08 & - \\
\hline & PDMA & $-0,09$ & 9,56 & 25,30 & 18,53 & 15,32 & 14,31 & 8,32 & 9,95 & $-1,21$ & 14,58 & 10,34 & - \\
\hline
\end{tabular}


Tabela 8.176: Constantes de acoplamento PBE0 com otimização de geometrias e constantes empíricas no nível BHandH $\left(50 \% E_{X}^{\mathrm{HF}}\right)$ e base aug-pcJ-2.

\begin{tabular}{|c|c|c|c|c|c|c|c|c|c|c|c|c|c|c|c|c|}
\hline & $\% E_{X}^{\mathrm{HF}}$ & 25,00 & 25,00 & 20,00 & 20,00 & $\begin{array}{l}25,00 \\
20,00 \\
\text { Otm. }\end{array}$ & 30,00 & 30,00 & $\begin{array}{l}25,00 \\
30,00 \\
\text { Otm. }\end{array}$ & 40,00 & 40,00 & $\begin{array}{l}25,00 \\
40,00 \\
\text { Otm. }\end{array}$ & 50,00 & 50,00 & $\begin{array}{l}25,00 \\
50,00 \\
\text { Otm. }\end{array}$ & Exp. \\
\hline HF & ${ }^{1} J_{\mathrm{HF}}$ & 430,8 & 427,7 & 419,7 & 409,3 & 416,6 & 441,9 & 445,9 & 438,8 & 464,3 & 482,0 & 461,3 & 486,9 & 517,7 & 484,0 & 532,8 \\
\hline $\mathrm{CO}$ & ${ }^{1} J_{\mathrm{CO}}$ & 19,9 & 18,4 & 20,8 & 19,9 & 19,2 & 19,1 & 16,9 & 17,5 & 17,3 & 13,8 & 15,7 & 15,4 & 10,9 & 13,9 & 15,7 \\
\hline $\mathrm{H}_{2} \mathrm{O}$ & ${ }^{1} J_{\mathrm{OH}}$ & $-73,0$ & $-73,5$ & $-71,8$ & $-71,5$ & $-72,3$ & $-74,2$ & $-75,4$ & $-74,7$ & $-76,6$ & $-79,6$ & $-77,0$ & $-79,0$ & $-83,4$ & $-79,4$ & $-81,7$ \\
\hline $\mathrm{H}_{2} \mathrm{O}$ & ${ }^{2} J_{\mathrm{HH}}$ & $-7,3$ & $-6,9$ & $-6,7$ & $-6,4$ & $-6,4$ & $-7,8$ & $-7,4$ & $-7,4$ & $-8,9$ & $-8,1$ & $-8,5$ & $-10,0$ & $-9,0$ & $-9,6$ & $-8,8$ \\
\hline $\mathrm{NH}_{3}$ & ${ }^{1} J_{\mathrm{NH}}$ & 42,5 & 43,0 & 42,2 & 42,3 & 42,6 & 42,9 & 43,6 & 43,4 & 43,6 & 44,8 & 44,1 & 44,3 & 45,9 & 44,8 & 43,0 \\
\hline $\mathrm{NH}_{3}$ & ${ }^{2} J_{\mathrm{HH}}$ & $-10,1$ & $-9,8$ & $-9,6$ & $-9,5$ & $-9,4$ & $-10,6$ & $-10,3$ & $-10,3$ & $-11,5$ & $-11,0$ & $-11,3$ & $-12,5$ & $-11,8$ & $-12,2$ & $-10,5$ \\
\hline $\mathrm{PH}_{3}$ & ${ }^{1} J_{\mathrm{PH}}$ & 154,6 & 161,3 & 150,4 & 155,5 & 157,2 & 158,7 & 166,9 & 165,3 & 166,9 & 178,0 & 173,2 & 175,1 & 188,6 & 181,1 & 195,0 \\
\hline $\mathrm{PF}_{3}$ & ${ }^{1} J_{\mathrm{PF}}$ & $-1732,1$ & $-1627,0$ & $-1748,1$ & $-1634,2$ & $-1639,7$ & $-1715,3$ & $-1612,1$ & $-1613,5$ & $-1679,4$ & $-1581,4$ & $-1583,9$ & $-1640,8$ & $-1543,9$ & $-1551,5$ & $-1441,7$ \\
\hline $\mathrm{BHF}_{2}$ & ${ }^{1} J_{\mathrm{BF}}$ & $-131,0$ & $-130,8$ & $-139,2$ & $-142,2$ & $-139,0$ & $-122,7$ & $-119,9$ & $-122,5$ & $-106,5$ & $-97,7$ & $-106,3$ & $-90,4$ & $-76,6$ & $-90,2$ & $-79,7$ \\
\hline $\mathrm{BF}_{3}$ & ${ }^{1} J_{\mathrm{BF}}$ & $-30,5$ & $-33,5$ & $-39,4$ & $-46,9$ & $-42,4$ & $-21,7$ & $-21,1$ & $-24,6$ & $-4,2$ & 3,6 & $-7,0$ & 12,9 & 27,3 & 10,2 & 17,1 \\
\hline $\mathrm{F}_{2} \mathrm{O}$ & ${ }^{1} J_{\mathrm{OF}}$ & $-374,9$ & $-251,0$ & $-354,9$ & $-261,4$ & $-236,3$ & $-395,6$ & $-241,6$ & $-266,0$ & $-440,5$ & $-222,0$ & $-297,4$ & $-493,5$ & $-202,0$ & $-331,8$ & $-285,7$ \\
\hline $\mathrm{CH}_{4}$ & ${ }^{1} J_{\mathrm{CH}}$ & 122,8 & 123,0 & 122,1 & 122,5 & 122,3 & 123,5 & 123,5 & 123,8 & 125,0 & 124,5 & 125,2 & 126,5 & 125,5 & 126,8 & 122,8 \\
\hline $\mathrm{CH}_{4}$ & ${ }^{2} J_{\mathrm{HH}}$ & $-13,8$ & $-13,7$ & $-13,4$ & $-13,3$ & $-13,3$ & $-14,2$ & $-14,2$ & $-14,1$ & $-15,0$ & $-15,0$ & $-15,0$ & $-15,8$ & $-15,8$ & $-15,8$ & $-12,5$ \\
\hline $\mathrm{C}_{2} \mathrm{H}_{2}$ & ${ }^{1} J_{\mathrm{CC}}$ & 196,4 & 196,6 & 194,6 & 195,0 & 195,0 & 198,3 & 198,3 & 198,4 & 202,6 & 202,0 & 202,4 & 207,6 & 206,0 & 207,1 & 174,1 \\
\hline $\mathrm{C}_{2} \mathrm{H}_{2}$ & ${ }^{1} J_{\mathrm{CH}}$ & 256,2 & 254,5 & 254,8 & 254,0 & 253,1 & 257,6 & 255,0 & 255,9 & 260,7 & 256,1 & 258,8 & 264,1 & 257,5 & 262,1 & 244,3 \\
\hline $\mathrm{C}_{2} \mathrm{H}_{2}$ & ${ }^{2} J_{\mathrm{CH}}$ & 53,5 & 53,7 & 53,7 & 53,9 & 53,9 & 53,2 & 53,5 & 53,4 & 52,2 & 52,8 & 52,6 & 50,9 & 52,0 & 51,4 & 49,8 \\
\hline $\mathrm{C}_{2} \mathrm{H}_{2}$ & ${ }^{3} J_{\mathrm{HH}}$ & 12,4 & 12,0 & 11,9 & 11,7 & 11,6 & 12,9 & 12,4 & 12,5 & 14,1 & 13,3 & 13,7 & 15,6 & 14,3 & 15,1 & 9,0 \\
\hline $\mathrm{C}_{2} \mathrm{H}_{4}$ & ${ }^{1} J_{\mathrm{CC}}$ & 68,7 & 71,3 & 67,0 & 69,8 & 69,8 & 70,4 & 72,9 & 72,9 & 74,4 & 76,2 & 76,5 & 79,1 & 79,9 & 80,6 & 66,9 \\
\hline $\mathrm{C}_{2} \mathrm{H}_{4}$ & ${ }^{1} J_{\mathrm{CH}}$ & 157,3 & 154,6 & 156,1 & 153,8 & 153,5 & 158,5 & 155,3 & 155,7 & 161,1 & 156,9 & 158,1 & 164,0 & 158,7 & 160,8 & 154,4 \\
\hline $\mathrm{C}_{2} \mathrm{H}_{4}$ & ${ }^{2} J_{\mathrm{CH}}$ & $-3,0$ & $-2,7$ & $-2,5$ & $-2,2$ & $-2,2$ & $-3,7$ & $-3,3$ & $-3,3$ & $-5,1$ & $-4,5$ & $-4,6$ & $-6,9$ & $-5,9$ & $-6,2$ & $-2,0$ \\
\hline $\mathrm{C}_{2} \mathrm{H}_{4}$ & ${ }^{2} J_{\mathrm{HH}}$ & 2,3 & 1,2 & 2,8 & 1,7 & 1,6 & 1,8 & 0,7 & 0,7 & 0,7 & $-0,3$ & $-0,2$ & $-0,5$ & $-1,4$ & $-1,4$ & 2,1 \\
\hline $\mathrm{C}_{2} \mathrm{H}_{4}$ & ${ }^{3} J_{\mathrm{HH}_{\mathrm{c}}}$ & 12,7 & 13,4 & 12,5 & 13,1 & 13,2 & 13,0 & 13,7 & 13,6 & 13,6 & 14,3 & 14,2 & 14,5 & 15,0 & 14,9 & 11,4 \\
\hline $\mathrm{C}_{2} \mathrm{H}_{4}$ & ${ }^{3} J_{\mathrm{HH}_{\mathrm{t}}}$ & 19,8 & 20,4 & 19,5 & 20,2 & 20,2 & 20,1 & 20,7 & 20,7 & 20,9 & 21,2 & 21,4 & 21,9 & 21,9 & 22,3 & 18,4 \\
\hline $\mathrm{C}_{2} \mathrm{H}_{6}$ & ${ }^{1} J_{\mathrm{CC}}$ & 30,4 & 32,6 & 29,4 & 31,7 & 31,7 & 31,3 & 33,5 & 33,6 & 33,3 & 35,3 & 35,5 & 35,2 & 37,1 & 37,4 & 33,6 \\
\hline $\mathrm{C}_{2} \mathrm{H}_{6}$ & ${ }^{1} J_{\mathrm{CH}}$ & 123,5 & 122,0 & 122,7 & 121,5 & 121,2 & 124,3 & 122,6 & 122,9 & 126,0 & 123,8 & 124,5 & 127,7 & 124,9 & 126,2 & 123,3 \\
\hline $\mathrm{C}_{2} \mathrm{H}_{6}$ & ${ }^{2} J_{\mathrm{CH}}$ & $-4,1$ & $-4,1$ & $-3,9$ & $-3,9$ & $-3,9$ & $-4,3$ & $-4,4$ & $-4,4$ & $-4,9$ & $-4,9$ & $-4,9$ & $-5,4$ & $-5,4$ & $-5,4$ & $-4,5$ \\
\hline \multirow[t]{3}{*}{ Total } & DM & $-21,64$ & $-12,84$ & $-22,92$ & $-15,47$ & $-14,18$ & $-20,35$ & $-10,03$ & $-11,47$ & $-17,79$ & $-4,33$ & $-8,67$ & $-15,37$ & 1,5 & $-5,82$ & - \\
\hline & DMA & 26,58 & 20,30 & 27,62 & 22,12 & 22,59 & 25,70 & 18,35 & 18,12 & 24,21 & 14,84 & 14,90 & 23,30 & 12,62 & 13,58 & - \\
\hline & PDMA & 25,71 & 25,82 & 28,42 & 28,28 & 27,37 & 24,75 & 23,88 & 24,70 & 25,89 & 22,66 & 24,88 & 30,17 & 28,54 & 28,89 & - \\
\hline \multirow[t]{3}{*}{ CPI } & DM & $-55,15$ & $-34,33$ & $-57,46$ & $-40,05$ & $-36,85$ & -52, & $-28,18$ & $-31,77$ & -48 & & $-26,60$ & & -2 , & $-21,47$ & - \\
\hline & DMA & 57,84 & 43,09 & 60,74 & 47,71 & 48,82 & 54,96 & 37,96 & 37,32 & 49,60 & 28,15 & 27,71 & & & 22,22 & - \\
\hline & PDMA & 44,85 & 43,41 & 52,14 & 54,15 & 51,55 & 37,94 & 33,31 & 35,27 & 25,87 & 16,67 & 21,11 & 16,75 & 14,55 & 12,48 & - \\
\hline \multirow[t]{3}{*}{ SPI } & DM & 2,93 & 2 & 2,4 & 2,56 & 2,44 & 3,4 & 3,2 & 3,4 & 4,5 & 4, & 4,47 & & & 5,65 & - \\
\hline & DMA & 3,67 & 3,59 & 3,33 & 3,36 & 3,36 & 4,24 & 3,97 & 4,04 & 5,59 & 5,08 & 5,51 & 7,39 & 6,43 & 7,24 & - \\
\hline & PDMA & 11,66 & 12,93 & 11,03 & 9,32 & 9,64 & 15,08 & 16,98 & 16,95 & 25,90 & 27,06 & 27,64 & 40,01 & 38,79 & 40,92 & - \\
\hline \multirow[t]{3}{*}{$\Delta \mathrm{CS}$} & DM & $-58,08$ & $-37,24$ & $-59,88$ & $-42,61$ & $-39,29$ & $-56,24$ & $-31,46$ & $-35,19$ & $-52,84$ & $-19,78$ & $-31,07$ & $-50,11$ & $-7,77$ & $-27,13$ & - \\
\hline & DMA & 54,17 & 39,50 & 57,40 & 44,35 & 45,46 & 50,72 & 34,00 & 33,28 & 44,01 & 23,07 & 22,20 & 37,62 & 14,63 & 14,98 & - \\
\hline & PDMA & 33,19 & 30,48 & 41,11 & 44,83 & 41,92 & 22,86 & 16,33 & 18,32 & $-0,02$ & $-10,39$ & $-6,53$ & $-23,26$ & $-24,23$ & $-28,43$ & - \\
\hline
\end{tabular}


Tabela 8.177: Constantes de acoplamento B971 com otimização de geometrias e constantes empíricas no nível BHandH $40 \% E_{X}^{\mathrm{HF}}$ e base aug-pcJ-2.

\begin{tabular}{|c|c|c|c|c|c|c|c|c|c|c|c|c|c|}
\hline & $\% E_{X}^{\mathrm{HF}}$ & 21,00 & 21,00 & 40,00 & 40,00 & $\begin{array}{l}21,00 \\
40,00 \\
\text { Otm. }\end{array}$ & 50,00 & 50,00 & $\begin{array}{l}21,00 \\
50,00 \\
\text { Otm. }\end{array}$ & 60,00 & 60,00 & $\begin{array}{l}21,00 \\
60,00 \\
\text { Otm. }\end{array}$ & Exp. \\
\hline $\mathrm{HF}$ & ${ }^{1} J_{\mathrm{HF}}$ & 449,1 & 441,3 & 499,7 & 438,6 & 492,5 & 520,6 & 485,9 & 513,5 & 542,8 & 533,4 & 535,7 & 533,2 \\
\hline $\mathrm{CO}$ & ${ }^{1} J_{\mathrm{CO}}$ & 17,4 & 16,9 & 10,7 & 14,6 & 10,2 & 9,0 & 10,4 & 8,6 & 7,3 & 6,2 & 6,8 & 15,6 \\
\hline $\mathrm{H}_{2} \mathrm{O}$ & ${ }^{1} J_{\mathrm{OH}}$ & $-74,4$ & $-74,2$ & $-77,0$ & $-70,0$ & $-76,8$ & $-79,7$ & $-76,0$ & $-79,5$ & $-82,5$ & $-81,9$ & $-82,4$ & $-81,8$ \\
\hline $\mathrm{H}_{2} \mathrm{O}$ & ${ }^{2} J_{\mathrm{HH}}$ & $-6,5$ & $-6,2$ & $-5,1$ & $-5,1$ & $-4,8$ & $-6,4$ & $-6,1$ & $-6,1$ & $-7,7$ & $-7,1$ & $-7,4$ & $-8,7$ \\
\hline $\mathrm{NH}_{3}$ & ${ }^{1} J_{\mathrm{NH}}$ & 43,3 & 43,4 & 41,9 & 40,0 & 42,0 & 43,1 & 42,4 & 43,2 & 44,4 & 44,8 & 44,6 & 43,1 \\
\hline $\mathrm{NH}_{3}$ & ${ }^{2} J_{\mathrm{HH}}$ & $-9,1$ & $-9,0$ & $-7,4$ & $-7,4$ & $-7,2$ & $-8,6$ & $-8,3$ & $-8,4$ & $-9,9$ & $-9,3$ & $-9,7$ & $-10,5$ \\
\hline $\mathrm{PH}_{3}$ & ${ }^{1} J_{\mathrm{PH}}$ & 190,7 & 196,4 & 188,9 & 182,7 & 194,0 & 196,6 & 195,7 & 201,5 & 204,6 & 208,5 & 209,3 & 195,5 \\
\hline $\mathrm{PF}_{3}$ & ${ }^{1} J_{\mathrm{PF}}$ & $-1656,7$ & $-1547,7$ & $-1562,1$ & $-1459,7$ & $-1478,1$ & $-1539,1$ & $-1449,7$ & $-1459,4$ & $-1513,4$ & $-1429,0$ & $-1438,0$ & $-1442,8$ \\
\hline $\mathrm{BHF}_{2}$ & ${ }^{1} J_{\mathrm{BF}}$ & $-123,8$ & $-129,8$ & $-85,1$ & $-118,1$ & $-91,1$ & $-69,6$ & $-88,3$ & $-75,5$ & $-54,0$ & $-59,4$ & $-59,8$ & $-79,5$ \\
\hline $\mathrm{BF}_{3}$ & ${ }^{1} J_{\mathrm{BF}}$ & $-27,9$ & $-39,4$ & 12,4 & $-28,7$ & 1,5 & 29,7 & 5,7 & 19,0 & 47,1 & 39,2 & 36,7 & 17,2 \\
\hline $\mathrm{F}_{2} \mathrm{O}$ & ${ }^{1} J_{\mathrm{OF}}$ & $-318,8$ & $-257,2$ & $-327,7$ & $-318,6$ & $-262,4$ & $-370,4$ & $-281,7$ & $-298,6$ & $-421,2$ & $-245,8$ & $-340,0$ & $-286,9$ \\
\hline $\mathrm{CH}_{4}$ & ${ }^{1} J_{\mathrm{CH}}$ & 128,8 & 129,3 & 116,5 & 121,4 & 116,9 & 120,6 & 124,4 & 121,1 & 125,0 & 127,5 & 125,4 & 123,0 \\
\hline $\mathrm{CH}_{4}$ & ${ }^{2} J_{\mathrm{HH}}$ & $-12,0$ & $-12,0$ & $-9,6$ & $-9,3$ & $-9,5$ & $-10,7$ & $-10,5$ & $-10,6$ & $-11,8$ & $-11,7$ & $-11,8$ & $-12,5$ \\
\hline $\mathrm{C}_{2} \mathrm{H}_{2}$ & ${ }^{1} J_{\mathrm{CC}}$ & 213,8 & 213,8 & 205,0 & 207,4 & 205,1 & 211,6 & 213,6 & 211,5 & 219,4 & 220,2 & 219,1 & 174,4 \\
\hline $\mathrm{C}_{2} \mathrm{H}_{2}$ & ${ }^{1} J_{\mathrm{CH}}$ & 261,3 & 260,2 & 229,5 & 239,0 & 228,6 & 237,9 & 243,9 & 236,9 & 247,0 & 249,0 & 245,9 & 244,5 \\
\hline $\mathrm{C}_{2} \mathrm{H}_{2}$ & ${ }^{2} J_{\mathrm{CH}}$ & 53,2 & 53,3 & 53,2 & 53,3 & 53,2 & 53,0 & 53,1 & 53,1 & 52,5 & 52,6 & 52,6 & 49,7 \\
\hline $\mathrm{C}_{2} \mathrm{H}_{2}$ & ${ }^{3} J_{\mathrm{HH}}$ & 10,5 & 10,3 & 8,4 & 9,1 & 8,2 & 9,3 & 9,7 & 9,1 & 10,5 & 10,5 & 10,3 & 9,1 \\
\hline $\mathrm{C}_{2} \mathrm{H}_{4}$ & ${ }^{1} J_{\mathrm{CC}}$ & 78,1 & 80,5 & 76,4 & 78,7 & 78,8 & 80,8 & 83,5 & 83,1 & 86,2 & 88,6 & 88,1 & 67,2 \\
\hline $\mathrm{C}_{2} \mathrm{H}_{4}$ & ${ }^{1} J_{\mathrm{CH}}$ & 162,8 & 160,7 & 145,4 & 149,6 & 143,6 & 151,2 & 153,5 & 149,2 & 157,4 & 157,6 & 155,2 & 154,5 \\
\hline $\mathrm{C}_{2} \mathrm{H}_{4}$ & ${ }^{2} J_{\mathrm{CH}}$ & $-2,1$ & $-1,8$ & $-0,8$ & $-0,4$ & $-0,6$ & $-2,1$ & $-1,9$ & $-1,8$ & $-3,7$ & $-3,5$ & $-3,3$ & $-2,1$ \\
\hline $\mathrm{C}_{2} \mathrm{H}_{4}$ & ${ }^{2} J_{\mathrm{HH}}$ & 3,6 & 2,4 & 4,1 & 4,3 & 3,0 & 3,4 & 3,3 & 2,3 & 2,5 & 2,1 & 1,4 & 2,0 \\
\hline $\mathrm{C}_{2} \mathrm{H}_{4}$ & ${ }^{3} J_{\mathrm{HH}_{\mathrm{c}}}$ & 11,7 & 12,2 & 10,5 & 10,3 & 11,0 & 11,0 & 11,1 & 11,5 & 11,6 & 12,0 & 12,1 & 11,4 \\
\hline $\mathrm{C}_{2} \mathrm{H}_{4}$ & ${ }^{3} J_{\mathrm{HH}_{\mathrm{t}}}$ & 18,4 & 19,0 & 15,6 & 16,6 & 16,1 & 16,4 & 17,3 & 16,9 & 17,4 & 18,2 & 17,9 & 18,5 \\
\hline $\mathrm{C}_{2} \mathrm{H}_{6}$ & ${ }^{1} J_{\mathrm{CC}}$ & 34,9 & 36,5 & 35,1 & 36,3 & 36,7 & 37,8 & 39,4 & 39,5 & 40,8 & 42,5 & 42,4 & 33,7 \\
\hline $\mathrm{C}_{2} \mathrm{H}_{6}$ & ${ }^{1} J_{\mathrm{CH}}$ & 129,1 & 128,5 & 116,5 & 120,7 & 115,9 & 120,9 & 123,9 & 120,3 & 125,5 & 127,0 & 125,0 & 123,4 \\
\hline $\mathrm{C}_{2} \mathrm{H}_{6}$ & ${ }^{2} J_{\mathrm{CH}}$ & $-3,6$ & $-3,5$ & $-2,8$ & $-2,6$ & $-2,8$ & $-3,5$ & $-3,4$ & $-3,4$ & $-4,2$ & $-4,1$ & $-4,1$ & $-4,5$ \\
\hline \multirow[t]{3}{*}{ Total } & DM & $-12,11$ & $-6,26$ & $-7,48$ & $-7,08$ & $-2,41$ & $-4,77$ & 0,16 & 0,40 & $-2,04$ & 7,75 & 3,28 & - \\
\hline & DMA & 20,52 & 17,10 & 12,42 & 13,10 & 9,54 & 11,87 & 6,58 & 6,13 & 14,62 & 8,61 & 8,27 & - \\
\hline & PDMA & 23,67 & 25,00 & 19,33 & 30,56 & 20,38 & 15,62 & 14,83 & 10,90 & 21,61 & 18,42 & 17,87 & - \\
\hline \multirow[t]{3}{*}{ CPI } & DM & $-37,37$ & $-23,63$ & $-18,65$ & $-20,55$ & $-6,78$ & $-15,38$ & $-5,85$ & $-3,28$ & $-12,45$ & 9,56 & 0,13 & - \\
\hline & DMA & 39,74 & 31,59 & 20,75 & 23,92 & 13,45 & 20,80 & 8,76 & 6,72 & 26,45 & 11,29 & 11,49 & - \\
\hline & PDMA & 38,34 & 44,45 & 16,19 & 40,99 & 22,25 & 19,39 & 16,55 & 11,39 & 30,76 & 24,48 & 22,52 & - \\
\hline \multirow[t]{3}{*}{ SPI } & $\mathrm{DM}$ & 6,41 & 6,47 & 0,71 & 2,81 & 0,79 & 3,02 & 4,57 & 3,09 & 5,59 & 6,41 & 5,59 & - \\
\hline & DMA & 6,43 & 6,47 & 6,31 & 5,17 & 6,67 & 5,33 & 4,99 & 5,69 & 5,95 & 6,64 & 5,91 & - \\
\hline & PDMA & 12,90 & 10,74 & 21,63 & 22,91 & 19,00 & 12,86 & 13,57 & 10,54 & 14,90 & 13,98 & 14,46 & - \\
\hline \multirow[t]{3}{*}{$\Delta \mathrm{CS}$} & $\mathrm{DM}$ & $-43,79$ & $-30,10$ & $-19,37$ & $-23,36$ & $-7,58$ & $-18,40$ & $-10,43$ & $-6,38$ & $-18,03$ & 3,15 & $-5,47$ & - \\
\hline & DMA & 33,31 & 25,12 & 14,43 & 18,75 & 6,78 & 15,47 & 3,78 & 1,02 & 20,50 & 4,65 & 5,58 & - \\
\hline & PDMA & 25,44 & 33,72 & $-5,44$ & 18,08 & 3,26 & 6,53 & 2,98 & 0,85 & 15,86 & 10,50 & 8,06 & - \\
\hline
\end{tabular}


Tabela 8.178: Constantes de acoplamento B972 com otimização de geometrias e constantes empíricas no nível BHandH $40 \% E_{X}^{\mathrm{HF}}$ e base aug-pcJ-2.

\begin{tabular}{|c|c|c|c|c|c|c|c|c|c|c|c|c|c|c|c|c|}
\hline & $\% E_{X}^{\mathrm{HF}}$ & 21,00 & 21,00 & 30,00 & 30,00 & $\begin{array}{l}21,00 \\
30,00 \\
\text { Otm. }\end{array}$ & 40,00 & 40,00 & $\begin{array}{l}21,00 \\
40,00 \\
\text { Otm. }\end{array}$ & 50,00 & 50,00 & $\begin{array}{l}21,00 \\
50,00 \\
\text { Otm. }\end{array}$ & 60,00 & 60,00 & $\begin{array}{l}21,00 \\
60,00 \\
\text { Otm. }\end{array}$ & Exp. \\
\hline $\mathrm{HF}$ & ${ }^{1} J_{\mathrm{HF}}$ & 442,8 & 447,0 & 487,2 & 401,9 & 491,1 & 512,0 & 452,6 & 515,9 & 538,2 & 503,7 & 542,0 & 565,8 & 555,5 & 569,7 & 533,2 \\
\hline $\mathrm{CO}$ & ${ }^{1} J_{\mathrm{CO}}$ & 18,3 & 17,1 & 11,5 & 17,6 & 10,2 & 9,2 & 12,9 & 8,0 & 6,8 & 8,0 & 5,6 & 4,2 & 3,0 & 3,0 & 15,6 \\
\hline $\mathrm{H}_{2} \mathrm{O}$ & ${ }^{1} J_{\mathrm{OH}}$ & $-73,5$ & $-74,4$ & $-75,6$ & $-65,7$ & $-76,4$ & $-78,9$ & $-72,4$ & $-79,7$ & $-82,3$ & $-79,0$ & $-83,2$ & $-86,0$ & $-85,6$ & $-86,9$ & $-81,8$ \\
\hline $\mathrm{H}_{2} \mathrm{O}$ & ${ }^{2} J_{\mathrm{HH}}$ & $-7,5$ & $-7,2$ & $-4,3$ & $-4,7$ & $-4,1$ & $-5,5$ & $-5,5$ & $-5,3$ & $-6,7$ & $-6,4$ & $-6,5$ & $-8,0$ & $-7,4$ & $-7,8$ & $-8,7$ \\
\hline $\mathrm{NH}_{3}$ & ${ }^{1} J_{\mathrm{NH}}$ & 41,7 & 42,0 & 40,3 & 37,6 & 40,6 & 41,8 & 40,3 & 42,1 & 43,4 & 43,0 & 43,7 & 45,1 & 45,7 & 45,4 & 43,1 \\
\hline $\mathrm{NH}_{3}$ & ${ }^{2} J_{\mathrm{HH}}$ & $-9,1$ & $-9,0$ & $-6,0$ & $-6,3$ & $-6,0$ & $-7,1$ & $-7,1$ & $-7,0$ & $-8,2$ & $-7,9$ & $-8,1$ & $-9,4$ & $-8,9$ & $-9,3$ & $-10,5$ \\
\hline $\mathrm{PH}_{3}$ & ${ }^{1} J_{\mathrm{PH}}$ & 184,0 & 191,6 & 175,0 & 158,0 & 182,2 & 183,4 & 173,7 & 190,5 & 192,2 & 189,1 & 199,2 & 201,4 & 204,8 & 208,4 & 195,5 \\
\hline $\mathrm{PF}_{3}$ & ${ }^{1} J_{\mathrm{PF}}$ & $-1661,2$ & $-1562,9$ & $-1595,3$ & $-1477,0$ & $-1516,3$ & $-1576,6$ & $-1482,9$ & $-1501,6$ & $-1555,0$ & $-1472,3$ & $-1484,0$ & $-1531,2$ & $-1451,5$ & $-1464,1$ & $-1442,8$ \\
\hline $\mathrm{BHF}_{2}$ & ${ }^{1} J_{\mathrm{BF}}$ & $-129,9$ & $-132,8$ & $-100,3$ & $-146,5$ & $-103,3$ & $-82,9$ & $-115,3$ & $-85,8$ & $-65,4$ & $-84,7$ & $-68,3$ & $-48,0$ & $-55,3$ & $-50,8$ & $-79,5$ \\
\hline $\mathrm{BF}_{3}$ & ${ }^{1} J_{\mathrm{BF}}$ & $-36,6$ & $-43,3$ & $-5,4$ & $-63,3$ & $-12,0$ & 14,1 & $-26,3$ & 7,7 & 33,8 & 9,3 & 27,6 & 53,5 & 43,6 & 47,4 & 17,2 \\
\hline $\mathrm{F}_{2} \mathrm{O}$ & ${ }^{1} J_{\mathrm{OF}}$ & $-316,0$ & $-219,7$ & $-283,7$ & $-341,6$ & $-189,4$ & $-320,6$ & $-310,4$ & $-218,4$ & $-362,5$ & $-278,7$ & $-250,3$ & $-412,9$ & $-247,5$ & $-286,6$ & $-286,9$ \\
\hline $\mathrm{CH}_{4}$ & ${ }^{1} J_{\mathrm{CH}}$ & 118,8 & 118,8 & 107,2 & 112,8 & 107,2 & 111,9 & 116,6 & 111,9 & 116,9 & 120,6 & 116,9 & 122,2 & 124,6 & 122,2 & 123,0 \\
\hline $\mathrm{CH}_{4}$ & ${ }^{2} J_{\mathrm{HH}}$ & $-11,3$ & $-11,3$ & $-7,8$ & $-7,4$ & $-7,8$ & $-8,7$ & $-8,4$ & $-8,7$ & $-9,7$ & $-9,5$ & $-9,7$ & $-10,7$ & $-10,6$ & $-10,7$ & $-12,5$ \\
\hline $\mathrm{C}_{2} \mathrm{H}_{2}$ & ${ }^{1} J_{\mathrm{CC}}$ & 197,5 & 197,6 & 188,8 & 189,7 & 189,1 & 195,6 & 197,1 & 195,7 & 203,4 & 204,9 & 203,2 & 212,5 & 213,3 & 212,0 & 174,4 \\
\hline $\mathrm{C}_{2} \mathrm{H}_{2}$ & ${ }^{1} J_{\mathrm{CH}}$ & 247,3 & 245,2 & 213,7 & 226,1 & 211,9 & 222,6 & 231,8 & 220,7 & 232,0 & 237,7 & 230,0 & 242,2 & 243,9 & 240,0 & 244,5 \\
\hline $\mathrm{C}_{2} \mathrm{H}_{2}$ & ${ }^{2} J_{\mathrm{CH}}$ & 50,7 & 50,8 & 51,4 & 51,7 & 51,5 & 51,8 & 51,9 & 51,9 & 51,9 & 51,9 & 52,0 & 51,5 & 51,7 & 51,7 & 49,7 \\
\hline $\mathrm{C}_{2} \mathrm{H}_{2}$ & ${ }^{3} J_{\mathrm{HH}}$ & 10,4 & 10,1 & 7,4 & 8,4 & 7,2 & 8,1 & 8,7 & 7,8 & 8,9 & 9,2 & 8,6 & 9,9 & 9,8 & 9,6 & 9,1 \\
\hline $\mathrm{C}_{2} \mathrm{H}_{4}$ & ${ }^{1} J_{\mathrm{CC}}$ & 68,1 & 70,6 & 66,0 & 67,6 & 68,7 & 70,8 & 73,1 & 73,3 & 76,3 & 78,9 & 78,5 & 82,9 & 85,2 & 84,7 & 67,2 \\
\hline $\mathrm{C}_{2} \mathrm{H}_{4}$ & ${ }^{1} J_{\mathrm{CH}}$ & 152,3 & 149,4 & 134,1 & 139,5 & 131,7 & 140,3 & 144,2 & 137,7 & 146,9 & 149,1 & 144,1 & 154,1 & 154,1 & 151,1 & 154,5 \\
\hline $\mathrm{C}_{2} \mathrm{H}_{4}$ & ${ }^{2} J_{\mathrm{CH}}$ & $-2,0$ & $-1,6$ & 0,5 & 1,0 & 0,7 & $-0,4$ & $-0,1$ & $-0,2$ & $-1,7$ & $-1,4$ & $-1,4$ & $-3,2$ & $-3,0$ & $-2,8$ & $-2,1$ \\
\hline $\mathrm{C}_{2} \mathrm{H}_{4}$ & ${ }^{2} J_{\mathrm{HH}}$ & 3,1 & 1,9 & 4,7 & 5,2 & 3,6 & 4,2 & 4,4 & 3,1 & 3,7 & 3,5 & 2,5 & 3,0 & 2,5 & 1,9 & 2,0 \\
\hline $\mathrm{C}_{2} \mathrm{H}_{4}$ & ${ }^{3} J_{\mathrm{HH}_{\mathrm{C}}}$ & 11,2 & 11,8 & 9,7 & 9,2 & 10,3 & 10,1 & 9,9 & 10,7 & 10,6 & 10,6 & 11,1 & 11,1 & 11,5 & 11,7 & 11,4 \\
\hline $\mathrm{C}_{2} \mathrm{H}_{4}$ & ${ }^{3} J_{\mathrm{HH}_{\mathrm{t}}}$ & 17,7 & 18,3 & 14,4 & 15,5 & 14,9 & 15,1 & 16,1 & 15,6 & 15,9 & 16,8 & 16,4 & 16,8 & 17,5 & 17,3 & 18,5 \\
\hline $\mathrm{C}_{2} \mathrm{H}_{6}$ & ${ }^{1} J_{\mathrm{CC}}$ & 30,6 & 32,4 & 30,2 & 31,6 & 32,1 & 33,3 & 35,0 & 35,2 & 36,6 & 38,4 & 38,5 & 40,1 & 41,9 & 42,0 & 33,7 \\
\hline $\mathrm{C}_{2} \mathrm{H}_{6}$ & ${ }^{1} J_{\mathrm{CH}}$ & 118,9 & 117,3 & 106,4 & 111,4 & 105,1 & 111,4 & 115,3 & 110,0 & 116,6 & 119,3 & 115,2 & 122,1 & 123,4 & 120,6 & 123,4 \\
\hline $\mathrm{C}_{2} \mathrm{H}_{6}$ & ${ }^{2} J_{\mathrm{CH}}$ & $-3,2$ & $-3,2$ & $-1,9$ & $-1,6$ & $-1,8$ & $-2,4$ & $-2,2$ & $-2,4$ & $-3,0$ & $-2,8$ & $-2,9$ & $-3,6$ & $-3,5$ & $-3,6$ & $-4,5$ \\
\hline \multirow[t]{3}{*}{ Total } & DM & $-16,29$ & $-8,85$ & $-12,25$ & $-16,00$ & $-5,60$ & $-9,00$ & $-8,99$ & $-2,23$ & $-5,66$ & $-1,36$ & 1,31 & $-2,36$ & 6,62 & 4,98 & - \\
\hline & DMA & 19,86 & 17,46 & 15,87 & 20,48 & 16,51 & 12,56 & 13,52 & 11,27 & 12,57 & 6,90 & 8,59 & 15,94 & 8,77 & 9,02 & - \\
\hline & PDMA & 24,47 & 24,64 & 31,09 & 48,45 & 32,00 & 20,72 & 31,65 & 21,24 & 19,24 & 16,23 & 16,20 & 24,59 & 20,28 & 19,67 & - \\
\hline \multirow[t]{3}{*}{ CPI } & DM & $-40,13$ & $-22,36$ & $-22,82$ & $-34,95$ & $-7,07$ & $-18,68$ & $-21,35$ & $-2,55$ & $-14,55$ & $-6,39$ & 2,12 & $-10,90$ & 9,27 & 6,73 & - \\
\hline & DMA & 42,60 & 36,75 & 26,15 & 39,73 & 27,44 & 20,41 & 24,25 & 16,64 & 21,88 & 9,28 & 11,68 & 30,92 & & 13,82 & - \\
\hline & PDMA & 43,83 & 47,40 & 29,29 & 68,07 & 36,02 & 15,48 & 39,97 & 20,27 & 23,06 & 15,43 & 19,01 & 37,38 & 29,89 & 30,98 & - \\
\hline \multirow[t]{3}{*}{ SPI } & DM & 1,19 & 1,05 & $-4,50$ & $-2,11$ & $-4,53$ & $-1,91$ & 0,07 & $-2,00$ & 0,8 & 2,3 & 0,71 & 3, & 4,6 & 3,69 & - \\
\hline & DMA & 3,19 & 3,32 & 8,33 & 6,37 & 8,50 & 6,80 & 5,65 & 7,33 & 5,75 & 5,15 & 6,33 & 4,96 & 5,05 & 5,49 & - \\
\hline & PDMA & 10,27 & 7,95 & 32,41 & 34,06 & 29,05 & 24,57 & 25,56 & 21,95 & 16,45 & 16,82 & 14,15 & 15,21 & 13,23 & 11,37 & - \\
\hline \multirow[t]{3}{*}{$\Delta \mathrm{CS}$} & DM & $-41,31$ & $-23,42$ & $-18,32$ & $-32,84$ & $-2,55$ & $-16,78$ & $-21,42$ & $-0,55$ & $-15,42$ & $-8,72$ & 1,40 & $-14,81$ & 4,61 & 3,03 & - \\
\hline & DMA & 39,41 & 33,43 & & 33,35 & 18,94 & & 18,61 & 9,30 & 16,14 & & 5,36 & & 8,78 & 8,32 & - \\
\hline & PDMA & 33,56 & 39,45 & $-3,13$ & 34,01 & 6,97 & $-9,10$ & 14,41 & $-1,69$ & 6,61 & $-1,38$ & 4,86 & 22,18 & 16,66 & 19,61 & - \\
\hline
\end{tabular}


Tabela 8.179: Constantes de acoplamento B98 com otimização de geometrias e constantes empíricas no nível BHandH $40 \% E_{X}^{\mathrm{HF}}$ e base aug-pcJ-2.

\begin{tabular}{|c|c|c|c|c|c|c|c|c|c|c|c|c|c|}
\hline & $\% E_{X}^{\mathrm{HF}}$ & 21,98 & 21,98 & 40,00 & 40,00 & $\begin{array}{l}21,98 \\
/ \\
40,00 \\
\text { Otm. }\end{array}$ & 50,00 & 50,00 & $\begin{array}{l}21,98 \\
50,00 \\
\text { Otm. }\end{array}$ & 60,00 & 60,00 & $\begin{array}{l}21,98 \\
60,00 \\
\text { Otm. }\end{array}$ & Exp. \\
\hline $\mathrm{HF}$ & ${ }^{1} J_{\mathrm{HF}}$ & 431,2 & 425,7 & 484,6 & 417,7 & 479,5 & 505,9 & 465,8 & 500,8 & 528,5 & 514,5 & 523,5 & 533,2 \\
\hline $\mathrm{CO}$ & ${ }^{1} J_{\mathrm{CO}}$ & 18,5 & 17,6 & 11,2 & 15,5 & 10,4 & 9,5 & 11,2 & 8,7 & 7,7 & 6,9 & 6,8 & 15,6 \\
\hline $\mathrm{H}_{2} \mathrm{O}$ & ${ }^{1} J_{\mathrm{OH}}$ & $-72,5$ & $-72,6$ & $-75,6$ & $-67,9$ & $-75,7$ & $-78,4$ & $-74,2$ & $-78,5$ & $-81,4$ & $-80,4$ & $-81,5$ & $-81,8$ \\
\hline $\mathrm{H}_{2} \mathrm{O}$ & ${ }^{2} J_{\mathrm{HH}}$ & $-6,9$ & $-6,5$ & $-5,1$ & $-5,1$ & $-4,7$ & $-6,4$ & $-6,1$ & $-6,1$ & $-7,9$ & $-7,2$ & $-7,5$ & $-8,7$ \\
\hline $\mathrm{NH}_{3}$ & ${ }^{1} J_{\mathrm{NH}}$ & 42,9 & 43,1 & 41,7 & 39,6 & 41,9 & 43,1 & 42,3 & 43,3 & 44,6 & 44,8 & 44,8 & 43,1 \\
\hline $\mathrm{NH}_{3}$ & ${ }^{2} J_{\mathrm{HH}}$ & $-9,5$ & $-9,3$ & $-7,6$ & $-7,5$ & $-7,4$ & $-8,8$ & $-8,5$ & $-8,6$ & $-10,2$ & $-9,6$ & $-10,0$ & $-10,5$ \\
\hline $\mathrm{PH}_{3}$ & ${ }^{1} J_{\mathrm{PH}}$ & 196,4 & 202,7 & 193,7 & 187,2 & 199,5 & 201,7 & 200,7 & 207,3 & 210,1 & 213,9 & 215,4 & 195,5 \\
\hline $\mathrm{PF}_{3}$ & ${ }^{1} J_{\mathrm{PF}}$ & $-1666,4$ & $-1560,1$ & $-1572,1$ & $-1468,9$ & $-1489,9$ & $-1549,1$ & $-1459,9$ & $-1470,8$ & $-1523,4$ & $-1439,8$ & $-1449,0$ & $-1442,8$ \\
\hline $\mathrm{BHF}_{2}$ & ${ }^{1} J_{\mathrm{BF}}$ & $-129,1$ & $-133,2$ & $-89,6$ & $-125,3$ & $-93,7$ & $-73,8$ & $-95,5$ & $-77,8$ & $-57,8$ & $-66,4$ & $-61,8$ & $-79,5$ \\
\hline $\mathrm{BF}_{3}$ & ${ }^{1} J_{\mathrm{BF}}$ & $-34,1$ & $-43,2$ & 7,0 & $-37,6$ & $-1,5$ & 24,5 & $-3,0$ & 16,1 & 42,2 & 30,6 & 34,0 & 17,2 \\
\hline $\mathrm{F}_{2} \mathrm{O}$ & ${ }^{1} J_{\mathrm{OF}}$ & $-336,9$ & $-264,6$ & $-338,2$ & $-347,7$ & $-262,5$ & $-383,0$ & $-312,7$ & $-299,3$ & $-437,3$ & $-278,5$ & $-341,9$ & $-286,9$ \\
\hline $\mathrm{CH}_{4}$ & ${ }^{1} J_{\mathrm{CH}}$ & 128,3 & 128,7 & 116,9 & 122,0 & 117,2 & 121,5 & 125,6 & 121,9 & 126,5 & 129,3 & 126,9 & 123,0 \\
\hline $\mathrm{CH}_{4}$ & ${ }^{2} J_{\mathrm{HH}}$ & $-12,5$ & $-12,5$ & $-9,8$ & $-9,5$ & $-9,8$ & $-11,0$ & $-10,8$ & $-11,0$ & $-12,2$ & $-12,1$ & $-12,2$ & $-12,5$ \\
\hline $\mathrm{C}_{2} \mathrm{H}_{2}$ & ${ }^{1} J_{\mathrm{CC}}$ & 212,9 & 212,7 & 205,0 & 207,5 & 205,0 & 212,2 & 214,3 & 211,9 & 220,6 & 221,6 & 220,0 & 174,4 \\
\hline $\mathrm{C}_{2} \mathrm{H}_{2}$ & ${ }^{1} J_{\mathrm{CH}}$ & 261,1 & 259,6 & 229,7 & 239,7 & 228,3 & 239,0 & 245,4 & 237,5 & 249,0 & 251,5 & 247,4 & 244,5 \\
\hline $\mathrm{C}_{2} \mathrm{H}_{2}$ & ${ }^{2} J_{\mathrm{CH}}$ & 52,8 & 52,9 & 53,2 & 53,4 & 53,3 & 53,2 & 53,2 & 53,3 & 52,6 & 52,7 & 52,8 & 49,7 \\
\hline $\mathrm{C}_{2} \mathrm{H}_{2}$ & ${ }^{3} J_{\mathrm{HH}}$ & 10,7 & 10,4 & 8,4 & 9,2 & 8,2 & 9,4 & 9,8 & 9,1 & 10,6 & 10,7 & 10,4 & 9,1 \\
\hline $\mathrm{C}_{2} \mathrm{H}_{4}$ & ${ }^{1} J_{\mathrm{CC}}$ & 77,3 & 79,7 & 76,4 & 78,8 & 78,9 & 81,3 & 84,1 & 83,6 & 87,2 & 89,7 & 89,1 & 67,2 \\
\hline $\mathrm{C}_{2} \mathrm{H}_{4}$ & ${ }^{1} J_{\mathrm{CH}}$ & 162,5 & 160,1 & 145,7 & 150,2 & 143,6 & 152,0 & 154,8 & 149,8 & 158,9 & 159,5 & 156,5 & 154,5 \\
\hline $\mathrm{C}_{2} \mathrm{H}_{4}$ & ${ }^{2} J_{\mathrm{CH}}$ & $-2,4$ & $-2,1$ & $-0,8$ & $-0,5$ & $-0,6$ & $-2,1$ & $-1,9$ & $-1,9$ & $-3,8$ & $-3,6$ & $-3,4$ & $-2,1$ \\
\hline $\mathrm{C}_{2} \mathrm{H}_{4}$ & ${ }^{2} J_{\mathrm{HH}}$ & 3,1 & 1,9 & 3,9 & 4,2 & 2,8 & 3,2 & 3,1 & 2,1 & 2,3 & 1,9 & 1,2 & 2,0 \\
\hline $\mathrm{C}_{2} \mathrm{H}_{4}$ & ${ }^{3} J_{\mathrm{HH}_{\mathrm{c}}}$ & 11,8 & 12,4 & 10,6 & 10,2 & 11,1 & 11,1 & 11,1 & 11,6 & 11,8 & 12,0 & 12,2 & 11,4 \\
\hline $\mathrm{C}_{2} \mathrm{H}_{4}$ & ${ }^{3} J_{\mathrm{HH}_{\mathrm{t}}}$ & 18,5 & 19,1 & 15,6 & 16,7 & 16,2 & 16,5 & 17,5 & 17,0 & 17,6 & 18,4 & 18,1 & 18,5 \\
\hline $\mathrm{C}_{2} \mathrm{H}_{6}$ & ${ }^{1} J_{\mathrm{CC}}$ & 34,4 & 36,0 & 35,1 & 36,2 & 36,7 & 38,2 & 39,6 & 39,8 & 41,5 & 43,1 & 43,1 & 33,7 \\
\hline $\mathrm{C}_{2} \mathrm{H}_{6}$ & ${ }^{1} J_{\mathrm{CH}}$ & 128,8 & 128,1 & 116,8 & 121,4 & 116,1 & 121,7 & 125,2 & 121,1 & 127,0 & 129,0 & 126,3 & 123,4 \\
\hline $\mathrm{C}_{2} \mathrm{H}_{6}$ & ${ }^{2} J_{\mathrm{CH}}$ & $-3,8$ & $-3,7$ & $-2,9$ & $-2,6$ & $-2,9$ & $-3,6$ & $-3,4$ & $-3,5$ & $-4,3$ & $-4,2$ & $-4,3$ & $-4,5$ \\
\hline \multirow[t]{3}{*}{ Total } & DM & $-14,22$ & $-7,84$ & $-8,96$ & $-9,61$ & $-3,33$ & $-6,11$ & $-2,27$ & $-0,36$ & $-3,32$ & 5,45 & 2,70 & - \\
\hline & DMA & 22,48 & 18,24 & 13,95 & 15,78 & 10,80 & 13,07 & 9,50 & 7,13 & 15,62 & 7,68 & 9,02 & - \\
\hline & PDMA & 24,84 & 24,63 & 20,23 & 32,80 & 20,71 & 13,96 & 17,17 & 10,08 & 20,35 & 16,06 & 17,84 & - \\
\hline \multirow[t]{3}{*}{ CPI } & DM & $-41,89$ & $-26,80$ & $-22,22$ & $-26,76$ & $-8,95$ & $-19,02$ & $-12,21$ & $-5,39$ & $-16,30$ & 3,13 & $-1,96$ & - \\
\hline & DMA & 44,78 & 34,82 & 24,53 & 30,49 & 16,52 & 23,85 & 15,37 & 9,30 & 27,99 & 8,11 & 12,53 & - \\
\hline & PDMA & 43,07 & 47,20 & 19,72 & 47,35 & 24,50 & 16,79 & 22,85 & 11,24 & 27,79 & 17,97 & 20,98 & - \\
\hline \multirow[t]{3}{*}{ SPI } & $\mathrm{DM}$ & 6,08 & 6,07 & 0,77 & 2,97 & 0,79 & 3,35 & 5,02 & 3,33 & 6,20 & 7,15 & 6,12 & - \\
\hline & DMA & 6,12 & 6,08 & 6,19 & 4,99 & 6,61 & 5,15 & 5,19 & 5,55 & 6,55 & 7,37 & 6,45 & - \\
\hline & PDMA & 11,47 & 8,08 & 20,60 & 22,14 & 17,93 & 11,88 & 13,00 & 9,23 & 14,89 & 14,66 & 15,54 & - \\
\hline \multirow[t]{3}{*}{$\Delta \mathrm{CS}$} & DM & $-47,97$ & $-32,87$ & $-22,98$ & $-29,74$ & $-9,74$ & $-22,37$ & $-17,23$ & $-8,72$ & $-22,50$ & $-4,02$ & $-8,08$ & - \\
\hline & DMA & 38,66 & 28,74 & 18,33 & 25,50 & 9,90 & 18,70 & 10,18 & 3,75 & 21,44 & 0,74 & 6,07 & - \\
\hline & PDMA & 31,61 & 39,13 & $-0,88$ & 25,21 & 6,57 & 4,90 & 9,85 & 2,00 & 12,90 & 3,31 & 5,44 & - \\
\hline
\end{tabular}


Tabela 8.180: Constantes de acoplamento B1B95 com otimização de geometrias e constantes empíricas no nível BHandH $40 \% E_{X}^{\mathrm{HF}}$ e base aug-pcJ-2.

\begin{tabular}{|c|c|c|c|c|c|c|c|c|c|c|c|c|c|}
\hline & $\% E_{X}^{\mathrm{HF}}$ & 28,00 & 28,00 & 40,00 & 40,00 & $\begin{array}{l}28,00 \\
40,00 \\
\text { Otm. }\end{array}$ & 50,00 & 50,00 & $\begin{array}{l}28,00 \\
50,00 \\
\text { Otm. }\end{array}$ & 60,00 & 60,00 & $\begin{array}{c}28,00 \\
60,00 \\
\text { Otm. }\end{array}$ & Exp. \\
\hline HF & ${ }^{1} J_{\mathrm{HF}}$ & 470,4 & 470,4 & 499,3 & 515,6 & 499,3 & 523,6 & 552,4 & 523,6 & 548,0 & 588,5 & 548,0 & 533,2 \\
\hline $\mathrm{CO}$ & ${ }^{1} J_{\mathrm{CO}}$ & 18,4 & 16,5 & 16,1 & 12,6 & 14,1 & 14,0 & 9,4 & 12,1 & 11,8 & 6,2 & 9,9 & 15,6 \\
\hline $\mathrm{H}_{2} \mathrm{O}$ & ${ }^{1} J_{\mathrm{OH}}$ & $-77,3$ & $-78,4$ & $-80,4$ & $-83,5$ & $-81,4$ & $-83,0$ & $-87,4$ & $-83,9$ & $-85,6$ & $-91,2$ & $-86,5$ & $-81,8$ \\
\hline $\mathrm{H}_{2} \mathrm{O}$ & ${ }^{2} J_{\mathrm{HH}}$ & $-7,0$ & $-6,6$ & $-8,2$ & $-7,3$ & $-7,8$ & $-9,2$ & $-8,1$ & $-8,8$ & $-10,3$ & $-8,9$ & $-9,8$ & $-8,7$ \\
\hline $\mathrm{NH}_{3}$ & ${ }^{1} J_{\mathrm{NH}}$ & 44,0 & 44,6 & 44,9 & 46,1 & 45,5 & 45,6 & 47,2 & 46,2 & 46,4 & 48,2 & 46,9 & 43,1 \\
\hline $\mathrm{NH}_{3}$ & ${ }^{2} J_{\mathrm{HH}}$ & $-9,3$ & $-9,1$ & $-10,4$ & $-9,8$ & $-10,1$ & $-11,3$ & $-10,5$ & $-11,0$ & $-12,1$ & $-11,2$ & $-11,8$ & $-10,5$ \\
\hline $\mathrm{PH}_{3}$ & ${ }^{1} J_{\mathrm{PH}}$ & 167,8 & 175,8 & 176,5 & 187,5 & 184,0 & 183,6 & 196,8 & 190,8 & 190,6 & 205,6 & 197,4 & 195,5 \\
\hline $\mathrm{PF}_{3}$ & ${ }^{1} J_{\mathrm{PF}}$ & $-1645,5$ & $-1532,2$ & $-1606,4$ & $-1500,6$ & $-1500,0$ & $-1571,1$ & $-1466,8$ & $-1470,3$ & $-1533,7$ & $-1427,8$ & $-1438,6$ & $-1442,8$ \\
\hline $\mathrm{BHF}_{2}$ & ${ }^{1} J_{\mathrm{BF}}$ & $-127,6$ & $-125,7$ & $-107,5$ & $-98,9$ & $-105,8$ & $-91,0$ & $-77,2$ & $-89,3$ & $-74,6$ & $-56,0$ & $-72,9$ & $-79,5$ \\
\hline $\mathrm{BF}_{3}$ & ${ }^{1} J_{\mathrm{BF}}$ & $-27,0$ & $-28,2$ & $-5,3$ & 2,1 & $-6,4$ & 12,6 & 26,6 & 11,4 & 30,3 & 50,2 & 29,2 & 17,2 \\
\hline $\mathrm{F}_{2} \mathrm{O}$ & ${ }^{1} J_{\mathrm{OF}}$ & $-361,9$ & $-249,0$ & $-404,3$ & $-221,1$ & $-280,1$ & $-443,7$ & $-199,3$ & $-307,4$ & $-490,0$ & $-179,2$ & $-337,1$ & $-286,9$ \\
\hline $\mathrm{CH}_{4}$ & ${ }^{1} J_{\mathrm{CH}}$ & 124,4 & 124,1 & 126,1 & 125,2 & 125,8 & 127,5 & 126,0 & 127,2 & 129,0 & 126,9 & 128,6 & 123,0 \\
\hline $\mathrm{CH}_{4}$ & ${ }^{2} J_{\mathrm{HH}}$ & $-12,2$ & $-12,2$ & $-13,0$ & $-13,1$ & $-13,0$ & $-13,7$ & $-13,7$ & $-13,7$ & $-14,4$ & $-14,4$ & $-14,4$ & $-12,5$ \\
\hline $\mathrm{C}_{2} \mathrm{H}_{2}$ & ${ }^{1} J_{\mathrm{CC}}$ & 195,2 & 195,5 & 199,3 & 199,1 & 199,2 & 203,2 & 202,4 & 202,8 & 207,7 & 205,9 & 207,0 & 174,4 \\
\hline $\mathrm{C}_{2} \mathrm{H}_{2}$ & ${ }^{1} J_{\mathrm{CH}}$ & 256,2 & 253,2 & 258,8 & 253,7 & 255,8 & 261,2 & 254,3 & 258,0 & 263,7 & 254,9 & 260,4 & 244,5 \\
\hline $\mathrm{C}_{2} \mathrm{H}_{2}$ & ${ }^{2} J_{\mathrm{CH}}$ & 55,6 & 55,7 & 55,2 & 55,5 & 55,4 & 54,6 & 55,1 & 54,9 & 53,8 & 54,6 & 54,2 & 49,7 \\
\hline $\mathrm{C}_{2} \mathrm{H}_{2}$ & ${ }^{3} J_{\mathrm{HH}}$ & 10,4 & 10,0 & 11,2 & 10,5 & 10,8 & 12,0 & 11,1 & 11,5 & 13,0 & 11,7 & 12,4 & 9,1 \\
\hline $\mathrm{C}_{2} \mathrm{H}_{4}$ & ${ }^{1} J_{\mathrm{CC}}$ & 66,0 & 68,9 & 69,6 & 72,1 & 72,1 & 73,0 & 74,9 & 75,1 & 76,8 & 77,9 & 78,5 & 67,2 \\
\hline $\mathrm{C}_{2} \mathrm{H}_{4}$ & ${ }^{1} J_{\mathrm{CH}}$ & 158,8 & 155,4 & 161,3 & 156,8 & 157,7 & 163,5 & 158,0 & 159,7 & 165,9 & 159,3 & 161,9 & 154,5 \\
\hline $\mathrm{C}_{2} \mathrm{H}_{4}$ & ${ }^{2} J_{\mathrm{CH}}$ & $-1,1$ & $-0,9$ & $-2,3$ & $-2,0$ & $-2,0$ & $-3,4$ & $-3,0$ & $-3,0$ & $-4,7$ & $-4,0$ & $-4,2$ & $-2,1$ \\
\hline $\mathrm{C}_{2} \mathrm{H}_{4}$ & ${ }^{2} J_{\mathrm{HH}}$ & 4,2 & 2,8 & 3,3 & 1,9 & 1,9 & 2,5 & 1,1 & 1,1 & 1,6 & 0,3 & 0,3 & 2,0 \\
\hline $\mathrm{C}_{2} \mathrm{H}_{4}$ & ${ }^{3} J_{\mathrm{HH}_{\mathrm{c}}}$ & 12,1 & 12,9 & 12,5 & 13,4 & 13,2 & 12,8 & 13,8 & 13,6 & 13,3 & 14,2 & 14,0 & 11,4 \\
\hline $\mathrm{C}_{2} \mathrm{H}_{4}$ & ${ }^{3} J_{\mathrm{HH}_{\mathrm{t}}}$ & 19,0 & 19,6 & 19,4 & 19,9 & 20,0 & 19,9 & 20,2 & 20,4 & 20,4 & 20,6 & 20,9 & 18,5 \\
\hline $\mathrm{C}_{2} \mathrm{H}_{6}$ & ${ }^{1} J_{\mathrm{CC}}$ & 30,6 & 32,5 & 33,0 & 34,7 & 34,8 & 35,0 & 36,6 & 36,8 & 37,1 & 38,7 & 38,8 & 33,7 \\
\hline $\mathrm{C}_{2} \mathrm{H}_{6}$ & ${ }^{1} J_{\mathrm{CH}}$ & 125,0 & 123,0 & 126,9 & 124,3 & 124,9 & 128,5 & 125,2 & 126,4 & 130,1 & 126,2 & 128,0 & 123,4 \\
\hline $\mathrm{C}_{2} \mathrm{H}_{6}$ & ${ }^{2} J_{\mathrm{CH}}$ & $-3,5$ & $-3,5$ & $-4,0$ & $-4,1$ & $-4,0$ & $-4,5$ & $-4,5$ & $-4,5$ & $-5,0$ & $-5,0$ & $-5,0$ & $-4,5$ \\
\hline \multirow[t]{3}{*}{ Total } & DM & $-15,42$ & $-6,60$ & $-12,12$ & 0,15 & $-3,18$ & $-9,40$ & 5,92 & $-0,27$ & $-6,83$ & 11,75 & 2,67 & - \\
\hline & DMA & 20,33 & 13,79 & 17,56 & 9,63 & 8,71 & 15,93 & 8,90 & 6,43 & 17,41 & 13,73 & 7,99 & - \\
\hline & PDMA & 26,55 & 23,10 & 16,31 & 11,74 & 12,79 & 13,50 & 13,99 & 12,05 & 21,24 & 27,15 & 20,71 & - \\
\hline \multirow[t]{3}{*}{ CPI } & DM & $-40,85$ & $-19,66$ & $-34,55$ & $-4,70$ & $-13,01$ & $-29,48$ & 8,06 & $-7,36$ & $-24,87$ & 20,91 & $-1,79$ & - \\
\hline & DMA & 42,87 & 28,25 & 35,34 & 17,59 & 14,99 & 29,94 & 14,57 & 7,93 & 31,44 & 24,49 & 9,66 & - \\
\hline & PDMA & 40,01 & 37,66 & 22,74 & 17,96 & 19,88 & 13,05 & 14,27 & 8,86 & 21,36 & 33,46 & 15,98 & - \\
\hline \multirow[t]{3}{*}{ SPI } & DM & 3,23 & 2,98 & 4,33 & 3,71 & 4,02 & 5,32 & 4,35 & 4,93 & 6,40 & 5,03 & 5,94 & - \\
\hline & DMA & 3,80 & 3,19 & 4,52 & 3,80 & 4,10 & 5,65 & 4,75 & 5,33 & 7,12 & 5,83 & 6,77 & - \\
\hline & PDMA & 16,68 & 12,43 & 11,59 & 7,19 & 7,59 & 13,84 & 13,79 & 14,39 & 21,14 & 22,52 & 24,17 & - \\
\hline \multirow[t]{3}{*}{$\Delta \mathrm{CS}$} & DM & $-44,08$ & $-22,64$ & $-38,89$ & $-8,41$ & $-17,03$ & $-34,80$ & 3,72 & $-12,30$ & $-31,27$ & 15,88 & $-7,73$ & - \\
\hline & DMA & 39,07 & 25,05 & 30,82 & 13,79 & 10,89 & 24,28 & 9,83 & 2,59 & 24,32 & 18,66 & 2,90 & - \\
\hline & PDMA & 23,33 & 25,23 & 11,15 & 10,77 & 12,29 & $-0,79$ & 0,48 & $-5,53$ & 0,22 & 10,95 & $-8,20$ & - \\
\hline
\end{tabular}


Tabela 8.181: Constantes de acoplamento BHandH com otimização de geometrias e constantes empíricas no nível BHandH $40 \% E_{X}^{\mathrm{HF}}$ e base aug-pcJ-2.

\begin{tabular}{|c|c|c|c|c|c|c|c|c|c|c|c|c|c|}
\hline & $\% E_{X}^{\mathrm{HF}}$ & 50,00 & 50,00 & 30,00 & 30,00 & $\begin{array}{l}50,00 \\
30,00 \\
\text { Otm. }\end{array}$ & 40,00 & 40,00 & $\begin{array}{l}50,00 \\
40,00 \\
\text { Otm. }\end{array}$ & 60,00 & 60,00 & $\begin{array}{l}50,00 \\
60,00 \\
\text { Otm. }\end{array}$ & Exp. \\
\hline $\mathrm{HF}$ & ${ }^{1} J_{\mathrm{HF}}$ & 530,8 & 546,7 & 484,4 & 472,9 & 500,8 & 507,2 & 509,6 & 523,4 & 555,3 & 584,3 & 570,9 & 533,2 \\
\hline $\mathrm{CO}$ & ${ }^{1} J_{\mathrm{CO}}$ & 13,7 & 8,0 & 18,7 & 14,9 & 12,8 & 16,3 & 11,5 & 10,4 & 11,0 & 4,4 & 5,3 & 15,6 \\
\hline $\mathrm{H}_{2} \mathrm{O}$ & ${ }^{1} J_{\mathrm{OH}}$ & $-83,7$ & $-87,5$ & $-77,8$ & $-78,5$ & $-81,7$ & $-80,7$ & $-83,1$ & $-84,6$ & $-86,9$ & $-92,0$ & $-90,6$ & $-81,8$ \\
\hline $\mathrm{H}_{2} \mathrm{O}$ & ${ }^{2} J_{\mathrm{HH}}$ & $-9,4$ & $-7,9$ & $-6,8$ & $-5,8$ & $-5,3$ & $-8,0$ & $-6,8$ & $-6,6$ & $-10,8$ & $-9,0$ & $-9,2$ & $-8,7$ \\
\hline $\mathrm{NH}_{3}$ & ${ }^{1} J_{\mathrm{NH}}$ & 45,5 & 47,7 & 42,9 & 44,5 & 45,1 & 44,2 & 46,2 & 46,4 & 47,0 & 49,5 & 49,2 & 43,1 \\
\hline $\mathrm{NH}_{3}$ & ${ }^{2} J_{\mathrm{HH}}$ & $-11,1$ & $-9,9$ & $-8,7$ & $-7,6$ & $-7,5$ & $-9,9$ & $-8,7$ & $-8,7$ & $-12,5$ & $-11,0$ & $-11,1$ & $-10,5$ \\
\hline $\mathrm{PH}_{3}$ & ${ }^{1} J_{\mathrm{PH}}$ & 183,1 & 195,1 & 163,0 & 167,4 & 175,8 & 172,9 & 181,3 & 185,3 & 193,7 & 208,9 & 205,2 & 195,5 \\
\hline $\mathrm{PF}_{3}$ & ${ }^{1} J_{\mathrm{PF}}$ & $-1670,4$ & $-1554,5$ & $-1743,5$ & $-1622,0$ & $-1624,2$ & $-1709,0$ & $-1591,4$ & $-1591,2$ & $-1628,3$ & $-1512,0$ & $-1514,8$ & $-1442,8$ \\
\hline $\mathrm{BHF}_{2}$ & ${ }^{1} J_{\mathrm{BF}}$ & $-95,2$ & $-72,8$ & $-132,8$ & $-116,4$ & $-109,5$ & $-114,0$ & $-94,5$ & $-91,2$ & $-76,1$ & $-51,3$ & $-54,3$ & $-79,5$ \\
\hline $\mathrm{BF}_{3}$ & ${ }^{1} J_{\mathrm{BF}}$ & 15,1 & 38,8 & $-23,3$ & $-7,3$ & 1,5 & $-4,1$ & 15,8 & 20,0 & 34,6 & 61,4 & 57,6 & 17,2 \\
\hline $\mathrm{F}_{2} \mathrm{O}$ & ${ }^{1} J_{\mathrm{OF}}$ & $-465,0$ & $-165,5$ & $-380,5$ & $-173,9$ & $-123,8$ & $-419,8$ & $-169,2$ & $-144,3$ & $-521,4$ & $-163,3$ & $-188,0$ & $-286,9$ \\
\hline $\mathrm{CH}_{4}$ & ${ }^{1} J_{\mathrm{CH}}$ & 124,9 & 124,4 & 116,8 & 117,4 & 116,3 & 120,7 & 120,7 & 120,3 & 129,4 & 128,1 & 128,8 & 123,0 \\
\hline $\mathrm{CH}_{4}$ & ${ }^{2} J_{\mathrm{HH}}$ & $-13,3$ & $-13,3$ & $-11,0$ & $-11,0$ & $-11,0$ & $-12,1$ & $-12,1$ & $-12,1$ & $-14,5$ & $-14,5$ & $-14,5$ & $-12,5$ \\
\hline $\mathrm{C}_{2} \mathrm{H}_{2}$ & ${ }^{1} J_{\mathrm{CC}}$ & 202,4 & 201,9 & 189,4 & 190,4 & 190,4 & 195,4 & 195,9 & 195,8 & 210,6 & 208,6 & 209,1 & 174,4 \\
\hline $\mathrm{C}_{2} \mathrm{H}_{2}$ & ${ }^{1} J_{\mathrm{CH}}$ & 259,5 & 253,3 & 245,0 & 243,0 & 239,4 & 252,0 & 248,0 & 246,1 & 267,8 & 259,1 & 261,1 & 244,5 \\
\hline $\mathrm{C}_{2} \mathrm{H}_{2}$ & ${ }^{2} J_{\mathrm{CH}}$ & 53,0 & 53,8 & 53,2 & 53,5 & 53,5 & 53,3 & 53,8 & 53,8 & 52,2 & 53,4 & 53,3 & 49,7 \\
\hline $\mathrm{C}_{2} \mathrm{H}_{2}$ & ${ }^{3} J_{\mathrm{HH}}$ & 11,8 & 10,7 & 9,4 & 8,9 & 8,6 & 10,5 & 9,8 & 9,6 & 13,4 & 11,9 & 12,2 & 9,1 \\
\hline $\mathrm{C}_{2} \mathrm{H}_{4}$ & ${ }^{1} J_{\mathrm{CC}}$ & 72,3 & 74,8 & 61,8 & 65,7 & 65,6 & 66,7 & 70,0 & 69,9 & 78,9 & 80,2 & 80,5 & 67,2 \\
\hline $\mathrm{C}_{2} \mathrm{H}_{4}$ & ${ }^{1} J_{\mathrm{CH}}$ & 160,6 & 155,7 & 149,9 & 147,1 & 145,6 & 155,0 & 151,3 & 150,5 & 166,8 & 160,4 & 161,4 & 154,5 \\
\hline $\mathrm{C}_{2} \mathrm{H}_{4}$ & ${ }^{2} J_{\mathrm{CH}}$ & $-3,8$ & $-3,4$ & $-1,3$ & $-1,2$ & $-1,2$ & $-2,4$ & $-2,2$ & $-2,2$ & $-5,6$ & $-4,8$ & $-4,8$ & $-2,1$ \\
\hline $\mathrm{C}_{2} \mathrm{H}_{4}$ & ${ }^{2} J_{\mathrm{HH}}$ & 2,2 & 1,2 & 3,8 & 3,0 & 2,8 & 3,1 & 2,1 & 2,0 & 1,1 & 0,2 & 0,3 & 2,0 \\
\hline $\mathrm{C}_{2} \mathrm{H}_{4}$ & ${ }^{3} J_{\mathrm{HH}_{\mathrm{c}}}$ & 13,3 & 14,4 & 12,2 & 13,3 & 13,4 & 12,7 & 13,8 & 13,9 & 14,1 & 15,1 & 15,1 & 11,4 \\
\hline $\mathrm{C}_{2} \mathrm{H}_{4}$ & ${ }^{3} J_{\mathrm{HH}_{\mathrm{t}}}$ & 19,6 & 20,2 & 17,9 & 18,9 & 18,6 & 18,7 & 19,5 & 19,4 & 20,8 & 21,1 & 21,2 & 18,5 \\
\hline $\mathrm{C}_{2} \mathrm{H}_{6}$ & ${ }^{1} J_{\mathrm{CC}}$ & 33,3 & 36,2 & 26,9 & 30,6 & 30,0 & 30,0 & 33,3 & 33,0 & 36,7 & 38,9 & 39,5 & 33,7 \\
\hline $\mathrm{C}_{2} \mathrm{H}_{6}$ & ${ }^{1} J_{\mathrm{CH}}$ & 125,8 & 122,8 & 117,3 & 115,3 & 114,6 & 121,5 & 119,0 & 118,6 & 130,4 & 126,8 & 127,2 & 123,4 \\
\hline $\mathrm{C}_{2} \mathrm{H}_{6}$ & ${ }^{2} J_{\mathrm{CH}}$ & $-4,3$ & $-4,4$ & $-3,1$ & $-3,3$ & $-3,2$ & $-3,7$ & $-3,8$ & $-3,8$ & $-4,9$ & $-5,0$ & $-5,0$ & $-4,5$ \\
\hline \multirow[t]{3}{*}{ Total } & DM & $-14,46$ & 3,84 & $-21,65$ & $-7,96$ & $-4,59$ & $-18,08$ & $-2,19$ & $-0,50$ & $-10,92$ & 10,10 & 8,42 & - \\
\hline & DMA & 19,87 & 13,75 & 24,45 & 19,51 & 19,82 & 21,32 & 14,63 & 14,92 & 23,11 & 17,67 & 16,04 & - \\
\hline & PDMA & 13,44 & 18,48 & 26,45 & 20,63 & 19,34 & 16,40 & 10,06 & 10,60 & 26,67 & 33,29 & 31,75 & - \\
\hline \multirow[t]{3}{*}{ CPI } & DM & $-40,09$ & 3,98 & $-50,80$ & $-18,75$ & $-10,04$ & $-45,39$ & $-7,61$ & $-3,23$ & $-35,35$ & 15,95 & 11,44 & - \\
\hline & DMA & 40,53 & 26,78 & 52,76 & 41,20 & 41,24 & 46,15 & 30,25 & 30,97 & 43,85 & 32,57 & 28,20 & - \\
\hline & PDMA & 13,68 & 24,37 & 40,54 & 30,82 & 27,72 & 24,60 & 14,92 & 16,70 & 26,64 & 42,19 & 38,22 & - \\
\hline \multirow[t]{3}{*}{ SPI } & DM & 4,33 & 3,73 & $-0,27$ & $-0,05$ & $-0,59$ & 1,94 & 1,79 & 1,50 & 6,99 & 5,81 & 6,21 & - \\
\hline & DMA & 4,72 & 4,20 & 3,69 & 3,61 & 4,11 & 3,10 & 3,17 & 3,14 & 7,90 & 6,75 & 7,13 & - \\
\hline & PDMA & 13,27 & 14,16 & 16,12 & 13,15 & 13,20 & 10,40 & 6,50 & 6,12 & 26,69 & 26,77 & 27,00 & - \\
\hline \multirow[t]{3}{*}{$\Delta \mathrm{CS}$} & DM & $-44,42$ & 0,25 & $-50,53$ & $-18,70$ & $-9,44$ & $-47,33$ & $-9,40$ & $-4,73$ & $-42,34$ & 10,14 & 5,23 & - \\
\hline & DMA & 35,81 & 22,58 & 49,08 & 37,59 & 37,12 & 43,05 & 27,07 & 27,83 & 35,95 & 25,83 & 21,07 & - \\
\hline & PDMA & 0,40 & 10,21 & 24,42 & 17,67 & 14,53 & 14,20 & 8,41 & 10,59 & $-0,05$ & 15,42 & 11,23 & - \\
\hline
\end{tabular}


Tabela 8.182: Constantes de acoplamento PBE0 com otimização de geometrias e constantes empíricas no nível BHandH $40 \% E_{X}^{\mathrm{HF}}$ e base aug-pcJ-2.

\begin{tabular}{|c|c|c|c|c|c|c|c|c|c|c|c|c|c|c|c|c|}
\hline & $\% E_{X}^{\mathrm{HF}}$ & 25,00 & 25,00 & 20,00 & 20,00 & $\begin{array}{l}25,00 \\
20,00 \\
\text { Otm. }\end{array}$ & 30,00 & 30,00 & $\begin{array}{l}25,00 \\
30,00 \\
\text { Otm. }\end{array}$ & 40,00 & 40,00 & $\begin{array}{l}25,00 \\
40,00 \\
\text { Otm. }\end{array}$ & 50,00 & 50,00 & $\begin{array}{l}25,00 \\
50,00 \\
\text { Otm. }\end{array}$ & Exp. \\
\hline $\mathrm{HF}$ & ${ }^{1} J_{\mathrm{HF}}$ & 430,8 & 427,7 & 419,7 & 409,3 & 416,6 & 441,9 & 445,9 & 438,8 & 464,3 & 482,0 & 461,3 & 486,9 & 517,7 & 484 & 533,2 \\
\hline $\mathrm{CO}$ & ${ }^{1} J_{\mathrm{CO}}$ & 19,9 & 18,4 & 20,8 & 19,9 & 19,2 & 19,1 & 16,9 & 17,5 & 17,3 & 13,8 & 15,7 & 15,4 & 10,9 & 13,9 & 15,6 \\
\hline $\mathrm{H}_{2} \mathrm{O}$ & ${ }^{1} J_{\mathrm{OH}}$ & $-73,0$ & $-73,5$ & $-71,8$ & $-71,5$ & $-72,3$ & $-74,2$ & $-75,4$ & $-74,7$ & $-76,6$ & $-79,6$ & -77 & $-79,0$ & $-83,4$ & $-79,4$ & $-81,8$ \\
\hline $\mathrm{H}_{2} \mathrm{O}$ & ${ }^{2} J_{\mathrm{HH}}$ & $-7,3$ & $-6,9$ & $-6,7$ & $-6,4$ & $-6,4$ & $-7,8$ & $-7,4$ & $-7,4$ & $-8,9$ & $-8,1$ & $-8,5$ & $-10,0$ & $-9,0$ & $-9,6$ & $-8,7$ \\
\hline $\mathrm{NH}_{3}$ & ${ }^{1} J_{\mathrm{NH}}$ & 42,5 & 43,0 & 42,2 & 42,3 & 42,6 & 42,9 & 43,6 & 43,4 & 43,6 & 44,8 & 44,1 & 44,3 & 45,9 & 44,8 & 43,1 \\
\hline $\mathrm{NH}_{3}$ & ${ }^{2} J_{\mathrm{HH}}$ & $-10,1$ & $-9,8$ & $-9,6$ & $-9,5$ & $-9,4$ & $-10,6$ & $-10,3$ & $-10,3$ & $-11,5$ & $-11,0$ & $-11,3$ & $-12,5$ & $-11,8$ & $-12,2$ & $-10,5$ \\
\hline $\mathrm{PH}_{3}$ & ${ }^{1} J_{\mathrm{PH}}$ & 154,6 & 161,3 & 150,4 & 155,5 & 157,2 & 158,7 & 166,9 & 165,3 & 166,9 & 178,0 & 173,2 & 175,1 & 188,6 & 181,1 & 195,5 \\
\hline $\mathrm{PF}_{3}$ & ${ }^{1} J_{\mathrm{PF}}$ & $-1732,1$ & $-1627,0$ & $-1748,1$ & $-1634,2$ & $-1639,7$ & $-1715,3$ & $-1612,1$ & $-1613,5$ & $-1679,4$ & $-1581,4$ & $-1583,9$ & $-1640,8$ & $-1543,9$ & $-1551,5$ & $-1442,8$ \\
\hline $\mathrm{BHF}_{2}$ & ${ }^{1} J_{\mathrm{BF}}$ & $-131,0$ & $-130,8$ & $-139,2$ & $-142,2$ & -139 & $-122,7$ & $-119,9$ & $-122,5$ & $-106,5$ & $-97,7$ & $-106,3$ & $-90,4$ & $-76,6$ & $-90,2$ & $-79,5$ \\
\hline $\mathrm{BF}_{3}$ & ${ }^{1} J_{\mathrm{BF}}$ & $-30,5$ & $-33,5$ & $-39,4$ & $-46,9$ & $-42,4$ & $-21,7$ & $-21,1$ & $-24,6$ & $-4,2$ & 3,6 & -7 & 12,9 & 27,3 & 10,2 & 17,2 \\
\hline $\mathrm{F}_{2} \mathrm{O}$ & ${ }^{1} J_{\mathrm{OF}}$ & $-374,9$ & $-251,0$ & $-354,9$ & $-261,4$ & $-236,3$ & $-395,6$ & $-241,6$ & -266 & $-440,5$ & $-222,0$ & $-297,4$ & $-493,5$ & $-202,0$ & $-331,8$ & $-286,9$ \\
\hline $\mathrm{CH}_{4}$ & ${ }^{1} J_{\mathrm{CH}}$ & 122,8 & 123,0 & 122,1 & 122,5 & 122,3 & 123,5 & 123,5 & 123,8 & 125,0 & 124,5 & 125,2 & 126,5 & 125,5 & 126,8 & 123,0 \\
\hline $\mathrm{CH}_{4}$ & ${ }^{2} J_{\mathrm{HH}}$ & $-13,8$ & $-13,7$ & $-13,4$ & $-13,3$ & $-13,3$ & $-14,2$ & $-14,2$ & $-14,1$ & $-15,0$ & $-15,0$ & -15 & $-15,8$ & $-15,8$ & $-15,8$ & $-12,5$ \\
\hline $\mathrm{C}_{2} \mathrm{H}_{2}$ & ${ }^{1} J_{\mathrm{CC}}$ & 196,4 & 196,6 & 194,6 & 195,0 & 195 & 198,3 & 198,3 & 198,4 & 202,6 & 202,0 & 202,4 & 207,6 & 206,0 & 207,1 & 174,4 \\
\hline $\mathrm{C}_{2} \mathrm{H}_{2}$ & ${ }^{1} J_{\mathrm{CH}}$ & 256,2 & 254,5 & 254,8 & 254,0 & 253,1 & 257,6 & 255,0 & 255,9 & 260,7 & 256,1 & 258,8 & 264,1 & 257,5 & 262,1 & 244,5 \\
\hline $\mathrm{C}_{2} \mathrm{H}_{2}$ & ${ }^{2} J_{\mathrm{CH}}$ & 53,5 & 53,7 & 53,7 & 53,9 & 53,9 & 53,2 & 53,5 & 53,4 & 52,2 & 52,8 & 52,6 & 50,9 & 52,0 & 51,4 & 49,7 \\
\hline $\mathrm{C}_{2} \mathrm{H}_{2}$ & ${ }^{3} J_{\mathrm{HH}}$ & 12,4 & 12,0 & 11,9 & 11,7 & 11,6 & 12,9 & 12,4 & 12,5 & 14,1 & 13,3 & 13,7 & 15,6 & 14,3 & 15,1 & 9,1 \\
\hline $\mathrm{C}_{2} \mathrm{H}_{4}$ & ${ }^{1} J_{\mathrm{CC}}$ & 68,7 & 71,3 & 67,0 & 69,8 & 69,8 & 70,4 & 72,9 & 72,9 & 74,4 & 76,2 & 76,5 & 79,1 & 79,9 & 80,6 & 67,2 \\
\hline $\mathrm{C}_{2} \mathrm{H}_{4}$ & ${ }^{1} J_{\mathrm{CH}}$ & 157,3 & 154,6 & 156,1 & 153,8 & 153,5 & 158,5 & 155,3 & 155,7 & 161,1 & 156,9 & 158,1 & 164,0 & 158,7 & 160,8 & 154,5 \\
\hline $\mathrm{C}_{2} \mathrm{H}_{4}$ & ${ }^{2} J_{\mathrm{CH}}$ & $-3,0$ & $-2,7$ & $-2,5$ & $-2,2$ & $-2,2$ & $-3,7$ & $-3,3$ & $-3,3$ & $-5,1$ & $-4,5$ & $-4,6$ & $-6,9$ & $-5,9$ & $-6,2$ & $-2,1$ \\
\hline $\mathrm{C}_{2} \mathrm{H}_{4}$ & ${ }^{2} J_{\mathrm{HH}}$ & 2,3 & 1,2 & 2,8 & 1,7 & 1,6 & 1,8 & 0,7 & 0,7 & 0,7 & $-0,3$ & $-0,2$ & $-0,5$ & $-1,4$ & $-1,4$ & 2,0 \\
\hline $\mathrm{C}_{2} \mathrm{H}_{4}$ & ${ }^{3} J_{\mathrm{HH}_{\mathrm{C}}}$ & 12,7 & 13,4 & 12,5 & 13,1 & 13,2 & 13,0 & 13,7 & 13,6 & 13,6 & 14,3 & 14,2 & 14,5 & 15,0 & 14,9 & 11,4 \\
\hline $\mathrm{C}_{2} \mathrm{H}_{4}$ & ${ }^{3} J_{\mathrm{HH}_{\mathrm{t}}}$ & 19,8 & 20,4 & 19,5 & 20,2 & 20,2 & 20,1 & 20,7 & 20,7 & 20,9 & 21,2 & 21,4 & 21,9 & 21,9 & 22,3 & 18,5 \\
\hline $\mathrm{C}_{2} \mathrm{H}_{6}$ & ${ }^{1} J_{\mathrm{CC}}$ & 30,4 & 32,6 & 29,4 & 31,7 & 31,7 & 31,3 & 33,5 & 33,6 & 33,3 & 35,3 & 35,5 & 35,2 & 37,1 & 37,4 & 33,7 \\
\hline $\mathrm{C}_{2} \mathrm{H}_{6}$ & ${ }^{1} J_{\mathrm{CH}}$ & 123,5 & 122,0 & 122,7 & 121,5 & 121,2 & 124,3 & 122,6 & 122,9 & 126,0 & 123,8 & 124,5 & 127,7 & 124,9 & 126,2 & 123,4 \\
\hline $\mathrm{C}_{2} \mathrm{H}_{6}$ & ${ }^{2} J_{\mathrm{CH}}$ & $-4,1$ & $-4,1$ & $-3,9$ & $-3,9$ & $-3,9$ & $-4,3$ & $-4,4$ & $-4,4$ & $-4,9$ & $-4,9$ & $-4,9$ & $-5,4$ & $-5,4$ & $-5,4$ & $-4,5$ \\
\hline \multirow[t]{3}{*}{ Total } & DM & $-21,64$ & $-12,85$ & $-22,92$ & $-15,47$ & $-14,19$ & $-20,36$ & $-10,04$ & $-11,48$ & $-17,79$ & $-4,33$ & $-8,68$ & $-15,38$ & 1,5 & $-5,83$ & - \\
\hline & DMA & 26,52 & 20,32 & 27,58 & 22,16 & 22,63 & 25,61 & 18,35 & 18,12 & 24,12 & 14,82 & 14,80 & 23,20 & 12,57 & 13,47 & - \\
\hline & PDMA & 25,52 & 25,37 & 28,35 & 27,84 & 26,94 & 24,12 & 23,41 & 24,23 & 25,30 & 22,11 & 24,31 & 29,47 & 27,97 & 28,34 & - \\
\hline \multirow[t]{3}{*}{ CPI } & DM & $-55,05$ & $-34,23$ & $-57,36$ & $-39,95$ & $-36,75$ & $-52,70$ & $-28,08$ & $-31,67$ & $-48,17$ & $-15,64$ & $-26,50$ & $-44,18$ & $-2,79$ & $-21,37$ & - \\
\hline & DMA & 57,75 & 43,23 & 60,65 & 47,85 & 48,95 & 54,88 & 38,08 & 37,44 & 49,52 & & 27,61 & 44,91 & 21,10 & 22,12 & - \\
\hline & PDMA & 44,78 & 43,41 & 52,05 & 54,12 & 51,53 & 37,88 & 33,29 & 35,25 & 26,01 & 16,60 & 21,04 & 16,82 & 14,53 & 12,57 & - \\
\hline \multirow[t]{3}{*}{ SPI } & DM & 2,85 & 2,83 & 2,33 & 2,48 & 2,36 & 3,36 & 3,1 & 3,33 & 4,49 & 3,96 & 4,39 & 5,7 & 4,80 & 5,57 & - \\
\hline & DMA & 3,61 & 3,51 & 3,32 & 3,32 & 3,32 & 4,15 & 3,89 & 3,96 & 5,50 & 4,97 & 5,41 & 7,28 & 6,32 & 7,13 & - \\
\hline & PDMA & 11,40 & 12,14 & 10,98 & 8,57 & 8,90 & 14,03 & 16,17 & 16,15 & 24,78 & 26,16 & 26,71 & 38,74 & 37,83 & 39,90 & - \\
\hline \multirow[t]{3}{*}{$\Delta \mathrm{CS}$} & DM & $-41,31$ & $-23,42$ & $-18,32$ & $-32,84$ & $-2,55$ & $-16,78$ & $-21,42$ & $-0,55$ & $-15,42$ & $-8,72$ & 1,40 & $-14,81$ & 4,61 & 3,03 & - \\
\hline & DMA & 39,41 & 33,43 & & 33,35 & 18,94 & & 18,61 & 9,30 & 16,14 & & 5,36 & & 8,78 & 8,32 & - \\
\hline & PDMA & 33,56 & 39,45 & $-3,13$ & 34,01 & 6,97 & $-9,10$ & 14,41 & $-1,69$ & 6,61 & $-1,38$ & 4,86 & 22,18 & 16,66 & 19,61 & - \\
\hline
\end{tabular}


Tabela 8.183: Constantes de acoplamento B971 com otimização de geometrias e constantes empíricas no nível PBE0 40\% $E_{X}^{\mathrm{HF}}$ e base aug-pcJ-2.

\begin{tabular}{|c|c|c|c|c|c|c|c|c|c|c|c|c|c|}
\hline & $\% E_{X}^{\mathrm{HF}}$ & 21,00 & 21,00 & 40,00 & 40,00 & $\begin{array}{l}21,00 \\
40,00 \\
\text { Otm. }\end{array}$ & 50,00 & 50,00 & $\begin{array}{l}21,00 \\
50,00 \\
\text { Otm. }\end{array}$ & 60,00 & 60,00 & $\begin{array}{l}21,00 \\
60,00 \\
\text { Otm. }\end{array}$ & Exp. \\
\hline HF & ${ }^{1} J_{\mathrm{HF}}$ & 449,1 & 441,3 & 499,7 & 438,6 & 492,5 & 520,6 & 485,9 & 513,5 & 542,8 & 533,4 & 535,7 & 534,8 \\
\hline $\mathrm{CO}$ & ${ }^{1} J_{\mathrm{CO}}$ & 17,4 & 16,9 & 10,7 & 14,6 & 10,2 & 9,0 & 10,4 & 8,6 & 7,3 & 6,2 & 6,8 & 15,7 \\
\hline $\mathrm{H}_{2} \mathrm{O}$ & ${ }^{1} J_{\mathrm{OH}}$ & $-74,4$ & $-74,2$ & $-77,0$ & $-70,0$ & $-76,8$ & $-79,7$ & $-76,0$ & $-79,5$ & $-82,5$ & $-81,9$ & $-82,4$ & $-82,0$ \\
\hline $\mathrm{H}_{2} \mathrm{O}$ & ${ }^{2} J_{\mathrm{HH}}$ & $-6,5$ & $-6,2$ & $-5,1$ & $-5,1$ & $-4,8$ & $-6,4$ & $-6,1$ & $-6,1$ & $-7,7$ & $-7,1$ & $-7,4$ & $-8,8$ \\
\hline $\mathrm{NH}_{3}$ & ${ }^{1} J_{\mathrm{NH}}$ & 43,3 & 43,4 & 41,9 & 40,0 & 42,0 & 43,1 & 42,4 & 43,2 & 44,4 & 44,8 & 44,6 & 43,3 \\
\hline $\mathrm{NH}_{3}$ & ${ }^{2} J_{\mathrm{HH}}$ & $-9,1$ & $-9,0$ & $-7,4$ & $-7,4$ & $-7,2$ & $-8,6$ & $-8,3$ & $-8,4$ & $-9,9$ & $-9,3$ & $-9,7$ & $-10,4$ \\
\hline $\mathrm{PH}_{3}$ & ${ }^{1} J_{\mathrm{PH}}$ & 190,7 & 196,4 & 188,9 & 182,7 & 194,0 & 196,6 & 195,7 & 201,5 & 204,6 & 208,5 & 209,3 & 195,7 \\
\hline $\mathrm{PF}_{3}$ & ${ }^{1} J_{\mathrm{PF}}$ & $-1656,7$ & $-1547,7$ & $-1562,1$ & $-1459,7$ & $-1478,1$ & $-1539,1$ & $-1449,7$ & $-1459,4$ & $-1513,4$ & $-1429,0$ & $-1438,0$ & $-1.443,2$ \\
\hline $\mathrm{BHF}_{2}$ & ${ }^{1} J_{\mathrm{BF}}$ & $-123,8$ & $-129,8$ & $-85,1$ & $-118,1$ & $-91,1$ & $-69,6$ & $-88,3$ & $-75,5$ & $-54,0$ & $-59,4$ & $-59,8$ & $-79,6$ \\
\hline $\mathrm{BF}_{3}$ & ${ }^{1} J_{\mathrm{BF}}$ & $-27,9$ & $-39,4$ & 12,4 & $-28,7$ & 1,5 & 29,7 & 5,7 & 19,0 & 47,1 & 39,2 & 36,7 & 17,2 \\
\hline $\mathrm{F}_{2} \mathrm{O}$ & ${ }^{1} J_{\mathrm{OF}}$ & $-318,8$ & $-257,2$ & $-327,7$ & $-318,6$ & $-262,4$ & $-370,4$ & $-281,7$ & $-298,6$ & $-421,2$ & $-245,8$ & $-340,0$ & $-284,7$ \\
\hline $\mathrm{CH}_{4}$ & ${ }^{1} J_{\mathrm{CH}}$ & 128,8 & 129,3 & 116,5 & 121,4 & 116,9 & 120,6 & 124,4 & 121,1 & 125,0 & 127,5 & 125,4 & 122,9 \\
\hline $\mathrm{CH}_{4}$ & ${ }^{2} J_{\mathrm{HH}}$ & $-12,0$ & $-12,0$ & $-9,6$ & $-9,3$ & $-9,5$ & $-10,7$ & $-10,5$ & $-10,6$ & $-11,8$ & $-11,7$ & $-11,8$ & $-12,5$ \\
\hline $\mathrm{C}_{2} \mathrm{H}_{2}$ & ${ }^{1} J_{\mathrm{CC}}$ & 213,8 & 213,8 & 205,0 & 207,4 & 205,1 & 211,6 & 213,6 & 211,5 & 219,4 & 220,2 & 219,1 & 173,9 \\
\hline $\mathrm{C}_{2} \mathrm{H}_{2}$ & ${ }^{1} J_{\mathrm{CH}}$ & 261,3 & 260,2 & 229,5 & 239,0 & 228,6 & 237,9 & 243,9 & 236,9 & 247,0 & 249,0 & 245,9 & 244,4 \\
\hline $\mathrm{C}_{2} \mathrm{H}_{2}$ & ${ }^{2} J_{\mathrm{CH}}$ & 53,2 & 53,3 & 53,2 & 53,3 & 53,2 & 53,0 & 53,1 & 53,1 & 52,5 & 52,6 & 52,6 & 49,9 \\
\hline $\mathrm{C}_{2} \mathrm{H}_{2}$ & ${ }^{3} J_{\mathrm{HH}}$ & 10,5 & 10,3 & 8,4 & 9,1 & 8,2 & 9,3 & 9,7 & 9,1 & 10,5 & 10,5 & 10,3 & 8,9 \\
\hline $\mathrm{C}_{2} \mathrm{H}_{4}$ & ${ }^{1} J_{\mathrm{CC}}$ & 78,1 & 80,5 & 76,4 & 78,7 & 78,8 & 80,8 & 83,5 & 83,1 & 86,2 & 88,6 & 88,1 & 66,6 \\
\hline $\mathrm{C}_{2} \mathrm{H}_{4}$ & ${ }^{1} J_{\mathrm{CH}}$ & 162,8 & 160,7 & 145,4 & 149,6 & 143,6 & 151,2 & 153,5 & 149,2 & 157,4 & 157,6 & 155,2 & 154,3 \\
\hline $\mathrm{C}_{2} \mathrm{H}_{4}$ & ${ }^{2} J_{\mathrm{CH}}$ & $-2,1$ & $-1,8$ & $-0,8$ & $-0,4$ & $-0,6$ & $-2,1$ & $-1,9$ & $-1,8$ & $-3,7$ & $-3,5$ & $-3,3$ & $-1,9$ \\
\hline $\mathrm{C}_{2} \mathrm{H}_{4}$ & ${ }^{2} J_{\mathrm{HH}}$ & 3,6 & 2,4 & 4,1 & 4,3 & 3,0 & 3,4 & 3,3 & 2,3 & 2,5 & 2,1 & 1,4 & 2,1 \\
\hline $\mathrm{C}_{2} \mathrm{H}_{4}$ & ${ }^{3} J_{\mathrm{HH}_{\mathrm{c}}}$ & 11,7 & 12,2 & 10,5 & 10,3 & 11,0 & 11,0 & 11,1 & 11,5 & 11,6 & 12,0 & 12,1 & 11,3 \\
\hline $\mathrm{C}_{2} \mathrm{H}_{4}$ & ${ }^{3} J_{\mathrm{HH}_{\mathrm{t}}}$ & 18,4 & 19,0 & 15,6 & 16,6 & 16,1 & 16,4 & 17,3 & 16,9 & 17,4 & 18,2 & 17,9 & 18,3 \\
\hline $\mathrm{C}_{2} \mathrm{H}_{6}$ & ${ }^{1} J_{\mathrm{CC}}$ & 34,9 & 36,5 & 35,1 & 36,3 & 36,7 & 37,8 & 39,4 & 39,5 & 40,8 & 42,5 & 42,4 & 33,6 \\
\hline $\mathrm{C}_{2} \mathrm{H}_{6}$ & ${ }^{1} J_{\mathrm{CH}}$ & 129,1 & 128,5 & 116,5 & 120,7 & 115,9 & 120,9 & 123,9 & 120,3 & 125,5 & 127,0 & 125,0 & 123,4 \\
\hline $\mathrm{C}_{2} \mathrm{H}_{6}$ & ${ }^{2} J_{\mathrm{CH}}$ & $-3,6$ & $-3,5$ & $-2,8$ & $-2,6$ & $-2,8$ & $-3,5$ & $-3,4$ & $-3,4$ & $-4,2$ & $-4,1$ & $-4,1$ & $-4,5$ \\
\hline \multirow[t]{3}{*}{ Total } & DM & $-12,19$ & $-6,34$ & $-7,56$ & $-7,15$ & $-2,49$ & $-4,84$ & 0,08 & 0,32 & $-2,12$ & 7,67 & 3,20 & - \\
\hline & DMA & 20,72 & 17,11 & 12,57 & 13,26 & 9,52 & 12,04 & 6,57 & 6,28 & 14,67 & 8,64 & 8,37 & - \\
\hline & PDMA & 23,94 & 24,61 & 18,78 & 30,23 & 19,90 & 15,86 & 14,25 & 10,53 & 22,27 & 19,05 & 18,80 & - \\
\hline \multirow[t]{3}{*}{ CPI } & $\mathrm{DM}$ & $-37,70$ & $-23,95$ & $-18,98$ & $-20,88$ & $-7,11$ & $-15,71$ & $-6,18$ & $-3,61$ & $-12,77$ & 9,24 & $-0,20$ & - \\
\hline & DMA & 40,05 & 31,46 & 21,11 & 24,28 & 13,42 & 21,15 & 8,69 & 7,05 & 26,43 & 11,22 & 11,55 & - \\
\hline & PDMA & 38,35 & 44,30 & 16,39 & 41,19 & 22,30 & 19,60 & 16,59 & 11,54 & 30,80 & 24,43 & 22,54 & - \\
\hline \multirow[t]{3}{*}{ SPI } & $\mathrm{DM}$ & 6,52 & 6,58 & 0,82 & 2,91 & 0,90 & 3,13 & 4,68 & 3,20 & 5,69 & 6,52 & 5,70 & - \\
\hline & DMA & 6,55 & 6,58 & 6,30 & 5,18 & 6,66 & 5,37 & 5,01 & 5,72 & 6,05 & 6,75 & 6,03 & - \\
\hline & PDMA & 13,37 & 10,17 & 20,53 & 22,19 & 18,14 & 13,12 & 12,54 & 9,79 & 16,02 & 15,10 & 16,06 & - \\
\hline \multirow[t]{3}{*}{$\Delta \mathrm{CS}$} & DM & $-44,22$ & $-30,53$ & $-19,80$ & $-23,80$ & $-8,01$ & $-18,84$ & $-10,86$ & $-6,81$ & $-18,47$ & 2,72 & $-5,90$ & - \\
\hline & DMA & 33,50 & 24,88 & 14,81 & 19,10 & 6,76 & 15,78 & 3,68 & 1,33 & 20,37 & 4,47 & 5,51 & - \\
\hline & PDMA & 24,98 & 34,13 & $-4,14$ & 19,00 & 4,17 & 6,48 & 4,05 & 1,76 & 14,78 & 9,33 & 6,48 & - \\
\hline
\end{tabular}


Tabela 8.184: Constantes de acoplamento B972 com otimização de geometrias e constantes empíricas no nível PBE0 $40 \% E_{X}^{\mathrm{HF}}$ e base aug-pcJ-2.

\begin{tabular}{|c|c|c|c|c|c|c|c|c|c|c|c|c|c|c|c|c|}
\hline & $\% E_{X}^{\mathrm{HF}}$ & 21,00 & Otm. & 30,00 & 30,00 & $\begin{array}{l}21,00 \\
30,00 \\
\text { Otm. }\end{array}$ & 40,00 & 40,00 & $\begin{array}{l}21,00 \\
40,00 \\
\text { Otm. }\end{array}$ & 50,00 & 50,00 & $\begin{array}{l}21,00 \\
50,00 \\
\text { Otm. }\end{array}$ & 60,00 & 60,00 & $\begin{array}{l}21,00 \\
60,00 \\
\text { Otm. }\end{array}$ & Exp. \\
\hline $\mathrm{HF}$ & ${ }^{1} J_{\mathrm{HF}}$ & 442,8 & 447,0 & 487,2 & 401,9 & 491,1 & 512,0 & 452,6 & 515,9 & 538,2 & 503,7 & 542,0 & 565,8 & 555,5 & 569,7 & 534,8 \\
\hline $\mathrm{CO}$ & ${ }^{1} J_{\mathrm{CO}}$ & 18,3 & 17,1 & 11,5 & 17,6 & 10,2 & 9,2 & 12,9 & 8,0 & 6,8 & 8,0 & 5,6 & 4,2 & 3,0 & 3,0 & 15,7 \\
\hline $\mathrm{H}_{2} \mathrm{O}$ & ${ }^{1} J_{\mathrm{OH}}$ & $-73,5$ & $-74,4$ & $-75,6$ & $-65,7$ & $-76,4$ & $-78,9$ & $-72,4$ & $-79,7$ & $-82,3$ & $-79,0$ & $-83,2$ & $-86,0$ & $-85,6$ & $-86,9$ & $-82,0$ \\
\hline $\mathrm{H}_{2} \mathrm{O}$ & ${ }^{2} J_{\mathrm{HH}}$ & $-7,5$ & $-7,2$ & $-4,3$ & $-4,7$ & $-4,1$ & $-5,5$ & $-5,5$ & $-5,3$ & $-6,7$ & $-6,4$ & $-6,5$ & $-8,0$ & $-7,4$ & $-7,8$ & $-8,8$ \\
\hline $\mathrm{NH}_{3}$ & ${ }^{1} J_{\mathrm{NH}}$ & 41,7 & 42,0 & 40,3 & 37,6 & 40,6 & 41,8 & 40,3 & 42,1 & 43,4 & 43,0 & 43,7 & 45,1 & 45,7 & 45,4 & 43,3 \\
\hline $\mathrm{NH}_{3}$ & ${ }^{2} J_{\mathrm{HH}}$ & $-9,1$ & $-9,0$ & $-6,0$ & $-6,3$ & $-6,0$ & $-7,1$ & $-7,1$ & $-7,0$ & $-8,2$ & $-7,9$ & $-8,1$ & $-9,4$ & $-8,9$ & $-9,3$ & $-10,4$ \\
\hline $\mathrm{PH}_{3}$ & ${ }^{1} J_{\mathrm{PH}}$ & 184,0 & 191,6 & 175,0 & 158,0 & 182,2 & 183,4 & 173,7 & 190,5 & 192,2 & 189,1 & 199,2 & 201,4 & 204,8 & 208,4 & 195,7 \\
\hline $\mathrm{PF}_{3}$ & ${ }^{1} J_{\mathrm{PF}}$ & $-1661,2$ & $-1562,9$ & $-1595,3$ & $-1477,0$ & $-1516,3$ & $-1576,6$ & $-1482,9$ & $-1501,6$ & $-1555,0$ & $-1472,3$ & $-1484,0$ & $-1531,2$ & $-1451,5$ & $-1464,1$ & -1.443 \\
\hline $\mathrm{BHF}_{2}$ & ${ }^{1} J_{\mathrm{BF}}$ & $-129,9$ & $-132,8$ & $-100,3$ & $-146,5$ & $-103,3$ & $-82,9$ & $-115,3$ & $-85,8$ & $-65,4$ & $-84,7$ & $-68,3$ & $-48,0$ & $-55,3$ & $-50,8$ & $-79,6$ \\
\hline $\mathrm{BF}_{3}$ & ${ }^{1} J_{\mathrm{BF}}$ & $-36,6$ & $-43,3$ & $-5,4$ & $-63,3$ & $-12,0$ & 14,1 & $-26,3$ & 7,7 & 33,8 & 9,3 & 27,6 & 53,5 & 43,6 & 47,4 & 17,2 \\
\hline $\mathrm{F}_{2} \mathrm{O}$ & ${ }^{1} J_{\mathrm{OF}}$ & $-316,0$ & $-219,7$ & $-283,7$ & $-341,6$ & $-189,4$ & $-320,6$ & $-310,4$ & $-218,4$ & $-362,5$ & $-278,7$ & $-250,3$ & $-412,9$ & $-247,5$ & $-286,6$ & $-284,7$ \\
\hline $\mathrm{CH}_{4}$ & ${ }^{1} J_{\mathrm{CH}}$ & 118,8 & 118,8 & 107,2 & 112,8 & 107,2 & 111,9 & 116,6 & 111,9 & 116,9 & 120,6 & 116,9 & 122,2 & 124,6 & 122,2 & 122,9 \\
\hline $\mathrm{CH}_{4}$ & ${ }^{2} J_{\mathrm{HH}}$ & $-11,3$ & $-11,3$ & $-7,8$ & $-7,4$ & $-7,8$ & $-8,7$ & $-8,4$ & $-8,7$ & $-9,7$ & $-9,5$ & $-9,7$ & $-10,7$ & $-10,6$ & $-10,7$ & $-12,5$ \\
\hline $\mathrm{C}_{2} \mathrm{H}_{2}$ & ${ }^{1} J_{\mathrm{CC}}$ & 197,5 & 197,6 & 188,8 & 189,7 & 189,1 & 195,6 & 197,1 & 195,7 & 203,4 & 204,9 & 203,2 & 212,5 & 213,3 & 212,0 & 173,9 \\
\hline $\mathrm{C}_{2} \mathrm{H}_{2}$ & ${ }^{1} J_{\mathrm{CH}}$ & 247,3 & 245,2 & 213,7 & 226,1 & 211,9 & 222,6 & 231,8 & 220,7 & 232,0 & 237,7 & 230,0 & 242,2 & 243,9 & 240,0 & 244,4 \\
\hline $\mathrm{C}_{2} \mathrm{H}_{2}$ & ${ }^{2} J_{\mathrm{CH}}$ & 50,7 & 50,8 & 51,4 & 51,7 & 51,5 & 51,8 & 51,9 & 51,9 & 51,9 & 51,9 & 52,0 & 51,5 & 51,7 & 51,7 & 49,9 \\
\hline $\mathrm{C}_{2} \mathrm{H}_{2}$ & ${ }^{3} J_{\mathrm{HH}}$ & 10,4 & 10,1 & 7,4 & 8,4 & 7,2 & 8,1 & 8,7 & 7,8 & 8,9 & 9,2 & 8,6 & 9,9 & 9,8 & 9,6 & 8,9 \\
\hline $\mathrm{C}_{2} \mathrm{H}_{4}$ & ${ }^{1} J_{\mathrm{CC}}$ & 68,1 & 70,6 & 66,0 & 67,6 & 68,7 & 70,8 & 73,1 & 73,3 & 76,3 & 78,9 & 78,5 & 82,9 & 85,2 & 84,7 & 66,6 \\
\hline $\mathrm{C}_{2} \mathrm{H}_{4}$ & ${ }^{1} J_{\mathrm{CH}}$ & 152,3 & 149,4 & 134,1 & 139,5 & 131,7 & 140,3 & 144,2 & 137,7 & 146,9 & 149,1 & 144,1 & 154,1 & 154,1 & 151,1 & 154,3 \\
\hline $\mathrm{C}_{2} \mathrm{H}_{4}$ & ${ }^{2} J_{\mathrm{CH}}$ & $-2,0$ & $-1,6$ & 0,5 & 1,0 & 0,7 & $-0,4$ & $-0,1$ & $-0,2$ & $-1,7$ & $-1,4$ & $-1,4$ & $-3,2$ & $-3,0$ & $-2,8$ & $-1,9$ \\
\hline $\mathrm{C}_{2} \mathrm{H}_{4}$ & ${ }^{2} J_{\mathrm{HH}}$ & 3,1 & 1,9 & 4,7 & 5,2 & 3,6 & 4,2 & 4,4 & 3,1 & 3,7 & 3,5 & 2,5 & 3,0 & 2,5 & 1,9 & 2,1 \\
\hline $\mathrm{C}_{2} \mathrm{H}_{4}$ & ${ }^{3} J_{\mathrm{HH}_{\mathrm{C}}}$ & 11,2 & 11,8 & 9,7 & 9,2 & 10,3 & 10,1 & 9,9 & 10,7 & 10,6 & 10,6 & 11,1 & 11,1 & 11,5 & 11,7 & 11,3 \\
\hline $\mathrm{C}_{2} \mathrm{H}_{4}$ & ${ }^{3} J_{\mathrm{HH}_{\mathrm{t}}}$ & 17,7 & 18,3 & 14,4 & 15,5 & 14,9 & 15,1 & 16,1 & 15,6 & 15,9 & 16,8 & 16,4 & 16,8 & 17,5 & 17,3 & 18,3 \\
\hline $\mathrm{C}_{2} \mathrm{H}_{6}$ & ${ }^{1} J_{\mathrm{CC}}{ }^{t}$ & 30,6 & 32,4 & 30,2 & 31,6 & 32,1 & 33,3 & 35,0 & 35,2 & 36,6 & 38,4 & 38,5 & 40,1 & 41,9 & 42,0 & 33,6 \\
\hline $\mathrm{C}_{2} \mathrm{H}_{6}$ & ${ }^{1} J_{\mathrm{CH}}$ & 118,9 & 117,3 & 106,4 & 111,4 & 105,1 & 111,4 & 115,3 & 110,0 & 116,6 & 119,3 & 115,2 & 122,1 & 123,4 & 120,6 & 123,4 \\
\hline $\mathrm{C}_{2} \mathrm{H}_{6}$ & ${ }^{2} J_{\mathrm{CH}}$ & $-3,2$ & $-3,2$ & $-1,9$ & $-1,6$ & $-1,8$ & $-2,4$ & $-2,2$ & $-2,4$ & $-3,0$ & $-2,8$ & $-2,9$ & $-3,6$ & $-3,5$ & $-3,6$ & $-4,5$ \\
\hline \multirow[t]{3}{*}{ Total } & DM & $-16,37$ & $-8,93$ & $-12,33$ & $-16,08$ & $-5,68$ & $-9,08$ & $-9,07$ & $-2,31$ & $-5,73$ & $-1,44$ & 1,23 & $-2,43$ & 6,54 & 4,90 & - \\
\hline & DMA & 20,02 & 17,46 & 15,79 & 20,62 & 16,48 & 12,70 & 13,67 & 11,25 & 12,57 & 6,89 & 8,41 & 15,96 & 8,63 & 9,02 & - \\
\hline & PDMA & 24,28 & 24,60 & 30,59 & 48,07 & 31,71 & 20,22 & 31,21 & 20,84 & 18,49 & 15,72 & 15,54 & 25,01 & 20,71 & 20,50 & - \\
\hline \multirow[t]{3}{*}{ CPI } & DM & $-40,45$ & $-22,69$ & $-23,15$ & $-35,27$ & $-7,40$ & $-19,01$ & $-21,67$ & $-2,87$ & $-14,88$ & $-6,72$ & 1,79 & $-11,23$ & 8,95 & 6,40 & - \\
\hline & DMA & 42,95 & 36,69 & 26,11 & 40,07 & 27,40 & 20,77 & 24,62 & 16,60 & 21,90 & 9,25 & 11,26 & 30,90 & 13,42 & 13,75 & - \\
\hline & PDMA & 43,92 & 47,37 & 29,34 & 68,15 & 36,09 & 15,68 & 40,17 & 20,33 & 23,10 & 15,49 & 18,88 & 37,42 & 29,76 & 30,96 & - \\
\hline \multirow[t]{3}{*}{ SPI } & DM & 1,29 & 1,16 & $-4,39$ & $-2,00$ & $-4,42$ & $-1,80$ & 0,18 & $-1,89$ & 0,97 & 2,43 & 0,8 & 4,0 & 4,7 & 3,80 & - \\
\hline & DMA & 3,21 & 3,36 & 8,22 & 6,35 & 8,47 & 6,77 & 5,63 & 7,32 & 5,73 & 5,17 & 6,31 & 5,00 & 5,12 & 5,56 & - \\
\hline & PDMA & 9,88 & 7,90 & 31,51 & 33,34 & 28,50 & 23,55 & 24,63 & 21,21 & 15,10 & 15,89 & 13,09 & 15,92 & 14,08 & 12,84 & - \\
\hline \multirow[t]{3}{*}{$\Delta \mathrm{CS}$} & DM & $-41,75$ & $-23,85$ & $-18,75$ & $-33,27$ & $-2,98$ & $-17,21$ & $-21,85$ & $-0,98$ & $-15,86$ & $-9,15$ & 0,97 & $-15,24$ & 4,1 & 2,60 & - \\
\hline & DMA & 39,73 & 33,33 & 17,89 & 33,73 & 18,93 & 14,00 & 18,98 & 9,28 & 16,17 & 4,08 & 4,95 & & 8,30 & 8,19 & - \\
\hline & PDMA & 34,04 & 39,47 & $-2,17$ & 34,81 & 7,59 & $-7,87$ & 15,53 & $-0,88$ & 8,01 & $-0,41$ & 5,79 & 21,50 & 15,68 & 18,12 & - \\
\hline
\end{tabular}


Tabela 8.185: Constantes de acoplamento B98 com otimização de geometrias e constantes empíricas no nível PBE0 $40 \% E_{X}^{\mathrm{HF}}$ e base aug-pcJ-2.

\begin{tabular}{|c|c|c|c|c|c|c|c|c|c|c|c|c|c|}
\hline & $\% E_{X}^{\mathrm{HF}}$ & 21,98 & 21,98 & 40,00 & 40,00 & $\begin{array}{c}21,98 \\
4 \\
40,00 \\
\text { Otm. }\end{array}$ & 50,00 & 50,00 & $\begin{array}{l}21,98 \\
50,00 \\
\text { Otm. }\end{array}$ & 60,00 & 60,00 & $\begin{array}{c}21,98 \\
/ \\
60,00 \\
\text { Otm. }\end{array}$ & Exp. \\
\hline HF & ${ }^{1} J_{\mathrm{HF}}$ & 431,2 & 425,7 & 484,6 & 417,7 & 479,5 & 505,9 & 465,8 & 500,8 & 528,5 & 514,5 & 523,5 & 534,8 \\
\hline $\mathrm{CO}$ & ${ }^{1} J_{\mathrm{CO}}$ & 18,5 & 17,6 & 11,2 & 15,5 & 10,4 & 9,5 & 11,2 & 8,7 & 7,7 & 6,9 & 6,8 & 15,7 \\
\hline $\mathrm{H}_{2} \mathrm{O}$ & ${ }^{1} J_{\mathrm{OH}}$ & $-72,5$ & $-72,6$ & $-75,6$ & $-67,9$ & $-75,7$ & $-78,4$ & $-74,2$ & $-78,5$ & $-81,4$ & $-80,4$ & $-81,5$ & $-82,0$ \\
\hline $\mathrm{H}_{2} \mathrm{O}$ & ${ }^{2} J_{\mathrm{HH}}$ & $-6,9$ & $-6,5$ & $-5,1$ & $-5,1$ & $-4,7$ & $-6,4$ & $-6,1$ & $-6,1$ & $-7,9$ & $-7,2$ & $-7,5$ & $-8,8$ \\
\hline $\mathrm{NH}_{3}$ & ${ }^{1} J_{\mathrm{NH}}$ & 42,9 & 43,1 & 41,7 & 39,6 & 41,9 & 43,1 & 42,3 & 43,3 & 44,6 & 44,8 & 44,8 & 43,3 \\
\hline $\mathrm{NH}_{3}$ & ${ }^{2} J_{\mathrm{HH}}$ & $-9,5$ & $-9,3$ & $-7,6$ & $-7,5$ & $-7,4$ & $-8,8$ & $-8,5$ & $-8,6$ & $-10,2$ & $-9,6$ & $-10,0$ & $-10,4$ \\
\hline $\mathrm{PH}_{3}$ & ${ }^{1} J_{\mathrm{PH}}$ & 196,4 & 202,7 & 193,7 & 187,2 & 199,5 & 201,7 & 200,7 & 207,3 & 210,1 & 213,9 & 215,4 & 195,7 \\
\hline $\mathrm{PF}_{3}$ & ${ }^{1} J_{\mathrm{PF}}$ & $-1666,4$ & $-1560,1$ & $-1572,1$ & $-1468,9$ & $-1489,9$ & $-1549,1$ & $-1459,9$ & $-1470,8$ & $-1523,4$ & $-1439,8$ & $-1449,0$ & $-1.443,2$ \\
\hline $\mathrm{BHF}_{2}$ & ${ }^{1} J_{\mathrm{BF}}$ & $-129,1$ & $-133,2$ & $-89,6$ & $-125,3$ & $-93,7$ & $-73,8$ & $-95,5$ & $-77,8$ & $-57,8$ & $-66,4$ & $-61,8$ & $-79,6$ \\
\hline $\mathrm{BF}_{3}$ & ${ }^{1} J_{\mathrm{BF}}$ & $-34,1$ & $-43,2$ & 7,0 & $-37,6$ & $-1,5$ & 24,5 & $-3,0$ & 16,1 & 42,2 & 30,6 & 34,0 & 17,2 \\
\hline $\mathrm{F}_{2} \mathrm{O}$ & ${ }^{1} J_{\mathrm{OF}}$ & $-336,9$ & $-264,6$ & $-338,2$ & $-347,7$ & $-262,5$ & $-383,0$ & $-312,7$ & $-299,3$ & $-437,3$ & $-278,5$ & $-341,9$ & $-284,7$ \\
\hline $\mathrm{CH}_{4}$ & ${ }^{1} J_{\mathrm{CH}}$ & 128,3 & 128,7 & 116,9 & 122,0 & 117,2 & 121,5 & 125,6 & 121,9 & 126,5 & 129,3 & 126,9 & 122,9 \\
\hline $\mathrm{CH}_{4}$ & ${ }^{2} J_{\mathrm{HH}}$ & $-12,5$ & $-12,5$ & $-9,8$ & $-9,5$ & $-9,8$ & $-11,0$ & $-10,8$ & $-11,0$ & $-12,2$ & $-12,1$ & $-12,2$ & $-12,5$ \\
\hline $\mathrm{C}_{2} \mathrm{H}_{2}$ & ${ }^{1} J_{\mathrm{CC}}$ & 212,9 & 212,7 & 205,0 & 207,5 & 205,0 & 212,2 & 214,3 & 211,9 & 220,6 & 221,6 & 220,0 & 173,9 \\
\hline $\mathrm{C}_{2} \mathrm{H}_{2}$ & ${ }^{1} J_{\mathrm{CH}}$ & 261,1 & 259,6 & 229,7 & 239,7 & 228,3 & 239,0 & 245,4 & 237,5 & 249,0 & 251,5 & 247,4 & 244,4 \\
\hline $\mathrm{C}_{2} \mathrm{H}_{2}$ & ${ }^{2} J_{\mathrm{CH}}$ & 52,8 & 52,9 & 53,2 & 53,4 & 53,3 & 53,2 & 53,2 & 53,3 & 52,6 & 52,7 & 52,8 & 49,9 \\
\hline $\mathrm{C}_{2} \mathrm{H}_{2}$ & ${ }^{3} J_{\mathrm{HH}}$ & 10,7 & 10,4 & 8,4 & 9,2 & 8,2 & 9,4 & 9,8 & 9,1 & 10,6 & 10,7 & 10,4 & 8,9 \\
\hline $\mathrm{C}_{2} \mathrm{H}_{4}$ & ${ }^{1} J_{\mathrm{CC}}$ & 77,3 & 79,7 & 76,4 & 78,8 & 78,9 & 81,3 & 84,1 & 83,6 & 87,2 & 89,7 & 89,1 & 66,6 \\
\hline $\mathrm{C}_{2} \mathrm{H}_{4}$ & ${ }^{1} J_{\mathrm{CH}}$ & 162,5 & 160,1 & 145,7 & 150,2 & 143,6 & 152,0 & 154,8 & 149,8 & 158,9 & 159,5 & 156,5 & 154,3 \\
\hline $\mathrm{C}_{2} \mathrm{H}_{4}$ & ${ }^{2} J_{\mathrm{CH}}$ & $-2,4$ & $-2,1$ & $-0,8$ & $-0,5$ & $-0,6$ & $-2,1$ & $-1,9$ & $-1,9$ & $-3,8$ & $-3,6$ & $-3,4$ & $-1,9$ \\
\hline $\mathrm{C}_{2} \mathrm{H}_{4}$ & ${ }^{2} J_{\mathrm{HH}}$ & 3,1 & 1,9 & 3,9 & 4,2 & 2,8 & 3,2 & 3,1 & 2,1 & 2,3 & 1,9 & 1,2 & 2,1 \\
\hline $\mathrm{C}_{2} \mathrm{H}_{4}$ & ${ }^{3} J_{\mathrm{HH}_{\mathrm{c}}}$ & 11,8 & 12,4 & 10,6 & 10,2 & 11,1 & 11,1 & 11,1 & 11,6 & 11,8 & 12,0 & 12,2 & 11,3 \\
\hline $\mathrm{C}_{2} \mathrm{H}_{4}$ & ${ }^{3} J_{\mathrm{HH}_{\mathrm{t}}}$ & 18,5 & 19,1 & 15,6 & 16,7 & 16,2 & 16,5 & 17,5 & 17,0 & 17,6 & 18,4 & 18,1 & 18,3 \\
\hline $\mathrm{C}_{2} \mathrm{H}_{6}$ & ${ }^{1} J_{\mathrm{CC}}$ & 34,4 & 36,0 & 35,1 & 36,2 & 36,7 & 38,2 & 39,6 & 39,8 & 41,5 & 43,1 & 43,1 & 33,6 \\
\hline $\mathrm{C}_{2} \mathrm{H}_{6}$ & ${ }^{1} J_{\mathrm{CH}}$ & 128,8 & 128,1 & 116,8 & 121,4 & 116,1 & 121,7 & 125,2 & 121,1 & 127,0 & 129,0 & 126,3 & 123,4 \\
\hline $\mathrm{C}_{2} \mathrm{H}_{6}$ & ${ }^{2} J_{\mathrm{CH}}$ & $-3,8$ & $-3,7$ & $-2,9$ & $-2,6$ & $-2,9$ & $-3,6$ & $-3,4$ & $-3,5$ & $-4,3$ & $-4,2$ & $-4,3$ & $-4,5$ \\
\hline \multirow[t]{3}{*}{ Total } & DM & $-14,29$ & $-7,92$ & $-9,03$ & $-9,68$ & $-3,41$ & $-6,19$ & $-2,35$ & $-0,43$ & $-3,40$ & 5,37 & 2,62 & - \\
\hline & DMA & 22,68 & 18,28 & 14,10 & 15,94 & 10,77 & 13,23 & 9,68 & 7,28 & 15,81 & 7,75 & 9,22 & - \\
\hline & PDMA & 25,28 & 25,42 & 19,69 & 32,47 & 20,24 & 14,22 & 16,68 & 9,70 & 21,09 & 17,12 & 18,82 & - \\
\hline \multirow[t]{3}{*}{ CPI } & DM & $-42,22$ & $-27,13$ & $-22,55$ & $-27,09$ & $-9,28$ & $-19,35$ & $-12,54$ & $-5,72$ & $-16,63$ & 2,80 & $-2,29$ & - \\
\hline & DMA & 45,09 & 34,73 & 24,89 & 30,85 & 16,45 & 24,20 & 15,70 & 9,61 & 28,30 & 8,09 & 12,84 & - \\
\hline & PDMA & 43,14 & 47,13 & 19,92 & 47,56 & 24,53 & 17,01 & 23,03 & 11,35 & 27,93 & 17,94 & 21,10 & - \\
\hline \multirow[t]{3}{*}{ SPI } & DM & 6,19 & 6,17 & 0,87 & 3,08 & 0,89 & 3,46 & 5,13 & 3,44 & 6,31 & 7,25 & 6,23 & - \\
\hline & DMA & 6,25 & 6,23 & 6,18 & 5,00 & 6,60 & 5,19 & 5,26 & 5,57 & 6,65 & 7,51 & 6,57 & - \\
\hline & PDMA & 12,19 & 9,50 & 19,52 & 21,41 & 17,10 & 12,18 & 12,02 & 8,49 & 16,08 & 16,52 & 17,15 & - \\
\hline \multirow[t]{3}{*}{$\Delta \mathrm{CS}$} & DM & $-48,40$ & $-33,30$ & $-23,42$ & $-30,17$ & $-10,18$ & $-22,81$ & $-17,66$ & $-9,16$ & $-22,93$ & $-4,45$ & $-8,52$ & - \\
\hline & DMA & 38,84 & 28,50 & 18,71 & 25,85 & 9,85 & 19,01 & 10,44 & 4,04 & 21,65 & 0,58 & 6,26 & - \\
\hline & PDMA & 30,95 & 37,63 & 0,40 & 26,15 & 7,43 & 4,82 & 11,01 & 2,86 & 11,86 & 1,42 & 3,95 & - \\
\hline
\end{tabular}


Tabela 8.186: Constantes de acoplamento B1B95 com otimização de geometrias e constantes empíricas no nível PBE0 $40 \% E_{X}^{\mathrm{HF}}$ e base aug-pcJ-2.

\begin{tabular}{|c|c|c|c|c|c|c|c|c|c|c|c|c|c|}
\hline & $\% E_{X}^{\mathrm{HF}}$ & 28,00 & 28,00 & 40,00 & 40,00 & $\begin{array}{l}28,00 \\
40,00 \\
\text { Otm. }\end{array}$ & 50,00 & 50,00 & $\begin{array}{l}28,00 \\
50,00 \\
\text { Otm. }\end{array}$ & 60,00 & 60,00 & $\begin{array}{l}28,00 \\
60,00 \\
\text { Otm. }\end{array}$ & Exp. \\
\hline HF & ${ }^{1} J_{\mathrm{HF}}$ & 470,4 & 470,4 & 499,3 & 515,6 & 499,3 & 523,6 & 552,4 & 523,6 & 548,0 & 588,5 & 548,0 & 534,8 \\
\hline $\mathrm{CO}$ & ${ }^{1} J_{\mathrm{CO}}$ & 18,4 & 16,5 & 16,1 & 12,6 & 14,1 & 14,0 & 9,4 & 12,1 & 11,8 & 6,2 & 9,9 & 15,7 \\
\hline $\mathrm{H}_{2} \mathrm{O}$ & ${ }^{1} J_{\mathrm{OH}}$ & $-77,3$ & $-78,4$ & $-80,4$ & $-83,5$ & $-81,4$ & $-83,0$ & $-87,4$ & $-83,9$ & $-85,6$ & $-91,2$ & $-86,5$ & $-82,0$ \\
\hline $\mathrm{H}_{2} \mathrm{O}$ & ${ }^{2} J_{\mathrm{HH}}$ & $-7,0$ & $-6,6$ & $-8,2$ & $-7,3$ & $-7,8$ & $-9,2$ & $-8,1$ & $-8,8$ & $-10,3$ & $-8,9$ & $-9,8$ & $-8,8$ \\
\hline $\mathrm{NH}_{3}$ & ${ }^{1} J_{\mathrm{NH}}$ & 44,0 & 44,6 & 44,9 & 46,1 & 45,5 & 45,6 & 47,2 & 46,2 & 46,4 & 48,2 & 46,9 & 43,3 \\
\hline $\mathrm{NH}_{3}$ & ${ }^{2} J_{\mathrm{HH}}$ & $-9,3$ & $-9,1$ & $-10,4$ & $-9,8$ & $-10,1$ & $-11,3$ & $-10,5$ & $-11,0$ & $-12,1$ & $-11,2$ & $-11,8$ & $-10,4$ \\
\hline $\mathrm{PH}_{3}$ & ${ }^{1} J_{\mathrm{PH}}$ & 167,8 & 175,8 & 176,5 & 187,5 & 184,0 & 183,6 & 196,8 & 190,8 & 190,6 & 205,6 & 197,4 & 195,7 \\
\hline $\mathrm{PF}_{3}$ & ${ }^{1} J_{\mathrm{PF}}$ & $-1645,5$ & $-1532,2$ & $-1606,4$ & $-1500,6$ & $-1500,0$ & $-1571,1$ & $-1466,8$ & $-1470,3$ & $-1533,7$ & $-1427,8$ & $-1438,6$ & $-1.443,2$ \\
\hline $\mathrm{BHF}_{2}$ & ${ }^{1} J_{\mathrm{BF}}$ & $-127,6$ & $-125,7$ & $-107,5$ & $-98,9$ & $-105,8$ & $-91,0$ & $-77,2$ & $-89,3$ & $-74,6$ & $-56,0$ & $-72,9$ & $-79,6$ \\
\hline $\mathrm{BF}_{3}$ & ${ }^{1} J_{\mathrm{BF}}$ & $-27,0$ & $-28,2$ & $-5,3$ & 2,1 & $-6,4$ & 12,6 & 26,6 & 11,4 & 30,3 & 50,2 & 29,2 & 17,2 \\
\hline $\mathrm{F}_{2} \mathrm{O}$ & ${ }^{1} J_{\mathrm{OF}}$ & $-361,9$ & $-249,0$ & $-404,3$ & $-221,1$ & $-280,1$ & $-443,7$ & $-199,3$ & $-307,4$ & $-490,0$ & $-179,2$ & $-337,1$ & $-284,7$ \\
\hline $\mathrm{CH}_{4}$ & ${ }^{1} J_{\mathrm{CH}}$ & 124,4 & 124,1 & 126,1 & 125,2 & 125,8 & 127,5 & 126,0 & 127,2 & 129,0 & 126,9 & 128,6 & 122,9 \\
\hline $\mathrm{CH}_{4}$ & ${ }^{2} J_{\mathrm{HH}}$ & $-12,2$ & $-12,2$ & $-13,0$ & $-13,1$ & $-13,0$ & $-13,7$ & $-13,7$ & $-13,7$ & $-14,4$ & $-14,4$ & $-14,4$ & $-12,5$ \\
\hline $\mathrm{C}_{2} \mathrm{H}_{2}$ & ${ }^{1} J_{\mathrm{CC}}$ & 195,2 & 195,5 & 199,3 & 199,1 & 199,2 & 203,2 & 202,4 & 202,8 & 207,7 & 205,9 & 207,0 & 173,9 \\
\hline $\mathrm{C}_{2} \mathrm{H}_{2}$ & ${ }^{1} J_{\mathrm{CH}}$ & 256,2 & 253,2 & 258,8 & 253,7 & 255,8 & 261,2 & 254,3 & 258,0 & 263,7 & 254,9 & 260,4 & 244,4 \\
\hline $\mathrm{C}_{2} \mathrm{H}_{2}$ & ${ }^{2} J_{\mathrm{CH}}$ & 55,6 & 55,7 & 55,2 & 55,5 & 55,4 & 54,6 & 55,1 & 54,9 & 53,8 & 54,6 & 54,2 & 49,9 \\
\hline $\mathrm{C}_{2} \mathrm{H}_{2}$ & ${ }^{3} J_{\mathrm{HH}}$ & 10,4 & 10,0 & 11,2 & 10,5 & 10,8 & 12,0 & 11,1 & 11,5 & 13,0 & 11,7 & 12,4 & 8,9 \\
\hline $\mathrm{C}_{2} \mathrm{H}_{4}$ & ${ }^{1} J_{\mathrm{CC}}$ & 66,0 & 68,9 & 69,6 & 72,1 & 72,1 & 73,0 & 74,9 & 75,1 & 76,8 & 77,9 & 78,5 & 66,6 \\
\hline $\mathrm{C}_{2} \mathrm{H}_{4}$ & ${ }^{1} J_{\mathrm{CH}}$ & 158,8 & 155,4 & 161,3 & 156,8 & 157,7 & 163,5 & 158,0 & 159,7 & 165,9 & 159,3 & 161,9 & 154,3 \\
\hline $\mathrm{C}_{2} \mathrm{H}_{4}$ & ${ }^{2} J_{\mathrm{CH}}$ & $-1,1$ & $-0,9$ & $-2,3$ & $-2,0$ & $-2,0$ & $-3,4$ & $-3,0$ & $-3,0$ & $-4,7$ & $-4,0$ & $-4,2$ & $-1,9$ \\
\hline $\mathrm{C}_{2} \mathrm{H}_{4}$ & ${ }^{2} J_{\mathrm{HH}}$ & 4,2 & 2,8 & 3,3 & 1,9 & 1,9 & 2,5 & 1,1 & 1,1 & 1,6 & 0,3 & 0,3 & 2,1 \\
\hline $\mathrm{C}_{2} \mathrm{H}_{4}$ & ${ }^{3} J_{\mathrm{HH}_{\mathrm{c}}}$ & 12,1 & 12,9 & 12,5 & 13,4 & 13,2 & 12,8 & 13,8 & 13,6 & 13,3 & 14,2 & 14,0 & 11,3 \\
\hline $\mathrm{C}_{2} \mathrm{H}_{4}$ & ${ }^{3} J_{\mathrm{HH}_{\mathrm{t}}}$ & 19,0 & 19,6 & 19,4 & 19,9 & 20,0 & 19,9 & 20,2 & 20,4 & 20,4 & 20,6 & 20,9 & 18,3 \\
\hline $\mathrm{C}_{2} \mathrm{H}_{6}$ & ${ }^{1} J_{\mathrm{CC}}$ & 30,6 & 32,5 & 33,0 & 34,7 & 34,8 & 35,0 & 36,6 & 36,8 & 37,1 & 38,7 & 38,8 & 33,6 \\
\hline $\mathrm{C}_{2} \mathrm{H}_{6}$ & ${ }^{1} J_{\mathrm{CH}}$ & 125,0 & 123,0 & 126,9 & 124,3 & 124,9 & 128,5 & 125,2 & 126,4 & 130,1 & 126,2 & 128,0 & 123,4 \\
\hline $\mathrm{C}_{2} \mathrm{H}_{6}$ & ${ }^{2} J_{\mathrm{CH}}$ & $-3,5$ & $-3,5$ & $-4,0$ & $-4,1$ & $-4,0$ & $-4,5$ & $-4,5$ & $-4,5$ & $-5,0$ & $-5,0$ & $-5,0$ & $-4,5$ \\
\hline \multirow[t]{3}{*}{ Total } & $\mathrm{DM}$ & $-15,50$ & $-6,68$ & $-12,20$ & 0,07 & $-3,26$ & $-9,48$ & 5,84 & $-0,35$ & $-6,91$ & 11,67 & 2,59 & - \\
\hline & DMA & 20,47 & 13,81 & 17,76 & 9,67 & 8,75 & 16,13 & 8,82 & 6,64 & 17,50 & 13,67 & 8,10 & - \\
\hline & PDMA & 26,10 & 22,82 & 16,68 & 12,16 & 13,22 & 14,22 & 14,95 & 13,01 & 22,58 & 28,15 & 21,81 & - \\
\hline \multirow[t]{3}{*}{ CPI } & DM & $-41,18$ & $-19,99$ & $-34,88$ & $-5,03$ & $-13,34$ & $-29,81$ & 7,74 & $-7,69$ & $-25,20$ & 20,58 & $-2,12$ & - \\
\hline & DMA & 43,18 & 28,15 & 35,65 & 17,48 & 14,92 & 30,23 & 14,17 & 8,22 & 31,45 & 24,15 & 9,72 & - \\
\hline & PDMA & 40,03 & 37,52 & 22,79 & 17,91 & 19,87 & 13,15 & 14,34 & 8,92 & 21,43 & 33,33 & 15,98 & - \\
\hline \multirow[t]{3}{*}{ SPI } & $\mathrm{DM}$ & 3,33 & 3,09 & 4,44 & 3,81 & 4,13 & 5,43 & 4,45 & 5,04 & 6,51 & 5,14 & 6,05 & - \\
\hline & DMA & 3,81 & 3,29 & 4,64 & 3,93 & 4,23 & 5,79 & 4,89 & 5,48 & 7,27 & 5,98 & 6,91 & - \\
\hline & PDMA & 15,88 & 12,04 & 12,21 & 7,94 & 8,35 & 15,01 & 15,40 & 16,01 & 23,43 & 24,35 & 26,09 & - \\
\hline \multirow[t]{3}{*}{$\Delta \mathrm{CS}$} & DM & $-44,52$ & $-23,08$ & $-39,32$ & $-8,84$ & $-17,46$ & $-35,24$ & 3,28 & $-12,73$ & $-31,71$ & 15,44 & $-8,16$ & - \\
\hline & DMA & 39,37 & 24,87 & 31,01 & 13,55 & 10,68 & 24,44 & 9,28 & 2,74 & 24,19 & 18,17 & 2,80 & - \\
\hline & PDMA & 24,14 & 25,49 & 10,57 & 9,97 & 11,52 & $-1,87$ & $-1,05$ & $-7,09$ & $-2,01$ & 8,98 & $-10,11$ & - \\
\hline
\end{tabular}


Tabela 8.187: Constantes de acoplamento BHandH com otimização de geometrias e constantes empíricas no nível PBE0 40\% $E_{X}^{\mathrm{HF}}$ e base aug-pcJ-2.

\begin{tabular}{|c|c|c|c|c|c|c|c|c|c|c|c|c|c|}
\hline & $\% E_{X}^{\mathrm{HF}}$ & 50,00 & 50,00 & 30,00 & 30,00 & $\begin{array}{l}50,00 \\
30,00 \\
\text { Otm. }\end{array}$ & 40,00 & 40,00 & $\begin{array}{l}50,00 \\
/ \\
40,00 \\
\text { Otm. }\end{array}$ & 60,00 & 60,00 & $\begin{array}{l}50,00 \\
60,00 \\
\text { Otm. }\end{array}$ & Exp. \\
\hline HF & ${ }^{1} J_{\mathrm{HF}}$ & 530,8 & 546,7 & 484,4 & 472,9 & 500,8 & 507,2 & 509,6 & 523,4 & 555,3 & 584,3 & 570,9 & 534,8 \\
\hline $\mathrm{CO}$ & ${ }^{1} J_{\mathrm{CO}}$ & 13,7 & 8,0 & 18,7 & 14,9 & 12,8 & 16,3 & 11,5 & 10,4 & 11,0 & 4,4 & 5,3 & 15,7 \\
\hline $\mathrm{H}_{2} \mathrm{O}$ & ${ }^{1} J_{\mathrm{OH}}$ & $-83,7$ & $-87,5$ & $-77,8$ & $-78,5$ & $-81,7$ & $-80,7$ & $-83,1$ & $-84,6$ & $-86,9$ & $-92,0$ & $-90,6$ & $-82,0$ \\
\hline $\mathrm{H}_{2} \mathrm{O}$ & ${ }^{2} J_{\mathrm{HH}}$ & $-9,4$ & $-7,9$ & $-6,8$ & $-5,8$ & $-5,3$ & $-8,0$ & $-6,8$ & $-6,6$ & $-10,8$ & $-9,0$ & $-9,2$ & $-8,8$ \\
\hline $\mathrm{NH}_{3}$ & ${ }^{1} J_{\mathrm{NH}}$ & 45,5 & 47,7 & 42,9 & 44,5 & 45,1 & 44,2 & 46,2 & 46,4 & 47,0 & 49,5 & 49,2 & 43,3 \\
\hline $\mathrm{NH}_{3}$ & ${ }^{2} J_{\mathrm{HH}}$ & $-11,1$ & $-9,9$ & $-8,7$ & $-7,6$ & $-7,5$ & $-9,9$ & $-8,7$ & $-8,7$ & $-12,5$ & $-11,0$ & $-11,1$ & $-10,4$ \\
\hline $\mathrm{PH}_{3}$ & ${ }^{1} J_{\mathrm{PH}}$ & 183,1 & 195,1 & 163,0 & 167,4 & 175,8 & 172,9 & 181,3 & 185,3 & 193,7 & 208,9 & 205,2 & 195,7 \\
\hline $\mathrm{PF}_{3}$ & ${ }^{1} J_{\mathrm{PF}}$ & $-1670,4$ & $-1554,5$ & $-1743,5$ & $-1622,0$ & $-1624,2$ & $-1709,0$ & $-1591,4$ & $-1591,2$ & $-1628,3$ & $-1512,0$ & $-1514,8$ & $-1.443,2$ \\
\hline $\mathrm{BHF}_{2}$ & ${ }^{1} J_{\mathrm{BF}}$ & $-95,2$ & $-72,8$ & $-132,8$ & $-116,4$ & $-109,5$ & $-114,0$ & $-94,5$ & $-91,2$ & $-76,1$ & $-51,3$ & $-54,3$ & $-79,6$ \\
\hline $\mathrm{BF}_{3}$ & ${ }^{1} J_{\mathrm{BF}}$ & 15,1 & 38,8 & $-23,3$ & $-7,3$ & 1,5 & $-4,1$ & 15,8 & 20,0 & 34,6 & 61,4 & 57,6 & 17,2 \\
\hline $\mathrm{F}_{2} \mathrm{O}$ & ${ }^{1} J_{\mathrm{OF}}$ & $-465,0$ & $-165,5$ & $-380,5$ & $-173,9$ & $-123,8$ & $-419,8$ & $-169,2$ & $-144,3$ & $-521,4$ & $-163,3$ & $-188,0$ & $-284,7$ \\
\hline $\mathrm{CH}_{4}$ & ${ }^{1} J_{\mathrm{CH}}$ & 124,9 & 124,4 & 116,8 & 117,4 & 116,3 & 120,7 & 120,7 & 120,3 & 129,4 & 128,1 & 128,8 & 122,9 \\
\hline $\mathrm{CH}_{4}$ & ${ }^{2} J_{\mathrm{HH}}$ & $-13,3$ & $-13,3$ & $-11,0$ & $-11,0$ & $-11,0$ & $-12,1$ & $-12,1$ & $-12,1$ & $-14,5$ & $-14,5$ & $-14,5$ & $-12,5$ \\
\hline $\mathrm{C}_{2} \mathrm{H}_{2}$ & ${ }^{1} J_{\mathrm{CC}}$ & 202,4 & 201,9 & 189,4 & 190,4 & 190,4 & 195,4 & 195,9 & 195,8 & 210,6 & 208,6 & 209,1 & 173,9 \\
\hline $\mathrm{C}_{2} \mathrm{H}_{2}$ & ${ }^{1} J_{\mathrm{CH}}$ & 259,5 & 253,3 & 245,0 & 243,0 & 239,4 & 252,0 & 248,0 & 246,1 & 267,8 & 259,1 & 261,1 & 244,4 \\
\hline $\mathrm{C}_{2} \mathrm{H}_{2}$ & ${ }^{2} J_{\mathrm{CH}}$ & 53,0 & 53,8 & 53,2 & 53,5 & 53,5 & 53,3 & 53,8 & 53,8 & 52,2 & 53,4 & 53,3 & 49,9 \\
\hline $\mathrm{C}_{2} \mathrm{H}_{2}$ & ${ }^{3} J_{\mathrm{HH}}$ & 11,8 & 10,7 & 9,4 & 8,9 & 8,6 & 10,5 & 9,8 & 9,6 & 13,4 & 11,9 & 12,2 & 8,9 \\
\hline $\mathrm{C}_{2} \mathrm{H}_{4}$ & ${ }^{1} J_{\mathrm{CC}}$ & 72,3 & 74,8 & 61,8 & 65,7 & 65,6 & 66,7 & 70,0 & 69,9 & 78,9 & 80,2 & 80,5 & 66,6 \\
\hline $\mathrm{C}_{2} \mathrm{H}_{4}$ & ${ }^{1} J_{\mathrm{CH}}$ & 160,6 & 155,7 & 149,9 & 147,1 & 145,6 & 155,0 & 151,3 & 150,5 & 166,8 & 160,4 & 161,4 & 154,3 \\
\hline $\mathrm{C}_{2} \mathrm{H}_{4}$ & ${ }^{2} J_{\mathrm{CH}}$ & $-3,8$ & $-3,4$ & $-1,3$ & $-1,2$ & $-1,2$ & $-2,4$ & $-2,2$ & $-2,2$ & $-5,6$ & $-4,8$ & $-4,8$ & $-1,9$ \\
\hline $\mathrm{C}_{2} \mathrm{H}_{4}$ & ${ }^{2} J_{\mathrm{HH}}$ & 2,2 & 1,2 & 3,8 & 3,0 & 2,8 & 3,1 & 2,1 & 2,0 & 1,1 & 0,2 & 0,3 & 2,1 \\
\hline $\mathrm{C}_{2} \mathrm{H}_{4}$ & ${ }^{3} J_{\mathrm{HH}_{\mathrm{c}}}$ & 13,3 & 14,4 & 12,2 & 13,3 & 13,4 & 12,7 & 13,8 & 13,9 & 14,1 & 15,1 & 15,1 & 11,3 \\
\hline $\mathrm{C}_{2} \mathrm{H}_{4}$ & ${ }^{3} J_{\mathrm{HH}_{\mathrm{t}}}$ & 19,6 & 20,2 & 17,9 & 18,9 & 18,6 & 18,7 & 19,5 & 19,4 & 20,8 & 21,1 & 21,2 & 18,3 \\
\hline $\mathrm{C}_{2} \mathrm{H}_{6}$ & ${ }^{1} J_{\mathrm{CC}}$ & 33,3 & 36,2 & 26,9 & 30,6 & 30,0 & 30,0 & 33,3 & 33,0 & 36,7 & 38,9 & 39,5 & 33,6 \\
\hline $\mathrm{C}_{2} \mathrm{H}_{6}$ & ${ }^{1} J_{\mathrm{CH}}$ & 125,8 & 122,8 & 117,3 & 115,3 & 114,6 & 121,5 & 119,0 & 118,6 & 130,4 & 126,8 & 127,2 & 123,4 \\
\hline $\mathrm{C}_{2} \mathrm{H}_{6}$ & ${ }^{2} J_{\mathrm{CH}}$ & $-4,3$ & $-4,4$ & $-3,1$ & $-3,3$ & $-3,2$ & $-3,7$ & $-3,8$ & $-3,8$ & $-4,9$ & $-5,0$ & $-5,0$ & $-4,5$ \\
\hline \multirow[t]{3}{*}{ Total } & DM & $-14,54$ & 3,76 & $-21,73$ & $-8,03$ & $-4,67$ & $-18,16$ & $-2,27$ & $-0,58$ & $-11,00$ & 10,03 & 8,34 & - \\
\hline & DMA & 20,06 & 13,68 & 24,57 & 19,44 & 19,75 & 21,47 & 14,63 & 14,92 & 23,20 & 17,58 & 15,95 & - \\
\hline & PDMA & 14,25 & 19,46 & 25,93 & 20,07 & 18,80 & 16,75 & 10,47 & 11,38 & 28,16 & 34,44 & 32,91 & - \\
\hline \multirow[t]{3}{*}{ CPI } & DM & $-40,42$ & 3,65 & $-51,13$ & $-19,07$ & $-10,36$ & $-45,72$ & $-7,94$ & $-3,55$ & $-35,67$ & 15,63 & 11,11 & - \\
\hline & DMA & 40,82 & 26,40 & 53,11 & 41,13 & 41,16 & 46,46 & 30,14 & 30,86 & 43,87 & 32,15 & 27,78 & - \\
\hline & PDMA & 13,77 & 24,29 & 40,65 & 30,83 & 27,73 & 24,65 & 14,88 & 16,66 & 26,71 & 42,04 & 38,08 & - \\
\hline \multirow[t]{3}{*}{ SPI } & DM & 4,44 & 3,84 & $-0,17$ & 0,06 & $-0,49$ & 2,05 & 1,89 & 1,61 & 7,10 & 5,92 & 6,31 & - \\
\hline & DMA & 4,84 & 4,35 & 3,63 & 3,54 & 4,05 & 3,14 & 3,25 & 3,23 & 8,05 & 6,89 & 7,27 & - \\
\hline & PDMA & 14,59 & 15,91 & 15,14 & 12,17 & 12,25 & 10,96 & 7,24 & 7,50 & 29,22 & 28,86 & 29,12 & - \\
\hline \multirow[t]{3}{*}{$\Delta \mathrm{CS}$} & DM & $-44,86$ & $-0,19$ & $-50,96$ & $-19,13$ & $-9,88$ & $-47,76$ & $-9,83$ & $-5,16$ & $-42,77$ & 9,71 & 4,80 & - \\
\hline & DMA & 35,98 & 22,05 & 49,48 & 37,59 & 37,12 & 43,32 & 26,88 & 27,63 & 35,83 & 25,26 & 20,51 & - \\
\hline & PDMA & $-0,82$ & 8,38 & 25,51 & 18,66 & 15,48 & 13,69 & 7,64 & 9,16 & $-2,51$ & 13,18 & 8,95 & - \\
\hline
\end{tabular}


Tabela 8.188: Constantes de acoplamento PBE0 com otimização de geometrias e constantes empíricas no nível PBE0 $40 \% E_{X}^{\mathrm{HF}}$ e base aug-pcJ-2.

\begin{tabular}{|c|c|c|c|c|c|c|c|c|c|c|c|c|c|c|c|c|}
\hline & $\% E_{X}^{\mathrm{HF}}$ & 25,00 & 25,00 & 20,00 & 20,00 & $\begin{array}{l}25,00 \\
20,00 \\
\text { Otm. }\end{array}$ & 30,00 & 30,00 & $\begin{array}{l}25,00 \\
30,00 \\
\text { Otm. }\end{array}$ & 40,00 & 40,00 & $\begin{array}{l}25,00 \\
40,00 \\
\text { Otm. }\end{array}$ & 50,00 & 50,00 & $\begin{array}{l}25,00 \\
50,00 \\
\text { Otm. }\end{array}$ & Exp. \\
\hline $\mathrm{HF}$ & ${ }^{1} J_{\mathrm{HF}}$ & 430,8 & 427,7 & 419,7 & 409,3 & 416,6 & 441,9 & 445,9 & 438,8 & 464,3 & 482,0 & 461,3 & 486,9 & 517,7 & 484 & 534,8 \\
\hline $\mathrm{CO}$ & ${ }^{1} J_{\mathrm{CO}}$ & 19,9 & 18,4 & 20,8 & 19,9 & 19,2 & 19,1 & 16,9 & 17,5 & 17,3 & 13,8 & 15,7 & 15,4 & 10,9 & 13,9 & 15,7 \\
\hline $\mathrm{H}_{2} \mathrm{O}$ & ${ }^{1} J_{\mathrm{OH}}$ & $-73,0$ & $-73,5$ & $-71,8$ & $-71,5$ & $-72,3$ & $-74,2$ & $-75,4$ & $-74,7$ & $-76,6$ & $-79,6$ & -77 & $-79,0$ & $-83,4$ & $-79,4$ & $-82,0$ \\
\hline $\mathrm{H}_{2} \mathrm{O}$ & ${ }^{2} J_{\mathrm{HH}}$ & $-7,3$ & $-6,9$ & $-6,7$ & $-6,4$ & $-6,4$ & $-7,8$ & $-7,4$ & $-7,4$ & $-8,9$ & $-8,1$ & $-8,5$ & $-10,0$ & $-9,0$ & $-9,6$ & $-8,8$ \\
\hline $\mathrm{NH}_{3}$ & ${ }^{1} J_{\mathrm{NH}}$ & 42,5 & 43,0 & 42,2 & 42,3 & 42,6 & 42,9 & 43,6 & 43,4 & 43,6 & 44,8 & 44,1 & 44,3 & 45,9 & 44,8 & 43,3 \\
\hline $\mathrm{NH}_{3}$ & ${ }^{2} J_{\mathrm{HH}}$ & $-10,1$ & $-9,8$ & $-9,6$ & $-9,5$ & $-9,4$ & $-10,6$ & $-10,3$ & $-10,3$ & $-11,5$ & $-11,0$ & $-11,3$ & $-12,5$ & $-11,8$ & $-12,2$ & $-10,4$ \\
\hline $\mathrm{PH}_{3}$ & ${ }^{1} J_{\mathrm{PH}}$ & 154,6 & 161,3 & 150,4 & 155,5 & 157,2 & 158,7 & 166,9 & 165,3 & 166,9 & 178,0 & 173,2 & 175,1 & 188,6 & 181,1 & 195,7 \\
\hline $\mathrm{PF}_{3}$ & ${ }^{1} J_{\mathrm{PF}}$ & $-1732,1$ & $-1627,0$ & $-1748,1$ & $-1634,2$ & $-1639,7$ & $-1715,3$ & $-1612,1$ & $-1613,5$ & $-1679,4$ & $-1581,4$ & $-1583,9$ & $-1640,8$ & $-1543,9$ & $-1551,5$ & $-1.443,2$ \\
\hline $\mathrm{BHF}_{2}$ & ${ }^{1} J_{\mathrm{BF}}$ & $-131,0$ & $-130,8$ & $-139,2$ & $-142,2$ & -139 & $-122,7$ & $-119,9$ & $-122,5$ & $-106,5$ & $-97,7$ & $-106,3$ & $-90,4$ & $-76,6$ & $-90,2$ & $-79,6$ \\
\hline $\mathrm{BF}_{3}$ & ${ }^{1} J_{\mathrm{BF}}$ & $-30,5$ & $-33,5$ & $-39,4$ & $-46,9$ & $-42,4$ & $-21,7$ & $-21,1$ & $-24,6$ & $-4,2$ & 3,6 & -7 & 12,9 & 27,3 & 10,2 & 17,2 \\
\hline $\mathrm{F}_{2} \mathrm{O}$ & ${ }^{1} J_{\mathrm{OF}}$ & $-374,9$ & $-251,0$ & $-354,9$ & $-261,4$ & $-236,3$ & $-395,6$ & $-241,6$ & -266 & $-440,5$ & $-222,0$ & $-297,4$ & $-493,5$ & $-202,0$ & $-331,8$ & $-284,7$ \\
\hline $\mathrm{CH}_{4}$ & ${ }^{1} J_{\mathrm{CH}}$ & 122,8 & 123,0 & 122,1 & 122,5 & 122,3 & 123,5 & 123,5 & 123,8 & 125,0 & 124,5 & 125,2 & 126,5 & 125,5 & 126,8 & 122,9 \\
\hline $\mathrm{CH}_{4}$ & ${ }^{2} J_{\mathrm{HH}}$ & $-13,8$ & $-13,7$ & $-13,4$ & $-13,3$ & $-13,3$ & $-14,2$ & $-14,2$ & $-14,1$ & $-15,0$ & $-15,0$ & -15 & $-15,8$ & $-15,8$ & $-15,8$ & $-12,5$ \\
\hline $\mathrm{C}_{2} \mathrm{H}_{2}$ & ${ }^{1} J_{\mathrm{CC}}$ & 196,4 & 196,6 & 194,6 & 195,0 & 195 & 198,3 & 198,3 & 198,4 & 202,6 & 202,0 & 202,4 & 207,6 & 206,0 & 207,1 & 173,9 \\
\hline $\mathrm{C}_{2} \mathrm{H}_{2}$ & ${ }^{1} J_{\mathrm{CH}}$ & 256,2 & 254,5 & 254,8 & 254,0 & 253,1 & 257,6 & 255,0 & 255,9 & 260,7 & 256,1 & 258,8 & 264,1 & 257,5 & 262,1 & 244,4 \\
\hline $\mathrm{C}_{2} \mathrm{H}_{2}$ & ${ }^{2} J_{\mathrm{CH}}$ & 53,5 & 53,7 & 53,7 & 53,9 & 53,9 & 53,2 & 53,5 & 53,4 & 52,2 & 52,8 & 52,6 & 50,9 & 52,0 & 51,4 & 49,9 \\
\hline $\mathrm{C}_{2} \mathrm{H}_{2}$ & ${ }^{3} J_{\mathrm{HH}}$ & 12,4 & 12,0 & 11,9 & 11,7 & 11,6 & 12,9 & 12,4 & 12,5 & 14,1 & 13,3 & 13,7 & 15,6 & 14,3 & 15,1 & 8,9 \\
\hline $\mathrm{C}_{2} \mathrm{H}_{4}$ & ${ }^{1} J_{\mathrm{CC}}$ & 68,7 & 71,3 & 67,0 & 69,8 & 69,8 & 70,4 & 72,9 & 72,9 & 74,4 & 76,2 & 76,5 & 79,1 & 79,9 & 80,6 & 66,6 \\
\hline $\mathrm{C}_{2} \mathrm{H}_{4}$ & ${ }^{1} J_{\mathrm{CH}}$ & 157,3 & 154,6 & 156,1 & 153,8 & 153,5 & 158,5 & 155,3 & 155,7 & 161,1 & 156,9 & 158,1 & 164,0 & 158,7 & 160,8 & 154,3 \\
\hline $\mathrm{C}_{2} \mathrm{H}_{4}$ & ${ }^{2} J_{\mathrm{CH}}$ & $-3,0$ & $-2,7$ & $-2,5$ & $-2,2$ & $-2,2$ & $-3,7$ & $-3,3$ & $-3,3$ & $-5,1$ & $-4,5$ & $-4,6$ & $-6,9$ & $-5,9$ & $-6,2$ & $-1,9$ \\
\hline $\mathrm{C}_{2} \mathrm{H}_{4}$ & ${ }^{2} J_{\mathrm{HH}}$ & 2,3 & 1,2 & 2,8 & 1,7 & 1,6 & 1,8 & 0,7 & 0,7 & 0,7 & $-0,3$ & $-0,2$ & $-0,5$ & $-1,4$ & $-1,4$ & 2,1 \\
\hline $\mathrm{C}_{2} \mathrm{H}_{4}$ & ${ }^{3} J_{\mathrm{HH}_{\mathrm{C}}}$ & 12,7 & 13,4 & 12,5 & 13,1 & 13,2 & 13,0 & 13,7 & 13,6 & 13,6 & 14,3 & 14,2 & 14,5 & 15,0 & 14,9 & 11,3 \\
\hline $\mathrm{C}_{2} \mathrm{H}_{4}$ & ${ }^{3} J_{\mathrm{HH}_{\mathrm{t}}}$ & 19,8 & 20,4 & 19,5 & 20,2 & 20,2 & 20,1 & 20,7 & 20,7 & 20,9 & 21,2 & 21,4 & 21,9 & 21,9 & 22,3 & 18,3 \\
\hline $\mathrm{C}_{2} \mathrm{H}_{6}$ & ${ }^{1} J_{\mathrm{CC}}{ }^{t}$ & 30,4 & 32,6 & 29,4 & 31,7 & 31,7 & 31,3 & 33,5 & 33,6 & 33,3 & 35,3 & 35,5 & 35,2 & 37,1 & 37,4 & 33,6 \\
\hline $\mathrm{C}_{2} \mathrm{H}_{6}$ & ${ }^{1} J_{\mathrm{CH}}$ & 123,5 & 122,0 & 122,7 & 121,5 & 121,2 & 124,3 & 122,6 & 122,9 & 126,0 & 123,8 & 124,5 & 127,7 & 124,9 & 126,2 & 123,4 \\
\hline $\mathrm{C}_{2} \mathrm{H}_{6}$ & ${ }^{2} J_{\mathrm{CH}}$ & $-4,1$ & $-4,1$ & $-3,9$ & $-3,9$ & $-3,9$ & $-4,3$ & $-4,4$ & $-4,4$ & $-4,9$ & $-4,9$ & $-4,9$ & $-5,4$ & $-5,4$ & $-5,4$ & $-4,5$ \\
\hline \multirow[t]{3}{*}{ Total } & DM & $-21,72$ & $-12,92$ & $-23,00$ & $-15,55$ & $-14,27$ & $-20,43$ & $-10,12$ & $-11,55$ & $-17,87$ & $-4,41$ & $-8,75$ & $-15,45$ & 1,5 & $-5,90$ & - \\
\hline & DMA & 26,73 & 20,37 & 27,77 & 22,19 & 22,66 & 25,84 & 18,39 & 18,16 & 24,33 & 14,88 & 15,02 & 23,42 & 12,62 & 13,70 & - \\
\hline & PDMA & 26,15 & 26,21 & 28,81 & 28,60 & 27,69 & 25,35 & 24,30 & 25,11 & 26,61 & 23,31 & 25,55 & 31,12 & 29,26 & 29,75 & - \\
\hline \multirow[t]{3}{*}{ CPI } & DM & $-55,37$ & $-34,55$ & $-57,69$ & $-40,28$ & $-37,08$ & $-53,03$ & $-28,41$ & $-32,00$ & $-48,50$ & $-15,96$ & $-26,83$ & $-44,51$ & $-3,12$ & $-21,70$ & - \\
\hline & DMA & 58,10 & 43,17 & 61,00 & 47,79 & 48,90 & 55,25 & 37,99 & 37,35 & 49,83 & 28,20 & 27,94 & 45,24 & & 22,45 & - \\
\hline & PDMA & 44,87 & 43,35 & 52,13 & 54,05 & 51,47 & 38,16 & 33,16 & 35,11 & 26,03 & 16,78 & 21,25 & 16,98 & 14,49 & 12,68 & - \\
\hline \multirow[t]{3}{*}{ SPI } & DM & 2,96 & 2,94 & & 2,59 & 2,47 & 3,47 & 3,30 & 3,44 & 4,59 & 4,0 & 4,50 & 5,85 & 4, & 5,68 & - \\
\hline & DMA & 3,72 & 3,65 & 3,40 & 3,41 & 3,41 & 4,28 & 4,02 & 4,09 & 5,63 & 5,12 & 5,55 & 7,43 & 6,47 & 7,28 & - \\
\hline & PDMA & 12,43 & 13,64 & 11,71 & 9,94 & 10,25 & 15,96 & 17,80 & 17,77 & 27,04 & 28,09 & 28,70 & 41,49 & 40,09 & 42,27 & - \\
\hline \multirow[t]{3}{*}{$\Delta \mathrm{CS}$} & DM & $-58,33$ & $-37,49$ & $-60,13$ & $-42,87$ & $-39,55$ & $-56,49$ & $-31,71$ & $-35,44$ & $-53,09$ & $-20,03$ & $-31,33$ & $-50,36$ & $-8,02$ & $-27,38$ & - \\
\hline & DMA & 54,38 & 39,53 & & 44,38 & 45,49 & 50,97 & 33,97 & 33,25 & 44,19 & & 22,38 & & & 15,17 & - \\
\hline & PDMA & 32,44 & 29,71 & 40,42 & 44,11 & 41,21 & 22,20 & 15,36 & 17,34 & $-1,00$ & $-11,32$ & $-7,45$ & $-24,51$ & $-25,60$ & $-29,59$ & - \\
\hline
\end{tabular}




\subsection{Geração de novos funcionais combinando $E_{X}^{\mathrm{HF}}, E_{X}^{\mathrm{DFT}}$ e $E_{C}^{\mathrm{DFT}}$}

\subsubsection{Geometrias Experimentais}

\subsubsection{Troca B}

Tabela 8.189: Constantes de acoplamento BB95 com base aug-pcJ-2.

\begin{tabular}{|c|c|c|c|c|c|c|c|c|c|c|c|c|c|}
\hline & $\% E_{X}^{\mathrm{HF}}$ & $0 \%$ & $10 \%$ & $20 \%$ & $30 \%$ & $40 \%$ & $50 \%$ & $60 \%$ & $70 \%$ & $80 \%$ & $90 \%$ & $100 \%$ & Exp. \\
\hline $\mathrm{HF}$ & ${ }^{1} J_{\mathrm{HF}}$ & 403,9 & 427,5 & 451,2 & 475,2 & 499,3 & 523,6 & 548,0 & 572,6 & 597,4 & 622,3 & 647,4 & 500 \\
\hline $\mathrm{CO}$ & ${ }^{1} J_{\mathrm{CO}}$ & 23,4 & 21,7 & 19,9 & 18,1 & 16,1 & 14,0 & 11,8 & 9,6 & 7,3 & 4,9 & 2,4 & 16,4 \\
\hline $\mathrm{H}_{2} \mathrm{O}$ & ${ }^{1} J_{\mathrm{OH}}$ & $-70,3$ & $-72,8$ & $-75,3$ & $-77,9$ & $-80,4$ & $-83,0$ & $-85,6$ & $-88,2$ & $-90,8$ & $-93,5$ & $-96,2$ & $-80,6$ \\
\hline $\mathrm{H}_{2} \mathrm{O}$ & ${ }^{2} J_{\mathrm{HH}}$ & $-4,2$ & $-5,2$ & $-6,2$ & $-7,2$ & $-8,2$ & $-9,2$ & $-10,3$ & $-11,3$ & $-12,4$ & $-13,5$ & $-14,7$ & $-7,3$ \\
\hline $\mathrm{NH}_{3}$ & ${ }^{1} J_{\mathrm{NH}}$ & 41,9 & 42,7 & 43,4 & 44,1 & 44,9 & 45,6 & 46,4 & 47,2 & 47,9 & 48,7 & 49,5 & 43,8 \\
\hline $\mathrm{NH}_{3}$ & ${ }^{2} J_{\mathrm{HH}}$ & $-7,0$ & $-7,8$ & $-8,7$ & $-9,5$ & $-10,4$ & $-11,3$ & $-12,1$ & $-13,0$ & $-13,9$ & $-14,8$ & $-15,8$ & $-9,6$ \\
\hline $\mathrm{PH}_{3}$ & ${ }^{1} J_{\mathrm{PH}}$ & 146,7 & 154,4 & 161,8 & 169,2 & 176,5 & 183,6 & 190,6 & 197,4 & 204,1 & 210,7 & 217,0 & 188,2 \\
\hline $\mathrm{PF}_{3}$ & ${ }^{1} J_{\mathrm{PF}}$ & $-1716,6$ & $-1695,0$ & $-1669,0$ & $-1639,2$ & $-1606,4$ & $-1571,1$ & $-1533,7$ & $-1494,9$ & $-1454,9$ & $-1414,1$ & $-1372,8$ & -1441 \\
\hline $\mathrm{BHF}_{2}$ & ${ }^{1} J_{\mathrm{BF}}$ & $-174,7$ & $-157,8$ & $-141,0$ & $-124,2$ & $-107,5$ & $-91,0$ & $-74,6$ & $-58,3$ & $-42,2$ & $-26,3$ & $-10,5$ & -84 \\
\hline $\mathrm{BF}_{3}$ & ${ }^{1} J_{\mathrm{BF}}$ & $-78,7$ & $-60,1$ & $-41,7$ & $-23,4$ & $-5,3$ & 12,6 & 30,3 & 47,9 & 65,3 & 82,6 & 99,7 & 15 \\
\hline $\mathrm{F}_{2} \mathrm{O}$ & ${ }^{1} J_{\mathrm{OF}}$ & $-266,9$ & $-301,3$ & $-334,9$ & $-368,7$ & $-404,3$ & $-443,7$ & $-490,0$ & $-548,8$ & $-631,2$ & $-765,1$ & $-1048,5$ & -300 \\
\hline $\mathrm{CH}_{4}$ & ${ }^{1} J_{\mathrm{CH}}$ & 120,7 & 122,0 & 123,3 & 124,7 & 126,1 & 127,5 & 129,0 & 130,4 & 131,9 & 133,4 & 134,9 & 125,3 \\
\hline $\mathrm{CH}_{4}$ & ${ }^{2} J_{\mathrm{HH}}$ & $-10,3$ & $-11,0$ & $-11,7$ & $-12,4$ & $-13,0$ & $-13,7$ & $-14,4$ & $-15,0$ & $-15,7$ & $-16,4$ & $-17,0$ & $-12,8$ \\
\hline $\mathrm{C}_{2} \mathrm{H}_{2}$ & ${ }^{1} J_{\mathrm{CC}}$ & 187,9 & 190,2 & 192,9 & 195,8 & 199,3 & 203,2 & 207,7 & 213,0 & 219,2 & 226,6 & 235,5 & 174,8 \\
\hline $\mathrm{C}_{2} \mathrm{H}_{2}$ & ${ }^{1} J_{\mathrm{CH}}$ & 250,6 & 252,5 & 254,5 & 256,6 & 258,8 & 261,2 & 263,7 & 266,5 & 269,6 & 273,2 & 277,3 & 247,6 \\
\hline $\mathrm{C}_{2} \mathrm{H}_{2}$ & ${ }^{2} J_{\mathrm{CH}}$ & 55,5 & 55,7 & 55,7 & 55,5 & 55,2 & 54,6 & 53,8 & 52,6 & 51,1 & 49,1 & 46,4 & 50,1 \\
\hline $\mathrm{C}_{2} \mathrm{H}_{2}$ & ${ }^{3} J_{\mathrm{HH}}$ & 9,1 & 9,5 & 10,0 & 10,6 & 11,2 & 12,0 & 13,0 & 14,1 & 15,4 & 17,0 & 18,9 & 9,6 \\
\hline $\mathrm{C}_{2} \mathrm{H}_{4}$ & ${ }^{1} J_{\mathrm{CC}}$ & 58,9 & 61,2 & 63,8 & 66,5 & 69,6 & 73,0 & 76,8 & 81,2 & 86,5 & 92,8 & 100,8 & 67,6 \\
\hline $\mathrm{C}_{2} \mathrm{H}_{4}$ & ${ }^{1} J_{\mathrm{CH}}$ & 153,4 & 155,3 & 157,2 & 159,2 & 161,3 & 163,5 & 165,9 & 168,5 & 171,4 & 174,7 & 178,7 & 156,3 \\
\hline $\mathrm{C}_{2} \mathrm{H}_{4}$ & ${ }^{2} J_{\mathrm{CH}}$ & 1,0 & 0,3 & $-0,4$ & $-1,3$ & $-2,3$ & $-3,4$ & $-4,7$ & $-6,3$ & $-8,1$ & $-10,4$ & $-13,4$ & $-2,4$ \\
\hline $\mathrm{C}_{2} \mathrm{H}_{4}$ & ${ }^{2} J_{\mathrm{HH}}$ & 6,0 & 5,4 & 4,7 & 4,0 & 3,3 & 2,5 & 1,6 & 0,6 & $-0,5$ & $-1,9$ & $-3,5$ & 2,3 \\
\hline $\mathrm{C}_{2} \mathrm{H}_{4}$ & ${ }^{3} J_{\mathrm{HH}_{\mathrm{c}}}$ & 11,5 & 11,7 & 11,9 & 12,2 & 12,5 & 12,8 & 13,3 & 13,9 & 14,7 & 15,6 & 16,9 & 11,7 \\
\hline $\mathrm{C}_{2} \mathrm{H}_{4}$ & ${ }^{3} J_{\mathrm{HH}_{\mathrm{t}}}{ }^{\mathrm{C}}$ & 18,3 & 18,5 & 18,8 & 19,0 & 19,4 & 19,9 & 20,4 & 21,1 & 22,0 & 23,2 & 24,7 & 19 \\
\hline $\mathrm{C}_{2} \mathrm{H}_{6}$ & ${ }^{1} J_{\mathrm{CC}}$ & 25,1 & 27,1 & 29,0 & 31,0 & 33,0 & 35,0 & 37,1 & 39,2 & 41,3 & 43,5 & 45,7 & 34,5 \\
\hline $\mathrm{C}_{2} \mathrm{H}_{6}$ & ${ }^{1} J_{\mathrm{CH}}$ & 120,6 & 122,2 & 123,7 & 125,3 & 126,9 & 128,5 & 130,1 & 131,8 & 133,4 & 135,0 & 136,7 & 125,2 \\
\hline $\mathrm{C}_{2} \mathrm{H}_{6}$ & ${ }^{2} J_{\mathrm{CH}}$ & $-2,2$ & $-2,7$ & $-3,1$ & $-3,6$ & $-4,0$ & $-4,5$ & $-5,0$ & $-5,4$ & $-5,9$ & $-6,4$ & $-6,9$ & $-4,7$ \\
\hline \multirow[t]{3}{*}{ Total } & $\mathrm{DM}$ & $-20,82$ & $-18,49$ & $-15,97$ & $-13,28$ & $-10,52$ & $-7,80$ & $-5,23$ & $-3,02$ & $-1,62$ & $-2,08$ & $-8,15$ & - \\
\hline & DMA & 27,72 & 22,53 & 19,82 & 17,06 & 14,84 & 15,13 & 18,06 & 22,59 & 28,10 & 37,87 & 54,82 & - \\
\hline & PDMA & 53,39 & 42,20 & 32,19 & 22,08 & 14,31 & 11,69 & 21,91 & 35,98 & 51,20 & 68,97 & 90,89 & - \\
\hline \multirow[t]{3}{*}{ CPI } & $\mathrm{DM}$ & $-49,40$ & $-44,96$ & $-40,13$ & $-34,95$ & $-29,69$ & $-24,62$ & $-20,01$ & $-16,43$ & $-14,94$ & $-18,09$ & $-34,85$ & - \\
\hline & DMA & 59,60 & 48,05 & 42,09 & 35,84 & 29,93 & 29,24 & 34,14 & 42,57 & 53,03 & 72,98 & 109,09 & - \\
\hline & PDMA & 84,86 & 66,46 & 50,03 & 33,85 & 21,92 & 13,99 & 27,38 & 45,90 & 65,14 & 86,28 & 112,26 & - \\
\hline \multirow[t]{3}{*}{ SPI } & $\mathrm{DM}$ & 0,13 & 0,92 & 1,75 & 2,60 & 3,55 & 4,53 & 5,61 & 6,81 & 8,15 & 9,66 & 11,44 & - \\
\hline & DMA & 4,35 & 3,81 & 3,48 & 3,29 & 3,77 & 4,79 & 6,27 & 7,94 & 9,83 & 12,13 & 15,03 & - \\
\hline & PDMA & 30,31 & 24,41 & 19,10 & 13,44 & 8,73 & 10,00 & 17,90 & 28,71 & 40,98 & 56,28 & 75,22 & - \\
\hline \multirow[t]{3}{*}{$\Delta \mathrm{CS}$} & $\mathrm{DM}$ & $-49,53$ & $-45,88$ & $-41,87$ & $-37,55$ & $-33,24$ & $-29,15$ & $-25,62$ & $-23,23$ & $-23,08$ & $-27,75$ & $-46,29$ & - \\
\hline & DMA & 55,25 & 44,24 & 38,61 & 32,54 & 26,15 & 24,45 & 27,87 & 34,63 & 43,20 & 60,86 & 94,06 & - \\
\hline & PDMA & 54,55 & 42,05 & 30,93 & 20,41 & 13,20 & 3,99 & 9,48 & 17,19 & 24,16 & 30,00 & 37,04 & - \\
\hline \multicolumn{14}{|c|}{ Desconsiderando ${ }^{1} J_{\mathrm{BF}}$ da molécula de $\mathrm{BF}_{3},{ }^{2} J_{\mathrm{CH}}$ e ${ }^{2} J_{\mathrm{HH}}$ da molécula de $\mathrm{C}_{2} \mathrm{H}_{4}$} \\
\hline \multirow[t]{3}{*}{ Total } & $\mathrm{DM}$ & $-19,77$ & $-17,89$ & $-15,78$ & $-13,47$ & $-11,05$ & $-8,68$ & $-6,44$ & $-4,60$ & $-3,65$ & $-4,76$ & $-12,16$ & - \\
\hline & DMA & 26,96 & 21,95 & 19,74 & 17,50 & 15,84 & 16,95 & 19,62 & 23,87 & 29,21 & 39,34 & 57,56 & - \\
\hline & PDMA & 20,04 & 15,18 & 11,79 & 8,62 & 8,22 & 10,32 & 14,84 & 20,86 & 27,68 & 35,94 & 47,30 & - \\
\hline \multirow[t]{3}{*}{ CPI } & DM & $-44,97$ & $-41,95$ & $-38,47$ & $-34,60$ & $-30,63$ & $-26,84$ & $-23,54$ & $-21,36$ & $-21,46$ & $-26,66$ & $-46,81$ & - \\
\hline & DMA & 56,19 & 45,35 & 40,63 & 35,58 & 30,89 & 31,92 & 36,02 & 43,54 & 53,30 & 73,52 & 111,53 & - \\
\hline & PDMA & 30,88 & 23,04 & 17,24 & 11,64 & 10,58 & 13,79 & 19,92 & 28,55 & 38,12 & 49,84 & 67,02 & - \\
\hline \multirow[t]{3}{*}{ SPI } & DM & $-0,39$ & 0,62 & 1,68 & 2,78 & 4,01 & 5,29 & 6,71 & 8,28 & 10,05 & 12,08 & 14,49 & - \\
\hline & DMA & 4,47 & 3,95 & 3,68 & 3,58 & 4,27 & 5,43 & 7,00 & 8,73 & 10,68 & 13,05 & 16,05 & - \\
\hline & PDMA & 11,70 & 9,14 & 7,60 & 6,29 & 6,41 & 7,66 & 10,94 & 14,94 & 19,65 & 25,25 & 32,14 & - \\
\hline \multirow[t]{3}{*}{$\Delta \mathrm{CS}$} & DM & $-44,58$ & $-42,57$ & $-40,15$ & $-37,38$ & $-34,64$ & $-32,13$ & $-30,25$ & $-29,64$ & $-31,51$ & $-38,74$ & $-61,30$ & - \\
\hline & DMA & 51,72 & 41,40 & 36,95 & 32,00 & 26,62 & 26,49 & 29,02 & 34,81 & 42,62 & 60,47 & 95,48 & - \\
\hline & PDMA & 19,17 & 13,90 & 9,64 & 5,34 & 4,18 & 6,13 & 8,98 & 13,62 & 18,47 & 24,59 & 34,88 & - \\
\hline
\end{tabular}


Tabela 8.190: Constantes de acoplamento BB971 com base aug-pcJ-2.

\begin{tabular}{|c|c|c|c|c|c|c|c|c|c|c|c|c|c|}
\hline & $\% E_{X}^{\mathrm{HF}}$ & $0 \%$ & $10 \%$ & $20 \%$ & $30 \%$ & $40 \%$ & $50 \%$ & $60 \%$ & $70 \%$ & $80 \%$ & $90 \%$ & $100 \%$ & Exp. \\
\hline $\mathrm{HF}$ & ${ }^{1} J_{\mathrm{HF}}$ & 411,4 & 434,0 & 456,8 & 479,7 & 502,8 & 526,0 & 549,3 & 572,8 & 596,4 & 620,1 & 643,9 & 500 \\
\hline $\mathrm{CO}$ & ${ }^{1} J_{\mathrm{CO}}$ & 21,7 & 19,9 & 17,9 & 15,8 & 13,7 & 11,4 & 9,0 & 6,6 & 4,0 & 1,4 & $-1,3$ & 16,4 \\
\hline $\mathrm{H}_{2} \mathrm{O}$ & ${ }^{1} J_{\mathrm{OH}}$ & $-71,1$ & $-73,5$ & $-76,0$ & $-78,4$ & $-80,8$ & $-83,3$ & $-85,7$ & $-88,2$ & $-90,7$ & $-93,2$ & $-95,7$ & $-80,6$ \\
\hline $\mathrm{H}_{2} \mathrm{O}$ & ${ }^{2} J_{\mathrm{HH}}$ & $-4,1$ & $-5,1$ & $-6,1$ & $-7,0$ & $-8,0$ & $-9,0$ & $-10,1$ & $-11,1$ & $-12,1$ & $-13,2$ & $-14,3$ & $-7,3$ \\
\hline $\mathrm{NH}_{3}$ & ${ }^{1} J_{\mathrm{NH}}$ & 42,9 & 43,7 & 44,4 & 45,1 & 45,9 & 46,7 & 47,4 & 48,2 & 49,0 & 49,8 & 50,6 & 43,8 \\
\hline $\mathrm{NH}_{3}$ & ${ }^{2} J_{\mathrm{HH}}$ & $-7,1$ & $-7,9$ & $-8,8$ & $-9,7$ & $-10,6$ & $-11,5$ & $-12,4$ & $-13,3$ & $-14,2$ & $-15,1$ & $-16,1$ & $-9,6$ \\
\hline $\mathrm{PH}_{3}$ & ${ }^{1} J_{\mathrm{PH}}$ & 174,0 & 181,6 & 188,9 & 196,0 & 203,0 & 209,8 & 216,3 & 222,7 & 228,9 & 234,9 & 240,7 & 188,2 \\
\hline $\mathrm{PF}_{3}$ & ${ }^{1} J_{\mathrm{PF}}$ & $-1762,4$ & $-1738,4$ & $-1709,9$ & $-1677,6$ & $-1642,3$ & $-1604,6$ & $-1564,9$ & $-1523,7$ & $-1481,4$ & $-1438,3$ & $-1394,8$ & -1441 \\
\hline $\mathrm{BHF}_{2}$ & ${ }^{1} J_{\mathrm{BF}}$ & $-163,3$ & $-145,5$ & $-127,7$ & $-110,0$ & $-92,5$ & $-75,2$ & $-58,1$ & $-41,2$ & $-24,5$ & $-8,0$ & 8,1 & -84 \\
\hline $\mathrm{BF}_{3}$ & ${ }^{1} J_{\mathrm{BF}}$ & $-66,7$ & $-47,4$ & $-28,2$ & $-9,3$ & 9,3 & 27,7 & 46,0 & 64,0 & 81,8 & 99,4 & 116,8 & 15 \\
\hline $\mathrm{F}_{2} \mathrm{O}$ & ${ }^{1} J_{\mathrm{OF}}$ & $-265,0$ & $-299,6$ & $-333,7$ & $-368,6$ & $-405,8$ & $-447,8$ & $-498,4$ & $-564,5$ & $-660,7$ & $-826,5$ & $-1221,3$ & -300 \\
\hline $\mathrm{CH}_{4}$ & ${ }^{1} J_{\mathrm{CH}}$ & 128,8 & 130,3 & 131,9 & 133,4 & 135,0 & 136,7 & 138,3 & 140,0 & 141,7 & 143,3 & 145,1 & 125,3 \\
\hline $\mathrm{CH}_{4}$ & ${ }^{2} J_{\mathrm{HH}}$ & $-10,3$ & $-11,0$ & $-11,7$ & $-12,4$ & $-13,1$ & $-13,9$ & $-14,6$ & $-15,3$ & $-16,0$ & $-16,7$ & $-17,3$ & $-12,8$ \\
\hline $\mathrm{C}_{2} \mathrm{H}_{2}$ & ${ }^{1} J_{\mathrm{CC}}$ & 208,5 & 211,8 & 215,5 & 219,7 & 224,5 & 230,0 & 236,3 & 243,7 & 252,4 & 262,7 & 275,1 & 174,8 \\
\hline $\mathrm{C}_{2} \mathrm{H}_{2}$ & ${ }^{1} J_{\mathrm{CH}}$ & 262,0 & 264,3 & 266,6 & 269,2 & 271,9 & 274,8 & 278,0 & 281,5 & 285,5 & 290,1 & 295,5 & 247,6 \\
\hline $\mathrm{C}_{2} \mathrm{H}_{2}$ & ${ }^{2} J_{\mathrm{CH}}$ & 54,4 & 54,3 & 54,1 & 53,7 & 53,0 & 52,1 & 50,7 & 49,0 & 46,8 & 43,9 & 40,1 & 50,1 \\
\hline $\mathrm{C}_{2} \mathrm{H}_{2}$ & ${ }^{3} J_{\mathrm{HH}}$ & 9,0 & 9,5 & 10,0 & 10,7 & 11,5 & 12,4 & 13,5 & 14,8 & 16,4 & 18,3 & 20,5 & 9,6 \\
\hline $\mathrm{C}_{2} \mathrm{H}_{4}$ & ${ }^{1} J_{\mathrm{CC}}$ & 71,5 & 74,5 & 77,8 & 81,4 & 85,5 & 90,0 & 95,2 & 101,4 & 108,8 & 118,2 & 130,5 & 67,6 \\
\hline $\mathrm{C}_{2} \mathrm{H}_{4}$ & ${ }^{1} J_{\mathrm{CH}}$ & 161,8 & 164,0 & 166,2 & 168,5 & 171,0 & 173,6 & 176,5 & 179,7 & 183,3 & 187,6 & 193,0 & 156,3 \\
\hline $\mathrm{C}_{2} \mathrm{H}_{4}$ & ${ }^{2} J_{\mathrm{CH}}$ & 0,0 & $-0,8$ & $-1,7$ & $-2,8$ & $-4,0$ & $-5,4$ & $-7,0$ & $-9,0$ & $-11,4$ & $-14,6$ & $-18,8$ & $-2,4$ \\
\hline $\mathrm{C}_{2} \mathrm{H}_{4}$ & ${ }^{2} J_{\mathrm{HH}}$ & 5,6 & 5,0 & 4,3 & 3,5 & 2,8 & 1,9 & 0,9 & $-0,1$ & $-1,4$ & $-3,0$ & $-5,1$ & 2,3 \\
\hline $\mathrm{C}_{2} \mathrm{H}_{4}$ & ${ }^{3} J_{\mathrm{HH}_{\mathrm{c}}}$ & 11,4 & 11,6 & 11,8 & 12,1 & 12,5 & 12,9 & 13,5 & 14,2 & 15,1 & 16,3 & 18,0 & 11,7 \\
\hline $\mathrm{C}_{2} \mathrm{H}_{4}$ & ${ }^{3} J_{\mathrm{HH}_{\mathrm{t}}}$ & 18,1 & 18,3 & 18,6 & 18,9 & 19,4 & 19,9 & 20,6 & 21,4 & 22,5 & 23,9 & 25,9 & 19 \\
\hline $\mathrm{C}_{2} \mathrm{H}_{6}$ & ${ }^{1} J_{\mathrm{CC}}$ & 30,4 & 32,6 & 34,9 & 37,2 & 39,5 & 41,9 & 44,3 & 46,8 & 49,3 & 51,8 & 54,4 & 34,5 \\
\hline $\mathrm{C}_{2} \mathrm{H}_{6}$ & ${ }^{1} J_{\mathrm{CH}}$ & 128,7 & 130,4 & 132,2 & 134,0 & 135,8 & 137,6 & 139,5 & 141,3 & 143,2 & 145,1 & 147,0 & 125,2 \\
\hline $\mathrm{C}_{2} \mathrm{H}_{6}$ & ${ }^{2} J_{\mathrm{CH}}$ & $-2,4$ & $-2,9$ & $-3,4$ & $-3,9$ & $-4,4$ & $-4,9$ & $-5,4$ & $-5,9$ & $-6,4$ & $-7,0$ & $-7,5$ & $-4,7$ \\
\hline \multirow[t]{3}{*}{ Total } & $\mathrm{DM}$ & $-17,58$ & $-15,05$ & $-12,32$ & $-9,45$ & $-6,52$ & $-3,66$ & $-1,01$ & 1,18 & 2,36 & 1,01 & $-8,92$ & - \\
\hline & DMA & 27,95 & 23,17 & 21,00 & 19,55 & 18,70 & 21,52 & 25,83 & 30,87 & 37,27 & 46,81 & 68,67 & - \\
\hline & PDMA & 46,16 & 35,08 & 25,07 & 17,33 & 14,76 & 22,56 & 37,03 & 52,59 & 70,15 & 90,98 & 118,03 & - \\
\hline \multirow[t]{3}{*}{ CPI } & DM & $-48,24$ & $-43,55$ & $-38,48$ & $-33,17$ & $-27,84$ & $-22,79$ & $-18,41$ & $-15,33$ & $-14,95$ & $-20,87$ & $-47,66$ & - \\
\hline & DMA & 58,33 & 46,26 & 40,19 & 35,28 & 31,42 & 35,88 & 43,48 & 52,33 & 63,78 & 81,95 & 128,26 & - \\
\hline & PDMA & 74,03 & 54,99 & 38,17 & 23,18 & 13,39 & 23,27 & 42,20 & 61,29 & 81,25 & 103,32 & 132,83 & - \\
\hline \multirow[t]{3}{*}{ SPI } & DM & 4,89 & 5,85 & 6,87 & 7,94 & 9,12 & 10,37 & 11,75 & 13,29 & 15,05 & 17,05 & 19,49 & - \\
\hline & DMA & 5,68 & 6,23 & 6,92 & 8,01 & 9,37 & 10,99 & 12,88 & 15,13 & 17,83 & 21,04 & 24,97 & - \\
\hline & PDMA & 25,73 & 20,47 & 15,46 & 13,04 & 15,77 & 22,04 & 33,24 & 46,21 & 62,02 & 81,93 & 107,17 & - \\
\hline \multirow[t]{3}{*}{$\Delta \mathrm{CS}$} & DM & $-53,13$ & $-49,41$ & $-45,35$ & $-41,11$ & $-36,96$ & $-33,16$ & $-30,16$ & $-28,62$ & $-29,99$ & $-37,93$ & $-67,15$ & - \\
\hline & DMA & 52,65 & 40,04 & 33,27 & 27,28 & 22,04 & 24,89 & 30,60 & 37,19 & 45,95 & 60,91 & 103,30 & - \\
\hline & PDMA & 48,30 & 34,52 & 22,72 & 10,14 & $-2,38$ & 1,23 & 8,97 & 15,09 & 19,24 & 21,39 & 25,65 & - \\
\hline \multicolumn{14}{|c|}{ Desconsiderando ${ }^{1} J_{\mathrm{BF}}$ da molécula de $\mathrm{BF}_{3},{ }^{2} J_{\mathrm{CH}}$ e ${ }^{2} J_{\mathrm{HH}}$ da molécula de $\mathrm{C}_{2} \mathrm{H}_{4}$} \\
\hline \multirow[t]{3}{*}{ Total } & DM & $-16,57$ & $-14,49$ & $-12,17$ & $-9,67$ & $-7,07$ & $-4,54$ & $-2,23$ & $-0,40$ & 0,31 & $-1,77$ & $-13,48$ & - \\
\hline & DMA & 27,80 & 23,29 & 21,74 & 20,97 & 20,80 & 23,63 & 27,59 & 32,37 & 38,68 & 48,48 & 72,17 & - \\
\hline & PDMA & 17,92 & 13,56 & 10,77 & 9,55 & 11,19 & 15,63 & 21,89 & 28,75 & 36,64 & 46,27 & 60,22 & - \\
\hline \multirow[t]{3}{*}{ CPI } & DM & $-44,89$ & $-41,67$ & $-38,01$ & $-34,06$ & $-30,05$ & $-26,34$ & $-23,35$ & $-21,76$ & $-23,12$ & $-31,40$ & $-62,61$ & - \\
\hline & DMA & 55,99 & 44,65 & 39,89 & 36,38 & 33,99 & 38,20 & 44,73 & 52,66 & 63,48 & 81,70 & 130,91 & - \\
\hline & PDMA & 26,97 & 18,89 & 13,19 & 9,30 & 10,93 & 17,13 & 25,75 & 34,76 & 44,85 & 57,39 & 78,24 & - \\
\hline \multirow[t]{3}{*}{ SPI } & DM & 5,21 & 6,42 & 7,72 & 9,10 & 10,61 & 12,22 & 14,02 & 16,03 & 18,34 & 21,02 & 24,32 & - \\
\hline & DMA & 6,12 & 6,85 & 7,78 & 9,12 & 10,65 & 12,42 & 14,40 & 16,77 & 19,60 & 22,93 & 26,98 & - \\
\hline & PDMA & 10,96 & 9,46 & 8,90 & 9,74 & 11,39 & 14,48 & 18,92 & 24,13 & 30,34 & 37,71 & 46,35 & - \\
\hline \multirow[t]{3}{*}{$\Delta \mathrm{CS}$} & $\mathrm{DM}$ & $-50,10$ & $-48,09$ & $-45,73$ & $-43,16$ & $-40,66$ & $-38,56$ & $-37,37$ & $-37,79$ & $-41,46$ & $-52,42$ & $-86,93$ & - \\
\hline & DMA & 49,87 & 37,80 & 32,11 & 27,26 & 23,34 & 25,78 & 30,33 & 35,89 & 43,88 & 58,77 & 103,93 & - \\
\hline & PDMA & 16,01 & 9,43 & 4,29 & $-0,45$ & $-0,46$ & 2,65 & 6,83 & 10,62 & 14,51 & 19,68 & 31,89 & - \\
\hline
\end{tabular}


Tabela 8.191: Constantes de acoplamento BB972 com base aug-pcJ-2.

\begin{tabular}{|c|c|c|c|c|c|c|c|c|c|c|c|c|c|}
\hline & $\% E_{X}^{\mathrm{HF}}$ & $0 \%$ & $10 \%$ & $20 \%$ & $30 \%$ & $40 \%$ & $50 \%$ & $60 \%$ & $70 \%$ & $80 \%$ & $90 \%$ & $100 \%$ & Exp. \\
\hline $\mathrm{HF}$ & ${ }^{1} J_{\mathrm{HF}}$ & 449,5 & 473,2 & 497,0 & 520,9 & 544,9 & 569,1 & 593,4 & 617,7 & 642,2 & 666,9 & 691,6 & 500 \\
\hline $\mathrm{CO}$ & ${ }^{1} J_{\mathrm{CO}}$ & 17,7 & 15,6 & 13,4 & 11,0 & 8,5 & 6,0 & 3,3 & 0,5 & $-2,2$ & $-5,2$ & $-8,3$ & 16,4 \\
\hline $\mathrm{H}_{2} \mathrm{O}$ & ${ }^{1} J_{\mathrm{OH}}$ & $-77,0$ & $-79,6$ & $-82,1$ & $-84,7$ & $-87,3$ & $-89,9$ & $-92,5$ & $-95,1$ & $-97,8$ & $-100,5$ & $-103,1$ & $-80,6$ \\
\hline $\mathrm{H}_{2} \mathrm{O}$ & ${ }^{2} J_{\mathrm{HH}}$ & $-3,8$ & $-4,8$ & $-5,8$ & $-6,9$ & $-7,9$ & $-8,9$ & $-10,0$ & $-11,0$ & $-12,1$ & $-13,2$ & $-14,3$ & $-7,3$ \\
\hline $\mathrm{NH}_{3}$ & ${ }^{1} J_{\mathrm{NH}}$ & 45,3 & 46,1 & 46,8 & 47,6 & 48,4 & 49,1 & 49,9 & 50,7 & 51,5 & 52,3 & 53,1 & 43,8 \\
\hline $\mathrm{NH}_{3}$ & ${ }^{2} J_{\mathrm{HH}}$ & $-6,3$ & $-7,2$ & $-8,0$ & $-8,9$ & $-9,8$ & $-10,7$ & $-11,6$ & $-12,5$ & $-13,4$ & $-14,3$ & $-15,2$ & $-9,6$ \\
\hline $\mathrm{PH}_{3}$ & ${ }^{1} J_{\mathrm{PH}}$ & 166,5 & 174,7 & 182,8 & 190,8 & 198,6 & 206,3 & 213,9 & 221,3 & 228,5 & 235,6 & 242,5 & 188,2 \\
\hline $\mathrm{PF}_{3}$ & ${ }^{1} J_{\mathrm{PF}}$ & $-1810,1$ & $-1784,5$ & $-1754,3$ & $-1720,3$ & $-1683,2$ & $-1643,5$ & $-1602,0$ & $-1558,9$ & $-1514,9$ & $-1470,1$ & $-1424,9$ & -1441 \\
\hline $\mathrm{BHF}_{2}$ & ${ }^{1} J_{\mathrm{BF}}$ & $-149,1$ & $-131,2$ & $-113,5$ & $-96,0$ & $-78,6$ & $-61,5$ & $-44,7$ & $-28,0$ & $-11,7$ & 4,4 & 20,3 & -84 \\
\hline $\mathrm{BF}_{3}$ & ${ }^{1} J_{\mathrm{BF}}$ & $-50,3$ & $-30,9$ & $-11,8$ & 6,9 & 25,4 & 43,7 & 61,7 & 79,5 & 97,1 & 114,4 & 131,6 & 15 \\
\hline $\mathrm{F}_{2} \mathrm{O}$ & ${ }^{1} J_{\mathrm{OF}}$ & $-257,6$ & $-291,6$ & $-325,2$ & $-359,6$ & $-396,4$ & $-438,2$ & $-489,0$ & $-556,6$ & $-658,1$ & $-843,0$ & $-1349,0$ & -300 \\
\hline $\mathrm{CH}_{4}$ & ${ }^{1} J_{\mathrm{CH}}$ & 131,6 & 133,0 & 134,4 & 135,9 & 137,4 & 138,9 & 140,4 & 141,9 & 143,4 & 145,0 & 146,5 & 125,3 \\
\hline $\mathrm{CH}_{4}$ & ${ }^{2} J_{\mathrm{HH}}$ & $-8,9$ & $-9,6$ & $-10,3$ & $-11,0$ & $-11,6$ & $-12,3$ & $-13,0$ & $-13,7$ & $-14,3$ & $-15,0$ & $-15,6$ & $-12,8$ \\
\hline $\mathrm{C}_{2} \mathrm{H}_{2}$ & ${ }^{1} J_{\mathrm{CC}}$ & 206,5 & 209,9 & 213,7 & 217,9 & 222,8 & 228,4 & 234,9 & 242,5 & 251,3 & 261,8 & 274,3 & 174,8 \\
\hline $\mathrm{C}_{2} \mathrm{H}_{2}$ & ${ }^{1} J_{\mathrm{CH}}$ & 263,7 & 265,8 & 268,0 & 270,3 & 272,8 & 275,4 & 278,3 & 281,5 & 285,2 & 289,3 & 294,1 & 247,6 \\
\hline $\mathrm{C}_{2} \mathrm{H}_{2}$ & ${ }^{2} J_{\mathrm{CH}}$ & 54,7 & 54,7 & 54,5 & 54,1 & 53,5 & 52,6 & 51,4 & 49,8 & 47,7 & 45,0 & 41,6 & 50,1 \\
\hline $\mathrm{C}_{2} \mathrm{H}_{2}$ & ${ }^{3} J_{\mathrm{HH}}$ & 8,4 & 8,8 & 9,2 & 9,8 & 10,4 & 11,2 & 12,2 & 13,3 & 14,6 & 16,1 & 18,0 & 9,6 \\
\hline $\mathrm{C}_{2} \mathrm{H}_{4}$ & ${ }^{1} J_{\mathrm{CC}}$ & 71,8 & 74,9 & 78,3 & 82,1 & 86,4 & 91,3 & 96,9 & 103,7 & 112,1 & 122,7 & 137,0 & 67,6 \\
\hline $\mathrm{C}_{2} \mathrm{H}_{4}$ & ${ }^{1} J_{\mathrm{CH}}$ & 163,8 & 165,8 & 167,9 & 170,1 & 172,4 & 174,9 & 177,7 & 180,8 & 184,3 & 188,6 & 194,0 & 156,3 \\
\hline $\mathrm{C}_{2} \mathrm{H}_{4}$ & ${ }^{2} J_{\mathrm{CH}}$ & 0,8 & 0,0 & $-0,8$ & $-1,9$ & $-3,1$ & $-4,5$ & $-6,1$ & $-8,1$ & $-10,5$ & $-13,8$ & $-18,1$ & $-2,4$ \\
\hline $\mathrm{C}_{2} \mathrm{H}_{4}$ & ${ }^{2} J_{\mathrm{HH}}$ & 6,9 & 6,3 & 5,6 & 5,0 & 4,2 & 3,4 & 2,5 & 1,5 & 0,3 & $-1,0$ & $-2,9$ & 2,3 \\
\hline $\mathrm{C}_{2} \mathrm{H}_{4}$ & ${ }^{3} J_{\mathrm{HH}_{\mathrm{c}}}$ & 11,1 & 11,2 & 11,4 & 11,6 & 11,9 & 12,2 & 12,7 & 13,3 & 14,1 & 15,1 & 16,6 & 11,7 \\
\hline $\mathrm{C}_{2} \mathrm{H}_{4}$ & ${ }^{3} J_{\mathrm{HH}_{\mathrm{t}}}$ & 17,8 & 17,9 & 18,1 & 18,4 & 18,7 & 19,1 & 19,7 & 20,4 & 21,4 & 22,6 & 24,4 & 19 \\
\hline $\mathrm{C}_{2} \mathrm{H}_{6}$ & ${ }^{1} J_{\mathrm{CC}}$ & 33,4 & 35,5 & 37,7 & 39,9 & 42,2 & 44,5 & 46,8 & 49,2 & 51,5 & 54,0 & 56,4 & 34,5 \\
\hline $\mathrm{C}_{2} \mathrm{H}_{6}$ & ${ }^{1} J_{\mathrm{CH}}$ & 130,6 & 132,2 & 133,9 & 135,5 & 137,2 & 138,9 & 140,6 & 142,3 & 144,0 & 145,7 & 147,5 & 125,2 \\
\hline $\mathrm{C}_{2} \mathrm{H}_{6}$ & ${ }^{2} J_{\mathrm{CH}}$ & $-1,7$ & $-2,2$ & $-2,6$ & $-3,1$ & $-3,6$ & $-4,0$ & $-4,5$ & $-5,0$ & $-5,5$ & $-6,0$ & $-6,5$ & $-4,7$ \\
\hline \multirow[t]{3}{*}{ Total } & $\mathrm{DM}$ & $-16,53$ & $-13,88$ & $-11,03$ & $-8,06$ & $-5,03$ & $-2,06$ & 0,69 & 2,92 & 3,99 & 2,02 & $-12,05$ & - \\
\hline & DMA & 27,77 & 23,05 & 20,46 & 20,34 & 22,28 & 26,03 & 30,20 & 35,19 & 41,77 & 51,82 & 75,85 & - \\
\hline & PDMA & 45,43 & 35,02 & 26,29 & 18,05 & 19,11 & 28,55 & 38,67 & 53,08 & 70,39 & 90,83 & 118,82 & - \\
\hline \multirow[t]{3}{*}{ CPI } & $\mathrm{DM}$ & $-46,92$ & $-41,92$ & $-36,51$ & $-30,92$ & $-25,30$ & $-19,95$ & $-15,32$ & $-12,12$ & $-11,98$ & $-19,42$ & $-56,05$ & - \\
\hline & DMA & 57,03 & 44,94 & 37,62 & 36,08 & 39,06 & 46,07 & 53,72 & 62,70 & 74,64 & 94,07 & 145,55 & - \\
\hline & PDMA & 61,12 & 42,91 & 28,33 & 15,69 & 19,68 & 38,37 & 57,37 & 76,65 & 96,86 & 119,55 & 152,13 & - \\
\hline \multirow[t]{3}{*}{ SPI } & DM & 5,76 & 6,67 & 7,66 & 8,70 & 9,83 & 11,06 & 12,43 & 13,95 & 15,70 & 17,73 & 20,21 & - \\
\hline & DMA & 6,31 & 6,99 & 7,87 & 8,79 & 9,97 & 11,34 & 12,95 & 15,02 & 17,67 & 20,84 & 24,75 & - \\
\hline & PDMA & 33,93 & 29,24 & 24,79 & 19,79 & 18,68 & 21,35 & 24,96 & 35,79 & 50,98 & 69,78 & 94,39 & - \\
\hline \multirow[t]{3}{*}{$\Delta \mathrm{CS}$} & $\mathrm{DM}$ & $-52,68$ & $-48,59$ & $-44,17$ & $-39,62$ & $-35,13$ & $-31,01$ & $-27,74$ & $-26,07$ & $-27,68$ & $-37,15$ & $-76,27$ & - \\
\hline & DMA & 50,72 & 37,94 & 29,74 & 27,29 & 29,10 & 34,73 & 40,77 & 47,68 & 56,96 & 73,23 & 120,80 & - \\
\hline & PDMA & 27,19 & 13,67 & 3,54 & $-4,10$ & 1,00 & 17,03 & 32,40 & 40,85 & 45,88 & 49,78 & 57,74 & - \\
\hline \multicolumn{14}{|c|}{ Desconsiderando ${ }^{1} J_{\mathrm{BF}}$ da molécula de $\mathrm{BF}_{3},{ }^{2} J_{\mathrm{CH}}$ e ${ }^{2} J_{\mathrm{HH}}$ da molécula de $\mathrm{C}_{2} \mathrm{H}_{4}$} \\
\hline \multirow[t]{3}{*}{ Total } & DM & $-16,18$ & $-13,98$ & $-11,51$ & $-8,90$ & $-6,19$ & $-3,53$ & $-1,10$ & 0,78 & 1,38 & $-1,40$ & $-17,79$ & - \\
\hline & DMA & 28,21 & 23,78 & 21,75 & 22,50 & 24,62 & 28,04 & 31,93 & 36,70 & 43,21 & 53,62 & 79,77 & - \\
\hline & PDMA & 17,94 & 14,38 & 12,81 & 12,05 & 13,72 & 18,07 & 23,10 & 29,47 & 37,32 & 46,98 & 62,25 & - \\
\hline \multirow[t]{3}{*}{ CPI } & $\mathrm{DM}$ & $-45,08$ & $-41,52$ & $-37,48$ & $-33,20$ & $-28,87$ & $-24,81$ & $-21,52$ & $-19,78$ & $-21,39$ & $-31,30$ & $-73,32$ & - \\
\hline & DMA & 56,20 & 44,84 & 38,70 & 38,88 & 41,93 & 47,81 & 54,42 & 62,52 & 73,89 & 93,54 & 148,44 & - \\
\hline & PDMA & 23,70 & 16,60 & 13,29 & 11,86 & 14,72 & 23,08 & 31,97 & 41,31 & 51,81 & 65,24 & 89,61 & - \\
\hline \multirow[t]{3}{*}{ SPI } & DM & 6,05 & 7,21 & 8,46 & 9,79 & 11,25 & 12,84 & 14,61 & 16,60 & 18,89 & 21,59 & 24,93 & - \\
\hline & DMA & 6,68 & 7,58 & 8,71 & 9,90 & 11,30 & 12,84 & 14,64 & 16,83 & 19,62 & 22,92 & 26,95 & - \\
\hline & PDMA & 13,51 & 12,67 & 12,44 & 12,20 & 12,96 & 14,22 & 16,27 & 20,35 & 26,17 & 32,93 & 41,20 & - \\
\hline \multirow[t]{3}{*}{$\Delta \mathrm{CS}$} & $\mathrm{DM}$ & $-51,13$ & $-48,73$ & $-45,94$ & $-42,99$ & $-40,12$ & $-37,65$ & $-36,13$ & $-36,38$ & $-40,28$ & $-52,89$ & $-98,25$ & - \\
\hline & DMA & 49,52 & 37,26 & 29,99 & 28,98 & 30,63 & 34,97 & 39,78 & 45,69 & 54,27 & 70,62 & 121,49 & - \\
\hline & PDMA & 10,19 & 3,93 & 0,86 & $-0,35$ & 1,76 & 8,85 & 15,70 & 20,95 & 25,64 & 32,31 & 48,41 & - \\
\hline
\end{tabular}


Tabela 8.192: Constantes de acoplamento BB98 com base aug-pcJ-2.

\begin{tabular}{|c|c|c|c|c|c|c|c|c|c|c|c|c|c|}
\hline & $\% E_{X}^{\mathrm{HF}}$ & $0 \%$ & $10 \%$ & $20 \%$ & $30 \%$ & $40 \%$ & $50 \%$ & $60 \%$ & $70 \%$ & $80 \%$ & $90 \%$ & $100 \%$ & Exp. \\
\hline $\mathrm{HF}$ & ${ }^{1} J_{\mathrm{HF}}$ & 399,0 & 421,7 & 444,6 & 467,7 & 490,9 & 514,3 & 537,8 & 561,4 & 585,2 & 609,1 & 633,1 & 500 \\
\hline $\mathrm{CO}$ & ${ }^{1} J_{\mathrm{CO}}$ & 21,5 & 19,6 & 17,6 & 15,6 & 13,4 & 11,2 & 8,8 & 6,3 & 3,8 & 1,2 & $-1,4$ & 16,4 \\
\hline $\mathrm{H}_{2} \mathrm{O}$ & ${ }^{1} J_{\mathrm{OH}}$ & $-70,5$ & $-73,0$ & $-75,4$ & $-77,9$ & $-80,4$ & $-82,9$ & $-85,4$ & $-87,9$ & $-90,4$ & $-93,0$ & $-95,6$ & $-80,6$ \\
\hline $\mathrm{H}_{2} \mathrm{O}$ & ${ }^{2} J_{\mathrm{HH}}$ & $-4,2$ & $-5,2$ & $-6,2$ & $-7,2$ & $-8,2$ & $-9,2$ & $-10,3$ & $-11,3$ & $-12,4$ & $-13,5$ & $-14,6$ & $-7,3$ \\
\hline $\mathrm{NH}_{3}$ & ${ }^{1} J_{\mathrm{NH}}$ & 43,5 & 44,2 & 45,0 & 45,8 & 46,6 & 47,4 & 48,2 & 49,0 & 49,8 & 50,6 & 51,5 & 43,8 \\
\hline $\mathrm{NH}_{3}$ & ${ }^{2} J_{\mathrm{HH}}$ & $-7,4$ & $-8,3$ & $-9,2$ & $-10,1$ & $-11,0$ & $-11,9$ & $-12,9$ & $-13,8$ & $-14,8$ & $-15,8$ & $-16,8$ & $-9,6$ \\
\hline $\mathrm{PH}_{3}$ & ${ }^{1} J_{\mathrm{PH}}$ & 180,4 & 188,0 & 195,4 & 202,7 & 209,7 & 216,6 & 223,3 & 229,7 & 236,0 & 242,0 & 247,9 & 188,2 \\
\hline $\mathrm{PF}_{3}$ & ${ }^{1} J_{\mathrm{PF}}$ & $-1778,1$ & $-1753,1$ & $-1723,7$ & $-1690,8$ & $-1654,8$ & $-1616,4$ & $-1576,2$ & $-1534,5$ & $-1491,8$ & $-1448,4$ & $-1404,5$ & -1441 \\
\hline $\mathrm{BHF}_{2}$ & ${ }^{1} J_{\mathrm{BF}}$ & $-163,6$ & $-145,9$ & $-128,3$ & $-110,8$ & $-93,5$ & $-76,4$ & $-59,4$ & $-42,6$ & $-26,1$ & $-9,8$ & 6,2 & -84 \\
\hline $\mathrm{BF}_{3}$ & ${ }^{1} J_{\mathrm{BF}}$ & $-67,8$ & $-48,7$ & $-29,8$ & $-11,1$ & 7,3 & 25,6 & 43,6 & 61,5 & 79,1 & 96,6 & 113,8 & 15 \\
\hline $\mathrm{F}_{2} \mathrm{O}$ & ${ }^{1} J_{\mathrm{OF}}$ & $-273,9$ & $-309,5$ & $-345,0$ & $-381,6$ & $-421,2$ & $-466,7$ & $-522,6$ & $-597,6$ & $-711,3$ & $-920,8$ & $-1507,1$ & -300 \\
\hline $\mathrm{CH}_{4}$ & ${ }^{1} J_{\mathrm{CH}}$ & 132,2 & 133,8 & 135,5 & 137,2 & 138,9 & 140,6 & 142,3 & 144,1 & 145,9 & 147,7 & 149,5 & 125,3 \\
\hline $\mathrm{CH}_{4}$ & ${ }^{2} J_{\mathrm{HH}}$ & $-10,8$ & $-11,5$ & $-12,3$ & $-13,0$ & $-13,8$ & $-14,5$ & $-15,2$ & $-16,0$ & $-16,7$ & $-17,4$ & $-18,1$ & $-12,8$ \\
\hline $\mathrm{C}_{2} \mathrm{H}_{2}$ & ${ }^{1} J_{\mathrm{CC}}$ & 212,2 & 215,6 & 219,4 & 223,8 & 228,7 & 234,4 & 241,0 & 248,7 & 257,9 & 268,8 & 282,1 & 174,8 \\
\hline $\mathrm{C}_{2} \mathrm{H}_{2}$ & ${ }^{1} J_{\mathrm{CH}}$ & 267,0 & 269,5 & 272,1 & 274,8 & 277,7 & 280,8 & 284,3 & 288,1 & 292,4 & 297,4 & 303,3 & 247,6 \\
\hline $\mathrm{C}_{2} \mathrm{H}_{2}$ & ${ }^{2} J_{\mathrm{CH}}$ & 55,0 & 54,9 & 54,7 & 54,2 & 53,5 & 52,4 & 51,0 & 49,1 & 46,6 & 43,4 & 39,3 & 50,1 \\
\hline $\mathrm{C}_{2} \mathrm{H}_{2}$ & ${ }^{3} J_{\mathrm{HH}}$ & 9,2 & 9,6 & 10,3 & 11,0 & 11,8 & 12,8 & 14,0 & 15,5 & 17,2 & 19,2 & 21,7 & 9,6 \\
\hline $\mathrm{C}_{2} \mathrm{H}_{4}$ & ${ }^{1} J_{\mathrm{CC}}$ & 73,9 & 77,1 & 80,5 & 84,3 & 88,5 & 93,3 & 98,9 & 105,6 & 113,7 & 124,2 & 138,3 & 67,6 \\
\hline $\mathrm{C}_{2} \mathrm{H}_{4}$ & ${ }^{1} J_{\mathrm{CH}}$ & 165,4 & 167,7 & 170,1 & 172,5 & 175,2 & 178,0 & 181,1 & 184,5 & 188,6 & 193,4 & 199,6 & 156,3 \\
\hline $\mathrm{C}_{2} \mathrm{H}_{4}$ & ${ }^{2} J_{\mathrm{CH}}$ & 0,0 & $-0,9$ & $-1,9$ & $-3,0$ & $-4,2$ & $-5,7$ & $-7,5$ & $-9,7$ & $-12,4$ & $-15,9$ & $-20,9$ & $-2,4$ \\
\hline $\mathrm{C}_{2} \mathrm{H}_{4}$ & ${ }^{2} J_{\mathrm{HH}}$ & 5,7 & 5,0 & 4,3 & 3,5 & 2,6 & 1,7 & 0,7 & $-0,4$ & $-1,9$ & $-3,7$ & $-6,2$ & 2,3 \\
\hline $\mathrm{C}_{2} \mathrm{H}_{4}$ & ${ }^{3} J_{\mathrm{HH}_{\mathrm{c}}}$ & 11,5 & 11,8 & 12,0 & 12,3 & 12,7 & 13,2 & 13,9 & 14,7 & 15,7 & 17,1 & 19,2 & 11,7 \\
\hline $\mathrm{C}_{2} \mathrm{H}_{4}$ & ${ }^{3} J_{\mathrm{HH}_{\mathrm{t}}}$ & 18,4 & 18,6 & 18,9 & 19,3 & 19,8 & 20,4 & 21,1 & 22,1 & 23,4 & 25,1 & 27,5 & 19 \\
\hline $\mathrm{C}_{2} \mathrm{H}_{6}$ & ${ }^{1} J_{\mathrm{CC}}$ & 31,9 & 34,2 & 36,5 & 38,9 & 41,4 & 43,9 & 46,4 & 49,0 & 51,7 & 54,4 & 57,1 & 34,5 \\
\hline $\mathrm{C}_{2} \mathrm{H}_{6}$ & ${ }^{1} J_{\mathrm{CH}}$ & 131,9 & 133,8 & 135,7 & 137,6 & 139,5 & 141,4 & 143,4 & 145,4 & 147,4 & 149,4 & 151,4 & 125,2 \\
\hline $\mathrm{C}_{2} \mathrm{H}_{6}$ & ${ }^{2} J_{\mathrm{CH}}$ & $-2,5$ & $-3,0$ & $-3,5$ & $-4,0$ & $-4,5$ & $-5,1$ & $-5,6$ & $-6,2$ & $-6,7$ & $-7,3$ & $-7,9$ & $-4,7$ \\
\hline \multirow[t]{3}{*}{ Total } & DM & $-17,89$ & $-15,35$ & $-12,60$ & $-9,74$ & $-6,86$ & $-4,07$ & $-1,55$ & 0,37 & 0,96 & $-1,96$ & $-19,10$ & - \\
\hline & DMA & 29,22 & 25,15 & 23,73 & 22,47 & 21,55 & 23,61 & 28,18 & 33,63 & 40,83 & 52,01 & 80,95 & - \\
\hline & PDMA & 46,34 & 35,30 & 26,12 & 19,74 & 17,45 & 25,13 & 40,09 & 56,55 & 75,40 & 97,92 & 129,89 & - \\
\hline \multirow[t]{3}{*}{ CPI } & DM & $-51,09$ & $-46,46$ & $-41,45$ & $-36,24$ & $-31,10$ & $-26,30$ & $-22,36$ & $-20,06$ & $-21,25$ & $-31,15$ & $-75,31$ & - \\
\hline & DMA & 59,56 & 49,12 & 44,41 & 39,75 & 35,55 & 38,03 & 46,09 & 55,70 & 68,71 & 90,34 & 152,76 & - \\
\hline & PDMA & 73,90 & 55,56 & 39,70 & 25,82 & 16,63 & 23,47 & 42,51 & 61,85 & 82,37 & 105,75 & 140,82 & - \\
\hline \multirow[t]{3}{*}{ SPI } & DM & 6,46 & 7,47 & 8,55 & 9,69 & 10,91 & 12,23 & 13,71 & 15,36 & 17,25 & 19,45 & 22,12 & - \\
\hline & DMA & 6,97 & 7,57 & 8,56 & 9,79 & 11,29 & 13,03 & 15,05 & 17,45 & 20,39 & 23,90 & 28,29 & - \\
\hline & PDMA & 26,12 & 20,45 & 16,16 & 15,29 & 18,06 & 26,35 & 38,33 & 52,66 & 70,29 & 92,17 & 121,88 & - \\
\hline \multirow[t]{3}{*}{$\Delta \mathrm{CS}$} & DM & $-57,55$ & $-53,94$ & $-49,99$ & $-45,92$ & $-42,01$ & $-38,53$ & $-36,08$ & $-35,42$ & $-38,50$ & $-50,60$ & $-97,43$ & - \\
\hline & DMA & 52,60 & 41,55 & 35,85 & 29,95 & 24,27 & 24,99 & 31,04 & 38,25 & 48,32 & 66,44 & 124,47 & - \\
\hline & PDMA & 47,78 & 35,10 & 23,53 & 10,53 & $-1,42$ & $-2,88$ & 4,18 & 9,19 & 12,08 & 13,59 & 18,94 & - \\
\hline \multicolumn{14}{|c|}{ Desconsiderando ${ }^{1} J_{\mathrm{BF}}$ da molécula de $\mathrm{BF}_{3},{ }^{2} J_{\mathrm{CH}}$ e ${ }^{2} J_{\mathrm{HH}}$ da molécula de $\mathrm{C}_{2} \mathrm{H}_{4}$} \\
\hline \multirow[t]{3}{*}{ Total } & DM & $-16,87$ & $-14,76$ & $-12,41$ & $-9,90$ & $-7,36$ & $-4,89$ & $-2,70$ & $-1,17$ & $-1,09$ & $-4,92$ & $-24,71$ & - \\
\hline & DMA & 29,18 & 25,47 & 24,77 & 24,18 & 23,94 & 26,06 & 30,32 & 35,57 & 42,76 & 54,40 & 86,04 & - \\
\hline & PDMA & 17,60 & 13,62 & 11,85 & 11,40 & 13,67 & 18,23 & 24,77 & 32,12 & 40,60 & 51,24 & 68,62 & - \\
\hline \multirow[t]{3}{*}{ CPI } & DM & $-47,92$ & $-44,74$ & $-41,11$ & $-37,25$ & $-33,44$ & $-29,99$ & $-27,46$ & $-26,72$ & $-29,79$ & $-42,43$ & $-92,72$ & - \\
\hline & DMA & 57,24 & 47,66 & 44,37 & 41,11 & 38,34 & 40,77 & 47,84 & 56,62 & 69,17 & 91,21 & 158,16 & - \\
\hline & PDMA & 26,09 & 18,64 & 13,80 & 11,00 & 13,16 & 18,75 & 27,69 & 37,04 & 47,87 & 61,93 & 89,03 & - \\
\hline \multirow[t]{3}{*}{ SPI } & $\mathrm{DM}$ & 7,01 & 8,30 & 9,67 & 11,13 & 12,71 & 14,42 & 16,34 & 18,49 & 20,99 & 23,94 & 27,60 & - \\
\hline & DMA & 7,59 & 8,41 & 9,68 & 11,16 & 12,86 & 14,74 & 16,85 & 19,37 & 22,44 & 26,08 & 30,57 & - \\
\hline & PDMA & 11,08 & 9,76 & 10,36 & 11,71 & 14,06 & 17,82 & 22,53 & 28,34 & 35,00 & 43,01 & 52,91 & - \\
\hline \multirow[t]{3}{*}{$\Delta \mathrm{CS}$} & $\mathrm{DM}$ & $-54,93$ & $-53,04$ & $-50,78$ & $-48,38$ & $-46,15$ & $-44,41$ & $-43,80$ & $-45,21$ & $-50,78$ & $-66,37$ & $-120,32$ & 一 \\
\hline & DMA & 49,65 & 39,25 & 34,69 & 29,95 & 25,48 & 26,03 & 30,99 & 37,25 & 46,73 & 65,13 & 127,59 & - \\
\hline & PDMA & 15,01 & 8,88 & 3,44 & $-0,71$ & $-0,90$ & 0,93 & 5,16 & 8,70 & 12,87 & 18,92 & 36,12 & - \\
\hline
\end{tabular}


8.4. GERAÇÃO DE NOVOS FUNCIONAIS COMBINANDO $E_{X}^{H F}, E_{X}^{D F T} E$

Tabela 8.193: Constantes de acoplamento BLYP com base aug-pcJ-2.

\begin{tabular}{|c|c|c|c|c|c|c|c|c|c|c|c|c|c|}
\hline & $\% E_{X}^{\mathrm{HF}}$ & $0 \%$ & $10 \%$ & $20 \%$ & $30 \%$ & $40 \%$ & $50 \%$ & $60 \%$ & $70 \%$ & $80 \%$ & $90 \%$ & $100 \%$ & Exp. \\
\hline $\mathrm{HF}$ & ${ }^{1} J_{\mathrm{HF}}$ & 397,2 & 422,6 & 448,3 & 474,2 & 500,4 & 526,8 & 553,4 & 580,3 & 607,5 & 634,8 & 662,5 & 500 \\
\hline $\mathrm{CO}$ & ${ }^{1} J_{\mathrm{CO}}$ & 21,5 & 19,6 & 17,5 & 15,4 & 13,2 & 10,9 & 8,5 & 6,0 & 3,4 & 0,8 & $-1,9$ & 16,4 \\
\hline $\mathrm{H}_{2} \mathrm{O}$ & ${ }^{1} J_{\mathrm{OH}}$ & $-72,6$ & $-75,3$ & $-78,1$ & $-80,9$ & $-83,7$ & $-86,5$ & $-89,3$ & $-92,2$ & $-95,1$ & $-98,1$ & $-101,1$ & $-80,6$ \\
\hline $\mathrm{H}_{2} \mathrm{O}$ & ${ }^{2} J_{\mathrm{HH}}$ & $-5,6$ & $-6,6$ & $-7,8$ & $-8,9$ & $-10,0$ & $-11,2$ & $-12,4$ & $-13,6$ & $-14,8$ & $-16,0$ & $-17,3$ & $-7,3$ \\
\hline $\mathrm{NH}_{3}$ & ${ }^{1} J_{\mathrm{NH}}$ & 44,8 & 45,6 & 46,4 & 47,3 & 48,1 & 49,0 & 49,8 & 50,7 & 51,6 & 52,5 & 53,4 & 43,8 \\
\hline $\mathrm{NH}_{3}$ & ${ }^{2} J_{\mathrm{HH}}$ & $-8,6$ & $-9,6$ & $-10,5$ & $-11,5$ & $-12,5$ & $-13,5$ & $-14,5$ & $-15,5$ & $-16,6$ & $-17,6$ & $-18,7$ & $-9,6$ \\
\hline $\mathrm{PH}_{3}$ & ${ }^{1} J_{\mathrm{PH}}$ & 159,7 & 168,2 & 176,7 & 185,0 & 193,2 & 201,3 & 209,2 & 217,0 & 224,6 & 232,0 & 239,2 & 188,2 \\
\hline $\mathrm{PF}_{3}$ & ${ }^{1} J_{\mathrm{PF}}$ & $-1815,0$ & $-1789,8$ & $-1760,2$ & $-1726,8$ & $-1690,3$ & $-1651,5$ & $-1610,7$ & $-1568,5$ & $-1525,3$ & $-1481,3$ & $-1437,0$ & -1441 \\
\hline $\mathrm{BHF}_{2}$ & ${ }^{1} J_{\mathrm{BF}}$ & $-168,9$ & $-151,2$ & $-133,7$ & $-116,3$ & $-99,0$ & $-81,9$ & $-65,0$ & $-48,3$ & $-31,8$ & $-15,5$ & 0,6 & -84 \\
\hline $\mathrm{BF}_{3}$ & ${ }^{1} J_{\mathrm{BF}}$ & $-69,9$ & $-50,6$ & $-31,5$ & $-12,7$ & 5,9 & 24,3 & 42,5 & 60,6 & 78,5 & 96,2 & 113,8 & 15 \\
\hline $\mathrm{F}_{2} \mathrm{O}$ & ${ }^{1} J_{\mathrm{OF}}$ & $-281,5$ & $-318,6$ & $-355,8$ & $-394,8$ & $-437,8$ & $-488,0$ & $-551,4$ & $-639,8$ & $-782,1$ & $-1075,1$ & $-2253,8$ & -300 \\
\hline $\mathrm{CH}_{4}$ & ${ }^{1} J_{\mathrm{CH}}$ & 132,6 & 134,2 & 135,8 & 137,4 & 139,1 & 140,7 & 142,4 & 144,1 & 145,9 & 147,6 & 149,4 & 125,3 \\
\hline $\mathrm{CH}_{4}$ & ${ }^{2} J_{\mathrm{HH}}$ & $-12,1$ & $-12,9$ & $-13,7$ & $-14,5$ & $-15,2$ & $-16,0$ & $-16,8$ & $-17,5$ & $-18,3$ & $-19,0$ & $-19,7$ & $-12,8$ \\
\hline $\mathrm{C}_{2} \mathrm{H}_{2}$ & ${ }^{1} J_{\mathrm{CC}}$ & 199,5 & 202,5 & 206,0 & 210,0 & 214,7 & 220,1 & 226,5 & 234,1 & 243,3 & 254,5 & 268,4 & 174,8 \\
\hline $\mathrm{C}_{2} \mathrm{H}_{2}$ & ${ }^{1} J_{\mathrm{CH}}$ & 274,3 & 276,8 & 279,4 & 282,2 & 285,2 & 288,5 & 292,1 & 296,3 & 301,1 & 306,7 & 313,5 & 247,6 \\
\hline $\mathrm{C}_{2} \mathrm{H}_{2}$ & ${ }^{2} J_{\mathrm{CH}}$ & 57,3 & 57,2 & 56,9 & 56,3 & 55,4 & 54,1 & 52,4 & 50,2 & 47,2 & 43,3 & 38,1 & 50,1 \\
\hline $\mathrm{C}_{2} \mathrm{H}_{2}$ & ${ }^{3} J_{\mathrm{HH}}$ & 10,3 & 10,9 & 11,7 & 12,5 & 13,6 & 14,8 & 16,3 & 18,0 & 20,2 & 22,8 & 26,0 & 9,6 \\
\hline $\mathrm{C}_{2} \mathrm{H}_{4}$ & ${ }^{1} J_{\mathrm{CC}}$ & 67,0 & 70,0 & 73,3 & 77,0 & 81,1 & 86,0 & 91,8 & 98,9 & 108,1 & 120,6 & 139,0 & 67,6 \\
\hline $\mathrm{C}_{2} \mathrm{H}_{4}$ & ${ }^{1} J_{\mathrm{CH}}$ & 167,4 & 169,6 & 172,0 & 174,5 & 177,2 & 180,1 & 183,4 & 187,2 & 191,7 & 197,6 & 205,7 & 156,3 \\
\hline $\mathrm{C}_{2} \mathrm{H}_{4}$ & ${ }^{2} J_{\mathrm{CH}}$ & 0,1 & $-0,7$ & $-1,7$ & $-2,9$ & $-4,3$ & $-6,0$ & $-8,0$ & $-10,5$ & $-13,8$ & $-18,4$ & $-25,4$ & $-2,4$ \\
\hline $\mathrm{C}_{2} \mathrm{H}_{4}$ & ${ }^{2} J_{\mathrm{HH}}$ & 6,1 & 5,3 & 4,5 & 3,6 & 2,7 & 1,6 & 0,3 & $-1,1$ & $-3,0$ & $-5,6$ & $-9,3$ & 2,3 \\
\hline $\mathrm{C}_{2} \mathrm{H}_{4}$ & ${ }^{3} J_{\mathrm{HH}_{\mathrm{c}}}$ & 12,8 & 13,0 & 13,3 & 13,7 & 14,2 & 14,9 & 15,7 & 16,8 & 18,2 & 20,4 & 23,7 & 11,7 \\
\hline $\mathrm{C}_{2} \mathrm{H}_{4}$ & ${ }^{3} J_{\mathrm{HH}_{\mathrm{t}}}$ & 20,2 & 20,5 & 20,9 & 21,3 & 21,9 & 22,7 & 23,6 & 24,9 & 26,6 & 29,1 & 32,9 & 19 \\
\hline $\mathrm{C}_{2} \mathrm{H}_{6}$ & ${ }^{1} J_{\mathrm{CC}}$ & 29,5 & 31,6 & 33,8 & 36,0 & 38,3 & 40,6 & 42,9 & 45,3 & 47,8 & 50,2 & 52,7 & 34,5 \\
\hline $\mathrm{C}_{2} \mathrm{H}_{6}$ & ${ }^{1} J_{\mathrm{CH}}$ & 132,2 & 133,9 & 135,7 & 137,6 & 139,4 & 141,3 & 143,2 & 145,1 & 147,0 & 149,0 & 150,9 & 125,2 \\
\hline $\mathrm{C}_{2} \mathrm{H}_{6}$ & ${ }^{2} J_{\mathrm{CH}}$ & $-2,5$ & $-3,0$ & $-3,5$ & $-4,0$ & $-4,6$ & $-5,1$ & $-5,6$ & $-6,2$ & $-6,7$ & $-7,3$ & $-7,8$ & $-4,7$ \\
\hline \multirow[t]{3}{*}{ Total } & $\mathrm{DM}$ & $-21,12$ & $-18,53$ & $-15,74$ & $-12,86$ & $-9,95$ & $-7,19$ & $-4,80$ & $-3,18$ & $-3,45$ & $-9,26$ & $-48,74$ & - \\
\hline & DMA & 31,24 & 27,67 & 25,60 & 23,80 & 22,92 & 25,55 & 30,60 & 36,76 & 45,43 & 60,33 & 110,36 & - \\
\hline & PDMA & 47,30 & 36,95 & 28,57 & 23,02 & 21,38 & 28,90 & 45,13 & 63,06 & 84,69 & 112,41 & 158,62 & - \\
\hline \multirow[t]{3}{*}{ CPI } & DM & $-58,16$ & $-53,33$ & $-48,15$ & $-42,81$ & $-37,58$ & $-32,84$ & $-29,16$ & $-27,65$ & $-31,00$ & $-48,02$ & $-145,56$ & - \\
\hline & DMA & 64,58 & 55,33 & 49,27 & 43,45 & 39,35 & 43,11 & 52,24 & 63,53 & 79,62 & 109,29 & 220,20 & - \\
\hline & PDMA & 73,81 & 55,78 & 41,67 & 30,69 & 22,26 & 27,35 & 46,99 & 67,39 & 89,42 & 115,77 & 169,20 & - \\
\hline \multirow[t]{3}{*}{ SPI } & DM & 6,04 & 6,99 & 8,02 & 9,11 & 10,31 & 11,61 & 13,07 & 14,77 & 16,75 & 19,16 & 22,27 & - \\
\hline & DMA & 6,79 & 7,39 & 8,23 & 9,40 & 10,88 & 12,67 & 14,74 & 17,13 & 20,36 & 24,43 & 29,81 & - \\
\hline & PDMA & 27,86 & 23,14 & 18,96 & 17,39 & 20,74 & 30,04 & 43,77 & 59,88 & 81,23 & 109,94 & 150,86 & - \\
\hline \multirow[t]{3}{*}{$\Delta \mathrm{CS}$} & DM & $-64,20$ & $-60,31$ & $-56,17$ & $-51,92$ & $-47,89$ & $-44,45$ & $-42,24$ & $-42,42$ & $-47,75$ & $-67,18$ & $-167,83$ & - \\
\hline & DMA & 57,80 & 47,94 & 41,04 & 34,05 & 28,47 & 30,44 & 37,50 & 46,40 & 59,26 & 84,86 & 190,39 & - \\
\hline & PDMA & 45,95 & 32,65 & 22,70 & 13,30 & 1,52 & $-2,69$ & 3,23 & 7,51 & 8,19 & 5,83 & 18,34 & - \\
\hline \multicolumn{14}{|c|}{ Desconsiderando ${ }^{1} J_{\mathrm{BF}}$ da molécula de $\mathrm{BF}_{3},{ }^{2} J_{\mathrm{CH}}$ e ${ }^{2} J_{\mathrm{HH}}$ da molécula de $\mathrm{C}_{2} \mathrm{H}_{4}$} \\
\hline \multirow[t]{3}{*}{ Total } & DM & $-20,46$ & $-18,30$ & $-15,90$ & $-13,37$ & $-10,79$ & $-8,35$ & $-6,29$ & $-5,08$ & $-5,94$ & $-12,96$ & $-57,89$ & - \\
\hline & DMA & 31,35 & 28,22 & 26,79 & 25,63 & 25,42 & 28,29 & 33,07 & 39,07 & 47,87 & 63,63 & 118,96 & - \\
\hline & PDMA & 17,15 & 14,01 & 13,39 & 14,63 & 17,33 & 22,13 & 29,12 & 36,96 & 46,67 & 59,61 & 87,08 & - \\
\hline \multirow[t]{3}{*}{ CPI } & DM & $-55,49$ & $-52,10$ & $-48,31$ & $-44,32$ & $-40,43$ & $-37,05$ & $-34,83$ & $-34,98$ & $-40,45$ & $-60,94$ & $-170,00$ & - \\
\hline & DMA & 62,55 & 54,30 & 49,55 & 45,02 & 42,37 & 46,49 & 54,71 & 65,32 & 81,23 & 112,10 & 232,34 & - \\
\hline & PDMA & 24,59 & 17,63 & 14,83 & 15,29 & 18,42 & 23,89 & 33,36 & 43,73 & 56,03 & 73,22 & 120,26 & - \\
\hline \multirow[t]{3}{*}{ SPI } & $\mathrm{DM}$ & 6,48 & 7,70 & 9,03 & 10,45 & 12,01 & 13,73 & 15,67 & 17,92 & 20,61 & 23,95 & 28,35 & - \\
\hline & DMA & 7,35 & 8,16 & 9,28 & 10,71 & 12,38 & 14,28 & 16,42 & 18,88 & 22,21 & 26,35 & 31,74 & - \\
\hline & PDMA & 11,42 & 11,22 & 12,28 & 14,12 & 16,50 & 20,78 & 25,86 & 31,76 & 39,46 & 49,15 & 61,56 & - \\
\hline \multirow[t]{3}{*}{$\Delta \mathrm{CS}$} & $\mathrm{DM}$ & $-61,97$ & $-59,80$ & $-57,34$ & $-54,77$ & $-52,44$ & $-50,78$ & $-50,50$ & $-52,90$ & $-61,06$ & $-84,89$ & $-198,35$ & 一 \\
\hline & DMA & 55,20 & 46,14 & 40,27 & 34,31 & 29,99 & 32,21 & 38,29 & 46,44 & 59,02 & 85,75 & 200,60 & - \\
\hline & PDMA & 13,17 & 6,41 & 2,55 & 1,17 & 1,92 & 3,10 & 7,50 & 11,97 & 16,56 & 24,07 & 58,70 & - \\
\hline
\end{tabular}


Tabela 8.194: Constantes de acoplamento BP86 com base aug-pcJ-2.

\begin{tabular}{|c|c|c|c|c|c|c|c|c|c|c|c|c|c|}
\hline & $\% E_{X}^{\mathrm{HF}}$ & $0 \%$ & $10 \%$ & $20 \%$ & $30 \%$ & $40 \%$ & $50 \%$ & $60 \%$ & $70 \%$ & $80 \%$ & $90 \%$ & $100 \%$ & Exp. \\
\hline $\mathrm{HF}$ & ${ }^{1} J_{\mathrm{HF}}$ & 355,3 & 378,9 & 402,8 & 426,9 & 451,3 & 475,8 & 500,7 & 525,7 & 551,0 & 576,5 & 602,2 & 500 \\
\hline $\mathrm{CO}$ & ${ }^{1} J_{\mathrm{CO}}$ & 24,9 & 23,2 & 21,5 & 19,7 & 17,7 & 15,8 & 13,7 & 11,6 & 9,4 & 7,1 & 4,8 & 16,4 \\
\hline $\mathrm{H}_{2} \mathrm{O}$ & ${ }^{1} J_{\mathrm{OH}}$ & $-64,8$ & $-67,3$ & $-69,8$ & $-72,4$ & $-75,0$ & $-77,6$ & $-80,2$ & $-82,9$ & $-85,5$ & $-88,3$ & $-91,0$ & $-80,6$ \\
\hline $\mathrm{H}_{2} \mathrm{O}$ & ${ }^{2} J_{\mathrm{HH}}$ & $-4,6$ & $-5,5$ & $-6,5$ & $-7,5$ & $-8,5$ & $-9,6$ & $-10,6$ & $-11,7$ & $-12,8$ & $-13,9$ & $-15,1$ & $-7,3$ \\
\hline $\mathrm{NH}_{3}$ & ${ }^{1} J_{\mathrm{NH}}$ & 40,0 & 40,7 & 41,5 & 42,2 & 43,0 & 43,8 & 44,6 & 45,4 & 46,2 & 47,0 & 47,8 & 43,8 \\
\hline $\mathrm{NH}_{3}$ & ${ }^{2} J_{\mathrm{HH}}$ & $-7,8$ & $-8,6$ & $-9,5$ & $-10,4$ & $-11,2$ & $-12,1$ & $-13,0$ & $-13,9$ & $-14,9$ & $-15,8$ & $-16,8$ & $-9,6$ \\
\hline $\mathrm{PH}_{3}$ & ${ }^{1} J_{\mathrm{PH}}$ & 136,9 & 144,9 & 152,8 & 160,7 & 168,4 & 176,0 & 183,5 & 190,8 & 198,1 & 205,1 & 212,1 & 188,2 \\
\hline $\mathrm{PF}_{3}$ & ${ }^{1} J_{\mathrm{PF}}$ & $-1802,5$ & $-1777,4$ & $-1747,9$ & $-1714,7$ & $-1678,5$ & $-1639,9$ & $-1599,5$ & $-1557,7$ & $-1514,9$ & $-1471,4$ & $-1427,5$ & -1441 \\
\hline $\mathrm{BHF}_{2}$ & ${ }^{1} J_{\mathrm{BF}}$ & $-177,9$ & $-160,9$ & $-144,0$ & $-127,2$ & $-110,6$ & $-94,0$ & $-77,7$ & $-61,5$ & $-45,5$ & $-29,7$ & $-14,1$ & -84 \\
\hline $\mathrm{BF}_{3}$ & ${ }^{1} J_{\mathrm{BF}}$ & $-83,3$ & $-64,6$ & $-46,2$ & $-27,9$ & $-9,8$ & 8,0 & 25,7 & 43,3 & 60,6 & 77,8 & 94,8 & 15 \\
\hline $\mathrm{F}_{2} \mathrm{O}$ & ${ }^{1} J_{\mathrm{OF}}$ & $-290,1$ & $-327,4$ & $-365,0$ & $-404,4$ & $-447,8$ & $-498,7$ & $-562,6$ & $-651,0$ & $-790,4$ & $-1064,3$ & $-1973,1$ & -300 \\
\hline $\mathrm{CH}_{4}$ & ${ }^{1} J_{\mathrm{CH}}$ & 117,5 & 118,9 & 120,4 & 121,9 & 123,4 & 124,9 & 126,5 & 128,1 & 129,7 & 131,4 & 133,0 & 125,3 \\
\hline $\mathrm{CH}_{4}$ & ${ }^{2} J_{\mathrm{HH}}$ & $-11,8$ & $-12,5$ & $-13,2$ & $-13,9$ & $-14,6$ & $-15,3$ & $-16,1$ & $-16,8$ & $-17,5$ & $-18,1$ & $-18,8$ & $-12,8$ \\
\hline $\mathrm{C}_{2} \mathrm{H}_{2}$ & ${ }^{1} J_{\mathrm{CC}}$ & 187,3 & 189,9 & 193,0 & 196,5 & 200,6 & 205,4 & 211,1 & 218,0 & 226,4 & 236,9 & 250,2 & 174,8 \\
\hline $\mathrm{C}_{2} \mathrm{H}_{2}$ & ${ }^{1} J_{\mathrm{CH}}$ & 247,4 & 249,7 & 252,1 & 254,7 & 257,5 & 260,6 & 264,1 & 268,1 & 272,8 & 278,4 & 285,3 & 247,6 \\
\hline $\mathrm{C}_{2} \mathrm{H}_{2}$ & ${ }^{2} J_{\mathrm{CH}}$ & 54,6 & 54,6 & 54,4 & 53,9 & 53,1 & 51,9 & 50,3 & 48,1 & 45,2 & 41,3 & 35,9 & 50,1 \\
\hline $\mathrm{C}_{2} \mathrm{H}_{2}$ & ${ }^{3} J_{\mathrm{HH}}$ & 10,2 & 10,9 & 11,6 & 12,5 & 13,5 & 14,8 & 16,4 & 18,2 & 20,5 & 23,3 & 26,9 & 9,6 \\
\hline $\mathrm{C}_{2} \mathrm{H}_{4}$ & ${ }^{1} J_{\mathrm{CC}}$ & 59,5 & 62,2 & 65,2 & 68,5 & 72,4 & 76,9 & 82,4 & 89,4 & 98,7 & 112,2 & 133,8 & 67,6 \\
\hline $\mathrm{C}_{2} \mathrm{H}_{4}$ & ${ }^{1} J_{\mathrm{CH}}$ & 149,7 & 151,8 & 154,0 & 156,3 & 158,8 & 161,6 & 164,7 & 168,5 & 173,2 & 179,6 & 189,3 & 156,3 \\
\hline $\mathrm{C}_{2} \mathrm{H}_{4}$ & ${ }^{2} J_{\mathrm{CH}}$ & 0,0 & $-0,8$ & $-1,7$ & $-2,9$ & $-4,2$ & $-5,7$ & $-7,7$ & $-10,3$ & $-13,9$ & $-19,1$ & $-27,6$ & $-2,4$ \\
\hline $\mathrm{C}_{2} \mathrm{H}_{4}$ & ${ }^{2} J_{\mathrm{HH}}$ & 4,6 & 3,9 & 3,1 & 2,2 & 1,2 & 0,0 & $-1,2$ & $-2,9$ & $-5,2$ & $-8,4$ & $-13,5$ & 2,3 \\
\hline $\mathrm{C}_{2} \mathrm{H}_{4}$ & ${ }^{3} J_{\mathrm{HH}_{\mathrm{c}}}$ & 11,6 & 11,9 & 12,3 & 12,7 & 13,3 & 14,0 & 15,0 & 16,3 & 18,1 & 21,0 & 25,7 & 11,7 \\
\hline $\mathrm{C}_{2} \mathrm{H}_{4}$ & ${ }^{3} J_{\mathrm{HH}_{\mathrm{t}}}$ & 18,5 & 18,9 & 19,3 & 19,8 & 20,4 & 21,3 & 22,4 & 23,9 & 26,1 & 29,3 & 34,7 & 19 \\
\hline $\mathrm{C}_{2} \mathrm{H}_{6}$ & ${ }^{1} J_{\mathrm{CC}}$ & 24,2 & 26,2 & 28,2 & 30,2 & 32,3 & 34,4 & 36,5 & 38,7 & 40,9 & 43,2 & 45,4 & 34,5 \\
\hline $\mathrm{C}_{2} \mathrm{H}_{6}$ & ${ }^{1} J_{\mathrm{CH}}$ & 117,6 & 119,2 & 120,9 & 122,6 & 124,3 & 126,0 & 127,8 & 129,6 & 131,3 & 133,2 & 135,0 & 125,2 \\
\hline $\mathrm{C}_{2} \mathrm{H}_{6}$ & ${ }^{2} J_{\mathrm{CH}}$ & $-2,7$ & $-3,1$ & $-3,6$ & $-4,1$ & $-4,5$ & $-5,0$ & $-5,5$ & $-6,0$ & $-6,5$ & $-7,1$ & $-7,6$ & $-4,7$ \\
\hline \multirow[t]{3}{*}{ Total } & DM & $-28,10$ & $-25,67$ & $-23,05$ & $-20,35$ & $-17,63$ & $-15,07$ & $-12,83$ & $-11,38$ & $-11,69$ & $-16,84$ & $-45,89$ & - \\
\hline & DMA & 33,03 & 29,60 & 26,84 & 24,22 & 22,25 & 20,73 & 21,63 & 27,38 & 35,80 & 49,96 & 90,58 & - \\
\hline & PDMA & 50,85 & 40,53 & 30,46 & 22,94 & 22,22 & 23,42 & 33,70 & 51,99 & 74,53 & 104,07 & 152,34 & - \\
\hline \multirow[t]{3}{*}{ CPI } & DM & $-64,98$ & $-60,45$ & $-55,56$ & $-50,54$ & $-45,63$ & $-41,22$ & $-37,85$ & $-36,62$ & $-39,96$ & $-55,53$ & $-128,80$ & - \\
\hline & DMA & 72,02 & 64,61 & 58,62 & 52,63 & 46,88 & 41,76 & 41,28 & 51,29 & 66,76 & 94,38 & 182,13 & - \\
\hline & PDMA & 89,78 & 72,91 & 56,58 & 42,32 & 30,26 & 19,53 & 25,40 & 44,36 & 65,33 & 90,28 & 134,69 & - \\
\hline \multirow[t]{3}{*}{ SPI } & DM & $-1,06$ & $-0,16$ & 0,79 & 1,79 & 2,89 & 4,11 & 5,51 & 7,12 & 9,05 & 11,53 & 14,91 & - \\
\hline & DMA & 4,43 & 3,93 & 3,54 & 3,39 & 4,19 & 5,30 & 7,23 & 9,84 & 13,10 & 17,39 & 23,45 & - \\
\hline & PDMA & 22,31 & 16,78 & 11,30 & 8,73 & 16,32 & 26,27 & 39,78 & 57,59 & 81,27 & 114,19 & 165,29 & - \\
\hline \multirow[t]{3}{*}{$\Delta \mathrm{CS}$} & DM & $-63,92$ & $-60,29$ & $-56,36$ & $-52,32$ & $-48,52$ & $-45,33$ & $-43,35$ & $-43,74$ & $-49,01$ & $-67,06$ & $-143,71$ & - \\
\hline & DMA & 67,58 & 60,68 & 55,08 & 49,24 & 42,70 & 36,46 & 34,06 & 41,45 & 53,66 & 77,00 & 158,67 & - \\
\hline & PDMA & 67,47 & 56,13 & 45,28 & 33,59 & 13,93 & $-6,74$ & $-14,38$ & $-13,23$ & $-15,94$ & $-23,91$ & $-30,60$ & - \\
\hline \multicolumn{14}{|c|}{ Desconsiderando ${ }^{1} J_{\mathrm{BF}}$ da molécula de $\mathrm{BF}_{3},{ }^{2} J_{\mathrm{CH}}$ e ${ }^{2} J_{\mathrm{HH}}$ da molécula de $\mathrm{C}_{2} \mathrm{H}_{4}$} \\
\hline \multirow[t]{3}{*}{ Total } & DM & $-27,70$ & $-25,69$ & $-23,46$ & $-21,11$ & $-18,73$ & $-16,48$ & $-14,59$ & $-13,53$ & $-14,37$ & $-20,57$ & $-53,57$ & - \\
\hline & DMA & 32,86 & 29,87 & 27,62 & 25,49 & 23,95 & 22,88 & 23,61 & 29,15 & 37,67 & 52,56 & 97,15 & - \\
\hline & PDMA & 20,30 & 16,82 & 13,91 & 12,40 & 12,59 & 14,12 & 18,77 & 26,43 & 36,02 & 48,96 & 73,57 & - \\
\hline \multirow[t]{3}{*}{ CPI } & DM & $-61,65$ & $-58,53$ & $-55,00$ & $-51,30$ & $-47,71$ & $-44,64$ & $-42,70$ & $-43,11$ & $-48,52$ & $-67,36$ & $-149,66$ & - \\
\hline & DMA & 69,39 & 63,11 & 58,36 & 53,60 & 49,09 & 45,24 & 44,34 & 53,59 & 68,88 & 97,54 & 192,36 & - \\
\hline & PDMA & 33,22 & 27,14 & 21,44 & 17,95 & 16,75 & 16,82 & 20,81 & 29,92 & 41,47 & 57,44 & 94,96 & - \\
\hline \multirow[t]{3}{*}{ SPI } & $\mathrm{DM}$ & $-1,58$ & $-0,43$ & 0,80 & 2,11 & 3,56 & 5,18 & 7,03 & 9,22 & 11,90 & 15,42 & 20,35 & - \\
\hline & DMA & 4,75 & 4,29 & 3,97 & 3,86 & 4,61 & 5,68 & 7,66 & 10,35 & 13,65 & 17,95 & 23,91 & - \\
\hline & PDMA & 10,36 & 8,88 & 8,12 & 8,14 & 9,39 & 12,05 & 17,20 & 23,74 & 31,84 & 42,44 & 57,11 & - \\
\hline \multirow[t]{3}{*}{$\Delta \mathrm{CS}$} & $\mathrm{DM}$ & $-60,07$ & $-58,10$ & $-55,80$ & $-53,41$ & $-51,27$ & $-49,82$ & $-49,73$ & $-52,33$ & $-60,42$ & $-82,78$ & $-170,01$ & 一 \\
\hline & DMA & 64,64 & 58,82 & 54,39 & 49,74 & 44,48 & 39,56 & 36,68 & 43,24 & 55,23 & 79,59 & 168,45 & - \\
\hline & PDMA & 22,86 & 18,26 & 13,32 & 9,81 & 7,36 & 4,77 & 3,60 & 6,19 & 9,63 & 14,99 & 37,85 & - \\
\hline
\end{tabular}


8.4. GERAÇÃO DE NOVOS FUNCIONAIS COMBINANDO $E_{X}^{H F}, E_{X}^{D F T} E$

Tabela 8.195: Constantes de acoplamento BPBE com base aug-pcJ-2.

\begin{tabular}{|c|c|c|c|c|c|c|c|c|c|c|c|c|c|}
\hline & $\% E_{X}^{\mathrm{HF}}$ & $0 \%$ & $10 \%$ & $20 \%$ & $30 \%$ & $40 \%$ & $50 \%$ & $60 \%$ & $70 \%$ & $80 \%$ & $90 \%$ & $100 \%$ & Exp. \\
\hline $\mathrm{HF}$ & ${ }^{1} J_{\mathrm{HF}}$ & 350,6 & 374,7 & 399,1 & 423,8 & 448,7 & 473,9 & 499,3 & 525,0 & 550,9 & 577,0 & 603,3 & 500 \\
\hline $\mathrm{CO}$ & ${ }^{1} J_{\mathrm{CO}}$ & 25,4 & 23,8 & 22,0 & 20,2 & 18,3 & 16,3 & 14,3 & 12,1 & 9,9 & 7,6 & 5,3 & 16,4 \\
\hline $\mathrm{H}_{2} \mathrm{O}$ & ${ }^{1} J_{\mathrm{OH}}$ & $-64,6$ & $-67,1$ & $-69,7$ & $-72,3$ & $-75,0$ & $-77,7$ & $-80,4$ & $-83,1$ & $-85,9$ & $-88,6$ & $-91,5$ & $-80,6$ \\
\hline $\mathrm{H}_{2} \mathrm{O}$ & ${ }^{2} J_{\mathrm{HH}}$ & $-5,0$ & $-6,0$ & $-7,1$ & $-8,1$ & $-9,1$ & $-10,2$ & $-11,3$ & $-12,4$ & $-13,6$ & $-14,7$ & $-15,9$ & $-7,3$ \\
\hline $\mathrm{NH}_{3}$ & ${ }^{1} J_{\mathrm{NH}}$ & 40,0 & 40,8 & 41,6 & 42,4 & 43,2 & 44,0 & 44,8 & 45,6 & 46,5 & 47,3 & 48,2 & 43,8 \\
\hline $\mathrm{NH}_{3}$ & ${ }^{2} J_{\mathrm{HH}}$ & $-8,3$ & $-9,2$ & $-10,1$ & $-11,0$ & $-11,9$ & $-12,8$ & $-13,8$ & $-14,7$ & $-15,7$ & $-16,6$ & $-17,6$ & $-9,6$ \\
\hline $\mathrm{PH}_{3}$ & ${ }^{1} J_{\mathrm{PH}}$ & 136,3 & 144,6 & 152,9 & 161,0 & 169,0 & 176,9 & 184,7 & 192,3 & 199,8 & 207,1 & 214,3 & 188,2 \\
\hline $\mathrm{PF}_{3}$ & ${ }^{1} J_{\mathrm{PF}}$ & $-1807,1$ & $-1781,1$ & $-1750,8$ & $-1716,9$ & $-1680,1$ & $-1641,0$ & $-1600,1$ & $-1557,8$ & $-1514,5$ & $-1470,7$ & $-1426,5$ & -1441 \\
\hline $\mathrm{BHF}_{2}$ & ${ }^{1} J_{\mathrm{BF}}$ & $-178,7$ & $-161,7$ & $-144,7$ & $-127,7$ & $-111,0$ & $-94,3$ & $-77,8$ & $-61,5$ & $-45,4$ & $-29,5$ & $-13,8$ & -84 \\
\hline $\mathrm{BF}_{3}$ & ${ }^{1} J_{\mathrm{BF}}$ & $-84,2$ & $-65,4$ & $-46,8$ & $-28,4$ & $-10,2$ & 7,7 & 25,6 & 43,2 & 60,7 & 78,0 & 95,2 & 15 \\
\hline $\mathrm{F}_{2} \mathrm{O}$ & ${ }^{1} J_{\mathrm{OF}}$ & $-292,0$ & $-330,2$ & $-368,9$ & $-409,6$ & $-454,7$ & $-508,0$ & $-575,8$ & $-671,2$ & $-826,0$ & $-1147,2$ & $-2453,2$ & -300 \\
\hline $\mathrm{CH}_{4}$ & ${ }^{1} J_{\mathrm{CH}}$ & 118,2 & 119,7 & 121,2 & 122,8 & 124,4 & 126,0 & 127,7 & 129,3 & 131,0 & 132,7 & 134,4 & 125,3 \\
\hline $\mathrm{CH}_{4}$ & ${ }^{2} J_{\mathrm{HH}}$ & $-12,5$ & $-13,3$ & $-14,0$ & $-14,7$ & $-15,5$ & $-16,2$ & $-16,9$ & $-17,7$ & $-18,4$ & $-19,1$ & $-19,8$ & $-12,8$ \\
\hline $\mathrm{C}_{2} \mathrm{H}_{2}$ & ${ }^{1} J_{\mathrm{CC}}$ & 186,6 & 189,4 & 192,7 & 196,4 & 200,8 & 206,1 & 212,3 & 220,0 & 229,5 & 241,5 & 257,1 & 174,8 \\
\hline $\mathrm{C}_{2} \mathrm{H}_{2}$ & ${ }^{1} J_{\mathrm{CH}}$ & 249,9 & 252,4 & 255,0 & 257,8 & 260,9 & 264,3 & 268,2 & 272,8 & 278,2 & 284,8 & 293,3 & 247,6 \\
\hline $\mathrm{C}_{2} \mathrm{H}_{2}$ & ${ }^{2} J_{\mathrm{CH}}$ & 54,7 & 54,6 & 54,2 & 53,6 & 52,6 & 51,1 & 49,2 & 46,5 & 42,9 & 38,0 & 31,2 & 50,1 \\
\hline $\mathrm{C}_{2} \mathrm{H}_{2}$ & ${ }^{3} J_{\mathrm{HH}}$ & 10,9 & 11,6 & 12,4 & 13,4 & 14,7 & 16,2 & 18,0 & 20,2 & 22,9 & 26,4 & 30,9 & 9,6 \\
\hline $\mathrm{C}_{2} \mathrm{H}_{4}$ & ${ }^{1} J_{\mathrm{CC}}$ & 59,3 & 62,1 & 65,3 & 68,8 & 73,0 & 77,9 & 84,1 & 92,2 & 103,3 & 120,4 & 150,7 & 67,6 \\
\hline $\mathrm{C}_{2} \mathrm{H}_{4}$ & ${ }^{1} J_{\mathrm{CH}}$ & 151,1 & 153,3 & 155,6 & 158,1 & 160,8 & 163,8 & 167,4 & 171,7 & 177,3 & 185,4 & 199,0 & 156,3 \\
\hline $\mathrm{C}_{2} \mathrm{H}_{4}$ & ${ }^{2} J_{\mathrm{CH}}$ & $-0,4$ & $-1,4$ & $-2,4$ & $-3,6$ & $-5,1$ & $-6,9$ & $-9,2$ & $-12,3$ & $-16,7$ & $-23,6$ & $-36,1$ & $-2,4$ \\
\hline $\mathrm{C}_{2} \mathrm{H}_{4}$ & ${ }^{2} J_{\mathrm{HH}}$ & 4,1 & 3,3 & 2,4 & 1,5 & 0,3 & $-0,9$ & $-2,5$ & $-4,6$ & $-7,4$ & $-11,8$ & $-19,4$ & 2,3 \\
\hline $\mathrm{C}_{2} \mathrm{H}_{4}$ & ${ }^{3} J_{\mathrm{HH}_{\mathrm{C}}}$ & 12,0 & 12,3 & 12,8 & 13,3 & 14,0 & 14,9 & 16,0 & 17,7 & 20,1 & 24,0 & 31,3 & 11,7 \\
\hline $\mathrm{C}_{2} \mathrm{H}_{4}$ & ${ }^{3} J_{\mathrm{HH}_{\mathrm{t}}}$ & 19,1 & 19,5 & 20,0 & 20,6 & 21,4 & 22,4 & 23,8 & 25,7 & 28,5 & 32,9 & 41,0 & 19 \\
\hline $\mathrm{C}_{2} \mathrm{H}_{6}$ & ${ }^{1} J_{\mathrm{CC}}$ & 24,2 & 26,1 & 28,1 & 30,2 & 32,3 & 34,4 & 36,6 & 38,8 & 41,0 & 43,3 & 45,6 & 34,5 \\
\hline $\mathrm{C}_{2} \mathrm{H}_{6}$ & ${ }^{1} J_{\mathrm{CH}}$ & 118,5 & 120,2 & 122,0 & 123,7 & 125,5 & 127,3 & 129,1 & 131,0 & 132,8 & 134,7 & 136,6 & 125,2 \\
\hline $\mathrm{C}_{2} \mathrm{H}_{6}$ & ${ }^{2} J_{\mathrm{CH}}$ & $-3,0$ & $-3,5$ & $-3,9$ & $-4,4$ & $-4,9$ & $-5,4$ & $-5,9$ & $-6,5$ & $-7,0$ & $-7,5$ & $-8,1$ & $-4,7$ \\
\hline \multirow[t]{3}{*}{ Total } & $\mathrm{DM}$ & $-28,46$ & $-25,98$ & $-23,31$ & $-20,54$ & $-17,79$ & $-15,20$ & $-12,98$ & $-11,64$ & $-12,32$ & $-18,97$ & $-62,67$ & - \\
\hline & DMA & 33,29 & 30,04 & 27,30 & 24,98 & 23,12 & 21,81 & 22,95 & 29,29 & 38,67 & 55,23 & 112,44 & - \\
\hline & PDMA & 49,16 & 38,71 & 28,94 & 26,87 & 27,34 & 29,40 & 41,16 & 61,77 & 87,46 & 123,54 & 190,22 & - \\
\hline \multirow[t]{3}{*}{ CPI } & $\mathrm{DM}$ & $-66,23$ & $-61,61$ & $-56,67$ & $-51,59$ & $-46,70$ & $-42,37$ & $-39,22$ & $-38,49$ & $-43,11$ & $-62,84$ & $-172,10$ & - \\
\hline & DMA & 72,88 & 65,72 & 59,71 & 53,79 & 48,06 & 42,94 & 42,49 & 53,33 & 70,29 & 102,27 & 226,41 & - \\
\hline & PDMA & 89,82 & 72,83 & 57,12 & 44,45 & 32,48 & 21,19 & 26,99 & 46,38 & 68,15 & 94,60 & 151,26 & - \\
\hline \multirow[t]{3}{*}{ SPI } & DM & $-0,76$ & 0,15 & 1,15 & 2,23 & 3,41 & 4,73 & 6,25 & 8,05 & 10,26 & 13,20 & 17,57 & - \\
\hline & DMA & 4,25 & 3,88 & 3,54 & 3,85 & 4,83 & 6,31 & 8,63 & 11,66 & 15,47 & 20,73 & 28,87 & - \\
\hline & PDMA & 19,34 & 13,69 & 8,28 & 13,98 & 23,58 & 35,42 & 51,55 & 73,05 & 101,62 & 144,77 & 218,79 & - \\
\hline \multirow[t]{3}{*}{$\Delta \mathrm{CS}$} & $\mathrm{DM}$ & $-65,47$ & $-61,76$ & $-57,83$ & $-53,82$ & $-50,11$ & $-47,10$ & $-45,47$ & $-46,54$ & $-53,37$ & $-76,04$ & $-189,67$ & - \\
\hline & DMA & 68,63 & 61,84 & 56,17 & 49,94 & 43,23 & 36,62 & 33,86 & 41,67 & 54,82 & 81,54 & 197,54 & - \\
\hline & PDMA & 70,48 & 59,14 & 48,84 & 30,47 & 8,90 & $-14,23$ & $-24,56$ & $-26,67$ & $-33,47$ & $-50,16$ & $-67,53$ & - \\
\hline \multicolumn{14}{|c|}{ Desconsiderando ${ }^{1} J_{\mathrm{BF}}$ da molécula de $\mathrm{BF}_{3},{ }^{2} J_{\mathrm{CH}}$ e ${ }^{2} J_{\mathrm{HH}}$ da molécula de $\mathrm{C}_{2} \mathrm{H}_{4}$} \\
\hline \multirow[t]{3}{*}{ Total } & DM & $-28,02$ & $-25,96$ & $-23,67$ & $-21,25$ & $-18,81$ & $-16,53$ & $-14,63$ & $-13,66$ & $-14,87$ & $-22,65$ & $-71,93$ & - \\
\hline & DMA & 33,15 & 30,38 & 28,17 & 26,27 & 24,84 & 24,00 & 24,98 & 31,15 & 40,68 & 58,16 & 121,21 & - \\
\hline & PDMA & 19,79 & 16,75 & 14,62 & 14,11 & 14,93 & 16,92 & 22,07 & 30,67 & 41,38 & 56,34 & 89,72 & - \\
\hline \multirow[t]{3}{*}{ CPI } & $\mathrm{DM}$ & $-62,93$ & $-59,73$ & $-56,16$ & $-52,41$ & $-48,85$ & $-45,88$ & $-44,20$ & $-45,16$ & $-51,99$ & $-75,42$ & $-197,33$ & - \\
\hline & DMA & 70,25 & 64,25 & 59,50 & 54,83 & 50,35 & 46,50 & 45,68 & 55,84 & 72,75 & 106,20 & 241,03 & - \\
\hline & PDMA & 32,67 & 26,51 & 21,63 & 19,96 & 18,93 & 18,44 & 22,62 & 32,22 & 44,49 & 62,06 & 112,92 & - \\
\hline \multirow[t]{3}{*}{ SPI } & DM & $-1,17$ & 0,02 & 1,32 & 2,72 & 4,29 & 6,05 & 8,11 & 10,58 & 13,68 & 17,95 & 24,54 & - \\
\hline & DMA & 4,62 & 4,32 & 4,08 & 4,29 & 5,22 & 6,69 & 9,06 & 12,16 & 16,01 & 21,21 & 29,05 & - \\
\hline & PDMA & 9,88 & 9,24 & 9,22 & 9,61 & 11,86 & 15,74 & 21,64 & 29,48 & 38,98 & 51,93 & 71,87 & - \\
\hline \multirow[t]{3}{*}{$\Delta \mathrm{CS}$} & DM & $-61,76$ & $-59,75$ & $-57,48$ & $-55,13$ & $-53,14$ & $-51,93$ & $-52,31$ & $-55,74$ & $-65,67$ & $-93,37$ & $-221,87$ & - \\
\hline & DMA & 65,63 & 59,93 & 55,42 & 50,54 & 45,13 & 39,81 & 36,62 & 43,68 & 56,74 & 84,99 & 211,98 & - \\
\hline & PDMA & 22,79 & 17,27 & 12,41 & 10,35 & 7,07 & 2,70 & 0,99 & 2,74 & 5,51 & 10,13 & 41,06 & - \\
\hline
\end{tabular}


Tabela 8.196: Constantes de acoplamento BPW91 com base aug-pcJ-2.

\begin{tabular}{|c|c|c|c|c|c|c|c|c|c|c|c|c|c|}
\hline & $\% E_{X}^{\mathrm{HF}}$ & $0 \%$ & $10 \%$ & $20 \%$ & $30 \%$ & $40 \%$ & $50 \%$ & $60 \%$ & $70 \%$ & $80 \%$ & $90 \%$ & $100 \%$ & Exp. \\
\hline $\mathrm{HF}$ & ${ }^{1} J_{\mathrm{HF}}$ & 353,3 & 377,4 & 401,9 & 426,6 & 451,5 & 476,7 & 502,2 & 527,9 & 553,8 & 579,9 & 606,3 & 500 \\
\hline $\mathrm{CO}$ & ${ }^{1} J_{\mathrm{CO}}$ & 25,2 & 23,6 & 21,8 & 20,0 & 18,1 & 16,1 & 14,0 & 11,8 & 9,6 & 7,3 & 4,9 & 16,4 \\
\hline $\mathrm{H}_{2} \mathrm{O}$ & ${ }^{1} J_{\mathrm{OH}}$ & $-64,9$ & $-67,5$ & $-70,1$ & $-72,7$ & $-75,4$ & $-78,1$ & $-80,8$ & $-83,5$ & $-86,3$ & $-89,1$ & $-91,9$ & $-80,6$ \\
\hline $\mathrm{H}_{2} \mathrm{O}$ & ${ }^{2} J_{\mathrm{HH}}$ & $-5,1$ & $-6,1$ & $-7,1$ & $-8,1$ & $-9,2$ & $-10,2$ & $-11,3$ & $-12,5$ & $-13,6$ & $-14,8$ & $-16,0$ & $-7,3$ \\
\hline $\mathrm{NH}_{3}$ & ${ }^{1} J_{\mathrm{NH}}$ & 40,2 & 41,0 & 41,8 & 42,6 & 43,4 & 44,2 & 45,0 & 45,8 & 46,7 & 47,5 & 48,4 & 43,8 \\
\hline $\mathrm{NH}_{3}$ & ${ }^{2} J_{\mathrm{HH}}$ & $-8,3$ & $-9,2$ & $-10,1$ & $-11,0$ & $-11,9$ & $-12,9$ & $-13,8$ & $-14,7$ & $-15,7$ & $-16,7$ & $-17,7$ & $-9,6$ \\
\hline $\mathrm{PH}_{3}$ & ${ }^{1} J_{\mathrm{PH}}$ & 137,3 & 145,6 & 153,9 & 162,0 & 170,1 & 178,0 & 185,8 & 193,4 & 200,9 & 208,3 & 215,5 & 188,2 \\
\hline $\mathrm{PF}_{3}$ & ${ }^{1} J_{\mathrm{PF}}$ & $-1810,6$ & $-1784,5$ & $-1754,1$ & $-1720,0$ & $-1683,1$ & $-1643,8$ & $-1602,7$ & $-1560,3$ & $-1516,9$ & $-1472,9$ & $-1428,5$ & -1441 \\
\hline $\mathrm{BHF}_{2}$ & ${ }^{1} J_{\mathrm{BF}}$ & $-178,0$ & $-160,8$ & $-143,8$ & $-126,8$ & $-110,0$ & $-93,3$ & $-76,8$ & $-60,4$ & $-44,3$ & $-28,3$ & $-12,5$ & -84 \\
\hline $\mathrm{BF}_{3}$ & ${ }^{1} J_{\mathrm{BF}}$ & $-83,3$ & $-64,5$ & $-45,8$ & $-27,4$ & $-9,1$ & 8,9 & 26,7 & 44,5 & 62,0 & 79,4 & 96,6 & 15 \\
\hline $\mathrm{F}_{2} \mathrm{O}$ & ${ }^{1} J_{\mathrm{OF}}$ & $-291,7$ & $-329,9$ & $-368,6$ & $-409,2$ & $-454,4$ & $-507,7$ & $-575,7$ & $-671,4$ & $-827,4$ & $-1153,6$ & $-2525,8$ & -300 \\
\hline $\mathrm{CH}_{4}$ & ${ }^{1} J_{\mathrm{CH}}$ & 118,9 & 120,4 & 121,9 & 123,5 & 125,1 & 126,7 & 128,4 & 130,0 & 131,7 & 133,4 & 135,2 & 125,3 \\
\hline $\mathrm{CH}_{4}$ & ${ }^{2} J_{\mathrm{HH}}$ & $-12,5$ & $-13,3$ & $-14,0$ & $-14,7$ & $-15,5$ & $-16,2$ & $-17,0$ & $-17,7$ & $-18,4$ & $-19,1$ & $-19,9$ & $-12,8$ \\
\hline $\mathrm{C}_{2} \mathrm{H}_{2}$ & ${ }^{1} J_{\mathrm{CC}}$ & 187,9 & 190,7 & 193,9 & 197,7 & 202,2 & 207,5 & 213,8 & 221,6 & 231,2 & 243,3 & 259,0 & 174,8 \\
\hline $\mathrm{C}_{2} \mathrm{H}_{2}$ & ${ }^{1} J_{\mathrm{CH}}$ & 251,1 & 253,6 & 256,2 & 259,1 & 262,1 & 265,6 & 269,5 & 274,1 & 279,5 & 286,1 & 294,6 & 247,6 \\
\hline $\mathrm{C}_{2} \mathrm{H}_{2}$ & ${ }^{2} J_{\mathrm{CH}}$ & 54,7 & 54,6 & 54,2 & 53,6 & 52,6 & 51,1 & 49,1 & 46,5 & 42,8 & 37,9 & 31,2 & 50,1 \\
\hline $\mathrm{C}_{2} \mathrm{H}_{2}$ & ${ }^{3} J_{\mathrm{HH}}$ & 10,8 & 11,5 & 12,4 & 13,4 & 14,6 & 16,1 & 17,9 & 20,1 & 22,8 & 26,3 & 30,7 & 9,6 \\
\hline $\mathrm{C}_{2} \mathrm{H}_{4}$ & ${ }^{1} J_{\mathrm{CC}}$ & 59,9 & 62,7 & 65,9 & 69,5 & 73,7 & 78,7 & 84,9 & 93,0 & 104,3 & 121,5 & 152,0 & 67,6 \\
\hline $\mathrm{C}_{2} \mathrm{H}_{4}$ & ${ }^{1} J_{\mathrm{CH}}$ & 151,9 & 154,1 & 156,4 & 158,9 & 161,6 & 164,7 & 168,3 & 172,6 & 178,2 & 186,4 & 200,0 & 156,3 \\
\hline $\mathrm{C}_{2} \mathrm{H}_{4}$ & ${ }^{2} J_{\mathrm{CH}}$ & $-0,4$ & $-1,4$ & $-2,4$ & $-3,6$ & $-5,1$ & $-6,9$ & $-9,2$ & $-12,4$ & $-16,8$ & $-23,7$ & $-36,2$ & $-2,4$ \\
\hline $\mathrm{C}_{2} \mathrm{H}_{4}$ & ${ }^{2} J_{\mathrm{HH}}$ & 4,2 & 3,3 & 2,5 & 1,5 & 0,4 & $-0,8$ & $-2,4$ & $-4,5$ & $-7,4$ & $-11,7$ & $-19,2$ & 2,3 \\
\hline $\mathrm{C}_{2} \mathrm{H}_{4}$ & ${ }^{3} J_{\mathrm{HH}_{\mathrm{c}}}$ & 12,0 & 12,3 & 12,7 & 13,3 & 14,0 & 14,8 & 16,0 & 17,7 & 20,1 & 24,0 & 31,2 & 11,7 \\
\hline $\mathrm{C}_{2} \mathrm{H}_{4}$ & ${ }^{3} J_{\mathrm{HH}_{\mathrm{t}}}$ & 19,1 & 19,5 & 20,0 & 20,6 & 21,4 & 22,4 & 23,7 & 25,6 & 28,4 & 32,8 & 40,9 & 19 \\
\hline $\mathrm{C}_{2} \mathrm{H}_{6}$ & ${ }^{1} J_{\mathrm{CC}}$ & 24,5 & 26,5 & 28,5 & 30,6 & 32,7 & 34,8 & 37,0 & 39,2 & 41,5 & 43,8 & 46,1 & 34,5 \\
\hline $\mathrm{C}_{2} \mathrm{H}_{6}$ & ${ }^{1} J_{\mathrm{CH}}$ & 119,2 & 120,9 & 122,6 & 124,4 & 126,2 & 128,0 & 129,8 & 131,7 & 133,5 & 135,4 & 137,3 & 125,2 \\
\hline $\mathrm{C}_{2} \mathrm{H}_{6}$ & ${ }^{2} J_{\mathrm{CH}}$ & $-3,0$ & $-3,5$ & $-3,9$ & $-4,4$ & $-4,9$ & $-5,4$ & $-6,0$ & $-6,5$ & $-7,0$ & $-7,5$ & $-8,1$ & $-4,7$ \\
\hline \multirow[t]{3}{*}{ Total } & DM & $-28,18$ & $-25,69$ & $-23,01$ & $-20,22$ & $-17,46$ & $-14,85$ & $-12,64$ & $-11,28$ & $-11,99$ & $-18,81$ & $-65,03$ & - \\
\hline & DMA & 33,18 & 29,88 & 27,15 & 24,92 & 23,10 & 21,89 & 23,41 & 29,92 & 39,35 & 56,13 & 115,74 & - \\
\hline & PDMA & 48,78 & 38,13 & 28,57 & 26,47 & 26,80 & 29,03 & 41,67 & 62,51 & 88,36 & 124,48 & 191,82 & - \\
\hline \multirow[t]{3}{*}{ CPI } & DM & $-66,07$ & $-61,44$ & $-56,46$ & $-51,35$ & $-46,45$ & $-42,09$ & $-38,94$ & $-38,21$ & $-42,92$ & $-63,08$ & $-178,33$ & - \\
\hline & DMA & 72,67 & 65,42 & 59,39 & 53,45 & 47,70 & 42,62 & 42,99 & 54,25 & 71,30 & 103,77 & 233,56 & - \\
\hline & PDMA & 88,82 & 71,78 & 56,13 & 43,46 & 31,54 & 20,46 & 27,96 & 47,80 & 69,47 & 96,38 & 155,08 & - \\
\hline \multirow[t]{3}{*}{ SPI } & DM & $-0,39$ & 0,52 & 1,52 & 2,62 & 3,80 & 5,13 & 6,65 & 8,46 & 10,69 & 13,65 & 18,05 & - \\
\hline & DMA & 4,21 & 3,83 & 3,51 & 4,01 & 5,07 & 6,69 & 9,05 & 12,07 & 15,93 & 21,20 & 29,34 & - \\
\hline & PDMA & 19,42 & 13,46 & 8,36 & 14,02 & 23,33 & 35,32 & 51,73 & 73,30 & 102,22 & 145,09 & 218,77 & - \\
\hline \multirow[t]{3}{*}{$\Delta \mathrm{CS}$} & DM & $-65,69$ & $-61,96$ & $-57,98$ & $-53,97$ & $-50,25$ & $-47,22$ & $-45,58$ & $-46,67$ & $-53,60$ & $-76,74$ & $-196,37$ & - \\
\hline & DMA & 68,46 & 61,59 & 55,88 & 49,44 & 42,63 & 35,92 & 33,94 & 42,17 & 55,37 & 82,57 & 204,22 & - \\
\hline & PDMA & 69,41 & 58,32 & 47,77 & 29,44 & 8,21 & $-14,86$ & $-23,77$ & $-25,51$ & $-32,75$ & $-48,71$ & $-63,69$ & - \\
\hline \multicolumn{14}{|c|}{ Desconsiderando ${ }^{1} J_{\mathrm{BF}}$ da molécula de $\mathrm{BF}_{3},{ }^{2} J_{\mathrm{CH}}$ e ${ }^{2} J_{\mathrm{HH}}$ da molécula de $\mathrm{C}_{2} \mathrm{H}_{4}$} \\
\hline \multirow[t]{3}{*}{ Total } & DM & $-27,75$ & $-25,67$ & $-23,38$ & $-20,92$ & $-18,49$ & $-16,19$ & $-14,30$ & $-13,31$ & $-14,55$ & $-22,53$ & $-74,66$ & - \\
\hline & DMA & 33,06 & 30,24 & 28,04 & 26,24 & 24,87 & 24,15 & 25,45 & 31,80 & 41,40 & 59,12 & 124,89 & - \\
\hline & PDMA & 19,44 & 16,36 & 14,30 & 13,95 & 14,83 & 17,04 & 22,51 & 31,14 & 41,84 & 57,00 & 91,32 & - \\
\hline \multirow[t]{3}{*}{ CPI } & DM & $-62,85$ & $-59,63$ & $-56,03$ & $-52,25$ & $-48,68$ & $-45,69$ & $-44,00$ & $-44,98$ & $-51,91$ & $-75,83$ & $-204,32$ & - \\
\hline & DMA & 70,11 & 64,01 & 59,25 & 54,55 & 50,06 & 46,27 & 46,12 & 56,72 & 73,73 & 107,71 & 248,76 & - \\
\hline & PDMA & 32,17 & 25,95 & 21,21 & 19,53 & 18,63 & 18,44 & 22,96 & 32,91 & 45,08 & 63,09 & 116,19 & - \\
\hline \multirow[t]{3}{*}{ SPI } & $\mathrm{DM}$ & $-0,75$ & 0,45 & 1,74 & 3,18 & 4,74 & 6,51 & 8,55 & 11,05 & 14,18 & 18,47 & 25,08 & - \\
\hline & DMA & 4,56 & 4,26 & 4,03 & 4,47 & 5,49 & 7,14 & 9,55 & 12,64 & 16,52 & 21,75 & 29,60 & - \\
\hline & PDMA & 9,64 & 8,98 & 8,98 & 9,65 & 11,91 & 15,97 & 22,17 & 29,78 & 39,35 & 52,32 & 72,19 & - \\
\hline \multirow[t]{3}{*}{$\Delta \mathrm{CS}$} & $\mathrm{DM}$ & $-62,10$ & $-60,08$ & $-57,77$ & $-55,43$ & $-53,42$ & $-52,20$ & $-52,55$ & $-56,03$ & $-66,09$ & $-94,30$ & $-229,40$ & 一 \\
\hline & DMA & 65,55 & 59,75 & 55,22 & 50,08 & 44,57 & 39,13 & 36,57 & 44,08 & 57,21 & 85,96 & 219,16 & - \\
\hline & PDMA & 22,54 & 16,98 & 12,23 & 9,88 & 6,72 & 2,48 & 0,79 & 3,12 & 5,74 & 10,77 & 44,00 & - \\
\hline
\end{tabular}




\subsection{GERAÇÃO DE NOVOS FUNCIONAIS COMBINANDO $E_{X}^{H F}, E_{X}^{D F T} E$}

Tabela 8.197: Constantes de acoplamento BTPSS com base aug-pcJ-2.

\begin{tabular}{|c|c|c|c|c|c|c|c|c|c|c|c|c|c|}
\hline & $\% E_{X}^{\mathrm{HF}}$ & $0 \%$ & $10 \%$ & $20 \%$ & $30 \%$ & $40 \%$ & $50 \%$ & $60 \%$ & $70 \%$ & $80 \%$ & $90 \%$ & $100 \%$ & Exp. \\
\hline $\mathrm{HF}$ & ${ }^{1} J_{\mathrm{HF}}$ & 352,6 & 377,4 & 402,5 & 427,7 & 453,2 & 478,9 & 504,7 & 530,8 & 557,0 & 583,4 & 610,0 & 500 \\
\hline $\mathrm{CO}$ & ${ }^{1} J_{\mathrm{CO}}$ & 25,3 & 23,7 & 21,9 & 20,1 & 18,1 & 16,1 & 14,0 & 11,9 & 9,6 & 7,3 & 4,9 & 16,4 \\
\hline $\mathrm{H}_{2} \mathrm{O}$ & ${ }^{1} J_{\mathrm{OH}}$ & $-65,6$ & $-68,3$ & $-71,0$ & $-73,7$ & $-76,5$ & $-79,2$ & $-82,0$ & $-84,8$ & $-87,6$ & $-90,5$ & $-93,4$ & $-80,6$ \\
\hline $\mathrm{H}_{2} \mathrm{O}$ & ${ }^{2} J_{\mathrm{HH}}$ & $-4,8$ & $-5,8$ & $-6,9$ & $-8,0$ & $-9,1$ & $-10,2$ & $-11,4$ & $-12,6$ & $-13,8$ & $-15,0$ & $-16,2$ & $-7,3$ \\
\hline $\mathrm{NH}_{3}$ & ${ }^{1} J_{\mathrm{NH}}$ & 41,5 & 42,3 & 43,1 & 44,0 & 44,8 & 45,7 & 46,5 & 47,4 & 48,3 & 49,2 & 50,1 & 43,8 \\
\hline $\mathrm{NH}_{3}$ & ${ }^{2} J_{\mathrm{HH}}$ & $-7,9$ & $-8,9$ & $-9,8$ & $-10,8$ & $-11,8$ & $-12,8$ & $-13,8$ & $-14,8$ & $-15,8$ & $-16,9$ & $-17,9$ & $-9,6$ \\
\hline $\mathrm{PH}_{3}$ & ${ }^{1} J_{\mathrm{PH}}$ & 146,1 & 155,2 & 164,2 & 173,1 & 182,0 & 190,7 & 199,3 & 207,8 & 216,2 & 224,5 & 232,6 & 188,2 \\
\hline $\mathrm{PF}_{3}$ & ${ }^{1} J_{\mathrm{PF}}$ & $-1811,4$ & $-1786,1$ & $-1756,4$ & $-1723,0$ & $-1686,7$ & $-1648,0$ & $-1607,5$ & $-1565,6$ & $-1522,7$ & $-1479,1$ & $-1435,2$ & -1441 \\
\hline $\mathrm{BHF}_{2}$ & ${ }^{1} J_{\mathrm{BF}}$ & $-179,7$ & $-162,7$ & $-145,8$ & $-129,1$ & $-112,4$ & $-96,0$ & $-79,7$ & $-63,5$ & $-47,6$ & $-31,9$ & $-16,4$ & -84 \\
\hline $\mathrm{BF}_{3}$ & ${ }^{1} J_{\mathrm{BF}}$ & $-81,6$ & $-62,9$ & $-44,4$ & $-26,1$ & $-8,0$ & 9,8 & 27,5 & 45,0 & 62,3 & 79,4 & 96,3 & 15 \\
\hline $\mathrm{F}_{2} \mathrm{O}$ & ${ }^{1} J_{\mathrm{OF}}$ & $-290,5$ & $-328,7$ & $-367,2$ & $-407,6$ & $-452,4$ & $-505,1$ & $-572,0$ & $-665,9$ & $-817,8$ & $-1132,1$ & $-2403,5$ & -300 \\
\hline $\mathrm{CH}_{4}$ & ${ }^{1} J_{\mathrm{CH}}$ & 126,6 & 128,3 & 130,0 & 131,8 & 133,6 & 135,4 & 137,3 & 139,1 & 141,0 & 143,0 & 144,9 & 125,3 \\
\hline $\mathrm{CH}_{4}$ & ${ }^{2} J_{\mathrm{HH}}$ & $-12,0$ & $-12,8$ & $-13,6$ & $-14,5$ & $-15,3$ & $-16,1$ & $-16,9$ & $-17,7$ & $-18,6$ & $-19,4$ & $-20,2$ & $-12,8$ \\
\hline $\mathrm{C}_{2} \mathrm{H}_{2}$ & ${ }^{1} J_{\mathrm{CC}}$ & 187,4 & 190,4 & 193,8 & 197,7 & 202,4 & 207,9 & 214,6 & 222,7 & 232,8 & 245,5 & 262,1 & 174,8 \\
\hline $\mathrm{C}_{2} \mathrm{H}_{2}$ & ${ }^{1} J_{\mathrm{CH}}$ & 265,3 & 268,0 & 271,0 & 274,1 & 277,6 & 281,4 & 285,7 & 290,7 & 296,6 & 303,8 & 312,9 & 247,6 \\
\hline $\mathrm{C}_{2} \mathrm{H}_{2}$ & ${ }^{2} J_{\mathrm{CH}}$ & 56,3 & 56,1 & 55,7 & 55,0 & 53,9 & 52,4 & 50,3 & 47,5 & 43,7 & 38,6 & 31,5 & 50,1 \\
\hline $\mathrm{C}_{2} \mathrm{H}_{2}$ & ${ }^{3} J_{\mathrm{HH}}$ & 11,3 & 12,0 & 12,9 & 13,9 & 15,2 & 16,7 & 18,5 & 20,8 & 23,6 & 27,2 & 31,8 & 9,6 \\
\hline $\mathrm{C}_{2} \mathrm{H}_{4}$ & ${ }^{1} J_{\mathrm{CC}}$ & 60,5 & 63,5 & 66,7 & 70,4 & 74,8 & 80,0 & 86,4 & 94,7 & 106,2 & 123,5 & 153,5 & 67,6 \\
\hline $\mathrm{C}_{2} \mathrm{H}_{4}$ & ${ }^{1} J_{\mathrm{CH}}$ & 161,0 & 163,5 & 166,1 & 168,8 & 171,8 & 175,2 & 179,0 & 183,7 & 189,6 & 198,0 & 211,7 & 156,3 \\
\hline $\mathrm{C}_{2} \mathrm{H}_{4}$ & ${ }^{2} J_{\mathrm{CH}}$ & $-0,6$ & $-1,5$ & $-2,7$ & $-4,0$ & $-5,5$ & $-7,4$ & $-9,8$ & $-13,0$ & $-17,6$ & $-24,6$ & $-36,8$ & $-2,4$ \\
\hline $\mathrm{C}_{2} \mathrm{H}_{4}$ & ${ }^{2} J_{\mathrm{HH}}$ & 5,8 & 4,9 & 4,0 & 3,0 & 1,8 & 0,4 & $-1,1$ & $-3,2$ & $-6,0$ & $-10,3$ & $-17,4$ & 2,3 \\
\hline $\mathrm{C}_{2} \mathrm{H}_{4}$ & ${ }^{3} J_{\mathrm{HH}}$ & 12,8 & 13,1 & 13,6 & 14,1 & 14,8 & 15,6 & 16,8 & 18,4 & 20,8 & 24,6 & 31,3 & 11,7 \\
\hline $\mathrm{C}_{2} \mathrm{H}_{4}$ & ${ }^{3} J_{\mathrm{HH}_{\mathrm{t}}}$ & 21,0 & 21,4 & 21,9 & 22,5 & 23,3 & 24,3 & 25,7 & 27,5 & 30,3 & 34,5 & 42,2 & 19 \\
\hline $\mathrm{C}_{2} \mathrm{H}_{6}$ & ${ }^{1} J_{\mathrm{CC}}$ & 25,1 & 27,1 & 29,2 & 31,2 & 33,4 & 35,5 & 37,7 & 40,0 & 42,3 & 44,6 & 46,9 & 34,5 \\
\hline $\mathrm{C}_{2} \mathrm{H}_{6}$ & ${ }^{1} J_{\mathrm{CH}}$ & 126,7 & 128,6 & 130,5 & 132,5 & 134,5 & 136,6 & 138,6 & 140,7 & 142,8 & 144,9 & 147,1 & 125,2 \\
\hline $\mathrm{C}_{2} \mathrm{H}_{6}$ & ${ }^{2} J_{\mathrm{CH}}$ & $-3,0$ & $-3,5$ & $-4,0$ & $-4,6$ & $-5,1$ & $-5,6$ & $-6,2$ & $-6,7$ & $-7,3$ & $-7,9$ & $-8,5$ & $-4,7$ \\
\hline \multirow[t]{3}{*}{ Total } & $\mathrm{DM}$ & $-26,03$ & $-23,49$ & $-20,76$ & $-17,94$ & $-15,10$ & $-12,42$ & $-10,11$ & $-8,62$ & $-9,10$ & $-15,41$ & $-57,72$ & - \\
\hline & DMA & 33,28 & 30,28 & 27,97 & 26,03 & 24,45 & 23,58 & 25,82 & 32,56 & 42,00 & 58,46 & 113,73 & - \\
\hline & PDMA & 51,76 & 41,22 & 32,18 & 27,76 & 26,64 & 29,88 & 43,16 & 64,10 & 90,33 & 126,58 & 191,26 & - \\
\hline \multirow[t]{3}{*}{ CPI } & DM & $-65,17$ & $-60,52$ & $-55,52$ & $-50,39$ & $-45,43$ & $-41,00$ & $-37,75$ & $-36,84$ & $-41,16$ & $-60,24$ & $-166,33$ & - \\
\hline & DMA & 72,01 & 64,48 & 58,34 & 52,35 & 46,66 & 42,05 & 44,17 & 55,84 & 72,65 & 104,16 & 223,67 & - \\
\hline & PDMA & 88,07 & 70,88 & 54,61 & 41,75 & 30,27 & 19,84 & 29,09 & 49,02 & 70,66 & 97,18 & 152,58 & - \\
\hline \multirow[t]{3}{*}{ SPI } & DM & 2,67 & 3,67 & 4,73 & 5,85 & 7,14 & 8,55 & 10,17 & 12,07 & 14,41 & 17,46 & 21,93 & - \\
\hline & DMA & 4,87 & 5,20 & 5,71 & 6,73 & 8,15 & 10,03 & 12,35 & 15,49 & 19,51 & 24,94 & 33,11 & - \\
\hline & PDMA & 25,13 & 19,47 & 15,73 & 17,50 & 23,98 & 37,25 & 53,47 & 75,15 & 104,75 & 148,15 & 219,63 & - \\
\hline \multirow[t]{3}{*}{$\Delta \mathrm{CS}$} & DM & $-67,85$ & $-64,18$ & $-60,25$ & $-56,24$ & $-52,57$ & $-49,55$ & $-47,92$ & $-48,91$ & $-55,57$ & $-77,70$ & $-188,25$ & - \\
\hline & DMA & 67,14 & 59,28 & 52,63 & 45,62 & 38,51 & 32,03 & 31,82 & 40,35 & 53,14 & 79,22 & 190,56 & - \\
\hline & PDMA & 62,94 & 51,41 & 38,89 & 24,25 & 6,29 & $-17,41$ & $-24,39$ & $-26,13$ & $-34,09$ & $-50,97$ & $-67,05$ & - \\
\hline \multicolumn{14}{|c|}{ Desconsiderando ${ }^{1} J_{\mathrm{BF}}$ da molécula de $\mathrm{BF}_{3},{ }^{2} J_{\mathrm{CH}}$ e ${ }^{2} J_{\mathrm{HH}}$ da molécula de $\mathrm{C}_{2} \mathrm{H}_{4}$} \\
\hline \multirow[t]{3}{*}{ Total } & $\mathrm{DM}$ & $-25,46$ & $-23,32$ & $-20,94$ & $-18,46$ & $-15,91$ & $-13,51$ & $-11,50$ & $-10,35$ & $-11,33$ & $-18,71$ & $-66,43$ & - \\
\hline & DMA & 33,19 & 30,69 & 28,95 & 27,54 & 26,48 & 26,13 & 28,17 & 34,80 & 44,40 & 61,77 & 122,68 & - \\
\hline & PDMA & 20,63 & 17,47 & 15,40 & 15,25 & 16,89 & 19,62 & 25,33 & 34,16 & 45,17 & 60,39 & 93,09 & - \\
\hline \multirow[t]{3}{*}{ CPI } & DM & $-62,03$ & $-58,78$ & $-55,13$ & $-51,32$ & $-47,67$ & $-44,58$ & $-42,78$ & $-43,52$ & $-50,01$ & $-72,70$ & $-191,09$ & - \\
\hline & DMA & 69,55 & 63,14 & 58,23 & 53,48 & 49,03 & 45,74 & 47,34 & 58,42 & 75,19 & 108,14 & 237,91 & - \\
\hline & PDMA & 32,47 & 26,03 & 20,47 & 18,53 & 17,96 & 18,35 & 23,66 & 33,92 & 46,19 & 63,96 & 113,64 & - \\
\hline \multirow[t]{3}{*}{ SPI } & $\mathrm{DM}$ & 2,68 & 3,96 & 5,35 & 6,82 & 8,52 & 10,39 & 12,56 & 15,17 & 18,43 & 22,82 & 29,46 & - \\
\hline & DMA & 5,22 & 5,73 & 6,43 & 7,59 & 9,13 & 11,04 & 13,42 & 16,63 & 20,71 & 26,10 & 34,05 & - \\
\hline & PDMA & 11,52 & 10,88 & 11,50 & 12,73 & 16,06 & 20,60 & 26,61 & 34,34 & 44,39 & 57,65 & 77,27 & - \\
\hline \multirow[t]{3}{*}{$\Delta \mathrm{CS}$} & $\mathrm{DM}$ & $-64,71$ & $-62,74$ & $-60,48$ & $-58,14$ & $-56,19$ & $-54,97$ & $-55,34$ & $-58,69$ & $-68,44$ & $-95,52$ & $-220,55$ & - \\
\hline & DMA & 64,33 & 57,41 & 51,80 & 45,89 & 39,90 & 34,70 & 33,92 & 41,79 & 54,48 & 82,04 & 203,86 & - \\
\hline & PDMA & 20,95 & 15,15 & 8,97 & 5,80 & 1,90 & $-2,25$ & $-2,95$ & $-0,42$ & 1,80 & 6,31 & 36,37 & - \\
\hline
\end{tabular}

Tabela 8.198: Valores de PDMA total obtidos para troca B com base HuzIIIsu3.

\begin{tabular}{lccccccccccc}
\hline$E_{X}^{\mathrm{HF}}(\%)$ & $0 \%$ & $10 \%$ & $20 \%$ & $30 \%$ & $40 \%$ & $50 \%$ & $60 \%$ & $70 \%$ & $80 \%$ & $90 \%$ & $100 \%$ \\
\hline BB95 & 53,5 & 42,0 & 31,9 & 23,0 & 15,8 & 13,9 & 22,7 & 36,8 & 52,2 & 70,3 & 92,6 \\
BB98 & 47,0 & 35,9 & 26,3 & 21,9 & 20,1 & 25,3 & 40,2 & 57,2 & 76,4 & 99,5 & 131,6 \\
BB971 & 46,4 & 35,2 & 24,8 & 18,5 & 16,1 & 23,0 & 37,6 & 53,3 & 71,4 & 92,8 & 120,6 \\
BB972 & 46,5 & 35,8 & 26,4 & 18,3 & 17,3 & 26,6 & 36,9 & 52,1 & 69,8 & 90,6 & 119,3 \\
BLYP & 47,7 & 37,6 & 29,9 & 24,6 & 22,9 & 28,8 & 44,7 & 62,9 & 84,9 & 114,2 & 161,5 \\
BP86 & 50,8 & 40,1 & 30,3 & 25,6 & 24,9 & 26,3 & 34,8 & 53,8 & 75,6 & 106,2 & 156,7 \\
BPBE & 49,1 & 38,4 & 30,8 & 29,6 & 30,6 & 32,6 & 42,1 & 62,8 & 88,9 & 126,5 & 196,2 \\
BPW91 & 48,4 & 37,9 & 30,1 & 29,2 & 30,0 & 32,3 & 42,7 & 63,6 & 89,7 & 127,3 & 197,9 \\
BTPSS & 51,7 & 41,0 & 33,3 & 29,5 & 30,1 & 33,2 & 43,7 & 65,3 & 92,0 & 129,2 & 197,2 \\
\hline
\end{tabular}




\subsubsection{Troca B971}

Tabela 8.199: Constantes de acoplamento B971B95 com base aug-pcJ-2.

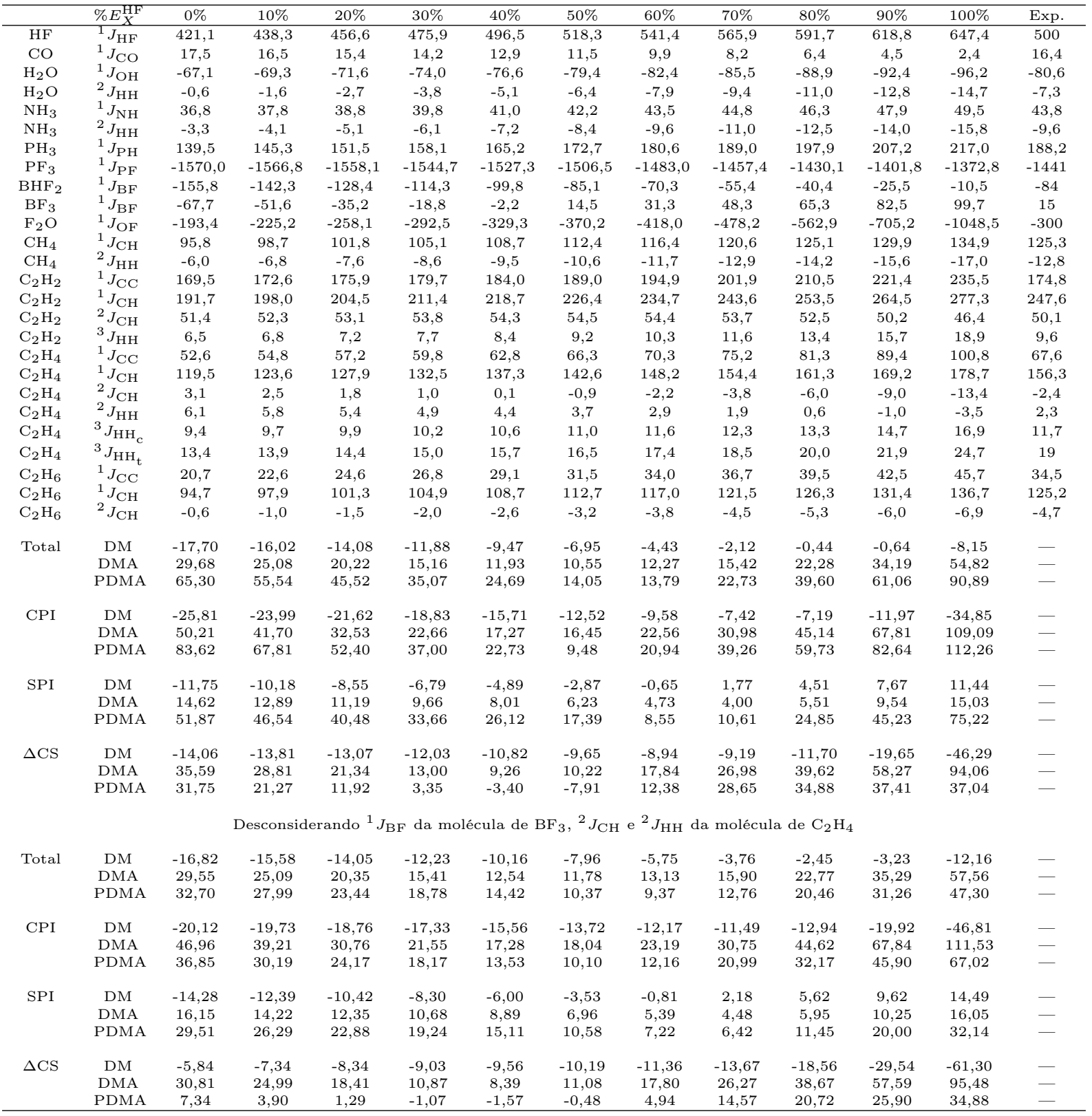


Tabela 8.200: Constantes de acoplamento B971B971 com base aug-pcJ-2.

\begin{tabular}{|c|c|c|c|c|c|c|c|c|c|c|c|c|c|}
\hline & $\% E_{X}^{\mathrm{HF}}$ & $0 \%$ & $10 \%$ & $20 \%$ & $30 \%$ & $40 \%$ & $50 \%$ & $60 \%$ & $70 \%$ & $80 \%$ & $90 \%$ & $100 \%$ & Exp. \\
\hline $\mathrm{HF}$ & $\frac{\Lambda}{{ }^{1} J_{\mathrm{HF}}}$ & 427,3 & 443,9 & 461,4 & 480,0 & 499,7 & 520,6 & 542,8 & 566,1 & 590,8 & 616,7 & 643,9 & 500 \\
\hline $\mathrm{CO}$ & ${ }^{1} J_{\mathrm{CO}}$ & 15,8 & 14,7 & 13,5 & 12,2 & 10,7 & 9,0 & 7,3 & 5,3 & 3,2 & 1,0 & $-1,3$ & 16,4 \\
\hline $\mathrm{H}_{2} \mathrm{O}$ & ${ }^{1} J_{\mathrm{OH}}$ & $-67,7$ & $-69,8$ & $-72,1$ & $-74,5$ & $-77,0$ & $-79,7$ & $-82,5$ & $-85,5$ & $-88,8$ & $-92,2$ & $-95,7$ & $-80,6$ \\
\hline $\mathrm{H}_{2} \mathrm{O}$ & ${ }^{2} J_{\mathrm{HH}}$ & $-0,6$ & $-1,6$ & $-2,7$ & $-3,8$ & $-5,1$ & $-6,4$ & $-7,7$ & $-9,2$ & $-10,8$ & $-12,5$ & $-14,3$ & $-7,3$ \\
\hline $\mathrm{NH}_{3}$ & ${ }^{1} J_{\mathrm{NH}}$ & 37,6 & 38,6 & 39,6 & 40,7 & 41,9 & 43,1 & 44,4 & 45,9 & 47,3 & 48,9 & 50,6 & 43,8 \\
\hline $\mathrm{NH}_{3}$ & ${ }^{2} J_{\mathrm{HH}}$ & $-3,4$ & $-4,3$ & $-5,2$ & $-6,3$ & $-7,4$ & $-8,6$ & $-9,9$ & $-11,2$ & $-12,7$ & $-14,3$ & $-16,1$ & $-9,6$ \\
\hline $\mathrm{PH}_{3}$ & ${ }^{1} J_{\mathrm{PH}}$ & 161,9 & 168,1 & 174,7 & 181,6 & 188,9 & 196,6 & 204,6 & 213,1 & 221,9 & 231,1 & 240,7 & 188,2 \\
\hline $\mathrm{PF}_{3}$ & ${ }^{1} J_{\mathrm{PF}}$ & $-1613,6$ & $-1608,3$ & $-1597,4$ & $-1581,8$ & $-1562,1$ & $-1539,1$ & $-1513,4$ & $-1485,6$ & $-1456,2$ & $-1425,8$ & $-1394,8$ & -1441 \\
\hline $\mathrm{BHF}_{2}$ & ${ }^{1} J_{\mathrm{BF}}$ & $-145,0$ & $-130,5$ & $-115,6$ & $-100,5$ & $-85,1$ & $-69,6$ & $-54,0$ & $-38,4$ & $-22,8$ & $-7,2$ & 8,1 & -84 \\
\hline $\mathrm{BF}_{3}$ & ${ }^{1} J_{\mathrm{BF}}$ & $-55,7$ & $-38,9$ & $-21,9$ & $-4,7$ & 12,4 & 29,7 & 47,1 & 64,5 & 81,9 & 99,3 & 116,8 & 15 \\
\hline $\mathrm{F}_{2} \mathrm{O}$ & ${ }^{1} J_{\mathrm{OF}}$ & $-189,8$ & $-221,6$ & $-254,8$ & $-289,8$ & $-327,7$ & $-370,4$ & $-421,2$ & $-486,9$ & $-582,5$ & $-752,8$ & $-1221,3$ & -300 \\
\hline $\mathrm{CH}_{4}$ & ${ }^{1} J_{\mathrm{CH}}$ & 102,5 & 105,7 & 109,1 & 112,7 & 116,5 & 120,6 & 125,0 & 129,6 & 134,4 & 139,6 & 145,1 & 125,3 \\
\hline $\mathrm{CH}_{4}$ & ${ }^{2} J_{\mathrm{HH}}$ & $-5,8$ & $-6,7$ & $-7,6$ & $-8,5$ & $-9,6$ & $-10,7$ & $-11,8$ & $-13,1$ & $-14,4$ & $-15,8$ & $-17,3$ & $-12,8$ \\
\hline $\mathrm{C}_{2} \mathrm{H}_{2}$ & ${ }^{1} J_{\mathrm{CC}}$ & 186,1 & 190,1 & 194,4 & 199,4 & 205,0 & 211,6 & 219,4 & 228,8 & 240,5 & 255,4 & 275,1 & 174,8 \\
\hline $\mathrm{C}_{2} \mathrm{H}_{2}$ & ${ }^{1} J_{\mathrm{CH}}$ & 200,6 & 207,3 & 214,3 & 221,7 & 229,5 & 237,9 & 247,0 & 256,9 & 268,0 & 280,6 & 295,5 & 247,6 \\
\hline $\mathrm{C}_{2} \mathrm{H}_{2}$ & ${ }^{2} J_{\mathrm{CH}}$ & 51,0 & 51,9 & 52,5 & 53,0 & 53,2 & 53,0 & 52,5 & 51,2 & 49,1 & 45,6 & 40,1 & 50,1 \\
\hline $\mathrm{C}_{2} \mathrm{H}_{2}$ & ${ }^{3} J_{\mathrm{HH}}$ & 6,2 & 6,6 & 7,1 & 7,6 & 8,4 & 9,3 & 10,5 & 12,0 & 14,0 & 16,7 & 20,5 & 9,6 \\
\hline $\mathrm{C}_{2} \mathrm{H}_{4}$ & ${ }^{1} J_{\mathrm{CC}}$ & 63,4 & 66,1 & 69,1 & 72,5 & 76,4 & 80,8 & 86,2 & 92,8 & 101,2 & 112,9 & 130,5 & 67,6 \\
\hline $\mathrm{C}_{2} \mathrm{H}_{4}$ & ${ }^{1} J_{\mathrm{CH}}$ & 126,1 & 130,5 & 135,2 & 140,1 & 145,4 & 151,2 & 157,4 & 164,3 & 172,1 & 181,3 & 193,0 & 156,3 \\
\hline $\mathrm{C}_{2} \mathrm{H}_{4}$ & ${ }^{2} J_{\mathrm{CH}}$ & 2,5 & 1,9 & 1,1 & 0,2 & $-0,8$ & $-2,1$ & $-3,7$ & $-5,8$ & $-8,5$ & $-12,5$ & $-18,8$ & $-2,4$ \\
\hline $\mathrm{C}_{2} \mathrm{H}_{4}$ & ${ }^{2} J_{\mathrm{HH}}$ & 6,0 & 5,6 & 5,2 & 4,7 & 4,1 & 3,4 & 2,5 & 1,4 & 0,0 & $-2,0$ & $-5,1$ & 2,3 \\
\hline $\mathrm{C}_{2} \mathrm{H}_{4}$ & ${ }^{3} J_{\mathrm{HH}_{\mathrm{c}}}$ & 9,3 & 9,6 & 9,8 & 10,2 & 10,5 & 11,0 & 11,6 & 12,4 & 13,6 & 15,3 & 18,0 & 11,7 \\
\hline $\mathrm{C}_{2} \mathrm{H}_{4}$ & ${ }^{3} J_{\mathrm{HH}_{\mathrm{t}}}$ & 13,3 & 13,8 & 14,3 & 14,9 & 15,6 & 16,4 & 17,4 & 18,6 & 20,2 & 22,5 & 25,9 & 19 \\
\hline $\mathrm{C}_{2} \mathrm{H}_{6}$ & ${ }^{1} J_{\mathrm{CC}}$ & 25,4 & 27,6 & 30,0 & 32,4 & 35,1 & 37,8 & 40,8 & 43,9 & 47,2 & 50,7 & 54,4 & 34,5 \\
\hline $\mathrm{C}_{2} \mathrm{H}_{6}$ & ${ }^{1} J_{\mathrm{CH}}$ & 101,2 & 104,7 & 108,4 & 112,3 & 116,5 & 120,9 & 125,5 & 130,4 & 135,6 & 141,2 & 147,0 & 125,2 \\
\hline $\mathrm{C}_{2} \mathrm{H}_{6}$ & ${ }^{2} J_{\mathrm{CH}}$ & $-0,6$ & $-1,1$ & $-1,7$ & $-2,2$ & $-2,8$ & $-3,5$ & $-4,2$ & $-4,9$ & $-5,7$ & $-6,6$ & $-7,5$ & $-4,7$ \\
\hline \multirow[t]{3}{*}{ Total } & $\mathrm{DM}$ & $-15,04$ & $-13,12$ & $-10,93$ & $-8,50$ & $-5,88$ & $-3,16$ & $-0,44$ & 1,98 & 3,60 & 2,77 & $-8,92$ & - \\
\hline & DMA & 27,95 & 23,47 & 18,69 & 13,67 & 10,48 & 12,53 & 15,65 & 21,69 & 29,58 & 42,27 & 68,67 & - \\
\hline & PDMA & 58,49 & 48,70 & 38,43 & 27,82 & 17,34 & 16,15 & 21,45 & 35,84 & 55,59 & 81,12 & 118,03 & - \\
\hline \multirow[t]{3}{*}{ CPI } & $\mathrm{DM}$ & $-24,92$ & $-22,78$ & $-20,13$ & $-17,07$ & $-13,79$ & $-10,52$ & $-7,58$ & $-5,71$ & $-6,33$ & $-13,52$ & $-47,66$ & - \\
\hline & DMA & 49,65 & 41,00 & 31,53 & 21,27 & 15,37 & 21,59 & 29,75 & 39,93 & 52,89 & 75,52 & 128,26 & - \\
\hline & PDMA & 73,76 & 58,48 & 42,83 & 26,75 & 12,12 & 20,42 & 34,57 & 54,31 & 75,37 & 99,24 & 132,83 & - \\
\hline \multirow[t]{3}{*}{ SPI } & $\mathrm{DM}$ & $-7,79$ & $-6,03$ & $-4,19$ & $-2,21$ & $-0,07$ & 2,23 & 4,80 & 7,63 & 10,88 & 14,72 & 19,49 & - \\
\hline & DMA & 12,05 & 10,62 & 9,27 & 8,10 & 6,90 & 5,89 & 5,32 & 8,32 & 12,48 & 17,89 & 24,97 & - \\
\hline & PDMA & 47,29 & 41,52 & 35,20 & 28,61 & 21,17 & 13,02 & 11,83 & 22,30 & 41,09 & 67,83 & 107,17 & - \\
\hline \multirow[t]{3}{*}{$\Delta \mathrm{CS}$} & $\mathrm{DM}$ & $-17,12$ & $-16,75$ & $-15,93$ & $-14,87$ & $-13,72$ & $-12,75$ & $-12,38$ & $-13,34$ & $-17,21$ & $-28,24$ & $-67,15$ & - \\
\hline & DMA & 37,60 & 30,38 & 22,25 & 13,17 & 8,47 & 15,70 & 24,43 & 31,61 & 40,41 & 57,62 & 103,30 & - \\
\hline & PDMA & 26,47 & 16,96 & 7,63 & $-1,86$ & $-9,04$ & 7,39 & 22,74 & 32,00 & 34,28 & 31,42 & 25,65 & - \\
\hline \multicolumn{14}{|c|}{ Desconsiderando ${ }^{1} J_{\mathrm{BF}}$ da molécula de $\mathrm{BF}_{3},{ }^{2} J_{\mathrm{CH}}$ e ${ }^{2} J_{\mathrm{HH}}$ da molécula de $\mathrm{C}_{2} \mathrm{H}_{4}$} \\
\hline \multirow[t]{3}{*}{ Total } & DM & $-14,30$ & $-12,82$ & $-11,03$ & $-8,97$ & $-6,68$ & $-4,27$ & $-1,84$ & 0,28 & 1,53 & 0,10 & $-13,48$ & - \\
\hline & DMA & 28,15 & 23,86 & 19,24 & 14,38 & 11,59 & 13,47 & 16,23 & 22,18 & 30,16 & 43,50 & 72,17 & - \\
\hline & PDMA & 29,76 & 25,40 & 20,92 & 16,49 & 12,55 & 11,37 & 12,21 & 18,31 & 28,05 & 40,84 & 60,22 & - \\
\hline \multirow[t]{3}{*}{ CPI } & $\mathrm{DM}$ & $-20,34$ & $-19,67$ & $-18,45$ & $-16,81$ & $-14,91$ & $-13,04$ & $-11,55$ & $-11,23$ & $-13,65$ & $-23,30$ & $-62,61$ & - \\
\hline & DMA & 47,54 & 39,71 & 30,99 & 21,43 & 16,65 & 22,28 & 29,51 & 38,97 & 51,49 & 74,64 & 130,91 & - \\
\hline & PDMA & 34,00 & 28,39 & 22,51 & 16,29 & 11,60 & 12,66 & 16,62 & 26,74 & 38,30 & 52,97 & 78,24 & - \\
\hline \multirow[t]{3}{*}{ SPI } & $\mathrm{DM}$ & $-9,65$ & $-7,55$ & $-5,33$ & $-2,93$ & $-0,35$ & 2,47 & 5,62 & 9,13 & 13,20 & 18,09 & 24,32 & - \\
\hline & DMA & 13,24 & 11,67 & 10,21 & 8,96 & 7,70 & 6,68 & 6,02 & 9,27 & 13,75 & 19,54 & 26,98 & - \\
\hline & PDMA & 26,49 & 23,09 & 19,69 & 16,65 & 13,27 & 10,39 & 8,82 & 11,83 & 20,17 & 31,51 & 46,35 & - \\
\hline \multirow[t]{3}{*}{$\Delta \mathrm{CS}$} & DM & $-10,69$ & $-12,12$ & $-13,12$ & $-13,88$ & $-14,56$ & $-15,51$ & $-17,17$ & $-20,36$ & $-26,85$ & $-41,39$ & $-86,93$ & - \\
\hline & DMA & 34,30 & 28,04 & 20,78 & 12,47 & 8,95 & 15,60 & 23,49 & 29,70 & 37,74 & 55,10 & 103,93 & - \\
\hline & PDMA & 7,51 & 5,30 & 2,81 & $-0,36$ & $-1,67$ & 2,27 & 7,81 & 14,91 & 18,14 & 21,46 & 31,89 & - \\
\hline
\end{tabular}


Tabela 8.201: Constantes de acoplamento B971B972 com base aug-pcJ-2.

\begin{tabular}{|c|c|c|c|c|c|c|c|c|c|c|c|c|c|}
\hline & $\% E_{X}^{\mathrm{HF}}$ & $0 \%$ & $10 \%$ & $20 \%$ & $30 \%$ & $40 \%$ & $50 \%$ & $60 \%$ & $70 \%$ & $80 \%$ & $90 \%$ & $100 \%$ & Exp. \\
\hline $\mathrm{HF}$ & ${ }^{1} J_{\mathrm{HF}}$ & 461,2 & 479,1 & 498,1 & 518,0 & 539,2 & 561,4 & 584,9 & 609,6 & 635,7 & 663,0 & 691,6 & 500 \\
\hline $\mathrm{CO}$ & ${ }^{1} J_{\mathrm{CO}}$ & 12,0 & 10,6 & 9,2 & 7,6 & 5,8 & 3,9 & 1,8 & $-0,4$ & $-2,9$ & $-5,5$ & $-8,3$ & 16,4 \\
\hline $\mathrm{H}_{2} \mathrm{O}$ & ${ }^{1} J_{\mathrm{OH}}$ & $-72,9$ & $-75,1$ & $-77,6$ & $-80,2$ & $-82,9$ & $-85,8$ & $-88,9$ & $-92,2$ & $-95,6$ & $-99,3$ & $-103,1$ & $-80,6$ \\
\hline $\mathrm{H}_{2} \mathrm{O}$ & ${ }^{2} J_{\mathrm{HH}}$ & $-0,4$ & $-1,4$ & $-2,5$ & $-3,7$ & $-4,9$ & $-6,2$ & $-7,6$ & $-9,2$ & $-10,8$ & $-12,5$ & $-14,3$ & $-7,3$ \\
\hline $\mathrm{NH}_{3}$ & ${ }^{1} J_{\mathrm{NH}}$ & 39,6 & 40,6 & 41,7 & 42,8 & 44,1 & 45,3 & 46,7 & 48,2 & 49,7 & 51,4 & 53,1 & 43,8 \\
\hline $\mathrm{NH}_{3}$ & ${ }^{2} J_{\mathrm{HH}}$ & $-2,8$ & $-3,7$ & $-4,6$ & $-5,6$ & $-6,7$ & $-7,9$ & $-9,2$ & $-10,5$ & $-12,0$ & $-13,5$ & $-15,2$ & $-9,6$ \\
\hline $\mathrm{PH}_{3}$ & ${ }^{1} J_{\mathrm{PH}}$ & 156,1 & 162,7 & 169,7 & 177,2 & 185,2 & 193,5 & 202,4 & 211,7 & 221,5 & 231,8 & 242,5 & 188,2 \\
\hline $\mathrm{PF}_{3}$ & ${ }^{1} J_{\mathrm{PF}}$ & $-1655,1$ & $-1649,0$ & $-1637,2$ & $-1620,4$ & $-1599,5$ & $-1575,2$ & $-1548,1$ & $-1519,0$ & $-1488,5$ & $-1457,0$ & $-1424,9$ & -1441 \\
\hline $\mathrm{BHF}_{2}$ & ${ }^{1} J_{\mathrm{BF}}$ & $-130,7$ & $-116,0$ & $-101,0$ & $-85,9$ & $-70,6$ & $-55,4$ & $-40,1$ & $-24,8$ & $-9,6$ & 5,3 & 20,3 & -84 \\
\hline $\mathrm{BF}_{3}$ & ${ }^{1} J_{\mathrm{BF}}$ & $-39,1$ & $-22,1$ & $-5,1$ & 11,9 & 29,0 & 46,1 & 63,2 & 80,3 & 97,4 & 114,5 & 131,6 & 15 \\
\hline $\mathrm{F}_{2} \mathrm{O}$ & ${ }^{1} J_{\mathrm{OF}}$ & $-181,2$ & $-212,7$ & $-245,4$ & $-280,0$ & $-317,5$ & $-359,9$ & $-410,6$ & $-476,9$ & $-575,6$ & $-760,2$ & $-1349,0$ & -300 \\
\hline $\mathrm{CH}_{4}$ & ${ }^{1} J_{\mathrm{CH}}$ & 104,7 & 107,9 & 111,3 & 114,9 & 118,7 & 122,7 & 126,9 & 131,4 & 136,2 & 141,2 & 146,5 & 125,3 \\
\hline $\mathrm{CH}_{4}$ & ${ }^{2} J_{\mathrm{HH}}$ & $-4,8$ & $-5,6$ & $-6,5$ & $-7,4$ & $-8,4$ & $-9,4$ & $-10,5$ & $-11,7$ & $-12,9$ & $-14,2$ & $-15,6$ & $-12,8$ \\
\hline $\mathrm{C}_{2} \mathrm{H}_{2}$ & ${ }^{1} J_{\mathrm{CC}}$ & 184,6 & 188,6 & 192,9 & 197,9 & 203,6 & 210,3 & 218,2 & 227,8 & 239,6 & 254,6 & 274,3 & 174,8 \\
\hline $\mathrm{C}_{2} \mathrm{H}_{2}$ & ${ }^{1} J_{\mathrm{CH}}$ & 202,4 & 209,0 & 215,9 & 223,1 & 230,8 & 239,0 & 247,8 & 257,4 & 268,0 & 280,0 & 294,1 & 247,6 \\
\hline $\mathrm{C}_{2} \mathrm{H}_{2}$ & ${ }^{2} J_{\mathrm{CH}}$ & 51,3 & 52,1 & 52,7 & 53,2 & 53,4 & 53,3 & 52,8 & 51,6 & 49,7 & 46,6 & 41,6 & 50,1 \\
\hline $\mathrm{C}_{2} \mathrm{H}_{2}$ & ${ }^{3} J_{\mathrm{HH}}$ & 6,0 & 6,3 & 6,6 & 7,1 & 7,8 & 8,6 & 9,6 & 10,9 & 12,6 & 14,9 & 18,0 & 9,6 \\
\hline $\mathrm{C}_{2} \mathrm{H}_{4}$ & ${ }^{1} J_{\mathrm{CC}}$ & 63,2 & 66,0 & 69,1 & 72,6 & 76,7 & 81,4 & 87,1 & 94,3 & 103,7 & 116,8 & 137,0 & 67,6 \\
\hline $\mathrm{C}_{2} \mathrm{H}_{4}$ & ${ }^{1} J_{\mathrm{CH}}$ & 127,8 & 132,1 & 136,7 & 141,6 & 146,9 & 152,5 & 158,6 & 165,4 & 173,1 & 182,3 & 194,0 & 156,3 \\
\hline $\mathrm{C}_{2} \mathrm{H}_{4}$ & ${ }^{2} J_{\mathrm{CH}}$ & 3,3 & 2,6 & 1,8 & 0,9 & 0,0 & $-1,3$ & $-2,9$ & $-4,9$ & $-7,7$ & $-11,7$ & $-18,1$ & $-2,4$ \\
\hline $\mathrm{C}_{2} \mathrm{H}_{4}$ & ${ }^{2} J_{\mathrm{HH}}$ & 6,8 & 6,5 & 6,1 & 5,7 & 5,1 & 4,5 & 3,8 & 2,8 & 1,5 & $-0,2$ & $-2,9$ & 2,3 \\
\hline $\mathrm{C}_{2} \mathrm{H}_{4}$ & ${ }^{3} J_{\mathrm{HH}_{\mathrm{c}}}$ & 9,2 & 9,4 & 9,6 & 9,9 & 10,2 & 10,6 & 11,1 & 11,8 & 12,7 & 14,2 & 16,6 & 11,7 \\
\hline $\mathrm{C}_{2} \mathrm{H}_{4}$ & ${ }^{3} J_{\mathrm{HH}_{\mathrm{t}}}$ & 13,2 & 13,6 & 14,1 & 14,6 & 15,2 & 16,0 & 16,8 & 17,9 & 19,3 & 21,3 & 24,4 & 19 \\
\hline $\mathrm{C}_{2} \mathrm{H}_{6}$ & ${ }^{1} J_{\mathrm{CC}}$ & 27,8 & 30,0 & 32,3 & 34,8 & 37,4 & 40,2 & 43,1 & 46,1 & 49,4 & 52,8 & 56,4 & 34,5 \\
\hline $\mathrm{C}_{2} \mathrm{H}_{6}$ & ${ }^{1} J_{\mathrm{CH}}$ & 102,7 & 106,2 & 109,8 & 113,7 & 117,7 & 122,0 & 126,6 & 131,4 & 136,5 & 141,8 & 147,5 & 125,2 \\
\hline $\mathrm{C}_{2} \mathrm{H}_{6}$ & ${ }^{2} J_{\mathrm{CH}}$ & $-0,1$ & $-0,5$ & $-1,1$ & $-1,6$ & $-2,2$ & $-2,8$ & $-3,4$ & $-4,1$ & $-4,9$ & $-5,7$ & $-6,5$ & $-4,7$ \\
\hline \multirow[t]{3}{*}{ Total } & $\mathrm{DM}$ & $-13,85$ & $-11,84$ & $-9,55$ & $-7,01$ & $-4,27$ & $-1,45$ & 1,35 & 3,84 & 5,43 & 4,14 & $-12,05$ & - \\
\hline & DMA & 27,24 & 22,68 & 17,82 & 14,14 & 14,14 & 16,64 & 20,13 & 26,13 & 33,90 & 45,96 & 75,85 & - \\
\hline & PDMA & 57,49 & 47,88 & 37,71 & 27,75 & 26,80 & 27,80 & 30,50 & 40,78 & 56,69 & 81,43 & 118,82 & - \\
\hline \multirow[t]{3}{*}{ CPI } & DM & $-23,11$ & $-20,72$ & $-17,78$ & $-14,47$ & $-10,88$ & $-7,37$ & $-4,22$ & $-2,19$ & $-2,87$ & $-11,17$ & $-56,05$ & - \\
\hline & DMA & 48,60 & 39,74 & 30,04 & 22,84 & 24,01 & 31,14 & 39,58 & 49,83 & 63,18 & 84,45 & 145,55 & - \\
\hline & PDMA & 64,26 & 48,95 & 33,32 & 18,08 & 24,26 & 36,78 & 50,60 & 69,72 & 90,96 & 115,08 & 152,13 & - \\
\hline \multirow[t]{3}{*}{ SPI } & DM & $-7,07$ & $-5,33$ & $-3,52$ & $-1,54$ & 0,59 & 2,90 & 5,43 & 8,27 & 11,51 & 15,37 & 20,21 & - \\
\hline & DMA & 11,57 & 10,18 & 8,87 & 7,77 & 6,91 & 6,01 & 5,87 & 8,75 & 12,42 & 17,73 & 24,75 & - \\
\hline & PDMA & 52,52 & 47,10 & 40,93 & 34,83 & 28,66 & 21,22 & 15,75 & 19,57 & 31,55 & 56,75 & 94,39 & - \\
\hline \multirow[t]{3}{*}{$\Delta \mathrm{CS}$} & $\mathrm{DM}$ & $-16,04$ & $-15,39$ & $-14,26$ & $-12,93$ & $-11,47$ & $-10,27$ & $-9,65$ & $-10,46$ & $-14,39$ & $-26,55$ & $-76,27$ & - \\
\hline & DMA & 37,03 & 29,56 & 21,17 & 15,07 & 17,10 & 25,13 & 33,71 & 41,08 & 50,76 & 66,71 & 120,80 & - \\
\hline & PDMA & 11,74 & 1,86 & $-7,61$ & $-16,75$ & $-4,40$ & 15,57 & 34,85 & 50,15 & 59,42 & 58,33 & 57,74 & - \\
\hline \multicolumn{14}{|c|}{ Desconsiderando ${ }^{1} J_{\mathrm{BF}}$ da molécula de $\mathrm{BF}_{3},{ }^{2} J_{\mathrm{CH}}$ e ${ }^{2} J_{\mathrm{HH}}$ da molécula de $\mathrm{C}_{2} \mathrm{H}_{4}$} \\
\hline \multirow[t]{3}{*}{ Total } & DM & $-13,75$ & $-12,17$ & $-10,27$ & $-8,08$ & $-5,66$ & $-3,13$ & $-0,61$ & 1,59 & 2,82 & 0,87 & $-17,79$ & - \\
\hline & DMA & 28,00 & 23,63 & 18,93 & 15,56 & 15,15 & 17,31 & 20,58 & 26,57 & 34,47 & 47,11 & 79,77 & - \\
\hline & PDMA & 30,47 & 26,38 & 22,01 & 18,06 & 16,59 & 16,26 & 16,76 & 21,70 & 29,08 & 41,63 & 62,25 & - \\
\hline \multirow[t]{3}{*}{ CPI } & DM & $-20,01$ & $-19,08$ & $-17,55$ & $-15,61$ & $-13,37$ & $-11,22$ & $-9,46$ & $-8,94$ & $-11,40$ & $-22,24$ & $-73,32$ & - \\
\hline & DMA & 48,05 & 40,00 & 31,03 & 24,81 & 25,01 & 31,14 & 38,72 & 48,28 & 61,26 & 82,94 & 148,44 & - \\
\hline & PDMA & 34,62 & 29,11 & 23,25 & 17,82 & 17,35 & 19,73 & 23,53 & 33,15 & 45,13 & 60,25 & 89,61 & - \\
\hline \multirow[t]{3}{*}{ SPI } & $\mathrm{DM}$ & $-8,94$ & $-6,85$ & $-4,68$ & $-2,29$ & 0,28 & 3,09 & 6,19 & 9,69 & 13,75 & 18,65 & 24,93 & - \\
\hline & DMA & 12,57 & 11,04 & 9,62 & 8,45 & 7,57 & 6,68 & 6,62 & 9,86 & 13,86 & 19,55 & 26,95 & - \\
\hline & PDMA & 27,28 & 24,27 & 21,06 & 18,24 & 16,01 & 13,60 & 11,56 & 12,89 & 16,74 & 27,31 & 41,20 & - \\
\hline \multirow[t]{3}{*}{$\Delta \mathrm{CS}$} & $\mathrm{DM}$ & $-11,07$ & $-12,23$ & $-12,87$ & $-13,32$ & $-13,65$ & $-14,31$ & $-15,65$ & $-18,63$ & $-25,15$ & $-40,89$ & $-98,25$ & - \\
\hline & DMA & 35,48 & 28,96 & 21,41 & 16,36 & 17,44 & 24,46 & 32,10 & 38,42 & 47,40 & 63,39 & 121,49 & - \\
\hline & PDMA & 7,34 & 4,84 & 2,19 & $-0,42$ & 1,34 & 6,13 & 11,97 & 20,26 & 28,39 & 32,94 & 48,41 & - \\
\hline
\end{tabular}


Tabela 8.202: Constantes de acoplamento B971B98 com base aug-pcJ-2.

\begin{tabular}{|c|c|c|c|c|c|c|c|c|c|c|c|c|c|}
\hline & $\% E_{X}^{\mathrm{HF}}$ & $0 \%$ & $10 \%$ & $20 \%$ & $30 \%$ & $40 \%$ & $50 \%$ & $60 \%$ & $70 \%$ & $80 \%$ & $90 \%$ & $100 \%$ & Exp. \\
\hline $\mathrm{HF}$ & ${ }^{1} J_{\mathrm{HF}}$ & 417,3 & 433,7 & 451,1 & 469,5 & 489,2 & 510,0 & 532,0 & 555,3 & 579,9 & 605,9 & 633,1 & 500 \\
\hline $\mathrm{CO}$ & ${ }^{1} J_{\mathrm{CO}}$ & 15,6 & 14,5 & 13,3 & 11,9 & 10,4 & 8,8 & 7,0 & 5,1 & 3,0 & 0,8 & $-1,4$ & 16,4 \\
\hline $\mathrm{H}_{2} \mathrm{O}$ & ${ }^{1} J_{\mathrm{OH}}$ & $-67,4$ & $-69,5$ & $-71,7$ & $-74,1$ & $-76,6$ & $-79,3$ & $-82,2$ & $-85,3$ & $-88,5$ & $-91,9$ & $-95,6$ & $-80,6$ \\
\hline $\mathrm{H}_{2} \mathrm{O}$ & ${ }^{2} J_{\mathrm{HH}}$ & $-0,7$ & $-1,7$ & $-2,8$ & $-4,0$ & $-5,2$ & $-6,5$ & $-7,9$ & $-9,5$ & $-11,1$ & $-12,8$ & $-14,6$ & $-7,3$ \\
\hline $\mathrm{NH}_{3}$ & ${ }^{1} J_{\mathrm{NH}}$ & 38,1 & 39,1 & 40,2 & 41,3 & 42,5 & 43,8 & 45,1 & 46,6 & 48,1 & 49,7 & 51,5 & 43,8 \\
\hline $\mathrm{NH}_{3}$ & ${ }^{2} J_{\mathrm{HH}}$ & $-3,6$ & $-4,5$ & $-5,5$ & $-6,6$ & $-7,7$ & $-9,0$ & $-10,3$ & $-11,7$ & $-13,3$ & $-15,0$ & $-16,8$ & $-9,6$ \\
\hline $\mathrm{PH}_{3}$ & ${ }^{1} J_{\mathrm{PH}}$ & 168,0 & 174,3 & 181,0 & 188,0 & 195,4 & 203,2 & 211,4 & 219,9 & 228,9 & 238,2 & 247,9 & 188,2 \\
\hline $\mathrm{PF}_{3}$ & ${ }^{1} J_{\mathrm{PF}}$ & $-1628,3$ & $-1622,4$ & $-1610,9$ & $-1594,7$ & $-1574,5$ & $-1550,9$ & $-1524,7$ & $-1496,4$ & $-1466,7$ & $-1435,9$ & $-1404,5$ & -1441 \\
\hline $\mathrm{BHF}_{2}$ & ${ }^{1} J_{\mathrm{BF}}$ & $-145,2$ & $-130,8$ & $-116,1$ & $-101,2$ & $-86,0$ & $-70,6$ & $-55,2$ & $-39,8$ & $-24,3$ & $-9,0$ & 6,2 & -84 \\
\hline $\mathrm{BF}_{3}$ & ${ }^{1} J_{\mathrm{BF}}$ & $-56,5$ & $-39,9$ & $-23,1$ & $-6,2$ & 10,7 & 27,8 & 44,9 & 62,1 & 79,3 & 96,6 & 113,8 & 15 \\
\hline $\mathrm{F}_{2} \mathrm{O}$ & ${ }^{1} J_{\mathrm{OF}}$ & $-195,8$ & $-228,5$ & $-262,7$ & $-299,0$ & $-338,7$ & $-383,9$ & $-438,7$ & $-511,1$ & $-620,5$ & $-827,8$ & $-1507,1$ & -300 \\
\hline $\mathrm{CH}_{4}$ & ${ }^{1} J_{\mathrm{CH}}$ & 105,3 & 108,6 & 112,2 & 115,9 & 119,9 & 124,2 & 128,7 & 133,4 & 138,5 & 143,8 & 149,5 & 125,3 \\
\hline $\mathrm{CH}_{4}$ & ${ }^{2} J_{\mathrm{HH}}$ & $-6,2$ & $-7,0$ & $-8,0$ & $-9,0$ & $-10,0$ & $-11,2$ & $-12,4$ & $-13,7$ & $-15,1$ & $-16,5$ & $-18,1$ & $-12,8$ \\
\hline $\mathrm{C}_{2} \mathrm{H}_{2}$ & ${ }^{1} J_{\mathrm{CC}}$ & 189,2 & 193,2 & 197,7 & 202,8 & 208,6 & 215,4 & 223,5 & 233,2 & 245,4 & 261,1 & 282,1 & 174,8 \\
\hline $\mathrm{C}_{2} \mathrm{H}_{2}$ & ${ }^{1} J_{\mathrm{CH}}$ & 204,8 & 211,6 & 218,8 & 226,4 & 234,5 & 243,2 & 252,6 & 262,8 & 274,3 & 287,6 & 303,3 & 247,6 \\
\hline $\mathrm{C}_{2} \mathrm{H}_{2}$ & ${ }^{2} J_{\mathrm{CH}}$ & 51,6 & 52,4 & 53,1 & 53,5 & 53,7 & 53,5 & 52,9 & 51,5 & 49,2 & 45,4 & 39,3 & 50,1 \\
\hline $\mathrm{C}_{2} \mathrm{H}_{2}$ & ${ }^{3} J_{\mathrm{HH}}$ & 6,3 & 6,7 & 7,2 & 7,8 & 8,6 & 9,5 & 10,8 & 12,5 & 14,6 & 17,6 & 21,7 & 9,6 \\
\hline $\mathrm{C}_{2} \mathrm{H}_{4}$ & ${ }^{1} J_{\mathrm{CC}}$ & 65,4 & 68,2 & 71,4 & 74,9 & 78,9 & 83,6 & 89,2 & 96,2 & 105,4 & 118,2 & 138,3 & 67,6 \\
\hline $\mathrm{C}_{2} \mathrm{H}_{4}$ & ${ }^{1} J_{\mathrm{CH}}$ & 129,1 & 133,6 & 138,4 & 143,5 & 149,0 & 155,0 & 161,4 & 168,6 & 176,9 & 186,7 & 199,6 & 156,3 \\
\hline $\mathrm{C}_{2} \mathrm{H}_{4}$ & ${ }^{2} J_{\mathrm{CH}}$ & 2,5 & 1,8 & 1,0 & 0,1 & $-0,9$ & $-2,3$ & $-4,0$ & $-6,2$ & $-9,2$ & $-13,6$ & $-20,9$ & $-2,4$ \\
\hline $\mathrm{C}_{2} \mathrm{H}_{4}$ & ${ }^{2} J_{\mathrm{HH}}$ & 6,0 & 5,6 & 5,2 & 4,7 & 4,1 & 3,3 & 2,4 & 1,2 & $-0,3$ & $-2,6$ & $-6,2$ & 2,3 \\
\hline $\mathrm{C}_{2} \mathrm{H}_{4}$ & ${ }^{3} J_{\mathrm{HH}_{\mathrm{c}}}$ & 9,4 & 9,7 & 10,0 & 10,3 & 10,7 & 11,2 & 11,9 & 12,7 & 14,0 & 15,9 & 19,2 & 11,7 \\
\hline $\mathrm{C}_{2} \mathrm{H}_{4}$ & ${ }^{3} J_{\mathrm{HH}_{\mathrm{t}}}$ & 13,5 & 14,0 & 14,5 & 15,2 & 15,9 & 16,8 & 17,8 & 19,1 & 20,9 & 23,4 & 27,5 & 19 \\
\hline $\mathrm{C}_{2} \mathrm{H}_{6}$ & ${ }^{1} J_{\mathrm{CC}}$ & 26,7 & 29,0 & 31,4 & 34,0 & 36,7 & 39,7 & 42,7 & 46,0 & 49,5 & 53,2 & 57,1 & 34,5 \\
\hline $\mathrm{C}_{2} \mathrm{H}_{6}$ & ${ }^{1} J_{\mathrm{CH}}$ & 103,9 & 107,5 & 111,3 & 115,4 & 119,7 & 124,3 & 129,1 & 134,2 & 139,6 & 145,3 & 151,4 & 125,2 \\
\hline $\mathrm{C}_{2} \mathrm{H}_{6}$ & ${ }^{2} J_{\mathrm{CH}}$ & $-0,7$ & $-1,2$ & $-1,8$ & $-2,4$ & $-3,0$ & $-3,6$ & $-4,4$ & $-5,1$ & $-6,0$ & $-6,9$ & $-7,9$ & $-4,7$ \\
\hline \multirow[t]{3}{*}{ Total } & $\mathrm{DM}$ & $-15,26$ & $-13,35$ & $-11,15$ & $-8,73$ & $-6,12$ & $-3,42$ & $-0,82$ & 1,41 & 2,60 & 0,48 & $-19,10$ & - \\
\hline & DMA & 27,96 & 23,45 & 18,72 & 13,62 & 11,80 & 12,88 & 17,45 & 23,95 & 32,51 & 46,04 & 80,95 & - \\
\hline & PDMA & 57,74 & 47,89 & 37,73 & 26,99 & 17,49 & 14,82 & 22,44 & 38,55 & 59,59 & 87,06 & 129,89 & - \\
\hline \multirow[t]{3}{*}{ CPI } & $\mathrm{DM}$ & $-27,22$ & $-25,15$ & $-22,55$ & $-19,64$ & $-16,49$ & $-13,41$ & $-10,86$ & $-9,61$ & $-11,46$ & $-22,01$ & $-75,31$ & - \\
\hline & DMA & 50,85 & 42,11 & 32,52 & 22,15 & 19,25 & 23,21 & 31,81 & 42,54 & 56,72 & 80,83 & 152,76 & - \\
\hline & PDMA & 73,79 & 58,61 & 42,96 & 26,97 & 13,84 & 19,27 & 34,74 & 54,72 & 76,17 & 101,05 & 140,82 & - \\
\hline \multirow[t]{3}{*}{ SPI } & DM & $-6,49$ & $-4,69$ & $-2,78$ & $-0,73$ & 1,49 & 3,90 & 6,54 & 9,49 & 12,91 & 16,97 & 22,12 & - \\
\hline & DMA & 11,17 & 9,77 & 8,61 & 7,36 & 6,34 & 5,30 & 6,91 & 10,31 & 14,76 & 20,53 & 28,29 & - \\
\hline & PDMA & 45,96 & 40,02 & 33,90 & 27,00 & 20,16 & 11,56 & 13,42 & 26,70 & 47,42 & 76,80 & 121,88 & - \\
\hline \multirow[t]{3}{*}{$\Delta \mathrm{CS}$} & $\mathrm{DM}$ & $-20,73$ & $-20,45$ & $-19,77$ & $-18,90$ & $-17,98$ & $-17,31$ & $-17,40$ & $-19,10$ & $-24,37$ & $-38,98$ & $-97,43$ & - \\
\hline & DMA & 39,69 & 32,34 & 23,91 & 14,79 & 12,91 & 17,91 & 24,90 & 32,22 & 41,96 & 60,30 & 124,47 & - \\
\hline & PDMA & 27,83 & 18,59 & 9,06 & $-0,03$ & $-6,31$ & 7,71 & 21,32 & 28,02 & 28,75 & 24,24 & 18,94 & - \\
\hline \multicolumn{14}{|c|}{ Desconsiderando ${ }^{1} J_{\mathrm{BF}}$ da molécula de $\mathrm{BF}_{3},{ }^{2} J_{\mathrm{CH}}$ e ${ }^{2} J_{\mathrm{HH}}$ da molécula de $\mathrm{C}_{2} \mathrm{H}_{4}$} \\
\hline \multirow[t]{3}{*}{ Total } & DM & $-14,51$ & $-13,03$ & $-11,22$ & $-9,16$ & $-6,87$ & $-4,47$ & $-2,17$ & $-0,24$ & 0,55 & $-2,31$ & $-24,71$ & - \\
\hline & DMA & 28,12 & 23,80 & 19,23 & 14,26 & 13,01 & 13,95 & 18,35 & 24,81 & 33,55 & 47,80 & 86,04 & - \\
\hline & PDMA & 28,67 & 24,37 & 19,97 & 15,30 & 12,40 & 10,98 & 13,62 & 20,97 & 31,49 & 45,21 & 68,62 & - \\
\hline \multirow[t]{3}{*}{ CPI } & $\mathrm{DM}$ & $-22,79$ & $-22,17$ & $-21,00$ & $-19,48$ & $-17,71$ & $-16,03$ & $-14,94$ & $-15,28$ & $-19,04$ & $-32,37$ & $-92,72$ & - \\
\hline & DMA & 48,79 & 40,83 & 31,96 & 22,24 & 20,75 & 24,25 & 32,00 & 42,08 & 55,96 & 80,75 & 158,16 & - \\
\hline & PDMA & 33,50 & 27,87 & 21,86 & 15,53 & 12,36 & 12,67 & 18,28 & 28,79 & 40,92 & 56,75 & 89,03 & - \\
\hline \multirow[t]{3}{*}{ SPI } & DM & $-8,15$ & $-5,99$ & $-3,69$ & $-1,22$ & 1,46 & 4,42 & 7,66 & 11,32 & 15,62 & 20,82 & 27,60 & - \\
\hline & DMA & 12,22 & 10,70 & 9,45 & 8,12 & 7,06 & 6,03 & 7,85 & 11,52 & 16,31 & 22,45 & 30,57 & - \\
\hline & PDMA & 24,95 & 21,68 & 18,52 & 15,11 & 12,43 & 9,67 & 10,02 & 14,95 & 24,23 & 36,33 & 52,91 & - \\
\hline \multirow[t]{3}{*}{$\Delta \mathrm{CS}$} & $\mathrm{DM}$ & $-14,64$ & $-16,18$ & $-17,31$ & $-18,26$ & $-19,17$ & $-20,45$ & $-22,60$ & $-26,60$ & $-34,66$ & $-53,19$ & $-120,32$ & - \\
\hline & DMA & 36,57 & 30,13 & 22,51 & 14,12 & 13,69 & 18,22 & 24,15 & 30,56 & 39,65 & 58,30 & 127,59 & - \\
\hline & PDMA & 8,55 & 6,19 & 3,34 & 0,42 & $-0,07$ & 2,99 & 8,26 & 13,84 & 16,69 & 20,42 & 36,12 & - \\
\hline
\end{tabular}


Tabela 8.203: Constantes de acoplamento B971LYP com base aug-pcJ-2.

\begin{tabular}{|c|c|c|c|c|c|c|c|c|c|c|c|c|c|}
\hline & $\% E_{X}^{\mathrm{HF}}$ & $0 \%$ & $10 \%$ & $20 \%$ & $30 \%$ & $40 \%$ & $50 \%$ & $60 \%$ & $70 \%$ & $80 \%$ & $90 \%$ & $100 \%$ & Exp. \\
\hline $\mathrm{HF}$ & ${ }^{1} J_{\mathrm{HF}}$ & 416,9 & 435,2 & 454,6 & 475,3 & 497,4 & 521,0 & 546,1 & 572,7 & 601,0 & 630,9 & 662,5 & 500 \\
\hline $\mathrm{CO}$ & ${ }^{1} J_{\mathrm{CO}}$ & 15,5 & 14,4 & 13,1 & 11,7 & 10,2 & 8,5 & 6,7 & 4,8 & 2,7 & 0,4 & $-1,9$ & 16,4 \\
\hline $\mathrm{H}_{2} \mathrm{O}$ & ${ }^{1} J_{\mathrm{OH}}$ & $-69,2$ & $-71,5$ & $-74,0$ & $-76,6$ & $-79,5$ & $-82,5$ & $-85,8$ & $-89,2$ & $-92,9$ & $-96,9$ & $-101,1$ & $-80,6$ \\
\hline $\mathrm{H}_{2} \mathrm{O}$ & ${ }^{2} J_{\mathrm{HH}}$ & $-1,5$ & $-2,6$ & $-3,8$ & $-5,1$ & $-6,5$ & $-8,0$ & $-9,6$ & $-11,3$ & $-13,2$ & $-15,2$ & $-17,3$ & $-7,3$ \\
\hline $\mathrm{NH}_{3}$ & ${ }^{1} J_{\mathrm{NH}}$ & 39,1 & 40,1 & 41,3 & 42,5 & 43,7 & 45,1 & 46,5 & 48,1 & 49,8 & 51,5 & 53,4 & 43,8 \\
\hline $\mathrm{NH}_{3}$ & ${ }^{2} J_{\mathrm{HH}}$ & $-4,4$ & $-5,4$ & $-6,4$ & $-7,6$ & $-8,8$ & $-10,2$ & $-11,6$ & $-13,2$ & $-14,8$ & $-16,7$ & $-18,7$ & $-9,6$ \\
\hline $\mathrm{PH}_{3}$ & ${ }^{1} J_{\mathrm{PH}}$ & 151,9 & 158,4 & 165,4 & 172,9 & 180,8 & 189,2 & 198,2 & 207,7 & 217,6 & 228,2 & 239,2 & 188,2 \\
\hline $\mathrm{PF}_{3}$ & ${ }^{1} J_{\mathrm{PF}}$ & $-1656,8$ & $-1651,5$ & $-1640,6$ & $-1624,8$ & $-1605,0$ & $-1581,8$ & $-1555,9$ & $-1527,9$ & $-1498,5$ & $-1468,0$ & $-1437,0$ & -1441 \\
\hline $\mathrm{BHF}_{2}$ & ${ }^{1} J_{\mathrm{BF}}$ & $-150,0$ & $-135,6$ & $-120,9$ & $-106,0$ & $-90,9$ & $-75,7$ & $-60,4$ & $-45,1$ & $-29,8$ & $-14,5$ & 0,6 & -84 \\
\hline $\mathrm{BF}_{3}$ & ${ }^{1} J_{\mathrm{BF}}$ & $-58,7$ & $-41,9$ & $-24,9$ & $-7,8$ & 9,2 & 26,5 & 43,8 & 61,2 & 78,6 & 96,2 & 113,8 & 15 \\
\hline $\mathrm{F}_{2} \mathrm{O}$ & ${ }^{1} J_{\mathrm{OF}}$ & $-197,3$ & $-231,1$ & $-266,7$ & $-304,8$ & $-346,9$ & $-395,7$ & $-456,0$ & $-538,1$ & $-668,4$ & $-941,2$ & $-2253,8$ & -300 \\
\hline $\mathrm{CH}_{4}$ & ${ }^{1} J_{\mathrm{CH}}$ & 104,7 & 108,0 & 111,6 & 115,3 & 119,3 & 123,6 & 128,2 & 133,0 & 138,1 & 143,6 & 149,4 & 125,3 \\
\hline $\mathrm{CH}_{4}$ & ${ }^{2} J_{\mathrm{HH}}$ & $-7,2$ & $-8,1$ & $-9,1$ & $-10,1$ & $-11,2$ & $-12,4$ & $-13,7$ & $-15,1$ & $-16,5$ & $-18,1$ & $-19,7$ & $-12,8$ \\
\hline $\mathrm{C}_{2} \mathrm{H}_{2}$ & ${ }^{1} J_{\mathrm{CC}}$ & 178,7 & 182,3 & 186,3 & 190,8 & 196,1 & 202,4 & 210,0 & 219,3 & 231,1 & 246,8 & 268,4 & 174,8 \\
\hline $\mathrm{C}_{2} \mathrm{H}_{2}$ & ${ }^{1} J_{\mathrm{CH}}$ & 208,6 & 215,7 & 223,2 & 231,1 & 239,5 & 248,6 & 258,5 & 269,3 & 281,6 & 296,0 & 313,5 & 247,6 \\
\hline $\mathrm{C}_{2} \mathrm{H}_{2}$ & ${ }^{2} J_{\mathrm{CH}}$ & 53,6 & 54,4 & 55,1 & 55,5 & 55,6 & 55,4 & 54,6 & 52,9 & 50,2 & 45,6 & 38,1 & 50,1 \\
\hline $\mathrm{C}_{2} \mathrm{H}_{2}$ & ${ }^{3} J_{\mathrm{HH}}$ & 6,9 & 7,4 & 7,9 & 8,7 & 9,6 & 10,8 & 12,3 & 14,3 & 17,0 & 20,7 & 26,0 & 9,6 \\
\hline $\mathrm{C}_{2} \mathrm{H}_{4}$ & ${ }^{1} J_{\mathrm{CC}}$ & 59,0 & 61,6 & 64,5 & 67,8 & 71,7 & 76,2 & 81,8 & 89,0 & 98,8 & 113,5 & 139,0 & 67,6 \\
\hline $\mathrm{C}_{2} \mathrm{H}_{4}$ & ${ }^{1} J_{\mathrm{CH}}$ & 129,6 & 134,1 & 139,0 & 144,3 & 149,9 & 156,0 & 162,7 & 170,2 & 179,0 & 190,1 & 205,7 & 156,3 \\
\hline $\mathrm{C}_{2} \mathrm{H}_{4}$ & ${ }^{2} J_{\mathrm{CH}}$ & 2,8 & 2,1 & 1,3 & 0,3 & $-0,8$ & $-2,2$ & $-4,0$ & $-6,5$ & $-10,0$ & $-15,5$ & $-25,4$ & $-2,4$ \\
\hline $\mathrm{C}_{2} \mathrm{H}_{4}$ & ${ }^{2} J_{\mathrm{HH}}$ & 6,4 & 6,0 & 5,5 & 4,9 & 4,3 & 3,4 & 2,4 & 1,0 & $-0,9$ & $-4,0$ & $-9,3$ & 2,3 \\
\hline $\mathrm{C}_{2} \mathrm{H}_{4}$ & ${ }^{3} J_{\mathrm{HH}_{\mathrm{c}}}$ & 10,3 & 10,6 & 10,9 & 11,3 & 11,7 & 12,4 & 13,2 & 14,3 & 16,0 & 18,7 & 23,7 & 11,7 \\
\hline $\mathrm{C}_{2} \mathrm{H}_{4}$ & ${ }^{3} J_{\mathrm{HH}_{\mathrm{t}}}$ & 14,5 & 15,1 & 15,7 & 16,5 & 17,3 & 18,3 & 19,6 & 21,2 & 23,5 & 26,9 & 32,9 & 19 \\
\hline $\mathrm{C}_{2} \mathrm{H}_{6}$ & ${ }^{1} J_{\mathrm{CC}}$ & 24,2 & 26,4 & 28,7 & 31,1 & 33,7 & 36,4 & 39,3 & 42,4 & 45,6 & 49,1 & 52,7 & 34,5 \\
\hline $\mathrm{C}_{2} \mathrm{H}_{6}$ & ${ }^{1} J_{\mathrm{CH}}$ & 103,1 & 106,7 & 110,5 & 114,6 & 118,9 & 123,5 & 128,3 & 133,5 & 139,0 & 144,8 & 150,9 & 125,2 \\
\hline $\mathrm{C}_{2} \mathrm{H}_{6}$ & ${ }^{2} J_{\mathrm{CH}}$ & $-0,7$ & $-1,2$ & $-1,7$ & $-2,3$ & $-3,0$ & $-3,6$ & $-4,4$ & $-5,1$ & $-6,0$ & $-6,9$ & $-7,8$ & $-4,7$ \\
\hline \multirow[t]{3}{*}{ Total } & $\mathrm{DM}$ & $-17,88$ & $-15,98$ & $-13,79$ & $-11,37$ & $-8,80$ & $-6,15$ & $-3,62$ & $-1,60$ & $-1,02$ & $-5,35$ & $-48,74$ & - \\
\hline & DMA & 29,53 & 24,83 & 19,69 & 14,46 & 11,91 & 13,24 & 18,88 & 26,16 & 35,82 & 52,11 & 110,36 & - \\
\hline & PDMA & 58,66 & 48,48 & 37,73 & 26,07 & 15,27 & 13,66 & 24,02 & 42,34 & 65,72 & 98,52 & 158,62 & - \\
\hline \multirow[t]{3}{*}{ CPI } & DM & $-32,31$ & $-30,22$ & $-27,62$ & $-24,65$ & $-21,56$ & $-18,59$ & $-16,26$ & $-15,56$ & $-18,98$ & $-35,11$ & $-145,56$ & - \\
\hline & DMA & 55,05 & 46,02 & 36,09 & 26,15 & 22,05 & 26,43 & 36,48 & 48,58 & 65,20 & 94,98 & 220,20 & - \\
\hline & PDMA & 74,45 & 58,84 & 42,85 & 26,65 & 12,46 & 18,39 & 38,06 & 58,92 & 81,69 & 109,51 & 169,20 & - \\
\hline \multirow[t]{3}{*}{ SPI } & DM & $-7,31$ & $-5,53$ & $-3,65$ & $-1,62$ & 0,57 & 2,98 & 5,65 & 8,64 & 12,16 & 16,48 & 22,27 & - \\
\hline & DMA & 10,81 & 9,29 & 7,66 & 5,89 & 4,47 & 3,57 & 5,98 & 9,72 & 14,27 & 20,67 & 29,81 & - \\
\hline & PDMA & 47,09 & 40,89 & 33,97 & 25,63 & 17,33 & 10,18 & 13,72 & 30,18 & 54,01 & 90,45 & 150,86 & - \\
\hline \multirow[t]{3}{*}{$\Delta \mathrm{CS}$} & $\mathrm{DM}$ & $-25,00$ & $-24,68$ & $-23,97$ & $-23,03$ & $-22,13$ & $-21,57$ & $-21,91$ & $-24,20$ & $-31,14$ & $-51,59$ & $-167,83$ & - \\
\hline & DMA & 44,24 & 36,72 & 28,43 & 20,26 & 17,58 & 22,86 & 30,50 & 38,86 & 50,93 & 74,32 & 190,39 & - \\
\hline & PDMA & 27,37 & 17,95 & 8,89 & 1,02 & $-4,87$ & 8,21 & 24,34 & 28,74 & 27,69 & 19,06 & 18,34 & - \\
\hline \multicolumn{14}{|c|}{ Desconsiderando ${ }^{1} J_{\mathrm{BF}}$ da molécula de $\mathrm{BF}_{3},{ }^{2} J_{\mathrm{CH}}$ e ${ }^{2} J_{\mathrm{HH}}$ da molécula de $\mathrm{C}_{2} \mathrm{H}_{4}$} \\
\hline \multirow[t]{3}{*}{ Total } & DM & $-17,42$ & $-15,94$ & $-14,15$ & $-12,09$ & $-9,85$ & $-7,50$ & $-5,28$ & $-3,58$ & $-3,44$ & $-8,73$ & $-57,89$ & - \\
\hline & DMA & 29,77 & 25,24 & 20,22 & 15,12 & 13,06 & 14,41 & 20,02 & 27,33 & 37,25 & 54,53 & 118,96 & - \\
\hline & PDMA & 27,78 & 23,16 & 18,33 & 13,05 & 8,90 & 9,66 & 15,72 & 24,58 & 36,04 & 52,19 & 87,08 & - \\
\hline \multirow[t]{3}{*}{ CPI } & DM & $-28,17$ & $-27,55$ & $-26,39$ & $-24,84$ & $-23,14$ & $-21,60$ & $-20,77$ & $-21,74$ & $-27,24$ & $-46,74$ & $-170,00$ & - \\
\hline & DMA & 53,19 & 44,93 & 35,71 & 26,48 & 23,68 & 27,92 & 37,25 & 48,82 & 65,36 & 96,36 & 232,34 & - \\
\hline & PDMA & 32,77 & 26,79 & 20,54 & 14,12 & 9,84 & 12,56 & 22,67 & 34,01 & 47,46 & 66,33 & 120,26 & - \\
\hline \multirow[t]{3}{*}{ SPI } & $\mathrm{DM}$ & $-9,15$ & $-7,02$ & $-4,74$ & $-2,28$ & 0,38 & 3,34 & 6,63 & 10,38 & 14,86 & 20,51 & 28,35 & - \\
\hline & DMA & 11,76 & 10,09 & 8,31 & 6,38 & 4,88 & 4,02 & 6,77 & 10,80 & 15,63 & 22,35 & 31,74 & - \\
\hline & PDMA & 23,95 & 20,38 & 16,63 & 12,23 & 8,18 & 7,43 & 10,37 & 17,33 & 27,25 & 41,31 & 61,56 & - \\
\hline \multirow[t]{3}{*}{$\Delta \mathrm{CS}$} & $\mathrm{DM}$ & $-19,02$ & $-20,53$ & $-21,65$ & $-22,56$ & $-23,52$ & $-24,94$ & $-27,40$ & $-32,12$ & $-42,10$ & $-67,25$ & $-198,35$ & 一 \\
\hline & DMA & 41,43 & 34,84 & 27,40 & 20,10 & 18,80 & 23,90 & 30,48 & 38,02 & 49,73 & 74,01 & 200,60 & - \\
\hline & PDMA & 8,82 & 6,41 & 3,91 & 1,89 & 1,66 & 5,13 & 12,30 & 16,68 & 20,21 & 25,02 & 58,70 & - \\
\hline
\end{tabular}


Tabela 8.204: Constantes de acoplamento B971P86 com base aug-pcJ-2.

\begin{tabular}{|c|c|c|c|c|c|c|c|c|c|c|c|c|c|}
\hline & $\% E_{X}^{\mathrm{HF}}$ & $0 \%$ & $10 \%$ & $20 \%$ & $30 \%$ & $40 \%$ & $50 \%$ & $60 \%$ & $70 \%$ & $80 \%$ & $90 \%$ & $100 \%$ & Exp. \\
\hline $\mathrm{HF}$ & ${ }^{1} J_{\mathrm{HF}}$ & 378,0 & 394,5 & 412,1 & 431,0 & 451,1 & 472,7 & 495,6 & 520,0 & 545,9 & 573,3 & 602,2 & 500 \\
\hline $\mathrm{CO}$ & ${ }^{1} J_{\mathrm{CO}}$ & 19,0 & 18,1 & 17,0 & 15,9 & 14,6 & 13,3 & 11,8 & 10,2 & 8,5 & 6,7 & 4,8 & 16,4 \\
\hline $\mathrm{H}_{2} \mathrm{O}$ & ${ }^{1} J_{\mathrm{OH}}$ & $-62,3$ & $-64,4$ & $-66,6$ & $-69,0$ & $-71,6$ & $-74,3$ & $-77,2$ & $-80,4$ & $-83,7$ & $-87,2$ & $-91,0$ & $-80,6$ \\
\hline $\mathrm{H}_{2} \mathrm{O}$ & ${ }^{2} J_{\mathrm{HH}}$ & $-1,0$ & $-2,0$ & $-3,1$ & $-4,3$ & $-5,5$ & $-6,8$ & $-8,2$ & $-9,8$ & $-11,4$ & $-13,2$ & $-15,1$ & $-7,3$ \\
\hline $\mathrm{NH}_{3}$ & ${ }^{1} J_{\mathrm{NH}}$ & 35,1 & 36,0 & 37,0 & 38,1 & 39,2 & 40,4 & 41,7 & 43,1 & 44,6 & 46,1 & 47,8 & 43,8 \\
\hline $\mathrm{NH}_{3}$ & ${ }^{2} J_{\mathrm{HH}}$ & $-4,1$ & $-5,0$ & $-5,9$ & $-6,9$ & $-8,0$ & $-9,2$ & $-10,5$ & $-11,9$ & $-13,4$ & $-15,0$ & $-16,8$ & $-9,6$ \\
\hline $\mathrm{PH}_{3}$ & ${ }^{1} J_{\mathrm{PH}}$ & 130,6 & 136,6 & 143,1 & 150,0 & 157,4 & 165,2 & 173,6 & 182,4 & 191,8 & 201,7 & 212,1 & 188,2 \\
\hline $\mathrm{PF}_{3}$ & ${ }^{1} J_{\mathrm{PF}}$ & $-1654,8$ & $-1648,5$ & $-1636,6$ & $-1620,0$ & $-1599,4$ & $-1575,5$ & $-1548,9$ & $-1520,3$ & $-1490,3$ & $-1459,2$ & $-1427,5$ & -1441 \\
\hline $\mathrm{BHF}_{2}$ & ${ }^{1} J_{\mathrm{BF}}$ & $-159,4$ & $-145,7$ & $-131,7$ & $-117,4$ & $-102,9$ & $-88,2$ & $-73,4$ & $-58,6$ & $-43,7$ & $-28,9$ & $-14,1$ & -84 \\
\hline $\mathrm{BF}_{3}$ & ${ }^{1} J_{\mathrm{BF}}$ & $-72,1$ & $-55,9$ & $-39,5$ & $-23,0$ & $-6,4$ & 10,2 & 26,9 & 43,8 & 60,7 & 77,8 & 94,8 & 15 \\
\hline $\mathrm{F}_{2} \mathrm{O}$ & ${ }^{1} J_{\mathrm{OF}}$ & $-206,1$ & $-239,8$ & $-275,5$ & $-313,8$ & $-356,3$ & $-405,6$ & $-466,5$ & $-549,3$ & $-679,0$ & $-940,6$ & $-1973,1$ & -300 \\
\hline $\mathrm{CH}_{4}$ & ${ }^{1} J_{\mathrm{CH}}$ & 92,9 & 95,8 & 99,0 & 102,4 & 106,0 & 109,8 & 113,9 & 118,3 & 122,9 & 127,8 & 133,0 & 125,3 \\
\hline $\mathrm{CH}_{4}$ & ${ }^{2} J_{\mathrm{HH}}$ & $-7,3$ & $-8,1$ & $-9,0$ & $-10,0$ & $-11,0$ & $-12,1$ & $-13,3$ & $-14,5$ & $-15,9$ & $-17,3$ & $-18,8$ & $-12,8$ \\
\hline $\mathrm{C}_{2} \mathrm{H}_{2}$ & ${ }^{1} J_{\mathrm{CC}}$ & 168,2 & 171,4 & 175,0 & 179,0 & 183,8 & 189,4 & 196,1 & 204,5 & 215,3 & 229,8 & 250,2 & 174,8 \\
\hline $\mathrm{C}_{2} \mathrm{H}_{2}$ & ${ }^{1} J_{\mathrm{CH}}$ & 188,3 & 194,8 & 201,6 & 208,7 & 216,4 & 224,7 & 233,7 & 243,7 & 255,1 & 268,5 & 285,3 & 247,6 \\
\hline $\mathrm{C}_{2} \mathrm{H}_{2}$ & ${ }^{2} J_{\mathrm{CH}}$ & 50,8 & 51,7 & 52,4 & 52,8 & 53,1 & 52,9 & 52,2 & 50,7 & 48,0 & 43,5 & 35,9 & 50,1 \\
\hline $\mathrm{C}_{2} \mathrm{H}_{2}$ & ${ }^{3} J_{\mathrm{HH}}$ & 6,9 & 7,3 & 7,9 & 8,7 & 9,6 & 10,8 & 12,4 & 14,4 & 17,2 & 21,1 & 26,9 & 9,6 \\
\hline $\mathrm{C}_{2} \mathrm{H}_{4}$ & ${ }^{1} J_{\mathrm{CC}}$ & 52,5 & 54,9 & 57,5 & 60,5 & 64,0 & 68,1 & 73,2 & 80,0 & 89,5 & 104,5 & 133,8 & 67,6 \\
\hline $\mathrm{C}_{2} \mathrm{H}_{4}$ & ${ }^{1} J_{\mathrm{CH}}$ & 116,0 & 120,1 & 124,6 & 129,3 & 134,4 & 139,9 & 146,1 & 153,1 & 161,4 & 172,3 & 189,3 & 156,3 \\
\hline $\mathrm{C}_{2} \mathrm{H}_{4}$ & ${ }^{2} J_{\mathrm{CH}}$ & 2,3 & 1,6 & 0,9 & 0,0 & $-1,0$ & $-2,3$ & $-4,1$ & $-6,4$ & $-10,0$ & $-15,9$ & $-27,6$ & $-2,4$ \\
\hline $\mathrm{C}_{2} \mathrm{H}_{4}$ & ${ }^{2} J_{\mathrm{HH}}$ & 5,1 & 4,7 & 4,2 & 3,6 & 2,9 & 2,1 & 0,9 & $-0,5$ & $-2,7$ & $-6,4$ & $-13,5$ & 2,3 \\
\hline $\mathrm{C}_{2} \mathrm{H}_{4}$ & ${ }^{3} J_{\mathrm{HH}_{\mathrm{c}}}$ & 9,3 & 9,6 & 9,9 & 10,3 & 10,9 & 11,5 & 12,4 & 13,7 & 15,6 & 18,9 & 25,7 & 11,7 \\
\hline $\mathrm{C}_{2} \mathrm{H}_{4}$ & ${ }^{3} J_{\mathrm{HH}_{\mathrm{t}}}$ & 13,3 & 13,9 & 14,5 & 15,2 & 16,1 & 17,1 & 18,4 & 20,1 & 22,7 & 26,7 & 34,7 & 19 \\
\hline $\mathrm{C}_{2} \mathrm{H}_{6}$ & ${ }^{1} J_{\mathrm{CC}}$ & 19,7 & 21,6 & 23,7 & 25,9 & 28,3 & 30,7 & 33,3 & 36,1 & 39,0 & 42,1 & 45,4 & 34,5 \\
\hline $\mathrm{C}_{2} \mathrm{H}_{6}$ & ${ }^{1} J_{\mathrm{CH}}$ & 91,9 & 95,1 & 98,6 & 102,2 & 106,1 & 110,2 & 114,6 & 119,3 & 124,2 & 129,4 & 135,0 & 125,2 \\
\hline $\mathrm{C}_{2} \mathrm{H}_{6}$ & ${ }^{2} J_{\mathrm{CH}}$ & $-1,0$ & $-1,4$ & $-2,0$ & $-2,5$ & $-3,1$ & $-3,7$ & $-4,4$ & $-5,1$ & $-5,9$ & $-6,7$ & $-7,6$ & $-4,7$ \\
\hline \multirow[t]{3}{*}{ Total } & $\mathrm{DM}$ & $-24,35$ & $-22,62$ & $-20,61$ & $-18,40$ & $-16,01$ & $-13,60$ & $-11,33$ & $-9,55$ & $-9,18$ & $-13,28$ & $-45,89$ & - \\
\hline & DMA & 35,43 & 30,62 & 25,32 & 20,93 & 18,30 & 15,77 & 15,85 & 19,29 & 26,95 & 42,24 & 90,58 & - \\
\hline & PDMA & 64,00 & 53,77 & 42,77 & 31,67 & 20,82 & 10,70 & 17,71 & 32,84 & 55,41 & 89,08 & 152,34 & - \\
\hline \multirow[t]{3}{*}{ CPI } & $\mathrm{DM}$ & $-39,82$ & $-37,91$ & $-35,51$ & $-32,75$ & $-29,88$ & $-27,15$ & $-25,09$ & $-24,70$ & $-28,26$ & $-43,58$ & $-128,80$ & - \\
\hline & DMA & 62,84 & 53,91 & 44,05 & 35,90 & 32,14 & 28,46 & 29,80 & 38,23 & 53,05 & 81,22 & 182,13 & - \\
\hline & PDMA & 88,51 & 72,54 & 56,00 & 40,35 & 26,82 & 13,16 & 20,21 & 37,80 & 58,46 & 84,60 & 134,69 & - \\
\hline \multirow[t]{3}{*}{ SPI } & $\mathrm{DM}$ & $-13,01$ & $-11,41$ & $-9,69$ & $-7,87$ & $-5,84$ & $-3,67$ & $-1,25$ & 1,55 & 4,82 & 8,95 & 14,91 & - \\
\hline & DMA & 15,33 & 13,54 & 11,58 & 9,95 & 8,16 & 6,45 & 5,62 & 5,41 & 7,81 & 13,65 & 23,45 & - \\
\hline & PDMA & 46,03 & 40,01 & 33,07 & 25,29 & 16,42 & 8,91 & 15,88 & 29,21 & 53,17 & 92,37 & 165,29 & - \\
\hline \multirow[t]{3}{*}{$\Delta \mathrm{CS}$} & $\mathrm{DM}$ & $-26,80$ & $-26,50$ & $-25,82$ & $-24,89$ & $-24,04$ & $-23,49$ & $-23,84$ & $-26,25$ & $-33,08$ & $-52,53$ & $-143,71$ & - \\
\hline & DMA & 47,50 & 40,37 & 32,47 & 25,95 & 23,98 & 22,01 & 24,18 & 32,82 & 45,24 & 67,56 & 158,67 & - \\
\hline & PDMA & 42,47 & 32,53 & 22,93 & 15,06 & 10,40 & 4,25 & 4,34 & 8,59 & 5,29 & $-7,78$ & $-30,60$ & - \\
\hline \multicolumn{14}{|c|}{ Desconsiderando ${ }^{1} J_{\mathrm{BF}}$ da molécula de $\mathrm{BF}_{3},{ }^{2} J_{\mathrm{CH}}$ e ${ }^{2} J_{\mathrm{HH}}$ da molécula de $\mathrm{C}_{2} \mathrm{H}_{4}$} \\
\hline \multirow[t]{3}{*}{ Total } & DM & $-24,07$ & $-22,77$ & $-21,16$ & $-19,30$ & $-17,26$ & $-15,17$ & $-13,20$ & $-11,76$ & $-11,81$ & $-16,77$ & $-53,57$ & - \\
\hline & DMA & 35,94 & 31,25 & 26,03 & 21,84 & 19,67 & 17,60 & 17,27 & 20,26 & 27,93 & 44,05 & 97,15 & - \\
\hline & PDMA & 33,30 & 28,45 & 22,99 & 17,98 & 13,66 & 10,15 & 10,85 & 16,24 & 26,17 & 41,60 & 73,57 & - \\
\hline \multirow[t]{3}{*}{ CPI } & $\mathrm{DM}$ & $-35,09$ & $-34,61$ & $-33,61$ & $-32,23$ & $-30,73$ & $-29,39$ & $-28,79$ & $-30,05$ & $-35,66$ & $-54,22$ & $-149,66$ & - \\
\hline & DMA & 60,41 & 52,21 & 43,01 & 35,69 & 33,21 & 30,83 & 31,59 & 39,17 & 53,78 & 83,06 & 192,36 & - \\
\hline & PDMA & 39,29 & 32,52 & 25,27 & 19,06 & 15,24 & 11,27 & 14,30 & 22,38 & 33,84 & 51,19 & 94,96 & - \\
\hline \multirow[t]{3}{*}{ SPI } & DM & $-15,59$ & $-13,65$ & $-11,58$ & $-9,36$ & $-6,89$ & $-4,22$ & $-1,20$ & 2,32 & 6,53 & 12,03 & 20,35 & - \\
\hline & DMA & 17,12 & 15,13 & 12,96 & 11,19 & 9,26 & 7,42 & 6,25 & 5,72 & 8,04 & 14,05 & 23,91 & - \\
\hline & PDMA & 28,69 & 25,31 & 21,23 & 17,14 & 12,45 & 9,29 & 8,19 & 11,52 & 20,27 & 34,22 & 57,11 & - \\
\hline \multirow[t]{3}{*}{$\Delta \mathrm{CS}$} & $\mathrm{DM}$ & $-19,50$ & $-20,96$ & $-22,03$ & $-22,87$ & $-23,84$ & $-25,17$ & $-27,59$ & $-32,37$ & $-42,19$ & $-66,25$ & $-170,01$ & - \\
\hline & DMA & 43,29 & 37,08 & 30,05 & 24,50 & 23,95 & 23,41 & 25,34 & 33,45 & 45,74 & 69,01 & 168,45 & - \\
\hline & PDMA & 10,61 & 7,21 & 4,04 & 1,91 & 2,78 & 1,98 & 6,11 & 10,86 & 13,57 & 16,97 & 37,85 & - \\
\hline
\end{tabular}


Tabela 8.205: Constantes de acoplamento B971PBE com base aug-pcJ-2.

\begin{tabular}{|c|c|c|c|c|c|c|c|c|c|c|c|c|c|}
\hline & $\% E_{X}^{\mathrm{HF}}$ & $0 \%$ & $10 \%$ & $20 \%$ & $30 \%$ & $40 \%$ & $50 \%$ & $60 \%$ & $70 \%$ & $80 \%$ & $90 \%$ & $100 \%$ & Exp. \\
\hline $\mathrm{HF}$ & ${ }^{1} J_{\mathrm{HF}}$ & 373,6 & 390,4 & 408,5 & 427,8 & 448,4 & 470,5 & 494,0 & 519,0 & 545,5 & 573,6 & 603,3 & 500 \\
\hline $\mathrm{CO}$ & ${ }^{1} J_{\mathrm{CO}}$ & 19,5 & 18,6 & 17,6 & 16,5 & 15,2 & 13,9 & 12,4 & 10,8 & 9,1 & 7,2 & 5,3 & 16,4 \\
\hline $\mathrm{H}_{2} \mathrm{O}$ & ${ }^{1} J_{\mathrm{OH}}$ & $-62,0$ & $-64,2$ & $-66,5$ & $-68,9$ & $-71,5$ & $-74,3$ & $-77,3$ & $-80,5$ & $-83,9$ & $-87,6$ & $-91,5$ & $-80,6$ \\
\hline $\mathrm{H}_{2} \mathrm{O}$ & ${ }^{2} J_{\mathrm{HH}}$ & $-1,3$ & $-2,4$ & $-3,5$ & $-4,7$ & $-6,0$ & $-7,3$ & $-8,8$ & $-10,4$ & $-12,1$ & $-13,9$ & $-15,9$ & $-7,3$ \\
\hline $\mathrm{NH}_{3}$ & ${ }^{1} J_{\mathrm{NH}}$ & 35,1 & 36,0 & 37,0 & 38,1 & 39,3 & 40,6 & 41,9 & 43,3 & 44,8 & 46,4 & 48,2 & 43,8 \\
\hline $\mathrm{NH}_{3}$ & ${ }^{2} J_{\mathrm{HH}}$ & $-4,4$ & $-5,3$ & $-6,3$ & $-7,4$ & $-8,5$ & $-9,8$ & $-11,1$ & $-12,5$ & $-14,1$ & $-15,8$ & $-17,6$ & $-9,6$ \\
\hline $\mathrm{PH}_{3}$ & ${ }^{1} J_{\mathrm{PH}}$ & 129,6 & 135,8 & 142,5 & 149,7 & 157,4 & 165,6 & 174,3 & 183,5 & 193,2 & 203,5 & 214,3 & 188,2 \\
\hline $\mathrm{PF}_{3}$ & ${ }^{1} J_{\mathrm{PF}}$ & $-1659,5$ & $-1652,4$ & $-1639,8$ & $-1622,5$ & $-1601,3$ & $-1576,8$ & $-1549,7$ & $-1520,6$ & $-1490,1$ & $-1458,6$ & $-1426,5$ & -1441 \\
\hline $\mathrm{BHF}_{2}$ & ${ }^{1} J_{\mathrm{BF}}$ & $-160,5$ & $-146,7$ & $-132,6$ & $-118,1$ & $-103,5$ & $-88,7$ & $-73,7$ & $-58,7$ & $-43,7$ & $-28,7$ & $-13,8$ & -84 \\
\hline $\mathrm{BF}_{3}$ & ${ }^{1} J_{\mathrm{BF}}$ & $-73,3$ & $-56,9$ & $-40,4$ & $-23,8$ & $-7,1$ & 9,7 & 26,6 & 43,6 & 60,8 & 77,9 & 95,2 & 15 \\
\hline $\mathrm{F}_{2} \mathrm{O}$ & ${ }^{1} J_{\mathrm{OF}}$ & $-205,8$ & $-240,2$ & $-276,6$ & $-315,9$ & $-359,7$ & $-410,7$ & $-474,4$ & $-562,1$ & $-702,7$ & $-1000,3$ & $-2453,2$ & -300 \\
\hline $\mathrm{CH}_{4}$ & ${ }^{1} J_{\mathrm{CH}}$ & 93,2 & 96,3 & 99,5 & 103,0 & 106,7 & 110,6 & 114,8 & 119,3 & 124,0 & 129,1 & 134,4 & 125,3 \\
\hline $\mathrm{CH}_{4}$ & ${ }^{2} J_{\mathrm{HH}}$ & $-7,7$ & $-8,6$ & $-9,5$ & $-10,5$ & $-11,6$ & $-12,8$ & $-14,0$ & $-15,3$ & $-16,7$ & $-18,2$ & $-19,8$ & $-12,8$ \\
\hline $\mathrm{C}_{2} \mathrm{H}_{2}$ & ${ }^{1} J_{\mathrm{CC}}$ & 167,3 & 170,5 & 174,2 & 178,4 & 183,3 & 189,2 & 196,4 & 205,4 & 217,3 & 233,4 & 257,1 & 174,8 \\
\hline $\mathrm{C}_{2} \mathrm{H}_{2}$ & ${ }^{1} J_{\mathrm{CH}}$ & 189,9 & 196,5 & 203,5 & 210,9 & 218,8 & 227,3 & 236,8 & 247,3 & 259,5 & 274,2 & 293,3 & 247,6 \\
\hline $\mathrm{C}_{2} \mathrm{H}_{2}$ & ${ }^{2} J_{\mathrm{CH}}$ & 51,0 & 51,9 & 52,5 & 52,9 & 53,0 & 52,6 & 51,7 & 49,8 & 46,5 & 40,9 & 31,2 & 50,1 \\
\hline $\mathrm{C}_{2} \mathrm{H}_{2}$ & ${ }^{3} J_{\mathrm{HH}}$ & 7,2 & 7,7 & 8,4 & 9,2 & 10,3 & 11,6 & 13,4 & 15,8 & 19,0 & 23,7 & 30,9 & 9,6 \\
\hline $\mathrm{C}_{2} \mathrm{H}_{4}$ & ${ }^{1} J_{\mathrm{CC}}$ & 52,1 & 54,5 & 57,2 & 60,3 & 63,9 & 68,3 & 73,9 & 81,3 & 92,2 & 110,6 & 150,7 & 67,6 \\
\hline $\mathrm{C}_{2} \mathrm{H}_{4}$ & ${ }^{1} J_{\mathrm{CH}}$ & 116,8 & 121,1 & 125,6 & 130,5 & 135,7 & 141,5 & 147,9 & 155,3 & 164,4 & 177,0 & 199,0 & 156,3 \\
\hline $\mathrm{C}_{2} \mathrm{H}_{4}$ & ${ }^{2} J_{\mathrm{CH}}$ & 2,0 & 1,3 & 0,5 & $-0,4$ & $-1,5$ & $-3,0$ & $-5,0$ & $-7,7$ & $-11,9$ & $-19,4$ & $-36,1$ & $-2,4$ \\
\hline $\mathrm{C}_{2} \mathrm{H}_{4}$ & ${ }^{2} J_{\mathrm{HH}}$ & 4,8 & 4,4 & 3,9 & 3,2 & 2,4 & 1,5 & 0,2 & $-1,5$ & $-4,3$ & $-9,0$ & $-19,4$ & 2,3 \\
\hline $\mathrm{C}_{2} \mathrm{H}_{4}$ & ${ }^{3} J_{\mathrm{HH}_{\mathrm{c}}}$ & 9,5 & 9,8 & 10,2 & 10,6 & 11,2 & 12,0 & 13,0 & 14,5 & 16,9 & 21,3 & 31,3 & 11,7 \\
\hline $\mathrm{C}_{2} \mathrm{H}_{4}$ & ${ }^{3} J_{\mathrm{HH}_{\mathrm{t}}}$ & 13,6 & 14,2 & 14,9 & 15,7 & 16,6 & 17,8 & 19,2 & 21,3 & 24,3 & 29,5 & 41,0 & 19 \\
\hline $\mathrm{C}_{2} \mathrm{H}_{6}$ & ${ }^{1} J_{\mathrm{CC}}$ & 19,5 & 21,5 & 23,6 & 25,8 & 28,2 & 30,7 & 33,3 & 36,1 & 39,1 & 42,2 & 45,6 & 34,5 \\
\hline $\mathrm{C}_{2} \mathrm{H}_{6}$ & ${ }^{1} J_{\mathrm{CH}}$ & 92,4 & 95,7 & 99,3 & 103,0 & 107,0 & 111,2 & 115,7 & 120,5 & 125,5 & 130,9 & 136,6 & 125,2 \\
\hline $\mathrm{C}_{2} \mathrm{H}_{6}$ & ${ }^{2} J_{\mathrm{CH}}$ & $-1,2$ & $-1,7$ & $-2,2$ & $-2,8$ & $-3,4$ & $-4,0$ & $-4,7$ & $-5,5$ & $-6,3$ & $-7,2$ & $-8,1$ & $-4,7$ \\
\hline \multirow[t]{3}{*}{ Total } & DM & $-24,75$ & $-22,97$ & $-20,90$ & $-18,63$ & $-16,22$ & $-13,76$ & $-11,47$ & $-9,73$ & $-9,57$ & $-14,70$ & $-62,67$ & - \\
\hline & DMA & 35,79 & 30,85 & 25,40 & 20,95 & 18,30 & 15,83 & 16,08 & 19,75 & 28,76 & 46,24 & 112,44 & - \\
\hline & PDMA & 62,78 & 52,24 & 40,97 & 29,27 & 18,39 & 11,84 & 21,06 & 38,60 & 64,47 & 104,50 & 190,22 & - \\
\hline \multirow[t]{3}{*}{ CPI } & DM & $-40,90$ & $-38,93$ & $-36,45$ & $-33,65$ & $-30,75$ & $-28,02$ & $-26,06$ & $-25,95$ & $-30,37$ & $-48,84$ & $-172,10$ & - \\
\hline & DMA & 64,01 & 54,85 & 44,78 & 36,66 & 32,84 & 29,16 & 30,65 & 39,23 & 55,39 & 86,96 & 226,41 & - \\
\hline & PDMA & 89,17 & 72,89 & 56,19 & 39,88 & 26,04 & 12,51 & 21,17 & 38,91 & 60,57 & 88,03 & 151,26 & - \\
\hline \multirow[t]{3}{*}{ SPI } & DM & $-12,91$ & $-11,27$ & $-9,50$ & $-7,62$ & $-5,57$ & $-3,31$ & $-0,77$ & 2,17 & 5,69 & 10,33 & 17,57 & - \\
\hline & DMA & 15,10 & 13,24 & 11,19 & 9,42 & 7,65 & 6,05 & 5,41 & 5,46 & 9,23 & 16,38 & 28,87 & - \\
\hline & PDMA & 43,43 & 37,09 & 29,81 & 21,49 & 12,78 & 11,35 & 20,99 & 38,37 & 67,34 & 116,57 & 218,79 & - \\
\hline \multirow[t]{3}{*}{$\Delta \mathrm{CS}$} & DM & $-27,99$ & $-27,66$ & $-26,95$ & $-26,03$ & $-25,18$ & $-24,71$ & $-25,30$ & $-28,12$ & $-36,07$ & $-59,16$ & $-189,67$ & - \\
\hline & DMA & 48,91 & 41,61 & 33,59 & 27,24 & 25,19 & 23,11 & 25,24 & 33,77 & 46,16 & 70,58 & 197,54 & - \\
\hline & PDMA & 45,74 & 35,80 & 26,39 & 18,40 & 13,26 & 1,16 & 0,18 & 0,55 & $-6,77$ & $-28,54$ & $-67,53$ & - \\
\hline \multicolumn{14}{|c|}{ Desconsiderando ${ }^{1} J_{\mathrm{BF}}$ da molécula de $\mathrm{BF}_{3},{ }^{2} J_{\mathrm{CH}}$ e ${ }^{2} J_{\mathrm{HH}}$ da molécula de $\mathrm{C}_{2} \mathrm{H}_{4}$} \\
\hline \multirow[t]{3}{*}{ Total } & DM & $-24,44$ & $-23,09$ & $-21,42$ & $-19,50$ & $-17,42$ & $-15,27$ & $-13,27$ & $-11,85$ & $-12,10$ & $-18,13$ & $-71,93$ & - \\
\hline & DMA & 36,32 & 31,49 & 26,11 & 21,87 & 19,69 & 17,60 & 17,47 & 20,68 & 29,82 & 48,31 & 121,21 & - \\
\hline & PDMA & 32,68 & 27,54 & 21,98 & 16,52 & 12,56 & 9,25 & 11,77 & 18,56 & 29,92 & 47,74 & 89,72 & - \\
\hline \multirow[t]{3}{*}{ CPI } & DM & $-36,16$ & $-35,63$ & $-34,56$ & $-33,13$ & $-31,61$ & $-30,29$ & $-29,83$ & $-31,41$ & $-37,99$ & $-60,01$ & $-197,33$ & - \\
\hline & DMA & 61,58 & 53,15 & 43,72 & 36,45 & 33,91 & 31,55 & 32,55 & 40,29 & 56,35 & 89,37 & 241,03 & - \\
\hline & PDMA & 39,23 & 32,25 & 24,88 & 18,01 & 13,91 & 10,23 & 15,55 & 23,74 & 36,09 & 54,91 & 112,92 & - \\
\hline \multirow[t]{3}{*}{ SPI } & $\mathrm{DM}$ & $-15,43$ & $-13,45$ & $-11,31$ & $-9,02$ & $-6,50$ & $-3,71$ & $-0,52$ & 3,20 & 7,81 & 14,09 & 24,54 & - \\
\hline & DMA & 16,89 & 14,83 & 12,57 & 10,65 & 8,75 & 6,88 & 5,88 & 5,60 & 9,41 & 16,72 & 29,05 & - \\
\hline & PDMA & 27,65 & 23,92 & 19,75 & 15,37 & 11,52 & 8,50 & 8,86 & 14,58 & 25,17 & 42,23 & 71,87 & - \\
\hline \multirow[t]{3}{*}{$\Delta \mathrm{CS}$} & $\mathrm{DM}$ & $-20,73$ & $-22,18$ & $-23,25$ & $-24,11$ & $-25,11$ & $-26,58$ & $-29,31$ & $-34,61$ & $-45,80$ & $-74,10$ & $-221,87$ & 一 \\
\hline & DMA & 44,69 & 38,32 & 31,15 & 25,80 & 25,16 & 24,67 & 26,67 & 34,69 & 46,94 & 72,65 & 211,98 & - \\
\hline & PDMA & 11,58 & 8,33 & 5,13 & 2,63 & 2,38 & 1,73 & 6,69 & 9,16 & 10,92 & 12,68 & 41,06 & - \\
\hline
\end{tabular}


Tabela 8.206: Constantes de acoplamento B971PW91 com base aug-pcJ-2.

\begin{tabular}{|c|c|c|c|c|c|c|c|c|c|c|c|c|c|}
\hline & $\% E_{X}^{\mathrm{HF}}$ & $0 \%$ & $10 \%$ & $20 \%$ & $30 \%$ & $40 \%$ & $50 \%$ & $60 \%$ & $70 \%$ & $80 \%$ & $90 \%$ & $100 \%$ & Exp. \\
\hline $\mathrm{HF}$ & ${ }^{1} J_{\mathrm{HF}}$ & 376,0 & 392,9 & 411,0 & 430,4 & 451,1 & 473,2 & 496,8 & 521,8 & 548,4 & 576,5 & 606,3 & 500 \\
\hline $\mathrm{CO}$ & ${ }^{1} J_{\mathrm{CO}}$ & 19,4 & 18,4 & 17,4 & 16,3 & 15,0 & 13,6 & 12,1 & 10,5 & 8,7 & 6,9 & 4,9 & 16,4 \\
\hline $\mathrm{H}_{2} \mathrm{O}$ & ${ }^{1} J_{\mathrm{OH}}$ & $-62,4$ & $-64,5$ & $-66,8$ & $-69,3$ & $-71,9$ & $-74,7$ & $-77,7$ & $-80,9$ & $-84,4$ & $-88,0$ & $-91,9$ & $-80,6$ \\
\hline $\mathrm{H}_{2} \mathrm{O}$ & ${ }^{2} J_{\mathrm{HH}}$ & $-1,3$ & $-2,4$ & $-3,5$ & $-4,7$ & $-6,0$ & $-7,4$ & $-8,8$ & $-10,4$ & $-12,1$ & $-14,0$ & $-16,0$ & $-7,3$ \\
\hline $\mathrm{NH}_{3}$ & ${ }^{1} J_{\mathrm{NH}}$ & 35,3 & 36,2 & 37,2 & 38,3 & 39,5 & 40,8 & 42,1 & 43,5 & 45,0 & 46,7 & 48,4 & 43,8 \\
\hline $\mathrm{NH}_{3}$ & ${ }^{2} J_{\mathrm{HH}}$ & $-4,4$ & $-5,3$ & $-6,3$ & $-7,4$ & $-8,5$ & $-9,8$ & $-11,1$ & $-12,6$ & $-14,1$ & $-15,8$ & $-17,7$ & $-9,6$ \\
\hline $\mathrm{PH}_{3}$ & ${ }^{1} J_{\mathrm{PH}}$ & 130,5 & 136,8 & 143,5 & 150,7 & 158,4 & 166,7 & 175,4 & 184,6 & 194,4 & 204,7 & 215,5 & 188,2 \\
\hline $\mathrm{PF}_{3}$ & ${ }^{1} J_{\mathrm{PF}}$ & $-1662,6$ & $-1655,4$ & $-1642,7$ & $-1625,3$ & $-1603,9$ & $-1579,3$ & $-1552,1$ & $-1522,9$ & $-1492,3$ & $-1460,7$ & $-1428,5$ & -1441 \\
\hline $\mathrm{BHF}_{2}$ & ${ }^{1} J_{\mathrm{BF}}$ & $-159,8$ & $-145,9$ & $-131,7$ & $-117,2$ & $-102,5$ & $-87,6$ & $-72,7$ & $-57,6$ & $-42,6$ & $-27,5$ & $-12,5$ & -84 \\
\hline $\mathrm{BF}_{3}$ & ${ }^{1} J_{\mathrm{BF}}$ & $-72,4$ & $-56,0$ & $-39,5$ & $-22,8$ & $-6,0$ & 10,8 & 27,8 & 44,9 & 62,0 & 79,3 & 96,6 & 15 \\
\hline $\mathrm{F}_{2} \mathrm{O}$ & ${ }^{1} J_{\mathrm{OF}}$ & $-205,6$ & $-240,1$ & $-276,5$ & $-315,8$ & $-359,5$ & $-410,5$ & $-474,2$ & $-562,1$ & $-703,3$ & $-1004,2$ & $-2525,8$ & -300 \\
\hline $\mathrm{CH}_{4}$ & ${ }^{1} J_{\mathrm{CH}}$ & 93,8 & 96,8 & 100,1 & 103,6 & 107,3 & 111,3 & 115,5 & 120,0 & 124,7 & 129,8 & 135,2 & 125,3 \\
\hline $\mathrm{CH}_{4}$ & ${ }^{2} J_{\mathrm{HH}}$ & $-7,7$ & $-8,6$ & $-9,5$ & $-10,6$ & $-11,6$ & $-12,8$ & $-14,0$ & $-15,3$ & $-16,7$ & $-18,2$ & $-19,9$ & $-12,8$ \\
\hline $\mathrm{C}_{2} \mathrm{H}_{2}$ & ${ }^{1} J_{\mathrm{CC}}$ & 168,3 & 171,6 & 175,3 & 179,6 & 184,5 & 190,5 & 197,7 & 206,9 & 218,8 & 235,2 & 259,0 & 174,8 \\
\hline $\mathrm{C}_{2} \mathrm{H}_{2}$ & ${ }^{1} J_{\mathrm{CH}}$ & 190,9 & 197,5 & 204,5 & 211,9 & 219,9 & 228,5 & 237,9 & 248,5 & 260,7 & 275,5 & 294,6 & 247,6 \\
\hline $\mathrm{C}_{2} \mathrm{H}_{2}$ & ${ }^{2} J_{\mathrm{CH}}$ & 51,1 & 51,9 & 52,5 & 52,9 & 53,0 & 52,7 & 51,7 & 49,8 & 46,5 & 40,8 & 31,2 & 50,1 \\
\hline $\mathrm{C}_{2} \mathrm{H}_{2}$ & ${ }^{3} J_{\mathrm{HH}}$ & 7,2 & 7,7 & 8,3 & 9,2 & 10,2 & 11,6 & 13,3 & 15,7 & 19,0 & 23,6 & 30,7 & 9,6 \\
\hline $\mathrm{C}_{2} \mathrm{H}_{4}$ & ${ }^{1} J_{\mathrm{CC}}$ & 52,6 & 55,0 & 57,7 & 60,8 & 64,5 & 69,0 & 74,6 & 82,1 & 93,1 & 111,6 & 152,0 & 67,6 \\
\hline $\mathrm{C}_{2} \mathrm{H}_{4}$ & ${ }^{1} J_{\mathrm{CH}}$ & 117,4 & 121,7 & 126,3 & 131,2 & 136,5 & 142,2 & 148,7 & 156,2 & 165,3 & 177,9 & 200,0 & 156,3 \\
\hline $\mathrm{C}_{2} \mathrm{H}_{4}$ & ${ }^{2} J_{\mathrm{CH}}$ & 2,0 & 1,3 & 0,5 & $-0,4$ & $-1,5$ & $-3,0$ & $-5,0$ & $-7,7$ & $-12,0$ & $-19,4$ & $-36,2$ & $-2,4$ \\
\hline $\mathrm{C}_{2} \mathrm{H}_{4}$ & ${ }^{2} J_{\mathrm{HH}}$ & 4,9 & 4,4 & 3,9 & 3,3 & 2,5 & 1,5 & 0,2 & $-1,5$ & $-4,2$ & $-8,9$ & $-19,2$ & 2,3 \\
\hline $\mathrm{C}_{2} \mathrm{H}_{4}$ & ${ }^{3} J_{\mathrm{HH}_{\mathrm{c}}}$ & 9,5 & 9,8 & 10,2 & 10,6 & 11,2 & 11,9 & 13,0 & 14,5 & 16,9 & 21,2 & 31,2 & 11,7 \\
\hline $\mathrm{C}_{2} \mathrm{H}_{4}$ & ${ }^{3} J_{\mathrm{HH}_{\mathrm{t}}}$ & 13,6 & 14,2 & 14,9 & 15,7 & 16,6 & 17,8 & 19,2 & 21,3 & 24,3 & 29,5 & 40,9 & 19 \\
\hline $\mathrm{C}_{2} \mathrm{H}_{6}$ & ${ }^{1} J_{\mathrm{CC}}{ }^{2}$ & 19,8 & 21,8 & 23,9 & 26,2 & 28,5 & 31,1 & 33,7 & 36,5 & 39,5 & 42,7 & 46,1 & 34,5 \\
\hline $\mathrm{C}_{2} \mathrm{H}_{6}$ & ${ }^{1} J_{\mathrm{CH}}$ & 92,9 & 96,3 & 99,8 & 103,6 & 107,6 & 111,8 & 116,4 & 121,1 & 126,2 & 131,6 & 137,3 & 125,2 \\
\hline $\mathrm{C}_{2} \mathrm{H}_{6}$ & ${ }^{2} J_{\mathrm{CH}}$ & $-1,2$ & $-1,7$ & $-2,2$ & $-2,8$ & $-3,4$ & $-4,0$ & $-4,7$ & $-5,5$ & $-6,3$ & $-7,2$ & $-8,1$ & $-4,7$ \\
\hline \multirow[t]{3}{*}{ Total } & $\mathrm{DM}$ & $-24,51$ & $-22,72$ & $-20,64$ & $-18,35$ & $-15,90$ & $-13,43$ & $-11,12$ & $-9,37$ & $-9,21$ & $-14,44$ & $-65,03$ & - \\
\hline & DMA & 35,54 & 30,56 & 25,15 & 20,72 & 18,05 & 15,62 & 16,02 & 20,05 & 29,34 & 47,03 & 115,74 & - \\
\hline & PDMA & 62,46 & 51,71 & 40,50 & 28,92 & 18,04 & 11,48 & 21,32 & 39,12 & 65,19 & 105,19 & 191,82 & - \\
\hline \multirow[t]{3}{*}{ CPI } & DM & $-40,75$ & $-38,75$ & $-36,25$ & $-33,43$ & $-30,47$ & $-27,74$ & $-25,75$ & $-25,65$ & $-30,11$ & $-48,82$ & $-178,33$ & - \\
\hline & DMA & 63,80 & 54,60 & 44,51 & 36,35 & 32,49 & 28,81 & 30,66 & 39,85 & 56,33 & 88,22 & 233,56 & - \\
\hline & PDMA & 88,35 & 72,00 & 55,29 & 39,01 & 25,20 & 11,84 & 21,99 & 40,08 & 61,87 & 89,65 & 155,08 & - \\
\hline \multirow[t]{3}{*}{ SPI } & DM & $-12,60$ & $-10,96$ & $-9,19$ & $-7,29$ & $-5,22$ & $-2,93$ & $-0,39$ & 2,57 & 6,11 & 10,77 & 18,05 & - \\
\hline & DMA & 14,81 & 12,93 & 10,95 & 9,25 & 7,46 & 5,95 & 5,29 & 5,53 & 9,55 & 16,83 & 29,34 & - \\
\hline & PDMA & 43,48 & 36,83 & 29,65 & 21,52 & 12,80 & 11,22 & 20,82 & 38,42 & 67,62 & 116,58 & 218,77 & - \\
\hline \multirow[t]{3}{*}{$\Delta \mathrm{CS}$} & $\mathrm{DM}$ & $-28,15$ & $-27,79$ & $-27,06$ & $-26,14$ & $-25,25$ & $-24,80$ & $-25,36$ & $-28,21$ & $-36,22$ & $-59,59$ & $-196,37$ & - \\
\hline & DMA & 48,99 & 41,67 & 33,56 & 27,11 & 25,03 & 22,86 & 25,38 & 34,32 & 46,77 & 71,39 & 204,22 & - \\
\hline & PDMA & 44,87 & 35,17 & 25,64 & 17,49 & 12,40 & 0,62 & 1,17 & 1,65 & $-5,74$ & $-26,93$ & $-63,69$ & - \\
\hline \multicolumn{14}{|c|}{ Desconsiderando ${ }^{1} J_{\mathrm{BF}}$ da molécula de $\mathrm{BF}_{3},{ }^{2} J_{\mathrm{CH}}$ e ${ }^{2} J_{\mathrm{HH}}$ da molécula de $\mathrm{C}_{2} \mathrm{H}_{4}$} \\
\hline \multirow[t]{3}{*}{ Total } & $\mathrm{DM}$ & $-24,21$ & $-22,84$ & $-21,16$ & $-19,23$ & $-17,11$ & $-14,93$ & $-12,93$ & $-11,50$ & $-11,76$ & $-17,89$ & $-74,66$ & - \\
\hline & DMA & 36,07 & 31,21 & 25,87 & 21,64 & 19,44 & 17,41 & 17,35 & 20,97 & 30,43 & 49,14 & 124,89 & - \\
\hline & PDMA & 32,39 & 27,20 & 21,71 & 16,23 & 12,30 & 9,16 & 11,71 & 18,77 & 30,39 & 48,30 & 91,32 & - \\
\hline \multirow[t]{3}{*}{ CPI } & DM & $-36,08$ & $-35,52$ & $-34,43$ & $-32,99$ & $-31,42$ & $-30,09$ & $-29,61$ & $-31,20$ & $-37,82$ & $-60,13$ & $-204,32$ & - \\
\hline & DMA & 61,44 & 52,96 & 43,51 & 36,21 & 33,64 & 31,27 & 32,45 & 40,84 & 57,26 & 90,61 & 248,76 & - \\
\hline & PDMA & 38,92 & 31,87 & 24,49 & 17,71 & 13,72 & 10,22 & 15,65 & 24,15 & 36,73 & 55,75 & 116,19 & - \\
\hline \multirow[t]{3}{*}{ SPI } & DM & $-15,08$ & $-13,09$ & $-10,95$ & $-8,64$ & $-6,11$ & $-3,28$ & $-0,09$ & 3,66 & 8,29 & 14,60 & 25,08 & - \\
\hline & DMA & 16,55 & 14,48 & 12,29 & 10,44 & 8,52 & 6,75 & 5,74 & 5,68 & 9,78 & 17,25 & 29,60 & - \\
\hline & PDMA & 27,37 & 23,62 & 19,57 & 15,08 & 11,21 & 8,34 & 8,67 & 14,64 & 25,51 & 42,57 & 72,19 & - \\
\hline \multirow[t]{3}{*}{$\Delta \mathrm{CS}$} & DM & $-21,00$ & $-22,43$ & $-23,48$ & $-24,35$ & $-25,31$ & $-26,81$ & $-29,52$ & $-34,86$ & $-46,11$ & $-74,73$ & $-229,40$ & - \\
\hline & DMA & 44,89 & 38,48 & 31,22 & 25,77 & 25,12 & 24,52 & 26,71 & 35,16 & 47,48 & 73,36 & 219,16 & - \\
\hline & PDMA & 11,55 & 8,25 & 4,92 & 2,63 & 2,50 & 1,88 & 6,99 & 9,51 & 11,22 & 13,18 & 44,00 & - \\
\hline
\end{tabular}


Tabela 8.207: Constantes de acoplamento B971TPSS com base aug-pcJ-2.

\begin{tabular}{|c|c|c|c|c|c|c|c|c|c|c|c|c|c|}
\hline & $\% E_{X}^{\mathrm{HF}}$ & $0 \%$ & $10 \%$ & $20 \%$ & $30 \%$ & $40 \%$ & $50 \%$ & $60 \%$ & $70 \%$ & $80 \%$ & $90 \%$ & $100 \%$ & Exp. \\
\hline $\mathrm{HF}$ & ${ }^{1} J_{\mathrm{HF}}$ & 374,5 & 392,1 & 410,9 & 430,9 & 452,3 & 474,9 & 499,0 & 524,5 & 551,5 & 580,0 & 610,0 & 500 \\
\hline $\mathrm{CO}$ & ${ }^{1} J_{\mathrm{CO}}$ & 19,3 & 18,4 & 17,4 & 16,2 & 15,0 & 13,6 & 12,1 & 10,5 & 8,7 & 6,9 & 4,9 & 16,4 \\
\hline $\mathrm{H}_{2} \mathrm{O}$ & ${ }^{1} J_{\mathrm{OH}}$ & $-62,9$ & $-65,1$ & $-67,5$ & $-70,1$ & $-72,8$ & $-75,8$ & $-78,9$ & $-82,2$ & $-85,7$ & $-89,4$ & $-93,4$ & $-80,6$ \\
\hline $\mathrm{H}_{2} \mathrm{O}$ & ${ }^{2} J_{\mathrm{HH}}$ & $-1,0$ & $-2,1$ & $-3,2$ & $-4,5$ & $-5,8$ & $-7,3$ & $-8,8$ & $-10,5$ & $-12,2$ & $-14,2$ & $-16,2$ & $-7,3$ \\
\hline $\mathrm{NH}_{3}$ & ${ }^{1} J_{\mathrm{NH}}$ & 36,3 & 37,3 & 38,4 & 39,6 & 40,8 & 42,1 & 43,5 & 45,0 & 46,6 & 48,3 & 50,1 & 43,8 \\
\hline $\mathrm{NH}_{3}$ & ${ }^{2} J_{\mathrm{HH}}$ & $-3,9$ & $-4,9$ & $-5,9$ & $-7,0$ & $-8,2$ & $-9,6$ & $-11,0$ & $-12,5$ & $-14,2$ & $-16,0$ & $-17,9$ & $-9,6$ \\
\hline $\mathrm{PH}_{3}$ & ${ }^{1} J_{\mathrm{PH}}$ & 138,8 & 145,7 & 153,1 & 161,1 & 169,5 & 178,6 & 188,2 & 198,4 & 209,2 & 220,6 & 232,6 & 188,2 \\
\hline $\mathrm{PF}_{3}$ & ${ }^{1} J_{\mathrm{PF}}$ & $-1663,2$ & $-1656,7$ & $-1644,8$ & $-1628,1$ & $-1607,4$ & $-1583,4$ & $-1556,8$ & $-1528,1$ & $-1498,0$ & $-1466,9$ & $-1435,2$ & -1441 \\
\hline $\mathrm{BHF}_{2}$ & ${ }^{1} J_{\mathrm{BF}}$ & $-161,0$ & $-147,4$ & $-133,3$ & $-119,1$ & $-104,6$ & $-90,0$ & $-75,2$ & $-60,5$ & $-45,8$ & $-31,1$ & $-16,4$ & -84 \\
\hline $\mathrm{BF}_{3}$ & ${ }^{1} J_{\mathrm{BF}}$ & $-70,5$ & $-54,3$ & $-37,8$ & $-21,3$ & $-4,7$ & 11,9 & 28,6 & 45,5 & 62,4 & 79,3 & 96,3 & 15 \\
\hline $\mathrm{F}_{2} \mathrm{O}$ & ${ }^{1} J_{\mathrm{OF}}$ & $-203,8$ & $-238,3$ & $-274,7$ & $-313,9$ & $-357,4$ & $-408,1$ & $-471,2$ & $-557,8$ & $-696,2$ & $-988,0$ & $-2403,5$ & -300 \\
\hline $\mathrm{CH}_{4}$ & ${ }^{1} J_{\mathrm{CH}}$ & 100,1 & 103,4 & 106,9 & 110,7 & 114,7 & 119,0 & 123,6 & 128,4 & 133,6 & 139,1 & 144,9 & 125,3 \\
\hline $\mathrm{CH}_{4}$ & ${ }^{2} J_{\mathrm{HH}}$ & $-7,0$ & $-7,9$ & $-8,9$ & $-10,0$ & $-11,2$ & $-12,4$ & $-13,8$ & $-15,2$ & $-16,8$ & $-18,4$ & $-20,2$ & $-12,8$ \\
\hline $\mathrm{C}_{2} \mathrm{H}_{2}$ & ${ }^{1} J_{\mathrm{CC}}$ & 167,9 & 171,2 & 175,0 & 179,3 & 184,4 & 190,6 & 198,1 & 207,6 & 220,0 & 237,1 & 262,1 & 174,8 \\
\hline $\mathrm{C}_{2} \mathrm{H}_{2}$ & ${ }^{1} J_{\mathrm{CH}}$ & 202,2 & 209,2 & 216,7 & 224,7 & 233,2 & 242,4 & 252,5 & 263,8 & 276,8 & 292,6 & 312,9 & 247,6 \\
\hline $\mathrm{C}_{2} \mathrm{H}_{2}$ & ${ }^{2} J_{\mathrm{CH}}$ & 52,6 & 53,5 & 54,1 & 54,5 & 54,6 & 54,2 & 53,1 & 51,1 & 47,6 & 41,6 & 31,5 & 50,1 \\
\hline $\mathrm{C}_{2} \mathrm{H}_{2}$ & ${ }^{3} J_{\mathrm{HH}}$ & 7,5 & 8,0 & 8,7 & 9,5 & 10,6 & 12,0 & 13,8 & 16,2 & 19,6 & 24,4 & 31,8 & 9,6 \\
\hline $\mathrm{C}_{2} \mathrm{H}_{4}$ & ${ }^{1} J_{\mathrm{CC}}$ & 53,1 & 55,5 & 58,4 & 61,6 & 65,4 & 69,9 & 75,7 & 83,5 & 94,8 & 113,6 & 153,5 & 67,6 \\
\hline $\mathrm{C}_{2} \mathrm{H}_{4}$ & ${ }^{1} J_{\mathrm{CH}}$ & 124,7 & 129,4 & 134,3 & 139,5 & 145,2 & 151,5 & 158,4 & 166,4 & 176,1 & 189,3 & 211,7 & 156,3 \\
\hline $\mathrm{C}_{2} \mathrm{H}_{4}$ & ${ }^{2} J_{\mathrm{CH}}$ & 2,1 & 1,3 & 0,5 & $-0,4$ & $-1,7$ & $-3,3$ & $-5,3$ & $-8,2$ & $-12,6$ & $-20,2$ & $-36,8$ & $-2,4$ \\
\hline $\mathrm{C}_{2} \mathrm{H}_{4}$ & ${ }^{2} J_{\mathrm{HH}}$ & 6,3 & 5,8 & 5,3 & 4,6 & 3,8 & 2,8 & 1,5 & $-0,2$ & $-2,9$ & $-7,6$ & $-17,4$ & 2,3 \\
\hline $\mathrm{C}_{2} \mathrm{H}_{4}$ & ${ }^{3} J_{\mathrm{HH}_{\mathrm{c}}}$ & 10,1 & 10,4 & 10,8 & 11,3 & 11,9 & 12,7 & 13,7 & 15,2 & 17,6 & 21,8 & 31,3 & 11,7 \\
\hline $\mathrm{C}_{2} \mathrm{H}_{4}$ & ${ }^{3} J_{\mathrm{HH}_{\mathrm{t}}}$ & 15,1 & 15,7 & 16,5 & 17,3 & 18,2 & 19,4 & 20,9 & 23,0 & 26,1 & 31,2 & 42,2 & 19 \\
\hline $\mathrm{C}_{2} \mathrm{H}_{6}$ & ${ }^{1} J_{\mathrm{CC}}$ & 20,4 & 22,4 & 24,5 & 26,8 & 29,2 & 31,7 & 34,4 & 37,2 & 40,3 & 43,5 & 46,9 & 34,5 \\
\hline $\mathrm{C}_{2} \mathrm{H}_{6}$ & ${ }^{1} J_{\mathrm{CH}}$ & 98,9 & 102,6 & 106,4 & 110,5 & 114,8 & 119,4 & 124,3 & 129,5 & 135,0 & 140,9 & 147,1 & 125,2 \\
\hline $\mathrm{C}_{2} \mathrm{H}_{6}$ & ${ }^{2} J_{\mathrm{CH}}$ & $-1,2$ & $-1,7$ & $-2,2$ & $-2,8$ & $-3,5$ & $-4,1$ & $-4,9$ & $-5,7$ & $-6,5$ & $-7,5$ & $-8,5$ & $-4,7$ \\
\hline \multirow[t]{3}{*}{ Total } & $\mathrm{DM}$ & $-22,68$ & $-20,83$ & $-18,67$ & $-16,31$ & $-13,80$ & $-11,24$ & $-8,83$ & $-6,93$ & $-6,54$ & $-11,31$ & $-57,72$ & - \\
\hline & DMA & 34,15 & 29,10 & 23,57 & 18,91 & 16,18 & 13,73 & 14,49 & 21,55 & 31,86 & 49,47 & 113,73 & - \\
\hline & PDMA & 63,51 & 52,59 & 41,20 & 29,38 & 18,37 & 10,20 & 19,47 & 39,60 & 66,66 & 107,15 & 191,26 & - \\
\hline \multirow[t]{3}{*}{ CPI } & DM & $-39,85$ & $-37,84$ & $-35,30$ & $-32,46$ & $-29,47$ & $-26,73$ & $-24,67$ & $-24,42$ & $-28,60$ & $-46,49$ & $-166,33$ & - \\
\hline & DMA & 63,26 & 54,04 & 43,88 & 35,35 & 31,42 & 27,60 & 29,05 & 40,76 & 57,85 & 89,05 & 223,67 & - \\
\hline & PDMA & 87,54 & 71,24 & 54,47 & 38,08 & 24,20 & 10,07 & 20,96 & 40,76 & 63,06 & 90,57 & 152,58 & - \\
\hline \multirow[t]{3}{*}{ SPI } & DM & $-10,09$ & $-8,35$ & $-6,47$ & $-4,47$ & $-2,30$ & 0,11 & 2,79 & 5,90 & 9,64 & 14,49 & 21,93 & - \\
\hline & DMA & 12,79 & 10,82 & 8,67 & 6,85 & 5,01 & 3,55 & 3,81 & 7,46 & 12,80 & 20,43 & 33,11 & - \\
\hline & PDMA & 45,88 & 38,91 & 31,47 & 23,00 & 14,10 & 10,29 & 18,37 & 38,74 & 69,29 & 119,31 & 219,63 & - \\
\hline \multirow[t]{3}{*}{$\Delta \mathrm{CS}$} & DM & $-29,76$ & $-29,48$ & $-28,83$ & $-28,00$ & $-27,17$ & $-26,84$ & $-27,47$ & $-30,32$ & $-38,24$ & $-60,98$ & $-188,25$ & - \\
\hline & DMA & 50,47 & 43,22 & 35,21 & 28,50 & 26,41 & 24,05 & 25,25 & 33,30 & 45,05 & 68,62 & 190,56 & - \\
\hline & PDMA & 41,66 & 32,33 & 22,99 & 15,08 & 10,10 & $-0,22$ & 2,60 & 2,02 & $-6,23$ & $-28,74$ & $-67,05$ & - \\
\hline \multicolumn{14}{|c|}{ Desconsiderando ${ }^{1} J_{\mathrm{BF}}$ da molécula de $\mathrm{BF}_{3},{ }^{2} J_{\mathrm{CH}}$ e ${ }^{2} J_{\mathrm{HH}}$ da molécula de $\mathrm{C}_{2} \mathrm{H}_{4}$} \\
\hline \multirow[t]{3}{*}{ Total } & DM & $-22,29$ & $-20,84$ & $-19,07$ & $-17,05$ & $-14,83$ & $-12,56$ & $-10,41$ & $-8,80$ & $-8,78$ & $-14,38$ & $-66,43$ & - \\
\hline & DMA & 34,51 & 29,57 & 24,09 & 19,61 & 17,34 & 15,32 & 15,63 & 22,67 & 33,29 & 51,92 & 122,68 & - \\
\hline & PDMA & 31,29 & 26,04 & 20,35 & 14,72 & 10,96 & 8,05 & 11,30 & 20,69 & 33,30 & 51,53 & 93,09 & - \\
\hline \multirow[t]{3}{*}{ CPI } & DM & $-35,28$ & $-34,69$ & $-33,55$ & $-32,08$ & $-30,45$ & $-29,09$ & $-28,50$ & $-29,91$ & $-36,20$ & $-57,57$ & $-191,09$ & - \\
\hline & DMA & 61,04 & 52,51 & 42,99 & 35,26 & 32,59 & 30,05 & 30,60 & 41,79 & 58,90 & 91,53 & 237,91 & - \\
\hline & PDMA & 39,29 & 32,16 & 24,71 & 17,69 & 13,49 & 9,01 & 13,99 & 24,50 & 37,77 & 56,76 & 113,64 & - \\
\hline \multirow[t]{3}{*}{ SPI } & $\mathrm{DM}$ & $-12,29$ & $-10,19$ & $-7,92$ & $-5,48$ & $-2,82$ & 0,16 & 3,51 & 7,45 & 12,31 & 18,85 & 29,46 & - \\
\hline & DMA & 14,11 & 11,93 & 9,55 & 7,58 & 5,61 & 3,99 & 4,11 & 7,97 & 13,58 & 21,45 & 34,05 & - \\
\hline & PDMA & 25,14 & 21,33 & 16,99 & 12,43 & 9,01 & 7,32 & 9,22 & 17,75 & 29,87 & 47,51 & 77,27 & - \\
\hline \multirow[t]{3}{*}{$\Delta \mathrm{CS}$} & $\mathrm{DM}$ & $-22,99$ & $-24,50$ & $-25,63$ & $-26,60$ & $-27,63$ & $-29,25$ & $-32,01$ & $-37,36$ & $-48,51$ & $-76,42$ & $-220,55$ & - \\
\hline & DMA & 46,93 & 40,58 & 33,44 & 27,68 & 26,98 & 26,06 & 26,49 & 33,82 & 45,32 & 70,08 & 203,86 & - \\
\hline & PDMA & 14,16 & 10,83 & 7,72 & 5,26 & 4,48 & 1,69 & 4,77 & 6,75 & 7,90 & 9,25 & 36,37 & - \\
\hline
\end{tabular}

Tabela 8.208: Valores de PDMA total obtidos para troca B971 com base HuzIII-su3.

\begin{tabular}{lccccccccccc}
\hline$E_{X}^{\mathrm{HF}}(\%)$ & $0 \%$ & $10 \%$ & $20 \%$ & $30 \%$ & $40 \%$ & $50 \%$ & $60 \%$ & $70 \%$ & $80 \%$ & $90 \%$ & $100 \%$ \\
\hline B971B95 & 64,8 & 54,9 & 44,6 & 34,4 & 24,0 & 13,6 & 12,8 & 23,1 & 40,1 & 62,0 & 92,6 \\
B971B98 & 56,8 & 47,1 & 37,1 & 26,6 & 16,5 & 12,7 & 22,3 & 39,3 & 60,5 & 88,7 & 132,9 \\
B971B971 & 57,6 & 47,9 & 38,1 & 27,3 & 17,4 & 13,6 & 20,8 & 36,1 & 55,9 & 81,9 & 119,3 \\
B971B972 & 57,5 & 47,9 & 38,1 & 28,0 & 24,7 & 25,4 & 28,8 & 39,2 & 55,9 & 80,8 & 119,3 \\
B971LYP & 58,2 & 48,1 & 37,5 & 26,0 & 15,1 & 12,1 & 23,5 & 42,2 & 66,0 & 99,3 & 161,6 \\
B971P86 & 63,4 & 53,2 & 42,7 & 31,4 & 20,3 & 11,6 & 17,8 & 33,5 & 56,2 & 90,4 & 156,5 \\
B971PBE & 62,2 & 51,9 & 40,6 & 28,9 & 17,9 & 13,9 & 21,3 & 39,4 & 65,4 & 106,3 & 195,8 \\
B971PW91 & 61,8 & 51,3 & 40,3 & 28,5 & 17,4 & 13,5 & 21,5 & 39,9 & 66,1 & 107,1 & 197,7 \\
B971TPSS & 63,1 & 52,3 & 41,1 & 28,9 & 17,8 & 11,4 & 20,1 & 40,2 & 67,8 & 109,3 & 197,2 \\
\hline
\end{tabular}




\subsubsection{Troca B972}

Tabela 8.209: Constantes de acoplamento B972B95 com base aug-pcJ-2.

\begin{tabular}{|c|c|c|c|c|c|c|c|c|c|c|c|c|c|}
\hline & $\% E_{X}^{\mathrm{HF}}$ & $0 \%$ & $10 \%$ & $20 \%$ & $30 \%$ & $40 \%$ & $50 \%$ & $60 \%$ & $70 \%$ & $80 \%$ & $90 \%$ & $100 \%$ & Exp. \\
\hline $\mathrm{HF}$ & ${ }^{1} J_{\mathrm{HF}}$ & 381,5 & 401,6 & 423,0 & 445,7 & 469,9 & 495,5 & 522,7 & 551,5 & 581,8 & 613,8 & 647,4 & 500 \\
\hline $\mathrm{CO}$ & ${ }^{1} J_{\mathrm{CO}}$ & 21,6 & 20,4 & 19,0 & 17,5 & 15,9 & 14,0 & 12,0 & 9,9 & 7,6 & 5,1 & 2,4 & 16,4 \\
\hline $\mathrm{H}_{2} \mathrm{O}$ & ${ }^{1} J_{\mathrm{OH}}$ & $-61,3$ & $-63,9$ & $-66,6$ & $-69,6$ & $-72,7$ & $-76,0$ & $-79,6$ & $-83,4$ & $-87,4$ & $-91,6$ & $-96,2$ & $-80,6$ \\
\hline $\mathrm{H}_{2} \mathrm{O}$ & ${ }^{2} J_{\mathrm{HH}}$ & $-1,3$ & $-2,3$ & $-3,3$ & $-4,4$ & $-5,6$ & $-6,9$ & $-8,2$ & $-9,7$ & $-11,2$ & $-12,9$ & $-14,7$ & $-7,3$ \\
\hline $\mathrm{NH}_{3}$ & ${ }^{1} J_{\mathrm{NH}}$ & 33,6 & 34,8 & 36,0 & 37,4 & 38,8 & 40,3 & 42,0 & 43,7 & 45,5 & 47,5 & 49,5 & 43,8 \\
\hline $\mathrm{NH}_{3}$ & ${ }^{2} J_{\mathrm{HH}}$ & $-3,8$ & $-4,6$ & $-5,5$ & $-6,4$ & $-7,5$ & $-8,6$ & $-9,8$ & $-11,1$ & $-12,6$ & $-14,1$ & $-15,8$ & $-9,6$ \\
\hline $\mathrm{PH}_{3}$ & ${ }^{1} J_{\mathrm{PH}}$ & 136,6 & 142,8 & 149,4 & 156,4 & 163,8 & 171,6 & 179,9 & 188,5 & 197,6 & 207,1 & 217,0 & 188,2 \\
\hline $\mathrm{PF}_{3}$ & ${ }^{1} J_{\mathrm{PF}}$ & $-1539,8$ & $-1537,8$ & $-1530,9$ & $-1519,7$ & $-1504,8$ & $-1486,9$ & $-1466,6$ & $-1444,6$ & $-1421,3$ & $-1397,2$ & $-1372,8$ & -1441 \\
\hline $\mathrm{BHF}_{2}$ & ${ }^{1} J_{\mathrm{BF}}$ & $-174,4$ & $-159,4$ & $-143,9$ & $-127,9$ & $-111,5$ & $-94,8$ & $-78,0$ & $-61,1$ & $-44,2$ & $-27,3$ & $-10,5$ & -84 \\
\hline $\mathrm{BF}_{3}$ & ${ }^{1} J_{\mathrm{BF}}$ & $-91,0$ & $-72,9$ & $-54,4$ & $-35,6$ & $-16,6$ & 2,5 & 21,8 & 41,2 & 60,7 & 80,2 & 99,7 & 15 \\
\hline $\mathrm{F}_{2} \mathrm{O}$ & ${ }^{1} J_{\mathrm{OF}}$ & $-200,9$ & $-231,8$ & $-263,8$ & $-297,5$ & $-333,7$ & $-374,2$ & $-421,6$ & $-481,6$ & $-566,0$ & $-707,7$ & $-1048,5$ & -300 \\
\hline $\mathrm{CH}_{4}$ & ${ }^{1} J_{\mathrm{CH}}$ & 86,0 & 89,7 & 93,6 & 97,7 & 102,1 & 106,8 & 111,8 & 117,1 & 122,7 & 128,6 & 134,9 & 125,3 \\
\hline $\mathrm{CH}_{4}$ & ${ }^{2} J_{\mathrm{HH}}$ & $-6,4$ & $-7,2$ & $-8,0$ & $-8,9$ & $-9,8$ & $-10,8$ & $-11,9$ & $-13,1$ & $-14,3$ & $-15,6$ & $-17,0$ & $-12,8$ \\
\hline $\mathrm{C}_{2} \mathrm{H}_{2}$ & ${ }^{1} J_{\mathrm{CC}}$ & 158,4 & 162,3 & 166,5 & 171,2 & 176,4 & 182,4 & 189,4 & 197,6 & 207,6 & 219,8 & 235,5 & 174,8 \\
\hline $\mathrm{C}_{2} \mathrm{H}_{2}$ & ${ }^{1} J_{\mathrm{CH}}$ & 179,2 & 186,4 & 194,0 & 201,9 & 210,3 & 219,3 & 228,9 & 239,2 & 250,5 & 263,0 & 277,3 & 247,6 \\
\hline $\mathrm{C}_{2} \mathrm{H}_{2}$ & ${ }^{2} J_{\mathrm{CH}}$ & 49,3 & 50,4 & 51,4 & 52,2 & 52,9 & 53,3 & 53,3 & 52,9 & 51,8 & 49,8 & 46,4 & 50,1 \\
\hline $\mathrm{C}_{2} \mathrm{H}_{2}$ & ${ }^{3} J_{\mathrm{HH}}$ & 6,6 & 7,0 & 7,4 & 8,0 & 8,7 & 9,5 & 10,6 & 11,9 & 13,6 & 15,9 & 18,9 & 9,6 \\
\hline $\mathrm{C}_{2} \mathrm{H}_{4}$ & ${ }^{1} J_{\mathrm{CC}}$ & 44,8 & 47,5 & 50,5 & 53,8 & 57,4 & 61,6 & 66,4 & 72,1 & 79,1 & 88,2 & 100,8 & 67,6 \\
\hline $\mathrm{C}_{2} \mathrm{H}_{4}$ & ${ }^{1} J_{\mathrm{CH}}$ & 109,6 & 114,5 & 119,6 & 125,0 & 130,8 & 136,9 & 143,6 & 150,8 & 158,8 & 167,9 & 178,7 & 156,3 \\
\hline $\mathrm{C}_{2} \mathrm{H}_{4}$ & ${ }^{2} J_{\mathrm{CH}}$ & 2,6 & 2,1 & 1,5 & 0,7 & 0,0 & $-1,1$ & $-2,4$ & $-4,0$ & $-6,1$ & $-9,1$ & $-13,4$ & $-2,4$ \\
\hline $\mathrm{C}_{2} \mathrm{H}_{4}$ & ${ }^{2} J_{\mathrm{HH}}$ & 5,0 & 4,7 & 4,4 & 4,0 & 3,5 & 2,9 & 2,2 & 1,4 & 0,2 & $-1,3$ & $-3,5$ & 2,3 \\
\hline $\mathrm{C}_{2} \mathrm{H}_{4}$ & ${ }^{3} J_{\mathrm{HH}_{\mathrm{c}}}$ & 9,1 & 9,4 & 9,7 & 10,1 & 10,5 & 11,0 & 11,6 & 12,4 & 13,4 & 14,8 & 16,9 & 11,7 \\
\hline $\mathrm{C}_{2} \mathrm{H}_{4}$ & ${ }^{3} J_{\mathrm{HH}_{\mathrm{t}}}$ & 13,0 & 13,5 & 14,1 & 14,8 & 15,5 & 16,4 & 17,4 & 18,5 & 20,0 & 22,0 & 24,7 & 19 \\
\hline $\mathrm{C}_{2} \mathrm{H}_{6}$ & ${ }^{1} J_{\mathrm{CC}}$ & 15,3 & 17,6 & 20,0 & 22,6 & 25,3 & 28,2 & 31,3 & 34,6 & 38,1 & 41,8 & 45,7 & 34,5 \\
\hline $\mathrm{C}_{2} \mathrm{H}_{6}$ & ${ }^{1} J_{\mathrm{CH}}$ & 85,4 & 89,3 & 93,4 & 97,8 & 102,5 & 107,4 & 112,6 & 118,1 & 124,0 & 130,2 & 136,7 & 125,2 \\
\hline $\mathrm{C}_{2} \mathrm{H}_{6}$ & ${ }^{2} J_{\mathrm{CH}}$ & $-0,9$ & $-1,3$ & $-1,8$ & $-2,2$ & $-2,8$ & $-3,3$ & $-3,9$ & $-4,6$ & $-5,3$ & $-6,1$ & $-6,9$ & $-4,7$ \\
\hline \multirow[t]{3}{*}{ Total } & $\mathrm{DM}$ & $-22,58$ & $-20,47$ & $-18,07$ & $-15,40$ & $-12,53$ & $-9,54$ & $-6,52$ & $-3,72$ & $-1,55$ & $-1,24$ & $-8,15$ & - \\
\hline & DMA & 34,38 & 29,32 & 23,90 & 18,02 & 14,42 & 11,24 & 10,90 & 14,05 & 21,54 & 33,75 & 54,82 & - \\
\hline & PDMA & 72,67 & 62,07 & 51,01 & 39,02 & 27,61 & 15,97 & 10,03 & 21,25 & 38,50 & 60,85 & 90,89 & - \\
\hline \multirow[t]{3}{*}{ CPI } & DM & $-30,92$ & $-28,55$ & $-25,63$ & $-22,27$ & $-18,63$ & $-14,95$ & $-11,48$ & $-8,87$ & $-8,22$ & $-12,55$ & $-34,85$ & - \\
\hline & DMA & 55,54 & 46,53 & 36,70 & 26,04 & 20,75 & 16,04 & 18,12 & 27,22 & 44,24 & 67,47 & 109,09 & - \\
\hline & PDMA & 102,44 & 85,02 & 66,98 & 48,33 & 31,59 & 16,19 & 13,67 & 33,18 & 55,83 & 80,77 & 112,26 & - \\
\hline \multirow[t]{3}{*}{ SPI } & $\mathrm{DM}$ & $-16,47$ & $-14,55$ & $-12,52$ & $-10,36$ & $-8,05$ & $-5,57$ & $-2,88$ & 0,05 & 3,33 & 7,05 & 11,44 & - \\
\hline & DMA & 18,86 & 16,71 & 14,52 & 12,13 & 9,77 & 7,72 & 5,61 & 4,39 & 4,89 & 9,03 & 15,03 & - \\
\hline & PDMA & 50,84 & 45,24 & 39,29 & 32,18 & 24,69 & 15,80 & 7,36 & 12,50 & 25,79 & 46,23 & 75,22 & - \\
\hline \multirow[t]{3}{*}{$\Delta \mathrm{CS}$} & $\mathrm{DM}$ & $-14,44$ & $-14,00$ & $-13,11$ & $-11,91$ & $-10,57$ & $-9,37$ & $-8,60$ & $-8,93$ & $-11,55$ & $-19,60$ & $-46,29$ & - \\
\hline & DMA & 36,68 & 29,82 & 22,18 & 13,90 & 10,98 & 8,32 & 12,50 & 22,83 & 39,34 & 58,45 & 94,06 & - \\
\hline & PDMA & 51,60 & 39,78 & 27,70 & 16,15 & 6,90 & 0,38 & 6,31 & 20,68 & 30,04 & 34,54 & 37,04 & - \\
\hline \multicolumn{14}{|c|}{ Desconsiderando ${ }^{1} J_{\mathrm{BF}}$ da molécula de $\mathrm{BF}_{3},{ }^{2} J_{\mathrm{CH}}$ e ${ }^{2} J_{\mathrm{HH}}$ da molécula de $\mathrm{C}_{2} \mathrm{H}_{4}$} \\
\hline \multirow[t]{3}{*}{ Total } & DM & $-21,26$ & $-19,62$ & $-17,67$ & $-15,42$ & $-12,94$ & $-10,32$ & $-7,66$ & $-5,24$ & $-3,49$ & $-3,79$ & $-12,16$ & - \\
\hline & DMA & 33,92 & 29,03 & 23,74 & 17,96 & 14,77 & 12,08 & 12,03 & 14,63 & 22,11 & 34,87 & 57,56 & - \\
\hline & PDMA & 37,26 & 32,00 & 26,51 & 20,61 & 15,44 & 10,94 & 9,18 & 11,83 & 19,60 & 30,94 & 47,30 & - \\
\hline \multirow[t]{3}{*}{ CPI } & $\mathrm{DM}$ & $-23,41$ & $-22,61$ & $-21,25$ & $-19,44$ & $-17,33$ & $-15,19$ & $-13,31$ & $-12,38$ & $-13,61$ & $-20,32$ & $-46,81$ & - \\
\hline & DMA & 50,49 & 42,39 & 33,43 & 23,58 & 19,67 & 16,39 & 19,25 & 27,32 & 44,09 & 67,70 & 111,53 & - \\
\hline & PDMA & 42,02 & 34,93 & 27,42 & 19,43 & 13,68 & 9,47 & 10,50 & 19,03 & 30,94 & 45,38 & 67,02 & - \\
\hline \multirow[t]{3}{*}{ SPI } & DM & $-19,60$ & $-17,32$ & $-14,91$ & $-12,32$ & $-9,57$ & $-6,58$ & $-3,32$ & 0,25 & 4,29 & 8,93 & 14,49 & - \\
\hline & DMA & 21,17 & 18,75 & 16,29 & 13,63 & 11,00 & 8,76 & 6,47 & 4,87 & 5,20 & 9,62 & 16,05 & - \\
\hline & PDMA & 33,61 & 29,75 & 25,81 & 21,51 & 16,78 & 12,06 & 8,16 & 6,29 & 10,87 & 19,83 & 32,14 & - \\
\hline \multirow[t]{3}{*}{$\triangle \mathrm{CS}$} & DM & $-3,81$ & $-5,29$ & $-6,34$ & $-7,12$ & $-7,76$ & $-8,61$ & $-9,99$ & $-12,63$ & $-17,90$ & $-29,25$ & $-61,30$ & - \\
\hline & DMA & 29,32 & 23,64 & 17,14 & 9,95 & 8,67 & 7,63 & 12,78 & 22,45 & 38,89 & 58,08 & 95,48 & - \\
\hline & PDMA & 8,41 & 5,17 & 1,61 & $-2,08$ & $-3,10$ & $-2,59$ & 2,34 & 12,75 & 20,07 & 25,55 & 34,88 & - \\
\hline
\end{tabular}


Tabela 8.210: Constantes de acoplamento B972B971 com base aug-pcJ-2.

\begin{tabular}{|c|c|c|c|c|c|c|c|c|c|c|c|c|c|}
\hline & $\% E_{X}^{\mathrm{HF}}$ & $0 \%$ & $10 \%$ & $20 \%$ & $30 \%$ & $40 \%$ & $50 \%$ & $60 \%$ & $70 \%$ & $80 \%$ & $90 \%$ & $100 \%$ & Exp. \\
\hline $\mathrm{HF}$ & ${ }^{1} J_{\mathrm{HF}}$ & 387,3 & 406,8 & 427,6 & 449,6 & 473,0 & 497,8 & 524,0 & 551,7 & 580,9 & 611,6 & 643,9 & 500 \\
\hline $\mathrm{CO}$ & ${ }^{1} J_{\mathrm{CO}}$ & 20,2 & 18,8 & 17,3 & 15,6 & 13,8 & 11,7 & 9,5 & 7,1 & 4,5 & 1,6 & $-1,3$ & 16,4 \\
\hline $\mathrm{H}_{2} \mathrm{O}$ & ${ }^{1} J_{\mathrm{OH}}$ & $-61,8$ & $-64,4$ & $-67,1$ & $-70,0$ & $-73,0$ & $-76,3$ & $-79,7$ & $-83,4$ & $-87,3$ & $-91,4$ & $-95,7$ & $-80,6$ \\
\hline $\mathrm{H}_{2} \mathrm{O}$ & ${ }^{2} J_{\mathrm{HH}}$ & $-1,4$ & $-2,3$ & $-3,3$ & $-4,4$ & $-5,6$ & $-6,8$ & $-8,1$ & $-9,5$ & $-11,0$ & $-12,6$ & $-14,3$ & $-7,3$ \\
\hline $\mathrm{NH}_{3}$ & ${ }^{1} J_{\mathrm{NH}}$ & 34,4 & 35,6 & 36,9 & 38,2 & 39,7 & 41,3 & 42,9 & 44,7 & 46,5 & 48,5 & 50,6 & 43,8 \\
\hline $\mathrm{NH}_{3}$ & ${ }^{2} J_{\mathrm{HH}}$ & $-3,9$ & $-4,7$ & $-5,6$ & $-6,6$ & $-7,7$ & $-8,8$ & $-10,1$ & $-11,4$ & $-12,8$ & $-14,4$ & $-16,1$ & $-9,6$ \\
\hline $\mathrm{PH}_{3}$ & ${ }^{1} J_{\mathrm{PH}}$ & 160,0 & 166,5 & 173,4 & 180,6 & 188,1 & 196,0 & 204,2 & 212,8 & 221,8 & 231,1 & 240,7 & 188,2 \\
\hline $\mathrm{PF}_{3}$ & ${ }^{1} J_{\mathrm{PF}}$ & $-1584,3$ & $-1580,1$ & $-1570,8$ & $-1557,2$ & $-1539,9$ & $-1519,7$ & $-1497,1$ & $-1472,9$ & $-1447,4$ & $-1421,2$ & $-1394,8$ & -1441 \\
\hline $\mathrm{BHF}_{2}$ & ${ }^{1} J_{\mathrm{BF}}$ & $-165,1$ & $-148,7$ & $-131,9$ & $-114,7$ & $-97,2$ & $-79,5$ & $-61,8$ & $-44,2$ & $-26,5$ & $-9,1$ & 8,1 & -84 \\
\hline $\mathrm{BF}_{3}$ & ${ }^{1} J_{\mathrm{BF}}$ & $-80,2$ & $-61,1$ & $-41,7$ & $-22,1$ & $-2,3$ & 17,5 & 37,4 & 57,3 & 77,2 & 97,0 & 116,8 & 15 \\
\hline $\mathrm{F}_{2} \mathrm{O}$ & ${ }^{1} J_{\mathrm{OF}}$ & $-197,5$ & $-228,5$ & $-260,8$ & $-295,1$ & $-332,4$ & $-374,6$ & $-425,1$ & $-490,5$ & $-585,8$ & $-755,5$ & $-1221,3$ & -300 \\
\hline $\mathrm{CH}_{4}$ & ${ }^{1} J_{\mathrm{CH}}$ & 92,6 & 96,6 & 100,8 & 105,2 & 110,0 & 115,0 & 120,3 & 126,0 & 132,0 & 138,3 & 145,1 & 125,3 \\
\hline $\mathrm{CH}_{4}$ & ${ }^{2} J_{\mathrm{HH}}$ & $-6,3$ & $-7,1$ & $-8,0$ & $-8,9$ & $-9,9$ & $-10,9$ & $-12,1$ & $-13,3$ & $-14,5$ & $-15,9$ & $-17,3$ & $-12,8$ \\
\hline $\mathrm{C}_{2} \mathrm{H}_{2}$ & ${ }^{1} J_{\mathrm{CC}}$ & 174,0 & 178,8 & 184,1 & 190,0 & 196,7 & 204,4 & 213,4 & 224,2 & 237,3 & 253,8 & 275,1 & 174,8 \\
\hline $\mathrm{C}_{2} \mathrm{H}_{2}$ & ${ }^{1} J_{\mathrm{CH}}$ & 188,2 & 195,8 & 203,8 & 212,3 & 221,3 & 231,0 & 241,3 & 252,6 & 265,1 & 279,2 & 295,5 & 247,6 \\
\hline $\mathrm{C}_{2} \mathrm{H}_{2}$ & ${ }^{2} J_{\mathrm{CH}}$ & 49,0 & 49,9 & 50,7 & 51,3 & 51,7 & 51,7 & 51,3 & 50,3 & 48,4 & 45,2 & 40,1 & 50,1 \\
\hline $\mathrm{C}_{2} \mathrm{H}_{2}$ & ${ }^{3} J_{\mathrm{HH}}$ & 6,4 & 6,8 & 7,3 & 7,9 & 8,7 & 9,6 & 10,8 & 12,4 & 14,3 & 17,0 & 20,5 & 9,6 \\
\hline $\mathrm{C}_{2} \mathrm{H}_{4}$ & ${ }^{1} J_{\mathrm{CC}}$ & 54,9 & 58,2 & 61,9 & 65,9 & 70,5 & 75,8 & 81,9 & 89,4 & 98,9 & 111,7 & 130,5 & 67,6 \\
\hline $\mathrm{C}_{2} \mathrm{H}_{4}$ & ${ }^{1} J_{\mathrm{CH}}$ & 116,3 & 121,5 & 126,9 & 132,7 & 138,9 & 145,6 & 152,8 & 160,8 & 169,7 & 180,1 & 193,0 & 156,3 \\
\hline $\mathrm{C}_{2} \mathrm{H}_{4}$ & ${ }^{2} J_{\mathrm{CH}}$ & 2,0 & 1,4 & 0,7 & $-0,1$ & $-1,1$ & $-2,4$ & $-4,0$ & $-6,0$ & $-8,7$ & $-12,7$ & $-18,8$ & $-2,4$ \\
\hline $\mathrm{C}_{2} \mathrm{H}_{4}$ & ${ }^{2} J_{\mathrm{HH}}$ & 4,8 & 4,5 & 4,1 & 3,7 & 3,2 & 2,6 & 1,8 & 0,8 & $-0,4$ & $-2,3$ & $-5,1$ & 2,3 \\
\hline $\mathrm{C}_{2} \mathrm{H}_{4}$ & ${ }^{3} J_{\mathrm{HH}_{\mathrm{c}}}$ & 9,0 & 9,3 & 9,7 & 10,0 & 10,5 & 11,0 & 11,7 & 12,5 & 13,7 & 15,4 & 18,0 & 11,7 \\
\hline $\mathrm{C}_{2} \mathrm{H}_{4}$ & ${ }^{3} J_{\mathrm{HH}_{\mathrm{t}}}$ & 12,9 & 13,5 & 14,1 & 14,7 & 15,5 & 16,4 & 17,4 & 18,7 & 20,3 & 22,6 & 25,9 & 19 \\
\hline $\mathrm{C}_{2} \mathrm{H}_{6}$ & ${ }^{1} J_{\mathrm{CC}}$ & 19,8 & 22,3 & 25,1 & 28,0 & 31,1 & 34,4 & 37,9 & 41,7 & 45,7 & 49,9 & 54,4 & 34,5 \\
\hline $\mathrm{C}_{2} \mathrm{H}_{6}$ & ${ }^{1} J_{\mathrm{CH}}$ & 91,9 & 96,1 & 100,6 & 105,3 & 110,2 & 115,5 & 121,1 & 127,0 & 133,3 & 140,0 & 147,0 & 125,2 \\
\hline $\mathrm{C}_{2} \mathrm{H}_{6}$ & ${ }^{2} J_{\mathrm{CH}}$ & $-1,0$ & $-1,5$ & $-1,9$ & $-2,5$ & $-3,0$ & $-3,7$ & $-4,3$ & $-5,0$ & $-5,8$ & $-6,6$ & $-7,5$ & $-4,7$ \\
\hline \multirow[t]{3}{*}{ Total } & $\mathrm{DM}$ & $-20,11$ & $-17,73$ & $-15,04$ & $-12,14$ & $-9,01$ & $-5,78$ & $-2,60$ & 0,34 & 2,48 & 2,17 & $-8,92$ & - \\
\hline & DMA & 31,94 & 26,88 & 21,50 & 15,80 & 12,42 & 10,63 & 13,78 & 19,16 & 27,95 & 41,86 & 68,67 & - \\
\hline & PDMA & 65,28 & 54,14 & 42,43 & 30,46 & 19,15 & 9,34 & 18,73 & 33,90 & 54,57 & 81,06 & 118,03 & - \\
\hline \multirow[t]{3}{*}{ CPI } & DM & $-30,29$ & $-27,55$ & $-24,26$ & $-20,64$ & $-16,76$ & $-12,94$ & $-9,53$ & $-7,20$ & $-7,35$ & $-14,12$ & $-47,66$ & - \\
\hline & DMA & 55,15 & 45,73 & 35,46 & 24,53 & 18,80 & 16,65 & 25,07 & 36,16 & 50,42 & 75,19 & 128,26 & - \\
\hline & PDMA & 92,82 & 74,64 & 55,81 & 37,23 & 21,08 & 10,17 & 26,92 & 48,15 & 71,27 & 97,38 & 132,83 & - \\
\hline \multirow[t]{3}{*}{ SPI } & DM & $-12,64$ & $-10,53$ & $-8,28$ & $-5,91$ & $-3,32$ & $-0,54$ & 2,48 & 5,87 & 9,68 & 14,11 & 19,49 & - \\
\hline & DMA & 14,92 & 13,05 & 11,27 & 9,40 & 7,75 & 6,22 & 5,49 & 6,69 & 11,48 & 17,41 & 24,97 & - \\
\hline & PDMA & 45,09 & 39,10 & 32,62 & 25,51 & 17,73 & 8,73 & 12,72 & 23,45 & 42,32 & 69,10 & 107,17 & - \\
\hline \multirow[t]{3}{*}{$\Delta \mathrm{CS}$} & DM & $-17,65$ & $-17,01$ & $-15,98$ & $-14,73$ & $-13,44$ & $-12,40$ & $-12,01$ & $-13,07$ & $-17,03$ & $-28,22$ & $-67,15$ & - \\
\hline & DMA & 40,23 & 32,67 & 24,20 & 15,13 & 11,05 & 10,43 & 19,58 & 29,47 & 38,94 & 57,78 & 103,30 & - \\
\hline & PDMA & 47,73 & 35,54 & 23,19 & 11,72 & 3,35 & 1,44 & 14,19 & 24,70 & 28,94 & 28,28 & 25,65 & - \\
\hline \multicolumn{14}{|c|}{ Desconsiderando ${ }^{1} J_{\mathrm{BF}}$ da molécula de $\mathrm{BF}_{3},{ }^{2} J_{\mathrm{CH}}$ e ${ }^{2} J_{\mathrm{HH}}$ da molécula de $\mathrm{C}_{2} \mathrm{H}_{4}$} \\
\hline \multirow[t]{3}{*}{ Total } & DM & $-18,89$ & $-17,00$ & $-14,75$ & $-12,27$ & $-9,53$ & $-6,66$ & $-3,82$ & $-1,23$ & 0,49 & $-0,47$ & $-13,48$ & - \\
\hline & DMA & 31,67 & 26,81 & 21,63 & 16,09 & 13,20 & 11,90 & 14,51 & 19,60 & 28,50 & 43,10 & 72,17 & - \\
\hline & PDMA & 33,51 & 28,10 & 22,51 & 16,87 & 12,58 & 9,26 & 10,83 & 16,70 & 27,14 & 40,51 & 60,22 & - \\
\hline \multirow[t]{3}{*}{ CPI } & DM & $-23,80$ & $-22,69$ & $-21,02$ & $-18,99$ & $-16,71$ & $-14,48$ & $-12,72$ & $-12,15$ & $-14,30$ & $-23,73$ & $-62,61$ & - \\
\hline & DMA & 51,14 & 42,69 & 33,34 & 23,27 & 18,95 & 18,06 & 25,34 & 35,55 & 49,24 & 74,51 & 130,91 & - \\
\hline & PDMA & 38,63 & 31,37 & 23,59 & 16,22 & 11,66 & 9,52 & 14,67 & 24,76 & 36,93 & 52,45 & 78,24 & - \\
\hline \multirow[t]{3}{*}{ SPI } & $\mathrm{DM}$ & $-15,12$ & $-12,62$ & $-9,93$ & $-7,10$ & $-4,00$ & $-0,65$ & 3,02 & 7,16 & 11,86 & 17,42 & 24,32 & - \\
\hline & DMA & 16,68 & 14,60 & 12,62 & 10,56 & 8,77 & 7,15 & 6,18 & 7,33 & 12,55 & 18,95 & 26,98 & - \\
\hline & PDMA & 29,57 & 25,58 & 21,68 & 17,38 & 13,28 & 9,07 & 7,88 & 10,50 & 19,61 & 31,33 & 46,35 & - \\
\hline \multirow[t]{3}{*}{$\Delta \mathrm{CS}$} & $\mathrm{DM}$ & $-8,68$ & $-10,07$ & $-11,09$ & $-11,89$ & $-12,71$ & $-13,83$ & $-15,74$ & $-19,31$ & $-26,16$ & $-41,15$ & $-86,93$ & - \\
\hline & DMA & 34,46 & 28,09 & 20,72 & 12,71 & 10,18 & 10,91 & 19,16 & 28,22 & 36,69 & 55,56 & 103,93 & - \\
\hline & PDMA & 9,07 & 5,79 & 1,91 & $-1,16$ & $-1,63$ & 0,45 & 6,79 & 14,26 & 17,31 & 21,11 & 31,89 & - \\
\hline
\end{tabular}


Tabela 8.211: Constantes de acoplamento B972B972 com base aug-pcJ-2.

\begin{tabular}{|c|c|c|c|c|c|c|c|c|c|c|c|c|c|}
\hline & $\% E_{X}^{\mathrm{HF}}$ & $0 \%$ & $10 \%$ & $20 \%$ & $30 \%$ & $40 \%$ & $50 \%$ & $60 \%$ & $70 \%$ & $80 \%$ & $90 \%$ & $100 \%$ & Exp. \\
\hline $\mathrm{HF}$ & ${ }^{1} J_{\mathrm{HF}}$ & 420,6 & 441,5 & 463,7 & 487,2 & 512,0 & 538,2 & 565,8 & 595,0 & 625,6 & 657,8 & 691,6 & 500 \\
\hline $\mathrm{CO}$ & ${ }^{1} J_{\mathrm{CO}}$ & 16,9 & 15,3 & 13,5 & 11,5 & 9,2 & 6,8 & 4,2 & 1,4 & $-1,6$ & $-4,8$ & $-8,3$ & 16,4 \\
\hline $\mathrm{H}_{2} \mathrm{O}$ & ${ }^{1} J_{\mathrm{OH}}$ & $-66,8$ & $-69,6$ & $-72,5$ & $-75,6$ & $-78,9$ & $-82,3$ & $-86,0$ & $-90,0$ & $-94,1$ & $-98,5$ & $-103,1$ & $-80,6$ \\
\hline $\mathrm{H}_{2} \mathrm{O}$ & ${ }^{2} J_{\mathrm{HH}}$ & $-1,2$ & $-2,2$ & $-3,2$ & $-4,3$ & $-5,5$ & $-6,7$ & $-8,0$ & $-9,5$ & $-11,0$ & $-12,6$ & $-14,3$ & $-7,3$ \\
\hline $\mathrm{NH}_{3}$ & ${ }^{1} J_{\mathrm{NH}}$ & 36,3 & 37,5 & 38,9 & 40,3 & 41,8 & 43,4 & 45,1 & 47,0 & 48,9 & 50,9 & 53,1 & 43,8 \\
\hline $\mathrm{NH}_{3}$ & ${ }^{2} J_{\mathrm{HH}}$ & $-3,3$ & $-4,2$ & $-5,1$ & $-6,0$ & $-7,1$ & $-8,2$ & $-9,4$ & $-10,7$ & $-12,1$ & $-13,6$ & $-15,2$ & $-9,6$ \\
\hline $\mathrm{PH}_{3}$ & ${ }^{1} J_{\mathrm{PH}}$ & 152,4 & 159,5 & 167,0 & 175,0 & 183,4 & 192,2 & 201,4 & 211,1 & 221,2 & 231,6 & 242,5 & 188,2 \\
\hline $\mathrm{PF}_{3}$ & ${ }^{1} J_{\mathrm{PF}}$ & $-1626,4$ & $-1621,0$ & $-1610,4$ & $-1595,3$ & $-1576,6$ & $-1555,0$ & $-1531,2$ & $-1505,7$ & $-1479,1$ & $-1452,1$ & $-1424,9$ & -1441 \\
\hline $\mathrm{BHF}_{2}$ & ${ }^{1} J_{\mathrm{BF}}$ & $-151,4$ & $-134,7$ & $-117,6$ & $-100,3$ & $-82,9$ & $-65,4$ & $-48,0$ & $-30,7$ & $-13,4$ & 3,5 & 20,3 & -84 \\
\hline $\mathrm{BF}_{3}$ & ${ }^{1} J_{\mathrm{BF}}$ & $-64,0$ & $-44,6$ & $-25,1$ & $-5,4$ & 14,1 & 33,8 & 53,5 & 73,1 & 92,7 & 112,2 & 131,6 & 15 \\
\hline $\mathrm{F}_{2} \mathrm{O}$ & ${ }^{1} J_{\mathrm{OF}}$ & $-187,3$ & $-217,9$ & $-249,8$ & $-283,7$ & $-320,6$ & $-362,5$ & $-412,9$ & $-478,9$ & $-577,4$ & $-761,7$ & $-1349,0$ & -300 \\
\hline $\mathrm{CH}_{4}$ & ${ }^{1} J_{\mathrm{CH}}$ & 94,6 & 98,6 & 102,8 & 107,2 & 111,9 & 116,9 & 122,2 & 127,8 & 133,7 & 139,9 & 146,5 & 125,3 \\
\hline $\mathrm{CH}_{4}$ & ${ }^{2} J_{\mathrm{HH}}$ & $-5,4$ & $-6,1$ & $-6,9$ & $-7,8$ & $-8,7$ & $-9,7$ & $-10,7$ & $-11,9$ & $-13,0$ & $-14,3$ & $-15,6$ & $-12,8$ \\
\hline $\mathrm{C}_{2} \mathrm{H}_{2}$ & ${ }^{1} J_{\mathrm{CC}}$ & 172,7 & 177,5 & 182,8 & 188,8 & 195,6 & 203,4 & 212,5 & 223,4 & 236,6 & 253,1 & 274,3 & 174,8 \\
\hline $\mathrm{C}_{2} \mathrm{H}_{2}$ & ${ }^{1} J_{\mathrm{CH}}$ & 189,9 & 197,4 & 205,4 & 213,7 & 222,6 & 232,0 & 242,2 & 253,1 & 265,2 & 278,6 & 294,1 & 247,6 \\
\hline $\mathrm{C}_{2} \mathrm{H}_{2}$ & ${ }^{2} J_{\mathrm{CH}}$ & 49,1 & 50,0 & 50,8 & 51,4 & 51,8 & 51,9 & 51,5 & 50,6 & 48,9 & 46,1 & 41,6 & 50,1 \\
\hline $\mathrm{C}_{2} \mathrm{H}_{2}$ & ${ }^{3} J_{\mathrm{HH}}$ & 6,1 & 6,5 & 6,9 & 7,4 & 8,1 & 8,9 & 9,9 & 11,2 & 12,9 & 15,1 & 18,0 & 9,6 \\
\hline $\mathrm{C}_{2} \mathrm{H}_{4}$ & ${ }^{1} J_{\mathrm{CC}}$ & 54,6 & 58,0 & 61,7 & 66,0 & 70,8 & 76,3 & 82,9 & 91,0 & 101,4 & 115,7 & 137,0 & 67,6 \\
\hline $\mathrm{C}_{2} \mathrm{H}_{4}$ & ${ }^{1} J_{\mathrm{CH}}$ & 117,8 & 122,9 & 128,4 & 134,1 & 140,3 & 146,9 & 154,1 & 161,9 & 170,8 & 181,1 & 194,0 & 156,3 \\
\hline $\mathrm{C}_{2} \mathrm{H}_{4}$ & ${ }^{2} J_{\mathrm{CH}}$ & 2,6 & 2,0 & 1,3 & 0,5 & $-0,4$ & $-1,7$ & $-3,2$ & $-5,2$ & $-8,0$ & $-11,9$ & $-18,1$ & $-2,4$ \\
\hline $\mathrm{C}_{2} \mathrm{H}_{4}$ & ${ }^{2} J_{\mathrm{HH}}$ & 5,6 & 5,4 & 5,1 & 4,7 & 4,2 & 3,7 & 3,0 & 2,2 & 1,1 & $-0,5$ & $-2,9$ & 2,3 \\
\hline $\mathrm{C}_{2} \mathrm{H}_{4}$ & ${ }^{3} J_{\mathrm{HH}_{\mathrm{c}}}$ & 8,9 & 9,1 & 9,4 & 9,7 & 10,1 & 10,6 & 11,1 & 11,8 & 12,8 & 14,3 & 16,6 & 11,7 \\
\hline $\mathrm{C}_{2} \mathrm{H}_{4}$ & ${ }^{3} J_{\mathrm{HH}_{\mathrm{t}}}$ & 12,8 & 13,3 & 13,8 & 14,4 & 15,1 & 15,9 & 16,8 & 17,9 & 19,4 & 21,4 & 24,4 & 19 \\
\hline $\mathrm{C}_{2} \mathrm{H}_{6}$ & ${ }^{1} J_{\mathrm{CC}}$ & 21,9 & 24,5 & 27,3 & 30,2 & 33,3 & 36,6 & 40,1 & 43,8 & 47,8 & 52,0 & 56,4 & 34,5 \\
\hline $\mathrm{C}_{2} \mathrm{H}_{6}$ & ${ }^{1} J_{\mathrm{CH}}$ & 93,2 & 97,4 & 101,8 & 106,4 & 111,4 & 116,6 & 122,1 & 127,9 & 134,1 & 140,6 & 147,5 & 125,2 \\
\hline $\mathrm{C}_{2} \mathrm{H}_{6}$ & ${ }^{2} J_{\mathrm{CH}}$ & $-0,5$ & $-0,9$ & $-1,4$ & $-1,9$ & $-2,4$ & $-3,0$ & $-3,6$ & $-4,2$ & $-4,9$ & $-5,7$ & $-6,5$ & $-4,7$ \\
\hline \multirow[t]{3}{*}{ Total } & $\mathrm{DM}$ & $-19,05$ & $-16,53$ & $-13,71$ & $-10,65$ & $-7,40$ & $-4,05$ & $-0,75$ & 2,25 & 4,37 & 3,58 & $-12,05$ & - \\
\hline & DMA & 31,30 & 26,09 & 20,73 & 14,98 & 11,64 & 14,03 & 17,62 & 23,42 & 32,18 & 45,12 & 75,85 & - \\
\hline & PDMA & 62,60 & 51,97 & 41,18 & 29,79 & 18,93 & 19,95 & 25,17 & 36,94 & 55,71 & 81,27 & 118,82 & - \\
\hline \multirow[t]{3}{*}{ CPI } & DM & $-28,65$ & $-25,57$ & $-21,95$ & $-17,95$ & $-13,82$ & $-9,69$ & $-6,04$ & $-3,53$ & $-3,75$ & $-11,65$ & $-56,05$ & - \\
\hline & DMA & 53,99 & 44,41 & 34,12 & 23,03 & 17,29 & 24,53 & 34,22 & 45,80 & 60,47 & 83,11 & 145,55 & - \\
\hline & PDMA & 79,88 & 62,30 & 45,12 & 27,62 & 11,80 & 24,58 & 41,76 & 63,46 & 86,79 & 113,04 & 152,13 & - \\
\hline \multirow[t]{3}{*}{ SPI } & DM & $-12,01$ & $-9,90$ & $-7,66$ & $-5,29$ & $-2,69$ & 0,08 & 3,12 & 6,48 & 10,31 & 14,76 & 20,21 & - \\
\hline & DMA & 14,67 & 12,66 & 10,91 & 9,07 & 7,49 & 6,33 & 5,44 & 7,01 & 11,43 & 17,27 & 24,75 & - \\
\hline & PDMA & 49,93 & 44,39 & 38,30 & 31,39 & 24,15 & 16,55 & 13,01 & 17,49 & 32,91 & 57,98 & 94,39 & - \\
\hline \multirow[t]{3}{*}{$\Delta \mathrm{CS}$} & $\mathrm{DM}$ & $-16,63$ & $-15,67$ & $-14,29$ & $-12,67$ & $-11,12$ & $-9,77$ & $-9,16$ & $-10,01$ & $-14,06$ & $-26,41$ & $-76,27$ & - \\
\hline & DMA & 39,32 & 31,75 & 23,20 & 13,95 & 9,80 & 18,19 & 28,78 & 38,79 & 49,04 & 65,84 & 120,80 & - \\
\hline & PDMA & 29,95 & 17,91 & 6,82 & $-3,77$ & $-12,35$ & 8,03 & 28,74 & 45,98 & 53,88 & 55,06 & 57,74 & - \\
\hline \multicolumn{14}{|c|}{ Desconsiderando ${ }^{1} J_{\mathrm{BF}}$ da molécula de $\mathrm{BF}_{3},{ }^{2} J_{\mathrm{CH}}$ e ${ }^{2} J_{\mathrm{HH}}$ da molécula de $\mathrm{C}_{2} \mathrm{H}_{4}$} \\
\hline \multirow[t]{3}{*}{ Total } & DM & $-18,46$ & $-16,42$ & $-14,03$ & $-11,38$ & $-8,50$ & $-5,49$ & $-2,52$ & 0,14 & 1,85 & 0,36 & $-17,79$ & - \\
\hline & DMA & 31,59 & 26,58 & 21,41 & 15,81 & 12,95 & 14,95 & 18,17 & 23,83 & 32,70 & 46,25 & 79,77 & - \\
\hline & PDMA & 32,57 & 27,64 & 22,94 & 17,98 & 13,92 & 13,18 & 14,52 & 19,66 & 28,04 & 41,20 & 62,25 & - \\
\hline \multirow[t]{3}{*}{ CPI } & DM & $-23,61$ & $-22,17$ & $-20,14$ & $-17,71$ & $-15,11$ & $-12,54$ & $-10,49$ & $-9,69$ & $-11,89$ & $-22,54$ & $-73,32$ & - \\
\hline & DMA & 51,49 & 42,89 & 33,52 & 23,29 & 18,93 & 25,10 & 33,79 & 44,57 & 58,75 & 81,70 & 148,44 & - \\
\hline & PDMA & 35,21 & 28,80 & 22,90 & 16,78 & 12,38 & 14,50 & 20,27 & 31,08 & 43,67 & 59,54 & 89,61 & - \\
\hline \multirow[t]{3}{*}{ SPI } & $\mathrm{DM}$ & $-14,50$ & $-12,00$ & $-9,34$ & $-6,51$ & $-3,41$ & $-0,07$ & 3,61 & 7,70 & 12,42 & 17,98 & 24,93 & - \\
\hline & DMA & 16,28 & 14,03 & 12,09 & 10,06 & 8,35 & 7,15 & 6,16 & 7,87 & 12,67 & 18,98 & 26,95 & - \\
\hline & PDMA & 30,55 & 26,75 & 22,97 & 18,90 & 15,10 & 12,17 & 10,11 & 10,87 & 16,02 & 27,09 & 41,20 & - \\
\hline \multirow[t]{3}{*}{$\Delta \mathrm{CS}$} & $\mathrm{DM}$ & $-9,11$ & $-10,17$ & $-10,80$ & $-11,20$ & $-11,70$ & $-12,47$ & $-14,10$ & $-17,39$ & $-24,31$ & $-40,52$ & $-98,25$ & - \\
\hline & DMA & 35,21 & 28,86 & 21,43 & 13,23 & 10,58 & 17,95 & 27,63 & 36,70 & 46,08 & 62,72 & 121,49 & - \\
\hline & PDMA & 4,66 & 2,05 & $-0,07$ & $-2,12$ & $-2,72$ & 2,33 & 10,16 & 20,21 & 27,65 & 32,45 & 48,41 & - \\
\hline
\end{tabular}


Tabela 8.212: Constantes de acoplamento B972B98 com base aug-pcJ-2.

\begin{tabular}{|c|c|c|c|c|c|c|c|c|c|c|c|c|c|}
\hline & $\% E_{X}^{\mathrm{HF}}$ & $0 \%$ & $10 \%$ & $20 \%$ & $30 \%$ & $40 \%$ & $50 \%$ & $60 \%$ & $70 \%$ & $80 \%$ & $90 \%$ & $100 \%$ & Exp. \\
\hline $\mathrm{HF}$ & ${ }^{1} J_{\mathrm{HF}}$ & 377,2 & 396,6 & 417,2 & 439,1 & 462,4 & 487,1 & 513,3 & 540,9 & 570,1 & 600,8 & 633,1 & 500 \\
\hline $\mathrm{CO}$ & ${ }^{1} J_{\mathrm{CO}}$ & 19,9 & 18,6 & 17,1 & 15,4 & 13,6 & 11,5 & 9,3 & 6,9 & 4,3 & 1,5 & $-1,4$ & 16,4 \\
\hline $\mathrm{H}_{2} \mathrm{O}$ & ${ }^{1} J_{\mathrm{OH}}$ & $-61,4$ & $-64,0$ & $-66,7$ & $-69,6$ & $-72,6$ & $-75,9$ & $-79,4$ & $-83,1$ & $-87,0$ & $-91,2$ & $-95,6$ & $-80,6$ \\
\hline $\mathrm{H}_{2} \mathrm{O}$ & ${ }^{2} J_{\mathrm{HH}}$ & $-1,5$ & $-2,5$ & $-3,5$ & $-4,6$ & $-5,8$ & $-7,0$ & $-8,3$ & $-9,7$ & $-11,3$ & $-12,9$ & $-14,6$ & $-7,3$ \\
\hline $\mathrm{NH}_{3}$ & ${ }^{1} J_{\mathrm{NH}}$ & 34,8 & 36,1 & 37,4 & 38,8 & 40,3 & 41,9 & 43,6 & 45,4 & 47,3 & 49,3 & 51,5 & 43,8 \\
\hline $\mathrm{NH}_{3}$ & ${ }^{2} J_{\mathrm{HH}}$ & $-4,1$ & $-5,0$ & $-6,0$ & $-7,0$ & $-8,1$ & $-9,3$ & $-10,5$ & $-11,9$ & $-13,4$ & $-15,0$ & $-16,8$ & $-9,6$ \\
\hline $\mathrm{PH}_{3}$ & ${ }^{1} J_{\mathrm{PH}}$ & 166,1 & 172,8 & 179,8 & 187,1 & 194,8 & 202,8 & 211,1 & 219,8 & 228,8 & 238,2 & 247,9 & 188,2 \\
\hline $\mathrm{PF}_{3}$ & ${ }^{1} J_{\mathrm{PF}}$ & $-1599,1$ & $-1594,3$ & $-1584,3$ & $-1570,1$ & $-1552,3$ & $-1531,5$ & $-1508,5$ & $-1483,7$ & $-1457,9$ & $-1431,3$ & $-1404,5$ & -1441 \\
\hline $\mathrm{BHF}_{2}$ & ${ }^{1} J_{\mathrm{BF}}$ & $-165,0$ & $-148,9$ & $-132,3$ & $-115,2$ & $-98,0$ & $-80,5$ & $-63,0$ & $-45,5$ & $-28,1$ & $-10,8$ & 6,2 & -84 \\
\hline $\mathrm{BF}_{3}$ & ${ }^{1} J_{\mathrm{BF}}$ & $-80,8$ & $-62,0$ & $-42,8$ & $-23,5$ & $-4,0$ & 15,6 & 35,3 & 54,9 & 74,6 & 94,2 & 113,8 & 15 \\
\hline $\mathrm{F}_{2} \mathrm{O}$ & ${ }^{1} J_{\mathrm{OF}}$ & $-203,9$ & $-235,7$ & $-269,1$ & $-304,7$ & $-343,8$ & $-388,6$ & $-443,1$ & $-515,3$ & $-624,4$ & $-831,1$ & $-1507,1$ & -300 \\
\hline $\mathrm{CH}_{4}$ & ${ }^{1} J_{\mathrm{CH}}$ & 95,3 & 99,4 & 103,7 & 108,3 & 113,2 & 118,4 & 124,0 & 129,8 & 136,0 & 142,6 & 149,5 & 125,3 \\
\hline $\mathrm{CH}_{4}$ & ${ }^{2} J_{\mathrm{HH}}$ & $-6,7$ & $-7,6$ & $-8,5$ & $-9,4$ & $-10,4$ & $-11,5$ & $-12,7$ & $-13,9$ & $-15,2$ & $-16,6$ & $-18,1$ & $-12,8$ \\
\hline $\mathrm{C}_{2} \mathrm{H}_{2}$ & ${ }^{1} J_{\mathrm{CC}}$ & 176,9 & 181,8 & 187,2 & 193,3 & 200,2 & 208,1 & 217,4 & 228,6 & 242,3 & 259,5 & 282,1 & 174,8 \\
\hline $\mathrm{C}_{2} \mathrm{H}_{2}$ & ${ }^{1} J_{\mathrm{CH}}$ & 192,2 & 200,0 & 208,2 & 216,9 & 226,2 & 236,1 & 246,8 & 258,5 & 271,5 & 286,2 & 303,3 & 247,6 \\
\hline $\mathrm{C}_{2} \mathrm{H}_{2}$ & ${ }^{2} J_{\mathrm{CH}}$ & 49,5 & 50,4 & 51,2 & 51,8 & 52,2 & 52,2 & 51,7 & 50,5 & 48,4 & 44,9 & 39,3 & 50,1 \\
\hline $\mathrm{C}_{2} \mathrm{H}_{2}$ & ${ }^{3} J_{\mathrm{HH}}$ & 6,5 & 6,9 & 7,5 & 8,1 & 8,9 & 9,9 & 11,2 & 12,8 & 15,0 & 17,8 & 21,7 & 9,6 \\
\hline $\mathrm{C}_{2} \mathrm{H}_{4}$ & ${ }^{1} J_{\mathrm{CC}}$ & 56,8 & 60,2 & 64,0 & 68,2 & 73,0 & 78,5 & 84,9 & 92,9 & 103,1 & 117,1 & 138,3 & 67,6 \\
\hline $\mathrm{C}_{2} \mathrm{H}_{4}$ & ${ }^{1} J_{\mathrm{CH}}$ & 119,2 & 124,4 & 130,1 & 136,0 & 142,4 & 149,3 & 156,8 & 165,1 & 174,5 & 185,6 & 199,6 & 156,3 \\
\hline $\mathrm{C}_{2} \mathrm{H}_{4}$ & ${ }^{2} J_{\mathrm{CH}}$ & 2,0 & 1,3 & 0,6 & $-0,2$ & $-1,3$ & $-2,6$ & $-4,3$ & $-6,5$ & $-9,4$ & $-13,8$ & $-20,9$ & $-2,4$ \\
\hline $\mathrm{C}_{2} \mathrm{H}_{4}$ & ${ }^{2} J_{\mathrm{HH}}$ & 4,8 & 4,5 & 4,1 & 3,6 & 3,1 & 2,4 & 1,6 & 0,5 & $-0,8$ & $-2,9$ & $-6,2$ & 2,3 \\
\hline $\mathrm{C}_{2} \mathrm{H}_{4}$ & ${ }^{3} J_{\mathrm{HH}_{\mathrm{c}}}$ & 9,2 & 9,5 & 9,8 & 10,2 & 10,7 & 11,2 & 11,9 & 12,9 & 14,2 & 16,1 & 19,2 & 11,7 \\
\hline $\mathrm{C}_{2} \mathrm{H}_{4}$ & ${ }^{3} J_{\mathrm{HH}_{\mathrm{t}}}$ & 13,1 & 13,7 & 14,3 & 15,0 & 15,8 & 16,7 & 17,8 & 19,2 & 21,0 & 23,6 & 27,5 & 19 \\
\hline $\mathrm{C}_{2} \mathrm{H}_{6}$ & ${ }^{1} J_{\mathrm{CC}}$ & 20,9 & 23,5 & 26,4 & 29,5 & 32,7 & 36,1 & 39,8 & 43,7 & 47,9 & 52,3 & 57,1 & 34,5 \\
\hline $\mathrm{C}_{2} \mathrm{H}_{6}$ & ${ }^{1} J_{\mathrm{CH}}$ & 94,5 & 98,8 & 103,4 & 108,3 & 113,4 & 118,9 & 124,6 & 130,8 & 137,2 & 144,1 & 151,4 & 125,2 \\
\hline $\mathrm{C}_{2} \mathrm{H}_{6}$ & ${ }^{2} J_{\mathrm{CH}}$ & $-1,1$ & $-1,6$ & $-2,1$ & $-2,6$ & $-3,2$ & $-3,8$ & $-4,5$ & $-5,3$ & $-6,1$ & $-6,9$ & $-7,9$ & $-4,7$ \\
\hline \multirow[t]{3}{*}{ Total } & $\mathrm{DM}$ & $-20,37$ & $-18,00$ & $-15,32$ & $-12,40$ & $-9,29$ & $-6,12$ & $-3,01$ & $-0,26$ & 1,45 & $-0,14$ & $-19,10$ & - \\
\hline & DMA & 31,82 & 26,77 & 21,33 & 15,94 & 13,62 & 11,85 & 14,40 & 21,46 & 30,92 & 45,66 & 80,95 & - \\
\hline & PDMA & 64,24 & 52,96 & 41,16 & 29,35 & 18,48 & 8,72 & 19,46 & 37,00 & 58,80 & 86,95 & 129,89 & - \\
\hline \multirow[t]{3}{*}{ CPI } & DM & $-32,61$ & $-29,93$ & $-26,74$ & $-23,20$ & $-19,49$ & $-15,89$ & $-12,83$ & $-11,11$ & $-12,54$ & $-22,65$ & $-75,31$ & - \\
\hline & DMA & 56,26 & 46,75 & 36,35 & 26,16 & 22,69 & 20,25 & 27,14 & 38,84 & 54,30 & 80,55 & 152,76 & - \\
\hline & PDMA & 92,44 & 74,25 & 55,43 & 37,48 & 22,53 & 9,24 & 26,90 & 48,46 & 72,08 & 99,01 & 140,82 & - \\
\hline \multirow[t]{3}{*}{ SPI } & DM & $-11,40$ & $-9,26$ & $-6,95$ & $-4,47$ & $-1,81$ & 1,05 & 4,19 & 7,70 & 11,70 & 16,37 & 22,12 & - \\
\hline & DMA & 13,89 & 12,13 & 10,31 & 8,45 & 6,97 & 5,68 & 5,06 & 8,71 & 13,78 & 20,07 & 28,29 & - \\
\hline & PDMA & 43,56 & 37,34 & 30,70 & 23,38 & 15,50 & 8,34 & 14,00 & 28,59 & 49,06 & 78,11 & 121,88 & - \\
\hline \multirow[t]{3}{*}{$\Delta \mathrm{CS}$} & $\mathrm{DM}$ & $-21,21$ & $-20,67$ & $-19,79$ & $-18,73$ & $-17,68$ & $-16,94$ & $-17,02$ & $-18,81$ & $-24,24$ & $-39,02$ & $-97,43$ & - \\
\hline & DMA & 42,37 & 34,62 & 26,05 & 17,72 & 15,72 & 14,57 & 22,08 & 30,12 & 40,52 & 60,47 & 124,47 & - \\
\hline & PDMA & 48,88 & 36,92 & 24,74 & 14,10 & 7,03 & 0,89 & 12,90 & 19,87 & 23,02 & 20,90 & 18,94 & - \\
\hline \multicolumn{14}{|c|}{ Desconsiderando ${ }^{1} J_{\mathrm{BF}}$ da molécula de $\mathrm{BF}_{3},{ }^{2} J_{\mathrm{CH}}$ e ${ }^{2} J_{\mathrm{HH}}$ da molécula de $\mathrm{C}_{2} \mathrm{H}_{4}$} \\
\hline \multirow[t]{3}{*}{ Total } & DM & $-19,17$ & $-17,26$ & $-15,01$ & $-12,49$ & $-9,76$ & $-6,93$ & $-4,17$ & $-1,77$ & $-0,52$ & $-2,88$ & $-24,71$ & - \\
\hline & DMA & 31,50 & 26,66 & 21,39 & 16,20 & 14,49 & 13,35 & 15,28 & 22,27 & 31,93 & 47,45 & 86,04 & - \\
\hline & PDMA & 32,15 & 26,68 & 20,94 & 15,57 & 11,87 & 9,13 & 11,34 & 19,43 & 30,65 & 44,86 & 68,62 & - \\
\hline \multirow[t]{3}{*}{ CPI } & DM & $-26,29$ & $-25,22$ & $-23,63$ & $-21,67$ & $-19,54$ & $-17,54$ & $-16,14$ & $-16,21$ & $-19,75$ & $-32,84$ & $-92,72$ & - \\
\hline & DMA & 52,31 & 43,72 & 34,21 & 24,93 & 23,06 & 22,22 & 27,82 & 38,73 & 53,77 & 80,68 & 158,16 & - \\
\hline & PDMA & 37,82 & 30,35 & 22,44 & 15,57 & 12,12 & 9,76 & 16,05 & 26,71 & 39,55 & 56,11 & 89,03 & - \\
\hline \multirow[t]{3}{*}{ SPI } & $\mathrm{DM}$ & $-13,68$ & $-11,14$ & $-8,38$ & $-5,43$ & $-2,24$ & 1,22 & 5,04 & 9,34 & 14,28 & 20,16 & 27,60 & - \\
\hline & DMA & 15,50 & 13,54 & 11,52 & 9,48 & 7,90 & 6,53 & 5,64 & 9,60 & 15,12 & 21,88 & 30,57 & - \\
\hline & PDMA & 27,79 & 23,86 & 19,78 & 15,58 & 11,68 & 8,65 & 7,72 & 13,83 & 23,81 & 36,20 & 52,91 & - \\
\hline \multirow[t]{3}{*}{$\Delta \mathrm{CS}$} & $\mathrm{DM}$ & $-12,61$ & $-14,08$ & $-15,25$ & $-16,24$ & $-17,30$ & $-18,76$ & $-21,18$ & $-25,55$ & $-34,03$ & $-53,00$ & $-120,32$ & 一 \\
\hline & DMA & 36,81 & 30,18 & 22,69 & 15,45 & 15,16 & 15,69 & 22,18 & 29,13 & 38,65 & 58,80 & 127,59 & - \\
\hline & PDMA & 10,02 & 6,48 & 2,66 & $-0,01$ & 0,43 & 1,11 & 8,33 & 12,88 & 15,75 & 19,91 & 36,12 & - \\
\hline
\end{tabular}


Tabela 8.213: Constantes de acoplamento B972LYP com base aug-pcJ-2.

\begin{tabular}{|c|c|c|c|c|c|c|c|c|c|c|c|c|c|}
\hline & $\% E_{X}^{\mathrm{HF}}$ & $0 \%$ & $10 \%$ & $20 \%$ & $30 \%$ & $40 \%$ & $50 \%$ & $60 \%$ & $70 \%$ & $80 \%$ & $90 \%$ & $100 \%$ & Exp. \\
\hline $\mathrm{HF}$ & ${ }^{1} J_{\mathrm{HF}}$ & 375,4 & 396,7 & 419,4 & 443,6 & 469,5 & 497,1 & 526,5 & 557,6 & 590,7 & 625,6 & 662,5 & 500 \\
\hline $\mathrm{CO}$ & ${ }^{1} J_{\mathrm{CO}}$ & 20,0 & 18,6 & 17,0 & 15,3 & 13,4 & 11,3 & 9,0 & 6,6 & 3,9 & 1,1 & $-1,9$ & 16,4 \\
\hline $\mathrm{H}_{2} \mathrm{O}$ & ${ }^{1} J_{\mathrm{OH}}$ & $-63,0$ & $-65,7$ & $-68,7$ & $-71,9$ & $-75,3$ & $-78,9$ & $-82,8$ & $-86,9$ & $-91,4$ & $-96,1$ & $-101,1$ & $-80,6$ \\
\hline $\mathrm{H}_{2} \mathrm{O}$ & ${ }^{2} J_{\mathrm{HH}}$ & $-2,4$ & $-3,4$ & $-4,6$ & $-5,8$ & $-7,1$ & $-8,5$ & $-10,0$ & $-11,7$ & $-13,4$ & $-15,3$ & $-17,3$ & $-7,3$ \\
\hline $\mathrm{NH}_{3}$ & ${ }^{1} J_{\mathrm{NH}}$ & 35,6 & 36,9 & 38,3 & 39,8 & 41,4 & 43,1 & 44,9 & 46,8 & 48,9 & 51,1 & 53,4 & 43,8 \\
\hline $\mathrm{NH}_{3}$ & ${ }^{2} J_{\mathrm{HH}}$ & $-4,9$ & $-5,9$ & $-6,9$ & $-8,0$ & $-9,2$ & $-10,4$ & $-11,8$ & $-13,3$ & $-15,0$ & $-16,7$ & $-18,7$ & $-9,6$ \\
\hline $\mathrm{PH}_{3}$ & ${ }^{1} J_{\mathrm{PH}}$ & 147,9 & 155,0 & 162,5 & 170,5 & 178,9 & 187,8 & 197,2 & 207,0 & 217,3 & 228,0 & 239,2 & 188,2 \\
\hline $\mathrm{PF}_{3}$ & ${ }^{1} J_{\mathrm{PF}}$ & $-1626,8$ & $-1622,6$ & $-1613,2$ & $-1599,5$ & $-1582,1$ & $-1561,8$ & $-1539,1$ & $-1514,8$ & $-1489,3$ & $-1463,3$ & $-1437,0$ & -1441 \\
\hline $\mathrm{BHF}_{2}$ & ${ }^{1} J_{\mathrm{BF}}$ & $-169,6$ & $-153,5$ & $-136,9$ & $-119,9$ & $-102,8$ & $-85,5$ & $-68,1$ & $-50,8$ & $-33,5$ & $-16,4$ & 0,6 & -84 \\
\hline $\mathrm{BF}_{3}$ & ${ }^{1} J_{\mathrm{BF}}$ & $-82,9$ & $-63,8$ & $-44,5$ & $-25,0$ & $-5,3$ & 14,3 & 34,2 & 54,1 & 74,0 & 93,9 & 113,8 & 15 \\
\hline $\mathrm{F}_{2} \mathrm{O}$ & ${ }^{1} J_{\mathrm{OF}}$ & $-205,6$ & $-238,4$ & $-273,1$ & $-310,5$ & $-352,1$ & $-400,4$ & $-460,4$ & $-542,4$ & $-672,5$ & $-945,1$ & $-2253,8$ & -300 \\
\hline $\mathrm{CH}_{4}$ & ${ }^{1} J_{\mathrm{CH}}$ & 94,0 & 98,2 & 102,6 & 107,3 & 112,2 & 117,5 & 123,2 & 129,2 & 135,5 & 142,2 & 149,4 & 125,3 \\
\hline $\mathrm{CH}_{4}$ & ${ }^{2} J_{\mathrm{HH}}$ & $-7,7$ & $-8,6$ & $-9,5$ & $-10,5$ & $-11,6$ & $-12,7$ & $-14,0$ & $-15,3$ & $-16,7$ & $-18,2$ & $-19,7$ & $-12,8$ \\
\hline $\mathrm{C}_{2} \mathrm{H}_{2}$ & ${ }^{1} J_{\mathrm{CC}}$ & 167,0 & 171,4 & 176,3 & 181,8 & 188,1 & 195,4 & 204,2 & 214,8 & 228,1 & 245,3 & 268,4 & 174,8 \\
\hline $\mathrm{C}_{2} \mathrm{H}_{2}$ & ${ }^{1} J_{\mathrm{CH}}$ & 195,1 & 203,2 & 211,8 & 220,9 & 230,6 & 241,0 & 252,3 & 264,7 & 278,6 & 294,5 & 313,5 & 247,6 \\
\hline $\mathrm{C}_{2} \mathrm{H}_{2}$ & ${ }^{2} J_{\mathrm{CH}}$ & 51,4 & 52,3 & 53,2 & 53,8 & 54,1 & 53,9 & 53,3 & 51,9 & 49,3 & 45,1 & 38,1 & 50,1 \\
\hline $\mathrm{C}_{2} \mathrm{H}_{2}$ & ${ }^{3} J_{\mathrm{HH}}$ & 7,2 & 7,7 & 8,3 & 9,1 & 10,0 & 11,2 & 12,8 & 14,8 & 17,4 & 21,0 & 26,0 & 9,6 \\
\hline $\mathrm{C}_{2} \mathrm{H}_{4}$ & ${ }^{1} J_{\mathrm{CC}}$ & 50,6 & 53,8 & 57,3 & 61,3 & 65,9 & 71,2 & 77,6 & 85,7 & 96,5 & 112,4 & 139,0 & 67,6 \\
\hline $\mathrm{C}_{2} \mathrm{H}_{4}$ & ${ }^{1} J_{\mathrm{CH}}$ & 118,9 & 124,3 & 130,1 & 136,2 & 142,8 & 149,9 & 157,7 & 166,5 & 176,5 & 188,9 & 205,7 & 156,3 \\
\hline $\mathrm{C}_{2} \mathrm{H}_{4}$ & ${ }^{2} J_{\mathrm{CH}}$ & 2,3 & 1,6 & 0,9 & 0,0 & $-1,1$ & $-2,5$ & $-4,3$ & $-6,8$ & $-10,3$ & $-15,7$ & $-25,4$ & $-2,4$ \\
\hline $\mathrm{C}_{2} \mathrm{H}_{4}$ & ${ }^{2} J_{\mathrm{HH}}$ & 5,0 & 4,7 & 4,3 & 3,8 & 3,2 & 2,5 & 1,5 & 0,2 & $-1,5$ & $-4,4$ & $-9,3$ & 2,3 \\
\hline $\mathrm{C}_{2} \mathrm{H}_{4}$ & ${ }^{3} J_{\mathrm{HH}_{\mathrm{c}}}$ & 10,0 & 10,3 & 10,7 & 11,2 & 11,7 & 12,4 & 13,3 & 14,5 & 16,2 & 18,9 & 23,7 & 11,7 \\
\hline $\mathrm{C}_{2} \mathrm{H}_{4}$ & ${ }^{3} J_{\mathrm{HH}_{\mathrm{t}}}$ & 14,1 & 14,8 & 15,5 & 16,3 & 17,2 & 18,3 & 19,6 & 21,3 & 23,6 & 27,0 & 32,9 & 19 \\
\hline $\mathrm{C}_{2} \mathrm{H}_{6}$ & ${ }^{1} J_{\mathrm{CC}}$ & 18,4 & 20,9 & 23,7 & 26,6 & 29,6 & 32,9 & 36,4 & 40,1 & 44,0 & 48,2 & 52,7 & 34,5 \\
\hline $\mathrm{C}_{2} \mathrm{H}_{6}$ & ${ }^{1} J_{\mathrm{CH}}$ & 93,1 & 97,4 & 102,1 & 107,0 & 112,2 & 117,7 & 123,6 & 129,8 & 136,5 & 143,5 & 150,9 & 125,2 \\
\hline $\mathrm{C}_{2} \mathrm{H}_{6}$ & ${ }^{2} J_{\mathrm{CH}}$ & $-1,0$ & $-1,5$ & $-2,0$ & $-2,6$ & $-3,2$ & $-3,8$ & $-4,5$ & $-5,2$ & $-6,0$ & $-6,9$ & $-7,8$ & $-4,7$ \\
\hline \multirow[t]{3}{*}{ Total } & $\mathrm{DM}$ & $-23,19$ & $-20,79$ & $-18,09$ & $-15,16$ & $-12,08$ & $-8,92$ & $-5,87$ & $-3,33$ & $-2,22$ & $-6,02$ & $-48,74$ & - \\
\hline & DMA & 34,17 & 28,66 & 22,76 & 17,53 & 14,27 & 11,48 & 15,71 & 23,58 & 34,19 & 51,36 & 110,36 & - \\
\hline & PDMA & 65,21 & 53,59 & 41,38 & 29,08 & 17,31 & 8,31 & 21,33 & 40,98 & 65,27 & 98,58 & 158,62 & - \\
\hline \multirow[t]{3}{*}{ CPI } & DM & $-37,93$ & $-35,18$ & $-31,96$ & $-28,39$ & $-24,69$ & $-21,16$ & $-18,30$ & $-17,15$ & $-20,11$ & $-35,83$ & $-145,56$ & - \\
\hline & DMA & 60,69 & 50,87 & 40,11 & 30,54 & 25,76 & 21,47 & 31,34 & 44,74 & 62,73 & 93,86 & 220,20 & - \\
\hline & PDMA & 93,08 & 74,47 & 55,13 & 37,13 & 21,20 & 9,88 & 29,78 & 52,81 & 77,79 & 107,46 & 169,20 & - \\
\hline \multirow[t]{3}{*}{ SPI } & $\mathrm{DM}$ & $-12,38$ & $-10,24$ & $-7,92$ & $-5,46$ & $-2,83$ & 0,05 & 3,24 & 6,81 & 10,91 & 15,85 & 22,27 & - \\
\hline & DMA & 14,71 & 12,37 & 10,04 & 7,99 & 5,84 & 4,15 & 4,25 & 8,07 & 13,27 & 20,19 & 29,81 & - \\
\hline & PDMA & 44,78 & 38,28 & 31,30 & 23,18 & 14,46 & 7,16 & 15,13 & 32,31 & 56,09 & 92,07 & 150,86 & - \\
\hline \multirow[t]{3}{*}{$\Delta \mathrm{CS}$} & $\mathrm{DM}$ & $-25,55$ & $-24,94$ & $-24,04$ & $-22,93$ & $-21,86$ & $-21,22$ & $-21,54$ & $-23,96$ & $-31,02$ & $-51,67$ & $-167,83$ & - \\
\hline & DMA & 45,98 & 38,50 & 30,07 & 22,54 & 19,92 & 17,33 & 27,08 & 36,66 & 49,46 & 73,67 & 190,39 & - \\
\hline & PDMA & 48,30 & 36,19 & 23,83 & 13,95 & 6,74 & 2,72 & 14,64 & 20,49 & 21,69 & 15,39 & 18,34 & - \\
\hline \multicolumn{14}{|c|}{ Desconsiderando ${ }^{1} J_{\mathrm{BF}}$ da molécula de $\mathrm{BF}_{3},{ }^{2} J_{\mathrm{CH}}$ e ${ }^{2} J_{\mathrm{HH}}$ da molécula de $\mathrm{C}_{2} \mathrm{H}_{4}$} \\
\hline \multirow[t]{3}{*}{ Total } & DM & $-22,28$ & $-20,36$ & $-18,10$ & $-15,57$ & $-12,87$ & $-10,06$ & $-7,36$ & $-5,18$ & $-4,56$ & $-9,36$ & $-57,89$ & - \\
\hline & DMA & 34,04 & 28,70 & 22,91 & 17,91 & 15,15 & 12,93 & 16,81 & 24,68 & 35,58 & 53,76 & 118,96 & - \\
\hline & PDMA & 31,73 & 25,95 & 19,78 & 14,10 & 9,63 & 8,63 & 13,59 & 23,06 & 35,19 & 51,81 & 87,08 & - \\
\hline \multirow[t]{3}{*}{ CPI } & DM & $-31,93$ & $-30,82$ & $-29,21$ & $-27,23$ & $-25,13$ & $-23,21$ & $-22,05$ & $-22,78$ & $-28,02$ & $-47,30$ & $-170,00$ & - \\
\hline & DMA & 56,97 & 48,08 & 38,17 & 29,59 & 26,31 & 23,55 & 32,55 & 45,30 & 63,10 & 95,36 & 232,34 & - \\
\hline & PDMA & 37,12 & 29,38 & 20,98 & 14,18 & 9,78 & 10,40 & 19,96 & 32,02 & 46,23 & 65,61 & 120,26 & - \\
\hline \multirow[t]{3}{*}{ SPI } & $\mathrm{DM}$ & $-14,85$ & $-12,31$ & $-9,55$ & $-6,60$ & $-3,43$ & 0,05 & 3,95 & 8,35 & 13,48 & 19,82 & 28,35 & - \\
\hline & DMA & 16,41 & 13,78 & 11,18 & 8,92 & 6,57 & 4,76 & 4,70 & 8,82 & 14,41 & 21,76 & 31,74 & - \\
\hline & PDMA & 27,58 & 23,32 & 18,85 & 14,04 & 9,51 & 7,27 & 8,70 & 16,16 & 26,70 & 41,20 & 61,56 & - \\
\hline \multirow[t]{3}{*}{$\Delta \mathrm{CS}$} & $\mathrm{DM}$ & $-17,08$ & $-18,51$ & $-19,66$ & $-20,63$ & $-21,70$ & $-23,26$ & $-26,00$ & $-31,13$ & $-41,50$ & $-67,12$ & $-198,35$ & - \\
\hline & DMA & 40,56 & 34,30 & 26,99 & 20,67 & 19,74 & 18,79 & 27,85 & 36,48 & 48,69 & 73,60 & 200,60 & - \\
\hline & PDMA & 9,54 & 6,06 & 2,12 & 0,14 & 0,28 & 3,13 & 11,26 & 15,86 & 19,54 & 24,41 & 58,70 & - \\
\hline
\end{tabular}


Tabela 8.214: Constantes de acoplamento B972P86 com base aug-pcJ-2.

\begin{tabular}{|c|c|c|c|c|c|c|c|c|c|c|c|c|c|}
\hline & $\% E_{X}^{\mathrm{HF}}$ & $0 \%$ & $10 \%$ & $20 \%$ & $30 \%$ & $40 \%$ & $50 \%$ & $60 \%$ & $70 \%$ & $80 \%$ & $90 \%$ & $100 \%$ & Exp. \\
\hline $\mathrm{HF}$ & ${ }^{1} J_{\mathrm{HF}}$ & 339,4 & 358,7 & 379,3 & 401,5 & 425,2 & 450,5 & 477,4 & 506,0 & 536,3 & 568,4 & 602,2 & 500 \\
\hline $\mathrm{CO}$ & ${ }^{1} J_{\mathrm{CO}}$ & 23,0 & 21,8 & 20,5 & 19,1 & 17,5 & 15,8 & 13,9 & 11,8 & 9,6 & 7,3 & 4,8 & 16,4 \\
\hline $\mathrm{H}_{2} \mathrm{O}$ & ${ }^{1} J_{\mathrm{OH}}$ & $-56,6$ & $-59,1$ & $-61,8$ & $-64,6$ & $-67,7$ & $-71,0$ & $-74,5$ & $-78,3$ & $-82,2$ & $-86,5$ & $-91,0$ & $-80,6$ \\
\hline $\mathrm{H}_{2} \mathrm{O}$ & ${ }^{2} J_{\mathrm{HH}}$ & $-1,8$ & $-2,7$ & $-3,8$ & $-4,9$ & $-6,0$ & $-7,3$ & $-8,6$ & $-10,1$ & $-11,6$ & $-13,3$ & $-15,1$ & $-7,3$ \\
\hline $\mathrm{NH}_{3}$ & ${ }^{1} J_{\mathrm{NH}}$ & 31,9 & 33,1 & 34,3 & 35,6 & 37,1 & 38,6 & 40,2 & 41,9 & 43,8 & 45,7 & 47,8 & 43,8 \\
\hline $\mathrm{NH}_{3}$ & ${ }^{2} J_{\mathrm{HH}}$ & $-4,5$ & $-5,4$ & $-6,3$ & $-7,3$ & $-8,3$ & $-9,5$ & $-10,7$ & $-12,0$ & $-13,5$ & $-15,1$ & $-16,8$ & $-9,6$ \\
\hline $\mathrm{PH}_{3}$ & ${ }^{1} J_{\mathrm{PH}}$ & 127,3 & 133,8 & 140,7 & 148,0 & 155,8 & 164,0 & 172,7 & 181,9 & 191,5 & 201,6 & 212,1 & 188,2 \\
\hline $\mathrm{PF}_{3}$ & ${ }^{1} J_{\mathrm{PF}}$ & $-1623,0$ & $-1618,3$ & $-1608,5$ & $-1594,3$ & $-1576,4$ & $-1555,5$ & $-1532,3$ & $-1507,4$ & $-1481,3$ & $-1454,6$ & $-1427,5$ & -1441 \\
\hline $\mathrm{BHF}_{2}$ & ${ }^{1} J_{\mathrm{BF}}$ & $-178,3$ & $-162,9$ & $-147,1$ & $-131,0$ & $-114,5$ & $-97,8$ & $-81,0$ & $-64,2$ & $-47,4$ & $-30,7$ & $-14,1$ & -84 \\
\hline $\mathrm{BF}_{3}$ & ${ }^{1} J_{\mathrm{BF}}$ & $-95,6$ & $-77,3$ & $-58,7$ & $-39,9$ & $-20,8$ & $-1,7$ & 17,5 & 36,8 & 56,1 & 75,5 & 94,8 & 15 \\
\hline $\mathrm{F}_{2} \mathrm{O}$ & ${ }^{1} J_{\mathrm{OF}}$ & $-215,1$ & $-247,9$ & $-282,7$ & $-320,3$ & $-362,3$ & $-411,1$ & $-471,8$ & $-554,3$ & $-683,7$ & $-944,7$ & $-1973,1$ & -300 \\
\hline $\mathrm{CH}_{4}$ & ${ }^{1} J_{\mathrm{CH}}$ & 83,1 & 86,8 & 90,8 & 95,0 & 99,5 & 104,2 & 109,3 & 114,7 & 120,5 & 126,5 & 133,0 & 125,3 \\
\hline $\mathrm{CH}_{4}$ & ${ }^{2} J_{\mathrm{HH}}$ & $-7,7$ & $-8,5$ & $-9,3$ & $-10,3$ & $-11,3$ & $-12,3$ & $-13,5$ & $-14,7$ & $-16,0$ & $-17,4$ & $-18,8$ & $-12,8$ \\
\hline $\mathrm{C}_{2} \mathrm{H}_{2}$ & ${ }^{1} J_{\mathrm{CC}}$ & 157,1 & 161,0 & 165,4 & 170,3 & 176,0 & 182,6 & 190,5 & 200,1 & 212,3 & 228,2 & 250,2 & 174,8 \\
\hline $\mathrm{C}_{2} \mathrm{H}_{2}$ & ${ }^{1} J_{\mathrm{CH}}$ & 175,8 & 183,2 & 191,0 & 199,2 & 208,1 & 217,6 & 227,9 & 239,3 & 252,2 & 267,1 & 285,3 & 247,6 \\
\hline $\mathrm{C}_{2} \mathrm{H}_{2}$ & ${ }^{2} J_{\mathrm{CH}}$ & 48,8 & 49,8 & 50,7 & 51,3 & 51,7 & 51,6 & 51,1 & 49,8 & 47,3 & 43,1 & 35,9 & 50,1 \\
\hline $\mathrm{C}_{2} \mathrm{H}_{2}$ & ${ }^{3} J_{\mathrm{HH}}$ & 7,2 & 7,7 & 8,3 & 9,1 & 10,0 & 11,3 & 12,9 & 14,9 & 17,7 & 21,5 & 26,9 & 9,6 \\
\hline $\mathrm{C}_{2} \mathrm{H}_{4}$ & ${ }^{1} J_{\mathrm{CC}}$ & 44,6 & 47,5 & 50,7 & 54,3 & 58,4 & 63,2 & 69,2 & 76,8 & 87,2 & 103,4 & 133,8 & 67,6 \\
\hline $\mathrm{C}_{2} \mathrm{H}_{4}$ & ${ }^{1} J_{\mathrm{CH}}$ & 106,2 & 111,1 & 116,3 & 121,8 & 127,8 & 134,3 & 141,5 & 149,5 & 159,0 & 171,1 & 189,3 & 156,3 \\
\hline $\mathrm{C}_{2} \mathrm{H}_{4}$ & ${ }^{2} J_{\mathrm{CH}}$ & 1,9 & 1,3 & 0,6 & $-0,1$ & $-1,2$ & $-2,5$ & $-4,2$ & $-6,6$ & $-10,2$ & $-16,0$ & $-27,6$ & $-2,4$ \\
\hline $\mathrm{C}_{2} \mathrm{H}_{4}$ & ${ }^{2} J_{\mathrm{HH}}$ & 3,9 & 3,6 & 3,1 & 2,6 & 2,0 & 1,2 & 0,1 & $-1,2$ & $-3,3$ & $-6,8$ & $-13,5$ & 2,3 \\
\hline $\mathrm{C}_{2} \mathrm{H}_{4}$ & ${ }^{3} J_{\mathrm{HH}_{\mathrm{c}}}$ & 9,1 & 9,4 & 9,8 & 10,3 & 10,9 & 11,6 & 12,5 & 13,8 & 15,8 & 19,1 & 25,7 & 11,7 \\
\hline $\mathrm{C}_{2} \mathrm{H}_{4}$ & ${ }^{3} J_{\mathrm{HH}_{\mathrm{t}}}$ & 12,9 & 13,6 & 14,3 & 15,1 & 16,0 & 17,1 & 18,5 & 20,3 & 22,9 & 26,9 & 34,7 & 19 \\
\hline $\mathrm{C}_{2} \mathrm{H}_{6}$ & ${ }^{1} J_{\mathrm{CC}}$ & 14,2 & 16,6 & 19,0 & 21,7 & 24,4 & 27,4 & 30,6 & 33,9 & 37,5 & 41,4 & 45,4 & 34,5 \\
\hline $\mathrm{C}_{2} \mathrm{H}_{6}$ & ${ }^{1} J_{\mathrm{CH}}$ & 82,7 & 86,6 & 90,8 & 95,2 & 99,9 & 104,9 & 110,2 & 115,9 & 121,9 & 128,2 & 135,0 & 125,2 \\
\hline $\mathrm{C}_{2} \mathrm{H}_{6}$ & ${ }^{2} J_{\mathrm{CH}}$ & $-1,3$ & $-1,7$ & $-2,2$ & $-2,7$ & $-3,2$ & $-3,8$ & $-4,5$ & $-5,2$ & $-5,9$ & $-6,7$ & $-7,6$ & $-4,7$ \\
\hline \multirow[t]{3}{*}{ Total } & $\mathrm{DM}$ & $-29,22$ & $-27,05$ & $-24,61$ & $-21,93$ & $-19,09$ & $-16,22$ & $-13,47$ & $-11,22$ & $-10,33$ & $-13,92$ & $-45,89$ & - \\
\hline & DMA & 40,03 & 34,75 & 29,02 & 24,37 & 20,94 & 17,92 & 16,10 & 18,38 & 25,77 & 41,55 & 90,58 & - \\
\hline & PDMA & 71,35 & 60,36 & 48,48 & 36,63 & 25,46 & 16,21 & 17,23 & 32,62 & 55,15 & 89,15 & 152,34 & - \\
\hline \multirow[t]{3}{*}{ CPI } & DM & $-44,93$ & $-42,46$ & $-39,55$ & $-36,27$ & $-32,85$ & $-29,63$ & $-27,10$ & $-26,25$ & $-29,39$ & $-44,30$ & $-128,80$ & - \\
\hline & DMA & 67,85 & 58,43 & 48,09 & 40,53 & 35,86 & 31,39 & 29,21 & 35,33 & 50,72 & 80,21 & 182,13 & - \\
\hline & PDMA & 107,33 & 89,72 & 71,41 & 53,84 & 36,97 & 20,36 & 14,26 & 32,86 & 54,57 & 82,73 & 134,69 & - \\
\hline \multirow[t]{3}{*}{ SPI } & DM & $-17,71$ & $-15,74$ & $-13,65$ & $-11,42$ & $-9,01$ & $-6,38$ & $-3,47$ & $-0,19$ & 3,65 & 8,37 & 14,91 & - \\
\hline & DMA & 19,63 & 17,38 & 15,04 & 12,53 & 9,99 & 8,03 & 6,48 & 5,95 & 7,48 & 13,21 & 23,45 & - \\
\hline & PDMA & 44,97 & 38,84 & 31,65 & 24,01 & 17,01 & 13,16 & 19,40 & 32,44 & 55,58 & 93,85 & 165,29 & - \\
\hline \multirow[t]{3}{*}{$\Delta \mathrm{CS}$} & DM & $-27,22$ & $-26,72$ & $-25,89$ & $-24,85$ & $-23,84$ & $-23,25$ & $-23,63$ & $-26,07$ & $-33,04$ & $-52,67$ & $-143,71$ & - \\
\hline & DMA & 48,23 & 41,05 & 33,05 & 28,00 & 25,87 & 23,36 & 22,73 & 29,38 & 43,24 & 67,00 & 158,67 & - \\
\hline & PDMA & 62,37 & 50,88 & 39,76 & 29,83 & 19,96 & 7,20 & $-5,14$ & 0,41 & $-1,01$ & $-11,12$ & $-30,60$ & - \\
\hline \multicolumn{14}{|c|}{ Desconsiderando ${ }^{1} J_{\mathrm{BF}}$ da molécula de $\mathrm{BF}_{3},{ }^{2} J_{\mathrm{CH}}$ e ${ }^{2} J_{\mathrm{HH}}$ da molécula de $\mathrm{C}_{2} \mathrm{H}_{4}$} \\
\hline \multirow[t]{3}{*}{ Total } & DM & $-28,48$ & $-26,78$ & $-24,78$ & $-22,52$ & $-20,07$ & $-17,55$ & $-15,16$ & $-13,29$ & $-12,88$ & $-17,37$ & $-53,57$ & - \\
\hline & DMA & 40,19 & 35,05 & 29,44 & 25,05 & 22,05 & 19,47 & 17,91 & 19,49 & 26,77 & 43,36 & 97,15 & - \\
\hline & PDMA & 37,79 & 32,32 & 26,49 & 20,76 & 15,66 & 11,22 & 11,33 & 16,33 & 25,72 & 41,40 & 73,57 & - \\
\hline \multirow[t]{3}{*}{ CPI } & DM & $-38,36$ & $-37,48$ & $-36,13$ & $-34,41$ & $-32,55$ & $-30,92$ & $-30,06$ & $-31,06$ & $-36,44$ & $-54,78$ & $-149,66$ & - \\
\hline & DMA & 63,58 & 55,04 & 45,53 & 39,09 & 35,87 & 32,86 & 31,88 & 36,68 & 51,68 & 82,18 & 192,36 & - \\
\hline & PDMA & 44,33 & 37,16 & 29,42 & 22,63 & 16,80 & 11,26 & 14,02 & 21,61 & 32,63 & 50,67 & 94,96 & - \\
\hline \multirow[t]{3}{*}{ SPI } & $\mathrm{DM}$ & $-20,88$ & $-18,55$ & $-16,05$ & $-13,38$ & $-10,46$ & $-7,27$ & $-3,69$ & 0,38 & 5,25 & 11,40 & 20,35 & - \\
\hline & DMA & 22,19 & 19,67 & 17,06 & 14,25 & 11,42 & 9,18 & 7,17 & 6,27 & 7,60 & 13,49 & 23,91 & - \\
\hline & PDMA & 32,75 & 28,61 & 24,23 & 19,33 & 14,78 & 11,19 & 9,26 & 12,27 & 20,40 & 34,27 & 57,11 & - \\
\hline \multirow[t]{3}{*}{$\Delta \mathrm{CS}$} & $\mathrm{DM}$ & $-17,48$ & $-18,93$ & $-20,08$ & $-21,03$ & $-22,09$ & $-23,65$ & $-26,37$ & $-31,44$ & $-41,69$ & $-66,18$ & $-170,01$ & 一 \\
\hline & DMA & 41,39 & 35,37 & 28,47 & 24,84 & 24,45 & 23,68 & 24,71 & 30,41 & 44,08 & 68,69 & 168,45 & - \\
\hline & PDMA & 11,58 & 8,55 & 5,19 & 3,30 & 2,02 & 0,08 & 4,76 & 9,34 & 12,22 & 16,41 & 37,85 & - \\
\hline
\end{tabular}


Tabela 8.215: Constantes de acoplamento B972PBE com base aug-pcJ-2.

\begin{tabular}{|c|c|c|c|c|c|c|c|c|c|c|c|c|c|}
\hline & $\% E_{X}^{\mathrm{HF}}$ & $0 \%$ & $10 \%$ & $20 \%$ & $30 \%$ & $40 \%$ & $50 \%$ & $60 \%$ & $70 \%$ & $80 \%$ & $90 \%$ & $100 \%$ & Exp. \\
\hline $\mathrm{HF}$ & ${ }^{1} J_{\mathrm{HF}}$ & 334,6 & 354,3 & 375,4 & 398,0 & 422,2 & 448,0 & 475,6 & 504,8 & 535,8 & 568,7 & 603,3 & 500 \\
\hline $\mathrm{CO}$ & ${ }^{1} J_{\mathrm{CO}}$ & 23,5 & 22,3 & 21,1 & 19,6 & 18,1 & 16,4 & 14,5 & 12,4 & 10,2 & 7,8 & 5,3 & 16,4 \\
\hline $\mathrm{H}_{2} \mathrm{O}$ & ${ }^{1} J_{\mathrm{OH}}$ & $-56,3$ & $-58,8$ & $-61,6$ & $-64,5$ & $-67,6$ & $-71,0$ & $-74,6$ & $-78,4$ & $-82,5$ & $-86,8$ & $-91,5$ & $-80,6$ \\
\hline $\mathrm{H}_{2} \mathrm{O}$ & ${ }^{2} J_{\mathrm{HH}}$ & $-2,1$ & $-3,1$ & $-4,1$ & $-5,3$ & $-6,5$ & $-7,8$ & $-9,2$ & $-10,7$ & $-12,3$ & $-14,1$ & $-15,9$ & $-7,3$ \\
\hline $\mathrm{NH}_{3}$ & ${ }^{1} J_{\mathrm{NH}}$ & 31,9 & 33,1 & 34,3 & 35,7 & 37,2 & 38,7 & 40,4 & 42,1 & 44,0 & 46,0 & 48,2 & 43,8 \\
\hline $\mathrm{NH}_{3}$ & ${ }^{2} J_{\mathrm{HH}}$ & $-4,9$ & $-5,7$ & $-6,7$ & $-7,7$ & $-8,8$ & $-10,0$ & $-11,3$ & $-12,7$ & $-14,2$ & $-15,9$ & $-17,6$ & $-9,6$ \\
\hline $\mathrm{PH}_{3}$ & ${ }^{1} J_{\mathrm{PH}}$ & 126,6 & 133,3 & 140,5 & 148,0 & 156,1 & 164,6 & 173,6 & 183,1 & 193,0 & 203,4 & 214,3 & 188,2 \\
\hline $\mathrm{PF}_{3}$ & ${ }^{1} J_{\mathrm{PF}}$ & $-1627,5$ & $-1622,1$ & $-1611,6$ & $-1596,8$ & $-1578,3$ & $-1556,9$ & $-1533,1$ & $-1507,7$ & $-1481,2$ & $-1453,9$ & $-1426,5$ & -1441 \\
\hline $\mathrm{BHF}_{2}$ & ${ }^{1} J_{\mathrm{BF}}$ & $-179,4$ & $-164,0$ & $-148,1$ & $-131,7$ & $-115,1$ & $-98,3$ & $-81,3$ & $-64,4$ & $-47,4$ & $-30,5$ & $-13,8$ & -84 \\
\hline $\mathrm{BF}_{3}$ & ${ }^{1} J_{\mathrm{BF}}$ & $-96,8$ & $-78,4$ & $-59,6$ & $-40,7$ & $-21,5$ & $-2,2$ & 17,1 & 36,6 & 56,1 & 75,7 & 95,2 & 15 \\
\hline $\mathrm{F}_{2} \mathrm{O}$ & ${ }^{1} J_{\mathrm{OF}}$ & $-215,0$ & $-248,6$ & $-284,2$ & $-322,8$ & $-365,9$ & $-416,5$ & $-480,0$ & $-567,5$ & $-707,9$ & $-1005,1$ & $-2453,2$ & -300 \\
\hline $\mathrm{CH}_{4}$ & ${ }^{1} J_{\mathrm{CH}}$ & 83,4 & 87,2 & 91,2 & 95,5 & 100,1 & 105,0 & 110,2 & 115,7 & 121,6 & 127,8 & 134,4 & 125,3 \\
\hline $\mathrm{CH}_{4}$ & ${ }^{2} J_{\mathrm{HH}}$ & $-8,1$ & $-8,9$ & $-9,8$ & $-10,8$ & $-11,9$ & $-13,0$ & $-14,2$ & $-15,5$ & $-16,8$ & $-18,3$ & $-19,8$ & $-12,8$ \\
\hline $\mathrm{C}_{2} \mathrm{H}_{2}$ & ${ }^{1} J_{\mathrm{CC}}$ & 156,1 & 160,1 & 164,6 & 169,7 & 175,5 & 182,4 & 190,7 & 201,0 & 214,2 & 231,9 & 257,1 & 174,8 \\
\hline $\mathrm{C}_{2} \mathrm{H}_{2}$ & ${ }^{1} J_{\mathrm{CH}}$ & 177,2 & 184,8 & 192,8 & 201,3 & 210,4 & 220,2 & 230,9 & 242,9 & 256,6 & 272,9 & 293,3 & 247,6 \\
\hline $\mathrm{C}_{2} \mathrm{H}_{2}$ & ${ }^{2} J_{\mathrm{CH}}$ & 49,0 & 50,0 & 50,8 & 51,4 & 51,6 & 51,4 & 50,6 & 48,8 & 45,7 & 40,3 & 31,2 & 50,1 \\
\hline $\mathrm{C}_{2} \mathrm{H}_{2}$ & ${ }^{3} J_{\mathrm{HH}}$ & 7,5 & 8,1 & 8,8 & 9,6 & 10,7 & 12,1 & 13,9 & 16,3 & 19,5 & 24,1 & 30,9 & 9,6 \\
\hline $\mathrm{C}_{2} \mathrm{H}_{4}$ & ${ }^{1} J_{\mathrm{CC}}$ & 44,2 & 47,1 & 50,4 & 54,1 & 58,3 & 63,4 & 69,8 & 78,1 & 90,0 & 109,5 & 150,7 & 67,6 \\
\hline $\mathrm{C}_{2} \mathrm{H}_{4}$ & ${ }^{1} J_{\mathrm{CH}}$ & 106,9 & 111,9 & 117,2 & 122,9 & 129,1 & 135,8 & 143,2 & 151,8 & 162,1 & 175,8 & 199,0 & 156,3 \\
\hline $\mathrm{C}_{2} \mathrm{H}_{4}$ & ${ }^{2} J_{\mathrm{CH}}$ & 1,6 & 1,0 & 0,3 & $-0,6$ & $-1,7$ & $-3,2$ & $-5,1$ & $-7,9$ & $-12,1$ & $-19,6$ & $-36,1$ & $-2,4$ \\
\hline $\mathrm{C}_{2} \mathrm{H}_{4}$ & ${ }^{2} J_{\mathrm{HH}}$ & 3,7 & 3,3 & 2,8 & 2,2 & 1,5 & 0,6 & $-0,6$ & $-2,3$ & $-4,9$ & $-9,4$ & $-19,4$ & 2,3 \\
\hline $\mathrm{C}_{2} \mathrm{H}_{4}$ & ${ }^{3} J_{\mathrm{HH}_{\mathrm{c}}}$ & 9,2 & 9,6 & 10,1 & 10,6 & 11,2 & 12,1 & 13,2 & 14,7 & 17,2 & 21,5 & 31,3 & 11,7 \\
\hline $\mathrm{C}_{2} \mathrm{H}_{4}$ & ${ }^{3} J_{\mathrm{HH}_{\mathrm{t}}}$ & 13,3 & 13,9 & 14,7 & 15,5 & 16,6 & 17,8 & 19,4 & 21,5 & 24,6 & 29,8 & 41,0 & 19 \\
\hline $\mathrm{C}_{2} \mathrm{H}_{6}$ & ${ }^{1} J_{\mathrm{CC}}$ & 14,1 & 16,4 & 18,9 & 21,6 & 24,4 & 27,4 & 30,5 & 33,9 & 37,6 & 41,4 & 45,6 & 34,5 \\
\hline $\mathrm{C}_{2} \mathrm{H}_{6}$ & ${ }^{1} J_{\mathrm{CH}}$ & 83,1 & 87,1 & 91,4 & 95,9 & 100,7 & 105,8 & 111,3 & 117,0 & 123,2 & 129,7 & 136,6 & 125,2 \\
\hline $\mathrm{C}_{2} \mathrm{H}_{6}$ & ${ }^{2} J_{\mathrm{CH}}$ & $-1,5$ & $-1,9$ & $-2,4$ & $-3,0$ & $-3,5$ & $-4,1$ & $-4,8$ & $-5,5$ & $-6,3$ & $-7,2$ & $-8,1$ & $-4,7$ \\
\hline \multirow[t]{3}{*}{ Total } & $\mathrm{DM}$ & $-29,64$ & $-27,42$ & $-24,92$ & $-22,20$ & $-19,31$ & $-16,40$ & $-13,63$ & $-11,42$ & $-10,74$ & $-15,37$ & $-62,67$ & - \\
\hline & DMA & 40,38 & 34,98 & 29,13 & 24,51 & 21,03 & 18,09 & 16,37 & 18,89 & 27,60 & 45,60 & 112,44 & - \\
\hline & PDMA & 70,24 & 58,97 & 46,90 & 34,71 & 24,95 & 18,58 & 20,82 & 38,63 & 64,25 & 104,83 & 190,22 & - \\
\hline \multirow[t]{3}{*}{ CPI } & DM & $-46,03$ & $-43,51$ & $-40,50$ & $-37,19$ & $-33,73$ & $-30,54$ & $-28,11$ & $-27,57$ & $-31,57$ & $-49,60$ & $-172,10$ & - \\
\hline & DMA & 68,99 & 59,36 & 48,79 & 41,41 & 36,69 & 32,28 & 30,07 & 36,34 & 53,12 & 86,02 & 226,41 & - \\
\hline & PDMA & 107,89 & 90,14 & 71,73 & 53,95 & 36,85 & 21,46 & 15,16 & 34,06 & 56,64 & 86,37 & 151,26 & - \\
\hline \multirow[t]{3}{*}{ SPI } & $\mathrm{DM}$ & $-17,63$ & $-15,63$ & $-13,49$ & $-11,21$ & $-8,74$ & $-6,03$ & $-3,01$ & 0,43 & 4,54 & 9,74 & 17,57 & - \\
\hline & DMA & 19,40 & 17,11 & 14,71 & 12,12 & 9,55 & 7,68 & 6,31 & 6,09 & 8,89 & 15,97 & 28,87 & - \\
\hline & PDMA & 42,62 & 36,11 & 28,70 & 20,61 & 16,23 & 16,46 & 24,97 & 41,98 & 69,83 & 118,38 & 218,79 & - \\
\hline \multirow[t]{3}{*}{$\Delta \mathrm{CS}$} & $\mathrm{DM}$ & $-28,40$ & $-27,88$ & $-27,01$ & $-25,98$ & $-24,99$ & $-24,51$ & $-25,10$ & $-28,00$ & $-36,11$ & $-59,34$ & $-189,67$ & - \\
\hline & DMA & 49,59 & 42,26 & 34,08 & 29,29 & 27,14 & 24,60 & 23,76 & 30,24 & 44,23 & 70,05 & 197,54 & - \\
\hline & PDMA & 65,27 & 54,03 & 43,02 & 33,34 & 20,62 & 5,00 & $-9,81$ & $-7,92$ & $-13,19$ & $-32,01$ & $-67,53$ & - \\
\hline \multicolumn{14}{|c|}{ Desconsiderando ${ }^{1} J_{\mathrm{BF}}$ da molécula de $\mathrm{BF}_{3},{ }^{2} J_{\mathrm{CH}}$ e ${ }^{2} J_{\mathrm{HH}}$ da molécula de $\mathrm{C}_{2} \mathrm{H}_{4}$} \\
\hline \multirow[t]{3}{*}{ Total } & $\mathrm{DM}$ & $-28,88$ & $-27,13$ & $-25,06$ & $-22,75$ & $-20,24$ & $-17,68$ & $-15,25$ & $-13,41$ & $-13,19$ & $-18,75$ & $-71,93$ & - \\
\hline & DMA & 40,55 & 35,30 & 29,55 & 25,20 & 22,13 & 19,59 & 18,17 & 19,97 & 28,68 & 47,66 & 121,21 & - \\
\hline & PDMA & 37,10 & 31,54 & 25,56 & 19,65 & 14,85 & 11,35 & 12,56 & 18,75 & 29,54 & 47,64 & 89,72 & - \\
\hline \multirow[t]{3}{*}{ CPI } & DM & $-39,45$ & $-38,52$ & $-37,09$ & $-35,34$ & $-33,45$ & $-31,87$ & $-31,13$ & $-32,49$ & $-38,84$ & $-60,63$ & $-197,33$ & - \\
\hline & DMA & 64,71 & 55,96 & 46,21 & 39,98 & 36,71 & 33,79 & 32,87 & 37,81 & 54,32 & 88,55 & 241,03 & - \\
\hline & PDMA & 44,15 & 36,89 & 29,16 & 22,21 & 16,20 & 12,14 & 15,28 & 23,07 & 34,91 & 54,54 & 112,92 & - \\
\hline \multirow[t]{3}{*}{ SPI } & $\mathrm{DM}$ & $-20,75$ & $-18,37$ & $-15,81$ & $-13,07$ & $-10,08$ & $-6,76$ & $-3,04$ & 1,27 & 6,54 & 13,46 & 24,54 & - \\
\hline & DMA & 21,97 & 19,40 & 16,73 & 13,84 & 10,91 & 8,67 & 6,85 & 6,25 & 8,95 & 16,20 & 29,05 & - \\
\hline & PDMA & 31,68 & 27,42 & 22,79 & 17,67 & 13,80 & 10,75 & 10,46 & 15,43 & 25,40 & 42,33 & 71,87 & - \\
\hline \multirow[t]{3}{*}{$\Delta \mathrm{CS}$} & $\mathrm{DM}$ & $-18,70$ & $-20,15$ & $-21,28$ & $-22,27$ & $-23,37$ & $-25,11$ & $-28,09$ & $-33,76$ & $-45,38$ & $-74,09$ & $-221,87$ & - \\
\hline & DMA & 42,74 & 36,56 & 29,48 & 26,14 & 25,80 & 25,12 & 26,02 & 31,56 & 45,37 & 72,35 & 211,98 & - \\
\hline & PDMA & 12,47 & 9,47 & 6,37 & 4,54 & 2,39 & 1,39 & 4,82 & 7,64 & 9,50 & 12,21 & 41,06 & - \\
\hline
\end{tabular}


Tabela 8.216: Constantes de acoplamento B972PW91 com base aug-pcJ-2.

\begin{tabular}{|c|c|c|c|c|c|c|c|c|c|c|c|c|c|}
\hline & $\% E_{X}^{\mathrm{HF}}$ & $0 \%$ & $10 \%$ & $20 \%$ & $30 \%$ & $40 \%$ & $50 \%$ & $60 \%$ & $70 \%$ & $80 \%$ & $90 \%$ & $100 \%$ & Exp. \\
\hline $\mathrm{HF}$ & ${ }^{1} J_{\mathrm{HF}}$ & 337,0 & 356,7 & 377,9 & 400,6 & 424,8 & 450,7 & 478,3 & 507,6 & 538,7 & 571,5 & 606,3 & 500 \\
\hline $\mathrm{CO}$ & ${ }^{1} J_{\mathrm{CO}}$ & 23,3 & 22,2 & 20,9 & 19,5 & 17,9 & 16,1 & 14,2 & 12,1 & 9,9 & 7,5 & 4,9 & 16,4 \\
\hline $\mathrm{H}_{2} \mathrm{O}$ & ${ }^{1} J_{\mathrm{OH}}$ & $-56,6$ & $-59,2$ & $-61,9$ & $-64,8$ & $-68,0$ & $-71,4$ & $-75,0$ & $-78,8$ & $-82,9$ & $-87,3$ & $-91,9$ & $-80,6$ \\
\hline $\mathrm{H}_{2} \mathrm{O}$ & ${ }^{2} J_{\mathrm{HH}}$ & $-2,1$ & $-3,1$ & $-4,2$ & $-5,3$ & $-6,5$ & $-7,8$ & $-9,2$ & $-10,7$ & $-12,4$ & $-14,1$ & $-16,0$ & $-7,3$ \\
\hline $\mathrm{NH}_{3}$ & ${ }^{1} J_{\mathrm{NH}}$ & 32,0 & 33,2 & 34,5 & 35,9 & 37,3 & 38,9 & 40,6 & 42,3 & 44,2 & 46,2 & 48,4 & 43,8 \\
\hline $\mathrm{NH}_{3}$ & ${ }^{2} J_{\mathrm{HH}}$ & $-4,9$ & $-5,8$ & $-6,7$ & $-7,7$ & $-8,8$ & $-10,0$ & $-11,3$ & $-12,7$ & $-14,2$ & $-15,9$ & $-17,7$ & $-9,6$ \\
\hline $\mathrm{PH}_{3}$ & ${ }^{1} J_{\mathrm{PH}}$ & 127,5 & 134,2 & 141,4 & 149,0 & 157,1 & 165,6 & 174,7 & 184,2 & 194,1 & 204,6 & 215,5 & 188,2 \\
\hline $\mathrm{PF}_{3}$ & ${ }^{1} J_{\mathrm{PF}}$ & $-1630,6$ & $-1625,1$ & $-1614,5$ & $-1599,5$ & $-1580,9$ & $-1559,4$ & $-1535,5$ & $-1510,0$ & $-1483,3$ & $-1456,0$ & $-1428,5$ & -1441 \\
\hline $\mathrm{BHF}_{2}$ & ${ }^{1} J_{\mathrm{BF}}$ & $-178,7$ & $-163,2$ & $-147,2$ & $-130,8$ & $-114,2$ & $-97,3$ & $-80,3$ & $-63,2$ & $-46,2$ & $-29,3$ & $-12,5$ & -84 \\
\hline $\mathrm{BF}_{3}$ & ${ }^{1} J_{\mathrm{BF}}$ & $-96,0$ & $-77,5$ & $-58,7$ & $-39,7$ & $-20,4$ & $-1,1$ & 18,3 & 37,8 & 57,4 & 77,0 & 96,6 & 15 \\
\hline $\mathrm{F}_{2} \mathrm{O}$ & ${ }^{1} J_{\mathrm{OF}}$ & $-214,8$ & $-248,4$ & $-284,0$ & $-322,6$ & $-365,7$ & $-416,3$ & $-479,8$ & $-567,4$ & $-708,5$ & $-1009,1$ & $-2525,8$ & -300 \\
\hline $\mathrm{CH}_{4}$ & ${ }^{1} J_{\mathrm{CH}}$ & 83,9 & 87,7 & 91,8 & 96,1 & 100,7 & 105,6 & 110,8 & 116,4 & 122,3 & 128,5 & 135,2 & 125,3 \\
\hline $\mathrm{CH}_{4}$ & ${ }^{2} J_{\mathrm{HH}}$ & $-8,1$ & $-8,9$ & $-9,9$ & $-10,8$ & $-11,9$ & $-13,0$ & $-14,2$ & $-15,5$ & $-16,8$ & $-18,3$ & $-19,9$ & $-12,8$ \\
\hline $\mathrm{C}_{2} \mathrm{H}_{2}$ & ${ }^{1} J_{\mathrm{CC}}$ & 157,1 & 161,1 & 165,6 & 170,8 & 176,7 & 183,6 & 192,0 & 202,4 & 215,8 & 233,6 & 259,0 & 174,8 \\
\hline $\mathrm{C}_{2} \mathrm{H}_{2}$ & ${ }^{1} J_{\mathrm{CH}}$ & 178,2 & 185,7 & 193,8 & 202,3 & 211,4 & 221,3 & 232,1 & 244,1 & 257,9 & 274,2 & 294,6 & 247,6 \\
\hline $\mathrm{C}_{2} \mathrm{H}_{2}$ & ${ }^{2} J_{\mathrm{CH}}$ & 49,1 & 50,1 & 50,8 & 51,4 & 51,6 & 51,4 & 50,6 & 48,8 & 45,7 & 40,3 & 31,2 & 50,1 \\
\hline $\mathrm{C}_{2} \mathrm{H}_{2}$ & ${ }^{3} J_{\mathrm{HH}}$ & 7,5 & 8,0 & 8,7 & 9,6 & 10,7 & 12,1 & 13,9 & 16,3 & 19,5 & 24,0 & 30,7 & 9,6 \\
\hline $\mathrm{C}_{2} \mathrm{H}_{4}$ & ${ }^{1} J_{\mathrm{CC}}$ & 44,6 & 47,5 & 50,8 & 54,6 & 58,9 & 64,0 & 70,4 & 78,8 & 90,8 & 110,5 & 152,0 & 67,6 \\
\hline $\mathrm{C}_{2} \mathrm{H}_{4}$ & ${ }^{1} J_{\mathrm{CH}}$ & 107,5 & 112,5 & 117,9 & 123,6 & 129,8 & 136,5 & 144,0 & 152,6 & 163,0 & 176,8 & 200,0 & 156,3 \\
\hline $\mathrm{C}_{2} \mathrm{H}_{4}$ & ${ }^{2} J_{\mathrm{CH}}$ & 1,7 & 1,0 & 0,3 & $-0,6$ & $-1,7$ & $-3,2$ & $-5,1$ & $-7,9$ & $-12,2$ & $-19,6$ & $-36,2$ & $-2,4$ \\
\hline $\mathrm{C}_{2} \mathrm{H}_{4}$ & ${ }^{2} J_{\mathrm{HH}}$ & 3,7 & 3,3 & 2,8 & 2,2 & 1,5 & 0,6 & $-0,5$ & $-2,3$ & $-4,9$ & $-9,4$ & $-19,2$ & 2,3 \\
\hline $\mathrm{C}_{2} \mathrm{H}_{4}$ & ${ }^{3} J_{\mathrm{HH}_{\mathrm{c}}}$ & 9,2 & 9,6 & 10,1 & 10,6 & 11,2 & 12,1 & 13,2 & 14,7 & 17,2 & 21,5 & 31,2 & 11,7 \\
\hline $\mathrm{C}_{2} \mathrm{H}_{4}$ & ${ }^{3} J_{\mathrm{HH}_{\mathrm{t}}}$ & 13,3 & 13,9 & 14,7 & 15,5 & 16,5 & 17,8 & 19,3 & 21,4 & 24,5 & 29,7 & 40,9 & 19 \\
\hline $\mathrm{C}_{2} \mathrm{H}_{6}$ & ${ }^{1} J_{\mathrm{CC}}$ & 14,4 & 16,7 & 19,2 & 21,9 & 24,7 & 27,7 & 30,9 & 34,4 & 38,0 & 41,9 & 46,1 & 34,5 \\
\hline $\mathrm{C}_{2} \mathrm{H}_{6}$ & ${ }^{1} J_{\mathrm{CH}}$ & 83,6 & 87,6 & 91,9 & 96,4 & 101,3 & 106,4 & 111,9 & 117,7 & 123,8 & 130,4 & 137,3 & 125,2 \\
\hline $\mathrm{C}_{2} \mathrm{H}_{6}$ & ${ }^{2} J_{\mathrm{CH}}$ & $-1,5$ & $-1,9$ & $-2,4$ & $-3,0$ & $-3,5$ & $-4,1$ & $-4,8$ & $-5,5$ & $-6,3$ & $-7,2$ & $-8,1$ & $-4,7$ \\
\hline \multirow[t]{3}{*}{ Total } & DM & $-29,41$ & $-27,20$ & $-24,67$ & $-21,92$ & $-19,02$ & $-16,08$ & $-13,29$ & $-11,05$ & $-10,38$ & $-15,12$ & $-65,03$ & - \\
\hline & DMA & 40,13 & 34,73 & 28,85 & 24,19 & 20,79 & 17,84 & 16,30 & 19,05 & 28,13 & 46,38 & 115,74 & - \\
\hline & PDMA & 69,92 & 58,48 & 46,34 & 34,17 & 24,43 & 18,13 & 20,92 & 38,94 & 65,12 & 105,61 & 191,82 & - \\
\hline \multirow[t]{3}{*}{ CPI } & DM & $-45,89$ & $-43,35$ & $-40,31$ & $-36,94$ & $-33,48$ & $-30,26$ & $-27,81$ & $-27,25$ & $-31,28$ & $-49,62$ & $-178,33$ & - \\
\hline & DMA & 68,80 & 59,14 & 48,53 & 41,08 & 36,34 & 31,94 & 30,10 & 36,88 & 54,05 & 87,25 & 233,56 & - \\
\hline & PDMA & 107,10 & 89,23 & 70,71 & 53,03 & 35,82 & 20,68 & 15,98 & 35,01 & 58,07 & 87,79 & 155,08 & - \\
\hline \multirow[t]{3}{*}{ SPI } & $\mathrm{DM}$ & $-17,33$ & $-15,35$ & $-13,20$ & $-10,90$ & $-8,41$ & $-5,69$ & $-2,64$ & 0,82 & 4,95 & 10,19 & 18,05 & - \\
\hline & DMA & 19,11 & 16,83 & 14,41 & 11,81 & 9,39 & 7,50 & 6,19 & 5,97 & 9,13 & 16,41 & 29,34 & - \\
\hline & PDMA & 42,64 & 35,92 & 28,47 & 20,34 & 16,07 & 16,27 & 24,55 & 41,83 & 70,29 & 118,69 & 218,77 & - \\
\hline \multirow[t]{3}{*}{$\Delta \mathrm{CS}$} & DM & $-28,56$ & $-28,01$ & $-27,11$ & $-26,04$ & $-25,07$ & $-24,58$ & $-25,17$ & $-28,07$ & $-36,23$ & $-59,80$ & $-196,37$ & - \\
\hline & DMA & 49,69 & 42,31 & 34,11 & 29,28 & 26,95 & 24,44 & 23,91 & 30,92 & 44,91 & 70,84 & 204,22 & - \\
\hline & PDMA & 64,46 & 53,30 & 42,24 & 32,69 & 19,75 & 4,41 & $-8,57$ & $-6,82$ & $-12,22$ & $-30,89$ & $-63,69$ & - \\
\hline \multicolumn{14}{|c|}{ Desconsiderando ${ }^{1} J_{\mathrm{BF}}$ da molécula de $\mathrm{BF}_{3},{ }^{2} J_{\mathrm{CH}}$ e ${ }^{2} J_{\mathrm{HH}}$ da molécula de $\mathrm{C}_{2} \mathrm{H}_{4}$} \\
\hline \multirow[t]{3}{*}{ Total } & $\mathrm{DM}$ & $-28,66$ & $-26,91$ & $-24,82$ & $-22,47$ & $-19,96$ & $-17,37$ & $-14,93$ & $-13,05$ & $-12,84$ & $-18,53$ & $-74,66$ & - \\
\hline & DMA & 40,30 & 35,04 & 29,27 & 24,89 & 21,90 & 19,36 & 18,05 & 20,10 & 29,22 & 48,48 & 124,89 & - \\
\hline & PDMA & 36,79 & 31,24 & 25,18 & 19,32 & 14,57 & 11,17 & 12,51 & 18,76 & 29,96 & 48,14 & 91,32 & - \\
\hline \multirow[t]{3}{*}{ CPI } & $\mathrm{DM}$ & $-39,38$ & $-38,44$ & $-36,97$ & $-35,16$ & $-33,29$ & $-31,68$ & $-30,92$ & $-32,25$ & $-38,65$ & $-60,78$ & $-204,32$ & - \\
\hline & DMA & 64,58 & 55,80 & 46,01 & 39,72 & 36,43 & 33,52 & 32,78 & 38,29 & 55,21 & 89,78 & 248,76 & - \\
\hline & PDMA & 43,81 & 36,48 & 28,64 & 21,87 & 15,80 & 12,01 & 15,38 & 23,31 & 35,62 & 55,24 & 116,19 & - \\
\hline \multirow[t]{3}{*}{ SPI } & $\mathrm{DM}$ & $-20,42$ & $-18,05$ & $-15,48$ & $-12,71$ & $-9,70$ & $-6,37$ & $-2,62$ & 1,72 & 7,02 & 13,98 & 25,08 & - \\
\hline & DMA & 21,63 & 19,08 & 16,38 & 13,48 & 10,72 & 8,46 & 6,72 & 6,11 & 9,23 & 16,72 & 29,60 & - \\
\hline & PDMA & 31,38 & 27,21 & 22,52 & 17,37 & 13,62 & 10,52 & 10,31 & 15,25 & 25,62 & 42,69 & 72,19 & - \\
\hline \multirow[t]{3}{*}{$\Delta \mathrm{CS}$} & DM & $-18,96$ & $-20,39$ & $-21,49$ & $-22,45$ & $-23,59$ & $-25,31$ & $-28,30$ & $-33,97$ & $-45,67$ & $-74,76$ & $-229,40$ & - \\
\hline & DMA & 42,95 & 36,72 & 29,63 & 26,24 & 25,71 & 25,06 & 26,06 & 32,18 & 45,98 & 73,06 & 219,16 & - \\
\hline & PDMA & 12,43 & 9,28 & 6,12 & 4,50 & 2,18 & 1,49 & 5,07 & 8,05 & 10,00 & 12,55 & 44,00 & - \\
\hline
\end{tabular}




\subsection{GERAÇÃO DE NOVOS FUNCIONAIS COMBINANDO $E_{X}^{H F}, E_{X}^{D F T} E$}

Tabela 8.217: Constantes de acoplamento B972TPSS com base aug-pcJ-2.

\begin{tabular}{|c|c|c|c|c|c|c|c|c|c|c|c|c|c|}
\hline & $\% E_{X}^{\mathrm{HF}}$ & $0 \%$ & $10 \%$ & $20 \%$ & $30 \%$ & $40 \%$ & $50 \%$ & $60 \%$ & $70 \%$ & $80 \%$ & $90 \%$ & $100 \%$ & Exp. \\
\hline $\mathrm{HF}$ & ${ }^{1} J_{\mathrm{HF}}$ & 334,5 & 355,1 & 377,1 & 400,5 & 425,4 & 452,0 & 480,2 & 510,0 & 541,6 & 574,9 & 610,0 & 500 \\
\hline $\mathrm{CO}$ & ${ }^{1} J_{\mathrm{CO}}$ & 23,4 & 22,2 & 21,0 & 19,5 & 17,9 & 16,2 & 14,3 & 12,2 & 9,9 & 7,5 & 4,9 & 16,4 \\
\hline $\mathrm{H}_{2} \mathrm{O}$ & ${ }^{1} J_{\mathrm{OH}}$ & $-57,0$ & $-59,6$ & $-62,5$ & $-65,6$ & $-68,8$ & $-72,3$ & $-76,0$ & $-80,0$ & $-84,2$ & $-88,6$ & $-93,4$ & $-80,6$ \\
\hline $\mathrm{H}_{2} \mathrm{O}$ & ${ }^{2} J_{\mathrm{HH}}$ & $-1,9$ & $-2,9$ & $-4,0$ & $-5,2$ & $-6,4$ & $-7,8$ & $-9,2$ & $-10,8$ & $-12,5$ & $-14,3$ & $-16,2$ & $-7,3$ \\
\hline $\mathrm{NH}_{3}$ & ${ }^{1} J_{\mathrm{NH}}$ & 33,0 & 34,2 & 35,6 & 37,0 & 38,6 & 40,2 & 41,9 & 43,8 & 45,8 & 47,9 & 50,1 & 43,8 \\
\hline $\mathrm{NH}_{3}$ & ${ }^{2} J_{\mathrm{HH}}$ & $-4,4$ & $-5,3$ & $-6,3$ & $-7,4$ & $-8,6$ & $-9,9$ & $-11,2$ & $-12,7$ & $-14,3$ & $-16,1$ & $-17,9$ & $-9,6$ \\
\hline $\mathrm{PH}_{3}$ & ${ }^{1} J_{\mathrm{PH}}$ & 136,7 & 144,0 & 151,7 & 160,0 & 168,8 & 178,1 & 187,9 & 198,2 & 209,1 & 220,6 & 232,6 & 188,2 \\
\hline $\mathrm{PF}_{3}$ & ${ }^{1} J_{\mathrm{PF}}$ & $-1631,9$ & $-1627,0$ & $-1617,0$ & $-1602,6$ & $-1584,6$ & $-1563,6$ & $-1540,2$ & $-1515,2$ & $-1489,1$ & $-1462,2$ & $-1435,2$ & -1441 \\
\hline $\mathrm{BHF}_{2}$ & ${ }^{1} J_{\mathrm{BF}}$ & $-180,1$ & $-164,8$ & $-148,9$ & $-132,7$ & $-116,3$ & $-99,6$ & $-82,9$ & $-66,1$ & $-49,4$ & $-32,9$ & $-16,4$ & -84 \\
\hline $\mathrm{BF}_{3}$ & ${ }^{1} J_{\mathrm{BF}}$ & $-94,2$ & $-75,8$ & $-57,1$ & $-38,3$ & $-19,2$ & 0,0 & 19,1 & 38,4 & 57,7 & 77,0 & 96,3 & 15 \\
\hline $\mathrm{F}_{2} \mathrm{O}$ & ${ }^{1} J_{\mathrm{OF}}$ & $-213,0$ & $-246,5$ & $-282,1$ & $-320,6$ & $-363,6$ & $-413,9$ & $-476,7$ & $-563,1$ & $-701,4$ & $-992,7$ & $-2403,5$ & -300 \\
\hline $\mathrm{CH}_{4}$ & ${ }^{1} J_{\mathrm{CH}}$ & 89,8 & 93,9 & 98,3 & 102,9 & 107,8 & 113,1 & 118,7 & 124,7 & 131,0 & 137,7 & 144,9 & 125,3 \\
\hline $\mathrm{CH}_{4}$ & ${ }^{2} J_{\mathrm{HH}}$ & $-7,4$ & $-8,3$ & $-9,3$ & $-10,3$ & $-11,5$ & $-12,7$ & $-14,0$ & $-15,4$ & $-16,9$ & $-18,5$ & $-20,2$ & $-12,8$ \\
\hline $\mathrm{C}_{2} \mathrm{H}_{2}$ & ${ }^{1} J_{\mathrm{CC}}$ & 156,5 & 160,6 & 165,2 & 170,5 & 176,5 & 183,7 & 192,4 & 203,1 & 217,0 & 235,6 & 262,1 & 174,8 \\
\hline $\mathrm{C}_{2} \mathrm{H}_{2}$ & ${ }^{1} J_{\mathrm{CH}}$ & 189,0 & 197,1 & 205,6 & 214,7 & 224,4 & 234,9 & 246,4 & 259,2 & 273,9 & 291,2 & 312,9 & 247,6 \\
\hline $\mathrm{C}_{2} \mathrm{H}_{2}$ & ${ }^{2} J_{\mathrm{CH}}$ & 50,5 & 51,5 & 52,3 & 52,8 & 53,0 & 52,8 & 51,9 & 50,0 & 46,7 & 41,1 & 31,5 & 50,1 \\
\hline $\mathrm{C}_{2} \mathrm{H}_{2}$ & ${ }^{3} J_{\mathrm{HH}}$ & 7,8 & 8,4 & 9,1 & 10,0 & 11,1 & 12,5 & 14,4 & 16,8 & 20,1 & 24,8 & 31,8 & 9,6 \\
\hline $\mathrm{C}_{2} \mathrm{H}_{4}$ & ${ }^{1} J_{\mathrm{CC}}$ & 45,0 & 48,0 & 51,4 & 55,2 & 59,7 & 65,0 & 71,6 & 80,2 & 92,5 & 112,5 & 153,5 & 67,6 \\
\hline $\mathrm{C}_{2} \mathrm{H}_{4}$ & ${ }^{1} J_{\mathrm{CH}}$ & 114,5 & 119,8 & 125,6 & 131,7 & 138,3 & 145,5 & 153,5 & 162,7 & 173,6 & 188,1 & 211,7 & 156,3 \\
\hline $\mathrm{C}_{2} \mathrm{H}_{4}$ & ${ }^{2} J_{\mathrm{CH}}$ & 1,7 & 1,0 & 0,2 & $-0,7$ & $-1,9$ & $-3,5$ & $-5,5$ & $-8,4$ & $-12,9$ & $-20,5$ & $-36,8$ & $-2,4$ \\
\hline $\mathrm{C}_{2} \mathrm{H}_{4}$ & ${ }^{2} J_{\mathrm{HH}}$ & 5,0 & 4,6 & 4,1 & 3,5 & 2,8 & 1,8 & 0,6 & $-1,0$ & $-3,6$ & $-8,0$ & $-17,4$ & 2,3 \\
\hline $\mathrm{C}_{2} \mathrm{H}_{4}$ & ${ }^{3} J_{\mathrm{HH}_{\mathrm{c}}}$ & 9,8 & 10,2 & 10,7 & 11,2 & 11,9 & 12,8 & 13,9 & 15,5 & 17,9 & 22,1 & 31,3 & 11,7 \\
\hline $\mathrm{C}_{2} \mathrm{H}_{4}$ & ${ }^{3} J_{\mathrm{HH}_{\mathrm{t}}}$ & 14,7 & 15,4 & 16,2 & 17,1 & 18,1 & 19,4 & 21,0 & 23,2 & 26,3 & 31,5 & 42,2 & 19 \\
\hline $\mathrm{C}_{2} \mathrm{H}_{6}$ & ${ }^{1} J_{\mathrm{CC}}$ & 14,9 & 17,3 & 19,8 & 22,5 & 25,3 & 28,4 & 31,6 & 35,1 & 38,8 & 42,7 & 46,9 & 34,5 \\
\hline $\mathrm{C}_{2} \mathrm{H}_{6}$ & ${ }^{1} J_{\mathrm{CH}}$ & 89,3 & 93,6 & 98,2 & 103,0 & 108,2 & 113,8 & 119,6 & 125,9 & 132,5 & 139,6 & 147,1 & 125,2 \\
\hline $\mathrm{C}_{2} \mathrm{H}_{6}$ & ${ }^{2} J_{\mathrm{CH}}$ & $-1,5$ & $-1,9$ & $-2,4$ & $-3,0$ & $-3,6$ & $-4,3$ & $-5,0$ & $-5,7$ & $-6,6$ & $-7,5$ & $-8,5$ & $-4,7$ \\
\hline \multirow[t]{3}{*}{ Total } & DM & $-27,70$ & $-25,39$ & $-22,79$ & $-19,97$ & $-16,99$ & $-13,94$ & $-11,03$ & $-8,63$ & $-7,75$ & $-11,98$ & $-57,72$ & - \\
\hline & DMA & 38,78 & 33,35 & 27,37 & 22,48 & 18,90 & 15,85 & 14,27 & 19,19 & 30,35 & 48,80 & 113,73 & - \\
\hline & PDMA & 70,57 & 59,14 & 46,79 & 34,38 & 22,04 & 15,05 & 19,32 & 38,28 & 66,57 & 107,59 & 191,26 & - \\
\hline \multirow[t]{3}{*}{ CPI } & DM & $-45,07$ & $-42,48$ & $-39,40$ & $-36,03$ & $-32,52$ & $-29,23$ & $-26,70$ & $-26,02$ & $-29,79$ & $-47,25$ & $-166,33$ & - \\
\hline & DMA & 68,38 & 58,66 & 47,98 & 40,10 & 35,28 & 30,74 & 28,48 & 37,27 & 55,57 & 88,07 & 223,67 & - \\
\hline & PDMA & 106,35 & 88,47 & 69,90 & 51,91 & 34,66 & 19,07 & 14,92 & 34,91 & 59,21 & 88,72 & 152,58 & - \\
\hline \multirow[t]{3}{*}{ SPI } & DM & $-14,97$ & $-12,86$ & $-10,61$ & $-8,20$ & $-5,60$ & $-2,73$ & 0,47 & 4,12 & 8,41 & 13,89 & 21,93 & - \\
\hline & DMA & 17,07 & 14,78 & 12,26 & 9,56 & 6,89 & 4,93 & 3,85 & 5,93 & 11,85 & 20,01 & 33,11 & - \\
\hline & PDMA & 44,34 & 37,63 & 29,84 & 21,52 & 12,78 & 12,10 & 22,54 & 40,75 & 71,97 & 121,43 & 219,63 & - \\
\hline \multirow[t]{3}{*}{$\Delta \mathrm{CS}$} & DM & $-30,11$ & $-29,62$ & $-28,79$ & $-27,83$ & $-26,92$ & $-26,50$ & $-27,17$ & $-30,14$ & $-38,20$ & $-61,14$ & $-188,25$ & - \\
\hline & DMA & 51,31 & 43,88 & 35,72 & 30,54 & 28,39 & 25,81 & 24,63 & 31,34 & 43,72 & 68,07 & 190,56 & - \\
\hline & PDMA & 62,02 & 50,83 & 40,06 & 30,39 & 21,88 & 6,97 & $-7,63$ & $-5,83$ & $-12,76$ & $-32,71$ & $-67,05$ & - \\
\hline \multicolumn{14}{|c|}{ Desconsiderando ${ }^{1} J_{\mathrm{BF}}$ da molécula de $\mathrm{BF}_{3},{ }^{2} J_{\mathrm{CH}}$ e ${ }^{2} J_{\mathrm{HH}}$ da molécula de $\mathrm{C}_{2} \mathrm{H}_{4}$} \\
\hline \multirow[t]{3}{*}{ Total } & DM & $-26,87$ & $-25,00$ & $-22,82$ & $-20,39$ & $-17,76$ & $-15,03$ & $-12,43$ & $-10,37$ & $-9,90$ & $-15,00$ & $-66,43$ & - \\
\hline & DMA & 38,80 & 33,50 & 27,62 & 22,97 & 19,84 & 17,19 & 15,75 & 20,27 & 31,74 & 51,24 & 122,68 & - \\
\hline & PDMA & 35,60 & 30,03 & 23,88 & 18,06 & 13,15 & 9,72 & 11,82 & 19,38 & 32,70 & 51,39 & 93,09 & - \\
\hline \multirow[t]{3}{*}{ CPI } & DM & $-38,66$ & $-37,65$ & $-36,13$ & $-34,30$ & $-32,35$ & $-30,65$ & $-29,78$ & $-30,96$ & $-37,04$ & $-58,18$ & $-191,09$ & - \\
\hline & DMA & 64,30 & 55,45 & 45,57 & 38,78 & 35,39 & 32,31 & 30,92 & 38,66 & 56,86 & 90,68 & 237,91 & - \\
\hline & PDMA & 44,19 & 36,78 & 28,82 & 21,57 & 15,32 & 10,97 & 13,68 & 22,81 & 36,66 & 56,26 & 113,64 & - \\
\hline \multirow[t]{3}{*}{ SPI } & $\mathrm{DM}$ & $-17,79$ & $-15,28$ & $-12,58$ & $-9,68$ & $-6,54$ & $-3,02$ & 0,91 & 5,47 & 10,97 & 18,21 & 29,46 & - \\
\hline & DMA & 19,18 & 16,62 & 13,81 & 10,81 & 7,88 & 5,56 & 4,08 & 6,13 & 12,42 & 20,90 & 34,05 & - \\
\hline & PDMA & 28,99 & 24,83 & 20,07 & 15,37 & 11,48 & 8,76 & 10,39 & 16,75 & 29,66 & 47,65 & 77,27 & - \\
\hline \multirow[t]{3}{*}{$\Delta \mathrm{CS}$} & $\mathrm{DM}$ & $-20,87$ & $-22,37$ & $-23,55$ & $-24,62$ & $-25,81$ & $-27,63$ & $-30,69$ & $-36,43$ & $-48,01$ & $-76,39$ & $-220,55$ & 一 \\
\hline & DMA & 45,12 & 38,83 & 31,76 & 27,97 & 27,51 & 26,75 & 26,84 & 32,53 & 44,44 & 69,78 & 203,86 & - \\
\hline & PDMA & 15,20 & 11,95 & 8,75 & 6,20 & 3,85 & 2,21 & 3,28 & 6,06 & 7,00 & 8,61 & 36,37 & - \\
\hline
\end{tabular}

Tabela 8.218: Valores de PDMA total obtidos para troca B972 com base HuzIII-su3.

\begin{tabular}{lccccccccccc}
\hline$E_{X}^{\mathrm{HF}}(\%)$ & $0 \%$ & $10 \%$ & $20 \%$ & $30 \%$ & $40 \%$ & $50 \%$ & $60 \%$ & $70 \%$ & $80 \%$ & $90 \%$ & $100 \%$ \\
\hline B972B95 & 70,6 & 60,0 & 49,1 & 37,3 & 25,9 & 15,3 & 10,7 & 22,4 & 39,5 & 62,0 & 92,6 \\
B972B98 & 62,1 & 51,0 & 39,5 & 27,6 & 16,6 & 8,7 & 20,3 & 38,3 & 60,5 & 88,9 & 132,9 \\
B972B971 & 63,2 & 52,2 & 40,7 & 28,7 & 17,5 & 8,9 & 19,5 & 35,4 & 56,2 & 82,7 & 120,6 \\
B972B972 & 61,5 & 50,9 & 40,1 & 28,9 & 18,4 & 18,7 & 24,6 & 37,0 & 55,8 & 81,6 & 120,0 \\
B972LYP & 63,7 & 52,2 & 40,3 & 27,8 & 16,8 & 9,6 & 21,9 & 41,3 & 66,1 & 99,9 & 161,6 \\
B972P86 & 69,3 & 58,6 & 46,9 & 34,9 & 24,8 & 17,4 & 18,0 & 33,7 & 56,4 & 90,9 & 156,5 \\
B972PBE & 68,3 & 57,1 & 45,1 & 33,7 & 24,1 & 20,2 & 21,9 & 39,8 & 65,9 & 107,1 & 195,8 \\
B972PW91 & 67,9 & 56,6 & 44,6 & 33,1 & 23,6 & 19,4 & 22,1 & 40,2 & 66,3 & 108,0 & 197,7 \\
B972TPSS & 68,5 & 57,2 & 45,0 & 32,7 & 20,3 & 16,5 & 20,5 & 39,7 & 68,1 & 110,1 & 197,2 \\
\hline
\end{tabular}




\subsubsection{Troca B98}

Tabela 8.219: Constantes de acoplamento B98B95 com base aug-pcJ-2.

\begin{tabular}{|c|c|c|c|c|c|c|c|c|c|c|c|c|c|}
\hline & $\% E_{X}^{\mathrm{HF}}$ & $0 \%$ & $10 \%$ & $20 \%$ & $30 \%$ & $40 \%$ & $50 \%$ & $60 \%$ & $70 \%$ & $80 \%$ & $90 \%$ & $100 \%$ & Exp. \\
\hline $\mathrm{HF}$ & ${ }^{1} J_{\mathrm{HF}}$ & 415,3 & 432,6 & 451,1 & 470,7 & 491,7 & 514,0 & 537,7 & 562,9 & 589,5 & 617,7 & 647,4 & 500 \\
\hline $\mathrm{CO}$ & ${ }^{1} J_{\mathrm{CO}}$ & 18,4 & 17,4 & 16,3 & 15,1 & 13,7 & 12,2 & 10,5 & 8,7 & 6,7 & 4,6 & 2,4 & 16,4 \\
\hline $\mathrm{H}_{2} \mathrm{O}$ & ${ }^{1} J_{\mathrm{OH}}$ & $-65,8$ & $-68,0$ & $-70,3$ & $-72,9$ & $-75,6$ & $-78,5$ & $-81,6$ & $-84,9$ & $-88,4$ & $-92,2$ & $-96,2$ & $-80,6$ \\
\hline $\mathrm{H}_{2} \mathrm{O}$ & ${ }^{2} J_{\mathrm{HH}}$ & $-0,5$ & $-1,5$ & $-2,6$ & $-3,7$ & $-5,0$ & $-6,3$ & $-7,8$ & $-9,3$ & $-11,0$ & $-12,7$ & $-14,7$ & $-7,3$ \\
\hline $\mathrm{NH}_{3}$ & ${ }^{1} J_{\mathrm{NH}}$ & 35,8 & 36,8 & 37,8 & 39,0 & 40,2 & 41,5 & 42,9 & 44,4 & 46,0 & 47,7 & 49,5 & 43,8 \\
\hline $\mathrm{NH}_{3}$ & ${ }^{2} J_{\mathrm{HH}}$ & $-3,1$ & $-4,0$ & $-4,9$ & $-5,9$ & $-7,0$ & $-8,2$ & $-9,5$ & $-10,9$ & $-12,4$ & $-14,0$ & $-15,8$ & $-9,6$ \\
\hline $\mathrm{PH}_{3}$ & ${ }^{1} J_{\mathrm{PH}}$ & 137,2 & 143,0 & 149,3 & 156,0 & 163,2 & 170,9 & 179,1 & 187,8 & 197,0 & 206,8 & 217,0 & 188,2 \\
\hline $\mathrm{PF}_{3}$ & ${ }^{1} J_{\mathrm{PF}}$ & $-1564,6$ & $-1562,3$ & $-1554,5$ & $-1541,8$ & $-1525,0$ & $-1504,8$ & $-1481,8$ & $-1456,6$ & $-1429,7$ & $-1401,6$ & $-1372,8$ & -1441 \\
\hline $\mathrm{BHF}_{2}$ & ${ }^{1} J_{\mathrm{BF}}$ & $-160,4$ & $-146,8$ & $-132,7$ & $-118,2$ & $-103,3$ & $-88,2$ & $-72,8$ & $-57,4$ & $-41,8$ & $-26,1$ & $-10,5$ & -84 \\
\hline $\mathrm{BF}_{3}$ & ${ }^{1} J_{\mathrm{BF}}$ & $-72,5$ & $-56,2$ & $-39,6$ & $-22,8$ & $-5,8$ & 11,3 & 28,7 & 46,3 & 63,9 & 81,7 & 99,7 & 15 \\
\hline $\mathrm{F}_{2} \mathrm{O}$ & ${ }^{1} J_{\mathrm{OF}}$ & $-194,4$ & $-225,9$ & $-258,6$ & $-292,7$ & $-329,3$ & $-369,8$ & $-417,3$ & $-477,0$ & $-561,1$ & $-702,8$ & $-1048,5$ & -300 \\
\hline $\mathrm{CH}_{4}$ & ${ }^{1} J_{\mathrm{CH}}$ & 91,8 & 95,0 & 98,4 & 102,0 & 105,9 & 110,0 & 114,4 & 119,0 & 124,0 & 129,3 & 134,9 & 125,3 \\
\hline $\mathrm{CH}_{4}$ & ${ }^{2} J_{\mathrm{HH}}$ & $-5,7$ & $-6,5$ & $-7,4$ & $-8,3$ & $-9,3$ & $-10,4$ & $-11,5$ & $-12,8$ & $-14,1$ & $-15,5$ & $-17,0$ & $-12,8$ \\
\hline $\mathrm{C}_{2} \mathrm{H}_{2}$ & ${ }^{1} J_{\mathrm{CC}}$ & 165,5 & 168,8 & 172,4 & 176,5 & 181,1 & 186,3 & 192,6 & 200,0 & 209,1 & 220,5 & 235,5 & 174,8 \\
\hline $\mathrm{C}_{2} \mathrm{H}_{2}$ & ${ }^{1} J_{\mathrm{CH}}$ & 185,3 & 191,9 & 198,9 & 206,3 & 214,1 & 222,4 & 231,3 & 241,0 & 251,6 & 263,5 & 277,3 & 247,6 \\
\hline $\mathrm{C}_{2} \mathrm{H}_{2}$ & ${ }^{2} J_{\mathrm{CH}}$ & 50,4 & 51,4 & 52,3 & 53,1 & 53,7 & 54,1 & 54,1 & 53,6 & 52,4 & 50,2 & 46,4 & 50,1 \\
\hline $\mathrm{C}_{2} \mathrm{H}_{2}$ & ${ }^{3} J_{\mathrm{HH}}$ & 6,3 & 6,6 & 7,0 & 7,6 & 8,2 & 9,1 & 10,1 & 11,5 & 13,3 & 15,6 & 18,9 & 9,6 \\
\hline $\mathrm{C}_{2} \mathrm{H}_{4}$ & ${ }^{1} J_{\mathrm{CC}}$ & 49,9 & 52,2 & 54,7 & 57,5 & 60,7 & 64,4 & 68,6 & 73,8 & 80,2 & 88,7 & 100,8 & 67,6 \\
\hline $\mathrm{C}_{2} \mathrm{H}_{4}$ & ${ }^{1} J_{\mathrm{CH}}$ & 115,0 & 119,4 & 124,0 & 128,9 & 134,2 & 139,8 & 145,9 & 152,5 & 159,9 & 168,4 & 178,7 & 156,3 \\
\hline $\mathrm{C}_{2} \mathrm{H}_{4}$ & ${ }^{2} J_{\mathrm{CH}}$ & 3,0 & 2,4 & 1,8 & 1,1 & 0,2 & $-0,8$ & $-2,1$ & $-3,7$ & $-5,9$ & $-8,9$ & $-13,4$ & $-2,4$ \\
\hline $\mathrm{C}_{2} \mathrm{H}_{4}$ & ${ }^{2} J_{\mathrm{HH}}$ & 5,9 & 5,6 & 5,2 & 4,8 & 4,3 & 3,6 & 2,9 & 1,9 & 0,6 & $-1,0$ & $-3,5$ & 2,3 \\
\hline $\mathrm{C}_{2} \mathrm{H}_{4}$ & ${ }^{3} J_{\mathrm{HH}_{\mathrm{c}}}$ & 9,3 & 9,5 & 9,8 & 10,1 & 10,5 & 10,9 & 11,5 & 12,2 & 13,2 & 14,7 & 16,9 & 11,7 \\
\hline $\mathrm{C}_{2} \mathrm{H}_{4}$ & ${ }^{3} J_{\mathrm{HH}_{\mathrm{t}}}$ & 13,0 & 13,5 & 14,1 & 14,7 & 15,4 & 16,2 & 17,2 & 18,4 & 19,8 & 21,8 & 24,7 & 19 \\
\hline $\mathrm{C}_{2} \mathrm{H}_{6}$ & ${ }^{1} J_{\mathrm{CC}}$ & 18,8 & 20,8 & 22,9 & 25,2 & 27,6 & 30,2 & 32,9 & 35,8 & 38,9 & 42,2 & 45,7 & 34,5 \\
\hline $\mathrm{C}_{2} \mathrm{H}_{6}$ & ${ }^{1} J_{\mathrm{CH}}$ & 90,8 & 94,2 & 97,9 & 101,8 & 105,9 & 110,3 & 115,0 & 119,9 & 125,2 & 130,8 & 136,7 & 125,2 \\
\hline $\mathrm{C}_{2} \mathrm{H}_{6}$ & ${ }^{2} J_{\mathrm{CH}}$ & $-0,5$ & $-1,0$ & $-1,5$ & $-2,0$ & $-2,5$ & $-3,1$ & $-3,8$ & $-4,5$ & $-5,2$ & $-6,0$ & $-6,9$ & $-4,7$ \\
\hline \multirow[t]{3}{*}{ Total } & DM & $-19,26$ & $-17,54$ & $-15,51$ & $-13,19$ & $-10,66$ & $-8,00$ & $-5,30$ & $-2,78$ & $-0,90$ & $-0,83$ & $-8,15$ & - \\
\hline & DMA & 31,28 & 26,66 & 21,58 & 16,28 & 12,98 & 11,14 & 12,15 & 15,11 & 21,67 & 33,77 & 54,82 & - \\
\hline & PDMA & 68,00 & 58,06 & 47,58 & 37,16 & 26,71 & 15,79 & 13,26 & 21,52 & 38,35 & 60,26 & 90,89 & - \\
\hline \multirow[t]{3}{*}{ CPI } & $\mathrm{DM}$ & $-26,86$ & $-25,07$ & $-22,69$ & $-19,83$ & $-16,65$ & $-13,35$ & $-10,25$ & $-7,90$ & $-7,47$ & $-11,98$ & $-34,85$ & - \\
\hline & DMA & 51,54 & 43,09 & 33,80 & 23,88 & 18,45 & 16,71 & 21,65 & 29,97 & 44,36 & 67,29 & 109,09 & - \\
\hline & PDMA & 88,34 & 72,32 & 55,87 & 40,13 & 25,61 & 11,92 & 18,74 & 37,07 & 58,21 & 81,73 & 112,26 & - \\
\hline \multirow[t]{3}{*}{ SPI } & $\mathrm{DM}$ & $-13,69$ & $-12,02$ & $-10,24$ & $-8,32$ & $-6,27$ & $-4,07$ & $-1,67$ & 0,97 & 3,93 & 7,35 & 11,44 & - \\
\hline & DMA & 16,43 & 14,61 & 12,63 & 10,71 & 8,97 & 7,06 & 5,19 & 4,21 & 5,03 & 9,19 & 15,03 & - \\
\hline & PDMA & 53,08 & 47,60 & 41,50 & 34,98 & 27,52 & 18,62 & 9,24 & 10,12 & 23,78 & 44,51 & 75,22 & - \\
\hline \multirow[t]{3}{*}{$\Delta \mathrm{CS}$} & DM & $-13,18$ & $-13,05$ & $-12,45$ & $-11,51$ & $-10,37$ & $-9,27$ & $-8,59$ & $-8,87$ & $-11,40$ & $-19,33$ & $-46,29$ & - \\
\hline & DMA & 35,10 & 28,48 & 21,17 & 13,18 & 9,48 & 9,65 & 16,47 & 25,77 & 39,33 & 58,10 & 94,06 & - \\
\hline & PDMA & 35,26 & 24,72 & 14,36 & 5,15 & $-1,91$ & $-6,71$ & 9,50 & 26,96 & 34,43 & 37,22 & 37,04 & - \\
\hline \multicolumn{14}{|c|}{ Desconsiderando ${ }^{1} J_{\mathrm{BF}}$ da molécula de $\mathrm{BF}_{3},{ }^{2} J_{\mathrm{CH}}$ e ${ }^{2} J_{\mathrm{HH}}$ da molécula de $\mathrm{C}_{2} \mathrm{H}_{4}$} \\
\hline \multirow[t]{3}{*}{ Total } & DM & $-18,36$ & $-17,09$ & $-15,47$ & $-13,53$ & $-11,35$ & $-9,00$ & $-6,63$ & $-4,43$ & $-2,91$ & $-3,41$ & $-12,16$ & - \\
\hline & DMA & 31,17 & 26,69 & 21,72 & 16,50 & 13,57 & 12,31 & 13,10 & 15,64 & 22,15 & 34,85 & 57,56 & - \\
\hline & PDMA & 34,92 & 30,06 & 24,87 & 19,98 & 15,67 & 11,42 & 9,34 & 12,14 & 19,62 & 30,77 & 47,30 & - \\
\hline \multirow[t]{3}{*}{ CPI } & DM & $-20,80$ & $-20,46$ & $-19,50$ & $-18,03$ & $-16,23$ & $-14,31$ & $-12,65$ & $-11,82$ & $-13,11$ & $-19,85$ & $-46,81$ & - \\
\hline & DMA & 47,94 & 40,28 & 31,72 & 22,49 & 18,21 & 18,01 & 22,45 & 29,84 & 43,91 & 67,35 & 111,53 & - \\
\hline & PDMA & 38,84 & 32,09 & 25,05 & 18,94 & 14,30 & 10,64 & 11,48 & 19,91 & 31,43 & 45,44 & 67,02 & - \\
\hline \multirow[t]{3}{*}{ SPI } & $\mathrm{DM}$ & $-16,48$ & $-14,49$ & $-12,36$ & $-10,06$ & $-7,59$ & $-4,92$ & $-1,99$ & 1,25 & 4,93 & 9,23 & 14,49 & - \\
\hline & DMA & 18,27 & 16,23 & 14,02 & 11,89 & 9,99 & 7,92 & 5,92 & 4,72 & 5,41 & 9,85 & 16,05 & - \\
\hline & PDMA & 31,90 & 28,50 & 24,73 & 20,78 & 16,73 & 12,01 & 7,70 & 6,17 & 10,53 & 19,49 & 32,14 & - \\
\hline \multirow[t]{3}{*}{$\Delta \mathrm{CS}$} & $\mathrm{DM}$ & $-4,32$ & $-5,97$ & $-7,14$ & $-7,97$ & $-8,64$ & $-9,39$ & $-10,66$ & $-13,07$ & $-18,04$ & $-29,08$ & $-61,30$ & - \\
\hline & DMA & 29,67 & 24,05 & 17,70 & 10,60 & 8,22 & 10,09 & 16,53 & 25,12 & 38,50 & 57,50 & 95,48 & - \\
\hline & PDMA & 6,94 & 3,59 & 0,33 & $-1,84$ & $-2,43$ & $-1,37$ & 3,78 & 13,75 & 20,90 & 25,95 & 34,88 & - \\
\hline
\end{tabular}


Tabela 8.220: Constantes de acoplamento B98B971 com base aug-pcJ-2.

\begin{tabular}{|c|c|c|c|c|c|c|c|c|c|c|c|c|c|}
\hline & $\% E_{X}^{\mathrm{HF}}$ & $0 \%$ & $10 \%$ & $20 \%$ & $30 \%$ & $40 \%$ & $50 \%$ & $60 \%$ & $70 \%$ & $80 \%$ & $90 \%$ & $100 \%$ & Exp. \\
\hline $\mathrm{HF}$ & ${ }^{1} J_{\mathrm{HF}}$ & 421,4 & 438,1 & 455,9 & 474,8 & 495,0 & 516,4 & 539,1 & 563,2 & 588,7 & 615,6 & 643,9 & 500 \\
\hline $\mathrm{CO}$ & ${ }^{1} J_{\mathrm{CO}}$ & 16,8 & 15,7 & 14,4 & 13,0 & 11,5 & 9,8 & 7,9 & 5,8 & 3,6 & 1,2 & $-1,3$ & 16,4 \\
\hline $\mathrm{H}_{2} \mathrm{O}$ & ${ }^{1} J_{\mathrm{OH}}$ & $-66,4$ & $-68,5$ & $-70,8$ & $-73,3$ & $-75,9$ & $-78,8$ & $-81,7$ & $-84,9$ & $-88,3$ & $-91,9$ & $-95,7$ & $-80,6$ \\
\hline $\mathrm{H}_{2} \mathrm{O}$ & ${ }^{2} J_{\mathrm{HH}}$ & $-0,5$ & $-1,5$ & $-2,6$ & $-3,7$ & $-4,9$ & $-6,2$ & $-7,6$ & $-9,1$ & $-10,7$ & $-12,4$ & $-14,3$ & $-7,3$ \\
\hline $\mathrm{NH}_{3}$ & ${ }^{1} J_{\mathrm{NH}}$ & 36,5 & 37,6 & 38,7 & 39,8 & 41,1 & 42,4 & 43,9 & 45,4 & 47,0 & 48,8 & 50,6 & 43,8 \\
\hline $\mathrm{NH}_{3}$ & ${ }^{2} J_{\mathrm{HH}}$ & $-3,2$ & $-4,1$ & $-5,0$ & $-6,1$ & $-7,2$ & $-8,4$ & $-9,7$ & $-11,1$ & $-12,6$ & $-14,3$ & $-16,1$ & $-9,6$ \\
\hline $\mathrm{PH}_{3}$ & ${ }^{1} J_{\mathrm{PH}}$ & 159,8 & 166,1 & 172,7 & 179,7 & 187,2 & 195,0 & 203,3 & 212,0 & 221,1 & 230,7 & 240,7 & 188,2 \\
\hline $\mathrm{PF}_{3}$ & ${ }^{1} J_{\mathrm{PF}}$ & $-1607,9$ & $-1603,6$ & $-1593,6$ & $-1578,8$ & $-1559,8$ & $-1537,4$ & $-1512,1$ & $-1484,7$ & $-1455,7$ & $-1425,6$ & $-1394,8$ & -1441 \\
\hline $\mathrm{BHF}_{2}$ & ${ }^{1} J_{\mathrm{BF}}$ & $-150,0$ & $-135,3$ & $-120,1$ & $-104,6$ & $-88,8$ & $-72,8$ & $-56,6$ & $-40,4$ & $-24,1$ & $-7,9$ & 8,1 & -84 \\
\hline $\mathrm{BF}_{3}$ & ${ }^{1} J_{\mathrm{BF}}$ & $-60,8$ & $-43,8$ & $-26,5$ & $-9,0$ & 8,6 & 26,4 & 44,4 & 62,4 & 80,5 & 98,6 & 116,8 & 15 \\
\hline $\mathrm{F}_{2} \mathrm{O}$ & ${ }^{1} J_{\mathrm{OF}}$ & $-190,5$ & $-222,1$ & $-255,0$ & $-289,8$ & $-327,4$ & $-369,7$ & $-420,1$ & $-485,2$ & $-580,0$ & $-749,5$ & $-1221,3$ & -300 \\
\hline $\mathrm{CH}_{4}$ & ${ }^{1} J_{\mathrm{CH}}$ & 98,3 & 101,8 & 105,5 & 109,4 & 113,6 & 118,1 & 122,8 & 127,9 & 133,3 & 139,0 & 145,1 & 125,3 \\
\hline $\mathrm{CH}_{4}$ & ${ }^{2} J_{\mathrm{HH}}$ & $-5,6$ & $-6,4$ & $-7,3$ & $-8,3$ & $-9,3$ & $-10,5$ & $-11,6$ & $-12,9$ & $-14,3$ & $-15,8$ & $-17,3$ & $-12,8$ \\
\hline $\mathrm{C}_{2} \mathrm{H}_{2}$ & ${ }^{1} J_{\mathrm{CC}}$ & 181,5 & 185,7 & 190,3 & 195,6 & 201,5 & 208,5 & 216,6 & 226,5 & 238,7 & 254,4 & 275,1 & 174,8 \\
\hline $\mathrm{C}_{2} \mathrm{H}_{2}$ & ${ }^{1} J_{\mathrm{CH}}$ & 194,0 & 201,1 & 208,5 & 216,4 & 224,8 & 233,8 & 243,5 & 254,2 & 266,0 & 279,5 & 295,5 & 247,6 \\
\hline $\mathrm{C}_{2} \mathrm{H}_{2}$ & ${ }^{2} J_{\mathrm{CH}}$ & 50,1 & 51,0 & 51,7 & 52,3 & 52,7 & 52,7 & 52,2 & 51,1 & 49,1 & 45,7 & 40,1 & 50,1 \\
\hline $\mathrm{C}_{2} \mathrm{H}_{2}$ & ${ }^{3} J_{\mathrm{HH}}$ & 6,0 & 6,4 & 6,9 & 7,5 & 8,2 & 9,1 & 10,3 & 11,9 & 13,9 & 16,7 & 20,5 & 9,6 \\
\hline $\mathrm{C}_{2} \mathrm{H}_{4}$ & ${ }^{1} J_{\mathrm{CC}}$ & 60,2 & 63,1 & 66,3 & 69,9 & 73,9 & 78,6 & 84,2 & 91,1 & 99,9 & 112,1 & 130,5 & 67,6 \\
\hline $\mathrm{C}_{2} \mathrm{H}_{4}$ & ${ }^{1} J_{\mathrm{CH}}$ & 121,5 & 126,2 & 131,2 & 136,5 & 142,1 & 148,3 & 154,9 & 162,3 & 170,7 & 180,5 & 193,0 & 156,3 \\
\hline $\mathrm{C}_{2} \mathrm{H}_{4}$ & ${ }^{2} J_{\mathrm{CH}}$ & 2,5 & 1,8 & 1,1 & 0,2 & $-0,7$ & $-2,0$ & $-3,6$ & $-5,6$ & $-8,4$ & $-12,4$ & $-18,8$ & $-2,4$ \\
\hline $\mathrm{C}_{2} \mathrm{H}_{4}$ & ${ }^{2} J_{\mathrm{HH}}$ & 5,7 & 5,4 & 5,0 & 4,5 & 4,0 & 3,3 & 2,4 & 1,4 & 0,0 & $-2,0$ & $-5,1$ & 2,3 \\
\hline $\mathrm{C}_{2} \mathrm{H}_{4}$ & ${ }^{3} J_{\mathrm{HH}_{\mathrm{C}}}$ & 9,2 & 9,4 & 9,7 & 10,0 & 10,4 & 10,9 & 11,5 & 12,3 & 13,5 & 15,2 & 18,0 & 11,7 \\
\hline $\mathrm{C}_{2} \mathrm{H}_{4}$ & ${ }^{3} J_{\mathrm{HH}_{\mathrm{t}}}$ & 12,9 & 13,4 & 14,0 & 14,6 & 15,3 & 16,2 & 17,2 & 18,4 & 20,1 & 22,4 & 25,9 & 19 \\
\hline $\mathrm{C}_{2} \mathrm{H}_{6}$ & ${ }^{1} J_{\mathrm{CC}}$ & 23,3 & 25,6 & 28,1 & 30,7 & 33,5 & 36,5 & 39,6 & 43,0 & 46,5 & 50,4 & 54,4 & 34,5 \\
\hline $\mathrm{C}_{2} \mathrm{H}_{6}$ & ${ }^{1} J_{\mathrm{CH}}$ & 97,2 & 100,9 & 104,9 & 109,1 & 113,6 & 118,4 & 123,4 & 128,8 & 134,5 & 140,6 & 147,0 & 125,2 \\
\hline $\mathrm{C}_{2} \mathrm{H}_{6}$ & ${ }^{2} J_{\mathrm{CH}}$ & $-0,6$ & $-1,1$ & $-1,6$ & $-2,2$ & $-2,8$ & $-3,4$ & $-4,1$ & $-4,9$ & $-5,7$ & $-6,6$ & $-7,5$ & $-4,7$ \\
\hline \multirow[t]{3}{*}{ Total } & $\mathrm{DM}$ & $-16,68$ & $-14,70$ & $-12,41$ & $-9,88$ & $-7,11$ & $-4,22$ & $-1,34$ & 1,30 & 3,17 & 2,62 & $-8,92$ & - \\
\hline & DMA & 29,26 & 24,73 & 19,79 & 14,62 & 11,25 & 12,24 & 15,13 & 20,70 & 28,81 & 41,80 & 68,67 & - \\
\hline & PDMA & 60,80 & 50,78 & 40,41 & 29,43 & 19,01 & 15,40 & 19,86 & 34,00 & 54,26 & 80,33 & 118,03 & - \\
\hline \multirow[t]{3}{*}{ CPI } & $\mathrm{DM}$ & $-25,97$ & $-23,85$ & $-21,16$ & $-18,08$ & $-14,68$ & $-11,29$ & $-8,19$ & $-6,14$ & $-6,49$ & $-13,42$ & $-47,66$ & - \\
\hline & DMA & 50,94 & 42,26 & 32,82 & 22,55 & 16,41 & 20,36 & 28,39 & 38,79 & 51,98 & 74,91 & 128,26 & - \\
\hline & PDMA & 78,12 & 62,24 & 46,42 & 30,16 & 15,19 & 18,13 & 31,64 & 51,99 & 73,66 & 98,32 & 132,83 & - \\
\hline \multirow[t]{3}{*}{ SPI } & DM & $-9,86$ & $-7,99$ & $-5,99$ & $-3,86$ & $-1,55$ & 0,96 & 3,68 & 6,76 & 10,25 & 14,37 & 19,49 & - \\
\hline & DMA & 13,37 & 11,87 & 10,24 & 8,81 & 7,47 & 6,28 & 5,41 & 7,43 & 11,82 & 17,52 & 24,97 & - \\
\hline & PDMA & 48,10 & 42,37 & 36,01 & 28,89 & 21,82 & 13,40 & 11,23 & 20,81 & 40,04 & 67,14 & 107,17 & - \\
\hline \multirow[t]{3}{*}{$\Delta \mathrm{CS}$} & $\mathrm{DM}$ & $-16,11$ & $-15,86$ & $-15,18$ & $-14,22$ & $-13,13$ & $-12,25$ & $-11,87$ & $-12,90$ & $-16,74$ & $-27,79$ & $-67,15$ & - \\
\hline & DMA & 37,57 & 30,40 & 22,58 & 13,75 & 8,94 & 14,08 & 22,98 & 31,36 & 40,16 & 57,39 & 103,30 & - \\
\hline & PDMA & 30,02 & 19,87 & 10,41 & 1,26 & $-6,63$ & 4,73 & 20,41 & 31,18 & 33,63 & 31,18 & 25,65 & - \\
\hline \multicolumn{14}{|c|}{ Desconsiderando ${ }^{1} J_{\mathrm{BF}}$ da molécula de $\mathrm{BF}_{3},{ }^{2} J_{\mathrm{CH}}$ e ${ }^{2} J_{\mathrm{HH}}$ da molécula de $\mathrm{C}_{2} \mathrm{H}_{4}$} \\
\hline \multirow[t]{3}{*}{ Total } & $\mathrm{DM}$ & $-15,92$ & $-14,37$ & $-12,49$ & $-10,33$ & $-7,90$ & $-5,33$ & $-2,75$ & $-0,41$ & 1,09 & $-0,06$ & $-13,48$ & - \\
\hline & DMA & 29,42 & 25,08 & 20,30 & 15,28 & 12,30 & 13,28 & 15,77 & 21,16 & 29,36 & 43,00 & 72,17 & - \\
\hline & PDMA & 31,46 & 26,89 & 22,21 & 17,44 & 13,34 & 11,49 & 11,57 & 17,20 & 27,14 & 40,33 & 60,22 & - \\
\hline \multirow[t]{3}{*}{ CPI } & $\mathrm{DM}$ & $-20,99$ & $-20,35$ & $-19,13$ & $-17,49$ & $-15,51$ & $-13,56$ & $-11,95$ & $-11,49$ & $-13,69$ & $-23,12$ & $-62,61$ & - \\
\hline & DMA & 48,45 & 40,61 & 31,95 & 22,41 & 17,41 & 21,26 & 28,29 & 37,93 & 50,63 & 74,04 & 130,91 & - \\
\hline & PDMA & 35,40 & 29,26 & 23,39 & 17,17 & 12,44 & 12,34 & 15,20 & 25,59 & 37,36 & 52,41 & 78,24 & - \\
\hline \multirow[t]{3}{*}{ SPI } & DM & $-12,02$ & $-9,78$ & $-7,38$ & $-4,82$ & $-2,05$ & 1,00 & 4,33 & 8,12 & 12,46 & 17,68 & 24,32 & - \\
\hline & DMA & 14,78 & 13,13 & 11,34 & 9,79 & 8,36 & 7,14 & 6,15 & 8,25 & 13,00 & 19,12 & 26,98 & - \\
\hline & PDMA & 28,43 & 25,06 & 21,30 & 17,65 & 14,04 & 10,83 & 8,77 & 10,75 & 19,27 & 31,04 & 46,35 & - \\
\hline \multirow[t]{3}{*}{$\Delta \mathrm{CS}$} & $\mathrm{DM}$ & $-8,97$ & $-10,57$ & $-11,75$ & $-12,67$ & $-13,46$ & $-14,56$ & $-16,28$ & $-19,61$ & $-26,15$ & $-40,80$ & $-86,93$ & - \\
\hline & DMA & 33,67 & 27,48 & 20,61 & 12,62 & 9,05 & 14,12 & 22,14 & 29,68 & 37,63 & 54,92 & 103,93 & - \\
\hline & PDMA & 6,98 & 4,20 & 2,09 & $-0,48$ & $-1,60$ & 1,51 & 6,43 & 14,84 & 18,09 & 21,38 & 31,89 & - \\
\hline
\end{tabular}


Tabela 8.221: Constantes de acoplamento B98B972 com base aug-pcJ-2.

\begin{tabular}{|c|c|c|c|c|c|c|c|c|c|c|c|c|c|}
\hline & $\% E_{X}^{\mathrm{HF}}$ & $0 \%$ & $10 \%$ & $20 \%$ & $30 \%$ & $40 \%$ & $50 \%$ & $60 \%$ & $70 \%$ & $80 \%$ & $90 \%$ & $100 \%$ & Exp. \\
\hline $\mathrm{HF}$ & ${ }^{1} J_{\mathrm{HF}}$ & 454,7 & 472,9 & 492,1 & 512,4 & 534,0 & 556,8 & 580,9 & 606,5 & 633,4 & 661,7 & 691,6 & 500 \\
\hline $\mathrm{CO}$ & ${ }^{1} J_{\mathrm{CO}}$ & 13,1 & 11,8 & 10,3 & 8,6 & 6,7 & 4,7 & 2,5 & 0,0 & $-2,5$ & $-5,3$ & $-8,3$ & 16,4 \\
\hline $\mathrm{H}_{2} \mathrm{O}$ & ${ }^{1} J_{\mathrm{OH}}$ & $-71,4$ & $-73,7$ & $-76,3$ & $-78,9$ & $-81,8$ & $-84,8$ & $-88,1$ & $-91,5$ & $-95,2$ & $-99,0$ & $-103,1$ & $-80,6$ \\
\hline $\mathrm{H}_{2} \mathrm{O}$ & ${ }^{2} J_{\mathrm{HH}}$ & $-0,3$ & $-1,3$ & $-2,4$ & $-3,6$ & $-4,8$ & $-6,1$ & $-7,6$ & $-9,1$ & $-10,7$ & $-12,5$ & $-14,3$ & $-7,3$ \\
\hline $\mathrm{NH}_{3}$ & ${ }^{1} J_{\mathrm{NH}}$ & 38,5 & 39,6 & 40,7 & 41,9 & 43,3 & 44,7 & 46,1 & 47,7 & 49,4 & 51,2 & 53,1 & 43,8 \\
\hline $\mathrm{NH}_{3}$ & ${ }^{2} J_{\mathrm{HH}}$ & $-2,6$ & $-3,5$ & $-4,5$ & $-5,5$ & $-6,6$ & $-7,7$ & $-9,0$ & $-10,4$ & $-11,9$ & $-13,5$ & $-15,2$ & $-9,6$ \\
\hline $\mathrm{PH}_{3}$ & ${ }^{1} J_{\mathrm{PH}}$ & 153,2 & 159,8 & 167,0 & 174,7 & 182,8 & 191,5 & 200,6 & 210,3 & 220,5 & 231,3 & 242,5 & 188,2 \\
\hline $\mathrm{PF}_{3}$ & ${ }^{1} J_{\mathrm{PF}}$ & $-1649,2$ & $-1644,2$ & $-1633,2$ & $-1617,3$ & $-1597,0$ & $-1573,3$ & $-1546,8$ & $-1518,1$ & $-1487,9$ & $-1456,7$ & $-1424,9$ & -1441 \\
\hline $\mathrm{BHF}_{2}$ & ${ }^{1} J_{\mathrm{BF}}$ & $-135,9$ & $-120,9$ & $-105,6$ & $-90,1$ & $-74,4$ & $-58,6$ & $-42,7$ & $-26,8$ & $-11,0$ & 4,7 & 20,3 & -84 \\
\hline $\mathrm{BF}_{3}$ & ${ }^{1} J_{\mathrm{BF}}$ & $-44,4$ & $-27,2$ & $-9,7$ & 7,6 & 25,2 & 42,9 & 60,5 & 78,3 & 96,0 & 113,8 & 131,6 & 15 \\
\hline $\mathrm{F}_{2} \mathrm{O}$ & ${ }^{1} J_{\mathrm{OF}}$ & $-181,6$ & $-212,7$ & $-245,3$ & $-279,6$ & $-316,8$ & $-358,8$ & $-409,0$ & $-474,6$ & $-572,5$ & $-756,1$ & $-1349,0$ & -300 \\
\hline $\mathrm{CH}_{4}$ & ${ }^{1} J_{\mathrm{CH}}$ & 100,5 & 103,9 & 107,6 & 111,5 & 115,7 & 120,1 & 124,8 & 129,7 & 135,0 & 140,6 & 146,5 & 125,3 \\
\hline $\mathrm{CH}_{4}$ & ${ }^{2} J_{\mathrm{HH}}$ & $-4,6$ & $-5,4$ & $-6,3$ & $-7,2$ & $-8,2$ & $-9,2$ & $-10,3$ & $-11,5$ & $-12,8$ & $-14,2$ & $-15,6$ & $-12,8$ \\
\hline $\mathrm{C}_{2} \mathrm{H}_{2}$ & ${ }^{1} J_{\mathrm{CC}}$ & 180,1 & 184,3 & 188,9 & 194,2 & 200,2 & 207,2 & 215,5 & 225,5 & 237,9 & 253,6 & 274,3 & 174,8 \\
\hline $\mathrm{C}_{2} \mathrm{H}_{2}$ & ${ }^{1} J_{\mathrm{CH}}$ & 195,8 & 202,8 & 210,1 & 217,9 & 226,1 & 234,9 & 244,4 & 254,7 & 266,1 & 279,0 & 294,1 & 247,6 \\
\hline $\mathrm{C}_{2} \mathrm{H}_{2}$ & ${ }^{2} J_{\mathrm{CH}}$ & 50,3 & 51,2 & 52,0 & 52,5 & 52,9 & 52,9 & 52,5 & 51,5 & 49,6 & 46,6 & 41,6 & 50,1 \\
\hline $\mathrm{C}_{2} \mathrm{H}_{2}$ & ${ }^{3} J_{\mathrm{HH}}$ & 5,8 & 6,1 & 6,5 & 7,0 & 7,6 & 8,4 & 9,4 & 10,8 & 12,5 & 14,8 & 18,0 & 9,6 \\
\hline $\mathrm{C}_{2} \mathrm{H}_{4}$ & ${ }^{1} J_{\mathrm{CC}}$ & 60,1 & 63,0 & 66,2 & 69,9 & 74,2 & 79,1 & 85,1 & 92,5 & 102,3 & 115,9 & 137,0 & 67,6 \\
\hline $\mathrm{C}_{2} \mathrm{H}_{4}$ & ${ }^{1} J_{\mathrm{CH}}$ & 123,1 & 127,8 & 132,7 & 138,0 & 143,6 & 149,6 & 156,2 & 163,5 & 171,7 & 181,5 & 194,0 & 156,3 \\
\hline $\mathrm{C}_{2} \mathrm{H}_{4}$ & ${ }^{2} J_{\mathrm{CH}}$ & 3,2 & 2,5 & 1,8 & 1,0 & 0,0 & $-1,2$ & $-2,8$ & $-4,8$ & $-7,6$ & $-11,6$ & $-18,1$ & $-2,4$ \\
\hline $\mathrm{C}_{2} \mathrm{H}_{4}$ & ${ }^{2} J_{\mathrm{HH}}$ & 6,5 & 6,2 & 5,9 & 5,5 & 5,0 & 4,4 & 3,7 & 2,7 & 1,5 & $-0,2$ & $-2,9$ & 2,3 \\
\hline $\mathrm{C}_{2} \mathrm{H}_{4}$ & ${ }^{3} J_{\mathrm{HH}_{\mathrm{c}}}$ & 9,1 & 9,3 & 9,5 & 9,8 & 10,1 & 10,5 & 11,0 & 11,7 & 12,7 & 14,2 & 16,6 & 11,7 \\
\hline $\mathrm{C}_{2} \mathrm{H}_{4}$ & ${ }^{3} J_{\mathrm{HH}_{\mathrm{t}}}$ & 12,8 & 13,3 & 13,8 & 14,3 & 15,0 & 15,7 & 16,6 & 17,7 & 19,2 & 21,2 & 24,4 & 19 \\
\hline $\mathrm{C}_{2} \mathrm{H}_{6}$ & ${ }^{1} J_{\mathrm{CC}}$ & 25,6 & 27,9 & 30,4 & 33,0 & 35,8 & 38,7 & 41,9 & 45,2 & 48,7 & 52,4 & 56,4 & 34,5 \\
\hline $\mathrm{C}_{2} \mathrm{H}_{6}$ & ${ }^{1} J_{\mathrm{CH}}$ & 98,6 & 102,3 & 106,3 & 110,4 & 114,8 & 119,5 & 124,5 & 129,8 & 135,3 & 141,2 & 147,5 & 125,2 \\
\hline $\mathrm{C}_{2} \mathrm{H}_{6}$ & ${ }^{2} J_{\mathrm{CH}}$ & $-0,1$ & $-0,5$ & $-1,0$ & $-1,6$ & $-2,1$ & $-2,7$ & $-3,4$ & $-4,1$ & $-4,8$ & $-5,6$ & $-6,5$ & $-4,7$ \\
\hline \multirow[t]{3}{*}{ Total } & $\mathrm{DM}$ & $-15,54$ & $-13,45$ & $-11,06$ & $-8,41$ & $-5,53$ & $-2,53$ & 0,44 & 3,16 & 5,00 & 4,00 & $-12,05$ & - \\
\hline & DMA & 28,60 & 24,01 & 18,98 & 14,69 & 13,81 & 16,16 & 19,27 & 25,11 & 33,09 & 45,42 & 75,85 & - \\
\hline & PDMA & 59,52 & 49,77 & 39,59 & 29,29 & 25,52 & 26,79 & 28,91 & 39,08 & 55,29 & 80,57 & 118,82 & - \\
\hline \multirow[t]{3}{*}{ CPI } & DM & $-24,25$ & $-21,85$ & $-18,89$ & $-15,52$ & $-11,85$ & $-8,15$ & $-4,86$ & $-2,60$ & $-3,03$ & $-11,03$ & $-56,05$ & - \\
\hline & DMA & 50,00 & 41,17 & 31,44 & 23,21 & 22,63 & 29,49 & 38,14 & 48,60 & 62,17 & 83,70 & 145,55 & - \\
\hline & PDMA & 68,35 & 52,81 & 36,79 & 21,15 & 21,16 & 33,91 & 48,06 & 67,46 & 89,23 & 114,23 & 152,13 & - \\
\hline \multirow[t]{3}{*}{ SPI } & DM & $-9,15$ & $-7,29$ & $-5,31$ & $-3,19$ & $-0,89$ & 1,59 & 4,33 & 7,39 & 10,88 & 15,02 & 20,21 & - \\
\hline & DMA & 12,90 & 11,43 & 9,85 & 8,45 & 7,35 & 6,39 & 5,43 & 7,88 & 11,76 & 17,35 & 24,75 & - \\
\hline & PDMA & 53,06 & 47,54 & 41,65 & 35,25 & 28,71 & 21,57 & 14,88 & 18,26 & 30,41 & 55,89 & 94,39 & - \\
\hline \multirow[t]{3}{*}{$\Delta \mathrm{CS}$} & $\mathrm{DM}$ & $-15,10$ & $-14,55$ & $-13,58$ & $-12,32$ & $-10,95$ & $-9,73$ & $-9,20$ & $-9,99$ & $-13,91$ & $-26,05$ & $-76,27$ & - \\
\hline & DMA & 37,10 & 29,75 & 21,59 & 14,76 & 15,28 & 23,10 & 32,71 & 40,72 & 50,41 & 66,35 & 120,80 & - \\
\hline & PDMA & 15,29 & 5,27 & $-4,86$ & $-14,10$ & $-7,55$ & 12,34 & 33,18 & 49,20 & 58,82 & 58,33 & 57,74 & - \\
\hline \multicolumn{14}{|c|}{ Desconsiderando ${ }^{1} J_{\mathrm{BF}}$ da molécula de $\mathrm{BF}_{3},{ }^{2} J_{\mathrm{CH}}$ e ${ }^{2} J_{\mathrm{HH}}$ da molécula de $\mathrm{C}_{2} \mathrm{H}_{4}$} \\
\hline \multirow[t]{3}{*}{ Total } & DM & $-15,41$ & $-13,75$ & $-11,77$ & $-9,47$ & $-6,91$ & $-4,22$ & $-1,52$ & 0,91 & 2,39 & 0,73 & $-17,79$ & - \\
\hline & DMA & 29,32 & 24,93 & 20,04 & 16,00 & 14,95 & 16,91 & 19,72 & 25,51 & 33,62 & 46,54 & 79,77 & - \\
\hline & PDMA & 31,99 & 27,78 & 23,18 & 18,75 & 16,44 & 16,05 & 16,13 & 20,73 & 28,09 & 41,05 & 62,25 & - \\
\hline \multirow[t]{3}{*}{ CPI } & DM & $-20,74$ & $-19,81$ & $-18,31$ & $-16,33$ & $-14,05$ & $-11,75$ & $-9,90$ & $-9,19$ & $-11,43$ & $-22,01$ & $-73,32$ & - \\
\hline & DMA & 49,06 & 41,07 & 32,11 & 24,79 & 23,87 & 29,65 & 37,40 & 47,13 & 60,29 & 82,19 & 148,44 & - \\
\hline & PDMA & 35,58 & 29,96 & 24,00 & 18,34 & 16,48 & 18,70 & 22,53 & 32,01 & 44,15 & 59,79 & 89,61 & - \\
\hline \multirow[t]{3}{*}{ SPI } & DM & $-11,32$ & $-9,09$ & $-6,73$ & $-4,19$ & $-1,42$ & 1,58 & 4,92 & 8,68 & 13,02 & 18,23 & 24,93 & - \\
\hline & DMA & 14,13 & 12,51 & 10,76 & 9,24 & 8,08 & 7,12 & 6,12 & 8,88 & 13,11 & 19,12 & 26,95 & - \\
\hline & PDMA & 29,22 & 26,11 & 22,56 & 19,07 & 16,40 & 14,02 & 11,20 & 12,04 & 15,74 & 26,65 & 41,20 & - \\
\hline \multirow[t]{3}{*}{$\Delta \mathrm{CS}$} & $\mathrm{DM}$ & $-9,42$ & $-10,72$ & $-11,58$ & $-12,14$ & $-12,63$ & $-13,33$ & $-14,82$ & $-17,87$ & $-24,45$ & $-40,24$ & $-98,25$ & - \\
\hline & DMA & 34,93 & 28,56 & 21,35 & 15,55 & 15,79 & 22,53 & 31,28 & 38,25 & 47,18 & 63,07 & 121,49 & - \\
\hline & PDMA & 6,36 & 3,85 & 1,44 & $-0,74$ & 0,08 & 4,68 & 11,33 & 19,97 & 28,41 & 33,14 & 48,41 & - \\
\hline
\end{tabular}


Tabela 8.222: Constantes de acoplamento B98B98 com base aug-pcJ-2.

\begin{tabular}{|c|c|c|c|c|c|c|c|c|c|c|c|c|c|}
\hline & $\% E_{X}^{\mathrm{HF}}$ & $0 \%$ & $10 \%$ & $20 \%$ & $30 \%$ & $40 \%$ & $50 \%$ & $60 \%$ & $70 \%$ & $80 \%$ & $90 \%$ & $100 \%$ & Exp. \\
\hline $\mathrm{HF}$ & ${ }^{1} J_{\mathrm{HF}}$ & 411,6 & 428,1 & 445,8 & 464,6 & 484,6 & 505,9 & 528,5 & 552,5 & 577,9 & 604,8 & 633,1 & 500 \\
\hline $\mathrm{CO}$ & ${ }^{1} J_{\mathrm{CO}}$ & 16,6 & 15,5 & 14,2 & 12,8 & 11,2 & 9,5 & 7,7 & 5,6 & 3,4 & 1,0 & $-1,4$ & 16,4 \\
\hline $\mathrm{H}_{2} \mathrm{O}$ & ${ }^{1} J_{\mathrm{OH}}$ & $-66,0$ & $-68,2$ & $-70,5$ & $-73,0$ & $-75,6$ & $-78,4$ & $-81,4$ & $-84,6$ & $-88,1$ & $-91,7$ & $-95,6$ & $-80,6$ \\
\hline $\mathrm{H}_{2} \mathrm{O}$ & ${ }^{2} J_{\mathrm{HH}}$ & $-0,7$ & $-1,7$ & $-2,7$ & $-3,9$ & $-5,1$ & $-6,4$ & $-7,9$ & $-9,4$ & $-11,0$ & $-12,7$ & $-14,6$ & $-7,3$ \\
\hline $\mathrm{NH}_{3}$ & ${ }^{1} J_{\mathrm{NH}}$ & 37,0 & 38,1 & 39,2 & 40,4 & 41,7 & 43,1 & 44,6 & 46,1 & 47,8 & 49,6 & 51,5 & 43,8 \\
\hline $\mathrm{NH}_{3}$ & ${ }^{2} J_{\mathrm{HH}}$ & $-3,5$ & $-4,4$ & $-5,4$ & $-6,4$ & $-7,6$ & $-8,8$ & $-10,2$ & $-11,6$ & $-13,2$ & $-14,9$ & $-16,8$ & $-9,6$ \\
\hline $\mathrm{PH}_{3}$ & ${ }^{1} J_{\mathrm{PH}}$ & 165,9 & 172,2 & 179,0 & 186,1 & 193,7 & 201,7 & 210,1 & 218,9 & 228,1 & 237,8 & 247,9 & 188,2 \\
\hline $\mathrm{PF}_{3}$ & ${ }^{1} J_{\mathrm{PF}}$ & $-1622,6$ & $-1617,6$ & $-1607,1$ & $-1591,6$ & $-1572,1$ & $-1549,1$ & $-1523,4$ & $-1495,6$ & $-1466,2$ & $-1435,7$ & $-1404,5$ & -1441 \\
\hline $\mathrm{BHF}_{2}$ & ${ }^{1} J_{\mathrm{BF}}$ & $-150,1$ & $-135,5$ & $-120,6$ & $-105,2$ & $-89,6$ & $-73,8$ & $-57,8$ & $-41,8$ & $-25,7$ & $-9,6$ & 6,2 & -84 \\
\hline $\mathrm{BF}_{3}$ & ${ }^{1} J_{\mathrm{BF}}$ & $-61,5$ & $-44,7$ & $-27,7$ & $-10,4$ & 7,0 & 24,5 & 42,2 & 60,0 & 77,9 & 95,8 & 113,8 & 15 \\
\hline $\mathrm{F}_{2} \mathrm{O}$ & ${ }^{1} J_{\mathrm{OF}}$ & $-196,5$ & $-228,9$ & $-262,8$ & $-298,9$ & $-338,2$ & $-383,0$ & $-437,3$ & $-509,0$ & $-617,4$ & $-823,5$ & $-1507,1$ & -300 \\
\hline $\mathrm{CH}_{4}$ & ${ }^{1} J_{\mathrm{CH}}$ & 101,1 & 104,7 & 108,5 & 112,6 & 116,9 & 121,5 & 126,5 & 131,7 & 137,3 & 143,2 & 149,5 & 125,3 \\
\hline $\mathrm{CH}_{4}$ & ${ }^{2} J_{\mathrm{HH}}$ & $-5,9$ & $-6,8$ & $-7,7$ & $-8,7$ & $-9,8$ & $-11,0$ & $-12,2$ & $-13,5$ & $-15,0$ & $-16,5$ & $-18,1$ & $-12,8$ \\
\hline $\mathrm{C}_{2} \mathrm{H}_{2}$ & ${ }^{1} J_{\mathrm{CC}}$ & 184,5 & 188,8 & 193,5 & 198,9 & 205,0 & 212,2 & 220,6 & 230,9 & 243,6 & 260,0 & 282,1 & 174,8 \\
\hline $\mathrm{C}_{2} \mathrm{H}_{2}$ & ${ }^{1} J_{\mathrm{CH}}$ & 198,0 & 205,3 & 212,9 & 221,1 & 229,7 & 239,0 & 249,0 & 260,0 & 272,3 & 286,5 & 303,3 & 247,6 \\
\hline $\mathrm{C}_{2} \mathrm{H}_{2}$ & ${ }^{2} J_{\mathrm{CH}}$ & 50,6 & 51,5 & 52,3 & 52,9 & 53,2 & 53,2 & 52,6 & 51,4 & 49,2 & 45,4 & 39,3 & 50,1 \\
\hline $\mathrm{C}_{2} \mathrm{H}_{2}$ & ${ }^{3} J_{\mathrm{HH}}$ & 6,1 & 6,5 & 7,0 & 7,6 & 8,4 & 9,4 & 10,6 & 12,3 & 14,5 & 17,5 & 21,7 & 9,6 \\
\hline $\mathrm{C}_{2} \mathrm{H}_{4}$ & ${ }^{1} J_{\mathrm{CC}}$ & 62,2 & 65,2 & 68,5 & 72,2 & 76,4 & 81,3 & 87,2 & 94,5 & 104,0 & 117,4 & 138,3 & 67,6 \\
\hline $\mathrm{C}_{2} \mathrm{H}_{4}$ & ${ }^{1} J_{\mathrm{CH}}$ & 124,4 & 129,2 & 134,3 & 139,8 & 145,7 & 152,0 & 158,9 & 166,6 & 175,4 & 185,9 & 199,6 & 156,3 \\
\hline $\mathrm{C}_{2} \mathrm{H}_{4}$ & ${ }^{2} J_{\mathrm{CH}}$ & 2,5 & 1,8 & 1,0 & 0,1 & $-0,8$ & $-2,1$ & $-3,8$ & $-6,0$ & $-9,0$ & $-13,5$ & $-20,9$ & $-2,4$ \\
\hline $\mathrm{C}_{2} \mathrm{H}_{4}$ & ${ }^{2} J_{\mathrm{HH}}$ & 5,7 & 5,4 & 5,0 & 4,5 & 3,9 & 3,2 & 2,3 & 1,2 & $-0,3$ & $-2,5$ & $-6,2$ & 2,3 \\
\hline $\mathrm{C}_{2} \mathrm{H}_{4}$ & ${ }^{3} J_{\mathrm{HH}_{\mathrm{C}}}$ & 9,3 & 9,5 & 9,8 & 10,2 & 10,6 & 11,1 & 11,8 & 12,7 & 13,9 & 15,9 & 19,2 & 11,7 \\
\hline $\mathrm{C}_{2} \mathrm{H}_{4}$ & ${ }^{3} J_{\mathrm{HH}_{\mathrm{t}}}$ & 13,1 & 13,6 & 14,2 & 14,9 & 15,6 & 16,5 & 17,6 & 18,9 & 20,8 & 23,3 & 27,5 & 19 \\
\hline $\mathrm{C}_{2} \mathrm{H}_{6}$ & ${ }^{1} J_{\mathrm{CC}}$ & 24,5 & 26,9 & 29,5 & 32,2 & 35,1 & 38,2 & 41,5 & 45,0 & 48,8 & 52,8 & 57,1 & 34,5 \\
\hline $\mathrm{C}_{2} \mathrm{H}_{6}$ & ${ }^{1} J_{\mathrm{CH}}$ & 99,8 & 103,7 & 107,8 & 112,1 & 116,8 & 121,7 & 127,0 & 132,5 & 138,4 & 144,7 & 151,4 & 125,2 \\
\hline $\mathrm{C}_{2} \mathrm{H}_{6}$ & ${ }^{2} J_{\mathrm{CH}}$ & $-0,7$ & $-1,2$ & $-1,7$ & $-2,3$ & $-2,9$ & $-3,6$ & $-4,3$ & $-5,1$ & $-5,9$ & $-6,9$ & $-7,9$ & $-4,7$ \\
\hline \multirow[t]{3}{*}{ Total } & $\mathrm{DM}$ & $-16,91$ & $-14,92$ & $-12,64$ & $-10,09$ & $-7,35$ & $-4,51$ & $-1,72$ & 0,74 & 2,17 & 0,35 & $-19,10$ & - \\
\hline & DMA & 29,25 & 24,65 & 19,73 & 14,55 & 12,38 & 12,58 & 16,22 & 22,92 & 31,70 & 45,52 & 80,95 & - \\
\hline & PDMA & 59,87 & 49,92 & 39,57 & 28,67 & 18,65 & 14,08 & 20,27 & 36,64 & 57,99 & 86,02 & 129,89 & - \\
\hline \multirow[t]{3}{*}{ CPI } & $\mathrm{DM}$ & $-28,25$ & $-26,18$ & $-23,59$ & $-20,58$ & $-17,35$ & $-14,15$ & $-11,44$ & $-9,98$ & $-11,58$ & $-21,82$ & $-75,31$ & - \\
\hline & DMA & 52,06 & 43,33 & 33,79 & 23,36 & 20,03 & 21,97 & 30,45 & 41,38 & 55,76 & 80,13 & 152,76 & - \\
\hline & PDMA & 77,65 & 62,08 & 46,46 & 30,24 & 16,50 & 16,91 & 31,97 & 52,38 & 74,45 & 99,96 & 140,82 & - \\
\hline \multirow[t]{3}{*}{ SPI } & $\mathrm{DM}$ & $-8,59$ & $-6,67$ & $-4,61$ & $-2,40$ & $-0,02$ & 2,57 & 5,41 & 8,60 & 12,26 & 16,61 & 22,12 & - \\
\hline & DMA & 12,51 & 10,96 & 9,41 & 8,09 & 6,78 & 5,70 & 5,79 & 9,39 & 14,06 & 20,14 & 28,29 & - \\
\hline & PDMA & 46,84 & 41,00 & 34,51 & 27,52 & 20,23 & 12,01 & 11,68 & 25,10 & 45,92 & 75,81 & 121,88 & - \\
\hline \multirow[t]{3}{*}{$\Delta \mathrm{CS}$} & $\mathrm{DM}$ & $-19,65$ & $-19,52$ & $-18,98$ & $-18,18$ & $-17,33$ & $-16,72$ & $-16,85$ & $-18,58$ & $-23,84$ & $-38,42$ & $-97,43$ & - \\
\hline & DMA & 39,55 & 32,37 & 24,38 & 15,27 & 13,25 & 16,27 & 24,67 & 32,00 & 41,70 & 59,99 & 124,47 & - \\
\hline & PDMA & 30,81 & 21,08 & 11,96 & 2,72 & $-3,73$ & 4,91 & 20,29 & 27,28 & 28,53 & 24,15 & 18,94 & - \\
\hline \multicolumn{14}{|c|}{ Desconsiderando ${ }^{1} J_{\mathrm{BF}}$ da molécula de $\mathrm{BF}_{3},{ }^{2} J_{\mathrm{CH}}$ e ${ }^{2} J_{\mathrm{HH}}$ da molécula de $\mathrm{C}_{2} \mathrm{H}_{4}$} \\
\hline \multirow[t]{3}{*}{ Total } & DM & $-16,15$ & $-14,59$ & $-12,70$ & $-10,51$ & $-8,10$ & $-5,56$ & $-3,06$ & $-0,92$ & 0,12 & $-2,43$ & $-24,71$ & - \\
\hline & DMA & 29,37 & 24,96 & 20,18 & 15,14 & 13,51 & 13,76 & 17,10 & 23,75 & 32,70 & 47,25 & 86,04 & - \\
\hline & PDMA & 30,21 & 25,66 & 21,09 & 16,36 & 12,84 & 10,92 & 12,49 & 19,77 & 30,45 & 44,64 & 68,62 & - \\
\hline \multirow[t]{3}{*}{ CPI } & $\mathrm{DM}$ & $-23,42$ & $-22,83$ & $-21,68$ & $-20,10$ & $-18,29$ & $-16,52$ & $-15,30$ & $-15,48$ & $-19,03$ & $-32,08$ & $-92,72$ & - \\
\hline & DMA & 49,62 & 41,69 & 32,90 & 23,16 & 21,23 & 23,22 & 30,78 & 41,02 & 55,05 & 80,06 & 158,16 & - \\
\hline & PDMA & 34,41 & 28,49 & 22,64 & 16,33 & 12,82 & 12,27 & 17,03 & 27,62 & 39,96 & 56,09 & 89,03 & - \\
\hline \multirow[t]{3}{*}{ SPI } & DM & $-10,55$ & $-8,25$ & $-5,79$ & $-3,13$ & $-0,27$ & 2,87 & 6,35 & 10,28 & 14,85 & 20,38 & 27,60 & - \\
\hline & DMA & 13,80 & 12,08 & 10,39 & 8,98 & 7,58 & 6,48 & 6,57 & 10,47 & 15,52 & 22,02 & 30,57 & - \\
\hline & PDMA & 26,97 & 23,48 & 19,89 & 16,39 & 12,86 & 9,88 & 9,00 & 13,74 & 23,14 & 35,84 & 52,91 & - \\
\hline \multirow[t]{3}{*}{$\Delta \mathrm{CS}$} & $\mathrm{DM}$ & $-12,87$ & $-14,58$ & $-15,89$ & $-16,97$ & $-18,02$ & $-19,39$ & $-21,65$ & $-25,76$ & $-33,88$ & $-52,46$ & $-120,32$ & - \\
\hline & DMA & 35,82 & 29,61 & 22,51 & 14,18 & 13,65 & 16,74 & 24,21 & 30,55 & 39,53 & 58,04 & 127,59 & - \\
\hline & PDMA & 7,44 & 5,01 & 2,75 & $-0,06$ & $-0,04$ & 2,39 & 8,04 & 13,88 & 16,82 & 20,25 & 36,12 & - \\
\hline
\end{tabular}


Tabela 8.223: Constantes de acoplamento B98LYP com base aug-pcJ-2.

\begin{tabular}{|c|c|c|c|c|c|c|c|c|c|c|c|c|c|}
\hline & $\% E_{X}^{\mathrm{HF}}$ & $0 \%$ & $10 \%$ & $20 \%$ & $30 \%$ & $40 \%$ & $50 \%$ & $60 \%$ & $70 \%$ & $80 \%$ & $90 \%$ & $100 \%$ & Exp. \\
\hline $\mathrm{HF}$ & ${ }^{1} J_{\mathrm{HF}}$ & 411,1 & 429,5 & 449,1 & 470,1 & 492,6 & 516,6 & 542,3 & 569,6 & 598,8 & 629,7 & 662,5 & 500 \\
\hline $\mathrm{CO}$ & ${ }^{1} J_{\mathrm{CO}}$ & 16,5 & 15,4 & 14,1 & 12,6 & 11,0 & 9,3 & 7,4 & 5,3 & 3,0 & 0,6 & $-1,9$ & 16,4 \\
\hline $\mathrm{H}_{2} \mathrm{O}$ & ${ }^{1} J_{\mathrm{OH}}$ & $-67,8$ & $-70,1$ & $-72,7$ & $-75,4$ & $-78,4$ & $-81,5$ & $-84,9$ & $-88,6$ & $-92,5$ & $-96,6$ & $-101,1$ & $-80,6$ \\
\hline $\mathrm{H}_{2} \mathrm{O}$ & ${ }^{2} J_{\mathrm{HH}}$ & $-1,4$ & $-2,5$ & $-3,7$ & $-5,0$ & $-6,4$ & $-7,9$ & $-9,5$ & $-11,2$ & $-13,1$ & $-15,1$ & $-17,3$ & $-7,3$ \\
\hline $\mathrm{NH}_{3}$ & ${ }^{1} J_{\mathrm{NH}}$ & 38,0 & 39,1 & 40,3 & 41,5 & 42,9 & 44,4 & 45,9 & 47,6 & 49,4 & 51,4 & 53,4 & 43,8 \\
\hline $\mathrm{NH}_{3}$ & ${ }^{2} J_{\mathrm{HH}}$ & $-4,2$ & $-5,2$ & $-6,2$ & $-7,4$ & $-8,6$ & $-10,0$ & $-11,4$ & $-13,0$ & $-14,7$ & $-16,6$ & $-18,7$ & $-9,6$ \\
\hline $\mathrm{PH}_{3}$ & ${ }^{1} J_{\mathrm{PH}}$ & 149,1 & 155,6 & 162,7 & 170,3 & 178,5 & 187,2 & 196,4 & 206,2 & 216,6 & 227,6 & 239,2 & 188,2 \\
\hline $\mathrm{PF}_{3}$ & ${ }^{1} J_{\mathrm{PF}}$ & $-1650,6$ & $-1646,3$ & $-1636,3$ & $-1621,5$ & $-1602,4$ & $-1579,8$ & $-1554,5$ & $-1527,0$ & $-1497,9$ & $-1467,8$ & $-1437,0$ & -1441 \\
\hline $\mathrm{BHF}_{2}$ & ${ }^{1} J_{\mathrm{BF}}$ & $-154,8$ & $-140,2$ & $-125,3$ & $-110,0$ & $-94,5$ & $-78,8$ & $-63,0$ & $-47,1$ & $-31,1$ & $-15,2$ & 0,6 & -84 \\
\hline $\mathrm{BF}_{3}$ & ${ }^{1} J_{\mathrm{BF}}$ & $-63,8$ & $-46,7$ & $-29,4$ & $-12,0$ & 5,5 & 23,3 & 41,1 & 59,1 & 77,2 & 95,4 & 113,8 & 15 \\
\hline $\mathrm{F}_{2} \mathrm{O}$ & ${ }^{1} J_{\mathrm{OF}}$ & $-197,8$ & $-231,2$ & $-266,5$ & $-304,3$ & $-346,1$ & $-394,4$ & $-454,0$ & $-535,3$ & $-664,2$ & $-934,7$ & $-2253,8$ & -300 \\
\hline $\mathrm{CH}_{4}$ & ${ }^{1} J_{\mathrm{CH}}$ & 100,3 & 103,9 & 107,7 & 111,8 & 116,2 & 120,9 & 125,9 & 131,2 & 136,9 & 143,0 & 149,4 & 125,3 \\
\hline $\mathrm{CH}_{4}$ & ${ }^{2} J_{\mathrm{HH}}$ & $-6,9$ & $-7,8$ & $-8,8$ & $-9,9$ & $-11,0$ & $-12,2$ & $-13,5$ & $-14,9$ & $-16,4$ & $-18,0$ & $-19,7$ & $-12,8$ \\
\hline $\mathrm{C}_{2} \mathrm{H}_{2}$ & ${ }^{1} J_{\mathrm{CC}}$ & 174,4 & 178,1 & 182,4 & 187,2 & 192,8 & 199,4 & 207,3 & 217,0 & 229,4 & 245,8 & 268,4 & 174,8 \\
\hline $\mathrm{C}_{2} \mathrm{H}_{2}$ & ${ }^{1} J_{\mathrm{CH}}$ & 201,5 & 209,0 & 217,0 & 225,4 & 234,4 & 244,1 & 254,7 & 266,3 & 279,5 & 294,8 & 313,5 & 247,6 \\
\hline $\mathrm{C}_{2} \mathrm{H}_{2}$ & ${ }^{2} J_{\mathrm{CH}}$ & 52,5 & 53,5 & 54,3 & 54,8 & 55,1 & 55,0 & 54,3 & 52,8 & 50,2 & 45,7 & 38,1 & 50,1 \\
\hline $\mathrm{C}_{2} \mathrm{H}_{2}$ & ${ }^{3} J_{\mathrm{HH}}$ & 6,7 & 7,1 & 7,7 & 8,5 & 9,4 & 10,6 & 12,1 & 14,1 & 16,8 & 20,6 & 26,0 & 9,6 \\
\hline $\mathrm{C}_{2} \mathrm{H}_{4}$ & ${ }^{1} J_{\mathrm{CC}}$ & 55,9 & 58,7 & 61,8 & 65,3 & 69,3 & 74,0 & 79,8 & 87,2 & 97,4 & 112,5 & 139,0 & 67,6 \\
\hline $\mathrm{C}_{2} \mathrm{H}_{4}$ & ${ }^{1} J_{\mathrm{CH}}$ & 124,7 & 129,5 & 134,8 & 140,3 & 146,3 & 152,8 & 160,0 & 168,1 & 177,5 & 189,2 & 205,7 & 156,3 \\
\hline $\mathrm{C}_{2} \mathrm{H}_{4}$ & ${ }^{2} J_{\mathrm{CH}}$ & 2,8 & 2,1 & 1,3 & 0,4 & $-0,7$ & $-2,1$ & $-3,9$ & $-6,3$ & $-9,8$ & $-15,3$ & $-25,4$ & $-2,4$ \\
\hline $\mathrm{C}_{2} \mathrm{H}_{4}$ & ${ }^{2} J_{\mathrm{HH}}$ & 6,1 & 5,7 & 5,3 & 4,7 & 4,1 & 3,3 & 2,3 & 0,9 & $-0,9$ & $-3,9$ & $-9,3$ & 2,3 \\
\hline $\mathrm{C}_{2} \mathrm{H}_{4}$ & ${ }^{3} J_{\mathrm{HH}_{\mathrm{c}}}$ & 10,1 & 10,4 & 10,7 & 11,1 & 11,6 & 12,2 & 13,1 & 14,2 & 15,9 & 18,6 & 23,7 & 11,7 \\
\hline $\mathrm{C}_{2} \mathrm{H}_{4}$ & ${ }^{3} J_{\mathrm{HH}_{\mathrm{t}}}$ & 14,1 & 14,7 & 15,4 & 16,1 & 17,0 & 18,0 & 19,3 & 21,0 & 23,3 & 26,7 & 32,9 & 19 \\
\hline $\mathrm{C}_{2} \mathrm{H}_{6}$ & ${ }^{1} J_{\mathrm{CC}}$ & 22,1 & 24,3 & 26,8 & 29,3 & 32,1 & 35,0 & 38,1 & 41,4 & 44,9 & 48,7 & 52,7 & 34,5 \\
\hline $\mathrm{C}_{2} \mathrm{H}_{6}$ & ${ }^{1} J_{\mathrm{CH}}$ & 98,9 & 102,7 & 106,8 & 111,2 & 115,9 & 120,8 & 126,1 & 131,8 & 137,7 & 144,1 & 150,9 & 125,2 \\
\hline $\mathrm{C}_{2} \mathrm{H}_{6}$ & ${ }^{2} J_{\mathrm{CH}}$ & $-0,6$ & $-1,2$ & $-1,7$ & $-2,3$ & $-2,9$ & $-3,6$ & $-4,3$ & $-5,1$ & $-5,9$ & $-6,8$ & $-7,8$ & $-4,7$ \\
\hline \multirow[t]{3}{*}{ Total } & $\mathrm{DM}$ & $-19,54$ & $-17,57$ & $-15,28$ & $-12,78$ & $-10,05$ & $-7,25$ & $-4,53$ & $-2,30$ & $-1,42$ & $-5,41$ & $-48,74$ & - \\
\hline & DMA & 30,91 & 26,16 & 20,97 & 15,65 & 12,81 & 12,75 & 17,54 & 25,05 & 34,94 & 51,43 & 110,36 & - \\
\hline & PDMA & 61,02 & 50,62 & 39,83 & 28,17 & 16,95 & 12,08 & 21,65 & 40,45 & 64,06 & 97,09 & 158,62 & - \\
\hline \multirow[t]{3}{*}{ CPI } & DM & $-33,33$ & $-31,23$ & $-28,62$ & $-25,64$ & $-22,44$ & $-19,32$ & $-16,83$ & $-15,94$ & $-19,04$ & $-34,75$ & $-145,56$ & - \\
\hline & DMA & 56,31 & 47,32 & 37,42 & 27,40 & 23,18 & 24,90 & 34,95 & 47,28 & 64,11 & 94,00 & 220,20 & - \\
\hline & PDMA & 78,51 & 62,57 & 46,38 & 29,97 & 15,41 & 14,97 & 34,99 & 56,45 & 79,97 & 108,32 & 169,20 & - \\
\hline \multirow[t]{3}{*}{ SPI } & DM & $-9,43$ & $-7,56$ & $-5,51$ & $-3,35$ & $-0,97$ & 1,61 & 4,48 & 7,71 & 11,49 & 16,11 & 22,27 & - \\
\hline & DMA & 12,29 & 10,64 & 8,91 & 7,03 & 5,21 & 3,85 & 4,77 & 8,75 & 13,55 & 20,21 & 29,81 & - \\
\hline & PDMA & 48,20 & 41,86 & 35,03 & 26,85 & 18,07 & 9,96 & 11,86 & 28,71 & 52,40 & 88,85 & 150,86 & - \\
\hline \multirow[t]{3}{*}{$\Delta \mathrm{CS}$} & DM & $-23,89$ & $-23,67$ & $-23,11$ & $-22,29$ & $-21,47$ & $-20,92$ & $-21,31$ & $-23,64$ & $-30,53$ & $-50,85$ & $-167,83$ & - \\
\hline & DMA & 44,02 & 36,68 & 28,51 & 20,37 & 17,98 & 21,05 & 30,18 & 38,54 & 50,56 & 73,79 & 190,39 & - \\
\hline & PDMA & 30,31 & 20,72 & 11,35 & 3,13 & $-2,66$ & 5,00 & 23,13 & 27,74 & 27,57 & 19,47 & 18,34 & - \\
\hline \multicolumn{14}{|c|}{ Desconsiderando ${ }^{1} J_{\mathrm{BF}}$ da molécula de $\mathrm{BF}_{3},{ }^{2} J_{\mathrm{CH}}$ e ${ }^{2} J_{\mathrm{HH}}$ da molécula de $\mathrm{C}_{2} \mathrm{H}_{4}$} \\
\hline \multirow[t]{3}{*}{ Total } & DM & $-19,06$ & $-17,53$ & $-15,64$ & $-13,50$ & $-11,10$ & $-8,61$ & $-6,20$ & $-4,28$ & $-3,85$ & $-8,78$ & $-57,89$ & - \\
\hline & DMA & 31,13 & 26,54 & 21,48 & 16,29 & 13,92 & 14,00 & 18,63 & 26,17 & 36,33 & 53,81 & 118,96 & - \\
\hline & PDMA & 29,54 & 24,76 & 19,78 & 14,41 & 9,92 & 8,82 & 14,19 & 23,23 & 34,94 & 51,36 & 87,08 & - \\
\hline \multirow[t]{3}{*}{ CPI } & DM & $-28,78$ & $-28,18$ & $-27,04$ & $-25,50$ & $-23,73$ & $-22,08$ & $-21,12$ & $-21,94$ & $-27,16$ & $-46,26$ & $-170,00$ & - \\
\hline & DMA & 54,06 & 45,88 & 36,72 & 27,44 & 24,55 & 26,56 & 35,84 & 47,60 & 64,30 & 95,36 & 232,34 & - \\
\hline & PDMA & 33,83 & 27,69 & 21,42 & 14,97 & 10,62 & 10,93 & 21,09 & 32,69 & 46,50 & 65,55 & 120,26 & - \\
\hline \multirow[t]{3}{*}{ SPI } & $\mathrm{DM}$ & $-11,58$ & $-9,33$ & $-6,87$ & $-4,26$ & $-1,38$ & 1,75 & 5,28 & 9,30 & 14,08 & 20,05 & 28,35 & - \\
\hline & DMA & 13,48 & 11,67 & 9,76 & 7,71 & 5,74 & 4,34 & 5,39 & 9,68 & 14,82 & 21,85 & 31,74 & - \\
\hline & PDMA & 26,24 & 22,50 & 18,53 & 13,98 & 9,38 & 7,19 & 8,88 & 15,95 & 26,04 & 40,44 & 61,56 & - \\
\hline \multirow[t]{3}{*}{$\Delta \mathrm{CS}$} & $\mathrm{DM}$ & $-17,20$ & $-18,85$ & $-20,17$ & $-21,24$ & $-22,35$ & $-23,83$ & $-26,40$ & $-31,24$ & $-41,24$ & $-66,31$ & $-198,35$ & 一 \\
\hline & DMA & 40,58 & 34,21 & 26,96 & 19,73 & 18,81 & 22,22 & 30,45 & 37,92 & 49,48 & 73,51 & 200,60 & - \\
\hline & PDMA & 7,59 & 5,19 & 2,89 & 0,99 & 1,23 & 3,74 & 12,21 & 16,75 & 20,46 & 25,11 & 58,70 & - \\
\hline
\end{tabular}


Tabela 8.224: Constantes de acoplamento B98P86 com base aug-pcJ-2.

\begin{tabular}{|c|c|c|c|c|c|c|c|c|c|c|c|c|c|}
\hline & $\% E_{X}^{\mathrm{HF}}$ & $0 \%$ & $10 \%$ & $20 \%$ & $30 \%$ & $40 \%$ & $50 \%$ & $60 \%$ & $70 \%$ & $80 \%$ & $90 \%$ & $100 \%$ & Exp. \\
\hline $\mathrm{HF}$ & ${ }^{1} J_{\mathrm{HF}}$ & 373,1 & 389,6 & 407,4 & 426,4 & 446,9 & 468,9 & 492,3 & 517,3 & 544,0 & 572,2 & 602,2 & 500 \\
\hline $\mathrm{CO}$ & ${ }^{1} J_{\mathrm{CO}}$ & 19,9 & 18,9 & 17,9 & 16,7 & 15,4 & 13,9 & 12,4 & 10,7 & 8,8 & 6,9 & 4,8 & 16,4 \\
\hline $\mathrm{H}_{2} \mathrm{O}$ & ${ }^{1} J_{\mathrm{OH}}$ & $-61,1$ & $-63,2$ & $-65,5$ & $-68,0$ & $-70,6$ & $-73,4$ & $-76,5$ & $-79,8$ & $-83,3$ & $-87,0$ & $-91,0$ & $-80,6$ \\
\hline $\mathrm{H}_{2} \mathrm{O}$ & ${ }^{2} J_{\mathrm{HH}}$ & $-1,0$ & $-2,0$ & $-3,0$ & $-4,2$ & $-5,4$ & $-6,7$ & $-8,1$ & $-9,7$ & $-11,3$ & $-13,1$ & $-15,1$ & $-7,3$ \\
\hline $\mathrm{NH}_{3}$ & ${ }^{1} J_{\mathrm{NH}}$ & 34,1 & 35,0 & 36,1 & 37,2 & 38,5 & 39,8 & 41,2 & 42,7 & 44,3 & 46,0 & 47,8 & 43,8 \\
\hline $\mathrm{NH}_{3}$ & ${ }^{2} J_{\mathrm{HH}}$ & $-3,9$ & $-4,8$ & $-5,7$ & $-6,7$ & $-7,8$ & $-9,0$ & $-10,3$ & $-11,7$ & $-13,3$ & $-14,9$ & $-16,8$ & $-9,6$ \\
\hline $\mathrm{PH}_{3}$ & ${ }^{1} J_{\mathrm{PH}}$ & 128,2 & 134,2 & 140,8 & 147,8 & 155,3 & 163,4 & 172,0 & 181,2 & 190,9 & 201,2 & 212,1 & 188,2 \\
\hline $\mathrm{PF}_{3}$ & ${ }^{1} J_{\mathrm{PF}}$ & $-1648,1$ & $-1642,9$ & $-1632,1$ & $-1616,4$ & $-1596,6$ & $-1573,4$ & $-1547,5$ & $-1519,4$ & $-1489,7$ & $-1458,9$ & $-1427,5$ & -1441 \\
\hline $\mathrm{BHF}_{2}$ & ${ }^{1} J_{\mathrm{BF}}$ & $-163,9$ & $-150,1$ & $-135,8$ & $-121,2$ & $-106,3$ & $-91,2$ & $-75,9$ & $-60,5$ & $-45,0$ & $-29,5$ & $-14,1$ & -84 \\
\hline $\mathrm{BF}_{3}$ & ${ }^{1} J_{\mathrm{BF}}$ & $-76,9$ & $-60,5$ & $-43,8$ & $-27,0$ & $-10,0$ & 7,1 & 24,4 & 41,8 & 59,4 & 77,1 & 94,8 & 15 \\
\hline $\mathrm{F}_{2} \mathrm{O}$ & ${ }^{1} J_{\mathrm{OF}}$ & $-206,8$ & $-240,2$ & $-275,5$ & $-313,5$ & $-355,6$ & $-404,5$ & $-464,8$ & $-546,7$ & $-675,0$ & $-934,7$ & $-1973,1$ & -300 \\
\hline $\mathrm{CH}_{4}$ & ${ }^{1} J_{\mathrm{CH}}$ & 88,9 & 92,1 & 95,6 & 99,2 & 103,2 & 107,4 & 111,9 & 116,7 & 121,8 & 127,2 & 133,0 & 125,3 \\
\hline $\mathrm{CH}_{4}$ & ${ }^{2} J_{\mathrm{HH}}$ & $-7,0$ & $-7,8$ & $-8,8$ & $-9,7$ & $-10,8$ & $-11,9$ & $-13,1$ & $-14,4$ & $-15,8$ & $-17,2$ & $-18,8$ & $-12,8$ \\
\hline $\mathrm{C}_{2} \mathrm{H}_{2}$ & ${ }^{1} J_{\mathrm{CC}}$ & 164,2 & 167,6 & 171,3 & 175,7 & 180,6 & 186,5 & 193,6 & 202,4 & 213,7 & 228,8 & 250,2 & 174,8 \\
\hline $\mathrm{C}_{2} \mathrm{H}_{2}$ & ${ }^{1} J_{\mathrm{CH}}$ & 181,9 & 188,7 & 195,9 & 203,6 & 211,8 & 220,6 & 230,2 & 240,9 & 253,1 & 267,4 & 285,3 & 247,6 \\
\hline $\mathrm{C}_{2} \mathrm{H}_{2}$ & ${ }^{2} J_{\mathrm{CH}}$ & 49,8 & 50,8 & 51,6 & 52,2 & 52,6 & 52,5 & 52,0 & 50,6 & 48,0 & 43,6 & 35,9 & 50,1 \\
\hline $\mathrm{C}_{2} \mathrm{H}_{2}$ & ${ }^{3} J_{\mathrm{HH}}$ & 6,7 & 7,1 & 7,7 & 8,5 & 9,4 & 10,6 & 12,2 & 14,3 & 17,1 & 21,0 & 26,9 & 9,6 \\
\hline $\mathrm{C}_{2} \mathrm{H}_{4}$ & ${ }^{1} J_{\mathrm{CC}}$ & 49,7 & 52,2 & 55,0 & 58,1 & 61,7 & 66,0 & 71,4 & 78,3 & 88,1 & 103,6 & 133,8 & 67,6 \\
\hline $\mathrm{C}_{2} \mathrm{H}_{4}$ & ${ }^{1} J_{\mathrm{CH}}$ & 111,6 & 116,0 & 120,7 & 125,7 & 131,2 & 137,1 & 143,7 & 151,1 & 159,9 & 171,4 & 189,3 & 156,3 \\
\hline $\mathrm{C}_{2} \mathrm{H}_{4}$ & ${ }^{2} J_{\mathrm{CH}}$ & 2,2 & 1,6 & 0,9 & 0,1 & $-0,8$ & $-2,1$ & $-3,9$ & $-6,2$ & $-9,7$ & $-15,6$ & $-27,6$ & $-2,4$ \\
\hline $\mathrm{C}_{2} \mathrm{H}_{4}$ & ${ }^{2} J_{\mathrm{HH}}$ & 4,8 & 4,4 & 4,0 & 3,5 & 2,8 & 2,0 & 0,9 & $-0,5$ & $-2,7$ & $-6,3$ & $-13,5$ & 2,3 \\
\hline $\mathrm{C}_{2} \mathrm{H}_{4}$ & ${ }^{3} J_{\mathrm{HH}_{\mathrm{c}}}$ & 9,1 & 9,4 & 9,8 & 10,2 & 10,7 & 11,4 & 12,3 & 13,5 & 15,5 & 18,8 & 25,7 & 11,7 \\
\hline $\mathrm{C}_{2} \mathrm{H}_{4}$ & ${ }^{3} J_{\mathrm{HH}_{\mathrm{t}}}$ & 12,9 & 13,5 & 14,2 & 14,9 & 15,8 & 16,8 & 18,2 & 19,9 & 22,5 & 26,6 & 34,7 & 19 \\
\hline $\mathrm{C}_{2} \mathrm{H}_{6}$ & ${ }^{1} J_{\mathrm{CC}}$ & 17,7 & 19,8 & 22,0 & 24,3 & 26,8 & 29,4 & 32,2 & 35,2 & 38,4 & 41,8 & 45,4 & 34,5 \\
\hline $\mathrm{C}_{2} \mathrm{H}_{6}$ & ${ }^{1} J_{\mathrm{CH}}$ & 88,1 & 91,5 & 95,2 & 99,2 & 103,4 & 107,9 & 112,6 & 117,7 & 123,1 & 128,9 & 135,0 & 125,2 \\
\hline $\mathrm{C}_{2} \mathrm{H}_{6}$ & ${ }^{2} J_{\mathrm{CH}}$ & $-0,9$ & $-1,4$ & $-1,9$ & $-2,4$ & $-3,0$ & $-3,6$ & $-4,3$ & $-5,0$ & $-5,8$ & $-6,7$ & $-7,6$ & $-4,7$ \\
\hline \multirow[t]{3}{*}{ Total } & $\mathrm{DM}$ & $-25,83$ & $-24,06$ & $-21,96$ & $-19,65$ & $-17,15$ & $-14,60$ & $-12,15$ & $-10,18$ & $-9,54$ & $-13,32$ & $-45,89$ & - \\
\hline & DMA & 36,98 & 32,13 & 26,78 & 22,03 & 19,28 & 16,58 & 15,97 & 19,05 & 26,29 & 41,62 & 90,58 & - \\
\hline & PDMA & 66,56 & 56,23 & 45,33 & 34,04 & 23,02 & 12,80 & 16,61 & 31,39 & 53,83 & 87,66 & 152,34 & - \\
\hline \multirow[t]{3}{*}{ CPI } & $\mathrm{DM}$ & $-40,66$ & $-38,81$ & $-36,37$ & $-33,62$ & $-30,65$ & $-27,82$ & $-25,61$ & $-25,00$ & $-28,28$ & $-43,24$ & $-128,80$ & - \\
\hline & DMA & 63,97 & 55,14 & 45,34 & 37,05 & 33,14 & 29,35 & 29,54 & 37,44 & 52,03 & 80,33 & 182,13 & - \\
\hline & PDMA & 93,08 & 76,93 & 60,34 & 43,85 & 29,64 & 15,68 & 18,04 & 35,86 & 56,84 & 83,51 & 134,69 & - \\
\hline \multirow[t]{3}{*}{ SPI } & $\mathrm{DM}$ & $-14,96$ & $-13,24$ & $-11,39$ & $-9,40$ & $-7,25$ & $-4,90$ & $-2,28$ & 0,69 & 4,21 & 8,61 & 14,91 & - \\
\hline & DMA & 17,19 & 15,25 & 13,17 & 11,01 & 9,13 & 7,22 & 6,03 & 5,56 & 7,42 & 13,24 & 23,45 & - \\
\hline & PDMA & 47,11 & 41,05 & 34,31 & 26,84 & 18,17 & 10,70 & 15,56 & 28,10 & 51,63 & 90,71 & 165,29 & - \\
\hline \multirow[t]{3}{*}{$\Delta \mathrm{CS}$} & $\mathrm{DM}$ & $-25,70$ & $-25,57$ & $-24,98$ & $-24,22$ & $-23,40$ & $-22,92$ & $-23,33$ & $-25,69$ & $-32,49$ & $-51,85$ & $-143,71$ & - \\
\hline & DMA & 46,79 & 39,88 & 32,17 & 26,04 & 24,01 & 22,13 & 23,51 & 31,88 & 44,61 & 67,09 & 158,67 & - \\
\hline & PDMA & 45,96 & 35,88 & 26,03 & 17,01 & 11,47 & 4,98 & 2,49 & 7,76 & 5,20 & $-7,20$ & $-30,60$ & - \\
\hline \multicolumn{14}{|c|}{ Desconsiderando ${ }^{1} J_{\mathrm{BF}}$ da molécula de $\mathrm{BF}_{3},{ }^{2} J_{\mathrm{CH}}$ e ${ }^{2} J_{\mathrm{HH}}$ da molécula de $\mathrm{C}_{2} \mathrm{H}_{4}$} \\
\hline \multirow[t]{3}{*}{ Total } & $\mathrm{DM}$ & $-25,52$ & $-24,18$ & $-22,49$ & $-20,54$ & $-18,39$ & $-16,16$ & $-14,02$ & $-12,38$ & $-12,18$ & $-16,81$ & $-53,57$ & - \\
\hline & DMA & 37,50 & 32,77 & 27,50 & 22,92 & 20,62 & 18,37 & 17,52 & 20,08 & 27,26 & 43,40 & 97,15 & - \\
\hline & PDMA & 35,54 & 30,47 & 25,00 & 19,51 & 14,94 & 11,07 & 10,68 & 15,54 & 25,31 & 40,93 & 73,57 & - \\
\hline \multirow[t]{3}{*}{ CPI } & $\mathrm{DM}$ & $-35,54$ & $-35,14$ & $-34,13$ & $-32,78$ & $-31,21$ & $-29,81$ & $-29,11$ & $-30,18$ & $-35,55$ & $-53,77$ & $-149,66$ & - \\
\hline & DMA & 61,18 & 53,10 & 43,99 & 36,56 & 33,95 & 31,49 & 31,55 & 38,50 & 52,79 & 82,15 & 192,36 & - \\
\hline & PDMA & 41,12 & 34,29 & 27,18 & 20,23 & 15,94 & 11,98 & 13,58 & 21,58 & 32,92 & 50,46 & 94,96 & - \\
\hline \multirow[t]{3}{*}{ SPI } & DM & $-17,81$ & $-15,75$ & $-13,53$ & $-11,13$ & $-8,52$ & $-5,65$ & $-2,41$ & 1,31 & 5,80 & 11,62 & 20,35 & - \\
\hline & DMA & 19,28 & 17,13 & 14,81 & 12,42 & 10,37 & 8,28 & 6,73 & 5,91 & 7,62 & 13,60 & 23,91 & - \\
\hline & PDMA & 31,26 & 27,52 & 23,33 & 18,94 & 14,17 & 10,38 & 8,46 & 10,88 & 19,46 & 33,60 & 57,11 & - \\
\hline \multirow[t]{3}{*}{$\Delta \mathrm{CS}$} & $\mathrm{DM}$ & $-17,73$ & $-19,39$ & $-20,60$ & $-21,65$ & $-22,69$ & $-24,16$ & $-26,70$ & $-31,49$ & $-41,35$ & $-65,39$ & $-170,01$ & - \\
\hline & DMA & 41,90 & 35,97 & 29,18 & 24,14 & 23,58 & 23,21 & 24,82 & 32,59 & 45,17 & 68,55 & 168,45 & - \\
\hline & PDMA & 9,86 & 6,77 & 3,85 & 1,29 & 1,77 & 1,60 & 5,12 & 10,70 & 13,46 & 16,86 & 37,85 & - \\
\hline
\end{tabular}


Tabela 8.225: Constantes de acoplamento B98PBE com base aug-pcJ-2.

\begin{tabular}{|c|c|c|c|c|c|c|c|c|c|c|c|c|c|}
\hline & $\% E_{X}^{\mathrm{HF}}$ & $0 \%$ & $10 \%$ & $20 \%$ & $30 \%$ & $40 \%$ & $50 \%$ & $60 \%$ & $70 \%$ & $80 \%$ & $90 \%$ & $100 \%$ & Exp. \\
\hline $\mathrm{HF}$ & ${ }^{1} J_{\mathrm{HF}}$ & 368,6 & 385,5 & 403,7 & 423,2 & 444,2 & 466,6 & 490,7 & 516,3 & 543,6 & 572,6 & 603,3 & 500 \\
\hline $\mathrm{CO}$ & ${ }^{1} J_{\mathrm{CO}}$ & 20,4 & 19,5 & 18,4 & 17,3 & 16,0 & 14,5 & 12,9 & 11,2 & 9,4 & 7,4 & 5,3 & 16,4 \\
\hline $\mathrm{H}_{2} \mathrm{O}$ & ${ }^{1} J_{\mathrm{OH}}$ & $-60,8$ & $-63,0$ & $-65,3$ & $-67,8$ & $-70,5$ & $-73,5$ & $-76,6$ & $-79,9$ & $-83,5$ & $-87,4$ & $-91,5$ & $-80,6$ \\
\hline $\mathrm{H}_{2} \mathrm{O}$ & ${ }^{2} J_{\mathrm{HH}}$ & $-1,3$ & $-2,3$ & $-3,4$ & $-4,6$ & $-5,8$ & $-7,2$ & $-8,7$ & $-10,3$ & $-12,0$ & $-13,9$ & $-15,9$ & $-7,3$ \\
\hline $\mathrm{NH}_{3}$ & ${ }^{1} J_{\mathrm{NH}}$ & 34,1 & 35,1 & 36,1 & 37,3 & 38,6 & 39,9 & 41,3 & 42,9 & 44,5 & 46,3 & 48,2 & 43,8 \\
\hline $\mathrm{NH}_{3}$ & ${ }^{2} J_{\mathrm{HH}}$ & $-4,2$ & $-5,1$ & $-6,1$ & $-7,2$ & $-8,3$ & $-9,6$ & $-10,9$ & $-12,4$ & $-14,0$ & $-15,7$ & $-17,6$ & $-9,6$ \\
\hline $\mathrm{PH}_{3}$ & ${ }^{1} J_{\mathrm{PH}}$ & 127,2 & 133,4 & 140,2 & 147,5 & 155,4 & 163,8 & 172,7 & 182,2 & 192,3 & 203,0 & 214,3 & 188,2 \\
\hline $\mathrm{PF}_{3}$ & ${ }^{1} J_{\mathrm{PF}}$ & $-1652,7$ & $-1646,8$ & $-1635,3$ & $-1619,0$ & $-1598,6$ & $-1574,8$ & $-1548,3$ & $-1519,7$ & $-1489,5$ & $-1458,3$ & $-1426,5$ & -1441 \\
\hline $\mathrm{BHF}_{2}$ & ${ }^{1} J_{\mathrm{BF}}$ & $-165,0$ & $-151,1$ & $-136,7$ & $-122,0$ & $-106,9$ & $-91,7$ & $-76,2$ & $-60,7$ & $-45,0$ & $-29,4$ & $-13,8$ & -84 \\
\hline $\mathrm{BF}_{3}$ & ${ }^{1} J_{\mathrm{BF}}$ & $-78,0$ & $-61,5$ & $-44,8$ & $-27,8$ & $-10,7$ & 6,5 & 24,0 & 41,6 & 59,4 & 77,2 & 95,2 & 15 \\
\hline $\mathrm{F}_{2} \mathrm{O}$ & ${ }^{1} J_{\mathrm{OF}}$ & $-206,5$ & $-240,6$ & $-276,7$ & $-315,6$ & $-358,9$ & $-409,4$ & $-472,5$ & $-559,2$ & $-698,2$ & $-993,3$ & $-2453,2$ & -300 \\
\hline $\mathrm{CH}_{4}$ & ${ }^{1} J_{\mathrm{CH}}$ & 89,2 & 92,5 & 96,0 & 99,8 & 103,8 & 108,2 & 112,8 & 117,7 & 122,9 & 128,5 & 134,4 & 125,3 \\
\hline $\mathrm{CH}_{4}$ & ${ }^{2} J_{\mathrm{HH}}$ & $-7,4$ & $-8,3$ & $-9,3$ & $-10,3$ & $-11,4$ & $-12,5$ & $-13,8$ & $-15,1$ & $-16,6$ & $-18,2$ & $-19,8$ & $-12,8$ \\
\hline $\mathrm{C}_{2} \mathrm{H}_{2}$ & ${ }^{1} J_{\mathrm{CC}}$ & 163,2 & 166,7 & 170,5 & 175,0 & 180,1 & 186,3 & 193,8 & 203,2 & 215,5 & 232,4 & 257,1 & 174,8 \\
\hline $\mathrm{C}_{2} \mathrm{H}_{2}$ & ${ }^{1} J_{\mathrm{CH}}$ & 183,4 & 190,4 & 197,8 & 205,6 & 214,1 & 223,2 & 233,2 & 244,5 & 257,5 & 273,1 & 293,3 & 247,6 \\
\hline $\mathrm{C}_{2} \mathrm{H}_{2}$ & ${ }^{2} J_{\mathrm{CH}}$ & 50,1 & 51,0 & 51,8 & 52,3 & 52,5 & 52,3 & 51,5 & 49,7 & 46,5 & 41,0 & 31,2 & 50,1 \\
\hline $\mathrm{C}_{2} \mathrm{H}_{2}$ & ${ }^{3} J_{\mathrm{HH}}$ & 7,0 & 7,5 & 8,2 & 9,0 & 10,0 & 11,4 & 13,2 & 15,6 & 18,9 & 23,6 & 30,9 & 9,6 \\
\hline $\mathrm{C}_{2} \mathrm{H}_{4}$ & ${ }^{1} J_{\mathrm{CC}}$ & 49,3 & 51,8 & 54,6 & 57,9 & 61,6 & 66,2 & 71,9 & 79,5 & 90,7 & 109,5 & 150,7 & 67,6 \\
\hline $\mathrm{C}_{2} \mathrm{H}_{4}$ & ${ }^{1} J_{\mathrm{CH}}$ & 112,3 & 116,8 & 121,7 & 126,8 & 132,4 & 138,6 & 145,4 & 153,3 & 162,9 & 176,0 & 199,0 & 156,3 \\
\hline $\mathrm{C}_{2} \mathrm{H}_{4}$ & ${ }^{2} J_{\mathrm{CH}}$ & 2,0 & 1,3 & 0,6 & $-0,3$ & $-1,4$ & $-2,8$ & $-4,7$ & $-7,4$ & $-11,6$ & $-19,1$ & $-36,1$ & $-2,4$ \\
\hline $\mathrm{C}_{2} \mathrm{H}_{4}$ & ${ }^{2} J_{\mathrm{HH}}$ & 4,6 & 4,2 & 3,7 & 3,1 & 2,3 & 1,4 & 0,1 & $-1,5$ & $-4,2$ & $-8,9$ & $-19,4$ & 2,3 \\
\hline $\mathrm{C}_{2} \mathrm{H}_{4}$ & ${ }^{3} J_{\mathrm{HH}_{\mathrm{c}}}$ & 9,3 & 9,6 & 10,0 & 10,5 & 11,1 & 11,8 & 12,9 & 14,4 & 16,8 & 21,1 & 31,3 & 11,7 \\
\hline $\mathrm{C}_{2} \mathrm{H}_{4}$ & ${ }^{3} J_{\mathrm{HH}_{\mathrm{t}}}$ & 13,2 & 13,8 & 14,5 & 15,3 & 16,3 & 17,5 & 19,0 & 21,0 & 24,1 & 29,3 & 41,0 & 19 \\
\hline $\mathrm{C}_{2} \mathrm{H}_{6}$ & ${ }^{1} J_{\mathrm{CC}}$ & 17,6 & 19,7 & 21,9 & 24,2 & 26,7 & 29,4 & 32,2 & 35,2 & 38,5 & 41,9 & 45,6 & 34,5 \\
\hline $\mathrm{C}_{2} \mathrm{H}_{6}$ & ${ }^{1} J_{\mathrm{CH}}$ & 88,5 & 92,1 & 95,9 & 99,9 & 104,2 & 108,8 & 113,7 & 118,9 & 124,4 & 130,3 & 136,6 & 125,2 \\
\hline $\mathrm{C}_{2} \mathrm{H}_{6}$ & ${ }^{2} J_{\mathrm{CH}}$ & $-1,2$ & $-1,6$ & $-2,2$ & $-2,7$ & $-3,3$ & $-4,0$ & $-4,7$ & $-5,4$ & $-6,2$ & $-7,1$ & $-8,1$ & $-4,7$ \\
\hline \multirow[t]{3}{*}{ Total } & DM & $-26,23$ & $-24,40$ & $-22,28$ & $-19,91$ & $-17,37$ & $-14,77$ & $-12,31$ & $-10,36$ & $-9,92$ & $-14,73$ & $-62,67$ & - \\
\hline & DMA & 37,33 & 32,38 & 26,90 & 22,11 & 19,27 & 16,60 & 16,18 & 19,48 & 28,04 & 45,57 & 112,44 & - \\
\hline & PDMA & 65,52 & 55,03 & 43,69 & 31,88 & 20,26 & 13,01 & 19,80 & 36,99 & 62,67 & 102,99 & 190,22 & - \\
\hline \multirow[t]{3}{*}{ CPI } & DM & $-41,74$ & $-39,80$ & $-37,35$ & $-34,51$ & $-31,49$ & $-28,71$ & $-26,59$ & $-26,26$ & $-30,35$ & $-48,40$ & $-172,10$ & - \\
\hline & DMA & 65,14 & 56,09 & 46,07 & 37,93 & 33,84 & 30,02 & 30,37 & 38,43 & 54,32 & 85,98 & 226,41 & - \\
\hline & PDMA & 93,68 & 77,45 & 60,55 & 43,94 & 28,97 & 14,72 & 19,01 & 37,12 & 58,87 & 87,03 & 151,26 & - \\
\hline \multirow[t]{3}{*}{ SPI } & DM & $-14,87$ & $-13,11$ & $-11,23$ & $-9,20$ & $-7,01$ & $-4,55$ & $-1,84$ & 1,30 & 5,07 & 9,95 & 17,57 & - \\
\hline & DMA & 16,95 & 14,99 & 12,84 & 10,51 & 8,59 & 6,77 & 5,77 & 5,59 & 8,77 & 15,93 & 28,87 & - \\
\hline & PDMA & 44,87 & 38,58 & 31,32 & 23,03 & 13,86 & 11,75 & 20,38 & 36,90 & 65,46 & 114,70 & 218,79 & - \\
\hline \multirow[t]{3}{*}{$\Delta \mathrm{CS}$} & DM & $-26,87$ & $-26,69$ & $-26,12$ & $-25,31$ & $-24,48$ & $-24,16$ & $-24,75$ & $-27,56$ & $-35,42$ & $-58,35$ & $-189,67$ & - \\
\hline & DMA & 48,19 & 41,10 & 33,23 & 27,42 & 25,24 & 23,25 & 24,60 & 32,83 & 45,54 & 70,06 & 197,54 & - \\
\hline & PDMA & 48,82 & 38,87 & 29,23 & 20,91 & 15,11 & 2,97 & $-1,37$ & 0,22 & $-6,59$ & $-27,67$ & $-67,53$ & - \\
\hline \multicolumn{14}{|c|}{ Desconsiderando ${ }^{1} J_{\mathrm{BF}}$ da molécula de $\mathrm{BF}_{3},{ }^{2} J_{\mathrm{CH}}$ e ${ }^{2} J_{\mathrm{HH}}$ da molécula de $\mathrm{C}_{2} \mathrm{H}_{4}$} \\
\hline \multirow[t]{3}{*}{ Total } & DM & $-25,90$ & $-24,50$ & $-22,77$ & $-20,77$ & $-18,56$ & $-16,27$ & $-14,11$ & $-12,49$ & $-12,46$ & $-18,15$ & $-71,93$ & - \\
\hline & DMA & 37,87 & 33,03 & 27,62 & 23,00 & 20,63 & 18,34 & 17,70 & 20,49 & 29,09 & 47,59 & 121,21 & - \\
\hline & PDMA & 34,79 & 29,74 & 23,97 & 18,31 & 13,64 & 9,81 & 11,45 & 17,86 & 29,02 & 46,97 & 89,72 & - \\
\hline \multirow[t]{3}{*}{ CPI } & DM & $-36,61$ & $-36,13$ & $-35,10$ & $-33,68$ & $-32,07$ & $-30,73$ & $-30,15$ & $-31,55$ & $-37,83$ & $-59,46$ & $-197,33$ & - \\
\hline & DMA & 62,35 & 54,05 & 44,70 & 37,44 & 34,65 & 32,17 & 32,51 & 39,61 & 55,31 & 88,36 & 241,03 & - \\
\hline & PDMA & 41,05 & 34,20 & 26,74 & 19,80 & 14,74 & 10,52 & 14,91 & 23,09 & 35,15 & 54,27 & 112,92 & - \\
\hline \multirow[t]{3}{*}{ SPI } & $\mathrm{DM}$ & $-17,67$ & $-15,55$ & $-13,29$ & $-10,84$ & $-8,16$ & $-5,15$ & $-1,78$ & 2,18 & 7,05 & 13,63 & 24,54 & - \\
\hline & DMA & 19,04 & 16,86 & 14,48 & 11,90 & 9,84 & 7,71 & 6,32 & 5,78 & 8,92 & 16,23 & 29,05 & - \\
\hline & PDMA & 29,97 & 26,31 & 21,84 & 17,17 & 12,79 & 9,27 & 8,79 & 13,84 & 24,30 & 41,36 & 71,87 & - \\
\hline \multirow[t]{3}{*}{$\Delta \mathrm{CS}$} & $\mathrm{DM}$ & $-18,94$ & $-20,58$ & $-21,81$ & $-22,84$ & $-23,91$ & $-25,58$ & $-28,37$ & $-33,73$ & $-44,88$ & $-73,09$ & $-221,87$ & 一 \\
\hline & DMA & 43,31 & 37,19 & 30,22 & 25,54 & 24,81 & 24,46 & 26,19 & 33,83 & 46,39 & 72,13 & 211,98 & - \\
\hline & PDMA & 11,08 & 7,89 & 4,90 & 2,63 & 1,94 & 1,26 & 6,12 & 9,25 & 10,85 & 12,90 & 41,06 & - \\
\hline
\end{tabular}


8.4. GERAÇÃO DE NOVOS FUNCIONAIS COMBINANDO $E_{X}^{H F}, E_{X}^{D F T} E$

Tabela 8.226: Constantes de acoplamento B98PW91 com base aug-pcJ-2.

\begin{tabular}{|c|c|c|c|c|c|c|c|c|c|c|c|c|c|}
\hline & $\% E_{X}^{\mathrm{HF}}$ & $0 \%$ & $10 \%$ & $20 \%$ & $30 \%$ & $40 \%$ & $50 \%$ & $60 \%$ & $70 \%$ & $80 \%$ & $90 \%$ & $100 \%$ & Exp. \\
\hline $\mathrm{HF}$ & ${ }^{1} J_{\mathrm{HF}}$ & 371,0 & 388,0 & 406,2 & 425,8 & 446,8 & 469,3 & 493,4 & 519,1 & 546,4 & 575,5 & 606,3 & 500 \\
\hline $\mathrm{CO}$ & ${ }^{1} J_{\mathrm{CO}}$ & 20,3 & 19,3 & 18,2 & 17,0 & 15,7 & 14,3 & 12,7 & 10,9 & 9,1 & 7,0 & 4,9 & 16,4 \\
\hline $\mathrm{H}_{2} \mathrm{O}$ & ${ }^{1} J_{\mathrm{OH}}$ & $-61,1$ & $-63,3$ & $-65,6$ & $-68,2$ & $-70,9$ & $-73,8$ & $-77,0$ & $-80,3$ & $-83,9$ & $-87,8$ & $-91,9$ & $-80,6$ \\
\hline $\mathrm{H}_{2} \mathrm{O}$ & ${ }^{2} J_{\mathrm{HH}}$ & $-1,3$ & $-2,3$ & $-3,4$ & $-4,6$ & $-5,9$ & $-7,2$ & $-8,7$ & $-10,3$ & $-12,1$ & $-13,9$ & $-16,0$ & $-7,3$ \\
\hline $\mathrm{NH}_{3}$ & ${ }^{1} J_{\mathrm{NH}}$ & 34,2 & 35,2 & 36,3 & 37,5 & 38,8 & 40,1 & 41,5 & 43,1 & 44,7 & 46,5 & 48,4 & 43,8 \\
\hline $\mathrm{NH}_{3}$ & ${ }^{2} J_{\mathrm{HH}}$ & $-4,2$ & $-5,1$ & $-6,1$ & $-7,2$ & $-8,3$ & $-9,6$ & $-11,0$ & $-12,4$ & $-14,0$ & $-15,8$ & $-17,7$ & $-9,6$ \\
\hline $\mathrm{PH}_{3}$ & ${ }^{1} J_{\mathrm{PH}}$ & 128,0 & 134,3 & 141,2 & 148,5 & 156,4 & 164,8 & 173,8 & 183,3 & 193,4 & 204,2 & 215,5 & 188,2 \\
\hline $\mathrm{PF}_{3}$ & ${ }^{1} J_{\mathrm{PF}}$ & $-1655,9$ & $-1649,9$ & $-1638,2$ & $-1621,8$ & $-1601,3$ & $-1577,3$ & $-1550,7$ & $-1522,0$ & $-1491,7$ & $-1460,4$ & $-1428,5$ & -1441 \\
\hline $\mathrm{BHF}_{2}$ & ${ }^{1} J_{\mathrm{BF}}$ & $-164,3$ & $-150,3$ & $-135,9$ & $-121,1$ & $-106,0$ & $-90,6$ & $-75,1$ & $-59,5$ & $-43,9$ & $-28,2$ & $-12,5$ & -84 \\
\hline $\mathrm{BF}_{3}$ & ${ }^{1} J_{\mathrm{BF}}$ & $-77,2$ & $-60,6$ & $-43,8$ & $-26,8$ & $-9,6$ & 7,7 & 25,2 & 42,9 & 60,6 & 78,6 & 96,6 & 15 \\
\hline $\mathrm{F}_{2} \mathrm{O}$ & ${ }^{1} J_{\mathrm{OF}}$ & $-206,3$ & $-240,4$ & $-276,5$ & $-315,4$ & $-358,8$ & $-409,3$ & $-472,3$ & $-559,1$ & $-698,8$ & $-997,1$ & $-2525,8$ & -300 \\
\hline $\mathrm{CH}_{4}$ & ${ }^{1} J_{\mathrm{CH}}$ & 89,7 & 93,1 & 96,6 & 100,4 & 104,4 & 108,8 & 113,4 & 118,3 & 123,6 & 129,2 & 135,2 & 125,3 \\
\hline $\mathrm{CH}_{4}$ & ${ }^{2} J_{\mathrm{HH}}$ & $-7,4$ & $-8,3$ & $-9,3$ & $-10,3$ & $-11,4$ & $-12,5$ & $-13,8$ & $-15,2$ & $-16,6$ & $-18,2$ & $-19,9$ & $-12,8$ \\
\hline $\mathrm{C}_{2} \mathrm{H}_{2}$ & ${ }^{1} J_{\mathrm{CC}}$ & 164,2 & 167,7 & 171,6 & 176,1 & 181,3 & 187,5 & 195,1 & 204,6 & 217,1 & 234,1 & 259,0 & 174,8 \\
\hline $\mathrm{C}_{2} \mathrm{H}_{2}$ & ${ }^{1} J_{\mathrm{CH}}$ & 184,3 & 191,3 & 198,8 & 206,7 & 215,1 & 224,3 & 234,4 & 245,7 & 258,7 & 274,4 & 294,6 & 247,6 \\
\hline $\mathrm{C}_{2} \mathrm{H}_{2}$ & ${ }^{2} J_{\mathrm{CH}}$ & 50,1 & 51,0 & 51,8 & 52,3 & 52,6 & 52,3 & 51,5 & 49,7 & 46,5 & 40,9 & 31,2 & 50,1 \\
\hline $\mathrm{C}_{2} \mathrm{H}_{2}$ & ${ }^{3} J_{\mathrm{HH}}$ & 6,9 & 7,5 & 8,1 & 8,9 & 10,0 & 11,4 & 13,1 & 15,5 & 18,8 & 23,5 & 30,7 & 9,6 \\
\hline $\mathrm{C}_{2} \mathrm{H}_{4}$ & ${ }^{1} J_{\mathrm{CC}}$ & 49,7 & 52,3 & 55,1 & 58,4 & 62,2 & 66,8 & 72,6 & 80,3 & 91,5 & 110,5 & 152,0 & 67,6 \\
\hline $\mathrm{C}_{2} \mathrm{H}_{4}$ & ${ }^{1} J_{\mathrm{CH}}$ & 113,0 & 117,5 & 122,3 & 127,5 & 133,2 & 139,3 & 146,2 & 154,1 & 163,8 & 177,0 & 200,0 & 156,3 \\
\hline $\mathrm{C}_{2} \mathrm{H}_{4}$ & ${ }^{2} J_{\mathrm{CH}}$ & 2,0 & 1,3 & 0,6 & $-0,2$ & $-1,4$ & $-2,8$ & $-4,7$ & $-7,5$ & $-11,7$ & $-19,1$ & $-36,2$ & $-2,4$ \\
\hline $\mathrm{C}_{2} \mathrm{H}_{4}$ & ${ }^{2} J_{\mathrm{HH}}$ & 4,6 & 4,2 & 3,7 & 3,1 & 2,4 & 1,4 & 0,2 & $-1,5$ & $-4,1$ & $-8,8$ & $-19,2$ & 2,3 \\
\hline $\mathrm{C}_{2} \mathrm{H}_{4}$ & ${ }^{3} J_{\mathrm{HH}_{\mathrm{c}}}$ & 9,3 & 9,6 & 10,0 & 10,5 & 11,1 & 11,8 & 12,8 & 14,3 & 16,7 & 21,1 & 31,2 & 11,7 \\
\hline $\mathrm{C}_{2} \mathrm{H}_{4}$ & ${ }^{3} J_{\mathrm{HH}_{\mathrm{t}}}$ & 13,2 & 13,8 & 14,5 & 15,3 & 16,3 & 17,5 & 19,0 & 21,0 & 24,0 & 29,3 & 40,9 & 19 \\
\hline $\mathrm{C}_{2} \mathrm{H}_{6}$ & ${ }^{1} J_{\mathrm{CC}}$ & 17,9 & 20,0 & 22,2 & 24,6 & 27,1 & 29,8 & 32,6 & 35,7 & 38,9 & 42,4 & 46,1 & 34,5 \\
\hline $\mathrm{C}_{2} \mathrm{H}_{6}$ & ${ }^{1} J_{\mathrm{CH}}$ & 89,0 & 92,6 & 96,4 & 100,5 & 104,8 & 109,4 & 114,3 & 119,5 & 125,1 & 131,0 & 137,3 & 125,2 \\
\hline $\mathrm{C}_{2} \mathrm{H}_{6}$ & ${ }^{2} J_{\mathrm{CH}}$ & $-1,2$ & $-1,6$ & $-2,2$ & $-2,7$ & $-3,3$ & $-4,0$ & $-4,7$ & $-5,4$ & $-6,2$ & $-7,1$ & $-8,1$ & $-4,7$ \\
\hline \multirow[t]{3}{*}{ Total } & $\mathrm{DM}$ & $-26,02$ & $-24,16$ & $-22,02$ & $-19,62$ & $-17,07$ & $-14,45$ & $-11,97$ & $-10,01$ & $-9,58$ & $-14,47$ & $-65,03$ & - \\
\hline & DMA & 37,10 & 32,11 & 26,62 & 21,86 & 19,04 & 16,35 & 16,12 & 19,70 & 28,55 & 46,35 & 115,74 & - \\
\hline & PDMA & 65,11 & 54,51 & 43,18 & 31,52 & 19,93 & 12,50 & 19,88 & 37,59 & 63,27 & 103,72 & 191,82 & - \\
\hline \multirow[t]{3}{*}{ CPI } & DM & $-41,61$ & $-39,64$ & $-37,14$ & $-34,29$ & $-31,27$ & $-28,41$ & $-26,28$ & $-25,93$ & $-30,10$ & $-48,39$ & $-178,33$ & - \\
\hline & DMA & 64,97 & 55,87 & 45,81 & 37,58 & 33,53 & 29,66 & 30,41 & 38,98 & 55,23 & 87,23 & 233,56 & - \\
\hline & PDMA & 92,96 & 76,59 & 59,60 & 42,90 & 28,08 & 13,82 & 19,88 & 38,12 & 60,23 & 88,65 & 155,08 & - \\
\hline \multirow[t]{3}{*}{ SPI } & DM & $-14,59$ & $-12,81$ & $-10,93$ & $-8,87$ & $-6,65$ & $-4,21$ & $-1,47$ & 1,67 & 5,47 & 10,41 & 18,05 & - \\
\hline & DMA & 16,67 & 14,69 & 12,54 & 10,33 & 8,42 & 6,58 & 5,65 & 5,56 & 8,99 & 16,38 & 29,34 & - \\
\hline & PDMA & 44,69 & 38,33 & 31,13 & 23,17 & 13,95 & 11,54 & 19,87 & 37,20 & 65,50 & 114,77 & 218,77 & - \\
\hline \multirow[t]{3}{*}{$\Delta \mathrm{CS}$} & $\mathrm{DM}$ & $-27,02$ & $-26,83$ & $-26,21$ & $-25,42$ & $-24,63$ & $-24,20$ & $-24,81$ & $-27,59$ & $-35,57$ & $-58,80$ & $-196,37$ & - \\
\hline & DMA & 48,31 & 41,19 & 33,27 & 27,25 & 25,11 & 23,08 & 24,76 & 33,42 & 46,24 & 70,85 & 204,22 & - \\
\hline & PDMA & 48,26 & 38,26 & 28,47 & 19,73 & 14,13 & 2,28 & 0,00 & 0,92 & $-5,27$ & $-26,12$ & $-63,69$ & - \\
\hline \multicolumn{14}{|c|}{ Desconsiderando ${ }^{1} J_{\mathrm{BF}}$ da molécula de $\mathrm{BF}_{3},{ }^{2} J_{\mathrm{CH}}$ e ${ }^{2} J_{\mathrm{HH}}$ da molécula de $\mathrm{C}_{2} \mathrm{H}_{4}$} \\
\hline \multirow[t]{3}{*}{ Total } & DM & $-25,70$ & $-24,27$ & $-22,52$ & $-20,50$ & $-18,27$ & $-15,96$ & $-13,78$ & $-12,14$ & $-12,13$ & $-17,91$ & $-74,66$ & - \\
\hline & DMA & 37,64 & 32,77 & 27,34 & 22,77 & 20,41 & 18,10 & 17,59 & 20,67 & 29,61 & 48,43 & 124,89 & - \\
\hline & PDMA & 34,56 & 29,42 & 23,68 & 18,01 & 13,40 & 9,59 & 11,38 & 17,98 & 29,36 & 47,57 & 91,32 & - \\
\hline \multirow[t]{3}{*}{ CPI } & DM & $-36,55$ & $-36,04$ & $-34,97$ & $-33,54$ & $-31,94$ & $-30,52$ & $-29,93$ & $-31,31$ & $-37,67$ & $-59,59$ & $-204,32$ & - \\
\hline & DMA & 62,25 & 53,90 & 44,51 & 37,16 & 34,42 & 31,90 & 32,43 & 40,09 & 56,19 & 89,59 & 248,76 & - \\
\hline & PDMA & 40,79 & 33,85 & 26,36 & 19,32 & 14,49 & 10,34 & 15,07 & 23,33 & 35,85 & 55,12 & 116,19 & - \\
\hline \multirow[t]{3}{*}{ SPI } & DM & $-17,35$ & $-15,21$ & $-12,95$ & $-10,46$ & $-7,75$ & $-4,75$ & $-1,36$ & 2,61 & 7,52 & 14,15 & 25,08 & - \\
\hline & DMA & 18,72 & 16,52 & 14,13 & 11,69 & 9,63 & 7,49 & 6,18 & 5,73 & 9,16 & 16,76 & 29,60 & - \\
\hline & PDMA & 29,77 & 26,01 & 21,62 & 17,01 & 12,56 & 9,02 & 8,54 & 13,87 & 24,36 & 41,77 & 72,19 & - \\
\hline \multirow[t]{3}{*}{$\Delta \mathrm{CS}$} & DM & $-19,20$ & $-20,83$ & $-22,02$ & $-23,08$ & $-24,19$ & $-25,77$ & $-28,57$ & $-33,92$ & $-45,19$ & $-73,74$ & $-229,40$ & - \\
\hline & DMA & 43,53 & 37,38 & 30,38 & 25,47 & 24,79 & 24,41 & 26,25 & 34,36 & 47,03 & 72,83 & 219,16 & - \\
\hline & PDMA & 11,01 & 7,84 & 4,74 & 2,31 & 1,93 & 1,32 & 6,53 & 9,47 & 11,49 & 13,34 & 44,00 & - \\
\hline
\end{tabular}


Tabela 8.227: Constantes de acoplamento B98TPSS com base aug-pcJ-2.

\begin{tabular}{|c|c|c|c|c|c|c|c|c|c|c|c|c|c|}
\hline & $\% E_{X}^{\mathrm{HF}}$ & $0 \%$ & $10 \%$ & $20 \%$ & $30 \%$ & $40 \%$ & $50 \%$ & $60 \%$ & $70 \%$ & $80 \%$ & $90 \%$ & $100 \%$ & Exp. \\
\hline $\mathrm{HF}$ & $\frac{\lambda}{{ }^{1} J_{\mathrm{HF}}}$ & 369,2 & 387,0 & 405,9 & 426,2 & 447,8 & 470,9 & 495,5 & 521,7 & 549,5 & 578,9 & 610,0 & 500 \\
\hline $\mathrm{CO}$ & ${ }^{1} J_{C O}$ & 20,2 & 19,3 & 18,2 & 17,0 & 15,7 & 14,3 & 12,7 & 10,9 & 9,1 & 7,0 & 4,9 & 16,4 \\
\hline $\mathrm{H}_{2} \mathrm{O}$ & ${ }^{1} J_{\mathrm{OH}}$ & $-61,6$ & $-63,9$ & $-66,3$ & $-69,0$ & $-71,8$ & $-74,9$ & $-78,1$ & $-81,6$ & $-85,3$ & $-89,2$ & $-93,4$ & $-80,6$ \\
\hline $\mathrm{H}_{2} \mathrm{O}$ & ${ }^{2} J_{\mathrm{HH}}$ & $-0,9$ & $-2,0$ & $-3,1$ & $-4,4$ & $-5,7$ & $-7,2$ & $-8,7$ & $-10,4$ & $-12,2$ & $-14,1$ & $-16,2$ & $-7,3$ \\
\hline $\mathrm{NH}_{3}$ & ${ }^{1} J_{\mathrm{NH}}$ & 35,2 & 36,3 & 37,5 & 38,7 & 40,0 & 41,4 & 42,9 & 44,6 & 46,3 & 48,1 & 50,1 & 43,8 \\
\hline $\mathrm{NH}_{3}$ & ${ }^{2} J_{\mathrm{HH}}$ & $-3,7$ & $-4,7$ & $-5,7$ & $-6,8$ & $-8,1$ & $-9,4$ & $-10,8$ & $-12,4$ & $-14,1$ & $-15,9$ & $-17,9$ & $-9,6$ \\
\hline $\mathrm{PH}_{3}$ & ${ }^{1} J_{\mathrm{PH}}$ & 136,3 & 143,3 & 150,7 & 158,8 & 167,4 & 176,6 & 186,5 & 197,0 & 208,2 & 220,0 & 232,6 & 188,2 \\
\hline $\mathrm{PF}_{3}$ & ${ }^{1} J_{\mathrm{PF}}$ & $-1656,6$ & $-1651,3$ & $-1640,4$ & $-1624,6$ & $-1604,7$ & $-1581,4$ & $-1555,4$ & $-1527,2$ & $-1497,4$ & $-1466,6$ & $-1435,2$ & -1441 \\
\hline $\mathrm{BHF}_{2}$ & ${ }^{1} J_{\mathrm{BF}}$ & $-165,6$ & $-151,8$ & $-137,5$ & $-122,9$ & $-108,0$ & $-92,9$ & $-77,7$ & $-62,4$ & $-47,1$ & $-31,7$ & $-16,4$ & -84 \\
\hline $\mathrm{BF}_{3}$ & ${ }^{1} J_{\mathrm{BF}}$ & $-75,4$ & $-58,9$ & $-42,2$ & $-25,4$ & $-8,3$ & 8,7 & 26,0 & 43,5 & 61,0 & 78,6 & 96,3 & 15 \\
\hline $\mathrm{F}_{2} \mathrm{O}$ & ${ }^{1} J_{\mathrm{OF}}$ & $-204,5$ & $-238,6$ & $-274,7$ & $-313,6$ & $-356,7$ & $-406,9$ & $-469,3$ & $-555,0$ & $-691,9$ & $-981,2$ & $-2403,5$ & -300 \\
\hline $\mathrm{CH}_{4}$ & ${ }^{1} J_{\mathrm{CH}}$ & 95,8 & 99,4 & 103,2 & 107,3 & 111,7 & 116,4 & 121,4 & 126,7 & 132,4 & 138,5 & 144,9 & 125,3 \\
\hline $\mathrm{CH}_{4}$ & ${ }^{2} J_{\mathrm{HH}}$ & $-6,7$ & $-7,6$ & $-8,6$ & $-9,7$ & $-10,9$ & $-12,2$ & $-13,6$ & $-15,0$ & $-16,6$ & $-18,3$ & $-20,2$ & $-12,8$ \\
\hline $\mathrm{C}_{2} \mathrm{H}_{2}$ & ${ }^{1} J_{\mathrm{CC}}$ & 163,7 & 167,2 & 171,2 & 175,8 & 181,2 & 187,6 & 195,4 & 205,3 & 218,2 & 236,0 & 262,1 & 174,8 \\
\hline $\mathrm{C}_{2} \mathrm{H}_{2}$ & ${ }^{1} J_{\mathrm{CH}}$ & 195,3 & 202,8 & 210,7 & 219,2 & 228,2 & 238,0 & 248,8 & 260,8 & 274,7 & 291,4 & 312,9 & 247,6 \\
\hline $\mathrm{C}_{2} \mathrm{H}_{2}$ & ${ }^{2} J_{\mathrm{CH}}$ & 51,6 & 52,6 & 53,3 & 53,9 & 54,1 & 53,8 & 52,9 & 51,0 & 47,6 & 41,7 & 31,5 & 50,1 \\
\hline $\mathrm{C}_{2} \mathrm{H}_{2}$ & ${ }^{3} J_{\mathrm{HH}}$ & 7,3 & 7,8 & 8,4 & 9,3 & 10,4 & 11,7 & 13,6 & 16,0 & 19,4 & 24,3 & 31,8 & 9,6 \\
\hline $\mathrm{C}_{2} \mathrm{H}_{4}$ & ${ }^{1} J_{\mathrm{CC}}$ & 50,2 & 52,8 & 55,7 & 59,1 & 63,0 & 67,7 & 73,7 & 81,7 & 93,2 & 112,5 & 153,5 & 67,6 \\
\hline $\mathrm{C}_{2} \mathrm{H}_{4}$ & ${ }^{1} J_{\mathrm{CH}}$ & 120,0 & 124,9 & 130,1 & 135,7 & 141,8 & 148,4 & 155,8 & 164,2 & 174,5 & 188,3 & 211,7 & 156,3 \\
\hline $\mathrm{C}_{2} \mathrm{H}_{4}$ & ${ }^{2} J_{\mathrm{CH}}$ & 2,0 & 1,4 & 0,5 & $-0,3$ & $-1,5$ & $-3,1$ & $-5,1$ & $-7,9$ & $-12,3$ & $-19,9$ & $-36,8$ & $-2,4$ \\
\hline $\mathrm{C}_{2} \mathrm{H}_{4}$ & ${ }^{2} J_{\mathrm{HH}}$ & 6,0 & 5,6 & 5,1 & 4,5 & 3,7 & 2,7 & 1,5 & $-0,2$ & $-2,9$ & $-7,5$ & $-17,4$ & 2,3 \\
\hline $\mathrm{C}_{2} \mathrm{H}_{4}$ & ${ }^{3} J_{\mathrm{HH}_{\mathrm{c}}}$ & 9,9 & 10,3 & 10,7 & 11,1 & 11,7 & 12,5 & 13,6 & 15,1 & 17,5 & 21,7 & 31,3 & 11,7 \\
\hline $\mathrm{C}_{2} \mathrm{H}_{4}$ & ${ }^{3} J_{\mathrm{HH}_{\mathrm{t}}}$ & 14,7 & 15,3 & 16,1 & 16,9 & 17,9 & 19,1 & 20,6 & 22,7 & 25,8 & 31,0 & 42,2 & 19 \\
\hline $\mathrm{C}_{2} \mathrm{H}_{6}$ & ${ }^{1} J_{\mathrm{CC}}$ & 18,4 & 20,5 & 22,8 & 25,1 & 27,7 & 30,4 & 33,3 & 36,4 & 39,7 & 43,2 & 46,9 & 34,5 \\
\hline $\mathrm{C}_{2} \mathrm{H}_{6}$ & ${ }^{1} J_{\mathrm{CH}}$ & 94,8 & 98,7 & 102,8 & 107,2 & 111,8 & 116,8 & 122,1 & 127,8 & 133,8 & 140,2 & 147,1 & 125,2 \\
\hline $\mathrm{C}_{2} \mathrm{H}_{6}$ & ${ }^{2} J_{\mathrm{CH}}$ & $-1,1$ & $-1,6$ & $-2,2$ & $-2,7$ & $-3,4$ & $-4,1$ & $-4,8$ & $-5,6$ & $-6,5$ & $-7,4$ & $-8,5$ & $-4,7$ \\
\hline \multirow[t]{3}{*}{ Total } & DM & $-24,25$ & $-22,32$ & $-20,11$ & $-17,64$ & $-15,00$ & $-12,31$ & $-9,70$ & $-7,59$ & $-6,94$ & $-11,36$ & $-57,72$ & - \\
\hline & DMA & 35,78 & 30,71 & 25,12 & 20,11 & 17,20 & 14,40 & 14,16 & 20,47 & 30,98 & 48,78 & 113,73 & - \\
\hline & PDMA & 66,16 & 55,56 & 43,82 & 32,02 & 20,34 & 10,83 & 17,87 & 37,41 & 64,91 & 105,61 & 191,26 & - \\
\hline \multirow[t]{3}{*}{ CPI } & $\mathrm{DM}$ & $-40,75$ & $-38,75$ & $-36,23$ & $-33,35$ & $-30,30$ & $-27,43$ & $-25,21$ & $-24,75$ & $-28,62$ & $-46,09$ & $-166,33$ & - \\
\hline & DMA & 64,50 & 55,33 & 45,23 & 36,61 & 32,46 & 28,52 & 28,81 & 39,55 & 56,78 & 88,07 & 223,67 & - \\
\hline & PDMA & 92,35 & 75,82 & 58,85 & 41,99 & 27,01 & 12,61 & 18,76 & 38,54 & 61,43 & 89,49 & 152,58 & - \\
\hline \multirow[t]{3}{*}{ SPI } & DM & $-12,15$ & $-10,27$ & $-8,29$ & $-6,11$ & $-3,78$ & $-1,23$ & 1,67 & 4,99 & 8,96 & 14,11 & 21,93 & - \\
\hline & DMA & 14,72 & 12,65 & 10,37 & 8,01 & 6,01 & 4,05 & 3,42 & 6,47 & 12,05 & 19,96 & 33,11 & - \\
\hline & PDMA & 46,96 & 40,69 & 32,80 & 24,71 & 15,46 & 9,52 & 17,22 & 36,57 & 67,46 & 117,43 & 219,63 & - \\
\hline \multirow[t]{3}{*}{$\Delta \mathrm{CS}$} & $\mathrm{DM}$ & $-28,61$ & $-28,48$ & $-27,94$ & $-27,24$ & $-26,52$ & $-26,20$ & $-26,88$ & $-29,74$ & $-37,58$ & $-60,20$ & $-188,25$ & - \\
\hline & DMA & 49,78 & 42,67 & 34,86 & 28,60 & 26,46 & 24,46 & 25,39 & 33,07 & 44,73 & 68,11 & 190,56 & - \\
\hline & PDMA & 45,39 & 35,13 & 26,04 & 17,28 & 11,55 & 3,10 & 1,55 & 1,97 & $-6,03$ & $-27,95$ & $-67,05$ & - \\
\hline \multicolumn{14}{|c|}{ Desconsiderando ${ }^{1} J_{\mathrm{BF}}$ da molécula de $\mathrm{BF}_{3},{ }^{2} J_{\mathrm{CH}}$ e ${ }^{2} J_{\mathrm{HH}}$ da molécula de $\mathrm{C}_{2} \mathrm{H}_{4}$} \\
\hline \multirow[t]{3}{*}{ Total } & DM & $-23,83$ & $-22,32$ & $-20,49$ & $-18,37$ & $-16,04$ & $-13,63$ & $-11,29$ & $-9,47$ & $-9,19$ & $-14,42$ & $-66,43$ & - \\
\hline & DMA & 36,17 & 31,19 & 25,66 & 20,79 & 18,33 & 15,96 & 15,38 & 21,55 & 32,36 & 51,19 & 122,68 & - \\
\hline & PDMA & 33,62 & 28,26 & 22,41 & 16,52 & 11,96 & 8,39 & 10,61 & 19,33 & 32,28 & 50,72 & 93,09 & - \\
\hline \multirow[t]{3}{*}{ CPI } & DM & $-35,79$ & $-35,23$ & $-34,13$ & $-32,65$ & $-31,00$ & $-29,54$ & $-28,83$ & $-30,07$ & $-36,08$ & $-57,06$ & $-191,09$ & - \\
\hline & DMA & 61,91 & 53,47 & 44,03 & 36,23 & 33,38 & 30,74 & 30,59 & 40,65 & 57,86 & 90,52 & 237,91 & - \\
\hline & PDMA & 41,32 & 34,14 & 26,60 & 19,26 & 14,17 & 9,68 & 13,31 & 23,39 & 36,91 & 56,04 & 113,64 & - \\
\hline \multirow[t]{3}{*}{ SPI } & DM & $-14,64$ & $-12,39$ & $-10,00$ & $-7,38$ & $-4,54$ & $-1,39$ & 2,20 & 6,38 & 11,50 & 18,38 & 29,46 & - \\
\hline & DMA & 16,36 & 14,05 & 11,52 & 8,91 & 6,75 & 4,59 & 3,68 & 6,85 & 12,75 & 20,93 & 34,05 & - \\
\hline & PDMA & 27,70 & 23,74 & 19,19 & 14,42 & 10,27 & 7,40 & 8,54 & 16,21 & 28,72 & 46,64 & 77,27 & - \\
\hline \multirow[t]{3}{*}{$\Delta \mathrm{CS}$} & $\mathrm{DM}$ & $-21,15$ & $-22,84$ & $-24,13$ & $-25,27$ & $-26,46$ & $-28,15$ & $-31,03$ & $-36,45$ & $-47,58$ & $-75,44$ & $-220,55$ & - \\
\hline & DMA & 45,55 & 39,42 & 32,51 & 27,32 & 26,63 & 26,15 & 26,91 & 33,80 & 45,11 & 69,59 & 203,86 & - \\
\hline & PDMA & 13,61 & 10,40 & 7,41 & 4,84 & 3,91 & 2,28 & 4,77 & 7,19 & 8,19 & 9,40 & 36,37 & - \\
\hline
\end{tabular}

Tabela 8.228: Valores de PDMA total obtidos para troca B98 com base HuzIII-su3.

\begin{tabular}{lccccccccccc}
\hline$E_{X}^{\mathrm{HF}}(\%)$ & $0 \%$ & $10 \%$ & $20 \%$ & $30 \%$ & $40 \%$ & $50 \%$ & $60 \%$ & $70 \%$ & $80 \%$ & $90 \%$ & $100 \%$ \\
\hline B98B95 & 66,9 & 57,1 & 46,8 & 36,1 & 25,7 & 15,0 & 12,3 & 22,2 & 39,0 & 61,3 & 92,6 \\
B98B98 & 59,6 & 49,2 & 39,2 & 28,4 & 18,4 & 11,1 & 20,2 & 37,0 & 58,4 & 87,2 & 131,6 \\
B98B971 & 59,9 & 49,5 & 39,4 & 28,6 & 18,0 & 13,3 & 19,7 & 34,7 & 55,0 & 81,6 & 120,6 \\
B98B972 & 59,4 & 49,7 & 39,6 & 29,3 & 23,5 & 24,4 & 27,2 & 37,7 & 54,6 & 80,0 & 119,3 \\
B98LYP & 60,8 & 50,3 & 39,3 & 27,8 & 16,9 & 10,7 & 21,7 & 40,3 & 64,4 & 98,3 & 161,5 \\
B98P86 & 66,1 & 55,7 & 44,9 & 33,7 & 22,3 & 12,8 & 16,6 & 33,0 & 54,5 & 89,5 & 156,7 \\
B98PBE & 65,0 & 54,5 & 43,1 & 31,5 & 20,2 & 14,5 & 19,9 & 38,0 & 63,6 & 104,9 & 196,2 \\
B98PW91 & 64,7 & 54,0 & 42,6 & 30,9 & 19,5 & 14,0 & 20,2 & 38,4 & 64,1 & 105,7 & 197,9 \\
B98TPSS & 65,4 & 54,7 & 43,3 & 31,2 & 19,4 & 11,7 & 18,5 & 38,0 & 66,1 & 107,9 & 197,2 \\
\hline
\end{tabular}




\subsubsection{Troca O}

Tabela 8.229: Constantes de acoplamento OB95 com base aug-pcJ-2.

\begin{tabular}{|c|c|c|c|c|c|c|c|c|c|c|c|c|c|}
\hline & $\% E_{X}^{\mathrm{HF}}$ & $0 \%$ & $10 \%$ & $20 \%$ & $30 \%$ & $40 \%$ & $50 \%$ & $60 \%$ & $70 \%$ & $80 \%$ & $90 \%$ & $100 \%$ & Exp. \\
\hline $\mathrm{HF}$ & $\frac{\Lambda}{{ }^{1} J_{\mathrm{HF}}}$ & 371,4 & 397,6 & 424,1 & 450,9 & 478,1 & 505,6 & 533,4 & 561,5 & 589,9 & 618,5 & 647,4 & 500 \\
\hline $\mathrm{CO}$ & ${ }^{1} J_{\mathrm{CO}}$ & 25,5 & 23,6 & 21,6 & 19,5 & 17,3 & 15,0 & 12,6 & 10,1 & 7,6 & 5,0 & 2,4 & 16,4 \\
\hline $\mathrm{H}_{2} \mathrm{O}$ & ${ }^{1} J_{\mathrm{OH}}$ & $-64,2$ & $-67,2$ & $-70,3$ & $-73,4$ & $-76,5$ & $-79,7$ & $-82,9$ & $-86,2$ & $-89,5$ & $-92,8$ & $-96,2$ & $-80,6$ \\
\hline $\mathrm{H}_{2} \mathrm{O}$ & ${ }^{2} J_{\mathrm{HH}}$ & $-5,8$ & $-6,6$ & $-7,5$ & $-8,3$ & $-9,1$ & $-10,0$ & $-10,9$ & $-11,8$ & $-12,7$ & $-13,7$ & $-14,7$ & $-7,3$ \\
\hline $\mathrm{NH}_{3}$ & ${ }^{1} J_{\mathrm{NH}}$ & 37,7 & 38,8 & 40,0 & 41,1 & 42,3 & 43,4 & 44,6 & 45,8 & 47,0 & 48,3 & 49,5 & 43,8 \\
\hline $\mathrm{NH}_{3}$ & ${ }^{2} J_{\mathrm{HH}}$ & $-7,8$ & $-8,5$ & $-9,3$ & $-10,0$ & $-10,8$ & $-11,6$ & $-12,4$ & $-13,2$ & $-14,0$ & $-14,9$ & $-15,8$ & $-9,6$ \\
\hline $\mathrm{PH}_{3}$ & ${ }^{1} J_{\mathrm{PH}}$ & 146,1 & 153,7 & 161,2 & 168,6 & 175,9 & 183,1 & 190,1 & 197,1 & 203,9 & 210,5 & 217,0 & 188,2 \\
\hline $\mathrm{PF}_{3}$ & ${ }^{1} J_{\mathrm{PF}}$ & $-1604,8$ & $-1592,1$ & $-1575,7$ & $-1556,0$ & $-1533,8$ & $-1509,6$ & $-1483,8$ & $-1456,9$ & $-1429,3$ & $-1401,1$ & $-1372,8$ & -1441 \\
\hline $\mathrm{BHF}_{2}$ & ${ }^{1} J_{\mathrm{BF}}$ & $-186,5$ & $-167,1$ & $-147,9$ & $-129,1$ & $-110,7$ & $-92,8$ & $-75,3$ & $-58,4$ & $-41,9$ & $-26,0$ & $-10,5$ & -84 \\
\hline $\mathrm{BF}_{3}$ & ${ }^{1} J_{\mathrm{BF}}$ & $-98,9$ & $-76,8$ & $-55,1$ & $-33,9$ & $-13,2$ & 6,9 & 26,5 & 45,6 & 64,1 & 82,1 & 99,7 & 15 \\
\hline $\mathrm{F}_{2} \mathrm{O}$ & ${ }^{1} J_{\mathrm{OF}}$ & $-241,8$ & $-275,5$ & $-308,9$ & $-343,2$ & $-379,7$ & $-420,5$ & $-468,6$ & $-529,8$ & $-615,4$ & $-754,2$ & $-1048,5$ & -300 \\
\hline $\mathrm{CH}_{4}$ & ${ }^{1} J_{\mathrm{CH}}$ & 107,2 & 109,9 & 112,5 & 115,2 & 117,9 & 120,6 & 123,4 & 126,2 & 129,1 & 132,0 & 134,9 & 125,3 \\
\hline $\mathrm{CH}_{4}$ & ${ }^{2} J_{\mathrm{HH}}$ & $-10,9$ & $-11,5$ & $-12,1$ & $-12,7$ & $-13,3$ & $-13,9$ & $-14,5$ & $-15,1$ & $-15,8$ & $-16,4$ & $-17,0$ & $-12,8$ \\
\hline $\mathrm{C}_{2} \mathrm{H}_{2}$ & ${ }^{1} J_{\mathrm{CC}}$ & 175,5 & 179,3 & 183,3 & 187,7 & 192,5 & 197,8 & 203,7 & 210,2 & 217,6 & 225,9 & 235,5 & 174,8 \\
\hline $\mathrm{C}_{2} \mathrm{H}_{2}$ & ${ }^{1} J_{\mathrm{CH}}$ & 230,7 & 234,6 & 238,7 & 242,8 & 247,1 & 251,5 & 256,1 & 260,9 & 266,0 & 271,4 & 277,3 & 247,6 \\
\hline $\mathrm{C}_{2} \mathrm{H}_{2}$ & ${ }^{2} J_{\mathrm{CH}}$ & 51,9 & 52,2 & 52,4 & 52,4 & 52,3 & 52,0 & 51,5 & 50,8 & 49,7 & 48,3 & 46,4 & 50,1 \\
\hline $\mathrm{C}_{2} \mathrm{H}_{2}$ & ${ }^{3} J_{\mathrm{HH}}$ & 10,0 & 10,4 & 10,8 & 11,3 & 12,0 & 12,7 & 13,6 & 14,6 & 15,8 & 17,2 & 18,9 & 9,6 \\
\hline $\mathrm{C}_{2} \mathrm{H}_{4}$ & ${ }^{1} J_{\mathrm{CC}}$ & 52,7 & 55,8 & 59,0 & 62,5 & 66,2 & 70,3 & 74,8 & 79,9 & 85,7 & 92,5 & 100,8 & 67,6 \\
\hline $\mathrm{C}_{2} \mathrm{H}_{4}$ & ${ }^{1} J_{\mathrm{CH}}$ & 139,5 & 142,8 & 146,1 & 149,5 & 153,0 & 156,6 & 160,4 & 164,4 & 168,7 & 173,4 & 178,7 & 156,3 \\
\hline $\mathrm{C}_{2} \mathrm{H}_{4}$ & ${ }^{2} J_{\mathrm{CH}}$ & 0,0 & $-0,6$ & $-1,4$ & $-2,2$ & $-3,2$ & $-4,2$ & $-5,5$ & $-6,9$ & $-8,6$ & $-10,7$ & $-13,4$ & $-2,4$ \\
\hline $\mathrm{C}_{2} \mathrm{H}_{4}$ & ${ }^{2} J_{\mathrm{HH}}$ & 3,8 & 3,3 & 2,8 & 2,3 & 1,8 & 1,2 & 0,5 & $-0,2$ & $-1,1$ & $-2,2$ & $-3,5$ & 2,3 \\
\hline $\mathrm{C}_{2} \mathrm{H}_{4}$ & ${ }^{3} J_{\mathrm{HH}_{\mathrm{c}}}$ & 10,9 & 11,2 & 11,5 & 11,8 & 12,2 & 12,7 & 13,3 & 13,9 & 14,7 & 15,7 & 16,9 & 11,7 \\
\hline $\mathrm{C}_{2} \mathrm{H}_{4}$ & ${ }^{3} J_{\mathrm{HH}_{\mathrm{t}}}{ }^{2}$ & 17,5 & 17,8 & 18,1 & 18,5 & 19,0 & 19,6 & 20,3 & 21,0 & 22,0 & 23,2 & 24,7 & 19 \\
\hline $\mathrm{C}_{2} \mathrm{H}_{6}$ & ${ }^{1} J_{\mathrm{CC}}$ & 21,3 & 23,6 & 25,8 & 28,1 & 30,5 & 32,9 & 35,4 & 37,9 & 40,4 & 43,0 & 45,7 & 34,5 \\
\hline $\mathrm{C}_{2} \mathrm{H}_{6}$ & ${ }^{1} J_{\mathrm{CH}}$ & 107,9 & 110,6 & 113,4 & 116,2 & 119,0 & 121,9 & 124,8 & 127,7 & 130,7 & 133,7 & 136,7 & 125,2 \\
\hline $\mathrm{C}_{2} \mathrm{H}_{6}$ & ${ }^{2} J_{\mathrm{CH}}$ & $-2,8$ & $-3,2$ & $-3,6$ & $-4,0$ & $-4,4$ & $-4,8$ & $-5,2$ & $-5,6$ & $-6,0$ & $-6,4$ & $-6,9$ & $-4,7$ \\
\hline \multirow[t]{3}{*}{ Total } & $\mathrm{DM}$ & $-21,50$ & $-18,80$ & $-15,98$ & $-13,05$ & $-10,10$ & $-7,24$ & $-4,58$ & $-2,37$ & $-1,02$ & $-1,64$ & $-8,15$ & - \\
\hline & DMA & 29,00 & 23,41 & 18,37 & 15,23 & 12,26 & 10,55 & 13,37 & 18,86 & 26,46 & 37,54 & 54,82 & - \\
\hline & PDMA & 55,34 & 43,64 & 32,03 & 22,27 & 17,34 & 15,11 & 22,85 & 36,77 & 52,18 & 69,70 & 90,89 & - \\
\hline \multirow[t]{3}{*}{ CPI } & $\mathrm{DM}$ & $-42,73$ & $-38,27$ & $-33,52$ & $-28,61$ & $-23,74$ & $-19,19$ & $-15,24$ & $-12,46$ & $-11,93$ & $-16,29$ & $-34,85$ & - \\
\hline & DMA & 58,55 & 46,80 & 36,39 & 30,48 & 24,65 & 20,37 & 25,47 & 35,85 & 50,42 & 72,71 & 109,09 & - \\
\hline & PDMA & 99,02 & 78,31 & 58,57 & 43,11 & 28,62 & 16,51 & 23,66 & 43,48 & 63,78 & 85,81 & 112,26 & - \\
\hline \multirow{3}{*}{ SPI } & $\mathrm{DM}$ & $-5,93$ & $-4,53$ & $-3,12$ & $-1,65$ & $-0,10$ & 1,52 & 3,23 & 5,04 & 6,99 & 9,10 & 11,44 & - \\
\hline & DMA & 7,34 & 6,26 & 5,16 & 4,05 & 3,18 & 3,35 & 4,49 & 6,40 & 8,89 & 11,75 & 15,03 & - \\
\hline & PDMA & 23,30 & 18,21 & 12,56 & 6,99 & 9,07 & 14,09 & 22,27 & 31,85 & 43,68 & 57,88 & 75,22 & - \\
\hline \multirow[t]{3}{*}{$\Delta \mathrm{CS}$} & DM & $-36,80$ & $-33,75$ & $-30,40$ & $-26,96$ & $-23,64$ & $-20,71$ & $-18,47$ & $-17,50$ & $-18,91$ & $-25,39$ & $-46,29$ & - \\
\hline & DMA & 51,21 & 40,54 & 31,23 & 26,44 & 21,47 & 17,03 & 20,99 & 29,45 & 41,52 & 60,96 & 94,06 & - \\
\hline & PDMA & 75,72 & 60,10 & 46,01 & 36,12 & 19,56 & 2,43 & 1,39 & 11,63 & 20,09 & 27,93 & 37,04 & - \\
\hline \multicolumn{14}{|c|}{ Desconsiderando ${ }^{1} J_{\mathrm{BF}}$ da molécula de $\mathrm{BF}_{3},{ }^{2} J_{\mathrm{CH}}$ e ${ }^{2} J_{\mathrm{HH}}$ da molécula de $\mathrm{C}_{2} \mathrm{H}_{4}$} \\
\hline \multirow[t]{3}{*}{ Total } & $\mathrm{DM}$ & $-19,52$ & $-17,39$ & $-15,08$ & $-12,64$ & $-10,13$ & $-7,71$ & $-5,47$ & $-3,70$ & $-2,87$ & $-4,22$ & $-12,16$ & - \\
\hline & DMA & 27,67 & 22,35 & 17,66 & 15,08 & 12,58 & 11,45 & 14,40 & 19,68 & 27,36 & 38,97 & 57,56 & - \\
\hline & PDMA & 22,36 & 17,57 & 13,13 & 10,64 & 9,03 & 9,39 & 13,48 & 19,82 & 27,10 & 35,80 & 47,30 & - \\
\hline \multirow[t]{3}{*}{ CPI } & $\mathrm{DM}$ & $-35,61$ & $-32,92$ & $-29,86$ & $-26,58$ & $-23,29$ & $-20,30$ & $-17,91$ & $-16,77$ & $-18,03$ & $-24,63$ & $-46,81$ & - \\
\hline & DMA & 53,01 & 42,30 & 33,02 & 28,64 & 24,29 & 21,60 & 26,87 & 36,37 & 50,55 & 73,27 & 111,53 & - \\
\hline & PDMA & 32,99 & 24,94 & 17,69 & 14,82 & 12,69 & 12,76 & 18,35 & 27,43 & 37,42 & 49,66 & 67,02 & - \\
\hline \multirow[t]{3}{*}{ SPI } & $\mathrm{DM}$ & $-7,14$ & $-5,44$ & $-3,72$ & $-1,92$ & $-0,02$ & 1,98 & 4,11 & 6,35 & 8,80 & 11,48 & 14,49 & - \\
\hline & DMA & 8,17 & 7,01 & 5,84 & 4,65 & 3,57 & 3,64 & 4,80 & 6,85 & 9,52 & 12,58 & 16,05 & - \\
\hline & PDMA & 14,18 & 11,90 & 9,61 & 7,42 & 6,22 & 6,80 & 9,74 & 13,96 & 19,16 & 25,13 & 32,14 & - \\
\hline \multirow[t]{3}{*}{$\Delta \mathrm{CS}$} & DM & $-28,47$ & $-27,48$ & $-26,14$ & $-24,66$ & $-23,27$ & $-22,28$ & $-22,02$ & $-23,12$ & $-26,83$ & $-36,11$ & $-61,30$ & - \\
\hline & DMA & 44,84 & 35,29 & 27,18 & 23,99 & 20,72 & 17,96 & 22,07 & 29,52 & 41,03 & 60,69 & 95,48 & - \\
\hline & PDMA & 18,82 & 13,04 & 8,08 & 7,40 & 6,46 & 5,96 & 8,62 & 13,47 & 18,26 & 24,52 & 34,88 & - \\
\hline
\end{tabular}


Tabela 8.230: Constantes de acoplamento OB971 com base aug-pcJ-2.

\begin{tabular}{|c|c|c|c|c|c|c|c|c|c|c|c|c|c|}
\hline & $\% E_{X}^{\mathrm{HF}}$ & $0 \%$ & $10 \%$ & $20 \%$ & $30 \%$ & $40 \%$ & $50 \%$ & $60 \%$ & $70 \%$ & $80 \%$ & $90 \%$ & $100 \%$ & Exp. \\
\hline $\mathrm{HF}$ & ${ }^{1} J_{\mathrm{HF}}$ & 376,5 & 402,0 & 427,8 & 453,9 & 480,3 & 506,9 & 533,9 & 561,0 & 588,4 & 616,1 & 643,9 & 500 \\
\hline $\mathrm{CO}$ & ${ }^{1} J_{\mathrm{CO}}$ & 24,1 & 22,0 & 19,8 & 17,5 & 15,1 & 12,5 & 9,9 & 7,2 & 4,4 & 1,5 & $-1,3$ & 16,4 \\
\hline $\mathrm{H}_{2} \mathrm{O}$ & ${ }^{1} J_{\mathrm{OH}}$ & $-64,7$ & $-67,7$ & $-70,7$ & $-73,7$ & $-76,7$ & $-79,8$ & $-82,9$ & $-86,1$ & $-89,3$ & $-92,5$ & $-95,7$ & $-80,6$ \\
\hline $\mathrm{H}_{2} \mathrm{O}$ & ${ }^{2} J_{\mathrm{HH}}$ & $-5,7$ & $-6,5$ & $-7,3$ & $-8,1$ & $-8,9$ & $-9,8$ & $-10,7$ & $-11,5$ & $-12,4$ & $-13,3$ & $-14,3$ & $-7,3$ \\
\hline $\mathrm{NH}_{3}$ & ${ }^{1} J_{\mathrm{NH}}$ & 38,6 & 39,7 & 40,9 & 42,0 & 43,2 & 44,4 & 45,6 & 46,8 & 48,1 & 49,3 & 50,6 & 43,8 \\
\hline $\mathrm{NH}_{3}$ & ${ }^{2} J_{\mathrm{HH}}$ & $-7,9$ & $-8,7$ & $-9,4$ & $-10,2$ & $-11,0$ & $-11,8$ & $-12,6$ & $-13,4$ & $-14,3$ & $-15,2$ & $-16,1$ & $-9,6$ \\
\hline $\mathrm{PH}_{3}$ & ${ }^{1} J_{\mathrm{PH}}$ & 172,8 & 180,3 & 187,6 & 194,9 & 201,9 & 208,8 & 215,5 & 222,1 & 228,4 & 234,6 & 240,7 & 188,2 \\
\hline $\mathrm{PF}_{3}$ & ${ }^{1} J_{\mathrm{PF}}$ & $-1652,4$ & $-1636,9$ & $-1617,6$ & $-1595,3$ & $-1570,4$ & $-1543,5$ & $-1515,2$ & $-1485,8$ & $-1455,8$ & $-1425,4$ & $-1394,8$ & -1441 \\
\hline $\mathrm{BHF}_{2}$ & ${ }^{1} J_{\mathrm{BF}}$ & $-175,4$ & $-154,8$ & $-134,5$ & $-114,7$ & $-95,5$ & $-76,8$ & $-58,7$ & $-41,1$ & $-24,1$ & $-7,7$ & 8,1 & -84 \\
\hline $\mathrm{BF}_{3}$ & ${ }^{1} J_{\mathrm{BF}}$ & $-87,1$ & $-64,0$ & $-41,5$ & $-19,6$ & 1,6 & 22,3 & 42,3 & 61,8 & 80,7 & 99,0 & 116,8 & 15 \\
\hline $\mathrm{F}_{2} \mathrm{O}$ & ${ }^{1} J_{\mathrm{OF}}$ & $-240,8$ & $-274,7$ & $-308,6$ & $-343,8$ & $-381,9$ & $-425,1$ & $-477,3$ & $-545,4$ & $-644,3$ & $-814,5$ & $-1221,3$ & -300 \\
\hline $\mathrm{CH}_{4}$ & ${ }^{1} J_{\mathrm{CH}}$ & 115,4 & 118,2 & 121,1 & 123,9 & 126,8 & 129,8 & 132,8 & 135,8 & 138,8 & 141,9 & 145,1 & 125,3 \\
\hline $\mathrm{CH}_{4}$ & ${ }^{2} J_{\mathrm{HH}}$ & $-11,0$ & $-11,7$ & $-12,3$ & $-12,9$ & $-13,5$ & $-14,2$ & $-14,8$ & $-15,4$ & $-16,1$ & $-16,7$ & $-17,3$ & $-12,8$ \\
\hline $\mathrm{C}_{2} \mathrm{H}_{2}$ & ${ }^{1} J_{\mathrm{CC}}$ & 196,4 & 201,2 & 206,4 & 212,1 & 218,3 & 225,1 & 232,8 & 241,4 & 251,1 & 262,2 & 275,1 & 174,8 \\
\hline $\mathrm{C}_{2} \mathrm{H}_{2}$ & ${ }^{1} J_{\mathrm{CH}}$ & 242,7 & 247,0 & 251,4 & 255,9 & 260,7 & 265,6 & 270,8 & 276,3 & 282,2 & 288,5 & 295,5 & 247,6 \\
\hline $\mathrm{C}_{2} \mathrm{H}_{2}$ & ${ }^{2} J_{\mathrm{CH}}$ & 50,6 & 50,7 & 50,6 & 50,3 & 49,9 & 49,2 & 48,2 & 46,9 & 45,2 & 43,0 & 40,1 & 50,1 \\
\hline $\mathrm{C}_{2} \mathrm{H}_{2}$ & ${ }^{3} J_{\mathrm{HH}}$ & 9,9 & 10,4 & 10,9 & 11,6 & 12,3 & 13,2 & 14,2 & 15,4 & 16,9 & 18,5 & 20,5 & 9,6 \\
\hline $\mathrm{C}_{2} \mathrm{H}_{4}$ & ${ }^{1} J_{\mathrm{CC}}$ & 65,6 & 69,3 & 73,3 & 77,7 & 82,5 & 87,7 & 93,6 & 100,4 & 108,4 & 118,1 & 130,5 & 67,6 \\
\hline $\mathrm{C}_{2} \mathrm{H}_{4}$ & ${ }^{1} J_{\mathrm{CH}}$ & 148,2 & 151,7 & 155,3 & 159,0 & 162,9 & 166,9 & 171,2 & 175,8 & 180,8 & 186,5 & 193,0 & 156,3 \\
\hline $\mathrm{C}_{2} \mathrm{H}_{4}$ & ${ }^{2} J_{\mathrm{CH}}$ & $-1,1$ & $-2,0$ & $-2,9$ & $-3,9$ & $-5,1$ & $-6,4$ & $-7,9$ & $-9,8$ & $-12,1$ & $-15,0$ & $-18,8$ & $-2,4$ \\
\hline $\mathrm{C}_{2} \mathrm{H}_{4}$ & ${ }^{2} J_{\mathrm{HH}}$ & 3,3 & 2,8 & 2,3 & 1,8 & 1,2 & 0,5 & $-0,2$ & $-1,0$ & $-2,1$ & $-3,4$ & $-5,1$ & 2,3 \\
\hline $\mathrm{C}_{2} \mathrm{H}_{4}$ & ${ }^{3} J_{\mathrm{HH}_{\mathrm{c}}}$ & 10,9 & 11,2 & 11,5 & 11,9 & 12,4 & 12,9 & 13,5 & 14,3 & 15,2 & 16,4 & 18,0 & 11,7 \\
\hline $\mathrm{C}_{2} \mathrm{H}_{4}$ & ${ }^{3} J_{\mathrm{HH}_{\mathrm{t}}}$ & 17,4 & 17,7 & 18,1 & 18,5 & 19,1 & 19,7 & 20,5 & 21,4 & 22,5 & 24,0 & 25,9 & 19 \\
\hline $\mathrm{C}_{2} \mathrm{H}_{6}$ & ${ }^{1} J_{\mathrm{CC}}$ & 26,5 & 29,0 & 31,6 & 34,3 & 37,0 & 39,7 & 42,6 & 45,4 & 48,4 & 51,4 & 54,4 & 34,5 \\
\hline $\mathrm{C}_{2} \mathrm{H}_{6}$ & ${ }^{1} J_{\mathrm{CH}}$ & 116,0 & 119,0 & 122,0 & 125,0 & 128,0 & 131,1 & 134,2 & 137,4 & 140,5 & 143,7 & 147,0 & 125,2 \\
\hline $\mathrm{C}_{2} \mathrm{H}_{6}$ & ${ }^{2} J_{\mathrm{CH}}$ & $-3,1$ & $-3,5$ & $-3,9$ & $-4,3$ & $-4,7$ & $-5,2$ & $-5,6$ & $-6,1$ & $-6,6$ & $-7,0$ & $-7,5$ & $-4,7$ \\
\hline \multirow[t]{3}{*}{ Total } & $\mathrm{DM}$ & $-18,43$ & $-15,51$ & $-12,43$ & $-9,28$ & $-6,13$ & $-3,13$ & $-0,36$ & 1,88 & 3,00 & 1,50 & $-8,92$ & - \\
\hline & DMA & 27,22 & 21,53 & 16,87 & 15,12 & 14,29 & 15,70 & 21,14 & 27,32 & 34,83 & 46,46 & 68,67 & - \\
\hline & PDMA & 46,19 & 33,74 & 23,62 & 19,39 & 18,04 & 23,74 & 38,34 & 54,19 & 71,90 & 92,04 & 118,03 & - \\
\hline \multirow[t]{3}{*}{ CPI } & DM & $-42,08$ & $-37,29$ & $-32,22$ & $-27,09$ & $-22,11$ & $-17,53$ & $-13,74$ & $-11,39$ & $-11,92$ & $-19,00$ & $-47,66$ & - \\
\hline & DMA & 57,74 & 45,56 & 34,67 & 29,76 & 25,31 & 25,42 & 34,75 & 45,50 & 58,92 & 81,53 & 128,26 & - \\
\hline & PDMA & 88,63 & 66,97 & 46,22 & 31,08 & 18,29 & 18,33 & 38,37 & 58,64 & 79,70 & 102,73 & 132,83 & - \\
\hline \multirow[t]{3}{*}{ SPI } & DM & $-1,09$ & 0,46 & 2,09 & 3,79 & 5,58 & 7,43 & 9,45 & 11,61 & 13,93 & 16,53 & 19,49 & - \\
\hline & DMA & 4,84 & 3,90 & 3,81 & 4,37 & 6,21 & 8,58 & 11,16 & 13,99 & 17,16 & 20,75 & 24,97 & - \\
\hline & PDMA & 15,07 & 9,37 & 7,05 & 10,82 & 17,86 & 27,71 & 38,32 & 50,93 & 66,18 & 84,21 & 107,17 & - \\
\hline \multirow[t]{3}{*}{$\Delta \mathrm{CS}$} & DM & $-40,99$ & $-37,75$ & $-34,30$ & $-30,88$ & $-27,69$ & $-24,96$ & $-23,19$ & $-23,00$ & $-25,85$ & $-35,53$ & $-67,15$ & - \\
\hline & DMA & 52,90 & 41,66 & 30,87 & 25,39 & 19,10 & 16,84 & 23,59 & 31,51 & 41,76 & 60,78 & 103,30 & - \\
\hline & PDMA & 73,56 & 57,60 & 39,17 & 20,26 & 0,42 & $-9,38$ & 0,05 & 7,71 & 13,52 & 18,52 & 25,65 & - \\
\hline \multicolumn{14}{|c|}{ Desconsiderando ${ }^{1} J_{\mathrm{BF}}$ da molécula de $\mathrm{BF}_{3},{ }^{2} J_{\mathrm{CH}}$ e ${ }^{2} J_{\mathrm{HH}}$ da molécula de $\mathrm{C}_{2} \mathrm{H}_{4}$} \\
\hline \multirow[t]{3}{*}{ Total } & DM & $-16,50$ & $-14,14$ & $-11,57$ & $-8,90$ & $-6,19$ & $-3,60$ & $-1,24$ & 0,55 & 1,14 & $-1,16$ & $-13,48$ & - \\
\hline & DMA & 26,23 & 20,86 & 16,59 & 15,50 & 15,40 & 17,18 & 22,37 & 28,39 & 35,90 & 48,07 & 72,17 & - \\
\hline & PDMA & 18,38 & 13,57 & 9,42 & 8,23 & 9,54 & 14,08 & 20,74 & 28,05 & 36,35 & 46,10 & 60,22 & - \\
\hline \multirow[t]{3}{*}{ CPI } & DM & $-36,08$ & $-33,12$ & $-29,79$ & $-26,34$ & $-22,98$ & $-20,01$ & $-17,84$ & $-17,21$ & $-19,68$ & $-29,30$ & $-62,61$ & - \\
\hline & DMA & 53,30 & 42,22 & 32,49 & 29,28 & 26,50 & 27,23 & 35,50 & 45,37 & 58,24 & 81,28 & 130,91 & - \\
\hline & PDMA & 29,43 & 21,00 & 13,17 & 11,12 & 11,18 & 15,30 & 24,01 & 33,31 & 43,87 & 57,00 & 78,24 & - \\
\hline \multirow[t]{3}{*}{ SPI } & DM & $-1,44$ & 0,46 & 2,45 & 4,52 & 6,73 & 9,02 & 11,52 & 14,22 & 17,16 & 20,48 & 24,32 & - \\
\hline & DMA & 5,41 & 4,43 & 4,35 & 4,89 & 6,87 & 9,45 & 12,26 & 15,32 & 18,72 & 22,53 & 26,98 & - \\
\hline & PDMA & 9,88 & 7,86 & 6,53 & 6,01 & 8,28 & 13,13 & 18,23 & 24,01 & 30,56 & 37,72 & 46,35 & - \\
\hline \multirow[t]{3}{*}{$\Delta \mathrm{CS}$} & $\mathrm{DM}$ & $-34,64$ & $-33,58$ & $-32,24$ & $-30,86$ & $-29,71$ & $-29,03$ & $-29,36$ & $-31,43$ & $-36,84$ & $-49,78$ & $-86,93$ & - \\
\hline & DMA & 47,89 & 37,79 & 28,14 & 24,39 & 19,63 & 17,78 & 23,24 & 30,05 & 39,52 & 58,75 & 103,93 & - \\
\hline & PDMA & 19,55 & 13,14 & 6,64 & 5,12 & 2,90 & 2,17 & 5,78 & 9,30 & 13,31 & 19,28 & 31,89 & - \\
\hline
\end{tabular}


Tabela 8.231: Constantes de acoplamento OB972 com base aug-pcJ-2.

\begin{tabular}{|c|c|c|c|c|c|c|c|c|c|c|c|c|c|}
\hline & $\% E_{X}^{\mathrm{HF}}$ & $0 \%$ & $10 \%$ & $20 \%$ & $30 \%$ & $40 \%$ & $50 \%$ & $60 \%$ & $70 \%$ & $80 \%$ & $90 \%$ & $100 \%$ & Exp. \\
\hline $\mathrm{HF}$ & ${ }^{1} J_{\mathrm{HF}}$ & 414,7 & 441,2 & 468,1 & 495,2 & 522,5 & 550,1 & 578,0 & 606,1 & 634,4 & 662,9 & 691,6 & 500 \\
\hline $\mathrm{CO}$ & ${ }^{1} J_{\mathrm{CO}}$ & 20,4 & 18,0 & 15,5 & 12,8 & 10,0 & 7,1 & 4,2 & 1,1 & $-1,9$ & $-5,1$ & $-8,3$ & 16,4 \\
\hline $\mathrm{H}_{2} \mathrm{O}$ & ${ }^{1} J_{\mathrm{OH}}$ & $-70,5$ & $-73,6$ & $-76,8$ & $-79,9$ & $-83,2$ & $-86,4$ & $-89,7$ & $-93,0$ & $-96,3$ & $-99,7$ & $-103,1$ & $-80,6$ \\
\hline $\mathrm{H}_{2} \mathrm{O}$ & ${ }^{2} J_{\mathrm{HH}}$ & $-5,6$ & $-6,4$ & $-7,2$ & $-8,0$ & $-8,9$ & $-9,8$ & $-10,6$ & $-11,5$ & $-12,5$ & $-13,4$ & $-14,3$ & $-7,3$ \\
\hline $\mathrm{NH}_{3}$ & ${ }^{1} J_{\mathrm{NH}}$ & 40,8 & 42,0 & 43,2 & 44,4 & 45,6 & 46,8 & 48,0 & 49,3 & 50,5 & 51,8 & 53,1 & 43,8 \\
\hline $\mathrm{NH}_{3}$ & ${ }^{2} J_{\mathrm{HH}}$ & $-7,3$ & $-8,0$ & $-8,8$ & $-9,5$ & $-10,3$ & $-11,1$ & $-11,9$ & $-12,7$ & $-13,5$ & $-14,4$ & $-15,2$ & $-9,6$ \\
\hline $\mathrm{PH}_{3}$ & ${ }^{1} J_{\mathrm{PH}}$ & 164,6 & 173,0 & 181,3 & 189,5 & 197,5 & 205,4 & 213,1 & 220,7 & 228,2 & 235,4 & 242,5 & 188,2 \\
\hline $\mathrm{PF}_{3}$ & ${ }^{1} J_{\mathrm{PF}}$ & $-1697,9$ & $-1680,5$ & $-1659,3$ & $-1635,0$ & $-1608,4$ & $-1579,9$ & $-1550,1$ & $-1519,3$ & $-1488,0$ & $-1456,5$ & $-1424,9$ & -1441 \\
\hline $\mathrm{BHF}_{2}$ & ${ }^{1} J_{\mathrm{BF}}$ & $-160,8$ & $-140,1$ & $-120,0$ & $-100,4$ & $-81,4$ & $-63,0$ & $-45,1$ & $-27,9$ & $-11,2$ & 4,7 & 20,3 & -84 \\
\hline $\mathrm{BF}_{3}$ & ${ }^{1} J_{\mathrm{BF}}$ & $-70,1$ & $-47,1$ & $-24,7$ & $-3,0$ & 18,0 & 38,4 & 58,2 & 77,4 & 96,0 & 114,1 & 131,6 & 15 \\
\hline $\mathrm{F}_{2} \mathrm{O}$ & ${ }^{1} J_{\mathrm{OF}}$ & $-231,2$ & $-264,7$ & $-298,2$ & $-332,9$ & $-370,6$ & $-413,6$ & $-466,0$ & $-535,6$ & $-639,6$ & $-828,6$ & $-1349,0$ & -300 \\
\hline $\mathrm{CH}_{4}$ & ${ }^{1} J_{\mathrm{CH}}$ & 117,6 & 120,3 & 123,1 & 125,9 & 128,8 & 131,6 & 134,6 & 137,5 & 140,5 & 143,5 & 146,5 & 125,3 \\
\hline $\mathrm{CH}_{4}$ & ${ }^{2} J_{\mathrm{HH}}$ & $-9,7$ & $-10,3$ & $-10,9$ & $-11,5$ & $-12,1$ & $-12,7$ & $-13,3$ & $-13,8$ & $-14,4$ & $-15,0$ & $-15,6$ & $-12,8$ \\
\hline $\mathrm{C}_{2} \mathrm{H}_{2}$ & ${ }^{1} J_{\mathrm{CC}}$ & 194,7 & 199,7 & 205,0 & 210,8 & 217,1 & 224,2 & 231,9 & 240,6 & 250,4 & 261,5 & 274,3 & 174,8 \\
\hline $\mathrm{C}_{2} \mathrm{H}_{2}$ & ${ }^{1} J_{\mathrm{CH}}$ & 243,9 & 248,1 & 252,4 & 256,8 & 261,4 & 266,1 & 271,0 & 276,2 & 281,8 & 287,7 & 294,1 & 247,6 \\
\hline $\mathrm{C}_{2} \mathrm{H}_{2}$ & ${ }^{2} J_{\mathrm{CH}}$ & 50,7 & 50,8 & 50,7 & 50,5 & 50,1 & 49,5 & 48,7 & 47,5 & 46,0 & 44,1 & 41,6 & 50,1 \\
\hline $\mathrm{C}_{2} \mathrm{H}_{2}$ & ${ }^{3} J_{\mathrm{HH}}$ & 9,3 & 9,7 & 10,1 & 10,7 & 11,3 & 12,0 & 12,9 & 13,9 & 15,0 & 16,4 & 18,0 & 9,6 \\
\hline $\mathrm{C}_{2} \mathrm{H}_{4}$ & ${ }^{1} J_{\mathrm{CC}}$ & 65,6 & 69,6 & 73,8 & 78,4 & 83,5 & 89,2 & 95,6 & 103,1 & 112,0 & 122,9 & 137,0 & 67,6 \\
\hline $\mathrm{C}_{2} \mathrm{H}_{4}$ & ${ }^{1} J_{\mathrm{CH}}$ & 149,7 & 153,1 & 156,7 & 160,4 & 164,2 & 168,1 & 172,3 & 176,9 & 181,8 & 187,4 & 194,0 & 156,3 \\
\hline $\mathrm{C}_{2} \mathrm{H}_{4}$ & ${ }^{2} J_{\mathrm{CH}}$ & $-0,4$ & $-1,2$ & $-2,1$ & $-3,2$ & $-4,3$ & $-5,6$ & $-7,2$ & $-9,0$ & $-11,3$ & $-14,2$ & $-18,1$ & $-2,4$ \\
\hline $\mathrm{C}_{2} \mathrm{H}_{4}$ & ${ }^{2} J_{\mathrm{HH}}$ & 4,5 & 4,1 & 3,6 & 3,1 & 2,6 & 2,0 & 1,3 & 0,5 & $-0,3$ & $-1,4$ & $-2,9$ & 2,3 \\
\hline $\mathrm{C}_{2} \mathrm{H}_{4}$ & ${ }^{3} J_{\mathrm{HH}_{\mathrm{c}}}$ & 10,5 & 10,7 & 11,0 & 11,4 & 11,7 & 12,2 & 12,7 & 13,4 & 14,2 & 15,2 & 16,6 & 11,7 \\
\hline $\mathrm{C}_{2} \mathrm{H}_{4}$ & ${ }^{3} J_{\mathrm{HH}_{\mathrm{t}}}$ & 17,0 & 17,2 & 17,6 & 18,0 & 18,4 & 19,0 & 19,6 & 20,4 & 21,4 & 22,7 & 24,4 & 19 \\
\hline $\mathrm{C}_{2} \mathrm{H}_{6}$ & ${ }^{1} J_{\mathrm{CC}}$ & 29,0 & 31,5 & 34,1 & 36,7 & 39,4 & 42,1 & 44,8 & 47,7 & 50,5 & 53,5 & 56,4 & 34,5 \\
\hline $\mathrm{C}_{2} \mathrm{H}_{6}$ & ${ }^{1} J_{\mathrm{CH}}$ & 117,3 & 120,2 & 123,1 & 126,0 & 129,0 & 132,0 & 135,0 & 138,1 & 141,2 & 144,3 & 147,5 & 125,2 \\
\hline $\mathrm{C}_{2} \mathrm{H}_{6}$ & ${ }^{2} J_{\mathrm{CH}}$ & $-2,5$ & $-2,8$ & $-3,2$ & $-3,6$ & $-4,0$ & $-4,4$ & $-4,8$ & $-5,2$ & $-5,7$ & $-6,1$ & $-6,5$ & $-4,7$ \\
\hline \multirow[t]{3}{*}{ Total } & $\mathrm{DM}$ & $-17,33$ & $-14,25$ & $-11,03$ & $-7,75$ & $-4,50$ & $-1,37$ & 1,47 & 3,75 & 4,78 & 2,64 & $-12,05$ & - \\
\hline & DMA & 26,33 & 20,56 & 15,20 & 13,22 & 14,87 & 19,83 & 25,30 & 31,55 & 39,23 & 50,39 & 75,85 & - \\
\hline & PDMA & 43,99 & 31,74 & 20,13 & 14,33 & 13,66 & 25,39 & 39,53 & 55,12 & 72,15 & 92,00 & 118,82 & - \\
\hline \multirow[t]{3}{*}{ CPI } & $\mathrm{DM}$ & $-40,35$ & $-35,19$ & $-29,80$ & $-24,34$ & $-19,10$ & $-14,26$ & $-10,25$ & $-7,85$ & $-8,62$ & $-17,25$ & $-56,05$ & - \\
\hline & DMA & 56,15 & 43,63 & 30,98 & 24,83 & 26,23 & 35,12 & 44,65 & 55,59 & 69,51 & 91,05 & 145,55 & - \\
\hline & PDMA & 74,56 & 52,78 & 32,24 & 18,22 & 13,02 & 33,48 & 53,68 & 74,21 & 95,41 & 118,89 & 152,13 & - \\
\hline \multirow[t]{3}{*}{ SPI } & DM & $-0,46$ & 1,11 & 2,73 & 4,42 & 6,20 & 8,08 & 10,07 & 12,25 & 14,60 & 17,23 & 20,21 & - \\
\hline & DMA & 4,46 & 3,64 & 3,63 & 4,70 & 6,53 & 8,63 & 11,11 & 13,91 & 17,03 & 20,57 & 24,75 & - \\
\hline & PDMA & 21,57 & 16,32 & 11,25 & 11,48 & 14,12 & 19,45 & 29,15 & 41,12 & 55,10 & 72,27 & 94,39 & - \\
\hline \multirow[t]{3}{*}{$\Delta \mathrm{CS}$} & $\mathrm{DM}$ & $-39,89$ & $-36,30$ & $-32,53$ & $-28,76$ & $-25,30$ & $-22,34$ & $-20,32$ & $-20,09$ & $-23,22$ & $-34,47$ & $-76,27$ & - \\
\hline & DMA & 51,69 & 39,99 & 27,35 & 20,13 & 19,69 & 26,49 & 33,55 & 41,68 & 52,48 & 70,47 & 120,80 & - \\
\hline & PDMA & 52,99 & 36,46 & 20,98 & 6,74 & $-1,10$ & 14,03 & 24,53 & 33,09 & 40,31 & 46,62 & 57,74 & - \\
\hline \multicolumn{14}{|c|}{ Desconsiderando ${ }^{1} J_{\mathrm{BF}}$ da molécula de $\mathrm{BF}_{3},{ }^{2} J_{\mathrm{CH}}$ e ${ }^{2} J_{\mathrm{HH}}$ da molécula de $\mathrm{C}_{2} \mathrm{H}_{4}$} \\
\hline \multirow[t]{3}{*}{ Total } & DM & $-16,08$ & $-13,54$ & $-10,82$ & $-7,97$ & $-5,15$ & $-2,42$ & 0,03 & 1,89 & 2,38 & $-0,65$ & $-17,79$ & - \\
\hline & DMA & 25,88 & 20,41 & 15,39 & 14,09 & 16,58 & 21,25 & 26,47 & 32,58 & 40,33 & 51,98 & 79,77 & - \\
\hline & PDMA & 17,28 & 12,31 & 8,25 & 8,02 & 10,56 & 15,55 & 21,58 & 28,86 & 37,05 & 46,90 & 62,25 & - \\
\hline \multirow[t]{3}{*}{ CPI } & $\mathrm{DM}$ & $-35,87$ & $-32,50$ & $-28,81$ & $-24,97$ & $-21,31$ & $-18,03$ & $-15,60$ & $-14,87$ & $-17,58$ & $-28,88$ & $-73,32$ & - \\
\hline & DMA & 53,25 & 41,78 & 30,11 & 25,51 & 28,55 & 36,29 & 44,80 & 54,91 & 68,36 & 90,24 & 148,44 & - \\
\hline & PDMA & 25,28 & 16,66 & 8,99 & 8,04 & 12,33 & 21,23 & 30,25 & 40,03 & 50,95 & 64,72 & 89,61 & - \\
\hline \multirow[t]{3}{*}{ SPI } & DM & $-0,85$ & 1,05 & 3,02 & 5,10 & 7,28 & 9,59 & 12,06 & 14,78 & 17,73 & 21,07 & 24,93 & - \\
\hline & DMA & 4,82 & 3,97 & 4,07 & 5,30 & 7,37 & 9,68 & 12,37 & 15,41 & 18,76 & 22,55 & 26,95 & - \\
\hline & PDMA & 11,12 & 8,97 & 7,67 & 8,00 & 9,20 & 11,18 & 14,91 & 20,27 & 26,35 & 33,19 & 41,20 & - \\
\hline \multirow[t]{3}{*}{$\Delta \mathrm{CS}$} & $\mathrm{DM}$ & $-35,02$ & $-33,55$ & $-31,83$ & $-30,07$ & $-28,59$ & $-27,62$ & $-27,66$ & $-29,65$ & $-35,31$ & $-49,95$ & $-98,25$ & - \\
\hline & DMA & 48,43 & 37,81 & 26,04 & 20,21 & 21,18 & 26,61 & 32,43 & 39,50 & 49,60 & 67,69 & 121,49 & - \\
\hline & PDMA & 14,16 & 7,69 & 1,32 & 0,04 & 3,13 & 10,05 & 15,34 & 19,76 & 24,60 & 31,52 & 48,41 & - \\
\hline
\end{tabular}


Tabela 8.232: Constantes de acoplamento OB98 com base aug-pcJ-2.

\begin{tabular}{|c|c|c|c|c|c|c|c|c|c|c|c|c|c|}
\hline & $\% E_{X}^{\mathrm{HF}}$ & $0 \%$ & $10 \%$ & $20 \%$ & $30 \%$ & $40 \%$ & $50 \%$ & $60 \%$ & $70 \%$ & $80 \%$ & $90 \%$ & $100 \%$ & Exp. \\
\hline $\mathrm{HF}$ & ${ }^{1} J_{\mathrm{HF}}$ & 364,1 & 389,7 & 415,6 & 441,8 & 468,4 & 495,2 & 522,3 & 549,6 & 577,2 & 605,1 & 633,1 & 500 \\
\hline $\mathrm{CO}$ & ${ }^{1} J_{\mathrm{CO}}$ & 24,0 & 21,9 & 19,7 & 17,3 & 14,9 & 12,3 & 9,7 & 7,0 & 4,2 & 1,4 & $-1,4$ & 16,4 \\
\hline $\mathrm{H}_{2} \mathrm{O}$ & ${ }^{1} J_{\mathrm{OH}}$ & $-64,1$ & $-67,1$ & $-70,1$ & $-73,2$ & $-76,2$ & $-79,4$ & $-82,5$ & $-85,7$ & $-89,0$ & $-92,2$ & $-95,6$ & $-80,6$ \\
\hline $\mathrm{H}_{2} \mathrm{O}$ & ${ }^{2} J_{\mathrm{HH}}$ & $-5,9$ & $-6,7$ & $-7,5$ & $-8,3$ & $-9,2$ & $-10,1$ & $-10,9$ & $-11,8$ & $-12,7$ & $-13,7$ & $-14,6$ & $-7,3$ \\
\hline $\mathrm{NH}_{3}$ & ${ }^{1} J_{\mathrm{NH}}$ & 39,1 & 40,3 & 41,4 & 42,6 & 43,8 & 45,1 & 46,3 & 47,6 & 48,9 & 50,2 & 51,5 & 43,8 \\
\hline $\mathrm{NH}_{3}$ & ${ }^{2} J_{\mathrm{HH}}$ & $-8,4$ & $-9,1$ & $-9,9$ & $-10,7$ & $-11,5$ & $-12,3$ & $-13,2$ & $-14,0$ & $-14,9$ & $-15,8$ & $-16,8$ & $-9,6$ \\
\hline $\mathrm{PH}_{3}$ & ${ }^{1} J_{\mathrm{PH}}$ & 179,5 & 187,1 & 194,6 & 201,9 & 209,0 & 215,9 & 222,7 & 229,2 & 235,6 & 241,8 & 247,9 & 188,2 \\
\hline $\mathrm{PF}_{3}$ & ${ }^{1} J_{\mathrm{PF}}$ & $-1668,2$ & $-1651,8$ & $-1631,7$ & $-1608,5$ & $-1582,9$ & $-1555,4$ & $-1526,6$ & $-1496,7$ & $-1466,2$ & $-1435,4$ & $-1404,5$ & -1441 \\
\hline $\mathrm{BHF}_{2}$ & ${ }^{1} J_{\mathrm{BF}}$ & $-176,0$ & $-155,5$ & $-135,4$ & $-115,8$ & $-96,6$ & $-78,1$ & $-60,1$ & $-42,6$ & $-25,8$ & $-9,4$ & 6,2 & -84 \\
\hline $\mathrm{BF}_{3}$ & ${ }^{1} J_{\mathrm{BF}}$ & $-88,5$ & $-65,7$ & $-43,3$ & $-21,6$ & $-0,5$ & 19,9 & 39,8 & 59,2 & 77,9 & 96,1 & 113,8 & 15 \\
\hline $\mathrm{F}_{2} \mathrm{O}$ & ${ }^{1} J_{\mathrm{OF}}$ & $-249,4$ & $-284,3$ & $-319,5$ & $-356,4$ & $-396,8$ & $-443,4$ & $-500,7$ & $-577,5$ & $-693,7$ & $-907,1$ & $-1507,1$ & -300 \\
\hline $\mathrm{CH}_{4}$ & ${ }^{1} J_{\mathrm{CH}}$ & 118,8 & 121,7 & 124,7 & 127,6 & 130,6 & 133,7 & 136,8 & 139,9 & 143,1 & 146,3 & 149,5 & 125,3 \\
\hline $\mathrm{CH}_{4}$ & ${ }^{2} J_{\mathrm{HH}}$ & $-11,6$ & $-12,3$ & $-12,9$ & $-13,6$ & $-14,2$ & $-14,9$ & $-15,5$ & $-16,2$ & $-16,8$ & $-17,5$ & $-18,1$ & $-12,8$ \\
\hline $\mathrm{C}_{2} \mathrm{H}_{2}$ & ${ }^{1} J_{\mathrm{CC}}$ & 200,0 & 205,0 & 210,3 & 216,1 & 222,6 & 229,7 & 237,6 & 246,6 & 256,7 & 268,4 & 282,1 & 174,8 \\
\hline $\mathrm{C}_{2} \mathrm{H}_{2}$ & ${ }^{1} J_{\mathrm{CH}}$ & 247,8 & 252,3 & 256,9 & 261,6 & 266,6 & 271,7 & 277,2 & 282,9 & 289,2 & 295,9 & 303,3 & 247,6 \\
\hline $\mathrm{C}_{2} \mathrm{H}_{2}$ & ${ }^{2} J_{\mathrm{CH}}$ & 51,0 & 51,1 & 51,0 & 50,7 & 50,2 & 49,4 & 48,3 & 46,9 & 44,9 & 42,5 & 39,3 & 50,1 \\
\hline $\mathrm{C}_{2} \mathrm{H}_{2}$ & ${ }^{3} J_{\mathrm{HH}}$ & 10,2 & 10,7 & 11,3 & 12,0 & 12,8 & 13,7 & 14,8 & 16,2 & 17,7 & 19,5 & 21,7 & 9,6 \\
\hline $\mathrm{C}_{2} \mathrm{H}_{4}$ & ${ }^{1} J_{\mathrm{CC}}$ & 68,0 & 71,9 & 76,1 & 80,6 & 85,6 & 91,2 & 97,5 & 104,8 & 113,5 & 124,3 & 138,3 & 67,6 \\
\hline $\mathrm{C}_{2} \mathrm{H}_{4}$ & ${ }^{1} J_{\mathrm{CH}}$ & 151,9 & 155,5 & 159,3 & 163,1 & 167,2 & 171,4 & 175,9 & 180,8 & 186,2 & 192,3 & 199,6 & 156,3 \\
\hline $\mathrm{C}_{2} \mathrm{H}_{4}$ & ${ }^{2} J_{\mathrm{CH}}$ & $-1,3$ & $-2,2$ & $-3,1$ & $-4,2$ & $-5,5$ & $-6,9$ & $-8,6$ & $-10,6$ & $-13,1$ & $-16,4$ & $-20,9$ & $-2,4$ \\
\hline $\mathrm{C}_{2} \mathrm{H}_{4}$ & ${ }^{2} J_{\mathrm{HH}}$ & 3,2 & 2,7 & 2,2 & 1,6 & 0,9 & 0,2 & $-0,5$ & $-1,5$ & $-2,7$ & $-4,2$ & $-6,2$ & 2,3 \\
\hline $\mathrm{C}_{2} \mathrm{H}_{4}$ & ${ }^{3} J_{\mathrm{HH}_{\mathrm{c}}}$ & 11,0 & 11,4 & 11,8 & 12,2 & 12,7 & 13,2 & 13,9 & 14,8 & 15,9 & 17,3 & 19,2 & 11,7 \\
\hline $\mathrm{C}_{2} \mathrm{H}_{4}$ & ${ }^{3} J_{\mathrm{HH}_{\mathrm{t}}}$ & 17,7 & 18,1 & 18,5 & 19,0 & 19,6 & 20,3 & 21,1 & 22,2 & 23,5 & 25,2 & 27,5 & 19 \\
\hline $\mathrm{C}_{2} \mathrm{H}_{6}$ & ${ }^{1} J_{\mathrm{CC}}$ & 28,0 & 30,6 & 33,3 & 36,0 & 38,9 & 41,7 & 44,7 & 47,7 & 50,8 & 53,9 & 57,1 & 34,5 \\
\hline $\mathrm{C}_{2} \mathrm{H}_{6}$ & ${ }^{1} J_{\mathrm{CH}}$ & 119,3 & 122,4 & 125,4 & 128,6 & 131,7 & 134,9 & 138,1 & 141,4 & 144,7 & 148,0 & 151,4 & 125,2 \\
\hline $\mathrm{C}_{2} \mathrm{H}_{6}$ & ${ }^{2} J_{\mathrm{CH}}$ & $-3,3$ & $-3,7$ & $-4,1$ & $-4,5$ & $-5,0$ & $-5,4$ & $-5,9$ & $-6,4$ & $-6,9$ & $-7,4$ & $-7,9$ & $-4,7$ \\
\hline \multirow[t]{3}{*}{ Total } & $\mathrm{DM}$ & $-18,77$ & $-15,81$ & $-12,71$ & $-9,58$ & $-6,46$ & $-3,52$ & $-0,88$ & 1,11 & 1,66 & $-1,38$ & $-19,10$ & - \\
\hline & DMA & 27,17 & 21,90 & 18,86 & 17,89 & 17,38 & 18,20 & 23,49 & 30,10 & 38,38 & 51,07 & 80,95 & - \\
\hline & PDMA & 44,80 & 32,75 & 24,89 & 22,38 & 22,37 & 27,00 & 42,04 & 58,80 & 77,35 & 99,40 & 129,89 & - \\
\hline \multirow[t]{3}{*}{ CPI } & $\mathrm{DM}$ & $-44,97$ & $-40,19$ & $-35,18$ & $-30,16$ & $-25,32$ & $-21,02$ & $-17,65$ & $-16,05$ & $-18,13$ & $-29,08$ & $-75,31$ & - \\
\hline & DMA & 59,03 & 46,70 & 38,85 & 34,16 & 29,90 & 28,47 & 37,28 & 48,78 & 63,73 & 88,43 & 152,76 & - \\
\hline & PDMA & 88,47 & 67,03 & 48,58 & 33,98 & 21,66 & 18,82 & 38,65 & 59,26 & 80,71 & 104,95 & 140,82 & - \\
\hline \multirow[t]{3}{*}{ SPI } & DM & 0,44 & 2,07 & 3,77 & 5,51 & 7,37 & 9,32 & 11,42 & 13,69 & 16,17 & 18,93 & 22,12 & - \\
\hline & DMA & 3,81 & 3,71 & 4,20 & 5,95 & 8,20 & 10,67 & 13,38 & 16,40 & 19,79 & 23,67 & 28,29 & - \\
\hline & PDMA & 12,78 & 7,61 & 7,52 & 13,88 & 22,89 & 32,99 & 44,53 & 58,47 & 74,89 & 95,34 & 121,88 & - \\
\hline \multirow[t]{3}{*}{$\Delta \mathrm{CS}$} & $\mathrm{DM}$ & $-45,41$ & $-42,26$ & $-38,96$ & $-35,68$ & $-32,69$ & $-30,34$ & $-29,07$ & $-29,75$ & $-34,30$ & $-48,02$ & $-97,43$ & - \\
\hline & DMA & 55,21 & 42,99 & 34,65 & 28,21 & 21,70 & 17,81 & 23,90 & 32,38 & 43,94 & 64,76 & 124,47 & - \\
\hline & PDMA & 75,69 & 59,42 & 41,06 & 20,10 & $-1,23$ & $-14,17$ & $-5,88$ & 0,79 & 5,83 & 9,61 & 18,94 & - \\
\hline \multicolumn{14}{|c|}{ Desconsiderando ${ }^{1} J_{\mathrm{BF}}$ da molécula de $\mathrm{BF}_{3},{ }^{2} J_{\mathrm{CH}}$ e ${ }^{2} J_{\mathrm{HH}}$ da molécula de $\mathrm{C}_{2} \mathrm{H}_{4}$} \\
\hline \multirow[t]{3}{*}{ Total } & DM & $-16,81$ & $-14,39$ & $-11,80$ & $-9,13$ & $-6,43$ & $-3,90$ & $-1,68$ & $-0,15$ & $-0,17$ & $-4,20$ & $-24,71$ & - \\
\hline & DMA & 26,13 & 21,22 & 18,75 & 18,52 & 18,78 & 20,07 & 25,09 & 31,58 & 39,97 & 53,31 & 86,04 & - \\
\hline & PDMA & 16,95 & 12,51 & 9,78 & 10,11 & 12,53 & 16,98 & 23,82 & 31,62 & 40,38 & 51,21 & 68,62 & - \\
\hline \multirow[t]{3}{*}{ CPI } & $\mathrm{DM}$ & $-39,12$ & $-36,14$ & $-32,87$ & $-29,52$ & $-26,30$ & $-23,61$ & $-21,89$ & $-22,08$ & $-26,23$ & $-40,10$ & $-92,72$ & - \\
\hline & DMA & 54,58 & 43,30 & 36,91 & 33,92 & 31,34 & 30,83 & 38,53 & 49,24 & 63,81 & 89,16 & 158,16 & - \\
\hline & PDMA & 28,32 & 19,93 & 14,57 & 12,98 & 13,49 & 17,44 & 25,98 & 35,72 & 46,85 & 61,38 & 89,03 & - \\
\hline \multirow[t]{3}{*}{ SPI } & DM & 0,35 & 2,35 & 4,42 & 6,55 & 8,85 & 11,26 & 13,87 & 16,72 & 19,87 & 23,42 & 27,60 & - \\
\hline & DMA & 4,25 & 4,24 & 4,78 & 6,68 & 9,12 & 11,80 & 14,75 & 18,00 & 21,62 & 25,73 & 30,57 & - \\
\hline & PDMA & 8,21 & 6,80 & 6,09 & 7,90 & 11,80 & 16,62 & 22,15 & 28,47 & 35,39 & 43,39 & 52,91 & - \\
\hline \multirow[t]{3}{*}{$\Delta \mathrm{CS}$} & $\mathrm{DM}$ & $-39,47$ & $-38,49$ & $-37,29$ & $-36,07$ & $-35,15$ & $-34,87$ & $-35,76$ & $-38,80$ & $-46,10$ & $-63,52$ & $-120,32$ & - \\
\hline & DMA & 50,33 & 39,06 & 32,13 & 27,24 & 22,22 & 19,03 & 23,78 & 31,24 & 42,19 & 63,43 & 127,59 & - \\
\hline & PDMA & 20,11 & 13,13 & 8,48 & 5,07 & 1,69 & 0,81 & 3,83 & 7,25 & 11,46 & 17,98 & 36,12 & - \\
\hline
\end{tabular}


8.4. GERAÇÃO DE NOVOS FUNCIONAIS COMBINANDO $E_{X}^{H F}, E_{X}^{D F T} E$

Tabela 8.233: Constantes de acoplamento OLYP com base aug-pcJ-2.

\begin{tabular}{|c|c|c|c|c|c|c|c|c|c|c|c|c|c|}
\hline & $\% E_{X}^{\mathrm{HF}}$ & $0 \%$ & $10 \%$ & $20 \%$ & $30 \%$ & $40 \%$ & $50 \%$ & $60 \%$ & $70 \%$ & $80 \%$ & $90 \%$ & $100 \%$ & Exp. \\
\hline $\mathrm{HF}$ & ${ }^{1} J_{\mathrm{HF}}$ & 363,4 & 391,6 & 420,1 & 449,1 & 478,5 & 508,2 & 538,4 & 568,9 & 599,7 & 630,9 & 662,5 & 500 \\
\hline $\mathrm{CO}$ & ${ }^{1} J_{\mathrm{CO}}$ & 24,0 & 21,8 & 19,5 & 17,1 & 14,6 & 12,0 & 9,4 & 6,6 & 3,8 & 0,9 & $-1,9$ & 16,4 \\
\hline $\mathrm{H}_{2} \mathrm{O}$ & ${ }^{1} J_{\mathrm{OH}}$ & $-66,1$ & $-69,4$ & $-72,7$ & $-76,1$ & $-79,5$ & $-83,0$ & $-86,5$ & $-90,1$ & $-93,7$ & $-97,3$ & $-101,1$ & $-80,6$ \\
\hline $\mathrm{H}_{2} \mathrm{O}$ & ${ }^{2} J_{\mathrm{HH}}$ & $-7,4$ & $-8,3$ & $-9,3$ & $-10,2$ & $-11,1$ & $-12,1$ & $-13,1$ & $-14,1$ & $-15,2$ & $-16,2$ & $-17,3$ & $-7,3$ \\
\hline $\mathrm{NH}_{3}$ & ${ }^{1} J_{\mathrm{NH}}$ & 40,2 & 41,5 & 42,7 & 44,0 & 45,3 & 46,6 & 47,9 & 49,3 & 50,6 & 52,0 & 53,4 & 43,8 \\
\hline $\mathrm{NH}_{3}$ & ${ }^{2} J_{\mathrm{HH}}$ & $-9,6$ & $-10,4$ & $-11,3$ & $-12,1$ & $-13,0$ & $-13,9$ & $-14,8$ & $-15,7$ & $-16,7$ & $-17,7$ & $-18,7$ & $-9,6$ \\
\hline $\mathrm{PH}_{3}$ & ${ }^{1} J_{\mathrm{PH}}$ & 158,8 & 167,5 & 176,1 & 184,5 & 192,8 & 201,0 & 209,0 & 216,8 & 224,5 & 231,9 & 239,2 & 188,2 \\
\hline $\mathrm{PF}_{3}$ & ${ }^{1} J_{\mathrm{PF}}$ & $-1702,2$ & $-1685,7$ & $-1665,4$ & $-1642,0$ & $-1616,2$ & $-1588,5$ & $-1559,4$ & $-1529,4$ & $-1498,8$ & $-1467,9$ & $-1437,0$ & -1441 \\
\hline $\mathrm{BHF}_{2}$ & ${ }^{1} J_{\mathrm{BF}}$ & $-181,4$ & $-160,8$ & $-140,7$ & $-121,1$ & $-102,0$ & $-83,5$ & $-65,6$ & $-48,2$ & $-31,4$ & $-15,1$ & 0,6 & -84 \\
\hline $\mathrm{BF}_{3}$ & ${ }^{1} J_{\mathrm{BF}}$ & $-90,5$ & $-67,4$ & $-45,0$ & $-23,1$ & $-1,8$ & 18,8 & 38,9 & 58,4 & 77,4 & 95,8 & 113,8 & 15 \\
\hline $\mathrm{F}_{2} \mathrm{O}$ & ${ }^{1} J_{\mathrm{OF}}$ & $-254,6$ & $-290,9$ & $-327,9$ & $-367,1$ & $-410,6$ & $-461,8$ & $-526,5$ & $-616,5$ & $-760,6$ & $-1056,6$ & $-2253,8$ & -300 \\
\hline $\mathrm{CH}_{4}$ & ${ }^{1} J_{\mathrm{CH}}$ & 118,2 & 121,1 & 124,1 & 127,1 & 130,2 & 133,3 & 136,4 & 139,6 & 142,9 & 146,1 & 149,4 & 125,3 \\
\hline $\mathrm{CH}_{4}$ & ${ }^{2} J_{\mathrm{HH}}$ & $-12,9$ & $-13,5$ & $-14,2$ & $-14,9$ & $-15,6$ & $-16,3$ & $-17,0$ & $-17,7$ & $-18,4$ & $-19,1$ & $-19,7$ & $-12,8$ \\
\hline $\mathrm{C}_{2} \mathrm{H}_{2}$ & ${ }^{1} J_{\mathrm{CC}}$ & 187,4 & 192,0 & 197,1 & 202,6 & 208,8 & 215,7 & 223,5 & 232,3 & 242,5 & 254,4 & 268,4 & 174,8 \\
\hline $\mathrm{C}_{2} \mathrm{H}_{2}$ & ${ }^{1} J_{\mathrm{CH}}$ & 253,4 & 258,1 & 263,0 & 268,0 & 273,2 & 278,7 & 284,6 & 290,9 & 297,7 & 305,1 & 313,5 & 247,6 \\
\hline $\mathrm{C}_{2} \mathrm{H}_{2}$ & ${ }^{2} J_{\mathrm{CH}}$ & 53,0 & 53,0 & 52,8 & 52,4 & 51,7 & 50,7 & 49,3 & 47,6 & 45,2 & 42,1 & 38,1 & 50,1 \\
\hline $\mathrm{C}_{2} \mathrm{H}_{2}$ & ${ }^{3} J_{\mathrm{HH}}$ & 11,6 & 12,2 & 12,9 & 13,7 & 14,7 & 15,9 & 17,3 & 18,9 & 20,9 & 23,2 & 26,0 & 9,6 \\
\hline $\mathrm{C}_{2} \mathrm{H}_{4}$ & ${ }^{1} J_{\mathrm{CC}}$ & 60,8 & 64,6 & 68,7 & 73,2 & 78,2 & 83,9 & 90,5 & 98,4 & 108,1 & 120,9 & 139,0 & 67,6 \\
\hline $\mathrm{C}_{2} \mathrm{H}_{4}$ & ${ }^{1} J_{\mathrm{CH}}$ & 152,7 & 156,5 & 160,4 & 164,4 & 168,6 & 173,1 & 177,9 & 183,2 & 189,3 & 196,5 & 205,7 & 156,3 \\
\hline $\mathrm{C}_{2} \mathrm{H}_{4}$ & ${ }^{2} J_{\mathrm{CH}}$ & $-1,1$ & $-2,0$ & $-3,1$ & $-4,3$ & $-5,6$ & $-7,2$ & $-9,2$ & $-11,6$ & $-14,8$ & $-19,1$ & $-25,4$ & $-2,4$ \\
\hline $\mathrm{C}_{2} \mathrm{H}_{4}$ & ${ }^{2} J_{\mathrm{HH}}$ & 3,4 & 2,8 & 2,2 & 1,5 & 0,8 & 0,0 & $-1,1$ & $-2,3$ & $-3,9$ & $-6,1$ & $-9,3$ & 2,3 \\
\hline $\mathrm{C}_{2} \mathrm{H}_{4}$ & ${ }^{3} J_{\mathrm{HH}_{\mathrm{c}}}$ & 12,2 & 12,6 & 13,1 & 13,6 & 14,2 & 14,9 & 15,8 & 17,0 & 18,5 & 20,6 & 23,7 & 11,7 \\
\hline $\mathrm{C}_{2} \mathrm{H}_{4}$ & ${ }^{3} J_{\mathrm{HH}_{\mathrm{t}}}$ & 19,4 & 19,8 & 20,3 & 21,0 & 21,7 & 22,6 & 23,6 & 25,0 & 26,8 & 29,3 & 32,9 & 19 \\
\hline $\mathrm{C}_{2} \mathrm{H}_{6}$ & ${ }^{1} J_{\mathrm{CC}}$ & 25,4 & 27,9 & 30,4 & 33,0 & 35,6 & 38,4 & 41,1 & 43,9 & 46,8 & 49,7 & 52,7 & 34,5 \\
\hline $\mathrm{C}_{2} \mathrm{H}_{6}$ & ${ }^{1} J_{\mathrm{CH}}$ & 118,4 & 121,5 & 124,6 & 127,8 & 131,0 & 134,2 & 137,5 & 140,8 & 144,1 & 147,5 & 150,9 & 125,2 \\
\hline $\mathrm{C}_{2} \mathrm{H}_{6}$ & ${ }^{2} J_{\mathrm{CH}}$ & $-3,3$ & $-3,7$ & $-4,1$ & $-4,5$ & $-5,0$ & $-5,4$ & $-5,9$ & $-6,4$ & $-6,8$ & $-7,3$ & $-7,8$ & $-4,7$ \\
\hline \multirow[t]{3}{*}{ Total } & DM & $-21,99$ & $-18,95$ & $-15,80$ & $-12,59$ & $-9,44$ & $-6,49$ & $-3,96$ & $-2,28$ & $-2,56$ & $-8,48$ & $-48,74$ & - \\
\hline & DMA & 29,34 & 23,77 & 20,66 & 18,92 & 18,17 & 19,40 & 25,67 & 33,10 & 42,85 & 58,80 & 110,36 & - \\
\hline & PDMA & 45,94 & 35,45 & 28,59 & 26,03 & 26,01 & 30,63 & 47,52 & 65,93 & 87,40 & 114,22 & 158,62 & - \\
\hline \multirow[t]{3}{*}{ CPI } & DM & $-51,48$ & $-46,49$ & $-41,35$ & $-36,17$ & $-31,26$ & $-27,01$ & $-23,93$ & $-23,17$ & $-27,39$ & $-45,47$ & $-145,56$ & - \\
\hline & DMA & 63,75 & 51,16 & 43,35 & 37,15 & 32,57 & 32,12 & 43,13 & 56,30 & 74,26 & 105,93 & 220,20 & - \\
\hline & PDMA & 88,13 & 69,78 & 53,74 & 38,43 & 26,58 & 22,30 & 43,33 & 64,85 & 87,83 & 114,95 & 169,20 & - \\
\hline \multirow[t]{3}{*}{ SPI } & DM & $-0,37$ & 1,25 & 2,94 & 4,70 & 6,56 & 8,56 & 10,68 & 13,03 & 15,65 & 18,65 & 22,27 & - \\
\hline & DMA & 4,10 & 3,68 & 4,02 & 5,54 & 7,60 & 10,07 & 12,87 & 16,09 & 19,81 & 24,25 & 29,81 & - \\
\hline & PDMA & 15,00 & 10,27 & 10,16 & 16,94 & 25,59 & 36,74 & 50,59 & 66,72 & 87,07 & 113,69 & 150,86 & - \\
\hline \multirow[t]{3}{*}{$\Delta \mathrm{CS}$} & DM & $-51,12$ & $-47,74$ & $-44,29$ & $-40,87$ & $-37,82$ & $-35,57$ & $-34,61$ & $-36,21$ & $-43,04$ & $-64,12$ & $-167,83$ & - \\
\hline & DMA & 59,65 & 47,48 & 39,33 & 31,61 & 24,97 & 22,05 & 30,26 & 40,21 & 54,45 & 81,68 & 190,39 & - \\
\hline & PDMA & 73,13 & 59,51 & 43,58 & 21,48 & 1,00 & $-14,44$ & $-7,26$ & $-1,87$ & 0,76 & 1,26 & 18,34 & - \\
\hline \multicolumn{14}{|c|}{ Desconsiderando ${ }^{1} J_{\mathrm{BF}}$ da molécula de $\mathrm{BF}_{3},{ }^{2} J_{\mathrm{CH}}$ e ${ }^{2} J_{\mathrm{HH}}$ da molécula de $\mathrm{C}_{2} \mathrm{H}_{4}$} \\
\hline \multirow[t]{3}{*}{ Total } & DM & $-20,38$ & $-17,87$ & $-15,21$ & $-12,46$ & $-9,74$ & $-7,19$ & $-5,07$ & $-3,87$ & $-4,80$ & $-12,01$ & $-57,89$ & - \\
\hline & DMA & 28,47 & 23,25 & 20,71 & 19,61 & 19,60 & 21,45 & 27,53 & 34,93 & 44,92 & 61,87 & 118,96 & - \\
\hline & PDMA & 16,91 & 14,51 & 13,48 & 13,43 & 15,90 & 20,48 & 28,05 & 36,59 & 46,52 & 59,56 & 87,08 & - \\
\hline \multirow[t]{3}{*}{ CPI } & DM & $-46,08$ & $-42,90$ & $-39,48$ & $-35,98$ & $-32,71$ & $-30,09$ & $-28,71$ & $-29,83$ & $-36,37$ & $-58,10$ & $-170,00$ & - \\
\hline & DMA & 59,58 & 48,04 & 41,68 & 37,06 & 34,15 & 34,95 & 45,05 & 57,59 & 75,45 & 108,44 & 232,34 & - \\
\hline & PDMA & 26,61 & 21,82 & 19,11 & 16,87 & 18,04 & 22,00 & 31,73 & 42,40 & 55,02 & 72,57 & 120,26 & - \\
\hline \multirow[t]{3}{*}{ SPI } & $\mathrm{DM}$ & $-0,61$ & 1,38 & 3,45 & 5,63 & 7,93 & 10,42 & 13,11 & 16,10 & 19,49 & 23,45 & 28,35 & - \\
\hline & DMA & 4,55 & 4,18 & 4,58 & 6,18 & 8,41 & 11,07 & 14,06 & 17,50 & 21,43 & 26,05 & 31,74 & - \\
\hline & PDMA & 9,46 & 8,89 & 9,14 & 10,78 & 14,25 & 19,31 & 25,21 & 32,11 & 39,99 & 49,56 & 61,56 & - \\
\hline \multirow[t]{3}{*}{$\Delta \mathrm{CS}$} & $\mathrm{DM}$ & $-45,47$ & $-44,28$ & $-42,93$ & $-41,61$ & $-40,64$ & $-40,51$ & $-41,82$ & $-45,93$ & $-55,86$ & $-81,55$ & $-198,35$ & 一 \\
\hline & DMA & 55,03 & 43,86 & 37,10 & 30,88 & 25,74 & 23,88 & 30,99 & 40,09 & 54,02 & 82,39 & 200,60 & - \\
\hline & PDMA & 17,15 & 12,93 & 9,97 & 6,09 & 3,80 & 2,68 & 6,52 & 10,29 & 15,03 & 23,02 & 58,70 & - \\
\hline
\end{tabular}


Tabela 8.234: Constantes de acoplamento OP86 com base aug-pcJ-2.

\begin{tabular}{|c|c|c|c|c|c|c|c|c|c|c|c|c|c|}
\hline & $\% E_{X}^{\mathrm{HF}}$ & $0 \%$ & $10 \%$ & $20 \%$ & $30 \%$ & $40 \%$ & $50 \%$ & $60 \%$ & $70 \%$ & $80 \%$ & $90 \%$ & $100 \%$ & Exp. \\
\hline $\mathrm{HF}$ & ${ }^{1} J_{\mathrm{HF}}$ & 324,5 & 350,5 & 377,0 & 403,8 & 431,1 & 458,7 & 486,7 & 515,1 & 543,8 & 572,9 & 602,2 & 500 \\
\hline $\mathrm{CO}$ & ${ }^{1} J_{\mathrm{CO}}$ & 27,3 & 25,5 & 23,5 & 21,4 & 19,2 & 16,9 & 14,6 & 12,2 & 9,7 & 7,3 & 4,8 & 16,4 \\
\hline $\mathrm{H}_{2} \mathrm{O}$ & ${ }^{1} J_{\mathrm{OH}}$ & $-58,9$ & $-61,9$ & $-65,0$ & $-68,1$ & $-71,2$ & $-74,4$ & $-77,6$ & $-80,9$ & $-84,2$ & $-87,6$ & $-91,0$ & $-80,6$ \\
\hline $\mathrm{H}_{2} \mathrm{O}$ & ${ }^{2} J_{\mathrm{HH}}$ & $-6,2$ & $-7,0$ & $-7,8$ & $-8,7$ & $-9,5$ & $-10,4$ & $-11,3$ & $-12,2$ & $-13,1$ & $-14,1$ & $-15,1$ & $-7,3$ \\
\hline $\mathrm{NH}_{3}$ & ${ }^{1} J_{\mathrm{NH}}$ & 35,8 & 36,9 & 38,1 & 39,2 & 40,4 & 41,6 & 42,8 & 44,0 & 45,3 & 46,5 & 47,8 & 43,8 \\
\hline $\mathrm{NH}_{3}$ & ${ }^{2} J_{\mathrm{HH}}$ & $-8,6$ & $-9,3$ & $-10,1$ & $-10,9$ & $-11,6$ & $-12,4$ & $-13,3$ & $-14,1$ & $-15,0$ & $-15,8$ & $-16,8$ & $-9,6$ \\
\hline $\mathrm{PH}_{3}$ & ${ }^{1} J_{\mathrm{PH}}$ & 135,9 & 144,0 & 152,0 & 159,9 & 167,8 & 175,5 & 183,1 & 190,5 & 197,9 & 205,0 & 212,1 & 188,2 \\
\hline $\mathrm{PF}_{3}$ & ${ }^{1} J_{\mathrm{PF}}$ & $-1693,8$ & $-1677,1$ & $-1656,7$ & $-1633,2$ & $-1607,2$ & $-1579,4$ & $-1550,3$ & $-1520,2$ & $-1489,5$ & $-1458,5$ & $-1427,5$ & -1441 \\
\hline $\mathrm{BHF}_{2}$ & ${ }^{1} J_{\mathrm{BF}}$ & $-191,2$ & $-171,2$ & $-151,7$ & $-132,7$ & $-114,1$ & $-96,1$ & $-78,6$ & $-61,6$ & $-45,2$ & $-29,4$ & $-14,1$ & -84 \\
\hline $\mathrm{BF}_{3}$ & ${ }^{1} J_{\mathrm{BF}}$ & $-104,7$ & $-82,2$ & $-60,2$ & $-38,8$ & $-18,0$ & 2,2 & 21,8 & 40,9 & 59,4 & 77,4 & 94,8 & 15 \\
\hline $\mathrm{F}_{2} \mathrm{O}$ & ${ }^{1} J_{\mathrm{OF}}$ & $-263,2$ & $-299,7$ & $-337,0$ & $-376,6$ & $-420,7$ & $-472,5$ & $-537,7$ & $-627,7$ & $-769,0$ & $-1046,3$ & $-1973,1$ & -300 \\
\hline $\mathrm{CH}_{4}$ & ${ }^{1} J_{\mathrm{CH}}$ & 104,1 & 106,8 & 109,6 & 112,4 & 115,2 & 118,1 & 121,0 & 123,9 & 126,9 & 129,9 & 133,0 & 125,3 \\
\hline $\mathrm{CH}_{4}$ & ${ }^{2} J_{\mathrm{HH}}$ & $-12,3$ & $-12,9$ & $-13,6$ & $-14,2$ & $-14,9$ & $-15,5$ & $-16,2$ & $-16,8$ & $-17,5$ & $-18,2$ & $-18,8$ & $-12,8$ \\
\hline $\mathrm{C}_{2} \mathrm{H}_{2}$ & ${ }^{1} J_{\mathrm{CC}}$ & 174,9 & 179,1 & 183,6 & 188,6 & 194,2 & 200,5 & 207,6 & 215,8 & 225,3 & 236,6 & 250,2 & 174,8 \\
\hline $\mathrm{C}_{2} \mathrm{H}_{2}$ & ${ }^{1} J_{\mathrm{CH}}$ & 227,9 & 232,3 & 236,8 & 241,5 & 246,3 & 251,5 & 257,1 & 263,0 & 269,6 & 276,9 & 285,3 & 247,6 \\
\hline $\mathrm{C}_{2} \mathrm{H}_{2}$ & ${ }^{2} J_{\mathrm{CH}}$ & 50,7 & 50,7 & 50,6 & 50,3 & 49,7 & 48,8 & 47,5 & 45,7 & 43,3 & 40,2 & 35,9 & 50,1 \\
\hline $\mathrm{C}_{2} \mathrm{H}_{2}$ & ${ }^{3} J_{\mathrm{HH}}$ & 11,4 & 12,0 & 12,7 & 13,6 & 14,6 & 15,9 & 17,3 & 19,1 & 21,2 & 23,7 & 26,9 & 9,6 \\
\hline $\mathrm{C}_{2} \mathrm{H}_{4}$ & ${ }^{1} J_{\mathrm{CC}}$ & 53,2 & 56,6 & 60,4 & 64,6 & 69,2 & 74,6 & 80,9 & 88,6 & 98,5 & 112,4 & 133,8 & 67,6 \\
\hline $\mathrm{C}_{2} \mathrm{H}_{4}$ & ${ }^{1} J_{\mathrm{CH}}$ & 136,1 & 139,5 & 143,1 & 146,9 & 150,8 & 155,1 & 159,7 & 164,9 & 171,0 & 178,6 & 189,3 & 156,3 \\
\hline $\mathrm{C}_{2} \mathrm{H}_{4}$ & ${ }^{2} J_{\mathrm{CH}}$ & $-1,1$ & $-1,9$ & $-2,9$ & $-4,0$ & $-5,3$ & $-6,9$ & $-8,8$ & $-11,3$ & $-14,7$ & $-19,7$ & $-27,6$ & $-2,4$ \\
\hline $\mathrm{C}_{2} \mathrm{H}_{4}$ & ${ }^{2} J_{\mathrm{HH}}$ & 2,3 & 1,7 & 1,1 & 0,3 & $-0,4$ & $-1,3$ & $-2,5$ & $-4,0$ & $-6,0$ & $-8,9$ & $-13,5$ & 2,3 \\
\hline $\mathrm{C}_{2} \mathrm{H}_{4}$ & ${ }^{3} J_{\mathrm{HH}_{\mathrm{c}}}$ & 11,2 & 11,6 & 12,1 & 12,6 & 13,3 & 14,1 & 15,2 & 16,5 & 18,4 & 21,2 & 25,7 & 11,7 \\
\hline $\mathrm{C}_{2} \mathrm{H}_{4}$ & ${ }^{3} J_{\mathrm{HH}_{\mathrm{t}}}$ & 17,8 & 18,2 & 18,8 & 19,5 & 20,3 & 21,2 & 22,5 & 24,1 & 26,3 & 29,5 & 34,7 & 19 \\
\hline $\mathrm{C}_{2} \mathrm{H}_{6}$ & ${ }^{1} J_{\mathrm{CC}}$ & 20,3 & 22,5 & 24,9 & 27,3 & 29,7 & 32,2 & 34,7 & 37,3 & 40,0 & 42,7 & 45,4 & 34,5 \\
\hline $\mathrm{C}_{2} \mathrm{H}_{6}$ & ${ }^{1} J_{\mathrm{CH}}$ & 104,9 & 107,7 & 110,6 & 113,5 & 116,5 & 119,4 & 122,5 & 125,5 & 128,7 & 131,8 & 135,0 & 125,2 \\
\hline $\mathrm{C}_{2} \mathrm{H}_{6}$ & ${ }^{2} J_{\mathrm{CH}}$ & $-3,3$ & $-3,7$ & $-4,1$ & $-4,5$ & $-4,9$ & $-5,3$ & $-5,7$ & $-6,2$ & $-6,7$ & $-7,1$ & $-7,6$ & $-4,7$ \\
\hline \multirow[t]{3}{*}{ Total } & DM & $-28,85$ & $-26,01$ & $-23,05$ & $-20,05$ & $-17,10$ & $-14,34$ & $-12,00$ & $-10,50$ & $-10,79$ & $-16,08$ & $-45,89$ & - \\
\hline & DMA & 34,78 & 28,90 & 25,82 & 22,90 & 20,26 & 18,51 & 18,85 & 23,91 & 33,29 & 48,47 & 90,58 & - \\
\hline & PDMA & 53,48 & 43,18 & 36,58 & 33,14 & 30,71 & 30,46 & 36,99 & 54,54 & 76,76 & 105,66 & 152,34 & - \\
\hline \multirow[t]{3}{*}{ CPI } & DM & $-58,55$ & $-53,85$ & $-48,98$ & $-44,15$ & $-39,52$ & $-35,56$ & $-32,79$ & $-32,26$ & $-36,44$ & $-53,05$ & $-128,80$ & - \\
\hline & DMA & 71,55 & 59,07 & 53,11 & 47,33 & 41,74 & 36,78 & 35,55 & 44,25 & 61,56 & 91,12 & 182,13 & - \\
\hline & PDMA & 105,04 & 83,94 & 67,34 & 52,64 & 38,15 & 24,48 & 23,12 & 41,70 & 63,66 & 89,32 & 134,69 & - \\
\hline \multirow[t]{3}{*}{ SPI } & DM & $-7,07$ & $-5,59$ & $-4,03$ & $-2,38$ & $-0,65$ & 1,22 & 3,25 & 5,47 & 8,01 & 11,03 & 14,91 & - \\
\hline & DMA & 7,83 & 6,77 & 5,81 & 4,99 & 4,51 & 5,11 & 6,61 & 9,00 & 12,56 & 17,19 & 23,45 & - \\
\hline & PDMA & 15,66 & 13,30 & 14,02 & 18,84 & 25,25 & 34,84 & 47,17 & 63,95 & 86,38 & 117,64 & 165,29 & - \\
\hline \multirow[t]{3}{*}{$\Delta \mathrm{CS}$} & DM & $-51,48$ & $-48,26$ & $-44,96$ & $-41,77$ & $-38,86$ & $-36,78$ & $-36,04$ & $-37,73$ & $-44,45$ & $-64,08$ & $-143,71$ & - \\
\hline & DMA & 63,72 & 52,31 & 47,30 & 42,33 & 37,23 & 31,67 & 28,95 & 35,25 & 49,00 & 73,92 & 158,67 & - \\
\hline & PDMA & 89,38 & 70,65 & 53,32 & 33,80 & 12,91 & $-10,37$ & $-24,06$ & $-22,25$ & $-22,72$ & $-28,31$ & $-30,60$ & - \\
\hline \multicolumn{14}{|c|}{ Desconsiderando ${ }^{1} J_{\mathrm{BF}}$ da molécula de $\mathrm{BF}_{3},{ }^{2} J_{\mathrm{CH}}$ e ${ }^{2} J_{\mathrm{HH}}$ da molécula de $\mathrm{C}_{2} \mathrm{H}_{4}$} \\
\hline \multirow[t]{3}{*}{ Total } & DM & $-27,46$ & $-25,17$ & $-22,71$ & $-20,17$ & $-17,65$ & $-15,30$ & $-13,37$ & $-12,33$ & $-13,23$ & $-19,65$ & $-53,57$ & - \\
\hline & DMA & 34,06 & 28,39 & 25,85 & 23,40 & 21,22 & 20,02 & 20,53 & 25,24 & 34,81 & 50,84 & 97,15 & - \\
\hline & PDMA & 23,40 & 18,60 & 16,38 & 15,18 & 14,79 & 15,76 & 19,18 & 26,11 & 35,94 & 48,84 & 73,57 & - \\
\hline \multirow[t]{3}{*}{ CPI } & DM & $-52,43$ & $-49,52$ & $-46,36$ & $-43,18$ & $-40,17$ & $-37,84$ & $-36,75$ & $-38,08$ & $-44,52$ & $-64,59$ & $-149,66$ & - \\
\hline & DMA & 66,73 & 55,26 & 50,90 & 46,68 & 42,61 & 39,18 & 38,43 & 46,08 & 63,28 & 93,99 & 192,36 & - \\
\hline & PDMA & 35,75 & 27,54 & 23,95 & 22,03 & 19,97 & 18,39 & 20,89 & 28,61 & 40,43 & 56,66 & 94,96 & - \\
\hline \multirow[t]{3}{*}{ SPI } & $\mathrm{DM}$ & $-8,25$ & $-6,45$ & $-4,52$ & $-2,47$ & $-0,32$ & 2,03 & 4,61 & 7,48 & 10,83 & 14,92 & 20,35 & - \\
\hline & DMA & 8,93 & 7,72 & 6,58 & 5,48 & 4,77 & 5,28 & 6,76 & 9,22 & 12,91 & 17,65 & 23,91 & - \\
\hline & PDMA & 13,90 & 11,73 & 10,56 & 9,92 & 10,81 & 13,74 & 17,86 & 24,19 & 32,48 & 42,83 & 57,11 & - \\
\hline \multirow[t]{3}{*}{$\Delta \mathrm{CS}$} & $\mathrm{DM}$ & $-44,18$ & $-43,07$ & $-41,84$ & $-40,71$ & $-39,85$ & $-39,87$ & $-41,36$ & $-45,56$ & $-55,35$ & $-79,51$ & $-170,01$ & 一 \\
\hline & DMA & 57,80 & 47,54 & 44,32 & 41,20 & 37,84 & 33,90 & 31,67 & 36,86 & 50,37 & 76,34 & 168,45 & - \\
\hline & PDMA & 21,84 & 15,80 & 13,38 & 12,12 & 9,16 & 4,65 & 3,03 & 4,42 & 7,94 & 13,83 & 37,85 & - \\
\hline
\end{tabular}


8.4. GERAÇÃO DE NOVOS FUNCIONAIS COMBINANDO $E_{X}^{H F}, E_{X}^{D F T} E$

Tabela 8.235: Constantes de acoplamento OPBE com base aug-pcJ-2.

\begin{tabular}{|c|c|c|c|c|c|c|c|c|c|c|c|c|c|}
\hline & $\% E_{X}^{\mathrm{HF}}$ & $0 \%$ & $10 \%$ & $20 \%$ & $30 \%$ & $40 \%$ & $50 \%$ & $60 \%$ & $70 \%$ & $80 \%$ & $90 \%$ & $100 \%$ & Exp. \\
\hline $\mathrm{HF}$ & ${ }^{1} J_{\mathrm{HF}}$ & 319,8 & 346,3 & 373,3 & 400,7 & 428,5 & 456,8 & 485,3 & 514,3 & 543,6 & 573,3 & 603,3 & 500 \\
\hline $\mathrm{CO}$ & ${ }^{1} J_{\mathrm{CO}}$ & 27,9 & 26,0 & 24,0 & 21,9 & 19,8 & 17,5 & 15,1 & 12,7 & 10,3 & 7,8 & 5,3 & 16,4 \\
\hline $\mathrm{H}_{2} \mathrm{O}$ & ${ }^{1} J_{\mathrm{OH}}$ & $-58,7$ & $-61,7$ & $-64,9$ & $-68,0$ & $-71,2$ & $-74,5$ & $-77,8$ & $-81,1$ & $-84,5$ & $-88,0$ & $-91,5$ & $-80,6$ \\
\hline $\mathrm{H}_{2} \mathrm{O}$ & ${ }^{2} J_{\mathrm{HH}}$ & $-6,7$ & $-7,5$ & $-8,4$ & $-9,2$ & $-10,1$ & $-11,0$ & $-12,0$ & $-12,9$ & $-13,9$ & $-14,9$ & $-15,9$ & $-7,3$ \\
\hline $\mathrm{NH}_{3}$ & ${ }^{1} J_{\mathrm{NH}}$ & 35,9 & 37,0 & 38,2 & 39,4 & 40,6 & 41,8 & 43,0 & 44,3 & 45,6 & 46,8 & 48,2 & 43,8 \\
\hline $\mathrm{NH}_{3}$ & ${ }^{2} J_{\mathrm{HH}}$ & $-9,1$ & $-9,9$ & $-10,7$ & $-11,5$ & $-12,3$ & $-13,1$ & $-14,0$ & $-14,9$ & $-15,8$ & $-16,7$ & $-17,6$ & $-9,6$ \\
\hline $\mathrm{PH}_{3}$ & ${ }^{1} J_{\mathrm{PH}}$ & 136,0 & 144,4 & 152,6 & 160,7 & 168,8 & 176,7 & 184,5 & 192,2 & 199,7 & 207,1 & 214,3 & 188,2 \\
\hline $\mathrm{PF}_{3}$ & ${ }^{1} J_{\mathrm{PF}}$ & $-1698,4$ & $-1681,0$ & $-1659,8$ & $-1635,6$ & $-1609,0$ & $-1580,7$ & $-1550,9$ & $-1520,3$ & $-1489,2$ & $-1457,8$ & $-1426,5$ & -1441 \\
\hline $\mathrm{BHF}_{2}$ & ${ }^{1} J_{\mathrm{BF}}$ & $-192,2$ & $-172,1$ & $-152,4$ & $-133,2$ & $-114,5$ & $-96,3$ & $-78,7$ & $-61,6$ & $-45,1$ & $-29,2$ & $-13,8$ & -84 \\
\hline $\mathrm{BF}_{3}$ & ${ }^{1} J_{\mathrm{BF}}$ & $-105,7$ & $-83,0$ & $-60,9$ & $-39,3$ & $-18,3$ & 1,9 & 21,7 & 40,9 & 59,6 & 77,6 & 95,2 & 15 \\
\hline $\mathrm{F}_{2} \mathrm{O}$ & ${ }^{1} J_{\mathrm{OF}}$ & $-264,9$ & $-302,2$ & $-340,5$ & $-381,4$ & $-427,1$ & $-481,2$ & $-550,2$ & $-647,0$ & $-803,3$ & $-1127,2$ & $-2453,2$ & -300 \\
\hline $\mathrm{CH}_{4}$ & ${ }^{1} J_{\mathrm{CH}}$ & 104,8 & 107,6 & 110,4 & 113,3 & 116,2 & 119,1 & 122,1 & 125,1 & 128,2 & 131,3 & 134,4 & 125,3 \\
\hline $\mathrm{CH}_{4}$ & ${ }^{2} J_{\mathrm{HH}}$ & $-13,0$ & $-13,6$ & $-14,3$ & $-15,0$ & $-15,7$ & $-16,3$ & $-17,0$ & $-17,7$ & $-18,4$ & $-19,1$ & $-19,8$ & $-12,8$ \\
\hline $\mathrm{C}_{2} \mathrm{H}_{2}$ & ${ }^{1} J_{\mathrm{CC}}$ & 174,4 & 178,7 & 183,5 & 188,7 & 194,7 & 201,4 & 209,1 & 218,1 & 228,7 & 241,4 & 257,1 & 174,8 \\
\hline $\mathrm{C}_{2} \mathrm{H}_{2}$ & ${ }^{1} J_{\mathrm{CH}}$ & 230,4 & 235,0 & 239,7 & 244,6 & 249,8 & 255,3 & 261,3 & 267,9 & 275,2 & 283,5 & 293,3 & 247,6 \\
\hline $\mathrm{C}_{2} \mathrm{H}_{2}$ & ${ }^{2} J_{\mathrm{CH}}$ & 50,6 & 50,5 & 50,3 & 49,8 & 48,9 & 47,8 & 46,1 & 43,9 & 40,8 & 36,7 & 31,2 & 50,1 \\
\hline $\mathrm{C}_{2} \mathrm{H}_{2}$ & ${ }^{3} J_{\mathrm{HH}}$ & 12,1 & 12,8 & 13,7 & 14,7 & 15,9 & 17,3 & 19,0 & 21,1 & 23,7 & 26,9 & 30,9 & 9,6 \\
\hline $\mathrm{C}_{2} \mathrm{H}_{4}$ & ${ }^{1} J_{\mathrm{CC}}$ & 53,1 & 56,6 & 60,6 & 65,0 & 69,9 & 75,7 & 82,7 & 91,5 & 103,4 & 120,9 & 150,7 & 67,6 \\
\hline $\mathrm{C}_{2} \mathrm{H}_{4}$ & ${ }^{1} J_{\mathrm{CH}}$ & 137,4 & 141,0 & 144,7 & 148,7 & 152,8 & 157,3 & 162,3 & 168,1 & 175,1 & 184,5 & 199,0 & 156,3 \\
\hline $\mathrm{C}_{2} \mathrm{H}_{4}$ & ${ }^{2} J_{\mathrm{CH}}$ & $-1,6$ & $-2,5$ & $-3,6$ & $-4,8$ & $-6,3$ & $-8,1$ & $-10,4$ & $-13,4$ & $-17,7$ & $-24,3$ & $-36,1$ & $-2,4$ \\
\hline $\mathrm{C}_{2} \mathrm{H}_{4}$ & ${ }^{2} J_{\mathrm{HH}}$ & 1,8 & 1,1 & 0,4 & $-0,3$ & $-1,3$ & $-2,4$ & $-3,9$ & $-5,7$ & $-8,3$ & $-12,3$ & $-19,4$ & 2,3 \\
\hline $\mathrm{C}_{2} \mathrm{H}_{4}$ & ${ }^{3} J_{\mathrm{HH}_{\mathrm{c}}}$ & 11,6 & 12,0 & 12,6 & 13,2 & 14,0 & 15,0 & 16,3 & 18,0 & 20,5 & 24,3 & 31,3 & 11,7 \\
\hline $\mathrm{C}_{2} \mathrm{H}_{4}$ & ${ }^{3} J_{\mathrm{HH}_{\mathrm{t}}}$ & 18,4 & 18,9 & 19,5 & 20,3 & 21,2 & 22,4 & 23,9 & 25,9 & 28,8 & 33,2 & 41,0 & 19 \\
\hline $\mathrm{C}_{2} \mathrm{H}_{6}$ & ${ }^{1} J_{\mathrm{CC}}$ & 20,2 & 22,5 & 24,9 & 27,3 & 29,7 & 32,2 & 34,8 & 37,4 & 40,1 & 42,8 & 45,6 & 34,5 \\
\hline $\mathrm{C}_{2} \mathrm{H}_{6}$ & ${ }^{1} J_{\mathrm{CH}}$ & 105,7 & 108,6 & 111,6 & 114,6 & 117,6 & 120,7 & 123,8 & 126,9 & 130,1 & 133,3 & 136,6 & 125,2 \\
\hline $\mathrm{C}_{2} \mathrm{H}_{6}$ & ${ }^{2} J_{\mathrm{CH}}$ & $-3,6$ & $-4,0$ & $-4,4$ & $-4,8$ & $-5,2$ & $-5,7$ & $-6,2$ & $-6,6$ & $-7,1$ & $-7,6$ & $-8,1$ & $-4,7$ \\
\hline \multirow[t]{3}{*}{ Total } & DM & $-29,18$ & $-26,29$ & $-23,27$ & $-20,20$ & $-17,22$ & $-14,44$ & $-12,12$ & $-10,69$ & $-11,34$ & $-18,10$ & $-62,67$ & - \\
\hline & DMA & 34,92 & 29,13 & 26,19 & 23,27 & 20,91 & 19,44 & 20,05 & 25,74 & 36,16 & 53,73 & 112,44 & - \\
\hline & PDMA & 53,11 & 43,97 & 40,24 & 37,05 & 36,15 & 36,94 & 44,80 & 64,41 & 90,21 & 125,50 & 190,22 & - \\
\hline \multirow[t]{3}{*}{ CPI } & DM & $-59,73$ & $-54,96$ & $-50,04$ & $-45,13$ & $-40,52$ & $-36,64$ & $-34,08$ & $-34,03$ & $-39,45$ & $-60,19$ & $-172,10$ & - \\
\hline & DMA & 72,38 & 60,15 & 54,27 & 48,42 & 42,85 & 37,95 & 36,77 & 46,23 & 64,97 & 98,85 & 226,41 & - \\
\hline & PDMA & 105,05 & 84,82 & 69,59 & 54,61 & 40,28 & 26,62 & 24,58 & 43,79 & 66,43 & 93,70 & 151,26 & - \\
\hline \multirow[t]{3}{*}{ SPI } & DM & $-6,79$ & $-5,26$ & $-3,63$ & $-1,92$ & $-0,13$ & 1,84 & 3,99 & 6,43 & 9,27 & 12,76 & 17,57 & - \\
\hline & DMA & 7,44 & 6,39 & 5,59 & 4,83 & 4,82 & 5,87 & 7,79 & 10,72 & 15,03 & 20,64 & 28,87 & - \\
\hline & PDMA & 15,01 & 14,02 & 18,71 & 24,17 & 33,12 & 44,50 & 59,63 & 79,53 & 107,66 & 148,83 & 218,79 & - \\
\hline \multirow[t]{3}{*}{$\Delta \mathrm{CS}$} & DM & $-52,94$ & $-49,70$ & $-46,40$ & $-43,21$ & $-40,39$ & $-38,48$ & $-38,07$ & $-40,45$ & $-48,71$ & $-72,95$ & $-189,67$ & - \\
\hline & DMA & 64,94 & 53,75 & 48,68 & 43,59 & 38,03 & 32,08 & 28,99 & 35,51 & 49,95 & 78,21 & 197,54 & - \\
\hline & PDMA & 90,04 & 70,80 & 50,88 & 30,44 & 7,17 & $-17,88$ & $-35,06$ & $-35,74$ & $-41,23$ & $-55,13$ & $-67,53$ & - \\
\hline \multicolumn{14}{|c|}{ Desconsiderando ${ }^{1} J_{\mathrm{BF}}$ da molécula de $\mathrm{BF}_{3},{ }^{2} J_{\mathrm{CH}}$ e ${ }^{2} J_{\mathrm{HH}}$ da molécula de $\mathrm{C}_{2} \mathrm{H}_{4}$} \\
\hline \multirow[t]{3}{*}{ Total } & DM & $-27,76$ & $-25,40$ & $-22,87$ & $-20,26$ & $-17,69$ & $-15,30$ & $-13,37$ & $-12,38$ & $-13,63$ & $-21,60$ & $-71,93$ & - \\
\hline & DMA & 34,17 & 28,62 & 26,17 & 23,73 & 21,86 & 20,95 & 21,76 & 27,15 & 37,81 & 56,43 & 121,21 & - \\
\hline & PDMA & 22,65 & 18,85 & 17,72 & 16,88 & 17,34 & 18,75 & 22,49 & 30,26 & 41,30 & 56,46 & 89,72 & - \\
\hline \multirow[t]{3}{*}{ CPI } & DM & $-53,63$ & $-50,66$ & $-47,45$ & $-44,21$ & $-41,24$ & $-38,99$ & $-38,16$ & $-40,02$ & $-47,85$ & $-72,47$ & $-197,33$ & - \\
\hline & DMA & 67,55 & 56,36 & 52,11 & 47,83 & 43,80 & 40,43 & 39,78 & 48,26 & 67,01 & 102,47 & 241,03 & - \\
\hline & PDMA & 35,09 & 27,97 & 25,95 & 23,87 & 22,11 & 20,55 & 22,57 & 30,91 & 43,34 & 61,34 & 112,92 & - \\
\hline \multirow[t]{3}{*}{ SPI } & $\mathrm{DM}$ & $-7,85$ & $-5,97$ & $-3,95$ & $-1,83$ & 0,43 & 2,92 & 5,69 & 8,88 & 12,68 & 17,53 & 24,54 & - \\
\hline & DMA & 8,48 & 7,28 & 6,22 & 5,18 & 4,98 & 5,97 & 7,89 & 10,91 & 15,35 & 21,01 & 29,05 & - \\
\hline & PDMA & 13,09 & 11,84 & 11,39 & 11,50 & 13,67 & 17,36 & 22,43 & 29,76 & 39,73 & 52,70 & 71,87 & - \\
\hline \multirow[t]{3}{*}{$\Delta \mathrm{CS}$} & $\mathrm{DM}$ & $-45,78$ & $-44,69$ & $-43,50$ & $-42,38$ & $-41,67$ & $-41,91$ & $-43,85$ & $-48,90$ & $-60,53$ & $-90,00$ & $-221,87$ & 一 \\
\hline & DMA & 59,07 & 49,08 & 45,89 & 42,65 & 38,82 & 34,46 & 31,89 & 37,35 & 51,66 & 81,46 & 211,98 & - \\
\hline & PDMA & 22,00 & 16,13 & 14,56 & 12,37 & 8,44 & 3,19 & 0,14 & 1,15 & 3,61 & 8,64 & 41,06 & - \\
\hline
\end{tabular}


Tabela 8.236: Constantes de acoplamento OPW91 com base aug-pcJ-2.

\begin{tabular}{|c|c|c|c|c|c|c|c|c|c|c|c|c|c|}
\hline & $\% E_{X}^{\mathrm{HF}}$ & $0 \%$ & $10 \%$ & $20 \%$ & $30 \%$ & $40 \%$ & $50 \%$ & $60 \%$ & $70 \%$ & $80 \%$ & $90 \%$ & $100 \%$ & Exp. \\
\hline $\mathrm{HF}$ & ${ }^{1} J_{\mathrm{HF}}$ & 322,3 & 348,9 & 375,9 & 403,4 & 431,2 & 459,5 & 488,1 & 517,1 & 546,5 & 576,2 & 606,3 & 500 \\
\hline $\mathrm{CO}$ & ${ }^{1} J_{\mathrm{CO}}$ & 27,7 & 25,8 & 23,8 & 21,7 & 19,5 & 17,2 & 14,8 & 12,4 & 9,9 & 7,4 & 4,9 & 16,4 \\
\hline $\mathrm{H}_{2} \mathrm{O}$ & ${ }^{1} J_{\mathrm{OH}}$ & $-59,0$ & $-62,1$ & $-65,2$ & $-68,4$ & $-71,6$ & $-74,9$ & $-78,2$ & $-81,5$ & $-84,9$ & $-88,4$ & $-91,9$ & $-80,6$ \\
\hline $\mathrm{H}_{2} \mathrm{O}$ & ${ }^{2} J_{\mathrm{HH}}$ & $-6,7$ & $-7,6$ & $-8,4$ & $-9,3$ & $-10,2$ & $-11,1$ & $-12,0$ & $-13,0$ & $-13,9$ & $-14,9$ & $-16,0$ & $-7,3$ \\
\hline $\mathrm{NH}_{3}$ & ${ }^{1} J_{\mathrm{NH}}$ & 36,0 & 37,2 & 38,4 & 39,6 & 40,8 & 42,0 & 43,2 & 44,5 & 45,8 & 47,1 & 48,4 & 43,8 \\
\hline $\mathrm{NH}_{3}$ & ${ }^{2} J_{\mathrm{HH}}$ & $-9,2$ & $-9,9$ & $-10,7$ & $-11,5$ & $-12,3$ & $-13,2$ & $-14,0$ & $-14,9$ & $-15,8$ & $-16,7$ & $-17,7$ & $-9,6$ \\
\hline $\mathrm{PH}_{3}$ & ${ }^{1} J_{\mathrm{PH}}$ & 137,0 & 145,4 & 153,7 & 161,8 & 169,9 & 177,8 & 185,6 & 193,3 & 200,9 & 208,3 & 215,5 & 188,2 \\
\hline $\mathrm{PF}_{3}$ & ${ }^{1} J_{\mathrm{PF}}$ & $-1701,6$ & $-1684,0$ & $-1662,7$ & $-1638,4$ & $-1611,7$ & $-1583,2$ & $-1553,3$ & $-1522,6$ & $-1491,4$ & $-1459,9$ & $-1428,5$ & -1441 \\
\hline $\mathrm{BHF}_{2}$ & ${ }^{1} J_{\mathrm{BF}}$ & $-191,4$ & $-171,2$ & $-151,5$ & $-132,2$ & $-113,5$ & $-95,3$ & $-77,6$ & $-60,5$ & $-44,0$ & $-28,0$ & $-12,5$ & -84 \\
\hline $\mathrm{BF}_{3}$ & ${ }^{1} J_{\mathrm{BF}}$ & $-104,8$ & $-82,0$ & $-59,8$ & $-38,2$ & $-17,2$ & 3,1 & 22,9 & 42,2 & 60,8 & 79,0 & 96,6 & 15 \\
\hline $\mathrm{F}_{2} \mathrm{O}$ & ${ }^{1} J_{\mathrm{OF}}$ & $-264,6$ & $-301,9$ & $-340,2$ & $-381,1$ & $-426,8$ & $-481,0$ & $-550,1$ & $-647,2$ & $-804,7$ & $-1133,4$ & $-2525,8$ & -300 \\
\hline $\mathrm{CH}_{4}$ & ${ }^{1} J_{\mathrm{CH}}$ & 105,5 & 108,2 & 111,1 & 113,9 & 116,8 & 119,8 & 122,8 & 125,8 & 128,9 & 132,0 & 135,2 & 125,3 \\
\hline $\mathrm{CH}_{4}$ & ${ }^{2} J_{\mathrm{HH}}$ & $-13,0$ & $-13,7$ & $-14,3$ & $-15,0$ & $-15,7$ & $-16,4$ & $-17,1$ & $-17,8$ & $-18,5$ & $-19,2$ & $-19,9$ & $-12,8$ \\
\hline $\mathrm{C}_{2} \mathrm{H}_{2}$ & ${ }^{1} J_{\mathrm{CC}}$ & 175,5 & 179,9 & 184,7 & 190,0 & 196,0 & 202,8 & 210,6 & 219,6 & 230,3 & 243,2 & 259,0 & 174,8 \\
\hline $\mathrm{C}_{2} \mathrm{H}_{2}$ & ${ }^{1} J_{\mathrm{CH}}$ & 231,6 & 236,1 & 240,8 & 245,8 & 251,0 & 256,6 & 262,6 & 269,1 & 276,5 & 284,8 & 294,6 & 247,6 \\
\hline $\mathrm{C}_{2} \mathrm{H}_{2}$ & ${ }^{2} J_{\mathrm{CH}}$ & 50,6 & 50,6 & 50,3 & 49,8 & 48,9 & 47,7 & 46,1 & 43,8 & 40,8 & 36,7 & 31,2 & 50,1 \\
\hline $\mathrm{C}_{2} \mathrm{H}_{2}$ & ${ }^{3} J_{\mathrm{HH}}$ & 12,0 & 12,8 & 13,6 & 14,6 & 15,8 & 17,3 & 19,0 & 21,1 & 23,6 & 26,7 & 30,7 & 9,6 \\
\hline $\mathrm{C}_{2} \mathrm{H}_{4}$ & ${ }^{1} J_{\mathrm{CC}}$ & 53,6 & 57,2 & 61,2 & 65,6 & 70,6 & 76,4 & 83,5 & 92,4 & 104,3 & 122,0 & 152,0 & 67,6 \\
\hline $\mathrm{C}_{2} \mathrm{H}_{4}$ & ${ }^{1} J_{\mathrm{CH}}$ & 138,2 & 141,8 & 145,5 & 149,5 & 153,7 & 158,2 & 163,2 & 169,0 & 176,1 & 185,5 & 200,0 & 156,3 \\
\hline $\mathrm{C}_{2} \mathrm{H}_{4}$ & ${ }^{2} J_{\mathrm{CH}}$ & $-1,6$ & $-2,5$ & $-3,6$ & $-4,8$ & $-6,3$ & $-8,1$ & $-10,4$ & $-13,5$ & $-17,8$ & $-24,5$ & $-36,2$ & $-2,4$ \\
\hline $\mathrm{C}_{2} \mathrm{H}_{4}$ & ${ }^{2} J_{\mathrm{HH}}$ & 1,8 & 1,1 & 0,4 & $-0,3$ & $-1,3$ & $-2,4$ & $-3,8$ & $-5,7$ & $-8,3$ & $-12,2$ & $-19,2$ & 2,3 \\
\hline $\mathrm{C}_{2} \mathrm{H}_{4}$ & ${ }^{3} J_{\mathrm{HH}_{\mathrm{c}}}$ & 11,6 & 12,0 & 12,6 & 13,2 & 14,0 & 15,0 & 16,3 & 18,0 & 20,4 & 24,3 & 31,2 & 11,7 \\
\hline $\mathrm{C}_{2} \mathrm{H}_{4}$ & ${ }^{3} J_{\mathrm{HH}_{\mathrm{t}}}$ & 18,4 & 18,9 & 19,5 & 20,3 & 21,2 & 22,4 & 23,9 & 25,9 & 28,7 & 33,1 & 40,9 & 19 \\
\hline $\mathrm{C}_{2} \mathrm{H}_{6}$ & ${ }^{1} J_{\mathrm{CC}}$ & 20,5 & 22,9 & 25,2 & 27,6 & 30,1 & 32,6 & 35,2 & 37,9 & 40,5 & 43,3 & 46,1 & 34,5 \\
\hline $\mathrm{C}_{2} \mathrm{H}_{6}$ & ${ }^{1} J_{\mathrm{CH}}$ & 106,3 & 109,2 & 112,2 & 115,2 & 118,2 & 121,3 & 124,4 & 127,6 & 130,8 & 134,1 & 137,3 & 125,2 \\
\hline $\mathrm{C}_{2} \mathrm{H}_{6}$ & ${ }^{2} J_{\mathrm{CH}}$ & $-3,6$ & $-4,0$ & $-4,4$ & $-4,8$ & $-5,3$ & $-5,7$ & $-6,2$ & $-6,6$ & $-7,1$ & $-7,6$ & $-8,1$ & $-4,7$ \\
\hline \multirow[t]{3}{*}{ Total } & DM & $-28,92$ & $-26,00$ & $-22,96$ & $-19,88$ & $-16,89$ & $-14,10$ & $-11,75$ & $-10,33$ & $-11,02$ & $-17,93$ & $-65,03$ & - \\
\hline & DMA & 34,67 & 28,90 & 25,93 & 23,00 & 20,77 & 19,38 & 20,20 & 26,36 & 36,83 & 54,62 & 115,74 & - \\
\hline & PDMA & 52,53 & 43,52 & 39,64 & 36,50 & 35,75 & 36,60 & 45,14 & 65,42 & 91,09 & 126,52 & 191,82 & - \\
\hline \multirow[t]{3}{*}{ CPI } & DM & $-59,56$ & $-54,75$ & $-49,78$ & $-44,86$ & $-40,25$ & $-36,36$ & $-33,77$ & $-33,74$ & $-39,25$ & $-60,38$ & $-178,33$ & - \\
\hline & DMA & 72,16 & 59,83 & 53,93 & 48,05 & 42,45 & 37,55 & 36,81 & 47,12 & 65,97 & 100,31 & 233,56 & - \\
\hline & PDMA & 104,10 & 83,96 & 68,55 & 53,67 & 39,29 & 25,66 & 25,41 & 45,20 & 67,75 & 95,32 & 155,08 & - \\
\hline \multirow[t]{3}{*}{ SPI } & DM & $-6,45$ & $-4,91$ & $-3,29$ & $-1,57$ & 0,24 & 2,23 & 4,40 & 6,83 & 9,67 & 13,21 & 18,05 & - \\
\hline & DMA & 7,18 & 6,21 & 5,39 & 4,63 & 4,87 & 6,05 & 8,03 & 11,14 & 15,46 & 21,11 & 29,34 & - \\
\hline & PDMA & 14,71 & 13,86 & 18,44 & 23,90 & 33,16 & 44,62 & 59,61 & 80,24 & 108,20 & 149,40 & 218,77 & - \\
\hline \multirow[t]{3}{*}{$\Delta \mathrm{CS}$} & DM & $-53,12$ & $-49,85$ & $-46,50$ & $-43,30$ & $-40,49$ & $-38,59$ & $-38,17$ & $-40,57$ & $-48,92$ & $-73,59$ & $-196,37$ & - \\
\hline & DMA & 64,98 & 53,61 & 48,53 & 43,41 & 37,59 & 31,49 & 28,78 & 35,98 & 50,51 & 79,20 & 204,22 & - \\
\hline & PDMA & 89,38 & 70,09 & 50,11 & 29,77 & 6,13 & $-18,96$ & $-34,20$ & $-35,04$ & $-40,45$ & $-54,08$ & $-63,69$ & - \\
\hline \multicolumn{14}{|c|}{ Desconsiderando ${ }^{1} J_{\mathrm{BF}}$ da molécula de $\mathrm{BF}_{3},{ }^{2} J_{\mathrm{CH}}$ e ${ }^{2} J_{\mathrm{HH}}$ da molécula de $\mathrm{C}_{2} \mathrm{H}_{4}$} \\
\hline \multirow[t]{3}{*}{ Total } & DM & $-27,50$ & $-25,11$ & $-22,57$ & $-19,95$ & $-17,37$ & $-14,97$ & $-13,01$ & $-12,03$ & $-13,32$ & $-21,46$ & $-74,66$ & - \\
\hline & DMA & 33,93 & 28,39 & 25,92 & 23,47 & 21,75 & 20,93 & 21,88 & 27,79 & 38,51 & 57,37 & 124,89 & - \\
\hline & PDMA & 22,26 & 18,63 & 17,36 & 16,57 & 17,21 & 18,71 & 22,72 & 30,84 & 41,76 & 57,03 & 91,32 & - \\
\hline \multirow[t]{3}{*}{ CPI } & DM & $-53,54$ & $-50,53$ & $-47,28$ & $-44,03$ & $-41,06$ & $-38,81$ & $-37,94$ & $-39,83$ & $-47,75$ & $-72,82$ & $-204,32$ & - \\
\hline & DMA & 67,40 & 56,11 & 51,84 & 47,53 & 43,48 & 40,11 & 39,70 & 49,11 & 67,99 & 103,94 & 248,76 & - \\
\hline & PDMA & 34,64 & 27,68 & 25,54 & 23,57 & 21,75 & 20,29 & 22,69 & 31,59 & 43,99 & 62,19 & 116,19 & - \\
\hline \multirow[t]{3}{*}{ SPI } & $\mathrm{DM}$ & $-7,46$ & $-5,56$ & $-3,55$ & $-1,42$ & 0,85 & 3,37 & 6,16 & 9,35 & 13,16 & 18,05 & 25,08 & - \\
\hline & DMA & 8,18 & 7,07 & 5,98 & 4,96 & 5,04 & 6,18 & 8,18 & 11,38 & 15,84 & 21,55 & 29,60 & - \\
\hline & PDMA & 12,74 & 11,66 & 11,07 & 11,19 & 13,72 & 17,49 & 22,74 & 30,25 & 40,04 & 53,06 & 72,19 & - \\
\hline \multirow[t]{3}{*}{$\Delta \mathrm{CS}$} & $\mathrm{DM}$ & $-46,08$ & $-44,97$ & $-43,73$ & $-42,61$ & $-41,91$ & $-42,18$ & $-44,10$ & $-49,18$ & $-60,91$ & $-90,87$ & $-229,40$ & - \\
\hline & DMA & 59,22 & 49,04 & 45,86 & 42,57 & 38,44 & 33,93 & 31,52 & 37,73 & 52,15 & 82,39 & 219,16 & - \\
\hline & PDMA & 21,90 & 16,02 & 14,46 & 12,38 & 8,03 & 2,80 & $-0,06$ & 1,34 & 3,95 & 9,13 & 44,00 & - \\
\hline
\end{tabular}


Tabela 8.237: Constantes de acoplamento OTPSS com base aug-pcJ-2.

\begin{tabular}{|c|c|c|c|c|c|c|c|c|c|c|c|c|c|}
\hline & $\% E_{X}^{\mathrm{HF}}$ & $0 \%$ & $10 \%$ & $20 \%$ & $30 \%$ & $40 \%$ & $50 \%$ & $60 \%$ & $70 \%$ & $80 \%$ & $90 \%$ & $100 \%$ & Exp. \\
\hline $\mathrm{HF}$ & ${ }^{1} J_{\mathrm{HF}}$ & 320,7 & 348,0 & 375,7 & 403,8 & 432,3 & 461,1 & 490,2 & 519,7 & 549,5 & 579,6 & 610,0 & 500 \\
\hline $\mathrm{CO}$ & ${ }^{1} J_{\mathrm{CO}}$ & 27,8 & 25,9 & 23,9 & 21,8 & 19,6 & 17,3 & 14,9 & 12,5 & 10,0 & 7,4 & 4,9 & 16,4 \\
\hline $\mathrm{H}_{2} \mathrm{O}$ & ${ }^{1} J_{\mathrm{OH}}$ & $-59,5$ & $-62,7$ & $-66,0$ & $-69,3$ & $-72,6$ & $-75,9$ & $-79,3$ & $-82,8$ & $-86,3$ & $-89,8$ & $-93,4$ & $-80,6$ \\
\hline $\mathrm{H}_{2} \mathrm{O}$ & ${ }^{2} J_{\mathrm{HH}}$ & $-6,6$ & $-7,5$ & $-8,4$ & $-9,3$ & $-10,2$ & $-11,2$ & $-12,1$ & $-13,1$ & $-14,1$ & $-15,2$ & $-16,2$ & $-7,3$ \\
\hline $\mathrm{NH}_{3}$ & ${ }^{1} J_{\mathrm{NH}}$ & 37,2 & 38,4 & 39,6 & 40,9 & 42,1 & 43,4 & 44,7 & 46,0 & 47,4 & 48,7 & 50,1 & 43,8 \\
\hline $\mathrm{NH}_{3}$ & ${ }^{2} J_{\mathrm{HH}}$ & $-8,9$ & $-9,7$ & $-10,6$ & $-11,4$ & $-12,3$ & $-13,2$ & $-14,1$ & $-15,0$ & $-16,0$ & $-16,9$ & $-17,9$ & $-9,6$ \\
\hline $\mathrm{PH}_{3}$ & ${ }^{1} J_{\mathrm{PH}}$ & 148,0 & 156,9 & 165,7 & 174,4 & 183,0 & 191,6 & 200,0 & 208,3 & 216,6 & 224,7 & 232,6 & 188,2 \\
\hline $\mathrm{PF}_{3}$ & ${ }^{1} J_{\mathrm{PF}}$ & $-1702,5$ & $-1685,7$ & $-1665,1$ & $-1641,4$ & $-1615,4$ & $-1587,5$ & $-1558,2$ & $-1528,0$ & $-1497,3$ & $-1466,2$ & $-1435,2$ & -1441 \\
\hline $\mathrm{BHF}_{2}$ & ${ }^{1} J_{\mathrm{BF}}$ & $-193,0$ & $-173,1$ & $-153,6$ & $-134,5$ & $-116,0$ & $-98,0$ & $-80,6$ & $-63,7$ & $-47,4$ & $-31,6$ & $-16,4$ & -84 \\
\hline $\mathrm{BF}_{3}$ & ${ }^{1} J_{\mathrm{BF}}$ & $-102,8$ & $-80,3$ & $-58,3$ & $-37,0$ & $-16,2$ & 3,9 & 23,5 & 42,6 & 61,0 & 78,9 & 96,3 & 15 \\
\hline $\mathrm{F}_{2} \mathrm{O}$ & ${ }^{1} J_{\mathrm{OF}}$ & $-263,6$ & $-300,9$ & $-339,0$ & $-379,7$ & $-425,0$ & $-478,6$ & $-546,7$ & $-642,0$ & $-795,5$ & $-1112,5$ & $-2403,5$ & -300 \\
\hline $\mathrm{CH}_{4}$ & ${ }^{1} J_{\mathrm{CH}}$ & 112,8 & 115,8 & 118,8 & 121,9 & 125,0 & 128,2 & 131,5 & 134,8 & 138,1 & 141,5 & 144,9 & 125,3 \\
\hline $\mathrm{CH}_{4}$ & ${ }^{2} J_{\mathrm{HH}}$ & $-12,6$ & $-13,3$ & $-14,1$ & $-14,8$ & $-15,6$ & $-16,3$ & $-17,1$ & $-17,9$ & $-18,6$ & $-19,4$ & $-20,2$ & $-12,8$ \\
\hline $\mathrm{C}_{2} \mathrm{H}_{2}$ & ${ }^{1} J_{\mathrm{CC}}$ & 175,4 & 179,8 & 184,8 & 190,3 & 196,5 & 203,5 & 211,6 & 221,0 & 232,1 & 245,5 & 262,1 & 174,8 \\
\hline $\mathrm{C}_{2} \mathrm{H}_{2}$ & ${ }^{1} J_{\mathrm{CH}}$ & 245,0 & 249,9 & 255,0 & 260,4 & 266,0 & 272,0 & 278,5 & 285,6 & 293,5 & 302,4 & 312,9 & 247,6 \\
\hline $\mathrm{C}_{2} \mathrm{H}_{2}$ & ${ }^{2} J_{\mathrm{CH}}$ & 51,9 & 51,8 & 51,6 & 51,0 & 50,1 & 48,9 & 47,1 & 44,7 & 41,6 & 37,3 & 31,5 & 50,1 \\
\hline $\mathrm{C}_{2} \mathrm{H}_{2}$ & ${ }^{3} J_{\mathrm{HH}}$ & 12,6 & 13,3 & 14,1 & 15,2 & 16,4 & 17,9 & 19,7 & 21,8 & 24,4 & 27,7 & 31,8 & 9,6 \\
\hline $\mathrm{C}_{2} \mathrm{H}_{4}$ & ${ }^{1} J_{\mathrm{CC}}$ & 54,4 & 58,1 & 62,1 & 66,7 & 71,8 & 77,8 & 85,1 & 94,2 & 106,3 & 124,0 & 153,5 & 67,6 \\
\hline $\mathrm{C}_{2} \mathrm{H}_{4}$ & ${ }^{1} J_{\mathrm{CH}}$ & 146,9 & 150,8 & 154,8 & 159,1 & 163,6 & 168,4 & 173,8 & 180,0 & 187,4 & 197,1 & 211,7 & 156,3 \\
\hline $\mathrm{C}_{2} \mathrm{H}_{4}$ & ${ }^{2} J_{\mathrm{CH}}$ & $-1,8$ & $-2,8$ & $-3,9$ & $-5,2$ & $-6,8$ & $-8,7$ & $-11,1$ & $-14,2$ & $-18,6$ & $-25,3$ & $-36,8$ & $-2,4$ \\
\hline $\mathrm{C}_{2} \mathrm{H}_{4}$ & ${ }^{2} J_{\mathrm{HH}}$ & 3,1 & 2,5 & 1,7 & 0,9 & 0,0 & $-1,2$ & $-2,6$ & $-4,5$ & $-7,0$ & $-10,9$ & $-17,4$ & 2,3 \\
\hline $\mathrm{C}_{2} \mathrm{H}_{4}$ & ${ }^{3} J_{\mathrm{HH}_{\mathrm{c}}}$ & 12,3 & 12,8 & 13,3 & 14,0 & 14,8 & 15,8 & 17,0 & 18,7 & 21,2 & 24,9 & 31,3 & 11,7 \\
\hline $\mathrm{C}_{2} \mathrm{H}_{4}$ & ${ }^{3} J_{\mathrm{HH}_{\mathrm{t}}}$ & 20,2 & 20,7 & 21,4 & 22,1 & 23,1 & 24,2 & 25,7 & 27,7 & 30,5 & 34,8 & 42,2 & 19 \\
\hline $\mathrm{C}_{2} \mathrm{H}_{6}$ & ${ }^{1} J_{\mathrm{CC}}$ & 21,2 & 23,5 & 25,9 & 28,3 & 30,8 & 33,4 & 36,0 & 38,6 & 41,3 & 44,1 & 46,9 & 34,5 \\
\hline $\mathrm{C}_{2} \mathrm{H}_{6}$ & ${ }^{1} J_{\mathrm{CH}}$ & 113,5 & 116,6 & 119,8 & 123,0 & 126,3 & 129,7 & 133,1 & 136,5 & 140,0 & 143,5 & 147,1 & 125,2 \\
\hline $\mathrm{C}_{2} \mathrm{H}_{6}$ & ${ }^{2} J_{\mathrm{CH}}$ & $-3,6$ & $-4,1$ & $-4,5$ & $-5,0$ & $-5,4$ & $-5,9$ & $-6,4$ & $-6,9$ & $-7,4$ & $-7,9$ & $-8,5$ & $-4,7$ \\
\hline \multirow[t]{3}{*}{ Total } & DM & $-26,80$ & $-23,86$ & $-20,78$ & $-17,65$ & $-14,58$ & $-11,71$ & $-9,26$ & $-7,71$ & $-8,17$ & $-14,56$ & $-57,72$ & - \\
\hline & DMA & 32,97 & 27,22 & 24,60 & 22,24 & 20,57 & 20,12 & 22,05 & 29,03 & 39,50 & 56,96 & 113,73 & - \\
\hline & PDMA & 51,77 & 41,23 & 37,20 & 34,95 & 34,57 & 36,54 & 46,46 & 67,40 & 93,22 & 128,59 & 191,26 & - \\
\hline \multirow[t]{3}{*}{ CPI } & DM & $-58,55$ & $-53,78$ & $-48,82$ & $-43,87$ & $-39,24$ & $-35,27$ & $-32,60$ & $-32,40$ & $-37,55$ & $-57,62$ & $-166,33$ & - \\
\hline & DMA & 71,34 & 58,76 & 52,84 & 46,91 & 41,27 & 36,91 & 37,31 & 48,75 & 67,38 & 100,76 & 223,67 & - \\
\hline & PDMA & 102,75 & 82,00 & 66,89 & 52,14 & 37,94 & 24,83 & 25,89 & 46,37 & 68,95 & 96,18 & 152,58 & - \\
\hline \multirow[t]{3}{*}{ SPI } & DM & $-3,52$ & $-1,91$ & $-0,22$ & 1,59 & 3,50 & 5,57 & 7,85 & 10,40 & 13,38 & 17,01 & 21,93 & - \\
\hline & DMA & 4,84 & 4,09 & 3,90 & 4,15 & 5,39 & 7,81 & 10,87 & 14,57 & 19,05 & 24,84 & 33,11 & - \\
\hline & PDMA & 14,39 & 11,33 & 15,43 & 22,35 & 32,11 & 45,13 & 61,55 & 82,82 & 111,01 & 152,35 & 219,63 & - \\
\hline \multirow[t]{3}{*}{$\Delta \mathrm{CS}$} & DM & $-55,03$ & $-51,87$ & $-48,60$ & $-45,46$ & $-42,74$ & $-40,85$ & $-40,45$ & $-42,80$ & $-50,93$ & $-74,63$ & $-188,25$ & - \\
\hline & DMA & 66,50 & 54,68 & 48,94 & 42,76 & 35,88 & 29,10 & 26,44 & 34,17 & 48,34 & 75,92 & 190,56 & - \\
\hline & PDMA & 88,36 & 70,66 & 51,46 & 29,79 & 5,83 & $-20,31$ & $-35,67$ & $-36,45$ & $-42,06$ & $-56,17$ & $-67,05$ & - \\
\hline \multicolumn{14}{|c|}{ Desconsiderando ${ }^{1} J_{\mathrm{BF}}$ da molécula de $\mathrm{BF}_{3},{ }^{2} J_{\mathrm{CH}}$ e ${ }^{2} J_{\mathrm{HH}}$ da molécula de $\mathrm{C}_{2} \mathrm{H}_{4}$} \\
\hline \multirow[t]{3}{*}{ Total } & DM & $-27,50$ & $-25,11$ & $-22,57$ & $-19,95$ & $-17,37$ & $-14,97$ & $-13,01$ & $-12,03$ & $-13,32$ & $-21,46$ & $-74,66$ & - \\
\hline & DMA & 33,93 & 28,39 & 25,92 & 23,47 & 21,75 & 20,93 & 21,88 & 27,79 & 38,51 & 57,37 & 124,89 & - \\
\hline & PDMA & 22,26 & 18,63 & 17,36 & 16,57 & 17,21 & 18,71 & 22,72 & 30,84 & 41,76 & 57,03 & 91,32 & - \\
\hline \multirow[t]{3}{*}{ CPI } & DM & $-53,54$ & $-50,53$ & $-47,28$ & $-44,03$ & $-41,06$ & $-38,81$ & $-37,94$ & $-39,83$ & $-47,75$ & $-72,82$ & $-204,32$ & - \\
\hline & DMA & 67,40 & 56,11 & 51,84 & 47,53 & 43,48 & 40,11 & 39,70 & 49,11 & 67,99 & 103,94 & 248,76 & - \\
\hline & PDMA & 34,64 & 27,68 & 25,54 & 23,57 & 21,75 & 20,29 & 22,69 & 31,59 & 43,99 & 62,19 & 116,19 & - \\
\hline \multirow[t]{3}{*}{ SPI } & $\mathrm{DM}$ & $-7,46$ & $-5,56$ & $-3,55$ & $-1,42$ & 0,85 & 3,37 & 6,16 & 9,35 & 13,16 & 18,05 & 25,08 & - \\
\hline & DMA & 8,18 & 7,07 & 5,98 & 4,96 & 5,04 & 6,18 & 8,18 & 11,38 & 15,84 & 21,55 & 29,60 & - \\
\hline & PDMA & 12,74 & 11,66 & 11,07 & 11,19 & 13,72 & 17,49 & 22,74 & 30,25 & 40,04 & 53,06 & 72,19 & - \\
\hline \multirow[t]{3}{*}{$\Delta \mathrm{CS}$} & $\mathrm{DM}$ & $-46,08$ & $-44,97$ & $-43,73$ & $-42,61$ & $-41,91$ & $-42,18$ & $-44,10$ & $-49,18$ & $-60,91$ & $-90,87$ & $-229,40$ & - \\
\hline & DMA & 59,22 & 49,04 & 45,86 & 42,57 & 38,44 & 33,93 & 31,52 & 37,73 & 52,15 & 82,39 & 219,16 & - \\
\hline & PDMA & 21,90 & 16,02 & 14,46 & 12,38 & 8,03 & 2,80 & $-0,06$ & 1,34 & 3,95 & 9,13 & 44,00 & - \\
\hline
\end{tabular}

Tabela 8.238: Valores de PDMA total obtidos para troca O com base HuzIIIsu3.

\begin{tabular}{lccccccccccc}
\hline$E_{X}^{\mathrm{HF}}(\%)$ & $0 \%$ & $10 \%$ & $20 \%$ & $30 \%$ & $40 \%$ & $50 \%$ & $60 \%$ & $70 \%$ & $80 \%$ & $90 \%$ & $100 \%$ \\
\hline OB95 & 53,3 & 41,9 & 31,1 & 22,6 & 18,9 & 17,2 & 24,3 & 38,1 & 53,8 & 71,2 & 92,6 \\
OB98 & 43,9 & 33,2 & 27,7 & 25,5 & 25,9 & 28,1 & 43,0 & 59,9 & 78,7 & 101,0 & 131,6 \\
OB971 & 43,7 & 32,0 & 24,6 & 21,2 & 20,4 & 25,6 & 40,1 & 56,0 & 73,6 & 93,9 & 120,6 \\
OB972 & 42,9 & 30,8 & 20,3 & 15,3 & 13,4 & 25,6 & 39,6 & 55,0 & 72,0 & 91,9 & 119,3 \\
OLYP & 53,3 & 41,1 & 28,6 & 18,7 & 14,5 & 18,0 & 34,4 & 53,4 & 76,9 & 107,9 & 161,5 \\
OP86 & 52,9 & 43,1 & 37,9 & 34,8 & 33,2 & 33,7 & 38,9 & 56,1 & 78,3 & 108,1 & 156,7 \\
OPBE & 52,7 & 45,7 & 41,5 & 39,3 & 39,0 & 40,4 & 46,5 & 66,3 & 92,2 & 128,6 & 196,2 \\
OPW91 & 51,5 & 44,6 & 40,5 & 38,1 & 37,8 & 39,3 & 46,8 & 67,1 & 93,0 & 129,5 & 197,7 \\
OTPSS & 49,9 & 41,9 & 38,4 & 37,0 & 37,3 & 39,6 & 48,1 & 69,2 & 95,4 & 131,7 & 197,2 \\
\hline
\end{tabular}




\subsubsection{Troca PBE}

Tabela 8.239: Constantes de acoplamento PBEB95 com base aug-pcJ-2.

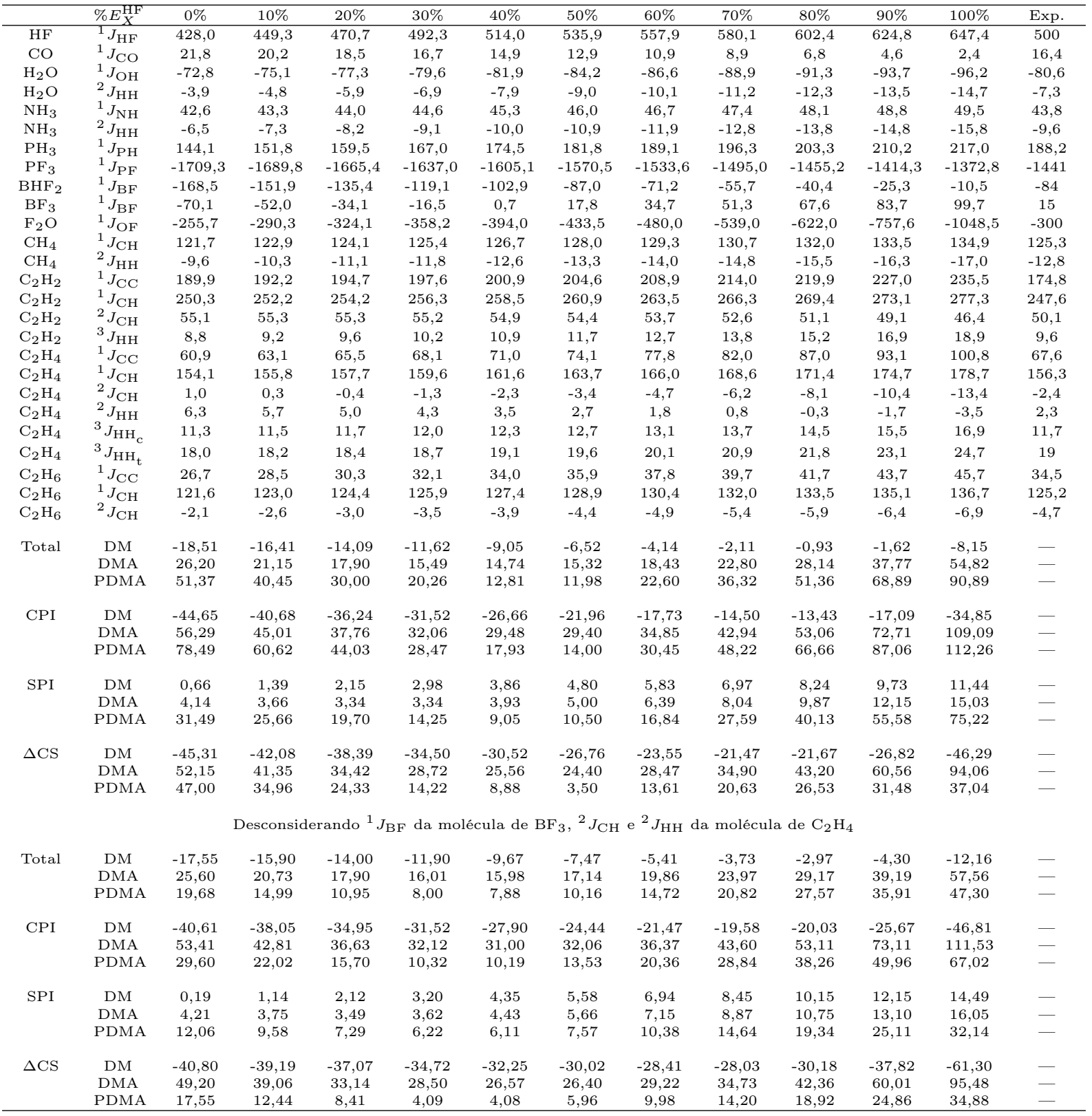


8.4. GERAÇÃO DE NOVOS FUNCIONAIS COMBINANDO $E_{X}^{H F}, E_{X}^{D F T} E$

Tabela 8.240: Constantes de acoplamento PBEB971 com base aug-pcJ-2.

\begin{tabular}{|c|c|c|c|c|c|c|c|c|c|c|c|c|c|}
\hline & $\% E_{X}^{\mathrm{HF}}$ & $0 \%$ & $10 \%$ & $20 \%$ & $30 \%$ & $40 \%$ & $50 \%$ & $60 \%$ & $70 \%$ & $80 \%$ & $90 \%$ & $100 \%$ & Exp. \\
\hline $\mathrm{HF}$ & ${ }^{1} J_{\mathrm{HF}}$ & 434,8 & 455,2 & 475,8 & 496,4 & 517,1 & 538,0 & 559,0 & 580,0 & 601,2 & 622,5 & 643,9 & 500 \\
\hline $\mathrm{CO}$ & ${ }^{1} J_{\mathrm{CO}}$ & 20,0 & 18,3 & 16,4 & 14,4 & 12,4 & 10,3 & 8,1 & 5,8 & 3,5 & 1,1 & $-1,3$ & 16,4 \\
\hline $\mathrm{H}_{2} \mathrm{O}$ & ${ }^{1} J_{\mathrm{OH}}$ & $-73,5$ & $-75,7$ & $-77,9$ & $-80,1$ & $-82,3$ & $-84,5$ & $-86,7$ & $-88,9$ & $-91,2$ & $-93,5$ & $-95,7$ & $-80,6$ \\
\hline $\mathrm{H}_{2} \mathrm{O}$ & ${ }^{2} J_{\mathrm{HH}}$ & $-3,8$ & $-4,8$ & $-5,8$ & $-6,8$ & $-7,8$ & $-8,8$ & $-9,9$ & $-11,0$ & $-12,0$ & $-13,1$ & $-14,3$ & $-7,3$ \\
\hline $\mathrm{NH}_{3}$ & ${ }^{1} J_{\mathrm{NH}}$ & 43,6 & 44,2 & 44,9 & 45,6 & 46,3 & 47,0 & 47,7 & 48,4 & 49,1 & 49,9 & 50,6 & 43,8 \\
\hline $\mathrm{NH}_{3}$ & ${ }^{2} J_{\mathrm{HH}}$ & $-6,6$ & $-7,5$ & $-8,4$ & $-9,3$ & $-10,2$ & $-11,1$ & $-12,1$ & $-13,1$ & $-14,0$ & $-15,0$ & $-16,1$ & $-9,6$ \\
\hline $\mathrm{PH}_{3}$ & ${ }^{1} J_{\mathrm{PH}}$ & 171,0 & 178,6 & 186,2 & 193,5 & 200,8 & 207,8 & 214,7 & 221,5 & 228,0 & 234,4 & 240,7 & 188,2 \\
\hline $\mathrm{PF}_{3}$ & ${ }^{1} J_{\mathrm{PF}}$ & $-1755,1$ & $-1733,1$ & $-1706,3$ & $-1675,4$ & $-1641,1$ & $-1604,0$ & $-1564,8$ & $-1523,9$ & $-1481,7$ & $-1438,5$ & $-1394,8$ & -1441 \\
\hline $\mathrm{BHF}_{2}$ & ${ }^{1} J_{\mathrm{BF}}$ & $-156,6$ & $-139,1$ & $-121,8$ & $-104,6$ & $-87,7$ & $-71,1$ & $-54,7$ & $-38,5$ & $-22,7$ & $-7,1$ & 8,1 & -84 \\
\hline $\mathrm{BF}_{3}$ & ${ }^{1} J_{\mathrm{BF}}$ & $-57,6$ & $-38,9$ & $-20,4$ & $-2,2$ & 15,5 & 33,1 & 50,4 & 67,4 & 84,1 & 100,6 & 116,8 & 15 \\
\hline $\mathrm{F}_{2} \mathrm{O}$ & ${ }^{1} J_{\mathrm{OF}}$ & $-253,7$ & $-288,4$ & $-322,7$ & $-357,7$ & $-395,1$ & $-437,2$ & $-487,8$ & $-553,9$ & $-650,4$ & $-817,6$ & $-1221,3$ & -300 \\
\hline $\mathrm{CH}_{4}$ & ${ }^{1} J_{\mathrm{CH}}$ & 129,7 & 131,1 & 132,5 & 134,0 & 135,5 & 137,0 & 138,6 & 140,2 & 141,8 & 143,4 & 145,1 & 125,3 \\
\hline $\mathrm{CH}_{4}$ & ${ }^{2} J_{\mathrm{HH}}$ & $-9,6$ & $-10,4$ & $-11,1$ & $-11,9$ & $-12,7$ & $-13,5$ & $-14,2$ & $-15,0$ & $-15,8$ & $-16,6$ & $-17,3$ & $-12,8$ \\
\hline $\mathrm{C}_{2} \mathrm{H}_{2}$ & ${ }^{1} J_{\mathrm{CC}}$ & 210,9 & 214,1 & 217,7 & 221,7 & 226,3 & 231,6 & 237,6 & 244,7 & 253,1 & 263,0 & 275,1 & 174,8 \\
\hline $\mathrm{C}_{2} \mathrm{H}_{2}$ & ${ }^{1} J_{\mathrm{CH}}$ & 261,5 & 263,8 & 266,2 & 268,7 & 271,4 & 274,4 & 277,6 & 281,2 & 285,2 & 289,9 & 295,5 & 247,6 \\
\hline $\mathrm{C}_{2} \mathrm{H}_{2}$ & ${ }^{2} J_{\mathrm{CH}}$ & 54,0 & 54,0 & 53,8 & 53,4 & 52,8 & 51,9 & 50,7 & 49,0 & 46,8 & 43,9 & 40,1 & 50,1 \\
\hline $\mathrm{C}_{2} \mathrm{H}_{2}$ & ${ }^{3} J_{\mathrm{HH}}$ & 8,7 & 9,1 & 9,7 & 10,3 & 11,1 & 12,1 & 13,2 & 14,5 & 16,1 & 18,1 & 20,5 & 9,6 \\
\hline $\mathrm{C}_{2} \mathrm{H}_{4}$ & ${ }^{1} J_{\mathrm{CC}}$ & 73,7 & 76,6 & 79,7 & 83,2 & 87,0 & 91,3 & 96,3 & 102,2 & 109,3 & 118,4 & 130,5 & 67,6 \\
\hline $\mathrm{C}_{2} \mathrm{H}_{4}$ & ${ }^{1} J_{\mathrm{CH}}$ & 162,3 & 164,3 & 166,5 & 168,7 & 171,1 & 173,7 & 176,5 & 179,6 & 183,2 & 187,6 & 193,0 & 156,3 \\
\hline $\mathrm{C}_{2} \mathrm{H}_{4}$ & ${ }^{2} J_{\mathrm{CH}}$ & 0,0 & $-0,7$ & $-1,7$ & $-2,7$ & $-3,9$ & $-5,3$ & $-6,9$ & $-8,9$ & $-11,3$ & $-14,5$ & $-18,8$ & $-2,4$ \\
\hline $\mathrm{C}_{2} \mathrm{H}_{4}$ & ${ }^{2} J_{\mathrm{HH}}$ & 5,9 & 5,3 & 4,6 & 3,8 & 3,0 & 2,2 & 1,2 & 0,0 & $-1,2$ & $-2,9$ & $-5,1$ & 2,3 \\
\hline $\mathrm{C}_{2} \mathrm{H}_{4}$ & ${ }^{3} J_{\mathrm{HH}_{\mathrm{c}}}$ & 11,2 & 11,4 & 11,7 & 11,9 & 12,3 & 12,7 & 13,3 & 14,0 & 14,9 & 16,2 & 18,0 & 11,7 \\
\hline $\mathrm{C}_{2} \mathrm{H}_{4}$ & ${ }^{3} J_{\mathrm{HH}_{\mathrm{t}}}$ & 17,8 & 18,0 & 18,2 & 18,6 & 19,0 & 19,6 & 20,2 & 21,1 & 22,3 & 23,8 & 25,9 & 19 \\
\hline $\mathrm{C}_{2} \mathrm{H}_{6}$ & ${ }^{1} J_{\mathrm{CC}}$ & 32,0 & 34,1 & 36,2 & 38,3 & 40,5 & 42,7 & 45,0 & 47,3 & 49,6 & 52,0 & 54,4 & 34,5 \\
\hline $\mathrm{C}_{2} \mathrm{H}_{6}$ & ${ }^{1} J_{\mathrm{CH}}$ & 129,5 & 131,1 & 132,8 & 134,5 & 136,2 & 137,9 & 139,7 & 141,5 & 143,3 & 145,1 & 147,0 & 125,2 \\
\hline $\mathrm{C}_{2} \mathrm{H}_{6}$ & ${ }^{2} J_{\mathrm{CH}}$ & $-2,3$ & $-2,8$ & $-3,3$ & $-3,8$ & $-4,3$ & $-4,8$ & $-5,3$ & $-5,8$ & $-6,4$ & $-7,0$ & $-7,5$ & $-4,7$ \\
\hline \multirow[t]{3}{*}{ Total } & $\mathrm{DM}$ & $-15,28$ & $-12,97$ & $-10,44$ & $-7,79$ & $-5,07$ & $-2,38$ & 0,09 & 2,09 & 3,07 & 1,50 & $-8,92$ & - \\
\hline & DMA & 26,80 & 22,24 & 19,42 & 18,07 & 18,56 & 22,00 & 26,15 & 31,02 & 37,23 & 46,63 & 68,67 & - \\
\hline & PDMA & 44,38 & 33,73 & 23,46 & 16,09 & 13,41 & 23,21 & 37,33 & 52,97 & 70,03 & 90,78 & 118,03 & - \\
\hline \multirow[t]{3}{*}{ CPI } & DM & $-43,49$ & $-39,28$ & $-34,63$ & $-29,74$ & $-24,82$ & $-20,13$ & $-16,09$ & $-13,37$ & $-13,36$ & $-19,75$ & $-47,66$ & - \\
\hline & DMA & 55,04 & 43,54 & 35,81 & 31,26 & 30,76 & 36,82 & 44,11 & 52,61 & 63,67 & 81,53 & 128,26 & - \\
\hline & PDMA & 67,30 & 48,89 & 31,98 & 18,65 & 9,89 & 26,96 & 45,15 & 63,65 & 82,62 & 103,90 & 132,83 & - \\
\hline \multirow[t]{3}{*}{ SPI } & DM & 5,41 & 6,33 & 7,29 & 8,31 & 9,41 & 10,63 & 11,96 & 13,43 & 15,12 & 17,09 & 19,49 & - \\
\hline & DMA & 6,09 & 6,62 & 7,40 & 8,40 & 9,61 & 11,13 & 12,97 & 15,19 & 17,84 & 21,03 & 24,97 & - \\
\hline & PDMA & 27,58 & 22,61 & 17,21 & 14,22 & 16,00 & 20,46 & 31,58 & 45,14 & 60,79 & 81,15 & 107,17 & - \\
\hline \multirow[t]{3}{*}{$\Delta \mathrm{CS}$} & $\mathrm{DM}$ & $-48,90$ & $-45,61$ & $-41,92$ & $-38,04$ & $-34,23$ & $-30,75$ & $-28,05$ & $-26,81$ & $-28,48$ & $-36,83$ & $-67,15$ & - \\
\hline & DMA & 48,94 & 36,92 & 28,41 & 22,86 & 21,15 & 25,68 & 31,14 & 37,42 & 45,83 & 60,49 & 103,30 & - \\
\hline & PDMA & 39,72 & 26,28 & 14,77 & 4,43 & $-6,11$ & 6,50 & 13,57 & 18,52 & 21,82 & 22,75 & 25,65 & - \\
\hline \multicolumn{14}{|c|}{ Desconsiderando ${ }^{1} J_{\mathrm{BF}}$ da molécula de $\mathrm{BF}_{3},{ }^{2} J_{\mathrm{CH}}$ e ${ }^{2} J_{\mathrm{HH}}$ da molécula de $\mathrm{C}_{2} \mathrm{H}_{4}$} \\
\hline \multirow[t]{3}{*}{ Total } & DM & $-14,37$ & $-12,52$ & $-10,40$ & $-8,11$ & $-5,72$ & $-3,35$ & $-1,19$ & 0,47 & 1,00 & $-1,27$ & $-13,48$ & - \\
\hline & DMA & 26,88 & 22,59 & 20,28 & 19,60 & 20,87 & 23,95 & 27,77 & 32,41 & 38,54 & 48,23 & 72,17 & - \\
\hline & PDMA & 17,97 & 13,76 & 10,64 & 9,83 & 10,97 & 15,55 & 21,70 & 28,57 & 36,39 & 46,06 & 60,22 & - \\
\hline \multirow[t]{3}{*}{ CPI } & DM & $-40,58$ & $-37,82$ & $-34,55$ & $-30,99$ & $-27,35$ & $-23,95$ & $-21,24$ & $-19,95$ & $-21,61$ & $-30,28$ & $-62,61$ & - \\
\hline & DMA & 53,28 & 42,50 & 35,85 & 32,67 & 33,79 & 38,69 & 44,98 & 52,63 & 63,13 & 81,12 & 130,91 & - \\
\hline & PDMA & 25,63 & 17,85 & 11,58 & 9,05 & 10,54 & 17,59 & 26,07 & 35,08 & 44,81 & 57,22 & 78,24 & - \\
\hline \multirow[t]{3}{*}{ SPI } & $\mathrm{DM}$ & 5,78 & 6,94 & 8,18 & 9,49 & 10,92 & 12,49 & 14,23 & 16,18 & 18,40 & 21,05 & 24,32 & - \\
\hline & DMA & 6,57 & 7,28 & 8,31 & 9,55 & 10,92 & 12,62 & 14,54 & 16,85 & 19,63 & 22,94 & 26,98 & - \\
\hline & PDMA & 12,09 & 10,61 & 9,92 & 10,43 & 11,31 & 13,98 & 18,34 & 23,55 & 29,91 & 37,47 & 46,35 & - \\
\hline \multirow[t]{3}{*}{$\Delta \mathrm{CS}$} & $\mathrm{DM}$ & $-46,36$ & $-44,76$ & $-42,73$ & $-40,48$ & $-38,27$ & $-36,44$ & $-35,47$ & $-36,13$ & $-40,01$ & $-51,33$ & $-86,93$ & - \\
\hline & DMA & 46,71 & 35,22 & 27,54 & 23,12 & 22,87 & 26,07 & 30,44 & 35,78 & 43,50 & 58,18 & 103,93 & - \\
\hline & PDMA & 13,54 & 7,24 & 1,66 & $-1,39$ & $-0,77$ & 3,62 & 7,73 & 11,53 & 14,90 & 19,76 & 31,89 & - \\
\hline
\end{tabular}


Tabela 8.241: Constantes de acoplamento PBEB972 com base aug-pcJ-2.

\begin{tabular}{|c|c|c|c|c|c|c|c|c|c|c|c|c|c|}
\hline & $\% E_{X}^{\mathrm{HF}}$ & $0 \%$ & $10 \%$ & $20 \%$ & $30 \%$ & $40 \%$ & $50 \%$ & $60 \%$ & $70 \%$ & $80 \%$ & $90 \%$ & $100 \%$ & Exp. \\
\hline $\mathrm{HF}$ & ${ }^{1} J_{\mathrm{HF}}$ & 473,0 & 494,5 & 516,0 & 537,6 & 559,3 & 581,1 & 603,0 & 625,0 & 647,1 & 669,3 & 691,6 & 500 \\
\hline $\mathrm{CO}$ & ${ }^{1} J_{\mathrm{CO}}$ & 15,8 & 13,8 & 11,7 & 9,4 & 7,1 & 4,7 & 2,3 & $-0,2$ & $-2,8$ & $-5,5$ & $-8,3$ & 16,4 \\
\hline $\mathrm{H}_{2} \mathrm{O}$ & ${ }^{1} J_{\mathrm{OH}}$ & $-79,4$ & $-81,8$ & $-84,1$ & $-86,4$ & $-88,7$ & $-91,1$ & $-93,5$ & $-95,9$ & $-98,3$ & $-100,7$ & $-103,1$ & $-80,6$ \\
\hline $\mathrm{H}_{2} \mathrm{O}$ & ${ }^{2} J_{\mathrm{HH}}$ & $-3,5$ & $-4,5$ & $-5,6$ & $-6,6$ & $-7,6$ & $-8,7$ & $-9,8$ & $-10,9$ & $-12,0$ & $-13,2$ & $-14,3$ & $-7,3$ \\
\hline $\mathrm{NH}_{3}$ & ${ }^{1} J_{\mathrm{NH}}$ & 46,0 & 46,6 & 47,3 & 48,0 & 48,7 & 49,4 & 50,1 & 50,9 & 51,6 & 52,3 & 53,1 & 43,8 \\
\hline $\mathrm{NH}_{3}$ & ${ }^{2} J_{\mathrm{HH}}$ & $-5,8$ & $-6,7$ & $-7,6$ & $-8,5$ & $-9,5$ & $-10,4$ & $-11,3$ & $-12,3$ & $-13,3$ & $-14,2$ & $-15,2$ & $-9,6$ \\
\hline $\mathrm{PH}_{3}$ & ${ }^{1} J_{\mathrm{PH}}$ & 163,2 & 171,5 & 179,8 & 188,0 & 196,2 & 204,2 & 212,1 & 219,9 & 227,6 & 235,1 & 242,5 & 188,2 \\
\hline $\mathrm{PF}_{3}$ & ${ }^{1} J_{\mathrm{PF}}$ & $-1801,9$ & $-1778,6$ & $-1750,2$ & $-1717,7$ & $-1681,7$ & $-1642,9$ & $-1601,9$ & $-1559,1$ & $-1515,2$ & $-1470,3$ & $-1424,9$ & -1441 \\
\hline $\mathrm{BHF}_{2}$ & ${ }^{1} J_{\mathrm{BF}}$ & $-142,1$ & $-124,6$ & $-107,4$ & $-90,4$ & $-73,7$ & $-57,3$ & $-41,2$ & $-25,3$ & $-9,8$ & 5,4 & 20,3 & -84 \\
\hline $\mathrm{BF}_{3}$ & ${ }^{1} J_{\mathrm{BF}}$ & $-41,0$ & $-22,3$ & $-3,9$ & 14,1 & 31,8 & 49,1 & 66,2 & 83,0 & 99,5 & 115,7 & 131,6 & 15 \\
\hline $\mathrm{F}_{2} \mathrm{O}$ & ${ }^{1} J_{\mathrm{OF}}$ & $-246,8$ & $-281,0$ & $-314,8$ & $-349,3$ & $-386,2$ & $-428,1$ & $-478,8$ & $-546,3$ & $-647,8$ & $-833,4$ & $-1349,0$ & -300 \\
\hline $\mathrm{CH}_{4}$ & ${ }^{1} J_{\mathrm{CH}}$ & 132,4 & 133,7 & 135,0 & 136,4 & 137,8 & 139,2 & 140,6 & 142,0 & 143,5 & 145,0 & 146,5 & 125,3 \\
\hline $\mathrm{CH}_{4}$ & ${ }^{2} J_{\mathrm{HH}}$ & $-8,3$ & $-9,0$ & $-9,7$ & $-10,5$ & $-11,2$ & $-12,0$ & $-12,7$ & $-13,4$ & $-14,2$ & $-14,9$ & $-15,6$ & $-12,8$ \\
\hline $\mathrm{C}_{2} \mathrm{H}_{2}$ & ${ }^{1} J_{\mathrm{CC}}$ & 208,9 & 212,2 & 215,8 & 220,0 & 224,7 & 230,0 & 236,3 & 243,5 & 252,0 & 262,1 & 274,3 & 174,8 \\
\hline $\mathrm{C}_{2} \mathrm{H}_{2}$ & ${ }^{1} J_{\mathrm{CH}}$ & 263,1 & 265,2 & 267,5 & 269,8 & 272,3 & 275,0 & 277,9 & 281,2 & 284,9 & 289,1 & 294,1 & 247,6 \\
\hline $\mathrm{C}_{2} \mathrm{H}_{2}$ & ${ }^{2} J_{\mathrm{CH}}$ & 54,4 & 54,4 & 54,2 & 53,9 & 53,3 & 52,5 & 51,3 & 49,7 & 47,7 & 45,1 & 41,6 & 50,1 \\
\hline $\mathrm{C}_{2} \mathrm{H}_{2}$ & ${ }^{3} J_{\mathrm{HH}}$ & 8,1 & 8,5 & 8,9 & 9,5 & 10,1 & 10,9 & 11,9 & 13,0 & 14,4 & 16,0 & 18,0 & 9,6 \\
\hline $\mathrm{C}_{2} \mathrm{H}_{4}$ & ${ }^{1} J_{\mathrm{CC}}$ & 74,1 & 77,0 & 80,3 & 83,9 & 87,9 & 92,6 & 98,0 & 104,5 & 112,5 & 122,9 & 137,0 & 67,6 \\
\hline $\mathrm{C}_{2} \mathrm{H}_{4}$ & ${ }^{1} J_{\mathrm{CH}}$ & 164,2 & 166,1 & 168,1 & 170,3 & 172,5 & 175,0 & 177,7 & 180,7 & 184,2 & 188,5 & 194,0 & 156,3 \\
\hline $\mathrm{C}_{2} \mathrm{H}_{4}$ & ${ }^{2} J_{\mathrm{CH}}$ & 0,9 & 0,0 & $-0,8$ & $-1,8$ & $-3,0$ & $-4,4$ & $-6,0$ & $-7,9$ & $-10,4$ & $-13,7$ & $-18,1$ & $-2,4$ \\
\hline $\mathrm{C}_{2} \mathrm{H}_{4}$ & ${ }^{2} J_{\mathrm{HH}}$ & 7,1 & 6,5 & 5,8 & 5,2 & 4,4 & 3,6 & 2,7 & 1,7 & 0,5 & $-0,9$ & $-2,9$ & 2,3 \\
\hline $\mathrm{C}_{2} \mathrm{H}_{4}$ & ${ }^{3} J_{\mathrm{HH}_{\mathrm{c}}}$ & 10,9 & 11,1 & 11,2 & 11,4 & 11,7 & 12,1 & 12,5 & 13,1 & 13,9 & 15,0 & 16,6 & 11,7 \\
\hline $\mathrm{C}_{2} \mathrm{H}_{4}$ & ${ }^{3} J_{\mathrm{HH}_{\mathrm{t}}}$ & 17,4 & 17,6 & 17,8 & 18,1 & 18,4 & 18,9 & 19,4 & 20,2 & 21,2 & 22,5 & 24,4 & 19 \\
\hline $\mathrm{C}_{2} \mathrm{H}_{6}$ & ${ }^{1} J_{\mathrm{CC}}$ & 35,0 & 37,0 & 39,0 & 41,1 & 43,2 & 45,3 & 47,5 & 49,7 & 51,9 & 54,1 & 56,4 & 34,5 \\
\hline $\mathrm{C}_{2} \mathrm{H}_{6}$ & ${ }^{1} J_{\mathrm{CH}}$ & 131,3 & 132,8 & 134,4 & 135,9 & 137,5 & 139,1 & 140,8 & 142,4 & 144,1 & 145,8 & 147,5 & 125,2 \\
\hline $\mathrm{C}_{2} \mathrm{H}_{6}$ & ${ }^{2} J_{\mathrm{CH}}$ & $-1,6$ & $-2,1$ & $-2,5$ & $-3,0$ & $-3,5$ & $-4,0$ & $-4,5$ & $-5,0$ & $-5,5$ & $-6,0$ & $-6,5$ & $-4,7$ \\
\hline \multirow[t]{3}{*}{ Total } & $\mathrm{DM}$ & $-14,22$ & $-11,81$ & $-9,18$ & $-6,41$ & $-3,58$ & $-0,82$ & 1,75 & 3,82 & 4,70 & 2,54 & $-12,05$ & - \\
\hline & DMA & 26,67 & 22,39 & 20,45 & 20,33 & 23,02 & 26,61 & 30,56 & 35,35 & 41,76 & 51,63 & 75,85 & - \\
\hline & PDMA & 44,04 & 34,53 & 25,96 & 17,81 & 21,61 & 30,52 & 40,03 & 53,24 & 70,43 & 90,71 & 118,82 & - \\
\hline \multirow[t]{3}{*}{ CPI } & DM & $-42,13$ & $-37,64$ & $-32,70$ & $-27,52$ & $-22,29$ & $-17,35$ & $-13,06$ & $-10,19$ & $-10,39$ & $-18,22$ & $-56,05$ & - \\
\hline & DMA & 53,80 & 42,64 & 36,92 & 35,45 & 40,36 & 47,08 & 54,37 & 63,01 & 74,57 & 93,64 & 145,55 & - \\
\hline & PDMA & 55,07 & 39,00 & 24,82 & 12,49 & 24,45 & 42,29 & 60,42 & 79,02 & 98,44 & 120,27 & 152,13 & - \\
\hline \multirow[t]{3}{*}{ SPI } & DM & 6,25 & 7,13 & 8,06 & 9,07 & 10,13 & 11,31 & 12,62 & 14,09 & 15,77 & 17,77 & 20,21 & - \\
\hline & DMA & 6,77 & 7,54 & 8,38 & 9,25 & 10,29 & 11,59 & 13,10 & 15,07 & 17,69 & 20,82 & 24,75 & - \\
\hline & PDMA & 35,95 & 31,26 & 26,79 & 21,71 & 19,53 & 21,89 & 25,08 & 34,33 & 49,89 & 69,03 & 94,39 & - \\
\hline \multirow[t]{3}{*}{$\Delta \mathrm{CS}$} & DM & $-48,38$ & $-44,76$ & $-40,76$ & $-36,59$ & $-32,42$ & $-28,67$ & $-25,68$ & $-24,28$ & $-26,16$ & $-35,98$ & $-76,27$ & - \\
\hline & DMA & 47,03 & 35,10 & 28,54 & 26,20 & 30,07 & 35,49 & 41,27 & 47,94 & 56,88 & 72,82 & 120,80 & - \\
\hline & PDMA & 19,12 & 7,75 & $-1,97$ & $-9,21$ & 4,91 & 20,40 & 35,35 & 44,68 & 48,56 & 51,25 & 57,74 & - \\
\hline \multicolumn{14}{|c|}{ Desconsiderando ${ }^{1} J_{\mathrm{BF}}$ da molécula de $\mathrm{BF}_{3},{ }^{2} J_{\mathrm{CH}}$ e ${ }^{2} J_{\mathrm{HH}}$ da molécula de $\mathrm{C}_{2} \mathrm{H}_{4}$} \\
\hline \multirow[t]{3}{*}{ Total } & DM & $-13,99$ & $-12,02$ & $-9,78$ & $-7,36$ & $-4,85$ & $-2,37$ & $-0,10$ & 1,62 & 2,07 & $-0,87$ & $-17,79$ & - \\
\hline & DMA & 27,36 & 23,40 & 22,08 & 22,79 & 25,17 & 28,45 & 32,15 & 36,74 & 43,10 & 53,35 & 79,77 & - \\
\hline & PDMA & 18,50 & 15,94 & 14,35 & 13,30 & 14,51 & 18,54 & 23,13 & 29,38 & 37,23 & 46,83 & 62,25 & - \\
\hline \multirow[t]{3}{*}{ CPI } & DM & $-40,74$ & $-37,67$ & $-34,08$ & $-30,18$ & $-26,20$ & $-22,50$ & $-19,49$ & $-18,01$ & $-19,88$ & $-30,11$ & $-73,32$ & - \\
\hline & DMA & 53,58 & 43,17 & 38,72 & 38,90 & 42,72 & 48,38 & 54,69 & 62,51 & 73,58 & 92,93 & 148,44 & - \\
\hline & PDMA & 23,24 & 18,04 & 14,70 & 13,14 & 15,69 & 23,79 & 32,33 & 41,59 & 51,95 & 65,17 & 89,61 & - \\
\hline \multirow[t]{3}{*}{ SPI } & DM & 6,59 & 7,72 & 8,91 & 10,20 & 11,58 & 13,11 & 14,81 & 16,72 & 18,95 & 21,62 & 24,93 & - \\
\hline & DMA & 7,19 & 8,19 & 9,28 & 10,40 & 11,67 & 13,12 & 14,81 & 16,92 & 19,66 & 22,91 & 26,95 & - \\
\hline & PDMA & 14,85 & 14,33 & 14,08 & 13,42 & 13,59 & 14,50 & 16,06 & 19,98 & 25,90 & 32,73 & 41,20 & - \\
\hline \multirow[t]{3}{*}{$\Delta \mathrm{CS}$} & DM & $-47,33$ & $-45,39$ & $-42,99$ & $-40,38$ & $-37,78$ & $-35,61$ & $-34,30$ & $-34,73$ & $-38,83$ & $-51,73$ & $-98,25$ & - \\
\hline & DMA & 46,39 & 34,98 & 29,44 & 28,50 & 31,05 & 35,26 & 39,88 & 45,59 & 53,92 & 70,02 & 121,49 & - \\
\hline & PDMA & 8,40 & 3,71 & 0,62 & $-0,28$ & 2,10 & 9,29 & 16,27 & 21,61 & 26,05 & 32,44 & 48,41 & - \\
\hline
\end{tabular}


8.4. GERAÇÃO DE NOVOS FUNCIONAIS COMBINANDO $E_{X}^{H F}, E_{X}^{D F T} E$

Tabela 8.242: Constantes de acoplamento PBEB98 com base aug-pcJ-2.

\begin{tabular}{|c|c|c|c|c|c|c|c|c|c|c|c|c|c|}
\hline & $\% E_{X}^{\mathrm{HF}}$ & $0 \%$ & $10 \%$ & $20 \%$ & $30 \%$ & $40 \%$ & $50 \%$ & $60 \%$ & $70 \%$ & $80 \%$ & $90 \%$ & $100 \%$ & Exp. \\
\hline $\mathrm{HF}$ & ${ }^{1} J_{\mathrm{HF}}$ & 422,8 & 443,3 & 463,9 & 484,6 & 505,5 & 526,5 & 547,6 & 568,8 & 590,1 & 611,5 & 633,1 & 500 \\
\hline $\mathrm{CO}$ & ${ }^{1} J_{\mathrm{CO}}$ & 19,8 & 18,0 & 16,2 & 14,2 & 12,2 & 10,1 & 7,9 & 5,6 & 3,3 & 0,9 & $-1,4$ & 16,4 \\
\hline $\mathrm{H}_{2} \mathrm{O}$ & ${ }^{1} J_{\mathrm{OH}}$ & $-73,0$ & $-75,2$ & $-77,4$ & $-79,6$ & $-81,8$ & $-84,1$ & $-86,3$ & $-88,6$ & $-90,9$ & $-93,2$ & $-95,6$ & $-80,6$ \\
\hline $\mathrm{H}_{2} \mathrm{O}$ & ${ }^{2} J_{\mathrm{HH}}$ & $-3,9$ & $-4,9$ & $-5,9$ & $-6,9$ & $-8,0$ & $-9,0$ & $-10,1$ & $-11,2$ & $-12,3$ & $-13,5$ & $-14,6$ & $-7,3$ \\
\hline $\mathrm{NH}_{3}$ & ${ }^{1} J_{\mathrm{NH}}$ & 44,1 & 44,8 & 45,5 & 46,2 & 47,0 & 47,7 & 48,4 & 49,2 & 49,9 & 50,7 & 51,5 & 43,8 \\
\hline $\mathrm{NH}_{3}$ & ${ }^{2} J_{\mathrm{HH}}$ & $-6,9$ & $-7,8$ & $-8,8$ & $-9,7$ & $-10,7$ & $-11,6$ & $-12,6$ & $-13,6$ & $-14,7$ & $-15,7$ & $-16,8$ & $-9,6$ \\
\hline $\mathrm{PH}_{3}$ & ${ }^{1} J_{\mathrm{PH}}$ & 177,2 & 185,0 & 192,6 & 200,1 & 207,5 & 214,6 & 221,6 & 228,5 & 235,1 & 241,6 & 247,9 & 188,2 \\
\hline $\mathrm{PF}_{3}$ & ${ }^{1} J_{\mathrm{PF}}$ & $-1770,6$ & $-1747,7$ & $-1720,1$ & $-1688,4$ & $-1653,5$ & $-1615,8$ & $-1576,1$ & $-1534,7$ & $-1492,1$ & $-1448,6$ & $-1404,5$ & -1441 \\
\hline $\mathrm{BHF}_{2}$ & ${ }^{1} J_{\mathrm{BF}}$ & $-157,0$ & $-139,7$ & $-122,5$ & $-105,5$ & $-88,8$ & $-72,3$ & $-56,0$ & $-40,0$ & $-24,3$ & $-8,8$ & 6,2 & -84 \\
\hline $\mathrm{BF}_{3}$ & ${ }^{1} J_{\mathrm{BF}}$ & $-58,9$ & $-40,4$ & $-22,1$ & $-4,1$ & 13,5 & 30,9 & 48,0 & 64,9 & 81,4 & 97,8 & 113,8 & 15 \\
\hline $\mathrm{F}_{2} \mathrm{O}$ & ${ }^{1} J_{\mathrm{OF}}$ & $-262,0$ & $-297,8$ & $-333,3$ & $-370,1$ & $-409,7$ & $-455,1$ & $-510,8$ & $-585,7$ & $-699,3$ & $-909,6$ & $-1507,1$ & -300 \\
\hline $\mathrm{CH}_{4}$ & ${ }^{1} J_{\mathrm{CH}}$ & 133,1 & 134,6 & 136,2 & 137,7 & 139,3 & 141,0 & 142,6 & 144,3 & 146,0 & 147,8 & 149,5 & 125,3 \\
\hline $\mathrm{CH}_{4}$ & ${ }^{2} J_{\mathrm{HH}}$ & $-10,1$ & $-10,9$ & $-11,7$ & $-12,5$ & $-13,3$ & $-14,1$ & $-14,9$ & $-15,7$ & $-16,5$ & $-17,3$ & $-18,1$ & $-12,8$ \\
\hline $\mathrm{C}_{2} \mathrm{H}_{2}$ & ${ }^{1} J_{\mathrm{CC}}$ & 214,5 & 217,9 & 221,6 & 225,8 & 230,5 & 236,0 & 242,3 & 249,8 & 258,6 & 269,1 & 282,1 & 174,8 \\
\hline $\mathrm{C}_{2} \mathrm{H}_{2}$ & ${ }^{1} J_{\mathrm{CH}}$ & 266,6 & 269,1 & 271,6 & 274,3 & 277,2 & 280,4 & 283,8 & 287,7 & 292,1 & 297,3 & 303,3 & 247,6 \\
\hline $\mathrm{C}_{2} \mathrm{H}_{2}$ & ${ }^{2} J_{\mathrm{CH}}$ & 54,6 & 54,6 & 54,4 & 53,9 & 53,3 & 52,3 & 50,9 & 49,1 & 46,7 & 43,5 & 39,3 & 50,1 \\
\hline $\mathrm{C}_{2} \mathrm{H}_{2}$ & ${ }^{3} J_{\mathrm{HH}}$ & 8,8 & 9,3 & 9,9 & 10,6 & 11,4 & 12,4 & 13,7 & 15,1 & 16,9 & 19,1 & 21,7 & 9,6 \\
\hline $\mathrm{C}_{2} \mathrm{H}_{4}$ & ${ }^{1} J_{\mathrm{CC}}$ & 76,1 & 79,1 & 82,4 & 86,0 & 90,0 & 94,6 & 100,0 & 106,3 & 114,2 & 124,4 & 138,3 & 67,6 \\
\hline $\mathrm{C}_{2} \mathrm{H}_{4}$ & ${ }^{1} J_{\mathrm{CH}}$ & 165,9 & 168,1 & 170,4 & 172,8 & 175,3 & 178,1 & 181,1 & 184,5 & 188,5 & 193,3 & 199,6 & 156,3 \\
\hline $\mathrm{C}_{2} \mathrm{H}_{4}$ & ${ }^{2} J_{\mathrm{CH}}$ & 0,0 & $-0,8$ & $-1,8$ & $-2,9$ & $-4,2$ & $-5,6$ & $-7,4$ & $-9,5$ & $-12,2$ & $-15,8$ & $-20,9$ & $-2,4$ \\
\hline $\mathrm{C}_{2} \mathrm{H}_{4}$ & ${ }^{2} J_{\mathrm{HH}}$ & 5,9 & 5,3 & 4,5 & 3,8 & 2,9 & 2,0 & 1,0 & $-0,2$ & $-1,7$ & $-3,6$ & $-6,2$ & 2,3 \\
\hline $\mathrm{C}_{2} \mathrm{H}_{4}$ & ${ }^{3} J_{\mathrm{HH}_{\mathrm{c}}}$ & 11,4 & 11,6 & 11,8 & 12,1 & 12,5 & 13,0 & 13,6 & 14,4 & 15,5 & 17,0 & 19,2 & 11,7 \\
\hline $\mathrm{C}_{2} \mathrm{H}_{4}$ & ${ }^{3} J_{\mathrm{HH}_{\mathrm{t}}}$ & 18,0 & 18,3 & 18,6 & 19,0 & 19,4 & 20,0 & 20,8 & 21,8 & 23,1 & 24,9 & 27,5 & 19 \\
\hline $\mathrm{C}_{2} \mathrm{H}_{6}$ & ${ }^{1} J_{\mathrm{CC}}$ & 33,5 & 35,7 & 37,9 & 40,1 & 42,4 & 44,7 & 47,1 & 49,5 & 52,0 & 54,5 & 57,1 & 34,5 \\
\hline $\mathrm{C}_{2} \mathrm{H}_{6}$ & ${ }^{1} J_{\mathrm{CH}}$ & 132,8 & 134,5 & 136,3 & 138,1 & 139,9 & 141,8 & 143,6 & 145,5 & 147,5 & 149,4 & 151,4 & 125,2 \\
\hline $\mathrm{C}_{2} \mathrm{H}_{6}$ & ${ }^{2} J_{\mathrm{CH}}$ & $-2,4$ & $-2,9$ & $-3,4$ & $-3,9$ & $-4,4$ & $-5,0$ & $-5,5$ & $-6,1$ & $-6,7$ & $-7,3$ & $-7,9$ & $-4,7$ \\
\hline \multirow[t]{3}{*}{ Total } & $\mathrm{DM}$ & $-15,57$ & $-13,23$ & $-10,70$ & $-8,05$ & $-5,37$ & $-2,75$ & $-0,41$ & 1,33 & 1,74 & $-1,37$ & $-19,10$ & - \\
\hline & DMA & 28,11 & 23,60 & 21,97 & 20,90 & 20,63 & 24,06 & 28,44 & 33,72 & 40,72 & 51,75 & 80,95 & - \\
\hline & PDMA & 44,54 & 34,01 & 24,47 & 18,10 & 15,93 & 25,74 & 40,37 & 56,48 & 75,10 & 97,73 & 129,89 & - \\
\hline \multirow[t]{3}{*}{ CPI } & DM & $-46,30$ & $-42,12$ & $-37,53$ & $-32,74$ & $-27,97$ & $-23,55$ & $-19,94$ & $-17,97$ & $-19,52$ & $-29,80$ & $-75,31$ & - \\
\hline & DMA & 56,37 & 44,74 & 39,62 & 35,59 & 33,06 & 38,89 & 46,59 & 55,86 & 68,46 & 89,76 & 152,76 & - \\
\hline & PDMA & 67,45 & 49,19 & 33,62 & 20,87 & 12,17 & 27,17 & 45,39 & 64,11 & 83,78 & 106,39 & 140,82 & - \\
\hline \multirow[t]{3}{*}{ SPI } & DM & 6,97 & 7,96 & 8,97 & 10,05 & 11,21 & 12,50 & 13,91 & 15,49 & 17,33 & 19,48 & 22,12 & - \\
\hline & DMA & 7,39 & 8,11 & 9,03 & 10,12 & 11,51 & 13,18 & 15,13 & 17,48 & 20,38 & 23,88 & 28,29 & - \\
\hline & PDMA & 27,73 & 22,87 & 17,76 & 16,07 & 18,69 & 24,69 & 36,69 & 50,89 & 68,74 & 91,39 & 121,88 & - \\
\hline \multirow[t]{3}{*}{$\Delta \mathrm{CS}$} & DM & $-53,27$ & $-50,08$ & $-46,50$ & $-42,79$ & $-39,18$ & $-36,05$ & $-33,84$ & $-33,47$ & $-36,84$ & $-49,28$ & $-97,43$ & - \\
\hline & DMA & 48,99 & 36,63 & 30,59 & 25,47 & 21,55 & 25,71 & 31,46 & 38,38 & 48,08 & 65,88 & 124,47 & - \\
\hline & PDMA & 39,72 & 26,31 & 15,86 & 4,80 & $-6,53$ & 2,48 & 8,70 & 13,22 & 15,04 & 15,00 & 18,94 & - \\
\hline \multicolumn{14}{|c|}{ Desconsiderando ${ }^{1} J_{\mathrm{BF}}$ da molécula de $\mathrm{BF}_{3},{ }^{2} J_{\mathrm{CH}}$ e ${ }^{2} J_{\mathrm{HH}}$ da molécula de $\mathrm{C}_{2} \mathrm{H}_{4}$} \\
\hline \multirow[t]{3}{*}{ Total } & DM & $-14,64$ & $-12,74$ & $-10,60$ & $-8,31$ & $-5,95$ & $-3,65$ & $-1,63$ & $-0,24$ & $-0,32$ & $-4,31$ & $-24,71$ & - \\
\hline & DMA & 28,30 & 24,07 & 23,10 & 22,70 & 23,15 & 26,35 & 30,44 & 35,53 & 42,55 & 54,07 & 86,04 & - \\
\hline & PDMA & 17,77 & 13,82 & 11,66 & 11,18 & 13,18 & 18,12 & 24,55 & 31,79 & 40,34 & 51,05 & 68,62 & - \\
\hline \multirow[t]{3}{*}{ CPI } & DM & $-43,54$ & $-40,79$ & $-37,57$ & $-34,10$ & $-30,62$ & $-27,49$ & $-25,23$ & $-24,76$ & $-28,11$ & $-41,06$ & $-92,72$ & - \\
\hline & DMA & 54,62 & 43,67 & 39,87 & 37,24 & 36,22 & 41,19 & 47,95 & 56,46 & 68,67 & 90,46 & 158,16 & - \\
\hline & PDMA & 24,93 & 17,17 & 12,24 & 10,22 & 12,38 & 19,29 & 27,93 & 37,25 & 47,89 & 61,83 & 89,03 & - \\
\hline \multirow[t]{3}{*}{ SPI } & DM & 7,58 & 8,83 & 10,14 & 11,52 & 13,02 & 14,69 & 16,53 & 18,62 & 21,05 & 23,96 & 27,60 & - \\
\hline & DMA & 8,06 & 9,00 & 10,20 & 11,52 & 13,10 & 14,94 & 16,98 & 19,43 & 22,45 & 26,07 & 30,57 & - \\
\hline & PDMA & 12,27 & 11,23 & 11,21 & 11,92 & 13,79 & 17,23 & 21,96 & 27,60 & 34,53 & 42,76 & 52,91 & - \\
\hline \multirow[t]{3}{*}{$\Delta \mathrm{CS}$} & $\mathrm{DM}$ & $-51,12$ & $-49,62$ & $-47,71$ & $-45,62$ & $-43,64$ & $-42,18$ & $-41,76$ & $-43,38$ & $-49,16$ & $-65,02$ & $-120,32$ & - \\
\hline & DMA & 46,56 & 34,67 & 29,67 & 25,72 & 23,12 & 26,25 & 30,97 & 37,03 & 46,22 & 64,39 & 127,59 & - \\
\hline & PDMA & 12,66 & 5,94 & 1,03 & $-1,70$ & $-1,41$ & 2,06 & 5,96 & 9,65 & 13,36 & 19,07 & 36,12 & - \\
\hline
\end{tabular}


Tabela 8.243: Constantes de acoplamento PBELYP com base aug-pcJ-2.

\begin{tabular}{|c|c|c|c|c|c|c|c|c|c|c|c|c|c|}
\hline & $\% E_{X}^{\mathrm{HF}}$ & $0 \%$ & $10 \%$ & $20 \%$ & $30 \%$ & $40 \%$ & $50 \%$ & $60 \%$ & $70 \%$ & $80 \%$ & $90 \%$ & $100 \%$ & Exp. \\
\hline $\mathrm{HF}$ & ${ }^{1} J_{\mathrm{HF}}$ & 423,5 & 446,4 & 469,5 & 492,9 & 516,4 & 540,2 & 564,2 & 588,4 & 612,8 & 637,5 & 662,5 & 500 \\
\hline $\mathrm{CO}$ & ${ }^{1} J_{\mathrm{CO}}$ & 19,8 & 17,9 & 16,0 & 14,0 & 12,0 & 9,8 & 7,6 & 5,3 & 2,9 & 0,5 & $-1,9$ & 16,4 \\
\hline $\mathrm{H}_{2} \mathrm{O}$ & ${ }^{1} J_{\mathrm{OH}}$ & $-75,3$ & $-77,8$ & $-80,3$ & $-82,8$ & $-85,3$ & $-87,8$ & $-90,4$ & $-93,0$ & $-95,7$ & $-98,4$ & $-101,1$ & $-80,6$ \\
\hline $\mathrm{H}_{2} \mathrm{O}$ & ${ }^{2} J_{\mathrm{HH}}$ & $-5,2$ & $-6,3$ & $-7,4$ & $-8,6$ & $-9,7$ & $-10,9$ & $-12,2$ & $-13,4$ & $-14,7$ & $-16,0$ & $-17,3$ & $-7,3$ \\
\hline $\mathrm{NH}_{3}$ & ${ }^{1} J_{\mathrm{NH}}$ & 45,5 & 46,3 & 47,0 & 47,8 & 48,6 & 49,3 & 50,1 & 50,9 & 51,8 & 52,6 & 53,4 & 43,8 \\
\hline $\mathrm{NH}_{3}$ & ${ }^{2} J_{\mathrm{HH}}$ & $-8,1$ & $-9,0$ & $-10,0$ & $-11,1$ & $-12,1$ & $-13,1$ & $-14,2$ & $-15,3$ & $-16,4$ & $-17,5$ & $-18,7$ & $-9,6$ \\
\hline $\mathrm{PH}_{3}$ & ${ }^{1} J_{\mathrm{PH}}$ & 157,1 & 165,8 & 174,3 & 182,8 & 191,2 & 199,5 & 207,7 & 215,8 & 223,7 & 231,5 & 239,2 & 188,2 \\
\hline $\mathrm{PF}_{3}$ & ${ }^{1} J_{\mathrm{PF}}$ & $-1806,9$ & $-1784,0$ & $-1756,1$ & $-1724,1$ & $-1688,8$ & $-1650,7$ & $-1610,5$ & $-1568,6$ & $-1525,5$ & $-1481,5$ & $-1437,0$ & -1441 \\
\hline $\mathrm{BHF}_{2}$ & ${ }^{1} J_{\mathrm{BF}}$ & $-162,4$ & $-145,1$ & $-128,0$ & $-111,0$ & $-94,3$ & $-77,9$ & $-61,7$ & $-45,7$ & $-30,0$ & $-14,5$ & 0,6 & -84 \\
\hline $\mathrm{BF}_{3}$ & ${ }^{1} J_{\mathrm{BF}}$ & $-61,0$ & $-42,3$ & $-23,8$ & $-5,7$ & 12,1 & 29,6 & 46,9 & 64,0 & 80,8 & 97,4 & 113,8 & 15 \\
\hline $\mathrm{F}_{2} \mathrm{O}$ & ${ }^{1} J_{\mathrm{OF}}$ & $-268,4$ & $-305,6$ & $-342,9$ & $-381,9$ & $-424,8$ & $-474,8$ & $-537,8$ & $-625,6$ & $-767,0$ & $-1059,2$ & $-2253,8$ & -300 \\
\hline $\mathrm{CH}_{4}$ & ${ }^{1} J_{\mathrm{CH}}$ & 133,7 & 135,1 & 136,6 & 138,1 & 139,6 & 141,2 & 142,7 & 144,4 & 146,0 & 147,7 & 149,4 & 125,3 \\
\hline $\mathrm{CH}_{4}$ & ${ }^{2} J_{\mathrm{HH}}$ & $-11,3$ & $-12,2$ & $-13,0$ & $-13,9$ & $-14,7$ & $-15,5$ & $-16,4$ & $-17,2$ & $-18,1$ & $-18,9$ & $-19,7$ & $-12,8$ \\
\hline $\mathrm{C}_{2} \mathrm{H}_{2}$ & ${ }^{1} J_{\mathrm{CC}}$ & 201,8 & 204,8 & 208,2 & 212,0 & 216,5 & 221,7 & 227,9 & 235,2 & 244,0 & 254,9 & 268,4 & 174,8 \\
\hline $\mathrm{C}_{2} \mathrm{H}_{2}$ & ${ }^{1} J_{\mathrm{CH}}$ & 273,9 & 276,4 & 279,0 & 281,8 & 284,8 & 288,1 & 291,8 & 295,9 & 300,8 & 306,5 & 313,5 & 247,6 \\
\hline $\mathrm{C}_{2} \mathrm{H}_{2}$ & ${ }^{2} J_{\mathrm{CH}}$ & 56,9 & 56,8 & 56,5 & 56,0 & 55,1 & 54,0 & 52,3 & 50,1 & 47,2 & 43,3 & 38,1 & 50,1 \\
\hline $\mathrm{C}_{2} \mathrm{H}_{2}$ & ${ }^{3} J_{\mathrm{HH}}$ & 9,9 & 10,5 & 11,2 & 12,0 & 13,1 & 14,3 & 15,8 & 17,6 & 19,8 & 22,6 & 26,0 & 9,6 \\
\hline $\mathrm{C}_{2} \mathrm{H}_{4}$ & ${ }^{1} J_{\mathrm{CC}}$ & 69,2 & 72,0 & 75,2 & 78,7 & 82,6 & 87,3 & 92,8 & 99,7 & 108,5 & 120,7 & 139,0 & 67,6 \\
\hline $\mathrm{C}_{2} \mathrm{H}_{4}$ & ${ }^{1} J_{\mathrm{CH}}$ & 168,0 & 170,2 & 172,4 & 174,8 & 177,4 & 180,3 & 183,4 & 187,1 & 191,6 & 197,5 & 205,7 & 156,3 \\
\hline $\mathrm{C}_{2} \mathrm{H}_{4}$ & ${ }^{2} J_{\mathrm{CH}}$ & 0,1 & $-0,7$ & $-1,7$ & $-2,9$ & $-4,3$ & $-5,9$ & $-7,9$ & $-10,4$ & $-13,7$ & $-18,3$ & $-25,4$ & $-2,4$ \\
\hline $\mathrm{C}_{2} \mathrm{H}_{4}$ & ${ }^{2} J_{\mathrm{HH}}$ & 6,4 & 5,7 & 4,8 & 4,0 & 3,0 & 1,9 & 0,6 & $-0,8$ & $-2,8$ & $-5,4$ & $-9,3$ & 2,3 \\
\hline $\mathrm{C}_{2} \mathrm{H}_{4}$ & ${ }^{3} J_{\mathrm{HH}_{\mathrm{c}}}$ & 12,5 & 12,8 & 13,1 & 13,5 & 14,0 & 14,6 & 15,4 & 16,5 & 18,0 & 20,2 & 23,7 & 11,7 \\
\hline $\mathrm{C}_{2} \mathrm{H}_{4}$ & ${ }^{3} J_{\mathrm{HH}_{\mathrm{t}}}$ & 19,8 & 20,1 & 20,4 & 20,9 & 21,5 & 22,2 & 23,2 & 24,5 & 26,3 & 28,9 & 32,9 & 19 \\
\hline $\mathrm{C}_{2} \mathrm{H}_{6}$ & ${ }^{1} J_{\mathrm{CC}}$ & 31,1 & 33,1 & 35,1 & 37,2 & 39,3 & 41,5 & 43,6 & 45,9 & 48,1 & 50,4 & 52,7 & 34,5 \\
\hline $\mathrm{C}_{2} \mathrm{H}_{6}$ & ${ }^{1} J_{\mathrm{CH}}$ & 133,1 & 134,8 & 136,4 & 138,2 & 139,9 & 141,7 & 143,5 & 145,3 & 147,1 & 149,0 & 150,9 & 125,2 \\
\hline $\mathrm{C}_{2} \mathrm{H}_{6}$ & ${ }^{2} J_{\mathrm{CH}}$ & $-2,4$ & $-2,9$ & $-3,4$ & $-3,9$ & $-4,5$ & $-5,0$ & $-5,6$ & $-6,1$ & $-6,7$ & $-7,2$ & $-7,8$ & $-4,7$ \\
\hline \multirow[t]{3}{*}{ Total } & $\mathrm{DM}$ & $-18,60$ & $-16,24$ & $-13,69$ & $-11,01$ & $-8,32$ & $-5,75$ & $-3,55$ & $-2,10$ & $-2,55$ & $-8,49$ & $-48,74$ & - \\
\hline & DMA & 29,96 & 25,64 & 23,72 & 22,39 & 22,72 & 25,97 & 30,85 & 36,78 & 45,22 & 59,90 & 110,36 & - \\
\hline & PDMA & 45,11 & 34,79 & 25,59 & 21,37 & 19,90 & 29,30 & 45,36 & 62,90 & 84,46 & 111,86 & 158,62 & - \\
\hline \multirow[t]{3}{*}{ CPI } & DM & $-52,94$ & $-48,60$ & $-43,87$ & $-38,96$ & $-34,15$ & $-29,79$ & $-26,47$ & $-25,28$ & $-28,93$ & $-46,23$ & $-145,56$ & - \\
\hline & DMA & 61,23 & 50,13 & 44,51 & 39,69 & 38,55 & 43,92 & 52,69 & 63,54 & 79,13 & 108,32 & 220,20 & - \\
\hline & PDMA & 67,58 & 49,21 & 34,21 & 25,57 & 17,98 & 30,82 & 49,88 & 69,47 & 90,68 & 116,28 & 169,20 & - \\
\hline \multirow[t]{3}{*}{ SPI } & DM & 6,57 & 7,49 & 8,45 & 9,49 & 10,61 & 11,89 & 13,27 & 14,91 & 16,80 & 19,19 & 22,27 & - \\
\hline & DMA & 7,03 & 7,68 & 8,47 & 9,71 & 11,12 & 12,81 & 14,83 & 17,16 & 20,35 & 24,39 & 29,81 & - \\
\hline & PDMA & 28,64 & 24,22 & 19,26 & 18,29 & 21,31 & 28,19 & 42,05 & 58,08 & 79,90 & 108,62 & 150,86 & - \\
\hline \multirow[t]{3}{*}{$\Delta \mathrm{CS}$} & DM & $-59,51$ & $-56,09$ & $-52,32$ & $-48,46$ & $-44,76$ & $-41,68$ & $-39,74$ & $-40,19$ & $-45,73$ & $-65,41$ & $-167,83$ & - \\
\hline & DMA & 54,20 & 42,45 & 36,04 & 29,98 & 27,43 & 31,11 & 37,86 & 46,38 & 58,78 & 83,93 & 190,39 & - \\
\hline & PDMA & 38,93 & 24,99 & 14,95 & 7,29 & $-3,32$ & 2,62 & 7,83 & 11,40 & 10,78 & 7,65 & 18,34 & - \\
\hline \multicolumn{14}{|c|}{ Desconsiderando ${ }^{1} J_{\mathrm{BF}}$ da molécula de $\mathrm{BF}_{3},{ }^{2} J_{\mathrm{CH}}$ e ${ }^{2} J_{\mathrm{HH}}$ da molécula de $\mathrm{C}_{2} \mathrm{H}_{4}$} \\
\hline \multirow[t]{3}{*}{ Total } & DM & $-18,01$ & $-16,09$ & $-13,93$ & $-11,60$ & $-9,23$ & $-6,96$ & $-5,08$ & $-4,02$ & $-5,03$ & $-12,15$ & $-57,89$ & - \\
\hline & DMA & 30,27 & 26,27 & 24,99 & 24,32 & 25,45 & 28,55 & 33,17 & 38,97 & 47,54 & 63,10 & 118,96 & - \\
\hline & PDMA & 16,69 & 13,22 & 11,68 & 14,04 & 16,89 & 21,80 & 28,86 & 36,55 & 46,29 & 59,21 & 87,08 & - \\
\hline \multirow[t]{3}{*}{ CPI } & DM & $-50,63$ & $-47,73$ & $-44,38$ & $-40,79$ & $-37,27$ & $-34,23$ & $-32,31$ & $-32,71$ & $-38,40$ & $-59,09$ & $-170,00$ & - \\
\hline & DMA & 59,75 & 49,41 & 45,08 & 41,59 & 42,11 & 46,85 & 54,77 & 64,99 & 80,46 & 110,91 & 232,34 & - \\
\hline & PDMA & 23,67 & 15,93 & 11,77 & 14,33 & 17,85 & 24,16 & 33,60 & 43,75 & 55,88 & 72,97 & 120,26 & - \\
\hline \multirow[t]{3}{*}{ SPI } & $\mathrm{DM}$ & 7,08 & 8,25 & 9,50 & 10,86 & 12,34 & 14,02 & 15,86 & 18,05 & 20,65 & 23,95 & 28,35 & - \\
\hline & DMA & 7,60 & 8,47 & 9,53 & 11,03 & 12,63 & 14,48 & 16,55 & 18,95 & 22,22 & 26,32 & 31,74 & - \\
\hline & PDMA & 11,32 & 11,13 & 11,62 & 13,81 & 16,15 & 19,98 & 25,21 & 31,00 & 38,91 & 48,62 & 61,56 & - \\
\hline \multirow[t]{3}{*}{$\Delta \mathrm{CS}$} & $\mathrm{DM}$ & $-57,71$ & $-55,98$ & $-53,88$ & $-51,65$ & $-49,61$ & $-48,25$ & $-48,17$ & $-50,76$ & $-59,05$ & $-83,04$ & $-198,35$ & 一 \\
\hline & DMA & 52,15 & 40,94 & 35,55 & 30,56 & 29,48 & 32,37 & 38,22 & 46,04 & 58,24 & 84,59 & 200,60 & - \\
\hline & PDMA & 12,34 & 4,80 & 0,15 & 0,52 & 1,69 & 4,19 & 8,39 & 12,75 & 16,96 & 24,35 & 58,70 & - \\
\hline
\end{tabular}


Tabela 8.244: Constantes de acoplamento PBEP86 com base aug-pcJ-2.

\begin{tabular}{|c|c|c|c|c|c|c|c|c|c|c|c|c|c|}
\hline & $\% E_{X}^{\mathrm{HF}}$ & $0 \%$ & $10 \%$ & $20 \%$ & $30 \%$ & $40 \%$ & $50 \%$ & $60 \%$ & $70 \%$ & $80 \%$ & $90 \%$ & $100 \%$ & Exp. \\
\hline $\mathrm{HF}$ & ${ }^{1} J_{\mathrm{HF}}$ & 380,3 & 401,5 & 423,0 & 444,7 & 466,5 & 488,6 & 510,9 & 533,4 & 556,2 & 579,1 & 602,2 & 500 \\
\hline $\mathrm{CO}$ & ${ }^{1} J_{\mathrm{CO}}$ & 23,5 & 21,9 & 20,2 & 18,5 & 16,7 & 14,8 & 12,9 & 10,9 & 8,9 & 6,8 & 4,8 & 16,4 \\
\hline $\mathrm{H}_{2} \mathrm{O}$ & ${ }^{1} J_{\mathrm{OH}}$ & $-67,4$ & $-69,6$ & $-71,9$ & $-74,2$ & $-76,5$ & $-78,9$ & $-81,3$ & $-83,6$ & $-86,1$ & $-88,5$ & $-91,0$ & $-80,6$ \\
\hline $\mathrm{H}_{2} \mathrm{O}$ & ${ }^{2} J_{\mathrm{HH}}$ & $-4,2$ & $-5,2$ & $-6,2$ & $-7,2$ & $-8,3$ & $-9,4$ & $-10,4$ & $-11,6$ & $-12,7$ & $-13,9$ & $-15,1$ & $-7,3$ \\
\hline $\mathrm{NH}_{3}$ & ${ }^{1} J_{\mathrm{NH}}$ & 40,7 & 41,3 & 42,0 & 42,7 & 43,4 & 44,1 & 44,8 & 45,6 & 46,3 & 47,1 & 47,8 & 43,8 \\
\hline $\mathrm{NH}_{3}$ & ${ }^{2} J_{\mathrm{HH}}$ & $-7,3$ & $-8,2$ & $-9,1$ & $-10,0$ & $-10,9$ & $-11,8$ & $-12,8$ & $-13,7$ & $-14,7$ & $-15,7$ & $-16,8$ & $-9,6$ \\
\hline $\mathrm{PH}_{3}$ & ${ }^{1} J_{\mathrm{PH}}$ & 134,4 & 142,5 & 150,5 & 158,5 & 166,4 & 174,3 & 182,0 & 189,7 & 197,3 & 204,7 & 212,1 & 188,2 \\
\hline $\mathrm{PF}_{3}$ & ${ }^{1} J_{\mathrm{PF}}$ & $-1796,2$ & $-1773,0$ & $-1744,9$ & $-1712,9$ & $-1677,6$ & $-1639,7$ & $-1599,7$ & $-1558,0$ & $-1515,2$ & $-1471,6$ & $-1427,5$ & -1441 \\
\hline $\mathrm{BHF}_{2}$ & ${ }^{1} J_{\mathrm{BF}}$ & $-171,9$ & $-155,2$ & $-138,6$ & $-122,3$ & $-106,1$ & $-90,1$ & $-74,4$ & $-59,0$ & $-43,7$ & $-28,8$ & $-14,1$ & -84 \\
\hline $\mathrm{BF}_{3}$ & ${ }^{1} J_{\mathrm{BF}}$ & $-74,9$ & $-56,7$ & $-38,8$ & $-21,2$ & $-3,8$ & 13,2 & 30,0 & 46,6 & 62,9 & 79,0 & 94,8 & 15 \\
\hline $\mathrm{F}_{2} \mathrm{O}$ & ${ }^{1} J_{\mathrm{OF}}$ & $-276,5$ & $-313,8$ & $-351,5$ & $-390,9$ & $-434,3$ & $-484,9$ & $-548,5$ & $-636,4$ & $-775,3$ & $-1049,3$ & $-1973,1$ & -300 \\
\hline $\mathrm{CH}_{4}$ & ${ }^{1} J_{\mathrm{CH}}$ & 118,5 & 119,8 & 121,2 & 122,5 & 123,9 & 125,4 & 126,8 & 128,3 & 129,9 & 131,4 & 133,0 & 125,3 \\
\hline $\mathrm{CH}_{4}$ & ${ }^{2} J_{\mathrm{HH}}$ & $-11,1$ & $-11,8$ & $-12,6$ & $-13,4$ & $-14,2$ & $-14,9$ & $-15,7$ & $-16,5$ & $-17,3$ & $-18,0$ & $-18,8$ & $-12,8$ \\
\hline $\mathrm{C}_{2} \mathrm{H}_{2}$ & ${ }^{1} J_{\mathrm{CC}}$ & 189,3 & 191,9 & 194,9 & 198,3 & 202,3 & 206,9 & 212,4 & 219,0 & 227,1 & 237,3 & 250,2 & 174,8 \\
\hline $\mathrm{C}_{2} \mathrm{H}_{2}$ & ${ }^{1} J_{\mathrm{CH}}$ & 247,2 & 249,5 & 251,9 & 254,5 & 257,3 & 260,4 & 263,8 & 267,8 & 272,5 & 278,2 & 285,3 & 247,6 \\
\hline $\mathrm{C}_{2} \mathrm{H}_{2}$ & ${ }^{2} J_{\mathrm{CH}}$ & 54,1 & 54,1 & 53,9 & 53,5 & 52,8 & 51,7 & 50,2 & 48,1 & 45,2 & 41,3 & 35,9 & 50,1 \\
\hline $\mathrm{C}_{2} \mathrm{H}_{2}$ & ${ }^{3} J_{\mathrm{HH}}$ & 9,8 & 10,4 & 11,1 & 12,0 & 13,0 & 14,3 & 15,9 & 17,8 & 20,1 & 23,1 & 26,9 & 9,6 \\
\hline $\mathrm{C}_{2} \mathrm{H}_{4}$ & ${ }^{1} J_{\mathrm{CC}}$ & 61,5 & 64,0 & 66,9 & 70,1 & 73,8 & 78,1 & 83,4 & 90,1 & 99,1 & 112,2 & 133,8 & 67,6 \\
\hline $\mathrm{C}_{2} \mathrm{H}_{4}$ & ${ }^{1} J_{\mathrm{CH}}$ & 150,4 & 152,4 & 154,5 & 156,7 & 159,1 & 161,8 & 164,9 & 168,5 & 173,1 & 179,4 & 189,3 & 156,3 \\
\hline $\mathrm{C}_{2} \mathrm{H}_{4}$ & ${ }^{2} J_{\mathrm{CH}}$ & 0,0 & $-0,9$ & $-1,8$ & $-2,9$ & $-4,2$ & $-5,7$ & $-7,7$ & $-10,2$ & $-13,7$ & $-18,9$ & $-27,6$ & $-2,4$ \\
\hline $\mathrm{C}_{2} \mathrm{H}_{4}$ & ${ }^{2} J_{\mathrm{HH}}$ & 4,9 & 4,2 & 3,4 & 2,5 & 1,5 & 0,4 & $-0,9$ & $-2,6$ & $-4,9$ & $-8,2$ & $-13,5$ & 2,3 \\
\hline $\mathrm{C}_{2} \mathrm{H}_{4}$ & ${ }^{3} J_{\mathrm{HH}_{\mathrm{c}}}$ & 11,4 & 11,7 & 12,0 & 12,5 & 13,0 & 13,7 & 14,7 & 16,0 & 17,8 & 20,7 & 25,7 & 11,7 \\
\hline $\mathrm{C}_{2} \mathrm{H}_{4}$ & ${ }^{3} J_{\mathrm{HH}_{\mathrm{t}}}$ & 18,1 & 18,4 & 18,8 & 19,4 & 20,0 & 20,9 & 22,0 & 23,5 & 25,7 & 29,0 & 34,7 & 19 \\
\hline $\mathrm{C}_{2} \mathrm{H}_{6}$ & ${ }^{1} J_{\mathrm{CC}}$ & 25,8 & 27,6 & 29,5 & 31,3 & 33,3 & 35,2 & 37,2 & 39,2 & 41,3 & 43,3 & 45,4 & 34,5 \\
\hline $\mathrm{C}_{2} \mathrm{H}_{6}$ & ${ }^{1} J_{\mathrm{CH}}$ & 118,5 & 120,0 & 121,6 & 123,2 & 124,8 & 126,4 & 128,1 & 129,8 & 131,5 & 133,2 & 135,0 & 125,2 \\
\hline $\mathrm{C}_{2} \mathrm{H}_{6}$ & ${ }^{2} J_{\mathrm{CH}}$ & $-2,6$ & $-3,0$ & $-3,5$ & $-4,0$ & $-4,5$ & $-5,0$ & $-5,5$ & $-6,0$ & $-6,5$ & $-7,0$ & $-7,6$ & $-4,7$ \\
\hline \multirow[t]{3}{*}{ Total } & $\mathrm{DM}$ & $-25,72$ & $-23,51$ & $-21,10$ & $-18,58$ & $-16,06$ & $-13,66$ & $-11,61$ & $-10,32$ & $-10,78$ & $-16,12$ & $-45,89$ & - \\
\hline & DMA & 31,62 & 27,35 & 24,73 & 22,41 & 20,62 & 19,44 & 21,93 & 27,37 & 35,58 & 49,53 & 90,58 & - \\
\hline & PDMA & 48,76 & 37,93 & 27,64 & 19,80 & 18,61 & 20,63 & 34,08 & 51,92 & 73,92 & 103,29 & 152,34 & - \\
\hline \multirow[t]{3}{*}{ CPI } & DM & $-60,04$ & $-55,95$ & $-51,47$ & $-46,84$ & $-42,31$ & $-38,25$ & $-35,22$ & $-34,27$ & $-37,91$ & $-53,82$ & $-128,80$ & - \\
\hline & DMA & 68,98 & 59,58 & 54,04 & 48,40 & 43,11 & 38,61 & 41,85 & 51,24 & 66,27 & 93,47 & 182,13 & - \\
\hline & PDMA & 83,83 & 66,42 & 50,52 & 35,61 & 24,20 & 15,33 & 28,28 & 46,47 & 66,58 & 90,79 & 134,69 & - \\
\hline \multirow[t]{3}{*}{ SPI } & $\mathrm{DM}$ & $-0,55$ & 0,28 & 1,18 & 2,14 & 3,19 & 4,37 & 5,70 & 7,25 & 9,12 & 11,53 & 14,91 & - \\
\hline & DMA & 4,22 & 3,71 & 3,23 & 3,35 & 4,12 & 5,38 & 7,33 & 9,87 & 13,08 & 17,30 & 23,45 & - \\
\hline & PDMA & 23,04 & 17,03 & 10,85 & 8,21 & 14,51 & 24,52 & 38,34 & 55,91 & 79,31 & 112,46 & 165,29 & - \\
\hline \multirow[t]{3}{*}{$\Delta \mathrm{CS}$} & DM & $-59,48$ & $-56,23$ & $-52,65$ & $-48,98$ & $-45,50$ & $-42,61$ & $-40,92$ & $-41,52$ & $-47,03$ & $-65,34$ & $-143,71$ & - \\
\hline & DMA & 64,76 & 55,88 & 50,80 & 45,05 & 38,99 & 33,23 & 34,53 & 41,36 & 53,19 & 76,17 & 158,67 & - \\
\hline & PDMA & 60,79 & 49,39 & 39,66 & 27,40 & 9,69 & $-9,19$ & $-10,07$ & $-9,44$ & $-12,73$ & $-21,67$ & $-30,60$ & - \\
\hline \multicolumn{14}{|c|}{ Desconsiderando ${ }^{1} J_{\mathrm{BF}}$ da molécula de $\mathrm{BF}_{3},{ }^{2} J_{\mathrm{CH}}$ e ${ }^{2} J_{\mathrm{HH}}$ da molécula de $\mathrm{C}_{2} \mathrm{H}_{4}$} \\
\hline \multirow[t]{3}{*}{ Total } & $\mathrm{DM}$ & $-25,38$ & $-23,60$ & $-21,58$ & $-19,42$ & $-17,23$ & $-15,14$ & $-13,41$ & $-12,49$ & $-13,46$ & $-19,83$ & $-53,57$ & - \\
\hline & DMA & 31,62 & 27,65 & 25,54 & 23,73 & 22,37 & 21,67 & 23,77 & 29,02 & 37,34 & 52,03 & 97,15 & - \\
\hline & PDMA & 19,80 & 15,78 & 12,48 & 10,61 & 10,82 & 13,23 & 18,53 & 26,14 & 35,60 & 48,48 & 73,57 & - \\
\hline \multirow[t]{3}{*}{ CPI } & DM & $-57,05$ & $-54,37$ & $-51,24$ & $-47,90$ & $-44,66$ & $-41,89$ & $-40,24$ & $-40,86$ & $-46,49$ & $-65,60$ & $-149,66$ & - \\
\hline & DMA & 66,89 & 58,37 & 54,06 & 49,62 & 45,54 & 42,29 & 44,54 & 53,20 & 68,11 & 96,42 & 192,36 & - \\
\hline & PDMA & 32,28 & 25,26 & 19,70 & 15,04 & 14,08 & 15,66 & 21,10 & 30,05 & 41,30 & 57,20 & 94,96 & - \\
\hline \multirow[t]{3}{*}{ SPI } & $\mathrm{DM}$ & $-1,02$ & 0,06 & 1,23 & 2,49 & 3,88 & 5,44 & 7,23 & 9,34 & 11,95 & 15,38 & 20,35 & - \\
\hline & DMA & 4,48 & 4,02 & 3,60 & 3,82 & 4,55 & 5,81 & 7,80 & 10,42 & 13,67 & 17,88 & 23,91 & - \\
\hline & PDMA & 10,20 & 8,49 & 6,92 & 7,20 & 8,30 & 11,36 & 16,55 & 23,13 & 31,21 & 41,76 & 57,11 & - \\
\hline \multirow[t]{3}{*}{$\Delta \mathrm{CS}$} & DM & $-56,03$ & $-54,43$ & $-52,47$ & $-50,39$ & $-48,54$ & $-47,33$ & $-47,47$ & $-50,20$ & $-58,44$ & $-80,98$ & $-170,01$ & - \\
\hline & DMA & 62,41 & 54,35 & 50,46 & 45,80 & 40,99 & 36,48 & 36,74 & 42,78 & 54,44 & 78,54 & 168,45 & - \\
\hline & PDMA & 22,08 & 16,77 & 12,78 & 7,84 & 5,78 & 4,30 & 4,55 & 6,92 & 10,09 & 15,44 & 37,85 & - \\
\hline
\end{tabular}


Tabela 8.245: Constantes de acoplamento PBEPBE com base aug-pcJ-2.

\begin{tabular}{|c|c|c|c|c|c|c|c|c|c|c|c|c|c|}
\hline & $\% E_{X}^{\mathrm{HF}}$ & $0 \%$ & $10 \%$ & $20 \%$ & $30 \%$ & $40 \%$ & $50 \%$ & $60 \%$ & $70 \%$ & $80 \%$ & $90 \%$ & $100 \%$ & Exp. \\
\hline $\mathrm{HF}$ & ${ }^{1} J_{\mathrm{HF}}$ & 376,0 & 397,8 & 419,7 & 441,9 & 464,3 & 486,9 & 509,8 & 532,8 & 556,1 & 579,6 & 603,3 & 500 \\
\hline $\mathrm{CO}$ & ${ }^{1} J_{\mathrm{CO}}$ & 24,1 & 22,5 & 20,8 & 19,1 & 17,3 & 15,4 & 13,5 & 11,5 & 9,5 & 7,4 & 5,3 & 16,4 \\
\hline $\mathrm{H}_{2} \mathrm{O}$ & ${ }^{1} J_{\mathrm{OH}}$ & $-67,2$ & $-69,5$ & $-71,8$ & $-74,2$ & $-76,6$ & $-79,0$ & $-81,4$ & $-83,9$ & $-86,4$ & $-88,9$ & $-91,5$ & $-80,6$ \\
\hline $\mathrm{H}_{2} \mathrm{O}$ & ${ }^{2} J_{\mathrm{HH}}$ & $-4,7$ & $-5,7$ & $-6,7$ & $-7,8$ & $-8,9$ & $-10,0$ & $-11,1$ & $-12,3$ & $-13,5$ & $-14,7$ & $-15,9$ & $-7,3$ \\
\hline $\mathrm{NH}_{3}$ & ${ }^{1} J_{\mathrm{NH}}$ & 40,8 & 41,5 & 42,2 & 42,9 & 43,6 & 44,3 & 45,1 & 45,8 & 46,6 & 47,4 & 48,2 & 43,8 \\
\hline $\mathrm{NH}_{3}$ & ${ }^{2} J_{\mathrm{HH}}$ & $-7,8$ & $-8,7$ & $-9,6$ & $-10,6$ & $-11,5$ & $-12,5$ & $-13,5$ & $-14,5$ & $-15,5$ & $-16,6$ & $-17,6$ & $-9,6$ \\
\hline $\mathrm{PH}_{3}$ & ${ }^{1} J_{\mathrm{PH}}$ & 133,7 & 142,1 & 150,4 & 158,7 & 166,9 & 175,1 & 183,1 & 191,1 & 198,9 & 206,7 & 214,3 & 188,2 \\
\hline $\mathrm{PF}_{3}$ & ${ }^{1} J_{\mathrm{PF}}$ & $-1801,0$ & $-1776,9$ & $-1748,1$ & $-1715,3$ & $-1679,4$ & $-1640,8$ & $-1600,3$ & $-1558,1$ & $-1514,9$ & $-1470,9$ & $-1426,5$ & -1441 \\
\hline $\mathrm{BHF}_{2}$ & ${ }^{1} J_{\mathrm{BF}}$ & $-172,8$ & $-155,9$ & $-139,2$ & $-122,7$ & $-106,5$ & $-90,4$ & $-74,6$ & $-59,0$ & $-43,7$ & $-28,6$ & $-13,8$ & -84 \\
\hline $\mathrm{BF}_{3}$ & ${ }^{1} J_{\mathrm{BF}}$ & $-75,8$ & $-57,5$ & $-39,4$ & $-21,7$ & $-4,2$ & 12,9 & 29,9 & 46,6 & 63,0 & 79,2 & 95,2 & 15 \\
\hline $\mathrm{F}_{2} \mathrm{O}$ & ${ }^{1} J_{\mathrm{OF}}$ & $-278,0$ & $-316,3$ & $-354,9$ & $-395,6$ & $-440,5$ & $-493,5$ & $-560,8$ & $-655,5$ & $-809,2$ & $-1129,5$ & $-2453,2$ & -300 \\
\hline $\mathrm{CH}_{4}$ & ${ }^{1} J_{\mathrm{CH}}$ & 119,3 & 120,7 & 122,1 & 123,5 & 125,0 & 126,5 & 128,0 & 129,6 & 131,2 & 132,8 & 134,4 & 125,3 \\
\hline $\mathrm{CH}_{4}$ & ${ }^{2} J_{\mathrm{HH}}$ & $-11,8$ & $-12,6$ & $-13,4$ & $-14,2$ & $-15,0$ & $-15,8$ & $-16,6$ & $-17,4$ & $-18,2$ & $-19,0$ & $-19,8$ & $-12,8$ \\
\hline $\mathrm{C}_{2} \mathrm{H}_{2}$ & ${ }^{1} J_{\mathrm{CC}}$ & 188,7 & 191,5 & 194,6 & 198,3 & 202,6 & 207,6 & 213,7 & 221,0 & 230,2 & 241,9 & 257,1 & 174,8 \\
\hline $\mathrm{C}_{2} \mathrm{H}_{2}$ & ${ }^{1} J_{\mathrm{CH}}$ & 249,8 & 252,2 & 254,8 & 257,6 & 260,7 & 264,1 & 268,0 & 272,5 & 277,9 & 284,6 & 293,3 & 247,6 \\
\hline $\mathrm{C}_{2} \mathrm{H}_{2}$ & ${ }^{2} J_{\mathrm{CH}}$ & 54,1 & 54,1 & 53,7 & 53,2 & 52,2 & 50,9 & 49,0 & 46,5 & 42,9 & 38,1 & 31,2 & 50,1 \\
\hline $\mathrm{C}_{2} \mathrm{H}_{2}$ & ${ }^{3} J_{\mathrm{HH}}$ & 10,4 & 11,1 & 11,9 & 12,9 & 14,1 & 15,6 & 17,4 & 19,6 & 22,5 & 26,1 & 30,9 & 9,6 \\
\hline $\mathrm{C}_{2} \mathrm{H}_{4}$ & ${ }^{1} J_{\mathrm{CC}}$ & 61,3 & 64,0 & 67,0 & 70,4 & 74,4 & 79,1 & 85,0 & 92,8 & 103,6 & 120,3 & 150,7 & 67,6 \\
\hline $\mathrm{C}_{2} \mathrm{H}_{4}$ & ${ }^{1} J_{\mathrm{CH}}$ & 151,8 & 153,9 & 156,1 & 158,5 & 161,1 & 164,0 & 167,5 & 171,6 & 177,1 & 185,2 & 199,0 & 156,3 \\
\hline $\mathrm{C}_{2} \mathrm{H}_{4}$ & ${ }^{2} J_{\mathrm{CH}}$ & $-0,5$ & $-1,4$ & $-2,5$ & $-3,7$ & $-5,1$ & $-6,9$ & $-9,1$ & $-12,2$ & $-16,5$ & $-23,4$ & $-36,1$ & $-2,4$ \\
\hline $\mathrm{C}_{2} \mathrm{H}_{4}$ & ${ }^{2} J_{\mathrm{HH}}$ & 4,5 & 3,7 & 2,8 & 1,8 & 0,7 & $-0,5$ & $-2,1$ & $-4,1$ & $-7,0$ & $-11,4$ & $-19,4$ & 2,3 \\
\hline $\mathrm{C}_{2} \mathrm{H}_{4}$ & ${ }^{3} J_{\mathrm{HH}_{\mathrm{c}}}$ & 11,7 & 12,1 & 12,5 & 13,0 & 13,6 & 14,5 & 15,7 & 17,3 & 19,7 & 23,7 & 31,3 & 11,7 \\
\hline $\mathrm{C}_{2} \mathrm{H}_{4}$ & ${ }^{3} J_{\mathrm{HH}_{\mathrm{t}}}$ & 18,7 & 19,0 & 19,5 & 20,1 & 20,9 & 21,9 & 23,3 & 25,2 & 28,0 & 32,5 & 41,0 & 19 \\
\hline $\mathrm{C}_{2} \mathrm{H}_{6}$ & ${ }^{1} J_{\mathrm{CC}}$ & 25,7 & 27,6 & 29,4 & 31,3 & 33,3 & 35,2 & 37,2 & 39,3 & 41,3 & 43,4 & 45,6 & 34,5 \\
\hline $\mathrm{C}_{2} \mathrm{H}_{6}$ & ${ }^{1} J_{\mathrm{CH}}$ & 119,5 & 121,1 & 122,7 & 124,3 & 126,0 & 127,7 & 129,4 & 131,2 & 133,0 & 134,8 & 136,6 & 125,2 \\
\hline $\mathrm{C}_{2} \mathrm{H}_{6}$ & ${ }^{2} J_{\mathrm{CH}}$ & $-2,9$ & $-3,4$ & $-3,9$ & $-4,3$ & $-4,9$ & $-5,4$ & $-5,9$ & $-6,4$ & $-7,0$ & $-7,5$ & $-8,1$ & $-4,7$ \\
\hline \multirow[t]{3}{*}{ Total } & DM & $-26,05$ & $-23,77$ & $-21,32$ & $-18,75$ & $-16,19$ & $-13,77$ & $-11,72$ & $-10,54$ & $-11,36$ & $-18,15$ & $-62,67$ & - \\
\hline & DMA & 31,85 & 27,68 & 25,11 & 23,12 & 21,47 & 20,50 & 23,18 & 29,22 & 38,35 & 54,68 & 112,44 & - \\
\hline & PDMA & 46,79 & 35,93 & 26,02 & 23,07 & 23,41 & 26,51 & 41,16 & 61,13 & 86,55 & 122,43 & 190,22 & - \\
\hline \multirow[t]{3}{*}{ CPI } & DM & $-61,24$ & $-57,05$ & $-52,50$ & $-47,84$ & $-43,31$ & $-39,32$ & $-36,47$ & $-36,04$ & $-40,91$ & $-60,89$ & $-172,10$ & - \\
\hline & DMA & 69,87 & 60,63 & 55,01 & 49,49 & 44,20 & 39,70 & 42,91 & 53,18 & 69,62 & 101,13 & 226,41 & - \\
\hline & PDMA & 83,81 & 66,37 & 50,34 & 37,51 & 26,29 & 16,91 & 29,77 & 48,48 & 69,25 & 95,09 & 151,26 & - \\
\hline \multirow[t]{3}{*}{ SPI } & DM & $-0,25$ & 0,63 & 1,55 & 2,57 & 3,70 & 4,96 & 6,43 & 8,16 & 10,31 & 13,20 & 17,57 & - \\
\hline & DMA & 3,96 & 3,51 & 3,19 & 3,79 & 4,79 & 6,43 & 8,72 & 11,64 & 15,41 & 20,63 & 28,87 & - \\
\hline & PDMA & 19,65 & 13,60 & 8,19 & 12,49 & 21,30 & 33,55 & 49,51 & 70,42 & 99,24 & 142,49 & 218,79 & - \\
\hline \multirow[t]{3}{*}{$\Delta \mathrm{CS}$} & DM & $-60,98$ & $-57,68$ & $-54,05$ & $-50,41$ & $-47,01$ & $-44,28$ & $-42,90$ & $-44,20$ & $-51,22$ & $-74,09$ & $-189,67$ & - \\
\hline & DMA & 65,91 & 57,11 & 51,82 & 45,70 & 39,41 & 33,27 & 34,19 & 41,54 & 54,20 & 80,50 & 197,54 & - \\
\hline & PDMA & 64,16 & 52,77 & 42,15 & 25,03 & 4,99 & $-16,64$ & $-19,74$ & $-21,94$ & $-29,99$ & $-47,40$ & $-67,53$ & - \\
\hline \multicolumn{14}{|c|}{ Desconsiderando ${ }^{1} J_{\mathrm{BF}}$ da molécula de $\mathrm{BF}_{3},{ }^{2} J_{\mathrm{CH}}$ e ${ }^{2} J_{\mathrm{HH}}$ da molécula de $\mathrm{C}_{2} \mathrm{H}_{4}$} \\
\hline \multirow[t]{3}{*}{ Total } & DM & $-25,68$ & $-23,82$ & $-21,75$ & $-19,53$ & $-17,28$ & $-15,16$ & $-13,42$ & $-12,58$ & $-13,91$ & $-21,80$ & $-71,93$ & - \\
\hline & DMA & 31,87 & 28,03 & 26,00 & 24,47 & 23,24 & 22,77 & 25,08 & 30,95 & 40,24 & 57,52 & 121,21 & - \\
\hline & PDMA & 18,98 & 15,14 & 12,52 & 12,15 & 12,99 & 15,91 & 21,76 & 30,10 & 40,81 & 55,85 & 89,72 & - \\
\hline \multirow[t]{3}{*}{ CPI } & DM & $-58,28$ & $-55,50$ & $-52,31$ & $-48,95$ & $-45,72$ & $-43,04$ & $-41,61$ & $-42,80$ & $-49,80$ & $-73,40$ & $-197,33$ & - \\
\hline & DMA & 67,78 & 59,44 & 55,07 & 50,77 & 46,70 & 43,46 & 45,71 & 55,34 & 71,78 & 104,82 & 241,03 & - \\
\hline & PDMA & 31,66 & 24,68 & 19,11 & 16,80 & 16,12 & 17,20 & 22,82 & 32,26 & 44,18 & 61,80 & 112,92 & - \\
\hline \multirow[t]{3}{*}{ SPI } & $\mathrm{DM}$ & $-0,61$ & 0,55 & 1,75 & 3,11 & 4,60 & 6,28 & 8,27 & 10,66 & 13,69 & 17,90 & 24,54 & - \\
\hline & DMA & 4,25 & 3,87 & 3,63 & 4,23 & 5,20 & 6,85 & 9,21 & 12,18 & 15,98 & 21,13 & 29,05 & - \\
\hline & PDMA & 9,22 & 7,81 & 7,45 & 8,57 & 10,57 & 14,92 & 20,94 & 28,43 & 38,21 & 51,28 & 71,87 & - \\
\hline \multirow[t]{3}{*}{$\Delta \mathrm{CS}$} & $\mathrm{DM}$ & $-57,67$ & $-56,05$ & $-54,06$ & $-52,06$ & $-50,32$ & $-49,32$ & $-49,88$ & $-53,46$ & $-63,49$ & $-91,30$ & $-221,87$ & 一 \\
\hline & DMA & 63,53 & 55,57 & 51,44 & 46,54 & 41,50 & 36,61 & 36,50 & 43,16 & 55,80 & 83,69 & 211,98 & - \\
\hline & PDMA & 22,44 & 16,87 & 11,65 & 8,23 & 5,55 & 2,28 & 1,88 & 3,82 & 5,97 & 10,51 & 41,06 & - \\
\hline
\end{tabular}


Tabela 8.246: Constantes de acoplamento PBEPW91 com base aug-pcJ-2.

\begin{tabular}{|c|c|c|c|c|c|c|c|c|c|c|c|c|c|}
\hline & $\% E_{X}^{\mathrm{HF}}$ & $0 \%$ & $10 \%$ & $20 \%$ & $30 \%$ & $40 \%$ & $50 \%$ & $60 \%$ & $70 \%$ & $80 \%$ & $90 \%$ & $100 \%$ & Exp. \\
\hline $\mathrm{HF}$ & ${ }^{1} J_{\mathrm{HF}}$ & 378,7 & 400,4 & 422,4 & 444,7 & 467,1 & 489,7 & 512,6 & 535,7 & 559,0 & 582,5 & 606,3 & 500 \\
\hline $\mathrm{CO}$ & ${ }^{1} J_{\mathrm{CO}}$ & 23,9 & 22,3 & 20,6 & 18,8 & 17,0 & 15,1 & 13,1 & 11,1 & 9,1 & 7,0 & 4,9 & 16,4 \\
\hline $\mathrm{H}_{2} \mathrm{O}$ & ${ }^{1} J_{\mathrm{OH}}$ & $-67,6$ & $-69,9$ & $-72,2$ & $-74,6$ & $-77,0$ & $-79,4$ & $-81,8$ & $-84,3$ & $-86,8$ & $-89,3$ & $-91,9$ & $-80,6$ \\
\hline $\mathrm{H}_{2} \mathrm{O}$ & ${ }^{2} J_{\mathrm{HH}}$ & $-4,7$ & $-5,7$ & $-6,8$ & $-7,8$ & $-8,9$ & $-10,0$ & $-11,2$ & $-12,3$ & $-13,5$ & $-14,7$ & $-16,0$ & $-7,3$ \\
\hline $\mathrm{NH}_{3}$ & ${ }^{1} J_{\mathrm{NH}}$ & 41,0 & 41,7 & 42,4 & 43,1 & 43,8 & 44,6 & 45,3 & 46,1 & 46,8 & 47,6 & 48,4 & 43,8 \\
\hline $\mathrm{NH}_{3}$ & ${ }^{2} J_{\mathrm{HH}}$ & $-7,8$ & $-8,7$ & $-9,7$ & $-10,6$ & $-11,6$ & $-12,5$ & $-13,5$ & $-14,5$ & $-15,6$ & $-16,6$ & $-17,7$ & $-9,6$ \\
\hline $\mathrm{PH}_{3}$ & ${ }^{1} J_{\mathrm{PH}}$ & 134,7 & 143,1 & 151,5 & 159,8 & 168,0 & 176,1 & 184,2 & 192,2 & 200,1 & 207,8 & 215,5 & 188,2 \\
\hline $\mathrm{PF}_{3}$ & ${ }^{1} J_{\mathrm{PF}}$ & $-1804,4$ & $-1780,2$ & $-1751,3$ & $-1718,4$ & $-1682,3$ & $-1643,6$ & $-1602,9$ & $-1560,6$ & $-1517,2$ & $-1473,1$ & $-1428,5$ & -1441 \\
\hline $\mathrm{BHF}_{2}$ & ${ }^{1} J_{\mathrm{BF}}$ & $-172,0$ & $-155,1$ & $-138,3$ & $-121,8$ & $-105,4$ & $-89,3$ & $-73,5$ & $-57,8$ & $-42,5$ & $-27,4$ & $-12,5$ & -84 \\
\hline $\mathrm{BF}_{3}$ & ${ }^{1} J_{\mathrm{BF}}$ & $-74,9$ & $-56,5$ & $-38,4$ & $-20,6$ & $-3,1$ & 14,1 & 31,1 & 47,8 & 64,3 & 80,5 & 96,6 & 15 \\
\hline $\mathrm{F}_{2} \mathrm{O}$ & ${ }^{1} J_{\mathrm{OF}}$ & $-277,8$ & $-316,0$ & $-354,6$ & $-395,3$ & $-440,2$ & $-493,2$ & $-560,7$ & $-655,7$ & $-810,5$ & $-1135,6$ & $-2525,8$ & -300 \\
\hline $\mathrm{CH}_{4}$ & ${ }^{1} J_{\mathrm{CH}}$ & 120,0 & 121,3 & 122,7 & 124,2 & 125,7 & 127,2 & 128,7 & 130,3 & 131,9 & 133,5 & 135,2 & 125,3 \\
\hline $\mathrm{CH}_{4}$ & ${ }^{2} J_{\mathrm{HH}}$ & $-11,8$ & $-12,6$ & $-13,4$ & $-14,2$ & $-15,0$ & $-15,8$ & $-16,6$ & $-17,4$ & $-18,2$ & $-19,0$ & $-19,9$ & $-12,8$ \\
\hline $\mathrm{C}_{2} \mathrm{H}_{2}$ & ${ }^{1} J_{\mathrm{CC}}$ & 189,9 & 192,7 & 195,9 & 199,6 & 203,9 & 209,0 & 215,2 & 222,6 & 231,9 & 243,6 & 259,0 & 174,8 \\
\hline $\mathrm{C}_{2} \mathrm{H}_{2}$ & ${ }^{1} J_{\mathrm{CH}}$ & 251,0 & 253,4 & 256,0 & 258,8 & 261,9 & 265,3 & 269,2 & 273,8 & 279,2 & 285,9 & 294,6 & 247,6 \\
\hline $\mathrm{C}_{2} \mathrm{H}_{2}$ & ${ }^{2} J_{\mathrm{CH}}$ & 54,2 & 54,1 & 53,8 & 53,2 & 52,2 & 50,9 & 49,0 & 46,4 & 42,9 & 38,0 & 31,2 & 50,1 \\
\hline $\mathrm{C}_{2} \mathrm{H}_{2}$ & ${ }^{3} J_{\mathrm{HH}}$ & 10,4 & 11,0 & 11,9 & 12,9 & 14,1 & 15,5 & 17,3 & 19,6 & 22,4 & 26,0 & 30,7 & 9,6 \\
\hline $\mathrm{C}_{2} \mathrm{H}_{4}$ & ${ }^{1} J_{\mathrm{CC}}$ & 61,9 & 64,6 & 67,6 & 71,1 & 75,1 & 79,9 & 85,8 & 93,6 & 104,5 & 121,4 & 152,0 & 67,6 \\
\hline $\mathrm{C}_{2} \mathrm{H}_{4}$ & ${ }^{1} J_{\mathrm{CH}}$ & 152,6 & 154,7 & 157,0 & 159,3 & 162,0 & 164,9 & 168,4 & 172,6 & 178,1 & 186,1 & 200,0 & 156,3 \\
\hline $\mathrm{C}_{2} \mathrm{H}_{4}$ & ${ }^{2} J_{\mathrm{CH}}$ & $-0,5$ & $-1,4$ & $-2,5$ & $-3,7$ & $-5,1$ & $-6,9$ & $-9,2$ & $-12,2$ & $-16,6$ & $-23,5$ & $-36,2$ & $-2,4$ \\
\hline $\mathrm{C}_{2} \mathrm{H}_{4}$ & ${ }^{2} J_{\mathrm{HH}}$ & 4,5 & 3,7 & 2,8 & 1,9 & 0,8 & $-0,4$ & $-2,0$ & $-4,1$ & $-6,9$ & $-11,3$ & $-19,2$ & 2,3 \\
\hline $\mathrm{C}_{2} \mathrm{H}_{4}$ & ${ }^{3} J_{\mathrm{HH}_{\mathrm{c}}}$ & 11,7 & 12,0 & 12,5 & 13,0 & 13,6 & 14,5 & 15,6 & 17,3 & 19,7 & 23,6 & 31,2 & 11,7 \\
\hline $\mathrm{C}_{2} \mathrm{H}_{4}$ & ${ }^{3} J_{\mathrm{HH}_{\mathrm{t}}}$ & 18,6 & 19,0 & 19,5 & 20,1 & 20,9 & 21,9 & 23,2 & 25,1 & 27,9 & 32,5 & 40,9 & 19 \\
\hline $\mathrm{C}_{2} \mathrm{H}_{6}$ & ${ }^{1} J_{\mathrm{CC}}$ & 26,1 & 27,9 & 29,8 & 31,7 & 33,7 & 35,7 & 37,7 & 39,7 & 41,8 & 43,9 & 46,1 & 34,5 \\
\hline $\mathrm{C}_{2} \mathrm{H}_{6}$ & ${ }^{1} J_{\mathrm{CH}}$ & 120,1 & 121,7 & 123,3 & 125,0 & 126,7 & 128,4 & 130,1 & 131,9 & 133,7 & 135,5 & 137,3 & 125,2 \\
\hline $\mathrm{C}_{2} \mathrm{H}_{6}$ & ${ }^{2} J_{\mathrm{CH}}$ & $-2,9$ & $-3,4$ & $-3,8$ & $-4,3$ & $-4,8$ & $-5,4$ & $-5,9$ & $-6,4$ & $-7,0$ & $-7,5$ & $-8,1$ & $-4,7$ \\
\hline \multirow[t]{3}{*}{ Total } & $\mathrm{DM}$ & $-25,77$ & $-23,50$ & $-21,01$ & $-18,43$ & $-15,84$ & $-13,41$ & $-11,38$ & $-10,17$ & $-11,02$ & $-17,98$ & $-65,03$ & - \\
\hline & DMA & 31,73 & 27,53 & 25,01 & 23,05 & 21,47 & 20,60 & 23,71 & 29,86 & 39,03 & 55,55 & 115,74 & - \\
\hline & PDMA & 46,35 & 35,36 & 25,62 & 22,46 & 22,81 & 26,20 & 41,83 & 61,89 & 87,35 & 123,25 & 191,82 & - \\
\hline \multirow[t]{3}{*}{ CPI } & DM & $-61,07$ & $-56,86$ & $-52,30$ & $-47,60$ & $-43,05$ & $-39,03$ & $-36,20$ & $-35,75$ & $-40,70$ & $-61,11$ & $-178,33$ & - \\
\hline & DMA & 69,64 & 60,34 & 54,68 & 49,13 & 43,81 & 39,39 & 43,60 & 54,11 & 70,65 & 102,56 & 233,56 & - \\
\hline & PDMA & 82,91 & 65,40 & 49,32 & 36,40 & 25,26 & 16,15 & 31,06 & 49,79 & 70,74 & 96,62 & 155,08 & - \\
\hline \multirow[t]{3}{*}{ SPI } & DM & 0,11 & 0,97 & 1,93 & 2,97 & 4,11 & 5,37 & 6,83 & 8,58 & 10,75 & 13,64 & 18,05 & - \\
\hline & DMA & 3,93 & 3,47 & 3,25 & 3,93 & 5,08 & 6,83 & 9,12 & 12,07 & 15,85 & 21,08 & 29,34 & - \\
\hline & PDMA & 19,53 & 13,34 & 8,25 & 12,23 & 21,02 & 33,56 & 49,72 & 70,76 & 99,53 & 142,78 & 218,77 & - \\
\hline \multirow[t]{3}{*}{$\Delta \mathrm{CS}$} & $\mathrm{DM}$ & $-61,19$ & $-57,84$ & $-54,23$ & $-50,57$ & $-47,15$ & $-44,40$ & $-43,03$ & $-44,33$ & $-51,45$ & $-74,75$ & $-196,37$ & - \\
\hline & DMA & 65,71 & 56,87 & 51,43 & 45,20 & 38,73 & 32,56 & 34,48 & 42,04 & 54,79 & 81,48 & 204,22 & - \\
\hline & PDMA & 63,38 & 52,06 & 41,07 & 24,18 & 4,23 & $-17,41$ & $-18,65$ & $-20,97$ & $-28,79$ & $-46,16$ & $-63,69$ & - \\
\hline \multicolumn{14}{|c|}{ Desconsiderando ${ }^{1} J_{\mathrm{BF}}$ da molécula de $\mathrm{BF}_{3},{ }^{2} J_{\mathrm{CH}}$ e ${ }^{2} J_{\mathrm{HH}}$ da molécula de $\mathrm{C}_{2} \mathrm{H}_{4}$} \\
\hline \multirow[t]{3}{*}{ Total } & $\mathrm{DM}$ & $-25,40$ & $-23,56$ & $-21,45$ & $-19,21$ & $-16,94$ & $-14,81$ & $-13,08$ & $-12,22$ & $-13,58$ & $-21,67$ & $-74,66$ & - \\
\hline & DMA & 31,78 & 27,90 & 25,93 & 24,43 & 23,30 & 22,94 & 25,62 & 31,62 & 40,97 & 58,44 & 124,89 & - \\
\hline & PDMA & 18,73 & 14,79 & 12,36 & 11,96 & 12,82 & 16,10 & 22,17 & 30,60 & 41,33 & 56,41 & 91,32 & - \\
\hline \multirow[t]{3}{*}{ CPI } & DM & $-58,19$ & $-55,40$ & $-52,19$ & $-48,80$ & $-45,54$ & $-42,84$ & $-41,43$ & $-42,60$ & $-49,70$ & $-73,77$ & $-204,32$ & - \\
\hline & DMA & 67,61 & 59,22 & 54,81 & 50,48 & 46,38 & 43,24 & 46,35 & 56,24 & 72,78 & 106,27 & 248,76 & - \\
\hline & PDMA & 31,27 & 24,27 & 18,65 & 16,31 & 15,71 & 17,17 & 23,44 & 32,90 & 44,95 & 62,61 & 116,19 & - \\
\hline \multirow[t]{3}{*}{ SPI } & $\mathrm{DM}$ & $-0,18$ & 0,94 & 2,20 & 3,55 & 5,06 & 6,75 & 8,73 & 11,15 & 14,20 & 18,41 & 25,08 & - \\
\hline & DMA & 4,22 & 3,82 & 3,71 & 4,40 & 5,54 & 7,32 & 9,67 & 12,68 & 16,49 & 21,65 & 29,60 & - \\
\hline & PDMA & 9,09 & 7,50 & 7,52 & 8,61 & 10,59 & 15,27 & 21,19 & 28,84 & 38,56 & 51,64 & 72,19 & - \\
\hline \multirow[t]{3}{*}{$\Delta \mathrm{CS}$} & DM & $-58,01$ & $-56,34$ & $-54,39$ & $-52,35$ & $-50,60$ & $-49,59$ & $-50,16$ & $-53,75$ & $-63,90$ & $-92,18$ & $-229,40$ & - \\
\hline & DMA & 63,39 & 55,40 & 51,10 & 46,08 & 40,84 & 35,92 & 36,68 & 43,56 & 56,29 & 84,62 & 219,16 & - \\
\hline & PDMA & 22,18 & 16,77 & 11,13 & 7,71 & 5,13 & 1,90 & 2,25 & 4,07 & 6,39 & 10,98 & 44,00 & - \\
\hline
\end{tabular}


Tabela 8.247: Constantes de acoplamento PBETPSS com base aug-pcJ-2.

\begin{tabular}{|c|c|c|c|c|c|c|c|c|c|c|c|c|c|}
\hline & $\% E_{X}^{\mathrm{HF}}$ & $0 \%$ & $10 \%$ & $20 \%$ & $30 \%$ & $40 \%$ & $50 \%$ & $60 \%$ & $70 \%$ & $80 \%$ & $90 \%$ & $100 \%$ & Exp. \\
\hline $\mathrm{HF}$ & ${ }^{1} J_{\mathrm{HF}}$ & 378,3 & 400,7 & 423,3 & 446,0 & 468,9 & 492,0 & 515,3 & 538,7 & 562,3 & 586,0 & 610,0 & 500 \\
\hline $\mathrm{CO}$ & ${ }^{1} J_{\mathrm{CO}}$ & 23,9 & 22,3 & 20,6 & 18,8 & 17,0 & 15,1 & 13,2 & 11,2 & 9,1 & 7,0 & 4,9 & 16,4 \\
\hline $\mathrm{H}_{2} \mathrm{O}$ & ${ }^{1} J_{\mathrm{OH}}$ & $-68,3$ & $-70,7$ & $-73,2$ & $-75,6$ & $-78,1$ & $-80,6$ & $-83,1$ & $-85,6$ & $-88,2$ & $-90,8$ & $-93,4$ & $-80,6$ \\
\hline $\mathrm{H}_{2} \mathrm{O}$ & ${ }^{2} J_{\mathrm{HH}}$ & $-4,4$ & $-5,5$ & $-6,6$ & $-7,7$ & $-8,9$ & $-10,0$ & $-11,2$ & $-12,4$ & $-13,7$ & $-14,9$ & $-16,2$ & $-7,3$ \\
\hline $\mathrm{NH}_{3}$ & ${ }^{1} J_{\mathrm{NH}}$ & 42,2 & 43,0 & 43,7 & 44,5 & 45,3 & 46,0 & 46,8 & 47,6 & 48,4 & 49,3 & 50,1 & 43,8 \\
\hline $\mathrm{NH}_{3}$ & ${ }^{2} J_{\mathrm{HH}}$ & $-7,4$ & $-8,4$ & $-9,4$ & $-10,4$ & $-11,4$ & $-12,4$ & $-13,5$ & $-14,6$ & $-15,7$ & $-16,8$ & $-17,9$ & $-9,6$ \\
\hline $\mathrm{PH}_{3}$ & ${ }^{1} J_{\mathrm{PH}}$ & 143,2 & 152,4 & 161,5 & 170,6 & 179,7 & 188,7 & 197,6 & 206,5 & 215,3 & 224,0 & 232,6 & 188,2 \\
\hline $\mathrm{PF}_{3}$ & ${ }^{1} J_{\mathrm{PF}}$ & $-1805,1$ & $-1781,6$ & $-1753,5$ & $-1721,3$ & $-1685,8$ & $-1647,8$ & $-1607,6$ & $-1565,9$ & $-1523,0$ & $-1479,3$ & $-1435,2$ & -1441 \\
\hline $\mathrm{BHF}_{2}$ & ${ }^{1} J_{\mathrm{BF}}$ & $-173,6$ & $-156,9$ & $-140,4$ & $-124,1$ & $-107,9$ & $-92,0$ & $-76,4$ & $-61,0$ & $-45,9$ & $-31,0$ & $-16,4$ & -84 \\
\hline $\mathrm{BF}_{3}$ & ${ }^{1} J_{\mathrm{BF}}$ & $-73,1$ & $-54,9$ & $-37,0$ & $-19,3$ & $-2,0$ & 15,0 & 31,7 & 48,3 & 64,5 & 80,5 & 96,3 & 15 \\
\hline $\mathrm{F}_{2} \mathrm{O}$ & ${ }^{1} J_{\mathrm{OF}}$ & $-276,8$ & $-314,9$ & $-353,5$ & $-393,9$ & $-438,5$ & $-490,9$ & $-557,3$ & $-650,5$ & $-801,4$ & $-1114,8$ & $-2403,5$ & -300 \\
\hline $\mathrm{CH}_{4}$ & ${ }^{1} J_{\mathrm{CH}}$ & 127,7 & 129,2 & 130,8 & 132,5 & 134,1 & 135,9 & 137,6 & 139,4 & 141,2 & 143,0 & 144,9 & 125,3 \\
\hline $\mathrm{CH}_{4}$ & ${ }^{2} J_{\mathrm{HH}}$ & $-11,2$ & $-12,1$ & $-13,0$ & $-13,9$ & $-14,7$ & $-15,6$ & $-16,5$ & $-17,5$ & $-18,4$ & $-19,3$ & $-20,2$ & $-12,8$ \\
\hline $\mathrm{C}_{2} \mathrm{H}_{2}$ & ${ }^{1} J_{\mathrm{CC}}$ & 189,7 & 192,6 & 195,9 & 199,7 & 204,2 & 209,6 & 216,0 & 223,8 & 233,5 & 245,9 & 262,1 & 174,8 \\
\hline $\mathrm{C}_{2} \mathrm{H}_{2}$ & ${ }^{1} J_{\mathrm{CH}}$ & 265,0 & 267,8 & 270,7 & 273,8 & 277,3 & 281,1 & 285,4 & 290,3 & 296,3 & 303,6 & 312,9 & 247,6 \\
\hline $\mathrm{C}_{2} \mathrm{H}_{2}$ & ${ }^{2} J_{\mathrm{CH}}$ & 55,7 & 55,6 & 55,3 & 54,6 & 53,6 & 52,2 & 50,2 & 47,5 & 43,8 & 38,7 & 31,5 & 50,1 \\
\hline $\mathrm{C}_{2} \mathrm{H}_{2}$ & ${ }^{3} J_{\mathrm{HH}}$ & 10,8 & 11,5 & 12,3 & 13,3 & 14,6 & 16,1 & 18,0 & 20,3 & 23,2 & 26,9 & 31,8 & 9,6 \\
\hline $\mathrm{C}_{2} \mathrm{H}_{4}$ & ${ }^{1} J_{\mathrm{CC}}$ & 62,6 & 65,4 & 68,5 & 72,1 & 76,2 & 81,2 & 87,3 & 95,3 & 106,5 & 123,5 & 153,5 & 67,6 \\
\hline $\mathrm{C}_{2} \mathrm{H}_{4}$ & ${ }^{1} J_{\mathrm{CH}}$ & 161,7 & 164,1 & 166,6 & 169,2 & 172,1 & 175,4 & 179,1 & 183,6 & 189,5 & 197,8 & 211,7 & 156,3 \\
\hline $\mathrm{C}_{2} \mathrm{H}_{4}$ & ${ }^{2} J_{\mathrm{CH}}$ & $-0,6$ & $-1,6$ & $-2,7$ & $-4,0$ & $-5,5$ & $-7,4$ & $-9,7$ & $-12,9$ & $-17,3$ & $-24,3$ & $-36,8$ & $-2,4$ \\
\hline $\mathrm{C}_{2} \mathrm{H}_{4}$ & ${ }^{2} J_{\mathrm{HH}}$ & 6,1 & 5,2 & 4,3 & 3,3 & 2,2 & 0,9 & $-0,7$ & $-2,8$ & $-5,6$ & $-9,9$ & $-17,4$ & 2,3 \\
\hline $\mathrm{C}_{2} \mathrm{H}_{4}$ & ${ }^{3} J_{\mathrm{HH}_{\mathrm{c}}}$ & 12,5 & 12,8 & 13,3 & 13,8 & 14,4 & 15,3 & 16,4 & 18,0 & 20,4 & 24,3 & 31,3 & 11,7 \\
\hline $\mathrm{C}_{2} \mathrm{H}_{4}$ & ${ }^{3} J_{\mathrm{HH}_{\mathrm{t}}}$ & 20,5 & 20,9 & 21,4 & 22,0 & 22,8 & 23,8 & 25,1 & 27,0 & 29,8 & 34,2 & 42,2 & 19 \\
\hline $\mathrm{C}_{2} \mathrm{H}_{6}$ & ${ }^{1} J_{\mathrm{CC}}$ & 26,7 & 28,6 & 30,5 & 32,4 & 34,4 & 36,4 & 38,4 & 40,5 & 42,6 & 44,8 & 46,9 & 34,5 \\
\hline $\mathrm{C}_{2} \mathrm{H}_{6}$ & ${ }^{1} J_{\mathrm{CH}}$ & 127,6 & 129,4 & 131,3 & 133,1 & 135,0 & 137,0 & 138,9 & 140,9 & 142,9 & 145,0 & 147,1 & 125,2 \\
\hline $\mathrm{C}_{2} \mathrm{H}_{6}$ & ${ }^{2} J_{\mathrm{CH}}$ & $-2,9$ & $-3,4$ & $-3,9$ & $-4,5$ & $-5,0$ & $-5,5$ & $-6,1$ & $-6,7$ & $-7,3$ & $-7,9$ & $-8,5$ & $-4,7$ \\
\hline \multirow[t]{3}{*}{ Total } & $\mathrm{DM}$ & $-23,62$ & $-21,29$ & $-18,78$ & $-16,15$ & $-13,50$ & $-10,98$ & $-8,85$ & $-7,54$ & $-8,16$ & $-14,60$ & $-57,72$ & - \\
\hline & DMA & 31,98 & 28,12 & 26,02 & 24,32 & 22,86 & 22,13 & 25,98 & 32,51 & 41,69 & 57,92 & 113,73 & - \\
\hline & PDMA & 49,42 & 38,48 & 29,33 & 24,83 & 22,70 & 26,68 & 42,97 & 63,73 & 89,30 & 125,26 & 191,26 & - \\
\hline \multirow[t]{3}{*}{ CPI } & DM & $-60,18$ & $-55,95$ & $-51,40$ & $-46,66$ & $-42,05$ & $-37,98$ & $-35,04$ & $-34,42$ & $-39,02$ & $-58,34$ & $-166,33$ & - \\
\hline & DMA & 68,93 & 59,36 & 53,67 & 48,14 & 42,89 & 38,47 & 44,49 & 55,71 & 72,04 & 103,03 & 223,67 & - \\
\hline & PDMA & 82,05 & 64,32 & 48,14 & 34,87 & 24,23 & 15,32 & 31,75 & 50,99 & 71,88 & 97,44 & 152,58 & - \\
\hline \multirow[t]{3}{*}{ SPI } & DM & 3,19 & 4,13 & 5,15 & 6,22 & 7,44 & 8,82 & 10,35 & 12,17 & 14,47 & 17,48 & 21,93 & - \\
\hline & DMA & 4,89 & 5,21 & 5,75 & 6,86 & 8,17 & 10,15 & 12,41 & 15,49 & 19,44 & 24,84 & 33,11 & - \\
\hline & PDMA & 25,48 & 19,52 & 15,54 & 17,48 & 21,58 & 35,01 & 51,19 & 73,07 & 102,08 & 145,65 & 219,63 & - \\
\hline \multirow[t]{3}{*}{$\Delta \mathrm{CS}$} & $\mathrm{DM}$ & $-63,37$ & $-60,07$ & $-56,55$ & $-52,88$ & $-49,49$ & $-46,80$ & $-45,39$ & $-46,59$ & $-53,48$ & $-75,82$ & $-188,25$ & - \\
\hline & DMA & 64,03 & 54,16 & 47,93 & 41,28 & 34,72 & 28,32 & 32,08 & 40,22 & 52,60 & 78,19 & 190,56 & - \\
\hline & PDMA & 56,56 & 44,79 & 32,61 & 17,39 & 2,65 & $-19,70$ & $-19,44$ & $-22,08$ & $-30,20$ & $-48,21$ & $-67,05$ & - \\
\hline \multicolumn{14}{|c|}{ Desconsiderando ${ }^{1} J_{\mathrm{BF}}$ da molécula de $\mathrm{BF}_{3},{ }^{2} J_{\mathrm{CH}}$ e ${ }^{2} J_{\mathrm{HH}}$ da molécula de $\mathrm{C}_{2} \mathrm{H}_{4}$} \\
\hline \multirow[t]{3}{*}{ Total } & DM & $-23,12$ & $-21,19$ & $-19,04$ & $-16,74$ & $-14,38$ & $-12,13$ & $-10,28$ & $-9,29$ & $-10,39$ & $-17,87$ & $-66,43$ & - \\
\hline & DMA & 32,08 & 28,59 & 27,06 & 25,89 & 24,97 & 24,74 & 28,20 & 34,62 & 43,99 & 61,14 & 122,68 & - \\
\hline & PDMA & 19,88 & 16,30 & 13,76 & 13,34 & 14,93 & 18,46 & 24,84 & 33,72 & 44,68 & 59,87 & 93,09 & - \\
\hline \multirow[t]{3}{*}{ CPI } & DM & $-57,39$ & $-54,55$ & $-51,34$ & $-47,90$ & $-44,56$ & $-41,78$ & $-40,21$ & $-41,19$ & $-47,87$ & $-70,72$ & $-191,09$ & - \\
\hline & DMA & 67,01 & 58,31 & 53,84 & 49,52 & 45,48 & 42,32 & 47,27 & 57,95 & 74,29 & 106,78 & 237,91 & - \\
\hline & PDMA & 31,52 & 24,15 & 18,29 & 15,49 & 15,32 & 16,85 & 23,79 & 33,89 & 46,07 & 63,52 & 113,64 & - \\
\hline \multirow[t]{3}{*}{ SPI } & $\mathrm{DM}$ & 3,25 & 4,48 & 5,81 & 7,22 & 8,83 & 10,67 & 12,74 & 15,25 & 18,45 & 22,79 & 29,46 & - \\
\hline & DMA & 5,22 & 5,72 & 6,45 & 7,72 & 9,18 & 11,22 & 13,52 & 16,68 & 20,68 & 26,04 & 34,05 & - \\
\hline & PDMA & 10,93 & 10,27 & 10,27 & 11,69 & 14,63 & 19,69 & 25,64 & 33,60 & 43,60 & 57,07 & 77,27 & - \\
\hline \multirow[t]{3}{*}{$\Delta \mathrm{CS}$} & $\mathrm{DM}$ & $-60,64$ & $-59,03$ & $-57,15$ & $-55,12$ & $-53,39$ & $-52,45$ & $-52,95$ & $-56,44$ & $-66,32$ & $-93,51$ & $-220,55$ & 一 \\
\hline & DMA & 61,79 & 52,59 & 47,39 & 41,80 & 36,30 & 31,10 & 33,75 & 41,27 & 53,61 & 80,74 & 203,86 & - \\
\hline & PDMA & 20,59 & 13,89 & 8,01 & 3,80 & 0,69 & $-2,84$ & $-1,84$ & 0,29 & 2,47 & 6,46 & 36,37 & - \\
\hline
\end{tabular}

Tabela 8.248: Valores de PDMA total obtidos para troca PBE com base HuzIII-su3.

\begin{tabular}{lccccccccccc}
\hline$E_{X}^{\mathrm{HF}}(\%)$ & $0 \%$ & $10 \%$ & $20 \%$ & $30 \%$ & $40 \%$ & $50 \%$ & $60 \%$ & $70 \%$ & $80 \%$ & $90 \%$ & $100 \%$ \\
\hline PBEB95 & 51,9 & 40,9 & 30,3 & 21,1 & 14,0 & 12,4 & 22,9 & 36,8 & 51,9 & 69,9 & 92,6 \\
PBEB98 & 45,7 & 35,2 & 25,0 & 20,1 & 18,5 & 25,7 & 40,1 & 57,3 & 75,7 & 99,1 & 131,6 \\
PBEB971 & 44,9 & 34,1 & 23,6 & 16,7 & 14,6 & 23,3 & 37,6 & 53,3 & 71,2 & 92,3 & 120,6 \\
PBEB972 & 44,9 & 35,3 & 26,2 & 18,3 & 19,4 & 28,4 & 37,9 & 52,2 & 69,5 & 90,4 & 119,3 \\
PBELYP & 46,1 & 35,5 & 27,2 & 23,0 & 21,5 & 28,8 & 44,8 & 62,6 & 84,2 & 113,4 & 161,5 \\
PBEP86 & 49,1 & 37,8 & 27,5 & 21,9 & 21,4 & 23,7 & 34,6 & 53,2 & 74,8 & 105,4 & 156,7 \\
PBEPBE & 47,1 & 35,5 & 27,0 & 25,6 & 26,5 & 29,3 & 41,7 & 62,4 & 87,7 & 125,0 & 196,2 \\
PBEPW91 & 46,5 & 34,9 & 26,8 & 25,2 & 26,0 & 29,1 & 42,3 & 63,1 & 88,5 & 126,0 & 197,9 \\
PBETPSS & 49,8 & 38,6 & 30,2 & 26,8 & 26,1 & 29,8 & 43,2 & 64,2 & 90,8 & 128,0 & 197,2 \\
\hline
\end{tabular}


8.4.1.7 Troca PW91

Tabela 8.249: Constantes de acoplamento PW91B95 com base aug-pcJ-2.

\begin{tabular}{|c|c|c|c|c|c|c|c|c|c|c|c|c|c|}
\hline & $\% E_{X}^{\mathrm{HF}}$ & $0 \%$ & $10 \%$ & $20 \%$ & $30 \%$ & $40 \%$ & $50 \%$ & $60 \%$ & $70 \%$ & $80 \%$ & $90 \%$ & $100 \%$ & Exp. \\
\hline $\mathrm{HF}$ & ${ }^{1} J_{\mathrm{HF}}$ & 414,1 & 436,7 & 459,5 & 482,5 & 505,6 & 528,8 & 552,2 & 575,8 & 599,5 & 623,4 & 647,4 & 500 \\
\hline $\mathrm{CO}$ & ${ }^{1} J_{\mathrm{CO}}$ & 23,0 & 21,3 & 19,5 & 17,7 & 15,7 & 13,7 & 11,6 & 9,4 & 7,1 & 4,8 & 2,4 & 16,4 \\
\hline $\mathrm{H}_{2} \mathrm{O}$ & ${ }^{1} J_{\mathrm{OH}}$ & $-71,5$ & $-73,9$ & $-76,3$ & $-78,7$ & $-81,2$ & $-83,6$ & $-86,1$ & $-88,6$ & $-91,1$ & $-93,6$ & $-96,2$ & $-80,6$ \\
\hline $\mathrm{H}_{2} \mathrm{O}$ & ${ }^{2} J_{\mathrm{HH}}$ & $-3,9$ & $-4,9$ & $-5,9$ & $-7,0$ & $-8,0$ & $-9,1$ & $-10,2$ & $-11,3$ & $-12,4$ & $-13,5$ & $-14,7$ & $-7,3$ \\
\hline $\mathrm{NH}_{3}$ & ${ }^{1} J_{\mathrm{NH}}$ & 42,4 & 43,1 & 43,8 & 44,5 & 45,2 & 45,9 & 46,6 & 47,3 & 48,0 & 48,8 & 49,5 & 43,8 \\
\hline $\mathrm{NH}_{3}$ & ${ }^{2} J_{\mathrm{HH}}$ & $-6,6$ & $-7,5$ & $-8,4$ & $-9,3$ & $-10,2$ & $-11,1$ & $-12,0$ & $-12,9$ & $-13,9$ & $-14,8$ & $-15,8$ & $-9,6$ \\
\hline $\mathrm{PH}_{3}$ & ${ }^{1} J_{\mathrm{PH}}$ & 147,1 & 154,6 & 162,0 & 169,3 & 176,5 & 183,6 & 190,5 & 197,4 & 204,1 & 210,6 & 217,0 & 188,2 \\
\hline $\mathrm{PF}_{3}$ & ${ }^{1} J_{\mathrm{PF}}$ & $-1720,0$ & $-1699,6$ & $-1674,3$ & $-1644,9$ & $-1612,0$ & $-1576,3$ & $-1538,3$ & $-1498,6$ & $-1457,5$ & $-1415,5$ & $-1372,8$ & -1441 \\
\hline $\mathrm{BHF}_{2}$ & ${ }^{1} J_{\mathrm{BF}}$ & $-174,3$ & $-157,4$ & $-140,6$ & $-123,8$ & $-107,2$ & $-90,7$ & $-74,3$ & $-58,1$ & $-42,0$ & $-26,2$ & $-10,5$ & -84 \\
\hline $\mathrm{BF}_{3}$ & ${ }^{1} J_{\mathrm{BF}}$ & $-76,3$ & $-57,9$ & $-39,7$ & $-21,6$ & $-3,7$ & 13,9 & 31,4 & 48,7 & 65,9 & 82,8 & 99,7 & 15 \\
\hline $\mathrm{F}_{2} \mathrm{O}$ & ${ }^{1} J_{\mathrm{OF}}$ & $-266,5$ & $-301,0$ & $-334,7$ & $-368,5$ & $-404,0$ & $-443,2$ & $-489,3$ & $-547,8$ & $-629,9$ & $-763,7$ & $-1048,5$ & -300 \\
\hline $\mathrm{CH}_{4}$ & ${ }^{1} J_{\mathrm{CH}}$ & 121,8 & 123,0 & 124,3 & 125,5 & 126,8 & 128,1 & 129,4 & 130,7 & 132,1 & 133,5 & 134,9 & 125,3 \\
\hline $\mathrm{CH}_{4}$ & ${ }^{2} J_{\mathrm{HH}}$ & $-9,8$ & $-10,5$ & $-11,3$ & $-12,0$ & $-12,7$ & $-13,4$ & $-14,2$ & $-14,9$ & $-15,6$ & $-16,3$ & $-17,0$ & $-12,8$ \\
\hline $\mathrm{C}_{2} \mathrm{H}_{2}$ & ${ }^{1} J_{\mathrm{CC}}$ & 188,8 & 191,1 & 193,7 & 196,6 & 199,9 & 203,7 & 208,2 & 213,3 & 219,4 & 226,7 & 235,5 & 174,8 \\
\hline $\mathrm{C}_{2} \mathrm{H}_{2}$ & ${ }^{1} J_{\mathrm{CH}}$ & 251,9 & 253,7 & 255,5 & 257,5 & 259,5 & 261,7 & 264,1 & 266,8 & 269,8 & 273,2 & 277,3 & 247,6 \\
\hline $\mathrm{C}_{2} \mathrm{H}_{2}$ & ${ }^{2} J_{\mathrm{CH}}$ & 55,4 & 55,6 & 55,6 & 55,5 & 55,2 & 54,6 & 53,8 & 52,7 & 51,1 & 49,1 & 46,4 & 50,1 \\
\hline $\mathrm{C}_{2} \mathrm{H}_{2}$ & ${ }^{3} J_{\mathrm{HH}}$ & 8,8 & 9,2 & 9,7 & 10,3 & 11,0 & 11,8 & 12,8 & 13,9 & 15,3 & 16,9 & 18,9 & 9,6 \\
\hline $\mathrm{C}_{2} \mathrm{H}_{4}$ & ${ }^{1} J_{\mathrm{CC}}$ & 59,6 & 61,9 & 64,4 & 67,1 & 70,0 & 73,3 & 77,1 & 81,4 & 86,6 & 92,9 & 100,8 & 67,6 \\
\hline $\mathrm{C}_{2} \mathrm{H}_{4}$ & ${ }^{1} J_{\mathrm{CH}}$ & 154,5 & 156,3 & 158,1 & 159,9 & 161,9 & 164,0 & 166,2 & 168,7 & 171,5 & 174,8 & 178,7 & 156,3 \\
\hline $\mathrm{C}_{2} \mathrm{H}_{4}$ & ${ }^{2} J_{\mathrm{CH}}$ & 1,1 & 0,3 & $-0,4$ & $-1,2$ & $-2,2$ & $-3,4$ & $-4,7$ & $-6,2$ & $-8,1$ & $-10,4$ & $-13,4$ & $-2,4$ \\
\hline $\mathrm{C}_{2} \mathrm{H}_{4}$ & ${ }^{2} J_{\mathrm{HH}}$ & 6,3 & 5,6 & 4,9 & 4,2 & 3,5 & 2,7 & 1,7 & 0,7 & $-0,4$ & $-1,8$ & $-3,5$ & 2,3 \\
\hline $\mathrm{C}_{2} \mathrm{H}_{4}$ & ${ }^{3} J_{\mathrm{HH}_{\mathrm{c}}}$ & 11,5 & 11,7 & 11,9 & 12,1 & 12,4 & 12,8 & 13,2 & 13,8 & 14,6 & 15,6 & 16,9 & 11,7 \\
\hline $\mathrm{C}_{2} \mathrm{H}_{4}$ & ${ }^{3} J_{\mathrm{HH}_{\mathrm{t}}}$ & 18,3 & 18,4 & 18,6 & 18,9 & 19,3 & 19,7 & 20,3 & 21,0 & 21,9 & 23,1 & 24,7 & 19 \\
\hline $\mathrm{C}_{2} \mathrm{H}_{6}$ & ${ }^{1} J_{\mathrm{CC}}$ & 25,7 & 27,6 & 29,5 & 31,4 & 33,4 & 35,4 & 37,4 & 39,4 & 41,5 & 43,6 & 45,7 & 34,5 \\
\hline $\mathrm{C}_{2} \mathrm{H}_{6}$ & ${ }^{1} J_{\mathrm{CH}}$ & 121,7 & 123,1 & 124,6 & 126,0 & 127,5 & 129,0 & 130,5 & 132,0 & 133,6 & 135,1 & 136,7 & 125,2 \\
\hline $\mathrm{C}_{2} \mathrm{H}_{6}$ & ${ }^{2} J_{\mathrm{CH}}$ & $-2,2$ & $-2,6$ & $-3,0$ & $-3,5$ & $-4,0$ & $-4,4$ & $-4,9$ & $-5,4$ & $-5,9$ & $-6,4$ & $-6,9$ & $-4,7$ \\
\hline \multirow[t]{3}{*}{ Total } & DM & $-20,16$ & $-17,97$ & $-15,54$ & $-12,94$ & $-10,26$ & $-7,60$ & $-5,08$ & $-2,92$ & $-1,53$ & $-2,01$ & $-8,15$ & - \\
\hline & DMA & 27,25 & 22,15 & 19,55 & 16,97 & 15,30 & 15,60 & 18,52 & 22,92 & 28,32 & 37,83 & 54,82 & - \\
\hline & PDMA & 53,57 & 42,21 & 32,06 & 22,18 & 14,28 & 11,71 & 21,89 & 35,83 & 51,20 & 68,82 & 90,89 & - \\
\hline \multirow[t]{3}{*}{ CPI } & $\mathrm{DM}$ & $-48,49$ & $-44,31$ & $-39,64$ & $-34,61$ & $-29,47$ & $-24,45$ & $-19,89$ & $-16,33$ & $-14,83$ & $-17,98$ & $-34,85$ & - \\
\hline & DMA & 58,60 & 47,24 & 41,45 & 35,43 & 30,75 & 30,07 & 35,05 & 43,25 & 53,46 & 72,87 & 109,09 & - \\
\hline & PDMA & 83,48 & 65,16 & 48,89 & 32,82 & 20,93 & 13,26 & 28,15 & 46,54 & 65,71 & 86,46 & 112,26 & - \\
\hline \multirow[t]{3}{*}{ SPI } & $\mathrm{DM}$ & 0,62 & 1,35 & 2,13 & 2,95 & 3,83 & 4,77 & 5,79 & 6,92 & 8,22 & 9,70 & 11,44 & - \\
\hline & DMA & 4,26 & 3,75 & 3,49 & 3,44 & 3,97 & 4,98 & 6,39 & 8,01 & 9,87 & 12,14 & 15,03 & - \\
\hline & PDMA & 31,63 & 25,38 & 19,72 & 14,38 & 9,40 & 10,57 & 17,30 & 27,98 & 40,56 & 55,88 & 75,22 & - \\
\hline \multirow[t]{3}{*}{$\Delta \mathrm{CS}$} & DM & $-49,11$ & $-45,66$ & $-41,77$ & $-37,56$ & $-33,30$ & $-29,22$ & $-25,68$ & $-23,25$ & $-23,05$ & $-27,68$ & $-46,29$ & - \\
\hline & DMA & 54,34 & 43,48 & 37,96 & 31,99 & 26,77 & 25,09 & 28,67 & 35,24 & 43,59 & 60,73 & 94,06 & - \\
\hline & PDMA & 51,85 & 39,78 & 29,17 & 18,44 & 11,53 & 2,69 & 10,84 & 18,56 & 25,14 & 30,59 & 37,04 & - \\
\hline \multicolumn{14}{|c|}{ Desconsiderando ${ }^{1} J_{\mathrm{BF}}$ da molécula de $\mathrm{BF}_{3},{ }^{2} J_{\mathrm{CH}}$ e ${ }^{2} J_{\mathrm{HH}}$ da molécula de $\mathrm{C}_{2} \mathrm{H}_{4}$} \\
\hline \multirow[t]{3}{*}{ Total } & DM & $-19,14$ & $-17,40$ & $-15,39$ & $-13,17$ & $-10,85$ & $-8,51$ & $-6,33$ & $-4,53$ & $-3,58$ & $-4,70$ & $-12,16$ & - \\
\hline & DMA & 26,51 & 21,61 & 19,53 & 17,46 & 16,42 & 17,52 & 20,09 & 24,21 & 29,43 & 39,30 & 57,56 & - \\
\hline & PDMA & 20,19 & 15,45 & 11,85 & 8,70 & 8,09 & 10,35 & 14,69 & 20,83 & 27,70 & 35,90 & 47,30 & - \\
\hline \multirow[t]{3}{*}{ CPI } & DM & $-44,21$ & $-41,45$ & $-38,13$ & $-34,41$ & $-30,55$ & $-26,79$ & $-23,52$ & $-21,33$ & $-21,40$ & $-26,56$ & $-46,81$ & - \\
\hline & DMA & 55,33 & 44,67 & 40,13 & 35,31 & 31,95 & 32,97 & 36,92 & 44,21 & 53,72 & 73,38 & 111,53 & - \\
\hline & PDMA & 30,96 & 23,07 & 17,31 & 11,70 & 10,55 & 13,86 & 20,03 & 28,72 & 38,34 & 49,91 & 67,02 & - \\
\hline \multirow[t]{3}{*}{ SPI } & $\mathrm{DM}$ & 0,14 & 1,10 & 2,11 & 3,16 & 4,31 & 5,55 & 6,90 & 8,40 & 10,13 & 12,12 & 14,49 & - \\
\hline & DMA & 4,34 & 3,87 & 3,68 & 3,73 & 4,48 & 5,64 & 7,15 & 8,83 & 10,75 & 13,08 & 16,05 & - \\
\hline & PDMA & 11,90 & 9,59 & 7,64 & 6,39 & 6,19 & 7,66 & 10,59 & 14,76 & 19,51 & 25,12 & 32,14 & - \\
\hline \multirow[t]{3}{*}{$\Delta \mathrm{CS}$} & $\mathrm{DM}$ & $-44,35$ & $-42,55$ & $-40,24$ & $-37,57$ & $-34,86$ & $-32,34$ & $-30,42$ & $-29,73$ & $-31,53$ & $-38,68$ & $-61,30$ & - \\
\hline & DMA & 50,99 & 40,80 & 36,45 & 31,58 & 27,47 & 27,33 & 29,77 & 35,38 & 42,97 & 60,30 & 95,48 & - \\
\hline & PDMA & 19,06 & 13,48 & 9,66 & 5,31 & 4,36 & 6,20 & 9,44 & 13,97 & 18,84 & 24,79 & 34,88 & - \\
\hline
\end{tabular}


Tabela 8.250: Constantes de acoplamento PW91B971 com base aug-pcJ-2.

\begin{tabular}{|c|c|c|c|c|c|c|c|c|c|c|c|c|c|}
\hline & $\% E_{X}^{\mathrm{HF}}$ & $0 \%$ & $10 \%$ & $20 \%$ & $30 \%$ & $40 \%$ & $50 \%$ & $60 \%$ & $70 \%$ & $80 \%$ & $90 \%$ & $100 \%$ & Exp. \\
\hline $\mathrm{HF}$ & ${ }^{1} J_{\mathrm{HF}}$ & 421,3 & 443,1 & 464,9 & 486,9 & 508,9 & 531,1 & 553,5 & 575,9 & 598,4 & 621,1 & 643,9 & 500 \\
\hline $\mathrm{CO}$ & ${ }^{1} J_{\mathrm{CO}}$ & 21,2 & 19,4 & 17,5 & 15,4 & 13,3 & 11,1 & 8,8 & 6,3 & 3,9 & 1,3 & $-1,3$ & 16,4 \\
\hline $\mathrm{H}_{2} \mathrm{O}$ & ${ }^{1} J_{\mathrm{OH}}$ & $-72,4$ & $-74,6$ & $-76,9$ & $-79,2$ & $-81,5$ & $-83,9$ & $-86,2$ & $-88,6$ & $-90,9$ & $-93,3$ & $-95,7$ & $-80,6$ \\
\hline $\mathrm{H}_{2} \mathrm{O}$ & ${ }^{2} J_{\mathrm{HH}}$ & $-3,9$ & $-4,9$ & $-5,9$ & $-6,9$ & $-7,9$ & $-8,9$ & $-9,9$ & $-11,0$ & $-12,1$ & $-13,2$ & $-14,3$ & $-7,3$ \\
\hline $\mathrm{NH}_{3}$ & ${ }^{1} J_{\mathrm{NH}}$ & 43,4 & 44,1 & 44,8 & 45,5 & 46,2 & 46,9 & 47,6 & 48,4 & 49,1 & 49,9 & 50,6 & 43,8 \\
\hline $\mathrm{NH}_{3}$ & ${ }^{2} J_{\mathrm{HH}}$ & $-6,7$ & $-7,6$ & $-8,5$ & $-9,4$ & $-10,4$ & $-11,3$ & $-12,2$ & $-13,2$ & $-14,1$ & $-15,1$ & $-16,1$ & $-9,6$ \\
\hline $\mathrm{PH}_{3}$ & ${ }^{1} J_{\mathrm{PH}}$ & 174,1 & 181,5 & 188,8 & 195,9 & 202,9 & 209,6 & 216,2 & 222,6 & 228,8 & 234,8 & 240,7 & 188,2 \\
\hline $\mathrm{PF}_{3}$ & ${ }^{1} J_{\mathrm{PF}}$ & $-1766,5$ & $-1743,5$ & $-1715,7$ & $-1683,7$ & $-1648,3$ & $-1610,1$ & $-1569,7$ & $-1527,6$ & $-1484,1$ & $-1439,8$ & $-1394,8$ & -1441 \\
\hline $\mathrm{BHF}_{2}$ & ${ }^{1} J_{\mathrm{BF}}$ & $-162,8$ & $-145,0$ & $-127,3$ & $-109,6$ & $-92,2$ & $-74,9$ & $-57,8$ & $-41,0$ & $-24,4$ & $-7,9$ & 8,1 & -84 \\
\hline $\mathrm{BF}_{3}$ & ${ }^{1} J_{\mathrm{BF}}$ & $-64,2$ & $-45,1$ & $-26,2$ & $-7,6$ & 10,8 & 29,0 & 47,0 & 64,8 & 82,3 & 99,7 & 116,8 & 15 \\
\hline $\mathrm{F}_{2} \mathrm{O}$ & ${ }^{1} J_{\mathrm{OF}}$ & $-264,5$ & $-299,2$ & $-333,4$ & $-368,3$ & $-405,4$ & $-447,2$ & $-497,5$ & $-563,2$ & $-659,0$ & $-824,6$ & $-1221,3$ & -300 \\
\hline $\mathrm{CH}_{4}$ & ${ }^{1} J_{\mathrm{CH}}$ & 129,8 & 131,2 & 132,7 & 134,1 & 135,6 & 137,1 & 138,7 & 140,2 & 141,8 & 143,4 & 145,1 & 125,3 \\
\hline $\mathrm{CH}_{4}$ & ${ }^{2} J_{\mathrm{HH}}$ & $-9,8$ & $-10,6$ & $-11,3$ & $-12,1$ & $-12,9$ & $-13,6$ & $-14,4$ & $-15,1$ & $-15,9$ & $-16,6$ & $-17,3$ & $-12,8$ \\
\hline $\mathrm{C}_{2} \mathrm{H}_{2}$ & ${ }^{1} J_{\mathrm{CC}}$ & 209,4 & 212,7 & 216,3 & 220,5 & 225,1 & 230,5 & 236,7 & 243,9 & 252,5 & 262,7 & 275,1 & 174,8 \\
\hline $\mathrm{C}_{2} \mathrm{H}_{2}$ & ${ }^{1} J_{\mathrm{CH}}$ & 263,1 & 265,2 & 267,5 & 269,9 & 272,4 & 275,2 & 278,3 & 281,7 & 285,6 & 290,1 & 295,5 & 247,6 \\
\hline $\mathrm{C}_{2} \mathrm{H}_{2}$ & ${ }^{2} J_{\mathrm{CH}}$ & 54,3 & 54,2 & 54,1 & 53,7 & 53,0 & 52,1 & 50,8 & 49,1 & 46,9 & 43,9 & 40,1 & 50,1 \\
\hline $\mathrm{C}_{2} \mathrm{H}_{2}$ & ${ }^{3} J_{\mathrm{HH}}$ & 8,7 & 9,2 & 9,8 & 10,4 & 11,2 & 12,2 & 13,3 & 14,6 & 16,2 & 18,2 & 20,5 & 9,6 \\
\hline $\mathrm{C}_{2} \mathrm{H}_{4}$ & ${ }^{1} J_{\mathrm{CC}}$ & 72,2 & 75,2 & 78,4 & 82,0 & 85,9 & 90,3 & 95,4 & 101,5 & 108,9 & 118,2 & 130,5 & 67,6 \\
\hline $\mathrm{C}_{2} \mathrm{H}_{4}$ & ${ }^{1} J_{\mathrm{CH}}$ & 162,8 & 164,8 & 166,9 & 169,1 & 171,5 & 174,0 & 176,7 & 179,8 & 183,4 & 187,7 & 193,0 & 156,3 \\
\hline $\mathrm{C}_{2} \mathrm{H}_{4}$ & ${ }^{2} J_{\mathrm{CH}}$ & 0,1 & $-0,7$ & $-1,6$ & $-2,7$ & $-3,9$ & $-5,2$ & $-6,9$ & $-8,9$ & $-11,3$ & $-14,5$ & $-18,8$ & $-2,4$ \\
\hline $\mathrm{C}_{2} \mathrm{H}_{4}$ & ${ }^{2} J_{\mathrm{HH}}$ & 5,9 & 5,2 & 4,5 & 3,8 & 3,0 & 2,1 & 1,1 & 0,0 & $-1,3$ & $-3,0$ & $-5,1$ & 2,3 \\
\hline $\mathrm{C}_{2} \mathrm{H}_{4}$ & ${ }^{3} J_{\mathrm{HH}_{\mathrm{c}}}$ & 11,4 & 11,6 & 11,8 & 12,1 & 12,4 & 12,9 & 13,4 & 14,1 & 15,0 & 16,2 & 18,0 & 11,7 \\
\hline $\mathrm{C}_{2} \mathrm{H}_{4}$ & ${ }^{3} J_{\mathrm{HH}_{\mathrm{t}}}$ & 18,0 & 18,2 & 18,5 & 18,8 & 19,2 & 19,7 & 20,4 & 21,3 & 22,4 & 23,9 & 25,9 & 19 \\
\hline $\mathrm{C}_{2} \mathrm{H}_{6}$ & ${ }^{1} J_{\mathrm{CC}}$ & 31,0 & 33,1 & 35,3 & 37,6 & 39,8 & 42,2 & 44,5 & 47,0 & 49,4 & 51,9 & 54,4 & 34,5 \\
\hline $\mathrm{C}_{2} \mathrm{H}_{6}$ & ${ }^{1} J_{\mathrm{CH}}$ & 129,6 & 131,3 & 133,0 & 134,6 & 136,4 & 138,1 & 139,8 & 141,6 & 143,4 & 145,2 & 147,0 & 125,2 \\
\hline $\mathrm{C}_{2} \mathrm{H}_{6}$ & ${ }^{2} J_{\mathrm{CH}}$ & $-2,3$ & $-2,8$ & $-3,3$ & $-3,8$ & $-4,3$ & $-4,8$ & $-5,3$ & $-5,9$ & $-6,4$ & $-7,0$ & $-7,5$ & $-4,7$ \\
\hline \multirow[t]{3}{*}{ Total } & DM & $-16,99$ & $-14,58$ & $-11,93$ & $-9,15$ & $-6,32$ & $-3,49$ & $-0,87$ & 1,28 & 2,44 & 1,08 & $-8,92$ & - \\
\hline & DMA & 27,81 & 23,11 & 21,00 & 19,60 & 19,23 & 22,05 & 26,24 & 31,17 & 37,42 & 46,74 & 68,67 & - \\
\hline & PDMA & 46,60 & 35,41 & 25,42 & 17,59 & 14,57 & 22,09 & 36,52 & 52,36 & 69,82 & 90,84 & 118,03 & - \\
\hline \multirow[t]{3}{*}{ CPI } & DM & $-47,45$ & $-42,97$ & $-38,07$ & $-32,90$ & $-27,68$ & $-22,68$ & $-18,28$ & $-15,23$ & $-14,82$ & $-20,73$ & $-47,66$ & - \\
\hline & DMA & 57,41 & 45,61 & 39,69 & 34,97 & 32,41 & 36,99 & 44,37 & 52,99 & 64,13 & 81,78 & 128,26 & - \\
\hline & PDMA & 72,42 & 53,60 & 37,09 & 22,43 & 12,63 & 24,15 & 42,68 & 61,87 & 81,57 & 103,55 & 132,83 & - \\
\hline \multirow[t]{3}{*}{ SPI } & DM & 5,34 & 6,25 & 7,23 & 8,26 & 9,35 & 10,58 & 11,89 & 13,39 & 15,10 & 17,08 & 19,49 & - \\
\hline & DMA & 6,10 & 6,61 & 7,30 & 8,33 & 9,57 & 11,10 & 12,95 & 15,16 & 17,83 & 21,04 & 24,97 & - \\
\hline & PDMA & 27,67 & 22,07 & 16,87 & 14,03 & 15,99 & 20,58 & 32,01 & 45,38 & 61,21 & 81,51 & 107,17 & - \\
\hline \multirow[t]{3}{*}{$\Delta \mathrm{CS}$} & DM & $-52,79$ & $-49,22$ & $-45,31$ & $-41,16$ & $-37,04$ & $-33,26$ & $-30,18$ & $-28,61$ & $-29,92$ & $-37,81$ & $-67,15$ & - \\
\hline & DMA & 51,31 & 39,00 & 32,39 & 26,65 & 22,84 & 25,89 & 31,43 & 37,83 & 46,29 & 60,74 & 103,30 & - \\
\hline & PDMA & 44,75 & 31,53 & 20,22 & 8,40 & $-3,36$ & 3,57 & 10,68 & 16,49 & 20,36 & 22,04 & 25,65 & - \\
\hline \multicolumn{14}{|c|}{ Desconsiderando ${ }^{1} J_{\mathrm{BF}}$ da molécula de $\mathrm{BF}_{3},{ }^{2} J_{\mathrm{CH}}$ e ${ }^{2} J_{\mathrm{HH}}$ da molécula de $\mathrm{C}_{2} \mathrm{H}_{4}$} \\
\hline \multirow[t]{3}{*}{ Total } & DM & $-16,03$ & $-14,07$ & $-11,83$ & $-9,42$ & $-6,92$ & $-4,43$ & $-2,13$ & $-0,33$ & 0,38 & $-1,70$ & $-13,48$ & - \\
\hline & DMA & 27,73 & 23,31 & 21,82 & 21,10 & 21,46 & 24,19 & 28,03 & 32,68 & 38,83 & 48,40 & 72,17 & - \\
\hline & PDMA & 18,39 & 14,05 & 11,19 & 9,95 & 11,21 & 15,46 & 21,59 & 28,63 & 36,49 & 46,19 & 60,22 & - \\
\hline \multirow[t]{3}{*}{ CPI } & DM & $-44,27$ & $-41,26$ & $-37,76$ & $-33,93$ & $-30,03$ & $-26,35$ & $-23,31$ & $-21,73$ & $-23,03$ & $-31,27$ & $-62,61$ & - \\
\hline & DMA & 55,23 & 44,16 & 39,54 & 36,21 & 35,23 & 39,29 & 45,61 & 53,31 & 63,81 & 81,49 & 130,91 & - \\
\hline & PDMA & 26,86 & 18,89 & 13,33 & 9,61 & 11,09 & 17,23 & 25,62 & 34,86 & 44,86 & 57,44 & 78,24 & - \\
\hline \multirow[t]{3}{*}{ SPI } & $\mathrm{DM}$ & 5,69 & 6,85 & 8,12 & 9,44 & 10,85 & 12,44 & 14,16 & 16,12 & 18,38 & 21,05 & 24,32 & - \\
\hline & DMA & 6,57 & 7,27 & 8,19 & 9,47 & 10,87 & 12,58 & 14,50 & 16,82 & 19,62 & 22,94 & 26,98 & - \\
\hline & PDMA & 11,87 & 10,32 & 9,54 & 10,21 & 11,30 & 14,10 & 18,49 & 23,84 & 30,06 & 37,54 & 46,35 & - \\
\hline \multirow[t]{3}{*}{$\Delta \mathrm{CS}$} & $\mathrm{DM}$ & $-49,96$ & $-48,11$ & $-45,88$ & $-43,37$ & $-40,88$ & $-38,79$ & $-37,47$ & $-37,85$ & $-41,41$ & $-52,32$ & $-86,93$ & - \\
\hline & DMA & 48,66 & 36,89 & 31,35 & 26,74 & 24,36 & 26,71 & 31,11 & 36,49 & 44,19 & 58,55 & 103,93 & - \\
\hline & PDMA & 14,99 & 8,58 & 3,79 & $-0,61$ & $-0,21$ & 3,13 & 7,13 & 11,02 & 14,80 & 19,90 & 31,89 & - \\
\hline
\end{tabular}


8.4. GERAÇÃO DE NOVOS FUNCIONAIS COMBINANDO $E_{X}^{H F}, E_{X}^{D F T} E$ $E_{C}^{D F T}$

Tabela 8.251: Constantes de acoplamento PW91B972 com base aug-pcJ-2.

\begin{tabular}{|c|c|c|c|c|c|c|c|c|c|c|c|c|c|}
\hline & $\% E_{X}^{\mathrm{HF}}$ & $0 \%$ & $10 \%$ & $20 \%$ & $30 \%$ & $40 \%$ & $50 \%$ & $60 \%$ & $70 \%$ & $80 \%$ & $90 \%$ & $100 \%$ & Exp. \\
\hline $\mathrm{HF}$ & ${ }^{1} J_{\mathrm{HF}}$ & 459,2 & 482,0 & 504,9 & 527,9 & 550,9 & 574,1 & 597,4 & 620,8 & 644,2 & 667,8 & 691,6 & 500 \\
\hline $\mathrm{CO}$ & ${ }^{1} J_{\mathrm{CO}}$ & 17,1 & 15,1 & 12,9 & 10,6 & 8,1 & 5,6 & 3,0 & 0,3 & $-2,4$ & $-5,3$ & $-8,3$ & 16,4 \\
\hline $\mathrm{H}_{2} \mathrm{O}$ & ${ }^{1} J_{\mathrm{OH}}$ & $-78,2$ & $-80,6$ & $-83,1$ & $-85,5$ & $-88,0$ & $-90,5$ & $-93,0$ & $-95,5$ & $-98,0$ & $-100,6$ & $-103,1$ & $-80,6$ \\
\hline $\mathrm{H}_{2} \mathrm{O}$ & ${ }^{2} J_{\mathrm{HH}}$ & $-3,6$ & $-4,6$ & $-5,6$ & $-6,7$ & $-7,7$ & $-8,8$ & $-9,9$ & $-11,0$ & $-12,1$ & $-13,2$ & $-14,3$ & $-7,3$ \\
\hline $\mathrm{NH}_{3}$ & ${ }^{1} J_{\mathrm{NH}}$ & 45,8 & 46,5 & 47,2 & 47,9 & 48,6 & 49,4 & 50,1 & 50,8 & 51,6 & 52,3 & 53,1 & 43,8 \\
\hline $\mathrm{NH}_{3}$ & ${ }^{2} J_{\mathrm{HH}}$ & $-6,0$ & $-6,9$ & $-7,8$ & $-8,7$ & $-9,6$ & $-10,5$ & $-11,4$ & $-12,4$ & $-13,3$ & $-14,3$ & $-15,2$ & $-9,6$ \\
\hline $\mathrm{PH}_{3}$ & ${ }^{1} J_{\mathrm{PH}}$ & 166,0 & 174,1 & 182,2 & 190,2 & 198,1 & 205,8 & 213,5 & 221,0 & 228,3 & 235,5 & 242,5 & 188,2 \\
\hline $\mathrm{PF}_{3}$ & ${ }^{1} J_{\mathrm{PF}}$ & $-1813,5$ & $-1789,2$ & $-1759,9$ & $-1726,2$ & $-1689,1$ & $-1649,1$ & $-1606,9$ & $-1562,9$ & $-1517,7$ & $-1471,6$ & $-1424,9$ & -1441 \\
\hline $\mathrm{BHF}_{2}$ & ${ }^{1} J_{\mathrm{BF}}$ & $-148,5$ & $-130,7$ & $-113,0$ & $-95,5$ & $-78,3$ & $-61,2$ & $-44,4$ & $-27,8$ & $-11,5$ & 4,5 & 20,3 & -84 \\
\hline $\mathrm{BF}_{3}$ & ${ }^{1} J_{\mathrm{BF}}$ & $-47,8$ & $-28,7$ & $-9,8$ & 8,6 & 26,9 & 45,0 & 62,8 & 80,3 & 97,6 & 114,7 & 131,6 & 15 \\
\hline $\mathrm{F}_{2} \mathrm{O}$ & ${ }^{1} J_{\mathrm{OF}}$ & $-257,4$ & $-291,5$ & $-325,2$ & $-359,5$ & $-396,2$ & $-437,8$ & $-488,3$ & $-555,5$ & $-656,5$ & $-840,9$ & $-1349,0$ & -300 \\
\hline $\mathrm{CH}_{4}$ & ${ }^{1} J_{\mathrm{CH}}$ & 132,6 & 133,9 & 135,2 & 136,6 & 137,9 & 139,3 & 140,7 & 142,1 & 143,6 & 145,1 & 146,5 & 125,3 \\
\hline $\mathrm{CH}_{4}$ & ${ }^{2} J_{\mathrm{HH}}$ & $-8,4$ & $-9,2$ & $-9,9$ & $-10,6$ & $-11,4$ & $-12,1$ & $-12,8$ & $-13,5$ & $-14,2$ & $-14,9$ & $-15,6$ & $-12,8$ \\
\hline $\mathrm{C}_{2} \mathrm{H}_{2}$ & ${ }^{1} J_{\mathrm{CC}}$ & 207,4 & 210,7 & 214,4 & 218,6 & 223,4 & 228,9 & 235,3 & 242,7 & 251,4 & 261,8 & 274,3 & 174,8 \\
\hline $\mathrm{C}_{2} \mathrm{H}_{2}$ & ${ }^{1} J_{\mathrm{CH}}$ & 264,7 & 266,7 & 268,8 & 271,0 & 273,3 & 275,8 & 278,6 & 281,7 & 285,2 & 289,3 & 294,1 & 247,6 \\
\hline $\mathrm{C}_{2} \mathrm{H}_{2}$ & ${ }^{2} J_{\mathrm{CH}}$ & 54,7 & 54,7 & 54,5 & 54,1 & 53,5 & 52,6 & 51,4 & 49,9 & 47,8 & 45,1 & 41,6 & 50,1 \\
\hline $\mathrm{C}_{2} \mathrm{H}_{2}$ & ${ }^{3} J_{\mathrm{HH}}$ & 8,1 & 8,5 & 9,0 & 9,5 & 10,2 & 11,0 & 12,0 & 13,1 & 14,4 & 16,1 & 18,0 & 9,6 \\
\hline $\mathrm{C}_{2} \mathrm{H}_{4}$ & ${ }^{1} J_{\mathrm{CC}}$ & 72,6 & 75,6 & 78,9 & 82,6 & 86,8 & 91,5 & 97,1 & 103,8 & 112,0 & 122,6 & 137,0 & 67,6 \\
\hline $\mathrm{C}_{2} \mathrm{H}_{4}$ & ${ }^{1} J_{\mathrm{CH}}$ & 164,7 & 166,6 & 168,6 & 170,7 & 172,9 & 175,3 & 177,9 & 180,9 & 184,4 & 188,6 & 194,0 & 156,3 \\
\hline $\mathrm{C}_{2} \mathrm{H}_{4}$ & ${ }^{2} J_{\mathrm{CH}}$ & 0,9 & 0,1 & $-0,7$ & $-1,8$ & $-2,9$ & $-4,3$ & $-5,9$ & $-7,9$ & $-10,4$ & $-13,7$ & $-18,1$ & $-2,4$ \\
\hline $\mathrm{C}_{2} \mathrm{H}_{4}$ & ${ }^{2} J_{\mathrm{HH}}$ & 7,1 & 6,5 & 5,8 & 5,1 & 4,4 & 3,6 & 2,7 & 1,7 & 0,4 & $-1,0$ & $-2,9$ & 2,3 \\
\hline $\mathrm{C}_{2} \mathrm{H}_{4}$ & ${ }^{3} J_{\mathrm{HH}_{\mathrm{c}}}$ & 11,1 & 11,2 & 11,4 & 11,6 & 11,8 & 12,2 & 12,6 & 13,2 & 14,0 & 15,1 & 16,6 & 11,7 \\
\hline $\mathrm{C}_{2} \mathrm{H}_{4}$ & ${ }^{3} J_{\mathrm{HH}_{\mathrm{t}}}$ & 17,7 & 17,8 & 18,0 & 18,3 & 18,6 & 19,0 & 19,6 & 20,3 & 21,3 & 22,6 & 24,4 & 19 \\
\hline $\mathrm{C}_{2} \mathrm{H}_{6}$ & ${ }^{1} J_{\mathrm{CC}}{ }^{2}$ & 34,0 & 36,1 & 38,2 & 40,4 & 42,6 & 44,8 & 47,1 & 49,4 & 51,7 & 54,0 & 56,4 & 34,5 \\
\hline $\mathrm{C}_{2} \mathrm{H}_{6}$ & ${ }^{1} J_{\mathrm{CH}}$ & 131,5 & 133,1 & 134,6 & 136,2 & 137,7 & 139,3 & 140,9 & 142,5 & 144,2 & 145,8 & 147,5 & 125,2 \\
\hline $\mathrm{C}_{2} \mathrm{H}_{6}$ & ${ }^{2} J_{\mathrm{CH}}$ & $-1,6$ & $-2,1$ & $-2,6$ & $-3,0$ & $-3,5$ & $-4,0$ & $-4,5$ & $-5,0$ & $-5,5$ & $-6,0$ & $-6,5$ & $-4,7$ \\
\hline \multirow[t]{3}{*}{ Total } & $\mathrm{DM}$ & $-15,95$ & $-13,43$ & $-10,69$ & $-7,79$ & $-4,85$ & $-1,93$ & 0,79 & 3,00 & 4,06 & 2,09 & $-12,05$ & - \\
\hline & DMA & 27,64 & 23,09 & 20,98 & 20,99 & 22,95 & 26,60 & 30,63 & 35,48 & 41,93 & 51,85 & 75,85 & - \\
\hline & PDMA & 45,75 & 35,78 & 27,07 & 18,67 & 19,71 & 29,02 & 38,87 & 52,53 & 70,08 & 90,73 & 118,82 & - \\
\hline \multirow[t]{3}{*}{ CPI } & DM & $-46,16$ & $-41,40$ & $-36,19$ & $-30,71$ & $-25,20$ & $-19,90$ & $-15,27$ & $-12,07$ & $-11,88$ & $-19,27$ & $-56,05$ & - \\
\hline & DMA & 56,16 & 44,42 & 38,34 & 37,16 & 40,33 & 47,19 & 54,62 & 63,36 & 75,01 & 94,15 & 145,55 & - \\
\hline & PDMA & 59,59 & 42,20 & 28,07 & 15,55 & 20,64 & 39,32 & 58,08 & 77,27 & 97,24 & 119,77 & 152,13 & - \\
\hline \multirow[t]{3}{*}{ SPI } & DM & 6,20 & 7,07 & 8,01 & 9,01 & 10,08 & 11,25 & 12,57 & 14,05 & 15,75 & 17,76 & 20,21 & - \\
\hline & DMA & 6,72 & 7,45 & 8,26 & 9,13 & 10,20 & 11,51 & 13,04 & 15,03 & 17,67 & 20,83 & 24,75 & - \\
\hline & PDMA & 35,60 & 31,06 & 26,34 & 20,97 & 19,02 & 21,47 & 24,79 & 34,40 & 50,17 & 69,43 & 94,39 & - \\
\hline \multirow[t]{3}{*}{$\Delta \mathrm{CS}$} & $\mathrm{DM}$ & $-52,36$ & $-48,47$ & $-44,20$ & $-39,72$ & $-35,28$ & $-31,15$ & $-27,85$ & $-26,13$ & $-27,63$ & $-37,03$ & $-76,27$ & - \\
\hline & DMA & 49,44 & 36,97 & 30,08 & 28,03 & 30,13 & 35,68 & 41,58 & 48,34 & 57,34 & 73,32 & 120,80 & - \\
\hline & PDMA & 23,99 & 11,14 & 1,73 & $-5,42$ & 1,62 & 17,85 & 33,29 & 42,87 & 47,07 & 50,34 & 57,74 & - \\
\hline \multicolumn{14}{|c|}{ Desconsiderando ${ }^{1} J_{\mathrm{BF}}$ da molécula de $\mathrm{BF}_{3},{ }^{2} J_{\mathrm{CH}}$ e ${ }^{2} J_{\mathrm{HH}}$ da molécula de $\mathrm{C}_{2} \mathrm{H}_{4}$} \\
\hline \multirow[t]{3}{*}{ Total } & $\mathrm{DM}$ & $-15,66$ & $-13,58$ & $-11,23$ & $-8,68$ & $-6,07$ & $-3,46$ & $-1,05$ & 0,82 & 1,43 & $-1,33$ & $-17,79$ & - \\
\hline & DMA & 28,16 & 23,91 & 22,42 & 23,30 & 25,31 & 28,63 & 32,38 & 37,00 & 43,37 & 53,64 & 79,77 & - \\
\hline & PDMA & 18,46 & 15,31 & 13,72 & 12,87 & 13,95 & 18,21 & 22,99 & 29,36 & 37,20 & 46,96 & 62,25 & - \\
\hline \multirow[t]{3}{*}{ CPI } & $\mathrm{DM}$ & $-44,50$ & $-41,17$ & $-37,33$ & $-33,14$ & $-28,91$ & $-24,89$ & $-21,58$ & $-19,81$ & $-21,33$ & $-31,17$ & $-73,32$ & - \\
\hline & DMA & 55,50 & 44,49 & 39,69 & 40,24 & 43,17 & 48,91 & 55,30 & 63,17 & 74,25 & 93,59 & 148,44 & - \\
\hline & PDMA & 23,68 & 17,29 & 14,35 & 12,84 & 14,77 & 23,25 & 32,02 & 41,46 & 51,89 & 65,28 & 89,61 & - \\
\hline \multirow[t]{3}{*}{ SPI } & DM & 6,53 & 7,65 & 8,84 & 10,14 & 11,51 & 13,03 & 14,75 & 16,68 & 18,93 & 21,62 & 24,93 & - \\
\hline & DMA & 7,13 & 8,08 & 9,13 & 10,28 & 11,57 & 13,03 & 14,75 & 16,87 & 19,62 & 22,91 & 26,95 & - \\
\hline & PDMA & 14,44 & 13,78 & 13,24 & 12,90 & 13,32 & 14,33 & 16,05 & 20,05 & 25,89 & 32,86 & 41,20 & - \\
\hline \multirow[t]{3}{*}{$\Delta \mathrm{CS}$} & DM & $-51,03$ & $-48,82$ & $-46,17$ & $-43,28$ & $-40,42$ & $-37,92$ & $-36,33$ & $-36,49$ & $-40,26$ & $-52,79$ & $-98,25$ & - \\
\hline & DMA & 48,37 & 36,41 & 30,56 & 29,96 & 31,60 & 35,88 & 40,55 & 46,30 & 54,63 & 70,68 & 121,49 & - \\
\hline & PDMA & 9,24 & 3,51 & 1,11 & $-0,07$ & 1,45 & 8,92 & 15,97 & 21,41 & 26,00 & 32,42 & 48,41 & - \\
\hline
\end{tabular}


Tabela 8.252: Constantes de acoplamento PW91B98 com base aug-pcJ-2.

\begin{tabular}{|c|c|c|c|c|c|c|c|c|c|c|c|c|c|}
\hline & $\% E_{X}^{\mathrm{HF}}$ & $0 \%$ & $10 \%$ & $20 \%$ & $30 \%$ & $40 \%$ & $50 \%$ & $60 \%$ & $70 \%$ & $80 \%$ & $90 \%$ & $100 \%$ & Exp. \\
\hline $\mathrm{HF}$ & ${ }^{1} J_{\mathrm{HF}}$ & 409,1 & 431,0 & 452,9 & 475,0 & 497,2 & 519,5 & 542,0 & 564,6 & 587,3 & 610,1 & 633,1 & 500 \\
\hline $\mathrm{CO}$ & ${ }^{1} J_{\mathrm{CO}}$ & 21,0 & 19,1 & 17,2 & 15,2 & 13,1 & 10,8 & 8,5 & 6,1 & 3,7 & 1,1 & $-1,4$ & 16,4 \\
\hline $\mathrm{H}_{2} \mathrm{O}$ & ${ }^{1} J_{\mathrm{OH}}$ & $-71,8$ & $-74,1$ & $-76,4$ & $-78,8$ & $-81,1$ & $-83,5$ & $-85,8$ & $-88,2$ & $-90,7$ & $-93,1$ & $-95,6$ & $-80,6$ \\
\hline $\mathrm{H}_{2} \mathrm{O}$ & ${ }^{2} J_{\mathrm{HH}}$ & $-4,0$ & $-5,0$ & $-6,0$ & $-7,0$ & $-8,1$ & $-9,1$ & $-10,2$ & $-11,3$ & $-12,4$ & $-13,5$ & $-14,6$ & $-7,3$ \\
\hline $\mathrm{NH}_{3}$ & ${ }^{1} J_{\mathrm{NH}}$ & 43,9 & 44,6 & 45,4 & 46,1 & 46,8 & 47,6 & 48,3 & 49,1 & 49,9 & 50,7 & 51,5 & 43,8 \\
\hline $\mathrm{NH}_{3}$ & ${ }^{2} J_{\mathrm{HH}}$ & $-7,1$ & $-8,0$ & $-8,9$ & $-9,9$ & $-10,8$ & $-11,8$ & $-12,7$ & $-13,7$ & $-14,7$ & $-15,7$ & $-16,8$ & $-9,6$ \\
\hline $\mathrm{PH}_{3}$ & ${ }^{1} J_{\mathrm{PH}}$ & 180,3 & 187,9 & 195,3 & 202,5 & 209,6 & 216,4 & 223,1 & 229,6 & 235,9 & 242,0 & 247,9 & 188,2 \\
\hline $\mathrm{PF}_{3}$ & ${ }^{1} J_{\mathrm{PF}}$ & $-1781,9$ & $-1758,0$ & $-1729,4$ & $-1696,7$ & $-1660,6$ & $-1621,9$ & $-1581,0$ & $-1538,4$ & $-1494,5$ & $-1449,8$ & $-1404,5$ & -1441 \\
\hline $\mathrm{BHF}_{2}$ & ${ }^{1} J_{\mathrm{BF}}$ & $-163,1$ & $-145,5$ & $-127,9$ & $-110,5$ & $-93,2$ & $-76,1$ & $-59,2$ & $-42,4$ & $-26,0$ & $-9,7$ & 6,2 & -84 \\
\hline $\mathrm{BF}_{3}$ & ${ }^{1} J_{\mathrm{BF}}$ & $-65,4$ & $-46,5$ & $-27,8$ & $-9,4$ & 8,8 & 26,9 & 44,7 & 62,3 & 79,7 & 96,9 & 113,8 & 15 \\
\hline $\mathrm{F}_{2} \mathrm{O}$ & ${ }^{1} J_{\mathrm{OF}}$ & $-273,2$ & $-309,0$ & $-344,5$ & $-381,1$ & $-420,6$ & $-465,8$ & $-521,3$ & $-595,9$ & $-709,1$ & $-918,2$ & $-1507,1$ & -300 \\
\hline $\mathrm{CH}_{4}$ & ${ }^{1} J_{\mathrm{CH}}$ & 133,3 & 134,8 & 136,3 & 137,9 & 139,5 & 141,1 & 142,7 & 144,4 & 146,1 & 147,8 & 149,5 & 125,3 \\
\hline $\mathrm{CH}_{4}$ & ${ }^{2} J_{\mathrm{HH}}$ & $-10,3$ & $-11,1$ & $-11,9$ & $-12,7$ & $-13,4$ & $-14,2$ & $-15,0$ & $-15,8$ & $-16,6$ & $-17,4$ & $-18,1$ & $-12,8$ \\
\hline $\mathrm{C}_{2} \mathrm{H}_{2}$ & ${ }^{1} J_{\mathrm{CC}}$ & 213,1 & 216,5 & 220,2 & 224,5 & 229,3 & 234,9 & 241,4 & 249,0 & 258,0 & 268,8 & 282,1 & 174,8 \\
\hline $\mathrm{C}_{2} \mathrm{H}_{2}$ & ${ }^{1} J_{\mathrm{CH}}$ & 268,2 & 270,5 & 272,9 & 275,5 & 278,2 & 281,2 & 284,5 & 288,2 & 292,5 & 297,4 & 303,3 & 247,6 \\
\hline $\mathrm{C}_{2} \mathrm{H}_{2}$ & ${ }^{2} J_{\mathrm{CH}}$ & 54,8 & 54,8 & 54,6 & 54,2 & 53,5 & 52,5 & 51,1 & 49,2 & 46,7 & 43,5 & 39,3 & 50,1 \\
\hline $\mathrm{C}_{2} \mathrm{H}_{2}$ & ${ }^{3} J_{\mathrm{HH}}$ & 8,9 & 9,4 & 10,0 & 10,7 & 11,5 & 12,6 & 13,8 & 15,2 & 17,0 & 19,1 & 21,7 & 9,6 \\
\hline $\mathrm{C}_{2} \mathrm{H}_{4}$ & ${ }^{1} J_{\mathrm{CC}}$ & 74,6 & 77,7 & 81,1 & 84,8 & 88,9 & 93,6 & 99,1 & 105,6 & 113,7 & 124,1 & 138,3 & 67,6 \\
\hline $\mathrm{C}_{2} \mathrm{H}_{4}$ & ${ }^{1} J_{\mathrm{CH}}$ & 166,4 & 168,5 & 170,8 & 173,1 & 175,6 & 178,3 & 181,3 & 184,7 & 188,6 & 193,4 & 199,6 & 156,3 \\
\hline $\mathrm{C}_{2} \mathrm{H}_{4}$ & ${ }^{2} J_{\mathrm{CH}}$ & 0,0 & $-0,8$ & $-1,8$ & $-2,9$ & $-4,1$ & $-5,6$ & $-7,4$ & $-9,5$ & $-12,2$ & $-15,8$ & $-20,9$ & $-2,4$ \\
\hline $\mathrm{C}_{2} \mathrm{H}_{4}$ & ${ }^{2} J_{\mathrm{HH}}$ & 5,9 & 5,2 & 4,5 & 3,7 & 2,9 & 1,9 & 0,9 & $-0,3$ & $-1,8$ & $-3,7$ & $-6,2$ & 2,3 \\
\hline $\mathrm{C}_{2} \mathrm{H}_{4}$ & ${ }^{3} J_{\mathrm{HH}_{\mathrm{c}}}$ & 11,5 & 11,7 & 12,0 & 12,3 & 12,7 & 13,1 & 13,8 & 14,5 & 15,6 & 17,1 & 19,2 & 11,7 \\
\hline $\mathrm{C}_{2} \mathrm{H}_{4}$ & ${ }^{3} J_{\mathrm{HH}_{\mathrm{t}}}$ & 18,3 & 18,5 & 18,8 & 19,2 & 19,7 & 20,2 & 21,0 & 22,0 & 23,2 & 25,0 & 27,5 & 19 \\
\hline $\mathrm{C}_{2} \mathrm{H}_{6}$ & ${ }^{1} J_{\mathrm{CC}}$ & 32,4 & 34,7 & 37,0 & 39,3 & 41,7 & 44,2 & 46,7 & 49,2 & 51,8 & 54,4 & 57,1 & 34,5 \\
\hline $\mathrm{C}_{2} \mathrm{H}_{6}$ & ${ }^{1} J_{\mathrm{CH}}$ & 132,9 & 134,7 & 136,4 & 138,2 & 140,1 & 141,9 & 143,8 & 145,6 & 147,5 & 149,5 & 151,4 & 125,2 \\
\hline $\mathrm{C}_{2} \mathrm{H}_{6}$ & ${ }^{2} J_{\mathrm{CH}}$ & $-2,4$ & $-2,9$ & $-3,4$ & $-3,9$ & $-4,5$ & $-5,0$ & $-5,6$ & $-6,1$ & $-6,7$ & $-7,3$ & $-7,9$ & $-4,7$ \\
\hline \multirow[t]{3}{*}{ Total } & $\mathrm{DM}$ & $-17,29$ & $-14,86$ & $-12,22$ & $-9,45$ & $-6,63$ & $-3,90$ & $-1,40$ & 0,49 & 1,06 & $-1,86$ & $-19,10$ & - \\
\hline & DMA & 29,08 & 25,07 & 23,70 & 22,45 & 21,57 & 24,14 & 28,59 & 33,90 & 40,96 & 52,01 & 80,95 & - \\
\hline & PDMA & 46,47 & 35,64 & 26,42 & 19,58 & 17,19 & 24,86 & 39,78 & 56,01 & 74,90 & 97,74 & 129,89 & - \\
\hline \multirow[t]{3}{*}{ CPI } & DM & $-50,28$ & $-45,85$ & $-41,00$ & $-35,95$ & $-30,89$ & $-26,17$ & $-22,23$ & $-19,92$ & $-21,07$ & $-30,92$ & $-75,31$ & - \\
\hline & DMA & 58,66 & 48,38 & 43,85 & 39,35 & 35,33 & 39,14 & 46,94 & 56,32 & 69,04 & 90,37 & 152,76 & - \\
\hline & PDMA & 72,33 & 54,25 & 38,59 & 24,88 & 15,52 & 24,49 & 43,17 & 62,46 & 82,74 & 105,89 & 140,82 & - \\
\hline \multirow[t]{3}{*}{ SPI } & DM & 6,90 & 7,87 & 8,89 & 9,99 & 11,17 & 12,44 & 13,87 & 15,45 & 17,29 & 19,45 & 22,12 & - \\
\hline & DMA & 7,39 & 7,97 & 8,92 & 10,05 & 11,47 & 13,15 & 15,13 & 17,45 & 20,37 & 23,88 & 28,29 & - \\
\hline & PDMA & 27,52 & 22,00 & 17,50 & 15,70 & 18,41 & 25,13 & 37,30 & 51,29 & 69,15 & 91,77 & 121,88 & - \\
\hline \multirow[t]{3}{*}{$\Delta \mathrm{CS}$} & DM & $-57,18$ & $-53,73$ & $-49,89$ & $-45,94$ & $-42,06$ & $-38,61$ & $-36,09$ & $-35,37$ & $-38,36$ & $-50,37$ & $-97,43$ & - \\
\hline & DMA & 51,27 & 40,42 & 34,93 & 29,30 & 23,85 & 25,99 & 31,80 & 38,86 & 48,67 & 66,49 & 124,47 & - \\
\hline & PDMA & 44,81 & 32,24 & 21,09 & 9,17 & $-2,89$ & $-0,63$ & 5,87 & 11,17 & 13,59 & 14,12 & 18,94 & - \\
\hline \multicolumn{14}{|c|}{ Desconsiderando ${ }^{1} J_{\mathrm{BF}}$ da molécula de $\mathrm{BF}_{3},{ }^{2} J_{\mathrm{CH}}$ e ${ }^{2} J_{\mathrm{HH}}$ da molécula de $\mathrm{C}_{2} \mathrm{H}_{4}$} \\
\hline \multirow[t]{3}{*}{ Total } & DM & $-16,31$ & $-14,32$ & $-12,07$ & $-9,66$ & $-7,17$ & $-4,77$ & $-2,60$ & $-1,08$ & $-1,01$ & $-4,82$ & $-24,71$ & - \\
\hline & DMA & 29,12 & 25,47 & 24,81 & 24,23 & 24,01 & 26,62 & 30,75 & 35,84 & 42,88 & 54,39 & 86,04 & - \\
\hline & PDMA & 18,08 & 14,09 & 12,22 & 11,51 & 13,42 & 18,10 & 24,66 & 31,83 & 40,41 & 51,14 & 68,62 & - \\
\hline \multirow[t]{3}{*}{ CPI } & DM & $-47,27$ & $-44,29$ & $-40,82$ & $-37,11$ & $-33,36$ & $-29,98$ & $-27,42$ & $-26,64$ & $-29,65$ & $-42,20$ & $-92,72$ & - \\
\hline & DMA & 56,49 & 47,07 & 43,96 & 40,85 & 38,24 & 41,86 & 48,66 & 57,22 & 69,47 & 91,22 & 158,16 & - \\
\hline & PDMA & 25,96 & 18,67 & 13,91 & 11,10 & 12,94 & 19,01 & 27,69 & 37,17 & 47,88 & 61,88 & 89,03 & - \\
\hline \multirow[t]{3}{*}{ SPI } & $\mathrm{DM}$ & 7,50 & 8,74 & 10,05 & 11,45 & 12,97 & 14,63 & 16,49 & 18,58 & 21,02 & 23,94 & 27,60 & - \\
\hline & DMA & 8,07 & 8,85 & 10,08 & 11,45 & 13,06 & 14,89 & 16,97 & 19,39 & 22,43 & 26,06 & 30,57 & - \\
\hline & PDMA & 12,02 & 10,56 & 10,91 & 11,84 & 13,79 & 17,40 & 22,33 & 27,73 & 34,67 & 42,87 & 52,91 & - \\
\hline \multirow[t]{3}{*}{$\Delta \mathrm{CS}$} & $\mathrm{DM}$ & $-54,77$ & $-53,03$ & $-50,87$ & $-48,56$ & $-46,33$ & $-44,61$ & $-43,91$ & $-45,22$ & $-50,67$ & $-66,14$ & $-120,32$ & 一 \\
\hline & DMA & 48,42 & 38,22 & 33,88 & 29,40 & 25,18 & 26,97 & 31,69 & 37,83 & 47,04 & 65,16 & 127,59 & - \\
\hline & PDMA & 13,94 & 8,11 & 3,00 & $-0,74$ & $-0,85$ & 1,61 & 5,36 & 9,44 & 13,21 & 19,00 & 36,12 & - \\
\hline
\end{tabular}


Tabela 8.253: Constantes de acoplamento PW91LYP com base aug-pcJ-2.

\begin{tabular}{|c|c|c|c|c|c|c|c|c|c|c|c|c|c|}
\hline & $\% E_{X}^{\mathrm{HF}}$ & $0 \%$ & $10 \%$ & $20 \%$ & $30 \%$ & $40 \%$ & $50 \%$ & $60 \%$ & $70 \%$ & $80 \%$ & $90 \%$ & $100 \%$ & Exp. \\
\hline $\mathrm{HF}$ & ${ }^{1} J_{\mathrm{HF}}$ & 408,6 & 433,0 & 457,5 & 482,3 & 507,3 & 532,6 & 558,1 & 583,8 & 609,8 & 636,0 & 662,5 & 500 \\
\hline $\mathrm{CO}$ & ${ }^{1} J_{\mathrm{CO}}$ & 20,9 & 19,1 & 17,1 & 15,0 & 12,8 & 10,6 & 8,2 & 5,8 & 3,3 & 0,7 & $-1,9$ & 16,4 \\
\hline $\mathrm{H}_{2} \mathrm{O}$ & ${ }^{1} J_{\mathrm{OH}}$ & $-74,0$ & $-76,6$ & $-79,2$ & $-81,8$ & $-84,5$ & $-87,2$ & $-89,9$ & $-92,6$ & $-95,4$ & $-98,2$ & $-101,1$ & $-80,6$ \\
\hline $\mathrm{H}_{2} \mathrm{O}$ & ${ }^{2} J_{\mathrm{HH}}$ & $-5,3$ & $-6,4$ & $-7,5$ & $-8,7$ & $-9,8$ & $-11,0$ & $-12,2$ & $-13,5$ & $-14,7$ & $-16,0$ & $-17,3$ & $-7,3$ \\
\hline $\mathrm{NH}_{3}$ & ${ }^{1} J_{\mathrm{NH}}$ & 45,3 & 46,1 & 46,9 & 47,6 & 48,4 & 49,2 & 50,1 & 50,9 & 51,7 & 52,6 & 53,4 & 43,8 \\
\hline $\mathrm{NH}_{3}$ & ${ }^{2} J_{\mathrm{HH}}$ & $-8,2$ & $-9,2$ & $-10,2$ & $-11,2$ & $-12,3$ & $-13,3$ & $-14,3$ & $-15,4$ & $-16,5$ & $-17,6$ & $-18,7$ & $-9,6$ \\
\hline $\mathrm{PH}_{3}$ & ${ }^{1} J_{\mathrm{PH}}$ & 160,1 & 168,5 & 176,9 & 185,2 & 193,3 & 201,3 & 209,2 & 216,9 & 224,5 & 231,9 & 239,2 & 188,2 \\
\hline $\mathrm{PF}_{3}$ & ${ }^{1} J_{\mathrm{PF}}$ & $-1817,5$ & $-1793,8$ & $-1765,0$ & $-1732,1$ & $-1695,7$ & $-1656,5$ & $-1615,2$ & $-1572,2$ & $-1527,9$ & $-1482,7$ & $-1437,0$ & -1441 \\
\hline $\mathrm{BHF}_{2}$ & ${ }^{1} J_{\mathrm{BF}}$ & $-168,4$ & $-150,8$ & $-133,3$ & $-115,9$ & $-98,7$ & $-81,7$ & $-64,8$ & $-48,1$ & $-31,7$ & $-15,4$ & 0,6 & -84 \\
\hline $\mathrm{BF}_{3}$ & ${ }^{1} J_{\mathrm{BF}}$ & $-67,4$ & $-48,4$ & $-29,5$ & $-10,9$ & 7,4 & 25,6 & 43,6 & 61,4 & 79,0 & 96,5 & 113,8 & 15 \\
\hline $\mathrm{F}_{2} \mathrm{O}$ & ${ }^{1} J_{\mathrm{OF}}$ & $-280,4$ & $-317,6$ & $-355,0$ & $-393,9$ & $-436,7$ & $-486,6$ & $-549,6$ & $-637,4$ & $-778,9$ & $-1071,0$ & $-2253,8$ & -300 \\
\hline $\mathrm{CH}_{4}$ & ${ }^{1} J_{\mathrm{CH}}$ & 133,8 & 135,3 & 136,7 & 138,2 & 139,7 & 141,3 & 142,9 & 144,5 & 146,1 & 147,7 & 149,4 & 125,3 \\
\hline $\mathrm{CH}_{4}$ & ${ }^{2} J_{\mathrm{HH}}$ & $-11,6$ & $-12,4$ & $-13,2$ & $-14,1$ & $-14,9$ & $-15,7$ & $-16,5$ & $-17,3$ & $-18,1$ & $-18,9$ & $-19,7$ & $-12,8$ \\
\hline $\mathrm{C}_{2} \mathrm{H}_{2}$ & ${ }^{1} J_{\mathrm{CC}}$ & 200,4 & 203,4 & 206,8 & 210,8 & 215,3 & 220,6 & 226,9 & 234,4 & 243,4 & 254,5 & 268,4 & 174,8 \\
\hline $\mathrm{C}_{2} \mathrm{H}_{2}$ & ${ }^{1} J_{\mathrm{CH}}$ & 275,6 & 277,9 & 280,4 & 283,0 & 285,8 & 289,0 & 292,5 & 296,5 & 301,1 & 306,7 & 313,5 & 247,6 \\
\hline $\mathrm{C}_{2} \mathrm{H}_{2}$ & ${ }^{2} J_{\mathrm{CH}}$ & 57,2 & 57,1 & 56,8 & 56,3 & 55,4 & 54,2 & 52,5 & 50,3 & 47,3 & 43,4 & 38,1 & 50,1 \\
\hline $\mathrm{C}_{2} \mathrm{H}_{2}$ & ${ }^{3} J_{\mathrm{HH}}$ & 10,0 & 10,6 & 11,3 & 12,2 & 13,2 & 14,4 & 15,9 & 17,7 & 19,9 & 22,6 & 26,0 & 9,6 \\
\hline $\mathrm{C}_{2} \mathrm{H}_{4}$ & ${ }^{1} J_{\mathrm{CC}}$ & 67,8 & 70,7 & 73,9 & 77,4 & 81,5 & 86,3 & 91,9 & 99,0 & 108,0 & 120,5 & 139,0 & 67,6 \\
\hline $\mathrm{C}_{2} \mathrm{H}_{4}$ & ${ }^{1} J_{\mathrm{CH}}$ & 168,5 & 170,6 & 172,8 & 175,2 & 177,7 & 180,5 & 183,7 & 187,3 & 191,8 & 197,5 & 205,7 & 156,3 \\
\hline $\mathrm{C}_{2} \mathrm{H}_{4}$ & ${ }^{2} J_{\mathrm{CH}}$ & 0,2 & $-0,6$ & $-1,6$ & $-2,8$ & $-4,2$ & $-5,8$ & $-7,8$ & $-10,3$ & $-13,6$ & $-18,3$ & $-25,4$ & $-2,4$ \\
\hline $\mathrm{C}_{2} \mathrm{H}_{4}$ & ${ }^{2} J_{\mathrm{HH}}$ & 6,4 & 5,6 & 4,8 & 3,9 & 2,9 & 1,8 & 0,6 & $-0,9$ & $-2,8$ & $-5,5$ & $-9,3$ & 2,3 \\
\hline $\mathrm{C}_{2} \mathrm{H}_{4}$ & ${ }^{3} J_{\mathrm{HH}_{\mathrm{c}}}$ & 12,7 & 13,0 & 13,3 & 13,6 & 14,1 & 14,7 & 15,5 & 16,6 & 18,1 & 20,3 & 23,7 & 11,7 \\
\hline $\mathrm{C}_{2} \mathrm{H}_{4}$ & ${ }^{3} J_{\mathrm{HH}_{\mathrm{t}}}$ & 20,1 & 20,4 & 20,7 & 21,2 & 21,7 & 22,5 & 23,4 & 24,7 & 26,4 & 29,0 & 32,9 & 19 \\
\hline $\mathrm{C}_{2} \mathrm{H}_{6}$ & ${ }^{1} J_{\mathrm{CC}}$ & 30,1 & 32,1 & 34,3 & 36,4 & 38,7 & 40,9 & 43,2 & 45,5 & 47,9 & 50,3 & 52,7 & 34,5 \\
\hline $\mathrm{C}_{2} \mathrm{H}_{6}$ & ${ }^{1} J_{\mathrm{CH}}$ & 133,3 & 134,9 & 136,6 & 138,3 & 140,1 & 141,8 & 143,6 & 145,4 & 147,2 & 149,0 & 150,9 & 125,2 \\
\hline $\mathrm{C}_{2} \mathrm{H}_{6}$ & ${ }^{2} J_{\mathrm{CH}}$ & $-2,5$ & $-3,0$ & $-3,5$ & $-4,0$ & $-4,5$ & $-5,0$ & $-5,6$ & $-6,1$ & $-6,7$ & $-7,2$ & $-7,8$ & $-4,7$ \\
\hline \multirow[t]{3}{*}{ Total } & $\mathrm{DM}$ & $-20,36$ & $-17,90$ & $-15,24$ & $-12,45$ & $-9,65$ & $-6,94$ & $-4,58$ & $-3,00$ & $-3,30$ & $-9,10$ & $-48,74$ & - \\
\hline & DMA & 30,97 & 27,46 & 25,38 & 23,76 & 23,45 & 26,06 & 31,00 & 37,01 & 45,50 & 60,26 & 110,36 & - \\
\hline & PDMA & 47,39 & 37,12 & 27,98 & 22,62 & 21,09 & 28,25 & 44,31 & 62,31 & 83,87 & 111,91 & 158,62 & - \\
\hline \multirow[t]{3}{*}{ CPI } & $\mathrm{DM}$ & $-57,02$ & $-52,45$ & $-47,47$ & $-42,30$ & $-37,22$ & $-32,54$ & $-28,88$ & $-27,39$ & $-30,70$ & $-47,65$ & $-145,56$ & - \\
\hline & DMA & 63,49 & 54,33 & 48,42 & 42,99 & 40,31 & 44,17 & 53,10 & 64,10 & 79,85 & 109,21 & 220,20 & - \\
\hline & PDMA & 72,43 & 54,51 & 39,34 & 29,26 & 21,39 & 28,10 & 47,60 & 67,88 & 89,58 & 115,95 & 169,20 & - \\
\hline \multirow[t]{3}{*}{ SPI } & DM & 6,53 & 7,43 & 8,40 & 9,43 & 10,56 & 11,83 & 13,24 & 14,88 & 16,79 & 19,17 & 22,27 & - \\
\hline & DMA & 7,11 & 7,75 & 8,48 & 9,66 & 11,08 & 12,77 & 14,80 & 17,15 & 20,31 & 24,37 & 29,81 & - \\
\hline & PDMA & 29,03 & 24,38 & 19,64 & 17,75 & 20,86 & 28,36 & 41,89 & 58,22 & 79,68 & 108,94 & 150,86 & - \\
\hline \multirow[t]{3}{*}{$\Delta \mathrm{CS}$} & $\mathrm{DM}$ & $-63,54$ & $-59,89$ & $-55,87$ & $-51,73$ & $-47,78$ & $-44,36$ & $-42,12$ & $-42,27$ & $-47,49$ & $-66,81$ & $-167,83$ & - \\
\hline & DMA & 56,38 & 46,57 & 39,94 & 33,33 & 29,23 & 31,40 & 38,30 & 46,95 & 59,53 & 84,84 & 190,39 & - \\
\hline & PDMA & 43,39 & 30,13 & 19,70 & 11,50 & 0,52 & $-0,25$ & 5,71 & 9,66 & 9,90 & 7,01 & 18,34 & - \\
\hline \multicolumn{14}{|c|}{ Desconsiderando ${ }^{1} J_{\mathrm{BF}}$ da molécula de $\mathrm{BF}_{3},{ }^{2} J_{\mathrm{CH}}$ e ${ }^{2} J_{\mathrm{HH}}$ da molécula de $\mathrm{C}_{2} \mathrm{H}_{4}$} \\
\hline \multirow[t]{3}{*}{ Total } & $\mathrm{DM}$ & $-19,72$ & $-17,70$ & $-15,43$ & $-13,00$ & $-10,53$ & $-8,14$ & $-6,11$ & $-4,93$ & $-5,80$ & $-12,80$ & $-57,89$ & - \\
\hline & DMA & 31,13 & 28,06 & 26,61 & 25,65 & 26,07 & 28,83 & 33,50 & 39,34 & 47,94 & 63,55 & 118,96 & - \\
\hline & PDMA & 17,23 & 14,09 & 12,55 & 14,31 & 17,24 & 21,76 & 28,80 & 36,63 & 46,33 & 59,33 & 87,08 & - \\
\hline \multirow[t]{3}{*}{ CPI } & DM & $-54,48$ & $-51,36$ & $-47,77$ & $-43,94$ & $-40,18$ & $-36,85$ & $-34,63$ & $-34,77$ & $-40,17$ & $-60,56$ & $-170,00$ & - \\
\hline & DMA & 61,60 & 53,42 & 48,81 & 44,70 & 43,58 & 47,53 & 55,55 & 65,87 & 81,43 & 111,98 & 232,34 & - \\
\hline & PDMA & 24,74 & 17,69 & 13,61 & 14,92 & 18,46 & 23,85 & 33,29 & 43,74 & 55,87 & 73,22 & 120,26 & - \\
\hline \multirow[t]{3}{*}{ SPI } & $\mathrm{DM}$ & 7,02 & 8,18 & 9,44 & 10,79 & 12,28 & 13,95 & 15,82 & 18,02 & 20,63 & 23,94 & 28,35 & - \\
\hline & DMA & 7,69 & 8,55 & 9,53 & 10,99 & 12,60 & 14,44 & 16,53 & 18,93 & 22,18 & 26,29 & 31,74 & - \\
\hline & PDMA & 11,46 & 11,32 & 11,74 & 13,85 & 16,30 & 20,15 & 25,34 & 31,16 & 38,99 & 48,66 & 61,56 & - \\
\hline \multirow[t]{3}{*}{$\Delta \mathrm{CS}$} & DM & $-61,50$ & $-59,54$ & $-57,21$ & $-54,73$ & $-52,46$ & $-50,80$ & $-50,45$ & $-52,79$ & $-60,80$ & $-84,50$ & $-198,35$ & - \\
\hline & DMA & 53,91 & 44,87 & 39,28 & 33,71 & 30,98 & 33,09 & 39,02 & 46,94 & 59,25 & 85,69 & 200,60 & - \\
\hline & PDMA & 13,28 & 6,37 & 1,87 & 1,06 & 2,16 & 3,70 & 7,95 & 12,58 & 16,88 & 24,56 & 58,70 & - \\
\hline
\end{tabular}


Tabela 8.254: Constantes de acoplamento PW91P86 com base aug-pcJ-2.

\begin{tabular}{|c|c|c|c|c|c|c|c|c|c|c|c|c|c|}
\hline & $\% E_{X}^{\mathrm{HF}}$ & $0 \%$ & $10 \%$ & $20 \%$ & $30 \%$ & $40 \%$ & $50 \%$ & $60 \%$ & $70 \%$ & $80 \%$ & $90 \%$ & $100 \%$ & Exp. \\
\hline $\mathrm{HF}$ & ${ }^{1} J_{\mathrm{HF}}$ & 366,1 & 388,7 & 411,6 & 434,6 & 457,9 & 481,4 & 505,1 & 529,1 & 553,2 & 577,6 & 602,2 & 500 \\
\hline $\mathrm{CO}$ & ${ }^{1} J_{\mathrm{CO}}$ & 24,5 & 22,8 & 21,1 & 19,3 & 17,4 & 15,5 & 13,5 & 11,4 & 9,2 & 7,0 & 4,8 & 16,4 \\
\hline $\mathrm{H}_{2} \mathrm{O}$ & ${ }^{1} J_{\mathrm{OH}}$ & $-66,1$ & $-68,5$ & $-70,9$ & $-73,3$ & $-75,8$ & $-78,2$ & $-80,7$ & $-83,3$ & $-85,8$ & $-88,4$ & $-91,0$ & $-80,6$ \\
\hline $\mathrm{H}_{2} \mathrm{O}$ & ${ }^{2} J_{\mathrm{HH}}$ & $-4,3$ & $-5,3$ & $-6,3$ & $-7,3$ & $-8,4$ & $-9,4$ & $-10,5$ & $-11,6$ & $-12,7$ & $-13,9$ & $-15,1$ & $-7,3$ \\
\hline $\mathrm{NH}_{3}$ & ${ }^{1} J_{\mathrm{NH}}$ & 40,5 & 41,2 & 41,9 & 42,6 & 43,3 & 44,0 & 44,8 & 45,5 & 46,3 & 47,0 & 47,8 & 43,8 \\
\hline $\mathrm{NH}_{3}$ & ${ }^{2} J_{\mathrm{HH}}$ & $-7,4$ & $-8,3$ & $-9,2$ & $-10,1$ & $-11,0$ & $-12,0$ & $-12,9$ & $-13,8$ & $-14,8$ & $-15,8$ & $-16,8$ & $-9,6$ \\
\hline $\mathrm{PH}_{3}$ & ${ }^{1} J_{\mathrm{PH}}$ & 137,3 & 145,2 & 153,0 & 160,7 & 168,4 & 176,0 & 183,4 & 190,8 & 198,0 & 205,1 & 212,1 & 188,2 \\
\hline $\mathrm{PF}_{3}$ & ${ }^{1} J_{\mathrm{PF}}$ & $-1807,0$ & $-1782,9$ & $-1754,0$ & $-1720,9$ & $-1684,6$ & $-1645,6$ & $-1604,4$ & $-1561,6$ & $-1517,7$ & $-1472,9$ & $-1427,5$ & -1441 \\
\hline $\mathrm{BHF}_{2}$ & ${ }^{1} J_{\mathrm{BF}}$ & $-177,5$ & $-160,5$ & $-143,7$ & $-126,9$ & $-110,2$ & $-93,7$ & $-77,4$ & $-61,3$ & $-45,4$ & $-29,6$ & $-14,1$ & -84 \\
\hline $\mathrm{BF}_{3}$ & ${ }^{1} J_{\mathrm{BF}}$ & $-80,9$ & $-62,5$ & $-44,2$ & $-26,1$ & $-8,3$ & 9,3 & 26,8 & 44,1 & 61,2 & 78,1 & 94,8 & 15 \\
\hline $\mathrm{F}_{2} \mathrm{O}$ & ${ }^{1} J_{\mathrm{OF}}$ & $-289,0$ & $-326,3$ & $-364,0$ & $-403,4$ & $-446,6$ & $-497,2$ & $-560,7$ & $-648,6$ & $-787,3$ & $-1060,5$ & $-1973,1$ & -300 \\
\hline $\mathrm{CH}_{4}$ & ${ }^{1} J_{\mathrm{CH}}$ & 118,6 & 120,0 & 121,3 & 122,7 & 124,1 & 125,5 & 126,9 & 128,4 & 129,9 & 131,5 & 133,0 & 125,3 \\
\hline $\mathrm{CH}_{4}$ & ${ }^{2} J_{\mathrm{HH}}$ & $-11,3$ & $-12,0$ & $-12,8$ & $-13,6$ & $-14,3$ & $-15,1$ & $-15,8$ & $-16,6$ & $-17,3$ & $-18,1$ & $-18,8$ & $-12,8$ \\
\hline $\mathrm{C}_{2} \mathrm{H}_{2}$ & ${ }^{1} J_{\mathrm{CC}}$ & 188,2 & 190,8 & 193,7 & 197,2 & 201,2 & 205,9 & 211,5 & 218,3 & 226,6 & 237,0 & 250,2 & 174,8 \\
\hline $\mathrm{C}_{2} \mathrm{H}_{2}$ & ${ }^{1} J_{\mathrm{CH}}$ & 248,7 & 250,8 & 253,1 & 255,5 & 258,2 & 261,1 & 264,4 & 268,3 & 272,8 & 278,4 & 285,3 & 247,6 \\
\hline $\mathrm{C}_{2} \mathrm{H}_{2}$ & ${ }^{2} J_{\mathrm{CH}}$ & 54,5 & 54,5 & 54,3 & 53,8 & 53,1 & 52,0 & 50,4 & 48,2 & 45,3 & 41,3 & 35,9 & 50,1 \\
\hline $\mathrm{C}_{2} \mathrm{H}_{2}$ & ${ }^{3} J_{\mathrm{HH}}$ & 9,9 & 10,5 & 11,2 & 12,1 & 13,2 & 14,5 & 16,0 & 17,9 & 20,3 & 23,2 & 26,9 & 9,6 \\
\hline $\mathrm{C}_{2} \mathrm{H}_{4}$ & ${ }^{1} J_{\mathrm{CC}}$ & 60,2 & 62,8 & 65,7 & 69,0 & 72,8 & 77,2 & 82,6 & 89,4 & 98,6 & 112,0 & 133,8 & 67,6 \\
\hline $\mathrm{C}_{2} \mathrm{H}_{4}$ & ${ }^{1} J_{\mathrm{CH}}$ & 150,8 & 152,7 & 154,8 & 157,0 & 159,4 & 162,0 & 165,0 & 168,7 & 173,2 & 179,5 & 189,3 & 156,3 \\
\hline $\mathrm{C}_{2} \mathrm{H}_{4}$ & ${ }^{2} J_{\mathrm{CH}}$ & 0,0 & $-0,7$ & $-1,7$ & $-2,8$ & $-4,1$ & $-5,6$ & $-7,6$ & $-10,1$ & $-13,7$ & $-18,9$ & $-27,6$ & $-2,4$ \\
\hline $\mathrm{C}_{2} \mathrm{H}_{4}$ & ${ }^{2} J_{\mathrm{HH}}$ & 4,9 & 4,1 & 3,3 & 2,4 & 1,5 & 0,3 & $-1,0$ & $-2,7$ & $-5,0$ & $-8,2$ & $-13,5$ & 2,3 \\
\hline $\mathrm{C}_{2} \mathrm{H}_{4}$ & ${ }^{3} J_{\mathrm{HH}_{\mathrm{c}}}$ & 11,6 & 11,9 & 12,2 & 12,6 & 13,2 & 13,9 & 14,8 & 16,1 & 18,0 & 20,8 & 25,7 & 11,7 \\
\hline $\mathrm{C}_{2} \mathrm{H}_{4}$ & ${ }^{3} J_{\mathrm{HH}_{\mathrm{t}}}$ & 18,4 & 18,7 & 19,1 & 19,6 & 20,3 & 21,1 & 22,2 & 23,7 & 25,9 & 29,1 & 34,7 & 19 \\
\hline $\mathrm{C}_{2} \mathrm{H}_{6}$ & ${ }^{1} J_{\mathrm{CC}}$ & 24,8 & 26,7 & 28,7 & 30,6 & 32,7 & 34,7 & 36,8 & 38,9 & 41,0 & 43,2 & 45,4 & 34,5 \\
\hline $\mathrm{C}_{2} \mathrm{H}_{6}$ & ${ }^{1} J_{\mathrm{CH}}$ & 118,7 & 120,2 & 121,7 & 123,3 & 124,9 & 126,5 & 128,2 & 129,9 & 131,5 & 133,2 & 135,0 & 125,2 \\
\hline $\mathrm{C}_{2} \mathrm{H}_{6}$ & ${ }^{2} J_{\mathrm{CH}}$ & $-2,6$ & $-3,1$ & $-3,5$ & $-4,0$ & $-4,5$ & $-5,0$ & $-5,5$ & $-6,0$ & $-6,5$ & $-7,1$ & $-7,6$ & $-4,7$ \\
\hline \multirow[t]{3}{*}{ Total } & DM & $-27,44$ & $-25,13$ & $-22,64$ & $-20,02$ & $-17,35$ & $-14,84$ & $-12,66$ & $-11,23$ & $-11,55$ & $-16,71$ & $-45,89$ & - \\
\hline & DMA & 32,56 & 29,17 & 26,45 & 23,95 & 22,02 & 20,63 & 22,01 & 27,63 & 35,89 & 49,90 & 90,58 & - \\
\hline & PDMA & 50,73 & 40,30 & 29,83 & 21,58 & 20,55 & 22,10 & 33,22 & 51,30 & 73,79 & 103,33 & 152,34 & - \\
\hline \multirow[t]{3}{*}{ CPI } & DM & $-64,06$ & $-59,75$ & $-55,05$ & $-50,15$ & $-45,35$ & $-40,98$ & $-37,63$ & $-36,38$ & $-39,70$ & $-55,20$ & $-128,80$ & - \\
\hline & DMA & 71,12 & 63,72 & 57,93 & 52,01 & 46,40 & 41,45 & 42,08 & 51,87 & 67,03 & 94,33 & 182,13 & - \\
\hline & PDMA & 88,41 & 71,48 & 55,28 & 40,12 & 28,55 & 18,40 & 26,06 & 44,83 & 65,61 & 90,45 & 134,69 & - \\
\hline \multirow[t]{3}{*}{ SPI } & DM & $-0,58$ & 0,25 & 1,13 & 2,09 & 3,17 & 4,33 & 5,65 & 7,22 & 9,10 & 11,52 & 14,91 & - \\
\hline & DMA & 4,29 & 3,83 & 3,36 & 3,37 & 4,15 & 5,37 & 7,29 & 9,85 & 13,06 & 17,32 & 23,45 & - \\
\hline & PDMA & 23,11 & 17,43 & 11,18 & 7,99 & 14,68 & 24,81 & 38,47 & 56,04 & 79,79 & 112,78 & 165,29 & - \\
\hline \multirow[t]{3}{*}{$\Delta \mathrm{CS}$} & DM & $-63,48$ & $-60,01$ & $-56,19$ & $-52,24$ & $-48,52$ & $-45,31$ & $-43,28$ & $-43,60$ & $-48,80$ & $-66,72$ & $-143,71$ & - \\
\hline & DMA & 66,83 & 59,89 & 54,57 & 48,64 & 42,25 & 36,09 & 34,79 & 42,03 & 53,97 & 77,01 & 158,67 & - \\
\hline & PDMA & 65,30 & 54,04 & 44,10 & 32,13 & 13,87 & $-6,42$ & $-12,41$ & $-11,20$ & $-14,18$ & $-22,34$ & $-30,60$ & - \\
\hline \multicolumn{14}{|c|}{ Desconsiderando ${ }^{1} J_{\mathrm{BF}}$ da molécula de $\mathrm{BF}_{3},{ }^{2} J_{\mathrm{CH}}$ e ${ }^{2} J_{\mathrm{HH}}$ da molécula de $\mathrm{C}_{2} \mathrm{H}_{4}$} \\
\hline \multirow[t]{3}{*}{ Total } & DM & $-27,07$ & $-25,20$ & $-23,09$ & $-20,83$ & $-18,50$ & $-16,30$ & $-14,45$ & $-13,40$ & $-14,25$ & $-20,46$ & $-53,57$ & - \\
\hline & DMA & 32,42 & 29,45 & 27,25 & 25,26 & 23,77 & 22,85 & 24,00 & 29,41 & 37,76 & 52,49 & 97,15 & - \\
\hline & PDMA & 20,29 & 16,61 & 13,41 & 11,57 & 11,88 & 13,75 & 18,47 & 26,15 & 35,76 & 48,78 & 73,57 & - \\
\hline \multirow[t]{3}{*}{ CPI } & DM & $-60,88$ & $-57,98$ & $-54,64$ & $-51,06$ & $-47,55$ & $-44,51$ & $-42,57$ & $-42,93$ & $-48,29$ & $-67,03$ & $-149,66$ & - \\
\hline & DMA & 68,64 & 62,34 & 57,80 & 53,10 & 48,71 & 45,03 & 45,11 & 54,15 & 69,11 & 97,45 & 192,36 & - \\
\hline & PDMA & 33,31 & 26,96 & 21,34 & 16,73 & 15,87 & 16,44 & 20,80 & 29,92 & 41,38 & 57,43 & 94,96 & - \\
\hline \multirow[t]{3}{*}{ SPI } & $\mathrm{DM}$ & $-1,05$ & 0,02 & 1,18 & 2,43 & 3,85 & 5,39 & 7,18 & 9,31 & 11,93 & 15,37 & 20,35 & - \\
\hline & DMA & 4,56 & 4,15 & 3,75 & 3,85 & 4,59 & 5,79 & 7,76 & 10,38 & 13,64 & 17,91 & 23,91 & - \\
\hline & PDMA & 10,27 & 8,65 & 7,31 & 7,60 & 8,82 & 11,69 & 16,69 & 23,26 & 31,44 & 42,13 & 57,11 & - \\
\hline \multirow[t]{3}{*}{$\Delta \mathrm{CS}$} & $\mathrm{DM}$ & $-59,83$ & $-58,00$ & $-55,82$ & $-53,49$ & $-51,40$ & $-49,90$ & $-49,75$ & $-52,24$ & $-60,22$ & $-82,40$ & $-170,01$ & 一 \\
\hline & DMA & 64,08 & 58,19 & 54,05 & 49,25 & 44,12 & 39,24 & 37,35 & 43,77 & 55,47 & 79,54 & 168,45 & - \\
\hline & PDMA & 23,04 & 18,31 & 14,03 & 9,13 & 7,06 & 4,75 & 4,11 & 6,66 & 9,94 & 15,29 & 37,85 & - \\
\hline
\end{tabular}


Tabela 8.255: Constantes de acoplamento PW91PBE com base aug-pcJ-2.

\begin{tabular}{|c|c|c|c|c|c|c|c|c|c|c|c|c|c|}
\hline & $\% E_{X}^{\mathrm{HF}}$ & $0 \%$ & $10 \%$ & $20 \%$ & $30 \%$ & $40 \%$ & $50 \%$ & $60 \%$ & $70 \%$ & $80 \%$ & $90 \%$ & $100 \%$ & Exp. \\
\hline $\mathrm{HF}$ & ${ }^{1} J_{\mathrm{HF}}$ & 361,6 & 384,8 & 408,1 & 431,7 & 455,6 & 479,6 & 503,9 & 528,4 & 553,1 & 578,1 & 603,3 & 500 \\
\hline $\mathrm{CO}$ & ${ }^{1} J_{\mathrm{CO}}$ & 25,0 & 23,4 & 21,7 & 19,9 & 18,0 & 16,1 & 14,0 & 11,9 & 9,8 & 7,6 & 5,3 & 16,4 \\
\hline $\mathrm{H}_{2} \mathrm{O}$ & ${ }^{1} J_{\mathrm{OH}}$ & $-65,9$ & $-68,3$ & $-70,8$ & $-73,3$ & $-75,8$ & $-78,3$ & $-80,9$ & $-83,5$ & $-86,1$ & $-88,8$ & $-91,5$ & $-80,6$ \\
\hline $\mathrm{H}_{2} \mathrm{O}$ & ${ }^{2} J_{\mathrm{HH}}$ & $-4,8$ & $-5,8$ & $-6,8$ & $-7,9$ & $-9,0$ & $-10,1$ & $-11,2$ & $-12,3$ & $-13,5$ & $-14,7$ & $-15,9$ & $-7,3$ \\
\hline $\mathrm{NH}_{3}$ & ${ }^{1} J_{\mathrm{NH}}$ & 40,5 & 41,3 & 42,0 & 42,7 & 43,5 & 44,2 & 45,0 & 45,8 & 46,6 & 47,4 & 48,2 & 43,8 \\
\hline $\mathrm{NH}_{3}$ & ${ }^{2} J_{\mathrm{HH}}$ & $-8,0$ & $-8,9$ & $-9,8$ & $-10,7$ & $-11,7$ & $-12,6$ & $-13,6$ & $-14,6$ & $-15,6$ & $-16,6$ & $-17,6$ & $-9,6$ \\
\hline $\mathrm{PH}_{3}$ & ${ }^{1} J_{\mathrm{PH}}$ & 136,7 & 144,9 & 153,0 & 161,0 & 169,0 & 176,8 & 184,6 & 192,2 & 199,7 & 207,1 & 214,3 & 188,2 \\
\hline $\mathrm{PF}_{3}$ & ${ }^{1} J_{\mathrm{PF}}$ & $-1811,6$ & $-1786,7$ & $-1757,0$ & $-1723,3$ & $-1686,3$ & $-1646,7$ & $-1605,0$ & $-1561,7$ & $-1517,3$ & $-1472,1$ & $-1426,5$ & -1441 \\
\hline $\mathrm{BHF}_{2}$ & ${ }^{1} J_{\mathrm{BF}}$ & $-178,3$ & $-161,3$ & $-144,3$ & $-127,4$ & $-110,6$ & $-94,0$ & $-77,6$ & $-61,3$ & $-45,3$ & $-29,4$ & $-13,8$ & -84 \\
\hline $\mathrm{BF}_{3}$ & ${ }^{1} J_{\mathrm{BF}}$ & $-81,8$ & $-63,2$ & $-44,8$ & $-26,7$ & $-8,7$ & 9,0 & 26,6 & 44,0 & 61,3 & 78,3 & 95,2 & 15 \\
\hline $\mathrm{F}_{2} \mathrm{O}$ & ${ }^{1} J_{\mathrm{OF}}$ & $-290,8$ & $-329,1$ & $-367,8$ & $-408,4$ & $-453,4$ & $-506,3$ & $-573,7$ & $-668,5$ & $-822,4$ & $-1142,7$ & $-2453,2$ & -300 \\
\hline $\mathrm{CH}_{4}$ & ${ }^{1} J_{\mathrm{CH}}$ & 119,4 & 120,8 & 122,2 & 123,6 & 125,1 & 126,6 & 128,1 & 129,6 & 131,2 & 132,8 & 134,4 & 125,3 \\
\hline $\mathrm{CH}_{4}$ & ${ }^{2} J_{\mathrm{HH}}$ & $-12,0$ & $-12,8$ & $-13,6$ & $-14,4$ & $-15,1$ & $-15,9$ & $-16,7$ & $-17,5$ & $-18,3$ & $-19,1$ & $-19,8$ & $-12,8$ \\
\hline $\mathrm{C}_{2} \mathrm{H}_{2}$ & ${ }^{1} J_{\mathrm{CC}}$ & 187,6 & 190,3 & 193,5 & 197,1 & 201,4 & 206,6 & 212,7 & 220,3 & 229,6 & 241,5 & 257,1 & 174,8 \\
\hline $\mathrm{C}_{2} \mathrm{H}_{2}$ & ${ }^{1} J_{\mathrm{CH}}$ & 251,3 & 253,6 & 256,0 & 258,7 & 261,6 & 264,8 & 268,6 & 273,0 & 278,3 & 284,8 & 293,3 & 247,6 \\
\hline $\mathrm{C}_{2} \mathrm{H}_{2}$ & ${ }^{2} J_{\mathrm{CH}}$ & 54,6 & 54,5 & 54,1 & 53,5 & 52,6 & 51,2 & 49,3 & 46,6 & 43,0 & 38,1 & 31,2 & 50,1 \\
\hline $\mathrm{C}_{2} \mathrm{H}_{2}$ & ${ }^{3} J_{\mathrm{HH}}$ & 10,5 & 11,2 & 12,0 & 13,1 & 14,3 & 15,8 & 17,6 & 19,8 & 22,6 & 26,2 & 30,9 & 9,6 \\
\hline $\mathrm{C}_{2} \mathrm{H}_{4}$ & ${ }^{1} J_{\mathrm{CC}}$ & 60,0 & 62,8 & 65,8 & 69,3 & 73,3 & 78,2 & 84,2 & 92,1 & 103,1 & 120,1 & 150,7 & 67,6 \\
\hline $\mathrm{C}_{2} \mathrm{H}_{4}$ & ${ }^{1} J_{\mathrm{CH}}$ & 152,2 & 154,3 & 156,4 & 158,8 & 161,3 & 164,2 & 167,6 & 171,8 & 177,3 & 185,2 & 199,0 & 156,3 \\
\hline $\mathrm{C}_{2} \mathrm{H}_{4}$ & ${ }^{2} J_{\mathrm{CH}}$ & $-0,4$ & $-1,3$ & $-2,3$ & $-3,5$ & $-5,0$ & $-6,8$ & $-9,0$ & $-12,1$ & $-16,5$ & $-23,4$ & $-36,1$ & $-2,4$ \\
\hline $\mathrm{C}_{2} \mathrm{H}_{4}$ & ${ }^{2} J_{\mathrm{HH}}$ & 4,4 & 3,6 & 2,7 & 1,7 & 0,6 & $-0,6$ & $-2,2$ & $-4,3$ & $-7,1$ & $-11,5$ & $-19,4$ & 2,3 \\
\hline $\mathrm{C}_{2} \mathrm{H}_{4}$ & ${ }^{3} J_{\mathrm{HH}_{\mathrm{c}}}$ & 11,9 & 12,3 & 12,7 & 13,2 & 13,8 & 14,7 & 15,8 & 17,5 & 19,9 & 23,8 & 31,3 & 11,7 \\
\hline $\mathrm{C}_{2} \mathrm{H}_{4}$ & ${ }^{3} J_{\mathrm{HH}_{\mathrm{t}}}$ & 19,0 & 19,3 & 19,8 & 20,4 & 21,2 & 22,2 & 23,5 & 25,4 & 28,2 & 32,7 & 41,0 & 19 \\
\hline $\mathrm{C}_{2} \mathrm{H}_{6}$ & ${ }^{1} J_{\mathrm{CC}}$ & 24,7 & 26,7 & 28,6 & 30,6 & 32,6 & 34,7 & 36,8 & 39,0 & 41,1 & 43,3 & 45,6 & 34,5 \\
\hline $\mathrm{C}_{2} \mathrm{H}_{6}$ & ${ }^{1} J_{\mathrm{CH}}$ & 119,6 & 121,2 & 122,8 & 124,5 & 126,1 & 127,8 & 129,5 & 131,3 & 133,0 & 134,8 & 136,6 & 125,2 \\
\hline $\mathrm{C}_{2} \mathrm{H}_{6}$ & ${ }^{2} J_{\mathrm{CH}}$ & $-2,9$ & $-3,4$ & $-3,9$ & $-4,4$ & $-4,9$ & $-5,4$ & $-5,9$ & $-6,4$ & $-7,0$ & $-7,5$ & $-8,1$ & $-4,7$ \\
\hline \multirow[t]{3}{*}{ Total } & $\mathrm{DM}$ & $-27,79$ & $-25,42$ & $-22,87$ & $-20,20$ & $-17,52$ & $-14,97$ & $-12,81$ & $-11,48$ & $-12,17$ & $-18,81$ & $-62,67$ & - \\
\hline & DMA & 32,82 & 29,54 & 26,90 & 24,70 & 22,91 & 21,72 & 23,26 & 29,50 & 38,71 & 55,12 & 112,44 & - \\
\hline & PDMA & 48,85 & 38,30 & 28,40 & 25,19 & 25,59 & 27,99 & 40,30 & 60,76 & 86,45 & 122,57 & 190,22 & - \\
\hline \multirow[t]{3}{*}{ CPI } & $\mathrm{DM}$ & $-65,30$ & $-60,89$ & $-56,13$ & $-51,21$ & $-46,39$ & $-42,11$ & $-38,98$ & $-38,23$ & $-42,78$ & $-62,43$ & $-172,10$ & - \\
\hline & DMA & 71,95 & 64,80 & 58,96 & 53,17 & 47,55 & 42,60 & 43,18 & 53,88 & 70,49 & 102,15 & 226,41 & - \\
\hline & PDMA & 88,23 & 71,33 & 55,42 & 42,37 & 30,77 & 20,03 & 27,55 & 46,87 & 68,34 & 94,73 & 151,26 & - \\
\hline \multirow[t]{3}{*}{ SPI } & $\mathrm{DM}$ & $-0,28$ & 0,60 & 1,51 & 2,54 & 3,65 & 4,93 & 6,39 & 8,13 & 10,29 & 13,18 & 17,57 & - \\
\hline & DMA & 4,12 & 3,68 & 3,38 & 3,82 & 4,84 & 6,41 & 8,65 & 11,63 & 15,41 & 20,63 & 28,87 & - \\
\hline & PDMA & 19,97 & 14,08 & 8,59 & 12,59 & 21,79 & 33,82 & 49,64 & 70,95 & 99,73 & 142,98 & 218,79 & - \\
\hline \multirow[t]{3}{*}{$\Delta \mathrm{CS}$} & $\mathrm{DM}$ & $-65,02$ & $-61,49$ & $-57,64$ & $-53,75$ & $-50,04$ & $-47,04$ & $-45,37$ & $-46,36$ & $-53,07$ & $-75,61$ & $-189,67$ & - \\
\hline & DMA & 67,83 & 61,12 & 55,58 & 49,35 & 42,71 & 36,19 & 34,53 & 42,26 & 55,08 & 81,52 & 197,54 & - \\
\hline & PDMA & 68,26 & 57,24 & 46,82 & 29,78 & 8,98 & $-13,80$ & $-22,09$ & $-24,09$ & $-31,39$ & $-48,25$ & $-67,53$ & - \\
\hline \multicolumn{14}{|c|}{ Desconsiderando ${ }^{1} J_{\mathrm{BF}}$ da molécula de $\mathrm{BF}_{3},{ }^{2} J_{\mathrm{CH}}$ e ${ }^{2} J_{\mathrm{HH}}$ da molécula de $\mathrm{C}_{2} \mathrm{H}_{4}$} \\
\hline \multirow[t]{3}{*}{ Total } & $\mathrm{DM}$ & $-27,38$ & $-25,43$ & $-23,28$ & $-20,95$ & $-18,59$ & $-16,34$ & $-14,50$ & $-13,53$ & $-14,74$ & $-22,50$ & $-71,93$ & - \\
\hline & DMA & 32,71 & 29,89 & 27,78 & 26,03 & 24,68 & 23,98 & 25,31 & 31,38 & 40,73 & 58,05 & 121,21 & - \\
\hline & PDMA & 19,57 & 16,18 & 13,84 & 13,26 & 14,13 & 16,44 & 21,73 & 30,23 & 41,00 & 56,08 & 89,72 & - \\
\hline \multirow[t]{3}{*}{ CPI } & DM & $-62,15$ & $-59,16$ & $-55,76$ & $-52,16$ & $-48,66$ & $-45,72$ & $-44,04$ & $-44,95$ & $-51,69$ & $-75,00$ & $-197,33$ & - \\
\hline & DMA & 69,47 & 63,46 & 58,88 & 54,32 & 49,94 & 46,26 & 46,34 & 56,37 & 72,91 & 106,04 & 241,03 & - \\
\hline & PDMA & 32,52 & 26,33 & 21,09 & 18,81 & 18,05 & 18,03 & 22,58 & 32,22 & 44,31 & 62,01 & 112,92 & - \\
\hline \multirow[t]{3}{*}{ SPI } & $\mathrm{DM}$ & $-0,64$ & 0,51 & 1,71 & 3,06 & 4,55 & 6,25 & 8,22 & 10,64 & 13,68 & 17,88 & 24,54 & - \\
\hline & DMA & 4,44 & 4,06 & 3,86 & 4,28 & 5,25 & 6,84 & 9,13 & 12,16 & 15,97 & 21,13 & 29,05 & - \\
\hline & PDMA & 9,61 & 8,38 & 8,26 & 8,99 & 11,12 & 15,23 & 21,07 & 28,71 & 38,44 & 51,51 & 71,87 & - \\
\hline \multirow[t]{3}{*}{$\Delta \mathrm{CS}$} & DM & $-61,51$ & $-59,67$ & $-57,47$ & $-55,22$ & $-53,21$ & $-51,97$ & $-52,26$ & $-55,59$ & $-65,37$ & $-92,88$ & $-221,87$ & - \\
\hline & DMA & 65,03 & 59,40 & 55,02 & 50,04 & 44,69 & 39,42 & 37,21 & 44,21 & 56,94 & 84,91 & 211,98 & - \\
\hline & PDMA & 22,92 & 17,95 & 12,84 & 9,82 & 6,92 & 2,80 & 1,50 & 3,52 & 5,87 & 10,49 & 41,06 & - \\
\hline
\end{tabular}


Tabela 8.256: Constantes de acoplamento PW91PW91 com base aug-pcJ-2.

\begin{tabular}{|c|c|c|c|c|c|c|c|c|c|c|c|c|c|}
\hline & $\% E_{X}^{\mathrm{HF}}$ & $0 \%$ & $10 \%$ & $20 \%$ & $30 \%$ & $40 \%$ & $50 \%$ & $60 \%$ & $70 \%$ & $80 \%$ & $90 \%$ & $100 \%$ & Exp. \\
\hline $\mathrm{HF}$ & ${ }^{1} J_{\mathrm{HF}}$ & 364,2 & 387,4 & 410,8 & 434,5 & 458,3 & 482,4 & 506,7 & 531,2 & 556,0 & 581,0 & 606,3 & 500 \\
\hline $\mathrm{CO}$ & ${ }^{1} J_{\mathrm{CO}}$ & 24,9 & 23,2 & 21,5 & 19,6 & 17,7 & 15,8 & 13,7 & 11,6 & 9,4 & 7,2 & 4,9 & 16,4 \\
\hline $\mathrm{H}_{2} \mathrm{O}$ & ${ }^{1} J_{\mathrm{OH}}$ & $-66,3$ & $-68,7$ & $-71,2$ & $-73,7$ & $-76,2$ & $-78,7$ & $-81,3$ & $-83,9$ & $-86,5$ & $-89,2$ & $-91,9$ & $-80,6$ \\
\hline $\mathrm{H}_{2} \mathrm{O}$ & ${ }^{2} J_{\mathrm{HH}}$ & $-4,8$ & $-5,8$ & $-6,8$ & $-7,9$ & $-9,0$ & $-10,1$ & $-11,2$ & $-12,4$ & $-13,5$ & $-14,7$ & $-16,0$ & $-7,3$ \\
\hline $\mathrm{NH}_{3}$ & ${ }^{1} J_{\mathrm{NH}}$ & 40,8 & 41,5 & 42,2 & 42,9 & 43,7 & 44,5 & 45,2 & 46,0 & 46,8 & 47,6 & 48,4 & 43,8 \\
\hline $\mathrm{NH}_{3}$ & ${ }^{2} J_{\mathrm{HH}}$ & $-8,0$ & $-8,9$ & $-9,8$ & $-10,8$ & $-11,7$ & $-12,7$ & $-13,6$ & $-14,6$ & $-15,6$ & $-16,6$ & $-17,7$ & $-9,6$ \\
\hline $\mathrm{PH}_{3}$ & ${ }^{1} J_{\mathrm{PH}}$ & 137,6 & 145,9 & 154,0 & 162,1 & 170,0 & 177,9 & 185,7 & 193,3 & 200,8 & 208,2 & 215,5 & 188,2 \\
\hline $\mathrm{PF}_{3}$ & ${ }^{1} J_{\mathrm{PF}}$ & $-1815,2$ & $-1790,1$ & $-1760,3$ & $-1726,4$ & $-1689,3$ & $-1649,5$ & $-1607,6$ & $-1564,2$ & $-1519,7$ & $-1474,3$ & $-1428,5$ & -1441 \\
\hline $\mathrm{BHF}_{2}$ & ${ }^{1} J_{\mathrm{BF}}$ & $-177,6$ & $-160,4$ & $-143,4$ & $-126,4$ & $-109,6$ & $-93,0$ & $-76,5$ & $-60,2$ & $-44,1$ & $-28,2$ & $-12,5$ & -84 \\
\hline $\mathrm{BF}_{3}$ & ${ }^{1} J_{\mathrm{BF}}$ & $-80,9$ & $-62,3$ & $-43,8$ & $-25,6$ & $-7,6$ & 10,2 & 27,8 & 45,3 & 62,5 & 79,6 & 96,6 & 15 \\
\hline $\mathrm{F}_{2} \mathrm{O}$ & ${ }^{1} J_{\mathrm{OF}}$ & $-290,5$ & $-328,8$ & $-367,5$ & $-408,1$ & $-453,0$ & $-506,0$ & $-573,5$ & $-668,7$ & $-823,8$ & $-1148,9$ & $-2525,8$ & -300 \\
\hline $\mathrm{CH}_{4}$ & ${ }^{1} J_{\mathrm{CH}}$ & 120,1 & 121,5 & 122,9 & 124,3 & 125,8 & 127,3 & 128,8 & 130,4 & 131,9 & 133,5 & 135,2 & 125,3 \\
\hline $\mathrm{CH}_{4}$ & ${ }^{2} J_{\mathrm{HH}}$ & $-12,0$ & $-12,8$ & $-13,6$ & $-14,4$ & $-15,2$ & $-15,9$ & $-16,7$ & $-17,5$ & $-18,3$ & $-19,1$ & $-19,9$ & $-12,8$ \\
\hline $\mathrm{C}_{2} \mathrm{H}_{2}$ & ${ }^{1} J_{\mathrm{CC}}$ & 188,8 & 191,6 & 194,7 & 198,5 & 202,8 & 208,0 & 214,2 & 221,8 & 231,3 & 243,3 & 259,0 & 174,8 \\
\hline $\mathrm{C}_{2} \mathrm{H}_{2}$ & ${ }^{1} J_{\mathrm{CH}}$ & 252,5 & 254,8 & 257,3 & 259,9 & 262,8 & 266,1 & 269,8 & 274,3 & 279,6 & 286,1 & 294,6 & 247,6 \\
\hline $\mathrm{C}_{2} \mathrm{H}_{2}$ & ${ }^{2} J_{\mathrm{CH}}$ & 54,6 & 54,5 & 54,1 & 53,5 & 52,6 & 51,2 & 49,2 & 46,6 & 43,0 & 38,0 & 31,2 & 50,1 \\
\hline $\mathrm{C}_{2} \mathrm{H}_{2}$ & ${ }^{3} J_{\mathrm{HH}}$ & 10,5 & 11,2 & 12,0 & 13,0 & 14,2 & 15,7 & 17,5 & 19,7 & 22,5 & 26,1 & 30,7 & 9,6 \\
\hline $\mathrm{C}_{2} \mathrm{H}_{4}$ & ${ }^{1} J_{\mathrm{CC}}$ & 60,6 & 63,3 & 66,4 & 69,9 & 74,0 & 78,9 & 85,0 & 92,9 & 104,1 & 121,2 & 152,0 & 67,6 \\
\hline $\mathrm{C}_{2} \mathrm{H}_{4}$ & ${ }^{1} J_{\mathrm{CH}}$ & 153,0 & 155,1 & 157,3 & 159,6 & 162,2 & 165,1 & 168,5 & 172,7 & 178,2 & 186,2 & 200,0 & 156,3 \\
\hline $\mathrm{C}_{2} \mathrm{H}_{4}$ & ${ }^{2} J_{\mathrm{CH}}$ & $-0,4$ & $-1,3$ & $-2,3$ & $-3,5$ & $-5,0$ & $-6,8$ & $-9,1$ & $-12,1$ & $-16,5$ & $-23,5$ & $-36,2$ & $-2,4$ \\
\hline $\mathrm{C}_{2} \mathrm{H}_{4}$ & ${ }^{2} J_{\mathrm{HH}}$ & 4,5 & 3,6 & 2,8 & 1,8 & 0,7 & $-0,5$ & $-2,1$ & $-4,2$ & $-7,1$ & $-11,4$ & $-19,2$ & 2,3 \\
\hline $\mathrm{C}_{2} \mathrm{H}_{4}$ & ${ }^{3} J_{\mathrm{HH}_{\mathrm{c}}}$ & 11,9 & 12,2 & 12,6 & 13,1 & 13,8 & 14,7 & 15,8 & 17,4 & 19,8 & 23,8 & 31,2 & 11,7 \\
\hline $\mathrm{C}_{2} \mathrm{H}_{4}$ & ${ }^{3} J_{\mathrm{HH}_{\mathrm{t}}}$ & 19,0 & 19,3 & 19,8 & 20,4 & 21,1 & 22,1 & 23,5 & 25,4 & 28,1 & 32,6 & 40,9 & 19 \\
\hline $\mathrm{C}_{2} \mathrm{H}_{6}$ & ${ }^{1} J_{\mathrm{CC}}$ & 25,1 & 27,0 & 29,0 & 31,0 & 33,1 & 35,1 & 37,3 & 39,4 & 41,6 & 43,8 & 46,1 & 34,5 \\
\hline $\mathrm{C}_{2} \mathrm{H}_{6}$ & ${ }^{1} J_{\mathrm{CH}}$ & 120,3 & 121,9 & 123,5 & 125,1 & 126,8 & 128,5 & 130,2 & 132,0 & 133,7 & 135,5 & 137,3 & 125,2 \\
\hline $\mathrm{C}_{2} \mathrm{H}_{6}$ & ${ }^{2} J_{\mathrm{CH}}$ & $-2,9$ & $-3,4$ & $-3,9$ & $-4,4$ & $-4,9$ & $-5,4$ & $-5,9$ & $-6,4$ & $-7,0$ & $-7,5$ & $-8,1$ & $-4,7$ \\
\hline \multirow[t]{3}{*}{ Total } & DM & $-27,51$ & $-25,13$ & $-22,57$ & $-19,88$ & $-17,19$ & $-14,62$ & $-12,45$ & $-11,12$ & $-11,84$ & $-18,64$ & $-65,03$ & - \\
\hline & DMA & 32,72 & 29,40 & 26,80 & 24,62 & 22,93 & 21,82 & 23,78 & 30,12 & 39,39 & 56,00 & 115,74 & - \\
\hline & PDMA & 48,56 & 37,80 & 28,07 & 24,53 & 25,00 & 27,68 & 40,94 & 61,33 & 87,16 & 123,40 & 191,82 & - \\
\hline \multirow[t]{3}{*}{ CPI } & DM & $-65,15$ & $-60,72$ & $-55,93$ & $-50,97$ & $-46,15$ & $-41,83$ & $-38,68$ & $-37,95$ & $-42,60$ & $-62,65$ & $-178,33$ & - \\
\hline & DMA & 71,77 & 64,52 & 58,65 & 52,81 & 47,18 & 42,30 & 43,85 & 54,79 & 71,51 & 103,60 & 233,56 & - \\
\hline & PDMA & 87,39 & 70,40 & 54,43 & 41,35 & 29,65 & 19,37 & 28,66 & 48,28 & 69,67 & 96,27 & 155,08 & - \\
\hline \multirow[t]{3}{*}{ SPI } & DM & 0,10 & 0,96 & 1,90 & 2,91 & 4,05 & 5,33 & 6,79 & 8,55 & 10,72 & 13,63 & 18,05 & - \\
\hline & DMA & 4,07 & 3,64 & 3,45 & 3,95 & 5,14 & 6,80 & 9,07 & 12,03 & 15,84 & 21,10 & 29,34 & - \\
\hline & PDMA & 20,09 & 13,89 & 8,73 & 12,20 & 21,60 & 33,78 & 49,95 & 70,90 & 99,98 & 143,30 & 218,77 & - \\
\hline \multirow[t]{3}{*}{$\Delta \mathrm{CS}$} & DM & $-65,25$ & $-61,68$ & $-57,83$ & $-53,89$ & $-50,19$ & $-47,16$ & $-45,48$ & $-46,51$ & $-53,32$ & $-76,29$ & $-196,37$ & - \\
\hline & DMA & 67,70 & 60,88 & 55,21 & 48,86 & 42,04 & 35,50 & 34,77 & 42,76 & 55,67 & 82,50 & 204,22 & - \\
\hline & PDMA & 67,30 & 56,51 & 45,70 & 29,14 & 8,05 & $-14,40$ & $-21,29$ & $-22,63$ & $-30,30$ & $-47,04$ & $-63,69$ & - \\
\hline \multicolumn{14}{|c|}{ Desconsiderando ${ }^{1} J_{\mathrm{BF}}$ da molécula de $\mathrm{BF}_{3},{ }^{2} J_{\mathrm{CH}}$ e ${ }^{2} J_{\mathrm{HH}}$ da molécula de $\mathrm{C}_{2} \mathrm{H}_{4}$} \\
\hline \multirow[t]{3}{*}{ Total } & DM & $-27,11$ & $-25,16$ & $-22,98$ & $-20,64$ & $-18,27$ & $-16,00$ & $-14,14$ & $-13,19$ & $-14,43$ & $-22,37$ & $-74,66$ & - \\
\hline & DMA & 32,63 & 29,77 & 27,72 & 26,00 & 24,75 & 24,14 & 25,85 & 32,03 & 41,44 & 58,99 & 124,89 & - \\
\hline & PDMA & 19,32 & 15,87 & 13,56 & 13,03 & 13,98 & 16,64 & 22,12 & 30,69 & 41,44 & 56,65 & 91,32 & - \\
\hline \multirow[t]{3}{*}{ CPI } & DM & $-62,08$ & $-59,06$ & $-55,64$ & $-52,01$ & $-48,50$ & $-45,53$ & $-43,83$ & $-44,78$ & $-51,61$ & $-75,38$ & $-204,32$ & - \\
\hline & DMA & 69,36 & 63,24 & 58,64 & 54,03 & 49,64 & 46,05 & 46,95 & 57,24 & 73,91 & 107,50 & 248,76 & - \\
\hline & PDMA & 32,19 & 25,91 & 20,67 & 18,41 & 17,55 & 18,11 & 22,99 & 32,91 & 44,97 & 62,83 & 116,19 & - \\
\hline \multirow[t]{3}{*}{ SPI } & $\mathrm{DM}$ & $-0,21$ & 0,92 & 2,15 & 3,48 & 4,99 & 6,71 & 8,69 & 11,12 & 14,18 & 18,41 & 25,08 & - \\
\hline & DMA & 4,38 & 4,02 & 3,93 & 4,44 & 5,61 & 7,29 & 9,62 & 12,64 & 16,47 & 21,67 & 29,60 & - \\
\hline & PDMA & 9,41 & 8,16 & 8,08 & 8,88 & 11,23 & 15,51 & 21,44 & 28,98 & 38,73 & 51,90 & 72,19 & - \\
\hline \multirow[t]{3}{*}{$\Delta \mathrm{CS}$} & $\mathrm{DM}$ & $-61,87$ & $-59,98$ & $-57,79$ & $-55,49$ & $-53,49$ & $-52,24$ & $-52,52$ & $-55,90$ & $-65,79$ & $-93,79$ & $-229,40$ & 一 \\
\hline & DMA & 64,98 & 59,22 & 54,71 & 49,59 & 44,03 & 38,76 & 37,33 & 44,60 & 57,44 & 85,83 & 219,16 & - \\
\hline & PDMA & 22,78 & 17,75 & 12,59 & 9,53 & 6,32 & 2,60 & 1,55 & 3,92 & 6,25 & 10,93 & 44,00 & - \\
\hline
\end{tabular}


Tabela 8.257: Constantes de acoplamento PW91TPSS com base aug-pcJ-2.

\begin{tabular}{|c|c|c|c|c|c|c|c|c|c|c|c|c|c|}
\hline & $\% E_{X}^{\mathrm{HF}}$ & $0 \%$ & $10 \%$ & $20 \%$ & $30 \%$ & $40 \%$ & $50 \%$ & $60 \%$ & $70 \%$ & $80 \%$ & $90 \%$ & $100 \%$ & Exp. \\
\hline $\mathrm{HF}$ & $\frac{\Lambda}{{ }^{1} J_{\mathrm{HF}}}$ & 363,8 & 387,6 & 411,6 & 435,7 & 460,1 & 484,6 & 509,3 & 534,2 & 559,3 & 584,5 & 610,0 & 500 \\
\hline $\mathrm{CO}$ & ${ }^{1} J_{\mathrm{CO}}$ & 24,9 & 23,3 & 21,5 & 19,7 & 17,8 & 15,8 & 13,8 & 11,6 & 9,4 & 7,2 & 4,9 & 16,4 \\
\hline $\mathrm{H}_{2} \mathrm{O}$ & ${ }^{1} J_{\mathrm{OH}}$ & $-67,0$ & $-69,5$ & $-72,1$ & $-74,7$ & $-77,3$ & $-79,9$ & $-82,5$ & $-85,2$ & $-87,9$ & $-90,6$ & $-93,4$ & $-80,6$ \\
\hline $\mathrm{H}_{2} \mathrm{O}$ & ${ }^{2} J_{\mathrm{HH}}$ & $-4,5$ & $-5,6$ & $-6,7$ & $-7,8$ & $-8,9$ & $-10,1$ & $-11,3$ & $-12,5$ & $-13,7$ & $-14,9$ & $-16,2$ & $-7,3$ \\
\hline $\mathrm{NH}_{3}$ & ${ }^{1} J_{\mathrm{NH}}$ & 42,0 & 42,8 & 43,6 & 44,3 & 45,1 & 45,9 & 46,8 & 47,6 & 48,4 & 49,3 & 50,1 & 43,8 \\
\hline $\mathrm{NH}_{3}$ & ${ }^{2} J_{\mathrm{HH}}$ & $-7,6$ & $-8,5$ & $-9,5$ & $-10,5$ & $-11,6$ & $-12,6$ & $-13,6$ & $-14,7$ & $-15,8$ & $-16,8$ & $-17,9$ & $-9,6$ \\
\hline $\mathrm{PH}_{3}$ & ${ }^{1} J_{\mathrm{PH}}$ & 146,2 & 155,2 & 164,1 & 173,0 & 181,8 & 190,5 & 199,1 & 207,6 & 216,1 & 224,4 & 232,6 & 188,2 \\
\hline $\mathrm{PF}_{3}$ & ${ }^{1} J_{\mathrm{PF}}$ & $-1815,8$ & $-1791,5$ & $-1762,4$ & $-1729,3$ & $-1692,8$ & $-1653,6$ & $-1612,4$ & $-1569,5$ & $-1525,4$ & $-1480,6$ & $-1435,2$ & -1441 \\
\hline $\mathrm{BHF}_{2}$ & ${ }^{1} J_{\mathrm{BF}}$ & $-179,3$ & $-162,3$ & $-145,4$ & $-128,7$ & $-112,1$ & $-95,7$ & $-79,4$ & $-63,4$ & $-47,5$ & $-31,9$ & $-16,4$ & -84 \\
\hline $\mathrm{BF}_{3}$ & ${ }^{1} J_{\mathrm{BF}}$ & $-79,2$ & $-60,7$ & $-42,4$ & $-24,3$ & $-6,5$ & 11,1 & 28,5 & 45,8 & 62,8 & 79,6 & 96,3 & 15 \\
\hline $\mathrm{F}_{2} \mathrm{O}$ & ${ }^{1} J_{\mathrm{OF}}$ & $-289,4$ & $-327,6$ & $-366,2$ & $-406,6$ & $-451,1$ & $-503,5$ & $-570,0$ & $-663,3$ & $-814,3$ & $-1127,7$ & $-2403,5$ & -300 \\
\hline $\mathrm{CH}_{4}$ & ${ }^{1} J_{\mathrm{CH}}$ & 127,8 & 129,4 & 131,0 & 132,6 & 134,3 & 136,0 & 137,7 & 139,5 & 141,2 & 143,1 & 144,9 & 125,3 \\
\hline $\mathrm{CH}_{4}$ & ${ }^{2} J_{\mathrm{HH}}$ & $-11,4$ & $-12,3$ & $-13,2$ & $-14,1$ & $-14,9$ & $-15,8$ & $-16,7$ & $-17,6$ & $-18,4$ & $-19,3$ & $-20,2$ & $-12,8$ \\
\hline $\mathrm{C}_{2} \mathrm{H}_{2}$ & ${ }^{1} J_{\mathrm{CC}}$ & 188,4 & 191,3 & 194,6 & 198,5 & 203,0 & 208,4 & 215,0 & 223,0 & 232,9 & 245,5 & 262,1 & 174,8 \\
\hline $\mathrm{C}_{2} \mathrm{H}_{2}$ & ${ }^{1} J_{\mathrm{CH}}$ & 266,6 & 269,2 & 272,0 & 275,0 & 278,2 & 281,9 & 286,0 & 290,9 & 296,6 & 303,8 & 312,9 & 247,6 \\
\hline $\mathrm{C}_{2} \mathrm{H}_{2}$ & ${ }^{2} J_{\mathrm{CH}}$ & 56,1 & 56,0 & 55,6 & 55,0 & 54,0 & 52,5 & 50,5 & 47,7 & 43,9 & 38,7 & 31,5 & 50,1 \\
\hline $\mathrm{C}_{2} \mathrm{H}_{2}$ & ${ }^{3} J_{\mathrm{HH}}$ & 10,9 & 11,6 & 12,5 & 13,5 & 14,8 & 16,3 & 18,2 & 20,5 & 23,3 & 27,0 & 31,8 & 9,6 \\
\hline $\mathrm{C}_{2} \mathrm{H}_{4}$ & ${ }^{1} J_{\mathrm{CC}}$ & 61,3 & 64,1 & 67,3 & 70,9 & 75,1 & 80,2 & 86,5 & 94,6 & 106,0 & 123,2 & 153,5 & 67,6 \\
\hline $\mathrm{C}_{2} \mathrm{H}_{4}$ & ${ }^{1} J_{\mathrm{CH}}$ & 162,1 & 164,4 & 166,9 & 169,5 & 172,4 & 175,6 & 179,3 & 183,8 & 189,6 & 197,9 & 211,7 & 156,3 \\
\hline $\mathrm{C}_{2} \mathrm{H}_{4}$ & ${ }^{2} J_{\mathrm{CH}}$ & $-0,5$ & $-1,5$ & $-2,6$ & $-3,9$ & $-5,4$ & $-7,3$ & $-9,6$ & $-12,8$ & $-17,3$ & $-24,3$ & $-36,8$ & $-2,4$ \\
\hline $\mathrm{C}_{2} \mathrm{H}_{4}$ & ${ }^{2} J_{\mathrm{HH}}$ & 6,1 & 5,2 & 4,3 & 3,3 & 2,1 & 0,7 & $-0,8$ & $-2,9$ & $-5,8$ & $-10,0$ & $-17,4$ & 2,3 \\
\hline $\mathrm{C}_{2} \mathrm{H}_{4}$ & ${ }^{3} J_{\mathrm{HH}_{\mathrm{c}}}$ & 12,7 & 13,1 & 13,5 & 14,0 & 14,6 & 15,5 & 16,6 & 18,2 & 20,6 & 24,4 & 31,3 & 11,7 \\
\hline $\mathrm{C}_{2} \mathrm{H}_{4}$ & ${ }^{3} J_{\mathrm{HH}_{\mathrm{t}}}$ & 20,9 & 21,2 & 21,7 & 22,3 & 23,0 & 24,1 & 25,4 & 27,3 & 30,0 & 34,3 & 42,2 & 19 \\
\hline $\mathrm{C}_{2} \mathrm{H}_{6}$ & ${ }^{1} J_{\mathrm{CC}}$ & 25,7 & 27,7 & 29,7 & 31,7 & 33,7 & 35,9 & 38,0 & 40,2 & 42,4 & 44,7 & 46,9 & 34,5 \\
\hline $\mathrm{C}_{2} \mathrm{H}_{6}$ & ${ }^{1} J_{\mathrm{CH}}$ & 127,8 & 129,6 & 131,4 & 133,3 & 135,2 & 137,1 & 139,0 & 141,0 & 143,0 & 145,0 & 147,1 & 125,2 \\
\hline $\mathrm{C}_{2} \mathrm{H}_{6}$ & ${ }^{2} J_{\mathrm{CH}}$ & $-3,0$ & $-3,5$ & $-4,0$ & $-4,5$ & $-5,0$ & $-5,6$ & $-6,1$ & $-6,7$ & $-7,3$ & $-7,9$ & $-8,5$ & $-4,7$ \\
\hline \multirow[t]{3}{*}{ Total } & $\mathrm{DM}$ & $-25,36$ & $-22,93$ & $-20,32$ & $-17,58$ & $-14,82$ & $-12,19$ & $-9,91$ & $-8,47$ & $-8,96$ & $-15,25$ & $-57,72$ & - \\
\hline & DMA & 33,05 & 30,05 & 27,75 & 25,91 & 24,32 & 23,49 & 26,20 & 32,79 & 42,04 & 58,34 & 113,73 & - \\
\hline & PDMA & 51,78 & 41,10 & 31,46 & 27,03 & 24,85 & 28,54 & 42,30 & 63,27 & 89,33 & 125,33 & 191,26 & - \\
\hline \multirow[t]{3}{*}{ CPI } & $\mathrm{DM}$ & $-64,25$ & $-59,79$ & $-54,98$ & $-50,01$ & $-45,13$ & $-40,76$ & $-37,51$ & $-36,61$ & $-40,86$ & $-59,85$ & $-166,33$ & - \\
\hline & DMA & 71,07 & 63,57 & 57,58 & 51,77 & 46,22 & 41,69 & 45,02 & 56,39 & 72,88 & 104,02 & 223,67 & - \\
\hline & PDMA & 86,60 & 69,48 & 52,91 & 39,68 & 28,58 & 18,70 & 29,69 & 49,55 & 70,96 & 97,06 & 152,58 & - \\
\hline \multirow[t]{3}{*}{ SPI } & $\mathrm{DM}$ & 3,16 & 4,09 & 5,11 & 6,20 & 7,40 & 8,76 & 10,33 & 12,17 & 14,44 & 17,47 & 21,93 & - \\
\hline & DMA & 5,17 & 5,47 & 5,87 & 6,95 & 8,25 & 10,15 & 12,41 & 15,48 & 19,43 & 24,84 & 33,11 & - \\
\hline & PDMA & 26,24 & 20,28 & 15,73 & 17,75 & 22,11 & 35,76 & 51,55 & 73,34 & 102,80 & 146,05 & 219,63 & - \\
\hline \multirow[t]{3}{*}{$\Delta \mathrm{CS}$} & $\mathrm{DM}$ & $-67,41$ & $-63,88$ & $-60,09$ & $-56,21$ & $-52,53$ & $-49,52$ & $-47,84$ & $-48,78$ & $-55,30$ & $-77,32$ & $-188,25$ & - \\
\hline & DMA & 65,90 & 58,11 & 51,72 & 44,83 & 37,96 & 31,54 & 32,61 & 40,91 & 53,46 & 79,18 & 190,56 & - \\
\hline & PDMA & 60,35 & 49,20 & 37,18 & 21,94 & 6,47 & $-17,05$ & $-21,86$ & $-23,79$ & $-31,84$ & $-49,00$ & $-67,05$ & - \\
\hline \multicolumn{14}{|c|}{ Desconsiderando ${ }^{1} J_{\mathrm{BF}}$ da molécula de $\mathrm{BF}_{3},{ }^{2} J_{\mathrm{CH}}$ e ${ }^{2} J_{\mathrm{HH}}$ da molécula de $\mathrm{C}_{2} \mathrm{H}_{4}$} \\
\hline \multirow[t]{3}{*}{ Total } & DM & $-24,82$ & $-22,80$ & $-20,55$ & $-18,14$ & $-15,68$ & $-13,33$ & $-11,34$ & $-10,23$ & $-11,20$ & $-18,56$ & $-66,43$ & - \\
\hline & DMA & 33,02 & 30,51 & 28,77 & 27,47 & 26,41 & 26,10 & 28,59 & 35,05 & 44,45 & 61,65 & 122,68 & - \\
\hline & PDMA & 20,60 & 17,40 & 14,78 & 14,55 & 16,04 & 19,23 & 25,00 & 33,93 & 44,83 & 60,02 & 93,09 & - \\
\hline \multirow[t]{3}{*}{ CPI } & DM & $-61,26$ & $-58,20$ & $-54,74$ & $-51,08$ & $-47,49$ & $-44,45$ & $-42,61$ & $-43,35$ & $-49,73$ & $-72,30$ & $-191,09$ & - \\
\hline & DMA & 68,76 & 62,36 & 57,60 & 53,02 & 48,69 & 45,47 & 48,17 & 58,95 & 75,39 & 107,96 & 237,91 & - \\
\hline & PDMA & 32,46 & 25,96 & 19,93 & 17,45 & 17,10 & 17,97 & 23,65 & 33,97 & 46,19 & 63,70 & 113,64 & - \\
\hline \multirow[t]{3}{*}{ SPI } & $\mathrm{DM}$ & 3,21 & 4,43 & 5,75 & 7,19 & 8,78 & 10,61 & 12,71 & 15,25 & 18,43 & 22,78 & 29,46 & - \\
\hline & DMA & 5,53 & 6,02 & 6,60 & 7,82 & 9,28 & 11,21 & 13,52 & 16,66 & 20,65 & 26,03 & 34,05 & - \\
\hline & PDMA & 11,48 & 10,82 & 10,82 & 12,32 & 15,23 & 20,20 & 26,03 & 33,90 & 43,77 & 57,20 & 77,27 & - \\
\hline \multirow[t]{3}{*}{$\Delta \mathrm{CS}$} & $\mathrm{DM}$ & $-64,47$ & $-62,63$ & $-60,49$ & $-58,27$ & $-56,27$ & $-55,06$ & $-55,32$ & $-58,60$ & $-68,16$ & $-95,08$ & $-220,55$ & - \\
\hline & DMA & 63,23 & 56,34 & 51,00 & 45,20 & 39,41 & 34,26 & 34,65 & 42,29 & 54,74 & 81,93 & 203,86 & - \\
\hline & PDMA & 20,98 & 15,15 & 9,11 & 5,13 & 1,88 & $-2,23$ & $-2,38$ & 0,07 & 2,42 & 6,50 & 36,37 & - \\
\hline
\end{tabular}

Tabela 8.258: Valores de PDMA total obtidos para troca PW91 com base HuzIII-su3.

\begin{tabular}{lccccccccccc}
\hline$E_{X}^{\mathrm{HF}}(\%)$ & $0 \%$ & $10 \%$ & $20 \%$ & $30 \%$ & $40 \%$ & $50 \%$ & $60 \%$ & $70 \%$ & $80 \%$ & $90 \%$ & $100 \%$ \\
\hline PW91B95 & 53,7 & 42,6 & 32,1 & 22,9 & 15,4 & 13,4 & 22,3 & 36,3 & 51,6 & 69,9 & 92,6 \\
PW91B98 & 47,5 & 36,6 & 26,7 & 21,3 & 19,6 & 24,7 & 39,3 & 56,6 & 75,6 & 99,1 & 131,6 \\
PW91B971 & 46,9 & 35,8 & 25,2 & 18,2 & 15,8 & 22,4 & 36,9 & 53,0 & 70,8 & 92,4 & 120,6 \\
PW91B972 & 47,0 & 36,4 & 27,4 & 19,1 & 17,9 & 27,0 & 37,0 & 51,7 & 69,2 & 90,2 & 119,3 \\
PW91LYP & 48,2 & 37,5 & 29,4 & 24,3 & 22,6 & 27,9 & 44,0 & 62,1 & 84,0 & 113,6 & 161,5 \\
PW91P86 & 51,2 & 39,8 & 29,8 & 23,9 & 23,4 & 25,0 & 33,8 & 52,8 & 74,7 & 105,4 & 156,7 \\
PW91PBE & 49,2 & 38,1 & 29,2 & 27,8 & 28,7 & 31,1 & 41,0 & 62,2 & 87,6 & 125,2 & 196,2 \\
PW91PW91 & 48,9 & 37,8 & 28,9 & 27,4 & 28,1 & 30,8 & 41,6 & 63,0 & 88,4 & 126,1 & 197,9 \\
PW91TPSS & 52,1 & 41,1 & 32,4 & 28,8 & 28,3 & 31,5 & 42,8 & 63,9 & 90,7 & 128,2 & 197,2 \\
\hline
\end{tabular}




\subsubsection{Troca S}

Tabela 8.259: Constantes de acoplamento SB95 com base aug-pcJ-2.

\begin{tabular}{|c|c|c|c|c|c|c|c|c|c|c|c|c|c|}
\hline & $\% E_{X}^{\mathrm{HF}}$ & $0 \%$ & $10 \%$ & $20 \%$ & $30 \%$ & $40 \%$ & $50 \%$ & $60 \%$ & $70 \%$ & $80 \%$ & $90 \%$ & $100 \%$ & Exp. \\
\hline $\mathrm{HF}$ & ${ }^{1} J_{\mathrm{HF}}$ & 422,2 & 441,6 & 461,6 & 482,3 & 503,6 & 526,3 & 548,4 & 571,9 & 596,3 & 621,4 & 647,4 & 500 \\
\hline $\mathrm{CO}$ & ${ }^{1} J_{\mathrm{CO}}$ & 26,6 & 24,9 & 23,0 & 21,0 & 18,8 & 16,5 & 14,0 & 11,4 & 8,6 & 5,6 & 2,4 & 16,4 \\
\hline $\mathrm{H}_{2} \mathrm{O}$ & ${ }^{1} J_{\mathrm{OH}}$ & $-67,7$ & $-70,0$ & $-72,5$ & $-75,0$ & $-77,7$ & $-80,4$ & $-83,3$ & $-86,3$ & $-89,5$ & $-92,7$ & $-96,2$ & $-80,6$ \\
\hline $\mathrm{H}_{2} \mathrm{O}$ & ${ }^{2} J_{\mathrm{HH}}$ & $-2,1$ & $-3,1$ & $-4,2$ & $-5,3$ & $-6,4$ & $-7,6$ & $-8,9$ & $-10,2$ & $-11,6$ & $-13,1$ & $-14,7$ & $-7,3$ \\
\hline $\mathrm{NH}_{3}$ & ${ }^{1} J_{\mathrm{NH}}$ & 37,1 & 38,1 & 39,1 & 40,2 & 41,4 & 42,6 & 43,8 & 45,2 & 46,5 & 48,0 & 49,5 & 43,8 \\
\hline $\mathrm{NH}_{3}$ & ${ }^{2} J_{\mathrm{HH}}$ & $-4,1$ & $-5,0$ & $-6,0$ & $-7,0$ & $-8,0$ & $-9,2$ & $-10,3$ & $-11,6$ & $-12,9$ & $-14,3$ & $-15,8$ & $-9,6$ \\
\hline $\mathrm{PH}_{3}$ & ${ }^{1} J_{\mathrm{PH}}$ & 126,1 & 133,8 & 141,8 & 150,2 & 158,8 & 167,8 & 177,1 & 186,6 & 196,5 & 206,6 & 217,0 & 188,2 \\
\hline $\mathrm{PF}_{3}$ & ${ }^{1} J_{\mathrm{PF}}$ & $-1722,6$ & $-1707,6$ & $-1686,2$ & $-1659,3$ & $-1627,6$ & $-1591,8$ & $-1552,6$ & $-1510,7$ & $-1466,4$ & $-1420,3$ & $-1372,8$ & -1441 \\
\hline $\mathrm{BHF}_{2}$ & ${ }^{1} J_{\mathrm{BF}}$ & $-192,9$ & $-175,8$ & $-158,4$ & $-140,6$ & $-122,5$ & $-104,2$ & $-85,7$ & $-67,1$ & $-48,3$ & $-29,4$ & $-10,5$ & -84 \\
\hline $\mathrm{BF}_{3}$ & ${ }^{1} J_{\mathrm{BF}}$ & $-88,3$ & $-70,4$ & $-52,2$ & $-33,8$ & $-15,2$ & 3,5 & 22,4 & 41,5 & 60,8 & 80,2 & 99,7 & 15 \\
\hline $\mathrm{F}_{2} \mathrm{O}$ & ${ }^{1} J_{\mathrm{OF}}$ & $-266,1$ & $-300,1$ & $-332,7$ & $-364,9$ & $-398,1$ & $-434,1$ & $-476,2$ & $-529,9$ & $-607,1$ & $-738,7$ & $-1048,5$ & -300 \\
\hline $\mathrm{CH}_{4}$ & ${ }^{1} J_{\mathrm{CH}}$ & 97,1 & 100,0 & 103,2 & 106,5 & 109,9 & 113,6 & 117,5 & 121,5 & 125,8 & 130,2 & 134,9 & 125,3 \\
\hline $\mathrm{CH}_{4}$ & ${ }^{2} J_{\mathrm{HH}}$ & $-6,4$ & $-7,3$ & $-8,2$ & $-9,2$ & $-10,2$ & $-11,2$ & $-12,3$ & $-13,4$ & $-14,6$ & $-15,8$ & $-17,0$ & $-12,8$ \\
\hline $\mathrm{C}_{2} \mathrm{H}_{2}$ & ${ }^{1} J_{\mathrm{CC}}$ & 166,5 & 170,1 & 173,9 & 178,3 & 183,1 & 188,6 & 195,0 & 202,5 & 211,3 & 222,1 & 235,5 & 174,8 \\
\hline $\mathrm{C}_{2} \mathrm{H}_{2}$ & ${ }^{1} J_{\mathrm{CH}}$ & 208,4 & 213,4 & 218,6 & 224,2 & 230,0 & 236,2 & 242,9 & 250,2 & 258,2 & 267,1 & 277,3 & 247,6 \\
\hline $\mathrm{C}_{2} \mathrm{H}_{2}$ & ${ }^{2} J_{\mathrm{CH}}$ & 49,3 & 50,3 & 51,2 & 51,9 & 52,5 & 52,8 & 52,7 & 52,2 & 51,2 & 49,3 & 46,4 & 50,1 \\
\hline $\mathrm{C}_{2} \mathrm{H}_{2}$ & ${ }^{3} J_{\mathrm{HH}}$ & 6,5 & 7,0 & 7,5 & 8,1 & 8,9 & 9,8 & 11,0 & 12,3 & 14,1 & 16,2 & 18,9 & 9,6 \\
\hline $\mathrm{C}_{2} \mathrm{H}_{4}$ & ${ }^{1} J_{\mathrm{CC}}$ & 44,4 & 47,4 & 50,5 & 54,0 & 57,9 & 62,2 & 67,2 & 73,0 & 80,1 & 89,0 & 100,8 & 67,6 \\
\hline $\mathrm{C}_{2} \mathrm{H}_{4}$ & ${ }^{1} J_{\mathrm{CH}}$ & 125,7 & 129,4 & 133,4 & 137,6 & 142,0 & 146,7 & 151,7 & 157,3 & 163,4 & 170,4 & 178,7 & 156,3 \\
\hline $\mathrm{C}_{2} \mathrm{H}_{4}$ & ${ }^{2} J_{\mathrm{CH}}$ & 1,4 & 0,9 & 0,3 & $-0,3$ & $-1,1$ & $-2,1$ & $-3,3$ & $-4,9$ & $-6,9$ & $-9,6$ & $-13,4$ & $-2,4$ \\
\hline $\mathrm{C}_{2} \mathrm{H}_{4}$ & ${ }^{2} J_{\mathrm{HH}}$ & 5,6 & 5,1 & 4,6 & 4,1 & 3,5 & 2,8 & 2,0 & 1,1 & 0,0 & $-1,5$ & $-3,5$ & 2,3 \\
\hline $\mathrm{C}_{2} \mathrm{H}_{4}$ & ${ }^{3} J_{\mathrm{HH}_{\mathrm{c}}}$ & 10,2 & 10,4 & 10,7 & 11,0 & 11,3 & 11,7 & 12,3 & 13,0 & 13,9 & 15,1 & 16,9 & 11,7 \\
\hline $\mathrm{C}_{2} \mathrm{H}_{4}$ & ${ }^{3} J_{\mathrm{HH}_{\mathrm{t}}}$ & 14,9 & 15,3 & 15,7 & 16,2 & 16,8 & 17,5 & 18,3 & 19,4 & 20,7 & 22,4 & 24,7 & 19 \\
\hline $\mathrm{C}_{2} \mathrm{H}_{6}$ & ${ }^{1} J_{\mathrm{CC}}$ & 15,7 & 18,0 & 20,4 & 23,0 & 25,7 & 28,6 & 31,7 & 34,9 & 38,3 & 41,9 & 45,7 & 34,5 \\
\hline $\mathrm{C}_{2} \mathrm{H}_{6}$ & ${ }^{1} J_{\mathrm{CH}}$ & 97,5 & 100,6 & 103,9 & 107,3 & 111,0 & 114,8 & 118,8 & 123,0 & 127,3 & 131,9 & 136,7 & 125,2 \\
\hline $\mathrm{C}_{2} \mathrm{H}_{6}$ & ${ }^{2} J_{\mathrm{CH}}$ & $-1,4$ & $-1,8$ & $-2,3$ & $-2,7$ & $-3,2$ & $-3,7$ & $-4,3$ & $-4,9$ & $-5,5$ & $-6,2$ & $-6,9$ & $-4,7$ \\
\hline \multirow[t]{3}{*}{ Total } & DM & $-28,52$ & $-26,15$ & $-23,40$ & $-20,28$ & $-16,92$ & $-13,36$ & $-9,81$ & $-6,42$ & $-3,65$ & $-2,66$ & $-8,15$ & - \\
\hline & DMA & 35,02 & 29,42 & 26,05 & 22,55 & 19,12 & 16,98 & 16,08 & 18,75 & 24,52 & 34,91 & 54,82 & - \\
\hline & PDMA & 68,60 & 57,48 & 46,73 & 35,90 & 24,31 & 12,64 & 11,87 & 24,50 & 41,94 & 63,25 & 90,89 & - \\
\hline \multirow{3}{*}{ CPI } & $\mathrm{DM}$ & $-52,06$ & $-48,59$ & $-44,33$ & $-39,37$ & $-33,98$ & $-28,32$ & $-22,93$ & $-18,19$ & $-15,27$ & $-17,05$ & $-34,85$ & - \\
\hline & DMA & 64,37 & 53,66 & 48,22 & 42,06 & 36,05 & 33,23 & 33,07 & 39,41 & 49,60 & 68,78 & 109,09 & - \\
\hline & PDMA & 101,79 & 83,74 & 67,07 & 50,08 & 32,90 & 16,71 & 16,42 & 35,89 & 57,61 & 81,84 & 112,26 & - \\
\hline \multirow[t]{3}{*}{ SPI } & $\mathrm{DM}$ & $-11,25$ & $-9,69$ & $-8,05$ & $-6,27$ & $-4,40$ & $-2,39$ & $-0,19$ & 2,21 & 4,88 & 7,89 & 11,44 & - \\
\hline & DMA & 13,49 & 11,65 & 9,79 & 8,25 & 6,71 & 5,07 & 3,62 & 3,61 & 6,13 & 10,07 & 15,03 & - \\
\hline & PDMA & 44,26 & 38,22 & 31,81 & 25,50 & 18,01 & 9,65 & 8,53 & 16,15 & 30,45 & 49,61 & 75,22 & - \\
\hline \multirow[t]{3}{*}{$\Delta \mathrm{CS}$} & $\mathrm{DM}$ & $-40,82$ & $-38,90$ & $-36,28$ & $-33,10$ & $-29,58$ & $-25,93$ & $-22,73$ & $-20,40$ & $-20,15$ & $-24,95$ & $-46,29$ & - \\
\hline & DMA & 50,89 & 42,02 & 38,42 & 33,82 & 29,35 & 28,16 & 29,45 & 35,80 & 43,47 & 58,72 & 94,06 & - \\
\hline & PDMA & 57,53 & 45,53 & 35,26 & 24,58 & 14,89 & 7,06 & 7,89 & 19,74 & 27,16 & 32,23 & 37,04 & - \\
\hline \multicolumn{14}{|c|}{ Desconsiderando ${ }^{1} J_{\mathrm{BF}}$ da molécula de $\mathrm{BF}_{3},{ }^{2} J_{\mathrm{CH}}$ e ${ }^{2} J_{\mathrm{HH}}$ da molécula de $\mathrm{C}_{2} \mathrm{H}_{4}$} \\
\hline \multirow[t]{3}{*}{ Total } & DM & $-28,05$ & $-26,11$ & $-23,74$ & $-20,97$ & $-17,92$ & $-14,63$ & $-11,36$ & $-8,25$ & $-5,82$ & $-5,37$ & $-12,16$ & - \\
\hline & DMA & 34,78 & 29,28 & 26,31 & 23,20 & 20,20 & 18,66 & 17,80 & 19,89 & 25,43 & 36,15 & 57,56 & - \\
\hline & PDMA & 34,49 & 28,95 & 24,11 & 19,23 & 14,10 & 9,47 & 9,07 & 13,22 & 21,63 & 32,37 & 47,30 & - \\
\hline \multirow[t]{3}{*}{ CPI } & DM & $-46,94$ & $-44,91$ & $-42,04$ & $-38,43$ & $-34,36$ & $-30,00$ & $-25,96$ & $-22,66$ & $-21,38$ & $-25,28$ & $-46,81$ & - \\
\hline & DMA & 60,48 & 50,49 & 46,32 & 41,39 & 36,64 & 35,40 & 35,64 & 40,70 & 49,98 & 69,14 & 111,53 & - \\
\hline & PDMA & 43,11 & 35,19 & 28,98 & 22,56 & 16,05 & 10,72 & 13,13 & 21,81 & 32,83 & 46,56 & 67,02 & - \\
\hline \multirow[t]{3}{*}{ SPI } & $\mathrm{DM}$ & $-13,52$ & $-11,65$ & $-9,67$ & $-7,54$ & $-5,27$ & $-2,82$ & $-0,13$ & 2,83 & 6,15 & 9,95 & 14,49 & - \\
\hline & DMA & 15,02 & 12,97 & 10,92 & 9,22 & 7,55 & 5,78 & 4,08 & 3,88 & 6,55 & 10,77 & 16,05 & - \\
\hline & PDMA & 27,85 & 24,15 & 20,36 & 16,68 & 12,60 & 8,50 & 5,96 & 6,61 & 13,01 & 21,46 & 32,14 & - \\
\hline \multirow[t]{3}{*}{$\Delta \mathrm{CS}$} & $\mathrm{DM}$ & $-33,42$ & $-33,26$ & $-32,37$ & $-30,89$ & $-29,09$ & $-27,18$ & $-25,83$ & $-25,49$ & $-27,53$ & $-35,23$ & $-61,30$ & - \\
\hline & DMA & 45,46 & 37,52 & 35,40 & 32,17 & 29,09 & 29,62 & 31,56 & 36,82 & 43,43 & 58,37 & 95,48 & - \\
\hline & PDMA & 15,25 & 11,03 & 8,62 & 5,88 & 3,45 & 2,22 & 7,17 & 15,20 & 19,82 & 25,10 & 34,88 & - \\
\hline
\end{tabular}


8.4. GERAÇÃO DE NOVOS FUNCIONAIS COMBINANDO $E_{X}^{H F}, E_{X}^{D F T} E$

Tabela 8.260: Constantes de acoplamento SB971 com base aug-pcJ-2.

\begin{tabular}{|c|c|c|c|c|c|c|c|c|c|c|c|c|c|}
\hline & $\% E_{X}^{\mathrm{HF}}$ & $0 \%$ & $10 \%$ & $20 \%$ & $30 \%$ & $40 \%$ & $50 \%$ & $60 \%$ & $70 \%$ & $80 \%$ & $90 \%$ & $100 \%$ & Exp. \\
\hline $\mathrm{HF}$ & ${ }^{1} J_{\mathrm{HF}}$ & 429,2 & 447,9 & 467,2 & 487,0 & 507,4 & 528,4 & 550,1 & 572,5 & 595,5 & 619,3 & 643,9 & 500 \\
\hline $\mathrm{CO}$ & ${ }^{1} J_{\mathrm{CO}}$ & 24,9 & 23,1 & 21,1 & 18,9 & 16,6 & 14,1 & 11,4 & 8,5 & 5,4 & 2,1 & $-1,3$ & 16,4 \\
\hline $\mathrm{H}_{2} \mathrm{O}$ & ${ }^{1} J_{\mathrm{OH}}$ & $-68,4$ & $-70,7$ & $-73,0$ & $-75,5$ & $-78,0$ & $-80,7$ & $-83,5$ & $-86,4$ & $-89,4$ & $-92,5$ & $-95,7$ & $-80,6$ \\
\hline $\mathrm{H}_{2} \mathrm{O}$ & ${ }^{2} J_{\mathrm{HH}}$ & $-2,2$ & $-3,2$ & $-4,2$ & $-5,3$ & $-6,4$ & $-7,5$ & $-8,8$ & $-10,0$ & $-11,4$ & $-12,8$ & $-14,3$ & $-7,3$ \\
\hline $\mathrm{NH}_{3}$ & ${ }^{1} J_{\mathrm{NH}}$ & 37,8 & 38,8 & 39,9 & 41,0 & 42,2 & 43,5 & 44,8 & 46,1 & 47,5 & 49,0 & 50,6 & 43,8 \\
\hline $\mathrm{NH}_{3}$ & ${ }^{2} J_{\mathrm{HH}}$ & $-4,3$ & $-5,2$ & $-6,2$ & $-7,2$ & $-8,2$ & $-9,4$ & $-10,6$ & $-11,8$ & $-13,2$ & $-14,6$ & $-16,1$ & $-9,6$ \\
\hline $\mathrm{PH}_{3}$ & ${ }^{1} J_{\mathrm{PH}}$ & 154,4 & 162,3 & 170,3 & 178,5 & 186,9 & 195,5 & 204,3 & 213,2 & 222,2 & 231,4 & 240,7 & 188,2 \\
\hline $\mathrm{PF}_{3}$ & ${ }^{1} J_{\mathrm{PF}}$ & $-1766,6$ & $-1749,4$ & $-1725,8$ & $-1696,7$ & $-1662,7$ & $-1624,8$ & $-1583,4$ & $-1539,2$ & $-1492,7$ & $-1444,5$ & $-1394,8$ & -1441 \\
\hline $\mathrm{BHF}_{2}$ & ${ }^{1} J_{\mathrm{BF}}$ & $-182,6$ & $-164,5$ & $-146,0$ & $-127,3$ & $-108,3$ & $-89,0$ & $-69,7$ & $-50,3$ & $-30,8$ & $-11,3$ & 8,1 & -84 \\
\hline $\mathrm{BF}_{3}$ & ${ }^{1} J_{\mathrm{BF}}$ & $-77,0$ & $-58,3$ & $-39,4$ & $-20,4$ & $-1,1$ & 18,2 & 37,8 & 57,4 & 77,1 & 96,9 & 116,8 & 15 \\
\hline $\mathrm{F}_{2} \mathrm{O}$ & ${ }^{1} J_{\mathrm{OF}}$ & $-260,9$ & $-295,0$ & $-328,0$ & $-361,1$ & $-395,6$ & $-434,0$ & $-479,7$ & $-539,8$ & $-629,2$ & $-790,7$ & $-1221,3$ & -300 \\
\hline $\mathrm{CH}_{4}$ & ${ }^{1} J_{\mathrm{CH}}$ & 103,6 & 106,9 & 110,3 & 113,9 & 117,8 & 121,8 & 126,0 & 130,4 & 135,1 & 140,0 & 145,1 & 125,3 \\
\hline $\mathrm{CH}_{4}$ & ${ }^{2} J_{\mathrm{HH}}$ & $-6,5$ & $-7,4$ & $-8,3$ & $-9,3$ & $-10,3$ & $-11,4$ & $-12,5$ & $-13,6$ & $-14,8$ & $-16,1$ & $-17,3$ & $-12,8$ \\
\hline $\mathrm{C}_{2} \mathrm{H}_{2}$ & ${ }^{1} J_{\mathrm{CC}}$ & 182,5 & 187,1 & 192,2 & 197,9 & 204,3 & 211,6 & 220,1 & 230,1 & 242,1 & 256,7 & 275,1 & 174,8 \\
\hline $\mathrm{C}_{2} \mathrm{H}_{2}$ & ${ }^{1} J_{\mathrm{CH}}$ & 217,3 & 222,8 & 228,5 & 234,6 & 241,1 & 248,1 & 255,6 & 263,9 & 273,0 & 283,4 & 295,5 & 247,6 \\
\hline $\mathrm{C}_{2} \mathrm{H}_{2}$ & ${ }^{2} J_{\mathrm{CH}}$ & 48,6 & 49,5 & 50,2 & 50,7 & 50,9 & 50,8 & 50,3 & 49,2 & 47,3 & 44,5 & 40,1 & 50,1 \\
\hline $\mathrm{C}_{2} \mathrm{H}_{2}$ & ${ }^{3} J_{\mathrm{HH}}$ & 6,4 & 6,8 & 7,4 & 8,1 & 9,0 & 10,0 & 11,3 & 12,9 & 14,9 & 17,3 & 20,5 & 9,6 \\
\hline $\mathrm{C}_{2} \mathrm{H}_{4}$ & ${ }^{1} J_{\mathrm{CC}}$ & 54,2 & 57,8 & 61,8 & 66,1 & 71,0 & 76,6 & 83,0 & 90,8 & 100,3 & 112,9 & 130,5 & 67,6 \\
\hline $\mathrm{C}_{2} \mathrm{H}_{4}$ & ${ }^{1} J_{\mathrm{CH}}$ & 132,4 & 136,5 & 140,8 & 145,4 & 150,3 & 155,5 & 161,2 & 167,4 & 174,5 & 182,8 & 193,0 & 156,3 \\
\hline $\mathrm{C}_{2} \mathrm{H}_{4}$ & ${ }^{2} J_{\mathrm{CH}}$ & 0,7 & 0,0 & $-0,6$ & $-1,4$ & $-2,4$ & $-3,6$ & $-5,1$ & $-7,1$ & $-9,7$ & $-13,3$ & $-18,8$ & $-2,4$ \\
\hline $\mathrm{C}_{2} \mathrm{H}_{4}$ & ${ }^{2} J_{\mathrm{HH}}$ & 5,3 & 4,8 & 4,3 & 3,7 & 3,1 & 2,3 & 1,5 & 0,4 & $-0,8$ & $-2,6$ & $-5,1$ & 2,3 \\
\hline $\mathrm{C}_{2} \mathrm{H}_{4}$ & ${ }^{3} J_{\mathrm{HH}_{\mathrm{C}}}$ & 10,2 & 10,4 & 10,6 & 10,9 & 11,3 & 11,8 & 12,4 & 13,1 & 14,2 & 15,7 & 18,0 & 11,7 \\
\hline $\mathrm{C}_{2} \mathrm{H}_{4}$ & ${ }^{3} J_{\mathrm{HH}_{\mathrm{t}}}$ & 14,8 & 15,1 & 15,6 & 16,1 & 16,7 & 17,5 & 18,4 & 19,5 & 21,0 & 23,0 & 25,9 & 19 \\
\hline $\mathrm{C}_{2} \mathrm{H}_{6}$ & ${ }^{1} J_{\mathrm{CC}}$ & 19,8 & 22,4 & 25,2 & 28,1 & 31,3 & 34,6 & 38,1 & 41,8 & 45,8 & 50,0 & 54,4 & 34,5 \\
\hline $\mathrm{C}_{2} \mathrm{H}_{6}$ & ${ }^{1} J_{\mathrm{CH}}$ & 103,9 & 107,4 & 111,0 & 114,8 & 118,8 & 123,0 & 127,4 & 131,9 & 136,7 & 141,8 & 147,0 & 125,2 \\
\hline $\mathrm{C}_{2} \mathrm{H}_{6}$ & ${ }^{2} J_{\mathrm{CH}}$ & $-1,5$ & $-2,0$ & $-2,5$ & $-3,0$ & $-3,5$ & $-4,1$ & $-4,7$ & $-5,3$ & $-6,0$ & $-6,8$ & $-7,5$ & $-4,7$ \\
\hline \multirow[t]{3}{*}{ Total } & $\mathrm{DM}$ & $-25,73$ & $-23,12$ & $-20,10$ & $-16,79$ & $-13,18$ & $-9,47$ & $-5,74$ & $-2,28$ & 0,37 & 0,64 & $-8,92$ & - \\
\hline & DMA & 32,92 & 27,38 & 23,70 & 20,12 & 17,08 & 16,29 & 20,15 & 25,83 & 33,05 & 43,54 & 68,67 & - \\
\hline & PDMA & 60,81 & 49,11 & 37,97 & 26,24 & 14,33 & 9,30 & 21,90 & 39,09 & 59,28 & 84,00 & 118,03 & - \\
\hline \multirow[t]{3}{*}{ CPI } & $\mathrm{DM}$ & $-50,60$ & $-46,83$ & $-42,27$ & $-37,18$ & $-31,65$ & $-26,05$ & $-20,75$ & $-16,43$ & $-14,54$ & $-18,96$ & $-47,66$ & - \\
\hline & DMA & 63,36 & 52,30 & 45,69 & 39,36 & 33,92 & 33,16 & 39,71 & 48,41 & 59,72 & 77,56 & 128,26 & - \\
\hline & PDMA & 91,29 & 72,57 & 55,14 & 37,62 & 20,06 & 10,36 & 29,52 & 50,71 & 73,45 & 98,58 & 132,83 & - \\
\hline \multirow[t]{3}{*}{ SPI } & $\mathrm{DM}$ & $-7,49$ & $-5,73$ & $-3,84$ & $-1,83$ & 0,35 & 2,69 & 5,26 & 8,09 & 11,30 & 15,01 & 19,49 & - \\
\hline & DMA & 10,60 & 9,11 & 7,57 & 6,01 & 4,74 & 3,92 & 5,81 & 9,27 & 13,50 & 18,59 & 24,97 & - \\
\hline & PDMA & 38,46 & 31,90 & 25,38 & 17,91 & 10,13 & 8,53 & 16,31 & 30,56 & 48,90 & 73,30 & 107,17 & - \\
\hline \multirow[t]{3}{*}{$\Delta \mathrm{CS}$} & $\mathrm{DM}$ & $-43,11$ & $-41,09$ & $-38,43$ & $-35,35$ & $-32,00$ & $-28,75$ & $-26,01$ & $-24,51$ & $-25,84$ & $-33,98$ & $-67,15$ & - \\
\hline & DMA & 52,76 & 43,19 & 38,12 & 33,36 & 29,18 & 29,24 & 33,90 & 39,14 & 46,22 & 58,98 & 103,30 & - \\
\hline & PDMA & 52,83 & 40,67 & 29,75 & 19,71 & 9,93 & 1,83 & 13,21 & 20,15 & 24,55 & 25,28 & 25,65 & - \\
\hline \multicolumn{14}{|c|}{ Desconsiderando ${ }^{1} J_{\mathrm{BF}}$ da molécula de $\mathrm{BF}_{3},{ }^{2} J_{\mathrm{CH}}$ e ${ }^{2} J_{\mathrm{HH}}$ da molécula de $\mathrm{C}_{2} \mathrm{H}_{4}$} \\
\hline \multirow[t]{3}{*}{ Total } & DM & $-25,35$ & $-23,16$ & $-20,52$ & $-17,54$ & $-14,24$ & $-10,79$ & $-7,33$ & $-4,14$ & $-1,83$ & $-2,15$ & $-13,48$ & - \\
\hline & DMA & 32,95 & 27,55 & 24,26 & 21,10 & 18,58 & 18,23 & 21,63 & 27,07 & 34,21 & 44,97 & 72,17 & - \\
\hline & PDMA & 30,79 & 25,19 & 20,12 & 14,95 & 10,02 & 7,41 & 11,74 & 19,79 & 29,93 & 42,20 & 60,22 & - \\
\hline \multirow[t]{3}{*}{ CPI } & $\mathrm{DM}$ & $-46,46$ & $-44,18$ & $-41,06$ & $-37,36$ & $-33,20$ & $-28,98$ & $-25,10$ & $-22,31$ & $-22,20$ & $-29,05$ & $-62,61$ & - \\
\hline & DMA & 60,50 & 50,20 & 44,82 & 39,76 & 35,70 & 36,16 & 41,40 & 49,01 & 59,48 & 77,13 & 130,91 & - \\
\hline & PDMA & 39,09 & 30,96 & 24,39 & 17,78 & 11,34 & 9,26 & 17,27 & 27,52 & 39,39 & 53,84 & 78,24 & - \\
\hline \multirow[t]{3}{*}{ SPI } & DM & $-9,12$ & $-6,99$ & $-4,72$ & $-2,30$ & 0,35 & 3,20 & 6,34 & 9,84 & 13,84 & 18,54 & 24,32 & - \\
\hline & DMA & 11,76 & 10,13 & 8,45 & 6,75 & 5,41 & 4,43 & 6,43 & 10,19 & 14,78 & 20,23 & 26,98 & - \\
\hline & PDMA & 24,40 & 20,76 & 16,83 & 12,77 & 9,01 & 6,00 & 7,49 & 13,85 & 22,65 & 33,25 & 46,35 & - \\
\hline \multirow[t]{3}{*}{$\Delta \mathrm{CS}$} & $\mathrm{DM}$ & $-37,34$ & $-37,19$ & $-36,34$ & $-35,06$ & $-33,55$ & $-32,18$ & $-31,44$ & $-32,15$ & $-36,04$ & $-47,59$ & $-86,93$ & - \\
\hline & DMA & 48,74 & 40,07 & 36,37 & 33,01 & 30,29 & 31,73 & 34,97 & 38,82 & 44,70 & 56,90 & 103,93 & - \\
\hline & PDMA & 14,68 & 10,21 & 7,55 & 5,00 & 2,32 & 3,26 & 9,78 & 13,67 & 16,74 & 20,59 & 31,89 & - \\
\hline
\end{tabular}


Tabela 8.261: Constantes de acoplamento SB972 com base aug-pcJ-2.

\begin{tabular}{|c|c|c|c|c|c|c|c|c|c|c|c|c|c|}
\hline & $\% E_{X}^{\mathrm{HF}}$ & $0 \%$ & $10 \%$ & $20 \%$ & $30 \%$ & $40 \%$ & $50 \%$ & $60 \%$ & $70 \%$ & $80 \%$ & $90 \%$ & $100 \%$ & Exp. \\
\hline $\mathrm{HF}$ & ${ }^{1} J_{\mathrm{HF}}$ & 463,6 & 483,4 & 503,8 & 524,8 & 546,5 & 568,8 & 591,8 & 615,6 & 640,1 & 665,4 & 691,6 & 500 \\
\hline $\mathrm{CO}$ & ${ }^{1} J_{\mathrm{CO}}$ & 21,4 & 19,3 & 17,0 & 14,6 & 11,9 & 9,0 & 6,0 & 2,7 & $-0,7$ & $-4,4$ & $-8,3$ & 16,4 \\
\hline $\mathrm{H}_{2} \mathrm{O}$ & ${ }^{1} J_{\mathrm{OH}}$ & $-73,6$ & $-76,1$ & $-78,6$ & $-81,3$ & $-84,0$ & $-86,9$ & $-89,9$ & $-93,0$ & $-96,2$ & $-99,6$ & $-103,1$ & $-80,6$ \\
\hline $\mathrm{H}_{2} \mathrm{O}$ & ${ }^{2} J_{\mathrm{HH}}$ & $-2,0$ & $-3,0$ & $-4,1$ & $-5,2$ & $-6,3$ & $-7,5$ & $-8,7$ & $-10,0$ & $-11,4$ & $-12,8$ & $-14,3$ & $-7,3$ \\
\hline $\mathrm{NH}_{3}$ & ${ }^{1} J_{\mathrm{NH}}$ & 39,9 & 41,0 & 42,1 & 43,3 & 44,5 & 45,8 & 47,1 & 48,5 & 50,0 & 51,5 & 53,1 & 43,8 \\
\hline $\mathrm{NH}_{3}$ & ${ }^{2} J_{\mathrm{HH}}$ & $-3,8$ & $-4,7$ & $-5,6$ & $-6,6$ & $-7,7$ & $-8,8$ & $-9,9$ & $-11,2$ & $-12,5$ & $-13,8$ & $-15,2$ & $-9,6$ \\
\hline $\mathrm{PH}_{3}$ & ${ }^{1} J_{\mathrm{PH}}$ & 141,0 & 149,6 & 158,6 & 167,9 & 177,6 & 187,6 & 198,0 & 208,7 & 219,7 & 231,0 & 242,5 & 188,2 \\
\hline $\mathrm{PF}_{3}$ & ${ }^{1} J_{\mathrm{PF}}$ & $-1811,0$ & $-1793,2$ & $-1768,7$ & $-1738,3$ & $-1703,0$ & $-1663,4$ & $-1620,4$ & $-1574,4$ & $-1526,2$ & $-1476,2$ & $-1424,9$ & -1441 \\
\hline $\mathrm{BHF}_{2}$ & ${ }^{1} J_{\mathrm{BF}}$ & $-169,3$ & $-150,9$ & $-132,2$ & $-113,4$ & $-94,4$ & $-75,3$ & $-56,2$ & $-37,0$ & $-17,8$ & 1,2 & 20,3 & -84 \\
\hline $\mathrm{BF}_{3}$ & ${ }^{1} J_{\mathrm{BF}}$ & $-61,4$ & $-42,5$ & $-23,5$ & $-4,4$ & 14,8 & 34,1 & 53,5 & 72,9 & 92,5 & 112,0 & 131,6 & 15 \\
\hline $\mathrm{F}_{2} \mathrm{O}$ & ${ }^{1} J_{\mathrm{OF}}$ & $-252,0$ & $-285,6$ & $-318,1$ & $-350,6$ & $-384,7$ & $-422,6$ & $-468,2$ & $-529,1$ & $-622,2$ & $-799,7$ & $-1349,0$ & -300 \\
\hline $\mathrm{CH}_{4}$ & ${ }^{1} J_{\mathrm{CH}}$ & 106,0 & 109,3 & 112,6 & 116,2 & 119,9 & 123,9 & 128,0 & 132,3 & 136,8 & 141,6 & 146,5 & 125,3 \\
\hline $\mathrm{CH}_{4}$ & ${ }^{2} J_{\mathrm{HH}}$ & $-5,5$ & $-6,3$ & $-7,2$ & $-8,1$ & $-9,1$ & $-10,1$ & $-11,1$ & $-12,2$ & $-13,3$ & $-14,4$ & $-15,6$ & $-12,8$ \\
\hline $\mathrm{C}_{2} \mathrm{H}_{2}$ & ${ }^{1} J_{\mathrm{CC}}$ & 181,4 & 185,9 & 191,0 & 196,7 & 203,1 & 210,4 & 219,0 & 229,1 & 241,2 & 255,9 & 274,3 & 174,8 \\
\hline $\mathrm{C}_{2} \mathrm{H}_{2}$ & ${ }^{1} J_{\mathrm{CH}}$ & 219,4 & 224,7 & 230,3 & 236,2 & 242,4 & 249,1 & 256,4 & 264,3 & 273,0 & 282,8 & 294,1 & 247,6 \\
\hline $\mathrm{C}_{2} \mathrm{H}_{2}$ & ${ }^{2} J_{\mathrm{CH}}$ & 48,9 & 49,7 & 50,4 & 50,9 & 51,2 & 51,1 & 50,7 & 49,7 & 48,1 & 45,5 & 41,6 & 50,1 \\
\hline $\mathrm{C}_{2} \mathrm{H}_{2}$ & ${ }^{3} J_{\mathrm{HH}}$ & 6,0 & 6,4 & 6,9 & 7,5 & 8,3 & 9,2 & 10,2 & 11,6 & 13,3 & 15,4 & 18,0 & 9,6 \\
\hline $\mathrm{C}_{2} \mathrm{H}_{4}$ & ${ }^{1} J_{\mathrm{CC}}$ & 54,5 & 58,1 & 62,1 & 66,6 & 71,6 & 77,4 & 84,2 & 92,5 & 102,9 & 116,9 & 137,0 & 67,6 \\
\hline $\mathrm{C}_{2} \mathrm{H}_{4}$ & ${ }^{1} J_{\mathrm{CH}}$ & 134,3 & 138,3 & 142,5 & 147,0 & 151,8 & 156,9 & 162,4 & 168,6 & 175,5 & 183,7 & 194,0 & 156,3 \\
\hline $\mathrm{C}_{2} \mathrm{H}_{4}$ & ${ }^{2} J_{\mathrm{CH}}$ & 1,3 & 0,7 & 0,0 & $-0,7$ & $-1,6$ & $-2,8$ & $-4,3$ & $-6,2$ & $-8,8$ & $-12,5$ & $-18,1$ & $-2,4$ \\
\hline $\mathrm{C}_{2} \mathrm{H}_{4}$ & ${ }^{2} J_{\mathrm{HH}}$ & 6,1 & 5,7 & 5,3 & 4,8 & 4,2 & 3,6 & 2,8 & 1,9 & 0,8 & $-0,7$ & $-2,9$ & 2,3 \\
\hline $\mathrm{C}_{2} \mathrm{H}_{4}$ & ${ }^{3} J_{\mathrm{HH}_{\mathrm{c}}}$ & 10,0 & 10,1 & 10,3 & 10,6 & 10,9 & 11,3 & 11,7 & 12,4 & 13,3 & 14,6 & 16,6 & 11,7 \\
\hline $\mathrm{C}_{2} \mathrm{H}_{4}$ & ${ }^{3} J_{\mathrm{HH}_{\mathrm{t}}}$ & 14,6 & 14,9 & 15,3 & 15,7 & 16,3 & 16,9 & 17,7 & 18,7 & 20,0 & 21,8 & 24,4 & 19 \\
\hline $\mathrm{C}_{2} \mathrm{H}_{6}$ & ${ }^{1} J_{\mathrm{CC}}$ & 22,3 & 25,0 & 27,7 & 30,7 & 33,8 & 37,1 & 40,5 & 44,2 & 48,1 & 52,1 & 56,4 & 34,5 \\
\hline $\mathrm{C}_{2} \mathrm{H}_{6}$ & ${ }^{1} J_{\mathrm{CH}}$ & 105,6 & 109,0 & 112,5 & 116,3 & 120,1 & 124,2 & 128,4 & 132,9 & 137,5 & 142,4 & 147,5 & 125,2 \\
\hline $\mathrm{C}_{2} \mathrm{H}_{6}$ & ${ }^{2} J_{\mathrm{CH}}$ & $-1,0$ & $-1,4$ & $-1,9$ & $-2,4$ & $-2,9$ & $-3,4$ & $-3,9$ & $-4,5$ & $-5,2$ & $-5,8$ & $-6,5$ & $-4,7$ \\
\hline \multirow[t]{3}{*}{ Total } & DM & $-24,93$ & $-22,22$ & $-19,10$ & $-15,62$ & $-11,92$ & $-8,05$ & $-4,20$ & $-0,62$ & 2,06 & 1,88 & $-12,05$ & - \\
\hline & DMA & 32,33 & 26,71 & 22,47 & 20,53 & 18,97 & 20,04 & 24,43 & 29,98 & 37,29 & 48,40 & 75,85 & - \\
\hline & PDMA & 58,22 & 46,82 & 35,46 & 25,23 & 15,36 & 17,87 & 27,37 & 40,81 & 59,88 & 84,04 & 118,82 & - \\
\hline \multirow[t]{3}{*}{ CPI } & DM & $-49,83$ & $-45,78$ & $-40,93$ & $-35,46$ & $-29,61$ & $-23,65$ & $-17,98$ & $-13,38$ & $-11,42$ & $-16,94$ & $-56,05$ & - \\
\hline & DMA & 62,75 & 51,42 & 43,40 & 40,90 & 38,72 & 41,72 & 49,11 & 58,05 & 69,87 & 89,32 & 145,55 & - \\
\hline & PDMA & 78,73 & 59,60 & 41,35 & 26,42 & 12,89 & 25,15 & 44,24 & 65,90 & 88,88 & 114,55 & 152,13 & - \\
\hline \multirow[t]{3}{*}{ SPI } & DM & $-6,68$ & $-4,93$ & $-3,09$ & $-1,07$ & 1,06 & 3,38 & 5,91 & 8,75 & 11,94 & 15,68 & 20,21 & - \\
\hline & DMA & 10,03 & 8,59 & 7,13 & 5,59 & 4,49 & 4,14 & 6,33 & 9,40 & 13,39 & 18,40 & 24,75 & - \\
\hline & PDMA & 43,18 & 37,45 & 31,14 & 24,36 & 17,16 & 12,53 & 14,99 & 22,42 & 38,60 & 61,68 & 94,39 & - \\
\hline \multirow[t]{3}{*}{$\Delta \mathrm{CS}$} & DM & $-43,15$ & $-40,85$ & $-37,84$ & $-34,39$ & $-30,67$ & $-27,03$ & $-23,89$ & $-22,13$ & $-23,36$ & $-32,62$ & $-76,27$ & - \\
\hline & DMA & 52,73 & 42,83 & 36,27 & 35,31 & 34,23 & 37,58 & 42,78 & 48,65 & 56,48 & 70,92 & 120,80 & - \\
\hline & PDMA & 35,54 & 22,15 & 10,21 & 2,06 & $-4,27$ & 12,62 & 29,25 & 43,48 & 50,28 & 52,87 & 57,74 & - \\
\hline \multicolumn{14}{|c|}{ Desconsiderando ${ }^{1} J_{\mathrm{BF}}$ da molécula de $\mathrm{BF}_{3},{ }^{2} J_{\mathrm{CH}}$ e ${ }^{2} J_{\mathrm{HH}}$ da molécula de $\mathrm{C}_{2} \mathrm{H}_{4}$} \\
\hline \multirow[t]{3}{*}{ Total } & DM & $-25,19$ & $-22,90$ & $-20,15$ & $-17,00$ & $-13,58$ & $-9,97$ & $-6,36$ & $-3,03$ & $-0,70$ & $-1,52$ & $-17,79$ & - \\
\hline & DMA & 32,90 & 27,41 & 23,50 & 22,18 & 21,32 & 21,75 & 25,84 & 31,20 & 38,44 & 49,93 & 79,77 & - \\
\hline & PDMA & 29,79 & 24,22 & 18,91 & 15,09 & 12,26 & 11,48 & 15,39 & 21,71 & 30,79 & 42,92 & 62,25 & - \\
\hline \multirow[t]{3}{*}{ CPI } & DM & $-47,17$ & $-44,61$ & $-41,17$ & $-37,07$ & $-32,55$ & $-27,92$ & $-23,63$ & $-20,51$ & $-20,31$ & $-28,33$ & $-73,32$ & - \\
\hline & DMA & 61,39 & 50,81 & 43,89 & 43,05 & 42,57 & 43,98 & 50,17 & 58,07 & 69,11 & 88,55 & 148,44 & - \\
\hline & PDMA & 35,67 & 27,23 & 19,82 & 16,12 & 14,05 & 14,93 & 23,00 & 33,89 & 46,10 & 61,33 & 89,61 & - \\
\hline \multirow[t]{3}{*}{ SPI } & $\mathrm{DM}$ & $-8,28$ & $-6,19$ & $-3,98$ & $-1,56$ & 1,02 & 3,83 & 6,92 & 10,42 & 14,38 & 19,10 & 24,93 & - \\
\hline & DMA & 10,99 & 9,41 & 7,81 & 6,13 & 4,97 & 4,65 & 7,12 & 10,52 & 14,85 & 20,22 & 26,95 & - \\
\hline & PDMA & 25,26 & 21,91 & 18,21 & 14,30 & 10,88 & 8,82 & 9,54 & 12,35 & 19,01 & 28,76 & 41,20 & - \\
\hline \multirow[t]{3}{*}{$\Delta \mathrm{CS}$} & $\mathrm{DM}$ & $-38,89$ & $-38,42$ & $-37,19$ & $-35,51$ & $-33,57$ & $-31,75$ & $-30,55$ & $-30,93$ & $-34,69$ & $-47,43$ & $-98,25$ & - \\
\hline & DMA & 50,40 & 41,40 & 36,08 & 36,92 & 37,60 & 39,33 & 43,05 & 47,55 & 54,26 & 68,33 & 121,49 & - \\
\hline & PDMA & 10,41 & 5,32 & 1,61 & 1,83 & 3,16 & 6,11 & 13,46 & 21,54 & 27,09 & 32,58 & 48,41 & - \\
\hline
\end{tabular}


Tabela 8.262: Constantes de acoplamento SB98 com base aug-pcJ-2.

\begin{tabular}{|c|c|c|c|c|c|c|c|c|c|c|c|c|c|}
\hline & $\% E_{X}^{\mathrm{HF}}$ & $0 \%$ & $10 \%$ & $20 \%$ & $30 \%$ & $40 \%$ & $50 \%$ & $60 \%$ & $70 \%$ & $80 \%$ & $90 \%$ & $100 \%$ & Exp. \\
\hline $\mathrm{HF}$ & ${ }^{1} J_{\mathrm{HF}}$ & 419,3 & 437,9 & 457,0 & 476,8 & 497,1 & 518,0 & 539,6 & 561,9 & 584,9 & 608,6 & 633,1 & 500 \\
\hline $\mathrm{CO}$ & ${ }^{1} J_{\mathrm{CO}}$ & 24,7 & 22,9 & 20,9 & 18,7 & 16,3 & 13,8 & 11,1 & 8,3 & 5,2 & 1,9 & $-1,4$ & 16,4 \\
\hline $\mathrm{H}_{2} \mathrm{O}$ & ${ }^{1} J_{\mathrm{OH}}$ & $-67,9$ & $-70,2$ & $-72,6$ & $-75,1$ & $-77,7$ & $-80,4$ & $-83,2$ & $-86,1$ & $-89,1$ & $-92,3$ & $-95,6$ & $-80,6$ \\
\hline $\mathrm{H}_{2} \mathrm{O}$ & ${ }^{2} J_{\mathrm{HH}}$ & $-2,3$ & $-3,3$ & $-4,4$ & $-5,4$ & $-6,6$ & $-7,7$ & $-9,0$ & $-10,3$ & $-11,7$ & $-13,1$ & $-14,6$ & $-7,3$ \\
\hline $\mathrm{NH}_{3}$ & ${ }^{1} J_{\mathrm{NH}}$ & 38,3 & 39,3 & 40,4 & 41,6 & 42,8 & 44,1 & 45,4 & 46,8 & 48,3 & 49,8 & 51,5 & 43,8 \\
\hline $\mathrm{NH}_{3}$ & ${ }^{2} J_{\mathrm{HH}}$ & $-4,6$ & $-5,5$ & $-6,5$ & $-7,6$ & $-8,7$ & $-9,9$ & $-11,1$ & $-12,4$ & $-13,8$ & $-15,2$ & $-16,8$ & $-9,6$ \\
\hline $\mathrm{PH}_{3}$ & ${ }^{1} J_{\mathrm{PH}}$ & 160,0 & 168,1 & 176,3 & 184,7 & 193,3 & 202,1 & 211,0 & 220,0 & 229,2 & 238,5 & 247,9 & 188,2 \\
\hline $\mathrm{PF}_{3}$ & ${ }^{1} J_{\mathrm{PF}}$ & $-1780,9$ & $-1763,1$ & $-1738,8$ & $-1709,1$ & $-1674,6$ & $-1636,2$ & $-1594,3$ & $-1549,8$ & $-1503,0$ & $-1454,4$ & $-1404,5$ & -1441 \\
\hline $\mathrm{BHF}_{2}$ & ${ }^{1} J_{\mathrm{BF}}$ & $-182,5$ & $-164,6$ & $-146,4$ & $-127,8$ & $-109,0$ & $-90,0$ & $-70,8$ & $-51,6$ & $-32,3$ & $-13,0$ & 6,2 & -84 \\
\hline $\mathrm{BF}_{3}$ & ${ }^{1} J_{\mathrm{BF}}$ & $-77,8$ & $-59,4$ & $-40,8$ & $-21,9$ & $-2,9$ & 16,2 & 35,6 & 55,0 & 74,5 & 94,2 & 113,8 & 15 \\
\hline $\mathrm{F}_{2} \mathrm{O}$ & ${ }^{1} J_{\mathrm{OF}}$ & $-268,0$ & $-303,0$ & $-337,3$ & $-371,8$ & $-408,4$ & $-449,6$ & $-499,8$ & $-567,4$ & $-671,9$ & $-872,8$ & $-1507,1$ & -300 \\
\hline $\mathrm{CH}_{4}$ & ${ }^{1} J_{\mathrm{CH}}$ & 106,4 & 109,8 & 113,4 & 117,2 & 121,1 & 125,3 & 129,7 & 134,3 & 139,2 & 144,2 & 149,5 & 125,3 \\
\hline $\mathrm{CH}_{4}$ & ${ }^{2} J_{\mathrm{HH}}$ & $-6,9$ & $-7,8$ & $-8,8$ & $-9,8$ & $-10,9$ & $-12,0$ & $-13,1$ & $-14,3$ & $-15,6$ & $-16,8$ & $-18,1$ & $-12,8$ \\
\hline $\mathrm{C}_{2} \mathrm{H}_{2}$ & ${ }^{1} J_{\mathrm{CC}}$ & 185,5 & 190,2 & 195,4 & 201,3 & 207,8 & 215,4 & 224,2 & 234,6 & 247,1 & 262,6 & 282,1 & 174,8 \\
\hline $\mathrm{C}_{2} \mathrm{H}_{2}$ & ${ }^{1} J_{\mathrm{CH}}$ & 221,6 & 227,3 & 233,2 & 239,5 & 246,2 & 253,5 & 261,3 & 269,9 & 279,6 & 290,5 & 303,3 & 247,6 \\
\hline $\mathrm{C}_{2} \mathrm{H}_{2}$ & ${ }^{2} J_{\mathrm{CH}}$ & 49,1 & 50,0 & 50,7 & 51,1 & 51,3 & 51,2 & 50,6 & 49,4 & 47,3 & 44,1 & 39,3 & 50,1 \\
\hline $\mathrm{C}_{2} \mathrm{H}_{2}$ & ${ }^{3} J_{\mathrm{HH}}$ & 6,5 & 7,0 & 7,6 & 8,3 & 9,2 & 10,4 & 11,7 & 13,4 & 15,5 & 18,2 & 21,7 & 9,6 \\
\hline $\mathrm{C}_{2} \mathrm{H}_{4}$ & ${ }^{1} J_{\mathrm{CC}}$ & 56,0 & 59,8 & 63,9 & 68,4 & 73,5 & 79,3 & 86,1 & 94,3 & 104,6 & 118,4 & 138,3 & 67,6 \\
\hline $\mathrm{C}_{2} \mathrm{H}_{4}$ & ${ }^{1} J_{\mathrm{CH}}$ & 135,4 & 139,6 & 144,1 & 148,9 & 153,9 & 159,4 & 165,3 & 171,9 & 179,4 & 188,3 & 199,6 & 156,3 \\
\hline $\mathrm{C}_{2} \mathrm{H}_{4}$ & ${ }^{2} J_{\mathrm{CH}}$ & 0,6 & 0,0 & $-0,7$ & $-1,6$ & $-2,6$ & $-3,9$ & $-5,5$ & $-7,6$ & $-10,4$ & $-14,5$ & $-20,9$ & $-2,4$ \\
\hline $\mathrm{C}_{2} \mathrm{H}_{4}$ & ${ }^{2} J_{\mathrm{HH}}$ & 5,2 & 4,7 & 4,2 & 3,6 & 2,9 & 2,2 & 1,3 & 0,2 & $-1,2$ & $-3,2$ & $-6,2$ & 2,3 \\
\hline $\mathrm{C}_{2} \mathrm{H}_{4}$ & ${ }^{3} J_{\mathrm{HH}_{\mathrm{c}}}$ & 10,3 & 10,5 & 10,8 & 11,1 & 11,5 & 12,0 & 12,7 & 13,5 & 14,7 & 16,4 & 19,2 & 11,7 \\
\hline $\mathrm{C}_{2} \mathrm{H}_{4}$ & ${ }^{3} J_{\mathrm{HH}_{\mathrm{t}}}$ & 15,0 & 15,4 & 15,9 & 16,4 & 17,1 & 17,9 & 18,9 & 20,1 & 21,8 & 24,0 & 27,5 & 19 \\
\hline $\mathrm{C}_{2} \mathrm{H}_{6}$ & ${ }^{1} J_{\mathrm{CC}}$ & 20,8 & 23,6 & 26,4 & 29,5 & 32,8 & 36,3 & 40,0 & 43,9 & 48,0 & 52,4 & 57,1 & 34,5 \\
\hline $\mathrm{C}_{2} \mathrm{H}_{6}$ & ${ }^{1} J_{\mathrm{CH}}$ & 106,6 & 110,2 & 114,0 & 117,9 & 122,1 & 126,4 & 131,0 & 135,7 & 140,7 & 145,9 & 151,4 & 125,2 \\
\hline $\mathrm{C}_{2} \mathrm{H}_{6}$ & ${ }^{2} J_{\mathrm{CH}}$ & $-1,7$ & $-2,1$ & $-2,6$ & $-3,1$ & $-3,7$ & $-4,3$ & $-4,9$ & $-5,6$ & $-6,3$ & $-7,1$ & $-7,9$ & $-4,7$ \\
\hline \multirow[t]{3}{*}{ Total } & $\mathrm{DM}$ & $-26,01$ & $-23,37$ & $-20,37$ & $-17,05$ & $-13,51$ & $-9,83$ & $-6,20$ & $-2,96$ & $-0,78$ & $-1,90$ & $-19,10$ & - \\
\hline & DMA & 32,82 & 27,43 & 24,17 & 20,64 & 17,60 & 17,62 & 22,18 & 28,27 & 36,21 & 48,39 & 80,95 & - \\
\hline & PDMA & 59,46 & 48,04 & 36,91 & 25,11 & 13,83 & 10,25 & 24,25 & 42,35 & 63,60 & 90,29 & 129,89 & - \\
\hline \multirow[t]{3}{*}{ CPI } & $\mathrm{DM}$ & $-52,96$ & $-49,25$ & $-44,83$ & $-39,80$ & $-34,48$ & $-29,14$ & $-24,22$ & $-20,59$ & $-20,05$ & $-28,06$ & $-75,31$ & - \\
\hline & DMA & 64,42 & 53,80 & 48,19 & 41,93 & 36,23 & 35,25 & 42,00 & 51,34 & 63,98 & 85,35 & 152,76 & - \\
\hline & PDMA & 90,98 & 72,61 & 55,59 & 38,17 & 20,93 & 10,45 & 29,86 & 51,32 & 74,40 & 100,66 & 140,82 & - \\
\hline \multirow[t]{3}{*}{ SPI } & $\mathrm{DM}$ & $-6,25$ & $-4,39$ & $-2,44$ & $-0,36$ & 1,87 & 4,33 & 7,01 & 9,97 & 13,35 & 17,29 & 22,12 & - \\
\hline & DMA & 9,65 & 8,10 & 6,56 & 5,03 & 3,94 & 4,69 & 7,64 & 11,36 & 15,85 & 21,29 & 28,29 & - \\
\hline & PDMA & 36,34 & 30,03 & 23,21 & 15,52 & 8,62 & 10,10 & 20,15 & 35,77 & 55,68 & 82,69 & 121,88 & - \\
\hline \multirow[t]{3}{*}{$\Delta \mathrm{CS}$} & $\mathrm{DM}$ & $-46,72$ & $-44,86$ & $-42,39$ & $-39,44$ & $-36,36$ & $-33,47$ & $-31,23$ & $-30,56$ & $-33,41$ & $-45,35$ & $-97,43$ & - \\
\hline & DMA & 54,77 & 45,70 & 41,63 & 36,90 & 32,29 & 30,55 & 34,36 & 39,98 & 48,14 & 64,07 & 124,47 & - \\
\hline & PDMA & 54,64 & 42,58 & 32,37 & 22,65 & 12,31 & 0,34 & 9,71 & 15,55 & 18,72 & 17,97 & 18,94 & - \\
\hline \multicolumn{14}{|c|}{ Desconsiderando ${ }^{1} J_{\mathrm{BF}}$ da molécula de $\mathrm{BF}_{3},{ }^{2} J_{\mathrm{CH}}$ e ${ }^{2} J_{\mathrm{HH}}$ da molécula de $\mathrm{C}_{2} \mathrm{H}_{4}$} \\
\hline \multirow[t]{3}{*}{ Total } & DM & $-25,63$ & $-23,40$ & $-20,76$ & $-17,76$ & $-14,51$ & $-11,09$ & $-7,73$ & $-4,77$ & $-2,97$ & $-4,83$ & $-24,71$ & - \\
\hline & DMA & 32,81 & 27,57 & 24,74 & 21,63 & 19,08 & 19,80 & 24,00 & 29,90 & 37,85 & 50,50 & 86,04 & - \\
\hline & PDMA & 29,40 & 23,86 & 18,88 & 13,78 & 8,94 & 8,33 & 13,94 & 22,89 & 33,54 & 46,80 & 68,62 & - \\
\hline \multirow[t]{3}{*}{ CPI } & $\mathrm{DM}$ & $-48,98$ & $-46,74$ & $-43,73$ & $-40,09$ & $-36,14$ & $-32,17$ & $-28,70$ & $-26,65$ & $-28,01$ & $-38,79$ & $-92,72$ & - \\
\hline & DMA & 61,58 & 51,74 & 47,43 & 42,43 & 38,06 & 38,65 & 44,14 & 52,47 & 64,43 & 85,97 & 158,16 & - \\
\hline & PDMA & 38,21 & 30,27 & 23,95 & 17,39 & 11,09 & 10,69 & 19,11 & 29,79 & 42,17 & 57,92 & 89,03 & - \\
\hline \multirow[t]{3}{*}{ SPI } & DM & $-7,66$ & $-5,44$ & $-3,09$ & $-0,58$ & 2,13 & 5,12 & 8,41 & 12,07 & 16,29 & 21,30 & 27,60 & - \\
\hline & DMA & 10,68 & 8,98 & 7,29 & 5,64 & 4,48 & 5,29 & 8,50 & 12,55 & 17,40 & 23,21 & 30,57 & - \\
\hline & PDMA & 22,62 & 18,93 & 14,98 & 11,00 & 7,30 & 6,52 & 9,97 & 17,58 & 26,90 & 38,23 & 52,91 & - \\
\hline \multirow[t]{3}{*}{$\Delta \mathrm{CS}$} & $\mathrm{DM}$ & $-41,32$ & $-41,30$ & $-40,64$ & $-39,51$ & $-38,27$ & $-37,29$ & $-37,11$ & $-38,72$ & $-44,30$ & $-60,09$ & $-120,32$ & - \\
\hline & DMA & 50,90 & 42,76 & 40,14 & 36,79 & 33,58 & 33,36 & 35,64 & 39,92 & 47,03 & 62,76 & 127,59 & - \\
\hline & PDMA & 15,60 & 11,35 & 8,96 & 6,39 & 3,79 & 4,18 & 9,14 & 12,21 & 15,27 & 19,69 & 36,12 & - \\
\hline
\end{tabular}


Tabela 8.263: Constantes de acoplamento SLYP com base aug-pcJ-2.

\begin{tabular}{|c|c|c|c|c|c|c|c|c|c|c|c|c|c|}
\hline & $\% E_{X}^{\mathrm{HF}}$ & $0 \%$ & $10 \%$ & $20 \%$ & $30 \%$ & $40 \%$ & $50 \%$ & $60 \%$ & $70 \%$ & $80 \%$ & $90 \%$ & $100 \%$ & Exp. \\
\hline $\mathrm{HF}$ & ${ }^{1} J_{\mathrm{HF}}$ & 420,6 & 441,1 & 462,4 & 484,4 & 507,2 & 530,8 & 555,3 & 580,6 & 606,9 & 634,2 & 662,5 & 500 \\
\hline $\mathrm{CO}$ & ${ }^{1} J_{\mathrm{CO}}$ & 24,8 & 22,9 & 20,9 & 18,7 & 16,3 & 13,7 & 11,0 & 8,0 & 4,9 & 1,6 & $-1,9$ & 16,4 \\
\hline $\mathrm{H}_{2} \mathrm{O}$ & ${ }^{1} J_{\mathrm{OH}}$ & $-69,9$ & $-72,4$ & $-75,1$ & $-77,8$ & $-80,7$ & $-83,7$ & $-86,9$ & $-90,2$ & $-93,7$ & $-97,3$ & $-101,1$ & $-80,6$ \\
\hline $\mathrm{H}_{2} \mathrm{O}$ & ${ }^{2} J_{\mathrm{HH}}$ & $-3,3$ & $-4,4$ & $-5,5$ & $-6,8$ & $-8,0$ & $-9,4$ & $-10,8$ & $-12,3$ & $-13,9$ & $-15,6$ & $-17,3$ & $-7,3$ \\
\hline $\mathrm{NH}_{3}$ & ${ }^{1} J_{\mathrm{NH}}$ & 39,4 & 40,5 & 41,7 & 42,9 & 44,2 & 45,5 & 47,0 & 48,5 & 50,0 & 51,7 & 53,4 & 43,8 \\
\hline $\mathrm{NH}_{3}$ & ${ }^{2} J_{\mathrm{HH}}$ & $-5,4$ & $-6,5$ & $-7,5$ & $-8,7$ & $-9,9$ & $-11,1$ & $-12,5$ & $-13,9$ & $-15,4$ & $-17,0$ & $-18,7$ & $-9,6$ \\
\hline $\mathrm{PH}_{3}$ & ${ }^{1} J_{\mathrm{PH}}$ & 135,5 & 144,3 & 153,5 & 163,0 & 172,9 & 183,1 & 193,7 & 204,6 & 215,9 & 227,4 & 239,2 & 188,2 \\
\hline $\mathrm{PF}_{3}$ & ${ }^{1} J_{\mathrm{PF}}$ & $-1814,4$ & $-1797,1$ & $-1773,1$ & $-1743,5$ & $-1709,0$ & $-1670,4$ & $-1628,3$ & $-1583,4$ & $-1536,2$ & $-1487,3$ & $-1437,0$ & -1441 \\
\hline $\mathrm{BHF}_{2}$ & ${ }^{1} J_{\mathrm{BF}}$ & $-187,4$ & $-169,5$ & $-151,2$ & $-132,8$ & $-114,0$ & $-95,2$ & $-76,1$ & $-57,0$ & $-37,8$ & $-18,6$ & 0,6 & -84 \\
\hline $\mathrm{BF}_{3}$ & ${ }^{1} J_{\mathrm{BF}}$ & $-79,8$ & $-61,1$ & $-42,3$ & $-23,3$ & $-4,1$ & 15,1 & 34,6 & 54,2 & 73,9 & 93,8 & 113,8 & 15 \\
\hline $\mathrm{F}_{2} \mathrm{O}$ & ${ }^{1} J_{\mathrm{OF}}$ & $-272,1$ & $-308,2$ & $-344,0$ & $-380,5$ & $-419,8$ & $-465,0$ & $-521,4$ & $-600,0$ & $-727,9$ & $-1000,8$ & $-2253,8$ & -300 \\
\hline $\mathrm{CH}_{4}$ & ${ }^{1} J_{\mathrm{CH}}$ & 106,0 & 109,4 & 113,0 & 116,8 & 120,7 & 124,9 & 129,4 & 134,0 & 138,9 & 144,0 & 149,4 & 125,3 \\
\hline $\mathrm{CH}_{4}$ & ${ }^{2} J_{\mathrm{HH}}$ & $-7,9$ & $-8,9$ & $-9,9$ & $-11,0$ & $-12,1$ & $-13,3$ & $-14,5$ & $-15,7$ & $-17,0$ & $-18,4$ & $-19,7$ & $-12,8$ \\
\hline $\mathrm{C}_{2} \mathrm{H}_{2}$ & ${ }^{1} J_{\mathrm{CC}}$ & 175,5 & 179,6 & 184,2 & 189,4 & 195,4 & 202,4 & 210,6 & 220,6 & 232,8 & 248,3 & 268,4 & 174,8 \\
\hline $\mathrm{C}_{2} \mathrm{H}_{2}$ & ${ }^{1} J_{\mathrm{CH}}$ & 226,4 & 232,3 & 238,4 & 245,0 & 252,0 & 259,5 & 267,8 & 276,9 & 287,3 & 299,2 & 313,5 & 247,6 \\
\hline $\mathrm{C}_{2} \mathrm{H}_{2}$ & ${ }^{2} J_{\mathrm{CH}}$ & 51,2 & 52,1 & 52,7 & 53,2 & 53,3 & 53,0 & 52,2 & 50,7 & 48,2 & 44,2 & 38,1 & 50,1 \\
\hline $\mathrm{C}_{2} \mathrm{H}_{2}$ & ${ }^{3} J_{\mathrm{HH}}$ & 7,2 & 7,8 & 8,5 & 9,4 & 10,5 & 11,8 & 13,4 & 15,5 & 18,1 & 21,5 & 26,0 & 9,6 \\
\hline $\mathrm{C}_{2} \mathrm{H}_{4}$ & ${ }^{1} J_{\mathrm{CC}}$ & 50,4 & 53,8 & 57,6 & 61,8 & 66,7 & 72,3 & 78,9 & 87,3 & 98,2 & 113,8 & 139,0 & 67,6 \\
\hline $\mathrm{C}_{2} \mathrm{H}_{4}$ & ${ }^{1} J_{\mathrm{CH}}$ & 136,2 & 140,5 & 145,0 & 149,9 & 155,0 & 160,6 & 166,8 & 173,7 & 181,8 & 191,8 & 205,7 & 156,3 \\
\hline $\mathrm{C}_{2} \mathrm{H}_{4}$ & ${ }^{2} J_{\mathrm{CH}}$ & 0,9 & 0,2 & $-0,4$ & $-1,3$ & $-2,4$ & $-3,8$ & $-5,6$ & $-8,0$ & $-11,4$ & $-16,5$ & $-25,4$ & $-2,4$ \\
\hline $\mathrm{C}_{2} \mathrm{H}_{4}$ & ${ }^{2} J_{\mathrm{HH}}$ & 5,5 & 5,0 & 4,4 & 3,8 & 3,1 & 2,2 & 1,1 & $-0,1$ & $-2,0$ & $-4,7$ & $-9,3$ & 2,3 \\
\hline $\mathrm{C}_{2} \mathrm{H}_{4}$ & ${ }^{3} J_{\mathrm{HH}}$ & 11,2 & 11,5 & 11,8 & 12,2 & 12,7 & 13,3 & 14,1 & 15,2 & 16,8 & 19,3 & 23,7 & 11,7 \\
\hline $\mathrm{C}_{2} \mathrm{H}_{4}$ & ${ }^{3} J_{\mathrm{HH}_{\mathrm{t}}}$ & 16,3 & 16,7 & 17,3 & 17,9 & 18,7 & 19,6 & 20,8 & 22,4 & 24,5 & 27,6 & 32,9 & 19 \\
\hline $\mathrm{C}_{2} \mathrm{H}_{6}$ & ${ }^{1} J_{\mathrm{CC}}$ & 18,7 & 21,3 & 24,0 & 26,9 & 30,0 & 33,3 & 36,7 & 40,4 & 44,3 & 48,4 & 52,7 & 34,5 \\
\hline $\mathrm{C}_{2} \mathrm{H}_{6}$ & ${ }^{1} J_{\mathrm{CH}}$ & 106,1 & 109,7 & 113,4 & 117,3 & 121,5 & 125,8 & 130,4 & 135,2 & 140,2 & 145,4 & 150,9 & 125,2 \\
\hline $\mathrm{C}_{2} \mathrm{H}_{6}$ & ${ }^{2} J_{\mathrm{CH}}$ & $-1,7$ & $-2,1$ & $-2,6$ & $-3,1$ & $-3,7$ & $-4,3$ & $-4,9$ & $-5,6$ & $-6,3$ & $-7,0$ & $-7,8$ & $-4,7$ \\
\hline \multirow[t]{3}{*}{ Total } & $\mathrm{DM}$ & $-29,04$ & $-26,40$ & $-23,38$ & $-20,05$ & $-16,48$ & $-12,86$ & $-9,32$ & $-6,28$ & $-4,77$ & $-8,31$ & $-48,74$ & - \\
\hline & DMA & 34,53 & 29,43 & 26,08 & 22,41 & 19,57 & 19,73 & 24,00 & 30,75 & 39,93 & 55,48 & 110,36 & - \\
\hline & PDMA & 59,82 & 48,15 & 36,94 & 24,93 & 14,17 & 12,21 & 27,30 & 46,76 & 70,77 & 102,43 & 158,62 & - \\
\hline \multirow[t]{3}{*}{ CPI } & DM & $-59,35$ & $-55,57$ & $-51,01$ & $-45,94$ & $-40,53$ & $-35,23$ & $-30,48$ & $-27,44$ & $-28,56$ & $-42,62$ & $-145,56$ & - \\
\hline & DMA & 69,39 & 59,34 & 53,54 & 47,12 & 41,91 & 41,15 & 47,12 & 57,96 & 73,27 & 101,80 & 220,20 & - \\
\hline & PDMA & 91,57 & 72,82 & 55,57 & 37,59 & 22,32 & 14,76 & 33,37 & 55,94 & 80,40 & 109,77 & 169,20 & - \\
\hline \multirow[t]{3}{*}{ SPI } & DM & $-6,81$ & $-5,01$ & $-3,11$ & $-1,06$ & 1,15 & 3,55 & 6,21 & 9,23 & 12,69 & 16,85 & 22,27 & - \\
\hline & DMA & 8,97 & 7,49 & 5,94 & 4,29 & 3,19 & 4,03 & 7,05 & 10,80 & 15,49 & 21,51 & 29,81 & - \\
\hline & PDMA & 36,54 & 30,06 & 23,28 & 15,65 & 8,19 & 10,35 & 22,85 & 40,02 & 63,71 & 97,05 & 150,86 & - \\
\hline \multirow[t]{3}{*}{$\Delta \mathrm{CS}$} & DM & $-52,55$ & $-50,56$ & $-47,90$ & $-44,88$ & $-41,68$ & $-38,77$ & $-36,69$ & $-36,66$ & $-41,25$ & $-59,47$ & $-167,83$ & - \\
\hline & DMA & 60,42 & 51,84 & 47,60 & 42,83 & 38,72 & 37,13 & 40,07 & 47,16 & 57,79 & 80,29 & 190,39 & - \\
\hline & PDMA & 55,03 & 42,76 & 32,29 & 21,95 & 14,13 & 4,41 & 10,52 & 15,92 & 16,68 & 12,72 & 18,34 & - \\
\hline \multicolumn{14}{|c|}{ Desconsiderando ${ }^{1} J_{\mathrm{BF}}$ da molécula de $\mathrm{BF}_{3},{ }^{2} J_{\mathrm{CH}}$ e ${ }^{2} J_{\mathrm{HH}}$ da molécula de $\mathrm{C}_{2} \mathrm{H}_{4}$} \\
\hline \multirow[t]{3}{*}{ Total } & DM & $-28,99$ & $-26,77$ & $-24,11$ & $-21,11$ & $-17,83$ & $-14,47$ & $-11,19$ & $-8,46$ & $-7,37$ & $-11,90$ & $-57,89$ & - \\
\hline & DMA & 34,63 & 29,73 & 26,81 & 23,55 & 21,26 & 22,24 & 26,09 & 32,71 & 42,00 & 58,37 & 118,96 & - \\
\hline & PDMA & 28,12 & 22,56 & 17,56 & 12,25 & 8,97 & 11,05 & 17,11 & 26,81 & 38,50 & 54,18 & 87,08 & - \\
\hline \multirow[t]{3}{*}{ CPI } & DM & $-55,81$ & $-53,52$ & $-50,38$ & $-46,70$ & $-42,67$ & $-38,76$ & $-35,49$ & $-34,10$ & $-37,31$ & $-54,76$ & $-170,00$ & - \\
\hline & DMA & 66,85 & 57,66 & 53,16 & 48,00 & 44,19 & 45,26 & 49,87 & 59,84 & 74,71 & 104,10 & 232,34 & - \\
\hline & PDMA & 37,53 & 29,37 & 22,93 & 15,82 & 11,82 & 16,17 & 23,64 & 35,40 & 49,17 & 68,21 & 120,26 & - \\
\hline \multirow[t]{3}{*}{ SPI } & $\mathrm{DM}$ & $-8,35$ & $-6,19$ & $-3,91$ & $-1,42$ & 1,27 & 4,21 & 7,50 & 11,26 & 15,66 & 21,07 & 28,35 & - \\
\hline & DMA & 9,85 & 8,24 & 6,54 & 4,75 & 3,62 & 4,53 & 7,79 & 11,85 & 16,85 & 23,19 & 31,74 & - \\
\hline & PDMA & 20,89 & 17,32 & 13,43 & 9,51 & 6,77 & 7,12 & 12,09 & 20,20 & 30,29 & 43,38 & 61,56 & - \\
\hline \multirow[t]{3}{*}{$\Delta \mathrm{CS}$} & DM & $-47,46$ & $-47,33$ & $-46,47$ & $-45,28$ & $-43,94$ & $-42,97$ & $-42,99$ & $-45,36$ & $-52,97$ & $-75,83$ & $-198,35$ & - \\
\hline & DMA & 57,00 & 49,42 & 46,62 & 43,25 & 40,57 & 40,73 & 42,08 & 47,99 & 57,86 & 80,91 & 200,60 & - \\
\hline & PDMA & 16,64 & 12,05 & 9,50 & 6,31 & 5,05 & 9,05 & 11,55 & 15,20 & 18,88 & 24,83 & 58,70 & - \\
\hline
\end{tabular}


Tabela 8.264: Constantes de acoplamento SP86 com base aug-pcJ-2.

\begin{tabular}{|c|c|c|c|c|c|c|c|c|c|c|c|c|c|}
\hline & $\% E_{X}^{\mathrm{HF}}$ & $0 \%$ & $10 \%$ & $20 \%$ & $30 \%$ & $40 \%$ & $50 \%$ & $60 \%$ & $70 \%$ & $80 \%$ & $90 \%$ & $100 \%$ & Exp. \\
\hline $\mathrm{HF}$ & ${ }^{1} J_{\mathrm{HF}}$ & 381,1 & 399,9 & 419,4 & 439,6 & 460,5 & 482,1 & 504,4 & 527,6 & 551,6 & 576,4 & 602,2 & 500 \\
\hline $\mathrm{CO}$ & ${ }^{1} J_{\mathrm{CO}}$ & 27,8 & 26,2 & 24,4 & 22,5 & 20,4 & 18,2 & 15,9 & 13,3 & 10,7 & 7,8 & 4,8 & 16,4 \\
\hline $\mathrm{H}_{2} \mathrm{O}$ & ${ }^{1} J_{\mathrm{OH}}$ & $-63,0$ & $-65,3$ & $-67,6$ & $-70,1$ & $-72,7$ & $-75,5$ & $-78,3$ & $-81,3$ & $-84,4$ & $-87,6$ & $-91,0$ & $-80,6$ \\
\hline $\mathrm{H}_{2} \mathrm{O}$ & ${ }^{2} J_{\mathrm{HH}}$ & $-2,6$ & $-3,6$ & $-4,6$ & $-5,7$ & $-6,8$ & $-8,0$ & $-9,3$ & $-10,6$ & $-12,0$ & $-13,5$ & $-15,1$ & $-7,3$ \\
\hline $\mathrm{NH}_{3}$ & ${ }^{1} J_{\mathrm{NH}}$ & 35,4 & 36,3 & 37,4 & 38,5 & 39,6 & 40,8 & 42,1 & 43,4 & 44,8 & 46,3 & 47,8 & 43,8 \\
\hline $\mathrm{NH}_{3}$ & ${ }^{2} J_{\mathrm{HH}}$ & $-4,9$ & $-5,8$ & $-6,8$ & $-7,8$ & $-8,9$ & $-10,0$ & $-11,2$ & $-12,5$ & $-13,8$ & $-15,3$ & $-16,8$ & $-9,6$ \\
\hline $\mathrm{PH}_{3}$ & ${ }^{1} J_{\mathrm{PH}}$ & 115,9 & 123,9 & 132,3 & 141,1 & 150,2 & 159,6 & 169,5 & 179,6 & 190,1 & 200,9 & 212,1 & 188,2 \\
\hline $\mathrm{PF}_{3}$ & ${ }^{1} J_{\mathrm{PF}}$ & $-1800,5$ & $-1783,2$ & $-1759,6$ & $-1730,3$ & $-1696,2$ & $-1658,1$ & $-1616,5$ & $-1572,2$ & $-1525,6$ & $-1477,3$ & $-1427,5$ & -1441 \\
\hline $\mathrm{BHF}_{2}$ & ${ }^{1} J_{\mathrm{BF}}$ & $-195,1$ & $-178,1$ & $-160,7$ & $-142,9$ & $-125,0$ & $-106,8$ & $-88,4$ & $-69,9$ & $-51,4$ & $-32,7$ & $-14,1$ & -84 \\
\hline $\mathrm{BF}_{3}$ & ${ }^{1} J_{\mathrm{BF}}$ & $-92,2$ & $-74,3$ & $-56,2$ & $-37,9$ & $-19,3$ & $-0,7$ & 18,1 & 37,1 & 56,2 & 75,5 & 94,8 & 15 \\
\hline $\mathrm{F}_{2} \mathrm{O}$ & ${ }^{1} J_{\mathrm{OF}}$ & $-281,6$ & $-317,8$ & $-353,7$ & $-390,5$ & $-430,3$ & $-476,0$ & $-533,1$ & $-612,1$ & $-738,7$ & $-997,4$ & $-1973,1$ & -300 \\
\hline $\mathrm{CH}_{4}$ & ${ }^{1} J_{\mathrm{CH}}$ & 94,1 & 97,1 & 100,3 & 103,7 & 107,2 & 111,0 & 115,0 & 119,1 & 123,5 & 128,2 & 133,0 & 125,3 \\
\hline $\mathrm{CH}_{4}$ & ${ }^{2} J_{\mathrm{HH}}$ & $-7,8$ & $-8,7$ & $-9,6$ & $-10,6$ & $-11,7$ & $-12,7$ & $-13,9$ & $-15,0$ & $-16,3$ & $-17,5$ & $-18,8$ & $-12,8$ \\
\hline $\mathrm{C}_{2} \mathrm{H}_{2}$ & ${ }^{1} J_{\mathrm{CC}}$ & 165,1 & 168,8 & 172,9 & 177,6 & 182,9 & 189,1 & 196,5 & 205,4 & 216,6 & 231,0 & 250,2 & 174,8 \\
\hline $\mathrm{C}_{2} \mathrm{H}_{2}$ & ${ }^{1} J_{\mathrm{CH}}$ & 204,8 & 210,1 & 215,6 & 221,5 & 227,8 & 234,7 & 242,2 & 250,6 & 260,2 & 271,5 & 285,3 & 247,6 \\
\hline $\mathrm{C}_{2} \mathrm{H}_{2}$ & ${ }^{2} J_{\mathrm{CH}}$ & 48,8 & 49,7 & 50,4 & 50,9 & 51,1 & 50,9 & 50,2 & 48,7 & 46,3 & 42,3 & 35,9 & 50,1 \\
\hline $\mathrm{C}_{2} \mathrm{H}_{2}$ & ${ }^{3} J_{\mathrm{HH}}$ & 7,2 & 7,8 & 8,5 & 9,4 & 10,5 & 11,8 & 13,5 & 15,7 & 18,4 & 22,0 & 26,9 & 9,6 \\
\hline $\mathrm{C}_{2} \mathrm{H}_{4}$ & ${ }^{1} J_{\mathrm{CC}}$ & 44,3 & 47,4 & 50,8 & 54,7 & 59,1 & 64,2 & 70,4 & 78,2 & 88,9 & 105,0 & 133,8 & 67,6 \\
\hline $\mathrm{C}_{2} \mathrm{H}_{4}$ & ${ }^{1} J_{\mathrm{CH}}$ & 122,0 & 125,9 & 130,0 & 134,3 & 139,0 & 144,1 & 149,7 & 156,1 & 163,9 & 173,9 & 189,3 & 156,3 \\
\hline $\mathrm{C}_{2} \mathrm{H}_{4}$ & ${ }^{2} J_{\mathrm{CH}}$ & 0,7 & 0,1 & $-0,5$ & $-1,3$ & $-2,3$ & $-3,6$ & $-5,3$ & $-7,7$ & $-11,2$ & $-16,8$ & $-27,6$ & $-2,4$ \\
\hline $\mathrm{C}_{2} \mathrm{H}_{4}$ & ${ }^{2} J_{\mathrm{HH}}$ & 4,4 & 3,9 & 3,3 & 2,6 & 1,9 & 0,9 & $-0,1$ & $-1,6$ & $-3,8$ & $-7,2$ & $-13,5$ & 2,3 \\
\hline $\mathrm{C}_{2} \mathrm{H}_{4}$ & ${ }^{3} J_{\mathrm{HH}_{\mathrm{C}}}$ & 10,2 & 10,5 & 10,8 & 11,2 & 11,8 & 12,4 & 13,3 & 14,6 & 16,5 & 19,6 & 25,7 & 11,7 \\
\hline $\mathrm{C}_{2} \mathrm{H}_{4}$ & ${ }^{3} J_{\mathrm{HH}_{\mathrm{t}}}$ & 14,9 & 15,4 & 15,9 & 16,6 & 17,4 & 18,3 & 19,6 & 21,3 & 23,7 & 27,6 & 34,7 & 19 \\
\hline $\mathrm{C}_{2} \mathrm{H}_{6}$ & ${ }^{1} J_{\mathrm{CC}}$ & 14,6 & 16,9 & 19,4 & 22,0 & 24,8 & 27,8 & 30,9 & 34,2 & 37,8 & 41,5 & 45,4 & 34,5 \\
\hline $\mathrm{C}_{2} \mathrm{H}_{6}$ & ${ }^{1} J_{\mathrm{CH}}$ & 94,6 & 97,7 & 101,1 & 104,6 & 108,4 & 112,3 & 116,4 & 120,7 & 125,2 & 130,0 & 135,0 & 125,2 \\
\hline $\mathrm{C}_{2} \mathrm{H}_{6}$ & ${ }^{2} J_{\mathrm{CH}}$ & $-1,8$ & $-2,2$ & $-2,7$ & $-3,2$ & $-3,7$ & $-4,2$ & $-4,8$ & $-5,5$ & $-6,1$ & $-6,8$ & $-7,6$ & $-4,7$ \\
\hline \multirow[t]{3}{*}{ Total } & $\mathrm{DM}$ & $-34,95$ & $-32,55$ & $-29,79$ & $-26,71$ & $-23,43$ & $-20,09$ & $-16,85$ & $-14,15$ & $-12,84$ & $-16,06$ & $-45,89$ & - \\
\hline & DMA & 40,32 & 35,88 & 32,47 & 28,92 & 25,39 & 22,05 & 19,97 & 23,32 & 30,78 & 45,45 & 90,58 & - \\
\hline & PDMA & 66,68 & 55,71 & 44,71 & 32,96 & 22,65 & 18,69 & 20,10 & 36,74 & 59,89 & 93,05 & 152,34 & - \\
\hline \multirow[t]{3}{*}{ CPI } & $\mathrm{DM}$ & $-65,51$ & $-62,06$ & $-57,87$ & $-53,13$ & $-48,13$ & $-43,21$ & $-38,88$ & $-36,23$ & $-37,58$ & $-50,71$ & $-128,80$ & - \\
\hline & DMA & 75,84 & 67,99 & 62,69 & 56,76 & 50,51 & 44,46 & 40,66 & 47,83 & 60,91 & 87,69 & 182,13 & - \\
\hline & PDMA & 105,82 & 88,85 & 72,50 & 55,74 & 38,60 & 23,84 & 16,40 & 34,86 & 56,98 & 84,78 & 134,69 & - \\
\hline \multirow[t]{3}{*}{ SPI } & $\mathrm{DM}$ & $-12,53$ & $-10,91$ & $-9,19$ & $-7,34$ & $-5,33$ & $-3,14$ & $-0,70$ & 2,05 & 5,30 & 9,35 & 14,91 & - \\
\hline & DMA & 14,28 & 12,34 & 10,31 & 8,50 & 6,97 & 5,62 & 4,79 & 5,35 & 8,69 & 14,48 & 23,45 & - \\
\hline & PDMA & 37,97 & 31,41 & 24,33 & 16,25 & 10,96 & 14,92 & 22,81 & 38,12 & 62,03 & 99,12 & 165,29 & - \\
\hline \multirow[t]{3}{*}{$\Delta \mathrm{CS}$} & $\mathrm{DM}$ & $-52,98$ & $-51,15$ & $-48,68$ & $-45,79$ & $-42,80$ & $-40,07$ & $-38,18$ & $-38,27$ & $-42,88$ & $-60,06$ & $-143,71$ & - \\
\hline & DMA & 61,56 & 55,65 & 52,38 & 48,26 & 43,54 & 38,84 & 35,87 & 42,47 & 52,22 & 73,21 & 158,67 & - \\
\hline & PDMA & 67,86 & 57,44 & 48,17 & 39,49 & 27,65 & 8,92 & $-6,41$ & $-3,26$ & $-5,05$ & $-14,34$ & $-30,60$ & - \\
\hline \multicolumn{14}{|c|}{ Desconsiderando ${ }^{1} J_{\mathrm{BF}}$ da molécula de $\mathrm{BF}_{3},{ }^{2} J_{\mathrm{CH}}$ e ${ }^{2} J_{\mathrm{HH}}$ da molécula de $\mathrm{C}_{2} \mathrm{H}_{4}$} \\
\hline \multirow[t]{3}{*}{ Total } & $\mathrm{DM}$ & $-35,07$ & $-33,10$ & $-30,70$ & $-27,96$ & $-24,99$ & $-21,92$ & $-18,96$ & $-16,55$ & $-15,66$ & $-19,75$ & $-53,57$ & - \\
\hline & DMA & 40,70 & 36,50 & 33,49 & 30,33 & 27,19 & 24,13 & 22,21 & 25,00 & 32,36 & 47,71 & 97,15 & - \\
\hline & PDMA & 34,71 & 29,54 & 24,57 & 19,36 & 14,73 & 11,76 & 12,03 & 18,15 & 28,29 & 43,61 & 73,57 & - \\
\hline \multirow[t]{3}{*}{ CPI } & $\mathrm{DM}$ & $-61,34$ & $-59,34$ & $-56,54$ & $-53,15$ & $-49,51$ & $-45,96$ & $-43,08$ & $-42,06$ & $-45,46$ & $-61,83$ & $-149,66$ & - \\
\hline & DMA & 72,70 & 65,86 & 61,84 & 57,15 & 52,13 & 47,34 & 44,42 & 50,40 & 62,88 & 90,41 & 192,36 & - \\
\hline & PDMA & 44,94 & 38,20 & 32,28 & 26,05 & 19,60 & 15,76 & 15,98 & 23,61 & 35,21 & 52,92 & 94,96 & - \\
\hline \multirow[t]{3}{*}{ SPI } & DM & $-14,86$ & $-12,91$ & $-10,83$ & $-8,58$ & $-6,12$ & $-3,42$ & $-0,40$ & 3,07 & 7,26 & 12,62 & 20,35 & - \\
\hline & DMA & 16,08 & 13,92 & 11,68 & 9,70 & 8,00 & 6,28 & 5,12 & 5,47 & 8,88 & 14,87 & 23,91 & - \\
\hline & PDMA & 26,85 & 22,87 & 18,64 & 14,22 & 10,98 & 8,69 & 9,00 & 13,95 & 22,96 & 36,44 & 57,11 & - \\
\hline \multirow[t]{3}{*}{$\Delta \mathrm{CS}$} & $\mathrm{DM}$ & $-46,48$ & $-46,43$ & $-45,71$ & $-44,57$ & $-43,39$ & $-42,54$ & $-42,68$ & $-45,13$ & $-52,72$ & $-74,45$ & $-170,01$ & - \\
\hline & DMA & 56,62 & 51,94 & 50,16 & 47,45 & 44,13 & 41,06 & 39,30 & 44,93 & 54,00 & 75,54 & 168,45 & - \\
\hline & PDMA & 18,09 & 15,33 & 13,64 & 11,82 & 8,61 & 7,07 & 6,98 & 9,66 & 12,25 & 16,48 & 37,85 & - \\
\hline
\end{tabular}


Tabela 8.265: Constantes de acoplamento SPBE com base aug-pcJ-2.

\begin{tabular}{|c|c|c|c|c|c|c|c|c|c|c|c|c|c|}
\hline & $\% E_{X}^{\mathrm{HF}}$ & $0 \%$ & $10 \%$ & $20 \%$ & $30 \%$ & $40 \%$ & $50 \%$ & $60 \%$ & $70 \%$ & $80 \%$ & $90 \%$ & $100 \%$ & Exp. \\
\hline $\mathrm{HF}$ & ${ }^{1} J_{\mathrm{HF}}$ & 377,2 & 396,5 & 416,4 & 437,0 & 458,3 & 480,4 & 503,3 & 526,9 & 551,5 & 576,9 & 603,3 & 500 \\
\hline $\mathrm{CO}$ & ${ }^{1} J_{\mathrm{CO}}$ & 28,4 & 26,8 & 25,0 & 23,1 & 21,0 & 18,8 & 16,5 & 13,9 & 11,2 & 8,3 & 5,3 & 16,4 \\
\hline $\mathrm{H}_{2} \mathrm{O}$ & ${ }^{1} J_{\mathrm{OH}}$ & $-62,8$ & $-65,1$ & $-67,5$ & $-70,1$ & $-72,7$ & $-75,5$ & $-78,4$ & $-81,5$ & $-84,6$ & $-88,0$ & $-91,5$ & $-80,6$ \\
\hline $\mathrm{H}_{2} \mathrm{O}$ & ${ }^{2} J_{\mathrm{HH}}$ & $-2,9$ & $-3,9$ & $-5,0$ & $-6,1$ & $-7,3$ & $-8,6$ & $-9,9$ & $-11,3$ & $-12,7$ & $-14,3$ & $-15,9$ & $-7,3$ \\
\hline $\mathrm{NH}_{3}$ & ${ }^{1} J_{\mathrm{NH}}$ & 35,4 & 36,4 & 37,5 & 38,6 & 39,7 & 41,0 & 42,3 & 43,6 & 45,1 & 46,6 & 48,2 & 43,8 \\
\hline $\mathrm{NH}_{3}$ & ${ }^{2} J_{\mathrm{HH}}$ & $-5,3$ & $-6,2$ & $-7,2$ & $-8,3$ & $-9,4$ & $-10,6$ & $-11,9$ & $-13,2$ & $-14,6$ & $-16,1$ & $-17,6$ & $-9,6$ \\
\hline $\mathrm{PH}_{3}$ & ${ }^{1} J_{\mathrm{PH}}$ & 114,8 & 123,1 & 131,8 & 140,8 & 150,2 & 160,0 & 170,2 & 180,7 & 191,6 & 202,8 & 214,3 & 188,2 \\
\hline $\mathrm{PF}_{3}$ & ${ }^{1} J_{\mathrm{PF}}$ & $-1805,8$ & $-1787,7$ & $-1763,2$ & $-1733,1$ & $-1698,3$ & $-1659,5$ & $-1617,4$ & $-1572,5$ & $-1525,5$ & $-1476,6$ & $-1426,5$ & -1441 \\
\hline $\mathrm{BHF}_{2}$ & ${ }^{1} J_{\mathrm{BF}}$ & $-196,0$ & $-178,8$ & $-161,3$ & $-143,5$ & $-125,4$ & $-107,1$ & $-88,7$ & $-70,1$ & $-51,4$ & $-32,6$ & $-13,8$ & -84 \\
\hline $\mathrm{BF}_{3}$ & ${ }^{1} J_{\mathrm{BF}}$ & $-93,2$ & $-75,2$ & $-57,0$ & $-38,5$ & $-19,9$ & $-1,1$ & 17,8 & 37,0 & 56,3 & 75,7 & 95,2 & 15 \\
\hline $\mathrm{F}_{2} \mathrm{O}$ & ${ }^{1} J_{\mathrm{OF}}$ & $-282,5$ & $-319,5$ & $-356,3$ & $-394,2$ & $-435,3$ & $-483,1$ & $-543,2$ & $-627,9$ & $-766,9$ & $-1065,7$ & $-2453,2$ & -300 \\
\hline $\mathrm{CH}_{4}$ & ${ }^{1} J_{\mathrm{CH}}$ & 94,4 & 97,5 & 100,8 & 104,3 & 107,9 & 111,8 & 115,9 & 120,2 & 124,7 & 129,4 & 134,4 & 125,3 \\
\hline $\mathrm{CH}_{4}$ & ${ }^{2} J_{\mathrm{HH}}$ & $-8,3$ & $-9,2$ & $-10,2$ & $-11,2$ & $-12,3$ & $-13,5$ & $-14,6$ & $-15,9$ & $-17,1$ & $-18,5$ & $-19,8$ & $-12,8$ \\
\hline $\mathrm{C}_{2} \mathrm{H}_{2}$ & ${ }^{1} J_{\mathrm{CC}}$ & 164,3 & 168,0 & 172,2 & 177,0 & 182,5 & 189,1 & 196,9 & 206,6 & 218,9 & 235,0 & 257,1 & 174,8 \\
\hline $\mathrm{C}_{2} \mathrm{H}_{2}$ & ${ }^{1} J_{\mathrm{CH}}$ & 206,7 & 212,1 & 217,8 & 223,9 & 230,5 & 237,6 & 245,6 & 254,6 & 265,0 & 277,5 & 293,3 & 247,6 \\
\hline $\mathrm{C}_{2} \mathrm{H}_{2}$ & ${ }^{2} J_{\mathrm{CH}}$ & 49,0 & 49,8 & 50,5 & 50,9 & 50,9 & 50,5 & 49,5 & 47,6 & 44,4 & 39,4 & 31,2 & 50,1 \\
\hline $\mathrm{C}_{2} \mathrm{H}_{2}$ & ${ }^{3} J_{\mathrm{HH}}$ & 7,6 & 8,2 & 9,0 & 10,0 & 11,3 & 12,8 & 14,7 & 17,2 & 20,4 & 24,8 & 30,9 & 9,6 \\
\hline $\mathrm{C}_{2} \mathrm{H}_{4}$ & ${ }^{1} J_{\mathrm{CC}}$ & 43,9 & 47,1 & 50,6 & 54,5 & 59,1 & 64,5 & 71,1 & 79,8 & 92,0 & 111,5 & 150,7 & 67,6 \\
\hline $\mathrm{C}_{2} \mathrm{H}_{4}$ & ${ }^{1} J_{\mathrm{CH}}$ & 122,9 & 126,9 & 131,1 & 135,6 & 140,4 & 145,7 & 151,7 & 158,6 & 167,1 & 178,9 & 199,0 & 156,3 \\
\hline $\mathrm{C}_{2} \mathrm{H}_{4}$ & ${ }^{2} J_{\mathrm{CH}}$ & 0,4 & $-0,2$ & $-0,9$ & $-1,8$ & $-2,9$ & $-4,4$ & $-6,3$ & $-9,1$ & $-13,3$ & $-20,6$ & $-36,1$ & $-2,4$ \\
\hline $\mathrm{C}_{2} \mathrm{H}_{4}$ & ${ }^{2} J_{\mathrm{HH}}$ & 4,1 & 3,5 & 2,9 & 2,1 & 1,3 & 0,2 & $-1,0$ & $-2,9$ & $-5,5$ & $-10,0$ & $-19,4$ & 2,3 \\
\hline $\mathrm{C}_{2} \mathrm{H}_{4}$ & ${ }^{3} J_{\mathrm{HH}_{\mathrm{c}}}$ & 10,4 & 10,8 & 11,1 & 11,6 & 12,2 & 13,0 & 14,1 & 15,6 & 18,0 & 22,2 & 31,3 & 11,7 \\
\hline $\mathrm{C}_{2} \mathrm{H}_{4}$ & ${ }^{3} J_{\mathrm{HH}_{\mathrm{t}}}$ & 15,3 & 15,8 & 16,4 & 17,1 & 18,0 & 19,1 & 20,6 & 22,6 & 25,6 & 30,6 & 41,0 & 19 \\
\hline $\mathrm{C}_{2} \mathrm{H}_{6}$ & ${ }^{1} J_{\mathrm{CC}}$ & 14,5 & 16,8 & 19,3 & 21,9 & 24,7 & 27,7 & 30,9 & 34,2 & 37,8 & 41,6 & 45,6 & 34,5 \\
\hline $\mathrm{C}_{2} \mathrm{H}_{6}$ & ${ }^{1} J_{\mathrm{CH}}$ & 95,1 & 98,4 & 101,8 & 105,4 & 109,3 & 113,3 & 117,5 & 121,9 & 126,6 & 131,5 & 136,6 & 125,2 \\
\hline $\mathrm{C}_{2} \mathrm{H}_{6}$ & ${ }^{2} J_{\mathrm{CH}}$ & $-2,0$ & $-2,5$ & $-2,9$ & $-3,5$ & $-4,0$ & $-4,6$ & $-5,2$ & $-5,9$ & $-6,6$ & $-7,3$ & $-8,1$ & $-4,7$ \\
\hline \multirow[t]{3}{*}{ Total } & DM & $-35,36$ & $-32,91$ & $-30,09$ & $-26,98$ & $-23,66$ & $-20,29$ & $-17,04$ & $-14,40$ & $-13,35$ & $-17,77$ & $-62,67$ & - \\
\hline & DMA & 40,58 & 36,13 & 32,65 & 29,02 & 25,55 & 22,36 & 20,35 & 24,49 & 32,98 & 49,91 & 112,44 & - \\
\hline & PDMA & 65,22 & 53,94 & 42,68 & 31,29 & 23,99 & 22,20 & 25,14 & 43,83 & 69,99 & 109,75 & 190,22 & - \\
\hline \multirow[t]{3}{*}{ CPI } & DM & $-66,69$ & $-63,14$ & $-58,88$ & $-54,11$ & $-49,09$ & $-44,20$ & $-40,03$ & $-37,75$ & $-40,08$ & $-56,72$ & $-172,10$ & - \\
\hline & DMA & 76,87 & 69,08 & 63,68 & 57,69 & 51,40 & 45,56 & 41,55 & 49,17 & 63,74 & 94,25 & 226,41 & - \\
\hline & PDMA & 106,26 & 89,23 & 72,67 & 55,70 & 38,43 & 25,96 & 17,65 & 36,37 & 59,40 & 88,66 & 151,26 & - \\
\hline \multirow[t]{3}{*}{ SPI } & DM & $-12,39$ & $-10,74$ & $-8,97$ & $-7,09$ & $-5,01$ & $-2,75$ & $-0,18$ & 2,73 & 6,26 & 10,79 & 17,57 & - \\
\hline & DMA & 13,96 & 11,97 & 9,89 & 7,99 & 6,60 & 5,34 & 4,81 & 6,39 & 10,42 & 17,39 & 28,87 & - \\
\hline & PDMA & 35,12 & 28,05 & 20,68 & 13,39 & 13,40 & 19,44 & 30,64 & 49,30 & 77,75 & 125,22 & 218,79 & - \\
\hline \multirow[t]{3}{*}{$\Delta \mathrm{CS}$} & $\mathrm{DM}$ & $-54,30$ & $-52,40$ & $-49,91$ & $-47,02$ & $-44,08$ & $-41,45$ & $-39,85$ & $-40,49$ & $-46,34$ & $-67,51$ & $-189,67$ & - \\
\hline & DMA & 62,91 & 57,12 & 53,79 & 49,70 & 44,80 & 40,22 & 36,75 & 42,79 & 53,32 & 76,85 & 197,54 & - \\
\hline & PDMA & 71,14 & 61,18 & 52,00 & 42,31 & 25,03 & 6,52 & $-12,99$ & $-12,93$ & $-18,34$ & $-36,56$ & $-67,53$ & - \\
\hline \multicolumn{14}{|c|}{ Desconsiderando ${ }^{1} J_{\mathrm{BF}}$ da molécula de $\mathrm{BF}_{3},{ }^{2} J_{\mathrm{CH}}$ e ${ }^{2} J_{\mathrm{HH}}$ da molécula de $\mathrm{C}_{2} \mathrm{H}_{4}$} \\
\hline \multirow[t]{3}{*}{ Total } & DM & $-35,47$ & $-33,43$ & $-30,97$ & $-28,19$ & $-25,17$ & $-22,06$ & $-19,07$ & $-16,71$ & $-16,07$ & $-21,40$ & $-71,93$ & - \\
\hline & DMA & 40,97 & 36,77 & 33,69 & 30,44 & 27,30 & 24,40 & 22,57 & 26,21 & 34,67 & 52,45 & 121,21 & - \\
\hline & PDMA & 33,89 & 28,57 & 23,52 & 18,40 & 14,21 & 12,83 & 14,31 & 21,21 & 32,65 & 50,25 & 89,72 & - \\
\hline \multirow[t]{3}{*}{ CPI } & DM & $-62,54$ & $-60,43$ & $-57,57$ & $-54,17$ & $-50,51$ & $-47,01$ & $-44,31$ & $-43,73$ & $-48,22$ & $-68,46$ & $-197,33$ & - \\
\hline & DMA & 73,74 & 66,97 & 62,85 & 58,11 & 53,05 & 48,51 & 45,43 & 51,89 & 65,98 & 97,60 & 241,03 & - \\
\hline & PDMA & 44,75 & 38,02 & 31,94 & 25,60 & 19,01 & 17,82 & 17,55 & 25,35 & 37,81 & 57,06 & 112,92 & - \\
\hline \multirow[t]{3}{*}{ SPI } & $\mathrm{DM}$ & $-14,65$ & $-12,65$ & $-10,52$ & $-8,21$ & $-5,67$ & $-2,86$ & 0,35 & 4,07 & 8,66 & 14,80 & 24,54 & - \\
\hline & DMA & 15,75 & 13,55 & 11,25 & 9,16 & 7,50 & 5,85 & 4,99 & 6,45 & 10,58 & 17,72 & 29,05 & - \\
\hline & PDMA & 25,53 & 21,30 & 17,04 & 12,86 & 10,51 & 9,00 & 11,82 & 18,02 & 28,68 & 45,01 & 71,87 & - \\
\hline \multirow[t]{3}{*}{$\Delta \mathrm{CS}$} & $\mathrm{DM}$ & $-47,89$ & $-47,78$ & $-47,05$ & $-45,96$ & $-44,84$ & $-44,15$ & $-44,66$ & $-47,80$ & $-56,88$ & $-83,26$ & $-221,87$ & 一 \\
\hline & DMA & 57,99 & 53,42 & 51,60 & 48,95 & 45,55 & 42,66 & 40,44 & 45,44 & 55,40 & 79,88 & 211,98 & - \\
\hline & PDMA & 19,23 & 16,72 & 14,90 & 12,74 & 8,49 & 8,82 & 5,73 & 7,32 & 9,13 & 12,05 & 41,06 & - \\
\hline
\end{tabular}


8.4. GERAÇÃO DE NOVOS FUNCIONAIS COMBINANDO $E_{X}^{H F}, E_{X}^{D F T} E$

Tabela 8.266: Constantes de acoplamento SPW91 com base aug-pcJ-2.

\begin{tabular}{|c|c|c|c|c|c|c|c|c|c|c|c|c|c|}
\hline & $\% E_{X}^{\mathrm{HF}}$ & $0 \%$ & $10 \%$ & $20 \%$ & $30 \%$ & $40 \%$ & $50 \%$ & $60 \%$ & $70 \%$ & $80 \%$ & $90 \%$ & $100 \%$ & Exp. \\
\hline $\mathrm{HF}$ & ${ }^{1} J_{\mathrm{HF}}$ & 379,7 & 399,0 & 419,0 & 439,6 & 461,0 & 483,1 & 506,0 & 529,7 & 554,3 & 579,8 & 606,3 & 500 \\
\hline $\mathrm{CO}$ & ${ }^{1} J_{\mathrm{CO}}$ & 28,2 & 26,6 & 24,8 & 22,9 & 20,8 & 18,6 & 16,2 & 13,6 & 10,9 & 8,0 & 4,9 & 16,4 \\
\hline $\mathrm{H}_{2} \mathrm{O}$ & ${ }^{1} J_{\mathrm{OH}}$ & $-63,1$ & $-65,4$ & $-67,9$ & $-70,4$ & $-73,1$ & $-75,9$ & $-78,8$ & $-81,9$ & $-85,1$ & $-88,4$ & $-91,9$ & $-80,6$ \\
\hline $\mathrm{H}_{2} \mathrm{O}$ & ${ }^{2} J_{\mathrm{HH}}$ & $-2,9$ & $-4,0$ & $-5,0$ & $-6,2$ & $-7,4$ & $-8,6$ & $-9,9$ & $-11,3$ & $-12,8$ & $-14,3$ & $-16,0$ & $-7,3$ \\
\hline $\mathrm{NH}_{3}$ & ${ }^{1} J_{\mathrm{NH}}$ & 35,6 & 36,6 & 37,6 & 38,8 & 39,9 & 41,2 & 42,5 & 43,9 & 45,3 & 46,8 & 48,4 & 43,8 \\
\hline $\mathrm{NH}_{3}$ & ${ }^{2} J_{\mathrm{HH}}$ & $-5,3$ & $-6,3$ & $-7,3$ & $-8,3$ & $-9,4$ & $-10,6$ & $-11,9$ & $-13,2$ & $-14,6$ & $-16,1$ & $-17,7$ & $-9,6$ \\
\hline $\mathrm{PH}_{3}$ & ${ }^{1} J_{\mathrm{PH}}$ & 115,6 & 123,9 & 132,7 & 141,7 & 151,2 & 161,0 & 171,2 & 181,8 & 192,7 & 203,9 & 215,5 & 188,2 \\
\hline $\mathrm{PF}_{3}$ & ${ }^{1} J_{\mathrm{PF}}$ & $-1809,4$ & $-1791,2$ & $-1766,6$ & $-1736,4$ & $-1701,4$ & $-1662,5$ & $-1620,1$ & $-1575,1$ & $-1527,9$ & $-1478,9$ & $-1428,5$ & -1441 \\
\hline $\mathrm{BHF}_{2}$ & ${ }^{1} J_{\mathrm{BF}}$ & $-195,3$ & $-178,1$ & $-160,6$ & $-142,7$ & $-124,5$ & $-106,2$ & $-87,6$ & $-69,0$ & $-50,2$ & $-31,4$ & $-12,5$ & -84 \\
\hline $\mathrm{BF}_{3}$ & ${ }^{1} J_{\mathrm{BF}}$ & $-92,4$ & $-74,3$ & $-56,0$ & $-37,5$ & $-18,8$ & 0,0 & 19,0 & 38,2 & 57,5 & 77,0 & 96,6 & 15 \\
\hline $\mathrm{F}_{2} \mathrm{O}$ & ${ }^{1} J_{\mathrm{OF}}$ & $-282,2$ & $-319,2$ & $-356,0$ & $-393,9$ & $-435,0$ & $-482,7$ & $-543,0$ & $-627,8$ & $-767,7$ & $-1070,4$ & $-2525,8$ & -300 \\
\hline $\mathrm{CH}_{4}$ & ${ }^{1} J_{\mathrm{CH}}$ & 95,0 & 98,1 & 101,4 & 104,9 & 108,6 & 112,4 & 116,5 & 120,8 & 125,4 & 130,2 & 135,2 & 125,3 \\
\hline $\mathrm{CH}_{4}$ & ${ }^{2} J_{\mathrm{HH}}$ & $-8,3$ & $-9,2$ & $-10,2$ & $-11,3$ & $-12,3$ & $-13,5$ & $-14,6$ & $-15,9$ & $-17,2$ & $-18,5$ & $-19,9$ & $-12,8$ \\
\hline $\mathrm{C}_{2} \mathrm{H}_{2}$ & ${ }^{1} J_{\mathrm{CC}}$ & 165,3 & 169,1 & 173,3 & 178,2 & 183,8 & 190,3 & 198,3 & 208,1 & 220,5 & 236,7 & 259,0 & 174,8 \\
\hline $\mathrm{C}_{2} \mathrm{H}_{2}$ & ${ }^{1} J_{\mathrm{CH}}$ & 207,7 & 213,1 & 218,9 & 225,0 & 231,6 & 238,8 & 246,8 & 255,8 & 266,3 & 278,8 & 294,6 & 247,6 \\
\hline $\mathrm{C}_{2} \mathrm{H}_{2}$ & ${ }^{2} J_{\mathrm{CH}}$ & 49,0 & 49,9 & 50,5 & 50,9 & 50,9 & 50,5 & 49,5 & 47,6 & 44,4 & 39,3 & 31,2 & 50,1 \\
\hline $\mathrm{C}_{2} \mathrm{H}_{2}$ & ${ }^{3} J_{\mathrm{HH}}$ & 7,5 & 8,2 & 9,0 & 10,0 & 11,2 & 12,8 & 14,7 & 17,1 & 20,4 & 24,7 & 30,7 & 9,6 \\
\hline $\mathrm{C}_{2} \mathrm{H}_{4}$ & ${ }^{1} J_{\mathrm{CC}}$ & 44,4 & 47,5 & 51,1 & 55,1 & 59,6 & 65,1 & 71,8 & 80,5 & 92,8 & 112,6 & 152,0 & 67,6 \\
\hline $\mathrm{C}_{2} \mathrm{H}_{4}$ & ${ }^{1} J_{\mathrm{CH}}$ & 123,6 & 127,6 & 131,8 & 136,3 & 141,2 & 146,5 & 152,5 & 159,5 & 168,0 & 179,8 & 200,0 & 156,3 \\
\hline $\mathrm{C}_{2} \mathrm{H}_{4}$ & ${ }^{2} J_{\mathrm{CH}}$ & 0,4 & $-0,2$ & $-0,9$ & $-1,8$ & $-3,0$ & $-4,4$ & $-6,4$ & $-9,1$ & $-13,4$ & $-20,7$ & $-36,2$ & $-2,4$ \\
\hline $\mathrm{C}_{2} \mathrm{H}_{4}$ & ${ }^{2} J_{\mathrm{HH}}$ & 4,1 & 3,5 & 2,9 & 2,2 & 1,3 & 0,3 & $-1,0$ & $-2,8$ & $-5,5$ & $-10,0$ & $-19,2$ & 2,3 \\
\hline $\mathrm{C}_{2} \mathrm{H}_{4}$ & ${ }^{3} J_{\mathrm{HH}_{\mathrm{c}}}$ & 10,4 & 10,8 & 11,1 & 11,6 & 12,2 & 13,0 & 14,0 & 15,6 & 18,0 & 22,2 & 31,2 & 11,7 \\
\hline $\mathrm{C}_{2} \mathrm{H}_{4}$ & ${ }^{3} J_{\mathrm{HH}_{\mathrm{t}}}$ & 15,3 & 15,8 & 16,4 & 17,1 & 18,0 & 19,1 & 20,6 & 22,6 & 25,6 & 30,6 & 40,9 & 19 \\
\hline $\mathrm{C}_{2} \mathrm{H}_{6}$ & ${ }^{1} J_{\mathrm{CC}}$ & 14,8 & 17,1 & 19,6 & 22,3 & 25,1 & 28,1 & 31,3 & 34,7 & 38,2 & 42,1 & 46,1 & 34,5 \\
\hline $\mathrm{C}_{2} \mathrm{H}_{6}$ & ${ }^{1} J_{\mathrm{CH}}$ & 95,6 & 98,9 & 102,4 & 106,0 & 109,9 & 113,9 & 118,1 & 122,6 & 127,3 & 132,2 & 137,3 & 125,2 \\
\hline $\mathrm{C}_{2} \mathrm{H}_{6}$ & ${ }^{2} J_{\mathrm{CH}}$ & $-2,0$ & $-2,5$ & $-2,9$ & $-3,5$ & $-4,0$ & $-4,6$ & $-5,2$ & $-5,9$ & $-6,6$ & $-7,3$ & $-8,1$ & $-4,7$ \\
\hline \multirow[t]{3}{*}{ Total } & $\mathrm{DM}$ & $-35,14$ & $-32,68$ & $-29,84$ & $-26,71$ & $-23,37$ & $-19,97$ & $-16,71$ & $-14,03$ & $-13,02$ & $-17,55$ & $-65,03$ & - \\
\hline & DMA & 40,34 & 35,85 & 32,35 & 28,78 & 25,31 & 22,09 & 20,44 & 24,87 & 33,59 & 50,73 & 115,74 & - \\
\hline & PDMA & 64,77 & 53,32 & 42,08 & 30,51 & 23,60 & 21,46 & 25,47 & 44,13 & 70,94 & 110,73 & 191,82 & - \\
\hline \multirow[t]{3}{*}{ CPI } & DM & $-66,58$ & $-63,03$ & $-58,75$ & $-53,94$ & $-48,87$ & $-43,95$ & $-39,75$ & $-37,45$ & $-39,86$ & $-56,81$ & $-178,33$ & - \\
\hline & DMA & 76,73 & 68,85 & 63,42 & 57,41 & 51,07 & 45,21 & 41,90 & 49,82 & 64,70 & 95,55 & 233,56 & - \\
\hline & PDMA & 105,46 & 88,14 & 71,64 & 54,62 & 37,51 & 24,90 & 18,24 & 37,42 & 60,79 & 90,09 & 155,08 & - \\
\hline \multirow[t]{3}{*}{ SPI } & DM & $-12,09$ & $-10,43$ & $-8,65$ & $-6,74$ & $-4,67$ & $-2,39$ & 0,19 & 3,14 & 6,67 & 11,24 & 18,05 & - \\
\hline & DMA & 13,66 & 11,65 & 9,57 & 7,79 & 6,41 & 5,13 & 4,71 & 6,57 & 10,78 & 17,87 & 29,34 & - \\
\hline & PDMA & 34,93 & 27,78 & 20,40 & 12,84 & 13,40 & 18,93 & 30,78 & 49,05 & 78,38 & 125,86 & 218,77 & - \\
\hline \multirow[t]{3}{*}{$\Delta \mathrm{CS}$} & $\mathrm{DM}$ & $-54,50$ & $-52,60$ & $-50,10$ & $-47,20$ & $-44,21$ & $-41,57$ & $-39,94$ & $-40,59$ & $-46,54$ & $-68,05$ & $-196,37$ & - \\
\hline & DMA & 63,07 & 57,19 & 53,85 & 49,62 & 44,66 & 40,08 & 37,19 & 43,25 & 53,92 & 77,69 & 204,22 & - \\
\hline & PDMA & 70,54 & 60,35 & 51,24 & 41,78 & 24,11 & 5,98 & $-12,54$ & $-11,63$ & $-17,58$ & $-35,77$ & $-63,69$ & - \\
\hline \multicolumn{14}{|c|}{ Desconsiderando ${ }^{1} J_{\mathrm{BF}}$ da molécula de $\mathrm{BF}_{3},{ }^{2} J_{\mathrm{CH}}$ e ${ }^{2} J_{\mathrm{HH}}$ da molécula de $\mathrm{C}_{2} \mathrm{H}_{4}$} \\
\hline \multirow[t]{3}{*}{ Total } & DM & $-35,26$ & $-33,21$ & $-30,74$ & $-27,93$ & $-24,88$ & $-21,75$ & $-18,75$ & $-16,36$ & $-15,74$ & $-21,20$ & $-74,66$ & - \\
\hline & DMA & 40,73 & 36,50 & 33,39 & 30,23 & 27,07 & 24,14 & 22,62 & 26,59 & 35,31 & 53,33 & 124,89 & - \\
\hline & PDMA & 33,61 & 28,13 & 23,14 & 18,00 & 13,90 & 12,50 & 14,15 & 21,39 & 33,20 & 50,80 & 91,32 & - \\
\hline \multirow[t]{3}{*}{ CPI } & DM & $-62,50$ & $-60,40$ & $-57,52$ & $-54,08$ & $-50,38$ & $-46,85$ & $-44,13$ & $-43,52$ & $-48,10$ & $-68,69$ & $-204,32$ & - \\
\hline & DMA & 73,66 & 66,80 & 62,66 & 57,90 & 52,80 & 48,23 & 45,69 & 52,48 & 66,92 & 98,91 & 248,76 & - \\
\hline & PDMA & 44,41 & 37,42 & 31,47 & 25,08 & 18,72 & 17,39 & 17,39 & 25,70 & 38,54 & 57,77 & 116,19 & - \\
\hline \multirow[t]{3}{*}{ SPI } & $\mathrm{DM}$ & $-14,30$ & $-12,29$ & $-10,14$ & $-7,82$ & $-5,26$ & $-2,45$ & 0,78 & 4,53 & 9,15 & 15,32 & 25,08 & - \\
\hline & DMA & 15,41 & 13,18 & 10,88 & 8,94 & 7,28 & 5,62 & 4,87 & 6,67 & 10,99 & 18,26 & 29,60 & - \\
\hline & PDMA & 25,31 & 20,99 & 16,73 & 12,55 & 10,19 & 8,74 & 11,65 & 18,07 & 29,09 & 45,43 & 72,19 & - \\
\hline \multirow[t]{3}{*}{$\Delta \mathrm{CS}$} & $\mathrm{DM}$ & $-48,20$ & $-48,11$ & $-47,38$ & $-46,26$ & $-45,12$ & $-44,40$ & $-44,91$ & $-48,05$ & $-57,25$ & $-84,01$ & $-229,40$ & 一 \\
\hline & DMA & 58,25 & 53,62 & 51,78 & 48,96 & 45,52 & 42,61 & 40,82 & 45,81 & 55,93 & 80,65 & 219,16 & - \\
\hline & PDMA & 19,10 & 16,42 & 14,74 & 12,52 & 8,53 & 8,65 & 5,74 & 7,63 & 9,45 & 12,34 & 44,00 & - \\
\hline
\end{tabular}


Tabela 8.267: Constantes de acoplamento STPSS com base aug-pcJ-2.

\begin{tabular}{|c|c|c|c|c|c|c|c|c|c|c|c|c|c|}
\hline & $\% E_{X}^{\mathrm{HF}}$ & $0 \%$ & $10 \%$ & $20 \%$ & $30 \%$ & $40 \%$ & $50 \%$ & $60 \%$ & $70 \%$ & $80 \%$ & $90 \%$ & $100 \%$ & Exp. \\
\hline $\mathrm{HF}$ & ${ }^{1} J_{\mathrm{HF}}$ & 378,8 & 398,7 & 419,2 & 440,4 & 462,2 & 484,8 & 508,2 & 532,3 & 557,3 & 583,2 & 610,0 & 500 \\
\hline $\mathrm{CO}$ & ${ }^{1} J_{\mathrm{CO}}$ & 28,3 & 26,7 & 24,9 & 23,0 & 20,9 & 18,7 & 16,3 & 13,7 & 10,9 & 8,0 & 4,9 & 16,4 \\
\hline $\mathrm{H}_{2} \mathrm{O}$ & ${ }^{1} J_{\mathrm{OH}}$ & $-63,6$ & $-66,1$ & $-68,6$ & $-71,3$ & $-74,1$ & $-76,9$ & $-80,0$ & $-83,1$ & $-86,4$ & $-89,8$ & $-93,4$ & $-80,6$ \\
\hline $\mathrm{H}_{2} \mathrm{O}$ & ${ }^{2} J_{\mathrm{HH}}$ & $-2,7$ & $-3,8$ & $-4,9$ & $-6,1$ & $-7,3$ & $-8,6$ & $-10,0$ & $-11,4$ & $-12,9$ & $-14,5$ & $-16,2$ & $-7,3$ \\
\hline $\mathrm{NH}_{3}$ & ${ }^{1} J_{\mathrm{NH}}$ & 36,6 & 37,6 & 38,8 & 40,0 & 41,2 & 42,5 & 43,9 & 45,3 & 46,8 & 48,4 & 50,1 & 43,8 \\
\hline $\mathrm{NH}_{3}$ & ${ }^{2} J_{\mathrm{HH}}$ & $-4,9$ & $-5,9$ & $-7,0$ & $-8,1$ & $-9,3$ & $-10,5$ & $-11,8$ & $-13,2$ & $-14,7$ & $-16,3$ & $-17,9$ & $-9,6$ \\
\hline $\mathrm{PH}_{3}$ & ${ }^{1} J_{\mathrm{PH}}$ & 122,8 & 131,9 & 141,4 & 151,3 & 161,6 & 172,4 & 183,6 & 195,2 & 207,3 & 219,8 & 232,6 & 188,2 \\
\hline $\mathrm{PF}_{3}$ & ${ }^{1} J_{\mathrm{PF}}$ & $-1810,4$ & $-1792,8$ & $-1768,8$ & $-1739,3$ & $-1704,9$ & $-1666,5$ & $-1624,8$ & $-1580,2$ & $-1533,5$ & $-1485,0$ & $-1435,2$ & -1441 \\
\hline $\mathrm{BHF}_{2}$ & ${ }^{1} J_{\mathrm{BF}}$ & $-197,2$ & $-180,1$ & $-162,6$ & $-144,9$ & $-126,9$ & $-108,7$ & $-90,4$ & $-72,0$ & $-53,5$ & $-35,0$ & $-16,4$ & -84 \\
\hline $\mathrm{BF}_{3}$ & ${ }^{1} J_{\mathrm{BF}}$ & $-90,9$ & $-72,9$ & $-54,7$ & $-36,4$ & $-17,8$ & 0,8 & 19,7 & 38,7 & 57,8 & 77,0 & 96,3 & 15 \\
\hline $\mathrm{F}_{2} \mathrm{O}$ & ${ }^{1} J_{\mathrm{OF}}$ & $-281,2$ & $-318,2$ & $-354,9$ & $-392,7$ & $-433,5$ & $-480,8$ & $-540,2$ & $-623,5$ & $-760,1$ & $-1052,6$ & $-2403,5$ & -300 \\
\hline $\mathrm{CH}_{4}$ & ${ }^{1} J_{\mathrm{CH}}$ & 101,1 & 104,5 & 108,1 & 111,9 & 115,9 & 120,1 & 124,6 & 129,3 & 134,2 & 139,4 & 144,9 & 125,3 \\
\hline $\mathrm{CH}_{4}$ & ${ }^{2} J_{\mathrm{HH}}$ & $-7,7$ & $-8,7$ & $-9,8$ & $-10,9$ & $-12,0$ & $-13,3$ & $-14,5$ & $-15,9$ & $-17,3$ & $-18,7$ & $-20,2$ & $-12,8$ \\
\hline $\mathrm{C}_{2} \mathrm{H}_{2}$ & ${ }^{1} J_{\mathrm{CC}}$ & 164,7 & 168,5 & 172,9 & 177,9 & 183,6 & 190,5 & 198,7 & 208,9 & 221,8 & 238,8 & 262,1 & 174,8 \\
\hline $\mathrm{C}_{2} \mathrm{H}_{2}$ & ${ }^{1} J_{\mathrm{CH}}$ & 219,6 & 225,4 & 231,6 & 238,2 & 245,3 & 253,1 & 261,7 & 271,4 & 282,6 & 296,0 & 312,9 & 247,6 \\
\hline $\mathrm{C}_{2} \mathrm{H}_{2}$ & ${ }^{2} J_{\mathrm{CH}}$ & 50,4 & 51,2 & 51,8 & 52,2 & 52,2 & 51,8 & 50,7 & 48,7 & 45,3 & 40,0 & 31,5 & 50,1 \\
\hline $\mathrm{C}_{2} \mathrm{H}_{2}$ & ${ }^{3} J_{\mathrm{HH}}$ & 7,8 & 8,5 & 9,3 & 10,4 & 11,6 & 13,2 & 15,2 & 17,7 & 21,1 & 25,6 & 31,8 & 9,6 \\
\hline $\mathrm{C}_{2} \mathrm{H}_{4}$ & ${ }^{1} J_{\mathrm{CC}}$ & 44,8 & 48,0 & 51,7 & 55,8 & 60,5 & 66,1 & 73,0 & 82,0 & 94,6 & 114,6 & 153,5 & 67,6 \\
\hline $\mathrm{C}_{2} \mathrm{H}_{4}$ & ${ }^{1} J_{\mathrm{CH}}$ & 131,1 & 135,4 & 140,0 & 144,9 & 150,1 & 155,9 & 162,4 & 169,8 & 178,9 & 191,3 & 211,7 & 156,3 \\
\hline $\mathrm{C}_{2} \mathrm{H}_{4}$ & ${ }^{2} J_{\mathrm{CH}}$ & 0,3 & $-0,3$ & $-1,1$ & $-2,1$ & $-3,3$ & $-4,8$ & $-6,9$ & $-9,8$ & $-14,1$ & $-21,6$ & $-36,8$ & $-2,4$ \\
\hline $\mathrm{C}_{2} \mathrm{H}_{4}$ & ${ }^{2} J_{\mathrm{HH}}$ & 5,4 & 4,8 & 4,1 & 3,4 & 2,5 & 1,5 & 0,1 & $-1,6$ & $-4,3$ & $-8,7$ & $-17,4$ & 2,3 \\
\hline $\mathrm{C}_{2} \mathrm{H}_{4}$ & ${ }^{3} J_{\mathrm{HH}}$ & 11,2 & 11,5 & 11,9 & 12,4 & 13,0 & 13,8 & 14,8 & 16,4 & 18,8 & 22,8 & 31,3 & 11,7 \\
\hline $\mathrm{C}_{2} \mathrm{H}_{4}$ & ${ }^{3} J_{\mathrm{HH}_{\mathrm{t}}}$ & 16,9 & 17,4 & 18,0 & 18,8 & 19,7 & 20,8 & 22,3 & 24,4 & 27,4 & 32,3 & 42,2 & 19 \\
\hline $\mathrm{C}_{2} \mathrm{H}_{6}$ & ${ }^{1} J_{\mathrm{CC}}$ & 15,3 & 17,7 & 20,2 & 22,9 & 25,7 & 28,7 & 32,0 & 35,4 & 39,0 & 42,9 & 46,9 & 34,5 \\
\hline $\mathrm{C}_{2} \mathrm{H}_{6}$ & ${ }^{1} J_{\mathrm{CH}}$ & 101,6 & 105,2 & 109,0 & 112,9 & 117,1 & 121,5 & 126,1 & 131,0 & 136,1 & 141,4 & 147,1 & 125,2 \\
\hline $\mathrm{C}_{2} \mathrm{H}_{6}$ & ${ }^{2} J_{\mathrm{CH}}$ & $-2,1$ & $-2,5$ & $-3,0$ & $-3,6$ & $-4,1$ & $-4,7$ & $-5,4$ & $-6,1$ & $-6,8$ & $-7,6$ & $-8,5$ & $-4,7$ \\
\hline \multirow[t]{3}{*}{ Total } & $\mathrm{DM}$ & $-33,42$ & $-30,90$ & $-27,98$ & $-24,77$ & $-21,35$ & $-17,83$ & $-14,45$ & $-11,60$ & $-10,33$ & $-14,36$ & $-57,72$ & - \\
\hline & DMA & 38,87 & 34,28 & 30,69 & 27,05 & 23,49 & 20,63 & 20,34 & 26,31 & 36,15 & 53,12 & 113,73 & - \\
\hline & PDMA & 65,06 & 53,75 & 42,06 & 30,52 & 21,68 & 19,41 & 25,07 & 45,15 & 72,82 & 112,88 & 191,26 & - \\
\hline \multirow[t]{3}{*}{ CPI } & DM & $-65,94$ & $-62,35$ & $-58,01$ & $-53,18$ & $-48,07$ & $-43,06$ & $-38,76$ & $-36,28$ & $-38,35$ & $-54,34$ & $-166,33$ & - \\
\hline & DMA & 76,30 & 68,16 & 62,65 & 56,56 & 50,13 & 44,15 & 41,24 & 50,19 & 66,12 & 96,23 & 223,67 & - \\
\hline & PDMA & 104,88 & 87,50 & 70,76 & 53,71 & 36,26 & 23,65 & 17,94 & 37,87 & 61,86 & 90,96 & 152,58 & - \\
\hline \multirow[t]{3}{*}{ SPI } & DM & $-9,58$ & $-7,83$ & $-5,96$ & $-3,93$ & $-1,75$ & 0,67 & 3,38 & 6,50 & 10,21 & 14,96 & 21,93 & - \\
\hline & DMA & 11,42 & 9,43 & 7,25 & 5,41 & 3,95 & 3,38 & 5,02 & 8,79 & 14,17 & 21,51 & 33,11 & - \\
\hline & PDMA & 35,86 & 29,00 & 21,01 & 13,51 & 11,00 & 16,31 & 30,30 & 50,48 & 80,86 & 128,96 & 219,63 & - \\
\hline \multirow[t]{3}{*}{$\Delta \mathrm{CS}$} & DM & $-56,36$ & $-54,51$ & $-52,05$ & $-49,25$ & $-46,32$ & $-43,74$ & $-42,14$ & $-42,78$ & $-48,57$ & $-69,30$ & $-188,25$ & - \\
\hline & DMA & 64,88 & 58,73 & 55,39 & 51,15 & 46,17 & 40,77 & 36,22 & 41,40 & 51,94 & 74,72 & 190,56 & - \\
\hline & PDMA & 69,03 & 58,50 & 49,75 & 40,20 & 25,26 & 7,35 & $-12,36$ & $-12,60$ & $-19,00$ & $-38,00$ & $-67,05$ & - \\
\hline \multicolumn{14}{|c|}{ Desconsiderando ${ }^{1} J_{\mathrm{BF}}$ da molécula de $\mathrm{BF}_{3},{ }^{2} J_{\mathrm{CH}}$ e ${ }^{2} J_{\mathrm{HH}}$ da molécula de $\mathrm{C}_{2} \mathrm{H}_{4}$} \\
\hline \multirow[t]{3}{*}{ Total } & DM & $-33,43$ & $-31,30$ & $-28,73$ & $-25,83$ & $-22,68$ & $-19,40$ & $-16,25$ & $-13,65$ & $-12,75$ & $-17,61$ & $-66,43$ & - \\
\hline & DMA & 39,08 & 34,73 & 31,53 & 28,29 & 25,08 & 22,57 & 22,50 & 28,22 & 38,21 & 56,04 & 122,68 & - \\
\hline & PDMA & 32,10 & 26,75 & 21,58 & 16,97 & 13,00 & 11,97 & 14,67 & 23,39 & 36,24 & 54,06 & 93,09 & - \\
\hline \multirow[t]{3}{*}{ CPI } & DM & $-61,94$ & $-59,79$ & $-56,84$ & $-53,36$ & $-49,60$ & $-45,95$ & $-43,11$ & $-42,28$ & $-46,47$ & $-65,97$ & $-191,09$ & - \\
\hline & DMA & 73,34 & 66,19 & 61,94 & 57,08 & 51,86 & 47,15 & 44,89 & 52,84 & 68,45 & 99,65 & 237,91 & - \\
\hline & PDMA & 44,77 & 37,65 & 31,37 & 24,81 & 18,01 & 16,55 & 16,60 & 25,86 & 39,51 & 58,72 & 113,64 & - \\
\hline \multirow[t]{3}{*}{ SPI } & $\mathrm{DM}$ & $-11,50$ & $-9,39$ & $-7,12$ & $-4,65$ & $-1,97$ & 1,02 & 4,42 & 8,37 & 13,19 & 19,58 & 29,46 & - \\
\hline & DMA & 12,73 & 10,53 & 8,13 & 6,14 & 4,48 & 3,65 & 5,28 & 9,28 & 14,95 & 22,49 & 34,05 & - \\
\hline & PDMA & 22,35 & 18,37 & 14,05 & 10,94 & 9,13 & 8,45 & 13,18 & 21,48 & 33,72 & 50,47 & 77,27 & - \\
\hline \multirow[t]{3}{*}{$\Delta \mathrm{CS}$} & DM & $-50,44$ & $-50,40$ & $-49,72$ & $-48,71$ & $-47,63$ & $-46,97$ & $-47,53$ & $-50,65$ & $-59,66$ & $-85,55$ & $-220,55$ & - \\
\hline & DMA & 60,61 & 55,66 & 53,81 & 50,94 & 47,38 & 43,50 & 39,61 & 43,56 & 53,50 & 77,16 & 203,86 & - \\
\hline & PDMA & 22,42 & 19,28 & 17,32 & 13,87 & 8,88 & 8,10 & 3,42 & 4,38 & 5,79 & 8,25 & 36,37 & - \\
\hline
\end{tabular}

Tabela 8.268: Valores de PDMA total obtidos para troca S com base HuzIIIsu3.

\begin{tabular}{lccccccccccc}
\hline$E_{X}^{\mathrm{HF}}(\%)$ & $0 \%$ & $10 \%$ & $20 \%$ & $30 \%$ & $40 \%$ & $50 \%$ & $60 \%$ & $70 \%$ & $80 \%$ & $90 \%$ & $100 \%$ \\
\hline SB95 & 68,1 & 57,0 & 46,3 & 35,5 & 24,1 & 13,3 & 12,2 & 25,2 & 42,6 & 64,3 & 92,6 \\
SB98 & 59,2 & 47,7 & 36,5 & 24,8 & 14,2 & 12,0 & 24,8 & 43,2 & 65,0 & 92,2 & 132,9 \\
SB971 & 60,4 & 48,9 & 37,7 & 25,8 & 14,6 & 9,5 & 22,5 & 39,8 & 60,3 & 85,5 & 120,6 \\
SB972 & 58,9 & 47,4 & 36,0 & 25,4 & 15,4 & 16,4 & 25,9 & 40,0 & 59,1 & 83,7 & 119,3 \\
SLYP & 60,1 & 48,4 & 37,2 & 25,4 & 15,9 & 14,8 & 27,2 & 46,8 & 71,1 & 103,7 & 161,6 \\
SP86 & 66,6 & 55,4 & 44,6 & 32,8 & 23,9 & 21,1 & 21,4 & 37,2 & 60,9 & 94,8 & 156,5 \\
SPBE & 64,9 & 53,7 & 42,2 & 31,7 & 26,2 & 24,6 & 26,9 & 44,4 & 71,3 & 112,0 & 195,8 \\
SPW91 & 64,6 & 53,2 & 41,8 & 31,2 & 25,5 & 24,0 & 26,6 & 44,8 & 72,0 & 112,8 & 197,7 \\
STPSS & 64,7 & 53,2 & 41,8 & 30,2 & 23,1 & 22,4 & 26,1 & 46,0 & 74,2 & 115,2 & 197,2 \\
\hline
\end{tabular}


8.4.1.9 Troca TPSS

Tabela 8.269: Constantes de acoplamento TPSSB95 com base aug-pcJ-2.

\begin{tabular}{|c|c|c|c|c|c|c|c|c|c|c|c|c|c|}
\hline & $\% E_{X}^{\mathrm{HF}}$ & $0 \%$ & $10 \%$ & $20 \%$ & $30 \%$ & $40 \%$ & $50 \%$ & $60 \%$ & $70 \%$ & $80 \%$ & $90 \%$ & $100 \%$ & Exp. \\
\hline $\mathrm{HF}$ & ${ }^{1} J_{\mathrm{HF}}$ & 418,0 & 441,1 & 464,3 & 487,3 & 510,4 & 533,4 & 556,3 & 579,2 & 602,0 & 624,7 & 647,4 & 500 \\
\hline $\mathrm{CO}$ & ${ }^{1} J_{\mathrm{CO}}$ & 19,7 & 18,2 & 16,7 & 15,1 & 13,5 & 11,8 & 10,0 & 8,2 & 6,3 & 4,4 & 2,4 & 16,4 \\
\hline $\mathrm{H}_{2} \mathrm{O}$ & ${ }^{1} J_{\mathrm{OH}}$ & $-74,8$ & $-77,0$ & $-79,2$ & $-81,4$ & $-83,5$ & $-85,7$ & $-87,8$ & $-89,9$ & $-92,0$ & $-94,1$ & $-96,2$ & $-80,6$ \\
\hline $\mathrm{H}_{2} \mathrm{O}$ & ${ }^{2} J_{\mathrm{HH}}$ & $-3,5$ & $-4,7$ & $-5,9$ & $-7,0$ & $-8,1$ & $-9,2$ & $-10,4$ & $-11,5$ & $-12,5$ & $-13,6$ & $-14,7$ & $-7,3$ \\
\hline $\mathrm{NH}_{3}$ & ${ }^{1} J_{\mathrm{NH}}$ & 45,5 & 45,9 & 46,4 & 46,8 & 47,2 & 47,6 & 48,0 & 48,4 & 48,8 & 49,2 & 49,5 & 43,8 \\
\hline $\mathrm{NH}_{3}$ & ${ }^{2} J_{\mathrm{HH}}$ & $-5,8$ & $-6,9$ & $-8,0$ & $-9,1$ & $-10,1$ & $-11,1$ & $-12,1$ & $-13,0$ & $-14,0$ & $-14,9$ & $-15,8$ & $-9,6$ \\
\hline $\mathrm{PH}_{3}$ & ${ }^{1} J_{\mathrm{PH}}$ & 188,6 & 192,4 & 196,1 & 199,5 & 202,6 & 205,6 & 208,3 & 210,8 & 213,1 & 215,2 & 217,0 & 188,2 \\
\hline $\mathrm{PF}_{3}$ & ${ }^{1} J_{\mathrm{PF}}$ & $-1662,2$ & $-1640,3$ & $-1615,8$ & $-1589,1$ & $-1560,7$ & $-1531,1$ & $-1500,4$ & $-1469,0$ & $-1437,1$ & $-1405,0$ & $-1372,8$ & -1441 \\
\hline $\mathrm{BHF}_{2}$ & ${ }^{1} J_{\mathrm{BF}}$ & $-151,5$ & $-137,4$ & $-123,3$ & $-109,1$ & $-95,0$ & $-80,9$ & $-66,8$ & $-52,7$ & $-38,6$ & $-24,5$ & $-10,5$ & -84 \\
\hline $\mathrm{BF}_{3}$ & ${ }^{1} J_{\mathrm{BF}}$ & $-61,0$ & $-44,4$ & $-28,0$ & $-11,7$ & 4,5 & 20,6 & 36,6 & 52,5 & 68,3 & 84,0 & 99,6 & 15 \\
\hline $\mathrm{F}_{2} \mathrm{O}$ & ${ }^{1} J_{\mathrm{OF}}$ & $-253,4$ & $-286,4$ & $-319,9$ & $-355,1$ & $-393,4$ & $-436,7$ & $-488,1$ & $-553,0$ & $-642,1$ & $-780,5$ & $-1048,5$ & -300 \\
\hline $\mathrm{CH}_{4}$ & ${ }^{1} J_{\mathrm{CH}}$ & 130,0 & 130,6 & 131,1 & 131,7 & 132,2 & 132,8 & 133,2 & 133,7 & 134,1 & 134,5 & 134,9 & 125,3 \\
\hline $\mathrm{CH}_{4}$ & ${ }^{2} J_{\mathrm{HH}}$ & $-8,4$ & $-9,3$ & $-10,3$ & $-11,2$ & $-12,1$ & $-12,9$ & $-13,8$ & $-14,6$ & $-15,4$ & $-16,2$ & $-17,0$ & $-12,8$ \\
\hline $\mathrm{C}_{2} \mathrm{H}_{2}$ & ${ }^{1} J_{\mathrm{CC}}$ & 187,3 & 189,9 & 192,7 & 195,9 & 199,5 & 203,6 & 208,3 & 213,7 & 219,9 & 227,1 & 235,5 & 174,8 \\
\hline $\mathrm{C}_{2} \mathrm{H}_{2}$ & ${ }^{1} J_{\mathrm{CH}}$ & 262,7 & 263,7 & 264,8 & 265,8 & 267,0 & 268,2 & 269,6 & 271,1 & 272,9 & 274,9 & 277,3 & 247,6 \\
\hline $\mathrm{C}_{2} \mathrm{H}_{2}$ & ${ }^{2} J_{\mathrm{CH}}$ & 57,4 & 57,3 & 57,0 & 56,6 & 56,0 & 55,2 & 54,1 & 52,7 & 51,0 & 49,0 & 46,4 & 50,1 \\
\hline $\mathrm{C}_{2} \mathrm{H}_{2}$ & ${ }^{3} J_{\mathrm{HH}}$ & 9,5 & 9,9 & 10,3 & 10,8 & 11,5 & 12,2 & 13,2 & 14,3 & 15,6 & 17,1 & 18,9 & 9,6 \\
\hline $\mathrm{C}_{2} \mathrm{H}_{4}$ & ${ }^{1} J_{\mathrm{CC}}$ & 66,0 & 68,0 & 70,2 & 72,5 & 75,1 & 77,9 & 81,2 & 84,9 & 89,2 & 94,4 & 100,8 & 67,6 \\
\hline $\mathrm{C}_{2} \mathrm{H}_{4}$ & ${ }^{1} J_{\mathrm{CH}}$ & 162,8 & 164,0 & 165,1 & 166,3 & 167,6 & 168,9 & 170,4 & 172,0 & 173,9 & 176,0 & 178,7 & 156,3 \\
\hline $\mathrm{C}_{2} \mathrm{H}_{4}$ & ${ }^{2} J_{\mathrm{CH}}$ & 1,3 & 0,5 & $-0,3$ & $-1,3$ & $-2,4$ & $-3,6$ & $-5,0$ & $-6,6$ & $-8,4$ & $-10,7$ & $-13,4$ & $-2,4$ \\
\hline $\mathrm{C}_{2} \mathrm{H}_{4}$ & ${ }^{2} J_{\mathrm{HH}}$ & 9,3 & 8,3 & 7,3 & 6,3 & 5,2 & 4,0 & 2,8 & 1,5 & 0,0 & $-1,6$ & $-3,5$ & 2,3 \\
\hline $\mathrm{C}_{2} \mathrm{H}_{4}$ & ${ }^{3} J_{\mathrm{HH}_{\mathrm{c}}}$ & 10,7 & 10,9 & 11,2 & 11,6 & 12,0 & 12,5 & 13,1 & 13,7 & 14,6 & 15,6 & 16,9 & 11,7 \\
\hline $\mathrm{C}_{2} \mathrm{H}_{4}$ & ${ }^{3} J_{\mathrm{HH}_{\mathrm{t}}}$ & 19,0 & 19,2 & 19,4 & 19,6 & 19,9 & 20,3 & 20,8 & 21,5 & 22,3 & 23,3 & 24,7 & 19 \\
\hline $\mathrm{C}_{2} \mathrm{H}_{6}$ & ${ }^{1} J_{\mathrm{CC}}$ & 32,6 & 34,0 & 35,3 & 36,7 & 38,0 & 39,3 & 40,6 & 41,9 & 43,2 & 44,4 & 45,7 & 34,5 \\
\hline $\mathrm{C}_{2} \mathrm{H}_{6}$ & ${ }^{1} J_{\mathrm{CH}}$ & 129,9 & 130,7 & 131,5 & 132,2 & 132,9 & 133,6 & 134,3 & 135,0 & 135,6 & 136,2 & 136,7 & 125,2 \\
\hline $\mathrm{C}_{2} \mathrm{H}_{6}$ & ${ }^{2} J_{\mathrm{CH}}$ & $-2,4$ & $-2,8$ & $-3,3$ & $-3,8$ & $-4,2$ & $-4,7$ & $-5,1$ & $-5,6$ & $-6,0$ & $-6,5$ & $-6,9$ & $-4,7$ \\
\hline \multirow[t]{3}{*}{ Total } & DM & $-12,22$ & $-10,37$ & $-8,45$ & $-6,50$ & $-4,59$ & $-2,82$ & $-1,30$ & $-0,22$ & $-0,01$ & $-1,64$ & $-8,15$ & - \\
\hline & DMA & 22,50 & 18,27 & 15,65 & 14,26 & 14,00 & 15,73 & 19,53 & 23,92 & 29,63 & 39,60 & 54,82 & - \\
\hline & PDMA & 52,16 & 41,60 & 31,89 & 23,12 & 16,18 & 17,07 & 26,19 & 38,35 & 53,30 & 70,43 & 90,87 & - \\
\hline \multirow[t]{3}{*}{ CPI } & DM & $-34,66$ & $-30,95$ & $-27,05$ & $-23,15$ & $-19,41$ & $-16,05$ & $-13,39$ & $-11,90$ & $-12,61$ & $-17,82$ & $-34,86$ & - \\
\hline & DMA & 46,55 & 36,51 & 29,81 & 25,90 & 24,54 & 27,56 & 35,10 & 43,75 & 55,25 & 76,29 & 109,08 & - \\
\hline & PDMA & 68,85 & 52,36 & 37,17 & 24,56 & 16,13 & 17,59 & 34,48 & 51,49 & 69,23 & 88,78 & 112,20 & - \\
\hline \multirow[t]{3}{*}{ SPI } & DM & 4,24 & 4,72 & 5,19 & 5,71 & 6,27 & 6,88 & 7,57 & 8,34 & 9,23 & 10,23 & 11,44 & - \\
\hline & DMA & 4,85 & 4,89 & 5,26 & 5,72 & 6,27 & 7,05 & 8,11 & 9,37 & 10,85 & 12,69 & 15,03 & - \\
\hline & PDMA & 39,92 & 33,71 & 28,02 & 22,07 & 16,21 & 16,69 & 20,12 & 28,72 & 41,61 & 56,97 & 75,22 & - \\
\hline \multirow[t]{3}{*}{$\Delta \mathrm{CS}$} & DM & $-38,90$ & $-35,67$ & $-32,24$ & $-28,86$ & $-25,68$ & $-22,93$ & $-20,96$ & $-20,24$ & $-21,84$ & $-28,04$ & $-46,30$ & - \\
\hline & DMA & 41,70 & 31,62 & 24,55 & 20,18 & 18,26 & 20,51 & 26,99 & 34,39 & 44,39 & 63,60 & 94,06 & - \\
\hline & PDMA & 28,93 & 18,65 & 9,15 & 2,49 & $-0,08$ & 0,90 & 14,36 & 22,77 & 27,62 & 31,81 & 36,98 & - \\
\hline \multicolumn{14}{|c|}{ Desconsiderando ${ }^{1} J_{\mathrm{BF}}$ da molécula de $\mathrm{BF}_{3},{ }^{2} J_{\mathrm{CH}}$ e ${ }^{2} J_{\mathrm{HH}}$ da molécula de $\mathrm{C}_{2} \mathrm{H}_{4}$} \\
\hline \multirow[t]{3}{*}{ Total } & DM & $-10,97$ & $-9,53$ & $-7,99$ & $-6,41$ & $-4,86$ & $-3,46$ & $-2,31$ & $-1,67$ & $-1,97$ & $-4,32$ & $-12,16$ & - \\
\hline & DMA & 21,66 & 17,68 & 15,51 & 14,73 & 15,24 & 17,41 & 21,00 & 25,19 & 30,82 & 41,23 & 57,56 & - \\
\hline & PDMA & 17,00 & 13,21 & 10,33 & 8,85 & 9,76 & 12,29 & 17,69 & 23,36 & 29,58 & 37,20 & 47,30 & - \\
\hline \multirow[t]{3}{*}{ CPI } & $\mathrm{DM}$ & $-30,53$ & $-28,10$ & $-25,45$ & $-22,80$ & $-20,30$ & $-18,22$ & $-16,89$ & $-16,84$ & $-19,20$ & $-26,50$ & $-46,81$ & - \\
\hline & DMA & 43,61 & 34,22 & 28,49 & 25,82 & 25,94 & 29,76 & 36,45 & 44,38 & 55,44 & 77,02 & 111,53 & - \\
\hline & PDMA & 25,07 & 17,99 & 12,22 & 9,22 & 10,75 & 15,61 & 23,53 & 31,64 & 40,62 & 51,65 & 67,02 & - \\
\hline \multirow[t]{3}{*}{ SPI } & DM & 4,07 & 4,76 & 5,45 & 6,19 & 7,02 & 7,90 & 8,90 & 10,01 & 11,28 & 12,74 & 14,49 & - \\
\hline & DMA & 4,78 & 4,96 & 5,52 & 6,21 & 7,02 & 7,92 & 9,12 & 10,42 & 11,88 & 13,71 & 16,05 & - \\
\hline & PDMA & 10,79 & 9,53 & 8,88 & 8,56 & 9,01 & 9,73 & 13,21 & 17,00 & 21,09 & 26,09 & 32,14 & - \\
\hline \multirow[t]{3}{*}{$\Delta \mathrm{CS}$} & DM & $-34,60$ & $-32,86$ & $-30,90$ & $-28,99$ & $-27,32$ & $-26,12$ & $-25,79$ & $-26,85$ & $-30,48$ & $-39,24$ & $-61,30$ & - \\
\hline & DMA & 38,83 & 29,26 & 22,97 & 19,61 & 18,92 & 21,84 & 27,33 & 33,96 & 43,56 & 63,31 & 95,48 & - \\
\hline & PDMA & 14,28 & 8,46 & 3,35 & 0,66 & 1,74 & 5,89 & 10,32 & 14,64 & 19,53 & 25,56 & 34,88 & - \\
\hline
\end{tabular}


Tabela 8.270: Constantes de acoplamento TPSSB971 com base aug-pcJ-2.

\begin{tabular}{|c|c|c|c|c|c|c|c|c|c|c|c|c|c|}
\hline & $\% E_{X}^{\mathrm{HF}}$ & $0 \%$ & $10 \%$ & $20 \%$ & $30 \%$ & $40 \%$ & $50 \%$ & $60 \%$ & $70 \%$ & $80 \%$ & $90 \%$ & $100 \%$ & Exp. \\
\hline $\mathrm{HF}$ & ${ }^{1} J_{\mathrm{HF}}$ & 425,7 & 447,8 & 469,9 & 491,9 & 513,9 & 535,7 & 557,5 & 579,3 & 600,9 & 622,4 & 643,9 & 500 \\
\hline $\mathrm{CO}$ & ${ }^{1} J_{\mathrm{CO}}$ & 17,7 & 16,1 & 14,5 & 12,7 & 10,9 & 9,0 & 7,1 & 5,1 & 3,0 & 0,8 & $-1,3$ & 16,4 \\
\hline $\mathrm{H}_{2} \mathrm{O}$ & ${ }^{1} J_{\mathrm{OH}}$ & $-75,8$ & $-77,8$ & $-79,9$ & $-81,9$ & $-83,9$ & $-86,0$ & $-87,9$ & $-89,9$ & $-91,9$ & $-93,8$ & $-95,7$ & $-80,6$ \\
\hline $\mathrm{H}_{2} \mathrm{O}$ & ${ }^{2} J_{\mathrm{HH}}$ & $-3,4$ & $-4,6$ & $-5,7$ & $-6,8$ & $-7,9$ & $-9,0$ & $-10,1$ & $-11,2$ & $-12,2$ & $-13,3$ & $-14,3$ & $-7,3$ \\
\hline $\mathrm{NH}_{3}$ & ${ }^{1} J_{\mathrm{NH}}$ & 46,6 & 47,1 & 47,5 & 47,9 & 48,3 & 48,7 & 49,1 & 49,5 & 49,9 & 50,3 & 50,6 & 43,8 \\
\hline $\mathrm{NH}_{3}$ & ${ }^{2} J_{\mathrm{HH}}$ & $-6,0$ & $-7,1$ & $-8,2$ & $-9,2$ & $-10,3$ & $-11,3$ & $-12,3$ & $-13,3$ & $-14,2$ & $-15,2$ & $-16,1$ & $-9,6$ \\
\hline $\mathrm{PH}_{3}$ & ${ }^{1} J_{\mathrm{PH}}$ & 213,2 & 217,1 & 220,6 & 224,0 & 227,0 & 229,9 & 232,5 & 234,9 & 237,0 & 238,9 & 240,7 & 188,2 \\
\hline $\mathrm{PF}_{3}$ & ${ }^{1} J_{\mathrm{PF}}$ & $-1703,6$ & $-1679,6$ & $-1653,0$ & $-1624,3$ & $-1594,0$ & $-1562,4$ & $-1529,7$ & $-1496,5$ & $-1462,7$ & $-1428,8$ & $-1394,8$ & -1441 \\
\hline $\mathrm{BHF}_{2}$ & ${ }^{1} J_{\mathrm{BF}}$ & $-139,2$ & $-124,2$ & $-109,3$ & $-94,3$ & $-79,5$ & $-64,7$ & $-50,0$ & $-35,3$ & $-20,7$ & $-6,2$ & 8,1 & -84 \\
\hline $\mathrm{BF}_{3}$ & ${ }^{1} J_{\mathrm{BF}}$ & $-48,2$ & $-30,9$ & $-13,9$ & 2,9 & 19,7 & 36,2 & 52,7 & 68,9 & 85,0 & 100,9 & 116,8 & 15 \\
\hline $\mathrm{F}_{2} \mathrm{O}$ & ${ }^{1} J_{\mathrm{OF}}$ & $-254,2$ & $-287,5$ & $-321,8$ & $-358,2$ & $-398,3$ & $-444,5$ & $-500,6$ & $-573,5$ & $-677,5$ & $-849,1$ & $-1221,3$ & -300 \\
\hline $\mathrm{CH}_{4}$ & ${ }^{1} J_{\mathrm{CH}}$ & 139,2 & 139,9 & 140,6 & 141,3 & 141,9 & 142,5 & 143,1 & 143,6 & 144,1 & 144,6 & 145,1 & 125,3 \\
\hline $\mathrm{CH}_{4}$ & ${ }^{2} J_{\mathrm{HH}}$ & $-8,4$ & $-9,4$ & $-10,3$ & $-11,3$ & $-12,2$ & $-13,1$ & $-14,0$ & $-14,8$ & $-15,7$ & $-16,5$ & $-17,3$ & $-12,8$ \\
\hline $\mathrm{C}_{2} \mathrm{H}_{2}$ & ${ }^{1} J_{\mathrm{CC}}$ & 210,4 & 213,8 & 217,7 & 222,0 & 226,8 & 232,3 & 238,6 & 245,8 & 254,1 & 263,8 & 275,1 & 174,8 \\
\hline $\mathrm{C}_{2} \mathrm{H}_{2}$ & ${ }^{1} J_{\mathrm{CH}}$ & 275,6 & 276,9 & 278,2 & 279,6 & 281,2 & 282,8 & 284,7 & 286,8 & 289,2 & 292,1 & 295,5 & 247,6 \\
\hline $\mathrm{C}_{2} \mathrm{H}_{2}$ & ${ }^{2} J_{\mathrm{CH}}$ & 56,5 & 56,1 & 55,5 & 54,8 & 53,8 & 52,5 & 50,9 & 49,0 & 46,6 & 43,7 & 40,1 & 50,1 \\
\hline $\mathrm{C}_{2} \mathrm{H}_{2}$ & ${ }^{3} J_{\mathrm{HH}}$ & 9,4 & 9,8 & 10,3 & 11,0 & 11,7 & 12,7 & 13,8 & 15,0 & 16,6 & 18,4 & 20,5 & 9,6 \\
\hline $\mathrm{C}_{2} \mathrm{H}_{4}$ & ${ }^{1} J_{\mathrm{CC}}$ & 80,8 & 83,4 & 86,2 & 89,3 & 92,8 & 96,7 & 101,1 & 106,4 & 112,7 & 120,5 & 130,5 & 67,6 \\
\hline $\mathrm{C}_{2} \mathrm{H}_{4}$ & ${ }^{1} J_{\mathrm{CH}}$ & 172,4 & 173,7 & 175,1 & 176,6 & 178,1 & 179,8 & 181,6 & 183,7 & 186,2 & 189,2 & 193,0 & 156,3 \\
\hline $\mathrm{C}_{2} \mathrm{H}_{4}$ & ${ }^{2} J_{\mathrm{CH}}$ & 0,3 & $-0,6$ & $-1,7$ & $-2,8$ & $-4,2$ & $-5,7$ & $-7,4$ & $-9,4$ & $-11,9$ & $-14,9$ & $-18,8$ & $-2,4$ \\
\hline $\mathrm{C}_{2} \mathrm{H}_{4}$ & ${ }^{2} J_{\mathrm{HH}}$ & 9,0 & 8,0 & 7,0 & 5,9 & 4,7 & 3,5 & 2,2 & 0,7 & $-0,9$ & $-2,8$ & $-5,1$ & 2,3 \\
\hline $\mathrm{C}_{2} \mathrm{H}_{4}$ & ${ }^{3} J_{\mathrm{HH}_{\mathrm{c}}}$ & 10,6 & 10,9 & 11,2 & 11,6 & 12,1 & 12,6 & 13,2 & 14,0 & 15,0 & 16,3 & 18,0 & 11,7 \\
\hline $\mathrm{C}_{2} \mathrm{H}_{4}$ & ${ }^{3} J_{\mathrm{HH}_{\mathrm{t}}}$ & 18,9 & 19,0 & 19,3 & 19,5 & 19,9 & 20,4 & 21,0 & 21,8 & 22,8 & 24,1 & 25,9 & 19 \\
\hline $\mathrm{C}_{2} \mathrm{H}_{6}$ & ${ }^{1} J_{\mathrm{CC}}$ & 39,1 & 40,6 & 42,2 & 43,8 & 45,3 & 46,9 & 48,4 & 50,0 & 51,5 & 53,0 & 54,4 & 34,5 \\
\hline $\mathrm{C}_{2} \mathrm{H}_{6}$ & ${ }^{1} J_{\mathrm{CH}}$ & 139,1 & 140,0 & 140,9 & 141,7 & 142,6 & 143,4 & 144,2 & 144,9 & 145,7 & 146,3 & 147,0 & 125,2 \\
\hline $\mathrm{C}_{2} \mathrm{H}_{6}$ & ${ }^{2} J_{\mathrm{CH}}$ & $-2,5$ & $-3,0$ & $-3,5$ & $-4,0$ & $-4,5$ & $-5,1$ & $-5,6$ & $-6,1$ & $-6,6$ & $-7,0$ & $-7,5$ & $-4,7$ \\
\hline \multirow[t]{3}{*}{ Total } & $\mathrm{DM}$ & $-8,53$ & $-6,52$ & $-4,45$ & $-2,36$ & $-0,35$ & 1,49 & 3,04 & 4,02 & 3,88 & 1,26 & $-8,92$ & - \\
\hline & DMA & 26,60 & 22,56 & 20,21 & 18,99 & 19,90 & 23,50 & 27,55 & 32,50 & 38,84 & 48,91 & 68,67 & - \\
\hline & PDMA & 48,72 & 38,17 & 28,90 & 21,36 & 20,98 & 29,86 & 40,04 & 55,56 & 72,88 & 92,79 & 118,03 & - \\
\hline \multirow[t]{3}{*}{ CPI } & DM & $-33,46$ & $-29,50$ & $-25,47$ & $-21,47$ & $-17,73$ & $-14,48$ & $-12,05$ & $-11,17$ & $-13,12$ & $-21,27$ & $-47,66$ & - \\
\hline & DMA & 49,32 & 39,08 & 32,71 & 28,89 & 29,80 & 36,81 & 44,56 & 53,77 & 65,68 & 85,91 & 128,26 & - \\
\hline & PDMA & 59,99 & 43,29 & 29,58 & 17,29 & 15,17 & 32,20 & 49,47 & 67,13 & 85,47 & 106,13 & 132,83 & - \\
\hline \multirow[t]{3}{*}{ SPI } & DM & 9,75 & 10,33 & 10,97 & 11,66 & 12,39 & 13,21 & 14,11 & 15,15 & 16,35 & 17,78 & 19,49 & - \\
\hline & DMA & 9,94 & 10,44 & 11,04 & 11,73 & 12,63 & 13,74 & 15,07 & 16,90 & 19,15 & 21,78 & 24,97 & - \\
\hline & PDMA & 40,45 & 34,42 & 28,40 & 24,34 & 25,25 & 28,14 & 33,12 & 47,08 & 63,65 & 83,01 & 107,17 & - \\
\hline \multirow[t]{3}{*}{$\Delta \mathrm{CS}$} & DM & $-43,22$ & $-39,83$ & $-36,45$ & $-33,13$ & $-30,12$ & $-27,69$ & $-26,17$ & $-26,33$ & $-29,47$ & $-39,05$ & $-67,15$ & - \\
\hline & DMA & 39,38 & 28,64 & 21,67 & 17,16 & 17,17 & 23,07 & 29,49 & 36,87 & 46,53 & 64,13 & 103,30 & - \\
\hline & PDMA & 19,54 & 8,88 & 1,18 & $-7,05$ & $-10,08$ & 4,06 & 16,35 & 20,05 & 21,82 & 23,13 & 25,65 & - \\
\hline \multicolumn{14}{|c|}{ Desconsiderando ${ }^{1} J_{\mathrm{BF}}$ da molécula de $\mathrm{BF}_{3},{ }^{2} J_{\mathrm{CH}}$ e ${ }^{2} J_{\mathrm{HH}}$ da molécula de $\mathrm{C}_{2} \mathrm{H}_{4}$} \\
\hline \multirow[t]{3}{*}{ Total } & DM & $-7,30$ & $-5,70$ & $-4,00$ & $-2,28$ & $-0,63$ & 0,86 & 2,02 & 2,57 & 1,90 & $-1,55$ & $-13,48$ & - \\
\hline & DMA & 26,91 & 23,18 & 21,35 & 20,77 & 22,10 & 25,45 & 29,28 & 34,02 & 40,31 & 50,79 & 72,17 & - \\
\hline & PDMA & 19,20 & 15,81 & 14,14 & 13,11 & 14,56 & 19,36 & 25,09 & 31,48 & 38,84 & 47,71 & 60,22 & - \\
\hline \multirow[t]{3}{*}{ CPI } & DM & $-30,49$ & $-27,86$ & $-25,13$ & $-22,41$ & $-19,97$ & $-18,05$ & $-17,03$ & $-17,68$ & $-21,43$ & $-31,99$ & $-62,61$ & - \\
\hline & DMA & 47,93 & 38,40 & 33,09 & 30,57 & 32,31 & 38,37 & 45,25 & 53,76 & 65,25 & 85,91 & 130,91 & - \\
\hline & PDMA & 23,85 & 17,02 & 13,27 & 10,96 & 13,56 & 21,29 & 29,29 & 37,91 & 47,35 & 59,48 & 78,24 & - \\
\hline \multirow[t]{3}{*}{ SPI } & $\mathrm{DM}$ & 10,53 & 11,35 & 12,25 & 13,21 & 14,25 & 15,40 & 16,68 & 18,15 & 19,85 & 21,87 & 24,32 & - \\
\hline & DMA & 10,75 & 11,47 & 12,32 & 13,22 & 14,25 & 15,51 & 17,00 & 18,84 & 21,12 & 23,78 & 26,98 & - \\
\hline & PDMA & 15,62 & 14,88 & 14,81 & 14,77 & 15,33 & 17,88 & 21,85 & 26,53 & 32,30 & 38,65 & 46,35 & - \\
\hline \multirow[t]{3}{*}{$\Delta \mathrm{CS}$} & $\mathrm{DM}$ & $-41,02$ & $-39,21$ & $-37,38$ & $-35,62$ & $-34,22$ & $-33,45$ & $-33,71$ & $-35,83$ & $-41,28$ & $-53,86$ & $-86,93$ & - \\
\hline & DMA & 37,18 & 26,93 & 20,77 & 17,35 & 18,06 & 22,86 & 28,25 & 34,92 & 44,13 & 62,13 & 103,93 & - \\
\hline & PDMA & 8,24 & 2,14 & $-1,53$ & $-3,81$ & $-1,78$ & 3,41 & 7,43 & 11,38 & 15,05 & 20,82 & 31,89 & - \\
\hline
\end{tabular}


Tabela 8.271: Constantes de acoplamento TPSSB972 com base aug-pcJ-2.

\begin{tabular}{|c|c|c|c|c|c|c|c|c|c|c|c|c|c|}
\hline & $\% E_{X}^{\mathrm{HF}}$ & $0 \%$ & $10 \%$ & $20 \%$ & $30 \%$ & $40 \%$ & $50 \%$ & $60 \%$ & $70 \%$ & $80 \%$ & $90 \%$ & $100 \%$ & Exp. \\
\hline $\mathrm{HF}$ & ${ }^{1} J_{\mathrm{HF}}$ & 465,8 & 488,7 & 511,6 & 534,4 & 557,1 & 579,7 & 602,3 & 624,8 & 647,1 & 669,4 & 691,6 & 500 \\
\hline $\mathrm{CO}$ & ${ }^{1} J_{\mathrm{CO}}$ & 13,3 & 11,4 & 9,5 & 7,6 & 5,5 & 3,4 & 1,2 & $-1,0$ & $-3,4$ & $-5,8$ & $-8,3$ & 16,4 \\
\hline $\mathrm{H}_{2} \mathrm{O}$ & ${ }^{1} J_{\mathrm{OH}}$ & $-82,1$ & $-84,3$ & $-86,4$ & $-88,6$ & $-90,7$ & $-92,8$ & $-94,9$ & $-97,0$ & $-99,1$ & $-101,1$ & $-103,1$ & $-80,6$ \\
\hline $\mathrm{H}_{2} \mathrm{O}$ & ${ }^{2} J_{\mathrm{HH}}$ & $-3,0$ & $-4,2$ & $-5,4$ & $-6,6$ & $-7,7$ & $-8,9$ & $-10,0$ & $-11,1$ & $-12,2$ & $-13,3$ & $-14,3$ & $-7,3$ \\
\hline $\mathrm{NH}_{3}$ & ${ }^{1} J_{\mathrm{NH}}$ & 49,2 & 49,6 & 50,0 & 50,5 & 50,9 & 51,3 & 51,6 & 52,0 & 52,4 & 52,7 & 53,1 & 43,8 \\
\hline $\mathrm{NH}_{3}$ & ${ }^{2} J_{\mathrm{HH}}$ & $-5,0$ & $-6,1$ & $-7,3$ & $-8,3$ & $-9,4$ & $-10,4$ & $-11,5$ & $-12,4$ & $-13,4$ & $-14,3$ & $-15,2$ & $-9,6$ \\
\hline $\mathrm{PH}_{3}$ & ${ }^{1} J_{\mathrm{PH}}$ & 210,4 & 214,7 & 218,7 & 222,5 & 226,1 & 229,4 & 232,5 & 235,3 & 237,9 & 240,3 & 242,5 & 188,2 \\
\hline $\mathrm{PF}_{3}$ & ${ }^{1} J_{\mathrm{PF}}$ & $-1748,5$ & $-1723,0$ & $-1694,9$ & $-1664,7$ & $-1632,7$ & $-1599,5$ & $-1565,4$ & $-1530,6$ & $-1495,5$ & $-1460,2$ & $-1424,9$ & -1441 \\
\hline $\mathrm{BHF}_{2}$ & ${ }^{1} J_{\mathrm{BF}}$ & $-125,6$ & $-110,6$ & $-95,7$ & $-80,9$ & $-66,1$ & $-51,5$ & $-37,0$ & $-22,5$ & $-8,1$ & 6,1 & 20,3 & -84 \\
\hline $\mathrm{BF}_{3}$ & ${ }^{1} J_{\mathrm{BF}}$ & $-32,3$ & $-15,0$ & 2,0 & 18,8 & 35,4 & 51,9 & 68,1 & 84,2 & 100,1 & 115,9 & 131,6 & 15 \\
\hline $\mathrm{F}_{2} \mathrm{O}$ & ${ }^{1} J_{\mathrm{OF}}$ & $-248,4$ & $-281,1$ & $-314,7$ & $-350,6$ & $-390,2$ & $-436,2$ & $-492,8$ & $-567,8$ & $-678,3$ & $-871,2$ & $-1349,0$ & -300 \\
\hline $\mathrm{CH}_{4}$ & ${ }^{1} J_{\mathrm{CH}}$ & 141,3 & 141,9 & 142,6 & 143,2 & 143,7 & 144,3 & 144,8 & 145,3 & 145,7 & 146,2 & 146,5 & 125,3 \\
\hline $\mathrm{CH}_{4}$ & ${ }^{2} J_{\mathrm{HH}}$ & $-6,8$ & $-7,7$ & $-8,6$ & $-9,6$ & $-10,5$ & $-11,4$ & $-12,3$ & $-13,1$ & $-14,0$ & $-14,8$ & $-15,6$ & $-12,8$ \\
\hline $\mathrm{C}_{2} \mathrm{H}_{2}$ & ${ }^{1} J_{\mathrm{CC}}$ & 207,5 & 211,0 & 215,0 & 219,5 & 224,5 & 230,3 & 236,8 & 244,2 & 252,8 & 262,7 & 274,3 & 174,8 \\
\hline $\mathrm{C}_{2} \mathrm{H}_{2}$ & ${ }^{1} J_{\mathrm{CH}}$ & 276,0 & 277,2 & 278,4 & 279,7 & 281,1 & 282,7 & 284,4 & 286,3 & 288,5 & 291,1 & 294,1 & 247,6 \\
\hline $\mathrm{C}_{2} \mathrm{H}_{2}$ & ${ }^{2} J_{\mathrm{CH}}$ & 56,9 & 56,5 & 56,0 & 55,3 & 54,3 & 53,1 & 51,6 & 49,8 & 47,6 & 44,9 & 41,6 & 50,1 \\
\hline $\mathrm{C}_{2} \mathrm{H}_{2}$ & ${ }^{3} J_{\mathrm{HH}}$ & 8,7 & 9,0 & 9,4 & 10,0 & 10,6 & 11,4 & 12,3 & 13,4 & 14,7 & 16,2 & 18,0 & 9,6 \\
\hline $\mathrm{C}_{2} \mathrm{H}_{4}$ & ${ }^{1} J_{\mathrm{CC}}$ & 80,7 & 83,4 & 86,4 & 89,8 & 93,5 & 97,8 & 102,8 & 108,8 & 116,0 & 125,1 & 137,0 & 67,6 \\
\hline $\mathrm{C}_{2} \mathrm{H}_{4}$ & ${ }^{1} J_{\mathrm{CH}}$ & 173,4 & 174,7 & 176,0 & 177,4 & 178,9 & 180,6 & 182,4 & 184,5 & 187,0 & 190,0 & 194,0 & 156,3 \\
\hline $\mathrm{C}_{2} \mathrm{H}_{4}$ & ${ }^{2} J_{\mathrm{CH}}$ & 1,3 & 0,4 & $-0,6$ & $-1,8$ & $-3,1$ & $-4,6$ & $-6,3$ & $-8,4$ & $-10,9$ & $-14,0$ & $-18,1$ & $-2,4$ \\
\hline $\mathrm{C}_{2} \mathrm{H}_{4}$ & ${ }^{2} J_{\mathrm{HH}}$ & 10,4 & 9,4 & 8,4 & 7,4 & 6,3 & 5,1 & 3,9 & 2,5 & 0,9 & $-0,8$ & $-2,9$ & 2,3 \\
\hline $\mathrm{C}_{2} \mathrm{H}_{4}$ & ${ }^{3} J_{\mathrm{HH}_{\mathrm{c}}}$ & 10,2 & 10,4 & 10,7 & 11,0 & 11,4 & 11,8 & 12,4 & 13,1 & 13,9 & 15,1 & 16,6 & 11,7 \\
\hline $\mathrm{C}_{2} \mathrm{H}_{4}$ & ${ }^{3} J_{\mathrm{HH}_{\mathrm{t}}}$ & 18,4 & 18,5 & 18,6 & 18,9 & 19,2 & 19,5 & 20,1 & 20,7 & 21,6 & 22,8 & 24,4 & 19 \\
\hline $\mathrm{C}_{2} \mathrm{H}_{6}$ & ${ }^{1} J_{\mathrm{CC}}$ & 42,0 & 43,5 & 45,0 & 46,5 & 47,9 & 49,4 & 50,8 & 52,3 & 53,7 & 55,1 & 56,4 & 34,5 \\
\hline $\mathrm{C}_{2} \mathrm{H}_{6}$ & ${ }^{1} J_{\mathrm{CH}}$ & 140,2 & 141,0 & 141,9 & 142,7 & 143,4 & 144,2 & 144,9 & 145,6 & 146,3 & 146,9 & 147,5 & 125,2 \\
\hline $\mathrm{C}_{2} \mathrm{H}_{6}$ & ${ }^{2} J_{\mathrm{CH}}$ & $-1,6$ & $-2,1$ & $-2,6$ & $-3,1$ & $-3,6$ & $-4,1$ & $-4,6$ & $-5,1$ & $-5,6$ & $-6,1$ & $-6,5$ & $-4,7$ \\
\hline \multirow[t]{3}{*}{ Total } & DM & $-7,41$ & $-5,30$ & $-3,12$ & $-0,92$ & 1,18 & 3,13 & 4,73 & 5,72 & 5,41 & 2,07 & $-12,05$ & - \\
\hline & DMA & 26,30 & 22,47 & 20,55 & 21,53 & 24,59 & 28,10 & 32,06 & 36,86 & 43,43 & 53,39 & 75,85 & - \\
\hline & PDMA & 51,04 & 41,31 & 31,95 & 25,51 & 29,41 & 37,14 & 45,79 & 55,97 & 72,64 & 92,52 & 118,82 & - \\
\hline \multirow[t]{3}{*}{ CPI } & DM & $-31,55$ & $-27,35$ & $-23,05$ & $-18,80$ & $-14,79$ & $-11,32$ & $-8,80$ & $-7,91$ & $-10,31$ & $-20,22$ & $-56,05$ & - \\
\hline & DMA & 47,57 & 37,85 & 32,59 & 34,13 & 40,35 & 47,28 & 55,07 & 64,42 & 76,93 & 96,84 & 145,55 & - \\
\hline & PDMA & 51,09 & 36,47 & 23,19 & 17,14 & 30,45 & 47,34 & 64,71 & 82,40 & 101,22 & 122,32 & 152,13 & - \\
\hline \multirow[t]{3}{*}{ SPI } & $\mathrm{DM}$ & 10,30 & 10,87 & 11,50 & 12,19 & 12,90 & 13,73 & 14,66 & 15,72 & 16,94 & 18,42 & 20,21 & - \\
\hline & DMA & 10,70 & 11,19 & 11,71 & 12,29 & 13,03 & 14,03 & 15,18 & 16,65 & 18,87 & 21,53 & 24,75 & - \\
\hline & PDMA & 51,01 & 44,87 & 38,38 & 31,65 & 28,64 & 29,67 & 31,91 & 36,59 & 51,69 & 70,66 & 94,39 & - \\
\hline \multirow[t]{3}{*}{$\Delta \mathrm{CS}$} & $\mathrm{DM}$ & $-41,85$ & $-38,21$ & $-34,55$ & $-30,99$ & $-27,69$ & $-25,05$ & $-23,46$ & $-23,63$ & $-27,25$ & $-38,64$ & $-76,27$ & - \\
\hline & DMA & 36,87 & 26,67 & 20,88 & 21,83 & 27,32 & 33,26 & 39,89 & 47,76 & 58,05 & 75,31 & 120,80 & - \\
\hline & PDMA & 0,08 & $-8,40$ & $-15,19$ & $-14,51$ & 1,81 & 17,67 & 32,81 & 45,81 & 49,53 & 51,66 & 57,74 & - \\
\hline \multicolumn{14}{|c|}{ Desconsiderando ${ }^{1} J_{\mathrm{BF}}$ da molécula de $\mathrm{BF}_{3},{ }^{2} J_{\mathrm{CH}}$ e ${ }^{2} J_{\mathrm{HH}}$ da molécula de $\mathrm{C}_{2} \mathrm{H}_{4}$} \\
\hline \multirow[t]{3}{*}{ Total } & $\mathrm{DM}$ & $-6,83$ & $-5,12$ & $-3,30$ & $-1,46$ & 0,31 & 1,91 & 3,14 & 3,71 & 2,85 & $-1,40$ & $-17,79$ & - \\
\hline & DMA & 27,16 & 23,67 & 22,32 & 23,93 & 26,71 & 29,94 & 33,69 & 38,39 & 44,97 & 55,33 & 79,77 & - \\
\hline & PDMA & 21,97 & 19,51 & 17,56 & 17,01 & 18,50 & 22,01 & 26,28 & 31,96 & 39,41 & 48,46 & 62,25 & - \\
\hline \multirow[t]{3}{*}{ CPI } & DM & $-29,98$ & $-27,08$ & $-24,05$ & $-21,06$ & $-18,31$ & $-16,14$ & $-14,99$ & $-15,62$ & $-19,85$ & $-32,33$ & $-73,32$ & - \\
\hline & DMA & 47,60 & 38,64 & 34,55 & 37,16 & 42,35 & 48,32 & 55,27 & 63,94 & 76,11 & 96,43 & 148,44 & - \\
\hline & PDMA & 24,66 & 20,11 & 16,84 & 16,32 & 19,90 & 27,47 & 35,79 & 44,51 & 54,61 & 67,28 & 89,61 & - \\
\hline \multirow[t]{3}{*}{ SPI } & $\mathrm{DM}$ & 10,98 & 11,78 & 12,66 & 13,62 & 14,63 & 15,80 & 17,09 & 18,58 & 20,31 & 22,38 & 24,93 & - \\
\hline & DMA & 11,44 & 12,15 & 12,91 & 13,75 & 14,68 & 15,80 & 17,09 & 18,74 & 21,02 & 23,71 & 26,95 & - \\
\hline & PDMA & 19,90 & 19,05 & 18,11 & 17,54 & 17,43 & 17,82 & 18,97 & 22,32 & 27,71 & 33,98 & 41,20 & - \\
\hline \multirow[t]{3}{*}{$\Delta \mathrm{CS}$} & DM & $-40,96$ & $-38,86$ & $-36,71$ & $-34,68$ & $-32,94$ & $-31,94$ & $-32,08$ & $-34,20$ & $-40,16$ & $-54,71$ & $-98,25$ & - \\
\hline & DMA & 36,16 & 26,49 & 21,64 & 23,41 & 27,67 & 32,52 & 38,18 & 45,20 & 55,09 & 72,72 & 121,49 & - \\
\hline & PDMA & 4,76 & 1,06 & $-1,27$ & $-1,22$ & 2,47 & 9,65 & 16,82 & 22,19 & 26,89 & 33,30 & 48,41 & - \\
\hline
\end{tabular}


Tabela 8.272: Constantes de acoplamento TPSSB98 com base aug-pcJ-2.

\begin{tabular}{|c|c|c|c|c|c|c|c|c|c|c|c|c|c|}
\hline & $\% E_{X}^{\mathrm{HF}}$ & $0 \%$ & $10 \%$ & $20 \%$ & $30 \%$ & $40 \%$ & $50 \%$ & $60 \%$ & $70 \%$ & $80 \%$ & $90 \%$ & $100 \%$ & Exp. \\
\hline $\mathrm{HF}$ & ${ }^{1} J_{\mathrm{HF}}$ & 412,9 & 435,2 & 457,4 & 479,6 & 501,8 & 523,9 & 545,9 & 567,8 & 589,6 & 611,4 & 633,1 & 500 \\
\hline $\mathrm{CO}$ & ${ }^{1} J_{\mathrm{CO}}$ & 17,5 & 15,9 & 14,2 & 12,5 & 10,7 & 8,8 & 6,9 & 4,9 & 2,8 & 0,7 & $-1,4$ & 16,4 \\
\hline $\mathrm{H}_{2} \mathrm{O}$ & ${ }^{1} J_{\mathrm{OH}}$ & $-75,2$ & $-77,3$ & $-79,3$ & $-81,4$ & $-83,5$ & $-85,5$ & $-87,6$ & $-89,6$ & $-91,6$ & $-93,6$ & $-95,6$ & $-80,6$ \\
\hline $\mathrm{H}_{2} \mathrm{O}$ & ${ }^{2} J_{\mathrm{HH}}$ & $-3,5$ & $-4,6$ & $-5,8$ & $-6,9$ & $-8,1$ & $-9,2$ & $-10,3$ & $-11,4$ & $-12,5$ & $-13,6$ & $-14,6$ & $-7,3$ \\
\hline $\mathrm{NH}_{3}$ & ${ }^{1} J_{\mathrm{NH}}$ & 47,2 & 47,7 & 48,1 & 48,6 & 49,0 & 49,5 & 49,9 & 50,3 & 50,7 & 51,1 & 51,5 & 43,8 \\
\hline $\mathrm{NH}_{3}$ & ${ }^{2} J_{\mathrm{HH}}$ & $-6,2$ & $-7,4$ & $-8,5$ & $-9,6$ & $-10,7$ & $-11,8$ & $-12,8$ & $-13,8$ & $-14,8$ & $-15,8$ & $-16,8$ & $-9,6$ \\
\hline $\mathrm{PH}_{3}$ & ${ }^{1} J_{\mathrm{PH}}$ & 219,3 & 223,3 & 226,9 & 230,4 & 233,6 & 236,5 & 239,2 & 241,7 & 244,0 & 246,0 & 247,9 & 188,2 \\
\hline $\mathrm{PF}_{3}$ & ${ }^{1} J_{\mathrm{PF}}$ & $-1719,0$ & $-1694,2$ & $-1666,8$ & $-1637,4$ & $-1606,4$ & $-1574,2$ & $-1541,1$ & $-1507,3$ & $-1473,2$ & $-1438,9$ & $-1404,5$ & -1441 \\
\hline $\mathrm{BHF}_{2}$ & ${ }^{1} J_{\mathrm{BF}}$ & $-139,3$ & $-124,5$ & $-109,8$ & $-95,1$ & $-80,4$ & $-65,8$ & $-51,2$ & $-36,7$ & $-22,3$ & $-7,9$ & 6,2 & -84 \\
\hline $\mathrm{BF}_{3}$ & ${ }^{1} J_{\mathrm{BF}}$ & $-49,2$ & $-32,2$ & $-15,3$ & 1,3 & 17,8 & 34,2 & 50,4 & 66,4 & 82,4 & 98,2 & 113,8 & 15 \\
\hline $\mathrm{F}_{2} \mathrm{O}$ & ${ }^{1} J_{\mathrm{OF}}$ & $-264,1$ & $-298,7$ & $-334,5$ & $-372,9$ & $-415,7$ & $-465,9$ & $-528,1$ & $-611,2$ & $-734,9$ & $-953,4$ & $-1507,1$ & -300 \\
\hline $\mathrm{CH}_{4}$ & ${ }^{1} J_{\mathrm{CH}}$ & 142,9 & 143,7 & 144,4 & 145,2 & 145,9 & 146,6 & 147,2 & 147,8 & 148,4 & 149,0 & 149,5 & 125,3 \\
\hline $\mathrm{CH}_{4}$ & ${ }^{2} J_{\mathrm{HH}}$ & $-8,8$ & $-9,8$ & $-10,8$ & $-11,8$ & $-12,7$ & $-13,7$ & $-14,6$ & $-15,5$ & $-16,4$ & $-17,3$ & $-18,1$ & $-12,8$ \\
\hline $\mathrm{C}_{2} \mathrm{H}_{2}$ & ${ }^{1} J_{\mathrm{CC}}$ & 214,4 & 217,9 & 221,9 & 226,3 & 231,3 & 237,0 & 243,5 & 251,1 & 259,8 & 270,0 & 282,1 & 174,8 \\
\hline $\mathrm{C}_{2} \mathrm{H}_{2}$ & ${ }^{1} J_{\mathrm{CH}}$ & 281,0 & 282,5 & 284,0 & 285,5 & 287,2 & 289,1 & 291,2 & 293,6 & 296,3 & 299,5 & 303,3 & 247,6 \\
\hline $\mathrm{C}_{2} \mathrm{H}_{2}$ & ${ }^{2} J_{\mathrm{CH}}$ & 57,1 & 56,7 & 56,1 & 55,3 & 54,2 & 52,8 & 51,1 & 49,0 & 46,4 & 43,2 & 39,3 & 50,1 \\
\hline $\mathrm{C}_{2} \mathrm{H}_{2}$ & ${ }^{3} J_{\mathrm{HH}}$ & 9,6 & 10,0 & 10,6 & 11,3 & 12,1 & 13,1 & 14,3 & 15,7 & 17,4 & 19,3 & 21,7 & 9,6 \\
\hline $\mathrm{C}_{2} \mathrm{H}_{4}$ & ${ }^{1} J_{\mathrm{CC}}$ & 83,6 & 86,3 & 89,3 & 92,6 & 96,2 & 100,4 & 105,2 & 110,9 & 117,9 & 126,7 & 138,3 & 67,6 \\
\hline $\mathrm{C}_{2} \mathrm{H}_{4}$ & ${ }^{1} J_{\mathrm{CH}}$ & 176,2 & 177,7 & 179,2 & 180,8 & 182,5 & 184,4 & 186,4 & 188,8 & 191,6 & 195,1 & 199,6 & 156,3 \\
\hline $\mathrm{C}_{2} \mathrm{H}_{4}$ & ${ }^{2} J_{\mathrm{CH}}$ & 0,2 & $-0,7$ & $-1,8$ & $-3,1$ & $-4,5$ & $-6,1$ & $-7,9$ & $-10,2$ & $-12,9$ & $-16,3$ & $-20,9$ & $-2,4$ \\
\hline $\mathrm{C}_{2} \mathrm{H}_{4}$ & ${ }^{2} J_{\mathrm{HH}}$ & 9,1 & 8,1 & 7,0 & 5,9 & 4,7 & 3,4 & 2,0 & 0,4 & $-1,3$ & $-3,5$ & $-6,2$ & 2,3 \\
\hline $\mathrm{C}_{2} \mathrm{H}_{4}$ & ${ }^{3} J_{\mathrm{HH}_{\mathrm{c}}}$ & 10,7 & 11,0 & 11,4 & 11,8 & 12,3 & 12,9 & 13,6 & 14,5 & 15,7 & 17,2 & 19,2 & 11,7 \\
\hline $\mathrm{C}_{2} \mathrm{H}_{4}$ & ${ }^{3} J_{\mathrm{HH}_{\mathrm{t}}}$ & 19,2 & 19,4 & 19,6 & 19,9 & 20,4 & 20,9 & 21,6 & 22,5 & 23,7 & 25,3 & 27,5 & 19 \\
\hline $\mathrm{C}_{2} \mathrm{H}_{6}$ & ${ }^{1} J_{\mathrm{CC}}$ & 41,0 & 42,6 & 44,3 & 45,9 & 47,6 & 49,2 & 50,8 & 52,4 & 54,0 & 55,5 & 57,1 & 34,5 \\
\hline $\mathrm{C}_{2} \mathrm{H}_{6}$ & ${ }^{1} J_{\mathrm{CH}}$ & 142,6 & 143,6 & 144,5 & 145,5 & 146,4 & 147,3 & 148,2 & 149,1 & 149,9 & 150,6 & 151,4 & 125,2 \\
\hline $\mathrm{C}_{2} \mathrm{H}_{6}$ & ${ }^{2} J_{\mathrm{CH}}$ & $-2,6$ & $-3,1$ & $-3,6$ & $-4,2$ & $-4,7$ & $-5,3$ & $-5,8$ & $-6,3$ & $-6,8$ & $-7,3$ & $-7,9$ & $-4,7$ \\
\hline \multirow[t]{3}{*}{ Total } & DM & $-8,78$ & $-6,77$ & $-4,70$ & $-2,65$ & $-0,69$ & 1,06 & 2,42 & 3,07 & 2,27 & $-2,07$ & $-19,10$ & - \\
\hline & DMA & 28,57 & 24,53 & 23,10 & 21,95 & 21,90 & 25,74 & 30,08 & 35,49 & 42,70 & 53,95 & 80,95 & - \\
\hline & PDMA & 49,63 & 39,51 & 30,38 & 23,48 & 22,62 & 32,27 & 43,26 & 59,70 & 78,06 & 100,01 & 129,89 & - \\
\hline \multirow[t]{3}{*}{ CPI } & DM & $-36,41$ & $-32,52$ & $-28,57$ & $-24,71$ & $-21,16$ & $-18,22$ & $-16,34$ & $-16,35$ & $-20,06$ & $-32,43$ & $-75,31$ & - \\
\hline & DMA & 51,70 & 41,34 & 37,10 & 33,33 & 31,85 & 39,18 & 47,46 & 57,53 & 71,23 & 93,86 & 152,76 & - \\
\hline & PDMA & 60,70 & 44,40 & 31,44 & 19,11 & 15,47 & 32,64 & 49,93 & 67,76 & 86,84 & 108,69 & 140,82 & - \\
\hline \multirow[t]{3}{*}{ SPI } & DM & 11,47 & 12,12 & 12,80 & 13,52 & 14,32 & 15,19 & 16,18 & 17,31 & 18,64 & 20,19 & 22,12 & - \\
\hline & DMA & 11,61 & 12,21 & 12,84 & 13,61 & 14,60 & 15,89 & 17,34 & 19,33 & 21,77 & 24,69 & 28,29 & - \\
\hline & PDMA & 41,52 & 35,93 & 29,60 & 26,69 & 27,87 & 32,00 & 38,36 & 53,79 & 71,62 & 93,64 & 121,88 & - \\
\hline \multirow[t]{3}{*}{$\Delta \mathrm{CS}$} & DM & $-47,88$ & $-44,64$ & $-41,37$ & $-38,23$ & $-35,48$ & $-33,41$ & $-32,52$ & $-33,66$ & $-38,70$ & $-52,62$ & $-97,43$ & - \\
\hline & DMA & 40,09 & 29,12 & 24,26 & 19,71 & 17,25 & 23,30 & 30,12 & 38,20 & 49,45 & 69,18 & 124,47 & - \\
\hline & PDMA & 19,18 & 8,48 & 1,84 & $-7,58$ & $-12,41$ & 0,64 & 11,57 & 13,97 & 15,22 & 15,06 & 18,94 & - \\
\hline \multicolumn{14}{|c|}{ Desconsiderando ${ }^{1} J_{\mathrm{BF}}$ da molécula de $\mathrm{BF}_{3},{ }^{2} J_{\mathrm{CH}}$ e ${ }^{2} J_{\mathrm{HH}}$ da molécula de $\mathrm{C}_{2} \mathrm{H}_{4}$} \\
\hline \multirow[t]{3}{*}{ Total } & DM & $-7,55$ & $-5,92$ & $-4,23$ & $-2,53$ & $-0,92$ & 0,47 & 1,45 & 1,66 & 0,24 & $-5,10$ & $-24,71$ & - \\
\hline & DMA & 29,10 & 25,36 & 24,57 & 24,03 & 24,44 & 28,06 & 32,22 & 37,46 & 44,72 & 56,52 & 86,04 & - \\
\hline & PDMA & 19,94 & 16,94 & 15,58 & 14,50 & 16,42 & 22,13 & 28,11 & 34,87 & 42,88 & 52,79 & 68,62 & - \\
\hline \multirow[t]{3}{*}{ CPI } & DM & $-33,63$ & $-31,05$ & $-28,40$ & $-25,81$ & $-23,56$ & $-21,96$ & $-21,51$ & $-23,12$ & $-28,81$ & $-43,99$ & $-92,72$ & - \\
\hline & DMA & 50,45 & 40,75 & 37,78 & 35,29 & 34,76 & 41,18 & 48,67 & 58,14 & 71,61 & 94,93 & 158,16 & - \\
\hline & PDMA & 23,97 & 17,38 & 14,38 & 11,89 & 15,15 & 23,10 & 31,33 & 40,27 & 50,60 & 64,09 & 89,03 & - \\
\hline \multirow[t]{3}{*}{ SPI } & $\mathrm{DM}$ & 12,52 & 13,41 & 14,36 & 15,38 & 16,50 & 17,73 & 19,12 & 20,72 & 22,59 & 24,82 & 27,60 & - \\
\hline & DMA & 12,67 & 13,52 & 14,41 & 15,38 & 16,50 & 17,96 & 19,56 & 21,55 & 24,04 & 26,97 & 30,57 & - \\
\hline & PDMA & 16,83 & 16,61 & 16,51 & 16,52 & 17,40 & 21,38 & 25,63 & 30,71 & 36,95 & 44,09 & 52,91 & - \\
\hline \multirow[t]{3}{*}{$\Delta \mathrm{CS}$} & $\mathrm{DM}$ & $-46,15$ & $-44,46$ & $-42,76$ & $-41,19$ & $-40,06$ & $-39,69$ & $-40,63$ & $-43,84$ & $-51,40$ & $-68,81$ & $-120,32$ & 一 \\
\hline & DMA & 37,78 & 27,23 & 23,37 & 19,91 & 18,26 & 23,22 & 29,11 & 36,59 & 47,57 & 67,96 & 127,59 & - \\
\hline & PDMA & 7,13 & 0,77 & $-2,13$ & $-4,63$ & $-2,26$ & 1,72 & 5,69 & 9,56 & 13,65 & 20,00 & 36,12 & - \\
\hline
\end{tabular}


Tabela 8.273: Constantes de acoplamento TPSSLYP com base aug-pcJ-2.

\begin{tabular}{|c|c|c|c|c|c|c|c|c|c|c|c|c|c|}
\hline & $\% E_{X}^{\mathrm{HF}}$ & $0 \%$ & $10 \%$ & $20 \%$ & $30 \%$ & $40 \%$ & $50 \%$ & $60 \%$ & $70 \%$ & $80 \%$ & $90 \%$ & $100 \%$ & Exp. \\
\hline $\mathrm{HF}$ & ${ }^{1} J_{\mathrm{HF}}$ & 412,8 & 437,7 & 462,7 & 487,7 & 512,7 & 537,7 & 562,7 & 587,6 & 612,6 & 637,5 & 662,5 & 500 \\
\hline $\mathrm{CO}$ & ${ }^{1} J_{\mathrm{CO}}$ & 17,5 & 15,9 & 14,1 & 12,4 & 10,5 & 8,6 & 6,6 & 4,6 & 2,4 & 0,3 & $-1,9$ & 16,4 \\
\hline $\mathrm{H}_{2} \mathrm{O}$ & ${ }^{1} J_{\mathrm{OH}}$ & $-77,7$ & $-80,0$ & $-82,4$ & $-84,8$ & $-87,1$ & $-89,5$ & $-91,8$ & $-94,1$ & $-96,5$ & $-98,8$ & $-101,1$ & $-80,6$ \\
\hline $\mathrm{H}_{2} \mathrm{O}$ & ${ }^{2} J_{\mathrm{HH}}$ & $-4,8$ & $-6,1$ & $-7,4$ & $-8,7$ & $-9,9$ & $-11,2$ & $-12,5$ & $-13,7$ & $-14,9$ & $-16,1$ & $-17,3$ & $-7,3$ \\
\hline $\mathrm{NH}_{3}$ & ${ }^{1} J_{\mathrm{NH}}$ & 48,8 & 49,3 & 49,8 & 50,3 & 50,8 & 51,2 & 51,7 & 52,1 & 52,6 & 53,0 & 53,4 & 43,8 \\
\hline $\mathrm{NH}_{3}$ & ${ }^{2} J_{\mathrm{HH}}$ & $-7,4$ & $-8,7$ & $-9,9$ & $-11,1$ & $-12,2$ & $-13,4$ & $-14,5$ & $-15,6$ & $-16,6$ & $-17,7$ & $-18,7$ & $-9,6$ \\
\hline $\mathrm{PH}_{3}$ & ${ }^{1} J_{\mathrm{PH}}$ & 205,9 & 210,3 & 214,5 & 218,4 & 222,1 & 225,5 & 228,7 & 231,7 & 234,4 & 236,9 & 239,2 & 188,2 \\
\hline $\mathrm{PF}_{3}$ & ${ }^{1} J_{\mathrm{PF}}$ & $-1758,5$ & $-1732,9$ & $-1704,8$ & $-1674,7$ & $-1642,9$ & $-1609,9$ & $-1576,1$ & $-1541,6$ & $-1506,8$ & $-1471,9$ & $-1437,0$ & -1441 \\
\hline $\mathrm{BHF}_{2}$ & ${ }^{1} J_{\mathrm{BF}}$ & $-145,2$ & $-130,5$ & $-115,7$ & $-101,1$ & $-86,4$ & $-71,8$ & $-57,2$ & $-42,7$ & $-28,2$ & $-13,8$ & 0,6 & -84 \\
\hline $\mathrm{BF}_{3}$ & ${ }^{1} J_{\mathrm{BF}}$ & $-51,7$ & $-34,5$ & $-17,5$ & $-0,6$ & 16,0 & 32,6 & 49,0 & 65,4 & 81,6 & 97,7 & 113,8 & 15 \\
\hline $\mathrm{F}_{2} \mathrm{O}$ & ${ }^{1} J_{\mathrm{OF}}$ & $-273,9$ & $-310,1$ & $-348,0$ & $-389,1$ & $-435,8$ & $-491,5$ & $-562,6$ & $-661,6$ & $-818,5$ & $-1130,5$ & $-2253,8$ & -300 \\
\hline $\mathrm{CH}_{4}$ & ${ }^{1} J_{\mathrm{CH}}$ & 143,1 & 143,9 & 144,6 & 145,3 & 146,0 & 146,6 & 147,3 & 147,8 & 148,4 & 148,9 & 149,4 & 125,3 \\
\hline $\mathrm{CH}_{4}$ & ${ }^{2} J_{\mathrm{HH}}$ & $-10,1$ & $-11,1$ & $-12,2$ & $-13,2$ & $-14,2$ & $-15,1$ & $-16,1$ & $-17,1$ & $-18,0$ & $-18,9$ & $-19,7$ & $-12,8$ \\
\hline $\mathrm{C}_{2} \mathrm{H}_{2}$ & ${ }^{1} J_{\mathrm{CC}}$ & 200,0 & 203,3 & 207,1 & 211,3 & 216,2 & 221,9 & 228,4 & 236,0 & 245,0 & 255,6 & 268,4 & 174,8 \\
\hline $\mathrm{C}_{2} \mathrm{H}_{2}$ & ${ }^{1} J_{\mathrm{CH}}$ & 288,4 & 289,9 & 291,5 & 293,1 & 295,0 & 297,0 & 299,3 & 302,0 & 305,1 & 308,9 & 313,5 & 247,6 \\
\hline $\mathrm{C}_{2} \mathrm{H}_{2}$ & ${ }^{2} J_{\mathrm{CH}}$ & 59,4 & 58,9 & 58,2 & 57,2 & 56,0 & 54,4 & 52,4 & 49,9 & 46,8 & 43,0 & 38,1 & 50,1 \\
\hline $\mathrm{C}_{2} \mathrm{H}_{2}$ & ${ }^{3} J_{\mathrm{HH}}$ & 10,8 & 11,4 & 12,1 & 12,9 & 13,9 & 15,2 & 16,6 & 18,3 & 20,4 & 23,0 & 26,0 & 9,6 \\
\hline $\mathrm{C}_{2} \mathrm{H}_{4}$ & ${ }^{1} J_{\mathrm{CC}}$ & 75,6 & 78,3 & 81,2 & 84,5 & 88,3 & 92,7 & 97,9 & 104,3 & 112,5 & 123,4 & 139,0 & 67,6 \\
\hline $\mathrm{C}_{2} \mathrm{H}_{4}$ & ${ }^{1} J_{\mathrm{CH}}$ & 178,1 & 179,6 & 181,1 & 182,8 & 184,6 & 186,5 & 188,8 & 191,6 & 195,0 & 199,4 & 205,7 & 156,3 \\
\hline $\mathrm{C}_{2} \mathrm{H}_{4}$ & ${ }^{2} J_{\mathrm{CH}}$ & 0,4 & $-0,6$ & $-1,8$ & $-3,1$ & $-4,7$ & $-6,5$ & $-8,6$ & $-11,2$ & $-14,6$ & $-19,0$ & $-25,4$ & $-2,4$ \\
\hline $\mathrm{C}_{2} \mathrm{H}_{4}$ & ${ }^{2} J_{\mathrm{HH}}$ & 9,8 & 8,6 & 7,4 & 6,2 & 4,8 & 3,3 & 1,6 & $-0,2$ & $-2,5$ & $-5,4$ & $-9,3$ & 2,3 \\
\hline $\mathrm{C}_{2} \mathrm{H}_{4}$ & ${ }^{3} J_{\mathrm{HH}_{\mathrm{c}}}$ & 11,9 & 12,2 & 12,7 & 13,2 & 13,8 & 14,5 & 15,5 & 16,7 & 18,3 & 20,5 & 23,7 & 11,7 \\
\hline $\mathrm{C}_{2} \mathrm{H}_{4}$ & ${ }^{3} J_{\mathrm{HH}_{\mathrm{t}}}$ & 21,0 & 21,3 & 21,6 & 22,0 & 22,5 & 23,3 & 24,2 & 25,4 & 27,1 & 29,4 & 32,9 & 19 \\
\hline $\mathrm{C}_{2} \mathrm{H}_{6}$ & ${ }^{1} J_{\mathrm{CC}}$ & 38,0 & 39,5 & 41,0 & 42,5 & 44,0 & 45,5 & 47,0 & 48,4 & 49,9 & 51,3 & 52,7 & 34,5 \\
\hline $\mathrm{C}_{2} \mathrm{H}_{6}$ & ${ }^{1} J_{\mathrm{CH}}$ & 142,6 & 143,5 & 144,4 & 145,4 & 146,2 & 147,1 & 147,9 & 148,7 & 149,5 & 150,2 & 150,9 & 125,2 \\
\hline $\mathrm{C}_{2} \mathrm{H}_{6}$ & ${ }^{2} J_{\mathrm{CH}}$ & $-2,6$ & $-3,1$ & $-3,7$ & $-4,2$ & $-4,7$ & $-5,3$ & $-5,8$ & $-6,3$ & $-6,8$ & $-7,3$ & $-7,8$ & $-4,7$ \\
\hline \multirow[t]{3}{*}{ Total } & $\mathrm{DM}$ & $-12,03$ & $-9,96$ & $-7,86$ & $-5,78$ & $-3,83$ & $-2,14$ & $-0,95$ & $-0,72$ & $-2,57$ & $-10,21$ & $-48,74$ & - \\
\hline & DMA & 28,94 & 25,48 & 24,28 & 23,45 & 23,97 & 28,00 & 32,91 & 39,08 & 47,92 & 63,08 & 110,36 & - \\
\hline & PDMA & 50,03 & 39,71 & 30,90 & 26,70 & 25,88 & 35,83 & 48,77 & 66,63 & 88,25 & 115,22 & 158,62 & - \\
\hline \multirow[t]{3}{*}{ CPI } & $\mathrm{DM}$ & $-43,19$ & $-39,14$ & $-35,05$ & $-31,11$ & $-27,55$ & $-24,78$ & $-23,35$ & $-24,44$ & $-30,80$ & $-51,30$ & $-145,56$ & - \\
\hline & DMA & 53,65 & 44,65 & 40,92 & 37,78 & 37,48 & 45,18 & 54,61 & 66,45 & 83,53 & 114,63 & 220,20 & - \\
\hline & PDMA & 59,45 & 43,21 & 31,33 & 24,37 & 19,28 & 36,66 & 54,86 & 73,74 & 94,28 & 119,45 & 169,20 & - \\
\hline \multirow[t]{3}{*}{ SPI } & $\mathrm{DM}$ & 10,82 & 11,43 & 12,07 & 12,79 & 13,57 & 14,47 & 15,49 & 16,68 & 18,13 & 19,93 & 22,27 & - \\
\hline & DMA & 10,82 & 11,43 & 12,07 & 12,93 & 14,07 & 15,40 & 16,99 & 19,00 & 21,81 & 25,27 & 29,81 & - \\
\hline & PDMA & 43,12 & 37,13 & 30,59 & 28,41 & 30,72 & 35,22 & 44,29 & 61,42 & 83,83 & 112,12 & 150,86 & - \\
\hline \multirow[t]{3}{*}{$\Delta \mathrm{CS}$} & $\mathrm{DM}$ & $-54,01$ & $-50,57$ & $-47,12$ & $-43,90$ & $-41,13$ & $-39,25$ & $-38,84$ & $-41,12$ & $-48,93$ & $-71,23$ & $-167,83$ & - \\
\hline & DMA & 42,83 & 33,21 & 28,84 & 24,85 & 23,42 & 29,78 & 37,62 & 47,45 & 61,71 & 89,35 & 190,39 & - \\
\hline & PDMA & 16,34 & 6,08 & 0,73 & $-4,04$ & $-11,44$ & 1,44 & 10,57 & 12,32 & 10,45 & 7,33 & 18,34 & - \\
\hline \multicolumn{14}{|c|}{ Desconsiderando ${ }^{1} J_{\mathrm{BF}}$ da molécula de $\mathrm{BF}_{3},{ }^{2} J_{\mathrm{CH}}$ e ${ }^{2} J_{\mathrm{HH}}$ da molécula de $\mathrm{C}_{2} \mathrm{H}_{4}$} \\
\hline \multirow[t]{3}{*}{ Total } & DM & $-11,15$ & $-9,46$ & $-7,72$ & $-6,00$ & $-4,38$ & $-3,05$ & $-2,25$ & $-2,51$ & $-5,06$ & $-14,08$ & $-57,89$ & - \\
\hline & DMA & 29,37 & 26,30 & 25,78 & 25,63 & 26,85 & 30,67 & 35,42 & 41,49 & 50,54 & 66,65 & 118,96 & - \\
\hline & PDMA & 17,97 & 15,37 & 14,79 & 17,02 & 20,07 & 26,08 & 32,72 & 40,05 & 49,29 & 61,65 & 87,08 & - \\
\hline \multirow[t]{3}{*}{ CPI } & DM & $-40,84$ & $-38,10$ & $-35,30$ & $-32,66$ & $-30,41$ & $-29,02$ & $-29,09$ & $-31,92$ & $-40,54$ & $-64,70$ & $-170,00$ & - \\
\hline & DMA & 52,34 & 44,16 & 41,76 & 40,00 & 41,13 & 47,94 & 56,67 & 68,06 & 85,22 & 117,82 & 232,34 & - \\
\hline & PDMA & 20,93 & 14,53 & 12,79 & 16,40 & 20,54 & 28,59 & 37,68 & 47,51 & 59,31 & 76,26 & 120,26 & - \\
\hline \multirow[t]{3}{*}{ SPI } & $\mathrm{DM}$ & 11,69 & 12,57 & 13,49 & 14,51 & 15,65 & 16,93 & 18,40 & 20,12 & 22,23 & 24,86 & 28,35 & - \\
\hline & DMA & 11,69 & 12,57 & 13,49 & 14,57 & 15,86 & 17,38 & 19,08 & 21,05 & 23,86 & 27,29 & 31,74 & - \\
\hline & PDMA & 15,69 & 16,01 & 16,32 & 17,49 & 19,71 & 24,15 & 28,89 & 34,30 & 41,58 & 50,41 & 61,56 & - \\
\hline \multirow[t]{3}{*}{$\Delta \mathrm{CS}$} & DM & $-52,53$ & $-50,67$ & $-48,79$ & $-47,17$ & $-46,06$ & $-45,95$ & $-47,49$ & $-52,04$ & $-62,77$ & $-89,56$ & $-198,35$ & - \\
\hline & DMA & 40,65 & 31,59 & 28,27 & 25,43 & 25,27 & 30,56 & 37,59 & 47,01 & 61,36 & 90,53 & 200,60 & - \\
\hline & PDMA & 5,24 & $-1,47$ & $-3,53$ & $-1,09$ & 0,83 & 4,45 & 8,79 & 13,21 & 17,74 & 25,85 & 58,70 & - \\
\hline
\end{tabular}


Tabela 8.274: Constantes de acoplamento TPSSP86 com base aug-pcJ-2.

\begin{tabular}{|c|c|c|c|c|c|c|c|c|c|c|c|c|c|}
\hline & $\% E_{X}^{\mathrm{HF}}$ & $0 \%$ & $10 \%$ & $20 \%$ & $30 \%$ & $40 \%$ & $50 \%$ & $60 \%$ & $70 \%$ & $80 \%$ & $90 \%$ & $100 \%$ & Exp. \\
\hline $\mathrm{HF}$ & ${ }^{1} J_{\mathrm{HF}}$ & 366,7 & 390,3 & 413,9 & 437,5 & 461,0 & 484,6 & 508,2 & 531,8 & 555,3 & 578,8 & 602,2 & 500 \\
\hline $\mathrm{CO}$ & ${ }^{1} J_{\mathrm{CO}}$ & 21,3 & 19,9 & 18,4 & 16,9 & 15,3 & 13,7 & 12,0 & 10,2 & 8,5 & 6,6 & 4,8 & 16,4 \\
\hline $\mathrm{H}_{2} \mathrm{O}$ & ${ }^{1} J_{\mathrm{OH}}$ & $-69,0$ & $-71,3$ & $-73,5$ & $-75,7$ & $-77,9$ & $-80,1$ & $-82,3$ & $-84,5$ & $-86,7$ & $-88,9$ & $-91,0$ & $-80,6$ \\
\hline $\mathrm{H}_{2} \mathrm{O}$ & ${ }^{2} J_{\mathrm{HH}}$ & $-3,8$ & $-5,0$ & $-6,2$ & $-7,3$ & $-8,4$ & $-9,6$ & $-10,7$ & $-11,8$ & $-12,9$ & $-14,0$ & $-15,1$ & $-7,3$ \\
\hline $\mathrm{NH}_{3}$ & ${ }^{1} J_{\mathrm{NH}}$ & 43,5 & 44,0 & 44,5 & 44,9 & 45,3 & 45,8 & 46,2 & 46,6 & 47,0 & 47,4 & 47,8 & 43,8 \\
\hline $\mathrm{NH}_{3}$ & ${ }^{2} J_{\mathrm{HH}}$ & $-6,8$ & $-7,8$ & $-8,9$ & $-10,0$ & $-11,0$ & $-12,0$ & $-13,0$ & $-14,0$ & $-14,9$ & $-15,9$ & $-16,8$ & $-9,6$ \\
\hline $\mathrm{PH}_{3}$ & ${ }^{1} J_{\mathrm{PH}}$ & 181,6 & 185,7 & 189,5 & 193,1 & 196,5 & 199,6 & 202,6 & 205,3 & 207,8 & 210,0 & 212,1 & 188,2 \\
\hline $\mathrm{PF}_{3}$ & ${ }^{1} J_{\mathrm{PF}}$ & $-1750,1$ & $-1724,2$ & $-1695,8$ & $-1665,4$ & $-1633,5$ & $-1600,4$ & $-1566,5$ & $-1532,0$ & $-1497,2$ & $-1462,3$ & $-1427,5$ & -1441 \\
\hline $\mathrm{BHF}_{2}$ & ${ }^{1} J_{\mathrm{BF}}$ & $-154,6$ & $-140,5$ & $-126,3$ & $-112,2$ & $-98,1$ & $-84,0$ & $-70,0$ & $-56,0$ & $-42,0$ & $-28,0$ & $-14,1$ & -84 \\
\hline $\mathrm{BF}_{3}$ & ${ }^{1} J_{\mathrm{BF}}$ & $-65,6$ & $-48,9$ & $-32,5$ & $-16,1$ & 0,0 & 16,1 & 32,0 & 47,9 & 63,6 & 79,3 & 94,8 & 15 \\
\hline $\mathrm{F}_{2} \mathrm{O}$ & ${ }^{1} J_{\mathrm{OF}}$ & $-281,7$ & $-318,4$ & $-356,8$ & $-398,6$ & $-445,9$ & $-502,3$ & $-573,9$ & $-672,4$ & $-825,0$ & $-1113,3$ & $-1973,1$ & -300 \\
\hline $\mathrm{CH}_{4}$ & ${ }^{1} J_{\mathrm{CH}}$ & 127,4 & 128,0 & 128,7 & 129,3 & 129,9 & 130,5 & 131,1 & 131,6 & 132,1 & 132,6 & 133,0 & 125,3 \\
\hline $\mathrm{CH}_{4}$ & ${ }^{2} J_{\mathrm{HH}}$ & $-10,1$ & $-11,0$ & $-12,0$ & $-12,9$ & $-13,8$ & $-14,7$ & $-15,5$ & $-16,4$ & $-17,2$ & $-18,0$ & $-18,8$ & $-12,8$ \\
\hline $\mathrm{C}_{2} \mathrm{H}_{2}$ & ${ }^{1} J_{\mathrm{CC}}$ & 187,2 & 190,1 & 193,4 & 197,2 & 201,6 & 206,7 & 212,7 & 219,7 & 228,0 & 238,0 & 250,2 & 174,8 \\
\hline $\mathrm{C}_{2} \mathrm{H}_{2}$ & ${ }^{1} J_{\mathrm{CH}}$ & 260,6 & 261,9 & 263,4 & 264,9 & 266,7 & 268,6 & 270,8 & 273,5 & 276,6 & 280,5 & 285,3 & 247,6 \\
\hline $\mathrm{C}_{2} \mathrm{H}_{2}$ & ${ }^{2} J_{\mathrm{CH}}$ & 56,5 & 56,1 & 55,5 & 54,7 & 53,5 & 52,1 & 50,2 & 47,8 & 44,7 & 40,9 & 35,9 & 50,1 \\
\hline $\mathrm{C}_{2} \mathrm{H}_{2}$ & ${ }^{3} J_{\mathrm{HH}}$ & 10,7 & 11,3 & 12,0 & 12,9 & 13,9 & 15,2 & 16,8 & 18,6 & 20,8 & 23,6 & 26,9 & 9,6 \\
\hline $\mathrm{C}_{2} \mathrm{H}_{4}$ & ${ }^{1} J_{\mathrm{CC}}$ & 67,3 & 69,8 & 72,5 & 75,5 & 79,0 & 83,2 & 88,3 & 94,7 & 103,2 & 115,2 & 133,8 & 67,6 \\
\hline $\mathrm{C}_{2} \mathrm{H}_{4}$ & ${ }^{1} J_{\mathrm{CH}}$ & 159,8 & 161,1 & 162,6 & 164,1 & 165,8 & 167,8 & 170,0 & 172,8 & 176,4 & 181,5 & 189,3 & 156,3 \\
\hline $\mathrm{C}_{2} \mathrm{H}_{4}$ & ${ }^{2} J_{\mathrm{CH}}$ & 0,1 & $-0,8$ & $-1,9$ & $-3,2$ & $-4,6$ & $-6,4$ & $-8,5$ & $-11,2$ & $-14,8$ & $-19,8$ & $-27,6$ & $-2,4$ \\
\hline $\mathrm{C}_{2} \mathrm{H}_{4}$ & ${ }^{2} J_{\mathrm{HH}}$ & 7,8 & 6,8 & 5,6 & 4,4 & 3,0 & 1,5 & $-0,2$ & $-2,3$ & $-4,9$ & $-8,4$ & $-13,5$ & 2,3 \\
\hline $\mathrm{C}_{2} \mathrm{H}_{4}$ & ${ }^{3} J_{\mathrm{HH}_{\mathrm{c}}}$ & 10,9 & 11,3 & 11,8 & 12,3 & 13,0 & 13,8 & 14,9 & 16,4 & 18,3 & 21,2 & 25,7 & 11,7 \\
\hline $\mathrm{C}_{2} \mathrm{H}_{4}$ & ${ }^{3} J_{\mathrm{HH}_{\mathrm{t}}}$ & 19,4 & 19,6 & 20,0 & 20,5 & 21,2 & 22,0 & 23,1 & 24,6 & 26,6 & 29,7 & 34,7 & 19 \\
\hline $\mathrm{C}_{2} \mathrm{H}_{6}$ & ${ }^{1} J_{\mathrm{CC}}$ & 31,9 & 33,3 & 34,7 & 36,1 & 37,5 & 38,8 & 40,2 & 41,5 & 42,8 & 44,1 & 45,4 & 34,5 \\
\hline $\mathrm{C}_{2} \mathrm{H}_{6}$ & ${ }^{1} J_{\mathrm{CH}}$ & 127,4 & 128,3 & 129,1 & 129,9 & 130,7 & 131,5 & 132,3 & 133,0 & 133,7 & 134,3 & 135,0 & 125,2 \\
\hline $\mathrm{C}_{2} \mathrm{H}_{6}$ & ${ }^{2} J_{\mathrm{CH}}$ & $-2,8$ & $-3,3$ & $-3,8$ & $-4,3$ & $-4,8$ & $-5,3$ & $-5,7$ & $-6,2$ & $-6,7$ & $-7,1$ & $-7,6$ & $-4,7$ \\
\hline \multirow[t]{3}{*}{ Total } & DM & $-19,59$ & $-17,64$ & $-15,66$ & $-13,71$ & $-11,89$ & $-10,32$ & $-9,23$ & $-9,07$ & $-10,84$ & $-17,58$ & $-45,89$ & - \\
\hline & DMA & 26,88 & 23,57 & 21,84 & 20,60 & 19,91 & 19,82 & 23,43 & 29,64 & 38,20 & 52,47 & 90,58 & - \\
\hline & PDMA & 48,66 & 38,36 & 28,19 & 21,49 & 19,35 & 22,19 & 37,78 & 56,47 & 78,61 & 107,36 & 152,34 & - \\
\hline \multirow[t]{3}{*}{ CPI } & DM & $-50,85$ & $-47,01$ & $-43,15$ & $-39,44$ & $-36,15$ & $-33,59$ & $-32,39$ & $-33,62$ & $-39,76$ & $-58,29$ & $-128,80$ & - \\
\hline & DMA & 58,33 & 50,12 & 45,49 & 41,51 & 38,42 & 36,32 & 42,57 & 54,09 & 70,44 & 99,11 & 182,13 & - \\
\hline & PDMA & 72,83 & 56,90 & 42,41 & 29,11 & 21,28 & 15,74 & 32,34 & 50,46 & 69,94 & 93,72 & 134,69 & - \\
\hline \multirow[t]{3}{*}{ SPI } & DM & 3,33 & 3,89 & 4,50 & 5,15 & 5,90 & 6,75 & 7,76 & 8,93 & 10,37 & 12,28 & 14,91 & - \\
\hline & DMA & 3,83 & 4,11 & 4,50 & 5,27 & 6,34 & 7,72 & 9,40 & 11,71 & 14,55 & 18,27 & 23,45 & - \\
\hline & PDMA & 30,93 & 24,76 & 17,75 & 15,90 & 17,94 & 26,93 & 41,77 & 60,87 & 84,96 & 117,37 & 165,29 & - \\
\hline \multirow[t]{3}{*}{$\Delta \mathrm{CS}$} & DM & $-54,19$ & $-50,90$ & $-47,65$ & $-44,59$ & $-42,05$ & $-40,34$ & $-40,15$ & $-42,55$ & $-50,13$ & $-70,57$ & $-143,71$ & - \\
\hline & DMA & 54,50 & 46,01 & 40,99 & 36,24 & 32,08 & 28,60 & 33,17 & 42,38 & 55,88 & 80,84 & 158,67 & - \\
\hline & PDMA & 41,90 & 32,14 & 24,66 & 13,21 & 3,35 & $-11,19$ & $-9,44$ & $-10,41$ & $-15,02$ & $-23,65$ & $-30,60$ & - \\
\hline \multicolumn{14}{|c|}{ Desconsiderando ${ }^{1} J_{\mathrm{BF}}$ da molécula de $\mathrm{BF}_{3},{ }^{2} J_{\mathrm{CH}}$ e ${ }^{2} J_{\mathrm{HH}}$ da molécula de $\mathrm{C}_{2} \mathrm{H}_{4}$} \\
\hline \multirow[t]{3}{*}{ Total } & DM & $-18,99$ & $-17,43$ & $-15,80$ & $-14,20$ & $-12,72$ & $-11,50$ & $-10,80$ & $-11,10$ & $-13,52$ & $-21,44$ & $-53,57$ & - \\
\hline & DMA & 26,54 & 23,60 & 22,46 & 21,81 & 21,73 & 22,15 & 25,38 & 31,49 & 40,21 & 55,30 & 97,15 & - \\
\hline & PDMA & 16,72 & 13,43 & 10,95 & 9,86 & 12,22 & 16,01 & 22,01 & 29,66 & 38,70 & 50,98 & 73,57 & - \\
\hline \multirow[t]{3}{*}{ CPI } & DM & $-47,88$ & $-45,32$ & $-42,71$ & $-40,27$ & $-38,26$ & $-37,06$ & $-37,33$ & $-40,27$ & $-48,60$ & $-70,55$ & $-149,66$ & - \\
\hline & DMA & 56,10 & 48,74 & 45,29 & 42,55 & 40,76 & 39,84 & 45,13 & 56,21 & 72,62 & 102,59 & 192,36 & - \\
\hline & PDMA & 26,38 & 19,99 & 14,98 & 11,29 & 13,41 & 16,58 & 24,24 & 33,57 & 44,53 & 60,23 & 94,96 & - \\
\hline \multirow[t]{3}{*}{ SPI } & DM & 3,23 & 4,02 & 4,90 & 5,85 & 6,92 & 8,15 & 9,62 & 11,34 & 13,47 & 16,33 & 20,35 & - \\
\hline & DMA & 3,80 & 4,27 & 4,90 & 5,86 & 7,09 & 8,54 & 10,18 & 12,48 & 15,28 & 18,92 & 23,91 & - \\
\hline & PDMA & 9,28 & 8,39 & 7,85 & 8,76 & 11,30 & 15,58 & 20,29 & 26,64 & 34,21 & 43,87 & 57,11 & - \\
\hline \multirow[t]{3}{*}{$\Delta \mathrm{CS}$} & $\mathrm{DM}$ & $-51,11$ & $-49,34$ & $-47,61$ & $-46,12$ & $-45,18$ & $-45,21$ & $-46,95$ & $-51,61$ & $-62,07$ & $-86,88$ & $-170,01$ & 一 \\
\hline & DMA & 52,30 & 44,47 & 40,39 & 36,69 & 33,67 & 31,30 & 34,95 & 43,73 & 57,34 & 83,67 & 168,45 & - \\
\hline & PDMA & 17,10 & 11,60 & 7,14 & 2,53 & 2,11 & 1,00 & 3,95 & 6,93 & 10,32 & 16,36 & 37,85 & - \\
\hline
\end{tabular}


Tabela 8.275: Constantes de acoplamento TPSSPBE com base aug-pcJ-2.

\begin{tabular}{|c|c|c|c|c|c|c|c|c|c|c|c|c|c|}
\hline & $\% E_{X}^{\mathrm{HF}}$ & $0 \%$ & $10 \%$ & $20 \%$ & $30 \%$ & $40 \%$ & $50 \%$ & $60 \%$ & $70 \%$ & $80 \%$ & $90 \%$ & $100 \%$ & Exp. \\
\hline $\mathrm{HF}$ & ${ }^{1} J_{\mathrm{HF}}$ & 362,6 & 386,7 & 410,8 & 434,9 & 459,0 & 483,1 & 507,2 & 531,3 & 555,3 & 579,3 & 603,3 & 500 \\
\hline $\mathrm{CO}$ & ${ }^{1} J_{\mathrm{CO}}$ & 21,9 & 20,5 & 19,0 & 17,5 & 15,9 & 14,2 & 12,6 & 10,8 & 9,0 & 7,2 & 5,3 & 16,4 \\
\hline $\mathrm{H}_{2} \mathrm{O}$ & ${ }^{1} J_{\mathrm{OH}}$ & $-68,9$ & $-71,2$ & $-73,5$ & $-75,8$ & $-78,0$ & $-80,3$ & $-82,5$ & $-84,8$ & $-87,0$ & $-89,2$ & $-91,5$ & $-80,6$ \\
\hline $\mathrm{H}_{2} \mathrm{O}$ & ${ }^{2} J_{\mathrm{HH}}$ & $-4,3$ & $-5,5$ & $-6,7$ & $-7,9$ & $-9,1$ & $-10,3$ & $-11,4$ & $-12,6$ & $-13,7$ & $-14,8$ & $-15,9$ & $-7,3$ \\
\hline $\mathrm{NH}_{3}$ & ${ }^{1} J_{\mathrm{NH}}$ & 43,7 & 44,2 & 44,7 & 45,1 & 45,6 & 46,0 & 46,5 & 46,9 & 47,3 & 47,8 & 48,2 & 43,8 \\
\hline $\mathrm{NH}_{3}$ & ${ }^{2} J_{\mathrm{HH}}$ & $-7,3$ & $-8,5$ & $-9,6$ & $-10,7$ & $-11,7$ & $-12,8$ & $-13,8$ & $-14,8$ & $-15,8$ & $-16,7$ & $-17,6$ & $-9,6$ \\
\hline $\mathrm{PH}_{3}$ & ${ }^{1} J_{\mathrm{PH}}$ & 182,5 & 186,8 & 190,8 & 194,5 & 198,0 & 201,3 & 204,4 & 207,2 & 209,8 & 212,2 & 214,3 & 188,2 \\
\hline $\mathrm{PF}_{3}$ & ${ }^{1} J_{\mathrm{PF}}$ & $-1754,3$ & $-1727,6$ & $-1698,5$ & $-1667,5$ & $-1635,0$ & $-1601,4$ & $-1567,0$ & $-1532,1$ & $-1496,9$ & $-1461,6$ & $-1426,5$ & -1441 \\
\hline $\mathrm{BHF}_{2}$ & ${ }^{1} J_{\mathrm{BF}}$ & $-155,5$ & $-141,2$ & $-127,0$ & $-112,7$ & $-98,5$ & $-84,3$ & $-70,1$ & $-56,0$ & $-41,9$ & $-27,8$ & $-13,8$ & -84 \\
\hline $\mathrm{BF}_{3}$ & ${ }^{1} J_{\mathrm{BF}}$ & $-66,4$ & $-49,7$ & $-33,1$ & $-16,6$ & $-0,3$ & 15,8 & 31,9 & 47,8 & 63,7 & 79,5 & 95,2 & 15 \\
\hline $\mathrm{F}_{2} \mathrm{O}$ & ${ }^{1} J_{\mathrm{OF}}$ & $-284,3$ & $-321,9$ & $-361,5$ & $-404,8$ & $-454,1$ & $-513,5$ & $-589,7$ & $-696,6$ & $-867,3$ & $-1209,6$ & $-2453,2$ & -300 \\
\hline $\mathrm{CH}_{4}$ & ${ }^{1} J_{\mathrm{CH}}$ & 128,5 & 129,2 & 129,9 & 130,6 & 131,2 & 131,8 & 132,4 & 133,0 & 133,5 & 134,0 & 134,4 & 125,3 \\
\hline $\mathrm{CH}_{4}$ & ${ }^{2} J_{\mathrm{HH}}$ & $-10,9$ & $-11,8$ & $-12,8$ & $-13,7$ & $-14,7$ & $-15,6$ & $-16,5$ & $-17,3$ & $-18,2$ & $-19,0$ & $-19,8$ & $-12,8$ \\
\hline $\mathrm{C}_{2} \mathrm{H}_{2}$ & ${ }^{1} J_{\mathrm{CC}}$ & 186,7 & 189,8 & 193,4 & 197,5 & 202,2 & 207,8 & 214,3 & 222,1 & 231,4 & 242,9 & 257,1 & 174,8 \\
\hline $\mathrm{C}_{2} \mathrm{H}_{2}$ & ${ }^{1} J_{\mathrm{CH}}$ & 263,7 & 265,2 & 266,8 & 268,6 & 270,5 & 272,8 & 275,4 & 278,6 & 282,4 & 287,2 & 293,3 & 247,6 \\
\hline $\mathrm{C}_{2} \mathrm{H}_{2}$ & ${ }^{2} J_{\mathrm{CH}}$ & 56,5 & 56,0 & 55,2 & 54,2 & 52,8 & 51,1 & 48,8 & 45,9 & 42,2 & 37,4 & 31,2 & 50,1 \\
\hline $\mathrm{C}_{2} \mathrm{H}_{2}$ & ${ }^{3} J_{\mathrm{HH}}$ & 11,4 & 12,1 & 12,9 & 13,9 & 15,2 & 16,7 & 18,5 & 20,7 & 23,3 & 26,7 & 30,9 & 9,6 \\
\hline $\mathrm{C}_{2} \mathrm{H}_{4}$ & ${ }^{1} J_{\mathrm{CC}}$ & 67,4 & 70,0 & 72,9 & 76,2 & 80,1 & 84,8 & 90,6 & 98,2 & 108,6 & 124,2 & 150,7 & 67,6 \\
\hline $\mathrm{C}_{2} \mathrm{H}_{4}$ & ${ }^{1} J_{\mathrm{CH}}$ & 161,6 & 163,0 & 164,6 & 166,3 & 168,2 & 170,4 & 173,1 & 176,4 & 180,9 & 187,7 & 199,0 & 156,3 \\
\hline $\mathrm{C}_{2} \mathrm{H}_{4}$ & ${ }^{2} J_{\mathrm{CH}}$ & $-0,4$ & $-1,5$ & $-2,7$ & $-4,1$ & $-5,8$ & $-7,8$ & $-10,2$ & $-13,5$ & $-18,0$ & $-24,7$ & $-36,1$ & $-2,4$ \\
\hline $\mathrm{C}_{2} \mathrm{H}_{4}$ & ${ }^{2} J_{\mathrm{HH}}$ & 7,4 & 6,2 & 4,9 & 3,6 & 2,1 & 0,4 & $-1,6$ & $-4,0$ & $-7,3$ & $-11,9$ & $-19,4$ & 2,3 \\
\hline $\mathrm{C}_{2} \mathrm{H}_{4}$ & ${ }^{3} J_{\mathrm{HH}_{\mathrm{c}}}$ & 11,3 & 11,7 & 12,2 & 12,9 & 13,7 & 14,7 & 16,1 & 17,9 & 20,5 & 24,4 & 31,3 & 11,7 \\
\hline $\mathrm{C}_{2} \mathrm{H}_{4}$ & ${ }^{3} J_{\mathrm{HH}_{\mathrm{t}}}$ & 20,0 & 20,4 & 20,8 & 21,4 & 22,2 & 23,2 & 24,6 & 26,5 & 29,2 & 33,5 & 41,0 & 19 \\
\hline $\mathrm{C}_{2} \mathrm{H}_{6}$ & ${ }^{1} J_{\mathrm{CC}}$ & 31,9 & 33,3 & 34,7 & 36,1 & 37,5 & 38,9 & 40,3 & 41,6 & 43,0 & 44,3 & 45,6 & 34,5 \\
\hline $\mathrm{C}_{2} \mathrm{H}_{6}$ & ${ }^{1} J_{\mathrm{CH}}$ & 128,7 & 129,6 & 130,5 & 131,3 & 132,2 & 133,0 & 133,8 & 134,5 & 135,3 & 136,0 & 136,6 & 125,2 \\
\hline $\mathrm{C}_{2} \mathrm{H}_{6}$ & ${ }^{2} J_{\mathrm{CH}}$ & $-3,2$ & $-3,7$ & $-4,2$ & $-4,7$ & $-5,2$ & $-5,7$ & $-6,2$ & $-6,7$ & $-7,1$ & $-7,6$ & $-8,1$ & $-4,7$ \\
\hline \multirow[t]{3}{*}{ Total } & $\mathrm{DM}$ & $-19,80$ & $-17,80$ & $-15,79$ & $-13,80$ & $-11,96$ & $-10,41$ & $-9,37$ & $-9,38$ & $-11,65$ & $-20,14$ & $-62,67$ & - \\
\hline & DMA & 27,33 & 24,22 & 22,64 & 21,66 & 21,06 & 21,17 & 25,09 & 31,85 & 41,47 & 58,39 & 112,44 & - \\
\hline & PDMA & 46,94 & 36,10 & 26,88 & 23,53 & 23,00 & 28,99 & 46,23 & 67,02 & 92,83 & 128,10 & 190,22 & - \\
\hline \multirow[t]{3}{*}{ CPI } & $\mathrm{DM}$ & $-51,93$ & $-48,03$ & $-44,14$ & $-40,45$ & $-37,19$ & $-34,83$ & $-33,89$ & $-35,80$ & $-43,49$ & $-66,78$ & $-172,10$ & - \\
\hline & DMA & 58,87 & 51,08 & 46,65 & 42,90 & 39,77 & 37,81 & 44,24 & 56,56 & 74,62 & 108,24 & 226,41 & - \\
\hline & PDMA & 72,60 & 56,70 & 42,22 & 31,56 & 23,13 & 17,42 & 34,20 & 52,73 & 73,06 & 98,43 & 151,26 & - \\
\hline \multirow[t]{3}{*}{ SPI } & $\mathrm{DM}$ & 3,77 & 4,36 & 5,00 & 5,73 & 6,54 & 7,49 & 8,62 & 9,99 & 11,71 & 14,07 & 17,57 & - \\
\hline & DMA & 4,19 & 4,52 & 5,04 & 6,08 & 7,34 & 8,97 & 11,05 & 13,73 & 17,16 & 21,84 & 28,87 & - \\
\hline & PDMA & 28,13 & 21,00 & 15,63 & 17,64 & 22,90 & 37,48 & 55,05 & 77,50 & 107,34 & 149,85 & 218,79 & - \\
\hline \multirow[t]{3}{*}{$\Delta \mathrm{CS}$} & $\mathrm{DM}$ & $-55,69$ & $-52,39$ & $-49,14$ & $-46,18$ & $-43,73$ & $-42,32$ & $-42,51$ & $-45,79$ & $-55,20$ & $-80,85$ & $-189,67$ & - \\
\hline & DMA & 54,68 & 46,56 & 41,61 & 36,82 & 32,43 & 28,84 & 33,19 & 42,83 & 57,46 & 86,40 & 197,54 & - \\
\hline & PDMA & 44,47 & 35,70 & 26,58 & 13,92 & 0,23 & $-20,06$ & $-20,85$ & $-24,76$ & $-34,28$ & $-51,42$ & $-67,53$ & - \\
\hline \multicolumn{14}{|c|}{ Desconsiderando ${ }^{1} J_{\mathrm{BF}}$ da molécula de $\mathrm{BF}_{3},{ }^{2} J_{\mathrm{CH}}$ e ${ }^{2} J_{\mathrm{HH}}$ da molécula de $\mathrm{C}_{2} \mathrm{H}_{4}$} \\
\hline \multirow[t]{3}{*}{ Total } & $\mathrm{DM}$ & $-19,15$ & $-17,52$ & $-15,86$ & $-14,21$ & $-12,70$ & $-11,49$ & $-10,81$ & $-11,28$ & $-14,19$ & $-23,98$ & $-71,93$ & - \\
\hline & DMA & 27,04 & 24,36 & 23,38 & 22,98 & 22,99 & 23,58 & 27,12 & 33,83 & 43,67 & 61,62 & 121,21 & - \\
\hline & PDMA & 16,21 & 13,06 & 10,99 & 11,90 & 15,03 & 19,16 & 25,85 & 34,24 & 44,42 & 58,87 & 89,72 & - \\
\hline \multirow[t]{3}{*}{ CPI } & $\mathrm{DM}$ & $-48,98$ & $-46,36$ & $-43,74$ & $-41,33$ & $-39,38$ & $-38,39$ & $-38,97$ & $-42,66$ & $-52,71$ & $-79,91$ & $-197,33$ & - \\
\hline & DMA & 56,62 & 49,72 & 46,50 & 44,03 & 42,22 & 41,51 & 46,97 & 58,94 & 77,21 & 112,61 & 241,03 & - \\
\hline & PDMA & 25,59 & 19,24 & 14,37 & 13,65 & 15,24 & 18,62 & 26,35 & 36,14 & 47,89 & 65,27 & 112,92 & - \\
\hline \multirow[t]{3}{*}{ SPI } & $\mathrm{DM}$ & 3,80 & 4,66 & 5,59 & 6,65 & 7,82 & 9,21 & 10,85 & 12,86 & 15,45 & 19,04 & 24,54 & - \\
\hline & DMA & 4,29 & 4,85 & 5,59 & 6,78 & 8,19 & 9,79 & 11,85 & 14,51 & 17,86 & 22,39 & 29,05 & - \\
\hline & PDMA & 8,99 & 8,30 & 8,38 & 10,56 & 14,86 & 19,58 & 25,47 & 32,77 & 41,75 & 53,94 & 71,87 & - \\
\hline \multirow[t]{3}{*}{$\Delta \mathrm{CS}$} & DM & $-52,78$ & $-51,02$ & $-49,33$ & $-47,98$ & $-47,20$ & $-47,60$ & $-49,82$ & $-55,52$ & $-68,16$ & $-98,95$ & $-221,87$ & - \\
\hline & DMA & 52,33 & 44,87 & 40,91 & 37,25 & 34,03 & 31,72 & 35,12 & 44,43 & 59,35 & 90,22 & 211,98 & - \\
\hline & PDMA & 16,61 & 10,94 & 5,99 & 3,09 & 0,38 & $-0,96$ & 0,88 & 3,37 & 6,15 & 11,33 & 41,06 & - \\
\hline
\end{tabular}


Tabela 8.276: Constantes de acoplamento TPSSPW91 com base aug-pcJ-2.

\begin{tabular}{|c|c|c|c|c|c|c|c|c|c|c|c|c|c|}
\hline & $\% E_{X}^{\mathrm{HF}}$ & $0 \%$ & $10 \%$ & $20 \%$ & $30 \%$ & $40 \%$ & $50 \%$ & $60 \%$ & $70 \%$ & $80 \%$ & $90 \%$ & $100 \%$ & Exp. \\
\hline $\mathrm{HF}$ & ${ }^{1} J_{\mathrm{HF}}$ & 365,5 & 389,5 & 413,7 & 437,8 & 461,9 & 486,0 & 510,1 & 534,2 & 558,3 & 582,3 & 606,3 & 500 \\
\hline $\mathrm{CO}$ & ${ }^{1} J_{\mathrm{CO}}$ & 21,7 & 20,3 & 18,8 & 17,2 & 15,6 & 13,9 & 12,2 & 10,5 & 8,7 & 6,8 & 4,9 & 16,4 \\
\hline $\mathrm{H}_{2} \mathrm{O}$ & ${ }^{1} J_{\mathrm{OH}}$ & $-69,3$ & $-71,6$ & $-73,9$ & $-76,2$ & $-78,5$ & $-80,7$ & $-83,0$ & $-85,2$ & $-87,5$ & $-89,7$ & $-91,9$ & $-80,6$ \\
\hline $\mathrm{H}_{2} \mathrm{O}$ & ${ }^{2} J_{\mathrm{HH}}$ & $-4,4$ & $-5,6$ & $-6,7$ & $-7,9$ & $-9,1$ & $-10,3$ & $-11,4$ & $-12,6$ & $-13,7$ & $-14,9$ & $-16,0$ & $-7,3$ \\
\hline $\mathrm{NH}_{3}$ & ${ }^{1} J_{\mathrm{NH}}$ & 43,9 & 44,4 & 44,9 & 45,3 & 45,8 & 46,3 & 46,7 & 47,1 & 47,6 & 48,0 & 48,4 & 43,8 \\
\hline $\mathrm{NH}_{3}$ & ${ }^{2} J_{\mathrm{HH}}$ & $-7,4$ & $-8,5$ & $-9,6$ & $-10,7$ & $-11,8$ & $-12,8$ & $-13,8$ & $-14,8$ & $-15,8$ & $-16,8$ & $-17,7$ & $-9,6$ \\
\hline $\mathrm{PH}_{3}$ & ${ }^{1} J_{\mathrm{PH}}$ & 183,4 & 187,7 & 191,7 & 195,5 & 199,0 & 202,4 & 205,4 & 208,3 & 210,9 & 213,3 & 215,5 & 188,2 \\
\hline $\mathrm{PF}_{3}$ & ${ }^{1} J_{\mathrm{PF}}$ & $-1757,4$ & $-1730,7$ & $-1701,5$ & $-1670,4$ & $-1637,7$ & $-1604,0$ & $-1569,5$ & $-1534,4$ & $-1499,1$ & $-1463,8$ & $-1428,5$ & -1441 \\
\hline $\mathrm{BHF}_{2}$ & ${ }^{1} J_{\mathrm{BF}}$ & $-154,6$ & $-140,3$ & $-126,0$ & $-111,8$ & $-97,5$ & $-83,3$ & $-69,0$ & $-54,9$ & $-40,7$ & $-26,6$ & $-12,5$ & -84 \\
\hline $\mathrm{BF}_{3}$ & ${ }^{1} J_{\mathrm{BF}}$ & $-65,5$ & $-48,7$ & $-32,0$ & $-15,6$ & 0,7 & 17,0 & 33,1 & 49,1 & 65,0 & 80,8 & 96,6 & 15 \\
\hline $\mathrm{F}_{2} \mathrm{O}$ & ${ }^{1} J_{\mathrm{OF}}$ & $-284,0$ & $-321,6$ & $-361,1$ & $-404,4$ & $-453,8$ & $-513,2$ & $-589,6$ & $-697,0$ & $-869,3$ & $-1217,5$ & $-2525,8$ & -300 \\
\hline $\mathrm{CH}_{4}$ & ${ }^{1} J_{\mathrm{CH}}$ & 129,1 & 129,9 & 130,6 & 131,2 & 131,9 & 132,5 & 133,1 & 133,7 & 134,2 & 134,7 & 135,2 & 125,3 \\
\hline $\mathrm{CH}_{4}$ & ${ }^{2} J_{\mathrm{HH}}$ & $-10,9$ & $-11,8$ & $-12,8$ & $-13,7$ & $-14,7$ & $-15,6$ & $-16,5$ & $-17,4$ & $-18,2$ & $-19,0$ & $-19,9$ & $-12,8$ \\
\hline $\mathrm{C}_{2} \mathrm{H}_{2}$ & ${ }^{1} J_{\mathrm{CC}}$ & 188,0 & 191,1 & 194,7 & 198,9 & 203,7 & 209,3 & 215,9 & 223,7 & 233,1 & 244,7 & 259,0 & 174,8 \\
\hline $\mathrm{C}_{2} \mathrm{H}_{2}$ & ${ }^{1} J_{\mathrm{CH}}$ & 264,9 & 266,4 & 268,0 & 269,8 & 271,8 & 274,1 & 276,7 & 279,9 & 283,7 & 288,5 & 294,6 & 247,6 \\
\hline $\mathrm{C}_{2} \mathrm{H}_{2}$ & ${ }^{2} J_{\mathrm{CH}}$ & 56,5 & 56,0 & 55,3 & 54,2 & 52,8 & 51,1 & 48,8 & 45,9 & 42,2 & 37,4 & 31,2 & 50,1 \\
\hline $\mathrm{C}_{2} \mathrm{H}_{2}$ & ${ }^{3} J_{\mathrm{HH}}$ & 11,4 & 12,0 & 12,9 & 13,9 & 15,1 & 16,6 & 18,4 & 20,6 & 23,2 & 26,6 & 30,7 & 9,6 \\
\hline $\mathrm{C}_{2} \mathrm{H}_{4}$ & ${ }^{1} J_{\mathrm{CC}}$ & 68,0 & 70,6 & 73,5 & 76,9 & 80,8 & 85,5 & 91,4 & 99,1 & 109,6 & 125,4 & 152,0 & 67,6 \\
\hline $\mathrm{C}_{2} \mathrm{H}_{4}$ & ${ }^{1} J_{\mathrm{CH}}$ & 162,4 & 163,9 & 165,4 & 167,2 & 169,1 & 171,3 & 174,0 & 177,3 & 181,9 & 188,7 & 200,0 & 156,3 \\
\hline $\mathrm{C}_{2} \mathrm{H}_{4}$ & ${ }^{2} J_{\mathrm{CH}}$ & $-0,4$ & $-1,5$ & $-2,7$ & $-4,1$ & $-5,8$ & $-7,8$ & $-10,3$ & $-13,5$ & $-18,0$ & $-24,8$ & $-36,2$ & $-2,4$ \\
\hline $\mathrm{C}_{2} \mathrm{H}_{4}$ & ${ }^{2} J_{\mathrm{HH}}$ & 7,4 & 6,2 & 5,0 & 3,6 & 2,1 & 0,4 & $-1,5$ & $-4,0$ & $-7,2$ & $-11,8$ & $-19,2$ & 2,3 \\
\hline $\mathrm{C}_{2} \mathrm{H}_{4}$ & ${ }^{3} J_{\mathrm{HH}_{\mathrm{c}}}$ & 11,2 & 11,7 & 12,2 & 12,9 & 13,7 & 14,7 & 16,0 & 17,8 & 20,4 & 24,3 & 31,2 & 11,7 \\
\hline $\mathrm{C}_{2} \mathrm{H}_{4}$ & ${ }^{3} J_{\mathrm{HH}_{\mathrm{t}}}$ & 20,0 & 20,3 & 20,8 & 21,4 & 22,2 & 23,2 & 24,5 & 26,4 & 29,2 & 33,4 & 40,9 & 19 \\
\hline $\mathrm{C}_{2} \mathrm{H}_{6}$ & ${ }^{1} J_{\mathrm{CC}}$ & 32,4 & 33,8 & 35,2 & 36,6 & 38,0 & 39,4 & 40,7 & 42,1 & 43,4 & 44,8 & 46,1 & 34,5 \\
\hline $\mathrm{C}_{2} \mathrm{H}_{6}$ & ${ }^{1} J_{\mathrm{CH}}$ & 129,3 & 130,2 & 131,1 & 132,0 & 132,9 & 133,7 & 134,5 & 135,2 & 136,0 & 136,7 & 137,3 & 125,2 \\
\hline $\mathrm{C}_{2} \mathrm{H}_{6}$ & ${ }^{2} J_{\mathrm{CH}}$ & $-3,2$ & $-3,7$ & $-4,2$ & $-4,7$ & $-5,2$ & $-5,7$ & $-6,2$ & $-6,7$ & $-7,2$ & $-7,6$ & $-8,1$ & $-4,7$ \\
\hline \multirow[t]{3}{*}{ Total } & $\mathrm{DM}$ & $-19,50$ & $-17,50$ & $-15,45$ & $-13,47$ & $-11,62$ & $-10,04$ & $-9,01$ & $-9,02$ & $-11,32$ & $-20,04$ & $-65,03$ & - \\
\hline & DMA & 27,38 & 24,27 & 22,80 & 21,82 & 21,25 & 21,51 & 25,70 & 32,48 & 42,18 & 59,35 & 115,74 & - \\
\hline & PDMA & 46,58 & 35,70 & 26,88 & 23,37 & 22,98 & 29,58 & 46,88 & 67,73 & 93,49 & 129,02 & 191,82 & - \\
\hline \multirow[t]{3}{*}{ CPI } & $\mathrm{DM}$ & $-51,73$ & $-47,82$ & $-43,87$ & $-40,19$ & $-36,94$ & $-34,51$ & $-33,61$ & $-35,51$ & $-43,32$ & $-67,18$ & $-178,33$ & - \\
\hline & DMA & 58,60 & 50,78 & 46,47 & 42,74 & 39,65 & 38,04 & 45,12 & 57,47 & 75,70 & 109,87 & 233,56 & - \\
\hline & PDMA & 71,51 & 55,67 & 41,32 & 30,69 & 22,66 & 18,40 & 35,48 & 54,03 & 74,44 & 100,25 & 155,08 & - \\
\hline \multirow[t]{3}{*}{ SPI } & DM & 4,13 & 4,73 & 5,39 & 6,13 & 6,95 & 7,91 & 9,03 & 10,40 & 12,15 & 14,53 & 18,05 & - \\
\hline & DMA & 4,48 & 4,83 & 5,43 & 6,48 & 7,75 & 9,39 & 11,45 & 14,16 & 17,60 & 22,30 & 29,34 & - \\
\hline & PDMA & 28,29 & 21,05 & 16,28 & 18,00 & 23,20 & 37,78 & 55,24 & 77,78 & 107,46 & 150,11 & 218,77 & - \\
\hline \multirow[t]{3}{*}{$\Delta \mathrm{CS}$} & $\mathrm{DM}$ & $-55,86$ & $-52,55$ & $-49,27$ & $-46,32$ & $-43,89$ & $-42,42$ & $-42,64$ & $-45,91$ & $-55,46$ & $-81,71$ & $-196,37$ & - \\
\hline & DMA & 54,12 & 45,96 & 41,04 & 36,26 & 31,89 & 28,65 & 33,66 & 43,31 & 58,10 & 87,57 & 204,22 & - \\
\hline & PDMA & 43,23 & 34,63 & 25,05 & 12,69 & $-0,54$ & $-19,38$ & $-19,76$ & $-23,75$ & $-33,02$ & $-49,87$ & $-63,69$ & - \\
\hline \multicolumn{14}{|c|}{ Desconsiderando ${ }^{1} J_{\mathrm{BF}}$ da molécula de $\mathrm{BF}_{3},{ }^{2} J_{\mathrm{CH}}$ e ${ }^{2} J_{\mathrm{HH}}$ da molécula de $\mathrm{C}_{2} \mathrm{H}_{4}$} \\
\hline \multirow[t]{3}{*}{ Total } & DM & $-18,85$ & $-17,22$ & $-15,53$ & $-13,87$ & $-12,35$ & $-11,12$ & $-10,47$ & $-10,93$ & $-13,88$ & $-23,93$ & $-74,66$ & - \\
\hline & DMA & 27,14 & 24,46 & 23,60 & 23,20 & 23,24 & 23,91 & 27,75 & 34,48 & 44,42 & 62,64 & 124,89 & - \\
\hline & PDMA & 16,05 & 12,89 & 11,11 & 12,01 & 15,29 & 19,48 & 26,25 & 34,66 & 44,97 & 59,54 & 91,32 & - \\
\hline \multirow[t]{3}{*}{ CPI } & $\mathrm{DM}$ & $-48,85$ & $-46,23$ & $-43,56$ & $-41,15$ & $-39,20$ & $-38,16$ & $-38,78$ & $-42,47$ & $-52,65$ & $-80,48$ & $-204,32$ & - \\
\hline & DMA & 56,41 & 49,49 & 46,42 & 43,95 & 42,18 & 41,64 & 47,82 & 59,81 & 78,27 & 114,28 & 248,76 & - \\
\hline & PDMA & 25,00 & 18,78 & 14,12 & 13,36 & 15,40 & 18,91 & 26,96 & 36,70 & 48,55 & 66,41 & 116,19 & - \\
\hline \multirow[t]{3}{*}{ SPI } & DM & 4,22 & 5,09 & 6,04 & 7,11 & 8,30 & 9,68 & 11,32 & 13,34 & 15,95 & 19,57 & 25,08 & - \\
\hline & DMA & 4,62 & 5,20 & 6,04 & 7,25 & 8,67 & 10,27 & 12,32 & 15,00 & 18,38 & 22,92 & 29,60 & - \\
\hline & PDMA & 9,17 & 8,36 & 8,79 & 10,97 & 15,21 & 19,93 & 25,71 & 33,10 & 42,22 & 54,26 & 72,19 & - \\
\hline \multirow[t]{3}{*}{$\Delta \mathrm{CS}$} & $\mathrm{DM}$ & $-53,07$ & $-51,32$ & $-49,60$ & $-48,26$ & $-47,50$ & $-47,84$ & $-50,10$ & $-55,81$ & $-68,60$ & $-100,05$ & $-229,40$ & - \\
\hline & DMA & 51,79 & 44,29 & 40,38 & 36,70 & 33,51 & 31,37 & 35,50 & 44,81 & 59,89 & 91,36 & 219,16 & - \\
\hline & PDMA & 15,83 & 10,42 & 5,33 & 2,39 & 0,19 & $-1,02$ & 1,25 & 3,60 & 6,33 & 12,15 & 44,00 & - \\
\hline
\end{tabular}


Tabela 8.277: Constantes de acoplamento TPSSTPSS com base aug-pcJ-2.

\begin{tabular}{|c|c|c|c|c|c|c|c|c|c|c|c|c|c|}
\hline & $\% E_{X}^{\mathrm{HF}}$ & $0 \%$ & $10 \%$ & $20 \%$ & $30 \%$ & $40 \%$ & $50 \%$ & $60 \%$ & $70 \%$ & $80 \%$ & $90 \%$ & $100 \%$ & Exp. \\
\hline $\mathrm{HF}$ & ${ }^{1} J_{\mathrm{HF}}$ & 366,0 & 390,6 & 415,1 & 439,7 & 464,2 & 488,7 & 513,1 & 537,4 & 561,6 & 585,8 & 610,0 & 500 \\
\hline $\mathrm{CO}$ & ${ }^{1} J_{\mathrm{CO}}$ & 21,7 & 20,3 & 18,8 & 17,3 & 15,7 & 14,0 & 12,3 & 10,5 & 8,7 & 6,8 & 4,9 & 16,4 \\
\hline $\mathrm{H}_{2} \mathrm{O}$ & ${ }^{1} J_{\mathrm{OH}}$ & $-70,2$ & $-72,5$ & $-74,9$ & $-77,3$ & $-79,6$ & $-82,0$ & $-84,3$ & $-86,6$ & $-88,9$ & $-91,1$ & $-93,4$ & $-80,6$ \\
\hline $\mathrm{H}_{2} \mathrm{O}$ & ${ }^{2} J_{\mathrm{HH}}$ & $-4,0$ & $-5,3$ & $-6,6$ & $-7,8$ & $-9,1$ & $-10,3$ & $-11,5$ & $-12,7$ & $-13,9$ & $-15,1$ & $-16,2$ & $-7,3$ \\
\hline $\mathrm{NH}_{3}$ & ${ }^{1} J_{\mathrm{NH}}$ & 45,3 & 45,8 & 46,4 & 46,9 & 47,3 & 47,8 & 48,3 & 48,8 & 49,2 & 49,7 & 50,1 & 43,8 \\
\hline $\mathrm{NH}_{3}$ & ${ }^{2} J_{\mathrm{HH}}$ & $-6,9$ & $-8,1$ & $-9,3$ & $-10,4$ & $-11,6$ & $-12,7$ & $-13,8$ & $-14,9$ & $-15,9$ & $-17,0$ & $-17,9$ & $-9,6$ \\
\hline $\mathrm{PH}_{3}$ & ${ }^{1} J_{\mathrm{PH}}$ & 195,7 & 200,5 & 205,0 & 209,3 & 213,4 & 217,2 & 220,8 & 224,1 & 227,2 & 230,0 & 232,6 & 188,2 \\
\hline $\mathrm{PF}_{3}$ & ${ }^{1} J_{\mathrm{PF}}$ & $-1757,5$ & $-1731,7$ & $-1703,3$ & $-1673,0$ & $-1641,1$ & $-1608,0$ & $-1574,1$ & $-1539,7$ & $-1504,9$ & $-1470,0$ & $-1435,2$ & -1441 \\
\hline $\mathrm{BHF}_{2}$ & ${ }^{1} J_{\mathrm{BF}}$ & $-156,7$ & $-142,5$ & $-128,4$ & $-114,3$ & $-100,2$ & $-86,1$ & $-72,1$ & $-58,1$ & $-44,2$ & $-30,3$ & $-16,4$ & -84 \\
\hline $\mathrm{BF}_{3}$ & ${ }^{1} J_{\mathrm{BF}}$ & $-63,8$ & $-47,2$ & $-30,7$ & $-14,3$ & 1,8 & 17,8 & 33,8 & 49,6 & 65,2 & 80,8 & 96,3 & 15 \\
\hline $\mathrm{F}_{2} \mathrm{O}$ & ${ }^{1} J_{\mathrm{OF}}$ & $-282,7$ & $-320,1$ & $-359,5$ & $-402,5$ & $-451,3$ & $-510,0$ & $-585,2$ & $-690,4$ & $-857,9$ & $-1192,7$ & $-2403,5$ & -300 \\
\hline $\mathrm{CH}_{4}$ & ${ }^{1} J_{\mathrm{CH}}$ & 138,0 & 138,8 & 139,6 & 140,4 & 141,1 & 141,9 & 142,6 & 143,2 & 143,8 & 144,4 & 144,9 & 125,3 \\
\hline $\mathrm{CH}_{4}$ & ${ }^{2} J_{\mathrm{HH}}$ & $-10,2$ & $-11,3$ & $-12,4$ & $-13,4$ & $-14,5$ & $-15,5$ & $-16,5$ & $-17,4$ & $-18,4$ & $-19,3$ & $-20,2$ & $-12,8$ \\
\hline $\mathrm{C}_{2} \mathrm{H}_{2}$ & ${ }^{1} J_{\mathrm{CC}}$ & 187,5 & 190,8 & 194,6 & 198,9 & 203,9 & 209,8 & 216,7 & 225,0 & 234,9 & 247,0 & 262,1 & 174,8 \\
\hline $\mathrm{C}_{2} \mathrm{H}_{2}$ & ${ }^{1} J_{\mathrm{CH}}$ & 280,6 & 282,3 & 284,1 & 286,1 & 288,3 & 290,8 & 293,7 & 297,1 & 301,3 & 306,4 & 312,9 & 247,6 \\
\hline $\mathrm{C}_{2} \mathrm{H}_{2}$ & ${ }^{2} J_{\mathrm{CH}}$ & 58,3 & 57,7 & 56,9 & 55,8 & 54,3 & 52,4 & 50,0 & 46,9 & 43,0 & 38,0 & 31,5 & 50,1 \\
\hline $\mathrm{C}_{2} \mathrm{H}_{2}$ & ${ }^{3} J_{\mathrm{HH}}$ & 12,0 & 12,6 & 13,5 & 14,5 & 15,7 & 17,3 & 19,1 & 21,4 & 24,1 & 27,5 & 31,8 & 9,6 \\
\hline $\mathrm{C}_{2} \mathrm{H}_{4}$ & ${ }^{1} J_{\mathrm{CC}}$ & 68,8 & 71,5 & 74,5 & 78,0 & 82,1 & 87,0 & 93,1 & 100,9 & 111,6 & 127,4 & 153,5 & 67,6 \\
\hline $\mathrm{C}_{2} \mathrm{H}_{4}$ & ${ }^{1} J_{\mathrm{CH}}$ & 172,7 & 174,3 & 176,1 & 178,0 & 180,1 & 182,5 & 185,3 & 188,9 & 193,6 & 200,5 & 211,7 & 156,3 \\
\hline $\mathrm{C}_{2} \mathrm{H}_{4}$ & ${ }^{2} J_{\mathrm{CH}}$ & $-0,6$ & $-1,7$ & $-3,0$ & $-4,5$ & $-6,2$ & $-8,3$ & $-10,9$ & $-14,3$ & $-18,9$ & $-25,6$ & $-36,8$ & $-2,4$ \\
\hline $\mathrm{C}_{2} \mathrm{H}_{4}$ & ${ }^{2} J_{\mathrm{HH}}$ & 9,4 & 8,2 & 6,8 & 5,4 & 3,8 & 2,0 & 0,0 & $-2,5$ & $-5,8$ & $-10,3$ & $-17,4$ & 2,3 \\
\hline $\mathrm{C}_{2} \mathrm{H}_{4}$ & ${ }^{3} J_{\mathrm{HH}_{\mathrm{c}}}$ & 12,0 & 12,5 & 13,0 & 13,7 & 14,5 & 15,5 & 16,9 & 18,6 & 21,1 & 24,9 & 31,3 & 11,7 \\
\hline $\mathrm{C}_{2} \mathrm{H}_{4}$ & ${ }^{3} J_{\mathrm{HH}_{\mathrm{t}}}$ & 22,1 & 22,5 & 22,9 & 23,5 & 24,2 & 25,2 & 26,6 & 28,4 & 31,1 & 35,2 & 42,2 & 19 \\
\hline $\mathrm{C}_{2} \mathrm{H}_{6}$ & ${ }^{1} J_{\mathrm{CC}}$ & 32,9 & 34,4 & 35,8 & 37,2 & 38,7 & 40,1 & 41,5 & 42,9 & 44,2 & 45,6 & 46,9 & 34,5 \\
\hline $\mathrm{C}_{2} \mathrm{H}_{6}$ & ${ }^{1} J_{\mathrm{CH}}$ & 137,9 & 138,9 & 140,0 & 141,0 & 141,9 & 142,9 & 143,8 & 144,7 & 145,5 & 146,3 & 147,1 & 125,2 \\
\hline $\mathrm{C}_{2} \mathrm{H}_{6}$ & ${ }^{2} J_{\mathrm{CH}}$ & $-3,3$ & $-3,8$ & $-4,3$ & $-4,9$ & $-5,4$ & $-5,9$ & $-6,4$ & $-7,0$ & $-7,5$ & $-8,0$ & $-8,5$ & $-4,7$ \\
\hline \multirow[t]{3}{*}{ Total } & $\mathrm{DM}$ & $-16,92$ & $-14,90$ & $-12,86$ & $-10,83$ & $-8,96$ & $-7,34$ & $-6,24$ & $-6,16$ & $-8,28$ & $-16,47$ & $-57,72$ & - \\
\hline & DMA & 29,51 & 26,71 & 25,40 & 24,44 & 23,91 & 24,23 & 28,44 & 35,26 & 44,86 & 61,59 & 113,73 & - \\
\hline & PDMA & 51,70 & 41,22 & 32,92 & 29,32 & 28,23 & 30,82 & 48,29 & 69,59 & 95,67 & 130,80 & 191,26 & - \\
\hline \multirow[t]{3}{*}{ CPI } & DM & $-50,36$ & $-46,46$ & $-42,57$ & $-38,85$ & $-35,58$ & $-33,14$ & $-32,15$ & $-33,90$ & $-41,34$ & $-64,00$ & $-166,33$ & - \\
\hline & DMA & 59,09 & 51,88 & 47,75 & 44,01 & 40,98 & 39,65 & 46,85 & 59,14 & 76,97 & 110,00 & 223,67 & - \\
\hline & PDMA & 72,03 & 56,46 & 41,98 & 30,62 & 22,83 & 19,94 & 36,81 & 55,37 & 75,56 & 100,96 & 152,58 & - \\
\hline \multirow[t]{3}{*}{ SPI } & DM & 7,60 & 8,24 & 8,93 & 9,71 & 10,56 & 11,57 & 12,76 & 14,18 & 15,97 & 18,39 & 21,93 & - \\
\hline & DMA & 7,81 & 8,25 & 9,01 & 10,09 & 11,39 & 12,92 & 14,93 & 17,75 & 21,31 & 26,09 & 33,11 & - \\
\hline & PDMA & 36,79 & 30,05 & 26,27 & 28,37 & 32,19 & 38,80 & 56,71 & 80,01 & 110,42 & 152,68 & 219,63 & - \\
\hline \multirow[t]{3}{*}{$\Delta \mathrm{CS}$} & $\mathrm{DM}$ & $-57,96$ & $-54,70$ & $-51,51$ & $-48,55$ & $-46,14$ & $-44,71$ & $-44,91$ & $-48,08$ & $-57,30$ & $-82,39$ & $-188,25$ & - \\
\hline & DMA & 51,28 & 43,63 & 38,74 & 33,92 & 29,60 & 26,73 & 31,92 & 41,38 & 55,66 & 83,91 & 190,56 & - \\
\hline & PDMA & 35,25 & 26,41 & 15,71 & 2,25 & $-9,36$ & $-18,86$ & $-19,90$ & $-24,64$ & $-34,87$ & $-51,73$ & $-67,05$ & - \\
\hline \multicolumn{14}{|c|}{ Desconsiderando ${ }^{1} J_{\mathrm{BF}}$ da molécula de $\mathrm{BF}_{3},{ }^{2} J_{\mathrm{CH}}$ e ${ }^{2} J_{\mathrm{HH}}$ da molécula de $\mathrm{C}_{2} \mathrm{H}_{4}$} \\
\hline \multirow[t]{3}{*}{ Total } & DM & $-16,09$ & $-14,43$ & $-12,72$ & $-11,02$ & $-9,46$ & $-8,15$ & $-7,40$ & $-7,74$ & $-10,47$ & $-19,92$ & $-66,43$ & - \\
\hline & DMA & 29,54 & 27,20 & 26,51 & 26,13 & 26,22 & 27,00 & 30,86 & 37,63 & 47,46 & 65,20 & 122,68 & - \\
\hline & PDMA & 18,92 & 16,15 & 14,37 & 14,99 & 18,37 & 22,77 & 29,39 & 38,00 & 48,40 & 62,94 & 93,09 & - \\
\hline \multirow[t]{3}{*}{ CPI } & $\mathrm{DM}$ & $-47,52$ & $-44,89$ & $-42,26$ & $-39,80$ & $-37,82$ & $-36,73$ & $-37,24$ & $-40,75$ & $-50,49$ & $-76,98$ & $-191,09$ & - \\
\hline & DMA & 57,12 & 50,85 & 47,96 & 45,48 & 43,76 & 43,33 & 49,66 & 61,59 & 79,65 & 114,42 & 237,91 & - \\
\hline & PDMA & 26,70 & 20,64 & 15,72 & 14,15 & 16,31 & 20,06 & 27,96 & 37,84 & 49,64 & 67,18 & 113,64 & - \\
\hline \multirow[t]{3}{*}{ SPI } & $\mathrm{DM}$ & 8,08 & 9,00 & 10,01 & 11,12 & 12,36 & 13,83 & 15,55 & 17,65 & 20,32 & 23,98 & 29,46 & - \\
\hline & DMA & 8,33 & 9,02 & 10,01 & 11,25 & 12,73 & 14,43 & 16,40 & 19,20 & 22,70 & 27,35 & 34,05 & - \\
\hline & PDMA & 12,93 & 12,69 & 13,34 & 15,63 & 19,94 & 24,85 & 30,50 & 38,13 & 47,44 & 59,67 & 77,27 & - \\
\hline \multirow[t]{3}{*}{$\Delta \mathrm{CS}$} & $\mathrm{DM}$ & $-55,60$ & $-53,89$ & $-52,27$ & $-50,92$ & $-50,18$ & $-50,56$ & $-52,79$ & $-58,40$ & $-70,81$ & $-100,96$ & $-220,55$ & - \\
\hline & DMA & 48,79 & 41,83 & 37,95 & 34,23 & 31,03 & 28,90 & 33,26 & 42,39 & 56,95 & 87,07 & 203,86 & - \\
\hline & PDMA & 13,77 & 7,94 & 2,38 & $-1,49$ & $-3,63$ & $-4,79$ & $-2,54$ & $-0,29$ & 2,21 & 7,51 & 36,37 & - \\
\hline
\end{tabular}

Tabela 8.278: Valores de PDMA total obtidos para troca TPSS com base HuzIII-su3.

\begin{tabular}{lccccccccccc}
\hline$E_{X}^{\mathrm{HF}}(\%)$ & $0 \%$ & $10 \%$ & $20 \%$ & $30 \%$ & $40 \%$ & $50 \%$ & $60 \%$ & $70 \%$ & $80 \%$ & $90 \%$ & $100 \%$ \\
\hline TPSSB95 & 53,1 & 42,4 & 32,4 & 23,4 & 17,9 & 16,8 & 25,7 & 38,9 & 54,0 & 71,5 & 92,6 \\
TPSSB98 & 50,6 & 39,9 & 29,9 & 24,5 & 23,0 & 31,5 & 44,1 & 61,0 & 79,7 & 102,2 & 132,9 \\
TPSSB971 & 49,7 & 39,0 & 28,6 & 22,1 & 19,9 & 29,2 & 40,7 & 56,6 & 74,2 & 94,5 & 120,6 \\
TPSSB972 & 52,1 & 42,3 & 32,5 & 23,7 & 27,2 & 35,0 & 43,6 & 54,6 & 71,9 & 92,1 & 119,3 \\
TPSSLYP & 51,1 & 40,4 & 31,8 & 28,3 & 27,3 & 34,2 & 48,5 & 67,1 & 89,1 & 116,9 & 161,6 \\
TPSSP6 & 49,9 & 38,6 & 28,7 & 23,7 & 21,4 & 24,9 & 38,3 & 57,2 & 79,7 & 109,6 & 156,5 \\
TPSSPBE & 47,8 & 36,5 & 28,7 & 26,3 & 26,5 & 31,8 & 46,8 & 68,2 & 94,5 & 131,1 & 195,8 \\
TPSSPW91 & 47,6 & 36,2 & 28,7 & 26,0 & 26,1 & 31,5 & 47,5 & 68,7 & 95,3 & 131,9 & 197,7 \\
TPSSTPSS & 52,5 & 41,3 & 34,2 & 31,7 & 30,4 & 33,0 & 49,1 & 70,7 & 97,5 & 133,9 & 197,2 \\
\hline
\end{tabular}




\subsubsection{Geometrias Otimizadas}

Tabela 8.279: Constantes de acoplamento BB95 com geometrias otimizadas na base aug-pcJ-2.

\begin{tabular}{|c|c|c|c|c|c|c|}
\hline & $\% E_{X}^{\mathrm{HF}}$ & $30 \%$ & $40 \%$ & $50 \%$ & $60 \%$ & Exp. \\
\hline HF & ${ }^{1} J_{\mathrm{HF}}$ & 478,2 & 515,6 & 552,4 & 588,5 & 500,0 \\
\hline $\mathrm{CO}$ & ${ }^{1} J_{\mathrm{CO}}$ & 15,8 & 12,6 & 9,4 & 6,2 & 16,4 \\
\hline $\mathrm{H}_{2} \mathrm{O}$ & ${ }^{1} J_{\mathrm{OH}}$ & $-79,1$ & $-83,5$ & $-87,4$ & $-91,2$ & $-80,6$ \\
\hline $\mathrm{H}_{2} \mathrm{O}$ & ${ }^{2} J_{\mathrm{HH}}$ & $-6,7$ & $-7,3$ & $-8,1$ & $-8,9$ & $-7,3$ \\
\hline $\mathrm{NH}_{3}$ & ${ }^{1} J_{\mathrm{NH}}$ & 44,9 & 46,1 & 47,2 & 48,2 & 43,8 \\
\hline $\mathrm{NH}_{3}$ & ${ }^{2} J_{\mathrm{HH}}$ & $-9,1$ & $-9,8$ & $-10,5$ & $-11,2$ & $-9,6$ \\
\hline $\mathrm{PH}_{3}$ & ${ }^{1} J_{\mathrm{PH}}$ & 177,8 & 187,5 & 196,8 & 205,6 & 188,2 \\
\hline $\mathrm{PF}_{3}$ & ${ }^{1} J_{\mathrm{PF}}$ & $-1527,7$ & $-1500,6$ & $-1466,8$ & $-1427,8$ & $-1441,0$ \\
\hline $\mathrm{BHF}_{2}$ & ${ }^{1} J_{\mathrm{BF}}$ & $-121,3$ & $-98,9$ & $-77,2$ & $-56,0$ & $-84,0$ \\
\hline $\mathrm{BF}_{3}$ & ${ }^{1} J_{\mathrm{BF}}$ & $-23,4$ & 2,1 & 26,6 & 50,2 & 15,0 \\
\hline $\mathrm{F}_{2} \mathrm{O}$ & ${ }^{1} J_{\mathrm{OF}}$ & $-244,3$ & $-221,1$ & $-199,3$ & $-179,2$ & $-300,0$ \\
\hline $\mathrm{CH}_{4}$ & ${ }^{1} J_{\mathrm{CH}}$ & 124,3 & 125,2 & 126,0 & 126,9 & 125,3 \\
\hline $\mathrm{CH}_{4}$ & ${ }^{2} J_{\mathrm{HH}}$ & $-12,4$ & $-13,1$ & $-13,7$ & $-14,4$ & $-12,8$ \\
\hline $\mathrm{C}_{2} \mathrm{H}_{2}$ & ${ }^{1} J_{\mathrm{CC}}$ & 196,1 & 199,1 & 202,4 & 205,9 & 174,8 \\
\hline $\mathrm{C}_{2} \mathrm{H}_{2}$ & ${ }^{1} J_{\mathrm{CH}}$ & 253,3 & 253,7 & 254,3 & 254,9 & 247,6 \\
\hline $\mathrm{C}_{2} \mathrm{H}_{2}$ & ${ }^{2} J_{\mathrm{CH}}$ & 55,7 & 55,5 & 55,1 & 54,6 & 50,1 \\
\hline $\mathrm{C}_{2} \mathrm{H}_{2}$ & ${ }^{3} J_{\mathrm{HH}}$ & 10,1 & 10,5 & 11,1 & 11,7 & 9,6 \\
\hline $\mathrm{C}_{2} \mathrm{H}_{4}$ & ${ }^{1} J_{\mathrm{CC}}$ & 69,4 & 72,1 & 74,9 & 77,9 & 67,6 \\
\hline $\mathrm{C}_{2} \mathrm{H}_{4}$ & ${ }^{1} J_{\mathrm{CH}}$ & 155,6 & 156,8 & 158,0 & 159,3 & 156,3 \\
\hline $\mathrm{C}_{2} \mathrm{H}_{4}$ & ${ }^{2} J_{\mathrm{CH}}$ & $-1,1$ & $-2,0$ & $-3,0$ & $-4,0$ & $-2,4$ \\
\hline $\mathrm{C}_{2} \mathrm{H}_{4}$ & ${ }^{2} J_{\mathrm{HH}}$ & 2,6 & 1,9 & 1,1 & 0,3 & 2,3 \\
\hline $\mathrm{C}_{2} \mathrm{H}_{4}$ & ${ }^{3} J_{\mathrm{HH}_{\mathrm{c}}}$ & 13,0 & 13,4 & 13,8 & 14,2 & 11,7 \\
\hline $\mathrm{C}_{2} \mathrm{H}_{4}$ & ${ }^{3} J_{\mathrm{HH}_{\mathrm{t}}}{ }^{\mathrm{C}}$ & 19,7 & 19,9 & 20,2 & 20,6 & 19,0 \\
\hline $\mathrm{C}_{2} \mathrm{H}_{6}$ & ${ }^{1} J_{\mathrm{CC}}$ & 32,9 & 34,7 & 36,6 & 38,7 & 34,5 \\
\hline $\mathrm{C}_{2} \mathrm{H}_{6}$ & ${ }^{1} J_{\mathrm{CH}}$ & 123,2 & 124,3 & 125,2 & 126,2 & 125,2 \\
\hline $\mathrm{C}_{2} \mathrm{H}_{6}$ & ${ }^{2} J_{\mathrm{CH}}$ & $-3,6$ & $-4,1$ & $-4,5$ & $-5,0$ & $-4,7$ \\
\hline \multirow[t]{3}{*}{ Total } & DM & $-3,89$ & 1,75 & 7,52 & 13,35 & - \\
\hline & DMA & 11,53 & 9,19 & 10,91 & 15,62 & - \\
\hline & PDMA & 19,46 & 10,96 & 15,02 & 28,67 & - \\
\hline \multirow[t]{3}{*}{ CPI } & $\mathrm{DM}$ & $-12,35$ & 0,16 & 12,93 & 25,77 & - \\
\hline & DMA & 23,15 & 17,44 & 20,44 & 30,14 & - \\
\hline & PDMA & 32,39 & 15,62 & 19,55 & 41,83 & - \\
\hline \multirow[t]{3}{*}{ SPI } & $\mathrm{DM}$ & 2,31 & 2,92 & 3,56 & 4,25 & - \\
\hline & DMA & 3,02 & 3,15 & 3,92 & 4,98 & - \\
\hline & PDMA & 9,97 & 7,55 & 11,69 & 19,02 & - \\
\hline \multirow[t]{3}{*}{$\Delta \mathrm{CS}$} & $\mathrm{DM}$ & $-14,66$ & $-2,76$ & 9,37 & 21,53 & - \\
\hline & DMA & 20,13 & 14,29 & 16,52 & 25,16 & - \\
\hline & PDMA & 22,42 & 8,06 & 7,86 & 22,81 & - \\
\hline \multicolumn{7}{|c|}{ Desconsiderando ${ }^{1} J_{\mathrm{BF}}$ da molécula de $\mathrm{BF}_{3},{ }^{2} J_{\mathrm{CH}}$ e ${ }^{2} J_{\mathrm{HH}}$ da molécula de $\mathrm{C}_{2} \mathrm{H}_{4}$} \\
\hline \multirow{3}{*}{ Total } & DM & $-2,80$ & 2,54 & 8,08 & 13,72 & - \\
\hline & DMA & 11,30 & 9,80 & 11,75 & 15,97 & - \\
\hline & PDMA & 7,94 & 7,17 & 10,26 & 15,53 & - \\
\hline \multirow[t]{3}{*}{ CPI } & DM & $-9,74$ & 1,47 & 13,06 & 24,83 & - \\
\hline & DMA & 21,62 & 17,89 & 21,32 & 29,63 & - \\
\hline & PDMA & 10,03 & 8,58 & 13,77 & 22,54 & - \\
\hline \multirow{3}{*}{ SPI } & DM & 2,55 & 3,37 & 4,25 & 5,18 & - \\
\hline & DMA & 3,36 & 3,57 & 4,38 & 5,47 & - \\
\hline & PDMA & 6,33 & 6,10 & 7,55 & 10,13 & - \\
\hline \multirow[t]{3}{*}{$\Delta \mathrm{CS}$} & $\mathrm{DM}$ & $-12,29$ & $-1,90$ & 8,81 & 19,65 & - \\
\hline & DMA & 18,26 & 14,32 & 16,94 & 24,16 & - \\
\hline & PDMA & 3,70 & 2,48 & 6,22 & 12,42 & - \\
\hline
\end{tabular}


Tabela 8.280: Constantes de acoplamento BB971 com geometrias otimizadas na base aug-pcJ-2.

\begin{tabular}{|c|c|c|c|c|c|c|}
\hline & $\% E_{X}^{\mathrm{HF}}$ & $20 \%$ & $30 \%$ & $40 \%$ & $50 \%$ & Exp. \\
\hline $\mathrm{HF}$ & ${ }^{1} J_{\mathrm{HF}}$ & 450,1 & 486,4 & 522,2 & 557,3 & 500,0 \\
\hline $\mathrm{CO}$ & ${ }^{1} J_{\mathrm{CO}}$ & 16,2 & 12,8 & 9,4 & 6,1 & 16,4 \\
\hline $\mathrm{H}_{2} \mathrm{O}$ & ${ }^{1} J_{\mathrm{OH}}$ & $-76,4$ & $-80,6$ & $-84,5$ & $-88,2$ & $-80,6$ \\
\hline $\mathrm{H}_{2} \mathrm{O}$ & ${ }^{2} J_{\mathrm{HH}}$ & $-5,5$ & $-6,2$ & $-7,0$ & $-7,7$ & $-7,3$ \\
\hline $\mathrm{NH}_{3}$ & ${ }^{1} J_{\mathrm{NH}}$ & 45,2 & 46,4 & 47,7 & 48,8 & 43,8 \\
\hline $\mathrm{NH}_{3}$ & ${ }^{2} J_{\mathrm{HH}}$ & $-8,3$ & $-9,1$ & $-9,7$ & $-10,4$ & $-9,6$ \\
\hline $\mathrm{PH}_{3}$ & ${ }^{1} J_{\mathrm{PH}}$ & 196,4 & 205,6 & 214,3 & 222,5 & 188,2 \\
\hline $\mathrm{PF}_{3}$ & ${ }^{1} J_{\mathrm{PF}}$ & $-1594,4$ & $-1571,5$ & $-1540,1$ & $-1502,1$ & $-1441,0$ \\
\hline $\mathrm{BHF}_{2}$ & ${ }^{1} J_{\mathrm{BF}}$ & $-125,5$ & $-101,5$ & $-78,1$ & $-55,5$ & $-84,0$ \\
\hline $\mathrm{BF}_{3}$ & ${ }^{1} J_{\mathrm{BF}}$ & $-30,2$ & $-3,9$ & 22,8 & 47,9 & 15,0 \\
\hline $\mathrm{F}_{2} \mathrm{O}$ & ${ }^{1} J_{\mathrm{OF}}$ & $-258,8$ & $-237,9$ & $-217,5$ & $-198,2$ & $-300,0$ \\
\hline $\mathrm{CH}_{4}$ & ${ }^{1} J_{\mathrm{CH}}$ & 131,7 & 132,8 & 133,9 & 134,9 & 125,3 \\
\hline $\mathrm{CH}_{4}$ & ${ }^{2} J_{\mathrm{HH}}$ & $-11,7$ & $-12,5$ & $-13,2$ & $-13,9$ & $-12,8$ \\
\hline $\mathrm{C}_{2} \mathrm{H}_{2}$ & ${ }^{1} J_{\mathrm{CC}}$ & 215,3 & 218,8 & 222,6 & 226,7 & 174,8 \\
\hline $\mathrm{C}_{2} \mathrm{H}_{2}$ & ${ }^{1} J_{\mathrm{CH}}$ & 263,7 & 264,4 & 265,2 & 266,1 & 247,6 \\
\hline $\mathrm{C}_{2} \mathrm{H}_{2}$ & ${ }^{2} J_{\mathrm{CH}}$ & 54,2 & 53,9 & 53,5 & 52,9 & 50,1 \\
\hline $\mathrm{C}_{2} \mathrm{H}_{2}$ & ${ }^{3} J_{\mathrm{HH}}$ & 9,6 & 10,1 & 10,6 & 11,2 & 9,6 \\
\hline $\mathrm{C}_{2} \mathrm{H}_{4}$ & ${ }^{1} J_{\mathrm{CC}}$ & 80,6 & 83,9 & 87,2 & 90,8 & 67,6 \\
\hline $\mathrm{C}_{2} \mathrm{H}_{4}$ & ${ }^{1} J_{\mathrm{CH}}$ & 163,0 & 164,4 & 165,9 & 167,4 & 156,3 \\
\hline $\mathrm{C}_{2} \mathrm{H}_{4}$ & ${ }^{2} J_{\mathrm{CH}}$ & $-1,5$ & $-2,5$ & $-3,5$ & $-4,7$ & $-2,4$ \\
\hline $\mathrm{C}_{2} \mathrm{H}_{4}$ & ${ }^{2} J_{\mathrm{HH}}$ & 3,0 & 2,2 & 1,4 & 0,6 & 2,3 \\
\hline $\mathrm{C}_{2} \mathrm{H}_{4}$ & ${ }^{3} J_{\mathrm{HH}_{\mathrm{c}}}$ & 12,6 & 13,0 & 13,4 & 13,8 & 11,7 \\
\hline $\mathrm{C}_{2} \mathrm{H}_{4}$ & ${ }^{3} J_{\mathrm{HH}_{\mathrm{t}}}$ & 19,2 & 19,4 & 19,7 & 20,1 & 19,0 \\
\hline $\mathrm{C}_{2} \mathrm{H}_{6}$ & ${ }^{1} J_{\mathrm{CC}}$ & 36,7 & 38,9 & 41,2 & 43,6 & 34,5 \\
\hline $\mathrm{C}_{2} \mathrm{H}_{6}$ & ${ }^{1} J_{\mathrm{CH}}$ & 130,7 & 132,0 & 133,2 & 134,3 & 125,2 \\
\hline $\mathrm{C}_{2} \mathrm{H}_{6}$ & ${ }^{2} J_{\mathrm{CH}}$ & $-3,4$ & $-3,9$ & $-4,4$ & $-4,9$ & $-4,7$ \\
\hline \multirow[t]{3}{*}{ Total } & $\mathrm{DM}$ & $-5,10$ & 0,40 & 6,20 & 12,09 & - \\
\hline & DMA & 17,23 & 14,58 & 14,85 & 18,67 & - \\
\hline & PDMA & 24,13 & 14,46 & 15,59 & 29,50 & - \\
\hline \multirow[t]{3}{*}{ CPI } & $\mathrm{DM}$ & $-21,10$ & $-9,13$ & 3,51 & 16,33 & - \\
\hline & DMA & 31,66 & 24,35 & 23,53 & 30,91 & - \\
\hline & PDMA & 39,75 & 21,52 & 15,75 & 38,05 & - \\
\hline \multirow[t]{3}{*}{ SPI } & DM & 6,64 & 7,39 & 8,17 & 8,99 & - \\
\hline & DMA & 6,64 & 7,41 & 8,49 & 9,69 & - \\
\hline & PDMA & 12,68 & 9,29 & 15,48 & 23,23 & - \\
\hline \multirow[t]{3}{*}{$\Delta \mathrm{CS}$} & $\mathrm{DM}$ & $-27,74$ & $-16,51$ & $-4,66$ & 7,34 & - \\
\hline & DMA & 25,02 & 16,93 & 15,03 & 21,22 & - \\
\hline & PDMA & 27,07 & 12,23 & 0,28 & 14,82 & - \\
\hline \multicolumn{7}{|c|}{ Desconsiderando ${ }^{1} J_{\mathrm{BF}}$ da molécula de $\mathrm{BF}_{3},{ }^{2} J_{\mathrm{CH}}$ e ${ }^{2} J_{\mathrm{HH}}$ da molécula de $\mathrm{C}_{2} \mathrm{H}_{4}$} \\
\hline \multirow[t]{3}{*}{ Total } & DM & $-3,87$ & 1,28 & 6,76 & 12,41 & - \\
\hline & DMA & 17,44 & 15,65 & 16,37 & 19,50 & - \\
\hline & PDMA & 11,23 & 10,50 & 11,67 & 16,43 & - \\
\hline \multirow[t]{3}{*}{ CPI } & DM & $-18,69$ & $-8,15$ & 3,08 & 14,67 & - \\
\hline & DMA & 30,31 & 24,89 & 25,10 & 30,71 & - \\
\hline & PDMA & 13,59 & 11,07 & 12,13 & 19,92 & - \\
\hline \multirow{3}{*}{ SPI } & $\mathrm{DM}$ & 7,54 & 8,54 & 9,58 & 10,68 & - \\
\hline & DMA & 7,54 & 8,54 & 9,65 & 10,88 & - \\
\hline & PDMA & 9,40 & 10,06 & 11,32 & 13,75 & - \\
\hline \multirow[t]{3}{*}{$\Delta \mathrm{CS}$} & DM & $-26,23$ & $-16,69$ & $-6,50$ & 3,99 & - \\
\hline & DMA & 22,77 & 16,35 & 15,45 & 19,83 & - \\
\hline & PDMA & 4,19 & 1,01 & 0,81 & 6,18 & - \\
\hline
\end{tabular}


Tabela 8.281: Constantes de acoplamento B971P86 com geometrias otimizadas na base aug-pcJ-2.

\begin{tabular}{|c|c|c|c|c|c|c|}
\hline & $\% E_{X}^{\mathrm{HF}}$ & $40 \%$ & $50 \%$ & $60 \%$ & $70 \%$ & Exp. \\
\hline $\mathrm{HF}$ & ${ }^{1} J_{\mathrm{HF}}$ & 380,4 & 430,1 & 480,2 & 529,7 & 500,0 \\
\hline $\mathrm{CO}$ & ${ }^{1} J_{\mathrm{CO}}$ & 19,5 & 15,6 & 11,7 & 7,7 & 16,4 \\
\hline $\mathrm{H}_{2} \mathrm{O}$ & ${ }^{1} J_{\mathrm{OH}}$ & $-62,9$ & $-69,2$ & $-75,5$ & $-81,7$ & $-80,6$ \\
\hline $\mathrm{H}_{2} \mathrm{O}$ & ${ }^{2} J_{\mathrm{HH}}$ & $-5,8$ & $-6,8$ & $-7,9$ & $-9,0$ & $-7,3$ \\
\hline $\mathrm{NH}_{3}$ & ${ }^{1} J_{\mathrm{NH}}$ & 36,6 & 39,0 & 41,4 & 43,6 & 43,8 \\
\hline $\mathrm{NH}_{3}$ & ${ }^{2} J_{\mathrm{HH}}$ & $-8,2$ & $-9,2$ & $-10,3$ & $-11,4$ & $-9,6$ \\
\hline $\mathrm{PH}_{3}$ & ${ }^{1} J_{\mathrm{PH}}$ & 143,8 & 158,8 & 173,9 & 189,0 & 188,2 \\
\hline $\mathrm{PF}_{3}$ & ${ }^{1} J_{\mathrm{PF}}$ & $-1497,3$ & $-1487,3$ & $-1467,1$ & $-1435,8$ & $-1441,0$ \\
\hline $\mathrm{BHF}_{2}$ & ${ }^{1} J_{\mathrm{BF}}$ & $-140,4$ & $-111,6$ & $-84,1$ & $-57,5$ & $-84,0$ \\
\hline $\mathrm{BF}_{3}$ & ${ }^{1} J_{\mathrm{BF}}$ & $-53,0$ & $-19,0$ & 13,5 & 44,8 & 15,0 \\
\hline $\mathrm{F}_{2} \mathrm{O}$ & ${ }^{1} J_{\mathrm{OF}}$ & $-344,8$ & $-306,3$ & $-268,3$ & $-232,3$ & $-300,0$ \\
\hline $\mathrm{CH}_{4}$ & ${ }^{1} J_{\mathrm{CH}}$ & 111,2 & 114,1 & 117,1 & 120,2 & 125,3 \\
\hline $\mathrm{CH}_{4}$ & ${ }^{2} J_{\mathrm{HH}}$ & $-10,6$ & $-11,8$ & $-13,1$ & $-14,5$ & $-12,8$ \\
\hline $\mathrm{C}_{2} \mathrm{H}_{2}$ & ${ }^{1} J_{\mathrm{CC}}$ & 184,7 & 190,8 & 197,3 & 204,5 & 174,8 \\
\hline $\mathrm{C}_{2} \mathrm{H}_{2}$ & ${ }^{1} J_{\mathrm{CH}}$ & 228,0 & 232,8 & 238,0 & 243,7 & 247,6 \\
\hline $\mathrm{C}_{2} \mathrm{H}_{2}$ & ${ }^{2} J_{\mathrm{CH}}$ & 53,1 & 52,8 & 52,2 & 51,2 & 50,1 \\
\hline $\mathrm{C}_{2} \mathrm{H}_{2}$ & ${ }^{3} J_{\mathrm{HH}}$ & 10,7 & 11,5 & 12,6 & 14,0 & 9,6 \\
\hline $\mathrm{C}_{2} \mathrm{H}_{4}$ & ${ }^{1} J_{\mathrm{CC}}$ & 65,8 & 70,6 & 75,7 & 81,5 & 67,6 \\
\hline $\mathrm{C}_{2} \mathrm{H}_{4}$ & ${ }^{1} J_{\mathrm{CH}}$ & 139,3 & 143,2 & 147,4 & 151,9 & 156,3 \\
\hline $\mathrm{C}_{2} \mathrm{H}_{4}$ & ${ }^{2} J_{\mathrm{CH}}$ & $-0,6$ & $-2,1$ & $-3,9$ & $-5,9$ & $-2,4$ \\
\hline $\mathrm{C}_{2} \mathrm{H}_{4}$ & ${ }^{2} J_{\mathrm{HH}}$ & 3,4 & 2,2 & 0,7 & $-0,8$ & 2,3 \\
\hline $\mathrm{C}_{2} \mathrm{H}_{4}$ & ${ }^{3} J_{\mathrm{HH}_{\mathrm{c}}}$ & 10,6 & 11,5 & 12,7 & 14,0 & 11,7 \\
\hline $\mathrm{C}_{2} \mathrm{H}_{4}$ & ${ }^{3} J_{\mathrm{HH}_{\mathrm{t}}}{ }^{\mathrm{C}}$ & 17,4 & 18,3 & 19,3 & 20,7 & 19,0 \\
\hline $\mathrm{C}_{2} \mathrm{H}_{6}$ & ${ }^{1} J_{\mathrm{CC}}$ & 29,6 & 32,5 & 35,2 & 38,0 & 34,5 \\
\hline $\mathrm{C}_{2} \mathrm{H}_{6}$ & ${ }^{1} J_{\mathrm{CH}}$ & 110,5 & 113,5 & 116,6 & 119,7 & 125,2 \\
\hline $\mathrm{C}_{2} \mathrm{H}_{6}$ & ${ }^{2} J_{\mathrm{CH}}$ & $-2,8$ & $-3,6$ & $-4,3$ & $-5,1$ & $-4,7$ \\
\hline \multirow[t]{3}{*}{ Total } & $\mathrm{DM}$ & $-16,42$ & $-9,02$ & $-1,31$ & 6,74 & - \\
\hline & DMA & 19,85 & 11,97 & 7,07 & 9,90 & - \\
\hline & PDMA & 36,90 & 17,93 & 12,63 & 30,62 & - \\
\hline \multirow[t]{3}{*}{ CPI } & $\mathrm{DM}$ & $-33,91$ & $-18,80$ & $-3,04$ & 13,29 & - \\
\hline & DMA & 38,22 & 21,04 & 9,73 & 15,75 & - \\
\hline & PDMA & 61,75 & 30,49 & 8,18 & 32,40 & - \\
\hline \multirow[t]{3}{*}{ SPI } & $\mathrm{DM}$ & $-3,59$ & $-1,85$ & $-0,04$ & 1,93 & - \\
\hline & DMA & 6,39 & 5,32 & 5,12 & 5,61 & - \\
\hline & PDMA & 18,67 & 8,71 & 15,89 & 29,31 & - \\
\hline \multirow[t]{3}{*}{$\Delta \mathrm{CS}$} & $\mathrm{DM}$ & $-30,32$ & $-16,95$ & $-3,00$ & 11,36 & - \\
\hline & DMA & 31,83 & 15,72 & 4,61 & 10,13 & - \\
\hline & PDMA & 43,08 & 21,78 & $-7,71$ & 3,10 & - \\
\hline \multicolumn{7}{|c|}{ Desconsiderando ${ }^{1} J_{\mathrm{BF}}$ da molécula de $\mathrm{BF}_{3},{ }^{2} J_{\mathrm{CH}}$ e ${ }^{2} J_{\mathrm{HH}}$ da molécula de $\mathrm{C}_{2} \mathrm{H}_{4}$} \\
\hline \multirow[t]{3}{*}{ Total } & $\mathrm{DM}$ & $-15,73$ & $-8,73$ & $-1,28$ & 6,61 & - \\
\hline & DMA & 19,36 & 12,03 & 7,79 & 9,61 & - \\
\hline & PDMA & 16,66 & 9,68 & 8,10 & 13,77 & - \\
\hline \multirow[t]{3}{*}{ CPI } & $\mathrm{DM}$ & $-30,50$ & $-17,28$ & $-3,19$ & 11,64 & - \\
\hline & DMA & 35,24 & 19,74 & 10,55 & 14,34 & - \\
\hline & PDMA & 22,59 & 10,88 & 8,00 & 15,77 & - \\
\hline \multirow[t]{3}{*}{ SPI } & DM & $-4,36$ & $-2,15$ & 0,19 & 2,74 & - \\
\hline & DMA & 7,15 & 6,11 & 5,67 & 5,97 & - \\
\hline & PDMA & 12,09 & 8,76 & 8,18 & 12,23 & - \\
\hline \multirow[t]{3}{*}{$\Delta \mathrm{CS}$} & DM & $-26,14$ & $-15,13$ & $-3,38$ & 8,90 & - \\
\hline & DMA & 28,09 & 13,63 & 4,88 & 8,37 & - \\
\hline & PDMA & 10,50 & 2,12 & $-0,17$ & 3,55 & - \\
\hline
\end{tabular}


Tabela 8.282: Constantes de acoplamento B971PBE com geometrias otimizadas na base aug-pcJ-2.

\begin{tabular}{|c|c|c|c|c|c|c|}
\hline & $\% E_{X}^{\mathrm{HF}}$ & $40 \%$ & $50 \%$ & $60 \%$ & $70 \%$ & Exp. \\
\hline $\mathrm{HF}$ & ${ }^{1} J_{\mathrm{HF}}$ & 382,1 & 432,5 & 483,1 & 533,3 & 500,0 \\
\hline $\mathrm{CO}$ & ${ }^{1} J_{\mathrm{CO}}$ & 19,9 & 16,0 & 12,1 & 8,2 & 16,4 \\
\hline $\mathrm{H}_{2} \mathrm{O}$ & ${ }^{1} J_{\mathrm{OH}}$ & $-63,3$ & $-69,7$ & $-76,0$ & $-82,1$ & $-80,6$ \\
\hline $\mathrm{H}_{2} \mathrm{O}$ & ${ }^{2} J_{\mathrm{HH}}$ & $-6,3$ & $-7,3$ & $-8,5$ & $-9,7$ & $-7,3$ \\
\hline $\mathrm{NH}_{3}$ & ${ }^{1} J_{\mathrm{NH}}$ & 36,7 & 39,2 & 41,6 & 43,9 & 43,8 \\
\hline $\mathrm{NH}_{3}$ & ${ }^{2} J_{\mathrm{HH}}$ & $-8,8$ & $-9,8$ & $-10,9$ & $-12,1$ & $-9,6$ \\
\hline $\mathrm{PH}_{3}$ & ${ }^{1} J_{\mathrm{PH}}$ & 144,2 & 159,6 & 174,9 & 190,3 & 188,2 \\
\hline $\mathrm{PF}_{3}$ & ${ }^{1} J_{\mathrm{PF}}$ & $-1502,1$ & $-1491,0$ & $-1470,1$ & $-1438,1$ & $-1441,0$ \\
\hline $\mathrm{BHF}_{2}$ & ${ }^{1} J_{\mathrm{BF}}$ & $-140,6$ & $-111,7$ & $-84,0$ & $-57,5$ & $-84,0$ \\
\hline $\mathrm{BF}_{3}$ & ${ }^{1} J_{\mathrm{BF}}$ & $-53,0$ & $-18,9$ & 13,7 & 45,0 & 15,0 \\
\hline $\mathrm{F}_{2} \mathrm{O}$ & ${ }^{1} J_{\mathrm{OF}}$ & $-338,2$ & $-299,9$ & $-262,1$ & $-226,4$ & $-300,0$ \\
\hline $\mathrm{CH}_{4}$ & ${ }^{1} J_{\mathrm{CH}}$ & 111,9 & 114,9 & 118,0 & 121,0 & 125,3 \\
\hline $\mathrm{CH}_{4}$ & ${ }^{2} J_{\mathrm{HH}}$ & $-11,2$ & $-12,5$ & $-13,9$ & $-15,3$ & $-12,8$ \\
\hline $\mathrm{C}_{2} \mathrm{H}_{2}$ & ${ }^{1} J_{\mathrm{CC}}$ & 184,4 & 190,8 & 197,6 & 205,2 & 174,8 \\
\hline $\mathrm{C}_{2} \mathrm{H}_{2}$ & ${ }^{1} J_{\mathrm{CH}}$ & 230,4 & 235,5 & 241,0 & 246,9 & 247,6 \\
\hline $\mathrm{C}_{2} \mathrm{H}_{2}$ & ${ }^{2} J_{\mathrm{CH}}$ & 53,0 & 52,5 & 51,7 & 50,4 & 50,1 \\
\hline $\mathrm{C}_{2} \mathrm{H}_{2}$ & ${ }^{3} J_{\mathrm{HH}}$ & 11,4 & 12,4 & 13,6 & 15,3 & 9,6 \\
\hline $\mathrm{C}_{2} \mathrm{H}_{4}$ & ${ }^{1} J_{\mathrm{CC}}$ & 66,0 & 70,9 & 76,4 & 82,5 & 67,6 \\
\hline $\mathrm{C}_{2} \mathrm{H}_{4}$ & ${ }^{1} J_{\mathrm{CH}}$ & 140,6 & 144,7 & 149,0 & 153,8 & 156,3 \\
\hline $\mathrm{C}_{2} \mathrm{H}_{4}$ & ${ }^{2} J_{\mathrm{CH}}$ & $-1,3$ & $-2,9$ & $-4,8$ & $-7,1$ & $-2,4$ \\
\hline $\mathrm{C}_{2} \mathrm{H}_{4}$ & ${ }^{2} J_{\mathrm{HH}}$ & 2,8 & 1,5 & 0,0 & $-1,9$ & 2,3 \\
\hline $\mathrm{C}_{2} \mathrm{H}_{4}$ & ${ }^{3} J_{\mathrm{HH}_{\mathrm{c}}}$ & 11,0 & 12,0 & 13,3 & 14,8 & 11,7 \\
\hline $\mathrm{C}_{2} \mathrm{H}_{4}$ & ${ }^{3} J_{\mathrm{HH}_{\mathrm{t}}}$ & 18,0 & 19,0 & 20,2 & 21,7 & 19,0 \\
\hline $\mathrm{C}_{2} \mathrm{H}_{6}$ & ${ }^{1} J_{\mathrm{CC}}$ & 29,6 & 32,4 & 35,2 & 38,1 & 34,5 \\
\hline $\mathrm{C}_{2} \mathrm{H}_{6}$ & ${ }^{1} J_{\mathrm{CH}}$ & 111,3 & 114,4 & 117,6 & 120,7 & 125,2 \\
\hline $\mathrm{C}_{2} \mathrm{H}_{6}$ & ${ }^{2} J_{\mathrm{CH}}$ & $-3,2$ & $-3,9$ & $-4,7$ & $-5,5$ & $-4,7$ \\
\hline \multirow[t]{3}{*}{ Total } & $\mathrm{DM}$ & $-16,14$ & $-8,63$ & $-0,81$ & 7,32 & - \\
\hline & DMA & 19,34 & 11,47 & 7,21 & 10,31 & - \\
\hline & PDMA & 33,63 & 18,48 & 16,21 & 36,52 & - \\
\hline \multirow[t]{3}{*}{ CPI } & $\mathrm{DM}$ & $-33,66$ & $-18,35$ & $-2,46$ & 13,99 & - \\
\hline & DMA & 37,77 & 20,35 & 10,19 & 16,65 & - \\
\hline & PDMA & 60,52 & 29,07 & 9,15 & 34,10 & - \\
\hline \multirow[t]{3}{*}{ SPI } & $\mathrm{DM}$ & $-3,29$ & $-1,49$ & 0,41 & 2,43 & - \\
\hline & DMA & 5,83 & 4,95 & 5,02 & 5,66 & - \\
\hline & PDMA & 13,91 & 10,72 & 21,38 & 38,30 & - \\
\hline \multirow[t]{3}{*}{$\Delta \mathrm{CS}$} & $\mathrm{DM}$ & $-30,37$ & $-16,86$ & $-2,87$ & 11,56 & - \\
\hline & DMA & 31,95 & 15,41 & 5,17 & 10,99 & - \\
\hline & PDMA & 46,61 & 18,34 & $-12,23$ & $-4,20$ & - \\
\hline \multicolumn{7}{|c|}{ Desconsiderando ${ }^{1} J_{\mathrm{BF}}$ da molécula de $\mathrm{BF}_{3},{ }^{2} J_{\mathrm{CH}}$ e ${ }^{2} J_{\mathrm{HH}}$ da molécula de $\mathrm{C}_{2} \mathrm{H}_{4}$} \\
\hline \multirow[t]{3}{*}{ Total } & $\mathrm{DM}$ & $-15,36$ & $-8,22$ & $-0,65$ & 7,36 & - \\
\hline & DMA & 18,84 & 11,43 & 7,89 & 9,96 & - \\
\hline & PDMA & 15,37 & 8,65 & 9,25 & 16,13 & - \\
\hline \multirow[t]{3}{*}{ CPI } & DM & $-30,23$ & $-16,80$ & $-2,58$ & 12,39 & - \\
\hline & DMA & 34,75 & 19,00 & 11,08 & 15,31 & - \\
\hline & PDMA & 21,24 & 9,37 & 9,20 & 17,51 & - \\
\hline \multirow[t]{3}{*}{ SPI } & DM & $-3,92$ & $-1,62$ & 0,83 & 3,49 & - \\
\hline & DMA & 6,60 & 5,61 & 5,43 & 5,85 & - \\
\hline & PDMA & 10,85 & 8,10 & 9,29 & 15,08 & - \\
\hline \multirow[t]{3}{*}{$\Delta \mathrm{CS}$} & $\mathrm{DM}$ & $-26,31$ & $-15,18$ & $-3,41$ & 8,90 & - \\
\hline & DMA & 28,15 & 13,39 & 5,65 & 9,46 & - \\
\hline & PDMA & 10,39 & 1,28 & $-0,09$ & 2,43 & - \\
\hline
\end{tabular}


Tabela 8.283: Constantes de acoplamento B971PW91 com geometrias otimizadas na base aug-pcJ-2.

\begin{tabular}{|c|c|c|c|c|c|c|}
\hline & $\% E_{X}^{\mathrm{HF}}$ & $40 \%$ & $50 \%$ & $60 \%$ & $70 \%$ & Exp. \\
\hline $\mathrm{HF}$ & ${ }^{1} J_{\mathrm{HF}}$ & 385,1 & 435,6 & 486,3 & 536,6 & 500,0 \\
\hline $\mathrm{CO}$ & ${ }^{1} J_{\mathrm{CO}}$ & 19,6 & 15,7 & 11,7 & 7,8 & 16,4 \\
\hline $\mathrm{H}_{2} \mathrm{O}$ & ${ }^{1} J_{\mathrm{OH}}$ & $-63,8$ & $-70,3$ & $-76,6$ & $-82,8$ & $-80,6$ \\
\hline $\mathrm{H}_{2} \mathrm{O}$ & ${ }^{2} J_{\mathrm{HH}}$ & $-6,3$ & $-7,3$ & $-8,4$ & $-9,6$ & $-7,3$ \\
\hline $\mathrm{NH}_{3}$ & ${ }^{1} J_{\mathrm{NH}}$ & 37,0 & 39,5 & 42,0 & 44,2 & 43,8 \\
\hline $\mathrm{NH}_{3}$ & ${ }^{2} J_{\mathrm{HH}}$ & $-8,8$ & $-9,8$ & $-10,8$ & $-12,1$ & $-9,6$ \\
\hline $\mathrm{PH}_{3}$ & ${ }^{1} J_{\mathrm{PH}}$ & 145,6 & 161,1 & 176,4 & 191,9 & 188,2 \\
\hline $\mathrm{PF}_{3}$ & ${ }^{1} J_{\mathrm{PF}}$ & $-1504,8$ & $-1493,6$ & $-1472,6$ & $-1440,4$ & $-1441,0$ \\
\hline $\mathrm{BHF}_{2}$ & ${ }^{1} J_{\mathrm{BF}}$ & $-139,5$ & $-110,5$ & $-82,8$ & $-56,1$ & $-84,0$ \\
\hline $\mathrm{BF}_{3}$ & ${ }^{1} J_{\mathrm{BF}}$ & $-51,9$ & $-17,7$ & 15,0 & 46,4 & 15,0 \\
\hline $\mathrm{F}_{2} \mathrm{O}$ & ${ }^{1} J_{\mathrm{OF}}$ & $-342,8$ & $-304,0$ & $-265,9$ & $-229,8$ & $-300,0$ \\
\hline $\mathrm{CH}_{4}$ & ${ }^{1} J_{\mathrm{CH}}$ & 112,5 & 115,4 & 118,5 & 121,6 & 125,3 \\
\hline $\mathrm{CH}_{4}$ & ${ }^{2} J_{\mathrm{HH}}$ & $-11,2$ & $-12,5$ & $-13,9$ & $-15,3$ & $-12,8$ \\
\hline $\mathrm{C}_{2} \mathrm{H}_{2}$ & ${ }^{1} J_{\mathrm{CC}}$ & 185,7 & 192,0 & 198,9 & 206,5 & 174,8 \\
\hline $\mathrm{C}_{2} \mathrm{H}_{2}$ & ${ }^{1} J_{\mathrm{CH}}$ & 231,2 & 236,3 & 241,8 & 247,8 & 247,6 \\
\hline $\mathrm{C}_{2} \mathrm{H}_{2}$ & ${ }^{2} J_{\mathrm{CH}}$ & 53,0 & 52,6 & 51,7 & 50,4 & 50,1 \\
\hline $\mathrm{C}_{2} \mathrm{H}_{2}$ & ${ }^{3} J_{\mathrm{HH}}$ & 11,3 & 12,3 & 13,5 & 15,1 & 9,6 \\
\hline $\mathrm{C}_{2} \mathrm{H}_{4}$ & ${ }^{1} J_{\mathrm{CC}}$ & 66,6 & 71,6 & 77,0 & 83,1 & 67,6 \\
\hline $\mathrm{C}_{2} \mathrm{H}_{4}$ & ${ }^{1} J_{\mathrm{CH}}$ & 141,2 & 145,3 & 149,7 & 154,4 & 156,3 \\
\hline $\mathrm{C}_{2} \mathrm{H}_{4}$ & ${ }^{2} J_{\mathrm{CH}}$ & $-1,2$ & $-2,9$ & $-4,8$ & $-7,1$ & $-2,4$ \\
\hline $\mathrm{C}_{2} \mathrm{H}_{4}$ & ${ }^{2} J_{\mathrm{HH}}$ & 2,8 & 1,5 & 0,0 & $-1,8$ & 2,3 \\
\hline $\mathrm{C}_{2} \mathrm{H}_{4}$ & ${ }^{3} J_{\mathrm{HH}_{\mathrm{c}}}$ & 11,0 & 12,0 & 13,3 & 14,8 & 11,7 \\
\hline $\mathrm{C}_{2} \mathrm{H}_{4}$ & ${ }^{3} J_{\mathrm{HH}_{\mathrm{t}}}{ }^{\mathrm{C}}$ & 17,9 & 18,9 & 20,1 & 21,6 & 19,0 \\
\hline $\mathrm{C}_{2} \mathrm{H}_{6}$ & ${ }^{1} J_{\mathrm{CC}}$ & 30,0 & 32,8 & 35,6 & 38,4 & 34,5 \\
\hline $\mathrm{C}_{2} \mathrm{H}_{6}$ & ${ }^{1} J_{\mathrm{CH}}$ & 111,9 & 115,0 & 118,1 & 121,3 & 125,2 \\
\hline $\mathrm{C}_{2} \mathrm{H}_{6}$ & ${ }^{2} J_{\mathrm{CH}}$ & $-3,2$ & $-3,9$ & $-4,7$ & $-5,5$ & $-4,7$ \\
\hline \multirow[t]{3}{*}{ Total } & $\mathrm{DM}$ & $-16,00$ & $-8,46$ & $-0,61$ & 7,55 & - \\
\hline & DMA & 19,24 & 11,39 & 6,93 & 10,42 & - \\
\hline & PDMA & 33,22 & 18,09 & 15,76 & 36,82 & - \\
\hline \multirow[t]{3}{*}{ CPI } & $\mathrm{DM}$ & $-33,77$ & $-18,38$ & $-2,42$ & 14,11 & - \\
\hline & DMA & 37,74 & 20,25 & 9,56 & 16,95 & - \\
\hline & PDMA & 59,48 & 28,25 & 8,12 & 35,36 & - \\
\hline \multirow[t]{3}{*}{ SPI } & $\mathrm{DM}$ & $-2,97$ & $-1,18$ & 0,71 & 2,75 & - \\
\hline & DMA & 5,68 & 4,89 & 4,99 & 5,63 & - \\
\hline & PDMA & 13,95 & 10,63 & 21,36 & 37,90 & - \\
\hline \multirow[t]{3}{*}{$\Delta \mathrm{CS}$} & $\mathrm{DM}$ & $-30,80$ & $-17,20$ & $-3,13$ & 11,36 & - \\
\hline & DMA & 32,06 & 15,37 & 4,57 & 11,32 & - \\
\hline & PDMA & 45,53 & 17,62 & $-13,24$ & $-2,54$ & - \\
\hline \multicolumn{7}{|c|}{ Desconsiderando ${ }^{1} J_{\mathrm{BF}}$ da molécula de $\mathrm{BF}_{3},{ }^{2} J_{\mathrm{CH}}$ e ${ }^{2} J_{\mathrm{HH}}$ da molécula de $\mathrm{C}_{2} \mathrm{H}_{4}$} \\
\hline \multirow[t]{3}{*}{ Total } & $\mathrm{DM}$ & $-15,26$ & $-8,08$ & $-0,49$ & 7,56 & - \\
\hline & DMA & 18,77 & 11,40 & 7,63 & 10,03 & - \\
\hline & PDMA & 15,04 & 8,55 & 9,12 & 16,26 & - \\
\hline \multirow[t]{3}{*}{ CPI } & $\mathrm{DM}$ & $-30,46$ & $-16,95$ & $-2,66$ & 12,38 & - \\
\hline & DMA & 34,82 & 19,01 & 10,52 & 15,50 & - \\
\hline & PDMA & 20,83 & 9,28 & 8,93 & 17,96 & - \\
\hline \multirow[t]{3}{*}{ SPI } & DM & $-3,56$ & $-1,26$ & 1,18 & 3,85 & - \\
\hline & DMA & 6,42 & 5,54 & 5,40 & 5,82 & - \\
\hline & PDMA & 10,58 & 7,99 & 9,26 & 14,95 & - \\
\hline \multirow[t]{3}{*}{$\Delta \mathrm{CS}$} & DM & $-26,90$ & $-15,69$ & $-3,84$ & 8,53 & - \\
\hline & DMA & 28,40 & 13,47 & 5,12 & 9,68 & - \\
\hline & PDMA & 10,25 & 1,28 & $-0,33$ & 3,01 & - \\
\hline
\end{tabular}


Tabela 8.284: Constantes de acoplamento B971TPSS com geometrias otimizadas na base aug-pcJ-2.

\begin{tabular}{|c|c|c|c|c|c|c|}
\hline & $\% E_{X}^{\mathrm{HF}}$ & $40 \%$ & $50 \%$ & $60 \%$ & $70 \%$ & Exp. \\
\hline $\mathrm{HF}$ & ${ }^{1} J_{\mathrm{HF}}$ & 385,3 & 436,5 & 487,9 & 538,7 & 500,0 \\
\hline $\mathrm{CO}$ & ${ }^{1} J_{\mathrm{CO}}$ & 19,8 & 15,8 & 11,9 & 7,9 & 16,4 \\
\hline $\mathrm{H}_{2} \mathrm{O}$ & ${ }^{1} J_{\mathrm{OH}}$ & $-64,5$ & $-71,1$ & $-77,6$ & $-83,7$ & $-80,6$ \\
\hline $\mathrm{H}_{2} \mathrm{O}$ & ${ }^{2} J_{\mathrm{HH}}$ & $-6,2$ & $-7,3$ & $-8,5$ & $-9,7$ & $-7,3$ \\
\hline $\mathrm{NH}_{3}$ & ${ }^{1} J_{\mathrm{NH}}$ & 38,1 & 40,7 & 43,3 & 45,6 & 43,8 \\
\hline $\mathrm{NH}_{3}$ & ${ }^{2} J_{\mathrm{HH}}$ & $-8,6$ & $-9,7$ & $-10,8$ & $-12,1$ & $-9,6$ \\
\hline $\mathrm{PH}_{3}$ & ${ }^{1} J_{\mathrm{PH}}$ & 154,5 & 171,1 & 187,7 & 204,4 & 188,2 \\
\hline $\mathrm{PF}_{3}$ & ${ }^{1} J_{\mathrm{PF}}$ & $-1507,0$ & $-1496,6$ & $-1476,7$ & $-1445,4$ & $-1441,0$ \\
\hline $\mathrm{BHF}_{2}$ & ${ }^{1} J_{\mathrm{BF}}$ & $-142,7$ & $-113,9$ & $-86,2$ & $-59,7$ & $-84,0$ \\
\hline $\mathrm{BF}_{3}$ & ${ }^{1} J_{\mathrm{BF}}$ & $-51,5$ & $-17,5$ & 15,0 & 46,2 & 15,0 \\
\hline $\mathrm{F}_{2} \mathrm{O}$ & ${ }^{1} J_{\mathrm{OF}}$ & $-339,7$ & $-300,5$ & $-262,2$ & $-226,0$ & $-300,0$ \\
\hline $\mathrm{CH}_{4}$ & ${ }^{1} J_{\mathrm{CH}}$ & 120,2 & 123,4 & 126,8 & 130,2 & 125,3 \\
\hline $\mathrm{CH}_{4}$ & ${ }^{2} J_{\mathrm{HH}}$ & $-10,8$ & $-12,2$ & $-13,7$ & $-15,2$ & $-12,8$ \\
\hline $\mathrm{C}_{2} \mathrm{H}_{2}$ & ${ }^{1} J_{\mathrm{CC}}$ & 185,6 & 192,2 & 199,4 & 207,3 & 174,8 \\
\hline $\mathrm{C}_{2} \mathrm{H}_{2}$ & ${ }^{1} J_{\mathrm{CH}}$ & 245,4 & 251,0 & 257,0 & 263,6 & 247,6 \\
\hline $\mathrm{C}_{2} \mathrm{H}_{2}$ & ${ }^{2} J_{\mathrm{CH}}$ & 54,6 & 54,1 & 53,1 & 51,7 & 50,1 \\
\hline $\mathrm{C}_{2} \mathrm{H}_{2}$ & ${ }^{3} J_{\mathrm{HH}}$ & 11,9 & 12,9 & 14,1 & 15,8 & 9,6 \\
\hline $\mathrm{C}_{2} \mathrm{H}_{4}$ & ${ }^{1} J_{\mathrm{CC}}$ & 67,5 & 72,6 & 78,3 & 84,6 & 67,6 \\
\hline $\mathrm{C}_{2} \mathrm{H}_{4}$ & ${ }^{1} J_{\mathrm{CH}}$ & 150,3 & 154,8 & 159,6 & 164,8 & 156,3 \\
\hline $\mathrm{C}_{2} \mathrm{H}_{4}$ & ${ }^{2} J_{\mathrm{CH}}$ & $-1,4$ & $-3,1$ & $-5,2$ & $-7,6$ & $-2,4$ \\
\hline $\mathrm{C}_{2} \mathrm{H}_{4}$ & ${ }^{2} J_{\mathrm{HH}}$ & 4,3 & 2,9 & 1,2 & $-0,6$ & 2,3 \\
\hline $\mathrm{C}_{2} \mathrm{H}_{4}$ & ${ }^{3} J_{\mathrm{HH}_{\mathrm{c}}}$ & 11,7 & 12,8 & 14,0 & 15,6 & 11,7 \\
\hline $\mathrm{C}_{2} \mathrm{H}_{4}$ & ${ }^{3} J_{\mathrm{HH}_{\mathrm{t}}}$ & 19,8 & 20,8 & 22,0 & 23,6 & 19,0 \\
\hline $\mathrm{C}_{2} \mathrm{H}_{6}$ & ${ }^{1} J_{\mathrm{CC}}$ & 30,7 & 33,6 & 36,4 & 39,3 & 34,5 \\
\hline $\mathrm{C}_{2} \mathrm{H}_{6}$ & ${ }^{1} J_{\mathrm{CH}}$ & 119,4 & 122,8 & 126,2 & 129,7 & 125,2 \\
\hline $\mathrm{C}_{2} \mathrm{H}_{6}$ & ${ }^{2} J_{\mathrm{CH}}$ & $-3,3$ & $-4,1$ & $-4,9$ & $-5,7$ & $-4,7$ \\
\hline \multirow[t]{3}{*}{ Total } & $\mathrm{DM}$ & $-13,91$ & $-6,27$ & 1,66 & 9,93 & - \\
\hline & DMA & 17,48 & 9,91 & 6,50 & 12,43 & - \\
\hline & PDMA & 34,35 & 17,74 & 14,96 & 37,77 & - \\
\hline \multirow[t]{3}{*}{ CPI } & $\mathrm{DM}$ & $-33,04$ & $-17,58$ & $-1,55$ & 15,03 & - \\
\hline & DMA & 36,96 & 19,31 & 8,97 & 18,83 & - \\
\hline & PDMA & 59,19 & 27,42 & 7,42 & 36,09 & - \\
\hline \multirow[t]{3}{*}{ SPI } & $\mathrm{DM}$ & 0,12 & 2,03 & 4,01 & 6,20 & - \\
\hline & DMA & 3,19 & 3,01 & 4,68 & 7,73 & - \\
\hline & PDMA & 16,13 & 10,64 & 20,49 & 39,01 & - \\
\hline \multirow[t]{3}{*}{$\Delta \mathrm{CS}$} & DM & $-33,16$ & $-19,61$ & $-5,57$ & 8,83 & - \\
\hline & DMA & 33,78 & 16,30 & 4,29 & 11,09 & - \\
\hline & PDMA & 43,06 & 16,78 & $-13,07$ & $-2,92$ & - \\
\hline \multicolumn{7}{|c|}{ Desconsiderando ${ }^{1} J_{\mathrm{BF}}$ da molécula de $\mathrm{BF}_{3},{ }^{2} J_{\mathrm{CH}}$ e ${ }^{2} J_{\mathrm{HH}}$ da molécula de $\mathrm{C}_{2} \mathrm{H}_{4}$} \\
\hline \multirow[t]{3}{*}{ Total } & DM & $-12,96$ & $-5,67$ & 2,04 & 10,23 & - \\
\hline & DMA & 16,73 & 9,73 & 7,17 & 12,34 & - \\
\hline & PDMA & 13,96 & 8,23 & 9,76 & 18,75 & - \\
\hline \multirow[t]{3}{*}{ CPI } & $\mathrm{DM}$ & $-29,69$ & $-16,09$ & $-1,71$ & 13,41 & - \\
\hline & DMA & 34,01 & 17,99 & 9,87 & 17,59 & - \\
\hline & PDMA & 20,77 & 8,50 & 8,16 & 18,90 & - \\
\hline \multirow[t]{3}{*}{ SPI } & $\mathrm{DM}$ & $-0,09$ & 2,35 & 4,93 & 7,78 & - \\
\hline & DMA & 3,45 & 3,38 & 5,10 & 8,30 & - \\
\hline & PDMA & 8,72 & 8,03 & 10,99 & 18,65 & - \\
\hline \multirow[t]{3}{*}{$\Delta \mathrm{CS}$} & $\mathrm{DM}$ & $-29,60$ & $-18,44$ & $-6,64$ & 5,63 & - \\
\hline & DMA & 30,56 & 14,61 & 4,77 & 9,29 & - \\
\hline & PDMA & 12,06 & 0,47 & $-2,83$ & 0,25 & - \\
\hline
\end{tabular}


Tabela 8.285: Constantes de acoplamento B972B95 com geometrias otimizadas na base aug-pcJ-2.

\begin{tabular}{|c|c|c|c|c|c|}
\hline & $\% E_{X}^{\mathrm{HF}}$ & $50 \%$ & $60 \%$ & $70 \%$ & Exp. \\
\hline $\mathrm{HF}$ & ${ }^{1} J_{\mathrm{HF}}$ & 467,1 & 517,9 & 568,9 & 500,0 \\
\hline $\mathrm{CO}$ & ${ }^{1} J_{\mathrm{CO}}$ & 15,6 & 11,3 & 7,0 & 16,4 \\
\hline $\mathrm{H}_{2} \mathrm{O}$ & ${ }^{1} J_{\mathrm{OH}}$ & $-72,6$ & $-79,1$ & $-85,5$ & $-80,6$ \\
\hline $\mathrm{H}_{2} \mathrm{O}$ & ${ }^{2} J_{\mathrm{HH}}$ & $-7,0$ & $-7,9$ & $-8,8$ & $-7,3$ \\
\hline $\mathrm{NH}_{3}$ & ${ }^{1} J_{\mathrm{NH}}$ & 39,2 & 41,9 & 44,4 & 43,8 \\
\hline $\mathrm{NH}_{3}$ & ${ }^{2} J_{\mathrm{HH}}$ & $-8,9$ & $-9,7$ & $-10,7$ & $-9,6$ \\
\hline $\mathrm{PH}_{3}$ & ${ }^{1} J_{\mathrm{PH}}$ & 167,6 & 181,4 & 195,4 & 188,2 \\
\hline $\mathrm{PF}_{3}$ & ${ }^{1} J_{\mathrm{PF}}$ & $-1393,8$ & $-1377,2$ & $-1352,3$ & $-1441,0$ \\
\hline $\mathrm{BHF}_{2}$ & ${ }^{1} J_{\mathrm{BF}}$ & $-112,5$ & $-84,3$ & $-56,6$ & $-84,0$ \\
\hline $\mathrm{BF}_{3}$ & ${ }^{1} J_{\mathrm{BF}}$ & $-19,7$ & 13,6 & 45,6 & 15,0 \\
\hline $\mathrm{F}_{2} \mathrm{O}$ & ${ }^{1} J_{\mathrm{OF}}$ & $-247,3$ & $-217,2$ & $-189,0$ & $-300,0$ \\
\hline $\mathrm{CH}_{4}$ & ${ }^{1} J_{\mathrm{CH}}$ & 110,5 & 114,3 & 118,2 & 125,3 \\
\hline $\mathrm{CH}_{4}$ & ${ }^{2} J_{\mathrm{HH}}$ & $-10,7$ & $-11,9$ & $-13,1$ & $-12,8$ \\
\hline $\mathrm{C}_{2} \mathrm{H}_{2}$ & ${ }^{1} J_{\mathrm{CC}}$ & 183,5 & 190,3 & 197,7 & 174,8 \\
\hline $\mathrm{C}_{2} \mathrm{H}_{2}$ & ${ }^{1} J_{\mathrm{CH}}$ & 226,0 & 231,8 & 238,0 & 247,6 \\
\hline $\mathrm{C}_{2} \mathrm{H}_{2}$ & ${ }^{2} J_{\mathrm{CH}}$ & 53,4 & 53,5 & 53,3 & 50,1 \\
\hline $\mathrm{C}_{2} \mathrm{H}_{2}$ & ${ }^{3} J_{\mathrm{HH}}$ & 10,0 & 10,7 & 11,5 & 9,6 \\
\hline $\mathrm{C}_{2} \mathrm{H}_{4}$ & ${ }^{1} J_{\mathrm{CC}}$ & 63,9 & 68,8 & 74,1 & 67,6 \\
\hline $\mathrm{C}_{2} \mathrm{H}_{4}$ & ${ }^{1} J_{\mathrm{CH}}$ & 139,2 & 143,9 & 148,7 & 156,3 \\
\hline $\mathrm{C}_{2} \mathrm{H}_{4}$ & ${ }^{2} J_{\mathrm{CH}}$ & $-0,8$ & $-2,1$ & $-3,6$ & $-2,4$ \\
\hline $\mathrm{C}_{2} \mathrm{H}_{4}$ & ${ }^{2} J_{\mathrm{HH}}$ & 2,8 & 1,8 & 0,6 & 2,3 \\
\hline $\mathrm{C}_{2} \mathrm{H}_{4}$ & ${ }^{3} J_{\mathrm{HH}_{\mathrm{c}}}$ & 11,2 & 12,0 & 13,0 & 11,7 \\
\hline $\mathrm{C}_{2} \mathrm{H}_{4}$ & ${ }^{3} J_{\mathrm{HH}_{\mathrm{t}}}$ & 17,4 & 18,2 & 19,2 & 19,0 \\
\hline $\mathrm{C}_{2} \mathrm{H}_{6}$ & ${ }^{1} J_{\mathrm{CC}}$ & 30,2 & 33,3 & 36,5 & 34,5 \\
\hline $\mathrm{C}_{2} \mathrm{H}_{6}$ & ${ }^{1} J_{\mathrm{CH}}$ & 109,8 & 113,7 & 117,6 & 125,2 \\
\hline $\mathrm{C}_{2} \mathrm{H}_{6}$ & ${ }^{2} J_{\mathrm{CH}}$ & $-3,3$ & $-4,0$ & $-4,6$ & $-4,7$ \\
\hline \multirow[t]{3}{*}{ Total } & DM & $-2,85$ & 4,62 & 12,33 & - \\
\hline & DMA & 12,62 & 9,95 & 16,33 & - \\
\hline & PDMA & 21,73 & 8,58 & 23,46 & - \\
\hline \multirow[t]{3}{*}{ CPI } & $\mathrm{DM}$ & $-1,20$ & 13,62 & 28,86 & - \\
\hline & DMA & 21,00 & 16,56 & 31,94 & - \\
\hline & PDMA & 30,94 & 8,68 & 35,83 & - \\
\hline \multirow[t]{3}{*}{ SPI } & DM & $-4,07$ & $-1,99$ & 0,20 & - \\
\hline & DMA & 6,47 & 5,11 & 4,88 & - \\
\hline & PDMA & 14,98 & 8,51 & 14,38 & - \\
\hline \multirow[t]{3}{*}{$\Delta \mathrm{CS}$} & $\mathrm{DM}$ & 2,87 & 15,60 & 28,66 & - \\
\hline & DMA & 14,53 & 11,46 & 27,06 & - \\
\hline & PDMA & 15,96 & 0,17 & 21,45 & - \\
\hline \multicolumn{6}{|c|}{ Desconsiderando ${ }^{1} J_{\mathrm{BF}}$ da molécula de $\mathrm{BF}_{3},{ }^{2} J_{\mathrm{CH}}$ e ${ }^{2} J_{\mathrm{HH}}$ da molécula de $\mathrm{C}_{2} \mathrm{H}_{4}$} \\
\hline \multirow[t]{3}{*}{ Total } & $\mathrm{DM}$ & $-1,81$ & 5,29 & 12,73 & - \\
\hline & DMA & 12,66 & 11,16 & 17,00 & - \\
\hline & PDMA & 10,67 & 7,80 & 12,26 & - \\
\hline \multirow[t]{3}{*}{ CPI } & DM & 2,15 & 15,12 & 28,69 & - \\
\hline & DMA & 19,63 & 18,08 & 32,07 & - \\
\hline & PDMA & 10,90 & 8,61 & 19,02 & - \\
\hline \multirow[t]{3}{*}{ SPI } & $\mathrm{DM}$ & $-4,85$ & $-2,28$ & 0,45 & - \\
\hline & DMA & 7,30 & 5,83 & 5,41 & - \\
\hline & PDMA & 10,49 & 7,18 & 7,06 & - \\
\hline \multirow[t]{3}{*}{$\triangle \mathrm{CS}$} & DM & 7,00 & 17,40 & 28,24 & - \\
\hline & DMA & 12,33 & 12,25 & 26,66 & - \\
\hline & PDMA & 0,41 & 1,43 & 11,95 & - \\
\hline
\end{tabular}


Tabela 8.286: Constantes de acoplamento B972B971 com geometrias otimizadas na base aug-pcJ-2.

\begin{tabular}{|c|c|c|c|c|c|}
\hline & $\% E_{X}^{\mathrm{HF}}$ & $40 \%$ & $50 \%$ & $60 \%$ & Exp. \\
\hline $\mathrm{HF}$ & ${ }^{1} J_{\mathrm{HF}}$ & 425,2 & 473,6 & 522,4 & 500,0 \\
\hline $\mathrm{CO}$ & ${ }^{1} J_{\mathrm{CO}}$ & 16,9 & 12,6 & 8,1 & 16,4 \\
\hline $\mathrm{H}_{2} \mathrm{O}$ & ${ }^{1} J_{\mathrm{OH}}$ & $-67,3$ & $-73,5$ & $-79,8$ & $-80,6$ \\
\hline $\mathrm{H}_{2} \mathrm{O}$ & ${ }^{2} J_{\mathrm{HH}}$ & $-5,7$ & $-6,6$ & $-7,5$ & $-7,3$ \\
\hline $\mathrm{NH}_{3}$ & ${ }^{1} J_{\mathrm{NH}}$ & 37,9 & 40,6 & 43,2 & 43,8 \\
\hline $\mathrm{NH}_{3}$ & ${ }^{2} J_{\mathrm{HH}}$ & $-7,8$ & $-8,7$ & $-9,6$ & $-9,6$ \\
\hline $\mathrm{PH}_{3}$ & ${ }^{1} J_{\mathrm{PH}}$ & 183,6 & 195,9 & 208,4 & 188,2 \\
\hline $\mathrm{PF}_{3}$ & ${ }^{1} J_{\mathrm{PF}}$ & $-1440,1$ & $-1432,0$ & $-1411,1$ & $-1441,0$ \\
\hline $\mathrm{BHF}_{2}$ & ${ }^{1} J_{\mathrm{BF}}$ & $-124,0$ & $-93,8$ & $-63,9$ & $-84,0$ \\
\hline $\mathrm{BF}_{3}$ & ${ }^{1} J_{\mathrm{BF}}$ & $-36,2$ & $-0,8$ & 33,9 & 15,0 \\
\hline $\mathrm{F}_{2} \mathrm{O}$ & ${ }^{1} J_{\mathrm{OF}}$ & $-272,6$ & $-244,4$ & $-217,1$ & $-300,0$ \\
\hline $\mathrm{CH}_{4}$ & ${ }^{1} J_{\mathrm{CH}}$ & 114,4 & 118,4 & 122,6 & 125,3 \\
\hline $\mathrm{CH}_{4}$ & ${ }^{2} J_{\mathrm{HH}}$ & $-9,7$ & $-10,8$ & $-12,0$ & $-12,8$ \\
\hline $\mathrm{C}_{2} \mathrm{H}_{2}$ & ${ }^{1} J_{\mathrm{CC}}$ & 198,8 & 206,2 & 214,1 & 174,8 \\
\hline $\mathrm{C}_{2} \mathrm{H}_{2}$ & ${ }^{1} J_{\mathrm{CH}}$ & 229,9 & 236,2 & 242,8 & 247,6 \\
\hline $\mathrm{C}_{2} \mathrm{H}_{2}$ & ${ }^{2} J_{\mathrm{CH}}$ & 51,7 & 51,7 & 51,5 & 50,1 \\
\hline $\mathrm{C}_{2} \mathrm{H}_{2}$ & ${ }^{3} J_{\mathrm{HH}}$ & 9,4 & 10,0 & 10,7 & 9,6 \\
\hline $\mathrm{C}_{2} \mathrm{H}_{4}$ & ${ }^{1} J_{\mathrm{CC}}$ & 73,0 & 78,4 & 84,3 & 67,6 \\
\hline $\mathrm{C}_{2} \mathrm{H}_{4}$ & ${ }^{1} J_{\mathrm{CH}}$ & 142,5 & 147,5 & 152,7 & 156,3 \\
\hline $\mathrm{C}_{2} \mathrm{H}_{4}$ & ${ }^{2} J_{\mathrm{CH}}$ & $-0,9$ & $-2,2$ & $-3,7$ & $-2,4$ \\
\hline $\mathrm{C}_{2} \mathrm{H}_{4}$ & ${ }^{2} J_{\mathrm{HH}}$ & 3,3 & 2,4 & 1,3 & 2,3 \\
\hline $\mathrm{C}_{2} \mathrm{H}_{4}$ & ${ }^{3} J_{\mathrm{HH}_{\mathrm{c}}}$ & 10,4 & 11,2 & 12,1 & 11,7 \\
\hline $\mathrm{C}_{2} \mathrm{H}_{4}$ & ${ }^{3} J_{\mathrm{HH}_{\mathrm{t}}}$ & 16,5 & 17,3 & 18,1 & 19,0 \\
\hline $\mathrm{C}_{2} \mathrm{H}_{6}$ & ${ }^{1} J_{\mathrm{CC}}$ & 32,7 & 36,3 & 39,9 & 34,5 \\
\hline $\mathrm{C}_{2} \mathrm{H}_{6}$ & ${ }^{1} J_{\mathrm{CH}}$ & 113,8 & 118,0 & 122,2 & 125,2 \\
\hline $\mathrm{C}_{2} \mathrm{H}_{6}$ & ${ }^{2} J_{\mathrm{CH}}$ & $-2,9$ & $-3,6$ & $-4,3$ & $-4,7$ \\
\hline \multirow[t]{3}{*}{ Total } & $\mathrm{DM}$ & $-5,85$ & 1,34 & 9,01 & - \\
\hline & DMA & 12,31 & 8,69 & 11,04 & - \\
\hline & PDMA & 28,77 & 12,95 & 17,58 & - \\
\hline \multirow[t]{3}{*}{ CPI } & $\mathrm{DM}$ & $-11,91$ & 2,00 & 16,92 & - \\
\hline & DMA & 20,18 & 12,73 & 18,57 & - \\
\hline & PDMA & 44,48 & 18,53 & 22,78 & - \\
\hline \multirow[t]{3}{*}{ SPI } & $\mathrm{DM}$ & $-1,41$ & 0,86 & 3,21 & - \\
\hline & DMA & 6,53 & 5,73 & 5,52 & - \\
\hline & PDMA & 17,25 & 8,86 & 13,76 & - \\
\hline \multirow[t]{3}{*}{$\Delta \mathrm{CS}$} & DM & $-10,50$ & 1,14 & 13,70 & - \\
\hline & DMA & 13,65 & 7,00 & 13,05 & - \\
\hline & PDMA & 27,23 & 9,66 & 9,02 & - \\
\hline \multicolumn{6}{|c|}{ Desconsiderando ${ }^{1} J_{\mathrm{BF}}$ da molécula de $\mathrm{BF}_{3},{ }^{2} J_{\mathrm{CH}}$ e ${ }^{2} J_{\mathrm{HH}}$ da molécula de $\mathrm{C}_{2} \mathrm{H}_{4}$} \\
\hline \multirow[t]{3}{*}{ Total } & DM & $-4,50$ & 2,19 & 9,47 & - \\
\hline & DMA & 11,58 & 9,12 & 11,56 & - \\
\hline & PDMA & 13,07 & 9,51 & 10,15 & - \\
\hline \multirow[t]{3}{*}{ CPI } & $\mathrm{DM}$ & $-7,98$ & 3,78 & 16,72 & - \\
\hline & DMA & 17,08 & 12,42 & 18,54 & - \\
\hline & PDMA & 14,79 & 9,84 & 12,46 & - \\
\hline \multirow[t]{3}{*}{ SPI } & $\mathrm{DM}$ & $-1,82$ & 0,97 & 3,88 & - \\
\hline & DMA & 7,35 & 6,58 & 6,19 & - \\
\hline & PDMA & 11,75 & 9,25 & 8,37 & - \\
\hline \multirow[t]{3}{*}{$\Delta \mathrm{CS}$} & DM & $-6,16$ & 2,81 & 12,84 & - \\
\hline & DMA & 9,73 & 5,84 & 12,35 & - \\
\hline & PDMA & 3,04 & 0,59 & 4,09 & - \\
\hline
\end{tabular}


Tabela 8.287: Constantes de acoplamento B972B98 com geometrias otimizadas na base aug-pcJ-2.

\begin{tabular}{|c|c|c|c|c|c|}
\hline & $\% E_{X}^{\mathrm{HF}}$ & $40 \%$ & $50 \%$ & $60 \%$ & Exp. \\
\hline $\mathrm{HF}$ & ${ }^{1} J_{\mathrm{HF}}$ & 409,0 & 458,0 & 507,5 & 500,0 \\
\hline $\mathrm{CO}$ & ${ }^{1} J_{\mathrm{CO}}$ & 17,1 & 12,7 & 8,2 & 16,4 \\
\hline $\mathrm{H}_{2} \mathrm{O}$ & ${ }^{1} J_{\mathrm{OH}}$ & $-66,3$ & $-72,7$ & $-79,1$ & $-80,6$ \\
\hline $\mathrm{H}_{2} \mathrm{O}$ & ${ }^{2} J_{\mathrm{HH}}$ & $-5,9$ & $-6,7$ & $-7,7$ & $-7,3$ \\
\hline $\mathrm{NH}_{3}$ & ${ }^{1} J_{\mathrm{NH}}$ & 38,4 & 41,2 & 43,9 & 43,8 \\
\hline $\mathrm{NH}_{3}$ & ${ }^{2} J_{\mathrm{HH}}$ & $-8,2$ & $-9,1$ & $-10,0$ & $-9,6$ \\
\hline $\mathrm{PH}_{3}$ & ${ }^{1} J_{\mathrm{PH}}$ & 190,5 & 203,1 & 215,7 & 188,2 \\
\hline $\mathrm{PF}_{3}$ & ${ }^{1} J_{\mathrm{PF}}$ & $-1454,5$ & $-1445,4$ & $-1427,0$ & $-1441,0$ \\
\hline $\mathrm{BHF}_{2}$ & ${ }^{1} J_{\mathrm{BF}}$ & $-129,0$ & $-98,6$ & $-69,0$ & $-84,0$ \\
\hline $\mathrm{BF}_{3}$ & ${ }^{1} J_{\mathrm{BF}}$ & $-42,9$ & $-7,5$ & 26,9 & 15,0 \\
\hline $\mathrm{F}_{2} \mathrm{O}$ & ${ }^{1} J_{\mathrm{OF}}$ & $-314,0$ & $-285,4$ & $-257,3$ & $-300,0$ \\
\hline $\mathrm{CH}_{4}$ & ${ }^{1} J_{\mathrm{CH}}$ & 118,0 & 122,1 & 126,5 & 125,3 \\
\hline $\mathrm{CH}_{4}$ & ${ }^{2} J_{\mathrm{HH}}$ & $-10,2$ & $-11,4$ & $-12,6$ & $-12,8$ \\
\hline $\mathrm{C}_{2} \mathrm{H}_{2}$ & ${ }^{1} J_{\mathrm{CC}}$ & 202,5 & 210,0 & 218,1 & 174,8 \\
\hline $\mathrm{C}_{2} \mathrm{H}_{2}$ & ${ }^{1} J_{\mathrm{CH}}$ & 235,2 & 241,7 & 248,5 & 247,6 \\
\hline $\mathrm{C}_{2} \mathrm{H}_{2}$ & ${ }^{2} J_{\mathrm{CH}}$ & 52,2 & 52,2 & 51,8 & 50,1 \\
\hline $\mathrm{C}_{2} \mathrm{H}_{2}$ & ${ }^{3} J_{\mathrm{HH}}$ & 9,7 & 10,3 & 11,1 & 9,6 \\
\hline $\mathrm{C}_{2} \mathrm{H}_{4}$ & ${ }^{1} J_{\mathrm{CC}}$ & 75,5 & 81,2 & 87,3 & 67,6 \\
\hline $\mathrm{C}_{2} \mathrm{H}_{4}$ & ${ }^{1} J_{\mathrm{CH}}$ & 146,4 & 151,5 & 156,9 & 156,3 \\
\hline $\mathrm{C}_{2} \mathrm{H}_{4}$ & ${ }^{2} J_{\mathrm{CH}}$ & $-1,0$ & $-2,4$ & $-4,0$ & $-2,4$ \\
\hline $\mathrm{C}_{2} \mathrm{H}_{4}$ & ${ }^{2} J_{\mathrm{HH}}$ & 3,2 & 2,2 & 1,1 & 2,3 \\
\hline $\mathrm{C}_{2} \mathrm{H}_{4}$ & ${ }^{3} J_{\mathrm{HH}_{\mathrm{c}}}$ & 10,5 & 11,3 & 12,3 & 11,7 \\
\hline $\mathrm{C}_{2} \mathrm{H}_{4}$ & ${ }^{3} J_{\mathrm{HH}_{\mathrm{t}}}$ & 16,9 & 17,7 & 18,6 & 19,0 \\
\hline $\mathrm{C}_{2} \mathrm{H}_{6}$ & ${ }^{1} J_{\mathrm{CC}}$ & 34,0 & 37,7 & 41,5 & 34,5 \\
\hline $\mathrm{C}_{2} \mathrm{H}_{6}$ & ${ }^{1} J_{\mathrm{CH}}$ & 117,5 & 121,8 & 126,2 & 125,2 \\
\hline $\mathrm{C}_{2} \mathrm{H}_{6}$ & ${ }^{2} J_{\mathrm{CH}}$ & $-3,0$ & $-3,7$ & $-4,5$ & $-4,7$ \\
\hline \multirow[t]{3}{*}{ Total } & DM & $-7,82$ & $-0,51$ & 7,15 & - \\
\hline & DMA & 12,78 & 7,87 & 8,09 & - \\
\hline & PDMA & 29,44 & 13,81 & 16,07 & - \\
\hline \multirow[t]{3}{*}{ CPI } & DM & $-18,79$ & $-4,66$ & 10,11 & - \\
\hline & DMA & 22,45 & 11,66 & 11,75 & - \\
\hline & PDMA & 48,43 & 21,87 & 17,29 & - \\
\hline \multirow[t]{3}{*}{ SPI } & DM & 0,22 & 2,54 & 4,98 & - \\
\hline & DMA & 5,70 & 5,09 & 5,41 & - \\
\hline & PDMA & 15,52 & 7,90 & 15,17 & - \\
\hline \multirow[t]{3}{*}{$\Delta \mathrm{CS}$} & $\mathrm{DM}$ & $-19,01$ & $-7,20$ & 5,13 & - \\
\hline & DMA & 16,75 & 6,58 & 6,34 & - \\
\hline & PDMA & 32,91 & 13,97 & 2,12 & - \\
\hline \multicolumn{6}{|c|}{ Desconsiderando ${ }^{1} J_{\mathrm{BF}}$ da molécula de $\mathrm{BF}_{3},{ }^{2} J_{\mathrm{CH}}$ e ${ }^{2} J_{\mathrm{HH}}$ da molécula de $\mathrm{C}_{2} \mathrm{H}_{4}$} \\
\hline \multirow[t]{3}{*}{ Total } & $\mathrm{DM}$ & $-6,43$ & 0,41 & 7,69 & - \\
\hline & DMA & 11,83 & 7,91 & 8,50 & - \\
\hline & PDMA & 12,26 & 8,90 & 9,55 & - \\
\hline \multirow[t]{3}{*}{ CPI } & DM & $-14,88$ & $-2,88$ & 9,93 & - \\
\hline & DMA & 18,90 & 10,58 & 11,73 & - \\
\hline & PDMA & 14,67 & 9,06 & 11,09 & - \\
\hline \multirow[t]{3}{*}{ SPI } & $\mathrm{DM}$ & 0,08 & 2,94 & 5,96 & - \\
\hline & DMA & 6,40 & 5,86 & 6,02 & - \\
\hline & PDMA & 10,41 & 8,79 & 8,37 & - \\
\hline \multirow[t]{3}{*}{$\triangle \mathrm{CS}$} & DM & $-14,96$ & $-5,82$ & 3,97 & - \\
\hline & DMA & 12,50 & 4,72 & 5,71 & - \\
\hline & PDMA & 4,26 & 0,27 & 2,72 & - \\
\hline
\end{tabular}


Tabela 8.288: Constantes de acoplamento B972LYP com geometrias otimizadas na base aug-pcJ-2.

\begin{tabular}{|c|c|c|c|c|c|}
\hline & $\% E_{X}^{\mathrm{HF}}$ & $40 \%$ & $50 \%$ & $60 \%$ & Exp. \\
\hline $\mathrm{HF}$ & ${ }^{1} J_{\mathrm{HF}}$ & 405,9 & 459,8 & 514,5 & 500,0 \\
\hline $\mathrm{CO}$ & ${ }^{1} J_{\mathrm{CO}}$ & 17,4 & 12,9 & 8,3 & 16,4 \\
\hline $\mathrm{H}_{2} \mathrm{O}$ & ${ }^{1} J_{\mathrm{OH}}$ & $-68,1$ & $-75,1$ & $-82,1$ & $-80,6$ \\
\hline $\mathrm{H}_{2} \mathrm{O}$ & ${ }^{2} J_{\mathrm{HH}}$ & $-7,4$ & $-8,4$ & $-9,4$ & $-7,3$ \\
\hline $\mathrm{NH}_{3}$ & ${ }^{1} J_{\mathrm{NH}}$ & 39,5 & 42,4 & 45,3 & 43,8 \\
\hline $\mathrm{NH}_{3}$ & ${ }^{2} J_{\mathrm{HH}}$ & $-9,4$ & $-10,3$ & $-11,3$ & $-9,6$ \\
\hline $\mathrm{PH}_{3}$ & ${ }^{1} J_{\mathrm{PH}}$ & 169,4 & 185,0 & 200,8 & 188,2 \\
\hline $\mathrm{PF}_{3}$ & ${ }^{1} J_{\mathrm{PF}}$ & $-1487,8$ & $-1479,4$ & $-1461,7$ & $-1441,0$ \\
\hline $\mathrm{BHF}_{2}$ & ${ }^{1} J_{\mathrm{BF}}$ & $-137,6$ & $-107,2$ & $-77,8$ & $-84,0$ \\
\hline $\mathrm{BF}_{3}$ & ${ }^{1} J_{\mathrm{BF}}$ & $-48,6$ & $-12,8$ & 21,8 & 15,0 \\
\hline $\mathrm{F}_{2} \mathrm{O}$ & ${ }^{1} J_{\mathrm{OF}}$ & $-337,9$ & $-306,9$ & $-276,1$ & $-300,0$ \\
\hline $\mathrm{CH}_{4}$ & ${ }^{1} J_{\mathrm{CH}}$ & 117,8 & 121,9 & 126,3 & 125,3 \\
\hline $\mathrm{CH}_{4}$ & ${ }^{2} J_{\mathrm{HH}}$ & $-11,3$ & $-12,6$ & $-13,9$ & $-12,8$ \\
\hline $\mathrm{C}_{2} \mathrm{H}_{2}$ & ${ }^{1} J_{\mathrm{CC}}$ & 189,3 & 196,9 & 205,1 & 174,8 \\
\hline $\mathrm{C}_{2} \mathrm{H}_{2}$ & ${ }^{1} J_{\mathrm{CH}}$ & 241,9 & 248,4 & 255,3 & 247,6 \\
\hline $\mathrm{C}_{2} \mathrm{H}_{2}$ & ${ }^{2} J_{\mathrm{CH}}$ & 54,1 & 54,0 & 53,5 & 50,1 \\
\hline $\mathrm{C}_{2} \mathrm{H}_{2}$ & ${ }^{3} J_{\mathrm{HH}}$ & 11,1 & 11,8 & 12,9 & 9,6 \\
\hline $\mathrm{C}_{2} \mathrm{H}_{4}$ & ${ }^{1} J_{\mathrm{CC}}$ & 68,2 & 73,8 & 80,1 & 67,6 \\
\hline $\mathrm{C}_{2} \mathrm{H}_{4}$ & ${ }^{1} J_{\mathrm{CH}}$ & 147,7 & 152,9 & 158,4 & 156,3 \\
\hline $\mathrm{C}_{2} \mathrm{H}_{4}$ & ${ }^{2} J_{\mathrm{CH}}$ & $-0,8$ & $-2,4$ & $-4,1$ & $-2,4$ \\
\hline $\mathrm{C}_{2} \mathrm{H}_{4}$ & ${ }^{2} J_{\mathrm{HH}}$ & 3,3 & 2,2 & 0,9 & 2,3 \\
\hline $\mathrm{C}_{2} \mathrm{H}_{4}$ & ${ }^{3} J_{\mathrm{HH}_{\mathrm{c}}}$ & 11,6 & 12,5 & 13,6 & 11,7 \\
\hline $\mathrm{C}_{2} \mathrm{H}_{4}$ & ${ }^{3} J_{\mathrm{HH}_{\mathrm{t}}}{ }^{\mathrm{C}}$ & 18,5 & 19,5 & 20,5 & 19,0 \\
\hline $\mathrm{C}_{2} \mathrm{H}_{6}$ & ${ }^{1} J_{\mathrm{CC}}$ & 31,2 & 34,7 & 38,2 & 34,5 \\
\hline $\mathrm{C}_{2} \mathrm{H}_{6}$ & ${ }^{1} J_{\mathrm{CH}}$ & 117,0 & 121,2 & 125,5 & 125,2 \\
\hline $\mathrm{C}_{2} \mathrm{H}_{6}$ & ${ }^{2} J_{\mathrm{CH}}$ & $-3,0$ & $-3,7$ & $-4,5$ & $-4,7$ \\
\hline \multirow[t]{3}{*}{ Total } & $\mathrm{DM}$ & $-12,04$ & $-4,38$ & 3,66 & - \\
\hline & DMA & 15,12 & 7,72 & 6,60 & - \\
\hline & PDMA & 30,45 & 14,60 & 16,72 & - \\
\hline \multirow[t]{3}{*}{ CPI } & $\mathrm{DM}$ & $-27,77$ & $-12,81$ & 2,85 & - \\
\hline & DMA & 30,26 & 13,81 & 9,05 & - \\
\hline & PDMA & 51,58 & 25,58 & 15,71 & - \\
\hline \multirow[t]{3}{*}{ SPI } & $\mathrm{DM}$ & $-0,50$ & 1,80 & 4,25 & - \\
\hline & DMA & 4,02 & 3,25 & 4,81 & - \\
\hline & PDMA & 14,95 & 6,54 & 17,46 & - \\
\hline \multirow[t]{3}{*}{$\Delta \mathrm{CS}$} & $\mathrm{DM}$ & $-27,27$ & $-14,61$ & $-1,39$ & - \\
\hline & DMA & 26,24 & 10,56 & 4,25 & - \\
\hline & PDMA & 36,63 & 19,04 & $-1,74$ & - \\
\hline \multicolumn{6}{|c|}{ Desconsiderando ${ }^{1} J_{\mathrm{BF}}$ da molécula de $\mathrm{BF}_{3},{ }^{2} J_{\mathrm{CH}}$ e ${ }^{2} J_{\mathrm{HH}}$ da molécula de $\mathrm{C}_{2} \mathrm{H}_{4}$} \\
\hline \multirow[t]{3}{*}{ Total } & $\mathrm{DM}$ & $-10,96$ & $-3,74$ & 3,97 & - \\
\hline & DMA & 14,22 & 7,51 & 7,03 & - \\
\hline & PDMA & 11,19 & 8,25 & 11,21 & - \\
\hline \multirow[t]{3}{*}{ CPI } & DM & $-24,19$ & $-11,31$ & 2,46 & - \\
\hline & DMA & 26,93 & 12,41 & 9,28 & - \\
\hline & PDMA & 14,34 & 9,60 & 12,75 & - \\
\hline \multirow[t]{3}{*}{ SPI } & $\mathrm{DM}$ & $-0,78$ & 2,08 & 5,14 & - \\
\hline & DMA & 4,44 & 3,75 & 5,31 & - \\
\hline & PDMA & 8,77 & 7,22 & 10,01 & - \\
\hline \multirow[t]{3}{*}{$\Delta \mathrm{CS}$} & $\mathrm{DM}$ & $-23,41$ & $-13,39$ & $-2,68$ & - \\
\hline & DMA & 22,49 & 8,66 & 3,97 & - \\
\hline & PDMA & 5,56 & 2,39 & 2,74 & - \\
\hline
\end{tabular}


Tabela 8.289: Constantes de acoplamento B98LYP com geometrias otimizadas na base aug-pcJ-2.

\begin{tabular}{|c|c|c|c|c|c|c|}
\hline & $\% E_{X}^{\mathrm{HF}}$ & $40 \%$ & $50 \%$ & $60 \%$ & $70 \%$ & Exp. \\
\hline $\mathrm{HF}$ & ${ }^{1} J_{\mathrm{HF}}$ & 414,4 & 467,6 & 521,7 & 574,5 & 500,0 \\
\hline $\mathrm{CO}$ & ${ }^{1} J_{\mathrm{CO}}$ & 15,9 & 11,5 & 7,0 & 2,6 & 16,4 \\
\hline $\mathrm{H}_{2} \mathrm{O}$ & ${ }^{1} J_{\mathrm{OH}}$ & $-69,8$ & $-76,6$ & $-83,4$ & $-90,1$ & $-80,6$ \\
\hline $\mathrm{H}_{2} \mathrm{O}$ & ${ }^{2} J_{\mathrm{HH}}$ & $-6,5$ & $-7,7$ & $-8,8$ & $-10,1$ & $-7,3$ \\
\hline $\mathrm{NH}_{3}$ & ${ }^{1} J_{\mathrm{NH}}$ & 40,9 & 43,6 & 46,3 & 48,7 & 43,8 \\
\hline $\mathrm{NH}_{3}$ & ${ }^{2} J_{\mathrm{HH}}$ & $-8,6$ & $-9,7$ & $-10,8$ & $-12,2$ & $-9,6$ \\
\hline $\mathrm{PH}_{3}$ & ${ }^{1} J_{\mathrm{PH}}$ & 165,9 & 182,3 & 198,8 & 215,2 & 188,2 \\
\hline $\mathrm{PF}_{3}$ & ${ }^{1} J_{\mathrm{PF}}$ & $-1502,7$ & $-1493,9$ & $-1476,4$ & $-1446,3$ & $-1441,0$ \\
\hline $\mathrm{BHF}_{2}$ & ${ }^{1} J_{\mathrm{BF}}$ & $-134,2$ & $-104,1$ & $-75,2$ & $-47,1$ & $-84,0$ \\
\hline $\mathrm{BF}_{3}$ & ${ }^{1} J_{\mathrm{BF}}$ & $-43,6$ & $-8,4$ & 25,4 & 58,2 & 15,0 \\
\hline $\mathrm{F}_{2} \mathrm{O}$ & ${ }^{1} J_{\mathrm{OF}}$ & $-376,1$ & $-337,2$ & $-299,7$ & $-263,7$ & $-300,0$ \\
\hline $\mathrm{CH}_{4}$ & ${ }^{1} J_{\mathrm{CH}}$ & 122,3 & 125,7 & 129,4 & 133,0 & 125,3 \\
\hline $\mathrm{CH}_{4}$ & ${ }^{2} J_{\mathrm{HH}}$ & $-10,6$ & $-12,0$ & $-13,4$ & $-14,9$ & $-12,8$ \\
\hline $\mathrm{C}_{2} \mathrm{H}_{2}$ & ${ }^{1} J_{\mathrm{CC}}$ & 194,1 & 200,9 & 208,3 & 216,4 & 174,8 \\
\hline $\mathrm{C}_{2} \mathrm{H}_{2}$ & ${ }^{1} J_{\mathrm{CH}}$ & 246,9 & 252,6 & 258,6 & 265,0 & 247,6 \\
\hline $\mathrm{C}_{2} \mathrm{H}_{2}$ & ${ }^{2} J_{\mathrm{CH}}$ & 55,3 & 55,1 & 54,4 & 53,4 & 50,1 \\
\hline $\mathrm{C}_{2} \mathrm{H}_{2}$ & ${ }^{3} J_{\mathrm{HH}}$ & 10,5 & 11,2 & 12,3 & 13,6 & 9,6 \\
\hline $\mathrm{C}_{2} \mathrm{H}_{4}$ & ${ }^{1} J_{\mathrm{CC}}$ & 71,4 & 76,7 & 82,4 & 88,6 & 67,6 \\
\hline $\mathrm{C}_{2} \mathrm{H}_{4}$ & ${ }^{1} J_{\mathrm{CH}}$ & 151,9 & 156,4 & 161,2 & 166,3 & 156,3 \\
\hline $\mathrm{C}_{2} \mathrm{H}_{4}$ & ${ }^{2} J_{\mathrm{CH}}$ & $-0,3$ & $-1,9$ & $-3,7$ & $-5,8$ & $-2,4$ \\
\hline $\mathrm{C}_{2} \mathrm{H}_{4}$ & ${ }^{2} J_{\mathrm{HH}}$ & 4,4 & 3,2 & 1,8 & 0,2 & 2,3 \\
\hline $\mathrm{C}_{2} \mathrm{H}_{4}$ & ${ }^{3} J_{\mathrm{HH}_{\mathrm{c}}}$ & 11,3 & 12,3 & 13,4 & 14,6 & 11,7 \\
\hline $\mathrm{C}_{2} \mathrm{H}_{4}$ & ${ }^{3} J_{\mathrm{HH}_{\mathrm{t}}}{ }^{\mathrm{C}}$ & 18,4 & 19,2 & 20,3 & 21,5 & 19,0 \\
\hline $\mathrm{C}_{2} \mathrm{H}_{6}$ & ${ }^{1} J_{\mathrm{CC}}$ & 33,5 & 36,7 & 39,9 & 43,1 & 34,5 \\
\hline $\mathrm{C}_{2} \mathrm{H}_{6}$ & ${ }^{1} J_{\mathrm{CH}}$ & 121,3 & 124,9 & 128,5 & 132,3 & 125,2 \\
\hline $\mathrm{C}_{2} \mathrm{H}_{6}$ & ${ }^{2} J_{\mathrm{CH}}$ & $-2,6$ & $-3,4$ & $-4,2$ & $-5,1$ & $-4,7$ \\
\hline \multirow[t]{3}{*}{ Total } & $\mathrm{DM}$ & $-12,37$ & $-4,62$ & 3,43 & 11,80 & - \\
\hline & DMA & 16,24 & 9,06 & 7,48 & 15,03 & - \\
\hline & PDMA & 32,64 & 15,83 & 15,82 & 38,28 & - \\
\hline \multirow[t]{3}{*}{ CPI } & $\mathrm{DM}$ & $-31,39$ & $-15,77$ & 0,36 & 17,16 & - \\
\hline & DMA & 33,68 & 16,50 & 9,51 & 23,35 & - \\
\hline & PDMA & 50,32 & 22,49 & 17,44 & 49,65 & - \\
\hline \multirow[t]{3}{*}{ SPI } & $\mathrm{DM}$ & 1,58 & 3,57 & 5,67 & 7,87 & - \\
\hline & DMA & 3,45 & 3,61 & 5,99 & 8,94 & - \\
\hline & PDMA & 19,68 & 10,94 & 14,63 & 29,94 & - \\
\hline \multirow[t]{3}{*}{$\Delta \mathrm{CS}$} & $\mathrm{DM}$ & $-33,16$ & $-19,61$ & $-5,57$ & 8,83 & - \\
\hline & DMA & 33,78 & 16,30 & 4,29 & 11,09 & - \\
\hline & PDMA & 43,06 & 16,78 & $-13,07$ & $-2,92$ & - \\
\hline \multicolumn{7}{|c|}{ Desconsiderando ${ }^{1} J_{\mathrm{BF}}$ da molécula de $\mathrm{BF}_{3},{ }^{2} J_{\mathrm{CH}}$ e ${ }^{2} J_{\mathrm{HH}}$ da molécula de $\mathrm{C}_{2} \mathrm{H}_{4}$} \\
\hline \multirow[t]{3}{*}{ Total } & $\mathrm{DM}$ & $-11,62$ & $-4,26$ & 3,50 & 11,70 & - \\
\hline & DMA & 15,63 & 9,17 & 7,93 & 14,88 & - \\
\hline & PDMA & 12,14 & 8,50 & 11,57 & 20,62 & - \\
\hline \multirow[t]{3}{*}{ CPI } & DM & $-28,67$ & $-15,01$ & $-0,64$ & 14,56 & - \\
\hline & DMA & 31,19 & 15,81 & 9,42 & 21,36 & - \\
\hline & PDMA & 16,28 & 9,14 & 12,26 & 25,82 & - \\
\hline \multirow[t]{3}{*}{ SPI } & DM & 1,50 & 4,01 & 6,68 & 9,51 & - \\
\hline & DMA & 3,65 & 4,05 & 6,78 & 9,89 & - \\
\hline & PDMA & 8,95 & 8,01 & 11,05 & 16,63 & - \\
\hline \multirow[t]{3}{*}{$\Delta \mathrm{CS}$} & DM & $-30,17$ & $-19,02$ & $-7,32$ & 5,05 & - \\
\hline & DMA & 27,54 & 11,76 & 2,64 & 11,47 & - \\
\hline & PDMA & 7,33 & 1,13 & 1,21 & 9,19 & - \\
\hline
\end{tabular}


Tabela 8.290: Constantes de acoplamento B98P86 com geometrias otimizadas na base aug-pcJ-2.

\begin{tabular}{|c|c|c|c|c|c|c|}
\hline & $\% E_{X}^{\mathrm{HF}}$ & $40 \%$ & $50 \%$ & $60 \%$ & $70 \%$ & Exp. \\
\hline $\mathrm{HF}$ & ${ }^{1} J_{\mathrm{HF}}$ & 376,3 & 426,2 & 476,7 & 526,7 & 500,0 \\
\hline $\mathrm{CO}$ & ${ }^{1} J_{\mathrm{CO}}$ & 20,2 & 16,2 & 12,2 & 8,2 & 16,4 \\
\hline $\mathrm{H}_{2} \mathrm{O}$ & ${ }^{1} J_{\mathrm{OH}}$ & $-61,9$ & $-68,3$ & $-74,7$ & $-81,0$ & $-80,6$ \\
\hline $\mathrm{H}_{2} \mathrm{O}$ & ${ }^{2} J_{\mathrm{HH}}$ & $-5,7$ & $-6,7$ & $-7,8$ & $-8,9$ & $-7,3$ \\
\hline $\mathrm{NH}_{3}$ & ${ }^{1} J_{\mathrm{NH}}$ & 35,8 & 38,3 & 40,9 & 43,2 & 43,8 \\
\hline $\mathrm{NH}_{3}$ & ${ }^{2} J_{\mathrm{HH}}$ & $-8,0$ & $-9,1$ & $-10,1$ & $-11,3$ & $-9,6$ \\
\hline $\mathrm{PH}_{3}$ & ${ }^{1} J_{\mathrm{PH}}$ & 141,2 & 156,5 & 171,8 & 187,3 & 188,2 \\
\hline $\mathrm{PF}_{3}$ & ${ }^{1} J_{\mathrm{PF}}$ & $-1494,0$ & $-1484,6$ & $-1464,4$ & $-1433,7$ & $-1441,0$ \\
\hline $\mathrm{BHF}_{2}$ & ${ }^{1} J_{\mathrm{BF}}$ & $-142,5$ & $-113,6$ & $-85,8$ & $-59,0$ & $-84,0$ \\
\hline $\mathrm{BF}_{3}$ & ${ }^{1} J_{\mathrm{BF}}$ & $-54,8$ & $-20,8$ & 11,9 & 43,4 & 15,0 \\
\hline $\mathrm{F}_{2} \mathrm{O}$ & ${ }^{1} J_{\mathrm{OF}}$ & $-329,1$ & $-293,2$ & $-258,3$ & $-225,1$ & $-300,0$ \\
\hline $\mathrm{CH}_{4}$ & ${ }^{1} J_{\mathrm{CH}}$ & 108,4 & 111,7 & 115,1 & 118,6 & 125,3 \\
\hline $\mathrm{CH}_{4}$ & ${ }^{2} J_{\mathrm{HH}}$ & $-10,3$ & $-11,6$ & $-12,9$ & $-14,3$ & $-12,8$ \\
\hline $\mathrm{C}_{2} \mathrm{H}_{2}$ & ${ }^{1} J_{\mathrm{CC}}$ & 181,5 & 187,9 & 194,9 & 202,5 & 174,8 \\
\hline $\mathrm{C}_{2} \mathrm{H}_{2}$ & ${ }^{1} J_{\mathrm{CH}}$ & 223,4 & 228,9 & 234,8 & 241,1 & 247,6 \\
\hline $\mathrm{C}_{2} \mathrm{H}_{2}$ & ${ }^{2} J_{\mathrm{CH}}$ & 52,7 & 52,5 & 52,0 & 51,0 & 50,1 \\
\hline $\mathrm{C}_{2} \mathrm{H}_{2}$ & ${ }^{3} J_{\mathrm{HH}}$ & 10,5 & 11,3 & 12,5 & 13,9 & 9,6 \\
\hline $\mathrm{C}_{2} \mathrm{H}_{4}$ & ${ }^{1} J_{\mathrm{CC}}$ & 63,5 & 68,5 & 73,9 & 79,9 & 67,6 \\
\hline $\mathrm{C}_{2} \mathrm{H}_{4}$ & ${ }^{1} J_{\mathrm{CH}}$ & 136,0 & 140,4 & 145,1 & 150,0 & 156,3 \\
\hline $\mathrm{C}_{2} \mathrm{H}_{4}$ & ${ }^{2} J_{\mathrm{CH}}$ & $-0,5$ & $-2,0$ & $-3,7$ & $-5,7$ & $-2,4$ \\
\hline $\mathrm{C}_{2} \mathrm{H}_{4}$ & ${ }^{2} J_{\mathrm{HH}}$ & 3,3 & 2,1 & 0,7 & $-0,8$ & 2,3 \\
\hline $\mathrm{C}_{2} \mathrm{H}_{4}$ & ${ }^{3} J_{\mathrm{HH}_{\mathrm{c}}}$ & 10,5 & 11,4 & 12,5 & 13,9 & 11,7 \\
\hline $\mathrm{C}_{2} \mathrm{H}_{4}$ & ${ }^{3} J_{\mathrm{HH}_{\mathrm{t}}}$ & 17,1 & 18,0 & 19,1 & 20,5 & 19,0 \\
\hline $\mathrm{C}_{2} \mathrm{H}_{6}$ & ${ }^{1} J_{\mathrm{CC}}$ & 28,3 & 31,3 & 34,2 & 37,3 & 34,5 \\
\hline $\mathrm{C}_{2} \mathrm{H}_{6}$ & ${ }^{1} J_{\mathrm{CH}}$ & 107,6 & 111,1 & 114,6 & 118,1 & 125,2 \\
\hline $\mathrm{C}_{2} \mathrm{H}_{6}$ & ${ }^{2} J_{\mathrm{CH}}$ & $-2,8$ & $-3,5$ & $-4,3$ & $-5,1$ & $-4,7$ \\
\hline \multirow[t]{3}{*}{ Total } & DM & $-16,86$ & $-9,47$ & $-1,70$ & 6,37 & - \\
\hline & DMA & 20,18 & 12,63 & 7,86 & 10,09 & - \\
\hline & PDMA & 38,34 & 19,30 & 12,63 & 29,52 & - \\
\hline \multirow[t]{3}{*}{ CPI } & $\mathrm{DM}$ & $-33,04$ & $-18,18$ & $-2,59$ & 13,54 & - \\
\hline & DMA & 37,71 & 21,85 & 11,25 & 15,97 & - \\
\hline & PDMA & 63,75 & 32,12 & 9,39 & 31,08 & - \\
\hline \multirow[t]{3}{*}{ SPI } & $\mathrm{DM}$ & $-4,99$ & $-3,07$ & $-1,04$ & 1,12 & - \\
\hline & DMA & 7,33 & 5,86 & 5,37 & 5,77 & - \\
\hline & PDMA & 19,71 & 9,90 & 15,00 & 28,38 & - \\
\hline \multirow[t]{3}{*}{$\Delta \mathrm{CS}$} & DM & $-28,04$ & $-15,11$ & $-1,55$ & 12,42 & - \\
\hline & DMA & 30,38 & 15,99 & 5,87 & 10,20 & - \\
\hline & PDMA & 44,05 & 22,21 & $-5,61$ & 2,70 & - \\
\hline \multicolumn{7}{|c|}{ Desconsiderando ${ }^{1} J_{\mathrm{BF}}$ da molécula de $\mathrm{BF}_{3},{ }^{2} J_{\mathrm{CH}}$ e ${ }^{2} J_{\mathrm{HH}}$ da molécula de $\mathrm{C}_{2} \mathrm{H}_{4}$} \\
\hline \multirow[t]{3}{*}{ Total } & $\mathrm{DM}$ & $-16,15$ & $-9,15$ & $-1,66$ & 6,25 & - \\
\hline & DMA & 19,65 & 12,69 & 8,62 & 9,89 & - \\
\hline & PDMA & 17,78 & 10,34 & 8,00 & 13,30 & - \\
\hline \multirow[t]{3}{*}{ CPI } & DM & $-29,36$ & $-16,42$ & $-2,54$ & 12,05 & - \\
\hline & DMA & 34,50 & 20,46 & 12,06 & 14,73 & - \\
\hline & PDMA & 23,60 & 11,46 & 8,26 & 15,25 & - \\
\hline \multirow[t]{3}{*}{ SPI } & $\mathrm{DM}$ & $-5,98$ & $-3,56$ & $-0,98$ & 1,78 & - \\
\hline & DMA & 8,23 & 6,72 & 5,98 & 6,17 & - \\
\hline & PDMA & 13,30 & 9,48 & 7,79 & 11,80 & - \\
\hline \multirow[t]{3}{*}{$\Delta \mathrm{CS}$} & DM & $-23,38$ & $-12,86$ & $-1,56$ & 10,27 & - \\
\hline & DMA & 26,27 & 13,74 & 6,08 & 8,56 & - \\
\hline & PDMA & 10,29 & 1,98 & 0,47 & 3,46 & - \\
\hline
\end{tabular}


Tabela 8.291: Constantes de acoplamento B98PBE com geometrias otimizadas na base aug-pcJ-2.

\begin{tabular}{|c|c|c|c|c|c|c|}
\hline & $\% E_{X}^{\mathrm{HF}}$ & $40 \%$ & $50 \%$ & $60 \%$ & $70 \%$ & Exp. \\
\hline $\mathrm{HF}$ & ${ }^{1} J_{\mathrm{HF}}$ & 378,0 & 428,5 & 479,5 & 530,2 & 500,0 \\
\hline $\mathrm{CO}$ & ${ }^{1} J_{\mathrm{CO}}$ & 20,6 & 16,6 & 12,7 & 8,7 & 16,4 \\
\hline $\mathrm{H}_{2} \mathrm{O}$ & ${ }^{1} J_{\mathrm{OH}}$ & $-62,3$ & $-68,8$ & $-75,2$ & $-81,4$ & $-80,6$ \\
\hline $\mathrm{H}_{2} \mathrm{O}$ & ${ }^{2} J_{\mathrm{HH}}$ & $-6,2$ & $-7,2$ & $-8,4$ & $-9,6$ & $-7,3$ \\
\hline $\mathrm{NH}_{3}$ & ${ }^{1} J_{\mathrm{NH}}$ & 36,0 & 38,5 & 41,1 & 43,4 & 43,8 \\
\hline $\mathrm{NH}_{3}$ & ${ }^{2} J_{\mathrm{HH}}$ & $-8,6$ & $-9,7$ & $-10,7$ & $-12,0$ & $-9,6$ \\
\hline $\mathrm{PH}_{3}$ & ${ }^{1} J_{\mathrm{PH}}$ & 141,6 & 157,2 & 172,8 & 188,6 & 188,2 \\
\hline $\mathrm{PF}_{3}$ & ${ }^{1} J_{\mathrm{PF}}$ & $-1498,8$ & $-1488,4$ & $-1467,5$ & $-1436,1$ & $-1441,0$ \\
\hline $\mathrm{BHF}_{2}$ & ${ }^{1} J_{\mathrm{BF}}$ & $-142,7$ & $-113,8$ & $-85,8$ & $-59,0$ & $-84,0$ \\
\hline $\mathrm{BF}_{3}$ & ${ }^{1} J_{\mathrm{BF}}$ & $-54,9$ & $-20,8$ & 12,0 & 43,6 & 15,0 \\
\hline $\mathrm{F}_{2} \mathrm{O}$ & ${ }^{1} J_{\mathrm{OF}}$ & $-322,8$ & $-286,9$ & $-252,1$ & $-219,2$ & $-300,0$ \\
\hline $\mathrm{CH}_{4}$ & ${ }^{1} J_{\mathrm{CH}}$ & 109,0 & 112,4 & 115,9 & 119,5 & 125,3 \\
\hline $\mathrm{CH}_{4}$ & ${ }^{2} J_{\mathrm{HH}}$ & $-11,0$ & $-12,3$ & $-13,7$ & $-15,1$ & $-12,8$ \\
\hline $\mathrm{C}_{2} \mathrm{H}_{2}$ & ${ }^{1} J_{\mathrm{CC}}$ & 181,1 & 187,8 & 195,1 & 203,1 & 174,8 \\
\hline $\mathrm{C}_{2} \mathrm{H}_{2}$ & ${ }^{1} J_{\mathrm{CH}}$ & 225,7 & 231,5 & 237,7 & 244,4 & 247,6 \\
\hline $\mathrm{C}_{2} \mathrm{H}_{2}$ & ${ }^{2} J_{\mathrm{CH}}$ & 52,5 & 52,2 & 51,5 & 50,3 & 50,1 \\
\hline $\mathrm{C}_{2} \mathrm{H}_{2}$ & ${ }^{3} J_{\mathrm{HH}}$ & 11,2 & 12,2 & 13,4 & 15,1 & 9,6 \\
\hline $\mathrm{C}_{2} \mathrm{H}_{4}$ & ${ }^{1} J_{\mathrm{CC}}$ & 63,7 & 68,8 & 74,4 & 80,8 & 67,6 \\
\hline $\mathrm{C}_{2} \mathrm{H}_{4}$ & ${ }^{1} J_{\mathrm{CH}}$ & 137,3 & 141,8 & 146,6 & 151,9 & 156,3 \\
\hline $\mathrm{C}_{2} \mathrm{H}_{4}$ & ${ }^{2} J_{\mathrm{CH}}$ & $-1,1$ & $-2,7$ & $-4,5$ & $-6,8$ & $-2,4$ \\
\hline $\mathrm{C}_{2} \mathrm{H}_{4}$ & ${ }^{2} J_{\mathrm{HH}}$ & 2,8 & 1,4 & 0,0 & $-1,8$ & 2,3 \\
\hline $\mathrm{C}_{2} \mathrm{H}_{4}$ & ${ }^{3} J_{\mathrm{HH}_{\mathrm{c}}}$ & 10,9 & 11,9 & 13,1 & 14,7 & 11,7 \\
\hline $\mathrm{C}_{2} \mathrm{H}_{4}$ & ${ }^{3} J_{\mathrm{HH}_{\mathrm{t}}}{ }^{\mathrm{C}}$ & 17,7 & 18,7 & 19,9 & 21,5 & 19,0 \\
\hline $\mathrm{C}_{2} \mathrm{H}_{6}$ & ${ }^{1} J_{\mathrm{CC}}$ & 28,3 & 31,3 & 34,2 & 37,3 & 34,5 \\
\hline $\mathrm{C}_{2} \mathrm{H}_{6}$ & ${ }^{1} J_{\mathrm{CH}}$ & 108,4 & 111,9 & 115,5 & 119,1 & 125,2 \\
\hline $\mathrm{C}_{2} \mathrm{H}_{6}$ & ${ }^{2} J_{\mathrm{CH}}$ & $-3,1$ & $-3,9$ & $-4,7$ & $-5,5$ & $-4,7$ \\
\hline \multirow[t]{3}{*}{ Total } & DM & $-16,60$ & $-9,11$ & $-1,24$ & 6,95 & - \\
\hline & DMA & 19,69 & 12,62 & 8,00 & 10,39 & - \\
\hline & PDMA & 35,47 & 19,43 & 15,99 & 34,99 & - \\
\hline \multirow[t]{3}{*}{ CPI } & DM & $-32,82$ & $-17,79$ & $-2,05$ & 14,21 & - \\
\hline & DMA & 37,29 & 22,37 & 11,74 & 16,68 & - \\
\hline & PDMA & 62,57 & 31,18 & 10,38 & 32,67 & - \\
\hline \multirow[t]{3}{*}{ SPI } & $\mathrm{DM}$ & $-4,71$ & $-2,74$ & $-0,65$ & 1,63 & - \\
\hline & DMA & 6,78 & 5,46 & 5,26 & 5,77 & - \\
\hline & PDMA & 15,59 & 10,82 & 20,11 & 36,70 & - \\
\hline \multirow[t]{3}{*}{$\Delta \mathrm{CS}$} & DM & $-28,10$ & $-15,05$ & $-1,40$ & 12,58 & - \\
\hline & DMA & 30,51 & 16,91 & 6,48 & 10,91 & - \\
\hline & PDMA & 46,97 & 20,36 & $-9,73$ & $-4,04$ & - \\
\hline \multicolumn{7}{|c|}{ Desconsiderando ${ }^{1} J_{\mathrm{BF}}$ da molécula de $\mathrm{BF}_{3},{ }^{2} J_{\mathrm{CH}}$ e ${ }^{2} J_{\mathrm{HH}}$ da molécula de $\mathrm{C}_{2} \mathrm{H}_{4}$} \\
\hline \multirow[t]{3}{*}{ Total } & $\mathrm{DM}$ & $-15,81$ & $-8,69$ & $-1,08$ & 6,98 & - \\
\hline & DMA & 19,14 & 12,65 & 8,72 & 10,13 & - \\
\hline & PDMA & 16,53 & 9,35 & 9,06 & 15,55 & - \\
\hline \multirow[t]{3}{*}{ CPI } & DM & $-29,11$ & $-15,99$ & $-1,95$ & 12,77 & - \\
\hline & DMA & 34,03 & 21,03 & 12,61 & 15,49 & - \\
\hline & PDMA & 22,23 & 10,43 & 9,42 & 16,87 & - \\
\hline \multirow[t]{3}{*}{ SPI } & DM & $-5,58$ & $-3,07$ & $-0,41$ & 2,53 & - \\
\hline & DMA & 7,68 & 6,21 & 5,73 & 6,01 & - \\
\hline & PDMA & 12,15 & 8,51 & 8,78 & 14,53 & - \\
\hline \multirow[t]{3}{*}{$\Delta \mathrm{CS}$} & $\mathrm{DM}$ & $-23,53$ & $-12,92$ & $-1,54$ & 10,24 & - \\
\hline & DMA & 26,35 & 14,82 & 6,88 & 9,48 & - \\
\hline & PDMA & 10,07 & 1,91 & 0,64 & 2,33 & - \\
\hline
\end{tabular}


Tabela 8.292: Constantes de acoplamento B98PW91 com geometrias otimizadas na base aug-pcJ-2.

\begin{tabular}{|c|c|c|c|c|c|c|}
\hline & $\% E_{X}^{\mathrm{HF}}$ & $40 \%$ & $50 \%$ & $60 \%$ & $70 \%$ & Exp. \\
\hline $\mathrm{HF}$ & ${ }^{1} J_{\mathrm{HF}}$ & 381,0 & 431,6 & 482,7 & 533,5 & 500,0 \\
\hline $\mathrm{CO}$ & ${ }^{1} J_{\mathrm{CO}}$ & 20,3 & 16,3 & 12,3 & 8,2 & 16,4 \\
\hline $\mathrm{H}_{2} \mathrm{O}$ & ${ }^{1} J_{\mathrm{OH}}$ & $-62,8$ & $-69,3$ & $-75,7$ & $-82,1$ & $-80,6$ \\
\hline $\mathrm{H}_{2} \mathrm{O}$ & ${ }^{2} J_{\mathrm{HH}}$ & $-6,2$ & $-7,2$ & $-8,3$ & $-9,5$ & $-7,3$ \\
\hline $\mathrm{NH}_{3}$ & ${ }^{1} J_{\mathrm{NH}}$ & 36,3 & 38,8 & 41,4 & 43,7 & 43,8 \\
\hline $\mathrm{NH}_{3}$ & ${ }^{2} J_{\mathrm{HH}}$ & $-8,6$ & $-9,6$ & $-10,7$ & $-12,0$ & $-9,6$ \\
\hline $\mathrm{PH}_{3}$ & ${ }^{1} J_{\mathrm{PH}}$ & 143,1 & 158,7 & 174,3 & 190,1 & 188,2 \\
\hline $\mathrm{PF}_{3}$ & ${ }^{1} J_{\mathrm{PF}}$ & $-1501,5$ & $-1491,0$ & $-1470,0$ & $-1438,4$ & $-1441,0$ \\
\hline $\mathrm{BHF}_{2}$ & ${ }^{1} J_{\mathrm{BF}}$ & $-141,7$ & $-112,6$ & $-84,6$ & $-57,7$ & $-84,0$ \\
\hline $\mathrm{BF}_{3}$ & ${ }^{1} J_{\mathrm{BF}}$ & $-53,7$ & $-19,5$ & 13,4 & 45,0 & 15,0 \\
\hline $\mathrm{F}_{2} \mathrm{O}$ & ${ }^{1} J_{\mathrm{OF}}$ & $-326,9$ & $-290,9$ & $-255,7$ & $-222,5$ & $-300,0$ \\
\hline $\mathrm{CH}_{4}$ & ${ }^{1} J_{\mathrm{CH}}$ & 109,6 & 112,9 & 116,5 & 120,0 & 125,3 \\
\hline $\mathrm{CH}_{4}$ & ${ }^{2} J_{\mathrm{HH}}$ & $-11,0$ & $-12,3$ & $-13,7$ & $-15,1$ & $-12,8$ \\
\hline $\mathrm{C}_{2} \mathrm{H}_{2}$ & ${ }^{1} J_{\mathrm{CC}}$ & 182,4 & 189,0 & 196,3 & 204,4 & 174,8 \\
\hline $\mathrm{C}_{2} \mathrm{H}_{2}$ & ${ }^{1} J_{\mathrm{CH}}$ & 226,6 & 232,3 & 238,5 & 245,2 & 247,6 \\
\hline $\mathrm{C}_{2} \mathrm{H}_{2}$ & ${ }^{2} J_{\mathrm{CH}}$ & 52,6 & 52,2 & 51,5 & 50,3 & 50,1 \\
\hline $\mathrm{C}_{2} \mathrm{H}_{2}$ & ${ }^{3} J_{\mathrm{HH}}$ & 11,1 & 12,1 & 13,4 & 15,0 & 9,6 \\
\hline $\mathrm{C}_{2} \mathrm{H}_{4}$ & ${ }^{1} J_{\mathrm{CC}}$ & 64,3 & 69,4 & 75,1 & 81,5 & 67,6 \\
\hline $\mathrm{C}_{2} \mathrm{H}_{4}$ & ${ }^{1} J_{\mathrm{CH}}$ & 137,9 & 142,5 & 147,3 & 152,5 & 156,3 \\
\hline $\mathrm{C}_{2} \mathrm{H}_{4}$ & ${ }^{2} J_{\mathrm{CH}}$ & $-1,1$ & $-2,7$ & $-4,6$ & $-6,8$ & $-2,4$ \\
\hline $\mathrm{C}_{2} \mathrm{H}_{4}$ & ${ }^{2} J_{\mathrm{HH}}$ & 2,8 & 1,4 & 0,0 & $-1,8$ & 2,3 \\
\hline $\mathrm{C}_{2} \mathrm{H}_{4}$ & ${ }^{3} J_{\mathrm{HH}_{\mathrm{c}}}$ & 10,9 & 11,9 & 13,1 & 14,6 & 11,7 \\
\hline $\mathrm{C}_{2} \mathrm{H}_{4}$ & ${ }^{3} J_{\mathrm{HH}_{\mathrm{t}}}$ & 17,6 & 18,6 & 19,9 & 21,4 & 19,0 \\
\hline $\mathrm{C}_{2} \mathrm{H}_{6}$ & ${ }^{1} J_{\mathrm{CC}}$ & 28,6 & 31,6 & 34,6 & 37,6 & 34,5 \\
\hline $\mathrm{C}_{2} \mathrm{H}_{6}$ & ${ }^{1} J_{\mathrm{CH}}$ & 109,0 & 112,5 & 116,1 & 119,7 & 125,2 \\
\hline $\mathrm{C}_{2} \mathrm{H}_{6}$ & ${ }^{2} J_{\mathrm{CH}}$ & $-3,1$ & $-3,9$ & $-4,7$ & $-5,5$ & $-4,7$ \\
\hline \multirow[t]{3}{*}{ Total } & $\mathrm{DM}$ & $-16,44$ & $-8,93$ & $-1,02$ & 7,17 & - \\
\hline & DMA & 19,57 & 12,21 & 7,62 & 10,47 & - \\
\hline & PDMA & 34,88 & 18,78 & 15,61 & 35,44 & - \\
\hline \multirow[t]{3}{*}{ CPI } & $\mathrm{DM}$ & $-32,87$ & $-17,78$ & $-1,98$ & 14,31 & - \\
\hline & DMA & 37,20 & 21,51 & 10,93 & 16,93 & - \\
\hline & PDMA & 61,46 & 29,76 & 9,16 & 33,84 & - \\
\hline \multirow[t]{3}{*}{ SPI } & $\mathrm{DM}$ & $-4,39$ & $-2,44$ & $-0,32$ & 1,93 & - \\
\hline & DMA & 6,63 & 5,39 & 5,20 & 5,74 & - \\
\hline & PDMA & 15,39 & 10,72 & 20,35 & 36,61 & - \\
\hline \multirow[t]{3}{*}{$\Delta \mathrm{CS}$} & $\mathrm{DM}$ & $-28,48$ & $-15,34$ & $-1,66$ & 12,38 & - \\
\hline & DMA & 30,57 & 16,12 & 5,73 & 11,19 & - \\
\hline & PDMA & 46,07 & 19,03 & $-11,19$ & $-2,77$ & - \\
\hline \multicolumn{7}{|c|}{ Desconsiderando ${ }^{1} J_{\mathrm{BF}}$ da molécula de $\mathrm{BF}_{3},{ }^{2} J_{\mathrm{CH}}$ e ${ }^{2} J_{\mathrm{HH}}$ da molécula de $\mathrm{C}_{2} \mathrm{H}_{4}$} \\
\hline \multirow[t]{3}{*}{ Total } & $\mathrm{DM}$ & $-15,68$ & $-8,54$ & $-0,89$ & 7,17 & - \\
\hline & DMA & 19,05 & 12,25 & 8,35 & 10,17 & - \\
\hline & PDMA & 16,22 & 8,98 & 8,85 & 15,64 & - \\
\hline \multirow[t]{3}{*}{ CPI } & DM & $-29,29$ & $-16,11$ & $-2,02$ & 12,74 & - \\
\hline & DMA & 34,05 & 20,21 & 11,86 & 15,62 & - \\
\hline & PDMA & 21,81 & 9,73 & 9,01 & 17,23 & - \\
\hline \multirow[t]{3}{*}{ SPI } & DM & $-5,21$ & $-2,72$ & $-0,02$ & 2,88 & - \\
\hline & DMA & 7,52 & 6,12 & 5,65 & 5,97 & - \\
\hline & PDMA & 11,92 & 8,40 & 8,73 & 14,43 & - \\
\hline \multirow[t]{3}{*}{$\Delta \mathrm{CS}$} & $\mathrm{DM}$ & $-24,08$ & $-13,39$ & $-2,00$ & 9,86 & - \\
\hline & DMA & 26,53 & 14,09 & 6,21 & 9,65 & - \\
\hline & PDMA & 9,89 & 1,33 & 0,27 & 2,80 & - \\
\hline
\end{tabular}


Tabela 8.293: Constantes de acoplamento B98TPSS com geometrias otimizadas na base aug-pcJ-2.

\begin{tabular}{|c|c|c|c|c|c|c|}
\hline & $\% E_{X}^{\mathrm{HF}}$ & $40 \%$ & $50 \%$ & $60 \%$ & $70 \%$ & Exp. \\
\hline $\mathrm{HF}$ & ${ }^{1} J_{\mathrm{HF}}$ & 381,1 & 432,4 & 484,1 & 535,6 & 500,0 \\
\hline $\mathrm{CO}$ & ${ }^{1} J_{\mathrm{CO}}$ & 20,5 & 16,5 & 12,5 & 8,4 & 16,4 \\
\hline $\mathrm{H}_{2} \mathrm{O}$ & ${ }^{1} J_{\mathrm{OH}}$ & $-63,5$ & $-70,1$ & $-76,7$ & $-83,0$ & $-80,6$ \\
\hline $\mathrm{H}_{2} \mathrm{O}$ & ${ }^{2} J_{\mathrm{HH}}$ & $-6,1$ & $-7,2$ & $-8,4$ & $-9,7$ & $-7,3$ \\
\hline $\mathrm{NH}_{3}$ & ${ }^{1} J_{\mathrm{NH}}$ & 37,3 & 40,0 & 42,7 & 45,1 & 43,8 \\
\hline $\mathrm{NH}_{3}$ & ${ }^{2} J_{\mathrm{HH}}$ & $-8,4$ & $-9,5$ & $-10,6$ & $-11,9$ & $-9,6$ \\
\hline $\mathrm{PH}_{3}$ & ${ }^{1} J_{\mathrm{PH}}$ & 151,6 & 168,7 & 185,5 & 202,6 & 188,2 \\
\hline $\mathrm{PF}_{3}$ & ${ }^{1} J_{\mathrm{PF}}$ & $-1503,8$ & $-1494,1$ & $-1474,1$ & $-1443,3$ & $-1441,0$ \\
\hline $\mathrm{BHF}_{2}$ & ${ }^{1} J_{\mathrm{BF}}$ & $-144,8$ & $-115,9$ & $-88,0$ & $-61,2$ & $-84,0$ \\
\hline $\mathrm{BF}_{3}$ & ${ }^{1} J_{\mathrm{BF}}$ & $-53,4$ & $-19,4$ & 13,3 & 44,8 & 15,0 \\
\hline $\mathrm{F}_{2} \mathrm{O}$ & ${ }^{1} J_{\mathrm{OF}}$ & $-323,8$ & $-287,4$ & $-252,0$ & $-218,7$ & $-300,0$ \\
\hline $\mathrm{CH}_{4}$ & ${ }^{1} J_{\mathrm{CH}}$ & 117,2 & 120,8 & 124,7 & 128,6 & 125,3 \\
\hline $\mathrm{CH}_{4}$ & ${ }^{2} J_{\mathrm{HH}}$ & $-10,6$ & $-12,0$ & $-13,5$ & $-15,0$ & $-12,8$ \\
\hline $\mathrm{C}_{2} \mathrm{H}_{2}$ & ${ }^{1} J_{\mathrm{CC}}$ & 182,2 & 189,1 & 196,7 & 205,2 & 174,8 \\
\hline $\mathrm{C}_{2} \mathrm{H}_{2}$ & ${ }^{1} J_{\mathrm{CH}}$ & 240,5 & 246,8 & 253,6 & 260,9 & 247,6 \\
\hline $\mathrm{C}_{2} \mathrm{H}_{2}$ & ${ }^{2} J_{\mathrm{CH}}$ & 54,1 & 53,7 & 52,9 & 51,6 & 50,1 \\
\hline $\mathrm{C}_{2} \mathrm{H}_{2}$ & ${ }^{3} J_{\mathrm{HH}}$ & 11,6 & 12,6 & 13,9 & 15,6 & 9,6 \\
\hline $\mathrm{C}_{2} \mathrm{H}_{4}$ & ${ }^{1} J_{\mathrm{CC}}$ & 65,1 & 70,4 & 76,3 & 82,9 & 67,6 \\
\hline $\mathrm{C}_{2} \mathrm{H}_{4}$ & ${ }^{1} J_{\mathrm{CH}}$ & 146,9 & 151,8 & 157,1 & 162,8 & 156,3 \\
\hline $\mathrm{C}_{2} \mathrm{H}_{4}$ & ${ }^{2} J_{\mathrm{CH}}$ & $-1,3$ & $-2,9$ & $-4,9$ & $-7,3$ & $-2,4$ \\
\hline $\mathrm{C}_{2} \mathrm{H}_{4}$ & ${ }^{2} J_{\mathrm{HH}}$ & 4,2 & 2,8 & 1,2 & $-0,6$ & 2,3 \\
\hline $\mathrm{C}_{2} \mathrm{H}_{4}$ & ${ }^{3} J_{\mathrm{HH}_{\mathrm{c}}}$ & 11,5 & 12,6 & 13,9 & 15,5 & 11,7 \\
\hline $\mathrm{C}_{2} \mathrm{H}_{4}$ & ${ }^{3} J_{\mathrm{HH}_{\mathrm{t}}}{ }^{\mathrm{C}}$ & 19,4 & 20,5 & 21,8 & 23,3 & 19,0 \\
\hline $\mathrm{C}_{2} \mathrm{H}_{6}$ & ${ }^{1} J_{\mathrm{CC}}$ & 29,3 & 32,4 & 35,4 & 38,5 & 34,5 \\
\hline $\mathrm{C}_{2} \mathrm{H}_{6}$ & ${ }^{1} J_{\mathrm{CH}}$ & 116,3 & 120,1 & 124,0 & 128,0 & 125,2 \\
\hline $\mathrm{C}_{2} \mathrm{H}_{6}$ & ${ }^{2} J_{\mathrm{CH}}$ & $-3,2$ & $-4,0$ & $-4,8$ & $-5,7$ & $-4,7$ \\
\hline \multirow[t]{3}{*}{ Total } & $\mathrm{DM}$ & $-14,43$ & $-6,78$ & 1,22 & 9,54 & - \\
\hline & DMA & 17,82 & 10,74 & 6,65 & 11,72 & - \\
\hline & PDMA & 35,75 & 18,11 & 14,29 & 35,95 & - \\
\hline \multirow[t]{3}{*}{ CPI } & $\mathrm{DM}$ & $-32,20$ & $-16,99$ & $-1,15$ & 15,25 & - \\
\hline & DMA & 36,49 & 21,25 & 10,58 & 18,42 & - \\
\hline & PDMA & 61,26 & 29,44 & 8,69 & 34,49 & - \\
\hline \multirow[t]{3}{*}{ SPI } & $\mathrm{DM}$ & $-1,39$ & 0,71 & 2,95 & 5,35 & - \\
\hline & DMA & 4,13 & 3,04 & 3,77 & 6,81 & - \\
\hline & PDMA & 17,04 & 9,80 & 18,39 & 37,02 & - \\
\hline \multirow[t]{3}{*}{$\Delta \mathrm{CS}$} & $\mathrm{DM}$ & $-30,81$ & $-17,70$ & $-4,09$ & 9,91 & - \\
\hline & DMA & 32,36 & 18,21 & 6,81 & 11,60 & - \\
\hline & PDMA & 44,22 & 19,64 & $-9,70$ & $-2,53$ & - \\
\hline \multicolumn{7}{|c|}{ Desconsiderando ${ }^{1} J_{\mathrm{BF}}$ da molécula de $\mathrm{BF}_{3},{ }^{2} J_{\mathrm{CH}}$ e ${ }^{2} J_{\mathrm{HH}}$ da molécula de $\mathrm{C}_{2} \mathrm{H}_{4}$} \\
\hline \multirow[t]{3}{*}{ Total } & $\mathrm{DM}$ & $-13,47$ & $-6,17$ & 1,60 & 9,83 & - \\
\hline & DMA & 17,04 & 10,60 & 7,29 & 11,62 & - \\
\hline & PDMA & 15,00 & 8,65 & 9,05 & 17,64 & - \\
\hline \multirow[t]{3}{*}{ CPI } & DM & $-28,58$ & $-15,25$ & $-1,09$ & 13,80 & - \\
\hline & DMA & 33,30 & 19,93 & 11,47 & 17,28 & - \\
\hline & PDMA & 21,79 & 9,45 & 8,43 & 18,07 & - \\
\hline \multirow[t]{3}{*}{ SPI } & DM & $-1,84$ & 0,82 & 3,68 & 6,77 & - \\
\hline & DMA & 4,53 & 3,43 & 4,08 & 7,26 & - \\
\hline & PDMA & 9,78 & 8,03 & 9,53 & 17,31 & - \\
\hline \multirow[t]{3}{*}{$\Delta \mathrm{CS}$} & DM & $-26,74$ & $-16,07$ & $-4,77$ & 7,03 & - \\
\hline & DMA & 28,77 & 16,50 & 7,39 & 10,02 & - \\
\hline & PDMA & 12,01 & 1,41 & $-1,10$ & 0,76 & - \\
\hline
\end{tabular}


Tabela 8.294: Constantes de acoplamento OB95 com geometrias otimizadas na base aug-pcJ-2.

\begin{tabular}{|c|c|c|c|c|c|c|}
\hline & $\% E_{X}^{\mathrm{HF}}$ & $30 \%$ & $40 \%$ & $50 \%$ & $60 \%$ & Exp. \\
\hline $\mathrm{HF}$ & ${ }^{1} J_{\mathrm{HF}}$ & 470,6 & 508,0 & 545,2 & 582,1 & 500,0 \\
\hline $\mathrm{CO}$ & ${ }^{1} J_{\mathrm{CO}}$ & 17,6 & 14,2 & 10,8 & 7,4 & 16,4 \\
\hline $\mathrm{H}_{2} \mathrm{O}$ & ${ }^{1} J_{\mathrm{OH}}$ & $-75,8$ & $-80,2$ & $-84,5$ & $-88,7$ & $-80,6$ \\
\hline $\mathrm{H}_{2} \mathrm{O}$ & ${ }^{2} J_{\mathrm{HH}}$ & $-8,0$ & $-8,5$ & $-9,0$ & $-9,6$ & $-7,3$ \\
\hline $\mathrm{NH}_{3}$ & ${ }^{1} J_{\mathrm{NH}}$ & 41,2 & 42,9 & 44,5 & 46,1 & 43,8 \\
\hline $\mathrm{NH}_{3}$ & ${ }^{2} J_{\mathrm{HH}}$ & $-10,1$ & $-10,6$ & $-11,1$ & $-11,6$ & $-9,6$ \\
\hline $\mathrm{PH}_{3}$ & ${ }^{1} J_{\mathrm{PH}}$ & 175,8 & 185,4 & 194,7 & 203,7 & 188,2 \\
\hline $\mathrm{PF}_{3}$ & ${ }^{1} J_{\mathrm{PF}}$ & $-1457,4$ & $-1437,7$ & $-1412,6$ & $-1382,8$ & $-1441,0$ \\
\hline $\mathrm{BHF}_{2}$ & ${ }^{1} J_{\mathrm{BF}}$ & $-125,1$ & $-101,5$ & $-78,7$ & $-56,8$ & $-84,0$ \\
\hline $\mathrm{BF}_{3}$ & ${ }^{1} J_{\mathrm{BF}}$ & $-31,6$ & $-4,0$ & 22,0 & 47,0 & 15,0 \\
\hline $\mathrm{F}_{2} \mathrm{O}$ & ${ }^{1} J_{\mathrm{OF}}$ & $-173,1$ & $-161,8$ & $-151,2$ & $-140,5$ & $-300,0$ \\
\hline $\mathrm{CH}_{4}$ & ${ }^{1} J_{\mathrm{CH}}$ & 114,6 & 116,8 & 119,1 & 121,3 & 125,3 \\
\hline $\mathrm{CH}_{4}$ & ${ }^{2} J_{\mathrm{HH}}$ & $-12,7$ & $-13,3$ & $-13,9$ & $-14,5$ & $-12,8$ \\
\hline $\mathrm{C}_{2} \mathrm{H}_{2}$ & ${ }^{1} J_{\mathrm{CC}}$ & 187,9 & 192,3 & 196,9 & 201,7 & 174,8 \\
\hline $\mathrm{C}_{2} \mathrm{H}_{2}$ & ${ }^{1} J_{\mathrm{CH}}$ & 240,1 & 242,5 & 245,0 & 247,6 & 247,6 \\
\hline $\mathrm{C}_{2} \mathrm{H}_{2}$ & ${ }^{2} J_{\mathrm{CH}}$ & 52,6 & 52,7 & 52,6 & 52,5 & 50,1 \\
\hline $\mathrm{C}_{2} \mathrm{H}_{2}$ & ${ }^{3} J_{\mathrm{HH}}$ & 11,0 & 11,3 & 11,8 & 12,3 & 9,6 \\
\hline $\mathrm{C}_{2} \mathrm{H}_{4}$ & ${ }^{1} J_{\mathrm{CC}}$ & 64,9 & 68,2 & 71,8 & 75,5 & 67,6 \\
\hline $\mathrm{C}_{2} \mathrm{H}_{4}$ & ${ }^{1} J_{\mathrm{CH}}$ & 145,9 & 148,5 & 151,1 & 153,8 & 156,3 \\
\hline $\mathrm{C}_{2} \mathrm{H}_{4}$ & ${ }^{2} J_{\mathrm{CH}}$ & $-1,9$ & $-2,7$ & $-3,7$ & $-4,6$ & $-2,4$ \\
\hline $\mathrm{C}_{2} \mathrm{H}_{4}$ & ${ }^{2} J_{\mathrm{HH}}$ & 1,1 & 0,6 & 0,0 & $-0,5$ & 2,3 \\
\hline $\mathrm{C}_{2} \mathrm{H}_{4}$ & ${ }^{3} J_{\mathrm{HH}_{\mathrm{c}}}$ & 12,6 & 13,1 & 13,5 & 14,1 & 11,7 \\
\hline $\mathrm{C}_{2} \mathrm{H}_{4}$ & ${ }^{3} J_{\mathrm{HH}_{\mathrm{t}}}$ & 19,1 & 19,4 & 19,8 & 20,3 & 19,0 \\
\hline $\mathrm{C}_{2} \mathrm{H}_{6}$ & ${ }^{1} J_{\mathrm{CC}}$ & 30,1 & 32,3 & 34,7 & 36,9 & 34,5 \\
\hline $\mathrm{C}_{2} \mathrm{H}_{6}$ & ${ }^{1} J_{\mathrm{CH}}$ & 113,7 & 116,1 & 118,3 & 120,7 & 125,2 \\
\hline $\mathrm{C}_{2} \mathrm{H}_{6}$ & ${ }^{2} J_{\mathrm{CH}}$ & $-4,0$ & $-4,4$ & $-4,8$ & $-5,2$ & $-4,7$ \\
\hline \multirow[t]{3}{*}{ Total } & $\mathrm{DM}$ & $-1,77$ & 3,64 & 9,13 & 14,74 & - \\
\hline & DMA & 13,47 & 9,78 & 12,08 & 17,78 & - \\
\hline & PDMA & 23,76 & 15,84 & 17,05 & 30,39 & - \\
\hline \multirow[t]{3}{*}{ CPI } & $\mathrm{DM}$ & $-1,53$ & 9,57 & 20,84 & 32,31 & - \\
\hline & DMA & 25,69 & 17,68 & 23,15 & 36,20 & - \\
\hline & PDMA & 40,86 & 21,79 & 17,87 & 40,92 & - \\
\hline \multirow[t]{3}{*}{ SPI } & $\mathrm{DM}$ & $-1,94$ & $-0,71$ & 0,54 & 1,85 & - \\
\hline & DMA & 4,51 & 3,98 & 3,97 & 4,28 & - \\
\hline & PDMA & 11,21 & 11,47 & 16,44 & 22,67 & - \\
\hline \multirow[t]{3}{*}{$\Delta \mathrm{CS}$} & $\mathrm{DM}$ & 0,41 & 10,29 & 20,30 & 30,46 & - \\
\hline & DMA & 21,18 & 13,70 & 19,18 & 31,92 & - \\
\hline & PDMA & 29,66 & 10,32 & 1,42 & 18,25 & - \\
\hline \multicolumn{7}{|c|}{ Desconsiderando ${ }^{1} J_{\mathrm{BF}}$ da molécula de $\mathrm{BF}_{3},{ }^{2} J_{\mathrm{CH}}$ e ${ }^{2} J_{\mathrm{HH}}$ da molécula de $\mathrm{C}_{2} \mathrm{H}_{4}$} \\
\hline \multirow[t]{3}{*}{ Total } & $\mathrm{DM}$ & 0,06 & 5,03 & 10,17 & 15,49 & - \\
\hline & DMA & 13,13 & 10,14 & 13,20 & 18,50 & - \\
\hline & PDMA & 10,17 & 8,64 & 10,54 & 15,80 & - \\
\hline \multirow[t]{3}{*}{ CPI } & DM & 2,98 & 12,43 & 22,22 & 32,34 & - \\
\hline & DMA & 23,60 & 17,55 & 24,76 & 36,62 & - \\
\hline & PDMA & 13,88 & 11,30 & 14,99 & 23,68 & - \\
\hline \multirow[t]{3}{*}{ SPI } & DM & $-2,18$ & $-0,67$ & 0,90 & 2,52 & - \\
\hline & DMA & 5,08 & 4,44 & 4,30 & 4,55 & - \\
\hline & PDMA & 7,32 & 6,59 & 7,12 & 9,74 & - \\
\hline \multirow[t]{3}{*}{$\Delta \mathrm{CS}$} & DM & 5,16 & 13,10 & 21,32 & 29,82 & - \\
\hline & DMA & 18,52 & 13,11 & 20,46 & 32,07 & - \\
\hline & PDMA & 6,57 & 4,72 & 7,87 & 13,94 & - \\
\hline
\end{tabular}


Tabela 8.295: Constantes de acoplamento OB972 com geometrias otimizadas na base aug-pcJ-2.

\begin{tabular}{|c|c|c|c|c|c|c|}
\hline & $\% E_{X}^{\mathrm{HF}}$ & $20 \%$ & $30 \%$ & $40 \%$ & $50 \%$ & Exp. \\
\hline $\mathrm{HF}$ & ${ }^{1} J_{\mathrm{HF}}$ & 471,0 & 508,8 & 547,1 & 583,7 & 500,0 \\
\hline $\mathrm{CO}$ & ${ }^{1} J_{\mathrm{CO}}$ & 14,2 & 10,3 & 6,3 & 2,4 & 16,4 \\
\hline $\mathrm{H}_{2} \mathrm{O}$ & ${ }^{1} J_{\mathrm{OH}}$ & $-77,7$ & $-82,4$ & $-86,9$ & $-91,3$ & $-80,6$ \\
\hline $\mathrm{H}_{2} \mathrm{O}$ & ${ }^{2} J_{\mathrm{HH}}$ & $-7,0$ & $-7,4$ & $-8,0$ & $-8,5$ & $-7,3$ \\
\hline $\mathrm{NH}_{3}$ & ${ }^{1} J_{\mathrm{NH}}$ & 43,5 & 45,2 & 46,9 & 48,5 & 43,8 \\
\hline $\mathrm{NH}_{3}$ & ${ }^{2} J_{\mathrm{HH}}$ & $-8,7$ & $-9,2$ & $-9,7$ & $-10,2$ & $-9,6$ \\
\hline $\mathrm{PH}_{3}$ & ${ }^{1} J_{\mathrm{PH}}$ & 189,2 & 200,1 & 210,7 & 220,9 & 188,2 \\
\hline $\mathrm{PF}_{3}$ & ${ }^{1} J_{\mathrm{PF}}$ & $-1558,4$ & $-1541,5$ & $-1517,4$ & $-1487,6$ & $-1441,0$ \\
\hline $\mathrm{BHF}_{2}$ & ${ }^{1} J_{\mathrm{BF}}$ & $-122,3$ & $-97,1$ & $-72,5$ & $-49,1$ & $-84,0$ \\
\hline $\mathrm{BF}_{3}$ & ${ }^{1} J_{\mathrm{BF}}$ & $-31,2$ & $-1,9$ & 26,0 & 52,6 & 15,0 \\
\hline $\mathrm{F}_{2} \mathrm{O}$ & ${ }^{1} J_{\mathrm{OF}}$ & $-211,6$ & $-199,6$ & $-187,8$ & $-175,6$ & $-300,0$ \\
\hline $\mathrm{CH}_{4}$ & ${ }^{1} J_{\mathrm{CH}}$ & 122,9 & 125,2 & 127,5 & 129,9 & 125,3 \\
\hline $\mathrm{CH}_{4}$ & ${ }^{2} J_{\mathrm{HH}}$ & $-10,9$ & $-11,5$ & $-12,1$ & $-12,7$ & $-12,8$ \\
\hline $\mathrm{C}_{2} \mathrm{H}_{2}$ & ${ }^{1} J_{\mathrm{CC}}$ & 204,9 & 210,1 & 215,6 & 221,4 & 174,8 \\
\hline $\mathrm{C}_{2} \mathrm{H}_{2}$ & ${ }^{1} J_{\mathrm{CH}}$ & 250,1 & 252,7 & 255,3 & 257,9 & 247,6 \\
\hline $\mathrm{C}_{2} \mathrm{H}_{2}$ & ${ }^{2} J_{\mathrm{CH}}$ & 50,8 & 50,8 & 50,6 & 50,4 & 50,1 \\
\hline $\mathrm{C}_{2} \mathrm{H}_{2}$ & ${ }^{3} J_{\mathrm{HH}}$ & 9,8 & 10,2 & 10,5 & 11,0 & 9,6 \\
\hline $\mathrm{C}_{2} \mathrm{H}_{4}$ & ${ }^{1} J_{\mathrm{CC}}$ & 76,0 & 80,2 & 84,6 & 89,2 & 67,6 \\
\hline $\mathrm{C}_{2} \mathrm{H}_{4}$ & ${ }^{1} J_{\mathrm{CH}}$ & 153,6 & 156,4 & 159,2 & 162,0 & 156,3 \\
\hline $\mathrm{C}_{2} \mathrm{H}_{4}$ & ${ }^{2} J_{\mathrm{CH}}$ & $-1,8$ & $-2,8$ & $-3,8$ & $-4,8$ & $-2,4$ \\
\hline $\mathrm{C}_{2} \mathrm{H}_{4}$ & ${ }^{2} J_{\mathrm{HH}}$ & 2,3 & 1,8 & 1,2 & 0,7 & 2,3 \\
\hline $\mathrm{C}_{2} \mathrm{H}_{4}$ & ${ }^{3} J_{\mathrm{HH}_{\mathrm{c}}}$ & 11,7 & 12,1 & 12,5 & 13,0 & 11,7 \\
\hline $\mathrm{C}_{2} \mathrm{H}_{4}$ & ${ }^{3} J_{\mathrm{HH}_{\mathrm{t}}}$ & 18,1 & 18,4 & 18,7 & 19,1 & 19,0 \\
\hline $\mathrm{C}_{2} \mathrm{H}_{6}$ & ${ }^{1} J_{\mathrm{CC}}$ & 35,9 & 38,3 & 40,7 & 43,4 & 34,5 \\
\hline $\mathrm{C}_{2} \mathrm{H}_{6}$ & ${ }^{1} J_{\mathrm{CH}}$ & 121,4 & 123,9 & 126,3 & 128,7 & 125,2 \\
\hline $\mathrm{C}_{2} \mathrm{H}_{6}$ & ${ }^{2} J_{\mathrm{CH}}$ & $-3,2$ & $-3,6$ & $-4,0$ & $-4,4$ & $-4,7$ \\
\hline \multirow[t]{3}{*}{ Total } & $\mathrm{DM}$ & $-3,94$ & 1,63 & 7,40 & 13,29 & - \\
\hline & DMA & 14,77 & 12,51 & 14,82 & 19,22 & - \\
\hline & PDMA & 21,16 & 14,01 & 17,60 & 30,97 & - \\
\hline \multirow[t]{3}{*}{ CPI } & $\mathrm{DM}$ & $-12,72$ & $-1,42$ & 10,35 & 22,26 & - \\
\hline & DMA & 29,72 & 23,76 & 27,36 & 35,55 & - \\
\hline & PDMA & 38,97 & 20,45 & 21,66 & 45,74 & - \\
\hline \multirow[t]{3}{*}{ SPI } & $\mathrm{DM}$ & 2,50 & 3,87 & 5,25 & 6,71 & - \\
\hline & DMA & 3,81 & 4,26 & 5,62 & 7,25 & - \\
\hline & PDMA & 8,09 & 9,29 & 14,62 & 20,15 & - \\
\hline \multirow[t]{3}{*}{$\Delta \mathrm{CS}$} & $\mathrm{DM}$ & $-15,22$ & $-5,29$ & 5,10 & 15,55 & - \\
\hline & DMA & 25,91 & 19,50 & 21,74 & 28,31 & - \\
\hline & PDMA & 30,88 & 11,16 & 7,03 & 25,59 & - \\
\hline \multicolumn{7}{|c|}{ Desconsiderando ${ }^{1} J_{\mathrm{BF}}$ da molécula de $\mathrm{BF}_{3},{ }^{2} J_{\mathrm{CH}}$ e ${ }^{2} J_{\mathrm{HH}}$ da molécula de $\mathrm{C}_{2} \mathrm{H}_{4}$} \\
\hline \multirow[t]{3}{*}{ Total } & $\mathrm{DM}$ & $-2,47$ & 2,62 & 8,00 & 13,57 & - \\
\hline & DMA & 14,66 & 13,37 & 16,17 & 19,92 & - \\
\hline & PDMA & 9,44 & 9,27 & 12,09 & 16,74 & - \\
\hline \multirow[t]{3}{*}{ CPI } & DM & $-9,37$ & 0,13 & 10,28 & 20,73 & - \\
\hline & DMA & 28,07 & 24,45 & 29,00 & 35,35 & - \\
\hline & PDMA & 12,07 & 11,23 & 16,49 & 25,24 & - \\
\hline \multirow[t]{3}{*}{ SPI } & DM & 2,84 & 4,54 & 6,25 & 8,05 & - \\
\hline & DMA & 4,35 & 4,85 & 6,29 & 8,05 & - \\
\hline & PDMA & 7,41 & 7,76 & 8,71 & 10,21 & - \\
\hline \multirow[t]{3}{*}{$\Delta \mathrm{CS}$} & DM & $-12,21$ & $-4,41$ & 4,03 & 12,68 & - \\
\hline & DMA & 23,72 & 19,60 & 22,71 & 27,30 & - \\
\hline & PDMA & 4,66 & 3,47 & 7,78 & 15,04 & - \\
\hline
\end{tabular}


Tabela 8.296: Constantes de acoplamento PBEB95 com geometrias otimizadas na base aug-pcJ-2.

\begin{tabular}{|c|c|c|c|c|c|c|}
\hline & $\% E_{X}^{\mathrm{HF}}$ & $30 \%$ & $40 \%$ & $50 \%$ & $60 \%$ & Exp. \\
\hline $\mathrm{HF}$ & ${ }^{1} J_{\mathrm{HF}}$ & 493,2 & 528,3 & 562,8 & 596,8 & 500,0 \\
\hline $\mathrm{CO}$ & ${ }^{1} J_{\mathrm{CO}}$ & 14,5 & 11,4 & 8,4 & 5,3 & 16,4 \\
\hline $\mathrm{H}_{2} \mathrm{O}$ & ${ }^{1} J_{\mathrm{OH}}$ & $-80,7$ & $-84,8$ & $-88,5$ & $-92,0$ & $-80,6$ \\
\hline $\mathrm{H}_{2} \mathrm{O}$ & ${ }^{2} J_{\mathrm{HH}}$ & $-6,4$ & $-7,1$ & $-7,9$ & $-8,7$ & $-7,3$ \\
\hline $\mathrm{NH}_{3}$ & ${ }^{1} J_{\mathrm{NH}}$ & 45,3 & 46,5 & 47,5 & 48,5 & 43,8 \\
\hline $\mathrm{NH}_{3}$ & ${ }^{2} J_{\mathrm{HH}}$ & $-8,8$ & $-9,4$ & $-10,2$ & $-10,9$ & $-9,6$ \\
\hline $\mathrm{PH}_{3}$ & ${ }^{1} J_{\mathrm{PH}}$ & 175,0 & 185,0 & 194,7 & 203,9 & 188,2 \\
\hline $\mathrm{PF}_{3}$ & ${ }^{1} J_{\mathrm{PF}}$ & $-1524,0$ & $-1497,8$ & $-1464,7$ & $-1426,2$ & $-1441,0$ \\
\hline $\mathrm{BHF}_{2}$ & ${ }^{1} J_{\mathrm{BF}}$ & $-115,6$ & $-93,7$ & $-72,6$ & $-52,2$ & $-84,0$ \\
\hline $\mathrm{BF}_{3}$ & ${ }^{1} J_{\mathrm{BF}}$ & $-15,8$ & 8,8 & 32,4 & 55,0 & 15,0 \\
\hline $\mathrm{F}_{2} \mathrm{O}$ & ${ }^{1} J_{\mathrm{OF}}$ & $-232,7$ & $-211,2$ & $-191,0$ & $-172,7$ & $-300,0$ \\
\hline $\mathrm{CH}_{4}$ & ${ }^{1} J_{\mathrm{CH}}$ & 125,0 & 125,8 & 126,5 & 127,3 & 125,3 \\
\hline $\mathrm{CH}_{4}$ & ${ }^{2} J_{\mathrm{HH}}$ & $-11,8$ & $-12,6$ & $-13,3$ & $-14,1$ & $-12,8$ \\
\hline $\mathrm{C}_{2} \mathrm{H}_{2}$ & ${ }^{1} J_{\mathrm{CC}}$ & 197,8 & 200,7 & 203,8 & 207,1 & 174,8 \\
\hline $\mathrm{C}_{2} \mathrm{H}_{2}$ & ${ }^{1} J_{\mathrm{CH}}$ & 253,3 & 253,7 & 254,2 & 254,8 & 247,6 \\
\hline $\mathrm{C}_{2} \mathrm{H}_{2}$ & ${ }^{2} J_{\mathrm{CH}}$ & 55,4 & 55,2 & 54,9 & 54,5 & 50,1 \\
\hline $\mathrm{C}_{2} \mathrm{H}_{2}$ & ${ }^{3} J_{\mathrm{HH}}$ & 9,8 & 10,2 & 10,8 & 11,4 & 9,6 \\
\hline $\mathrm{C}_{2} \mathrm{H}_{4}$ & ${ }^{1} J_{\mathrm{CC}}$ & 70,9 & 73,4 & 76,0 & 78,8 & 67,6 \\
\hline $\mathrm{C}_{2} \mathrm{H}_{4}$ & ${ }^{1} J_{\mathrm{CH}}$ & 156,1 & 157,2 & 158,3 & 159,5 & 156,3 \\
\hline $\mathrm{C}_{2} \mathrm{H}_{4}$ & ${ }^{2} J_{\mathrm{CH}}$ & $-1,1$ & $-2,0$ & $-3,0$ & $-4,0$ & $-2,4$ \\
\hline $\mathrm{C}_{2} \mathrm{H}_{4}$ & ${ }^{2} J_{\mathrm{HH}}$ & 3,0 & 2,2 & 1,4 & 0,6 & 2,3 \\
\hline $\mathrm{C}_{2} \mathrm{H}_{4}$ & ${ }^{3} J_{\mathrm{HH}_{\mathrm{c}}}$ & 12,8 & 13,2 & 13,6 & 14,1 & 11,7 \\
\hline $\mathrm{C}_{2} \mathrm{H}_{4}$ & ${ }^{3} J_{\mathrm{HH}_{\mathrm{t}}}$ & 19,3 & 19,6 & 19,9 & 20,3 & 19,0 \\
\hline $\mathrm{C}_{2} \mathrm{H}_{6}$ & ${ }^{1} J_{\mathrm{CC}}$ & 34,1 & 35,8 & 37,5 & 39,4 & 34,5 \\
\hline $\mathrm{C}_{2} \mathrm{H}_{6}$ & ${ }^{1} J_{\mathrm{CH}}$ & 123,8 & 124,7 & 125,6 & 126,5 & 125,2 \\
\hline $\mathrm{C}_{2} \mathrm{H}_{6}$ & ${ }^{2} J_{\mathrm{CH}}$ & $-3,5$ & $-4,0$ & $-4,5$ & $-4,9$ & $-4,7$ \\
\hline \multirow[t]{3}{*}{ Total } & $\mathrm{DM}$ & $-2,16$ & 3,23 & 8,75 & 14,35 & - \\
\hline & DMA & 10,90 & 9,83 & 12,05 & 16,66 & - \\
\hline & PDMA & 18,46 & 9,28 & 16,28 & 29,53 & - \\
\hline \multirow[t]{3}{*}{ CPI } & $\mathrm{DM}$ & $-8,81$ & 3,19 & 15,45 & 27,81 & - \\
\hline & DMA & 21,63 & 18,66 & 22,87 & 32,39 & - \\
\hline & PDMA & 28,67 & 12,77 & 24,10 & 45,54 & - \\
\hline \multirow[t]{3}{*}{ SPI } & $\mathrm{DM}$ & 2,72 & 3,27 & 3,84 & 4,48 & - \\
\hline & DMA & 3,03 & 3,35 & 4,11 & 5,12 & - \\
\hline & PDMA & 10,97 & 6,73 & 10,55 & 17,78 & - \\
\hline \multirow[t]{3}{*}{$\Delta \mathrm{CS}$} & $\mathrm{DM}$ & $-11,53$ & $-0,08$ & 11,61 & 23,33 & - \\
\hline & DMA & 18,60 & 15,32 & 18,77 & 27,27 & - \\
\hline & PDMA & 17,69 & 6,04 & 13,54 & 27,76 & - \\
\hline \multicolumn{7}{|c|}{ Desconsiderando ${ }^{1} J_{\mathrm{BF}}$ da molécula de $\mathrm{BF}_{3},{ }^{2} J_{\mathrm{CH}}$ e ${ }^{2} J_{\mathrm{HH}}$ da molécula de $\mathrm{C}_{2} \mathrm{H}_{4}$} \\
\hline \multirow[t]{3}{*}{ Total } & $\mathrm{DM}$ & $-1,19$ & 3,91 & 9,20 & 14,63 & - \\
\hline & DMA & 10,89 & 10,82 & 12,80 & 16,95 & - \\
\hline & PDMA & 8,26 & 7,78 & 10,57 & 15,67 & - \\
\hline \multirow[t]{3}{*}{ CPI } & DM & $-6,61$ & 4,13 & 15,26 & 26,59 & - \\
\hline & DMA & 20,71 & 19,91 & 23,42 & 31,63 & - \\
\hline & PDMA & 11,00 & 9,91 & 14,91 & 23,43 & - \\
\hline \multirow[t]{3}{*}{ SPI } & $\mathrm{DM}$ & 2,98 & 3,75 & 4,55 & 5,42 & - \\
\hline & DMA & 3,34 & 3,82 & 4,62 & 5,65 & - \\
\hline & PDMA & 6,15 & 6,14 & 7,24 & 9,70 & - \\
\hline \multirow[t]{3}{*}{$\Delta \mathrm{CS}$} & DM & $-9,59$ & 0,38 & 10,71 & 21,17 & - \\
\hline & DMA & 17,37 & 16,09 & 18,80 & 25,98 & - \\
\hline & PDMA & 4,85 & 3,77 & 7,66 & 13,73 & - \\
\hline
\end{tabular}


Tabela 8.297: Constantes de acoplamento PBEB971 com geometrias otimizadas na base aug-pcJ-2.

\begin{tabular}{|c|c|c|c|c|c|c|}
\hline & $\% E_{X}^{\mathrm{HF}}$ & $20 \%$ & $30 \%$ & $40 \%$ & $50 \%$ & Exp. \\
\hline $\mathrm{HF}$ & ${ }^{1} J_{\mathrm{HF}}$ & 466,9 & 500,9 & 534,5 & 567,5 & 500,0 \\
\hline $\mathrm{CO}$ & ${ }^{1} J_{\mathrm{CO}}$ & 14,7 & 11,4 & 8,2 & 5,0 & 16,4 \\
\hline $\mathrm{H}_{2} \mathrm{O}$ & ${ }^{1} J_{\mathrm{OH}}$ & $-78,2$ & $-82,1$ & $-85,7$ & $-89,2$ & $-80,6$ \\
\hline $\mathrm{H}_{2} \mathrm{O}$ & ${ }^{2} J_{\mathrm{HH}}$ & $-5,2$ & $-6,0$ & $-6,7$ & $-7,5$ & $-7,3$ \\
\hline $\mathrm{NH}_{3}$ & ${ }^{1} J_{\mathrm{NH}}$ & 45,7 & 46,8 & 48,0 & 49,0 & 43,8 \\
\hline $\mathrm{NH}_{3}$ & ${ }^{2} J_{\mathrm{HH}}$ & $-7,9$ & $-8,7$ & $-9,4$ & $-10,1$ & $-9,6$ \\
\hline $\mathrm{PH}_{3}$ & ${ }^{1} J_{\mathrm{PH}}$ & 193,2 & 202,7 & 211,8 & 220,4 & 188,2 \\
\hline $\mathrm{PF}_{3}$ & ${ }^{1} J_{\mathrm{PF}}$ & $-1589,4$ & $-1567,6$ & $-1537,2$ & $-1499,9$ & $-1441,0$ \\
\hline $\mathrm{BHF}_{2}$ & ${ }^{1} J_{\mathrm{BF}}$ & $-118,9$ & $-95,4$ & $-72,7$ & $-50,7$ & $-84,0$ \\
\hline $\mathrm{BF}_{3}$ & ${ }^{1} J_{\mathrm{BF}}$ & $-21,7$ & 4,4 & 29,6 & 53,8 & 15,0 \\
\hline $\mathrm{F}_{2} \mathrm{O}$ & ${ }^{1} J_{\mathrm{OF}}$ & $-246,0$ & $-226,4$ & $-207,6$ & $-190,0$ & $-300,0$ \\
\hline $\mathrm{CH}_{4}$ & ${ }^{1} J_{\mathrm{CH}}$ & 132,5 & 133,4 & 134,4 & 135,3 & 125,3 \\
\hline $\mathrm{CH}_{4}$ & ${ }^{2} J_{\mathrm{HH}}$ & $-11,1$ & $-11,9$ & $-12,7$ & $-13,5$ & $-12,8$ \\
\hline $\mathrm{C}_{2} \mathrm{H}_{2}$ & ${ }^{1} J_{\mathrm{CC}}$ & 217,5 & 220,9 & 224,5 & 228,3 & 174,8 \\
\hline $\mathrm{C}_{2} \mathrm{H}_{2}$ & ${ }^{1} J_{\mathrm{CH}}$ & 263,5 & 264,2 & 265,1 & 266,0 & 247,6 \\
\hline $\mathrm{C}_{2} \mathrm{H}_{2}$ & ${ }^{2} J_{\mathrm{CH}}$ & 53,9 & 53,7 & 53,3 & 52,7 & 50,1 \\
\hline $\mathrm{C}_{2} \mathrm{H}_{2}$ & ${ }^{3} J_{\mathrm{HH}}$ & 9,3 & 9,7 & 10,3 & 10,9 & 9,6 \\
\hline $\mathrm{C}_{2} \mathrm{H}_{4}$ & ${ }^{1} J_{\mathrm{CC}}$ & 82,5 & 85,5 & 88,7 & 92,0 & 67,6 \\
\hline $\mathrm{C}_{2} \mathrm{H}_{4}$ & ${ }^{1} J_{\mathrm{CH}}$ & 163,5 & 164,8 & 166,2 & 167,6 & 156,3 \\
\hline $\mathrm{C}_{2} \mathrm{H}_{4}$ & ${ }^{2} J_{\mathrm{CH}}$ & $-1,5$ & $-2,5$ & $-3,5$ & $-4,6$ & $-2,4$ \\
\hline $\mathrm{C}_{2} \mathrm{H}_{4}$ & ${ }^{2} J_{\mathrm{HH}}$ & 3,3 & 2,5 & 1,7 & 0,9 & 2,3 \\
\hline $\mathrm{C}_{2} \mathrm{H}_{4}$ & ${ }^{3} J_{\mathrm{HH}_{\mathrm{c}}}$ & 12,4 & 12,8 & 13,2 & 13,6 & 11,7 \\
\hline $\mathrm{C}_{2} \mathrm{H}_{4}$ & ${ }^{3} J_{\mathrm{HH}_{\mathrm{t}}}{ }^{\mathrm{C}}$ & 18,9 & 19,1 & 19,4 & 19,8 & 19,0 \\
\hline $\mathrm{C}_{2} \mathrm{H}_{6}$ & ${ }^{1} J_{\mathrm{CC}}$ & 38,2 & 40,2 & 42,3 & 44,5 & 34,5 \\
\hline $\mathrm{C}_{2} \mathrm{H}_{6}$ & ${ }^{1} J_{\mathrm{CH}}$ & 131,3 & 132,5 & 133,6 & 134,6 & 125,2 \\
\hline $\mathrm{C}_{2} \mathrm{H}_{6}$ & ${ }^{2} J_{\mathrm{CH}}$ & $-3,3$ & $-3,8$ & $-4,3$ & $-4,9$ & $-4,7$ \\
\hline \multirow[t]{3}{*}{ Total } & $\mathrm{DM}$ & $-3,11$ & 2,16 & 7,69 & 13,33 & - \\
\hline & DMA & 16,52 & 14,10 & 16,25 & 19,80 & - \\
\hline & PDMA & 23,39 & 13,19 & 17,82 & 30,65 & - \\
\hline \multirow[t]{3}{*}{ CPI } & $\mathrm{DM}$ & $-17,06$ & $-5,54$ & 6,54 & 18,85 & - \\
\hline & DMA & 29,26 & 22,66 & 26,45 & 33,33 & - \\
\hline & PDMA & 35,27 & 17,44 & 22,17 & 42,70 & - \\
\hline \multirow[t]{3}{*}{ SPI } & $\mathrm{DM}$ & 7,12 & 7,80 & 8,54 & 9,27 & - \\
\hline & DMA & 7,17 & 7,81 & 8,77 & 9,87 & - \\
\hline & PDMA & 14,67 & 10,07 & 14,63 & 21,82 & - \\
\hline \multirow[t]{3}{*}{$\Delta \mathrm{CS}$} & $\mathrm{DM}$ & $-24,18$ & $-13,34$ & $-2,00$ & 9,58 & - \\
\hline & DMA & 22,09 & 14,85 & 17,68 & 23,45 & - \\
\hline & PDMA & 20,59 & 7,37 & 7,54 & 20,88 & - \\
\hline \multicolumn{7}{|c|}{ Desconsiderando ${ }^{1} J_{\mathrm{BF}}$ da molécula de $\mathrm{BF}_{3},{ }^{2} J_{\mathrm{CH}}$ e ${ }^{2} J_{\mathrm{HH}}$ da molécula de $\mathrm{C}_{2} \mathrm{H}_{4}$} \\
\hline \multirow[t]{3}{*}{ Total } & $\mathrm{DM}$ & $-2,00$ & 2,90 & 8,13 & 13,53 & - \\
\hline & DMA & 17,00 & 15,46 & 17,66 & 20,53 & - \\
\hline & PDMA & 12,28 & 11,27 & 12,79 & 16,77 & - \\
\hline \multirow[t]{3}{*}{ CPI } & DM & $-15,10$ & $-5,03$ & 5,73 & 16,86 & - \\
\hline & DMA & 28,52 & 23,87 & 27,63 & 32,78 & - \\
\hline & PDMA & 14,33 & 12,12 & 14,66 & 21,10 & - \\
\hline \multirow[t]{3}{*}{ SPI } & DM & 8,07 & 8,99 & 9,98 & 10,98 & - \\
\hline & DMA & 8,13 & 8,99 & 9,98 & 11,12 & - \\
\hline & PDMA & 10,70 & 10,63 & 11,35 & 13,44 & - \\
\hline \multirow[t]{3}{*}{$\Delta \mathrm{CS}$} & DM & $-23,17$ & $-14,02$ & $-4,25$ & 5,88 & - \\
\hline & DMA & 20,39 & 14,88 & 17,65 & 21,66 & - \\
\hline & PDMA & 3,63 & 1,49 & 3,31 & 7,66 & - \\
\hline
\end{tabular}


Tabela 8.298: Constantes de acoplamento PW91B95 com geometrias otimizadas na base aug-pcJ-2.

\begin{tabular}{|c|c|c|c|c|c|c|}
\hline & $\% E_{X}^{\mathrm{HF}}$ & $30 \%$ & $40 \%$ & $50 \%$ & $60 \%$ & Exp. \\
\hline $\mathrm{HF}$ & ${ }^{1} J_{\mathrm{HF}}$ & 484,8 & 521,1 & 556,9 & 592,1 & 500,0 \\
\hline $\mathrm{CO}$ & ${ }^{1} J_{\mathrm{CO}}$ & 15,2 & 12,1 & 8,9 & 5,8 & 16,4 \\
\hline $\mathrm{H}_{2} \mathrm{O}$ & ${ }^{1} J_{\mathrm{OH}}$ & $-80,4$ & $-84,3$ & $-88,1$ & $-91,7$ & $-80,6$ \\
\hline $\mathrm{H}_{2} \mathrm{O}$ & ${ }^{2} J_{\mathrm{HH}}$ & $-6,3$ & $-7,1$ & $-7,9$ & $-8,7$ & $-7,3$ \\
\hline $\mathrm{NH}_{3}$ & ${ }^{1} J_{\mathrm{NH}}$ & 45,4 & 46,5 & 47,6 & 48,5 & 43,8 \\
\hline $\mathrm{NH}_{3}$ & ${ }^{2} J_{\mathrm{HH}}$ & $-8,8$ & $-9,5$ & $-10,3$ & $-11,0$ & $-9,6$ \\
\hline $\mathrm{PH}_{3}$ & ${ }^{1} J_{\mathrm{PH}}$ & 178,0 & 187,7 & 196,9 & 205,7 & 188,2 \\
\hline $\mathrm{PF}_{3}$ & ${ }^{1} J_{\mathrm{PF}}$ & $-1531,9$ & $-1504,4$ & $-1470,0$ & $-1430,4$ & $-1441,0$ \\
\hline $\mathrm{BHF}_{2}$ & ${ }^{1} J_{\mathrm{BF}}$ & $-119,4$ & $-97,0$ & $-75,6$ & $-54,7$ & $-84,0$ \\
\hline $\mathrm{BF}_{3}$ & ${ }^{1} J_{\mathrm{BF}}$ & $-19,7$ & 5,3 & 29,3 & 52,4 & 15,0 \\
\hline $\mathrm{F}_{2} \mathrm{O}$ & ${ }^{1} J_{\mathrm{OF}}$ & $-238,6$ & $-216,3$ & $-195,4$ & $-176,2$ & $-300,0$ \\
\hline $\mathrm{CH}_{4}$ & ${ }^{1} J_{\mathrm{CH}}$ & 125,0 & 125,8 & 126,6 & 127,3 & 125,3 \\
\hline $\mathrm{CH}_{4}$ & ${ }^{2} J_{\mathrm{HH}}$ & $-12,0$ & $-12,7$ & $-13,5$ & $-14,2$ & $-12,8$ \\
\hline $\mathrm{C}_{2} \mathrm{H}_{2}$ & ${ }^{1} J_{\mathrm{CC}}$ & 196,8 & 199,8 & 202,9 & 206,4 & 174,8 \\
\hline $\mathrm{C}_{2} \mathrm{H}_{2}$ & ${ }^{1} J_{\mathrm{CH}}$ & 254,0 & 254,3 & 254,7 & 255,2 & 247,6 \\
\hline $\mathrm{C}_{2} \mathrm{H}_{2}$ & ${ }^{2} J_{\mathrm{CH}}$ & 55,6 & 55,4 & 55,1 & 54,6 & 50,1 \\
\hline $\mathrm{C}_{2} \mathrm{H}_{2}$ & ${ }^{3} J_{\mathrm{HH}}$ & 9,8 & 10,3 & 10,8 & 11,5 & 9,6 \\
\hline $\mathrm{C}_{2} \mathrm{H}_{4}$ & ${ }^{1} J_{\mathrm{CC}}$ & 69,9 & 72,5 & 75,2 & 78,2 & 67,6 \\
\hline $\mathrm{C}_{2} \mathrm{H}_{4}$ & ${ }^{1} J_{\mathrm{CH}}$ & 156,3 & 157,3 & 158,4 & 159,6 & 156,3 \\
\hline $\mathrm{C}_{2} \mathrm{H}_{4}$ & ${ }^{2} J_{\mathrm{CH}}$ & $-1,0$ & $-1,9$ & $-2,9$ & $-4,0$ & $-2,4$ \\
\hline $\mathrm{C}_{2} \mathrm{H}_{4}$ & ${ }^{2} J_{\mathrm{HH}}$ & 2,9 & 2,1 & 1,3 & 0,5 & 2,3 \\
\hline $\mathrm{C}_{2} \mathrm{H}_{4}$ & ${ }^{3} J_{\mathrm{HH}_{\mathrm{c}}}$ & 13,0 & 13,3 & 13,7 & 14,2 & 11,7 \\
\hline $\mathrm{C}_{2} \mathrm{H}_{4}$ & ${ }^{3} J_{\mathrm{HH}_{\mathrm{t}}}$ & 19,5 & 19,8 & 20,1 & 20,4 & 19,0 \\
\hline $\mathrm{C}_{2} \mathrm{H}_{6}$ & ${ }^{1} J_{\mathrm{CC}}$ & 33,4 & 35,2 & 37,2 & 39,0 & 34,5 \\
\hline $\mathrm{C}_{2} \mathrm{H}_{6}$ & ${ }^{1} J_{\mathrm{CH}}$ & 123,8 & 124,8 & 125,6 & 126,5 & 125,2 \\
\hline $\mathrm{C}_{2} \mathrm{H}_{6}$ & ${ }^{2} J_{\mathrm{CH}}$ & $-3,5$ & $-4,0$ & $-4,5$ & $-5,0$ & $-4,7$ \\
\hline \multirow[t]{3}{*}{ Total } & $\mathrm{DM}$ & $-3,20$ & 2,35 & 8,00 & 13,73 & - \\
\hline & DMA & 11,45 & 9,67 & 11,65 & 16,01 & - \\
\hline & PDMA & 19,54 & 10,24 & 15,29 & 28,89 & - \\
\hline \multirow[t]{3}{*}{ CPI } & $\mathrm{DM}$ & $-11,15$ & 1,20 & 13,76 & 26,45 & - \\
\hline & DMA & 22,96 & 18,40 & 22,00 & 30,90 & - \\
\hline & PDMA & 31,09 & 14,33 & 21,59 & 43,35 & - \\
\hline \multirow[t]{3}{*}{ SPI } & $\mathrm{DM}$ & 2,63 & 3,19 & 3,77 & 4,41 & - \\
\hline & DMA & 3,00 & 3,27 & 4,07 & 5,09 & - \\
\hline & PDMA & 11,08 & 7,24 & 10,67 & 18,29 & - \\
\hline \multirow[t]{3}{*}{$\Delta \mathrm{CS}$} & $\mathrm{DM}$ & $-13,77$ & $-1,99$ & 9,99 & 22,04 & - \\
\hline & DMA & 19,96 & 15,13 & 17,93 & 25,81 & - \\
\hline & PDMA & 20,01 & 7,09 & 10,91 & 25,06 & - \\
\hline \multicolumn{7}{|c|}{ Desconsiderando ${ }^{1} J_{\mathrm{BF}}$ da molécula de $\mathrm{BF}_{3},{ }^{2} J_{\mathrm{CH}}$ e ${ }^{2} J_{\mathrm{HH}}$ da molécula de $\mathrm{C}_{2} \mathrm{H}_{4}$} \\
\hline \multirow[t]{3}{*}{ Total } & $\mathrm{DM}$ & $-2,20$ & 3,07 & 8,49 & 14,04 & - \\
\hline & DMA & 11,34 & 10,48 & 12,49 & 16,32 & - \\
\hline & PDMA & 8,36 & 7,48 & 10,34 & 15,52 & - \\
\hline \multirow[t]{3}{*}{ CPI } & DM & $-8,79$ & 2,29 & 13,71 & 25,35 & - \\
\hline & DMA & 21,79 & 19,27 & 22,77 & 30,25 & - \\
\hline & PDMA & 11,06 & 9,30 & 14,21 & 22,75 & - \\
\hline \multirow[t]{3}{*}{ SPI } & $\mathrm{DM}$ & 2,88 & 3,66 & 4,47 & 5,35 & - \\
\hline & DMA & 3,31 & 3,72 & 4,58 & 5,61 & - \\
\hline & PDMA & 6,29 & 6,08 & 7,37 & 9,96 & - \\
\hline \multirow[t]{3}{*}{$\Delta \mathrm{CS}$} & DM & $-11,67$ & $-1,37$ & 9,24 & 20,00 & - \\
\hline & DMA & 18,48 & 15,55 & 18,19 & 24,64 & - \\
\hline & PDMA & 4,78 & 3,22 & 6,84 & 12,79 & - \\
\hline
\end{tabular}


Tabela 8.299: Constantes de acoplamento PW91B971 com geometrias otimizadas na base aug-pcJ-2.

\begin{tabular}{|c|c|c|c|c|c|c|}
\hline PW91 & $\% E_{X}^{\mathrm{HF}}$ & $20 \%$ & $30 \%$ & $40 \%$ & $50 \%$ & Exp. \\
\hline $\mathrm{HF}$ & ${ }^{1} J_{\mathrm{HF}}$ & 457,6 & 492,9 & 527,6 & 561,8 & 500,0 \\
\hline $\mathrm{CO}$ & ${ }^{1} J_{\mathrm{CO}}$ & 15,5 & 12,2 & 8,9 & 5,6 & 16,4 \\
\hline $\mathrm{H}_{2} \mathrm{O}$ & ${ }^{1} J_{\mathrm{OH}}$ & $-77,5$ & $-81,5$ & $-85,2$ & $-88,8$ & $-80,6$ \\
\hline $\mathrm{H}_{2} \mathrm{O}$ & ${ }^{2} J_{\mathrm{HH}}$ & $-5,2$ & $-6,0$ & $-6,8$ & $-7,5$ & $-7,3$ \\
\hline $\mathrm{NH}_{3}$ & ${ }^{1} J_{\mathrm{NH}}$ & 45,8 & 46,9 & 48,0 & 49,1 & 43,8 \\
\hline $\mathrm{NH}_{3}$ & ${ }^{2} J_{\mathrm{HH}}$ & $-8,0$ & $-8,8$ & $-9,4$ & $-10,2$ & $-9,6$ \\
\hline $\mathrm{PH}_{3}$ & ${ }^{1} J_{\mathrm{PH}}$ & 196,5 & 205,7 & 214,4 & 222,5 & 188,2 \\
\hline $\mathrm{PF}_{3}$ & ${ }^{1} J_{\mathrm{PF}}$ & $-1599,1$ & $-1575,7$ & $-1543,9$ & $-1505,4$ & $-1441,0$ \\
\hline $\mathrm{BHF}_{2}$ & ${ }^{1} J_{\mathrm{BF}}$ & $-123,1$ & $-99,2$ & $-76,1$ & $-53,8$ & $-84,0$ \\
\hline $\mathrm{BF}_{3}$ & ${ }^{1} J_{\mathrm{BF}}$ & $-26,2$ & 0,5 & 26,0 & 50,6 & 15,0 \\
\hline $\mathrm{F}_{2} \mathrm{O}$ & ${ }^{1} J_{\mathrm{OF}}$ & $-252,5$ & $-232,3$ & $-212,7$ & $-194,3$ & $-300,0$ \\
\hline $\mathrm{CH}_{4}$ & ${ }^{1} J_{\mathrm{CH}}$ & 132,5 & 133,5 & 134,4 & 135,4 & 125,3 \\
\hline $\mathrm{CH}_{4}$ & ${ }^{2} J_{\mathrm{HH}}$ & $-11,3$ & $-12,1$ & $-12,9$ & $-13,6$ & $-12,8$ \\
\hline $\mathrm{C}_{2} \mathrm{H}_{2}$ & ${ }^{1} J_{\mathrm{CC}}$ & 216,1 & 219,5 & 223,2 & 227,2 & 174,8 \\
\hline $\mathrm{C}_{2} \mathrm{H}_{2}$ & ${ }^{1} J_{\mathrm{CH}}$ & 264,4 & 265,0 & 265,6 & 266,5 & 247,6 \\
\hline $\mathrm{C}_{2} \mathrm{H}_{2}$ & ${ }^{2} J_{\mathrm{CH}}$ & 54,2 & 53,9 & 53,5 & 52,9 & 50,1 \\
\hline $\mathrm{C}_{2} \mathrm{H}_{2}$ & ${ }^{3} J_{\mathrm{HH}}$ & 9,4 & 9,8 & 10,3 & 11,0 & 9,6 \\
\hline $\mathrm{C}_{2} \mathrm{H}_{4}$ & ${ }^{1} J_{\mathrm{CC}}$ & 81,2 & 84,3 & 87,6 & 91,1 & 67,6 \\
\hline $\mathrm{C}_{2} \mathrm{H}_{4}$ & ${ }^{1} J_{\mathrm{CH}}$ & 163,7 & 165,0 & 166,3 & 167,7 & 156,3 \\
\hline $\mathrm{C}_{2} \mathrm{H}_{4}$ & ${ }^{2} J_{\mathrm{CH}}$ & $-1,4$ & $-2,4$ & $-3,5$ & $-4,6$ & $-2,4$ \\
\hline $\mathrm{C}_{2} \mathrm{H}_{4}$ & ${ }^{2} J_{\mathrm{HH}}$ & 3,2 & 2,4 & 1,6 & 0,8 & 2,3 \\
\hline $\mathrm{C}_{2} \mathrm{H}_{4}$ & ${ }^{3} J_{\mathrm{HH}_{\mathrm{c}}}$ & 12,6 & 13,0 & 13,3 & 13,8 & 11,7 \\
\hline $\mathrm{C}_{2} \mathrm{H}_{4}$ & ${ }^{3} J_{\mathrm{HH}_{\mathrm{t}}}{ }^{\mathrm{C}}$ & 19,1 & 19,3 & 19,6 & 20,0 & 19,0 \\
\hline $\mathrm{C}_{2} \mathrm{H}_{6}$ & ${ }^{1} J_{\mathrm{CC}}$ & 37,3 & 39,4 & 41,6 & 44,0 & 34,5 \\
\hline $\mathrm{C}_{2} \mathrm{H}_{6}$ & ${ }^{1} J_{\mathrm{CH}}$ & 131,4 & 132,5 & 133,6 & 134,7 & 125,2 \\
\hline $\mathrm{C}_{2} \mathrm{H}_{6}$ & ${ }^{2} J_{\mathrm{CH}}$ & $-3,3$ & $-3,8$ & $-4,4$ & $-4,9$ & $-4,7$ \\
\hline \multirow[t]{3}{*}{ Total } & $\mathrm{DM}$ & $-4,31$ & 1,12 & 6,75 & 12,56 & - \\
\hline & DMA & 17,37 & 14,70 & 15,75 & 19,40 & - \\
\hline & PDMA & 24,43 & 13,77 & 16,47 & 29,78 & - \\
\hline \multirow[t]{3}{*}{ CPI } & $\mathrm{DM}$ & $-19,74$ & $-7,84$ & 4,54 & 17,15 & - \\
\hline & DMA & 31,48 & 24,27 & 25,45 & 32,46 & - \\
\hline & PDMA & 38,20 & 19,76 & 18,94 & 40,06 & - \\
\hline \multirow[t]{3}{*}{ SPI } & $\mathrm{DM}$ & 7,00 & 7,68 & 8,38 & 9,19 & - \\
\hline & DMA & 7,03 & 7,68 & 8,63 & 9,82 & - \\
\hline & PDMA & 14,32 & 9,38 & 14,66 & 22,24 & - \\
\hline \multirow[t]{3}{*}{$\Delta \mathrm{CS}$} & DM & $-26,74$ & $-15,52$ & $-3,84$ & 7,96 & - \\
\hline & DMA & 24,46 & 16,59 & 16,81 & 22,64 & - \\
\hline & PDMA & 23,88 & 10,37 & 4,29 & 17,82 & - \\
\hline \multicolumn{7}{|c|}{ Desconsiderando ${ }^{1} J_{\mathrm{BF}}$ da molécula de $\mathrm{BF}_{3},{ }^{2} J_{\mathrm{CH}}$ e ${ }^{2} J_{\mathrm{HH}}$ da molécula de $\mathrm{C}_{2} \mathrm{H}_{4}$} \\
\hline \multirow[t]{3}{*}{ Total } & $\mathrm{DM}$ & $-3,17$ & 1,89 & 7,23 & 12,81 & - \\
\hline & DMA & 17,77 & 15,98 & 17,24 & 20,22 & - \\
\hline & PDMA & 12,16 & 11,18 & 12,11 & 16,53 & - \\
\hline \multirow[t]{3}{*}{ CPI } & DM & $-17,59$ & $-7,17$ & 3,89 & 15,31 & - \\
\hline & DMA & 30,51 & 25,25 & 26,89 & 32,15 & - \\
\hline & PDMA & 14,56 & 12,07 & 13,50 & 20,34 & - \\
\hline \multirow[t]{3}{*}{ SPI } & DM & 7,93 & 8,85 & 9,81 & 10,89 & - \\
\hline & DMA & 7,96 & 8,85 & 9,82 & 11,05 & - \\
\hline & PDMA & 10,31 & 10,49 & 11,04 & 13,60 & - \\
\hline \multirow[t]{3}{*}{$\Delta \mathrm{CS}$} & DM & $-25,52$ & $-16,02$ & $-5,92$ & 4,42 & - \\
\hline & DMA & 22,55 & 16,40 & 17,07 & 21,10 & - \\
\hline & PDMA & 4,24 & 1,57 & 2,46 & 6,74 & - \\
\hline
\end{tabular}


Tabela 8.300: Constantes de acoplamento SB971 com geometrias otimizadas na base aug-pcJ-2.

\begin{tabular}{|c|c|c|c|c|c|c|}
\hline & $\% E_{X}^{\mathrm{HF}}$ & $30 \%$ & $40 \%$ & $50 \%$ & $60 \%$ & Exp. \\
\hline $\mathrm{HF}$ & ${ }^{1} J_{\mathrm{HF}}$ & 486,1 & 519,4 & 552,9 & 586,7 & 500,0 \\
\hline $\mathrm{CO}$ & ${ }^{1} J_{\mathrm{CO}}$ & 14,5 & 11,2 & 7,7 & 4,2 & 16,4 \\
\hline $\mathrm{H}_{2} \mathrm{O}$ & ${ }^{1} J_{\mathrm{OH}}$ & $-77,0$ & $-81,0$ & $-85,0$ & $-88,9$ & $-80,6$ \\
\hline $\mathrm{H}_{2} \mathrm{O}$ & ${ }^{2} J_{\mathrm{HH}}$ & $-4,3$ & $-5,2$ & $-6,1$ & $-7,1$ & $-7,3$ \\
\hline $\mathrm{NH}_{3}$ & ${ }^{1} J_{\mathrm{NH}}$ & 42,5 & 44,1 & 45,7 & 47,2 & 43,8 \\
\hline $\mathrm{NH}_{3}$ & ${ }^{2} J_{\mathrm{HH}}$ & $-6,3$ & $-7,3$ & $-8,2$ & $-9,3$ & $-9,6$ \\
\hline $\mathrm{PH}_{3}$ & ${ }^{1} J_{\mathrm{PH}}$ & 182,3 & 193,3 & 204,3 & 215,1 & 188,2 \\
\hline $\mathrm{PF}_{3}$ & ${ }^{1} J_{\mathrm{PF}}$ & $-1570,7$ & $-1537,8$ & $-1501,2$ & $-1459,3$ & $-1441,0$ \\
\hline $\mathrm{BHF}_{2}$ & ${ }^{1} J_{\mathrm{BF}}$ & $-101,8$ & $-79,7$ & $-57,8$ & $-36,1$ & $-84,0$ \\
\hline $\mathrm{BF}_{3}$ & ${ }^{1} J_{\mathrm{BF}}$ & 5,7 & 28,8 & 51,5 & 73,9 & 15,0 \\
\hline $\mathrm{F}_{2} \mathrm{O}$ & ${ }^{1} J_{\mathrm{OF}}$ & $-129,5$ & $-125,7$ & $-123,0$ & $-121,5$ & $-300,0$ \\
\hline $\mathrm{CH}_{4}$ & ${ }^{1} J_{\mathrm{CH}}$ & 114,2 & 117,5 & 121,0 & 124,6 & 125,3 \\
\hline $\mathrm{CH}_{4}$ & ${ }^{2} J_{\mathrm{HH}}$ & $-9,3$ & $-10,3$ & $-11,4$ & $-12,5$ & $-12,8$ \\
\hline $\mathrm{C}_{2} \mathrm{H}_{2}$ & ${ }^{1} J_{\mathrm{CC}}$ & 198,6 & 204,2 & 210,3 & 217,0 & 174,8 \\
\hline $\mathrm{C}_{2} \mathrm{H}_{2}$ & ${ }^{1} J_{\mathrm{CH}}$ & 231,8 & 236,6 & 241,6 & 247,0 & 247,6 \\
\hline $\mathrm{C}_{2} \mathrm{H}_{2}$ & ${ }^{2} J_{\mathrm{CH}}$ & 50,9 & 51,3 & 51,4 & 51,3 & 50,1 \\
\hline $\mathrm{C}_{2} \mathrm{H}_{2}$ & ${ }^{3} J_{\mathrm{HH}}$ & 7,7 & 8,3 & 9,1 & 10,0 & 9,6 \\
\hline $\mathrm{C}_{2} \mathrm{H}_{4}$ & ${ }^{1} J_{\mathrm{CC}}$ & 70,0 & 74,4 & 79,1 & 84,3 & 67,6 \\
\hline $\mathrm{C}_{2} \mathrm{H}_{4}$ & ${ }^{1} J_{\mathrm{CH}}$ & 142,3 & 146,3 & 150,6 & 155,0 & 156,3 \\
\hline $\mathrm{C}_{2} \mathrm{H}_{4}$ & ${ }^{2} J_{\mathrm{CH}}$ & $-1,3$ & $-2,2$ & $-3,3$ & $-4,5$ & $-2,4$ \\
\hline $\mathrm{C}_{2} \mathrm{H}_{4}$ & ${ }^{2} J_{\mathrm{HH}}$ & 3,0 & 2,3 & 1,5 & 0,7 & 2,3 \\
\hline $\mathrm{C}_{2} \mathrm{H}_{4}$ & ${ }^{3} J_{\mathrm{HH}_{\mathrm{c}}}$ & 12,1 & 12,5 & 13,0 & 13,5 & 11,7 \\
\hline $\mathrm{C}_{2} \mathrm{H}_{4}$ & ${ }^{3} J_{\mathrm{HH}_{\mathrm{t}}}{ }^{\mathrm{C}}$ & 17,0 & 17,5 & 18,1 & 18,7 & 19,0 \\
\hline $\mathrm{C}_{2} \mathrm{H}_{6}$ & ${ }^{1} J_{\mathrm{CC}}$ & 32,4 & 35,1 & 38,0 & 41,1 & 34,5 \\
\hline $\mathrm{C}_{2} \mathrm{H}_{6}$ & ${ }^{1} J_{\mathrm{CH}}$ & 112,3 & 115,9 & 119,7 & 123,5 & 125,2 \\
\hline $\mathrm{C}_{2} \mathrm{H}_{6}$ & ${ }^{2} J_{\mathrm{CH}}$ & $-3,1$ & $-3,7$ & $-4,3$ & $-4,8$ & $-4,7$ \\
\hline \multirow[t]{3}{*}{ Total } & DM & $-0,96$ & 4,65 & 10,39 & 16,34 & - \\
\hline & DMA & 17,47 & 15,67 & 17,92 & 19,97 & - \\
\hline & PDMA & 18,47 & 14,89 & 24,13 & 34,48 & - \\
\hline \multirow[t]{3}{*}{ CPI } & DM & 0,05 & 10,84 & 21,81 & 33,09 & - \\
\hline & DMA & 32,75 & 29,45 & 35,14 & 40,15 & - \\
\hline & PDMA & 22,68 & 23,10 & 40,97 & 58,22 & - \\
\hline \multirow[t]{3}{*}{ SPI } & $\mathrm{DM}$ & $-1,70$ & 0,11 & 2,02 & 4,05 & - \\
\hline & DMA & 6,27 & 5,56 & 5,30 & 5,17 & - \\
\hline & PDMA & 15,38 & 8,86 & 11,78 & 17,07 & - \\
\hline \multirow[t]{3}{*}{$\Delta \mathrm{CS}$} & DM & 1,75 & 10,73 & 19,79 & 29,04 & - \\
\hline & DMA & 26,47 & 23,89 & 29,84 & 34,97 & - \\
\hline & PDMA & 7,29 & 14,24 & 29,19 & 41,15 & - \\
\hline \multicolumn{7}{|c|}{ Desconsiderando ${ }^{1} J_{\mathrm{BF}}$ da molécula de $\mathrm{BF}_{3},{ }^{2} J_{\mathrm{CH}}$ e ${ }^{2} J_{\mathrm{HH}}$ da molécula de $\mathrm{C}_{2} \mathrm{H}_{4}$} \\
\hline \multirow[t]{3}{*}{ Total } & $\mathrm{DM}$ & $-0,76$ & 4,64 & 10,23 & 16,07 & - \\
\hline & DMA & 19,27 & 17,10 & 18,60 & 19,85 & - \\
\hline & PDMA & 14,87 & 12,47 & 13,56 & 15,07 & - \\
\hline \multirow[t]{3}{*}{ CPI } & DM & 0,99 & 10,54 & 20,34 & 30,51 & - \\
\hline & DMA & 35,09 & 31,02 & 35,00 & 38,27 & - \\
\hline & PDMA & 18,74 & 16,21 & 20,74 & 24,77 & - \\
\hline \multirow[t]{3}{*}{ SPI } & DM & $-2,10$ & 0,11 & 2,46 & 4,96 & - \\
\hline & DMA & 7,10 & 6,40 & 5,98 & 5,68 & - \\
\hline & PDMA & 11,88 & 9,58 & 8,04 & 7,61 & - \\
\hline \multirow[t]{3}{*}{$\Delta \mathrm{CS}$} & $\mathrm{DM}$ & 3,09 & 10,43 & 17,88 & 25,55 & - \\
\hline & DMA & 27,99 & 24,62 & 29,02 & 32,59 & - \\
\hline & PDMA & 6,86 & 6,63 & 12,70 & 17,16 & - \\
\hline
\end{tabular}


Tabela 8.301: Constantes de acoplamento SB972 com geometrias otimizadas na base aug-pcJ-2.

\begin{tabular}{|c|c|c|c|c|c|c|}
\hline & $\% E_{X}^{\mathrm{HF}}$ & $20 \%$ & $30 \%$ & $40 \%$ & $50 \%$ & Exp. \\
\hline $\mathrm{HF}$ & ${ }^{1} J_{\mathrm{HF}}$ & 478,2 & 514,4 & 549,4 & 584,7 & 500,0 \\
\hline $\mathrm{CO}$ & ${ }^{1} J_{\mathrm{CO}}$ & 13,9 & 10,3 & 6,6 & 2,8 & 16,4 \\
\hline $\mathrm{H}_{2} \mathrm{O}$ & ${ }^{1} J_{\mathrm{OH}}$ & $-77,9$ & $-82,2$ & $-86,5$ & $-90,7$ & $-80,6$ \\
\hline $\mathrm{H}_{2} \mathrm{O}$ & ${ }^{2} J_{\mathrm{HH}}$ & $-3,3$ & $-4,2$ & $-5,1$ & $-6,0$ & $-7,3$ \\
\hline $\mathrm{NH}_{3}$ & ${ }^{1} J_{\mathrm{NH}}$ & 43,5 & 44,9 & 46,6 & 48,1 & 43,8 \\
\hline $\mathrm{NH}_{3}$ & ${ }^{2} J_{\mathrm{HH}}$ & $-4,8$ & $-5,7$ & $-6,6$ & $-7,5$ & $-9,6$ \\
\hline $\mathrm{PH}_{3}$ & ${ }^{1} J_{\mathrm{PH}}$ & 159,7 & 172,5 & 186,0 & 199,5 & 188,2 \\
\hline $\mathrm{PF}_{3}$ & ${ }^{1} J_{\mathrm{PF}}$ & $-1636,2$ & $-1612,3$ & $-1580,3$ & $-1542,0$ & $-1441,0$ \\
\hline $\mathrm{BHF}_{2}$ & ${ }^{1} J_{\mathrm{BF}}$ & $-117,2$ & $-94,8$ & $-72,7$ & $-50,9$ & $-84,0$ \\
\hline $\mathrm{BF}_{3}$ & ${ }^{1} J_{\mathrm{BF}}$ & $-9,9$ & 13,7 & 37,0 & 59,8 & 15,0 \\
\hline $\mathrm{F}_{2} \mathrm{O}$ & ${ }^{1} J_{\mathrm{OF}}$ & $-163,3$ & $-156,5$ & $-150,6$ & $-145,8$ & $-300,0$ \\
\hline $\mathrm{CH}_{4}$ & ${ }^{1} J_{\mathrm{CH}}$ & 113,4 & 116,5 & 119,8 & 123,1 & 125,3 \\
\hline $\mathrm{CH}_{4}$ & ${ }^{2} J_{\mathrm{HH}}$ & $-7,2$ & $-8,1$ & $-9,1$ & $-10,1$ & $-12,8$ \\
\hline $\mathrm{C}_{2} \mathrm{H}_{2}$ & ${ }^{1} J_{\mathrm{CC}}$ & 192,3 & 197,6 & 203,4 & 209,7 & 174,8 \\
\hline $\mathrm{C}_{2} \mathrm{H}_{2}$ & ${ }^{1} J_{\mathrm{CH}}$ & 229,3 & 233,6 & 238,1 & 242,8 & 247,6 \\
\hline $\mathrm{C}_{2} \mathrm{H}_{2}$ & ${ }^{2} J_{\mathrm{CH}}$ & 50,6 & 51,1 & 51,5 & 51,7 & 50,1 \\
\hline $\mathrm{C}_{2} \mathrm{H}_{2}$ & ${ }^{3} J_{\mathrm{HH}}$ & 6,6 & 7,1 & 7,6 & 8,3 & 9,6 \\
\hline $\mathrm{C}_{2} \mathrm{H}_{4}$ & ${ }^{1} J_{\mathrm{CC}}$ & 66,1 & 70,3 & 74,8 & 79,7 & 67,6 \\
\hline $\mathrm{C}_{2} \mathrm{H}_{4}$ & ${ }^{1} J_{\mathrm{CH}}$ & 140,4 & 144,1 & 148,0 & 152,1 & 156,3 \\
\hline $\mathrm{C}_{2} \mathrm{H}_{4}$ & ${ }^{2} J_{\mathrm{CH}}$ & 0,2 & $-0,5$ & $-1,4$ & $-2,5$ & $-2,4$ \\
\hline $\mathrm{C}_{2} \mathrm{H}_{4}$ & ${ }^{2} J_{\mathrm{HH}}$ & 4,6 & 4,0 & 3,3 & 2,6 & 2,3 \\
\hline $\mathrm{C}_{2} \mathrm{H}_{4}$ & ${ }^{3} J_{\mathrm{HH}_{\mathrm{c}}}$ & 11,4 & 11,7 & 12,0 & 12,4 & 11,7 \\
\hline $\mathrm{C}_{2} \mathrm{H}_{4}$ & ${ }^{3} J_{\mathrm{HH}_{\mathrm{t}}}$ & 16,3 & 16,6 & 17,0 & 17,5 & 19,0 \\
\hline $\mathrm{C}_{2} \mathrm{H}_{6}$ & ${ }^{1} J_{\mathrm{CC}}$ & 31,6 & 34,2 & 37,0 & 39,8 & 34,5 \\
\hline $\mathrm{C}_{2} \mathrm{H}_{6}$ & ${ }^{1} J_{\mathrm{CH}}$ & 110,7 & 114,1 & 117,5 & 121,1 & 125,2 \\
\hline $\mathrm{C}_{2} \mathrm{H}_{6}$ & ${ }^{2} J_{\mathrm{CH}}$ & $-2,0$ & $-2,5$ & $-3,0$ & $-3,5$ & $-4,7$ \\
\hline \multirow[t]{3}{*}{ Total } & $\mathrm{DM}$ & $-7,62$ & $-2,12$ & 3,67 & 9,68 & - \\
\hline & DMA & 21,42 & 17,73 & 18,45 & 20,67 & - \\
\hline & PDMA & 31,77 & 20,84 & 23,32 & 27,76 & - \\
\hline \multirow[t]{3}{*}{ CPI } & $\mathrm{DM}$ & $-14,38$ & $-3,71$ & 7,54 & 19,19 & - \\
\hline & DMA & 41,33 & 33,89 & 36,12 & 41,86 & - \\
\hline & PDMA & 37,11 & 19,75 & 33,23 & 51,31 & - \\
\hline \multirow[t]{3}{*}{ SPI } & $\mathrm{DM}$ & $-2,65$ & $-0,95$ & 0,83 & 2,71 & - \\
\hline & DMA & 6,81 & 5,89 & 5,49 & 5,13 & - \\
\hline & PDMA & 27,86 & 21,64 & 16,06 & 10,49 & - \\
\hline \multirow[t]{3}{*}{$\Delta \mathrm{CS}$} & $\mathrm{DM}$ & $-11,73$ & $-2,76$ & 6,71 & 16,48 & - \\
\hline & DMA & 34,51 & 28,00 & 30,62 & 36,73 & - \\
\hline & PDMA & 9,25 & $-1,89$ & 17,17 & 40,82 & - \\
\hline \multicolumn{7}{|c|}{ Desconsiderando ${ }^{1} J_{\mathrm{BF}}$ da molécula de $\mathrm{BF}_{3},{ }^{2} J_{\mathrm{CH}}$ e ${ }^{2} J_{\mathrm{HH}}$ da molécula de $\mathrm{C}_{2} \mathrm{H}_{4}$} \\
\hline \multirow[t]{3}{*}{ Total } & DM & $-7,74$ & $-2,50$ & 3,10 & 8,99 & - \\
\hline & DMA & 22,91 & 19,83 & 19,81 & 21,40 & - \\
\hline & PDMA & 19,64 & 16,52 & 16,29 & 17,65 & - \\
\hline \multirow[t]{3}{*}{ CPI } & DM & $-13,33$ & $-3,95$ & 6,09 & 16,63 & - \\
\hline & DMA & 42,97 & 37,15 & 37,53 & 41,57 & - \\
\hline & PDMA & 24,22 & 20,86 & 21,88 & 26,57 & - \\
\hline \multirow[t]{3}{*}{ SPI } & $\mathrm{DM}$ & $-3,44$ & $-1,38$ & 0,80 & 3,11 & - \\
\hline & DMA & 7,48 & 6,52 & 6,18 & 5,89 & - \\
\hline & PDMA & 16,12 & 13,19 & 11,98 & 10,78 & - \\
\hline \multirow[t]{3}{*}{$\Delta \mathrm{CS}$} & $\mathrm{DM}$ & $-9,89$ & $-2,57$ & 5,29 & 13,52 & - \\
\hline & DMA & 35,49 & 30,63 & 31,35 & 35,68 & - \\
\hline & PDMA & 8,11 & 7,67 & 9,90 & 15,79 & - \\
\hline
\end{tabular}


Tabela 8.302: Constantes de acoplamento SB98 com geometrias otimizadas na base aug-pcJ-2.

\begin{tabular}{|c|c|c|c|c|c|c|}
\hline & $\% E_{X}^{\mathrm{HF}}$ & $30 \%$ & $40 \%$ & $50 \%$ & $60 \%$ & Exp. \\
\hline $\mathrm{HF}$ & ${ }^{1} J_{\mathrm{HF}}$ & 471,7 & 505,2 & 538,9 & 572,9 & 500,0 \\
\hline $\mathrm{CO}$ & ${ }^{1} J_{\mathrm{CO}}$ & 14,6 & 11,2 & 7,8 & 4,3 & 16,4 \\
\hline $\mathrm{H}_{2} \mathrm{O}$ & ${ }^{1} J_{\mathrm{OH}}$ & $-76,2$ & $-80,3$ & $-84,4$ & $-88,4$ & $-80,6$ \\
\hline $\mathrm{H}_{2} \mathrm{O}$ & ${ }^{2} J_{\mathrm{HH}}$ & $-4,5$ & $-5,4$ & $-6,3$ & $-7,3$ & $-7,3$ \\
\hline $\mathrm{NH}_{3}$ & ${ }^{1} J_{\mathrm{NH}}$ & 43,2 & 44,8 & 46,4 & 48,0 & 43,8 \\
\hline $\mathrm{NH}_{3}$ & ${ }^{2} J_{\mathrm{HH}}$ & $-6,6$ & $-7,6$ & $-8,6$ & $-9,7$ & $-9,6$ \\
\hline $\mathrm{PH}_{3}$ & ${ }^{1} J_{\mathrm{PH}}$ & 189,2 & 200,5 & 211,6 & 222,6 & 188,2 \\
\hline $\mathrm{PF}_{3}$ & ${ }^{1} J_{\mathrm{PF}}$ & $-1586,1$ & $-1554,4$ & $-1516,3$ & $-1475,5$ & $-1441,0$ \\
\hline $\mathrm{BHF}_{2}$ & ${ }^{1} J_{\mathrm{BF}}$ & $-106,5$ & $-84,5$ & $-62,6$ & $-41,0$ & $-84,0$ \\
\hline $\mathrm{BF}_{3}$ & ${ }^{1} J_{\mathrm{BF}}$ & $-0,6$ & 22,4 & 45,1 & 67,4 & 15,0 \\
\hline $\mathrm{F}_{2} \mathrm{O}$ & ${ }^{1} J_{\mathrm{OF}}$ & $-162,2$ & $-158,4$ & $-155,6$ & $-154,0$ & $-300,0$ \\
\hline $\mathrm{CH}_{4}$ & ${ }^{1} J_{\mathrm{CH}}$ & 117,6 & 121,1 & 124,7 & 128,4 & 125,3 \\
\hline $\mathrm{CH}_{4}$ & ${ }^{2} J_{\mathrm{HH}}$ & $-9,8$ & $-10,9$ & $-12,0$ & $-13,1$ & $-12,8$ \\
\hline $\mathrm{C}_{2} \mathrm{H}_{2}$ & ${ }^{1} J_{\mathrm{CC}}$ & 201,8 & 207,6 & 213,9 & 220,8 & 174,8 \\
\hline $\mathrm{C}_{2} \mathrm{H}_{2}$ & ${ }^{1} J_{\mathrm{CH}}$ & 236,9 & 241,8 & 247,1 & 252,7 & 247,6 \\
\hline $\mathrm{C}_{2} \mathrm{H}_{2}$ & ${ }^{2} J_{\mathrm{CH}}$ & 51,4 & 51,7 & 51,8 & 51,7 & 50,1 \\
\hline $\mathrm{C}_{2} \mathrm{H}_{2}$ & ${ }^{3} J_{\mathrm{HH}}$ & 7,9 & 8,6 & 9,4 & 10,4 & 9,6 \\
\hline $\mathrm{C}_{2} \mathrm{H}_{4}$ & ${ }^{1} J_{\mathrm{CC}}$ & 72,2 & 76,7 & 81,7 & 87,1 & 67,6 \\
\hline $\mathrm{C}_{2} \mathrm{H}_{4}$ & ${ }^{1} J_{\mathrm{CH}}$ & 146,0 & 150,2 & 154,6 & 159,2 & 156,3 \\
\hline $\mathrm{C}_{2} \mathrm{H}_{4}$ & ${ }^{2} J_{\mathrm{CH}}$ & $-1,4$ & $-2,4$ & $-3,5$ & $-4,8$ & $-2,4$ \\
\hline $\mathrm{C}_{2} \mathrm{H}_{4}$ & ${ }^{2} J_{\mathrm{HH}}$ & 2,9 & 2,1 & 1,3 & 0,4 & 2,3 \\
\hline $\mathrm{C}_{2} \mathrm{H}_{4}$ & ${ }^{3} J_{\mathrm{HH}_{\mathrm{c}}}$ & 12,2 & 12,6 & 13,1 & 13,7 & 11,7 \\
\hline $\mathrm{C}_{2} \mathrm{H}_{4}$ & ${ }^{3} J_{\mathrm{HH}_{\mathrm{t}}}$ & 17,3 & 17,8 & 18,5 & 19,2 & 19,0 \\
\hline $\mathrm{C}_{2} \mathrm{H}_{6}$ & ${ }^{1} J_{\mathrm{CC}}$ & 33,3 & 36,3 & 39,3 & 42,2 & 34,5 \\
\hline $\mathrm{C}_{2} \mathrm{H}_{6}$ & ${ }^{1} J_{\mathrm{CH}}$ & 115,8 & 119,6 & 123,5 & 127,5 & 125,2 \\
\hline $\mathrm{C}_{2} \mathrm{H}_{6}$ & ${ }^{2} J_{\mathrm{CH}}$ & $-3,3$ & $-3,8$ & $-4,4$ & $-5,0$ & $-4,7$ \\
\hline \multirow[t]{3}{*}{ Total } & $\mathrm{DM}$ & $-2,62$ & 2,98 & 8,85 & 14,80 & - \\
\hline & DMA & 17,12 & 14,00 & 16,15 & 19,37 & - \\
\hline & PDMA & 18,66 & 12,14 & 21,89 & 34,05 & - \\
\hline \multirow[t]{3}{*}{ CPI } & $\mathrm{DM}$ & $-5,90$ & 4,78 & 15,92 & 27,13 & - \\
\hline & DMA & 32,99 & 26,44 & 31,86 & 37,04 & - \\
\hline & PDMA & 25,49 & 17,62 & 35,17 & 52,59 & - \\
\hline \multirow[t]{3}{*}{ SPI } & $\mathrm{DM}$ & $-0,22$ & 1,66 & 3,66 & 5,75 & - \\
\hline & DMA & 5,47 & 4,87 & 4,63 & 6,41 & - \\
\hline & PDMA & 13,65 & 8,12 & 12,15 & 20,45 & - \\
\hline \multirow[t]{3}{*}{$\Delta \mathrm{CS}$} & $\mathrm{DM}$ & $-5,68$ & 3,12 & 12,26 & 21,37 & - \\
\hline & DMA & 27,52 & 21,56 & 27,23 & 30,63 & - \\
\hline & PDMA & 11,84 & 9,50 & 23,02 & 32,15 & - \\
\hline \multicolumn{7}{|c|}{ Desconsiderando ${ }^{1} J_{\mathrm{BF}}$ da molécula de $\mathrm{BF}_{3},{ }^{2} J_{\mathrm{CH}}$ e ${ }^{2} J_{\mathrm{HH}}$ da molécula de $\mathrm{C}_{2} \mathrm{H}_{4}$} \\
\hline \multirow[t]{3}{*}{ Total } & DM & $-2,36$ & 3,06 & 8,78 & 14,63 & - \\
\hline & DMA & 18,60 & 15,49 & 16,86 & 19,43 & - \\
\hline & PDMA & 13,63 & 11,20 & 12,14 & 15,36 & - \\
\hline \multirow[t]{3}{*}{ CPI } & DM & $-4,93$ & 4,52 & 14,50 & 24,60 & - \\
\hline & DMA & 34,73 & 28,34 & 32,04 & 35,50 & - \\
\hline & PDMA & 17,64 & 14,45 & 18,63 & 22,92 & - \\
\hline \multirow[t]{3}{*}{ SPI } & $\mathrm{DM}$ & $-0,38$ & 1,93 & 4,38 & 6,97 & - \\
\hline & DMA & 6,19 & 5,61 & 5,18 & 7,06 & - \\
\hline & PDMA & 10,54 & 8,70 & 7,15 & 9,55 & - \\
\hline \multirow[t]{3}{*}{$\Delta \mathrm{CS}$} & $\mathrm{DM}$ & $-4,55$ & 2,59 & 10,12 & 17,63 & - \\
\hline & DMA & 28,54 & 22,73 & 26,86 & 28,44 & - \\
\hline & PDMA & 7,10 & 5,74 & 11,47 & 13,37 & - \\
\hline
\end{tabular}


Tabela 8.303: Constantes de acoplamento TPSSB95 com geometrias otimizadas na base aug-pcJ-2.

\begin{tabular}{|c|c|c|c|c|c|}
\hline & $\% E_{X}^{\mathrm{HF}}$ & $30 \%$ & $40 \%$ & $50 \%$ & Exp. \\
\hline $\mathrm{HF}$ & ${ }^{1} J_{\mathrm{HF}}$ & 491,0 & 527,3 & 562,7 & 500,0 \\
\hline $\mathrm{CO}$ & ${ }^{1} J_{\mathrm{CO}}$ & 12,6 & 9,8 & 7,1 & 16,4 \\
\hline $\mathrm{H}_{2} \mathrm{O}$ & ${ }^{1} J_{\mathrm{OH}}$ & $-83,1$ & $-86,8$ & $-90,3$ & $-80,6$ \\
\hline $\mathrm{H}_{2} \mathrm{O}$ & ${ }^{2} J_{\mathrm{HH}}$ & $-6,4$ & $-7,2$ & $-8,1$ & $-7,3$ \\
\hline $\mathrm{NH}_{3}$ & ${ }^{1} J_{\mathrm{NH}}$ & 47,6 & 48,4 & 49,2 & 43,8 \\
\hline $\mathrm{NH}_{3}$ & ${ }^{2} J_{\mathrm{HH}}$ & $-8,8$ & $-9,6$ & $-10,4$ & $-9,6$ \\
\hline $\mathrm{PH}_{3}$ & ${ }^{1} J_{\mathrm{PH}}$ & 211,5 & 216,2 & 220,4 & 188,2 \\
\hline $\mathrm{PF}_{3}$ & ${ }^{1} J_{\mathrm{PF}}$ & $-1485,4$ & $-1459,1$ & $-1428,6$ & $-1441,0$ \\
\hline $\mathrm{BHF}_{2}$ & ${ }^{1} J_{\mathrm{BF}}$ & $-104,3$ & $-85,0$ & $-66,1$ & $-84,0$ \\
\hline $\mathrm{BF}_{3}$ & ${ }^{1} J_{\mathrm{BF}}$ & $-9,0$ & 14,0 & 36,1 & 15,0 \\
\hline $\mathrm{F}_{2} \mathrm{O}$ & ${ }^{1} J_{\mathrm{OF}}$ & $-239,9$ & $-218,6$ & $-198,0$ & $-300,0$ \\
\hline $\mathrm{CH}_{4}$ & ${ }^{1} J_{\mathrm{CH}}$ & 130,8 & 130,8 & 130,8 & 125,3 \\
\hline $\mathrm{CH}_{4}$ & ${ }^{2} J_{\mathrm{HH}}$ & $-11,2$ & $-12,1$ & $-13,0$ & $-12,8$ \\
\hline $\mathrm{C}_{2} \mathrm{H}_{2}$ & ${ }^{1} J_{\mathrm{CC}}$ & 195,9 & 199,0 & 202,3 & 174,8 \\
\hline $\mathrm{C}_{2} \mathrm{H}_{2}$ & ${ }^{1} J_{\mathrm{CH}}$ & 260,8 & 260,3 & 259,9 & 247,6 \\
\hline $\mathrm{C}_{2} \mathrm{H}_{2}$ & ${ }^{2} J_{\mathrm{CH}}$ & 56,8 & 56,4 & 55,8 & 50,1 \\
\hline $\mathrm{C}_{2} \mathrm{H}_{2}$ & ${ }^{3} J_{\mathrm{HH}}$ & 10,2 & 10,6 & 11,1 & 9,6 \\
\hline $\mathrm{C}_{2} \mathrm{H}_{4}$ & ${ }^{1} J_{\mathrm{CC}}$ & 74,8 & 76,9 & 79,2 & 67,6 \\
\hline $\mathrm{C}_{2} \mathrm{H}_{4}$ & ${ }^{1} J_{\mathrm{CH}}$ & 161,9 & 162,3 & 162,6 & 156,3 \\
\hline $\mathrm{C}_{2} \mathrm{H}_{4}$ & ${ }^{2} J_{\mathrm{CH}}$ & $-1,1$ & $-2,1$ & $-3,1$ & $-2,4$ \\
\hline $\mathrm{C}_{2} \mathrm{H}_{4}$ & ${ }^{2} J_{\mathrm{HH}}$ & 4,7 & 3,6 & 2,6 & 2,3 \\
\hline $\mathrm{C}_{2} \mathrm{H}_{4}$ & ${ }^{3} J_{\mathrm{HH}_{\mathrm{c}}}$ & 12,4 & 12,9 & 13,4 & 11,7 \\
\hline $\mathrm{C}_{2} \mathrm{H}_{4}$ & ${ }^{3} J_{\mathrm{HH}_{\mathrm{t}}}{ }^{\mathrm{C}}$ & 20,1 & 20,3 & 20,5 & 19,0 \\
\hline $\mathrm{C}_{2} \mathrm{H}_{6}$ & ${ }^{1} J_{\mathrm{CC}}$ & 37,8 & 39,0 & 40,4 & 34,5 \\
\hline $\mathrm{C}_{2} \mathrm{H}_{6}$ & ${ }^{1} J_{\mathrm{CH}}$ & 130,0 & 130,1 & 130,1 & 125,2 \\
\hline $\mathrm{C}_{2} \mathrm{H}_{6}$ & ${ }^{2} J_{\mathrm{CH}}$ & $-3,8$ & $-4,3$ & $-4,7$ & $-4,7$ \\
\hline \multirow[t]{3}{*}{ Total } & DM & 2,34 & 7,23 & 12,19 & - \\
\hline & DMA & 10,34 & 9,77 & 13,84 & - \\
\hline & PDMA & 21,08 & 11,44 & 18,74 & - \\
\hline \multirow[t]{3}{*}{ CPI } & DM & $-1,37$ & 9,86 & 21,19 & - \\
\hline & DMA & 17,54 & 15,85 & 24,94 & - \\
\hline & PDMA & 25,19 & 10,58 & 29,71 & - \\
\hline \multirow[t]{3}{*}{ SPI } & DM & 5,07 & 5,31 & 5,59 & - \\
\hline & DMA & 5,07 & 5,31 & 5,71 & - \\
\hline & PDMA & 18,07 & 12,07 & 10,70 & - \\
\hline \multirow[t]{3}{*}{$\Delta \mathrm{CS}$} & $\mathrm{DM}$ & $-6,44$ & 4,56 & 15,60 & - \\
\hline & DMA & 12,47 & 10,54 & 19,23 & - \\
\hline & PDMA & 7,12 & $-1,49$ & 19,01 & - \\
\hline \multicolumn{6}{|c|}{ Desconsiderando ${ }^{1} J_{\mathrm{BF}}$ da molécula de $\mathrm{BF}_{3},{ }^{2} J_{\mathrm{CH}}$ e ${ }^{2} J_{\mathrm{HH}}$ da molécula de $\mathrm{C}_{2} \mathrm{H}_{4}$} \\
\hline \multirow[t]{3}{*}{ Total } & $\mathrm{DM}$ & 3,53 & 8,15 & 12,88 & - \\
\hline & DMA & 10,49 & 10,93 & 14,69 & - \\
\hline & PDMA & 9,98 & 9,64 & 13,24 & - \\
\hline \multirow[t]{3}{*}{ CPI } & DM & 0,89 & 10,95 & 21,20 & - \\
\hline & DMA & 16,89 & 17,33 & 25,32 & - \\
\hline & PDMA & 11,71 & 10,97 & 18,62 & - \\
\hline \multirow[t]{3}{*}{ SPI } & $\mathrm{DM}$ & 5,56 & 6,00 & 6,48 & - \\
\hline & DMA & 5,56 & 6,00 & 6,51 & - \\
\hline & PDMA & 8,65 & 8,61 & 9,10 & - \\
\hline \multirow[t]{3}{*}{$\triangle \mathrm{CS}$} & DM & $-4,67$ & 4,95 & 14,72 & - \\
\hline & DMA & 11,33 & 11,33 & 18,81 & - \\
\hline & PDMA & 3,06 & 2,36 & 9,52 & - \\
\hline
\end{tabular}


Tabela 8.304: Constantes de acoplamento TPSSP86 com geometrias otimizadas na base aug-pcJ-2.

\begin{tabular}{|c|c|c|c|c|c|}
\hline & $\% E_{X}^{\mathrm{HF}}$ & $30 \%$ & $40 \%$ & $50 \%$ & Exp. \\
\hline $\mathrm{HF}$ & ${ }^{1} J_{\mathrm{HF}}$ & 439,2 & 476,4 & 512,7 & 500,0 \\
\hline $\mathrm{CO}$ & ${ }^{1} J_{\mathrm{CO}}$ & 14,5 & 11,8 & 9,1 & 16,4 \\
\hline $\mathrm{H}_{2} \mathrm{O}$ & ${ }^{1} J_{\mathrm{OH}}$ & $-76,8$ & $-80,8$ & $-84,4$ & $-80,6$ \\
\hline $\mathrm{H}_{2} \mathrm{O}$ & ${ }^{2} J_{\mathrm{HH}}$ & $-6,8$ & $-7,6$ & $-8,5$ & $-7,3$ \\
\hline $\mathrm{NH}_{3}$ & ${ }^{1} J_{\mathrm{NH}}$ & 45,6 & 46,5 & 47,3 & 43,8 \\
\hline $\mathrm{NH}_{3}$ & ${ }^{2} J_{\mathrm{HH}}$ & $-9,7$ & $-10,6$ & $-11,4$ & $-9,6$ \\
\hline $\mathrm{PH}_{3}$ & ${ }^{1} J_{\mathrm{PH}}$ & 205,7 & 210,6 & 215,2 & 188,2 \\
\hline $\mathrm{PF}_{3}$ & ${ }^{1} J_{\mathrm{PF}}$ & $-1568,7$ & $-1538,6$ & $-1504,4$ & $-1441,0$ \\
\hline $\mathrm{BHF}_{2}$ & ${ }^{1} J_{\mathrm{BF}}$ & $-108,2$ & $-89,0$ & $-70,2$ & $-84,0$ \\
\hline $\mathrm{BF}_{3}$ & ${ }^{1} J_{\mathrm{BF}}$ & $-14,2$ & 8,8 & 30,9 & 15,0 \\
\hline $\mathrm{F}_{2} \mathrm{O}$ & ${ }^{1} J_{\mathrm{OF}}$ & $-261,7$ & $-240,9$ & $-220,8$ & $-300,0$ \\
\hline $\mathrm{CH}_{4}$ & ${ }^{1} J_{\mathrm{CH}}$ & 129,1 & 129,2 & 129,4 & 125,3 \\
\hline $\mathrm{CH}_{4}$ & ${ }^{2} J_{\mathrm{HH}}$ & $-12,9$ & $-13,8$ & $-14,7$ & $-12,8$ \\
\hline $\mathrm{C}_{2} \mathrm{H}_{2}$ & ${ }^{1} J_{\mathrm{CC}}$ & 197,0 & 200,7 & 204,7 & 174,8 \\
\hline $\mathrm{C}_{2} \mathrm{H}_{2}$ & ${ }^{1} J_{\mathrm{CH}}$ & 260,7 & 260,7 & 260,8 & 247,6 \\
\hline $\mathrm{C}_{2} \mathrm{H}_{2}$ & ${ }^{2} J_{\mathrm{CH}}$ & 55,1 & 54,3 & 53,2 & 50,1 \\
\hline $\mathrm{C}_{2} \mathrm{H}_{2}$ & ${ }^{3} J_{\mathrm{HH}}$ & 12,2 & 12,9 & 13,8 & 9,6 \\
\hline $\mathrm{C}_{2} \mathrm{H}_{4}$ & ${ }^{1} J_{\mathrm{CC}}$ & 77,5 & 80,3 & 83,3 & 67,6 \\
\hline $\mathrm{C}_{2} \mathrm{H}_{4}$ & ${ }^{1} J_{\mathrm{CH}}$ & 160,3 & 161,1 & 161,9 & 156,3 \\
\hline $\mathrm{C}_{2} \mathrm{H}_{4}$ & ${ }^{2} J_{\mathrm{CH}}$ & $-2,8$ & $-4,0$ & $-5,4$ & $-2,4$ \\
\hline $\mathrm{C}_{2} \mathrm{H}_{4}$ & ${ }^{2} J_{\mathrm{HH}}$ & 3,0 & 1,8 & 0,4 & 2,3 \\
\hline $\mathrm{C}_{2} \mathrm{H}_{4}$ & ${ }^{3} J_{\mathrm{HH}_{\mathrm{c}}}$ & 13,0 & 13,6 & 14,4 & 11,7 \\
\hline $\mathrm{C}_{2} \mathrm{H}_{4}$ & ${ }^{3} J_{\mathrm{HH}_{\mathrm{t}}}$ & 21,0 & 21,4 & 21,9 & 19,0 \\
\hline $\mathrm{C}_{2} \mathrm{H}_{6}$ & ${ }^{1} J_{\mathrm{CC}}$ & 37,5 & 38,8 & 40,1 & 34,5 \\
\hline $\mathrm{C}_{2} \mathrm{H}_{6}$ & ${ }^{1} J_{\mathrm{CH}}$ & 128,3 & 128,6 & 128,8 & 125,2 \\
\hline $\mathrm{C}_{2} \mathrm{H}_{6}$ & ${ }^{2} J_{\mathrm{CH}}$ & $-4,3$ & $-4,9$ & $-5,3$ & $-4,7$ \\
\hline \multirow[t]{3}{*}{ Total } & DM & $-4,28$ & 0,86 & 6,07 & - \\
\hline & DMA & 14,52 & 11,77 & 12,60 & - \\
\hline & PDMA & 17,67 & 14,30 & 25,29 & - \\
\hline \multirow[t]{3}{*}{ CPI } & $\mathrm{DM}$ & $-16,55$ & $-4,94$ & 6,78 & - \\
\hline & DMA & 27,80 & 20,25 & 20,87 & - \\
\hline & PDMA & 26,81 & 12,67 & 23,87 & - \\
\hline \multirow[t]{3}{*}{ SPI } & $\mathrm{DM}$ & 4,71 & 5,11 & 5,55 & - \\
\hline & DMA & 4,77 & 5,55 & 6,53 & - \\
\hline & PDMA & 10,97 & 15,49 & 26,34 & - \\
\hline \multirow[t]{3}{*}{$\Delta \mathrm{CS}$} & $\mathrm{DM}$ & $-21,25$ & $-10,04$ & 1,24 & - \\
\hline & DMA & 23,03 & 14,70 & 14,34 & - \\
\hline & PDMA & 15,84 & $-2,82$ & $-2,48$ & - \\
\hline \multicolumn{6}{|c|}{ Desconsiderando ${ }^{1} J_{\mathrm{BF}}$ da molécula de $\mathrm{BF}_{3},{ }^{2} J_{\mathrm{CH}}$ e ${ }^{2} J_{\mathrm{HH}}$ da molécula de $\mathrm{C}_{2} \mathrm{H}_{4}$} \\
\hline \multirow[t]{3}{*}{ Total } & $\mathrm{DM}$ & $-3,59$ & 1,33 & 6,38 & - \\
\hline & DMA & 15,09 & 12,94 & 13,34 & - \\
\hline & PDMA & 9,46 & 10,52 & 14,96 & - \\
\hline \multirow[t]{3}{*}{ CPI } & $\mathrm{DM}$ & $-15,28$ & $-4,81$ & 5,87 & - \\
\hline & DMA & 27,66 & 21,65 & 21,37 & - \\
\hline & PDMA & 10,02 & 9,80 & 15,65 & - \\
\hline \multirow[t]{3}{*}{ SPI } & $\mathrm{DM}$ & 5,41 & 6,05 & 6,78 & - \\
\hline & DMA & 5,42 & 6,24 & 7,16 & - \\
\hline & PDMA & 9,03 & 11,07 & 14,42 & - \\
\hline \multirow[t]{3}{*}{$\Delta \mathrm{CS}$} & $\mathrm{DM}$ & $-20,69$ & $-10,86$ & $-0,91$ & - \\
\hline & DMA & 22,24 & 15,41 & 14,21 & - \\
\hline & PDMA & 0,99 & $-1,27$ & 1,23 & - \\
\hline
\end{tabular}




\subsection{Variação da porcentagem de $E_{X}^{\mathrm{HF}}$ para os funcionais de longo alcance}

\subsubsection{Geometrias Experimentais}

Tabela 8.305: Constantes de acoplamento CAM-B3LYP variando $\alpha$ com $\alpha+\beta=100 \%$ na base aug-pcJ-2.

\begin{tabular}{|c|c|c|c|c|c|c|c|c|c|c|c|}
\hline & $\alpha$ & $10 \%$ & $20 \%$ & $30 \%$ & $40 \%$ & $50 \%$ & $60 \%$ & $70 \%$ & $80 \%$ & $90 \%$ & Exp. \\
\hline $\mathrm{HF}$ & ${ }^{1} J_{\mathrm{HF}}$ & 446,5 & 468,4 & 490,6 & 513,0 & 535,8 & 558,9 & 582,4 & 606,4 & 630,7 & 500 \\
\hline $\mathrm{CO}$ & ${ }^{1} J_{\mathrm{CO}}$ & 20,2 & 18,3 & 16,2 & 14,1 & 11,8 & 9,4 & 6,9 & 4,2 & 1,4 & 16,4 \\
\hline $\mathrm{H}_{2} \mathrm{O}$ & ${ }^{1} J_{\mathrm{OH}}$ & $-76,1$ & $-78,5$ & $-81,0$ & $-83,5$ & $-86,1$ & $-88,7$ & $-91,4$ & $-94,2$ & $-97,0$ & $-80,6$ \\
\hline $\mathrm{H}_{2} \mathrm{O}$ & ${ }^{2} J_{\mathrm{HH}}$ & $-6,4$ & $-7,5$ & $-8,5$ & $-9,6$ & $-10,8$ & $-12,0$ & $-13,2$ & $-14,4$ & $-15,7$ & $-7,3$ \\
\hline $\mathrm{NH}_{3}$ & ${ }^{1} J_{\mathrm{NH}}$ & 43,8 & 44,7 & 45,6 & 46,6 & 47,6 & 48,6 & 49,6 & 50,7 & 51,7 & 43,8 \\
\hline $\mathrm{NH}_{3}$ & ${ }^{2} J_{\mathrm{HH}}$ & $-9,3$ & $-10,2$ & $-11,1$ & $-12,1$ & $-13,1$ & $-14,1$ & $-15,1$ & $-16,2$ & $-17,3$ & $-9,6$ \\
\hline $\mathrm{PH}_{3}$ & ${ }^{1} J_{\mathrm{PH}}$ & 144,2 & 154,7 & 165,2 & 175,6 & 186,0 & 196,4 & 206,7 & 217,0 & 227,2 & 188,2 \\
\hline $\mathrm{PF}_{3}$ & ${ }^{1} J_{\mathrm{PF}}$ & $-1770,3$ & $-1738,5$ & $-1704,7$ & $-1669,0$ & $-1631,8$ & $-1593,3$ & $-1553,6$ & $-1513,1$ & $-1471,9$ & -1441 \\
\hline $\mathrm{BHF}_{2}$ & ${ }^{1} J_{\mathrm{BF}}$ & $-132,5$ & $-118,1$ & $-103,5$ & $-88,8$ & $-74,0$ & $-59,1$ & $-44,2$ & $-29,1$ & $-14,0$ & -84 \\
\hline $\mathrm{BF}_{3}$ & ${ }^{1} J_{\mathrm{BF}}$ & $-27,8$ & $-12,6$ & 2,6 & 18,0 & 33,5 & 49,1 & 64,9 & 80,7 & 96,7 & 15 \\
\hline $\mathrm{F}_{2} \mathrm{O}$ & ${ }^{1} J_{\mathrm{OF}}$ & $-387,3$ & $-418,1$ & $-451,8$ & $-490,7$ & $-537,9$ & $-599,4$ & $-687,2$ & 1847,1 & $-1126,2$ & -300 \\
\hline $\mathrm{CH}_{4}$ & ${ }^{1} J_{\mathrm{CH}}$ & 122,5 & 125,1 & 127,8 & 130,5 & 133,3 & 136,1 & 139,0 & 142,0 & 145,0 & 125,3 \\
\hline $\mathrm{CH}_{4}$ & ${ }^{2} J_{\mathrm{HH}}$ & $-12,3$ & $-13,0$ & $-13,8$ & $-14,6$ & $-15,4$ & $-16,2$ & $-17,0$ & $-17,9$ & $-18,7$ & $-12,8$ \\
\hline $\mathrm{C}_{2} \mathrm{H}_{2}$ & ${ }^{1} J_{\mathrm{CC}}$ & 195,4 & 199,7 & 204,4 & 209,9 & 216,2 & 223,4 & 231,9 & 241,9 & 253,9 & 174,8 \\
\hline $\mathrm{C}_{2} \mathrm{H}_{2}$ & ${ }^{1} J_{\mathrm{CH}}$ & 255,7 & 260,0 & 264,7 & 269,6 & 274,9 & 280,6 & 286,9 & 294,0 & 301,9 & 247,6 \\
\hline $\mathrm{C}_{2} \mathrm{H}_{2}$ & ${ }^{2} J_{\mathrm{CH}}$ & 57,9 & 57,4 & 56,6 & 55,6 & 54,2 & 52,3 & 49,9 & 46,8 & 42,8 & 50,1 \\
\hline $\mathrm{C}_{2} \mathrm{H}_{2}$ & ${ }^{3} J_{\mathrm{HH}}$ & 10,0 & 10,9 & 11,9 & 13,1 & 14,4 & 16,0 & 17,9 & 20,1 & 22,7 & 9,6 \\
\hline $\mathrm{C}_{2} \mathrm{H}_{4}$ & ${ }^{1} J_{\mathrm{CC}}$ & 65,6 & 69,3 & 73,4 & 78,1 & 83,6 & 90,1 & 98,1 & 108,1 & 121,4 & 67,6 \\
\hline $\mathrm{C}_{2} \mathrm{H}_{4}$ & ${ }^{1} J_{\mathrm{CH}}$ & 157,0 & 160,4 & 164,0 & 167,9 & 172,1 & 176,7 & 181,9 & 187,9 & 195,2 & 156,3 \\
\hline $\mathrm{C}_{2} \mathrm{H}_{4}$ & ${ }^{2} J_{\mathrm{CH}}$ & $-0,9$ & $-1,9$ & $-3,1$ & $-4,5$ & $-6,2$ & $-8,2$ & $-10,9$ & $-14,3$ & $-19,0$ & $-2,4$ \\
\hline $\mathrm{C}_{2} \mathrm{H}_{4}$ & ${ }^{2} J_{\mathrm{HH}}$ & 4,3 & 3,6 & 2,8 & 1,9 & 0,8 & $-0,3$ & $-1,8$ & $-3,7$ & $-6,3$ & 2,3 \\
\hline $\mathrm{C}_{2} \mathrm{H}_{4}$ & ${ }^{3} J_{\mathrm{HH}_{\mathrm{c}}}$ & 13,2 & 13,5 & 13,9 & 14,4 & 15,0 & 15,9 & 17,0 & 18,5 & 20,6 & 11,7 \\
\hline $\mathrm{C}_{2} \mathrm{H}_{4}$ & ${ }^{3} J_{\mathrm{HH}_{\mathrm{t}}}$ & 19,1 & 19,7 & 20,3 & 21,1 & 22,1 & 23,2 & 24,7 & 26,6 & 29,2 & 19 \\
\hline $\mathrm{C}_{2} \mathrm{H}_{6}$ & ${ }^{1} J_{\mathrm{CC}}$ & 29,8 & 32,0 & 34,3 & 36,6 & 39,1 & 41,6 & 44,2 & 46,9 & 49,6 & 34,5 \\
\hline $\mathrm{C}_{2} \mathrm{H}_{6}$ & ${ }^{1} J_{\mathrm{CH}}$ & 122,8 & 125,6 & 128,4 & 131,2 & 134,1 & 137,1 & 140,1 & 143,2 & 146,3 & 125,2 \\
\hline $\mathrm{C}_{2} \mathrm{H}_{6}$ & ${ }^{2} J_{\mathrm{CH}}$ & $-3,2$ & $-3,6$ & $-4,1$ & $-4,6$ & $-5,1$ & $-5,6$ & $-6,1$ & $-6,6$ & $-7,2$ & $-4,7$ \\
\hline \multirow[t]{3}{*}{ Total } & $\mathrm{DM}$ & $-21,66$ & $-18,60$ & $-15,53$ & $-12,51$ & $-9,65$ & $-7,17$ & $-5,52$ & 97,22 & $-11,62$ & - \\
\hline & DMA & 25,83 & 23,40 & 21,77 & 22,14 & 25,45 & 30,42 & 36,78 & 107,97 & 61,12 & - \\
\hline & PDMA & 28,00 & 19,83 & 15,51 & 17,91 & 31,33 & 46,70 & 64,77 & 107,14 & 114,28 & - \\
\hline \multirow[t]{3}{*}{ CPI } & $\mathrm{DM}$ & $-54,17$ & $-48,94$ & $-43,75$ & $-38,85$ & $-34,54$ & $-31,37$ & $-30,46$ & 208,93 & $-52,30$ & - \\
\hline & DMA & 55,90 & 49,83 & 44,08 & 42,26 & 46,92 & 55,17 & 66,17 & 229,22 & 112,17 & - \\
\hline & PDMA & 43,03 & 30,36 & 20,62 & 17,81 & 33,10 & 50,77 & 69,63 & 139,42 & 116,14 & - \\
\hline \multirow[t]{3}{*}{ SPI } & $\mathrm{DM}$ & 2,19 & 3,64 & 5,16 & 6,81 & 8,60 & 10,57 & 12,78 & 15,29 & 18,22 & - \\
\hline & DMA & 3,77 & 4,03 & 5,41 & 7,38 & 9,71 & 12,27 & 15,23 & 19,05 & 23,67 & - \\
\hline & PDMA & 16,97 & 12,11 & 11,77 & 17,97 & 30,03 & 43,71 & 61,21 & 83,46 & 112,91 & - \\
\hline \multirow[t]{3}{*}{$\Delta \mathrm{CS}$} & DM & $-56,36$ & $-52,58$ & $-48,91$ & $-45,65$ & $-43,14$ & $-41,95$ & $-43,24$ & 193,63 & $-70,52$ & - \\
\hline & DMA & 52,13 & 45,80 & 38,67 & 34,88 & 37,21 & 42,91 & 50,94 & 210,16 & 88,50 & - \\
\hline & PDMA & 26,06 & 18,25 & 8,85 & $-0,16$ & 3,07 & 7,06 & 8,42 & 55,96 & 3,23 & - \\
\hline
\end{tabular}


Tabela 8.306: Constantes de acoplamento CAM-B3LYP variando $\alpha$ com $\alpha+\beta=80 \%$ na base aug-pcJ-2.

\begin{tabular}{|c|c|c|c|c|c|c|c|c|c|}
\hline & $\alpha$ & $10 \%$ & $20 \%$ & $30 \%$ & $40 \%$ & $50 \%$ & $60 \%$ & $70 \%$ & Exp. \\
\hline $\mathrm{HF}$ & ${ }^{1} J_{\mathrm{HF}}$ & 440,4 & 462,4 & 484,7 & 507,3 & 530,2 & 553,5 & 577,2 & 500 \\
\hline $\mathrm{CO}$ & ${ }^{1} J_{\mathrm{CO}}$ & 20,1 & 18,1 & 16,1 & 13,9 & 11,6 & 9,1 & 6,6 & 16,4 \\
\hline $\mathrm{H}_{2} \mathrm{O}$ & ${ }^{1} J_{\mathrm{OH}}$ & $-75,8$ & $-78,2$ & $-80,7$ & $-83,3$ & $-85,9$ & $-88,5$ & $-91,3$ & $-80,6$ \\
\hline $\mathrm{H}_{2} \mathrm{O}$ & ${ }^{2} J_{\mathrm{HH}}$ & $-6,5$ & $-7,5$ & $-8,6$ & $-9,7$ & $-10,9$ & $-12,1$ & $-13,3$ & $-7,3$ \\
\hline $\mathrm{NH}_{3}$ & ${ }^{1} J_{\mathrm{NH}}$ & 44,1 & 45,0 & 46,0 & 46,9 & 47,9 & 48,9 & 50,0 & 43,8 \\
\hline $\mathrm{NH}_{3}$ & ${ }^{2} J_{\mathrm{HH}}$ & $-9,3$ & $-10,2$ & $-11,2$ & $-12,2$ & $-13,2$ & $-14,2$ & $-15,3$ & $-9,6$ \\
\hline $\mathrm{PH}_{3}$ & ${ }^{1} J_{\mathrm{PH}}$ & 148,9 & 159,6 & 170,2 & 180,8 & 191,4 & 201,9 & 212,4 & 188,2 \\
\hline $\mathrm{PF}_{3}$ & ${ }^{1} J_{\mathrm{PF}}$ & $-1773,8$ & $-1742,8$ & $-1709,5$ & $-1674,2$ & $-1637,2$ & $-1598,8$ & $-1559,2$ & -1441 \\
\hline $\mathrm{BHF}_{2}$ & ${ }^{1} J_{\mathrm{BF}}$ & $-136,2$ & $-121,5$ & $-106,7$ & $-91,8$ & $-76,8$ & $-61,7$ & $-46,5$ & -84 \\
\hline $\mathrm{BF}_{3}$ & ${ }^{1} J_{\mathrm{BF}}$ & $-32,7$ & $-17,3$ & $-1,7$ & 13,9 & 29,7 & 45,6 & 61,6 & 15 \\
\hline $\mathrm{F}_{2} \mathrm{O}$ & ${ }^{1} J_{\mathrm{OF}}$ & $-371,5$ & $-401,7$ & $-434,6$ & $-471,9$ & $-516,6$ & $-573,9$ & $-654,0$ & -300 \\
\hline $\mathrm{CH}_{4}$ & ${ }^{1} J_{\mathrm{CH}}$ & 124,8 & 127,4 & 130,1 & 132,9 & 135,7 & 138,6 & 141,5 & 125,3 \\
\hline $\mathrm{CH}_{4}$ & ${ }^{2} J_{\mathrm{HH}}$ & $-12,4$ & $-13,2$ & $-14,0$ & $-14,8$ & $-15,6$ & $-16,4$ & $-17,3$ & $-12,8$ \\
\hline $\mathrm{C}_{2} \mathrm{H}_{2}$ & ${ }^{1} J_{\mathrm{CC}}$ & 197,0 & 201,2 & 206,0 & 211,5 & 217,7 & 224,9 & 233,3 & 174,8 \\
\hline $\mathrm{C}_{2} \mathrm{H}_{2}$ & ${ }^{1} J_{\mathrm{CH}}$ & 259,7 & 264,2 & 268,9 & 273,9 & 279,3 & 285,1 & 291,5 & 247,6 \\
\hline $\mathrm{C}_{2} \mathrm{H}_{2}$ & ${ }^{2} J_{\mathrm{CH}}$ & 57,7 & 57,2 & 56,4 & 55,4 & 54,0 & 52,2 & 49,8 & 50,1 \\
\hline $\mathrm{C}_{2} \mathrm{H}_{2}$ & ${ }^{3} J_{\mathrm{HH}}$ & 10,1 & 11,0 & 12,0 & 13,2 & 14,5 & 16,1 & 17,9 & 9,6 \\
\hline $\mathrm{C}_{2} \mathrm{H}_{4}$ & ${ }^{1} J_{\mathrm{CC}}$ & 66,6 & 70,3 & 74,4 & 79,1 & 84,5 & 90,9 & 98,6 & 67,6 \\
\hline $\mathrm{C}_{2} \mathrm{H}_{4}$ & ${ }^{1} J_{\mathrm{CH}}$ & 159,4 & 162,9 & 166,6 & 170,5 & 174,7 & 179,3 & 184,4 & 156,3 \\
\hline $\mathrm{C}_{2} \mathrm{H}_{4}$ & ${ }^{2} J_{\mathrm{CH}}$ & $-0,8$ & $-1,8$ & $-3,0$ & $-4,4$ & $-6,1$ & $-8,1$ & $-10,6$ & $-2,4$ \\
\hline $\mathrm{C}_{2} \mathrm{H}_{4}$ & ${ }^{2} J_{\mathrm{HH}}$ & 4,5 & 3,8 & 3,0 & 2,1 & 1,1 & 0,0 & $-1,5$ & 2,3 \\
\hline $\mathrm{C}_{2} \mathrm{H}_{4}$ & ${ }^{3} J_{\mathrm{HH}_{\mathrm{c}}}$ & 13,1 & 13,4 & 13,8 & 14,3 & 14,9 & 15,7 & 16,7 & 11,7 \\
\hline $\mathrm{C}_{2} \mathrm{H}_{4}$ & ${ }^{3} J_{\mathrm{HH}_{\mathrm{t}}}^{\mathrm{c}}$ & 19,4 & 19,9 & 20,5 & 21,3 & 22,2 & 23,3 & 24,6 & 19 \\
\hline $\mathrm{C}_{2} \mathrm{H}_{6}$ & ${ }^{1} J_{\mathrm{CC}}$ & 30,2 & 32,4 & 34,7 & 37,1 & 39,6 & 42,2 & 44,8 & 34,5 \\
\hline $\mathrm{C}_{2} \mathrm{H}_{6}$ & ${ }^{1} J_{\mathrm{CH}}$ & 124,9 & 127,7 & 130,6 & 133,5 & 136,4 & 139,5 & 142,5 & 125,2 \\
\hline $\mathrm{C}_{2} \mathrm{H}_{6}$ & ${ }^{2} J_{\mathrm{CH}}$ & $-3,2$ & $-3,6$ & $-4,1$ & $-4,6$ & $-5,1$ & $-5,6$ & $-6,1$ & $-4,7$ \\
\hline \multirow[t]{3}{*}{ Total } & $\mathrm{DM}$ & $-21,01$ & $-17,93$ & $-14,81$ & $-11,70$ & $-8,73$ & $-6,06$ & $-4,10$ & - \\
\hline & DMA & 25,85 & 23,82 & 22,18 & 21,82 & 24,98 & 30,00 & 36,10 & - \\
\hline & PDMA & 29,58 & 21,81 & 17,26 & 17,36 & 29,92 & 45,43 & 63,13 & - \\
\hline \multirow[t]{3}{*}{ CPI } & DM & $-53,93$ & $-48,64$ & $-43,35$ & $-38,29$ & $-33,70$ & $-30,10$ & $-28,43$ & - \\
\hline & DMA & 55,73 & 49,60 & 43,75 & 40,18 & 44,50 & 52,86 & 63,28 & - \\
\hline & PDMA & 45,74 & 32,96 & 23,27 & 16,47 & 30,20 & 48,22 & 67,14 & - \\
\hline \multirow[t]{3}{*}{ SPI } & DM & 3,13 & 4,58 & 6,12 & 7,79 & 9,58 & 11,57 & 13,73 & - \\
\hline & DMA & 3,94 & 4,91 & 6,36 & 8,35 & 10,66 & 13,24 & 16,16 & - \\
\hline & PDMA & 17,73 & 13,64 & 12,85 & 18,01 & 29,73 & 43,39 & 60,18 & - \\
\hline \multirow[t]{3}{*}{$\Delta \mathrm{CS}$} & DM & $-57,05$ & $-53,22$ & $-49,47$ & $-46,08$ & $-43,28$ & $-41,67$ & $-42,16$ & - \\
\hline & DMA & 51,79 & 44,69 & 37,39 & 31,83 & 33,84 & 39,62 & 47,12 & - \\
\hline & PDMA & 28,01 & 19,33 & 10,41 & $-1,54$ & 0,47 & 4,83 & 6,96 & - \\
\hline
\end{tabular}


Tabela 8.307: Constantes de acoplamento CAM-B3LYP variando $\alpha$ com $\alpha+\beta=60 \%$ na base aug-pcJ-2.

\begin{tabular}{|c|c|c|c|c|c|c|c|}
\hline & $\alpha$ & $10 \%$ & $20 \%$ & $30 \%$ & $40 \%$ & $50 \%$ & Exp. \\
\hline $\mathrm{HF}$ & ${ }^{\mathrm{I}} J_{\mathrm{HF}}$ & 434,2 & 456,3 & 478,7 & 501,4 & 524,5 & 500 \\
\hline $\mathrm{CO}$ & ${ }^{1} J_{\mathrm{CO}}$ & 20,0 & 18,0 & 15,9 & 13,7 & 11,3 & 16,4 \\
\hline $\mathrm{H}_{2} \mathrm{O}$ & ${ }^{1} J_{\mathrm{OH}}$ & $-75,4$ & $-77,9$ & $-80,4$ & $-83,0$ & $-85,6$ & $-80,6$ \\
\hline $\mathrm{H}_{2} \mathrm{O}$ & ${ }^{2} J_{\mathrm{HH}}$ & $-6,5$ & $-7,5$ & $-8,6$ & $-9,8$ & $-10,9$ & $-7,3$ \\
\hline $\mathrm{NH}_{3}$ & ${ }^{1} J_{\mathrm{NH}}$ & 44,4 & 45,3 & 46,3 & 47,3 & 48,3 & 43,8 \\
\hline $\mathrm{NH}_{3}$ & ${ }^{2} J_{\mathrm{HH}}$ & $-9,4$ & $-10,3$ & $-11,3$ & $-12,3$ & $-13,3$ & $-9,6$ \\
\hline $\mathrm{PH}_{3}$ & ${ }^{1} J_{\mathrm{PH}}$ & 153,8 & 164,6 & 175,4 & 186,2 & 196,9 & 188,2 \\
\hline $\mathrm{PF}_{3}$ & ${ }^{1} J_{\mathrm{PF}}$ & $-1777,3$ & $-1747,1$ & $-1714,3$ & $-1679,5$ & $-1642,8$ & -1441 \\
\hline $\mathrm{BHF}_{2}$ & ${ }^{1} J_{\mathrm{BF}}$ & $-140,0$ & $-125,1$ & $-110,1$ & $-94,9$ & $-79,7$ & -84 \\
\hline $\mathrm{BF}_{3}$ & ${ }^{1} J_{\mathrm{BF}}$ & $-37,7$ & $-22,0$ & $-6,2$ & 9,7 & 25,7 & 15 \\
\hline $\mathrm{F}_{2} \mathrm{O}$ & ${ }^{1} J_{\mathrm{OF}}$ & $-355,8$ & $-385,7$ & $-417,8$ & $-453,7$ & $-496,2$ & -300 \\
\hline $\mathrm{CH}_{4}$ & ${ }^{1} J_{\mathrm{CH}}$ & 127,0 & 129,7 & 132,5 & 135,3 & 138,2 & 125,3 \\
\hline $\mathrm{CH}_{4}$ & ${ }^{2} J_{\mathrm{HH}}$ & $-12,5$ & $-13,3$ & $-14,1$ & $-15,0$ & $-15,8$ & $-12,8$ \\
\hline $\mathrm{C}_{2} \mathrm{H}_{2}$ & ${ }^{1} J_{\mathrm{CC}}$ & 198,6 & 202,8 & 207,6 & 213,1 & 219,3 & 174,8 \\
\hline $\mathrm{C}_{2} \mathrm{H}_{2}$ & ${ }^{1} J_{\mathrm{CH}}$ & 263,8 & 268,4 & 273,2 & 278,3 & 283,7 & 247,6 \\
\hline $\mathrm{C}_{2} \mathrm{H}_{2}$ & ${ }^{2} J_{\mathrm{CH}}$ & 57,4 & 56,9 & 56,2 & 55,2 & 53,8 & 50,1 \\
\hline $\mathrm{C}_{2} \mathrm{H}_{2}$ & ${ }^{3} J_{\mathrm{HH}}$ & 10,3 & 11,2 & 12,2 & 13,3 & 14,6 & 9,6 \\
\hline $\mathrm{C}_{2} \mathrm{H}_{4}$ & ${ }^{1} J_{\mathrm{CC}}$ & 67,5 & 71,2 & 75,3 & 80,0 & 85,3 & 67,6 \\
\hline $\mathrm{C}_{2} \mathrm{H}_{4}$ & ${ }^{1} J_{\mathrm{CH}}$ & 161,9 & 165,4 & 169,1 & 173,0 & 177,3 & 156,3 \\
\hline $\mathrm{C}_{2} \mathrm{H}_{4}$ & ${ }^{2} J_{\mathrm{CH}}$ & $-0,8$ & $-1,8$ & $-3,0$ & $-4,3$ & $-6,0$ & $-2,4$ \\
\hline $\mathrm{C}_{2} \mathrm{H}_{4}$ & ${ }^{2} J_{\mathrm{HH}}$ & 4,7 & 4,0 & 3,2 & 2,3 & 1,3 & 2,3 \\
\hline $\mathrm{C}_{2} \mathrm{H}_{4}$ & ${ }^{3} J_{\mathrm{HH}_{\mathrm{c}}}$ & 13,0 & 13,3 & 13,7 & 14,1 & 14,7 & 11,7 \\
\hline $\mathrm{C}_{2} \mathrm{H}_{4}$ & ${ }^{3} J_{\mathrm{HH}_{\mathrm{t}}}$ & 19,6 & 20,1 & 20,7 & 21,4 & 22,3 & 19 \\
\hline $\mathrm{C}_{2} \mathrm{H}_{6}$ & ${ }^{1} J_{\mathrm{CC}}$ & 30,6 & 32,8 & 35,2 & 37,6 & 40,1 & 34,5 \\
\hline $\mathrm{C}_{2} \mathrm{H}_{6}$ & ${ }^{1} J_{\mathrm{CH}}$ & 127,1 & 129,9 & 132,8 & 135,8 & 138,8 & 125,2 \\
\hline $\mathrm{C}_{2} \mathrm{H}_{6}$ & ${ }^{2} J_{\mathrm{CH}}$ & $-3,1$ & $-3,6$ & $-4,1$ & $-4,6$ & $-5,1$ & $-4,7$ \\
\hline \multirow[t]{3}{*}{ Total } & DM & $-20,37$ & $-17,28$ & $-14,11$ & $-10,94$ & $-7,86$ & - \\
\hline & DMA & 26,17 & 24,28 & 22,65 & 21,74 & 24,71 & - \\
\hline & PDMA & 31,38 & 23,73 & 19,27 & 18,32 & 28,68 & - \\
\hline \multirow[t]{3}{*}{ CPI } & DM & $-53,69$ & $-48,39$ & $-43,03$ & $-37,80$ & $-32,97$ & - \\
\hline & DMA & 55,58 & 49,45 & 43,52 & 38,69 & 42,55 & - \\
\hline & PDMA & 48,56 & 35,75 & 26,02 & 18,84 & 27,35 & - \\
\hline \multirow[t]{3}{*}{ SPI } & $\mathrm{DM}$ & 4,07 & 5,53 & 7,09 & 8,76 & 10,56 & - \\
\hline & DMA & 4,60 & 5,82 & 7,35 & 9,31 & 11,63 & - \\
\hline & PDMA & 18,77 & 14,91 & 14,33 & 17,94 & 29,66 & - \\
\hline \multirow[t]{3}{*}{$\Delta \mathrm{CS}$} & $\mathrm{DM}$ & $-57,76$ & $-53,92$ & $-50,12$ & $-46,56$ & $-43,53$ & - \\
\hline & DMA & 50,98 & 43,63 & 36,17 & 29,38 & 30,93 & - \\
\hline & PDMA & 29,79 & 20,84 & 11,69 & 0,90 & $-2,32$ & - \\
\hline
\end{tabular}


Tabela 8.308: Constantes de acoplamento CAMB3LYP variando $\alpha \operatorname{com} \alpha+\beta=40 \%$ na base augpcJ-2.

\begin{tabular}{|c|c|c|c|c|c|}
\hline & $\alpha$ & $10 \%$ & $20 \%$ & $30 \%$ & Exp. \\
\hline $\mathrm{HF}$ & ${ }^{1} J_{\mathrm{HF}}$ & 428,0 & 450,2 & 472,7 & 500 \\
\hline $\mathrm{CO}$ & ${ }^{1} J_{\mathrm{CO}}$ & 19,9 & 17,9 & 15,8 & 16,4 \\
\hline $\mathrm{H}_{2} \mathrm{O}$ & ${ }^{1} J_{\mathrm{OH}}$ & $-75,0$ & $-77,6$ & $-80,1$ & $-80,6$ \\
\hline $\mathrm{H}_{2} \mathrm{O}$ & ${ }^{2} J_{\mathrm{HH}}$ & $-6,5$ & $-7,6$ & $-8,7$ & $-7,3$ \\
\hline $\mathrm{NH}_{3}$ & ${ }^{1} J_{\mathrm{NH}}$ & 44,7 & 45,6 & 46,6 & 43,8 \\
\hline $\mathrm{NH}_{3}$ & ${ }^{2} J_{\mathrm{HH}}$ & $-9,4$ & $-10,4$ & $-11,3$ & $-9,6$ \\
\hline $\mathrm{PH}_{3}$ & ${ }^{1} J_{\mathrm{PH}}$ & 158,9 & 169,9 & 180,8 & 188,2 \\
\hline $\mathrm{PF}_{3}$ & ${ }^{1} J_{\mathrm{PF}}$ & $-1780,8$ & $-1751,3$ & $-1719,3$ & -1441 \\
\hline $\mathrm{BHF}_{2}$ & ${ }^{1} J_{\mathrm{BF}}$ & $-144,0$ & $-128,8$ & $-113,6$ & -84 \\
\hline $\mathrm{BF}_{3}$ & ${ }^{1} J_{\mathrm{BF}}$ & $-42,9$ & $-26,9$ & $-10,8$ & 15 \\
\hline $\mathrm{F}_{2} \mathrm{O}$ & ${ }^{1} J_{\mathrm{OF}}$ & $-340,4$ & $-370,0$ & $-401,4$ & -300 \\
\hline $\mathrm{CH}_{4}$ & ${ }^{1} J_{\mathrm{CH}}$ & 129,4 & 132,1 & 134,9 & 125,3 \\
\hline $\mathrm{CH}_{4}$ & ${ }^{2} J_{\mathrm{HH}}$ & $-12,7$ & $-13,5$ & $-14,3$ & $-12,8$ \\
\hline $\mathrm{C}_{2} \mathrm{H}_{2}$ & ${ }^{1} J_{\mathrm{CC}}$ & 200,2 & 204,4 & 209,2 & 174,8 \\
\hline $\mathrm{C}_{2} \mathrm{H}_{2}$ & ${ }^{1} J_{\mathrm{CH}}$ & 268,0 & 272,6 & 277,5 & 247,6 \\
\hline $\mathrm{C}_{2} \mathrm{H}_{2}$ & ${ }^{2} J_{\mathrm{CH}}$ & 57,2 & 56,7 & 56,0 & 50,1 \\
\hline $\mathrm{C}_{2} \mathrm{H}_{2}$ & ${ }^{3} J_{\mathrm{HH}}$ & 10,5 & 11,4 & 12,3 & 9,6 \\
\hline $\mathrm{C}_{2} \mathrm{H}_{4}$ & ${ }^{1} J_{\mathrm{CC}}$ & 68,4 & 72,1 & 76,3 & 67,6 \\
\hline $\mathrm{C}_{2} \mathrm{H}_{4}$ & ${ }^{1} J_{\mathrm{CH}}$ & 164,4 & 167,9 & 171,7 & 156,3 \\
\hline $\mathrm{C}_{2} \mathrm{H}_{4}$ & ${ }^{2} J_{\mathrm{CH}}$ & $-0,7$ & $-1,8$ & $-2,9$ & $-2,4$ \\
\hline $\mathrm{C}_{2} \mathrm{H}_{4}$ & ${ }^{2} J_{\mathrm{HH}}$ & 4,9 & 4,2 & 3,4 & 2,3 \\
\hline $\mathrm{C}_{2} \mathrm{H}_{4}$ & ${ }^{3} J_{\mathrm{HH}_{\mathrm{c}}}$ & 12,9 & 13,2 & 13,5 & 11,7 \\
\hline $\mathrm{C}_{2} \mathrm{H}_{4}$ & ${ }^{3} J_{\mathrm{HH}_{\mathrm{t}}}$ & 19,8 & 20,3 & 20,9 & 19 \\
\hline $\mathrm{C}_{2} \mathrm{H}_{6}$ & ${ }^{1} J_{\mathrm{CC}}$ & 30,9 & 33,2 & 35,6 & 34,5 \\
\hline $\mathrm{C}_{2} \mathrm{H}_{6}$ & ${ }^{1} J_{\mathrm{CH}}$ & 129,3 & 132,2 & 135,1 & 125,2 \\
\hline $\mathrm{C}_{2} \mathrm{H}_{6}$ & ${ }^{2} J_{\mathrm{CH}}$ & $-3,1$ & $-3,6$ & $-4,0$ & $-4,7$ \\
\hline \multirow[t]{3}{*}{ Total } & DM & $-19,73$ & $-16,64$ & $-13,43$ & - \\
\hline & DMA & 26,65 & 24,76 & 23,15 & - \\
\hline & PDMA & 33,49 & 25,79 & 21,20 & - \\
\hline \multirow[t]{3}{*}{ CPI } & DM & $-53,49$ & $-48,17$ & $-42,75$ & - \\
\hline & DMA & 55,49 & 49,32 & 43,35 & - \\
\hline & PDMA & 51,62 & 38,79 & 28,85 & - \\
\hline \multirow[t]{3}{*}{ SPI } & DM & 5,02 & 6,49 & 8,07 & - \\
\hline & DMA & 5,50 & 6,75 & 8,34 & - \\
\hline & PDMA & 20,19 & 16,26 & 15,59 & - \\
\hline \multirow[t]{3}{*}{$\Delta \mathrm{CS}$} & $\mathrm{DM}$ & $-58,51$ & $-54,66$ & $-50,82$ & - \\
\hline & DMA & 49,99 & 42,56 & 35,01 & - \\
\hline & PDMA & 31,43 & 22,52 & 13,26 & - \\
\hline
\end{tabular}


Tabela 8.309: Constantes de acoplamento CAM-B3LYP variando $\alpha$ com $\alpha+\beta=20 \%$ na base aug-pcJ-2.

\begin{tabular}{|c|c|c|c|}
\hline & $\alpha$ & $10 \%$ & Exp. \\
\hline $\mathrm{HF}$ & ${ }^{1} J_{\mathrm{HF}}$ & 421,9 & 500 \\
\hline $\mathrm{CO}$ & ${ }^{1} J_{\mathrm{CO}}$ & 19,8 & 16,4 \\
\hline $\mathrm{H}_{2} \mathrm{O}$ & ${ }^{1} J_{\mathrm{OH}}$ & $-74,7$ & $-80,6$ \\
\hline $\mathrm{H}_{2} \mathrm{O}$ & ${ }^{2} J_{\mathrm{HH}}$ & $-6,5$ & $-7,3$ \\
\hline $\mathrm{NH}_{3}$ & ${ }^{1} J_{\mathrm{NH}}$ & 45,0 & 43,8 \\
\hline $\mathrm{NH}_{3}$ & ${ }^{2} J_{\mathrm{HH}}$ & $-9,4$ & $-9,6$ \\
\hline $\mathrm{PH}_{3}$ & ${ }^{1} J_{\mathrm{PH}}$ & 164,1 & 188,2 \\
\hline $\mathrm{PF}_{3}$ & ${ }^{1} J_{\mathrm{PF}}$ & $-1784,2$ & -1441 \\
\hline $\mathrm{BHF}_{2}$ & ${ }^{1} J_{\mathrm{BF}}$ & $-148,1$ & -84 \\
\hline $\mathrm{BF}_{3}$ & ${ }^{1} J_{\mathrm{BF}}$ & $-48,2$ & 15 \\
\hline $\mathrm{F}_{2} \mathrm{O}$ & ${ }^{1} J_{\mathrm{OF}}$ & $-325,1$ & -300 \\
\hline $\mathrm{CH}_{4}$ & ${ }^{1} J_{\mathrm{CH}}$ & 131,7 & 125,3 \\
\hline $\mathrm{CH}_{4}$ & ${ }^{2} J_{\mathrm{HH}}$ & $-12,8$ & $-12,8$ \\
\hline $\mathrm{C}_{2} \mathrm{H}_{2}$ & ${ }^{1} J_{\mathrm{CC}}$ & 201,8 & 174,8 \\
\hline $\mathrm{C}_{2} \mathrm{H}_{2}$ & ${ }^{1} J_{\mathrm{CH}}$ & 272,2 & 247,6 \\
\hline $\mathrm{C}_{2} \mathrm{H}_{2}$ & ${ }^{2} J_{\mathrm{CH}}$ & 56,9 & 50,1 \\
\hline $\mathrm{C}_{2} \mathrm{H}_{2}$ & ${ }^{3} J_{\mathrm{HH}}$ & 10,7 & 9,6 \\
\hline $\mathrm{C}_{2} \mathrm{H}_{4}$ & ${ }^{1} J_{\mathrm{CC}}$ & 69,3 & 67,6 \\
\hline $\mathrm{C}_{2} \mathrm{H}_{4}$ & ${ }^{1} J_{\mathrm{CH}}$ & 166,9 & 156,3 \\
\hline $\mathrm{C}_{2} \mathrm{H}_{4}$ & ${ }^{2} J_{\mathrm{CH}}$ & $-0,7$ & $-2,4$ \\
\hline $\mathrm{C}_{2} \mathrm{H}_{4}$ & ${ }^{2} J_{\mathrm{HH}}$ & 5,1 & 2,3 \\
\hline $\mathrm{C}_{2} \mathrm{H}_{4}$ & ${ }^{3} J_{\mathrm{HH}_{\mathrm{c}}}$ & 12,8 & 11,7 \\
\hline $\mathrm{C}_{2} \mathrm{H}_{4}$ & ${ }^{3} J_{\mathrm{HH}_{\mathrm{t}}}$ & 20,0 & 19 \\
\hline $\mathrm{C}_{2} \mathrm{H}_{6}$ & ${ }^{1} J_{\mathrm{CC}}{ }^{2}$ & 31,3 & 34,5 \\
\hline $\mathrm{C}_{2} \mathrm{H}_{6}$ & ${ }^{1} J_{\mathrm{CH}}$ & 131,5 & 125,2 \\
\hline $\mathrm{C}_{2} \mathrm{H}_{6}$ & ${ }^{2} J_{\mathrm{CH}}$ & $-3,1$ & $-4,7$ \\
\hline \multirow[t]{3}{*}{ Total } & $\mathrm{DM}$ & $-19,11$ & - \\
\hline & DMA & 27,12 & - \\
\hline & PDMA & 35,48 & - \\
\hline \multirow[t]{3}{*}{ CPI } & $\mathrm{DM}$ & $-53,30$ & - \\
\hline & DMA & 55,39 & - \\
\hline & PDMA & 54,74 & - \\
\hline \multirow[t]{3}{*}{ SPI } & DM & 5,97 & - \\
\hline & DMA & 6,39 & - \\
\hline & PDMA & 21,36 & - \\
\hline \multirow[t]{3}{*}{$\Delta \mathrm{CS}$} & $\mathrm{DM}$ & $-59,27$ & - \\
\hline & DMA & 49,00 & - \\
\hline & PDMA & 33,37 & - \\
\hline
\end{tabular}


Tabela 8.310: Constantes de acoplamento $\omega$ B97 variando $\alpha$ com $\alpha+\beta=100 \%$ na base aug-pcJ-2.

\begin{tabular}{|c|c|c|c|c|c|c|c|c|c|c|c|}
\hline & $\alpha$ & $10 \%$ & $20 \%$ & $30 \%$ & $40 \%$ & $50 \%$ & $60 \%$ & $70 \%$ & $80 \%$ & $90 \%$ & Exp. \\
\hline $\mathrm{HF}$ & ${ }^{\mathrm{I}} J_{\mathrm{HF}}$ & 489,1 & 522,9 & 556,9 & 591,1 & 625,6 & 660,3 & 695,3 & 730,6 & 766,1 & 500 \\
\hline $\mathrm{CO}$ & ${ }^{1} J_{\mathrm{CO}}$ & 20,6 & 17,0 & 13,2 & 9,0 & 4,6 & $-0,1$ & $-5,1$ & $-10,4$ & $-16,1$ & 16,4 \\
\hline $\mathrm{H}_{2} \mathrm{O}$ & ${ }^{1} J_{\mathrm{OH}}$ & $-75,4$ & $-79,1$ & $-82,8$ & $-86,5$ & $-90,2$ & $-94,0$ & $-97,8$ & $-101,6$ & $-105,4$ & $-80,6$ \\
\hline $\mathrm{H}_{2} \mathrm{O}$ & ${ }^{2} J_{\mathrm{HH}}$ & $-7,2$ & $-7,8$ & $-8,5$ & $-9,1$ & $-9,7$ & $-10,4$ & $-11,1$ & $-11,7$ & $-12,4$ & $-7,3$ \\
\hline $\mathrm{NH}_{3}$ & ${ }^{1} J_{\mathrm{NH}}$ & 40,3 & 41,6 & 42,9 & 44,2 & 45,5 & 46,8 & 48,1 & 49,4 & 50,7 & 43,8 \\
\hline $\mathrm{NH}_{3}$ & ${ }^{2} J_{\mathrm{HH}}$ & $-9,0$ & $-9,4$ & $-9,9$ & $-10,4$ & $-10,8$ & $-11,3$ & $-11,8$ & $-12,2$ & $-12,7$ & $-9,6$ \\
\hline $\mathrm{PH}_{3}$ & ${ }^{1} J_{\mathrm{PH}}$ & 165,5 & 171,5 & 177,5 & 183,3 & 188,9 & 194,5 & 199,9 & 205,2 & 210,4 & 188,2 \\
\hline $\mathrm{PF}_{3}$ & ${ }^{1} J_{\mathrm{PF}}$ & $-1633,0$ & $-1602,1$ & $-1570,5$ & $-1538,4$ & $-1506,1$ & $-1473,6$ & $-1441,2$ & $-1408,9$ & $-1376,9$ & -1441 \\
\hline $\mathrm{BHF}_{2}$ & ${ }^{1} J_{\mathrm{BF}}$ & $-91,9$ & $-71,9$ & $-51,8$ & $-31,6$ & $-11,3$ & 9,0 & 29,3 & 49,8 & 70,2 & -84 \\
\hline $\mathrm{BF}_{3}$ & ${ }^{1} J_{\mathrm{BF}}$ & 7,0 & 29,1 & 51,3 & 73,6 & 96,0 & 118,5 & 141,2 & 163,8 & 186,6 & 15 \\
\hline $\mathrm{F}_{2} \mathrm{O}$ & ${ }^{1} J_{\mathrm{OF}}$ & $-326,4$ & $-343,2$ & $-361,7$ & $-382,5$ & $-406,7$ & $-436,0$ & $-473,3$ & 1762,4 & $-598,8$ & -300 \\
\hline $\mathrm{CH}_{4}$ & ${ }^{1} J_{\mathrm{CH}}$ & 112,4 & 115,3 & 118,3 & 121,2 & 124,2 & 127,1 & 130,0 & 133,0 & 135,9 & 125,3 \\
\hline $\mathrm{CH}_{4}$ & ${ }^{2} J_{\mathrm{HH}}$ & $-11,5$ & $-11,8$ & $-12,1$ & $-12,4$ & $-12,7$ & $-13,0$ & $-13,3$ & $-13,5$ & $-13,8$ & $-12,8$ \\
\hline $\mathrm{C}_{2} \mathrm{H}_{2}$ & ${ }^{1} J_{\mathrm{CC}}$ & 201,3 & 209,2 & 217,9 & 227,5 & 238,0 & 249,5 & 262,3 & 276,3 & 291,7 & 174,8 \\
\hline $\mathrm{C}_{2} \mathrm{H}_{2}$ & ${ }^{1} J_{\mathrm{CH}}$ & 240,8 & 245,4 & 250,2 & 255,1 & 260,1 & 265,4 & 270,8 & 276,5 & 282,5 & 247,6 \\
\hline $\mathrm{C}_{2} \mathrm{H}_{2}$ & ${ }^{2} J_{\mathrm{CH}}$ & 50,9 & 49,9 & 48,6 & 47,2 & 45,6 & 43,8 & 41,8 & 39,5 & 36,9 & 50,1 \\
\hline $\mathrm{C}_{2} \mathrm{H}_{2}$ & ${ }^{3} J_{\mathrm{HH}}$ & 10,9 & 11,4 & 12,0 & 12,6 & 13,3 & 14,0 & 14,8 & 15,6 & 16,5 & 9,6 \\
\hline $\mathrm{C}_{2} \mathrm{H}_{4}$ & ${ }^{1} J_{\mathrm{CC}}$ & 71,3 & 77,5 & 84,4 & 92,0 & 100,4 & 109,9 & 120,6 & 132,8 & 146,8 & 67,6 \\
\hline $\mathrm{C}_{2} \mathrm{H}_{4}$ & ${ }^{1} J_{\mathrm{CH}}$ & 146,6 & 150,5 & 154,5 & 158,7 & 163,0 & 167,6 & 172,3 & 177,4 & 182,8 & 156,3 \\
\hline $\mathrm{C}_{2} \mathrm{H}_{4}$ & ${ }^{2} J_{\mathrm{CH}}$ & $-3,3$ & $-4,5$ & $-5,9$ & $-7,4$ & $-9,0$ & $-10,9$ & $-13,0$ & $-15,4$ & $-18,2$ & $-2,4$ \\
\hline $\mathrm{C}_{2} \mathrm{H}_{4}$ & ${ }^{2} J_{\mathrm{HH}}$ & 1,9 & 1,5 & 1,1 & 0,6 & 0,1 & $-0,3$ & $-0,9$ & $-1,6$ & $-2,4$ & 2,3 \\
\hline $\mathrm{C}_{2} \mathrm{H}_{4}$ & ${ }^{3} J_{\mathrm{HH}_{\mathrm{c}}}$ & 11,7 & 11,9 & 12,1 & 12,4 & 12,6 & 13,0 & 13,4 & 13,8 & 14,4 & 11,7 \\
\hline $\mathrm{C}_{2} \mathrm{H}_{4}$ & ${ }^{3} J_{\mathrm{HH}_{\mathrm{t}}}$ & 17,3 & 17,6 & 17,9 & 18,2 & 18,6 & 19,1 & 19,6 & 20,2 & 20,9 & 19 \\
\hline $\mathrm{C}_{2} \mathrm{H}_{6}$ & ${ }^{1} J_{\mathrm{CC}}$ & 31,4 & 34,4 & 37,4 & 40,5 & 43,6 & 46,8 & 50,1 & 53,4 & 56,8 & 34,5 \\
\hline $\mathrm{C}_{2} \mathrm{H}_{6}$ & ${ }^{1} J_{\mathrm{CH}}$ & 112,1 & 115,2 & 118,3 & 121,4 & 124,5 & 127,6 & 130,7 & 133,7 & 136,8 & 125,2 \\
\hline $\mathrm{C}_{2} \mathrm{H}_{6}$ & ${ }^{2} J_{\mathrm{CH}}$ & $-3,5$ & $-3,9$ & $-4,2$ & $-4,5$ & $-4,9$ & $-5,2$ & $-5,5$ & $-5,9$ & $-6,2$ & $-4,7$ \\
\hline \multirow[t]{3}{*}{ Total } & $\mathrm{DM}$ & $-10,58$ & $-6,03$ & $-1,46$ & 3,11 & 7,62 & 12,04 & 16,24 & 107,97 & 23,00 & - \\
\hline & DMA & 14,03 & 13,68 & 16,44 & 19,95 & 23,97 & 29,07 & 34,82 & 114,45 & 53,81 & - \\
\hline & PDMA & 12,34 & 15,29 & 26,67 & 39,46 & 53,08 & 68,31 & 84,93 & 126,28 & 122,10 & - \\
\hline \multirow[t]{3}{*}{ CPI } & DM & $-23,75$ & $-15,66$ & $-7,66$ & 0,16 & 7,72 & 14,80 & 21,15 & 234,14 & 29,16 & - \\
\hline & DMA & 25,59 & 25,01 & 30,46 & 36,65 & 43,50 & 51,76 & 60,82 & 244,10 & 95,40 & - \\
\hline & PDMA & 13,34 & 15,17 & 33,71 & 54,04 & 75,02 & 97,09 & 119,68 & 198,70 & 167,59 & - \\
\hline \multirow[t]{3}{*}{ SPI } & DM & $-0,92$ & 1,03 & 3,09 & 5,27 & 7,55 & 10,02 & 12,64 & 15,45 & 18,49 & - \\
\hline & DMA & 5,56 & 5,38 & 6,16 & 7,71 & 9,65 & 12,43 & 15,76 & 19,37 & 23,31 & - \\
\hline & PDMA & 11,60 & 15,37 & 21,50 & 28,76 & 36,99 & 47,21 & 59,44 & 73,17 & 88,74 & - \\
\hline \multirow[t]{3}{*}{$\Delta \mathrm{CS}$} & $\mathrm{DM}$ & $-22,83$ & $-16,70$ & $-10,76$ & $-5,10$ & 0,16 & 4,78 & 8,51 & 218,69 & 10,68 & - \\
\hline & DMA & 20,03 & 19,63 & 24,30 & 28,95 & 33,85 & 39,33 & 45,06 & 224,73 & 72,09 & - \\
\hline & PDMA & 1,74 & $-0,19$ & 12,21 & 25,29 & 38,03 & 49,88 & 60,24 & 125,53 & 78,85 & - \\
\hline
\end{tabular}


Tabela 8.311: Constantes de acoplamento $\omega$ B97 variando $\alpha$ com $\alpha+\beta=80 \%$ na base aug-pcJ-2.

\begin{tabular}{|c|c|c|c|c|c|c|c|c|c|}
\hline & $\alpha$ & $10 \%$ & $20 \%$ & $30 \%$ & $40 \%$ & $50 \%$ & $60 \%$ & $70 \%$ & Exp. \\
\hline $\mathrm{HF}$ & ${ }^{1} J_{\mathrm{HF}}$ & 474,5 & 508,4 & 542,6 & 577,0 & 611,7 & 646,7 & 682,0 & 500 \\
\hline $\mathrm{CO}$ & ${ }^{1} J_{\mathrm{CO}}$ & 21,3 & 17,7 & 13,9 & 9,8 & 5,3 & 0,6 & $-4,3$ & 16,4 \\
\hline $\mathrm{H}_{2} \mathrm{O}$ & ${ }^{1} J_{\mathrm{OH}}$ & $-73,8$ & $-77,5$ & $-81,2$ & $-84,9$ & $-88,7$ & $-92,5$ & $-96,3$ & $-80,6$ \\
\hline $\mathrm{H}_{2} \mathrm{O}$ & ${ }^{2} J_{\mathrm{HH}}$ & $-7,2$ & $-7,9$ & $-8,5$ & $-9,2$ & $-9,8$ & $-10,5$ & $-11,2$ & $-7,3$ \\
\hline $\mathrm{NH}_{3}$ & ${ }^{1} J_{\mathrm{NH}}$ & 39,8 & 41,1 & 42,5 & 43,8 & 45,1 & 46,4 & 47,7 & 43,8 \\
\hline $\mathrm{NH}_{3}$ & ${ }^{2} J_{\mathrm{HH}}$ & $-9,1$ & $-9,6$ & $-10,0$ & $-10,5$ & $-11,0$ & $-11,4$ & $-11,9$ & $-9,6$ \\
\hline $\mathrm{PH}_{3}$ & ${ }^{1} J_{\mathrm{PH}}$ & 167,7 & 173,9 & 179,9 & 185,9 & 191,7 & 197,4 & 203,0 & 188,2 \\
\hline $\mathrm{PF}_{3}$ & ${ }^{1} J_{\mathrm{PF}}$ & $-1632,8$ & $-1601,7$ & $-1569,6$ & $-1537,0$ & $-1504,0$ & $-1470,7$ & $-1437,4$ & -1441 \\
\hline $\mathrm{BHF}_{2}$ & ${ }^{1} J_{\mathrm{BF}}$ & $-100,4$ & $-80,0$ & $-59,5$ & $-38,9$ & $-18,2$ & 2,5 & 23,3 & -84 \\
\hline $\mathrm{BF}_{3}$ & ${ }^{1} J_{\mathrm{BF}}$ & $-4,3$ & 18,1 & 40,7 & 63,5 & 86,3 & 109,3 & 132,4 & 15 \\
\hline $\mathrm{F}_{2} \mathrm{O}$ & ${ }^{1} J_{\mathrm{OF}}$ & $-307,8$ & $-324,2$ & $-342,0$ & $-361,7$ & $-384,4$ & $-411,3$ & $-444,7$ & -300 \\
\hline $\mathrm{CH}_{4}$ & ${ }^{1} J_{\mathrm{CH}}$ & 112,1 & 115,1 & 118,1 & 121,1 & 124,1 & 127,1 & 130,0 & 125,3 \\
\hline $\mathrm{CH}_{4}$ & ${ }^{2} J_{\mathrm{HH}}$ & $-11,8$ & $-12,1$ & $-12,4$ & $-12,7$ & $-13,0$ & $-13,3$ & $-13,6$ & $-12,8$ \\
\hline $\mathrm{C}_{2} \mathrm{H}_{2}$ & ${ }^{1} J_{\mathrm{CC}}$ & 199,5 & 207,1 & 215,5 & 224,7 & 234,9 & 246,1 & 258,3 & 174,8 \\
\hline $\mathrm{C}_{2} \mathrm{H}_{2}$ & ${ }^{1} J_{\mathrm{CH}}$ & 241,3 & 246,0 & 250,8 & 255,7 & 260,9 & 266,2 & 271,7 & 247,6 \\
\hline $\mathrm{C}_{2} \mathrm{H}_{2}$ & ${ }^{2} J_{\mathrm{CH}}$ & 50,8 & 49,8 & 48,6 & 47,2 & 45,7 & 43,9 & 41,9 & 50,1 \\
\hline $\mathrm{C}_{2} \mathrm{H}_{2}$ & ${ }^{3} J_{\mathrm{HH}}$ & 11,1 & 11,6 & 12,2 & 12,8 & 13,5 & 14,2 & 14,9 & 9,6 \\
\hline $\mathrm{C}_{2} \mathrm{H}_{4}$ & ${ }^{1} J_{\mathrm{CC}}$ & 69,5 & 75,5 & 82,1 & 89,4 & 97,4 & 106,4 & 116,4 & 67,6 \\
\hline $\mathrm{C}_{2} \mathrm{H}_{4}$ & ${ }^{1} J_{\mathrm{CH}}$ & 146,2 & 150,2 & 154,2 & 158,4 & 162,7 & 167,2 & 171,9 & 156,3 \\
\hline $\mathrm{C}_{2} \mathrm{H}_{4}$ & ${ }^{2} J_{\mathrm{CH}}$ & $-3,0$ & $-4,1$ & $-5,4$ & $-6,9$ & $-8,5$ & $-10,2$ & $-12,3$ & $-2,4$ \\
\hline $\mathrm{C}_{2} \mathrm{H}_{4}$ & ${ }^{2} J_{\mathrm{HH}}$ & 1,9 & 1,5 & 1,1 & 0,6 & 0,1 & $-0,3$ & $-0,9$ & 2,3 \\
\hline $\mathrm{C}_{2} \mathrm{H}_{4}$ & ${ }^{3} J_{\mathrm{HH}_{\mathrm{C}}}$ & 11,6 & 11,7 & 12,0 & 12,2 & 12,5 & 12,8 & 13,2 & 11,7 \\
\hline $\mathrm{C}_{2} \mathrm{H}_{4}$ & ${ }^{3} J_{\mathrm{HH}_{\mathrm{t}}}$ & 17,4 & 17,6 & 17,9 & 18,3 & 18,7 & 19,1 & 19,6 & 19 \\
\hline $\mathrm{C}_{2} \mathrm{H}_{6}$ & ${ }^{1} J_{\mathrm{CC}}$ & 30,3 & 33,3 & 36,3 & 39,4 & 42,5 & 45,8 & 49,0 & 34,5 \\
\hline $\mathrm{C}_{2} \mathrm{H}_{6}$ & ${ }^{1} J_{\mathrm{CH}}$ & 111,8 & 115,0 & 118,1 & 121,3 & 124,4 & 127,5 & 130,6 & 125,2 \\
\hline $\mathrm{C}_{2} \mathrm{H}_{6}$ & ${ }^{2} J_{\mathrm{CH}}$ & $-3,5$ & $-3,8$ & $-4,1$ & $-4,5$ & $-4,8$ & $-5,2$ & $-5,5$ & $-4,7$ \\
\hline \multirow[t]{3}{*}{ Total } & $\mathrm{DM}$ & $-11,23$ & $-6,63$ & $-1,97$ & 2,68 & 7,31 & 11,88 & 16,26 & - \\
\hline & DMA & 14,56 & 11,53 & 14,04 & 17,42 & 21,60 & 26,59 & 32,43 & - \\
\hline & PDMA & 15,21 & 11,29 & 21,98 & 34,67 & 48,61 & 63,70 & 80,28 & - \\
\hline \multirow[t]{3}{*}{ CPI } & DM & $-24,82$ & $-16,60$ & $-8,37$ & $-0,28$ & 7,55 & 15,05 & 21,97 & - \\
\hline & DMA & 27,05 & 20,22 & 25,25 & 31,30 & 38,55 & 46,64 & 56,03 & - \\
\hline & PDMA & 21,28 & 7,28 & 25,08 & 45,62 & 67,26 & 89,51 & 112,29 & - \\
\hline \multirow[t]{3}{*}{ SPI } & DM & $-1,26$ & 0,69 & 2,73 & 4,86 & 7,13 & 9,55 & 12,07 & - \\
\hline & DMA & 5,39 & 5,15 & 5,82 & 7,25 & 9,17 & 11,89 & 15,13 & - \\
\hline & PDMA & 10,76 & 14,23 & 19,70 & 26,64 & 34,94 & 44,77 & 56,81 & - \\
\hline \multirow[t]{3}{*}{$\Delta \mathrm{CS}$} & DM & $-23,56$ & $-17,29$ & $-11,10$ & $-5,14$ & 0,42 & 5,51 & 9,90 & - \\
\hline & DMA & 21,66 & 15,06 & 19,43 & 24,05 & 29,38 & 34,74 & 40,90 & - \\
\hline & PDMA & 10,52 & $-6,95$ & 5,38 & 18,98 & 32,33 & 44,75 & 55,47 & - \\
\hline
\end{tabular}


Tabela 8.312: Constantes de acoplamento $\omega$ B97 variando $\alpha$ com $\alpha+\beta=60 \%$ na base aug-pcJ-2.

\begin{tabular}{|c|c|c|c|c|c|c|c|}
\hline & $\alpha$ & $10 \%$ & $20 \%$ & $30 \%$ & $40 \%$ & $50 \%$ & Exp. \\
\hline $\mathrm{HF}$ & ${ }^{1} J_{\mathrm{HF}}$ & 459,9 & 494,0 & 528,3 & 562,9 & 597,8 & 500 \\
\hline $\mathrm{CO}$ & ${ }^{1} J_{\mathrm{CO}}$ & 21,9 & 18,4 & 14,6 & 10,5 & 6,1 & 16,4 \\
\hline $\mathrm{H}_{2} \mathrm{O}$ & ${ }^{1} J_{\mathrm{OH}}$ & $\begin{array}{l}-72,1 \\
\end{array}$ & $-75,8$ & $-79,5$ & $-83,3$ & $-87,1$ & $-80,6$ \\
\hline $\mathrm{H}_{2} \mathrm{O}$ & ${ }^{2} J_{\mathrm{HH}}$ & $-7,3$ & $-7,9$ & $-8,6$ & $-9,2$ & $-9,9$ & $-7,3$ \\
\hline $\mathrm{NH}_{3}$ & ${ }^{1} J_{\mathrm{NH}}$ & 39,4 & 40,7 & 42,0 & 43,4 & 44,7 & 43,8 \\
\hline $\mathrm{NH}_{3}$ & ${ }^{2} J_{\mathrm{HH}}$ & $-9,2$ & $-9,7$ & $-10,1$ & $-10,6$ & $-11,1$ & $-9,6$ \\
\hline $\mathrm{PH}_{3}$ & ${ }^{1} J_{\mathrm{PH}}$ & 169,8 & 176,2 & 182,4 & 188,5 & 194,5 & 188,2 \\
\hline $\mathrm{PF}_{3}$ & ${ }^{1} J_{\mathrm{PF}}$ & $-1633,7$ & $-1602,4$ & $-1570,0$ & $-1536,8$ & $-1503,0$ & -1441 \\
\hline $\mathrm{BHF}_{2}$ & ${ }^{1} J_{\mathrm{BF}}$ & $-109,4$ & $-88,5$ & $-67,6$ & $-46,5$ & $-25,4$ & -84 \\
\hline $\mathrm{BF}_{3}$ & ${ }^{1} J_{\mathrm{BF}}$ & $-16,1$ & 6,8 & 29,9 & 53,1 & 76,4 & 15 \\
\hline $\mathrm{F}_{2} \mathrm{O}$ & ${ }^{1} J_{\mathrm{OF}}$ & $-289,2$ & $-305,5$ & $-322,8$ & $-341,7$ & $-363,0$ & -300 \\
\hline $\mathrm{CH}_{4}$ & ${ }^{1} J_{\mathrm{CH}}$ & 111,8 & 114,9 & 117,9 & 121,0 & 124,0 & 125,3 \\
\hline $\mathrm{CH}_{4}$ & ${ }^{2} J_{\mathrm{HH}}$ & $-12,0$ & $-12,3$ & $-12,7$ & $-13,0$ & $-13,3$ & $-12,8$ \\
\hline $\mathrm{C}_{2} \mathrm{H}_{2}$ & ${ }^{1} J_{\mathrm{CC}}$ & 197,7 & 205,1 & 213,2 & 222,1 & 231,9 & 174,8 \\
\hline $\mathrm{C}_{2} \mathrm{H}_{2}$ & ${ }^{1} J_{\mathrm{CH}}$ & 241,7 & 246,4 & 251,3 & 256,3 & 261,5 & 247,6 \\
\hline $\mathrm{C}_{2} \mathrm{H}_{2}$ & ${ }^{2} J_{\mathrm{CH}}$ & 50,7 & 49,7 & 48,5 & 47,2 & 45,7 & 50,1 \\
\hline $\mathrm{C}_{2} \mathrm{H}_{2}$ & ${ }^{3} J_{\mathrm{HH}}$ & 11,4 & 11,9 & 12,4 & 13,0 & 13,7 & 9,6 \\
\hline $\mathrm{C}_{2} \mathrm{H}_{4}$ & ${ }^{1} J_{\mathrm{CC}}$ & 67,8 & 73,6 & 79,9 & 86,9 & 94,5 & 67,6 \\
\hline $\mathrm{C}_{2} \mathrm{H}_{4}$ & ${ }^{1} J_{\mathrm{CH}}$ & 145,8 & 149,8 & 153,9 & 158,0 & 162,4 & 156,3 \\
\hline $\mathrm{C}_{2} \mathrm{H}_{4}$ & ${ }^{2} J_{\mathrm{CH}}$ & $-2,6$ & $-3,8$ & $-5,0$ & $-6,4$ & $-7,9$ & $-2,4$ \\
\hline $\mathrm{C}_{2} \mathrm{H}_{4}$ & ${ }^{2} J_{\mathrm{HH}}$ & 1,9 & 1,5 & 1,0 & 0,6 & 0,1 & 2,3 \\
\hline $\mathrm{C}_{2} \mathrm{H}_{4}$ & ${ }^{3} J_{\mathrm{HH}_{\mathrm{c}}}$ & 11,4 & 11,6 & 11,8 & 12,0 & 12,3 & 11,7 \\
\hline $\mathrm{C}_{2} \mathrm{H}_{4}$ & ${ }^{3} J_{\mathrm{HH}_{\mathrm{t}}}$ & 17,4 & 17,7 & 18,0 & 18,3 & 18,7 & 19 \\
\hline $\mathrm{C}_{2} \mathrm{H}_{6}$ & ${ }^{1} J_{\mathrm{CC}}$ & 29,2 & 32,2 & 35,2 & 38,3 & 41,4 & 34,5 \\
\hline $\mathrm{C}_{2} \mathrm{H}_{6}$ & ${ }^{1} J_{\mathrm{CH}}$ & 111,5 & 114,7 & 117,9 & 121,1 & 124,2 & 125,2 \\
\hline $\mathrm{C}_{2} \mathrm{H}_{6}$ & ${ }^{2} J_{\mathrm{CH}}$ & $-3,4$ & $-3,8$ & $-4,1$ & $-4,5$ & $-4,8$ & $-4,7$ \\
\hline \multirow[t]{3}{*}{ Total } & DM & $-11,95$ & $-7,29$ & $-2,58$ & 2,16 & 6,90 & - \\
\hline & DMA & 16,01 & 10,89 & 11,77 & 15,03 & 19,30 & - \\
\hline & PDMA & 18,49 & 12,23 & 17,59 & 30,02 & 44,01 & - \\
\hline \multirow[t]{3}{*}{ CPI } & DM & $-26,08$ & $-17,69$ & $-9,30$ & $-0,96$ & 7,19 & - \\
\hline & DMA & 30,66 & 18,93 & 20,34 & 26,20 & 33,72 & - \\
\hline & PDMA & 30,06 & 10,47 & 16,69 & 37,15 & 59,22 & - \\
\hline \multirow[t]{3}{*}{ SPI } & $\mathrm{DM}$ & $-1,59$ & 0,34 & 2,34 & 4,45 & 6,69 & - \\
\hline & DMA & 5,27 & 4,99 & 5,49 & 6,84 & 8,73 & - \\
\hline & PDMA & 10,01 & 13,52 & 18,26 & 24,79 & 32,86 & - \\
\hline \multirow[t]{3}{*}{$\Delta \mathrm{CS}$} & DM & $-24,50$ & $-18,03$ & $-11,64$ & $-5,42$ & 0,50 & - \\
\hline & DMA & 25,40 & 13,93 & 14,85 & 19,36 & 24,99 & - \\
\hline & PDMA & 20,05 & $-3,06$ & $-1,56$ & 12,36 & 26,37 & - \\
\hline
\end{tabular}


Tabela 8.313: Constantes de acoplamento $\omega$ B97 variando $\alpha$ com $\alpha+\beta=40 \%$ na base aug-pcJ-2.

\begin{tabular}{|c|c|c|c|c|c|}
\hline & $\alpha$ & $10 \%$ & $20 \%$ & $30 \%$ & Exp. \\
\hline $\mathrm{HF}$ & ${ }^{\mathrm{I}} J_{\mathrm{HF}}$ & 445,5 & 479,6 & 514,0 & 500 \\
\hline $\mathrm{CO}$ & ${ }^{1} J_{\mathrm{CO}}$ & 22,5 & 19,1 & 15,3 & 16,4 \\
\hline $\mathrm{H}_{2} \mathrm{O}$ & ${ }^{1} J_{\mathrm{OH}}$ & $-70,4$ & $-74,1$ & $-77,9$ & $-80,6$ \\
\hline $\mathrm{H}_{2} \mathrm{O}$ & ${ }^{2} J_{\mathrm{HH}}$ & $-7,4$ & $-8,0$ & $-8,7$ & $-7,3$ \\
\hline $\mathrm{NH}_{3}$ & ${ }^{1} J_{\mathrm{NH}}$ & 38,9 & 40,2 & 41,6 & 43,8 \\
\hline $\mathrm{NH}_{3}$ & ${ }^{2} J_{\mathrm{HH}}$ & $-9,3$ & $-9,8$ & $-10,3$ & $-9,6$ \\
\hline $\mathrm{PH}_{3}$ & ${ }^{1} J_{\mathrm{PH}}$ & 172,1 & 178,6 & 185,0 & 188,2 \\
\hline $\mathrm{PF}_{3}$ & ${ }^{1} J_{\mathrm{PF}}$ & $-1635,6$ & $-1604,1$ & $-1571,4$ & -1441 \\
\hline $\mathrm{BHF}_{2}$ & ${ }^{1} J_{\mathrm{BF}}$ & $-118,8$ & $-97,4$ & $-76,0$ & -84 \\
\hline $\mathrm{BF}_{3}$ & ${ }^{1} J_{\mathrm{BF}}$ & $-28,4$ & $-4,8$ & 18,7 & 15 \\
\hline $\mathrm{F}_{2} \mathrm{O}$ & ${ }^{1} J_{\mathrm{OF}}$ & $-270,8$ & $-287,0$ & $-303,9$ & -300 \\
\hline $\mathrm{CH}_{4}$ & ${ }^{1} J_{\mathrm{CH}}$ & 111,5 & 114,6 & 117,7 & 125,3 \\
\hline $\mathrm{CH}_{4}$ & ${ }^{2} J_{\mathrm{HH}}$ & $-12,3$ & $-12,6$ & $-12,9$ & $-12,8$ \\
\hline $\mathrm{C}_{2} \mathrm{H}_{2}$ & ${ }^{1} J_{\mathrm{CC}}$ & 196,0 & 203,1 & 211,0 & 174,8 \\
\hline $\mathrm{C}_{2} \mathrm{H}_{2}$ & ${ }^{1} J_{\mathrm{CH}}$ & 242,1 & 246,9 & 251,8 & 247,6 \\
\hline $\mathrm{C}_{2} \mathrm{H}_{2}$ & ${ }^{2} J_{\mathrm{CH}}$ & 50,5 & 49,6 & 48,5 & 50,1 \\
\hline $\mathrm{C}_{2} \mathrm{H}_{2}$ & ${ }^{3} J_{\mathrm{HH}}$ & 11,6 & 12,1 & 12,7 & 9,6 \\
\hline $\mathrm{C}_{2} \mathrm{H}_{4}$ & ${ }^{1} J_{\mathrm{CC}}$ & 66,2 & 71,7 & 77,8 & 67,6 \\
\hline $\mathrm{C}_{2} \mathrm{H}_{4}$ & ${ }^{1} J_{\mathrm{CH}}$ & 145,4 & 149,4 & 153,5 & 156,3 \\
\hline $\mathrm{C}_{2} \mathrm{H}_{4}$ & ${ }^{2} J_{\mathrm{CH}}$ & $-2,3$ & $-3,4$ & $-4,6$ & $-2,4$ \\
\hline $\mathrm{C}_{2} \mathrm{H}_{4}$ & ${ }^{2} J_{\mathrm{HH}}$ & 1,9 & 1,4 & 1,0 & 2,3 \\
\hline $\mathrm{C}_{2} \mathrm{H}_{4}$ & ${ }^{3} J_{\mathrm{HH}_{\mathrm{C}}}$ & 11,2 & 11,4 & 11,6 & 11,7 \\
\hline $\mathrm{C}_{2} \mathrm{H}_{4}$ & ${ }^{3} J_{\mathrm{HH}_{\mathrm{t}}}$ & 17,5 & 17,8 & 18,1 & 19 \\
\hline $\mathrm{C}_{2} \mathrm{H}_{6}$ & ${ }^{1} J_{\mathrm{CC}}$ & 28,1 & 31,0 & 34,1 & 34,5 \\
\hline $\mathrm{C}_{2} \mathrm{H}_{6}$ & ${ }^{1} J_{\mathrm{CH}}$ & 111,1 & 114,4 & 117,6 & 125,2 \\
\hline $\mathrm{C}_{2} \mathrm{H}_{6}$ & ${ }^{2} J_{\mathrm{CH}}$ & $-3,4$ & $-3,7$ & $-4,1$ & $-4,7$ \\
\hline \multirow[t]{3}{*}{ Total } & DM & $-12,75$ & $-8,04$ & $-3,26$ & - \\
\hline & DMA & 18,24 & 12,52 & 9,62 & - \\
\hline & PDMA & 22,70 & 15,81 & 13,31 & - \\
\hline \multirow[t]{3}{*}{ CPI } & DM & $-27,51$ & $-18,96$ & $-10,41$ & - \\
\hline & DMA & 35,84 & 23,00 & 15,57 & - \\
\hline & PDMA & 39,91 & 19,75 & 8,24 & - \\
\hline \multirow[t]{3}{*}{ SPI } & DM & $-1,93$ & $-0,03$ & 1,98 & - \\
\hline & DMA & 5,33 & 4,84 & 5,26 & - \\
\hline & PDMA & 10,08 & 12,92 & 17,03 & - \\
\hline \multirow[t]{3}{*}{$\Delta \mathrm{CS}$} & $\mathrm{DM}$ & $-25,58$ & $-18,94$ & $-12,39$ & - \\
\hline & DMA & 30,50 & 18,16 & 10,31 & - \\
\hline & PDMA & 29,83 & 6,82 & $-8,79$ & - \\
\hline
\end{tabular}


Tabela 8.314: Constantes de acoplamento $\omega$ B97 variando $\alpha$ com $\alpha+$ $\beta=20 \%$ na base aug-pcJ-2.

\begin{tabular}{|c|c|c|c|}
\hline & $\alpha$ & $10 \%$ & Exp. \\
\hline $\mathrm{HF}$ & ${ }^{1} J_{\mathrm{HF}}$ & 431,3 & 500 \\
\hline $\mathrm{CO}$ & ${ }^{1} J_{\mathrm{CO}}$ & 23,2 & 16,4 \\
\hline $\mathrm{H}_{2} \mathrm{O}$ & ${ }^{1} J_{\mathrm{OH}}$ & $-68,7$ & $-80,6$ \\
\hline $\mathrm{H}_{2} \mathrm{O}$ & ${ }^{2} J_{\mathrm{HH}}$ & $-7,4$ & $-7,3$ \\
\hline $\mathrm{NH}_{3}$ & ${ }^{1} J_{\mathrm{NH}}$ & 38,4 & 43,8 \\
\hline $\mathrm{NH}_{3}$ & ${ }^{2} J_{\mathrm{HH}}$ & $-9,4$ & $-9,6$ \\
\hline $\mathrm{PH}_{3}$ & ${ }^{1} J_{\mathrm{PH}}$ & 174,3 & 188,2 \\
\hline $\mathrm{PF}_{3}$ & ${ }^{1} J_{\mathrm{PF}}$ & $-1638,4$ & -1441 \\
\hline $\mathrm{BHF}_{2}$ & ${ }^{1} J_{\mathrm{BF}}$ & $-128,6$ & -84 \\
\hline $\mathrm{BF}_{3}$ & ${ }^{1} J_{\mathrm{BF}}$ & $-41,0$ & 15 \\
\hline $\mathrm{F}_{2} \mathrm{O}$ & ${ }^{1} J_{\mathrm{OF}}$ & $-252,3$ & -300 \\
\hline $\mathrm{CH}_{4}$ & ${ }^{1} J_{\mathrm{CH}}$ & 111,2 & 125,3 \\
\hline $\mathrm{CH}_{4}$ & ${ }^{2} J_{\mathrm{HH}}$ & $-12,5$ & $-12,8$ \\
\hline $\mathrm{C}_{2} \mathrm{H}_{2}$ & ${ }^{1} J_{\mathrm{CC}}$ & 194,3 & 174,8 \\
\hline $\mathrm{C}_{2} \mathrm{H}_{2}$ & ${ }^{1} J_{\mathrm{CH}}$ & 242,4 & 247,6 \\
\hline $\mathrm{C}_{2} \mathrm{H}_{2}$ & ${ }^{2} J_{\mathrm{CH}}$ & 50,4 & 50,1 \\
\hline $\mathrm{C}_{2} \mathrm{H}_{2}$ & ${ }^{3} J_{\mathrm{HH}}$ & 11,9 & 9,6 \\
\hline $\mathrm{C}_{2} \mathrm{H}_{4}$ & ${ }^{1} J_{\mathrm{CC}}$ & 64,5 & 67,6 \\
\hline $\mathrm{C}_{2} \mathrm{H}_{4}$ & ${ }^{1} J_{\mathrm{CH}}$ & 145,0 & 156,3 \\
\hline $\mathrm{C}_{2} \mathrm{H}_{4}$ & ${ }^{2} J_{\mathrm{CH}}$ & $-1,9$ & $-2,4$ \\
\hline $\mathrm{C}_{2} \mathrm{H}_{4}$ & ${ }^{2} J_{\mathrm{HH}}$ & 1,8 & 2,3 \\
\hline $\mathrm{C}_{2} \mathrm{H}_{4}$ & ${ }^{3} J_{\mathrm{HH}_{\mathrm{c}}}$ & 11,0 & 11,7 \\
\hline $\mathrm{C}_{2} \mathrm{H}_{4}$ & ${ }^{3} J_{\mathrm{HH}_{\mathrm{t}}}$ & 17,6 & 19 \\
\hline $\mathrm{C}_{2} \mathrm{H}_{6}$ & ${ }^{1} J_{\mathrm{CC}}$ & 26,9 & 34,5 \\
\hline $\mathrm{C}_{2} \mathrm{H}_{6}$ & ${ }^{1} J_{\mathrm{CH}}$ & 110,7 & 125,2 \\
\hline $\mathrm{C}_{2} \mathrm{H}_{6}$ & ${ }^{2} J_{\mathrm{CH}}$ & $-3,3$ & $-4,7$ \\
\hline \multirow[t]{3}{*}{ Total } & $\mathrm{DM}$ & $-13,60$ & - \\
\hline & DMA & 20,59 & - \\
\hline & PDMA & 28,14 & - \\
\hline \multirow[t]{3}{*}{ CPI } & $\mathrm{DM}$ & $-29,05$ & - \\
\hline & DMA & 41,15 & - \\
\hline & PDMA & 49,92 & - \\
\hline \multirow[t]{3}{*}{ SPI } & $\mathrm{DM}$ & $-2,27$ & - \\
\hline & DMA & 5,51 & - \\
\hline & PDMA & 12,17 & - \\
\hline \multirow[t]{3}{*}{$\Delta \mathrm{CS}$} & $\mathrm{DM}$ & $-26,77$ & - \\
\hline & DMA & 35,64 & - \\
\hline & PDMA & 37,75 & - \\
\hline
\end{tabular}


Tabela 8.315: Constantes de acoplamento $\omega \mathrm{B} 97 \mathrm{X}$ variando $\alpha \operatorname{com} \alpha+\beta=100 \%$ na base aug-pcJ-2.

\begin{tabular}{|c|c|c|c|c|c|c|c|c|c|c|c|}
\hline & $\alpha$ & $10 \%$ & $20 \%$ & $30 \%$ & $40 \%$ & $50 \%$ & $60 \%$ & $70 \%$ & $80 \%$ & $90 \%$ & Exp. \\
\hline $\mathrm{HF}$ & ${ }^{1} J_{\mathrm{HF}}$ & 486,5 & 507,3 & 533,4 & 565,9 & 606,0 & 654,9 & 713,6 & 783,1 & 863,7 & 500 \\
\hline $\mathrm{CO}$ & ${ }^{1} J_{\mathrm{CO}}$ & 18,9 & 19,2 & 18,8 & 17,5 & 15,0 & 10,6 & 3,5 & $-7,6$ & $-24,5$ & 16,4 \\
\hline $\mathrm{H}_{2} \mathrm{O}$ & ${ }^{1} J_{\mathrm{OH}}$ & $-74,1$ & $-78,4$ & $-83,5$ & $-89,7$ & $-97,3$ & $-106,4$ & $-117,5$ & $-131,1$ & $-147,8$ & $-80,6$ \\
\hline $\mathrm{H}_{2} \mathrm{O}$ & ${ }^{2} J_{\mathrm{HH}}$ & $-4,6$ & $-7,9$ & $-12,0$ & $-17,3$ & $-23,9$ & $-32,5$ & $-43,4$ & $-57,4$ & $-75,6$ & $-7,3$ \\
\hline $\mathrm{NH}_{3}$ & ${ }^{1} J_{\mathrm{NH}}$ & 39,7 & 42,8 & 46,5 & 50,7 & 55,8 & 62,0 & 69,6 & 79,0 & 91,0 & 43,8 \\
\hline $\mathrm{NH}_{3}$ & ${ }^{2} J_{\mathrm{HH}}$ & $-7,0$ & $-10,1$ & $-14,2$ & $-19,6$ & $-26,6$ & $-36,1$ & $-48,9$ & $-66,4$ & $-90,9$ & $-9,6$ \\
\hline $\mathrm{PH}_{3}$ & ${ }^{1} J_{\mathrm{PH}}$ & 153,0 & 174,7 & 201,1 & 233,3 & 272,9 & 322,1 & 383,9 & 463,2 & 567,6 & 188,2 \\
\hline $\mathrm{PF}_{3}$ & ${ }^{1} J_{\mathrm{PF}}$ & $-1641,6$ & $-1642,9$ & $-1639,3$ & $-1631,3$ & $-1619,7$ & $-1605,2$ & $-1588,7$ & $-1570,8$ & $-1551,5$ & -1441 \\
\hline $\mathrm{BHF}_{2}$ & ${ }^{1} J_{\mathrm{BF}}$ & $-103,0$ & $-93,0$ & $-81,1$ & $-67,4$ & $-52,2$ & $-35,5$ & $-17,6$ & 1,0 & 20,1 & -84 \\
\hline $\mathrm{BF}_{3}$ & ${ }^{1} J_{\mathrm{BF}}$ & $-3,6$ & 8,8 & 23,3 & 40,0 & 58,9 & 80,1 & 103,8 & 129,8 & 157,8 & 15 \\
\hline $\mathrm{F}_{2} \mathrm{O}$ & ${ }^{1} J_{\mathrm{OF}}$ & $-288,1$ & $-358,9$ & $-459,2$ & $-642,6$ & $-1421,8$ & $-4923,4$ & 199,5 & $-142,1$ & $-320,9$ & -300 \\
\hline $\mathrm{CH}_{4}$ & ${ }^{1} J_{\mathrm{CH}}$ & 105,5 & 118,0 & 132,6 & 150,1 & 171,0 & 196,5 & 228,1 & 268,0 & 319,7 & 125,3 \\
\hline $\mathrm{CH}_{4}$ & ${ }^{2} J_{\mathrm{HH}}$ & $-9,5$ & $-12,7$ & $-17,0$ & $-22,5$ & $-29,8$ & $-39,7$ & $-53,1$ & $-71,9$ & $-98,8$ & $-12,8$ \\
\hline $\mathrm{C}_{2} \mathrm{H}_{2}$ & ${ }^{1} J_{\mathrm{CC}}$ & 185,6 & 199,6 & 221,6 & 264,1 & 395,3 & $-1875,9$ & $-25,7$ & 87,3 & 185,9 & 174,8 \\
\hline $\mathrm{C}_{2} \mathrm{H}_{2}$ & ${ }^{1} J_{\mathrm{CH}}$ & 223,5 & 253,8 & 291,7 & 345,8 & 459,8 & $-966,8$ & 256,4 & 360,8 & 427,9 & 247,6 \\
\hline $\mathrm{C}_{2} \mathrm{H}_{2}$ & ${ }^{2} J_{\mathrm{CH}}$ & 53,7 & 52,6 & 47,4 & 30,3 & $-42,0$ & 1432,0 & 262,7 & 220,3 & 225,2 & 50,1 \\
\hline $\mathrm{C}_{2} \mathrm{H}_{2}$ & ${ }^{3} J_{\mathrm{HH}}$ & 8,4 & 11,6 & 17,8 & 32,0 & 82,4 & $-868,0$ & $-106,0$ & $-72,0$ & $-63,3$ & 9,6 \\
\hline $\mathrm{C}_{2} \mathrm{H}_{4}$ & ${ }^{1} J_{\mathrm{CC}}$ & 60,3 & 68,5 & 83,2 & 119,1 & 382,4 & $-114,0$ & $-22,2$ & 1,8 & 13,0 & 67,6 \\
\hline $\mathrm{C}_{2} \mathrm{H}_{4}$ & ${ }^{1} J_{\mathrm{CH}}$ & 135,5 & 153,6 & 177,0 & 213,4 & 366,0 & 143,2 & 218,2 & 264,7 & 311,8 & 156,3 \\
\hline $\mathrm{C}_{2} \mathrm{H}_{4}$ & ${ }^{2} J_{\mathrm{CH}}$ & 0,2 & $-2,9$ & $-9,2$ & $-25,9$ & $-155,7$ & 93,5 & 49,8 & 40,3 & 37,8 & $-2,4$ \\
\hline $\mathrm{C}_{2} \mathrm{H}_{4}$ & ${ }^{2} J_{\mathrm{HH}}$ & 3,9 & 1,8 & $-2,5$ & $-13,9$ & $-99,6$ & 61,5 & 30,7 & 21,2 & 14,6 & 2,3 \\
\hline $\mathrm{C}_{2} \mathrm{H}_{4}$ & ${ }^{3} J_{\mathrm{HH}_{\mathrm{c}}}$ & 10,6 & 12,4 & 16,1 & 26,3 & 110,2 & $-53,5$ & $-26,5$ & $-22,4$ & $-23,6$ & 11,7 \\
\hline $\mathrm{C}_{2} \mathrm{H}_{4}$ & ${ }^{3} J_{\mathrm{HH}_{\mathrm{t}}}$ & 15,6 & 18,7 & 24,1 & 36,8 & 129,6 & $-45,5$ & $-13,4$ & $-5,6$ & $-2,6$ & 19 \\
\hline $\mathrm{C}_{2} \mathrm{H}_{6}$ & ${ }^{1} J_{\mathrm{CC}}$ & 26,8 & 31,0 & 36,3 & 43,0 & 51,6 & 62,8 & 77,8 & 98,4 & 128,1 & 34,5 \\
\hline $\mathrm{C}_{2} \mathrm{H}_{6}$ & ${ }^{1} J_{\mathrm{CH}}$ & 105,1 & 118,2 & 133,8 & 152,3 & 174,7 & 202,2 & 236,5 & 280,4 & 338,4 & 125,2 \\
\hline $\mathrm{C}_{2} \mathrm{H}_{6}$ & ${ }^{2} J_{\mathrm{CH}}$ & $-2,4$ & $-3,8$ & $-5,7$ & $-8,2$ & $-11,5$ & $-16,0$ & $-22,4$ & $-31,8$ & $-46,4$ & $-4,7$ \\
\hline \multirow[t]{3}{*}{ Total } & DM & $-13,31$ & $-10,12$ & $-6,31$ & $-2,42$ & $-3,60$ & $-278,54$ & 34,76 & 41,35 & 54,30 & - \\
\hline & DMA & 17,19 & 13,99 & 23,63 & 46,41 & 128,97 & 442,70 & 96,87 & 94,51 & 108,23 & - \\
\hline & PDMA & 26,02 & 10,27 & 41,39 & 123,87 & 601,66 & 955,18 & 342,14 & 332,06 & 374,51 & - \\
\hline \multirow[t]{3}{*}{ CPI } & DM & $-24,07$ & $-25,39$ & $-27,92$ & $-36,49$ & $-97,62$ & $-404,57$ & 74,26 & 58,16 & 58,92 & - \\
\hline & DMA & 28,84 & 27,63 & 39,30 & 65,69 & 148,24 & 481,05 & 123,88 & 114,75 & 129,66 & - \\
\hline & PDMA & 25,70 & 11,80 & 25,08 & 56,90 & 113,11 & 261,51 & 189,25 & 245,29 & 326,17 & - \\
\hline \multirow[t]{3}{*}{ SPI } & $\mathrm{DM}$ & $-5,42$ & 1,09 & 9,54 & 22,57 & 65,35 & $-186,12$ & 5,79 & 29,03 & 50,91 & - \\
\hline & DMA & 8,65 & 3,99 & 12,14 & 32,27 & 114,83 & 414,59 & 77,05 & 79,67 & 92,52 & - \\
\hline & PDMA & 26,25 & 9,15 & 53,35 & 172,98 & 959,92 & 1463,87 & 454,26 & 395,69 & 409,96 & - \\
\hline \multirow[t]{3}{*}{$\Delta \mathrm{CS}$} & $\mathrm{DM}$ & $-18,65$ & $-26,48$ & $-37,46$ & $-59,06$ & $-162,97$ & $-218,45$ & 68,48 & 29,14 & 8,01 & - \\
\hline & DMA & 20,19 & 23,63 & 27,16 & 33,42 & 33,40 & 66,46 & 46,83 & 35,08 & 37,14 & - \\
\hline & PDMA & $-0,56$ & 2,66 & $-28,27$ & $-116,08$ & $-846,81$ & $-1202,36$ & $-265,01$ & $-150,40$ & $-83,78$ & - \\
\hline
\end{tabular}


Tabela 8.316: Constantes de acoplamento $\omega$ B97X variando $\alpha$ com $\alpha+$ $\beta=80 \%$ na base aug-pcJ-2.

\begin{tabular}{|c|c|c|c|c|c|c|c|c|c|}
\hline & $\alpha$ & $10 \%$ & $20 \%$ & $30 \%$ & $40 \%$ & $50 \%$ & $60 \%$ & $70 \%$ & Exp. \\
\hline $\mathrm{HF}$ & ${ }^{\mathrm{I}} J_{\mathrm{HF}}$ & 488,2 & 508,1 & 533,3 & 564,8 & 603,8 & 651,6 & 709,2 & 500 \\
\hline $\mathrm{CO}$ & ${ }^{1} J_{\mathrm{CO}}$ & 18,5 & 18,8 & 18,4 & 17,1 & 14,6 & 10,2 & 3,0 & 16,4 \\
\hline $\mathrm{H}_{2} \mathrm{O}$ & ${ }^{1} J_{\mathrm{OH}}$ & $-74,2$ & $-78,3$ & $-83,3$ & $-89,4$ & $-96,8$ & $-105,7$ & $-116,6$ & $-80,6$ \\
\hline $\mathrm{H}_{2} \mathrm{O}$ & ${ }^{2} J_{\mathrm{HH}}$ & $-4,3$ & $-7,5$ & $-11,6$ & $-16,7$ & $-23,3$ & $-31,7$ & $-42,4$ & $-7,3$ \\
\hline $\mathrm{NH}_{3}$ & ${ }^{1} J_{\mathrm{NH}}$ & 39,7 & 42,7 & 46,3 & 50,5 & 55,5 & 61,5 & 68,9 & 43,8 \\
\hline $\mathrm{NH}_{3}$ & ${ }^{2} J_{\mathrm{HH}}$ & $-6,5$ & $-9,6$ & $-13,6$ & $-18,8$ & $-25,7$ & $-34,9$ & $-47,3$ & $-9,6$ \\
\hline $\mathrm{PH}_{3}$ & ${ }^{1} J_{\mathrm{PH}}$ & 157,2 & 178,3 & 204,0 & 235,5 & 274,2 & 322,2 & 382,5 & 188,2 \\
\hline $\mathrm{PF}_{3}$ & ${ }^{1} J_{\mathrm{PF}}$ & $-1639,8$ & $-1643,6$ & $-1642,0$ & $-1635,6$ & $-1625,2$ & $-1611,5$ & $-1595,6$ & -1441 \\
\hline $\mathrm{BHF}_{2}$ & ${ }^{1} J_{\mathrm{BF}}$ & $-108,8$ & $-98,8$ & $-87,0$ & $-73,3$ & $-58,0$ & $-41,2$ & $-23,2$ & -84 \\
\hline $\mathrm{BF}_{3}$ & ${ }^{1} J_{\mathrm{BF}}$ & $-9,4$ & 3,0 & 17,6 & 34,3 & 53,2 & 74,5 & 98,3 & 15 \\
\hline $\mathrm{F}_{2} \mathrm{O}$ & ${ }^{1} J_{\mathrm{OF}}$ & $-277,5$ & $-345,7$ & $-440,1$ & $-603,6$ & $-1159,6$ & $-1651,0$ & 272,3 & -300 \\
\hline $\mathrm{CH}_{4}$ & ${ }^{1} J_{\mathrm{CH}}$ & 104,9 & 117,1 & 131,4 & 148,5 & 169,0 & 193,9 & 224,7 & 125,3 \\
\hline $\mathrm{CH}_{4}$ & ${ }^{2} J_{\mathrm{HH}}$ & $-8,9$ & $-12,1$ & $-16,1$ & $-21,5$ & $-28,5$ & $-38,0$ & $-51,0$ & $-12,8$ \\
\hline $\mathrm{C}_{2} \mathrm{H}_{2}$ & ${ }^{1} J_{\mathrm{CC}}$ & 184,2 & 197,4 & 217,5 & 254,4 & 353,6 & 2242,1 & $-86,0$ & 174,8 \\
\hline $\mathrm{C}_{2} \mathrm{H}_{2}$ & ${ }^{1} J_{\mathrm{CH}}$ & 221,3 & 250,9 & 287,5 & 337,8 & 430,8 & 1667,5 & 218,8 & 247,6 \\
\hline $\mathrm{C}_{2} \mathrm{H}_{2}$ & ${ }^{2} J_{\mathrm{CH}}$ & 53,2 & 52,6 & 48,4 & 34,6 & $-17,1$ & $-1207,0$ & 295,0 & 50,1 \\
\hline $\mathrm{C}_{2} \mathrm{H}_{2}$ & ${ }^{3} J_{\mathrm{HH}}$ & 8,0 & 10,9 & 16,3 & 28,2 & 64,8 & 832,6 & $-127,0$ & 9,6 \\
\hline $\mathrm{C}_{2} \mathrm{H}_{4}$ & ${ }^{1} J_{\mathrm{CC}}$ & 59,4 & 66,8 & 79,5 & 107,3 & 226,0 & $-236,7$ & $-39,8$ & 67,6 \\
\hline $\mathrm{C}_{2} \mathrm{H}_{4}$ & ${ }^{1} J_{\mathrm{CH}}$ & 134,1 & 151,7 & 174,0 & 206,1 & 286,9 & 78,3 & 206,1 & 156,3 \\
\hline $\mathrm{C}_{2} \mathrm{H}_{4}$ & ${ }^{2} J_{\mathrm{CH}}$ & 0,6 & $-2,2$ & $-7,5$ & $-20,3$ & $-78,6$ & 155,9 & 58,9 & $-2,4$ \\
\hline $\mathrm{C}_{2} \mathrm{H}_{4}$ & ${ }^{2} J_{\mathrm{HH}}$ & 4,2 & 2,4 & $-1,2$ & $-10,0$ & $-48,5$ & 101,5 & 36,7 & 2,3 \\
\hline $\mathrm{C}_{2} \mathrm{H}_{4}$ & ${ }^{3} J_{\mathrm{HH}_{\mathrm{C}}}$ & 10,4 & 11,9 & 15,0 & 22,6 & 59,4 & $-93,1$ & $-32,0$ & 11,7 \\
\hline $\mathrm{C}_{2} \mathrm{H}_{4}$ & ${ }^{3} J_{\mathrm{HH}_{\mathrm{t}}}$ & 15,3 & 18,1 & 22,8 & 32,6 & 74,3 & $-88,1$ & $-19,4$ & 19 \\
\hline $\mathrm{C}_{2} \mathrm{H}_{6}$ & ${ }^{1} J_{\mathrm{CC}}$ & 26,0 & 30,1 & 35,3 & 41,8 & 50,1 & 60,9 & 75,4 & 34,5 \\
\hline $\mathrm{C}_{2} \mathrm{H}_{6}$ & ${ }^{1} J_{\mathrm{CH}}$ & 104,2 & 117,1 & 132,4 & 150,5 & 172,5 & 199,3 & 232,7 & 125,2 \\
\hline $\mathrm{C}_{2} \mathrm{H}_{6}$ & ${ }^{2} J_{\mathrm{CH}}$ & $-2,1$ & $-3,5$ & $-5,4$ & $-7,7$ & $-10,9$ & $-15,3$ & $-21,4$ & $-4,7$ \\
\hline \multirow[t]{3}{*}{ Total } & $\mathrm{DM}$ & $-13,35$ & $-10,32$ & $-6,66$ & $-2,90$ & $-4,94$ & 63,57 & 32,15 & - \\
\hline & DMA & 18,04 & 13,78 & 21,76 & 41,95 & 95,83 & 332,00 & 105,02 & - \\
\hline & PDMA & 30,10 & 10,36 & 31,83 & 99,37 & 336,70 & 1078,38 & 379,14 & - \\
\hline \multirow[t]{3}{*}{ CPI } & $\mathrm{DM}$ & $-23,44$ & $-24,86$ & $-27,17$ & $-34,19$ & $-75,29$ & $-108,81$ & 78,93 & - \\
\hline & DMA & 30,18 & 27,19 & 37,39 & 61,37 & 123,60 & 182,55 & 129,25 & - \\
\hline & PDMA & 30,53 & 14,23 & 19,86 & 49,94 & 99,64 & 156,22 & 184,68 & - \\
\hline \multirow[t]{3}{*}{ SPI } & $\mathrm{DM}$ & $-5,95$ & 0,34 & 8,39 & 20,05 & 46,65 & 189,98 & $-2,16$ & - \\
\hline & DMA & 9,14 & 3,94 & 10,29 & 27,71 & 75,46 & 441,59 & 87,25 & - \\
\hline & PDMA & 29,79 & 7,52 & 40,61 & 135,62 & 510,54 & 1754,63 & 521,75 & - \\
\hline \multirow[t]{3}{*}{$\Delta \mathrm{CS}$} & DM & $-17,48$ & $-25,20$ & $-35,56$ & $-54,24$ & $-121,94$ & $-298,79$ & 81,09 & - \\
\hline & DMA & 21,04 & 23,25 & 27,10 & 33,67 & 48,14 & $-259,04$ & 42,00 & - \\
\hline & PDMA & 0,74 & 6,71 & $-20,75$ & $-85,68$ & $-410,90$ & $-1598,41$ & $-337,07$ & - \\
\hline
\end{tabular}


Tabela 8.317: Constantes de acoplamento $\omega$ B97X variando $\alpha$ com $\alpha+\beta=60 \%$ na base aug-pcJ-2.

\begin{tabular}{|c|c|c|c|c|c|c|c|}
\hline & $\alpha$ & $10 \%$ & $20 \%$ & $30 \%$ & $40 \%$ & $50 \%$ & Exp. \\
\hline $\mathrm{HF}$ & ${ }^{1} J_{\mathrm{HF}}$ & 490,1 & 509,2 & 533,4 & 563,9 & 601,8 & 500 \\
\hline $\mathrm{CO}$ & ${ }^{1} J_{\mathrm{CO}}$ & 18,1 & 18,3 & 17,9 & 16,6 & 14,1 & 16,4 \\
\hline $\mathrm{H}_{2} \mathrm{O}$ & ${ }^{1} J_{\mathrm{OH}}$ & $-74,3$ & $-78,3$ & $-83,2$ & $-89,1$ & $-96,3$ & $-80,6$ \\
\hline $\mathrm{H}_{2} \mathrm{O}$ & ${ }^{2} J_{\mathrm{HH}}$ & $-4,0$ & $-7,1$ & $-11,1$ & $-16,2$ & $-22,7$ & $-7,3$ \\
\hline $\mathrm{NH}_{3}$ & ${ }^{1} J_{\mathrm{NH}}$ & 39,7 & 42,7 & 46,1 & 50,2 & 55,1 & 43,8 \\
\hline $\mathrm{NH}_{3}$ & ${ }^{2} J_{\mathrm{HH}}$ & $-6,1$ & $-9,1$ & $-13,0$ & $-18,0$ & $-24,7$ & $-9,6$ \\
\hline $\mathrm{PH}_{3}$ & ${ }^{1} J_{\mathrm{PH}}$ & 161,9 & 182,4 & 207,5 & 238,1 & 275,9 & 188,2 \\
\hline $\mathrm{PF}_{3}$ & ${ }^{1} J_{\mathrm{PF}}$ & $-1636,1$ & $-1642,7$ & $-1643,4$ & $-1638,8$ & $-1629,8$ & -1441 \\
\hline $\mathrm{BHF}_{2}$ & ${ }^{1} J_{\mathrm{BF}}$ & $-114,6$ & $-104,7$ & $-92,9$ & $-79,3$ & $-63,9$ & -84 \\
\hline $\mathrm{BF}_{3}$ & ${ }^{1} J_{\mathrm{BF}}$ & $-15,3$ & $-2,8$ & 11,7 & 28,5 & 47,5 & 15 \\
\hline $\mathrm{F}_{2} \mathrm{O}$ & ${ }^{1} J_{\mathrm{OF}}$ & $-267,1$ & $-333,2$ & $-422,3$ & $-569,6$ & $-993,8$ & -300 \\
\hline $\mathrm{CH}_{4}$ & ${ }^{1} J_{\mathrm{CH}}$ & 104,3 & 116,2 & 130,3 & 146,9 & 167,0 & 125,3 \\
\hline $\mathrm{CH}_{4}$ & ${ }^{2} J_{\mathrm{HH}}$ & $-8,4$ & $-11,4$ & $-15,3$ & $-20,5$ & $-27,3$ & $-12,8$ \\
\hline $\mathrm{C}_{2} \mathrm{H}_{2}$ & ${ }^{1} J_{\mathrm{CC}}$ & 182,9 & 195,3 & 213,8 & 246,3 & 324,8 & 174,8 \\
\hline $\mathrm{C}_{2} \mathrm{H}_{2}$ & ${ }^{1} J_{\mathrm{CH}}$ & 219,2 & 248,2 & 283,6 & 330,9 & 410,3 & 247,6 \\
\hline $\mathrm{C}_{2} \mathrm{H}_{2}$ & ${ }^{2} J_{\mathrm{CH}}$ & 52,6 & 52,4 & 49,1 & 37,9 & $-0,6$ & 50,1 \\
\hline $\mathrm{C}_{2} \mathrm{H}_{2}$ & ${ }^{3} J_{\mathrm{HH}}$ & 7,7 & 10,3 & 15,0 & 25,0 & 52,9 & 9,6 \\
\hline $\mathrm{C}_{2} \mathrm{H}_{4}$ & ${ }^{1} J_{\mathrm{CC}}$ & 58,5 & 65,3 & 76,5 & 98,9 & 170,7 & 67,6 \\
\hline $\mathrm{C}_{2} \mathrm{H}_{4}$ & ${ }^{1} J_{\mathrm{CH}}$ & 132,9 & 150,0 & 171,3 & 200,6 & 257,7 & 156,3 \\
\hline $\mathrm{C}_{2} \mathrm{H}_{4}$ & ${ }^{2} J_{\mathrm{CH}}$ & 0,9 & $-1,6$ & $-6,2$ & $-16,4$ & $-51,4$ & $-2,4$ \\
\hline $\mathrm{C}_{2} \mathrm{H}_{4}$ & ${ }^{2} J_{\mathrm{HH}}$ & 4,5 & 2,8 & $-0,2$ & $-7,2$ & $-30,3$ & 2,3 \\
\hline $\mathrm{C}_{2} \mathrm{H}_{4}$ & ${ }^{3} J_{\mathrm{HH}_{\mathrm{c}}}$ & 10,2 & 11,5 & 14,1 & 20,0 & 41,5 & 11,7 \\
\hline $\mathrm{C}_{2} \mathrm{H}_{4}$ & ${ }^{3} J_{\mathrm{HH}_{\mathrm{t}}}$ & 14,9 & 17,6 & 21,7 & 29,7 & 54,8 & 19 \\
\hline $\mathrm{C}_{2} \mathrm{H}_{6}$ & ${ }^{1} J_{\mathrm{CC}}$ & 25,2 & 29,2 & 34,2 & 40,5 & 48,6 & 34,5 \\
\hline $\mathrm{C}_{2} \mathrm{H}_{6}$ & ${ }^{1} J_{\mathrm{CH}}$ & 103,5 & 116,1 & 131,0 & 148,8 & 170,3 & 125,2 \\
\hline $\mathrm{C}_{2} \mathrm{H}_{6}$ & ${ }^{2} J_{\mathrm{CH}}$ & $-1,9$ & $-3,3$ & $-5,0$ & $-7,3$ & $-10,4$ & $-4,7$ \\
\hline \multirow[t]{3}{*}{ Total } & DM & $-13,30$ & $-10,45$ & $-6,94$ & $-3,25$ & $-3,97$ & - \\
\hline & DMA & 18,76 & 13,70 & 20,53 & 38,22 & 79,38 & - \\
\hline & PDMA & 33,84 & 14,01 & 25,56 & 80,80 & 236,44 & - \\
\hline \multirow[t]{3}{*}{ CPI } & DM & $-22,60$ & $-24,20$ & $-26,38$ & $-32,24$ & $-61,61$ & - \\
\hline & DMA & 31,27 & 26,76 & 36,65 & 57,44 & 107,68 & - \\
\hline & PDMA & 35,28 & 18,02 & 19,04 & 43,12 & 89,04 & - \\
\hline \multirow[t]{3}{*}{ SPI } & $\mathrm{DM}$ & $-6,47$ & $-0,37$ & 7,32 & 18,00 & 38,30 & - \\
\hline & DMA & 9,58 & 4,13 & 8,71 & 24,13 & 58,63 & - \\
\hline & PDMA & 32,79 & 11,07 & 30,33 & 108,44 & 344,54 & - \\
\hline \multirow[t]{3}{*}{$\Delta \mathrm{CS}$} & $\mathrm{DM}$ & $-16,13$ & $-23,83$ & $-33,70$ & $-50,24$ & $-99,91$ & - \\
\hline & DMA & 21,69 & 22,64 & 27,95 & 33,30 & 49,05 & - \\
\hline & PDMA & 2,49 & 6,95 & $-11,29$ & $-65,32$ & $-255,49$ & - \\
\hline
\end{tabular}


Tabela 8.318: Constantes de acoplamento $\omega \mathrm{B} 97 \mathrm{X}$ variando $\alpha$ com $\alpha+\beta=40 \%$ na base aug-pcJ-2.

\begin{tabular}{|c|c|c|c|c|c|}
\hline & $\alpha$ & $10 \%$ & $20 \%$ & $30 \%$ & Exp. \\
\hline $\mathrm{HF}$ & ${ }^{1} J_{\mathrm{HF}}$ & 492,3 & 510,6 & 533,9 & 500 \\
\hline $\mathrm{CO}$ & ${ }^{1} J_{\mathrm{CO}}$ & 17,6 & 17,8 & 17,4 & 16,4 \\
\hline $\mathrm{H}_{2} \mathrm{O}$ & ${ }^{1} J_{\mathrm{OH}}$ & $-74,4$ & $-78,4$ & $-83,1$ & $-80,6$ \\
\hline $\mathrm{H}_{2} \mathrm{O}$ & ${ }^{2} J_{\mathrm{HH}}$ & $-3,7$ & $-6,8$ & $-10,7$ & $-7,3$ \\
\hline $\mathrm{NH}_{3}$ & ${ }^{1} J_{\mathrm{NH}}$ & 39,8 & 42,6 & 46,0 & 43,8 \\
\hline $\mathrm{NH}_{3}$ & ${ }^{2} J_{\mathrm{HH}}$ & $-5,7$ & $-8,6$ & $-12,4$ & $-9,6$ \\
\hline $\mathrm{PH}_{3}$ & ${ }^{1} J_{\mathrm{PH}}$ & 167,1 & 187,0 & 211,4 & 188,2 \\
\hline $\mathrm{PF}_{3}$ & ${ }^{1} J_{\mathrm{PF}}$ & $-1630,0$ & $-1639,8$ & $-1643,2$ & -1441 \\
\hline $\mathrm{BHF}_{2}$ & ${ }^{1} J_{\mathrm{BF}}$ & $-120,4$ & $-110,7$ & $-99,0$ & -84 \\
\hline $\mathrm{BF}_{3}$ & ${ }^{1} J_{\mathrm{BF}}$ & $-21,3$ & $-8,7$ & 5,8 & 15 \\
\hline $\mathrm{F}_{2} \mathrm{O}$ & ${ }^{1} J_{\mathrm{OF}}$ & $-257,0$ & $-321,0$ & $-405,7$ & -300 \\
\hline $\mathrm{CH}_{4}$ & ${ }^{1} J_{\mathrm{CH}}$ & 103,8 & 115,5 & 129,2 & 125,3 \\
\hline $\mathrm{CH}_{4}$ & ${ }^{2} J_{\mathrm{HH}}$ & $-7,8$ & $-10,8$ & $-14,5$ & $-12,8$ \\
\hline $\mathrm{C}_{2} \mathrm{H}_{2}$ & ${ }^{1} J_{\mathrm{CC}}$ & 181,6 & 193,3 & 210,4 & 174,8 \\
\hline $\mathrm{C}_{2} \mathrm{H}_{2}$ & ${ }^{1} J_{\mathrm{CH}}$ & 217,2 & 245,6 & 280,0 & 247,6 \\
\hline $\mathrm{C}_{2} \mathrm{H}_{2}$ & ${ }^{2} J_{\mathrm{CH}}$ & 52,1 & 52,1 & 49,5 & 50,1 \\
\hline $\mathrm{C}_{2} \mathrm{H}_{2}$ & ${ }^{3} J_{\mathrm{HH}}$ & 7,4 & 9,7 & 13,9 & 9,6 \\
\hline $\mathrm{C}_{2} \mathrm{H}_{4}$ & ${ }^{1} J_{\mathrm{CC}}$ & 57,7 & 64,0 & 74,0 & 67,6 \\
\hline $\mathrm{C}_{2} \mathrm{H}_{4}$ & ${ }^{1} J_{\mathrm{CH}}$ & 131,7 & 148,4 & 168,9 & 156,3 \\
\hline $\mathrm{C}_{2} \mathrm{H}_{4}$ & ${ }^{2} J_{\mathrm{CH}}$ & 1,3 & $-1,0$ & $-5,1$ & $-2,4$ \\
\hline $\mathrm{C}_{2} \mathrm{H}_{4}$ & ${ }^{2} J_{\mathrm{HH}}$ & 4,7 & 3,3 & 0,5 & 2,3 \\
\hline $\mathrm{C}_{2} \mathrm{H}_{4}$ & ${ }^{3} J_{\mathrm{HH}_{\mathrm{c}}}$ & 10,0 & 11,2 & 13,4 & 11,7 \\
\hline $\mathrm{C}_{2} \mathrm{H}_{4}$ & ${ }^{3} J_{\mathrm{HH}_{\mathrm{t}}}$ & 14,6 & 17,1 & 20,9 & 19 \\
\hline $\mathrm{C}_{2} \mathrm{H}_{6}$ & ${ }^{1} J_{\mathrm{CC}}$ & 24,4 & 28,2 & 33,1 & 34,5 \\
\hline $\mathrm{C}_{2} \mathrm{H}_{6}$ & ${ }^{1} J_{\mathrm{CH}}$ & 102,8 & 115,2 & 129,8 & 125,2 \\
\hline $\mathrm{C}_{2} \mathrm{H}_{6}$ & ${ }^{2} J_{\mathrm{CH}}$ & $-1,6$ & $-3,0$ & $-4,7$ & $-4,7$ \\
\hline \multirow[t]{3}{*}{ Total } & $\mathrm{DM}$ & $-13,11$ & $-10,47$ & $-7,13$ & - \\
\hline & DMA & 19,33 & 13,73 & 19,72 & - \\
\hline & PDMA & 37,64 & 18,21 & 22,07 & - \\
\hline \multirow[t]{3}{*}{ CPI } & DM & $-21,51$ & $-23,35$ & $-25,50$ & - \\
\hline & DMA & 32,04 & 26,21 & 36,46 & - \\
\hline & PDMA & 39,97 & 22,24 & 21,59 & - \\
\hline \multirow[t]{3}{*}{ SPI } & $\mathrm{DM}$ & $-6,95$ & $-1,02$ & 6,35 & - \\
\hline & DMA & 10,01 & 4,58 & 7,44 & - \\
\hline & PDMA & 35,93 & 15,25 & 22,43 & - \\
\hline \multirow[t]{3}{*}{$\Delta \mathrm{CS}$} & DM & $-14,56$ & $-22,33$ & $-31,85$ & - \\
\hline & DMA & 22,02 & 21,63 & 29,02 & - \\
\hline & PDMA & 4,03 & 6,99 & $-0,83$ & - \\
\hline
\end{tabular}


Tabela 8.319: Constantes de acoplamento $\omega$ B97X variando $\alpha$ com $\alpha+\beta=20 \%$ na base aug-pcJ-2.

\begin{tabular}{|c|c|c|c|}
\hline & $\alpha$ & $10 \%$ & Exp. \\
\hline $\mathrm{HF}$ & ${ }^{1} J_{\mathrm{HF}}$ & 494,7 & 500 \\
\hline $\mathrm{CO}$ & ${ }^{1} J_{\mathrm{CO}}$ & 17,1 & 16,4 \\
\hline $\mathrm{H}_{2} \mathrm{O}$ & ${ }^{1} J_{\mathrm{OH}}$ & $-74,6$ & $-80,6$ \\
\hline $\mathrm{H}_{2} \mathrm{O}$ & ${ }^{2} J_{\mathrm{HH}}$ & $-3,3$ & $-7,3$ \\
\hline $\mathrm{NH}_{3}$ & ${ }^{1} J_{\mathrm{NH}}$ & 39,9 & 43,8 \\
\hline $\mathrm{NH}_{3}$ & ${ }^{2} J_{\mathrm{HH}}$ & $-5,3$ & $-9,6$ \\
\hline $\mathrm{PH}_{3}$ & ${ }^{1} J_{\mathrm{PH}}$ & 172,8 & 188,2 \\
\hline $\mathrm{PF}_{3}$ & ${ }^{1} J_{\mathrm{PF}}$ & $-1621,2$ & -1441 \\
\hline $\mathrm{BHF}_{2}$ & ${ }^{1} J_{\mathrm{BF}}$ & $-126,2$ & -84 \\
\hline $\mathrm{BF}_{3}$ & ${ }^{1} J_{\mathrm{BF}}$ & $-27,5$ & 15 \\
\hline $\mathrm{F}_{2} \mathrm{O}$ & ${ }^{1} J_{\mathrm{OF}}$ & $-247,1$ & -300 \\
\hline $\mathrm{CH}_{4}$ & ${ }^{1} J_{\mathrm{CH}}$ & 103,4 & 125,3 \\
\hline $\mathrm{CH}_{4}$ & ${ }^{2} J_{\mathrm{HH}}$ & $-7,3$ & $-12,8$ \\
\hline $\mathrm{C}_{2} \mathrm{H}_{2}$ & ${ }^{1} J_{\mathrm{CC}}$ & 180,4 & 174,8 \\
\hline $\mathrm{C}_{2} \mathrm{H}_{2}$ & ${ }^{1} J_{\mathrm{CH}}$ & 215,4 & 247,6 \\
\hline $\mathrm{C}_{2} \mathrm{H}_{2}$ & ${ }^{2} J_{\mathrm{CH}}$ & 51,4 & 50,1 \\
\hline $\mathrm{C}_{2} \mathrm{H}_{2}$ & ${ }^{3} J_{\mathrm{HH}}$ & 7,1 & 9,6 \\
\hline $\mathrm{C}_{2} \mathrm{H}_{4}$ & ${ }^{1} J_{\mathrm{CC}}$ & 57,0 & 67,6 \\
\hline $\mathrm{C}_{2} \mathrm{H}_{4}$ & ${ }^{1} J_{\mathrm{CH}}$ & 130,7 & 156,3 \\
\hline $\mathrm{C}_{2} \mathrm{H}_{4}$ & ${ }^{2} J_{\mathrm{CH}}$ & 1,6 & $-2,4$ \\
\hline $\mathrm{C}_{2} \mathrm{H}_{4}$ & ${ }^{2} J_{\mathrm{HH}}$ & 4,9 & 2,3 \\
\hline $\mathrm{C}_{2} \mathrm{H}_{4}$ & ${ }^{3} J_{\mathrm{HH}_{\mathrm{c}}}$ & 9,8 & 11,7 \\
\hline $\mathrm{C}_{2} \mathrm{H}_{4}$ & ${ }^{3} J_{\mathrm{HH}_{\mathrm{t}}}$ & 14,3 & 19 \\
\hline $\mathrm{C}_{2} \mathrm{H}_{6}$ & ${ }^{1} J_{\mathrm{CC}}$ & 23,5 & 34,5 \\
\hline $\mathrm{C}_{2} \mathrm{H}_{6}$ & ${ }^{1} J_{\mathrm{CH}}$ & 102,2 & 125,2 \\
\hline $\mathrm{C}_{2} \mathrm{H}_{6}$ & ${ }^{2} J_{\mathrm{CH}}$ & $-1,4$ & $-4,7$ \\
\hline \multirow[t]{3}{*}{ Total } & DM & $-12,80$ & - \\
\hline & DMA & 19,73 & - \\
\hline & PDMA & 41,22 & - \\
\hline \multirow[t]{3}{*}{ CPI } & $\mathrm{DM}$ & $-20,15$ & - \\
\hline & DMA & 32,49 & - \\
\hline & PDMA & 44,83 & - \\
\hline \multirow[t]{3}{*}{ SPI } & DM & $-7,41$ & - \\
\hline & DMA & 10,38 & - \\
\hline & PDMA & 38,57 & - \\
\hline \multirow[t]{3}{*}{$\Delta \mathrm{CS}$} & $\mathrm{DM}$ & $-12,74$ & - \\
\hline & DMA & 22,11 & - \\
\hline & PDMA & 6,27 & - \\
\hline
\end{tabular}


Tabela 8.320: Constantes de acoplamento $\omega$ B97XD variando $\alpha \operatorname{com} \alpha+\beta=100 \%$ na base aug-pcJ-2.

\begin{tabular}{|c|c|c|c|c|c|c|c|c|c|c|c|}
\hline & $\alpha$ & $10 \%$ & $20 \%$ & $30 \%$ & $40 \%$ & $50 \%$ & $60 \%$ & $70 \%$ & $80 \%$ & $90 \%$ & Exp. \\
\hline $\mathrm{HF}$ & ${ }^{1} J_{\mathrm{HF}}$ & 464,8 & 480,1 & 500,6 & 527,4 & 561,8 & 605,0 & 658,1 & 722,0 & 797,3 & 500 \\
\hline $\mathrm{CO}$ & ${ }^{1} J_{\mathrm{CO}}$ & 18,6 & 19,5 & 19,9 & 19,7 & 18,8 & 16,6 & 12,6 & 6,0 & $-4,1$ & 16,4 \\
\hline $\mathrm{H}_{2} \mathrm{O}$ & ${ }^{1} J_{\mathrm{OH}}$ & $-70,3$ & $-73,8$ & $-78,1$ & $-83,5$ & $-90,0$ & $-98,1$ & $-108,0$ & $-120,1$ & $-135,0$ & $-80,6$ \\
\hline $\mathrm{H}_{2} \mathrm{O}$ & ${ }^{2} J_{\mathrm{HH}}$ & $-2,8$ & $-5,7$ & $-9,4$ & $-14,0$ & $-20,0$ & $-27,6$ & $-37,3$ & $-49,8$ & $-66,0$ & $-7,3$ \\
\hline $\mathrm{NH}_{3}$ & ${ }^{1} J_{\mathrm{NH}}$ & 38,5 & 41,2 & 44,6 & 48,5 & 53,2 & 59,0 & 66,1 & 75,0 & 86,4 & 43,8 \\
\hline $\mathrm{NH}_{3}$ & ${ }^{2} J_{\mathrm{HH}}$ & $-5,5$ & $-8,3$ & $-12,0$ & $-16,9$ & $-23,3$ & $-32,0$ & $-43,7$ & $-59,9$ & $-82,7$ & $-9,6$ \\
\hline $\mathrm{PH}_{3}$ & ${ }^{1} J_{\mathrm{PH}}$ & 154,6 & 172,3 & 194,2 & 221,5 & 255,2 & 297,3 & 350,3 & 418,3 & 507,5 & 188,2 \\
\hline $\mathrm{PF}_{3}$ & ${ }^{1} J_{\mathrm{PF}}$ & $-1626,0$ & $-1636,4$ & $-1640,3$ & $-1638,3$ & $-1631,2$ & $-1620,1$ & $-1605,8$ & $-1589,6$ & $-1571,8$ & -1441 \\
\hline $\mathrm{BHF}_{2}$ & ${ }^{1} J_{\mathrm{BF}}$ & $-115,5$ & $-105,6$ & $-93,7$ & $-79,9$ & $-64,4$ & $-47,3$ & $-28,8$ & $-9,1$ & 11,0 & -84 \\
\hline $\mathrm{BF}_{3}$ & ${ }^{1} J_{\mathrm{BF}}$ & $-18,6$ & $-6,0$ & 8,4 & 24,8 & 43,4 & 64,4 & 87,9 & 113,8 & 142,2 & 15 \\
\hline $\mathrm{F}_{2} \mathrm{O}$ & ${ }^{1} J_{\mathrm{OF}}$ & $-252,9$ & $-317,1$ & $-400,7$ & $-529,6$ & $-826,1$ & 2507,8 & 766,4 & $-14,0$ & $-232,5$ & -300 \\
\hline $\mathrm{CH}_{4}$ & ${ }^{1} J_{\mathrm{CH}}$ & 100,4 & 111,9 & 125,6 & 141,9 & 161,7 & 185,8 & 215,7 & 253,4 & 302,4 & 125,3 \\
\hline $\mathrm{CH}_{4}$ & ${ }^{2} J_{\mathrm{HH}}$ & $-8,0$ & $-11,0$ & $-14,9$ & $-20,0$ & $-26,8$ & $-36,0$ & $-48,6$ & $-66,2$ & $-91,5$ & $-12,8$ \\
\hline $\mathrm{C}_{2} \mathrm{H}_{2}$ & ${ }^{1} J_{\mathrm{CC}}$ & 178,0 & 188,4 & 203,5 & 228,9 & 286,1 & 600,8 & $-139,5$ & 74,7 & 171,4 & 174,8 \\
\hline $\mathrm{C}_{2} \mathrm{H}_{2}$ & ${ }^{1} J_{\mathrm{CH}}$ & 210,7 & 238,7 & 272,5 & 316,3 & 385,2 & 635,5 & 157,5 & 339,1 & 418,0 & 247,6 \\
\hline $\mathrm{C}_{2} \mathrm{H}_{2}$ & ${ }^{2} J_{\mathrm{CH}}$ & 53,0 & 53,8 & 52,3 & 44,9 & 17,2 & $-186,1$ & 345,5 & 225,7 & 218,7 & 50,1 \\
\hline $\mathrm{C}_{2} \mathrm{H}_{2}$ & ${ }^{3} J_{\mathrm{HH}}$ & 7,1 & 9,4 & 13,5 & 22,1 & 45,4 & 192,3 & $-174,6$ & $-83,9$ & $-67,5$ & 9,6 \\
\hline $\mathrm{C}_{2} \mathrm{H}_{4}$ & ${ }^{1} J_{\mathrm{CC}}$ & 56,7 & 62,2 & 71,0 & 88,1 & 141,6 & $-709,5$ & $-32,6$ & 5,6 & 19,9 & 67,6 \\
\hline $\mathrm{C}_{2} \mathrm{H}_{4}$ & ${ }^{1} J_{\mathrm{CH}}$ & 127,7 & 144,0 & 164,2 & 191,1 & 240,2 & $-187,8$ & 200,1 & 254,2 & 302,5 & 156,3 \\
\hline $\mathrm{C}_{2} \mathrm{H}_{4}$ & ${ }^{2} J_{\mathrm{CH}}$ & 1,6 & $-0,4$ & $-4,1$ & $-12,0$ & $-39,1$ & 414,7 & 57,0 & 39,1 & 34,3 & $-2,4$ \\
\hline $\mathrm{C}_{2} \mathrm{H}_{4}$ & ${ }^{2} J_{\mathrm{HH}}$ & 4,9 & 3,4 & 0,7 & $-5,3$ & $-25,6$ & 301,3 & 40,7 & 24,7 & 16,7 & 2,3 \\
\hline $\mathrm{C}_{2} \mathrm{H}_{4}$ & ${ }^{3} J_{\mathrm{HH}_{\mathrm{c}}}$ & 9,9 & 11,2 & 13,4 & 18,6 & 37,3 & $-291,8$ & $-34,6$ & $-23,6$ & $-22,8$ & 11,7 \\
\hline $\mathrm{C}_{2} \mathrm{H}_{4}$ & ${ }^{3} J_{\mathrm{HH}_{\mathrm{t}}}$ & 14,4 & 16,9 & 20,6 & 27,8 & 49,9 & $-302,9$ & $-22,8$ & $-7,5$ & $-2,5$ & 19 \\
\hline $\mathrm{C}_{2} \mathrm{H}_{6}$ & ${ }^{1} J_{\mathrm{CC}}$ & 24,2 & 28,0 & 32,8 & 38,9 & 46,7 & 57,0 & 70,7 & 89,5 & 116,6 & 34,5 \\
\hline $\mathrm{C}_{2} \mathrm{H}_{6}$ & ${ }^{1} J_{\mathrm{CH}}$ & 99,9 & 112,2 & 126,8 & 144,3 & 165,5 & 191,6 & 224,1 & 265,8 & 320,8 & 125,2 \\
\hline $\mathrm{C}_{2} \mathrm{H}_{6}$ & ${ }^{2} J_{\mathrm{CH}}$ & $-1,6$ & $-2,9$ & $-4,6$ & $-6,9$ & $-9,9$ & $-14,0$ & $-19,7$ & $-28,3$ & $-41,4$ & $-4,7$ \\
\hline \multirow[t]{3}{*}{ Total } & DM & $-14,66$ & $-12,27$ & $-9,16$ & $-5,64$ & $-3,55$ & 105,03 & 42,76 & 38,84 & 50,11 & - \\
\hline & DMA & 21,49 & 15,10 & 16,06 & 30,95 & 63,28 & 278,47 & 126,43 & 91,59 & 99,12 & - \\
\hline & PDMA & 39,74 & 20,83 & 17,55 & 62,22 & 191,34 & 1589,50 & 401,02 & 320,02 & 344,08 & - \\
\hline \multirow[t]{3}{*}{ CPI } & DM & $-23,27$ & $-25,52$ & $-27,95$ & $-32,84$ & $-51,23$ & 262,19 & 116,08 & 59,25 & 55,58 & - \\
\hline & DMA & 35,67 & 27,85 & 30,38 & 47,85 & 85,52 & 305,70 & 163,37 & 112,21 & 116,95 & - \\
\hline & PDMA & 41,60 & 24,19 & 16,94 & 35,08 & 73,97 & 179,04 & 173,69 & 210,00 & 279,74 & - \\
\hline \multirow[t]{3}{*}{ SPI } & $\mathrm{DM}$ & $-8,35$ & $-2,55$ & 4,61 & 14,31 & 31,42 & $-10,21$ & $-11,01$ & 23,88 & 46,10 & - \\
\hline & DMA & 11,09 & 5,75 & 5,56 & 18,55 & 46,98 & 258,49 & 99,35 & 76,47 & 86,05 & - \\
\hline & PDMA & 38,38 & 18,36 & 17,99 & 82,13 & 277,42 & 2623,85 & 567,73 & 400,70 & 391,27 & - \\
\hline \multirow[t]{3}{*}{$\Delta \mathrm{CS}$} & $\mathrm{DM}$ & $-14,93$ & $-22,96$ & $-32,56$ & $-47,14$ & $-82,65$ & 272,40 & 127,10 & 35,37 & 9,48 & - \\
\hline & DMA & 24,58 & 22,09 & 24,82 & 29,31 & 38,54 & 47,21 & 64,03 & 35,74 & 30,90 & - \\
\hline & PDMA & 3,22 & 5,83 & $-1,06$ & $-47,05$ & $-203,45$ & $-2444,81$ & $-394,04$ & $-190,71$ & $-111,53$ & - \\
\hline
\end{tabular}


Tabela 8.321: Constantes de acoplamento $\omega$ B97XD variando $\alpha$ com $\alpha+$ $\beta=80 \%$ na base aug-pcJ-2.

\begin{tabular}{|c|c|c|c|c|c|c|c|c|c|}
\hline & $\alpha$ & $10 \%$ & $20 \%$ & $30 \%$ & $40 \%$ & $50 \%$ & $60 \%$ & $70 \%$ & Exp. \\
\hline $\mathrm{HF}$ & ${ }^{1} J_{\mathrm{HF}}$ & 465,9 & 480,9 & 501,0 & 527,4 & 561,4 & 604,1 & 656,8 & 500 \\
\hline $\mathrm{CO}$ & ${ }^{1} J_{\mathrm{CO}}$ & 18,5 & 19,3 & 19,7 & 19,6 & 18,6 & 16,4 & 12,4 & 16,4 \\
\hline $\mathrm{H}_{2} \mathrm{O}$ & ${ }^{1} J_{\mathrm{OH}}$ & $-70,4$ & $-73,9$ & $-78,1$ & $-83,4$ & $-89,9$ & $-97,9$ & $-107,7$ & $-80,6$ \\
\hline $\mathrm{H}_{2} \mathrm{O}$ & ${ }^{2} J_{\mathrm{HH}}$ & $-2,7$ & $-5,6$ & $-9,2$ & $-13,9$ & $-19,8$ & $-27,3$ & $-37,0$ & $-7,3$ \\
\hline $\mathrm{NH}_{3}$ & ${ }^{1} J_{\mathrm{NH}}$ & 38,5 & 41,3 & 44,5 & 48,4 & 53,1 & 58,9 & 65,9 & 43,8 \\
\hline $\mathrm{NH}_{3}$ & ${ }^{2} J_{\mathrm{HH}}$ & $-5,3$ & $-8,1$ & $-11,8$ & $-16,6$ & $-23,0$ & $-31,6$ & $-43,2$ & $-9,6$ \\
\hline $\mathrm{PH}_{3}$ & ${ }^{1} J_{\mathrm{PH}}$ & 157,7 & 175,1 & 196,8 & 223,7 & 257,1 & 298,8 & 351,4 & 188,2 \\
\hline $\mathrm{PF}_{3}$ & ${ }^{1} J_{\mathrm{PF}}$ & $-1624,3$ & $-1636,2$ & $-1641,3$ & $-1640,2$ & $-1633,8$ & $-1623,1$ & $-1609,2$ & -1441 \\
\hline $\mathrm{BHF}_{2}$ & ${ }^{1} J_{\mathrm{BF}}$ & $-117,9$ & $-108,0$ & $-96,1$ & $-82,3$ & $-66,8$ & $-49,6$ & $-31,0$ & -84 \\
\hline $\mathrm{BF}_{3}$ & ${ }^{1} J_{\mathrm{BF}}$ & $-21,0$ & $-8,4$ & 6,0 & 22,6 & 41,2 & 62,3 & 85,8 & 15 \\
\hline $\mathrm{F}_{2} \mathrm{O}$ & ${ }^{1} J_{\mathrm{OF}}$ & $-248,9$ & $-312,4$ & $-394,7$ & $-519,8$ & $-798,5$ & 5952,5 & 875,2 & -300 \\
\hline $\mathrm{CH}_{4}$ & ${ }^{1} J_{\mathrm{CH}}$ & 100,4 & 111,8 & 125,3 & 141,5 & 161,1 & 185,0 & 214,6 & 125,3 \\
\hline $\mathrm{CH}_{4}$ & ${ }^{2} J_{\mathrm{HH}}$ & $-7,8$ & $-10,8$ & $-14,6$ & $-19,7$ & $-26,4$ & $-35,5$ & $-47,9$ & $-12,8$ \\
\hline $\mathrm{C}_{2} \mathrm{H}_{2}$ & ${ }^{1} J_{\mathrm{CC}}$ & 177,5 & 187,8 & 202,5 & 226,9 & 280,4 & 536,7 & $-193,9$ & 174,8 \\
\hline $\mathrm{C}_{2} \mathrm{H}_{2}$ & ${ }^{1} J_{\mathrm{CH}}$ & 210,3 & 238,1 & 271,5 & 314,6 & 380,8 & 590,2 & 120,9 & 247,6 \\
\hline $\mathrm{C}_{2} \mathrm{H}_{2}$ & ${ }^{2} J_{\mathrm{CH}}$ & 52,7 & 53,5 & 52,3 & 45,5 & 20,3 & $-142,3$ & 380,4 & 50,1 \\
\hline $\mathrm{C}_{2} \mathrm{H}_{2}$ & ${ }^{3} J_{\mathrm{HH}}$ & 7,0 & 9,2 & 13,2 & 21,3 & 42,7 & 160,6 & $-198,8$ & 9,6 \\
\hline $\mathrm{C}_{2} \mathrm{H}_{4}$ & ${ }^{1} J_{\mathrm{CC}}$ & 56,4 & 61,7 & 70,2 & 86,3 & 132,7 & $-7262,0$ & $-42,7$ & 67,6 \\
\hline $\mathrm{C}_{2} \mathrm{H}_{4}$ & ${ }^{1} J_{\mathrm{CH}}$ & 127,4 & 143,7 & 163,5 & 189,8 & 235,2 & $-3686,0$ & 193,7 & 156,3 \\
\hline $\mathrm{C}_{2} \mathrm{H}_{4}$ & ${ }^{2} J_{\mathrm{CH}}$ & 1,7 & $-0,2$ & $-3,8$ & $-11,2$ & $-34,6$ & 3912,2 & 62,5 & $-2,4$ \\
\hline $\mathrm{C}_{2} \mathrm{H}_{4}$ & ${ }^{2} J_{\mathrm{HH}}$ & 4,9 & 3,6 & 0,9 & $-4,6$ & $-22,2$ & 2815,2 & 44,6 & 2,3 \\
\hline $\mathrm{C}_{2} \mathrm{H}_{4}$ & ${ }^{3} J_{\mathrm{HH}_{\mathrm{c}}}$ & 9,9 & 11,0 & 13,2 & 17,9 & 34,0 & $-2805,6$ & $-38,3$ & 11,7 \\
\hline $\mathrm{C}_{2} \mathrm{H}_{4}$ & ${ }^{3} J_{\mathrm{HH}_{\mathrm{t}}}$ & 14,3 & 16,7 & 20,4 & 27,1 & 46,2 & $-3011,1$ & $-26,8$ & 19 \\
\hline $\mathrm{C}_{2} \mathrm{H}_{6}$ & ${ }^{1} J_{\mathrm{CC}}$ & 23,9 & 27,6 & 32,4 & 38,4 & 46,1 & 56,3 & 69,8 & 34,5 \\
\hline $\mathrm{C}_{2} \mathrm{H}_{6}$ & ${ }^{1} J_{\mathrm{CH}}$ & 99,8 & 112,0 & 126,5 & 143,9 & 164,9 & 190,7 & 223,0 & 125,2 \\
\hline $\mathrm{C}_{2} \mathrm{H}_{6}$ & ${ }^{2} J_{\mathrm{CH}}$ & $-1,5$ & $-2,8$ & $-4,5$ & $-6,7$ & $-9,7$ & $-13,7$ & $-19,4$ & $-4,7$ \\
\hline \multirow[t]{3}{*}{ Total } & $\mathrm{DM}$ & $-14,54$ & $-12,23$ & $-9,20$ & $-5,71$ & $-3,61$ & $-122,72$ & 42,93 & - \\
\hline & DMA & 21,65 & 15,05 & 15,95 & 30,03 & 60,36 & 1222,26 & 136,95 & - \\
\hline & PDMA & 40,94 & 22,55 & 16,89 & 57,53 & 172,81 & 13256,26 & 432,75 & - \\
\hline \multirow[t]{3}{*}{ CPI } & DM & $-22,80$ & $-25,17$ & $-27,65$ & $-32,31$ & $-49,21$ & 574,78 & 125,32 & - \\
\hline & DMA & 35,95 & 27,50 & 30,57 & 46,85 & 82,88 & 618,67 & 173,06 & - \\
\hline & PDMA & 43,50 & 25,79 & 18,04 & 32,81 & 70,96 & 281,07 & 174,72 & - \\
\hline \multirow[t]{3}{*}{ SPI } & $\mathrm{DM}$ & $-8,48$ & $-2,75$ & 4,33 & 13,79 & 29,83 & $-634,23$ & $-17,49$ & - \\
\hline & DMA & 11,17 & 5,92 & 5,22 & 17,69 & 43,84 & 1664,89 & 110,47 & - \\
\hline & PDMA & 39,06 & 20,18 & 16,05 & 75,66 & 247,50 & 22771,40 & 621,98 & - \\
\hline \multirow[t]{3}{*}{$\Delta \mathrm{CS}$} & DM & $-14,32$ & $-22,43$ & $-31,97$ & $-46,10$ & $-79,04$ & 1209,01 & 142,81 & - \\
\hline & DMA & 24,77 & 21,58 & 25,35 & 29,17 & 39,04 & $-1046,22$ & 62,60 & - \\
\hline & PDMA & 4,44 & 5,61 & 1,99 & $-42,85$ & $-176,53$ & $-22490,33$ & $-447,26$ & - \\
\hline
\end{tabular}


Tabela 8.322: Constantes de acoplamento $\omega$ B97XD variando $\alpha \operatorname{com} \alpha+\beta=60 \%$ na base aug-pcJ-2.

\begin{tabular}{|c|c|c|c|c|c|c|c|}
\hline & $\alpha$ & $10 \%$ & $20 \%$ & $30 \%$ & $40 \%$ & $50 \%$ & Exp. \\
\hline $\mathrm{HF}$ & ${ }^{1} J_{\mathrm{HF}}$ & 467,1 & 481,7 & 501,4 & 527,4 & 561,0 & 500 \\
\hline $\mathrm{CO}$ & ${ }^{1} J_{\mathrm{CO}}$ & 18,3 & 19,2 & 19,6 & 19,4 & 18,4 & 16,4 \\
\hline $\mathrm{H}_{2} \mathrm{O}$ & ${ }^{1} J_{\mathrm{OH}}$ & $-70,5$ & $-73,9$ & $-78,1$ & $-83,3$ & $-89,8$ & $-80,6$ \\
\hline $\mathrm{H}_{2} \mathrm{O}$ & ${ }^{2} J_{\mathrm{HH}}$ & $-2,6$ & $-5,5$ & $-9,1$ & $-13,7$ & $-19,6$ & $-7,3$ \\
\hline $\mathrm{NH}_{3}$ & ${ }^{1} J_{\mathrm{NH}}$ & 38,6 & 41,3 & 44,5 & 48,4 & 53,0 & 43,8 \\
\hline $\mathrm{NH}_{3}$ & ${ }^{2} J_{\mathrm{HH}}$ & $-5,2$ & $-7,9$ & $-11,6$ & $-16,3$ & $-22,7$ & $-9,6$ \\
\hline $\mathrm{PH}_{3}$ & ${ }^{1} J_{\mathrm{PH}}$ & 161,0 & 178,1 & 199,5 & 226,0 & 259,1 & 188,2 \\
\hline $\mathrm{PF}_{3}$ & ${ }^{1} J_{\mathrm{PF}}$ & $-1622,1$ & $-1635,7$ & $-1642,0$ & $-1641,9$ & $-1636,2$ & -1441 \\
\hline $\mathrm{BHF}_{2}$ & ${ }^{1} J_{\mathrm{BF}}$ & $-120,4$ & $-110,5$ & $-98,6$ & $-84,8$ & $-69,2$ & -84 \\
\hline $\mathrm{BF}_{3}$ & ${ }^{1} J_{\mathrm{BF}}$ & $-23,4$ & $-10,7$ & 3,7 & 20,3 & 39,0 & 15 \\
\hline $\mathrm{F}_{2} \mathrm{O}$ & ${ }^{1} J_{\mathrm{OF}}$ & $-244,8$ & $-307,8$ & $-388,7$ & $-510,3$ & $-773,0$ & -300 \\
\hline $\mathrm{CH}_{4}$ & ${ }^{1} J_{\mathrm{CH}}$ & 100,3 & 111,7 & 125,1 & 141,2 & 160,6 & 125,3 \\
\hline $\mathrm{CH}_{4}$ & ${ }^{2} J_{\mathrm{HH}}$ & $-7,6$ & $-10,5$ & $-14,3$ & $-19,3$ & $-26,0$ & $-12,8$ \\
\hline $\mathrm{C}_{2} \mathrm{H}_{2}$ & ${ }^{1} J_{\mathrm{CC}}$ & 177,1 & 187,2 & 201,5 & 225,0 & 275,2 & 174,8 \\
\hline $\mathrm{C}_{2} \mathrm{H}_{2}$ & ${ }^{1} J_{\mathrm{CH}}$ & 209,9 & 237,5 & 270,6 & 313,0 & 376,8 & 247,6 \\
\hline $\mathrm{C}_{2} \mathrm{H}_{2}$ & ${ }^{2} J_{\mathrm{CH}}$ & 52,3 & 53,3 & 52,2 & 45,9 & 23,0 & 50,1 \\
\hline $\mathrm{C}_{2} \mathrm{H}_{2}$ & ${ }^{3} J_{\mathrm{HH}}$ & 6,9 & 9,1 & 12,9 & 20,6 & 40,3 & 9,6 \\
\hline $\mathrm{C}_{2} \mathrm{H}_{4}$ & ${ }^{1} J_{\mathrm{CC}}$ & 56,1 & 61,3 & 69,5 & 84,6 & 125,5 & 67,6 \\
\hline $\mathrm{C}_{2} \mathrm{H}_{4}$ & ${ }^{1} J_{\mathrm{CH}}$ & 127,2 & 143,3 & 162,9 & 188,6 & 231,0 & 156,3 \\
\hline $\mathrm{C}_{2} \mathrm{H}_{4}$ & ${ }^{2} J_{\mathrm{CH}}$ & 1,8 & $-0,1$ & $-3,5$ & $-10,4$ & $-31,0$ & $-2,4$ \\
\hline $\mathrm{C}_{2} \mathrm{H}_{4}$ & ${ }^{2} J_{\mathrm{HH}}$ & 5,0 & 3,7 & 1,2 & $-4,0$ & $-19,4$ & 2,3 \\
\hline $\mathrm{C}_{2} \mathrm{H}_{4}$ & ${ }^{3} J_{\mathrm{HH}_{\mathrm{c}}}$ & 9,8 & 10,9 & 12,9 & 17,3 & 31,2 & 11,7 \\
\hline $\mathrm{C}_{2} \mathrm{H}_{4}$ & ${ }^{3} J_{\mathrm{HH}_{\mathrm{t}}}$ & 14,2 & 16,6 & 20,1 & 26,4 & 43,2 & 19 \\
\hline $\mathrm{C}_{2} \mathrm{H}_{6}$ & ${ }^{1} J_{\mathrm{CC}}$ & 23,5 & 27,2 & 31,9 & 37,9 & 45,5 & 34,5 \\
\hline $\mathrm{C}_{2} \mathrm{H}_{6}$ & ${ }^{1} J_{\mathrm{CH}}$ & 99,8 & 111,9 & 126,2 & 143,4 & 164,3 & 125,2 \\
\hline $\mathrm{C}_{2} \mathrm{H}_{6}$ & ${ }^{2} J_{\mathrm{CH}}$ & $-1,4$ & $-2,7$ & $-4,4$ & $-6,6$ & $-9,5$ & $-4,7$ \\
\hline \multirow[t]{3}{*}{ Total } & $\mathrm{DM}$ & $-14,39$ & $-12,17$ & $-9,22$ & $-5,78$ & $-3,63$ & - \\
\hline & DMA & 21,79 & 14,98 & 15,85 & 29,20 & 57,77 & - \\
\hline & PDMA & 42,27 & 23,89 & 16,10 & 53,14 & 157,34 & - \\
\hline \multirow[t]{3}{*}{ CPI } & DM & $-22,26$ & $-24,78$ & $-27,30$ & $-31,79$ & $-47,35$ & - \\
\hline & DMA & 36,14 & 27,15 & 30,77 & 45,99 & 80,43 & - \\
\hline & PDMA & 45,23 & 27,41 & 19,29 & 30,50 & 68,02 & - \\
\hline \multirow[t]{3}{*}{ SPI } & $\mathrm{DM}$ & $-8,61$ & $-2,91$ & 4,05 & 13,30 & 28,44 & - \\
\hline & DMA & 11,27 & 6,06 & 4,91 & 16,89 & 41,16 & - \\
\hline & PDMA & 40,10 & 21,32 & 13,76 & 69,75 & 222,84 & - \\
\hline \multirow[t]{3}{*}{$\Delta \mathrm{CS}$} & $\mathrm{DM}$ & $-13,65$ & $-21,87$ & $-31,35$ & $-45,09$ & $-75,79$ & - \\
\hline & DMA & 24,87 & 21,09 & 25,86 & 29,10 & 39,27 & - \\
\hline & PDMA & 5,13 & 6,09 & 5,53 & $-39,25$ & $-154,82$ & - \\
\hline
\end{tabular}


Tabela 8.323: Constantes de acoplamento $\omega \mathrm{B} 97 \mathrm{XD}$ variando $\alpha \operatorname{com} \alpha+\beta=40 \%$ na base aug-pcJ-2.

\begin{tabular}{|c|c|c|c|c|c|}
\hline & $\alpha$ & $10 \%$ & $20 \%$ & $30 \%$ & Exp. \\
\hline $\mathrm{HF}$ & ${ }^{1} J_{\mathrm{HF}}$ & 468,3 & 482,6 & 501,9 & 500 \\
\hline $\mathrm{CO}$ & ${ }^{1} J_{\mathrm{CO}}$ & 18,2 & 19,0 & 19,4 & 16,4 \\
\hline $\mathrm{H}_{2} \mathrm{O}$ & ${ }^{1} J_{\mathrm{OH}}$ & $-70,7$ & $-74,0$ & $-78,2$ & $-80,6$ \\
\hline $\mathrm{H}_{2} \mathrm{O}$ & ${ }^{2} J_{\mathrm{HH}}$ & $-2,5$ & $-5,3$ & $-8,9$ & $-7,3$ \\
\hline $\mathrm{NH}_{3}$ & ${ }^{1} J_{\mathrm{NH}}$ & 38,6 & 41,3 & 44,5 & 43,8 \\
\hline $\mathrm{NH}_{3}$ & ${ }^{2} J_{\mathrm{HH}}$ & $-5,0$ & $-7,8$ & $-11,4$ & $-9,6$ \\
\hline $\mathrm{PH}_{3}$ & ${ }^{1} J_{\mathrm{PH}}$ & 164,3 & 181,2 & 202,2 & 188,2 \\
\hline $\mathrm{PF}_{3}$ & ${ }^{1} J_{\mathrm{PF}}$ & $-1619,4$ & $-1634,7$ & $-1642,4$ & -1441 \\
\hline $\mathrm{BHF}_{2}$ & ${ }^{1} J_{\mathrm{BF}}$ & $-122,8$ & $-113,0$ & $-101,1$ & -84 \\
\hline $\mathrm{BF}_{3}$ & ${ }^{1} J_{\mathrm{BF}}$ & $-25,9$ & $-13,1$ & 1,4 & 15 \\
\hline $\mathrm{F}_{2} \mathrm{O}$ & ${ }^{1} J_{\mathrm{OF}}$ & $-240,8$ & $-303,2$ & $-382,9$ & -300 \\
\hline $\mathrm{CH}_{4}$ & ${ }^{1} J_{\mathrm{CH}}$ & 100,4 & 111,6 & 124,9 & 125,3 \\
\hline $\mathrm{CH}_{4}$ & ${ }^{2} J_{\mathrm{HH}}$ & $-7,5$ & $-10,3$ & $-14,1$ & $-12,8$ \\
\hline $\mathrm{C}_{2} \mathrm{H}_{2}$ & ${ }^{1} J_{\mathrm{CC}}$ & 176,6 & 186,6 & 200,6 & 174,8 \\
\hline $\mathrm{C}_{2} \mathrm{H}_{2}$ & ${ }^{1} J_{\mathrm{CH}}$ & 209,5 & 236,9 & 269,7 & 247,6 \\
\hline $\mathrm{C}_{2} \mathrm{H}_{2}$ & ${ }^{2} J_{\mathrm{CH}}$ & 52,0 & 53,0 & 52,1 & 50,1 \\
\hline $\mathrm{C}_{2} \mathrm{H}_{2}$ & ${ }^{3} J_{\mathrm{HH}}$ & 6,9 & 8,9 & 12,6 & 9,6 \\
\hline $\mathrm{C}_{2} \mathrm{H}_{4}$ & ${ }^{1} J_{\mathrm{CC}}$ & 55,8 & 60,9 & 68,7 & 67,6 \\
\hline $\mathrm{C}_{2} \mathrm{H}_{4}$ & ${ }^{1} J_{\mathrm{CH}}$ & 127,0 & 143,0 & 162,4 & 156,3 \\
\hline $\mathrm{C}_{2} \mathrm{H}_{4}$ & ${ }^{2} J_{\mathrm{CH}}$ & 1,8 & 0,0 & $-3,2$ & $-2,4$ \\
\hline $\mathrm{C}_{2} \mathrm{H}_{4}$ & ${ }^{2} J_{\mathrm{HH}}$ & 5,0 & 3,8 & 1,4 & 2,3 \\
\hline $\mathrm{C}_{2} \mathrm{H}_{4}$ & ${ }^{3} J_{\mathrm{HH}_{\mathrm{c}}}$ & 9,7 & 10,8 & 12,7 & 11,7 \\
\hline $\mathrm{C}_{2} \mathrm{H}_{4}$ & ${ }^{3} J_{\mathrm{HH}_{\mathrm{t}}}$ & 14,0 & 16,4 & 19,8 & 19 \\
\hline $\mathrm{C}_{2} \mathrm{H}_{6}$ & ${ }^{1} J_{\mathrm{CC}}{ }^{2}$ & 23,1 & 26,7 & 31,4 & 34,5 \\
\hline $\mathrm{C}_{2} \mathrm{H}_{6}$ & ${ }^{1} J_{\mathrm{CH}}$ & 99,7 & 111,7 & 125,9 & 125,2 \\
\hline $\mathrm{C}_{2} \mathrm{H}_{6}$ & ${ }^{2} J_{\mathrm{CH}}$ & $-1,3$ & $-2,6$ & $-4,3$ & $-4,7$ \\
\hline \multirow[t]{3}{*}{ Total } & $\mathrm{DM}$ & $-14,23$ & $-12,10$ & $-9,23$ & - \\
\hline & DMA & 21,89 & 14,88 & 15,77 & - \\
\hline & PDMA & 43,31 & 25,28 & 15,47 & - \\
\hline \multirow[t]{3}{*}{ CPI } & $\mathrm{DM}$ & $-21,69$ & $-24,35$ & $-26,95$ & - \\
\hline & DMA & 36,29 & 26,72 & 30,95 & - \\
\hline & PDMA & 47,16 & 29,04 & 20,36 & - \\
\hline \multirow[t]{3}{*}{ SPI } & $\mathrm{DM}$ & $-8,76$ & $-3,11$ & 3,77 & - \\
\hline & DMA & 11,33 & 6,21 & 4,63 & - \\
\hline & PDMA & 40,49 & 22,51 & 11,88 & - \\
\hline \multirow[t]{3}{*}{$\Delta \mathrm{CS}$} & $\mathrm{DM}$ & $-12,93$ & $-21,24$ & $-30,71$ & - \\
\hline & DMA & 24,96 & 20,51 & 26,31 & - \\
\hline & PDMA & 6,67 & 6,53 & 8,48 & - \\
\hline
\end{tabular}


Tabela 8.324: Constantes de acoplamento $\omega \mathrm{B} 97 \mathrm{XD}$ variando $\alpha$ com $\alpha+\beta=20 \%$ na base aug-pcJ-2.

\begin{tabular}{|c|c|c|c|}
\hline & $\alpha$ & $10 \%$ & Exp. \\
\hline $\mathrm{HF}$ & ${ }^{1} J_{\mathrm{HF}}$ & 469,5 & 500 \\
\hline $\mathrm{CO}$ & ${ }^{1} J_{\mathrm{CO}}$ & 18,0 & 16,4 \\
\hline $\mathrm{H}_{2} \mathrm{O}$ & ${ }^{1} J_{\mathrm{OH}}$ & $-70,8$ & $-80,6$ \\
\hline $\mathrm{H}_{2} \mathrm{O}$ & ${ }^{2} J_{\mathrm{HH}}$ & $-2,4$ & $-7,3$ \\
\hline $\mathrm{NH}_{3}$ & ${ }^{1} J_{\mathrm{NH}}$ & 38,7 & 43,8 \\
\hline $\mathrm{NH}_{3}$ & ${ }^{2} J_{\mathrm{HH}}$ & $-4,9$ & $-9,6$ \\
\hline $\mathrm{PH}_{3}$ & ${ }^{1} J_{\mathrm{PH}}$ & 167,9 & 188,2 \\
\hline $\mathrm{PF}_{3}$ & ${ }^{1} J_{\mathrm{PF}}$ & $-1616,0$ & -1441 \\
\hline $\mathrm{BHF}_{2}$ & ${ }^{1} J_{\mathrm{BF}}$ & $-125,3$ & -84 \\
\hline $\mathrm{BF}_{3}$ & ${ }^{1} J_{\mathrm{BF}}$ & $-28,3$ & 15 \\
\hline $\mathrm{F}_{2} \mathrm{O}$ & ${ }^{1} J_{\mathrm{OF}}$ & $-236,8$ & -300 \\
\hline $\mathrm{CH}_{4}$ & ${ }^{1} J_{\mathrm{CH}}$ & 100,4 & 125,3 \\
\hline $\mathrm{CH}_{4}$ & ${ }^{2} J_{\mathrm{HH}}$ & $-7,3$ & $-12,8$ \\
\hline $\mathrm{C}_{2} \mathrm{H}_{2}$ & ${ }^{1} J_{\mathrm{CC}}$ & 176,2 & 174,8 \\
\hline $\mathrm{C}_{2} \mathrm{H}_{2}$ & ${ }^{1} J_{\mathrm{CH}}$ & 209,1 & 247,6 \\
\hline $\mathrm{C}_{2} \mathrm{H}_{2}$ & ${ }^{2} J_{\mathrm{CH}}$ & 51,6 & 50,1 \\
\hline $\mathrm{C}_{2} \mathrm{H}_{2}$ & ${ }^{3} J_{\mathrm{HH}}$ & 6,8 & 9,6 \\
\hline $\mathrm{C}_{2} \mathrm{H}_{4}$ & ${ }^{1} J_{\mathrm{CC}}$ & 55,5 & 67,6 \\
\hline $\mathrm{C}_{2} \mathrm{H}_{4}$ & ${ }^{1} J_{\mathrm{CH}}$ & 126,9 & 156,3 \\
\hline $\mathrm{C}_{2} \mathrm{H}_{4}$ & ${ }^{2} J_{\mathrm{CH}}$ & 1,9 & $-2,4$ \\
\hline $\mathrm{C}_{2} \mathrm{H}_{4}$ & ${ }^{2} J_{\mathrm{HH}}$ & 5,1 & 2,3 \\
\hline $\mathrm{C}_{2} \mathrm{H}_{4}$ & ${ }^{3} J_{\mathrm{HH}_{\mathrm{c}}}$ & 9,6 & 11,7 \\
\hline $\mathrm{C}_{2} \mathrm{H}_{4}$ & ${ }^{3} J_{\mathrm{HH}_{\mathrm{t}}}$ & 13,9 & 19 \\
\hline $\mathrm{C}_{2} \mathrm{H}_{6}$ & ${ }^{1} J_{\mathrm{CC}}{ }^{2}$ & 22,6 & 34,5 \\
\hline $\mathrm{C}_{2} \mathrm{H}_{6}$ & ${ }^{1} J_{\mathrm{CH}}$ & 99,7 & 125,2 \\
\hline $\mathrm{C}_{2} \mathrm{H}_{6}$ & ${ }^{2} J_{\mathrm{CH}}$ & $-1,2$ & $-4,7$ \\
\hline \multirow[t]{3}{*}{ Total } & $\mathrm{DM}$ & $-14,02$ & - \\
\hline & DMA & 21,96 & - \\
\hline & PDMA & 44,64 & - \\
\hline \multirow[t]{3}{*}{ CPI } & DM & $-21,03$ & - \\
\hline & DMA & 36,34 & - \\
\hline & PDMA & 48,87 & - \\
\hline \multirow[t]{3}{*}{ SPI } & $\mathrm{DM}$ & $-8,89$ & - \\
\hline & DMA & 11,42 & - \\
\hline & PDMA & 41,54 & - \\
\hline \multirow[t]{3}{*}{$\Delta \mathrm{CS}$} & DM & $-12,14$ & - \\
\hline & DMA & 24,92 & - \\
\hline & PDMA & 7,33 & - \\
\hline
\end{tabular}


Tabela 8.325: Constantes de acoplamento CAM-B3LYP variando $\gamma$ na base aug-pcJ-2.

\begin{tabular}{|c|c|c|c|c|c|c|c|c|c|c|c|c|c|}
\hline & $\gamma$ & 0,25 & 0,3 & 0,35 & 0,4 & 0,45 & 0,5 & 0,55 & 0,6 & 0,65 & 0,7 & 0,75 & Exp. \\
\hline $\mathrm{HF}$ & ${ }^{1} J_{\mathrm{HF}}$ & 451,7 & 454,0 & 456,7 & 459,8 & 463,3 & 467,0 & 470,9 & 475,0 & 479,1 & 483,2 & 487,3 & 500 \\
\hline $\mathrm{CO}$ & ${ }^{1} J_{\mathrm{CO}}$ & 18,2 & 18,3 & 18,3 & 18,2 & 18,1 & 17,9 & 17,6 & 17,3 & 16,9 & 16,4 & 15,9 & 16,4 \\
\hline $\mathrm{H}_{2} \mathrm{O}$ & ${ }^{1} J_{\mathrm{OH}}$ & $-77,4$ & $-77,6$ & $-77,8$ & $-78,2$ & $-78,6$ & $-79,0$ & $-79,5$ & $-80,1$ & $-80,6$ & $-81,2$ & $-81,8$ & $-80,6$ \\
\hline $\mathrm{H}_{2} \mathrm{O}$ & ${ }^{2} J_{\mathrm{HH}}$ & $-7,2$ & $-7,3$ & $-7,5$ & $-7,7$ & $-8,0$ & $-8,3$ & $-8,5$ & $-8,8$ & $-9,1$ & $-9,4$ & $-9,6$ & $-7,3$ \\
\hline $\mathrm{NH}_{3}$ & ${ }^{1} J_{\mathrm{NH}}$ & 45,2 & 45,2 & 45,2 & 45,2 & 45,3 & 45,5 & 45,7 & 46,0 & 46,3 & 46,5 & 46,8 & 43,8 \\
\hline $\mathrm{NH}_{3}$ & ${ }^{2} J_{\mathrm{HH}}$ & $-9,9$ & $-10,1$ & $-10,3$ & $-10,6$ & $-10,8$ & $-11,2$ & $-11,5$ & $-11,8$ & $-12,1$ & $-12,4$ & $-12,6$ & $-9,6$ \\
\hline $\mathrm{PH}_{3}$ & ${ }^{1} J_{\mathrm{PH}}$ & 164,2 & 162,6 & 162,3 & 163,2 & 165,2 & 167,9 & 171,1 & 174,5 & 178,0 & 181,4 & 184,6 & 188,2 \\
\hline $\mathrm{PF}_{3}$ & ${ }^{1} J_{\mathrm{PF}}$ & $-1750,9$ & $-1749,7$ & $-1748,8$ & $-1747,5$ & $-1745,6$ & $-1742,7$ & $-1738,8$ & $-1733,9$ & $-1728,2$ & $-1722,0$ & $-1715,5$ & -1441 \\
\hline $\mathrm{BHF}_{2}$ & ${ }^{1} J_{\mathrm{BF}}$ & $-131,2$ & $-127,8$ & $-124,2$ & $-120,3$ & $-116,4$ & $-112,4$ & $-108,4$ & $-104,5$ & $-100,8$ & $-97,3$ & $-94,0$ & -84 \\
\hline $\mathrm{BF}_{3}$ & ${ }^{1} J_{\mathrm{BF}}$ & $-28,7$ & $-24,9$ & $-20,7$ & $-16,2$ & $-11,7$ & $-7,3$ & $-3,0$ & 1,1 & 5,0 & 8,6 & 12,1 & 15 \\
\hline $\mathrm{F}_{2} \mathrm{O}$ & ${ }^{1} J_{\mathrm{OF}}$ & $-371,9$ & $-380,9$ & $-390,5$ & $-400,1$ & $-409,7$ & $-419,2$ & $-428,4$ & $-437,5$ & $-446,5$ & $-455,4$ & $-464,0$ & -300 \\
\hline $\mathrm{CH}_{4}$ & ${ }^{1} J_{\mathrm{CH}}$ & 129,4 & 129,0 & 128,9 & 129,1 & 129,7 & 130,4 & 131,3 & 132,2 & 133,2 & 134,2 & 135,2 & 125,3 \\
\hline $\mathrm{CH}_{4}$ & ${ }^{2} J_{\mathrm{HH}}$ & $-12,9$ & $-13,1$ & $-13,3$ & $-13,6$ & $-13,9$ & $-14,3$ & $-14,6$ & $-14,9$ & $-15,2$ & $-15,5$ & $-15,7$ & $-12,8$ \\
\hline $\mathrm{C}_{2} \mathrm{H}_{2}$ & ${ }^{1} J_{\mathrm{CC}}$ & 201,6 & 201,7 & 202,2 & 203,0 & 204,2 & 205,6 & 207,3 & 209,1 & 211,0 & 213,0 & 215,0 & 174,8 \\
\hline $\mathrm{C}_{2} \mathrm{H}_{2}$ & ${ }^{1} J_{\mathrm{CH}}$ & 267,8 & 267,0 & 266,9 & 267,4 & 268,4 & 269,8 & 271,5 & 273,3 & 275,2 & 277,2 & 279,0 & 247,6 \\
\hline $\mathrm{C}_{2} \mathrm{H}_{2}$ & ${ }^{2} J_{\mathrm{CH}}$ & 56,9 & 57,0 & 57,0 & 57,0 & 56,8 & 56,5 & 56,2 & 55,9 & 55,4 & 55,0 & 54,6 & 50,1 \\
\hline $\mathrm{C}_{2} \mathrm{H}_{2}$ & ${ }^{3} J_{\mathrm{HH}}$ & 10,8 & 10,9 & 11,1 & 11,4 & 11,8 & 12,2 & 12,6 & 13,0 & 13,4 & 13,8 & 14,2 & 9,6 \\
\hline $\mathrm{C}_{2} \mathrm{H}_{4}$ & ${ }^{1} J_{\mathrm{CC}}$ & 70,2 & 70,4 & 70,8 & 71,5 & 72,4 & 73,5 & 74,9 & 76,4 & 78,0 & 79,6 & 81,2 & 67,6 \\
\hline $\mathrm{C}_{2} \mathrm{H}_{4}$ & ${ }^{1} J_{\mathrm{CH}}$ & 164,7 & 164,4 & 164,5 & 165,0 & 165,9 & 167,0 & 168,3 & 169,7 & 171,2 & 172,6 & 174,1 & 156,3 \\
\hline $\mathrm{C}_{2} \mathrm{H}_{4}$ & ${ }^{2} J_{\mathrm{CH}}$ & $-1,4$ & $-1,6$ & $-1,8$ & $-2,2$ & $-2,6$ & $-3,0$ & $-3,5$ & $-4,0$ & $-4,6$ & $-5,1$ & $-5,6$ & $-2,4$ \\
\hline $\mathrm{C}_{2} \mathrm{H}_{4}$ & ${ }^{2} J_{\mathrm{HH}}$ & 4,4 & 4,2 & 3,9 & 3,5 & 3,2 & 2,8 & 2,5 & 2,1 & 1,8 & 1,4 & 1,1 & 2,3 \\
\hline $\mathrm{C}_{2} \mathrm{H}_{4}$ & ${ }^{3} J_{\mathrm{HH}_{\mathrm{c}}}$ & 13,1 & 13,2 & 13,3 & 13,5 & 13,7 & 13,9 & 14,1 & 14,3 & 14,5 & 14,7 & 14,9 & 11,7 \\
\hline $\mathrm{C}_{2} \mathrm{H}_{4}$ & ${ }^{3} J_{\mathrm{HH}_{\mathrm{t}}}$ & 19,9 & 19,9 & 20,0 & 20,2 & 20,4 & 20,6 & 20,9 & 21,2 & 21,5 & 21,7 & 22,0 & 19 \\
\hline $\mathrm{C}_{2} \mathrm{H}_{6}$ & ${ }^{1} J_{\mathrm{CC}}$ & 32,2 & 32,4 & 32,6 & 33,0 & 33,5 & 34,1 & 34,8 & 35,5 & 36,3 & 37,1 & 37,8 & 34,5 \\
\hline $\mathrm{C}_{2} \mathrm{H}_{6}$ & ${ }^{1} J_{\mathrm{CH}}$ & 129,5 & 129,1 & 129,1 & 129,4 & 130,0 & 130,8 & 131,7 & 132,8 & 133,8 & 134,9 & 135,9 & 125,2 \\
\hline $\mathrm{C}_{2} \mathrm{H}_{6}$ & ${ }^{2} J_{\mathrm{CH}}$ & $-3,4$ & $-3,5$ & $-3,6$ & $-3,7$ & $-3,9$ & $-4,1$ & $-4,3$ & $-4,4$ & $-4,6$ & $-4,8$ & $-4,9$ & $-4,7$ \\
\hline \multirow[t]{3}{*}{ Total } & DM & $-17,70$ & $-17,78$ & $-17,72$ & $-17,49$ & $-17,09$ & $-16,58$ & $-15,93$ & $-15,21$ & $-14,47$ & $-13,72$ & $-12,96$ & - \\
\hline & DMA & 24,43 & 24,36 & 24,33 & 24,28 & 24,24 & 24,19 & 24,13 & 24,10 & 24,07 & 24,09 & 24,13 & - \\
\hline & PDMA & 26,47 & 24,86 & 23,20 & 21,10 & 19,80 & 19,08 & 18,66 & 19,04 & 20,05 & 21,32 & 22,66 & - \\
\hline \multirow[t]{3}{*}{ CPI } & DM & $-48,98$ & $-49,01$ & $-48,93$ & $-48,65$ & $-48,16$ & $-47,52$ & $-46,70$ & $-45,78$ & $-44,81$ & $-43,86$ & $-42,88$ & - \\
\hline & DMA & 50,16 & 50,15 & 50,04 & 49,66 & 49,11 & 48,39 & 47,46 & 46,44 & 45,35 & 44,35 & 43,43 & - \\
\hline & PDMA & 39,82 & 37,55 & 35,28 & 32,75 & 30,20 & 27,81 & 25,15 & 22,74 & 20,41 & 18,33 & 16,69 & - \\
\hline \multirow[t]{3}{*}{ SPI } & $\mathrm{DM}$ & 5,25 & 5,13 & 5,17 & 5,36 & 5,70 & 6,11 & 6,64 & 7,21 & 7,79 & 8,38 & 8,98 & - \\
\hline & DMA & 5,57 & 5,45 & 5,49 & 5,67 & 6,01 & 6,45 & 7,03 & 7,73 & 8,47 & 9,23 & 9,98 & - \\
\hline & PDMA & 16,68 & 15,56 & 14,34 & 12,56 & 12,17 & 12,68 & 13,91 & 16,33 & 19,78 & 23,51 & 27,04 & - \\
\hline \multirow[t]{3}{*}{$\Delta \mathrm{CS}$} & $\mathrm{DM}$ & $-54,23$ & $-54,14$ & $-54,09$ & $-54,01$ & $-53,86$ & $-53,63$ & $-53,34$ & $-52,99$ & $-52,60$ & $-52,24$ & $-51,86$ & - \\
\hline & DMA & 44,60 & 44,71 & 44,55 & 44,00 & 43,10 & 41,94 & 40,44 & 38,71 & 36,89 & 35,12 & 33,45 & - \\
\hline & PDMA & 23,14 & 21,99 & 20,94 & 20,18 & 18,03 & 15,13 & 11,24 & 6,40 & 0,63 & $-5,18$ & $-10,36$ & - \\
\hline
\end{tabular}


Tabela 8.326: Constantes de acoplamento $\omega$ B97 variando $\gamma$ na base aug-pcJ-2.

\begin{tabular}{|c|c|c|c|c|c|c|c|c|c|c|c|c|c|}
\hline & $\gamma$ & 0,25 & 0,3 & 0,35 & 0,4 & 0,45 & 0,5 & 0,55 & 0,6 & 0,65 & 0,7 & 0,75 & Exp. \\
\hline $\mathrm{HF}$ & ${ }^{1} J_{\mathrm{HF}}$ & 427,3 & 436,1 & 445,5 & 455,6 & 466,3 & 477,6 & 489,2 & 501,0 & 512,7 & 524,4 & 535,9 & 500 \\
\hline $\mathrm{CO}$ & ${ }^{1} J_{\mathrm{CO}}$ & 24,9 & 24,6 & 24,3 & 23,9 & 23,4 & 22,6 & 21,7 & 20,6 & 19,2 & 17,8 & 16,2 & 16,4 \\
\hline $\mathrm{H}_{2} \mathrm{O}$ & ${ }^{1} J_{\mathrm{OH}}$ & $-68,5$ & $-69,5$ & $-70,6$ & $-71,8$ & $-73,1$ & $-74,6$ & $-76,0$ & $-77,6$ & $-79,1$ & $-80,7$ & $-82,2$ & $-80,6$ \\
\hline $\mathrm{H}_{2} \mathrm{O}$ & ${ }^{2} J_{\mathrm{HH}}$ & $-5,8$ & $-6,0$ & $-6,2$ & $-6,6$ & $-7,0$ & $-7,4$ & $-7,9$ & $-8,3$ & $-8,8$ & $-9,3$ & $-9,7$ & $-7,3$ \\
\hline $\mathrm{NH}_{3}$ & ${ }^{1} J_{\mathrm{NH}}$ & 38,0 & 38,2 & 38,6 & 39,0 & 39,5 & 40,1 & 40,7 & 41,4 & 42,1 & 42,9 & 43,6 & 43,8 \\
\hline $\mathrm{NH}_{3}$ & ${ }^{2} J_{\mathrm{HH}}$ & $-7,7$ & $-7,9$ & $-8,1$ & $-8,5$ & $-9,0$ & $-9,4$ & $-9,9$ & $-10,4$ & $-10,9$ & $-11,3$ & $-11,8$ & $-9,6$ \\
\hline $\mathrm{PH}_{3}$ & ${ }^{1} J_{\mathrm{PH}}$ & 158,3 & 156,7 & 157,1 & 159,3 & 163,0 & 167,7 & 173,0 & 178,6 & 184,0 & 189,2 & 194,0 & 188,2 \\
\hline $\mathrm{PF}_{3}$ & ${ }^{1} J_{\mathrm{PF}}$ & $-1663,7$ & $-1663,4$ & $-1663,7$ & $-1663,0$ & $-1660,3$ & $-1654,8$ & $-1646,6$ & $-1636,2$ & $-1624,0$ & $-1610,7$ & $-1596,8$ & -1441 \\
\hline $\mathrm{BHF}_{2}$ & ${ }^{1} J_{\mathrm{BF}}$ & $-142,2$ & $-132,5$ & $-122,3$ & $-111,8$ & $-101,2$ & $-90,7$ & $-80,4$ & $-70,6$ & $-61,2$ & $-52,4$ & $-44,1$ & -84 \\
\hline $\mathrm{BF}_{3}$ & ${ }^{1} J_{\mathrm{BF}}$ & $-51,2$ & $-39,5$ & $-27,2$ & $-14,8$ & $-2,4$ & 9,4 & 20,8 & 31,6 & 41,8 & 51,2 & 60,1 & 15 \\
\hline $\mathrm{F}_{2} \mathrm{O}$ & ${ }^{1} J_{\mathrm{OF}}$ & $-261,3$ & $-277,6$ & $-294,3$ & $-310,7$ & $-326,6$ & $-342,1$ & $-357,7$ & $-373,5$ & $-389,8$ & $-406,7$ & $-424,3$ & -300 \\
\hline $\mathrm{CH}_{4}$ & ${ }^{1} J_{\mathrm{CH}}$ & 106,7 & 107,1 & 108,0 & 109,4 & 111,2 & 113,2 & 115,5 & 117,9 & 120,2 & 122,5 & 124,7 & 125,3 \\
\hline $\mathrm{CH}_{4}$ & ${ }^{2} J_{\mathrm{HH}}$ & $-10,4$ & $-10,6$ & $-10,9$ & $-11,2$ & $-11,7$ & $-12,2$ & $-12,6$ & $-13,1$ & $-13,5$ & $-13,9$ & $-14,3$ & $-12,8$ \\
\hline $\mathrm{C}_{2} \mathrm{H}_{2}$ & ${ }^{1} J_{\mathrm{CC}}$ & 187,4 & 188,9 & 191,1 & 194,2 & 198,1 & 203,0 & 208,6 & 214,9 & 221,7 & 228,8 & 236,1 & 174,8 \\
\hline $\mathrm{C}_{2} \mathrm{H}_{2}$ & ${ }^{1} J_{\mathrm{CH}}$ & 232,5 & 232,7 & 234,0 & 236,3 & 239,4 & 243,2 & 247,5 & 252,1 & 256,8 & 261,5 & 266,0 & 247,6 \\
\hline $\mathrm{C}_{2} \mathrm{H}_{2}$ & ${ }^{2} J_{\mathrm{CH}}$ & 51,8 & 52,1 & 52,1 & 51,8 & 51,3 & 50,5 & 49,5 & 48,4 & 47,1 & 45,6 & 44,2 & 50,1 \\
\hline $\mathrm{C}_{2} \mathrm{H}_{2}$ & ${ }^{3} J_{\mathrm{HH}}$ & 9,7 & 9,7 & 10,0 & 10,4 & 11,0 & 11,7 & 12,4 & 13,2 & 14,0 & 14,8 & 15,6 & 9,6 \\
\hline $\mathrm{C}_{2} \mathrm{H}_{4}$ & ${ }^{1} J_{\mathrm{CC}}$ & 60,0 & 61,3 & 63,2 & 65,6 & 68,8 & 72,8 & 77,4 & 82,7 & 88,5 & 94,6 & 101,0 & 67,6 \\
\hline $\mathrm{C}_{2} \mathrm{H}_{4}$ & ${ }^{1} J_{\mathrm{CH}}$ & 138,7 & 139,3 & 140,7 & 142,7 & 145,4 & 148,5 & 151,9 & 155,6 & 159,4 & 163,2 & 166,9 & 156,3 \\
\hline $\mathrm{C}_{2} \mathrm{H}_{4}$ & ${ }^{2} J_{\mathrm{CH}}$ & $-0,5$ & $-0,9$ & $-1,4$ & $-2,2$ & $-3,2$ & $-4,4$ & $-5,7$ & $-7,1$ & $-8,7$ & $-10,3$ & $-12,0$ & $-2,4$ \\
\hline $\mathrm{C}_{2} \mathrm{H}_{4}$ & ${ }^{2} J_{\mathrm{HH}}$ & 3,4 & 3,1 & 2,8 & 2,3 & 1,8 & 1,2 & 0,5 & $-0,1$ & $-0,7$ & $-1,4$ & $-2,0$ & 2,3 \\
\hline $\mathrm{C}_{2} \mathrm{H}_{4}$ & ${ }^{3} J_{\mathrm{HH}_{\mathrm{C}}}$ & 10,8 & 11,0 & 11,2 & 11,5 & 11,9 & 12,3 & 12,7 & 13,2 & 13,7 & 14,2 & 14,7 & 11,7 \\
\hline $\mathrm{C}_{2} \mathrm{H}_{4}$ & ${ }^{3} J_{\mathrm{HH}_{\mathrm{t}}}$ & 16,6 & 16,6 & 16,8 & 17,0 & 17,4 & 17,9 & 18,4 & 19,0 & 19,7 & 20,3 & 20,9 & 19 \\
\hline $\mathrm{C}_{2} \mathrm{H}_{6}$ & ${ }^{1} J_{\mathrm{CC}}$ & 25,1 & 26,1 & 27,2 & 28,5 & 30,0 & 31,7 & 33,6 & 35,5 & 37,4 & 39,4 & 41,3 & 34,5 \\
\hline $\mathrm{C}_{2} \mathrm{H}_{6}$ & ${ }^{1} J_{\mathrm{CH}}$ & 106,1 & 106,5 & 107,5 & 109,0 & 110,9 & 113,1 & 115,4 & 117,9 & 120,3 & 122,7 & 125,0 & 125,2 \\
\hline $\mathrm{C}_{2} \mathrm{H}_{6}$ & ${ }^{2} J_{\mathrm{CH}}$ & $-2,6$ & $-2,8$ & $-3,0$ & $-3,2$ & $-3,5$ & $-3,8$ & $-4,1$ & $-4,5$ & $-4,8$ & $-5,1$ & $-5,3$ & $-4,7$ \\
\hline \multirow[t]{3}{*}{ Total } & DM & $-17,75$ & $-17,14$ & $-16,25$ & $-15,09$ & $-13,60$ & $-11,84$ & $-9,89$ & $-7,80$ & $-5,69$ & $-3,60$ & $-1,59$ & - \\
\hline & DMA & 24,26 & 22,32 & 20,10 & 18,42 & 17,06 & 15,72 & 15,08 & 15,82 & 17,74 & 19,78 & 22,21 & - \\
\hline & PDMA & 38,39 & 32,78 & 26,68 & 19,64 & 16,55 & 15,13 & 18,09 & 24,98 & 33,20 & 41,74 & 50,40 & - \\
\hline \multirow[t]{3}{*}{ CPI } & DM & $-35,71$ & $-34,70$ & $-33,44$ & $-31,85$ & $-29,85$ & $-27,50$ & $-24,91$ & $-22,21$ & $-19,54$ & $-16,95$ & $-14,55$ & - \\
\hline & DMA & 47,11 & 42,83 & 38,20 & 35,14 & 32,65 & 29,75 & 28,42 & 29,15 & 31,65 & 34,15 & 37,58 & - \\
\hline & PDMA & 62,71 & 53,23 & 43,17 & 33,06 & 22,99 & 13,34 & 13,01 & 20,62 & 28,19 & 35,23 & 42,74 & - \\
\hline \multirow[t]{3}{*}{ SPI } & DM & $-4,59$ & $-4,27$ & $-3,65$ & $-2,80$ & $-1,69$ & $-0,36$ & 1,13 & 2,77 & 4,47 & 6,19 & 7,91 & - \\
\hline & DMA & 7,51 & 7,28 & 6,83 & 6,16 & 5,63 & 5,43 & 5,30 & 6,03 & 7,55 & 9,24 & 10,94 & - \\
\hline & PDMA & 20,56 & 17,78 & 14,59 & 9,80 & 11,83 & 16,44 & 21,81 & 28,18 & 36,86 & 46,52 & 56,03 & - \\
\hline \multirow[t]{3}{*}{$\Delta \mathrm{CS}$} & $\mathrm{DM}$ & $-31,12$ & $-30,43$ & $-29,78$ & $-29,05$ & $-28,16$ & $-27,14$ & $-26,04$ & $-24,98$ & $-24,00$ & $-23,14$ & $-22,46$ & - \\
\hline & DMA & 39,60 & 35,55 & 31,37 & 28,98 & 27,01 & 24,33 & 23,12 & 23,12 & 24,10 & 24,91 & 26,64 & - \\
\hline & PDMA & 42,16 & 35,46 & 28,58 & 23,25 & 11,16 & $-3,10$ & $-8,79$ & $-7,56$ & $-8,67$ & $-11,29$ & $-13,29$ & - \\
\hline
\end{tabular}


Tabela 8.327: Constantes de acoplamento $\omega$ B97X variando $\gamma$ na base aug-pcJ-2.

\begin{tabular}{|c|c|c|c|c|c|c|c|c|c|c|c|c|c|}
\hline & $\gamma$ & 0,25 & 0,3 & 0,35 & 0,4 & 0,45 & 0,5 & 0,55 & 0,6 & 0,65 & 0,7 & 0,75 & Exp. \\
\hline $\mathrm{HF}$ & ${ }^{1} J_{\mathrm{HF}}$ & 491,9 & 497,9 & 504,3 & 511,3 & 518,7 & 526,6 & 534,7 & 542,9 & 551,2 & 559,5 & 567,6 & 500 \\
\hline $\mathrm{CO}$ & ${ }^{1} J_{C O}$ & 19,4 & 19,1 & 18,9 & 18,6 & 18,2 & 17,6 & 16,8 & 15,9 & 14,9 & 13,8 & 12,6 & 16,4 \\
\hline $\mathrm{H}_{2} \mathrm{O}$ & ${ }^{1} J_{\mathrm{OH}}$ & $-75,8$ & $-76,5$ & $-77,2$ & $-78,1$ & $-79,0$ & $-80,0$ & $-81,1$ & $-82,2$ & $-83,4$ & $-84,5$ & $-85,7$ & $-80,6$ \\
\hline $\mathrm{H}_{2} \mathrm{O}$ & ${ }^{2} J_{\mathrm{HH}}$ & $-6,3$ & $-6,4$ & $-6,7$ & $-7,0$ & $-7,4$ & $-7,8$ & $-8,2$ & $-8,7$ & $-9,1$ & $-9,5$ & $-9,9$ & $-7,3$ \\
\hline $\mathrm{NH}_{3}$ & ${ }^{1} J_{\mathrm{NH}}$ & 41,3 & 41,5 & 41,7 & 42,0 & 42,4 & 42,8 & 43,3 & 43,9 & 44,4 & 45,0 & 45,6 & 43,8 \\
\hline $\mathrm{NH}_{3}$ & ${ }^{2} J_{\mathrm{HH}}$ & $-8,5$ & $-8,7$ & $-9,0$ & $-9,3$ & $-9,8$ & $-10,2$ & $-10,7$ & $-11,2$ & $-11,6$ & $-12,1$ & $-12,5$ & $-9,6$ \\
\hline $\mathrm{PH}_{3}$ & ${ }^{1} J_{\mathrm{PH}}$ & 165,9 & 165,0 & 165,8 & 168,2 & 172,0 & 176,8 & 182,1 & 187,6 & 193,1 & 198,3 & 203,2 & 188,2 \\
\hline $\mathrm{PF}_{3}$ & ${ }^{1} J_{\mathrm{PF}}$ & $-1644,2$ & $-1643,0$ & $-1641,6$ & $-1639,2$ & $-1635,0$ & $-1628,6$ & $-1620,2$ & $-1610,0$ & $-1598,4$ & $-1586,1$ & $-1573,4$ & -1441 \\
\hline $\mathrm{BHF}_{2}$ & ${ }^{1} J_{\mathrm{BF}}$ & $-104,2$ & $-97,5$ & $-90,1$ & $-82,5$ & $-74,6$ & $-66,8$ & $-59,0$ & $-51,6$ & $-44,4$ & $-37,7$ & $-31,3$ & -84 \\
\hline $\mathrm{BF}_{3}$ & ${ }^{1} J_{\mathrm{BF}}$ & $-4,7$ & 3,3 & 11,9 & 20,9 & 29,8 & 38,5 & 47,0 & 55,0 & 62,6 & 69,6 & 76,3 & 15 \\
\hline $\mathrm{F}_{2} \mathrm{O}$ & ${ }^{1} J_{\mathrm{OF}}$ & $-312,2$ & $-326,5$ & $-341,5$ & $-356,7$ & $-371,9$ & $-387,3$ & $-403,0$ & $-419,3$ & $-436,4$ & $-454,2$ & $-472,9$ & -300 \\
\hline $\mathrm{CH}_{4}$ & ${ }^{1} J_{\mathrm{CH}}$ & 112,3 & 112,5 & 113,1 & 114,2 & 115,7 & 117,4 & 119,3 & 121,3 & 123,2 & 125,2 & 127,0 & 125,3 \\
\hline $\mathrm{CH}_{4}$ & ${ }^{2} J_{\mathrm{HH}}$ & $-11,1$ & $-11,3$ & $-11,5$ & $-11,9$ & $-12,4$ & $-12,8$ & $-13,3$ & $-13,7$ & $-14,1$ & $-14,5$ & $-14,8$ & $-12,8$ \\
\hline $\mathrm{C}_{2} \mathrm{H}_{2}$ & ${ }^{1} J_{\mathrm{CC}}$ & 191,9 & 193,0 & 194,8 & 197,2 & 200,3 & 204,2 & 208,6 & 213,5 & 218,7 & 224,1 & 229,6 & 174,8 \\
\hline $\mathrm{C}_{2} \mathrm{H}_{2}$ & ${ }^{1} J_{\mathrm{CH}}$ & 240,2 & 240,2 & 241,2 & 243,1 & 245,7 & 248,9 & 252,5 & 256,4 & 260,4 & 264,3 & 268,1 & 247,6 \\
\hline $\mathrm{C}_{2} \mathrm{H}_{2}$ & ${ }^{2} J_{\mathrm{CH}}$ & 53,2 & 53,4 & 53,4 & 53,1 & 52,7 & 52,0 & 51,1 & 50,1 & 49,0 & 47,8 & 46,6 & 50,1 \\
\hline $\mathrm{C}_{2} \mathrm{H}_{2}$ & ${ }^{3} J_{\mathrm{HH}}$ & 9,9 & 10,0 & 10,3 & 10,8 & 11,3 & 12,0 & 12,7 & 13,5 & 14,3 & 15,0 & 15,7 & 9,6 \\
\hline $\mathrm{C}_{2} \mathrm{H}_{4}$ & ${ }^{1} J_{\mathrm{CC}}$ & 63,5 & 64,5 & 66,0 & 68,0 & 70,5 & 73,7 & 77,4 & 81,5 & 86,0 & 90,8 & 95,6 & 67,6 \\
\hline $\mathrm{C}_{2} \mathrm{H}_{4}$ & ${ }^{1} J_{\mathrm{CH}}$ & 145,0 & 145,4 & 146,5 & 148,2 & 150,4 & 153,0 & 155,9 & 159,0 & 162,2 & 165,5 & 168,6 & 156,3 \\
\hline $\mathrm{C}_{2} \mathrm{H}_{4}$ & ${ }^{2} J_{\mathrm{CH}}$ & $-1,0$ & $-1,3$ & $-1,8$ & $-2,5$ & $-3,4$ & $-4,4$ & $-5,6$ & $-6,8$ & $-8,2$ & $-9,5$ & $-10,9$ & $-2,4$ \\
\hline $\mathrm{C}_{2} \mathrm{H}_{4}$ & ${ }^{2} J_{\mathrm{HH}}$ & 3,1 & 2,9 & 2,5 & 2,0 & 1,5 & 0,9 & 0,2 & $-0,3$ & $-1,0$ & $-1,6$ & $-2,3$ & 2,3 \\
\hline $\mathrm{C}_{2} \mathrm{H}_{4}$ & ${ }^{3} J_{\mathrm{HH}}$ & 11,4 & 11,5 & 11,8 & 12,1 & 12,4 & 12,8 & 13,3 & 13,7 & 14,2 & 14,7 & 15,2 & 11,7 \\
\hline $\mathrm{C}_{2} \mathrm{H}_{4}$ & ${ }^{3} J_{\mathrm{HH}_{\mathrm{t}}}$ & 17,2 & 17,2 & 17,4 & 17,7 & 18,1 & 18,6 & 19,2 & 19,8 & 20,4 & 21,1 & 21,7 & 19 \\
\hline $\mathrm{C}_{2} \mathrm{H}_{6}$ & ${ }^{1} J_{\mathrm{CC}}$ & 28,4 & 29,1 & 30,0 & 31,1 & 32,3 & 33,7 & 35,2 & 36,8 & 38,4 & 39,9 & 41,5 & 34,5 \\
\hline $\mathrm{C}_{2} \mathrm{H}_{6}$ & ${ }^{1} J_{\mathrm{CH}}$ & 112,1 & 112,4 & 113,1 & 114,3 & 115,8 & 117,6 & 119,6 & 121,7 & 123,7 & 125,8 & 127,7 & 125,2 \\
\hline $\mathrm{C}_{2} \mathrm{H}_{6}$ & ${ }^{2} J_{\mathrm{CH}}$ & $-3,0$ & $-3,2$ & $-3,3$ & $-3,6$ & $-3,8$ & $-4,1$ & $-4,4$ & $-4,7$ & $-5,0$ & $-5,3$ & $-5,5$ & $-4,7$ \\
\hline \multirow[t]{3}{*}{ Total } & DM & $-11,90$ & $-11,56$ & $-10,96$ & $-10,12$ & $-9,02$ & $-7,69$ & $-6,22$ & $-4,65$ & $-3,07$ & $-1,52$ & $-0,06$ & - \\
\hline & DMA & 14,67 & 14,27 & 13,96 & 14,22 & 15,25 & 16,30 & 17,56 & 19,15 & 21,33 & 23,57 & 26,02 & - \\
\hline & PDMA & 18,10 & 14,49 & 9,96 & 9,18 & 13,71 & 19,02 & 25,36 & 32,03 & 40,39 & 48,38 & 56,66 & - \\
\hline \multirow[t]{3}{*}{ CPI } & $\mathrm{DM}$ & $-25,30$ & $-24,79$ & $-24,04$ & $-22,97$ & $-21,59$ & $-19,94$ & $-18,11$ & $-16,24$ & $-14,36$ & $-12,62$ & $-11,03$ & - \\
\hline & DMA & 27,10 & 26,35 & 26,11 & 27,34 & 30,01 & 32,50 & 34,85 & 37,22 & 40,53 & 43,84 & 47,10 & - \\
\hline & PDMA & 22,01 & 16,20 & 9,74 & 10,41 & 16,29 & 23,10 & 29,82 & 36,98 & 44,84 & 52,50 & 59,92 & - \\
\hline \multirow[t]{3}{*}{ SPI } & DM & $-2,07$ & $-1,85$ & $-1,37$ & $-0,69$ & 0,20 & 1,29 & 2,51 & 3,85 & 5,21 & 6,61 & 7,98 & - \\
\hline & DMA & 5,55 & 5,40 & 5,05 & 4,61 & 4,43 & 4,41 & 4,88 & 5,90 & 7,26 & 8,71 & 10,57 & - \\
\hline & PDMA & 15,23 & 13,24 & 10,13 & 8,28 & 11,82 & 16,03 & 22,09 & 28,40 & 37,14 & 45,36 & 54,27 & - \\
\hline \multirow[t]{3}{*}{$\Delta \mathrm{CS}$} & $\mathrm{DM}$ & $-23,23$ & $-22,94$ & $-22,66$ & $-22,29$ & $-21,79$ & $-21,23$ & $-20,62$ & $-20,08$ & $-19,57$ & $-19,23$ & $-19,01$ & - \\
\hline & DMA & 21,55 & 20,95 & 21,06 & 22,73 & 25,58 & 28,09 & 29,97 & 31,32 & 33,27 & 35,13 & 36,53 & - \\
\hline & PDMA & 6,78 & 2,96 & $-0,38$ & 2,13 & 4,47 & 7,07 & 7,73 & 8,58 & 7,70 & 7,14 & 5,65 & - \\
\hline
\end{tabular}


Tabela 8.328: Constantes de acoplamento $\omega$ B97XD variando $\gamma$ na base aug-pcJ-2.

\begin{tabular}{|c|c|c|c|c|c|c|c|c|c|c|c|c|c|}
\hline & $\gamma$ & 0,25 & 0,3 & 0,35 & 0,4 & 0,45 & 0,5 & 0,55 & 0,6 & 0,65 & 0,7 & 0,75 & Exp. \\
\hline $\mathrm{HF}$ & ${ }^{1} J_{\mathrm{HF}}$ & 489,0 & 494,0 & 499,4 & 505,3 & 511,7 & 518,4 & 525,5 & 532,6 & 539,9 & 547,0 & 554,1 & 500 \\
\hline $\mathrm{CO}$ & ${ }^{1} J_{\mathrm{CO}}$ & 19,3 & 19,1 & 18,9 & 18,6 & 18,2 & 17,7 & 17,1 & 16,3 & 15,4 & 14,4 & 13,4 & 16,4 \\
\hline $\mathrm{H}_{2} \mathrm{O}$ & ${ }^{1} J_{\mathrm{OH}}$ & $-75,2$ & $-75,7$ & $-76,3$ & $-77,1$ & $-77,9$ & $-78,8$ & $-79,7$ & $-80,7$ & $-81,7$ & $-82,7$ & $-83,8$ & $-80,6$ \\
\hline $\mathrm{H}_{2} \mathrm{O}$ & ${ }^{2} J_{\mathrm{HH}}$ & $-6,5$ & $-6,7$ & $-7,0$ & $-7,3$ & $-7,7$ & $-8,1$ & $-8,6$ & $-9,0$ & $-9,4$ & $-9,8$ & $-10,2$ & $-7,3$ \\
\hline $\mathrm{NH}_{3}$ & ${ }^{1} J_{\mathrm{NH}}$ & 42,0 & 42,1 & 42,3 & 42,5 & 42,9 & 43,3 & 43,8 & 44,3 & 44,8 & 45,4 & 45,9 & 43,8 \\
\hline $\mathrm{NH}_{3}$ & ${ }^{2} J_{\mathrm{HH}}$ & $-9,1$ & $-9,3$ & $-9,7$ & $-10,1$ & $-10,5$ & $-11,0$ & $-11,5$ & $-11,9$ & $-12,4$ & $-12,8$ & $-13,3$ & $-9,6$ \\
\hline $\mathrm{PH}_{3}$ & ${ }^{1} J_{\mathrm{PH}}$ & 174,6 & 173,6 & 174,3 & 176,6 & 180,3 & 184,8 & 190,0 & 195,4 & 200,7 & 205,9 & 210,7 & 188,2 \\
\hline $\mathrm{PF}_{3}$ & ${ }^{1} J_{\mathrm{PF}}$ & $-1634,7$ & $-1631,8$ & $-1628,7$ & $-1624,6$ & $-1619,1$ & $-1611,7$ & $-1602,6$ & $-1592,0$ & $-1580,4$ & $-1568,1$ & $-1555,6$ & -1441 \\
\hline $\mathrm{BHF}_{2}$ & ${ }^{1} J_{\mathrm{BF}}$ & $-97,9$ & $-91,7$ & $-85,0$ & $-77,9$ & $-70,7$ & $-63,5$ & $-56,4$ & $-49,6$ & $-43,0$ & $-36,8$ & $-31,0$ & -84 \\
\hline $\mathrm{BF}_{3}$ & ${ }^{1} J_{\mathrm{BF}}$ & 3,1 & 10,2 & 17,9 & 25,9 & 33,9 & 41,8 & 49,3 & 56,6 & 63,4 & 69,8 & 75,7 & 15 \\
\hline $\mathrm{F}_{2} \mathrm{O}$ & ${ }^{1} J_{\mathrm{OF}}$ & $-345,5$ & $-359,3$ & $-373,9$ & $-389,0$ & $-404,3$ & $-420,0$ & $-436,2$ & $-453,1$ & $-470,8$ & $-489,3$ & $-508,7$ & -300 \\
\hline $\mathrm{CH}_{4}$ & ${ }^{1} J_{\mathrm{CH}}$ & 114,5 & 114,7 & 115,2 & 116,2 & 117,6 & 119,2 & 120,9 & 122,8 & 124,6 & 126,4 & 128,1 & 125,3 \\
\hline $\mathrm{CH}_{4}$ & ${ }^{2} J_{\mathrm{HH}}$ & $-11,8$ & $-12,0$ & $-12,3$ & $-12,7$ & $-13,2$ & $-13,7$ & $-14,1$ & $-14,6$ & $-15,0$ & $-15,4$ & $-15,7$ & $-12,8$ \\
\hline $\mathrm{C}_{2} \mathrm{H}_{2}$ & ${ }^{1} J_{\mathrm{CC}}$ & 191,8 & 192,9 & 194,4 & 196,6 & 199,5 & 202,9 & 206,8 & 211,1 & 215,7 & 220,5 & 225,3 & 174,8 \\
\hline $\mathrm{C}_{2} \mathrm{H}_{2}$ & ${ }^{1} J_{\mathrm{CH}}$ & 244,8 & 244,8 & 245,8 & 247,6 & 250,1 & 253,2 & 256,7 & 260,4 & 264,2 & 267,9 & 271,6 & 247,6 \\
\hline $\mathrm{C}_{2} \mathrm{H}_{2}$ & ${ }^{2} J_{\mathrm{CH}}$ & 54,0 & 54,2 & 54,2 & 53,9 & 53,5 & 52,9 & 52,1 & 51,1 & 50,1 & 48,9 & 47,8 & 50,1 \\
\hline $\mathrm{C}_{2} \mathrm{H}_{2}$ & ${ }^{3} J_{\mathrm{HH}}$ & 10,1 & 10,3 & 10,6 & 11,1 & 11,8 & 12,5 & 13,3 & 14,1 & 14,9 & 15,6 & 16,4 & 9,6 \\
\hline $\mathrm{C}_{2} \mathrm{H}_{4}$ & ${ }^{1} J_{\mathrm{CC}}$ & 64,4 & 65,3 & 66,6 & 68,4 & 70,7 & 73,4 & 76,7 & 80,3 & 84,2 & 88,3 & 92,5 & 67,6 \\
\hline $\mathrm{C}_{2} \mathrm{H}_{4}$ & ${ }^{1} J_{\mathrm{CH}}$ & 147,9 & 148,3 & 149,2 & 150,8 & 152,9 & 155,3 & 158,0 & 160,9 & 163,9 & 166,9 & 169,8 & 156,3 \\
\hline $\mathrm{C}_{2} \mathrm{H}_{4}$ & ${ }^{2} J_{\mathrm{CH}}$ & $-1,2$ & $-1,5$ & $-2,0$ & $-2,7$ & $-3,5$ & $-4,4$ & $-5,5$ & $-6,7$ & $-7,9$ & $-9,2$ & $-10,5$ & $-2,4$ \\
\hline $\mathrm{C}_{2} \mathrm{H}_{4}$ & ${ }^{2} J_{\mathrm{HH}}$ & 2,8 & 2,6 & 2,2 & 1,7 & 1,1 & 0,5 & $-0,1$ & $-0,8$ & $-1,5$ & $-2,1$ & $-2,8$ & 2,3 \\
\hline $\mathrm{C}_{2} \mathrm{H}_{4}$ & ${ }^{3} J_{\mathrm{HH}_{\mathrm{c}}}$ & 11,7 & 11,9 & 12,1 & 12,4 & 12,8 & 13,2 & 13,7 & 14,2 & 14,7 & 15,2 & 15,7 & 11,7 \\
\hline $\mathrm{C}_{2} \mathrm{H}_{4}$ & ${ }^{3} J_{\mathrm{HH}_{\mathrm{t}}}$ & 17,5 & 17,6 & 17,8 & 18,2 & 18,6 & 19,2 & 19,8 & 20,4 & 21,1 & 21,8 & 22,4 & 19 \\
\hline $\mathrm{C}_{2} \mathrm{H}_{6}$ & ${ }^{1} J_{\mathrm{CC}}$ & 29,6 & 30,3 & 31,2 & 32,1 & 33,3 & 34,6 & 36,0 & 37,5 & 39,0 & 40,4 & 41,9 & 34,5 \\
\hline $\mathrm{C}_{2} \mathrm{H}_{6}$ & ${ }^{1} J_{\mathrm{CH}}$ & 115,0 & 115,2 & 115,8 & 116,9 & 118,3 & 120,0 & 121,9 & 123,8 & 125,7 & 127,6 & 129,4 & 125,2 \\
\hline $\mathrm{C}_{2} \mathrm{H}_{6}$ & ${ }^{2} J_{\mathrm{CH}}$ & $-3,3$ & $-3,5$ & $-3,7$ & $-3,9$ & $-4,2$ & $-4,4$ & $-4,7$ & $-5,0$ & $-5,3$ & $-5,6$ & $-5,8$ & $-4,7$ \\
\hline \multirow[t]{3}{*}{ Total } & $\mathrm{DM}$ & $-11,47$ & $-11,13$ & $-10,60$ & $-9,83$ & $-8,80$ & $-7,60$ & $-6,26$ & $-4,87$ & $-3,47$ & $-2,11$ & $-0,83$ & - \\
\hline & DMA & 14,17 & 13,81 & 13,45 & 14,25 & 15,41 & 16,53 & 18,01 & 19,88 & 21,92 & 24,21 & 26,52 & - \\
\hline & PDMA & 13,87 & 10,63 & 8,17 & 10,90 & 16,03 & 21,49 & 27,76 & 35,03 & 42,70 & 50,52 & 58,36 & - \\
\hline \multirow[t]{3}{*}{ CPI } & $\mathrm{DM}$ & $-25,62$ & $-25,13$ & $-24,43$ & $-23,45$ & $-22,19$ & $-20,73$ & $-19,11$ & $-17,45$ & $-15,85$ & $-14,35$ & $-13,06$ & - \\
\hline & DMA & 27,36 & 26,67 & 26,25 & 28,55 & 30,99 & 33,24 & 35,62 & 38,60 & 41,82 & 44,95 & 48,05 & - \\
\hline & PDMA & 16,23 & 10,99 & 8,62 & 14,14 & 20,61 & 27,02 & 33,38 & 39,93 & 47,31 & 54,39 & 61,22 & - \\
\hline \multirow[t]{3}{*}{ SPI } & $\mathrm{DM}$ & $-1,09$ & $-0,87$ & $-0,47$ & 0,17 & 1,01 & 2,02 & 3,16 & 4,36 & 5,62 & 6,87 & 8,13 & - \\
\hline & DMA & 4,49 & 4,37 & 4,07 & 3,77 & 3,99 & 4,29 & 5,09 & 6,15 & 7,33 & 8,99 & 10,73 & - \\
\hline & PDMA & 12,14 & 10,37 & 7,84 & 8,52 & 12,67 & 17,44 & 23,64 & 31,43 & 39,32 & 47,69 & 56,26 & - \\
\hline \multirow[t]{3}{*}{$\Delta \mathrm{CS}$} & DM & $-24,53$ & $-24,26$ & $-23,96$ & $-23,62$ & $-23,20$ & $-22,75$ & $-22,27$ & $-21,81$ & $-21,47$ & $-21,23$ & $-21,20$ & - \\
\hline & DMA & 22,88 & 22,30 & 22,18 & 24,78 & 27,00 & 28,95 & 30,52 & 32,45 & 34,49 & 35,96 & 37,31 & - \\
\hline & PDMA & 4,09 & 0,62 & 0,78 & 5,61 & 7,94 & 9,59 & 9,74 & 8,50 & 7,99 & 6,70 & 4,96 & - \\
\hline
\end{tabular}




\subsubsection{Geometrias Otimizadas}

Tabela 8.329: Constantes de acoplamento CAM-B3LYP com otimização de geometrias na base aug-pcJ-2.

\begin{tabular}{|c|c|c|c|c|}
\hline & $\begin{array}{c}\text { Func. } \\
\alpha \\
\alpha+\beta \\
\gamma \\
\text { Geom. }\end{array}$ & $\begin{array}{c}\text { CAMB3 } \\
19 \% \\
65 \% \\
0,33 \\
\text { Exp. }\end{array}$ & $\begin{array}{c}\text { CAMB3 } \\
19 \% \\
65 \% \\
0,33 \\
\text { Otm. }\end{array}$ & $\begin{array}{l}\text { Exp. } \\
- \\
- \\
\text { Exp. }\end{array}$ \\
\hline $\mathrm{HF}$ & ${ }^{1} J_{\mathrm{HF}}$ & 455,6 & 441,8 & 500 \\
\hline $\mathrm{CO}$ & ${ }^{1} J_{\mathrm{CO}}$ & 18,3 & 15,8 & 16,4 \\
\hline $\mathrm{H}_{2} \mathrm{O}$ & ${ }^{1} J_{\mathrm{OH}}$ & $-77,7$ & $-78,6$ & $-80,6$ \\
\hline $\mathrm{H}_{2} \mathrm{O}$ & ${ }^{2} J_{\mathrm{HH}}$ & $-7,4$ & $-6,4$ & $-7,3$ \\
\hline $\mathrm{NH}_{3}$ & ${ }^{1} J_{\mathrm{NH}}$ & 45,2 & 47,0 & 43,8 \\
\hline $\mathrm{NH}_{3}$ & ${ }^{2} J_{\mathrm{HH}}$ & $-10,2$ & $-9,1$ & $-9,6$ \\
\hline $\mathrm{PH}_{3}$ & ${ }^{1} J_{\mathrm{PH}}$ & 162,3 & 175,1 & 188,2 \\
\hline $\mathrm{PF}_{3}$ & ${ }^{1} J_{\mathrm{PF}}$ & $-1749,1$ & $-1638,7$ & -1441 \\
\hline $\mathrm{BHF}_{2}$ & ${ }^{1} J_{\mathrm{BF}}$ & $-125,7$ & $-124,4$ & -84 \\
\hline $\mathrm{BF}_{3}$ & ${ }^{1} J_{\mathrm{BF}}$ & $-22,4$ & $-25,1$ & 15 \\
\hline $\mathrm{F}_{2} \mathrm{O}$ & ${ }^{1} J_{\mathrm{OF}}$ & $-386,6$ & $-279,4$ & -300 \\
\hline $\mathrm{CH}_{4}$ & ${ }^{1} J_{\mathrm{CH}}$ & 128,9 & 128,9 & 125,3 \\
\hline $\mathrm{CH}_{4}$ & ${ }^{2} J_{\mathrm{HH}}$ & $-13,2$ & $-13,2$ & $-12,8$ \\
\hline $\mathrm{C}_{2} \mathrm{H}_{2}$ & ${ }^{1} J_{\mathrm{CC}}$ & 202,0 & 202,1 & 174,8 \\
\hline $\mathrm{C}_{2} \mathrm{H}_{2}$ & ${ }^{1} J_{\mathrm{CH}}$ & 266,9 & 262,9 & 247,6 \\
\hline $\mathrm{C}_{2} \mathrm{H}_{2}$ & ${ }^{2} J_{\mathrm{CH}}$ & 57,0 & 57,3 & 50,1 \\
\hline $\mathrm{C}_{2} \mathrm{H}_{2}$ & ${ }^{3} J_{\mathrm{HH}}$ & 11,1 & 10,4 & 9,6 \\
\hline $\mathrm{C}_{2} \mathrm{H}_{4}$ & ${ }^{1} J_{\mathrm{CC}}$ & 70,6 & 73,4 & 67,6 \\
\hline $\mathrm{C}_{2} \mathrm{H}_{4}$ & ${ }^{1} J_{\mathrm{CH}}$ & 164,4 & 160,8 & 156,3 \\
\hline $\mathrm{C}_{2} \mathrm{H}_{4}$ & ${ }^{2} J_{\mathrm{CH}}$ & $-1,7$ & $-1,4$ & $-2,4$ \\
\hline $\mathrm{C}_{2} \mathrm{H}_{4}$ & ${ }^{2} J_{\mathrm{HH}}$ & 4,0 & 2,7 & 2,3 \\
\hline $\mathrm{C}_{2} \mathrm{H}_{4}$ & ${ }^{3} J_{\mathrm{HH}_{\mathrm{c}}}$ & 13,3 & 14,2 & 11,7 \\
\hline $\mathrm{C}_{2} \mathrm{H}_{4}$ & ${ }^{3} J_{\mathrm{HH}_{\mathrm{t}}}$ & 20,0 & 20,7 & 19 \\
\hline $\mathrm{C}_{2} \mathrm{H}_{6}$ & ${ }^{1} J_{\mathrm{CC}}$ & 32,5 & 34,3 & 34,5 \\
\hline $\mathrm{C}_{2} \mathrm{H}_{6}$ & ${ }^{1} J_{\mathrm{CH}}$ & 129,1 & 127,5 & 125,2 \\
\hline $\mathrm{C}_{2} \mathrm{H}_{6}$ & ${ }^{2} J_{\mathrm{CH}}$ & $-3,6$ & $-3,5$ & $-4,7$ \\
\hline \multirow[t]{3}{*}{ Total } & $\mathrm{DM}$ & $-17,75$ & $-9,61$ & - \\
\hline & DMA & 24,35 & 17,37 & - \\
\hline & PDMA & 23,87 & 21,73 & - \\
\hline \multirow[t]{3}{*}{ CPI } & DM & $-48,96$ & $-29,35$ & - \\
\hline & DMA & 50,09 & 34,30 & - \\
\hline & PDMA & 36,17 & 35,05 & - \\
\hline \multirow[t]{3}{*}{ SPI } & $\mathrm{DM}$ & 5,15 & 4,87 & - \\
\hline & DMA & 5,47 & 4,95 & - \\
\hline & PDMA & 14,85 & 11,95 & - \\
\hline \multirow[t]{3}{*}{$\Delta \mathrm{CS}$} & DM & $-54,11$ & $-34,22$ & - \\
\hline & DMA & 44,62 & 29,35 & - \\
\hline & PDMA & 21,32 & 23,10 & - \\
\hline
\end{tabular}


Tabela 8.330: Constantes de acoplamento $\omega$ B97 com otimização de geometrias para $\alpha+$ $\beta=100 \%$ na base aug-pcJ-2.

\begin{tabular}{|c|c|c|c|c|c|c|c|c|c|c|c|c|c|}
\hline & $\begin{array}{c}\text { Func. } \\
\alpha\end{array}$ & $\begin{array}{c}\omega \mathrm{B} 97 \\
0 \%\end{array}$ & $\begin{array}{c}\omega \mathrm{B} 97 \\
0 \%\end{array}$ & $\begin{array}{c}\omega \mathrm{B} 97 \\
10 \%\end{array}$ & $\begin{array}{c}\omega \mathrm{B} 97 \\
10 \%\end{array}$ & $\begin{array}{c}\omega \mathrm{B} 97 \\
0 \% / \\
10 \%\end{array}$ & $\begin{array}{c}\omega \mathrm{B} 97 \\
20 \%\end{array}$ & $\begin{array}{c}\omega \mathrm{B} 97 \\
20 \%\end{array}$ & $\begin{array}{l}\omega \mathrm{B} 97 \\
0 \% / \\
20 \%\end{array}$ & $\begin{array}{c}\omega \mathrm{B} 97 \\
30 \%\end{array}$ & $\begin{array}{c}\omega \mathrm{B} 97 \\
30 \%\end{array}$ & $\begin{array}{l}\omega \mathrm{B} 97 \\
0 \% / \\
30 \%\end{array}$ & Exp. \\
\hline & $\alpha+\beta$ & $100 \%$ & $100 \%$ & $100 \%$ & $100 \%$ & $100 \%$ & $100 \%$ & $100 \%$ & $100 \%$ & $100 \%$ & $100 \%$ & $100 \%$ & - \\
\hline & $\gamma$ & 0,40 & 0,40 & 0,40 & 0,40 & 0,40 & 0,40 & 0,40 & 0,40 & 0,40 & 0,40 & 0,40 & - \\
\hline & Geom. & Exp. & Otm. & Exp. & Otm. & Otm. & Exp. & Otm. & Otm. & Exp. & Otm. & Otm. & Exp. \\
\hline $\mathrm{HF}$ & ${ }^{1} J_{\mathrm{HF}}$ & 455,6 & 443,8 & 489,1 & 489,1 & 477,7 & 522,9 & 533,0 & 511,7 & 556,9 & 533,0 & 546,0 & 500 \\
\hline $\mathrm{CO}$ & ${ }^{1} J_{\mathrm{CO}}$ & 23,9 & 23,5 & 20,6 & 19,1 & 20,2 & 17,0 & 14,5 & 16,6 & 13,2 & 14,5 & 12,7 & 16,4 \\
\hline $\mathrm{H}_{2} \mathrm{O}$ & ${ }^{1} J_{\mathrm{OH}}$ & $-71,8$ & $-72,4$ & $-75,4$ & $-77,3$ & $-76,1$ & $-79,1$ & $-82,0$ & $-79,7$ & $-82,8$ & $-82,0$ & $-83,4$ & $-80,6$ \\
\hline $\mathrm{H}_{2} \mathrm{O}$ & ${ }^{2} J_{\mathrm{HH}}$ & $-6,6$ & $-6,0$ & $-7,2$ & $-6,4$ & $-6,6$ & $-7,8$ & $-6,8$ & $-7,2$ & $-8,5$ & $-6,8$ & $-7,9$ & $-7,3$ \\
\hline $\mathrm{NH}_{3}$ & ${ }^{1} J_{\mathrm{NH}}$ & 39,0 & 40,0 & 40,3 & 41,5 & 41,3 & 41,6 & 43,1 & 42,6 & 42,9 & 43,1 & 43,9 & 43,8 \\
\hline $\mathrm{NH}_{3}$ & ${ }^{2} J_{\mathrm{HH}}$ & $-8,5$ & $-7,9$ & $-9,0$ & $-8,3$ & $-8,4$ & $-9,4$ & $-8,6$ & $-8,8$ & $-9,9$ & $-8,6$ & $-9,3$ & $-9,6$ \\
\hline $\mathrm{PH}_{3}$ & ${ }^{1} J_{\mathrm{PH}}$ & 159,3 & 169,5 & 165,5 & 177,0 & 175,6 & 171,5 & 184,2 & 181,4 & 177,5 & 184,2 & 187,2 & 188,2 \\
\hline $\mathrm{PF}_{3}$ & ${ }^{1} J_{\mathrm{PF}}$ & $-1663,0$ & $-1551,8$ & $-1633,0$ & $-1530,8$ & $-1529,0$ & $-1602,1$ & $-1505,2$ & $-1505,2$ & $-1570,5$ & $-1505,2$ & $-1480,5$ & -1441 \\
\hline $\mathrm{BHF}_{2}$ & ${ }^{1} J_{\mathrm{BF}}$ & $-111,8$ & $-125,6$ & $-91,9$ & $-99,3$ & $-105,6$ & $-71,9$ & $-73,0$ & $-85,5$ & $-51,8$ & $-73,0$ & $-65,3$ & -84 \\
\hline $\mathrm{BF}_{3}$ & ${ }^{1} J_{\mathrm{BF}}$ & $-14,8$ & $-35,0$ & 7,0 & $-4,5$ & $-12,6$ & 29,1 & 25,8 & 9,8 & 51,3 & 25,8 & 32,5 & 15 \\
\hline $\mathrm{F}_{2} \mathrm{O}$ & ${ }^{1} J_{\mathrm{OF}}$ & $-310,7$ & $-200,6$ & $-326,4$ & $-178,6$ & $-211,1$ & $-343,2$ & $-157,6$ & $-222,2$ & $-361,7$ & $-157,6$ & $-234,1$ & -300 \\
\hline $\mathrm{CH}_{4}$ & ${ }^{1} J_{\mathrm{CH}}$ & 109,4 & 109,8 & 112,4 & 112,4 & 112,7 & 115,3 & 114,8 & 115,7 & 118,3 & 114,8 & 118,7 & 125,3 \\
\hline $\mathrm{CH}_{4}$ & ${ }^{2} J_{\mathrm{HH}}$ & $-11,2$ & $-11,2$ & $-11,5$ & $-11,5$ & $-11,5$ & $-11,8$ & $-11,8$ & $-11,8$ & $-12,1$ & $-11,8$ & $-12,1$ & $-12,8$ \\
\hline $\mathrm{C}_{2} \mathrm{H}_{2}$ & ${ }^{1} J_{\mathrm{CC}}$ & 194,2 & 194,5 & 201,3 & 201,1 & 201,4 & 209,2 & 208,2 & 209,0 & 217,9 & 208,2 & 217,3 & 174,8 \\
\hline $\mathrm{C}_{2} \mathrm{H}_{2}$ & ${ }^{1} J_{\mathrm{CH}}$ & 236,3 & 235,0 & 240,8 & 238,1 & 239,5 & 245,4 & 241,3 & 244,1 & 250,2 & 241,3 & 248,8 & 247,6 \\
\hline $\mathrm{C}_{2} \mathrm{H}_{2}$ & ${ }^{2} J_{\mathrm{CH}}$ & 51,8 & 52,1 & 50,9 & 51,3 & 51,3 & 49,9 & 50,5 & 50,3 & 48,6 & 50,5 & 49,1 & 50,1 \\
\hline $\mathrm{C}_{2} \mathrm{H}_{2}$ & ${ }^{3} J_{\mathrm{HH}}$ & 10,4 & 10,1 & 10,9 & 10,4 & 10,6 & 11,4 & 10,7 & 11,1 & 12,0 & 10,7 & 11,6 & 9,6 \\
\hline $\mathrm{C}_{2} \mathrm{H}_{4}$ & ${ }^{1} J_{\mathrm{CC}}$ & 65,6 & 67,5 & 71,3 & 72,7 & 72,9 & 77,5 & 78,2 & 78,7 & 84,4 & 78,2 & 85,0 & 67,6 \\
\hline $\mathrm{C}_{2} \mathrm{H}_{4}$ & ${ }^{1} J_{\mathrm{CH}}$ & 142,7 & 140,5 & 146,6 & 143,5 & 144,2 & 150,5 & 146,6 & 148,0 & 154,5 & 146,6 & 151,9 & 156,3 \\
\hline $\mathrm{C}_{2} \mathrm{H}_{4}$ & ${ }^{2} J_{\mathrm{CH}}$ & $-2,2$ & $-1,8$ & $-3,3$ & $-2,8$ & $-2,8$ & $-4,5$ & $-3,8$ & $-3,9$ & $-5,9$ & $-3,8$ & $-5,2$ & $-2,4$ \\
\hline $\mathrm{C}_{2} \mathrm{H}_{4}$ & ${ }^{2} J_{\mathrm{HH}}$ & 2,3 & 1,5 & 1,9 & 1,1 & 1,2 & 1,5 & 0,7 & 0,8 & 1,1 & 0,7 & 0,4 & 2,3 \\
\hline $\mathrm{C}_{2} \mathrm{H}_{4}$ & ${ }^{3} J_{\mathrm{HH}_{\mathrm{c}}}$ & 11,5 & 12,1 & 11,7 & 12,3 & 12,2 & 11,9 & 12,5 & 12,4 & 12,1 & 12,5 & 12,6 & 11,7 \\
\hline $\mathrm{C}_{2} \mathrm{H}_{4}$ & ${ }^{3} J_{\mathrm{HH}_{\mathrm{t}}}$ & 17,0 & 17,5 & 17,3 & 17,7 & 17,8 & 17,6 & 17,9 & 18,0 & 17,9 & 17,9 & 18,3 & 19 \\
\hline $\mathrm{C}_{2} \mathrm{H}_{6}$ & ${ }^{1} J_{\mathrm{CC}}$ & 28,5 & 30,2 & 31,4 & 33,0 & 33,1 & 34,4 & 35,8 & 36,0 & 37,4 & 35,8 & 39,1 & 34,5 \\
\hline $\mathrm{C}_{2} \mathrm{H}_{6}$ & ${ }^{1} J_{\mathrm{CH}}$ & 109,0 & 108,0 & 112,1 & 110,7 & 111,1 & 115,2 & 113,3 & 114,3 & 118,3 & 113,3 & 117,4 & 125,2 \\
\hline $\mathrm{C}_{2} \mathrm{H}_{6}$ & ${ }^{2} J_{\mathrm{CH}}$ & $-3,2$ & $-3,2$ & $-3,5$ & $-3,5$ & $-3,5$ & $-3,9$ & $-3,8$ & $-3,8$ & $-4,2$ & $-3,8$ & $-4,2$ & $-4,7$ \\
\hline \multirow[t]{3}{*}{ Total } & DM & $-15,09$ & $-7,88$ & $-10,58$ & $-1,42$ & $-3,44$ & $-6,03$ & 5,13 & 1,05 & $-1,46$ & 5,13 & 5,60 & - \\
\hline & DMA & 18,42 & 18,96 & 14,03 & 14,20 & 13,92 & 13,68 & 13,96 & 9,92 & 16,44 & 13,96 & 11,20 & - \\
\hline & PDMA & 19,64 & 28,17 & 12,34 & 17,03 & 19,08 & 15,29 & 16,26 & 12,81 & 26,67 & 16,26 & 20,72 & - \\
\hline \multirow[t]{3}{*}{ CPI } & DM & $-31,85$ & $-14,85$ & $-23,75$ & $-1,76$ & $-6,86$ & $-15,66$ & 11,50 & 1,15 & $-7,66$ & 11,50 & 9,17 & - \\
\hline & DMA & 35,14 & 36,25 & 25,59 & 25,33 & 24,88 & 25,01 & 24,63 & 15,49 & 30,46 & 24,63 & 17,83 & - \\
\hline & PDMA & 33,06 & 49,32 & 13,34 & 23,16 & 28,47 & 15,17 & 16,18 & 7,96 & 33,71 & 16,18 & 19,18 & - \\
\hline \multirow[t]{3}{*}{ SPI } & $\mathrm{DM}$ & $-2,80$ & $-2,77$ & $-0,92$ & $-1,17$ & $-0,93$ & 1,03 & 0,47 & 0,99 & 3,09 & 0,47 & 2,97 & - \\
\hline & DMA & 6,16 & 6,27 & 5,56 & 6,04 & 5,87 & 5,38 & 6,13 & 5,83 & 6,16 & 6,13 & 6,33 & - \\
\hline & PDMA & 9,80 & 12,66 & 11,60 & 12,54 & 12,20 & 15,37 & 16,33 & 16,36 & 21,50 & 16,33 & 21,85 & - \\
\hline \multirow[t]{3}{*}{$\Delta \mathrm{CS}$} & DM & $-29,05$ & $-12,09$ & $-22,83$ & $-0,59$ & $-5,94$ & $-16,70$ & 11,03 & 0,16 & $-10,76$ & 11,03 & 6,20 & - \\
\hline & DMA & 28,98 & 29,98 & 20,03 & 19,29 & 19,01 & 19,63 & 18,49 & 9,66 & 24,30 & 18,49 & 11,49 & - \\
\hline & PDMA & 23,25 & 36,66 & 1,74 & 10,62 & 16,27 & $-0,19$ & $-0,15$ & $-8,40$ & 12,21 & $-0,15$ & $-2,67$ & - \\
\hline
\end{tabular}


Tabela 8.331: Constantes de acoplamento $\omega$ B97 com otimização de geometrias para $\alpha+$ $\beta=80 \%$ na base aug-pcJ-2.

\begin{tabular}{|c|c|c|c|c|c|c|c|c|c|c|c|c|c|}
\hline & $\begin{array}{c}\text { Func. } \\
\alpha\end{array}$ & $\begin{array}{c}\omega \mathrm{B} 97 \\
0 \%\end{array}$ & $\begin{array}{c}\omega \mathrm{B} 97 \\
0 \%\end{array}$ & $\begin{array}{c}\omega \mathrm{B} 97 \\
10 \%\end{array}$ & $\begin{array}{c}\omega \mathrm{B} 97 \\
10 \%\end{array}$ & $\begin{array}{c}\omega \mathrm{B} 97 \\
0 \% \\
10 \%\end{array}$ & $\begin{array}{c}\omega \mathrm{B} 97 \\
20 \%\end{array}$ & $\begin{array}{c}\omega \mathrm{B} 97 \\
20 \%\end{array}$ & $\begin{array}{l}\omega \mathrm{B} 97 \\
0 \% / \\
20 \%\end{array}$ & $\begin{array}{c}\omega \mathrm{B} 97 \\
30 \%\end{array}$ & $\begin{array}{c}\omega \mathrm{B} 97 \\
30 \%\end{array}$ & $\begin{array}{l}\omega \mathrm{B} 97 \\
0 \% / \\
30 \%\end{array}$ & Exp. \\
\hline & $\alpha+\beta$ & $100 \%$ & $100 \%$ & $80 \%$ & $80 \%$ & $80 \%$ & $80 \%$ & $80 \%$ & $80 \%$ & $80 \%$ & $80 \%$ & $80 \%$ & - \\
\hline & $\gamma$ & 0,40 & 0,40 & 0,40 & 0,40 & 0,40 & 0,40 & 0,40 & 0,40 & 0,40 & 0,40 & 0,40 & - \\
\hline & Geom. & Exp. & Otm. & Exp. & Otm. & Otm. & Exp. & Otm. & Otm. & Exp. & Otm. & Otm. & Exp. \\
\hline $\mathrm{HF}$ & ${ }^{1} J_{\mathrm{HF}}$ & 455,6 & 443,8 & 474,5 & 472,2 & 462,9 & 508,4 & 517,1 & 497,1 & 542,6 & 561,6 & 531,5 & 500 \\
\hline $\mathrm{CO}$ & ${ }^{1} J_{\mathrm{CO}}$ & 23,9 & 23,5 & 21,3 & 20,8 & 20,8 & 17,7 & 16,2 & 17,3 & 13,9 & 11,4 & 13,5 & 16,4 \\
\hline $\mathrm{H}_{2} \mathrm{O}$ & ${ }^{1} J_{\mathrm{OH}}$ & $-71,8$ & $-72,4$ & $-73,8$ & $-74,7$ & $-74,4$ & $-77,5$ & $-79,7$ & $-78,1$ & $-81,2$ & $-84,4$ & $-81,8$ & $-80,6$ \\
\hline $\mathrm{H}_{2} \mathrm{O}$ & ${ }^{2} J_{\mathrm{HH}}$ & $-6,6$ & $-6,0$ & $-7,2$ & $-6,8$ & $-6,7$ & $-7,9$ & $-7,2$ & $-7,3$ & $-8,5$ & $-7,6$ & $-7,9$ & $-7,3$ \\
\hline $\mathrm{NH}_{3}$ & ${ }^{1} J_{\mathrm{NH}}$ & 39,0 & 40,0 & 39,8 & 40,5 & 40,9 & 41,1 & 42,1 & 42,2 & 42,5 & 43,6 & 43,5 & 43,8 \\
\hline $\mathrm{NH}_{3}$ & ${ }^{2} J_{\mathrm{HH}}$ & $-8,5$ & $-7,9$ & $-9,1$ & $-8,7$ & $-8,5$ & $-9,6$ & $-9,1$ & $-8,9$ & $-10,0$ & $-9,4$ & $-9,4$ & $-9,6$ \\
\hline $\mathrm{PH}_{3}$ & ${ }^{1} J_{\mathrm{PH}}$ & 159,3 & 169,5 & 167,7 & 177,2 & 177,6 & 173,9 & 184,6 & 183,7 & 179,9 & 191,9 & 189,5 & 188,2 \\
\hline $\mathrm{PF}_{3}$ & ${ }^{1} J_{\mathrm{PF}}$ & $-1663,0$ & $-1551,8$ & $-1632,8$ & $-1532,9$ & $-1527,3$ & $-1601,7$ & $-1510,4$ & $-1503,2$ & $-1569,6$ & $-1483,2$ & $-1478,0$ & -1441 \\
\hline $\mathrm{BHF}_{2}$ & ${ }^{1} J_{\mathrm{BF}}$ & $-111,8$ & $-125,6$ & $-100,4$ & $-114,5$ & $-114,3$ & $-80,0$ & $-87,7$ & $-93,7$ & $-59,5$ & $-60,5$ & $-73,1$ & -84 \\
\hline $\mathrm{BF}_{3}$ & ${ }^{1} J_{\mathrm{BF}}$ & $-14,8$ & $-35,0$ & $-4,3$ & $-24,2$ & $-24,4$ & 18,1 & 6,8 & $-1,4$ & 40,7 & 37,6 & 21,7 & 15 \\
\hline $\mathrm{F}_{2} \mathrm{O}$ & ${ }^{1} J_{\mathrm{OF}}$ & $-310,7$ & $-200,6$ & $-307,8$ & $-203,4$ & $-197,5$ & $-324,2$ & $-182,2$ & $-208,6$ & $-342,0$ & $-161,4$ & $-220,3$ & -300 \\
\hline $\mathrm{CH}_{4}$ & ${ }^{1} J_{\mathrm{CH}}$ & 109,4 & 109,8 & 112,1 & 112,4 & 112,5 & 115,1 & 115,0 & 115,5 & 118,1 & 117,5 & 118,5 & 125,3 \\
\hline $\mathrm{CH}_{4}$ & ${ }^{2} J_{\mathrm{HH}}$ & $-11,2$ & $-11,2$ & $-11,8$ & $-11,8$ & $-11,8$ & $-12,1$ & $-12,1$ & $-12,1$ & $-12,4$ & $-12,4$ & $-12,4$ & $-12,8$ \\
\hline $\mathrm{C}_{2} \mathrm{H}_{2}$ & ${ }^{1} J_{\mathrm{CC}}$ & 194,2 & 194,5 & 199,5 & 199,6 & 199,8 & 207,1 & 206,6 & 207,1 & 215,5 & 214,1 & 215,1 & 174,8 \\
\hline $\mathrm{C}_{2} \mathrm{H}_{2}$ & ${ }^{1} J_{\mathrm{CH}}$ & 236,3 & 235,0 & 241,3 & 239,9 & 239,9 & 246,0 & 243,1 & 244,6 & 250,8 & 246,4 & 249,4 & 247,6 \\
\hline $\mathrm{C}_{2} \mathrm{H}_{2}$ & ${ }^{2} J_{\mathrm{CH}}$ & 51,8 & 52,1 & 50,8 & 51,1 & 51,1 & 49,8 & 50,2 & 50,2 & 48,6 & 49,2 & 49,0 & 50,1 \\
\hline $\mathrm{C}_{2} \mathrm{H}_{2}$ & ${ }^{3} J_{\mathrm{HH}}$ & 10,4 & 10,1 & 11,1 & 10,8 & 10,8 & 11,6 & 11,2 & 11,3 & 12,2 & 11,5 & 11,8 & 9,6 \\
\hline $\mathrm{C}_{2} \mathrm{H}_{4}$ & ${ }^{1} J_{\mathrm{CC}}$ & 65,6 & 67,5 & 69,5 & 71,4 & 71,3 & 75,5 & 76,8 & 76,9 & 82,1 & 82,6 & 83,1 & 67,6 \\
\hline $\mathrm{C}_{2} \mathrm{H}_{4}$ & ${ }^{1} J_{\mathrm{CH}}$ & 142,7 & 140,5 & 146,2 & 143,8 & 143,9 & 150,2 & 147,0 & 147,7 & 154,2 & 150,1 & 151,7 & 156,3 \\
\hline $\mathrm{C}_{2} \mathrm{H}_{4}$ & ${ }^{2} J_{\mathrm{CH}}$ & $-2,2$ & $-1,8$ & $-3,0$ & $-2,5$ & $-2,5$ & $-4,1$ & $-3,6$ & $-3,6$ & $-5,4$ & $-4,7$ & $-4,8$ & $-2,4$ \\
\hline $\mathrm{C}_{2} \mathrm{H}_{4}$ & ${ }^{2} J_{\mathrm{HH}}$ & 2,3 & 1,5 & 1,9 & 1,0 & 1,1 & 1,5 & 0,5 & 0,7 & 1,1 & 0,1 & 0,3 & 2,3 \\
\hline $\mathrm{C}_{2} \mathrm{H}_{4}$ & ${ }^{3} J_{\mathrm{HH}_{\mathrm{c}}}$ & 11,5 & 12,1 & 11,6 & 12,0 & 12,1 & 11,7 & 12,3 & 12,3 & 12,0 & 12,5 & 12,4 & 11,7 \\
\hline $\mathrm{C}_{2} \mathrm{H}_{4}$ & ${ }^{3} J_{\mathrm{HH}_{\mathrm{t}}}$ & 17,0 & 17,5 & 17,4 & 17,8 & 17,9 & 17,6 & 18,0 & 18,1 & 17,9 & 18,2 & 18,4 & 19 \\
\hline $\mathrm{C}_{2} \mathrm{H}_{6}$ & ${ }^{1} J_{\mathrm{CC}}$ & 28,5 & 30,2 & 30,3 & 31,9 & 32,0 & 33,3 & 34,8 & 35,0 & 36,3 & 37,7 & 38,0 & 34,5 \\
\hline $\mathrm{C}_{2} \mathrm{H}_{6}$ & ${ }^{1} J_{\mathrm{CH}}$ & 109,0 & 108,0 & 111,8 & 110,9 & 110,8 & 115,0 & 113,5 & 114,0 & 118,1 & 116,2 & 117,1 & 125,2 \\
\hline $\mathrm{C}_{2} \mathrm{H}_{6}$ & ${ }^{2} J_{\mathrm{CH}}$ & $-3,2$ & $-3,2$ & $-3,5$ & $-3,4$ & $-3,5$ & $-3,8$ & $-3,8$ & $-3,8$ & $-4,1$ & $-4,1$ & $-4,1$ & $-4,7$ \\
\hline \multirow[t]{3}{*}{ Total } & DM & $-15,09$ & $-7,88$ & $-11,23$ & $-4,41$ & $-4,25$ & $-6,63$ & 2,12 & 0,31 & $-1,97$ & 8,83 & 4,91 & - \\
\hline & DMA & 18,42 & 18,96 & 14,56 & 15,31 & 15,66 & 11,53 & 11,85 & 10,58 & 14,04 & 15,13 & 10,11 & - \\
\hline & PDMA & 19,64 & 28,17 & 15,21 & 22,51 & 22,54 & 11,29 & 13,82 & 15,67 & 21,98 & 22,91 & 16,64 & - \\
\hline \multirow[t]{3}{*}{ CPI } & DM & $-31,85$ & $-14,85$ & $-24,82$ & $-8,67$ & $-8,35$ & $-16,60$ & 4,51 & $-0,16$ & $-8,37$ & 18,06 & 8,03 & - \\
\hline & DMA & 35,14 & 36,25 & 27,05 & 28,36 & 29,22 & 20,22 & 20,29 & 17,53 & 25,25 & 27,43 & 15,66 & - \\
\hline & PDMA & 33,06 & 49,32 & 21,28 & 36,87 & 37,52 & 7,28 & 11,03 & 16,20 & 25,08 & 25,81 & 11,27 & - \\
\hline \multirow[t]{3}{*}{ SPI } & $\mathrm{DM}$ & $-2,80$ & $-2,77$ & $-1,26$ & $-1,28$ & $-1,25$ & 0,69 & 0,36 & 0,65 & 2,73 & 2,05 & 2,63 & - \\
\hline & DMA & 6,16 & 6,27 & 5,39 & 5,73 & 5,71 & 5,15 & 5,67 & 5,49 & 5,82 & 6,11 & 6,04 & - \\
\hline & PDMA & 9,80 & 12,66 & 10,76 & 11,98 & 11,54 & 14,23 & 15,88 & 15,27 & 19,70 & 20,79 & 20,59 & - \\
\hline \multirow[t]{3}{*}{$\Delta \mathrm{CS}$} & DM & $-29,05$ & $-12,09$ & $-23,56$ & $-7,39$ & $-7,10$ & $-17,29$ & 4,15 & $-0,82$ & $-11,10$ & 16,01 & 5,40 & - \\
\hline & DMA & 28,98 & 29,98 & 21,66 & 22,63 & 23,50 & 15,06 & 14,62 & 12,03 & 19,43 & 21,32 & 9,62 & - \\
\hline & PDMA & 23,25 & 36,66 & 10,52 & 24,89 & 25,98 & $-6,95$ & $-4,85$ & 0,92 & 5,38 & 5,02 & $-9,32$ & - \\
\hline
\end{tabular}


Tabela 8.332: Constantes de acoplamento $\omega$ B97 com otimização de geometrias para $\alpha+$ $\beta=60 \%$ na base aug-pcJ-2.

\begin{tabular}{|c|c|c|c|c|c|c|c|c|c|c|c|c|c|}
\hline & $\begin{array}{c}\text { Func. } \\
\alpha\end{array}$ & $\begin{array}{c}\omega \mathrm{B} 97 \\
0 \%\end{array}$ & $\begin{array}{c}\omega \mathrm{B} 97 \\
0 \%\end{array}$ & $\begin{array}{c}\omega \mathrm{B} 97 \\
10 \%\end{array}$ & $\begin{array}{c}\omega \mathrm{B} 97 \\
10 \%\end{array}$ & $\begin{array}{c}\omega \mathrm{B} 97 \\
0 \% \\
10 \%\end{array}$ & $\begin{array}{c}\omega \mathrm{B} 97 \\
20 \%\end{array}$ & $\begin{array}{c}\omega \mathrm{B} 97 \\
20 \%\end{array}$ & $\begin{array}{l}\omega \mathrm{B} 97 \\
0 \% / \\
20 \%\end{array}$ & $\begin{array}{c}\omega \mathrm{B} 97 \\
30 \%\end{array}$ & $\begin{array}{c}\omega \mathrm{B} 97 \\
30 \%\end{array}$ & $\begin{array}{l}\omega \mathrm{B} 97 \\
0 \% / \\
30 \%\end{array}$ & Exp. \\
\hline & $\alpha+\beta$ & $100 \%$ & $100 \%$ & $60 \%$ & $60 \%$ & $60 \%$ & $60 \%$ & $60 \%$ & $60 \%$ & $60 \%$ & $60 \%$ & $60 \%$ & - \\
\hline & $\gamma$ & 0,40 & 0,40 & 0,40 & 0,40 & 0,40 & 0,40 & 0,40 & 0,40 & 0,40 & 0,40 & 0,40 & - \\
\hline & Geom. & Exp. & Otm. & Exp. & Otm. & Otm. & Exp. & Otm. & Otm. & Exp. & Otm. & Otm. & Exp. \\
\hline $\mathrm{HF}$ & ${ }^{1} J_{\mathrm{HF}}$ & 455,6 & 443,8 & 459,9 & 455,4 & 448,1 & 494,0 & 500,8 & 482,5 & 528,3 & 545,8 & 517,1 & 500 \\
\hline $\mathrm{CO}$ & ${ }^{1} J_{\mathrm{CO}}$ & 23,9 & 23,5 & 21,9 & 22,4 & 21,5 & 18,4 & 17,9 & 18,0 & 14,6 & 13,1 & 14,2 & 16,4 \\
\hline $\mathrm{H}_{2} \mathrm{O}$ & ${ }^{1} J_{\mathrm{OH}}$ & $-71,8$ & $-72,4$ & $-72,1$ & $-72,4$ & $-72,7$ & $-75,8$ & $-77,4$ & $-76,4$ & $-79,5$ & $-82,2$ & $-80,1$ & $-80,6$ \\
\hline $\mathrm{H}_{2} \mathrm{O}$ & ${ }^{2} J_{\mathrm{HH}}$ & $-6,6$ & $-6,0$ & $-7,3$ & $-7,1$ & $-6,7$ & $-7,9$ & $-7,6$ & $-7,4$ & $-8,6$ & $-8,0$ & $-8,0$ & $-7,3$ \\
\hline $\mathrm{NH}_{3}$ & ${ }^{1} J_{\mathrm{NH}}$ & 39,0 & 40,0 & 39,4 & 39,4 & 40,5 & 40,7 & 41,0 & 41,8 & 42,0 & 42,7 & 43,1 & 43,8 \\
\hline $\mathrm{NH}_{3}$ & ${ }^{2} J_{\mathrm{HH}}$ & $-8,5$ & $-7,9$ & $-9,2$ & $-9,2$ & $-8,6$ & $-9,7$ & $-9,6$ & $-9,0$ & $-10,1$ & $-9,9$ & $-9,5$ & $-9,6$ \\
\hline $\mathrm{PH}_{3}$ & ${ }^{1} J_{\mathrm{PH}}$ & 159,3 & 169,5 & 169,8 & 177,3 & 179,7 & 176,2 & 185,0 & 185,9 & 182,4 & 192,5 & 191,9 & 188,2 \\
\hline $\mathrm{PF}_{3}$ & ${ }^{1} J_{\mathrm{PF}}$ & $-1663,0$ & $-1551,8$ & $-1633,7$ & $-1530,7$ & $-1526,7$ & $-1602,4$ & $-1513,2$ & $-1502,4$ & $-1570,0$ & $-1489,2$ & $-1476,8$ & -1441 \\
\hline $\mathrm{BHF}_{2}$ & ${ }^{1} J_{\mathrm{BF}}$ & $-111,8$ & $-125,6$ & $-109,4$ & $-130,5$ & $-123,4$ & $-88,5$ & $-102,9$ & $-102,3$ & $-67,6$ & $-75,4$ & $-81,2$ & -84 \\
\hline $\mathrm{BF}_{3}$ & ${ }^{1} J_{\mathrm{BF}}$ & $-14,8$ & $-35,0$ & $-16,1$ & $-44,8$ & $-36,5$ & 6,8 & $-12,7$ & $-13,0$ & 29,9 & 18,8 & 10,6 & 15 \\
\hline $\mathrm{F}_{2} \mathrm{O}$ & ${ }^{1} J_{\mathrm{OF}}$ & $-310,7$ & $-200,6$ & $-289,2$ & $-229,4$ & $-183,8$ & $-305,5$ & $-207,5$ & $-194,9$ & $-322,8$ & $-185,9$ & $-206,5$ & -300 \\
\hline $\mathrm{CH}_{4}$ & ${ }^{1} J_{\mathrm{CH}}$ & 109,4 & 109,8 & 111,8 & 112,4 & 112,2 & 114,9 & 115,1 & 115,3 & 117,9 & 117,7 & 118,3 & 125,3 \\
\hline $\mathrm{CH}_{4}$ & ${ }^{2} J_{\mathrm{HH}}$ & $-11,2$ & $-11,2$ & $-12,0$ & $-12,0$ & $-12,0$ & $-12,3$ & $-12,3$ & $-12,3$ & $-12,7$ & $-12,7$ & $-12,7$ & $-12,8$ \\
\hline $\mathrm{C}_{2} \mathrm{H}_{2}$ & ${ }^{1} J_{\mathrm{CC}}$ & 194,2 & 194,5 & 197,7 & 198,0 & 198,2 & 205,1 & 205,0 & 205,2 & 213,2 & 212,5 & 213,0 & 174,8 \\
\hline $\mathrm{C}_{2} \mathrm{H}_{2}$ & ${ }^{1} J_{\mathrm{CH}}$ & 236,3 & 235,0 & 241,7 & 241,6 & 240,4 & 246,4 & 244,9 & 245,1 & 251,3 & 248,3 & 249,9 & 247,6 \\
\hline $\mathrm{C}_{2} \mathrm{H}_{2}$ & ${ }^{2} J_{\mathrm{CH}}$ & 51,8 & 52,1 & 50,7 & 50,8 & 51,0 & 49,7 & 49,9 & 50,0 & 48,5 & 48,9 & 48,9 & 50,1 \\
\hline $\mathrm{C}_{2} \mathrm{H}_{2}$ & ${ }^{3} J_{\mathrm{HH}}$ & 10,4 & 10,1 & 11,4 & 11,3 & 11,0 & 11,9 & 11,6 & 11,5 & 12,4 & 11,9 & 12,0 & 9,6 \\
\hline $\mathrm{C}_{2} \mathrm{H}_{4}$ & ${ }^{1} J_{\mathrm{CC}}$ & 65,6 & 67,5 & 67,8 & 69,8 & 69,8 & 73,6 & 75,4 & 75,2 & 79,9 & 81,1 & 81,2 & 67,6 \\
\hline $\mathrm{C}_{2} \mathrm{H}_{4}$ & ${ }^{1} J_{\mathrm{CH}}$ & 142,7 & 140,5 & 145,8 & 144,2 & 143,6 & 149,8 & 147,3 & 147,4 & 153,9 & 150,6 & 151,4 & 156,3 \\
\hline $\mathrm{C}_{2} \mathrm{H}_{4}$ & ${ }^{2} J_{\mathrm{CH}}$ & $-2,2$ & $-1,8$ & $-2,6$ & $-2,3$ & $-2,2$ & $-3,8$ & $-3,3$ & $-3,3$ & $-5,0$ & $-4,4$ & $-4,4$ & $-2,4$ \\
\hline $\mathrm{C}_{2} \mathrm{H}_{4}$ & ${ }^{2} J_{\mathrm{HH}}$ & 2,3 & 1,5 & 1,9 & 0,9 & 1,1 & 1,5 & 0,4 & 0,7 & 1,0 & 0,0 & 0,3 & 2,3 \\
\hline $\mathrm{C}_{2} \mathrm{H}_{4}$ & ${ }^{3} J_{\mathrm{HH}_{\mathrm{c}}}$ & 11,5 & 12,1 & 11,4 & 11,8 & 11,9 & 11,6 & 12,0 & 12,1 & 11,8 & 12,2 & 12,3 & 11,7 \\
\hline $\mathrm{C}_{2} \mathrm{H}_{4}$ & ${ }^{3} J_{\mathrm{HH}_{\mathrm{t}}}$ & 17,0 & 17,5 & 17,4 & 17,9 & 18,0 & 17,7 & 18,2 & 18,2 & 18,0 & 18,4 & 18,5 & 19 \\
\hline $\mathrm{C}_{2} \mathrm{H}_{6}$ & ${ }^{1} J_{\mathrm{CC}}$ & 28,5 & 30,2 & 29,2 & 30,7 & 30,9 & 32,2 & 33,7 & 33,9 & 35,2 & 36,6 & 36,9 & 34,5 \\
\hline $\mathrm{C}_{2} \mathrm{H}_{6}$ & ${ }^{1} J_{\mathrm{CH}}$ & 109,0 & 108,0 & 111,5 & 111,1 & 110,5 & 114,7 & 113,8 & 113,7 & 117,9 & 116,5 & 116,9 & 125,2 \\
\hline $\mathrm{C}_{2} \mathrm{H}_{6}$ & ${ }^{2} J_{\mathrm{CH}}$ & $-3,2$ & $-3,2$ & $-3,4$ & $-3,4$ & $-3,4$ & $-3,8$ & $-3,7$ & $-3,7$ & $-4,1$ & $-4,0$ & $-4,1$ & $-4,7$ \\
\hline \multirow[t]{3}{*}{ Total } & DM & $-15,09$ & $-7,88$ & $-11,95$ & $-7,38$ & $-5,10$ & $-7,29$ & $-0,89$ & $-0,51$ & $-2,58$ & 5,80 & 4,16 & - \\
\hline & DMA & 18,42 & 18,96 & 16,01 & 16,26 & 17,50 & 10,89 & 11,65 & 12,30 & 11,77 & 12,21 & 9,52 & - \\
\hline & PDMA & 19,64 & 28,17 & 18,49 & 28,70 & 26,73 & 12,23 & 19,12 & 18,99 & 17,59 & 16,27 & 14,70 & - \\
\hline \multirow[t]{3}{*}{ CPI } & DM & $-31,85$ & $-14,85$ & $-26,08$ & $-15,50$ & $-9,95$ & $-17,69$ & $-2,46$ & $-1,65$ & $-9,30$ & 11,04 & 6,72 & - \\
\hline & DMA & 35,14 & 36,25 & 30,66 & 31,03 & 33,74 & 18,93 & 20,28 & 21,92 & 20,34 & 21,07 & 14,68 & - \\
\hline & PDMA & 33,06 & 49,32 & 30,06 & 51,11 & 46,99 & 10,47 & 24,41 & 25,42 & 16,69 & 11,43 & 8,91 & - \\
\hline \multirow[t]{3}{*}{ SPI } & $\mathrm{DM}$ & $-2,80$ & $-2,77$ & $-1,59$ & $-1,42$ & $-1,54$ & 0,34 & 0,26 & 0,33 & 2,34 & 1,97 & 2,29 & - \\
\hline & DMA & 6,16 & 6,27 & 5,27 & 5,43 & 5,59 & 4,99 & 5,31 & 5,25 & 5,49 & 5,71 & 5,74 & - \\
\hline & PDMA & 9,80 & 12,66 & 10,01 & 12,26 & 11,87 & 13,52 & 15,24 & 14,27 & 18,26 & 19,82 & 18,95 & - \\
\hline \multirow[t]{3}{*}{$\Delta \mathrm{CS}$} & DM & $-29,05$ & $-12,09$ & $-24,50$ & $-14,08$ & $-8,41$ & $-18,03$ & $-2,72$ & $-1,97$ & $-11,64$ & 9,07 & 4,43 & - \\
\hline & DMA & 28,98 & 29,98 & 25,40 & 25,59 & 28,14 & 13,93 & 14,97 & 16,67 & 14,85 & 15,36 & 8,94 & - \\
\hline & PDMA & 23,25 & 36,66 & 20,05 & 38,85 & 35,12 & $-3,06$ & 9,17 & 11,15 & $-1,56$ & $-8,39$ & $-10,04$ & - \\
\hline
\end{tabular}


Tabela 8.333: Constantes de acoplamento $\omega$ B97X com otimização de geometrias para $\alpha+\beta=100 \%$ na base aug-pcJ-2.

\begin{tabular}{|c|c|c|c|c|c|c|c|c|c|c|c|c|c|}
\hline & $\begin{array}{c}\text { Func. } \\
\alpha\end{array}$ & $\begin{array}{l}\omega \mathrm{B} 97 \mathrm{X} \\
15,77 \%\end{array}$ & $\begin{array}{l}\omega \mathrm{B} 97 \mathrm{X} \\
15,77 \%\end{array}$ & $\begin{array}{c}\omega \mathrm{B} 97 \mathrm{X} \\
10 \%\end{array}$ & $\begin{array}{c}\omega \mathrm{B} 97 \mathrm{X} \\
10 \%\end{array}$ & $\begin{array}{c}\omega \mathrm{B} 97 \mathrm{X} \\
15,77 \% \\
/ 10 \%\end{array}$ & $\begin{array}{c}\omega \mathrm{B} 97 \mathrm{X} \\
20 \%\end{array}$ & $\begin{array}{c}\omega \mathrm{B} 97 \mathrm{X} \\
20 \%\end{array}$ & $\begin{array}{l}\omega \mathrm{B} 97 \mathrm{X} \\
15,77 \% \\
/ 20 \%\end{array}$ & $\begin{array}{c}\omega \mathrm{B} 97 \mathrm{X} \\
30 \%\end{array}$ & $\begin{array}{c}\omega \mathrm{B} 97 \mathrm{X} \\
30 \%\end{array}$ & $\begin{array}{c}\omega \mathrm{B} 97 \mathrm{X} \\
15,77 \% \\
/ 30 \%\end{array}$ & Exp. \\
\hline & $\alpha+\beta$ & $100 \%$ & $100 \%$ & $100 \%$ & $100 \%$ & $100 \%$ & $100 \%$ & $100 \%$ & $100 \%$ & $100 \%$ & $100 \%$ & $100 \%$ & - \\
\hline & $\gamma$ & 0,30 & 0,30 & 0,30 & 0,30 & 0,30 & 0,30 & 0,30 & 0,30 & 0,30 & 0,30 & 0,30 & - \\
\hline & Geom. & Exp. & Otm. & Exp. & Otm. & Otm. & Exp. & Otm. & Otm. & Exp. & Otm. & Otm. & Exp. \\
\hline $\mathrm{HF}$ & ${ }^{1} J_{\mathrm{HF}}$ & 497,9 & 494,5 & 486,5 & 438,9 & 483,1 & 507,3 & 535,6 & 503,9 & 533,4 & 635,1 & 529,9 & 500 \\
\hline $\mathrm{CO}$ & ${ }^{1} J_{\mathrm{CO}}$ & 19,1 & 17,7 & 18,9 & 21,4 & 17,5 & 19,2 & 14,9 & 17,7 & 18,8 & 8,1 & 17,4 & 16,4 \\
\hline $\mathrm{H}_{2} \mathrm{O}$ & ${ }^{1} J_{\mathrm{OH}}$ & $-76,5$ & $-77,7$ & $-74,1$ & $-70,1$ & $-75,3$ & $-78,4$ & $-83,3$ & $-79,6$ & $-83,5$ & $-96,9$ & $-84,8$ & $-80,6$ \\
\hline $\mathrm{H}_{2} \mathrm{O}$ & ${ }^{2} J_{\mathrm{HH}}$ & $-6,4$ & $-5,8$ & $-4,6$ & $-4,5$ & $-4,0$ & $-7,9$ & $-6,8$ & $-7,2$ & $-12,0$ & $-9,4$ & $-11,3$ & $-7,3$ \\
\hline $\mathrm{NH}_{3}$ & ${ }^{1} J_{\mathrm{NH}}$ & 41,5 & 42,7 & 39,7 & 39,4 & 40,9 & 42,8 & 45,1 & 44,1 & 46,5 & 50,9 & 47,8 & 43,8 \\
\hline $\mathrm{NH}_{3}$ & ${ }^{2} J_{\mathrm{HH}}$ & $-8,7$ & $-8,0$ & $-7,0$ & $-6,6$ & $-6,3$ & $-10,1$ & $-9,1$ & $-9,4$ & $-14,2$ & $-12,0$ & $-13,3$ & $-9,6$ \\
\hline $\mathrm{PH}_{3}$ & ${ }^{1} J_{\mathrm{PH}}$ & 165,0 & 175,4 & 153,0 & 152,5 & 163,3 & 174,7 & 192,1 & 185,0 & 201,1 & 233,1 & 211,2 & 188,2 \\
\hline $\mathrm{PF}_{3}$ & ${ }^{1} J_{\mathrm{PF}}$ & $-1643,0$ & $-1537,0$ & $-1641,6$ & $-1518,7$ & $-1536,7$ & $-1642,9$ & $-1542,1$ & $-1536,3$ & $-1639,3$ & $-1525,0$ & $-1531,7$ & -1441 \\
\hline $\mathrm{BHF}_{2}$ & ${ }^{1} J_{\mathrm{BF}}$ & $-97,5$ & $-103,2$ & $-103,0$ & $-131,2$ & $-108,9$ & $-93,0$ & $-83,1$ & $-98,6$ & $-81,1$ & $-37,3$ & $-86,3$ & -84 \\
\hline $\mathrm{BF}_{3}$ & ${ }^{1} J_{\mathrm{BF}}$ & 3,3 & $-6,5$ & $-3,6$ & $-40,9$ & $-13,7$ & 8,8 & 17,7 & $-0,8$ & 23,3 & 72,1 & 14,0 & 15 \\
\hline $\mathrm{F}_{2} \mathrm{O}$ & ${ }^{1} J_{\mathrm{OF}}$ & $-326,5$ & $-210,6$ & $-288,1$ & $-264,9$ & $-180,2$ & $-358,9$ & $-172,7$ & $-235,4$ & $-459,2$ & $-86,7$ & $-307,0$ & -300 \\
\hline $\mathrm{CH}_{4}$ & ${ }^{1} J_{\mathrm{CH}}$ & 112,5 & 112,5 & 105,5 & 108,0 & 105,5 & 118,0 & 115,9 & 118,0 & 132,6 & 124,3 & 132,6 & 125,3 \\
\hline $\mathrm{CH}_{4}$ & ${ }^{2} J_{\mathrm{HH}}$ & $-11,3$ & $-11,3$ & $-9,5$ & $-9,4$ & $-9,5$ & $-12,7$ & $-12,7$ & $-12,7$ & $-17,0$ & $-16,6$ & $-17,0$ & $-12,8$ \\
\hline $\mathrm{C}_{2} \mathrm{H}_{2}$ & ${ }^{1} J_{\mathrm{CC}}$ & 193,0 & 193,5 & 185,6 & 186,6 & 186,4 & 199,6 & 199,0 & 199,7 & 221,6 & 213,7 & 220,2 & 174,8 \\
\hline $\mathrm{C}_{2} \mathrm{H}_{2}$ & ${ }^{1} J_{\mathrm{CH}}$ & 240,2 & 237,9 & 223,5 & 227,9 & 221,3 & 253,8 & 245,7 & 251,3 & 291,7 & 265,7 & 288,5 & 247,6 \\
\hline $\mathrm{C}_{2} \mathrm{H}_{2}$ & ${ }^{2} J_{\mathrm{CH}}$ & 53,4 & 53,6 & 53,7 & 53,9 & 53,8 & 52,6 & 53,2 & 53,0 & 47,4 & 51,2 & 48,4 & 50,1 \\
\hline $\mathrm{C}_{2} \mathrm{H}_{2}$ & ${ }^{3} J_{\mathrm{HH}}$ & 10,0 & 9,6 & 8,4 & 8,6 & 8,0 & 11,6 & 10,5 & 11,1 & 17,8 & 13,6 & 16,9 & 9,6 \\
\hline $\mathrm{C}_{2} \mathrm{H}_{4}$ & ${ }^{1} J_{\mathrm{CC}}$ & 64,5 & 66,9 & 60,3 & 62,5 & 63,0 & 68,5 & 70,0 & 70,4 & 83,2 & 78,4 & 83,1 & 67,6 \\
\hline $\mathrm{C}_{2} \mathrm{H}_{4}$ & ${ }^{1} J_{\mathrm{CH}}$ & 145,4 & 142,7 & 135,5 & 136,5 & 133,0 & 153,6 & 147,6 & 150,6 & 177,0 & 160,1 & 172,9 & 156,3 \\
\hline $\mathrm{C}_{2} \mathrm{H}_{4}$ & ${ }^{2} J_{\mathrm{CH}}$ & $-1,3$ & $-1,0$ & 0,2 & 0,5 & 0,4 & $-2,9$ & $-2,3$ & $-2,4$ & $-9,2$ & $-6,1$ & $-7,9$ & $-2,4$ \\
\hline $\mathrm{C}_{2} \mathrm{H}_{4}$ & ${ }^{2} J_{\mathrm{HH}}$ & 2,9 & 2,0 & 3,9 & 3,6 & 3,0 & 1,8 & 0,7 & 0,9 & $-2,5$ & $-3,1$ & $-3,0$ & 2,3 \\
\hline $\mathrm{C}_{2} \mathrm{H}_{4}$ & ${ }^{3} J_{\mathrm{HH}_{\mathrm{C}}}$ & 11,5 & 12,2 & 10,6 & 10,9 & 11,3 & 12,4 & 13,3 & 13,0 & 16,1 & 16,4 & 16,3 & 11,7 \\
\hline $\mathrm{C}_{2} \mathrm{H}_{4}$ & ${ }^{3} J_{\mathrm{HH}_{\mathrm{t}}}$ & 17,2 & 17,8 & 15,6 & 16,4 & 16,2 & 18,7 & 18,8 & 19,2 & 24,1 & 22,0 & 24,1 & 19 \\
\hline $\mathrm{C}_{2} \mathrm{H}_{6}$ & ${ }^{1} J_{\mathrm{CC}}$ & 29,1 & 30,9 & 26,8 & 28,2 & 28,5 & 31,0 & 32,7 & 32,8 & 36,3 & 36,9 & 38,0 & 34,5 \\
\hline $\mathrm{C}_{2} \mathrm{H}_{6}$ & ${ }^{1} J_{\mathrm{CH}}$ & 112,4 & 111,1 & 105,1 & 106,6 & 103,8 & 118,2 & 114,5 & 116,8 & 133,8 & 123,2 & 132,2 & 125,2 \\
\hline $\mathrm{C}_{2} \mathrm{H}_{6}$ & ${ }^{2} J_{\mathrm{CH}}$ & $-3,2$ & $-3,1$ & $-2,4$ & $-2,3$ & $-2,3$ & $-3,8$ & $-3,8$ & $-3,8$ & $-5,7$ & $-5,5$ & $-5,7$ & $-4,7$ \\
\hline \multirow[t]{3}{*}{ Total } & $\mathrm{DM}$ & $-11,56$ & $-3,39$ & $-13,31$ & $-11,20$ & $-5,50$ & $-10,12$ & 2,55 & $-1,68$ & $-6,31$ & 17,74 & 3,10 & - \\
\hline & DMA & 14,27 & 12,92 & 17,19 & 17,51 & 17,60 & 13,99 & 13,29 & 10,12 & 23,63 & 27,72 & 13,14 & - \\
\hline & PDMA & 14,49 & 17,41 & 26,02 & 37,53 & 28,43 & 10,27 & 10,55 & 12,39 & 41,39 & 49,91 & 34,88 & - \\
\hline \multirow[t]{3}{*}{ CPI } & $\mathrm{DM}$ & $-24,79$ & $-5,40$ & $-24,07$ & $-20,51$ & $-5,56$ & $-25,39$ & 6,13 & $-5,23$ & $-27,92$ & 35,55 & $-5,00$ & - \\
\hline & DMA & 26,35 & 22,98 & 28,84 & 30,76 & 29,71 & 27,63 & 25,27 & 18,21 & 39,30 & 56,12 & 15,53 & - \\
\hline & PDMA & 16,20 & 23,80 & 25,70 & 54,57 & 34,88 & 11,80 & 9,57 & 15,15 & 25,08 & 64,08 & 13,64 & - \\
\hline \multirow[t]{3}{*}{ SPI } & DM & $-1,85$ & $-1,92$ & $-5,42$ & $-4,37$ & $-5,45$ & 1,09 & $-0,07$ & 0,92 & 9,54 & 4,67 & 9,03 & - \\
\hline & DMA & 5,40 & 5,55 & 8,65 & 7,79 & 8,71 & 3,99 & 4,51 & 4,19 & 12,14 & 6,90 & 11,39 & - \\
\hline & PDMA & 13,24 & 12,73 & 26,25 & 25,02 & 23,69 & 9,15 & 11,26 & 10,36 & 53,35 & 39,52 & 50,46 & - \\
\hline \multirow[t]{3}{*}{$\Delta \mathrm{CS}$} & $\mathrm{DM}$ & $-22,94$ & $-3,48$ & $-18,65$ & $-16,14$ & $-0,12$ & $-26,48$ & 6,19 & $-6,15$ & $-37,46$ & 30,88 & $-14,03$ & - \\
\hline & DMA & 20,95 & 17,44 & 20,19 & 22,98 & 21,00 & 23,63 & 20,77 & 14,02 & 27,16 & 49,22 & 4,13 & - \\
\hline & PDMA & 2,96 & 11,07 & $-0,56$ & 29,55 & 11,18 & 2,66 & $-1,70$ & 4,79 & $-28,27$ & 24,56 & $-36,82$ & - \\
\hline
\end{tabular}


Tabela 8.334: Constantes de acoplamento $\omega$ B97X com otimização de geometrias para $\alpha+\beta=80 \%$ na base aug-pcJ-2.

\begin{tabular}{|c|c|c|c|c|c|c|c|c|c|c|c|c|c|}
\hline & $\begin{array}{c}\text { Func. } \\
\alpha\end{array}$ & $\begin{array}{l}\omega \mathrm{B} 97 \mathrm{X} \\
15,77 \%\end{array}$ & $\begin{array}{l}\omega \mathrm{B} 97 \mathrm{X} \\
15,77 \%\end{array}$ & $\begin{array}{c}\omega \mathrm{B} 97 \mathrm{X} \\
10 \%\end{array}$ & $\begin{array}{c}\omega \mathrm{B} 97 \mathrm{X} \\
10 \%\end{array}$ & $\begin{array}{l}\omega \mathrm{B} 97 \mathrm{X} \\
15,77 \% \\
/ 10 \%\end{array}$ & $\begin{array}{c}\omega \mathrm{B} 97 \mathrm{X} \\
20 \%\end{array}$ & $\begin{array}{c}\omega \mathrm{B} 97 \mathrm{X} \\
20 \%\end{array}$ & $\begin{array}{l}\omega \mathrm{B} 97 \mathrm{X} \\
15,77 \% \\
/ 20 \%\end{array}$ & $\begin{array}{c}\omega \mathrm{B} 97 \mathrm{X} \\
30 \%\end{array}$ & $\begin{array}{c}\omega \mathrm{B} 97 \mathrm{X} \\
30 \%\end{array}$ & $\begin{array}{l}\omega \mathrm{B} 97 \mathrm{X} \\
15,77 \% \\
/ 30 \%\end{array}$ & Exp. \\
\hline & $\alpha+\beta$ & $100 \%$ & $100 \%$ & $80 \%$ & $80 \%$ & $80 \%$ & $80 \%$ & $80 \%$ & $80 \%$ & $80 \%$ & $80 \%$ & $80 \%$ & - \\
\hline & $\gamma$ & 0,30 & 0,30 & 0,30 & 0,30 & 0,30 & 0,30 & 0,30 & 0,30 & 0,30 & 0,30 & 0,30 & - \\
\hline & Geom. & Exp. & Otm. & Exp. & Otm. & Otm. & Exp. & Otm. & Otm. & Exp. & Otm. & Otm. & Exp. \\
\hline $\mathrm{HF}$ & ${ }^{1} J_{\mathrm{HF}}$ & 497,9 & 494,5 & 488,2 & 431,7 & 484,8 & 508,1 & 528,4 & 504,7 & 533,3 & 628,3 & 529,8 & 500 \\
\hline $\mathrm{CO}$ & ${ }^{1} J_{\mathrm{CO}}$ & 19,1 & 17,7 & 18,5 & 21,8 & 17,0 & 18,8 & 15,2 & 17,3 & 18,4 & 8,3 & 16,9 & 16,4 \\
\hline $\mathrm{H}_{2} \mathrm{O}$ & ${ }^{1} J_{\mathrm{OH}}$ & $-76,5$ & $-77,7$ & $-74,2$ & $-68,9$ & $-75,3$ & $-78,3$ & $-82,1$ & $-79,5$ & $-83,3$ & $-95,8$ & $-84,6$ & $-80,6$ \\
\hline $\mathrm{H}_{2} \mathrm{O}$ & ${ }^{2} J_{\mathrm{HH}}$ & $-6,4$ & $-5,8$ & $-4,3$ & $-4,3$ & $-3,7$ & $-7,5$ & $-6,6$ & $-6,9$ & $-11,6$ & $-9,2$ & $-10,9$ & $-7,3$ \\
\hline $\mathrm{NH}_{3}$ & ${ }^{1} J_{\mathrm{NH}}$ & 41,5 & 42,7 & 39,7 & 38,8 & 40,9 & 42,7 & 44,6 & 44,0 & 46,3 & 50,5 & 47,6 & 43,8 \\
\hline $\mathrm{NH}_{3}$ & ${ }^{2} J_{\mathrm{HH}}$ & $-8,7$ & $-8,0$ & $-6,5$ & $-6,3$ & $-5,9$ & $-9,6$ & $-8,8$ & $-8,9$ & $-13,6$ & $-11,6$ & $-12,7$ & $-9,6$ \\
\hline $\mathrm{PH}_{3}$ & ${ }^{1} J_{\mathrm{PH}}$ & 165,0 & 175,4 & 157,2 & 152,3 & 167,5 & 178,3 & 191,9 & 188,7 & 204,0 & 233,1 & 214,2 & 188,2 \\
\hline $\mathrm{PF}_{3}$ & ${ }^{1} J_{\mathrm{PF}}$ & $-1643,0$ & $-1537,0$ & $-1639,8$ & $-1509,7$ & $-1534,7$ & $-1643,6$ & $-1542,4$ & $-1536,5$ & $-1642,0$ & $-1532,3$ & $-1533,6$ & -1441 \\
\hline $\mathrm{BHF}_{2}$ & ${ }^{1} J_{\mathrm{BF}}$ & $-97,5$ & $-103,2$ & $-108,8$ & $-141,7$ & $-114,7$ & $-98,8$ & $-92,6$ & $-104,5$ & $-87,0$ & $-45,8$ & $-92,3$ & -84 \\
\hline $\mathrm{BF}_{3}$ & ${ }^{1} J_{\mathrm{BF}}$ & 3,3 & $-6,5$ & $-9,4$ & $-52,3$ & $-19,6$ & 3,0 & 7,1 & $-6,7$ & 17,6 & 63,3 & 8,2 & 15 \\
\hline $\mathrm{F}_{2} \mathrm{O}$ & ${ }^{1} J_{\mathrm{OF}}$ & $-326,5$ & $-210,6$ & $-277,5$ & $-278,7$ & $-172,0$ & $-345,7$ & $-184,2$ & $-225,8$ & $-440,1$ & $-95,7$ & $-294,4$ & -300 \\
\hline $\mathrm{CH}_{4}$ & ${ }^{1} J_{\mathrm{CH}}$ & 112,5 & 112,5 & 104,9 & 107,9 & 104,9 & 117,1 & 115,9 & 117,1 & 131,4 & 124,2 & 131,4 & 125,3 \\
\hline $\mathrm{CH}_{4}$ & ${ }^{2} J_{\mathrm{HH}}$ & $-11,3$ & $-11,3$ & $-8,9$ & $-8,8$ & $-8,9$ & $-12,1$ & $-12,1$ & $-12,1$ & $-16,1$ & $-15,9$ & $-16,1$ & $-12,8$ \\
\hline $\mathrm{C}_{2} \mathrm{H}_{2}$ & ${ }^{1} J_{\mathrm{CC}}$ & 193,0 & 193,5 & 184,2 & 185,0 & 185,1 & 197,4 & 197,4 & 197,7 & 217,5 & 211,9 & 216,6 & 174,8 \\
\hline $\mathrm{C}_{2} \mathrm{H}_{2}$ & ${ }^{1} J_{\mathrm{CH}}$ & 240,2 & 237,9 & 221,3 & 227,5 & 219,1 & 250,9 & 245,1 & 248,4 & 287,5 & 264,9 & 284,4 & 247,6 \\
\hline $\mathrm{C}_{2} \mathrm{H}_{2}$ & ${ }^{2} J_{\mathrm{CH}}$ & 53,4 & 53,6 & 53,2 & 53,4 & 53,3 & 52,6 & 52,9 & 52,9 & 48,4 & 51,2 & 49,2 & 50,1 \\
\hline $\mathrm{C}_{2} \mathrm{H}_{2}$ & ${ }^{3} J_{\mathrm{HH}}$ & 10,0 & 9,6 & 8,0 & 8,4 & 7,7 & 10,9 & 10,1 & 10,4 & 16,3 & 12,9 & 15,5 & 9,6 \\
\hline $\mathrm{C}_{2} \mathrm{H}_{4}$ & ${ }^{1} J_{\mathrm{CC}}$ & 64,5 & 66,9 & 59,4 & 61,4 & 62,2 & 66,8 & 68,9 & 69,0 & 79,5 & 77,1 & 80,2 & 67,6 \\
\hline $\mathrm{C}_{2} \mathrm{H}_{4}$ & ${ }^{1} J_{\mathrm{CH}}$ & 145,4 & 142,7 & 134,1 & 136,1 & 131,7 & 151,7 & 147,1 & 148,8 & 174,0 & 159,3 & 170,2 & 156,3 \\
\hline $\mathrm{C}_{2} \mathrm{H}_{4}$ & ${ }^{2} J_{\mathrm{CH}}$ & $-1,3$ & $-1,0$ & 0,6 & 0,9 & 0,8 & $-2,2$ & $-1,8$ & $-1,8$ & $-7,5$ & $-5,4$ & $-6,6$ & $-2,4$ \\
\hline $\mathrm{C}_{2} \mathrm{H}_{4}$ & ${ }^{2} J_{\mathrm{HH}}$ & 2,9 & 2,0 & 4,2 & 4,1 & 3,3 & 2,4 & 1,3 & 1,4 & $-1,2$ & $-2,3$ & $-2,0$ & 2,3 \\
\hline $\mathrm{C}_{2} \mathrm{H}_{4}$ & ${ }^{3} J_{\mathrm{HH}_{\mathrm{c}}}$ & 11,5 & 12,2 & 10,4 & 10,5 & 11,1 & 11,9 & 12,8 & 12,6 & 15,0 & 15,7 & 15,4 & 11,7 \\
\hline $\mathrm{C}_{2} \mathrm{H}_{4}$ & ${ }^{3} J_{\mathrm{HH}_{\mathrm{t}}}$ & 17,2 & 17,8 & 15,3 & 16,2 & 15,8 & 18,1 & 18,4 & 18,7 & 22,8 & 21,4 & 23,0 & 19 \\
\hline $\mathrm{C}_{2} \mathrm{H}_{6}$ & ${ }^{1} J_{\mathrm{CC}}$ & 29,1 & 30,9 & 26,0 & 27,4 & 27,8 & 30,1 & 31,8 & 31,9 & 35,3 & 36,3 & 37,0 & 34,5 \\
\hline $\mathrm{C}_{2} \mathrm{H}_{6}$ & ${ }^{1} J_{\mathrm{CH}}$ & 112,4 & 111,1 & 104,2 & 106,4 & 103,0 & 117,1 & 114,4 & 115,8 & 132,4 & 122,9 & 130,8 & 125,2 \\
\hline $\mathrm{C}_{2} \mathrm{H}_{6}$ & ${ }^{2} J_{\mathrm{CH}}$ & $-3,2$ & $-3,1$ & $-2,1$ & $-2,0$ & $-2,1$ & $-3,5$ & $-3,5$ & $-3,5$ & $-5,4$ & $-5,2$ & $-5,3$ & $-4,7$ \\
\hline \multirow[t]{3}{*}{ Total } & $\mathrm{DM}$ & $-11,56$ & $-3,39$ & $-13,35$ & $-12,61$ & $-5,61$ & $-10,32$ & 0,93 & $-1,99$ & $-6,66$ & 16,04 & 2,57 & - \\
\hline & DMA & 14,27 & 12,92 & 18,04 & 18,00 & 18,33 & 13,78 & 12,99 & 10,82 & 21,76 & 26,28 & 12,70 & - \\
\hline & PDMA & 14,49 & 17,41 & 30,10 & 43,48 & 32,32 & 10,36 & 12,06 & 14,69 & 31,83 & 42,97 & 30,03 & - \\
\hline \multirow[t]{3}{*}{ CPI } & DM & $-24,79$ & $-5,40$ & $-23,44$ & $-23,47$ & $-5,15$ & $-24,86$ & 2,69 & $-5,00$ & $-27,17$ & 32,02 & $-4,79$ & - \\
\hline & DMA & 26,35 & 22,98 & 30,18 & 31,60 & 30,82 & 27,19 & 24,62 & 20,04 & 37,39 & 53,56 & 16,74 & - \\
\hline & PDMA & 16,20 & 23,80 & 30,53 & 63,30 & 39,56 & 14,23 & 13,19 & 20,16 & 19,86 & 56,53 & 16,51 & - \\
\hline \multirow[t]{3}{*}{ SPI } & DM & $-1,85$ & $-1,92$ & $-5,95$ & $-4,65$ & $-5,95$ & 0,34 & $-0,36$ & 0,21 & 8,39 & 4,33 & 7,97 & - \\
\hline & DMA & 5,40 & 5,55 & 9,14 & 8,02 & 9,18 & 3,94 & 4,47 & 4,07 & 10,29 & 6,27 & 9,75 & - \\
\hline & PDMA & 13,24 & 12,73 & 29,79 & 28,94 & 27,02 & 7,52 & 11,24 & 10,68 & 40,61 & 33,02 & 39,96 & - \\
\hline \multirow[t]{3}{*}{$\Delta \mathrm{CS}$} & DM & $-22,94$ & $-3,48$ & $-17,48$ & $-18,83$ & 0,81 & $-25,20$ & 3,05 & $-5,21$ & $-35,56$ & 27,69 & $-12,76$ & - \\
\hline & DMA & 20,95 & 17,44 & 21,04 & 23,58 & 21,64 & 23,25 & 20,15 & 15,97 & 27,10 & 47,29 & 6,99 & - \\
\hline & PDMA & 2,96 & 11,07 & 0,74 & 34,36 & 12,54 & 6,71 & 1,96 & 9,48 & $-20,75$ & 23,51 & $-23,45$ & - \\
\hline
\end{tabular}


Tabela 8.335: Constantes de acoplamento $\omega$ B97X com otimização de geometrias para $\alpha+\beta=60 \%$ na base aug-pcJ-2.

\begin{tabular}{|c|c|c|c|c|c|c|c|c|c|c|c|c|c|}
\hline & $\begin{array}{c}\text { Func. } \\
\alpha\end{array}$ & $\begin{array}{l}\omega \mathrm{B} 97 \mathrm{X} \\
15,77 \%\end{array}$ & $\begin{array}{l}\omega \mathrm{B} 97 \mathrm{X} \\
15,77 \%\end{array}$ & $\begin{array}{c}\omega \mathrm{B} 97 \mathrm{X} \\
10 \%\end{array}$ & $\begin{array}{c}\omega \mathrm{B} 97 \mathrm{X} \\
10 \%\end{array}$ & $\begin{array}{l}\omega \mathrm{B} 97 \mathrm{X} \\
15,77 \% \\
/ 10 \%\end{array}$ & $\begin{array}{c}\omega \mathrm{B} 97 \mathrm{X} \\
20 \%\end{array}$ & $\begin{array}{c}\omega \mathrm{B} 97 \mathrm{X} \\
20 \%\end{array}$ & $\begin{array}{l}\omega \mathrm{B} 97 \mathrm{X} \\
15,77 \% \\
/ 20 \%\end{array}$ & $\begin{array}{c}\omega \mathrm{B} 97 \mathrm{X} \\
30 \%\end{array}$ & $\begin{array}{c}\omega \mathrm{B} 97 \mathrm{X} \\
30 \%\end{array}$ & $\begin{array}{l}\omega \mathrm{B} 97 \mathrm{X} \\
15,77 \% \\
/ 30 \%\end{array}$ & Exp. \\
\hline & $\alpha+\beta$ & $100 \%$ & $100 \%$ & $60 \%$ & $60 \%$ & $60 \%$ & $60 \%$ & $60 \%$ & $60 \%$ & $60 \%$ & $60 \%$ & $60 \%$ & - \\
\hline & $\gamma$ & 0,30 & 0,30 & 0,30 & 0,30 & 0,30 & 0,30 & 0,30 & 0,30 & 0,30 & 0,30 & 0,30 & - \\
\hline & Geom. & Exp. & Otm. & Exp. & Otm. & Otm. & Exp. & Otm. & Otm. & Exp. & Otm. & Otm. & Exp. \\
\hline $\mathrm{HF}$ & ${ }^{1} J_{\mathrm{HF}}$ & 497,9 & 494,5 & 490,1 & 424,6 & 486,7 & 509,2 & 520,5 & 505,8 & 533,4 & 621,2 & 530,0 & 500 \\
\hline $\mathrm{CO}$ & ${ }^{1} J_{\mathrm{CO}}$ & 19,1 & 17,7 & 18,1 & 22,3 & 16,6 & 18,3 & 15,6 & 16,8 & 17,9 & 8,6 & 16,5 & 16,4 \\
\hline $\mathrm{H}_{2} \mathrm{O}$ & ${ }^{1} J_{\mathrm{OH}}$ & $-76,5$ & $-77,7$ & $-74,3$ & $-67,6$ & $-75,4$ & $-78,3$ & $-80,9$ & $-79,5$ & $-83,2$ & $-94,7$ & $-84,5$ & $-80,6$ \\
\hline $\mathrm{H}_{2} \mathrm{O}$ & ${ }^{2} J_{\mathrm{HH}}$ & $-6,4$ & $-5,8$ & $-4,0$ & $-4,1$ & $-3,4$ & $-7,1$ & $-6,4$ & $-6,5$ & $-11,1$ & $-9,0$ & $-10,4$ & $-7,3$ \\
\hline $\mathrm{NH}_{3}$ & ${ }^{1} J_{\mathrm{NH}}$ & 41,5 & 42,7 & 39,7 & 38,2 & 40,9 & 42,7 & 44,1 & 43,9 & 46,1 & 50,0 & 47,5 & 43,8 \\
\hline $\mathrm{NH}_{3}$ & ${ }^{2} J_{\mathrm{HH}}$ & $-8,7$ & $-8,0$ & $-6,1$ & $-6,1$ & $-5,5$ & $-9,1$ & $-8,4$ & $-8,4$ & $-13,0$ & $-11,2$ & $-12,1$ & $-9,6$ \\
\hline $\mathrm{PH}_{3}$ & ${ }^{1} J_{\mathrm{PH}}$ & 165,0 & 175,4 & 161,9 & 151,8 & 172,2 & 182,4 & 191,8 & 192,8 & 207,5 & 233,3 & 217,7 & 188,2 \\
\hline $\mathrm{PF}_{3}$ & ${ }^{1} J_{\mathrm{PF}}$ & $-1643,0$ & $-1537,0$ & $-1636,1$ & $-1497,5$ & $-1531,1$ & $-1642,7$ & $-1540,4$ & $-1535,3$ & $-1643,4$ & $-1538,0$ & $-1534,5$ & -1441 \\
\hline $\mathrm{BHF}_{2}$ & ${ }^{1} J_{\mathrm{BF}}$ & $-97,5$ & $-103,2$ & $-114,6$ & $-152,5$ & $-120,5$ & $-104,7$ & $-102,7$ & $-110,4$ & $-92,9$ & $-54,7$ & $-98,3$ & -84 \\
\hline $\mathrm{BF}_{3}$ & ${ }^{1} J_{\mathrm{BF}}$ & 3,3 & $-6,5$ & $-15,3$ & $-64,2$ & $-25,6$ & $-2,8$ & $-2,8$ & $-12,7$ & 11,7 & 54,2 & 2,2 & 15 \\
\hline $\mathrm{F}_{2} \mathrm{O}$ & ${ }^{1} J_{\mathrm{OF}}$ & $-326,5$ & $-210,6$ & $-267,1$ & $-292,6$ & $-163,9$ & $-333,2$ & $-196,4$ & $-216,4$ & $-422,3$ & $-105,3$ & $-282,5$ & -300 \\
\hline $\mathrm{CH}_{4}$ & ${ }^{1} J_{\mathrm{CH}}$ & 112,5 & 112,5 & 104,3 & 108,0 & 104,3 & 116,2 & 115,9 & 116,2 & 130,3 & 124,1 & 130,3 & 125,3 \\
\hline $\mathrm{CH}_{4}$ & ${ }^{2} J_{\mathrm{HH}}$ & $-11,3$ & $-11,3$ & $-8,4$ & $-8,2$ & $-8,4$ & $-11,4$ & $-11,4$ & $-11,4$ & $-15,3$ & $-15,1$ & $-15,3$ & $-12,8$ \\
\hline $\mathrm{C}_{2} \mathrm{H}_{2}$ & ${ }^{1} J_{\mathrm{CC}}$ & 193,0 & 193,5 & 182,9 & 183,3 & 184,0 & 195,3 & 195,7 & 195,9 & 213,8 & 210,1 & 213,3 & 174,8 \\
\hline $\mathrm{C}_{2} \mathrm{H}_{2}$ & ${ }^{1} J_{\mathrm{CH}}$ & 240,2 & 237,9 & 219,2 & 227,3 & 217,0 & 248,2 & 244,7 & 245,7 & 283,6 & 264,1 & 280,7 & 247,6 \\
\hline $\mathrm{C}_{2} \mathrm{H}_{2}$ & ${ }^{2} J_{\mathrm{CH}}$ & 53,4 & 53,6 & 52,6 & 53,0 & 52,8 & 52,4 & 52,6 & 52,6 & 49,1 & 51,1 & 49,7 & 50,1 \\
\hline $\mathrm{C}_{2} \mathrm{H}_{2}$ & ${ }^{3} J_{\mathrm{HH}}$ & 10,0 & 9,6 & 7,7 & 8,2 & 7,3 & 10,3 & 9,8 & 9,8 & 15,0 & 12,3 & 14,3 & 9,6 \\
\hline $\mathrm{C}_{2} \mathrm{H}_{4}$ & ${ }^{1} J_{\mathrm{CC}}$ & 64,5 & 66,9 & 58,5 & 60,2 & 61,5 & 65,3 & 67,7 & 67,8 & 76,5 & 75,8 & 77,8 & 67,6 \\
\hline $\mathrm{C}_{2} \mathrm{H}_{4}$ & ${ }^{1} J_{\mathrm{CH}}$ & 145,4 & 142,7 & 132,9 & 135,8 & 130,5 & 150,0 & 146,6 & 147,2 & 171,3 & 158,7 & 167,8 & 156,3 \\
\hline $\mathrm{C}_{2} \mathrm{H}_{4}$ & ${ }^{2} J_{\mathrm{CH}}$ & $-1,3$ & $-1,0$ & 0,9 & 1,3 & 1,1 & $-1,6$ & $-1,3$ & $-1,3$ & $-6,2$ & $-4,7$ & $-5,5$ & $-2,4$ \\
\hline $\mathrm{C}_{2} \mathrm{H}_{4}$ & ${ }^{2} J_{\mathrm{HH}}$ & 2,9 & 2,0 & 4,5 & 4,6 & 3,6 & 2,8 & 1,8 & 1,9 & $-0,2$ & $-1,5$ & $-1,1$ & 2,3 \\
\hline $\mathrm{C}_{2} \mathrm{H}_{4}$ & ${ }^{3} J_{\mathrm{HH}_{\mathrm{c}}}$ & 11,5 & 12,2 & 10,2 & 10,1 & 10,9 & 11,5 & 12,3 & 12,2 & 14,1 & 15,1 & 14,6 & 11,7 \\
\hline $\mathrm{C}_{2} \mathrm{H}_{4}$ & ${ }^{3} J_{\mathrm{HH}_{\mathrm{t}}}$ & 17,2 & 17,8 & 14,9 & 15,9 & 15,5 & 17,6 & 18,1 & 18,2 & 21,7 & 20,9 & 22,1 & 19 \\
\hline $\mathrm{C}_{2} \mathrm{H}_{6}$ & ${ }^{1} J_{\mathrm{CC}}$ & 29,1 & 30,9 & 25,2 & 26,5 & 27,0 & 29,2 & 31,1 & 31,0 & 34,2 & 35,7 & 35,9 & 34,5 \\
\hline $\mathrm{C}_{2} \mathrm{H}_{6}$ & ${ }^{1} J_{\mathrm{CH}}$ & 112,4 & 111,1 & 103,5 & 106,3 & 102,2 & 116,1 & 114,1 & 114,8 & 131,0 & 122,6 & 129,5 & 125,2 \\
\hline $\mathrm{C}_{2} \mathrm{H}_{6}$ & ${ }^{2} J_{\mathrm{CH}}$ & $-3,2$ & $-3,1$ & $-1,9$ & $-1,7$ & $-1,8$ & $-3,3$ & $-3,3$ & $-3,2$ & $-5,0$ & $-5,0$ & $-5,0$ & $-4,7$ \\
\hline \multirow[t]{3}{*}{ Total } & DM & $-11,56$ & $-3,39$ & $-13,30$ & $-13,93$ & $-5,63$ & $-10,45$ & $-0,64$ & $-2,21$ & $-6,94$ & 14,37 & 2,14 & - \\
\hline & DMA & 14,27 & 12,92 & 18,76 & 18,39 & 18,98 & 13,70 & 12,82 & 11,91 & 20,53 & 24,73 & 12,90 & - \\
\hline & PDMA & 14,49 & 17,41 & 33,84 & 49,58 & 36,17 & 14,01 & 15,00 & 17,23 & 25,56 & 36,03 & 26,22 & - \\
\hline \multirow[t]{3}{*}{ CPI } & DM & $-24,79$ & $-5,40$ & $-22,60$ & $-26,24$ & $-4,54$ & $-24,20$ & $-0,63$ & $-4,62$ & $-26,38$ & 28,50 & $-4,48$ & - \\
\hline & DMA & 26,35 & 22,98 & 31,27 & 32,24 & 31,72 & 26,76 & 24,28 & 22,36 & 36,65 & 50,72 & 19,17 & - \\
\hline & PDMA & 16,20 & 23,80 & 35,28 & 72,32 & 44,30 & 18,02 & 19,92 & 25,60 & 19,04 & 48,66 & 19,89 & - \\
\hline \multirow[t]{3}{*}{ SPI } & DM & $-1,85$ & $-1,92$ & $-6,47$ & $-4,90$ & $-6,44$ & $-0,37$ & $-0,65$ & $-0,45$ & 7,32 & 4,01 & 7,00 & - \\
\hline & DMA & 5,40 & 5,55 & 9,58 & 8,23 & 9,64 & 4,13 & 4,41 & 4,25 & 8,71 & 5,67 & 8,29 & - \\
\hline & PDMA & 13,24 & 12,73 & 32,79 & 32,90 & 30,20 & 11,07 & 11,40 & 11,09 & 30,33 & 26,77 & 30,87 & - \\
\hline \multirow[t]{3}{*}{$\Delta \mathrm{CS}$} & $\mathrm{DM}$ & $-22,94$ & $-3,48$ & $-16,13$ & $-21,34$ & 1,90 & $-23,83$ & 0,02 & $-4,17$ & $-33,70$ & 24,49 & $-11,48$ & - \\
\hline & DMA & 20,95 & 17,44 & 21,69 & 24,00 & 22,08 & 22,64 & 19,88 & 18,12 & 27,95 & 45,04 & 10,88 & - \\
\hline & PDMA & 2,96 & 11,07 & 2,49 & 39,42 & 14,10 & 6,95 & 8,53 & 14,51 & $-11,29$ & 21,88 & $-10,99$ & - \\
\hline
\end{tabular}


Tabela 8.336: Constantes de acoplamento $\omega$ B97X com otimização de geometrias na base aug-pcJ-2.

\begin{tabular}{|c|c|c|c|c|c|c|c|c|c|c|c|c|c|}
\hline & Func. & $\omega \mathrm{B} 97 \mathrm{X}$ & $\omega \mathrm{B} 97 \mathrm{X}$ & $\omega \mathrm{B} 97 \mathrm{X}$ & $\omega \mathrm{B} 97 \mathrm{X}$ & $\omega \mathrm{B} 97 \mathrm{X}$ & $\omega \mathrm{B} 97 \mathrm{X}$ & $\omega \mathrm{B} 97 \mathrm{X}$ & $\omega \mathrm{B} 97 \mathrm{X}$ & $\omega \mathrm{B} 97 \mathrm{X}$ & $\omega \mathrm{B} 97 \mathrm{X}$ & $\omega \mathrm{B} 97 \mathrm{X}$ & Exp. \\
\hline & $\alpha$ & $15,77 \%$ & $15,77 \%$ & $15,77 \%$ & $15,77 \%$ & $15,77 \%$ & $15,77 \%$ & $15,77 \%$ & $15,77 \%$ & $15,77 \%$ & $15,77 \%$ & $15,77 \%$ & - \\
\hline & $\alpha+\beta$ & $100 \%$ & $100 \%$ & $100 \%$ & $100 \%$ & $100 \%$ & $100 \%$ & $100 \%$ & $100 \%$ & $100 \%$ & $100 \%$ & $100 \%$ & - \\
\hline & $\gamma$ & 0,30 & 0,30 & 0,35 & 0,35 & $\begin{array}{c}0,30 / \\
0,35\end{array}$ & 0,40 & 0,40 & $\begin{array}{c}0,30 / \\
0,40\end{array}$ & 0,45 & 0,45 & $\begin{array}{c}0,30 / \\
0,45\end{array}$ & - \\
\hline & Geom. & Exp. & Otm. & Exp. & Otm. & Otm. & Exp. & Otm. & Otm. & Exp. & Otm. & Otm. & Exp. \\
\hline $\mathrm{HF}$ & ${ }^{1} J_{\mathrm{HF}}$ & 497,9 & 494,5 & 504,3 & 504,3 & 500,9 & 511,3 & 515,3 & 507,9 & 518,7 & 527,7 & 515,4 & 500 \\
\hline $\mathrm{CO}$ & ${ }^{1} J_{\mathrm{CO}}$ & 19,1 & 17,7 & 18,9 & 16,7 & 17,4 & 18,6 & 15,7 & 17,1 & 18,2 & 14,5 & 16,7 & 16,4 \\
\hline $\mathrm{H}_{2} \mathrm{O}$ & ${ }^{1} J_{\mathrm{OH}}$ & $-76,5$ & $-77,7$ & $-77,2$ & $-79,1$ & $-78,4$ & $-78,1$ & $-80,8$ & $-79,3$ & $-79,0$ & $-82,5$ & $-80,2$ & $-80,6$ \\
\hline $\mathrm{H}_{2} \mathrm{O}$ & ${ }^{2} J_{\mathrm{HH}}$ & $-6,4$ & $-5,8$ & $-6,7$ & $-5,8$ & $-6,0$ & $-7,0$ & $-5,9$ & $-6,4$ & $-7,4$ & $-6,1$ & $-6,8$ & $-7,3$ \\
\hline $\mathrm{NH}_{3}$ & ${ }^{1} J_{\mathrm{NH}}$ & 41,5 & 42,7 & 41,7 & 43,3 & 42,9 & 42,0 & 43,9 & 43,2 & 42,4 & 44,8 & 43,6 & 43,8 \\
\hline $\mathrm{NH}_{3}$ & ${ }^{2} J_{\mathrm{HH}}$ & $-8,7$ & $-8,0$ & $-9,0$ & $-8,1$ & $-8,3$ & $-9,3$ & $-8,3$ & $-8,7$ & $-9,8$ & $-8,5$ & $-9,1$ & $-9,6$ \\
\hline $\mathrm{PH}_{3}$ & ${ }^{1} J_{\mathrm{PH}}$ & 165,0 & 175,4 & 165,8 & 178,1 & 176,1 & 168,2 & 182,5 & 178,4 & 172,0 & 188,0 & 182,1 & 188,2 \\
\hline $\mathrm{PF}_{3}$ & ${ }^{1} J_{\mathrm{PF}}$ & $-1643,0$ & $-1537,0$ & $-1641,6$ & $-1539,7$ & $-1538,2$ & $-1639,2$ & $-1538,2$ & $-1538,9$ & $-1635,0$ & $-1535,6$ & $-1538,0$ & -1441 \\
\hline $\mathrm{BHF}_{2}$ & ${ }^{1} J_{\mathrm{BF}}$ & $-97,5$ & $-103,2$ & $-90,1$ & $-93,1$ & $-95,8$ & $-82,5$ & $-82,4$ & $-88,1$ & $-74,6$ & $-72,2$ & $-80,3$ & -84 \\
\hline $\mathrm{BF}_{3}$ & ${ }^{1} J_{\mathrm{BF}}$ & 3,3 & $-6,5$ & 11,9 & 5,5 & 2,1 & 20,9 & 18,1 & 11,2 & 29,8 & 29,8 & 20,2 & 15 \\
\hline $\mathrm{F}_{2} \mathrm{O}$ & ${ }^{1} J_{\mathrm{OF}}$ & $-326,5$ & $-210,6$ & $-341,5$ & $-198,0$ & $-221,2$ & $-356,7$ & $-185,0$ & $-231,5$ & $-371,9$ & $-171,9$ & $-241,3$ & -300 \\
\hline $\mathrm{CH}_{4}$ & ${ }^{1} J_{\mathrm{CH}}$ & 112,5 & 112,5 & 113,1 & 113,0 & 113,1 & 114,2 & 113,7 & 114,2 & 115,7 & 114,8 & 115,7 & 125,3 \\
\hline $\mathrm{CH}_{4}$ & ${ }^{2} J_{\mathrm{HH}}$ & $-11,3$ & $-11,3$ & $-11,5$ & $-11,5$ & $-11,5$ & $-11,9$ & $-11,9$ & $-11,9$ & $-12,4$ & $-12,3$ & $-12,4$ & $-12,8$ \\
\hline $\mathrm{C}_{2} \mathrm{H}_{2}$ & ${ }^{1} J_{\mathrm{CC}}$ & 193,0 & 193,5 & 194,8 & 195,0 & 195,0 & 197,2 & 197,0 & 197,2 & 200,3 & 199,6 & 200,1 & 174,8 \\
\hline $\mathrm{C}_{2} \mathrm{H}_{2}$ & ${ }^{1} J_{\mathrm{CH}}$ & 240,2 & 237,9 & 241,2 & 237,8 & 238,9 & 243,1 & 238,4 & 240,7 & 245,7 & 239,7 & 243,2 & 247,6 \\
\hline $\mathrm{C}_{2} \mathrm{H}_{2}$ & ${ }^{2} J_{\mathrm{CH}}$ & 53,4 & 53,6 & 53,4 & 53,7 & 53,7 & 53,1 & 53,6 & 53,5 & 52,7 & 53,4 & 53,1 & 50,1 \\
\hline $\mathrm{C}_{2} \mathrm{H}_{2}$ & ${ }^{3} J_{\mathrm{HH}}$ & 10,0 & 9,6 & 10,3 & 9,7 & 9,9 & 10,8 & 10,0 & 10,3 & 11,3 & 10,3 & 10,8 & 9,6 \\
\hline $\mathrm{C}_{2} \mathrm{H}_{4}$ & ${ }^{1} J_{\mathrm{CC}}$ & 64,5 & 66,9 & 66,0 & 68,1 & 68,1 & 68,0 & 69,8 & 69,8 & 70,5 & 71,8 & 72,0 & 67,6 \\
\hline $\mathrm{C}_{2} \mathrm{H}_{4}$ & ${ }^{1} J_{\mathrm{CH}}$ & 145,4 & 142,7 & 146,5 & 143,2 & 143,7 & 148,2 & 144,2 & 145,3 & 150,4 & 145,7 & 147,4 & 156,3 \\
\hline $\mathrm{C}_{2} \mathrm{H}_{4}$ & ${ }^{2} J_{\mathrm{CH}}$ & $-1,3$ & $-1,0$ & $-1,8$ & $-1,4$ & $-1,5$ & $-2,5$ & $-2,0$ & $-2,1$ & $-3,4$ & $-2,7$ & $-2,8$ & $-2,4$ \\
\hline $\mathrm{C}_{2} \mathrm{H}_{4}$ & ${ }^{2} J_{\mathrm{HH}}$ & 2,9 & 2,0 & 2,5 & 1,6 & 1,6 & 2,0 & 1,1 & 1,2 & 1,5 & 0,6 & 0,7 & 2,3 \\
\hline $\mathrm{C}_{2} \mathrm{H}_{4}$ & ${ }^{3} J_{\mathrm{HH}_{\mathrm{c}}}$ & 11,5 & 12,2 & 11,8 & 12,5 & 12,4 & 12,1 & 12,8 & 12,7 & 12,4 & 13,1 & 13,0 & 11,7 \\
\hline $\mathrm{C}_{2} \mathrm{H}_{4}$ & ${ }^{3} J_{\mathrm{HH}_{\mathrm{t}}}$ & 17,2 & 17,8 & 17,4 & 17,9 & 17,9 & 17,7 & 18,1 & 18,1 & 18,1 & 18,4 & 18,5 & 19 \\
\hline $\mathrm{C}_{2} \mathrm{H}_{6}$ & ${ }^{1} J_{\mathrm{CC}}$ & 29,1 & 30,9 & 30,0 & 31,6 & 31,7 & 31,1 & 32,6 & 32,7 & 32,3 & 33,7 & 33,9 & 34,5 \\
\hline $\mathrm{C}_{2} \mathrm{H}_{6}$ & ${ }^{1} J_{\mathrm{CH}}$ & 112,4 & 111,1 & 113,1 & 111,5 & 111,8 & 114,3 & 112,3 & 113,0 & 115,8 & 113,5 & 114,5 & 125,2 \\
\hline $\mathrm{C}_{2} \mathrm{H}_{6}$ & ${ }^{2} J_{\mathrm{CH}}$ & $-3,2$ & $-3,1$ & $-3,3$ & $-3,3$ & $-3,3$ & $-3,6$ & $-3,6$ & $-3,6$ & $-3,8$ & $-3,8$ & $-3,8$ & $-4,7$ \\
\hline \multirow[t]{3}{*}{ Total } & DM & $-11,56$ & $-3,39$ & $-10,96$ & $-1,60$ & $-2,77$ & $-10,12$ & 0,62 & $-1,88$ & $-9,02$ & 3,03 & $-0,72$ & - \\
\hline & DMA & 14,27 & 12,92 & 13,96 & 12,37 & 11,57 & 14,22 & 12,43 & 10,52 & 15,25 & 14,01 & 10,05 & - \\
\hline & PDMA & 14,49 & 17,41 & 9,96 & 13,42 & 14,01 & 9,18 & 11,09 & 10,13 & 13,71 & 15,41 & 10,53 & - \\
\hline \multirow[t]{3}{*}{ CPI } & DM & $-24,79$ & $-5,40$ & $-24,04$ & $-1,53$ & $-4,49$ & $-22,97$ & 3,09 & $-3,27$ & $-21,59$ & 7,92 & $-1,69$ & - \\
\hline & DMA & 26,35 & 22,98 & 26,11 & 21,73 & 20,04 & 27,34 & 21,96 & 17,85 & 30,01 & 25,85 & 17,09 & - \\
\hline & PDMA & 16,20 & 23,80 & 9,74 & 14,75 & 16,54 & 10,41 & 10,11 & 8,69 & 16,29 & 19,25 & 7,87 & - \\
\hline \multirow[t]{3}{*}{ SPI } & $\mathrm{DM}$ & $-1,85$ & $-1,92$ & $-1,37$ & $-1,65$ & $-1,51$ & $-0,69$ & $-1,20$ & $-0,87$ & 0,20 & $-0,55$ & $-0,01$ & - \\
\hline & DMA & 5,40 & 5,55 & 5,05 & 5,50 & 5,36 & 4,61 & 5,44 & 5,13 & 4,43 & 5,33 & 4,88 & - \\
\hline & PDMA & 13,24 & 12,73 & 10,13 & 12,45 & 12,16 & 8,28 & 11,80 & 11,19 & 11,82 & 12,59 & 12,48 & - \\
\hline \multirow[t]{3}{*}{$\Delta \mathrm{CS}$} & DM & $-22,94$ & $-3,48$ & $-22,66$ & 0,12 & $-2,98$ & $-22,29$ & 4,29 & $-2,41$ & $-21,79$ & 8,47 & $-1,68$ & - \\
\hline & DMA & 20,95 & 17,44 & 21,06 & 16,23 & 14,68 & 22,73 & 16,52 & 12,72 & 25,58 & 20,52 & 12,21 & - \\
\hline & PDMA & 2,96 & 11,07 & $-0,38$ & 2,30 & 4,38 & 2,13 & $-1,69$ & $-2,50$ & 4,47 & 6,66 & $-4,61$ & - \\
\hline
\end{tabular}


Tabela 8.337: Constantes de acoplamento $\omega$ B97XD com otimização de geometrias na base aug-pcJ-2.

\begin{tabular}{|c|c|c|c|c|c|c|c|c|c|c|c|c|c|c|c|c|}
\hline & \multirow{3}{*}{$\begin{array}{c}\text { Func. } \\
\alpha \\
\alpha+ \\
\beta\end{array}$} & \multirow{3}{*}{$\begin{array}{l}\omega 97 \mathrm{XD} \\
22,20 \% \\
100 \%\end{array}$} & \multirow{3}{*}{$\begin{array}{l}\omega 97 \mathrm{XD} \\
22,20 \% \\
100 \%\end{array}$} & \multirow{3}{*}{$\begin{array}{l}\omega 97 \mathrm{XD} \\
22,20 \% \\
100 \%\end{array}$} & \multirow{3}{*}{$\begin{array}{l}\omega 97 \mathrm{XD} \\
22,20 \% \\
100 \%\end{array}$} & \multirow{3}{*}{$\begin{array}{l}\omega 97 \mathrm{XD} \\
22,20 \% \\
100 \%\end{array}$} & \multirow{3}{*}{$\begin{array}{l}\omega 97 \mathrm{XD} \\
22,20 \% \\
100 \%\end{array}$} & \multirow{3}{*}{$\begin{array}{l}\omega 97 \mathrm{XD} \\
22,20 \% \\
100 \%\end{array}$} & \multirow{3}{*}{$\begin{array}{l}\omega 97 \mathrm{XD} \\
22,20 \% \\
100 \%\end{array}$} & \multirow{3}{*}{$\begin{array}{l}\omega 97 \mathrm{XD} \\
22,20 \% \\
100 \%\end{array}$} & \multirow{3}{*}{$\begin{array}{l}\omega 97 \mathrm{XD} \\
22,20 \% \\
100 \%\end{array}$} & \multirow{3}{*}{$\begin{array}{l}\omega 97 \mathrm{XD} \\
22,20 \% \\
100 \%\end{array}$} & \multirow{3}{*}{$\begin{array}{l}\omega 97 \mathrm{XD} \\
22,20 \% \\
100 \%\end{array}$} & \multirow{3}{*}{$\begin{array}{l}\omega 97 \mathrm{XD} \\
22,20 \% \\
100 \%\end{array}$} & \multirow{3}{*}{$\begin{array}{l}\omega 97 \mathrm{XD} \\
22,20 \% \\
100 \%\end{array}$} & \multirow{3}{*}{$\begin{array}{c}\text { Exp. } \\
-\end{array}$} \\
\hline & & & & & & & & & & & & & & & & \\
\hline & & & & & & & & & & & & & & & & \\
\hline & $\gamma$ & 0,20 & 0,20 & 0,30 & 0,30 & $\begin{array}{l}0,20 \\
0,30\end{array}$ & 0,35 & 0,35 & $\begin{array}{c}0,20 \\
0,35 \\
0,3\end{array}$ & 0,40 & 0,40 & $\begin{array}{l}0,20 \\
0,40\end{array}$ & 0,45 & 0,45 & $\begin{array}{l}0,20 \\
0,45 \\
0,4\end{array}$ & - \\
\hline & Geom. & Exp. & Otm. & Exp. & Otm. & Otm. & Exp. & Otm. & Otm. & Exp. & Otm. & Otm. & Exp. & Otm. & Otm. & Exp. \\
\hline $\mathrm{HF}$ & ${ }^{1} J_{\mathrm{HF}}$ & 484,2 & 487,1 & 494,0 & 499,4 & 496,8 & 499,4 & 507,9 & 502,2 & 505,3 & 517,7 & 508,1 & 511,7 & 528,6 & 514,4 & 500 \\
\hline $\mathrm{CO}$ & ${ }^{1} J_{\mathrm{CO}}$ & 19,6 & 17,9 & 19,1 & 16,4 & 17,4 & 18,9 & 15,6 & 17,2 & 18,6 & 14,7 & 16,9 & 18,2 & 13,7 & 16,5 & 16,4 \\
\hline $\mathrm{H}_{2} \mathrm{O}$ & ${ }^{1} J_{\mathrm{OH}}$ & $-74,7$ & $-75,8$ & $-75,7$ & $-78,0$ & $-76,9$ & $-76,3$ & $-79,3$ & $-77,5$ & $-77,1$ & $-80,7$ & $-78,2$ & $-77,9$ & $-82,3$ & $-79,0$ & $-80,6$ \\
\hline $\mathrm{H}_{2} \mathrm{O}$ & ${ }^{2} J_{\mathrm{HH}}$ & $-6,4$ & $-6,0$ & $-6,7$ & $-5,8$ & $-6,2$ & $-7,0$ & $-5,9$ & $-6,5$ & $-7,3$ & $-6,0$ & $-6,8$ & $-7,7$ & $-6,2$ & $-7,2$ & $-7,3$ \\
\hline $\mathrm{NH}_{3}$ & ${ }^{1} J_{\mathrm{NH}}$ & 41,9 & 43,0 & 42,1 & 43,8 & 43,1 & 42,3 & 44,3 & 43,3 & 42,5 & 45,0 & 43,5 & 42,9 & 45,7 & 43,9 & 43,8 \\
\hline $\mathrm{NH}_{3}$ & ${ }^{2} J_{\mathrm{HH}}$ & $-9,0$ & $-8,4$ & $-9,3$ & $-8,4$ & $-8,8$ & $-9,7$ & $-8,5$ & $-9,1$ & $-10,1$ & $-8,7$ & $-9,5$ & $-10,5$ & $-9,0$ & $-9,9$ & $-9,6$ \\
\hline $\mathrm{PH}_{3}$ & ${ }^{1} J_{\mathrm{PH}}$ & 176,7 & 186,4 & 173,6 & 186,2 & 183,1 & 174,3 & 188,5 & 183,7 & 176,6 & 192,4 & 185,9 & 180,3 & 197,5 & 189,3 & 188,2 \\
\hline $\mathrm{PF}_{3}$ & ${ }^{1} J_{\mathrm{PF}}$ & $-1637,8$ & $-1533,9$ & $-1631,8$ & $-1529,0$ & $-1531,5$ & $-1628,7$ & $-1527,7$ & $-1530,9$ & $-1624,6$ & $-1525,2$ & $-1529,8$ & $-1619,1$ & $-1520,8$ & $-1527,4$ & -1441 \\
\hline $\mathrm{BHF}_{2}$ & ${ }^{1} J_{\mathrm{BF}}$ & $-103,1$ & $-104,8$ & $-91,7$ & $-90,2$ & $-93,3$ & $-85,0$ & $-81,7$ & $-86,6$ & $-77,9$ & $-72,8$ & $-79,5$ & $-70,7$ & $-63,1$ & $-72,3$ & -84 \\
\hline $\mathrm{BF}_{3}$ & ${ }^{1} J_{\mathrm{BF}}$ & $-3,0$ & $-8,4$ & 10,2 & 9,3 & 4,9 & 17,9 & 19,3 & 12,6 & 25,9 & 29,6 & 20,7 & 33,9 & 40,6 & 28,7 & 15 \\
\hline $\mathrm{F}_{2} \mathrm{O}$ & ${ }^{1} J_{\mathrm{OF}}$ & $-333,4$ & $-220,1$ & $-359,3$ & $-203,2$ & $-239,2$ & $-373,9$ & $-193,2$ & $-249,5$ & $-389,0$ & $-182,6$ & $-259,6$ & $-404,3$ & $-170,6$ & $-269,4$ & -300 \\
\hline $\mathrm{CH}_{4}$ & ${ }^{1} J_{\mathrm{CH}}$ & 114,7 & 114,7 & 114,7 & 114,4 & 114,7 & 115,2 & 114,7 & 115,2 & 116,2 & 115,4 & 116,2 & 117,6 & 116,3 & 117,6 & 125,3 \\
\hline $\mathrm{CH}_{4}$ & ${ }^{2} J_{\mathrm{HH}}$ & $-11,8$ & $-11,8$ & $-12,0$ & $-12,0$ & $-12,0$ & $-12,3$ & $-12,3$ & $-12,3$ & $-12,7$ & $-12,7$ & $-12,7$ & $-13,2$ & $-13,1$ & $-13,2$ & $-12,8$ \\
\hline $\mathrm{C}_{2} \mathrm{H}_{2}$ & ${ }^{1} J_{\mathrm{CC}}$ & 191,3 & 191,8 & 192,9 & 193,2 & 193,1 & 194,4 & 194,5 & 194,5 & 196,6 & 196,2 & 196,5 & 199,5 & 198,3 & 199,0 & 174,8 \\
\hline $\mathrm{C}_{2} \mathrm{H}_{2}$ & ${ }^{1} J_{\mathrm{CH}}$ & 245,6 & 243,0 & 244,8 & 240,9 & 242,3 & 245,8 & 240,8 & 243,2 & 247,6 & 241,4 & 244,9 & 250,1 & 242,6 & 247,4 & 247,6 \\
\hline $\mathrm{C}_{2} \mathrm{H}_{2}$ & ${ }^{2} J_{\mathrm{CH}}$ & 53,7 & 53,9 & 54,2 & 54,5 & 54,4 & 54,2 & 54,6 & 54,4 & 53,9 & 54,6 & 54,3 & 53,5 & 54,3 & 53,9 & 50,1 \\
\hline $\mathrm{C}_{2} \mathrm{H}_{2}$ & ${ }^{3} J_{\mathrm{HH}}$ & 10,1 & 9,7 & 10,3 & 9,6 & 9,8 & 10,6 & 9,8 & 10,2 & 11,1 & 10,1 & 10,6 & 11,8 & 10,5 & 11,2 & 9,6 \\
\hline $\mathrm{C}_{2} \mathrm{H}_{4}$ & ${ }^{1} J_{\mathrm{CC}}$ & 63,7 & 66,1 & 65,3 & 67,5 & 67,4 & 66,6 & 68,5 & 68,5 & 68,4 & 69,9 & 70,0 & 70,7 & 71,6 & 71,9 & 67,6 \\
\hline $\mathrm{C}_{2} \mathrm{H}_{4}$ & ${ }^{1} J_{\mathrm{CH}}$ & 148,1 & 145,3 & 148,3 & 144,8 & 145,4 & 149,2 & 145,2 & 146,3 & 150,8 & 146,1 & 147,7 & 152,9 & 147,4 & 149,6 & 156,3 \\
\hline $\mathrm{C}_{2} \mathrm{H}_{4}$ & ${ }^{2} J_{\mathrm{CH}}$ & $-1,0$ & $-0,8$ & $-1,5$ & $-1,2$ & $-1,2$ & $-2,0$ & $-1,6$ & $-1,6$ & $-2,7$ & $-2,1$ & $-2,2$ & $-3,5$ & $-2,7$ & $-2,9$ & $-2,4$ \\
\hline $\mathrm{C}_{2} \mathrm{H}_{4}$ & ${ }^{2} J_{\mathrm{HH}}$ & 3,0 & 2,0 & 2,6 & 1,7 & 1,6 & 2,2 & 1,3 & 1,3 & 1,7 & 0,8 & 0,8 & 1,1 & 0,3 & 0,3 & 2,3 \\
\hline $\mathrm{C}_{2} \mathrm{H}_{4}$ & ${ }^{3} J_{\mathrm{HH}_{\mathrm{c}}}$ & 11,5 & 12,2 & 11,9 & 12,6 & 12,5 & 12,1 & 12,9 & 12,7 & 12,4 & 13,2 & 13,0 & 12,8 & 13,6 & 13,3 & 11,7 \\
\hline $\mathrm{C}_{2} \mathrm{H}_{4}$ & ${ }^{3} J_{\mathrm{HH}_{\mathrm{t}}}$ & 17,5 & 18,1 & 17,6 & 18,1 & 18,1 & 17,8 & 18,3 & 18,3 & 18,2 & 18,5 & 18,6 & 18,6 & 18,8 & 18,9 & 19 \\
\hline $\mathrm{C}_{2} \mathrm{H}_{6}$ & ${ }^{1} J_{\mathrm{CC}}{ }^{\imath}$ & 29,0 & 30,7 & 30,3 & 31,9 & 31,9 & 31,2 & 32,6 & 32,7 & 32,1 & 33,5 & 33,7 & 33,3 & 34,5 & 34,8 & 34,5 \\
\hline $\mathrm{C}_{2} \mathrm{H}_{6}$ & ${ }^{1} J_{\mathrm{CH}}$ & 115,2 & 113,9 & 115,2 & 113,5 & 113,8 & 115,8 & 113,8 & 114,5 & 116,9 & 114,6 & 115,6 & 118,3 & 115,6 & 117,0 & 125,2 \\
\hline $\mathrm{C}_{2} \mathrm{H}_{6}$ & ${ }^{2} J_{\mathrm{CH}}$ & $-3,3$ & $-3,3$ & $-3,5$ & $-3,5$ & $-3,5$ & $-3,7$ & $-3,7$ & $-3,6$ & $-3,9$ & $-3,9$ & $-3,9$ & $-4,2$ & $-4,1$ & $-4,1$ & $-4,7$ \\
\hline Total & $\mathrm{DM}$ & $-11,64$ & $-3,17$ & $-11,13$ & $-0,71$ & $-2,59$ & $-10,60$ & 0,91 & $-1,99$ & $-9,83$ & 2,85 & $-1,16$ & $-8,80$ & 5,12 & $-0,10$ & - \\
\hline & DMA & 14,39 & 11,95 & 13,81 & 10,63 & 9,83 & 13,45 & 10,99 & 8,67 & & 12,53 & 8,38 & & 14,31 & 8,55 & - \\
\hline & PDMA & 16,48 & 17,27 & 10,63 & 11,41 & 12,44 & 8,17 & 10,98 & 9,42 & 10,90 & 14,27 & 9,37 & 16,03 & 18,87 & 12,79 & - \\
\hline CPI & DM & $-25,99$ & $-5,81$ & $-25,13$ & $-0,04$ & $-4,68$ & $-24,43$ & 3,49 & $-3,82$ & $-23,45$ & 7,5 & $-2,65$ & $-22,19$ & 12,11 & $-1,21$ & - \\
\hline & DMA & 27,92 & 21,94 & 26,67 & 18,60 & 16,94 & 26,25 & 19,40 & 14,35 & 28,55 & 23,14 & 13,96 & 30,99 & 27,42 & 14,55 & - \\
\hline & PDMA & 20,60 & 24,06 & 10,99 & 11,02 & 13,09 & 8,62 & 10,28 & 6,46 & 14,14 & 18,35 & 7,31 & 20,61 & 27,19 & 12,02 & - \\
\hline SPI & $\mathrm{DM}$ & $-1,12$ & $-1,24$ & $-0,87$ & $-1,21$ & $-1,05$ & $-0,47$ & $-0,98$ & $-0,65$ & 0,17 & $-0,57$ & $-0,07$ & 1,01 & $-0,01$ & 0,71 & - \\
\hline & DMA & 4,47 & 4,63 & 4,37 & 4,79 & 4,63 & 4,07 & 4,82 & 4,51 & 3,77 & 4,75 & 4,29 & 3,99 & 4,69 & 4,15 & - \\
\hline & PDMA & 13,47 & 12,29 & 10,37 & 11,69 & 11,96 & 7,84 & 11,50 & 11,59 & 8,52 & 11,27 & 10,88 & 12,67 & 12,77 & 13,35 & - \\
\hline$\Delta \mathrm{CS}$ & $\mathrm{DM}$ & $-24,87$ & $-4,57$ & $-24,26$ & 1,17 & $-3,63$ & $-23,96$ & 4,47 & $-3,16$ & $-23,62$ & 8,07 & $-2,59$ & $-23,20$ & 12,12 & $-1,92$ & - \\
\hline & DMA & 23,45 & 17,31 & 22,30 & 13,81 & 12,31 & 22,18 & 14,58 & 9,84 & 24,78 & 18,38 & 9,67 & 27,00 & 22,72 & 10,41 & - \\
\hline & PDMA & 7,13 & 11,77 & 0,62 & $-0,67$ & 1,13 & 0,78 & $-1,23$ & $-5,13$ & 5,61 & 7,07 & $-3,57$ & 7,94 & 14,42 & $-1,33$ & - \\
\hline
\end{tabular}




\subsection{Geração de novos funcionais de longo alcance}

\subsubsection{Geometrias Experimentais}

Tabela 8.338: Constantes de acoplamento LC-BLYP variando $\alpha$ com $\alpha+\beta=100 \%$ na base aug-pcJ-2. O valor de $\gamma=0,33$ corresponde ao CAM-B3LYP.

\begin{tabular}{|c|c|c|c|c|c|c|c|c|c|c|c|}
\hline & $\alpha$ & $10 \%$ & $20 \%$ & $30 \%$ & $40 \%$ & $50 \%$ & $60 \%$ & $70 \%$ & $80 \%$ & $90 \%$ & Exp. \\
\hline $\mathrm{HF}$ & ${ }^{1} J_{\mathrm{HF}}$ & 450,6 & 472,8 & 495,2 & 518,0 & 541,0 & 564,5 & 588,3 & 612,6 & 637,3 & 500 \\
\hline $\mathrm{CO}$ & ${ }^{1} J_{\mathrm{CO}}$ & 20,0 & 18,0 & 16,0 & 13,8 & 11,5 & 9,1 & 6,5 & 3,8 & 1,0 & 16,4 \\
\hline $\mathrm{H}_{2} \mathrm{O}$ & ${ }^{1} J_{\mathrm{OH}}$ & $-76,9$ & $-79,4$ & $-81,9$ & $-84,5$ & $-87,1$ & $-89,7$ & $-92,5$ & $-95,3$ & $-98,1$ & $-80,6$ \\
\hline $\mathrm{H}_{2} \mathrm{O}$ & ${ }^{2} J_{\mathrm{HH}}$ & $-6,6$ & $-7,6$ & $-8,7$ & $-9,8$ & $-11,0$ & $-12,2$ & $-13,4$ & $-14,7$ & $-16,0$ & $-7,3$ \\
\hline $\mathrm{NH}_{3}$ & ${ }^{1} J_{\mathrm{NH}}$ & 44,3 & 45,2 & 46,1 & 47,1 & 48,1 & 49,1 & 50,2 & 51,2 & 52,3 & 43,8 \\
\hline $\mathrm{NH}_{3}$ & ${ }^{2} J_{\mathrm{HH}}$ & $-9,4$ & $-10,3$ & $-11,2$ & $-12,2$ & $-13,2$ & $-14,2$ & $-15,3$ & $-16,4$ & $-17,5$ & $-9,6$ \\
\hline $\mathrm{PH}_{3}$ & ${ }^{1} J_{\mathrm{PH}}$ & 145,3 & 155,9 & 166,4 & 176,9 & 187,4 & 197,9 & 208,3 & 218,6 & 228,9 & 188,2 \\
\hline $\mathrm{PF}_{3}$ & ${ }^{1} J_{\mathrm{PF}}$ & $-1775,7$ & $-1744,2$ & $-1710,6$ & $-1675,1$ & $-1638,1$ & $-1599,7$ & $-1560,3$ & $-1519,9$ & $-1478,7$ & -1441 \\
\hline $\mathrm{BHF}_{2}$ & ${ }^{1} J_{\mathrm{BF}}$ & $-133,4$ & $-119,0$ & $-104,3$ & $-89,6$ & $-74,8$ & $-59,8$ & $-44,8$ & $-29,7$ & $-14,6$ & -84 \\
\hline $\mathrm{BF}_{3}$ & ${ }^{1} J_{\mathrm{BF}}$ & $-27,4$ & $-12,2$ & 3,1 & 18,5 & 34,1 & 49,8 & 65,7 & 81,6 & 97,6 & 15 \\
\hline $\mathrm{F}_{2} \mathrm{O}$ & ${ }^{1} J_{\mathrm{OF}}$ & $-388,5$ & $-419,3$ & $-453,2$ & $-492,2$ & $-539,5$ & $-600,9$ & $-688,5$ & 1846,0 & $-1124,5$ & -300 \\
\hline $\mathrm{CH}_{4}$ & ${ }^{1} J_{\mathrm{CH}}$ & 123,7 & 126,3 & 129,0 & 131,7 & 134,5 & 137,4 & 140,3 & 143,3 & 146,3 & 125,3 \\
\hline $\mathrm{CH}_{4}$ & ${ }^{2} J_{\mathrm{HH}}$ & $-12,3$ & $-13,1$ & $-13,9$ & $-14,7$ & $-15,5$ & $-16,3$ & $-17,2$ & $-18,0$ & $-18,9$ & $-12,8$ \\
\hline $\mathrm{C}_{2} \mathrm{H}_{2}$ & ${ }^{1} J_{\mathrm{CC}}$ & 195,4 & 199,6 & 204,4 & 209,9 & 216,2 & 223,4 & 231,9 & 241,9 & 253,9 & 174,8 \\
\hline $\mathrm{C}_{2} \mathrm{H}_{2}$ & ${ }^{1} J_{\mathrm{CH}}$ & 257,9 & 262,3 & 266,9 & 271,9 & 277,2 & 283,0 & 289,4 & 296,4 & 304,4 & 247,6 \\
\hline $\mathrm{C}_{2} \mathrm{H}_{2}$ & ${ }^{2} J_{\mathrm{CH}}$ & 58,3 & 57,8 & 57,1 & 56,0 & 54,6 & 52,7 & 50,3 & 47,2 & 43,3 & 50,1 \\
\hline $\mathrm{C}_{2} \mathrm{H}_{2}$ & ${ }^{3} J_{\mathrm{HH}}$ & 10,1 & 10,9 & 12,0 & 13,1 & 14,5 & 16,1 & 17,9 & 20,2 & 22,8 & 9,6 \\
\hline $\mathrm{C}_{2} \mathrm{H}_{4}$ & ${ }^{1} J_{\mathrm{CC}}$ & 65,8 & 69,5 & 73,6 & 78,3 & 83,8 & 90,3 & 98,1 & 108,0 & 121,0 & 67,6 \\
\hline $\mathrm{C}_{2} \mathrm{H}_{4}$ & ${ }^{1} J_{\mathrm{CH}}$ & 158,4 & 161,8 & 165,4 & 169,3 & 173,5 & 178,1 & 183,3 & 189,3 & 196,5 & 156,3 \\
\hline $\mathrm{C}_{2} \mathrm{H}_{4}$ & ${ }^{2} J_{\mathrm{CH}}$ & $-0,9$ & $-1,9$ & $-3,1$ & $-4,5$ & $-6,2$ & $-8,2$ & $-10,8$ & $-14,2$ & $-18,8$ & $-2,4$ \\
\hline $\mathrm{C}_{2} \mathrm{H}_{4}$ & ${ }^{2} J_{\mathrm{HH}}$ & 4,5 & 3,8 & 3,0 & 2,0 & 1,0 & $-0,1$ & $-1,6$ & $-3,5$ & $-5,9$ & 2,3 \\
\hline $\mathrm{C}_{2} \mathrm{H}_{4}$ & ${ }^{3} J_{\mathrm{HH}_{\mathrm{c}}}$ & 13,4 & 13,7 & 14,1 & 14,6 & 15,3 & 16,1 & 17,2 & 18,6 & 20,7 & 11,7 \\
\hline $\mathrm{C}_{2} \mathrm{H}_{4}$ & ${ }^{3} J_{\mathrm{HH}_{\mathrm{t}}}$ & 19,4 & 20,0 & 20,6 & 21,4 & 22,3 & 23,5 & 24,9 & 26,8 & 29,3 & 19 \\
\hline $\mathrm{C}_{2} \mathrm{H}_{6}$ & ${ }^{1} J_{\mathrm{CC}}$ & 30,0 & 32,2 & 34,5 & 36,8 & 39,3 & 41,8 & 44,4 & 47,1 & 49,9 & 34,5 \\
\hline $\mathrm{C}_{2} \mathrm{H}_{6}$ & ${ }^{1} J_{\mathrm{CH}}$ & 124,0 & 126,7 & 129,5 & 132,4 & 135,4 & 138,3 & 141,4 & 144,5 & 147,7 & 125,2 \\
\hline $\mathrm{C}_{2} \mathrm{H}_{6}$ & ${ }^{2} J_{\mathrm{CH}}$ & $-3,2$ & $-3,6$ & $-4,1$ & $-4,6$ & $-5,1$ & $-5,6$ & $-6,1$ & $-6,7$ & $-7,2$ & $-4,7$ \\
\hline \multirow[t]{3}{*}{ Total } & $\mathrm{DM}$ & $-21,47$ & $-18,43$ & $-15,35$ & $-12,33$ & $-9,45$ & $-6,95$ & $-5,28$ & 97,45 & $-11,24$ & - \\
\hline & DMA & 25,95 & 23,71 & 22,20 & 22,99 & 26,26 & 31,37 & 37,75 & 108,84 & 61,97 & - \\
\hline & PDMA & 28,22 & 20,40 & 16,37 & 18,62 & 31,88 & 47,34 & 65,29 & 107,72 & 114,29 & - \\
\hline \multirow[t]{3}{*}{ CPI } & DM & $-54,42$ & $-49,18$ & $-44,00$ & $-39,09$ & $-34,77$ & $-31,55$ & $-30,61$ & 208,81 & $-52,11$ & - \\
\hline & DMA & 56,00 & 49,95 & 44,42 & 43,60 & 48,15 & 56,73 & 67,83 & 230,70 & 113,65 & - \\
\hline & PDMA & 42,38 & 30,20 & 21,00 & 19,04 & 34,22 & 52,10 & 71,22 & 141,12 & 117,85 & - \\
\hline \multirow[t]{3}{*}{ SPI } & DM & 2,69 & 4,13 & 5,66 & 7,30 & 9,11 & 11,09 & 13,29 & 15,79 & 18,73 & - \\
\hline & DMA & 3,91 & 4,47 & 5,90 & 7,87 & 10,21 & 12,77 & 15,70 & 19,48 & 24,06 & - \\
\hline & PDMA & 17,83 & 13,21 & 12,98 & 18,32 & 30,18 & 43,84 & 60,95 & 83,24 & 111,68 & - \\
\hline \multirow[t]{3}{*}{$\Delta \mathrm{CS}$} & $\mathrm{DM}$ & $-57,11$ & $-53,31$ & $-49,66$ & $-46,39$ & $-43,89$ & $-42,64$ & $-43,90$ & 193,02 & $-70,84$ & - \\
\hline & DMA & 52,09 & 45,47 & 38,52 & 35,73 & 37,95 & 43,95 & 52,13 & 211,22 & 89,59 & - \\
\hline & PDMA & 24,56 & 16,99 & 8,02 & 0,73 & 4,04 & 8,26 & 10,28 & 57,88 & 6,17 & - \\
\hline
\end{tabular}


Tabela 8.339: Constantes de acoplamento LC-BLYP variando $\alpha$ com $\alpha+$ $\beta=80 \%$ na base aug-pcJ-2. O valor de $\gamma=0,33$ corresponde ao CAMB3LYP.

\begin{tabular}{|c|c|c|c|c|c|c|c|c|c|}
\hline & $\alpha$ & $10 \%$ & $20 \%$ & $30 \%$ & $40 \%$ & $50 \%$ & $60 \%$ & $70 \%$ & Exp. \\
\hline $\mathrm{HF}$ & ${ }^{1} J_{\mathrm{HF}}$ & 444,4 & 466,7 & 489,3 & 512,1 & 535,4 & 559,0 & 583,0 & 500 \\
\hline $\mathrm{CO}$ & ${ }^{1} J_{\mathrm{CO}}$ & 19,9 & 17,9 & 15,8 & 13,6 & 11,3 & 8,8 & 6,2 & 16,4 \\
\hline $\mathrm{H}_{2} \mathrm{O}$ & ${ }^{1} J_{\mathrm{OH}}$ & $-76,6$ & $-79,1$ & $-81,6$ & $-84,2$ & $-86,8$ & $-89,5$ & $-92,3$ & $-80,6$ \\
\hline $\mathrm{H}_{2} \mathrm{O}$ & ${ }^{2} J_{\mathrm{HH}}$ & $-6,6$ & $-7,7$ & $-8,8$ & $-9,9$ & $-11,1$ & $-12,3$ & $-13,5$ & $-7,3$ \\
\hline $\mathrm{NH}_{3}$ & ${ }^{1} J_{\mathrm{NH}}$ & 44,6 & 45,5 & 46,5 & 47,5 & 48,5 & 49,5 & 50,5 & 43,8 \\
\hline $\mathrm{NH}_{3}$ & ${ }^{2} J_{\mathrm{HH}}$ & $-9,4$ & $-10,4$ & $-11,3$ & $-12,3$ & $-13,3$ & $-14,4$ & $-15,5$ & $-9,6$ \\
\hline $\mathrm{PH}_{3}$ & ${ }^{1} J_{\mathrm{PH}}$ & 150,1 & 160,8 & 171,5 & 182,2 & 192,9 & 203,5 & 214,0 & 188,2 \\
\hline $\mathrm{PF}_{3}$ & ${ }^{1} J_{\mathrm{PF}}$ & $-1779,0$ & $-1748,2$ & $-1715,1$ & $-1680,1$ & $-1643,3$ & $-1605,1$ & $-1565,7$ & -1441 \\
\hline $\mathrm{BHF}_{2}$ & ${ }^{1} J_{\mathrm{BF}}$ & $-137,1$ & $-122,4$ & $-107,6$ & $-92,6$ & $-77,5$ & $-62,4$ & $-47,1$ & -84 \\
\hline $\mathrm{BF}_{3}$ & ${ }^{1} J_{\mathrm{BF}}$ & $-32,3$ & $-16,8$ & $-1,2$ & 14,4 & 30,3 & 46,2 & 62,3 & 15 \\
\hline $\mathrm{F}_{2} \mathrm{O}$ & ${ }^{1} J_{\mathrm{OF}}$ & $-372,6$ & $-403,0$ & $-436,0$ & $-473,4$ & $-518,2$ & $-575,4$ & $-655,4$ & -300 \\
\hline $\mathrm{CH}_{4}$ & ${ }^{1} J_{\mathrm{CH}}$ & 125,9 & 128,6 & 131,3 & 134,1 & 137,0 & 139,9 & 142,8 & 125,3 \\
\hline $\mathrm{CH}_{4}$ & ${ }^{2} J_{\mathrm{HH}}$ & $-12,5$ & $-13,3$ & $-14,1$ & $-14,9$ & $-15,7$ & $-16,6$ & $-17,4$ & $-12,8$ \\
\hline $\mathrm{C}_{2} \mathrm{H}_{2}$ & ${ }^{1} J_{\mathrm{CC}}$ & 196,9 & 201,2 & 206,0 & 211,5 & 217,7 & 225,0 & 233,4 & 174,8 \\
\hline $\mathrm{C}_{2} \mathrm{H}_{2}$ & ${ }^{1} J_{\mathrm{CH}}$ & 262,0 & 266,5 & 271,2 & 276,3 & 281,7 & 287,6 & 294,0 & 247,6 \\
\hline $\mathrm{C}_{2} \mathrm{H}_{2}$ & ${ }^{2} J_{\mathrm{CH}}$ & 58,1 & 57,6 & 56,8 & 55,8 & 54,4 & 52,6 & 50,2 & 50,1 \\
\hline $\mathrm{C}_{2} \mathrm{H}_{2}$ & ${ }^{3} J_{\mathrm{HH}}$ & 10,2 & 11,1 & 12,1 & 13,3 & 14,6 & 16,2 & 18,0 & 9,6 \\
\hline $\mathrm{C}_{2} \mathrm{H}_{4}$ & ${ }^{1} J_{\mathrm{CC}}$ & 66,8 & 70,5 & 74,6 & 79,3 & 84,7 & 91,0 & 98,7 & 67,6 \\
\hline $\mathrm{C}_{2} \mathrm{H}_{4}$ & ${ }^{1} J_{\mathrm{CH}}$ & 160,8 & 164,3 & 168,0 & 171,9 & 176,1 & 180,7 & 185,9 & 156,3 \\
\hline $\mathrm{C}_{2} \mathrm{H}_{4}$ & ${ }^{2} J_{\mathrm{CH}}$ & $-0,9$ & $-1,9$ & $-3,0$ & $-4,4$ & $-6,1$ & $-8,1$ & $-10,6$ & $-2,4$ \\
\hline $\mathrm{C}_{2} \mathrm{H}_{4}$ & ${ }^{2} J_{\mathrm{HH}}$ & 4,6 & 3,9 & 3,1 & 2,3 & 1,2 & 0,0 & $-1,3$ & 2,3 \\
\hline $\mathrm{C}_{2} \mathrm{H}_{4}$ & ${ }^{3} J_{\mathrm{HH}_{\mathrm{c}}}$ & 13,3 & 13,6 & 14,0 & 14,5 & 15,1 & 15,9 & 16,9 & 11,7 \\
\hline $\mathrm{C}_{2} \mathrm{H}_{4}$ & ${ }^{3} J_{\mathrm{HH}_{\mathrm{t}}}$ & 19,7 & 20,2 & 20,8 & 21,6 & 22,4 & 23,5 & 24,9 & 19 \\
\hline $\mathrm{C}_{2} \mathrm{H}_{6}$ & ${ }^{1} J_{\mathrm{CC}}$ & 30,3 & 32,6 & 34,9 & 37,3 & 39,8 & 42,4 & 45,0 & 34,5 \\
\hline $\mathrm{C}_{2} \mathrm{H}_{6}$ & ${ }^{1} J_{\mathrm{CH}}$ & 126,1 & 128,9 & 131,8 & 134,7 & 137,7 & 140,7 & 143,9 & 125,2 \\
\hline $\mathrm{C}_{2} \mathrm{H}_{6}$ & ${ }^{2} J_{\mathrm{CH}}$ & $-3,2$ & $-3,6$ & $-4,1$ & $-4,6$ & $-5,1$ & $-5,6$ & $-6,2$ & $-4,7$ \\
\hline \multirow[t]{3}{*}{ Total } & $\mathrm{DM}$ & $-20,83$ & $-17,75$ & $-14,62$ & $-11,50$ & $-8,51$ & $-5,84$ & $-3,86$ & - \\
\hline & DMA & 26,07 & 24,15 & 22,61 & 22,62 & 25,90 & 30,97 & 37,07 & - \\
\hline & PDMA & 29,60 & 22,21 & 18,02 & 17,69 & 30,69 & 46,44 & 63,88 & - \\
\hline \multirow[t]{3}{*}{ CPI } & DM & $-54,14$ & $-48,87$ & $-43,58$ & $-38,51$ & $-33,88$ & $-30,27$ & $-28,58$ & - \\
\hline & DMA & 55,81 & 49,73 & 44,07 & 41,38 & 45,99 & 54,42 & 64,89 & - \\
\hline & PDMA & 45,22 & 33,03 & 23,71 & 17,09 & 31,47 & 49,61 & 68,64 & - \\
\hline \multirow[t]{3}{*}{ SPI } & $\mathrm{DM}$ & 3,60 & 5,07 & 6,62 & 8,31 & 10,09 & 12,07 & 14,27 & - \\
\hline & DMA & 4,27 & 5,39 & 6,87 & 8,85 & 11,17 & 13,77 & 16,66 & - \\
\hline & PDMA & 18,15 & 14,27 & 13,85 & 18,13 & 30,12 & 44,11 & 60,39 & - \\
\hline \multirow[t]{3}{*}{$\Delta \mathrm{CS}$} & DM & $-57,74$ & $-53,95$ & $-50,20$ & $-46,82$ & $-43,98$ & $-42,35$ & $-42,86$ & - \\
\hline & DMA & 51,54 & 44,33 & 37,20 & 32,53 & 34,82 & 40,65 & 48,23 & - \\
\hline & PDMA & 27,07 & 18,75 & 9,86 & $-1,05$ & 1,36 & 5,50 & 8,26 & - \\
\hline
\end{tabular}


Tabela 8.340: Constantes de acoplamento LC-BLYP variando $\alpha$ com $\alpha+\beta=60 \%$ na base aug-pcJ-2. O valor de $\gamma=0,33$ corresponde ao CAM-B3LYP.

\begin{tabular}{|c|c|c|c|c|c|c|c|}
\hline & $\alpha$ & $10 \%$ & $20 \%$ & $30 \%$ & $40 \%$ & $50 \%$ & Exp. \\
\hline $\mathrm{HF}$ & ${ }^{1} J_{\mathrm{HF}}$ & 438,2 & 460,6 & 483,3 & 506,3 & 529,6 & 500 \\
\hline $\mathrm{CO}$ & ${ }^{1} J_{\mathrm{CO}}$ & 19,8 & 17,8 & 15,7 & 13,4 & 11,0 & 16,4 \\
\hline $\mathrm{H}_{2} \mathrm{O}$ & ${ }^{1} J_{\mathrm{OH}}$ & $-76,3$ & $-78,8$ & $-81,3$ & $-83,9$ & $-86,6$ & $-80,6$ \\
\hline $\mathrm{H}_{2} \mathrm{O}$ & ${ }^{2} J_{\mathrm{HH}}$ & $-6,6$ & $-7,7$ & $-8,8$ & $-10,0$ & $-11,1$ & $-7,3$ \\
\hline $\mathrm{NH}_{3}$ & ${ }^{1} J_{\mathrm{NH}}$ & 44,9 & 45,8 & 46,8 & 47,8 & 48,8 & 43,8 \\
\hline $\mathrm{NH}_{3}$ & ${ }^{2} J_{\mathrm{HH}}$ & $-9,5$ & $-10,4$ & $-11,4$ & $-12,4$ & $-13,4$ & $-9,6$ \\
\hline $\mathrm{PH}_{3}$ & ${ }^{1} J_{\mathrm{PH}}$ & 155,0 & 165,9 & 176,8 & 187,6 & 198,5 & 188,2 \\
\hline $\mathrm{PF}_{3}$ & ${ }^{1} J_{\mathrm{PF}}$ & $-1782,2$ & $-1752,2$ & $-1719,8$ & $-1685,2$ & $-1648,7$ & -1441 \\
\hline $\mathrm{BHF}_{2}$ & ${ }^{1} J_{\mathrm{BF}}$ & $-141,0$ & $-126,0$ & $-111,0$ & $-95,8$ & $-80,4$ & -84 \\
\hline $\mathrm{BF}_{3}$ & ${ }^{1} J_{\mathrm{BF}}$ & $-37,4$ & $-21,6$ & $-5,7$ & 10,2 & 26,3 & 15 \\
\hline $\mathrm{F}_{2} \mathrm{O}$ & ${ }^{1} J_{\mathrm{OF}}$ & $-356,9$ & $-387,0$ & $-419,2$ & $-455,2$ & $-497,8$ & -300 \\
\hline $\mathrm{CH}_{4}$ & ${ }^{1} J_{\mathrm{CH}}$ & 128,2 & 131,0 & 133,7 & 136,6 & 139,5 & 125,3 \\
\hline $\mathrm{CH}_{4}$ & ${ }^{2} J_{\mathrm{HH}}$ & $-12,6$ & $-13,4$ & $-14,2$ & $-15,1$ & $-15,9$ & $-12,8$ \\
\hline $\mathrm{C}_{2} \mathrm{H}_{2}$ & ${ }^{1} J_{\mathrm{CC}}$ & 198,5 & 202,8 & 207,6 & 213,1 & 219,3 & 174,8 \\
\hline $\mathrm{C}_{2} \mathrm{H}_{2}$ & ${ }^{1} J_{\mathrm{CH}}$ & 266,2 & 270,7 & 275,6 & 280,7 & 286,2 & 247,6 \\
\hline $\mathrm{C}_{2} \mathrm{H}_{2}$ & ${ }^{2} J_{\mathrm{CH}}$ & 57,9 & 57,4 & 56,6 & 55,6 & 54,2 & 50,1 \\
\hline $\mathrm{C}_{2} \mathrm{H}_{2}$ & ${ }^{3} J_{\mathrm{HH}}$ & 10,4 & 11,3 & 12,3 & 13,4 & 14,7 & 9,6 \\
\hline $\mathrm{C}_{2} \mathrm{H}_{4}$ & ${ }^{1} J_{\mathrm{CC}}$ & 67,7 & 71,4 & 75,5 & 80,2 & 85,6 & 67,6 \\
\hline $\mathrm{C}_{2} \mathrm{H}_{4}$ & ${ }^{1} J_{\mathrm{CH}}$ & 163,3 & 166,8 & 170,6 & 174,5 & 178,8 & 156,3 \\
\hline $\mathrm{C}_{2} \mathrm{H}_{4}$ & ${ }^{2} J_{\mathrm{CH}}$ & $-0,8$ & $-1,8$ & $-3,0$ & $-4,4$ & $-6,0$ & $-2,4$ \\
\hline $\mathrm{C}_{2} \mathrm{H}_{4}$ & ${ }^{2} J_{\mathrm{HH}}$ & 4,8 & 4,1 & 3,3 & 2,5 & 1,5 & 2,3 \\
\hline $\mathrm{C}_{2} \mathrm{H}_{4}$ & ${ }^{3} J_{\mathrm{HH}_{\mathrm{c}}}$ & 13,3 & 13,6 & 13,9 & 14,4 & 14,9 & 11,7 \\
\hline $\mathrm{C}_{2} \mathrm{H}_{4}$ & ${ }^{3} J_{\mathrm{HH}_{\mathrm{t}}}$ & 19,9 & 20,4 & 21,0 & 21,7 & 22,6 & 19 \\
\hline $\mathrm{C}_{2} \mathrm{H}_{6}$ & ${ }^{1} J_{\mathrm{CC}}$ & 30,7 & 33,0 & 35,4 & 37,8 & 40,3 & 34,5 \\
\hline $\mathrm{C}_{2} \mathrm{H}_{6}$ & ${ }^{1} J_{\mathrm{CH}}$ & 128,3 & 131,2 & 134,1 & 137,1 & 140,1 & 125,2 \\
\hline $\mathrm{C}_{2} \mathrm{H}_{6}$ & ${ }^{2} J_{\mathrm{CH}}$ & $-3,1$ & $-3,6$ & $-4,1$ & $-4,6$ & $-5,1$ & $-4,7$ \\
\hline \multirow[t]{3}{*}{ Total } & DM & $-20,17$ & $-17,07$ & $-13,90$ & $-10,72$ & $-7,62$ & - \\
\hline & DMA & 26,47 & 24,61 & 23,07 & 22,57 & 25,64 & - \\
\hline & PDMA & 31,69 & 24,31 & 19,99 & 19,52 & 29,31 & - \\
\hline \multirow[t]{3}{*}{ CPI } & $\mathrm{DM}$ & $-53,90$ & $-48,59$ & $-43,23$ & $-38,01$ & $-33,15$ & - \\
\hline & DMA & 55,65 & 49,54 & 43,77 & 39,88 & 44,03 & - \\
\hline & PDMA & 48,09 & 35,77 & 26,36 & 19,45 & 28,62 & - \\
\hline \multirow[t]{3}{*}{ SPI } & $\mathrm{DM}$ & 4,57 & 6,05 & 7,61 & 9,29 & 11,11 & - \\
\hline & DMA & 5,08 & 6,33 & 7,88 & 9,87 & 12,16 & - \\
\hline & PDMA & 19,65 & 15,91 & 15,33 & 19,58 & 29,82 & - \\
\hline \multirow[t]{3}{*}{$\Delta \mathrm{CS}$} & $\mathrm{DM}$ & $-58,47$ & $-54,64$ & $-50,84$ & $-47,30$ & $-44,26$ & - \\
\hline & DMA & 50,57 & 43,20 & 35,89 & 30,02 & 31,87 & - \\
\hline & PDMA & 28,44 & 19,86 & 11,03 & $-0,12$ & $-1,20$ & - \\
\hline
\end{tabular}


Tabela 8.341: Constantes de acoplamento LCBLYP variando $\alpha$ com $\alpha+\beta=40 \%$ na base augpcJ-2. O valor de $\gamma=0,33$ corresponde ao CAMB3LYP.

\begin{tabular}{|c|c|c|c|c|c|}
\hline & $\alpha$ & $10 \%$ & $20 \%$ & $30 \%$ & Exp. \\
\hline $\mathrm{HF}$ & ${ }^{1} J_{\mathrm{HF}}$ & 432,0 & 454,4 & 477,2 & 500 \\
\hline $\mathrm{CO}$ & ${ }^{1} J_{\mathrm{CO}}$ & 19,7 & 17,7 & 15,5 & 16,4 \\
\hline $\mathrm{H}_{2} \mathrm{O}$ & ${ }^{1} J_{\mathrm{OH}}$ & $-75,9$ & $-78,4$ & $-81,0$ & $-80,6$ \\
\hline $\mathrm{H}_{2} \mathrm{O}$ & ${ }^{2} J_{\mathrm{HH}}$ & $-6,6$ & $-7,7$ & $-8,9$ & $-7,3$ \\
\hline $\mathrm{NH}_{3}$ & ${ }^{1} J_{\mathrm{NH}}$ & 45,2 & 46,1 & 47,1 & 43,8 \\
\hline $\mathrm{NH}_{3}$ & ${ }^{2} J_{\mathrm{HH}}$ & $-9,5$ & $-10,5$ & $-11,5$ & $-9,6$ \\
\hline $\mathrm{PH}_{3}$ & ${ }^{1} J_{\mathrm{PH}}$ & 160,2 & 171,2 & 182,3 & 188,2 \\
\hline $\mathrm{PF}_{3}$ & ${ }^{1} J_{\mathrm{PF}}$ & $-1785,3$ & $-1756,2$ & $-1724,4$ & -1441 \\
\hline $\mathrm{BHF}_{2}$ & ${ }^{1} J_{\mathrm{BF}}$ & $-144,9$ & $-129,8$ & $-114,5$ & -84 \\
\hline $\mathrm{BF}_{3}$ & ${ }^{1} J_{\mathrm{BF}}$ & $-42,5$ & $-26,5$ & $-10,3$ & 15 \\
\hline $\mathrm{F}_{2} \mathrm{O}$ & ${ }^{1} J_{\mathrm{OF}}$ & $-341,5$ & $-371,3$ & $-402,8$ & -300 \\
\hline $\mathrm{CH}_{4}$ & ${ }^{1} J_{\mathrm{CH}}$ & 130,6 & 133,4 & 136,2 & 125,3 \\
\hline $\mathrm{CH}_{4}$ & ${ }^{2} J_{\mathrm{HH}}$ & $-12,7$ & $-13,6$ & $-14,4$ & $-12,8$ \\
\hline $\mathrm{C}_{2} \mathrm{H}_{2}$ & ${ }^{1} J_{\mathrm{CC}}$ & 200,1 & 204,4 & 209,2 & 174,8 \\
\hline $\mathrm{C}_{2} \mathrm{H}_{2}$ & ${ }^{1} J_{\mathrm{CH}}$ & 270,4 & 275,0 & 280,0 & 247,6 \\
\hline $\mathrm{C}_{2} \mathrm{H}_{2}$ & ${ }^{2} J_{\mathrm{CH}}$ & 57,6 & 57,1 & 56,4 & 50,1 \\
\hline $\mathrm{C}_{2} \mathrm{H}_{2}$ & ${ }^{3} J_{\mathrm{HH}}$ & 10,6 & 11,4 & 12,4 & 9,6 \\
\hline $\mathrm{C}_{2} \mathrm{H}_{4}$ & ${ }^{1} J_{\mathrm{CC}}$ & 68,7 & 72,4 & 76,5 & 67,6 \\
\hline $\mathrm{C}_{2} \mathrm{H}_{4}$ & ${ }^{1} J_{\mathrm{CH}}$ & 165,8 & 169,4 & 173,2 & 156,3 \\
\hline $\mathrm{C}_{2} \mathrm{H}_{4}$ & ${ }^{2} J_{\mathrm{CH}}$ & $-0,8$ & $-1,8$ & $-3,0$ & $-2,4$ \\
\hline $\mathrm{C}_{2} \mathrm{H}_{4}$ & ${ }^{2} J_{\mathrm{HH}}$ & 5,0 & 4,3 & 3,5 & 2,3 \\
\hline $\mathrm{C}_{2} \mathrm{H}_{4}$ & ${ }^{3} J_{\mathrm{HH}_{\mathrm{c}}}$ & 13,2 & 13,5 & 13,8 & 11,7 \\
\hline $\mathrm{C}_{2} \mathrm{H}_{4}$ & ${ }^{3} J_{\mathrm{HH}_{\mathrm{t}}}$ & 20,1 & 20,6 & 21,2 & 19 \\
\hline $\mathrm{C}_{2} \mathrm{H}_{6}$ & ${ }^{1} J_{\mathrm{CC}}$ & 31,1 & 33,4 & 35,8 & 34,5 \\
\hline $\mathrm{C}_{2} \mathrm{H}_{6}$ & ${ }^{1} J_{\mathrm{CH}}$ & 130,5 & 133,4 & 136,4 & 125,2 \\
\hline $\mathrm{C}_{2} \mathrm{H}_{6}$ & ${ }^{2} J_{\mathrm{CH}}$ & $-3,1$ & $-3,6$ & $-4,1$ & $-4,7$ \\
\hline \multirow[t]{3}{*}{ Total } & DM & $-19,50$ & $-16,41$ & $-13,20$ & - \\
\hline & DMA & 26,93 & 25,10 & 23,55 & - \\
\hline & PDMA & 33,63 & 26,29 & 22,07 & - \\
\hline \multirow[t]{3}{*}{ CPI } & $\mathrm{DM}$ & $-53,64$ & $-48,35$ & $-42,93$ & - \\
\hline & DMA & 55,49 & 49,41 & 43,53 & - \\
\hline & PDMA & 51,07 & 38,70 & 29,26 & - \\
\hline \multirow[t]{3}{*}{ SPI } & DM & 5,53 & 7,01 & 8,60 & - \\
\hline & DMA & 5,99 & 7,27 & 8,89 & - \\
\hline & PDMA & 20,84 & 17,19 & 16,79 & - \\
\hline \multirow[t]{3}{*}{$\Delta \mathrm{CS}$} & $\mathrm{DM}$ & $-59,17$ & $-55,37$ & $-51,53$ & - \\
\hline & DMA & 49,50 & 42,14 & 34,63 & - \\
\hline & PDMA & 30,24 & 21,52 & 12,47 & - \\
\hline
\end{tabular}


Tabela 8.342: Constantes de acoplamento LC-BLYP variando $\alpha$ com $\alpha+\beta=20 \%$ na base aug-pcJ-2. O valor de $\gamma=0,33$ corresponde ao CAM-B3LYP.

\begin{tabular}{|c|c|c|c|}
\hline & $\alpha$ & $10 \%$ & Exp. \\
\hline $\mathrm{HF}$ & ${ }^{1} J_{\mathrm{HF}}$ & 425,7 & 500 \\
\hline $\mathrm{CO}$ & ${ }^{1} J_{\mathrm{CO}}$ & 19,6 & 16,4 \\
\hline $\mathrm{H}_{2} \mathrm{O}$ & ${ }^{1} J_{\mathrm{OH}}$ & $-75,5$ & $-80,6$ \\
\hline $\mathrm{H}_{2} \mathrm{O}$ & ${ }^{2} J_{\mathrm{HH}}$ & $-6,6$ & $-7,3$ \\
\hline $\mathrm{NH}_{3}$ & ${ }^{1} J_{\mathrm{NH}}$ & 45,5 & 43,8 \\
\hline $\mathrm{NH}_{3}$ & ${ }^{2} J_{\mathrm{HH}}$ & $-9,5$ & $-9,6$ \\
\hline $\mathrm{PH}_{3}$ & ${ }^{1} J_{\mathrm{PH}}$ & 165,5 & 188,2 \\
\hline $\mathrm{PF}_{3}$ & ${ }^{1} J_{\mathrm{PF}}$ & $-1788,4$ & -1441 \\
\hline $\mathrm{BHF}_{2}$ & ${ }^{1} J_{\mathrm{BF}}$ & $-149,1$ & -84 \\
\hline $\mathrm{BF}_{3}$ & ${ }^{1} J_{\mathrm{BF}}$ & $-47,9$ & 15 \\
\hline $\mathrm{F}_{2} \mathrm{O}$ & ${ }^{1} J_{\mathrm{OF}}$ & $-326,2$ & -300 \\
\hline $\mathrm{CH}_{4}$ & ${ }^{1} J_{\mathrm{CH}}$ & 133,0 & 125,3 \\
\hline $\mathrm{CH}_{4}$ & ${ }^{2} J_{\mathrm{HH}}$ & $-12,9$ & $-12,8$ \\
\hline $\mathrm{C}_{2} \mathrm{H}_{2}$ & ${ }^{1} J_{\mathrm{CC}}$ & 201,7 & 174,8 \\
\hline $\mathrm{C}_{2} \mathrm{H}_{2}$ & ${ }^{1} J_{\mathrm{CH}}$ & 274,6 & 247,6 \\
\hline $\mathrm{C}_{2} \mathrm{H}_{2}$ & ${ }^{2} J_{\mathrm{CH}}$ & 57,4 & 50,1 \\
\hline $\mathrm{C}_{2} \mathrm{H}_{2}$ & ${ }^{3} J_{\mathrm{HH}}$ & 10,8 & 9,6 \\
\hline $\mathrm{C}_{2} \mathrm{H}_{4}$ & ${ }^{1} J_{\mathrm{CC}}$ & 69,6 & 67,6 \\
\hline $\mathrm{C}_{2} \mathrm{H}_{4}$ & ${ }^{1} J_{\mathrm{CH}}$ & 168,4 & 156,3 \\
\hline $\mathrm{C}_{2} \mathrm{H}_{4}$ & ${ }^{2} J_{\mathrm{CH}}$ & $-0,7$ & $-2,4$ \\
\hline $\mathrm{C}_{2} \mathrm{H}_{4}$ & ${ }^{2} J_{\mathrm{HH}}$ & 5,2 & 2,3 \\
\hline $\mathrm{C}_{2} \mathrm{H}_{4}$ & ${ }^{3} J_{\mathrm{HH}_{\mathrm{c}}}$ & 13,1 & 11,7 \\
\hline $\mathrm{C}_{2} \mathrm{H}_{4}$ & ${ }^{3} J_{\mathrm{HH}_{\mathrm{t}}}$ & 20,4 & 19 \\
\hline $\mathrm{C}_{2} \mathrm{H}_{6}$ & ${ }^{1} J_{\mathrm{CC}}$ & 31,4 & 34,5 \\
\hline $\mathrm{C}_{2} \mathrm{H}_{6}$ & ${ }^{1} J_{\mathrm{CH}}$ & 132,8 & 125,2 \\
\hline $\mathrm{C}_{2} \mathrm{H}_{6}$ & ${ }^{2} J_{\mathrm{CH}}$ & $-3,1$ & $-4,7$ \\
\hline \multirow[t]{3}{*}{ Total } & DM & $-18,85$ & - \\
\hline & DMA & 27,44 & - \\
\hline & PDMA & 35,90 & - \\
\hline \multirow[t]{3}{*}{ CPI } & $\mathrm{DM}$ & $-53,44$ & - \\
\hline & DMA & 55,40 & - \\
\hline & PDMA & 54,27 & - \\
\hline \multirow[t]{3}{*}{ SPI } & $\mathrm{DM}$ & 6,51 & - \\
\hline & DMA & 6,93 & - \\
\hline & PDMA & 22,42 & - \\
\hline \multirow[t]{3}{*}{$\Delta \mathrm{CS}$} & DM & $-59,94$ & - \\
\hline & DMA & 48,47 & - \\
\hline & PDMA & 31,85 & - \\
\hline
\end{tabular}


Tabela 8.343: Constantes de acoplamento LC-B98 variando $\alpha \operatorname{com} \alpha+\beta=100 \%$ na base aug-pcJ-2. O valor de $\gamma=0,40$ corresponde ao $\omega$ B97.

\begin{tabular}{|c|c|c|c|c|c|c|c|c|c|c|c|}
\hline & $\alpha$ & $10 \%$ & $20 \%$ & $30 \%$ & $40 \%$ & $50 \%$ & $60 \%$ & $70 \%$ & $80 \%$ & $90 \%$ & Exp. \\
\hline $\mathrm{HF}$ & ${ }^{1} J_{\mathrm{HF}}$ & 442,6 & 460,2 & 478,5 & 497,7 & 517,7 & 538,7 & 560,6 & 583,6 & 607,8 & 500 \\
\hline $\mathrm{CO}$ & ${ }^{1} J_{\mathrm{CO}}$ & 16,2 & 14,9 & 13,5 & 11,9 & 10,2 & 8,2 & 6,1 & 3,8 & 1,3 & 16,4 \\
\hline $\mathrm{H}_{2} \mathrm{O}$ & ${ }^{1} J_{\mathrm{OH}}$ & $-69,8$ & $-72,1$ & $-74,6$ & $-77,1$ & $-79,8$ & $-82,6$ & $-85,6$ & $-88,7$ & $-92,0$ & $-80,6$ \\
\hline $\mathrm{H}_{2} \mathrm{O}$ & ${ }^{2} J_{\mathrm{HH}}$ & $-2,7$ & $-3,7$ & $-4,7$ & $-5,9$ & $-7,1$ & $-8,4$ & $-9,8$ & $-11,3$ & $-12,9$ & $-7,3$ \\
\hline $\mathrm{NH}_{3}$ & ${ }^{1} J_{\mathrm{NH}}$ & 38,1 & 39,3 & 40,6 & 41,9 & 43,3 & 44,8 & 46,3 & 47,9 & 49,7 & 43,8 \\
\hline $\mathrm{NH}_{3}$ & ${ }^{2} J_{\mathrm{HH}}$ & $-5,5$ & $-6,4$ & $-7,4$ & $-8,5$ & $-9,6$ & $-10,8$ & $-12,1$ & $-13,6$ & $-15,1$ & $-9,6$ \\
\hline $\mathrm{PH}_{3}$ & ${ }^{1} J_{\mathrm{PH}}$ & 150,7 & 160,1 & 169,8 & 179,9 & 190,3 & 201,0 & 212,2 & 223,7 & 235,5 & 188,2 \\
\hline $\mathrm{PF}_{3}$ & ${ }^{1} J_{\mathrm{PF}}$ & $-1644,4$ & $-1622,6$ & $-1599,2$ & $-1574,4$ & $-1548,4$ & $-1521,3$ & $-1493,2$ & $-1464,3$ & $-1434,7$ & -1441 \\
\hline $\mathrm{BHF}_{2}$ & ${ }^{1} J_{\mathrm{BF}}$ & $-104,4$ & $-93,6$ & $-82,3$ & $-70,6$ & $-58,6$ & $-46,2$ & $-33,5$ & $-20,5$ & $-7,2$ & -84 \\
\hline $\mathrm{BF}_{3}$ & ${ }^{1} J_{\mathrm{BF}}$ & $-6,4$ & 5,2 & 17,3 & 29,9 & 42,8 & 56,3 & 70,2 & 84,4 & 99,0 & 15 \\
\hline $\mathrm{F}_{2} \mathrm{O}$ & ${ }^{1} J_{\mathrm{OF}}$ & $-305,7$ & $-334,1$ & $-365,5$ & $-401,1$ & $-443,2$ & $-495,9$ & $-567,3$ & 2007,3 & $-882,1$ & -300 \\
\hline $\mathrm{CH}_{4}$ & ${ }^{1} J_{\mathrm{CH}}$ & 104,3 & 108,3 & 112,6 & 117,1 & 121,8 & 126,8 & 132,0 & 137,6 & 143,4 & 125,3 \\
\hline $\mathrm{CH}_{4}$ & ${ }^{2} J_{\mathrm{HH}}$ & $-8,0$ & $-8,9$ & $-9,8$ & $-10,8$ & $-11,8$ & $-12,9$ & $-14,1$ & $-15,3$ & $-16,7$ & $-12,8$ \\
\hline $\mathrm{C}_{2} \mathrm{H}_{2}$ & ${ }^{1} J_{\mathrm{CC}}$ & 190,0 & 195,3 & 201,3 & 208,0 & 215,6 & 224,5 & 234,9 & 247,4 & 262,7 & 174,8 \\
\hline $\mathrm{C}_{2} \mathrm{H}_{2}$ & ${ }^{1} J_{\mathrm{CH}}$ & 206,6 & 214,3 & 222,5 & 231,2 & 240,6 & 250,7 & 261,7 & 273,9 & 287,6 & 247,6 \\
\hline $\mathrm{C}_{2} \mathrm{H}_{2}$ & ${ }^{2} J_{\mathrm{CH}}$ & 54,4 & 54,6 & 54,6 & 54,4 & 53,8 & 52,7 & 51,0 & 48,5 & 44,7 & 50,1 \\
\hline $\mathrm{C}_{2} \mathrm{H}_{2}$ & ${ }^{3} J_{\mathrm{HH}}$ & 6,8 & 7,4 & 8,2 & 9,1 & 10,2 & 11,6 & 13,3 & 15,4 & 18,1 & 9,6 \\
\hline $\mathrm{C}_{2} \mathrm{H}_{4}$ & ${ }^{1} J_{\mathrm{CC}}$ & 65,8 & 69,4 & 73,5 & 78,1 & 83,5 & 89,9 & 97,7 & 107,5 & 120,3 & 67,6 \\
\hline $\mathrm{C}_{2} \mathrm{H}_{4}$ & ${ }^{1} J_{\mathrm{CH}}$ & 130,6 & 135,8 & 141,4 & 147,3 & 153,7 & 160,7 & 168,4 & 177,1 & 187,3 & 156,3 \\
\hline $\mathrm{C}_{2} \mathrm{H}_{4}$ & ${ }^{2} J_{\mathrm{CH}}$ & 0,6 & $-0,1$ & $-1,0$ & $-2,1$ & $-3,5$ & $-5,3$ & $-7,5$ & $-10,5$ & $-14,7$ & $-2,4$ \\
\hline $\mathrm{C}_{2} \mathrm{H}_{4}$ & ${ }^{2} J_{\mathrm{HH}}$ & 4,8 & 4,3 & 3,8 & 3,2 & 2,4 & 1,5 & 0,3 & $-1,1$ & $-3,2$ & 2,3 \\
\hline $\mathrm{C}_{2} \mathrm{H}_{4}$ & ${ }^{3} J_{\mathrm{HH}_{\mathrm{c}}}$ & 10,3 & 10,6 & 11,0 & 11,4 & 11,9 & 12,6 & 13,5 & 14,8 & 16,5 & 11,7 \\
\hline $\mathrm{C}_{2} \mathrm{H}_{4}$ & ${ }^{3} J_{\mathrm{HH}_{\mathrm{t}}}{ }^{\mathrm{C}}$ & 14,1 & 14,7 & 15,4 & 16,3 & 17,2 & 18,4 & 19,8 & 21,6 & 24,0 & 19 \\
\hline $\mathrm{C}_{2} \mathrm{H}_{6}$ & ${ }^{1} J_{\mathrm{CC}}$ & 29,4 & 31,8 & 34,3 & 37,0 & 39,8 & 42,8 & 46,0 & 49,5 & 53,2 & 34,5 \\
\hline $\mathrm{C}_{2} \mathrm{H}_{6}$ & ${ }^{1} J_{\mathrm{CH}}$ & 104,0 & 108,3 & 112,8 & 117,5 & 122,4 & 127,6 & 133,1 & 138,9 & 145,0 & 125,2 \\
\hline $\mathrm{C}_{2} \mathrm{H}_{6}$ & ${ }^{2} J_{\mathrm{CH}}$ & $-2,0$ & $-2,5$ & $-3,0$ & $-3,5$ & $-4,1$ & $-4,8$ & $-5,4$ & $-6,2$ & $-7,0$ & $-4,7$ \\
\hline \multirow[t]{3}{*}{ Total } & DM & $-16,33$ & $-13,63$ & $-10,82$ & $-7,97$ & $-5,15$ & $-2,48$ & $-0,25$ & 104,09 & $-1,33$ & - \\
\hline & DMA & 20,33 & 17,67 & 15,38 & 14,83 & 16,09 & 20,08 & 26,59 & 109,41 & 48,60 & - \\
\hline & PDMA & 32,49 & 24,46 & 17,35 & 16,16 & 18,67 & 29,85 & 46,25 & 91,02 & 92,03 & - \\
\hline \multirow[t]{3}{*}{ CPI } & DM & $-30,20$ & $-26,70$ & $-23,17$ & $-19,75$ & $-16,66$ & $-14,28$ & $-13,36$ & 228,31 & $-26,51$ & - \\
\hline & DMA & 33,75 & 29,48 & 25,86 & 25,98 & 30,12 & 38,21 & 48,42 & 237,76 & 86,16 & - \\
\hline & PDMA & 31,61 & 21,48 & 14,11 & 20,90 & 28,92 & 44,37 & 61,88 & 139,75 & 104,21 & - \\
\hline \multirow[t]{3}{*}{ SPI } & $\mathrm{DM}$ & $-6,16$ & $-4,05$ & $-1,77$ & 0,67 & 3,29 & 6,18 & 9,37 & 13,00 & 17,14 & - \\
\hline & DMA & 10,49 & 9,01 & 7,70 & 6,65 & 5,80 & 6,78 & 10,59 & 15,28 & 21,06 & - \\
\hline & PDMA & 33,13 & 26,66 & 19,72 & 12,68 & 11,15 & 19,20 & 34,78 & 55,29 & 83,09 & - \\
\hline \multirow[t]{3}{*}{$\Delta \mathrm{CS}$} & $\mathrm{DM}$ & $-24,04$ & $-22,65$ & $-21,41$ & $-20,42$ & $-19,96$ & $-20,46$ & $-22,74$ & 215,31 & $-43,65$ & - \\
\hline & DMA & 23,25 & 20,47 & 18,16 & 19,34 & 24,32 & 31,43 & 37,83 & 222,48 & 65,10 & - \\
\hline & PDMA & $-1,52$ & $-5,18$ & $-5,61$ & 8,22 & 17,76 & 25,17 & 27,10 & 84,47 & 21,11 & - \\
\hline
\end{tabular}


Tabela 8.344: Constantes de acoplamento LC-B98 variando $\alpha$ com $\alpha+$ $\beta=80 \%$ na base aug-pcJ-2. O valor de $\gamma=0,40$ corresponde ao $\omega \mathrm{B} 97$.

\begin{tabular}{|c|c|c|c|c|c|c|c|c|c|}
\hline & $\alpha$ & $10 \%$ & $20 \%$ & $30 \%$ & $40 \%$ & $50 \%$ & $60 \%$ & $70 \%$ & Exp. \\
\hline $\mathrm{HF}$ & ${ }^{1} J_{\mathrm{HF}}$ & 438,6 & 456,0 & 474,1 & 493,0 & 512,7 & 533,4 & 555,1 & 500 \\
\hline $\mathrm{CO}$ & ${ }^{1} J_{\mathrm{CO}}$ & 16,1 & 14,8 & 13,3 & 11,7 & 9,9 & 8,0 & 5,8 & 16,4 \\
\hline $\mathrm{H}_{2} \mathrm{O}$ & ${ }^{1} J_{\mathrm{OH}}$ & $-69,4$ & $-71,7$ & $-74,1$ & $-76,6$ & $-79,2$ & $-82,0$ & $-85,0$ & $-80,6$ \\
\hline $\mathrm{H}_{2} \mathrm{O}$ & ${ }^{2} J_{\mathrm{HH}}$ & $-2,5$ & $-3,4$ & $-4,5$ & $-5,6$ & $-6,8$ & $-8,1$ & $-9,5$ & $-7,3$ \\
\hline $\mathrm{NH}_{3}$ & ${ }^{1} J_{\mathrm{NH}}$ & 38,1 & 39,3 & 40,5 & 41,8 & 43,2 & 44,7 & 46,2 & 43,8 \\
\hline $\mathrm{NH}_{3}$ & ${ }^{2} J_{\mathrm{HH}}$ & $-5,3$ & $-6,2$ & $-7,1$ & $-8,2$ & $-9,3$ & $-10,5$ & $-11,8$ & $-9,6$ \\
\hline $\mathrm{PH}_{3}$ & ${ }^{1} J_{\mathrm{PH}}$ & 155,0 & 164,5 & 174,2 & 184,3 & 194,7 & 205,4 & 216,6 & 188,2 \\
\hline $\mathrm{PF}_{3}$ & ${ }^{1} J_{\mathrm{PF}}$ & $-1641,6$ & $-1621,0$ & $-1598,7$ & $-1574,7$ & $-1549,4$ & $-1522,7$ & $-1494,9$ & -1441 \\
\hline $\mathrm{BHF}_{2}$ & ${ }^{1} J_{\mathrm{BF}}$ & $-111,0$ & $-100,0$ & $-88,6$ & $-76,8$ & $-64,5$ & $-51,9$ & $-39,0$ & -84 \\
\hline $\mathrm{BF}_{3}$ & ${ }^{1} J_{\mathrm{BF}}$ & $-14,5$ & $-2,6$ & 9,7 & 22,5 & 35,7 & 49,3 & 63,5 & 15 \\
\hline $\mathrm{F}_{2} \mathrm{O}$ & ${ }^{1} J_{\mathrm{OF}}$ & $-288,0$ & $-315,5$ & $-345,4$ & $-378,9$ & $-417,8$ & $-465,2$ & $-527,2$ & -300 \\
\hline $\mathrm{CH}_{4}$ & ${ }^{1} J_{\mathrm{CH}}$ & 104,2 & 108,3 & 112,5 & 117,0 & 121,7 & 126,6 & 131,8 & 125,3 \\
\hline $\mathrm{CH}_{4}$ & ${ }^{2} J_{\mathrm{HH}}$ & $-7,8$ & $-8,6$ & $-9,5$ & $-10,5$ & $-11,5$ & $-12,6$ & $-13,7$ & $-12,8$ \\
\hline $\mathrm{C}_{2} \mathrm{H}_{2}$ & ${ }^{1} J_{\mathrm{CC}}$ & 189,6 & 194,7 & 200,4 & 206,8 & 214,1 & 222,4 & 232,1 & 174,8 \\
\hline $\mathrm{C}_{2} \mathrm{H}_{2}$ & ${ }^{1} J_{\mathrm{CH}}$ & 206,2 & 213,9 & 222,0 & 230,6 & 239,9 & 249,8 & 260,5 & 247,6 \\
\hline $\mathrm{C}_{2} \mathrm{H}_{2}$ & ${ }^{2} J_{\mathrm{CH}}$ & 53,8 & 54,1 & 54,2 & 54,0 & 53,6 & 52,7 & 51,3 & 50,1 \\
\hline $\mathrm{C}_{2} \mathrm{H}_{2}$ & ${ }^{3} J_{\mathrm{HH}}$ & 6,6 & 7,2 & 8,0 & 8,8 & 9,8 & 11,1 & 12,6 & 9,6 \\
\hline $\mathrm{C}_{2} \mathrm{H}_{4}$ & ${ }^{1} J_{\mathrm{CC}}$ & 65,6 & 69,1 & 73,0 & 77,5 & 82,5 & 88,4 & 95,4 & 67,6 \\
\hline $\mathrm{C}_{2} \mathrm{H}_{4}$ & ${ }^{1} J_{\mathrm{CH}}$ & 130,2 & 135,3 & 140,8 & 146,7 & 153,0 & 159,7 & 167,2 & 156,3 \\
\hline $\mathrm{C}_{2} \mathrm{H}_{4}$ & ${ }^{2} J_{\mathrm{CH}}$ & 0,9 & 0,1 & $-0,6$ & $-1,7$ & $-2,9$ & $-4,5$ & $-6,5$ & $-2,4$ \\
\hline $\mathrm{C}_{2} \mathrm{H}_{4}$ & ${ }^{2} J_{\mathrm{HH}}$ & 4,9 & 4,5 & 4,0 & 3,5 & 2,8 & 1,9 & 0,9 & 2,3 \\
\hline $\mathrm{C}_{2} \mathrm{H}_{4}$ & ${ }^{3} J_{\mathrm{HH}_{\mathrm{c}}}$ & 10,1 & 10,4 & 10,7 & 11,1 & 11,6 & 12,2 & 12,9 & 11,7 \\
\hline $\mathrm{C}_{2} \mathrm{H}_{4}$ & ${ }^{3} J_{\mathrm{HH}_{\mathrm{t}}}$ & 14,0 & 14,6 & 15,3 & 16,0 & 16,9 & 18,0 & 19,2 & 19 \\
\hline $\mathrm{C}_{2} \mathrm{H}_{6}$ & ${ }^{1} J_{\mathrm{CC}}$ & 28,9 & 31,2 & 33,7 & 36,4 & 39,2 & 42,2 & 45,4 & 34,5 \\
\hline $\mathrm{C}_{2} \mathrm{H}_{6}$ & ${ }^{1} J_{\mathrm{CH}}$ & 103,9 & 108,1 & 112,5 & 117,2 & 122,1 & 127,3 & 132,7 & 125,2 \\
\hline $\mathrm{C}_{2} \mathrm{H}_{6}$ & ${ }^{2} J_{\mathrm{CH}}$ & $-1,8$ & $-2,3$ & $-2,8$ & $-3,3$ & $-3,9$ & $-4,5$ & $-5,2$ & $-4,7$ \\
\hline \multirow[t]{3}{*}{ Total } & DM & $-16,16$ & $-13,47$ & $-10,67$ & $-7,78$ & $-4,88$ & $-2,07$ & 0,44 & - \\
\hline & DMA & 21,13 & 17,54 & 14,95 & 13,56 & 14,63 & 18,07 & 24,08 & - \\
\hline & PDMA & 36,18 & 27,84 & 19,69 & 15,55 & 16,39 & 24,84 & 39,78 & - \\
\hline \multirow[t]{3}{*}{ CPI } & DM & $-29,58$ & $-26,06$ & $-22,50$ & $-18,95$ & $-15,61$ & $-12,77$ & $-11,01$ & - \\
\hline & DMA & 35,45 & 29,01 & 24,65 & 22,91 & 26,81 & 34,21 & 43,63 & - \\
\hline & PDMA & 37,81 & 26,85 & 16,22 & 15,79 & 24,25 & 38,07 & 55,56 & - \\
\hline \multirow[t]{3}{*}{ SPI } & DM & $-6,32$ & $-4,23$ & $-1,99$ & 0,40 & 2,99 & 5,77 & 8,83 & - \\
\hline & DMA & 10,63 & 9,13 & 7,83 & 6,71 & 5,71 & 6,24 & 9,75 & - \\
\hline & PDMA & 34,99 & 28,56 & 22,24 & 15,37 & 10,63 & 15,14 & 28,21 & - \\
\hline \multirow[t]{3}{*}{$\Delta \mathrm{CS}$} & DM & $-23,26$ & $-21,83$ & $-20,51$ & $-19,35$ & $-18,60$ & $-18,55$ & $-19,84$ & - \\
\hline & DMA & 24,83 & 19,88 & 16,81 & 16,20 & 21,10 & 27,97 & 33,87 & - \\
\hline & PDMA & 2,82 & $-1,71$ & $-6,02$ & 0,41 & 13,62 & 22,93 & 27,34 & - \\
\hline
\end{tabular}


Tabela 8.345: Constantes de acoplamento LC-B98 variando $\alpha$ com $\alpha+\beta=60 \%$ na base aug-pcJ-2. O valor de $\gamma=0,40$ corresponde ao $\omega \mathrm{B} 97$.

\begin{tabular}{|c|c|c|c|c|c|c|c|}
\hline & $\% E_{X}^{\mathrm{HF}}$ & $10 \%$ & $20 \%$ & $30 \%$ & $40 \%$ & $50 \%$ & Exp. \\
\hline HF & ${ }^{1} J_{\mathrm{HF}}$ & 435,1 & 452,2 & 470,0 & 488,6 & 508,1 & 500 \\
\hline $\mathrm{CO}$ & ${ }^{1} J_{\mathrm{CO}}$ & 15,9 & 14,6 & 13,1 & 11,5 & 9,7 & 16,4 \\
\hline $\mathrm{H}_{2} \mathrm{O}$ & ${ }^{1} J_{\mathrm{OH}}$ & $-69,0$ & $-71,2$ & $-73,6$ & $-76,1$ & $-78,7$ & $-80,6$ \\
\hline $\mathrm{H}_{2} \mathrm{O}$ & ${ }^{2} J_{\mathrm{HH}}$ & $-2,2$ & $-3,2$ & $-4,2$ & $-5,4$ & $-6,6$ & $-7,3$ \\
\hline $\mathrm{NH}_{3}$ & ${ }^{1} J_{\mathrm{NH}}$ & 38,1 & 39,2 & 40,5 & 41,8 & 43,1 & 43,8 \\
\hline $\mathrm{NH}_{3}$ & ${ }^{2} J_{\mathrm{HH}}$ & $-5,0$ & $-5,9$ & $-6,8$ & $-7,9$ & $-9,0$ & $-9,6$ \\
\hline $\mathrm{PH}_{3}$ & ${ }^{1} J_{\mathrm{PH}}$ & 159,6 & 169,1 & 178,8 & 188,9 & 199,3 & 188,2 \\
\hline $\mathrm{PF}_{3}$ & ${ }^{1} J_{\mathrm{PF}}$ & $-1637,2$ & $-1618,1$ & $-1597,0$ & $-1574,0$ & $-1549,5$ & -1441 \\
\hline $\mathrm{BHF}_{2}$ & ${ }^{1} J_{\mathrm{BF}}$ & $-117,8$ & $-106,7$ & $-95,1$ & $-83,1$ & $-70,6$ & -84 \\
\hline $\mathrm{BF}_{3}$ & ${ }^{1} J_{\mathrm{BF}}$ & $-22,8$ & $-10,7$ & 1,8 & 14,8 & 28,3 & 15 \\
\hline $\mathrm{F}_{2} \mathrm{O}$ & ${ }^{1} J_{\mathrm{OF}}$ & $-270,7$ & $-297,4$ & $-326,3$ & $-358,0$ & $-394,2$ & -300 \\
\hline $\mathrm{CH}_{4}$ & ${ }^{1} J_{\mathrm{CH}}$ & 104,3 & 108,3 & 112,5 & 116,9 & 121,6 & 125,3 \\
\hline $\mathrm{CH}_{4}$ & ${ }^{2} J_{\mathrm{HH}}$ & $-7,5$ & $-8,3$ & $-9,2$ & $-10,1$ & $-11,1$ & $-12,8$ \\
\hline $\mathrm{C}_{2} \mathrm{H}_{2}$ & ${ }^{1} J_{\mathrm{CC}}$ & 189,2 & 194,2 & 199,7 & 205,8 & 212,7 & 174,8 \\
\hline $\mathrm{C}_{2} \mathrm{H}_{2}$ & ${ }^{1} J_{\mathrm{CH}}$ & 205,8 & 213,5 & 221,6 & 230,1 & 239,2 & 247,6 \\
\hline $\mathrm{C}_{2} \mathrm{H}_{2}$ & ${ }^{2} J_{\mathrm{CH}}$ & 53,2 & 53,5 & 53,7 & 53,6 & 53,3 & 50,1 \\
\hline $\mathrm{C}_{2} \mathrm{H}_{2}$ & ${ }^{3} J_{\mathrm{HH}}$ & 6,6 & 7,1 & 7,8 & 8,6 & 9,5 & 9,6 \\
\hline $\mathrm{C}_{2} \mathrm{H}_{4}$ & ${ }^{1} J_{\mathrm{CC}}$ & 65,5 & 68,9 & 72,7 & 76,9 & 81,7 & 67,6 \\
\hline $\mathrm{C}_{2} \mathrm{H}_{4}$ & ${ }^{1} J_{\mathrm{CH}}$ & 129,8 & 134,9 & 140,4 & 146,1 & 152,3 & 156,3 \\
\hline $\mathrm{C}_{2} \mathrm{H}_{4}$ & ${ }^{2} J_{\mathrm{CH}}$ & 1,2 & 0,5 & $-0,3$ & $-1,2$ & $-2,4$ & $-2,4$ \\
\hline $\mathrm{C}_{2} \mathrm{H}_{4}$ & ${ }^{2} J_{\mathrm{HH}}$ & 5,1 & 4,7 & 4,2 & 3,7 & 3,1 & 2,3 \\
\hline $\mathrm{C}_{2} \mathrm{H}_{4}$ & ${ }^{3} J_{\mathrm{HH}_{\mathrm{c}}}$ & 10,0 & 10,2 & 10,5 & 10,8 & 11,2 & 11,7 \\
\hline $\mathrm{C}_{2} \mathrm{H}_{4}$ & ${ }^{3} J_{\mathrm{HH}_{\mathrm{t}}}$ & 13,9 & 14,4 & 15,1 & 15,8 & 16,6 & 19 \\
\hline $\mathrm{C}_{2} \mathrm{H}_{6}$ & ${ }^{1} J_{\mathrm{CC}}$ & 28,3 & 30,7 & 33,1 & 35,8 & 38,5 & 34,5 \\
\hline $\mathrm{C}_{2} \mathrm{H}_{6}$ & ${ }^{1} J_{\mathrm{CH}}$ & 103,7 & 107,9 & 112,3 & 117,0 & 121,8 & 125,2 \\
\hline $\mathrm{C}_{2} \mathrm{H}_{6}$ & ${ }^{2} J_{\mathrm{CH}}$ & $-1,7$ & $-2,1$ & $-2,6$ & $-3,1$ & $-3,7$ & $-4,7$ \\
\hline \multirow[t]{3}{*}{ Total } & $\mathrm{DM}$ & $-15,91$ & $-13,26$ & $-10,47$ & $-7,58$ & $-4,65$ & - \\
\hline & DMA & 22,28 & 17,59 & 14,80 & 12,33 & 13,25 & - \\
\hline & PDMA & 40,19 & 31,67 & 23,32 & 14,90 & 14,27 & - \\
\hline \multirow[t]{3}{*}{ CPI } & DM & $-28,81$ & $-25,36$ & $-21,79$ & $-18,16$ & $-14,64$ & - \\
\hline & DMA & 38,01 & 28,96 & 24,14 & 19,93 & 23,56 & - \\
\hline & PDMA & 44,73 & 32,64 & 21,80 & 10,67 & 19,25 & - \\
\hline \multirow[t]{3}{*}{ SPI } & $\mathrm{DM}$ & $-6,45$ & $-4,38$ & $-2,17$ & 0,17 & 2,68 & - \\
\hline & DMA & 10,74 & 9,25 & 7,95 & 6,76 & 5,68 & - \\
\hline & PDMA & 36,86 & 30,96 & 24,44 & 18,00 & 10,63 & - \\
\hline \multirow[t]{3}{*}{$\Delta \mathrm{CS}$} & DM & $-22,36$ & $-20,98$ & $-19,62$ & $-18,34$ & $-17,32$ & - \\
\hline & DMA & 27,27 & 19,72 & 16,19 & 13,17 & 17,88 & - \\
\hline & PDMA & 7,87 & 1,68 & $-2,65$ & $-7,33$ & 8,62 & - \\
\hline
\end{tabular}


Tabela 8.346: Constantes de acoplamento LCB98 variando $\alpha$ com $\alpha+\beta=40 \%$ na base augpcJ-2. O valor de $\gamma=0,40$ corresponde ao $\omega$ B97.

\begin{tabular}{|c|c|c|c|c|c|}
\hline & $\% E_{X}^{\mathrm{HF}}$ & $10 \%$ & $20 \%$ & $30 \%$ & Exp. \\
\hline $\mathrm{HF}$ & ${ }^{1} J_{\mathrm{HF}}$ & 432,0 & 448,7 & 466,3 & 500 \\
\hline $\mathrm{CO}$ & ${ }^{1} J_{\mathrm{CO}}$ & 15,7 & 14,4 & 12,9 & 16,4 \\
\hline $\mathrm{H}_{2} \mathrm{O}$ & ${ }^{1} J_{\mathrm{OH}}$ & $-68,6$ & $-70,8$ & $-73,2$ & $-80,6$ \\
\hline $\mathrm{H}_{2} \mathrm{O}$ & ${ }^{2} J_{\mathrm{HH}}$ & $-2,0$ & $-3,0$ & $-4,0$ & $-7,3$ \\
\hline $\mathrm{NH}_{3}$ & ${ }^{1} J_{\mathrm{NH}}$ & 38,0 & 39,2 & 40,4 & 43,8 \\
\hline $\mathrm{NH}_{3}$ & ${ }^{2} J_{\mathrm{HH}}$ & $-4,8$ & $-5,6$ & $-6,6$ & $-9,6$ \\
\hline $\mathrm{PH}_{3}$ & ${ }^{1} J_{\mathrm{PH}}$ & 164,5 & 173,9 & 183,6 & 188,2 \\
\hline $\mathrm{PF}_{3}$ & ${ }^{1} J_{\mathrm{PF}}$ & $-1631,0$ & $-1613,5$ & $-1593,8$ & -1441 \\
\hline $\mathrm{BHF}_{2}$ & ${ }^{1} J_{\mathrm{BF}}$ & $-124,8$ & $-113,6$ & $-101,8$ & -84 \\
\hline $\mathrm{BF}_{3}$ & ${ }^{1} J_{\mathrm{BF}}$ & $-31,4$ & $-19,0$ & $-6,2$ & 15 \\
\hline $\mathrm{F}_{2} \mathrm{O}$ & ${ }^{1} J_{\mathrm{OF}}$ & $-253,8$ & $-279,9$ & $-307,8$ & -300 \\
\hline $\mathrm{CH}_{4}$ & ${ }^{1} J_{\mathrm{CH}}$ & 104,4 & 108,3 & 112,5 & 125,3 \\
\hline $\mathrm{CH}_{4}$ & ${ }^{2} J_{\mathrm{HH}}$ & $-7,2$ & $-8,0$ & $-8,9$ & $-12,8$ \\
\hline $\mathrm{C}_{2} \mathrm{H}_{2}$ & ${ }^{1} J_{\mathrm{CC}}$ & 189,0 & 193,8 & 199,1 & 174,8 \\
\hline $\mathrm{C}_{2} \mathrm{H}_{2}$ & ${ }^{1} J_{\mathrm{CH}}$ & 205,6 & 213,2 & 221,2 & 247,6 \\
\hline $\mathrm{C}_{2} \mathrm{H}_{2}$ & ${ }^{2} J_{\mathrm{CH}}$ & 52,6 & 52,9 & 53,2 & 50,1 \\
\hline $\mathrm{C}_{2} \mathrm{H}_{2}$ & ${ }^{3} J_{\mathrm{HH}}$ & 6,5 & 7,0 & 7,6 & 9,6 \\
\hline $\mathrm{C}_{2} \mathrm{H}_{4}$ & ${ }^{1} J_{\mathrm{CC}}$ & 65,3 & 68,7 & 72,3 & 67,6 \\
\hline $\mathrm{C}_{2} \mathrm{H}_{4}$ & ${ }^{1} J_{\mathrm{CH}}$ & 129,5 & 134,6 & 140,0 & 156,3 \\
\hline $\mathrm{C}_{2} \mathrm{H}_{4}$ & ${ }^{2} J_{\mathrm{CH}}$ & 1,4 & 0,7 & 0,0 & $-2,4$ \\
\hline $\mathrm{C}_{2} \mathrm{H}_{4}$ & ${ }^{2} J_{\mathrm{HH}}$ & 5,2 & 4,8 & 4,4 & 2,3 \\
\hline $\mathrm{C}_{2} \mathrm{H}_{4}$ & ${ }^{3} J_{\mathrm{HH}_{\mathrm{c}}}$ & 9,8 & 10,0 & 10,3 & 11,7 \\
\hline $\mathrm{C}_{2} \mathrm{H}_{4}$ & ${ }^{3} J_{\mathrm{HH}_{\mathrm{t}}}$ & 13,8 & 14,3 & 14,9 & 19 \\
\hline $\mathrm{C}_{2} \mathrm{H}_{6}$ & ${ }^{1} J_{\mathrm{CC}}$ & 27,8 & 30,1 & 32,5 & 34,5 \\
\hline $\mathrm{C}_{2} \mathrm{H}_{6}$ & ${ }^{1} J_{\mathrm{CH}}$ & 103,7 & 107,8 & 112,2 & 125,2 \\
\hline $\mathrm{C}_{2} \mathrm{H}_{6}$ & ${ }^{2} J_{\mathrm{CH}}$ & $-1,5$ & $-1,9$ & $-2,4$ & $-4,7$ \\
\hline \multirow[t]{3}{*}{ Total } & $\mathrm{DM}$ & $-15,59$ & $-13,00$ & $-10,24$ & - \\
\hline & DMA & 23,32 & 18,71 & 14,59 & - \\
\hline & PDMA & 43,99 & 35,43 & 26,89 & - \\
\hline \multirow[t]{3}{*}{ CPI } & $\mathrm{DM}$ & $-27,92$ & $-24,55$ & $-21,01$ & - \\
\hline & DMA & 40,34 & 31,50 & 23,50 & - \\
\hline & PDMA & 51,61 & 39,44 & 27,24 & - \\
\hline \multirow[t]{3}{*}{ SPI } & $\mathrm{DM}$ & $-6,55$ & $-4,52$ & $-2,35$ & - \\
\hline & DMA & 10,84 & 9,33 & 8,05 & - \\
\hline & PDMA & 38,40 & 32,49 & 26,64 & - \\
\hline \multirow[t]{3}{*}{$\Delta \mathrm{CS}$} & DM & $-21,37$ & $-20,03$ & $-18,66$ & - \\
\hline & DMA & 29,50 & 22,17 & 15,45 & - \\
\hline & PDMA & 13,20 & 6,95 & 0,60 & - \\
\hline
\end{tabular}


Tabela 8.347: Constantes de acoplamento LC-B98 variando $\alpha$ com $\alpha+\beta=20 \%$ na base aug-pcJ-2. O valor de $\gamma=0,40$ corresponde ao $\omega \mathrm{B} 97$.

\begin{tabular}{|c|c|c|c|}
\hline & $\alpha$ & $10 \%$ & Exp. \\
\hline HF & ${ }^{1} J_{\mathrm{HF}}$ & 429,3 & 500 \\
\hline $\mathrm{CO}$ & ${ }^{1} J_{\mathrm{CO}}$ & 15,6 & 16,4 \\
\hline $\mathrm{H}_{2} \mathrm{O}$ & ${ }^{1} J_{\mathrm{OH}}$ & $-68,3$ & $-80,6$ \\
\hline $\mathrm{H}_{2} \mathrm{O}$ & ${ }^{2} J_{\mathrm{HH}}$ & $-1,8$ & $-7,3$ \\
\hline $\mathrm{NH}_{3}$ & ${ }^{1} J_{\mathrm{NH}}$ & 38,1 & 43,8 \\
\hline $\mathrm{NH}_{3}$ & ${ }^{2} J_{\mathrm{HH}}$ & $-4,5$ & $-9,6$ \\
\hline $\mathrm{PH}_{3}$ & ${ }^{1} J_{\mathrm{PH}}$ & 169,6 & 188,2 \\
\hline $\mathrm{PF}_{3}$ & ${ }^{1} J_{\mathrm{PF}}$ & $-1622,7$ & -1441 \\
\hline $\mathrm{BHF}_{2}$ & ${ }^{1} J_{\mathrm{BF}}$ & $-131,9$ & -84 \\
\hline $\mathrm{BF}_{3}$ & ${ }^{1} J_{\mathrm{BF}}$ & $-40,2$ & 15 \\
\hline $\mathrm{F}_{2} \mathrm{O}$ & ${ }^{1} J_{\mathrm{OF}}$ & $-237,1$ & -300 \\
\hline $\mathrm{CH}_{4}$ & ${ }^{1} J_{\mathrm{CH}}$ & 104,5 & 125,3 \\
\hline $\mathrm{CH}_{4}$ & ${ }^{2} J_{\mathrm{HH}}$ & $-6,9$ & $-12,8$ \\
\hline $\mathrm{C}_{2} \mathrm{H}_{2}$ & ${ }^{1} J_{\mathrm{CC}}$ & 188,8 & 174,8 \\
\hline $\mathrm{C}_{2} \mathrm{H}_{2}$ & ${ }^{1} J_{\mathrm{CH}}$ & 205,3 & 247,6 \\
\hline $\mathrm{C}_{2} \mathrm{H}_{2}$ & ${ }^{2} J_{\mathrm{CH}}$ & 51,9 & 50,1 \\
\hline $\mathrm{C}_{2} \mathrm{H}_{2}$ & ${ }^{3} J_{\mathrm{HH}}$ & 6,5 & 9,6 \\
\hline $\mathrm{C}_{2} \mathrm{H}_{4}$ & ${ }^{1} J_{\mathrm{CC}}$ & 65,2 & 67,6 \\
\hline $\mathrm{C}_{2} \mathrm{H}_{4}$ & ${ }^{1} J_{\mathrm{CH}}$ & 129,3 & 156,3 \\
\hline $\mathrm{C}_{2} \mathrm{H}_{4}$ & ${ }^{2} J_{\mathrm{CH}}$ & 1,7 & $-2,4$ \\
\hline $\mathrm{C}_{2} \mathrm{H}_{4}$ & ${ }^{2} J_{\mathrm{HH}}$ & 5,3 & 2,3 \\
\hline $\mathrm{C}_{2} \mathrm{H}_{4}$ & ${ }^{3} J_{\mathrm{HH}_{\mathrm{c}}}$ & 9,6 & 11,7 \\
\hline $\mathrm{C}_{2} \mathrm{H}_{4}$ & ${ }^{3} J_{\mathrm{HH}_{\mathrm{t}}}$ & 13,7 & 19 \\
\hline $\mathrm{C}_{2} \mathrm{H}_{6}$ & ${ }^{1} J_{\mathrm{CC}}$ & 27,2 & 34,5 \\
\hline $\mathrm{C}_{2} \mathrm{H}_{6}$ & ${ }^{1} J_{\mathrm{CH}}$ & 103,7 & 125,2 \\
\hline $\mathrm{C}_{2} \mathrm{H}_{6}$ & ${ }^{2} J_{\mathrm{CH}}$ & $-1,3$ & $-4,7$ \\
\hline \multirow[t]{3}{*}{ Total } & DM & $-15,17$ & - \\
\hline & DMA & 24,25 & - \\
\hline & PDMA & 47,94 & - \\
\hline \multirow[t]{3}{*}{ CPI } & DM & $-26,80$ & - \\
\hline & DMA & 42,40 & - \\
\hline & PDMA & 58,57 & - \\
\hline \multirow[t]{3}{*}{ SPI } & DM & $-6,64$ & - \\
\hline & DMA & 10,93 & - \\
\hline & PDMA & 40,15 & - \\
\hline \multirow[t]{3}{*}{$\Delta \mathrm{CS}$} & DM & $-20,16$ & - \\
\hline & DMA & 31,47 & - \\
\hline & PDMA & 18,42 & - \\
\hline
\end{tabular}


Tabela 8.348: Constantes de acoplamento LC-B98(X) variando $\alpha$ com $\alpha+\beta=100 \%$ na base aug-pcJ-2. O valor de $\gamma=0,30$ corresponde ao $\omega$ B97X.

\begin{tabular}{|c|c|c|c|c|c|c|c|c|c|c|c|}
\hline & $\alpha$ & $10 \%$ & $20 \%$ & $30 \%$ & $40 \%$ & $50 \%$ & $60 \%$ & $70 \%$ & $80 \%$ & $90 \%$ & Exp. \\
\hline $\mathrm{HF}$ & ${ }^{1} J_{\mathrm{HF}}$ & 432,2 & 447,3 & 466,9 & 491,8 & 523,1 & 561,8 & 608,9 & 665,2 & 731,2 & 500 \\
\hline $\mathrm{CO}$ & ${ }^{1} J_{\mathrm{CO}}$ & 18,0 & 18,7 & 19,0 & 18,7 & 17,7 & 15,7 & 12,3 & 6,9 & $-0,8$ & 16,4 \\
\hline $\mathrm{H}_{2} \mathrm{O}$ & ${ }^{1} J_{\mathrm{OH}}$ & $-69,9$ & $-73,5$ & $-77,9$ & $-83,3$ & $-89,7$ & $-97,4$ & $-106,9$ & $-118,3$ & $-132,2$ & $-80,6$ \\
\hline $\mathrm{H}_{2} \mathrm{O}$ & ${ }^{2} J_{\mathrm{HH}}$ & $-3,2$ & $-6,1$ & $-9,7$ & $-14,2$ & $-20,0$ & $-27,4$ & $-36,7$ & $-48,7$ & $-64,0$ & $-7,3$ \\
\hline $\mathrm{NH}_{3}$ & ${ }^{1} J_{\mathrm{NH}}$ & 39,2 & 42,1 & 45,6 & 49,6 & 54,4 & 60,2 & 67,2 & 75,8 & 86,7 & 43,8 \\
\hline $\mathrm{NH}_{3}$ & ${ }^{2} J_{\mathrm{HH}}$ & $-5,9$ & $-8,7$ & $-12,4$ & $-17,2$ & $-23,4$ & $-31,8$ & $-43,1$ & $-58,4$ & $-79,7$ & $-9,6$ \\
\hline $\mathrm{PH}_{3}$ & ${ }^{1} J_{\mathrm{PH}}$ & 157,2 & 175,3 & 197,0 & 223,1 & 255,0 & 294,0 & 342,3 & 403,1 & 480,9 & 188,2 \\
\hline $\mathrm{PF}_{3}$ & ${ }^{1} J_{\mathrm{PF}}$ & $-1664,0$ & $-1670,5$ & $-1672,7$ & $-1671,3$ & $-1667,2$ & $-1661,5$ & $-1655,1$ & $-1649,1$ & $-1644,0$ & -1441 \\
\hline $\mathrm{BHF}_{2}$ & ${ }^{1} J_{\mathrm{BF}}$ & $-125,0$ & $-118,0$ & $-108,9$ & $-97,6$ & $-84,2$ & $-69,0$ & $-52,1$ & $-33,7$ & $-14,3$ & -84 \\
\hline $\mathrm{BF}_{3}$ & ${ }^{1} J_{\mathrm{BF}}$ & $-28,1$ & $-18,8$ & $-7,2$ & 6,5 & 22,7 & 41,4 & 62,5 & 86,1 & 112,2 & 15 \\
\hline $\mathrm{F}_{2} \mathrm{O}$ & ${ }^{1} J_{\mathrm{OF}}$ & $-307,0$ & $-376,9$ & $-470,9$ & $-622,6$ & $-1000,7$ & 1370,2 & 704,0 & $-31,1$ & $-266,8$ & -300 \\
\hline $\mathrm{CH}_{4}$ & ${ }^{1} J_{\mathrm{CH}}$ & 109,0 & 121,7 & 136,8 & 154,7 & 176,2 & 202,3 & 234,8 & 275,8 & 329,0 & 125,3 \\
\hline $\mathrm{CH}_{4}$ & ${ }^{2} J_{\mathrm{HH}}$ & $-8,4$ & $-11,4$ & $-15,3$ & $-20,4$ & $-27,2$ & $-36,4$ & $-49,0$ & $-66,5$ & $-91,7$ & $-12,8$ \\
\hline $\mathrm{C}_{2} \mathrm{H}_{2}$ & ${ }^{1} J_{\mathrm{CC}}$ & 193,1 & 207,0 & 226,9 & 260,3 & 334,1 & 701,0 & $-306,0$ & 25,5 & 129,0 & 174,8 \\
\hline $\mathrm{C}_{2} \mathrm{H}_{2}$ & ${ }^{1} J_{\mathrm{CH}}$ & 218,8 & 247,7 & 282,9 & 329,1 & 402,9 & 657,3 & 82,5 & 319,1 & 407,6 & 247,6 \\
\hline $\mathrm{C}_{2} \mathrm{H}_{2}$ & ${ }^{2} J_{\mathrm{CH}}$ & 54,2 & 54,3 & 51,7 & 42,1 & 9,6 & $-197,9$ & 430,4 & 255,1 & 237,5 & 50,1 \\
\hline $\mathrm{C}_{2} \mathrm{H}_{2}$ & ${ }^{3} J_{\mathrm{HH}}$ & 7,1 & 9,5 & 13,8 & 22,5 & 45,6 & 175,6 & $-201,9$ & $-89,8$ & $-70,6$ & 9,6 \\
\hline $\mathrm{C}_{2} \mathrm{H}_{4}$ & ${ }^{1} J_{\mathrm{CC}}$ & 66,3 & 73,8 & 85,7 & 108,7 & 177,2 & $-2365,7$ & $-67,8$ & $-8,6$ & 12,6 & 67,6 \\
\hline $\mathrm{C}_{2} \mathrm{H}_{4}$ & ${ }^{1} J_{\mathrm{CH}}$ & 137,0 & 154,7 & 176,6 & 206,4 & 261,2 & $-951,1$ & 196,6 & 260,4 & 313,1 & 156,3 \\
\hline $\mathrm{C}_{2} \mathrm{H}_{4}$ & ${ }^{2} J_{\mathrm{CH}}$ & 0,5 & $-1,9$ & $-6,4$ & $-16,1$ & $-47,8$ & 1191,7 & 75,8 & 49,9 & 42,9 & $-2,4$ \\
\hline $\mathrm{C}_{2} \mathrm{H}_{4}$ & ${ }^{2} J_{\mathrm{HH}}$ & 4,9 & 3,4 & 0,5 & $-5,7$ & $-25,7$ & 726,2 & 46,2 & 27,5 & 18,8 & 2,3 \\
\hline $\mathrm{C}_{2} \mathrm{H}_{4}$ & ${ }^{3} J_{\mathrm{HH}_{\mathrm{c}}}$ & 10,6 & 12,0 & 14,4 & 19,8 & 38,2 & $-715,9$ & $-39,2$ & $-25,3$ & $-23,7$ & 11,7 \\
\hline $\mathrm{C}_{2} \mathrm{H}_{4}$ & ${ }^{3} J_{\mathrm{HH}_{\mathrm{t}}}$ & 15,1 & 17,7 & 21,6 & 29,0 & 50,8 & $-760,1$ & $-27,8$ & $-9,5$ & $-3,6$ & 19 \\
\hline $\mathrm{C}_{2} \mathrm{H}_{6}$ & ${ }^{1} J_{\mathrm{CC}}$ & 29,1 & 33,4 & 38,8 & 45,5 & 54,1 & 65,3 & 80,1 & 100,5 & 129,6 & 34,5 \\
\hline $\mathrm{C}_{2} \mathrm{H}_{6}$ & ${ }^{1} J_{\mathrm{CH}}$ & 108,8 & 122,3 & 138,3 & 157,3 & 180,2 & 208,2 & 243,2 & 287,8 & 346,5 & 125,2 \\
\hline $\mathrm{C}_{2} \mathrm{H}_{6}$ & ${ }^{2} J_{\mathrm{CH}}$ & $-2,1$ & $-3,5$ & $-5,3$ & $-7,7$ & $-10,8$ & $-15,1$ & $-21,1$ & $-29,9$ & $-43,3$ & $-4,7$ \\
\hline \multirow[t]{3}{*}{ Total } & DM & $-17,60$ & $-15,13$ & $-12,12$ & $-9,08$ & $-9,18$ & $-19,36$ & 28,27 & 31,72 & 42,23 & - \\
\hline & DMA & 21,83 & 19,65 & 26,10 & 40,21 & 75,21 & 412,15 & 139,85 & 94,40 & 100,31 & - \\
\hline & PDMA & 37,62 & 20,70 & 31,70 & 76,56 & 208,75 & 3868,17 & 461,33 & 342,87 & 357,41 & - \\
\hline \multirow[t]{3}{*}{ CPI } & DM & $-36,13$ & $-39,09$ & $-42,92$ & $-50,67$ & $-77,56$ & 146,85 & 96,58 & 41,54 & 33,48 & - \\
\hline & DMA & 39,78 & 41,18 & 45,81 & 58,49 & 97,47 & 197,81 & 152,47 & 104,35 & 105,95 & - \\
\hline & PDMA & 46,57 & 34,30 & 31,58 & 38,26 & 63,83 & 127,60 & 151,87 & 185,31 & 248,33 & - \\
\hline \multirow[t]{3}{*}{ SPI } & DM & $-4,01$ & 2,44 & 10,46 & 21,43 & 40,97 & $-141,25$ & $-21,82$ & 24,53 & 48,64 & - \\
\hline & DMA & 8,66 & 3,85 & 11,65 & 26,80 & 58,89 & 569,34 & 130,59 & 87,10 & 96,17 & - \\
\hline & PDMA & 31,06 & 10,73 & 31,79 & 104,65 & 315,03 & 6611,25 & 688,26 & 458,42 & 437,40 & - \\
\hline \multirow[t]{3}{*}{$\Delta \mathrm{CS}$} & $\mathrm{DM}$ & $-32,12$ & $-41,53$ & $-53,38$ & $-72,10$ & $-118,53$ & 288,09 & 118,40 & 17,01 & $-15,16$ & - \\
\hline & DMA & 31,12 & 37,33 & 34,16 & 31,69 & 38,59 & $-371,53$ & 21,88 & 17,25 & 9,78 & - \\
\hline & PDMA & 15,51 & 23,57 & $-0,21$ & $-66,39$ & $-251,21$ & $-6483,65$ & $-536,39$ & $-273,11$ & $-189,07$ & - \\
\hline
\end{tabular}


Tabela 8.349: Constantes de acoplamento LC-B98(X) variando $\alpha$ com $\alpha+$ $\beta=80 \%$ na base aug-pcJ-2. O valor de $\gamma=0,30$ corresponde ao $\omega \mathrm{B} 97 \mathrm{X}$.

\begin{tabular}{|c|c|c|c|c|c|c|c|c|c|}
\hline & $\alpha$ & $10 \%$ & $20 \%$ & $30 \%$ & $40 \%$ & $50 \%$ & $60 \%$ & $70 \%$ & Exp. \\
\hline $\mathrm{HF}$ & ${ }^{\mathrm{I}} J_{\mathrm{HF}}$ & 434,2 & 448,5 & 467,2 & 491,2 & 521,5 & 559,1 & 605,2 & 500 \\
\hline $\mathrm{CO}$ & ${ }^{1} J_{\mathrm{CO}}$ & 17,6 & 18,3 & 18,5 & 18,3 & 17,3 & 15,2 & 11,7 & 16,4 \\
\hline $\mathrm{H}_{2} \mathrm{O}$ & ${ }^{1} J_{\mathrm{OH}}$ & $-70,0$ & $-73,5$ & $-77,8$ & $-83,0$ & $-89,3$ & $-96,9$ & $-106,1$ & $-80,6$ \\
\hline $\mathrm{H}_{2} \mathrm{O}$ & ${ }^{2} J_{\mathrm{HH}}$ & $-2,9$ & $-5,7$ & $-9,3$ & $-13,8$ & $-19,4$ & $-26,7$ & $-35,9$ & $-7,3$ \\
\hline $\mathrm{NH}_{3}$ & ${ }^{1} J_{\mathrm{NH}}$ & 39,1 & 42,0 & 45,4 & 49,4 & 54,0 & 59,7 & 66,5 & 43,8 \\
\hline $\mathrm{NH}_{3}$ & ${ }^{2} J_{\mathrm{HH}}$ & $-5,5$ & $-8,3$ & $-11,8$ & $-16,4$ & $-22,6$ & $-30,7$ & $-41,6$ & $-9,6$ \\
\hline $\mathrm{PH}_{3}$ & ${ }^{1} J_{\mathrm{PH}}$ & 162,9 & 180,6 & 201,8 & 227,5 & 258,7 & 296,9 & 344,3 & 188,2 \\
\hline $\mathrm{PF}_{3}$ & ${ }^{1} J_{\mathrm{PF}}$ & $-1660,4$ & $-1669,4$ & $-1673,7$ & $-1674,0$ & $-1671,2$ & $-1666,3$ & $-1660,5$ & -1441 \\
\hline $\mathrm{BHF}_{2}$ & ${ }^{1} J_{\mathrm{BF}}$ & $-130,2$ & $-123,4$ & $-114,4$ & $-103,2$ & $-90,0$ & $-74,8$ & $-57,8$ & -84 \\
\hline $\mathrm{BF}_{3}$ & ${ }^{1} J_{\mathrm{BF}}$ & $-33,4$ & $-24,1$ & $-12,6$ & 1,1 & 17,2 & 35,9 & 57,0 & 15 \\
\hline $\mathrm{F}_{2} \mathrm{O}$ & ${ }^{1} J_{\mathrm{OF}}$ & $-296,1$ & $-363,7$ & $-452,9$ & $-591,7$ & $-906,6$ & 11760,5 & 1012,4 & -300 \\
\hline $\mathrm{CH}_{4}$ & ${ }^{1} J_{\mathrm{CH}}$ & 108,3 & 120,8 & 135,5 & 153,0 & 174,0 & 199,6 & 231,3 & 125,3 \\
\hline $\mathrm{CH}_{4}$ & ${ }^{2} J_{\mathrm{HH}}$ & $-7,9$ & $-10,8$ & $-14,5$ & $-19,5$ & $-26,0$ & $-34,8$ & $-46,9$ & $-12,8$ \\
\hline $\mathrm{C}_{2} \mathrm{H}_{2}$ & ${ }^{1} J_{\mathrm{CC}}$ & 191,8 & 205,0 & 223,6 & 253,6 & 315,3 & 543,8 & $-688,0$ & 174,8 \\
\hline $\mathrm{C}_{2} \mathrm{H}_{2}$ & ${ }^{1} J_{\mathrm{CH}}$ & 216,6 & 245,0 & 279,2 & 323,1 & 389,2 & 558,9 & $-145,2$ & 247,6 \\
\hline $\mathrm{C}_{2} \mathrm{H}_{2}$ & ${ }^{2} J_{\mathrm{CH}}$ & 53,6 & 54,0 & 52,0 & 44,2 & 19,0 & $-104,2$ & 652,8 & 50,1 \\
\hline $\mathrm{C}_{2} \mathrm{H}_{2}$ & ${ }^{3} J_{\mathrm{HH}}$ & 6,8 & 9,0 & 12,8 & 20,3 & 38,7 & 116,6 & $-335,3$ & 9,6 \\
\hline $\mathrm{C}_{2} \mathrm{H}_{4}$ & ${ }^{1} J_{\mathrm{CC}}$ & 65,6 & 72,6 & 83,3 & 102,7 & 151,3 & 595,1 & $-123,2$ & 67,6 \\
\hline $\mathrm{C}_{2} \mathrm{H}_{4}$ & ${ }^{1} J_{\mathrm{CH}}$ & 135,6 & 153,0 & 174,1 & 201,9 & 246,9 & 489,1 & 166,0 & 156,3 \\
\hline $\mathrm{C}_{2} \mathrm{H}_{4}$ & ${ }^{2} J_{\mathrm{CH}}$ & 0,8 & $-1,4$ & $-5,4$ & $-13,4$ & $-35,6$ & $-251,1$ & 103,3 & $-2,4$ \\
\hline $\mathrm{C}_{2} \mathrm{H}_{4}$ & ${ }^{2} J_{\mathrm{HH}}$ & 5,2 & 3,8 & 1,3 & $-3,8$ & $-17,8$ & $-148,5$ & 62,7 & 2,3 \\
\hline $\mathrm{C}_{2} \mathrm{H}_{4}$ & ${ }^{3} J_{\mathrm{HH}_{\mathrm{c}}}$ & 10,5 & 11,6 & 13,7 & 18,0 & 30,6 & 159,2 & $-55,1$ & 11,7 \\
\hline $\mathrm{C}_{2} \mathrm{H}_{4}$ & ${ }^{3} J_{\mathrm{HH}_{\mathrm{t}}}$ & 14,8 & 17,2 & 20,8 & 27,0 & 42,4 & 182,8 & $-45,0$ & 19 \\
\hline $\mathrm{C}_{2} \mathrm{H}_{6}$ & ${ }^{1} J_{\mathrm{CC}}$ & 28,4 & 32,5 & 37,8 & 44,3 & 52,6 & 63,4 & 77,8 & 34,5 \\
\hline $\mathrm{C}_{2} \mathrm{H}_{6}$ & ${ }^{1} J_{\mathrm{CH}}$ & 108,0 & 121,2 & 136,8 & 155,4 & 177,8 & 205,2 & 239,3 & 125,2 \\
\hline $\mathrm{C}_{2} \mathrm{H}_{6}$ & ${ }^{2} J_{\mathrm{CH}}$ & $-1,9$ & $-3,2$ & $-5,0$ & $-7,2$ & $-10,3$ & $-14,4$ & $-20,1$ & $-4,7$ \\
\hline \multirow[t]{3}{*}{ Total } & $\mathrm{DM}$ & $-17,44$ & $-15,13$ & $-12,25$ & $-9,23$ & $-8,74$ & 521,06 & 16,33 & - \\
\hline & DMA & 21,94 & 19,52 & 25,18 & 38,04 & 66,63 & 587,89 & 191,86 & - \\
\hline & PDMA & 40,93 & 24,54 & 27,90 & 66,09 & 161,72 & 1045,57 & 625,96 & - \\
\hline \multirow[t]{3}{*}{ CPI } & DM & $-35,05$ & $-38,15$ & $-41,86$ & $-48,68$ & $-70,12$ & 1090,09 & 123,12 & - \\
\hline & DMA & 39,45 & 40,31 & 45,52 & 57,19 & 89,26 & 1141,60 & 179,54 & - \\
\hline & PDMA & 50,45 & 38,09 & 33,76 & 39,89 & 56,59 & 436,82 & 155,01 & - \\
\hline \multirow[t]{3}{*}{ SPI } & $\mathrm{DM}$ & $-4,53$ & 1,75 & 9,46 & 19,70 & 36,27 & 103,77 & $-61,98$ & - \\
\hline & DMA & 9,10 & 4,27 & 10,26 & 23,99 & 50,03 & 181,84 & 200,90 & - \\
\hline & PDMA & 33,95 & 14,61 & 23,61 & 85,31 & 238,81 & 1491,98 & 971,32 & - \\
\hline \multirow[t]{3}{*}{$\Delta \mathrm{CS}$} & $\mathrm{DM}$ & $-30,53$ & $-39,89$ & $-51,32$ & $-68,38$ & $-106,38$ & 986,32 & 185,10 & - \\
\hline & DMA & 30,35 & 36,04 & 35,26 & 33,20 & 39,24 & 959,76 & $-21,36$ & - \\
\hline & PDMA & 16,50 & 23,47 & 10,15 & $-45,42$ & $-182,22$ & $-1055,16$ & $-816,31$ & - \\
\hline
\end{tabular}


Tabela 8.350: Constantes de acoplamento LC-B98(X) variando $\alpha$ com $\alpha+\beta=60 \%$ na base aug-pcJ-2. O valor de $\gamma=0,30$ corresponde ao $\omega \mathrm{B} 97 \mathrm{X}$.

\begin{tabular}{|c|c|c|c|c|c|c|c|}
\hline & $\alpha$ & $10 \%$ & $20 \%$ & $30 \%$ & $40 \%$ & $50 \%$ & Exp. \\
\hline $\mathrm{HF}$ & ${ }^{1} J_{\mathrm{HF}}$ & 436,4 & 450,0 & 467,8 & 490,8 & 520,1 & 500 \\
\hline $\mathrm{CO}$ & ${ }^{1} J_{\mathrm{CO}}$ & 17,2 & 17,8 & 18,1 & 17,8 & 16,8 & 16,4 \\
\hline $\mathrm{H}_{2} \mathrm{O}$ & ${ }^{1} J_{\mathrm{OH}}$ & $-70,1$ & $-73,6$ & $-77,7$ & $-82,8$ & $-88,9$ & $-80,6$ \\
\hline $\mathrm{H}_{2} \mathrm{O}$ & ${ }^{2} J_{\mathrm{HH}}$ & $-2,6$ & $-5,4$ & $-8,9$ & $-13,3$ & $-18,9$ & $-7,3$ \\
\hline $\mathrm{NH}_{3}$ & ${ }^{1} J_{\mathrm{NH}}$ & 39,2 & 42,0 & 45,3 & 49,1 & 53,7 & 43,8 \\
\hline $\mathrm{NH}_{3}$ & ${ }^{2} J_{\mathrm{HH}}$ & $-5,1$ & $-7,8$ & $-11,2$ & $-15,7$ & $-21,7$ & $-9,6$ \\
\hline $\mathrm{PH}_{3}$ & ${ }^{1} J_{\mathrm{PH}}$ & 169,1 & 186,4 & 207,2 & 232,3 & 262,9 & 188,2 \\
\hline $\mathrm{PF}_{3}$ & ${ }^{1} J_{\mathrm{PF}}$ & $-1654,6$ & $-1666,6$ & $-1673,3$ & $-1675,5$ & $-1674,1$ & -1441 \\
\hline $\mathrm{BHF}_{2}$ & ${ }^{1} J_{\mathrm{BF}}$ & $-135,4$ & $-128,8$ & $-120,0$ & $-108,9$ & $-95,8$ & -84 \\
\hline $\mathrm{BF}_{3}$ & ${ }^{1} J_{\mathrm{BF}}$ & $-38,8$ & $-29,6$ & $-18,1$ & $-4,4$ & 11,7 & 15 \\
\hline $\mathrm{F}_{2} \mathrm{O}$ & ${ }^{1} J_{\mathrm{OF}}$ & $-285,4$ & $-351,0$ & $-436,0$ & $-563,9$ & $-831,5$ & -300 \\
\hline $\mathrm{CH}_{4}$ & ${ }^{1} J_{\mathrm{CH}}$ & 107,7 & 120,0 & 134,4 & 151,5 & 172,0 & 125,3 \\
\hline $\mathrm{CH}_{4}$ & ${ }^{2} J_{\mathrm{HH}}$ & $-7,4$ & $-10,2$ & $-13,8$ & $-18,5$ & $-24,8$ & $-12,8$ \\
\hline $\mathrm{C}_{2} \mathrm{H}_{2}$ & ${ }^{1} J_{\mathrm{CC}}$ & 190,6 & 203,2 & 220,6 & 247,8 & 300,4 & 174,8 \\
\hline $\mathrm{C}_{2} \mathrm{H}_{2}$ & ${ }^{1} J_{\mathrm{CH}}$ & 214,5 & 242,4 & 275,7 & 317,8 & 378,2 & 247,6 \\
\hline $\mathrm{C}_{2} \mathrm{H}_{2}$ & ${ }^{2} J_{\mathrm{CH}}$ & 53,0 & 53,6 & 52,1 & 45,9 & 25,9 & 50,1 \\
\hline $\mathrm{C}_{2} \mathrm{H}_{2}$ & ${ }^{3} J_{\mathrm{HH}}$ & 6,6 & 8,5 & 11,9 & 18,4 & 33,4 & 9,6 \\
\hline $\mathrm{C}_{2} \mathrm{H}_{4}$ & ${ }^{1} J_{\mathrm{CC}}$ & 65,0 & 71,5 & 81,3 & 98,0 & 135,1 & 67,6 \\
\hline $\mathrm{C}_{2} \mathrm{H}_{4}$ & ${ }^{1} J_{\mathrm{CH}}$ & 134,4 & 151,3 & 171,8 & 198,1 & 237,2 & 156,3 \\
\hline $\mathrm{C}_{2} \mathrm{H}_{4}$ & ${ }^{2} J_{\mathrm{CH}}$ & 1,1 & $-0,9$ & $-4,5$ & $-11,3$ & $-28,0$ & $-2,4$ \\
\hline $\mathrm{C}_{2} \mathrm{H}_{4}$ & ${ }^{2} J_{\mathrm{HH}}$ & 5,3 & 4,1 & 1,9 & $-2,3$ & $-12,8$ & 2,3 \\
\hline $\mathrm{C}_{2} \mathrm{H}_{4}$ & ${ }^{3} J_{\mathrm{HH}_{\mathrm{c}}}$ & 10,3 & 11,4 & 13,2 & 16,7 & 25,9 & 11,7 \\
\hline $\mathrm{C}_{2} \mathrm{H}_{4}$ & ${ }^{3} J_{\mathrm{HH}_{\mathrm{t}}}$ & 14,5 & 16,8 & 20,1 & 25,5 & 37,2 & 19 \\
\hline $\mathrm{C}_{2} \mathrm{H}_{6}$ & ${ }^{1} J_{\mathrm{CC}}$ & 27,6 & 31,7 & 36,7 & 43,1 & 51,2 & 34,5 \\
\hline $\mathrm{C}_{2} \mathrm{H}_{6}$ & ${ }^{1} J_{\mathrm{CH}}$ & 107,2 & 120,2 & 135,5 & 153,7 & 175,6 & 125,2 \\
\hline $\mathrm{C}_{2} \mathrm{H}_{6}$ & ${ }^{2} J_{\mathrm{CH}}$ & $-1,6$ & $-3,0$ & $-4,6$ & $-6,8$ & $-9,7$ & $-4,7$ \\
\hline \multirow[t]{3}{*}{ Total } & $\mathrm{DM}$ & $-17,17$ & $-15,04$ & $-12,29$ & $-9,30$ & $-8,23$ & - \\
\hline & DMA & 22,46 & 19,31 & 24,35 & 36,21 & 60,51 & - \\
\hline & PDMA & 44,15 & 28,23 & 24,94 & 57,89 & 132,01 & - \\
\hline \multirow[t]{3}{*}{ CPI } & $\mathrm{DM}$ & $-33,73$ & $-37,05$ & $-40,70$ & $-46,85$ & $-64,24$ & - \\
\hline & DMA & 40,11 & 39,25 & 45,26 & 56,09 & 83,35 & - \\
\hline & PDMA & 54,73 & 41,85 & 36,14 & 41,60 & 53,94 & - \\
\hline \multirow[t]{3}{*}{ SPI } & $\mathrm{DM}$ & $-5,02$ & 1,10 & 8,55 & 18,23 & 32,85 & - \\
\hline & DMA & 9,51 & 4,69 & 9,01 & 21,63 & 43,77 & - \\
\hline & PDMA & 36,39 & 18,23 & 16,73 & 69,83 & 189,26 & - \\
\hline \multirow[t]{3}{*}{$\Delta \mathrm{CS}$} & $\mathrm{DM}$ & $-28,71$ & $-38,15$ & $-49,25$ & $-65,09$ & $-97,08$ & - \\
\hline & DMA & 30,60 & 34,56 & 36,25 & 34,46 & 39,58 & - \\
\hline & PDMA & 18,35 & 23,62 & 19,40 & $-28,23$ & $-135,31$ & - \\
\hline
\end{tabular}


Tabela 8.351: Constantes de acoplamento LC$\mathrm{B} 98(\mathrm{X})$ variando $\alpha$ com $\alpha+\beta=40 \%$ na base aug-pcJ-2. O valor de $\gamma=0,30$ corresponde ao $\omega \mathrm{B} 97 \mathrm{X}$.

\begin{tabular}{|c|c|c|c|c|c|}
\hline & $\alpha$ & $10 \%$ & $20 \%$ & $30 \%$ & Exp. \\
\hline $\mathrm{HF}$ & ${ }^{1} J_{\mathrm{HF}}$ & 438,9 & 451,8 & 468,7 & 500 \\
\hline $\mathrm{CO}$ & ${ }^{1} J_{\mathrm{CO}}$ & 16,7 & 17,3 & 17,6 & 16,4 \\
\hline $\mathrm{H}_{2} \mathrm{O}$ & ${ }^{1} J_{\mathrm{OH}}$ & $-70,3$ & $-73,7$ & $-77,7$ & $-80,6$ \\
\hline $\mathrm{H}_{2} \mathrm{O}$ & ${ }^{2} J_{\mathrm{HH}}$ & $-2,3$ & $-5,0$ & $-8,4$ & $-7,3$ \\
\hline $\mathrm{NH}_{3}$ & ${ }^{1} J_{\mathrm{NH}}$ & 39,2 & 42,0 & 45,2 & 43,8 \\
\hline $\mathrm{NH}_{3}$ & ${ }^{2} J_{\mathrm{HH}}$ & $-4,8$ & $-7,3$ & $-10,7$ & $-9,6$ \\
\hline $\mathrm{PH}_{3}$ & ${ }^{1} J_{\mathrm{PH}}$ & 175,8 & 192,7 & 213,0 & 188,2 \\
\hline $\mathrm{PF}_{3}$ & ${ }^{1} J_{\mathrm{PF}}$ & $-1646,3$ & $-1661,6$ & $-1671,1$ & -1441 \\
\hline $\mathrm{BHF}_{2}$ & ${ }^{1} J_{\mathrm{BF}}$ & $-140,6$ & $-134,3$ & $-125,6$ & -84 \\
\hline $\mathrm{BF}_{3}$ & ${ }^{1} J_{\mathrm{BF}}$ & $-44,3$ & $-35,1$ & $-23,7$ & 15 \\
\hline $\mathrm{F}_{2} \mathrm{O}$ & ${ }^{1} J_{\mathrm{OF}}$ & $-274,9$ & $-338,6$ & $-420,1$ & -300 \\
\hline $\mathrm{CH}_{4}$ & ${ }^{1} J_{\mathrm{CH}}$ & 107,2 & 119,2 & 133,3 & 125,3 \\
\hline $\mathrm{CH}_{4}$ & ${ }^{2} J_{\mathrm{HH}}$ & $-6,9$ & $-9,6$ & $-13,0$ & $-12,8$ \\
\hline $\mathrm{C}_{2} \mathrm{H}_{2}$ & ${ }^{1} J_{\mathrm{CC}}$ & 189,5 & 201,5 & 217,8 & 174,8 \\
\hline $\mathrm{C}_{2} \mathrm{H}_{2}$ & ${ }^{1} J_{\mathrm{CH}}$ & 212,6 & 240,0 & 272,5 & 247,6 \\
\hline $\mathrm{C}_{2} \mathrm{H}_{2}$ & ${ }^{2} J_{\mathrm{CH}}$ & 52,3 & 53,1 & 52,1 & 50,1 \\
\hline $\mathrm{C}_{2} \mathrm{H}_{2}$ & ${ }^{3} J_{\mathrm{HH}}$ & 6,4 & 8,1 & 11,1 & 9,6 \\
\hline $\mathrm{C}_{2} \mathrm{H}_{4}$ & ${ }^{1} J_{\mathrm{CC}}$ & 64,4 & 70,5 & 79,5 & 67,6 \\
\hline $\mathrm{C}_{2} \mathrm{H}_{4}$ & ${ }^{1} J_{\mathrm{CH}}$ & 133,3 & 149,8 & 169,7 & 156,3 \\
\hline $\mathrm{C}_{2} \mathrm{H}_{4}$ & ${ }^{2} J_{\mathrm{CH}}$ & 1,4 & $-0,5$ & $-3,7$ & $-2,4$ \\
\hline $\mathrm{C}_{2} \mathrm{H}_{4}$ & ${ }^{2} J_{\mathrm{HH}}$ & 5,5 & 4,4 & 2,5 & 2,3 \\
\hline $\mathrm{C}_{2} \mathrm{H}_{4}$ & ${ }^{3} J_{\mathrm{HH}_{\mathrm{c}}}$ & 10,1 & 11,1 & 12,7 & 11,7 \\
\hline $\mathrm{C}_{2} \mathrm{H}_{4}$ & ${ }^{3} J_{\mathrm{HH}_{\mathrm{t}}}$ & 14,2 & 16,4 & 19,5 & 19 \\
\hline $\mathrm{C}_{2} \mathrm{H}_{6}$ & ${ }^{1} J_{\mathrm{CC}}$ & 26,8 & 30,8 & 35,7 & 34,5 \\
\hline $\mathrm{C}_{2} \mathrm{H}_{6}$ & ${ }^{1} J_{\mathrm{CH}}$ & 106,5 & 119,2 & 134,2 & 125,2 \\
\hline $\mathrm{C}_{2} \mathrm{H}_{6}$ & ${ }^{2} J_{\mathrm{CH}}$ & $-1,4$ & $-2,7$ & $-4,3$ & $-4,7$ \\
\hline \multirow[t]{3}{*}{ Total } & DM & $-16,77$ & $-14,83$ & $-12,24$ & - \\
\hline & DMA & 22,82 & 19,34 & 23,57 & - \\
\hline & PDMA & 47,38 & 32,05 & 23,28 & - \\
\hline \multirow[t]{3}{*}{ CPI } & $\mathrm{DM}$ & $-32,16$ & $-35,70$ & $-39,43$ & - \\
\hline & DMA & 40,44 & 38,77 & 44,94 & - \\
\hline & PDMA & 58,89 & 46,16 & 38,51 & - \\
\hline \multirow[t]{3}{*}{ SPI } & DM & $-5,48$ & 0,48 & 7,70 & - \\
\hline & DMA & 9,89 & 5,09 & 7,90 & - \\
\hline & PDMA & 38,94 & 21,71 & 12,11 & - \\
\hline \multirow[t]{3}{*}{$\Delta \mathrm{CS}$} & $\mathrm{DM}$ & $-26,68$ & $-36,18$ & $-47,13$ & - \\
\hline & DMA & 30,54 & 33,68 & 37,04 & - \\
\hline & PDMA & 19,94 & 24,45 & 26,40 & - \\
\hline
\end{tabular}


Tabela 8.352: Constantes de acoplamento LC-B98(X) variando $\alpha$ com $\alpha+\beta=20 \%$ na base aug-pcJ-2. O valor de $\gamma=0,30$ corresponde ao $\omega \mathrm{B} 97 \mathrm{X}$.

\begin{tabular}{|c|c|c|c|}
\hline & $\alpha$ & $10 \%$ & Exp. \\
\hline $\mathrm{HF}$ & ${ }^{1} J_{\mathrm{HF}}$ & 441,7 & 500 \\
\hline $\mathrm{CO}$ & ${ }^{1} J_{\mathrm{CO}}$ & 16,2 & 16,4 \\
\hline $\mathrm{H}_{2} \mathrm{O}$ & ${ }^{1} J_{\mathrm{OH}}$ & $-70,6$ & $-80,6$ \\
\hline $\mathrm{H}_{2} \mathrm{O}$ & ${ }^{2} J_{\mathrm{HH}}$ & $-2,0$ & $-7,3$ \\
\hline $\mathrm{NH}_{3}$ & ${ }^{1} J_{\mathrm{NH}}$ & 39,3 & 43,8 \\
\hline $\mathrm{NH}_{3}$ & ${ }^{2} J_{\mathrm{HH}}$ & $-4,4$ & $-9,6$ \\
\hline $\mathrm{PH}_{3}$ & ${ }^{1} J_{\mathrm{PH}}$ & 183,0 & 188,2 \\
\hline $\mathrm{PF}_{3}$ & ${ }^{1} J_{\mathrm{PF}}$ & $-1634,9$ & -1441 \\
\hline $\mathrm{BHF}_{2}$ & ${ }^{1} J_{\mathrm{BF}}$ & $-145,8$ & -84 \\
\hline $\mathrm{BF}_{3}$ & ${ }^{1} J_{\mathrm{BF}}$ & $-49,8$ & 15 \\
\hline $\mathrm{F}_{2} \mathrm{O}$ & ${ }^{1} J_{\mathrm{OF}}$ & $-264,6$ & -300 \\
\hline $\mathrm{CH}_{4}$ & ${ }^{1} J_{\mathrm{CH}}$ & 106,8 & 125,3 \\
\hline $\mathrm{CH}_{4}$ & ${ }^{2} J_{\mathrm{HH}}$ & $-6,4$ & $-12,8$ \\
\hline $\mathrm{C}_{2} \mathrm{H}_{2}$ & ${ }^{1} J_{\mathrm{CC}}$ & 188,3 & 174,8 \\
\hline $\mathrm{C}_{2} \mathrm{H}_{2}$ & ${ }^{1} J_{\mathrm{CH}}$ & 210,8 & 247,6 \\
\hline $\mathrm{C}_{2} \mathrm{H}_{2}$ & ${ }^{2} J_{\mathrm{CH}}$ & 51,6 & 50,1 \\
\hline $\mathrm{C}_{2} \mathrm{H}_{2}$ & ${ }^{3} J_{\mathrm{HH}}$ & 6,2 & 9,6 \\
\hline $\mathrm{C}_{2} \mathrm{H}_{4}$ & ${ }^{1} J_{\mathrm{CC}}$ & 63,8 & 67,6 \\
\hline $\mathrm{C}_{2} \mathrm{H}_{4}$ & ${ }^{1} J_{\mathrm{CH}}$ & 132,2 & 156,3 \\
\hline $\mathrm{C}_{2} \mathrm{H}_{4}$ & ${ }^{2} J_{\mathrm{CH}}$ & 1,7 & $-2,4$ \\
\hline $\mathrm{C}_{2} \mathrm{H}_{4}$ & ${ }^{2} J_{\mathrm{HH}}$ & 5,6 & 2,3 \\
\hline $\mathrm{C}_{2} \mathrm{H}_{4}$ & ${ }^{3} J_{\mathrm{HH}_{\mathrm{c}}}$ & 9,9 & 11,7 \\
\hline $\mathrm{C}_{2} \mathrm{H}_{4}$ & ${ }^{3} J_{\mathrm{HH}_{\mathrm{t}}}$ & 13,9 & 19 \\
\hline $\mathrm{C}_{2} \mathrm{H}_{6}$ & ${ }^{1} J_{\mathrm{CC}}$ & 26,1 & 34,5 \\
\hline $\mathrm{C}_{2} \mathrm{H}_{6}$ & ${ }^{1} J_{\mathrm{CH}}$ & 105,9 & 125,2 \\
\hline $\mathrm{C}_{2} \mathrm{H}_{6}$ & ${ }^{2} J_{\mathrm{CH}}$ & $-1,2$ & $-4,7$ \\
\hline \multirow[t]{3}{*}{ Total } & DM & $-16,22$ & - \\
\hline & DMA & 23,00 & - \\
\hline & PDMA & 50,52 & - \\
\hline \multirow[t]{3}{*}{ CPI } & DM & $-30,25$ & - \\
\hline & DMA & 40,42 & - \\
\hline & PDMA & 63,27 & - \\
\hline \multirow[t]{3}{*}{ SPI } & DM & $-5,93$ & - \\
\hline & DMA & 10,23 & - \\
\hline & PDMA & 41,17 & - \\
\hline \multirow[t]{3}{*}{$\Delta \mathrm{CS}$} & DM & $-24,33$ & - \\
\hline & DMA & 30,18 & - \\
\hline & PDMA & 22,09 & - \\
\hline
\end{tabular}


Tabela 8.353: Constantes de acoplamento LC-B98(XD) variando $\alpha$ com $\alpha+\beta=100 \%$ na base aug-pcJ-2. O valor de $\gamma=0,20$ corresponde ao $\omega$ B97XD.

\begin{tabular}{|c|c|c|c|c|c|c|c|c|c|c|c|}
\hline & $\alpha$ & $10 \%$ & $20 \%$ & $30 \%$ & $40 \%$ & $50 \%$ & $60 \%$ & $70 \%$ & $80 \%$ & $90 \%$ & Exp. \\
\hline $\mathrm{HF}$ & ${ }^{1} J_{\mathrm{HF}}$ & 427,8 & 440,6 & 458,3 & 482,0 & 512,8 & 551,9 & 600,3 & 658,9 & 728,1 & 500 \\
\hline $\mathrm{CO}$ & ${ }^{1} J_{\mathrm{CO}}$ & 17,7 & 18,5 & 18,9 & 18,8 & 17,8 & 15,8 & 12,3 & 6,9 & $-0,9$ & 16,4 \\
\hline $\mathrm{H}_{2} \mathrm{O}$ & ${ }^{1} J_{\mathrm{OH}}$ & $-69,4$ & $-72,8$ & $-77,1$ & $-82,3$ & $-88,8$ & $-96,7$ & $-106,4$ & $-118,3$ & $-132,9$ & $-80,6$ \\
\hline $\mathrm{H}_{2} \mathrm{O}$ & ${ }^{2} J_{\mathrm{HH}}$ & $-2,8$ & $-5,7$ & $-9,4$ & $-14,2$ & $-20,2$ & $-27,9$ & $-37,8$ & $-50,5$ & $-66,9$ & $-7,3$ \\
\hline $\mathrm{NH}_{3}$ & ${ }^{1} J_{\mathrm{NH}}$ & 39,2 & 42,1 & 45,5 & 49,5 & 54,4 & 60,4 & 67,7 & 76,8 & 88,4 & 43,8 \\
\hline $\mathrm{NH}_{3}$ & ${ }^{2} J_{\mathrm{HH}}$ & $-5,4$ & $-8,3$ & $-12,0$ & $-17,0$ & $-23,6$ & $-32,4$ & $-44,4$ & $-60,9$ & $-84,2$ & $-9,6$ \\
\hline $\mathrm{PH}_{3}$ & ${ }^{1} J_{\mathrm{PH}}$ & 165,7 & 182,4 & 203,0 & 228,5 & 260,1 & 299,5 & 349,2 & 412,7 & 495,3 & 188,2 \\
\hline $\mathrm{PF}_{3}$ & ${ }^{1} J_{\mathrm{PF}}$ & $-1656,6$ & $-1668,9$ & $-1674,5$ & $-1674,5$ & $-1670,3$ & $-1663,1$ & $-1654,3$ & $-1645,0$ & $-1635,7$ & -1441 \\
\hline $\mathrm{BHF}_{2}$ & ${ }^{1} J_{\mathrm{BF}}$ & $-137,0$ & $-128,7$ & $-117,8$ & $-104,7$ & $-89,2$ & $-71,8$ & $-52,6$ & $-31,9$ & $-10,3$ & -84 \\
\hline $\mathrm{BF}_{3}$ & ${ }^{1} J_{\mathrm{BF}}$ & $-42,2$ & $-31,1$ & $-17,7$ & $-1,9$ & 16,3 & 37,1 & 60,4 & 86,3 & 114,7 & 15 \\
\hline $\mathrm{F}_{2} \mathrm{O}$ & ${ }^{1} J_{\mathrm{OF}}$ & $-279,0$ & $-347,5$ & $-437,6$ & $-577,8$ & $-902,9$ & 3724,6 & 775,2 & $-31,7$ & $-269,4$ & -300 \\
\hline $\mathrm{CH}_{4}$ & ${ }^{1} J_{\mathrm{CH}}$ & 109,1 & 122,0 & 137,3 & 155,7 & 178,0 & 205,4 & 239,7 & 283,6 & 341,3 & 125,3 \\
\hline $\mathrm{CH}_{4}$ & ${ }^{2} J_{\mathrm{HH}}$ & $-7,8$ & $-10,9$ & $-14,9$ & $-20,3$ & $-27,5$ & $-37,2$ & $-50,8$ & $-70,0$ & $-98,1$ & $-12,8$ \\
\hline $\mathrm{C}_{2} \mathrm{H}_{2}$ & ${ }^{1} J_{\mathrm{CC}}$ & 192,3 & 205,7 & 225,1 & 257,4 & 329,2 & 688,6 & $-281,8$ & 36,4 & 150,2 & 174,8 \\
\hline $\mathrm{C}_{2} \mathrm{H}_{2}$ & ${ }^{1} J_{\mathrm{CH}}$ & 218,4 & 247,9 & 283,7 & 330,4 & 404,3 & 656,3 & 103,7 & 333,4 & 421,9 & 247,6 \\
\hline $\mathrm{C}_{2} \mathrm{H}_{2}$ & ${ }^{2} J_{\mathrm{CH}}$ & 53,2 & 53,7 & 51,7 & 43,0 & 12,3 & $-190,4$ & 418,3 & 253,6 & 240,6 & 50,1 \\
\hline $\mathrm{C}_{2} \mathrm{H}_{2}$ & ${ }^{3} J_{\mathrm{HH}}$ & 6,9 & 9,2 & 13,2 & 21,6 & 43,9 & 171,5 & $-194,7$ & $-88,1$ & $-70,0$ & 9,6 \\
\hline $\mathrm{C}_{2} \mathrm{H}_{4}$ & ${ }^{1} J_{\mathrm{CC}}$ & 65,9 & 72,9 & 84,1 & 105,2 & 165,0 & 7009,8 & $-69,7$ & $-6,6$ & 15,4 & 67,6 \\
\hline $\mathrm{C}_{2} \mathrm{H}_{4}$ & ${ }^{1} J_{\mathrm{CH}}$ & 136,5 & 154,4 & 176,5 & 206,1 & 257,9 & 3652,7 & 199,6 & 267,9 & 324,0 & 156,3 \\
\hline $\mathrm{C}_{2} \mathrm{H}_{4}$ & ${ }^{2} J_{\mathrm{CH}}$ & 0,9 & $-1,4$ & $-5,6$ & $-14,5$ & $-42,2$ & $-3408,7$ & 77,9 & 49,8 & 42,7 & $-2,4$ \\
\hline $\mathrm{C}_{2} \mathrm{H}_{4}$ & ${ }^{2} J_{\mathrm{HH}}$ & 5,3 & 3,9 & 1,2 & $-4,5$ & $-22,0$ & $-2066,4$ & 47,4 & 27,2 & 17,8 & 2,3 \\
\hline $\mathrm{C}_{2} \mathrm{H}_{4}$ & ${ }^{3} J_{\mathrm{HH}_{\mathrm{c}}}$ & 10,4 & 11,6 & 13,8 & 18,6 & 34,6 & 2076,6 & $-40,8$ & $-25,8$ & $-24,3$ & 11,7 \\
\hline $\mathrm{C}_{2} \mathrm{H}_{4}$ & ${ }^{3} J_{\mathrm{HH}_{\mathrm{t}}}$ & 15,0 & 17,5 & 21,2 & 28,1 & 47,2 & 2243,5 & $-28,6$ & $-9,0$ & $-2,9$ & 19 \\
\hline $\mathrm{C}_{2} \mathrm{H}_{6}$ & ${ }^{1} J_{\mathrm{CC}}$ & 28,2 & 32,5 & 38,0 & 45,0 & 54,0 & 65,7 & 81,6 & 103,6 & 135,6 & 34,5 \\
\hline $\mathrm{C}_{2} \mathrm{H}_{6}$ & ${ }^{1} J_{\mathrm{CH}}$ & 108,7 & 122,4 & 138,7 & 158,2 & 182,0 & 211,4 & 248,4 & 296,2 & 360,0 & 125,2 \\
\hline $\mathrm{C}_{2} \mathrm{H}_{6}$ & ${ }^{2} J_{\mathrm{CH}}$ & $-1,8$ & $-3,2$ & $-5,1$ & $-7,5$ & $-10,8$ & $-15,3$ & $-21,8$ & $-31,4$ & $-46,3$ & $-4,7$ \\
\hline \multirow[t]{3}{*}{ Total } & DM & $-17,15$ & $-14,85$ & $-11,79$ & $-8,31$ & $-6,64$ & 546,77 & 32,81 & 33,81 & 45,73 & - \\
\hline & DMA & 23,07 & 19,38 & 25,95 & 39,32 & 69,91 & 1010,82 & 140,95 & 95,77 & 102,63 & - \\
\hline & PDMA & 44,12 & 26,33 & 30,82 & 72,53 & 187,65 & 10737,31 & 466,03 & 346,95 & 365,75 & - \\
\hline \multirow[t]{3}{*}{ CPI } & DM & $-34,81$ & $-38,21$ & $-41,94$ & $-48,59$ & $-70,41$ & 359,68 & 102,61 & 42,04 & 35,03 & - \\
\hline & DMA & 42,48 & 40,54 & 46,03 & 57,39 & 88,23 & 410,99 & 158,70 & 104,89 & 107,48 & - \\
\hline & PDMA & 57,32 & 42,63 & 37,61 & 42,95 & 58,00 & 197,23 & 155,52 & 190,75 & 259,15 & - \\
\hline \multirow[t]{3}{*}{ SPI } & DM & $-4,19$ & 2,27 & 10,32 & 21,23 & 40,12 & 683,96 & $-18,38$ & 27,78 & 53,59 & - \\
\hline & DMA & 8,83 & 3,87 & 11,23 & 26,07 & 56,48 & 1450,69 & 127,93 & 89,07 & 99,08 & - \\
\hline & PDMA & 34,44 & 14,37 & 25,83 & 94,22 & 282,74 & 18466,71 & 693,74 & 461,50 & 443,93 & - \\
\hline \multirow[t]{3}{*}{$\Delta \mathrm{CS}$} & $\mathrm{DM}$ & $-30,62$ & $-40,48$ & $-52,26$ & $-69,82$ & $-110,53$ & $-324,28$ & 120,99 & 14,26 & $-18,56$ & - \\
\hline & DMA & 33,65 & 36,66 & 34,80 & 31,32 & 31,75 & $-1039,70$ & 30,77 & 15,82 & 8,40 & - \\
\hline & PDMA & 22,88 & 28,26 & 11,78 & $-51,26$ & $-224,74$ & $-18269,48$ & $-538,22$ & $-270,76$ & $-184,78$ & - \\
\hline
\end{tabular}


Tabela 8.354: Constantes de acoplamento LC-B98(XD) variando $\alpha$ com $\alpha+$ $\beta=80 \%$ na base aug-pcJ-2. O valor de $\gamma=0,20$ corresponde ao $\omega$ B97XD.

\begin{tabular}{|c|c|c|c|c|c|c|c|c|c|}
\hline & $\alpha$ & $10 \%$ & $20 \%$ & $30 \%$ & $40 \%$ & $50 \%$ & $60 \%$ & $70 \%$ & Exp. \\
\hline $\mathrm{HF}$ & ${ }^{1} J_{\mathrm{HF}}$ & 428,9 & 441,4 & 458,7 & 482,0 & 512,4 & 551,1 & 599,1 & 500 \\
\hline $\mathrm{CO}$ & ${ }^{1} J_{\mathrm{CO}}$ & 17,6 & 18,4 & 18,8 & 18,6 & 17,7 & 15,6 & 12,1 & 16,4 \\
\hline $\mathrm{H}_{2} \mathrm{O}$ & ${ }^{1} J_{\mathrm{OH}}$ & $-69,5$ & $-72,9$ & $-77,1$ & $-82,3$ & $-88,6$ & $-96,5$ & $-106,1$ & $-80,6$ \\
\hline $\mathrm{H}_{2} \mathrm{O}$ & ${ }^{2} J_{\mathrm{HH}}$ & $-2,7$ & $-5,6$ & $-9,3$ & $-14,0$ & $-20,0$ & $-27,6$ & $-37,5$ & $-7,3$ \\
\hline $\mathrm{NH}_{3}$ & ${ }^{1} J_{\mathrm{NH}}$ & 39,2 & 42,1 & 45,4 & 49,5 & 54,3 & 60,2 & 67,4 & 43,8 \\
\hline $\mathrm{NH}_{3}$ & ${ }^{2} J_{\mathrm{HH}}$ & $-5,2$ & $-8,1$ & $-11,8$ & $-16,7$ & $-23,2$ & $-32,0$ & $-43,9$ & $-9,6$ \\
\hline $\mathrm{PH}_{3}$ & ${ }^{1} J_{\mathrm{PH}}$ & 169,3 & 185,7 & 206,1 & 231,2 & 262,5 & 301,5 & 350,8 & 188,2 \\
\hline $\mathrm{PF}_{3}$ & ${ }^{1} J_{\mathrm{PF}}$ & $-1654,2$ & $-1668,1$ & $-1675,0$ & $-1676,1$ & $-1672,5$ & $-1665,9$ & $-1657,4$ & -1441 \\
\hline $\mathrm{BHF}_{2}$ & ${ }^{1} J_{\mathrm{BF}}$ & $-139,3$ & $-131,0$ & $-120,3$ & $-107,1$ & $-91,7$ & $-74,2$ & $-54,9$ & -84 \\
\hline $\mathrm{BF}_{3}$ & ${ }^{1} J_{\mathrm{BF}}$ & $-44,5$ & $-33,4$ & $-20,0$ & $-4,2$ & 14,0 & 34,9 & 58,3 & 15 \\
\hline $\mathrm{F}_{2} \mathrm{O}$ & ${ }^{1} J_{\mathrm{OF}}$ & $-274,6$ & $-342,4$ & $-431,0$ & $-567,0$ & $-872,3$ & 10530,6 & 884,8 & -300 \\
\hline $\mathrm{CH}_{4}$ & ${ }^{1} J_{\mathrm{CH}}$ & 109,0 & 121,8 & 137,0 & 155,2 & 177,3 & 204,5 & 238,5 & 125,3 \\
\hline $\mathrm{CH}_{4}$ & ${ }^{2} J_{\mathrm{HH}}$ & $-7,6$ & $-10,7$ & $-14,6$ & $-19,9$ & $-27,0$ & $-36,7$ & $-50,0$ & $-12,8$ \\
\hline $\mathrm{C}_{2} \mathrm{H}_{2}$ & ${ }^{1} J_{\mathrm{CC}}$ & 191,8 & 205,0 & 223,8 & 255,0 & 322,1 & 619,5 & $-372,0$ & 174,8 \\
\hline $\mathrm{C}_{2} \mathrm{H}_{2}$ & ${ }^{1} J_{\mathrm{CH}}$ & 217,9 & 247,2 & 282,6 & 328,5 & 399,5 & 613,2 & 50,1 & 247,6 \\
\hline $\mathrm{C}_{2} \mathrm{H}_{2}$ & ${ }^{2} J_{\mathrm{CH}}$ & 52,8 & 53,5 & 51,7 & 43,7 & 15,7 & $-149,0$ & 470,1 & 50,1 \\
\hline $\mathrm{C}_{2} \mathrm{H}_{2}$ & ${ }^{3} J_{\mathrm{HH}}$ & 6,8 & 9,0 & 12,9 & 20,8 & 41,3 & 145,4 & $-225,9$ & 9,6 \\
\hline $\mathrm{C}_{2} \mathrm{H}_{4}$ & ${ }^{1} J_{\mathrm{CC}}$ & 65,6 & 72,5 & 83,2 & 103,1 & 155,9 & 1046,0 & $-87,6$ & 67,6 \\
\hline $\mathrm{C}_{2} \mathrm{H}_{4}$ & ${ }^{1} J_{\mathrm{CH}}$ & 136,2 & 153,9 & 175,8 & 204,7 & 252,9 & 718,2 & 189,6 & 156,3 \\
\hline $\mathrm{C}_{2} \mathrm{H}_{4}$ & ${ }^{2} J_{\mathrm{CH}}$ & 1,0 & $-1,2$ & $-5,3$ & $-13,6$ & $-37,9$ & $-475,0$ & 86,8 & $-2,4$ \\
\hline $\mathrm{C}_{2} \mathrm{H}_{4}$ & ${ }^{2} J_{\mathrm{HH}}$ & 5,4 & 4,0 & 1,5 & $-3,8$ & $-19,2$ & $-284,7$ & 52,8 & 2,3 \\
\hline $\mathrm{C}_{2} \mathrm{H}_{4}$ & ${ }^{3} J_{\mathrm{HH}_{\mathrm{c}}}$ & 10,3 & 11,5 & 13,6 & 18,0 & 31,9 & 295,0 & $-46,0$ & 11,7 \\
\hline $\mathrm{C}_{2} \mathrm{H}_{4}$ & ${ }^{3} J_{\mathrm{HH}_{\mathrm{t}}}$ & 14,9 & 17,3 & 21,0 & 27,4 & 44,3 & 329,0 & $-34,2$ & 19 \\
\hline $\mathrm{C}_{2} \mathrm{H}_{6}$ & ${ }^{1} J_{\mathrm{CC}}$ & 27,8 & 32,1 & 37,5 & 44,4 & 53,3 & 65,0 & 80,6 & 34,5 \\
\hline $\mathrm{C}_{2} \mathrm{H}_{6}$ & ${ }^{1} J_{\mathrm{CH}}$ & 108,6 & 122,2 & 138,3 & 157,7 & 181,3 & 210,4 & 247,0 & 125,2 \\
\hline $\mathrm{C}_{2} \mathrm{H}_{6}$ & ${ }^{2} J_{\mathrm{CH}}$ & $-1,7$ & $-3,1$ & $-5,0$ & $-7,4$ & $-10,6$ & $-15,1$ & $-21,4$ & $-4,7$ \\
\hline \multirow[t]{3}{*}{ Total } & DM & $-16,97$ & $-14,77$ & $-11,79$ & $-8,36$ & $-6,60$ & 501,48 & 31,00 & - \\
\hline & DMA & 23,21 & 19,23 & 25,72 & 38,67 & 67,12 & 599,73 & 154,89 & - \\
\hline & PDMA & 45,49 & 27,79 & 29,76 & 69,01 & 171,39 & 1741,75 & 511,92 & - \\
\hline \multirow[t]{3}{*}{ CPI } & $\mathrm{DM}$ & $-34,17$ & $-37,71$ & $-41,49$ & $-47,91$ & $-68,03$ & 977,89 & 111,98 & - \\
\hline & DMA & 42,66 & 40,05 & 46,11 & 57,16 & 85,94 & 1029,58 & 168,47 & - \\
\hline & PDMA & 59,13 & 44,19 & 38,83 & 43,78 & 56,55 & 401,28 & 156,56 & - \\
\hline \multirow[t]{3}{*}{ SPI } & $\mathrm{DM}$ & $-4,35$ & 2,06 & 9,99 & 20,65 & 38,45 & 152,11 & $-28,38$ & - \\
\hline & DMA & 8,94 & 3,95 & 10,77 & 25,11 & 53,31 & 284,51 & 144,93 & - \\
\hline & PDMA & 35,48 & 15,76 & 23,11 & 87,52 & 255,60 & 2724,76 & 772,51 & - \\
\hline \multirow[t]{3}{*}{$\Delta \mathrm{CS}$} & $\mathrm{DM}$ & $-29,82$ & $-39,77$ & $-51,48$ & $-68,56$ & $-106,47$ & 825,78 & 140,36 & - \\
\hline & DMA & 33,72 & 36,10 & 35,34 & 32,05 & 32,62 & 745,08 & 23,55 & - \\
\hline & PDMA & 23,65 & 28,43 & 15,73 & $-43,75$ & $-199,04$ & $-2323,49$ & $-615,94$ & - \\
\hline
\end{tabular}


Tabela 8.355: Constantes de acoplamento LC-B98(XD) variando $\alpha$ com $\alpha+\beta=60 \%$ na base aug-pcJ-2. O valor de $\gamma=0,20$ corresponde ao $\omega \mathrm{B} 97 \mathrm{XD}$.

\begin{tabular}{|c|c|c|c|c|c|c|c|}
\hline & $\alpha$ & $10 \%$ & $20 \%$ & $30 \%$ & $40 \%$ & $50 \%$ & Exp. \\
\hline HF & ${ }^{1} J_{\mathrm{HF}}$ & 430,1 & 442,3 & 459,2 & 482,0 & 512,0 & 500 \\
\hline $\mathrm{CO}$ & ${ }^{1} J_{\mathrm{CO}}$ & 17,4 & 18,2 & 18,6 & 18,4 & 17,5 & 16,4 \\
\hline $\mathrm{H}_{2} \mathrm{O}$ & ${ }^{1} J_{\mathrm{OH}}$ & $-69,6$ & $-73,0$ & $-77,1$ & $-82,2$ & $-88,5$ & $-80,6$ \\
\hline $\mathrm{H}_{2} \mathrm{O}$ & ${ }^{2} J_{\mathrm{HH}}$ & $-2,6$ & $-5,5$ & $-9,1$ & $-13,8$ & $-19,8$ & $-7,3$ \\
\hline $\mathrm{NH}_{3}$ & ${ }^{1} J_{\mathrm{NH}}$ & 39,3 & 42,1 & 45,4 & 49,4 & 54,2 & 43,8 \\
\hline $\mathrm{NH}_{3}$ & ${ }^{2} J_{\mathrm{HH}}$ & $-5,1$ & $-7,9$ & $-11,6$ & $-16,5$ & $-22,9$ & $-9,6$ \\
\hline $\mathrm{PH}_{3}$ & ${ }^{1} J_{\mathrm{PH}}$ & 173,0 & 189,1 & 209,2 & 234,0 & 265,0 & 188,2 \\
\hline $\mathrm{PF}_{3}$ & ${ }^{1} J_{\mathrm{PF}}$ & $-1651,3$ & $-1667,0$ & $-1675,3$ & $-1677,4$ & $-1674,6$ & -1441 \\
\hline $\mathrm{BHF}_{2}$ & ${ }^{1} J_{\mathrm{BF}}$ & $-141,7$ & $-133,5$ & $-122,7$ & $-109,6$ & $-94,1$ & -84 \\
\hline $\mathrm{BF}_{3}$ & ${ }^{1} J_{\mathrm{BF}}$ & $-46,8$ & $-35,7$ & $-22,3$ & $-6,5$ & 11,8 & 15 \\
\hline $\mathrm{F}_{2} \mathrm{O}$ & ${ }^{1} J_{\mathrm{OF}}$ & $-270,3$ & $-337,4$ & $-424,5$ & $-556,5$ & $-844,0$ & -300 \\
\hline $\mathrm{CH}_{4}$ & ${ }^{1} J_{\mathrm{CH}}$ & 109,0 & 121,6 & 136,7 & 154,7 & 176,7 & 125,3 \\
\hline $\mathrm{CH}_{4}$ & ${ }^{2} J_{\mathrm{HH}}$ & $-7,4$ & $-10,4$ & $-14,4$ & $-19,6$ & $-26,6$ & $-12,8$ \\
\hline $\mathrm{C}_{2} \mathrm{H}_{2}$ & ${ }^{1} J_{\mathrm{CC}}$ & 191,3 & 204,3 & 222,7 & 252,7 & 315,7 & 174,8 \\
\hline $\mathrm{C}_{2} \mathrm{H}_{2}$ & ${ }^{1} J_{\mathrm{CH}}$ & 217,4 & 246,5 & 281,5 & 326,7 & 395,0 & 247,6 \\
\hline $\mathrm{C}_{2} \mathrm{H}_{2}$ & ${ }^{2} J_{\mathrm{CH}}$ & 52,5 & 53,2 & 51,7 & 44,3 & 18,8 & 50,1 \\
\hline $\mathrm{C}_{2} \mathrm{H}_{2}$ & ${ }^{3} J_{\mathrm{HH}}$ & 6,8 & 8,8 & 12,6 & 20,1 & 39,0 & 9,6 \\
\hline $\mathrm{C}_{2} \mathrm{H}_{4}$ & ${ }^{1} J_{\mathrm{CC}}$ & 65,3 & 72,0 & 82,4 & 101,2 & 148,3 & 67,6 \\
\hline $\mathrm{C}_{2} \mathrm{H}_{4}$ & ${ }^{1} J_{\mathrm{CH}}$ & 135,9 & 153,5 & 175,1 & 203,3 & 248,7 & 156,3 \\
\hline $\mathrm{C}_{2} \mathrm{H}_{4}$ & ${ }^{2} J_{\mathrm{CH}}$ & 1,2 & $-1,0$ & $-4,9$ & $-12,7$ & $-34,3$ & $-2,4$ \\
\hline $\mathrm{C}_{2} \mathrm{H}_{4}$ & ${ }^{2} J_{\mathrm{HH}}$ & 5,4 & 4,1 & 1,7 & $-3,2$ & $-16,9$ & 2,3 \\
\hline $\mathrm{C}_{2} \mathrm{H}_{4}$ & ${ }^{3} J_{\mathrm{HH}_{\mathrm{c}}}$ & 10,2 & 11,4 & 13,3 & 17,5 & 29,7 & 11,7 \\
\hline $\mathrm{C}_{2} \mathrm{H}_{4}$ & ${ }^{3} J_{\mathrm{HH}_{\mathrm{t}}}$ & 14,8 & 17,2 & 20,7 & 26,8 & 41,8 & 19 \\
\hline $\mathrm{C}_{2} \mathrm{H}_{6}$ & ${ }^{1} J_{\mathrm{CC}}$ & 27,4 & 31,7 & 37,1 & 43,9 & 52,7 & 34,5 \\
\hline $\mathrm{C}_{2} \mathrm{H}_{6}$ & ${ }^{1} J_{\mathrm{CH}}$ & 108,5 & 121,9 & 137,9 & 157,2 & 180,5 & 125,2 \\
\hline $\mathrm{C}_{2} \mathrm{H}_{6}$ & ${ }^{2} J_{\mathrm{CH}}$ & $-1,6$ & $-3,0$ & $-4,8$ & $-7,2$ & $-10,4$ & $-4,7$ \\
\hline \multirow[t]{3}{*}{ Total } & DM & $-16,77$ & $-14,67$ & $-11,77$ & $-8,38$ & $-6,53$ & - \\
\hline & DMA & 23,30 & 19,14 & 25,48 & 38,07 & 64,74 & - \\
\hline & PDMA & 46,74 & 29,27 & 28,56 & 65,78 & 158,32 & - \\
\hline \multirow[t]{3}{*}{ CPI } & $\mathrm{DM}$ & $-33,50$ & $-37,20$ & $-41,01$ & $-47,24$ & $-65,85$ & - \\
\hline & DMA & 42,75 & 39,71 & 46,15 & 56,95 & 84,08 & - \\
\hline & PDMA & 60,77 & 45,80 & 39,88 & 44,68 & 56,74 & - \\
\hline \multirow[t]{3}{*}{ SPI } & $\mathrm{DM}$ & $-4,49$ & 1,85 & 9,68 & 20,11 & 36,97 & - \\
\hline & DMA & 9,04 & 4,06 & 10,32 & 24,23 & 50,56 & - \\
\hline & PDMA & 36,46 & 17,16 & 20,25 & 81,25 & 232,81 & - \\
\hline \multirow[t]{3}{*}{$\Delta \mathrm{CS}$} & $\mathrm{DM}$ & $-29,01$ & $-39,05$ & $-50,69$ & $-67,34$ & $-102,82$ & - \\
\hline & DMA & 33,71 & 35,65 & 35,83 & 32,72 & 33,52 & - \\
\hline & PDMA & 24,32 & 28,64 & 19,63 & $-36,56$ & $-176,07$ & - \\
\hline
\end{tabular}


Tabela 8.356: Constantes de acoplamento LCB98(XD) variando $\alpha$ com $\alpha+\beta=40 \%$ na base aug-pcJ-2. O valor de $\gamma=0,20$ corresponde ao $\omega \mathrm{B} 97 \mathrm{XD}$.

\begin{tabular}{|c|c|c|c|c|c|}
\hline & $\alpha$ & $10 \%$ & $20 \%$ & $30 \%$ & Exp. \\
\hline HF & ${ }^{1} J_{\mathrm{HF}}$ & 431,3 & 443,1 & 459,7 & 500 \\
\hline $\mathrm{CO}$ & ${ }^{1} J_{\mathrm{CO}}$ & 17,3 & 18,1 & 18,5 & 16,4 \\
\hline $\mathrm{H}_{2} \mathrm{O}$ & ${ }^{1} J_{\mathrm{OH}}$ & $-69,7$ & $-73,0$ & $-77,1$ & $-80,6$ \\
\hline $\mathrm{H}_{2} \mathrm{O}$ & ${ }^{2} J_{\mathrm{HH}}$ & $-2,4$ & $-5,3$ & $-9,0$ & $-7,3$ \\
\hline $\mathrm{NH}_{3}$ & ${ }^{1} J_{\mathrm{NH}}$ & 39,3 & 42,1 & 45,4 & 43,8 \\
\hline $\mathrm{NH}_{3}$ & ${ }^{2} J_{\mathrm{HH}}$ & $-5,0$ & $-7,7$ & $-11,4$ & $-9,6$ \\
\hline $\mathrm{PH}_{3}$ & ${ }^{1} J_{\mathrm{PH}}$ & 176,8 & 192,7 & 212,4 & 188,2 \\
\hline $\mathrm{PF}_{3}$ & ${ }^{1} J_{\mathrm{PF}}$ & $-1647,7$ & $-1665,3$ & $-1675,2$ & -1441 \\
\hline $\mathrm{BHF}_{2}$ & ${ }^{1} J_{\mathrm{BF}}$ & $-144,0$ & $-135,9$ & $-125,2$ & -84 \\
\hline $\mathrm{BF}_{3}$ & ${ }^{1} J_{\mathrm{BF}}$ & $-49,2$ & $-38,1$ & $-24,6$ & 15 \\
\hline $\mathrm{F}_{2} \mathrm{O}$ & ${ }^{1} J_{\mathrm{OF}}$ & $-266,0$ & $-332,4$ & $-418,1$ & -300 \\
\hline $\mathrm{CH}_{4}$ & ${ }^{1} J_{\mathrm{CH}}$ & 108,9 & 121,5 & 136,4 & 125,3 \\
\hline $\mathrm{CH}_{4}$ & ${ }^{2} J_{\mathrm{HH}}$ & $-7,3$ & $-10,2$ & $-14,1$ & $-12,8$ \\
\hline $\mathrm{C}_{2} \mathrm{H}_{2}$ & ${ }^{1} J_{\mathrm{CC}}$ & 190,8 & 203,6 & 221,5 & 174,8 \\
\hline $\mathrm{C}_{2} \mathrm{H}_{2}$ & ${ }^{1} J_{\mathrm{CH}}$ & 216,9 & 245,8 & 280,5 & 247,6 \\
\hline $\mathrm{C}_{2} \mathrm{H}_{2}$ & ${ }^{2} J_{\mathrm{CH}}$ & 52,2 & 53,0 & 51,6 & 50,1 \\
\hline $\mathrm{C}_{2} \mathrm{H}_{2}$ & ${ }^{3} J_{\mathrm{HH}}$ & 6,7 & 8,7 & 12,3 & 9,6 \\
\hline $\mathrm{C}_{2} \mathrm{H}_{4}$ & ${ }^{1} J_{\mathrm{CC}}$ & 65,0 & 71,5 & 81,6 & 67,6 \\
\hline $\mathrm{C}_{2} \mathrm{H}_{4}$ & ${ }^{1} J_{\mathrm{CH}}$ & 135,6 & 153,1 & 174,4 & 156,3 \\
\hline $\mathrm{C}_{2} \mathrm{H}_{4}$ & ${ }^{2} J_{\mathrm{CH}}$ & 1,3 & $-0,9$ & $-4,6$ & $-2,4$ \\
\hline $\mathrm{C}_{2} \mathrm{H}_{4}$ & ${ }^{2} J_{\mathrm{HH}}$ & 5,5 & 4,2 & 1,9 & 2,3 \\
\hline $\mathrm{C}_{2} \mathrm{H}_{4}$ & ${ }^{3} J_{\mathrm{HH}_{\mathrm{c}}}$ & 10,2 & 11,3 & 13,1 & 11,7 \\
\hline $\mathrm{C}_{2} \mathrm{H}_{4}$ & ${ }^{3} J_{\mathrm{HH}_{\mathrm{t}}}$ & 14,6 & 17,1 & 20,5 & 19 \\
\hline $\mathrm{C}_{2} \mathrm{H}_{6}$ & ${ }^{1} J_{\mathrm{CC}}$ & 27,0 & 31,2 & 36,6 & 34,5 \\
\hline $\mathrm{C}_{2} \mathrm{H}_{6}$ & ${ }^{1} J_{\mathrm{CH}}$ & 108,4 & 121,7 & 137,6 & 125,2 \\
\hline $\mathrm{C}_{2} \mathrm{H}_{6}$ & ${ }^{2} J_{\mathrm{CH}}$ & $-1,5$ & $-2,9$ & $-4,7$ & $-4,7$ \\
\hline \multirow[t]{3}{*}{ Total } & DM & $-16,54$ & $-14,54$ & $-11,73$ & - \\
\hline & DMA & 23,38 & 19,24 & 25,25 & - \\
\hline & PDMA & 48,11 & 30,75 & 27,68 & - \\
\hline \multirow[t]{3}{*}{ CPI } & $\mathrm{DM}$ & $-32,75$ & $-36,60$ & $-40,50$ & - \\
\hline & DMA & 42,80 & 39,82 & 46,21 & - \\
\hline & PDMA & 62,66 & 47,89 & 41,13 & - \\
\hline \multirow[t]{3}{*}{ SPI } & DM & $-4,65$ & 1,64 & 9,37 & - \\
\hline & DMA & 9,15 & 4,15 & 9,89 & - \\
\hline & PDMA & 37,44 & 18,18 & 17,82 & - \\
\hline \multirow[t]{3}{*}{$\Delta \mathrm{CS}$} & DM & $-28,09$ & $-38,24$ & $-49,87$ & - \\
\hline & DMA & 33,65 & 35,67 & 36,32 & - \\
\hline & PDMA & 25,22 & 29,71 & 23,31 & - \\
\hline
\end{tabular}


Tabela 8.357: Constantes de acoplamento LC-B98(XD) variando $\alpha$ com $\alpha+\beta=20 \%$ na base aug-pcJ2. O valor de $\gamma=0,20$ corresponde ao $\omega$ B97XD.

\begin{tabular}{|c|c|c|c|}
\hline & $\alpha$ & $10 \%$ & Exp. \\
\hline HF & ${ }^{1} J_{\mathrm{HF}}$ & 432,6 & 500 \\
\hline $\mathrm{CO}$ & ${ }^{1} J_{\mathrm{CO}}$ & 17,1 & 16,4 \\
\hline $\mathrm{H}_{2} \mathrm{O}$ & ${ }^{1} J_{\mathrm{OH}}$ & $-69,9$ & $-80,6$ \\
\hline $\mathrm{H}_{2} \mathrm{O}$ & ${ }^{2} J_{\mathrm{HH}}$ & $-2,3$ & $-7,3$ \\
\hline $\mathrm{NH}_{3}$ & ${ }^{1} J_{\mathrm{NH}}$ & 39,4 & 43,8 \\
\hline $\mathrm{NH}_{3}$ & ${ }^{2} J_{\mathrm{HH}}$ & $-4,8$ & $-9,6$ \\
\hline $\mathrm{PH}_{3}$ & ${ }^{1} J_{\mathrm{PH}}$ & 180,7 & 188,2 \\
\hline $\mathrm{PF}_{3}$ & ${ }^{1} J_{\mathrm{PF}}$ & $-1643,4$ & -1441 \\
\hline $\mathrm{BHF}_{2}$ & ${ }^{1} J_{\mathrm{BF}}$ & $-146,4$ & -84 \\
\hline $\mathrm{BF}_{3}$ & ${ }^{1} J_{\mathrm{BF}}$ & $-51,6$ & 15 \\
\hline $\mathrm{F}_{2} \mathrm{O}$ & ${ }^{1} J_{\mathrm{OF}}$ & $-261,7$ & -300 \\
\hline $\mathrm{CH}_{4}$ & ${ }^{1} J_{\mathrm{CH}}$ & 108,9 & 125,3 \\
\hline $\mathrm{CH}_{4}$ & ${ }^{2} J_{\mathrm{HH}}$ & $-7,1$ & $-12,8$ \\
\hline $\mathrm{C}_{2} \mathrm{H}_{2}$ & ${ }^{1} J_{\mathrm{CC}}$ & 190,3 & 174,8 \\
\hline $\mathrm{C}_{2} \mathrm{H}_{2}$ & ${ }^{1} J_{\mathrm{CH}}$ & 216,5 & 247,6 \\
\hline $\mathrm{C}_{2} \mathrm{H}_{2}$ & ${ }^{2} J_{\mathrm{CH}}$ & 51,8 & 50,1 \\
\hline $\mathrm{C}_{2} \mathrm{H}_{2}$ & ${ }^{3} J_{\mathrm{HH}}$ & 6,6 & 9,6 \\
\hline $\mathrm{C}_{2} \mathrm{H}_{4}$ & ${ }^{1} J_{\mathrm{CC}}$ & 64,6 & 67,6 \\
\hline $\mathrm{C}_{2} \mathrm{H}_{4}$ & ${ }^{1} J_{\mathrm{CH}}$ & 135,4 & 156,3 \\
\hline $\mathrm{C}_{2} \mathrm{H}_{4}$ & ${ }^{2} J_{\mathrm{CH}}$ & 1,4 & $-2,4$ \\
\hline $\mathrm{C}_{2} \mathrm{H}_{4}$ & ${ }^{2} J_{\mathrm{HH}}$ & 5,5 & 2,3 \\
\hline $\mathrm{C}_{2} \mathrm{H}_{4}$ & ${ }^{3} J_{\mathrm{HH}_{\mathrm{c}}}$ & 10,1 & 11,7 \\
\hline $\mathrm{C}_{2} \mathrm{H}_{4}$ & ${ }^{3} J_{\mathrm{HH}_{\mathrm{t}}}$ & 14,5 & 19 \\
\hline $\mathrm{C}_{2} \mathrm{H}_{6}$ & ${ }^{1} J_{\mathrm{CC}}$ & 26,6 & 34,5 \\
\hline $\mathrm{C}_{2} \mathrm{H}_{6}$ & ${ }^{1} J_{\mathrm{CH}}$ & 108,3 & 125,2 \\
\hline $\mathrm{C}_{2} \mathrm{H}_{6}$ & ${ }^{2} J_{\mathrm{CH}}$ & $-1,4$ & $-4,7$ \\
\hline \multirow[t]{3}{*}{ Total } & $\mathrm{DM}$ & $-16,28$ & - \\
\hline & DMA & 23,41 & - \\
\hline & PDMA & 49,29 & - \\
\hline \multirow[t]{3}{*}{ CPI } & $\mathrm{DM}$ & $-31,93$ & - \\
\hline & DMA & 42,75 & - \\
\hline & PDMA & 64,42 & - \\
\hline \multirow[t]{3}{*}{ SPI } & $\mathrm{DM}$ & $-4,81$ & - \\
\hline & DMA & 9,23 & - \\
\hline & PDMA & 38,20 & - \\
\hline \multirow[t]{3}{*}{$\Delta \mathrm{CS}$} & DM & $-27,12$ & - \\
\hline & DMA & 33,51 & - \\
\hline & PDMA & 26,23 & - \\
\hline
\end{tabular}




\subsubsection{B1B95 (LC-BB95)}

Tabela 8.358: Constantes de acoplamento LC-BB95 com $\alpha=0 \%$ e $\alpha+\beta=100 \%$, variando $\gamma$, na base aug-pcJ-2.

\begin{tabular}{|c|c|c|c|c|c|c|c|c|c|c|c|c|c|c|c|c|c|}
\hline & $\gamma$ & 0,05 & 0,10 & 0,15 & 0,20 & 0,25 & 0,30 & 0,35 & 0,40 & 0,45 & 0,50 & 0,55 & 0,60 & 0,65 & 0,70 & 0,75 & Exp. \\
\hline $\mathrm{HF}$ & ${ }^{1} J_{\mathrm{HF}}$ & 406,9 & 411,0 & 415,1 & 419,1 & 423,1 & 427,6 & 433,0 & 439,4 & 446,6 & 454,4 & 462,7 & 471,2 & 479,7 & 488,2 & 496,6 & 500 \\
\hline $\mathrm{CO}$ & ${ }^{1} J_{\mathrm{CO}}$ & 23,8 & 23,9 & 23,8 & 23,8 & 23,8 & 23,8 & 23,8 & 23,8 & 23,6 & 23,3 & 22,8 & 22,1 & 21,3 & 20,5 & 19,5 & 16,4 \\
\hline $\mathrm{H}_{2} \mathrm{O}$ & ${ }^{1} J_{\mathrm{OH}}$ & $-70,5$ & $-70,7$ & $-70,9$ & $-71,1$ & $-71,3$ & $-71,6$ & $-72,1$ & $-72,8$ & $-73,6$ & $-74,5$ & $-75,5$ & $-76,6$ & $-77,7$ & $-78,8$ & $-79,9$ & $-80,6$ \\
\hline $\mathrm{H}_{2} \mathrm{O}$ & ${ }^{2} J_{\mathrm{HH}}$ & $-3,9$ & $-3,7$ & $-3,6$ & $-3,6$ & $-3,7$ & $-4,0$ & $-4,3$ & $-4,7$ & $-5,2$ & $-5,7$ & $-6,2$ & $-6,8$ & $-7,3$ & $-7,8$ & $-8,3$ & $-7,3$ \\
\hline $\mathrm{NH}_{3}$ & ${ }^{1} J_{\mathrm{NH}}$ & 41,7 & 41,5 & 41,3 & 41,0 & 40,7 & 40,6 & 40,6 & 40,7 & 40,9 & 41,2 & 41,6 & 42,1 & 42,6 & 43,2 & 43,7 & 43,8 \\
\hline $\mathrm{NH}_{3}$ & ${ }^{2} J_{\mathrm{HH}}$ & $-6,6$ & $-6,3$ & $-6,1$ & $-6,1$ & $-6,3$ & $-6,6$ & $-7,0$ & $-7,5$ & $-8,0$ & $-8,6$ & $-9,2$ & $-9,7$ & $-10,3$ & $-10,8$ & $-11,4$ & $-9,6$ \\
\hline $\mathrm{PH}_{3}$ & ${ }^{1} J_{\mathrm{PH}}$ & 145,3 & 143,1 & 138,6 & 132,8 & 127,7 & 124,7 & 124,2 & 126,1 & 129,9 & 135,1 & 141,1 & 147,6 & 154,2 & 160,7 & 166,8 & 188,2 \\
\hline $\mathrm{PF}_{3}$ & ${ }^{1} J_{\mathrm{PF}}$ & $-1712,6$ & $-1708,4$ & $-1706,2$ & $-1706,2$ & $-1708,0$ & $-1711,0$ & $-1713,7$ & $-1714,8$ & $-1713,0$ & $-1707,9$ & $-1699,6$ & $-1688,6$ & $-1675,7$ & $-1661,4$ & $-1646,5$ & -1441 \\
\hline $\mathrm{BHF}_{2}$ & ${ }^{1} J_{\mathrm{BF}}$ & $-177,7$ & $-178,4$ & $-176,4$ & $-172,0$ & $-166,0$ & $-159,1$ & $-151,6$ & $-143,7$ & $-135,5$ & $-127,2$ & $-119,0$ & $-111,0$ & $-103,3$ & $-95,9$ & $-89,1$ & -84 \\
\hline $\mathrm{BF}_{3}$ & ${ }^{1} J_{\mathrm{BF}}$ & $-80,7$ & $-80,6$ & $-77,9$ & $-72,7$ & $-65,7$ & $-57,5$ & $-48,6$ & $-39,3$ & $-30,0$ & $-20,7$ & $-11,8$ & $-3,3$ & 4,6 & 12,1 & 19,1 & 15 \\
\hline $\mathrm{F}_{2} \mathrm{O}$ & ${ }^{1} J_{\mathrm{OF}}$ & $-270,3$ & $-275,4$ & $-284,3$ & $-297,4$ & $-313,6$ & $-331,7$ & $-350,1$ & $-368,0$ & $-385,2$ & $-401,9$ & $-418,2$ & $-434,5$ & $-451,2$ & $-468,3$ & $-485,9$ & -300 \\
\hline $\mathrm{CH}_{4}$ & ${ }^{1} J_{\mathrm{CH}}$ & 118,8 & 116,8 & 114,7 & 112,8 & 111,3 & 110,5 & 110,3 & 110,7 & 111,7 & 113,1 & 114,7 & 116,6 & 118,5 & 120,4 & 122,3 & 125,3 \\
\hline $\mathrm{CH}_{4}$ & ${ }^{2} J_{\mathrm{HH}}$ & $-9,9$ & $-9,4$ & $-9,1$ & $-9,0$ & $-9,2$ & $-9,5$ & $-10,0$ & $-10,5$ & $-11,1$ & $-11,7$ & $-12,3$ & $-12,9$ & $-13,5$ & $-14,0$ & -14 & $-12,8$ \\
\hline $\mathrm{C}_{2} \mathrm{H}_{2}$ & ${ }^{1} J_{\mathrm{CC}}$ & 185,4 & 183,5 & 182,2 & 181,3 & 180 , & 180,6 & 181,0 & 182,0 & 183,6 & 185,8 & 188,6 & & 195,2 & 199,0 & 202,8 & 174,8 \\
\hline $\mathrm{C}_{2} \mathrm{H}_{2}$ & ${ }^{1} J_{\mathrm{CH}}$ & 247,9 & 244,3 & 240,4 & 236,9 & 234,2 & 232,6 & 232,1 & 232,8 & 234,4 & 236,7 & 239,5 & 242,7 & 246,1 & 249,6 & 253,1 & 247,6 \\
\hline $\mathrm{C}_{2} \mathrm{H}_{2}$ & ${ }^{2} J_{\mathrm{CH}}$ & 55,2 & 55,0 & 55,2 & 55,6 & 56,1 & 56,6 & 56,9 & 57,2 & 57,2 & 57,1 & 56,8 & 56,4 & 55,9 & 55,3 & 54,6 & 50,1 \\
\hline $\mathrm{C}_{2} \mathrm{H}_{2}$ & ${ }^{3} J_{\mathrm{HH}}$ & 8,9 & 8,5 & 8,2 & 8,0 & 7,8 & 7,9 & 8,1 & 8,5 & 8,9 & 9,5 & 10,1 & 10,8 & 11,5 & 12,2 & 12,9 & 9,6 \\
\hline $\mathrm{C}_{2} \mathrm{H}_{4}$ & ${ }^{1} J_{\mathrm{CC}}$ & 57,2 & 56,0 & 55,3 & 54,9 & 54,6 & 54,6 & 54,8 & 55,5 & 56,7 & 58,3 & 60,3 & 62,7 & 65,3 & 68,2 & 71,2 & 67,6 \\
\hline $\mathrm{C}_{2} \mathrm{H}_{4}$ & ${ }^{1} J_{\mathrm{CH}}$ & 151,5 & 149,2 & 146,8 & 144,6 & 143,1 & 142,3 & 142,4 & 143,2 & 144,6 & 146,5 & 148,8 & 151,3 & 154,0 & 156,7 & 159,4 & 156,3 \\
\hline $\mathrm{C}_{2} \mathrm{H}_{4}$ & ${ }^{2} J_{\mathrm{CH}}$ & 1,1 & 1,2 & 1,2 & 1,2 & 1,2 & 1,0 & 0,6 & 0,2 & $-0,3$ & $-0,9$ & $-1,7$ & $-2,5$ & $-3,4$ & $-4,3$ & $-5,2$ & $-2,4$ \\
\hline $\mathrm{C}_{2} \mathrm{H}_{4}$ & ${ }^{2} J_{\mathrm{HH}}$ & 6,1 & 6,2 & 6,2 & 6,1 & 5,8 & 5,5 & 5,1 & 4,6 & 4,0 & 3,4 & 2,8 & 2,2 & 1,5 & 0,9 & 0,3 & 2,3 \\
\hline $\mathrm{C}_{2} \mathrm{H}_{4}$ & ${ }^{3} J_{\mathrm{HH}_{\mathrm{c}}}$ & 11,5 & 11,5 & 11,5 & 11,6 & 11,6 & 11,8 & 11,9 & 12,1 & 12,3 & 12,6 & 12,9 & 13,2 & 13,6 & 13,9 & 14,3 & 11,7 \\
\hline $\mathrm{C}_{2} \mathrm{H}_{4}$ & ${ }^{3} J_{\mathrm{HH}_{\mathrm{t}}}$ & 18,2 & 18,0 & 17,7 & 17,4 & 17,2 & 17,1 & 17,1 & 17,3 & 17,5 & 17,8 & 18,3 & 18,7 & 19,2 & 19,8 & 20,3 & 19 \\
\hline $\mathrm{C}_{2} \mathrm{H}_{6}$ & ${ }^{1} J_{\mathrm{CC}}$ & 24,1 & 23,4 & 23,2 & 23,2 & 23,3 & 23,5 & 24,0 & 24,6 & 25,5 & 26,7 & 28,0 & 29,4 & 30,8 & 32,3 & 33,8 & 34,5 \\
\hline $\mathrm{C}_{2} \mathrm{H}_{6}$ & ${ }^{1} J_{\mathrm{CH}}$ & 119,0 & 117,0 & 114,9 & 113,0 & 111,6 & 110,9 & 110,8 & 111,4 & 112,5 & 14,0 & 115,7 & 117,7 & 119,7 & 121,7 & 123,7 & 125,2 \\
\hline $\mathrm{C}_{2} \mathrm{H}_{6}$ & ${ }^{2} J_{\mathrm{CH}}$ & $-2,2$ & $-2,1$ & $-2,0$ & $-2,0$ & $-2,1$ & $-2,3$ & $-2,5$ & $-2,7$ & $-3,0$ & $-3,4$ & $-3,7$ & $-4,0$ & $-4,4$ & $-4,7$ & $-5,0$ & $-4,7$ \\
\hline \multirow[t]{3}{*}{ Total } & DN & & & & & & & & & & & & & & & & - \\
\hline & DMA & & 2 & 27 & & & & & & & & & & & & & - \\
\hline & PDMA & 55,20 & 56,48 & 56,40 & 55,03 & 52,74 & 49,31 & 44,87 & 39,76 & 33,90 & 27,49 & 21,16 & 15,71 & 15,36 & 15,71 & 19,27 & - \\
\hline \multirow[t]{3}{*}{ CPI } & M & & & & & & & & & & & & & & & & - \\
\hline & DMA & & & & & & & & & & & & & & & & - \\
\hline & PDMA & 87,27 & 87,74 & 86,03 & 82,25 & 77,60 & 71,85 & 65,33 & 58,11 & 50,44 & 42,47 & 34,53 & 26,82 & 20,42 & 15,44 & 15,83 & - \\
\hline \multirow[t]{3}{*}{ SPI } & & & & & & & & & & & & & & & & & - \\
\hline & DMA & & & & & & & & & & & & & & & & - \\
\hline & PDMA & 31,68 & 33,55 & 34,67 & 35,07 & 34,51 & 32,79 & 29,86 & 26,31 & 21,76 & 16,51 & 11,35 & 7,56 & 11,64 & 15,92 & 21,79 & - \\
\hline \multirow[t]{3}{*}{$\Delta \mathrm{CS}$} & DM & $-48,8$ & 7 & & & & & & & & & & & & & & - \\
\hline & & & & & & & & & & & & & & & & & - \\
\hline & PDMA & 55,59 & 54,20 & 51,36 & 47,18 & 43,09 & 39,06 & 35,47 & 31,80 & 28,68 & 25,96 & 23,17 & 19,25 & 8,78 & $-0,48$ & $-5,96$ & - \\
\hline
\end{tabular}


Tabela 8.359: Constantes de acoplamento LC-BB95 com $\alpha=10 \%$ e $\alpha+\beta=100 \%$, variando $\gamma$, na base aug-pcJ-2.

\begin{tabular}{|c|c|c|c|c|c|c|c|c|c|c|c|c|c|c|c|c|c|}
\hline & $\gamma$ & 0,05 & 0,10 & 0,15 & 0,20 & 0,25 & 0,30 & 0,35 & 0,40 & 0,45 & 0,50 & 0,55 & 0,60 & 0,65 & 0,70 & 0,75 & Exp. \\
\hline $\mathrm{HF}$ & ${ }^{1} J_{\mathrm{HF}}$ & 430,1 & 433,7 & 437,3 & 440,8 & 444,4 & 448,5 & 453,4 & 459,0 & 465,4 & 472,5 & 479,7 & 487,3 & 494,9 & 502,5 & 510,1 & 500 \\
\hline $\mathrm{CO}$ & ${ }^{1} J_{\mathrm{CO}}$ & 22,1 & 22,2 & 22,2 & 22,1 & 22,1 & 22,2 & 22,2 & 22,1 & 21,9 & 21,6 & 21,2 & 20,5 & 19,8 & 19,0 & 18,1 & 16,4 \\
\hline $\mathrm{H}_{2} \mathrm{O}$ & ${ }^{1} J_{\mathrm{OH}}$ & $-72,9$ & $-73,1$ & $-73,3$ & $-73,4$ & $-73,6$ & $-73,9$ & $-74,3$ & $-74,9$ & $-75,6$ & $-76,5$ & $-77,4$ & $-78,3$ & $-79,3$ & $-80,3$ & $-81,4$ & $-80,6$ \\
\hline $\mathrm{H}_{2} \mathrm{O}$ & ${ }^{2} J_{\mathrm{HH}}$ & $-4,9$ & $-4,7$ & $-4,6$ & $-4,6$ & $-4,7$ & $-4,9$ & $-5,2$ & $-5,6$ & $-6,0$ & $-6,5$ & $-7,0$ & $-7,5$ & $-7,9$ & $-8,4$ & $-8,9$ & $-7,3$ \\
\hline $\mathrm{NH}_{3}$ & ${ }^{1} J_{\mathrm{NH}}$ & 42,5 & 42,3 & 42,0 & 41,8 & 41,5 & 41,4 & 41,4 & 41,5 & 41,7 & 42,0 & 42,4 & 42,8 & 43,3 & 43,8 & 44,3 & 43,8 \\
\hline $\mathrm{NH}_{3}$ & ${ }^{2} J_{\mathrm{HH}}$ & $-7,5$ & $-7,2$ & $-7,0$ & $-7,0$ & $-7,1$ & $-7,4$ & $-7,8$ & $-8,2$ & $-8,7$ & $-9,2$ & $-9,8$ & $-10,3$ & $-10,8$ & $-11,3$ & $-11,8$ & $-9,6$ \\
\hline $\mathrm{PH}_{3}$ & ${ }^{1} J_{\mathrm{PH}}$ & 152,9 & 150,8 & 146,7 & 141,5 & 136,9 & 134,1 & 133,6 & 135,3 & 138,7 & 143,3 & 148,8 & 154,6 & 160,6 & 166,4 & 171,9 & 188,2 \\
\hline $\mathrm{PF}_{3}$ & ${ }^{1} J_{\mathrm{PF}}$ & $-1692,8$ & $-1689,7$ & $-1687,3$ & $-1686,0$ & $-1685,8$ & $-1686,3$ & $-1686,6$ & $-1685,7$ & $-1682,5$ & $-1676,8$ & $-1668,5$ & $-1658,0$ & $-1646,0$ & $-1632,9$ & $-1619,3$ & -1441 \\
\hline $\mathrm{BHF}_{2}$ & ${ }^{1} J_{\mathrm{BF}}$ & $-160,8$ & $-161,7$ & $-160,0$ & $-156,2$ & $-151,0$ & $-144,8$ & $-138,1$ & $-131,0$ & $-123,7$ & $-116,2$ & $-108,8$ & $-101,6$ & $-94,7$ & $-88,1$ & $-81,9$ & -84 \\
\hline $\mathrm{BF}_{3}$ & ${ }^{1} J_{\mathrm{BF}}$ & $-62,1$ & $-62,2$ & $-60,0$ & $-55,6$ & $-49,5$ & $-42,3$ & $-34,4$ & $-26,1$ & $-17,8$ & $-9,6$ & $-1,6$ & 6,0 & 13,2 & 19,9 & 26,2 & 15 \\
\hline $\mathrm{F}_{2} \mathrm{O}$ & ${ }^{1} J_{\mathrm{OF}}$ & $-304,4$ & $-308,9$ & $-316,6$ & $-328,0$ & $-342,4$ & $-358,4$ & $-375,0$ & $-391,5$ & $-407,7$ & $-423,6$ & $-439,5$ & $-455,7$ & $-472,2$ & $-489,3$ & $-506,9$ & -300 \\
\hline $\mathrm{CH}_{4}$ & ${ }^{1} J_{\mathrm{CH}}$ & 120,3 & 118,5 & 116,5 & 114,8 & 113,4 & 112,7 & 112,5 & 113,0 & 113,8 & 115,1 & 116,6 & 118,3 & 120,0 & 121,8 & 123,5 & 125,3 \\
\hline $\mathrm{CH}_{4}$ & ${ }^{2} J_{\mathrm{HH}}$ & $-10,6$ & $-10,2$ & $-9,9$ & $-9,8$ & $-9,9$ & $-10,2$ & $-10,6$ & $-11,1$ & $-11,6$ & $-12,2$ & $-12,8$ & $-13,3$ & $-13,8$ & $-14,3$ & $-14,7$ & $-12,8$ \\
\hline $\mathrm{C}_{2} \mathrm{H}_{2}$ & ${ }^{1} J_{\mathrm{CC}}$ & 187,9 & 186,1 & 184,9 & 184,1 & 183,6 & 183,5 & 184,0 & 185,1 & 186,7 & 188,9 & 191,6 & 194,7 & 198,1 & 201,7 & 205,3 & 174,8 \\
\hline $\mathrm{C}_{2} \mathrm{H}_{2}$ & ${ }^{1} J_{\mathrm{CH}}$ & 250,0 & 246,7 & 243,1 & 239,9 & 237,4 & 236,0 & 235,6 & 236,3 & 237,8 & 239,9 & 242,6 & 245,6 & 248,7 & 252,0 & 255,2 & 247,6 \\
\hline $\mathrm{C}_{2} \mathrm{H}_{2}$ & ${ }^{2} J_{\mathrm{CH}}$ & 55,4 & 55,3 & 55,4 & 55,8 & 56,2 & 56,6 & 56,9 & 57,0 & 57,0 & 56,8 & 56,5 & 56,0 & 55,4 & 54,8 & 54,1 & 50,1 \\
\hline $\mathrm{C}_{2} \mathrm{H}_{2}$ & ${ }^{3} J_{\mathrm{HH}}$ & 9,2 & 8,9 & 8,6 & 8,4 & 8,4 & 8,4 & 8,7 & 9,0 & 9,5 & 10,1 & 10,7 & 11,4 & 12,1 & 12,7 & 13,4 & 9,6 \\
\hline $\mathrm{C}_{2} \mathrm{H}_{4}$ & ${ }^{1} J_{\mathrm{CC}}$ & 59,6 & 58,5 & 57,8 & 57,4 & 57,2 & 57,1 & 57,5 & 58,2 & 59,4 & 61,0 & 63,0 & 65,3 & 67,9 & 70,7 & 73,5 & 67,6 \\
\hline $\mathrm{C}_{2} \mathrm{H}_{4}$ & ${ }^{1} J_{\mathrm{CH}}$ & 153,5 & 151,3 & 149,1 & 147,2 & 145,8 & 145,1 & 145,2 & 146,0 & 147,3 & 149,1 & 151,2 & 153,6 & 156,0 & 158,6 & 161,1 & 156,3 \\
\hline $\mathrm{C}_{2} \mathrm{H}_{4}$ & ${ }^{2} J_{\mathrm{CH}}$ & 0,4 & 0,5 & 0,6 & 0,6 & 0,5 & 0,3 & 0,0 & $-0,4$ & $-1,0$ & $-1,6$ & $-2,4$ & $-3,2$ & $-4,0$ & $-4,9$ & $-5,8$ & $-2,4$ \\
\hline $\mathrm{C}_{2} \mathrm{H}_{4}$ & ${ }^{2} J_{\mathrm{HH}}$ & 5,5 & 5,6 & 5,6 & 5,5 & 5,3 & 4,9 & 4,5 & 4,0 & 3,5 & 2,9 & 2,3 & 1,7 & 1,1 & 0,5 & 0,0 & 2,3 \\
\hline $\mathrm{C}_{2} \mathrm{H}_{4}$ & ${ }^{3} J_{\mathrm{HH}_{\mathrm{c}}}$ & 11,7 & 11,7 & 11,7 & 11,7 & 11,8 & 11,9 & 12,1 & 12,2 & 12,5 & 12,8 & 13,1 & 13,4 & 13,8 & 14,1 & 14,5 & 11,7 \\
\hline $\mathrm{C}_{2} \mathrm{H}_{4}$ & ${ }^{3} J_{\mathrm{HH}_{\mathrm{t}}}$ & 18,4 & 18,2 & 17,9 & 17,7 & 17,5 & 17,5 & 17,5 & 17,7 & 17,9 & 18,3 & 18,7 & 19,1 & 19,6 & 20,1 & 20,7 & 19 \\
\hline $\mathrm{C}_{2} \mathrm{H}_{6}$ & ${ }^{1} J_{\mathrm{CC}}$ & 26,0 & 25,4 & 25,1 & 25,1 & 25,2 & 25,4 & 25,8 & 26,5 & 27,3 & 28,3 & 29,5 & 30,8 & 32,2 & 33,6 & 34,9 & 34,5 \\
\hline $\mathrm{C}_{2} \mathrm{H}_{6}$ & ${ }^{1} J_{\mathrm{CH}}$ & 120,6 & 118,8 & 116,9 & 115,2 & 113,9 & 113,2 & 113,2 & 113,7 & 114,7 & 116,1 & 117,7 & 119,5 & 121,3 & 123,1 & 124,9 & 125,2 \\
\hline $\mathrm{C}_{2} \mathrm{H}_{6}$ & ${ }^{2} J_{\mathrm{CH}}$ & $-2,6$ & $-2,5$ & $-2,5$ & $-2,5$ & $-2,5$ & $-2,7$ & $-2,9$ & $-3,1$ & $-3,4$ & $-3,7$ & $-4,0$ & $-4,3$ & $-4,6$ & $-4,9$ & $-5,2$ & $-4,7$ \\
\hline \multirow[t]{3}{*}{ Total } & DM & $-19,13$ & $-19,64$ & $-20,18$ & $-20,71$ & $-21,17$ & $-21,43$ & $-21,38$ & $-21,00$ & $-20,30$ & $-19,32$ & $-18,12$ & $-16,79$ & $-15,40$ & $-14,00$ & ,66 & - \\
\hline & DMA & 22,90 & 23,17 & 23,6 & 24,14 & 24,54 & 24,69 & 24,53 & $24, \mathrm{C}$ & & 22,08 & & & 18,47 & & & - \\
\hline & PDMA & 44,20 & 45,50 & 45,87 & 45,00 & 43,10 & 39,87 & 35,88 & 31,06 & 25,60 & 20,05 & 14,30 & 14,00 & 14,28 & 18,14 & 23,43 & - \\
\hline \multirow[t]{3}{*}{ CPI } & DM & $-45,34$ & $-45,40$ & $-45,59$ & $-45,95$ & $-46,37$ & $-46,61$ & $-46,52$ & $-46,00$ & $-45,02$ & $-43,63$ & $-41,95$ & $-40,10$ & $-38,18$ & $-36,33$ & $-34,59$ & - \\
\hline & DMA & 48,59 & 48,73 & 48,94 & 49,26 & 49,61 & 49,72 & 49,43 & 48,64 & 47,33 & 45,54 & 43,45 & 41,26 & 39,04 & 38,20 & 39,25 & - \\
\hline & PDMA & 69,01 & 69,93 & 69,12 & 66,54 & 62,69 & 57,72 & 51,84 & 45,34 & 38,50 & 31,39 & 24,55 & 18,95 & 14,20 & 15,91 & 20,59 & - \\
\hline \multirow[t]{3}{*}{ SPI } & DM & 0,08 & $-0,75$ & $-1,55$ & $-2,20$ & $-2,69$ & $-2,96$ & $-2,94$ & $-2,67$ & $-2,1$ & $-1,49$ & $-0,65$ & 0,3 & 1,3 & 2,37 & 3,42 & - \\
\hline & DMA & 4,07 & 4,42 & 5,13 & 5,72 & 6,15 & 6,33 & 6,27 & 5,96 & 5,47 & 4, & 4,17 & 3,67 & 3,39 & 4,03 & 4,78 & - \\
\hline & PDMA & 26,00 & 27,58 & 28,82 & 29,20 & 28,73 & 26,79 & 24,17 & 20,59 & 16,14 & 11,73 & 6,79 & 10,37 & 14,33 & 19,78 & 25,52 & - \\
\hline \multirow[t]{3}{*}{$\Delta \mathrm{CS}$} & DM & $-45,42$ & $-44,65$ & $-44,04$ & -43 & $-43,69$ & $-43,65$ & $-43,58$ & -43 & & $-42,14$ & $-41,29$ & & $-39,50$ & $-38,69$ & $-38,01$ & - \\
\hline & DMA & 44,52 & 44,31 & 43,81 & 43,54 & 43,46 & 43,38 & 43,15 & 42,68 & 41, & 40,66 & 39,28 & & 35,64 & 34,17 & 34,47 & - \\
\hline & PDMA & 43,01 & 42,35 & 40,30 & 37,34 & 33,97 & 30,92 & 27,67 & 24,75 & 22,36 & 19,66 & 17,77 & 8,58 & $-0,12$ & $-3,86$ & $-4,92$ & - \\
\hline
\end{tabular}


Tabela 8.360: Constantes de acoplamento LC-BB95 com $\alpha=20 \%$ e $\alpha+\beta=100 \%$, variando $\gamma$, na base aug-pcJ-2.

\begin{tabular}{|c|c|c|c|c|c|c|c|c|c|c|c|c|c|c|c|c|c|}
\hline & $\gamma$ & 0,05 & 0,10 & 0,15 & 0,20 & 0,25 & 0,30 & 0,35 & 0,40 & 0,45 & 0,50 & 0,55 & 0,60 & 0,65 & 0,70 & 0,75 & Exp. \\
\hline $\mathrm{HF}$ & ${ }^{1} J_{\mathrm{HF}}$ & 453,4 & 456,5 & 459,6 & 462,7 & 465,9 & 469,6 & 473,9 & 478,9 & 484,5 & 490,6 & 497,1 & 503,7 & 510,4 & 517,1 & 523,9 & 500 \\
\hline $\mathrm{CO}$ & ${ }^{1} J_{\mathrm{CO}}$ & 20,3 & 20,4 & 20,4 & 20,3 & 20,4 & 20,4 & 20,4 & 20,4 & 20,2 & 19,9 & 19,5 & 18,9 & 18,2 & 17,5 & 16,7 & 16,4 \\
\hline $\mathrm{H}_{2} \mathrm{O}$ & ${ }^{1} J_{\mathrm{OH}}$ & $-75,4$ & $-75,5$ & $-75,7$ & $-75,8$ & $-75,9$ & $-76,2$ & $-76,6$ & $-77,1$ & $-77,7$ & $-78,5$ & $-79,3$ & $-80,1$ & $-81,0$ & $-81,9$ & $-82,8$ & $-80,6$ \\
\hline $\mathrm{H}_{2} \mathrm{O}$ & ${ }^{2} J_{\mathrm{HH}}$ & $-5,9$ & $-5,7$ & $-5,6$ & $-5,6$ & $-5,7$ & $-5,9$ & $-6,1$ & $-6,5$ & $-6,9$ & $-7,3$ & $-7,7$ & $-8,2$ & $-8,6$ & $-9,0$ & $-9,5$ & $-7,3$ \\
\hline $\mathrm{NH}_{3}$ & ${ }^{1} J_{\mathrm{NH}}$ & 43,2 & 43,0 & 42,8 & 42,6 & 42,4 & 42,2 & 42,2 & 42,3 & 42,5 & 42,8 & 43,1 & 43,5 & 43,9 & 44,4 & 44,8 & 43,8 \\
\hline $\mathrm{NH}_{3}$ & ${ }^{2} J_{\mathrm{HH}}$ & $-8,3$ & $-8,1$ & $-7,9$ & $-7,9$ & $-8,0$ & $-8,2$ & $-8,6$ & $-9,0$ & $-9,4$ & $-9,9$ & $-10,4$ & $-10,8$ & $-11,3$ & $-11,8$ & $-12,2$ & $-9,6$ \\
\hline $\mathrm{PH}_{3}$ & ${ }^{1} J_{\mathrm{PH}}$ & 160,4 & 158,4 & 154,7 & 150,1 & 146,0 & 143,5 & 143,1 & 144,5 & 147,5 & 151,6 & 156,5 & 161,7 & 166,9 & 172,1 & 177,0 & 188,2 \\
\hline $\mathrm{PF}_{3}$ & ${ }^{1} J_{\mathrm{PF}}$ & $-1668,2$ & $-1666,0$ & $-1663,7$ & $-1661,6$ & $-1659,9$ & $-1658,7$ & $-1657,4$ & $-1655,0$ & $-1651,0$ & $-1645,0$ & $-1636,9$ & $-1627,2$ & $-1616,2$ & $-1604,3$ & $-1592,1$ & -1441 \\
\hline $\mathrm{BHF}_{2}$ & ${ }^{1} J_{\mathrm{BF}}$ & $-143,8$ & $-144,8$ & $-143,5$ & $-140,3$ & $-135,8$ & $-130,4$ & $-124,5$ & $-118,2$ & $-111,7$ & $-105,1$ & $-98,5$ & $-92,1$ & $-86,0$ & $-80,1$ & $-74,6$ & -84 \\
\hline $\mathrm{BF}_{3}$ & ${ }^{1} J_{\mathrm{BF}}$ & $-43,6$ & $-43,9$ & $-42,1$ & $-38,4$ & $-33,1$ & $-26,9$ & $-20,0$ & $-12,8$ & $-5,4$ & 1,7 & 8,8 & 15,6 & 22,0 & 28,0 & 33,6 & 15 \\
\hline $\mathrm{F}_{2} \mathrm{O}$ & ${ }^{1} J_{\mathrm{OF}}$ & $-337,7$ & $-341,6$ & $-348,4$ & $-358,4$ & $-371,1$ & $-385,5$ & $-400,7$ & $-416,1$ & $-431,5$ & $-447,0$ & $-462,6$ & $-478,6$ & $-495,2$ & $-512,3$ & $-529,9$ & -300 \\
\hline $\mathrm{CH}_{4}$ & ${ }^{1} J_{\mathrm{CH}}$ & 121,8 & 120,1 & 118,4 & 116,8 & 115,6 & 115,0 & 114,8 & 115,2 & 116,0 & 117,2 & 118,5 & 120,0 & 121,6 & 123,2 & 124,7 & 125,3 \\
\hline $\mathrm{CH}_{4}$ & ${ }^{2} J_{\mathrm{HH}}$ & $-11,3$ & $-10,9$ & $-10,6$ & $-10,6$ & $-10,7$ & $-10,9$ & $-11,3$ & $-11,7$ & $-12,2$ & $-12,7$ & $-13,2$ & $-13,7$ & $-14,2$ & $-14,6$ & $-15,0$ & $-12,8$ \\
\hline $\mathrm{C}_{2} \mathrm{H}_{2}$ & ${ }^{1} J_{\mathrm{CC}}$ & 190,7 & 189,0 & 187,9 & 187,1 & 186,8 & 186,8 & 187,4 & 188,5 & 190,2 & 192,3 & 195,0 & 197,9 & 201,1 & 204,5 & 208,0 & 174,8 \\
\hline $\mathrm{C}_{2} \mathrm{H}_{2}$ & ${ }^{1} J_{\mathrm{CH}}$ & 252,2 & 249,2 & 245,9 & 243,0 & 240,8 & 239,5 & 239,2 & 239,9 & 241,3 & 243,3 & 245,7 & 248,5 & 251,4 & 254,4 & 257,3 & 247,6 \\
\hline $\mathrm{C}_{2} \mathrm{H}_{2}$ & ${ }^{2} J_{\mathrm{CH}}$ & 55,5 & 55,4 & 55,6 & 55,9 & 56,2 & 56,5 & 56,7 & 56,8 & 56,6 & 56,4 & 56,0 & 55,5 & 54,9 & 54,2 & 53,5 & 50,1 \\
\hline $\mathrm{C}_{2} \mathrm{H}_{2}$ & ${ }^{3} J_{\mathrm{HH}}$ & 9,7 & 9,4 & 9,1 & 9,0 & 8,9 & 9,1 & 9,3 & 9,7 & 10,2 & 10,7 & 11,3 & 12,0 & 12,6 & 13,3 & 13,9 & 9,6 \\
\hline $\mathrm{C}_{2} \mathrm{H}_{4}$ & ${ }^{1} J_{\mathrm{CC}}$ & 62,2 & 61,1 & 60,5 & 60,1 & 59,9 & 60,0 & 60,4 & 61,1 & 62,3 & 63,9 & 65,9 & 68,1 & 70,6 & 73,3 & 76,0 & 67,6 \\
\hline $\mathrm{C}_{2} \mathrm{H}_{4}$ & ${ }^{1} J_{\mathrm{CH}}$ & 155,5 & 153,6 & 151,5 & 149,8 & 148,6 & 148,0 & 148,1 & 148,8 & 150,1 & 151,7 & 153,7 & 155,9 & 158,2 & 160,5 & 162,8 & 156,3 \\
\hline $\mathrm{C}_{2} \mathrm{H}_{4}$ & ${ }^{2} J_{\mathrm{CH}}$ & $-0,3$ & $-0,2$ & $-0,1$ & $-0,1$ & $-0,2$ & $-0,4$ & $-0,7$ & $-1,2$ & $-1,7$ & $-2,4$ & $-3,1$ & $-3,9$ & $-4,7$ & $-5,6$ & $-6,5$ & $-2,4$ \\
\hline $\mathrm{C}_{2} \mathrm{H}_{4}$ & ${ }^{2} J_{\mathrm{HH}}$ & 4,8 & 4,9 & 4,9 & 4,9 & 4,7 & 4,4 & 4,0 & 3,5 & 3,0 & 2,4 & 1,9 & 1,3 & 0,7 & 0,2 & $-0,3$ & 2,3 \\
\hline $\mathrm{C}_{2} \mathrm{H}_{4}$ & ${ }^{3} J_{\mathrm{HH}_{\mathrm{c}}}$ & 11,9 & 11,8 & 11,8 & 11,9 & 12,0 & 12,1 & 12,3 & 12,5 & 12,7 & 13,0 & 13,3 & 13,6 & 14,0 & 14,3 & 14,7 & 11,7 \\
\hline $\mathrm{C}_{2} \mathrm{H}_{4}$ & ${ }^{3} J_{\mathrm{HH}_{\mathrm{t}}}$ & 18,6 & 18,4 & 18,2 & 18,0 & 17,9 & 17,8 & 17,9 & 18,1 & 18,4 & 18,7 & 19,1 & 19,6 & 20,1 & 20,5 & 21,0 & 19 \\
\hline $\mathrm{C}_{2} \mathrm{H}_{6}$ & ${ }^{1} J_{\mathrm{CC}}$ & 28,0 & 27,4 & 27,2 & 27,1 & 27,2 & 27,4 & 27,8 & 28,4 & 29,1 & 30,1 & 31,2 & 32,3 & 33,6 & 34,8 & 36,0 & 34,5 \\
\hline $\mathrm{C}_{2} \mathrm{H}_{6}$ & ${ }^{1} J_{\mathrm{CH}}$ & 122,3 & 120,6 & 118,9 & 117,4 & 116,3 & 115,7 & 115,6 & 116,1 & 117,0 & 118,2 & 119,7 & 121,3 & 122,9 & 124,6 & 126,2 & 125,2 \\
\hline $\mathrm{C}_{2} \mathrm{H}_{6}$ & ${ }^{2} J_{\mathrm{CH}}$ & $-3,0$ & $-2,9$ & $-2,9$ & $-2,9$ & $-3,0$ & $-3,1$ & $-3,3$ & $-3,5$ & $-3,7$ & $-4,0$ & $-4,3$ & $-4,6$ & $-4,8$ & $-5,1$ & $-5,3$ & $-4,7$ \\
\hline \multirow[t]{3}{*}{ Total } & DM & $-16,62$ & $-17,13$ & $-17,62$ & $-18,07$ & $-18,42$ & -18 & -18 & $-18,13$ & $-17,48$ & & & $-14,42$ & $-13,23$ & $-12,03$ & $-10,89$ & - \\
\hline & DMA & 20,14 & 20,35 & 20,69 & 21,10 & 21,39 & 21,48 & 21,30 & 20,82 & 20,08 & 19,15 & 18,20 & 17,66 & 18,27 & 19,28 & 20,60 & - \\
\hline & PDMA & 33,91 & 35,08 & 35,45 & 34,87 & 33,11 & 30,37 & 26,72 & 22,19 & 17,64 & 12,67 & 12,21 & 13,11 & 17,74 & 23,05 & 28,61 & - \\
\hline \multirow[t]{3}{*}{ CPI } & DM & $-40,59$ & $-40,75$ & $-40,94$ & $-41,20$ & $-41,43$ & $-41,55$ & $-41,38$ & $-40,86$ & $-39,98$ & $-38,83$ & $-37,39$ & $-35,86$ & $-34,35$ & $-32,84$ & $-31,45$ & - \\
\hline & DMA & 42,74 & 42,96 & 43,17 & 43,40 & 43,59 & 43,58 & 43,24 & 42,48 & 41,31 & & 38,19 & 37,19 & 37 & 39,33 & 41,13 & - \\
\hline & PDMA & 52,60 & 53,56 & 52,97 & 50,82 & 47,50 & 43,21 & 38,11 & 32,40 & 26,31 & 20,69 & 16,34 & 12,94 & 16,99 & 21,93 & 27,01 & - \\
\hline \multirow[t]{3}{*}{ SPI } & DM & 0,97 & 0,19 & $-0,5$ & $-1,11$ & $-1,5$ & $-1,75$ & $-1,7$ & $-1,46$ & -0, & -0 , & 0,4 & 1,3 & 2, & 3,23 & 4,1 & - \\
\hline & DMA & 3,57 & 3,77 & 4,20 & & & 5,27 & 5,21 & & & & & & & 4,59 & 5,54 & - \\
\hline & PDMA & 20,21 & 21,54 & 22,60 & 23,18 & 22,56 & 20,95 & 18,36 & 14,71 & 11,29 & 6,78 & 9,18 & 13,24 & 18,29 & 23,86 & 29,78 & - \\
\hline \multirow[t]{3}{*}{$\Delta \mathrm{CS}$} & DM & $-41,56$ & $-40,93$ & $-40,42$ & $-40,09$ & $-39,89$ & $-39,80$ & $-39,66$ & $-39,40$ & $-39,00$ & $-38,47$ & $-37,83$ & $-37,18$ & $-36,61$ & $-36,06$ & $-35,65$ & - \\
\hline & DMA & 39,17 & 39,19 & 38,97 & 38,66 & 38,48 & 38,32 & 38,03 & 37,56 & 36,79 & 35,88 & 34,64 & 33,85 & 33, & 34,74 & 35,59 & - \\
\hline & PDMA & 32,39 & 32,02 & 30,37 & 27,63 & 24,94 & 22,25 & 19,74 & 17,69 & 15,02 & 13,91 & 7,16 & $-0,30$ & $-1,30$ & $-1,93$ & $-2,77$ & - \\
\hline
\end{tabular}


Tabela 8.361: Constantes de acoplamento LC-BB95 com $\alpha=30 \%$ e $\alpha+\beta=100 \%$, variando $\gamma$, na base aug-pcJ-2.

\begin{tabular}{|c|c|c|c|c|c|c|c|c|c|c|c|c|c|c|c|c|c|}
\hline & $\gamma$ & 0,05 & 0,10 & 0,15 & 0,20 & 0,25 & 0,30 & 0,35 & 0,40 & 0,45 & 0,50 & 0,55 & 0,60 & 0,65 & 0,70 & 0,75 & Exp. \\
\hline $\mathrm{HF}$ & ${ }^{1} J_{\mathrm{HF}}$ & 477,0 & 479,5 & 482,2 & 484,8 & 487,7 & 490,9 & 494,6 & 498,9 & 503,8 & 509,1 & 514,7 & 520,4 & 526,3 & 532,1 & 538,0 & 500 \\
\hline $\mathrm{CO}$ & ${ }^{1} J_{\mathrm{CO}}$ & 18,4 & 18,5 & 18,5 & 18,5 & 18,5 & 18,5 & 18,5 & 18,5 & 18,4 & 18,1 & 17,7 & 17,2 & 16,6 & 15,9 & 15,1 & 16,4 \\
\hline $\mathrm{H}_{2} \mathrm{O}$ & ${ }^{1} J_{\mathrm{OH}}$ & $-77,9$ & $-78,0$ & $-78,1$ & $-78,2$ & $-78,3$ & $-78,5$ & $-78,9$ & $-79,3$ & $-79,9$ & $-80,5$ & $-81,2$ & $-81,9$ & $-82,7$ & $-83,5$ & $-84,4$ & $-80,6$ \\
\hline $\mathrm{H}_{2} \mathrm{O}$ & ${ }^{2} J_{\mathrm{HH}}$ & $-6,9$ & $-6,8$ & $-6,6$ & $-6,6$ & $-6,7$ & $-6,9$ & $-7,1$ & $-7,4$ & $-7,8$ & $-8,1$ & $-8,5$ & $-8,9$ & $-9,3$ & $-9,7$ & $-10,1$ & $-7,3$ \\
\hline $\mathrm{NH}_{3}$ & ${ }^{1} J_{\mathrm{NH}}$ & 44,0 & 43,8 & 43,6 & 43,4 & 43,2 & 43,1 & 43,1 & 43,2 & 43,3 & 43,6 & 43,8 & 44,2 & 44,6 & 45,0 & 45,4 & 43,8 \\
\hline $\mathrm{NH}_{3}$ & ${ }^{2} J_{\mathrm{HH}}$ & $-9,2$ & $-9,0$ & $-8,8$ & $-8,8$ & $-8,9$ & $-9,1$ & $-9,4$ & $-9,7$ & $-10,1$ & $-10,6$ & $-11,0$ & $-11,4$ & $-11,8$ & $-12,2$ & $-12,6$ & $-9,6$ \\
\hline $\mathrm{PH}_{3}$ & ${ }^{1} J_{\mathrm{PH}}$ & 167,8 & 166,0 & 162,7 & 158,7 & 155,1 & 152,9 & 152,4 & 153,7 & 156,3 & 159,9 & 164,1 & 168,7 & 173,3 & 177,8 & 182,1 & 188,2 \\
\hline $\mathrm{PF}_{3}$ & ${ }^{1} J_{\mathrm{PF}}$ & $-1639,5$ & $-1638,1$ & $-1635,9$ & $-1633,4$ & $-1630,9$ & $-1628,6$ & $-1626,2$ & $-1623,0$ & $-1618,6$ & $-1612,6$ & $-1605,0$ & $-1596,1$ & $-1586,2$ & $-1575,7$ & $-1564,9$ & -1441 \\
\hline $\mathrm{BHF}_{2}$ & ${ }^{1} J_{\mathrm{BF}}$ & $-126,8$ & $-127,9$ & $-127,0$ & $-124,3$ & $-120,4$ & $-115,8$ & $-110,7$ & $-105,2$ & $-99,5$ & $-93,8$ & $-88,0$ & $-82,5$ & $-77,1$ & $-72,0$ & $-67,1$ & -84 \\
\hline $\mathrm{BF}_{3}$ & ${ }^{1} J_{\mathrm{BF}}$ & $-25,2$ & $-25,6$ & $-24,2$ & $-21,2$ & $-16,7$ & $-11,4$ & $-5,5$ & 0,7 & 7,0 & 13,3 & 19,5 & 25,4 & 31,0 & 36,2 & 41,2 & 15 \\
\hline $\mathrm{F}_{2} \mathrm{O}$ & ${ }^{1} J_{\mathrm{OF}}$ & $-371,1$ & $-374,5$ & $-380,4$ & $-389,3$ & $-400,7$ & $-413,9$ & $-428,0$ & $-442,6$ & $-457,4$ & $-472,6$ & $-488,1$ & $-504,2$ & $-520,8$ & $-538,0$ & $-555,7$ & -300 \\
\hline $\mathrm{CH}_{4}$ & ${ }^{1} J_{\mathrm{CH}}$ & 123,3 & 121,8 & 120,3 & 118,9 & 117,9 & 117,3 & 117,2 & 117,5 & 118,2 & 119,2 & 120,5 & 121,8 & 123,2 & 124,6 & 125,9 & 125,3 \\
\hline $\mathrm{CH}_{4}$ & ${ }^{2} J_{\mathrm{HH}}$ & $-12,0$ & $-11,7$ & $-11,4$ & $-11,3$ & $-11,4$ & $-11,6$ & $-12,0$ & $-12,4$ & $-12,8$ & $-13,2$ & $-13,7$ & $-14,1$ & $-14,5$ & $-14,9$ & $-15,2$ & $-12,8$ \\
\hline $\mathrm{C}_{2} \mathrm{H}_{2}$ & ${ }^{1} J_{\mathrm{CC}}$ & 193,8 & 192,3 & 191,2 & 190,6 & 190,3 & 190,5 & 191,1 & 192,3 & 193,9 & 196,1 & 198,6 & 201,4 & 204,4 & 207,6 & 210,8 & 174,8 \\
\hline $\mathrm{C}_{2} \mathrm{H}_{2}$ & ${ }^{1} J_{\mathrm{CH}}$ & 254,5 & 251,7 & 248,9 & 246,3 & 244,3 & 243,2 & 243,0 & 243,6 & 244,9 & 246,8 & 249,0 & 251,6 & 254,2 & 256,9 & 259,5 & 247,6 \\
\hline $\mathrm{C}_{2} \mathrm{H}_{2}$ & ${ }^{2} J_{\mathrm{CH}}$ & 55,4 & 55,4 & 55,5 & 55,8 & 56,1 & 56,3 & 56,4 & 56,3 & 56,2 & 55,8 & 55,4 & 54,8 & 54,2 & 53,6 & 52,9 & 50,1 \\
\hline $\mathrm{C}_{2} \mathrm{H}_{2}$ & ${ }^{3} J_{\mathrm{HH}}$ & 10,3 & 10,0 & 9,8 & 9,6 & 9,6 & 9,8 & 10,0 & 10,4 & 10,9 & 11,4 & 12,0 & 12,7 & 13,3 & 13,9 & 14 & 9,6 \\
\hline $\mathrm{C}_{2} \mathrm{H}_{4}$ & ${ }^{1} J_{\mathrm{CC}}$ & 65,1 & 64,0 & 63,4 & 63,0 & 62,9 & 63,0 & 63,5 & 64,3 & 65,5 & 67,1 & 69,0 & 71,2 & 73,5 & 76,0 & 78,5 & 67,6 \\
\hline $\mathrm{C}_{2} \mathrm{H}_{4}$ & ${ }^{1} J_{\mathrm{CH}}$ & 157,7 & 155,9 & 154,1 & 152,5 & 151,4 & 151,0 & 151,1 & 151,8 & 153,0 & 154,5 & 156,3 & 158,3 & 160,4 & 162,5 & 164,6 & 156,3 \\
\hline $\mathrm{C}_{2} \mathrm{H}_{4}$ & ${ }^{2} J_{\mathrm{CH}}$ & $-1,2$ & $-1,0$ & $-0,9$ & $-0,9$ & $-1,0$ & $-1,2$ & $-1,6$ & $-2,0$ & $-2,6$ & $-3,2$ & $-3,9$ & $-4,7$ & $-5,5$ & $-6,3$ & $-7,2$ & $-2,4$ \\
\hline $\mathrm{C}_{2} \mathrm{H}_{4}$ & ${ }^{2} J_{\mathrm{HH}}$ & 4,1 & 4,2 & 4,3 & 4,2 & 4,0 & 3,7 & 3,4 & 2,9 & 2,4 & 1,9 & 1,4 & 0,8 & 0,3 & $-0,1$ & $-0,6$ & 2,3 \\
\hline $\mathrm{C}_{2} \mathrm{H}_{4}$ & ${ }^{3} J_{\mathrm{HH}_{\mathrm{c}}}$ & 12,1 & 12,1 & 12,1 & 12,1 & 12,2 & 12,3 & 12,5 & 12,7 & 13,0 & 13,3 & 13,6 & 13,9 & 14,2 & 14,6 & 14,9 & 11,7 \\
\hline $\mathrm{C}_{2} \mathrm{H}_{4}$ & ${ }^{3} J_{\mathrm{HH}_{\mathrm{t}}}$ & 18,9 & 18,7 & 18,5 & 18,3 & 18,2 & 18,3 & 18,4 & 18,6 & 18,8 & 19,2 & 19,6 & 20,0 & 20,5 & 21,0 & 21,4 & 19 \\
\hline $\mathrm{C}_{2} \mathrm{H}_{6}$ & ${ }^{1} J_{\mathrm{CC}}$ & 30,1 & 29,5 & 29,2 & 29,2 & 29,3 & 29,5 & 29,8 & 30,3 & 31,0 & 31,9 & 32,8 & 33,9 & 35,0 & 36,1 & 37,2 & 34,5 \\
\hline $\mathrm{C}_{2} \mathrm{H}_{6}$ & ${ }^{1} J_{\mathrm{CH}}$ & 124,0 & 122,5 & 121,0 & 119,6 & 118,6 & 118,1 & 118,1 & 118,5 & 119,3 & 120,4 & 121,7 & 123,1 & 124,6 & 126,0 & 127,5 & 125,2 \\
\hline $\mathrm{C}_{2} \mathrm{H}_{6}$ & ${ }^{2} J_{\mathrm{CH}}$ & $-3,5$ & $-3,4$ & $-3,3$ & $-3,3$ & $-3,4$ & $-3,5$ & $-3,7$ & $-3,9$ & $-4,1$ & $-4,3$ & $-4,6$ & $-4,8$ & $-5,1$ & $-5,3$ & $-5,5$ & $-4,7$ \\
\hline \multirow[t]{3}{*}{ Total } & $\mathrm{DM}$ & -13, & 14,43 & -14 & & 4 & & & & & & & & & & & - \\
\hline & DMA & & & & & & & & & & & & & & & & - \\
\hline & PDMA & 23,57 & 24,62 & 25,14 & 24,41 & 22,76 & 20,37 & 17,20 & 13,65 & 10,83 & 10,75 & 13,76 & 18,51 & 23,70 & 28,98 & 34,61 & - \\
\hline \multirow[t]{3}{*}{ CPI } & DM & $-35,48$ & 35,73 & & $-36,12$ & & & & & & & & & & & & - \\
\hline & DMA & 36,52 & 36,7 & 37, & 37 & 3 & 37 & 36 , & & & & 36 & & & 41,64 & & - \\
\hline & PDMA & 36,14 & 36,95 & 36,75 & 35,07 & 32,18 & 28,47 & 24,13 & 19,77 & 16,41 & 12,87 & 14,93 & 19,31 & 24,34 & 29,60 & 35,03 & - \\
\hline \multirow[t]{3}{*}{ SPI } & DM & & & & & & & -( & & & & & & & & & - \\
\hline & MA & & & & & & & & & & & & & & & & - \\
\hline & PDMA & 14,36 & 15,58 & 16,62 & 16,59 & 15,86 & 14,44 & 12,12 & 9,16 & 6,74 & 9,19 & 12,90 & 17,91 & 23,23 & 28,52 & 34,29 & - \\
\hline \multirow[t]{3}{*}{$\Delta C S$} & & & & & & & & & & & & & & & & & - \\
\hline & MA & & & & & & & & & & & & & & & & - \\
\hline & & 21,78 & 21,38 & 20,13 & 18,48 & 16,33 & 14,03 & 12,01 & 10,61 & 9,67 & 3,68 & 2,03 & 1,40 & 1,11 & 1,08 & 0,74 & - \\
\hline
\end{tabular}


Tabela 8.362: Constantes de acoplamento LC-BB95 com $\alpha=40 \%$ e $\alpha+\beta=100 \%$, variando $\gamma$, na base aug-pcJ-2.

\begin{tabular}{|c|c|c|c|c|c|c|c|c|c|c|c|c|c|c|c|c|c|}
\hline & $\gamma$ & 0,05 & 0,10 & 0,15 & 0,20 & 0,25 & 0,30 & 0,35 & 0,40 & 0,45 & 0,50 & 0,55 & 0,60 & 0,65 & 0,70 & 0,75 & Exp. \\
\hline $\mathrm{HF}$ & ${ }^{1} J_{\mathrm{HF}}$ & 500,8 & 502,8 & 505,0 & 507,2 & 509,6 & 512,3 & 515,5 & 519,2 & 523,4 & 527,9 & 532,6 & 537,5 & 542,5 & 547,5 & 552,5 & 500 \\
\hline $\mathrm{CO}$ & ${ }^{1} J_{\mathrm{CO}}$ & 16,4 & 16,5 & 16,5 & 16,5 & 16,5 & 16,6 & 16,6 & 16,5 & 16,4 & 16,2 & 15,8 & 15,4 & 14,8 & 14,2 & 13,5 & 16,4 \\
\hline $\mathrm{H}_{2} \mathrm{O}$ & ${ }^{1} J_{\mathrm{OH}}$ & $-80,4$ & $-80,5$ & $-80,5$ & $-80,6$ & $-80,7$ & $-80,9$ & $-81,2$ & $-81,6$ & $-82,0$ & $-82,6$ & $-83,2$ & $-83,8$ & $-84,5$ & $-85,2$ & $-85,9$ & $-80,6$ \\
\hline $\mathrm{H}_{2} \mathrm{O}$ & ${ }^{2} J_{\mathrm{HH}}$ & $-8,0$ & $-7,8$ & $-7,7$ & $-7,7$ & $-7,7$ & $-7,9$ & $-8,1$ & $-8,4$ & $-8,7$ & $-9,0$ & $-9,3$ & $-9,7$ & $-10,0$ & $-10,3$ & $-10,7$ & $-7,3$ \\
\hline $\mathrm{NH}_{3}$ & ${ }^{1} J_{\mathrm{NH}}$ & 44,7 & 44,5 & 44,4 & 44,2 & 44,0 & 44,0 & 43,9 & 44,0 & 44,2 & 44,4 & 44,6 & 44,9 & 45,2 & 45,6 & 45,9 & 43,8 \\
\hline $\mathrm{NH}_{3}$ & ${ }^{2} J_{\mathrm{HH}}$ & $-10,1$ & $-9,9$ & $-9,7$ & $-9,7$ & $-9,8$ & $-10,0$ & $-10,2$ & $-10,5$ & $-10,9$ & $-11,3$ & $-11,6$ & $-12,0$ & $-12,4$ & $-12,7$ & $-13,0$ & $-9,6$ \\
\hline $\mathrm{PH}_{3}$ & ${ }^{1} J_{\mathrm{PH}}$ & 175,1 & 173,4 & 170,6 & 167,2 & 164,1 & 162,2 & 161,8 & 162,8 & 165,0 & 168,1 & 171,7 & 175,6 & 179,6 & 183,5 & 187,2 & 188,2 \\
\hline $\mathrm{PF}_{3}$ & ${ }^{1} J_{\mathrm{PF}}$ & $-1607,4$ & $-1606,7$ & $-1604,8$ & $-1602,2$ & $-1599,3$ & $-1596,4$ & $-1593,4$ & $-1589,8$ & $-1585,3$ & $-1579,6$ & $-1572,6$ & $-1564,7$ & $-1556,1$ & $-1546,9$ & $-1537,6$ & -1441 \\
\hline $\mathrm{BHF}_{2}$ & ${ }^{1} J_{\mathrm{BF}}$ & $-109,9$ & $-110,9$ & $-110,3$ & $-108,2$ & $-105,0$ & $-101,1$ & $-96,7$ & $-92,0$ & $-87,2$ & $-82,3$ & $-77,4$ & $-72,6$ & $-68,0$ & $-63,6$ & $-59,5$ & -84 \\
\hline $\mathrm{BF}_{3}$ & ${ }^{1} J_{\mathrm{BF}}$ & $-7,0$ & $-7,4$ & $-6,4$ & $-3,9$ & $-0,3$ & 4,1 & 9,1 & 14,3 & 19,7 & 25,1 & 30,3 & 35,4 & 40,2 & 44,7 & 48,9 & 15 \\
\hline $\mathrm{F}_{2} \mathrm{O}$ & ${ }^{1} J_{\mathrm{OF}}$ & $-406,3$ & $-409,1$ & $-414,3$ & $-422,2$ & $-432,6$ & $-444,8$ & $-458,1$ & $-472,1$ & $-486,6$ & $-501,6$ & $-517,1$ & $-533,3$ & $-550,0$ & $-567,3$ & $-585,1$ & -300 \\
\hline $\mathrm{CH}_{4}$ & ${ }^{1} J_{\mathrm{CH}}$ & 124,9 & 123,5 & 122,2 & 121,0 & 120,1 & 119,6 & 119,6 & 119,9 & 120,5 & 121,4 & 122,4 & 123,6 & 124,8 & 126,0 & 127,2 & 125,3 \\
\hline $\mathrm{CH}_{4}$ & ${ }^{2} J_{\mathrm{HH}}$ & $-12,7$ & $-12,4$ & $-12,2$ & $-12,1$ & $-12,2$ & $-12,4$ & $-12,7$ & $-13,0$ & $-13,4$ & $-13,8$ & $-14,1$ & $-14,5$ & $-14,9$ & $-15,2$ & $-15,5$ & $-12,8$ \\
\hline $\mathrm{C}_{2} \mathrm{H}_{2}$ & ${ }^{1} J_{\mathrm{CC}}$ & 197,4 & 196,0 & 195,0 & 194,5 & 194,3 & 194,6 & 195,3 & 196,4 & 198,1 & 200,1 & 202,5 & 205,2 & 208,0 & 210,8 & 213,7 & 174,8 \\
\hline $\mathrm{C}_{2} \mathrm{H}_{2}$ & ${ }^{1} J_{\mathrm{CH}}$ & 256,9 & 254,5 & 251,9 & 249,7 & 248,0 & 247,1 & 247,0 & 247,6 & 248,8 & 250,5 & 252,5 & 254,8 & 257,1 & 259,5 & 261,8 & 247,6 \\
\hline $\mathrm{C}_{2} \mathrm{H}_{2}$ & ${ }^{2} J_{\mathrm{CH}}$ & 55,1 & 55,1 & 55,3 & 55,5 & 55,7 & 55,8 & 55,9 & 55,8 & 55,5 & 55,1 & 54,6 & 54,1 & 53,5 & 52,8 & 52,2 & 50,1 \\
\hline $\mathrm{C}_{2} \mathrm{H}_{2}$ & ${ }^{3} J_{\mathrm{HH}}$ & 11,0 & 10,7 & 10,5 & 10,4 & 10,4 & 10,6 & 10,8 & 11,2 & 11,7 & 12,2 & 12,8 & 13,4 & 13,9 & 14,5 & 15,0 & 9,6 \\
\hline $\mathrm{C}_{2} \mathrm{H}_{4}$ & ${ }^{1} J_{\mathrm{CC}}$ & 68,2 & 67,2 & 66,6 & 66,3 & 66,2 & 66,4 & 67,0 & 67,8 & 69,0 & 70,6 & 72,4 & 74,4 & 76,6 & 78,9 & 81,2 & 67,6 \\
\hline $\mathrm{C}_{2} \mathrm{H}_{4}$ & ${ }^{1} J_{\mathrm{CH}}$ & 159,9 & 158,3 & 156,7 & 155,4 & 154,5 & 154,1 & 154,2 & 154,9 & 156,0 & 157,4 & 159,0 & 160,8 & 162,7 & 164,6 & 166,4 & 156,3 \\
\hline $\mathrm{C}_{2} \mathrm{H}_{4}$ & ${ }^{2} J_{\mathrm{CH}}$ & $-2,1$ & $-2,0$ & $-1,9$ & $-1,9$ & $-2,0$ & $-2,2$ & $-2,5$ & $-3,0$ & $-3,6$ & $-4,2$ & $-4,9$ & $-5,6$ & $-6,4$ & $-7,1$ & $-7,9$ & $-2,4$ \\
\hline $\mathrm{C}_{2} \mathrm{H}_{4}$ & ${ }^{2} J_{\mathrm{HH}}$ & 3,4 & 3,5 & 3,5 & 3,5 & 3,3 & 3,0 & 2,7 & 2,3 & 1,8 & 1,3 & 0,8 & 0,3 & $-0,1$ & $-0,5$ & $-1,0$ & 2,3 \\
\hline $\mathrm{C}_{2} \mathrm{H}_{4}$ & ${ }^{3} J_{\mathrm{HH}}$ & 12,4 & 12,4 & 12,3 & 12,4 & 12,5 & 12,6 & 12,8 & 13,0 & 13,3 & 13,6 & 13,9 & 14,2 & 14,5 & 14,8 & 15,1 & 11,7 \\
\hline $\mathrm{C}_{2} \mathrm{H}_{4}$ & ${ }^{3} J_{\mathrm{HH}_{\mathrm{t}}}{ }^{c}$ & 19,3 & 19,1 & 18,9 & 18,8 & 18,7 & 18,8 & 18,9 & 19,1 & 19,4 & 19,7 & 20,1 & 20,6 & 21,0 & 21,4 & 21,8 & 19 \\
\hline $\mathrm{C}_{2} \mathrm{H}_{6}$ & ${ }^{1} J_{\mathrm{CC}}$ & 32,2 & 31,6 & 31,4 & 31,3 & 31,4 & 31,6 & 31,9 & 32,3 & 32,9 & 33,7 & 34,5 & 35,5 & 36,4 & 37,4 & 38,3 & 34,5 \\
\hline $\mathrm{C}_{2} \mathrm{H}_{6}$ & ${ }^{1} J_{\mathrm{CH}}$ & 125,7 & 124,4 & 123,1 & 121,9 & 121,1 & 120,6 & 120,6 & 121,0 & 121,7 & 122,7 & 123,8 & 125,0 & 126,3 & 127,5 & 128,7 & 125,2 \\
\hline $\mathrm{C}_{2} \mathrm{H}_{6}$ & ${ }^{2} J_{\mathrm{CH}}$ & $-3,9$ & $-3,9$ & $-3,8$ & $-3,8$ & $-3,9$ & $-3,9$ & $-4,1$ & $-4,3$ & $-4,5$ & $-4,7$ & $-4,9$ & $-5,1$ & $-5,3$ & $-5,5$ & $-5,7$ & $-4,7$ \\
\hline \multirow[t]{3}{*}{ Total } & DM & $-11,13$ & $-11,62$ & $-12,03$ & $-12,37$ & $-12,62$ & $-12,72$ & -12, & $-12,37$ & -11 & $-11,31$ & $-10,61$ & $-9,83$ & $-9,06$ & $-8,29$ & $-7,60$ & - \\
\hline & DMA & 14,84 & 14,97 & 15,15 & 15,42 & 15,68 & 15 & 16,1 & & & 17,68 & & & & & & - \\
\hline & PDMA & 14,85 & 15,16 & 15,11 & 14,66 & 13,32 & 11,68 & 9,74 & 8,78 & 12,16 & 16,15 & 20,94 & 26,06 & 31,10 & 35,94 & 41,08 & - \\
\hline \multirow[t]{3}{*}{ CPI } & DM & $-30,27$ & $-30,55$ & $-30,74$ & $-30,94$ & $-31,10$ & $-31,16$ & $-31,06$ & $-30,77$ & $-30,26$ & $-29,60$ & $-28,83$ & $-28,02$ & $-27,24$ & $-26,49$ & $-25,88$ & - \\
\hline & DMA & 30,62 & 31,22 & 31,79 & 32,34 & 32,90 & 33,47 & 33,94 & 34,32 & 35,45 & 36,93 & 38,88 & 40,82 & 42,71 & 44,56 & 46,43 & - \\
\hline & PDMA & 22,61 & 22,72 & 22,04 & 20,67 & 18,70 & 16,62 & 14,02 & 11,45 & 14,52 & 18,95 & 23,96 & 29,14 & 34,13 & 38,85 & 43,54 & - \\
\hline \multirow[t]{3}{*}{ SPI } & $\mathrm{DM}$ & 2,91 & 2,26 & 1,69 & 1,25 & 0,93 & 0,81 & 0,89 & 1,13 & 1,54 & 2,10 & 2,7 & 3,51 & 4,27 & 5,0 & 5,81 & - \\
\hline & DMA & 3,27 & 3,05 & 2,95 & 3,01 & 3,05 & 3,12 & 3,0 & 2,9 & 3,21 & 3,57 & 4,06 & 4,73 & 5,55 & 6,48 & 7,48 & - \\
\hline & PDMA & 9,17 & 9,61 & 10,03 & 10,25 & 9,38 & 8,05 & 6,60 & 6,82 & 10,43 & 14,10 & 18,72 & 23,81 & 28,88 & 33,81 & 39,28 & - \\
\hline \multirow[t]{3}{*}{$\Delta \mathrm{CS}$} & DM & $-33,18$ & $-32,81$ & $-32,43$ & $-32,19$ & $-32,03$ & & & & & $-31,70$ & & & $-31,50$ & & $-31,70$ & - \\
\hline & DMA & 27,35 & 28,17 & 28,84 & 29,32 & 29,85 & 30,35 & 30,86 & 31,32 & 32,24 & 33,36 & 34,82 & 36,08 & 37,16 & 38,08 & 38,95 & - \\
\hline & PDMA & 13,44 & 13,11 & 12,01 & 10,42 & 9,31 & 8,56 & 7,42 & 4,63 & 4,09 & 4,86 & 5,24 & 5,34 & 5,24 & 5,04 & 4,27 & - \\
\hline
\end{tabular}


Tabela 8.363: Constantes de acoplamento LC-BB95 com $\alpha=50 \%$ e $\alpha+\beta=100 \%$, variando $\gamma$, na base aug-pcJ-2.

\begin{tabular}{|c|c|c|c|c|c|c|c|c|c|c|c|c|c|c|c|c|c|}
\hline & $\gamma$ & 0,05 & 0,10 & 0,15 & 0,20 & 0,25 & 0,30 & 0,35 & 0,40 & 0,45 & 0,50 & 0,55 & 0,60 & 0,65 & 0,70 & 0,75 & Exp. \\
\hline HF & ${ }^{1} J_{\mathrm{HF}}$ & 524,7 & 526,3 & 528,1 & 529,9 & 531,8 & 534,1 & 536,7 & 539,8 & 543,2 & 546,9 & 550,8 & 554,9 & 559,0 & 563,2 & 567,4 & 500 \\
\hline $\mathrm{CO}$ & ${ }^{1} J_{\mathrm{CO}}$ & 14,3 & 14,4 & 14,4 & 14,4 & 14,4 & 14,5 & 14,5 & 14,5 & 14,4 & 14,2 & 13,9 & 13,5 & 13,0 & 12,5 & 11,9 & 16,4 \\
\hline $\mathrm{H}_{2} \mathrm{O}$ & ${ }^{1} J_{\mathrm{OH}}$ & $-83,0$ & $-83,0$ & $-83,0$ & $-83,1$ & $-83,2$ & $-83,3$ & $-83,6$ & $-83,9$ & $-84,3$ & $-84,7$ & $-85,2$ & $-85,8$ & $-86,3$ & $-86,9$ & $-87,5$ & $-80,6$ \\
\hline $\mathrm{H}_{2} \mathrm{O}$ & ${ }^{2} J_{\mathrm{HH}}$ & $-9,0$ & $-8,9$ & $-8,8$ & $-8,8$ & $-8,8$ & $-8,9$ & $-9,1$ & $-9,3$ & $-9,6$ & $-9,9$ & $-10,2$ & $-10,4$ & $-10,7$ & $-11,0$ & $-11,3$ & $-7,3$ \\
\hline $\mathrm{NH}_{3}$ & ${ }^{1} J_{\mathrm{NH}}$ & 45,5 & 45,3 & 45,2 & 45,0 & 44,9 & 44,8 & 44,8 & 44,9 & 45,0 & 45,2 & 45,4 & 45,6 & 45,9 & 46,2 & 46,5 & 43,8 \\
\hline $\mathrm{NH}_{3}$ & ${ }^{2} J_{\mathrm{HH}}$ & $-11,0$ & $-10,8$ & $-10,7$ & $-10,7$ & $-10,7$ & $-10,9$ & $-11,1$ & $-11,4$ & $-11,6$ & $-12,0$ & $-12,3$ & $-12,6$ & $-12,9$ & $-13,2$ & $-13,5$ & $-9,6$ \\
\hline $\mathrm{PH}_{3}$ & ${ }^{1} J_{\mathrm{PH}}$ & 182,4 & 180,9 & 178,5 & 175,6 & 173,0 & 171,4 & 171,1 & 171,9 & 173,7 & 176,3 & 179,3 & 182,6 & 185,9 & 189,1 & 192,2 & 188,2 \\
\hline $\mathrm{PF}_{3}$ & ${ }^{1} J_{\mathrm{PF}}$ & $-1572,5$ & $-1572,3$ & $-1570,7$ & $-1568,2$ & $-1565,3$ & $-1562,3$ & $-1559,2$ & $-1555,6$ & $-1551,3$ & $-1546,1$ & $-1540,0$ & $-1533,2$ & $-1525,8$ & $-1518,1$ & $-1510,3$ & -1441 \\
\hline $\mathrm{BHF}_{2}$ & ${ }^{1} J_{\mathrm{BF}}$ & $-93,1$ & $-94,0$ & $-93,6$ & $-92,0$ & $-89,4$ & $-86,2$ & $-82,6$ & $-78,8$ & $-74,8$ & $-70,7$ & $-66,6$ & $-62,7$ & $-58,8$ & $-55,2$ & $-51,7$ & -84 \\
\hline $\mathrm{BF}_{3}$ & ${ }^{1} J_{\mathrm{BF}}$ & 11,1 & 10,6 & 11,3 & 13,3 & 16,2 & 19,8 & 23,9 & 28,2 & 32,6 & 37,1 & 41,4 & 45,6 & 49,6 & 53,4 & 57,0 & 15 \\
\hline $\mathrm{F}_{2} \mathrm{O}$ & ${ }^{1} J_{\mathrm{OF}}$ & $-445,1$ & $-447,4$ & $-451,9$ & $-459,0$ & $-468,6$ & $-480,0$ & $-492,7$ & $-506,3$ & $-520,7$ & $-535,7$ & $-551,3$ & $-567,6$ & $-584,4$ & $-601,8$ & $-619,7$ & -300 \\
\hline $\mathrm{CH}_{4}$ & ${ }^{1} J_{\mathrm{CH}}$ & 126,5 & 125,3 & 124,2 & 123,2 & 122,5 & 122,0 & 122,0 & 122,3 & 122,8 & 123,5 & 124,4 & 125,4 & 126,4 & 127,4 & 128,4 & 125,3 \\
\hline $\mathrm{CH}_{4}$ & ${ }^{2} J_{\mathrm{HH}}$ & $-13,4$ & $-13,2$ & $-13,0$ & $-12,9$ & $-13,0$ & $-13,1$ & $-13,4$ & $-13,6$ & $-14,0$ & $-14,3$ & $-14,6$ & $-14,9$ & $-15,2$ & $-15,5$ & $-15,7$ & $-12,8$ \\
\hline $\mathrm{C}_{2} \mathrm{H}_{2}$ & ${ }^{1} J_{\mathrm{CC}}$ & 201,5 & 200,3 & 199,4 & 198,9 & 198,9 & 199,2 & 200,0 & 201,1 & 202,7 & 204,6 & 206,8 & 209,2 & 211,7 & 214,3 & 216,9 & 174,8 \\
\hline $\mathrm{C}_{2} \mathrm{H}_{2}$ & ${ }^{1} J_{\mathrm{CH}}$ & 259,5 & 257,4 & 255,2 & 253,3 & 251,9 & 251,2 & 251,1 & 251,7 & 253,2 & 254,3 & 256,1 & 258,1 & 260,1 & 262,2 & 264,2 & 247,6 \\
\hline $\mathrm{C}_{2} \mathrm{H}_{2}$ & ${ }^{2} J_{\mathrm{CH}}$ & 54,6 & 54,7 & 54,8 & 55,0 & 55,1 & 55,2 & 55,1 & 55,0 & 55,0 & 54,3 & 53,8 & 53,2 & 52,6 & 52,0 & 51,4 & 50,1 \\
\hline $\mathrm{C}_{2} \mathrm{H}_{2}$ & ${ }^{3} J_{\mathrm{HH}}$ & 11,8 & 11,5 & 11,4 & 11,3 & 11,3 & 11,5 & 11,8 & 12,1 & 9,3 & 13,1 & 13,6 & 14,1 & 14,6 & 15,1 & 15,6 & 9,6 \\
\hline $\mathrm{C}_{2} \mathrm{H}_{4}$ & ${ }^{1} J_{\mathrm{CC}}$ & 71,7 & 70,8 & 70,2 & 70,0 & 70,0 & 70,3 & 70,8 & 71,7 & 72,9 & 74,4 & 76,1 & 78,0 & 80,0 & 82,0 & 84,1 & 67,6 \\
\hline $\mathrm{C}_{2} \mathrm{H}_{4}$ & ${ }^{1} J_{\mathrm{CH}}$ & 162,3 & 160,9 & 159,5 & 158,4 & 157,7 & 157,4 & 157,6 & 158,2 & 159,2 & 160,4 & 161,9 & 163,4 & 165,1 & 166,7 & 168,3 & 156,3 \\
\hline $\mathrm{C}_{2} \mathrm{H}_{4}$ & ${ }^{2} J_{\mathrm{CH}}$ & $-3,2$ & $-3,1$ & $-3,0$ & $-3,0$ & $-3,1$ & $-3,3$ & $-3,7$ & $-4,1$ & $-4,7$ & $-5,3$ & $-5,9$ & $-6,6$ & $-7,3$ & $-8,0$ & $-8,7$ & $-2,4$ \\
\hline $\mathrm{C}_{2} \mathrm{H}_{4}$ & ${ }^{2} J_{\mathrm{HH}}$ & 2,6 & 2,7 & 2,7 & 2,7 & 2,5 & 2,3 & 2,0 & 1,6 & 1,2 & 0,7 & 0,3 & $-0,1$ & $-0,5$ & $-1,0$ & $-1,3$ & 2,3 \\
\hline $\mathrm{C}_{2} \mathrm{H}_{4}$ & ${ }^{3} J_{\mathrm{HH}_{\mathrm{c}}}$ & 12,8 & 12,7 & 12,7 & 12,7 & 12,8 & 13,0 & 13,2 & 13,4 & 13,6 & 13,9 & 14,2 & 14,5 & 14,8 & 15,1 & 15,4 & 11,7 \\
\hline $\mathrm{C}_{2} \mathrm{H}_{4}$ & ${ }^{3} J_{\mathrm{HH}_{\mathrm{t}}}$ & 19,7 & 19,5 & 19,4 & 19,3 & 19,3 & 19,3 & 19,5 & 19,7 & 20,0 & 20,3 & 20,7 & 21,1 & 21,5 & 21,9 & 22,2 & 19 \\
\hline $\mathrm{C}_{2} \mathrm{H}_{6}$ & ${ }^{1} J_{\mathrm{CC}}$ & 34,3 & 33,8 & 33,6 & 33,6 & 33,6 & 33,8 & 34,0 & 34,4 & 34,9 & 35,6 & 36,3 & 37,1 & 37,9 & 38,7 & 39,5 & 34,5 \\
\hline $\mathrm{C}_{2} \mathrm{H}_{6}$ & ${ }^{1} J_{\mathrm{CH}}$ & 127,5 & 126,4 & 125,3 & 124,3 & 123,6 & 123,2 & 123,2 & 123,5 & 124,1 & 124,9 & 125,9 & 126 & 127,9 & 129,0 & 130,0 & 125,2 \\
\hline $\mathrm{C}_{2} \mathrm{H}_{6}$ & ${ }^{2} J_{\mathrm{CH}}$ & $-4,4$ & $-4,3$ & $-4,3$ & $-4,3$ & $-4,3$ & $-4,4$ & $-4,5$ & $-4,7$ & $-4,8$ & $-5,0$ & $-5,2$ & $-5,4$ & $-5,6$ & $-5,7$ & $-5,9$ & $-4,7$ \\
\hline \multirow[t]{3}{*}{ Total } & DM & -8 & 8,79 & & & & & & & & & & & & & & - \\
\hline & DMA & & & & & & & & & & & & & & & & - \\
\hline & PDMA & 11,37 & 11,12 & 10,57 & 10,03 & 9,86 & 11,03 & 13,82 & 16,98 & 19,97 & 25,51 & 29,84 & 34,32 & 38,90 & 43,56 & 47,98 & - \\
\hline \multirow[t]{3}{*}{ CPI } & DM & $-25,15$ & $-25,44$ & $-25,65$ & $-25,86$ & -26 & -26 & -26 & & & & & & & 88 & & - \\
\hline & DMA &, 95 & 30,4 & 31, & 31,52 & 32 & 3 & 34 & & & & & & & & & - \\
\hline & PDMA & 14,53 & 14,69 & 14,26 & 13,22 & 13,06 & 15,59 & 18,89 & 22,90 & 27,07 & 31,55 & 35,88 & 40,08 & 44,36 & 48,60 & 53,00 & - \\
\hline \multirow[t]{3}{*}{ SPI } & DM & 3,9 & & & & & & & & & & & & & & & - \\
\hline & & & & & & & & & & & & & & & & & - \\
\hline & PDMA & 9,05 & 8,50 & 7,86 & 7,69 & 7,51 & 7,68 & 10,11 & 12,64 & 14,77 & 21,09 & 25,42 & 30,10 & 34,90 & 39,86 & 44,30 & - \\
\hline \multirow[t]{3}{*}{$\Delta \mathrm{CS}$} & & & & & & & & & & & & & & & & & - \\
\hline & MA & & 26,83 & 27 & & & & & & & & & & & & & - \\
\hline & PDM & 5,48 & 6,19 & 6,40 & 5,53 & 5,54 & 7,90 & 8,78 & 10,26 & 12,30 & 10,46 & 10,46 & 9,98 & 9,45 & 8,74 & 8,71 & - \\
\hline
\end{tabular}


Tabela 8.364: Constantes de acoplamento LC-BB95 com $\alpha=0 \%$ e $\alpha+\beta=90 \%$, variando $\gamma$, na base aug-pcJ-2.

\begin{tabular}{|c|c|c|c|c|c|c|c|c|c|c|c|c|c|c|c|c|c|}
\hline & $\gamma$ & 0,05 & 0,10 & 0,15 & 0,20 & 0,25 & 0,30 & 0,35 & 0,40 & 0,45 & 0,50 & 0,55 & 0,60 & 0,65 & 0,70 & 0,75 & Exp. \\
\hline $\mathrm{HF}$ & ${ }^{1} J_{\mathrm{HF}}$ & 406,6 & 410,3 & 414,1 & 417,6 & 421,2 & 425,2 & 430,0 & 435,7 & 442,1 & 449,2 & 456,6 & 464,2 & 471,9 & 479,5 & 487,1 & 500 \\
\hline $\mathrm{CO}$ & ${ }^{1} J_{\mathrm{CO}}$ & 23,8 & 23,8 & 23,8 & 23,7 & 23,7 & 23,8 & 23,8 & 23,8 & 23,6 & 23,3 & 22,8 & 22,3 & 21,6 & 20,8 & 19,9 & 16,4 \\
\hline $\mathrm{H}_{2} \mathrm{O}$ & ${ }^{1} J_{\mathrm{OH}}$ & $-70,5$ & $-70,7$ & $-70,8$ & $-71,0$ & $-71,2$ & $-71,5$ & $-71,9$ & $-72,5$ & $-73,3$ & $-74,1$ & $-75,0$ & $-76,0$ & $-77,0$ & $-78,0$ & $-79,0$ & $-80,6$ \\
\hline $\mathrm{H}_{2} \mathrm{O}$ & ${ }^{2} J_{\mathrm{HH}}$ & $-4,0$ & $-3,7$ & $-3,6$ & $-3,6$ & $-3,8$ & $-4,0$ & $-4,3$ & $-4,7$ & $-5,1$ & $-5,6$ & $-6,0$ & $-6,5$ & $-7,0$ & $-7,4$ & $-7,9$ & $-7,3$ \\
\hline $\mathrm{NH}_{3}$ & ${ }^{1} J_{\mathrm{NH}}$ & 41,8 & 41,6 & 41,3 & 41,1 & 40,9 & 40,7 & 40,7 & 40,8 & 41,0 & 41,3 & 41,7 & 42,1 & 42,6 & 43,1 & 43,6 & 43,8 \\
\hline $\mathrm{NH}_{3}$ & ${ }^{2} J_{\mathrm{HH}}$ & $-6,6$ & $-6,4$ & $-6,2$ & $-6,2$ & $-6,4$ & $-6,6$ & $-7,0$ & $-7,4$ & $-7,9$ & $-8,4$ & $-9,0$ & $-9,5$ & $-10,0$ & $-10,5$ & $-10,9$ & $-9,6$ \\
\hline $\mathrm{PH}_{3}$ & ${ }^{1} J_{\mathrm{PH}}$ & 145,4 & 143,5 & 139,4 & 134,2 & 129,5 & 126,7 & 126,2 & 127,9 & 131,4 & 136,0 & 141,5 & 147,4 & 153,4 & 159,2 & 164,8 & 188,2 \\
\hline $\mathrm{PF}_{3}$ & ${ }^{1} J_{\mathrm{PF}}$ & $-1713,0$ & $-1709,2$ & $-1707,1$ & $-1707,0$ & $-1708,7$ & $-1711,5$ & $-1714,3$ & $-1715,8$ & $-1715,0$ & $-1711,3$ & $-1704,8$ & $-1695,8$ & $-1685,0$ & $-1672,9$ & $-1660,1$ & -1441 \\
\hline $\mathrm{BHF}_{2}$ & ${ }^{1} J_{\mathrm{BF}}$ & $-177,4$ & $-178,1$ & $-176,2$ & $-172,2$ & $-166,8$ & $-160,5$ & $-153,7$ & $-146,6$ & $-139,2$ & $-131,7$ & $-124,2$ & $-117,0$ & $-110,0$ & $-103,4$ & $-97,2$ & -84 \\
\hline $\mathrm{BF}_{3}$ & ${ }^{1} J_{\mathrm{BF}}$ & $-80,5$ & $-80,4$ & $-78,0$ & $-73,3$ & $-67,0$ & $-59,5$ & $-51,4$ & $-43,0$ & $-34,5$ & $-26,2$ & $-18,1$ & $-10,3$ & $-3,1$ & 3,7 & 10,0 & 15 \\
\hline $\mathrm{F}_{2} \mathrm{O}$ & ${ }^{1} J_{\mathrm{OF}}$ & $-270,0$ & $-274,6$ & $-282,6$ & $-294,3$ & $-309,0$ & $-325,2$ & $-341,7$ & $-357,8$ & $-373,2$ & $-387,8$ & $-402,0$ & $-416,1$ & $-430,1$ & $-444,2$ & $-458,5$ & -300 \\
\hline $\mathrm{CH}_{4}$ & ${ }^{1} J_{\mathrm{CH}}$ & 119,0 & 117,2 & 115,3 & 113,6 & 112,2 & 111,4 & 111,3 & 111,7 & 112,5 & 113,8 & 115,3 & 116,9 & 118,6 & 120,4 & 122,1 & 125,3 \\
\hline $\mathrm{CH}_{4}$ & ${ }^{2} J_{\mathrm{HH}}$ & $-9,9$ & $-9,5$ & $-9,2$ & $-9,2$ & $-9,3$ & $-9,6$ & $-10,0$ & $-10,5$ & $-11,0$ & $-11,6$ & $-12,1$ & $-12,7$ & $-13,2$ & $-13,6$ & $-14,1$ & $-12,8$ \\
\hline $\mathrm{C}_{2} \mathrm{H}_{2}$ & ${ }^{1} J_{\mathrm{CC}}$ & 185,7 & 184,0 & 182,8 & 182,0 & 181,5 & 181,3 & 181,6 & 182,5 & 183,9 & 185,8 & 188,2 & 190,9 & 193,9 & 197,0 & 200,3 & 174,8 \\
\hline $\mathrm{C}_{2} \mathrm{H}_{2}$ & ${ }^{1} J_{\mathrm{CH}}$ & 248,1 & 244,9 & 241,4 & 238,2 & 235,8 & 234,3 & 233,9 & 234,5 & 236,0 & 238,0 & 240,6 & 243,4 & 246,4 & 249,5 & 252,6 & 247,6 \\
\hline $\mathrm{C}_{2} \mathrm{H}_{2}$ & ${ }^{2} J_{\mathrm{CH}}$ & 55,2 & 55,0 & 55,2 & 55,6 & 56,0 & 56,5 & 56,8 & 57,0 & 57,1 & 57,0 & 56,8 & 56,5 & 56,1 & 55,6 & 55,1 & 50,1 \\
\hline $\mathrm{C}_{2} \mathrm{H}_{2}$ & ${ }^{3} J_{\mathrm{HH}}$ & 8,9 & 8,6 & 8,3 & 8,1 & 8,0 & 8,0 & 8,2 & 8,5 & 8,9 & 9,4 & 9,9 & 10,5 & 11,1 & 11,7 & 12,2 & 9,6 \\
\hline $\mathrm{C}_{2} \mathrm{H}_{4}$ & ${ }^{1} J_{\mathrm{CC}}$ & 57,4 & 56,3 & 55,7 & 55,3 & 55,1 & 55,0 & 55,3 & 55,9 & 56,9 & 58,3 & 60,0 & 62,1 & 64,3 & 66,7 & 69,2 & 67,6 \\
\hline $\mathrm{C}_{2} \mathrm{H}_{4}$ & ${ }^{1} J_{\mathrm{CH}}$ & 151,7 & 149,6 & 147,4 & 145,5 & 144,1 & 143,4 & 143,5 & 144,2 & 145,5 & 147,2 & 149,2 & 151,4 & 153,8 & 156,1 & 158,5 & 156,3 \\
\hline $\mathrm{C}_{2} \mathrm{H}_{4}$ & ${ }^{2} J_{\mathrm{CH}}$ & 1,1 & 1,2 & 1,2 & 1,2 & 1,1 & 1,0 & 0,7 & 0,3 & $-0,1$ & $-0,7$ & $-1,4$ & $-2,0$ & $-2,8$ & $-3,5$ & $-4,3$ & $-2,4$ \\
\hline $\mathrm{C}_{2} \mathrm{H}_{4}$ & ${ }^{2} J_{\mathrm{HH}}$ & 6,1 & 6,2 & 6,2 & 6,1 & 5,8 & 5,5 & 5,1 & 4,7 & 4,2 & 3,7 & 3,1 & 2,6 & 2,1 & 1,6 & 1,1 & 2,3 \\
\hline $\mathrm{C}_{2} \mathrm{H}_{4}$ & ${ }^{3} J_{\mathrm{HH}}$ & 11,5 & 11,5 & 11,5 & 11,6 & 11,6 & 11,7 & 11,9 & 12,0 & 12,2 & 12,4 & 12,7 & 13,0 & 13,3 & 13,5 & 13,8 & 11,7 \\
\hline $\mathrm{C}_{2} \mathrm{H}_{4}$ & ${ }^{3} J_{\mathrm{HH}_{\mathrm{t}}}$ & 18,3 & 18,0 & 17,8 & 17,5 & 17,4 & 17,3 & 17,3 & 17,4 & 17,6 & 17,8 & 18,2 & 18,6 & 19,0 & 19,4 & 19,8 & 19 \\
\hline $\mathrm{C}_{2} \mathrm{H}_{6}$ & ${ }^{1} J_{\mathrm{CC}}$ & 24,2 & 23,6 & 23,4 & 23,4 & 23,5 & 23,7 & 24,1 & 24,7 & 25,5 & 26,5 & 27,7 & 29,0 & 30,3 & 31,6 & 32,9 & 34,5 \\
\hline $\mathrm{C}_{2} \mathrm{H}_{6}$ & ${ }^{1} J_{\mathrm{CH}}$ & 119,1 & 117,4 & 115,5 & 113,8 & 112,5 & 111,8 & 111,8 & 112,3 & 113,2 & 114,6 & 116,2 & 117,9 & 119,7 & 121,5 & 123,3 & 125,2 \\
\hline $\mathrm{C}_{2} \mathrm{H}_{6}$ & ${ }^{2} J_{\mathrm{CH}}$ & $-2,2$ & $-2,1$ & $-2,0$ & $-2,1$ & $-2,1$ & $-2,3$ & $-2,5$ & $-2,7$ & $-3,0$ & $-3,3$ & $-3,6$ & $-3,9$ & $-4,2$ & $-4,4$ & $-4,7$ & $-4,7$ \\
\hline \multirow[t]{3}{*}{ Total } & DM & $-21,35$ & $-21,81$ & $-22,32$ & $-22,90$ & $-23,44$ & $-23,78$ & $-23,83$ & $-23,54$ & $-22,91$ & $-21,98$ & $-20,80$ & $-19,46$ & $-18,05$ & ,62 & 21 & - \\
\hline & DMA & 27,74 & 27,73 & 27,60 & 27,21 & 27,22 & & 27,39 & 26 , & & 25,10 & 23,79 & & & & & - \\
\hline & PDMA & 55,03 & 56,21 & 56,21 & 54,83 & 52,45 & 49,49 & 45,49 & 40,88 & 35,70 & 29,95 & 24,03 & 18,63 & 15,52 & 15,15 & 15,67 & - \\
\hline \multirow[t]{3}{*}{ CPI } & DM & $-49,57$ & $-49,53$ & $-49,71$ & $-50,17$ & $-50,77$ & $-51,21$ & $-51,32$ & $-50,95$ & $-50,09$ & $-48,75$ & $-47,04$ & $-45,10$ & $-43,05$ & $-41,00$ & $-39,01$ & - \\
\hline & DMA & 59,35 & 58,53 & 57,29 & 55,57 & 55,03 & 55,35 & 55,26 & 54,65 & 53,44 & 51,71 & 49,56 & 47,17 & 44,71 & 42,27 & 39,94 & - \\
\hline & PDMA & 86,98 & 87,44 & 86,02 & 82,54 & 77,99 & 72,95 & 66,97 & 60,45 & 53,46 & 46,27 & 39,01 & 31,89 & 25,75 & 20,41 & 16,15 & - \\
\hline \multirow[t]{3}{*}{ SPI } & DM & $-0,66$ & $-1,48$ & $-2,24$ & $-2,90$ & $-3,39$ & $-3,67$ & $-3,67$ & $-3,44$ & $-2,98$ & $-2,35$ & $-1,55$ & $-0,66$ & 0,29 & 1,27 & 2,25 & - \\
\hline & DMA & 4,55 & 5,15 & 5,83 & 6,41 & 6,82 & 7,02 & 6,95 & 6,68 & 6,22 & 5,59 & & 4,17 & 3,54 & & 3,73 & - \\
\hline & PDMA & 31,60 & 33,30 & 34,34 & 34,51 & 33,72 & 32,29 & 29,74 & 26,53 & 22,67 & 17,97 & 13,05 & 8,90 & 8,01 & 11,30 & 15,32 & - \\
\hline \multirow[t]{3}{*}{$\Delta \mathrm{CS}$} & DM & $-48,91$ & $-48,05$ & $-47,47$ & $-47,27$ & $-47,38$ & $-47,54$ & $-47,64$ & -47 & ,11 &, 40 & & & $-43,34$ & & & - \\
\hline & DMA & 54,80 & 53,38 & 51,46 & 49,17 & 48,21 & 48,33 & 48,31 & 47,97 & & 46,12 & 44,68 & 43,01 & 41,17 & 38 & 36,21 & - \\
\hline & PDMA & 55,39 & 54,14 & 51,68 & 48,03 & 44,27 & 40,67 & 37,23 & 33,93 & 30,79 & 28,30 & 25,96 & 22,98 & 17,73 & 9,11 & 0,83 & - \\
\hline
\end{tabular}


Tabela 8.365: Constantes de acoplamento LC-BB95 com $\alpha=10 \%$ e $\alpha+\beta=90 \%$, variando $\gamma$, na base aug-pcJ-2.

\begin{tabular}{|c|c|c|c|c|c|c|c|c|c|c|c|c|c|c|c|c|c|}
\hline & $\gamma$ & 0,05 & 0,10 & 0,15 & 0,20 & 0,25 & 0,30 & 0,35 & 0,40 & 0,45 & 0,50 & 0,55 & 0,60 & 0,65 & 0,70 & 0,75 & Exp. \\
\hline HF & ${ }^{1} J_{\mathrm{HF}}$ & 429,8 & 433,0 & 436,2 & 439,3 & 442,6 & 446,2 & 450,5 & 455,5 & 461,1 & 467,2 & 473,7 & 480,4 & 487,2 & 494,0 & 500,7 & 500 \\
\hline $\mathrm{CO}$ & ${ }^{1} J_{\mathrm{CO}}$ & 22,1 & 22,1 & 22,1 & 22,1 & 22,1 & 22,1 & 22,1 & 22,1 & 21,9 & 21,6 & 21,2 & 20,7 & 20,0 & 19,3 & 18,5 & 16,4 \\
\hline $\mathrm{H}_{2} \mathrm{O}$ & ${ }^{1} J_{\mathrm{OH}}$ & $-72,9$ & $-73,1$ & $-73,2$ & $-73,3$ & $-73,5$ & $-73,8$ & $-74,2$ & $-74,7$ & $-75,3$ & $-76,1$ & $-76,9$ & $-77,7$ & $-78,6$ & $-79,5$ & $-80,4$ & $-80,6$ \\
\hline $\mathrm{H}_{2} \mathrm{O}$ & ${ }^{2} J_{\mathrm{HH}}$ & $-4,9$ & $-4,7$ & $-4,6$ & $-4,6$ & $-4,7$ & $-4,9$ & $-5,2$ & $-5,5$ & $-5,9$ & $-6,3$ & $-6,8$ & $-7,2$ & $-7,6$ & $-8,1$ & $-8,5$ & $-7,3$ \\
\hline $\mathrm{NH}_{3}$ & ${ }^{1} J_{\mathrm{NH}}$ & 42,5 & 42,3 & 42,1 & 41,9 & 41,7 & 41,6 & 41,5 & 41,6 & 41,8 & 42,1 & 42,4 & 42,8 & 43,2 & 43,6 & 44,1 & 43,8 \\
\hline $\mathrm{NH}_{3}$ & ${ }^{2} J_{\mathrm{HH}}$ & $-7,5$ & $-7,3$ & $-7,1$ & $-7,1$ & $-7,2$ & $-7,4$ & $-7,8$ & $-8,2$ & $-8,6$ & $-9,1$ & $-9,6$ & $-10,0$ & $-10,5$ & $-10,9$ & $-11,3$ & $-9,6$ \\
\hline $\mathrm{PH}_{3}$ & ${ }^{1} J_{\mathrm{PH}}$ & 153,0 & 151,2 & 147,5 & 142,9 & 138,8 & 136,2 & 135,8 & 137,2 & 140,3 & 144,4 & 149,3 & 154,5 & 159,8 & 165,1 & 170,0 & 188,2 \\
\hline $\mathrm{PF}_{3}$ & ${ }^{1} J_{\mathrm{PF}}$ & $-1693,1$ & $-1690,3$ & $-1688,1$ & $-1686,9$ & $-1686,6$ & $-1687,2$ & $-1687,8$ & $-1687,4$ & $-1685,2$ & $-1680,8$ & $-1674,2$ & $-1665,6$ & $-1655,6$ & $-1644,6$ & $-1633,0$ & -1441 \\
\hline $\mathrm{BHF}_{2}$ & ${ }^{1} J_{\mathrm{BF}}$ & $-160,4$ & $-161,2$ & $-159,8$ & $-156,4$ & $-151,7$ & $-146,2$ & $-140,2$ & $-133,8$ & $-127,2$ & $-120,6$ & $-114,0$ & $-107,5$ & $-101,3$ & $-95,4$ & $-89,9$ & -84 \\
\hline $\mathrm{BF}_{3}$ & ${ }^{1} J_{\mathrm{BF}}$ & $-61,9$ & $-62,0$ & $-60,0$ & $-56,1$ & $-50,6$ & $-44,1$ & $-37,1$ & $-29,7$ & $-22,2$ & $-14,8$ & $-7,7$ & $-0,8$ & 5,5 & 11,6 & 17,3 & 15 \\
\hline $\mathrm{F}_{2} \mathrm{O}$ & ${ }^{1} J_{\mathrm{OF}}$ & $-304,1$ & $-308,0$ & $-314,9$ & $-325,0$ & $-337,8$ & $-352,0$ & $-366,7$ & $-381,2$ & $-395,3$ & $-409,1$ & $-422,6$ & $-436,1$ & $-449,7$ & $-463,4$ & $-477,3$ & -300 \\
\hline $\mathrm{CH}_{4}$ & ${ }^{1} J_{\mathrm{CH}}$ & 120,5 & 118,8 & 117,1 & 115,6 & 114,4 & 113,7 & 113,5 & 113,9 & 114,7 & 115,8 & 117,2 & 118,6 & 120,2 & 121,7 & 123,3 & 125,3 \\
\hline $\mathrm{CH}_{4}$ & ${ }^{2} J_{\mathrm{HH}}$ & $-10,6$ & $-10,2$ & $-10,0$ & $-9,9$ & $-10,0$ & $-10,3$ & $-10,7$ & $-11,1$ & $-11,6$ & $-12,1$ & $-12,6$ & $-13,1$ & $-13,5$ & $-13,9$ & $-14,3$ & $-12,8$ \\
\hline $\mathrm{C}_{2} \mathrm{H}_{2}$ & ${ }^{1} J_{\mathrm{CC}}$ & 188,2 & 186,6 & 185,5 & 184,8 & 184,3 & 184,3 & 184,7 & 185,6 & 187,0 & 188,9 & 191,2 & 193,8 & 196,6 & 199,6 & 202,6 & 174,8 \\
\hline $\mathrm{C}_{2} \mathrm{H}_{2}$ & ${ }^{1} J_{\mathrm{CH}}$ & 250,3 & 247,3 & 244,2 & 241,3 & 239,1 & 237,8 & 237,5 & 238,0 & 239,4 & 241,3 & 243,6 & 246,2 & 249,0 & 251,8 & 254,6 & 247,6 \\
\hline $\mathrm{C}_{2} \mathrm{H}_{2}$ & ${ }^{2} J_{\mathrm{CH}}$ & 55,4 & 55,3 & 55,4 & 55,8 & 56,2 & 56,5 & 56,8 & 56,9 & 56,9 & 56,7 & 56,5 & 56,1 & 55,7 & 55,2 & 54,6 & 50,1 \\
\hline $\mathrm{C}_{2} \mathrm{H}_{2}$ & ${ }^{3} J_{\mathrm{HH}}$ & 9,3 & 9,0 & 8,7 & 8,5 & 8,5 & 8,5 & 8,7 & 9,1 & 9,5 & 9,9 & 10,5 & 11,0 & 11,6 & 12,1 & 12,7 & 9,6 \\
\hline $\mathrm{C}_{2} \mathrm{H}_{4}$ & ${ }^{1} J_{\mathrm{CC}}$ & 59,8 & 58,8 & 58,2 & 57,8 & 57,6 & 57,6 & 57,9 & 58,6 & 59,6 & 61,0 & 62,6 & 64,6 & 66,7 & 69,0 & 71,4 & 67,6 \\
\hline $\mathrm{C}_{2} \mathrm{H}_{4}$ & ${ }^{1} J_{\mathrm{CH}}$ & 153,7 & 151,8 & 149,8 & 148,1 & 146,8 & 146,2 & 146,3 & 147,0 & 148,1 & 149,7 & 151,6 & 153,6 & 155,8 & 158,0 & 160,1 & 156,3 \\
\hline $\mathrm{C}_{2} \mathrm{H}_{4}$ & ${ }^{2} J_{\mathrm{CH}}$ & 0,4 & 0,5 & 0,5 & 0,5 & 0,5 & 0,3 & 0,0 & $-0,3$ & $-0,8$ & $-1,4$ & $-2,0$ & $-2,7$ & $-3,4$ & $-4,1$ & $-4,8$ & $-2,4$ \\
\hline $\mathrm{C}_{2} \mathrm{H}_{4}$ & ${ }^{2} J_{\mathrm{HH}}$ & 5,5 & 5,6 & 5,6 & 5,5 & 5,3 & 5,0 & 4,6 & 4,2 & 3,7 & 3,2 & 2,7 & 2,2 & 1,7 & 1,2 & 0,8 & 2,3 \\
\hline $\mathrm{C}_{2} \mathrm{H}_{4}$ & ${ }^{3} J_{\mathrm{HH}_{\mathrm{c}}}$ & 11,7 & 11,7 & 11,7 & 11,7 & 11,8 & 11,9 & 12,0 & 12,2 & 12,4 & 12,6 & 12,9 & 13,1 & 13,4 & 13,7 & 14,0 & 11,7 \\
\hline $\mathrm{C}_{2} \mathrm{H}_{4}$ & ${ }^{3} J_{\mathrm{HH}_{\mathrm{t}}}$ & 18,4 & 18,2 & 18,0 & 17,8 & 17,6 & 17,6 & 17,6 & 17,7 & 17,9 & 18,2 & 18,6 & 18,9 & 19,3 & 19,7 & 20,1 & 19 \\
\hline $\mathrm{C}_{2} \mathrm{H}_{6}$ & ${ }^{1} J_{\mathrm{CC}}$ & 26,1 & 25,6 & 25,3 & 25,3 & 25,4 & 25,6 & 26,0 & 26,5 & 27,3 & 28,2 & 29,3 & 30 & 31 & 32,8 & 34,0 & 34,5 \\
\hline $\mathrm{C}_{2} \mathrm{H}_{6}$ & ${ }^{1} J_{\mathrm{CH}}$ & 120,8 & 119,2 & 117,5 & 116,0 & 114,8 & 114,2 & 114,2 & 114,6 & 115,5 & 116,7 & 118,1 & 119 & 121,3 & 123,0 & 124,6 & 125,2 \\
\hline $\mathrm{C}_{2} \mathrm{H}_{6}$ & ${ }^{2} J_{\mathrm{CH}}$ & $-2,6$ & $-2,5$ & $-2,5$ & $-2,5$ & $-2,5$ & $-2,7$ & $-2,8$ & $-3,1$ & $-3,3$ & $-3,6$ & $-3,9$ & $-4,1$ & $-4,4$ & $-4,7$ & $-4,9$ & $-4,7$ \\
\hline \multirow[t]{3}{*}{ Total } & $\mathrm{DM}$ & -19 & 51 & -19 & $-20,46$ & $-20,85$ & & & & & & & & & & & - \\
\hline & DMA & & & & & & & & & & & & & & & & - \\
\hline & PDMA & 44,06 & 45,24 & 45,41 & 44,67 & 43,05 & 40,18 & 36,52 & 32,35 & 27,43 & 22,32 & 17,30 & 14,00 & 13,99 & 14,43 & 16,57 & - \\
\hline \multirow[t]{3}{*}{ CPI } & DM & $-45,30$ & -45 & -45 & -45 & & & & & & & & & & & & - \\
\hline & DMA &, 55 & 48,6 & 48, & 49,1 & & & & & & & & & & & & - \\
\hline & PDMA & 68,84 & 69,58 & 68,87 & 66,63 & 63,12 & 58,62 & 53,35 & 47,62 & 41,42 & 35,01 & 28,54 & 23,07 & 18,70 & 14,76 & 13,86 & - \\
\hline \multirow[t]{3}{*}{ SPI } & DM & 0,1 & - & -1 & & & & -2, & & & & & & & & & - \\
\hline & & & & & & & & & & & & & & & & & - \\
\hline & PDMA & 25,88 & 27,39 & 28,21 & 28,56 & 28,33 & 26,65 & 24,19 & 21,16 & 17,17 & 13,01 & 9,05 & 7,35 & 10,53 & 14,19 & 18,55 & - \\
\hline \multirow[t]{3}{*}{$\Delta C S$} & & & & & & & & & & & & & & & & & - \\
\hline & MA & & & & & & & & & & & & & & & & - \\
\hline & PDI & 42,96 & 42,19 & 40,66 & 38,08 & 34,79 & 31,97 & 29,16 & 26,46 & 24,25 & 22,01 & 19,49 & 15,72 & 8,16 & 0,57 & $-4,69$ & - \\
\hline
\end{tabular}


Tabela 8.366: Constantes de acoplamento LC-BB95 com $\alpha=20 \%$ e $\alpha+\beta=90 \%$, variando $\gamma$, na base aug-pcJ-2.

\begin{tabular}{|c|c|c|c|c|c|c|c|c|c|c|c|c|c|c|c|c|c|}
\hline & $\gamma$ & 0,05 & 0,10 & 0,15 & 0,20 & 0,25 & 0,30 & 0,35 & 0,40 & 0,45 & 0,50 & 0,55 & 0,60 & 0,65 & 0,70 & 0,75 & Exp. \\
\hline $\mathrm{HF}$ & ${ }^{1} J_{\mathrm{HF}}$ & 453,2 & 455,8 & 458,6 & 461,3 & 464,1 & 467,3 & 471,0 & 475,4 & 480,3 & 485,5 & 491,2 & 497,0 & 502,9 & 508,8 & 514,7 & 500 \\
\hline $\mathrm{CO}$ & ${ }^{1} J_{\mathrm{CO}}$ & 20,3 & 20,3 & 20,3 & 20,3 & 20,3 & 20,3 & 20,4 & 20,3 & 20,2 & 19,9 & 19,5 & 19,0 & 18,5 & 17,8 & 17,1 & 16,4 \\
\hline $\mathrm{H}_{2} \mathrm{O}$ & ${ }^{1} J_{\mathrm{OH}}$ & $-75,4$ & $-75,5$ & $-75,6$ & $-75,7$ & $-75,9$ & $-76,1$ & $-76,4$ & $-76,9$ & $-77,4$ & $-78,1$ & $-78,8$ & $-79,5$ & $-80,3$ & $-81,1$ & $-81,9$ & $-80,6$ \\
\hline $\mathrm{H}_{2} \mathrm{O}$ & ${ }^{2} J_{\mathrm{HH}}$ & $-6,0$ & $-5,8$ & $-5,7$ & $-5,6$ & $-5,7$ & $-5,9$ & $-6,1$ & $-6,5$ & $-6,8$ & $-7,2$ & $-7,5$ & $-7,9$ & $-8,3$ & $-8,7$ & $-9,1$ & $-7,3$ \\
\hline $\mathrm{NH}_{3}$ & ${ }^{1} J_{\mathrm{NH}}$ & 43,2 & 43,1 & 42,9 & 42,7 & 42,5 & 42,4 & 42,4 & 42,5 & 42,6 & 42,8 & 43,1 & 43,5 & 43,8 & 44,2 & 44,6 & 43,8 \\
\hline $\mathrm{NH}_{3}$ & ${ }^{2} J_{\mathrm{HH}}$ & $-8,4$ & $-8,1$ & $-8,0$ & $-8,0$ & $-8,1$ & $-8,3$ & $-8,6$ & $-8,9$ & $-9,3$ & $-9,7$ & $-10,2$ & $-10,6$ & $-11,0$ & $-11,4$ & $-11,8$ & $-9,6$ \\
\hline $\mathrm{PH}_{3}$ & ${ }^{1} J_{\mathrm{PH}}$ & 160,5 & 158,8 & 155,6 & 151,5 & 147,9 & 145,7 & 145,3 & 146,5 & 149,1 & 152,8 & 157,0 & 161,6 & 166,3 & 170,8 & 175,2 & 188,2 \\
\hline $\mathrm{PF}_{3}$ & ${ }^{1} J_{\mathrm{PF}}$ & $-1668,3$ & $-1666,4$ & $-1664,3$ & $-1662,4$ & $-1660,9$ & $-1659,9$ & $-1658,9$ & $-1657,2$ & $-1654,2$ & $-1649,5$ & $-1643,0$ & $-1635,1$ & $-1626,0$ & $-1616,2$ & $-1605,9$ & -1441 \\
\hline $\mathrm{BHF}_{2}$ & ${ }^{1} J_{\mathrm{BF}}$ & $-143,5$ & $-144,3$ & $-143,2$ & $-140,4$ & $-136,4$ & $-131,6$ & $-126,4$ & $-120,9$ & $-115,1$ & $-109,3$ & $-103,6$ & $-97,9$ & $-92,5$ & $-87,4$ & $-82,5$ & -84 \\
\hline $\mathrm{BF}_{3}$ & ${ }^{1} J_{\mathrm{BF}}$ & $-43,4$ & $-43,6$ & $-42,1$ & $-38,8$ & $-34,2$ & $-28,7$ & $-22,6$ & $-16,2$ & $-9,7$ & $-3,3$ & 2,8 & 8,8 & 14,5 & 19,8 & 24,7 & 15 \\
\hline $\mathrm{F}_{2} \mathrm{O}$ & ${ }^{1} J_{\mathrm{OF}}$ & $-337,3$ & $-340,7$ & $-346,7$ & $-355,4$ & $-366,5$ & $-379,0$ & $-392,2$ & $-405,5$ & $-418,6$ & $-431,6$ & $-444,5$ & $-457,6$ & $-470,8$ & $-484,1$ & $-497,6$ & -300 \\
\hline $\mathrm{CH}_{4}$ & ${ }^{1} J_{\mathrm{CH}}$ & 122,0 & 120,5 & 119,0 & 117,6 & 116,6 & 116,0 & 115,9 & 116,2 & 116,9 & 117,9 & 119,1 & 120,4 & 121,8 & 123,1 & 124,5 & 125,3 \\
\hline $\mathrm{CH}_{4}$ & ${ }^{2} J_{\mathrm{HH}}$ & $-11,3$ & $-11,0$ & $-10,8$ & $-10,7$ & $-10,8$ & $-11,0$ & $-11,3$ & $-11,7$ & $-12,2$ & $-12,6$ & $-13,0$ & $-13,5$ & $-13,9$ & $-14,2$ & $-14,6$ & $-12,8$ \\
\hline $\mathrm{C}_{2} \mathrm{H}_{2}$ & ${ }^{1} J_{\mathrm{CC}}$ & 191,0 & 189,5 & 188,5 & 187,8 & 187,5 & 187,6 & 188,0 & 189,0 & 190,4 & 192,2 & 194,4 & 196,9 & 199,5 & 202,3 & 205,1 & 174,8 \\
\hline $\mathrm{C}_{2} \mathrm{H}_{2}$ & ${ }^{1} J_{\mathrm{CH}}$ & 252,5 & 249,8 & 247,0 & 244,4 & 242,5 & 241,4 & 241,1 & 241,7 & 242,9 & 244,6 & 246,8 & 249,2 & 251,7 & 254,2 & 256,7 & 247,6 \\
\hline $\mathrm{C}_{2} \mathrm{H}_{2}$ & ${ }^{2} J_{\mathrm{CH}}$ & 55,5 & 55,4 & 55,6 & 55,8 & 56,2 & 56,4 & 56,6 & 56,6 & 56,5 & 56,3 & 56,0 & 55,6 & 55,2 & 54,7 & 54,1 & 50,1 \\
\hline $\mathrm{C}_{2} \mathrm{H}_{2}$ & ${ }^{3} J_{\mathrm{HH}}$ & 9,7 & 9,5 & 9,2 & 9,1 & 9,1 & 9,2 & 9,4 & 9,7 & 10,1 & 10,6 & 11,1 & 11,6 & 12,1 & 12,6 & 13,1 & 9,6 \\
\hline $\mathrm{C}_{2} \mathrm{H}_{4}$ & ${ }^{1} J_{\mathrm{CC}}$ & 62,4 & 61,5 & 60,9 & 60,5 & 60,4 & 60,4 & 60,8 & 61,5 & 62,5 & 63,8 & 65,4 & 67,3 & 69,3 & 71,4 & 73,6 & 67,6 \\
\hline $\mathrm{C}_{2} \mathrm{H}_{4}$ & ${ }^{1} J_{\mathrm{CH}}$ & 155,7 & 154,0 & 152,3 & 150,7 & 149,6 & 149,1 & 149,2 & 149,8 & 150,9 & 152,4 & 154,1 & 155,9 & 157,9 & 159,8 & 161,8 & 156,3 \\
\hline $\mathrm{C}_{2} \mathrm{H}_{4}$ & ${ }^{2} J_{\mathrm{CH}}$ & $-0,3$ & $-0,2$ & $-0,1$ & $-0,1$ & $-0,2$ & $-0,4$ & $-0,7$ & $-1,1$ & $-1,6$ & $-2,1$ & $-2,7$ & $-3,4$ & $-4,0$ & $-4,7$ & $-5,4$ & $-2,4$ \\
\hline $\mathrm{C}_{2} \mathrm{H}_{4}$ & ${ }^{2} J_{\mathrm{HH}}$ & 4,8 & 4,9 & 4,9 & 4,8 & 4,7 & 4,4 & 4,1 & 3,7 & 3,2 & 2,8 & 2,3 & 1,8 & 1,3 & 0,9 & 0,5 & 2,3 \\
\hline $\mathrm{C}_{2} \mathrm{H}_{4}$ & ${ }^{3} J_{\mathrm{HH}_{\mathrm{c}}}$ & 11,9 & 11,8 & 11,9 & 11,9 & 12,0 & 12,1 & 12,2 & 12,4 & 12,6 & 12,8 & 13,1 & 13,3 & 13,6 & 13,9 & 14,1 & 11,7 \\
\hline $\mathrm{C}_{2} \mathrm{H}_{4}$ & ${ }^{3} J_{\mathrm{HH}_{\mathrm{t}}}$ & 18,6 & 18,4 & 18,2 & 18,1 & 18,0 & 17,9 & 18,0 & 18,1 & 18,4 & 18,7 & 19,0 & 19,3 & 19,7 & 20,1 & 20,5 & 19 \\
\hline $\mathrm{C}_{2} \mathrm{H}_{6}$ & ${ }^{1} J_{\mathrm{CC}}$ & 28,1 & 27,6 & 27,4 & 27,4 & 27,4 & 27,6 & 28,0 & 28,5 & 29,1 & 30,0 & 30,9 & 31,9 & 33,0 & 34,1 & 35,1 & 34,5 \\
\hline $\mathrm{C}_{2} \mathrm{H}_{6}$ & ${ }^{1} J_{\mathrm{CH}}$ & 122,5 & 121,0 & 119,5 & 118,2 & 117,2 & 116,7 & 116,6 & 117,0 & 117,8 & 118,9 & 120,2 & 121,5 & 123,0 & 124,4 & 125,8 & 125,2 \\
\hline $\mathrm{C}_{2} \mathrm{H}_{6}$ & ${ }^{2} J_{\mathrm{CH}}$ & $-3,0$ & $-3,0$ & $-2,9$ & $-2,9$ & $-3,0$ & $-3,1$ & $-3,2$ & $-3,4$ & $-3,7$ & $-3,9$ & $-4,1$ & $-4,4$ & $-4,6$ & $-4,9$ & $-5,1$ & $-4,7$ \\
\hline \multirow[t]{3}{*}{ Total } & DM & $-16,54$ & $-16,99$ & $-17,41$ & $-17,80$ & $-18,10$ & $-18,25$ & $-18,17$ & $-17,86$ & $-17,31$ & $-16,55$ & $-15,63$ & $-14,63$ & $-13,55$ & $-12,49$ & & - \\
\hline & DMA & 20,09 & 20,27 & 20 , & 20 , & 21,11 & 21,18 & 21, & & & & 18,24 & & & & & - \\
\hline & PDMA & 33,72 & 34,68 & 35,12 & 34,48 & 32,99 & 30,46 & 27,33 & 23,45 & 19,15 & 15,04 & 12,26 & 12,53 & 13,16 & 16,74 & 20,92 & - \\
\hline \multirow[t]{3}{*}{ CPI } & DM & $-40,55$ & $-40,66$ & $-40,83$ & $-41,04$ & $-41,25$ & $-41,34$ & $-41,18$ & $-40,75$ & $-39,98$ & $-38,96$ & $-37,72$ & $-36,33$ & $-34,89$ & $-33,49$ & $-32,13$ & 一 \\
\hline & DMA & 42,65 & 42,85 & 43,03 & 43,24 & 43,38 & 43,35 & 43,07 & 42,41 & 41,40 & 40,07 & 38,61 & 37,00 & 35,85 & 36,29 & 37,11 & - \\
\hline & PDMA & 52,21 & 53,09 & 52,58 & 50,84 & 47,87 & 43,99 & 39,57 & 34,43 & 29,14 & 23,75 & 19,72 & 15,92 & 12,45 & 15,33 & 18,99 & - \\
\hline \multirow[t]{3}{*}{ SPI } & DM & 1,07 & 0,37 & $-0,23$ & $-0,77$ & $-1,13$ & $-1,32$ & $-1,29$ & $-1,0$ & $-0,69$ & $-0,11$ & 0,5 & 1,2 & 2,10 & 2,91 & 3,71 & - \\
\hline & DMA & 3,55 & 3,71 & 3,98 & 4,45 & 4,78 & 4,92 & 4,85 & 4,62 & 4,25 & 3,78 & 3,30 & 3,17 & 3,55 & 4,07 & 4,75 & - \\
\hline & PDMA & 20,16 & 21,17 & 22,30 & 22,49 & 22,08 & 20,53 & 18,35 & 15,39 & 11,82 & 8,66 & 6,78 & 10,05 & 13,68 & 17,78 & 22,33 & - \\
\hline \multirow[t]{3}{*}{$\Delta \mathrm{CS}$} & DM & $-41,61$ & $-41,04$ & $-40,59$ & $-40,27$ & $-40,13$ & $-40,02$ & $-39,89$ & $-39,68$ & & & $-38,28$ & & & $-36,40$ & & 一 \\
\hline & DMA & 39,11 & 39,14 & 39,05 & 38,79 & 38,60 & 38,43 & 38,22 & 37,79 & 37, & 36,29 & 35,31 & 33,83 & 32,30 & 32,22 & 32,36 & - \\
\hline & & 32,06 & 31,92 & 30,28 & 28,34 & 25,79 & 23,46 & 21,21 & 19,04 & 17,32 & 15,10 & 12,93 & 5,88 & $-1,24$ & $-2,46$ & $-3,34$ & - \\
\hline
\end{tabular}


Tabela 8.367: Constantes de acoplamento LC-BB95 com $\alpha=30 \%$ e $\alpha+\beta=90 \%$, variando $\gamma$, na base aug-pcJ-2.

\begin{tabular}{|c|c|c|c|c|c|c|c|c|c|c|c|c|c|c|c|c|c|}
\hline & $\gamma$ & 0,05 & 0,10 & 0,15 & 0,20 & 0,25 & 0,30 & 0,35 & 0,40 & 0,45 & 0,50 & 0,55 & 0,60 & 0,65 & 0,70 & 0,75 & Exp. \\
\hline $\mathrm{HF}$ & ${ }^{1} J_{\mathrm{HF}}$ & 476,8 & 478,9 & 481,2 & 483,5 & 485,9 & 488,6 & 491,8 & 495,5 & 499,7 & 504,2 & 508,9 & 513,9 & 518,9 & 523,9 & 528,9 & 500 \\
\hline $\mathrm{CO}$ & ${ }^{1} J_{\mathrm{CO}}$ & 18,3 & 18,4 & 18,4 & 18,4 & 18,4 & 18,5 & 18,5 & 18,4 & 18,3 & 18,1 & 17,7 & 17,3 & 16,8 & 16,2 & 15,6 & 16,4 \\
\hline $\mathrm{H}_{2} \mathrm{O}$ & ${ }^{1} J_{\mathrm{OH}}$ & $-77,9$ & $-78,0$ & $-78,0$ & $-78,1$ & $-78,2$ & $-78,4$ & $-78,7$ & $-79,1$ & $-79,6$ & $-80,1$ & $-80,7$ & $-81,4$ & $-82,1$ & $-82,7$ & $-83,5$ & $-80,6$ \\
\hline $\mathrm{H}_{2} \mathrm{O}$ & ${ }^{2} J_{\mathrm{HH}}$ & $-7,0$ & $-6,8$ & $-6,7$ & $-6,7$ & $-6,8$ & $-6,9$ & $-7,1$ & $-7,4$ & $-7,7$ & $-8,0$ & $-8,3$ & $-8,7$ & $-9,0$ & $-9,3$ & $-9,7$ & $-7,3$ \\
\hline $\mathrm{NH}_{3}$ & ${ }^{1} J_{\mathrm{NH}}$ & 44,0 & 43,8 & 43,6 & 43,5 & 43,3 & 43,2 & 43,2 & 43,3 & 43,4 & 43,6 & 43,9 & 44,2 & 44,5 & 44,8 & 45,2 & 43,8 \\
\hline $\mathrm{NH}_{3}$ & ${ }^{2} J_{\mathrm{HH}}$ & $-9,3$ & $-9,0$ & $-8,9$ & $-8,9$ & $-9,0$ & $-9,2$ & $-9,4$ & $-9,7$ & $-10,1$ & $-10,4$ & $-10,8$ & $-11,2$ & $-11,5$ & $-11,9$ & $-12,2$ & $-9,6$ \\
\hline $\mathrm{PH}_{3}$ & ${ }^{1} J_{\mathrm{PH}}$ & 168,0 & 166,4 & 163,6 & 160,1 & 157,0 & 155,1 & 154,7 & 155,8 & 158,0 & 161,1 & 164,8 & 168,7 & 172,7 & 176,6 & 180,3 & 188,2 \\
\hline $\mathrm{PF}_{3}$ & ${ }^{1} J_{\mathrm{PF}}$ & $-1639,5$ & $-1638,3$ & $-1636,4$ & $-1634,1$ & $-1632,0$ & $-1630,1$ & $-1628,1$ & $-1625,7$ & $-1622,2$ & $-1617,5$ & $-1611,4$ & $-1604,3$ & $-1596,2$ & $-1587,6$ & $-1578,7$ & -1441 \\
\hline $\mathrm{BHF}_{2}$ & ${ }^{1} J_{\mathrm{BF}}$ & $-126,5$ & $-127,4$ & $-126,6$ & $-124,3$ & $-120,9$ & $-116,9$ & $-112,5$ & $-107,8$ & $-102,9$ & $-97,9$ & $-93,0$ & $-88,2$ & $-83,5$ & $-79,1$ & $-74,9$ & -84 \\
\hline $\mathrm{BF}_{3}$ & ${ }^{1} J_{\mathrm{BF}}$ & $-25,0$ & $-25,3$ & $-24,1$ & $-21,5$ & $-17,7$ & $-13,0$ & $-7,9$ & $-2,5$ & 2,8 & 8,3 & 13,6 & 18,7 & 23,6 & 28,1 & 32,4 & 15 \\
\hline $\mathrm{F}_{2} \mathrm{O}$ & ${ }^{1} J_{\mathrm{OF}}$ & $-370,8$ & $-373,7$ & $-378,7$ & $-386,3$ & $-396,1$ & $-407,3$ & $-419,2$ & $-431,4$ & $-443,7$ & $-456,1$ & $-468,5$ & $-481,1$ & $-493,9$ & $-506,8$ & $-519,9$ & -300 \\
\hline $\mathrm{CH}_{4}$ & ${ }^{1} J_{\mathrm{CH}}$ & 123,5 & 122,2 & 120,9 & 119,7 & 118,8 & 118,3 & 118,2 & 118,5 & 119,1 & 120,0 & 121,0 & 122,2 & 123,4 & 124,5 & 125,7 & 125,3 \\
\hline $\mathrm{CH}_{4}$ & ${ }^{2} J_{\mathrm{HH}}$ & $-12,0$ & $-11,8$ & $-11,6$ & $-11,5$ & $-11,6$ & $-11,7$ & $-12,0$ & $-12,4$ & $-12,7$ & $-13,1$ & $-13,5$ & $-13,9$ & $-14,2$ & $-14,5$ & $-14,8$ & $-12,8$ \\
\hline $\mathrm{C}_{2} \mathrm{H}_{2}$ & ${ }^{1} J_{\mathrm{CC}}$ & 194,1 & 192,8 & 191,9 & 191,3 & 191,1 & 191,2 & 191,8 & 192,7 & 194,1 & 195,8 & 197,9 & 200,2 & 202,6 & 205,1 & 207,7 & 174,8 \\
\hline $\mathrm{C}_{2} \mathrm{H}_{2}$ & ${ }^{1} J_{\mathrm{CH}}$ & 254,8 & 252,4 & 250,0 & 247,7 & 246,0 & 245,1 & 244,9 & 245,4 & 246,6 & 248,1 & 250,1 & 252,2 & 254,4 & 256,6 & 258,8 & 247,6 \\
\hline $\mathrm{C}_{2} \mathrm{H}_{2}$ & ${ }^{2} J_{\mathrm{CH}}$ & 55,4 & 55,4 & 55,5 & 55,7 & 56,0 & 56,2 & 56,3 & 56,2 & 56,1 & 55,8 & 55,5 & 55,1 & 54,6 & 54,1 & 53,6 & 50,1 \\
\hline $\mathrm{C}_{2} \mathrm{H}_{2}$ & ${ }^{3} J_{\mathrm{HH}}$ & 10,3 & 10,1 & 9,9 & 9,8 & 9,7 & 9,9 & 10,1 & 10,4 & 10,8 & 11,3 & 11,7 & 12,2 & 12,7 & 13,2 & 13,6 & 9,6 \\
\hline $\mathrm{C}_{2} \mathrm{H}_{4}$ & ${ }^{1} J_{\mathrm{CC}}$ & 65,3 & 64,4 & 63,8 & 63,5 & 63,4 & 63,6 & 63,9 & 64,6 & 65,6 & 66,9 & 68,5 & 70,2 & 72,1 & 74,0 & 76,0 & 67,6 \\
\hline $\mathrm{C}_{2} \mathrm{H}_{4}$ & ${ }^{1} J_{\mathrm{CH}}$ & 157,9 & 156,3 & 154,8 & 153,5 & 152,5 & 152,1 & 152,2 & 152,8 & 153,8 & 155,1 & 156,6 & 158,3 & 160,0 & 161,8 & 163,5 & 156,3 \\
\hline $\mathrm{C}_{2} \mathrm{H}_{4}$ & ${ }^{2} J_{\mathrm{CH}}$ & $-1,2$ & $-1,1$ & $-1,0$ & $-1,0$ & $-1,1$ & $-1,2$ & $-1,5$ & $-1,9$ & $-2,4$ & $-2,9$ & $-3,5$ & $-4,1$ & $-4,7$ & $-5,4$ & $-6,0$ & $-2,4$ \\
\hline $\mathrm{C}_{2} \mathrm{H}_{4}$ & ${ }^{2} J_{\mathrm{HH}}$ & 4,1 & 4,2 & 4,2 & 4,2 & 4,0 & 3,8 & 3,4 & 3,1 & 2,7 & 2,2 & 1,8 & 1,4 & 1,0 & 0,6 & 0,2 & 2,3 \\
\hline $\mathrm{C}_{2} \mathrm{H}_{4}$ & ${ }^{3} J_{\mathrm{HH}_{\mathrm{c}}}$ & 12,1 & 12,1 & 12,1 & 12,1 & 12,2 & 12,3 & 12,5 & 12,6 & 12,8 & 13,1 & 13,3 & 13,6 & 13,8 & 14,1 & 14,3 & 11,7 \\
\hline $\mathrm{C}_{2} \mathrm{H}_{4}$ & ${ }^{3} J_{\mathrm{HH}_{\mathrm{t}}}$ & 18,9 & 18,7 & 18,6 & 18,4 & 18,4 & 18,4 & 18,5 & 18,6 & 18,8 & 19,1 & 19,4 & 19,8 & 20,1 & 20,5 & 20,8 & 19 \\
\hline $\mathrm{C}_{2} \mathrm{H}_{6}$ & ${ }^{1} J_{\mathrm{CC}}$ & 30,2 & 29,7 & 29,5 & 29,5 & 29,5 & 29,7 & 30,0 & 30 & 31,0 & 31,7 & 32,6 & 33,5 & 34,4 & 35,3 & 36,3 & 34,5 \\
\hline $\mathrm{C}_{2} \mathrm{H}_{6}$ & ${ }^{1} J_{\mathrm{CH}}$ & 124,2 & 122,9 & 121,6 & 120,4 & 119,6 & 9,1 & 119,1 & 119,5 & 120,2 & 121,1 & 122,2 & 123,4 & 124,6 & 125,9 & 127,1 & 125,2 \\
\hline $\mathrm{C}_{2} \mathrm{H}_{6}$ & ${ }^{2} J_{\mathrm{CH}}$ & $-3,5$ & $-3,4$ & $-3,4$ & $-3,4$ & $-3,4$ & $-3,5$ & $-3,7$ & $-3,8$ & $-4,0$ & $-4,2$ & $-4,4$ & $-4,7$ & $-4,9$ & $-5,1$ & $-5,3$ & $-4,7$ \\
\hline \multirow[t]{3}{*}{ Total } & $\mathrm{DM}$ & $-13,8$ & 14,27 & -14 & & 3 & & & & & & & & & & & - \\
\hline & DMA & 17 & & & & & & & & & & & & & & & - \\
\hline & PDMA & 23,37 & 24,27 & 24,42 & 23,92 & 22,47 & 20,67 & 17,79 & 14,82 & 11,84 & 10,75 & 11,22 & 13,93 & 17,57 & 22,03 & 26,49 & - \\
\hline \multirow[t]{3}{*}{ CPI } & DM & $-35,44$ & 35,63 & & & - & & & & & & & & & & & - \\
\hline & DMA &, 42 & 36,66 & 36 , & 36,9 & 37 & & 36,7 & & & & & & & & & - \\
\hline & PDMA & 35,69 & 36,63 & 36,31 & 34,84 & 32,37 & 29,19 & 25,46 & 21,58 & 18,62 & 15,46 & 12,43 & 14,34 & 17,67 & 21,88 & 26,48 & - \\
\hline \multirow[t]{3}{*}{ SPI } & DM & & & & & & & & & & & & & & & & - \\
\hline & & & & & & & & & & & & & & & & & - \\
\hline & PDMA & 14,33 & 15,22 & 15,71 & 15,92 & 15,21 & 14,42 & 12,16 & 9,86 & 6,87 & 7,29 & 10,33 & 13,63 & 17,50 & 22,14 & 26,50 & - \\
\hline \multirow[t]{3}{*}{$\Delta C S$} & & & & & & & & & & & & & & & & & - \\
\hline & MA & & & & & & & & & & & & & & & & - \\
\hline & & 21,37 & 21,41 & 20,60 & 18,92 & 17,16 & 14,77 & 13,30 & 11,72 & 11,75 & 8,17 & 2,10 & 0,71 & 0,16 & $-0,26$ & $-0,02$ & - \\
\hline
\end{tabular}


Tabela 8.368: Constantes de acoplamento LC-BB95 com $\alpha=40 \%$ e $\alpha+\beta=90 \%$, variando $\gamma$, na base aug-pcJ-2.

\begin{tabular}{|c|c|c|c|c|c|c|c|c|c|c|c|c|c|c|c|c|c|}
\hline & $\gamma$ & 0,05 & 0,10 & 0,15 & 0,20 & 0,25 & 0,30 & 0,35 & 0,40 & 0,45 & 0,50 & 0,55 & 0,60 & 0,65 & 0,70 & 0,75 & Exp. \\
\hline $\mathrm{HF}$ & ${ }^{1} J_{\mathrm{HF}}$ & 500,5 & 502,2 & 504,1 & 505,9 & 507,9 & 510,2 & 512,9 & 515,9 & 519,3 & 523,0 & 527,0 & 531,0 & 535,2 & 539,4 & 543,6 & 500 \\
\hline $\mathrm{CO}$ & ${ }^{1} J_{\mathrm{CO}}$ & 16,3 & 16,4 & 16,4 & 16,4 & 16,4 & 16,5 & 16,5 & 16,5 & 16,4 & 16,2 & 15,9 & 15,5 & 15,0 & 14,5 & 14,0 & 16,4 \\
\hline $\mathrm{H}_{2} \mathrm{O}$ & ${ }^{1} J_{\mathrm{OH}}$ & $-80,4$ & $-80,5$ & $-80,5$ & $-80,6$ & $-80,7$ & $-80,8$ & $-81,1$ & $-81,4$ & $-81,8$ & $-82,2$ & $-82,7$ & $-83,3$ & $-83,8$ & $-84,4$ & $-85,0$ & $-80,6$ \\
\hline $\mathrm{H}_{2} \mathrm{O}$ & ${ }^{2} J_{\mathrm{HH}}$ & $-8,0$ & $-7,9$ & $-7,8$ & $-7,8$ & $-7,8$ & $-7,9$ & $-8,1$ & $-8,3$ & $-8,6$ & $-8,9$ & $-9,1$ & $-9,4$ & $-9,7$ & $-10,0$ & $-10,3$ & $-7,3$ \\
\hline $\mathrm{NH}_{3}$ & ${ }^{1} J_{\mathrm{NH}}$ & 44,7 & 44,6 & 44,4 & 44,3 & 44,2 & 44,1 & 44,1 & 44,2 & 44,3 & 44,4 & 44,7 & 44,9 & 45,2 & 45,5 & 45,8 & 43,8 \\
\hline $\mathrm{NH}_{3}$ & ${ }^{2} J_{\mathrm{HH}}$ & $-10,2$ & $-10,0$ & $-9,9$ & $-9,8$ & $-9,9$ & $-10,0$ & $-10,3$ & $-10,5$ & $-10,8$ & $-11,1$ & $-11,4$ & $-11,7$ & $-12,0$ & $-12,3$ & $-12,6$ & $-9,6$ \\
\hline $\mathrm{PH}_{3}$ & ${ }^{1} J_{\mathrm{PH}}$ & 175,3 & 173,9 & 171,6 & 168,7 & 166,1 & 164,5 & 164,1 & 165,0 & 166,8 & 169,4 & 172,5 & 175,7 & 179,1 & 182,3 & 185,4 & 188,2 \\
\hline $\mathrm{PF}_{3}$ & ${ }^{1} J_{\mathrm{PF}}$ & $-1607,3$ & $-1606,6$ & $-1605,0$ & $-1602,8$ & $-1600,4$ & $-1598,0$ & $-1595,6$ & $-1592,8$ & $-1589,3$ & $-1584,8$ & $-1579,4$ & $-1573,2$ & $-1566,3$ & $-1559,0$ & $-1551,5$ & -1441 \\
\hline $\mathrm{BHF}_{2}$ & ${ }^{1} J_{\mathrm{BF}}$ & $-109,5$ & $-110,4$ & $-109,8$ & $-108,1$ & $-105,4$ & $-102,1$ & $-98,4$ & $-94,5$ & $-90,5$ & $-86,3$ & $-82,2$ & $-78,2$ & $-74,4$ & $-70,7$ & $-67,2$ & -84 \\
\hline $\mathrm{BF}_{3}$ & ${ }^{1} J_{\mathrm{BF}}$ & $-6,7$ & $-7,1$ & $-6,2$ & $-4,1$ & $-1,1$ & 2,6 & 6,7 & 11,2 & 15,7 & 20,2 & 24,6 & 28,9 & 32,9 & 36,7 & 40,3 & 15 \\
\hline $\mathrm{F}_{2} \mathrm{O}$ & ${ }^{1} J_{\mathrm{OF}}$ & $-405,9$ & $-408,3$ & $-412,6$ & $-419,2$ & $-427,8$ & $-437,8$ & $-448,7$ & $-460,0$ & $-471,6$ & $-483,4$ & $-495,3$ & $-507,4$ & $-519,7$ & $-532,2$ & $-544,7$ & -300 \\
\hline $\mathrm{CH}_{4}$ & ${ }^{1} J_{\mathrm{CH}}$ & 125,1 & 124,0 & 122,9 & 121,9 & 121,1 & 120,7 & 120,6 & 120,9 & 121,4 & 122,1 & 123,0 & 124,0 & 125,0 & 126,0 & 127,0 & 125,3 \\
\hline $\mathrm{CH}_{4}$ & ${ }^{2} J_{\mathrm{HH}}$ & $-12,8$ & $-12,5$ & $-12,3$ & $-12,3$ & $-12,3$ & $-12,5$ & $-12,7$ & $-13,0$ & $-13,3$ & $-13,6$ & $-14,0$ & $-14,3$ & $-14,6$ & $-14,8$ & $-15,1$ & $-12,8$ \\
\hline $\mathrm{C}_{2} \mathrm{H}_{2}$ & ${ }^{1} J_{\mathrm{CC}}$ & 197,7 & 196,5 & 195,7 & 195,3 & 195,1 & 195,3 & 195,9 & 196,9 & 198,2 & 199,8 & 201,7 & 203,8 & 206,0 & 208,2 & 210,4 & 174,8 \\
\hline $\mathrm{C}_{2} \mathrm{H}_{2}$ & ${ }^{1} J_{\mathrm{CH}}$ & 257,2 & 255,2 & 253,1 & 251,2 & 249,8 & 249,0 & 248,9 & 249,4 & 250,4 & 251,8 & 253,5 & 255,3 & 257,2 & 259,2 & 261,1 & 247,6 \\
\hline $\mathrm{C}_{2} \mathrm{H}_{2}$ & ${ }^{2} J_{\mathrm{CH}}$ & 55,1 & 55,2 & 55,3 & 55,4 & 55,6 & 55,7 & 55,8 & 55,7 & 55,5 & 55,2 & 54,8 & 54,4 & 53,9 & 53,5 & 53,0 & 50,1 \\
\hline $\mathrm{C}_{2} \mathrm{H}_{2}$ & ${ }^{3} J_{\mathrm{HH}}$ & 11,0 & 10,8 & 10,6 & 10,5 & 10,5 & 10,7 & 10,9 & 11,2 & 11,6 & 12,0 & 12,4 & 12,9 & 13,3 & 13,7 & 14,1 & 9,6 \\
\hline $\mathrm{C}_{2} \mathrm{H}_{4}$ & ${ }^{1} J_{\mathrm{CC}}$ & 68,4 & 67,6 & 67,1 & 66,8 & 66,8 & 67,0 & 67,4 & 68,1 & 69,1 & 70,3 & 71,7 & 73,3 & 75,0 & 76,7 & 78,4 & 67,6 \\
\hline $\mathrm{C}_{2} \mathrm{H}_{4}$ & ${ }^{1} J_{\mathrm{CH}}$ & 160,1 & 158,8 & 157,5 & 156,4 & 155,6 & 155,3 & 155,4 & 155,9 & 156,8 & 158,0 & 159,3 & 160,8 & 162,3 & 163,7 & 165,2 & 156,3 \\
\hline $\mathrm{C}_{2} \mathrm{H}_{4}$ & ${ }^{2} J_{\mathrm{CH}}$ & $-2,2$ & $-2,0$ & $-1,9$ & $-1,9$ & $-2,0$ & $-2,2$ & $-2,5$ & $-2,9$ & $-3,3$ & $-3,8$ & $-4,4$ & $-4,9$ & $-5,5$ & $-6,1$ & $-6,6$ & $-2,4$ \\
\hline $\mathrm{C}_{2} \mathrm{H}_{4}$ & ${ }^{2} J_{\mathrm{HH}}$ & 3,4 & 3,5 & 3,5 & 3,4 & 3,3 & 3,1 & 2,8 & 2,4 & 2,1 & 1,7 & 1,3 & 0,9 & 0,5 & 0,2 & 0,0 & 2,3 \\
\hline $\mathrm{C}_{2} \mathrm{H}_{4}$ & ${ }^{3} J_{\mathrm{HH}}$ & 12,4 & 12,4 & 12,4 & 12,4 & 12,5 & 12,6 & 12,7 & 12,9 & 13,1 & 13,3 & 13,6 & 13,8 & 14,0 & 14,3 & 14,5 & 11,7 \\
\hline $\mathrm{C}_{2} \mathrm{H}_{4}$ & ${ }^{3} J_{\mathrm{HH}_{\mathrm{t}}}$ & 19,3 & 19,1 & 19,0 & 18,9 & 18,8 & 18,9 & 19,0 & 19,1 & 19,4 & 19,6 & 19,9 & 20,2 & 20,6 & 20,9 & 21,2 & 19 \\
\hline $\mathrm{C}_{2} \mathrm{H}_{6}$ & ${ }^{1} J_{\mathrm{CC}}$ & 32,3 & 31,9 & 31,7 & 31,6 & 31,7 & 31,8 & 32,1 & 32,5 & 33,0 & 33,6 & 34,3 & 35,1 & 35,8 & 36,6 & 37,4 & 34,5 \\
\hline $\mathrm{C}_{2} \mathrm{H}_{6}$ & ${ }^{1} J_{\mathrm{CH}}$ & 125,9 & 124,8 & 123,7 & 122,8 & 122,0 & 121,7 & 121,7 & 122,0 & 122,5 & 123,3 & 124,3 & 125,3 & 126,3 & 127,4 & 128,4 & 125,2 \\
\hline $\mathrm{C}_{2} \mathrm{H}_{6}$ & ${ }^{2} J_{\mathrm{CH}}$ & $-4,0$ & $-3,9$ & $-3,9$ & $-3,8$ & $-3,9$ & $-4,0$ & $-4,1$ & $-4,2$ & $-4,4$ & $-4,6$ & $-4,8$ & $-4,9$ & $-5,1$ & $-5,3$ & $-5,4$ & $-4,7$ \\
\hline \multirow[t]{3}{*}{ Total } & DM & $-11,05$ & $-11,43$ & $-11,77$ & $-12,06$ & $-12,27$ & $-12,33$ & $-12,27$ & $-12,03$ & -11 & $-11,15$ & ,53 & $-9,87$ & $-9,18$ & $-8,50$ & $-7,83$ & - \\
\hline & DMA & 14,8 & 14,87 & 15,02 & 15,17 & 15,40 & & & 15, & & 16,70 & & & & & & - \\
\hline & PDMA & 14,56 & 15,08 & 14,99 & 14,39 & 13,40 & 11,88 & 10,32 & 9,42 & 9,88 & 12,99 & 16,63 & 20,57 & 24,76 & 28,78 & 32,34 & - \\
\hline \multirow[t]{3}{*}{ CPI } & DM & $-30,19$ & $-30,42$ & $-30,56$ & $-30,73$ & $-30,85$ & $-30,87$ & $-30,80$ & $-30,51$ & $-30,09$ & $-29,49$ & $-28,75$ & $-28,01$ & $-27,22$ & $-26,46$ & $-25,74$ & - \\
\hline & DMA & 30,48 & 30,98 & 31,44 & 31,89 & 32,36 & 32,80 & 33,22 & 33,49 & 33,82 & 34,73 & 35,90 & 37,43 & 38,87 & 40,30 & 41,68 & - \\
\hline & PDMA & 22,51 & 22,61 & 22,01 & 20,78 & 19,16 & 17,24 & 15,30 & 12,98 & 11,64 & 15,02 & 18,70 & 22,97 & 27,10 & 31,13 & 35,01 & - \\
\hline \multirow[t]{3}{*}{ SPI } & DM & 2,99 & 2,49 & 2,02 & 1,63 & 1,37 & 1,27 & 1,32 & 1,52 & 1,8 & 2,31 & 2,83 & 3,44 & 4,04 & 4,67 & 5,30 & - \\
\hline & DMA & 3,31 & 3,06 & 2,98 & 2,91 & 2,95 & 2,93 & 2,89 & 2,95 & 3,16 & 3,48 & 3,86 & 4,36 & 5,03 & 5,79 & 6,57 & - \\
\hline & PDMA & 8,72 & 9,56 & 9,84 & 9,71 & 9,16 & 7,95 & 6,66 & 6,82 & 8,59 & 11,50 & 15,12 & 18,81 & 23,04 & 27,06 & 30,39 & - \\
\hline \multirow[t]{3}{*}{$\Delta \mathrm{CS}$} & DM & $-33,18$ & $-32,90$ & $-32,58$ & $-32,36$ & $-32,22$ & & $-32,12$ & $-32,03$ & $-31,96$ & $-31,80$ & & $-31,45$ & $-31,26$ & & $-31,04$ & - \\
\hline & DMA & 27,18 & 27,92 & 28,46 & 28,98 & 29,41 & 29,87 & 30,32 & 30,54 & 30,66 & 31,25 & 32,04 & 33,07 & 33,85 & 34,51 & 35,12 & - \\
\hline & PDMA & 13,78 & 13,05 & 12,16 & 11,07 & 10,00 & 9,28 & 8,64 & 6,17 & 3,05 & 3,52 & 3,59 & 4,17 & 4,06 & 4,06 & 4,62 & - \\
\hline
\end{tabular}


Tabela 8.369: Constantes de acoplamento LC-BB95 com $\alpha=50 \%$ e $\alpha+\beta=90 \%$, variando $\gamma$, na base aug-pcJ-2.

\begin{tabular}{|c|c|c|c|c|c|c|c|c|c|c|c|c|c|c|c|c|c|}
\hline & $\gamma$ & 0,05 & 0,10 & 0,15 & 0,20 & 0,25 & 0,30 & 0,35 & 0,40 & 0,45 & 0,50 & 0,55 & 0,60 & 0,65 & 0,70 & 0,75 & Exp. \\
\hline $\mathrm{HF}$ & ${ }^{1} J_{\mathrm{HF}}$ & 524,5 & 525,8 & 527,2 & 528,6 & 530,2 & 532,0 & 534,1 & 536,6 & 539,3 & 542,2 & 545,3 & 548,6 & 551,9 & 555,2 & 558,6 & 500 \\
\hline $\mathrm{CO}$ & ${ }^{1} J_{\mathrm{CO}}$ & 14,2 & 14,3 & 14,3 & 14,3 & 14,3 & 14,4 & 14,4 & 14,4 & 14,3 & 14,1 & 13,9 & 13,6 & 13,2 & 12,8 & 12,3 & 16,4 \\
\hline $\mathrm{H}_{2} \mathrm{O}$ & ${ }^{1} J_{\mathrm{OH}}$ & $-83,0$ & $-83,0$ & $-83,0$ & $-83,1$ & $-83,1$ & $-83,3$ & $-83,4$ & $-83,7$ & $-84,0$ & $-84,4$ & $-84,8$ & $-85,2$ & $-85,7$ & $-86,1$ & $-86,6$ & $-80,6$ \\
\hline $\mathrm{H}_{2} \mathrm{O}$ & ${ }^{2} J_{\mathrm{HH}}$ & $-9,1$ & $-9,0$ & $-8,9$ & $-8,9$ & $-8,9$ & $-9,0$ & $-9,1$ & $-9,3$ & $-9,5$ & $-9,7$ & $-10,0$ & $-10,2$ & $-10,4$ & $-10,7$ & $-10,9$ & $-7,3$ \\
\hline $\mathrm{NH}_{3}$ & ${ }^{1} J_{\mathrm{NH}}$ & 45,5 & 45,4 & 45,3 & 45,1 & 45,0 & 45,0 & 45,0 & 45,0 & 45,1 & 45,3 & 45,4 & 45,6 & 45,9 & 46,1 & 46,3 & 43,8 \\
\hline $\mathrm{NH}_{3}$ & ${ }^{2} J_{\mathrm{HH}}$ & $-11,1$ & $-10,9$ & $-10,8$ & $-10,8$ & $-10,8$ & $-11,0$ & $-11,1$ & $-11,3$ & $-11,6$ & $-11,8$ & $-12,1$ & $-12,3$ & $-12,6$ & $-12,8$ & $-13,0$ & $-9,6$ \\
\hline $\mathrm{PH}_{3}$ & ${ }^{1} J_{\mathrm{PH}}$ & 182,6 & 181,4 & 179,5 & 177,2 & 175,1 & 173,8 & 173,5 & 174,2 & 175,6 & 177,7 & 180,1 & 182,8 & 185,4 & 188,1 & 190,5 & 188,2 \\
\hline $\mathrm{PF}_{3}$ & ${ }^{1} J_{\mathrm{PF}}$ & $-1572,2$ & $-1572,0$ & $-1570,7$ & $-1568,7$ & $-1566,4$ & $-1564,0$ & $-1561,5$ & $-1558,8$ & $-1555,5$ & $-1551,6$ & $-1547,0$ & $-1541,8$ & $-1536,1$ & $-1530,2$ & $-1524,1$ & -1441 \\
\hline $\mathrm{BHF}_{2}$ & ${ }^{1} J_{\mathrm{BF}}$ & $-92,7$ & $-93,4$ & $-93,1$ & $-91,8$ & $-89,7$ & $-87,1$ & $-84,2$ & $-81,1$ & $-77,9$ & $-74,6$ & $-71,3$ & $-68,2$ & $-65,1$ & $-62,1$ & $-59,3$ & -84 \\
\hline $\mathrm{BF}_{3}$ & ${ }^{1} J_{\mathrm{BF}}$ & 11,4 & 11,0 & 11,6 & 13,1 & 15,5 & 18,4 & 21,7 & 25,1 & 28,7 & 32,3 & 35,8 & 39,2 & 42,4 & 45,5 & 48,3 & 15 \\
\hline $\mathrm{F}_{2} \mathrm{O}$ & ${ }^{1} J_{\mathrm{OF}}$ & $-444,8$ & $-446,6$ & $-450,2$ & $-455,9$ & $-463,5$ & $-472,5$ & $-482,4$ & $-492,9$ & $-503,8$ & $-515,0$ & $-526,3$ & $-537,9$ & $-549,5$ & $-561,3$ & $-573,0$ & -300 \\
\hline $\mathrm{CH}_{4}$ & ${ }^{1} J_{\mathrm{CH}}$ & 126,7 & 125,8 & 124,9 & 124,1 & 123,5 & 123,1 & 123,1 & 123,3 & 123,7 & 124,3 & 125,0 & 125,8 & 126,6 & 127,4 & 128,2 & 125,3 \\
\hline $\mathrm{CH}_{4}$ & ${ }^{2} J_{\mathrm{HH}}$ & $-13,5$ & $-13,3$ & $-13,1$ & $-13,1$ & $-13,1$ & $-13,2$ & $-13,4$ & $-13,7$ & $-13,9$ & $-14,2$ & $-14,4$ & $-14,7$ & $-14,9$ & $-15,1$ & $-15,3$ & $-12,8$ \\
\hline $\mathrm{C}_{2} \mathrm{H}_{2}$ & ${ }^{1} J_{\mathrm{CC}}$ & 201,9 & 200,8 & 200,1 & 199,8 & 199,7 & 200,0 & 200,6 & 201,5 & 202,7 & 204,2 & 205,8 & 207,6 & 209,5 & 211,4 & 213,3 & 174,8 \\
\hline $\mathrm{C}_{2} \mathrm{H}_{2}$ & ${ }^{1} J_{\mathrm{CH}}$ & 259,8 & 258,1 & 256,4 & 254,9 & 253,8 & 253,2 & 253,1 & 253,6 & 254,4 & 255,6 & 257,0 & 258,6 & 260,2 & 261,8 & 263,3 & 247,6 \\
\hline $\mathrm{C}_{2} \mathrm{H}_{2}$ & ${ }^{2} J_{\mathrm{CH}}$ & 54,6 & 54,7 & 54,8 & 54,9 & 55,0 & 55,1 & 55,0 & 54,9 & 54,7 & 54,4 & 54,0 & 53,6 & 53,2 & 52,8 & 52,3 & 50,1 \\
\hline $\mathrm{C}_{2} \mathrm{H}_{2}$ & ${ }^{3} J_{\mathrm{HH}}$ & 11,8 & 11,6 & 11,5 & 11,4 & 11,5 & 11,6 & 11,8 & 12,1 & 12,4 & 12,8 & 13,2 & 13,6 & 14,0 & 14,3 & 14,7 & 9,6 \\
\hline $\mathrm{C}_{2} \mathrm{H}_{4}$ & ${ }^{1} J_{\mathrm{CC}}$ & 72,0 & 71,2 & 70,8 & 70,6 & 70,6 & 70,8 & 71,2 & 71,9 & 72,8 & 74,0 & 75,2 & 76,6 & 78,1 & 79,6 & 81,0 & 67,6 \\
\hline $\mathrm{C}_{2} \mathrm{H}_{4}$ & ${ }^{1} J_{\mathrm{CH}}$ & 162,5 & 161,4 & 160,3 & 159,4 & 158,8 & 158,6 & 158,7 & 159,2 & 160,0 & 161,0 & 162,1 & 163,3 & 164,6 & 165,8 & 167,0 & 156,3 \\
\hline $\mathrm{C}_{2} \mathrm{H}_{4}$ & ${ }^{2} J_{\mathrm{CH}}$ & $-3,3$ & $-3,1$ & $-3,1$ & $-3,1$ & $-3,2$ & $-3,3$ & $-3,6$ & $-4,0$ & $-4,4$ & $-4,8$ & $-5,3$ & $-5,8$ & $-6,3$ & $-6,8$ & $-7,3$ & $-2,4$ \\
\hline $\mathrm{C}_{2} \mathrm{H}_{4}$ & ${ }^{2} J_{\mathrm{HH}}$ & 2,6 & 2,7 & 2,7 & 2,6 & 2,5 & 2,3 & 2,1 & 1,8 & 1,4 & 1,1 & 0,8 & 0,4 & 0,1 & $-0,1$ & $-0,4$ & 2,3 \\
\hline $\mathrm{C}_{2} \mathrm{H}_{4}$ & ${ }^{3} J_{\mathrm{HH}}$ & 12,8 & 12,7 & 12,7 & 12,8 & 12,8 & 13,0 & 13,1 & 13,3 & 13,5 & 13,7 & 13,9 & 14,1 & 14,3 & 14,5 & 14,7 & 11,7 \\
\hline $\mathrm{C}_{2} \mathrm{H}_{4}$ & ${ }^{3} J_{\mathrm{HH}_{\mathrm{t}}}$ & 19,7 & 19,6 & 19,5 & 19,4 & 19,4 & 19,4 & 19,6 & 19,7 & 19,9 & 20,2 & 20,5 & 20,7 & 21,0 & 21,3 & 21,5 & 19 \\
\hline $\mathrm{C}_{2} \mathrm{H}_{6}$ & ${ }^{1} J_{\mathrm{CC}}$ & 34,5 & 34,1 & 33,9 & 33,9 & 33,9 & 34,0 & 34,2 & 34,5 & 35,0 & 35,5 & 36,0 & 36,7 & 37,3 & 38,0 & 38,6 & 34,5 \\
\hline $\mathrm{C}_{2} \mathrm{H}_{6}$ & ${ }^{1} J_{\mathrm{CH}}$ & 127,7 & 126,8 & 125,9 & 125,1 & 124,5 & 124,2 & 124,2 & 124,5 & 125,0 & 125,6 & 126,4 & 127,2 & 128,0 & 128,9 & 129,7 & 125,2 \\
\hline $\mathrm{C}_{2} \mathrm{H}_{6}$ & ${ }^{2} J_{\mathrm{CH}}$ & $-4,4$ & $-4,4$ & $-4,3$ & $-4,3$ & $-4,4$ & $-4,4$ & $-4,5$ & $-4,6$ & $-4,8$ & $-4,9$ & $-5,1$ & $-5,2$ & $-5,4$ & $-5,5$ & $-5,6$ & $-4,7$ \\
\hline \multirow[t]{3}{*}{ Total } & DM & $-8,24$ & $-8,59$ & $-8,88$ & $-9,13$ & $-9,31$ & $-9,38$ & $-9,34$ & $-9,18$ & $-8,92$ & $-8,54$ & $-8,11$ & $-7,63$ & $-7,13$ & $-6,62$ & $-6,16$ & - \\
\hline & DMA & 15 , & 15,02 & 15,00 & & & & 16,15 & & & & 19,50 & & & & & - \\
\hline & PDMA & 11,60 & 11,15 & 10,84 & 10,27 & 9,91 & 10,79 & 12,70 & 15,40 & 18,59 & 21,81 & 25,31 & 28,89 & 32,41 & 35,62 & 38,98 & - \\
\hline \multirow[t]{3}{*}{ CPI } & DM & $-25,05$ & $-25,26$ & $-25,43$ & $-25,62$ & $-25,75$ & $-25,84$ & $-25,81$ & $-25,70$ & $-25,47$ & $-25,13$ & $-24,72$ & $-24,25$ & $-23,77$ & $-23,31$ & $-22,89$ & - \\
\hline & DMA & 29,82 & 30,25 & 30,65 & 31,05 & 31,55 & 32,49 & 33,45 & 34,94 & 36,45 & 37,93 & 39,34 & 40,68 & 42,01 & 43,29 & 44,96 & - \\
\hline & PDMA & 14,56 & 14,62 & 14,21 & 13,42 & 12,67 & 14,78 & 17,04 & 20,17 & 23,64 & 27,08 & 30,64 & 33,98 & 37,38 & 40,70 & 44,00 & - \\
\hline \multirow[t]{3}{*}{ SPI } & DM & 4,09 & 3,64 & 3,26 & 2,95 & 2,75 & 2,69 & 2,74 & 2,93 & 3,22 & 3,63 & 4,07 & 4,56 & 5,08 & 5,61 & 6,11 & - \\
\hline & DMA & 4,30 & 3,85 & 3,53 & 3,34 & 3,31 & 3,35 & 3,47 & 3,69 & 4,01 & 4,45 & 4,96 & 5,59 & 6,27 & 6,93 & 7,57 & - \\
\hline & PDMA & 9,43 & 8,61 & 8,38 & 7,96 & 7,89 & 7,86 & 9,52 & 11,91 & 14,89 & 17,95 & 21,40 & 25,15 & 28,76 & 31,89 & 35,29 & - \\
\hline \multirow[t]{3}{*}{$\Delta \mathrm{CS}$} & DM & $-29,14$ & $-28,90$ & $-28,69$ & $-28,57$ & $-28,49$ & & $-28,55$ & $-28,63$ & $-28,69$ & $-28,75$ & & & $-28,85$ & & & - \\
\hline & DMA & 25,52 & 26,39 & 27,12 & 27,71 & 28,24 & 29,14 & 29,97 & 31,25 & 32,45 & 33,47 & 34,38 & 35,10 & 35,74 & 36,36 & 37,39 & - \\
\hline & PDMA & 5,13 & 6,02 & 5,82 & 5,46 & 4,78 & 6,92 & 7,52 & 8,27 & 8,75 & 9,13 & 9,24 & 8,83 & 8,62 & 8,81 & 8,71 & - \\
\hline
\end{tabular}


Tabela 8.370: Constantes de acoplamento LC-BB95 com $\alpha=0 \%$ e $\alpha+\beta=80 \%$, variando $\gamma$, na base aug-pcJ-2.

\begin{tabular}{|c|c|c|c|c|c|c|c|c|c|c|c|c|c|c|c|c|c|}
\hline & $\gamma$ & 0,05 & 0,10 & 0,15 & 0,20 & 0,25 & 0,30 & 0,35 & 0,40 & 0,45 & 0,50 & 0,55 & 0,60 & 0,65 & 0,70 & 0,75 & Exp. \\
\hline $\mathrm{HF}$ & ${ }^{1} J_{\mathrm{HF}}$ & 406,3 & 409,6 & 412,9 & 416,1 & 419,3 & 422,9 & 427,1 & 432,1 & 437,7 & 443,9 & 450,5 & 457,2 & 464,0 & 470,8 & 477,6 & 500 \\
\hline $\mathrm{CO}$ & ${ }^{1} J_{\mathrm{CO}}$ & 23,7 & 23,8 & 23,8 & 23,7 & 23,7 & 23,7 & 23,8 & 23,7 & 23,6 & 23,3 & 22,9 & 22,4 & 21,8 & 21,1 & 20,4 & 16,4 \\
\hline $\mathrm{H}_{2} \mathrm{O}$ & ${ }^{1} J_{\mathrm{OH}}$ & $-70,4$ & $-70,6$ & $-70,8$ & $-70,9$ & $-71,1$ & $-71,4$ & $-71,8$ & $-72,3$ & $-72,9$ & $-73,7$ & $-74,5$ & $-75,3$ & $-76,2$ & $-77,1$ & $-78,1$ & $-80,6$ \\
\hline $\mathrm{H}_{2} \mathrm{O}$ & ${ }^{2} J_{\mathrm{HH}}$ & $-4,0$ & $-3,8$ & $-3,7$ & $-3,7$ & $-3,8$ & $-4,0$ & $-4,3$ & $-4,6$ & $-5,0$ & $-5,4$ & $-5,8$ & $-6,3$ & $-6,7$ & $-7,1$ & $-7,5$ & $-7,3$ \\
\hline $\mathrm{NH}_{3}$ & ${ }^{1} J_{\mathrm{NH}}$ & 41,8 & 41,6 & 41,4 & 41,2 & 41,0 & 40,9 & 40,9 & 40,9 & 41,1 & 41,4 & 41,7 & 42,1 & 42,5 & 42,9 & 43,4 & 43,8 \\
\hline $\mathrm{NH}_{3}$ & ${ }^{2} J_{\mathrm{HH}}$ & $-6,7$ & $-6,4$ & $-6,3$ & $-6,3$ & $-6,4$ & $-6,7$ & $-7,0$ & $-7,4$ & $-7,8$ & $-8,3$ & $-8,8$ & $-9,2$ & $-9,7$ & $-10,1$ & $-10,5$ & $-9,6$ \\
\hline $\mathrm{PH}_{3}$ & ${ }^{1} J_{\mathrm{PH}}$ & 145,6 & 143,8 & 140,2 & 135,5 & 131,4 & 128,8 & 128,3 & 129,8 & 132,9 & 137,1 & 142,0 & 147,2 & 152,6 & 157,8 & 162,8 & 188,2 \\
\hline $\mathrm{PF}_{3}$ & ${ }^{1} J_{\mathrm{PF}}$ & $-1713,4$ & $-1710,0$ & $-1708,1$ & $-1707,9$ & $-1709,4$ & $-1712,0$ & $-1714,9$ & $-1716,8$ & $-1716,7$ & $-1714,3$ & $-1709,3$ & $-1702,2$ & $-1693,4$ & $-1683,4$ & $-1672,7$ & -1441 \\
\hline $\mathrm{BHF}_{2}$ & ${ }^{1} J_{\mathrm{BF}}$ & $-177,1$ & $-177,7$ & $-176,0$ & $-172,5$ & $-167,6$ & $-162,0$ & $-155,9$ & $-149,5$ & $-142,9$ & $-136,2$ & $-129,6$ & $-123,1$ & $-116,9$ & $-110,9$ & $-105,4$ & -84 \\
\hline $\mathrm{BF}_{3}$ & ${ }^{1} J_{\mathrm{BF}}$ & $-80,3$ & $-80,3$ & $-78,1$ & $-73,9$ & $-68,2$ & $-61,5$ & $-54,3$ & $-46,8$ & $-39,2$ & $-31,7$ & $-24,4$ & $-17,5$ & $-10,9$ & $-4,8$ & 0,8 & 15 \\
\hline $\mathrm{F}_{2} \mathrm{O}$ & ${ }^{1} J_{\mathrm{OF}}$ & $-269,7$ & $-273,7$ & $-280,8$ & $-291,2$ & $-304,3$ & $-318,7$ & $-333,4$ & $-347,7$ & $-361,2$ & $-374,0$ & $-386,3$ & $-398,2$ & $-410,0$ & $-421,7$ & $-433,3$ & -300 \\
\hline $\mathrm{CH}_{4}$ & ${ }^{1} J_{\mathrm{CH}}$ & 119,2 & 117,6 & 115,9 & 114,3 & 113,1 & 112,4 & 112,3 & 112,6 & 113,4 & 114,5 & 115,8 & 117,3 & 118,8 & 120,3 & 121,8 & 125,3 \\
\hline $\mathrm{CH}_{4}$ & ${ }^{2} J_{\mathrm{HH}}$ & $-9,9$ & $-9,6$ & $-9,4$ & $-9,3$ & $-9,4$ & $-9,7$ & $-10,0$ & $-10,5$ & $-11,0$ & $-11,5$ & $-11,9$ & $-12,4$ & $-12,9$ & $-13,3$ & $-13,7$ & $-12,8$ \\
\hline $\mathrm{C}_{2} \mathrm{H}_{2}$ & ${ }^{1} J_{\mathrm{CC}}$ & 185,9 & 184,4 & 183,4 & 182,7 & 182,2 & 182,1 & 182,3 & 183,1 & 184,3 & 185,9 & 187,9 & 190,2 & 192,7 & 195,4 & 198,1 & 174,8 \\
\hline $\mathrm{C}_{2} \mathrm{H}_{2}$ & ${ }^{1} J_{\mathrm{CH}}$ & 248,4 & 245,6 & 242,5 & 239,6 & 237,4 & 236,1 & 235,7 & 236,3 & 237,5 & 239,4 & 241,6 & 244,1 & 246,8 & 249,5 & 252,1 & 247,6 \\
\hline $\mathrm{C}_{2} \mathrm{H}_{2}$ & ${ }^{2} J_{\mathrm{CH}}$ & 55,2 & 55,1 & 55,2 & 55,6 & 56,0 & 56,4 & 56,7 & 56,9 & 56,9 & 56,9 & 56,7 & 56,5 & 56,2 & 55,8 & 55,4 & 50,1 \\
\hline $\mathrm{C}_{2} \mathrm{H}_{2}$ & ${ }^{3} J_{\mathrm{HH}}$ & 8,9 & 8,6 & 8,4 & 8,2 & 8,1 & 8,1 & 8,3 & 8,5 & 8,9 & 9,3 & 9,7 & 10,2 & 10,7 & 11,2 & 11,6 & 9,6 \\
\hline $\mathrm{C}_{2} \mathrm{H}_{4}$ & ${ }^{1} J_{\mathrm{CC}}$ & 57,5 & 56,6 & 56,0 & 55,7 & 55,5 & 55,5 & 55,7 & 56,2 & 57,1 & 58,3 & 59,8 & 61,5 & 63,4 & 65,4 & 67,5 & 67,6 \\
\hline $\mathrm{C}_{2} \mathrm{H}_{4}$ & ${ }^{1} J_{\mathrm{CH}}$ & 151,9 & 150,0 & 148,1 & 146,4 & 145,1 & 144,5 & 144,6 & 145,2 & 146,3 & 147,8 & 149,6 & 151,6 & 153,6 & 155,7 & 157,7 & 156,3 \\
\hline $\mathrm{C}_{2} \mathrm{H}_{4}$ & ${ }^{2} J_{\mathrm{CH}}$ & 1,1 & 1,1 & 1,2 & 1,2 & 1,1 & 1,0 & 0,7 & 0,3 & 0,0 & $-0,5$ & $-1,0$ & $-1,6$ & $-2,2$ & $-2,9$ & $-3,5$ & $-2,4$ \\
\hline $\mathrm{C}_{2} \mathrm{H}_{4}$ & ${ }^{2} J_{\mathrm{HH}}$ & 6,1 & 6,2 & 6,1 & 6,1 & 5,9 & 5,6 & 5,2 & 4,8 & 4,4 & 3,9 & 3,5 & 3,0 & 2,6 & 2,2 & 1,8 & 2,3 \\
\hline $\mathrm{C}_{2} \mathrm{H}_{4}$ & ${ }^{3} J_{\mathrm{HH}_{c}}$ & 11,5 & 11,5 & 11,5 & 11,6 & 11,6 & 11,7 & 11,8 & 12,0 & 12,1 & 12,3 & 12,5 & 12,7 & 13,0 & 13,2 & 13,4 & 11,7 \\
\hline $\mathrm{C}_{2} \mathrm{H}_{4}$ & ${ }^{3} J_{\mathrm{HH}_{\mathrm{t}}}$ & 18,3 & 18,1 & 17,8 & 17,6 & 17,5 & 17,4 & 17,4 & 17,5 & 17,6 & 17,9 & 18,1 & 18,4 & 18,8 & 19,1 & 19,4 & 19 \\
\hline $\mathrm{C}_{2} \mathrm{H}_{6}$ & ${ }^{1} J_{\mathrm{CC}}$ & 24,3 & 23,7 & 23,6 & 23,6 & 23,7 & 23,9 & 24,2 & 24,8 & 25,5 & 26,4 & 27,4 & 28,5 & 29,7 & 30,9 & 32,1 & 34,5 \\
\hline $\mathrm{C}_{2} \mathrm{H}_{6}$ & ${ }^{1} J_{\mathrm{CH}}$ & 119,3 & 117,7 & 116,1 & 114,5 & 113,4 & 112,8 & 112,7 & 113,2 & 114,0 & 115,2 & 116,6 & 118,2 & 119,8 & 121,4 & 123,0 & 125,2 \\
\hline $\mathrm{C}_{2} \mathrm{H}_{6}$ & ${ }^{2} J_{\mathrm{CH}}$ & $-2,2$ & $-2,1$ & $-2,1$ & $-2,1$ & $-2,1$ & $-2,3$ & $-2,4$ & $-2,7$ & $-2,9$ & $-3,2$ & $-3,4$ & $-3,7$ & $-4,0$ & $-4,2$ & $-4,4$ & $-4,7$ \\
\hline \multirow[t]{3}{*}{ Total } & DM & $-21,30$ & $-21,70$ & $-22,16$ & $-22,66$ & $-23,13$ & $-23,44$ & $-23,51$ & $-23,28$ & $-22,74$ & & & & & $-17,22$ & & - \\
\hline & DMA & 27,73 & 27,72 & 27,58 & 27,25 & 26,97 & 27,17 & 27,13 & 26,78 & 26,11 & 25,15 & 24,01 & 22,75 & 21,42 & 20,32 & 19,46 & - \\
\hline & PDMA & 54,89 & 55,86 & 55,69 & 54,72 & 52,65 & 49,81 & 46,21 & 41,90 & 37,46 & 32,25 & 27,36 & 22,30 & 17,60 & 15,43 & 15,23 & - \\
\hline \multirow[t]{3}{*}{ CPI } & DM & $-49,55$ & $-49,51$ & $-49,67$ & $-50,07$ & $-50,57$ & $-50,99$ & $-51,13$ & $-50,86$ & $-50,12$ & $-48,98$ & $-47,50$ & $-45,80$ & $-43,98$ & $-42,13$ & $-40,31$ & - \\
\hline & DMA & 59,37 & 58,67 & 57,55 & 56,02 & 54,85 & 55,12 & 55,09 & 54,59 & 53,57 & 52,07 & 50,21 & 48,11 & 45,87 & 43,65 & 41,49 & - \\
\hline & PDMA & 86,70 & 87,26 & 85,86 & 82,77 & 78,59 & 73,89 & 68,63 & 62,81 & 56,61 & 50,11 & 43,61 & 37,21 & 31,16 & 26,04 & 21,74 & - \\
\hline \multirow[t]{3}{*}{ SPI } & DM & $-0,57$ & $-1,31$ & $-1,99$ & $-2,56$ & $-3,00$ & $-3,24$ & $-3,26$ & $-3,0$ & $-2,67$ & $-2,10$ & -1, & -0, & 0,19 & 1,04 & 1,8 & - \\
\hline & DMA & & & & & & & & & & & & & 3, & 3,21 & & - \\
\hline & PDMA & 31,56 & 32,84 & 33,57 & 34,15 & 33,62 & 32,15 & 29,76 & 26,55 & 23,42 & 19,16 & 15,45 & 11,37 & 7,65 & 7,65 & 10,45 & - \\
\hline \multirow[t]{3}{*}{$\Delta \mathrm{CS}$} & DM & $-48,98$ & $-48,20$ & $-47,69$ & $-47,51$ & $-47,57$ & $-47,75$ & $-47,87$ & $-47,80$ & $-47,45$ & $-46,88$ & $-46,09$ & $-45,16$ & -44 & $-43,17$ & $-42,19$ & - \\
\hline & DMA & 54,84 & 53,66 & 51,95 & 49,87 & 48,33 & 48,44 & 48,46 & 48,21 & 47,60 & 46,67 & 45,41 & 43,96 & 42,3 & 40,44 & 38,18 & - \\
\hline & & 55,14 & 54,42 & 52,29 & 48,62 & 44,98 & 41,75 & 38, & 36,26 & 33,19 & ,95 & 28,16 & 25,84 & 23,51 & 18,39 & ,29 & - \\
\hline
\end{tabular}


Tabela 8.371: Constantes de acoplamento LC-BB95 com $\alpha=10 \%$ e $\alpha+\beta=80 \%$, variando $\gamma$, na base aug-pcJ-2.

\begin{tabular}{|c|c|c|c|c|c|c|c|c|c|c|c|c|c|c|c|c|c|}
\hline & $\gamma$ & 0,05 & 0,10 & 0,15 & 0,20 & 0,25 & 0,30 & 0,35 & 0,40 & 0,45 & 0,50 & 0,55 & 0,60 & 0,65 & 0,70 & 0,75 & Exp. \\
\hline $\mathrm{HF}$ & ${ }^{1} J_{\mathrm{HF}}$ & 429,5 & 432,3 & 435,1 & 437,9 & 440,7 & 443,9 & 447,6 & 451,9 & 456,8 & 462,1 & 467,8 & 473,6 & 479,5 & 485,4 & 491,4 & 500 \\
\hline $\mathrm{CO}$ & ${ }^{1} J_{\mathrm{CO}}$ & 22,0 & 22,1 & 22,1 & 22,0 & 22,0 & 22,1 & 22,1 & 22,0 & 21,9 & 21,7 & 21,3 & 20,8 & 20,3 & 19,6 & 19,0 & 16,4 \\
\hline $\mathrm{H}_{2} \mathrm{O}$ & ${ }^{1} J_{\mathrm{OH}}$ & $-72,9$ & $-73,0$ & $-73,2$ & $-73,3$ & $-73,4$ & $-73,7$ & $-74,0$ & $-74,5$ & $-75,0$ & $-75,7$ & $-76,4$ & $-77,1$ & $-77,9$ & $-78,7$ & $-79,5$ & $-80,6$ \\
\hline $\mathrm{H}_{2} \mathrm{O}$ & ${ }^{2} J_{\mathrm{HH}}$ & $-5,0$ & $-4,8$ & $-4,7$ & $-4,7$ & $-4,8$ & $-5,0$ & $-5,2$ & $-5,5$ & $-5,8$ & $-6,2$ & $-6,6$ & $-7,0$ & $-7,3$ & $-7,7$ & $-8,1$ & $-7,3$ \\
\hline $\mathrm{NH}_{3}$ & ${ }^{1} J_{\mathrm{NH}}$ & 42,5 & 42,3 & 42,2 & 42,0 & 41,8 & 41,7 & 41,7 & 41,8 & 41,9 & 42,1 & 42,4 & 42,8 & 43,1 & 43,5 & 43,9 & 43,8 \\
\hline $\mathrm{NH}_{3}$ & ${ }^{2} J_{\mathrm{HH}}$ & $-7,5$ & $-7,3$ & $-7,2$ & $-7,2$ & $-7,3$ & $-7,5$ & $-7,8$ & $-8,1$ & $-8,5$ & $-8,9$ & $-9,4$ & $-9,8$ & $-10,2$ & $-10,5$ & $-10,9$ & $-9,6$ \\
\hline $\mathrm{PH}_{3}$ & ${ }^{1} J_{\mathrm{PH}}$ & 153,2 & 151,6 & 148,4 & 144,3 & 140,6 & 138,4 & 137,9 & 139,2 & 141,9 & 145,5 & 149,8 & 154,4 & 159,1 & 163,7 & 168,1 & 188,2 \\
\hline $\mathrm{PF}_{3}$ & ${ }^{1} J_{\mathrm{PF}}$ & $-1693,3$ & $-1690,9$ & $-1688,9$ & $-1687,7$ & $-1687,5$ & $-1688,1$ & $-1688,9$ & $-1688,9$ & $-1687,6$ & $-1684,4$ & $-1679,3$ & $-1672,5$ & $-1664,4$ & $-1655,4$ & $-1645,8$ & -1441 \\
\hline $\mathrm{BHF}_{2}$ & ${ }^{1} J_{\mathrm{BF}}$ & $-160,1$ & $-160,8$ & $-159,5$ & $-156,5$ & $-152,4$ & $-147,5$ & $-142,2$ & $-136,6$ & $-130,9$ & $-125,0$ & $-119,2$ & $-113,5$ & $-108,1$ & $-102,9$ & $-98,0$ & -84 \\
\hline $\mathrm{BF}_{3}$ & ${ }^{1} J_{\mathrm{BF}}$ & $-61,7$ & $-61,8$ & $-60,0$ & $-56,5$ & $-51,7$ & $-46,0$ & $-39,8$ & $-33,3$ & $-26,7$ & $-20,2$ & $-13,9$ & $-7,8$ & $-2,1$ & 3,1 & 8,2 & 15 \\
\hline $\mathrm{F}_{2} \mathrm{O}$ & ${ }^{1} J_{\mathrm{OF}}$ & $-303,7$ & $-307,2$ & $-313,2$ & $-322,1$ & $-333,2$ & $-345,6$ & $-358,4$ & $-371,0$ & $-383,2$ & $-394,9$ & $-406,2$ & $-417,4$ & $-428,5$ & $-439,5$ & $-450,5$ & -300 \\
\hline $\mathrm{CH}_{4}$ & ${ }^{1} J_{\mathrm{CH}}$ & 120,7 & 119,2 & 117,7 & 116,4 & 115,3 & 114,7 & 114,6 & 114,9 & 115,6 & 116,5 & 117,7 & 119,0 & 120,4 & 121,7 & 123,0 & 125,3 \\
\hline $\mathrm{CH}_{4}$ & ${ }^{2} J_{\mathrm{HH}}$ & $-10,7$ & $-10,3$ & $-10,1$ & $-10,1$ & $-10,2$ & $-10,4$ & $-10,7$ & $-11,1$ & $-11,5$ & $-12,0$ & $-12,4$ & $-12,8$ & $-13,2$ & $-13,6$ & $-13,9$ & $-12,8$ \\
\hline $\mathrm{C}_{2} \mathrm{H}_{2}$ & ${ }^{1} J_{\mathrm{CC}}$ & 188,4 & 187,0 & 186,1 & 185,4 & 185,1 & 185,0 & 185,4 & 186,1 & 187,3 & 188,9 & 190,8 & 193,0 & 195,3 & 197,8 & 200,2 & 174,8 \\
\hline $\mathrm{C}_{2} \mathrm{H}_{2}$ & ${ }^{1} J_{\mathrm{CH}}$ & 250,5 & 248,0 & 245,2 & 242,7 & 240,7 & 239,6 & 239,3 & 239,8 & 241,0 & 242,6 & 244,7 & 246,9 & 249,3 & 251,8 & 254,1 & 247,6 \\
\hline $\mathrm{C}_{2} \mathrm{H}_{2}$ & ${ }^{2} J_{\mathrm{CH}}$ & 55,4 & 55,4 & 55,5 & 55,8 & 56,1 & 56,4 & 56,6 & 56,7 & 56,7 & 56,6 & 56,4 & 56,2 & 55,8 & 55,5 & 55,1 & 50,1 \\
\hline $\mathrm{C}_{2} \mathrm{H}_{2}$ & ${ }^{3} J_{\mathrm{HH}}$ & 9,3 & 9,1 & 8,8 & 8,7 & 8,6 & 8,7 & 8,8 & 9,1 & 9,4 & 9,8 & 10,3 & 10,7 & 11,2 & 11,6 & 12,0 & 9,6 \\
\hline $\mathrm{C}_{2} \mathrm{H}_{4}$ & ${ }^{1} J_{\mathrm{CC}}$ & 60,0 & 59,1 & 58,6 & 58,2 & 58,1 & 58,1 & 58,3 & 58,9 & 59,8 & 60,9 & 62,3 & 64,0 & 65,7 & 67,6 & 69,5 & 67,6 \\
\hline $\mathrm{C}_{2} \mathrm{H}_{4}$ & ${ }^{1} J_{\mathrm{CH}}$ & 153,9 & 152,2 & 150,5 & 149,0 & 147,9 & 147,3 & 147,4 & 148,0 & 149,0 & 150,4 & 152,0 & 153,8 & 155,6 & 157,5 & 159,3 & 156,3 \\
\hline $\mathrm{C}_{2} \mathrm{H}_{4}$ & ${ }^{2} J_{\mathrm{CH}}$ & 0,3 & 0,4 & 0,5 & 0,5 & 0,4 & 0,3 & 0,0 & $-0,2$ & $-0,7$ & $-1,1$ & $-1,7$ & $-2,2$ & $-2,8$ & $-3,4$ & $-3,9$ & $-2,4$ \\
\hline $\mathrm{C}_{2} \mathrm{H}_{4}$ & ${ }^{2} J_{\mathrm{HH}}$ & 5,5 & 5,5 & 5,5 & 5,5 & 5,3 & 5,0 & 4,7 & 4,3 & 3,9 & 3,5 & 3,1 & 2,7 & 2,3 & 1,9 & 1,5 & 2,3 \\
\hline $\mathrm{C}_{2} \mathrm{H}_{4}$ & ${ }^{3} J_{\mathrm{HH}}$ & 11,7 & 11,7 & 11,7 & 11,7 & 11,8 & 11,9 & 12,0 & 12,1 & 12,3 & 12,5 & 12,7 & 12,9 & 13,1 & 13,3 & 13,5 & 11,7 \\
\hline $\mathrm{C}_{2} \mathrm{H}_{4}$ & ${ }^{3} J_{\mathrm{HH}_{\mathrm{t}}}$ & 18,4 & 18,2 & 18,0 & 17,9 & 17,7 & 17,7 & 17,7 & 17,8 & 18,0 & 18,2 & 18,5 & 18,8 & 19,1 & 19,4 & 19,7 & 19 \\
\hline $\mathrm{C}_{2} \mathrm{H}_{6}$ & ${ }^{1} J_{\mathrm{CC}}$ & 26,2 & 25,7 & 25,6 & 25,5 & 25,6 & 25,8 & 26,1 & 26,6 & 27,3 & 28,1 & 29,0 & 30,0 & 31,1 & 32,1 & 33,1 & 34,5 \\
\hline $\mathrm{C}_{2} \mathrm{H}_{6}$ & ${ }^{1} J_{\mathrm{CH}}$ & 121,0 & 119,6 & 118,1 & 116,7 & 115,7 & 115,2 & 115,1 & 115,5 & 116,3 & 117,4 & 118,6 & 120,0 & 121,4 & 122,8 & 124,2 & 125,2 \\
\hline $\mathrm{C}_{2} \mathrm{H}_{6}$ & ${ }^{2} J_{\mathrm{CH}}$ & $-2,6$ & $-2,5$ & $-2,5$ & $-2,5$ & $-2,6$ & $-2,7$ & $-2,8$ & $-3,0$ & $-3,2$ & $-3,5$ & $-3,7$ & $-4,0$ & $-4,2$ & $-4,4$ & $-4,6$ & $-4,7$ \\
\hline \multirow[t]{3}{*}{ Total } & DM & $-19,00$ & $-19,39$ & -19 & $-20,21$ & $-20,57$ & $-20,76$ & $-20,75$ & -20 & $-19,96$ & 23 & -18 & 29 & -16 & ,11 & 02 & - \\
\hline & DMA & 22,82 & 22,98 & 23,32 & 23,68 & 23,99 & & & 23, & 23,00 & & & & 19 , & & & - \\
\hline & PDMA & 43,69 & 44,67 & 44,93 & 44,31 & 42,65 & 40,23 & 37,13 & 33,49 & 29,18 & 24,87 & 20,42 & 16,18 & 13,81 & 13,96 & 14,28 & - \\
\hline \multirow[t]{3}{*}{ CPI } & DM & $-45,26$ & $-45,31$ & $-45,44$ & $-45,70$ & $-46,01$ & $-46,20$ & $-46,17$ & $-45,81$ & $-45,10$ & $-44,07$ & $-42,78$ & $-41,31$ & $-39,76$ & $-38,21$ & $-36,65$ & - \\
\hline & DMA & 48,48 & 48,60 & 48,73 & 48,95 & 49,21 & 49,29 & 49,12 & 48,54 & 47,59 & 46,25 & 44,60 & 42,80 & 40,96 & 39,14 & 37,34 & - \\
\hline & PDMA & 68,49 & 69,27 & 68,53 & 66,47 & 63,39 & 59,43 & 54,89 & 49,79 & 44,43 & 38,81 & 33,03 & 27,75 & 23,23 & 19,69 & 16,43 & - \\
\hline \multirow[t]{3}{*}{ SPI } & DM & 0,26 & $-0,39$ & $-0,99$ & $-1,51$ & $-1,91$ & $-2,10$ & $-2,11$ & $-1,91$ & $-1,53$ & $-1,0$ & -0, & 0,33 & 1,07 & 1,83 & 2,58 & - \\
\hline & DMA & 3,99 & 4,20 & 4,69 & 5,15 & 5,49 & & 5,60 & & 4,97 & & & 3,39 & 3,1 & 3,25 & 3,66 & - \\
\hline & PDMA & 25,49 & 26,62 & 27,62 & 28,07 & 27,44 & 26,15 & 24,11 & 21,53 & 17,99 & 14,65 & 11,17 & 7,69 & 6,90 & 9,76 & 12,71 & - \\
\hline \multirow[t]{3}{*}{$\Delta \mathrm{CS}$} & DM & $-45,52$ & $-44,92$ & $-44,44$ & $-44,19$ & $-44,10$ & $-44,10$ & $-44,07$ & $-43,90$ & $-43,57$ & -43 & -42 & $-41,64$ & $-40,83$ & $-40,04$ & $-39,23$ & - \\
\hline & DMA & 44,49 & 44,40 & 44,04 & 43,80 & 43,72 & 43,66 & 43,52 & 43,18 & 42,62 & 41,75 & 40,63 & 39,41 & 37,83 & 35,89 & 33,68 & - \\
\hline & PDMA & 43,00 & 42,65 & 40,91 & 38,40 & 35,94 & 33,29 & 30,77 & 28,26 & 26,44 & 24,16 & 21,86 & 20,05 & 16,34 & 9,92 & 3,72 & - \\
\hline
\end{tabular}


Tabela 8.372: Constantes de acoplamento LC-BB95 com $\alpha=20 \%$ e $\alpha+\beta=80 \%$, variando $\gamma$, na base aug-pcJ-2.

\begin{tabular}{|c|c|c|c|c|c|c|c|c|c|c|c|c|c|c|c|c|c|}
\hline & $\gamma$ & 0,05 & 0,10 & 0,15 & 0,20 & 0,25 & 0,30 & 0,35 & 0,40 & 0,45 & 0,50 & 0,55 & 0,60 & 0,65 & 0,70 & 0,75 & Exp. \\
\hline $\mathrm{HF}$ & ${ }^{1} J_{\mathrm{HF}}$ & 452,9 & 455,2 & 457,6 & 459,9 & 462,3 & 465,0 & 468,2 & 471,9 & 476,0 & 480,6 & 485,3 & 490,3 & 495,3 & 500,4 & 505,4 & 500 \\
\hline $\mathrm{CO}$ & ${ }^{1} J_{\mathrm{CO}}$ & 20,2 & 20,3 & 20,3 & 20,2 & 20,3 & 20,3 & 20,3 & 20,3 & 20,1 & 19,9 & 19,6 & 19,2 & 18,7 & 18,1 & 17,5 & 16,4 \\
\hline $\mathrm{H}_{2} \mathrm{O}$ & ${ }^{1} J_{\mathrm{OH}}$ & $-75,4$ & $-75,5$ & $-75,6$ & $-75,7$ & $-75,8$ & $-76,0$ & $-76,3$ & $-76,7$ & $-77,1$ & $-77,7$ & $-78,3$ & $-78,9$ & $-79,6$ & $-80,3$ & $-81,0$ & $-80,6$ \\
\hline $\mathrm{H}_{2} \mathrm{O}$ & ${ }^{2} J_{\mathrm{HH}}$ & $-6,0$ & $-5,8$ & $-5,7$ & $-5,7$ & $-5,8$ & $-5,9$ & $-6,2$ & $-6,4$ & $-6,7$ & $-7,0$ & $-7,4$ & $-7,7$ & $-8,0$ & $-8,3$ & $-8,7$ & $-7,3$ \\
\hline $\mathrm{NH}_{3}$ & ${ }^{1} J_{\mathrm{NH}}$ & 43,3 & 43,1 & 42,9 & 42,8 & 42,6 & 42,5 & 42,5 & 42,6 & 42,7 & 42,9 & 43,2 & 43,5 & 43,8 & 44,1 & 44,5 & 43,8 \\
\hline $\mathrm{NH}_{3}$ & ${ }^{2} J_{\mathrm{HH}}$ & $-8,4$ & $-8,2$ & $-8,1$ & $-8,1$ & $-8,2$ & $-8,3$ & $-8,6$ & $-8,9$ & $-9,2$ & $-9,6$ & $-10,0$ & $-10,3$ & $-10,7$ & $-11,0$ & $-11,3$ & $-9,6$ \\
\hline $\mathrm{PH}_{3}$ & ${ }^{1} J_{\mathrm{PH}}$ & 160,7 & 159,2 & 156,5 & 153,0 & 149,9 & 147,9 & 147,5 & 148,6 & 150,8 & 154,0 & 157,6 & 161,6 & 165,6 & 169,6 & 173,3 & 188,2 \\
\hline $\mathrm{PF}_{3}$ & ${ }^{1} J_{\mathrm{PF}}$ & $-1668,4$ & $-1666,8$ & $-1664,9$ & $-1663,2$ & $-1661,9$ & $-1661,1$ & $-1660,5$ & $-1659,3$ & $-1657,2$ & $-1653,6$ & $-1648,6$ & $-1642,4$ & $-1635,1$ & $-1627,2$ & $-1618,8$ & -1441 \\
\hline $\mathrm{BHF}_{2}$ & ${ }^{1} J_{\mathrm{BF}}$ & $-143,1$ & $-143,8$ & $-142,9$ & $-140,5$ & $-137,0$ & $-132,9$ & $-128,4$ & $-123,6$ & $-118,7$ & $-113,7$ & $-108,7$ & $-103,8$ & $-99,2$ & $-94,7$ & $-90,5$ & -84 \\
\hline $\mathrm{BF}_{3}$ & ${ }^{1} J_{\mathrm{BF}}$ & $-43,1$ & $-43,3$ & $-42,0$ & $-39,2$ & $-35,2$ & $-30,4$ & $-25,2$ & $-19,7$ & $-14,1$ & $-8,5$ & $-3,2$ & 1,9 & 6,8 & 11,4 & 15,7 & 15 \\
\hline $\mathrm{F}_{2} \mathrm{O}$ & ${ }^{1} J_{\mathrm{OF}}$ & $-337,0$ & $-339,9$ & $-345,0$ & $-352,4$ & $-361,9$ & $-372,6$ & $-383,8$ & $-395,0$ & $-406,0$ & $-416,7$ & $-427,3$ & $-437,7$ & $-448,1$ & $-458,4$ & $-468,7$ & -300 \\
\hline $\mathrm{CH}_{4}$ & ${ }^{1} J_{\mathrm{CH}}$ & 122,2 & 120,9 & 119,6 & 118,4 & 117,5 & 117,0 & 116,9 & 117,2 & 117,8 & 118,6 & 119,6 & 120,8 & 121,9 & 123,1 & 124,3 & 125,3 \\
\hline $\mathrm{CH}_{4}$ & ${ }^{2} J_{\mathrm{HH}}$ & $-11,4$ & $-11,1$ & $-10,9$ & $-10,8$ & $-10,9$ & $-11,1$ & $-11,4$ & $-11,7$ & $-12,1$ & $-12,5$ & $-12,9$ & $-13,2$ & $-13,6$ & $-13,9$ & $-14,2$ & $-12,8$ \\
\hline $\mathrm{C}_{2} \mathrm{H}_{2}$ & ${ }^{1} J_{\mathrm{CC}}$ & 191,2 & 190,0 & 189,1 & 188,6 & 188,3 & 188,3 & 188,7 & 189,5 & 190,7 & 192,2 & 194,0 & 196,0 & 198,1 & 200,3 & 202,5 & 174,8 \\
\hline $\mathrm{C}_{2} \mathrm{H}_{2}$ & ${ }^{1} J_{\mathrm{CH}}$ & 252,8 & 250,5 & 248,1 & 245,9 & 244,2 & 243,2 & 243,0 & 243,5 & 244,5 & 246,0 & 247,8 & 249,8 & 252,0 & 254,1 & 256,2 & 247,6 \\
\hline $\mathrm{C}_{2} \mathrm{H}_{2}$ & ${ }^{2} J_{\mathrm{CH}}$ & 55,5 & 55,5 & 55,6 & 55,8 & 56,1 & 56,3 & 56,5 & 56,5 & 56,5 & 56,3 & 56,1 & 55,8 & 55,4 & 55,0 & 54,6 & 50,1 \\
\hline $\mathrm{C}_{2} \mathrm{H}_{2}$ & ${ }^{3} J_{\mathrm{HH}}$ & 9,8 & 9,6 & 9,4 & 9,2 & 9,2 & 9,3 & 9,4 & 9,7 & 10,0 & 10,4 & 10,8 & 11,3 & 11,7 & 12,1 & 12,5 & 9,6 \\
\hline $\mathrm{C}_{2} \mathrm{H}_{4}$ & ${ }^{1} J_{\mathrm{CC}}$ & 62,6 & 61,8 & 61,3 & 61,0 & 60,9 & 60,9 & 61,2 & 61,8 & 62,6 & 63,7 & 65,1 & 66,6 & 68,2 & 69,9 & 71,6 & 67,6 \\
\hline $\mathrm{C}_{2} \mathrm{H}_{4}$ & ${ }^{1} J_{\mathrm{CH}}$ & 156,0 & 154,5 & 153,0 & 151,6 & 150,7 & 150,3 & 150,3 & 150,9 & 151,8 & 153,0 & 154,5 & 156,0 & 157,6 & 159,3 & 160,9 & 156,3 \\
\hline $\mathrm{C}_{2} \mathrm{H}_{4}$ & ${ }^{2} J_{\mathrm{CH}}$ & $-0,3$ & $-0,2$ & $-0,2$ & $-0,2$ & $-0,2$ & $-0,4$ & $-0,6$ & $-1,0$ & $-1,4$ & $-1,8$ & $-2,3$ & $-2,9$ & $-3,4$ & $-3,9$ & $-4,4$ & $-2,4$ \\
\hline $\mathrm{C}_{2} \mathrm{H}_{4}$ & ${ }^{2} J_{\mathrm{HH}}$ & 4,8 & 4,9 & 4,9 & 4,8 & 4,7 & 4,4 & 4,1 & 3,8 & 3,4 & 3,0 & 2,7 & 2,3 & 1,9 & 1,6 & 1,2 & 2,3 \\
\hline $\mathrm{C}_{2} \mathrm{H}_{4}$ & ${ }^{3} J_{\mathrm{HH}_{\mathrm{c}}}$ & 11,9 & 11,9 & 11,9 & 11,9 & 12,0 & 12,1 & 12,2 & 12,3 & 12,5 & 12,7 & 12,9 & 13,1 & 13,3 & 13,5 & 13,7 & 11,7 \\
\hline $\mathrm{C}_{2} \mathrm{H}_{4}$ & ${ }^{3} J_{\mathrm{HH}_{\mathrm{t}}}$ & 18,7 & 18,5 & 18,3 & 18,2 & 18,1 & 18,1 & 18,1 & 18,2 & 18,4 & 18,6 & 18,9 & 19,2 & 19,5 & 19,7 & 20,0 & 19 \\
\hline $\mathrm{C}_{2} \mathrm{H}_{6}$ & ${ }^{1} J_{\mathrm{CC}}$ & 28,3 & 27,8 & 27,6 & 27,6 & 27,7 & 27,8 & 28,1 & 28,5 & 29,1 & 29,8 & 30,6 & 31,5 & 32,4 & 33,3 & 34,3 & 34,5 \\
\hline $\mathrm{C}_{2} \mathrm{H}_{6}$ & ${ }^{1} J_{\mathrm{CH}}$ & 122,7 & 121,4 & 120,1 & 119,0 & 118,1 & 117,6 & 117,6 & 118,0 & 118,6 & 119,5 & 120,6 & 121,8 & 123,1 & 124,3 & 125,5 & 125,2 \\
\hline $\mathrm{C}_{2} \mathrm{H}_{6}$ & ${ }^{2} J_{\mathrm{CH}}$ & $-3,1$ & $-3,0$ & $-3,0$ & $-3,0$ & $-3,0$ & $-3,1$ & $-3,2$ & $-3,4$ & $-3,6$ & $-3,8$ & $-4,0$ & $-4,2$ & $-4,4$ & $-4,6$ & $-4,8$ & $-4,7$ \\
\hline \multirow[t]{3}{*}{ Total } & $\mathrm{DM}$ & $-16,45$ & $-16,83$ & $-17,20$ & $-17,53$ & $-17,78$ & $-17,92$ & -17, & $-17,59$ & $-17,14$ & & & & $-13,92$ & $-12,98$ & 07 & - \\
\hline & DMA & 20,02 & 20,20 & 20,34 & 20,60 & 20,83 & 20,89 & 20,76 & 20,40 & 19,88 & 19,15 & 18,36 & 17,70 & 17,20 & 16,83 & 16,95 & - \\
\hline & PDMA & 33,45 & 34,42 & 34,55 & 33,95 & 32,84 & 30,57 & 27,85 & 24,52 & 20,96 & 17,27 & 14,00 & 12,53 & 12,79 & 13,04 & 14,28 & - \\
\hline \multirow[t]{3}{*}{ CPI } & DM & $-40,47$ & $-40,58$ & $-40,71$ & $-40,89$ & $-41,05$ & $-41,13$ & $-41,04$ & $-40,65$ & $-40,03$ & $-39,12$ & $-38,06$ & $-36,84$ & $-35,58$ & $-34,29$ & $-33,05$ & - \\
\hline & DMA & 42,56 & 42,75 & 42,89 & 43,04 & 43,16 & 43,16 & 42,91 & 42,35 & 41,52 & 40,34 & 39,06 & 37,65 & 36,1 & 34,78 & 34,48 & - \\
\hline & PDMA & 51,90 & 52,73 & 52,32 & 50,66 & 48,11 & 44,90 & 40,87 & 36,63 & 32,01 & 27,17 & 23,28 & 19,95 & 16,81 & 13,83 & 12,33 & - \\
\hline \multirow[t]{3}{*}{ SPI } & DM & 1,17 & 0,59 & 0,0 & $-0,41$ & $-0,71$ & $-0,89$ & $-0,8$ & -0, & -0 & 0,1 & 0,6 & 1,3 & 1, & 2,6 & 3, & - \\
\hline & DMA & 3,49 & & & & & 4,56 & & 4,30 & & & 3,18 & 3,07 & 3,28 & 3,66 & & - \\
\hline & PDMA & 19,92 & 20,99 & 21,51 & 21,70 & 21,64 & 20,07 & 18,29 & 15,64 & 12,86 & 10,02 & 7,20 & 7,09 & 9,85 & 12,47 & 15,70 & - \\
\hline \multirow[t]{3}{*}{$\Delta \mathrm{CS}$} & DM & $-41,65$ & $-41,18$ & $-40,76$ & $-40,48$ & $-40,34$ & $-40,23$ & $-40,16$ & $-39,96$ & $-39,67$ & $-39,22$ & $-38,75$ & $-38,16$ & $-37,56$ & $-36,94$ & $-36,37$ & - \\
\hline & DMA & 39,07 & 39,09 & 39,08 & 38,88 & 38,72 & 38,60 & 38,39 & 38,05 & 37,51 & 36,72 & 35,88 & 34,59 & 32,90 & 31,12 & 30,39 & - \\
\hline & PDMA & 31,98 & 31,74 & 30,82 & 28,97 & 26,47 & 24,84 & 22,58 & 20,99 & 19,16 & 17,15 & 16,08 & 12,86 & 6,96 & 1,36 & $-3,37$ & - \\
\hline
\end{tabular}


Tabela 8.373: Constantes de acoplamento LC-BB95 com $\alpha=30 \%$ e $\alpha+\beta=80 \%$, variando $\gamma$, na base aug-pcJ-2.

\begin{tabular}{|c|c|c|c|c|c|c|c|c|c|c|c|c|c|c|c|c|c|}
\hline & $\gamma$ & 0,05 & 0,10 & 0,15 & 0,20 & 0,25 & 0,30 & 0,35 & 0,40 & 0,45 & 0,50 & 0,55 & 0,60 & 0,65 & 0,70 & 0,75 & Exp. \\
\hline HF & ${ }^{1} J_{\mathrm{HF}}$ & 476,5 & 478,3 & 480,2 & 482,1 & 484,1 & 486,4 & 489,1 & 492,1 & 495,5 & 499,3 & 503,2 & 507,3 & 511,5 & 515,7 & 519,9 & 500 \\
\hline $\mathrm{CO}$ & ${ }^{1} J_{\mathrm{CO}}$ & 18,3 & 18,4 & 18,4 & 18,3 & 18,4 & 18,4 & 18,4 & 18,4 & 18,3 & 18,1 & 17,8 & 17,4 & 17,0 & 16,5 & 16,0 & 16,4 \\
\hline $\mathrm{H}_{2} \mathrm{O}$ & ${ }^{1} J_{\mathrm{OH}}$ & $-77,9$ & $-78,0$ & $-78,0$ & $-78,1$ & $-78,2$ & $-78,3$ & $-78,6$ & $-78,9$ & $-79,3$ & $-79,8$ & $-80,3$ & $-80,8$ & $-81,4$ & $-81,9$ & $-82,5$ & $-80,6$ \\
\hline $\mathrm{H}_{2} \mathrm{O}$ & ${ }^{2} J_{\mathrm{HH}}$ & $-7,0$ & $-6,9$ & $-6,8$ & $-6,8$ & $-6,8$ & $-6,9$ & $-7,1$ & $-7,3$ & $-7,6$ & $-7,9$ & $-8,1$ & $-8,4$ & $-8,7$ & $-9,0$ & $-9,2$ & $-7,3$ \\
\hline $\mathrm{NH}_{3}$ & ${ }^{1} J_{\mathrm{NH}}$ & 44,0 & 43,9 & 43,7 & 43,6 & 43,5 & 43,4 & 43,4 & 43,4 & 43,6 & 43,7 & 43,9 & 44,2 & 44,4 & 44,7 & 45,0 & 43,8 \\
\hline $\mathrm{NH}_{3}$ & ${ }^{2} J_{\mathrm{HH}}$ & $-9,3$ & $-9,1$ & $-9,0$ & $-9,0$ & $-9,1$ & $-9,2$ & $-9,4$ & $-9,7$ & $-10,0$ & $-10,3$ & $-10,6$ & $-10,9$ & $-11,2$ & $-11,5$ & $-11,7$ & $-9,6$ \\
\hline $\mathrm{PH}_{3}$ & ${ }^{1} J_{\mathrm{PH}}$ & 168,2 & 166,9 & 164,5 & 161,6 & 159,0 & 157,4 & 157,0 & 157,9 & 159,8 & 162,4 & 165,4 & 168,7 & 172,1 & 175,4 & 178,5 & 188,2 \\
\hline $\mathrm{PF}_{3}$ & ${ }^{1} J_{\mathrm{PF}}$ & $-1639,4$ & $-1638,4$ & $-1636,8$ & $-1634,9$ & $-1633,1$ & $-1631,5$ & $-1630,0$ & $-1628,2$ & $-1625,6$ & $-1622,1$ & $-1617,4$ & $=-1611,9$ & $-1605,6$ & $-1598,8$ & $-1591,7$ & -1441 \\
\hline $\mathrm{BHF}_{2}$ & ${ }^{1} J_{\mathrm{BF}}$ & $-126,1$ & $-126,8$ & $-126,2$ & $-124,3$ & $-121,4$ & $-118,1$ & $-114,3$ & $-110,4$ & $-106,3$ & $-102,1$ & $-98,0$ & $-94,0$ & $-90,1$ & $-86,4$ & $-82,9$ & -84 \\
\hline $\mathrm{BF}_{3}$ & ${ }^{1} J_{\mathrm{BF}}$ & $-24,7$ & $-25,0$ & $-24,0$ & $-21,8$ & $-18,6$ & $-14,7$ & $-10,4$ & $-5,9$ & $-1,3$ & 3,2 & 7,7 & 12,0 & 16,0 & 19,9 & 23,5 & 15 \\
\hline $\mathrm{F}_{2} \mathrm{O}$ & ${ }^{1} J_{\mathrm{OF}}$ & $-370,4$ & $-372,8$ & $-377,1$ & $-383,4$ & $-391,5$ & $-400,7$ & $-410,5$ & $-420,5$ & $-430,4$ & $-440,2$ & $-449,9$ & $-459,6$ & $-469,2$ & $-478,8$ & $-488,3$ & -300 \\
\hline $\mathrm{CH}_{4}$ & ${ }^{1} J_{\mathrm{CH}}$ & 123,7 & 122,6 & 121,5 & 120,5 & 119,8 & 119,4 & 119,3 & 119,5 & 120,0 & 120,7 & 121,6 & 122,6 & 123,5 & 124,5 & 125,5 & 125,3 \\
\hline $\mathrm{CH}_{4}$ & ${ }^{2} J_{\mathrm{HH}}$ & $-12,1$ & $-11,9$ & $-11,7$ & $-11,6$ & $-11,7$ & $-11,8$ & $-12,1$ & $-12,4$ & $-12,7$ & $-13,0$ & $-13,3$ & $-13,6$ & $-13,9$ & $-14,2$ & $-14,4$ & $-12,8$ \\
\hline $\mathrm{C}_{2} \mathrm{H}_{2}$ & ${ }^{1} J_{\mathrm{CC}}$ & 194,4 & 193,3 & 192,5 & 192,1 & 191,9 & 192,0 & 192,4 & 193,2 & 194,3 & 195,7 & 197,3 & 199,1 & 201,1 & 203,0 & 205,0 & 174,8 \\
\hline $\mathrm{C}_{2} \mathrm{H}_{2}$ & ${ }^{1} J_{\mathrm{CH}}$ & 255,1 & 253,1 & 251,1 & 249,2 & 247,8 & 247,0 & 246,8 & 247,3 & 248,2 & 249,5 & 251,1 & 252,8 & 254,7 & 256,5 & 258,3 & 247,6 \\
\hline $\mathrm{C}_{2} \mathrm{H}_{2}$ & ${ }^{2} J_{\mathrm{CH}}$ & 55,4 & 55,4 & 55,5 & 55,7 & 55,9 & 56,1 & 56,1 & 56,1 & 56,0 & 55,8 & 55,6 & 55,3 & 54,9 & 54,6 & 54,2 & 50,1 \\
\hline $\mathrm{C}_{2} \mathrm{H}_{2}$ & ${ }^{3} J_{\mathrm{HH}}$ & 10,4 & 10,2 & 10,0 & 9,9 & 9,9 & 10,0 & 10,2 & 10,4 & 10,7 & 11,1 & 11,5 & 11,8 & 12,2 & 12,6 & 12,9 & 9,6 \\
\hline $\mathrm{C}_{2} \mathrm{H}_{4}$ & ${ }^{1} J_{\mathrm{CC}}$ & 65,5 & 64,7 & 64,3 & 64,0 & 64,0 & 64,1 & 64,4 & 64,9 & 65,7 & 66,8 & 68,0 & 69,4 & 70,8 & 72,3 & 73,8 & 67,6 \\
\hline $\mathrm{C}_{2} \mathrm{H}_{4}$ & ${ }^{1} J_{\mathrm{CH}}$ & 158,1 & 156,8 & 155,5 & 154,4 & 153,6 & 153,3 & 153,4 & 153,9 & 154,7 & 155,8 & 157,0 & 158,4 & 159,8 & 161,2 & 162,5 & 156,3 \\
\hline $\mathrm{C}_{2} \mathrm{H}_{4}$ & ${ }^{2} J_{\mathrm{CH}}$ & $-1,2$ & $-1,1$ & $-1,0$ & $-1,0$ & $-1,1$ & $-1,3$ & $-1,5$ & $-1,8$ & $-2,2$ & $-2,6$ & $-3,1$ & $-3,6$ & $-4,0$ & $-4,5$ & $-5,0$ & $-2,4$ \\
\hline $\mathrm{C}_{2} \mathrm{H}_{4}$ & ${ }^{2} J_{\mathrm{HH}}$ & 4,1 & 4,2 & 4,2 & 4,1 & 4,0 & 3,8 & 3,5 & 3,2 & 2,9 & 2,6 & 2,2 & 1,9 & 1,5 & 1,2 & 1,0 & 2,3 \\
\hline $\mathrm{C}_{2} \mathrm{H}_{4}$ & ${ }^{3} J_{\mathrm{HH}_{\mathrm{c}}}$ & 12,1 & 12,1 & 12,1 & 12,1 & 12,2 & 12,3 & 12,4 & 12,6 & 12,7 & 12,9 & 13,1 & 13,3 & 13,5 & 13,6 & 13,8 & 11,7 \\
\hline $\mathrm{C}_{2} \mathrm{H}_{4}$ & ${ }^{3} J_{\mathrm{HH}_{\mathrm{t}}}$ & 18,9 & 18,8 & 18,6 & 18,5 & 18,5 & 18,5 & 18,5 & 18,7 & 18,9 & 19,1 & 19,3 & 19,6 & 19,8 & 20,1 & 20,3 & 19 \\
\hline $\mathrm{C}_{2} \mathrm{H}_{6}$ & ${ }^{1} J_{\mathrm{CC}}$ & 30,3 & 29,9 & 29,7 & 29,7 & 29,8 & 29,9 & 30,2 & 30 & 31,0 & 31,6 & 32,3 & 33,1 & 33,8 & 34,6 & 35,4 & 34,5 \\
\hline $\mathrm{C}_{2} \mathrm{H}_{6}$ & ${ }^{1} J_{\mathrm{CH}}$ & 124,4 & 123,3 & 122,2 & 121,2 & 120,5 & 0,1 & 120,1 & 120,4 & 121,0 & 121,8 & 122,7 & 123 & 124,7 & 125,8 & 126,8 & 125,2 \\
\hline $\mathrm{C}_{2} \mathrm{H}_{6}$ & ${ }^{2} J_{\mathrm{CH}}$ & $-3,5$ & $-3,4$ & $-3,4$ & $-3,4$ & $-3,5$ & $-3,5$ & $-3,6$ & $-3,8$ & $-4,0$ & $-4,1$ & $-4,3$ & $-4,5$ & $-4,7$ & $-4,8$ & $-5,0$ & $-4,7$ \\
\hline \multirow[t]{3}{*}{ Total } & $\mathrm{DM}$ & $-13,74$ & 10 & -14 & & & & & & & & & & & & & - \\
\hline & DMA & 17,25 & & & & & & & & & & & & & & & - \\
\hline & PDMA & 23,26 & 24,03 & 24,18 & 23,56 & 22,36 & 20,68 & 18,39 & 15,77 & 13,26 & 11,65 & 11,07 & 11,54 & 12,67 & 15,59 & 18,68 & - \\
\hline \multirow[t]{3}{*}{ CPI } & DM & $-35,34$ & 35,49 & -35 & & & & & & & & & & & & & - \\
\hline & DMA & 36,32 & 36,5 & 36 , & 36, & 36,8 & 36 , & 36 & & & & & & & & & - \\
\hline & PDMA & 35,45 & 36,14 & 35,89 & 34,59 & 32,63 & 30,01 & 26,77 & 23,44 & 20,86 & 18,22 & 15,53 & 13,15 & 12,22 & 14,85 & 17,80 & - \\
\hline \multirow[t]{3}{*}{ SPI } & DM & & & & & & & & & & & & & & & & - \\
\hline & MA & & & & & & & & & & & & & & & & - \\
\hline & PDMA & 14,31 & 15,15 & 15,60 & 15,47 & 14,83 & 13,84 & 12,25 & 10,15 & 7,69 & 6,83 & 7,79 & 10,36 & 13,00 & 16,12 & 19,32 & - \\
\hline \multirow[t]{3}{*}{$\Delta C S$} & & & & & & & & & & & & & & & & & - \\
\hline & MA & & & & & & & & & & & & & & & & - \\
\hline & & 21,14 & 21,00 & 20,30 & 19,13 & 17,80 & 16,17 & 14,53 & 13,29 & 13,16 & 11,39 & 7,73 & 2,7 & $-0,78$ & $-1,27$ & $-1,53$ & - \\
\hline
\end{tabular}


Tabela 8.374: Constantes de acoplamento LC-BB95 com $\alpha=40 \%$ e $\alpha+\beta=80 \%$, variando $\gamma$, na base aug-pcJ-2.

\begin{tabular}{|c|c|c|c|c|c|c|c|c|c|c|c|c|c|c|c|c|c|}
\hline & $\gamma$ & 0,05 & 0,10 & 0,15 & 0,20 & 0,25 & 0,30 & 0,35 & 0,40 & 0,45 & 0,50 & 0,55 & 0,60 & 0,65 & 0,70 & 0,75 & Exp. \\
\hline $\mathrm{HF}$ & ${ }^{\mathrm{I}} J_{\mathrm{HF}}$ & 500,3 & 501,7 & 503,1 & 504,6 & 506,2 & 508,0 & 510,2 & 512,6 & 515,3 & 518,2 & 521,4 & 524,6 & 527,9 & 531,3 & 534,6 & 500 \\
\hline $\mathrm{CO}$ & ${ }^{1} J_{\mathrm{CO}}$ & 16,3 & 16,3 & 16,3 & 16,3 & 16,4 & 16,4 & 16,4 & 16,4 & 16,3 & 16,1 & 15,9 & 15,6 & 15,2 & 14,8 & 14,4 & 16,4 \\
\hline $\mathrm{H}_{2} \mathrm{O}$ & ${ }^{1} J_{\mathrm{OH}}$ & $-80,4$ & $-80,5$ & $-80,5$ & $-80,5$ & $-80,6$ & $-80,7$ & $-80,9$ & $-81,2$ & $-81,5$ & $-81,9$ & $-82,3$ & $-82,7$ & $-83,2$ & $-83,6$ & $-84,1$ & $-80,6$ \\
\hline $\mathrm{H}_{2} \mathrm{O}$ & ${ }^{2} J_{\mathrm{HH}}$ & $-8,1$ & $-7,9$ & $-7,9$ & $-7,8$ & $-7,9$ & $-8,0$ & $-8,1$ & $-8,3$ & $-8,5$ & $-8,7$ & $-9,0$ & $-9,2$ & $-9,4$ & $-9,6$ & $-9,9$ & $-7,3$ \\
\hline $\mathrm{NH}_{3}$ & ${ }^{1} J_{\mathrm{NH}}$ & 44,8 & 44,7 & 44,5 & 44,4 & 44,3 & 44,3 & 44,3 & 44,3 & 44,4 & 44,5 & 44,7 & 44,9 & 45,1 & 45,4 & 45,6 & 43,8 \\
\hline $\mathrm{NH}_{3}$ & ${ }^{2} J_{\mathrm{HH}}$ & $-10,2$ & $-10,1$ & $-10,0$ & $-9,9$ & $-10,0$ & $-10,1$ & $-10,3$ & $-10,5$ & $-10,7$ & $-11,0$ & $-11,2$ & $-11,5$ & $-11,7$ & $-11,9$ & $-12,2$ & $-9,6$ \\
\hline $\mathrm{PH}_{3}$ & ${ }^{1} J_{\mathrm{PH}}$ & 175,6 & 174,4 & 172,6 & 170,2 & 168,1 & 166,8 & 166,5 & 167,2 & 168,7 & 170,8 & 173,2 & 175,9 & 178,5 & 181,2 & 183,7 & 188,2 \\
\hline $\mathrm{PF}_{3}$ & ${ }^{1} J_{\mathrm{PF}}$ & $-1607,1$ & $-1606,6$ & $-1605,3$ & $-1603,4$ & $-1601,5$ & $-1599,6$ & $-1597,7$ & $-1595,7$ & $-1593,1$ & $-1589,8$ & $-1585,8$ & $-1581,1$ & $-1575,9$ & $-1570,3$ & $-1564,5$ & -1441 \\
\hline $\mathrm{BHF}_{2}$ & ${ }^{1} J_{\mathrm{BF}}$ & $-109,1$ & $-109,8$ & $-109,4$ & $-107,9$ & $-105,8$ & $-103,1$ & $-100,2$ & $-97,0$ & $-93,8$ & $-90,4$ & $-87,1$ & $-83,9$ & $-80,8$ & $-77,8$ & $-75,0$ & -84 \\
\hline $\mathrm{BF}_{3}$ & ${ }^{1} J_{\mathrm{BF}}$ & $-6,4$ & $-6,7$ & $-6,0$ & $-4,4$ & $-1,9$ & 1,0 & 4,4 & 8,0 & 11,6 & 15,3 & 18,8 & 22,2 & 25,5 & 28,6 & 31,5 & 15 \\
\hline $\mathrm{F}_{2} \mathrm{O}$ & ${ }^{1} J_{\mathrm{OF}}$ & $-405,6$ & $-407,5$ & $-410,9$ & $-416,2$ & $-423,0$ & $-431,0$ & $-439,5$ & $-448,3$ & $-457,2$ & $-466,1$ & $-474,9$ & $-483,7$ & $-492,5$ & $-501,2$ & $-509,7$ & -300 \\
\hline $\mathrm{CH}_{4}$ & ${ }^{1} J_{\mathrm{CH}}$ & 125,3 & 124,4 & 123,5 & 122,7 & 122,1 & 121,8 & 121,7 & 121,9 & 122,3 & 122,9 & 123,6 & 124,4 & 125,2 & 126,0 & 126,8 & 125,3 \\
\hline $\mathrm{CH}_{4}$ & ${ }^{2} J_{\mathrm{HH}}$ & $-12,8$ & $-12,6$ & $-12,5$ & $-12,4$ & $-12,5$ & $-12,6$ & $-12,8$ & $-13,0$ & $-13,3$ & $-13,5$ & $-13,8$ & $-14,0$ & $-14,3$ & $-14,5$ & $-14,7$ & $-12,8$ \\
\hline $\mathrm{C}_{2} \mathrm{H}_{2}$ & ${ }^{1} J_{\mathrm{CC}}$ & 198,0 & 197,1 & 196,4 & 196,1 & 196,0 & 196,1 & 196,6 & 197,3 & 198,3 & 199,6 & 201,0 & 202,6 & 204,2 & 205,9 & 207,5 & 174,8 \\
\hline $\mathrm{C}_{2} \mathrm{H}_{2}$ & ${ }^{1} J_{\mathrm{CH}}$ & 257,5 & 255,9 & 254,2 & 252,7 & 251,6 & 251,0 & 250,9 & 251,3 & 252,1 & 253,2 & 254,5 & 255,9 & 257,4 & 259,0 & 260,4 & 247,6 \\
\hline $\mathrm{C}_{2} \mathrm{H}_{2}$ & ${ }^{2} J_{\mathrm{CH}}$ & 55,2 & 55,2 & 55,3 & 55,4 & 55,5 & 55,6 & 55,6 & 55,6 & 55,4 & 55,2 & 55,0 & 54,7 & 54,3 & 54,0 & 53,7 & 50,1 \\
\hline $\mathrm{C}_{2} \mathrm{H}_{2}$ & ${ }^{3} J_{\mathrm{HH}}$ & 11,1 & 10,9 & 10,7 & 10,7 & 10,7 & 10,8 & 11,0 & 11,2 & 11,5 & 11,8 & 12,1 & 12,5 & 12,8 & 13,1 & 13,4 & 9,6 \\
\hline $\mathrm{C}_{2} \mathrm{H}_{4}$ & ${ }^{1} J_{\mathrm{CC}}$ & 68,7 & 68,0 & 67,6 & 67,4 & 67,4 & 67,5 & 67,8 & 68,4 & 69,1 & 70,1 & 71,1 & 72,3 & 73,6 & 74,8 & 76,1 & 67,6 \\
\hline $\mathrm{C}_{2} \mathrm{H}_{4}$ & ${ }^{1} J_{\mathrm{CH}}$ & 160,4 & 159,3 & 158,2 & 157,3 & 156,7 & 156,5 & 156,6 & 157,0 & 157,7 & 158,6 & 159,6 & 160,8 & 161,9 & 163,1 & 164,2 & 156,3 \\
\hline $\mathrm{C}_{2} \mathrm{H}_{4}$ & ${ }^{2} J_{\mathrm{CH}}$ & $-2,2$ & $-2,1$ & $-2,0$ & $-2,0$ & $-2,1$ & $-2,2$ & $-2,5$ & $-2,8$ & $-3,1$ & $-3,5$ & $-3,9$ & $-4,3$ & $-4,7$ & $-5,1$ & $-5,5$ & $-2,4$ \\
\hline $\mathrm{C}_{2} \mathrm{H}_{4}$ & ${ }^{2} J_{\mathrm{HH}}$ & 3,4 & 3,4 & 3,4 & 3,4 & 3,3 & 3,1 & 2,9 & 2,6 & 2,3 & 2,0 & 1,7 & 1,4 & 1,2 & 0,9 & 0,7 & 2,3 \\
\hline $\mathrm{C}_{2} \mathrm{H}_{4}$ & ${ }^{3} J_{\mathrm{HH}}$ & 12,4 & 12,4 & 12,4 & 12,4 & 12,5 & 12,6 & 12,7 & 12,8 & 13,0 & 13,1 & 13,3 & 13,5 & 13,6 & 13,8 & 13,9 & 11,7 \\
\hline $\mathrm{C}_{2} \mathrm{H}_{4}$ & ${ }^{3} J_{\mathrm{HH}_{\mathrm{t}}}$ & 19,3 & 19,2 & 19,1 & 19,0 & 18,9 & 19,0 & 19,1 & 19,2 & 19,4 & 19,6 & 19,8 & 20,0 & 20,2 & 20,4 & 20,6 & 19 \\
\hline $\mathrm{C}_{2} \mathrm{H}_{6}$ & ${ }^{1} J_{\mathrm{CC}}$ & 32,5 & 32,1 & 31,9 & 31,9 & 31,9 & 32,1 & 32,3 & 32,6 & 33,0 & 33,5 & 34,0 & 34,6 & 35,3 & 35,9 & 36,5 & 34,5 \\
\hline $\mathrm{C}_{2} \mathrm{H}_{6}$ & ${ }^{1} J_{\mathrm{CH}}$ & 126,1 & 125,3 & 124,4 & 123,6 & 123,0 & 122,7 & 122,7 & 122,9 & 123,4 & 124,0 & 124,8 & 125,6 & 126,4 & 127,3 & 128,1 & 125,2 \\
\hline $\mathrm{C}_{2} \mathrm{H}_{6}$ & ${ }^{2} J_{\mathrm{CH}}$ & $-4,0$ & $-3,9$ & $-3,9$ & $-3,9$ & $-3,9$ & $-4,0$ & $-4,1$ & $-4,2$ & $-4,3$ & $-4,5$ & $-4,6$ & $-4,8$ & $-4,9$ & $-5,0$ & $-5,2$ & $-4,7$ \\
\hline \multirow[t]{3}{*}{ Total } & DM & $-10,92$ & $-11,25$ & $-11,53$ & $-11,74$ & $-11,91$ & $-11,96$ & $-11,90$ & $-11,72$ & $-11,41$ & $-11,00$ & -10 & $-9,95$ & $-9,39$ & $-8,79$ & -8 & - \\
\hline & DMA & 14,79 & 14,82 & 14,89 & 15,01 & 15,14 & & & & & & & 16,80 & & & & - \\
\hline & PDMA & 14,57 & 14,72 & 14,63 & 14,20 & 13,36 & 12,16 & 10,92 & 10,27 & 9,75 & 10,43 & 12,97 & 15,64 & 18,57 & 21,65 & 24,65 & - \\
\hline \multirow[t]{3}{*}{ CPI } & DM & $-30,07$ & $-30,26$ & $-30,40$ & $-30,50$ & $-30,60$ & $-30,63$ & $-30,53$ & $-30,31$ & $-29,95$ & $-29,45$ & $-28,84$ & $-28,16$ & $-27,47$ & $-26,73$ & $-26,05$ & - \\
\hline & DMA & 30,35 & 30,75 & 31,11 & 31,46 & 31,82 & 32,17 & 32,47 & 32,69 & 32,84 & 32,94 & 33,58 & 34,16 & 35,27 & 36,31 & 37,30 & - \\
\hline & PDMA & 22,40 & 22,42 & 22,02 & 20,94 & 19,65 & 18,16 & 16,42 & 14,63 & 12,88 & 11,55 & 14,25 & 16,94 & 20,20 & 23,33 & 26,53 & - \\
\hline \multirow[t]{3}{*}{ SPI } & DM & 3,1 & 2,70 & 2,31 & 2,01 & 1,80 & 1,73 & 1,76 & 1,9 & 2,18 & 2,53 & 2,94 & 3,41 & 3,87 & 4,37 & 4,83 & - \\
\hline & DMA & 3,39 & 3,14 & 3,00 & 2,95 & 2,91 & 2,8 & 2,88 & 3,01 & 3,1 & 3,43 & 3,70 & 4,07 & 4,57 & 5,18 & 5,77 & - \\
\hline & PDMA & 8,83 & 9,07 & 9,20 & 9,25 & 8,74 & 7,75 & 6,88 & 7,07 & 7,45 & 9,61 & 12,03 & 14,68 & 17,37 & 20,42 & 23,27 & - \\
\hline \multirow[t]{3}{*}{$\Delta \mathrm{CS}$} & DM & $-33,19$ & $-32,96$ & $-32,71$ & $-32,51$ & $-32,40$ & & $-32,29$ & $-32,22$ & $-32,13$ & & & & $-31,35$ & & & - \\
\hline & DMA & 26,96 & 27,61 & 28,11 & 28,52 & 28,91 & 29,31 & 29,59 & 29,68 & 29,66 & 29,51 & 29,88 & 30,09 & 30,71 & 31,13 & 31,53 & - \\
\hline & PDMA & 13,57 & 13,35 & 12,82 & 11,69 & 10,92 & 10,41 & 9,54 & 7,56 & 5,43 & 1,93 & 2,23 & 2,26 & 2,84 & 2,91 & 3,26 & - \\
\hline
\end{tabular}


Tabela 8.375: Constantes de acoplamento LC-BB95 com $\alpha=50 \%$ e $\alpha+\beta=80 \%$, variando $\gamma$, na base aug-pcJ-2.

\begin{tabular}{|c|c|c|c|c|c|c|c|c|c|c|c|c|c|c|c|c|c|}
\hline & $\gamma$ & 0,05 & 0,10 & 0,15 & 0,20 & 0,25 & 0,30 & 0,35 & 0,40 & 0,45 & 0,50 & 0,55 & 0,60 & 0,65 & 0,70 & 0,75 & Exp. \\
\hline $\mathrm{HF}$ & ${ }^{1} J_{\mathrm{HF}}$ & 524,3 & 525,2 & 526,3 & 527,4 & 528,6 & 530,5 & 531,5 & 533,3 & 535,3 & 537,5 & 539,9 & 542,3 & 544,7 & 547,2 & 549,8 & 500 \\
\hline $\mathrm{CO}$ & ${ }^{1} J_{\mathrm{CO}}$ & 14,2 & 14,2 & 14,2 & 14,2 & 14,3 & 14,3 & 14,3 & 14,3 & 14,2 & 14,1 & 13,9 & 13,7 & 13,4 & 13,1 & 12,7 & 16,4 \\
\hline $\mathrm{H}_{2} \mathrm{O}$ & ${ }^{1} J_{\mathrm{OH}}$ & $-83,0$ & $-83,0$ & $-83,0$ & $-83,0$ & $-83,1$ & $-83,2$ & $-83,3$ & $-83,5$ & $-83,8$ & $-84,0$ & $-84,3$ & $-84,7$ & $-85,0$ & $-85,4$ & $-85,7$ & $-80,6$ \\
\hline $\mathrm{H}_{2} \mathrm{O}$ & ${ }^{2} J_{\mathrm{HH}}$ & $-9,1$ & $-9,0$ & $-9,0$ & $-8,9$ & $-9,0$ & $-9,0$ & $-9,2$ & $-9,3$ & $-9,4$ & $-9,6$ & $-9,8$ & $-10,0$ & $-10,1$ & $-10,3$ & $-10,5$ & $-7,3$ \\
\hline $\mathrm{NH}_{3}$ & ${ }^{1} J_{\mathrm{NH}}$ & 45,5 & 45,5 & 45,4 & 45,3 & 45,2 & 45,2 & 45,2 & 45,2 & 45,3 & 45,4 & 45,5 & 45,6 & 45,8 & 46,0 & 46,2 & 43,8 \\
\hline $\mathrm{NH}_{3}$ & ${ }^{2} J_{\mathrm{HH}}$ & $-11,1$ & $-11,0$ & $-10,9$ & $-10,9$ & $-10,9$ & $-11,0$ & $-11,2$ & $-11,3$ & $-11,5$ & $-11,7$ & $-11,9$ & $-12,1$ & $-12,3$ & $-12,4$ & $-12,6$ & $-9,6$ \\
\hline $\mathrm{PH}_{3}$ & ${ }^{1} J_{\mathrm{PH}}$ & 182,9 & 182,0 & 180,5 & 178,8 & 177,2 & 176,2 & 176,0 & 176,5 & 177,6 & 179,1 & 181,0 & 183,0 & 185,0 & 186,9 & 188,8 & 188,2 \\
\hline $\mathrm{PF}_{3}$ & ${ }^{1} J_{\mathrm{PF}}$ & $-1571,9$ & $-1571,8$ & $-1570,8$ & $-1569,3$ & $-1567,5$ & $-1565,7$ & $-1563,9$ & $-1561,9$ & $-1559,6$ & $-1556,9$ & $-1553,6$ & $-1549,9$ & $-1545,9$ & $-1541,7$ & $-1537,3$ & -1441 \\
\hline $\mathrm{BHF}_{2}$ & ${ }^{1} J_{\mathrm{BF}}$ & $-92,2$ & $-92,8$ & $-92,6$ & $-91,6$ & $-90,0$ & $-88,0$ & $-85,9$ & $-83,5$ & $-81,1$ & $-78,6$ & $-76,1$ & $-73,7$ & $-71,4$ & $-69,2$ & $-67,1$ & -84 \\
\hline $\mathrm{BF}_{3}$ & ${ }^{1} J_{\mathrm{BF}}$ & 11,7 & 11,4 & 11,8 & 13,0 & 14,8 & 17,0 & 19,4 & 22,1 & 24,8 & 27,5 & 30,1 & 32,7 & 35,1 & 37,4 & 39,6 & 15 \\
\hline $\mathrm{F}_{2} \mathrm{O}$ & ${ }^{1} J_{\mathrm{OF}}$ & $-444,5$ & $-445,9$ & $-448,6$ & $-452,8$ & $-458,5$ & $-465,1$ & $-472,4$ & $-480,0$ & $-487,8$ & $-495,5$ & $-503,3$ & $-511,0$ & $-518,7$ & $-526,2$ & $-533,6$ & -300 \\
\hline $\mathrm{CH}_{4}$ & ${ }^{1} J_{\mathrm{CH}}$ & 126,9 & 126,2 & 125,5 & 124,9 & 124,5 & 124,2 & 124,2 & 124,3 & 124,7 & 125,1 & 125,6 & 126,2 & 126,8 & 127,4 & 128,0 & 125,3 \\
\hline $\mathrm{CH}_{4}$ & ${ }^{2} J_{\mathrm{HH}}$ & $-13,5$ & $-13,4$ & $-13,3$ & $-13,2$ & $-13,3$ & $-13,4$ & $-13,5$ & $-13,7$ & $-13,9$ & $-14,1$ & $-14,3$ & $-14,4$ & $-14,6$ & $-14,8$ & $-14,9$ & $-12,8$ \\
\hline $\mathrm{C}_{2} \mathrm{H}_{2}$ & ${ }^{1} J_{\mathrm{CC}}$ & 202,2 & 201,4 & 200,9 & 200,6 & 200,6 & 200,8 & 201,2 & 201,9 & 202,7 & 203,8 & 205,0 & 206,3 & 207,6 & 208,9 & 210,2 & 174,8 \\
\hline $\mathrm{C}_{2} \mathrm{H}_{2}$ & ${ }^{1} J_{\mathrm{CH}}$ & 260,1 & 258,9 & 257,6 & 256,4 & 255,6 & 255,2 & 255,1 & 255,5 & 256,1 & 257,0 & 258,0 & 259,2 & 260,3 & 261,5 & 262,6 & 247,6 \\
\hline $\mathrm{C}_{2} \mathrm{H}_{2}$ & ${ }^{2} J_{\mathrm{CH}}$ & 54,6 & 54,7 & 54,7 & 54,8 & 54,9 & 55,0 & 54,9 & 54,8 & 54,7 & 54,5 & 54,2 & 54,0 & 53,7 & 53,4 & 53,1 & 50,1 \\
\hline $\mathrm{C}_{2} \mathrm{H}_{2}$ & ${ }^{3} J_{\mathrm{HH}}$ & 11,9 & 11,7 & 11,6 & 11,6 & 11,6 & 11,7 & 11,9 & 12,1 & 12,3 & 12,6 & 12,9 & 13,1 & 13,4 & 13,6 & 13,9 & 9,6 \\
\hline $\mathrm{C}_{2} \mathrm{H}_{4}$ & ${ }^{1} J_{\mathrm{CC}}$ & 72,2 & 71,6 & 71,3 & 71,2 & 71,2 & 71,3 & 71,7 & 72,2 & 72,8 & 73,6 & 74,5 & 75,5 & 76,5 & 77,5 & 78,5 & 67,6 \\
\hline $\mathrm{C}_{2} \mathrm{H}_{4}$ & ${ }^{1} J_{\mathrm{CH}}$ & 162,8 & 161,9 & 161,1 & 160,4 & 160,0 & 159,8 & 159,9 & 160,3 & 160,8 & 161,6 & 162,4 & 163,3 & 164,2 & 165,1 & 165,9 & 156,3 \\
\hline $\mathrm{C}_{2} \mathrm{H}_{4}$ & ${ }^{2} J_{\mathrm{CH}}$ & $-3,3$ & $-3,2$ & $-3,2$ & $-3,2$ & $-3,2$ & $-3,4$ & $-3,6$ & $-3,8$ & $-4,1$ & $-4,5$ & $-4,8$ & $-5,2$ & $-5,5$ & $-5,8$ & $-6,1$ & $-2,4$ \\
\hline $\mathrm{C}_{2} \mathrm{H}_{4}$ & ${ }^{2} J_{\mathrm{HH}}$ & 2,5 & 2,6 & 2,6 & 2,6 & 2,5 & 2,3 & 2,2 & 1,9 & 1,7 & 1,5 & 1,2 & 1,0 & 0,8 & 0,6 & 0,4 & 2,3 \\
\hline $\mathrm{C}_{2} \mathrm{H}_{4}$ & ${ }^{3} J_{\mathrm{HH}_{\mathrm{c}}}$ & 12,8 & 12,8 & 12,8 & 12,8 & 12,8 & 12,9 & 13,0 & 13,2 & 13,3 & 13,4 & 13,6 & 13,7 & 13,9 & 14,0 & 14,1 & 11,7 \\
\hline $\mathrm{C}_{2} \mathrm{H}_{4}$ & ${ }^{3} J_{\mathrm{HH}_{\mathrm{t}}}$ & 19,8 & 19,7 & 19,6 & 19,5 & 19,5 & 19,5 & 19,6 & 19,8 & 19,9 & 20,1 & 20,3 & 20,4 & 20,6 & 20,8 & 21,0 & 19 \\
\hline $\mathrm{C}_{2} \mathrm{H}_{6}$ & ${ }^{1} J_{\mathrm{CC}}$ & 34,6 & 34,3 & 34,2 & 34,1 & 34,2 & 34,3 & 34,4 & 34,7 & 35,0 & 35,4 & 35,8 & 36,3 & 36,7 & 37,2 & 37,7 & 34,5 \\
\hline $\mathrm{C}_{2} \mathrm{H}_{6}$ & ${ }^{1} J_{\mathrm{CH}}$ & 127,9 & 127,2 & 126,5 & 126,0 & 125,5 & 125,3 & 125,3 & 125,5 & 125,8 & 6,3 & 126,9 & 127,5 & 128,1 & 128,8 & 129,4 & 125,2 \\
\hline $\mathrm{C}_{2} \mathrm{H}_{6}$ & ${ }^{2} J_{\mathrm{CH}}$ & $-4,4$ & $-4,4$ & $-4,4$ & $-4,4$ & $-4,4$ & $-4,4$ & $-4,5$ & $-4,6$ & $-4,7$ & $-4,8$ & $-4,9$ & $-5,0$ & $-5,1$ & $-5,2$ & $-5,3$ & $-4,7$ \\
\hline \multirow[t]{3}{*}{ Total } & DM & -8 & 8,39 & $-8,62$ & & & & & & & & & & & & & - \\
\hline & DMA & & & & & & & & & & & & & & & & - \\
\hline & PDMA & 11,43 & 11,25 & 10,97 & 10,56 & 9,99 & 10,61 & 12,00 & 13,88 & 15,97 & 18,53 & 21,15 & 23,67 & 26,06 & 28,38 & 30,75 & - \\
\hline \multirow[t]{3}{*}{ CPI } & DM & $-24,92$ & $-25,10$ & $-25,24$ & & -25 & -25 & & & & & & & &, 23 & & - \\
\hline & DMA & 29,65 & 29,99 & 30,3 & 30 , & 30,8 & 31,5 & 32 , & & & & 36 , & & & 38,97 & & - \\
\hline & PDMA & 14,29 & 14,42 & 14,21 & 13,45 & 12,51 & 13,76 & 15,67 & 17,63 & 20,15 & 22,78 & 25,40 & 28,01 & 30,42 & 32,80 & 35,31 & - \\
\hline \multirow[t]{3}{*}{ SPI } & DM & 4,20 & 3,8 & & & & & & & & & & & & & & - \\
\hline & & & & & & & & & & & & & & & & & - \\
\hline & PDMA & 9,33 & 8,92 & 8,59 & 8,43 & 8,15 & 8,30 & 9,31 & 11,13 & 12,91 & 15,41 & 18,03 & 20,49 & 22,86 & 25,13 & 27,41 & - \\
\hline \multirow[t]{3}{*}{$\Delta \mathrm{CS}$} & & & & & & & & & & & & & & & & & - \\
\hline & MA &, 23 & 25,92 & & & & & & & & & & & & 32,70 & & - \\
\hline & & 4,96 & 5,51 & 5,62 & 5,02 & 4,36 & 5,46 & 6,37 & 6,49 & 7,25 & 7,37 & 7,37 & 7,51 & 7,56 & 7,67 & 7,90 & - \\
\hline
\end{tabular}


Tabela 8.376: Constantes de acoplamento LC-BB95 com $\alpha=0 \%$ e $\alpha+\beta=70 \%$, variando $\gamma$, na base aug-pcJ-2.

\begin{tabular}{|c|c|c|c|c|c|c|c|c|c|c|c|c|c|c|c|c|c|}
\hline & $\gamma$ & 0,05 & 0,10 & 0,15 & 0,20 & 0,25 & 0,30 & 0,35 & 0,40 & 0,45 & 0,50 & 0,55 & 0,60 & 0,65 & 0,70 & 0,75 & Exp. \\
\hline $\mathrm{HF}$ & ${ }^{1} J_{\mathrm{HF}}$ & 406,0 & 408,9 & 411,8 & 414,6 & 417,4 & 420,5 & 424,1 & 428,4 & 433,3 & 438,7 & 444,4 & 450,2 & 456,2 & 462,2 & 468,1 & 500 \\
\hline $\mathrm{CO}$ & ${ }^{1} J_{\mathrm{CO}}$ & 23,7 & 23,8 & 23,7 & 23,7 & 23,7 & 23,7 & 23,7 & 23,7 & 23,6 & 23,4 & 23,0 & 22,6 & 22,0 & 21,4 & 20,8 & 16,4 \\
\hline $\mathrm{H}_{2} \mathrm{O}$ & ${ }^{1} J_{\mathrm{OH}}$ & $-70,4$ & $-70,6$ & $-70,7$ & $-70,8$ & $-71,0$ & $-71,2$ & $-71,6$ & $-72,0$ & $-72,6$ & $-73,3$ & $-74,0$ & $-74,7$ & $-75,5$ & $-76,3$ & $-77,1$ & $-80,6$ \\
\hline $\mathrm{H}_{2} \mathrm{O}$ & ${ }^{2} J_{\mathrm{HH}}$ & $-4,0$ & $-3,8$ & $-3,8$ & $-3,8$ & $-3,9$ & $-4,0$ & $-4,3$ & $-4,6$ & $-4,9$ & $-5,3$ & $-5,6$ & $-6,0$ & $-6,4$ & $-6,8$ & $-7,1$ & $-7,3$ \\
\hline $\mathrm{NH}_{3}$ & ${ }^{1} J_{\mathrm{NH}}$ & 41,8 & 41,6 & 41,5 & 41,3 & 41,1 & 41,0 & 41,0 & 41,1 & 41,2 & 41,5 & 41,7 & 42,1 & 42,4 & 42,8 & 43,2 & 43,8 \\
\hline $\mathrm{NH}_{3}$ & ${ }^{2} J_{\mathrm{HH}}$ & $-6,7$ & $-6,5$ & $-6,4$ & $-6,4$ & $-6,5$ & $-6,7$ & $-7,0$ & $-7,3$ & $-7,7$ & $-8,1$ & $-8,5$ & $-8,9$ & $-9,3$ & $-9,7$ & $-10,1$ & $-9,6$ \\
\hline $\mathrm{PH}_{3}$ & ${ }^{1} J_{\mathrm{PH}}$ & 145,7 & 144,2 & 141,0 & 136,9 & 133,2 & 130,9 & 130,5 & 131,8 & 134,4 & 138,1 & 142,4 & 147,1 & 151,8 & 156,4 & 160,8 & 188,2 \\
\hline $\mathrm{PF}_{3}$ & ${ }^{1} J_{\mathrm{PF}}$ & $-1713,8$ & $-1710,8$ & $-1709,1$ & $-1708,9$ & $-1710,2$ & $-1712,6$ & $-1715,4$ & $-1717,5$ & $-1718,1$ & $-1716,7$ & $-1713,2$ & $-1707,8$ & $-1700,9$ & $-1692,8$ & $-1684,1$ & -1441 \\
\hline $\mathrm{BHF}_{2}$ & ${ }^{1} J_{\mathrm{BF}}$ & $-176,8$ & $-177,3$ & $-175,9$ & $-172,7$ & $-168,4$ & $-163,5$ & $-158,1$ & $-152,5$ & $-146,7$ & $-140,8$ & $-135,0$ & $-129,3$ & $-123,8$ & $-118,6$ & $-113,7$ & -84 \\
\hline $\mathrm{BF}_{3}$ & ${ }^{1} J_{\mathrm{BF}}$ & $-80,1$ & $-80,1$ & $-78,1$ & $-74,5$ & $-69,5$ & $-63,6$ & $-57,2$ & $-50,6$ & $-43,9$ & $-37,3$ & $-30,8$ & $-24,7$ & $-19,0$ & $-13,5$ & $-8,5$ & 15 \\
\hline $\mathrm{F}_{2} \mathrm{O}$ & ${ }^{1} J_{\mathrm{OF}}$ & $-269,3$ & $-272,9$ & $-279,1$ & $-288,2$ & $-299,6$ & $-312,2$ & $-325,1$ & $-337,6$ & $-349,3$ & $-360,4$ & $-370,9$ & $-381,0$ & $-390,8$ & $-400,4$ & $-409,8$ & -300 \\
\hline $\mathrm{CH}_{4}$ & ${ }^{1} J_{\mathrm{CH}}$ & 119,4 & 118,0 & 116,5 & 115,1 & 114,1 & 113,4 & 113,3 & 113,6 & 114,2 & 115,2 & 116,4 & 117,6 & 119,0 & 120,3 & 121,6 & 125,3 \\
\hline $\mathrm{CH}_{4}$ & ${ }^{2} J_{\mathrm{HH}}$ & $-10,0$ & $-9,7$ & $-9,5$ & $-9,4$ & $-9,5$ & $-9,7$ & $-10,1$ & $-10,5$ & $-10,9$ & $-11,3$ & $-11,8$ & $-12,2$ & $-12,6$ & $-12,9$ & $-13,2$ & $-12,8$ \\
\hline $\mathrm{C}_{2} \mathrm{H}_{2}$ & ${ }^{1} J_{\mathrm{CC}}$ & 186,2 & 184,8 & 183,9 & 183,3 & 182,9 & 182,8 & 183,0 & 183,6 & 184,7 & 186,0 & 187,7 & 189,6 & 191,7 & 193,9 & 196,1 & 174,8 \\
\hline $\mathrm{C}_{2} \mathrm{H}_{2}$ & ${ }^{1} J_{\mathrm{CH}}$ & 248,7 & 246,2 & 243,5 & 240,9 & 239,0 & 237,9 & 237,6 & 238,0 & 239,1 & 240,7 & 242,7 & 244,9 & 247,2 & 249,5 & 251,8 & 247,6 \\
\hline $\mathrm{C}_{2} \mathrm{H}_{2}$ & ${ }^{2} J_{\mathrm{CH}}$ & 55,3 & 55,1 & 55,3 & 55,5 & 55,9 & 56,3 & 56,5 & 56,7 & 56,8 & 56,8 & 56,7 & 56,5 & 56,2 & 56,0 & 55,7 & 50,1 \\
\hline $\mathrm{C}_{2} \mathrm{H}_{2}$ & ${ }^{3} J_{\mathrm{HH}}$ & 8,9 & 8,7 & 8,5 & 8,3 & 8,2 & 8,2 & 8,4 & 8,6 & 8,9 & 9,2 & 9,6 & 10,0 & 10,4 & 10,7 & 11,1 & 9,6 \\
\hline $\mathrm{C}_{2} \mathrm{H}_{4}$ & ${ }^{1} J_{\mathrm{CC}}$ & 57,7 & 56,9 & 56,4 & 56,1 & 55,9 & 55,9 & 56,1 & 56,6 & 57,3 & 58,3 & 59,6 & 61,0 & 62,6 & 64,3 & 66,0 & 67,6 \\
\hline $\mathrm{C}_{2} \mathrm{H}_{4}$ & ${ }^{1} J_{\mathrm{CH}}$ & 152,1 & 150,5 & 148,8 & 147,2 & 146,2 & 145,6 & 145,6 & 146,2 & 147,2 & 148,5 & 150,0 & 151,7 & 153,5 & 155,3 & 157,0 & 156,3 \\
\hline $\mathrm{C}_{2} \mathrm{H}_{4}$ & ${ }^{2} J_{\mathrm{CH}}$ & 1,0 & 1,1 & 1,2 & 1,2 & 1,1 & 1,0 & 0,7 & 0,4 & 0,0 & $-0,3$ & $-0,8$ & $-1,2$ & $-1,7$ & $-2,2$ & $-2,7$ & $-2,4$ \\
\hline $\mathrm{C}_{2} \mathrm{H}_{4}$ & ${ }^{2} J_{\mathrm{HH}}$ & 6,1 & 6,1 & 6,1 & 6,0 & 5,9 & 5,6 & 5,3 & 5,0 & 4,6 & 4,2 & 3,8 & 3,4 & 3,1 & 2,7 & 2,4 & 2,3 \\
\hline $\mathrm{C}_{2} \mathrm{H}_{4}$ & ${ }^{3} J_{\mathrm{HH}_{\mathrm{c}}}$ & 11,5 & 11,5 & 11,5 & 11,6 & 11,6 & 11,7 & 11,8 & 11,9 & 12,1 & 12,2 & 12,4 & 12,5 & 12,7 & 12,9 & 13,1 & 11,7 \\
\hline $\mathrm{C}_{2} \mathrm{H}_{4}$ & ${ }^{3} J_{\mathrm{HH}_{\mathrm{t}}}$ & 18,3 & 18,1 & 17,9 & 17,7 & 17,6 & 17,5 & 17,5 & 17,6 & 17,7 & 17,9 & 18,1 & 18,4 & 18,6 & 18,9 & 19,1 & 19 \\
\hline $\mathrm{C}_{2} \mathrm{H}_{6}$ & ${ }^{1} J_{\mathrm{CC}}$ & 24,4 & 23,9 & 23,8 & 23,8 & 23,9 & 24,0 & 24,3 & 24,8 & 25,5 & 26,2 & 27,1 & 28,1 & 29,1 & 30,2 & 31,2 & 34,5 \\
\hline $\mathrm{C}_{2} \mathrm{H}_{6}$ & ${ }^{1} J_{\mathrm{CH}}$ & 119,5 & 118,1 & 116,6 & 115,3 & 114,3 & 113,7 & 113,7 & 114,0 & 114,8 & 115,8 & 117,1 & 118,4 & 119,8 & 121,2 & 122,6 & 125,2 \\
\hline $\mathrm{C}_{2} \mathrm{H}_{6}$ & ${ }^{2} J_{\mathrm{CH}}$ & $-2,2$ & $-2,1$ & $-2,1$ & $-2,1$ & $-2,2$ & $-2,3$ & $-2,4$ & $-2,6$ & $-2,8$ & $-3,1$ & $-3,3$ & $-3,5$ & $-3,8$ & $-4,0$ & $-4,2$ & $-4,7$ \\
\hline \multirow[t]{3}{*}{ Total } & DM & $-21,23$ & $-21,59$ & $-21,99$ & $-22,43$ & $-22,84$ & $-23,12$ & $-23,20$ & $-23,01$ & $-22,56$ & $-21,88$ & $-21,01$ & $-20,01$ & $-18,94$ & $-17,83$ & 73 & - \\
\hline & DMA & 27,74 & 27,67 & 27 & 27, & 26,73 & 26,91 & & & 02 & & 24,22 & & & & & - \\
\hline & PDMA & 54,62 & 55,45 & 55,40 & 54,42 & 52,53 & 50,11 & 46,83 & 43,25 & 39,11 & 34,83 & 30,22 & 26,05 & 21,90 & 17,88 & 15,70 & - \\
\hline \multirow[t]{3}{*}{ CPI } & DM & $-49,53$ & $-49,49$ & $-49,64$ & $-49,97$ & $-50,42$ & $-50,78$ & $-50,94$ & $-50,73$ & $-50,15$ & $-49,19$ & $-47,95$ & $-46,48$ & $-44,93$ & $-43,29$ & $-41,67$ & 一 \\
\hline & DMA & 59,42 & 58,78 & 57,78 & 56,45 & 54,75 & 54,95 & 54,92 & 54,53 & 53,69 & 52,43 & 50,85 & 49,05 & 47,09 & 45,07 & 43,15 & - \\
\hline & PDMA & 86,56 & 87,02 & 85,61 & 82,98 & 79,07 & 75,08 & 70,28 & 65,20 & 59,76 & 54,04 & 48,36 & 42,73 & 37,23 & 32,05 & 27,90 & - \\
\hline \multirow[t]{3}{*}{ SPI } & DM & $-0,48$ & $-1,13$ & $-1,71$ & $-2,24$ & $-2,61$ & $-2,83$ & $-2,8$ & $-2,6$ & $-2,33$ & $-1,85$ & $-1,25$ & $-0,5$ & 0,11 & 0,85 & 1,57 & - \\
\hline & DMA & 4,51 & 4,86 & 5,39 & 5,87 & 6,19 & 6,35 & 6,29 & 6,08 & 5,73 & 5,25 & 4,68 & 4,13 & 3,54 & 3,22 & 3,15 & - \\
\hline & PDMA & 31,19 & 32,30 & 33,25 & 33,48 & 33,06 & 31,80 & 29,64 & 27,16 & 23,97 & 20,74 & 16,91 & 13,82 & 10,66 & 7,49 & 6,75 & - \\
\hline \multirow[t]{3}{*}{$\Delta \mathrm{CS}$} & DM & $-49,05$ & $-48,36$ & $-47,92$ & ,73 & $-47,80$ & $-47,95$ & $-48,08$ & -48 & $-47,82$ & ,34 & $-46,69$ & & & 14 & & 一 \\
\hline & DMA & 54,91 & 53,92 & 52,39 & 50 , & 48,56 & 48,59 & 48,62 & & 47,96 & 47,17 & 46,17 & 44,92 & & 41,85 & & - \\
\hline & & 55,37 & 54,72 & 52,36 & 49,50 & 46,01 & 43,28 & 40,64 & 38,04 & 35,78 & 33,30 & 31,46 & 28,90 & 26,58 & 24,57 & 21,16 & - \\
\hline
\end{tabular}


Tabela 8.377: Constantes de acoplamento LC-BB95 com $\alpha=10 \%$ e $\alpha+\beta=70 \%$, variando $\gamma$, na base aug-pcJ-2.

\begin{tabular}{|c|c|c|c|c|c|c|c|c|c|c|c|c|c|c|c|c|c|}
\hline & $\gamma$ & 0,05 & 0,10 & 0,15 & 0,20 & 0,25 & 0,30 & 0,35 & 0,40 & 0,45 & 0,50 & 0,55 & 0,60 & 0,65 & 0,70 & 0,75 & Exp. \\
\hline $\mathrm{HF}$ & ${ }^{\mathrm{I}} J_{\mathrm{HF}}$ & 429,2 & 431,6 & 434,1 & 436,4 & 438,8 & 441,5 & 444,7 & 448,3 & 452,5 & 457,0 & 461,8 & 466,8 & 471,8 & 476,9 & 482,0 & 500 \\
\hline $\mathrm{CO}$ & ${ }^{1} J_{\mathrm{CO}}$ & 22,0 & 22,0 & 22,0 & 22,0 & 22,0 & 22,0 & 22,0 & 22,0 & 21,9 & 21,7 & 21,4 & 21,0 & 20,5 & 20,0 & 19,4 & 16,4 \\
\hline $\mathrm{H}_{2} \mathrm{O}$ & ${ }^{1} J_{\mathrm{OH}}$ & $-72,9$ & $-73,0$ & $-73,1$ & $-73,2$ & $-73,3$ & $-73,5$ & $-73,8$ & $-74,2$ & $-74,7$ & $-75,3$ & $-75,9$ & $-76,5$ & $-77,2$ & $-77,9$ & $-78,6$ & $-80,6$ \\
\hline $\mathrm{H}_{2} \mathrm{O}$ & ${ }^{2} J_{\mathrm{HH}}$ & $-5,0$ & $-4,9$ & $-4,8$ & $-4,8$ & $-4,8$ & $-5,0$ & $-5,2$ & $-5,5$ & $-5,8$ & $-6,1$ & $-6,4$ & $-6,7$ & $-7,0$ & $-7,4$ & $-7,7$ & $-7,3$ \\
\hline $\mathrm{NH}_{3}$ & ${ }^{1} J_{\mathrm{NH}}$ & 42,5 & 42,4 & 42,2 & 42,1 & 41,9 & 41,8 & 41,8 & 41,9 & 42,0 & 42,2 & 42,5 & 42,8 & 43,1 & 43,4 & 43,7 & 43,8 \\
\hline $\mathrm{NH}_{3}$ & ${ }^{2} J_{\mathrm{HH}}$ & $-7,6$ & $-7,4$ & $-7,3$ & $-7,3$ & $-7,4$ & $-7,5$ & $-7,8$ & $-8,1$ & $-8,4$ & $-8,8$ & $-9,1$ & $-9,5$ & $-9,8$ & $-10,2$ & $-10,5$ & $-9,6$ \\
\hline $\mathrm{PH}_{3}$ & ${ }^{1} J_{\mathrm{PH}}$ & 153,3 & 152,0 & 149,2 & 145,7 & 142,5 & 140,6 & 140,2 & 141,2 & 143,5 & 146,7 & 150,4 & 154,3 & 158,4 & 162,4 & 166,1 & 188,2 \\
\hline $\mathrm{PF}_{3}$ & ${ }^{1} J_{\mathrm{PF}}$ & $-1693,6$ & $-1691,4$ & $-1689,7$ & $-1688,7$ & $-1688,5$ & $-1689,0$ & $-1689,9$ & $-1690,3$ & $-1689,7$ & $-1687,5$ & $-1683,8$ & $-1678,6$ & $-1672,3$ & $-1665,1$ & $-1657,4$ & -1441 \\
\hline $\mathrm{BHF}_{2}$ & ${ }^{1} J_{\mathrm{BF}}$ & $-159,8$ & $-160,4$ & $-159,3$ & $-156,7$ & $-153,1$ & $-148,9$ & $-144,3$ & $-139,5$ & $-134,5$ & $-129,5$ & $-124,5$ & $-119,6$ & $-114,9$ & $-110,5$ & $-106,3$ & -84 \\
\hline $\mathrm{BF}_{3}$ & ${ }^{1} J_{\mathrm{BF}}$ & $-61,4$ & $-61,5$ & $-60,0$ & $-57,0$ & $-52,9$ & $-48,0$ & $-42,6$ & $-37,0$ & $-31,3$ & $-25,7$ & $-20,2$ & $-15,0$ & $-10,0$ & $-5,4$ & $-1,0$ & 15 \\
\hline $\mathrm{F}_{2} \mathrm{O}$ & ${ }^{1} J_{\mathrm{OF}}$ & $-303,4$ & $-306,3$ & $-311,5$ & $-319,1$ & $-328,6$ & $-339,2$ & $-350,1$ & $-360,9$ & $-371,1$ & $-381,0$ & $-390,4$ & $-399,5$ & $-408,4$ & $-417,2$ & $-425,8$ & -300 \\
\hline $\mathrm{CH}_{4}$ & ${ }^{1} J_{\mathrm{CH}}$ & 120,9 & 119,6 & 118,3 & 117,2 & 116,2 & 115,7 & 115,6 & 115,9 & 116,4 & 117,3 & 118,3 & 119,4 & 120,5 & 121,7 & 122,8 & 125,3 \\
\hline $\mathrm{CH}_{4}$ & ${ }^{2} J_{\mathrm{HH}}$ & $-10,7$ & $-10,4$ & $-10,3$ & $-10,2$ & $-10,3$ & $-10,5$ & $-10,7$ & $-11,1$ & $-11,5$ & $-11,8$ & $-12,2$ & $-12,6$ & -12 & -13 & -1 & $-12,8$ \\
\hline $\mathrm{C}_{2} \mathrm{H}_{2}$ & ${ }^{1} J_{\mathrm{CC}}$ & 188,7 & 187,5 & 186,7 & 186,1 & 185,8 & 185,8 & 186,0 & 186,7 & 187,7 & 189,0 & 190,6 & 192,3 & 194,2 & 196,2 & 198,2 & 174,8 \\
\hline $\mathrm{C}_{2} \mathrm{H}_{2}$ & ${ }^{1} J_{\mathrm{CH}}$ & 250,8 & 248,6 & 246,2 & 244,1 & 242,4 & 241,4 & 241,2 & 241,6 & 242,6 & 244,0 & 245,8 & 247,7 & 249,7 & 251,7 & 3,7 & 247,6 \\
\hline $\mathrm{C}_{2} \mathrm{H}_{2}$ & ${ }^{2} J_{\mathrm{CH}}$ & 55,5 & 55,4 & 55,5 & 55,7 & 56,0 & 56,3 & 56,5 & 56,6 & 56,6 & 56,5 & 56,4 & 56,2 & 56,0 & 55,7 & 55,4 & 50,1 \\
\hline $\mathrm{C}_{2} \mathrm{H}_{2}$ & ${ }^{3} J_{\mathrm{HH}}$ & 9,3 & 9,1 & 8,9 & 8,8 & 8,7 & 8,8 & 8,9 & 9,1 & 9,4 & 9,7 & 10,1 & 10,4 & 10,8 & 11,2 & 11,5 & 9,6 \\
\hline $\mathrm{C}_{2} \mathrm{H}_{4}$ & ${ }^{1} J_{\mathrm{CC}}$ & 60,2 & 59,4 & 58,9 & 58,7 & 58,5 & 58,5 & 58,8 & 59,2 & 60,0 & 60,9 & 62,1 & 63,4 & 64,9 & 66,4 & 67,9 & 67,6 \\
\hline $\mathrm{C}_{2} \mathrm{H}_{4}$ & ${ }^{1} J_{\mathrm{CH}}$ & 154,1 & 152,7 & 151,2 & 149,9 & 148,9 & 148,5 & 148,5 & 149,0 & 149,9 & 151,0 & 152,4 & 153,9 & 155,5 & 157,0 & 158,5 & 156,3 \\
\hline $\mathrm{C}_{2} \mathrm{H}_{4}$ & ${ }^{2} J_{\mathrm{CH}}$ & 0,3 & 0,4 & 0,5 & 0,5 & 0,4 & 0,3 & 0,0 & $-0,2$ & $-0,5$ & $-0,9$ & $-1,3$ & $-1,8$ & $-2,3$ & $-2,7$ & $-3,1$ & $-2,4$ \\
\hline $\mathrm{C}_{2} \mathrm{H}_{4}$ & ${ }^{2} J_{\mathrm{HH}}$ & 5,5 & 5,5 & 5,5 & 5,4 & 5,3 & 5,1 & 4,8 & 4,5 & 4, & 3,8 & 3,4 & 3,1 & 2,8 & 2,4 & 2,2 & 2,3 \\
\hline $\mathrm{C}_{2} \mathrm{H}_{4}$ & ${ }^{3} J_{\mathrm{HH}_{\mathrm{c}}}$ & 11,7 & 11,7 & 11,7 & 11,7 & 11,8 & 11,8 & 11,9 & 12,1 & 12,2 & 12,4 & 12,5 & 12,7 & 12,8 & 13,0 & 13,2 & 11,7 \\
\hline $\mathrm{C}_{2} \mathrm{H}_{4}$ & ${ }^{3} J_{\mathrm{HH}_{\mathrm{t}}}$ & 18,4 & 18,3 & 18,1 & 18,0 & 17,9 & 17,8 & 17,8 & 17,9 & 18,0 & 18,2 & 18,4 & 18,7 & 18,9 & 19,2 & 19,4 & 19 \\
\hline $\mathrm{C}_{2} \mathrm{H}_{6}$ & ${ }^{1} J_{\mathrm{CC}}$ & 26,4 & 25,9 & 25,8 & 25,8 & 25,8 & 26,0 & 26,3 & 26,7 & 27,3 & 27,9 & 28,7 & 29,6 & 30,5 & 31,4 & 32,3 & 34,5 \\
\hline $\mathrm{C}_{2} \mathrm{H}_{6}$ & ${ }^{1} J_{\mathrm{CH}}$ & 121,1 & 119,9 & 118,7 & 117,5 & 116,6 & 116,2 & 116,1 & 116,4 & 117,1 & 118,0 & 119,1 & 120,3 & 121,5 & 122,7 & 123,9 & 125,2 \\
\hline $\mathrm{C}_{2} \mathrm{H}_{6}$ & ${ }^{2} J_{\mathrm{CH}}$ & $-2,6$ & $-2,6$ & $-2,5$ & $-2,5$ & $-2,6$ & $-2,7$ & $-2,8$ & $-3,0$ & $-3,2$ & $-3,4$ & $-3,6$ & $-3,8$ & $-4,0$ & $-4,2$ & $-4,3$ & $-4,7$ \\
\hline \multirow[t]{3}{*}{ Total } & $\mathrm{DM}$ & -18, & r & & & 20,27 & & & $-20,22$ & & & & & & & & - \\
\hline & DMA & 22,79 & 22,90 & 23,1 & 23,46 & 23,73 & 23,8 & 23,73 & 23,44 & & 22,2 & 21,36 & 20,42 & & 18,89 & 18,31 & - \\
\hline & PDMA & 43,52 & 44,25 & 44,56 & 43,90 & 42,61 & 40,57 & 37,71 & 34,61 & 30,93 & 27,27 & 23,52 & 19,74 & 16,34 & 14,42 & 13,89 & - \\
\hline \multirow[t]{3}{*}{ CPI } & DM & -4 & & & & & & & & & & & & & & & - \\
\hline & & & & & & & & & & & & & & & & & - \\
\hline & PDMA & 68,18 & 68,72 & 68,18 & 66,44 & 63,90 & 60,49 & 56,45 & 52,03 & 47,36 & 42,51 & 37,67 & 32,85 & 28,56 & 24,94 & 21,94 & - \\
\hline \multirow[t]{3}{*}{ SPI } & DM & & & & & & & & & & & & & & & & - \\
\hline & DMA & & & & & & & & & & & & & & & & - \\
\hline & PDMA & 25,44 & 26,30 & 27,24 & 27,37 & 27,00 & 25,96 & 23,96 & 21,84 & 18,88 & 16,09 & 13,15 & 10,12 & 7,37 & 6,71 & 7,99 & - \\
\hline \multirow[t]{3}{*}{$\Delta C S$} & DM & $-45,60$ & -45 & & $-44,4$ & & & & & & & & & & & & - \\
\hline & DMA & 44,46 & & & & & & 43, & & & & & & & & & - \\
\hline & PDMA & 42,73 & 42,42 & 40,94 & 39,07 & 36,89 & 34,54 & 32,49 & 30,19 & 28,48 & 26,42 & 24,53 & 22,73 & 21,18 & 18,23 & 13,95 & - \\
\hline
\end{tabular}


Tabela 8.378: Constantes de acoplamento LC-BB95 com $\alpha=20 \%$ e $\alpha+\beta=70 \%$, variando $\gamma$, na base aug-pcJ-2.

\begin{tabular}{|c|c|c|c|c|c|c|c|c|c|c|c|c|c|c|c|c|c|}
\hline & $\gamma$ & 0,05 & 0,10 & 0,15 & 0,20 & 0,25 & 0,30 & 0,35 & 0,40 & 0,45 & 0,50 & 0,55 & 0,60 & 0,65 & 0,70 & 0,75 & Exp. \\
\hline $\mathrm{HF}$ & ${ }^{1} J_{\mathrm{HF}}$ & 452,6 & 454,5 & 456,5 & 458,5 & 460,5 & 462,7 & 465,4 & 468,4 & 471,8 & 475,6 & 479,5 & 483,6 & 487,8 & 492,0 & 496,2 & 500 \\
\hline $\mathrm{CO}$ & ${ }^{1} J_{\mathrm{CO}}$ & 20,2 & 20,2 & 20,2 & 20,2 & 20,2 & 20,2 & 20,2 & 20,2 & 20,1 & 19,9 & 19,7 & 19,3 & 18,9 & 18,4 & 17,9 & 16,4 \\
\hline $\mathrm{H}_{2} \mathrm{O}$ & ${ }^{1} J_{\mathrm{OH}}$ & $-75,4$ & $-75,5$ & $-75,5$ & $-75,6$ & $-75,7$ & $-75,9$ & $-76,1$ & $-76,4$ & $-76,8$ & $-77,3$ & $-77,8$ & $-78,3$ & $-78,9$ & $-79,5$ & $-80,1$ & $-80,6$ \\
\hline $\mathrm{H}_{2} \mathrm{O}$ & ${ }^{2} J_{\mathrm{HH}}$ & $-6,0$ & $-5,9$ & $-5,8$ & $-5,8$ & $-5,9$ & $-6,0$ & $-6,2$ & $-6,4$ & $-6,6$ & $-6,9$ & $-7,2$ & $-7,4$ & $-7,7$ & $-8,0$ & $-8,2$ & $-7,3$ \\
\hline $\mathrm{NH}_{3}$ & ${ }^{1} J_{\mathrm{NH}}$ & 43,3 & 43,2 & 43,0 & 42,9 & 42,8 & 42,7 & 42,7 & 42,7 & 42,8 & 43,0 & 43,2 & 43,5 & 43,7 & 44,0 & 44,3 & 43,8 \\
\hline $\mathrm{NH}_{3}$ & ${ }^{2} J_{\mathrm{HH}}$ & $-8,5$ & $-8,3$ & $-8,2$ & $-8,2$ & $-8,2$ & $-8,4$ & $-8,6$ & $-8,9$ & $-9,2$ & $-9,5$ & $-9,8$ & $-10,1$ & $-10,3$ & $-10,6$ & $-10,9$ & $-9,6$ \\
\hline $\mathrm{PH}_{3}$ & ${ }^{1} J_{\mathrm{PH}}$ & 160,9 & 159,7 & 157,4 & 154,4 & 151,8 & 150,2 & 149,8 & 150,7 & 152,6 & 155,2 & 158,3 & 161,6 & 165,0 & 168,3 & 171,4 & 188,2 \\
\hline $\mathrm{PF}_{3}$ & ${ }^{1} J_{\mathrm{PF}}$ & $-1668,5$ & $-1667,1$ & $-1665,5$ & $-1664,1$ & $-1663,0$ & $-1662,4$ & $-1662,0$ & $-1661,3$ & $-1659,9$ & $-1657,4$ & $-1653,7$ & $-1649,0$ & $-1643,4$ & $-1637,2$ & $-1630,6$ & -1441 \\
\hline $\mathrm{BHF}_{2}$ & ${ }^{1} J_{\mathrm{BF}}$ & $-142,8$ & $-143,4$ & $-142,6$ & $-140,5$ & $-137,6$ & $-134,2$ & $-130,4$ & $-126,4$ & $-122,2$ & $-118,0$ & $-113,9$ & $-109,8$ & $-105,9$ & $-102,2$ & $-98,7$ & -84 \\
\hline $\mathrm{BF}_{3}$ & ${ }^{1} J_{\mathrm{BF}}$ & $-42,9$ & $-43,1$ & $-41,9$ & $-39,6$ & $-36,2$ & $-32,3$ & $-27,8$ & $-23,2$ & $-18,5$ & $-13,9$ & $-9,3$ & $-5,0$ & $-0,9$ & 2,9 & 6,5 & 15 \\
\hline $\mathrm{F}_{2} \mathrm{O}$ & ${ }^{1} J_{\mathrm{OF}}$ & $-336,6$ & $-339,0$ & $-343,3$ & $-349,5$ & $-357,4$ & $-366,2$ & $-375,5$ & $-384,7$ & $-393,7$ & $-402,3$ & $-410,7$ & $-418,9$ & $-426,9$ & $-434,8$ & $-442,5$ & -300 \\
\hline $\mathrm{CH}_{4}$ & ${ }^{1} J_{\mathrm{CH}}$ & 122,4 & 121,3 & 120,2 & 119,2 & 118,5 & 118,0 & 117,9 & 118,2 & 118,7 & 119,4 & 120,2 & 121,2 & 122,1 & 123,1 & 124,1 & 125,3 \\
\hline $\mathrm{CH}_{4}$ & ${ }^{2} J_{\mathrm{HH}}$ & $-11,4$ & $-11,2$ & $-11,0$ & $-11,0$ & $-11,0$ & $-11,2$ & $-11,4$ & $-11,7$ & $-12,0$ & $-12,4$ & $-12,7$ & $-13,0$ & $-13,3$ & $-13,5$ & $-13,8$ & $-12,8$ \\
\hline $\mathrm{C}_{2} \mathrm{H}_{2}$ & ${ }^{1} J_{\mathrm{CC}}$ & 191,5 & 190,4 & 189,7 & 189,3 & 189,0 & 189,1 & 189,4 & 190,0 & 191,0 & 192,2 & 193,6 & 195,2 & 196,9 & 198,6 & 200,3 & 174,8 \\
\hline $\mathrm{C}_{2} \mathrm{H}_{2}$ & ${ }^{1} J_{\mathrm{CH}}$ & 253,0 & 251,2 & 249,1 & 247,3 & 245,9 & 245,1 & 244,9 & 245,3 & 246,1 & 247,4 & 248,9 & 250,6 & 252,3 & 254,0 & 255,7 & 247,6 \\
\hline $\mathrm{C}_{2} \mathrm{H}_{2}$ & ${ }^{2} J_{\mathrm{CH}}$ & 55,6 & 55,5 & 55,6 & 55,8 & 56,0 & 56,2 & 56,3 & 56,4 & 56,3 & 56,2 & 56,1 & 55,8 & 55,6 & 55,3 & 55,0 & 50,1 \\
\hline $\mathrm{C}_{2} \mathrm{H}_{2}$ & ${ }^{3} J_{\mathrm{HH}}$ & 9,8 & 9,6 & 9,5 & 9,3 & 9,3 & 9,4 & 9,5 & 9,7 & 10,0 & 10,3 & 10,6 & 11,0 & 11,3 & 11,6 & 11,9 & 9,6 \\
\hline $\mathrm{C}_{2} \mathrm{H}_{4}$ & ${ }^{1} J_{\mathrm{CC}}$ & 62,8 & 62,1 & 61,7 & 61,5 & 61,4 & 61,4 & 61,7 & 62,1 & 62,8 & 63,7 & 64,8 & 66,0 & 67,2 & 68,6 & 69,9 & 67,6 \\
\hline $\mathrm{C}_{2} \mathrm{H}_{4}$ & ${ }^{1} J_{\mathrm{CH}}$ & 156,2 & 154,9 & 153,7 & 152,6 & 151,8 & 151,4 & 151,5 & 151,9 & 152,7 & 153,7 & 154,9 & 156,2 & 157,5 & 158,8 & 160,1 & 156,3 \\
\hline $\mathrm{C}_{2} \mathrm{H}_{4}$ & ${ }^{2} J_{\mathrm{CH}}$ & $-0,3$ & $-0,3$ & $-0,2$ & $-0,2$ & $-0,3$ & $-0,4$ & $-0,6$ & $-0,9$ & $-1,2$ & $-1,6$ & $-2,0$ & $-2,4$ & $-2,8$ & $-3,2$ & $-3,6$ & $-2,4$ \\
\hline $\mathrm{C}_{2} \mathrm{H}_{4}$ & ${ }^{2} J_{\mathrm{HH}}$ & 4,8 & 4,8 & 4,9 & 4,8 & 4,7 & 4,5 & 4,2 & 4,0 & 3,7 & 3,3 & 3,0 & 2,7 & 2,4 & 2,2 & 1,9 & 2,3 \\
\hline $\mathrm{C}_{2} \mathrm{H}_{4}$ & ${ }^{3} J_{\mathrm{HH}_{\mathrm{c}}}$ & 11,9 & 11,9 & 11,9 & 11,9 & 12,0 & 12,0 & 12,1 & 12,3 & 12,4 & 12,5 & 12,7 & 12,8 & 13,0 & 13,1 & 13,3 & 11,7 \\
\hline $\mathrm{C}_{2} \mathrm{H}_{4}$ & ${ }^{3} J_{\mathrm{HH}_{\mathrm{t}}}$ & 18,7 & 18,5 & 18,4 & 18,3 & 18,2 & 18,2 & 18,2 & 18,3 & 18,4 & 18,6 & 18,8 & 19,0 & 19,2 & 19,5 & 19,7 & 19 \\
\hline $\mathrm{C}_{2} \mathrm{H}_{6}$ & ${ }^{1} J_{\mathrm{CC}}$ & 28,4 & 28,0 & 27,8 & 27,8 & 27,9 & 28,0 & 28,3 & 28,6 & 29,1 & 29,7 & 30,4 & 31,1 & 31,9 & 32,6 & 33,4 & 34,5 \\
\hline $\mathrm{C}_{2} \mathrm{H}_{6}$ & ${ }^{1} J_{\mathrm{CH}}$ & 122,8 & 121,8 & 120,7 & 119,7 & 119,0 & 118,6 & 118,6 & 118,9 & 119,4 & 120,2 & 121,1 & 122,1 & 123,1 & 124,2 & 125,2 & 125,2 \\
\hline $\mathrm{C}_{2} \mathrm{H}_{6}$ & ${ }^{2} J_{\mathrm{CH}}$ & $-3,1$ & $-3,0$ & $-3,0$ & $-3,0$ & $-3,0$ & $-3,1$ & $-3,2$ & $-3,4$ & $-3,5$ & $-3,7$ & $-3,9$ & $-4,0$ & $-4,2$ & $-4,4$ & $-4,5$ & $-4,7$ \\
\hline \multirow[t]{3}{*}{ Total } & DM & $-16,37$ & $-16,70$ & $-16,99$ & $-17,27$ & $-17,47$ & -17 & -17 & -17 & $-16,95$ & & ,78 & -15 & & $-13,51$ & ,73 & - \\
\hline & DMA & 19,98 & 20,11 & 20,23 & 20,37 & 20,54 & & 20,4 & 20 & 19, & & & & & 17,08 & & - \\
\hline & PDMA & 33,32 & 33,80 & 34,19 & 33,66 & 32,55 & 30,77 & 28,35 & 25,73 & 22,93 & 19,54 & 16,54 & 13,98 & 12,99 & 12,68 & 13,06 & - \\
\hline \multirow[t]{3}{*}{ CPI } & DM & $-40,42$ & $-40,51$ & $-40,60$ & $-40,75$ & $-40,87$ & $-40,95$ & $-40,85$ & $-40,56$ & $-40,05$ & $-39,32$ & $-38,42$ & $-37,40$ & $-36,32$ & $-35,24$ & $-34,15$ & - \\
\hline & DMA & 42,49 & 42,62 & 42,75 & 42,87 & 42,96 & 42,95 & 42,75 & 42,31 & 41,61 & 40,65 & 39,55 & 38,35 & 37,08 & 35,84 & 34,60 & - \\
\hline & PDMA & 51,64 & 52,23 & 51,88 & 50,55 & 48,38 & 45,64 & 42,29 & 38,67 & 34,83 & 30,77 & 27,06 & 23,94 & 21,23 & 18,83 & 16,48 & - \\
\hline \multirow[t]{3}{*}{ SPI } & DM & 1,27 & 0,76 & 0,33 & $-0,05$ & $-0,31$ & $-0,46$ & $-0,45$ & $-0,29$ & $-0,0$ & 0,36 & 0,83 & 1,3 & 1,8 & 2,43 & 2,97 & - \\
\hline & DMA & 3,48 & 3,60 & 3,73 & 3,8 & 4, & 4, & 4, & $4, \mathrm{C}$ & 3, & 3, & 3,1 & 3,0 & 3,1 & 3,32 & 3,62 & - \\
\hline & PDMA & 19,89 & 20,28 & 21,23 & 21,27 & 20,94 & 19,87 & 18,13 & 16,23 & 14,21 & 11,31 & 8,83 & 6,68 & 6,94 & 8,18 & 10,56 & - \\
\hline \multirow[t]{3}{*}{$\Delta \mathrm{CS}$} & DM & $-41,68$ & $-41,27$ & $-40,93$ & $-40,69$ & $-40,56$ & $-40,49$ & $-40,41$ & $-40,27$ & -40 & & & & $-38,19$ & $-37,66$ & $-37,11$ & - \\
\hline & DMA & 39,01 & 39,02 & 39,02 & 39,01 & 38,86 & 38,75 & 38,59 & 38,31 & 37,85 & 37,25 & 36,36 & 35,33 & 33,98 & 32,52 & 30,98 & - \\
\hline & PDMA & 31,75 & 31,96 & 30,65 & 29,29 & 27,44 & 25,77 & 24,16 & 22,44 & 20,62 & 19,46 & 18,23 & 17,26 & 14,29 & 10,65 & 5,92 & - \\
\hline
\end{tabular}


Tabela 8.379: Constantes de acoplamento LC-BB95 com $\alpha=30 \%$ e $\alpha+\beta=70 \%$, variando $\gamma$, na base aug-pcJ-2.

\begin{tabular}{|c|c|c|c|c|c|c|c|c|c|c|c|c|c|c|c|c|c|}
\hline & $\gamma$ & 0,05 & 0,10 & 0,15 & 0,20 & 0,25 & 0,30 & 0,35 & 0,40 & 0,45 & 0,50 & 0,55 & 0,60 & 0,65 & 0,70 & 0,75 & Exp. \\
\hline $\mathrm{HF}$ & ${ }^{1} J_{\mathrm{HF}}$ & 476,2 & 477,7 & 479,2 & 480,8 & 482,4 & 484,2 & 486,3 & 488,7 & 491,4 & 494,4 & 497,5 & 500,8 & 504,1 & 507,4 & 510,8 & 500 \\
\hline $\mathrm{CO}$ & ${ }^{1} J_{\mathrm{CO}}$ & 18,2 & 18,3 & 18,3 & 18,3 & 18,3 & 18,3 & 18,3 & 18,3 & 18,2 & 18,1 & 17,9 & 17,6 & 17,2 & 16,8 & 16,4 & 16,4 \\
\hline $\mathrm{H}_{2} \mathrm{O}$ & ${ }^{1} J_{\mathrm{OH}}$ & $-77,9$ & $-77,9$ & $-78,0$ & $-78,0$ & $-78,1$ & $-78,2$ & $-78,4$ & $-78,7$ & $-79,0$ & $-79,4$ & $-79,8$ & $-80,2$ & $-80,7$ & $-81,1$ & $-81,6$ & $-80,6$ \\
\hline $\mathrm{H}_{2} \mathrm{O}$ & ${ }^{2} J_{\mathrm{HH}}$ & $-7,0$ & $-6,9$ & $-6,9$ & $-6,8$ & $-6,9$ & $-7,0$ & $-7,1$ & $-7,3$ & $-7,5$ & $-7,7$ & $-8,0$ & $-8,2$ & $-8,4$ & $-8,6$ & $-8,8$ & $-7,3$ \\
\hline $\mathrm{NH}_{3}$ & ${ }^{1} J_{\mathrm{NH}}$ & 44,0 & 43,9 & 43,8 & 43,7 & 43,6 & 43,5 & 43,5 & 43,6 & 43,7 & 43,8 & 44,0 & 44,2 & 44,4 & 44,6 & 44,8 & 43,8 \\
\hline $\mathrm{NH}_{3}$ & ${ }^{2} J_{\mathrm{HH}}$ & $-9,3$ & $-9,2$ & $-9,1$ & $-9,1$ & $-9,2$ & $-9,3$ & $-9,4$ & $-9,7$ & $-9,9$ & $-10,1$ & $-10,4$ & $-10,6$ & $-10,9$ & $-11,1$ & $-11,3$ & $-9,6$ \\
\hline $\mathrm{PH}_{3}$ & ${ }^{1} J_{\mathrm{PH}}$ & 168,4 & 167,3 & 165,5 & 163,1 & 161,0 & 159,7 & 159,4 & 160,1 & 161,6 & 163,7 & 166,1 & 168,8 & 171,5 & 174,1 & 176,6 & 188,2 \\
\hline $\mathrm{PF}_{3}$ & ${ }^{1} J_{\mathrm{PF}}$ & $-1639,4$ & $-1638,6$ & $-1637,3$ & $-1635,7$ & $-1634,2$ & $-1633,0$ & $-1631,9$ & $-1630,6$ & $-1628,8$ & $-1626,3$ & $-1623,0$ & $-1618,9$ & $-1614,2$ & $-1609,1$ & $-1603,7$ & -1441 \\
\hline $\mathrm{BHF}_{2}$ & ${ }^{1} J_{\mathrm{BF}}$ & $-125,7$ & $-126,3$ & $-125,8$ & $-124,2$ & $-122,0$ & $-119,3$ & $-116,2$ & $-113,1$ & $-109,8$ & $-106,4$ & $-103,1$ & $-99,8$ & $-96,7$ & $-93,7$ & $-90,9$ & -84 \\
\hline $\mathrm{BF}_{3}$ & ${ }^{1} J_{\mathrm{BF}}$ & $-24,4$ & $-24,7$ & $-23,9$ & $-22,1$ & $-19,5$ & $-16,4$ & $-12,9$ & $-9,3$ & $-5,6$ & $-1,9$ & 1,6 & 5,1 & 8,4 & 11,5 & 14,4 & 15 \\
\hline $\mathrm{F}_{2} \mathrm{O}$ & ${ }^{1} J_{\mathrm{OF}}$ & $-370,1$ & $-372,0$ & $-375,4$ & $-380,4$ & $-386,9$ & $-394,2$ & $-401,9$ & $-409,7$ & $-417,4$ & $-424,9$ & $-432,3$ & $-439,5$ & $-446,5$ & $-453,4$ & $-460,1$ & -300 \\
\hline $\mathrm{CH}_{4}$ & ${ }^{1} J_{\mathrm{CH}}$ & 123,9 & 123,0 & 122,2 & 121,4 & 120,8 & 120,4 & 120,3 & 120,5 & 120,9 & 121,5 & 122,2 & 123,0 & 123,8 & 124,5 & 125,3 & 125,3 \\
\hline $\mathrm{CH}_{4}$ & ${ }^{2} J_{\mathrm{HH}}$ & $-12,2$ & $-12,0$ & $-11,8$ & $-11,8$ & $-11,8$ & $-12,0$ & $-12,1$ & $-12,4$ & $-12,6$ & $-12,9$ & $-13,1$ & $-13,4$ & $-13,6$ & $-13,8$ & $-14,0$ & $-12,8$ \\
\hline $\mathrm{C}_{2} \mathrm{H}_{2}$ & ${ }^{1} J_{\mathrm{CC}}$ & 194,7 & 193,8 & 193,2 & 192,8 & 192,7 & 192,8 & 193,1 & 193,7 & 194,5 & 195,6 & 196,9 & 198,2 & 199,7 & 201,2 & 202,6 & 174,8 \\
\hline $\mathrm{C}_{2} \mathrm{H}_{2}$ & ${ }^{1} J_{\mathrm{CH}}$ & 255,4 & 253,8 & 252,2 & 250,7 & 249,5 & 248,9 & 248,8 & 249,1 & 249,9 & 250,9 & 252,2 & 253,5 & 255,0 & 256,4 & 257,8 & 247,6 \\
\hline $\mathrm{C}_{2} \mathrm{H}_{2}$ & ${ }^{2} J_{\mathrm{CH}}$ & 55,5 & 55,4 & 55,5 & 55,7 & 55,8 & 56,0 & 56,0 & 56,0 & 55,9 & 55,8 & 55,6 & 55,4 & 55,2 & 54,9 & 54,7 & 50,1 \\
\hline $\mathrm{C}_{2} \mathrm{H}_{2}$ & ${ }^{3} J_{\mathrm{HH}}$ & 10,4 & 10,2 & 10,1 & 10,0 & 10,0 & 10,1 & 10,2 & 10,4 & 10,7 & 10,9 & 11,2 & 11,5 & 11,8 & 12,1 & 12,4 & 9,6 \\
\hline $\mathrm{C}_{2} \mathrm{H}_{4}$ & ${ }^{1} J_{\mathrm{CC}}$ & 65,7 & 65,1 & 64,7 & 64,5 & 64,5 & 64,6 & 64,8 & 65,3 & 65,9 & 66,7 & 67,6 & 68,6 & 69,7 & 70,8 & 72,0 & 67,6 \\
\hline $\mathrm{C}_{2} \mathrm{H}_{4}$ & ${ }^{1} J_{\mathrm{CH}}$ & 158,3 & 157,3 & 156,3 & 155,4 & 154,8 & 154,5 & 154,5 & 154,9 & 155,6 & 156,4 & 157,4 & 158,5 & 159,6 & 160,6 & 161,7 & 156,3 \\
\hline $\mathrm{C}_{2} \mathrm{H}_{4}$ & ${ }^{2} J_{\mathrm{CH}}$ & $-1,2$ & $-1,1$ & $-1,1$ & $-1,1$ & $-1,1$ & $-1,3$ & $-1,5$ & $-1,7$ & $-2,0$ & $-2,3$ & $-2,7$ & $-3,1$ & $-3,4$ & $-3,8$ & $-4,1$ & $-2,4$ \\
\hline $\mathrm{C}_{2} \mathrm{H}_{4}$ & ${ }^{2} J_{\mathrm{HH}}$ & 4,1 & 4,1 & 4,2 & 4,1 & 4,0 & 3,8 & 3,6 & 3,4 & 3,1 & 2,9 & 2,6 & 2,3 & 2,1 & 1,9 & 1,7 & 2,3 \\
\hline $\mathrm{C}_{2} \mathrm{H}_{4}$ & ${ }^{3} J_{\mathrm{HH}_{\mathrm{c}}}$ & 12,1 & 12,1 & 12,1 & 12,1 & 12,2 & 12,3 & 12,4 & 12,5 & 12,6 & 12,7 & 12,9 & 13,0 & 13,1 & 13,3 & 13,4 & 11,7 \\
\hline $\mathrm{C}_{2} \mathrm{H}_{4}$ & ${ }^{3} J_{\mathrm{HH}_{\mathrm{t}}}$ & 19,0 & 18,8 & 18,7 & 18,6 & 18,6 & 18,6 & 18,6 & 18,7 & 18,9 & 19,0 & 19,2 & 19,4 & 19,6 & 19,8 & 19,9 & 19 \\
\hline $\mathrm{C}_{2} \mathrm{H}_{6}$ & ${ }^{1} J_{\mathrm{CC}}$ & 30,5 & 30,1 & 30,0 & 30,0 & 30,0 & 30,1 & 30,3 & 30,6 & 31,0 & 31,5 & 32,1 & 32,6 & 33,3 & 33,9 & 34,5 & 34,5 \\
\hline $\mathrm{C}_{2} \mathrm{H}_{6}$ & ${ }^{1} J_{\mathrm{CH}}$ & 124,6 & 123,7 & 122,8 & 122,1 & 121,5 & 121,2 & 121,1 & 121,4 & 121,8 & 122,4 & 123 & 124 & 124,8 & 125,6 & 126,4 & 125,2 \\
\hline $\mathrm{C}_{2} \mathrm{H}_{6}$ & ${ }^{2} J_{\mathrm{CH}}$ & $-3,5$ & $-3,5$ & $-3,4$ & $-3,4$ & $-3,5$ & $-3,5$ & $-3,6$ & $-3,7$ & $-3,9$ & $-4,0$ & $-4,2$ & $-4,3$ & $-4,4$ & $-4,6$ & $-4,7$ & $-4,7$ \\
\hline \multirow[t]{3}{*}{ Total } & $\mathrm{DM}$ & $-13,64$ & 5 & & & 6 & & & & & & & & & & & - \\
\hline & DMA & 17 & & & & & & & & & & & & & & & - \\
\hline & PDMA & 23,06 & 23,54 & 23,73 & 23,23 & 22,30 & 20,78 & 19,00 & 17,03 & 14,92 & 13,02 & 12,05 & 11,48 & 11,67 & 12,04 & 12,38 & - \\
\hline \multirow[t]{3}{*}{ CPI } & DM & $-35,26$ & 35,39 & -35 & & -35 , & & & -35 & & & & & & & & - \\
\hline & DMA &, 23 & 36,39 & 36 , & 36 , & 36,62 & 36 , & 36 & & & & & & & & & - \\
\hline & PDMA & 35,16 & 35,74 & 35,42 & 34,53 & 32,76 & 30,62 & 28,13 & 25,36 & 23,19 & 20,96 & 19,05 & 16,87 & 14,97 & 13,18 & 11,54 & - \\
\hline \multirow[t]{3}{*}{ SPI } & DM & 2,2 & & & & & & & & & & & & & & & - \\
\hline & & & & & & & & & & & & & & & & & - \\
\hline & PDMA & 14,19 & 14,60 & 15,16 & 14,94 & 14,63 & 13,55 & 12,31 & 10,92 & 8,85 & 7,20 & 6,91 & 7,53 & 9,24 & 11,20 & 12,99 & - \\
\hline \multirow[t]{3}{*}{$\Delta C S$} & & -3 & & & & & & & & & & & & & & & - \\
\hline & MA & 32,96 & & & & & & & & & & & & & & & - \\
\hline & & 20,97 & 21,14 & 20,26 & 19,58 & 18,13 & 17,07 & 15,82 & 14,44 & 14,34 & 13,76 & 12,14 & 9,35 & 5,72 & 1,98 & $-1,45$ & - \\
\hline
\end{tabular}


Tabela 8.380: Constantes de acoplamento LC-BB95 com $\alpha=40 \%$ e $\alpha+\beta=70 \%$, variando $\gamma$, na base aug-pcJ-2.

\begin{tabular}{|c|c|c|c|c|c|c|c|c|c|c|c|c|c|c|c|c|c|}
\hline & $\gamma$ & 0,05 & 0,10 & 0,15 & 0,20 & 0,25 & 0,30 & 0,35 & 0,40 & 0,45 & 0,50 & 0,55 & 0,60 & 0,65 & 0,70 & 0,75 & Exp. \\
\hline $\mathrm{HF}$ & ${ }^{1} J_{\mathrm{HF}}$ & 500,0 & 501,1 & 502,2 & 503,3 & 504,5 & 505,9 & 507,4 & 509,2 & 511,3 & 513,5 & 515,8 & 518,2 & 520,7 & 523,2 & 525,7 & 500 \\
\hline $\mathrm{CO}$ & ${ }^{1} J_{\mathrm{CO}}$ & 16,2 & 16,3 & 16,3 & 16,3 & 16,3 & 16,3 & 16,3 & 16,3 & 16,2 & 16,1 & 15,9 & 15,7 & 15,4 & 15,1 & 14,8 & 16,4 \\
\hline $\mathrm{H}_{2} \mathrm{O}$ & ${ }^{1} J_{\mathrm{OH}}$ & $-80,4$ & $-80,4$ & $-80,5$ & $-80,5$ & $-80,6$ & $-80,7$ & $-80,8$ & $-81,0$ & $-81,2$ & $-81,5$ & $-81,8$ & $-82,1$ & $-82,5$ & $-82,8$ & $-83,2$ & $-80,6$ \\
\hline $\mathrm{H}_{2} \mathrm{O}$ & ${ }^{2} J_{\mathrm{HH}}$ & $-8,1$ & $-8,0$ & $-7,9$ & $-7,9$ & $-8,0$ & $-8,0$ & $-8,1$ & $-8,3$ & $-8,4$ & $-8,6$ & $-8,8$ & $-8,9$ & $-9,1$ & $-9,3$ & $-9,4$ & $-7,3$ \\
\hline $\mathrm{NH}_{3}$ & ${ }^{1} J_{\mathrm{NH}}$ & 44,8 & 44,7 & 44,6 & 44,5 & 44,5 & 44,4 & 44,4 & 44,5 & 44,5 & 44,6 & 44,8 & 44,9 & 45,1 & 45,2 & 45,4 & 43,8 \\
\hline $\mathrm{NH}_{3}$ & ${ }^{2} J_{\mathrm{HH}}$ & $-10,2$ & $-10,1$ & $-10,1$ & $-10,0$ & $-10,1$ & $-10,2$ & $-10,3$ & $-10,5$ & $-10,6$ & $-10,8$ & $-11,0$ & $-11,2$ & $-11,4$ & $-11,6$ & $-11,7$ & $-9,6$ \\
\hline $\mathrm{PH}_{3}$ & ${ }^{1} J_{\mathrm{PH}}$ & 175,8 & 174,9 & 173,5 & 171,8 & 170,2 & 169,2 & 168,9 & 169,4 & 170,6 & 172,1 & 174,0 & 176,0 & 178,0 & 180,0 & 181,9 & 188,2 \\
\hline $\mathrm{PF}_{3}$ & ${ }^{1} J_{\mathrm{PF}}$ & $-1606,9$ & $-1606,5$ & $-1605,5$ & $-1604,1$ & $-1602,6$ & $-1601,2$ & $-1599,9$ & $-1598,5$ & $-1596,7$ & $-1594,5$ & $-1591,7$ & $-1588,4$ & $=-1584,7$ & $-1580,8$ & $-1576,7$ & -1441 \\
\hline $\mathrm{BHF}_{2}$ & ${ }^{1} J_{\mathrm{BF}}$ & $-108,7$ & $-109,2$ & $-108,9$ & $-107,8$ & $-106,2$ & $-104,2$ & $-102,0$ & $-99,6$ & $-97,1$ & $-94,6$ & $-92,1$ & $-89,7$ & $-87,4$ & $-85,1$ & $-83,0$ & -84 \\
\hline $\mathrm{BF}_{3}$ & ${ }^{1} J_{\mathrm{BF}}$ & $-6,1$ & $-6,4$ & $-5,8$ & $-4,6$ & $-2,7$ & $-0,5$ & 2,0 & 4,7 & 7,5 & 10,2 & 12,9 & 15,5 & 18,0 & 20,3 & 22,5 & 15 \\
\hline $\mathrm{F}_{2} \mathrm{O}$ & ${ }^{1} J_{\mathrm{OF}}$ & $-405,3$ & $-406,7$ & $-409,3$ & $-413,2$ & $-418,3$ & $-424,2$ & $-430,5$ & $-436,9$ & $-443,3$ & $-449,6$ & $-455,8$ & $-461,8$ & $-467,7$ & $-473,5$ & $-479,1$ & -300 \\
\hline $\mathrm{CH}_{4}$ & ${ }^{1} J_{\mathrm{CH}}$ & 125,5 & 124,8 & 124,2 & 123,6 & 123,1 & 122,8 & 122,8 & 122,9 & 123,3 & 123,7 & 124,2 & 124,8 & 125,4 & 126,0 & 126,6 & 125,3 \\
\hline $\mathrm{CH}_{4}$ & ${ }^{2} J_{\mathrm{HH}}$ & $-12,9$ & $-12,7$ & $-12,6$ & $-12,6$ & $-12,6$ & $-12,7$ & $-12,8$ & $-13,0$ & $-13,2$ & $-13,4$ & $-13,6$ & $-13,8$ & $-14,0$ & $-14,1$ & $-14,3$ & $-12,8$ \\
\hline $\mathrm{C}_{2} \mathrm{H}_{2}$ & ${ }^{1} J_{\mathrm{CC}}$ & 198,3 & 197,6 & 197,1 & 196,9 & 196,8 & 196,9 & 197,2 & 197,8 & 198,5 & 199,4 & 200,4 & 201,5 & 202,7 & 203,9 & 205,0 & 174,8 \\
\hline $\mathrm{C}_{2} \mathrm{H}_{2}$ & ${ }^{1} J_{\mathrm{CH}}$ & 257,8 & 256,6 & 255,4 & 254,2 & 253,4 & 252,9 & 252,8 & 253,1 & 253,7 & 254,5 & 255,5 & 256,6 & 257,7 & 258,8 & 259,9 & 247,6 \\
\hline $\mathrm{C}_{2} \mathrm{H}_{2}$ & ${ }^{2} J_{\mathrm{CH}}$ & 55,2 & 55,2 & 55,2 & 55,3 & 55,4 & 55,5 & 55,5 & 55,5 & 55,4 & 55,2 & 55,1 & 54,9 & 54,7 & 54,4 & 54,2 & 50,1 \\
\hline $\mathrm{C}_{2} \mathrm{H}_{2}$ & ${ }^{3} J_{\mathrm{HH}}$ & 11,1 & 11,0 & 10,8 & 10,8 & 10,8 & 10,9 & 11,0 & 11,2 & 11,4 & 11,6 & 11,8 & 12,1 & 12,3 & 12,5 & 12,7 & 9,6 \\
\hline $\mathrm{C}_{2} \mathrm{H}_{4}$ & ${ }^{1} J_{\mathrm{CC}}$ & 68,9 & 68,4 & 68,1 & 67,9 & 67,9 & 68,0 & 68,3 & 68,7 & 69,2 & 69,9 & 70,7 & 71,5 & 72,4 & 73,3 & 74,1 & 67,6 \\
\hline $\mathrm{C}_{2} \mathrm{H}_{4}$ & ${ }^{1} J_{\mathrm{CH}}$ & 160,6 & 159,8 & 159,0 & 158,3 & 157,9 & 157,7 & 157,7 & 158,1 & 158,6 & 159,2 & 160,0 & 160,8 & 161,7 & 162,5 & 163,3 & 156,3 \\
\hline $\mathrm{C}_{2} \mathrm{H}_{4}$ & ${ }^{2} J_{\mathrm{CH}}$ & $-2,2$ & $-2,1$ & $-2,1$ & $-2,1$ & $-2,1$ & $-2,3$ & $-2,4$ & $-2,6$ & $-2,9$ & $-3,2$ & $-3,5$ & $-3,8$ & $-4,0$ & $-4,3$ & $-4,6$ & $-2,4$ \\
\hline $\mathrm{C}_{2} \mathrm{H}_{4}$ & ${ }^{2} J_{\mathrm{HH}}$ & 3,3 & 3,4 & 3,4 & 3,4 & 3,3 & 3,1 & 3,0 & 2,8 & 2,6 & 2,3 & 2,1 & 1,9 & 1,7 & 1,6 & 1,4 & 2,3 \\
\hline $\mathrm{C}_{2} \mathrm{H}_{4}$ & ${ }^{3} J_{\mathrm{HH}}$ & 12,4 & 12,4 & 12,4 & 12,4 & 12,5 & 12,5 & 12,6 & 12,7 & 12,8 & 13,0 & 13,1 & 13,2 & 13,3 & 13,4 & 13,5 & 11,7 \\
\hline $\mathrm{C}_{2} \mathrm{H}_{4}$ & ${ }^{3} J_{\mathrm{HH}_{\mathrm{t}}}$ & 19,3 & 19,2 & 19,1 & 19,1 & 19,1 & 19,1 & 19,1 & 19,2 & 19,3 & 19,5 & 19,6 & 19,8 & 19,9 & 20,1 & 20,2 & 19 \\
\hline $\mathrm{C}_{2} \mathrm{H}_{6}$ & ${ }^{1} J_{\mathrm{CC}}$ & 32,6 & 32,3 & 32,2 & 32,2 & 32,2 & 32,3 & 32,5 & 32,7 & 33,0 & 33,4 & 33,8 & 34,2 & 34,7 & 35,2 & 35,6 & 34,5 \\
\hline $\mathrm{C}_{2} \mathrm{H}_{6}$ & ${ }^{1} J_{\mathrm{CH}}$ & 126,3 & 125,7 & 125,0 & 124,4 & 124,0 & 123,7 & 123,7 & 123,9 & 124,3 & 124,7 & 125,3 & 125,9 & 126,5 & 127,1 & 127,8 & 125,2 \\
\hline $\mathrm{C}_{2} \mathrm{H}_{6}$ & ${ }^{2} J_{\mathrm{CH}}$ & $-4,0$ & $-3,9$ & $-3,9$ & $-3,9$ & $-3,9$ & $-4,0$ & $-4,1$ & $-4,2$ & $-4,3$ & $-4,4$ & $-4,5$ & $-4,6$ & $-4,7$ & $-4,8$ & $-4,9$ & $-4,7$ \\
\hline \multirow[t]{3}{*}{ Total } & DM & $-10,83$ & $-11,06$ & $-11,27$ & $-11,43$ & $-11,55$ & $-11,61$ & $-11,57$ & $-11,42$ & -11 & $-10,87$ & $-10,49$ & $-10,07$ & $-9,63$ & $-9,18$ & $-8,74$ & - \\
\hline & DMA & 14,7 & 14,79 & 14,80 & 14,87 & 14,98 & & 15,17 & & & & & & & & & - \\
\hline & PDMA & 14,38 & 14,69 & 14,41 & 14,08 & 13,59 & 12,36 & 11,44 & 11,04 & 10,66 & 10,29 & 10,75 & 11,51 & 13,25 & 15,15 & 17,22 & - \\
\hline \multirow[t]{3}{*}{ CPI } & DM & $-29,98$ & $-30,11$ & $-30,21$ & $-30,28$ & $-30,35$ & $-30,37$ & $-30,32$ & $-30,15$ & $-29,83$ & $-29,45$ & $-28,97$ & $-28,43$ & $-27,86$ & $-27,29$ & $-26,70$ & - \\
\hline & DMA & 30,20 & 30,51 & 30,77 & 31,03 & 31,30 & 31,55 & 31,77 & 31,95 & 32,01 & 32,05 & 32,03 & 32,03 & 32,41 & 32,73 & 33,21 & - \\
\hline & PDMA & 22,20 & 22,25 & 21,85 & 21,10 & 20,23 & 19,01 & 17,71 & 16,49 & 14,98 & 13,77 & 12,61 & 11,97 & 14,03 & 15,93 & 17,82 & - \\
\hline \multirow[t]{3}{*}{ SPI } & DM & 3,21 & 2,91 & 2,61 & 2,39 & 2,25 & 2,15 & 2,19 & 2,3 & 2,5 & 2,75 & 3,06 & 3,39 & 3,75 & 4,10 & 4,43 & - \\
\hline & DMA & 3,47 & 3,27 & 3,09 & 3,03 & 3,01 & 2,98 & 2,99 & 3,10 & 3,21 & 3,37 & 3,58 & 3,87 & 4,20 & 4,63 & 5,07 & - \\
\hline & PDMA & 8,64 & 9,15 & 8,95 & 8,93 & 8,72 & 7,48 & 6,84 & 7,04 & 7,49 & 7,74 & 9,39 & 11,18 & 12,68 & 14,58 & 16,77 & - \\
\hline \multirow[t]{3}{*}{$\Delta \mathrm{CS}$} & DM & $-33,19$ & $-33,02$ & $-32,82$ & $-32,67$ & $-32,60$ & & $-32,50$ & $-32,46$ & $-32,33$ & $-32,21$ & & & $-31,61$ & & $-31,13$ & - \\
\hline & DMA & 26,73 & 27,24 & 27,68 & 28,00 & 28,29 & 28,57 & 28,79 & 28,85 & 28,80 & 28,69 & 28,45 & 28,15 & 28,21 & 28,09 & 28,14 & - \\
\hline & PDMA & 13,56 & 13,10 & 12,91 & 12,17 & 11,51 & 11,53 & 10,87 & 9,45 & 7,49 & 6,03 & 3,22 & 0,79 & 1,35 & 1,35 & 1,05 & - \\
\hline
\end{tabular}


Tabela 8.381: Constantes de acoplamento LC-BB95 com $\alpha=50 \%$ e $\alpha+\beta=70 \%$, variando $\gamma$, na base aug-pcJ-2.

\begin{tabular}{|c|c|c|c|c|c|c|c|c|c|c|c|c|c|c|c|c|c|}
\hline & $\gamma$ & 0,05 & 0,10 & 0,15 & 0,20 & 0,25 & 0,30 & 0,35 & 0,40 & 0,45 & 0,50 & 0,55 & 0,60 & 0,65 & 0,70 & 0,75 & Exp. \\
\hline $\mathrm{HF}$ & ${ }^{1} J_{\mathrm{HF}}$ & 524,0 & 524,7 & 525,4 & 526,1 & 526,9 & 527,8 & 528,9 & 530,1 & 531,4 & 532,9 & 534,4 & 536,0 & 537,6 & 539,3 & 541,0 & 500 \\
\hline $\mathrm{CO}$ & ${ }^{1} J_{\mathrm{CO}}$ & 14,1 & 14,1 & 14,2 & 14,2 & 14,2 & 14,2 & 14,2 & 14,2 & 14,1 & 14,1 & 13,9 & 13,8 & 13,6 & 13,4 & 13,2 & 16,4 \\
\hline $\mathrm{H}_{2} \mathrm{O}$ & ${ }^{1} J_{\mathrm{OH}}$ & $-83,0$ & $-83,0$ & $-83,0$ & $-83,0$ & $-83,1$ & $-83,1$ & $-83,2$ & $-83,3$ & $-83,5$ & $-83,7$ & $-83,9$ & $-84,1$ & $-84,3$ & $-84,6$ & $-84,8$ & $-80,6$ \\
\hline $\mathrm{H}_{2} \mathrm{O}$ & ${ }^{2} J_{\mathrm{HH}}$ & $-9,2$ & $-9,1$ & $-9,1$ & $-9,0$ & $-9,1$ & $-9,1$ & $-9,2$ & $-9,3$ & $-9,4$ & $-9,5$ & $-9,6$ & $-9,7$ & $-9,8$ & $-10,0$ & $-10,1$ & $-7,3$ \\
\hline $\mathrm{NH}_{3}$ & ${ }^{1} J_{\mathrm{NH}}$ & 45,6 & 45,5 & 45,5 & 45,4 & 45,3 & 45,3 & 45,3 & 45,3 & 45,4 & 45,5 & 45,5 & 45,6 & 45,8 & 45,9 & 46,0 & 43,8 \\
\hline $\mathrm{NH}_{3}$ & ${ }^{2} J_{\mathrm{HH}}$ & $-11,2$ & $-11,1$ & $-11,0$ & $-11,0$ & $-11,0$ & $-11,1$ & $-11,2$ & $-11,3$ & $-11,4$ & $-11,5$ & $-11,7$ & $-11,8$ & $-11,9$ & $-12,0$ & $-12,2$ & $-9,6$ \\
\hline $\mathrm{PH}_{3}$ & ${ }^{1} J_{\mathrm{PH}}$ & 183,1 & 182,5 & 181,5 & 180,4 & 179,3 & 178,6 & 178,5 & 178,8 & 179,5 & 180,6 & 181,8 & 183,2 & 184,5 & 185,8 & 187,1 & 188,2 \\
\hline $\mathrm{PF}_{3}$ & ${ }^{1} J_{\mathrm{PF}}$ & $-1571,6$ & $-1571,5$ & $-1570,9$ & $-1569,8$ & $-1568,6$ & $-1567,4$ & $-1566,3$ & $-1565,0$ & $-1563,6$ & $-1561,9$ & $-1559,9$ & $-1557,6$ & $-1555,0$ & $-1552,3$ & $-1549,6$ & -1441 \\
\hline $\mathrm{BHF}_{2}$ & ${ }^{1} J_{\mathrm{BF}}$ & $-91,8$ & $-92,2$ & $-92,0$ & $-91,4$ & $-90,3$ & $-89,0$ & $-87,5$ & $-86,0$ & $-84,3$ & $-82,7$ & $-81,0$ & $-79,4$ & $-77,8$ & $-76,3$ & $-74,9$ & -84 \\
\hline $\mathrm{BF}_{3}$ & ${ }^{1} J_{\mathrm{BF}}$ & 12,0 & 11,8 & 12,1 & 12,8 & 14,0 & 15,5 & 17,2 & 18,9 & 20,8 & 22,6 & 24,4 & 26,1 & 27,7 & 29,3 & 30,8 & 15 \\
\hline $\mathrm{F}_{2} \mathrm{O}$ & ${ }^{1} J_{\mathrm{OF}}$ & $-444,2$ & $-445,1$ & $-446,9$ & $-449,8$ & $-453,5$ & $-457,9$ & $-462,6$ & $-467,5$ & $-472,4$ & $-477,3$ & $-482,0$ & $-486,7$ & $-491,2$ & $-495,5$ & $-499,7$ & -300 \\
\hline $\mathrm{CH}_{4}$ & ${ }^{1} J_{\mathrm{CH}}$ & 127,1 & 126,7 & 126,2 & 125,8 & 125,5 & 125,3 & 125,3 & 125,4 & 125,6 & 125,9 & 126,3 & 126,6 & 127,1 & 127,5 & 127,8 & 125,3 \\
\hline $\mathrm{CH}_{4}$ & ${ }^{2} J_{\mathrm{HH}}$ & $-13,6$ & $-13,5$ & $-13,4$ & $-13,4$ & $-13,4$ & $-13,5$ & $-13,6$ & $-13,7$ & $-13,8$ & $-13,9$ & $-14,1$ & $-14,2$ & $-14,3$ & $-14,4$ & $-14,5$ & $-12,8$ \\
\hline $\mathrm{C}_{2} \mathrm{H}_{2}$ & ${ }^{1} J_{\mathrm{CC}}$ & 202,5 & 202,0 & 201,6 & 201,5 & 201,4 & 201,6 & 201,9 & 202,3 & 202,8 & 203,5 & 204,3 & 205,1 & 205,9 & 206,7 & 207,5 & 174,8 \\
\hline $\mathrm{C}_{2} \mathrm{H}_{2}$ & ${ }^{1} J_{\mathrm{CH}}$ & 260,5 & 259,6 & 258,8 & 258,0 & 257,5 & 257,2 & 257,1 & 257,3 & 257,8 & 258,4 & 259,0 & 259,8 & 260,5 & 261,3 & 262,0 & 247,6 \\
\hline $\mathrm{C}_{2} \mathrm{H}_{2}$ & ${ }^{2} J_{\mathrm{CH}}$ & 54,6 & 54,6 & 54,7 & 54,8 & 54,8 & 54,9 & 54,8 & 54,8 & 54,7 & 54,5 & 54,4 & 54,2 & 54,1 & 53,9 & 53,7 & 50,1 \\
\hline $\mathrm{C}_{2} \mathrm{H}_{2}$ & ${ }^{3} J_{\mathrm{HH}}$ & 11,9 & 11,8 & 11,8 & 11,7 & 11,7 & 11,8 & 11,9 & 12,0 & 12,2 & 12,4 & 12,5 & 12,7 & 12,9 & 13,0 & 13,2 & 9,6 \\
\hline $\mathrm{C}_{2} \mathrm{H}_{4}$ & ${ }^{1} J_{\mathrm{CC}}$ & 72,5 & 72,1 & 71,9 & 71,8 & 71,8 & 71,9 & 72,1 & 72,4 & 72,8 & 73,4 & 73,9 & 74,5 & 75,2 & 75,8 & 76,4 & 67,6 \\
\hline $\mathrm{C}_{2} \mathrm{H}_{4}$ & ${ }^{1} J_{\mathrm{CH}}$ & 163,0 & 162,5 & 161,9 & 161,5 & 161,2 & 161,0 & 161,1 & 161,3 & 161,7 & 162,2 & 162,7 & 163,3 & 163,9 & 164,5 & 165,0 & 156,3 \\
\hline $\mathrm{C}_{2} \mathrm{H}_{4}$ & ${ }^{2} J_{\mathrm{CH}}$ & $-3,4$ & $-3,3$ & $-3,2$ & $-3,2$ & $-3,3$ & $-3,4$ & $-3,5$ & $-3,7$ & $-3,9$ & $-4,1$ & $-4,3$ & $-4,5$ & $-4,7$ & $-4,9$ & $-5,1$ & $-2,4$ \\
\hline $\mathrm{C}_{2} \mathrm{H}_{4}$ & ${ }^{2} J_{\mathrm{HH}}$ & 2,5 & 2,6 & 2,6 & 2,5 & 2,5 & 2,4 & 2,3 & 2,1 & 2,0 & 1,8 & 1,6 & 1,5 & 1,4 & 1,2 & 1,1 & 2,3 \\
\hline $\mathrm{C}_{2} \mathrm{H}_{4}$ & ${ }^{3} J_{\mathrm{HH}}$ & 12,8 & 12,8 & 12,8 & 12,8 & 12,8 & 12,9 & 13,0 & 13,1 & 13,1 & 13,2 & 13,3 & 13,4 & 13,5 & 13,6 & 13,6 & 11,7 \\
\hline $\mathrm{C}_{2} \mathrm{H}_{4}$ & ${ }^{3} J_{\mathrm{HH}_{\mathrm{t}}}$ & 19,8 & 19,7 & 19,7 & 19,6 & 19,6 & 19,7 & 19,7 & 19,8 & 19,9 & 20,0 & 20,1 & 20,2 & 20,3 & 20,4 & 20,5 & 19 \\
\hline $\mathrm{C}_{2} \mathrm{H}_{6}$ & ${ }^{1} J_{\mathrm{CC}}$ & 34,8 & 34,6 & 34,5 & 34,4 & 34,5 & 34,5 & 34,6 & 34,8 & 35,0 & 35,3 & 35,6 & 35,9 & 36,2 & 36,5 & 36,8 & 34,5 \\
\hline $\mathrm{C}_{2} \mathrm{H}_{6}$ & ${ }^{1} J_{\mathrm{CH}}$ & 128,1 & 127,7 & 127,2 & 126,8 & 126,5 & 126,4 & 126,4 & 126,5 & 126,7 & 127,0 & 127,4 & 127,8 & 128,2 & 128,7 & 129,1 & 125,2 \\
\hline $\mathrm{C}_{2} \mathrm{H}_{6}$ & ${ }^{2} J_{\mathrm{CH}}$ & $-4,5$ & $-4,4$ & $-4,4$ & $-4,4$ & $-4,4$ & $-4,5$ & $-4,5$ & $-4,6$ & $-4,6$ & $-4,7$ & $-4,8$ & $-4,9$ & $-4,9$ & $-5,0$ & $-5,1$ & $-4,7$ \\
\hline \multirow[t]{3}{*}{ Total } & DM & $-8,02$ & $-8,19$ & $-8,33$ & $-8,46$ & $-8,55$ & $-8,58$ & $-8,55$ & $-8,47$ & $-8,32$ & $-8,12$ & $-7,89$ & $-7,62$ & $-7,33$ & $-7,05$ & $-6,78$ & - \\
\hline & DMA & 15,11 & 15,07 & 15, & 15,02 & & & 15,40 & & & 39 & & & & & & - \\
\hline & PDMA & 11,63 & 11,52 & 11,14 & 10,67 & 10,55 & 10,51 & 11,16 & 12,45 & 13,74 & 15,25 & 17,03 & 18,56 & 20,04 & 21,75 & 23,25 & - \\
\hline \multirow[t]{3}{*}{ CPI } & DM & $-24,83$ & $-24,94$ & $-25,01$ & $-25,09$ & $-25,16$ & $-25,19$ & $-25,16$ & $-25,09$ & $-24,94$ & $-24,71$ & $-24,45$ & $-24,14$ & $-23,79$ & $-23,45$ & $-23,10$ & - \\
\hline & DMA & 29,52 & 29,74 & 29,94 & 30,13 & 30,33 & 30,61 & 31,09 & 31,55 & 31,99 & 32,62 & 33,27 & 33,86 & 34,43 & 34,97 & 35,48 & - \\
\hline & PDMA & 14,34 & 14,33 & 14,09 & 13,60 & 13,04 & 12,87 & 14,13 & 15,38 & 16,79 & 18,36 & 20,19 & 21,80 & 23,42 & 25,14 & 26,75 & - \\
\hline \multirow[t]{3}{*}{ SPI } & DM & 4,30 & 4,09 & 3,91 & 3,74 & 3,64 & 3,61 & 3,63 & 3,7 & 3,86 & 4,05 & 4,25 & 4,49 & 4,75 & 4,98 & 5,19 & - \\
\hline & DMA & 4,54 & 4,31 & 4,09 & 3,94 & 3,84 & 3,83 & 3,89 & 4,03 & 4,23 & 4,49 & 4,79 & 5,09 & 5,40 & 5,71 & 5,99 & - \\
\hline & PDMA & 9,64 & 9,45 & 8,98 & 8,53 & 8,72 & 8,78 & 8,99 & 10,30 & 11,51 & 12,97 & 14,72 & 16,19 & 17,56 & 19,27 & 20,68 & - \\
\hline \multirow[t]{3}{*}{$\Delta \mathrm{CS}$} & DM & $-29,13$ & $-29,03$ & $-28,92$ & $-28,83$ & $-28,80$ & & $-28,80$ & $-28,80$ & $-28,80$ & $-28,76$ & $-28,71$ & 62 & $-28,54$ & $-28,43$ & $-28,29$ & - \\
\hline & DMA & 24,98 & 25,43 & 25,84 & 26,19 & 26,49 & 26,78 & 27,20 & 27,51 & 27,76 & 28,12 & 28,49 & 28,78 & 29,03 & 29,26 & 29,49 & - \\
\hline & PDMA & 4,70 & 4,88 & 5,11 & 5,08 & 4,32 & 4,09 & 5,14 & 5,07 & 5,28 & 5,39 & 5,47 & 5,60 & 5,86 & 5,88 & 6,07 & - \\
\hline
\end{tabular}




\subsubsection{BHandH (LC-SLYP)}

Tabela 8.382: Constantes de acoplamento LC-SLYP com $\alpha=0 \%$ e $\alpha+\beta=100 \%$, variando $\gamma$, na base aug-pcJ-2.

\begin{tabular}{|c|c|c|c|c|c|c|c|c|c|c|c|c|c|c|c|c|c|}
\hline & $\gamma$ & 0,05 & 0,10 & 0,15 & 0,20 & 0,25 & 0,30 & 0,35 & 0,40 & 0,45 & 0,50 & 0,55 & 0,60 & 0,65 & 0,70 & 0,75 & Exp. \\
\hline $\mathrm{HF}$ & ${ }^{1} J_{\mathrm{HF}}$ & 421,2 & 422,6 & 424,2 & 426,0 & 428,3 & 431,6 & 436,1 & 441,9 & 448,8 & 456,7 & 465,1 & 473,9 & 483,0 & 492,1 & 501,2 & 500 \\
\hline $\mathrm{CO}$ & ${ }^{1} J_{\mathrm{CO}}$ & 24,7 & 24,4 & 24,1 & 23,8 & 23,5 & 23,4 & 23,2 & 22,9 & 22,5 & 21,9 & 21,2 & 20,4 & 19,4 & 18,3 & 17,1 & 16,4 \\
\hline $\mathrm{H}_{2} \mathrm{O}$ & ${ }^{1} J_{\mathrm{OH}}$ & $-70,0$ & $-70,1$ & $-70,2$ & $-70,4$ & $-70,6$ & $-71,1$ & $-71,7$ & $-72,6$ & $-73,6$ & $-74,7$ & $-76,0$ & $-77,3$ & $-78,6$ & $-80,0$ & $-81,5$ & $-80,6$ \\
\hline $\mathrm{H}_{2} \mathrm{O}$ & ${ }^{2} J_{\mathrm{HH}}$ & $-3,3$ & $-3,3$ & $-3,4$ & $-3,6$ & $-3,9$ & $-4,3$ & $-4,8$ & $-5,3$ & $-5,9$ & $-6,6$ & $-7,2$ & $-7,9$ & $-8,5$ & $-9,2$ & $-9,8$ & $-7,3$ \\
\hline $\mathrm{NH}_{3}$ & ${ }^{1} J_{\mathrm{NH}}$ & 39,4 & 39,4 & 39,4 & 39,3 & 39,3 & 39,5 & 39,7 & 40,1 & 40,6 & 41,2 & 41,8 & 42,6 & 43,3 & 44,1 & 44,9 & 43,8 \\
\hline $\mathrm{NH}_{3}$ & ${ }^{2} J_{\mathrm{HH}}$ & $-5,4$ & $-5,4$ & $-5,5$ & $-5,8$ & $-6,2$ & $-6,7$ & $-7,2$ & $-7,9$ & $-8,6$ & $-9,4$ & $-10,1$ & $-10,9$ & $-11,6$ & $-12,3$ & $-13,0$ & $-9,6$ \\
\hline $\mathrm{PH}_{3}$ & ${ }^{1} J_{\mathrm{PH}}$ & 135,9 & 135,0 & 131,6 & 127,0 & 123,2 & 121,7 & 122,8 & 126,3 & 131,8 & 138,6 & 146,3 & 154,4 & 162,5 & 170,4 & 177,8 & 188,2 \\
\hline $\mathrm{PF}_{3}$ & ${ }^{1} J_{\mathrm{PF}}$ & $-1812,9$ & $-1811,2$ & $-1811,5$ & $-1813,2$ & $-1815,6$ & $-1817,6$ & $-1818,3$ & $-1816,4$ & $-1811,1$ & $-1802,1$ & $-1789,9$ & $-1775,0$ & $-1758,4$ & $-1740,8$ & $-1722,8$ & -1441 \\
\hline $\mathrm{BHF}_{2}$ & ${ }^{1} J_{\mathrm{BF}}$ & $-187,0$ & $-184,7$ & $-180,0$ & $-173,2$ & $-165,0$ & $-156,0$ & $-146,6$ & $-137,0$ & $-127,3$ & $-117,7$ & $-108,3$ & $-99,3$ & $-90,8$ & $-82,8$ & $-75,4$ & -84 \\
\hline $\mathrm{BF}_{3}$ & ${ }^{1} J_{\mathrm{BF}}$ & $-79,4$ & $-77,3$ & $-72,8$ & $-66,0$ & $-57,5$ & $-47,9$ & $-37,7$ & $-27,3$ & $-16,9$ & $-6,8$ & 2,8 & 11,9 & 20,5 & 28,4 & 35,8 & 15 \\
\hline $\mathrm{F}_{2} \mathrm{O}$ & ${ }^{1} J_{\mathrm{OF}}$ & $-272,4$ & $-275,3$ & $-282,7$ & $-294,8$ & $-310,7$ & $-328,7$ & $-347,3$ & $-365,8$ & $-383,9$ & $-401,7$ & $-419,7$ & $-438,1$ & $-457,4$ & $-477,6$ & $-499,0$ & -300 \\
\hline $\mathrm{CH}_{4}$ & ${ }^{1} J_{\mathrm{CH}}$ & 105,9 & 105,6 & 105,1 & 104,7 & 104,7 & 105,2 & 106,4 & 108,1 & 110,3 & 112,8 & 115,6 & 118,5 & 121,4 & 124,3 & 127,1 & 125,3 \\
\hline $\mathrm{CH}_{4}$ & ${ }^{2} J_{\mathrm{HH}}$ & $-7,9$ & $-7,8$ & $-7,9$ & $-8,2$ & $-8,6$ & $-9,2$ & $-9,9$ & $-10,7$ & $-11,5$ & $-12,3$ & $-13,1$ & $-13,9$ & $-14,7$ & $-15,4$ & $-16,0$ & $-12,8$ \\
\hline $\mathrm{C}_{2} \mathrm{H}_{2}$ & ${ }^{1} J_{\mathrm{CC}}$ & 175,5 & 175,7 & 176,2 & 176,9 & 177,7 & 178,9 & 180,5 & 182,7 & 185,6 & $18 \mathrm{~s}$ & 193,3 & & 203,0 & 208,3 & & 174,8 \\
\hline $\mathrm{C}_{2} \mathrm{H}_{2}$ & ${ }^{1} J_{\mathrm{CH}}$ & 226,1 & 225,2 & 224,0 & 223,1 & 223,0 & 223,9 & 226,0 & 229,0 & 232,9 & $23^{\prime}$ & 242,6 & & & 259,2 & 264 & 247,6 \\
\hline $\mathrm{C}_{2} \mathrm{H}_{2}$ & ${ }^{2} J_{\mathrm{CH}}$ & 51,2 & 51,4 & 51,9 & 52,6 & 53,5 & 54,2 & 54,8 & 55,1 & 55,3 & 55,2 & 54,8 & 54,2 & 53,4 & 52,3 & 51,2 & 50,1 \\
\hline $\mathrm{C}_{2} \mathrm{H}_{2}$ & ${ }^{3} J_{\mathrm{HH}}$ & 7,1 & 7,0 & 6,9 & 6,9 & 7,1 & 7,3 & 7,8 & 8,4 & 9,1 & 9,9 & 10,9 & 11,9 & 13,0 & 14,1 & 15,3 & 9,6 \\
\hline $\mathrm{C}_{2} \mathrm{H}_{4}$ & ${ }^{1} J_{\mathrm{CC}}$ & 50,5 & 50,8 & 51,4 & 52,1 & 52,9 & 53,8 & 55,0 & 56,7 & 58,9 & 61,6 & 64,8 & 68,6 & 72,8 & 77,4 & 82,2 & 67,6 \\
\hline $\mathrm{C}_{2} \mathrm{H}_{4}$ & ${ }^{1} J_{\mathrm{CH}}$ & 136,1 & 135,6 & 135,0 & 134,6 & 134,8 & 135,7 & 137,3 & 139,7 & 142,6 & 146,1 & 149,8 & 153,9 & 158,0 & 162,3 & 166,6 & 156,3 \\
\hline $\mathrm{C}_{2} \mathrm{H}_{4}$ & ${ }^{2} J_{\mathrm{CH}}$ & 0,9 & 0,9 & 1,0 & 0,9 & 0,8 & 0,5 & 0,1 & $-0,4$ & $-1,1$ & $-2,0$ & $-3,0$ & $-4,1$ & $-5,5$ & $-6,9$ & $-8,4$ & $-2,4$ \\
\hline $\mathrm{C}_{2} \mathrm{H}_{4}$ & ${ }^{2} J_{\mathrm{HH}}$ & 5,5 & 5,5 & 5,5 & 5,3 & 5,1 & 4,7 & 4,2 & 3,6 & 3,0 & 2,3 & 1,5 & 0,7 & $-0,1$ & $-1,0$ & $-2,0$ & 2,3 \\
\hline $\mathrm{C}_{2} \mathrm{H}_{4}$ & ${ }^{3} J_{\mathrm{HH}_{\mathrm{c}}}$ & 11,2 & 11,3 & 11,3 & 11,4 & 11,6 & 11,8 & 12,0 & 12,3 & 12,7 & 13,2 & 13,7 & 14,4 & 15,0 & 15,8 & 16,5 & 11,7 \\
\hline $\mathrm{C}_{2} \mathrm{H}_{4}$ & ${ }^{3} J_{\mathrm{HH}_{\mathrm{t}}}$ & 16,2 & 16,1 & 16,0 & 16,0 & 16,0 & 16,1 & 16,4 & 16,8 & 17,3 & 17,9 & 18,7 & 19,5 & 20,4 & 21,4 & 22,5 & 19 \\
\hline $\mathrm{C}_{2} \mathrm{H}_{6}$ & ${ }^{1} J_{\mathrm{CC}}$ & 18,8 & 19,2 & 19,9 & 20,6 & 21,5 & 22,3 & 23,4 & 24,6 & 26 , & 27,7 & 29,5 & 31,3 & 33,2 & 35,1 & 37,0 & 34,5 \\
\hline $\mathrm{C}_{2} \mathrm{H}_{6}$ & ${ }^{1} J_{\mathrm{CH}}$ & 106,0 & 105,6 & 105,0 & 104,6 & 104, & 105,3 & 106,6 & & 110 & 113,4 & 116,3 & 119,2 & 122,3 & 125,2 & 128,1 & 125,2 \\
\hline $\mathrm{C}_{2} \mathrm{H}_{6}$ & ${ }^{2} J_{\mathrm{CH}}$ & $-1,7$ & $-1,7$ & $-1,7$ & $-1,8$ & $-1,9$ & $-2,1$ & $-2,4$ & $-2,8$ & $-3,1$ & $-3,5$ & $-3,9$ & $-4,3$ & $-4,7$ & $-5,1$ & $-5,5$ & $-4,7$ \\
\hline \multirow[t]{3}{*}{ Total } & DM & & & & & & & & & & & & & & & & - \\
\hline & DMA & & & & & & & & & & & & & & & & - \\
\hline & PDMA & 59,71 & 59,02 & 57,64 & 54,52 & 50,80 & 45,96 & 40,16 & 33,51 & 26,33 & 18,57 & 16,18 & 16,75 & 21,46 & 28,94 & 37,95 & - \\
\hline \multirow[t]{3}{*}{ CPI } & D & & & & & & & & & & & & & & & & - \\
\hline & DMA & & & & & & & & & & & & & & & & - \\
\hline & PDMA & 91,17 & 89,39 & 85,67 & 79,94 & 73,29 & 65,94 & 57,86 & 49,15 & 40,08 & 30,72 & 22,70 & 16,75 & 17,77 & 22,63 & 28,92 & - \\
\hline \multirow[t]{3}{*}{ SPI } & M & & & & -6 & & & & & & & & & & & & - \\
\hline & & & & & & & & & & & & & & & & & - \\
\hline & PDMA & 36,64 & 36,75 & 37,09 & 35,88 & 34,30 & 31,31 & 27,18 & 22,03 & 16,25 & 9,66 & 11,40 & 16,75 & 24,16 & 33,56 & 44,57 & - \\
\hline \multirow[t]{3}{*}{$\Delta \mathrm{CS}$} & & & & & & & & & & & & & & & & & - \\
\hline & $\mathrm{DM}$ & & & & & & & & & & & & & & & & - \\
\hline & & & & & 44,07 & & 34,63 & 30,68 & & 23,82 & 21,0 & 11,30 & 0,00 & $-6,39$ & $-10,93$ & $-15,65$ & - \\
\hline
\end{tabular}


Tabela 8.383: Constantes de acoplamento LC-SLYP $\operatorname{com} \alpha=10 \%$ e $\alpha+\beta=100 \%$, variando $\gamma$, na base aug-pcJ-2.

\begin{tabular}{|c|c|c|c|c|c|c|c|c|c|c|c|c|c|c|c|c|c|}
\hline & $\gamma$ & 0,05 & 0,10 & 0,15 & 0,20 & 0,25 & 0,30 & 0,35 & 0,40 & 0,45 & 0,50 & 0,55 & 0,60 & 0,65 & 0,70 & 0,75 & Exp. \\
\hline HF & ${ }^{1} J_{\mathrm{HF}}$ & 441,7 & 443,0 & 444,5 & 446,2 & 448,4 & 451,5 & 455,7 & 461,0 & 467,3 & 474,4 & 482,0 & 490,0 & 498,2 & 506,4 & 514,7 & 500 \\
\hline $\mathrm{CO}$ & ${ }^{1} J_{\mathrm{CO}}$ & 22,8 & 22,5 & 22,2 & 22,0 & 21,7 & 21,6 & 21,4 & 21,1 & 20,7 & 20,2 & 19,5 & 18,7 & 17,8 & 16,7 & 15,7 & 16,4 \\
\hline $\mathrm{H}_{2} \mathrm{O}$ & ${ }^{1} J_{\mathrm{OH}}$ & $-72,5$ & $-72,6$ & $-72,7$ & $-72,9$ & $-73,2$ & $-73,6$ & $-74,2$ & $-74,9$ & $-75,9$ & $-76,9$ & $-78,1$ & $-79,3$ & $-80,5$ & $-81,8$ & $-83,1$ & $-80,6$ \\
\hline $\mathrm{H}_{2} \mathrm{O}$ & ${ }^{2} J_{\mathrm{HH}}$ & $-4,4$ & $-4,4$ & $-4,5$ & $-4,7$ & $-4,9$ & $-5,3$ & $-5,8$ & $-6,3$ & $-6,9$ & $-7,5$ & $-8,1$ & $-8,7$ & $-9,3$ & $-9,9$ & $-10,5$ & $-7,3$ \\
\hline $\mathrm{NH}_{3}$ & ${ }^{1} J_{\mathrm{NH}}$ & 40,5 & 40,5 & 40,5 & 40,5 & 40,5 & 40,6 & 40,8 & 41,2 & 41,7 & 42,2 & 42,8 & 43,5 & 44,2 & 45,0 & 45,7 & 43,8 \\
\hline $\mathrm{NH}_{3}$ & ${ }^{2} J_{\mathrm{HH}}$ & $-6,4$ & $-6,4$ & $-6,5$ & $-6,8$ & $-7,1$ & $-7,6$ & $-8,2$ & $-8,8$ & $-9,4$ & $-10,1$ & $-10,8$ & $-11,5$ & $-12,2$ & $-12,9$ & $-13,5$ & $-9,6$ \\
\hline $\mathrm{PH}_{3}$ & ${ }^{1} J_{\mathrm{PH}}$ & 144,7 & 143,9 & 141,0 & 137,0 & 133,8 & 132,5 & 133,6 & 136,9 & 141,9 & 148,2 & 155,2 & 162,5 & 169,9 & 177,0 & 183,8 & 188,2 \\
\hline $\mathrm{PF}_{3}$ & ${ }^{1} J_{\mathrm{PF}}$ & $-1795,6$ & $-1793,4$ & $-1792,1$ & $-1791,2$ & $-1790,6$ & $-1789,6$ & $-1787,7$ & $-1783,8$ & $-1777,3$ & $-1768,0$ & $-1756,1$ & $-1742,2$ & $-1726,9$ & $-1710,9$ & $-1694,5$ & -1441 \\
\hline $\mathrm{BHF}_{2}$ & ${ }^{1} J_{\mathrm{BF}}$ & $-169,1$ & $-167,1$ & $-162,9$ & $-156,8$ & $-149,5$ & $-141,4$ & $-132,9$ & $-124,3$ & $-115,5$ & $-106,9$ & $-98,4$ & $-90,3$ & $-82,7$ & $-75,5$ & $-68,8$ & -84 \\
\hline $\mathrm{BF}_{3}$ & ${ }^{1} J_{\mathrm{BF}}$ & $-60,8$ & $-59,0$ & $-55,0$ & $-49,0$ & $-41,4$ & $-32,9$ & $-23,8$ & $-14,5$ & $-5,2$ & 3,8 & 12,5 & 20,7 & 28,4 & 35,6 & 42,3 & 15 \\
\hline $\mathrm{F}_{2} \mathrm{O}$ & ${ }^{1} J_{\mathrm{OF}}$ & $-308,5$ & $-310,9$ & $-317,4$ & $-328,1$ & $-342,2$ & $-358,4$ & $-375,5$ & $-392,9$ & $-410,3$ & $-427,9$ & $-445,9$ & $-464,7$ & $-484,4$ & $-505,3$ & $-527,4$ & -300 \\
\hline $\mathrm{CH}_{4}$ & ${ }^{1} J_{\mathrm{CH}}$ & 109,3 & 109,0 & 108,6 & 108,3 & 108,3 & 108,9 & 110,0 & 111,6 & 113,7 & 116,0 & 118,6 & 121,3 & 123,9 & 126,6 & 129,1 & 125,3 \\
\hline $\mathrm{CH}_{4}$ & ${ }^{2} J_{\mathrm{HH}}$ & $-8,8$ & $-8,8$ & $-8,9$ & $-9,1$ & $-9,5$ & $-10,1$ & $-10,7$ & $-11,4$ & $-12,2$ & $-13,0$ & $-13,7$ & $-14,4$ & $-15,1$ & $-15,8$ & $-16,4$ & $-12,8$ \\
\hline $\mathrm{C}_{2} \mathrm{H}_{2}$ & ${ }^{1} J_{\mathrm{CC}}$ & 179,6 & 179,8 & 180,3 & 181,0 & 181,9 & 183,1 & 184,8 & 187,1 & 190,1 & 193,6 & 197,7 & 202,3 & 207,3 & 212,5 & 217,8 & 174,8 \\
\hline $\mathrm{C}_{2} \mathrm{H}_{2}$ & ${ }^{1} J_{\mathrm{CH}}$ & 232,0 & 231,1 & 230,0 & 229,3 & 229,3 & 230,2 & 232,2 & 235,1 & 238,8 & 243,2 & 248,0 & 253,1 & 258,4 & 263,7 & 268,8 & 247,6 \\
\hline $\mathrm{C}_{2} \mathrm{H}_{2}$ & ${ }^{2} J_{\mathrm{CH}}$ & 52,1 & 52,2 & 52,7 & 53,3 & 54,0 & 54,6 & 55,0 & 55,2 & 55,2 & 54,9 & 54,4 & 53,7 & 52,8 & 51,7 & 50,5 & 50,1 \\
\hline $\mathrm{C}_{2} \mathrm{H}_{2}$ & ${ }^{3} J_{\mathrm{HH}}$ & 7,7 & 7,6 & 7,6 & 7,6 & 7,8 & 8,1 & 8,6 & 9,2 & 9,9 & 10,8 & 11,8 & 12,8 & 13,9 & 15,0 & 16,1 & 9,6 \\
\hline $\mathrm{C}_{2} \mathrm{H}_{4}$ & ${ }^{1} J_{\mathrm{CC}}$ & 53,9 & 54,2 & 54,8 & 55,5 & 56,3 & 57,2 & 58,5 & 60,3 & 62,6 & 65,3 & 68,6 & 72,4 & 76,6 & 81,1 & 86,0 & 67,6 \\
\hline $\mathrm{C}_{2} \mathrm{H}_{4}$ & ${ }^{1} J_{\mathrm{CH}}$ & 140,3 & 139,9 & 139,4 & 139,1 & 139,3 & 140,2 & 141,8 & 144,1 & 146,9 & 150,2 & 153,8 & 157,6 & 161,6 & 165,6 & 169,6 & 156,3 \\
\hline $\mathrm{C}_{2} \mathrm{H}_{4}$ & ${ }^{2} J_{\mathrm{CH}}$ & 0,2 & 0,3 & 0,3 & 0,2 & 0,1 & $-0,1$ & $-0,6$ & $-1,2$ & $-1,9$ & $-2,8$ & $-3,9$ & $-5,1$ & $-6,4$ & $-7,9$ & $-9,4$ & $-2,4$ \\
\hline $\mathrm{C}_{2} \mathrm{H}_{4}$ & ${ }^{2} J_{\mathrm{HH}}$ & 5,0 & 5,0 & 5,0 & 4,8 & 4,6 & 4,2 & 3,7 & 3,1 & 2,5 & 1,8 & 1,0 & 0,1 & $-0,6$ & $-1,5$ & $-2,4$ & 2,3 \\
\hline $\mathrm{C}_{2} \mathrm{H}_{4}$ & ${ }^{3} J_{\mathrm{HH}_{\mathrm{c}}}$ & 11,5 & 11,5 & 11,6 & 11,7 & 11,8 & 12,1 & 12,3 & 12,7 & 13,1 & 13,6 & 14,2 & 14,8 & 15,5 & 16,2 & 17,0 & 11,7 \\
\hline $\mathrm{C}_{2} \mathrm{H}_{4}$ & ${ }^{3} J_{\mathrm{HH}_{\mathrm{t}}}$ & 16,7 & 16,6 & 16,5 & 16,5 & 16,6 & 16,7 & 17,0 & 17,4 & 18,0 & 18,6 & 19,4 & 20,3 & 21,2 & 22,2 & 23,2 & 19 \\
\hline $\mathrm{C}_{2} \mathrm{H}_{6}$ & ${ }^{1} J_{\mathrm{CC}}$ & 21,4 & 21,7 & 22,3 & 23,1 & 23,9 & 24,7 & 25,7 & 26,9 & 28,2 & 29,8 & 31 & 33,1 & 34,9 & 36,7 & 38,4 & 34,5 \\
\hline $\mathrm{C}_{2} \mathrm{H}_{6}$ & ${ }^{1} J_{\mathrm{CH}}$ & 109,6 & 109,2 & 108,7 & 108,4 & 108,5 & & 110,3 & 112,1 & 114,2 & 116,7 & 119,3 & 122,1 & 124,8 & 127,6 & 130,2 & 125,2 \\
\hline $\mathrm{C}_{2} \mathrm{H}_{6}$ & ${ }^{2} J_{\mathrm{CH}}$ & $-2,1$ & $-2,1$ & $-2,1$ & $-2,2$ & $-2,4$ & $-2,6$ & $-2,8$ & $-3,2$ & $-3,5$ & $-3,9$ & $-4,3$ & $-4,6$ & $-5,0$ & $-5,4$ & $-5,7$ & $-4,7$ \\
\hline \multirow[t]{3}{*}{ Total } & $\mathrm{DM}$ & $-26,32$ & 26,22 & $-26,20$ & $-26,20$ & $-26,12$ & & & & -23 & & & & & & & - \\
\hline & DMA & 29,34 & 29,2 & & & & & & & & & & & & & & - \\
\hline & PDMA & 48,12 & 47,75 & 46,46 & 43,86 & 40,58 & 36,26 & 30,66 & 24,28 & 17,70 & 14,54 & 15,31 & 20,17 & 26,92 & 35,72 & 44,75 & - \\
\hline \multirow[t]{3}{*}{ CPI } & DM & $-55,32$ & 54,98 & $-54,89$ & -5 & & & & & & & & & & & & - \\
\hline & DMA & 59,06 & 58,6 & & & 58 & & & & & & & & & & & - \\
\hline & PDMA & 72,59 & 71,18 & 68,21 & 63,73 & 58,13 & 51,50 & 44,04 & 36,20 & 27,98 & 21,18 & 15,74 & 17,48 & 22,39 & 28,90 & 35,90 & - \\
\hline \multirow[t]{3}{*}{ SPI } & DM & $-5,05$ & $-5,1$ & -5 & - & $-4, \mathrm{~s}$ & & & & & & & & & & & - \\
\hline & & & & & & & & & & & & & & & & & - \\
\hline & PDMA & 30,18 & 30,57 & 30,51 & 29,29 & 27,71 & 25,08 & 20,86 & 15,54 & 10,15 & 9,67 & 14,99 & 22,15 & 30,24 & 40,72 & 51,24 & - \\
\hline \multirow[t]{3}{*}{$\Delta C S$} & & & & & & & & & & & & & & & & & - \\
\hline & MA & & & & & & & & & & & & & & & & - \\
\hline & $\mathrm{PD}$ & 42,42 & 40,61 & 37,70 & 34,43 & 30,43 & 26,43 & 23,18 & 20,66 & 17,83 & 11,51 & 0,75 & $-4,67$ & $-7,8$ & $-11,82$ & $-15,33$ & - \\
\hline
\end{tabular}


Tabela 8.384: Constantes de acoplamento LC-SLYP $\operatorname{com} \alpha=20 \%$ e $\alpha+\beta=100 \%$, variando $\gamma$, na base aug-pcJ-2.

\begin{tabular}{|c|c|c|c|c|c|c|c|c|c|c|c|c|c|c|c|c|c|}
\hline & $\gamma$ & 0,05 & 0,10 & 0,15 & 0,20 & 0,25 & 0,30 & 0,35 & 0,40 & 0,45 & 0,50 & 0,55 & 0,60 & 0,65 & 0,70 & 0,75 & Exp. \\
\hline $\mathrm{HF}$ & ${ }^{1} J_{\mathrm{HF}}$ & 462,9 & 464,0 & 465,4 & 467,0 & 469,2 & 472,1 & 475,9 & 480,7 & 486,3 & 492,7 & 499,5 & 506,6 & 513,9 & 521,3 & 528,8 & 500 \\
\hline $\mathrm{CO}$ & ${ }^{1} J_{\mathrm{CO}}$ & 20,8 & 20,5 & 20,2 & 20,0 & 19,8 & 19,6 & 19,4 & 19,2 & 18,8 & 18,3 & 17,7 & 16,9 & 16,1 & 15,1 & 14,1 & 16,4 \\
\hline $\mathrm{H}_{2} \mathrm{O}$ & ${ }^{1} J_{\mathrm{OH}}$ & $-75,1$ & $-75,2$ & $-75,3$ & $-75,5$ & $-75,8$ & $-76,1$ & $-76,7$ & $-77,4$ & $-78,3$ & $-79,2$ & $-80,2$ & $-81,3$ & $-82,5$ & $-83,6$ & $-84,8$ & $-80,6$ \\
\hline $\mathrm{H}_{2} \mathrm{O}$ & ${ }^{2} J_{\mathrm{HH}}$ & $-5,5$ & $-5,5$ & $-5,6$ & $-5,8$ & $-6,0$ & $-6,4$ & $-6,8$ & $-7,3$ & $-7,8$ & $-8,4$ & $-8,9$ & $-9,5$ & $-10,1$ & $-10,6$ & $-11,1$ & $-7,3$ \\
\hline $\mathrm{NH}_{3}$ & ${ }^{1} J_{\mathrm{NH}}$ & 41,7 & 41,7 & 41,7 & 41,7 & 41,7 & 41,8 & 42,0 & 42,4 & 42,8 & 43,3 & 43,9 & 44,5 & 45,1 & 45,8 & 46,5 & 43,8 \\
\hline $\mathrm{NH}_{3}$ & ${ }^{2} J_{\mathrm{HH}}$ & $-7,5$ & $-7,5$ & $-7,6$ & $-7,8$ & $-8,1$ & $-8,6$ & $-9,1$ & $-9,7$ & $-10,3$ & $-10,9$ & $-11,6$ & $-12,2$ & $-12,8$ & $-13,4$ & $-14,0$ & $-9,6$ \\
\hline $\mathrm{PH}_{3}$ & ${ }^{1} J_{\mathrm{PH}}$ & 153,8 & 153,1 & 150,7 & 147,3 & 144,5 & 143,5 & 144,6 & 147,6 & 152,1 & 157,8 & 164,1 & 170,7 & 177,3 & 183,8 & 189,8 & 188,2 \\
\hline $\mathrm{PF}_{3}$ & ${ }^{1} J_{\mathrm{PF}}$ & $-1771,8$ & $-1769,3$ & $-1766,8$ & $-1764,3$ & $-1761,5$ & $-1758,5$ & $-1754,7$ & $-1749,5$ & $-1742,4$ & $-1733,1$ & $-1721,9$ & $-1709,1$ & $-1695,3$ & $-1680,8$ & $-1666,2$ & -1441 \\
\hline $\mathrm{BHF}_{2}$ & ${ }^{1} J_{\mathrm{BF}}$ & $-150,9$ & $-149,2$ & $-145,5$ & $-140,2$ & $-133,7$ & $-126,5$ & $-119,0$ & $-111,3$ & $-103,5$ & $-95,8$ & $-88,3$ & $-81,1$ & $-74,3$ & $-67,9$ & $-61,9$ & -84 \\
\hline $\mathrm{BF}_{3}$ & ${ }^{1} J_{\mathrm{BF}}$ & $-42,0$ & $-40,4$ & $-37,0$ & $-31,7$ & $-25,2$ & $-17,7$ & $-9,6$ & $-1,4$ & 6,7 & 14,8 & 22,5 & 29,8 & 36,7 & 43,1 & 49,1 & 15 \\
\hline $\mathrm{F}_{2} \mathrm{O}$ & ${ }^{1} J_{\mathrm{OF}}$ & $-344,2$ & $-346,3$ & $-352,0$ & $-361,5$ & $-374,2$ & $-389,1$ & $-405,2$ & $-421,8$ & $-439,0$ & $-456,6$ & $-475,0$ & $-494,4$ & $-514,9$ & $-536,7$ & $-559,7$ & -300 \\
\hline $\mathrm{CH}_{4}$ & ${ }^{1} J_{\mathrm{CH}}$ & 112,9 & 112,6 & 112,3 & 112,1 & 112,1 & 112,7 & 113,8 & 115,3 & 117,1 & 119,3 & 121,7 & 124,1 & 126,5 & 128,9 & 131,2 & 125,3 \\
\hline $\mathrm{CH}_{4}$ & ${ }^{2} J_{\mathrm{HH}}$ & $-9,9$ & $-9,8$ & $-9,9$ & $-10,1$ & $-10,5$ & $-11,0$ & $-11,6$ & $-12,3$ & $-12,9$ & $-13,6$ & $-14,3$ & $-15,0$ & $-15,6$ & $-16,2$ & $-16,7$ & $-12,8$ \\
\hline $\mathrm{C}_{2} \mathrm{H}_{2}$ & ${ }^{1} J_{\mathrm{CC}}$ & 184,2 & 184,4 & 184,9 & 185,6 & 186,5 & 187,8 & 189,6 & 192,0 & 195,0 & 198,5 & 202,6 & 207,1 & 211,9 & 216,9 & 222,0 & 174,8 \\
\hline $\mathrm{C}_{2} \mathrm{H}_{2}$ & ${ }^{1} J_{\mathrm{CH}}$ & 238,1 & 237,4 & 236,4 & 235,8 & 235,9 & 236,8 & 238,7 & 241,5 & 245,0 & 249,1 & 253,7 & 258,5 & 263,4 & 268,3 & 273,1 & 247,6 \\
\hline $\mathrm{C}_{2} \mathrm{H}_{2}$ & ${ }^{2} J_{\mathrm{CH}}$ & 52,7 & 52,9 & 53,3 & 53,8 & 54,3 & 54,8 & 55,0 & 55,1 & 54,9 & 54,5 & 53,9 & 53,0 & 52,0 & 50,9 & 49,7 & 50,1 \\
\hline $\mathrm{C}_{2} \mathrm{H}_{2}$ & ${ }^{3} J_{\mathrm{HH}}$ & 8,4 & 8,4 & 8,3 & 8,4 & 8,6 & 8,9 & 9,5 & 10,1 & 10,9 & 11,8 & 12,8 & 13,8 & 14,8 & 15,9 & 16,9 & 9,6 \\
\hline $\mathrm{C}_{2} \mathrm{H}_{4}$ & ${ }^{1} J_{\mathrm{CC}}$ & 57,7 & 57,9 & 58,5 & 59,2 & 60,0 & 61,1 & 62,5 & 64,3 & 66,6 & 69,5 & 72,8 & 76,6 & 80,8 & 85,3 & 90,0 & 67,6 \\
\hline $\mathrm{C}_{2} \mathrm{H}_{4}$ & ${ }^{1} J_{\mathrm{CH}}$ & 144,9 & 144,5 & 144,1 & 143,8 & 144,1 & 145,0 & 146,6 & 148,7 & 151,4 & 154,5 & 157,9 & 161,5 & 165,3 & 169,1 & 172,8 & 156,3 \\
\hline $\mathrm{C}_{2} \mathrm{H}_{4}$ & ${ }^{2} J_{\mathrm{CH}}$ & $-0,4$ & $-0,4$ & $-0,4$ & $-0,5$ & $-0,7$ & $-1,0$ & $-1,5$ & $-2,1$ & $-2,9$ & $-3,9$ & $-5,0$ & $-6,2$ & $-7,6$ & $-9,0$ & $-10,5$ & $-2,4$ \\
\hline $\mathrm{C}_{2} \mathrm{H}_{4}$ & ${ }^{2} J_{\mathrm{HH}}$ & 4,4 & 4,4 & 4,4 & 4,2 & 4,0 & 3,6 & 3,1 & 2,6 & 1,9 & 1,2 & 0,4 & $-0,3$ & $-1,2$ & $-2,1$ & $-2,9$ & 2,3 \\
\hline $\mathrm{C}_{2} \mathrm{H}_{4}$ & ${ }^{3} J_{\mathrm{HH}}$ & 11,8 & 11,8 & 11,9 & 12,0 & 12,2 & 12,4 & 12,7 & 13,1 & 13,5 & 14,0 & 14,6 & 15,3 & 16,0 & 16,7 & 17,4 & 11,7 \\
\hline $\mathrm{C}_{2} \mathrm{H}_{4}$ & ${ }^{3} J_{\mathrm{HH}_{\mathrm{t}}}$ & 17,2 & 17,1 & 17,1 & 17,1 & 17,2 & 17,4 & 17,7 & 18,2 & 18,8 & 19,4 & 20,2 & 21,1 & 22,0 & 23,0 & 23,9 & 19 \\
\hline $\mathrm{C}_{2} \mathrm{H}_{6}$ & ${ }^{1} J_{\mathrm{CC}}$ & 24,1 & 24,4 & 25,0 & 25,7 & 26,4 & 27,2 & 28,1 & 29,2 & 30,5 & 31,9 & 33,4 & 35,0 & 36,6 & 38,3 & 39,8 & 34,5 \\
\hline $\mathrm{C}_{2} \mathrm{H}_{6}$ & ${ }^{1} J_{\mathrm{CH}}$ & 113,3 & 113,0 & 112,6 & 112,3 & 112,5 & 113,1 & 114,2 & 115,8 & 117,8 & 120,0 & 122,5 & 125,0 & 127,5 & 130,0 & 132,3 & 125,2 \\
\hline $\mathrm{C}_{2} \mathrm{H}_{6}$ & ${ }^{2} J_{\mathrm{CH}}$ & $-2,6$ & $-2,6$ & $-2,6$ & $-2,7$ & $-2,9$ & $-3,0$ & $-3,3$ & $-3,6$ & $-3,9$ & $-4,3$ & $-4,6$ & $-5,0$ & $-5,3$ & $-5,6$ & $-5,9$ & $-4,7$ \\
\hline \multirow[t]{3}{*}{ Total } & DM & $-23,31$ & $-23,20$ & $-23,11$ & $-23,04$ & $-22,87$ & $-22,50$ & $-21,89$ & $-20,98$ & -19 & $-18,47$ & -16 & ,37 & & $-12,25$ & ,82 & - \\
\hline & DMA & 26,00 & 25,90 & 25,83 & 25,76 & 25,55 & & 24,42 & 23, & & & & & & 26,80 & & - \\
\hline & PDMA & 36,87 & 36,40 & 35,33 & 32,98 & 29,87 & 25,68 & 20,38 & 15,06 & 13,02 & 13,91 & 19,59 & 26,43 & 34,95 & 43,74 & 52,44 & - \\
\hline \multirow[t]{3}{*}{ CPI } & DM & $-50,79$ & $-50,45$ & $-50,25$ & $-50,15$ & $-50,02$ & $-49,71$ & $-49,10$ & $-48,13$ & $-46,86$ & $-45,27$ & $-43,55$ & $-41,82$ & $-40,15$ & $-38,62$ & $-37,30$ & - \\
\hline & DMA & 53,30 & 52,89 & 52,57 & 52,34 & 52,02 & 51,45 & 50,54 & 49,22 & 47,72 & 45,87 & 45,25 & 46,45 & 48,63 & 50,89 & 53,54 & - \\
\hline & PDMA & 55,27 & 54,00 & 51,39 & 47,44 & 42,59 & 36,55 & 29,98 & 23,14 & 18,33 & 13,50 & 17,93 & 23,53 & 30,26 & 37,24 & 44,16 & - \\
\hline \multirow[t]{3}{*}{ SPI } & DM & $-3,15$ & $-3,21$ & $-3,21$ & $-3,16$ & $-2,96$ & $-2,55$ & $-1,93$ & $-1,08$ & $-0,03$ & 1,19 & 2,57 & 4,0 & 5,53 & 7,09 & 8,60 & - \\
\hline & DMA & 5,98 & 6,10 & 6,23 & 6,27 & 6,15 & 5,83 & & 4,59 & & 3,72 & & & & 9,13 & 11,11 & - \\
\hline & PDMA & 23,38 & 23,49 & 23,54 & 22,37 & 20,55 & 17,71 & 13,33 & 9,14 & 9,12 & 14,21 & 20,81 & 28,56 & 38,38 & 48,50 & 58,51 & - \\
\hline \multirow[t]{3}{*}{$\Delta \mathrm{CS}$} & DM & $-47,64$ & $-47,25$ & $-47,03$ & $-46,99$ & $-47,06$ & $-47,16$ & $-47,17$ & $-47,05$ & & $-46,46$ & ,12 & & $-45,69$ & $-45,70$ & $-45,90$ & - \\
\hline & DMA & 47,32 & 46,79 & 46,35 & 46,07 & 45,87 & 45,62 & 45,27 & 44,63 & 43,84 & 42,15 & 40,89 & 41,05 & 41,48 & 41,76 & 42,43 & - \\
\hline & PDMA & 31,89 & 30,51 & 27,85 & 25,07 & 22,04 & 18,84 & 16,65 & 14,00 & 9,21 & $-0,71$ & $-2,88$ & $-5,03$ & $-8,12$ & $-11,26$ & $-14,35$ & - \\
\hline
\end{tabular}


Tabela 8.385: Constantes de acoplamento LC-SLYP $\operatorname{com} \alpha=30 \%$ e $\alpha+\beta=100 \%$, variando $\gamma$, na base aug-pcJ-2.

\begin{tabular}{|c|c|c|c|c|c|c|c|c|c|c|c|c|c|c|c|c|c|}
\hline & $\gamma$ & 0,05 & 0,10 & 0,15 & 0,20 & 0,25 & 0,30 & 0,35 & 0,40 & 0,45 & 0,50 & 0,55 & 0,60 & 0,65 & 0,70 & 0,75 & Exp. \\
\hline HF & ${ }^{1} J_{\mathrm{HF}}$ & 484,8 & 485,8 & 487,0 & 488,6 & 490,5 & 493,2 & 496,6 & 500,9 & 505,9 & 511,5 & 517,5 & 523,8 & 530,3 & 536,8 & 543,4 & 500 \\
\hline $\mathrm{CO}$ & ${ }^{1} J_{\mathrm{CO}}$ & 18,6 & 18,3 & 18,1 & 17,9 & 17,7 & 17,5 & 17,4 & 17,1 & 16,8 & 16,3 & 15,7 & 15,0 & 14,2 & 13,4 & 12,5 & 16,4 \\
\hline $\mathrm{H}_{2} \mathrm{O}$ & ${ }^{1} J_{\mathrm{OH}}$ & $-77,9$ & $-78,0$ & $-78,1$ & $-78,2$ & $-78,5$ & $-78,8$ & $-79,3$ & $-80,0$ & $-80,7$ & $-81,6$ & $-82,5$ & $-83,5$ & $-84,5$ & $-85,6$ & $-86,6$ & $-80,6$ \\
\hline $\mathrm{H}_{2} \mathrm{O}$ & ${ }^{2} J_{\mathrm{HH}}$ & $-6,8$ & $-6,8$ & $-6,8$ & $-7,0$ & $-7,2$ & $-7,5$ & $-7,9$ & $-8,4$ & $-8,8$ & $-9,3$ & $-9,8$ & $-10,4$ & $-10,9$ & $-11,3$ & $-11,8$ & $-7,3$ \\
\hline $\mathrm{NH}_{3}$ & ${ }^{1} J_{\mathrm{NH}}$ & 42,9 & 42,9 & 42,9 & 42,9 & 42,9 & 43,1 & 43,3 & 43,6 & 44,0 & 44,4 & 44,9 & 45,5 & 46,1 & 46,7 & 47,3 & 43,8 \\
\hline $\mathrm{NH}_{3}$ & ${ }^{2} J_{\mathrm{HH}}$ & $-8,6$ & $-8,7$ & $-8,7$ & $-8,9$ & $-9,2$ & $-9,6$ & $-10,1$ & $-10,6$ & $-11,2$ & $-11,8$ & $-12,4$ & $-12,9$ & $-13,5$ & $-14,0$ & $-14,5$ & $-9,6$ \\
\hline $\mathrm{PH}_{3}$ & ${ }^{1} J_{\mathrm{PH}}$ & 163,2 & 162,7 & 160,7 & 157,8 & 155,5 & 154,7 & 155,7 & 158,4 & 162,5 & 167,5 & 173,2 & 179,0 & 184,9 & 190,5 & 195,9 & 188,2 \\
\hline $\mathrm{PF}_{3}$ & ${ }^{1} J_{\mathrm{PF}}$ & $-1742,3$ & $-1739,8$ & $-1736,6$ & $-1732,9$ & $-1728,9$ & $-1724,6$ & $-1719,7$ & $-1713,9$ & $-1706,6$ & $-1697,7$ & $-1687,3$ & $-1675,8$ & $-1663,4$ & $-1650,7$ & $-1637,8$ & -1441 \\
\hline $\mathrm{BHF}_{2}$ & ${ }^{1} J_{\mathrm{BF}}$ & $-132,5$ & $-131,0$ & $-127,9$ & $-123,2$ & $-117,6$ & $-111,4$ & $-104,8$ & $-98,1$ & $-91,3$ & $-84,6$ & $-78,0$ & $-71,7$ & $-65,7$ & $-60,1$ & $-54,9$ & -84 \\
\hline $\mathrm{BF}_{3}$ & ${ }^{1} J_{\mathrm{BF}}$ & $-23,0$ & $-21,7$ & $-18,8$ & $-14,3$ & $-8,6$ & $-2,1$ & 4,7 & 11,9 & 19,1 & 26,1 & 32,8 & 39,2 & 45,3 & 50,9 & 56,2 & 15 \\
\hline $\mathrm{F}_{2} \mathrm{O}$ & ${ }^{1} J_{\mathrm{OF}}$ & $-380,7$ & $-382,6$ & $-387,7$ & $-396,4$ & $-408,1$ & $-422,1$ & $-437,5$ & $-453,9$ & $-471,1$ & $-489,2$ & $-508,3$ & $-528,5$ & $-550,1$ & $-573,0$ & $-597,3$ & -300 \\
\hline $\mathrm{CH}_{4}$ & ${ }^{1} J_{\mathrm{CH}}$ & 116,7 & 116,5 & 116,2 & 116,0 & 116,1 & 116,7 & 117,6 & 119,0 & 120,7 & 122,7 & 124,8 & 127,0 & 129,2 & 131,3 & 133,3 & 125,3 \\
\hline $\mathrm{CH}_{4}$ & ${ }^{2} J_{\mathrm{HH}}$ & $-10,9$ & $-10,9$ & $-11,0$ & $-11,2$ & $-11,5$ & $-12,0$ & $-12,5$ & $-13,1$ & $-13,7$ & $-14,3$ & $-15,0$ & $-15,5$ & $-16,1$ & $-16,6$ & $-17,1$ & $-12,8$ \\
\hline $\mathrm{C}_{2} \mathrm{H}_{2}$ & ${ }^{1} J_{\mathrm{CC}}$ & 189,4 & 189,6 & 190,0 & 190,7 & 191,8 & 193,1 & 195,0 & 197,5 & 200,5 & 204,0 & 208,0 & 212,3 & 216,9 & 221,7 & 226,5 & 174,8 \\
\hline $\mathrm{C}_{2} \mathrm{H}_{2}$ & ${ }^{1} J_{\mathrm{CH}}$ & 244,7 & 244,0 & 243,2 & 242,7 & 242,8 & 243,8 & 245,6 & 248,3 & 251,6 & 255,4 & 259,6 & 264,0 & 268,6 & 273,1 & 277,4 & 247,6 \\
\hline $\mathrm{C}_{2} \mathrm{H}_{2}$ & ${ }^{2} J_{\mathrm{CH}}$ & 53,2 & 53,3 & 53,6 & 54,0 & 54,4 & 54,7 & 54,8 & 54,7 & 54,4 & 53,8 & 53,1 & 52,2 & 51,1 & 50,0 & 48,8 & 50,1 \\
\hline $\mathrm{C}_{2} \mathrm{H}_{2}$ & ${ }^{3} J_{\mathrm{HH}}$ & 9,3 & 9,3 & 9,3 & 9,4 & 9,6 & 10,0 & 10,5 & 11,2 & 12,0 & 12,9 & 13,8 & 14,8 & 15,9 & 16,9 & 17,8 & 9,6 \\
\hline $\mathrm{C}_{2} \mathrm{H}_{4}$ & ${ }^{1} J_{\mathrm{CC}}$ & 61,9 & 62,1 & 62,6 & 63,3 & 64,2 & 65,4 & 66,9 & 68,8 & 71,2 & 74,1 & 77,5 & 81,3 & 85,4 & 89,8 & 94,3 & 67,6 \\
\hline $\mathrm{C}_{2} \mathrm{H}_{4}$ & ${ }^{1} J_{\mathrm{CH}}$ & 149,7 & 149,4 & 149,0 & 148,9 & 149,2 & 150,1 & 151,6 & 153,6 & 156,2 & 159,1 & 162,3 & 165,7 & 169,2 & 172,7 & 176,2 & 156,3 \\
\hline $\mathrm{C}_{2} \mathrm{H}_{4}$ & ${ }^{2} J_{\mathrm{CH}}$ & $-1,3$ & $-1,3$ & $-1,3$ & $-1,4$ & $-1,6$ & $-2,0$ & $-2,5$ & $-3,2$ & $-4,1$ & $-5,1$ & $-6,2$ & $-7,5$ & $-8,8$ & $-10,3$ & $-11,8$ & $-2,4$ \\
\hline $\mathrm{C}_{2} \mathrm{H}_{4}$ & ${ }^{2} J_{\mathrm{HH}}$ & 3,8 & 3,8 & 3,8 & 3,6 & 3,3 & 3,0 & 2,5 & 1,9 & 1,3 & 0,5 & $-0,1$ & $-1,0$ & $-1,8$ & $-2,6$ & $-3,5$ & 2,3 \\
\hline $\mathrm{C}_{2} \mathrm{H}_{4}$ & ${ }^{3} J_{\mathrm{HH}_{\mathrm{c}}}$ & 12,2 & 12,2 & 12,3 & 12,4 & 12,6 & 12,8 & 13,2 & 13,6 & 14,0 & 14,6 & 15,2 & 15,8 & 16,5 & 17,2 & 18,0 & 11,7 \\
\hline $\mathrm{C}_{2} \mathrm{H}_{4}$ & ${ }^{3} J_{\mathrm{HH}_{\mathrm{t}}}$ & 17,9 & 17,8 & 17,8 & 17,8 & 17,9 & 18,2 & 18,5 & 19,0 & 19,6 & 20,3 & 21,1 & 22,0 & 22,9 & 23,8 & 24,8 & 19 \\
\hline $\mathrm{C}_{2} \mathrm{H}_{6}$ & ${ }^{1} J_{\mathrm{CC}}$ & 27,0 & 27,3 & 27,8 & 28,4 & 29,1 & 29,9 & 30,7 & 31, & 32,9 & 34,2 & 35,5 & 37,0 & 38,4 & 39,9 & 41,3 & 34,5 \\
\hline $\mathrm{C}_{2} \mathrm{H}_{6}$ & ${ }^{1} J_{\mathrm{CH}}$ & 117,2 & 17,0 & 116,6 & 116,5 & 116,6 & 117,2 & 118,3 & 119,7 & 121,5 & 123,5 & 125,7 & 128 & 130,2 & 132,4 & 134,5 & 125,2 \\
\hline $\mathrm{C}_{2} \mathrm{H}_{6}$ & ${ }^{2} J_{\mathrm{CH}}$ & $-3,1$ & $-3,1$ & $-3,2$ & $-3,2$ & $-3,4$ & $-3,5$ & $-3,8$ & $-4,0$ & $-4,3$ & $-4,6$ & $-5,0$ & $-5,3$ & $-5,6$ & $-5,9$ & $-6,1$ & $-4,7$ \\
\hline \multirow[t]{3}{*}{ Total } & $\mathrm{DM}$ & -19 & 8 & & $-19,65$ & 19,44 & & & & & & & & & & & - \\
\hline & DMA & & & & & & & & & & & & & & & & - \\
\hline & PDMA & 24,91 & 24,44 & 23,50 & 21,44 & 18,41 & 15,04 & 11,79 & 11,50 & 14,84 & 20,61 & 27,67 & 35,97 & 44,17 & 52,55 & 61,30 & - \\
\hline \multirow[t]{3}{*}{ CPI } & DM & $-45,75$ & 45,44 & & 6 & -44, & -44, & & & & & & & & & & - \\
\hline & DMA &, 91 & 46,5 & 46 & & 45 & 44 & 44 & & & & & & & & & - \\
\hline & PDMA & 37,39 & 36,22 & 34,21 & 30,76 & 26,43 & 21,77 & 18,08 & 14,06 & 15,14 & 20,22 & 26,94 & 33,72 & 40,35 & 46,70 & 53,34 & - \\
\hline \multirow[t]{3}{*}{ SPI } & DM & $-1,0$ & & & & & & & & & & & & & & & - \\
\hline & & & & & & & & & & & & & & & & & - \\
\hline & PDMA & 15,77 & 15,80 & 15,64 & 14,60 & 12,52 & 10,11 & 7,18 & 9,62 & 14,61 & 20,90 & 28,20 & 37,62 & 46,97 & 56,84 & 67,13 & - \\
\hline \multirow[t]{3}{*}{$\Delta C S$} & & & & & & & & & & & & & & & & & - \\
\hline & DMA & & & & 41,32 & & & & & & & & & & & & - \\
\hline & PDMA & 21,62 & 20,42 & 18,56 & 16,16 & 13,91 & 11,66 & 10,90 & 4,44 & 0,53 & $-0,68$ & $-1,26$ & $-3,89$ & $-6,62$ & $-10,14$ & $-13,79$ & - \\
\hline
\end{tabular}


Tabela 8.386: Constantes de acoplamento LC-SLYP $\operatorname{com} \alpha=40 \%$ e $\alpha+\beta=100 \%$, variando $\gamma$, na base aug-pcJ-2.

\begin{tabular}{|c|c|c|c|c|c|c|c|c|c|c|c|c|c|c|c|c|c|}
\hline & $\gamma$ & 0,05 & 0,10 & 0,15 & 0,20 & 0,25 & 0,30 & 0,35 & 0,40 & 0,45 & 0,50 & 0,55 & 0,60 & 0,65 & 0,70 & 0,75 & Exp. \\
\hline $\mathrm{HF}$ & ${ }^{1} J_{\mathrm{HF}}$ & 507,5 & 508,4 & 509,4 & 510,8 & 512,6 & 515,0 & 518,0 & 521,8 & 526,1 & 531,0 & 536,2 & 541,6 & 547,2 & 552,8 & 558,6 & 500 \\
\hline $\mathrm{CO}$ & ${ }^{1} J_{\mathrm{CO}}$ & 16,2 & 16,0 & 15,8 & 15,6 & 15,4 & 15,3 & 15,1 & 14,9 & 14,6 & 14,2 & 13,7 & 13,0 & 12,3 & 11,5 & 10,7 & 16,4 \\
\hline $\mathrm{H}_{2} \mathrm{O}$ & ${ }^{1} J_{\mathrm{OH}}$ & $-80,8$ & $-80,8$ & $-80,9$ & $-81,1$ & $-81,3$ & $-81,6$ & $-82,1$ & $-82,6$ & $-83,3$ & $-84,1$ & $-84,9$ & $-85,7$ & $-86,6$ & $-87,5$ & $-88,5$ & $-80,6$ \\
\hline $\mathrm{H}_{2} \mathrm{O}$ & ${ }^{2} J_{\mathrm{HH}}$ & $-8,0$ & $-8,0$ & $-8,1$ & $-8,2$ & $-8,4$ & $-8,7$ & $-9,1$ & $-9,5$ & $-9,9$ & $-10,3$ & $-10,8$ & $-11,2$ & $-11,7$ & $-12,1$ & $-12,5$ & $-7,3$ \\
\hline $\mathrm{NH}_{3}$ & ${ }^{1} J_{\mathrm{NH}}$ & 44,2 & 44,2 & 44,2 & 44,2 & 44,3 & 44,4 & 44,6 & 44,8 & 45,2 & 45,6 & 46,0 & 46,5 & 47,1 & 47,6 & 48,1 & 43,8 \\
\hline $\mathrm{NH}_{3}$ & ${ }^{2} J_{\mathrm{HH}}$ & $-9,9$ & $-9,9$ & $-9,9$ & $-10,1$ & $-10,4$ & $-10,7$ & $-11,1$ & $-11,6$ & $-12,1$ & $-12,6$ & $-13,2$ & $-13,7$ & $-14,2$ & $-14,6$ & $-15,1$ & $-9,6$ \\
\hline $\mathrm{PH}_{3}$ & ${ }^{1} J_{\mathrm{PH}}$ & 173,1 & 172,7 & 171,0 & 168,6 & 166,8 & 166,1 & 167,1 & 169,4 & 173,0 & 177,4 & 182,3 & 187,4 & 192,5 & 197,4 & 202,0 & 188,2 \\
\hline $\mathrm{PF}_{3}$ & ${ }^{1} J_{\mathrm{PF}}$ & $-1708,0$ & $-1705,5$ & $-1702,1$ & $-1697,9$ & $-1693,2$ & $-1688,3$ & $-1683,0$ & $-1677,0$ & $-1669,9$ & $-1661,7$ & $-1652,4$ & $-1642,2$ & $-1631,5$ & $-1620,4$ & $-1609,4$ & -1441 \\
\hline $\mathrm{BHF}_{2}$ & ${ }^{1} J_{\mathrm{BF}}$ & $-113,8$ & $-112,6$ & $-109,9$ & $-106,1$ & $-101,3$ & $-96,0$ & $-90,4$ & $-84,6$ & $-78,8$ & $-73,1$ & $-67,5$ & $-62,1$ & $-56,9$ & $-52,1$ & $-47,6$ & -84 \\
\hline $\mathrm{BF}_{3}$ & ${ }^{1} J_{\mathrm{BF}}$ & $-3,9$ & $-2,8$ & $-0,3$ & 3,3 & 8,1 & 13,6 & 19,5 & 25,6 & 31,7 & 37,7 & 43,5 & 49,0 & 54,2 & 59,0 & 63,6 & 15 \\
\hline $\mathrm{F}_{2} \mathrm{O}$ & ${ }^{1} J_{\mathrm{OF}}$ & $-420,0$ & $-421,7$ & $-426,4$ & $-434,6$ & $-445,7$ & $-459,2$ & $-474,5$ & $-491,1$ & $-508,8$ & $-527,6$ & $-547,7$ & $-569,2$ & $-592,2$ & $-616,6$ & $-642,5$ & -300 \\
\hline $\mathrm{CH}_{4}$ & ${ }^{1} J_{\mathrm{CH}}$ & 120,7 & 120,5 & 120,3 & 120,1 & 120,3 & 120,8 & 121,7 & 122,9 & 124,5 & 126,2 & 128,0 & 130,0 & 131,9 & 133,7 & 135,5 & 125,3 \\
\hline $\mathrm{CH}_{4}$ & ${ }^{2} J_{\mathrm{HH}}$ & $-12,1$ & $-12,0$ & $-12,1$ & $-12,3$ & $-12,6$ & $-13,0$ & $-13,4$ & $-14,0$ & $-14,5$ & $-15,1$ & $-15,6$ & $-16,1$ & $-16,6$ & $-17,0$ & $-17,5$ & $-12,8$ \\
\hline $\mathrm{C}_{2} \mathrm{H}_{2}$ & ${ }^{1} J_{\mathrm{CC}}$ & 195,4 & 195,5 & 196,0 & 196,7 & 197,8 & 199,2 & 201,2 & 203,6 & 206,6 & 210,1 & 213,9 & 218,1 & 222,4 & 226,9 & 231,3 & 174,8 \\
\hline $\mathrm{C}_{2} \mathrm{H}_{2}$ & ${ }^{1} J_{\mathrm{CH}}$ & 251,7 & 251,1 & 250,5 & 250,1 & 250,3 & 251,3 & 253,0 & 255,4 & 258,5 & 262,0 & 265,9 & 269,9 & 274,0 & 278,1 & 282,0 & 247,6 \\
\hline $\mathrm{C}_{2} \mathrm{H}_{2}$ & ${ }^{2} J_{\mathrm{CH}}$ & 53,3 & 53,4 & 53,7 & 54,0 & 54,2 & 54,3 & 54,3 & 54,0 & 53,6 & 52,9 & 52,1 & 51,1 & 50,0 & 48,9 & 47,7 & 50,1 \\
\hline $\mathrm{C}_{2} \mathrm{H}_{2}$ & ${ }^{3} J_{\mathrm{HH}}$ & 10,4 & 10,4 & 10,4 & 10,5 & 10,8 & 11,2 & 11,7 & 12,4 & 13,2 & 14,1 & 15,0 & 16,0 & 17,0 & 17,9 & 18,8 & 9,6 \\
\hline $\mathrm{C}_{2} \mathrm{H}_{4}$ & ${ }^{1} J_{\mathrm{CC}}$ & 66,7 & 66,9 & 67,4 & 68,1 & 69,1 & 70,3 & 71,9 & 73,9 & 76,4 & 79,4 & 82,8 & 86,6 & 90,6 & 94,8 & 99,1 & 67,6 \\
\hline $\mathrm{C}_{2} \mathrm{H}_{4}$ & ${ }^{1} J_{\mathrm{CH}}$ & 154,9 & 154,6 & 154,3 & 154,3 & 154,6 & 155,5 & 157,0 & 158,9 & 161,3 & 164,0 & 167,0 & 170,1 & 173,4 & 176,6 & 179,7 & 156,3 \\
\hline $\mathrm{C}_{2} \mathrm{H}_{4}$ & ${ }^{2} J_{\mathrm{CH}}$ & $-2,4$ & $-2,4$ & $-2,4$ & $-2,6$ & $-2,8$ & $-3,2$ & $-3,8$ & $-4,6$ & $-5,4$ & $-6,5$ & $-7,7$ & $-8,9$ & $-10,3$ & $-11,7$ & $-13,1$ & $-2,4$ \\
\hline $\mathrm{C}_{2} \mathrm{H}_{4}$ & ${ }^{2} J_{\mathrm{HH}}$ & 3,1 & 3,1 & 3,0 & 2,9 & 2,6 & 2,2 & 1,7 & 1,2 & 0,5 & $-0,1$ & $-0,9$ & $-1,7$ & $-2,5$ & $-3,3$ & $-4,1$ & 2,3 \\
\hline $\mathrm{C}_{2} \mathrm{H}_{4}$ & ${ }^{3} J_{\mathrm{HH}_{\mathrm{c}}}$ & 12,7 & 12,7 & 12,8 & 12,9 & 13,1 & 13,4 & 13,7 & 14,2 & 14,6 & 15,2 & 15,8 & 16,5 & 17,2 & 17,9 & 18,6 & 11,7 \\
\hline $\mathrm{C}_{2} \mathrm{H}_{4}$ & ${ }^{3} J_{\mathrm{HH}_{\mathrm{t}}}$ & 18,6 & 18,6 & 18,6 & 18,7 & 18,8 & 19,1 & 19,5 & 20,0 & 20,6 & 21,4 & 22,2 & 23,0 & 23,9 & 24,8 & 25,7 & 19 \\
\hline $\mathrm{C}_{2} \mathrm{H}_{6}$ & ${ }^{1} J_{\mathrm{CC}}$ & 30,1 & 30,3 & 30,7 & 31,3 & 31,9 & 32,6 & 33,4 & 34,3 & 35,4 & 36,5 & 37,7 & 39 & 40,3 & 41,6 & 42,8 & 34,5 \\
\hline $\mathrm{C}_{2} \mathrm{H}_{6}$ & ${ }^{1} J_{\mathrm{CH}}$ & 121,4 & 121,2 & 120,9 & 120 & 120,9 & 121,5 & 122 & 123,7 & 125 &, 1 & 129,0 & 131,0 & 133,0 & 134,9 & 136,7 & 125,2 \\
\hline $\mathrm{C}_{2} \mathrm{H}_{6}$ & ${ }^{2} J_{\mathrm{CH}}$ & $-3,7$ & $-3,7$ & $-3,7$ & $-3,8$ & $-3,9$ & $-4,1$ & $-4,3$ & $-4,5$ & $-4,8$ & $-5,0$ & $-5,3$ & $-5,6$ & $-5,9$ & $-6,1$ & $-6,4$ & $-4,7$ \\
\hline \multirow[t]{3}{*}{ Total } & $\mathrm{DM}$ & -16 , & 34 & & & & & & & & & & & & & & - \\
\hline & DMA & 19 & & & & & & & & & & & & & & & - \\
\hline & PDMA & 14,10 & 13,86 & 13,10 & 12,40 & 11,25 & 10,49 & 13,82 & 18,53 & 24,38 & 31,25 & 38,84 & 46,43 & 54,56 & 62,54 & 70,62 & - \\
\hline \multirow[t]{3}{*}{ CPI } & DM & $-40,39$ & $-40,08$ & & & & -39 & & & & & & & & & & - \\
\hline & DMA &, 83 & 41,6 & 41 , & 41, & & 42 , & & & & & 51, & & & & & - \\
\hline & PDMA & 22,24 & 21,62 & 20,28 & 18,50 & 16,19 & 13,50 & 16,30 & 20,97 & 26,86 & 32,88 & 39,05 & 44,96 & 51,28 & 57,24 & 63,19 & - \\
\hline \multirow[t]{3}{*}{ SPI } & DM & & & & & & & & & & & & & & & & - \\
\hline & & & & & & & & & & & & & & & & & - \\
\hline & PDMA & 8,14 & 8,16 & 7,83 & 7,93 & 7,63 & 8,28 & 12,00 & 16,73 & 22,57 & 30,06 & 38,69 & 47,50 & 56,96 & 66,42 & 76,07 & - \\
\hline \multirow[t]{3}{*}{$\Delta C S$} & & & & & & & & & & & & & & & & & - \\
\hline & DMA & & & & & & & & & & & & & & & & - \\
\hline & PDMA & 4,10 & 13,46 & 12,45 & 10,57 & 8,55 & 5,23 & 4,30 & 4,24 & 4,30 & 2,81 & 0,36 & $-2,55$ & $-5,67$ & $-9,18$ & $-12,87$ & - \\
\hline
\end{tabular}


Tabela 8.387: Constantes de acoplamento LC-SLYP $\operatorname{com} \alpha=50 \%$ e $\alpha+\beta=100 \%$, variando $\gamma$, na base aug-pcJ-2.

\begin{tabular}{|c|c|c|c|c|c|c|c|c|c|c|c|c|c|c|c|c|c|}
\hline & $\gamma$ & 0,05 & 0,10 & 0,15 & 0,20 & 0,25 & 0,30 & 0,35 & 0,40 & 0,45 & 0,50 & 0,55 & 0,60 & 0,65 & 0,70 & 0,75 & Exp. \\
\hline HF & ${ }^{1} J_{\mathrm{HF}}$ & 531,1 & 531,7 & 532,7 & 533,8 & 535,4 & 537,5 & 540,1 & 543,3 & 547,0 & 551,1 & 555,4 & 560,0 & 564,7 & 569,5 & 574,3 & 500 \\
\hline $\mathrm{CO}$ & ${ }^{1} J_{\mathrm{CO}}$ & 13,6 & 13,5 & 13,3 & 13,1 & 13,0 & 12,9 & 12,7 & 12,6 & 12,3 & 11,9 & 11,5 & 10,9 & 10,3 & 9,6 & 8,9 & 16,4 \\
\hline $\mathrm{H}_{2} \mathrm{O}$ & ${ }^{1} J_{\mathrm{OH}}$ & $-83,8$ & $-83,8$ & $-83,9$ & $-84,0$ & $-84,2$ & $-84,5$ & $-84,9$ & $-85,4$ & $-86,0$ & $-86,6$ & $-87,3$ & $-88,0$ & $-88,8$ & $-89,6$ & $-90,4$ & $-80,6$ \\
\hline $\mathrm{H}_{2} \mathrm{O}$ & ${ }^{2} J_{\mathrm{HH}}$ & $-9,4$ & $-9,4$ & $-9,4$ & $-9,5$ & $-9,7$ & $-10,0$ & $-10,3$ & $-10,6$ & $-11,0$ & $-11,4$ & $-11,8$ & $-12,2$ & $-12,5$ & $-12,9$ & $-13,3$ & $-7,3$ \\
\hline $\mathrm{NH}_{3}$ & ${ }^{1} J_{\mathrm{NH}}$ & 45,5 & 45,5 & 45,5 & 45,6 & 45,6 & 45,7 & 45,9 & 46,1 & 46,4 & 46,8 & 47,2 & 47,6 & 48,0 & 48,5 & 48,9 & 43,8 \\
\hline $\mathrm{NH}_{3}$ & ${ }^{2} J_{\mathrm{HH}}$ & $-11,1$ & $-11,1$ & $-11,2$ & $-11,3$ & $-11,6$ & $-11,9$ & $-12,2$ & $-12,7$ & $-13,1$ & $-13,5$ & $-14,0$ & $-14,4$ & $-14,9$ & $-15,3$ & $-15,6$ & $-9,6$ \\
\hline $\mathrm{PH}_{3}$ & ${ }^{1} J_{\mathrm{PH}}$ & 183,3 & 182,9 & 181,6 & 179,7 & 178,3 & 177,8 & 178,6 & 180,6 & 183,7 & 187,4 & 191,5 & 195,8 & 200,1 & 204,2 & 208,1 & 188,2 \\
\hline $\mathrm{PF}_{3}$ & ${ }^{1} J_{\mathrm{PF}}$ & $-1669,5$ & $-1667,2$ & $-1663,9$ & $-1659,7$ & $-1655,0$ & $-1649,9$ & $-1644,7$ & $-1639,0$ & $-1632,5$ & $-1625,2$ & $-1617,2$ & $-1608,5$ & $-1599,4$ & $-1590,1$ & $-1580,9$ & -1441 \\
\hline $\mathrm{BHF}_{2}$ & ${ }^{1} J_{\mathrm{BF}}$ & $-95,0$ & $-94,0$ & $-91,8$ & $-88,6$ & $-84,7$ & $-80,3$ & $-75,7$ & $-70,9$ & $-66,1$ & $-61,3$ & $-56,7$ & $-52,2$ & $-47,9$ & $-43,9$ & $-40,1$ & -84 \\
\hline $\mathrm{BF}_{3}$ & ${ }^{1} J_{\mathrm{BF}}$ & 15,3 & 16,2 & 18,2 & 21,2 & 25,2 & 29,7 & 34,5 & 39,5 & 44,6 & 49,6 & 54,4 & 59,0 & 63,3 & 67,4 & 71,2 & 15 \\
\hline $\mathrm{F}_{2} \mathrm{O}$ & ${ }^{1} J_{\mathrm{OF}}$ & $-465,1$ & $-466,7$ & $-471,3$ & $-479,1$ & $-490,1$ & $-503,6$ & $-519,2$ & $-536,4$ & $-555,0$ & $-575,2$ & $-596,8$ & $-620,0$ & $-644,8$ & $-671,2$ & $-699,1$ & -300 \\
\hline $\mathrm{CH}_{4}$ & ${ }^{1} J_{\mathrm{CH}}$ & 124,9 & 124,7 & 124,5 & 124,5 & 124,6 & 125,1 & 125,9 & 127,0 & 128,3 & 129,8 & 131,4 & 133,0 & 134,6 & 136,2 & 137,7 & 125,3 \\
\hline $\mathrm{CH}_{4}$ & ${ }^{2} J_{\mathrm{HH}}$ & $-13,2$ & $-13,2$ & $-13,2$ & $-13,4$ & $-13,6$ & $-14,0$ & $-14,4$ & $-14,8$ & $-15,3$ & $-15,8$ & $-16,3$ & $-16,7$ & $-17,1$ & $-17,5$ & $-17,8$ & $-12,8$ \\
\hline $\mathrm{C}_{2} \mathrm{H}_{2}$ & ${ }^{1} J_{\mathrm{CC}}$ & 202,4 & 202,5 & 202,9 & 203,7 & 204,8 & 206,3 & 208,3 & 210,7 & 213,6 & 216,9 & 220,6 & 224,4 & 228,4 & 232,4 & 236,4 & 174,8 \\
\hline $\mathrm{C}_{2} \mathrm{H}_{2}$ & ${ }^{1} J_{\mathrm{CH}}$ & 259,3 & 258,8 & 258,3 & 258,0 & 258,3 & 259,3 & 260,9 & 263,1 & 265,9 & 269,1 & 272,6 & 276,2 & 279,8 & 283,3 & 286,7 & 247,6 \\
\hline $\mathrm{C}_{2} \mathrm{H}_{2}$ & ${ }^{2} J_{\mathrm{CH}}$ & 53,1 & 53,2 & 53,3 & 53,5 & 53,6 & 53,6 & 53,4 & 53,0 & 52,4 & 51,7 & 50,8 & 49,8 & 48,7 & 47,7 & 46,6 & 50,1 \\
\hline $\mathrm{C}_{2} \mathrm{H}_{2}$ & ${ }^{3} J_{\mathrm{HH}}$ & 11,8 & 11,7 & 11,7 & 11,9 & 12,2 & 12,6 & 13,2 & 13,9 & 14,7 & 15,5 & 16,4 & 17,3 & 18,2 & 19,0 & 19,8 & 9,6 \\
\hline $\mathrm{C}_{2} \mathrm{H}_{4}$ & ${ }^{1} J_{\mathrm{CC}}$ & 72,3 & 72,5 & 72,9 & 73,7 & 74,7 & 76,1 & 77,8 & 79,9 & 82,5 & 85,5 & 88,8 & 92,5 & 96,3 & 100,3 & 104,3 & 67,6 \\
\hline $\mathrm{C}_{2} \mathrm{H}_{4}$ & ${ }^{1} J_{\mathrm{CH}}$ & 160,5 & 160,3 & 160,1 & 160,1 & 160,5 & 161,4 & 162,8 & 164,6 & 166,8 & 169,3 & 172,0 & 174,9 & 177,8 & 180,6 & 183,5 & 156,3 \\
\hline $\mathrm{C}_{2} \mathrm{H}_{4}$ & ${ }^{2} J_{\mathrm{CH}}$ & $-3,8$ & $-3,8$ & $-3,8$ & $-4,0$ & $-4,3$ & $-4,8$ & $-5,4$ & $-6,2$ & $-7,1$ & $-8,2$ & $-9,4$ & $-10,6$ & $-12,0$ & $-13,3$ & $-14,7$ & $-2,4$ \\
\hline $\mathrm{C}_{2} \mathrm{H}_{4}$ & ${ }^{2} J_{\mathrm{HH}}$ & 2,2 & 2,2 & 2,1 & 2,0 & 1,7 & 1,3 & 0,8 & 0,3 & $-0,3$ & $-1,0$ & $-1,7$ & $-2,5$ & $-3,3$ & $-4,0$ & $-4,8$ & 2,3 \\
\hline $\mathrm{C}_{2} \mathrm{H}_{4}$ & ${ }^{3} J_{\mathrm{HH}_{\mathrm{c}}}$ & 13,3 & 13,3 & 13,4 & 13,5 & 13,7 & 14,0 & 14,4 & 14,9 & 15,4 & 16,0 & 16,6 & 17,2 & 17,9 & 18,6 & 19,2 & 11,7 \\
\hline $\mathrm{C}_{2} \mathrm{H}_{4}$ & ${ }^{3} J_{\mathrm{HH}_{\mathrm{t}}}$ & 19,6 & 19,6 & 19,6 & 19,7 & 19,9 & 20,2 & 20,6 & 21,2 & 21,8 & 22,5 & 23,3 & 24,1 & 25,0 & 25,8 & 26,6 & 19 \\
\hline $\mathrm{C}_{2} \mathrm{H}_{6}$ & ${ }^{1} J_{\mathrm{CC}}$ & 33,3 & 33,5 & 33,9 & 34,4 & 34,9 & 35,6 & 36,3 & 37,1 & 38,0 & 39,0 & 40,0 & 41 & 42,2 & 43,3 & 44,3 & 34,5 \\
\hline $\mathrm{C}_{2} \mathrm{H}_{6}$ & ${ }^{1} J_{\mathrm{CH}}$ & 125,7 & 125,5 & 125,3 & 125,3 & 125,4 & 125,9 & 126,8 & 127,9 & 12 ? & 130,8 & 132,4 & 134 & 135,8 & 137,4 & 139,0 & 125,2 \\
\hline $\mathrm{C}_{2} \mathrm{H}_{6}$ & ${ }^{2} J_{\mathrm{CH}}$ & $-4,3$ & $-4,3$ & $-4,3$ & $-4,4$ & $-4,5$ & $-4,6$ & $-4,8$ & $-5,0$ & $-5,2$ & $-5,5$ & $-5,7$ & $-5,9$ & $-6,2$ & $-6,4$ & $-6,6$ & $-4,7$ \\
\hline \multirow[t]{3}{*}{ Total } & $\mathrm{DM}$ & -1 & 12,73 & & & 44 & -12 & & & & & & & & & & - \\
\hline & DMA & & & & & & & & & & & & & & & & - \\
\hline & PDMA & 12,25 & 12,43 & 13,20 & 14,73 & 17,33 & 21,19 & 25,86 & 31,32 & 37,34 & 44,06 & 51,07 & 58,31 & 66,06 & 73,33 & 80,75 & - \\
\hline \multirow[t]{3}{*}{ CPI } & DM & $-35,0$ & 34,85 & & & & -34 & & & & & & & &, 15 & & - \\
\hline & DMA & 41 & 41,1 & 41, & & 43 & 44 , & 46 , & & & & & & & & & - \\
\hline & PDMA & 14,92 & 15,48 & 16,87 & 19,02 & 22,04 & 26,30 & 31,01 & 36,00 & 41,23 & 46,49 & 52,05 & 57,64 & 63,05 & 68,45 & 73,58 & - \\
\hline \multirow[t]{3}{*}{ SPI } & DM & & & & & & & & & & & & & & & & - \\
\hline & & & & & & & & & & & & & & & & & - \\
\hline & PDMA & 10,29 & 10,20 & 10,52 & 11,59 & 13,88 & 17,45 & 22,08 & 27,88 & 34,49 & 42,27 & 50,35 & 58,80 & 68,27 & 76,91 & 86,00 & - \\
\hline \multirow[t]{3}{*}{$\Delta C S$} & & & & & & & & & & & & & & & & & - \\
\hline & MA & & & & & & & & & & & & & & & & - \\
\hline & & 4,63 & 5,28 & 6,35 & 7,44 & 8,16 & 8,85 & 8,93 & 8,13 & 6,74 & 4,22 & 1,71 & $-1,16$ & $-5,22$ & $-8,46$ & $-12,43$ & - \\
\hline
\end{tabular}


Tabela 8.388: Constantes de acoplamento LC-SLYP com $\alpha=0 \%$ e $\alpha+\beta=90 \%$, variando $\gamma$, na base aug-pcJ-2.

\begin{tabular}{|c|c|c|c|c|c|c|c|c|c|c|c|c|c|c|c|c|c|}
\hline & $\gamma$ & 0,05 & 0,10 & 0,15 & 0,20 & 0,25 & 0,30 & 0,35 & 0,40 & 0,45 & 0,50 & 0,55 & 0,60 & 0,65 & 0,70 & 0,75 & Exp. \\
\hline $\mathrm{HF}$ & ${ }^{1} J_{\mathrm{HF}}$ & 421,2 & 422,4 & 423,9 & 425,5 & 427,5 & 430,4 & 434,4 & 439,5 & 445,6 & 452,6 & 460,1 & 467,9 & 475,9 & 484,1 & 492,2 & 500 \\
\hline $\mathrm{CO}$ & ${ }^{1} J_{\mathrm{CO}}$ & 24,7 & 24,5 & 24,1 & 23,9 & 23,7 & 23,5 & 23,3 & 23,1 & 22,8 & 22,3 & 21,6 & 20,9 & 20,0 & 19,0 & 18,0 & 16,4 \\
\hline $\mathrm{H}_{2} \mathrm{O}$ & ${ }^{1} J_{\mathrm{OH}}$ & $-70,0$ & $-70,1$ & $-70,2$ & $-70,3$ & $-70,6$ & $-71,0$ & $-71,5$ & $-72,3$ & $-73,2$ & $-74,2$ & $-75,3$ & $-76,5$ & $-77,7$ & $-78,9$ & $-80,2$ & $-80,6$ \\
\hline $\mathrm{H}_{2} \mathrm{O}$ & ${ }^{2} J_{\mathrm{HH}}$ & $-3,3$ & $-3,3$ & $-3,4$ & $-3,5$ & $-3,8$ & $-4,2$ & $-4,6$ & $-5,1$ & $-5,7$ & $-6,2$ & $-6,8$ & $-7,4$ & $-8,0$ & $-8,5$ & $-9,1$ & $-7,3$ \\
\hline $\mathrm{NH}_{3}$ & ${ }^{1} J_{\mathrm{NH}}$ & 39,4 & 39,4 & 39,4 & 39,3 & 39,3 & 39,4 & 39,7 & 40,0 & 40,4 & 41,0 & 41,6 & 42,2 & 42,9 & 43,6 & 44,3 & 43,8 \\
\hline $\mathrm{NH}_{3}$ & ${ }^{2} J_{\mathrm{HH}}$ & $-5,4$ & $-5,4$ & $-5,5$ & $-5,7$ & $-6,1$ & $-6,5$ & $-7,1$ & $-7,7$ & $-8,3$ & $-9,0$ & $-9,6$ & $-10,3$ & $-10,9$ & $-11,5$ & $-12,1$ & $-9,6$ \\
\hline $\mathrm{PH}_{3}$ & ${ }^{1} J_{\mathrm{PH}}$ & 135,9 & 135,1 & 132,0 & 127,8 & 124,4 & 122,9 & 123,8 & 126,9 & 131,7 & 137,8 & 144,7 & 151,8 & 159,1 & 166,1 & 172,7 & 188,2 \\
\hline $\mathrm{PF}_{3}$ & ${ }^{1} J_{\mathrm{PF}}$ & $-1813,1$ & $-1811,5$ & $-1811,8$ & $-1813,5$ & $-1816,0$ & $-1818,5$ & $-1820,0$ & $-1819,4$ & $-1815,9$ & $-1809,2$ & $-1799,5$ & $-1787,4$ & $-1773,6$ & $-1758,7$ & $-1743,4$ & -1441 \\
\hline $\mathrm{BHF}_{2}$ & ${ }^{1} J_{\mathrm{BF}}$ & $-187,0$ & $-185,0$ & $-180,7$ & $-174,6$ & $-167,2$ & $-159,1$ & $-150,6$ & $-142,0$ & $-133,2$ & $-124,6$ & $-116,1$ & $-108,0$ & $-100,3$ & $-93,1$ & $-86,4$ & -84 \\
\hline $\mathrm{BF}_{3}$ & ${ }^{1} J_{\mathrm{BF}}$ & $-79,4$ & $-77,5$ & $-73,5$ & $-67,3$ & $-59,7$ & $-51,0$ & $-41,8$ & $-32,4$ & $-23,0$ & $-13,9$ & $-5,2$ & 3,0 & 10,7 & 17,9 & 24,6 & 15 \\
\hline $\mathrm{F}_{2} \mathrm{O}$ & ${ }^{1} J_{\mathrm{OF}}$ & $-272,4$ & $-275,0$ & $-281,6$ & $-292,6$ & $-306,9$ & $-323,0$ & $-339,8$ & $-356,3$ & $-372,3$ & $-387,9$ & $-403,3$ & $-418,8$ & $-434,7$ & $-450,9$ & $-467,7$ & -300 \\
\hline $\mathrm{CH}_{4}$ & ${ }^{1} J_{\mathrm{CH}}$ & 105,9 & 105,7 & 105,2 & 104,8 & 104,8 & 105,3 & 106,3 & 107,8 & 109,8 & 112,0 & 114,4 & 117,0 & 119,6 & 122,1 & 124,5 & 125,3 \\
\hline $\mathrm{CH}_{4}$ & ${ }^{2} J_{\mathrm{HH}}$ & $-7,9$ & $-7,8$ & $-7,9$ & $-8,1$ & $-8,5$ & $-9,0$ & $-9,7$ & $-10,4$ & $-11,1$ & $-11,8$ & $-12,6$ & $-13,3$ & $-13,9$ & $-14,5$ & $-15,1$ & $-12,8$ \\
\hline $\mathrm{C}_{2} \mathrm{H}_{2}$ & ${ }^{1} J_{\mathrm{CC}}$ & 175,5 & 175,7 & 176,1 & 176,8 & 177,5 & 178,5 & 179,9 & 181,9 & 184,4 & 187,3 & 190,8 & 194,6 & 198,7 & 203,1 & 207,5 & 174,8 \\
\hline $\mathrm{C}_{2} \mathrm{H}_{2}$ & ${ }^{1} J_{\mathrm{CH}}$ & 226,1 & 225,3 & 224,2 & 223,4 & 223,3 & 224,1 & 226,0 & 228,7 & 232,1 & 236,2 & 240,6 & 245,3 & 250,1 & 254,9 & 259,6 & 247,6 \\
\hline $\mathrm{C}_{2} \mathrm{H}_{2}$ & ${ }^{2} J_{\mathrm{CH}}$ & 51,2 & 51,4 & 51,8 & 52,5 & 53,2 & 53,9 & 54,5 & 54,8 & 55,0 & 54,9 & 54,7 & 54,3 & 53,8 & 53,1 & 52,3 & 50,1 \\
\hline $\mathrm{C}_{2} \mathrm{H}_{2}$ & ${ }^{3} J_{\mathrm{HH}}$ & 7,1 & 7,0 & 7,0 & 7,0 & 7,1 & 7,3 & 7,7 & 8,2 & 8,8 & 9,5 & 10,3 & 11,1 & 11,9 & 12,8 & 13,7 & 9,6 \\
\hline $\mathrm{C}_{2} \mathrm{H}_{4}$ & ${ }^{1} J_{\mathrm{CC}}$ & 50,5 & 50,8 & 51,3 & 52,0 & 52,7 & 53,5 & 54,5 & 56,0 & 57,8 & 60,1 & 62,7 & 65,7 & 69,0 & 72,5 & 76,1 & 67,6 \\
\hline $\mathrm{C}_{2} \mathrm{H}_{4}$ & ${ }^{1} J_{\mathrm{CH}}$ & 136,1 & 135,6 & 135,1 & 134,8 & 134,9 & 135,7 & 137,2 & 139,3 & 141,8 & 144,8 & 148,1 & 151,6 & 155,1 & 158,7 & 162,1 & 156,3 \\
\hline $\mathrm{C}_{2} \mathrm{H}_{4}$ & ${ }^{2} J_{\mathrm{CH}}$ & 0,9 & 0,9 & 0,9 & 0,9 & 0,8 & 0,5 & 0,2 & $-0,2$ & $-0,8$ & $-1,5$ & $-2,4$ & $-3,3$ & $-4,2$ & $-5,3$ & $-6,4$ & $-2,4$ \\
\hline $\mathrm{C}_{2} \mathrm{H}_{4}$ & ${ }^{2} J_{\mathrm{HH}}$ & 5,5 & 5,5 & 5,5 & 5,3 & 5,1 & 4,8 & 4,3 & 3,9 & 3,3 & 2,7 & 2,1 & 1,4 & 0,7 & 0,1 & $-0,5$ & 2,3 \\
\hline $\mathrm{C}_{2} \mathrm{H}_{4}$ & ${ }^{3} J_{\mathrm{HH}}$ & 11,2 & 11,3 & 11,3 & 11,4 & 11,5 & 11,7 & 11,9 & 12,2 & 12,5 & 12,9 & 13,3 & 13,8 & 14,3 & 14,8 & 15,3 & 11,7 \\
\hline $\mathrm{C}_{2} \mathrm{H}_{4}$ & ${ }^{3} J_{\mathrm{HH}_{\mathrm{t}}}{ }^{c}$ & 16,2 & 16,1 & 16,0 & 16,0 & 16,0 & 16,1 & 16,3 & 16,7 & 17,1 & 17,6 & 18,2 & 18,8 & 19,5 & 20,3 & 21,0 & 19 \\
\hline $\mathrm{C}_{2} \mathrm{H}_{6}$ & ${ }^{1} J_{\mathrm{CC}}$ & 18,8 & 19,1 & 19,7 & 20,5 & 21,2 & 22,0 & 22,9 & 24,0 & 25,3 & 26,7 & 28,3 & 29,9 & 31,6 & 33,3 & 34,9 & 34,5 \\
\hline $\mathrm{C}_{2} \mathrm{H}_{6}$ & ${ }^{1} J_{\mathrm{CH}}$ & 106,0 & 105,7 & 105,2 & 104,8 & 104,8 & 105,4 & 106,5 & 108,1 & 110,2 & 112,5 & 115,0 & 117,7 & 120,3 & 123,0 & 125,5 & 125,2 \\
\hline $\mathrm{C}_{2} \mathrm{H}_{6}$ & ${ }^{2} J_{\mathrm{CH}}$ & $-1,7$ & $-1,7$ & $-1,7$ & $-1,8$ & $-1,9$ & $-2,1$ & $-2,3$ & $-2,6$ & $-3,0$ & $-3,3$ & $-3,7$ & $-4,0$ & $-4,4$ & $-4,7$ & $-5,0$ & $-4,7$ \\
\hline \multirow[t]{3}{*}{ Total } & DM & $-28,96$ & $-28,88$ & $-28,95$ & $-29,07$ & $-29,15$ & $-29,02$ & $-28,58$ & $-27,78$ & $-26,65$ & $-25,22$ & $-23,58$ & $-21,81$ & $-19,98$ & $-18,14$ &, 41 & - \\
\hline & DMA & 34,42 & 34 , & 33,71 & 33,00 & 32,47 & 32,2 & 31,73 & & & 28,00 & 26 , & & & & & - \\
\hline & PDMA & 59,71 & 59,12 & 57,67 & 55,03 & 51,60 & 47,19 & 42,02 & 36,43 & 29,82 & 23,00 & 16,87 & 16,36 & 16,82 & 19,62 & 25,33 & - \\
\hline \multirow[t]{3}{*}{ CPI } & DM & $-59,12$ & $-58,85$ & $-58,93$ & $-59,26$ & $-59,66$ & $-59,82$ & $-59,55$ & $-58,78$ & $-57,45$ & $-55,65$ & $-53,52$ & $-51,23$ & $-48,86$ & $-46,53$ & $-44,36$ & 一 \\
\hline & DMA & 69,06 & 68,26 & 67,02 & 65,25 & 64,08 & 63,98 & 63,41 & 62,25 & 60,49 & 58,20 & 55,52 & 52,79 & 50,05 & 47,84 & 46,56 & - \\
\hline & PDMA & 91,17 & 89,61 & 86,19 & 81,21 & 75,03 & 68,35 & 60,96 & 53,14 & 44,94 & 36,70 & 28,49 & 22,07 & 17,01 & 15,64 & 19,60 & - \\
\hline \multirow[t]{3}{*}{ SPI } & DM & $-6,85$ & $-6,90$ & $-6,96$ & $-6,92$ & $-6,77$ & $-6,43$ & $-5,86$ & $-5,05$ & $-4,06$ & $-2,90$ & $-1,62$ & $-0,23$ & 1,20 & 2,6 & 4,09 & - \\
\hline & DMA & 9,01 & 9,13 & 9,28 & 9,36 & 9,29 & 9,00 & 8,50 & & 6,90 & 5,86 & 4,8 & 4,01 & 3,76 & & 5,45 & - \\
\hline & PDMA & 36,64 & 36,76 & 36,75 & 35,84 & 34,42 & 31,67 & 28,14 & 24,19 & 18,74 & 12,95 & 8,35 & 12,16 & 16,68 & 22,54 & 29,54 & - \\
\hline \multirow[t]{3}{*}{$\Delta \mathrm{CS}$} & $\mathrm{DM}$ & $-52,27$ & $-51,95$ & $-51,97$ & $-52,34$ & $-52,89$ & $-53,39$ & $-53,69$ & & & $-52,75$ & & & $-50,06$ & 20 & $-48,46$ & - \\
\hline & DMA & 60,06 & 59,14 & 57,74 & 55,89 & 54,79 & 54,98 & 54,91 & 54,46 & & 52,34 & & 48,78 & 46,29 & & 41,11 & - \\
\hline & & 4,53 & 52,85 & 49,44 & 45,37 & 40,62 & 36,69 & 32,83 & 28,95 & 26,20 & 23,75 & 20,15 & 9,91 & 0,33 & $-6,90$ & $-9,93$ & - \\
\hline
\end{tabular}


Tabela 8.389: Constantes de acoplamento LC-SLYP com $\alpha=10 \%$ e $\alpha+\beta=90 \%$, variando $\gamma$, na base aug-pcJ-2.

\begin{tabular}{|c|c|c|c|c|c|c|c|c|c|c|c|c|c|c|c|c|c|}
\hline & $\gamma$ & 0,05 & 0,10 & 0,15 & 0,20 & 0,25 & 0,30 & 0,35 & 0,40 & 0,45 & 0,50 & 0,55 & 0,60 & 0,65 & 0,70 & 0,75 & Exp. \\
\hline $\mathrm{HF}$ & ${ }^{1} J_{\mathrm{HF}}$ & 441,6 & 442,8 & 444,1 & 445,6 & 447,6 & 450,3 & 454,0 & 458,6 & 464,1 & 470,3 & 477,0 & 484,0 & 491,2 & 498,4 & 505,7 & 500 \\
\hline $\mathrm{CO}$ & ${ }^{1} J_{\mathrm{CO}}$ & 22,8 & 22,6 & 22,3 & 22,1 & 21,9 & 21,7 & 21,6 & 21,3 & 21,0 & 20,5 & 19,9 & 19,2 & 18,4 & 17,5 & 16,6 & 16,4 \\
\hline $\mathrm{H}_{2} \mathrm{O}$ & ${ }^{1} J_{\mathrm{OH}}$ & $-72,5$ & $-72,6$ & $-72,7$ & $-72,8$ & $-73,1$ & $-73,4$ & $-74,0$ & $-74,6$ & $-75,5$ & $-76,4$ & $-77,4$ & $-78,4$ & $-79,5$ & $-80,7$ & $-81,8$ & $-80,6$ \\
\hline $\mathrm{H}_{2} \mathrm{O}$ & ${ }^{2} J_{\mathrm{HH}}$ & $-4,4$ & $-4,4$ & $-4,5$ & $-4,6$ & $-4,9$ & $-5,2$ & $-5,6$ & $-6,1$ & $-6,6$ & $-7,1$ & $-7,6$ & $-8,2$ & $-8,7$ & $-9,2$ & $-9,7$ & $-7,3$ \\
\hline $\mathrm{NH}_{3}$ & ${ }^{1} J_{\mathrm{NH}}$ & 40,5 & 40,5 & 40,5 & 40,5 & 40,5 & 40,6 & 40,8 & 41,1 & 41,5 & 42,0 & 42,5 & 43,1 & 43,8 & 44,4 & 45,0 & 43,8 \\
\hline $\mathrm{NH}_{3}$ & ${ }^{2} J_{\mathrm{HH}}$ & $-6,4$ & $-6,4$ & $-6,5$ & $-6,7$ & $-7,0$ & $-7,5$ & $-8,0$ & $-8,5$ & $-9,1$ & $-9,7$ & $-10,3$ & $-10,9$ & $-11,5$ & $-12,1$ & $-12,6$ & $-9,6$ \\
\hline $\mathrm{PH}_{3}$ & ${ }^{1} J_{\mathrm{PH}}$ & 144,6 & 144,0 & 141,4 & 137,8 & 134,9 & 133,6 & 134,5 & 137,4 & 141,8 & 147,3 & 153,5 & 159,9 & 166,4 & 172,7 & 178,7 & 188,2 \\
\hline $\mathrm{PF}_{3}$ & ${ }^{1} J_{\mathrm{PF}}$ & $-1795,8$ & $-1793,8$ & $-1792,6$ & $-1792,0$ & $-1791,7$ & $-1791,4$ & $-1790,4$ & $-1787,8$ & $-1783,1$ & $-1775,9$ & $-1766,5$ & $-1755,2$ & $-1742,5$ & $-1729,1$ & $-1715,3$ & -1441 \\
\hline $\mathrm{BHF}_{2}$ & ${ }^{1} J_{\mathrm{BF}}$ & $-169,1$ & $-167,4$ & $-163,7$ & $-158,2$ & $-151,7$ & $-144,5$ & $-136,9$ & $-129,2$ & $-121,5$ & $-113,7$ & $-106,2$ & $-99,0$ & $-92,2$ & $-85,8$ & $-79,8$ & -84 \\
\hline $\mathrm{BF}_{3}$ & ${ }^{1} J_{\mathrm{BF}}$ & $-60,8$ & $-59,2$ & $-55,7$ & $-50,3$ & $-43,6$ & $-36,0$ & $-27,9$ & $-19,6$ & $-11,3$ & $-3,2$ & 4,5 & 11,9 & 18,8 & 25,2 & 31,2 & 15 \\
\hline $\mathrm{F}_{2} \mathrm{O}$ & ${ }^{1} J_{\mathrm{OF}}$ & $-308,5$ & $-310,6$ & $-316,4$ & $-325,9$ & $-338,4$ & $-352,7$ & $-367,9$ & $-383,1$ & $-398,2$ & $-413,1$ & $-428,2$ & $-443,5$ & $-459,3$ & $-475,5$ & $-492,3$ & -300 \\
\hline $\mathrm{CH}_{4}$ & ${ }^{1} J_{\mathrm{CH}}$ & 109,3 & 109,1 & 108,7 & 108,4 & 108,4 & 108,9 & 109,9 & 111,3 & 113,1 & 115,2 & 117,4 & 119,7 & 122,0 & 124,3 & 126,5 & 125,3 \\
\hline $\mathrm{CH}_{4}$ & ${ }^{2} J_{\mathrm{HH}}$ & $-8,8$ & $-8,8$ & $-8,9$ & $-9,1$ & $-9,4$ & $-9,9$ & $-10,5$ & $-11,1$ & $-11,8$ & $-12,5$ & $-13,1$ & $-13,8$ & $-14,4$ & $-14,9$ & $-15,4$ & $-12,8$ \\
\hline $\mathrm{C}_{2} \mathrm{H}_{2}$ & ${ }^{1} J_{\mathrm{CC}}$ & 179,6 & 179,8 & 180,2 & 180,8 & 181,6 & 182,7 & 184,2 & 186,1 & 188,6 & 191,6 & 194,9 & 198,7 & 202,6 & 206,7 & 210,9 & 174,8 \\
\hline $\mathrm{C}_{2} \mathrm{H}_{2}$ & ${ }^{1} J_{\mathrm{CH}}$ & 232,0 & 231,2 & 230,3 & 229,6 & 229,6 & 230,4 & 232,1 & 234,7 & 237,9 & 241,7 & 245,9 & 250,2 & 254,7 & 259,1 & 263,4 & 247,6 \\
\hline $\mathrm{C}_{2} \mathrm{H}_{2}$ & ${ }^{2} J_{\mathrm{CH}}$ & 52,1 & 52,2 & 52,6 & 53,2 & 53,8 & 54,3 & 54,7 & 54,9 & 55,0 & 54,8 & 54,5 & 54,0 & 53,3 & 52,6 & 51,8 & 50,1 \\
\hline $\mathrm{C}_{2} \mathrm{H}_{2}$ & ${ }^{3} J_{\mathrm{HH}}$ & 7,7 & 7,7 & 7,6 & 7,6 & 7,8 & 8,0 & 8,4 & 8,9 & 9,6 & 10,3 & 11,1 & 11,9 & 12,7 & 13,5 & 14,3 & 9,6 \\
\hline $\mathrm{C}_{2} \mathrm{H}_{4}$ & ${ }^{1} J_{\mathrm{CC}}$ & 53,9 & 54,2 & 54,7 & 55,3 & 56,0 & 56,9 & 58,0 & 59,4 & 61,3 & 63,6 & 66,2 & 69,2 & 72,3 & 75,7 & 79,2 & 67,6 \\
\hline $\mathrm{C}_{2} \mathrm{H}_{4}$ & ${ }^{1} J_{\mathrm{CH}}$ & 140,4 & 140,0 & 139,5 & 139,2 & 139,4 & 140,2 & 141,6 & 143,6 & 146,0 & 148,8 & 151,9 & 155,1 & 158,4 & 161,7 & 164,9 & 156,3 \\
\hline $\mathrm{C}_{2} \mathrm{H}_{4}$ & ${ }^{2} J_{\mathrm{CH}}$ & 0,2 & 0,3 & 0,3 & 0,2 & 0,1 & $-0,1$ & $-0,5$ & $-1,0$ & $-1,6$ & $-2,3$ & $-3,2$ & $-4,1$ & $-5,1$ & $-6,1$ & $-7,1$ & $-2,4$ \\
\hline $\mathrm{C}_{2} \mathrm{H}_{4}$ & ${ }^{2} J_{\mathrm{HH}}$ & 5,0 & 5,0 & 5,0 & 4,8 & 4,6 & 4,3 & 3,9 & 3,4 & 2,8 & 2,3 & 1,6 & 1,0 & 0,3 & $-0,2$ & $-0,8$ & 2,3 \\
\hline $\mathrm{C}_{2} \mathrm{H}_{4}$ & ${ }^{3} J_{\mathrm{HH}_{\mathrm{c}}}$ & 11,5 & 11,5 & 11,6 & 11,7 & 11,8 & 12,0 & 12,2 & 12,5 & 12,9 & 13,2 & 13,7 & 14,1 & 14,6 & 15,1 & 15,6 & 11,7 \\
\hline $\mathrm{C}_{2} \mathrm{H}_{4}$ & ${ }^{3} J_{\mathrm{HH}_{\mathrm{t}}}$ & 16,7 & 16,6 & 16,5 & 16,5 & 16,6 & 16,7 & 16,9 & 17,3 & 17,7 & 18,3 & 18,9 & 19,5 & 20,2 & 20,9 & 21,6 & 19 \\
\hline $\mathrm{C}_{2} \mathrm{H}_{6}$ & ${ }^{1} J_{\mathrm{CC}}$ & 21,4 & 21,7 & 22,2 & 22,9 & 23,6 & 24,3 & 25,2 & 26,2 & 27,4 & 28,7 & 30,2 & 31,7 & 33,2 & 34,7 & 36,2 & 34,5 \\
\hline $\mathrm{C}_{2} \mathrm{H}_{6}$ & ${ }^{1} J_{\mathrm{CH}}$ & 109,6 & 109,3 & 108,8 & 108,5 & 108,6 & 109,2 & 110,2 & 111,7 & 113,6 & 115,8 & 118,1 & 120,5 & 122,9 & 125,3 & 127,5 & 125,2 \\
\hline $\mathrm{C}_{2} \mathrm{H}_{6}$ & ${ }^{2} J_{\mathrm{CH}}$ & $-2,1$ & $-2,1$ & $-2,1$ & $-2,2$ & $-2,3$ & $-2,5$ & $-2,8$ & $-3,0$ & $-3,3$ & $-3,7$ & $-4,0$ & $-4,3$ & $-4,7$ & $-5,0$ & $-5,2$ & $-4,7$ \\
\hline \multirow[t]{3}{*}{ Total } & DM & $-26,33$ & $-26,22$ & $-26,22$ & $-26,23$ & $-26,17$ & $-25,93$ & $-25,43$ & $-24,64$ & $-23,57$ & $-22,24$ & $-20,76$ & $-19,18$ & $-17,58$ & $-15,99$ & & - \\
\hline & DMA & 29,35 & 29,25 & 29,26 & 29,27 & 29,18 & & 28,30 & 27, & 26,22 & 24,82 & & & 22,12 & & & - \\
\hline & PDMA & 48,12 & 47,79 & 46,67 & 44,35 & 41,40 & 37,58 & 32,73 & 27,27 & 21,14 & 15,36 & 14,96 & 15,63 & 18,92 & 24,14 & 30,39 & - \\
\hline \multirow[t]{3}{*}{ CPI } & DM & $-55,35$ & $-55,04$ & $-54,97$ & $-55,04$ & $-55,13$ & $-55,04$ & $-54,61$ & $-53,76$ & $-52,53$ & $-50,90$ & $-49,06$ & $-47,09$ & $-45,09$ & $-43,19$ & $-41,38$ & - \\
\hline & DMA & 59,10 & 58,73 & 58,55 & 58,51 & 58,40 & 58,07 & 57,35 & 56,16 & 54,51 & 52,45 & 50,28 & 48,00 & 46,35 & 45,35 & 46,38 & - \\
\hline & PDMA & 72,60 & 71,38 & 68,74 & 64,86 & 59,78 & 53,82 & 47,30 & 40,26 & 32,97 & 25,76 & 20,41 & 15,79 & 15,91 & 19,77 & 24,72 & - \\
\hline \multirow[t]{3}{*}{ SPI } & DM & $-5,04$ & $-5,09$ & $-5,14$ & $-5,11$ & $-4,93$ & $-4,58$ & $-4,04$ & $-3,28$ & $-2,33$ & $-1,22$ & 0,00 & 1,29 & 2,59 & 3,95 & 5,29 & - \\
\hline & DMA & 7,53 & 7,64 & 7,78 & 7,83 & 7,75 & 7,49 & 7,00 & 6,32 & 5,47 & 4,57 & 3,83 & 3,73 & 4,35 & 5,23 & 6,74 & - \\
\hline & PDMA & 30,17 & 30,48 & 30,49 & 29,31 & 27,93 & 25,67 & 22,04 & 17,75 & 12,46 & 7,74 & 10,97 & 15,52 & 21,14 & 27,34 & 34,56 & - \\
\hline \multirow[t]{3}{*}{$\Delta \mathrm{CS}$} & DM & $-50,31$ & $-49,94$ & $-49,83$ & $-49,92$ & $-50,20$ & & $-50,57$ & $-50,48$ &, 20 & $-4 \mathrm{~s}$ & & & $-47,68$ & & & - \\
\hline & DMA & 51,57 & 51,09 & 50,77 & 50,68 & 50,65 & & 50,35 & 49,84 & & & 46,46 & 44,27 & 41,99 & 40,12 & 39,64 & - \\
\hline & PDMA & 42,43 & 40,90 & 38,24 & 35,56 & 31,85 & 28,16 & 25,26 & 22,52 & 20,52 & 18,03 & 9,44 & 0,27 & $-5,23$ & $-7,57$ & $-9,84$ & - \\
\hline
\end{tabular}


Tabela 8.390: Constantes de acoplamento LC-SLYP com $\alpha=20 \%$ e $\alpha+\beta=90 \%$, variando $\gamma$, na base aug-pcJ-2.

\begin{tabular}{|c|c|c|c|c|c|c|c|c|c|c|c|c|c|c|c|c|c|}
\hline & $\gamma$ & 0,05 & 0,10 & 0,15 & 0,20 & 0,25 & 0,30 & 0,35 & 0,40 & 0,45 & 0,50 & 0,55 & 0,60 & 0,65 & 0,70 & 0,75 & Exp. \\
\hline $\mathrm{HF}$ & ${ }^{1} J_{\mathrm{HF}}$ & 462,8 & 463,8 & 465,0 & 466,5 & 468,3 & 470,8 & 474,1 & 478,2 & 483,1 & 488,5 & 494,4 & 500,6 & 506,9 & 513,3 & 519,7 & 500 \\
\hline $\mathrm{CO}$ & ${ }^{1} J_{\mathrm{CO}}$ & 20,8 & 20,6 & 20,3 & 20,1 & 19,9 & 19,8 & 19,6 & 19,4 & 19,1 & 18,7 & 18,1 & 17,5 & 16,7 & 15,9 & 15,0 & 16,4 \\
\hline $\mathrm{H}_{2} \mathrm{O}$ & ${ }^{1} J_{\mathrm{OH}}$ & $-75,1$ & $-75,2$ & $-75,3$ & $-75,4$ & $-75,7$ & $-76,0$ & $-76,5$ & $-77,1$ & $-77,8$ & $-78,7$ & $-79,6$ & $-80,5$ & $-81,5$ & $-82,5$ & $-83,5$ & $-80,6$ \\
\hline $\mathrm{H}_{2} \mathrm{O}$ & ${ }^{2} J_{\mathrm{HH}}$ & $-5,5$ & $-5,5$ & $-5,6$ & $-5,8$ & $-6,0$ & $-6,3$ & $-6,7$ & $-7,1$ & $-7,5$ & $-8,0$ & $-8,5$ & $-9,0$ & $-9,5$ & $-9,9$ & $-10,4$ & $-7,3$ \\
\hline $\mathrm{NH}_{3}$ & ${ }^{1} J_{\mathrm{NH}}$ & 41,7 & 41,7 & 41,7 & 41,7 & 41,7 & 41,8 & 42,0 & 42,3 & 42,6 & 43,1 & 43,6 & 44,1 & 44,7 & 45,2 & 45,8 & 43,8 \\
\hline $\mathrm{NH}_{3}$ & ${ }^{2} J_{\mathrm{HH}}$ & $-7,5$ & $-7,5$ & $-7,6$ & $-7,8$ & $-8,1$ & $-8,4$ & $-8,9$ & $-9,4$ & $-9,9$ & $-10,5$ & $-11,0$ & $-11,6$ & $-12,1$ & $-12,6$ & $-13,1$ & $-9,6$ \\
\hline $\mathrm{PH}_{3}$ & ${ }^{1} J_{\mathrm{PH}}$ & 153,7 & 153,2 & 151,0 & 148,0 & 145,6 & 144,6 & 145,5 & 148,0 & 152,0 & 156,9 & 162,4 & 168,1 & 173,8 & 179,4 & 184,6 & 188,2 \\
\hline $\mathrm{PF}_{3}$ & ${ }^{1} J_{\mathrm{PF}}$ & $-1772,0$ & $-1769,8$ & $-1767,6$ & $-1765,5$ & $-1763,3$ & $-1761,0$ & $-1758,3$ & $-1754,5$ & $-1749,1$ & $-1741,9$ & $-1732,9$ & $-1722,6$ & $-1711,2$ & $-1699,3$ & $-1687,1$ & -1441 \\
\hline $\mathrm{BHF}_{2}$ & ${ }^{1} J_{\mathrm{BF}}$ & $-151,0$ & $-149,5$ & $-146,3$ & $-141,6$ & $-135,9$ & $-129,6$ & $-123,0$ & $-116,2$ & $-109,4$ & $-102,7$ & $-96,1$ & $-89,8$ & $-83,8$ & $-78,2$ & $-72,9$ & -84 \\
\hline $\mathrm{BF}_{3}$ & ${ }^{1} J_{\mathrm{BF}}$ & $-42,0$ & $-40,7$ & $-37,6$ & $-33,1$ & $-27,3$ & $-20,7$ & $-13,7$ & $-6,4$ & 0,7 & 7,8 & 14,6 & 21,0 & 27,1 & 32,7 & 38,0 & 15 \\
\hline $\mathrm{F}_{2} \mathrm{O}$ & ${ }^{1} J_{\mathrm{OF}}$ & $-344,1$ & $-346,0$ & $-351,0$ & $-359,3$ & $-370,4$ & $-383,3$ & $-397,2$ & $-411,4$ & $-425,8$ & $-440,4$ & $-455,3$ & $-470,6$ & $-486,4$ & $-502,7$ & $-519,5$ & -300 \\
\hline $\mathrm{CH}_{4}$ & ${ }^{1} J_{\mathrm{CH}}$ & 112,9 & 112,7 & 112,4 & 112,2 & 112,2 & 112,7 & 113,6 & 114,9 & 116,5 & 118,4 & 120,4 & 122,5 & 124,6 & 126,6 & 128,6 & 125,3 \\
\hline $\mathrm{CH}_{4}$ & ${ }^{2} J_{\mathrm{HH}}$ & $-9,9$ & $-9,8$ & $-9,9$ & $-10,1$ & $-10,4$ & $-10,9$ & $-11,4$ & $-12,0$ & $-12,6$ & $-13,2$ & $-13,7$ & $-14,3$ & $-14,8$ & $-15,3$ & $-15,8$ & $-12,8$ \\
\hline $\mathrm{C}_{2} \mathrm{H}_{2}$ & ${ }^{1} J_{\mathrm{CC}}$ & 184,2 & 184,4 & 184,8 & 185,4 & 186,2 & 187,3 & 188,9 & 190,8 & 193,3 & 196,2 & 199,5 & 203,1 & 206,8 & 210,7 & 214,6 & 174,8 \\
\hline $\mathrm{C}_{2} \mathrm{H}_{2}$ & ${ }^{1} J_{\mathrm{CH}}$ & 238,2 & 237,5 & 236,7 & 236,1 & 236,2 & 237,0 & 238,6 & 241,0 & 244,0 & 247,5 & 251,3 & 255,4 & 259,4 & 263,5 & 267,4 & 247,6 \\
\hline $\mathrm{C}_{2} \mathrm{H}_{2}$ & ${ }^{2} J_{\mathrm{CH}}$ & 52,7 & 52,9 & 53,2 & 53,7 & 54,1 & 54,5 & 54,8 & 54,9 & 54,8 & 54,5 & 54,1 & 53,5 & 52,8 & 52,1 & 51,3 & 50,1 \\
\hline $\mathrm{C}_{2} \mathrm{H}_{2}$ & ${ }^{3} J_{\mathrm{HH}}$ & 8,5 & 8,4 & 8,4 & 8,4 & 8,6 & 8,9 & 9,3 & 9,8 & 10,5 & 11,2 & 11,9 & 12,7 & 13,5 & 14,3 & 15,1 & 9,6 \\
\hline $\mathrm{C}_{2} \mathrm{H}_{4}$ & ${ }^{1} J_{\mathrm{CC}}$ & 57,7 & 57,9 & 58,4 & 59,0 & 59,7 & 60,6 & 61,8 & 63,3 & 65,2 & 67,4 & 70,0 & 72,9 & 76,0 & 79,2 & 82,5 & 67,6 \\
\hline $\mathrm{C}_{2} \mathrm{H}_{4}$ & ${ }^{1} J_{\mathrm{CH}}$ & 144,9 & 144,6 & 144,2 & 144,0 & 144,2 & 145,0 & 146,3 & 148,2 & 150,4 & 153,0 & 155,9 & 158,9 & 161,9 & 164,9 & 167,8 & 156,3 \\
\hline $\mathrm{C}_{2} \mathrm{H}_{4}$ & ${ }^{2} J_{\mathrm{CH}}$ & $-0,4$ & $-0,4$ & $-0,4$ & $-0,5$ & $-0,6$ & $-0,9$ & $-1,3$ & $-1,8$ & $-2,5$ & $-3,2$ & $-4,1$ & $-5,0$ & $-6,0$ & $-7,0$ & $-8,0$ & $-2,4$ \\
\hline $\mathrm{C}_{2} \mathrm{H}_{4}$ & ${ }^{2} J_{\mathrm{HH}}$ & 4,4 & 4,4 & 4,4 & 4,3 & 4,0 & 3,7 & 3,3 & 2,9 & 2,3 & 1,7 & 1,1 & 0,5 & 0,0 & $-0,6$ & $-1,2$ & 2,3 \\
\hline $\mathrm{C}_{2} \mathrm{H}_{4}$ & ${ }^{3} J_{\mathrm{HH}}$ & 11,8 & 11,8 & 11,9 & 12,0 & 12,1 & 12,3 & 12,6 & 12,9 & 13,2 & 13,6 & 14,1 & 14,5 & 15,0 & 15,5 & 15,9 & 11,7 \\
\hline $\mathrm{C}_{2} \mathrm{H}_{4}$ & ${ }^{3} J_{\mathrm{HH}_{\mathrm{t}}}$ & 17,2 & 17,2 & 17,1 & 17,1 & 17,2 & 17,4 & 17,6 & 18,0 & 18,4 & 19,0 & 19,6 & 20,2 & 20,9 & 21,5 & 22,2 & 19 \\
\hline $\mathrm{C}_{2} \mathrm{H}_{6}$ & ${ }^{1} J_{\mathrm{CC}}$ & 24,1 & 24,3 & 24,8 & 25,5 & 26,1 & 26,8 & 27,6 & 28,6 & 29,6 & 30,9 & 32,2 & 33,5 & 34,9 & 36,3 & 37,6 & 34,5 \\
\hline $\mathrm{C}_{2} \mathrm{H}_{6}$ & ${ }^{1} J_{\mathrm{CH}}$ & 113,3 & 113,0 & 112,7 & 112,5 & 112,6 & 113,1 & 114,1 & 115,5 & 117,2 & 119,1 & 121,2 & 123,3 & 125,5 & 127,6 & 129,6 & 125,2 \\
\hline $\mathrm{C}_{2} \mathrm{H}_{6}$ & ${ }^{2} J_{\mathrm{CH}}$ & $-2,6$ & $-2,6$ & $-2,6$ & $-2,7$ & $-2,8$ & $-3,0$ & $-3,2$ & $-3,5$ & $-3,7$ & $-4,0$ & $-4,3$ & $-4,6$ & $-4,9$ & $-5,2$ & $-5,4$ & $-4,7$ \\
\hline \multirow[t]{3}{*}{ Total } & DM & $-23,32$ & $-23,22$ & $-23,15$ & $-23,09$ & $-22,95$ & $-22,65$ & $-22,13$ & -21 , & -20 & $-19,23$ & ,93 & $-16,57$ & 18 & $-13,83$ &, 55 & - \\
\hline & DMA & 26,0 & 25,92 & 25 & 25 , & 25,63 & & 24,7 & 23, & & & & & & & & - \\
\hline & PDMA & 36,84 & 36,50 & 35,49 & 33,57 & 30,73 & 27,06 & 22,65 & 17,81 & 13,41 & 13,40 & 14,40 & 18,89 & 24,12 & 30,67 & 37,30 & - \\
\hline \multirow[t]{3}{*}{ CPI } & DM & $-50,83$ & $-50,53$ & $-50,35$ & $-50,28$ & $-50,19$ & $-49,93$ & $-49,45$ & $-48,65$ & $-47,54$ & $-46,19$ & $-44,65$ & $-43,06$ & $-41,47$ & $-39,96$ & $-38,57$ & - \\
\hline & DMA & 53,34 & 52,98 & 52,70 & 52,50 & 52,23 & 51,78 & 51,02 & 49,90 & 48,54 & 46,95 & 45,15 & 44,54 & 45,18 & 46,91 & 48,72 & - \\
\hline & PDMA & 55,29 & 54,27 & 51,87 & 48,43 & 44,02 & 38,95 & 33,12 & 26,95 & 21,82 & 17,62 & 13,36 & 16,89 & 21,09 & 26,65 & 32,57 & - \\
\hline \multirow[t]{3}{*}{ SPI } & DM & $-3,14$ & $-3,19$ & $-3,20$ & $-3,15$ & $-2,98$ & $-2,64$ & $-2,10$ & $-1,37$ & $-0,50$ & 0,53 & 1,67 & 2,8 & 4,10 & 5,33 & 6,54 & - \\
\hline & DMA & 5,97 & 6,08 & 6,19 & 6,23 & 6,13 & 5,84 & 5,39 & 4,76 & 4,0 & 3,47 & 3,73 & 4,41 & 5,27 & 6,73 & 8,25 & - \\
\hline & PDMA & 23,31 & 23,46 & 23,48 & 22,67 & 20,99 & 18,34 & 14,97 & 11,10 & 7,25 & 10,31 & 15,16 & 20,35 & 26,34 & 33,62 & 40,77 & - \\
\hline \multirow[t]{3}{*}{$\Delta \mathrm{CS}$} & $\mathrm{DM}$ & $-47,69$ & $-47,34$ & $-47,15$ & $-47,14$ & $-47,21$ & $-47,29$ & $-47,35$ & $-47,27$ & & $-46,72$ & & $-45,93$ & $-45,57$ & $-45,30$ & $-45,11$ & - \\
\hline & DMA & 47,37 & 46,90 & 46,51 & 46,27 & 46,10 & & 45,62 & 45,14 & 44,46 & 43,49 & 41,42 & 40,12 & 39,91 & 40,18 & 40,47 & - \\
\hline & PDMA & 31,98 & 30,80 & 28,38 & 25,76 & 23,04 & 20,61 & 18,14 & 15,85 & 14,57 & 7,31 & $-1,79$ & $-3,46$ & $-5,25$ & $-6,97$ & $-8,20$ & - \\
\hline
\end{tabular}


Tabela 8.391: Constantes de acoplamento LC-SLYP com $\alpha=30 \%$ e $\alpha+\beta=90 \%$, variando $\gamma$, na base aug-pcJ-2.

\begin{tabular}{|c|c|c|c|c|c|c|c|c|c|c|c|c|c|c|c|c|c|}
\hline & $\gamma$ & 0,05 & 0,10 & 0,15 & 0,20 & 0,25 & 0,30 & 0,35 & 0,40 & 0,45 & 0,50 & 0,55 & 0,60 & 0,65 & 0,70 & 0,75 & Exp. \\
\hline HF & ${ }^{1} J_{\mathrm{HF}}$ & 484,8 & 485,6 & 486,7 & 488,0 & 489,7 & 491,9 & 494,8 & 498,4 & 502,6 & 507,4 & 512,4 & 517,8 & 523,2 & 528,8 & 534,3 & 500 \\
\hline $\mathrm{CO}$ & ${ }^{1} J_{\mathrm{CO}}$ & 18,6 & 18,4 & 18,2 & 18,0 & 17,8 & 17,7 & 17,6 & 17,4 & 17,1 & 16,7 & 16,2 & 15,6 & 14,9 & 14,2 & 13,4 & 16,4 \\
\hline $\mathrm{H}_{2} \mathrm{O}$ & ${ }^{1} J_{\mathrm{OH}}$ & $-77,9$ & $-77,9$ & $-78,0$ & $-78,2$ & $-78,4$ & $-78,7$ & $-79,1$ & $-79,7$ & $-80,3$ & $-81,0$ & $-81,8$ & $-82,6$ & $-83,5$ & $-84,4$ & $-85,3$ & $-80,6$ \\
\hline $\mathrm{H}_{2} \mathrm{O}$ & ${ }^{2} J_{\mathrm{HH}}$ & $-6,8$ & $-6,8$ & $-6,8$ & $-6,9$ & $-7,1$ & $-7,4$ & $-7,7$ & $-8,1$ & $-8,5$ & $-9,0$ & $-9,4$ & $-9,8$ & $-10,2$ & $-10,7$ & $-11,0$ & $-7,3$ \\
\hline $\mathrm{NH}_{3}$ & ${ }^{1} J_{\mathrm{NH}}$ & 42,9 & 42,9 & 42,9 & 42,9 & 42,9 & 43,0 & 43,2 & 43,5 & 43,8 & 44,2 & 44,6 & 45,1 & 45,6 & 46,1 & 46,6 & 43,8 \\
\hline $\mathrm{NH}_{3}$ & ${ }^{2} J_{\mathrm{HH}}$ & $-8,7$ & $-8,7$ & $-8,7$ & $-8,9$ & $-9,1$ & $-9,5$ & $-9,9$ & $-10,3$ & $-10,8$ & $-11,3$ & $-11,8$ & $-12,3$ & $-12,7$ & $-13,2$ & $-13,6$ & $-9,6$ \\
\hline $\mathrm{PH}_{3}$ & ${ }^{1} J_{\mathrm{PH}}$ & 163,2 & 162,8 & 161,0 & 158,6 & 156,6 & 155,8 & 156,6 & 158,9 & 162,3 & 166,6 & 171,4 & 176,3 & 181,3 & 186,1 & 190,7 & 188,2 \\
\hline $\mathrm{PF}_{3}$ & ${ }^{1} J_{\mathrm{PF}}$ & $-1742,5$ & $-1740,3$ & $-1737,6$ & $-1734,5$ & $-1731,2$ & $-1727,8$ & $-1724,1$ & $-1719,6$ & $-1714,0$ & $-1707,1$ & $-1698,9$ & $-1689,7$ & $-1679,8$ & $-1669,4$ & $-1658,9$ & -1441 \\
\hline $\mathrm{BHF}_{2}$ & ${ }^{1} J_{\mathrm{BF}}$ & $-132,5$ & $-131,3$ & $-128,6$ & $-124,6$ & $-119,7$ & $-114,4$ & $-108,7$ & $-102,9$ & $-97,1$ & $-91,4$ & $-85,7$ & $-80,3$ & $-75,2$ & $-70,3$ & $-65,8$ & -84 \\
\hline $\mathrm{BF}_{3}$ & ${ }^{1} J_{\mathrm{BF}}$ & $-23,1$ & $-21,9$ & $-19,4$ & $-15,6$ & $-10,7$ & $-5,1$ & 0,8 & 6,9 & 13,1 & 19,1 & 25,0 & 30,5 & 35,7 & 40,6 & 45,1 & 15 \\
\hline $\mathrm{F}_{2} \mathrm{O}$ & ${ }^{1} J_{\mathrm{OF}}$ & $-380,7$ & $-382,3$ & $-386,7$ & $-394,1$ & $-404,1$ & $-415,9$ & $-428,9$ & $-442,4$ & $-456,4$ & $-470,8$ & $-485,6$ & $-501,0$ & $-516,9$ & $-533,3$ & $-550,2$ & -300 \\
\hline $\mathrm{CH}_{4}$ & ${ }^{1} J_{\mathrm{CH}}$ & 116,7 & 116,5 & 116,3 & 116,1 & 116,2 & 116,7 & 117,5 & 118,7 & 120,1 & 121,7 & 123,5 & 125,3 & 127,2 & 129,0 & 130,7 & 125,3 \\
\hline $\mathrm{CH}_{4}$ & ${ }^{2} J_{\mathrm{HH}}$ & $-10,9$ & $-10,9$ & $-11,0$ & $-11,1$ & $-11,4$ & $-11,8$ & $-12,3$ & $-12,8$ & $-13,3$ & $-13,8$ & $-14,4$ & $-14,9$ & $-15,3$ & $-15,8$ & $-16,1$ & $-12,8$ \\
\hline $\mathrm{C}_{2} \mathrm{H}_{2}$ & ${ }^{1} J_{\mathrm{CC}}$ & 189,4 & 189,6 & 189,9 & 190,6 & 191,4 & 192,6 & 194,1 & 196,1 & 198,5 & 201,3 & 204,5 & 207,8 & 211,4 & 215,0 & 218,5 & 174,8 \\
\hline $\mathrm{C}_{2} \mathrm{H}_{2}$ & ${ }^{1} J_{\mathrm{CH}}$ & 244,7 & 244,2 & 243,5 & 243,0 & 243,1 & 243,9 & 245,5 & 247,7 & 250,4 & 253,6 & 257,1 & 260,7 & 264,4 & 268,0 & 271,5 & 247,6 \\
\hline $\mathrm{C}_{2} \mathrm{H}_{2}$ & ${ }^{2} J_{\mathrm{CH}}$ & 53,2 & 53,3 & 53,6 & 53,9 & 54,3 & 54,5 & 54,6 & 54,6 & 54,4 & 54,0 & 53,5 & 52,8 & 52,1 & 51,4 & 50,6 & 50,1 \\
\hline $\mathrm{C}_{2} \mathrm{H}_{2}$ & ${ }^{3} J_{\mathrm{HH}}$ & 9,3 & 9,3 & 9,3 & 9,4 & 9,5 & 9,9 & 10,3 & 10,9 & 11,5 & 12,2 & 12,9 & 13,7 & 14,4 & 15,1 & 15,8 & 9,6 \\
\hline $\mathrm{C}_{2} \mathrm{H}_{4}$ & ${ }^{1} J_{\mathrm{CC}}$ & 61,9 & 62,1 & 62,5 & 63,1 & 63,9 & 64,8 & 66,0 & 67,6 & 69,5 & 71,7 & 74,3 & 77,0 & 80,0 & 83,0 & 86,1 & 67,6 \\
\hline $\mathrm{C}_{2} \mathrm{H}_{4}$ & ${ }^{1} J_{\mathrm{CH}}$ & 149,7 & 149,4 & 149,1 & 149,0 & 149,3 & 150,0 & 151,3 & 153,0 & 155,1 & 157,5 & 160,1 & 162,8 & 165,5 & 168,2 & 170,8 & 156,3 \\
\hline $\mathrm{C}_{2} \mathrm{H}_{4}$ & ${ }^{2} J_{\mathrm{CH}}$ & $-1,3$ & $-1,3$ & $-1,3$ & $-1,4$ & $-1,6$ & $-1,9$ & $-2,3$ & $-2,9$ & $-3,5$ & $-4,3$ & $-5,1$ & $-6,0$ & $-7,0$ & $-7,9$ & $-8,9$ & $-2,4$ \\
\hline $\mathrm{C}_{2} \mathrm{H}_{4}$ & ${ }^{2} J_{\mathrm{HH}}$ & 3,8 & 3,8 & 3,8 & 3,6 & 3,4 & 3,1 & 2,7 & 2,2 & 1,7 & 1,2 & 0,6 & 0,0 & $-0,5$ & $-1,0$ & $-1,6$ & 2,3 \\
\hline $\mathrm{C}_{2} \mathrm{H}_{4}$ & ${ }^{3} J_{\mathrm{HH}_{\mathrm{c}}}$ & 12,2 & 12,2 & 12,3 & 12,4 & 12,5 & 12,7 & 13,0 & 13,3 & 13,7 & 14,1 & 14,5 & 15,0 & 15,4 & 15,9 & 16,3 & 11,7 \\
\hline $\mathrm{C}_{2} \mathrm{H}_{4}$ & ${ }^{3} J_{\mathrm{HH}_{\mathrm{t}}}$ & 17,9 & 17,8 & 17,8 & 17,8 & 17,9 & 18,1 & 18,4 & 18,8 & 19,3 & 19,8 & 20,4 & 21,0 & 21,6 & 22,2 & 22,8 & 19 \\
\hline $\mathrm{C}_{2} \mathrm{H}_{6}$ & ${ }^{1} J_{\mathrm{CC}}$ & 27,0 & 27,2 & 27,6 & 28,2 & 28,8 & 29,4 & 30,2 & 31, & 32,0 & 33,1 & 34,2 & 35 & 36,6 & 37,8 & 39,0 & 34,5 \\
\hline $\mathrm{C}_{2} \mathrm{H}_{6}$ & ${ }^{1} J_{\mathrm{CH}}$ & 117,3 & 117,0 & 116,7 & 116,6 & 116,7 & 117,2 & 118,1 & 119,3 & 120,8 & 122,5 & 124,4 & 126,3 & 3,2 & 130,0 & 131,8 & 125,2 \\
\hline $\mathrm{C}_{2} \mathrm{H}_{6}$ & ${ }^{2} J_{\mathrm{CH}}$ & $-3,1$ & $-3,1$ & $-3,2$ & $-3,2$ & $-3,3$ & $-3,5$ & $-3,7$ & $-3,9$ & $-4,2$ & $-4,4$ & $-4,7$ & $-4,9$ & $-5,2$ & $-5,4$ & $-5,7$ & $-4,7$ \\
\hline \multirow[t]{3}{*}{ Total } & $\mathrm{DM}$ & -20 , & 90 & -19 & $-19,7$ & 52 & & & & & & & & & & & - \\
\hline & DMA & 22 & & & & & & & & & & & & & & & - \\
\hline & PDMA & 24,90 & 24,53 & 23,71 & 21,92 & 19,41 & 16,31 & 13,18 & 11,51 & 12,07 & 15,50 & 20,14 & 26,07 & 32,28 & 38,33 & 44,55 & - \\
\hline \multirow[t]{3}{*}{ CPI } & DM & $-45,78$ & $-45,49$ & $-45,26$ & $-45,11$ & & & -44 & & & & & & & & & - \\
\hline & DMA & ,93 & 46,6 & 46,3 & & 45 & & 44, & & & & & & & & & - \\
\hline & PDMA & 37,36 & 36,43 & 34,68 & 31,80 & 28,07 & 23,83 & 20,33 & 16,85 & 13,38 & 15,34 & 19,64 & 24,96 & 30,41 & 35,90 & 41,08 & - \\
\hline \multirow[t]{3}{*}{ SPI } & DM & $-1,0$ & $-1,1$ & -1 & & & & -0 & & & & & & & & & - \\
\hline & & & & & & & & & & & & & & & & & - \\
\hline & PDMA & 15,76 & 15,81 & 15,67 & 14,67 & 13,05 & 10,80 & 7,94 & 7,59 & 11,11 & 15,62 & 20,50 & 26,88 & 33,66 & 40,11 & 47,09 & - \\
\hline \multirow[t]{3}{*}{$\Delta C S$} & & & & & & & & & & & & & & & & & - \\
\hline & MA & & & & & & & & & & & & & & & & - \\
\hline & & 21,60 & 20,62 & 19,02 & 17,13 & 15,02 & 13,02 & 12,39 & 9,2 & 2,27 & $-0,28$ & $-0,86$ & $-1,92$ & $-3,24$ & $-4,20$ & $-6,00$ & - \\
\hline
\end{tabular}


Tabela 8.392: Constantes de acoplamento LC-SLYP com $\alpha=40 \%$ e $\alpha+\beta=90 \%$, variando $\gamma$, na base aug-pcJ-2.

\begin{tabular}{|c|c|c|c|c|c|c|c|c|c|c|c|c|c|c|c|c|c|}
\hline & $\gamma$ & 0,05 & 0,10 & 0,15 & 0,20 & 0,25 & 0,30 & 0,35 & 0,40 & 0,45 & 0,50 & 0,55 & 0,60 & 0,65 & 0,70 & 0,75 & Exp. \\
\hline $\mathrm{HF}$ & ${ }^{1} J_{\mathrm{HF}}$ & 507,5 & 508,2 & 509,1 & 510,2 & 511,7 & 513,6 & 516,2 & 519,2 & 522,8 & 526,8 & 531,0 & 535,5 & 540,1 & 544,8 & 549,5 & 500 \\
\hline $\mathrm{CO}$ & ${ }^{1} J_{\mathrm{CO}}$ & 16,2 & 16,0 & 15,9 & 15,7 & 15,6 & 15,4 & 15,3 & 15,1 & 14,9 & 14,6 & 14,1 & 13,6 & 13,0 & 12,4 & 11,7 & 16,4 \\
\hline $\mathrm{H}_{2} \mathrm{O}$ & ${ }^{1} J_{\mathrm{OH}}$ & $-80,8$ & $-80,8$ & $-80,9$ & $-81,0$ & $-81,2$ & $-81,5$ & $-81,8$ & $-82,3$ & $\begin{array}{l}-82,9 \\
\end{array}$ & $-83,5$ & $-84,1$ & $-84,9$ & $-85,6$ & $-86,3$ & $-87,1$ & $-80,6$ \\
\hline $\mathrm{H}_{2} \mathrm{O}$ & ${ }^{2} J_{\mathrm{HH}}$ & $-8,0$ & $-8,0$ & $-8,1$ & $-8,2$ & $-8,4$ & $-8,6$ & $-8,9$ & $-9,2$ & $-9,6$ & $-9,9$ & $-10,3$ & $-10,7$ & $-11,0$ & $-11,4$ & $-11,7$ & $-7,3$ \\
\hline $\mathrm{NH}_{3}$ & ${ }^{1} J_{\mathrm{NH}}$ & 44,2 & 44,2 & 44,2 & 44,2 & 44,2 & 44,3 & 44,5 & 44,7 & 45,0 & 45,3 & 45,7 & 46,1 & 46,5 & 47,0 & 47,4 & 43,8 \\
\hline $\mathrm{NH}_{3}$ & ${ }^{2} J_{\mathrm{HH}}$ & $-9,9$ & $-9,9$ & $-9,9$ & $-10,1$ & $-10,3$ & $-10,6$ & $-10,9$ & $-11,3$ & $-11,7$ & $-12,2$ & $-12,6$ & $-13,0$ & $-13,4$ & $-13,8$ & $-14,1$ & $-9,6$ \\
\hline $\mathrm{PH}_{3}$ & ${ }^{1} J_{\mathrm{PH}}$ & 173,1 & 172,7 & 171,3 & 169,3 & 167,8 & 167,2 & 167,9 & 169,8 & 172,8 & 176,4 & 180,4 & 184,7 & 188,8 & 192,9 & 196,7 & 188,2 \\
\hline $\mathrm{PF}_{3}$ & ${ }^{1} J_{\mathrm{PF}}$ & $-1708,1$ & $-1706,1$ & $-1703,2$ & $-1699,8$ & $-1696,0$ & $-1692,1$ & $-1688,0$ & $-1683,4$ & $-1678,1$ & $-1671,7$ & $-1664,5$ & $-1656,6$ & $-1648,1$ & $-1639,3$ & $-1630,5$ & -1441 \\
\hline $\mathrm{BHF}_{2}$ & ${ }^{1} J_{\mathrm{BF}}$ & $-113,8$ & $-112,8$ & $-110,6$ & $-107,4$ & $-103,4$ & $-98,9$ & $-94,3$ & $-89,4$ & $-84,6$ & $-79,8$ & $-75,1$ & $-70,6$ & $-66,3$ & $-62,3$ & $-58,5$ & -84 \\
\hline $\mathrm{BF}_{3}$ & ${ }^{1} J_{\mathrm{BF}}$ & $-4,0$ & $-3,0$ & $-1,0$ & 2,1 & 6,1 & 10,6 & 15,6 & 20,7 & 25,8 & 30,8 & 35,7 & 40,3 & 44,6 & 48,7 & 52,5 & 15 \\
\hline $\mathrm{F}_{2} \mathrm{O}$ & ${ }^{1} J_{\mathrm{OF}}$ & $-419,9$ & $-421,4$ & $-425,3$ & $-432,1$ & $-441,3$ & $-452,3$ & $-464,7$ & $-477,8$ & $-491,6$ & $-506,0$ & $-520,9$ & $-536,4$ & $-552,4$ & $-568,9$ & $-585,8$ & -300 \\
\hline $\mathrm{CH}_{4}$ & ${ }^{1} J_{\mathrm{CH}}$ & 120,7 & 120,5 & 120,3 & 120,2 & 120,4 & 120,8 & 121,5 & 122,5 & 123,8 & 125,2 & 126,7 & 128,3 & 129,8 & 131,3 & 132,8 & 125,3 \\
\hline $\mathrm{CH}_{4}$ & ${ }^{2} J_{\mathrm{HH}}$ & $-12,1$ & $-12,0$ & $-12,1$ & $-12,2$ & $-12,5$ & $-12,8$ & $-13,2$ & $-13,6$ & $-14,1$ & $-14,5$ & $-15,0$ & $-15,4$ & $-15,8$ & $-16,2$ & $-16,5$ & $-12,8$ \\
\hline $\mathrm{C}_{2} \mathrm{H}_{2}$ & ${ }^{1} J_{\mathrm{CC}}$ & 195,4 & 195,5 & 195,9 & 196,5 & 197,4 & 198,6 & 200,1 & 202,1 & 204,4 & 207,0 & 210,0 & 213,1 & 216,3 & 219,5 & 222,7 & 174,8 \\
\hline $\mathrm{C}_{2} \mathrm{H}_{2}$ & ${ }^{1} J_{\mathrm{CH}}$ & 251,8 & 251,3 & 250,7 & 250,4 & 250,6 & 251,3 & 252,8 & 254,8 & 257,2 & 260,1 & 263,1 & 266,3 & 269,5 & 272,7 & 275,7 & 247,6 \\
\hline $\mathrm{C}_{2} \mathrm{H}_{2}$ & ${ }^{2} J_{\mathrm{CH}}$ & 53,3 & 53,4 & 53,6 & 53,9 & 54,1 & 54,2 & 54,2 & 54,0 & 53,7 & 53,2 & 52,7 & 52,0 & 51,3 & 50,6 & 49,8 & 50,1 \\
\hline $\mathrm{C}_{2} \mathrm{H}_{2}$ & ${ }^{3} J_{\mathrm{HH}}$ & 10,4 & 10,4 & 10,4 & 10,5 & 10,7 & 11,0 & 11,5 & 12,0 & 12,6 & 13,3 & 14,0 & 14,7 & 15,4 & 16,0 & 16,7 & 9,6 \\
\hline $\mathrm{C}_{2} \mathrm{H}_{4}$ & ${ }^{1} J_{\mathrm{CC}}$ & 66,7 & 66,9 & 67,3 & 67,9 & 68,7 & 69,6 & 70,9 & 72,5 & 74,4 & 76,5 & 79,0 & 81,6 & 84,3 & 87,1 & 89,9 & 67,6 \\
\hline $\mathrm{C}_{2} \mathrm{H}_{4}$ & ${ }^{1} J_{\mathrm{CH}}$ & 154,9 & 154,7 & 154,4 & 154,4 & 154,7 & 155,4 & 156,6 & 158,1 & 160,0 & 162,2 & 164,5 & 166,9 & 169,3 & 171,7 & 174,0 & 156,3 \\
\hline $\mathrm{C}_{2} \mathrm{H}_{4}$ & ${ }^{2} J_{\mathrm{CH}}$ & $-2,4$ & $-2,4$ & $-2,4$ & $-2,5$ & $-2,8$ & $-3,1$ & $-3,5$ & $-4,1$ & $-4,8$ & $-5,5$ & $-6,3$ & $-7,2$ & $-8,1$ & $-9,0$ & $-9,9$ & $-2,4$ \\
\hline $\mathrm{C}_{2} \mathrm{H}_{4}$ & ${ }^{2} J_{\mathrm{HH}}$ & 3,1 & 3,1 & 3,0 & 2,9 & 2,7 & 2,4 & 2,0 & 1,5 & 1,1 & 0,5 & 0,0 & $-0,5$ & $-1,0$ & $-1,5$ & $-2,0$ & 2,3 \\
\hline $\mathrm{C}_{2} \mathrm{H}_{4}$ & ${ }^{3} J_{\mathrm{HH}}$ & 12,7 & 12,7 & 12,8 & 12,9 & 13,0 & 13,3 & 13,5 & 13,8 & 14,2 & 14,6 & 15,0 & 15,4 & 15,9 & 16,3 & 16,7 & 11,7 \\
\hline $\mathrm{C}_{2} \mathrm{H}_{4}$ & ${ }^{3} J_{\mathrm{HH}_{\mathrm{t}}}{ }^{c}$ & 18,7 & 18,6 & 18,6 & 18,7 & 18,8 & 19,0 & 19,3 & 19,7 & 20,2 & 20,7 & 21,2 & 21,8 & 22,4 & 23,0 & 23,5 & 19 \\
\hline $\mathrm{C}_{2} \mathrm{H}_{6}$ & ${ }^{1} J_{\mathrm{CC}}$ & 30,1 & 30,2 & 30,6 & 31,1 & 31,6 & 32,2 & 32,9 & 33,6 & 34,4 & 35,4 & 36,4 & 37,4 & 38,5 & 39,5 & 40,5 & 34,5 \\
\hline $\mathrm{C}_{2} \mathrm{H}_{6}$ & ${ }^{1} J_{\mathrm{CH}}$ & 121,4 & 121,2 & 121,0 & 120,9 & 121,0 & 121,5 & 122,2 & 123,3 & 124,6 & 126,1 & 127,7 & 129,3 & 130,9 & 132,4 & 133,9 & 125,2 \\
\hline $\mathrm{C}_{2} \mathrm{H}_{6}$ & ${ }^{2} J_{\mathrm{CH}}$ & $-3,7$ & $-3,7$ & $-3,7$ & $-3,8$ & $-3,9$ & $-4,0$ & $-4,2$ & $-4,4$ & $-4,6$ & $-4,8$ & $-5,0$ & $-5,3$ & $-5,5$ & $-5,7$ & $-5,9$ & $-4,7$ \\
\hline \multirow[t]{3}{*}{ Total } & DM & $-16,44$ & $-16,37$ & $-16,27$ & $-16,17$ & $-15,99$ & $-15,71$ & $-15,29$ & $-14,73$ & -14 & $-13,24$ & $-12,37$ & & $-10,60$ & $-9,75$ & $-8,96$ & - \\
\hline & DMA & 19,5 & 19,50 & & 19 & 19,58 & 19 & 19,92 & & & 22,55 & & & & & & - \\
\hline & PDMA & 14,11 & 13,93 & 13,28 & 12,56 & 11,80 & 10,86 & 11,42 & 15,23 & 19,22 & 24,33 & 29,89 & 35,62 & 41,23 & 46,91 & 52,44 & - \\
\hline \multirow[t]{3}{*}{ CPI } & DM & $-40,40$ & $-40,16$ & $-39,95$ & $-39,82$ & $-39,65$ & $-39,44$ & $-39,09$ & $-38,62$ & $-38,01$ & $-37,28$ & $-36,50$ & $-35,72$ & $-34,97$ & $-34,28$ & $-33,71$ & 一 \\
\hline & DMA & 41,84 & 41,73 & 41,67 & 41,75 & 41,85 & 42,00 & 42,27 & 43,31 & 44,34 & 46,06 & 47,86 & 49,63 & 51,46 & 53,94 & 56,36 & - \\
\hline & PDMA & 22,30 & 21,76 & 20,68 & 19,20 & 17,21 & 15,07 & 13,42 & 17,27 & 21,26 & 26,12 & 31,19 & 36,09 & 40,78 & 45,82 & 50,48 & - \\
\hline \multirow[t]{3}{*}{ SPI } & $\mathrm{DM}$ & 1,13 & 1,09 & 1,09 & 1,18 & 1,36 & 1,69 & 2,17 & 2,7 & 3,53 & 4,39 & 5,33 & 6,29 & 7,27 & 8,2 & 9,19 & - \\
\hline & DMA & 3,18 & 3,19 & 3,1 & 3,19 & 3,25 & 3,30 & 3,53 & 3,9 & 4,48 & 5,30 & 6,49 & 7,73 & 8,98 & & 11,45 & - \\
\hline & PDMA & 8,10 & 8,18 & 7,84 & 7,70 & 7,83 & 7,78 & 9,95 & 13,73 & 17,72 & 23,01 & 28,93 & 35,28 & 41,56 & 47,70 & 53,88 & - \\
\hline \multirow[t]{3}{*}{$\Delta \mathrm{CS}$} & DM & $-41,53$ & $-41,25$ & $-41,03$ & $-41,00$ & $-41,01$ & $-41,12$ & $-41,26$ & & & $-41,68$ & & & $-42,25$ &, 52 & $-42,90$ & - \\
\hline & DMA & 38,66 & 38,53 & 38,49 & 38,55 & 38,59 & 38,70 & 38,75 & 39,34 & 39,86 & 40,76 & 41,38 & 41,90 & 42,48 & 43,72 & 44,91 & - \\
\hline & PDMA & 14,19 & 13,57 & 12,84 & 11,50 & 9,38 & 7,29 & 3,46 & 3,54 & 3,54 & 3,11 & 2,26 & 0,82 & $-0,78$ & $-1,88$ & $-3,40$ & - \\
\hline
\end{tabular}


Tabela 8.393: Constantes de acoplamento LC-SLYP com $\alpha=50 \%$ e $\alpha+\beta=90 \%$, variando $\gamma$, na base aug-pcJ-2.

\begin{tabular}{|c|c|c|c|c|c|c|c|c|c|c|c|c|c|c|c|c|c|}
\hline & $\gamma$ & 0,05 & 0,10 & 0,15 & 0,20 & 0,25 & 0,30 & 0,35 & 0,40 & 0,45 & 0,50 & 0,55 & 0,60 & 0,65 & 0,70 & 0,75 & Exp. \\
\hline $\mathrm{HF}$ & ${ }^{\mathrm{I}} J_{\mathrm{HF}}$ & 531,0 & 531,6 & 532,3 & 533,2 & 534,5 & 536,1 & 538,2 & 540,7 & 543,6 & 546,8 & 550,3 & 553,9 & 557,6 & 561,4 & 565,2 & 500 \\
\hline $\mathrm{CO}$ & ${ }^{1} J_{\mathrm{CO}}$ & 13,7 & 13,5 & 13,4 & 13,2 & 13,1 & 13,0 & 12,9 & 12,8 & 12,6 & 12,3 & 11,9 & 11,5 & 11,0 & 10,5 & 9,9 & 16,4 \\
\hline $\mathrm{H}_{2} \mathrm{O}$ & ${ }^{1} J_{\mathrm{OH}}$ & $-83,8$ & $-83,8$ & $-83,9$ & $-84,0$ & $-84,1$ & $-84,4$ & $-84,7$ & $-85,1$ & $-85,5$ & $-86,0$ & $-86,6$ & $-87,2$ & $-87,8$ & $-88,4$ & $-89,0$ & $-80,6$ \\
\hline $\mathrm{H}_{2} \mathrm{O}$ & ${ }^{2} J_{\mathrm{HH}}$ & $-9,4$ & $-9,4$ & $-9,4$ & $-9,5$ & $-9,7$ & $-9,9$ & $-10,1$ & $-10,4$ & $-10,7$ & $-11,0$ & $-11,3$ & $-11,6$ & $-11,9$ & $-12,2$ & $-12,5$ & $-7,3$ \\
\hline $\mathrm{NH}_{3}$ & ${ }^{1} J_{\mathrm{NH}}$ & 45,5 & 45,5 & 45,5 & 45,6 & 45,6 & 45,7 & 45,8 & 46,0 & 46,3 & 46,5 & 46,8 & 47,2 & 47,5 & 47,9 & 48,2 & 43,8 \\
\hline $\mathrm{NH}_{3}$ & ${ }^{2} J_{\mathrm{HH}}$ & $-11,1$ & $-11,1$ & $-11,2$ & $-11,3$ & $-11,5$ & $-11,7$ & $-12,0$ & $-12,3$ & $-12,7$ & $-13,0$ & $-13,4$ & $-13,7$ & $-14,1$ & $-14,4$ & $-14,7$ & $-9,6$ \\
\hline $\mathrm{PH}_{3}$ & ${ }^{1} J_{\mathrm{PH}}$ & 183,2 & 183,0 & 181,9 & 180,4 & 179,2 & 178,8 & 179,4 & 181,0 & 183,4 & 186,4 & 189,6 & 193,0 & 196,4 & 199,7 & 202,8 & 188,2 \\
\hline $\mathrm{PF}_{3}$ & ${ }^{1} J_{\mathrm{PF}}$ & $-1669,7$ & $-1667,9$ & $-1665,2$ & $-1661,9$ & $-1658,2$ & $-1654,3$ & $-1650,3$ & $-1646,0$ & $-1641,2$ & $-1635,8$ & $-1629,7$ & $-1623,2$ & $-1616,3$ & $-1609,2$ & $-1602,1$ & -1441 \\
\hline $\mathrm{BHF}_{2}$ & ${ }^{1} J_{\mathrm{BF}}$ & $-95,0$ & $-94,2$ & $-92,5$ & $-89,9$ & $-86,8$ & $-83,3$ & $-79,5$ & $-75,7$ & $-71,8$ & $-68,0$ & $-64,3$ & $-60,7$ & $-57,2$ & $-54,0$ & $-51,0$ & -84 \\
\hline $\mathrm{BF}_{3}$ & ${ }^{1} J_{\mathrm{BF}}$ & 15,2 & 16,0 & 17,6 & 20,0 & 23,2 & 26,8 & 30,7 & 34,7 & 38,8 & 42,8 & 46,7 & 50,4 & 53,9 & 57,1 & 60,2 & 15 \\
\hline $\mathrm{F}_{2} \mathrm{O}$ & ${ }^{1} J_{\mathrm{OF}}$ & $-465,1$ & $-466,4$ & $-470,0$ & $-476,3$ & $-484,9$ & $-495,5$ & $-507,4$ & $-520,3$ & $-534,1$ & $-548,5$ & $-563,5$ & $-579,0$ & $-595,1$ & $-611,6$ & $-628,4$ & -300 \\
\hline $\mathrm{CH}_{4}$ & ${ }^{1} J_{\mathrm{CH}}$ & 124,9 & 124,8 & 124,6 & 124,6 & 124,7 & 125,1 & 125,7 & 126,5 & 127,6 & 128,7 & 130,0 & 131,3 & 132,5 & 133,8 & 135,0 & 125,3 \\
\hline $\mathrm{CH}_{4}$ & ${ }^{2} J_{\mathrm{HH}}$ & $-13,2$ & $-13,2$ & $-13,2$ & $-13,4$ & $-13,6$ & $-13,8$ & $-14,2$ & $-14,5$ & $-14,9$ & $-15,3$ & $-15,6$ & $-16,0$ & $-16,3$ & $-16,6$ & $-16,9$ & $-12,8$ \\
\hline $\mathrm{C}_{2} \mathrm{H}_{2}$ & ${ }^{1} J_{\mathrm{CC}}$ & 202,4 & 202,5 & 202,8 & 203,4 & 204,3 & 205,5 & 207,0 & 208,8 & 211,0 & 213,4 & 216,1 & 218,8 & 221,6 & 224,4 & 227,2 & 174,8 \\
\hline $\mathrm{C}_{2} \mathrm{H}_{2}$ & ${ }^{1} J_{\mathrm{CH}}$ & 259,3 & 259,0 & 258,5 & 258,3 & 258,5 & 259,3 & 260,5 & 262,3 & 264,5 & 266,9 & 269,5 & 272,2 & 274,9 & 277,6 & 280,1 & 247,6 \\
\hline $\mathrm{C}_{2} \mathrm{H}_{2}$ & ${ }^{2} J_{\mathrm{CH}}$ & 53,1 & 53,1 & 53,3 & 53,4 & 53,5 & 53,5 & 53,4 & 53,1 & 52,7 & 52,2 & 51,6 & 51,0 & 50,3 & 49,6 & 49,0 & 50,1 \\
\hline $\mathrm{C}_{2} \mathrm{H}_{2}$ & ${ }^{3} J_{\mathrm{HH}}$ & 11,8 & 11,7 & 11,7 & 11,9 & 12,1 & 12,4 & 12,9 & 13,4 & 13,9 & 14,6 & 15,2 & 15,8 & 16,4 & 17,0 & 17,5 & 9,6 \\
\hline $\mathrm{C}_{2} \mathrm{H}_{4}$ & ${ }^{1} J_{\mathrm{CC}}$ & 72,3 & 72,4 & 72,8 & 73,4 & 74,2 & 75,2 & 76,5 & 78,1 & 79,9 & 82,0 & 84,2 & 86,6 & 89,1 & 91,6 & 94,0 & 67,6 \\
\hline $\mathrm{C}_{2} \mathrm{H}_{4}$ & ${ }^{1} J_{\mathrm{CH}}$ & 160,5 & 160,3 & 160,2 & 160,2 & 160,5 & 161,2 & 162,2 & 163,6 & 165,3 & 167,2 & 169,2 & 171,2 & 173,3 & 175,3 & 177,2 & 156,3 \\
\hline $\mathrm{C}_{2} \mathrm{H}_{4}$ & ${ }^{2} J_{\mathrm{CH}}$ & $-3,8$ & $-3,8$ & $-3,8$ & $-4,0$ & $-4,2$ & $-4,6$ & $-5,0$ & $-5,6$ & $-6,3$ & $-7,0$ & $-7,8$ & $-8,6$ & $-9,4$ & $-10,2$ & $-11,0$ & $-2,4$ \\
\hline $\mathrm{C}_{2} \mathrm{H}_{4}$ & ${ }^{2} J_{\mathrm{HH}}$ & 2,2 & 2,2 & 2,2 & 2,0 & 1,8 & 1,5 & 1,2 & 0,7 & 0,3 & $-0,1$ & $-0,6$ & $-1,1$ & $-1,6$ & $-2,0$ & $-2,5$ & 2,3 \\
\hline $\mathrm{C}_{2} \mathrm{H}_{4}$ & ${ }^{3} J_{\mathrm{HH}}$ & 13,3 & 13,3 & 13,4 & 13,5 & 13,7 & 13,9 & 14,2 & 14,5 & 14,8 & 15,2 & 15,6 & 16,0 & 16,4 & 16,8 & 17,2 & 11,7 \\
\hline $\mathrm{C}_{2} \mathrm{H}_{4}$ & ${ }^{3} J_{\mathrm{HH}_{\mathrm{t}}}$ & 19,6 & 19,6 & 19,6 & 19,7 & 19,8 & 20,1 & 20,4 & 20,8 & 21,2 & 21,7 & 22,2 & 22,7 & 23,2 & 23,7 & 24,2 & 19 \\
\hline $\mathrm{C}_{2} \mathrm{H}_{6}$ & ${ }^{1} J_{\mathrm{CC}}$ & 33,3 & 33,5 & 33,8 & 34,2 & 34,6 & 35,1 & 35,7 & 36,3 & 37,0 & 37,8 & 38,6 & 39,5 & 40,3 & 41,2 & 42,0 & 34,5 \\
\hline $\mathrm{C}_{2} \mathrm{H}_{6}$ & ${ }^{1} J_{\mathrm{CH}}$ & 125,8 & 125,6 & 125,4 & 125,4 & 125,5 & 125,9 & 126,6 & 127,4 & 128,5 & 129,7 & 131,0 & 132,4 & 133,7 & 134,9 & 136,1 & 125,2 \\
\hline $\mathrm{C}_{2} \mathrm{H}_{6}$ & ${ }^{2} J_{\mathrm{CH}}$ & $-4,3$ & $-4,3$ & $-4,3$ & $-4,3$ & $-4,4$ & $-4,5$ & $-4,7$ & $-4,9$ & $-5,0$ & $-5,2$ & $-5,4$ & $-5,6$ & $-5,8$ & $-5,9$ & $-6,1$ & $-4,7$ \\
\hline \multirow[t]{3}{*}{ Total } & DM & $-12,82$ & $-12,75$ & $-12,67$ & $-12,58$ & $-12,45$ & $-12,23$ & $-11,91$ & $-11,50$ & $-10,99$ & $-10,41$ & $-9,80$ & $-9,16$ & $-8,55$ & $-7,96$ & $-7,44$ & - \\
\hline & DMA & 19,70 & 19,70 & 19,81 & 20,10 & 20,53 & 21,18 & 22,20 & & & & & & & & & - \\
\hline & PDMA & 12,21 & 12,38 & 12,88 & 14,49 & 16,38 & 19,12 & 22,41 & 26,80 & 31,30 & 35,99 & 41,06 & 46,19 & 51,28 & 56,08 & 61,07 & - \\
\hline \multirow[t]{3}{*}{ CPI } & DM & $-35,13$ & $-34,92$ & $-34,76$ & $-34,67$ & $-34,59$ & $-34,51$ & $-34,35$ & $-34,14$ & $-33,84$ & $-33,49$ & $-33,13$ & $-32,75$ & $-32,45$ & $-32,19$ & $-32,03$ & - \\
\hline & DMA & 41,11 & 41,15 & 41,42 & 41,95 & 42,68 & 43,69 & 45,34 & 47,03 & 48,76 & 50,45 & 52,42 & 54,72 & 57,03 & 59,30 & 61,55 & - \\
\hline & PDMA & 14,81 & 15,37 & 16,47 & 18,27 & 20,69 & 23,54 & 27,30 & 31,27 & 35,47 & 39,55 & 43,88 & 48,20 & 52,53 & 56,59 & 60,59 & - \\
\hline \multirow[t]{3}{*}{ SPI } & DM & 3,54 & 3,51 & 3,53 & 3,6 & 3,79 & 4,1 & 4,55 & 5,09 & 5,76 & 6,51 & 7,31 & 8,14 & 8,97 & 9,81 & 10,59 & - \\
\hline & DMA & 4,01 & 3,96 & 3,97 & 4,08 & 4,29 & 4,67 & 5,23 & 5,99 & 6,87 & 7,85 & 8,89 & 9,97 & 11,03 & 12,15 & 13,26 & - \\
\hline & PDMA & 10,30 & 10,18 & 10,24 & 11,72 & 13,22 & 15,88 & 18,82 & 23,53 & 28,23 & 33,37 & 38,99 & 44,71 & 50,35 & 55,71 & 61,43 & - \\
\hline \multirow[t]{3}{*}{$\Delta \mathrm{CS}$} & DM & $-38,67$ & $-38,42$ & $-38,29$ & $-38,29$ & $-38,38$ & & $-38,91$ & $-39,23$ & -39 & $-40,00$ & & & $-41,41$ & $-42,00$ & & - \\
\hline & DMA & 37,10 & 37,19 & 37,45 & 37,87 & 38,40 & 39,02 & 40,10 & 41,04 & 41,90 & 42,61 & 43,53 & 44,75 & 45,99 & 47,15 & 48,29 & - \\
\hline & PDMA & 4,51 & 5,18 & 6,23 & 6,54 & 7,48 & 7,66 & 8,49 & 7,74 & 7,24 & 6,17 & 4,88 & 3,48 & 2,18 & 0,87 & $-0,84$ & - \\
\hline
\end{tabular}


Tabela 8.394: Constantes de acoplamento LC-SLYP $\operatorname{com} \alpha=0 \%$ e $\alpha+\beta=80 \%$, variando $\gamma$, na base aug-pcJ-2.

\begin{tabular}{|c|c|c|c|c|c|c|c|c|c|c|c|c|c|c|c|c|c|}
\hline & $\gamma$ & 0,05 & 0,10 & 0,15 & 0,20 & 0,25 & 0,30 & 0,35 & 0,40 & 0,45 & 0,50 & 0,55 & 0,60 & 0,65 & 0,70 & 0,75 & Exp. \\
\hline $\mathrm{HF}$ & ${ }^{1} J_{\mathrm{HF}}$ & 421,1 & 422,2 & 423,5 & 424,9 & 426,7 & 429,3 & 432,7 & 437,2 & 442,5 & 448,6 & 455,1 & 462,0 & 469,1 & 476,2 & 483,3 & 500 \\
\hline $\mathrm{CO}$ & ${ }^{1} J_{\mathrm{CO}}$ & 24,7 & 24,5 & 24,2 & 24,0 & 23,8 & 23,7 & 23,5 & 23,3 & 23,0 & 22,6 & 22,0 & 21,4 & 20,6 & 19,8 & 18,9 & 16,4 \\
\hline $\mathrm{H}_{2} \mathrm{O}$ & ${ }^{1} J_{\mathrm{OH}}$ & $-70,0$ & $-70,1$ & $-70,2$ & $-70,3$ & $-70,5$ & $-70,8$ & $-71,3$ & $-72,0$ & $-72,8$ & $-73,7$ & $-74,6$ & $-75,7$ & $-76,7$ & $-77,8$ & $-78,9$ & $-80,6$ \\
\hline $\mathrm{H}_{2} \mathrm{O}$ & ${ }^{2} J_{\mathrm{HH}}$ & $-3,3$ & $-3,3$ & $-3,4$ & $-3,5$ & $-3,8$ & $-4,1$ & $-4,5$ & $-4,9$ & $-5,4$ & $-5,9$ & $-6,4$ & $-6,9$ & $-7,4$ & $-7,9$ & $-8,4$ & $-7,3$ \\
\hline $\mathrm{NH}_{3}$ & ${ }^{1} J_{\mathrm{NH}}$ & 39,4 & 39,4 & 39,4 & 39,3 & 39,3 & 39,4 & 39,6 & 39,9 & 40,3 & 40,8 & 41,3 & 41,8 & 42,4 & 43,1 & 43,7 & 43,8 \\
\hline $\mathrm{NH}_{3}$ & ${ }^{2} J_{\mathrm{HH}}$ & $-5,4$ & $-5,4$ & $-5,5$ & $-5,7$ & $-6,0$ & $-6,4$ & $-6,9$ & $-7,4$ & $-8,0$ & $-8,5$ & $-9,1$ & $-9,7$ & $-10,2$ & $-10,8$ & $-11,3$ & $-9,6$ \\
\hline $\mathrm{PH}_{3}$ & ${ }^{1} J_{\mathrm{PH}}$ & 135,8 & 135,1 & 132,4 & 128,7 & 125,5 & 124,1 & 124,8 & 127,5 & 131,8 & 137,1 & 143,1 & 149,5 & 155,8 & 162,0 & 167,8 & 188,2 \\
\hline $\mathrm{PF}_{3}$ & ${ }^{1} J_{\mathrm{PF}}$ & $-1813,2$ & $-1811,9$ & $-1812,1$ & $-1813,8$ & $-1816,3$ & $-1819,1$ & $-1821,3$ & $-1821,8$ & $-1819,8$ & $-1815,1$ & $-1807,8$ & $-1798,3$ & $-1787,1$ & $-1774,9$ & $-1762,1$ & -1441 \\
\hline $\mathrm{BHF}_{2}$ & ${ }^{1} J_{\mathrm{BF}}$ & $-187,0$ & $-185,2$ & $-181,5$ & $-176,0$ & $-169,4$ & $-162,2$ & $-154,7$ & $-147,0$ & $-139,2$ & $-131,5$ & $-124,0$ & $-116,8$ & $-110,0$ & $-103,5$ & $-97,6$ & -84 \\
\hline $\mathrm{BF}_{3}$ & ${ }^{1} J_{\mathrm{BF}}$ & $-79,5$ & $-77,8$ & $-74,2$ & $-68,7$ & $-61,9$ & $-54,2$ & $-46,0$ & $-37,6$ & $-29,2$ & $-21,1$ & $-13,3$ & $-5,9$ & 1,0 & 7,4 & 13,3 & 15 \\
\hline $\mathrm{F}_{2} \mathrm{O}$ & ${ }^{1} J_{\mathrm{OF}}$ & $-272,3$ & $-274,7$ & $-280,6$ & $-290,3$ & $-303,0$ & $-317,4$ & $-332,3$ & $-346,9$ & $-361,0$ & $-374,5$ & $-387,6$ & $-400,7$ & $-413,7$ & $-426,8$ & $-440,0$ & -300 \\
\hline $\mathrm{CH}_{4}$ & ${ }^{1} J_{\mathrm{CH}}$ & 106,0 & 105,7 & 105,3 & 105,0 & 104,9 & 105,3 & 106,2 & 107,5 & 109,2 & 111,2 & 113,3 & 115,6 & 117,8 & 120,0 & 122,1 & 125,3 \\
\hline $\mathrm{CH}_{4}$ & ${ }^{2} J_{\mathrm{HH}}$ & $-7,9$ & $-7,8$ & $-7,9$ & $-8,1$ & $-8,4$ & $-8,9$ & $-9,5$ & $-10,1$ & $-10,7$ & $-11,4$ & $-12,0$ & $-12,6$ & $-13,2$ & $-13,7$ & $-14,2$ & $-12,8$ \\
\hline $\mathrm{C}_{2} \mathrm{H}_{2}$ & ${ }^{1} J_{\mathrm{CC}}$ & 175,5 & 175,7 & 176,1 & 176,6 & 177,3 & 178,2 & 179,4 & 181,0 & 183,1 & 185,7 & 188,5 & 191,7 & 195,0 & 198,5 & 202,0 & 174,8 \\
\hline $\mathrm{C}_{2} \mathrm{H}_{2}$ & ${ }^{1} J_{\mathrm{CH}}$ & 226,2 & 225,4 & 224,5 & 223,7 & 223,6 & 224,4 & 226,0 & 228,3 & 231,4 & 234,9 & 238,7 & 242,8 & 246,9 & 251,0 & 254,9 & 247,6 \\
\hline $\mathrm{C}_{2} \mathrm{H}_{2}$ & ${ }^{2} J_{\mathrm{CH}}$ & 51,2 & 51,4 & 51,8 & 52,4 & 53,0 & 53,6 & 54,1 & 54,5 & 54,7 & 54,7 & 54,6 & 54,3 & 53,9 & 53,5 & 53,0 & 50,1 \\
\hline $\mathrm{C}_{2} \mathrm{H}_{2}$ & ${ }^{3} J_{\mathrm{HH}}$ & 7,1 & 7,1 & 7,0 & 7,0 & 7,1 & 7,3 & 7,6 & 8,0 & 8,5 & 9,1 & 9,7 & 10,4 & 11,0 & 11,7 & 12,3 & 9,6 \\
\hline $\mathrm{C}_{2} \mathrm{H}_{4}$ & ${ }^{1} J_{\mathrm{CC}}$ & 50,5 & 50,7 & 51,2 & 51,8 & 52,4 & 53,1 & 54,0 & 55,3 & 56,8 & 58,7 & 60,8 & 63,3 & 65,8 & 68,5 & 71,3 & 67,6 \\
\hline $\mathrm{C}_{2} \mathrm{H}_{4}$ & ${ }^{1} J_{\mathrm{CH}}$ & 136,1 & 135,7 & 135,2 & 134,9 & 135,0 & 135,7 & 137,0 & 138,8 & 141,1 & 143,7 & 146,5 & 149,5 & 152,5 & 155,4 & 158,3 & 156,3 \\
\hline $\mathrm{C}_{2} \mathrm{H}_{4}$ & ${ }^{2} J_{\mathrm{CH}}$ & 0,9 & 0,9 & 0,9 & 0,9 & 0,8 & 0,6 & 0,3 & 0,0 & $-0,6$ & $-1,1$ & $-1,8$ & $-2,5$ & $-3,3$ & $-4,1$ & $-4,8$ & $-2,4$ \\
\hline $\mathrm{C}_{2} \mathrm{H}_{4}$ & ${ }^{2} J_{\mathrm{HH}}$ & 5,5 & 5,5 & 5,5 & 5,4 & 5,2 & 4,9 & 4,5 & 4,1 & 3,6 & 3,1 & 2,6 & 2,1 & 1,6 & 1,1 & 0,6 & 2,3 \\
\hline $\mathrm{C}_{2} \mathrm{H}_{4}$ & ${ }^{3} J_{\mathrm{HH}_{c}}$ & 11,2 & 11,3 & 11,3 & 11,4 & 11,5 & 11,7 & 11,8 & 12,1 & 12,3 & 12,6 & 13,0 & 13,3 & 13,7 & 14,0 & 14,4 & 11,7 \\
\hline $\mathrm{C}_{2} \mathrm{H}_{4}$ & ${ }^{3} J_{\mathrm{HH}_{\mathrm{t}}}$ & 16,2 & 16,1 & 16,1 & 16,0 & 16,0 & 16,1 & 16,3 & 16,6 & 16,9 & 17,3 & 17,8 & 18,3 & 18,8 & 19,4 & 19,9 & 19 \\
\hline $\mathrm{C}_{2} \mathrm{H}_{6}$ & ${ }^{1} J_{\mathrm{CC}}$ & 18,8 & 19,1 & 19,6 & 20,3 & 20,9 & 21,6 & 22,4 & 23,4 & 24,5 & 25,7 & 27,1 & 28,5 & 30,0 & 31,4 & 32,8 & 34,5 \\
\hline $\mathrm{C}_{2} \mathrm{H}_{6}$ & ${ }^{1} J_{\mathrm{CH}}$ & 106,0 & 105,7 & 105,3 & 104,9 & 104,9 & 105,4 & 106,4 & 107,8 & 109,6 & 111,7 & 113,9 & 116,2 & 118,5 & 120,8 & 122,9 & 125,2 \\
\hline $\mathrm{C}_{2} \mathrm{H}_{6}$ & ${ }^{2} J_{\mathrm{CH}}$ & $-1,7$ & $-1,7$ & $-1,7$ & $-1,8$ & $-1,9$ & $-2,0$ & $-2,3$ & $-2,5$ & $-2,8$ & $-3,1$ & $-3,4$ & $-3,7$ & $-4,0$ & $-4,3$ & $-4,6$ & $-4,7$ \\
\hline \multirow[t]{3}{*}{ Total } & $\mathrm{DM}$ & $-28,97$ & $-28,90$ & $-28,95$ & $-29,08$ & $-29,17$ & $-29,07$ & $-28,74$ & $-28,07$ & $-27,12$ & & & $-22,97$ & $-21,39$ & $-19,81$ & $-18,28$ & - \\
\hline & DMA & 34,43 & 34,19 & 33,80 & 33,18 & 32,50 & 32,34 & 31,91 & 31,17 & 30,08 & 28,75 & 27,24 & 25,66 & 24,18 & 23,10 & 22,42 & - \\
\hline & PDMA & 59,74 & 59,17 & 57,90 & 55,67 & 52,48 & 48,69 & 44,00 & 39,18 & 33,29 & 27,48 & 21,38 & 16,81 & 16,09 & 16,43 & 17,09 & - \\
\hline \multirow[t]{3}{*}{ CPI } & DM & $-59,15$ & $-58,92$ & $-58,99$ & $-59,30$ & $-59,68$ & $-59,87$ & $-59,75$ & $-59,15$ & $-58,06$ & $-56,55$ & $-54,75$ & $-52,75$ & $-50,65$ & $-48,55$ & $-46,56$ & - \\
\hline & DMA & 69,11 & 68,39 & 67,28 & 65,72 & 64,15 & 64,15 & 63,74 & 62,80 & 61,32 & 59,39 & 57,11 & 54,62 & 52,12 & 49,68 & 47,33 & - \\
\hline & PDMA & 91,24 & 89,83 & 86,78 & 82,30 & 76,61 & 70,78 & 64,19 & 57,27 & 49,92 & 42,66 & 35,34 & 28,41 & 22,81 & 18,59 & 14,64 & - \\
\hline \multirow[t]{3}{*}{ SPI } & DM & $-6,83$ & $-6,89$ & $-6,93$ & $-6,91$ & $-6,79$ & $-6,47$ & $-5,99$ & $-5,29$ & $-4,43$ & -3 & -2 & $-1,13$ & 0,0 & 1,27 & 2,4 & - \\
\hline & DMA & 8,99 & & 9,25 & & & & & & & & & 4,42 & & & & - \\
\hline & PDMA & 36,63 & 36,69 & 36,72 & 36,14 & 34,79 & 32,49 & 29,20 & 25,91 & 21,10 & 16,34 & 11,15 & 8,29 & 11,17 & 14,84 & 18,89 & - \\
\hline \multirow[t]{3}{*}{$\Delta \mathrm{CS}$} & DM & $-52,31$ & $-52,03$ & $-52,06$ & $-52,39$ & $-52,90$ & $-53,40$ & $-53,76$ & $-53,86$ & $-53,63$ & $-53,13$ & $-52,43$ & $-51,62$ & $-50,71$ & $-49,83$ & $-49,02$ & - \\
\hline & DMA & 60,12 & 59,28 & 58,04 & 56,39 & 54,87 & 55,13 & 55,17 & 54,83 & 54,14 & 53,10 & 51,78 & 50,20 & 48 & 46,08 & 43,18 & - \\
\hline & & 4,61 & 53,14 & 50,06 & 46,17 & 41,82 & 38,29 & 34,98 & 31,36 & 28,82 & 26,32 & 24,19 & 20,12 & 11,63 & 3,76 & $-4,25$ & - \\
\hline
\end{tabular}


Tabela 8.395: Constantes de acoplamento LC-SLYP com $\alpha=10 \%$ e $\alpha+\beta=80 \%$, variando $\gamma$, na base aug-pcJ-2.

\begin{tabular}{|c|c|c|c|c|c|c|c|c|c|c|c|c|c|c|c|c|c|}
\hline & $\gamma$ & 0,05 & 0,10 & 0,15 & 0,20 & 0,25 & 0,30 & 0,35 & 0,40 & 0,45 & 0,50 & 0,55 & 0,60 & 0,65 & 0,70 & 0,75 & Exp. \\
\hline HF & ${ }^{1} J_{\mathrm{HF}}$ & 441,6 & 442,6 & 443,7 & 445,1 & 446,8 & 449,1 & 452,3 & 456,2 & 461,0 & 466,3 & 472,0 & 478,1 & 484,3 & 490,6 & 496,9 & 500 \\
\hline $\mathrm{CO}$ & ${ }^{1} J_{\mathrm{CO}}$ & 22,8 & 22,6 & 22,4 & 22,2 & 22,0 & 21,9 & 21,7 & 21,5 & 21,3 & 20,9 & 20,3 & 19,7 & 19,0 & 18,3 & 17,4 & 16,4 \\
\hline $\mathrm{H}_{2} \mathrm{O}$ & ${ }^{1} J_{\mathrm{OH}}$ & $-72,5$ & $-72,6$ & $-72,7$ & $-72,8$ & $-73,0$ & $-73,3$ & $-73,8$ & $-74,3$ & $-75,0$ & $-75,8$ & $-76,7$ & $-77,6$ & $-78,6$ & $-79,6$ & $-80,5$ & $-80,6$ \\
\hline $\mathrm{H}_{2} \mathrm{O}$ & ${ }^{2} J_{\mathrm{HH}}$ & $-4,4$ & $-4,4$ & $-4,5$ & $-4,6$ & $-4,8$ & $-5,1$ & $-5,5$ & $-5,9$ & $-6,3$ & $-6,8$ & $-7,2$ & $-7,7$ & $-8,1$ & $-8,6$ & $-9,0$ & $-7,3$ \\
\hline $\mathrm{NH}_{3}$ & ${ }^{1} J_{\mathrm{NH}}$ & 40,5 & 40,5 & 40,5 & 40,5 & 40,5 & 40,6 & 40,8 & 41,0 & 41,4 & 41,8 & 42,3 & 42,8 & 43,3 & 43,9 & 44,4 & 43,8 \\
\hline $\mathrm{NH}_{3}$ & ${ }^{2} J_{\mathrm{HH}}$ & $-6,4$ & $-6,4$ & $-6,5$ & $-6,7$ & $-7,0$ & $-7,3$ & $-7,8$ & $-8,2$ & $-8,8$ & $-9,3$ & $-9,8$ & $-10,3$ & $-10,8$ & $-11,3$ & $-11,7$ & $-9,6$ \\
\hline $\mathrm{PH}_{3}$ & ${ }^{1} J_{\mathrm{PH}}$ & 144,6 & 144,0 & 141,7 & 138,6 & 136,0 & 134,8 & 135,5 & 138,0 & 141,8 & 146,5 & 151,9 & 157,5 & 163,1 & 168,5 & 173,7 & 188,2 \\
\hline $\mathrm{PF}_{3}$ & ${ }^{1} J_{\mathrm{PF}}$ & $-1796,0$ & $-1794,3$ & $-1793,2$ & $-1792,8$ & $-1792,8$ & $-1792,9$ & $-1792,7$ & $-1791,3$ & $-1788,1$ & $-1782,8$ & $-1775,6$ & $-1766,7$ & $-1756,6$ & $-1745,6$ & $-1734,3$ & -1441 \\
\hline $\mathrm{BHF}_{2}$ & ${ }^{1} J_{\mathrm{BF}}$ & $-169,2$ & $-167,6$ & $-164,4$ & $-159,6$ & $-153,9$ & $-147,6$ & $-141,0$ & $-134,2$ & $-127,4$ & $-120,7$ & $-114,1$ & $-107,8$ & $-101,8$ & $-96,1$ & $-90,9$ & -84 \\
\hline $\mathrm{BF}_{3}$ & ${ }^{1} J_{\mathrm{BF}}$ & $-60,9$ & $-59,4$ & $-56,3$ & $-51,7$ & $-45,8$ & $-39,1$ & $-32,0$ & $-24,7$ & $-17,4$ & $-10,3$ & $-3,4$ & 2,9 & 9,0 & 14,7 & 19,9 & 15 \\
\hline $\mathrm{F}_{2} \mathrm{O}$ & ${ }^{1} J_{\mathrm{OF}}$ & $-308,4$ & $-310,3$ & $-315,4$ & $-323,7$ & $-334,6$ & $-347,1$ & $-360,3$ & $-373,4$ & $-386,3$ & $-398,9$ & $-411,4$ & $-423,9$ & $-436,4$ & $-449,1$ & $-461,8$ & -300 \\
\hline $\mathrm{CH}_{4}$ & ${ }^{1} J_{\mathrm{CH}}$ & 109,3 & 109,1 & 108,8 & 108,5 & 108,5 & 109,0 & 109,8 & 111,0 & 112,5 & 114,3 & 116,2 & 118,2 & 120,2 & 122,2 & 124,1 & 125,3 \\
\hline $\mathrm{CH}_{4}$ & ${ }^{2} J_{\mathrm{HH}}$ & $-8,8$ & $-8,8$ & $-8,9$ & $-9,1$ & $-9,4$ & $-9,8$ & $-10,3$ & $-10,9$ & $-11,4$ & $-12,0$ & $-12,6$ & $-13,1$ & $-13,6$ & $-14,1$ & $-14,5$ & $-12,8$ \\
\hline $\mathrm{C}_{2} \mathrm{H}_{2}$ & ${ }^{1} J_{\mathrm{CC}}$ & 179,6 & 179,8 & 180,1 & 180,7 & 181,4 & 182,3 & 183,5 & 185,2 & 187,2 & 189,7 & 192,4 & 195,4 & 198,6 & 201,8 & 205,1 & 174,8 \\
\hline $\mathrm{C}_{2} \mathrm{H}_{2}$ & ${ }^{1} J_{\mathrm{CH}}$ & 232,0 & 231,4 & 230,5 & 229,9 & 229,9 & 230,6 & 232,1 & 234,3 & 237,1 & 240,3 & 243,8 & 247,5 & 251,3 & 255,0 & 258,5 & 247,6 \\
\hline $\mathrm{C}_{2} \mathrm{H}_{2}$ & ${ }^{2} J_{\mathrm{CH}}$ & 52,1 & 52,2 & 52,5 & 53,0 & 53,6 & 54,1 & 54,4 & 54,6 & 54,7 & 54,6 & 54,4 & 54,1 & 53,7 & 53,2 & 52,7 & 50,1 \\
\hline $\mathrm{C}_{2} \mathrm{H}_{2}$ & ${ }^{3} J_{\mathrm{HH}}$ & 7,7 & 7,7 & 7,6 & 7,6 & 7,7 & 8,0 & 8,3 & 8,7 & 9,2 & 9,8 & 10,4 & 11,1 & 11,7 & 12,3 & 12,9 & 9,6 \\
\hline $\mathrm{C}_{2} \mathrm{H}_{4}$ & ${ }^{1} J_{\mathrm{CC}}$ & 53,9 & 54,1 & 54,6 & 55,1 & 55,7 & 56,5 & 57,4 & 58,6 & 60,2 & 62,0 & 64,1 & 66,4 & 68,9 & 71,4 & 74,0 & 67,6 \\
\hline $\mathrm{C}_{2} \mathrm{H}_{4}$ & ${ }^{1} J_{\mathrm{CH}}$ & 140,4 & 140,0 & 139,6 & 139,4 & 139,6 & 140,2 & 141,4 & 143,1 & 145,2 & 147,6 & 150,2 & 152,9 & 155,6 & 158,3 & 160,9 & 156,3 \\
\hline $\mathrm{C}_{2} \mathrm{H}_{4}$ & ${ }^{2} J_{\mathrm{CH}}$ & 0,2 & 0,3 & 0,3 & 0,2 & 0,1 & 0,0 & $-0,3$ & $-0,8$ & $-1,3$ & $-1,9$ & $-2,5$ & $-3,2$ & $-4,0$ & $-4,7$ & $-5,4$ & $-2,4$ \\
\hline $\mathrm{C}_{2} \mathrm{H}_{4}$ & ${ }^{2} J_{\mathrm{HH}}$ & 5,0 & 5,0 & 5,0 & 4,9 & 4,7 & 4,4 & 4,0 & 3,6 & 3,2 & 2,7 & 2,2 & 1,7 & 1,2 & 0,8 & 0,3 & 2,3 \\
\hline $\mathrm{C}_{2} \mathrm{H}_{4}$ & ${ }^{3} J_{\mathrm{HH}_{\mathrm{c}}}$ & 11,5 & 11,5 & 11,6 & 11,6 & 11,8 & 11,9 & 12,1 & 12,4 & 12,6 & 12,9 & 13,3 & 13,6 & 13,9 & 14,3 & 14,6 & 11,7 \\
\hline $\mathrm{C}_{2} \mathrm{H}_{4}$ & ${ }^{3} J_{\mathrm{HH}_{\mathrm{t}}}$ & 16,7 & 16,6 & 16,6 & 16,5 & 16,6 & 16,7 & 16,9 & 17,2 & 17,5 & 17,9 & 18,4 & 18,9 & 19,4 & 19,9 & 20,4 & 19 \\
\hline $\mathrm{C}_{2} \mathrm{H}_{6}$ & ${ }^{1} J_{\mathrm{CC}}$ & 21,4 & 21,6 & 22,1 & 22,7 & 23,3 & 24,0 & 24,7 & 25,6 & 26,6 & 27,7 & 29,0 & 30 & 31,6 & 32,9 & 34,1 & 34,5 \\
\hline $\mathrm{C}_{2} \mathrm{H}_{6}$ & ${ }^{1} J_{\mathrm{CH}}$ & 109,6 & 109,3 & ,9 & 108,7 & 108,7 & & 110,1 & 111,4 & 3,0 & 4,9 & 116,9 & 118,9 & 121,0 & 123,0 & 125,0 & 125,2 \\
\hline $\mathrm{C}_{2} \mathrm{H}_{6}$ & ${ }^{2} J_{\mathrm{CH}}$ & $-2,1$ & $-2,1$ & $-2,1$ & $-2,2$ & $-2,3$ & $-2,5$ & $-2,7$ & $-2,9$ & $-3,2$ & $-3,5$ & $-3,7$ & $-4,0$ & $-4,3$ & $-4,6$ & $-4,8$ & $-4,7$ \\
\hline \multirow[t]{3}{*}{ Total } & $\mathrm{DM}$ & -26 & 26,25 & $-26,25$ & $-26,27$ & $-26,22$ & & & $-24,97$ & & & & & & & & - \\
\hline & DMA & 29,3 & 29,2 & & & & & & & & & & & & & & - \\
\hline & PDMA & 48,15 & 47,86 & 46,84 & 44,95 & 42,31 & 38,97 & 34,73 & 29,97 & 24,86 & 19,42 & 15,19 & 14,93 & 15,40 & 16,04 & 19,68 & - \\
\hline \multirow[t]{3}{*}{ CPI } & DM & $-55,38$ & 55,11 & $-55,0$ & 5,13 & & & & & & & & & & & & - \\
\hline & DMA & 59,1 & 58,8 & & & & & & & & & & & & & & - \\
\hline & PDMA & 72,67 & 71,52 & 69,20 & 65,83 & 61,39 & 56,28 & 50,39 & 44,34 & 37,94 & 31,44 & 25,39 & 21,14 & 17,09 & 13,47 & 16,02 & - \\
\hline \multirow[t]{3}{*}{ SPI } & DM & $-5,0$ & $-5,09$ & $-5,1$ & - & $-4, \mathrm{~S}$ & -4 & -4 , & & & & & & & & & - \\
\hline & & & & & & & & & & & & & & & & & - \\
\hline & PDMA & 30,17 & 30,51 & 30,45 & 29,65 & 28,31 & 26,27 & 23,25 & 19,43 & 15,27 & 10,61 & 7,71 & 10,38 & 14,17 & 17,92 & 22,37 & - \\
\hline \multirow[t]{3}{*}{$\Delta C S$} & & & & & & & & & & & & & & & & & - \\
\hline & MA & & & & & & & & & & & & & & & & - \\
\hline & & 42,50 & 41,02 & 38,74 & 36,18 & 33,08 & 30,00 & 27,13 & 24,91 & 22,67 & 20,83 & 17,68 & 10,76 & 2,92 & $-4,45$ & $-6,34$ & - \\
\hline
\end{tabular}


Tabela 8.396: Constantes de acoplamento LC-SLYP com $\alpha=20 \%$ e $\alpha+\beta=80 \%$, variando $\gamma$, na base aug-pcJ-2.

\begin{tabular}{|c|c|c|c|c|c|c|c|c|c|c|c|c|c|c|c|c|c|}
\hline & $\gamma$ & 0,05 & 0,10 & 0,15 & 0,20 & 0,25 & 0,30 & 0,35 & 0,40 & 0,45 & 0,50 & 0,55 & 0,60 & 0,65 & 0,70 & 0,75 & Exp. \\
\hline $\mathrm{HF}$ & ${ }^{1} J_{\mathrm{HF}}$ & 462,8 & 463,6 & 464,7 & 465,9 & 467,5 & 469,6 & 472,3 & 475,8 & 479,9 & 484,5 & 489,5 & 494,7 & 500,0 & 505,5 & 510,9 & 500 \\
\hline $\mathrm{CO}$ & ${ }^{1} J_{\mathrm{CO}}$ & 20,8 & 20,6 & 20,4 & 20,2 & 20,1 & 19,9 & 19,8 & 19,6 & 19,4 & 19,0 & 18,5 & 18,0 & 17,4 & 16,7 & 15,9 & 16,4 \\
\hline $\mathrm{H}_{2} \mathrm{O}$ & ${ }^{1} J_{\mathrm{OH}}$ & $-75,1$ & $-75,2$ & $-75,3$ & $-75,4$ & $-75,6$ & $-75,9$ & $-76,3$ & $-76,8$ & $-77,4$ & $-78,1$ & $-78,9$ & $-79,7$ & $-80,5$ & $-81,4$ & $-82,2$ & $-80,6$ \\
\hline $\mathrm{H}_{2} \mathrm{O}$ & ${ }^{2} J_{\mathrm{HH}}$ & $-5,5$ & $-5,5$ & $-5,6$ & $-5,7$ & $-5,9$ & $-6,2$ & $-6,5$ & $-6,9$ & $-7,2$ & $-7,6$ & $-8,1$ & $-8,5$ & $-8,9$ & $-9,3$ & $-9,6$ & $-7,3$ \\
\hline $\mathrm{NH}_{3}$ & ${ }^{1} J_{\mathrm{NH}}$ & 41,7 & 41,7 & 41,7 & 41,7 & 41,7 & 41,8 & 41,9 & 42,2 & 42,5 & 42,9 & 43,3 & 43,7 & 44,2 & 44,7 & 45,2 & 43,8 \\
\hline $\mathrm{NH}_{3}$ & ${ }^{2} J_{\mathrm{HH}}$ & $-7,5$ & $-7,5$ & $-7,6$ & $-7,7$ & $-8,0$ & $-8,3$ & $-8,7$ & $-9,1$ & $-9,6$ & $-10,1$ & $-10,5$ & $-11,0$ & $-11,4$ & $-11,8$ & $-12,2$ & $-9,6$ \\
\hline $\mathrm{PH}_{3}$ & ${ }^{1} J_{\mathrm{PH}}$ & 153,7 & 153,2 & 151,4 & 148,8 & 146,7 & 145,8 & 146,4 & 148,6 & 151,9 & 156,1 & 160,7 & 165,6 & 170,5 & 175,2 & 179,6 & 188,2 \\
\hline $\mathrm{PF}_{3}$ & ${ }^{1} J_{\mathrm{PF}}$ & $-1772,1$ & $-1770,3$ & $-1768,4$ & $-1766,7$ & $-1765,0$ & $-1763,4$ & $-1761,5$ & $-1758,9$ & $-1755,0$ & $-1749,7$ & $-1742,8$ & $-1734,8$ & $-1725,8$ & $-1716,2$ & $-1706,3$ & -1441 \\
\hline $\mathrm{BHF}_{2}$ & ${ }^{1} J_{\mathrm{BF}}$ & $-151,0$ & $-149,7$ & $-147,0$ & $-142,9$ & $-138,0$ & $-132,6$ & $-127,0$ & $-121,2$ & $-115,3$ & $-109,5$ & $-103,9$ & $-98,5$ & $-93,3$ & $-88,5$ & $-84,0$ & -84 \\
\hline $\mathrm{BF}_{3}$ & ${ }^{1} J_{\mathrm{BF}}$ & $-42,1$ & $-40,9$ & $-38,3$ & $-34,4$ & $-29,4$ & $-23,7$ & $-17,7$ & $-11,5$ & $-5,2$ & 0,7 & 6,6 & 12,2 & 17,4 & 22,2 & 26,8 & 15 \\
\hline $\mathrm{F}_{2} \mathrm{O}$ & ${ }^{1} J_{\mathrm{OF}}$ & $-344,1$ & $-345,7$ & $-350,0$ & $-357,1$ & $-366,6$ & $-377,6$ & $-389,3$ & $-401,2$ & $-413,2$ & $-425,0$ & $-436,9$ & $-448,9$ & $-460,9$ & $-473,1$ & $-485,4$ & -300 \\
\hline $\mathrm{CH}_{4}$ & ${ }^{1} J_{\mathrm{CH}}$ & 112,9 & 112,7 & 112,5 & 112,3 & 112,3 & 112,7 & 113,5 & 114,6 & 115,9 & 117,5 & 119,2 & 121,0 & 122,7 & 124,4 & 126,1 & 125,3 \\
\hline $\mathrm{CH}_{4}$ & ${ }^{2} J_{\mathrm{HH}}$ & $-9,9$ & $-9,9$ & $-9,9$ & $-10,1$ & $-10,3$ & $-10,7$ & $-11,2$ & $-11,7$ & $-12,2$ & $-12,7$ & $-13,2$ & $-13,6$ & $-14,1$ & $-14,5$ & $-14,9$ & $-12,8$ \\
\hline $\mathrm{C}_{2} \mathrm{H}_{2}$ & ${ }^{1} J_{\mathrm{CC}}$ & 184,2 & 184,3 & 184,7 & 185,2 & 185,9 & 186,9 & 188,1 & 189,8 & 191,8 & 194,1 & 196,7 & 199,5 & 202,4 & 205,4 & 208,3 & 174,8 \\
\hline $\mathrm{C}_{2} \mathrm{H}_{2}$ & ${ }^{1} J_{\mathrm{CH}}$ & 238,2 & 237,6 & 236,9 & 236,5 & 236,5 & 237,2 & 238,5 & 240,5 & 243,1 & 246,0 & 249,2 & 252,5 & 255,8 & 259,1 & 262,2 & 247,6 \\
\hline $\mathrm{C}_{2} \mathrm{H}_{2}$ & ${ }^{2} J_{\mathrm{CH}}$ & 52,7 & 52,9 & 53,1 & 53,5 & 53,9 & 54,3 & 54,5 & 54,6 & 54,6 & 54,4 & 54,1 & 53,8 & 53,3 & 52,8 & 52,3 & 50,1 \\
\hline $\mathrm{C}_{2} \mathrm{H}_{2}$ & ${ }^{3} J_{\mathrm{HH}}$ & 8,5 & 8,4 & 8,4 & 8,4 & 8,6 & 8,8 & 9,1 & 9,6 & 10,1 & 10,6 & 11,2 & 11,8 & 12,4 & 13,0 & 13,6 & 9,6 \\
\hline $\mathrm{C}_{2} \mathrm{H}_{4}$ & ${ }^{1} J_{\mathrm{CC}}$ & 57,7 & 57,9 & 58,3 & 58,8 & 59,4 & 60,2 & 61,1 & 62,3 & 63,9 & 65,6 & 67,6 & 69,8 & 72,1 & 74,5 & 76,8 & 67,6 \\
\hline $\mathrm{C}_{2} \mathrm{H}_{4}$ & ${ }^{1} J_{\mathrm{CH}}$ & 144,9 & 144,6 & 144,3 & 144,1 & 144,3 & 145,0 & 146,1 & 147,6 & 149,5 & 151,7 & 154,0 & 156,4 & 158,9 & 161,3 & 163,6 & 156,3 \\
\hline $\mathrm{C}_{2} \mathrm{H}_{4}$ & ${ }^{2} J_{\mathrm{CH}}$ & $-0,4$ & $-0,4$ & $-0,4$ & $-0,5$ & $-0,6$ & $-0,8$ & $-1,2$ & $-1,6$ & $-2,1$ & $-2,7$ & $-3,3$ & $-4,0$ & $-4,7$ & $-5,4$ & $-6,1$ & $-2,4$ \\
\hline $\mathrm{C}_{2} \mathrm{H}_{4}$ & ${ }^{2} J_{\mathrm{HH}}$ & 4,4 & 4,4 & 4,4 & 4,3 & 4,1 & 3,8 & 3,5 & 3,1 & 2,7 & 2,2 & 1,8 & 1,3 & 0,9 & 0,4 & 0,0 & 2,3 \\
\hline $\mathrm{C}_{2} \mathrm{H}_{4}$ & ${ }^{3} J_{\mathrm{HH}_{c}}$ & 11,8 & 11,8 & 11,9 & 12,0 & 12,1 & 12,3 & 12,5 & 12,7 & 13,0 & 13,3 & 13,6 & 13,9 & 14,2 & 14,6 & 14,9 & 11,7 \\
\hline $\mathrm{C}_{2} \mathrm{H}_{4}$ & ${ }^{3} J_{\mathrm{HH}_{\mathrm{t}}}$ & 17,2 & 17,2 & 17,1 & 17,1 & 17,2 & 17,3 & 17,6 & 17,8 & 18,2 & 18,6 & 19,0 & 19,5 & 20,0 & 20,4 & 20,9 & 19 \\
\hline $\mathrm{C}_{2} \mathrm{H}_{6}$ & ${ }^{1} J_{\mathrm{CC}}$ & 24,1 & 24,3 & 24,7 & 25,3 & 25,8 & 26,4 & 27,1 & 27,9 & 28,8 & 29,8 & 30,9 & 32,1 & 33,2 & 34,3 & 35,4 & 34,5 \\
\hline $\mathrm{C}_{2} \mathrm{H}_{6}$ & ${ }^{1} J_{\mathrm{CH}}$ & 113,3 & 113,1 & 112,8 & 112,6 & 112,7 & 113,1 & 113,9 & 115,1 & 116,5 & 118,2 & 119,9 & 121,8 & 123,6 & 125,3 & 127,0 & 125,2 \\
\hline $\mathrm{C}_{2} \mathrm{H}_{6}$ & ${ }^{2} J_{\mathrm{CH}}$ & $-2,6$ & $-2,6$ & $-2,6$ & $-2,7$ & $-2,8$ & $-2,9$ & $-3,1$ & $-3,3$ & $-3,6$ & $-3,8$ & $-4,1$ & $-4,3$ & $-4,6$ & $-4,8$ & $-5,0$ & $-4,7$ \\
\hline \multirow[t]{3}{*}{ Total } & $\mathrm{DM}$ & $-23,32$ & $-23,25$ & $-23,18$ & $-23,13$ & $-23,02$ & $-22,77$ & $-22,37$ & $-21,75$ & $-20,92$ & & & & & $-15,39$ & $-14,28$ & - \\
\hline & DMA & 26,02 & 25,94 & 25,89 & 25,84 & 25,71 & 25,42 & 24,95 & 24,25 & 23,38 & 22,45 & 21,60 & 21,06 & 20,88 & 21,42 & 22,24 & - \\
\hline & PDMA & 36,86 & 36,52 & 35,71 & 34,04 & 31,66 & 28,57 & 24,77 & 20,47 & 16,20 & 13,61 & 13,45 & 14,24 & 16,28 & 20,24 & 24,65 & - \\
\hline \multirow[t]{3}{*}{ CPI } & DM & $-50,85$ & $-50,60$ & $-50,45$ & $-50,38$ & $-50,31$ & $-50,14$ & $-49,77$ & $-49,12$ & $-48,19$ & $-47,06$ & $-45,76$ & $-44,37$ & $-42,93$ & $-41,54$ & $-40,20$ & - \\
\hline & DMA & 53,35 & 53,05 & 52,81 & 52,65 & 52,44 & 52,06 & 51,48 & 50 , & 49,34 & 47,99 & 46,45 & 44,83 & 43,64 & 44,06 & 44,58 & - \\
\hline & PDMA & 55,35 & 54,41 & 52,38 & 49,54 & 45,72 & 41,19 & 36,34 & 31,02 & 25,58 & 21,75 & 18,12 & 14,65 & 14,33 & 17,58 & 21,13 & - \\
\hline \multirow[t]{3}{*}{ SPI } & DM & $-3,14$ & $-3,19$ & $-3,19$ & $-3,15$ & $-3,00$ & $-2,70$ & $-2,27$ & $-1,6$ & $-0,93$ & $-0,09$ & 0,8 & 1,8 & 2,8 & 3,78 & 4,7 & - \\
\hline & DMA & 5,97 & 6,05 & 6,15 & & & & & & & & & & & & & - \\
\hline & PDMA & 23,31 & 23,40 & 23,47 & 22,67 & 21,36 & 19,33 & 16,28 & 12,73 & 9,32 & 7,64 & 10,01 & 13,94 & 17,71 & 22,19 & 27,23 & - \\
\hline \multirow[t]{3}{*}{$\Delta \mathrm{CS}$} & DM & $-47,71$ & $-47,41$ & $-47,25$ & $-47,23$ & $-47,31$ & $-47,44$ & $-47,50$ & $-47,44$ & $-47,26$ & $-46,98$ & $-46,60$ & $-46,20$ & $-45,73$ & $-45,32$ & $-44,93$ & - \\
\hline & DMA & 47,39 & 47,00 & 46,66 & 46,47 & 46,33 & 46,18 & 46,00 & & 44,98 & 44,28 & 43,07 & 41,20 & 39,44 & 39,24 & 38,73 & - \\
\hline & & 32,04 & 31,01 & 28,91 & 26,88 & 24,37 & 21,86 & 20 , & 18, & 16,26 & 14,11 & 8,11 & 0,70 & $-3,38$ & $-4,62$ & $-6,09$ & - \\
\hline
\end{tabular}


Tabela 8.397: Constantes de acoplamento LC-SLYP com $\alpha=30 \%$ e $\alpha+\beta=80 \%$, variando $\gamma$, na base aug-pcJ-2.

\begin{tabular}{|c|c|c|c|c|c|c|c|c|c|c|c|c|c|c|c|c|c|}
\hline & $\gamma$ & 0,05 & 0,10 & 0,15 & 0,20 & 0,25 & 0,30 & 0,35 & 0,40 & 0,45 & 0,50 & 0,55 & 0,60 & 0,65 & 0,70 & 0,75 & Exp. \\
\hline $\mathrm{HF}$ & ${ }^{\mathrm{I}} J_{\mathrm{HF}}$ & 484,7 & 485,4 & 486,3 & 487,4 & 488,8 & 490,6 & 493,0 & 496,0 & 499,4 & 503,3 & 507,5 & 511,8 & 516,3 & 520,9 & 525,5 & 500 \\
\hline $\mathrm{CO}$ & ${ }^{1} J_{\mathrm{CO}}$ & 18,6 & 18,4 & 18,3 & 18,1 & 18,0 & 17,9 & 17,7 & 17,6 & 17,3 & 17,0 & 16,6 & 16,1 & 15,6 & 15,0 & 14,3 & 16,4 \\
\hline $\mathrm{H}_{2} \mathrm{O}$ & ${ }^{1} J_{\mathrm{OH}}$ & $-77,9$ & $-77,9$ & $-78,0$ & $-78,1$ & $-78,3$ & $-78,5$ & $-78,9$ & $-79,3$ & $-79,9$ & $-80,5$ & $-81,1$ & $-81,8$ & $-82,5$ & $-83,2$ & $-84,0$ & $-80,6$ \\
\hline $\mathrm{H}_{2} \mathrm{O}$ & ${ }^{2} J_{\mathrm{HH}}$ & $-6,8$ & $-6,8$ & $-6,8$ & $-6,9$ & $-7,1$ & $-7,3$ & $-7,6$ & $-7,9$ & $-8,2$ & $-8,6$ & $-8,9$ & $-9,3$ & $-9,6$ & $-10,0$ & $-10,3$ & $-7,3$ \\
\hline $\mathrm{NH}_{3}$ & ${ }^{1} J_{\mathrm{NH}}$ & 42,9 & 42,9 & 42,9 & 42,9 & 42,9 & 43,0 & 43,2 & 43,4 & 43,6 & 44,0 & 44,3 & 44,7 & 45,1 & 45,5 & 45,9 & 43,8 \\
\hline $\mathrm{NH}_{3}$ & ${ }^{2} J_{\mathrm{HH}}$ & $-8,7$ & $-8,7$ & $-8,7$ & $-8,9$ & $-9,1$ & $-9,3$ & $-9,7$ & $-10,1$ & $-10,4$ & $-10,9$ & $-11,3$ & $-11,6$ & $-12,0$ & $-12,4$ & $-12,7$ & $-9,6$ \\
\hline $\mathrm{PH}_{3}$ & ${ }^{1} J_{\mathrm{PH}}$ & 163,2 & 162,8 & 161,3 & 159,3 & 157,6 & 156,9 & 157,5 & 159,4 & 162,2 & 165,7 & 169,7 & 173,8 & 177,9 & 181,8 & 185,6 & 188,2 \\
\hline $\mathrm{PF}_{3}$ & ${ }^{1} J_{\mathrm{PF}}$ & $-1742,7$ & $-1740,8$ & $-1738,6$ & $-1736,1$ & $-1733,5$ & $-1730,9$ & $-1728,2$ & $-1724,9$ & $-1720,8$ & $-1715,7$ & $-1709,5$ & $-1702,4$ & $-1694,7$ & $-1686,6$ & $-1678,3$ & -1441 \\
\hline $\mathrm{BHF}_{2}$ & ${ }^{1} J_{\mathrm{BF}}$ & $-132,6$ & $-131,5$ & $-129,3$ & $-125,9$ & $-121,9$ & $-117,4$ & $-112,7$ & $-107,9$ & $-103,0$ & $-98,2$ & $-93,5$ & $-89,0$ & $-84,7$ & $-80,6$ & $-76,8$ & -84 \\
\hline $\mathrm{BF}_{3}$ & ${ }^{1} J_{\mathrm{BF}}$ & $-23,1$ & $-22,2$ & $-20,1$ & $-16,8$ & $-12,8$ & $-8,1$ & $-3,1$ & 1,9 & 7,1 & 12,2 & 17,0 & 21,7 & 26,0 & 30,1 & 33,9 & 15 \\
\hline $\mathrm{F}_{2} \mathrm{O}$ & ${ }^{1} J_{\mathrm{OF}}$ & $-380,6$ & $-382,0$ & $-385,6$ & $-391,8$ & $-400,1$ & $-409,8$ & $-420,4$ & $-431,3$ & $-442,4$ & $-453,7$ & $-465,0$ & $-476,4$ & $-488,0$ & $-499,7$ & $-511,4$ & -300 \\
\hline $\mathrm{CH}_{4}$ & ${ }^{1} J_{\mathrm{CH}}$ & 116,7 & 116,5 & 116,3 & 116,2 & 116,3 & 116,7 & 117,3 & 118,3 & 119,5 & 120,8 & 122,3 & 123,8 & 125,3 & 126,7 & 128,1 & 125,3 \\
\hline $\mathrm{CH}_{4}$ & ${ }^{2} J_{\mathrm{HH}}$ & $-11,0$ & $-10,9$ & $-11,0$ & $-11,1$ & $-11,3$ & $-11,7$ & $-12,1$ & $-12,5$ & $-12,9$ & $-13,3$ & $-13,8$ & $-14,2$ & $-14,6$ & $-14,9$ & $-15,2$ & $-12,8$ \\
\hline $\mathrm{C}_{2} \mathrm{H}_{2}$ & ${ }^{1} J_{\mathrm{CC}}$ & 189,4 & 189,5 & 189,9 & 190,4 & 191,1 & 192,0 & 193,3 & 194,9 & 196,8 & 198,9 & 201,3 & 203,9 & 206,5 & 209,2 & 211,8 & 174,8 \\
\hline $\mathrm{C}_{2} \mathrm{H}_{2}$ & ${ }^{1} J_{\mathrm{CH}}$ & 244,8 & 244,3 & 243, & 243 & 243,4 & 244,1 & 245,3 & 247 & 249,4 & 252,0 & 254,7 & 257,6 & 260,5 & 263,4 & 266,1 & 247,6 \\
\hline $\mathrm{C}_{2} \mathrm{H}_{2}$ & ${ }^{2} J_{\mathrm{CH}}$ & 53,2 & 53,3 & 53,5 & 53,8 & 54,1 & 54,3 & 54,4 & 54,4 & 54,3 & 54,0 & 53,7 & 53,3 & 52,8 & 52,3 & 51,8 & 50,1 \\
\hline $\mathrm{C}_{2} \mathrm{H}_{2}$ & ${ }^{3} J_{\mathrm{HH}}$ & 9,3 & 9,3 & 9,3 & 9,4 & 9,5 & 9,8 & 10,1 & 10,5 & 11,0 & 11,6 & 12,1 & 12,7 & 13,2 & 13,7 & 14,2 & 9,6 \\
\hline $\mathrm{C}_{2} \mathrm{H}_{4}$ & ${ }^{1} J_{\mathrm{CC}}$ & 61,9 & 62,1 & 62,4 & 62,9 & 63,5 & 64,3 & 65,3 & 66,5 & 67,9 & 69,6 & 71,5 & 73,5 & 75,6 & 77,8 & 79,9 & 67,6 \\
\hline $\mathrm{C}_{2} \mathrm{H}_{4}$ & ${ }^{1} J_{\mathrm{CH}}$ & 149,8 & 149,5 & 149,3 & 149,2 & 149,4 & 150,0 & 151,0 & 152,4 & 154,1 & 156,0 & 158,0 & 160,2 & 162,3 & 164,4 & 166,4 & 156,3 \\
\hline $\mathrm{C}_{2} \mathrm{H}_{4}$ & ${ }^{2} J_{\mathrm{CH}}$ & $-1,3$ & $-1,3$ & $-1,3$ & $-1,4$ & $-1,5$ & $-1,8$ & $-2,1$ & $-2,6$ & $-3,1$ & $-3,6$ & $-4,2$ & $-4,9$ & $-5,5$ & $-6,2$ & $-6,8$ & $-2,4$ \\
\hline $\mathrm{C}_{2} \mathrm{H}_{4}$ & ${ }^{2} J_{\mathrm{HH}}$ & 3,8 & 3,8 & 3,8 & 3,7 & 3,5 & 3,2 & 2,9 & 2,5 & 2, & 1,7 & 1, & 0,9 & 0,5 & 0,1 & $-0,2$ & 2,3 \\
\hline $\mathrm{C}_{2} \mathrm{H}_{4}$ & ${ }^{3} J_{\mathrm{HH}_{\mathrm{c}}}$ & 12,2 & 12,2 & 12,3 & 12,4 & 12,5 & 12,7 & 12,9 & 13,1 & 13,4 & 13,7 & 14,0 & 14,3 & 14,6 & 14,9 & 15,1 & 11,7 \\
\hline $\mathrm{C}_{2} \mathrm{H}_{4}$ & ${ }^{3} J_{\mathrm{HH}_{\mathrm{t}}}$ & 17,9 & 17,8 & 17,8 & 17,8 & 17,9 & 18,1 & 18,3 & 18,6 & 18,9 & 19,3 & 19,7 & 20,2 & 20,6 & 21,0 & 21,4 & 19 \\
\hline $\mathrm{C}_{2} \mathrm{H}_{6}$ & ${ }^{1} J_{\mathrm{CC}}$ & 27,0 & 27,2 & 27,5 & 28,0 & 28,5 & 29,0 & 29,6 & 30,3 & 31,1 & 32,0 & 32,9 & 33,9 & 34,9 & 35,9 & 36,8 & 34,5 \\
\hline $\mathrm{C}_{2} \mathrm{H}_{6}$ & ${ }^{1} J_{\mathrm{CH}}$ & 117,3 & 117,1 & 116,8 & 116,7 & 116,8 & 117,2 & 117,9 & 118,9 & 120,2 & 121,6 & 123,1 & 124,6 & 126,2 & 127,7 & 129,1 & 125,2 \\
\hline $\mathrm{C}_{2} \mathrm{H}_{6}$ & ${ }^{2} J_{\mathrm{CH}}$ & $-3,1$ & $-3,1$ & $-3,2$ & $-3,2$ & $-3,3$ & $-3,4$ & $-3,6$ & $-3,8$ & $-4,0$ & $-4,2$ & $-4,4$ & $-4,6$ & $-4,8$ & $-5,0$ & $-5,2$ & $-4,7$ \\
\hline \multirow[t]{3}{*}{ Total } & $\mathrm{DM}$ & $-20, c$ & 1903 & & & & & & & & & & & & & & - \\
\hline & DMA & 22,35 & 22,28 & 22,2 & 22,13 & 21,98 & 21,70 & 21,3 & 20,80 & 20,34 & 20,27 & 20, & 21,12 & & 22,92 & 24,05 & - \\
\hline & PDMA & 24,87 & 24,61 & 23,93 & 22,45 & 20,42 & 17,66 & 14,96 & 12,61 & 11,88 & 12,48 & 14,43 & 18,15 & 21,95 & 26,65 & 30,88 & - \\
\hline \multirow[t]{3}{*}{ CPI } & DM & -4 & & & & & & & & & & & & & & & - \\
\hline & & & & & & & & & & & & & & & & & - \\
\hline & PDMA & 37,37 & 36,63 & 35,20 & 32,65 & 29,57 & 25,97 & 22,65 & 19,88 & 16,69 & 14,01 & 13,84 & 17,38 & 20,90 & 25,25 & 29,38 & - \\
\hline \multirow[t]{3}{*}{ SPI } & DM & & & & & & & & & & & & & & & & - \\
\hline & MA & & & & & & & & & & & & & & & & - \\
\hline & PDMA & 15,70 & 15,79 & 15,66 & 14,97 & 13,71 & 11,57 & 9,33 & 7,28 & 8,35 & 11,36 & 14,86 & 18,71 & 22,71 & 27,68 & 31,98 & - \\
\hline \multirow[t]{3}{*}{$\Delta C S$} & DM & $-44,73$ & -44 & -44, & -44, & -44 & -44 & & & & & & & & 32 & 15 & - \\
\hline & & 42,65 & & & & & & & & & & & & & 39,42 & 39,71 & - \\
\hline & PDMA & 21,67 & 20,84 & 19,54 & 17,68 & 15,86 & 14,41 & 13,32 & 12,60 & 8,34 & 2,65 & $-1,02$ & $-1,33$ & $-1,81$ & $-2,44$ & $-2,60$ & - \\
\hline
\end{tabular}


Tabela 8.398: Constantes de acoplamento LC-SLYP com $\alpha=40 \%$ e $\alpha+\beta=80 \%$, variando $\gamma$, na base aug-pcJ-2.

\begin{tabular}{|c|c|c|c|c|c|c|c|c|c|c|c|c|c|c|c|c|c|}
\hline & $\gamma$ & 0,05 & 0,10 & 0,15 & 0,20 & 0,25 & 0,30 & 0,35 & 0,40 & 0,45 & 0,50 & 0,55 & 0,60 & 0,65 & 0,70 & 0,75 & Exp. \\
\hline $\mathrm{HF}$ & ${ }^{1} J_{\mathrm{HF}}$ & 507,4 & 508,0 & 508,7 & 509,6 & 510,8 & 512,3 & 514,3 & 516,7 & 519,6 & 522,7 & 526,0 & 529,6 & 533,2 & 536,9 & 540,6 & 500 \\
\hline $\mathrm{CO}$ & ${ }^{1} J_{\mathrm{CO}}$ & 16,2 & 16,1 & 15,9 & 15,8 & 15,7 & 15,6 & 15,5 & 15,4 & 15,2 & 14,9 & 14,6 & 14,2 & 13,7 & 13,2 & 12,7 & 16,4 \\
\hline $\mathrm{H}_{2} \mathrm{O}$ & ${ }^{1} J_{\mathrm{OH}}$ & $-80,7$ & $-80,8$ & $-80,9$ & $-81,0$ & $-81,1$ & $-81,3$ & $-81,6$ & $-82,0$ & $-82,4$ & $-82,9$ & $-83,4$ & $-84,0$ & $-84,6$ & $-85,2$ & $-85,8$ & $-80,6$ \\
\hline $\mathrm{H}_{2} \mathrm{O}$ & ${ }^{2} J_{\mathrm{HH}}$ & $-8,0$ & $-8,0$ & $-8,1$ & $-8,2$ & $-8,3$ & $-8,5$ & $-8,7$ & $-9,0$ & $-9,3$ & $-9,5$ & $-9,8$ & $-10,1$ & $-10,4$ & $-10,7$ & $-11,0$ & $-7,3$ \\
\hline $\mathrm{NH}_{3}$ & ${ }^{1} J_{\mathrm{NH}}$ & 44,2 & 44,2 & 44,2 & 44,2 & 44,2 & 44,3 & 44,4 & 44,6 & 44,8 & 45,1 & 45,4 & 45,7 & 46,0 & 46,4 & 46,7 & 43,8 \\
\hline $\mathrm{NH}_{3}$ & ${ }^{2} J_{\mathrm{HH}}$ & $-9,9$ & $-9,9$ & $-9,9$ & $-10,0$ & $-10,2$ & $-10,4$ & $-10,7$ & $-11,0$ & $-11,4$ & $-11,7$ & $-12,0$ & $-12,3$ & $-12,7$ & $-13,0$ & $-13,2$ & $-9,6$ \\
\hline $\mathrm{PH}_{3}$ & ${ }^{1} J_{\mathrm{PH}}$ & 173,0 & 172,7 & 171,6 & 170,0 & 168,7 & 168,3 & 168,8 & 170,3 & 172,6 & 175,5 & 178,7 & 182,0 & 185,4 & 188,6 & 191,6 & 188,2 \\
\hline $\mathrm{PF}_{3}$ & ${ }^{1} J_{\mathrm{PF}}$ & $-1708,3$ & $-1706,7$ & $-1704,4$ & $-1701,7$ & $-1698,8$ & $-1695,8$ & $-1692,8$ & $-1689,5$ & $-1685,6$ & $-1681,0$ & $-1675,7$ & $-1669,8$ & $-1663,4$ & $-1656,8$ & $-1650,1$ & -1441 \\
\hline $\mathrm{BHF}_{2}$ & ${ }^{1} J_{\mathrm{BF}}$ & $-113,9$ & $-113,1$ & $-111,3$ & $-108,7$ & $-105,5$ & $-101,9$ & $-98,2$ & $-94,3$ & $-90,4$ & $-86,6$ & $-82,8$ & $-79,2$ & $-75,8$ & $-72,5$ & $-69,5$ & -84 \\
\hline $\mathrm{BF}_{3}$ & ${ }^{1} J_{\mathrm{BF}}$ & $-4,0$ & $-3,2$ & $-1,6$ & 0,8 & 4,0 & 7,7 & 11,7 & 15,7 & 19,9 & 23,9 & 27,8 & 31,5 & 35,0 & 38,3 & 41,4 & 15 \\
\hline $\mathrm{F}_{2} \mathrm{O}$ & ${ }^{1} J_{\mathrm{OF}}$ & $-419,9$ & $-421,1$ & $-424,2$ & $-429,6$ & $-436,9$ & $-445,6$ & $-455,2$ & $-465,2$ & $-475,6$ & $-486,1$ & $-496,8$ & $-507,7$ & $-518,6$ & $-529,6$ & $-540,5$ & -300 \\
\hline $\mathrm{CH}_{4}$ & ${ }^{1} J_{\mathrm{CH}}$ & 120,7 & 120,6 & 120,4 & 120,3 & 120,4 & 120,8 & 121,3 & 122,1 & 123,1 & 124,2 & 125,4 & 126,6 & 127,9 & 129,1 & 130,2 & 125,3 \\
\hline $\mathrm{CH}_{4}$ & ${ }^{2} J_{\mathrm{HH}}$ & $-12,1$ & $-12,1$ & $-12,1$ & $-12,2$ & $-12,4$ & $-12,7$ & $-13,0$ & $-13,3$ & $-13,7$ & $-14,0$ & $-14,4$ & $-14,7$ & $-15,0$ & $-15,3$ & $-15,6$ & $-12,8$ \\
\hline $\mathrm{C}_{2} \mathrm{H}_{2}$ & ${ }^{1} J_{\mathrm{CC}}$ & 195,4 & 195,5 & 195,8 & 196,3 & 197,0 & 197,9 & 199,1 & 200,6 & 202,3 & 204,3 & 206,4 & 208,7 & 211,0 & 213,3 & 215,5 & 174,8 \\
\hline $\mathrm{C}_{2} \mathrm{H}_{2}$ & ${ }^{1} J_{\mathrm{CH}}$ & 251,8 & 251,4 & 251,0 & 250,7 & 250,8 & 251,4 & 252,5 & 254,1 & 256,0 & 258,2 & 260,6 & 263,0 & 265,5 & 267,8 & 270,1 & 247,6 \\
\hline $\mathrm{C}_{2} \mathrm{H}_{2}$ & ${ }^{2} J_{\mathrm{CH}}$ & 53,3 & 53,4 & 53,6 & 53,7 & 53,9 & 54,0 & 54,0 & 53,9 & 53,7 & 53,4 & 53,1 & 52,7 & 52,2 & 51,8 & 51,3 & 50,1 \\
\hline $\mathrm{C}_{2} \mathrm{H}_{2}$ & ${ }^{3} J_{\mathrm{HH}}$ & 10,4 & 10,4 & 10,4 & 10,5 & 10,6 & 10,9 & 11,2 & 11,6 & 12,1 & 12,6 & 13,1 & 13,6 & 14,0 & 14,5 & 14,9 & 9,6 \\
\hline $\mathrm{C}_{2} \mathrm{H}_{4}$ & ${ }^{1} J_{\mathrm{CC}}$ & 66,7 & 66,8 & 67,2 & 67,6 & 68,2 & 69,0 & 70,0 & 71,1 & 72,5 & 74,1 & 75,8 & 77,6 & 79,4 & 81,3 & 83,1 & 67,6 \\
\hline $\mathrm{C}_{2} \mathrm{H}_{4}$ & ${ }^{1} J_{\mathrm{CH}}$ & 154,9 & 154,7 & 154,5 & 154,5 & 154,7 & 155,3 & 156,2 & 157,4 & 158,9 & 160,5 & 162,3 & 164,0 & 165,8 & 167,6 & 169,2 & 156,3 \\
\hline $\mathrm{C}_{2} \mathrm{H}_{4}$ & ${ }^{2} J_{\mathrm{CH}}$ & $-2,4$ & $-2,4$ & $-2,4$ & $-2,5$ & $-2,7$ & $-2,9$ & $-3,3$ & $-3,7$ & $-4,2$ & $-4,7$ & $-5,3$ & $-5,9$ & $-6,5$ & $-7,0$ & $-7,6$ & $-2,4$ \\
\hline $\mathrm{C}_{2} \mathrm{H}_{4}$ & ${ }^{2} J_{\mathrm{HH}}$ & 3,1 & 3,1 & 3,0 & 2,9 & 2,8 & 2,5 & 2,2 & 1,9 & 1,5 & 1,2 & 0,8 & 0,4 & 0,1 & $-0,2$ & $-0,5$ & 2,3 \\
\hline $\mathrm{C}_{2} \mathrm{H}_{4}$ & ${ }^{3} J_{\mathrm{HH}_{\mathrm{c}}}$ & 12,7 & 12,7 & 12,7 & 12,8 & 13,0 & 13,1 & 13,3 & 13,6 & 13,8 & 14,1 & 14,4 & 14,7 & 14,9 & 15,2 & 15,4 & 11,7 \\
\hline $\mathrm{C}_{2} \mathrm{H}_{4}$ & ${ }^{3} J_{\mathrm{HH}_{\mathrm{t}}}$ & 18,7 & 18,6 & 18,6 & 18,7 & 18,8 & 18,9 & 19,2 & 19,4 & 19,8 & 20,1 & 20,5 & 20,9 & 21,3 & 21,6 & 22,0 & 19 \\
\hline $\mathrm{C}_{2} \mathrm{H}_{6}$ & ${ }^{1} J_{\mathrm{CC}}$ & 30,1 & 30,2 & 30,5 & 30,9 & 31,3 & 31,8 & 32,3 & 32,9 & 33,5 & 34,3 & 35,0 & 35,9 & 36,7 & 37,5 & 38,2 & 34,5 \\
\hline $\mathrm{C}_{2} \mathrm{H}_{6}$ & ${ }^{1} J_{\mathrm{CH}}$ & 121,4 & 121,3 & 121,1 & 121,0 & 121,1 & 121,5 & 122,1 & 122 & 123,9 & 125,1 & 126,3 & 127,6 & 128,9 & 130,1 & 131,2 & 125,2 \\
\hline $\mathrm{C}_{2} \mathrm{H}_{6}$ & ${ }^{2} J_{\mathrm{CH}}$ & $-3,7$ & $-3,7$ & $-3,7$ & $-3,8$ & $-3,8$ & $-3,9$ & $-4,1$ & $-4,2$ & $-4,4$ & $-4,6$ & $-4,8$ & $-4,9$ & $-5,1$ & $-5,3$ & $-5,4$ & $-4,7$ \\
\hline \multirow[t]{3}{*}{ Total } & $\mathrm{DM}$ & -16 & 16,40 & $-16,32$ & & & & & & & & & & & & & - \\
\hline & DMA & 19 & & & & & & & & & & & & & & & - \\
\hline & PDMA & 14,11 & 13,94 & 13,42 & 12,79 & 12,30 & 11,30 & 11,04 & 12,11 & 15,32 & 18,22 & 22,00 & 26,19 & 30,20 & 34,05 & 37,88 & - \\
\hline \multirow[t]{3}{*}{ CPI } & DM & $-40,44$ & 40,25 & $-40,08$ & $-39,97$ & -39 & -39 & -39 & $-39,02$ & & & & & & & & - \\
\hline & DMA & 41 & 41,7 & 41, & 41 , & 4 & 41 , & 42, & & & & & & & & & - \\
\hline & PDMA & 22,30 & 21,85 & 21,07 & 19,87 & 18,25 & 16,44 & 14,55 & 13,60 & 16,91 & 19,94 & 23,30 & 27,14 & 30,98 & 34,66 & 38,33 & - \\
\hline \multirow[t]{3}{*}{ SPI } & DM & 1,1 & & & & & & & & & & & & & & & - \\
\hline & & & & & & & & & & & & & & & & & - \\
\hline & PDMA & 8,10 & 8,13 & 7,80 & 7,61 & 7,94 & 7,53 & 8,46 & 11,01 & 14,15 & 16,95 & 21,05 & 25,49 & 29,64 & 33,60 & 37,54 & - \\
\hline \multirow[t]{3}{*}{$\Delta C S$} & & & & & & & & & & & & & & & & & - \\
\hline & MA & & & & & & & & & & & & & & & 41,60 & - \\
\hline & $\mathrm{PD}$ & 14,20 & 13,71 & 13,27 & 12,26 & 10,31 & 8,91 & 6,09 & 2,5 & 2,75 & 2,99 & 2,24 & 1,64 & 1,34 & 1,06 & 0,79 & - \\
\hline
\end{tabular}


Tabela 8.399: Constantes de acoplamento LC-SLYP com $\alpha=50 \%$ e $\alpha+\beta=80 \%$, variando $\gamma$, na base aug-pcJ-2.

\begin{tabular}{|c|c|c|c|c|c|c|c|c|c|c|c|c|c|c|c|c|c|}
\hline & $\gamma$ & 0,05 & 0,10 & 0,15 & 0,20 & 0,25 & 0,30 & 0,35 & 0,40 & 0,45 & 0,50 & 0,55 & 0,60 & 0,65 & 0,70 & 0,75 & Exp. \\
\hline $\mathrm{HF}$ & ${ }^{1} J_{\mathrm{HF}}$ & 531,0 & 531,4 & 531,9 & 532,6 & 533,6 & 534,8 & 536,3 & 538,2 & 540,3 & 542,7 & 545,2 & 547,9 & 550,7 & 553,5 & 556,3 & 500 \\
\hline $\mathrm{CO}$ & ${ }^{1} J_{\mathrm{CO}}$ & 13,7 & 13,6 & 13,5 & 13,4 & 13,3 & 13,2 & 13,1 & 13,0 & 12,9 & 12,7 & 12,4 & 12,1 & 11,7 & 11,3 & 10,9 & 16,4 \\
\hline $\mathrm{H}_{2} \mathrm{O}$ & ${ }^{1} J_{\mathrm{OH}}$ & $-83,8$ & $-83,8$ & $-83,8$ & $-83,9$ & $-84,0$ & $-84,2$ & $-84,4$ & $-84,7$ & $-85,1$ & $-85,4$ & $-85,8$ & $-86,3$ & $-86,7$ & $-87,2$ & $-87,6$ & $-80,6$ \\
\hline $\mathrm{H}_{2} \mathrm{O}$ & ${ }^{2} J_{\mathrm{HH}}$ & $-9,4$ & $-9,4$ & $-9,4$ & $-9,5$ & $-9,6$ & $-9,7$ & $-9,9$ & $-10,1$ & $-10,3$ & $-10,6$ & $-10,8$ & $-11,0$ & $-11,2$ & $-11,5$ & $-11,7$ & $-7,3$ \\
\hline $\mathrm{NH}_{3}$ & ${ }^{1} J_{\mathrm{NH}}$ & 45,5 & 45,5 & 45,5 & 45,6 & 45,6 & 45,7 & 45,8 & 45,9 & 46,1 & 46,3 & 46,5 & 46,7 & 47,0 & 47,3 & 47,5 & 43,8 \\
\hline $\mathrm{NH}_{3}$ & ${ }^{2} J_{\mathrm{HH}}$ & $-11,1$ & $-11,1$ & $-11,2$ & $-11,3$ & $-11,4$ & $-11,6$ & $-11,8$ & $-12,0$ & $-12,3$ & $-12,6$ & $-12,8$ & $-13,1$ & $-13,3$ & $-13,5$ & $-13,7$ & $-9,6$ \\
\hline $\mathrm{PH}_{3}$ & ${ }^{1} J_{\mathrm{PH}}$ & 183,2 & 183,0 & 182,2 & 181,1 & 180,2 & 179,8 & 180,3 & 181,4 & 183,2 & 185,4 & 187,8 & 190,4 & 192,9 & 195,3 & 197,6 & 188,2 \\
\hline $\mathrm{PF}_{3}$ & ${ }^{1} J_{\mathrm{PF}}$ & $-1669,8$ & $-1668,5$ & $-1666,5$ & $-1664,0$ & $-1661,3$ & $-1658,5$ & $-1655,7$ & $-1652,7$ & $-1649,4$ & $-1645,6$ & $-1641,4$ & $-1636,8$ & $-1631,9$ & $-1626,9$ & $-1621,8$ & -1441 \\
\hline $\mathrm{BHF}_{2}$ & ${ }^{1} J_{\mathrm{BF}}$ & $-95,0$ & $-94,4$ & $-93,2$ & $-91,2$ & $-88,9$ & $-86,2$ & $-83,4$ & $-80,5$ & $-77,6$ & $-74,7$ & $-71,9$ & $-69,2$ & $-66,6$ & $-64,2$ & $-61,9$ & -84 \\
\hline $\mathrm{BF}_{3}$ & ${ }^{1} J_{\mathrm{BF}}$ & 15,2 & 15,8 & 17,0 & 18,8 & 21,2 & 23,9 & 26,8 & 29,9 & 32,9 & 35,9 & 38,9 & 41,6 & 44,3 & 46,8 & 49,1 & 15 \\
\hline $\mathrm{F}_{2} \mathrm{O}$ & ${ }^{1} J_{\mathrm{OF}}$ & $-465,1$ & $-466,0$ & $-468,8$ & $-473,4$ & $-479,8$ & $-487,5$ & $-496,1$ & $-505,3$ & $-514,8$ & $-524,5$ & $-534,4$ & $-544,3$ & $-554,3$ & $-564,3$ & $-574,1$ & -300 \\
\hline $\mathrm{CH}_{4}$ & ${ }^{1} J_{\mathrm{CH}}$ & 124,9 & 124,8 & 124,7 & 124,7 & 124,8 & 125,0 & 125,5 & 126,1 & 126,9 & 127,7 & 128,7 & 129,6 & 130,5 & 131,4 & 132,3 & 125,3 \\
\hline $\mathrm{CH}_{4}$ & ${ }^{2} J_{\mathrm{HH}}$ & $-13,2$ & $-13,2$ & $-13,2$ & $-13,3$ & $-13,5$ & $-13,7$ & $-13,9$ & $-14,2$ & $-14,5$ & $-14,8$ & $-15,0$ & $-15,3$ & $-15,5$ & $-15,7$ & $-15,9$ & $-12,8$ \\
\hline $\mathrm{C}_{2} \mathrm{H}_{2}$ & ${ }^{1} J_{\mathrm{CC}}$ & 202,4 & 202,4 & 202,7 & 203,1 & 203,8 & 204,7 & 205,7 & 207,1 & 208,6 & 210,3 & 212,1 & 213,9 & 215,8 & 217,7 & 219,4 & 174,8 \\
\hline $\mathrm{C}_{2} \mathrm{H}_{2}$ & ${ }^{1} J_{\mathrm{CH}}$ & 259,4 & 259,1 & 258,8 & 258,6 & 258,8 & 259,3 & 260,2 & 261,5 & 263,1 & 264,9 & 266,7 & 268,7 & 270,6 & 272,4 & 274,2 & 247,6 \\
\hline $\mathrm{C}_{2} \mathrm{H}_{2}$ & ${ }^{2} J_{\mathrm{CH}}$ & 53,1 & 53,1 & 53,2 & 53,3 & 53,4 & 53,4 & 53,3 & 53,2 & 52,9 & 52,6 & 52,2 & 51,9 & 51,5 & 51,1 & 50,7 & 50,1 \\
\hline $\mathrm{C}_{2} \mathrm{H}_{2}$ & ${ }^{3} J_{\mathrm{HH}}$ & 11,8 & 11,7 & 11,8 & 11,8 & 12,0 & 12,2 & 12,6 & 12,9 & 13,3 & 13,7 & 14,2 & 14,6 & 15,0 & 15,3 & 15,7 & 9,6 \\
\hline $\mathrm{C}_{2} \mathrm{H}_{4}$ & ${ }^{1} J_{\mathrm{CC}}$ & 72,3 & 72,4 & 72,7 & 73,1 & 73,7 & 74,4 & 75,3 & 76,4 & 77,6 & 79,0 & 80,5 & 82,0 & 83,5 & 85,1 & 86,5 & 67,6 \\
\hline $\mathrm{C}_{2} \mathrm{H}_{4}$ & ${ }^{1} J_{\mathrm{CH}}$ & 160,5 & 160,4 & 160,3 & 160,3 & 160,5 & 161,0 & 161,8 & 162,8 & 164,0 & 165,3 & 166,7 & 168,1 & 169,5 & 170,9 & 172,2 & 156,3 \\
\hline $\mathrm{C}_{2} \mathrm{H}_{4}$ & ${ }^{2} J_{\mathrm{CH}}$ & $-3,8$ & $-3,8$ & $-3,8$ & $-3,9$ & $-4,1$ & $-4,4$ & $-4,7$ & $-5,1$ & $-5,5$ & $-6,0$ & $-6,5$ & $-7,0$ & $-7,5$ & $-8,0$ & $-8,4$ & $-2,4$ \\
\hline $\mathrm{C}_{2} \mathrm{H}_{4}$ & ${ }^{2} J_{\mathrm{HH}}$ & 2,2 & 2,2 & 2,2 & 2,1 & 1,9 & 1,7 & 1,4 & 1,1 & 0,8 & 0,5 & 0,2 & 0,0 & $-0,3$ & $-0,6$ & $-0,8$ & 2,3 \\
\hline $\mathrm{C}_{2} \mathrm{H}_{4}$ & ${ }^{3} J_{\mathrm{HH}_{\mathrm{c}}}$ & 13,3 & 13,3 & 13,4 & 13,4 & 13,6 & 13,7 & 13,9 & 14,1 & 14,4 & 14,6 & 14,9 & 15,1 & 15,3 & 15,5 & 15,7 & 11,7 \\
\hline $\mathrm{C}_{2} \mathrm{H}_{4}$ & ${ }^{3} J_{\mathrm{HH}_{\mathrm{t}}}$ & 19,6 & 19,6 & 19,6 & 19,7 & 19,8 & 19,9 & 20,2 & 20,4 & 20,7 & 21,0 & 21,3 & 21,7 & 22,0 & 22,3 & 22,6 & 19 \\
\hline $\mathrm{C}_{2} \mathrm{H}_{6}$ & ${ }^{1} J_{\mathrm{CC}}$ & 33,3 & 33,4 & 33,6 & 33,9 & 34,3 & 34,7 & 35,1 & 35,5 & 36,1 & 36,6 & 37,2 & 37 & 38,5 & 39,1 & 39,7 & 34,5 \\
\hline $\mathrm{C}_{2} \mathrm{H}_{6}$ & ${ }^{1} J_{\mathrm{CH}}$ & 125,8 & 125,7 & 125,5 & 125,5 & 125,6 & 125,9 & 126,4 & 127,0 & 127,8 & 128,7 & 129,7 & 130 & 131,6 & 132,5 & 133,4 & 125,2 \\
\hline $\mathrm{C}_{2} \mathrm{H}_{6}$ & ${ }^{2} J_{\mathrm{CH}}$ & $-4,3$ & $-4,3$ & $-4,3$ & $-4,3$ & $-4,4$ & $-4,5$ & $-4,6$ & $-4,7$ & $-4,8$ & $-5,0$ & $-5,1$ & $-5,3$ & $-5,4$ & $-5,5$ & $-5,6$ & $-4,7$ \\
\hline \multirow[t]{3}{*}{ Total } & $\mathrm{DM}$ & $-12,8$ & 77 & & $-12,65$ & & & & & & & & & & & & - \\
\hline & DMA & & & & & & & & & & & & & & & & - \\
\hline & PDMA & 12,21 & 12,32 & 12,76 & 13,72 & 15,27 & 17,13 & 19,54 & 22,39 & 25,55 & 29,01 & 32,37 & 35,69 & 39,03 & 42,33 & 45,20 & - \\
\hline \multirow[t]{3}{*}{ CPI } & DM & $-35,14$ & - & & $-34,7$ & -34 , & -34 & & & & & & & & & & - \\
\hline & DMA & 41,12 & 41,1 & 41, & 41,74 & 42 & 42 , & 43 & & & & 48 & & & & & - \\
\hline & PDMA & 14,81 & 15,20 & 16,07 & 17,44 & 19,17 & 21,18 & 23,55 & 26,53 & 29,56 & 32,74 & 35,76 & 38,89 & 42,02 & 45,13 & 47,95 & - \\
\hline \multirow[t]{3}{*}{ SPI } & DM & & & & & & & & & & & & & & & & - \\
\hline & & & & & & & & & & & & & & & & & - \\
\hline & PDMA & 10,30 & 10,21 & 10,33 & 10,99 & 12,42 & 14,17 & 16,60 & 19,35 & 22,62 & 26,27 & 29,89 & 33,35 & 36,85 & 40,28 & 43,17 & - \\
\hline \multirow[t]{3}{*}{$\Delta \mathrm{CS}$} & & & & & & & & & & & & & & & & & - \\
\hline & MA & & & & 37,6 & & & & & & & 41,22 & & & & & 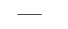 \\
\hline & $\mathrm{P}$ & 4,51 & 4,99 & 5,7 & 6,44 & 6,75 & 7,02 & 6,95 & 7,18 & 6,94 & 6,47 & 5,87 & 5,54 & 5,17 & 4,86 & 4,78 & - \\
\hline
\end{tabular}


Tabela 8.400: Constantes de acoplamento LC-SLYP com $\alpha=0 \%$ e $\alpha+\beta=70 \%$, variando $\gamma$, na base aug-pcJ-2.

\begin{tabular}{|c|c|c|c|c|c|c|c|c|c|c|c|c|c|c|c|c|c|}
\hline & $\gamma$ & 0,05 & 0,10 & 0,15 & 0,20 & 0,25 & 0,30 & 0,35 & 0,40 & 0,45 & 0,50 & 0,55 & 0,60 & 0,65 & 0,70 & 0,75 & Exp. \\
\hline $\mathrm{HF}$ & ${ }^{1} J_{\mathrm{HF}}$ & 421,0 & 422,0 & 423,1 & 424,4 & 425,9 & 428,1 & 431,1 & 434,9 & 439,5 & 444,7 & 450,3 & 456,3 & 462,4 & 468,5 & 474,7 & 500 \\
\hline $\mathrm{CO}$ & ${ }^{1} J_{\mathrm{CO}}$ & 24,7 & 24,5 & 24,3 & 24,1 & 23,9 & 23,8 & 23,7 & 23,5 & 23,3 & 22,9 & 22,4 & 21,9 & 21,2 & 20,5 & 19,7 & 16,4 \\
\hline $\mathrm{H}_{2} \mathrm{O}$ & ${ }^{1} J_{\mathrm{OH}}$ & $-70,0$ & $-70,0$ & $-70,1$ & $-70,2$ & $-70,4$ & $-70,7$ & $-71,1$ & $-71,7$ & $-72,4$ & $-73,2$ & $-74,0$ & $-74,9$ & $-75,8$ & $-76,8$ & $-77,7$ & $-80,6$ \\
\hline $\mathrm{H}_{2} \mathrm{O}$ & ${ }^{2} J_{\mathrm{HH}}$ & $-3,3$ & $-3,3$ & $-3,4$ & $-3,5$ & $-3,7$ & $-4,0$ & $-4,3$ & $-4,7$ & $-5,1$ & $-5,6$ & $-6,0$ & $-6,4$ & $-6,9$ & $-7,3$ & $-7,7$ & $-7,3$ \\
\hline $\mathrm{NH}_{3}$ & ${ }^{1} J_{\mathrm{NH}}$ & 39,4 & 39,4 & 39,4 & 39,4 & 39,4 & 39,4 & 39,6 & 39,8 & 40,2 & 40,6 & 41,0 & 41,5 & 42,0 & 42,5 & 43,1 & 43,8 \\
\hline $\mathrm{NH}_{3}$ & ${ }^{2} J_{\mathrm{HH}}$ & $-5,4$ & $-5,4$ & $-5,5$ & $-5,7$ & $-5,9$ & $-6,3$ & $-6,7$ & $-7,1$ & $-7,6$ & $-8,1$ & $-8,6$ & $-9,1$ & $-9,6$ & $-10,0$ & $-10,5$ & $-9,6$ \\
\hline $\mathrm{PH}_{3}$ & ${ }^{1} J_{\mathrm{PH}}$ & 135,8 & 135,2 & 132,8 & 129,5 & 126,7 & 125,4 & 126,0 & 128,2 & 131,9 & 136,5 & 141,7 & 147,2 & 152,7 & 158,0 & 163,0 & 188,2 \\
\hline $\mathrm{PF}_{3}$ & ${ }^{1} J_{\mathrm{PF}}$ & $-1813,4$ & $-1812,2$ & $-1812,5$ & $-1814,0$ & $-1816,5$ & $-1819,5$ & $-1822,1$ & $-1823,5$ & $-1822,9$ & $-1819,9$ & $-1814,7$ & $-1807,5$ & $-1798,8$ & $-1789,1$ & $-1778,8$ & -1441 \\
\hline $\mathrm{BHF}_{2}$ & ${ }^{1} J_{\mathrm{BF}}$ & $-187,1$ & $-185,5$ & $-182,2$ & $-177,4$ & $-171,6$ & $-165,3$ & $-158,7$ & $-152,0$ & $-145,2$ & $-138,5$ & $-131,9$ & $-125,6$ & $-119,6$ & $-114,0$ & $-108,7$ & -84 \\
\hline $\mathrm{BF}_{3}$ & ${ }^{1} J_{\mathrm{BF}}$ & $-79,5$ & $-78,0$ & $-74,9$ & $-70,1$ & $-64,1$ & $-57,3$ & $-50,1$ & $-42,8$ & $-35,4$ & $-28,3$ & $-21,4$ & $-14,9$ & $-8,8$ & $-3,2$ & 2,0 & 15 \\
\hline $\mathrm{F}_{2} \mathrm{O}$ & ${ }^{1} J_{\mathrm{OF}}$ & $-272,3$ & $-274,3$ & $-279,5$ & $-288,0$ & $-299,2$ & $-311,8$ & $-324,8$ & $-337,6$ & $-349,7$ & $-361,3$ & $-372,5$ & $-383,3$ & $-394,0$ & $-404,6$ & $-415,0$ & -300 \\
\hline $\mathrm{CH}_{4}$ & ${ }^{1} J_{\mathrm{CH}}$ & 106,0 & 105,7 & 105,4 & 105,1 & 105,0 & 105,4 & 106,1 & 107,3 & 108,7 & 110,4 & 112,3 & 114,2 & 116,1 & 118,0 & 119,8 & 125,3 \\
\hline $\mathrm{CH}_{4}$ & ${ }^{2} J_{\mathrm{HH}}$ & $-7,9$ & $-7,8$ & $-7,9$ & $-8,1$ & $-8,4$ & $-8,8$ & $-9,3$ & $-9,8$ & $-10,4$ & $-10,9$ & $-11,5$ & $-12,0$ & $-12,5$ & $-12,9$ & $-13,3$ & $-12,8$ \\
\hline $\mathrm{C}_{2} \mathrm{H}_{2}$ & ${ }^{1} J_{\mathrm{CC}}$ & 175,5 & 175,6 & 176,0 & 176,5 & 177,1 & 177,8 & 178,9 & 180,3 & 182,0 & 184,1 & 186,4 & 189,0 & 191,7 & 194,4 & 197,2 & 174,8 \\
\hline $\mathrm{C}_{2} \mathrm{H}_{2}$ & ${ }^{1} J_{\mathrm{CH}}$ & 226,2 & 225,5 & 224,7 & 224,1 & 224,0 & 224,6 & 226,0 & 228,0 & 230,6 & 233,6 & 236,9 & 240,4 & 243,9 & 247,3 & 250,6 & 247,6 \\
\hline $\mathrm{C}_{2} \mathrm{H}_{2}$ & ${ }^{2} J_{\mathrm{CH}}$ & 51,2 & 51,3 & 51,7 & 52,2 & 52,8 & 53,3 & 53,8 & 54,1 & 54,3 & 54,4 & 54,3 & 54,2 & 54,0 & 53,7 & 53,4 & 50,1 \\
\hline $\mathrm{C}_{2} \mathrm{H}_{2}$ & ${ }^{3} J_{\mathrm{HH}}$ & 7,1 & 7,1 & 7,0 & 7,0 & 7,1 & 7,2 & 7,5 & 7,8 & 8,2 & 8,7 & 9,2 & 9,7 & 10,2 & 10,7 & 11,2 & 9,6 \\
\hline $\mathrm{C}_{2} \mathrm{H}_{4}$ & ${ }^{1} J_{\mathrm{CC}}$ & 50,5 & 50,7 & 51,1 & 51,6 & 52,2 & 52,8 & 53,6 & 54,6 & 55,9 & 57,4 & 59,2 & 61,1 & 63,1 & 65,3 & 67,4 & 67,6 \\
\hline $\mathrm{C}_{2} \mathrm{H}_{4}$ & ${ }^{1} J_{\mathrm{CH}}$ & 136,1 & 135,8 & 135,3 & 135,1 & 135,2 & 135,8 & 136,9 & 138,4 & 140,4 & 142,6 & 145,0 & 147,5 & 150,0 & 152,5 & 154,8 & 156,3 \\
\hline $\mathrm{C}_{2} \mathrm{H}_{4}$ & ${ }^{2} J_{\mathrm{CH}}$ & 0,9 & 0,9 & 0,9 & 0,9 & 0,8 & 0,6 & 0,4 & 0,0 & $-0,3$ & $-0,8$ & $-1,3$ & $-1,9$ & $-2,5$ & $-3,1$ & $-3,6$ & $-2,4$ \\
\hline $\mathrm{C}_{2} \mathrm{H}_{4}$ & ${ }^{2} J_{\mathrm{HH}}$ & 5,5 & 5,5 & 5,5 & 5,4 & 5,2 & 4,9 & 4,6 & 4,3 & 3,9 & 3,5 & 3,1 & 2,6 & 2,2 & 1,9 & 1,5 & 2,3 \\
\hline $\mathrm{C}_{2} \mathrm{H}_{4}$ & ${ }^{3} J_{\mathrm{HH}_{\mathrm{c}}}$ & 11,2 & 11,3 & 11,3 & 11,4 & 11,5 & 11,6 & 11,8 & 12,0 & 12,2 & 12,4 & 12,7 & 12,9 & 13,2 & 13,4 & 13,7 & 11,7 \\
\hline $\mathrm{C}_{2} \mathrm{H}_{4}$ & ${ }^{3} J_{\mathrm{HH}_{\mathrm{t}}}$ & 16,2 & 16,2 & 16,1 & 16,0 & 16,1 & 16,1 & 16,3 & 16,5 & 16,8 & 17,1 & 17,5 & 17,9 & 18,3 & 18,7 & 19,1 & 19 \\
\hline $\mathrm{C}_{2} \mathrm{H}_{6}$ & ${ }^{1} J_{\mathrm{CC}}$ & 18,8 & 19,0 & 19,5 & 20,1 & 20,7 & 21,3 & 22,0 & 22,8 & 23,7 & 24,8 & 26,0 & 27,2 & 28,4 & 29,6 & 30,8 & 34,5 \\
\hline $\mathrm{C}_{2} \mathrm{H}_{6}$ & ${ }^{1} J_{\mathrm{CH}}$ & 106,0 & 105,8 & 105,4 & 105,1 & 105,1 & & 106,3 & 107,5 & 109,1 & 110,8 & 112,8 & 114,7 & 116,7 & 118,7 & 120,5 & 125,2 \\
\hline $\mathrm{C}_{2} \mathrm{H}_{6}$ & ${ }^{2} J_{\mathrm{CH}}$ & $-1,7$ & $-1,7$ & $-1,7$ & $-1,7$ & $-1,8$ & $-2,0$ & $-2,2$ & $-2,4$ & $-2,7$ & $-2,9$ & $-3,2$ & $-3,5$ & $-3,7$ & $-4,0$ & $-4,2$ & $-4,7$ \\
\hline \multirow[t]{3}{*}{ Total } & $\mathrm{DM}$ & $-28,98$ & 28,91 & $-28,97$ & $-29,07$ & $-29,15$ & & & $-28,3$ & $-27,54$ & & & & & & & - \\
\hline & DMA & 34 & & & & & & & & & & & & & & & - \\
\hline & PDMA & 59,74 & 59,22 & 58,14 & 56,21 & 53,27 & 49,77 & 45,92 & 41,59 & 36,86 & 31,77 & 26,58 & 21,22 & 17,11 & 15,95 & 15,80 & - \\
\hline \multirow[t]{3}{*}{ CPI } & DM & $-59,18$ & & $-59,04$ & & & -59 & & -59 , & & & & & & & & - \\
\hline & DMA & 15 & & 67 , & & & 64, & 63 & & & & & & & & & - \\
\hline & PDMA & 91,26 & 90,00 & 87,37 & 83,39 & 78,34 & 73,07 & 67,42 & 61,40 & 55,03 & 48,53 & 42,17 & 36,00 & 29,86 & 25,02 & 21,50 & - \\
\hline \multirow[t]{3}{*}{ SPI } & DM & $-6,8$ & $-6,8$ & $-6,9$ & - & -6, & -6 , & -6 , & & & & & & & & & - \\
\hline & & & & & & & & & & & & & & & & & - \\
\hline & PDMA & 36,63 & 36,65 & 36,71 & 36,27 & 34,89 & 32,68 & 30,16 & 27,06 & 23,54 & 19,48 & 15,15 & 10,37 & 7,76 & 9,29 & 11,62 & - \\
\hline \multirow[t]{3}{*}{$\Delta C S$} & & & & & & & & & & & & & & & & & - \\
\hline & MA & & & & & & & & & & & & & & & & - \\
\hline & & 4,62 & 53,36 & 50,66 & 47,12 & 43,45 & 40,39 & 37,27 & 34,34 & 31,50 & 29,05 & 27,02 & 25,62 & 22,10 & 15,73 & 9,87 & - \\
\hline
\end{tabular}


Tabela 8.401: Constantes de acoplamento LC-SLYP com $\alpha=10 \%$ e $\alpha+\beta=70 \%$, variando $\gamma$, na base aug-pcJ-2.

\begin{tabular}{|c|c|c|c|c|c|c|c|c|c|c|c|c|c|c|c|c|c|}
\hline & $\gamma$ & 0,05 & 0,10 & 0,15 & 0,20 & 0,25 & 0,30 & 0,35 & 0,40 & 0,45 & 0,50 & 0,55 & 0,60 & 0,65 & 0,70 & 0,75 & Exp. \\
\hline HF & ${ }^{1} J_{\mathrm{HF}}$ & 441,5 & 442,4 & 443,4 & 444,5 & 446,0 & 447,9 & 450,6 & 453,9 & 457,9 & 462,4 & 467,2 & 472,3 & 477,6 & 482,9 & 488,2 & 500 \\
\hline $\mathrm{CO}$ & ${ }^{1} J_{\mathrm{CO}}$ & 22,9 & 22,7 & 22,5 & 22,3 & 22,1 & 22,0 & 21,9 & 21,8 & 21,5 & 21,2 & 20,8 & 20,2 & 19,6 & 19,0 & 18,3 & 16,4 \\
\hline $\mathrm{H}_{2} \mathrm{O}$ & ${ }^{1} J_{\mathrm{OH}}$ & $-72,5$ & $-72,5$ & $-72,6$ & $-72,7$ & $-72,9$ & $-73,2$ & $-73,6$ & $-74,1$ & $-74,6$ & $-75,3$ & $-76,1$ & $-76,8$ & $-77,6$ & $-78,5$ & $-79,3$ & $-80,6$ \\
\hline $\mathrm{H}_{2} \mathrm{O}$ & ${ }^{2} J_{\mathrm{HH}}$ & $-4,4$ & $-4,4$ & $-4,4$ & $-4,6$ & $-4,8$ & $-5,0$ & $-5,3$ & $-5,7$ & $-6,0$ & $-6,4$ & $-6,8$ & $-7,2$ & $-7,6$ & $-7,9$ & $-8,3$ & $-7,3$ \\
\hline $\mathrm{NH}_{3}$ & ${ }^{1} J_{\mathrm{NH}}$ & 40,5 & 40,5 & 40,5 & 40,5 & 40,5 & 40,6 & 40,7 & 40,9 & 41,2 & 41,6 & 42,0 & 42,4 & 42,9 & 43,3 & 43,8 & 43,8 \\
\hline $\mathrm{NH}_{3}$ & ${ }^{2} J_{\mathrm{HH}}$ & $-6,4$ & $-6,4$ & $-6,5$ & $-6,7$ & $-6,9$ & $-7,2$ & $-7,6$ & $-8,0$ & $-8,4$ & $-8,9$ & $-9,3$ & $-9,7$ & $-10,1$ & $-10,5$ & $-10,9$ & $-9,6$ \\
\hline $\mathrm{PH}_{3}$ & ${ }^{1} J_{\mathrm{PH}}$ & 144,5 & 144,0 & 142,1 & 139,4 & 137,1 & 136,1 & 136,6 & 138,6 & 141,8 & 145,9 & 150,4 & 155,2 & 159,9 & 164,5 & 168,9 & 188,2 \\
\hline $\mathrm{PF}_{3}$ & ${ }^{1} J_{\mathrm{PF}}$ & $-1796,1$ & $-1794,7$ & $-1793,8$ & $-1793,5$ & $-1793,7$ & $-1794,2$ & $-1794,6$ & $-1794,1$ & $-1792,3$ & $-1788,7$ & $-1783,5$ & $-1776,7$ & $-1768,9$ & $-1760,3$ & $-1751,3$ & -1441 \\
\hline $\mathrm{BHF}_{2}$ & ${ }^{1} J_{\mathrm{BF}}$ & $-169,2$ & $-167,9$ & $-165,1$ & $-161,0$ & $-156,1$ & $-150,7$ & $-145,0$ & $-139,2$ & $-133,4$ & $-127,6$ & $-121,9$ & $-116,5$ & $-111,4$ & $-106,5$ & $-102,0$ & -84 \\
\hline $\mathrm{BF}_{3}$ & ${ }^{1} J_{\mathrm{BF}}$ & $-60,9$ & $-59,7$ & $-57,0$ & $-53,0$ & $-48,0$ & $-42,2$ & $-36,1$ & $-29,8$ & $-23,5$ & $-17,4$ & $-11,5$ & $-6,0$ & $-0,7$ & 4,0 & 8,6 & 15 \\
\hline $\mathrm{F}_{2} \mathrm{O}$ & ${ }^{1} J_{\mathrm{OF}}$ & $-308,4$ & $-310,1$ & $-314,3$ & $-321,5$ & $-330,8$ & $-341,5$ & $-352,8$ & $-363,9$ & $-374,7$ & $-385,2$ & $-395,4$ & $-405,4$ & $-415,3$ & $-425,2$ & $-434,9$ & -300 \\
\hline $\mathrm{CH}_{4}$ & ${ }^{1} J_{\mathrm{CH}}$ & 109,4 & 109,2 & 108,9 & 108,7 & 108,7 & 109,0 & 109,7 & 110,7 & 112,0 & 113,5 & 115,1 & 116,8 & 118,5 & 120,1 & 121,7 & 125,3 \\
\hline $\mathrm{CH}_{4}$ & ${ }^{2} J_{\mathrm{HH}}$ & $-8,9$ & $-8,8$ & $-8,9$ & $-9,0$ & $-9,3$ & $-9,7$ & $-10,1$ & $-10,6$ & $-11,1$ & $-11,5$ & $-12,0$ & $-12,5$ & $-12,9$ & $-13,3$ & $-13,7$ & $-12,8$ \\
\hline $\mathrm{C}_{2} \mathrm{H}_{2}$ & ${ }^{1} J_{\mathrm{CC}}$ & 179,6 & 179,7 & 180,1 & 180,5 & 181,1 & 181,9 & 182,9 & 184,3 & 186,0 & 187,9 & 190,1 & 192,5 & 195,0 & 197,5 & 200,0 & 174,8 \\
\hline $\mathrm{C}_{2} \mathrm{H}_{2}$ & ${ }^{1} J_{\mathrm{CH}}$ & 232,1 & 231,5 & 230,8 & 230,3 & 230,2 & 230,8 & 232,1 & 233,9 & 236,3 & 239,0 & 241,9 & 245,0 & 248,1 & 251,1 & 254,0 & 247,6 \\
\hline $\mathrm{C}_{2} \mathrm{H}_{2}$ & ${ }^{2} J_{\mathrm{CH}}$ & 52,1 & 52,2 & 52,5 & 52,9 & 53,4 & 53,8 & 54,1 & 54,3 & 54,4 & 54,4 & 54,3 & 54,1 & 53,8 & 53,5 & 53,2 & 50,1 \\
\hline $\mathrm{C}_{2} \mathrm{H}_{2}$ & ${ }^{3} J_{\mathrm{HH}}$ & 7,7 & 7,7 & 7,6 & 7,6 & 7,7 & 7,9 & 8,2 & 8,5 & 8,9 & 9,4 & 9,9 & 10,4 & 10,8 & 11,3 & 11,7 & 9,6 \\
\hline $\mathrm{C}_{2} \mathrm{H}_{4}$ & ${ }^{1} J_{\mathrm{CC}}$ & 53,9 & 54,1 & 54,5 & 54,9 & 55,5 & 56,1 & 56,9 & 57,9 & 59,1 & 60,6 & 62,2 & 64,0 & 65,9 & 67,8 & 69,8 & 67,6 \\
\hline $\mathrm{C}_{2} \mathrm{H}_{4}$ & ${ }^{1} J_{\mathrm{CH}}$ & 140,4 & 140,1 & 139,8 & 139,6 & 139,7 & 140,3 & 141,3 & 142,7 & 144,4 & 146,4 & 148,6 & 150,8 & 153,0 & 155,2 & 157,3 & 156,3 \\
\hline $\mathrm{C}_{2} \mathrm{H}_{4}$ & ${ }^{2} J_{\mathrm{CH}}$ & 0,2 & 0,3 & 0,3 & 0,2 & 0,1 & 0,0 & $-0,2$ & $-0,6$ & $-1,0$ & $-1,5$ & $-2,0$ & $-2,5$ & $-3,0$ & $-3,6$ & $-4,1$ & $-2,4$ \\
\hline $\mathrm{C}_{2} \mathrm{H}_{4}$ & ${ }^{2} J_{\mathrm{HH}}$ & 5,0 & 5,0 & 5,0 & 4,9 & 4,7 & 4,5 & 4,2 & 3,8 & 3,5 & 3,1 & 2,7 & 2,3 & 2,0 & 1,6 & 1,3 & 2,3 \\
\hline $\mathrm{C}_{2} \mathrm{H}_{4}$ & ${ }^{3} J_{\mathrm{HH}_{\mathrm{c}}}$ & 11,5 & 11,5 & 11,6 & 11,6 & 11,7 & 11,9 & 12,0 & 12,2 & 12,4 & 12,7 & 12,9 & 13,2 & 13,4 & 13,6 & 13,9 & 11,7 \\
\hline $\mathrm{C}_{2} \mathrm{H}_{4}$ & ${ }^{3} J_{\mathrm{HH}_{\mathrm{t}}}$ & 16,7 & 16,6 & 16,6 & 16,6 & 16,6 & 16,7 & 16,8 & 17,1 & 17,3 & 17,7 & 18,0 & 18,4 & 18,8 & 19,1 & 19,5 & 19 \\
\hline $\mathrm{C}_{2} \mathrm{H}_{6}$ & ${ }^{1} J_{\mathrm{CC}}$ & 21,4 & 21,6 & 22,0 & 22,5 & 23,0 & 23,6 & 24,2 & 25,0 & 25,8 & 26,8 & 27,8 & 28,9 & 30,0 & 31,0 & 32 & 34,5 \\
\hline $\mathrm{C}_{2} \mathrm{H}_{6}$ & ${ }^{1} J_{\mathrm{CH}}$ & 109,6 & 109,4 & 109 & 108,8 & 108,9 & 109,2 & 110,0 & 111,1 & 112,5 & 1,0 & 115,7 & 117,4 & 119,2 & 120,9 & 122,5 & 125,2 \\
\hline $\mathrm{C}_{2} \mathrm{H}_{6}$ & ${ }^{2} J_{\mathrm{CH}}$ & $-2,1$ & $-2,1$ & $-2,1$ & $-2,2$ & $-2,3$ & $-2,4$ & $-2,6$ & $-2,8$ & $-3,0$ & $-3,3$ & $-3,5$ & $-3,7$ & $-4,0$ & $-4,2$ & $-4,4$ & $-4,7$ \\
\hline \multirow[t]{3}{*}{ Total } & $\mathrm{DM}$ & $-26,3$ & 26,27 & $-26,25$ & $-26,28$ & $-26,26$ & -26 , & & $-25,27$ & & & & & & & & - \\
\hline & DMA & 29,37 & 29 & & & & & & & & & & & & & & - \\
\hline & PDMA & 48,14 & 47,97 & 47,12 & 45,35 & 42,98 & 40,29 & 36,84 & 32,63 & 28,48 & 23,75 & 19,33 & 15,50 & 14,67 & 14,87 & 15,14 & - \\
\hline \multirow[t]{3}{*}{ CPI } & DM & $-55,40$ & 55,18 & & & & & & & & & & & & & & - \\
\hline & DMA & 59,16 & 58,9 & 58, & 58, & & 58 & & & & & & & & & & - \\
\hline & PDMA & 72,73 & 71,81 & 69,84 & 66,74 & 62,98 & 58,58 & 53,66 & 48,36 & 42,97 & 37,36 & 31,86 & 26,70 & 22,96 & 19,75 & 16,70 & - \\
\hline \multirow[t]{3}{*}{ SPI } & DM & $-5,0$ & $-5,0$ & $-5,0$ & - & $-4, \mathrm{~s}$ & -4 & -4 , & & & & & & & & & - \\
\hline & & & & & & & & & & & & & & & & & - \\
\hline & PDMA & 30,11 & 30,49 & 30,45 & 29,67 & 28,31 & 26,88 & 24,50 & 21,09 & 17,86 & 13,77 & 10,13 & 7,29 & 8,59 & 11,29 & 14,01 & - \\
\hline \multirow[t]{3}{*}{$\Delta C S$} & & & & & & & & & & & & & & & & & - \\
\hline & MA & & & & & & & & & & & & & & & & - \\
\hline & & 42,62 & 41,32 & 39,39 & 37,07 & 34,66 & 31,70 & 29,16 & 27,27 & 25,11 & 23,58 & 21,73 & 19,41 & 14,37 & 8,46 & 2,69 & - \\
\hline
\end{tabular}


Tabela 8.402: Constantes de acoplamento LC-SLYP com $\alpha=20 \%$ e $\alpha+\beta=70 \%$, variando $\gamma$, na base aug-pcJ-2.

\begin{tabular}{|c|c|c|c|c|c|c|c|c|c|c|c|c|c|c|c|c|c|}
\hline & $\gamma$ & 0,05 & 0,10 & 0,15 & 0,20 & 0,25 & 0,30 & 0,35 & 0,40 & 0,45 & 0,50 & 0,55 & 0,60 & 0,65 & 0,70 & 0,75 & Exp. \\
\hline HF & ${ }^{1} J_{\mathrm{HF}}$ & 462,7 & 463,4 & 464,3 & 465,3 & 466,6 & 468,3 & 470,6 & 473,5 & 476,8 & 480,6 & 484,6 & 488,9 & 493,3 & 497,8 & 502,3 & 500 \\
\hline $\mathrm{CO}$ & ${ }^{1} J_{\mathrm{CO}}$ & 20,8 & 20,7 & 20,5 & 20,3 & 20,2 & 20,1 & 20,0 & 19,9 & 19,6 & 19,3 & 19,0 & 18,5 & 18,0 & 17,4 & 16,8 & 16,4 \\
\hline $\mathrm{H}_{2} \mathrm{O}$ & ${ }^{1} J_{\mathrm{OH}}$ & $-75,1$ & $-75,2$ & $-75,2$ & $-75,3$ & $-75,5$ & $-75,7$ & $-76,1$ & $-76,5$ & $-77,0$ & $-77,6$ & $-78,2$ & $-78,9$ & $-79,6$ & $-80,3$ & $-81,0$ & $-80,6$ \\
\hline $\mathrm{H}_{2} \mathrm{O}$ & ${ }^{2} J_{\mathrm{HH}}$ & $-5,5$ & $-5,5$ & $-5,6$ & $-5,7$ & $-5,9$ & $-6,1$ & $-6,3$ & $-6,6$ & $-7,0$ & $-7,3$ & $-7,6$ & $-8,0$ & $-8,3$ & $-8,6$ & $-8,9$ & $-7,3$ \\
\hline $\mathrm{NH}_{3}$ & ${ }^{1} J_{\mathrm{NH}}$ & 41,7 & 41,7 & 41,7 & 41,7 & 41,7 & 41,8 & 41,9 & 42,1 & 42,3 & 42,6 & 43,0 & 43,4 & 43,7 & 44,1 & 44,5 & 43,8 \\
\hline $\mathrm{NH}_{3}$ & ${ }^{2} J_{\mathrm{HH}}$ & $-7,5$ & $-7,5$ & $-7,6$ & $-7,7$ & $-7,9$ & $-8,2$ & $-8,5$ & $-8,9$ & $-9,2$ & $-9,6$ & $-10,0$ & $-10,4$ & $-10,7$ & $-11,1$ & $-11,4$ & $-9,6$ \\
\hline $\mathrm{PH}_{3}$ & ${ }^{1} J_{\mathrm{PH}}$ & 153,7 & 153,3 & 151,7 & 149,6 & 147,7 & 147,0 & 147,5 & 149,2 & 151,9 & 155,4 & 159,2 & 163,2 & 167,2 & 171,1 & 174,8 & 188,2 \\
\hline $\mathrm{PF}_{3}$ & ${ }^{1} J_{\mathrm{PF}}$ & $-1772,3$ & $-1770,8$ & $-1769,2$ & $-1767,8$ & $-1766,6$ & $-1765,5$ & $-1764,4$ & $-1762,8$ & $-1760,2$ & $-1756,5$ & $-1751,5$ & $-1745,5$ & $-1738,7$ & $-1731,3$ & $-1723,7$ & -1441 \\
\hline $\mathrm{BHF}_{2}$ & ${ }^{1} J_{\mathrm{BF}}$ & $-151,0$ & $-150,0$ & $-147,7$ & $-144,3$ & $-140,2$ & $-135,7$ & $-131,0$ & $-126,1$ & $-121,3$ & $-116,4$ & $-111,7$ & $-107,2$ & $-102,9$ & $-98,9$ & $-95,1$ & -84 \\
\hline $\mathrm{BF}_{3}$ & ${ }^{1} J_{\mathrm{BF}}$ & $-42,1$ & $-41,1$ & $-39,0$ & $-35,7$ & $-31,5$ & $-26,8$ & $-21,8$ & $-16,5$ & $-11,3$ & $-6,3$ & $-1,4$ & 3,2 & 7,6 & 11,7 & 15,5 & 15 \\
\hline $\mathrm{F}_{2} \mathrm{O}$ & ${ }^{1} J_{\mathrm{OF}}$ & $-344,1$ & $-345,4$ & $-349,0$ & $-354,9$ & $-362,8$ & $-371,9$ & $-381,5$ & $-391,3$ & $-400,9$ & $-410,4$ & $-419,6$ & $-428,8$ & $-437,9$ & $-447,0$ & $-455,9$ & -300 \\
\hline $\mathrm{CH}_{4}$ & ${ }^{1} J_{\mathrm{CH}}$ & 112,9 & 112,8 & 112,6 & 112,4 & 112,4 & 112,8 & 113,4 & 114,3 & 115,4 & 116,7 & 118,1 & 119,5 & 120,9 & 122,3 & 123,6 & 125,3 \\
\hline $\mathrm{CH}_{4}$ & ${ }^{2} J_{\mathrm{HH}}$ & $-9,9$ & $-9,9$ & $-9,9$ & $-10,0$ & $-10,3$ & $-10,6$ & $-10,9$ & $-11,4$ & $-11,8$ & $-12,2$ & $-12,6$ & $-13,0$ & $-13,4$ & $-13,7$ & $-14,0$ & $-12,8$ \\
\hline $\mathrm{C}_{2} \mathrm{H}_{2}$ & ${ }^{1} J_{\mathrm{CC}}$ & 184,2 & 184,3 & 184,6 & 185,1 & 185,6 & 186,4 & 187,4 & 188,7 & 190,3 & 192,1 & 194,1 & 196,3 & 198,5 & 200,7 & 202,9 & 174,8 \\
\hline $\mathrm{C}_{2} \mathrm{H}_{2}$ & ${ }^{1} J_{\mathrm{CH}}$ & 238,2 & 237,8 & 237,2 & 236,8 & 236,8 & 237,3 & 238,5 & 240,1 & 242,2 & 244,6 & 247,1 & 249,8 & 252,5 & 255,1 & 257,6 & 247,6 \\
\hline $\mathrm{C}_{2} \mathrm{H}_{2}$ & ${ }^{2} J_{\mathrm{CH}}$ & 52,7 & 52,8 & 53,1 & 53,4 & 53,7 & 54,0 & 54,3 & 54,4 & 54,4 & 54,3 & 54,1 & 53,9 & 53,6 & 53,3 & 52,9 & 50,1 \\
\hline $\mathrm{C}_{2} \mathrm{H}_{2}$ & ${ }^{3} J_{\mathrm{HH}}$ & 8,5 & 8,4 & 8,4 & 8,4 & 8,5 & 8,7 & 9,0 & 9,3 & 9,7 & 10,2 & 10,6 & 11,0 & 11,5 & 11,9 & 12,3 & 9,6 \\
\hline $\mathrm{C}_{2} \mathrm{H}_{4}$ & ${ }^{1} J_{\mathrm{CC}}$ & 57,6 & 57,8 & 58,2 & 58,6 & 59,1 & 59,7 & 60,5 & 61,5 & 62,6 & 64,0 & 65,5 & 67,2 & 68,9 & 70,6 & 72,3 & 67,6 \\
\hline $\mathrm{C}_{2} \mathrm{H}_{4}$ & ${ }^{1} J_{\mathrm{CH}}$ & 144,9 & 144,7 & 144,4 & 144,3 & 144,4 & 145,0 & 145,9 & 147,1 & 148,7 & 150,4 & 152,3 & 154,2 & 156,2 & 158,0 & 159,8 & 156,3 \\
\hline $\mathrm{C}_{2} \mathrm{H}_{4}$ & ${ }^{2} J_{\mathrm{CH}}$ & $-0,4$ & $-0,4$ & $-0,4$ & $-0,5$ & $-0,6$ & $-0,8$ & $-1,0$ & $-1,4$ & $-1,8$ & $-2,2$ & $-2,7$ & $-3,2$ & $-3,7$ & $-4,2$ & $-4,6$ & $-2,4$ \\
\hline $\mathrm{C}_{2} \mathrm{H}_{4}$ & ${ }^{2} J_{\mathrm{HH}}$ & 4,4 & 4,4 & 4,4 & 4,3 & 4,2 & 3,9 & 3,7 & 3,4 & 3,0 & 2,7 & 2,3 & 2,0 & 1,7 & 1,4 & 1,1 & 2,3 \\
\hline $\mathrm{C}_{2} \mathrm{H}_{4}$ & ${ }^{3} J_{\mathrm{HH}_{\mathrm{c}}}$ & 11,8 & 11,8 & 11,9 & 11,9 & 12,0 & 12,2 & 12,3 & 12,5 & 12,7 & 13,0 & 13,2 & 13,4 & 13,6 & 13,9 & 14,1 & 11,7 \\
\hline $\mathrm{C}_{2} \mathrm{H}_{4}$ & ${ }^{3} J_{\mathrm{HH}_{\mathrm{t}}}$ & 17,2 & 17,2 & 17,2 & 17,2 & 17,2 & 17,3 & 17,5 & 17,7 & 18,0 & 18,3 & 18,6 & 18,9 & 19,3 & 19,6 & 19,9 & 19 \\
\hline $\mathrm{C}_{2} \mathrm{H}_{6}$ & ${ }^{1} J_{\mathrm{CC}}$ & 24,1 & 24,3 & 24,6 & 25,1 & 25,5 & 26,0 & 26,6 & 27,2 & 28,0 & 28,8 & 29,7 & 30,6 & 31,6 & 32,5 & 33,4 & 34,5 \\
\hline $\mathrm{C}_{2} \mathrm{H}_{6}$ & ${ }^{1} J_{\mathrm{CH}}$ & 113,4 & 113,2 & 112,9 & 112,7 & 112,8 & 113,2 & 113,8 & 114,8 & 116,0 & 117,3 & 118,7 & 120,2 & 121,7 & 123,1 & 124,5 & 125,2 \\
\hline $\mathrm{C}_{2} \mathrm{H}_{6}$ & ${ }^{2} J_{\mathrm{CH}}$ & $-2,6$ & $-2,6$ & $-2,6$ & $-2,7$ & $-2,8$ & $-2,9$ & $-3,0$ & $-3,2$ & $-3,4$ & $-3,6$ & $-3,8$ & $-4,0$ & $-4,2$ & $-4,4$ & $-4,6$ & $-4,7$ \\
\hline \multirow[t]{3}{*}{ Total } & $\mathrm{DM}$ & $-23,33$ & 23,26 & $-23,21$ & $-23,17$ & $-23,10$ & & & & $-21,43$ & & & & & & & - \\
\hline & DMA & & & & & & & & & & & & & & & & - \\
\hline & PDMA & 36,87 & 36,59 & 35,91 & 34,41 & 32,50 & 29,81 & 27,03 & 23,38 & 19,49 & 16,07 & 13,82 & 13,64 & 13,84 & 14,31 & 14,99 & - \\
\hline \multirow[t]{3}{*}{ CPI } & DM & $-50,8$ & 50.66 & & & - & & & & & & & & & -43 & & - \\
\hline & DMA & 53 & 53,1 & & 52 , & 52,6 & & & & & & & & & & & - \\
\hline & PDMA & 55,35 & 54,61 & 52,92 & 50,46 & 47,26 & 43,56 & 39,58 & 35,10 & 30,47 & 25,88 & 22,83 & 19,96 & 17,03 & 14,45 & 12,81 & - \\
\hline \multirow[t]{3}{*}{ SPI } & DM & $-3,14$ & - & -3 & & -3, & & & & & & & & & & & - \\
\hline & & & & & & & & & & & & & & & & & - \\
\hline & PDMA & 23,31 & 23,38 & 23,44 & 22,64 & 21,68 & 19,73 & 17,83 & 14,79 & 11,45 & 8,88 & 7,22 & 9,01 & 11,49 & 14,21 & 16,58 & - \\
\hline \multirow[t]{3}{*}{$\Delta C S$} & & & & & & & & & & & & & & & & & - \\
\hline & MA & & & & & & & & & & & & & & & & - \\
\hline & PDMA & 32,04 & 31,23 & 29,48 & 27,82 & 25,57 & 23,83 & 21,76 & 20,31 & 19,02 & 17,01 & 15,61 & 10,96 & 5,54 & 0,25 & $-3,77$ & - \\
\hline
\end{tabular}


Tabela 8.403: Constantes de acoplamento LC-SLYP com $\alpha=30 \%$ e $\alpha+\beta=70 \%$, variando $\gamma$, na base aug-pcJ-2.

\begin{tabular}{|c|c|c|c|c|c|c|c|c|c|c|c|c|c|c|c|c|c|}
\hline & $\gamma$ & 0,05 & 0,10 & 0,15 & 0,20 & 0,25 & 0,30 & 0,35 & 0,40 & 0,45 & 0,50 & 0,55 & 0,60 & 0,65 & 0,70 & 0,75 & Exp. \\
\hline $\mathrm{HF}$ & ${ }^{1} J_{\mathrm{HF}}$ & 484,7 & 485,2 & 485,9 & 486,8 & 487,9 & 489,4 & 491,2 & 493,6 & 496,3 & 499,3 & 502,6 & 506,0 & 509,6 & 513,2 & 516,8 & 500 \\
\hline $\mathrm{CO}$ & ${ }^{1} J_{\mathrm{CO}}$ & 18,6 & 18,5 & 18,3 & 18,2 & 18,1 & 18,0 & 17,9 & 17,8 & 17,6 & 17,4 & 17,1 & 16,7 & 16,2 & 15,8 & 15,3 & 16,4 \\
\hline $\mathrm{H}_{2} \mathrm{O}$ & ${ }^{1} J_{\mathrm{OH}}$ & $-77,9$ & $-77,9$ & $-78,0$ & $-78,1$ & $-78,2$ & $-78,4$ & $-78,7$ & $-79,0$ & $-79,4$ & $-79,9$ & $-80,4$ & $-81,0$ & $-81,5$ & $-82,1$ & $-82,7$ & $-80,6$ \\
\hline $\mathrm{H}_{2} \mathrm{O}$ & ${ }^{2} J_{\mathrm{HH}}$ & $-6,8$ & $-6,8$ & $-6,8$ & $-6,9$ & $-7,0$ & $-7,2$ & $-7,4$ & $-7,7$ & $-7,9$ & $-8,2$ & $-8,5$ & $-8,8$ & $-9,0$ & $-9,3$ & $-9,6$ & $-7,3$ \\
\hline $\mathrm{NH}_{3}$ & ${ }^{1} J_{\mathrm{NH}}$ & 42,9 & 42,9 & 42,9 & 42,9 & 42,9 & 43,0 & 43,1 & 43,3 & 43,5 & 43,7 & 44,0 & 44,3 & 44,6 & 45,0 & 45,3 & 43,8 \\
\hline $\mathrm{NH}_{3}$ & ${ }^{2} J_{\mathrm{HH}}$ & $-8,7$ & $-8,7$ & $-8,7$ & $-8,8$ & $-9,0$ & $-9,2$ & $-9,5$ & $-9,8$ & $-10,1$ & $-10,4$ & $-10,7$ & $-11,0$ & $-11,3$ & $-11,6$ & $-11,9$ & $-9,6$ \\
\hline $\mathrm{PH}_{3}$ & ${ }^{1} J_{\mathrm{PH}}$ & 163,1 & 162,8 & 161,7 & 160,0 & 158,6 & 158,1 & 158,5 & 159,9 & 162,2 & 165,0 & 168,1 & 171,3 & 174,6 & 177,7 & 180,7 & 188,2 \\
\hline $\mathrm{PF}_{3}$ & ${ }^{1} J_{\mathrm{PF}}$ & $-1742,8$ & $-1741,4$ & $-1739,6$ & $-1737,6$ & $-1735,7$ & $-1733,8$ & $-1731,9$ & $-1729,7$ & $-1726,9$ & $-1723,4$ & $-1718,9$ & $-1713,8$ & $-1708,1$ & $-1702,1$ & $-1695,9$ & -1441 \\
\hline $\mathrm{BHF}_{2}$ & ${ }^{1} J_{\mathrm{BF}}$ & $-132,6$ & $-131,8$ & $-130,0$ & $-127,3$ & $-124,1$ & $-120,5$ & $-116,7$ & $-112,8$ & $-108,9$ & $-105,0$ & $-101,3$ & $-97,7$ & $-94,2$ & $-91,0$ & $-87,9$ & -84 \\
\hline $\mathrm{BF}_{3}$ & ${ }^{1} J_{\mathrm{BF}}$ & $-23,2$ & $-22,4$ & $-20,7$ & $-18,1$ & $-14,9$ & $-11,1$ & $-7,1$ & $-3,0$ & 1,1 & 5,1 & 9,1 & 12,8 & 16,3 & 19,6 & 22,6 & 15 \\
\hline $\mathrm{F}_{2} \mathrm{O}$ & ${ }^{1} J_{\mathrm{OF}}$ & $-380,6$ & $-381,7$ & $-384,6$ & $-389,5$ & $-396,1$ & $-403,8$ & $-412,1$ & $-420,6$ & $-429,1$ & $-437,5$ & $-445,9$ & $-454,2$ & $-462,4$ & $-470,5$ & $-478,5$ & -300 \\
\hline $\mathrm{CH}_{4}$ & ${ }^{1} J_{\mathrm{CH}}$ & 116,7 & 116,6 & 116,4 & 116,3 & 116,4 & 116,7 & 117,2 & 117,9 & 118,9 & 119,9 & 121,1 & 122,2 & 123,4 & 124,6 & 125,6 & 125,3 \\
\hline $\mathrm{CH}_{4}$ & ${ }^{2} J_{\mathrm{HH}}$ & $-11,0$ & $-10,9$ & $-11,0$ & $-11,1$ & $-11,3$ & $-11,5$ & $-11,8$ & $-12,2$ & $-12,5$ & $-12,9$ & $-13,2$ & $-13,5$ & $-13,8$ & $-14,1$ & $-14,3$ & $-12,8$ \\
\hline $\mathrm{C}_{2} \mathrm{H}_{2}$ & ${ }^{1} J_{\mathrm{CC}}$ & 189,4 & 189,5 & 189,8 & 190,2 & 190,7 & 191,5 & 192,5 & 193,7 & 195,1 & 196,7 & 198,5 & 200,4 & 202,3 & 204,2 & 206,1 & 174,8 \\
\hline $\mathrm{C}_{2} \mathrm{H}_{2}$ & ${ }^{1} J_{\mathrm{CH}}$ & 244,8 & 244,4 & 244,0 & 243,7 & 243,7 & 244,2 & 245,2 & 246,6 & 248,4 & 250,4 & 252,6 & 254,8 & 257,0 & 259,2 & 261,2 & 247,6 \\
\hline $\mathrm{C}_{2} \mathrm{H}_{2}$ & ${ }^{2} J_{\mathrm{CH}}$ & 53,2 & 53,3 & 53,4 & 53,7 & 53,9 & 54,1 & 54,2 & 54,2 & 54,1 & 54,0 & 53,8 & 53,5 & 53,2 & 52,9 & 52,6 & 50,1 \\
\hline $\mathrm{C}_{2} \mathrm{H}_{2}$ & ${ }^{3} J_{\mathrm{HH}}$ & 9,4 & 9,3 & 9,3 & 9,4 & 9,5 & 9,7 & 9,9 & 10,3 & 10,6 & 11,0 & 11,4 & 11,8 & 12,2 & 12,5 & 12,9 & 9,6 \\
\hline $\mathrm{C}_{2} \mathrm{H}_{4}$ & ${ }^{1} J_{\mathrm{CC}}$ & 61,9 & 62,0 & 62,3 & 62,7 & 63,2 & 63,8 & 64,5 & 65,4 & 66,5 & 67,8 & 69,1 & 70,6 & 72,0 & 73,5 & 75,0 & 67,6 \\
\hline $\mathrm{C}_{2} \mathrm{H}_{4}$ & ${ }^{1} J_{\mathrm{CH}}$ & 149,8 & 149,6 & 149,4 & 149,3 & 149,5 & 149,9 & 150,7 & 151,8 & 153,1 & 154,6 & 156,2 & 157,8 & 159,4 & 161,0 & 162,4 & 156,3 \\
\hline $\mathrm{C}_{2} \mathrm{H}_{4}$ & ${ }^{2} J_{\mathrm{CH}}$ & $-1,3$ & $-1,3$ & $-1,3$ & $-1,4$ & $-1,5$ & $-1,7$ & $-2,0$ & $-2,3$ & $-2,6$ & $-3,1$ & $-3,5$ & $-3,9$ & $-4,4$ & $-4,8$ & $-5,2$ & $-2,4$ \\
\hline $\mathrm{C}_{2} \mathrm{H}_{4}$ & ${ }^{2} J_{\mathrm{HH}}$ & 3,8 & 3,8 & 3,8 & 3,7 & 3,5 & 3,3 & 3,1 & 2,8 & 2,5 & 2,2 & 1,9 & 1,6 & 1,3 & 1,1 & 0,8 & 2,3 \\
\hline $\mathrm{C}_{2} \mathrm{H}_{4}$ & ${ }^{3} J_{\mathrm{HH}_{\mathrm{c}}}$ & 12,2 & 12,2 & 12,3 & 12,3 & 12,4 & 12,6 & 12,7 & 12,9 & 13,1 & 13,3 & 13,5 & 13,7 & 13,9 & 14,1 & 14,3 & 11,7 \\
\hline $\mathrm{C}_{2} \mathrm{H}_{4}$ & ${ }^{3} J_{\mathrm{HH}_{\mathrm{t}}}$ & 17,9 & 17,9 & 17,8 & 17,9 & 17,9 & 18,0 & 18,2 & 18,4 & 18,7 & 18,9 & 19,2 & 19,5 & 19,8 & 20,1 & 20,4 & 19 \\
\hline $\mathrm{C}_{2} \mathrm{H}_{6}$ & ${ }^{1} J_{\mathrm{CC}}$ & 27,0 & 27,1 & 27,4 & 27,8 & 28,2 & 28,6 & 29,1 & 29,6 & 30,3 & 31,0 & 31,7 & 32,4 & 33,2 & 34,0 & 34,7 & 34,5 \\
\hline $\mathrm{C}_{2} \mathrm{H}_{6}$ & ${ }^{1} J_{\mathrm{CH}}$ & 117,3 & 17,1 & 116,9 & 116,8 & 116,9 & 117,2 & 117,8 & 118,6 & 119,6 & 120,7 & 121,9 & 123 & 124,3 & 125,5 & 126,6 & 125,2 \\
\hline $\mathrm{C}_{2} \mathrm{H}_{6}$ & ${ }^{2} J_{\mathrm{CH}}$ & $-3,1$ & $-3,1$ & $-3,1$ & $-3,2$ & $-3,3$ & $-3,4$ & $-3,5$ & $-3,6$ & $-3,8$ & $-4,0$ & $-4,1$ & $-4,3$ & $-4,5$ & $-4,6$ & $-4,8$ & $-4,7$ \\
\hline \multirow[t]{3}{*}{ Total } & $\mathrm{DM}$ & $-20,0$ & 5 & & $-19,8$ & 19,72 & & & & & & & & & & & - \\
\hline & DMA & 22,36 & & & & & & & & & & & & & & & - \\
\hline & PDMA & 24,86 & 24,69 & 24,18 & 22,83 & 21,10 & 18,99 & 16,65 & 14,45 & 12,71 & 12,14 & 12,52 & 13,06 & 14,50 & 16,95 & 19,73 & - \\
\hline \multirow[t]{3}{*}{ CPI } & DM & $-45,84$ & 45,65 & & & -45 & & & & & & & & & & & - \\
\hline & DMA &, 98 & 46,7 & & 46,3 & & & & & & & & & & & & - \\
\hline & PDMA & 37,43 & 36,84 & 35,61 & 33,65 & 31,22 & 28,21 & 25,17 & 22,73 & 20,24 & 17,89 & 15,63 & 13,64 & 13,43 & 16,24 & 18,91 & - \\
\hline \multirow[t]{3}{*}{ SPI } & DM & $-1,0$ & - & & & & & & & & & & & & & & - \\
\hline & & & & & & & & & & & & & & & & & - \\
\hline & PDMA & 15,63 & 15,78 & 15,79 & 14,89 & 13,67 & 12,23 & 10,41 & 8,37 & 7,19 & 7,92 & 10,24 & 12,64 & 15,28 & 17,47 & 20,32 & - \\
\hline \multirow[t]{3}{*}{$\Delta \mathrm{CS}$} & & & & & & & & & & & & & & & & & - \\
\hline & MA & & & & & & & & & & & & & & & & 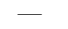 \\
\hline & & 21,80 & 21,06 & 19,81 & 18,76 & 17,55 & 15,98 & 14,76 & 14,36 & 13,05 & 9,96 & 5,39 & 1,01 & $-1,84$ & $-1,23$ & $-1,41$ & - \\
\hline
\end{tabular}


Tabela 8.404: Constantes de acoplamento LC-SLYP com $\alpha=40 \%$ e $\alpha+\beta=70 \%$, variando $\gamma$, na base aug-pcJ-2.

\begin{tabular}{|c|c|c|c|c|c|c|c|c|c|c|c|c|c|c|c|c|c|}
\hline & $\gamma$ & 0,05 & 0,10 & 0,15 & 0,20 & 0,25 & 0,30 & 0,35 & 0,40 & 0,45 & 0,50 & 0,55 & 0,60 & 0,65 & 0,70 & 0,75 & Exp. \\
\hline $\mathrm{HF}$ & ${ }^{1} J_{\mathrm{HF}}$ & 507,4 & 507,8 & 508,3 & 509,0 & 509,9 & 511,0 & 512,5 & 514,3 & 516,4 & 518,7 & 521,2 & 523,8 & 526,4 & 529,2 & 531,9 & 500 \\
\hline $\mathrm{CO}$ & ${ }^{1} J_{\mathrm{CO}}$ & 16,2 & 16,1 & 16,0 & 15,9 & 15,8 & 15,8 & 15,7 & 15,6 & 15,5 & 15,3 & 15,0 & 14,7 & 14,4 & 14,0 & 13,6 & 16,4 \\
\hline $\mathrm{H}_{2} \mathrm{O}$ & ${ }^{1} J_{\mathrm{OH}}$ & $-80,7$ & $-80,8$ & $-80,8$ & $-80,9$ & $-81,0$ & $-81,2$ & $-81,4$ & $-81,7$ & $-82,0$ & $-82,3$ & $-82,7$ & $-83,1$ & $-83,6$ & $-84,0$ & $-84,5$ & $-80,6$ \\
\hline $\mathrm{H}_{2} \mathrm{O}$ & ${ }^{2} J_{\mathrm{HH}}$ & $-8,0$ & $-8,0$ & $-8,1$ & $-8,1$ & $-8,2$ & $-8,4$ & $-8,5$ & $-8,7$ & $-9,0$ & $-9,2$ & $-9,4$ & $-9,6$ & $-9,8$ & $-10,0$ & $-10,2$ & $-7,3$ \\
\hline $\mathrm{NH}_{3}$ & ${ }^{1} J_{\mathrm{NH}}$ & 44,2 & 44,2 & 44,2 & 44,2 & 44,2 & 44,3 & 44,4 & 44,5 & 44,7 & 44,9 & 45,1 & 45,3 & 45,6 & 45,8 & 46,0 & 43,8 \\
\hline $\mathrm{NH}_{3}$ & ${ }^{2} J_{\mathrm{HH}}$ & $-9,9$ & $-9,9$ & $-9,9$ & $-10,0$ & $-10,1$ & $-10,3$ & $-10,5$ & $-10,7$ & $-11,0$ & $-11,2$ & $-11,5$ & $-11,7$ & $-11,9$ & $-12,1$ & $-12,3$ & $-9,6$ \\
\hline $\mathrm{PH}_{3}$ & ${ }^{1} J_{\mathrm{PH}}$ & 173,0 & 172,8 & 171,9 & 170,7 & 169,8 & 169,4 & 169,7 & 170,9 & 172,6 & 174,7 & 177,1 & 179,5 & 182,0 & 184,4 & 186,6 & 188,2 \\
\hline $\mathrm{PF}_{3}$ & ${ }^{1} J_{\mathrm{PF}}$ & $-1708,5$ & $-1707,2$ & $-1705,6$ & $-1703,6$ & $-1701,4$ & $-1699,4$ & $-1697,3$ & $-1695,1$ & $-1692,5$ & $-1689,4$ & $-1685,8$ & $-1681,8$ & $-1677,3$ & $-1672,7$ & $-1668,0$ & -1441 \\
\hline $\mathrm{BHF}_{2}$ & ${ }^{1} J_{\mathrm{BF}}$ & $-113,9$ & $-113,3$ & $-112,0$ & $-110,0$ & $-107,6$ & $-104,9$ & $-102,1$ & $-99,2$ & $-96,3$ & $-93,4$ & $-90,6$ & $-87,9$ & $-85,3$ & $-82,8$ & $-80,5$ & -84 \\
\hline $\mathrm{BF}_{3}$ & ${ }^{1} J_{\mathrm{BF}}$ & $-4,0$ & $-3,5$ & $-2,2$ & $-0,3$ & 2,0 & 4,7 & 7,7 & 10,8 & 13,9 & 16,9 & 19,9 & 22,7 & 25,3 & 27,8 & 30,1 & 15 \\
\hline $\mathrm{F}_{2} \mathrm{O}$ & ${ }^{1} J_{\mathrm{OF}}$ & $-419,9$ & $-420,8$ & $-423,1$ & $-427,1$ & $-432,5$ & $-439,0$ & $-445,9$ & $-453,2$ & $-460,5$ & $-467,8$ & $-475,1$ & $-482,3$ & $-489,4$ & $-496,4$ & $-503,2$ & -300 \\
\hline $\mathrm{CH}_{4}$ & ${ }^{1} J_{\mathrm{CH}}$ & 120,7 & 120,6 & 120,5 & 120,4 & 120,5 & 120,7 & 121,2 & 121,8 & 122,5 & 123,3 & 124,2 & 125,1 & 126,0 & 126,8 & 127,7 & 125,3 \\
\hline $\mathrm{CH}_{4}$ & ${ }^{2} J_{\mathrm{HH}}$ & $-12,1$ & $-12,1$ & $-12,1$ & $-12,2$ & $-12,3$ & $-12,5$ & $-12,8$ & $-13,0$ & $-13,3$ & $-13,5$ & $-13,8$ & $-14,0$ & $-14,3$ & $-14,5$ & $-14,7$ & $-12,8$ \\
\hline $\mathrm{C}_{2} \mathrm{H}_{2}$ & ${ }^{1} J_{\mathrm{CC}}$ & 195,4 & 195,5 & 195,7 & 196,1 & 196,6 & 197,3 & 198,1 & 199,2 & 200,4 & 201,8 & 203,3 & 204,8 & 206,4 & 207,9 & 209,4 & 174,8 \\
\hline $\mathrm{C}_{2} \mathrm{H}_{2}$ & ${ }^{1} J_{\mathrm{CH}}$ & 251,8 & 251,5 & 251,2 & 251,0 & 251,1 & 251,6 & 252,4 & 253,5 & 254,9 & 256,5 & 258,2 & 260,0 & 261,7 & 263,4 & 265,0 & 247,6 \\
\hline $\mathrm{C}_{2} \mathrm{H}_{2}$ & ${ }^{2} J_{\mathrm{CH}}$ & 53,3 & 53,4 & 53,5 & 53,6 & 53,8 & 53,9 & 53,9 & 53,8 & 53,7 & 53,5 & 53,3 & 53,1 & 52,8 & 52,5 & 52,3 & 50,1 \\
\hline $\mathrm{C}_{2} \mathrm{H}_{2}$ & ${ }^{3} J_{\mathrm{HH}}$ & 10,4 & 10,4 & 10,4 & 10,5 & 10,6 & 10,8 & 11,0 & 11,3 & 11,6 & 12,0 & 12,3 & 12,6 & 12,9 & 13,2 & 13,5 & 9,6 \\
\hline $\mathrm{C}_{2} \mathrm{H}_{4}$ & ${ }^{1} J_{\mathrm{CC}}$ & 66,7 & 66,8 & 67,0 & 67,4 & 67,8 & 68,4 & 69,1 & 69,9 & 70,8 & 71,9 & 73,0 & 74,2 & 75,4 & 76,6 & 77,8 & 67,6 \\
\hline $\mathrm{C}_{2} \mathrm{H}_{4}$ & ${ }^{1} J_{\mathrm{CH}}$ & 155,0 & 154,8 & 154,7 & 154,6 & 154,8 & 155,2 & 155,9 & 156,8 & 157,8 & 159,0 & 160,2 & 161,5 & 162,8 & 164,0 & 165,1 & 156,3 \\
\hline $\mathrm{C}_{2} \mathrm{H}_{4}$ & ${ }^{2} J_{\mathrm{CH}}$ & $-2,4$ & $-2,4$ & $-2,4$ & $-2,5$ & $-2,6$ & $-2,8$ & $-3,1$ & $-3,3$ & $-3,7$ & $-4,0$ & $-4,4$ & $-4,8$ & $-5,1$ & $-5,5$ & $-5,8$ & $-2,4$ \\
\hline $\mathrm{C}_{2} \mathrm{H}_{4}$ & ${ }^{2} J_{\mathrm{HH}}$ & 3,1 & 3,1 & 3,0 & 3,0 & 2,8 & 2,7 & 2,5 & 2,2 & 2,0 & 1,7 & 1,5 & 1,2 & 1,0 & 0,8 & 0,6 & 2,3 \\
\hline $\mathrm{C}_{2} \mathrm{H}_{4}$ & ${ }^{3} J_{\mathrm{HH}_{\mathrm{c}}}$ & 12,7 & 12,7 & 12,7 & 12,8 & 12,9 & 13,0 & 13,2 & 13,3 & 13,5 & 13,7 & 13,8 & 14,0 & 14,2 & 14,3 & 14,5 & 11,7 \\
\hline $\mathrm{C}_{2} \mathrm{H}_{4}$ & ${ }^{3} J_{\mathrm{HH}_{\mathrm{t}}}$ & 18,7 & 18,6 & 18,6 & 18,7 & 18,7 & 18,9 & 19,0 & 19,2 & 19,4 & 19,7 & 19,9 & 20,2 & 20,4 & 20,6 & 20,8 & 19 \\
\hline $\mathrm{C}_{2} \mathrm{H}_{6}$ & ${ }^{1} J_{\mathrm{CC}}$ & 30,0 & 30,2 & 30,4 & 30,7 & 31,0 & 31,3 & 31,7 & 32,1 & 32,6 & 33,2 & 33,7 & 34,3 & 34,9 & 35,5 & 36,1 & 34,5 \\
\hline $\mathrm{C}_{2} \mathrm{H}_{6}$ & ${ }^{1} J_{\mathrm{CH}}$ & 121,4 & 121,3 & 121,2 & 121,1 & 121,2 & 121,5 & 121,9 & 122,5 & 123,3 & 124,1 & 125,1 & 126,0 & 126,9 & 127,8 & 128,7 & 125,2 \\
\hline $\mathrm{C}_{2} \mathrm{H}_{6}$ & ${ }^{2} J_{\mathrm{CH}}$ & $-3,7$ & $-3,7$ & $-3,7$ & $-3,7$ & $-3,8$ & $-3,9$ & $-4,0$ & $-4,1$ & $-4,2$ & $-4,3$ & $-4,5$ & $-4,6$ & $-4,7$ & $-4,8$ & $-5,0$ & $-4,7$ \\
\hline \multirow[t]{3}{*}{ Total } & DM & $-16,47$ & $-16,42$ & $-16,37$ & $-16,30$ & $-16,19$ & $-16,03$ & $-15,80$ & $-15,47$ & $-15,07$ & $-14,58$ & $-14,08$ & $-13,53$ & 97 & & 90 & - \\
\hline & DMA & 19,55 & 19,5 & 19,51 & 19,52 & 19,55 & 19,62 & 19, & & 19,93 & & 20 , & & & & & - \\
\hline & PDMA & 14,12 & 14,02 & 13,56 & 13,28 & 12,56 & 12,13 & 11,57 & 11,28 & 11,98 & 13,64 & 15,79 & 18,17 & 20,32 & 22,89 & 25,48 & - \\
\hline \multirow[t]{3}{*}{ CPI } & DM & $-40,45$ & $-40,32$ & $-40,20$ & $-40,10$ & $-40,00$ & $-39,90$ & $-39,69$ & $-39,40$ & $-39,01$ & $-38,52$ & $-37,97$ & $-37,39$ & $-36,77$ & $-36,15$ & $-35,58$ & 一 \\
\hline & DMA & 41,87 & 41,81 & 41,78 & 41,81 & 41,87 & 41,99 & 42,07 & 42,13 & 42,15 & 42,46 & 42,95 & 43,39 & 43,77 & 44,37 & 45,16 & - \\
\hline & PDMA & 22,30 & 22,04 & 21,40 & 20,37 & 19,21 & 17,99 & 16,49 & 15,03 & 13,79 & 14,72 & 17,15 & 19,37 & 21,50 & 23,87 & 26,39 & - \\
\hline \multirow[t]{3}{*}{ SPI } & DM & 1,13 & 1,11 & 1,11 & 1,1 & 1,27 & 1,47 & 1,7 & 2,07 & 2,48 & 2,97 & 3,45 & 3,97 & 4,48 & 4,97 & 5,46 & - \\
\hline & DMA & 3,18 & 3,19 & 3,17 & 3,1 & 3,17 & 3,21 & 3,23 & 3,38 & 3,64 & 3,94 & 4,22 & 4,65 & 5,21 & 5,82 & 6,43 & - \\
\hline & PDMA & 8,12 & 8,13 & 7,81 & 8,07 & 7,67 & 7,83 & 7,97 & 8,53 & 10,65 & 12,84 & 14,78 & 17,28 & 19,45 & 22,16 & 24,81 & - \\
\hline \multirow[t]{3}{*}{$\Delta \mathrm{CS}$} & DM & $-41,58$ & $-41,42$ & $-41,31$ & $-41,26$ & $-41,27$ & $-41,37$ & $-41,42$ & $-41,47$ & $-41,49$ & $-41,48$ & $-41,42$ & $-41,36$ & & $-41,12$ & $-41,04$ & 一 \\
\hline & DMA & 38,69 & 38,62 & 38,61 & 38,64 & 38,70 & 38,78 & 38,84 & 38,75 & 38,51 & 38,52 & 38,73 & 38,74 & 38,56 & 38,55 & 38,73 & - \\
\hline & PDMA & 14,18 & 13,90 & 13,59 & 12,30 & 11,54 & 10,16 & 8,52 & 6,50 & 3,13 & 1,88 & 2,37 & 2,10 & 2,05 & 1,71 & 1,59 & - \\
\hline
\end{tabular}


Tabela 8.405: Constantes de acoplamento LC-SLYP com $\alpha=50 \%$ e $\alpha+\beta=70 \%$, variando $\gamma$, na base aug-pcJ-2.

\begin{tabular}{|c|c|c|c|c|c|c|c|c|c|c|c|c|c|c|c|c|c|}
\hline & $\gamma$ & 0,05 & 0,10 & 0,15 & 0,20 & 0,25 & 0,30 & 0,35 & 0,40 & 0,45 & 0,50 & 0,55 & 0,60 & 0,65 & 0,70 & 0,75 & Exp. \\
\hline $\mathrm{HF}$ & ${ }^{1} J_{\mathrm{HF}}$ & 530,9 & 531,2 & 531,5 & 532,0 & 532,6 & 533,4 & 534,5 & 535,7 & 537,1 & 538,6 & 540,3 & 542,1 & 543,9 & 545,7 & 547,6 & 500 \\
\hline $\mathrm{CO}$ & ${ }^{1} J_{\mathrm{CO}}$ & 13,7 & 13,6 & 13,5 & 13,5 & 13,4 & 13,4 & 13,3 & 13,3 & 13,2 & 13,0 & 12,8 & 12,6 & 12,4 & 12,1 & 11,8 & 16,4 \\
\hline $\mathrm{H}_{2} \mathrm{O}$ & ${ }^{1} J_{\mathrm{OH}}$ & $-83,8$ & $-83,8$ & $-83,8$ & $-83,9$ & $-83,9$ & $-84,1$ & $-84,2$ & $-84,4$ & $-84,6$ & $-84,9$ & $-85,1$ & $-85,4$ & $-85,7$ & $-86,0$ & $-86,3$ & $-80,6$ \\
\hline $\mathrm{H}_{2} \mathrm{O}$ & ${ }^{2} J_{\mathrm{HH}}$ & $-9,4$ & $-9,4$ & $-9,4$ & $-9,5$ & $-9,5$ & $-9,6$ & $-9,7$ & $-9,9$ & $-10,0$ & $-10,2$ & $-10,3$ & $-10,5$ & $-10,6$ & $-10,8$ & $-10,9$ & $-7,3$ \\
\hline $\mathrm{NH}_{3}$ & ${ }^{1} J_{\mathrm{NH}}$ & 45,5 & 45,5 & 45,5 & 45,6 & 45,6 & 45,6 & 45,7 & 45,8 & 45,9 & 46,0 & 46,2 & 46,3 & 46,5 & 46,7 & 46,8 & 43,8 \\
\hline $\mathrm{NH}_{3}$ & ${ }^{2} J_{\mathrm{HH}}$ & $-11,1$ & $-11,1$ & $-11,2$ & $-11,2$ & $-11,3$ & $-11,4$ & $-11,6$ & $-11,7$ & $-11,9$ & $-12,1$ & $-12,2$ & $-12,4$ & $-12,6$ & $-12,7$ & $-12,8$ & $-9,6$ \\
\hline $\mathrm{PH}_{3}$ & ${ }^{1} J_{\mathrm{PH}}$ & 183,2 & 183,0 & 182,5 & 181,8 & 181,1 & 180,9 & 181,2 & 181,9 & 183,1 & 184,5 & 186,2 & 187,8 & 189,5 & 191,1 & 192,6 & 188,2 \\
\hline $\mathrm{PF}_{3}$ & ${ }^{1} J_{\mathrm{PF}}$ & $-1670,0$ & $-1669,1$ & $-1667,8$ & $-1666,1$ & $-1664,4$ & $-1662,6$ & $-1660,9$ & $-1659,0$ & $-1657,0$ & $-1654,7$ & $-1652,2$ & $-1649,3$ & $-1646,3$ & $-1643,1$ & $-1639,9$ & -1441 \\
\hline $\mathrm{BHF}_{2}$ & ${ }^{1} J_{\mathrm{BF}}$ & $-95,1$ & $-94,7$ & $-93,8$ & $-92,5$ & $-90,9$ & $-89,2$ & $-87,3$ & $-85,4$ & $-83,4$ & $-81,5$ & $-79,6$ & $-77,8$ & $-76,1$ & $-74,5$ & $-72,9$ & -84 \\
\hline $\mathrm{BF}_{3}$ & ${ }^{1} J_{\mathrm{BF}}$ & 15,2 & 15,5 & 16,3 & 17,6 & 19,1 & 21,0 & 22,9 & 25,0 & 27,0 & 29,0 & 31,0 & 32,9 & 34,6 & 36,3 & 37,8 & 15 \\
\hline $\mathrm{F}_{2} \mathrm{O}$ & ${ }^{1} J_{\mathrm{OF}}$ & $-465,0$ & $-465,7$ & $-467,5$ & $-470,6$ & $-474,8$ & $-479,8$ & $-485,3$ & $-491,1$ & $-497,0$ & $-502,9$ & $-508,7$ & $-514,4$ & $-520,1$ & $-525,5$ & $-530,8$ & -300 \\
\hline $\mathrm{CH}_{4}$ & ${ }^{1} J_{\mathrm{CH}}$ & 124,9 & 124,9 & 124,8 & 124,8 & 124,8 & 125,0 & 125,3 & 125,7 & 126,2 & 126,8 & 127,4 & 128,0 & 128,6 & 129,2 & 129,7 & 125,3 \\
\hline $\mathrm{CH}_{4}$ & ${ }^{2} J_{\mathrm{HH}}$ & $-13,2$ & $-13,2$ & $-13,2$ & $-13,3$ & $-13,4$ & $-13,5$ & $-13,7$ & $-13,9$ & $-14,1$ & $-14,2$ & $-14,4$ & $-14,6$ & $-14,7$ & $-14,9$ & $-15,0$ & $-12,8$ \\
\hline $\mathrm{C}_{2} \mathrm{H}_{2}$ & ${ }^{1} J_{\mathrm{CC}}$ & 202,4 & 202,4 & 202,6 & 202,9 & 203,3 & 203,9 & 204,6 & 205,4 & 206,3 & 207,4 & 208,5 & 209,6 & 210,7 & 211,8 & 212,9 & 174,8 \\
\hline $\mathrm{C}_{2} \mathrm{H}_{2}$ & ${ }^{1} J_{\mathrm{CH}}$ & 259,4 & 259,2 & 259,0 & 258,9 & 259,0 & 259,4 & 260,0 & 260,8 & 261,8 & 262,9 & 264,2 & 265,4 & 266,6 & 267,7 & 268,8 & 247,6 \\
\hline $\mathrm{C}_{2} \mathrm{H}_{2}$ & ${ }^{2} J_{\mathrm{CH}}$ & 53,1 & 53,1 & 53,2 & 53,2 & 53,3 & 53,3 & 53,3 & 53,2 & 53,0 & 52,9 & 52,7 & 52,5 & 52,2 & 52,0 & 51,8 & 50,1 \\
\hline $\mathrm{C}_{2} \mathrm{H}_{2}$ & ${ }^{3} J_{\mathrm{HH}}$ & 11,8 & 11,8 & 11,8 & 11,8 & 11,9 & 12,1 & 12,3 & 12,5 & 12,7 & 13,0 & 13,3 & 13,5 & 13,7 & 13,9 & 14,1 & 9,6 \\
\hline $\mathrm{C}_{2} \mathrm{H}_{4}$ & ${ }^{1} J_{\mathrm{CC}}$ & 72,3 & 72,3 & 72,5 & 72,8 & 73,2 & 73,7 & 74,2 & 74,9 & 75,7 & 76,5 & 77,3 & 78,2 & 79,1 & 80,0 & 80,8 & 67,6 \\
\hline $\mathrm{C}_{2} \mathrm{H}_{4}$ & ${ }^{1} J_{\mathrm{CH}}$ & 160,6 & 160,5 & 160,4 & 160,4 & 160,5 & 160,9 & 161,4 & 162,0 & 162,8 & 163,6 & 164,5 & 165,4 & 166,3 & 167,1 & 167,9 & 156,3 \\
\hline $\mathrm{C}_{2} \mathrm{H}_{4}$ & ${ }^{2} J_{\mathrm{CH}}$ & $-3,8$ & $-3,8$ & $-3,8$ & $-3,9$ & $-4,0$ & $-4,2$ & $-4,4$ & $-4,6$ & $-4,9$ & $-5,2$ & $-5,4$ & $-5,7$ & $-6,0$ & $-6,3$ & $-6,5$ & $-2,4$ \\
\hline $\mathrm{C}_{2} \mathrm{H}_{4}$ & ${ }^{2} J_{\mathrm{HH}}$ & 2,2 & 2,2 & 2,2 & 2,1 & 2,0 & 1,9 & 1,7 & 1,5 & 1,3 & 1,1 & 1,0 & 0,8 & 0,6 & 0,5 & 0,3 & 2,3 \\
\hline $\mathrm{C}_{2} \mathrm{H}_{4}$ & ${ }^{3} J_{\mathrm{HH}}$ & 13,3 & 13,3 & 13,3 & 13,4 & 13,5 & 13,6 & 13,7 & 13,8 & 14,0 & 14,1 & 14,3 & 14,4 & 14,5 & 14,6 & 14,7 & 11,7 \\
\hline $\mathrm{C}_{2} \mathrm{H}_{4}$ & ${ }^{3} J_{\mathrm{HH}_{\mathrm{t}}}$ & 19,6 & 19,6 & 19,6 & 19,6 & 19,7 & 19,8 & 20,0 & 20,1 & 20,3 & 20,5 & 20,7 & 20,8 & 21,0 & 21,2 & 21,3 & 19 \\
\hline $\mathrm{C}_{2} \mathrm{H}_{6}$ & ${ }^{1} J_{\mathrm{CC}}$ & 33,3 & 33,4 & 33,5 & 33,7 & 34,0 & 34,2 & 34,5 & 34,8 & 35,1 & 35,5 & 35,9 & 36,3 & 36,7 & 37,1 & 37,5 & 34,5 \\
\hline $\mathrm{C}_{2} \mathrm{H}_{6}$ & ${ }^{1} J_{\mathrm{CH}}$ & 125,8 & 125,7 & 125,6 & 125,6 & 125,7 & 125,8 & 126,2 & 126,6 & 127,1 & 127,7 & 128,3 & 129,0 & 129,6 & 130,2 & 130,8 & 125,2 \\
\hline $\mathrm{C}_{2} \mathrm{H}_{6}$ & ${ }^{2} J_{\mathrm{CH}}$ & $-4,3$ & $-4,3$ & $-4,3$ & $-4,3$ & $-4,4$ & $-4,4$ & $-4,5$ & $-4,6$ & $-4,7$ & $-4,7$ & $-4,8$ & $-4,9$ & $-5,0$ & $-5,1$ & $-5,2$ & $-4,7$ \\
\hline \multirow[t]{3}{*}{ Total } & DM & $-12,83$ & $-12,80$ & $-12,77$ & $-12,72$ & $-12,65$ & $-12,53$ & $-12,38$ & -12 & -11 & $-11,63$ & ,27 & $-10,94$ & -10 & & -9 & - \\
\hline & DMA & 19,72 & 19,71 & 19,77 & 19,91 & 20,11 & & 20,71 & & & 22,13 & 22,70 & & & & & - \\
\hline & PDMA & 12,21 & 12,29 & 12,56 & 13,34 & 14,16 & 15,43 & 16,89 & 18,47 & 20,31 & 22,43 & 24,28 & 26,43 & 28,51 & 30,49 & 32,31 & - \\
\hline \multirow[t]{3}{*}{ CPI } & DM & $-35,16$ & $-35,08$ & $-35,01$ & $-34,93$ & $-34,90$ & $-34,85$ & $-34,75$ & $-34,61$ & $-34,41$ & $-34,19$ & $-33,86$ & $-33,55$ & $-33,22$ & $-32,87$ & $-32,54$ & - \\
\hline & DMA & 41,13 & 41,15 & 41,28 & 41,55 & 41,90 & 42,34 & 42,81 & 43,28 & 43,83 & 44,61 & 45,34 & 46,04 & 46,93 & 47,84 & 48,70 & - \\
\hline & PDMA & 14,82 & 15,04 & 15,65 & 16,58 & 17,63 & 19,01 & 20,51 & 22,12 & 23,79 & 25,94 & 27,86 & 29,92 & 31,86 & 33,91 & 35,68 & - \\
\hline \multirow[t]{3}{*}{ SPI } & DM & 3,55 & 3,53 & 3,54 & 3,57 & 3,67 & 3,83 & 4,03 & 4,27 & 4,5 & 4,92 & 5,29 & 5,64 & 5,99 & 6,33 & 6,65 & - \\
\hline & DMA & 4,02 & 3,99 & 3,99 & 4,04 & 4,13 & 4,29 & 4,50 & 4,82 & 5,21 & 5,64 & 6,09 & 6,55 & 6,99 & 7,42 & 7,83 & - \\
\hline & PDMA & 10,31 & 10,27 & 10,28 & 10,96 & 11,62 & 12,81 & 14,23 & 15,79 & 17,75 & 19,86 & 21,66 & 23,87 & 26,04 & 27,99 & 29,84 & - \\
\hline \multirow[t]{3}{*}{$\Delta \mathrm{CS}$} & DM & $-38,72$ & $-38,62$ & $-38,55$ & $-38,50$ & $-38,57$ & & $-38,79$ & $-38,88$ & $-38,98$ & $-39,11$ & & $-39,19$ & $-39,20$ & & $-39,19$ & - \\
\hline & DMA & 37,11 & 37,17 & 37,29 & 37,51 & 37,77 & 38,04 & 38,31 & 38,46 & 38,62 & 38,97 & 39,24 & 39,49 & 39,94 & 40,42 & 40,87 & - \\
\hline & PDMA & 4,51 & 4,77 & 5,37 & 5,62 & 6,01 & 6,20 & 6,28 & 6,33 & 6,04 & 6,07 & 6,20 & 6,05 & 5,82 & 5,92 & 5,83 & - \\
\hline
\end{tabular}




\subsubsection{Geometrias Otimizadas}

Tabela 8.406: Constantes de acoplamento LC-BB95 com otimização de geometrias para $\alpha=30 \%$ e $\alpha+\beta=100 \%$, variando $\gamma$, na base aug-pcJ-2.

\begin{tabular}{|c|c|c|c|c|c|c|c|c|}
\hline & $\begin{array}{c}\text { Func. } \\
\alpha \\
\alpha+\beta \\
\gamma \\
\end{array}$ & $\begin{array}{c}\text { LCB95 } \\
30 \% \\
100 \% \\
0,20 \\
\end{array}$ & $\begin{array}{c}\text { LCB95 } \\
30 \% \\
100 \% \\
0,25 \\
\end{array}$ & $\begin{array}{c}\text { LCB95 } \\
30 \% \\
100 \% \\
0,30 \\
\end{array}$ & $\begin{array}{c}\text { LCB95 } \\
30 \% \\
100 \% \\
0,35 \\
\end{array}$ & $\begin{array}{c}\text { LCB95 } \\
30 \% \\
100 \% \\
0,40 \\
\end{array}$ & $\begin{array}{c}\text { LCB95 } \\
30 \% \\
100 \% \\
0,45 \\
\end{array}$ & $\begin{array}{c}\text { Exp. } \\
- \\
- \\
-\end{array}$ \\
\hline $\mathrm{HF}$ & ${ }^{1} J_{\mathrm{HF}}$ & 487,8 & 491,5 & 496,7 & 503,4 & 511,3 & 520,4 & 500 \\
\hline $\mathrm{CO}$ & ${ }^{1} J_{\mathrm{CO}}$ & 15,2 & 14,8 & 14,4 & 13,9 & 13,3 & 12,7 & 16,4 \\
\hline $\mathrm{H}_{2} \mathrm{O}$ & ${ }^{1} J_{\mathrm{OH}}$ & $-80,1$ & $-80,6$ & $-81,3$ & $-82,2$ & $-83,2$ & $-84,4$ & $-80,6$ \\
\hline $\mathrm{H}_{2} \mathrm{O}$ & ${ }^{2} J_{\mathrm{HH}}$ & $-5,8$ & $-5,8$ & $-5,8$ & $-5,8$ & $-6,0$ & $-6,1$ & $-7,3$ \\
\hline $\mathrm{NH}_{3}$ & ${ }^{1} J_{\mathrm{NH}}$ & 44,6 & 44,7 & 45,0 & 45,3 & 45,6 & 46,0 & 43,8 \\
\hline $\mathrm{NH}_{3}$ & ${ }^{2} J_{\mathrm{HH}}$ & $-8,1$ & $-8,1$ & $-8,0$ & $-8,2$ & $-8,3$ & $-8,6$ & $-9,6$ \\
\hline $\mathrm{PH}_{3}$ & ${ }^{1} J_{\mathrm{PH}}$ & 167,5 & 165,1 & 164,3 & 165,4 & 168,2 & 172,3 & 188,2 \\
\hline $\mathrm{PF}_{3}$ & ${ }^{1} J_{\mathrm{PF}}$ & $-1514,1$ & $-1511,1$ & $-1508,6$ & $-1506,1$ & $-1503,0$ & $-1498,5$ & -1441 \\
\hline $\mathrm{BHF}_{2}$ & ${ }^{1} J_{\mathrm{BF}}$ & $-113,0$ & $-107,9$ & $-102,0$ & $-95,5$ & $-88,7$ & $-81,6$ & -84 \\
\hline $\mathrm{BF}_{3}$ & ${ }^{1} J_{\mathrm{BF}}$ & $-11,0$ & $-5,0$ & 1,9 & 9,6 & 17,6 & 25,7 & 15 \\
\hline $\mathrm{F}_{2} \mathrm{O}$ & ${ }^{1} J_{\mathrm{OF}}$ & $-201,7$ & $-193,6$ & $-185,0$ & $-176,0$ & $-166,7$ & $-157,4$ & -300 \\
\hline $\mathrm{CH}_{4}$ & ${ }^{1} J_{\mathrm{CH}}$ & 118,5 & 117,4 & 116,7 & 116,4 & 116,5 & 116,9 & 125,3 \\
\hline $\mathrm{CH}_{4}$ & ${ }^{2} J_{\mathrm{HH}}$ & $-11,3$ & $-11,4$ & $-11,6$ & $-12,0$ & $-12,4$ & $-12,8$ & $-12,8$ \\
\hline $\mathrm{C}_{2} \mathrm{H}_{2}$ & ${ }^{1} J_{\mathrm{CC}}$ & 191,2 & 190,9 & 191,0 & 191,4 & 192,2 & 193,4 & 174,8 \\
\hline $\mathrm{C}_{2} \mathrm{H}_{2}$ & ${ }^{1} J_{\mathrm{CH}}$ & 242,6 & 240,2 & 238,4 & 237,4 & 237,1 & 237,4 & 247,6 \\
\hline $\mathrm{C}_{2} \mathrm{H}_{2}$ & ${ }^{2} J_{\mathrm{CH}}$ & 56,0 & 56,3 & 56,6 & 56,8 & 56,9 & 56,8 & 50,1 \\
\hline $\mathrm{C}_{2} \mathrm{H}_{2}$ & ${ }^{3} J_{\mathrm{HH}}$ & 9,1 & 9,0 & 9,0 & 9,2 & 9,4 & 9,7 & 9,6 \\
\hline $\mathrm{C}_{2} \mathrm{H}_{4}$ & ${ }^{1} J_{\mathrm{CC}}$ & 66,0 & 65,9 & 66,0 & 66,4 & 67,0 & 67,9 & 67,6 \\
\hline $\mathrm{C}_{2} \mathrm{H}_{4}$ & ${ }^{1} J_{\mathrm{CH}}$ & 148,8 & 147,6 & 146,8 & 146,5 & 146,7 & 147,3 & 156,3 \\
\hline $\mathrm{C}_{2} \mathrm{H}_{4}$ & ${ }^{2} J_{\mathrm{CH}}$ & $-0,7$ & $-0,8$ & $-1,0$ & $-1,3$ & $-1,6$ & $-2,1$ & $-2,4$ \\
\hline $\mathrm{C}_{2} \mathrm{H}_{4}$ & ${ }^{2} J_{\mathrm{HH}}$ & 3,2 & 3,0 & 2,8 & 2,4 & 2,0 & 1,5 & 2,3 \\
\hline $\mathrm{C}_{2} \mathrm{H}_{4}$ & ${ }^{3} J_{\mathrm{HH}_{\mathrm{c}}}$ & 13,1 & 13,3 & 13,5 & 13,7 & 13,9 & 14,1 & 11,7 \\
\hline $\mathrm{C}_{2} \mathrm{H}_{4}$ & ${ }^{3} J_{\mathrm{HH}_{\mathrm{t}}}$ & 19,0 & 18,9 & 18,9 & 19,0 & 19,1 & 19,3 & 19 \\
\hline $\mathrm{C}_{2} \mathrm{H}_{6}$ & ${ }^{1} J_{\mathrm{CC}}$ & 31,7 & 31,8 & 31,9 & 32,2 & 32,3 & 32,9 & 34,5 \\
\hline $\mathrm{C}_{2} \mathrm{H}_{6}$ & ${ }^{1} J_{\mathrm{CH}}$ & 117,1 & 116,0 & 115,4 & 115,1 & 115,4 & 115,9 & 125,2 \\
\hline $\mathrm{C}_{2} \mathrm{H}_{6}$ & ${ }^{2} J_{\mathrm{CH}}$ & $-3,4$ & $-3,5$ & $-3,6$ & $-3,7$ & $-3,9$ & $-4,1$ & $-4,7$ \\
\hline \multirow[t]{3}{*}{ Total } & DM & $-2,42$ & $-1,78$ & $-0,87$ & 0,32 & 1,76 & 3,45 & - \\
\hline & DMA & 12,55 & 12,48 & 12,25 & 12,00 & 12,10 & 12,69 & 一 \\
\hline & PDMA & 20,07 & 18,16 & 15,76 & 12,31 & 11,00 & 12,83 & - \\
\hline \multirow[t]{3}{*}{ CPI } & DM & $-5,42$ & $-3,35$ & $-0,85$ & 2,08 & 5,38 & 9,05 & - \\
\hline & DMA & 24,07 & 23,41 & 22,54 & 21,88 & 22,18 & 23,76 & - \\
\hline & PDMA & 27,73 & 24,01 & 19,83 & 14,92 & 12,92 & 17,95 & - \\
\hline \multirow[t]{3}{*}{ SPI } & $\mathrm{DM}$ & $-0,21$ & $-0,63$ & $-0,89$ & $-0,97$ & $-0,90$ & $-0,67$ & - \\
\hline & DMA & 4,09 & 4,47 & 4,71 & 4,75 & 4,70 & 4,57 & - \\
\hline & PDMA & 14,46 & 13,88 & 12,78 & 10,39 & 9,60 & 9,09 & - \\
\hline \multirow[t]{3}{*}{$\Delta \mathrm{CS}$} & DM & $-5,20$ & $-2,72$ & 0,04 & 3,06 & 6,28 & 9,72 & - \\
\hline & DMA & 19,98 & 18,94 & 17,82 & 17,14 & 17,48 & 19,19 & - \\
\hline & PDMA & 13,28 & 10,13 & 7,06 & 4,53 & 3,32 & 8,86 & - \\
\hline
\end{tabular}


Tabela 8.407: Constantes de acoplamento LC-BB95 com otimização de geometrias para $\alpha=30 \%$ e $\alpha+\beta=90 \%$, variando $\gamma$, na base aug-pcJ-2.

\begin{tabular}{|c|c|c|c|c|c|c|c|c|}
\hline & $\begin{array}{c}\text { Func. } \\
\alpha \\
\alpha+\beta \\
\gamma \\
\end{array}$ & $\begin{array}{c}\text { LCB95 } \\
30 \% \\
90 \% \\
0,20\end{array}$ & $\begin{array}{c}\text { LCB95 } \\
30 \% \\
90 \% \\
0,25\end{array}$ & $\begin{array}{c}\text { LCB95 } \\
30 \% \\
90 \% \\
0,30 \\
\end{array}$ & $\begin{array}{c}\text { LCB95 } \\
30 \% \\
90 \% \\
0,35 \\
\end{array}$ & $\begin{array}{c}\text { LCB95 } \\
30 \% \\
90 \% \\
0,40\end{array}$ & $\begin{array}{c}\text { LCB95 } \\
30 \% \\
90 \% \\
0,45\end{array}$ & $\begin{array}{c}\text { Exp. } \\
- \\
- \\
\end{array}$ \\
\hline $\mathrm{HF}$ & ${ }^{1} J_{\mathrm{HF}}$ & 486,5 & 489,7 & 494,2 & 499,9 & 506,8 & 514,5 & 500 \\
\hline $\mathrm{CO}$ & ${ }^{1} J_{\mathrm{CO}}$ & 15,3 & 14,9 & 14,6 & 14,1 & 13,7 & 13,1 & 16,4 \\
\hline $\mathrm{H}_{2} \mathrm{O}$ & ${ }^{1} J_{\mathrm{OH}}$ & $-80,0$ & $-80,4$ & $-81,0$ & $-81,8$ & $-82,7$ & $-83,8$ & $-80,6$ \\
\hline $\mathrm{H}_{2} \mathrm{O}$ & ${ }^{2} J_{\mathrm{HH}}$ & $-5,9$ & $-5,9$ & $-5,9$ & $-5,9$ & $-6,1$ & $-6,2$ & $-7,3$ \\
\hline $\mathrm{NH}_{3}$ & ${ }^{1} J_{\mathrm{NH}}$ & 44,7 & 44,7 & 45,0 & 45,3 & 45,6 & 45,9 & 43,8 \\
\hline $\mathrm{NH}_{3}$ & ${ }^{2} J_{\mathrm{HH}}$ & $-8,3$ & $-8,2$ & $-8,2$ & $-8,3$ & $-8,5$ & $-8,7$ & $-9,6$ \\
\hline $\mathrm{PH}_{3}$ & ${ }^{1} J_{\mathrm{PH}}$ & 169,0 & 166,9 & 166,2 & 167,2 & 169,6 & 173,1 & 188,2 \\
\hline $\mathrm{PF}_{3}$ & ${ }^{1} J_{\mathrm{PF}}$ & $-1516,2$ & $-1513,8$ & $-1511,9$ & $-1510,2$ & $-1508,0$ & $-1504,8$ & -1441 \\
\hline $\mathrm{BHF}_{2}$ & ${ }^{1} J_{\mathrm{BF}}$ & $-114,2$ & $-109,8$ & $-104,6$ & $-99,0$ & $-93,0$ & $-86,9$ & -84 \\
\hline $\mathrm{BF}_{3}$ & ${ }^{1} J_{\mathrm{BF}}$ & $-12,7$ & $-7,5$ & $-1,4$ & 5,1 & 12,1 & 19,2 & 15 \\
\hline $\mathrm{F}_{2} \mathrm{O}$ & ${ }^{1} J_{\mathrm{OF}}$ & $-207,4$ & $-200,2$ & $-192,7$ & $-184,7$ & $-176,4$ & $-168,1$ & -300 \\
\hline $\mathrm{CH}_{4}$ & ${ }^{1} J_{\mathrm{CH}}$ & 119,3 & 118,4 & 117,7 & 117,5 & 117,5 & 117,9 & 125,3 \\
\hline $\mathrm{CH}_{4}$ & ${ }^{2} J_{\mathrm{HH}}$ & $-11,5$ & $-11,6$ & $-11,8$ & $-12,0$ & $-12,4$ & $-12,7$ & $-12,8$ \\
\hline $\mathrm{C}_{2} \mathrm{H}_{2}$ & ${ }^{1} J_{\mathrm{CC}}$ & 191,9 & 191,7 & 191,7 & 192,1 & 192,8 & 193,8 & 174,8 \\
\hline $\mathrm{C}_{2} \mathrm{H}_{2}$ & ${ }^{1} J_{\mathrm{CH}}$ & 244,1 & 242,0 & 240,5 & 239,6 & 239,3 & 239,6 & 247,6 \\
\hline $\mathrm{C}_{2} \mathrm{H}_{2}$ & ${ }^{2} J_{\mathrm{CH}}$ & 55,9 & 56,2 & 56,5 & 56,6 & 56,7 & 56,7 & 50,1 \\
\hline $\mathrm{C}_{2} \mathrm{H}_{2}$ & ${ }^{3} J_{\mathrm{HH}}$ & 9,2 & 9,1 & 9,2 & 9,3 & 9,5 & 9,7 & 9,6 \\
\hline $\mathrm{C}_{2} \mathrm{H}_{4}$ & ${ }^{1} J_{\mathrm{CC}}$ & 66,5 & 66,4 & 66,5 & 66,8 & 67,4 & 68,1 & 67,6 \\
\hline $\mathrm{C}_{2} \mathrm{H}_{4}$ & ${ }^{1} J_{\mathrm{CH}}$ & 149,8 & 148,7 & 148,0 & 147,8 & 147,9 & 148,4 & 156,3 \\
\hline $\mathrm{C}_{2} \mathrm{H}_{4}$ & ${ }^{2} J_{\mathrm{CH}}$ & $-0,8$ & $-0,9$ & $-1,0$ & $-1,3$ & $-1,6$ & $-2,0$ & $-2,4$ \\
\hline $\mathrm{C}_{2} \mathrm{H}_{4}$ & ${ }^{2} J_{\mathrm{HH}}$ & 3,1 & 3,0 & 2,7 & 2,4 & 2,1 & 1,6 & 2,3 \\
\hline $\mathrm{C}_{2} \mathrm{H}_{4}$ & ${ }^{3} J_{\mathrm{HH}_{\mathrm{c}}}$ & 13,1 & 13,2 & 13,4 & 13,6 & 13,8 & 14,0 & 11,7 \\
\hline $\mathrm{C}_{2} \mathrm{H}_{4}$ & ${ }^{3} J_{\mathrm{HH}_{\mathrm{t}}}$ & 19,1 & 19,0 & 19,0 & 19,1 & 19,2 & 19,3 & 19 \\
\hline $\mathrm{C}_{2} \mathrm{H}_{6}$ & ${ }^{1} J_{\mathrm{CC}}$ & 31,9 & 32,0 & 32,1 & 32,3 & 32,4 & 32,9 & 34,5 \\
\hline $\mathrm{C}_{2} \mathrm{H}_{6}$ & ${ }^{1} J_{\mathrm{CH}}$ & 118,0 & 117,0 & 116,4 & 116,2 & 116,4 & 116,9 & 125,2 \\
\hline $\mathrm{C}_{2} \mathrm{H}_{6}$ & ${ }^{2} J_{\mathrm{CH}}$ & $-3,4$ & $-3,5$ & $-3,6$ & $-3,7$ & $-3,9$ & $-4,1$ & $-4,7$ \\
\hline \multirow[t]{3}{*}{ Total } & DM & $-2,62$ & $-2,07$ & $-1,28$ & $-0,27$ & 0,97 & 2,40 & - \\
\hline & DMA & 12,32 & 12,29 & 12,07 & 11,68 & 11,60 & 11,80 & - \\
\hline & PDMA & 19,78 & 18,21 & 15,90 & 13,08 & 10,47 & 10,66 & - \\
\hline \multirow[t]{3}{*}{ CPI } & $\mathrm{DM}$ & $-6,37$ & $-4,59$ & $-2,42$ & 0,07 & 2,93 & 6,04 & - \\
\hline & DMA & 23,97 & 23,45 & 22,65 & 21,65 & 21,53 & 22,09 & - \\
\hline & PDMA & 28,35 & 25,24 & 21,40 & 17,27 & 12,57 & 13,10 & - \\
\hline \multirow[t]{3}{*}{ SPI } & DM & 0,14 & $-0,23$ & $-0,45$ & $-0,52$ & $-0,47$ & $-0,27$ & - \\
\hline & DMA & 3,78 & 4,11 & 4,31 & 4,36 & 4,32 & 4,25 & - \\
\hline & PDMA & 13,50 & 13,06 & 11,86 & 10,01 & 8,94 & 8,88 & - \\
\hline \multirow[t]{3}{*}{$\Delta \mathrm{CS}$} & $\mathrm{DM}$ & $-6,51$ & $-4,36$ & $-1,96$ & 0,59 & 3,39 & 6,30 & - \\
\hline & DMA & 20,19 & 19,34 & 18,35 & 17,29 & 17,21 & 17,84 & - \\
\hline & PDMA & 14,84 & 12,18 & 9,53 & 7,26 & 3,63 & 4,22 & - \\
\hline
\end{tabular}


Tabela 8.408: Constantes de acoplamento LC-BB95 com otimização de geometrias para $\alpha=30 \%$ e $\alpha+\beta=80 \%$, variando $\gamma$, na base aug-pcJ-2.

\begin{tabular}{|c|c|c|c|c|c|c|c|c|}
\hline & $\begin{array}{c}\text { Func. } \\
\alpha \\
\alpha+\beta \\
\gamma \\
\end{array}$ & $\begin{array}{c}\text { LCB95 } \\
30 \% \\
80 \% \\
0,20\end{array}$ & $\begin{array}{c}\text { LCB95 } \\
30 \% \\
80 \% \\
0,25 \\
\end{array}$ & $\begin{array}{c}\text { LCB95 } \\
30 \% \\
80 \% \\
0,30 \\
\end{array}$ & $\begin{array}{c}\text { LCB95 } \\
30 \% \\
80 \% \\
0,35\end{array}$ & $\begin{array}{c}\text { LCB95 } \\
30 \% \\
80 \% \\
0,40 \\
\end{array}$ & $\begin{array}{c}\text { LCB95 } \\
30 \% \\
80 \% \\
0,45\end{array}$ & $\begin{array}{c}\text { Exp. } \\
- \\
-\end{array}$ \\
\hline $\mathrm{HF}$ & ${ }^{1} J_{\mathrm{HF}}$ & 485,2 & 487,9 & 491,6 & 496,4 & 502,1 & 508,7 & 500 \\
\hline $\mathrm{CO}$ & ${ }^{1} J_{\mathrm{CO}}$ & 15,4 & 15,1 & 14,8 & 14,4 & 14,0 & 13,5 & 16,4 \\
\hline $\mathrm{H}_{2} \mathrm{O}$ & ${ }^{1} J_{\mathrm{OH}}$ & $-79,9$ & $-80,3$ & $-80,8$ & $-81,4$ & $-82,2$ & $-83,1$ & $-80,6$ \\
\hline $\mathrm{H}_{2} \mathrm{O}$ & ${ }^{2} J_{\mathrm{HH}}$ & $-6,0$ & $-6,0$ & $-6,0$ & $-6,1$ & $-6,1$ & $-6,3$ & $-7,3$ \\
\hline $\mathrm{NH}_{3}$ & ${ }^{1} J_{\mathrm{NH}}$ & 44,7 & 44,8 & 45,0 & 45,2 & 45,5 & 45,8 & 43,8 \\
\hline $\mathrm{NH}_{3}$ & ${ }^{2} J_{\mathrm{HH}}$ & $-8,4$ & $-8,4$ & $-8,4$ & $-8,4$ & $-8,6$ & $-8,7$ & $-9,6$ \\
\hline $\mathrm{PH}_{3}$ & ${ }^{1} J_{\mathrm{PH}}$ & 170,5 & 168,7 & 168,1 & 168,9 & 170,9 & 173,9 & 188,2 \\
\hline $\mathrm{PF}_{3}$ & ${ }^{1} J_{\mathrm{PF}}$ & $-1518,2$ & $-1516,3$ & $-1515,0$ & $-1513,9$ & $-1512,6$ & $-1510,5$ & -1441 \\
\hline $\mathrm{BHF}_{2}$ & ${ }^{1} J_{\mathrm{BF}}$ & $-115,3$ & $-111,6$ & $-107,3$ & $-102,5$ & $-97,5$ & $-92,3$ & -84 \\
\hline $\mathrm{BF}_{3}$ & ${ }^{1} J_{\mathrm{BF}}$ & $-14,4$ & $-10,0$ & $-4,9$ & 0,6 & 6,5 & 12,5 & 15 \\
\hline $\mathrm{F}_{2} \mathrm{O}$ & ${ }^{1} J_{\mathrm{OF}}$ & $-213,2$ & $-207,1$ & $-200,6$ & $-193,7$ & $-186,6$ & $-179,4$ & -300 \\
\hline $\mathrm{CH}_{4}$ & ${ }^{1} J_{\mathrm{CH}}$ & 120,1 & 119,3 & 118,8 & 118,6 & 118,6 & 118,9 & 125,3 \\
\hline $\mathrm{CH}_{4}$ & ${ }^{2} J_{\mathrm{HH}}$ & $-11,6$ & $-11,7$ & $-11,9$ & $-12,1$ & $-12,4$ & $-12,7$ & $-12,8$ \\
\hline $\mathrm{C}_{2} \mathrm{H}_{2}$ & ${ }^{1} J_{\mathrm{CC}}$ & 192,6 & 192,4 & 192,4 & 192,7 & 193,3 & 194,2 & 174,8 \\
\hline $\mathrm{C}_{2} \mathrm{H}_{2}$ & ${ }^{1} J_{\mathrm{CH}}$ & 245,6 & 243,9 & 242,6 & 241,8 & 241,6 & 241,8 & 247,6 \\
\hline $\mathrm{C}_{2} \mathrm{H}_{2}$ & ${ }^{2} J_{\mathrm{CH}}$ & 55,9 & 56,1 & 56,3 & 56,5 & 56,5 & 56,5 & 50,1 \\
\hline $\mathrm{C}_{2} \mathrm{H}_{2}$ & ${ }^{3} J_{\mathrm{HH}}$ & 9,4 & 9,3 & 9,3 & 9,4 & 9,5 & 9,7 & 9,6 \\
\hline $\mathrm{C}_{2} \mathrm{H}_{4}$ & ${ }^{1} J_{\mathrm{CC}}$ & 67,0 & 66,9 & 67,0 & 67,3 & 67,7 & 68,4 & 67,6 \\
\hline $\mathrm{C}_{2} \mathrm{H}_{4}$ & ${ }^{1} J_{\mathrm{CH}}$ & 150,7 & 149,8 & 149,2 & 149,0 & 149,2 & 149,6 & 156,3 \\
\hline $\mathrm{C}_{2} \mathrm{H}_{4}$ & ${ }^{2} J_{\mathrm{CH}}$ & $-0,8$ & $-0,9$ & $-1,0$ & $-1,2$ & $-1,5$ & $-1,8$ & $-2,4$ \\
\hline $\mathrm{C}_{2} \mathrm{H}_{4}$ & ${ }^{2} J_{\mathrm{HH}}$ & 3,0 & 2,9 & 2,7 & 2,5 & 2,1 & 1,8 & 2,3 \\
\hline $\mathrm{C}_{2} \mathrm{H}_{4}$ & ${ }^{3} J_{\mathrm{HH}_{\mathrm{c}}}$ & 13,1 & 13,2 & 13,3 & 13,5 & 13,7 & 13,8 & 11,7 \\
\hline $\mathrm{C}_{2} \mathrm{H}_{4}$ & ${ }^{3} J_{\mathrm{HH}_{\mathrm{t}}}$ & 19,2 & 19,1 & 19,1 & 19,2 & 19,3 & 19,4 & 19 \\
\hline $\mathrm{C}_{2} \mathrm{H}_{6}$ & ${ }^{1} J_{\mathrm{CC}}$ & 32,1 & 32,2 & 32,0 & 32,2 & 32,5 & 32,9 & 34,5 \\
\hline $\mathrm{C}_{2} \mathrm{H}_{6}$ & ${ }^{1} J_{\mathrm{CH}}$ & 118,8 & 118,0 & 117,6 & 117,4 & 117,5 & 117,9 & 125,2 \\
\hline $\mathrm{C}_{2} \mathrm{H}_{6}$ & ${ }^{2} J_{\mathrm{CH}}$ & $-3,5$ & $-3,5$ & $-3,6$ & $-3,7$ & $-3,8$ & $-4,0$ & $-4,7$ \\
\hline \multirow[t]{3}{*}{ Total } & DM & $-2,81$ & $-2,35$ & $-1,72$ & $-0,86$ & 0,16 & 1,37 & - \\
\hline & DMA & 12,10 & 12,07 & 11,90 & 11,59 & 11,29 & 11,23 & - \\
\hline & PDMA & 19,60 & 18,25 & 16,38 & 14,13 & 11,86 & 10,00 & - \\
\hline \multirow[t]{3}{*}{ CPI } & DM & $-7,32$ & $-5,83$ & $-4,04$ & $-1,95$ & 0,41 & 3,02 & - \\
\hline & DMA & 23,85 & 23,41 & 22,78 & 21,96 & 21,30 & 21,20 & - \\
\hline & PDMA & 29,02 & 26,31 & 23,10 & 19,53 & 15,68 & 11,76 & - \\
\hline \multirow[t]{3}{*}{ SPI } & DM & 0,50 & 0,19 & $-0,02$ & $-0,07$ & $-0,02$ & 0,15 & - \\
\hline & DMA & 3,49 & 3,75 & 3,93 & 3,99 & 3,95 & 3,93 & - \\
\hline & PDMA & 12,69 & 12,34 & 11,46 & 10,18 & 9,06 & 8,72 & - \\
\hline \multirow[t]{3}{*}{$\Delta \mathrm{CS}$} & DM & $-7,82$ & $-6,02$ & $-4,02$ & $-1,88$ & 0,43 & 2,86 & - \\
\hline & DMA & 20,36 & 19,66 & 18,86 & 17,98 & 17,35 & 17,27 & - \\
\hline & PDMA & 16,33 & 13,97 & 11,64 & 9,35 & 6,62 & 3,04 & - \\
\hline
\end{tabular}


Tabela 8.409: Constantes de acoplamento LC-BB95 com otimização de geometrias para $\alpha=30 \%$ e $\alpha+\beta=70 \%$, variando $\gamma$, na base aug-pcJ-2.

\begin{tabular}{|c|c|c|c|c|c|c|c|c|}
\hline & $\begin{array}{c}\text { Func. } \\
\alpha \\
\alpha+\beta \\
\gamma \\
\end{array}$ & $\begin{array}{c}\text { LCB95 } \\
30 \% \\
70 \% \\
0,20\end{array}$ & $\begin{array}{c}\text { LCB95 } \\
30 \% \\
70 \% \\
0,25 \\
\end{array}$ & $\begin{array}{c}\text { LCB95 } \\
30 \% \\
70 \% \\
0,30 \\
\end{array}$ & $\begin{array}{c}\text { LCB95 } \\
30 \% \\
70 \% \\
0,35\end{array}$ & $\begin{array}{c}\text { LCB95 } \\
30 \% \\
70 \% \\
0,40 \\
\end{array}$ & $\begin{array}{c}\text { LCB95 } \\
30 \% \\
70 \% \\
0,45\end{array}$ & $\begin{array}{c}\text { Exp. } \\
- \\
-\end{array}$ \\
\hline $\mathrm{HF}$ & ${ }^{1} J_{\mathrm{HF}}$ & 483,8 & 486,0 & 489,0 & 492,8 & 497,5 & 502,7 & 500 \\
\hline $\mathrm{CO}$ & ${ }^{1} J_{\mathrm{CO}}$ & 15,4 & 15,2 & 15,0 & 14,7 & 14,3 & 14,0 & 16,4 \\
\hline $\mathrm{H}_{2} \mathrm{O}$ & ${ }^{1} J_{\mathrm{OH}}$ & $-79,8$ & $-80,1$ & $-80,5$ & $-81,0$ & $-81,7$ & $-82,4$ & $-80,6$ \\
\hline $\mathrm{H}_{2} \mathrm{O}$ & ${ }^{2} J_{\mathrm{HH}}$ & $-6,2$ & $-6,1$ & $-6,1$ & $-6,2$ & $-6,2$ & $-6,3$ & $-7,3$ \\
\hline $\mathrm{NH}_{3}$ & ${ }^{1} J_{\mathrm{NH}}$ & 44,7 & 44,8 & 45,0 & 45,2 & 45,4 & 45,7 & 43,8 \\
\hline $\mathrm{NH}_{3}$ & ${ }^{2} J_{\mathrm{HH}}$ & $-8,6$ & $-8,6$ & $-8,5$ & $-8,6$ & $-8,7$ & $-8,8$ & $-9,6$ \\
\hline $\mathrm{PH}_{3}$ & ${ }^{1} J_{\mathrm{PH}}$ & 171,9 & 170,5 & 170,0 & 170,7 & 172,3 & 174,7 & 188,2 \\
\hline $\mathrm{PF}_{3}$ & ${ }^{1} J_{\mathrm{PF}}$ & $-1520,2$ & $-1518,8$ & $-1517,9$ & $-1517,4$ & $-1516,8$ & $-1515,6$ & -1441 \\
\hline $\mathrm{BHF}_{2}$ & ${ }^{1} J_{\mathrm{BF}}$ & $-116,5$ & $-113,5$ & $-110,0$ & $-106,1$ & $-102,0$ & $-97,9$ & -84 \\
\hline $\mathrm{BF}_{3}$ & ${ }^{1} J_{\mathrm{BF}}$ & $-16,1$ & $-12,6$ & $-8,5$ & $-3,9$ & 0,8 & 5,7 & 15 \\
\hline $\mathrm{F}_{2} \mathrm{O}$ & ${ }^{1} J_{\mathrm{OF}}$ & $-219,1$ & $-214,1$ & $-208,8$ & $-203,1$ & $-197,2$ & $-191,2$ & -300 \\
\hline $\mathrm{CH}_{4}$ & ${ }^{1} J_{\mathrm{CH}}$ & 120,9 & 120,3 & 119,9 & 119,7 & 119,7 & 120,0 & 125,3 \\
\hline $\mathrm{CH}_{4}$ & ${ }^{2} J_{\mathrm{HH}}$ & $-11,8$ & $-11,8$ & $-12,0$ & $-12,1$ & $-12,4$ & $-12,6$ & $-12,8$ \\
\hline $\mathrm{C}_{2} \mathrm{H}_{2}$ & ${ }^{1} J_{\mathrm{CC}}$ & 193,3 & 193,1 & 193,2 & 193,4 & 193,9 & 194,6 & 174,8 \\
\hline $\mathrm{C}_{2} \mathrm{H}_{2}$ & ${ }^{1} J_{\mathrm{CH}}$ & 247,1 & 245,7 & 244,7 & 244,1 & 243,9 & 244,0 & 247,6 \\
\hline $\mathrm{C}_{2} \mathrm{H}_{2}$ & ${ }^{2} J_{\mathrm{CH}}$ & 55,9 & 56,0 & 56,2 & 56,3 & 56,4 & 56,3 & 50,1 \\
\hline $\mathrm{C}_{2} \mathrm{H}_{2}$ & ${ }^{3} J_{\mathrm{HH}}$ & 9,5 & 9,5 & 9,5 & 9,5 & 9,6 & 9,8 & 9,6 \\
\hline $\mathrm{C}_{2} \mathrm{H}_{4}$ & ${ }^{1} J_{\mathrm{CC}}$ & 67,5 & 67,4 & 67,5 & 67,7 & 68,1 & 68,6 & 67,6 \\
\hline $\mathrm{C}_{2} \mathrm{H}_{4}$ & ${ }^{1} J_{\mathrm{CH}}$ & 151,7 & 151,0 & 150,5 & 150,3 & 150,4 & 150,8 & 156,3 \\
\hline $\mathrm{C}_{2} \mathrm{H}_{4}$ & ${ }^{2} J_{\mathrm{CH}}$ & $-0,9$ & $-0,9$ & $-1,0$ & $-1,2$ & $-1,4$ & $-1,7$ & $-2,4$ \\
\hline $\mathrm{C}_{2} \mathrm{H}_{4}$ & ${ }^{2} J_{\mathrm{HH}}$ & 2,9 & 2,9 & 2,7 & 2,5 & 2,2 & 2,0 & 2,3 \\
\hline $\mathrm{C}_{2} \mathrm{H}_{4}$ & ${ }^{3} J_{\mathrm{HH}_{\mathrm{c}}}$ & 13,1 & 13,2 & 13,3 & 13,4 & 13,5 & 13,7 & 11,7 \\
\hline $\mathrm{C}_{2} \mathrm{H}_{4}$ & ${ }^{3} J_{\mathrm{HH}_{\mathrm{t}}}$ & 19,3 & 19,2 & 19,2 & 19,3 & 19,3 & 19,4 & 19 \\
\hline $\mathrm{C}_{2} \mathrm{H}_{6}$ & ${ }^{1} J_{\mathrm{CC}}$ & 32,1 & 32,1 & 32,2 & 32,4 & 32,6 & 32,9 & 34,5 \\
\hline $\mathrm{C}_{2} \mathrm{H}_{6}$ & ${ }^{1} J_{\mathrm{CH}}$ & 119,7 & 119,1 & 118,7 & 118,6 & 118,6 & 118,9 & 125,2 \\
\hline $\mathrm{C}_{2} \mathrm{H}_{6}$ & ${ }^{2} J_{\mathrm{CH}}$ & $-3,5$ & $-3,5$ & $-3,6$ & $-3,7$ & $-3,8$ & $-3,9$ & $-4,7$ \\
\hline \multirow[t]{3}{*}{ Total } & DM & $-3,03$ & $-2,65$ & $-2,13$ & $-1,45$ & $-0,64$ & 0,32 & - \\
\hline & DMA & 11,88 & 11,87 & 11,73 & 11,48 & 11,16 & 10,95 & - \\
\hline & PDMA & 19,30 & 18,53 & 16,91 & 14,89 & 12,96 & 11,43 & - \\
\hline \multirow[t]{3}{*}{ CPI } & DM & $-8,33$ & $-7,11$ & $-5,65$ & $-3,98$ & $-2,11$ & $-0,03$ & - \\
\hline & DMA & 23,73 & 23,40 & 22,89 & 22,24 & 21,45 & 20,97 & - \\
\hline & PDMA & 29,55 & 27,49 & 24,96 & 21,84 & 18,80 & 15,54 & - \\
\hline \multirow[t]{3}{*}{ SPI } & DM & 0,85 & 0,61 & 0,46 & 0,41 & 0,43 & 0,58 & - \\
\hline & DMA & 3,19 & 3,41 & 3,54 & 3,59 & 3,61 & 3,59 & - \\
\hline & PDMA & 11,79 & 11,96 & 11,00 & 9,79 & 8,67 & 8,41 & - \\
\hline \multirow[t]{3}{*}{$\Delta \mathrm{CS}$} & DM & $-9,17$ & $-7,72$ & $-6,11$ & $-4,39$ & $-2,54$ & $-0,61$ & - \\
\hline & DMA & 20,53 & 19,99 & 19,35 & 18,64 & 17,85 & 17,38 & - \\
\hline & PDMA & 17,76 & 15,54 & 13,95 & 12,05 & 10,14 & 7,13 & - \\
\hline
\end{tabular}


Tabela 8.410: Constantes de acoplamento LC-BB95 com otimização de geometrias para $\alpha=40 \%$ e $\alpha+\beta=100 \%$, variando $\gamma$, na base aug-pcJ-2.

\begin{tabular}{|c|c|c|c|c|c|c|c|c|}
\hline & $\begin{array}{c}\text { Func. } \\
\alpha \\
\alpha+\beta \\
\gamma \\
\end{array}$ & $\begin{array}{c}\text { LCB95 } \\
40 \% \\
100 \% \\
0,20 \\
\end{array}$ & $\begin{array}{c}\text { LCB95 } \\
40 \% \\
100 \% \\
0,25 \\
\end{array}$ & $\begin{array}{c}\text { LCB95 } \\
40 \% \\
100 \% \\
0,30 \\
\end{array}$ & $\begin{array}{c}\text { LCB95 } \\
40 \% \\
100 \% \\
0,35 \\
\end{array}$ & $\begin{array}{c}\text { LCB95 } \\
40 \% \\
100 \% \\
0,40 \\
\end{array}$ & $\begin{array}{c}\text { LCB95 } \\
40 \% \\
100 \% \\
0,45 \\
\end{array}$ & $\begin{array}{c}\text { Exp. } \\
- \\
- \\
\end{array}$ \\
\hline $\mathrm{HF}$ & ${ }^{1} J_{\mathrm{HF}}$ & 523,0 & 526,0 & 530,3 & 535,8 & 542,5 & 550,0 & 500 \\
\hline $\mathrm{CO}$ & ${ }^{1} J_{\mathrm{CO}}$ & 12,2 & 11,9 & 11,5 & 11,1 & 10,7 & 10,1 & 16,4 \\
\hline $\mathrm{H}_{2} \mathrm{O}$ & ${ }^{1} J_{\mathrm{OH}}$ & $-83,9$ & $-84,3$ & $-84,8$ & $-85,6$ & $-86,4$ & $-87,4$ & $-80,6$ \\
\hline $\mathrm{H}_{2} \mathrm{O}$ & ${ }^{2} J_{\mathrm{HH}}$ & $-6,6$ & $-6,6$ & $-6,6$ & $-6,7$ & $-6,8$ & $-6,9$ & $-7,3$ \\
\hline $\mathrm{NH}_{3}$ & ${ }^{1} J_{\mathrm{NH}}$ & 45,8 & 45,9 & 46,0 & 46,2 & 46,5 & 46,9 & 43,8 \\
\hline $\mathrm{NH}_{3}$ & ${ }^{2} J_{\mathrm{HH}}$ & $-8,9$ & $-8,8$ & $-8,8$ & $-8,9$ & $-9,1$ & $-9,3$ & $-9,6$ \\
\hline $\mathrm{PH}_{3}$ & ${ }^{1} J_{\mathrm{PH}}$ & 178,3 & 176,1 & 175,4 & 176,2 & 178,5 & 181,8 & 188,2 \\
\hline $\mathrm{PF}_{3}$ & ${ }^{1} J_{\mathrm{PF}}$ & $-1486,4$ & $-1482,4$ & $-1478,7$ & $-1475,1$ & $-1470,4$ & $-1465,3$ & -1441 \\
\hline $\mathrm{BHF}_{2}$ & ${ }^{1} J_{\mathrm{BF}}$ & $-92,7$ & $-88,6$ & $-83,7$ & $-78,3$ & $-72,5$ & $-66,6$ & -84 \\
\hline $\mathrm{BF}_{3}$ & ${ }^{1} J_{\mathrm{BF}}$ & 11,6 & 16,4 & 22,1 & 28,4 & 35,1 & 41,8 & 15 \\
\hline $\mathrm{F}_{2} \mathrm{O}$ & ${ }^{1} J_{\mathrm{OF}}$ & $-186,3$ & $-179,7$ & $-172,8$ & $-165,4$ & $-157,8$ & $-150,2$ & -300 \\
\hline $\mathrm{CH}_{4}$ & ${ }^{1} J_{\mathrm{CH}}$ & 120,1 & 119,2 & 118,6 & 118,3 & 118,4 & 118,7 & 125,3 \\
\hline $\mathrm{CH}_{4}$ & ${ }^{2} J_{\mathrm{HH}}$ & $-12,1$ & $-12,2$ & $-12,4$ & $-12,7$ & $-13,0$ & $-13,4$ & $-12,8$ \\
\hline $\mathrm{C}_{2} \mathrm{H}_{2}$ & ${ }^{1} J_{\mathrm{CC}}$ & 194,6 & 194,4 & 194,5 & 194,9 & 195,7 & 196,8 & 174,8 \\
\hline $\mathrm{C}_{2} \mathrm{H}_{2}$ & ${ }^{1} J_{\mathrm{CH}}$ & 244,4 & 242,3 & 240,8 & 240,0 & 239,7 & 240,0 & 247,6 \\
\hline $\mathrm{C}_{2} \mathrm{H}_{2}$ & ${ }^{2} J_{\mathrm{CH}}$ & 55,8 & 56,1 & 56,3 & 56,4 & 56,5 & 56,4 & 50,1 \\
\hline $\mathrm{C}_{2} \mathrm{H}_{2}$ & ${ }^{3} J_{\mathrm{HH}}$ & 9,6 & 9,6 & 9,6 & 9,8 & 10,0 & 10,3 & 9,6 \\
\hline $\mathrm{C}_{2} \mathrm{H}_{4}$ & ${ }^{1} J_{\mathrm{CC}}$ & 68,9 & 68,8 & 69,0 & 69,3 & 69,9 & 70,8 & 67,6 \\
\hline $\mathrm{C}_{2} \mathrm{H}_{4}$ & ${ }^{1} J_{\mathrm{CH}}$ & 150,9 & 149,8 & 149,1 & 148,9 & 149,0 & 149,6 & 156,3 \\
\hline $\mathrm{C}_{2} \mathrm{H}_{4}$ & ${ }^{2} J_{\mathrm{CH}}$ & $-1,6$ & $-1,7$ & $-1,9$ & $-2,1$ & $-2,5$ & $-2,9$ & $-2,4$ \\
\hline $\mathrm{C}_{2} \mathrm{H}_{4}$ & ${ }^{2} J_{\mathrm{HH}}$ & 2,4 & 2,3 & 2,1 & 1,7 & 1,3 & 0,9 & 2,3 \\
\hline $\mathrm{C}_{2} \mathrm{H}_{4}$ & ${ }^{3} J_{\mathrm{HH}_{\mathrm{c}}}$ & 13,5 & 13,6 & 13,7 & 13,9 & 14,2 & 14,4 & 11,7 \\
\hline $\mathrm{C}_{2} \mathrm{H}_{4}$ & ${ }^{3} J_{\mathrm{HH}_{\mathrm{t}}}$ & 19,3 & 19,2 & 19,3 & 19,3 & 19,5 & 19,7 & 19 \\
\hline $\mathrm{C}_{2} \mathrm{H}_{6}$ & ${ }^{1} J_{\mathrm{CC}}$ & 33,7 & 33,7 & 33,6 & 33,8 & 34,2 & 34,9 & 34,5 \\
\hline $\mathrm{C}_{2} \mathrm{H}_{6}$ & ${ }^{1} J_{\mathrm{CH}}$ & 118,9 & 118,0 & 117,5 & 117,3 & 117,4 & 117,8 & 125,2 \\
\hline $\mathrm{C}_{2} \mathrm{H}_{6}$ & ${ }^{2} J_{\mathrm{CH}}$ & $-3,9$ & $-3,9$ & $-4,0$ & $-4,2$ & $-4,3$ & $-4,5$ & $-4,7$ \\
\hline \multirow[t]{3}{*}{ Total } & DM & 2,91 & 3,47 & 4,26 & 5,28 & 6,59 & 8,05 & - \\
\hline & DMA & 10,28 & 10,56 & 11,11 & 12,02 & 12,90 & 13,79 & - \\
\hline & PDMA & 9,73 & 9,10 & 10,65 & 12,97 & 15,59 & 19,28 & - \\
\hline \multirow[t]{3}{*}{ CPI } & DM & 5,93 & 7,73 & 9,91 & 12,44 & 15,40 & 18,55 & - \\
\hline & DMA & 19,55 & 19,78 & 20,75 & 22,69 & 24,60 & 26,51 & - \\
\hline & PDMA & 12,28 & 11,29 & 14,87 & 19,67 & 24,63 & 29,72 & - \\
\hline \multirow[t]{3}{*}{ SPI } & DM & 0,69 & 0,34 & 0,11 & 0,03 & 0,13 & 0,36 & - \\
\hline & DMA & 3,48 & 3,79 & 4,05 & 4,19 & 4,33 & 4,47 & - \\
\hline & PDMA & 7,87 & 7,49 & 7,56 & 8,05 & 8,97 & 11,62 & - \\
\hline \multirow[t]{3}{*}{$\Delta \mathrm{CS}$} & DM & 5,23 & 7,39 & 9,80 & 12,40 & 15,27 & 18,19 & - \\
\hline & DMA & 16,07 & 15,99 & 16,70 & 18,50 & 20,27 & 22,04 & - \\
\hline & PDMA & 4,41 & 3,80 & 7,31 & 11,62 & 15,67 & 18,10 & - \\
\hline
\end{tabular}


Tabela 8.411: Constantes de acoplamento LC-BB95 com otimização de geometrias para $\alpha=40 \%$ e $\alpha+\beta=90 \%$, variando $\gamma$, na base aug-pcJ-2.

\begin{tabular}{|c|c|c|c|c|c|c|c|c|}
\hline & $\begin{array}{c}\text { Func. } \\
\alpha \\
\alpha+\beta \\
\gamma \\
\end{array}$ & $\begin{array}{c}\text { LCB95 } \\
40 \% \\
90 \% \\
0,20\end{array}$ & $\begin{array}{c}\text { LCB95 } \\
40 \% \\
90 \% \\
0,25\end{array}$ & $\begin{array}{c}\text { LCB95 } \\
40 \% \\
90 \% \\
0,30 \\
\end{array}$ & $\begin{array}{c}\text { LCB95 } \\
40 \% \\
90 \% \\
0,35 \\
\end{array}$ & $\begin{array}{c}\text { LCB95 } \\
40 \% \\
90 \% \\
0,40\end{array}$ & $\begin{array}{c}\text { LCB95 } \\
40 \% \\
90 \% \\
0,45\end{array}$ & $\begin{array}{c}\text { Exp. } \\
- \\
- \\
\end{array}$ \\
\hline $\mathrm{HF}$ & ${ }^{1} J_{\mathrm{HF}}$ & 521,8 & 524,4 & 527,9 & 532,6 & 538,2 & 544,5 & 500 \\
\hline $\mathrm{CO}$ & ${ }^{1} J_{\mathrm{CO}}$ & 12,2 & 12,0 & 11,7 & 11,4 & 11,0 & 10,5 & 16,4 \\
\hline $\mathrm{H}_{2} \mathrm{O}$ & ${ }^{1} J_{\mathrm{OH}}$ & $-83,9$ & $-84,2$ & $-84,6$ & $-85,2$ & $-86,0$ & $-86,8$ & $-80,6$ \\
\hline $\mathrm{H}_{2} \mathrm{O}$ & ${ }^{2} J_{\mathrm{HH}}$ & $-6,8$ & $-6,7$ & $-6,7$ & $-6,8$ & $-6,9$ & $-7,0$ & $-7,3$ \\
\hline $\mathrm{NH}_{3}$ & ${ }^{1} J_{\mathrm{NH}}$ & 45,9 & 45,9 & 46,0 & 46,2 & 46,5 & 46,8 & 43,8 \\
\hline $\mathrm{NH}_{3}$ & ${ }^{2} J_{\mathrm{HH}}$ & $-9,0$ & $-9,0$ & $-9,0$ & $-9,1$ & $-9,2$ & $-9,4$ & $-9,6$ \\
\hline $\mathrm{PH}_{3}$ & ${ }^{1} J_{\mathrm{PH}}$ & 179,8 & 178,0 & 177,4 & 178,1 & 180,0 & 182,8 & 188,2 \\
\hline $\mathrm{PF}_{3}$ & ${ }^{1} J_{\mathrm{PF}}$ & $-1488,9$ & $-1485,6$ & $-1482,7$ & $-1479,9$ & $-1476,9$ & $-1473,1$ & -1441 \\
\hline $\mathrm{BHF}_{2}$ & ${ }^{1} J_{\mathrm{BF}}$ & $-93,7$ & $-90,2$ & $-86,1$ & $-81,6$ & $-76,7$ & $-71,7$ & -84 \\
\hline $\mathrm{BF}_{3}$ & ${ }^{1} J_{\mathrm{BF}}$ & 10,0 & 14,1 & 18,9 & 24,2 & 29,9 & 35,6 & 15 \\
\hline $\mathrm{F}_{2} \mathrm{O}$ & ${ }^{1} J_{\mathrm{OF}}$ & $-191,7$ & $-186,1$ & $-180,1$ & $-173,8$ & $-167,1$ & $-160,5$ & -300 \\
\hline $\mathrm{CH}_{4}$ & ${ }^{1} J_{\mathrm{CH}}$ & 121,0 & 120,2 & 119,7 & 119,4 & 119,5 & 119,8 & 125,3 \\
\hline $\mathrm{CH}_{4}$ & ${ }^{2} J_{\mathrm{HH}}$ & $-12,3$ & $-12,3$ & $-12,5$ & $-12,7$ & $-13,0$ & $-13,3$ & $-12,8$ \\
\hline $\mathrm{C}_{2} \mathrm{H}_{2}$ & ${ }^{1} J_{\mathrm{CC}}$ & 195,4 & 195,2 & 195,3 & 195,6 & 196,2 & 197,2 & 174,8 \\
\hline $\mathrm{C}_{2} \mathrm{H}_{2}$ & ${ }^{1} J_{\mathrm{CH}}$ & 245,9 & 244,2 & 243,0 & 242,2 & 242,0 & 242,2 & 247,6 \\
\hline $\mathrm{C}_{2} \mathrm{H}_{2}$ & ${ }^{2} J_{\mathrm{CH}}$ & 55,8 & 56,0 & 56,2 & 56,3 & 56,3 & 56,2 & 50,1 \\
\hline $\mathrm{C}_{2} \mathrm{H}_{2}$ & ${ }^{3} J_{\mathrm{HH}}$ & 9,8 & 9,7 & 9,8 & 9,9 & 10,1 & 10,3 & 9,6 \\
\hline $\mathrm{C}_{2} \mathrm{H}_{4}$ & ${ }^{1} J_{\mathrm{CC}}$ & 69,5 & 69,4 & 69,5 & 69,8 & 70,3 & 71,0 & 67,6 \\
\hline $\mathrm{C}_{2} \mathrm{H}_{4}$ & ${ }^{1} J_{\mathrm{CH}}$ & 151,8 & 150,9 & 150,3 & 150,1 & 150,3 & 150,7 & 156,3 \\
\hline $\mathrm{C}_{2} \mathrm{H}_{4}$ & ${ }^{2} J_{\mathrm{CH}}$ & $-1,7$ & $-1,7$ & $-1,9$ & $-2,1$ & $-2,4$ & $-2,7$ & $-2,4$ \\
\hline $\mathrm{C}_{2} \mathrm{H}_{4}$ & ${ }^{2} J_{\mathrm{HH}}$ & 2,3 & 2,2 & 2,0 & 1,7 & 1,4 & 1,1 & 2,3 \\
\hline $\mathrm{C}_{2} \mathrm{H}_{4}$ & ${ }^{3} J_{\mathrm{HH}_{\mathrm{c}}}$ & 13,4 & 13,5 & 13,7 & 13,8 & 14,0 & 14,2 & 11,7 \\
\hline $\mathrm{C}_{2} \mathrm{H}_{4}$ & ${ }^{3} J_{\mathrm{HH}_{\mathrm{t}}}$ & 19,4 & 19,4 & 19,4 & 19,4 & 19,6 & 19,7 & 19 \\
\hline $\mathrm{C}_{2} \mathrm{H}_{6}$ & ${ }^{1} J_{\mathrm{CC}}$ & 33,6 & 33,7 & 33,8 & 34,0 & 34,3 & 34,9 & 34,5 \\
\hline $\mathrm{C}_{2} \mathrm{H}_{6}$ & ${ }^{1} J_{\mathrm{CH}}$ & 119,8 & 119,1 & 118,6 & 118,4 & 118,5 & 118,8 & 125,2 \\
\hline $\mathrm{C}_{2} \mathrm{H}_{6}$ & ${ }^{2} J_{\mathrm{CH}}$ & $-3,9$ & $-4,0$ & $-4,0$ & $-4,1$ & $-4,3$ & $-4,4$ & $-4,7$ \\
\hline \multirow[t]{3}{*}{ Total } & DM & 2,71 & 3,20 & 3,87 & 4,72 & 5,79 & 7,02 & - \\
\hline & DMA & 10,04 & 10,18 & 10,57 & 11,18 & 11,97 & 12,75 & - \\
\hline & PDMA & 9,59 & 8,78 & 9,71 & 11,35 & 13,26 & 16,27 & - \\
\hline \multirow[t]{3}{*}{ CPI } & DM & 4,98 & 6,52 & 8,35 & 10,47 & 12,90 & 15,53 & - \\
\hline & DMA & 19,25 & 19,23 & 19,85 & 21,13 & 22,88 & 24,55 & - \\
\hline & PDMA & 12,79 & 10,48 & 12,34 & 15,87 & 20,20 & 24,47 & - \\
\hline \multirow[t]{3}{*}{ SPI } & DM & 1,05 & 0,76 & 0,59 & 0,51 & 0,58 & 0,77 & - \\
\hline & DMA & 3,29 & 3,55 & 3,76 & 3,89 & 3,97 & 4,09 & - \\
\hline & PDMA & 7,25 & 7,54 & 7,77 & 8,04 & 8,17 & 10,25 & - \\
\hline \multirow[t]{3}{*}{$\Delta \mathrm{CS}$} & $\mathrm{DM}$ & 3,94 & 5,76 & 7,76 & 9,97 & 12,32 & 14,75 & - \\
\hline & DMA & 15,97 & 15,68 & 16,09 & 17,23 & 18,92 & 20,45 & - \\
\hline & PDMA & 5,55 & 2,95 & 4,57 & 7,83 & 12,04 & 14,22 & - \\
\hline
\end{tabular}


Tabela 8.412: Constantes de acoplamento LC-BB95 com otimização de geometrias para $\alpha=40 \%$ e $\alpha+\beta=80 \%$, variando $\gamma$, na base aug-pcJ-2.

\begin{tabular}{|c|c|c|c|c|c|c|c|c|}
\hline & $\begin{array}{c}\text { Func. } \\
\alpha \\
\alpha+\beta \\
\gamma \\
\end{array}$ & $\begin{array}{c}\text { LCB95 } \\
40 \% \\
80 \% \\
0,20 \\
\end{array}$ & $\begin{array}{c}\text { LCB95 } \\
40 \% \\
80 \% \\
0,25\end{array}$ & $\begin{array}{c}\text { LCB95 } \\
40 \% \\
80 \% \\
0,30 \\
\end{array}$ & $\begin{array}{c}\text { LCB95 } \\
40 \% \\
80 \% \\
0,35 \\
\end{array}$ & $\begin{array}{c}\text { LCB95 } \\
40 \% \\
80 \% \\
0,40 \\
\end{array}$ & $\begin{array}{c}\text { LCB95 } \\
40 \% \\
80 \% \\
0,45 \\
\end{array}$ & $\begin{array}{c}\text { Exp. } \\
- \\
- \\
-\end{array}$ \\
\hline $\mathrm{HF}$ & ${ }^{1} J_{\mathrm{HF}}$ & 520,6 & 522,7 & 525,5 & 529,3 & 533,8 & 538,8 & 500 \\
\hline $\mathrm{CO}$ & ${ }^{1} J_{\mathrm{CO}}$ & 12,3 & 12,1 & 11,9 & 11,6 & 11,3 & 10,9 & 16,4 \\
\hline $\mathrm{H}_{2} \mathrm{O}$ & ${ }^{1} J_{\mathrm{OH}}$ & $-83,8$ & $-84,0$ & $-84,4$ & $-84,9$ & $-85,5$ & $-86,2$ & $-80,6$ \\
\hline $\mathrm{H}_{2} \mathrm{O}$ & ${ }^{2} J_{\mathrm{HH}}$ & $-6,9$ & $-6,8$ & $-6,8$ & $-6,9$ & $-7,0$ & $-7,1$ & $-7,3$ \\
\hline $\mathrm{NH}_{3}$ & ${ }^{1} J_{\mathrm{NH}}$ & 45,9 & 46,0 & 46,1 & 46,2 & 46,4 & 46,7 & 43,8 \\
\hline $\mathrm{NH}_{3}$ & ${ }^{2} J_{\mathrm{HH}}$ & $-9,2$ & $-9,1$ & $-9,2$ & $-9,2$ & $-9,3$ & $-9,5$ & $-9,6$ \\
\hline $\mathrm{PH}_{3}$ & ${ }^{1} J_{\mathrm{PH}}$ & 181,4 & 179,9 & 179,4 & 179,9 & 181,5 & 183,8 & 188,2 \\
\hline $\mathrm{PF}_{3}$ & ${ }^{1} J_{\mathrm{PF}}$ & $-1491,3$ & $-1488,8$ & $-1486,6$ & $-1484,6$ & $-1482,4$ & $-1479,8$ & -1441 \\
\hline $\mathrm{BHF}_{2}$ & ${ }^{1} J_{\mathrm{BF}}$ & $-94,7$ & $-91,9$ & $-88,6$ & $-84,9$ & $-81,0$ & $-76,9$ & -84 \\
\hline $\mathrm{BF}_{3}$ & ${ }^{1} J_{\mathrm{BF}}$ & 8,5 & 11,8 & 15,7 & 20,0 & 24,5 & 29,2 & 15 \\
\hline $\mathrm{F}_{2} \mathrm{O}$ & ${ }^{1} J_{\mathrm{OF}}$ & $-197,4$ & $-192,7$ & $-187,7$ & $-182,5$ & $-177,0$ & $-171,4$ & -300 \\
\hline $\mathrm{CH}_{4}$ & ${ }^{1} J_{\mathrm{CH}}$ & 121,8 & 121,2 & 120,7 & 120,6 & 120,6 & 120,8 & 125,3 \\
\hline $\mathrm{CH}_{4}$ & ${ }^{2} J_{\mathrm{HH}}$ & $-12,4$ & $-12,5$ & $-12,6$ & $-12,8$ & $-13,0$ & $-13,3$ & $-12,8$ \\
\hline $\mathrm{C}_{2} \mathrm{H}_{2}$ & ${ }^{1} J_{\mathrm{CC}}$ & 196,1 & 196,0 & 196,0 & 196,3 & 196,8 & 197,6 & 174,8 \\
\hline $\mathrm{C}_{2} \mathrm{H}_{2}$ & ${ }^{1} J_{\mathrm{CH}}$ & 247,5 & 246,1 & 245,1 & 244,5 & 244,3 & 244,5 & 247,6 \\
\hline $\mathrm{C}_{2} \mathrm{H}_{2}$ & ${ }^{2} J_{\mathrm{CH}}$ & 55,7 & 55,9 & 56,0 & 56,1 & 56,1 & 56,1 & 50,1 \\
\hline $\mathrm{C}_{2} \mathrm{H}_{2}$ & ${ }^{3} J_{\mathrm{HH}}$ & 9,9 & 9,9 & 9,9 & 10,0 & 10,1 & 10,3 & 9,6 \\
\hline $\mathrm{C}_{2} \mathrm{H}_{4}$ & ${ }^{1} J_{\mathrm{CC}}$ & 70,0 & 69,9 & 70,0 & 70,3 & 70,7 & 71,2 & 67,6 \\
\hline $\mathrm{C}_{2} \mathrm{H}_{4}$ & ${ }^{1} J_{\mathrm{CH}}$ & 152,8 & 152,1 & 151,6 & 151,5 & 151,6 & 151,9 & 156,3 \\
\hline $\mathrm{C}_{2} \mathrm{H}_{4}$ & ${ }^{2} J_{\mathrm{CH}}$ & $-1,7$ & $-1,8$ & $-1,9$ & $-2,1$ & $-2,3$ & $-2,6$ & $-2,4$ \\
\hline $\mathrm{C}_{2} \mathrm{H}_{4}$ & ${ }^{2} J_{\mathrm{HH}}$ & 2,2 & 2,1 & 2,0 & 1,8 & 1,5 & 1,2 & 2,3 \\
\hline $\mathrm{C}_{2} \mathrm{H}_{4}$ & ${ }^{3} J_{\mathrm{HH}_{\mathrm{c}}}$ & 13,4 & 13,5 & 13,6 & 13,8 & 13,9 & 14,1 & 11,7 \\
\hline $\mathrm{C}_{2} \mathrm{H}_{4}$ & ${ }^{3} J_{\mathrm{HH}_{\mathrm{t}}}$ & 19,5 & 19,5 & 19,5 & 19,5 & 19,6 & 19,7 & 19 \\
\hline $\mathrm{C}_{2} \mathrm{H}_{6}$ & ${ }^{1} J_{\mathrm{CC}}$ & 33,8 & 33,9 & 34,0 & 34,1 & 34,4 & 35,0 & 34,5 \\
\hline $\mathrm{C}_{2} \mathrm{H}_{6}$ & ${ }^{1} J_{\mathrm{CH}}$ & 120,7 & 120,1 & 119,7 & 119,5 & 119,6 & 119,8 & 125,2 \\
\hline $\mathrm{C}_{2} \mathrm{H}_{6}$ & ${ }^{2} J_{\mathrm{CH}}$ & $-3,9$ & $-4,0$ & $-4,0$ & $-4,1$ & $-4,2$ & $-4,4$ & $-4,7$ \\
\hline \multirow[t]{3}{*}{ Total } & DM & 2,53 & 2,93 & 3,46 & 4,15 & 5,00 & 5,98 & - \\
\hline & DMA & 9,76 & 9,90 & 10,03 & 10,39 & 10,96 & 11,63 & - \\
\hline & PDMA & 9,86 & 9,15 & 8,55 & 9,63 & 11,22 & 13,51 & - \\
\hline \multirow[t]{3}{*}{ CPI } & DM & 4,05 & 5,30 & 6,76 & 8,46 & 10,40 & 12,51 & - \\
\hline & DMA & 18,88 & 18,92 & 19,00 & 19,72 & 20,96 & 22,38 & - \\
\hline & PDMA & 13,17 & 11,48 & 9,90 & 12,42 & 15,59 & 19,06 & - \\
\hline \multirow[t]{3}{*}{ SPI } & DM & 1,42 & 1,19 & 1,03 & 0,99 & 1,04 & 1,19 & - \\
\hline & DMA & 3,07 & 3,28 & 3,45 & 3,55 & 3,63 & 3,75 & - \\
\hline & PDMA & 7,44 & 7,44 & 7,55 & 7,59 & 8,02 & 9,45 & - \\
\hline \multirow[t]{3}{*}{$\Delta \mathrm{CS}$} & DM & 2,63 & 4,11 & 5,73 & 7,47 & 9,36 & 11,32 & - \\
\hline & DMA & 15,81 & 15,64 & 15,55 & 16,16 & 17,34 & 18,64 & - \\
\hline & PDMA & 5,74 & 4,04 & 2,35 & 4,83 & 7,56 & 9,61 & - \\
\hline
\end{tabular}


Tabela 8.413: Constantes de acoplamento LC-BB95 com otimização de geometrias para $\alpha=40 \%$ e $\alpha+\beta=70 \%$, variando $\gamma$, na base aug-pcJ-2.

\begin{tabular}{|c|c|c|c|c|c|c|c|c|}
\hline & $\begin{array}{c}\text { Func. } \\
\alpha \\
\alpha+\beta \\
\gamma \\
\end{array}$ & $\begin{array}{c}\text { LCB95 } \\
40 \% \\
70 \% \\
0,20\end{array}$ & $\begin{array}{c}\text { LCB95 } \\
40 \% \\
70 \% \\
0,25 \\
\end{array}$ & $\begin{array}{c}\text { LCB95 } \\
40 \% \\
70 \% \\
0,30 \\
\end{array}$ & $\begin{array}{c}\text { LCB95 } \\
40 \% \\
70 \% \\
0,35 \\
\end{array}$ & $\begin{array}{c}\text { LCB95 } \\
40 \% \\
70 \% \\
0,40\end{array}$ & $\begin{array}{c}\text { LCB95 } \\
40 \% \\
70 \% \\
0,45 \\
\end{array}$ & $\begin{array}{c}\text { Exp. } \\
- \\
- \\
\end{array}$ \\
\hline $\mathrm{HF}$ & ${ }^{1} J_{\mathrm{HF}}$ & 519,4 & 520,9 & 523,1 & 525,9 & 529,3 & 533,1 & 500 \\
\hline $\mathrm{CO}$ & ${ }^{1} J_{\mathrm{CO}}$ & 12,4 & 12,2 & 12,1 & 11,9 & 11,6 & 11,3 & 16,4 \\
\hline $\mathrm{H}_{2} \mathrm{O}$ & ${ }^{1} J_{\mathrm{OH}}$ & $-83,7$ & $-83,9$ & $-84,2$ & $-84,6$ & $-85,0$ & $-85,6$ & $-80,6$ \\
\hline $\mathrm{H}_{2} \mathrm{O}$ & ${ }^{2} J_{\mathrm{HH}}$ & $-7,0$ & $-7,0$ & $-7,0$ & $-7,0$ & $-7,1$ & $-7,1$ & $-7,3$ \\
\hline $\mathrm{NH}_{3}$ & ${ }^{1} J_{\mathrm{NH}}$ & 46,0 & 46,0 & 46,1 & 46,2 & 46,4 & 46,6 & 43,8 \\
\hline $\mathrm{NH}_{3}$ & ${ }^{2} J_{\mathrm{HH}}$ & $-9,3$ & $-9,3$ & $-9,3$ & $-9,4$ & $-9,5$ & $-9,6$ & $-9,6$ \\
\hline $\mathrm{PH}_{3}$ & ${ }^{1} J_{\mathrm{PH}}$ & 182,9 & 181,8 & 181,4 & 181,8 & 183,0 & 184,7 & 188,2 \\
\hline $\mathrm{PF}_{3}$ & ${ }^{1} J_{\mathrm{PF}}$ & $-1493,7$ & $-1491,9$ & $-1490,3$ & $-1489,0$ & $-1487,6$ & $-1486,0$ & -1441 \\
\hline $\mathrm{BHF}_{2}$ & ${ }^{1} J_{\mathrm{BF}}$ & $-95,8$ & $-93,6$ & $-91,1$ & $-88,3$ & $-85,3$ & $-82,2$ & -84 \\
\hline $\mathrm{BF}_{3}$ & ${ }^{1} J_{\mathrm{BF}}$ & 6,9 & 9,4 & 12,4 & 15,6 & 19,1 & 22,7 & 15 \\
\hline $\mathrm{F}_{2} \mathrm{O}$ & ${ }^{1} J_{\mathrm{OF}}$ & $-203,1$ & $-199,5$ & $-195,7$ & $-191,5$ & $-187,3$ & $-182,9$ & -300 \\
\hline $\mathrm{CH}_{4}$ & ${ }^{1} J_{\mathrm{CH}}$ & 122,6 & 122,2 & 121,8 & 121,7 & 121,7 & 121,9 & 125,3 \\
\hline $\mathrm{CH}_{4}$ & ${ }^{2} J_{\mathrm{HH}}$ & $-12,6$ & $-12,6$ & $-12,7$ & $-12,9$ & $-13,0$ & $-13,2$ & $-12,8$ \\
\hline $\mathrm{C}_{2} \mathrm{H}_{2}$ & ${ }^{1} J_{\mathrm{CC}}$ & 196,9 & 196,8 & 196,8 & 197,0 & 197,4 & 198,0 & 174,8 \\
\hline $\mathrm{C}_{2} \mathrm{H}_{2}$ & ${ }^{1} J_{\mathrm{CH}}$ & 249,0 & 248,0 & 247,2 & 246,8 & 246,6 & 246,8 & 247,6 \\
\hline $\mathrm{C}_{2} \mathrm{H}_{2}$ & ${ }^{2} J_{\mathrm{CH}}$ & 55,6 & 55,8 & 55,9 & 56,0 & 56,0 & 55,9 & 50,1 \\
\hline $\mathrm{C}_{2} \mathrm{H}_{2}$ & ${ }^{3} J_{\mathrm{HH}}$ & 10,1 & 10,0 & 10,1 & 10,1 & 10,2 & 10,4 & 9,6 \\
\hline $\mathrm{C}_{2} \mathrm{H}_{4}$ & ${ }^{1} J_{\mathrm{CC}}$ & 70,5 & 70,5 & 70,5 & 70,7 & 71,0 & 71,4 & 67,6 \\
\hline $\mathrm{C}_{2} \mathrm{H}_{4}$ & ${ }^{1} J_{\mathrm{CH}}$ & 153,8 & 153,2 & 152,9 & 152,8 & 152,9 & 153,1 & 156,3 \\
\hline $\mathrm{C}_{2} \mathrm{H}_{4}$ & $2 J_{\mathrm{CH}}$ & $-1,8$ & $-1,8$ & $-1,9$ & $-2,1$ & $-2,2$ & $-2,5$ & $-2,4$ \\
\hline $\mathrm{C}_{2} \mathrm{H}_{4}$ & ${ }^{2} J_{\mathrm{HH}}$ & 2,1 & 2,1 & 2,0 & 1,8 & 1,6 & 1,4 & 2,3 \\
\hline $\mathrm{C}_{2} \mathrm{H}_{4}$ & ${ }^{3} J_{\mathrm{HH}_{\mathrm{c}}}$ & 13,4 & 13,5 & 13,6 & 13,7 & 13,8 & 13,9 & 11,7 \\
\hline $\mathrm{C}_{2} \mathrm{H}_{4}$ & ${ }^{3} J_{\mathrm{HH}_{\mathrm{t}}}$ & 19,6 & 19,6 & 19,6 & 19,6 & 19,7 & 19,8 & 19 \\
\hline $\mathrm{C}_{2} \mathrm{H}_{6}$ & ${ }^{1} J_{\mathrm{CC}}$ & 34,1 & 34,1 & 34,2 & 34,3 & 34,5 & 34,7 & 34,5 \\
\hline $\mathrm{C}_{2} \mathrm{H}_{6}$ & ${ }^{1} J_{\mathrm{CH}}$ & 121,6 & 121,1 & 120,8 & 120,7 & 120,8 & 121,0 & 125,2 \\
\hline $\mathrm{C}_{2} \mathrm{H}_{6}$ & ${ }^{2} J_{\mathrm{CH}}$ & $-4,0$ & $-4,0$ & $-4,0$ & $-4,1$ & $-4,2$ & $-4,3$ & $-4,7$ \\
\hline \multirow[t]{3}{*}{ Total } & DM & 2,34 & 2,64 & 3,05 & 3,57 & 4,21 & 4,93 & - \\
\hline & DMA & 9,60 & 9,63 & 9,67 & 9,75 & 10,02 & 10,44 & - \\
\hline & PDMA & 10,02 & 9,44 & 8,75 & 8,20 & 9,24 & 10,63 & - \\
\hline \multirow[t]{3}{*}{ CPI } & DM & 3,10 & 4,02 & 5,15 & 6,43 & 7,88 & 9,46 & - \\
\hline & DMA & 18,55 & 18,56 & 18,55 & 18,65 & 19,21 & 20,12 & - \\
\hline & PDMA & 13,74 & 12,30 & 10,49 & 9,21 & 11,16 & 13,69 & - \\
\hline \multirow[t]{3}{*}{ SPI } & DM & 1,79 & 1,63 & 1,51 & 1,47 & 1,51 & 1,61 & - \\
\hline & DMA & 3,04 & 3,08 & 3,15 & 3,23 & 3,29 & 3,35 & - \\
\hline & PDMA & 7,29 & 7,34 & 7,47 & 7,46 & 7,84 & 8,38 & - \\
\hline \multirow[t]{3}{*}{$\Delta \mathrm{CS}$} & DM & 1,31 & 2,39 & 3,63 & 4,96 & 6,37 & 7,85 & - \\
\hline & DMA & 15,51 & 15,48 & 15,39 & 15,42 & 15,92 & 16,77 & - \\
\hline & PDMA & 6,46 & 4,96 & 3,01 & 1,75 & 3,32 & 5,30 & - \\
\hline
\end{tabular}


Tabela 8.414: Constantes de acoplamento LC-BB95 com otimização de geometrias para $\alpha=50 \%$ e $\alpha+\beta=100 \%$, variando $\gamma$, na base aug-pcJ-2.

\begin{tabular}{|c|c|c|c|c|c|c|c|c|}
\hline & $\begin{array}{c}\text { Func. } \\
\alpha \\
\alpha+\beta \\
\gamma \\
\end{array}$ & $\begin{array}{c}\text { LCB95 } \\
50 \% \\
100 \% \\
0,20 \\
\end{array}$ & $\begin{array}{c}\text { LCB95 } \\
50 \% \\
100 \% \\
0,25 \\
\end{array}$ & $\begin{array}{c}\text { LCB95 } \\
50 \% \\
100 \% \\
0,30 \\
\end{array}$ & $\begin{array}{c}\text { LCB95 } \\
50 \% \\
100 \% \\
0,35\end{array}$ & $\begin{array}{c}\text { LCB95 } \\
50 \% \\
100 \% \\
0,40 \\
\end{array}$ & $\begin{array}{c}\text { LCB95 } \\
50 \% \\
100 \% \\
0,45\end{array}$ & $\begin{array}{c}\text { Exp. } \\
- \\
-\end{array}$ \\
\hline $\mathrm{HF}$ & ${ }^{1} J_{\mathrm{HF}}$ & 557,9 & 560,3 & 563,7 & 568,1 & 573,5 & 579,6 & 500 \\
\hline $\mathrm{CO}$ & ${ }^{1} J_{\mathrm{CO}}$ & 9,1 & 8,9 & 8,7 & 8,4 & 8,0 & 7,5 & 16,4 \\
\hline $\mathrm{H}_{2} \mathrm{O}$ & ${ }^{1} J_{\mathrm{OH}}$ & $-87,7$ & $-87,9$ & $-88,3$ & $-88,9$ & $-89,6$ & $-90,3$ & $-80,6$ \\
\hline $\mathrm{H}_{2} \mathrm{O}$ & ${ }^{2} J_{\mathrm{HH}}$ & $-7,5$ & $-7,4$ & $-7,5$ & $-7,5$ & $-7,6$ & $-7,7$ & $-7,3$ \\
\hline $\mathrm{NH}_{3}$ & ${ }^{1} J_{\mathrm{NH}}$ & 46,9 & 46,9 & 47,0 & 47,2 & 47,4 & 47,7 & 43,8 \\
\hline $\mathrm{NH}_{3}$ & ${ }^{2} J_{\mathrm{HH}}$ & $-9,7$ & $-9,6$ & $-9,7$ & $-9,7$ & $-9,9$ & $-10,0$ & $-9,6$ \\
\hline $\mathrm{PH}_{3}$ & ${ }^{1} J_{\mathrm{PH}}$ & 188,8 & 186,9 & 186,2 & 186,8 & 188,6 & 191,3 & 188,2 \\
\hline $\mathrm{PF}_{3}$ & ${ }^{1} J_{\mathrm{PF}}$ & $-1453,5$ & $-1448,8$ & $-1444,6$ & $-1440,5$ & $-1436,0$ & $-1432,1$ & -1441 \\
\hline $\mathrm{BHF}_{2}$ & ${ }^{1} J_{\mathrm{BF}}$ & $-72,7$ & $-69,4$ & $-65,5$ & $-61,1$ & $-56,5$ & $-51,6$ & -84 \\
\hline $\mathrm{BF}_{3}$ & ${ }^{1} J_{\mathrm{BF}}$ & 33,7 & 37,4 & 42,0 & 47,0 & 52,4 & 57,9 & 15 \\
\hline $\mathrm{F}_{2} \mathrm{O}$ & ${ }^{1} J_{\mathrm{OF}}$ & $-171,8$ & $-166,7$ & $-161,3$ & $-155,6$ & $-149,6$ & $-143,5$ & -300 \\
\hline $\mathrm{CH}_{4}$ & ${ }^{1} J_{\mathrm{CH}}$ & 121,8 & 121,0 & 120,5 & 120,3 & 120,3 & 120,6 & 125,3 \\
\hline $\mathrm{CH}_{4}$ & ${ }^{2} J_{\mathrm{HH}}$ & $-12,9$ & $-13,0$ & $-13,1$ & $-13,4$ & $-13,6$ & $-13,9$ & $-12,8$ \\
\hline $\mathrm{C}_{2} \mathrm{H}_{2}$ & ${ }^{1} J_{\mathrm{CC}}$ & 198,4 & 198,2 & 198,3 & 198,7 & 199,4 & 200,4 & 174,8 \\
\hline $\mathrm{C}_{2} \mathrm{H}_{2}$ & ${ }^{1} J_{\mathrm{CH}}$ & 246,3 & 244,6 & 243,4 & 242,7 & 242,5 & 242,8 & 247,6 \\
\hline $\mathrm{C}_{2} \mathrm{H}_{2}$ & ${ }^{2} J_{\mathrm{CH}}$ & 55,5 & 55,7 & 55,9 & 56,0 & 55,9 & 55,8 & 50,1 \\
\hline $\mathrm{C}_{2} \mathrm{H}_{2}$ & ${ }^{3} J_{\mathrm{HH}}$ & 10,3 & 10,2 & 10,3 & 10,4 & 10,6 & 10,9 & 9,6 \\
\hline $\mathrm{C}_{2} \mathrm{H}_{4}$ & ${ }^{1} J_{\mathrm{CC}}$ & 72,1 & 72,0 & 72,1 & 72,5 & 73,0 & 73,8 & 67,6 \\
\hline $\mathrm{C}_{2} \mathrm{H}_{4}$ & ${ }^{1} J_{\mathrm{CH}}$ & 152,9 & 152,0 & 151,5 & 151,3 & 151,5 & 151,9 & 156,3 \\
\hline $\mathrm{C}_{2} \mathrm{H}_{4}$ & ${ }^{2} J_{\mathrm{CH}}$ & $-2,6$ & $-2,6$ & $-2,8$ & $-3,0$ & $-3,4$ & $-3,7$ & $-2,4$ \\
\hline $\mathrm{C}_{2} \mathrm{H}_{4}$ & ${ }^{2} J_{\mathrm{HH}}$ & 1,6 & 1,5 & 1,3 & 1,0 & 0,7 & 0,3 & 2,3 \\
\hline $\mathrm{C}_{2} \mathrm{H}_{4}$ & ${ }^{3} J_{\mathrm{HH}_{\mathrm{c}}}$ & 13,8 & 13,9 & 14,1 & 14,2 & 14,4 & 14,6 & 11,7 \\
\hline $\mathrm{C}_{2} \mathrm{H}_{4}$ & ${ }^{3} J_{\mathrm{HH}_{\mathrm{t}}}$ & 19,7 & 19,6 & 19,7 & 19,8 & 19,9 & 20,1 & 19 \\
\hline $\mathrm{C}_{2} \mathrm{H}_{6}$ & ${ }^{1} J_{\mathrm{CC}}$ & 35,4 & 35,4 & 35,8 & 36,0 & 36,3 & 36,7 & 34,5 \\
\hline $\mathrm{C}_{2} \mathrm{H}_{6}$ & ${ }^{1} J_{\mathrm{CH}}$ & 120,8 & 120,0 & 119,5 & 119,3 & 119,4 & 119,8 & 125,2 \\
\hline $\mathrm{C}_{2} \mathrm{H}_{6}$ & ${ }^{2} J_{\mathrm{CH}}$ & $-4,4$ & $-4,4$ & $-4,5$ & $-4,6$ & $-4,7$ & $-4,9$ & $-4,7$ \\
\hline \multirow[t]{3}{*}{ Total } & DM & 8,35 & 8,83 & 9,53 & 10,40 & 11,46 & 12,65 & - \\
\hline & DMA & 11,49 & 12,07 & 12,80 & 13,58 & 14,70 & 15,98 & - \\
\hline & PDMA & 14,43 & 15,85 & 18,34 & 21,04 & 24,37 & 28,16 & - \\
\hline \multirow[t]{3}{*}{ CPI } & DM & 17,51 & 19,06 & 20,89 & 23,03 & 25,44 & 27,99 & - \\
\hline & DMA & 22,45 & 23,43 & 24,76 & 26,30 & 28,71 & 31,52 & - \\
\hline & PDMA & 23,44 & 26,15 & 29,99 & 33,98 & 38,66 & 43,62 & - \\
\hline \multirow[t]{3}{*}{ SPI } & DM & 1,64 & 1,33 & 1,19 & 1,14 & 1,21 & 1,41 & - \\
\hline & DMA & 3,45 & 3,73 & 4,02 & 4,25 & 4,42 & 4,59 & - \\
\hline & PDMA & 7,83 & 8,30 & 9,79 & 11,54 & 13,89 & 16,83 & - \\
\hline \multirow[t]{3}{*}{$\Delta \mathrm{CS}$} & DM & 15,87 & 17,73 & 19,70 & 21,89 & 24,23 & 26,58 & - \\
\hline & DMA & 19,00 & 19,69 & 20,74 & 22,05 & 24,29 & 26,92 & - \\
\hline & PDMA & 15,61 & 17,85 & 20,20 & 22,43 & 24,78 & 26,78 & - \\
\hline
\end{tabular}


Tabela 8.415: Constantes de acoplamento LC-BB95 com otimização de geometrias para $\alpha=50 \%$ e $\alpha+\beta=90 \%$, variando $\gamma$, na base aug-pcJ-2.

\begin{tabular}{|c|c|c|c|c|c|c|c|c|}
\hline & $\begin{array}{c}\text { Func. } \\
\alpha \\
\alpha+\beta \\
\gamma \\
\end{array}$ & $\begin{array}{c}\text { LCB95 } \\
50 \% \\
90 \% \\
0,20\end{array}$ & $\begin{array}{c}\text { LCB95 } \\
50 \% \\
90 \% \\
0,25\end{array}$ & $\begin{array}{c}\text { LCB95 } \\
50 \% \\
90 \% \\
0,30 \\
\end{array}$ & $\begin{array}{c}\text { LCB95 } \\
50 \% \\
90 \% \\
0,35 \\
\end{array}$ & $\begin{array}{c}\text { LCB95 } \\
50 \% \\
90 \% \\
0,40\end{array}$ & $\begin{array}{c}\text { LCB95 } \\
50 \% \\
90 \% \\
0,45 \\
\end{array}$ & $\begin{array}{c}\text { Exp. } \\
- \\
- \\
\end{array}$ \\
\hline $\mathrm{HF}$ & ${ }^{1} J_{\mathrm{HF}}$ & 556,8 & 558,7 & 561,5 & 565,1 & 569,4 & 574,3 & 500 \\
\hline $\mathrm{CO}$ & ${ }^{1} J_{\mathrm{CO}}$ & 9,2 & 9,0 & 8,8 & 8,6 & 8,3 & 7,9 & 16,4 \\
\hline $\mathrm{H}_{2} \mathrm{O}$ & ${ }^{1} J_{\mathrm{OH}}$ & $-87,6$ & $-87,8$ & $-88,2$ & $-88,6$ & $-89,2$ & $-89,8$ & $-80,6$ \\
\hline $\mathrm{H}_{2} \mathrm{O}$ & ${ }^{2} J_{\mathrm{HH}}$ & $-7,6$ & $-7,6$ & $-7,6$ & $-7,6$ & $-7,7$ & $-7,8$ & $-7,3$ \\
\hline $\mathrm{NH}_{3}$ & ${ }^{1} J_{\mathrm{NH}}$ & 47,0 & 47,0 & 47,1 & 47,2 & 47,4 & 47,6 & 43,8 \\
\hline $\mathrm{NH}_{3}$ & ${ }^{2} J_{\mathrm{HH}}$ & $-9,8$ & $-9,8$ & $-9,8$ & $-9,9$ & $-10,0$ & $-10,1$ & $-9,6$ \\
\hline $\mathrm{PH}_{3}$ & ${ }^{1} J_{\mathrm{PH}}$ & 190,4 & 188,9 & 188,3 & 188,7 & 190,2 & 192,4 & 188,2 \\
\hline $\mathrm{PF}_{3}$ & ${ }^{1} J_{\mathrm{PF}}$ & $-1456,2$ & $-1452,9$ & $-1449,7$ & $-1446,0$ & $-1442,7$ & $-1439,0$ & -1441 \\
\hline $\mathrm{BHF}_{2}$ & ${ }^{1} J_{\mathrm{BF}}$ & $-73,6$ & $-70,9$ & $-67,7$ & $-64,2$ & $-60,4$ & $-56,5$ & -84 \\
\hline $\mathrm{BF}_{3}$ & ${ }^{1} J_{\mathrm{BF}}$ & 32,3 & 35,3 & 39,0 & 43,1 & 47,4 & 51,9 & 15 \\
\hline $\mathrm{F}_{2} \mathrm{O}$ & ${ }^{1} J_{\mathrm{OF}}$ & $-177,0$ & $-172,8$ & $-168,3$ & $-163,5$ & $-158,5$ & $-153,4$ & -300 \\
\hline $\mathrm{CH}_{4}$ & ${ }^{1} J_{\mathrm{CH}}$ & 122,6 & 122,0 & 121,6 & 121,4 & 121,4 & 121,7 & 125,3 \\
\hline $\mathrm{CH}_{4}$ & ${ }^{2} J_{\mathrm{HH}}$ & $-13,1$ & $-13,1$ & $-13,2$ & $-13,4$ & $-13,7$ & $-13,9$ & $-12,8$ \\
\hline $\mathrm{C}_{2} \mathrm{H}_{2}$ & ${ }^{1} J_{\mathrm{CC}}$ & 199,2 & 199,0 & 199,1 & 199,4 & 200,0 & 200,8 & 174,8 \\
\hline $\mathrm{C}_{2} \mathrm{H}_{2}$ & ${ }^{1} J_{\mathrm{CH}}$ & 247,9 & 246,5 & 245,5 & 245,0 & 244,8 & 245,0 & 247,6 \\
\hline $\mathrm{C}_{2} \mathrm{H}_{2}$ & ${ }^{2} J_{\mathrm{CH}}$ & 55,4 & 55,6 & 55,7 & 55,8 & 55,8 & 55,7 & 50,1 \\
\hline $\mathrm{C}_{2} \mathrm{H}_{2}$ & ${ }^{3} J_{\mathrm{HH}}$ & 10,4 & 10,4 & 10,4 & 10,5 & 10,7 & 10,9 & 9,6 \\
\hline $\mathrm{C}_{2} \mathrm{H}_{4}$ & ${ }^{1} J_{\mathrm{CC}}$ & 72,6 & 72,6 & 72,7 & 73,0 & 73,4 & 74,0 & 67,6 \\
\hline $\mathrm{C}_{2} \mathrm{H}_{4}$ & ${ }^{1} J_{\mathrm{CH}}$ & 153,9 & 153,2 & 152,8 & 152,6 & 152,8 & 153,1 & 156,3 \\
\hline $\mathrm{C}_{2} \mathrm{H}_{4}$ & $2 J_{\mathrm{CH}}$ & $-2,7$ & $-2,7$ & $-2,8$ & $-3,0$ & $-3,3$ & $-3,6$ & $-2,4$ \\
\hline $\mathrm{C}_{2} \mathrm{H}_{4}$ & ${ }^{2} J_{\mathrm{HH}}$ & 1,5 & 1,4 & 1,3 & 1,0 & 0,7 & 0,4 & 2,3 \\
\hline $\mathrm{C}_{2} \mathrm{H}_{4}$ & ${ }^{3} J_{\mathrm{HH}_{\mathrm{c}}}$ & 13,8 & 13,9 & 14,0 & 14,2 & 14,3 & 14,5 & 11,7 \\
\hline $\mathrm{C}_{2} \mathrm{H}_{4}$ & ${ }^{3} J_{\mathrm{HH}_{\mathrm{t}}}$ & 19,8 & 19,7 & 19,8 & 19,8 & 20,0 & 20,1 & 19 \\
\hline $\mathrm{C}_{2} \mathrm{H}_{6}$ & ${ }^{1} J_{\mathrm{CC}}$ & 35,6 & 35,7 & 36,0 & 36,1 & 36,4 & 36,7 & 34,5 \\
\hline $\mathrm{C}_{2} \mathrm{H}_{6}$ & ${ }^{1} J_{\mathrm{CH}}$ & 121,7 & 121,0 & 120,6 & 120,4 & 120,5 & 120,8 & 125,2 \\
\hline $\mathrm{C}_{2} \mathrm{H}_{6}$ & ${ }^{2} J_{\mathrm{CH}}$ & $-4,4$ & $-4,4$ & $-4,5$ & $-4,6$ & $-4,7$ & $-4,8$ & $-4,7$ \\
\hline \multirow[t]{3}{*}{ Total } & DM & 8,20 & 8,57 & 9,13 & 9,85 & 10,70 & 11,69 & - \\
\hline & DMA & 11,27 & 11,67 & 12,22 & 12,84 & 13,59 & 14,52 & - \\
\hline & PDMA & 14,49 & 15,74 & 17,39 & 19,78 & 22,59 & 25,65 & - \\
\hline \multirow[t]{3}{*}{ CPI } & DM & 16,64 & 17,84 & 19,32 & 21,09 & 23,03 & 25,15 & - \\
\hline & DMA & 22,07 & 22,75 & 23,75 & 24,98 & 26,52 & 28,55 & - \\
\hline & PDMA & 22,58 & 24,89 & 27,80 & 31,14 & 34,93 & 38,98 & - \\
\hline \multirow[t]{3}{*}{ SPI } & DM & 2,01 & 1,78 & 1,66 & 1,61 & 1,67 & 1,82 & - \\
\hline & DMA & 3,34 & 3,54 & 3,75 & 3,94 & 4,11 & 4,23 & - \\
\hline & PDMA & 8,55 & 9,02 & 9,76 & 11,45 & 13,54 & 15,86 & - \\
\hline \multirow[t]{3}{*}{$\Delta \mathrm{CS}$} & DM & 14,63 & 16,06 & 17,66 & 19,48 & 21,36 & 23,33 & - \\
\hline & DMA & 18,73 & 19,21 & 20,00 & 21,04 & 22,41 & 24,31 & - \\
\hline & PDMA & 14,03 & 15,87 & 18,04 & 19,69 & 21,39 & 23,12 & - \\
\hline
\end{tabular}


Tabela 8.416: Constantes de acoplamento LC-BB95 com otimização de geometrias para $\alpha=50 \%$ e $\alpha+\beta=80 \%$, variando $\gamma$, na base aug-pcJ-2.

\begin{tabular}{|c|c|c|c|c|c|c|c|c|}
\hline & $\begin{array}{c}\text { Func. } \\
\alpha \\
\alpha+\beta \\
\gamma \\
\end{array}$ & $\begin{array}{c}\text { LCB95 } \\
50 \% \\
80 \% \\
0,20 \\
\end{array}$ & $\begin{array}{c}\text { LCB95 } \\
50 \% \\
80 \% \\
0,25 \\
\end{array}$ & $\begin{array}{c}\text { LCB95 } \\
50 \% \\
80 \% \\
0,30 \\
\end{array}$ & $\begin{array}{c}\text { LCB95 } \\
50 \% \\
80 \% \\
0,35\end{array}$ & $\begin{array}{c}\text { LCB95 } \\
50 \% \\
80 \% \\
0,40 \\
\end{array}$ & $\begin{array}{c}\text { LCB95 } \\
50 \% \\
80 \% \\
0,45\end{array}$ & $\begin{array}{c}\text { Exp. } \\
- \\
-\end{array}$ \\
\hline $\mathrm{HF}$ & ${ }^{1} J_{\mathrm{HF}}$ & 555,7 & 557,2 & 559,3 & 562,0 & 565,2 & 569,0 & 500 \\
\hline $\mathrm{CO}$ & ${ }^{1} J_{\mathrm{CO}}$ & 9,2 & 9,1 & 9,0 & 8,8 & 8,5 & 8,3 & 16,4 \\
\hline $\mathrm{H}_{2} \mathrm{O}$ & ${ }^{1} J_{\mathrm{OH}}$ & $-87,6$ & $-87,7$ & $-88,0$ & $-88,3$ & $-88,8$ & $-89,2$ & $-80,6$ \\
\hline $\mathrm{H}_{2} \mathrm{O}$ & ${ }^{2} J_{\mathrm{HH}}$ & $-7,7$ & $-7,7$ & $-7,7$ & $-7,7$ & $-7,8$ & $-7,9$ & $-7,3$ \\
\hline $\mathrm{NH}_{3}$ & ${ }^{1} J_{\mathrm{NH}}$ & 47,0 & 47,0 & 47,1 & 47,2 & 47,4 & 47,5 & 43,8 \\
\hline $\mathrm{NH}_{3}$ & ${ }^{2} J_{\mathrm{HH}}$ & $-10,0$ & $-10,0$ & $-10,0$ & $-10,0$ & $-10,1$ & $-10,2$ & $-9,6$ \\
\hline $\mathrm{PH}_{3}$ & ${ }^{1} J_{\mathrm{PH}}$ & 192,0 & 190,8 & 190,4 & 190,7 & 191,8 & 193,5 & 188,2 \\
\hline $\mathrm{PF}_{3}$ & ${ }^{1} J_{\mathrm{PF}}$ & $-1458,9$ & $-1456,4$ & $-1454,1$ & $-1451,9$ & $-1449,7$ & $-1446,5$ & -1441 \\
\hline $\mathrm{BHF}_{2}$ & ${ }^{1} J_{\mathrm{BF}}$ & $-74,4$ & $-72,4$ & $-70,0$ & $-67,4$ & $-64,5$ & $-61,5$ & -84 \\
\hline $\mathrm{BF}_{3}$ & ${ }^{1} J_{\mathrm{BF}}$ & 30,9 & 33,2 & 36,0 & 39,1 & 42,4 & 45,8 & 15 \\
\hline $\mathrm{F}_{2} \mathrm{O}$ & ${ }^{1} J_{\mathrm{OF}}$ & $-182,4$ & $-179,1$ & $-175,6$ & $-171,8$ & $-167,9$ & $-163,9$ & -300 \\
\hline $\mathrm{CH}_{4}$ & ${ }^{1} J_{\mathrm{CH}}$ & 123,5 & 123,0 & 122,7 & 122,5 & 122,6 & 122,7 & 125,3 \\
\hline $\mathrm{CH}_{4}$ & ${ }^{2} J_{\mathrm{HH}}$ & $-13,3$ & $-13,3$ & $-13,4$ & $-13,5$ & $-13,7$ & $-13,9$ & $-12,8$ \\
\hline $\mathrm{C}_{2} \mathrm{H}_{2}$ & ${ }^{1} J_{\mathrm{CC}}$ & 200,0 & 199,9 & 199,9 & 200,2 & 200,6 & 201,2 & 174,8 \\
\hline $\mathrm{C}_{2} \mathrm{H}_{2}$ & ${ }^{1} J_{\mathrm{CH}}$ & 249,5 & 248,5 & 247,7 & 247,3 & 247,1 & 247,3 & 247,6 \\
\hline $\mathrm{C}_{2} \mathrm{H}_{2}$ & ${ }^{2} J_{\mathrm{CH}}$ & 55,4 & 55,5 & 55,6 & 55,6 & 55,6 & 55,5 & 50,1 \\
\hline $\mathrm{C}_{2} \mathrm{H}_{2}$ & ${ }^{3} J_{\mathrm{HH}}$ & 10,5 & 10,4 & 10,6 & 10,7 & 10,8 & 11,0 & 9,6 \\
\hline $\mathrm{C}_{2} \mathrm{H}_{4}$ & ${ }^{1} J_{\mathrm{CC}}$ & 73,2 & 73,1 & 73,2 & 73,4 & 73,8 & 74,3 & 67,6 \\
\hline $\mathrm{C}_{2} \mathrm{H}_{4}$ & ${ }^{1} J_{\mathrm{CH}}$ & 154,9 & 154,4 & 154,1 & 153,9 & 154,0 & 154,3 & 156,3 \\
\hline $\mathrm{C}_{2} \mathrm{H}_{4}$ & ${ }^{2} J_{\mathrm{CH}}$ & $-2,7$ & $-2,8$ & $-2,9$ & $-3,0$ & $-3,2$ & $-3,4$ & $-2,4$ \\
\hline $\mathrm{C}_{2} \mathrm{H}_{4}$ & ${ }^{2} J_{\mathrm{HH}}$ & 1,4 & 1,3 & 1,2 & 1,0 & 0,8 & 0,6 & 2,3 \\
\hline $\mathrm{C}_{2} \mathrm{H}_{4}$ & ${ }^{3} J_{\mathrm{HH}_{\mathrm{c}}}$ & 13,8 & 13,9 & 14,0 & 14,1 & 14,2 & 14,3 & 11,7 \\
\hline $\mathrm{C}_{2} \mathrm{H}_{4}$ & ${ }^{3} J_{\mathrm{HH}_{\mathrm{t}}}$ & 19,9 & 19,9 & 19,9 & 19,9 & 20,0 & 20,1 & 19 \\
\hline $\mathrm{C}_{2} \mathrm{H}_{6}$ & ${ }^{1} J_{\mathrm{CC}}$ & 35,9 & 35,9 & 36,2 & 36,3 & 36,5 & 36,8 & 34,5 \\
\hline $\mathrm{C}_{2} \mathrm{H}_{6}$ & ${ }^{1} J_{\mathrm{CH}}$ & 122,6 & 122,1 & 121,7 & 121,6 & 121,7 & 121,9 & 125,2 \\
\hline $\mathrm{C}_{2} \mathrm{H}_{6}$ & ${ }^{2} J_{\mathrm{CH}}$ & $-4,4$ & $-4,4$ & $-4,5$ & $-4,6$ & $-4,6$ & $-4,7$ & $-4,7$ \\
\hline \multirow[t]{3}{*}{ Total } & DM & 8,04 & 8,32 & 8,75 & 9,27 & 9,91 & 10,69 & - \\
\hline & DMA & 11,15 & 11,38 & 11,76 & 12,25 & 12,83 & 13,41 & - \\
\hline & PDMA & 14,50 & 15,58 & 16,96 & 18,57 & 20,70 & 22,80 & - \\
\hline \multirow[t]{3}{*}{ CPI } & DM & 15,72 & 16,65 & 17,77 & 19,07 & 20,51 & 22,18 & - \\
\hline & DMA & 21,70 & 22,21 & 22,99 & 23,98 & 25,20 & 26,44 & - \\
\hline & PDMA & 21,87 & 23,60 & 25,78 & 28,27 & 31,28 & 34,31 & - \\
\hline \multirow[t]{3}{*}{ SPI } & DM & 2,41 & 2,22 & 2,13 & 2,09 & 2,14 & 2,26 & - \\
\hline & DMA & 3,41 & 3,45 & 3,53 & 3,65 & 3,77 & 3,86 & - \\
\hline & PDMA & 9,10 & 9,70 & 10,49 & 11,46 & 12,94 & 14,36 & - \\
\hline \multirow[t]{3}{*}{$\Delta \mathrm{CS}$} & DM & 13,31 & 14,43 & 15,65 & 16,99 & 18,37 & 19,92 & - \\
\hline & DMA & 18,29 & 18,76 & 19,46 & 20,34 & 21,43 & 22,58 & - \\
\hline & PDMA & 12,77 & 13,90 & 15,29 & 16,81 & 18,34 & 19,96 & - \\
\hline
\end{tabular}


Tabela 8.417: Constantes de acoplamento LC-BB95 com otimização de geometrias para $\alpha=50 \%$ e $\alpha+\beta=70 \%$, variando $\gamma$, na base aug-pcJ-2.

\begin{tabular}{|c|c|c|c|c|c|c|c|c|}
\hline & $\begin{array}{c}\text { Func. } \\
\alpha \\
\alpha+\beta \\
\gamma \\
\end{array}$ & $\begin{array}{c}\text { LCB95 } \\
50 \% \\
70 \% \\
0,20 \\
\end{array}$ & $\begin{array}{c}\text { LCB95 } \\
50 \% \\
70 \% \\
0,25 \\
\end{array}$ & $\begin{array}{c}\text { LCB95 } \\
50 \% \\
70 \% \\
0,30 \\
\end{array}$ & $\begin{array}{c}\text { LCB95 } \\
50 \% \\
70 \% \\
0,35 \\
\end{array}$ & $\begin{array}{c}\text { LCB95 } \\
50 \% \\
70 \% \\
0,40 \\
\end{array}$ & $\begin{array}{c}\text { LCB95 } \\
50 \% \\
70 \% \\
0,45\end{array}$ & $\begin{array}{c}\text { Exp. } \\
- \\
-\end{array}$ \\
\hline $\mathrm{HF}$ & ${ }^{1} J_{\mathrm{HF}}$ & 554,6 & 555,6 & 557,0 & 558,8 & 561,0 & 563,5 & 500 \\
\hline $\mathrm{CO}$ & ${ }^{1} J_{\mathrm{CO}}$ & 9,3 & 9,2 & 9,1 & 9,0 & 8,8 & 8,6 & 16,4 \\
\hline $\mathrm{H}_{2} \mathrm{O}$ & ${ }^{1} J_{\mathrm{OH}}$ & $-87,5$ & $-87,6$ & $-87,8$ & $-88,0$ & $-88,3$ & $-88,7$ & $-80,6$ \\
\hline $\mathrm{H}_{2} \mathrm{O}$ & ${ }^{2} J_{\mathrm{HH}}$ & $-7,9$ & $-7,8$ & $-7,8$ & $-7,9$ & $-7,9$ & $-7,9$ & $-7,3$ \\
\hline $\mathrm{NH}_{3}$ & ${ }^{1} J_{\mathrm{NH}}$ & 47,1 & 47,1 & 47,1 & 47,2 & 47,3 & 47,4 & 43,8 \\
\hline $\mathrm{NH}_{3}$ & ${ }^{2} J_{\mathrm{HH}}$ & $-10,2$ & $-10,1$ & $-10,2$ & $-10,2$ & $-10,2$ & $-10,3$ & $-9,6$ \\
\hline $\mathrm{PH}_{3}$ & ${ }^{1} J_{\mathrm{PH}}$ & 193,6 & 192,8 & 192,5 & 192,7 & 193,5 & 194,6 & 188,2 \\
\hline $\mathrm{PF}_{3}$ & ${ }^{1} J_{\mathrm{PF}}$ & $-1461,5$ & $-1459,9$ & $-1458,4$ & $-1457,1$ & $-1455,7$ & $-1454,2$ & -1441 \\
\hline $\mathrm{BHF}_{2}$ & ${ }^{1} J_{\mathrm{BF}}$ & $-75,3$ & $-74,0$ & $-72,4$ & $-70,6$ & $-68,6$ & $-66,6$ & -84 \\
\hline $\mathrm{BF}_{3}$ & ${ }^{1} J_{\mathrm{BF}}$ & 29,5 & 31,0 & 32,9 & 35,0 & 37,3 & 39,6 & 15 \\
\hline $\mathrm{F}_{2} \mathrm{O}$ & ${ }^{1} J_{\mathrm{OF}}$ & $-187,9$ & $-185,6$ & $-183,2$ & $-180,6$ & $-177,8$ & $-175,1$ & -300 \\
\hline $\mathrm{CH}_{4}$ & ${ }^{1} J_{\mathrm{CH}}$ & 124,3 & 124,0 & 123,8 & 123,7 & 123,7 & 123,8 & 125,3 \\
\hline $\mathrm{CH}_{4}$ & ${ }^{2} J_{\mathrm{HH}}$ & $-13,4$ & $-13,4$ & $-13,5$ & $-13,6$ & $-13,7$ & $-13,8$ & $-12,8$ \\
\hline $\mathrm{C}_{2} \mathrm{H}_{2}$ & ${ }^{1} J_{\mathrm{CC}}$ & 200,8 & 200,7 & 200,7 & 200,9 & 201,2 & 201,6 & 174,8 \\
\hline $\mathrm{C}_{2} \mathrm{H}_{2}$ & ${ }^{1} J_{\mathrm{CH}}$ & 251,1 & 250,4 & 249,9 & 249,6 & 249,5 & 249,6 & 247,6 \\
\hline $\mathrm{C}_{2} \mathrm{H}_{2}$ & ${ }^{2} J_{\mathrm{CH}}$ & 55,3 & 55,4 & 55,4 & 55,5 & 55,4 & 55,4 & 50,1 \\
\hline $\mathrm{C}_{2} \mathrm{H}_{2}$ & ${ }^{3} J_{\mathrm{HH}}$ & 10,7 & 10,7 & 10,7 & 10,8 & 10,9 & 11,0 & 9,6 \\
\hline $\mathrm{C}_{2} \mathrm{H}_{4}$ & ${ }^{1} J_{\mathrm{CC}}$ & 73,7 & 73,7 & 73,8 & 73,9 & 74,2 & 74,5 & 67,6 \\
\hline $\mathrm{C}_{2} \mathrm{H}_{4}$ & ${ }^{1} J_{\mathrm{CH}}$ & 156,0 & 155,6 & 155,4 & 155,3 & 155,4 & 155,5 & 156,3 \\
\hline $\mathrm{C}_{2} \mathrm{H}_{4}$ & ${ }^{2} J_{\mathrm{CH}}$ & $-2,8$ & $-2,8$ & $-2,9$ & $-3,0$ & $-3,1$ & $-3,3$ & $-2,4$ \\
\hline $\mathrm{C}_{2} \mathrm{H}_{4}$ & ${ }^{2} J_{\mathrm{HH}}$ & 1,3 & 1,3 & 1,2 & 1,1 & 0,9 & 0,8 & 2,3 \\
\hline $\mathrm{C}_{2} \mathrm{H}_{4}$ & ${ }^{3} J_{\mathrm{HH}_{\mathrm{c}}}$ & 13,8 & 13,8 & 13,9 & 14,0 & 14,0 & 14,1 & 11,7 \\
\hline $\mathrm{C}_{2} \mathrm{H}_{4}$ & ${ }^{3} J_{\mathrm{HH}_{\mathrm{t}}}$ & 20,0 & 20,0 & 20,0 & 20,0 & 20,1 & 20,1 & 19 \\
\hline $\mathrm{C}_{2} \mathrm{H}_{6}$ & ${ }^{1} J_{\mathrm{CC}}$ & 36,1 & 36,4 & 36,4 & 36,5 & 36,6 & 36,8 & 34,5 \\
\hline $\mathrm{C}_{2} \mathrm{H}_{6}$ & ${ }^{1} J_{\mathrm{CH}}$ & 123,4 & 123,1 & 122,9 & 122,8 & 122,8 & 123,0 & 125,2 \\
\hline $\mathrm{C}_{2} \mathrm{H}_{6}$ & ${ }^{2} J_{\mathrm{CH}}$ & $-4,5$ & $-4,5$ & $-4,5$ & $-4,5$ & $-4,6$ & $-4,7$ & $-4,7$ \\
\hline \multirow[t]{3}{*}{ Total } & DM & 7,87 & 8,08 & 8,35 & 8,70 & 9,14 & 9,63 & - \\
\hline & DMA & 11,01 & 11,17 & 11,42 & 11,76 & 12,15 & 12,57 & - \\
\hline & PDMA & 14,61 & 15,07 & 16,14 & 17,36 & 18,71 & 20,12 & - \\
\hline \multirow[t]{3}{*}{ CPI } & DM & 14,81 & 15,44 & 16,17 & 17,04 & 18,05 & 19,09 & - \\
\hline & DMA & 21,30 & 21,64 & 22,17 & 22,87 & 23,72 & 24,62 & - \\
\hline & PDMA & 21,22 & 22,16 & 23,73 & 25,54 & 27,47 & 29,52 & - \\
\hline \multirow[t]{3}{*}{ SPI } & DM & 2,78 & 2,69 & 2,61 & 2,59 & 2,61 & 2,69 & - \\
\hline & DMA & 3,46 & 3,50 & 3,54 & 3,61 & 3,67 & 3,74 & - \\
\hline & PDMA & 9,77 & 9,87 & 10,57 & 11,37 & 12,28 & 13,23 & - \\
\hline \multirow[t]{3}{*}{$\Delta \mathrm{CS}$} & DM & 12,03 & 12,75 & 13,57 & 14,44 & 15,43 & 16,40 & - \\
\hline & DMA & 17,84 & 18,14 & 18,63 & 19,27 & 20,05 & 20,88 & - \\
\hline & PDMA & 11,46 & 12,29 & 13,16 & 14,16 & 15,18 & 16,29 & - \\
\hline
\end{tabular}


Tabela 8.418: Constantes de acoplamento LC-SLYP com otimização de geometrias para $\alpha=30 \%$ e $\alpha+\beta=100 \%$, variando $\gamma$, na base aug-pcJ-2.

\begin{tabular}{|c|c|c|c|c|c|c|c|c|c|}
\hline & $\begin{array}{c}\text { Func. } \\
\alpha \\
\alpha+\beta \\
\gamma \\
\end{array}$ & $\begin{array}{c}\text { LCSLP } \\
30 \% \\
100 \% \\
0,05\end{array}$ & $\begin{array}{c}\text { LCSLP } \\
30 \% \\
100 \% \\
0,10\end{array}$ & $\begin{array}{c}\text { LCSLP } \\
30 \% \\
100 \% \\
0,15\end{array}$ & $\begin{array}{c}\text { LCSLP } \\
30 \% \\
100 \% \\
0,20\end{array}$ & $\begin{array}{c}\text { LCSLP } \\
30 \% \\
100 \% \\
0,25\end{array}$ & $\begin{array}{c}\text { LCSLP } \\
30 \% \\
100 \% \\
0,30\end{array}$ & $\begin{array}{c}\text { LCSLP } \\
30 \% \\
100 \% \\
0,35\end{array}$ & $\begin{array}{c}\text { Exp. } \\
- \\
- \\
-\end{array}$ \\
\hline $\mathrm{HF}$ & ${ }^{1} J_{\mathrm{HF}}$ & 472,6 & 472,3 & 472,7 & 474,4 & 477,8 & 483,1 & 490,2 & 500 \\
\hline $\mathrm{CO}$ & ${ }^{1} J_{\mathrm{CO}}$ & 14,8 & 14,7 & 14,4 & 14,0 & 13,6 & 13,0 & 12,4 & 16,4 \\
\hline $\mathrm{H}_{2} \mathrm{O}$ & ${ }^{1} J_{\mathrm{OH}}$ & $-78,5$ & $-78,4$ & $-78,6$ & $-78,9$ & $-79,5$ & $-80,5$ & $-81,7$ & $-80,6$ \\
\hline $\mathrm{H}_{2} \mathrm{O}$ & ${ }^{2} J_{\mathrm{HH}}$ & $-5,8$ & $-5,8$ & $-5,8$ & $-5,8$ & $-5,9$ & $-6,1$ & $-6,3$ & $-7,3$ \\
\hline $\mathrm{NH}_{3}$ & ${ }^{1} J_{\mathrm{NH}}$ & 44,5 & 44,6 & 44,7 & 44,9 & 45,2 & 45,5 & 46,1 & 43,8 \\
\hline $\mathrm{NH}_{3}$ & ${ }^{2} J_{\mathrm{HH}}$ & $-7,6$ & $-7,6$ & $-7,6$ & $-7,7$ & $-7,8$ & $-8,1$ & $-8,3$ & $-9,6$ \\
\hline $\mathrm{PH}_{3}$ & ${ }^{1} J_{\mathrm{PH}}$ & 167,5 & 166,9 & 165,4 & 163,9 & 163,6 & 164,9 & 168,2 & 188,2 \\
\hline $\mathrm{PF}_{3}$ & ${ }^{1} J_{\mathrm{PF}}$ & $-1621,3$ & $-1619,6$ & $-1617,2$ & $-1614,2$ & $-1611,1$ & $-1607,8$ & $-1604,1$ & -1441 \\
\hline $\mathrm{BHF}_{2}$ & ${ }^{1} J_{\mathrm{BF}}$ & $-116,6$ & $-116,0$ & $-113,7$ & $-109,7$ & $-104,2$ & $-97,8$ & $-90,7$ & -84 \\
\hline $\mathrm{BF}_{3}$ & ${ }^{1} J_{\mathrm{BF}}$ & $-7,5$ & $-7,1$ & $-5,1$ & $-1,3$ & 4,2 & 11,0 & 18,7 & 15 \\
\hline $\mathrm{F}_{2} \mathrm{O}$ & ${ }^{1} J_{\mathrm{OF}}$ & $-175,0$ & $-177,2$ & $-179,3$ & $-180,3$ & $-179,7$ & $-177,4$ & $-173,5$ & -300 \\
\hline $\mathrm{CH}_{4}$ & ${ }^{1} J_{\mathrm{CH}}$ & 117,4 & 117,3 & 117,1 & 116,9 & 116,9 & 117,3 & 118,0 & 125,3 \\
\hline $\mathrm{CH}_{4}$ & ${ }^{2} J_{\mathrm{HH}}$ & $-10,9$ & $-10,9$ & $-11,0$ & $-11,2$ & $-11,5$ & $-12,0$ & $-12,5$ & $-12,8$ \\
\hline $\mathrm{C}_{2} \mathrm{H}_{2}$ & ${ }^{1} J_{\mathrm{CC}}$ & 190,4 & 190,6 & 191,1 & 191,8 & 192,7 & 193,8 & 195,3 & 174,8 \\
\hline $\mathrm{C}_{2} \mathrm{H}_{2}$ & ${ }^{1} J_{\mathrm{CH}}$ & 242,9 & 242,4 & 241,7 & 240,9 & 240,5 & 240,6 & 241,4 & 247,6 \\
\hline $\mathrm{C}_{2} \mathrm{H}_{2}$ & ${ }^{2} J_{\mathrm{CH}}$ & 53,5 & 53,6 & 54,0 & 54,4 & 54,9 & 55,2 & 55,5 & 50,1 \\
\hline $\mathrm{C}_{2} \mathrm{H}_{2}$ & ${ }^{3} J_{\mathrm{HH}}$ & 8,9 & 8,9 & 8,8 & 8,9 & 9,0 & 9,2 & 9,6 & 9,6 \\
\hline $\mathrm{C}_{2} \mathrm{H}_{4}$ & ${ }^{1} J_{\mathrm{CC}}$ & 65,7 & 65,9 & 66,4 & 67,1 & 67,9 & 68,8 & 70,0 & 67,6 \\
\hline $\mathrm{C}_{2} \mathrm{H}_{4}$ & ${ }^{1} J_{\mathrm{CH}}$ & 147,0 & 146,8 & 146,5 & 146,3 & 146,4 & 146,9 & 147,9 & 156,3 \\
\hline $\mathrm{C}_{2} \mathrm{H}_{4}$ & ${ }^{2} J_{\mathrm{CH}}$ & $-1,1$ & $-1,1$ & $-1,1$ & $-1,2$ & $-1,4$ & $-1,7$ & $-2,1$ & $-2,4$ \\
\hline $\mathrm{C}_{2} \mathrm{H}_{4}$ & ${ }^{2} J_{\mathrm{HH}}$ & 3,0 & 3,0 & 3,0 & 2,8 & 2,6 & 2,2 & 1,7 & 2,3 \\
\hline $\mathrm{C}_{2} \mathrm{H}_{4}$ & ${ }^{3} J_{\mathrm{HH}_{\mathrm{c}}}$ & 13,3 & 13,3 & 13,4 & 13,5 & 13,7 & 14,0 & 14,3 & 11,7 \\
\hline $\mathrm{C}_{2} \mathrm{H}_{4}$ & ${ }^{3} J_{\mathrm{HH}_{\mathrm{t}}}$ & 18,9 & 18,8 & 18,8 & 18,8 & 18,9 & 19,1 & 19,4 & 19 \\
\hline $\mathrm{C}_{2} \mathrm{H}_{6}$ & ${ }^{1} J_{\mathrm{CC}}$ & 30,6 & 30,8 & 31,2 & 31,6 & 32,1 & 32,7 & 33,4 & 34,5 \\
\hline $\mathrm{C}_{2} \mathrm{H}_{6}$ & ${ }^{1} J_{\mathrm{CH}}$ & 115,3 & 115,1 & 115,0 & 114,9 & 115,0 & 115,5 & 116,3 & 125,2 \\
\hline $\mathrm{C}_{2} \mathrm{H}_{6}$ & ${ }^{2} J_{\mathrm{CH}}$ & $-3,2$ & $-3,2$ & $-3,3$ & $-3,3$ & $-3,5$ & $-3,6$ & $-3,9$ & $-4,7$ \\
\hline \multirow[t]{3}{*}{ Total } & DM & $-6,39$ & $-6,42$ & $-6,29$ & $-5,90$ & $-5,18$ & $-4,12$ & $-2,68$ & - \\
\hline & DMA & 18,49 & 18,39 & 18,15 & 17,73 & 17,08 & 16,23 & 15,57 & - \\
\hline & PDMA & 19,98 & 19,89 & 19,29 & 17,62 & 15,02 & 11,79 & 11,13 & - \\
\hline \multirow[t]{3}{*}{ CPI } & DM & $-13,98$ & $-14,01$ & $-13,73$ & $-12,87$ & $-11,34$ & $-9,19$ & $-6,35$ & - \\
\hline & DMA & 37,85 & 37,52 & 36,84 & 35,76 & 34,25 & 32,30 & 30,86 & - \\
\hline & PDMA & 28,62 & 28,36 & 27,05 & 24,44 & 20,46 & 15,28 & 14,27 & - \\
\hline \multirow[t]{3}{*}{ SPI } & $\mathrm{DM}$ & $-0,83$ & $-0,85$ & $-0,83$ & $-0,79$ & $-0,66$ & $-0,41$ & 0,01 & - \\
\hline & DMA & 4,29 & 4,36 & 4,45 & 4,50 & 4,50 & 4,45 & 4,35 & - \\
\hline & PDMA & 13,65 & 13,68 & 13,61 & 12,62 & 11,04 & 9,24 & 8,82 & - \\
\hline \multirow[t]{3}{*}{$\Delta \mathrm{CS}$} & $\mathrm{DM}$ & $-13,16$ & $-13,16$ & $-12,89$ & $-12,08$ & $-10,68$ & $-8,78$ & $-6,37$ & - \\
\hline & DMA & 33,56 & 33,16 & 32,39 & 31,26 & 29,75 & 27,85 & 26,52 & - \\
\hline & PDMA & 14,97 & 14,67 & 13,44 & 11,82 & 9,42 & 6,05 & 5,45 & - \\
\hline
\end{tabular}


Tabela 8.419: Constantes de acoplamento LC-SLYP com otimização de geometrias para $\alpha=30 \%$ e $\alpha+\beta=90 \%$, variando $\gamma$, na base aug-pcJ-2.

\begin{tabular}{|c|c|c|c|c|c|c|c|c|c|}
\hline & $\begin{array}{c}\text { Func. } \\
\alpha \\
\alpha+\beta \\
\gamma\end{array}$ & $\begin{array}{c}\text { LCSLP } \\
30 \% \\
90 \% \\
0,05\end{array}$ & $\begin{array}{c}\text { LCSLP } \\
30 \% \\
90 \% \\
0,10\end{array}$ & $\begin{array}{c}\text { LCSLP } \\
30 \% \\
90 \% \\
0,15\end{array}$ & $\begin{array}{c}\text { LCSLP } \\
30 \% \\
90 \% \\
0,20\end{array}$ & $\begin{array}{c}\text { LCSLP } \\
30 \% \\
90 \% \\
0,25\end{array}$ & $\begin{array}{c}\text { LCSLP } \\
30 \% \\
90 \% \\
0,30\end{array}$ & $\begin{array}{c}\text { LCSLP } \\
30 \% \\
90 \% \\
0,35\end{array}$ & $\begin{array}{l}\text { Exp. } \\
- \\
-\end{array}$ \\
\hline HF & ${ }^{1} J_{\mathrm{HF}}$ & 472,6 & 472,4 & 472,7 & 474,2 & 477,1 & 481,6 & 487,7 & 500 \\
\hline $\mathrm{CO}$ & ${ }^{1} J_{C O}$ & 14,8 & 14,7 & 14,5 & 14,1 & 13,7 & 13,3 & 12,8 & 16,4 \\
\hline $\mathrm{H}_{2} \mathrm{O}$ & ${ }^{1} J_{\mathrm{OH}}$ & $-78,5$ & $-78,5$ & $-78,6$ & $-78,8$ & $-79,4$ & $-80,2$ & $-81,2$ & $-80,6$ \\
\hline $\mathrm{H}_{2} \mathrm{O}$ & ${ }^{2} J_{\mathrm{HH}}$ & $-5,8$ & $-5,8$ & $-5,8$ & $-5,8$ & $-5,9$ & $-6,0$ & $-6,2$ & $-7,3$ \\
\hline $\mathrm{NH}_{3}$ & ${ }^{1} J_{\mathrm{NH}}$ & 44,5 & 44,6 & 44,6 & 44,8 & 45,1 & 45,3 & 45,9 & 43,8 \\
\hline $\mathrm{NH}_{3}$ & ${ }^{2} J_{\mathrm{HH}}$ & $-7,6$ & $-7,6$ & $-7,6$ & $-7,7$ & $-7,8$ & $-8,0$ & $-8,2$ & $-9,6$ \\
\hline $\mathrm{PH}_{3}$ & ${ }^{1} J_{\mathrm{PH}}$ & 167,5 & 167,0 & 165,7 & 164,4 & 164,1 & 165,2 & 168,1 & 188,2 \\
\hline $\mathrm{PF}_{3}$ & ${ }^{1} J_{\mathrm{PF}}$ & $-1621,4$ & $-1619,9$ & $-1617,9$ & $-1615,4$ & $-1612,8$ & $-1610,3$ & $-1607,5$ & -1441 \\
\hline $\mathrm{BHF}_{2}$ & ${ }^{1} J_{\mathrm{BF}}$ & $-116,5$ & $-116,0$ & $-114,1$ & $-110,6$ & $-105,9$ & $-100,4$ & $-94,3$ & -84 \\
\hline $\mathrm{BF}_{3}$ & ${ }^{1} J_{\mathrm{BF}}$ & $-7,5$ & $-7,2$ & $-5,4$ & $-2,1$ & 2,6 & 8,4 & 15,1 & 15 \\
\hline $\mathrm{F}_{2} \mathrm{O}$ & ${ }^{1} J_{\mathrm{OF}}$ & $-174,8$ & $-176,8$ & $-178,5$ & $-179,4$ & $-178,8$ & $-176,8$ & $-173,3$ & -300 \\
\hline $\mathrm{CH}_{4}$ & ${ }^{1} J_{\mathrm{CH}}$ & 117,4 & 117,3 & 117,1 & 117,0 & 117,0 & 117,3 & 117,9 & 125,3 \\
\hline $\mathrm{CH}_{4}$ & ${ }^{2} J_{\mathrm{HH}}$ & $-10,9$ & $-10,9$ & $-11,0$ & $-11,1$ & $-11,4$ & $-11,8$ & $-12,3$ & $-12,8$ \\
\hline $\mathrm{C}_{2} \mathrm{H}_{2}$ & ${ }^{1} J_{\mathrm{CC}}$ & 190,4 & 190,6 & 191,0 & 191,6 & 192,3 & 193,3 & 194,6 & 174,8 \\
\hline $\mathrm{C}_{2} \mathrm{H}_{2}$ & ${ }^{1} J_{\mathrm{CH}}$ & 242,9 & 242,5 & 241,9 & 241,2 & 240,8 & 240,9 & 241,6 & 247,6 \\
\hline $\mathrm{C}_{2} \mathrm{H}_{2}$ & ${ }^{2} J_{\mathrm{CH}}$ & 53,5 & 53,6 & 53,9 & 54,3 & 54,7 & 55,0 & 55,2 & 50,1 \\
\hline $\mathrm{C}_{2} \mathrm{H}_{2}$ & ${ }^{3} J_{\mathrm{HH}}$ & 8,9 & 8,9 & 8,8 & 8,9 & 9,0 & 9,2 & 9,5 & 9,6 \\
\hline $\mathrm{C}_{2} \mathrm{H}_{4}$ & ${ }^{1} J_{\mathrm{CC}}$ & 65,7 & 65,9 & 66,3 & 66,9 & 67,5 & 68,4 & 69,4 & 67,6 \\
\hline $\mathrm{C}_{2} \mathrm{H}_{4}$ & ${ }^{1} J_{\mathrm{CH}}$ & 147,0 & 146,9 & 146,6 & 146,4 & 146,5 & 146,9 & 147,7 & 156,3 \\
\hline $\mathrm{C}_{2} \mathrm{H}_{4}$ & ${ }^{2} J_{\mathrm{CH}}$ & $-1,1$ & $-1,1$ & $-1,1$ & $-1,2$ & $-1,3$ & $-1,6$ & $-2,0$ & $-2,4$ \\
\hline $\mathrm{C}_{2} \mathrm{H}_{4}$ & ${ }^{2} J_{\mathrm{HH}}$ & 3,0 & 3,0 & 3,0 & 2,9 & 2,6 & 2,3 & 1,9 & 2,3 \\
\hline $\mathrm{C}_{2} \mathrm{H}_{4}$ & ${ }^{3} J_{\mathrm{HH}_{\mathrm{c}}}$ & 13,3 & 13,3 & 13,4 & 13,5 & 13,7 & 13,9 & 14,1 & 11,7 \\
\hline $\mathrm{C}_{2} \mathrm{H}_{4}$ & ${ }^{3} J_{\mathrm{HH}_{\mathrm{t}}}$ & 18,9 & 18,8 & 18,8 & 18,8 & 18,9 & 19,1 & 19,3 & 19 \\
\hline $\mathrm{C}_{2} \mathrm{H}_{6}$ & ${ }^{1} J_{\mathrm{CC}}$ & 30,6 & 30,8 & 31,1 & 31,4 & 31,9 & 32,4 & 33,0 & 34,5 \\
\hline $\mathrm{C}_{2} \mathrm{H}_{6}$ & ${ }^{1} J_{\mathrm{CH}}$ & 115,3 & 115,2 & 115,0 & 115,0 & 115,1 & 115,5 & 116,2 & 125,2 \\
\hline $\mathrm{C}_{2} \mathrm{H}_{6}$ & ${ }^{2} J_{\mathrm{CH}}$ & $-3,2$ & $-3,2$ & $-3,3$ & $-3,3$ & $-3,4$ & $-3,6$ & $-3,8$ & $-4,7$ \\
\hline \multirow[t]{3}{*}{ Total } & $\mathrm{DM}$ & $-6,38$ & $-6,40$ & $-6,30$ & $-5,96$ & $-5,35$ & $-4,45$ & $-3,22$ & - \\
\hline & DMA & 18,50 & 18,40 & 18,20 & 17,85 & 17,28 & 16,56 & 15,73 & - \\
\hline & PDMA & 19,98 & 19,91 & 19,37 & 18,05 & 15,74 & 12,62 & 10,26 & - \\
\hline \multirow[t]{3}{*}{ CPI } & DM & $-13,96$ & $-14,00$ & $-13,75$ & $-13,02$ & $-11,72$ & $-9,89$ & $-7,45$ & - \\
\hline & DMA & 37,87 & 37,56 & 36,99 & 36,07 & 34,79 & 33,16 & 31,35 & - \\
\hline & PDMA & 28,61 & 28,41 & 27,21 & 24,97 & 21,57 & 17,23 & 12,45 & - \\
\hline \multirow[t]{3}{*}{ SPI } & $\mathrm{DM}$ & $-0,83$ & $-0,83$ & $-0,84$ & $-0,79$ & $-0,68$ & $-0,46$ & $-0,12$ & - \\
\hline & DMA & 4,29 & 4,34 & 4,43 & 4,48 & 4,44 & 4,38 & 4,28 & - \\
\hline & PDMA & 13,65 & 13,67 & 13,61 & 12,97 & 11,46 & 9,24 & 8,65 & - \\
\hline \multirow[t]{3}{*}{$\Delta \mathrm{CS}$} & DM & $-13,14$ & $-13,17$ & $-12,91$ & $-12,23$ & $-11,04$ & $-9,43$ & $-7,33$ & - \\
\hline & DMA & 33,58 & 33,22 & 32,56 & 31,59 & 30,35 & 28,78 & 27,07 & - \\
\hline & PDMA & 14,97 & 14,74 & 13,60 & 12,00 & 10,11 & 8,00 & 3,80 & - \\
\hline
\end{tabular}


Tabela 8.420: Constantes de acoplamento LC-SLYP com otimização de geometrias para $\alpha=30 \%$ e $\alpha+\beta=80 \%$, variando $\gamma$, na base aug-pcJ-2.

\begin{tabular}{|c|c|c|c|c|c|c|c|c|c|}
\hline & $\begin{array}{c}\text { Func. } \\
\alpha \\
\alpha+\beta \\
\gamma\end{array}$ & $\begin{array}{c}\text { LCSLP } \\
30 \% \\
80 \% \\
0,05\end{array}$ & $\begin{array}{c}\text { LCSLP } \\
30 \% \\
80 \% \\
0,10\end{array}$ & $\begin{array}{c}\text { LCSLP } \\
30 \% \\
80 \% \\
0,15\end{array}$ & $\begin{array}{c}\text { LCSLP } \\
30 \% \\
80 \% \\
0,20\end{array}$ & $\begin{array}{c}\text { LCSLP } \\
30 \% \\
80 \% \\
0,25\end{array}$ & $\begin{array}{c}\text { LCSLP } \\
30 \% \\
80 \% \\
0,30\end{array}$ & $\begin{array}{c}\text { LCSLP } \\
30 \% \\
80 \% \\
0,35\end{array}$ & $\begin{array}{l}\text { Exp. } \\
- \\
-\end{array}$ \\
\hline $\mathrm{HF}$ & ${ }^{1} J_{\mathrm{HF}}$ & 472,7 & 472,5 & 472,8 & 474,0 & 476,4 & 480,1 & 485,2 & 500 \\
\hline $\mathrm{CO}$ & ${ }^{1} J_{\mathrm{CO}}$ & 14,8 & 14,7 & 14,5 & 14,3 & 13,9 & 13,5 & 13,1 & 16,4 \\
\hline $\mathrm{H}_{2} \mathrm{O}$ & ${ }^{1} J_{\mathrm{OH}}$ & $-78,5$ & $-78,5$ & $-78,5$ & $-78,8$ & $-79,3$ & $-79,9$ & $-80,8$ & $-80,6$ \\
\hline $\mathrm{H}_{2} \mathrm{O}$ & ${ }^{2} J_{\mathrm{HH}}$ & $-5,8$ & $-5,8$ & $-5,8$ & $-5,8$ & $-5,9$ & $-6,0$ & $-6,1$ & $-7,3$ \\
\hline $\mathrm{NH}_{3}$ & ${ }^{1} J_{\mathrm{NH}}$ & 44,5 & 44,6 & 44,6 & 44,8 & 45,0 & 45,3 & 45,7 & 43,8 \\
\hline $\mathrm{NH}_{3}$ & ${ }^{2} J_{\mathrm{HH}}$ & $-7,6$ & $-7,6$ & $-7,6$ & $-7,7$ & $-7,8$ & $-7,9$ & $-8,1$ & $-9,6$ \\
\hline $\mathrm{PH}_{3}$ & ${ }^{1} J_{\mathrm{PH}}$ & 167,5 & 167,0 & 166,0 & 164,9 & 164,6 & 165,6 & 167,9 & 188,2 \\
\hline $\mathrm{PF}_{3}$ & ${ }^{1} J_{\mathrm{PF}}$ & $-1621,5$ & $-1620,3$ & $-1618,6$ & $-1616,5$ & $-1614,5$ & $-1612,7$ & $-1610,7$ & -1441 \\
\hline $\mathrm{BHF}_{2}$ & ${ }^{1} J_{\mathrm{BF}}$ & $-116,5$ & $-116,1$ & $-114,5$ & $-111,6$ & $-107,6$ & $-103,0$ & $-97,9$ & -84 \\
\hline $\mathrm{BF}_{3}$ & ${ }^{1} J_{\mathrm{BF}}$ & $-7,5$ & $-7,2$ & $-5,8$ & $-3,0$ & 0,9 & 5,8 & 11,4 & 15 \\
\hline $\mathrm{F}_{2} \mathrm{O}$ & ${ }^{1} J_{\mathrm{OF}}$ & $-174,7$ & $-176,3$ & $-177,8$ & $-178,4$ & $-177,9$ & $-176,2$ & $-173,2$ & -300 \\
\hline $\mathrm{CH}_{4}$ & ${ }^{1} J_{\mathrm{CH}}$ & 117,4 & 117,3 & 117,2 & 117,0 & 117,1 & 117,3 & 117,8 & 125,3 \\
\hline $\mathrm{CH}_{4}$ & ${ }^{2} J_{\mathrm{HH}}$ & $-10,9$ & $-10,9$ & $-11,0$ & $-11,1$ & $-11,3$ & $-11,7$ & $-12,1$ & $-12,8$ \\
\hline $\mathrm{C}_{2} \mathrm{H}_{2}$ & ${ }^{1} J_{\mathrm{CC}}$ & 190,4 & 190,6 & 190,9 & 191,4 & 192,0 & 192,8 & 193,9 & 174,8 \\
\hline $\mathrm{C}_{2} \mathrm{H}_{2}$ & ${ }^{1} J_{\mathrm{CH}}$ & 242,9 & 242,6 & 242,0 & 241,5 & 241,2 & 241,2 & 241,8 & 247,6 \\
\hline $\mathrm{C}_{2} \mathrm{H}_{2}$ & ${ }^{2} J_{\mathrm{CH}}$ & 53,5 & 53,6 & 53,8 & 54,1 & 54,5 & 54,8 & 54,9 & 50,1 \\
\hline $\mathrm{C}_{2} \mathrm{H}_{2}$ & ${ }^{3} J_{\mathrm{HH}}$ & 8,9 & 8,9 & 8,9 & 8,9 & 9,0 & 9,1 & 9,4 & 9,6 \\
\hline $\mathrm{C}_{2} \mathrm{H}_{4}$ & ${ }^{1} J_{\mathrm{CC}}$ & 65,7 & 65,9 & 66,2 & 66,7 & 67,2 & 67,9 & 68,7 & 67,6 \\
\hline $\mathrm{C}_{2} \mathrm{H}_{4}$ & ${ }^{1} J_{\mathrm{CH}}$ & 147,0 & 146,9 & 146,7 & 146,5 & 146,6 & 146,9 & 147,6 & 156,3 \\
\hline $\mathrm{C}_{2} \mathrm{H}_{4}$ & ${ }^{2} J_{\mathrm{CH}}$ & $-1,1$ & $-1,1$ & $-1,1$ & $-1,2$ & $-1,3$ & $-1,5$ & $-1,8$ & $-2,4$ \\
\hline $\mathrm{C}_{2} \mathrm{H}_{4}$ & ${ }^{2} J_{\mathrm{HH}}$ & 3,0 & 3,0 & 3,0 & 2,9 & 2,7 & 2,4 & 2,1 & 2,3 \\
\hline $\mathrm{C}_{2} \mathrm{H}_{4}$ & ${ }^{3} J_{\mathrm{HH}_{\mathrm{c}}}$ & 13,3 & 13,3 & 13,4 & 13,5 & 13,6 & 13,8 & 14,0 & 11,7 \\
\hline $\mathrm{C}_{2} \mathrm{H}_{4}$ & ${ }^{3} J_{\mathrm{HH}_{\mathrm{t}}}$ & 18,9 & 18,8 & 18,8 & 18,8 & 18,9 & 19,0 & 19,2 & 19 \\
\hline $\mathrm{C}_{2} \mathrm{H}_{6}$ & ${ }^{1} J_{\mathrm{CC}}$ & 30,6 & 30,7 & 31,0 & 31,4 & 31,8 & 32,0 & 32,7 & 34,5 \\
\hline $\mathrm{C}_{2} \mathrm{H}_{6}$ & ${ }^{1} J_{\mathrm{CH}}$ & 115,3 & 115,2 & 115,0 & 115,0 & 115,0 & 115,4 & 116,0 & 125,2 \\
\hline $\mathrm{C}_{2} \mathrm{H}_{6}$ & ${ }^{2} J_{\mathrm{CH}}$ & $-3,3$ & $-3,2$ & $-3,3$ & $-3,3$ & $-3,4$ & $-3,5$ & $-3,7$ & $-4,7$ \\
\hline \multirow[t]{3}{*}{ Total } & $\mathrm{DM}$ & $-6,38$ & $-6,40$ & $-6,32$ & $-6,03$ & $-5,52$ & $-4,79$ & $-3,77$ & - \\
\hline & DMA & 18,50 & 18,43 & 18,26 & 17,96 & 17,49 & 16,90 & 16,17 & - \\
\hline & PDMA & 19,90 & 19,93 & 19,45 & 18,27 & 16,38 & 13,84 & 11,42 & - \\
\hline \multirow[t]{3}{*}{ CPI } & DM & $-13,95$ & $-13,99$ & $-13,78$ & $-13,15$ & $-12,10$ & $-10,57$ & $-8,58$ & - \\
\hline & DMA & 37,88 & 37,65 & 37,16 & 36,39 & 35,34 & 34,03 & 32,47 & - \\
\hline & PDMA & 28,62 & 28,44 & 27,52 & 25,53 & 22,69 & 19,15 & 15,01 & - \\
\hline \multirow[t]{3}{*}{ SPI } & DM & $-0,83$ & $-0,83$ & $-0,84$ & $-0,80$ & $-0,70$ & $-0,55$ & $-0,24$ & - \\
\hline & DMA & 4,29 & 4,34 & 4,40 & 4,44 & 4,41 & 4,33 & 4,21 & - \\
\hline & PDMA & 13,51 & 13,69 & 13,54 & 12,95 & 11,74 & 9,95 & 8,79 & - \\
\hline \multirow[t]{3}{*}{$\Delta \mathrm{CS}$} & DM & $-13,12$ & $-13,16$ & $-12,94$ & $-12,35$ & $-11,40$ & $-10,03$ & $-8,34$ & - \\
\hline & DMA & 33,60 & 33,31 & 32,76 & 31,95 & 30,93 & 29,69 & 28,26 & - \\
\hline & PDMA & 15,11 & 14,75 & 13,97 & 12,58 & 10,95 & 9,19 & 6,22 & - \\
\hline
\end{tabular}


Tabela 8.421: Constantes de acoplamento LC-SLYP com otimização de geometrias para $\alpha=40 \%$ e $\alpha+\beta=100 \%$, variando $\gamma$, na base aug-pcJ-2.

\begin{tabular}{|c|c|c|c|c|c|c|c|c|c|}
\hline & $\begin{array}{c}\text { Func. } \\
\alpha \\
\alpha+\beta \\
\gamma\end{array}$ & $\begin{array}{c}\text { LCSLP } \\
40 \% \\
100 \% \\
0,05\end{array}$ & $\begin{array}{c}\text { LCSLP } \\
40 \% \\
100 \% \\
0,10\end{array}$ & $\begin{array}{c}\text { LCSLP } \\
40 \% \\
100 \% \\
0,15\end{array}$ & $\begin{array}{c}\text { LCSLP } \\
40 \% \\
100 \% \\
0,20\end{array}$ & $\begin{array}{c}\text { LCSLP } \\
40 \% \\
100 \% \\
0,25\end{array}$ & $\begin{array}{c}\text { LCSLP } \\
40 \% \\
100 \% \\
0,30\end{array}$ & $\begin{array}{c}\text { LCSLP } \\
40 \% \\
100 \% \\
0,35\end{array}$ & $\begin{array}{l}\text { Exp. } \\
- \\
-\end{array}$ \\
\hline $\mathrm{HF}$ & ${ }^{1} J_{\mathrm{HF}}$ & 509,4 & 508,4 & 509,4 & 510,8 & 513,8 & 518,3 & 524,4 & 500 \\
\hline $\mathrm{CO}$ & ${ }^{1} J_{C O}$ & 11,4 & 11,3 & 11,0 & 10,7 & 10,3 & 9,9 & 9,4 & 16,4 \\
\hline $\mathrm{H}_{2} \mathrm{O}$ & ${ }^{1} J_{\mathrm{OH}}$ & $-83,0$ & $-83,0$ & $-83,1$ & $-83,4$ & $-83,9$ & $-84,7$ & $-85,7$ & $-80,6$ \\
\hline $\mathrm{H}_{2} \mathrm{O}$ & ${ }^{2} J_{\mathrm{HH}}$ & $-6,8$ & $-6,8$ & $-6,8$ & $-6,8$ & $-6,9$ & $-7,1$ & $-7,3$ & $-7,3$ \\
\hline $\mathrm{NH}_{3}$ & ${ }^{1} J_{\mathrm{NH}}$ & 46,2 & 46,2 & 46,3 & 46,5 & 46,7 & 47,1 & 47,5 & 43,8 \\
\hline $\mathrm{NH}_{3}$ & ${ }^{2} J_{\mathrm{HH}}$ & $-8,7$ & $-8,6$ & $-8,7$ & $-8,7$ & $-8,9$ & $-9,1$ & $-9,3$ & $-9,6$ \\
\hline $\mathrm{PH}_{3}$ & ${ }^{1} J_{\mathrm{PH}}$ & 181,3 & 180,8 & 179,6 & 178,3 & 178,0 & 179,1 & 181,9 & 188,2 \\
\hline $\mathrm{PF}_{3}$ & ${ }^{1} J_{\mathrm{PF}}$ & $-1590,8$ & $-1589,2$ & $-1586,5$ & $-1582,8$ & $-1578,6$ & $-1574,2$ & $-1569,4$ & -1441 \\
\hline $\mathrm{BHF}_{2}$ & ${ }^{1} J_{\mathrm{BF}}$ & $-94,6$ & $-94,2$ & $-92,3$ & $-89,0$ & $-84,4$ & $-79,0$ & $-73,1$ & -84 \\
\hline $\mathrm{BF}_{3}$ & ${ }^{1} J_{\mathrm{BF}}$ & 15,7 & 16,0 & 17,6 & 20,8 & 25,4 & 31,0 & 37,4 & 15 \\
\hline $\mathrm{F}_{2} \mathrm{O}$ & ${ }^{1} J_{\mathrm{OF}}$ & $-170,1$ & $-172,0$ & $-173,9$ & $-174,9$ & $-174,7$ & $-173,0$ & $-170,0$ & -300 \\
\hline $\mathrm{CH}_{4}$ & ${ }^{1} J_{\mathrm{CH}}$ & 120,8 & 120,8 & 120,6 & 120,5 & 120,5 & 120,8 & 121,5 & 125,3 \\
\hline $\mathrm{CH}_{4}$ & ${ }^{2} J_{\mathrm{HH}}$ & $-12,1$ & $-12,0$ & $-12,1$ & $-12,3$ & $-12,6$ & $-13,0$ & $-13,4$ & $-12,8$ \\
\hline $\mathrm{C}_{2} \mathrm{H}_{2}$ & ${ }^{1} J_{\mathrm{CC}}$ & 195,9 & 196,0 & 196,5 & 197,1 & 197,9 & 199,0 & 200,5 & 174,8 \\
\hline $\mathrm{C}_{2} \mathrm{H}_{2}$ & ${ }^{1} J_{\mathrm{CH}}$ & 247,9 & 247,5 & 246,9 & 246,3 & 246,0 & 246,2 & 246,9 & 247,6 \\
\hline $\mathrm{C}_{2} \mathrm{H}_{2}$ & ${ }^{2} J_{\mathrm{CH}}$ & 53,8 & 53,9 & 54,1 & 54,5 & 54,8 & 55,1 & 55,2 & 50,1 \\
\hline $\mathrm{C}_{2} \mathrm{H}_{2}$ & ${ }^{3} J_{\mathrm{HH}}$ & 9,7 & 9,7 & 9,7 & 9,7 & 9,9 & 10,2 & 10,5 & 9,6 \\
\hline $\mathrm{C}_{2} \mathrm{H}_{4}$ & ${ }^{1} J_{\mathrm{CC}}$ & 70,0 & 70,2 & 70,7 & 71,3 & 72,1 & 73,0 & 74,2 & 67,6 \\
\hline $\mathrm{C}_{2} \mathrm{H}_{4}$ & ${ }^{1} J_{\mathrm{CH}}$ & 151,2 & 151,1 & 150,8 & 150,7 & 150,8 & 151,3 & 152,2 & 156,3 \\
\hline $\mathrm{C}_{2} \mathrm{H}_{4}$ & ${ }^{2} J_{\mathrm{CH}}$ & $-2,1$ & $-2,1$ & $-2,1$ & $-2,2$ & $-2,4$ & $-2,8$ & $-3,2$ & $-2,4$ \\
\hline $\mathrm{C}_{2} \mathrm{H}_{4}$ & ${ }^{2} J_{\mathrm{HH}}$ & 2,1 & 2,2 & 2,1 & 2,0 & 1,8 & 1,4 & 0,9 & 2,3 \\
\hline $\mathrm{C}_{2} \mathrm{H}_{4}$ & ${ }^{3} J_{\mathrm{HH}_{\mathrm{c}}}$ & 13,8 & 13,8 & 13,9 & 14,0 & 14,2 & 14,5 & 14,8 & 11,7 \\
\hline $\mathrm{C}_{2} \mathrm{H}_{4}$ & ${ }^{3} J_{\mathrm{HH}_{\mathrm{t}}}{ }^{\mathrm{C}}$ & 19,5 & 19,4 & 19,4 & 19,5 & 19,6 & 19,8 & 20,1 & 19 \\
\hline $\mathrm{C}_{2} \mathrm{H}_{6}$ & ${ }^{1} J_{\mathrm{CC}}$ & 33,3 & 33,5 & 33,9 & 34,3 & 34,7 & 35,2 & 35,8 & 34,5 \\
\hline $\mathrm{C}_{2} \mathrm{H}_{6}$ & ${ }^{1} J_{\mathrm{CH}}$ & 119,0 & 118,9 & 118,7 & 118,7 & 118,8 & 119,2 & 120,0 & 125,2 \\
\hline $\mathrm{C}_{2} \mathrm{H}_{6}$ & ${ }^{2} J_{\mathrm{CH}}$ & $-3,8$ & $-3,8$ & $-3,8$ & $-3,9$ & $-4,0$ & $-4,2$ & $-4,4$ & $-4,7$ \\
\hline \multirow[t]{3}{*}{ Total } & $\mathrm{DM}$ & $-0,62$ & $-0,65$ & $-0,50$ & $-0,13$ & 0,53 & 1,50 & 2,78 & - \\
\hline & DMA & 14,15 & 14,00 & 14,00 & 14,02 & 14,10 & 14,68 & 15,35 & - \\
\hline & PDMA & 9,14 & 9,08 & 9,65 & 10,41 & 11,49 & 14,66 & 18,42 & - \\
\hline \multirow[t]{3}{*}{ CPI } & DM & $-2,81$ & $-2,91$ & $-2,57$ & $-1,76$ & $-0,37$ & 1,58 & 4,08 & - \\
\hline & DMA & 28,95 & 28,60 & 28,39 & 28,27 & 28,28 & 29,38 & 30,77 & - \\
\hline & PDMA & 11,97 & 12,20 & 13,07 & 14,93 & 17,27 & 21,17 & 25,76 & - \\
\hline \multirow[t]{3}{*}{ SPI } & $\mathrm{DM}$ & 0,99 & 1,00 & 1,01 & 1,07 & 1,20 & 1,44 & 1,83 & - \\
\hline & DMA & 3,29 & 3,29 & 3,44 & 3,57 & 3,71 & 3,89 & 4,05 & - \\
\hline & PDMA & 7,06 & 6,79 & 7,15 & 7,09 & 7,25 & 9,89 & 13,03 & - \\
\hline \multirow[t]{3}{*}{$\Delta \mathrm{CS}$} & $\mathrm{DM}$ & $-3,80$ & $-3,91$ & $-3,59$ & $-2,84$ & $-1,57$ & 0,14 & 2,25 & - \\
\hline & DMA & 25,67 & 25,31 & 24,95 & 24,71 & 24,58 & 25,49 & 26,73 & - \\
\hline & PDMA & 4,92 & 5,41 & 5,92 & 7,84 & 10,02 & 11,28 & 12,73 & - \\
\hline
\end{tabular}


Tabela 8.422: Constantes de acoplamento LC-SLYP com otimização de geometrias para $\alpha=40 \%$ e $\alpha+\beta=90 \%$, variando $\gamma$, na base aug-pcJ-2.

\begin{tabular}{|c|c|c|c|c|c|c|c|c|c|}
\hline & $\begin{array}{c}\text { Func. } \\
\alpha \\
\alpha+\beta \\
\gamma \\
\end{array}$ & $\begin{array}{c}\text { LCSLP } \\
40 \% \\
90 \% \\
0,05\end{array}$ & $\begin{array}{c}\text { LCSLP } \\
40 \% \\
90 \% \\
0,10 \\
\end{array}$ & $\begin{array}{c}\text { LCSLP } \\
40 \% \\
90 \% \\
0,15 \\
\end{array}$ & $\begin{array}{c}\text { LCSLP } \\
40 \% \\
90 \% \\
0,20\end{array}$ & $\begin{array}{c}\text { LCSLP } \\
40 \% \\
90 \% \\
0,25 \\
\end{array}$ & $\begin{array}{c}\text { LCSLP } \\
40 \% \\
90 \% \\
0,30\end{array}$ & $\begin{array}{c}\text { LCSLP } \\
40 \% \\
90 \% \\
0,35\end{array}$ & $\begin{array}{c}\text { Exp. } \\
- \\
-\end{array}$ \\
\hline $\mathrm{HF}$ & ${ }^{1} J_{\mathrm{HF}}$ & 509,4 & 509,2 & 509,1 & 510,2 & 513,1 & 516,9 & 521,9 & 500 \\
\hline $\mathrm{CO}$ & ${ }^{1} J_{\mathrm{CO}}$ & 11,4 & 11,3 & 11,1 & 10,8 & 10,5 & 10,2 & 9,7 & 16,4 \\
\hline $\mathrm{H}_{2} \mathrm{O}$ & ${ }^{1} J_{\mathrm{OH}}$ & $-83,0$ & $-83,0$ & $-83,1$ & $-83,3$ & $-83,8$ & $-84,4$ & $-85,2$ & $-80,6$ \\
\hline $\mathrm{H}_{2} \mathrm{O}$ & ${ }^{2} J_{\mathrm{HH}}$ & $-6,8$ & $-6,8$ & $-6,8$ & $-6,8$ & $-6,9$ & $-7,0$ & $-7,2$ & $-7,3$ \\
\hline $\mathrm{NH}_{3}$ & ${ }^{1} J_{\mathrm{NH}}$ & 46,2 & 46,2 & 46,3 & 46,4 & 46,6 & 46,9 & 47,3 & 43,8 \\
\hline $\mathrm{NH}_{3}$ & ${ }^{2} J_{\mathrm{HH}}$ & $-8,7$ & $-8,6$ & $-8,7$ & $-8,7$ & $-8,8$ & $-9,0$ & $-9,2$ & $-9,6$ \\
\hline $\mathrm{PH}_{3}$ & ${ }^{1} J_{\mathrm{PH}}$ & 181,3 & 180,9 & 179,9 & 178,8 & 178,5 & 179,4 & 181,7 & 188,2 \\
\hline $\mathrm{PF}_{3}$ & ${ }^{1} J_{\mathrm{PF}}$ & $-1590,9$ & $-1589,5$ & $-1587,3$ & $-1584,3$ & $-1580,9$ & $-1577,4$ & $-1573,7$ & -1441 \\
\hline $\mathrm{BHF}_{2}$ & ${ }^{1} J_{\mathrm{BF}}$ & $-94,6$ & $-94,2$ & $-92,7$ & $-89,9$ & $-86,1$ & $-81,6$ & $-76,6$ & -84 \\
\hline $\mathrm{BF}_{3}$ & ${ }^{1} J_{\mathrm{BF}}$ & 15,7 & 16,0 & 17,3 & 20,0 & 23,8 & 28,5 & 33,9 & 15 \\
\hline $\mathrm{F}_{2} \mathrm{O}$ & ${ }^{1} J_{\mathrm{OF}}$ & $-169,9$ & $-171,5$ & $-173,1$ & $-173,9$ & $-173,7$ & $-172,2$ & $-169,7$ & -300 \\
\hline $\mathrm{CH}_{4}$ & ${ }^{1} J_{\mathrm{CH}}$ & 120,8 & 120,8 & 120,6 & 120,5 & 120,6 & 120,8 & 121,4 & 125,3 \\
\hline $\mathrm{CH}_{4}$ & ${ }^{2} J_{\mathrm{HH}}$ & $-12,1$ & $-12,0$ & $-12,1$ & $-12,2$ & $-12,5$ & $-12,8$ & $-13,2$ & $-12,8$ \\
\hline $\mathrm{C}_{2} \mathrm{H}_{2}$ & ${ }^{1} J_{\mathrm{CC}}$ & 195,9 & 196,0 & 196,4 & 196,9 & 197,6 & 198,5 & 199,7 & 174,8 \\
\hline $\mathrm{C}_{2} \mathrm{H}_{2}$ & ${ }^{1} J_{\mathrm{CH}}$ & 247,9 & 247,6 & 247,1 & 246,6 & 246,3 & 246,5 & 247,1 & 247,6 \\
\hline $\mathrm{C}_{2} \mathrm{H}_{2}$ & ${ }^{2} J_{\mathrm{CH}}$ & 53,8 & 53,9 & 54,1 & 54,4 & 54,7 & 54,9 & 55,0 & 50,1 \\
\hline $\mathrm{C}_{2} \mathrm{H}_{2}$ & ${ }^{3} J_{\mathrm{HH}}$ & 9,7 & 9,7 & 9,7 & 9,7 & 9,9 & 10,1 & 10,4 & 9,6 \\
\hline $\mathrm{C}_{2} \mathrm{H}_{4}$ & ${ }^{1} J_{\mathrm{CC}}$ & 70,0 & 70,2 & 70,6 & 71,1 & 71,7 & 72,5 & 73,5 & 67,6 \\
\hline $\mathrm{C}_{2} \mathrm{H}_{4}$ & ${ }^{1} J_{\mathrm{CH}}$ & 151,2 & 151,1 & 150,9 & 150,8 & 150,9 & 151,3 & 152,0 & 156,3 \\
\hline $\mathrm{C}_{2} \mathrm{H}_{4}$ & ${ }^{2} J_{\mathrm{CH}}$ & $-2,2$ & $-2,1$ & $-2,1$ & $-2,2$ & $-2,4$ & $-2,7$ & $-3,0$ & $-2,4$ \\
\hline $\mathrm{C}_{2} \mathrm{H}_{4}$ & ${ }^{2} J_{\mathrm{HH}}$ & 2,1 & 2,2 & 2,1 & 2,0 & 1,8 & 1,5 & 1,1 & 2,3 \\
\hline $\mathrm{C}_{2} \mathrm{H}_{4}$ & ${ }^{3} J_{\mathrm{HH}_{\mathrm{C}}}$ & 13,8 & 13,8 & 13,8 & 14,0 & 14,1 & 14,3 & 14,6 & 11,7 \\
\hline $\mathrm{C}_{2} \mathrm{H}_{4}$ & ${ }^{3} J_{\mathrm{HH}_{\mathrm{t}}}$ & 19,5 & 19,4 & 19,4 & 19,5 & 19,6 & 19,7 & 20,0 & 19 \\
\hline $\mathrm{C}_{2} \mathrm{H}_{6}$ & ${ }^{1} J_{\mathrm{CC}}$ & 33,3 & 33,5 & 33,8 & 34,2 & 34,6 & 34,8 & 35,3 & 34,5 \\
\hline $\mathrm{C}_{2} \mathrm{H}_{6}$ & ${ }^{1} J_{\mathrm{CH}}$ & 119,0 & 118,9 & 118,8 & 118,7 & 118,8 & 119,2 & 119,8 & 125,2 \\
\hline $\mathrm{C}_{2} \mathrm{H}_{6}$ & ${ }^{2} J_{\mathrm{CH}}$ & $-3,8$ & $-3,8$ & $-3,8$ & $-3,9$ & $-4,0$ & $-4,1$ & $-4,3$ & $-4,7$ \\
\hline \multirow[t]{3}{*}{ Total } & DM & $-0,62$ & $-0,61$ & $-0,53$ & $-0,22$ & 0,35 & 1,15 & 2,20 & - \\
\hline & DMA & 14,15 & 14,05 & 14,01 & 14,04 & 14,12 & 14,45 & 15,03 & - \\
\hline & PDMA & 8,98 & 9,09 & 9,54 & 10,22 & 11,08 & 13,36 & 16,46 & - \\
\hline \multirow[t]{3}{*}{ CPI } & DM & $-2,80$ & $-2,81$ & $-2,63$ & $-1,96$ & $-0,78$ & 0,85 & 2,91 & - \\
\hline & DMA & 28,98 & 28,74 & 28,48 & 28,38 & 28,45 & 29,07 & 30,27 & - \\
\hline & PDMA & 11,98 & 12,23 & 12,88 & 14,46 & 16,45 & 19,36 & 23,22 & - \\
\hline \multirow[t]{3}{*}{ SPI } & DM & 0,99 & 1,01 & 1,01 & 1,07 & 1,17 & 1,36 & 1,69 & - \\
\hline & DMA & 3,28 & 3,29 & 3,40 & 3,52 & 3,61 & 3,72 & 3,86 & - \\
\hline & PDMA & 6,78 & 6,78 & 7,08 & 7,11 & 7,15 & 8,96 & 11,51 & - \\
\hline \multirow[t]{3}{*}{$\Delta \mathrm{CS}$} & $\mathrm{DM}$ & $-3,79$ & $-3,82$ & $-3,64$ & $-3,03$ & $-1,96$ & $-0,51$ & 1,22 & - \\
\hline & DMA & 25,70 & 25,45 & 25,08 & 24,86 & 24,84 & 25,35 & 26,41 & - \\
\hline & PDMA & 5,20 & 5,44 & 5,80 & 7,35 & 9,30 & 10,39 & 11,71 & - \\
\hline
\end{tabular}


Tabela 8.423: Constantes de acoplamento LC-SLYP com otimização de geometrias para $\alpha=40 \%$ e $\alpha+\beta=80 \%$, variando $\gamma$, na base aug-pcJ-2.

\begin{tabular}{|c|c|c|c|c|c|c|c|c|c|}
\hline & $\begin{array}{c}\text { Func. } \\
\alpha \\
\alpha+\beta \\
\gamma\end{array}$ & $\begin{array}{c}\text { LCSLP } \\
40 \% \\
80 \% \\
0,05\end{array}$ & $\begin{array}{c}\text { LCSLP } \\
40 \% \\
80 \% \\
0,10\end{array}$ & $\begin{array}{c}\text { LCSLP } \\
40 \% \\
80 \% \\
0,15\end{array}$ & $\begin{array}{c}\text { LCSLP } \\
40 \% \\
80 \% \\
0,20\end{array}$ & $\begin{array}{c}\text { LCSLP } \\
40 \% \\
80 \% \\
0,25\end{array}$ & $\begin{array}{c}\text { LCSLP } \\
40 \% \\
80 \% \\
0,30\end{array}$ & $\begin{array}{c}\text { LCSLP } \\
40 \% \\
80 \% \\
0,35\end{array}$ & $\begin{array}{l}\text { Exp. } \\
- \\
-\end{array}$ \\
\hline $\mathrm{HF}$ & ${ }^{1} J_{\mathrm{HF}}$ & 509,4 & 509,3 & 509,5 & 510,4 & 512,4 & 515,4 & 519,5 & 500 \\
\hline $\mathrm{CO}$ & ${ }^{1} J_{C O}$ & 11,4 & 11,3 & 11,2 & 11,0 & 10,7 & 10,4 & 10,1 & 16,4 \\
\hline $\mathrm{H}_{2} \mathrm{O}$ & ${ }^{1} J_{\mathrm{OH}}$ & $-83,0$ & $-83,0$ & $-83,1$ & $-83,3$ & $-83,6$ & $-84,1$ & $-84,8$ & $-80,6$ \\
\hline $\mathrm{H}_{2} \mathrm{O}$ & ${ }^{2} J_{\mathrm{HH}}$ & $-6,8$ & $-6,8$ & $-6,8$ & $-6,8$ & $-6,9$ & $-7,0$ & $-7,1$ & $-7,3$ \\
\hline $\mathrm{NH}_{3}$ & ${ }^{1} J_{\mathrm{NH}}$ & 46,2 & 46,2 & 46,3 & 46,4 & 46,5 & 46,8 & 47,1 & 43,8 \\
\hline $\mathrm{NH}_{3}$ & ${ }^{2} J_{\mathrm{HH}}$ & $-8,7$ & $-8,7$ & $-8,7$ & $-8,7$ & $-8,8$ & $-8,9$ & $-9,1$ & $-9,6$ \\
\hline $\mathrm{PH}_{3}$ & ${ }^{1} J_{\mathrm{PH}}$ & 181,3 & 180,9 & 180,1 & 179,3 & 179,0 & 179,8 & 181,6 & 188,2 \\
\hline $\mathrm{PF}_{3}$ & ${ }^{1} J_{\mathrm{PF}}$ & $-1591,0$ & $-1589,9$ & $-1588,1$ & $-1585,7$ & $-1583,1$ & $-1580,5$ & $-1577,7$ & -1441 \\
\hline $\mathrm{BHF}_{2}$ & ${ }^{1} J_{\mathrm{BF}}$ & $-94,6$ & $-94,3$ & $-93,0$ & $-90,8$ & $-87,8$ & $-84,1$ & $-80,1$ & -84 \\
\hline $\mathrm{BF}_{3}$ & ${ }^{1} J_{\mathrm{BF}}$ & 15,7 & 15,9 & 17,0 & 19,2 & 22,2 & 26,0 & 30,3 & 15 \\
\hline $\mathrm{F}_{2} \mathrm{O}$ & ${ }^{1} J_{\mathrm{OF}}$ & $-169,8$ & $-171,1$ & $-172,3$ & $-173,0$ & $-172,7$ & $-171,5$ & $-169,4$ & -300 \\
\hline $\mathrm{CH}_{4}$ & ${ }^{1} J_{\mathrm{CH}}$ & 120,8 & 120,8 & 120,7 & 120,6 & 120,6 & 120,8 & 121,3 & 125,3 \\
\hline $\mathrm{CH}_{4}$ & ${ }^{2} J_{\mathrm{HH}}$ & $-12,1$ & $-12,1$ & $-12,1$ & $-12,2$ & $-12,4$ & $-12,7$ & $-13,0$ & $-12,8$ \\
\hline $\mathrm{C}_{2} \mathrm{H}_{2}$ & ${ }^{1} J_{\mathrm{CC}}$ & 195,9 & 196,0 & 196,3 & 196,7 & 197,3 & 198,0 & 198,9 & 174,8 \\
\hline $\mathrm{C}_{2} \mathrm{H}_{2}$ & ${ }^{1} J_{\mathrm{CH}}$ & 247,9 & 247,7 & 247,3 & 246,9 & 246,6 & 246,7 & 247,2 & 247,6 \\
\hline $\mathrm{C}_{2} \mathrm{H}_{2}$ & ${ }^{2} J_{\mathrm{CH}}$ & 53,8 & 53,8 & 54,0 & 54,2 & 54,5 & 54,7 & 54,8 & 50,1 \\
\hline $\mathrm{C}_{2} \mathrm{H}_{2}$ & ${ }^{3} J_{\mathrm{HH}}$ & 9,7 & 9,7 & 9,7 & 9,7 & 9,8 & 10,0 & 10,2 & 9,6 \\
\hline $\mathrm{C}_{2} \mathrm{H}_{4}$ & ${ }^{1} J_{\mathrm{CC}}$ & 70,0 & 70,2 & 70,5 & 70,9 & 71,4 & 72,0 & 72,7 & 67,6 \\
\hline $\mathrm{C}_{2} \mathrm{H}_{4}$ & ${ }^{1} J_{\mathrm{CH}}$ & 151,2 & 151,1 & 151,0 & 150,9 & 151,0 & 151,3 & 151,8 & 156,3 \\
\hline $\mathrm{C}_{2} \mathrm{H}_{4}$ & ${ }^{2} J_{\mathrm{CH}}$ & $-2,2$ & $-2,1$ & $-2,2$ & $-2,2$ & $-2,3$ & $-2,6$ & $-2,8$ & $-2,4$ \\
\hline $\mathrm{C}_{2} \mathrm{H}_{4}$ & ${ }^{2} J_{\mathrm{HH}}$ & 2,1 & 2,2 & 2,1 & 2,1 & 1,9 & 1,7 & 1,4 & 2,3 \\
\hline $\mathrm{C}_{2} \mathrm{H}_{4}$ & ${ }^{3} J_{\mathrm{HH}_{\mathrm{c}}}$ & 13,8 & 13,8 & 13,8 & 13,9 & 14,1 & 14,2 & 14,4 & 11,7 \\
\hline $\mathrm{C}_{2} \mathrm{H}_{4}$ & ${ }^{3} J_{\mathrm{HH}_{\mathrm{t}}}{ }^{\mathrm{C}}$ & 19,5 & 19,5 & 19,4 & 19,5 & 19,6 & 19,7 & 19,8 & 19 \\
\hline $\mathrm{C}_{2} \mathrm{H}_{6}$ & ${ }^{1} J_{\mathrm{CC}}$ & 33,3 & 33,5 & 33,7 & 34,0 & 34,3 & 34,7 & 34,9 & 34,5 \\
\hline $\mathrm{C}_{2} \mathrm{H}_{6}$ & ${ }^{1} J_{\mathrm{CH}}$ & 119,0 & 118,9 & 118,8 & 118,8 & 118,8 & 119,1 & 119,6 & 125,2 \\
\hline $\mathrm{C}_{2} \mathrm{H}_{6}$ & ${ }^{2} J_{\mathrm{CH}}$ & $-3,8$ & $-3,8$ & $-3,8$ & $-3,9$ & $-3,9$ & $-4,0$ & $-4,2$ & $-4,7$ \\
\hline \multirow[t]{3}{*}{ Total } & $\mathrm{DM}$ & $-0,62$ & $-0,62$ & $-0,53$ & $-0,27$ & 0,16 & 0,80 & 1,63 & - \\
\hline & DMA & 14,16 & 14,08 & 14,05 & 14,07 & 14,15 & 14,25 & 14,69 & - \\
\hline & PDMA & 8,98 & 9,02 & 9,29 & 9,79 & 10,72 & 12,06 & 14,24 & - \\
\hline \multirow[t]{3}{*}{ CPI } & DM & $-2,80$ & $-2,83$ & $-2,62$ & $-2,08$ & $-1,18$ & 0,13 & 1,77 & - \\
\hline & DMA & 29,00 & 28,81 & 28,64 & 28,55 & 28,60 & 28,76 & 29,74 & - \\
\hline & PDMA & 11,98 & 12,10 & 12,71 & 13,97 & 15,51 & 17,52 & 20,56 & - \\
\hline \multirow[t]{3}{*}{ SPI } & $\mathrm{DM}$ & 0,99 & 1,01 & 1,01 & 1,05 & 1,15 & 1,30 & 1,53 & - \\
\hline & DMA & 3,28 & 3,29 & 3,35 & 3,44 & 3,55 & 3,61 & 3,66 & - \\
\hline & PDMA & 6,78 & 6,76 & 6,78 & 6,72 & 7,20 & 8,06 & 9,61 & - \\
\hline \multirow[t]{3}{*}{$\Delta \mathrm{CS}$} & DM & $-3,79$ & $-3,83$ & $-3,62$ & $-3,14$ & $-2,33$ & $-1,17$ & 0,25 & - \\
\hline & DMA & 25,72 & 25,52 & 25,28 & 25,11 & 25,05 & 25,16 & 26,08 & - \\
\hline & PDMA & 5,20 & 5,34 & 5,92 & 7,25 & 8,31 & 9,46 & 10,95 & - \\
\hline
\end{tabular}


Tabela 8.424: Constantes de acoplamento LC-SLYP com otimização de geometrias para $\alpha=50 \%$ e $\alpha+\beta=100 \%$, variando $\gamma$, na base aug-pcJ-2.

\begin{tabular}{|c|c|c|c|c|c|c|c|c|c|}
\hline & $\begin{array}{c}\text { Func. } \\
\alpha \\
\alpha+\beta \\
\gamma\end{array}$ & $\begin{array}{c}\text { LCSLP } \\
50 \% \\
100 \% \\
0,05\end{array}$ & $\begin{array}{c}\text { LCSLP } \\
50 \% \\
100 \% \\
0,10\end{array}$ & $\begin{array}{c}\text { LCSLP } \\
50 \% \\
100 \% \\
0,15\end{array}$ & $\begin{array}{c}\text { LCSLP } \\
50 \% \\
100 \% \\
0,20\end{array}$ & $\begin{array}{c}\text { LCSLP } \\
50 \% \\
100 \% \\
0,25\end{array}$ & $\begin{array}{c}\text { LCSLP } \\
50 \% \\
100 \% \\
0,30\end{array}$ & $\begin{array}{c}\text { LCSLP } \\
50 \% \\
100 \% \\
0,35\end{array}$ & $\begin{array}{l}\text { Exp. } \\
- \\
-\end{array}$ \\
\hline $\mathrm{HF}$ & ${ }^{1} J_{\mathrm{HF}}$ & 546,5 & 546,3 & 546,5 & 547,7 & 550,2 & 554,0 & 559,1 & 500 \\
\hline $\mathrm{CO}$ & ${ }^{1} J_{C O}$ & 7,9 & 7,8 & 7,6 & 7,3 & 7,1 & 6,7 & 6,3 & 16,4 \\
\hline $\mathrm{H}_{2} \mathrm{O}$ & ${ }^{1} J_{\mathrm{OH}}$ & $-87,5$ & $-87,5$ & $-87,5$ & $-87,8$ & $-88,2$ & $-88,8$ & $-89,6$ & $-80,6$ \\
\hline $\mathrm{H}_{2} \mathrm{O}$ & ${ }^{2} J_{\mathrm{HH}}$ & $-7,9$ & $-7,9$ & $-7,9$ & $-7,9$ & $-8,0$ & $-8,1$ & $-8,3$ & $-7,3$ \\
\hline $\mathrm{NH}_{3}$ & ${ }^{1} J_{\mathrm{NH}}$ & 47,8 & 47,8 & 47,9 & 48,0 & 48,2 & 48,4 & 48,9 & 43,8 \\
\hline $\mathrm{NH}_{3}$ & ${ }^{2} J_{\mathrm{HH}}$ & $-9,8$ & $-9,8$ & $-9,8$ & $-9,9$ & $-10,0$ & $-10,2$ & $-10,4$ & $-9,6$ \\
\hline $\mathrm{PH}_{3}$ & ${ }^{1} J_{\mathrm{PH}}$ & 195,1 & 194,7 & 193,7 & 192,7 & 192,4 & 193,3 & 195,5 & 188,2 \\
\hline $\mathrm{PF}_{3}$ & ${ }^{1} J_{\mathrm{PF}}$ & $-1554,1$ & $-1552,6$ & $-1549,9$ & $-1546,1$ & $-1541,7$ & $-1536,9$ & $-1531,8$ & -1441 \\
\hline $\mathrm{BHF}_{2}$ & ${ }^{1} J_{\mathrm{BF}}$ & $-72,9$ & $-72,5$ & $-71,0$ & $-68,4$ & $-64,7$ & $-60,3$ & $-55,5$ & -84 \\
\hline $\mathrm{BF}_{3}$ & ${ }^{1} J_{\mathrm{BF}}$ & 38,6 & 38,9 & 40,2 & 42,7 & 46,4 & 50,9 & 56,1 & 15 \\
\hline $\mathrm{F}_{2} \mathrm{O}$ & ${ }^{1} J_{\mathrm{OF}}$ & $-166,3$ & $-167,9$ & $-169,6$ & $-170,6$ & $-170,6$ & $-169,5$ & $-167,4$ & -300 \\
\hline $\mathrm{CH}_{4}$ & ${ }^{1} J_{\mathrm{CH}}$ & 124,4 & 124,3 & 124,2 & 124,2 & 124,2 & 124,5 & 125,1 & 125,3 \\
\hline $\mathrm{CH}_{4}$ & ${ }^{2} J_{\mathrm{HH}}$ & $-13,2$ & $-13,2$ & $-13,2$ & $-13,4$ & $-13,6$ & $-14,0$ & $-14,4$ & $-12,8$ \\
\hline $\mathrm{C}_{2} \mathrm{H}_{2}$ & ${ }^{1} J_{\mathrm{CC}}$ & 201,9 & 202,0 & 202,4 & 203,0 & 203,8 & 204,8 & 206,2 & 174,8 \\
\hline $\mathrm{C}_{2} \mathrm{H}_{2}$ & ${ }^{1} J_{\mathrm{CH}}$ & 253,2 & 252,9 & 252,5 & 252,0 & 251,8 & 252,0 & 252,7 & 247,6 \\
\hline $\mathrm{C}_{2} \mathrm{H}_{2}$ & ${ }^{2} J_{\mathrm{CH}}$ & 53,8 & 53,9 & 54,1 & 54,3 & 54,5 & 54,7 & 54,7 & 50,1 \\
\hline $\mathrm{C}_{2} \mathrm{H}_{2}$ & ${ }^{3} J_{\mathrm{HH}}$ & 10,7 & 10,7 & 10,7 & 10,8 & 11,0 & 11,2 & 11,6 & 9,6 \\
\hline $\mathrm{C}_{2} \mathrm{H}_{4}$ & ${ }^{1} J_{\mathrm{CC}}$ & 74,8 & 75,0 & 75,4 & 76,0 & 76,8 & 77,7 & 78,9 & 67,6 \\
\hline $\mathrm{C}_{2} \mathrm{H}_{4}$ & ${ }^{1} J_{\mathrm{CH}}$ & 155,7 & 155,5 & 155,4 & 155,3 & 155,5 & 155,9 & 156,8 & 156,3 \\
\hline $\mathrm{C}_{2} \mathrm{H}_{4}$ & ${ }^{2} J_{\mathrm{CH}}$ & $-3,3$ & $-3,3$ & $-3,4$ & $-3,5$ & $-3,7$ & $-4,0$ & $-4,5$ & $-2,4$ \\
\hline $\mathrm{C}_{2} \mathrm{H}_{4}$ & ${ }^{2} J_{\mathrm{HH}}$ & 1,2 & 1,2 & 1,2 & 1,1 & 0,8 & 0,5 & 0,1 & 2,3 \\
\hline $\mathrm{C}_{2} \mathrm{H}_{4}$ & ${ }^{3} J_{\mathrm{HH}_{\mathrm{c}}}$ & 14,4 & 14,4 & 14,4 & 14,6 & 14,8 & 15,0 & 15,3 & 11,7 \\
\hline $\mathrm{C}_{2} \mathrm{H}_{4}$ & ${ }^{3} J_{\mathrm{HH}_{\mathrm{t}}}{ }^{\mathrm{C}}$ & 20,2 & 20,2 & 20,2 & 20,2 & 20,4 & 20,6 & 20,9 & 19 \\
\hline $\mathrm{C}_{2} \mathrm{H}_{6}$ & ${ }^{1} J_{\mathrm{CC}}$ & 36,2 & 36,4 & 36,7 & 36,9 & 37,3 & 37,8 & 38,3 & 34,5 \\
\hline $\mathrm{C}_{2} \mathrm{H}_{6}$ & ${ }^{1} J_{\mathrm{CH}}$ & 122,8 & 122,7 & 122,6 & 122,6 & 122,7 & 123,1 & 123,7 & 125,2 \\
\hline $\mathrm{C}_{2} \mathrm{H}_{6}$ & ${ }^{2} J_{\mathrm{CH}}$ & $-4,4$ & $-4,4$ & $-4,4$ & $-4,5$ & $-4,6$ & $-4,7$ & $-4,9$ & $-4,7$ \\
\hline \multirow[t]{3}{*}{ Total } & $\mathrm{DM}$ & 5,42 & 5,41 & 5,54 & 5,86 & 6,45 & 7,29 & 8,40 & 一 \\
\hline & DMA & 15,85 & 15,76 & 15,73 & 15,85 & 16,20 & 16,76 & 17,59 & - \\
\hline & PDMA & 19,05 & 19,18 & 19,83 & 21,18 & 23,58 & 26,58 & 30,80 & - \\
\hline \multirow[t]{3}{*}{ CPI } & DM & 8,77 & 8,76 & 9,03 & 9,71 & 10,93 & 12,60 & 14,73 & - \\
\hline & DMA & 32,28 & 32,02 & 31,83 & 31,95 & 32,51 & 33,55 & 35,04 & - \\
\hline & PDMA & 28,70 & 28,90 & 29,87 & 31,90 & 34,97 & 38,93 & 43,69 & - \\
\hline \multirow[t]{3}{*}{ SPI } & $\mathrm{DM}$ & 2,95 & 2,95 & 2,98 & 3,03 & 3,17 & 3,40 & 3,76 & - \\
\hline & DMA & 3,79 & 3,84 & 3,93 & 4,05 & 4,24 & 4,45 & 4,80 & - \\
\hline & PDMA & 11,96 & 12,05 & 12,47 & 13,32 & 15,23 & 17,52 & 21,34 & - \\
\hline \multirow[t]{3}{*}{$\Delta \mathrm{CS}$} & $\mathrm{DM}$ & 5,82 & 5,82 & 6,05 & 6,68 & 7,75 & 9,20 & 10,97 & - \\
\hline & DMA & 28,49 & 28,18 & 27,90 & 27,90 & 28,27 & 29,09 & 30,24 & - \\
\hline & PDMA & 16,74 & 16,86 & 17,40 & 18,58 & 19,74 & 21,41 & 22,35 & - \\
\hline
\end{tabular}


Tabela 8.425: Constantes de acoplamento LC-SLYP com otimização de geometrias para $\alpha=50 \%$ e $\alpha+\beta=90 \%$, variando $\gamma$, na base aug-pcJ-2.

\begin{tabular}{|c|c|c|c|c|c|c|c|c|c|}
\hline & $\begin{array}{c}\text { Func. } \\
\alpha \\
\alpha+\beta \\
\gamma\end{array}$ & $\begin{array}{c}\text { LCSLP } \\
50 \% \\
90 \% \\
0,05\end{array}$ & $\begin{array}{c}\text { LCSLP } \\
50 \% \\
90 \% \\
0,10\end{array}$ & $\begin{array}{c}\text { LCSLP } \\
50 \% \\
90 \% \\
0,15\end{array}$ & $\begin{array}{c}\text { LCSLP } \\
50 \% \\
90 \% \\
0,20\end{array}$ & $\begin{array}{c}\text { LCSLP } \\
50 \% \\
90 \% \\
0,25\end{array}$ & $\begin{array}{c}\text { LCSLP } \\
50 \% \\
90 \% \\
0,30\end{array}$ & $\begin{array}{c}\text { LCSLP } \\
50 \% \\
90 \% \\
0,35\end{array}$ & $\begin{array}{l}\text { Exp. } \\
- \\
-\end{array}$ \\
\hline $\mathrm{HF}$ & ${ }^{1} J_{\mathrm{HF}}$ & 546,6 & 546,4 & 546,6 & 547,5 & 549,5 & 552,5 & 556,6 & 500 \\
\hline $\mathrm{CO}$ & ${ }^{1} J_{\mathrm{CO}}$ & 7,9 & 7,8 & 7,7 & 7,5 & 7,2 & 7,0 & 6,6 & 16,4 \\
\hline $\mathrm{H}_{2} \mathrm{O}$ & ${ }^{1} J_{\mathrm{OH}}$ & $-87,5$ & $-87,5$ & $-87,5$ & $-87,7$ & $-88,1$ & $-88,6$ & $-89,2$ & $-80,6$ \\
\hline $\mathrm{H}_{2} \mathrm{O}$ & ${ }^{2} J_{\mathrm{HH}}$ & $-7,9$ & $-7,9$ & $-7,9$ & $-7,9$ & $-8,0$ & $-8,1$ & $-8,2$ & $-7,3$ \\
\hline $\mathrm{NH}_{3}$ & ${ }^{1} J_{\mathrm{NH}}$ & 47,8 & 47,8 & 47,8 & 47,9 & 48,1 & 48,3 & 48,7 & 43,8 \\
\hline $\mathrm{NH}_{3}$ & ${ }^{2} J_{\mathrm{HH}}$ & $-9,8$ & $-9,8$ & $-9,8$ & $-9,9$ & $-10,0$ & $-10,1$ & $-10,2$ & $-9,6$ \\
\hline $\mathrm{PH}_{3}$ & ${ }^{1} J_{\mathrm{PH}}$ & 195,1 & 194,8 & 194,0 & 193,2 & 192,9 & 193,6 & 195,4 & 188,2 \\
\hline $\mathrm{PF}_{3}$ & ${ }^{1} J_{\mathrm{PF}}$ & $-1554,2$ & $-1553,0$ & $-1550,8$ & $-1547,8$ & $-1544,3$ & $-1540,7$ & $-1536,8$ & -1441 \\
\hline $\mathrm{BHF}_{2}$ & ${ }^{1} J_{\mathrm{BF}}$ & $-72,9$ & $-72,6$ & $-71,4$ & $-69,3$ & $-66,3$ & $-62,8$ & $-58,9$ & -84 \\
\hline $\mathrm{BF}_{3}$ & ${ }^{1} J_{\mathrm{BF}}$ & 38,7 & 38,9 & 39,9 & 41,9 & 44,8 & 48,5 & 52,7 & 15 \\
\hline $\mathrm{F}_{2} \mathrm{O}$ & ${ }^{1} J_{\mathrm{OF}}$ & $-166,1$ & $-167,4$ & $-168,7$ & $-169,6$ & $-169,6$ & $-168,6$ & $-166,9$ & -300 \\
\hline $\mathrm{CH}_{4}$ & ${ }^{1} J_{\mathrm{CH}}$ & 124,4 & 124,4 & 124,3 & 124,2 & 124,3 & 124,5 & 124,9 & 125,3 \\
\hline $\mathrm{CH}_{4}$ & ${ }^{2} J_{\mathrm{HH}}$ & $-13,2$ & $-13,2$ & $-13,2$ & $-13,4$ & $-13,6$ & $-13,8$ & $-14,2$ & $-12,8$ \\
\hline $\mathrm{C}_{2} \mathrm{H}_{2}$ & ${ }^{1} J_{\mathrm{CC}}$ & 201,9 & 202,0 & 202,3 & 202,8 & 203,4 & 204,2 & 205,3 & 174,8 \\
\hline $\mathrm{C}_{2} \mathrm{H}_{2}$ & ${ }^{1} J_{\mathrm{CH}}$ & 253,3 & 253,0 & 252,6 & 252,3 & 252,1 & 252,3 & 252,8 & 247,6 \\
\hline $\mathrm{C}_{2} \mathrm{H}_{2}$ & ${ }^{2} J_{\mathrm{CH}}$ & 53,8 & 53,9 & 54,0 & 54,2 & 54,4 & 54,5 & 54,5 & 50,1 \\
\hline $\mathrm{C}_{2} \mathrm{H}_{2}$ & ${ }^{3} J_{\mathrm{HH}}$ & 10,7 & 10,7 & 10,7 & 10,8 & 10,9 & 11,1 & 11,4 & 9,6 \\
\hline $\mathrm{C}_{2} \mathrm{H}_{4}$ & ${ }^{1} J_{\mathrm{CC}}$ & 74,8 & 75,0 & 75,3 & 75,8 & 76,4 & 77,1 & 78,0 & 67,6 \\
\hline $\mathrm{C}_{2} \mathrm{H}_{4}$ & ${ }^{1} J_{\mathrm{CH}}$ & 155,7 & 155,6 & 155,4 & 155,4 & 155,5 & 155,9 & 156,5 & 156,3 \\
\hline $\mathrm{C}_{2} \mathrm{H}_{4}$ & ${ }^{2} J_{\mathrm{CH}}$ & $-3,3$ & $-3,3$ & $-3,4$ & $-3,4$ & $-3,6$ & $-3,9$ & $-4,2$ & $-2,4$ \\
\hline $\mathrm{C}_{2} \mathrm{H}_{4}$ & ${ }^{2} J_{\mathrm{HH}}$ & 1,2 & 1,2 & 1,2 & 1,1 & 0,9 & 0,7 & 0,3 & 2,3 \\
\hline $\mathrm{C}_{2} \mathrm{H}_{4}$ & ${ }^{3} J_{\mathrm{HH}_{\mathrm{c}}}$ & 14,4 & 14,4 & 14,4 & 14,5 & 14,7 & 14,9 & 15,1 & 11,7 \\
\hline $\mathrm{C}_{2} \mathrm{H}_{4}$ & ${ }^{3} J_{\mathrm{HH}_{\mathrm{t}}}{ }^{\mathrm{C}}$ & 20,2 & 20,2 & 20,2 & 20,2 & 20,3 & 20,5 & 20,7 & 19 \\
\hline $\mathrm{C}_{2} \mathrm{H}_{6}$ & ${ }^{1} J_{\mathrm{CC}}$ & 36,2 & 36,3 & 36,6 & 36,7 & 37,0 & 37,4 & 37,8 & 34,5 \\
\hline $\mathrm{C}_{2} \mathrm{H}_{6}$ & ${ }^{1} J_{\mathrm{CH}}$ & 122,8 & 122,7 & 122,7 & 122,6 & 122,7 & 123,0 & 123,5 & 125,2 \\
\hline $\mathrm{C}_{2} \mathrm{H}_{6}$ & ${ }^{2} J_{\mathrm{CH}}$ & $-4,4$ & $-4,4$ & $-4,4$ & $-4,5$ & $-4,5$ & $-4,6$ & $-4,8$ & $-4,7$ \\
\hline \multirow[t]{3}{*}{ Total } & $\mathrm{DM}$ & 5,43 & 5,42 & 5,52 & 5,77 & 6,23 & 6,92 & 7,78 & - \\
\hline & DMA & 15,87 & 15,79 & 15,76 & 15,86 & 16,14 & 16,60 & 17,25 & - \\
\hline & PDMA & 19,08 & 19,17 & 19,69 & 20,67 & 22,67 & 25,07 & 28,25 & - \\
\hline \multirow[t]{3}{*}{ CPI } & $\mathrm{DM}$ & 8,80 & 8,78 & 9,00 & 9,54 & 10,48 & 11,83 & 13,54 & - \\
\hline & DMA & 32,33 & 32,11 & 31,95 & 32,03 & 32,50 & 33,35 & 34,57 & - \\
\hline & PDMA & 28,77 & 28,92 & 29,62 & 31,24 & 33,80 & 36,94 & 40,69 & - \\
\hline \multirow[t]{3}{*}{ SPI } & DM & 2,96 & 2,96 & 2,97 & 3,01 & 3,12 & 3,31 & 3,57 & - \\
\hline & DMA & 3,80 & 3,83 & 3,89 & 4,00 & 4,15 & 4,31 & 4,55 & - \\
\hline & PDMA & 11,96 & 12,02 & 12,42 & 12,91 & 14,52 & 16,37 & 19,12 & - \\
\hline \multirow[t]{3}{*}{$\Delta \mathrm{CS}$} & DM & 5,84 & 5,82 & 6,03 & 6,52 & 7,36 & 8,51 & 9,97 & - \\
\hline & DMA & 28,53 & 28,28 & 28,05 & 28,03 & 28,35 & 29,04 & 30,02 & - \\
\hline & PDMA & 16,81 & 16,90 & 17,21 & 18,33 & 19,28 & 20,57 & 21,56 & - \\
\hline
\end{tabular}


Tabela 8.426: Constantes de acoplamento LC-SLYP com otimização de geometrias para $\alpha=50 \%$ e $\alpha+\beta=80 \%$, variando $\gamma$, na base aug-pcJ-2.

\begin{tabular}{|c|c|c|c|c|c|c|c|c|c|}
\hline & $\begin{array}{c}\text { Func. } \\
\alpha \\
\alpha+\beta \\
\gamma\end{array}$ & $\begin{array}{c}\text { LCSLP } \\
50 \% \\
80 \% \\
0,05\end{array}$ & $\begin{array}{c}\text { LCSLP } \\
50 \% \\
80 \% \\
0,10\end{array}$ & $\begin{array}{c}\text { LCSLP } \\
50 \% \\
80 \% \\
0,15\end{array}$ & $\begin{array}{c}\text { LCSLP } \\
50 \% \\
80 \% \\
0,20\end{array}$ & $\begin{array}{c}\text { LCSLP } \\
50 \% \\
80 \% \\
0,25\end{array}$ & $\begin{array}{c}\text { LCSLP } \\
50 \% \\
80 \% \\
0,30\end{array}$ & $\begin{array}{c}\text { LCSLP } \\
50 \% \\
80 \% \\
0,35\end{array}$ & $\begin{array}{l}\text { Exp. } \\
- \\
-\end{array}$ \\
\hline $\mathrm{HF}$ & ${ }^{1} J_{\mathrm{HF}}$ & 546,6 & 546,5 & 546,6 & 547,3 & 548,8 & 551,1 & 554,1 & 500 \\
\hline $\mathrm{CO}$ & ${ }^{1} J_{\mathrm{CO}}$ & 7,9 & 7,9 & 7,7 & 7,6 & 7,4 & 7,2 & 7,0 & 16,4 \\
\hline $\mathrm{H}_{2} \mathrm{O}$ & ${ }^{1} J_{\mathrm{OH}}$ & $-87,5$ & $-87,5$ & $-87,5$ & $-87,7$ & $-87,9$ & $-88,3$ & $-88,8$ & $-80,6$ \\
\hline $\mathrm{H}_{2} \mathrm{O}$ & ${ }^{2} J_{\mathrm{HH}}$ & $-7,9$ & $-7,9$ & $-7,9$ & $-7,9$ & $-8,0$ & $-8,0$ & $-8,1$ & $-7,3$ \\
\hline $\mathrm{NH}_{3}$ & ${ }^{1} J_{\mathrm{NH}}$ & 47,8 & 47,8 & 47,8 & 47,9 & 48,0 & 48,2 & 48,5 & 43,8 \\
\hline $\mathrm{NH}_{3}$ & ${ }^{2} J_{\mathrm{HH}}$ & $-9,8$ & $-9,8$ & $-9,8$ & $-9,9$ & $-9,9$ & $-10,1$ & $-10,1$ & $-9,6$ \\
\hline $\mathrm{PH}_{3}$ & ${ }^{1} J_{\mathrm{PH}}$ & 195,1 & 194,9 & 194,3 & 193,6 & 193,4 & 194,0 & 195,3 & 188,2 \\
\hline $\mathrm{PF}_{3}$ & ${ }^{1} J_{\mathrm{PF}}$ & $-1554,2$ & $-1553,4$ & $-1551,7$ & $-1549,5$ & $-1547,0$ & $-1544,3$ & $-1541,5$ & -1441 \\
\hline $\mathrm{BHF}_{2}$ & ${ }^{1} J_{\mathrm{BF}}$ & $-72,9$ & $-72,6$ & $-71,8$ & $-70,1$ & $-67,9$ & $-65,3$ & $-62,3$ & -84 \\
\hline $\mathrm{BF}_{3}$ & ${ }^{1} J_{\mathrm{BF}}$ & 38,7 & 38,8 & 39,6 & 41,1 & 43,3 & 46,1 & 49,2 & 15 \\
\hline $\mathrm{F}_{2} \mathrm{O}$ & ${ }^{1} J_{\mathrm{OF}}$ & $-166,0$ & $-167,0$ & $-167,9$ & $-168,6$ & $-168,5$ & $-167,8$ & $-166,4$ & -300 \\
\hline $\mathrm{CH}_{4}$ & ${ }^{1} J_{\mathrm{CH}}$ & 124,4 & 124,4 & 124,3 & 124,3 & 124,3 & 124,5 & 124,8 & 125,3 \\
\hline $\mathrm{CH}_{4}$ & ${ }^{2} J_{\mathrm{HH}}$ & $-13,2$ & $-13,2$ & $-13,2$ & $-13,3$ & $-13,5$ & $-13,7$ & $-13,9$ & $-12,8$ \\
\hline $\mathrm{C}_{2} \mathrm{H}_{2}$ & ${ }^{1} J_{\mathrm{CC}}$ & 201,9 & 202,0 & 202,2 & 202,6 & 203,0 & 203,6 & 204,4 & 174,8 \\
\hline $\mathrm{C}_{2} \mathrm{H}_{2}$ & ${ }^{1} J_{\mathrm{CH}}$ & 253,3 & 253,1 & 252,8 & 252,5 & 252,4 & 252,5 & 252,9 & 247,6 \\
\hline $\mathrm{C}_{2} \mathrm{H}_{2}$ & ${ }^{2} J_{\mathrm{CH}}$ & 53,8 & 53,8 & 53,9 & 54,1 & 54,2 & 54,3 & 54,4 & 50,1 \\
\hline $\mathrm{C}_{2} \mathrm{H}_{2}$ & ${ }^{3} J_{\mathrm{HH}}$ & 10,7 & 10,7 & 10,7 & 10,8 & 10,9 & 11,0 & 11,2 & 9,6 \\
\hline $\mathrm{C}_{2} \mathrm{H}_{4}$ & ${ }^{1} J_{\mathrm{CC}}$ & 74,8 & 74,9 & 75,2 & 75,5 & 76,0 & 76,5 & 77,2 & 67,6 \\
\hline $\mathrm{C}_{2} \mathrm{H}_{4}$ & ${ }^{1} J_{\mathrm{CH}}$ & 155,7 & 155,6 & 155,5 & 155,5 & 155,5 & 155,8 & 156,3 & 156,3 \\
\hline $\mathrm{C}_{2} \mathrm{H}_{4}$ & ${ }^{2} J_{\mathrm{CH}}$ & $-3,3$ & $-3,3$ & $-3,4$ & $-3,4$ & $-3,5$ & $-3,7$ & $-4,0$ & $-2,4$ \\
\hline $\mathrm{C}_{2} \mathrm{H}_{4}$ & ${ }^{2} J_{\mathrm{HH}}$ & 1,2 & 1,2 & 1,2 & 1,1 & 1,0 & 0,8 & 0,6 & 2,3 \\
\hline $\mathrm{C}_{2} \mathrm{H}_{4}$ & ${ }^{3} J_{\mathrm{HH}_{\mathrm{c}}}$ & 14,4 & 14,4 & 14,4 & 14,5 & 14,6 & 14,8 & 14,9 & 11,7 \\
\hline $\mathrm{C}_{2} \mathrm{H}_{4}$ & ${ }^{3} J_{\mathrm{HH}_{\mathrm{t}}}{ }^{\mathrm{C}}$ & 20,2 & 20,2 & 20,2 & 20,2 & 20,3 & 20,4 & 20,6 & 19 \\
\hline $\mathrm{C}_{2} \mathrm{H}_{6}$ & ${ }^{1} J_{\mathrm{CC}}$ & 36,2 & 36,3 & 36,5 & 36,7 & 36,8 & 37,0 & 37,3 & 34,5 \\
\hline $\mathrm{C}_{2} \mathrm{H}_{6}$ & ${ }^{1} J_{\mathrm{CH}}$ & 122,8 & 122,8 & 122,7 & 122,7 & 122,8 & 123,0 & 123,4 & 125,2 \\
\hline $\mathrm{C}_{2} \mathrm{H}_{6}$ & ${ }^{2} J_{\mathrm{CH}}$ & $-4,4$ & $-4,4$ & $-4,4$ & $-4,4$ & $-4,5$ & $-4,6$ & $-4,7$ & $-4,7$ \\
\hline \multirow[t]{3}{*}{ Total } & $\mathrm{DM}$ & 5,43 & 5,43 & 5,50 & 5,70 & 6,04 & 6,54 & 7,20 & - \\
\hline & DMA & 15,87 & 15,82 & 15,80 & 15,88 & 16,08 & 16,43 & 16,90 & - \\
\hline & PDMA & 19,08 & 19,12 & 19,59 & 20,44 & 21,68 & 23,52 & 25,68 & - \\
\hline \multirow[t]{3}{*}{ CPI } & DM & 8,81 & 8,80 & 8,95 & 9,35 & 10,07 & 11,08 & 12,36 & - \\
\hline & DMA & 32,34 & 32,18 & 32,06 & 32,14 & 32,49 & 33,15 & 34,07 & - \\
\hline & PDMA & 28,78 & 28,82 & 29,44 & 30,67 & 32,53 & 34,97 & 37,67 & - \\
\hline \multirow[t]{3}{*}{ SPI } & $\mathrm{DM}$ & 2,96 & 2,96 & 2,97 & 3,02 & 3,08 & 3,21 & 3,42 & - \\
\hline & DMA & 3,80 & 3,81 & 3,87 & 3,95 & 4,05 & 4,17 & 4,31 & - \\
\hline & PDMA & 11,96 & 12,00 & 12,37 & 12,94 & 13,72 & 15,13 & 16,89 & - \\
\hline \multirow[t]{3}{*}{$\Delta \mathrm{CS}$} & DM & 5,85 & 5,84 & 5,99 & 6,33 & 6,99 & 7,88 & 8,94 & - \\
\hline & DMA & 28,54 & 28,37 & 28,19 & 28,18 & 28,44 & 28,99 & 29,76 & - \\
\hline & PDMA & 16,81 & 16,83 & 17,07 & 17,73 & 18,80 & 19,84 & 20,77 & 一 \\
\hline
\end{tabular}




\subsection{Comparação com SOPPA(CC2) e SOPPA(CCSD}

Tabela 8.427: Constantes de acoplamento nos níveis SOPPA(CCSD) e SOPPA(CC2) com base aug-cc-pVTZ-J.

\begin{tabular}{|c|c|c|c|c|}
\hline & & $\begin{array}{l}\text { SOPPA } \\
\text { (CCSD) }\end{array}$ & $\begin{array}{c}\text { SOPPA } \\
(\mathrm{CC} 2)\end{array}$ & Exp. \\
\hline $\mathrm{HF}$ & ${ }^{1} J_{\mathrm{HF}}$ & 528,3 & 528,3 & 500,0 \\
\hline $\mathrm{CO}$ & ${ }^{1} J_{\mathrm{CO}}$ & 18,5 & 18,5 & 16,4 \\
\hline $\mathrm{H}_{2} \mathrm{O}$ & ${ }^{1} J_{\mathrm{OH}}$ & $-80,8$ & $-80,8$ & $-80,6$ \\
\hline $\mathrm{H}_{2} \mathrm{O}$ & ${ }^{2} J_{\mathrm{HH}}$ & $-9,0$ & $-9,0$ & $-7,3$ \\
\hline $\mathrm{NH}_{3}$ & ${ }^{1} J_{\mathrm{NH}}$ & 44,0 & 44,0 & 43,8 \\
\hline $\mathrm{NH}_{3}$ & ${ }^{2} J_{\mathrm{HH}}$ & $-11,6$ & $-11,6$ & $-9,6$ \\
\hline $\mathrm{PH}_{3}$ & ${ }^{1} J_{\mathrm{PH}}$ & 184,6 & 184,6 & 188,2 \\
\hline $\mathrm{PF}_{3}$ & ${ }^{1} J_{\mathrm{PF}}$ & $-1500,2$ & $-1500,2$ & $-1441,0$ \\
\hline $\mathrm{BHF}_{2}$ & ${ }^{1} J_{\mathrm{BF}}$ & $-66,9$ & $-66,9$ & $-84,0$ \\
\hline $\mathrm{BF}_{3}$ & ${ }^{1} J_{\mathrm{BF}}$ & 24,3 & 24,3 & 15,0 \\
\hline $\mathrm{F}_{2} \mathrm{O}$ & ${ }^{1} J_{\mathrm{OF}}$ & $-379,4$ & $-379,4$ & $-300,0$ \\
\hline $\mathrm{CH}_{4}$ & ${ }^{1} J_{\mathrm{CH}}$ & 122,9 & 122,9 & 125,3 \\
\hline $\mathrm{CH}_{4}$ & ${ }^{2} J_{\mathrm{HH}}$ & $-14,1$ & $-14,1$ & $-12,8$ \\
\hline $\mathrm{C}_{2} \mathrm{H}_{2}$ & ${ }^{1} J_{\mathrm{CC}}$ & 190,1 & 190,1 & 174,8 \\
\hline $\mathrm{C}_{2} \mathrm{H}_{2}$ & ${ }^{1} J_{\mathrm{CH}}$ & 254,9 & 254,9 & 247,6 \\
\hline $\mathrm{C}_{2} \mathrm{H}_{2}$ & ${ }^{2} J_{\mathrm{CH}}$ & 51,7 & 51,7 & 50,1 \\
\hline $\mathrm{C}_{2} \mathrm{H}_{2}$ & ${ }^{3} J_{\mathrm{HH}}$ & 11,2 & 11,2 & 9,6 \\
\hline $\mathrm{C}_{2} \mathrm{H}_{4}$ & ${ }^{1} J_{\mathrm{CC}}$ & 70,3 & 70,3 & 67,6 \\
\hline $\mathrm{C}_{2} \mathrm{H}_{4}$ & ${ }^{1} J_{\mathrm{CH}}$ & 157,7 & 157,7 & 156,3 \\
\hline $\mathrm{C}_{2} \mathrm{H}_{4}$ & ${ }^{2} J_{\mathrm{CH}}$ & $-3,1$ & $-3,1$ & $-2,4$ \\
\hline $\mathrm{C}_{2} \mathrm{H}_{4}$ & ${ }^{2} J_{\mathrm{HH}}$ & 1,1 & 1,1 & 2,3 \\
\hline $\mathrm{C}_{2} \mathrm{H}_{4}$ & ${ }^{3} J_{\mathrm{HH}_{\mathrm{c}}}$ & 11,8 & 11,8 & 11,7 \\
\hline $\mathrm{C}_{2} \mathrm{H}_{4}$ & ${ }^{3} J_{\mathrm{HH}_{\mathrm{t}}}$ & 18,2 & 18,2 & 19,0 \\
\hline $\mathrm{C}_{2} \mathrm{H}_{6}$ & ${ }^{1} J_{\mathrm{CC}}$ & 34,2 & 34,2 & 34,5 \\
\hline $\mathrm{C}_{2} \mathrm{H}_{6}$ & ${ }^{1} J_{\mathrm{CH}}$ & 123,7 & 123,7 & 125,2 \\
\hline $\mathrm{C}_{2} \mathrm{H}_{6}$ & ${ }^{2} J_{\mathrm{CH}}$ & $-5,0$ & $-5,0$ & $-4,7$ \\
\hline \multirow[t]{3}{*}{ Total } & $\mathrm{DM}$ & $-2,61$ & $-2,61$ & - \\
\hline & DMA & 9,30 & 9,30 & - \\
\hline & PDMA & 12,42 & 12,42 & - \\
\hline \multirow[t]{3}{*}{ CPI } & DM & $-8,12$ & $-8,12$ & - \\
\hline & DMA & 18,48 & 18,48 & - \\
\hline & PDMA & 16,25 & 16,25 & - \\
\hline \multirow[t]{3}{*}{ SPI } & $\mathrm{DM}$ & 1,43 & 1,43 & - \\
\hline & DMA & 2,58 & 2,58 & - \\
\hline & PDMA & 9,60 & 9,60 & - \\
\hline \multirow[t]{3}{*}{$\Delta \mathrm{CS}$} & $\mathrm{DM}$ & $-9,54$ & $-9,54$ & - \\
\hline & DMA & 15,90 & 15,90 & - \\
\hline & PDMA & 6,65 & 6,65 & - \\
\hline \multicolumn{5}{|c|}{ Desconsiderando ${ }^{1} J_{\mathrm{BF}}$ da molécula de $\mathrm{BF}_{3},{ }^{2} J_{\mathrm{CH}}$ e ${ }^{2} J_{\mathrm{HH}}$ da molécula de $\mathrm{C}_{2} \mathrm{H}_{4}$} \\
\hline \multirow[t]{3}{*}{ Total } & $\mathrm{DM}$ & $-3,27$ & $-3,27$ & - \\
\hline & DMA & 10,03 & 10,03 & - \\
\hline & PDMA & 7,76 & 7,76 & - \\
\hline \multirow[t]{3}{*}{ CPI } & $\mathrm{DM}$ & $-9,85$ & $-9,85$ & - \\
\hline & DMA & 19,40 & 19,40 & - \\
\hline & PDMA & 11,71 & 11,71 & - \\
\hline \multirow[t]{3}{*}{ SPI } & $\mathrm{DM}$ & 1,80 & 1,80 & - \\
\hline & DMA & 2,82 & 2,82 & - \\
\hline & PDMA & 4,73 & 4,73 & - \\
\hline \multirow[t]{3}{*}{$\Delta \mathrm{CS}$} & $\mathrm{DM}$ & $-11,65$ & $-11,65$ & - \\
\hline & DMA & 16,57 & 16,57 & - \\
\hline & PDMA & 6,97 & 6,97 & - \\
\hline
\end{tabular}




\subsection{Análise dos termos FC, SD, PSO e DSO}

Tabela 8.428: Contribuições FC, SD, PSO e DSO para ${ }^{1} J_{\mathrm{HF}}$ da molécula de HF para os melhores funcionais com geometrias experimentais na base aug-pcJ-2.

\begin{tabular}{lccccc}
\hline & TOTAL & FC & SD & PSO & DSO \\
\hline B1B95 & 470,4 & 265,6 & $-1,1$ & 206,0 & $-0,1$ \\
B1B95 40\% & 499,3 & 296,9 & $-2,5$ & 205,1 & $-0,2$ \\
LC-B1B95(40\%|100\%|0,40) & 519,2 & 322,5 & $-3,4$ & 200,5 & $-0,2$ \\
B971 & 449,1 & 247,5 & $-1,3$ & 203,1 & $-0,1$ \\
B971 50\% & 520,6 & 317,7 & $-0,8$ & 203,9 & $-0,1$ \\
B98 & 431,2 & 229,3 & $-1,2$ & 203,2 & $-0,1$ \\
B98 50\% & 505,9 & 301,8 & $-0,4$ & 204,6 & $-0,1$ \\
BHandH & 530,8 & 332,1 & $-3,1$ & 202,1 & $-0,2$ \\
BHandH 40\% & 507,2 & 306,6 & $-1,7$ & 202,5 & $-0,2$ \\
LC-BHandH(40\%|100\%|0,30) & 515,0 & 316,9 & $-2,5$ & 200,8 & $-0,3$ \\
B972 & 442,8 & 243,0 & $-1,6$ & 201,7 & $-0,1$ \\
B972B95 60\% & 522,7 & 321,0 & $-1,6$ & 203,5 & $-0,1$ \\
wB97X & 497,9 & 300,5 & $-2,6$ & 200,2 & $-0,2$ \\
wB97X(20\%|100\%|\#) & 507,3 & 312,6 & $-4,5$ & 199,4 & $-0,2$ \\
wB97XD & 484,2 & 283,2 & $-1,2$ & 202,4 & $-0,1$ \\
wB97XD(\#|\#|0,35) & 499,4 & 302,9 & $-2,6$ & 199,3 & $-0,2$ \\
B3LYP & 445,4 & 241,2 & $-0,8$ & 205,3 & $-0,1$ \\
PBE0 & 430,8 & 231,0 & $-2,5$ & 202,6 & $-0,1$ \\
SOPPA(CCSD) & 528,3 & 341,0 & $-1,1$ & 188,3 & 0,1 \\
Experimental & 500 & - & - & - & - \\
\hline
\end{tabular}

Tabela 8.429: Contribuições FC, SD, PSO e DSO para ${ }^{1} J_{\mathrm{CO}}$ da molécula de CO para os melhores funcionais com geometrias experimentais na base aug-pcJ-2.

\begin{tabular}{lccccc}
\hline & TOTAL & FC & SD & PSO & DSO \\
\hline B1B95 & 18,4 & 9,6 & $-5,9$ & 14,7 & 0,1 \\
B1B95 40\% & 16,1 & 7,6 & $-6,1$ & 14,5 & 0,1 \\
LC-B1B95(40\%|100\%|0,40) & 16,5 & 8,4 & $-6,2$ & 14,3 & 0,1 \\
B971 & 17,4 & 9,2 & $-6,1$ & 14,2 & 0,1 \\
B971 50\% & 9,0 & 1,9 & $-6,1$ & 13,2 & 0,1 \\
B98 & 18,5 & 10,4 & $-6,2$ & 14,2 & 0,1 \\
B98 50\% & 9,5 & 2,5 & $-6,2$ & 13,1 & 0,1 \\
BHandH & 13,7 & 6,3 & $-6,7$ & 14,1 & 0,1 \\
BHandH 40\% & 16,3 & 8,2 & $-6,4$ & 14,3 & 0,1 \\
LC-BHandH(40\%|100\%|0,30) & 15,3 & 7,9 & $-6,7$ & 13,9 & 0,1 \\
B972 & 18,3 & 10,1 & $-6,0$ & 14,1 & 0,1 \\
B972B95 60\% & 12,0 & 4,2 & $-5,7$ & 13,4 & 0,1 \\
wB97X & 19,1 & 11,2 & $-6,3$ & 14,1 & 0,1 \\
wB97X(20\%|100\%|\#) & 19,2 & 11,4 & $-6,6$ & 14,3 & 0,1 \\
wB97XD & 19,6 & 11,3 & $-6,2$ & 14,4 & 0,1 \\
wB97XD(\#|\#|0,35) & 18,9 & 11,2 & $-6,5$ & 14,1 & 0,1 \\
B3LYP & 18,2 & 10,4 & $-6,6$ & 14,3 & 0,1 \\
PBE0 & 19,9 & 12,2 & $-6,7$ & 14,3 & 0,1 \\
SOPPA(CCSD) & 18,5 & 8,6 & $-4,4$ & 14,2 & 0,1 \\
Experimental & 16,4 & - & - & - & - \\
\hline
\end{tabular}

Tabela 8.430: Contribuições FC, SD, PSO e DSO para ${ }^{1} J_{\mathrm{OH}}$ da molécula de $\mathrm{H}_{2} \mathrm{O}$ para os melhores funcionais com geometrias experimentais na base aug-pcJ-2.

\begin{tabular}{lccccc}
\hline & TOTAL & FC & SD & PSO & DSO \\
\hline B1B95 & $-77,3$ & $-63,8$ & $-0,6$ & $-12,8$ & 0,0 \\
B1B95 40\% & $-80,4$ & $-67,0$ & $-0,5$ & $-12,8$ & 0,0 \\
LC-B1B95(40\%|100\%|0,40) & $-81,6$ & $-68,5$ & $-0,3$ & $-12,6$ & 0,0 \\
B971 & $-74,4$ & $-61,0$ & $-0,6$ & $-12,6$ & 0,0 \\
B971 50\% & $-79,7$ & $-66,3$ & $-0,7$ & $-12,6$ & 0,0 \\
B98 & $-72,5$ & $-59,1$ & $-0,7$ & $-12,6$ & 0,0 \\
B98 50\% & $-78,4$ & $-64,9$ & $-0,7$ & $-12,6$ & 0,0 \\
BHandH & $-83,7$ & $-70,3$ & $-0,5$ & $-12,8$ & 0,0 \\
BHandH 40\% & $-80,7$ & $-67,2$ & $-0,6$ & $-12,8$ & 0,0 \\
LC-BHandH(40\%|100\%|0,30) & $-81,6$ & $-68,3$ & $-0,5$ & $-12,7$ & 0,0 \\
B972 & $-73,5$ & $-60,3$ & $-0,5$ & $-12,5$ & 0,0 \\
B972B95 60\% & $-79,6$ & $-66,3$ & $-0,6$ & $-12,6$ & 0,0 \\
wB97X & $-76,5$ & $-63,6$ & $-0,3$ & $-12,4$ & 0,0 \\
wB97X(20\%|100\%|\#) & $-78,4$ & $-65,6$ & $-0,2$ & $-12,4$ & 0,0 \\
wB97XD & $-74,7$ & $-61,5$ & $-0,5$ & $-12,6$ & 0,0 \\
wB97XD(\#|\#|0,35) & $-76,3$ & $-63,4$ & $-0,3$ & $-12,5$ & 0,0 \\
B3LYP & $-76,8$ & $-63,3$ & $-0,6$ & $-12,8$ & 0,0 \\
PBE0 & $-73,0$ & $-59,8$ & $-0,5$ & $-12,6$ & 0,0 \\
SOPPA(CCSD) & $-80,8$ & $-68,9$ & $-0,5$ & $-11,4$ & $-0,1$ \\
Experimental & $-80,6$ & - & - & - & - \\
\hline
\end{tabular}


Tabela 8.431: Contribuições FC, SD, PSO e DSO para ${ }^{2} J_{\mathrm{HH}}$ da molécula de $\mathrm{H}_{2} \mathrm{O}$ para os melhores funcionais com geometrias experimentais na base aug-pcJ-2.

\begin{tabular}{lccccc}
\hline & TOTAL & FC & SD & PSO & DSO \\
\hline B1B95 & $-7,0$ & $-10,3$ & 0,9 & 9,6 & $-7,2$ \\
B1B95 40\% & $-8,2$ & $-11,5$ & 0,9 & 9,5 & $-7,2$ \\
LC-B1B95(40\%|100\%|0,40) & $-8,4$ & $-11,5$ & 0,9 & 9,4 & $-7,2$ \\
B971 & $-6,5$ & $-9,8$ & 0,9 & 9,5 & $-7,2$ \\
B971 50\% & $-6,4$ & $-9,6$ & 0,9 & 9,4 & $-7,1$ \\
B98 & $-6,9$ & $-10,2$ & 0,9 & 9,5 & $-7,2$ \\
B98 50\% & $-6,4$ & $-9,7$ & 0,9 & 9,4 & $-7,1$ \\
BHandH & $-9,4$ & $-12,6$ & 1,0 & 9,4 & $-7,2$ \\
BHandH 40\% & $-8,0$ & $-11,3$ & 1,0 & 9,4 & $-7,2$ \\
LC-BHandH(40\%|100\%|0,30) & $-8,7$ & $-11,9$ & 0,9 & 9,4 & $-7,2$ \\
B972 & $-7,5$ & $-10,7$ & 0,9 & 9,5 & $-7,2$ \\
B972B95 60\% & $-8,2$ & $-11,6$ & 1,0 & 9,5 & $-7,2$ \\
wB97X & $-6,4$ & $-9,6$ & 0,9 & 9,5 & $-7,2$ \\
wB97X(20\%|100\%|\#) & $-7,9$ & $-11,1$ & 0,9 & 9,5 & $-7,2$ \\
wB97XD & $-6,4$ & $-9,7$ & 0,9 & 9,5 & $-7,2$ \\
wB97XD(\#|\#|0,35) & $-7,0$ & $-10,1$ & 0,9 & 9,4 & $-7,2$ \\
B3LYP & $-7,2$ & $-10,6$ & 0,9 & 9,5 & $-7,2$ \\
PBE0 & $-7,3$ & $-10,6$ & 0,9 & 9,5 & $-7,2$ \\
SOPPA(CCSD) & $-9,0$ & $-12,0$ & 0,9 & 9,2 & $-7,2$ \\
Experimental & $-7,3$ & - & - & - & - \\
\hline
\end{tabular}

Tabela 8.432: Contribuições FC, SD, PSO e DSO para ${ }^{1} J_{\mathrm{NH}}$ da molécula de $\mathrm{NH}_{3}$ para os melhores funcionais com geometrias experimentais na base aug-pcJ-2.

\begin{tabular}{lccccc}
\hline & TOTAL & FC & SD & PSO & DSO \\
\hline B1B95 & 44,0 & 41,4 & 0,1 & 2,3 & 0,0 \\
B1B95 40\% & 44,9 & 42,4 & 0,1 & 2,3 & 0,0 \\
LC-B1B95(40\%|100\%|0,40) & 44,0 & 41,6 & 0,0 & 2,2 & 0,0 \\
B971 & 43,3 & 40,7 & 0,2 & 2,2 & 0,0 \\
B971 50\% & 43,1 & 40,6 & 0,2 & 2,2 & 0,0 \\
B98 & 42,9 & 40,3 & 0,2 & 2,3 & 0,0 \\
B98 50\% & 43,1 & 40,5 & 0,2 & 2,2 & 0,0 \\
BHandH & 45,5 & 43,0 & 0,1 & 2,3 & 0,0 \\
BHandH 40\% & 44,2 & 41,6 & 0,1 & 2,3 & 0,0 \\
LC-BHandH(40\%|100\%|0,30) & 44,4 & 41,9 & 0,1 & 2,3 & 0,0 \\
B972 & 41,7 & 39,2 & 0,1 & 2,2 & 0,0 \\
B972B95 60\% & 42,0 & 39,5 & 0,1 & 2,2 & 0,0 \\
wB97X & 41,5 & 39,0 & 0,1 & 2,2 & 0,0 \\
wB97X(20\%|100\%|\#) & 42,8 & 40,4 & 0,1 & 2,2 & 0,0 \\
wB97XD & 41,9 & 39,4 & 0,1 & 2,2 & 0,0 \\
wB97XD(\#|\#|0,35) & 42,3 & 39,8 & 0,1 & 2,2 & 0,0 \\
B3LYP & 45,3 & 42,7 & 0,1 & 2,3 & 0,0 \\
PBE0 & 42,5 & 40,0 & 0,1 & 2,2 & 0,0 \\
SOPPA(CCSD) & 44,0 & 41,8 & 0,1 & 2,0 & 0,1 \\
Experimental & 43,8 & - & - & - & - \\
\hline
\end{tabular}

Tabela 8.433: Contribuições FC, SD, PSO e DSO para ${ }^{2} J_{\mathrm{HH}}$ da molécula de $\mathrm{NH}_{3}$ para os melhores funcionais com geometrias experimentais na base aug-pcJ-2.

\begin{tabular}{lccccc}
\hline & TOTAL & FC & SD & PSO & DSO \\
\hline B1B95 & $-9,3$ & $-11,1$ & 0,6 & 6,4 & $-5,2$ \\
B1B95 40\% & $-10,4$ & $-12,2$ & 0,6 & 6,4 & $-5,2$ \\
LC-B1B95(40\%|100\%|0,40) & $-10,5$ & $-12,3$ & 0,6 & 6,3 & $-5,2$ \\
B971 & $-9,1$ & $-10,8$ & 0,6 & 6,3 & $-5,2$ \\
B971 50\% & $-8,6$ & $-10,2$ & 0,5 & 6,2 & $-5,2$ \\
B98 & $-9,5$ & $-11,3$ & 0,6 & 6,3 & $-5,2$ \\
B98 50\% & $-8,8$ & $-10,5$ & 0,5 & 6,2 & $-5,1$ \\
BHandH & $-11,1$ & $-12,8$ & 0,6 & 6,3 & $-5,2$ \\
BHandH 40\% & $-9,9$ & $-11,6$ & 0,6 & 6,3 & $-5,2$ \\
LC-BHandH(40\%|100\%|0,30) & $-10,7$ & $-12,4$ & 0,6 & 6,3 & $-5,2$ \\
B972 & $-9,1$ & $-10,8$ & 0,6 & 6,3 & $-5,2$ \\
B972B95 60\% & $-9,8$ & $-11,6$ & 0,6 & 6,3 & $-5,2$ \\
wB97X & $-8,7$ & $-10,4$ & 0,6 & 6,3 & $-5,2$ \\
wB97X(20\%|100\%|\#) & $-10,1$ & $-11,8$ & 0,6 & 6,3 & $-5,3$ \\
wB97XD & $-9,0$ & $-10,7$ & 0,6 & 6,3 & $-5,2$ \\
wB97XD(\#|\#|0,35) & $-9,7$ & $-11,3$ & 0,6 & 6,3 & $-5,2$ \\
B3LYP & $-9,9$ & $-11,7$ & 0,6 & 6,3 & $-5,2$ \\
PBE0 & $-10,1$ & $-11,8$ & 0,6 & 6,3 & $-5,2$ \\
SOPPA(CCSD) & $-11,6$ & $-13,1$ & 0,6 & 6,1 & $-5,2$ \\
Experimental & $-9,6$ & - & - & - & - \\
\hline
\end{tabular}


Tabela 8.434: Contribuições FC, SD, PSO e DSO para ${ }^{1} J_{\mathrm{PH}}$ da molécula de $\mathrm{PH}_{3}$ para os melhores funcionais com geometrias experimentais na base aug-pcJ-2.

\begin{tabular}{lccccc}
\hline & TOTAL & FC & SD & PSO & DSO \\
\hline B1B95 & 167,8 & 162,5 & $-0,7$ & 5,9 & 0,0 \\
B1B95 40\% & 176,5 & 171,6 & $-0,9$ & 5,8 & 0,0 \\
LC-B1B95(40\%|100\%|0,40) & 162,8 & 158,4 & $-1,3$ & 5,7 & 0,0 \\
B971 50\% & 190,7 & 185,3 & $-0,5$ & 5,9 & 0,0 \\
B971 50\% & 196,6 & 191,4 & $-0,7$ & 5,8 & 0,0 \\
B98 & 196,4 & 191,0 & $-0,6$ & 5,9 & 0,0 \\
B98 50\% & 201,7 & 196,5 & $-0,7$ & 5,8 & 0,0 \\
BHandH & 183,1 & 177,9 & $-0,9$ & 6,1 & 0,0 \\
BHandH 40\% & 172,9 & 167,2 & $-0,7$ & 6,4 & 0,0 \\
LC-BHandH(40\%|100\%|0,30) & 166,1 & 161,2 & $-1,1$ & 6,1 & 0,0 \\
B972 & 184,0 & 178,4 & $-0,3$ & 5,9 & 0,0 \\
B972B95 60\% & 179,9 & 175,1 & $-0,8$ & 5,6 & 0,0 \\
wB97X & 165,0 & 159,9 & $-0,8$ & 5,8 & 0,0 \\
wB97X(20\%|100\%|\#) & 174,7 & 169,9 & $-1,0$ & 5,7 & 0,0 \\
wB97XD & 176,7 & 171,6 & $-0,8$ & 5,9 & 0,0 \\
wB97XD(\#|\#|0,35) & 174,3 & 169,7 & $-1,1$ & 5,7 & 0,0 \\
B3LYP & 171,9 & 166,6 & $-0,7$ & 6,0 & 0,0 \\
PBE0 & 154,6 & 149,5 & $-0,9$ & 6,0 & 0,0 \\
SOPPA(CCSD) & 184,6 & 180,4 & $-1,2$ & 5,3 & 0,0 \\
Experimental & 188,2 & - & - & - & - \\
\hline
\end{tabular}

Tabela 8.435: Contribuições FC, SD, PSO e DSO para ${ }^{1} J_{\mathrm{PF}}$ da molécula de $\mathrm{PF}_{3}$ para os melhores funcionais com geometrias experimentais na base aug-pcJ-2.

\begin{tabular}{|c|c|c|c|c|c|}
\hline & TOTAL & $\mathrm{FC}$ & SD & $\mathrm{PSO}$ & $\mathrm{DSO}$ \\
\hline B1B95 & $-1645,5$ & $-1370,9$ & 29,2 & $-304,7$ & 0,8 \\
\hline B1B95 40\% & $-1606,4$ & $-1337,7$ & 30,0 & $-299,6$ & 0,8 \\
\hline LC-B1B95 $(40 \%|100 \%| 0,40)$ & $-1589,8$ & $-1326,2$ & 31,2 & $-295,7$ & 0,8 \\
\hline B971 & $-1656,7$ & $-1389,5$ & 28,7 & $-296,8$ & 0,8 \\
\hline B971 50\% & $-1539,1$ & $-1277,3$ & 27,1 & $-289,8$ & 0,8 \\
\hline B98 & $-1666,4$ & $-1399,5$ & 29,1 & $-296,9$ & 0,8 \\
\hline B98 $50 \%$ & $-1549,1$ & $-1287,3$ & 27,2 & $-289,8$ & 0,8 \\
\hline BHandH & $-1670,4$ & $-1401,1$ & 31,6 & $-301,7$ & 0,8 \\
\hline BHandH $40 \%$ & $-1709,0$ & $-1432,6$ & 30,6 & $-307,8$ & 0,8 \\
\hline LC-BHandH $(40 \%|100 \%| 0,30)$ & $-1688,3$ & $-1419,6$ & 31,2 & $-300,8$ & 0,8 \\
\hline B972 & $-1661,2$ & $-1398,6$ & 28,9 & $-292,4$ & 0,8 \\
\hline B972B95 60\% & $-1466,6$ & $-1209,5$ & 27,3 & $-285,3$ & 0,8 \\
\hline wB97X & $-1643,0$ & $-1378,8$ & 29,9 & $-295,0$ & 0,8 \\
\hline wB97X $(20 \%|100 \%| \#)$ & $-1642,9$ & $-1381,9$ & 31,8 & $-293,7$ & 0,8 \\
\hline wB97XD & $-1637,8$ & $-1369,0$ & 30,0 & $-299,7$ & 0,8 \\
\hline wB97XD $(\#|\#| 0,35)$ & $-1628,7$ & $-1367,0$ & $\begin{array}{l}50,0 \\
30,9\end{array}$ & $-293,5$ & 0,8 \\
\hline B3LYP & $-1755,9$ & $-1481,4$ & 30,4 & $-305,7$ & 0,8 \\
\hline PBEO & $-1732,1$ & $-1465,2$ & 30,9 & $-298,8$ & 0,8 \\
\hline SOPPA (CCSD) & $-1500,2$ & $-1278,1$ & 28,7 & $-251,7$ & 0,9 \\
\hline Experimental & -1441 & - & - & - & - \\
\hline
\end{tabular}

Tabela 8.436: Contribuições FC, SD, PSO e DSO para ${ }^{1} J_{\mathrm{BF}}$ da molécula de $\mathrm{BHF}_{2}$ para os melhores funcionais com geometrias experimentais na base aug-pcJ-2.

\begin{tabular}{lccccc}
\hline & TOTAL & FC & SD & PSO & DSO \\
\hline B1B95 & $-127,6$ & $-71,4$ & 0,3 & $-57,1$ & 0,6 \\
B1B95 40\% & $-107,5$ & $-52,1$ & 0,0 & $-56,0$ & 0,6 \\
LC-B1B95(40\%|100\%|0,40) & $-92,0$ & $-36,6$ & $-0,2$ & $-55,8$ & 0,6 \\
B971 & $-123,8$ & $-69,3$ & 0,0 & $-55,0$ & 0,6 \\
B971 50\% & $-69,6$ & $-16,1$ & $-0,5$ & $-53,5$ & 0,6 \\
B98 & $-129,1$ & $-74,8$ & 0,0 & $-54,8$ & 0,6 \\
B98 50\% & $-73,8$ & $-20,4$ & $-0,5$ & $-53,4$ & 0,6 \\
BHandH & $-95,2$ & $-39,3$ & $-0,5$ & $-55,8$ & 0,6 \\
BHandH 40\% & $-114,0$ & $-57,2$ & $-0,3$ & $-57,1$ & 0,6 \\
LC-BHandH(40\%|100\%|0,30) & $-96,0$ & $-39,9$ & $-0,5$ & $-56,0$ & 0,6 \\
B972 & $-129,9$ & $-77,1$ & 0,0 & $-53,3$ & 0,6 \\
B972B95 60\% & $-78,0$ & $-25,7$ & $-0,1$ & $-52,7$ & 0,6 \\
wB97X & $-97,5$ & $-44,3$ & $-0,3$ & $-53,4$ & 0,6 \\
wB97X(20\%|100\%|\#) & $-93,0$ & $-40,0$ & $-0,4$ & $-53,0$ & 0,6 \\
wB97XD & $-103,1$ & $-49,1$ & $-0,3$ & $-54,3$ & 0,6 \\
wB97XD(\#|\#|0,35) & $-85,0$ & $-31,4$ & $-0,5$ & $-53,6$ & 0,6 \\
B3LYP & $-134,5$ & $-78,3$ & 0,0 & $-56,7$ & 0,6 \\
PBE0 & $-131,0$ & $-75,8$ & $-0,3$ & $-55,4$ & 0,6 \\
SOPPA(CCSD) & $-66,9$ & $-21,9$ & $-0,6$ & $-45,1$ & 0,6 \\
Experimental & -84 & - & - & - & - \\
\hline
\end{tabular}


Tabela 8.437: Contribuições FC, SD, PSO e DSO para ${ }^{1} J_{\mathrm{BF}}$ da molécula de $\mathrm{BF}_{3}$ para os melhores funcionais com geometrias experimentais na base aug-pcJ-2.

\begin{tabular}{lccccc}
\hline & TOTAL & FC & SD & PSO & DSO \\
\hline B1B95 & $-27,0$ & 13,9 & 0,8 & $-43,0$ & 1,2 \\
B1B95 40\% & $-5,3$ & 35,4 & 0,6 & $-42,6$ & 1,2 \\
LC-B1B95(40\%|100\%|0,40) & 14,3 & 55,0 & 0,4 & $-42,3$ & 1,1 \\
B971 & $-27,9$ & 12,2 & 0,4 & $-41,8$ & 1,2 \\
B971 50\% & 29,7 & 69,2 & 0,0 & $-40,7$ & 1,1 \\
B98 & $-34,1$ & 5,9 & 0,4 & $-41,7$ & 1,2 \\
B98 50\% & 24,5 & 64,0 & 0,0 & $-40,7$ & 1,1 \\
BHandH & 15,1 & 56,4 & 0,2 & $-42,7$ & 1,1 \\
BHandH 40\% & $-4,1$ & 37,4 & 0,4 & $-43,2$ & 1,1 \\
LC-BHandH(40\%|100\%|0,30) & 13,6 & 54,8 & 0,2 & $-42,6$ & 1,1 \\
B972 & $-36,6$ & 2,5 & 0,3 & $-40,7$ & 1,2 \\
B972B95 60\% & 21,8 & 60,2 & 0,3 & $-39,9$ & 1,2 \\
wB97X & 3,3 & 42,7 & 0,1 & $-40,8$ & 1,1 \\
wB97X(20\%|100\%|\#) & 8,8 & 48,5 & 0,0 & $-40,9$ & 1,1 \\
wB97XD & $-3,0$ & 37,1 & 0,2 & $-41,6$ & 1,2 \\
wB97XD(\#|\#|0,35) & 17,9 & 57,9 & 0,0 & $-41,2$ & 1,1 \\
B3LYP & $-33,2$ & 8,1 & 0,6 & $-43,2$ & 1,1 \\
PBE0 & $-30,5$ & 9,9 & 0,3 & $-42,0$ & 1,2 \\
SOPPA(CCSD) & 24,3 & 57,7 & $-0,1$ & $-34,5$ & 1,2 \\
Experimental & 15 & - & - & - & - \\
\hline
\end{tabular}

Tabela 8.438: Contribuições FC, SD, PSO e DSO para ${ }^{1} J_{\mathrm{OF}}$ da molécula de $\mathrm{F}_{2} \mathrm{O}$ para os melhores funcionais com geometrias experimentais na base aug-pcJ-2.

\begin{tabular}{lccccc}
\hline & TOTAL & FC & SD & PSO & DSO \\
\hline B1B95 & $-361,9$ & 132,8 & $-208,2$ & $-286,1$ & $-0,3$ \\
B1B95 40\% & $-404,3$ & 131,8 & $-228,9$ & $-306,8$ & $-0,3$ \\
LC-B1B95(40\%|100\%|0,40) & $-472,1$ & 111,6 & $-246,0$ & $-337,2$ & $-0,3$ \\
B971 & $-318,8$ & 137,0 & $-199,9$ & $-255,6$ & $-0,3$ \\
B971 50\% & $-370,4$ & 145,8 & $-214,6$ & $-301,3$ & $-0,3$ \\
B98 & $-336,9$ & 126,7 & $-204,6$ & $-258,6$ & $-0,3$ \\
B98 50\% & $-383,0$ & 137,2 & $-218,8$ & $-301,1$ & $-0,3$ \\
BHandH & $-465,0$ & 121,9 & $-258,1$ & $-328,5$ & $-0,3$ \\
BHandH 40\% & $-419,8$ & 129 & $-231,7$ & $-316,7$ & $-0,3$ \\
LC-BHandH(40\%|100\%|0,30) & $-459,2$ & 116,8 & $-247,5$ & $-328,2$ & $-0,3$ \\
B972 & $-316,0$ & 134,2 & $-198,0$ & $-251,8$ & $-0,3$ \\
B972B95 60\% & $-421,6$ & 124,9 & $-224,2$ & $-321,9$ & $-0,3$ \\
wB97X & $-326,5$ & 150,6 & $-204,8$ & $-272,0$ & $-0,3$ \\
wB97X(20\%|100\%|\#) & $-358,9$ & 146,7 & $-225,5$ & $-279,7$ & $-0,3$ \\
wB97XD & $-333,4$ & 144,0 & $-203,2$ & $-273,7$ & $-0,3$ \\
wB97XD(\#|\#|0,35) & $-373,9$ & 138,6 & $-218,8$ & $-293,2$ & $-0,3$ \\
B3LYP & $-352,0$ & 129,4 & $-219,3$ & $-261,7$ & $-0,3$ \\
PBE0 & $-374,9$ & 124,5 & $-230,5$ & $-268,4$ & $-0,3$ \\
SOPPA(CCSD) & $-379,4$ & 151,3 & $-194,3$ & $-336,0$ & $-0,4$ \\
Experimental & -300 & - & - & - & - \\
\hline
\end{tabular}

Tabela 8.439: Contribuições FC, SD, PSO e DSO para ${ }^{1} J_{\mathrm{CH}}$ da molécula de $\mathrm{CH}_{4}$ para os melhores funcionais com geometrias experimentais na base aug-pcJ-2.

\begin{tabular}{lccccc}
\hline & TOTAL & FC & SD & PSO & DSO \\
\hline B1B95 & 124,4 & 122,3 & 0,1 & 1,7 & 0,2 \\
B1B95 40\% & 126,1 & 124,1 & 0,0 & 1,6 & 0,2 \\
LC-B1B95(40\%|100\%|0,40) & 119,9 & 117,9 & 0,0 & 1,6 & 0,2 \\
B971 & 128,8 & 126,5 & 0,3 & 1,7 & 0,2 \\
B971 50\% & 120,6 & 118,4 & 0,2 & 1,6 & 0,2 \\
B98 & 128,3 & 126,0 & 0,3 & 1,7 & 0,2 \\
B98 50\% & 121,5 & 119,3 & 0,2 & 1,6 & 0,2 \\
BHandH & 124,9 & 122,8 & 0,1 & 1,7 & 0,2 \\
BHandH 40\% & 120,7 & 118,5 & 0,1 & 1,7 & 0,2 \\
LC-BHandH(40\%|100\%|0,30) & 120,8 & 118,7 & 0,0 & 1,7 & 0,2 \\
B972 & 118,8 & 116,6 & 0,2 & 1,6 & 0,2 \\
B972B95 60\% & 111,8 & 109,8 & 0,0 & 1,6 & 0,2 \\
wB97X & 112,5 & 110,4 & 0,1 & 1,6 & 0,2 \\
wB97X(20\%|100\%|\#) & 118,0 & 116,0 & 0,0 & 1,6 & 0,2 \\
wB97XD & 114,7 & 112,6 & 0,1 & 1,7 & 0,2 \\
wB97XD(\#|\#|0,35) & 115,2 & 113,2 & 0,1 & 1,6 & 0,2 \\
B3LYP & 131,7 & 129,5 & 0,1 & 1,7 & 0,2 \\
PBE0 & 122,8 & 120,6 & 0,1 & 1,7 & 0,2 \\
SOPPA(CCSD) & 122,9 & 121,1 & 0,0 & 1,5 & 0,3 \\
Experimental & 125,3 & - & - & - & - \\
\hline
\end{tabular}


Tabela 8.440: Contribuições FC, SD, PSO e DSO para ${ }^{2} J_{\mathrm{HH}}$ da molécula de $\mathrm{CH}_{4}$ para os melhores funcionais com geometrias experimentais na base aug-pcJ-2.

\begin{tabular}{lccccc}
\hline & TOTAL & FC & SD & PSO & DSO \\
\hline B1B95 & $-12,2$ & $-12,9$ & 0,3 & 3,8 & $-3,5$ \\
B1B95 40\% & $-13,0$ & $-13,8$ & 0,3 & 3,8 & $-3,5$ \\
LC-B1B95 $(40 \%|100 \%| 0,40)$ & $-13,0$ & $-13,7$ & 0,3 & 3,8 & $-3,5$ \\
B971 & $-12,0$ & $-12,7$ & 0,3 & 3,8 & $-3,5$ \\
B971 50\% & $-10,7$ & $-11,3$ & 0,3 & 3,7 & $-3,4$ \\
B98 & $-12,5$ & $-13,2$ & 0,3 & 3,8 & $-3,5$ \\
B98 50\% & $-11,0$ & $-11,6$ & 0,3 & 3,7 & $-3,4$ \\
BHandH & $-13,3$ & $-13,9$ & 0,3 & 3,8 & $-3,5$ \\
BHandH 40\% & $-12,1$ & $-12,8$ & 0,3 & 3,8 & $-3,5$ \\
LC-BHandH(40\%|100\%|0,30) & $-13,0$ & $-13,6$ & 0,3 & 3,8 & $-3,5$ \\
B972 & $-11,3$ & $-12,0$ & 0,3 & 3,8 & $-3,5$ \\
B972B95 60\% & $-11,9$ & $-12,6$ & 0,3 & 3,8 & $-3,4$ \\
wB97X & $-11,3$ & $-11,9$ & 0,3 & 3,8 & $-3,5$ \\
wB97X(20\%|100\%|\#) & $-12,7$ & $-13,4$ & 0,3 & 3,8 & $-3,5$ \\
wB97XD & $-11,8$ & $-12,4$ & 0,3 & 3,8 & $-3,5$ \\
wB97XD(\#|\#|0,35) & $-12,3$ & $-13,0$ & 0,3 & 3,8 & $-3,5$ \\
B3LYP & $-13,0$ & $-13,7$ & 0,3 & 3,8 & $-3,5$ \\
PBE0 & $-13,8$ & $-14,4$ & 0,3 & 3,8 & $-3,5$ \\
SOPPA(CCSD) & $-14,1$ & $-14,6$ & 0,4 & 3,6 & $-3,5$ \\
Experimental & $-12,8$ & - & - & - & - \\
\hline
\end{tabular}

Tabela 8.441: Contribuições FC, SD, PSO e DSO para ${ }^{1} J_{\mathrm{CC}}$ da molécula de $\mathrm{C}_{2} \mathrm{H}_{2}$ para os melhores funcionais com geometrias experimentais na base aug-pcJ-2.

\begin{tabular}{lccccc}
\hline & TOTAL & FC & SD & PSO & DSO \\
\hline B1B95 & 195,2 & 175,2 & 10,9 & 9,1 & 0,0 \\
B1B95 40\% & 199,3 & 177,7 & 11,4 & 10,0 & 0,0 \\
LC-B1B95(40\%|100\%|0,40) & 196,4 & 171,4 & 12,4 & 12,5 & 0,0 \\
B971 & 213,8 & 194,4 & 11,2 & 8,0 & 0,0 \\
B971 50\% & 211,6 & 192,1 & 10,3 & 9,1 & 0,0 \\
B98 & 212,9 & 193,1 & 11,5 & 8,1 & 0,0 \\
B98 50\% & 212,2 & 192,4 & 10,6 & 9,1 & 0,0 \\
BHandH & 202,4 & 179,1 & 12,8 & 10,4 & 0,0 \\
BHandH 40\% & 195,4 & 174 & 11,9 & 9,4 & 0,0 \\
LC-BHandH(40\%|100\%|0,30) & 199,2 & 174,8 & 13,3 & 11,0 & 0,0 \\
B972 & 197,5 & 178,1 & 11,3 & 8,0 & 0,0 \\
B972B95 60\% & 189,4 & 169,0 & 10,0 & 10,3 & 0,0 \\
wB97X & 193,0 & 171,5 & 12,1 & 9,3 & 0,0 \\
wB97X(20\%|100\%|\#) & 199,6 & 176,2 & 13,3 & 10,0 & 0,0 \\
wB97XD & 191,3 & 170,7 & 11,6 & 8,8 & 0,0 \\
wB97XD(\#|\#|0,35) & 194,4 & 170,9 & 12,9 & 10,5 & 0,0 \\
B3LYP & 203,3 & 182,0 & 12,8 & 8,4 & 0,0 \\
PBE0 & 196,4 & 174,5 & 13,5 & 8,4 & 0,0 \\
SOPPA(CCSD) & 190,1 & 175,3 & 8,5 & 6,4 & 0,0 \\
Experimental & 174,8 & - & - & - & - \\
\hline
\end{tabular}

Tabela 8.442: Contribuições FC, SD, PSO e DSO para ${ }^{1} J_{\mathrm{CH}}$ da molécula de $\mathrm{C}_{2} \mathrm{H}_{2}$ para os melhores funcionais com geometrias experimentais na base aug-pcJ-2.

\begin{tabular}{lccccc}
\hline & TOTAL & FC & SD & PSO & DSO \\
\hline B1B95 & 256,2 & 256,6 & 0,5 & $-1,2$ & 0,2 \\
B1B95 40\% & 258,8 & 259,6 & 0,5 & $-1,6$ & 0,2 \\
LC-B1B95(40\%|100\%|0,40) & 247,6 & 249,5 & 0,4 & $-2,6$ & 0,2 \\
B971 & 261,3 & 261,3 & 0,6 & $-0,9$ & 0,2 \\
B971 50\% & 237,9 & 238,9 & 0,4 & $-1,6$ & 0,2 \\
B98 & 261,1 & 261,1 & 0,6 & $-0,9$ & 0,2 \\
B98 50\% & 239,0 & 239,9 & 0,4 & $-1,6$ & 0,2 \\
BHandH & 259,5 & 260,6 & 0,4 & $-1,8$ & 0,2 \\
BHandH 40\% & 252,0 & 252,7 & 0,5 & $-1,5$ & 0,2 \\
LC-BHandH(40\%|100\%|0,30) & 251,3 & 252,7 & 0,3 & $-2,1$ & 0,2 \\
B972 & 247,3 & 247,4 & 0,6 & $-0,9$ & 0,2 \\
B972B95 60\% & 228,9 & 230,3 & 0,4 & $-2,1$ & 0,3 \\
wB97X & 240,2 & 241,0 & 0,4 & $-1,5$ & 0,2 \\
wB97X(20\%|100\%|\#) & 253,8 & 254,7 & 0,5 & $-1,7$ & 0,2 \\
wB97XD & 245,6 & 246,0 & 0,5 & $-1,3$ & 0,2 \\
wB97XD(\#|\#|0,35) & 245,8 & 247,0 & 0,4 & $-1,9$ & 0,2 \\
B3LYP & 271,8 & 271,9 & 0,5 & $-0,9$ & 0,2 \\
PBE0 & 256,2 & 256,5 & 0,4 & $-1,1$ & 0,3 \\
SOPPA(CCSD) & 254,9 & 255,0 & 0,4 & $-0,8$ & 0,3 \\
Experimental & 247,6 & - & - & - & - \\
\hline
\end{tabular}


Tabela 8.443: Contribuições FC, SD, PSO e DSO para ${ }^{2} J_{\mathrm{CH}}$ da molécula de $\mathrm{C}_{2} \mathrm{H}_{2}$ para os melhores funcionais com geometrias experimentais na base aug-pcJ-2.

\begin{tabular}{lccccc}
\hline & TOTAL & FC & SD & PSO & DSO \\
\hline B1B95 & 55,6 & 49,4 & 1,0 & 6,5 & $-1,3$ \\
B1B95 40\% & 55,2 & 48,7 & 1,0 & 6,8 & $-1,3$ \\
LC-B1B95(40\%|100\%|0,40) & 55,8 & 48,4 & 1,0 & 7,6 & $-1,3$ \\
B971 & 53,2 & 47,2 & 1,1 & 6,1 & $-1,3$ \\
B971 50\% & 53,0 & 46,6 & 1,2 & 6,6 & $-1,3$ \\
B98 & 52,8 & 46,8 & 1,1 & 6,2 & $-1,3$ \\
B98 50\% & 53,2 & 46,6 & 1,2 & 6,6 & $-1,3$ \\
BHandH & 53,0 & 46,2 & 1,1 & 7,0 & $-1,3$ \\
BHandH 40\% & 53,3 & 46,8 & 1,1 & 6,7 & $-1,3$ \\
LC-BHandH(40\%|100\%|0,30) & 54,3 & 47,3 & 1,2 & 7,2 & $-1,3$ \\
B972 & 50,7 & 44,9 & 0,9 & 6,1 & $-1,3$ \\
B972B95 60\% & 53,3 & 46,7 & 0,9 & 6,9 & $-1,3$ \\
wB97X & 53,4 & 47,1 & 1,0 & 6,5 & $-1,3$ \\
wB97X(20\%|100\%|\#) & 52,6 & 46,2 & 1,0 & 6,7 & $-1,3$ \\
wB97XD & 53,7 & 47,5 & 1,0 & 6,4 & $-1,3$ \\
wB97XD(\#|\#|0,35) & 54,2 & 47,4 & 1,1 & 6,9 & $-1,3$ \\
B3LYP & 56,1 & 49,9 & 1,2 & 6,2 & $-1,3$ \\
PBE0 & 53,5 & 47,2 & 1,3 & 6,2 & $-1,3$ \\
SOPPA(CCSD) & 51,7 & 46,6 & 1,0 & 5,5 & $-1,3$ \\
Experimental & 50,1 & - & - & - & - \\
\hline
\end{tabular}

Tabela 8.444: Contribuições FC, SD, PSO e DSO para ${ }^{3} J_{\mathrm{HH}}$ da molécula de $\mathrm{C}_{2} \mathrm{H}_{2}$ para os melhores funcionais com geometrias experimentais na base aug-pcJ-2.

\begin{tabular}{lccccc}
\hline & TOTAL & FC & SD & PSO & DSO \\
\hline B1B95 & 10,4 & 8,4 & 0,6 & 5,0 & $-3,5$ \\
B1B95 40\% & 11,2 & 9,0 & 0,6 & 5,1 & $-3,5$ \\
LC-B1B95 $(40 \%|100 \%| 0,40)$ & 11,2 & 8,8 & 0,7 & 5,2 & $-3,5$ \\
B971 & 10,5 & 8,5 & 0,6 & 4,9 & $-3,5$ \\
B971 50\% & 9,3 & 7,2 & 0,6 & 5,0 & $-3,5$ \\
B98 & 10,7 & 8,7 & 0,6 & 4,9 & $-3,5$ \\
B98 50\% & 9,4 & 7,2 & 0,6 & 5,0 & $-3,5$ \\
BHandH & 11,8 & 9,5 & 0,7 & 5,1 & $-3,5$ \\
BHandH 40\% & 10,5 & 8,3 & 0,6 & 5,0 & $-3,5$ \\
LC-BHandH(40\%|100\%|0,30) & 11,2 & 8,8 & 0,7 & 5,1 & $-3,5$ \\
B972 & 10,4 & 8,3 & 0,6 & 4,9 & $-3,5$ \\
B972B95 60\% & 10,6 & 8,3 & 0,6 & 5,1 & $-3,5$ \\
wB97X & 10,0 & 7,8 & 0,7 & 5,0 & $-3,5$ \\
wB97X(20\%|100\%|\#) & 11,6 & 9,3 & 0,8 & 5,0 & $-3,6$ \\
wB97XD & 10,1 & 8,0 & 0,6 & 4,9 & $-3,5$ \\
wB97XD(\#|\#|0,35) & 10,6 & 8,3 & 0,7 & 5,1 & $-3,5$ \\
B3LYP & 11,1 & 9,1 & 0,6 & 4,9 & $-3,5$ \\
PBE0 & 12,4 & 10,3 & 0,7 & 4,9 & $-3,5$ \\
SOPPA(CCSD) & 11,2 & 9,5 & 0,6 & 4,7 & $-3,6$ \\
Experimental & 9,6 & - & - & - & - \\
\hline
\end{tabular}


Tabela 8.445: Contribuições FC, SD, PSO e DSO para ${ }^{1} J_{\mathrm{CC}}$ da molécula de $\mathrm{C}_{2} \mathrm{H}_{4}$ para os melhores funcionais com geometrias experimentais na base aug-pcJ-2.

\begin{tabular}{lccccc}
\hline & TOTAL & FC & SD & PSO & DSO \\
\hline B1B95 & 66,0 & 72,9 & 3,5 & $-10,5$ & 0,0 \\
B1B95 40\% & 69,6 & 76,1 & 4,0 & $-10,6$ & 0,0 \\
LC-B1B95(40\%|100\%|0,40) & 67,8 & 73,9 & 5,0 & $-11,2$ & 0,0 \\
B971 & 78,1 & 84,5 & 3,6 & $-10,0$ & 0,0 \\
B971 50\% & 80,8 & 87,1 & 3,4 & $-9,8$ & 0,0 \\
B98 & 77,3 & 83,6 & 3,7 & $-10,1$ & 0,0 \\
B98 50\% & 81,3 & 87,5 & 3,5 & $-9,8$ & 0,0 \\
BHandH & 72,3 & 77,9 & 4,8 & $-10,6$ & 0,0 \\
BHandH 40\% & 66,7 & 73,1 & 4,1 & $-10,6$ & 0,0 \\
LC-BHandH(40\%|100\%|0,30) & 70,3 & 75,8 & 5,3 & $-10,9$ & 0,0 \\
B972 & 68,1 & 74,1 & 3,8 & $-9,8$ & 0,0 \\
B972B95 60\% & 66,4 & 72,6 & 3,6 & $-9,9$ & 0,0 \\
wB97X & 64,5 & 70,3 & 4,5 & $-10,4$ & 0,0 \\
wB97X(20\%|100\%|\#) & 68,5 & 73,6 & 5,3 & $-10,6$ & 0,0 \\
wB97XD & 63,7 & 70,1 & 4,0 & $-10,4$ & 0,0 \\
wB97XD(\#|\#|0,35) & 66,6 & 72,2 & 5,1 & $-10,7$ & 0,0 \\
B3LYP & 71,0 & 77,0 & 4,2 & $-10,3$ & 0,0 \\
PBE0 & 68,7 & 73,7 & 4,9 & $-10,1$ & 0,0 \\
SOPPA(CCSD) & 70,3 & 76,3 & 3,0 & $-9,0$ & 0,1 \\
Experimental & 67,6 & - & - & - & - \\
\hline
\end{tabular}

Tabela 8.446: Contribuições FC, SD, PSO e DSO para ${ }^{1} J_{\mathrm{CH}}$ da molécula de $\mathrm{C}_{2} \mathrm{H}_{4}$ para os melhores funcionais com geometrias experimentais na base aug-pcJ-2.

\begin{tabular}{lccccc}
\hline & TOTAL & FC & SD & PSO & DSO \\
\hline B1B95 & 158,8 & 157,7 & 0,2 & 0,4 & 0,4 \\
B1B95 40\% & 161,3 & 160,3 & 0,2 & 0,3 & 0,4 \\
LC-B1B95 $(40 \%|100 \%| 0,40)$ & 154,9 & 154,2 & 0,0 & 0,2 & 0,4 \\
B971 & 162,8 & 161,5 & 0,4 & 0,5 & 0,4 \\
B971 50\% & 151,2 & 150,1 & 0,3 & 0,3 & 0,4 \\
B98 & 162,5 & 161,1 & 0,4 & 0,5 & 0,4 \\
B98 50\% & 152,0 & 150,9 & 0,3 & 0,3 & 0,4 \\
BHandH & 160,6 & 159,7 & 0,1 & 0,3 & 0,4 \\
BHandH 40\% & 155,0 & 154 & 0,2 & 0,4 & 0,4 \\
LC-BHandH(40\%|100\%|0,30) & 155,5 & 154,7 & 0,1 & 0,3 & 0,4 \\
B972 & 152,3 & 151,0 & 0,3 & 0,4 & 0,4 \\
B972B95 60\% & 143,6 & 142,8 & 0,1 & 0,2 & 0,4 \\
wB97X & 145,4 & 144,5 & 0,2 & 0,3 & 0,4 \\
wB97X(20\%|100\%|\#) & 153,6 & 152,6 & 0,1 & 0,3 & 0,4 \\
wB97XD & 148,1 & 146,9 & 0,3 & 0,4 & 0,4 \\
wB97XD(\#|\#|0,35) & 149,2 & 148,3 & 0,2 & 0,3 & 0,4 \\
B3LYP & 167,1 & 165,9 & 0,3 & 0,5 & 0,4 \\
PBE0 & 157,3 & 156,2 & 0,2 & 0,4 & 0,4 \\
SOPPA(CCSD) & 157,7 & 156,9 & 0,1 & 0,4 & 0,3 \\
Experimental & 156,3 & - & - & - & - \\
\hline
\end{tabular}

Tabela 8.447: Contribuições FC, SD, PSO e DSO para ${ }^{2} J_{\mathrm{CH}}$ da molécula de $\mathrm{C}_{2} \mathrm{H}_{4}$ para os melhores funcionais com geometrias experimentais na base aug-pcJ-2.

\begin{tabular}{lccccc}
\hline & TOTAL & FC & SD & PSO & DSO \\
\hline B1B95 & $-1,1$ & 0,6 & 0,0 & $-1,2$ & $-0,6$ \\
B1B95 40\% & $-2,3$ & $-0,4$ & 0,0 & $-1,2$ & $-0,6$ \\
LC-B1B95 $(40 \%|100 \%| 0,40)$ & $-3,0$ & $-1,1$ & 0,1 & $-1,3$ & $-0,6$ \\
B971 & $-2,1$ & $-0,3$ & 0,0 & $-1,1$ & $-0,6$ \\
B971 50\% & $-2,1$ & $-0,4$ & 0,1 & $-1,1$ & $-0,6$ \\
B98 & $-2,4$ & $-0,6$ & 0,0 & $-1,1$ & $-0,6$ \\
B98 50\% & $-2,1$ & $-0,4$ & 0,1 & $-1,1$ & $-0,6$ \\
BHandH & $-3,8$ & $-2,1$ & 0,1 & $-1,2$ & $-0,6$ \\
BHandH 40\% & $-2,4$ & $-0,6$ & 0,1 & $-1,2$ & $-0,6$ \\
LC-BHandH(40\%|100\%|0,30) & $-3,2$ & $-1,5$ & 0,1 & $-1,2$ & $-0,6$ \\
B972 & $-2,0$ & $-0,2$ & 0,0 & $-1,1$ & $-0,6$ \\
B972B95 60\% & $-2,4$ & $-0,6$ & 0,1 & $-1,2$ & $-0,6$ \\
wB97X & $-1,3$ & 0,4 & 0,0 & $-1,2$ & $-0,6$ \\
wB97X(20\%|100\%|\#) & $-2,9$ & $-1,1$ & 0,0 & $-1,2$ & $-0,6$ \\
wB97XD & $-1,0$ & 0,7 & 0,0 & $-1,2$ & $-0,6$ \\
wB97XD(\#|\#|0,35) & $-2,0$ & $-0,2$ & 0,0 & $-1,2$ & $-0,6$ \\
B3LYP & $-1,4$ & 0,3 & 0,1 & $-1,1$ & $-0,6$ \\
PBE0 & $-3,0$ & $-1,3$ & 0,1 & $-1,1$ & $-0,6$ \\
SOPPA(CCSD) & $-3,1$ & $-1,5$ & 0,1 & $-1,0$ & $-0,7$ \\
Experimental & $-2,4$ & - & - & - & - \\
\hline
\end{tabular}


Tabela 8.448: Contribuições FC, SD, PSO e DSO para ${ }^{2} J_{\mathrm{HH}}$ da molécula de $\mathrm{C}_{2} \mathrm{H}_{4}$ para os melhores funcionais com geometrias experimentais na base aug-pcJ-2.

\begin{tabular}{lccccc}
\hline & TOTAL & FC & SD & PSO & DSO \\
\hline B1B95 & 4,2 & 3,4 & 0,3 & 4,2 & $-3,8$ \\
B1B95 40\% & 3,3 & 2,5 & 0,3 & 4,2 & $-3,8$ \\
LC-B1B95 $(40 \%|100 \%| 0,40)$ & 2,3 & 1,6 & 0,3 & 4,2 & $-3,8$ \\
B971 & 3,6 & 2,9 & 0,3 & 4,2 & $-3,8$ \\
B971 50\% & 3,4 & 2,7 & 0,3 & 4,1 & $-3,8$ \\
B98 & 3,1 & 2,4 & 0,3 & 4,2 & $-3,8$ \\
B98 50\% & 3,2 & 2,5 & 0,3 & 4,1 & $-3,8$ \\
BHandH & 2,2 & 1,5 & 0,3 & 4,2 & $-3,8$ \\
BHandH 40\% & 3,1 & 2,4 & 0,3 & 4,2 & $-3,8$ \\
LC-BHandH(40\%|100\%|0,30) & 2,2 & 1,5 & 0,3 & 4,1 & $-3,8$ \\
B972 & 3,1 & 2,4 & 0,3 & 4,2 & $-3,8$ \\
B972B95 60\% & 2,2 & 1,5 & 0,3 & 4,1 & $-3,8$ \\
wB97X & 2,9 & 2,2 & 0,3 & 4,1 & $-3,8$ \\
wB97X(20\%|100\%|\#) & 1,8 & 1,1 & 0,3 & 4,2 & $-3,8$ \\
wB97XD & 3,0 & 2,3 & 0,3 & 4,2 & $-3,8$ \\
wB97XD(\#|\#|0,35) & 2,2 & 1,5 & 0,3 & 4,1 & $-3,8$ \\
B3LYP & 4,5 & 3,7 & 0,3 & 4,2 & $-3,8$ \\
PBE0 & 2,3 & 1,6 & 0,3 & 4,2 & $-3,8$ \\
SOPPA(CCSD) & 1,1 & 0,6 & 0,3 & 4,0 & $-3,9$ \\
Experimental & 2,3 & - & - & - & - \\
\hline
\end{tabular}


Tabela 8.449: Contribuições FC, SD, PSO e DSO para ${ }^{3} J_{\mathrm{HH}_{\mathrm{c}}}$ da molécula de $\mathrm{C}_{2} \mathrm{H}_{4}$ para os melhores funcionais com geometrias experimentais na base aug-pcJ-2.

\begin{tabular}{lccccc}
\hline & TOTAL & FC & SD & PSO & DSO \\
\hline B1B95 & 12,1 & 12,4 & 0,0 & 0,7 & $-1,0$ \\
B1B95 40\% & 12,5 & 12,8 & 0,0 & 0,7 & $-1,0$ \\
LC-B1B95 $(40 \%|100 \%| 0,40)$ & 13,0 & 13,4 & 0,0 & 0,7 & $-1,0$ \\
B971 & 11,7 & 12,0 & 0,0 & 0,7 & $-1,0$ \\
B971 50\% & 11,0 & 11,4 & 0,0 & 0,7 & $-1,0$ \\
B98 & 11,8 & 12,2 & 0,0 & 0,7 & $-1,0$ \\
B98 50\% & 11,1 & 11,4 & 0,0 & 0,7 & $-1,0$ \\
BHandH & 13,3 & 13,7 & 0,0 & 0,7 & $-1,0$ \\
BHandH 40\% & 12,7 & 13,1 & 0,0 & 0,7 & $-1,0$ \\
LC-BHandH(40\%|100\%|0,30) & 13,4 & 13,7 & 0,0 & 0,7 & $-1,0$ \\
B972 & 11,2 & 11,5 & 0,0 & 0,7 & $-1,0$ \\
B972B95 60\% & 11,6 & 12,0 & 0,0 & 0,7 & $-1,0$ \\
wB97X & 11,5 & 11,9 & 0,0 & 0,7 & $-1,0$ \\
wB97X(20\%|100\%|\#) & 12,4 & 12,8 & 0,0 & 0,7 & $-1,0$ \\
wB97XD & 11,5 & 11,9 & 0,0 & 0,7 & $-1,0$ \\
wB97XD(\#|\#|0,35) & 12,1 & 12,5 & 0,0 & 0,7 & $-1,0$ \\
B3LYP & 12,8 & 13,2 & 0,0 & 0,7 & $-1,0$ \\
PBE0 & 12,7 & 13,1 & 0,0 & 0,7 & $-1,0$ \\
SOPPA(CCSD) & 11,8 & 12,1 & $-0,1$ & 0,7 & $-1,0$ \\
Experimental & 11,7 & - & - & - & - \\
\hline
\end{tabular}

Tabela 8.450: Contribuições FC, SD, PSO e DSO para ${ }^{3} J_{\mathrm{HH}_{\mathrm{t}}}$ da molécula de $\mathrm{C}_{2} \mathrm{H}_{4}$ para os melhores funcionais com geometrias experimentais na base aug-pcJ-2.

\begin{tabular}{lccccc}
\hline & TOTAL & FC & SD & PSO & DSO \\
\hline B1B95 & 19,0 & 19,1 & 0,2 & 3,1 & $-3,5$ \\
B1B95 40\% & 19,4 & 19,5 & 0,3 & 3,1 & $-3,5$ \\
LC-B1B95(40\%|100\%|0,40) & 19,1 & 19,1 & 0,3 & 3,1 & $-3,5$ \\
B971 & 18,4 & 18,5 & 0,2 & 3,1 & $-3,5$ \\
B971 50\% & 16,4 & 16,5 & 0,2 & 3,0 & $-3,4$ \\
B98 & 18,5 & 18,6 & 0,2 & 3,1 & $-3,5$ \\
B98 50\% & 16,5 & 16,6 & 0,2 & 3,0 & $-3,4$ \\
BHandH & 19,6 & 19,7 & 0,3 & 3,1 & $-3,5$ \\
BHandH 40\% & 18,7 & 18,8 & 0,3 & 3,0 & $-3,5$ \\
LC-BHandH(40\%|100\%|0,30) & 19,1 & 19,1 & 0,4 & 3,0 & $-3,5$ \\
B972 & 17,7 & 17,8 & 0,3 & 3,1 & $-3,5$ \\
B972B95 60\% & 17,4 & 17,5 & 0,3 & 3,0 & $-3,4$ \\
wB97X & 17,2 & 17,3 & 0,3 & 3,1 & $-3,5$ \\
wB97X(20\%|100\%|\#) & 18,7 & 18,7 & 0,4 & 3,1 & $-3,5$ \\
wB97XD & 17,5 & 17,6 & 0,3 & 3,1 & $-3,5$ \\
wB97XD(\#|\#|0,35) & 17,8 & 17,9 & 0,4 & 3,1 & $-3,5$ \\
B3LYP & 20,0 & 20,1 & 0,2 & 3,1 & $-3,5$ \\
PBE0 & 19,8 & 19,9 & 0,3 & 3,1 & $-3,5$ \\
SOPPA(CCSD) & 18,2 & 18,4 & 0,3 & 3,0 & $-3,5$ \\
Experimental & 19 & - & - & - & - \\
\hline
\end{tabular}

Tabela 8.451: Contribuições FC, SD, PSO e DSO para ${ }^{1} J_{\mathrm{CC}}$ da molécula de $\mathrm{C}_{2} \mathrm{H}_{6}$ para os melhores funcionais com geometrias experimentais na base aug-pcJ-2.

\begin{tabular}{lccccc}
\hline & TOTAL & FC & SD & PSO & DSO \\
\hline B1B95 & 30,6 & 29,2 & 1,1 & 0,0 & 0,1 \\
B1B95 40\% & 33,0 & 31,6 & 1,1 & 0,0 & 0,1 \\
LC-B1B95(40\%|100\%|0,40) & 32,3 & 30,8 & 1,2 & 0,2 & 0,1 \\
B971 & 34,9 & 33,5 & 1,1 & 0,0 & 0,1 \\
B971 50\% & 37,8 & 36,5 & 1,0 & 0,1 & 0,1 \\
B98 & 34,4 & 33,0 & 1,1 & 0,0 & 0,1 \\
B98 50\% & 38,2 & 36,9 & 1,1 & 0,1 & 0,1 \\
BHandH & 33,3 & 31,8 & 1,1 & 0,1 & 0,1 \\
BHandH 40\% & 30,0 & 28,5 & 1,1 & 0,2 & 0,1 \\
LC-BHandH(40\%|100\%|0,30) & 32,6 & 31,0 & 1,2 & 0,2 & 0,1 \\
B972 & 30,6 & 29,3 & 1,1 & 0,0 & 0,1 \\
B972B95 60\% & 31,3 & 30,1 & 1,0 & 0,0 & 0,1 \\
wB97X & 29,1 & 27,6 & 1,1 & 0,2 & 0,1 \\
wB97X(20\%|100\%|\#) & 31,0 & 29,5 & 1,2 & 0,2 & 0,1 \\
wB97XD & 29,0 & 27,5 & 1,2 & 0,1 & 0,1 \\
wB97XD(\#|\#|0,35) & 31,2 & 29,6 & 1,2 & 0,2 & 0,1 \\
B3LYP & 32,4 & 30,9 & 1,2 & 0,0 & 0,1 \\
PBE0 & 30,4 & 28,9 & 1,2 & 0,0 & 0,1 \\
SOPPA(CCSD) & 34,2 & 32,8 & 1,0 & 0,2 & 0,1 \\
Experimental & 34,5 & - & - & - & - \\
\hline
\end{tabular}


Tabela 8.452: Contribuições FC, SD, PSO e DSO para ${ }^{1} J_{\mathrm{CH}}$ da molécula de $\mathrm{C}_{2} \mathrm{H}_{6}$ para os melhores funcionais com geometrias experimentais na base aug-pcJ-2.

\begin{tabular}{lccccc}
\hline & TOTAL & FC & SD & PSO & DSO \\
\hline B1B95 & 125,0 & 123,0 & 0,0 & 1,3 & 0,4 \\
B1B95 40\% & 126,9 & 125,0 & 0,0 & 1,3 & 0,4 \\
LC-B1B95(40\%|100\%|0,40) & 121,0 & 119,2 & 0,0 & 1,3 & 0,4 \\
B971 & 129,1 & 127,0 & 0,2 & 1,3 & 0,4 \\
B971 50\% & 120,9 & 118,8 & 0,2 & 1,3 & 0,4 \\
B98 & 128,8 & 126,6 & 0,2 & 1,3 & 0,4 \\
B98 50\% & 121,7 & 119,6 & 0,2 & 1,3 & 0,4 \\
BHandH & 125,8 & 123,9 & 0,0 & 1,4 & 0,4 \\
BHandH 40\% & 121,5 & 119,5 & 0,0 & 1,4 & 0,4 \\
LC-BHandH(40\%|100\%|0,30) & 121,5 & 119,6 & 0,0 & 1,4 & 0,4 \\
B972 & 118,9 & 116,9 & 0,1 & 1,3 & 0,4 \\
B972B95 60\% & 112,6 & 110,8 & 0,0 & 1,2 & 0,4 \\
wB97X & 112,4 & 110,5 & 0,1 & 1,3 & 0,4 \\
wB97X(20\%|100\%|\#) & 118,2 & 116,3 & 0,0 & 1,3 & 0,4 \\
wB97XD & 115,2 & 113,2 & 0,1 & 1,3 & 0,4 \\
wB97XD(\#|\#|0,35) & 115,8 & 113,9 & 0,1 & 1,3 & 0,4 \\
B3LYP & 131,7 & 129,7 & 0,1 & 1,4 & 0,4 \\
PBE0 & 123,5 & 121,5 & 0,1 & 1,3 & 0,4 \\
SOPPA(CCSD) & 123,7 & 122,1 & 0,0 & 1,1 & 0,5 \\
Experimental & 125,2 & - & - & - & - \\
\hline
\end{tabular}

Tabela 8.453: Contribuições FC, SD, PSO e DSO para ${ }^{2} J_{\mathrm{CH}}$ da molécula de $\mathrm{C}_{2} \mathrm{H}_{6}$ para os melhores funcionais com geometrias experimentais na base aug-pcJ-2.

\begin{tabular}{lccccc}
\hline & TOTAL & FC & SD & PSO & DSO \\
\hline B1B95 & $-3,5$ & $-3,6$ & 0,0 & 0,4 & $-0,3$ \\
B1B95 40\% & $-4,0$ & $-4,2$ & 0,0 & 0,4 & $-0,3$ \\
LC-B1B95(40\%|100\%|0,40) & $-4,3$ & $-4,4$ & 0,0 & 0,4 & $-0,3$ \\
B971 & $-3,6$ & $-3,7$ & 0,0 & 0,4 & $-0,3$ \\
B971 50\% & $-3,5$ & $-3,6$ & 0,0 & 0,4 & $-0,3$ \\
B98 & $-3,8$ & $-3,9$ & 0,0 & 0,4 & $-0,3$ \\
B98 50\% & $-3,6$ & $-3,7$ & 0,0 & 0,4 & $-0,3$ \\
BHandH & $-4,3$ & $-4,4$ & 0,0 & 0,4 & $-0,3$ \\
BHandH 40\% & $-3,7$ & $-3,8$ & 0,0 & 0,4 & $-0,3$ \\
LC-BHandH(40\%|100\%|0,30) & $-4,1$ & $-4,2$ & 0,0 & 0,4 & $-0,3$ \\
B972 & $-3,2$ & $-3,3$ & 0,0 & 0,4 & $-0,3$ \\
B972B95 60\% & $-3,9$ & $-4,1$ & 0,0 & 0,4 & $-0,3$ \\
wB97X & $-3,2$ & $-3,3$ & 0,0 & 0,4 & $-0,3$ \\
wB97X(20\%|100\%|\#) & $-3,8$ & $-3,9$ & 0,0 & 0,4 & $-0,3$ \\
wB97XD & $-3,3$ & $-3,4$ & 0,0 & 0,4 & $-0,3$ \\
wB97XD(\#|\#|0,35) & $-3,7$ & $-3,8$ & 0,0 & 0,4 & $-0,3$ \\
B3LYP & $-3,4$ & $-3,5$ & 0,0 & 0,4 & $-0,3$ \\
PBE0 & $-4,1$ & $-4,2$ & 0,0 & 0,4 & $-0,3$ \\
SOPPA(CCSD) & $-5,0$ & $-5,1$ & 0,1 & 0,4 & $-0,3$ \\
Experimental & $-4,7$ & - & - & - & - \\
\hline
\end{tabular}




\subsection{Teste de precisão e Teorema de Janak}

Tabela 8.454: Energias utilizadas (em hartree) e concavidades (Conc.) obtidas pelo Teorema de Janak para B1B95 com geometrias experimentais na base aug-pcJ-2.

\begin{tabular}{|c|c|c|c|c|c|c|c|c|c|}
\hline Molécula & $\mathrm{E}_{\text {cátion }}$ & Eneutra & Eânion & $\varepsilon_{\text {cátion }}^{\text {LUMO }}$ & $\varepsilon_{\text {neutra }}^{\text {HOMO }}$ & $\varepsilon_{\text {neutra }}^{L U M O}$ & $\varepsilon_{\text {ânion }}^{\text {HOMO }}$ & Conc.cátion & Conc.ânion \\
\hline $\mathrm{BF}_{3}$ & $-324,08178$ & $-324,64301$ & $-324,61714$ & $-0,66951$ & $-0,45497$ & $-0,00200$ & 0,05285 & 2,92 & 0,75 \\
\hline $\mathrm{BHF}_{2}$ & $-224,78381$ & $-225,29723$ & $-225,27532$ & $-0,62459$ & $-0,40150$ & $-0,01286$ & 0,04930 & 3,04 & 0,85 \\
\hline $\mathrm{C}_{2} \mathrm{H}_{2}$ & $-76,90761$ & $-77,32260$ & $-77,30304$ & $-0,52151$ & $-0,30983$ & 0,00653 & 0,04407 & 2,88 & 0,51 \\
\hline $\mathrm{C}_{2} \mathrm{H}_{4}$ & $-78,18647$ & $-78,57139$ & $-78,54651$ & $-0,48108$ & $-0,28881$ & 0,00256 & 0,04820 & 2,62 & 0,62 \\
\hline $\mathrm{C}_{2} \mathrm{H}_{6}$ & $-79,35594$ & $-79,80354$ & $-79,78490$ & $-0,54213$ & $-0,35428$ & 0,00190 & 0,04655 & 2,56 & 0,61 \\
\hline $\mathrm{CH}_{4}$ & $-39,98358$ & $-40,50107$ & $-40,48136$ & $-0,63323$ & $-0,40425$ & 0,00168 & 0,04881 & 3,12 & 0,64 \\
\hline $\mathrm{CO}$ & $-112,81087$ & $-113,32735$ & $-113,28980$ & $-0,62858$ & $-0,39639$ & $-0,02113$ & 0,07934 & 3,16 & 1,37 \\
\hline $\mathrm{F}_{2} \mathrm{O}$ & $-274,23342$ & $-274,72258$ & $-274,71521$ & $-0,60889$ & $-0,37118$ & $-0,09105$ & 0,09328 & 3,23 & 2,51 \\
\hline $\mathrm{H}_{2} \mathrm{O}$ & $-75,97344$ & $-76,43816$ & $-76,41949$ & $-0,59775$ & $-0,33654$ & $-0,00993$ & 0,05511 & 3,55 & 0,88 \\
\hline $\mathrm{HF}$ & $-99,87679$ & $-100,46997$ & $-100,44927$ & $-0,75302$ & $-0,43982$ & $-0,01013$ & 0,06236 & 4,26 & 0,99 \\
\hline $\mathrm{NH}_{3}$ & $-56,15628$ & $-56,55572$ & $-56,53665$ & $-0,51409$ & $-0,28557$ & $-0,00550$ & 0,05164 & 3,11 & 0,78 \\
\hline $\mathrm{PF}_{3}$ & $-639,93217$ & $-640,35591$ & $-640,32169$ & $-0,52300$ & $-0,32259$ & 0,00274 & 0,06745 & 2,73 & 0,88 \\
\hline $\mathrm{PH}_{3}$ & $-342,02496$ & $-342,41067$ & $-342,39265$ & $-0,48057$ & $-0,28929$ & $-0,00409$ & 0,04744 & 2,60 & 0,70 \\
\hline
\end{tabular}

Tabela 8.455: Energias utilizadas (em hartree) e concavidades (Conc.) obtidas pelo Teorema de Janak para B971 com geometrias experimentais na base aug-pcJ-2.

\begin{tabular}{|c|c|c|c|c|c|c|c|c|c|}
\hline Molécula & $\mathrm{E}_{\text {cátion }}$ & E neutra & $\mathrm{E}_{\text {ânion }}$ & $\varepsilon_{\text {cátion }}^{\text {LUMO }}$ & $\varepsilon_{\text {neutra }}^{\text {HOMO }}$ & $\varepsilon_{\text {neutra }}^{\text {LUMO }}$ & $\varepsilon_{\text {ânion }}^{\text {HOMO }}$ & Conc.cátion & Conc.ânion \\
\hline $\mathrm{BF}_{3}$ & $-324,07507$ & $\begin{array}{l}-324,63023 \\
\end{array}$ & $\begin{array}{l}-324,60314 \\
\end{array}$ & $-0,67612$ & $-0,43602$ & $-0,00692$ & 0,06493 & 3,27 & 0,98 \\
\hline $\mathrm{BHF}_{2}$ & $-224,78265$ & $-225,29490$ & $-225,27427$ & $-0,63499$ & $-0,38888$ & $-0,01950$ & 0,05192 & 3,35 & 0,97 \\
\hline $\mathrm{C}_{2} \mathrm{H}_{2}$ & $-76,92243$ & $-77,33721$ & $-77,32092$ & $-0,53393$ & $-0,29906$ & 0,00783 & 0,04195 & 3,20 & 0,46 \\
\hline $\mathrm{C}_{2} \mathrm{H}_{4}$ & $-78,20929$ & $-78,59407$ & $-78,57130$ & $-0,49396$ & $-0,27855$ & $-0,00687$ & 0,04662 & 2,93 & 0,73 \\
\hline $\mathrm{C}_{2} \mathrm{H}_{6}$ & $-79,38421$ & $-79,83241$ & $-79,81399$ & $-0,55260$ & $-0,34481$ & 0,00084 & 0,04611 & 2,83 & 0,62 \\
\hline $\mathrm{CH}_{4}$ & $-39,99968$ & $-40,51801$ & $-40,49915$ & $-0,64530$ & $-0,39398$ & 0,00183 & 0,04804 & 3,42 & 0,63 \\
\hline $\mathrm{CO}$ & $-112,81377$ & $-113,33261$ & $-113,29752$ & $-0,67074$ & $-0,38454$ & $-0,03321$ & 0,07946 & 3,89 & 1,53 \\
\hline $\mathrm{F}_{2} \mathrm{O}$ & $-274,23158$ & $-274,71709$ & $-274,71057$ & $-0,62037$ & $-0,35203$ & $-0,10598$ & 0,10442 & 3,65 & 2,86 \\
\hline $\mathrm{H}_{2} \mathrm{O}$ & $-75,97773$ & $-76,44407$ & $-76,42619$ & $-0,61530$ & $-0,32175$ & $-0,01276$ & 0,05594 & 3,99 & 0,93 \\
\hline $\mathrm{HF}$ & $-99,87126$ & $-100,46607$ & $-100,44672$ & $-0,77271$ & $-0,42151$ & $-0,01227$ & 0,06370 & 4,78 & 1,03 \\
\hline $\mathrm{NH}_{3}$ & $-56,16757$ & $-56,56843$ & $-56,55035$ & $-0,53465$ & $-0,27351$ & $-0,00772$ & 0,05248 & 3,55 & 0,82 \\
\hline $\mathrm{PF}_{3}$ & $-639,83837$ & $-640,26018$ & $-640,22750$ & $-0,53491$ & $-0,31113$ & $-0,00400$ & 0,06765 & 3,04 & 0,97 \\
\hline $\mathrm{PH}_{3}$ & $-341,95830$ & $-342,34535$ & $-342,32737$ & $-0,50045$ & $-0,28103$ & $-0,00637$ & 0,04849 & 2,99 & 0,75 \\
\hline
\end{tabular}

Tabela 8.456: Energias utilizadas (em hartree) e concavidades (Conc.) obtidas pelo Teorema de Janak para B972 com geometrias experimentais na base aug-pcJ-2.

\begin{tabular}{|c|c|c|c|c|c|c|c|c|c|}
\hline Molécula & $\mathrm{E}_{\text {cátion }}$ & $\mathrm{E}_{\text {neutra }}$ & $\mathrm{E}_{\hat{a} \text { nion }}$ & $\varepsilon_{\text {cátion }}^{\text {LUMO }}$ & $\varepsilon_{\text {neutra }}^{\text {HOMO }}$ & $\varepsilon_{\text {neutra }}^{\text {LUMO }}$ & $\varepsilon_{\text {ânion }}^{\text {HOMO }}$ & Conc.cátion & Conc.ânion \\
\hline $\mathrm{BF}_{3}$ & $-324,06193$ & $-324,61884$ & $-324,58862$ & $-0,67780$ & $-0,43768$ & $-0,00587$ & 0,06693 & 3,27 & 0,99 \\
\hline $\mathrm{BHF}_{2}$ & $-224,77413$ & $-225,28749$ & $-225,26610$ & $-0,63659$ & $-0,38966$ & $-0,01697$ & 0,04896 & 3,36 & 0,90 \\
\hline $\mathrm{C}_{2} \mathrm{H}_{2}$ & $-76,91861$ & $-77,33287$ & $-77,31711$ & $-0,53235$ & $-0,29997$ & 0,00670 & 0,04188 & 3,16 & 0,48 \\
\hline $\mathrm{C}_{2} \mathrm{H}_{4}$ & $-78,20867$ & $-78,59251$ & $-78,57039$ & $-0,49235$ & $-0,27882$ & $-0,00557$ & 0,04632 & 2,91 & 0,71 \\
\hline $\mathrm{C}_{2} \mathrm{H}_{6}$ & $-79,38537$ & $-79,83433$ & $-79,81504$ & $-0,55368$ & $-0,34519$ & 0,00023 & 0,04655 & 2,84 & 0,63 \\
\hline $\mathrm{CH}_{4}$ & $-40,00235$ & $-40,52115$ & $-40,50175$ & $-0,64538$ & $-0,39449$ & 0,00085 & 0,04844 & 3,41 & 0,65 \\
\hline $\mathrm{CO}$ & $-112,80405$ & $-113,32179$ & $-113,28629$ & $-0,67149$ & $-0,38474$ & $-0,03198$ & 0,07887 & 3,90 & 1,51 \\
\hline $\mathrm{F}_{2} \mathrm{O}$ & $-274,21632$ & $-274,70304$ & $-274,69604$ & $-0,62097$ & $-0,35346$ & $-0,10607$ & 0,10717 & 3,64 & 2,90 \\
\hline $\mathrm{H}_{2} \mathrm{O}$ & $-75,97638$ & $-76,44251$ & $-76,42288$ & $-0,61345$ & $-0,32228$ & $-0,01267$ & 0,05653 & 3,96 & 0,94 \\
\hline $\mathrm{HF}$ & $-99,87136$ & $-100,46652$ & $-100,44535$ & $-0,77115$ & $-0,42252$ & $-0,01245$ & 0,06513 & 4,74 & 1,06 \\
\hline $\mathrm{NH}_{3}$ & $-56,16773$ & $-56,56836$ & $-56,54908$ & $-0,53343$ & $-0,27402$ & $-0,00785$ & 0,05215 & 3,53 & 0,82 \\
\hline $\mathrm{PF}_{3}$ & $-639,88218$ & $-640,30379$ & $-640,27019$ & $-0,53468$ & $-0,31154$ & $-0,00269$ & 0,06806 & 3,04 & 0,96 \\
\hline $\mathrm{PH}_{3}$ & $-342,01702$ & $-342,40279$ & $-342,38368$ & $-0,49975$ & $-0,28080$ & $-0,00681$ & 0,04862 & 2,98 & 0,75 \\
\hline
\end{tabular}

Tabela 8.457: Energias utilizadas (em hartree) e concavidades (Conc.) obtidas pelo Teorema de Janak para B98 com geometrias experimentais na base aug-pcJ-2.

\begin{tabular}{|c|c|c|c|c|c|c|c|c|c|}
\hline Molécula & $\mathrm{E}_{\text {cátion }}$ & Eneutra & Eânion & $\varepsilon_{\text {cátion }}^{\text {LUMO }}$ & $\varepsilon_{\text {neutra }}^{\text {HOMO }}$ & $\varepsilon_{\text {neutra }}^{\text {LUMO }}$ & $\varepsilon_{\text {ânion }}^{\text {HOMO }}$ & Conc.cátion & Conc.ânion \\
\hline $\mathrm{BF}_{3}$ & $-324,05222$ & $-324,61118$ & $-324,58452$ & $-0,67773$ & $-0,44195$ & $-0,00781$ & 0,06425 & 3,21 & 0,98 \\
\hline $\mathrm{BHF}_{2}$ & $-224,76783$ & $-225,28300$ & $-225,26278$ & $-0,63615$ & $-0,39349$ & $-0,01983$ & 0,05132 & 3,30 & 0,97 \\
\hline $\mathrm{C}_{2} \mathrm{H}_{2}$ & $-76,91451$ & $-77,33000$ & $-77,31400$ & $-0,53188$ & $-0,30216$ & 0,00651 & 0,04145 & 3,13 & 0,48 \\
\hline $\mathrm{C}_{2} \mathrm{H}_{4}$ & $-78,20451$ & $-78,58983$ & $-78,56726$ & $-0,49189$ & $-0,28138$ & $-0,00694$ & 0,04621 & 2,86 & 0,72 \\
\hline $\mathrm{C}_{2} \mathrm{H}_{6}$ & $-79,38098$ & $-79,83111$ & $-79,81284$ & $-0,55262$ & $-0,34858$ & $-0,00039$ & 0,04572 & 2,78 & 0,63 \\
\hline $\mathrm{CH}_{4}$ & $-39,99982$ & $-40,51945$ & $-40,50070$ & $-0,64393$ & $-0,39784$ & 0,00054 & 0,04769 & 3,35 & 0,64 \\
\hline $\mathrm{CO}$ & $-112,80074$ & $-113,32150$ & $-113,28710$ & $-0,66848$ & $-0,38926$ & $-0,03343$ & 0,07888 & 3,80 & 1,53 \\
\hline $\mathrm{F}_{2} \mathrm{O}$ & $-274,20796$ & $-274,69694$ & $-274,69268$ & $-0,62083$ & $-0,35818$ & $-0,10646$ & 0,10166 & 3,57 & 2,83 \\
\hline $\mathrm{H}_{2} \mathrm{O}$ & $-75,97389$ & $-76,44145$ & $-76,42404$ & $-0,61261$ & $-0,32655$ & $-0,01394$ & 0,05537 & 3,89 & 0,94 \\
\hline $\mathrm{HF}$ & $-99,86573$ & $-100,46227$ & $-100,44342$ & $-0,77023$ & $-0,42714$ & $-0,01347$ & 0,06302 & 4,67 & 1,04 \\
\hline $\mathrm{NH}_{3}$ & $-56,16575$ & $-56,56744$ & $-56,54968$ & $-0,53120$ & $-0,27751$ & $-0,00895$ & 0,05203 & 3,45 & 0,83 \\
\hline $\mathrm{PF}_{3}$ & $-639,82022$ & $-640,24425$ & $-640,21206$ & $-0,53465$ & $-0,31510$ & $-0,00448$ & 0,06693 & 2,99 & 0,97 \\
\hline $\mathrm{PH}_{3}$ & $-341,96254$ & $-342,35072$ & $-342,33291$ & $-0,49857$ & $-0,28412$ & $-0,00760$ & 0,04872 & 2,92 & 0,77 \\
\hline
\end{tabular}


Tabela 8.458: Energias utilizadas (em hartree) e concavidades (Conc.) obtidas pelo Teorema de Janak para BHandH com geometrias experimentais na base aug-pcJ-2.

\begin{tabular}{|c|c|c|c|c|c|c|c|c|c|}
\hline Molécula & $\mathrm{E}_{\text {cátion }}$ & $\mathrm{E}_{\text {neutra }}$ & $\mathrm{E}_{\text {ânion }}$ & $\varepsilon_{\text {cátion }}^{\text {LUMO }}$ & $\varepsilon_{\text {neutra }}^{\text {HOMO }}$ & $\varepsilon_{\text {neutra }}^{\text {LUMO }}$ & $\varepsilon_{\text {ânion }}^{\text {HOMO }}$ & Conc.cátion & Conc.ânion \\
\hline $\mathrm{BF}_{3}$ & $-322,40442$ & $-322,99023$ & $-322,96144$ & $-0,64608$ & $-0,52759$ & 0,00694 & 0,05550 & 1,61 & 0,66 \\
\hline $\mathrm{BHF}_{2}$ & $-223,58328$ & $-224,10535$ & $-224,07819$ & $-0,59015$ & $-0,45483$ & 0,00981 & 0,04613 & 1,84 & 0,49 \\
\hline $\mathrm{C}_{2} \mathrm{H}_{2}$ & $-76,33203$ & $-76,73878$ & $-76,71302$ & $-0,47013$ & $-0,34811$ & 0,01446 & 0,04278 & 1,66 & 0,39 \\
\hline $\mathrm{C}_{2} \mathrm{H}_{4}$ & $-77,58706$ & $-77,96254$ & $-77,90468$ & $-0,43239$ & $-0,32237$ & 0,01297 & 0,08234 & 1,50 & 0,94 \\
\hline $\mathrm{C}_{2} \mathrm{H}_{6}$ & $-78,71933$ & $-79,16941$ & $-79,14616$ & $-0,50503$ & $-0,39632$ & 0,01053 & 0,04244 & 1,48 & 0,43 \\
\hline $\mathrm{CH}_{4}$ & $-39,64934$ & $-40,16297$ & $-40,13929$ & $-0,58039$ & $-0,45031$ & 0,01083 & 0,04397 & 1,77 & 0,45 \\
\hline $\mathrm{CO}$ & $-112,11823$ & $-112,63370$ & $-112,58919$ & $-0,58563$ & $-0,44961$ & 0,01270 & 0,07350 & 1,85 & 0,83 \\
\hline $\mathrm{F}_{2} \mathrm{O}$ & $-272,82563$ & $-273,32568$ & $-273,31951$ & $-0,55488$ & $-0,44327$ & $-0,04086$ & 0,05026 & 1,52 & 1,24 \\
\hline $\mathrm{H}_{2} \mathrm{O}$ & $-75,53822$ & $-75,99342$ & $-75,97213$ & $-0,52518$ & $-0,39581$ & 0,00153 & 0,04756 & 1,76 & 0,63 \\
\hline $\mathrm{HF}$ & $-99,38204$ & $-99,96508$ & $-99,94173$ & $-0,66678$ & $-0,51135$ & 0,00224 & 0,05332 & 2,11 & 0,69 \\
\hline $\mathrm{NH}_{3}$ & $-55,77732$ & $-56,16765$ & $-56,14572$ & $-0,45536$ & $-0,33431$ & 0,00478 & 0,04550 & 1,65 & 0,55 \\
\hline $\mathrm{PF}_{3}$ & $-637,56404$ & $-637,99032$ & $-637,95092$ & $-0,48975$ & $-0,36588$ & 0,01955 & 0,06340 & 1,69 & 0,60 \\
\hline $\mathrm{PH}_{3}$ & $-341,05441$ & $-341,43296$ & $-341,41154$ & $-0,43883$ & $-0,32208$ & 0,00537 & 0,04267 & 1,59 & 0,51 \\
\hline
\end{tabular}

Tabela 8.459: Energias utilizadas (em hartree) e concavidades (Conc.) obtidas pelo Teorema de Janak para $\omega$ B97X com geometrias experimentais na base aug-pcJ-2.

\begin{tabular}{|c|c|c|c|c|c|c|c|c|c|}
\hline Molécula & $\mathrm{E}_{\text {cátion }}$ & Eneutra & Eânion & $\varepsilon_{\text {cátion }}^{\text {LUMO }}$ & $\varepsilon_{\text {neutra }}^{\text {HOMO }}$ & $\varepsilon_{\text {neutra }}^{\text {LUMO }}$ & $\varepsilon_{\text {ânion }}^{\text {HOMO }}$ & Conc.cátion & Conc.ânion \\
\hline $\mathrm{BF}_{3}$ & $-324,07580$ & $-324,64647$ & $-324,61094$ & $-0,59956$ & $-0,54330$ & 0,04025 & 0,03436 & 0,77 & $-0,08$ \\
\hline $\mathrm{BHF}_{2}$ & $-224,78381$ & $-225,30574$ & $-225,27790$ & $-0,54976$ & $-0,49409$ & 0,03630 & 0,02634 & 0,76 & $-0,14$ \\
\hline $\mathrm{C}_{2} \mathrm{H}_{2}$ & $-76,92401$ & $-77,33725$ & $-77,31324$ & $-0,42801$ & $-0,40087$ & 0,03237 & 0,02243 & 0,37 & $-0,14$ \\
\hline $\mathrm{C}_{2} \mathrm{H}_{4}$ & $-78,21298$ & $-78,59560$ & $-78,57033$ & $-0,39034$ & $-0,37747$ & 0,03441 & 0,02373 & 0,18 & $-0,15$ \\
\hline $\mathrm{C}_{2} \mathrm{H}_{6}$ & $-79,38046$ & $-79,83854$ & $-79,81418$ & $-0,47022$ & $-0,44612$ & 0,03316 & 0,02272 & 0,33 & $-0,14$ \\
\hline $\mathrm{CH}_{4}$ & $-39,99994$ & $-40,52114$ & $-40,49798$ & $-0,54363$ & $-0,49931$ & 0,03235 & 0,02128 & 0,60 & $-0,15$ \\
\hline $\mathrm{CO}$ & $-112,81567$ & $-113,33544$ & $-113,29030$ & $-0,56369$ & $-0,49335$ & 0,05015 & 0,04468 & 0,96 & $-0,07$ \\
\hline $\mathrm{F}_{2} \mathrm{O}$ & $-274,23489$ & $-274,72626$ & $-274,71854$ & $-0,52199$ & $-0,46069$ & $-0,00695$ & 0,01932 & 0,83 & 0,36 \\
\hline $\mathrm{H}_{2} \mathrm{O}$ & $-75,98104$ & $-76,44758$ & $-76,42555$ & $-0,50137$ & $-0,43001$ & 0,03207 & 0,02008 & 0,97 & $-0,16$ \\
\hline $\mathrm{HF}$ & $-99,87776$ & $-100,47187$ & $-100,44909$ & $-0,65516$ & $-0,53106$ & 0,03364 & 0,02113 & 1,69 & $-0,17$ \\
\hline $\mathrm{NH}_{3}$ & $-56,17036$ & $-56,57117$ & $-56,54882$ & $-0,42579$ & $-0,37886$ & 0,03240 & 0,02038 & 0,64 & $-0,16$ \\
\hline $\mathrm{PF}_{3}$ & $-639,88089$ & $-640,30685$ & $-640,26367$ & $-0,44874$ & $-0,41087$ & 0,05271 & 0,04149 & 0,52 & $-0,15$ \\
\hline $\mathrm{PH}_{3}$ & $-341,98603$ & $-342,37324$ & $-342,35068$ & $-0,41030$ & $-0,37689$ & 0,03205 & 0,02046 & 0,45 & $-0,16$ \\
\hline
\end{tabular}

Tabela 8.460: Energias utilizadas (em hartree) e concavidades (Conc.) obtidas pelo Teorema de Janak para $\omega$ B97XD com geometrias experimentais na base aug-pcJ-2.

\begin{tabular}{|c|c|c|c|c|c|c|c|c|c|}
\hline Molécula & $\mathrm{E}_{\text {cátion }}$ & Eneutra & Eânion & $\varepsilon_{\text {cátion }}^{\text {LUMO }}$ & $\varepsilon_{\text {neutra }}^{\text {HOMO }}$ & $\varepsilon_{\text {neutra }}^{\text {LUMO }}$ & $\varepsilon_{\text {ânion }}^{\text {HOMO }}$ & Conc.cátion & Conc.ânion \\
\hline $\mathrm{BF}_{3}$ & $-324,06297$ & $-324,62848$ & $-324,59604$ & $-0,61080$ & $-0,52196$ & 0,03729 & 0,03070 & 1,21 & $-0,09$ \\
\hline $\mathrm{BHF}_{2}$ & $-224,77570$ & $-225,29436$ & $-225,26884$ & $-0,56467$ & $-0,47223$ & 0,03245 & 0,02460 & 1,26 & $-0,11$ \\
\hline $\mathrm{C}_{2} \mathrm{H}_{2}$ & $-76,91822$ & $-77,33262$ & $-77,31048$ & $-0,44851$ & $-0,38031$ & 0,02910 & 0,02106 & 0,93 & $-0,11$ \\
\hline $\mathrm{C}_{2} \mathrm{H}_{4}$ & $-78,21040$ & $-78,59400$ & $-78,56490$ & $-0,40889$ & $-0,35794$ & 0,03016 & 0,02784 & 0,69 & $-0,03$ \\
\hline $\mathrm{C}_{2} \mathrm{H}_{6}$ & $-79,38483$ & $-79,83910$ & $-79,81666$ & $-0,48365$ & $-0,42542$ & 0,02878 & 0,02133 & 0,79 & $-0,10$ \\
\hline $\mathrm{CH}_{4}$ & $-40,00285$ & $-40,52337$ & $-40,50203$ & $-0,56393$ & $-0,47703$ & 0,02810 & 0,01981 & 1,18 & $-0,11$ \\
\hline $\mathrm{CO}$ & $-112,80659$ & $-113,32539$ & $-113,28511$ & $-0,56463$ & $-0,47015$ & 0,03665 & 0,04281 & 1,29 & 0,08 \\
\hline $\mathrm{F}_{2} \mathrm{O}$ & $-274,21839$ & $-274,70917$ & $-274,70133$ & $-0,54375$ & $-0,43842$ & $-0,02616$ & 0,03499 & 1,43 & 0,83 \\
\hline $\mathrm{H}_{2} \mathrm{O}$ & $-75,97956$ & $-76,44592$ & $-76,42655$ & $-0,52403$ & $-0,40685$ & 0,02601 & 0,01843 & 1,59 & $-0,10$ \\
\hline $\mathrm{HF}$ & $-99,87523$ & $-100,46934$ & $-100,44929$ & $-0,67894$ & $-0,50797$ & 0,02723 & 0,02030 & 2,33 & $-0,09$ \\
\hline $\mathrm{NH}_{3}$ & $-56,17051$ & $-56,57106$ & $-56,55096$ & $-0,44419$ & $-0,35650$ & 0,02699 & 0,01868 & 1,19 & $-0,11$ \\
\hline $\mathrm{PF}_{3}$ & $-639,86682$ & $-640,29238$ & $-640,25287$ & $-0,46251$ & $-0,39122$ & 0,04591 & 0,03869 & 0,97 & $-0,10$ \\
\hline $\mathrm{PH}_{3}$ & $-341,99385$ & $-342,38226$ & $-342,36174$ & $-0,42284$ & $-0,35901$ & 0,02683 & 0,01895 & 0,87 & $-0,11$ \\
\hline
\end{tabular}

Tabela 8.461: Energias utilizadas (em hartree) e concavidades (Conc.) obtidas pelo Teorema de Janak para B3LYP com geometrias experimentais na base aug-pcJ-2.

\begin{tabular}{|c|c|c|c|c|c|c|c|c|c|}
\hline Molécula & $\mathrm{E}_{\text {cátion }}$ & $\mathrm{E}_{\text {neutra }}$ & $E_{\text {ânion }}$ & $\varepsilon_{\text {cátion }}^{L U M O}$ & $\varepsilon_{\text {neutra }}^{\text {HOMO }}$ & $\varepsilon_{\text {neutra }}^{\text {LUMO }}$ & $\varepsilon_{\text {ânion }}^{\text {HOMO }}$ & Conc.cátion & Conc.ânion \\
\hline $\mathrm{BF}_{3}$ & $-324,16555$ & $-324,72510$ & $-324,70455$ & $-0,68200$ & $-0,43891$ & $-0,01932$ & 0,06289 & 3,31 & 1,12 \\
\hline $\mathrm{BHF}_{2}$ & $-224,84885$ & $-225,36512$ & $-225,34739$ & $-0,63984$ & $-0,39219$ & $-0,02865$ & 0,05225 & 3,37 & 1,10 \\
\hline $\mathrm{C}_{2} \mathrm{H}_{2}$ & $-76,95204$ & $-77,36945$ & $-77,35464$ & $-0,53596$ & $-0,30108$ & $-0,00241$ & 0,04179 & 3,20 & 0,60 \\
\hline $\mathrm{C}_{2} \mathrm{H}_{4}$ & $-78,24191$ & $-78,62904$ & $-78,60793$ & $-0,49535$ & $-0,28029$ & $-0,01371$ & 0,04663 & 2,93 & 0,82 \\
\hline $\mathrm{C}_{2} \mathrm{H}_{6}$ & $-79,41902$ & $-79,87034$ & $-79,85455$ & $-0,55627$ & $-0,34720$ & $-0,00956$ & 0,04592 & 2,84 & 0,75 \\
\hline $\mathrm{CH}_{4}$ & $-40,02040$ & $-40,54149$ & $-40,52513$ & $-0,64788$ & $-0,39604$ & $-0,00923$ & 0,04817 & 3,43 & 0,78 \\
\hline $\mathrm{CO}$ & $-112,84477$ & $-113,36642$ & $-113,33579$ & $-0,64994$ & $-0,38701$ & $-0,04179$ & 0,07915 & 3,58 & 1,65 \\
\hline $\mathrm{F}_{2} \mathrm{O}$ & $-274,30288$ & $-274,79431$ & $-274,79737$ & $-0,62783$ & $-0,35635$ & $-0,11733$ & 0,09518 & 3,69 & 2,89 \\
\hline $\mathrm{H}_{2} \mathrm{O}$ & $-76,00117$ & $-76,47184$ & $-76,45864$ & $-0,62013$ & $-0,32474$ & $-0,02538$ & 0,05558 & 4,02 & 1,10 \\
\hline $\mathrm{HF}$ & $-99,89745$ & $-100,49762$ & $-100,48258$ & $-0,78031$ & $-0,42480$ & $-0,02628$ & 0,06357 & 4,84 & 1,22 \\
\hline $\mathrm{NH}_{3}$ & $-56,18866$ & $-56,59288$ & $-56,57865$ & $-0,53326$ & $-0,27582$ & $-0,01929$ & 0,05193 & 3,50 & 0,97 \\
\hline $\mathrm{PF}_{3}$ & $-639,97441$ & $-640,40158$ & $-640,37312$ & $-0,53810$ & $-0,31471$ & $-0,01267$ & 0,06664 & 3,04 & 1,08 \\
\hline $\mathrm{PH}_{3}$ & $-342,02164$ & $-342,41080$ & $-342,39657$ & $-0,49564$ & $-0,28206$ & $-0,01671$ & 0,04799 & 2,91 & 0,88 \\
\hline
\end{tabular}


Tabela 8.462: Energias utilizadas (em hartree) e concavidades (Conc.) obtidas pelo Teorema de Janak para PBE0 com geometrias experimentais na base aug-pcJ-2.

\begin{tabular}{|c|c|c|c|c|c|c|c|c|c|}
\hline Molécula & $\mathrm{E}_{\text {cátion }}$ & $E_{\text {neutra }}$ & $E_{\text {ânion }}$ & $\varepsilon_{\text {cátion }}^{\text {LUMO }}$ & $\varepsilon_{\text {neutra }}^{\text {HOMO }}$ & $\varepsilon_{\text {neutra }}^{\text {LUMO }}$ & $\varepsilon_{\text {ânion }}^{\text {HOMO }}$ & Conc.cátion & Conc.ânion \\
\hline $\mathrm{BF}_{3}$ & $-323,83793$ & $-324,39895$ & $-324,37623$ & $-0,67301$ & $-0,45059$ & $-0,00715$ & 0,05883 & 3,03 & 0,90 \\
\hline $\mathrm{BHF}_{2}$ & $-224,61308$ & $-225,12762$ & $-225,10863$ & $-0,62724$ & $-0,39989$ & $-0,01744$ & 0,04488 & 3,09 & 0,85 \\
\hline $\mathrm{C}_{2} \mathrm{H}_{2}$ & $-76,84577$ & $-77,26024$ & $-77,24492$ & $-0,51843$ & $-0,31019$ & 0,00606 & 0,03899 & 2,83 & 0,45 \\
\hline $\mathrm{C}_{2} \mathrm{H}_{4}$ & $-78,13263$ & $-78,51662$ & $-78,49500$ & $-0,47821$ & $-0,28885$ & $-0,00417$ & 0,04414 & 2,58 & 0,66 \\
\hline $\mathrm{C}_{2} \mathrm{H}_{6}$ & $-79,30551$ & $-79,75550$ & $-79,73975$ & $-0,54651$ & $-0,35395$ & $-0,00045$ & 0,04184 & 2,62 & 0,58 \\
\hline $\mathrm{CH}_{4}$ & $-39,95943$ & $-40,47741$ & $-40,46130$ & $-0,63187$ & $-0,40423$ & 0,00034 & 0,04373 & 3,10 & 0,59 \\
\hline $\mathrm{CO}$ & $-112,71959$ & $-113,23429$ & $-113,20162$ & $-0,62346$ & $-0,39507$ & $-0,02890$ & 0,07461 & 3,11 & 1,41 \\
\hline $\mathrm{F}_{2} \mathrm{O}$ & $-274,03529$ & $-274,52378$ & $-274,52035$ & $-0,61141$ & $-0,36571$ & $-0,09910$ & 0,09338 & 3,34 & 2,62 \\
\hline $\mathrm{H}_{2} \mathrm{O}$ & $-75,92180$ & $-76,38535$ & $-76,37118$ & $-0,59282$ & $-0,33407$ & $-0,01317$ & 0,05041 & 3,52 & 0,87 \\
\hline $\mathrm{HF}$ & $-99,80651$ & $-100,39825$ & $-100,38247$ & $-0,74889$ & $-0,43559$ & $-0,01272$ & 0,05790 & 4,26 & 0,96 \\
\hline $\mathrm{NH}_{3}$ & $-56,12142$ & $-56,51948$ & $-56,50482$ & $-0,50819$ & $-0,28452$ & $-0,00848$ & 0,04683 & 3,04 & 0,75 \\
\hline $\mathrm{PF}_{3}$ & $-639,54374$ & $-639,96610$ & $-639,93622$ & $-0,51943$ & $-0,32095$ & $-0,00254$ & 0,06325 & 2,70 & 0,90 \\
\hline $\mathrm{PH}_{3}$ & $-341,86130$ & $-342,24643$ & $-342,23201$ & $-0,47754$ & $-0,28945$ & $-0,00755$ & 0,04314 & 2,56 & 0,69 \\
\hline
\end{tabular}

Tabela 8.463: Energias utilizadas (em hartree) e concavidades (Conc.) obtidas pelo Teorema de Janak para BHandH 0\% $E_{X}^{\mathrm{HF}}$ com geometrias experimentais na base aug-pcJ-2.

\begin{tabular}{|c|c|c|c|c|c|c|c|c|c|}
\hline Molécula & $\mathrm{E}_{\text {cátion }}$ & $E_{\text {neutra }}$ & $E_{\text {ânion }}$ & $\varepsilon_{\text {cátion }}^{\text {LUMO }}$ & $\varepsilon_{\text {neutra }}^{\text {HOMO }}$ & $\varepsilon_{\text {neutra }}^{\text {LUMO }}$ & $\varepsilon_{\text {ânion }}^{\text {HOMO }}$ & Conc.cátion & Conc.ânion \\
\hline $\mathrm{BF}_{3}$ & $-320,95178$ & $-321,47666$ & $-321,45114$ & $-0,69108$ & $-0,36145$ & $-0,02763$ & 0,08042 & 4,48 & 1,47 \\
\hline $\mathrm{BHF}_{2}$ & $-222,52104$ & $-223,00338$ & $-222,97856$ & $-0,64407$ & $-0,32182$ & $-0,05441$ & 0,07250 & 4,38 & 1,73 \\
\hline $\mathrm{C}_{2} \mathrm{H}_{2}$ & $-75,77585$ & $-76,19297$ & $-76,16898$ & $-0,58423$ & $-0,25570$ & $-0,00996$ & 0,05838 & 4,47 & 0,93 \\
\hline $\mathrm{C}_{2} \mathrm{H}_{4}$ & $-76,98651$ & $-77,37535$ & $-77,35123$ & $-0,54220$ & $-0,23979$ & $-0,03580$ & 0,06294 & 4,11 & 1,34 \\
\hline $\mathrm{C}_{2} \mathrm{H}_{6}$ & $-78,12210$ & $-78,54031$ & $-78,51833$ & $-0,55729$ & $-0,28121$ & $-0,01119$ & 0,06135 & 3,76 & 0,99 \\
\hline $\mathrm{CH}_{4}$ & $-39,32107$ & $-39,82438$ & $-39,80076$ & $-0,67961$ & $-0,33013$ & $-0,00839$ & 0,06461 & 4,75 & 0,99 \\
\hline $\mathrm{CO}$ & $-111,51244$ & $-112,01156$ & $-111,97298$ & $-0,67931$ & $-0,31763$ & $-0,06823$ & 0,10291 & 4,92 & 2,33 \\
\hline $\mathrm{F}_{2} \mathrm{O}$ & $-271,68219$ & $-272,13919$ & $-272,13218$ & $-0,64577$ & $-0,27124$ & $-0,15483$ & 0,12794 & 5,10 & 3,85 \\
\hline $\mathrm{H}_{2} \mathrm{O}$ & $-75,12254$ & $-75,58996$ & $-75,56905$ & $-0,69024$ & $-0,25583$ & $-0,02888$ & 0,07447 & 5,91 & 1,41 \\
\hline $\mathrm{HF}$ & $-98,91136$ & $-99,50949$ & $-99,48530$ & $-0,86545$ & $-0,34412$ & $-0,02945$ & 0,08472 & 7,09 & 1,55 \\
\hline $\mathrm{NH}_{3}$ & $-55,40518$ & $-55,80237$ & $-55,78095$ & $-0,58748$ & $-0,21462$ & $-0,02143$ & 0,06939 & 5,07 & 1,24 \\
\hline $\mathrm{PF}_{3}$ & $-635,41458$ & $-635,82227$ & $-635,78665$ & $-0,55695$ & $-0,25932$ & $-0,02949$ & 0,08634 & 4,05 & 1,58 \\
\hline $\mathrm{PH}_{3}$ & $-340,12256$ & $-340,49713$ & $-340,47698$ & $-0,51952$ & $-0,23188$ & $-0,02000$ & 0,06377 & 3,91 & 1,14 \\
\hline
\end{tabular}

Tabela 8.464: Energias utilizadas (em hartree) e concavidades (Conc.) obtidas pelo Teorema de Janak para BHandH $10 \% E_{X}^{\mathrm{HF}}$ com geometrias experimentais na base aug-pcJ-2.

\begin{tabular}{|c|c|c|c|c|c|c|c|c|c|}
\hline Molécula & $\mathrm{E}_{\text {cátion }}$ & Eneutra & $E_{\text {ânion }}$ & $\varepsilon_{\text {cátion }}^{\text {LUMO }}$ & $\varepsilon_{\text {neutra }}^{\text {HOMO }}$ & $\varepsilon_{\text {neutra }}^{\text {LUMO }}$ & $\varepsilon_{\text {ânion }}^{\text {HOMO }}$ & Conc.cátion & Conc.ânion \\
\hline $\mathrm{BF}_{3}$ & $-321,23881$ & $-321,77594$ & $-321,74969$ & $-0,68270$ & $-0,39399$ & $-0,01945$ & 0,07531 & 3,93 & 1,29 \\
\hline $\mathrm{BHF}_{2}$ & $-222,73059$ & $-223,22119$ & $-223,19537$ & $-0,63373$ & $-0,34803$ & $-0,03948$ & 0,06785 & 3,89 & 1,46 \\
\hline $\mathrm{C}_{2} \mathrm{H}_{2}$ & $-75,88609$ & $-76,30110$ & $-76,27672$ & $-0,56084$ & $-0,27411$ & 0,00353 & 0,05524 & 3,90 & 0,70 \\
\hline $\mathrm{C}_{2} \mathrm{H}_{4}$ & $-77,10549$ & $-77,49157$ & $-77,46134$ & $-0,51959$ & $-0,25624$ & $-0,02116$ & 0,05996 & 3,58 & 1,10 \\
\hline $\mathrm{C}_{2} \mathrm{H}_{6}$ & $-78,24029$ & $-78,66478$ & $-78,64248$ & $-0,54686$ & $-0,30376$ & $-0,00581$ & 0,05749 & 3,31 & 0,86 \\
\hline $\mathrm{CH}_{4}$ & $-39,38991$ & $-39,89141$ & $-39,86774$ & $-0,65326$ & $-0,35381$ & $-0,00369$ & 0,06044 & 4,07 & 0,87 \\
\hline $\mathrm{CO}$ & $-111,63214$ & $-112,13471$ & $-112,09479$ & $-0,66023$ & $-0,34359$ & $-0,05035$ & 0,09693 & 4,31 & 2,00 \\
\hline $\mathrm{F}_{2} \mathrm{O}$ & $-271,90587$ & $-272,37320$ & $-272,36541$ & $-0,63241$ & $-0,30518$ & $-0,13213$ & 0,11810 & 4,45 & 3,40 \\
\hline $\mathrm{H}_{2} \mathrm{O}$ & $-75,20506$ & $-75,66992$ & $-75,64884$ & $-0,65595$ & $-0,28316$ & $-0,02145$ & 0,06904 & 5,07 & 1,23 \\
\hline $\mathrm{HF}$ & $-99,00485$ & $-99,59982$ & $-99,57570$ & $-0,82437$ & $-0,37689$ & $-0,02158$ & 0,07844 & 6,09 & 1,36 \\
\hline $\mathrm{NH}_{3}$ & $-55,47905$ & $-55,87475$ & $-55,85316$ & $-0,55999$ & $-0,23799$ & $-0,01508$ & 0,06456 & 4,38 & 1,08 \\
\hline $\mathrm{PF}_{3}$ & $-635,83998$ & $-636,25174$ & $-636,21529$ & $-0,54413$ & $-0,28020$ & $-0,01759$ & 0,08160 & 3,59 & 1,35 \\
\hline $\mathrm{PH}_{3}$ & $-340,30787$ & $-340,68320$ & $-340,66276$ & $-0,50306$ & $-0,24960$ & $-0,01394$ & 0,05946 & 3,45 & 1,00 \\
\hline
\end{tabular}

Tabela 8.465: Energias utilizadas (em hartree) e concavidades (Conc.) obtidas pelo Teorema de Janak para BHandH 20\% $E_{X}^{\mathrm{HF}}$ com geometrias experimentais na base aug-pcJ-2.

\begin{tabular}{|c|c|c|c|c|c|c|c|c|c|}
\hline Molécula & $\mathrm{E}_{\text {cátion }}$ & $E_{\text {neutra }}$ & $E_{\text {ânion }}$ & $\varepsilon_{\text {cátion }}^{\text {LUMO }}$ & $\varepsilon_{\text {neutra }}^{\text {HOMO }}$ & $\varepsilon_{\text {neutra }}^{\text {LUMO }}$ & $\varepsilon_{\text {ânion }}^{\text {HOMO }}$ & Conc. cátion & Conc.ânion \\
\hline $\mathrm{BF}_{3}$ & $-321,52763$ & $-322,07698$ & $-322,05003$ & $-0,67401$ & $-0,42689$ & $-0,01192$ & 0,07027 & 3,36 & 1,12 \\
\hline $\mathrm{BHF}_{2}$ & $-222,94161$ & $-223,44032$ & $-223,41359$ & $-0,62316$ & $-0,37444$ & $-0,02523$ & 0,06328 & 3,38 & 1,20 \\
\hline $\mathrm{C}_{2} \mathrm{H}_{2}$ & $-75,99683$ & $-76,40976$ & $-76,38500$ & $-0,53773$ & $-0,29255$ & 0,00697 & 0,05212 & 3,34 & 0,61 \\
\hline $\mathrm{C}_{2} \mathrm{H}_{4}$ & $-77,22504$ & $-77,60841$ & $-77,57788$ & $-0,49730$ & $-0,27272$ & $-0,00703$ & 0,05689 & 3,06 & 0,87 \\
\hline $\mathrm{C}_{2} \mathrm{H}_{6}$ & $-78,35911$ & $-78,78993$ & $-78,76735$ & $-0,53643$ & $-0,32655$ & $-0,00098$ & 0,05367 & 2,86 & 0,74 \\
\hline $\mathrm{CH}_{4}$ & $-39,45433$ & $-39,95878$ & $-39,93508$ & $-0,63475$ & $-0,37767$ & 0,00054 & 0,05630 & 3,50 & 0,76 \\
\hline $\mathrm{CO}$ & $-111,75259$ & $-112,25851$ & $-112,21732$ & $-0,64126$ & $-0,36977$ & $-0,03308$ & 0,09097 & 3,69 & 1,69 \\
\hline $\mathrm{F}_{2} \mathrm{O}$ & $-272,13194$ & $-272,60895$ & $-272,60072$ & $-0,61737$ & $-0,33933$ & $-0,10919$ & 0,10639 & 3,78 & 2,93 \\
\hline $\mathrm{H}_{2} \mathrm{O}$ & $-75,28790$ & $-75,75024$ & $-75,72905$ & $-0,62228$ & $-0,31083$ & $-0,01474$ & 0,06363 & 4,24 & 1,07 \\
\hline $\mathrm{HF}$ & $-99,09867$ & $-99,69054$ & $-99,66655$ & $-0,78395$ & $-0,41002$ & $-0,01453$ & 0,07216 & 5,09 & 1,18 \\
\hline $\mathrm{NH}_{3}$ & $-55,55320$ & $-55,94747$ & $-55,92575$ & $-0,53303$ & $-0,26165$ & $-0,00931$ & 0,05976 & 3,69 & 0,94 \\
\hline $\mathrm{PF}_{3}$ & $-636,26769$ & $-636,68333$ & $-636,64611$ & $-0,53094$ & $-0,30130$ & $-0,00652$ & 0,07696 & 3,12 & 1,14 \\
\hline $\mathrm{PH}_{3}$ & $-340,49371$ & $-340,86982$ & $-340,84911$ & $-0,48676$ & $-0,26748$ & $-0,00840$ & 0,05520 & 2,98 & 0,87 \\
\hline
\end{tabular}


Tabela 8.466: Energias utilizadas (em hartree) e concavidades (Conc.) obtidas pelo Teorema de Janak para BHandH $30 \% E_{X}^{\mathrm{HF}}$ com geometrias experimentais na base aug-pcJ-2.

\begin{tabular}{|c|c|c|c|c|c|c|c|c|c|}
\hline Molécula & $\mathrm{E}_{\text {cátion }}$ & $E_{\text {neutra }}$ & $E_{\text {ânion }}$ & $\varepsilon_{\text {cátion }}^{\text {LUMO }}$ & $\varepsilon_{\text {neutra }}^{\text {HOMO }}$ & $\varepsilon_{\text {neutra }}^{\text {LUMO }}$ & $\varepsilon_{\text {ânion }}^{\text {HOMO }}$ & Conc.cátion & Conc.ânion \\
\hline $\mathrm{BF}_{3}$ & $-321,81819$ & $-322,37974$ & $-322,35214$ & $-0,66502$ & $-0,46014$ & $-0,00504$ & 0,06529 & 2,79 & 0,96 \\
\hline $\mathrm{BHF}_{2}$ & $-223,15407$ & $-223,66075$ & $-223,63371$ & $-0,61236$ & $-0,40105$ & $-0,01195$ & 0,05359 & 2,88 & 0,89 \\
\hline $\mathrm{C}_{2} \mathrm{H}_{2}$ & $-76,10807$ & $-76,51892$ & $-76,49382$ & $-0,51490$ & $-0,31103$ & 0,00971 & 0,04900 & 2,77 & 0,53 \\
\hline $\mathrm{C}_{2} \mathrm{H}_{4}$ & $-77,34515$ & $-77,72585$ & $-77,69503$ & $-0,47533$ & $-0,28923$ & 0,00646 & 0,05383 & 2,53 & 0,64 \\
\hline $\mathrm{C}_{2} \mathrm{H}_{6}$ & $-78,47856$ & $-78,91575$ & $-78,89292$ & $-0,52599$ & $-0,34958$ & 0,00332 & 0,04990 & 2,40 & 0,63 \\
\hline $\mathrm{CH}_{4}$ & $-39,51904$ & $-40,02650$ & $-40,00279$ & $-0,61644$ & $-0,40171$ & 0,00435 & 0,05217 & 2,92 & 0,65 \\
\hline $\mathrm{CO}$ & $-111,87378$ & $-112,38294$ & $-112,34056$ & $-0,62247$ & $-0,39617$ & $-0,01659$ & 0,08506 & 3,08 & 1,38 \\
\hline $\mathrm{F}_{2} \mathrm{O}$ & $-272,36048$ & $-272,84633$ & $-272,83815$ & $-0,59997$ & $-0,37372$ & $-0,08622$ & 0,09173 & 3,08 & 2,42 \\
\hline $\mathrm{H}_{2} \mathrm{O}$ & $-75,37104$ & $-75,83094$ & $-75,80968$ & $-0,58925$ & $-0,33884$ & $-0,00870$ & 0,05825 & 3,41 & 0,91 \\
\hline $\mathrm{HF}$ & $-99,19281$ & $-99,78167$ & $-99,75785$ & $-0,74420$ & $-0,44348$ & $-0,00826$ & 0,06589 & 4,09 & 1,01 \\
\hline $\mathrm{NH}_{3}$ & $-55,62763$ & $-56,02053$ & $-55,99871$ & $-0,50659$ & $-0,28559$ & $-0,00410$ & 0,05498 & 3,01 & 0,80 \\
\hline $\mathrm{PF}_{3}$ & $-636,69764$ & $-637,11699$ & $-637,07901$ & $-0,51744$ & $-0,32262$ & 0,00346 & 0,07237 & 2,65 & 0,94 \\
\hline $\mathrm{PH}_{3}$ & $-340,68008$ & $-341,05699$ & $-341,03602$ & $-0,47062$ & $-0,28552$ & $-0,00335$ & 0,05098 & 2,52 & 0,74 \\
\hline
\end{tabular}

Tabela 8.467: Energias utilizadas (em hartree) e concavidades (Conc.) obtidas pelo Teorema de Janak para BHandH $40 \% E_{X}^{\mathrm{HF}}$ com geometrias experimentais na base aug-pcJ-2.

\begin{tabular}{|c|c|c|c|c|c|c|c|c|c|}
\hline Molécula & $\mathrm{E}_{\text {cátion }}$ & E neutra & Eânion & $\varepsilon_{\text {cátion }}^{\text {LUMO }}$ & $\varepsilon_{\text {neutra }}^{\text {HOMO }}$ & $\varepsilon_{\text {neutra }}^{\text {LUMO }}$ & $\varepsilon_{\text {ânion }}^{\text {HOMO }}$ & Conc.cátion & Conc.ânion \\
\hline $\mathrm{BF}_{3}$ & $-322,11047$ & $-322,68417$ & $-322,65596$ & $-0,65571$ & $-0,49370$ & 0,00124 & 0,06037 & 2,20 & 0,80 \\
\hline $\mathrm{BHF}_{2}$ & $-223,36797$ & $-223,88243$ & $-223,85533$ & $-0,60135$ & $-0,42785$ & $-0,00007$ & 0,04986 & 2,36 & 0,68 \\
\hline $\mathrm{C}_{2} \mathrm{H}_{2}$ & $-76,21981$ & $-76,62860$ & $-76,60316$ & $-0,49237$ & $-0,32955$ & 0,01220 & 0,04589 & 2,22 & 0,46 \\
\hline $\mathrm{C}_{2} \mathrm{H}_{4}$ & $-77,46583$ & $-77,84390$ & $-77,81281$ & $-0,45369$ & $-0,30578$ & 0,01005 & 0,05078 & 2,01 & 0,55 \\
\hline $\mathrm{C}_{2} \mathrm{H}_{6}$ & $-78,59863$ & $-79,04225$ & $-79,01919$ & $-0,51553$ & $-0,37283$ & 0,00714 & 0,04615 & 1,94 & 0,53 \\
\hline $\mathrm{CH}_{4}$ & $-39,58405$ & $-40,09456$ & $-40,07086$ & $-0,59832$ & $-0,42592$ & 0,00777 & 0,04806 & 2,35 & 0,55 \\
\hline $\mathrm{CO}$ & $-111,99566$ & $-112,50801$ & $-112,46452$ & $-0,60391$ & $-0,42279$ & $-0,00117$ & 0,07923 & 2,46 & 1,09 \\
\hline $\mathrm{F}_{2} \mathrm{O}$ & $-272,59165$ & $-273,08526$ & $-273,07775$ & $-0,57935$ & $-0,40836$ & $-0,06337$ & 0,07308 & 2,33 & 1,86 \\
\hline $\mathrm{H}_{2} \mathrm{O}$ & $-75,45448$ & $-75,91200$ & $-75,89071$ & $-0,55687$ & $-0,36717$ & $-0,00330$ & 0,05290 & 2,58 & 0,76 \\
\hline $\mathrm{HF}$ & $-99,28727$ & $-99,87318$ & $-99,84958$ & $-0,70513$ & $-0,47726$ & $-0,00269$ & 0,05961 & 3,10 & 0,85 \\
\hline $\mathrm{NH}_{3}$ & $-55,70233$ & $-56,09393$ & $-56,07204$ & $-0,48070$ & $-0,30981$ & 0,00058 & 0,05023 & 2,33 & 0,68 \\
\hline $\mathrm{PF}_{3}$ & $-637,12978$ & $-637,55267$ & $-637,51396$ & $-0,50369$ & $-0,34415$ & 0,01218 & 0,06784 & 2,17 & 0,76 \\
\hline $\mathrm{PH}_{3}$ & $-340,86698$ & $-341,24471$ & $-341,22350$ & $-0,45464$ & $-0,30372$ & 0,00123 & 0,04681 & 2,05 & 0,62 \\
\hline
\end{tabular}

Tabela 8.468: Energias utilizadas (em hartree) e concavidades (Conc.) obtidas pelo Teorema de Janak para BHandH $50 \% E_{X}^{\mathrm{HF}}$ com geometrias experimentais na base aug-pcJ-2.

\begin{tabular}{|c|c|c|c|c|c|c|c|c|c|}
\hline Molécula & $\mathrm{E}_{\text {cátion }}$ & Eneutra & Eânion & $\varepsilon_{\text {cátion }}^{\text {LUMO }}$ & $\varepsilon_{\text {neutra }}^{\text {HOMO }}$ & $\varepsilon_{\text {neutra }}^{\text {LUMO }}$ & $\varepsilon_{\text {ânion }}^{\text {HOMO }}$ & Conc.cátion & Conc.ânion \\
\hline $\mathrm{BF}_{3}$ & $-322,40442$ & $-322,99023$ & $-322,96144$ & $-0,64608$ & $-0,52759$ & 0,00694 & 0,05550 & 1,61 & 0,66 \\
\hline $\mathrm{BHF}_{2}$ & $-223,58328$ & $-224,10535$ & $-224,07819$ & $-0,59015$ & $-0,45483$ & 0,00981 & 0,04613 & 1,84 & 0,49 \\
\hline $\mathrm{C}_{2} \mathrm{H}_{2}$ & $-76,33203$ & $-76,73878$ & $-76,71302$ & $-0,47013$ & $-0,34811$ & 0,01446 & 0,04278 & 1,66 & 0,39 \\
\hline $\mathrm{C}_{2} \mathrm{H}_{4}$ & $-77,58706$ & $-77,96254$ & $-77,90468$ & $-0,43239$ & $-0,32237$ & 0,01297 & 0,08234 & 1,50 & 0,94 \\
\hline $\mathrm{C}_{2} \mathrm{H}_{6}$ & $-78,71933$ & $-79,16941$ & $-79,14616$ & $-0,50503$ & $-0,39632$ & 0,01053 & 0,04244 & 1,48 & 0,43 \\
\hline $\mathrm{CH}_{4}$ & $-39,64934$ & $-40,16297$ & $-40,13929$ & $-0,58039$ & $-0,45031$ & 0,01083 & 0,04397 & 1,77 & 0,45 \\
\hline $\mathrm{CO}$ & $-112,11823$ & $-112,63370$ & $-112,58919$ & $-0,58563$ & $-0,44961$ & 0,01270 & 0,07350 & 1,85 & 0,83 \\
\hline $\mathrm{F}_{2} \mathrm{O}$ & $-272,82563$ & $-273,32568$ & $-273,31951$ & $-0,55488$ & $-0,44327$ & $-0,04086$ & 0,05026 & 1,52 & 1,24 \\
\hline $\mathrm{H}_{2} \mathrm{O}$ & $-75,53822$ & $-75,99342$ & $-75,97213$ & $-0,52518$ & $-0,39581$ & 0,00153 & 0,04756 & 1,76 & 0,63 \\
\hline $\mathrm{HF}$ & $-99,38204$ & $-99,96508$ & $-99,94173$ & $-0,66678$ & $-0,51135$ & 0,00224 & 0,05332 & 2,11 & 0,69 \\
\hline $\mathrm{NH}_{3}$ & $-55,77732$ & $-56,16765$ & $-56,14572$ & $-0,45536$ & $-0,33431$ & 0,00478 & 0,04550 & 1,65 & 0,55 \\
\hline $\mathrm{PF}_{3}$ & $-637,56404$ & $-637,99032$ & $-637,95092$ & $-0,48975$ & $-0,36588$ & 0,01955 & 0,06340 & 1,69 & 0,60 \\
\hline $\mathrm{PH}_{3}$ & $-341,05441$ & $-341,43296$ & $-341,41154$ & $-0,43883$ & $-0,32208$ & 0,00537 & 0,04267 & 1,59 & 0,51 \\
\hline
\end{tabular}

Tabela 8.469: Energias utilizadas (em hartree) e concavidades (Conc.) obtidas pelo Teorema de Janak para BHandH $60 \% E_{X}^{\mathrm{HF}}$ com geometrias experimentais na base aug-pcJ-2.

\begin{tabular}{|c|c|c|c|c|c|c|c|c|c|}
\hline Molécula & $\mathrm{E}_{\text {cátion }}$ & E neutra & $\mathrm{E}_{\text {ânion }}$ & $\varepsilon_{\text {cátion }}^{\text {LUMO }}$ & $\varepsilon_{\text {neutra }}^{\text {HOMO }}$ & $\varepsilon_{\text {neutra }}^{\text {LUMO }}$ & $\varepsilon_{\text {ânion }}^{\text {HOMO }}$ & Conc.cátion & Conc.ânion \\
\hline $\mathrm{BF}_{3}$ & $-322,70001$ & $-323,29788$ & $-323,26856$ & $-0,63613$ & $-0,56177$ & 0,01210 & 0,05068 & 1,01 & 0,52 \\
\hline $\mathrm{BHF}_{2}$ & $-223,80000$ & $-224,32946$ & $-224,30228$ & $-0,57879$ & $-0,48198$ & 0,01720 & 0,04240 & 1,32 & 0,34 \\
\hline $\mathrm{C}_{2} \mathrm{H}_{2}$ & $-76,44473$ & $-76,84946$ & $-76,82339$ & $-0,44820$ & $-0,36671$ & 0,01652 & 0,03968 & 1,11 & 0,32 \\
\hline $\mathrm{C}_{2} \mathrm{H}_{4}$ & $-77,70885$ & $-78,08178$ & $-78,02244$ & $-0,41143$ & $-0,33901$ & 0,01559 & 0,07835 & 0,99 & 0,85 \\
\hline $\mathrm{C}_{2} \mathrm{H}_{6}$ & $-78,84070$ & $-79,29724$ & $-79,27383$ & $-0,49435$ & $-0,42004$ & 0,01353 & 0,03875 & 1,01 & 0,34 \\
\hline $\mathrm{CH}_{4}$ & $-39,71493$ & $-40,23171$ & $-40,20807$ & $-0,56263$ & $-0,47489$ & 0,01356 & 0,03988 & 1,19 & 0,36 \\
\hline $\mathrm{CO}$ & $-112,24146$ & $-112,76001$ & $-112,71457$ & $-0,56766$ & $-0,47663$ & 0,02436 & 0,06793 & 1,24 & 0,59 \\
\hline $\mathrm{F}_{2} \mathrm{O}$ & $-273,06255$ & $-273,56753$ & $-273,56331$ & $-0,52665$ & $-0,47844$ & $-0,01892$ & 0,02400 & 0,66 & 0,58 \\
\hline $\mathrm{H}_{2} \mathrm{O}$ & $-75,62226$ & $-76,07519$ & $-76,05395$ & $-0,49418$ & $-0,42476$ & 0,00582 & 0,04224 & 0,94 & 0,50 \\
\hline $\mathrm{HF}$ & $-99,47712$ & $-100,05735$ & $-100,03430$ & $-0,62916$ & $-0,54574$ & 0,00660 & 0,04701 & 1,13 & 0,55 \\
\hline $\mathrm{NH}_{3}$ & $-55,85257$ & $-56,24171$ & $-56,21977$ & $-0,43059$ & $-0,35906$ & 0,00854 & 0,04078 & 0,97 & 0,44 \\
\hline $\mathrm{PF}_{3}$ & $-638,00036$ & $-638,42990$ & $-638,38983$ & $-0,47569$ & $-0,38781$ & 0,02561 & 0,05902 & 1,20 & 0,45 \\
\hline $\mathrm{PH}_{3}$ & $-341,24236$ & $-341,62177$ & $-341,60014$ & $-0,42320$ & $-0,34061$ & 0,00911 & 0,03857 & 1,12 & 0,40 \\
\hline
\end{tabular}


Tabela 8.470: Energias utilizadas (em hartree) e concavidades (Conc.) obtidas pelo Teorema de Janak para BHandH $70 \% E_{X}^{\mathrm{HF}}$ com geometrias experimentais na base aug-pcJ-2.

\begin{tabular}{|c|c|c|c|c|c|c|c|c|c|}
\hline Molécula & $\mathrm{E}_{\text {cátion }}$ & Eneutra & $\mathrm{E}_{\text {ânion }}$ & $\varepsilon_{\text {cátion }}^{\text {LUMO }}$ & $\varepsilon_{\text {neutra }}^{\text {HOMO }}$ & $\varepsilon_{\text {neutra }}^{\text {LUMO }}$ & $\varepsilon_{\text {ânion }}^{\text {HOMO }}$ & Conc.cátion & Conc.ânion \\
\hline $\mathrm{BF}_{3}$ & $-322,99720$ & $-323,60708$ & $-323,57727$ & $-0,62585$ & $-0,59623$ & 0,01678 & 0,04591 & 0,40 & 0,40 \\
\hline $\mathrm{BHF}_{2}$ & $-224,01811$ & $-224,55475$ & $-224,52757$ & $-0,56730$ & $-0,50929$ & 0,02089 & 0,03866 & 0,79 & 0,24 \\
\hline $\mathrm{C}_{2} \mathrm{H}_{2}$ & $-76,55792$ & $-76,96064$ & $-76,93428$ & $-0,42659$ & $-0,38535$ & 0,01840 & 0,03658 & 0,56 & 0,25 \\
\hline $\mathrm{C}_{2} \mathrm{H}_{4}$ & $-77,83118$ & $-78,20161$ & $-78,14083$ & $-0,39084$ & $-0,35568$ & 0,01794 & 0,07449 & 0,48 & 0,77 \\
\hline $\mathrm{C}_{2} \mathrm{H}_{6}$ & $-78,96287$ & $-79,42574$ & $-79,40218$ & $-0,48260$ & $-0,44399$ & 0,01619 & 0,03508 & 0,53 & 0,26 \\
\hline $\mathrm{CH}_{4}$ & $-39,78081$ & $-40,30080$ & $-40,27722$ & $-0,54504$ & $-0,49964$ & 0,01601 & 0,03581 & 0,62 & 0,27 \\
\hline $\mathrm{CO}$ & $-112,36535$ & $-112,88693$ & $-112,84066$ & $-0,55001$ & $-0,50386$ & 0,03325 & 0,06253 & 0,63 & 0,40 \\
\hline $\mathrm{F}_{2} \mathrm{O}$ & $-273,30247$ & $-273,81074$ & $-273,80905$ & $-0,49553$ & $-0,51389$ & 0,00206 & $-0,00480$ & $-0,25$ & $-0,09$ \\
\hline $\mathrm{H}_{2} \mathrm{O}$ & $-75,70659$ & $-76,15730$ & $-76,13614$ & $-0,46392$ & $-0,45400$ & 0,00964 & 0,03693 & 0,13 & 0,37 \\
\hline $\mathrm{HF}$ & $-99,57251$ & $-100,14999$ & $-100,12727$ & $-0,59230$ & $-0,58041$ & 0,01045 & 0,04068 & 0,16 & 0,41 \\
\hline $\mathrm{NH}_{3}$ & $-55,92810$ & $-56,31608$ & $-56,29416$ & $-0,40641$ & $-0,38407$ & 0,01190 & 0,03608 & 0,30 & 0,33 \\
\hline $\mathrm{PF}_{3}$ & $-638,43869$ & $-638,87135$ & $-638,83066$ & $-0,46154$ & $-0,40993$ & 0,03056 & 0,05473 & 0,70 & 0,33 \\
\hline $\mathrm{PH}_{3}$ & $-341,43084$ & $-341,81111$ & $-341,78930$ & $-0,40776$ & $-0,35929$ & 0,01248 & 0,03450 & 0,66 & 0,30 \\
\hline
\end{tabular}

Tabela 8.471: Energias utilizadas (em hartree) e concavidades (Conc.) obtidas pelo Teorema de Janak para BHandH $80 \% E_{X}^{\mathrm{HF}}$ com geometrias experimentais na base aug-pcJ-2.

\begin{tabular}{|c|c|c|c|c|c|c|c|c|c|}
\hline Molécula & $\mathrm{E}_{\text {cátion }}$ & $E_{\text {neutra }}$ & Eânion & $\varepsilon_{\text {cátion }}^{\text {LUMO }}$ & $\varepsilon_{\text {neutra }}^{\text {HOMO }}$ & $\varepsilon_{\text {neutra }}^{L U M O}$ & $\varepsilon_{\text {ânion }}^{\text {HOMO }}$ & Conc.cátion & Conc.ânion \\
\hline $\mathrm{BF}_{3}$ & $-323,29596$ & $-323,91779$ & $-323,88753$ & $-0,61524$ & $-0,63098$ & 0,02102 & 0,04119 & $-0,21$ & 0,27 \\
\hline $\mathrm{BHF}_{2}$ & $-224,23762$ & $-224,78118$ & $-224,75097$ & $-0,55572$ & $-0,53677$ & 0,02272 & 0,03843 & 0,26 & 0,21 \\
\hline $\mathrm{C}_{2} \mathrm{H}_{2}$ & $-76,67158$ & $-77,07231$ & $-77,04567$ & $-0,40531$ & $-0,40404$ & 0,02010 & 0,03348 & 0,02 & 0,18 \\
\hline $\mathrm{C}_{2} \mathrm{H}_{4}$ & $-77,95407$ & $-78,32202$ & $-78,25985$ & $-0,37062$ & $-0,37241$ & 0,02006 & 0,07081 & $-0,02$ & 0,69 \\
\hline $\mathrm{C}_{2} \mathrm{H}_{6}$ & $-79,08657$ & $-79,55490$ & $-79,53122$ & $-0,46512$ & $-0,46817$ & 0,01855 & 0,03143 & $-0,04$ & 0,18 \\
\hline $\mathrm{CH}_{4}$ & $-39,84698$ & $-40,37024$ & $-40,34673$ & $-0,52760$ & $-0,52458$ & 0,01821 & 0,03175 & 0,04 & 0,18 \\
\hline $\mathrm{CO}$ & $-112,48988$ & $-113,01446$ & $-112,96746$ & $-0,53271$ & $-0,53127$ & 0,03953 & 0,05734 & 0,02 & 0,24 \\
\hline $\mathrm{F}_{2} \mathrm{O}$ & $-273,54547$ & $-274,05529$ & $-274,05662$ & $-0,46277$ & $-0,54961$ & 0,02148 & $-0,03550$ & $-1,18$ & $-0,78$ \\
\hline $\mathrm{H}_{2} \mathrm{O}$ & $-75,79120$ & $-76,23976$ & $-76,21870$ & $-0,43442$ & $-0,48352$ & 0,01305 & 0,03162 & $-0,67$ & 0,25 \\
\hline $\mathrm{HF}$ & $-99,66820$ & $-100,24299$ & $-100,22064$ & $-0,55622$ & $-0,61536$ & 0,01387 & 0,03433 & $-0,80$ & 0,28 \\
\hline $\mathrm{NH}_{3}$ & $-56,00390$ & $-56,39078$ & $-56,36890$ & $-0,38283$ & $-0,40933$ & 0,01491 & 0,03138 & $-0,36$ & 0,22 \\
\hline $\mathrm{PF}_{3}$ & $-638,87897$ & $-639,31464$ & $-639,27337$ & $-0,44738$ & $-0,43224$ & 0,03461 & 0,05050 & 0,21 & 0,22 \\
\hline $\mathrm{PH}_{3}$ & $-341,61983$ & $-342,00099$ & $-341,97902$ & $-0,39251$ & $-0,37815$ & 0,01551 & 0,03047 & 0,20 & 0,20 \\
\hline
\end{tabular}

Tabela 8.472: Energias utilizadas (em hartree) e concavidades (Conc.) obtidas pelo Teorema de Janak para BHandH $90 \% E_{X}^{\mathrm{HF}}$ com geometrias experimentais na base aug-pcJ-2.

\begin{tabular}{|c|c|c|c|c|c|c|c|c|c|}
\hline Molécula & $\mathrm{E}_{\text {cátion }}$ & Eneutra & Eânion & $\varepsilon_{\text {cátion }}^{\text {LUMO }}$ & $\varepsilon_{\text {neutra }}^{\text {HOMO }}$ & $\varepsilon_{\text {neutra }}^{\text {LUMO }}$ & $\varepsilon_{\text {ânion }}^{\text {HOMO }}$ & Conc.cátion & Conc.ânion \\
\hline $\mathrm{BF}_{3}$ & $-323,59626$ & $-324,22998$ & $-324,19930$ & $-0,60429$ & $-0,66598$ & 0,02485 & 0,03650 & $-0,84$ & 0,16 \\
\hline $\mathrm{BHF}_{2}$ & $-224,45851$ & $-225,00873$ & $-224,97821$ & $-0,54409$ & $-0,56441$ & 0,02435 & 0,03463 & $-0,28$ & 0,14 \\
\hline $\mathrm{C}_{2} \mathrm{H}_{2}$ & $-76,78571$ & $-77,18447$ & $-77,15755$ & $-0,38437$ & $-0,42278$ & 0,02166 & 0,03037 & $-0,52$ & 0,12 \\
\hline $\mathrm{C}_{2} \mathrm{H}_{4}$ & $-78,07749$ & $-78,44302$ & $-78,41076$ & $-0,35079$ & $-0,38918$ & 0,02197 & 0,03564 & $-0,52$ & 0,19 \\
\hline $\mathrm{C}_{2} \mathrm{H}_{6}$ & $-79,20751$ & $-79,68473$ & $-79,66095$ & $-0,46237$ & $-0,49258$ & 0,02066 & 0,02779 & $-0,41$ & 0,10 \\
\hline $\mathrm{CH}_{4}$ & $-39,91344$ & $-40,44001$ & $-40,41659$ & $-0,51032$ & $-0,54970$ & 0,02018 & 0,02770 & $-0,54$ & 0,10 \\
\hline $\mathrm{CO}$ & $-112,61504$ & $-113,14260$ & $-113,09496$ & $-0,51577$ & $-0,55888$ & 0,04392 & 0,05233 & $-0,59$ & 0,11 \\
\hline $\mathrm{F}_{2} \mathrm{O}$ & $-273,79167$ & $-274,30113$ & $-274,30595$ & $-0,42985$ & $-0,58560$ & 0,03845 & $-0,06768$ & $-2,12$ & $-1,44$ \\
\hline $\mathrm{H}_{2} \mathrm{O}$ & $-75,87610$ & $-76,32256$ & $-76,30164$ & $-0,40573$ & $-0,51331$ & 0,01608 & 0,02630 & $-1,46$ & 0,14 \\
\hline $\mathrm{HF}$ & $-99,76420$ & $-100,33635$ & $-100,31440$ & $-0,52098$ & $-0,65058$ & 0,01690 & 0,02794 & $-1,76$ & 0,15 \\
\hline $\mathrm{NH}_{3}$ & $-56,07996$ & $-56,46580$ & $-56,44398$ & $-0,35987$ & $-0,43483$ & 0,01760 & 0,02669 & $-1,02$ & 0,12 \\
\hline $\mathrm{PF}_{3}$ & $-639,32116$ & $-639,75973$ & $-639,71791$ & $-0,43326$ & $-0,45473$ & 0,03797 & 0,04633 & $-0,29$ & 0,11 \\
\hline $\mathrm{PH}_{3}$ & $-341,80934$ & $-342,19141$ & $-342,16929$ & $-0,37746$ & $-0,39717$ & 0,01825 & 0,02646 & $-0,27$ & 0,11 \\
\hline
\end{tabular}

Tabela 8.473: Energias utilizadas (em hartree) e concavidades (Conc.) obtidas pelo Teorema de Janak para BHandH $100 \% E_{X}^{\mathrm{HF}}$ com geometrias experimentais na base aug-pcJ-2.

\begin{tabular}{|c|c|c|c|c|c|c|c|c|c|}
\hline Molécula & $\mathrm{E}_{\text {cátion }}$ & E neutra & $\mathrm{E}_{\text {ânion }}$ & $\varepsilon_{\text {cátion }}^{\text {LUMO }}$ & $\varepsilon_{\text {neutra }}^{\text {HOMO }}$ & $\varepsilon_{\text {neutra }}^{\text {LUMO }}$ & $\varepsilon_{\text {ânion }}^{\text {HOMO }}$ & Conc.cátion & Conc.ânion \\
\hline $\mathrm{BF}_{3}$ & $-323,89808$ & $-324,54361$ & $-324,51256$ & $-0,59300$ & $-0,70125$ & 0,02833 & 0,03184 & $-1,47$ & 0,05 \\
\hline $\mathrm{BHF}_{2}$ & $-224,68075$ & $-225,23737$ & $-225,20660$ & $-0,53245$ & $-0,59220$ & 0,02581 & 0,03087 & $-0,81$ & 0,07 \\
\hline $\mathrm{C}_{2} \mathrm{H}_{2}$ & $-76,90032$ & $-77,29711$ & $-77,26993$ & $-0,36378$ & $-0,44157$ & 0,02309 & 0,02727 & $-1,06$ & 0,06 \\
\hline $\mathrm{C}_{2} \mathrm{H}_{4}$ & $-78,20146$ & $-78,56459$ & $-78,53213$ & $-0,33136$ & $-0,40601$ & 0,02371 & 0,03262 & $-1,02$ & 0,12 \\
\hline $\mathrm{C}_{2} \mathrm{H}_{6}$ & $-79,33131$ & $-79,81522$ & $-79,79136$ & $-0,45227$ & $-0,51721$ & 0,02254 & 0,02417 & $-0,88$ & 0,02 \\
\hline $\mathrm{CH}_{4}$ & $-39,98020$ & $-40,51014$ & $-40,48681$ & $-0,49318$ & $-0,57500$ & 0,02196 & 0,02365 & $-1,11$ & 0,02 \\
\hline $\mathrm{CO}$ & $-112,74084$ & $-113,27134$ & $-113,22315$ & $-0,49920$ & $-0,58667$ & 0,04713 & 0,04748 & $-1,19$ & 0,00 \\
\hline $\mathrm{F}_{2} \mathrm{O}$ & $-274,04108$ & $-274,54823$ & $-274,55697$ & $-0,39781$ & $-0,62186$ & 0,05196 & $-0,10107$ & $-3,05$ & $-2,08$ \\
\hline $\mathrm{H}_{2} \mathrm{O}$ & $-75,96129$ & $-76,40568$ & $-76,38493$ & $-0,37787$ & $-0,54337$ & 0,01878 & 0,02099 & $-2,25$ & 0,03 \\
\hline $\mathrm{HF}$ & $-99,86049$ & $-100,43007$ & $-100,40855$ & $-0,48660$ & $-0,68605$ & 0,01960 & 0,02152 & $-2,71$ & 0,03 \\
\hline $\mathrm{NH}_{3}$ & $-56,15630$ & $-56,54114$ & $-56,51940$ & $-0,33757$ & $-0,46057$ & 0,02002 & 0,02200 & $-1,67$ & 0,03 \\
\hline $\mathrm{PF}_{3}$ & $-639,76519$ & $-640,20658$ & $-640,16424$ & $-0,41921$ & $-0,47740$ & 0,04081 & 0,04223 & $-0,79$ & 0,02 \\
\hline $\mathrm{PH}_{3}$ & $-341,99937$ & $-342,38237$ & $-342,36011$ & $-0,36263$ & $-0,41636$ & 0,02072 & 0,02247 & $-0,73$ & 0,02 \\
\hline
\end{tabular}


Tabela 8.474: Energias utilizadas (em hartree) e concavidades (Conc.) obtidas pelo Teorema de Janak para B1B95 30\% $E_{X}^{\mathrm{HF}}$ com geometrias experimentais na base aug-pcJ-2.

\begin{tabular}{|c|c|c|c|c|c|c|c|c|c|}
\hline Molécula & $\mathrm{E}_{\text {cátion }}$ & $E_{\text {neutra }}$ & $E_{\text {ânion }}$ & $\varepsilon_{\text {cátion }}^{\text {LUMO }}$ & $\varepsilon_{\text {neutra }}^{\text {HOMO }}$ & $\varepsilon_{\text {neutra }}^{\text {LUMO }}$ & $\varepsilon_{\text {ânion }}^{\text {HOMO }}$ & Conc.cátion & Conc.ânion \\
\hline $\mathrm{BF}_{3}$ & $-324,07601$ & $-324,63965$ & $-324,61356$ & $-0,66771$ & $-0,46156$ & $-0,00067$ & 0,05233 & 2,80 & 0,72 \\
\hline $\mathrm{BHF}_{2}$ & $-224,78020$ & $-225,29500$ & $-225,27298$ & $-0,62220$ & $-0,40662$ & $-0,01028$ & 0,04872 & 2,93 & 0,80 \\
\hline $\mathrm{C}_{2} \mathrm{H}_{2}$ & $-76,90702$ & $-77,32166$ & $-77,30187$ & $-0,51714$ & $-0,31351$ & 0,00643 & 0,04362 & 2,77 & 0,51 \\
\hline $\mathrm{C}_{2} \mathrm{H}_{4}$ & $-78,18645$ & $-78,57091$ & $-78,54583$ & $-0,47686$ & $-0,29214$ & 0,00529 & 0,04777 & 2,51 & 0,58 \\
\hline $\mathrm{C}_{2} \mathrm{H}_{6}$ & $-79,35500$ & $-79,80359$ & $-79,78483$ & $-0,53977$ & $-0,35859$ & 0,00277 & 0,04593 & 2,47 & 0,59 \\
\hline $\mathrm{CH}_{4}$ & $-39,98324$ & $-40,50113$ & $-40,48133$ & $-0,62945$ & $-0,40882$ & 0,00252 & 0,04812 & 3,00 & 0,62 \\
\hline $\mathrm{CO}$ & $-112,80862$ & $-113,32555$ & $-113,28762$ & $-0,62460$ & $-0,40147$ & $-0,01778$ & 0,07840 & 3,04 & 1,31 \\
\hline $\mathrm{F}_{2} \mathrm{O}$ & $-274,22648$ & $-274,71718$ & $-274,70973$ & $-0,60508$ & $-0,37788$ & $-0,08639$ & 0,09032 & 3,09 & 2,40 \\
\hline $\mathrm{H}_{2} \mathrm{O}$ & $-75,97289$ & $-76,43710$ & $-76,41833$ & $-0,59138$ & $-0,34204$ & $-0,00867$ & 0,05418 & 3,39 & 0,86 \\
\hline $\mathrm{HF}$ & $-99,87618$ & $-100,46875$ & $-100,44797$ & $-0,74537$ & $-0,44638$ & $-0,00880$ & 0,06125 & 4,07 & 0,95 \\
\hline $\mathrm{NH}_{3}$ & $-56,15605$ & $-56,55516$ & $-56,53598$ & $-0,50896$ & $-0,29024$ & $-0,00441$ & 0,05084 & 2,98 & 0,75 \\
\hline $\mathrm{PF}_{3}$ & $-639,92781$ & $-640,35219$ & $-640,31773$ & $-0,52023$ & $-0,32675$ & 0,00470 & 0,06674 & 2,63 & 0,84 \\
\hline $\mathrm{PH}_{3}$ & $-342,02494$ & $-342,41067$ & $-342,39254$ & $-0,47726$ & $-0,29276$ & $-0,00306$ & 0,04675 & 2,51 & 0,68 \\
\hline
\end{tabular}

Tabela 8.475: Energias utilizadas (em hartree) e concavidades (Conc.) obtidas pelo Teorema de Janak para B1B95 $40 \% E_{X}^{\mathrm{HF}}$ com geometrias experimentais na base aug-pcJ-2.

\begin{tabular}{|c|c|c|c|c|c|c|c|c|c|}
\hline Molécula & $\mathrm{E}_{\text {cátion }}$ & $\mathrm{E}_{\text {neutra }}$ & Eânion & $\varepsilon_{\text {cátion }}^{\text {LUMO }}$ & $\varepsilon_{\text {neutra }}^{\text {HOMO }}$ & $\varepsilon_{\text {neutra }}^{\text {LUMO }}$ & $\varepsilon_{\text {ânion }}^{\text {HOMO }}$ & Conc.cátion & Conc.ânion \\
\hline $\mathrm{BF}_{3}$ & $-324,04791$ & $-324,62353$ & $\begin{array}{l}-324,59639 \\
\end{array}$ & $-0,65855$ & $-0,49467$ & 0,00571 & 0,04966 & 2,23 & 0,60 \\
\hline $\mathrm{BHF}_{2}$ & $-224,76285$ & $-225,28441$ & $-225,26181$ & $-0,61012$ & $-0,43226$ & 0,00159 & 0,04582 & 2,42 & 0,60 \\
\hline $\mathrm{C}_{2} \mathrm{H}_{2}$ & $-76,90431$ & $-77,31719$ & $-77,29627$ & $-0,49542$ & $-0,33193$ & 0,01040 & 0,04135 & 2,22 & 0,42 \\
\hline $\mathrm{C}_{2} \mathrm{H}_{4}$ & $-78,18654$ & $-78,56877$ & $-78,54269$ & $-0,45595$ & $-0,30877$ & 0,00913 & 0,04561 & 2,00 & 0,50 \\
\hline $\mathrm{C}_{2} \mathrm{H}_{6}$ & $-79,35060$ & $-79,80411$ & $-79,78478$ & $-0,52795$ & $-0,38025$ & 0,00689 & 0,04284 & 2,01 & 0,49 \\
\hline $\mathrm{CH}_{4}$ & $-39,98168$ & $-40,50156$ & $-40,48133$ & $-0,61063$ & $-0,43171$ & 0,00652 & 0,04467 & 2,43 & 0,52 \\
\hline $\mathrm{CO}$ & $-112,79775$ & $-113,31681$ & $-113,27702$ & $-0,60481$ & $-0,42691$ & $-0,00175$ & 0,07377 & 2,42 & 1,03 \\
\hline $\mathrm{F}_{2} \mathrm{O}$ & $-274,19314$ & $-274,69092$ & $-274,68342$ & $-0,58415$ & $-0,41147$ & $-0,06319$ & 0,07282 & 2,35 & 1,85 \\
\hline $\mathrm{H}_{2} \mathrm{O}$ & $-75,97025$ & $-76,43200$ & $-76,41275$ & $-0,55987$ & $-0,36969$ & $-0,00270$ & 0,04951 & 2,59 & 0,71 \\
\hline $\mathrm{HF}$ & $-99,87324$ & $-100,46282$ & $-100,44170$ & $-0,70751$ & $-0,47934$ & $-0,00256$ & 0,05571 & 3,10 & 0,79 \\
\hline $\mathrm{NH}_{3}$ & $-56,15504$ & $-56,55250$ & $-56,53284$ & $-0,48358$ & $-0,31374$ & 0,00077 & 0,04684 & 2,31 & 0,63 \\
\hline $\mathrm{PF}_{3}$ & $-639,90700$ & $-640,33448$ & $-640,29871$ & $-0,50626$ & $-0,34764$ & 0,01366 & 0,06319 & 2,16 & 0,67 \\
\hline $\mathrm{PH}_{3}$ & $-342,02509$ & $-342,41088$ & $-342,39222$ & $-0,46080$ & $-0,31012$ & 0,00181 & 0,04333 & 2,05 & 0,56 \\
\hline
\end{tabular}

Tabela 8.476: Energias utilizadas (em hartree) e concavidades (Conc.) obtidas pelo Teorema de Janak para B1B95 50\% $E_{X}^{\mathrm{HF}}$ com geometrias experimentais na base aug-pcJ-2.

\begin{tabular}{|c|c|c|c|c|c|c|c|c|c|}
\hline Molécula & $\mathrm{E}_{\text {cátion }}$ & Eneutra & $E_{\text {ânion }}$ & $\varepsilon_{\text {cátion }}^{\text {LUMO }}$ & $\varepsilon_{\text {neutra }}^{\text {HOMO }}$ & $\varepsilon_{\text {neutra }}^{\text {LUMO }}$ & $\varepsilon_{\text {ânion }}^{\text {HOMO }}$ & Conc.cátion & Conc.ânion \\
\hline $\mathrm{BF}_{3}$ & $-324,02103$ & $-324,60855$ & $-324,58038$ & $-0,64909$ & $-0,52802$ & 0,01160 & 0,04692 & 1,65 & 0,48 \\
\hline $\mathrm{BHF}_{2}$ & $-224,74665$ & $-225,27468$ & $-225,25152$ & $-0,59780$ & $-0,45792$ & 0,01131 & 0,04283 & 1,90 & 0,43 \\
\hline $\mathrm{C}_{2} \mathrm{H}_{2}$ & $-76,90195$ & $-77,31312$ & $-77,29225$ & $-0,47397$ & $-0,35039$ & 0,01336 & 0,04031 & 1,68 & 0,37 \\
\hline $\mathrm{C}_{2} \mathrm{H}_{4}$ & $-78,18703$ & $-78,56706$ & $-78,54000$ & $-0,43534$ & $-0,32543$ & 0,01260 & 0,04343 & 1,50 & 0,42 \\
\hline $\mathrm{C}_{2} \mathrm{H}_{6}$ & $-79,34670$ & $-79,80509$ & $-79,78521$ & $-0,51605$ & $-0,40203$ & 0,01067 & 0,03972 & 1,55 & 0,40 \\
\hline $\mathrm{CH}_{4}$ & $-39,98035$ & $-40,50222$ & $-40,48157$ & $-0,59192$ & $-0,45469$ & 0,01020 & 0,04118 & 1,87 & 0,42 \\
\hline $\mathrm{CO}$ & $-112,78746$ & $-113,30854$ & $-113,26699$ & $-0,58518$ & $-0,45247$ & 0,01278 & 0,06924 & 1,81 & 0,77 \\
\hline $\mathrm{F}_{2} \mathrm{O}$ & $-274,16225$ & $-274,66583$ & $-274,65892$ & $-0,55976$ & $-0,44521$ & $-0,04023$ & 0,05110 & 1,56 & 1,24 \\
\hline $\mathrm{H}_{2} \mathrm{O}$ & $-75,96783$ & $-76,42718$ & $-76,40749$ & $-0,52895$ & $-0,39757$ & 0,00270 & 0,04484 & 1,79 & 0,57 \\
\hline $\mathrm{HF}$ & $-99,87053$ & $-100,45719$ & $-100,43576$ & $-0,67026$ & $-0,51254$ & 0,00308 & 0,05017 & 2,15 & 0,64 \\
\hline $\mathrm{NH}_{3}$ & $-56,15423$ & $-56,55011$ & $-56,52998$ & $-0,45867$ & $-0,33743$ & 0,00551 & 0,04282 & 1,65 & 0,51 \\
\hline $\mathrm{PF}_{3}$ & $-639,88775$ & $-640,31814$ & $-640,28110$ & $-0,49215$ & $-0,36864$ & 0,02127 & 0,05969 & 1,68 & 0,52 \\
\hline $\mathrm{PH}_{3}$ & $-342,02560$ & $-342,41146$ & $-342,39228$ & $-0,44450$ & $-0,32757$ & 0,00631 & 0,03990 & 1,59 & 0,46 \\
\hline
\end{tabular}

Tabela 8.477: Energias utilizadas (em hartree) e concavidades (Conc.) obtidas pelo Teorema de Janak para B972B95 50\% $E_{X}^{\mathrm{HF}}$ com geometrias experimentais na base aug-pcJ-2.

\begin{tabular}{|c|c|c|c|c|c|c|c|c|c|}
\hline Molécula & $\mathrm{E}_{\text {cátion }}$ & $E_{\text {neutra }}$ & $E_{\text {ânion }}$ & $\varepsilon_{\text {cátion }}^{L U M O}$ & $\varepsilon_{\text {neutra }}^{\text {HOMO }}$ & $\varepsilon_{\text {neutra }}^{\text {LUMO }}$ & $\varepsilon_{\text {ânion }}^{\text {HOMO }}$ & Conc.cátion & Conc.ânion \\
\hline $\mathrm{BF}_{3}$ & $-320,35139$ & $-320,89214$ & $-320,85522$ & $-0,60357$ & $-0,48021$ & 0,01306 & 0,06260 & 1,68 & 0,67 \\
\hline $\mathrm{BHF}_{2}$ & $-222,13539$ & $-222,62294$ & $-222,58927$ & $-0,55966$ & $-0,41620$ & 0,01583 & 0,05495 & 1,95 & 0,53 \\
\hline $\mathrm{C}_{2} \mathrm{H}_{2}$ & $-75,74325$ & $-76,12776$ & $-76,09981$ & $-0,44829$ & $-0,32240$ & 0,01312 & 0,04665 & 1,71 & 0,46 \\
\hline $\mathrm{C}_{2} \mathrm{H}_{4}$ & $-76,95286$ & $-77,30776$ & $-77,27535$ & $-0,41129$ & $-0,29901$ & 0,01257 & 0,05018 & 1,53 & 0,51 \\
\hline $\mathrm{C}_{2} \mathrm{H}_{6}$ & $-78,04686$ & $-78,47076$ & $-78,44528$ & $-0,48325$ & $-0,36625$ & 0,01092 & 0,04720 & 1,59 & 0,49 \\
\hline $\mathrm{CH}_{4}$ & $-39,31029$ & $-39,80010$ & $-39,77365$ & $-0,56228$ & $-0,42059$ & 0,01063 & 0,04876 & 1,93 & 0,52 \\
\hline $\mathrm{CO}$ & $-111,37779$ & $-111,86256$ & $-111,80965$ & $-0,55362$ & $-0,41375$ & 0,02894 & 0,08005 & 1,90 & 0,70 \\
\hline $\mathrm{F}_{2} \mathrm{O}$ & $-271,15050$ & $-271,60537$ & $-271,55743$ & $-0,51708$ & $-0,39312$ & 0,00108 & 0,09027 & 1,69 & 1,21 \\
\hline $\mathrm{H}_{2} \mathrm{O}$ & $-75,03500$ & $-75,46094$ & $-75,43292$ & $-0,49950$ & $-0,36041$ & 0,00399 & 0,05383 & 1,89 & 0,68 \\
\hline $\mathrm{HF}$ & $-98,78243$ & $-99,32936$ & $-99,29859$ & $-0,63452$ & $-0,46899$ & 0,00496 & 0,06027 & 2,25 & 0,75 \\
\hline $\mathrm{NH}_{3}$ & $-55,36021$ & $-55,72656$ & $-55,69937$ & $-0,43145$ & $-0,30475$ & 0,00616 & 0,05123 & 1,72 & 0,61 \\
\hline $\mathrm{PF}_{3}$ & $-634,22182$ & $-634,61227$ & $-634,56607$ & $-0,45121$ & $-0,32827$ & 0,02652 & 0,06980 & 1,67 & 0,59 \\
\hline $\mathrm{PH}_{3}$ & $-339,54466$ & $-339,90284$ & $-339,87728$ & $-0,41636$ & $-0,29891$ & 0,00690 & 0,04798 & 1,60 & 0,56 \\
\hline
\end{tabular}


Tabela 8.478: Energias utilizadas (em hartree) e concavidades (Conc.) obtidas pelo Teorema de Janak para B972B95 60\% $E_{X}^{\mathrm{HF}}$ com geometrias experimentais na base aug-pcJ-2.

\begin{tabular}{|c|c|c|c|c|c|c|c|c|c|}
\hline Molécula & $\mathrm{E}_{\text {cátion }}$ & $\mathrm{E}_{\text {neutra }}$ & $\mathrm{E}_{\text {ânion }}$ & $\varepsilon_{\text {cátion }}^{\text {LUMO }}$ & $\varepsilon_{\text {neutra }}^{\text {HOMO }}$ & $\varepsilon_{\text {neutra }}^{\text {LUMO }}$ & $\varepsilon_{\text {ânion }}^{\text {HOMO }}$ & Conc.cátion & Conc.ânion \\
\hline $\mathrm{BF}_{3}$ & $-321,05773$ & $-321,61926$ & $-321,58339$ & $-0,60272$ & $-0,52271$ & 0,01792 & 0,05663 & 1,09 & 0,53 \\
\hline $\mathrm{BHF}_{2}$ & $-222,64090$ & $-223,14264$ & $-223,10939$ & $-0,55513$ & $-0,44975$ & 0,01897 & 0,05035 & 1,43 & 0,43 \\
\hline $\mathrm{C}_{2} \mathrm{H}_{2}$ & $-75,97261$ & $-76,36079$ & $-76,33295$ & $-0,43244$ & $-0,34627$ & 0,01650 & 0,04288 & 1,17 & 0,36 \\
\hline $\mathrm{C}_{2} \mathrm{H}_{4}$ & $-77,20008$ & $-77,55788$ & $-77,52558$ & $-0,39599$ & $-0,32079$ & 0,01587 & 0,04666 & 1,02 & 0,42 \\
\hline $\mathrm{C}_{2} \mathrm{H}_{6}$ & $-78,30301$ & $-78,73847$ & $-78,71357$ & $-0,47791$ & $-0,39489$ & 0,01439 & 0,04268 & 1,13 & 0,38 \\
\hline $\mathrm{CH}_{4}$ & $-39,44292$ & $-39,94105$ & $-39,91534$ & $-0,54976$ & $-0,45011$ & 0,01402 & 0,04384 & 1,36 & 0,41 \\
\hline $\mathrm{CO}$ & $-111,64944$ & $-112,14330$ & $-112,09108$ & $-0,54160$ & $-0,44651$ & 0,03457 & 0,07396 & 1,29 & 0,54 \\
\hline $\mathrm{F}_{2} \mathrm{O}$ & $-271,72255$ & $-272,19203$ & $-272,15106$ & $-0,50040$ & $-0,43658$ & 0,01392 & 0,06446 & 0,87 & 0,69 \\
\hline $\mathrm{H}_{2} \mathrm{O}$ & $-75,21885$ & $-75,64907$ & $-75,62227$ & $-0,47545$ & $-0,39529$ & 0,00849 & 0,04763 & 1,09 & 0,53 \\
\hline $\mathrm{HF}$ & $-98,99686$ & $-99,54881$ & $-99,51958$ & $-0,60540$ & $-0,51047$ & 0,00959 & 0,05301 & 1,29 & 0,59 \\
\hline $\mathrm{NH}_{3}$ & $-55,51804$ & $-55,88871$ & $-55,86244$ & $-0,41280$ & $-0,33456$ & 0,01031 & 0,04570 & 1,06 & 0,48 \\
\hline $\mathrm{PF}_{3}$ & $-635,33449$ & $-635,73547$ & $-635,68985$ & $-0,44518$ & $-0,35688$ & 0,03072 & 0,06445 & 1,20 & 0,46 \\
\hline $\mathrm{PH}_{3}$ & $-340,04085$ & $-340,40455$ & $-340,37974$ & $-0,40604$ & $-0,32180$ & 0,01083 & 0,04306 & 1,15 & 0,44 \\
\hline
\end{tabular}

Tabela 8.479: Energias utilizadas (em hartree) e concavidades (Conc.) obtidas pelo Teorema de Janak para B972B95 70\% $E_{X}^{\mathrm{HF}}$ com geometrias experimentais na base aug-pcJ-2.

\begin{tabular}{|c|c|c|c|c|c|c|c|c|c|}
\hline Molécula & $\mathrm{E}_{\text {cátion }}$ & Eneutra & Eânion & $\varepsilon_{\text {cátion }}^{\text {LUMO }}$ & $\varepsilon_{\text {neutra }}^{\text {HOMO }}$ & $\varepsilon_{\text {neutra }}^{L U M O}$ & $\varepsilon_{\text {ânion }}^{\text {HOMO }}$ & Conc.cátion & Conc.ânion \\
\hline $\mathrm{BF}_{3}$ & $-321,76616$ & $-322,34859$ & $-322,31378$ & $-0,60165$ & $-0,56576$ & 0,02267 & 0,05057 & 0,49 & 0,38 \\
\hline $\mathrm{BHF}_{2}$ & $-223,14834$ & $-223,66401$ & $-223,63121$ & $-0,55034$ & $-0,48359$ & 0,02182 & 0,04567 & 0,91 & 0,32 \\
\hline $\mathrm{C}_{2} \mathrm{H}_{2}$ & $-76,20250$ & $-76,59436$ & $-76,56665$ & $-0,41678$ & $-0,37029$ & 0,01888 & 0,03906 & 0,63 & 0,27 \\
\hline $\mathrm{C}_{2} \mathrm{H}_{4}$ & $-77,44790$ & $-77,80865$ & $-77,77646$ & $-0,38089$ & $-0,34270$ & 0,01894 & 0,04313 & 0,52 & 0,33 \\
\hline $\mathrm{C}_{2} \mathrm{H}_{6}$ & $-78,55990$ & $-79,00691$ & $-78,98260$ & $-0,47225$ & $-0,42385$ & 0,01759 & 0,03807 & 0,66 & 0,28 \\
\hline $\mathrm{CH}_{4}$ & $-39,57591$ & $-40,08241$ & $-40,05745$ & $-0,53729$ & $-0,47989$ & 0,01716 & 0,03885 & 0,78 & 0,30 \\
\hline $\mathrm{CO}$ & $-111,92192$ & $-112,42482$ & $-112,37333$ & $-0,52936$ & $-0,47968$ & 0,03944 & 0,06778 & 0,68 & 0,39 \\
\hline $\mathrm{F}_{2} \mathrm{O}$ & $-272,29789$ & $-272,78051$ & $-272,74865$ & $-0,47998$ & $-0,48063$ & 0,02619 & 0,02998 & $-0,01$ & 0,05 \\
\hline $\mathrm{H}_{2} \mathrm{O}$ & $-75,40318$ & $-75,83777$ & $-75,81222$ & $-0,45185$ & $-0,43071$ & 0,01270 & 0,04129 & 0,29 & 0,39 \\
\hline $\mathrm{HF}$ & $-99,21188$ & $-99,76893$ & $-99,74129$ & $-0,57655$ & $-0,55252$ & 0,01387 & 0,04560 & 0,33 & 0,43 \\
\hline $\mathrm{NH}_{3}$ & $-55,67626$ & $-56,05131$ & $-56,02601$ & $-0,39447$ & $-0,36484$ & 0,01418 & 0,04006 & 0,40 & 0,35 \\
\hline $\mathrm{PF}_{3}$ & $-636,44999$ & $-636,86144$ & $-636,81643$ & $-0,43914$ & $-0,38589$ & 0,03466 & 0,05915 & 0,72 & 0,33 \\
\hline $\mathrm{PH}_{3}$ & $-340,53782$ & $-340,90708$ & $-340,88303$ & $-0,39582$ & $-0,34496$ & 0,01456 & 0,03807 & 0,69 & 0,32 \\
\hline
\end{tabular}

Tabela 8.480: Energias utilizadas (em hartree) e concavidades (Conc.) obtidas pelo Teorema de Janak para B971 $50 \% E_{X}^{\mathrm{HF}}$ com geometrias experimentais na base aug-pcJ-2.

\begin{tabular}{|c|c|c|c|c|c|c|c|c|c|}
\hline Molécula & $\mathrm{E}_{\text {cátion }}$ & Eneutra & $\mathrm{E}_{\text {ânion }}$ & $\varepsilon_{\text {cátion }}^{\text {LUMO }}$ & $\varepsilon_{\text {neutra }}^{\text {HOMO }}$ & $\varepsilon_{\text {neutra }}^{\text {LUMO }}$ & $\varepsilon_{\text {ânion }}^{\text {HOMO }}$ & Conc.cátion & Conc.ânion \\
\hline $\mathrm{BF}_{3}$ & $-320,55426$ & $-321,10175$ & $-321,06451$ & $-0,60838$ & $-0,48870$ & 0,02199 & 0,06122 & 1,63 & 0,53 \\
\hline $\mathrm{BHF}_{2}$ & $-222,28014$ & $-222,77579$ & $-222,74396$ & $-0,56560$ & $-0,42606$ & 0,02467 & 0,05149 & 1,90 & 0,36 \\
\hline $\mathrm{C}_{2} \mathrm{H}_{2}$ & $-75,81119$ & $-76,19811$ & $-76,17173$ & $-0,45354$ & $-0,32668$ & 0,02176 & 0,04336 & 1,73 & 0,29 \\
\hline $\mathrm{C}_{2} \mathrm{H}_{4}$ & $-77,03014$ & $-77,38729$ & $-77,35526$ & $-0,41751$ & $-0,30243$ & 0,02155 & 0,04804 & 1,57 & 0,36 \\
\hline $\mathrm{C}_{2} \mathrm{H}_{6}$ & $-78,12685$ & $-78,55754$ & $-78,53119$ & $-0,48786$ & $-0,37496$ & 0,01982 & 0,04445 & 1,54 & 0,34 \\
\hline $\mathrm{CH}_{4}$ & $-39,35111$ & $-39,84580$ & $-39,81929$ & $-0,56507$ & $-0,42899$ & 0,01964 & 0,04580 & 1,85 & 0,36 \\
\hline $\mathrm{CO}$ & $-111,44808$ & $-111,94396$ & $-111,89309$ & $-0,60092$ & $-0,42368$ & 0,03191 & 0,07646 & 2,41 & 0,61 \\
\hline $\mathrm{F}_{2} \mathrm{O}$ & $-271,31305$ & $-271,77546$ & $-271,73387$ & $-0,52113$ & $-0,40305$ & $-0,00285$ & 0,08390 & 1,61 & 1,18 \\
\hline $\mathrm{H}_{2} \mathrm{O}$ & $-75,08676$ & $-75,51717$ & $-75,49066$ & $-0,50345$ & $-0,36849$ & 0,01356 & 0,05075 & 1,84 & 0,51 \\
\hline $\mathrm{HF}$ & $-98,83761$ & $-99,38916$ & $-99,36032$ & $-0,63717$ & $-0,47779$ & 0,01517 & 0,05713 & 2,17 & 0,57 \\
\hline $\mathrm{NH}_{3}$ & $-55,40653$ & $-55,77730$ & $-55,75118$ & $-0,44409$ & $-0,31163$ & 0,01546 & 0,04833 & 1,80 & 0,45 \\
\hline $\mathrm{PF}_{3}$ & $-634,46854$ & $-634,86626$ & $-634,82117$ & $-0,46940$ & $-0,33603$ & 0,03413 & 0,06693 & 1,81 & 0,45 \\
\hline $\mathrm{PH}_{3}$ & $-339,61997$ & $-339,98391$ & $-339,95817$ & $-0,43622$ & $-0,30481$ & 0,01562 & 0,04599 & 1,79 & 0,41 \\
\hline
\end{tabular}

Tabela 8.481: Energias utilizadas (em hartree) e concavidades (Conc.) obtidas pelo Teorema de Janak para B98 50\% $E_{X}^{\mathrm{HF}}$ com geometrias experimentais na base aug-pcJ-2.

\begin{tabular}{|c|c|c|c|c|c|c|c|c|c|}
\hline Molécula & $\mathrm{E}_{\text {cátion }}$ & Eneutra & $\mathrm{E}_{\text {ânion }}$ & $\varepsilon_{\text {cátion }}^{\text {LUMO }}$ & $\varepsilon_{\text {neutra }}^{\text {HOMO }}$ & $\varepsilon_{\text {neutra }}^{\text {LUMO }}$ & $\varepsilon_{\text {ânion }}^{\text {HOMO }}$ & Conc.cátion & Conc.ânion \\
\hline $\mathrm{BF}_{3}$ & $-320,44107$ & $-320,98793$ & $-320,95126$ & $-0,60746$ & $-0,48837$ & 0,01989 & 0,06117 & 1,62 & 0,56 \\
\hline $\mathrm{BHF}_{2}$ & $-222,20218$ & $-222,69807$ & $-222,66659$ & $-0,56589$ & $-0,42619$ & 0,02344 & 0,05139 & 1,90 & 0,38 \\
\hline $\mathrm{C}_{2} \mathrm{H}_{2}$ & $-75,78111$ & $-76,16706$ & $-76,14098$ & $-0,45206$ & $-0,32613$ & 0,02020 & 0,04334 & 1,71 & 0,31 \\
\hline $\mathrm{C}_{2} \mathrm{H}_{4}$ & $-76,99993$ & $-77,35616$ & $-77,32433$ & $-0,41618$ & $-0,30182$ & 0,01984 & 0,04810 & 1,56 & 0,38 \\
\hline $\mathrm{C}_{2} \mathrm{H}_{6}$ & $-78,09517$ & $-78,52594$ & $-78,49975$ & $-0,48764$ & $-0,37526$ & 0,01812 & 0,04463 & 1,53 & 0,36 \\
\hline $\mathrm{CH}_{4}$ & $-39,33742$ & $-39,83174$ & $-39,80532$ & $-0,56422$ & $-0,42912$ & 0,01796 & 0,04634 & 1,84 & 0,39 \\
\hline $\mathrm{CO}$ & $-111,40534$ & $-111,90149$ & $-111,85098$ & $-0,59967$ & $-0,42410$ & 0,03073 & 0,07649 & 2,39 & 0,62 \\
\hline $\mathrm{F}_{2} \mathrm{O}$ & $-271,21725$ & $-271,67929$ & $-271,63819$ & $-0,51984$ & $-0,40318$ & $-0,00318$ & 0,08321 & 1,59 & 1,18 \\
\hline $\mathrm{H}_{2} \mathrm{O}$ & $-75,06100$ & $-75,49080$ & $-75,46471$ & $-0,50202$ & $-0,36864$ & 0,01147 & 0,05087 & 1,81 & 0,54 \\
\hline $\mathrm{HF}$ & $-98,80508$ & $-99,35601$ & $-99,32755$ & $-0,63581$ & $-0,47781$ & 0,01310 & 0,05730 & 2,15 & 0,60 \\
\hline $\mathrm{NH}_{3}$ & $-55,38680$ & $-55,75698$ & $-55,73119$ & $-0,44232$ & $-0,31169$ & 0,01346 & 0,04848 & 1,78 & 0,48 \\
\hline $\mathrm{PF}_{3}$ & $-634,27916$ & $-634,67670$ & $-634,63202$ & $-0,46847$ & $-0,33588$ & 0,03248 & 0,06692 & 1,80 & 0,47 \\
\hline $\mathrm{PH}_{3}$ & $-339,53756$ & $-339,90142$ & $-339,87600$ & $-0,43536$ & $-0,30481$ & 0,01370 & 0,04611 & 1,78 & 0,44 \\
\hline
\end{tabular}


Tabela 8.482: Energias utilizadas (em hartree) e concavidades (Conc.) obtidas pelo Teorema de Janak para $\omega \mathrm{B} 97 \mathrm{X}(20 \%|100 \%| \#)$ com geometrias experimentais na base augpcJ-2.

\begin{tabular}{|c|c|c|c|c|c|c|c|c|c|}
\hline Molécula & $\mathrm{E}_{\text {cátion }}$ & Eneutra & $\mathrm{E}_{\text {ânion }}$ & $\varepsilon_{\text {cátion }}^{\text {LUMO }}$ & $\varepsilon_{\text {neutra }}^{\text {HOMO }}$ & $\varepsilon_{\text {neutra }}^{\text {LUMO }}$ & $\varepsilon_{\text {ânion }}^{\text {HOMO }}$ & Conc.cátion & Conc.ânion \\
\hline $\mathrm{BF}_{3}$ & $-325,29051$ & $-325,87695$ & $-325,84158$ & $-0,61128$ & $-0,56298$ & 0,03995 & 0,03410 & 0,66 & $-0,08$ \\
\hline $\mathrm{BHF}_{2}$ & $-225,64432$ & $-226,17786$ & $-226,15010$ & $-0,55779$ & $-0,50889$ & 0,03618 & 0,02621 & 0,67 & $-0,14$ \\
\hline $\mathrm{C}_{2} \mathrm{H}_{2}$ & $-77,29342$ & $-77,71059$ & $-77,68668$ & $-0,42803$ & $-0,40866$ & 0,03225 & 0,02227 & 0,26 & $-0,14$ \\
\hline $\mathrm{C}_{2} \mathrm{H}_{4}$ & $-78,60189$ & $-78,98766$ & $-78,96251$ & $-0,39001$ & $-0,38411$ & 0,03426 & 0,02353 & 0,08 & $-0,15$ \\
\hline $\mathrm{C}_{2} \mathrm{H}_{6}$ & $-79,78277$ & $-80,24978$ & $-80,22555$ & $-0,47658$ & $-0,45753$ & 0,03303 & 0,02255 & 0,26 & $-0,14$ \\
\hline $\mathrm{CH}_{4}$ & $-40,20646$ & $-40,73489$ & $-40,71186$ & $-0,54680$ & $-0,51050$ & 0,03223 & 0,02109 & 0,49 & $-0,15$ \\
\hline $\mathrm{CO}$ & $-113,27782$ & $-113,80529$ & $-113,76148$ & $-0,56739$ & $-0,50675$ & 0,04836 & 0,04330 & 0,83 & $-0,07$ \\
\hline $\mathrm{F}_{2} \mathrm{O}$ & $-275,23005$ & $-275,73646$ & $-275,73921$ & $-0,52958$ & $-0,48160$ & $-0,01324$ & 0,00549 & 0,65 & 0,25 \\
\hline $\mathrm{H}_{2} \mathrm{O}$ & $-76,28650$ & $-76,75868$ & $-76,73685$ & $-0,49875$ & $-0,44357$ & 0,03200 & 0,01969 & 0,75 & $-0,17$ \\
\hline $\mathrm{HF}$ & $-100,24238$ & $-100,84419$ & $-100,82182$ & $-0,65224$ & $-0,54875$ & 0,03337 & 0,02045 & 1,41 & $-0,18$ \\
\hline $\mathrm{NH}_{3}$ & $-56,42413$ & $-56,82958$ & $-56,80734$ & $-0,42418$ & $-0,38974$ & 0,03236 & 0,02016 & 0,47 & $-0,17$ \\
\hline $\mathrm{PF}_{3}$ & $-641,81762$ & $-642,25338$ & $-642,21089$ & $-0,45607$ & $-0,42370$ & 0,05204 & 0,04059 & 0,44 & $-0,16$ \\
\hline $\mathrm{PH}_{3}$ & $-342,85332$ & $-343,24533$ & $-343,22286$ & $-0,41224$ & $-0,38483$ & 0,03202 & 0,02028 & 0,37 & $-0,16$ \\
\hline
\end{tabular}

Tabela 8.483: Energias utilizadas (em hartree) e concavidades (Conc.) obtidas pelo Teorema de Janak para $\omega \mathrm{B} 97 \mathrm{XD}(\#|\#| 0,35)$ com geometrias experimentais na base aug-pcJ-2.

\begin{tabular}{|c|c|c|c|c|c|c|c|c|c|}
\hline Molécula & $\mathrm{E}_{\text {cátion }}$ & E $_{\text {neutra }}$ & $\mathrm{E}_{\text {ânion }}$ & $\varepsilon_{\text {cátion }}^{\text {LUMO }}$ & $\varepsilon_{\text {neutra }}^{\text {HOMO }}$ & $\varepsilon_{\text {neutra }}^{\text {LUMO }}$ & $\varepsilon_{\text {ânion }}^{\text {HOMO }}$ & Conc.cátion & Conc.ânion \\
\hline $\mathrm{BF}_{3}$ & $-324,04660$ & $-324,63770$ & $-324,60463$ & $-0,60734$ & $-0,57641$ & 0,03732 & 0,03198 & 0,42 & $-0,07$ \\
\hline $\mathrm{BHF}_{2}$ & $-224,76873$ & $-225,30337$ & $-225,27796$ & $-0,55027$ & $-0,51893$ & 0,03262 & 0,02422 & 0,43 & $-0,11$ \\
\hline $\mathrm{C}_{2} \mathrm{H}_{2}$ & $-76,91571$ & $-77,33239$ & $-77,31041$ & $-0,41904$ & $-0,41682$ & 0,02902 & 0,02075 & 0,03 & $-0,11$ \\
\hline $\mathrm{C}_{2} \mathrm{H}_{4}$ & $-78,21638$ & $-78,60166$ & $-78,57857$ & $-0,38156$ & $-0,39154$ & 0,03035 & 0,02204 & $-0,14$ & $-0,11$ \\
\hline $\mathrm{C}_{2} \mathrm{H}_{6}$ & $-79,38885$ & $-79,85654$ & $-79,83441$ & $-0,46955$ & $-0,46596$ & 0,02913 & 0,02106 & 0,05 & $-0,11$ \\
\hline $\mathrm{CH}_{4}$ & $-40,00733$ & $-40,53513$ & $-40,51377$ & $-0,53628$ & $-0,52045$ & 0,02846 & 0,02026 & 0,22 & $-0,11$ \\
\hline $\mathrm{CO}$ & $-112,79478$ & $-113,32337$ & $-113,28039$ & $-0,55124$ & $-0,51814$ & 0,04881 & 0,04198 & 0,45 & $-0,09$ \\
\hline $\mathrm{F}_{2} \mathrm{O}$ & $-274,19670$ & $-274,70339$ & $-274,70288$ & $-0,51724$ & $-0,49452$ & 0,00033 & $-0,00133$ & 0,31 & $-0,02$ \\
\hline $\mathrm{H}_{2} \mathrm{O}$ & $-75,98132$ & $-76,45300$ & $-76,43392$ & $-0,48700$ & $-0,45681$ & 0,02678 & 0,01744 & 0,41 & $-0,13$ \\
\hline HF & $-99,87351$ & $-100,47441$ & $-100,45490$ & $-0,63818$ & $-0,56387$ & 0,02819 & 0,01788 & 1,01 & $-0,14$ \\
\hline $\mathrm{NH}_{3}$ & $-56,17507$ & $-56,57998$ & $-56,56015$ & $-0,41346$ & $-0,40065$ & 0,02751 & 0,01827 & 0,17 & $-0,13$ \\
\hline $\mathrm{PF}_{3}$ & $-639,86360$ & $-640,29904$ & $-640,25867$ & $-0,44788$ & $-0,43076$ & 0,04810 & 0,03876 & 0,23 & $-0,13$ \\
\hline $\mathrm{PH}_{3}$ & $-341,99416$ & $-342,38605$ & $-342,36572$ & $-0,40254$ & $-0,39171$ & 0,02749 & 0,01891 & 0,15 & $-0,12$ \\
\hline
\end{tabular}

Tabela 8.484: Energias utilizadas (em hartree) e concavidades (Conc.) obtidas pelo Teorema de Janak para LC-B1B95 $(40 \%|100 \%| 0,40)$ com geometrias experimentais na base aug-pcJ-2.

\begin{tabular}{|c|c|c|c|c|c|c|c|c|c|}
\hline Molécula & $\mathrm{E}_{\text {cátion }}$ & Eneutra $_{\text {ne }}$ & Eânion & $\varepsilon_{\text {cátion }}^{\text {LUMO }}$ & $\varepsilon_{\text {neutra }}^{\text {HOMO }}$ & $\varepsilon_{\text {neutra }}^{\text {LUMO }}$ & $\varepsilon_{\text {ânion }}^{\text {HOMO }}$ & Conc.cátion & Conc.ânion \\
\hline $\mathrm{BF}_{3}$ & $-323,72100$ & $-324,32838$ & $-324,29536$ & $-0,60592$ & $-0,61081$ & 0,03329 & 0,03294 & $-0,07$ & $-0,00$ \\
\hline $\mathrm{BHF}_{2}$ & $-224,52926$ & $-225,06664$ & $-225,03576$ & $-0,53999$ & $-0,53627$ & 0,02852 & 0,03079 & 0,05 & 0,03 \\
\hline $\mathrm{C}_{2} \mathrm{H}_{2}$ & $-76,77441$ & $-77,19040$ & $-77,16771$ & $-0,40959$ & $-0,42626$ & 0,02557 & 0,02400 & $-0,23$ & $-0,02$ \\
\hline $\mathrm{C}_{2} \mathrm{H}_{4}$ & $-78,05686$ & $-78,44136$ & $-78,41801$ & $-0,37262$ & $-0,39914$ & 0,02641 & 0,02465 & $-0,36$ & $-0,02$ \\
\hline $\mathrm{C}_{2} \mathrm{H}_{6}$ & $-79,21178$ & $-79,67920$ & $-79,65724$ & $-0,46066$ & $-0,47576$ & 0,02520 & 0,02336 & $-0,21$ & $-0,03$ \\
\hline $\mathrm{CH}_{4}$ & $-39,90824$ & $-40,43453$ & $-40,41233$ & $-0,52425$ & $-0,53229$ & 0,02462 & 0,02308 & $-0,11$ & $-0,02$ \\
\hline $\mathrm{CO}$ & $-112,65121$ & $-113,17917$ & $-113,13214$ & $-0,52341$ & $-0,53436$ & 0,04829 & 0,04647 & $-0,15$ & $-0,02$ \\
\hline $\mathrm{F}_{2} \mathrm{O}$ & $-273,92268$ & $-274,43580$ & $-274,43462$ & $-0,49521$ & $-0,52816$ & 0,01980 & $-0,02196$ & $-0,45$ & $-0,57$ \\
\hline $\mathrm{H}_{2} \mathrm{O}$ & $-75,88580$ & $-76,35226$ & $-76,33188$ & $-0,46276$ & $-0,48000$ & 0,02209 & 0,02017 & $-0,23$ & $-0,03$ \\
\hline $\mathrm{HF}$ & $-99,78005$ & $-100,37524$ & $-100,35379$ & $-0,60479$ & $-0,59647$ & 0,02309 & 0,02127 & 0,11 & $-0,02$ \\
\hline $\mathrm{NH}_{3}$ & $-56,07849$ & $-56,47966$ & $-56,45832$ & $-0,39379$ & $-0,41662$ & 0,02314 & 0,02145 & $-0,31$ & $-0,02$ \\
\hline $\mathrm{PF}_{3}$ & $-639,52282$ & $-639,96063$ & $-639,91871$ & $-0,43611$ & $-0,44335$ & 0,04373 & 0,04139 & $-0,10$ & $-0,03$ \\
\hline $\mathrm{PH}_{3}$ & $-341,87940$ & $-342,26814$ & $-342,24719$ & $-0,38418$ & $-0,39740$ & 0,02356 & 0,02172 & $-0,18$ & $-0,03$ \\
\hline
\end{tabular}

Tabela 8.485: Energias utilizadas (em hartree) e concavidades (Conc.) obtidas pelo Teorema de Janak para LC-BHandH $(40 \%|100 \%| 0,30)$ com geometrias experimentais na base aug-pcJ-2 .

\begin{tabular}{|c|c|c|c|c|c|c|c|c|c|}
\hline Molécula & $\mathrm{E}_{\text {cátion }}$ & Eneutra $_{\text {ne }}$ & $\mathrm{E}_{\text {ânion }}$ & $\varepsilon_{\text {cátion }}^{\text {LUMO }}$ & $\varepsilon_{\text {neutra }}^{\text {HOMO }}$ & $\varepsilon_{\text {neutra }}^{\text {LUMO }}$ & $\varepsilon_{\text {ânion }}^{\text {HOMO }}$ & Conc.cátion & Conc.ânion \\
\hline $\mathrm{BF}_{3}$ & $-322,30423$ & $-322,90085$ & $-322,87283$ & $-0,60467$ & $-0,59045$ & 0,02486 & 0,02924 & 0,19 & 0,06 \\
\hline $\mathrm{BHF}_{2}$ & $-223,52185$ & $-224,05264$ & $-224,02610$ & $-0,54290$ & $-0,52022$ & 0,02515 & 0,02691 & 0,31 & 0,02 \\
\hline $\mathrm{C}_{2} \mathrm{H}_{2}$ & $-76,31945$ & $-76,73293$ & $-76,70904$ & $-0,41845$ & $-0,41365$ & 0,02261 & 0,02422 & 0,07 & 0,02 \\
\hline $\mathrm{C}_{2} \mathrm{H}_{4}$ & $-77,58651$ & $-77,96852$ & $-77,94418$ & $-0,38145$ & $-0,38713$ & 0,02288 & 0,02472 & $-0,08$ & 0,03 \\
\hline $\mathrm{C}_{2} \mathrm{H}_{6}$ & $-78,72911$ & $-79,18885$ & $-79,16601$ & $-0,45984$ & $-0,46082$ & 0,02136 & 0,02326 & $-0,01$ & 0,03 \\
\hline $\mathrm{CH}_{4}$ & $-39,66134$ & $-40,18195$ & $-40,15951$ & $-0,52811$ & $-0,51678$ & 0,02089 & 0,02289 & 0,15 & 0,03 \\
\hline $\mathrm{CO}$ & $-112,08313$ & $-112,60737$ & $-112,56304$ & $-0,53729$ & $-0,51753$ & 0,04238 & 0,04478 & 0,27 & 0,03 \\
\hline $\mathrm{F}_{2} \mathrm{O}$ & $-272,74442$ & $-273,25179$ & $-273,25261$ & $-0,50599$ & $-0,50701$ & 0,00466 & $-0,00965$ & $-0,01$ & $-0,19$ \\
\hline $\mathrm{H}_{2} \mathrm{O}$ & $-75,52423$ & $-75,98919$ & $-75,97056$ & $-0,47775$ & $-0,46237$ & 0,01610 & 0,01941 & 0,21 & 0,05 \\
\hline $\mathrm{HF}$ & $-99,35273$ & $-99,94669$ & $-99,92719$ & $-0,62277$ & $-0,57640$ & 0,01665 & 0,02059 & 0,63 & 0,05 \\
\hline $\mathrm{NH}_{3}$ & $-55,77656$ & $-56,17524$ & $-56,15517$ & $-0,40595$ & $-0,40071$ & 0,01802 & 0,02062 & 0,07 & 0,04 \\
\hline $\mathrm{PF}_{3}$ & $-637,37730$ & $-637,81080$ & $-637,76432$ & $-0,44139$ & $-0,42981$ & 0,03846 & 0,04622 & 0,16 & 0,11 \\
\hline $\mathrm{PH}_{3}$ & $-340,97492$ & $-341,35940$ & $-341,33880$ & $-0,38939$ & $-0,38472$ & 0,01888 & 0,02096 & 0,06 & 0,03 \\
\hline
\end{tabular}


Tabela 8.486: Energias utilizadas (em hartree) e concavidades (Conc.) obtidas pelo Teorema de Janak para B1B95 com geometrias otimizadas na base aug-pcJ-2.

\begin{tabular}{|c|c|c|c|c|c|c|c|c|c|}
\hline Molécula & $\mathrm{E}_{\text {cátion }}$ & Eneutra & $\mathrm{E}_{\hat{a} \text { nion }}$ & $\varepsilon_{\text {cátion }}^{\text {LUMO }}$ & $\varepsilon_{\text {neutra }}^{\text {HOMO }}$ & $\varepsilon_{\text {neutra }}^{\text {LUMO }}$ & $\varepsilon_{\text {ânion }}^{\text {HOMO }}$ & Conc.cátion & Conc.ânion \\
\hline $\mathrm{BF}_{3}$ & $-324,08177$ & $-324,64301$ & $-324,61713$ & $-0,66949$ & $-0,45501$ & $-0,00200$ & 0,05292 & 2,92 & 0,75 \\
\hline $\mathrm{BHF}_{2}$ & $-224,78311$ & $-225,29724$ & $-225,27534$ & $-0,62536$ & $-0,40220$ & $-0,01286$ & 0,04928 & 3,04 & 0,85 \\
\hline $\mathrm{C}_{2} \mathrm{H}_{2}$ & $-76,90613$ & $-77,32276$ & $-77,30283$ & $-0,52349$ & $-0,31116$ & 0,00653 & 0,04723 & 2,89 & 0,55 \\
\hline $\mathrm{C}_{2} \mathrm{H}_{4}$ & $-78,18341$ & $-78,57190$ & $-78,54709$ & $-0,48521$ & $-0,29182$ & 0,00256 & 0,04808 & 2,63 & 0,62 \\
\hline $\mathrm{C}_{2} \mathrm{H}_{6}$ & $-79,35703$ & $-79,80378$ & $-79,78510$ & $-0,54216$ & $-0,35281$ & 0,00190 & 0,04661 & 2,58 & 0,61 \\
\hline $\mathrm{CH}_{4}$ & $-39,98313$ & $-40,50108$ & $-40,48135$ & $-0,63382$ & $-0,40459$ & 0,00168 & 0,04882 & 3,12 & 0,64 \\
\hline $\mathrm{CO}$ & $-112,81157$ & $-113,32747$ & $-113,28935$ & $-0,62784$ & $-0,39570$ & $-0,02113$ & 0,07921 & 3,16 & 1,37 \\
\hline $\mathrm{F}_{2} \mathrm{O}$ & $-274,24160$ & $-274,72384$ & $-274,69799$ & $-0,60360$ & $-0,36295$ & $-0,09105$ & 0,10011 & 3,27 & 2,60 \\
\hline $\mathrm{H}_{2} \mathrm{O}$ & $-75,97333$ & $-76,43817$ & $-76,41944$ & $-0,59796$ & $-0,33657$ & $-0,00993$ & 0,05512 & 3,56 & 0,89 \\
\hline $\mathrm{HF}$ & $-99,87679$ & $-100,46997$ & $-100,44927$ & $-0,75302$ & $-0,43982$ & $-0,01013$ & 0,06236 & 4,26 & 0,99 \\
\hline $\mathrm{NH}_{3}$ & $-56,15687$ & $-56,55575$ & $-56,53660$ & $-0,51373$ & $-0,28485$ & $-0,00550$ & 0,05167 & 3,11 & 0,78 \\
\hline $\mathrm{PF}_{3}$ & $-639,91850$ & $-640,35875$ & $-640,32780$ & $-0,53889$ & $-0,33996$ & 0,00274 & 0,06697 & 2,71 & 0,87 \\
\hline $\mathrm{PH}_{3}$ & $-342,02553$ & $-342,41091$ & $-342,39274$ & $-0,48058$ & $-0,28858$ & $-0,00409$ & 0,04756 & 2,61 & 0,70 \\
\hline
\end{tabular}

Tabela 8.487: Energias utilizadas (em hartree) e concavidades (Conc.) obtidas pelo Teorema de Janak para B971 com geometrias otimizadas na base aug-pcJ-2.

\begin{tabular}{|c|c|c|c|c|c|c|c|c|c|}
\hline Molécula & $\mathrm{E}_{\text {cátion }}$ & Eneutra & Eânion & $\varepsilon_{\text {cátion }}^{\text {LUMO }}$ & $\varepsilon_{\text {neutra }}^{\text {HOMO }}$ & $\varepsilon_{\text {neutra }}^{\text {LUMO }}$ & $\varepsilon_{\text {ânion }}^{\text {HOMO }}$ & Conc.cátion & Conc.ânion \\
\hline $\mathrm{BF}_{3}$ & $-324,07515$ & $-324,63040$ & $-324,60349$ & $-0,67586$ & $-0,43642$ & $-0,00692$ & 0,06486 & 3,26 & 0,98 \\
\hline $\mathrm{BHF}_{2}$ & $-224,78188$ & $-225,29495$ & $-225,27450$ & $-0,63565$ & $-0,38996$ & $-0,01950$ & 0,05197 & 3,34 & 0,97 \\
\hline $\mathrm{C}_{2} \mathrm{H}_{2}$ & $-76,92177$ & $-77,33724$ & $-77,32093$ & $-0,53474$ & $-0,29962$ & 0,00783 & 0,04197 & 3,20 & 0,46 \\
\hline $\mathrm{C}_{2} \mathrm{H}_{4}$ & $-78,20740$ & $-78,59425$ & $-78,57158$ & $-0,49633$ & $-0,28031$ & $-0,00687$ & 0,04648 & 2,94 & 0,73 \\
\hline $\mathrm{C}_{2} \mathrm{H}_{6}$ & $-79,38491$ & $-79,83246$ & $-79,81404$ & $-0,55274$ & $-0,34370$ & 0,00084 & 0,04612 & 2,84 & 0,62 \\
\hline $\mathrm{CH}_{4}$ & $-39,99607$ & $-40,51802$ & $-40,49919$ & $-0,64900$ & $-0,39355$ & 0,00183 & 0,04804 & 3,48 & 0,63 \\
\hline $\mathrm{CO}$ & $-112,81390$ & $-113,33262$ & $-113,29740$ & $-0,67086$ & $-0,38438$ & $-0,03321$ & 0,07933 & 3,90 & 1,53 \\
\hline $\mathrm{F}_{2} \mathrm{O}$ & $-274,23598$ & $-274,71751$ & $-274,70102$ & $-0,61724$ & $-0,34734$ & $-0,10598$ & 0,10831 & 3,67 & 2,92 \\
\hline $\mathrm{H}_{2} \mathrm{O}$ & $-75,97815$ & $-76,44408$ & $-76,42621$ & $-0,61472$ & $-0,32152$ & $-0,01276$ & 0,05594 & 3,99 & 0,93 \\
\hline $\mathrm{HF}$ & $-99,87164$ & $-100,46608$ & $-100,44681$ & $-0,77219$ & $-0,42128$ & $-0,01227$ & 0,06367 & 4,77 & 1,03 \\
\hline $\mathrm{NH}_{3}$ & $-56,16815$ & $-56,56843$ & $-56,55036$ & $-0,53387$ & $-0,27308$ & $-0,00772$ & 0,05247 & 3,55 & 0,82 \\
\hline $\mathrm{PF}_{3}$ & $-639,82446$ & $-640,26413$ & $-640,23502$ & $-0,55037$ & $-0,33019$ & $-0,00400$ & 0,06743 & 3,00 & 0,97 \\
\hline $\mathrm{PH}_{3}$ & $-341,95976$ & $-342,34550$ & $-342,32741$ & $-0,49965$ & $-0,27946$ & $-0,00637$ & 0,04859 & 3,00 & 0,75 \\
\hline
\end{tabular}

Tabela 8.488: Energias utilizadas (em hartree) e concavidades (Conc.) obtidas pelo Teorema de Janak para B972 com geometrias otimizadas na base aug-pcJ-2.

\begin{tabular}{|c|c|c|c|c|c|c|c|c|c|}
\hline Molécula & $\mathrm{E}_{\text {cátion }}$ & Eneutra & Eânion & $\varepsilon_{\text {cátion }}^{\text {LUMO }}$ & $\varepsilon_{\text {neutra }}^{\text {HOMO }}$ & $\varepsilon_{\text {neutra }}^{\text {LUMO }}$ & $\varepsilon_{\text {ânion }}^{\text {HOMO }}$ & Conc.cátion & Conc.ânion \\
\hline $\mathrm{BF}_{3}$ & $-324,06195$ & $-324,61890$ & $-324,58877$ & $-0,67763$ & $-0,43792$ & $-0,00587$ & 0,06694 & 3,26 & 0,99 \\
\hline $\mathrm{BHF}_{2}$ & $-224,77372$ & $-225,28750$ & $-225,26612$ & $-0,63692$ & $-0,39023$ & $-0,01697$ & 0,04895 & 3,36 & 0,90 \\
\hline $\mathrm{C}_{2} \mathrm{H}_{2}$ & $-76,91753$ & $-77,33295$ & $-77,31716$ & $-0,53375$ & $-0,30089$ & 0,00670 & 0,04191 & 3,17 & 0,48 \\
\hline $\mathrm{C}_{2} \mathrm{H}_{4}$ & $-78,20613$ & $-78,59286$ & $-78,57085$ & $-0,49572$ & $-0,28123$ & $-0,00557$ & 0,04617 & 2,92 & 0,70 \\
\hline $\mathrm{C}_{2} \mathrm{H}_{6}$ & $-79,38627$ & $-79,83448$ & $-79,81517$ & $-0,55401$ & $-0,34374$ & 0,00023 & 0,04657 & 2,86 & 0,63 \\
\hline $\mathrm{CH}_{4}$ & $-40,00235$ & $-40,52115$ & $-40,50175$ & $-0,64538$ & $-0,39449$ & 0,00085 & 0,04844 & 3,41 & 0,65 \\
\hline $\mathrm{CO}$ & $-112,80444$ & $-113,32184$ & $-113,28606$ & $-0,67191$ & $-0,38429$ & $-0,03198$ & 0,07862 & 3,91 & 1,50 \\
\hline $\mathrm{F}_{2} \mathrm{O}$ & $-274,22367$ & $-274,70408$ & $-274,68075$ & $-0,61608$ & $-0,34598$ & $-0,10607$ & 0,11169 & 3,67 & 2,96 \\
\hline $\mathrm{H}_{2} \mathrm{O}$ & $-75,97612$ & $-76,44252$ & $-76,42285$ & $-0,61387$ & $-0,32241$ & $-0,01267$ & 0,05653 & 3,97 & 0,94 \\
\hline $\mathrm{HF}$ & $-99,87116$ & $-100,46653$ & $-100,44532$ & $-0,77143$ & $-0,42265$ & $-0,01245$ & 0,06514 & 4,75 & 1,06 \\
\hline $\mathrm{NH}_{3}$ & $-56,16778$ & $-56,56838$ & $-56,54907$ & $-0,53359$ & $-0,27381$ & $-0,00785$ & 0,05217 & 3,53 & 0,82 \\
\hline $\mathrm{PF}_{3}$ & $-639,86896$ & $-640,30690$ & $-640,27626$ & $-0,54875$ & $-0,32886$ & $-0,00269$ & 0,06777 & 2,99 & 0,96 \\
\hline $\mathrm{PH}_{3}$ & $-342,01841$ & $-342,40296$ & $-342,38376$ & $-0,49912$ & $-0,27928$ & $-0,00681$ & 0,04870 & 2,99 & 0,76 \\
\hline
\end{tabular}

Tabela 8.489: Energias utilizadas (em hartree) e concavidades (Conc.) obtidas pelo Teorema de Janak para B98 com geometrias otimizadas na base aug-pcJ-2.

\begin{tabular}{|c|c|c|c|c|c|c|c|c|c|}
\hline Molécula & $\mathrm{E}_{\text {cátion }}$ & $E_{\text {neutra }}$ & $\mathrm{E}_{\text {ânion }}$ & $\varepsilon_{\text {cátion }}^{\text {LUMO }}$ & $\varepsilon_{\text {neutra }}^{\text {HOMO }}$ & $\varepsilon_{\text {neutra }}^{\text {LUMO }}$ & $\varepsilon_{\text {annion }}^{\text {HOMO }}$ & Conc. cátion & Conc.ânion \\
\hline $\mathrm{BF}_{3}$ & $-324,05226$ & $-324,61128$ & $-324,58477$ & $-0,67753$ & $-0,44226$ & $-0,00781$ & 0,06418 & 3,20 & 0,98 \\
\hline $\mathrm{BHF}_{2}$ & $-224,76709$ & $-225,28302$ & $-225,26294$ & $-0,63681$ & $-0,39445$ & $-0,01983$ & 0,05136 & 3,30 & 0,97 \\
\hline $\mathrm{C}_{2} \mathrm{H}_{2}$ & $-76,91363$ & $-77,33006$ & $-77,31402$ & $-0,53300$ & $-0,30291$ & 0,00651 & 0,04148 & 3,13 & 0,48 \\
\hline $\mathrm{C}_{2} \mathrm{H}_{4}$ & $-78,20241$ & $-78,59005$ & $-78,56758$ & $-0,49454$ & $-0,28333$ & $-0,00694$ & 0,04608 & 2,87 & 0,72 \\
\hline $\mathrm{C}_{2} \mathrm{H}_{6}$ & $-79,38158$ & $-79,83116$ & $-79,81289$ & $-0,55290$ & $-0,34754$ & $-0,00039$ & 0,04573 & 2,79 & 0,63 \\
\hline $\mathrm{CH}_{4}$ & $-40,00033$ & $-40,51946$ & $-40,50072$ & $-0,64329$ & $-0,39748$ & 0,00054 & 0,04769 & 3,34 & 0,64 \\
\hline $\mathrm{CO}$ & $-112,80100$ & $-113,32153$ & $-113,28694$ & $-0,66869$ & $-0,38895$ & $-0,03343$ & 0,07857 & 3,81 & 1,52 \\
\hline $\mathrm{F}_{2} \mathrm{O}$ & $-274,21307$ & $-274,69749$ & $-274,68149$ & $-0,61728$ & $-0,35280$ & $-0,10646$ & 0,10661 & 3,60 & 2,90 \\
\hline $\mathrm{H}_{2} \mathrm{O}$ & $-75,97425$ & $-76,44146$ & $-76,42404$ & $-0,61214$ & $-0,32634$ & $-0,01394$ & 0,05537 & 3,89 & 0,94 \\
\hline HF & $-99,86600$ & $-100,46227$ & $-100,44348$ & $-0,76987$ & $-0,42699$ & $-0,01347$ & 0,06300 & 4,67 & 1,04 \\
\hline $\mathrm{NH}_{3}$ & $-56,16647$ & $-56,56744$ & $-56,54968$ & $-0,53030$ & $-0,27692$ & $-0,00895$ & 0,05203 & 3,45 & 0,83 \\
\hline $\mathrm{PF}_{3}$ & $-639,80651$ & $-640,24776$ & $-640,21904$ & $-0,54978$ & $-0,33338$ & $-0,00448$ & 0,06674 & 2,94 & 0,97 \\
\hline $\mathrm{PH}_{3}$ & $-341,96434$ & $-342,35091$ & $-342,33308$ & $-0,49750$ & $-0,28222$ & $-0,00760$ & 0,04820 & 2,93 & 0,76 \\
\hline
\end{tabular}


Tabela 8.490: Energias utilizadas (em hartree) e concavidades (Conc.) obtidas pelo Teorema de Janak para BHandH com geometrias otimizadas na base aug-pcJ-2.

\begin{tabular}{|c|c|c|c|c|c|c|c|c|c|}
\hline Molécula & $\mathrm{E}_{\text {cátion }}$ & $E_{\text {neutra }}$ & $E_{\text {ânion }}$ & $\varepsilon_{\text {cátion }}^{\text {LUMO }}$ & $\varepsilon_{\text {neutra }}^{\text {HOMO }}$ & $\varepsilon_{\text {neutra }}^{\text {LUMO }}$ & $\varepsilon_{\text {ânion }}^{\text {HOMO }}$ & Conc.cátion & Conc.ânion \\
\hline $\mathrm{BF}_{3}$ & $-322,40581$ & $-322,99112$ & $-322,96180$ & $-0,64603$ & $-0,52664$ & 0,00694 & 0,05581 & 1,62 & 0,66 \\
\hline $\mathrm{BHF}_{2}$ & $-223,58535$ & $-224,10606$ & $-224,07880$ & $-0,58947$ & $-0,45294$ & 0,00981 & 0,04618 & 1,86 & 0,49 \\
\hline $\mathrm{C}_{2} \mathrm{H}_{2}$ & $-76,32932$ & $-76,73947$ & $-76,71357$ & $-0,47382$ & $-0,35126$ & 0,01446 & 0,04290 & 1,67 & 0,39 \\
\hline $\mathrm{C}_{2} \mathrm{H}_{4}$ & $-77,58263$ & $-77,96363$ & $-77,93228$ & $-0,43828$ & $-0,32757$ & 0,01297 & 0,04768 & 1,51 & 0,47 \\
\hline $\mathrm{C}_{2} \mathrm{H}_{6}$ & $-78,72272$ & $-79,17005$ & $-79,14673$ & $-0,50246$ & $-0,39336$ & 0,01053 & 0,04250 & 1,48 & 0,43 \\
\hline $\mathrm{CH}_{4}$ & $-39,64848$ & $-40,16298$ & $-40,13927$ & $-0,58141$ & $-0,45087$ & 0,01083 & 0,04398 & 1,78 & 0,45 \\
\hline $\mathrm{CO}$ & $-112,12114$ & $-112,63470$ & $-112,58862$ & $-0,58408$ & $-0,44748$ & 0,01270 & 0,07377 & 1,86 & 0,83 \\
\hline $\mathrm{F}_{2} \mathrm{O}$ & $-272,84885$ & $-273,33313$ & $-273,27881$ & $-0,54635$ & $-0,42303$ & $-0,04086$ & 0,09139 & 1,68 & 1,80 \\
\hline $\mathrm{H}_{2} \mathrm{O}$ & $-75,53768$ & $-75,99354$ & $-75,97200$ & $-0,52624$ & $-0,39607$ & 0,00153 & 0,04769 & 1,77 & 0,63 \\
\hline $\mathrm{HF}$ & $-99,38124$ & $-99,96511$ & $-99,94159$ & $-0,66789$ & $-0,51188$ & 0,00224 & 0,05342 & 2,12 & 0,70 \\
\hline $\mathrm{NH}_{3}$ & $-55,78065$ & $-56,16783$ & $-56,14560$ & $-0,45247$ & $-0,33089$ & 0,00478 & 0,04566 & 1,65 & 0,56 \\
\hline $\mathrm{PF}_{3}$ & $-637,55443$ & $-637,99180$ & $-637,95446$ & $-0,50065$ & $-0,37693$ & 0,01955 & 0,06220 & 1,68 & 0,58 \\
\hline $\mathrm{PH}_{3}$ & $-341,05682$ & $-341,43334$ & $-341,41171$ & $-0,43720$ & $-0,31973$ & 0,00537 & 0,04283 & 1,60 & 0,51 \\
\hline
\end{tabular}

Tabela 8.491: Energias utilizadas (em hartree) e concavidades (Conc.) obtidas pelo Teorema de Janak para $\omega$ B97X com geometrias otimizadas na base aug-pcJ-2.

\begin{tabular}{|c|c|c|c|c|c|c|c|c|c|}
\hline Molécula & $\mathrm{E}_{\text {cátion }}$ & E $_{\text {neutra }}$ & $\mathrm{E}_{\hat{a} \text { anion }}$ & $\varepsilon_{\text {cátion }}^{\text {LUMO }}$ & $\varepsilon_{\text {neutra }}^{\text {HOMO }}$ & $\varepsilon_{\text {neutra }}^{\mathrm{LUMO}}$ & $\varepsilon_{\text {ânion }}^{\text {HOMO }}$ & Conc.cátion & Conc.ânion \\
\hline $\mathrm{BF}_{3}$ & $-324,07571$ & $-324,64660$ & $-324,61106$ & $-0,59964$ & $-0,54365$ & 0,04025 & 0,03438 & 0,76 & $-0,08$ \\
\hline $\mathrm{BHF}_{2}$ & $-224,78287$ & $-225,30579$ & $-225,27789$ & $-0,55063$ & $-0,49523$ & 0,03630 & 0,02644 & 0,75 & $-0,13$ \\
\hline $\mathrm{C}_{2} \mathrm{H}_{2}$ & $-76,92259$ & $-77,33744$ & $-77,31340$ & $-0,42971$ & $-0,40240$ & 0,03237 & 0,02246 & 0,37 & $-0,13$ \\
\hline $\mathrm{C}_{2} \mathrm{H}_{4}$ & $-78,21003$ & $-78,59600$ & $-78,57070$ & $-0,39395$ & $-0,38057$ & 0,03441 & 0,02376 & 0,18 & $-0,14$ \\
\hline $\mathrm{C}_{2} \mathrm{H}_{6}$ & $-79,38200$ & $-79,83866$ & $-79,81429$ & $-0,46923$ & $-0,44452$ & 0,03316 & 0,02273 & 0,34 & $-0,14$ \\
\hline $\mathrm{CH}_{4}$ & $-39,99627$ & $-40,52114$ & $-40,49798$ & $-0,54988$ & $-0,49931$ & 0,03235 & 0,02128 & 0,69 & $-0,15$ \\
\hline $\mathrm{CO}$ & $-112,81616$ & $-113,33551$ & $-113,28995$ & $-0,56402$ & $-0,49286$ & 0,05015 & 0,04496 & 0,97 & $-0,07$ \\
\hline $\mathrm{F}_{2} \mathrm{O}$ & $-274,24397$ & $-274,72771$ & $-274,69706$ & $-0,51615$ & $-0,45183$ & $-0,00695$ & 0,04021 & 0,88 & 0,64 \\
\hline $\mathrm{H}_{2} \mathrm{O}$ & $-75,98106$ & $-76,44760$ & $-76,42549$ & $-0,50142$ & $-0,42997$ & 0,03207 & 0,02015 & 0,97 & $-0,16$ \\
\hline $\mathrm{HF}$ & $-99,87793$ & $-100,47187$ & $-100,44913$ & $-0,65494$ & $-0,53096$ & 0,03364 & 0,02109 & 1,69 & $-0,17$ \\
\hline $\mathrm{NH}_{3}$ & $-56,17245$ & $-56,57121$ & $-56,54874$ & $-0,42357$ & $-0,37680$ & 0,03240 & 0,02052 & 0,64 & $-0,16$ \\
\hline $\mathrm{PF}_{3}$ & $-639,86678$ & $-640,31020$ & $-640,27046$ & $-0,46399$ & $-0,42870$ & 0,05271 & 0,03818 & 0,48 & $-0,20$ \\
\hline $\mathrm{PH}_{3}$ & $-341,98851$ & $-342,37355$ & $-342,35088$ & $-0,40880$ & $-0,37445$ & 0,03205 & 0,02057 & 0,47 & $-0,16$ \\
\hline
\end{tabular}

Tabela 8.492: Energias utilizadas (em hartree) e concavidades (Conc.) obtidas pelo Teorema de Janak para $\omega$ B97XD com geometrias otimizadas na base aug-pcJ-2.

\begin{tabular}{|c|c|c|c|c|c|c|c|c|c|}
\hline Molécula & $\mathrm{E}_{\text {cátion }}$ & Eneutra & Eânion & $\varepsilon_{\text {cátion }}^{\text {LUMO }}$ & $\varepsilon_{\text {neutra }}^{\text {HOMO }}$ & $\varepsilon_{\text {neutra }}^{\text {LUMO }}$ & $\varepsilon_{\text {ânion }}^{\text {HOMO }}$ & Conc.cátion & Conc.ânion \\
\hline $\mathrm{BF}_{3}$ & $-324,06294$ & $-324,62852$ & $-324,59616$ & $-0,61076$ & $-0,52216$ & 0,03729 & 0,03069 & 1,21 & $-0,09$ \\
\hline $\mathrm{BHF}_{2}$ & $-224,77541$ & $-225,29437$ & $-225,26883$ & $-0,56493$ & $-0,47259$ & 0,03245 & 0,02462 & 1,26 & $-0,11$ \\
\hline $\mathrm{C}_{2} \mathrm{H}_{2}$ & $-76,91686$ & $-77,33279$ & $-77,31062$ & $-0,45015$ & $-0,38171$ & 0,02910 & 0,02109 & 0,93 & $-0,11$ \\
\hline $\mathrm{C}_{2} \mathrm{H}_{4}$ & $-78,20750$ & $-78,59440$ & $-78,56538$ & $-0,41260$ & $-0,36083$ & 0,03016 & 0,02780 & 0,70 & $-0,03$ \\
\hline $\mathrm{C}_{2} \mathrm{H}_{6}$ & $-79,38619$ & $-79,83921$ & $-79,81675$ & $-0,48265$ & $-0,42399$ & 0,02878 & 0,02135 & 0,80 & $-0,10$ \\
\hline $\mathrm{CH}_{4}$ & $-40,00285$ & $-40,52337$ & $-40,50203$ & $-0,56393$ & $-0,47703$ & 0,02810 & 0,01981 & 1,18 & $-0,11$ \\
\hline $\mathrm{CO}$ & $-112,80718$ & $-113,32548$ & $-113,28465$ & $-0,56434$ & $-0,46958$ & 0,03665 & 0,04299 & 1,29 & 0,09 \\
\hline $\mathrm{F}_{2} \mathrm{O}$ & $-274,22717$ & $-274,71054$ & $-274,68209$ & $-0,53804$ & $-0,42972$ & $-0,02616$ & 0,05008 & 1,47 & 1,04 \\
\hline $\mathrm{H}_{2} \mathrm{O}$ & $-75,97948$ & $-76,44594$ & $-76,42649$ & $-0,52422$ & $-0,40687$ & 0,02601 & 0,01850 & 1,60 & $-0,10$ \\
\hline $\mathrm{HF}$ & $-99,87509$ & $-100,46934$ & $-100,44926$ & $-0,67915$ & $-0,50805$ & 0,02723 & 0,02032 & 2,33 & $-0,09$ \\
\hline $\mathrm{NH}_{3}$ & $-56,17223$ & $-56,57108$ & $-56,55088$ & $-0,44246$ & $-0,35481$ & 0,02699 & 0,01880 & 1,19 & $-0,11$ \\
\hline $\mathrm{PF}_{3}$ & $-639,85349$ & $-640,29539$ & $-640,25933$ & $-0,47744$ & $-0,40822$ & 0,04591 & 0,03600 & 0,94 & $-0,13$ \\
\hline $\mathrm{PH}_{3}$ & $-341,99620$ & $-342,38253$ & $-342,36187$ & $-0,42116$ & $-0,35664$ & 0,02683 & 0,01908 & 0,88 & $-0,11$ \\
\hline
\end{tabular}

Tabela 8.493: Energias utilizadas (em hartree) e concavidades (Conc.) obtidas pelo Teorema de Janak para BHandH $30 \% E_{X}^{\mathrm{HF}}$ com geometrias otimizadas na base aug-pcJ-2.

\begin{tabular}{|c|c|c|c|c|c|c|c|c|c|}
\hline Molécula & $\mathrm{E}_{\text {cátion }}$ & Eneutra & $\mathrm{E}_{\hat{a n n i o n}}$ & $\varepsilon_{\text {cátion }}^{\text {LUMO }}$ & $\varepsilon_{\text {neutra }}^{\text {HOMO }}$ & $\varepsilon_{\text {neutra }}^{\text {LUMO }}$ & $\varepsilon_{\text {ânion }}^{\text {HOMO }}$ & Conc. cátion & Conc.ânion \\
\hline $\mathrm{BF}_{3}$ & $-321,81875$ & $-322,38010$ & $-322,35211$ & $-0,66525$ & $-0,45951$ & $-0,00504$ & 0,06545 & 2,80 & 0,96 \\
\hline $\mathrm{BHF}_{2}$ & $-223,15578$ & $-223,66113$ & $-223,63396$ & $-0,61144$ & $-0,39928$ & $-0,01195$ & 0,05366 & 2,89 & 0,89 \\
\hline $\mathrm{C}_{2} \mathrm{H}_{2}$ & $-76,10661$ & $-76,51921$ & $-76,49404$ & $-0,51685$ & $-0,31259$ & 0,00971 & 0,04908 & 2,78 & 0,54 \\
\hline $\mathrm{C}_{2} \mathrm{H}_{4}$ & $-77,34148$ & $-77,72649$ & $-77,69570$ & $-0,48006$ & $-0,29314$ & 0,00646 & 0,05374 & 2,54 & 0,64 \\
\hline $\mathrm{C}_{2} \mathrm{H}_{6}$ & $-78,48296$ & $-78,91629$ & $-78,89345$ & $-0,52236$ & $-0,34558$ & 0,00332 & 0,04992 & 2,41 & 0,63 \\
\hline $\mathrm{CH}_{4}$ & $-39,51791$ & $-40,02654$ & $-40,00287$ & $-0,61859$ & $-0,40102$ & 0,00435 & 0,05214 & 2,96 & 0,65 \\
\hline $\mathrm{CO}$ & $-111,87523$ & $-112,38335$ & $-112,33979$ & $-0,62159$ & $-0,39489$ & $-0,01659$ & 0,08490 & 3,08 & 1,38 \\
\hline $\mathrm{F}_{2} \mathrm{O}$ & $-272,37741$ & $-272,85067$ & $-272,80931$ & $-0,59025$ & $-0,35879$ & $-0,08622$ & 0,10534 & 3,15 & 2,61 \\
\hline $\mathrm{H}_{2} \mathrm{O}$ & $-75,37178$ & $-75,83099$ & $-75,80970$ & $-0,58833$ & $-0,33838$ & $-0,00870$ & 0,05824 & 3,40 & 0,91 \\
\hline $\mathrm{HF}$ & $-99,19341$ & $-99,78168$ & $-99,75800$ & $-0,74340$ & $-0,44311$ & $-0,00826$ & 0,06584 & 4,09 & 1,01 \\
\hline $\mathrm{NH}_{3}$ & $-55,63113$ & $-56,02062$ & $-55,99866$ & $-0,50295$ & $-0,28246$ & $-0,00410$ & 0,05500 & 3,00 & 0,80 \\
\hline $\mathrm{PF}_{3}$ & $-636,68606$ & $-637,11872$ & $-637,08355$ & $-0,53021$ & $-0,33628$ & 0,00346 & 0,07151 & 2,64 & 0,93 \\
\hline $\mathrm{PH}_{3}$ & $-340,68008$ & $-341,05707$ & $-341,03597$ & $-0,47094$ & $-0,28537$ & $-0,00335$ & 0,05106 & 2,52 & 0,74 \\
\hline
\end{tabular}


Tabela 8.494: Energias utilizadas (em hartree) e concavidades (Conc.) obtidas pelo Teorema de Janak para BHandH $40 \% E_{X}^{\mathrm{HF}}$ com geometrias otimizadas na base aug-pcJ-2.

\begin{tabular}{|c|c|c|c|c|c|c|c|c|c|}
\hline Molécula & $\mathrm{E}_{\text {cátion }}$ & $\mathrm{E}_{\text {neutra }}$ & $\mathrm{E}_{\text {ânion }}$ & $\varepsilon_{\text {cátion }}^{\text {LUMO }}$ & $\varepsilon_{\text {neutra }}^{\text {HOMO }}$ & $\varepsilon_{\text {neutra }}^{\text {LUMO }}$ & $\varepsilon_{\text {ânion }}^{\text {HOMO }}$ & Conc.cátion & Conc.ânion \\
\hline $\mathrm{BF}_{3}$ & $-322,11141$ & $-322,68477$ & $-322,65609$ & $-0,65583$ & $-0,49292$ & 0,00124 & 0,06060 & 2,22 & 0,81 \\
\hline $\mathrm{BHF}_{2}$ & $-223,36985$ & $-223,88296$ & $-223,85574$ & $-0,60057$ & $-0,42598$ & $-0,00007$ & 0,04992 & 2,38 & 0,68 \\
\hline $\mathrm{C}_{2} \mathrm{H}_{2}$ & $-76,21767$ & $-76,62905$ & $-76,60422$ & $-0,49523$ & $-0,33188$ & 0,01220 & 0,04702 & 2,22 & 0,47 \\
\hline $\mathrm{C}_{2} \mathrm{H}_{4}$ & $-77,46173$ & $-77,84472$ & $-77,81364$ & $-0,45903$ & $-0,31032$ & 0,01005 & 0,05070 & 2,02 & 0,55 \\
\hline $\mathrm{C}_{2} \mathrm{H}_{6}$ & $-78,60249$ & $-79,04279$ & $-79,01969$ & $-0,51244$ & $-0,36932$ & 0,00714 & 0,04619 & 1,95 & 0,53 \\
\hline $\mathrm{CH}_{4}$ & $-39,58405$ & $-40,09456$ & $-40,07086$ & $-0,59832$ & $-0,42592$ & 0,00777 & 0,04806 & 2,35 & 0,55 \\
\hline $\mathrm{CO}$ & $-111,99780$ & $-112,50869$ & $-112,46378$ & $-0,60270$ & $-0,42109$ & $-0,00117$ & 0,07923 & 2,47 & 1,09 \\
\hline $\mathrm{F}_{2} \mathrm{O}$ & $-272,61197$ & $-273,09110$ & $-273,04308$ & $-0,56935$ & $-0,39075$ & $-0,06337$ & 0,09808 & 2,43 & 2,20 \\
\hline $\mathrm{H}_{2} \mathrm{O}$ & $-75,45452$ & $-75,91205$ & $-75,89061$ & $-0,55699$ & $-0,36708$ & $-0,00330$ & 0,05295 & 2,58 & 0,77 \\
\hline $\mathrm{HF}$ & $-99,28715$ & $-99,87318$ & $-99,84956$ & $-0,70530$ & $-0,47734$ & $-0,00269$ & 0,05962 & 3,10 & 0,85 \\
\hline $\mathrm{NH}_{3}$ & $-55,70584$ & $-56,09402$ & $-56,07191$ & $-0,47733$ & $-0,30642$ & 0,00058 & 0,05032 & 2,33 & 0,68 \\
\hline $\mathrm{PF}_{3}$ & $-637,11914$ & $-637,55421$ & $-637,51791$ & $-0,51552$ & $-0,35646$ & 0,01218 & 0,06678 & 2,16 & 0,74 \\
\hline $\mathrm{PH}_{3}$ & $-340,86814$ & $-341,24490$ & $-341,22352$ & $-0,45400$ & $-0,30248$ & 0,00123 & 0,04693 & 2,06 & 0,62 \\
\hline
\end{tabular}

Tabela 8.495: Energias utilizadas (em hartree) e concavidades (Conc.) obtidas pelo Teorema de Janak para BHandH BHandH $50 \% E_{X}^{\mathrm{HF}}$ com geometrias otimizadas na base aug-pcJ-2.

\begin{tabular}{|c|c|c|c|c|c|c|c|c|c|}
\hline Molécula & $\mathrm{E}_{\text {cátion }}$ & $E_{\text {neutra }}$ & Eânion & $\varepsilon_{\text {cátion }}^{L U M O}$ & $\varepsilon_{\text {neutra }}^{\text {HOMO }}$ & $\varepsilon_{\text {neutra }}^{\text {LUMO }}$ & $\varepsilon_{\text {ânion }}^{\text {HOMO }}$ & Conc.cátion & Conc.ânion \\
\hline $\mathrm{BF}_{3}$ & $-322,40581$ & $-322,99112$ & $-322,96180$ & $-0,64603$ & $-0,52664$ & 0,00694 & 0,05581 & 1,62 & 0,66 \\
\hline $\mathrm{BHF}_{2}$ & $-223,58535$ & $-224,10606$ & $-224,07880$ & $-0,58947$ & $-0,45294$ & 0,00981 & 0,04618 & 1,86 & 0,49 \\
\hline $\mathrm{C}_{2} \mathrm{H}_{2}$ & $-76,32932$ & $-76,73947$ & $-76,71357$ & $-0,47382$ & $-0,35126$ & 0,01446 & 0,04290 & 1,67 & 0,39 \\
\hline $\mathrm{C}_{2} \mathrm{H}_{4}$ & $-77,58263$ & $-77,96363$ & $-77,93228$ & $-0,43828$ & $-0,32757$ & 0,01297 & 0,04768 & 1,51 & 0,47 \\
\hline $\mathrm{C}_{2} \mathrm{H}_{6}$ & $-78,72272$ & $-79,17005$ & $-79,14673$ & $-0,50246$ & $-0,39336$ & 0,01053 & 0,04250 & 1,48 & 0,43 \\
\hline $\mathrm{CH}_{4}$ & $-39,64848$ & $-40,16298$ & $-40,13927$ & $-0,58141$ & $-0,45087$ & 0,01083 & 0,04398 & 1,78 & 0,45 \\
\hline $\mathrm{CO}$ & $-112,12114$ & $-112,63470$ & $-112,58862$ & $-0,58408$ & $-0,44748$ & 0,01270 & 0,07377 & 1,86 & 0,83 \\
\hline $\mathrm{F}_{2} \mathrm{O}$ & $-272,84885$ & $-273,33313$ & $-273,27881$ & $-0,54635$ & $-0,42303$ & $-0,04086$ & 0,09139 & 1,68 & 1,80 \\
\hline $\mathrm{H}_{2} \mathrm{O}$ & $-75,53768$ & $-75,99354$ & $-75,97200$ & $-0,52624$ & $-0,39607$ & 0,00153 & 0,04769 & 1,77 & 0,63 \\
\hline $\mathrm{HF}$ & $-99,38124$ & $-99,96511$ & $-99,94159$ & $-0,66789$ & $-0,51188$ & 0,00224 & 0,05342 & 2,12 & 0,70 \\
\hline $\mathrm{NH}_{3}$ & $-55,78065$ & $-56,16783$ & $-56,14560$ & $-0,45247$ & $-0,33089$ & 0,00478 & 0,04566 & 1,65 & 0,56 \\
\hline $\mathrm{PF}_{3}$ & $-637,55443$ & $-637,99180$ & $-637,95446$ & $-0,50065$ & $-0,37693$ & 0,01955 & 0,06220 & 1,68 & 0,58 \\
\hline $\mathrm{PH}_{3}$ & $-341,05682$ & $-341,43334$ & $-341,41171$ & $-0,43720$ & $-0,31973$ & 0,00537 & 0,04283 & 1,60 & 0,51 \\
\hline
\end{tabular}

Tabela 8.496: Energias utilizadas (em hartree) e concavidades (Conc.) obtidas pelo Teorema de Janak para BHandH $60 \% E_{X}^{\mathrm{HF}}$ com geometrias otimizadas na base aug-pcJ-2.

\begin{tabular}{|c|c|c|c|c|c|c|c|c|c|}
\hline Molécula & $\mathrm{E}_{\text {cátion }}$ & $E_{\text {neutra }}$ & $\mathrm{E}_{\text {ânion }}$ & $\varepsilon_{\text {cátion }}^{\text {LUMO }}$ & $\varepsilon_{\text {neutra }}^{\text {HOMO }}$ & $\varepsilon_{\text {neutra }}^{\text {LUMO }}$ & $\varepsilon_{\text {ânion }}^{\text {HOMO }}$ & Conc.cátion & Conc.ânion \\
\hline $\mathrm{BF}_{3}$ & $-322,70191$ & $-323,29909$ & $-323,26919$ & $-0,63585$ & $-0,56068$ & 0,01210 & 0,05107 & 1,02 & 0,53 \\
\hline $\mathrm{BHF}_{2}$ & $-223,80226$ & $-224,33038$ & $-224,30312$ & $-0,57819$ & $-0,48015$ & 0,01720 & 0,04243 & 1,33 & 0,34 \\
\hline $\mathrm{C}_{2} \mathrm{H}_{2}$ & $-76,44154$ & $-76,85048$ & $-76,82424$ & $-0,45264$ & $-0,37073$ & 0,01652 & 0,03982 & 1,11 & 0,32 \\
\hline $\mathrm{C}_{2} \mathrm{H}_{4}$ & $-77,70418$ & $-78,08320$ & $-78,02228$ & $-0,41782$ & $-0,34488$ & 0,01559 & 0,07904 & 0,99 & 0,86 \\
\hline $\mathrm{C}_{2} \mathrm{H}_{6}$ & $-78,84335$ & $-79,29805$ & $-79,27454$ & $-0,49271$ & $-0,41797$ & 0,01353 & 0,03882 & 1,02 & 0,34 \\
\hline $\mathrm{CH}_{4}$ & $-39,71430$ & $-40,23180$ & $-40,20810$ & $-0,56297$ & $-0,47618$ & 0,01356 & 0,03993 & 1,18 & 0,36 \\
\hline $\mathrm{CO}$ & $-112,24522$ & $-112,76138$ & $-112,71429$ & $-0,56579$ & $-0,47407$ & 0,02436 & 0,06856 & 1,25 & 0,60 \\
\hline $\mathrm{F}_{2} \mathrm{O}$ & $-273,08798$ & $-273,57667$ & $-273,51655$ & $-0,52129$ & $-0,45561$ & $-0,01892$ & 0,08588 & 0,89 & 1,43 \\
\hline $\mathrm{H}_{2} \mathrm{O}$ & $-75,62121$ & $-76,07545$ & $-76,05387$ & $-0,49614$ & $-0,42535$ & 0,00582 & 0,04246 & 0,96 & 0,50 \\
\hline $\mathrm{HF}$ & $-99,47569$ & $-100,05746$ & $-100,03410$ & $-0,63119$ & $-0,54673$ & 0,00660 & 0,04723 & 1,15 & 0,55 \\
\hline $\mathrm{NH}_{3}$ & $-55,85621$ & $-56,24203$ & $-56,21972$ & $-0,42773$ & $-0,35527$ & 0,00854 & 0,04103 & 0,99 & 0,44 \\
\hline $\mathrm{PF}_{3}$ & $-637,99177$ & $-638,43141$ & $-638,39315$ & $-0,48574$ & $-0,39774$ & 0,02561 & 0,05774 & 1,20 & 0,44 \\
\hline $\mathrm{PH}_{3}$ & $-341,24610$ & $-341,62239$ & $-341,60053$ & $-0,42056$ & $-0,33713$ & 0,00911 & 0,03876 & 1,14 & 0,40 \\
\hline
\end{tabular}

Tabela 8.497: Energias utilizadas (em hartree) e concavidades (Conc.) obtidas pelo Teorema de Janak para B1B95 $40 \% E_{X}^{\mathrm{HF}}$ com geometrias otimizadas na base aug-pcJ-2.

\begin{tabular}{|c|c|c|c|c|c|c|c|c|c|}
\hline Molécula & $\mathrm{E}_{\text {cátion }}$ & Eneutra $_{\text {n }}$ & $\mathrm{E}_{\text {ânion }}$ & $\varepsilon_{\text {cátion }}^{\text {LUMO }}$ & $\varepsilon_{\text {neutra }}^{\text {HOMO }}$ & $\varepsilon_{\text {neutra }}^{\text {LUMO }}$ & $\varepsilon_{\text {ânion }}^{\text {HOMO }}$ & Conc.cátion & Conc.ânion \\
\hline $\mathrm{BF}_{3}$ & $-324,04812$ & $-324,62362$ & $-324,59623$ & $-0,65862$ & $-0,49438$ & 0,00571 & 0,05615 & 2,23 & 0,69 \\
\hline $\mathrm{BHF}_{2}$ & $-224,76241$ & $-225,28453$ & $-225,26194$ & $-0,61091$ & $-0,43260$ & 0,00159 & 0,04580 & 2,43 & 0,60 \\
\hline $\mathrm{C}_{2} \mathrm{H}_{2}$ & $-76,90210$ & $-77,31759$ & $-77,29711$ & $-0,49835$ & $-0,33416$ & 0,01040 & 0,04352 & 2,23 & 0,45 \\
\hline $\mathrm{C}_{2} \mathrm{H}_{4}$ & $-78,18291$ & $-78,56962$ & $-78,54359$ & $-0,46101$ & $-0,31268$ & 0,00913 & 0,04551 & 2,02 & 0,49 \\
\hline $\mathrm{C}_{2} \mathrm{H}_{6}$ & $-79,35177$ & $-79,80456$ & $-79,78518$ & $-0,52798$ & $-0,37900$ & 0,00689 & 0,04292 & 2,03 & 0,49 \\
\hline $\mathrm{CH}_{4}$ & $-39,98052$ & $-40,50162$ & $-40,48135$ & $-0,61213$ & $-0,43267$ & 0,00652 & 0,04470 & 2,44 & 0,52 \\
\hline $\mathrm{CO}$ & $-112,79927$ & $-113,31719$ & $-113,27648$ & $-0,60337$ & $-0,42565$ & $-0,00175$ & 0,07373 & 2,42 & 1,03 \\
\hline $\mathrm{F}_{2} \mathrm{O}$ & $-274,20691$ & $-274,69401$ & $-274,65540$ & $-0,57712$ & $-0,39837$ & $-0,06319$ & 0,09234 & 2,43 & 2,12 \\
\hline $\mathrm{H}_{2} \mathrm{O}$ & $-75,96948$ & $-76,43209$ & $-76,41267$ & $-0,56118$ & $-0,37009$ & $-0,00270$ & 0,04958 & 2,60 & 0,71 \\
\hline $\mathrm{HF}$ & $-99,87249$ & $-100,46285$ & $-100,44158$ & $-0,70840$ & $-0,47984$ & $-0,00256$ & 0,05578 & 3,11 & 0,79 \\
\hline $\mathrm{NH}_{3}$ & $-56,15623$ & $-56,55264$ & $-56,53282$ & $-0,48295$ & $-0,31232$ & 0,00077 & 0,04693 & 2,32 & 0,63 \\
\hline $\mathrm{PF}_{3}$ & $-639,89443$ & $-640,33640$ & $-640,30322$ & $-0,52038$ & $-0,36257$ & 0,01366 & 0,06230 & 2,15 & 0,66 \\
\hline $\mathrm{PH}_{3}$ & $-342,02671$ & $-342,41132$ & $-342,39248$ & $-0,45997$ & $-0,30851$ & 0,00181 & 0,04349 & 2,06 & 0,57 \\
\hline
\end{tabular}


Tabela 8.498: Energias utilizadas (em hartree) e concavidades (Conc.) obtidas pelo Teorema de Janak para B971//B971 50\% $E_{X}^{\mathrm{HF}}$ na base aug-pcJ-2.

\begin{tabular}{|c|c|c|c|c|c|c|c|c|c|}
\hline Molécula & $\mathrm{E}_{\text {cátion }}$ & $\mathrm{E}_{\text {neutra }}$ & $\mathrm{E}_{\text {ânion }}$ & $\varepsilon_{\text {cátion }}^{\text {LUMO }}$ & $\varepsilon_{\text {neutra }}^{\text {HOMO }}$ & $\varepsilon_{\text {neutra }}^{\text {LUMO }}$ & $\varepsilon_{\text {ânion }}^{\text {HOMO }}$ & Conc.cátion & Conc.ânion \\
\hline $\mathrm{BF}_{3}$ & $-320,55459$ & $-321,10234$ & $-321,06523$ & $-0,60845$ & $-0,48915$ & $-0,00692$ & 0,06111 & 1,62 & 0,93 \\
\hline $\mathrm{BHF}_{2}$ & $-222,27938$ & $-222,77601$ & $-222,74426$ & $-0,56630$ & $-0,42727$ & $-0,01950$ & 0,05146 & 1,89 & 0,97 \\
\hline $\mathrm{C}_{2} \mathrm{H}_{2}$ & $-75,81038$ & $-76,19797$ & $-76,17157$ & $-0,45426$ & $-0,32733$ & 0,00783 & 0,04338 & 1,73 & 0,48 \\
\hline $\mathrm{C}_{2} \mathrm{H}_{4}$ & $-77,02763$ & $-77,38687$ & $-77,35494$ & $-0,41970$ & $-0,30443$ & $-0,00687$ & 0,04791 & 1,57 & 0,75 \\
\hline $\mathrm{C}_{2} \mathrm{H}_{6}$ & $-78,12810$ & $-78,55769$ & $-78,53133$ & $-0,48714$ & $-0,37375$ & 0,00084 & 0,04445 & 1,54 & 0,59 \\
\hline $\mathrm{CH}_{4}$ & $-39,34974$ & $-39,84608$ & $-39,81958$ & $-0,56875$ & $-0,42850$ & 0,00183 & 0,04580 & 1,91 & 0,60 \\
\hline $\mathrm{CO}$ & $-111,44817$ & $-111,94391$ & $-111,89301$ & $-0,60106$ & $-0,42352$ & $-0,03321$ & 0,07643 & 2,42 & 1,49 \\
\hline $\mathrm{F}_{2} \mathrm{O}$ & $-271,31776$ & $-271,77613$ & $-271,72437$ & $-0,51872$ & $-0,39803$ & $-0,10598$ & 0,09234 & 1,64 & 2,70 \\
\hline $\mathrm{H}_{2} \mathrm{O}$ & $-75,08728$ & $-75,51729$ & $-75,49078$ & $-0,50291$ & $-0,36825$ & $-0,01276$ & 0,05075 & 1,83 & 0,86 \\
\hline $\mathrm{HF}$ & $-98,83804$ & $-99,38922$ & $-99,36044$ & $-0,63667$ & $-0,47757$ & $-0,01227$ & 0,05709 & 2,16 & 0,94 \\
\hline $\mathrm{NH}_{3}$ & $-55,40725$ & $-55,77745$ & $-55,75133$ & $-0,44334$ & $-0,31119$ & $-0,00772$ & 0,04832 & 1,80 & 0,76 \\
\hline $\mathrm{PF}_{3}$ & $-634,45510$ & $-634,87133$ & $-634,82856$ & $-0,48459$ & $-0,35542$ & $-0,00400$ & 0,06578 & 1,76 & 0,95 \\
\hline $\mathrm{PH}_{3}$ & $-339,62090$ & $-339,98354$ & $-339,95772$ & $-0,43542$ & $-0,30328$ & $-0,00637$ & 0,04606 & 1,80 & 0,71 \\
\hline
\end{tabular}

Tabela 8.499: Energias utilizadas (em hartree) e concavidades (Conc.) obtidas pelo Teorema de Janak para B972B95 60\% $E_{X}^{\mathrm{HF}}$ com geometrias otimizadas na base aug-pcJ-2.

\begin{tabular}{|c|c|c|c|c|c|c|c|c|c|}
\hline Molécula & $\mathrm{E}_{\text {cátion }}$ & $E_{\text {neutra }}$ & Eânion & $\varepsilon_{\text {cátion }}^{\text {LUMO }}$ & $\varepsilon_{\text {neutra }}^{\text {HOMO }}$ & $\varepsilon_{\text {neutra }}^{L U M O}$ & $\varepsilon_{\text {ânion }}^{\text {HOMO }}$ & Conc.cátion & Conc.ânion \\
\hline $\mathrm{BF}_{3}$ & $-321,05763$ & $-321,61938$ & $-321,58360$ & $-0,60281$ & $-0,52307$ & 0,01792 & 0,05652 & 1,08 & 0,53 \\
\hline $\mathrm{BHF}_{2}$ & $-222,64198$ & $-223,14283$ & $-223,11452$ & $-0,55433$ & $-0,44880$ & 0,01897 & 0,04606 & 1,44 & 0,37 \\
\hline $\mathrm{C}_{2} \mathrm{H}_{2}$ & $-75,97347$ & $-76,36102$ & $-76,08438$ & $-0,43143$ & $-0,34598$ & 0,01650 & 0,01719 & 1,16 & 0,01 \\
\hline $\mathrm{C}_{2} \mathrm{H}_{4}$ & $-77,19930$ & $-77,55817$ & $-77,52593$ & $-0,39667$ & $-0,32224$ & 0,01587 & 0,04659 & 1,01 & 0,42 \\
\hline $\mathrm{C}_{2} \mathrm{H}_{6}$ & $-78,30688$ & $-78,73906$ & $-78,71422$ & $-0,47442$ & $-0,39184$ & 0,01439 & 0,04263 & 1,12 & 0,38 \\
\hline $\mathrm{CH}_{4}$ & $-39,44664$ & $-39,94152$ & $-39,91588$ & $-0,54604$ & $-0,44729$ & 0,01402 & 0,04379 & 1,34 & 0,41 \\
\hline $\mathrm{CO}$ & $-111,64974$ & $-112,14332$ & $-112,09104$ & $-0,54131$ & $-0,44623$ & 0,03457 & 0,07397 & 1,29 & 0,54 \\
\hline $\mathrm{F}_{2} \mathrm{O}$ & $-271,73726$ & $-272,19579$ & $-272,12764$ & $-0,49571$ & $-0,42192$ & 0,01392 & 0,09352 & 1,00 & 1,08 \\
\hline $\mathrm{H}_{2} \mathrm{O}$ & $-75,21963$ & $-75,64911$ & $-75,62233$ & $-0,47445$ & $-0,39485$ & 0,00849 & 0,04761 & 1,08 & 0,53 \\
\hline $\mathrm{HF}$ & $-98,99714$ & $-99,54881$ & $-99,51962$ & $-0,60483$ & $-0,51032$ & 0,00959 & 0,05298 & 1,29 & 0,59 \\
\hline $\mathrm{NH}_{3}$ & $-55,51939$ & $-55,88884$ & $-55,86263$ & $-0,41128$ & $-0,33374$ & 0,01031 & 0,04564 & 1,05 & 0,48 \\
\hline $\mathrm{PF}_{3}$ & $-635,32020$ & $-635,73813$ & $-635,69438$ & $-0,46175$ & $-0,37418$ & 0,03072 & 0,06315 & 1,19 & 0,44 \\
\hline $\mathrm{PH}_{3}$ & $-340,04251$ & $-340,40458$ & $-340,37981$ & $-0,40436$ & $-0,32024$ & 0,01083 & 0,04303 & 1,14 & 0,44 \\
\hline
\end{tabular}

Tabela 8.500: Energias utilizadas (em hartree) e concavidades (Conc.) obtidas pelo Teorema de Janak para B98//B98 45\% $E_{X}^{\mathrm{HF}}$ na base aug-pcJ-2.

\begin{tabular}{|c|c|c|c|c|c|c|c|c|c|}
\hline Molécula & $\mathrm{E}_{\text {cátion }}$ & E $_{\text {neutra }}$ & Eânion & $\varepsilon_{\text {cátion }}^{\text {LUMO }}$ & $\varepsilon_{\text {neutra }}^{\text {HOMO }}$ & $\varepsilon_{\text {neutra }}^{\text {LUMO }}$ & $\varepsilon_{\text {ânion }}^{\text {HOMO }}$ & Conc.cátion & Conc.ânion \\
\hline $\mathrm{BF}_{3}$ & $-320,44144$ & $-320,98851$ & $-320,95195$ & $-0,60752$ & $-0,48872$ & $-0,00781$ & 0,06108 & 1,62 & 0,94 \\
\hline $\mathrm{BHF}_{2}$ & $-222,20148$ & $-222,69824$ & $-222,66683$ & $-0,56654$ & $-0,42725$ & $-0,01983$ & 0,05136 & 1,90 & 0,97 \\
\hline $\mathrm{C}_{2} \mathrm{H}_{2}$ & $-75,77993$ & $-76,16681$ & $-76,14070$ & $-0,45306$ & $-0,32698$ & 0,00651 & 0,04336 & 1,72 & 0,50 \\
\hline $\mathrm{C}_{2} \mathrm{H}_{4}$ & $-76,99701$ & $-77,35555$ & $-77,32383$ & $-0,41862$ & $-0,30403$ & $-0,00694$ & 0,04796 & 1,56 & 0,75 \\
\hline $\mathrm{C}_{2} \mathrm{H}_{6}$ & $-78,09617$ & $-78,52598$ & $-78,49978$ & $-0,48717$ & $-0,37413$ & $-0,00039$ & 0,04464 & 1,54 & 0,61 \\
\hline $\mathrm{CH}_{4}$ & $-39,33621$ & $-39,83198$ & $-39,80558$ & $-0,56758$ & $-0,42872$ & 0,00054 & 0,04635 & 1,89 & 0,62 \\
\hline $\mathrm{CO}$ & $-111,40548$ & $-111,90136$ & $-111,85076$ & $-0,59994$ & $-0,42379$ & $-0,03343$ & 0,07646 & 2,40 & 1,50 \\
\hline $\mathrm{F}_{2} \mathrm{O}$ & $-271,22227$ & $-271,67969$ & $-271,62704$ & $-0,51712$ & $-0,39742$ & $-0,10646$ & 0,09248 & 1,63 & 2,71 \\
\hline $\mathrm{H}_{2} \mathrm{O}$ & $-75,06144$ & $-75,49091$ & $-75,46481$ & $-0,50158$ & $-0,36843$ & $-0,01394$ & 0,05088 & 1,81 & 0,88 \\
\hline $\mathrm{HF}$ & $-98,80539$ & $-99,35606$ & $-99,32764$ & $-0,63547$ & $-0,47766$ & $-0,01347$ & 0,05726 & 2,15 & 0,96 \\
\hline $\mathrm{NH}_{3}$ & $-55,38765$ & $-55,75712$ & $-55,73131$ & $-0,44143$ & $-0,31109$ & $-0,00895$ & 0,04849 & 1,77 & 0,78 \\
\hline $\mathrm{PF}_{3}$ & $-634,26688$ & $-634,68213$ & $-634,63969$ & $-0,48318$ & $-0,35438$ & $-0,00448$ & 0,06575 & 1,75 & 0,96 \\
\hline $\mathrm{PH}_{3}$ & $-339,53870$ & $-339,90095$ & $-339,87543$ & $-0,43431$ & $-0,30296$ & $-0,00760$ & 0,04619 & 1,79 & 0,73 \\
\hline
\end{tabular}

Tabela 8.501: Energias utilizadas (em hartree) e concavidades (Conc.) obtidas pelo Teorema de Janak para $\omega \mathrm{B} 97 \mathrm{X}(20 \%|100 \%| \#)$ com geometrias otimizadas na base aug-pcJ-2.

\begin{tabular}{|c|c|c|c|c|c|c|c|c|c|}
\hline Molécula & $\mathrm{E}_{\text {cátion }}$ & Eneutra & $\mathrm{E}_{\text {ânion }}$ & $\varepsilon_{\text {cátion }}^{\text {LUMO }}$ & $\varepsilon_{\text {neutra }}^{\text {HOMO }}$ & $\varepsilon_{\text {neutra }}^{\text {LUMO }}$ & $\varepsilon_{\text {ânion }}^{\text {HOMO }}$ & Conc.cátion & Conc.ânion \\
\hline $\mathrm{BF}_{3}$ & $-325,29082$ & $-325,87706$ & $-325,84171$ & $-0,61120$ & $-0,56267$ & 0,03995 & 0,03409 & 0,66 & $-0,08$ \\
\hline $\mathrm{BHF}_{2}$ & $-225,64350$ & $-226,17805$ & $-226,15057$ & $-0,55905$ & $-0,50968$ & 0,03618 & 0,02571 & 0,67 & $-0,14$ \\
\hline $\mathrm{C}_{2} \mathrm{H}_{2}$ & $-77,29035$ & $-77,71156$ & $-77,68762$ & $-0,43261$ & $-0,41218$ & 0,03225 & 0,02228 & 0,28 & $-0,14$ \\
\hline $\mathrm{C}_{2} \mathrm{H}_{4}$ & $-78,59768$ & $-78,98928$ & $-78,96408$ & $-0,39662$ & $-0,38923$ & 0,03426 & 0,02357 & 0,10 & $-0,15$ \\
\hline $\mathrm{C}_{2} \mathrm{H}_{6}$ & $-79,78420$ & $-80,25083$ & $-80,22654$ & $-0,47716$ & $-0,45655$ & 0,03303 & 0,02260 & 0,28 & $-0,14$ \\
\hline $\mathrm{CH}_{4}$ & $-40,20102$ & $-40,73521$ & $-40,71211$ & $-0,55489$ & $-0,51266$ & 0,03223 & 0,02116 & 0,57 & $-0,15$ \\
\hline $\mathrm{CO}$ & $-113,27970$ & $-113,80587$ & $-113,76074$ & $-0,56832$ & $-0,50526$ & 0,04836 & 0,04424 & 0,86 & $-0,06$ \\
\hline $\mathrm{F}_{2} \mathrm{O}$ & $-275,24566$ & $-275,74014$ & $-275,70490$ & $-0,52121$ & $-0,46747$ & $-0,01324$ & 0,04162 & 0,73 & 0,75 \\
\hline $\mathrm{H}_{2} \mathrm{O}$ & $-76,28512$ & $-76,75899$ & $-76,73687$ & $-0,50125$ & $-0,44444$ & 0,03200 & 0,01996 & 0,77 & $-0,16$ \\
\hline $\mathrm{HF}$ & $-100,24105$ & $-100,84429$ & $-100,82163$ & $-0,65422$ & $-0,54964$ & 0,03337 & 0,02072 & 1,42 & $-0,17$ \\
\hline $\mathrm{NH}_{3}$ & $-56,42648$ & $-56,83005$ & $-56,80752$ & $-0,42285$ & $-0,38719$ & 0,03236 & 0,02048 & 0,49 & $-0,16$ \\
\hline $\mathrm{PF}_{3}$ & $-641,80575$ & $-642,25502$ & $-642,21525$ & $-0,46812$ & $-0,43735$ & 0,05204 & 0,03797 & 0,42 & $-0,19$ \\
\hline $\mathrm{PH}_{3}$ & $-342,85713$ & $-343,24638$ & $-343,22369$ & $-0,41076$ & $-0,38153$ & 0,03202 & 0,02052 & 0,40 & $-0,16$ \\
\hline
\end{tabular}


Tabela 8.502: Energias utilizadas (em hartree) e concavidades (Conc.) obtidas pelo Teorema de Janak para $\omega \mathrm{B} 97 \mathrm{XD}(\#|\#| 0,35)$ com geometrias otimizadas na base aug-pcJ-2.

\begin{tabular}{|c|c|c|c|c|c|c|c|c|c|}
\hline Molécula & $\mathrm{E}_{\text {cátion }}$ & $E_{\text {neutra }}$ & $\mathrm{E}_{\text {ânion }}$ & $\varepsilon_{\text {cátion }}^{\text {LUMO }}$ & $\varepsilon_{\text {neutra }}^{\text {HOMO }}$ & $\varepsilon_{\text {neutra }}^{\text {LUMO }}$ & $\varepsilon_{\text {ânion }}^{\text {HOMO }}$ & Conc.cátion & Conc.ânion \\
\hline $\mathrm{BF}_{3}$ & $-324,04664$ & $-324,63770$ & $-324,60464$ & $-0,60731$ & $-0,57636$ & 0,03732 & 0,03198 & 0,42 & $-0,07$ \\
\hline $\mathrm{BHF}_{2}$ & $-224,76811$ & $-225,30339$ & $-225,27815$ & $-0,55097$ & $-0,51953$ & 0,03262 & 0,02393 & 0,43 & $-0,12$ \\
\hline $\mathrm{C}_{2} \mathrm{H}_{2}$ & $-76,91328$ & $-77,33294$ & $-77,31089$ & $-0,42214$ & $-0,41967$ & 0,02902 & 0,02091 & 0,03 & $-0,11$ \\
\hline $\mathrm{C}_{2} \mathrm{H}_{4}$ & $-78,21248$ & $-78,60246$ & $-78,57933$ & $-0,38656$ & $-0,39598$ & 0,03035 & 0,02209 & $-0,13$ & $-0,11$ \\
\hline $\mathrm{C}_{2} \mathrm{H}_{6}$ & $-79,39014$ & $-79,85680$ & $-79,83464$ & $-0,46920$ & $-0,46465$ & 0,02913 & 0,02109 & 0,06 & $-0,11$ \\
\hline $\mathrm{CH}_{4}$ & $-40,00429$ & $-40,53515$ & $-40,51377$ & $-0,54131$ & $-0,52097$ & 0,02846 & 0,02028 & 0,28 & $-0,11$ \\
\hline $\mathrm{CO}$ & $-112,79616$ & $-113,32371$ & $-113,27983$ & $-0,55107$ & $-0,51702$ & 0,04881 & 0,04275 & 0,46 & $-0,08$ \\
\hline $\mathrm{F}_{2} \mathrm{O}$ & $-274,21148$ & $-274,70677$ & $-274,67023$ & $-0,50933$ & $-0,48105$ & 0,00033 & 0,03561 & 0,38 & 0,48 \\
\hline $\mathrm{H}_{2} \mathrm{O}$ & $-75,98091$ & $-76,45307$ & $-76,43381$ & $-0,48778$ & $-0,45701$ & 0,02678 & 0,01764 & 0,42 & $-0,12$ \\
\hline $\mathrm{HF}$ & $-99,87308$ & $-100,47442$ & $-100,45482$ & $-0,63877$ & $-0,56415$ & 0,02819 & 0,01797 & 1,02 & $-0,14$ \\
\hline $\mathrm{NH}_{3}$ & $-56,17828$ & $-56,58012$ & $-56,56004$ & $-0,41036$ & $-0,39744$ & 0,02751 & 0,01855 & 0,18 & $-0,12$ \\
\hline $\mathrm{PF}_{3}$ & $-639,85055$ & $-640,30113$ & $-640,26348$ & $-0,46168$ & $-0,44603$ & 0,04810 & 0,03598 & 0,21 & $-0,16$ \\
\hline $\mathrm{PH}_{3}$ & $-341,99831$ & $-342,38667$ & $-342,36618$ & $-0,39968$ & $-0,38783$ & 0,02749 & 0,01904 & 0,16 & $-0,11$ \\
\hline
\end{tabular}

Tabela 8.503: Energias utilizadas (em hartree) e concavidades (Conc.) obtidas pelo Teorema de Janak para LC-B1B95(40\%|100\%|0,25) com geometrias otimizadas na base augpcJ-2.

\begin{tabular}{|c|c|c|c|c|c|c|c|c|c|}
\hline Molécula & $\mathrm{E}_{\text {cátion }}$ & $\mathrm{E}_{\text {neutra }}$ & $\mathrm{E}_{\text {ânion }}$ & $\varepsilon_{\text {cátion }}^{\text {LUMO }}$ & $\varepsilon_{\text {neutra }}^{\text {HOMO }}$ & $\varepsilon_{\text {neutra }}^{\text {LUMO }}$ & $\varepsilon_{\text {ânion }}^{\text {HOMO }}$ & Conc.cátion & Conc.ânion \\
\hline $\mathrm{BF}_{3}$ & $\begin{array}{l}-323,76889 \\
\end{array}$ & $-324,35813$ & $-324,32538$ & $-0,60637$ & $-0,57415$ & 0,03112 & 0,03280 & 0,44 & 0,02 \\
\hline $\mathrm{BHF}_{2}$ & $-224,49750$ & $-225,08620$ & $-225,06118$ & $-0,60442$ & $-0,50645$ & 0,02802 & 0,02612 & 1,33 & $-0,03$ \\
\hline $\mathrm{C}_{2} \mathrm{H}_{2}$ & $-76,78640$ & $-77,20670$ & $-77,18439$ & $-0,43571$ & $-0,40800$ & 0,02511 & 0,02365 & 0,38 & $-0,02$ \\
\hline $\mathrm{C}_{2} \mathrm{H}_{4}$ & $-78,06009$ & $-78,45199$ & $-78,42914$ & $-0,40009$ & $-0,38555$ & 0,02576 & 0,02422 & 0,20 & $-0,02$ \\
\hline $\mathrm{C}_{2} \mathrm{H}_{6}$ & $-79,22476$ & $-79,68163$ & $-79,66025$ & $-0,46682$ & $-0,44835$ & 0,02442 & 0,02280 & 0,25 & $-0,02$ \\
\hline $\mathrm{CH}_{4}$ & $-39,90807$ & $-40,43197$ & $-40,41033$ & $-0,54501$ & $-0,50628$ & 0,02387 & 0,02260 & 0,53 & $-0,02$ \\
\hline $\mathrm{CO}$ & $-112,67615$ & $-113,19822$ & $-113,15098$ & $-0,54099$ & $-0,50227$ & 0,04412 & 0,04921 & 0,53 & 0,07 \\
\hline $\mathrm{F}_{2} \mathrm{O}$ & $-273,98613$ & $-274,47563$ & $-274,42533$ & $-0,50754$ & $-0,47304$ & 0,00071 & 0,05184 & 0,47 & 0,70 \\
\hline $\mathrm{H}_{2} \mathrm{O}$ & $-75,88880$ & $-76,35503$ & $-76,33540$ & $-0,49257$ & $-0,44827$ & 0,02065 & 0,02003 & 0,60 & $-0,01$ \\
\hline $\mathrm{HF}$ & $-99,78564$ & $-100,37954$ & $-100,35874$ & $-0,63719$ & $-0,56023$ & 0,02157 & 0,02174 & 1,05 & 0,00 \\
\hline $\mathrm{NH}_{3}$ & $-56,08203$ & $-56,48050$ & $-56,45981$ & $-0,41652$ & $-0,38641$ & 0,02195 & 0,02108 & 0,41 & $-0,01$ \\
\hline $\mathrm{PF}_{3}$ & $-639,56302$ & $-640,00865$ & $-639,97064$ & $-0,46069$ & $-0,43229$ & 0,04184 & 0,03796 & 0,39 & $-0,05$ \\
\hline $\mathrm{PH}_{3}$ & $-341,89785$ & $-342,28483$ & $-342,26449$ & $-0,39952$ & $-0,37680$ & 0,02244 & 0,02115 & 0,31 & $-0,02$ \\
\hline
\end{tabular}

Tabela 8.504: Energias utilizadas (em hartree) e concavidades (Conc.) obtidas pelo Teorema de Janak para LC-BHandH $(40 \%|100 \%| 0,10)$ com geometrias otimizadas na base aug-pcJ-2.

\begin{tabular}{|c|c|c|c|c|c|c|c|c|c|}
\hline Molécula & $\mathrm{E}_{\text {cátion }}$ & Eneutra & Eânion $_{\text {ân }}$ & $\varepsilon_{\text {cátion }}^{\text {LUMO }}$ & $\varepsilon_{\text {neutra }}^{\text {HOMO }}$ & $\varepsilon_{\text {neutra }}^{\text {LUMO }}$ & $\varepsilon_{\text {ânion }}^{\text {HOMO }}$ & Conc.cátion & Conc.ânion \\
\hline $\mathrm{BF}_{3}$ & $-322,14415$ & $-322,72026$ & $-322,69432$ & $\frac{-c a t i n}{-0,62618}$ & $\begin{array}{l}\text { neutra } \\
-0,52807\end{array}$ & neutra & 0,03416 & 1,33 & 0,23 \\
\hline $\mathrm{BHF}_{2}$ & $-223,39608$ & $-223,91171$ & $-223,88657$ & $-0,57071$ & $-0,46102$ & 0,02001 & 0,02816 & 1,49 & 0,11 \\
\hline $\mathrm{C}_{2} \mathrm{H}_{2}$ & $-76,23643$ & $-76,64991$ & $-76,62728$ & $-0,46471$ & $-0,36676$ & 0,02033 & 0,02530 & 1,33 & 0,07 \\
\hline $\mathrm{C}_{2} \mathrm{H}_{4}$ & $-77,48422$ & $-77,86927$ & $-77,84660$ & $-0,42869$ & $-0,34500$ & 0,01978 & 0,02574 & 1,14 & 0,08 \\
\hline $\mathrm{C}_{2} \mathrm{H}_{6}$ & $-78,62821$ & $-79,07113$ & $-79,05020$ & $-0,48287$ & $-0,40414$ & 0,01773 & 0,02414 & 1,07 & 0,09 \\
\hline $\mathrm{CH}_{4}$ & $-39,59901$ & $-40,11151$ & $-40,09044$ & $-0,56747$ & $-0,46082$ & 0,01761 & 0,02485 & 1,45 & 0,10 \\
\hline $\mathrm{CO}$ & $-112,01333$ & $-112,52687$ & $-112,47887$ & $-0,57329$ & $-0,45662$ & 0,02426 & 0,05543 & 1,59 & 0,42 \\
\hline $\mathrm{F}_{2} \mathrm{O}$ & $-272,63787$ & $-273,11929$ & $-273,07412$ & $-0,53848$ & $-0,42616$ & $-0,03347$ & 0,06736 & 1,53 & 1,37 \\
\hline $\mathrm{H}_{2} \mathrm{O}$ & $-75,46623$ & $-75,92585$ & $-75,90776$ & $-0,52597$ & $-0,40253$ & 0,01030 & 0,02610 & 1,68 & 0,21 \\
\hline $\mathrm{HF}$ & $-99,29747$ & $-99,88540$ & $-99,86549$ & $-0,67381$ & $-0,51279$ & 0,01062 & 0,03094 & 2,19 & 0,28 \\
\hline $\mathrm{NH}_{3}$ & $-55,71906$ & $-56,10941$ & $-56,09030$ & $-0,44679$ & $-0,34164$ & 0,01314 & 0,02501 & 1,43 & 0,16 \\
\hline $\mathrm{PF}_{3}$ & $-637,15968$ & $-637,59725$ & $-637,56284$ & $-0,48597$ & $-0,39132$ & 0,03014 & 0,04199 & 1,29 & 0,16 \\
\hline $\mathrm{PH}_{3}$ & $-340,88822$ & $-341,26722$ & $-341,24839$ & $-0,42435$ & $-0,33699$ & 0,01409 & 0,02325 & 1,19 & 0,12 \\
\hline
\end{tabular}




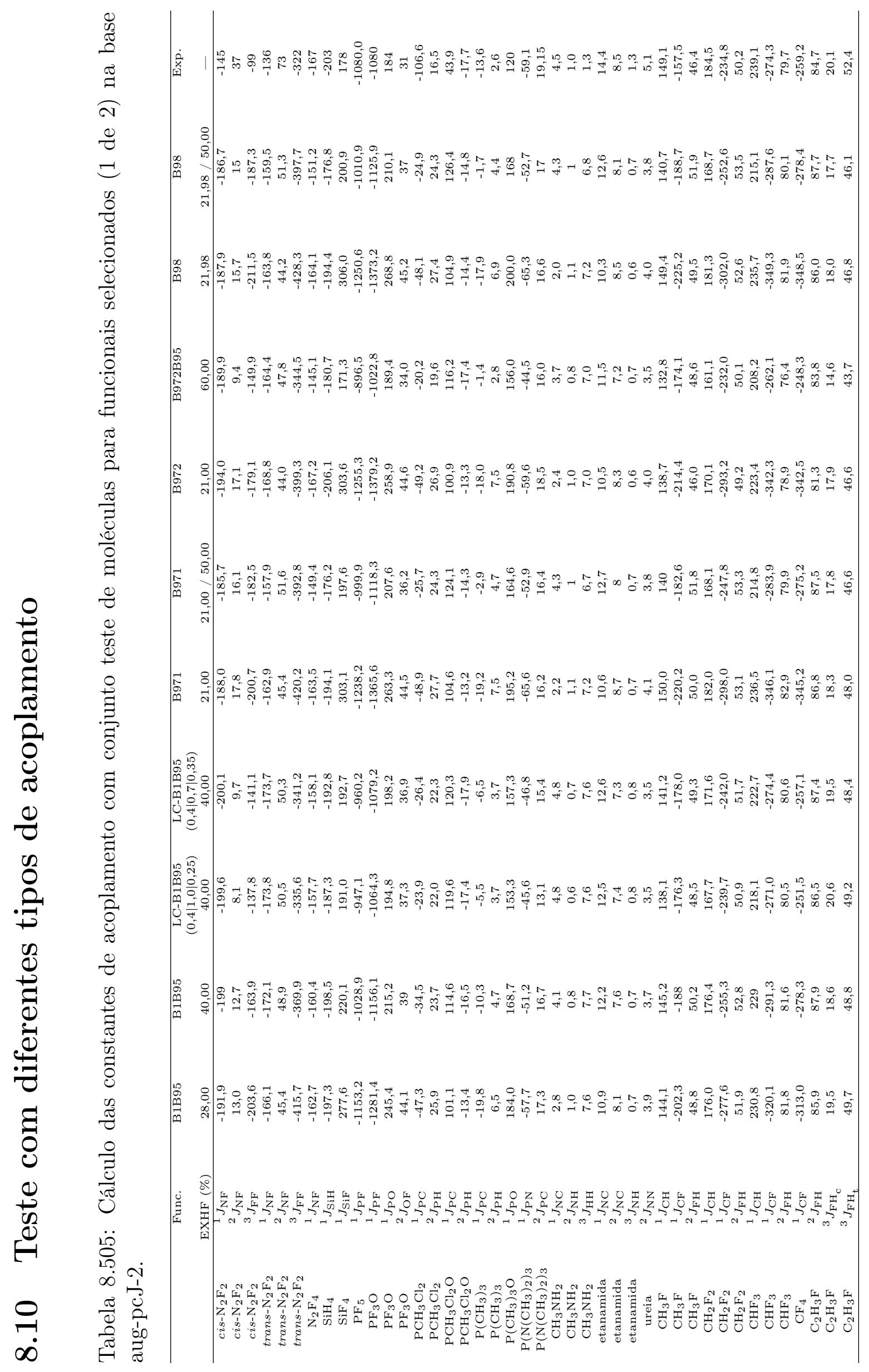




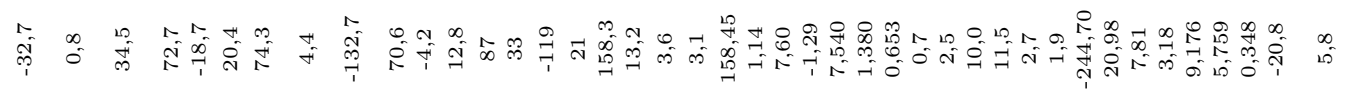

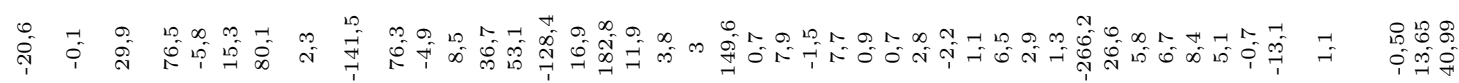

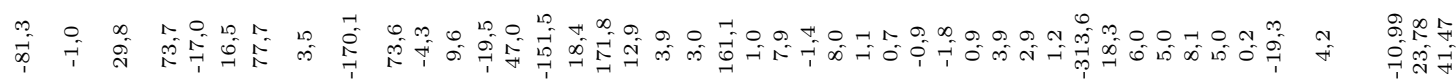

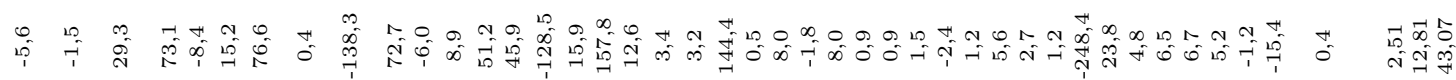

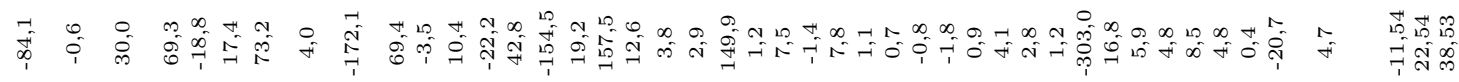

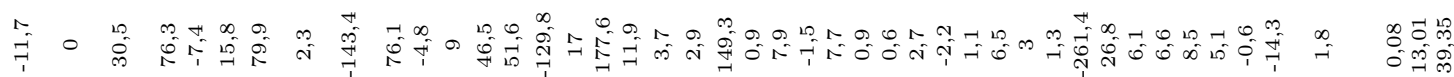

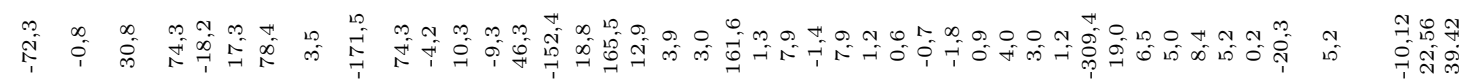

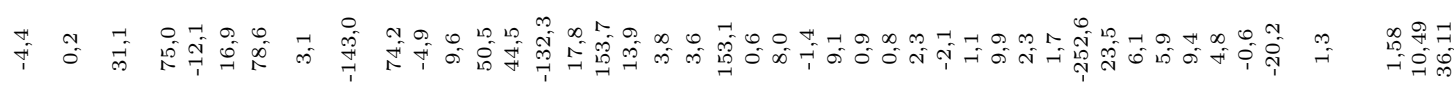

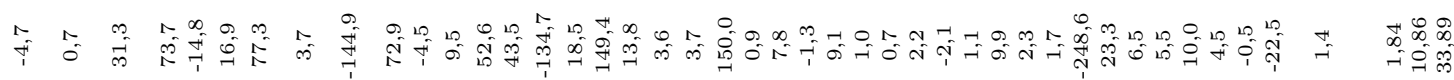

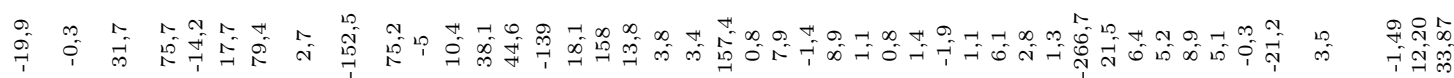

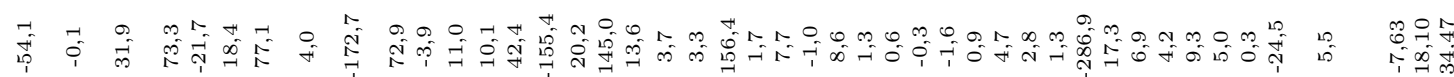

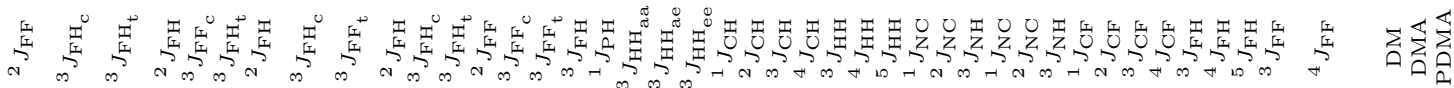

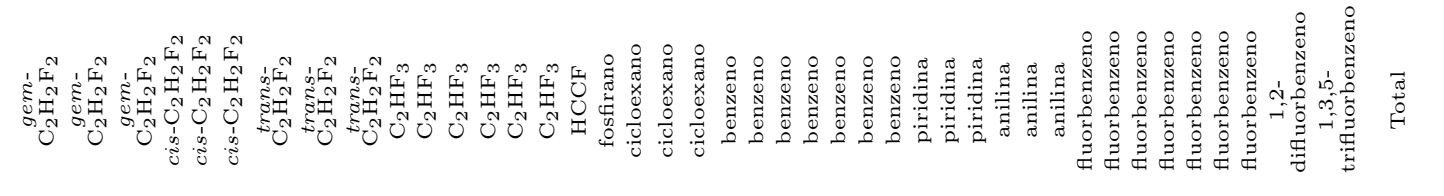




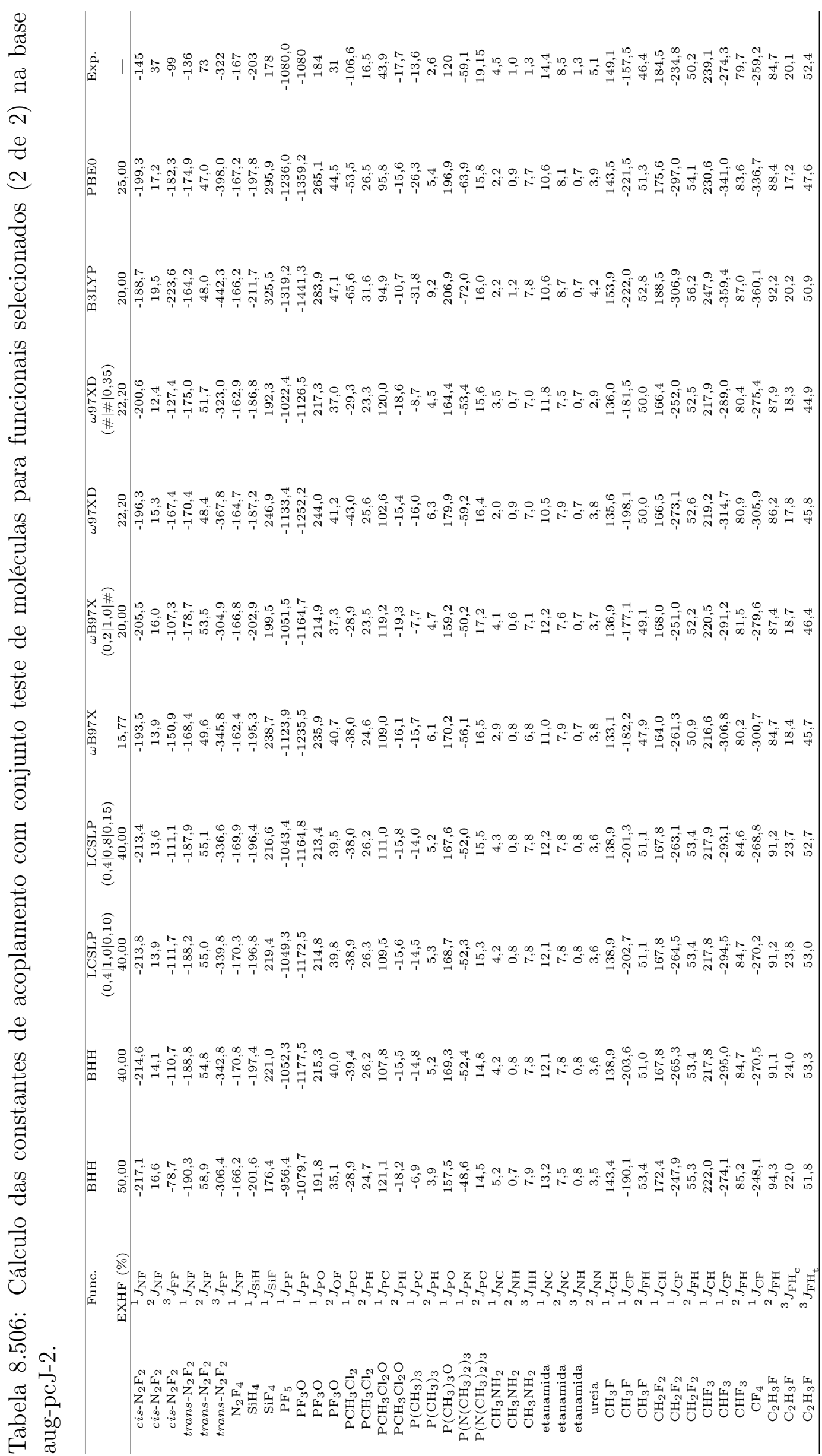




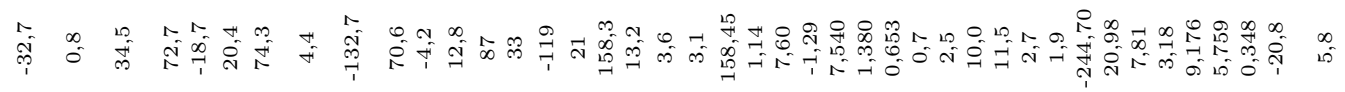

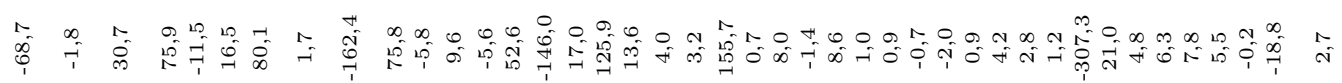

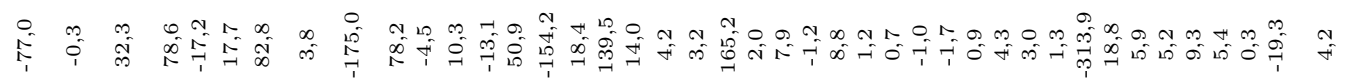

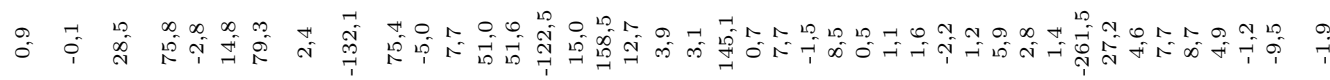

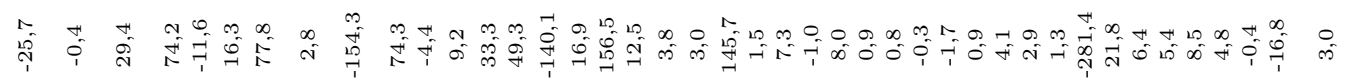

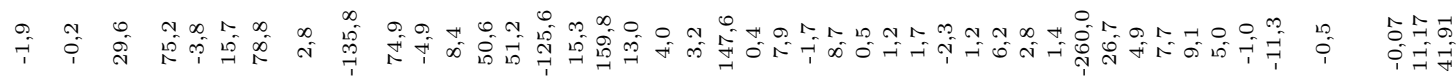

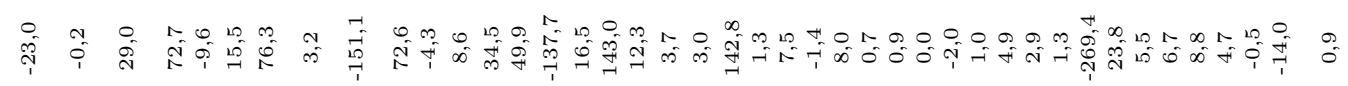

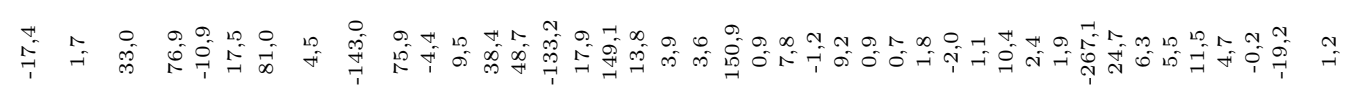

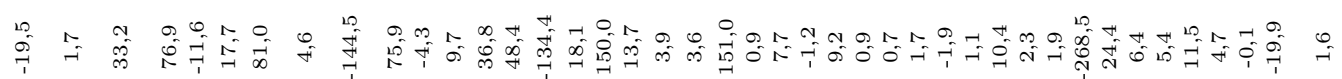

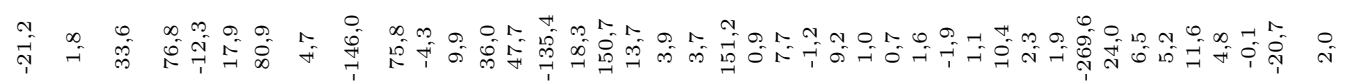

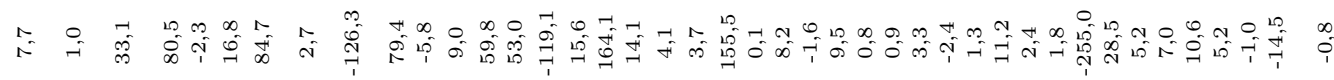

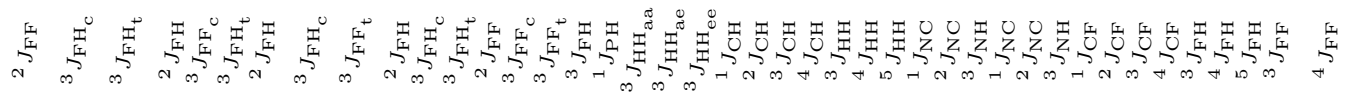

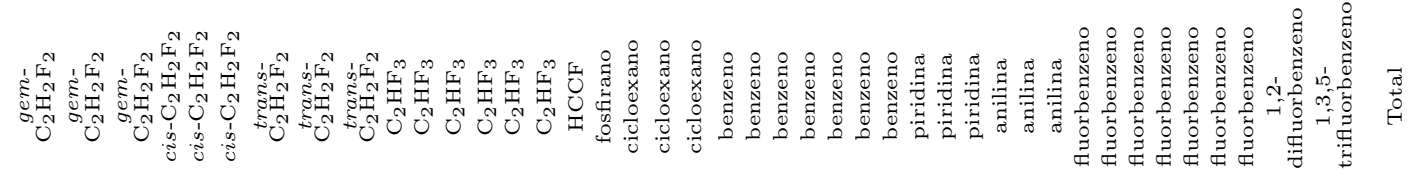




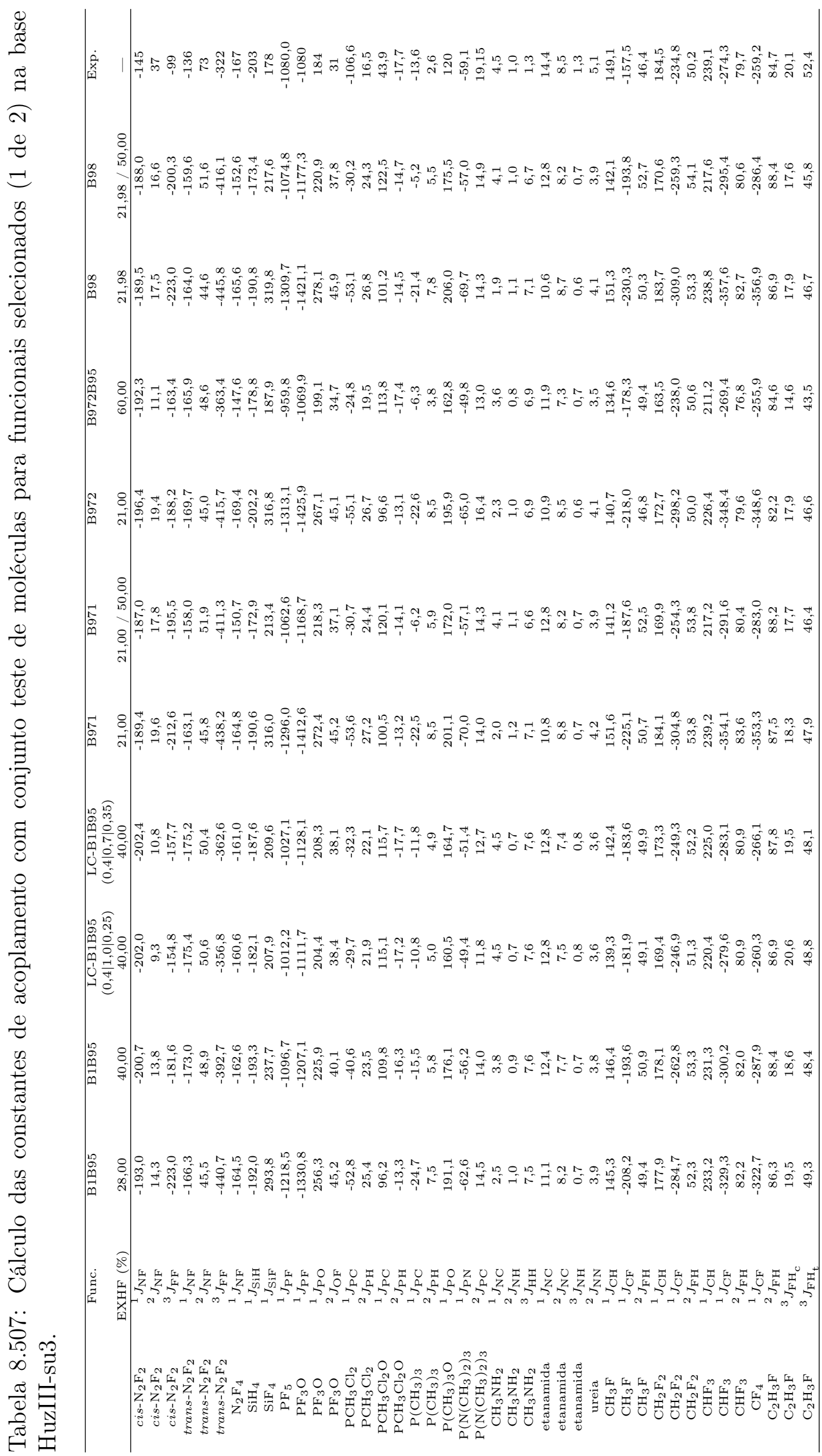




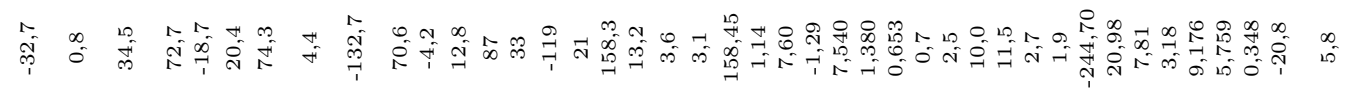

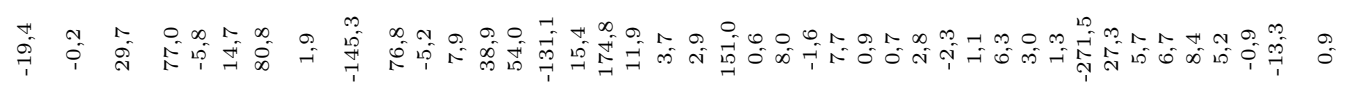

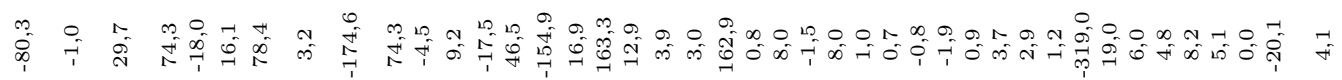

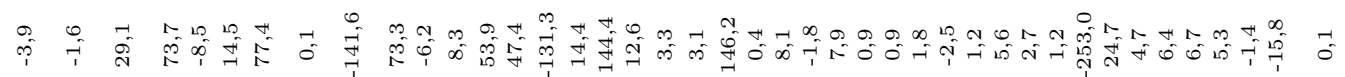

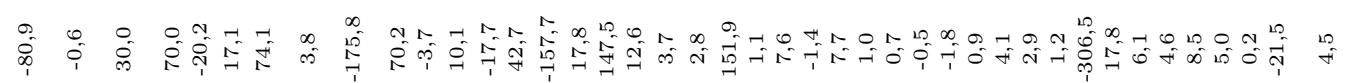

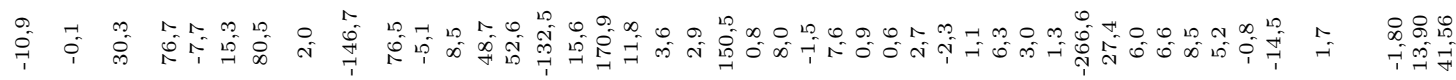

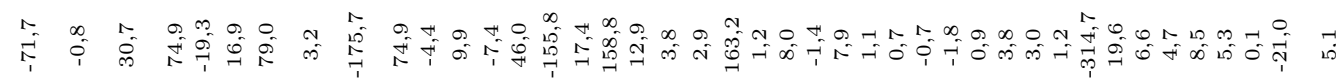

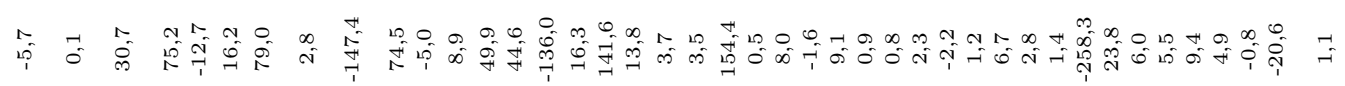

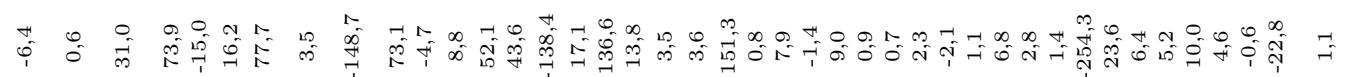

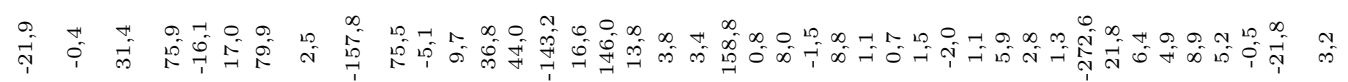

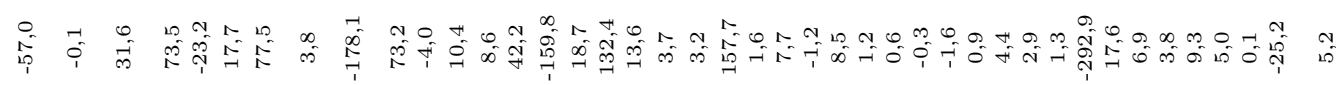

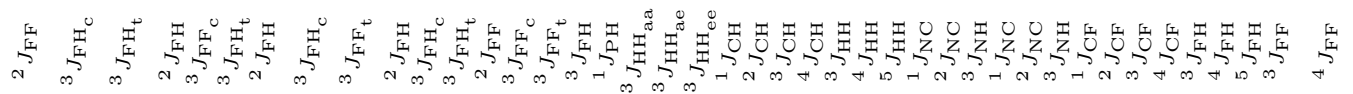

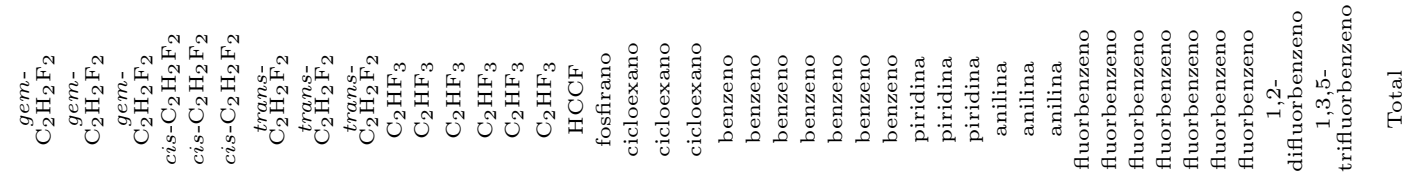




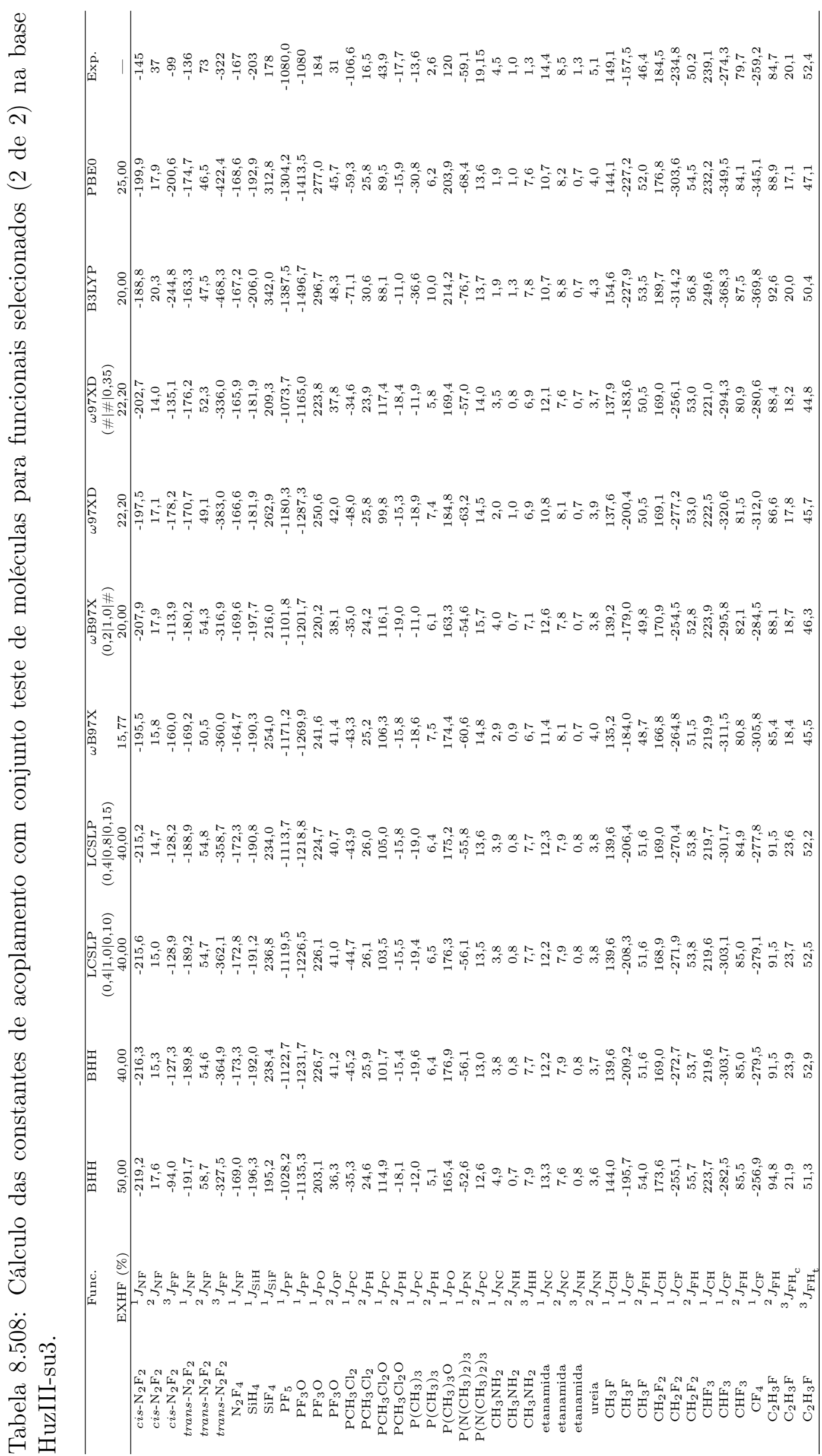




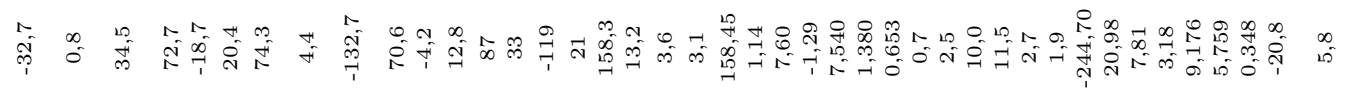

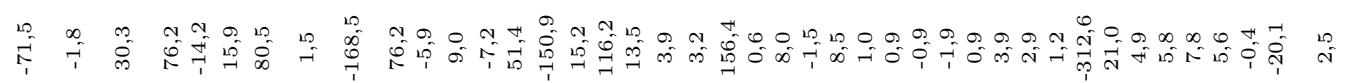

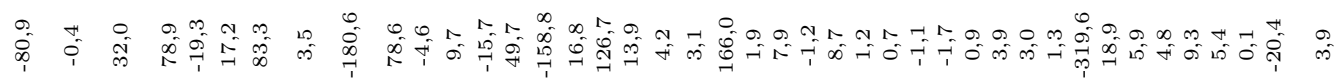

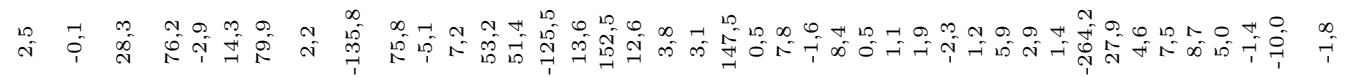

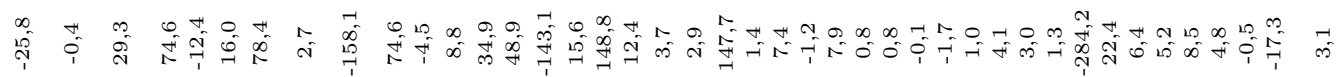

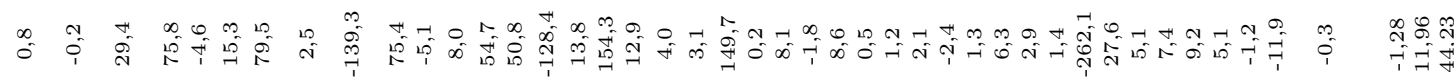

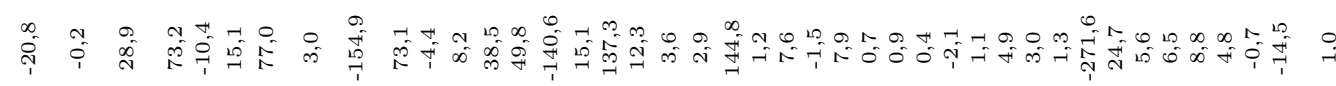

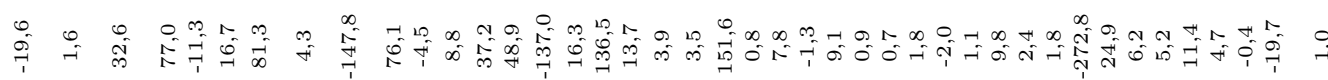

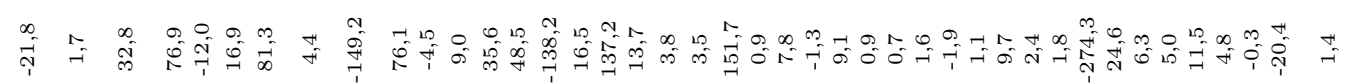

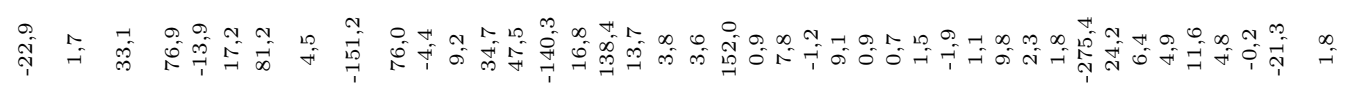

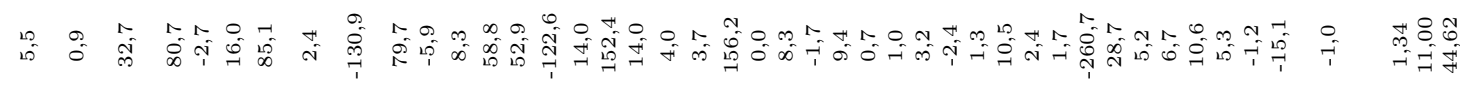

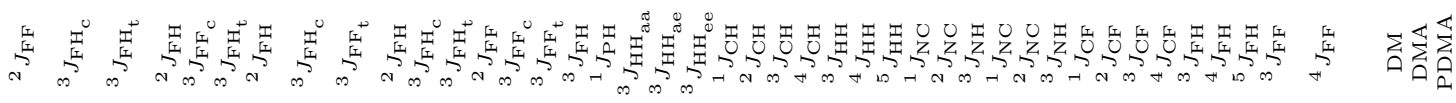

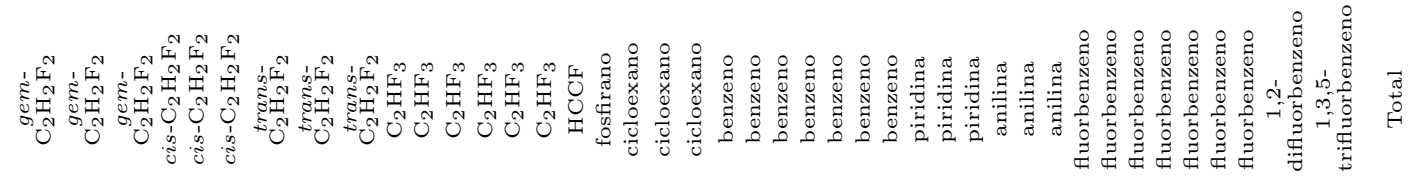




\section{Súmula Curricular}

\section{Dados pessoais}

- Luiz Felipe Guain Teixeira

- São Paulo, 02/08/1994

\section{Educação}

- Colégio Santa Maria, São Paulo, 2011.

- Universidade de São Paulo, São Paulo, 2016.

Ciências Moleculares (Bacharelado)

\section{Participações em Congressos}

1. Guain Teixeira, L. F. ; Ducati, L. C. Density Functional Calibration for Indirect SpinSpin Coupling Constant Calculations. $16^{\text {th }}$ International Congress of Quantum Chemistry, Menton - França, 2018

2. Guain Teixeira, L. F. ; Ducati, L. C. Density Functional Calibration for Indirect SpinSpin Coupling Constant Calculations. XIX Simpósio Brasileiro de Química Teórica, Águas de Lindóia - SP - Brasil, 2017. 